Aus dem Institut für Anatomie und Embryologie

(Prof. Dr. med. C. Viebahn)

im Zentrum Anatomie

der Medizinischen Fakultät der Universität Göttingen

\title{
Ätiologie und Epidemiologie pathologischer Veränderungen an den Skeletfunden der neolithischen Populationen aus Calden, Rheine und Großenrode
}

\author{
INAUGURAL-DISSERTATION \\ zur Erlangung des Doktorgrades \\ für Zahnheilkunde \\ der Medizinischen Fakultät der \\ Georg-August-Universität zu Göttingen
}

\author{
vorgelegt von \\ Jan Christian Cyris \\ aus \\ Lingen
}

Göttingen 2019 
Dekan:

Referent/in

Ko-Referent/in:

Drittreferent/in:
Prof. Dr. rer. nat. H.K. Kroemer

Prof. Dr. med. Dr. phil. nat. M. Schultz

PD Dr. med. Felix Bremmer

Datum der mündlichen Prüfung: $\quad$ 17.08.2020 
Hiermit erkläre ich, die Dissertation mit dem Titel "Ätiologie und Epidemiologie pathologischer Veränderungen an den Skeletfunden der neolithischen Populationen aus Calden, Rheine und Großenrode" eigenständig angefertigt und keine anderen als die von mir angegebenen Quellen und Hilfsmittel verwendet zu haben.

Göttingen, den 


\section{Inhalt}

Abbildungsverzeichnis..........................................................................................................

Tabellenverzeichnis....................................................................................................................

Abkürzungsverzeichnis..............................................................................................................

1. Einleitung ........................................................................................................... 1

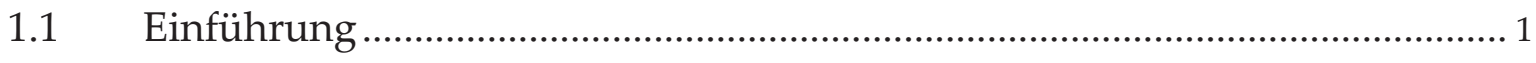

$1.2 \quad$ Ziele dieser Dissertation................................................................................ 4

2. Fundgut und Methoden....................................................................................... 5

$2.1 \quad$ Generelle Vorbemerkung............................................................................. 5

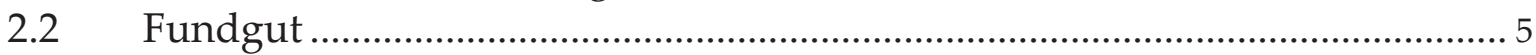

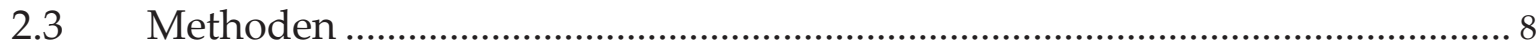

2.3.1 Vorbemerkungen zur Alters- und Geschlechtsbestimmung .................................... 8

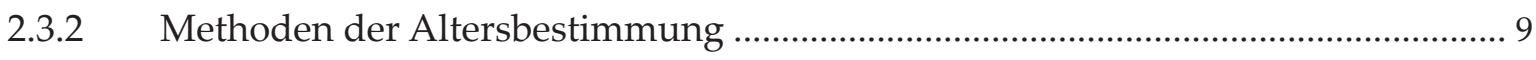

2.3.3 Methoden der Geschlechtsbestimmung ................................................................12

2.3.4 Rekonstruktion der Körperhöhe und Bestimmung der MIZ ...................................14

2.3.5 Paläopathologische Befunderhebung und -dokumentation......................................14

2.3.5.1 Oberflächenbefundung und Befunddokumentation...................................................... 15

2.3.5.2 Frakturen ................................................................................................................... 22

2.3.5.3 Befundung der Zähne und Zahnhalteapparate............................................................. 22

2.3.5.4 Krankheiten und ihre vereinfachte Betrachtung im Ergebnisteil .................................... 26

2.3.6 Datenbank zur Befunddokumentation und -auswertung ....................................26

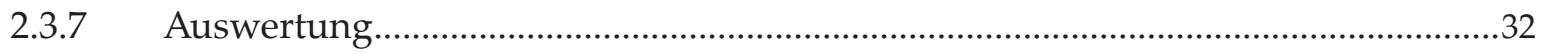

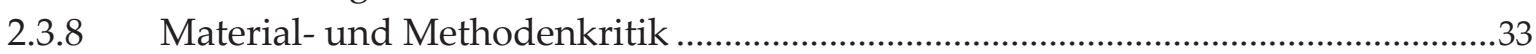

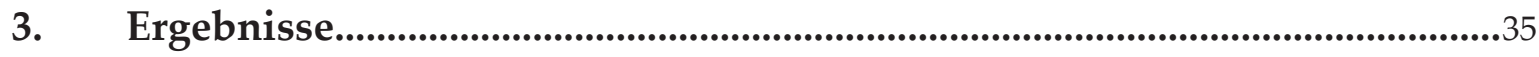

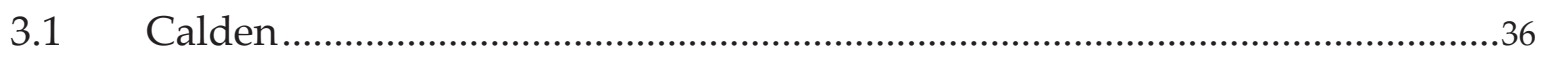

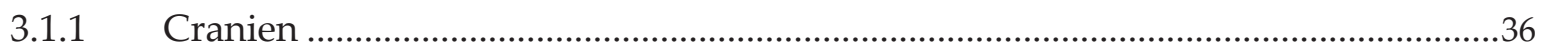

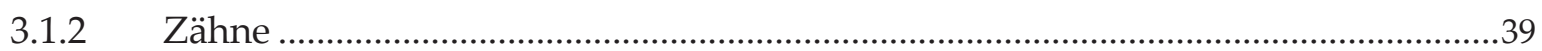

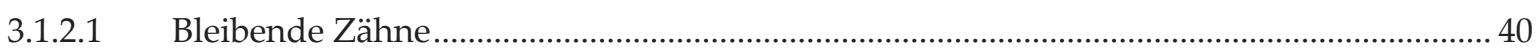

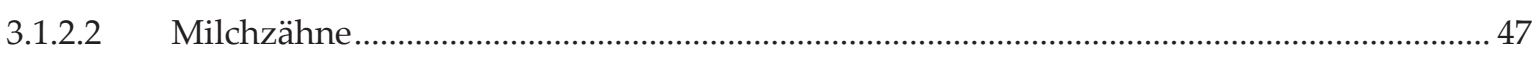

3.1.2.3 Apicale Prozesse und Parodontalveränderungen an Milch- und Dauergebissen............. 49

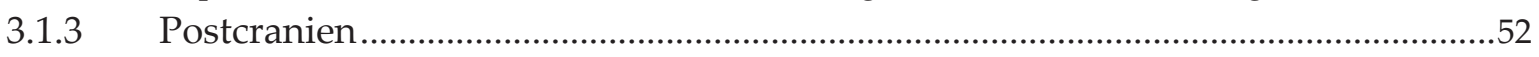

3.1.4 Ermittlung des Sterbealters .........................................................................70

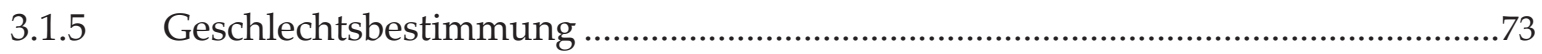

3.1.6 Rekonstruktion der Körperhöhe....................................................................74

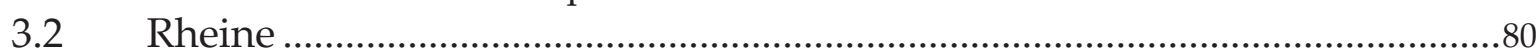

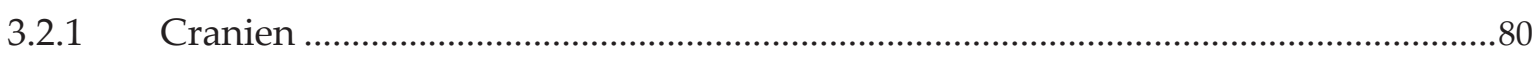

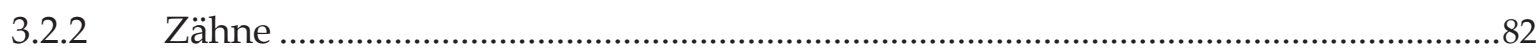




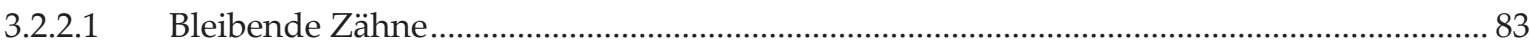

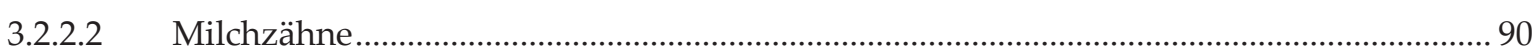

3.2.2.3 Nicht eindeutig zuzuordnende Zähne.......................................................................... 91

3.2.2.4 Apicale Prozesse und Parodontalveränderungen an Milch- und Dauergebissen............. 94

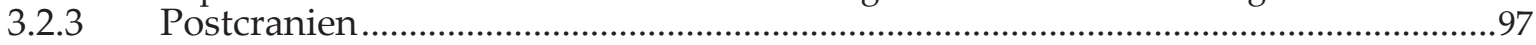

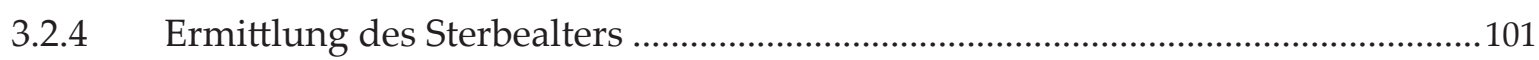

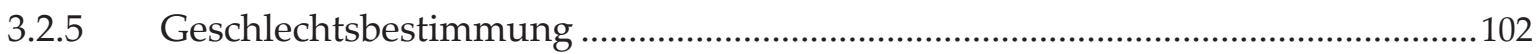

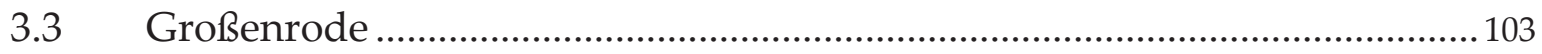

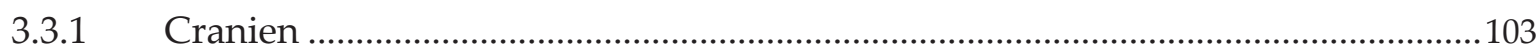

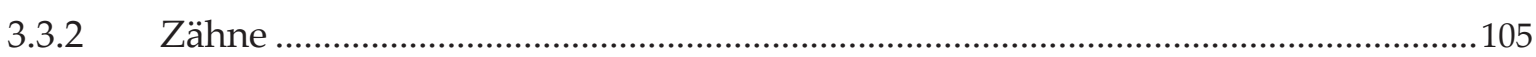

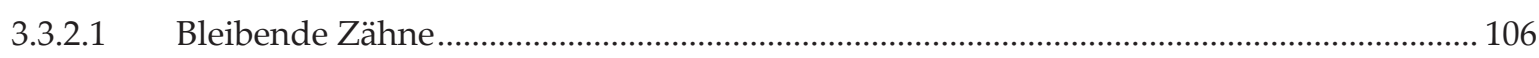

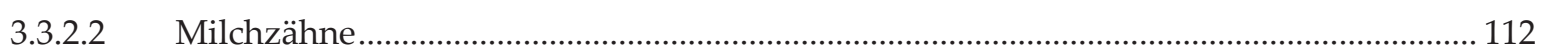

3.3.2.3 Apicale Prozesse und Parodontalveränderungen an Milch- und Dauergebissen............ 115

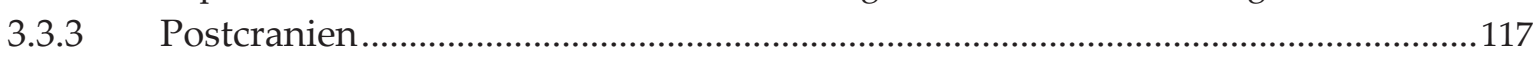

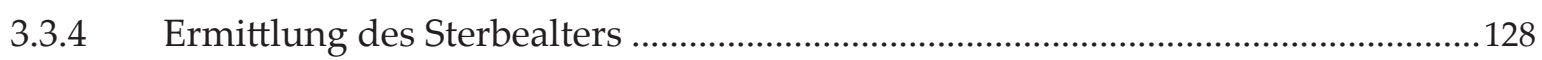

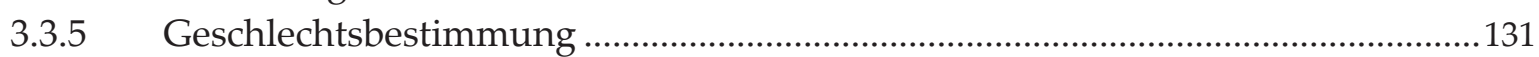

3.4 Zusammenfassung der Ergebnisse....................................................... 133

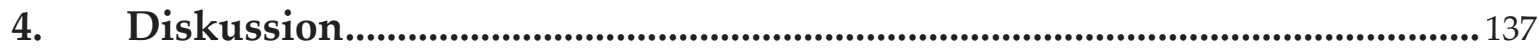

4.1 Fundgut, Befunderhebung und Auswertung ........................................... 137

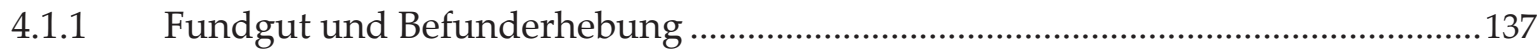

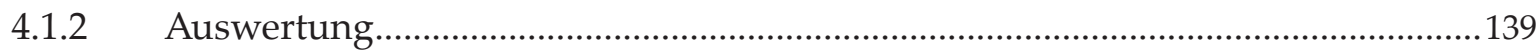

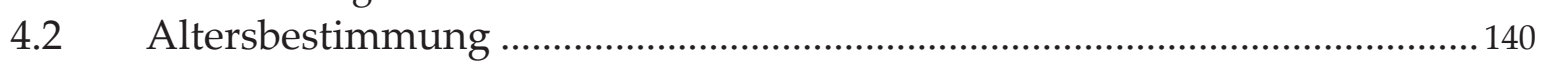

4.3 Vergleich der Skeletfunde der drei Populationen ....................................... 145

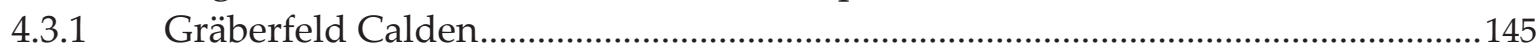

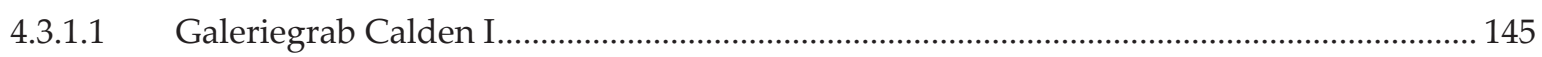

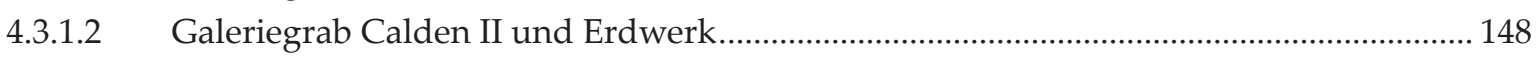

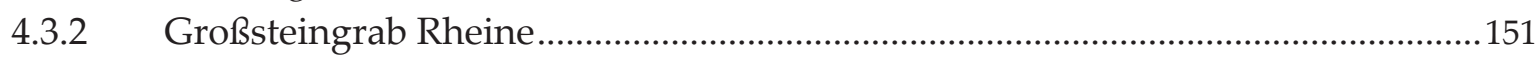

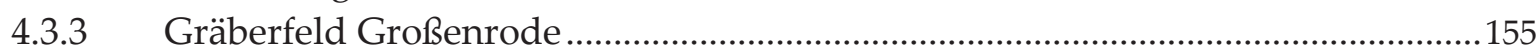

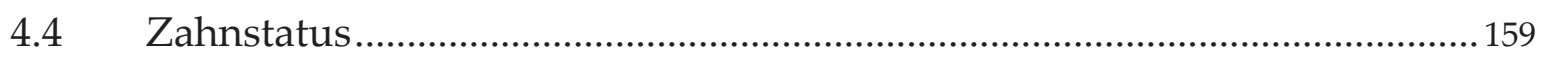

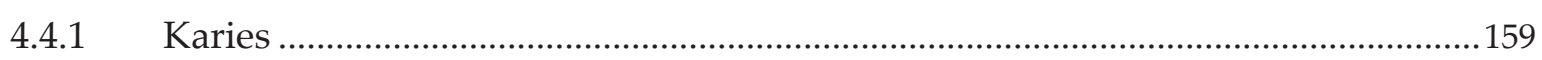

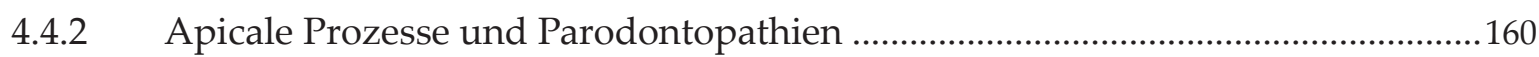

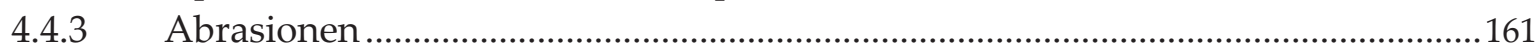

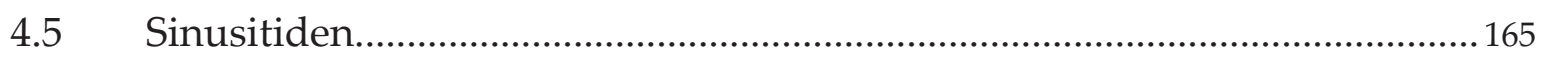

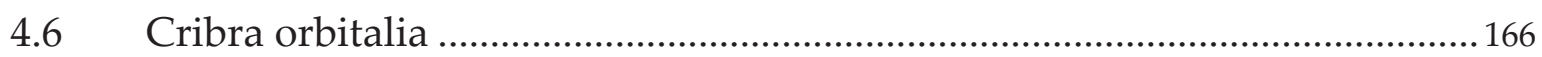

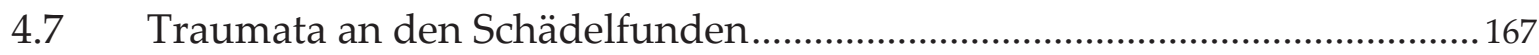

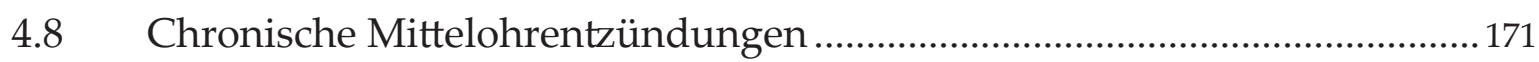

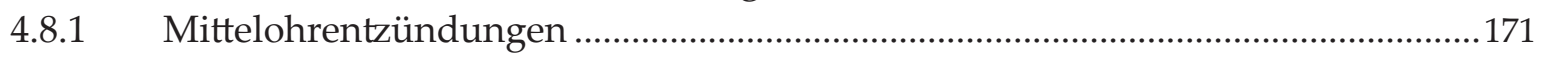

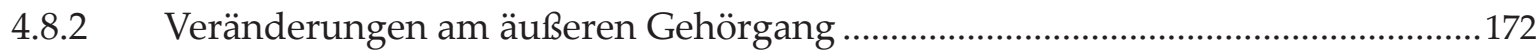

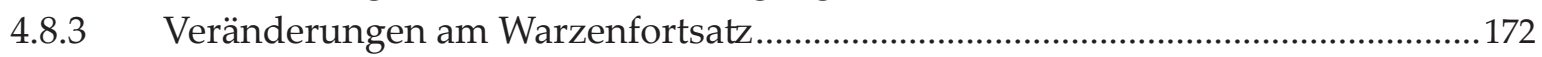

4.9 Degenerative Veränderungen an Gelenken ................................................. 173

4.9.1 Befunde zu degenerativen Gelenkerkrankungen .................................................174

4.9.2 Geschlechtsunterschiede bei degenerativen Gelenkerkrankungen.........................175

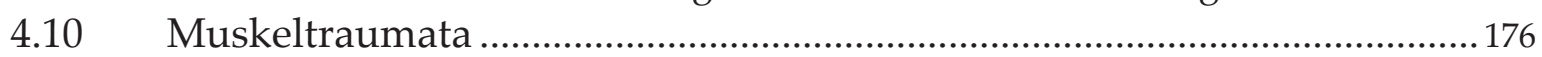

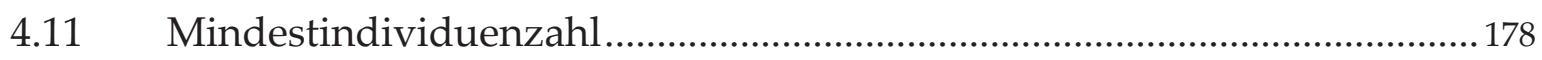

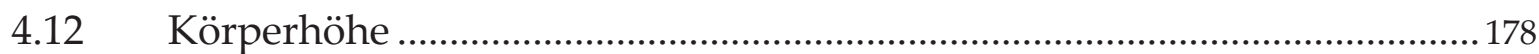




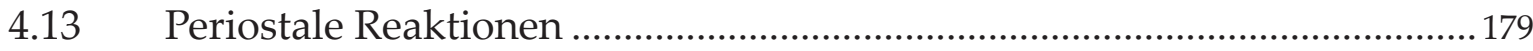

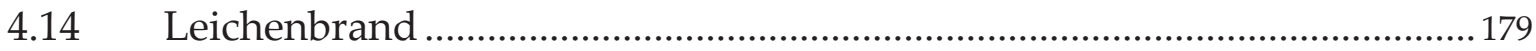

4.15 Postmortale Artefakte am Fundgut.............................................................. 180

4.16 Rekonstruktion damaliger Lebensbedingungen ........................................... 181

5. Zusammenfassung.................................................................................................... 183

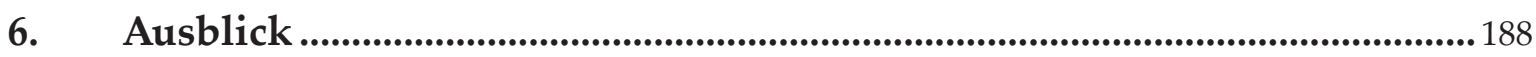

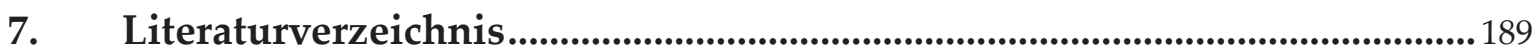

8. Anhang............................................................................................................. 200

8.1 Befund 1: Cranium 3 der Population aus Calden........................................... 201

8.2 Befund 2: Cranium 28 der Population aus Calden.......................................... 205

8.3 Befund 3: Oberkiefer 25 der Population aus Calden ......................................210

8.4 Befund 4: Ober- und Unterkiefer 32/18 der Population aus Calden ............213

8.5 Befund 5: Oberkiefer 27 der Population aus Calden ......................................216

8.6 Befund 6: Oberkiefer 23 der Population aus Calden .......................................219

8.7 Befund 7: Unterkiefer 3 der Population aus Calden ........................................221

8.8 Befund 8: Teilskelet 11 der Population aus Calden..........................................223

8.9 Befund 9: Teilskelet 12 der Population aus Calden..........................................226

8.10 Befund 10: Teilskelet 14 der Population aus Calden........................................ 230

8.11 Befund 11: Teilskelet 33 der Population aus Calden........................................234

8.12 Befund 12: Teilskelet 39 der Population aus Calden........................................238

8.13 Befund 13: Teilskelet 46 der Population aus Calden.........................................244

8.14 Befund 14: Teilskelet 50 der Population aus Calden........................................248

8.15 Befund 15: Teilskelet 57 der Population aus Calden........................................255

8.16 Befund 16: Teilskelet 63 der Population aus Calden.......................................257

8.17 Lichtmikroskopischer Befund 1 der Population aus Calden......................... 260

8.18 Lichtmikroskopischer Befund 2 der Population aus Calden.......................... 264

8.19 Lichtmikroskopischer Befund 3 der Population aus Calden..........................266

8.20 Lichtmikroskopischer Befund 4 der Population aus Calden..........................270

8.21 Lichtmikroskopischer Befund 5 der Population aus Calden.........................274

8.22 Lichtmikroskopischer Befund 6 der Population aus Calden......................... 277

8.23 Lichtmikroskopischer Befund 7 der Population aus Calden...........................286

8.24 Lichtmikroskopischer Befund 8 der Population aus Calden..........................292

8.25 Lichtmikroskopischer Befund 9 der Population aus Calden...........................300

8.26 Lichtmikroskopischer Befund der Population aus Rheine ..............................304

8.27 Lichtmikroskopischer Befund 1 der Population aus Großenrode..................310

8.28 Lichtmikroskopischer Befund 2 der Population aus Großenrode..................325

8.29 REM-Befund 1 der Population aus Calden (Vgl. 7.19) .................................... 333

8.30 REM-Befund 2 der Population aus Calden (Vgl. 7.19) .....................................337 


\section{Abbildungsverzeichnis}

Abb. 1 Abrasionsschema der Molaren und Einteilung in eine Alterskategorie ......................... 12

Abb. 2 Screenshot 1 aus FileMaker Pro ${ }^{\circledR}$; Cranien mit Fotografien ............................................. 28

Abb. 3 Screenshot 2 aus FileMaker Pro ${ }^{\circledR}$; Cranien mit Röntgenbildern......................................2 29

Abb. $4 \quad$ Screenshot 3 aus FileMaker Pro ${ }^{\circledR}$; Cranien mit Endoskopfotografien ............................ 29

Abb. 5 Screenshot 5 aus FileMaker Pro ${ }^{\circledR}$; Spuren von Krankheiten ............................................. 30

Abb. 6 Screenshot 6 aus FileMaker Pro ${ }^{\circledR}$; Befunde von Langknochen..........................................3 30

Abb. 7 Screenshot 7 aus FileMaker Pro ${ }^{\circledR}$; Arthrosegrad der Gelenke ........................................3 31

Abb. 8 Screenshot 8 aus FileMaker Pro ${ }^{\circledR}$; Arthrosegrad von Wirbeln......................................... 31

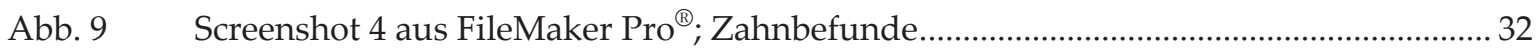

Abb. $10 \quad$ Verteilung der Schädelfragmente; Calden ...................................................................... 37

Abb.11 Absolute Anzahl der Erhaltungsmenge je Cranium eines Individuums; Calden .......... 37

Abb.12 Gesamtheit der Datensätze für die Schädelfunde; Calden..............................................3 38

Abb.13 Diagnostizierte Veränderungen an den Schädelfunden; Calden .................................... 39

Abb. 14 Erhaltene Zähne und leere Alveolen des Dauergebisses; Calden ................................... 40

Abb. 15 Veränderungen an allen bleibenden ersten Incisivi; Calden............................................4 41

Abb. 16 Veränderungen an allen bleibenden zweiten Incisivi; Calden .........................................42

Abb. 17 Veränderungen an allen bleibenden Canini; Calden .....................................................42

Abb. 18 Veränderungen an allen ersten Prämolaren; Calden .....................................................4 43

Abb. 19 Veränderungen an allen zweiten Prämolaren; Calden ....................................................4 43

Abb. 20 Veränderungen an allen bleibenden ersten Molaren; Calden.......................................... 44

Abb. 21 Veränderungen an allen bleibenden zweiten Molaren; Calden .......................................4 44

Abb. 22 Veränderungen an allen dritten Molaren; Calden ...............................................................4 45

Abb. 23 Veränderungen an allen Zahntypen des 1. Quadranten; Calden.....................................4 45

Abb. 24 Veränderungen an allen Zahntypen des 2. Quadranten; Calden.....................................46

Abb. 25 Veränderungen an allen Zahntypen des 3. Quadranten; Calden.....................................46

Abb. 26 Veränderungen an allen Zahntypen des 4. Quadranten; Calden.....................................46

Abb. 27 Die vier Sechs-Jahres-Molaren aller Quadranten im Vergleich; Calden .........................4 47

Abb. 28 Erhaltene Zähne und leere Alveolen des Milchgebisses; Calden................................... 47

Abb. 29 Veränderungen an allen ersten Milchmolaren; Calden ...................................................4 48

Abb. $30 \quad$ Veränderungen an allen zweiten Milchmolaren; Calden .................................................4 48

Abb. 31 Diagramm zur Häufigkeit apicaler Prozesse; Calden.................................................... 49

Abb. 32 Graduierung apicaler Prozesse („Ja“-Anteil aus Diagramm 31); Calden ....................... 50

Abb. 33 Diagramm zur Häufigkeit von Parodontopathien; Calden ...........................................5 50

Abb. 34 Graduierung der Parodontopathien („Ja“-Anteil aus Diagramm 33); Calden................ 51

Abb. 35 Darstellung der verschiedenen Parodontopathien; Calden ............................................5 51

Abb.36 Darstellung der Befunde der Wirbel; Calden..................................................................5 57

Abb.37 Anatomisch orientierte Darstellung der Wirbelregionen; Calden ...................................55

Abb. 38 Befundbare Fundstücke (außer Schädel und den Zähnen) - Teil 1; Calden ...................59

Abb.39 Befundbare Fundstücke (außer Schädel und den Zähnen) - Teil 2; Calden ...................59 
Abb. 40

Abb. 41

Abb. 42

Abb. 43

Abb. 44

Abb. 45

Abb. 46

Abb. 47

Abb. 48

Abb. 49

Abb. 50

Abb. 51

Abb. 52

Abb. 53

Abb. 54

Abb. 55

Abb. 56

Abb. 57

Abb. 58

Abb. 59

Abb. 60

Abb. 61

Abb. 62

Abb. 63

Abb. 64

Abb. 65

Abb. 66

Abb. 67

Abb. 68

Abb. 69

Abb. 70

Abb. 71

Abb. 72

Abb. 73

Abb. 74

Abb. 75

Abb. 76

Abb. 77

Abb. 78

Abb. 79

Abb. 80

Abb. 81

Abb. 82

Abb. 83

Abb. 84

Abb. 85
Veränderungen an Vertebrae (gesamt befundbare: $\mathrm{n}=241$ ); Calden

Veränderungen an Claviculae (gesamt befundbare: $n=20$ ); Calden 61

Veränderungen an Scapulae (gesamt befundbare: $\mathrm{n}=31$ ); Calden.

Veränderungen an Costae (gesamt befundbare: $\mathrm{n}=130$ ); Calden

Veränderungen an Humeri (gesamt befundbare: $n=62$ ); Calden

Veränderungen an Radii (gesamt befundbare: $n=50$ ); Calden .

Veränderungen an Ulnae (gesamt befundbare: $n=49$ ); Calden .

Veränderungen an Phalanges manus (gesamt befundbare: $n=7$ ); Calden

Veränderungen an Ossa coxae (gesamt befundbare: $n=58$ ); Calden 63

Veränderungen an Ossa sacra (gesamt befundbare: $n=24$ ); Calden.

Veränderungen an Ossa femoris (gesamt befundbare: $n=115$ ); Calden ...................... 64

Veränerungen an Patellae (gesamt befundbare: $\mathrm{n}=23$ ); Calden ................................... 65

Veränderungen an Tibiae (gesamt befundbare: $\mathrm{n}=79$ ); Calden .................................... 65

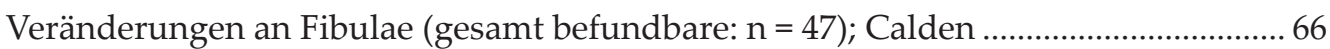

Muskeltraumta an verschiedenen Skeletelementen; Calden ......................................... 66

Arthrose an verschiedenen Skeletelementen; Calden ................................................. 67

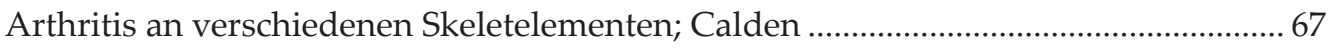

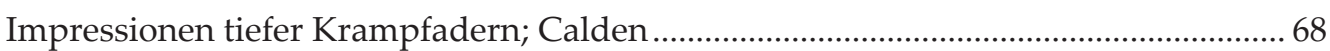

Kapselverletzungen an verschiedenen Skeletelementen; Calden ................................. 68

Periostreizungen an verschiedenen Skeletelementen; Calden....................................... 68

Spondylitis an Vertebrae und Ossa sacra; Calden ..........................................................6 69

Spondylophyten an Vertebrae und Ossa sacra; Calden.................................................6. 69

Spondylosis an Vertebrae und Ossa sacra; Calden........................................................ 69

Subperiostale Hämatome an Tibiae und Fibulae; Calden ............................................ 70

Links: Sterbealterbestimmung aller Fundstücke (außer den Zähnen) Teil 1; Calden .. 71

Rechts: Sterbealterbestimmung aller Fundstücke (außer den Zähnen) Teil 2; Calden 71

Links: Sterbealterbestimmung rechter Femora (MIZ); Calden...................................... 72

Mitte: Sterbealterbestimmung aller Zähne; Calden...................................................... 72

Rechts: Sterbealterbestimmung der Zähne 36 (MIZ); Calden......................................... 72

Alterseinteilung der Fundstücke in ,,adult" u. „,subadult"; Calden............................... 73

Geschlechtsverteilung Diagramm 1; Calden .................................................................... 73

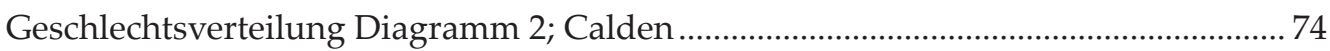

Femora $(\mathrm{n}=29)$ für die Körperhöhenrekonstruktion; Calden ........................................ 75

Verteilung der Schädelfragmente; Rheine .................................................................. 80

Absolute Anzahl der Erhaltungsmenge je Cranium eines Individuums; Rheine......... 81

Gesamtheit der Datensätze für die Schädelfunde; Rheine .......................................... 81

Diagnostizierte Veränderungen an den Schädelfunden; Rheine.................................. 82

Erhaltene Zähne und leere Alveolen des Dauergebisses; Rheine ............................... 83

Bleibende Zähne, die nicht bestimmbar waren; Rheine ............................................... 83

Veränderungen an allen bleibenden ersten Incisivi; Rheine ....................................... 84

Veränderungen an allen bleibenden zweiten Incisivi; Rheine..................................... 84

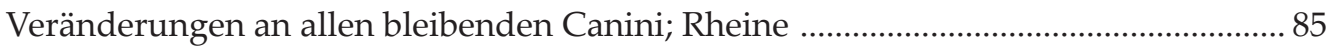

Veränderungen an allen ersten Prämolaren; Rheine .................................................... 85

Veränderungen an allen zweiten Prämolaren; Rheine.................................................... 86

Veränderungen an allen bleibenden ersten Molaren; Rheine ........................................ 86

Veränderungen an allen bleibenden zweiten Molaren; Rheine ................................... 87 
Abb. 86

Abb. 87

Abb. 88

Abb. 89

Abb. 90

Abb. 91

Abb. 92

Abb. 93

Abb. 94

Abb. 95

Abb. 96

Abb. 97

Abb. 98

Abb. 99

Abb. 100

Abb. 101

Abb. 102

Abb. 103

Abb. 104

Abb. 105

Abb. 106

Abb. 107

Abb. 108

Abb. 109

Abb. 110

Abb. 111

Abb. 112

Abb. 113

Abb. 114

Abb. 115

Abb. 116

Abb. 117

Abb. 118

Abb. 119

Abb. 120

Abb. 121

Abb. 122

Abb. 123

Abb. 124

Abb. 125

Abb. 126

Abb. 127

Abb. 128

Abb. 129

Abb. 130

Abb. 131

Veränderungen an allen dritten Molaren; Rheine

Veränderungen an allen Zahntypen des 1. Quadranten; Rheine ..................................... 88

Veränderungen an allen Zahntypen des 2. Quadranten; Rheine .................................... 88

Veränderungen an allen Zahntypen des 3. Quadranten; Rheine .................................... 88

Veränderungen an allen Zahntypen des 4. Quadranten; Rheine ...................................... 89

Die vier Sechs-Jahres-Molaren aller Quadranten im Vergleich; Rheine........................... 89

Erhaltene Zähne und leere Alveolen des Milchgebisses; Rheine ..................................... 90

Veränderungen an allen ersten Milchmolaren; Rheine................................................... 90

Veränderungen an allen zweiten Milchmolaren; Rheine ................................................. 91

Ein Zahn, der keiner Zahngruppe zuzuordnen war, $\mathrm{n}=1$; Rheine ................................ 91

Incisivi, die nicht genau einer Position zuzuordnen waren, $\mathrm{n}=3$; Rheine .................... 92

Canini, die einer Zahngruppe nicht genau zuzuordnen waren, $n=8$; Rheine ............. 92

Erste Prämolaren, die nicht genau zugeordnet werden konnten, $n=25$; Rheine ......... 93

Ein zweiter Prämolar, der nicht eindeutig zugeordnet werden konnte, $\mathrm{n}=1$; Rheine 93

Dritte Molaren, die nicht genau zuzuordnen waren, $\mathrm{n}=16$; Rheine ............................... 94

Diagramm zur Häufigkeit apicaler Prozesse; Rheine ................................................... 94

Graduierung apicaler Prozesse („Ja“-Anteil aus Diagramm 101); Rheine..................... 95

Diagramm zur Häufigkeit von Parodontopathien; Rheine............................................ 95

Graduierung der Parodontopathien (,Ja“-Anteil aus Diagramm 103); Rheine ............ 96

Darstellung der verschiedenen Parodontopathien; Rheine ............................................ 96

Darstellung der Befunde der Wirbel; Rheine ............................................................... 99

Anatomisch orientierte Darstellung der Wirbelregionen; Rheine ................................. 99

Befundbare Fundstücke (außer Schädel und den Zähnen) - Teil 1; Rheine................... 100

Befundbare Fundstücke (außer Schädel und den Zähnen) - Teil 2; Rheine................... 100

Links: Sterbealterbestimmung anh. aller Fundstücke ohne Zähne; Rheine .................. 101

Mitte: Sterbealterbestimmung anh. der Zahnfundstücke; Rheine ............................... 101

Rechts: Sterbealterbestimmung anh. von Zähnen der MIZ-Bestimmung; Rheine ..... 101

Alterseinteilung der Fundstücke in „,adult" und „subadult"; Rheine ........................... 102

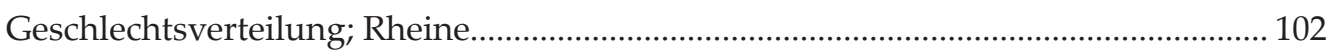

Verteilung der Schädelfragmente; Großenrode .............................................................. 104

Absolute Zahl der Erhaltungsmenge je Cranium eines Individuums; Großenrode .. 104 Gesamtheit der Datensätze für die Schädelfunde; Großenrode .................................... 105

Diagnostizierte Veränderungen an den Schädelfunden; Großenrode .......................... 105

Erhaltene Zähne und leere Alveolen des Dauergebisses; Großenrode .......................... 106

Veränderungen an allen bleibenden ersten Incisivi; Großenrode................................... 106

Veränderungen an allen bleibenden zweiten Incisivi; Großenrode............................... 107

Veränderungen an allen bleibenden Canini; Großenrode ............................................ 107

Veränderungen an allen ersten Prämolaren; Großenrode............................................... 108

Veränderungen an allen zweiten Prämolaren; Großenrode............................................ 108

Veränderungen an allen bleibenden ersten Molaren; Großenrode............................... 109

Veränderungen an allen bleibenden zweiten Molaren; Großenrode............................ 109

Veränderungen an allen dritten Molaren; Großenrode .................................................. 110

Veränderungen an allen Zahntypen des 1. Quadranten; Großenrode ........................... 110

Veränderungen an allen Zahntypen des 2. Quadranten; Großenrode .......................... 111

Veränderungen an allen Zahntypen des 3. Quadranten; Großenrode .......................... 111

Veränderungen an allen Zahntypen des 4. Quadranten; Großenrode .......................... 111 
Abb. 133

Abb. 132

Abb. 134

Abb. 135

Abb. 136

Abb. 137

Abb. 138

Abb. 139

Abb. 140

Abb. 141

Abb. 142

Abb. 143

Abb. 144

Abb. 145

Abb. 146

Abb. 147

Abb. 148

Abb. 149

Abb. 150

Abb. 151

Abb. 152

Abb. 153

Abb. 154

Abb. 155

Abb. 156

Abb. 157

Abb. 158

Abb. 159

Abb. 160

Abb. 161

Abb. 162

Abb. 163

Abb. 164

Abb. 165

Abb. 166

Abb. 167

Abb. 168

Abb. 169

Abb. 170

Abb. 171

Abb. 172

Abb. 173

Abb. 174

Abb. 175

Abb. 176

Abb. 177
Erhaltene Zähne und leere Alveolen des Milchgebisses; Großenrode..... 112

Die vier Sechs-Jahres-Molaren aller Quadranten im Vergleich; Großenrode............ 112

Veränderungen an allen zweiten Milchincisivi; Großenrode .....

113

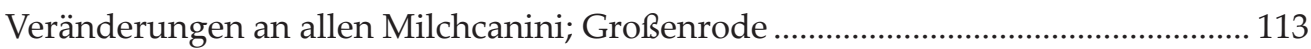

Veränderungen an allen ersten Milchmolaren; Großenrode ..................................... 114

Veränderungen an allen zweiten Milchmolaren; Großenrode .................................. 114

Diagramm zur Häufigkeit apicaler Prozesse; Großenrode ......................................... 115

Graduierung apicaler Prozesse („Ja“-Anteil aus Diagramm 138); Großenrode........ 115

Diagramm zur Häufigkeit von Parodontopathien; Großenrode.

Graduierung der Parodontopathien („Ja“-Anteil aus Diagramm 140); Großenrode116

Darstellung der verschiedenen Parodontopathien; Großenrode

117

Darstellung der Befunde der Wirbel; Großenrode ..................................................... 120

Anatomisch orientierte Darstellung der Wirbelregionen; Großenrode ..................... 121

Befundbare Fundstücke (außer Schädel und den Zähnen) - Teil 1; Großenrode...... 121

Befundbare Fundstücke (außer Schädel und den Zähnen) - Teil 2; Großenrode...... 122

Veränderungen an Vertebrae (gesamt befundbare: $n=191$ ); Großenrode................. 123

Veränderungen an Claviculae (gesamt befundbare: $n=15$ ); Großenrode................. 123

Veränderungen an Costae (gesamt befundbare: $\mathrm{n}=7$ ); Großenrode.......................... 124

Veränderungen an Ossa sacra (gesamt befundbare: $n=10$ ); Großenrode .................. 124

Veränderungen an Ossa femoris (gesamt befundbare: $n$ = 52); Großenrode............. 124

Veränderungen an Tibiae (gesamt befundbare: $\mathrm{n}=58$ ); Großenrode......................... 125

Veränderungen an Fibulae (gesamt befundbare: $\mathrm{n}=20$ ); Großenrode....................... 125

Veränderungen an Ossa metatarsales (gesamt befundbare: $n=5$ ); Großenrode ...... 125

Veränderungen an Phalanges pedis (gesamt befundbare: $n=6$ ); Großenrode......... 126

Muskeltraumta an verschiedenen Skeletelementen; Großenrode .............................. 126

Arthrose an verschiedenen Skeletelementen; Großenrode ....................................... 127

Arthritis an verschiedenen Skeletelementen; Großenrode........................................ 127

Impressionen tiefer Krampfadern; Großenrode ..................................................... 128

Periostreizungen an verschiedenen Skeletelementen; Großenrode............................ 128

Links: Sterbealterbestimmung aller Fundstücke (außer den Zähnen); Großenrode 129

Rechts: Sterbealterbestimmung linker Femora; Großenrode..................................... 129

Links: Sterbealterbestimmung aller Zähne; Großenrode ............................................ 130

Rechts: Sterbealterbestimmung der Zähne 46 (MIZ); Großenrode ............................ 130

Alterseinteilung der Fundstücke in „,adult" u. „subadult"; Großenrode................... 131

Geschlechtsverteilung Diagramm 1; Großenrode .................................................... 131

Geschlechtsverteilung Diagramm 2; Großenrode .................................................... 132

Fundgut in Fragmenten (Beispiel) ............................................................................ 137

Fundgut unsachgemäß in einer Tüte aufbewahrt (Beispiel) .................................... 138

Fundgut mit Erdmaterialien geborgen (Beispiel) ..................................................... 138

Wirbelfragment eines jungen Individuums ............................................................. 145

Verheilte Fraktur eines linken Unterkieferastes (Bild Nr. 1); Rheine......................... 153

Verheilte Fraktur eines linken Unterkieferastes (Bild Nr. 2); Rheine.......................... 153

Durch Feuer verfärbte Knochen der Population aus Rheine (Beispiel 1).................. 154

Leichenbrand der Population aus Rheine (Beispiel 2) ............................................. 155

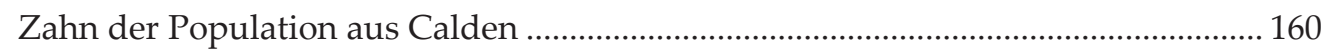

Beispiel für sehr stark abradierte Zähne (linke Oberkieferseite)............................... 163 
Abb. 178

Beispielzeichnung zur Verwendung der Zähne als Werkzeug. 163

Abb. 179

Kiefer der Population aus Calden (Beispiel 1)

164

Abb. 180

Kiefer der Population aus Calden (Beispiel 2)

164

Abb. 181

Links oben: Übersichtsaufnahme der linken Seite des Craniums „Calden 30“ 169

Abb. 182

Rechts oben: DVT des Cranium „Calden 30“

169

Abb. 183

Links unten: DVT des Cranium „Calden 30“ in sagittaler Ansicht ....

169

Abb. 184

Rechts unten: DVT des Cranium „Calden 30“ in coronaler Ansicht 169

Abb. 185

Trauma am Schädel C28; Calden

170 


\section{Tabellenverzeichnis}

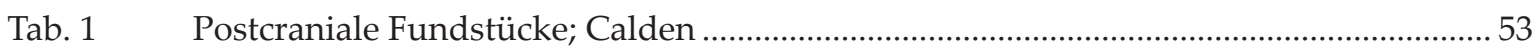

Tab. 2 Arthrose/Arthritis langer Extremitätenknochen; Calden ................................................55

Tab. 3 (Einzelne) Veränderungen an (einzelnen) Knochen; Calden ..........................................6 60

Tab. $4 \quad$ Körperhöhenbestimmung anhand von Femora; Calden .................................................. 75

Tab. 5 Postcraniale Fundstücke; Rheine........................................................................9. 97

Tab. 6 Arthrose/Arthritis langer Extremitätenknochen; Rheine...............................................98

Tab. 7 (Einzelne) Veränderungen an (einzelnen) Knochen; Rheine......................................... 101

Tab. 8 Postcraniale Fundstücke; Großenrode......................................................................... 118

Tab. 9 Arthrose/Arthritis langer Extremitätenknochen; Großenrode ...................................... 119

Tab. 10 (Einzelne) Veränderungen an (einzelnen) Knochen; Großenrode ................................. 122

Tab. 11 Übersicht über die Einteilung der Fundstücke in die jeweiligen Altersstufen.............. 141 


\section{Abkürzungsverzeichnis}

BWZ Bewertungsziffer des Gelenks

DVT Digitales Volumentomogramm

MIZ Mindestindividuenzahl

REM Rasterelektronenmikroskop

UMG Universitätsmedizin Göttingen

14C (C14) Radiokarbondatierung 


\section{Einleitung}

\subsection{Einführung}

Die Paläopathologie befasst sich mit der Erforschung und Diagnose von Krankheiten sowie Spuren von intravitalen Gewalteinwirkungen an sterblichen Überresten menschlicher Individuen prähistorischer Völker (Schultz 1988b). Die „Lehre der alten Krankheiten“ - so wörtlich aus dem Griechischen zu übersetzen - bedient sich verschiedener Fachdisziplinen wie der Humanmedizin, Zahnmedizin, Anthropologie, Archäologie sowie verschiedener Disziplinen der Geisteswissenschaften. Damit sind nur die wichtigsten der Fachrichtungen genannt, die der Paläopathologie zum Verständnis und zur Erforschung von Ernährungszustand, Arbeitsleben und Wohnbedingungen alter Völker dienen.

Um die Lebensbedingungen prähistorischer Populationen rekonstruieren zu können, ist das Wissen über Krankheiten der damaligen Zeit ein wichtiger Faktor (Schultz 1982, 1994). Doch sind Ausbreitung und Entstehung von Krankheiten vergangener Völker immer noch nicht vollständig verstanden oder erforscht (Schultz 1998). Paläopathologie kann unter anderem auch als eine „biografische Geschichte“ aus lange vergangenen Zeiten verstanden werden, was Schultz (2011b) mit „Paläobiografie“" (bzw. Osteobiografie) beschrieb. Die für eine adäquat angefertigte Biografie nötigen schriftlich festgehaltenen Geschehnisse stehen jedoch nicht beliebig für alle Zeitalter an den verschiedensten Orten der Erde zur Verfügung; stattdessen bedient man sich „biohistorischer Urkunden“ (Schultz 2011b). Die damit gemeinten, als Zeitzeugen zu verstehenden menschlichen Überreste, sind Mumien, Skeletfunde ${ }^{1}$ oder Moorleichen aus dem jeweiligen Zeitalter (Schultz 1982). Aus archäologischen Grabungen geborgene Skeletfunde können also als wichtigstes primäres Quellenmaterial betrachtet werden, weil aus der Vor- und Frühgeschichte nur selten schriftliche Quellen vorliegen, die über Lebensbedingungen und Krankheiten damaliger Populationen Auskunft geben könnten (Schultz 1988b).

Bei der paläopathologischen Untersuchung werden am Knochen entstandene Spuren von Krankheiten, aber auch ganz alltäglicher Faktoren äußerer Lebensbedingungen - also u. a. Arbeit, Sport und möglicherweise kämpferischer Auseinandersetzungen - unter die Lupe genommen (Schultz 2011b). Jedoch manifestieren sich nicht alle Krankheiten und Verletzungen an Knochen und sind somit nicht mehr der paläopathologischen Befundung zugänglich (Schultz 2001).

\footnotetext{
In dieser Arbeit wird die medizinische Schreibweise des Fachbegriffs verwendet. Das Wort Skelet kommt aus dem Griechischen ( $\sigma x \dot{\varepsilon} \lambda \varepsilon \tau \dot{\imath} \vee$ ) und wird deshalb in fast allen Sprachen mit nur einem „t“ geschrieben. In der Anatomie bedienen sich bestimmte Fachrichtungen (z. B. Schule von D. Starck oder von H.-J. Kuhn) der klassischen Schreibweise.
} 
Paläopathologen verwenden sowohl einfache als auch sehr aufwändige Hilfsmittel, um Veränderungen an den Skeleten - mehr ist von den Individuen zur Untersuchung in der Regel nicht erhalten - festzustellen. Hierzu zählen unter anderem die Handlupe, das Endoskop, das binokulare Lupenmikroskop mit Auflicht, das Durchlicht- und Rasterelektronenmikroskop sowie das Röntgen. Als moderne Form der dreidimensionalen Bildgebung wurde im Rahmen dieser Arbeit zusätzlich von verschiedenen Schädeln ein DVT (Digitales Volumentomogramm) angefertigt. Werden im Rahmen paläopathologischer Untersuchungen Mumien oder Moorleichen befundet, kommt bei bestimmten Fragestellungen die Computertomografie hinzu. Für mazeriertes Knochenmaterial genügt allerdings meist das konventionelle Röntgenverfahren. Mit den heute zur Verfügung stehenden Mitteln ist eine gute Diagnostik möglich (Schultz und Schmidt-Schultz 1999).

Weiß der*die Paläopathologe*in ${ }^{1}$ über die gesunde Knochenstruktur Bescheid, ist es möglich, Veränderungen an dem Fundmaterial festzustellen. Ist er*sie geübt im Umgang mit menschlichen Knochen, so kann eine Zuordnung des Fundmaterials und eine Diagnose der Knochenoberflächen und -strukturen über "gesund und normal“ oder „nicht normal“ zügig getätigt werden. Die Herausforderung der Fachdisziplin ist es nun, bei den „nicht normal“ kategorisierten Knochen zwischen Grabungsartefakten, Bodenerosionen, physiologischen Prozessen im Sinne von Alterungsveränderungen und tatsächlichen pathologischen Veränderungen zu unterscheiden. Die Beurteilung der Veränderungen und die Differentialdiagnostik sollte dem*der Spezialisten*in vorbehalten bleiben (Schultz 1988b). Hinzu kommt, dass es besonders schwierig sein kann, zwischen perimortalen Gewalteinwirkungen und postmortalen Knochenveränderungen zu differenzieren.

Für sämtliche aufgezählte Aspekte ist ein geschultes Auge nötig, welches es sich in mühevoller Arbeit erst einmal anzutrainieren gilt. Ist ein Knochen verdächtig, Spuren pathologischer Geschehnisse oder eines Gewaltaktes aufzuweisen, werden die nötigen diagnostischen Maßnahmen ergriffen, um den Verdacht zu erhärten oder zu widerlegen.

Manchmal ist es möglich, anhand der Befunde sogenannte Kausalketten verschiedener Mangelerscheinungen und Krankheiten aufzustellen. Hierbei wird ein bestimmter Verlauf des pathologischen Vorgangs angenommen, der zu einer weiteren krankhaften Veränderung geführt haben könnte. In diesem Zusammenhang u. a. bei bestimmten Tumoren (Schultz et al. 2007) - ist die Untersuchung mit modernen biochemischen Methoden möglich, um eine genaue Krankheitsdiagnose zu erstellen. Tumorerkrankungen waren nämlich bereits für das prähistorische Zeitalter nachweisbar und sind nicht nur eine Krankheit der Neuzeit (Schultz 1982).

Auf die Verwendung des generischen Maskulinums wird in dieser Arbeit verzichtet, um alle Geschlechter sichtbar zu machen; es wird das „Gender-Sternchen“ (*) zwischen den Formen verwendet. 
Nach Anwendung ausgewählter Methoden für die Bestimmung von Alter und Geschlecht sowie für die Untersuchung der Individuen auf Spuren pathologischer Prozesse kann ein Vergleich der Ergebnisse erstellt werden, der Unterschiede und Gemeinsamkeiten verschiedener epidemiologischer Gruppen sowie deren Lebensweise und Gesundheitszustand aufzeigt.

Neben den untersuchten Funden ist auch das Wissen über das Alter des Gräberfeldes und seine geschichtliche Einordnung in einen Gesamtkontext von geografischer Lage und Epoche unerlässlich, um Rückschlüsse und Vergleiche mit anderen Populationen anstellen zu können.

Insgesamt ist festzuhalten, dass Spuren pathologischer Veränderungen sowie Alter und Geschlecht nachvollziehbarer Weise immer am zuverlässigsten festgestellt werden können, wenn ein Skelet vollständig und in gutem Erhaltungszustand vorliegt. Anders gesagt: Befunde sind umso genauer, je mehr Daten eines Individuums erhoben werden können. Dies sind Idealzustände, die bei der Untersuchung der Populationen aus Calden (Hessen), Rheine (Nordrhein-Westfalen) und Großenrode (Niedersachsen) nicht vorlagen. Selten war hier ein anatomischer Verband mehrerer Knochen wiederherzustellen. An fragmentierten und zerfallenen Knochenmaterial ist die Befundung erheblich erschwert; Skeletfunde sind jedoch häufig - so auch für die vorgelegte Arbeit - die einzig verfügbare Quellsubstanz zur Erforschung vorgeschichtlicher Krankheiten und Lebensverhältnisse (z. B. Schultz 1988b).

Ein großer Teil der Befundungsarbeit bestand zunächst darin, die meist ohne System einsortierten Kisten zu begutachten - wobei häufig verschiedene Knochen ungeordnet vorlagen - und dann Fragment für Fragment und Knochen für Knochen zu sichten. Danach wurden die Fundstücke in den anatomischen Kontext eingeordnet. Das Sortieren und Bestimmen der Fundstücke war ein sehr langwieriges Unterfangen, bevor die eigentliche Befundarbeit beginnen konnte.

Da es bis zu Beginn der Arbeit kein einheitliches Vorgehen bei einer derartigen Fülle an zu befundendem Fundgut gab, wurde eine neue und speziell auf diese Arbeit zugeschnittene Datenbank in FileMaker Pro ${ }^{\circledR}$ entwickelt, in die alle erhobenen Befunde und Dokumente eingepflegt werden konnten. Diese programmierte Datenbank soll später noch im Detail vorgestellt, hier aber dennoch kurz erwähnt werden, da sie einen wesentlichen Bestandteil der Arbeit ausmacht. Mithilfe dieser Datenbank war es möglich, die 4.352 Datensätze mit schätzungsweise deutlich über 10.000 Fundstücken von insgesamt mindestens 105 Individuen mit Befunden für die Knochenfunde festzuhalten, zu vergleichen und auszuwerten. Über die Jahre der Befunderhebung wurden die Funktionen der Datenbank in einem kontinuierlichen Prozess zunehmend den Erfordernissen angepasst und optimiert. 


\subsection{Ziele dieser Dissertation}

Ziel dieser Arbeit ist es, die Skeletfunde der Populationen aus Calden, Rheine und Großenrode unter paläopathologischen Gesichtspunkten zu untersuchen und die Ergebnisse im ätiologischen und epidemiologischen Zusammenhang - mit Rekonstruktion der damaligen Lebensbedingungen - auszuwerten; die Ergebnisse sollen anschließend miteinander und mit bereits veröffentlichten Daten und Befunden von Untersuchungen zu den drei Populationen verglichen und diskutiert werden. Dabei soll die Auswertung der Daten mit der neuartigen Methode der Befunddokumentation (Datenbank) mithilfe von FileMaker Pro $^{\circledR}$ besonders beleuchtet werden.

Die Paläopathologie beschäftigt sich mit Krankheiten früherer Populationen, deren Entwicklung und Geschichte sowie deren Häufigkeit und Ausbreitung. Zu diesem Forschungsgebiet zählen Fallstudien, wie auch die Betrachtung der Krankheitshäufigkeit (Schultz 1982 und 1994). Für diese Arbeit sollen die Resultate der Untersuchungen sowohl verglichen als auch in einen Gesamtzusammenhang eingeordnet werden, der in Form von Bildern, Text und Diagrammen dargestellt werden soll.

Bei der Untersuchung werden - unter Berücksichtigung soziobiologischer Faktoren - Art und Häufigkeit von pathologischen und altersbedingten Veränderungen am Fundmaterial diagnostiziert. Zusätzlich sollen Informationen bezüglich des Alters und Geschlechts sowie postmortal bedingte Auffälligkeiten wie Bodenerosionen oder Tierverbiss und Erhaltungszustand festgehalten werden.

Die Untersuchungsergebnisse dieser Arbeit sollen einen Beitrag zum Verständnis der Lebensbedingungen neolithischer Populationen leisten. Dafür sollen das Auftreten von Krankheiten, das Vorkommen verschiedener Altersstufen und das zahlenmäßige Verhältnis von Frauen und Männern genauer betrachtet werden. Um diese Arbeit in einen überregionalen Gesamtzusammenhang zu stellen, soll auch ein Vergleich der Populationen untereinander erfolgen. Weiterhin gibt es zum Teil bereits anthropologische Untersuchungsergebnisse zu den Skeletfunden der Populationen aus Calden (Galeriegräber I und II sowie Erdwerk), Großenrode (Galeriegrab I) und Rheine. Auch diese älteren, schon publizierten Ergebnisse sollen mit den hier neu erarbeiteten Ergebnissen im Gesamtzusammenhang verglichen und zusammen analysiert werden. Zudem sollen Details der Gräber der drei untersuchten Populationen, deren Umfeld und weitere geschichtliche Aspekte der Populationen vorgestellt und diskutiert werden.

Schließlich werden in dieser Arbeit exemplarisch einzelne außergewöhnliche Funde gezeigt und charakteristische Krankheiten oder besonders anschauliche Krankheitsfälle darstellt. Im Gesamtanhang finden sich alle dokumentierten Fundstücke (als PDF-Dateien auf einer CD). 


\section{Fundgut und Methoden}

\subsection{Generelle Vorbemerkung}

Es ist wichtig, daran zu denken, dass bei einer paläopathologischen Befundung primär keine Krankheiten, sondern nur Spuren pathologischer Prozesse im verbliebenen Hartgewebe (Knochen, mineralisierter Knorpel, Sehnen- und gegebenenfalls mumifiziertem Weichgewebe) nachgewiesen werden können; solche Spuren müssen entsprechend erkannt werden (Schultz 1988b). Sie erlauben es, sekundär auf Krankheiten rückzuschließen. Für diese Arbeit stand mazeriertes Knochenfundgut zur Verfügung, anhand dessen die Oberflächenbefundung durchgeführt wurde.

Die Arbeit gliedert sich in drei Abschnitte: „Ergebnisse“, „Diskussion“ und „Befundkatalog". Für den Abschnitt „Ergebnisse“ wurde das zu Grunde liegende Fundgut der Populationen aus Calden, Rheine und Großenrode einer Alters- und Geschlechtsbestimmung sowie einer grundsätzlichen paläopathologischen Untersuchung unterzogen. Weiterhin wurden die einzeln vorliegenden Fundstücke nach Bedarf nochmals gesäubert und fragmentierte Knochen je nach Möglichkeit und Notwendigkeit mit wasserlöslichem Holzleim der Marke Ponal ${ }^{\circledR}$ geklebt (zahlreiche Knochen wurden bereits vor der Bereitstellung für diese Arbeit mit verschiedenen Klebern von anderen Personen geklebt). Außerdem wurde grundsätzlich versucht, die einzelnen Knochen möglichst einem Individuum zuzuordnen, sodass in einigen Fällen mehrere Knochen zu einem anatomischen Verband zusammengefügt werden konnten. Dafür war es hin und wieder notwendig, mehrere Fundkisten nach einem zugehörigen Skeletsegment zu durchsuchen.

\section{$2.2 \quad$ Fundgut}

Die Knochenfunde der drei untersuchten Populationen unterscheiden sich teilweise erheblich durch den Erhaltungszustand sowie verschiedene Lagerungsweisen in Kartons oder Tüten. Aus Calden waren überwiegend gut erhaltene Fundstücke aus dem Steingrab 1 zur Verfügung gestellt worden sowie auch zahlreiche kleine Fragmente, während die Funde aus dem Großsteingrab Rheine äußerst stark fragmentiert und daher schwer zu befunden waren. Die Skeletfunde der Population aus Großenrode (Galeriegrab II) lagen auch größtenteils in erodiertem Zustand und in Form von unzähligen kleinen Fragmenten vor. Von den Populationen aus Rheine und Großenrode galt es also unter diesen eingeschränkten Bedingungen, das bestmögliche Ergebnis zu generieren. Allen drei Populationen ist gemeinsam, dass bei der Ausgrabung anscheinend nicht immer das erforderliche Augenmerk auf den menschlichen Überresten lag: Die Skeletelemente verschiedener Individuen wurden in unterschiedlichen Kisten verstaut; teilweise sind die Knochen 
im Zuge der Ausgrabung auch durch Werkzeuge beschädigt worden. Spuren von Bodenerosionen waren bei der Population aus Calden eher weniger augenscheinlich, bei den Populationen aus Rheine und Großenrode aber deutlich sichtbar anzutreffen. Die Beschädigungen kamen durch die lange Bodenlagerung (Diagenese) und möglicherweise auch durch krankhaft geschwächte Knochensubstanz zustande, wobei auch die Ausgrabung bzw. die Lagerung der Knochen - in den Kisten, ungepolstert und oft in direktem Kontakt miteinander - zu postmortalen Beschädigungen beitrugen. Weiterhin könnten unterschiedliche Böden und abweichende Bestattungsverhältnisse zu den unterschiedlich erhaltenen Skeletfunden der drei Populationen geführt haben. Das Fundgut aller drei Populationen wurde von anderen Personen gereinigt, bevor es zur Untersuchung für diese Arbeit zur Verfügung gestellt wurde. Dabei wurden die Knochenfunde so gut wie möglich von Erdmaterial befreit, ohne sie dabei zu sehr zu beschädigen. Um die Knochen möglichst gut zu erhalten und nicht weiter durch Reinigungsarbeiten postmortal zu beschädigen, wurden die fragilen Knochen aus Rheine oft in Bodenmaterialien - wie Wurzeln und Erde - integriert eingepackt. Weiterhin wurden einige Fundstücke von anderen Personen durch Klebearbeiten rekonstruiert und stabilisiert. Dabei kamen Klebemasse, Halteelemente aus Fasermaterial und Gips zum Einsatz.

Für keine der Populationen ist eine aussagekräftige Dokumentation über die $\mathrm{Zu}$ sammengehörigkeit verschiedener - auch oft nummerierter Knochen - vorhanden. Offenbar sind die Knochen bereits außerhalb ihres Skeletverbands und nicht mehr in situ - also nicht in anatomischer Lage - erschlossen und nachfolgend, entsprechend archäologischen Standards, größtenteils nummeriert worden. In einer Fundkiste aus Calden lagen anthropologische handschriftliche Notizen zu manchen Funden vor. In manchen Fundkisten fanden sich Kurznotizen mit Nummern und spärlichen Informationen zur Alters- und Geschlechtsbestimmung einzelner Knochen. Auch bei der Population aus Rheine gab es in manchen Kisten kurze Notizen zu einigen Fundstücken. Hier stellten überwiegend Splitter und sehr kleine Fragmente das zu befundene Knochenmaterial dar. Die einzelnen Splitter waren zumeist sorgfältig in Plastiktütchen aufbewahrt, auf denen Kurzinformationen wie Fundnummern notiert worden waren. Die Population aus Großenrode ist nach einem einheitlichen Schema nummeriert und die Fragmente sind in Plastiktüten verpackt worden. Auf den Tütchen sind Fundnummern und andere archäologische Informationen notiert worden. Selten waren jedoch klar identifizierbare, zusammenhängende Skeletpartien aus mehreren Knochen erhalten. Den Kisten lagen auch hier teilweise Notizzettel bei, auf denen in Listen die Fundnummern der Tütchen aufgeführt waren. Diese Listen enthielten katalogartig die Fundnummern der Tütchen. Leider fanden sich auf den vorhandenen Notizen keine für diese Arbeit auswertbaren Informationen. 
Insgesamt wurden aus Calden 34, aus Rheine zehn und aus Großenrode ebenfalls zehn Fundkisten zur paläopathologischen Untersuchung für diese Dissertation zur Verfügung gestellt. Da die Fundstücke nicht nach einer anatomischen Region verpackt waren, war es meist unmöglich, mit ausreichender Sicherheit eine anatomische Zusammengehörigkeit wiederherzustellen. Denn um beispielsweise einen Oberarm- und Oberschenkelknochen demselben Individuum zuordnen zu können, wäre ein Becken, ein Kreuzbein und eine nahezu vollständige Wirbelsäule, das Schlüsselbein und Schulterblatt - und das alles von derselben Körperseite, die paarig angelegten Knochen betreffend - nötig. Und nicht einmal dann könnte man mit Sicherheit eine Zusammengehörigkeit garantieren, denn die Knochen lagen völlig durcheinander in den Kisten vor. Wie bereits erwähnt, fanden sich in den Kisten der Population aus Calden hin und wieder Notizen. Manchmal ließen diese vermuten, dass es sich um ein Individuum handelte, welches nach der Bergung in einer Kiste verpackt worden war. Dies erwies sich allerdings häufig als nicht zutreffend, wenn sich nämlich bei näherer Sichtung herausstellte, dass beispielsweise drei Oberschenkelknochen zusammenlagen, bei denen nicht einmal ein Paar zusammengeführt werden konnte, weil sie sich morphologisch erheblich unterschieden.

Nach Möglichkeit wurden auch andere Fundkisten nach passenden Skeletelementen durchsucht, um wenigstens ein paar wenige Fundstücke einem Individuum zuordnen zu können. Das eben beschriebene Verfahren konnte aber meist nur für die Population aus Calden angewendet werden, weil sich die dort geborgenen Fundstücke in ihrer makroskopischen Struktur oft gut erhalten haben. Bei den insgesamt 20 weiteren Kisten der Populationen aus Rheine und Großenrode war es aufgrund des Erhaltungszustandes oft nicht einmal möglich, auch nur halb vollständige Knochen aus Fragmenten und Splittern zusammenzusetzen. Unzählige Splitter und Fragmente konnten nur als „vorhanden“ dokumentiert werden, da sie aufgrund ihrer Größe und ihres schlechten Erhaltungszustandes weder einem Knochen zuzuordnen, noch befundbar waren. Wenn möglich, wurde festgehalten, aus welcher Körperregion die Knochensplitter herstammen könnten (z. B. Ober- oder Unterextremität). Bei Schädelfragmenten war oft nur noch eine Aussage darüber möglich, ob sie von der Schädeldecke oder der Schädelbasis stammten. Die Knochenoberfläche konnte dennoch erhalten sein, sodass sich Spuren krankhafter Veränderungen diagnostizieren ließen, wenn das Fragment auch nur beispielsweise $10 \mathrm{~mm}$ x $10 \mathrm{~mm}$ groß war. Jene Fragmente, die keine Leitstrukturen oder signifikante Regionen aufwiesen, ließen keine genaue Aussage über ihre anatomische Herkunft zu.

Bei der sorgfältigen Katalogisierung war es nicht immer möglich, Fehler in Bezug auf die Zuordnung von Fragmenten zu einer bestimmten Region oder zu einem 
Individuum auszuschließen, obwohl sämtliche Arbeiten nach bestem Wissen und Gewissen durchgeführt wurden. Weiterhin sind nachgewiesene Krankheitsspuren häufig nicht sicher einer bestimmten Krankheit zuzuordnen, sodass vielfach nur Verdachtsdiagnosen gestellt werden konnten. Fundgut, wie es für diese Arbeit vorlag, lässt leider in vielen Fällen keine sichere Diagnose zu.

\subsection{Methoden}

\subsubsection{Vorbemerkungen zur Alters- und Geschlechtsbestimmung}

Für die Bestimmung von Alter und Geschlecht wurden von mehreren Autoren Tabellen mit Richtwerten erstellt, die nach statistischen Untersuchungen rezenter und nicht rezenter Populationen erhoben wurden. Dabei mussten Alter und Geschlecht der untersuchten Individuen so sicher wie möglich bekannt sein. Tabellen mit Vergleichswerten finden sich z. B. in Sjøvold (1988) für die Geschlechtsbestimmung und in Szilvássy (1988) für die Altersbestimmung.

Für eine Altersbestimmung an archäologischen Skeletfunden stehen der Wissenschaft verschiedene Methoden zur Verfügung. Bei subadulten Individuen sind in der Regel diese Bestimmungen genauer als bei adulten, denn mit zunehmendem Alter wird die Altersdiagnose - besonders nach Schluss der Epiphysenfugen schwieriger (Szilvássy und Kritscher 1990, Rösing et al. 2005).

Als sehr verlässlich gilt hier die Altersbestimmung des Gebisses, bei dem je nach Wachstumsstadium bestimmte Zahngruppen mehr und andere weniger ausgewachsen sind (Szilvássy 1988). Dies betrifft sowohl Zahnanlagen als auch bereits durchgebrochene Zähne junger Individuen und ihr unterschiedlich weit entwickeltes Wurzelwachstum (Beyer-Olsen und Risnes 1994). Auch bei bereits ausgewachsenen Individuen ist durch einen Abrasionsbefund der Zähne eine Einordnung des Sterbealters erzielbar (Brothwell 1981, Szilvássy 1988). Die Altersbestimmung anhand der Zähne war also durch die Beurteilung des Abrasionsgrades oder des Wechselgebisses möglich (z. B. Schour und Massler 1941, Miles 1963, Ubelaker 1978, Perizonius und Pot 1981, Brothwell 1981, Szilvássy 1988).

Die Längenmaße nicht ausgewachsener Knochen - wie z. B. die von Femora oder Tibiae - sind ebenso für Rückschlüsse auf das Alter zum Zeitpunkt des Todes nützlich wie bestimmte morphologische Veränderungen des Beckens (McKern und Stewart 1957, Nemeskéri et al. 1960, Stloukal und Hanáková 1978, Szilvássy 1988). Weiterhin können Verschleißerscheinungen und altersbedingte Krankheiten - wie z. B. degenerative Veränderungen im Sinne einer Arthrose oder Arthritis - am Skelet einen Hinweis auf das Sterbealter geben (Szilvássy 1988). Auch die radiologischen Untersuchungen an Langknochen (Nemeskéri et al. 1960) und die makroskopische 
Begutachtung von Schädelnähten (Broca 1861, Vallois 1937, Olivier 1960) ermöglichen den Paläopathologen, eine relativ sichere Altersschätzung durchzuführen.

Um Individuen innerhalb einer Population vergleichen zu können, sind nicht nur Kenntnisse über das Alter wichtig, sondern auch eine Zuordnung der Individuen zu einem Geschlecht. Diese gelingt unter anderem bei Betrachtung des Beckens (Phenice 1969, Novotný 1975, 1982). Hier sind die spezifischen Geschlechtsmerkmale oft gut erkennbar. Doch auch Schädel und bestimmte Maße von Femora und Tibiae eignen sich zur Bestimmung des Geschlechts (Acsádi und Nemeskéri 1970, Sjøvold 1988). In der Forensik nutzt man sogar Maße von Tali und anderen kleineren Knochen. Für diese Arbeit wurden sie anhand ihrer Größe als eher männlich oder eher weiblich eingeschätzt. Männliche Skelete und ihre Elemente sind üblicherweise größer und massiver als weibliche; weiterhin weisen sie in der Regel stärkere Muskelmarken auf (Steele 1976, Sjøvold 1988, Grupe et al. 2005).

\subsubsection{Methoden der Altersbestimmung}

Bei jedem Knochen - bei dem dies möglich war - wurde ein Lebensalter zum Todeszeitpunkt rekonstruiert.

Besonders aussagekräftig für diese Arbeit war die genaue Betrachtung der Ergebnisse jener Fundstücke, die aufgrund ihrer Anzahl die Mindestindividuenzahl der Populationen aus Calden, Rheine und Großenrode repräsentieren: Für die Population aus Calden wurden Oberschenkelknochen jener Seite, die am häufigsten vorhanden war, herangezogen (Femur rechts; es musste mindestens das proximale, zweite Fünftel vorhanden sein), für die Populationen aus Rheine und Großenrode jeweils 6-Jahres-Molaren. In der Population aus Rheine hat sich der Zahn 26 am häufigsten erhalten, aus Großenrode der Zahn 46. 
Die Einteilung in verschiedene Altersstufen erfolgte nach Martin (1928), modifiziert durch die Arbeitsgruppe Paläopathologie Göttingen.

- Infans I: Neugeboren bis 6,9 Jahre

- Infans II: 7 bis 13,9 Jahre

- Juvenis: 14 bis 19,9 Jahre

- Adultus: 20 bis 39,9 Jahre

- Frühadultus: 20 bis 29,9 Jahre

- Spätadultus: 30 bis 39,9 Jahre

- Maturus: 40 bis 59,9 Jahre

- Frühmaturus: 40 bis 49,9 Jahre

- Spätmaturus: 50 bis 59,9 Jahre

- Senilis: Älter als 60 Jahre

Die Ossifikationsstadien der Epiphysen der Skeletelemente sind in einer Übersicht nach Brothwell (1972) zu sehen. Daran orientierten sich die Angaben des Sterbealters, wenn Individuen den Altersbereichen Juvenis oder Subadultus zuzuordnen waren. Hier sind jedoch nicht alle Epiphysen repräsentiert, weswegen für Wirbel das Schema zum "Auftreten der Knochenkerne im Bereich der Wirbelsäule“ nach Schwörer (1975) verwendet wurde.

Ging es um andere Skeletelemente, so war eine Altersbestimmung für nicht erwachsene Individuen zu realisieren, indem die Verknöcherungszeitpunkte der untersuchten Knochen tabellarisch verglichen wurden (Brothwell 1972, 1981). Ein maximales Sterbealter konnte folglich angegeben werden. Weiterhin wurden Oberarm- und Oberschenkelknochen nach röntgenologischer Untersuchung der mehr oder weniger stark ausgebildeten Spongiosatrabekel für eine Altersdiagnose herangezogen (Nemeskéri et al. 1960). Ein wichtiges Skeletsegment für die Altersbestimmung ist auch der Schädel, welcher aufgrund der in verschiedenen Altersstufen verknöchernden Schädelnähte Auskunft über das Alter des Individuums zum Zeitpunkt des Todes gibt (Broca 1861, Nemeskéri et al. 1960, Olivier 1960, Rösing 1977). Ebenso können verschiedene Regionen eines Beckenknochens für die Bestimmung des Sterbealters nützlich sein (McKern und Stewart 1957). Teilweise konnte anhand der Knochenkonstitution von Schulterblättern, Brustbeinen, Wirbeln sowie Handund Fußknochen auch ein Sterbealter in Näherung rekonstruiert werden (Schwörer 1975). 
Die „Stadien der Altersveränderungen an der Facies symphysialis ossis pubis“ nach McKern und Stewart (1957) gab eine Annäherung an das Alter von Beckenknochen, deren Symphysen damit eingestuft wurden. Das „,Schema der Schädelnähte zur Bestimmung des biologischen Lebensalters" nach Olivier (1960) wurde herangezogen, um die endocranialen Schädelnähte zu beurteilen und den Schädel in eine Altersstufe einzuordnen. Für die Einschätzung des Alters nach der Verknöcherung der äußeren Schädelnähte wurde das Schema nach Vallois (1937), modifiziert nach Rösing (1977), verwendet. Wenn möglich, wurden die inneren Schädelnähte für eine Altersdiagnose verwendet, zum Vergleich wurden die Verknöcherungszeitpunkte der äußeren Schädelnähte hinzugezogen. Eine höhere Aussagekraft besitzen jedoch die inneren Schädelnähte (Nemeskéri et al. 1960). Ein weiteres Schema zur Beurteilung des Stadiums der Nahtobliterationen am Schädel nach Broca (1861), wurde vergleichsweise verwendet. Die Einordnung in die Altersklassen mithilfe der Tabelle „Gruppenwerte des chronologischen Lebensalters für fünf Stadien der Obliterationskoeffizienten der endocranialen Schädelnähte“, wurde nach Nemeskéri et al. (1960) vorgenommen. Röntgenologisch kann an ausgewählten Langknochen des Oberschenkels und des Oberarms die Spongiosastruktur beurteilt werden (Szilvássy und Kritscher 1990). Nach dem Schema „, die sechsStufen derSpongiosastruktur desFemurkopfes“ für den Oberschenkelknochen und „die sechs Stufen der Spongiosastruktur des Humeruskopfes" für den Oberarmknochen, wurden die untersuchten Langknochen mithilfe von Gruppenwerten des chronologischen Lebensalters für die sechs Stadien nach Nemeskéri et al. (1960) in entsprechende Altersstufen eingeordnet.

Bei der Altersbestimmung der Zähne wurde für ausgewachsene Individuen zumeist der Abrasionsgrad der Molaren herangezogen, um eine Einschätzung des Alters zu bekommen (z. B. Miles 1963, Szilvássy 1988). Bei jungen, nicht ausgewachsenen Individuen wurde neben dem Abrasionsgrad der Molaren der Stand des Wechselgebisses als Hauptkriterium einbezogen (Ubelaker 1978). Besonders Frontzähne wurden nach dem Schema von Schour und Massler (1941) beurteilt. Diese Altersnäherung ist wohl die verlässlichste, wenn sie denn Anwendung finden konnte. Hier waren Abweichungen meist in engem Rahmen anzugeben; je mehr Zähne eines Wechselgebisses vorhanden waren, desto genauer konnte die Altersbestimmung erfolgen.

Um das Sterbealter von Individuen mithilfe der Zahnabrasionen feststellen zu können, wurde ein Schema der Abnutzungsgrade der Mahlzähne (Abb. 1) von Szilvássy (1988) nach Miles (1963) und Brothwell (1981) (modifiziert) zur Hilfe genommen. 


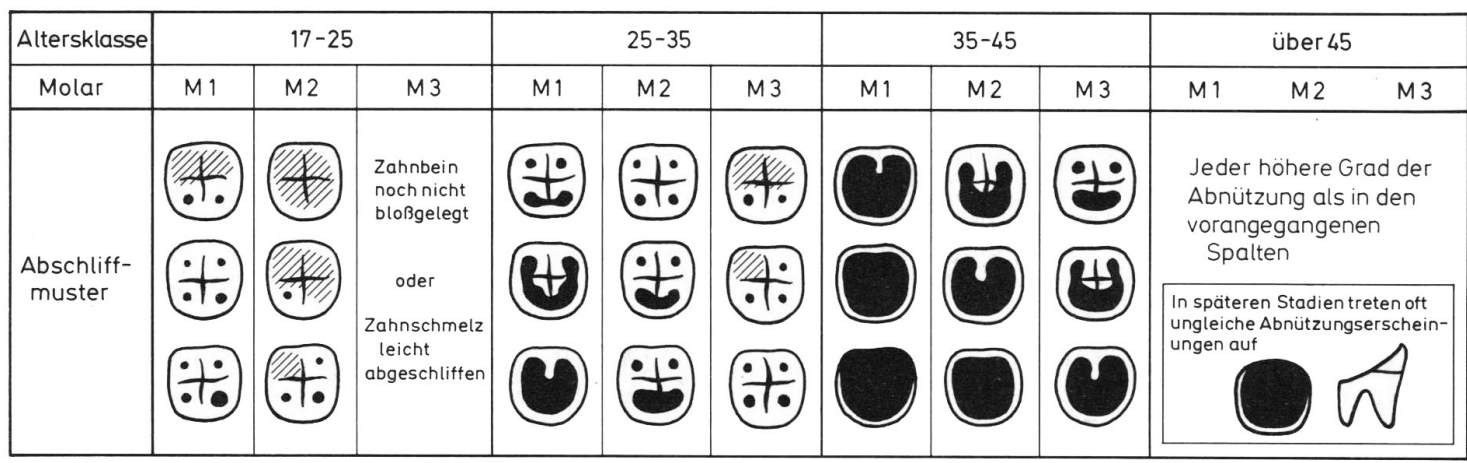

(0) (1) (2)

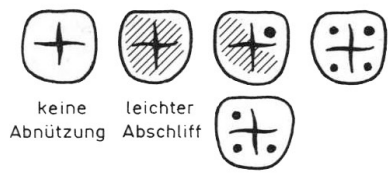

$\underset{\substack{\text { keine } \\ \text { Abnützung }}}{\substack{\text { Abschter } \\ \text { (t) }}}$

$A b b .1$
(3)

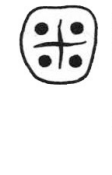

(4)

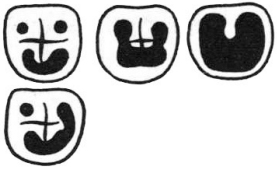

(5)

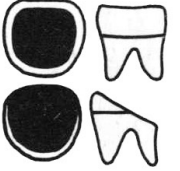

ungleiche Abnützun
(6)
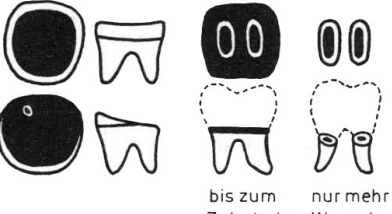

(7)

Abrasionsschema der Molaren und Einteilung in eine Alterskategorie Abnutzungen der oberen und unteren Zähne können sich unterscheiden; Schema von Szilvássy (1988), nach Miles (1963), Brothwell (1981), modifiziert. Trotz intensiver Recherche konnte kein Rechtsnachfolger des Herausgebers nachgewiesen werden.

Dieses Schema wurde für die vorgelegte Arbeit von mir weiter modifiziert, sodass die Abnutzungsgrade der Molaren der untersuchten Individuen deutlicher werden. Die Modifikation bezieht sich dabei auf eine für die untersuchten Populationen angepasste Graduierung der niedrigen Abrasionsgrade von 0 bis 5. Auf die Zusatzeinteilungen von ",+“ oder ",++“ wurde verzichtet, da diese genauen Abstufungen aufgrund der Variabilität der Abrasionen nicht anzuwenden waren. Das bedeutet, dass eine Einteilung nach dem Schema von Szilvássy (1988) die Einstufungen hätte undurchsichtig werden lassen. Um das zu vermeiden, wurde auf weitere Abstufungen der einzelnen Grade verzichtet, stattdessen aber der Grad „0“ hinzugefügt, um besonders bei den niedrigen Abrasionsgraden genauer zu differenzieren. Die Einteilung in Bereiche, die das Sterbealter angeben, wurde nach wie vor in dem genannten Schema von Szilvássy (1988) vorgenommen.

Handelte es sich um Individuen mit Milch- oder Wechselgebiss, konnte u. a. der Status der Mineralisation der Wurzeln herangezogen werden. Dafür wurde das „Schema der Zahnentwicklung“ nach Ubelaker (1978) angewandt.

\subsubsection{Methoden der Geschlechtsbestimmung}

Ähnlich wie bei der Altersbestimmung wurden auch für die Bestimmung des Geschlechts ausgewählter Skeletelemente eine Reihe bewährter Schemata mit Kriterien zur Geschlechtsbestimmung aus der Paläopathologie und Anthropologie angewendet. Sowohl Konstitution als auch Größe und bestimmte 
geschlechtsspezifische Ausprägungsmerkmale

können

bei

einigen Skeletelementen eine Einteilung

in "wohl"

weib-

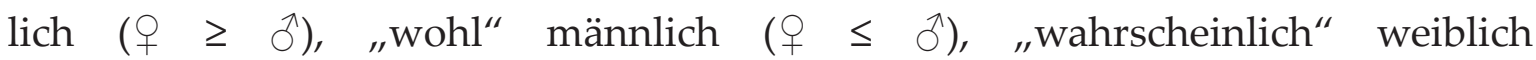

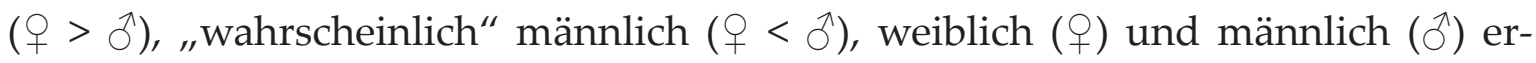
möglichen. Gibt es keine geschlechtsspezifischen Merkmale oder waren diese nicht festzustellen, wurde das Skeletelement als „indifferent“ $(\uparrow=\widehat{\dagger})$ bezeichnet, was bedeutet, dass postmortal das Fundstück nicht einem Individuum bestimmten Geschlechts zugeteilt werden konnte. War der Erhaltungszustand des Knochens nicht ausreichend gut, sodass keine Geschlechtsbestimmung durchführbar war, wurde zum Geschlecht keine Angabe gemacht. Das kann mit der Art des Fundstücks (handelte es sich z. B. nur um einen Knochensplitter) oder auch mit postmortalen Artefakten in Form von Bodenerosionen oder Ausgrabungsbeschädigungen zusammenhängen.

Für die Geschlechtsbestimmung an Schädeln wurde das Schema nach Acsádi und Nemeskéri (1970) verwendet. Folgende verschiedene Merkmale des Schädels wurden hier berücksichtigt: Glabellaentwicklung und Tiefe der Nasenwurzel, Entwicklung der Protuberantia occipitalis externa, Entwicklung des Processus mastoideus, Umriss der Orbita, Form des Unterkieferwinkels und Kinnform. Ein fortführendes Schema von Acsádi und Nemeskéri (1970) und Ferembach et al. (1979), welches die Merkmale am Schädel gewichtet, wurde ebenfalls herangezogen. Insgesamt konnten manchmal nur einzelne Merkmale betrachtet werden, da die Fundstücke nur als Fragmente erhalten waren. Dementsprechend war dann nur eine bestmögliche Näherung zu erreichen.

Am Oberschenkelknochen kann mit metrischen Methoden ebenfalls ein Geschlecht bestimmt werden (Pearson und Bell 1919, Stewart 1968), auch an Schienbeinen ist es teilweise möglich (Pettener und Brasili Gualandi 1979). Das Sprungbein und das Fersenbein sind weitere Knochen, die sich für eine Tendenz zur Bestimmung des Geschlechts aufgrund ihrer Größe eignen (Steele 1976). Außerdem sind neben den anfänglich genannten noch der Oberarmknochen (Černý und Komenda 1980) und das Schlüsselbein (Steel 1966) relevant. Insgesamt geht aus dem Artikel von Sjøvold (1988) hervor, dass Knochen männlicher Individuen in ihrer Größe durchschnittlich immer etwas größer sind als weibliche. So konnte auch beispielsweise an den Unterarmknochen eine Tendenz ermittelt werden. Diese allein reicht jedoch meist nicht für eine hinreichende Genauigkeit aus.

Becken und Oberschenkelknochen weisen einen signifikanten Geschlechtsunterschied auf (Purcell 2013); sie lieferten neben den Schädeln die verlässlichsten Daten für diese Arbeit. Am Becken kann der sogenannte „Arc composé" nach Novotný 
(1982) beurteilt werden. Er kann bei männlichen und weiblichen Individuen sehr unterschiedlich sein. Weiterhin kann die Schambein- sowie Sitzbeinlänge herangezogen werden. Diese Längen wurden zur Geschlechtsbestimmung nach Novotný (1975) verwendet. Das Schambein wurde zusätzlich nach der Methodik von Phenice (1969) zur Beurteilung des Geschlechts herangezogen.

Manchmal kann man an Wirbeln und dem Kreuzbein ebenfalls eine Näherung für „eher weiblich“ oder „eher männlich“ finden (Sjøvold 1988, Strádaloá 1975).

\subsubsection{Rekonstruktion der Körperhöhe und Bestimmung der MIZ}

Die Bestimmung der Körperhöhe wurde mithilfe der Gesamtlängen der Oberschenkelknochen realisiert. Dafür wurden Errechnungsformeln nach Pearson (1899), Breitinger (1938), Telkkä (1950), Bach (1965), Cerný und Komenda (1982), Sjøvold (1990), Raxter et al. (2008) und Siegmund (2010) verwendet.

Die MIZ wurde für jede der drei untersuchten Populationen jeweils anhand der Zahnfunde und unabhängig davon anhand der cranialen und postcranialen Fundstücke bestimt. Die am häufigsten erhaltenen Fundstücke einer Körperregion wurde dabei gezählt.

\subsubsection{Paläopathologische Befunderhebung und -dokumentation}

Eine gesunde, nicht über die physiologischen Maße hinaus muskulär beanspruchte Knochenoberfläche ist in der Regel glatt und ohne Unregelmäßigkeiten in ihrer Struktur. Wellen, Rillen oder Löcher kommen hier nicht vor. Weiterhin findet man an gesunden Knochenoberflächen keine Auswülste, knöcherne Neubildungen kleiner und größerer Art oder Stufenbildungen mit glattem oder scharfem Übergang. Unregelmäßigkeiten der knöchernen Struktur sprechen entweder für Spuren einer pathologischen Veränderung, können jedoch auch lediglich auf postmortale Beschädigungen durch Störungen des Grabes, Bodenerosionen oder Ausgrabungsarbeiten im Sinne eines Artefakts hinweisen; intravitale Knochenauflagerungen gehen dabei immer auf eine Periostreaktion zurück (Schultz 1988b). Wurde der Knochen intravital durch muskelbedingten Stress verändert, finden sich unter Umständen Wulstungen, Stacheln, Leisten o. ä., die nicht unbedingt krankhafter Natur sein müssen. Makroskopisch sind postmortale nicht sicher von intravitalen Veränderungen abzugrenzen; lichtmikroskopische Untersuchungen können dabei helfen, sowohl differentialdiagnostische Fragestellungen bezüglich makroskopisch vermuteter Spuren von Erkrankungen zu beantworten als auch diese klar von postmortalen Artefakten abzugrenzen (Schultz 2001). 


\subsubsection{Oberflächenbefundung und Befunddokumentation}

Der*die Untersuchende muss bei auffälligen Unregelmäßigkeiten an den Knochenoberflächen erst einmal zwischen intravitalen und postmortalen Veränderungen unterscheiden - was oft nur mithilfe lichtmikroskopischer Untersuchungen von Knochendünnschliffpräparaten der Fundstücke mit ausreichender Sicherheit möglich ist (Schultz 1988a, 2001, 2003, 2011a, Schultz und Nováček 2012). In diesem Zusammenhang sei nochmals erwähnt, dass viele Fundstücke der Populationen aus Calden, Rheine und Großenrode postmortale Veränderungen und Beschädigungen aufweisen, die mögliche pathologische Auffälligkeiten überdecken könnten. Die Knochen sind vor der Bereitstellung überwiegend mehr oder weniger gereinigt worden, wodurch ebenfalls Spuren pathologischer Prozesse an den Fundstücken entfernt worden sein könnten. Jegliche unsachgemäße Behandlung von skeletalem Fundgut kann die Befundung erheblich erschweren oder sogar unmöglich machen. Besondere Aufmerksamkeit war also der Befundung zu widmen, um Artefakte und Spuren pathologischer Veränderungen bestmöglich auseinanderzuhalten.

Untersucht und befundet wurden die Fundstücke durch makroskopische Begutachtung und Beleuchtung mit Streiflicht. Die Arbeitsplatzbeleuchtung wurde durch eine Leuchtröhrenlampe der Marke Hansa ${ }^{\circledR}$ (Typ T5 24W) sichergestellt. Streiflicht bedeutet, dass das schräg von oben oder seitlich einfallende Licht (optimal tangentiale Lichtführung) Unebenheiten wie kleine Furchen und Rillen oder Erhabenheiten wie plattenförmige Knochenneubildungen und wallartige Aufwölbungen sichtbar macht. Hier kommt der Schatten des mit Licht bestrahlten Bereiches zum Tragen, der neben dem eigentlichen Merkmal erscheint und den Bereich herausstellt. Die Auffälligkeit lässt sich unter Streiflicht mit gutem Kontrast ansehen, sodass die Gefahr, dass man auch kleinste Veränderungen übersieht oder falsch deutet, minimiert wird. Außerdem lässt diese Methode eine differenziertere Beurteilung von Bereichen besonderen Interesses zu.

Eine intravitale Auflagerung auf der Knochenoberfläche ist immer auf eine periostale Reaktion zurückzuführen, die verschiedene Ursachen haben kann (Schultz 1988b). Eine differentialdiagnostisch abklärende, genaue Diagnose ist meist nur mithilfe von Knochendünnschliffen für eine lichtmikroskopische Untersuchung möglich (Schultz 1986). Geschwulstartige Neubildungen fallen ebenso in das paläopathologische Befundschema. Sie sind mit den gleichen Methoden zu untersuchen.

Handlupen sind oft hilfreich, um auch detaillierte, kleine Veränderungen genauer betrachten zu können. 
Waren die Veränderungen derart klein, dass selbst mit einer Lupe die genaue Befundung unmöglich war, wurde ein binokulares Lupenmikroskop mit Auflicht (kurz: Binokular) der Firma Leica ${ }^{\circledR}$ (Typ S8AP0) verwendet. Durch die integrierte Kamera der Marke Leica ${ }^{\circledR}$ (Typ DC 500) und das Computerprogramm Leica ${ }^{\circledR}$ Application Suite ${ }^{\circledR}$ (Version 2.8.1.) konnten hier auch Fotos von besonderen Bereichen des Fundstücks erstellt werden; es wurden über 260 Fotos für die Dokumentation aufgenommen.

Weiterführende Diagnostik, die nur durch Anfertigung eines Röntgenbildes betrieben werden konnte, wurde mit einem Vollschutzröntgengerät der Firma Hewlett-Packard ${ }^{\circledR}$ (Typ 43805N X-RAY SYSTEM, FAXITRON SERIES) gemacht. Dies war z. B. für die röntgenologische Altersbestimmung, diagnostische Abklärungen und differentialdiagnostische Fragestellungen erforderlich; insgesamt wurden über 310 Röntgenbilder für diese Arbeit angefertigt. Verdickte Compacta und Krankheitsbilder wie die Myositis ossificans waren ebenfalls gute Gründe für die Erstellung einer anschaulichen Röntgenaufnahme. Bei dem Röntgengerät ist es möglich, konventionelle und digitale Aufnahmen anzufertigen. Digitale Aufnahmen wurden mithilfe der Computersoftware „iX-Pect for EZ“ ermöglicht. Weiterhin wurde jeder Schädel - wenn er entsprechend erhalten war - geröntgt, um hier Strukturunterbrechungen festzustellen und die Pneumatisation der Nasennebenhöhlen und des Warzenfortsatzes zu begutachten. So ist z. B. die Ausdehnung der Stirnhöhle von diagnostischer Bedeutung - war sie beispielsweise verkleinert, war dies möglicherweise auf eine Sutura metopica oder eine mangelhafte Pneumatisation im Kindesalter zurückzuführen. Bei zahlreichen Schädeln konnte man sie nur mithilfe einer Röntgenaufnahme erkennen und befunden, da sie nicht künstlich eröffnet werden sollten.

Röntgenologische Aufnahmen wurden digital aufgenommen; so konnten durch Kontrastveränderungen die Bereiche des Interesses deutlicher herausgestellt und gezeigt werden. Helligkeitskorrekturen des aufgenommenen Digitalbildes zwecks besserer Sichtbarkeit - konnten ebenfalls vorgenommen werden. Bei vier Schädeln wurde in Zusammenarbeit mit dem Zentrum für Zahn-, Mund- und Kieferheilkunde der Universitätsmedizin Göttingen mit freundlicher Hilfe von Alexander Klenke (Zahnarzt) und Frau Degenhardt (zahnmedizinische Fachangestellte) eine DVT (Digitale Volumentomografie)- Aufnahme angefertigt. Solche Aufnahmen erlauben die überlagerungsfreie Darstellung von Objekten im Schichtbildverfahren (Herrmann 1988b). Bei der Befunderhebung für diese Arbeit waren Fragestellungen bezüglich Schädelfrakturen und -traumata die Indikation für ein dreidimensionales Bild, das in sehr anschaulicher Weise die knöchernen 
Strukturen zeigt und mithilfe der computergestützten Schnittbildtechnik Frakturen und Traumata leicht erkennbar darstellt.

Fotos von makroskopischen Strukturen wurden mit einer Casio ${ }^{\circledR}$ Exilim Digitalkamera mit 10X optischem Zoom erstellt (insgesamt über 7000).

Besonders für Schädel, doch auch für andere schwer einsehbare Bereiche an verschiedenen Knochen, standen Endoskope (optisches Endoskop (VOLPI; Baujahr ca. 1977), digitales Endoskop (SCHWEITZER; Baujahr 2009)) mit Kaltlichtquelle (Typ LUX - STA; W12010A - 3093) und Kamera der Marke Canon ${ }^{\circledR}$ (Typ LA-DC58F) zur Verfügung; es wurden über 320 Aufnahmen angefertigt. Mit der Computersoftware „Intravision Capture“ konnten Fotos digital aufgenommen und gespeichert werden. Somit war die Einsicht - beispielsweise in den Gehörgang eines Schädels - möglich und die herausgestellten Bereiche konnten fotografisch festgehalten werden. Für die verschiedenen Anforderungen standen ein Endoskop mit geradem Tubus und eines mit $30^{\circ}$-Winkel-Optik zur Verfügung.

Die erhaltenen Fundstücke wurden meist in ein Skeletschema eingetragen (Erhebungsbogen von M. Schultz 1994 für die AG-Paläopathologie Göttingen, unveröffentlicht). Für Schädel wurde häufig ein anderes Schema verwendet, welches von Dmitrij v. Pozndnjakov (Schädelschemazeichnung 1993) entwickelt wurde. Weiterhin wurden ausgewählte Oberschenkel- und Oberarmknochen sowie Schienbeine, Wadenbeine, Ellen und Speichen in spezielle größere Befundschemata der AG Paläopathologie Göttingen eingezeichnet, wenn bestimmte pathologische Veränderungen, der Erhaltungszustand des Knochens oder andere Besonderheiten wie Varietäten detaillierter gezeigt und zeichnerisch festgehalten werden sollten. Waren die Fundstücke stark erodiert oder nur Fragmente erhalten, wurde meist auf eine detaillierte Zeichnung verzichtet. Dies betrifft viele Fundstücke der Populationen aus Rheine und Großenrode, während sich die meisten Fundstücke aus Calden noch so gut erhalten haben, dass ein Einzeichnen auf dem Skeletbogen lohnenswert war, um das erhaltene Fundstück bildlich zu dokumentieren. Teile der über 600 Befundbögen werden in dieser Arbeit exemplarisch aufgeführt, jedoch ist dies nicht für alle erstellten Befundbögen sinnvoll, sofern kein weiterer Erkenntnisgewinn zu erwarten ist. Befundbögen wurden zu Dokumentationszwecken angefertigt, genauso wie zahlreiche Fotografien, von denen nur solche abgebildet werden, die exemplarisch Spuren von Veränderungen oder andere Besonderheiten zeigen. Die gesamte Originaldokumentation ist in den Räumlichkeiten der AG Paläopathologie in Göttingen einzusehen.

Waren Befunde fraglich oder besonders interessant, wurden ein oder mehrere Proben für die Dünnschliffherstellung aus den relevanten Bereichen entnommen, 
die lichtmikroskopisch untersucht wurden. Für diese Arbeit wurden von acht Fundstücken der Population aus Calden 22 Dünnschliffe aus elf Regionen angefertigt. Von einem Fundstück aus der Population aus Rheine wurden vier Dünnschliffe aus zwei Regionen hergestellt und von zwei Fundstücken aus der Population aus Großenrode zehn Dünnschliffe aus fünf Regionen. Die Probenentnahme und die Anfertigung der Dünnschliffe wurden freundlicherweise von Michael Brandt, AG Paläopathologie am Institut für Anatomie und Embryologie der Universitätsmedizin Göttingen vorgenommen.

Von den ausgewählten Präparaten wurden stets mindestens zwei Dünnschliffe in zwei verschiedenen Stärken hergestellt $(50 \mu \mathrm{m}$ und $70 \mu \mathrm{m})$. Die Methode wurde von M. Schultz und M. Brandt entwickelt und beschrieben (z. B. Schultz und Drommer 1983, Schultz 1988a, 2001). Für die Präparateherstellung wurde eine Knochenprobe aus dem Bereich ausgesägt, der die Veränderungen aufwies. Diese Probe wurde zunächst in Dichlormethan (Intermedium) eingelegt und dann in einer Schale aus Aluminium in das Einbettungsmedium, den Kunststoff Biodur (Biodur E12 ${ }^{\circledR}$ und Härter E1 ${ }^{\circledR}$ (von Hagens 1978, von Hagens und von Hagens 1984)), gelegt. Anschließend wurde die Schale in einen Exsikkator mit Vakuumpumpe gestellt, wo der Austausch von Dichlormethan gegen den Kunststoff stattfand. Dieser Vorgang wird als forcierte Imprägnierung bezeichnet. Das Verfahren der Plastination beruht auf der Dampfdruckdifferenz zwischen dem Intermedium und dem Kunststoff. Der Kunststoff musste vollständig aushärten und wurde dann zurechtgesägt, sodass er auf einen Objektträger passte, auf den er dann aufgesetzt wurde. Der Kunststoffblock konnte anschließend auf eine bestimmte Dicke (50 $\mu$ m oder $70 \mu \mathrm{m})$ geschliffen und poliert werden, wobei regelmäßig eine Kontrolle der Dicke mit einer Mikrometerschraube erfolgte (Schultz und Drommer 1983, Schultz 1988a).

Für die lichtmikroskopische Untersuchung wurde ein Lichtmikroskop (Polarisationmikroskop) der Firma Leica ${ }^{\circledR}$ verwendet. Es handelte sich um das Modell DM-RXP. Die Proben wurden in einfachem und polarisiertem Durchlicht mit und ohne Hilfsobjekt Rot 1. Ordnung (Quarz) als Kompensator untersucht; weiterhin stand ein Graufilter zur Verfügung (Schultz 1986, 1988a, 2001). AnschlieBend wurden die Befunde fotografisch dokumentiert (insgesamt 259 Aufnahmen). Die $70 \mu \mathrm{m}$-Dünnschliffe wurden alle zwecks Übersicht mit einem EPSON ${ }^{\circledR}$ Scanner (Typ EPSON PERFECTION 4870 PHOTO) eingescannt. Die Speicherung der Daten wurde mit dem EPSON ${ }^{\circledR}$ Scan-Computerprogramm vorgenommen.

Zwei Knochenoberflächen einer Fibula der Population aus Calden konnten nur mithilfe eines Rasterelektronenmikroskops der Marke ZEISS ${ }^{\circledast}$ (Typ DS 960) genau untersucht werden, um sicher postmortale von intravitalen Veränderungen abzugrenzen. Die rasterelektronenmikroskopischen Untersuchungen wurden am Institut 
für Anatomie und Embryologie der Universitätsmedizin Göttingen durchgeführt. Dazu wurden von Herrn M. Brandt zwei Knochenproben aus der Fibula ausgesägt. Die Proben wurden auf einen kleinen Metallstift geklebt und konnten dann unter Vakuum mit einem Gold-Palladium Target von Frau Ingrid Hettwer-Steeger - einem Mitglied der AG Paläopathologie der UMG - bedampft werden, damit die zu untersuchenden Oberflächen im Rasterelektronenmikroskop darstellbar wurden.

Fotografien der REM-Untersuchungen wurden mit einer Kleinbildkamera aufgenommen (insgesamt 17 Bilder). Dazu wurde ein Schwarzweißfilm (Ilford Pan F plus) verwendet. Die entwickelten Negative wurden dann wie die Knochendünnschliffe mit dem EPSON ${ }^{\circledR}$ Scanner (Typ EPSON PERFECTION 4870 PHOTO) eingescannt. Die Speicherung der Daten erfolgte ebenfalls mit dem EPSON ${ }^{\circledR}$ Scan-Computerprogramm.

Langknochen, Kreuzbeine, Schlüsselbeine, Sprungbeine und Fersenbeine wurden nach Bräuer (1988) gemessen und - bei paarigen Knochen - die Körperseite bestimmt. Weiterhin wurde jedes Fundstück in „detailliert untersucht" oder „nicht detailliert untersucht" eingestuft. Diese beiden Einteilungen sind als eine vorläufige Sortierung in befundbare und nicht befundbare Fundstücke zu verstehen. Nach der Einordnung in „nicht detailliert untersucht“ wurde keine nähere Beschreibung des Fundstückes vorgenommen, da dieses zu stark erodiert war, zu klein frakturiert vorlag oder das Fundstück an sich keine weiteren Befunde zulässt, weil entsprechende Gebiete trotz großer Erhaltungsmenge erosionsbedingt nicht befundbar waren. Wurde ein Fundstück als „detailliert untersucht" eingeteilt, so wurde immer eine weitere Einteilung in "gesund" und "krank" vorgenommen. "Gesund" heißt, dass die dort einkategorisierten Fundstücke keine Spuren eines intravitalen - beispielsweise pathologischen - Prozesses aufwiesen. Wurde die Kategorie "krank“ gewählt, heißt das, dass es Spuren von intravitalen, pathologischen Veränderungen gab oder dass - wie beispielsweise bei Kiefern möglich - eine Anomalie vorlag. Ebenfalls wurden jene Fundstücke in dieser Zuordnung erfasst, welche Frakturen oder verheilte Spuren solcher aufwiesen.

Weiterhin wurden die Schädel und Langknochen im Befund in prozentuale Erhaltungsparameter eingeteilt. Schädel wurden wie folgt kategorisiert: „1-25\%“, "26-60\%" und „>61\%" erhaltenes Fundmaterial. Weiterhin wurde genau festgehalten, welche Anteile vorhanden waren. So wurde in der Datenbank eine Tabelle gewählt, in der Schädelkompartimente je Datensatz festgehalten wurden. Die Tabelle wurde so geführt, dass hinter den Schädelkompartimenten entweder eine 1 für "gesund“ oder eine 2 für "krank" geschrieben werden konnte. Dies erleichterte die Auswertung der zahlreichen Daten. 
Für Langknochen wurden in der Datenbank die anzukreuzenden Einteilungen "proximales Gelenk“, „proximaler Schaft", „mittlerer Schaft", „distaler Schaft" und „distales Gelenk" gewählt. Zusätzlich wurde ein anzukreuzendes Feld in der Datenbank verwendet, welches „vollständig“ genannt wurde. Dieses Feld wurde angekreuzt, wenn sich ein Knochen im Ganzen erhalten hatte. Problematisch wurde die zuvor beschriebene Fünfteleinteilung nämlich dann, wenn ein Knochen in seiner Länge zwar alle „Fünftel“ zusammen ergab, aber dennoch Teile fehlten. Die verwendete Fünfteleinteilung bedeutete nur eine Näherung an die Länge der vorhandenen Fragmente; in ganz exakte Prozentanteile waren die Fundstücke meist nicht zu kategorisieren. So kam es vor, dass Knochen nur in ihrem anterioren Bereich erhalten waren oder dass von jedem Fünftelabschnitt des Knochens nur ein Teilfragment vorlag, diese aber nicht aneinander passten. In all diesen Fällen könnte trotz eines vollständig angekreuzten Fünftelschemas ein unvollständiger Knochen gemeint sein. Deshalb wurde eine extra Kategorie für "vollständig“ verwendet.

Für die paläopathologische Befunderhebung war es - wie bereits beschrieben - zunächst erst einmal wichtig, eine gesunde Knochenoberfläche von einer krankhaft veränderten abzugrenzen. Die Befundung der Gelenkflächen erfolgte nach den Vorschlägen von Schultz (1988b). Nach dieser Einteilung, die Gradierungen von 0 bis VI vorgibt, werden degenerativ und entzündlich veränderte Gelenke geordnet. Die Schwierigkeit der Gelenkbefundung lag vor allem darin, die morphologischen Veränderungen erst einmal genau zu erkennen und zu beschreiben und dann dem Klassifikationsschema entsprechend einzuordnen.

Nach Schultz (1988b) gibt es für die verschiedenen Schweregrade einer degenerativen Veränderung folgende Beschreibung der sieben Grade: Grad 0 beschreibt ein gesundes Gelenk, während Grad I bereits ein Gelenk mit geringfügigen VerschleiBerscheinungen kennzeichnet, das aber noch nicht als krankhaft bezeichnet wird. Grad II steht für ein Gelenk mit geringgradig krankhaften Veränderungen. Der Gelenkrand weist Randleistenbildungen auf, die bis $3 \mathrm{~mm}$ breit sein können und die Gelenkfläche besitzt kleine Buckel und/oder kleine Lochdefekte, die aber die Corticalis nicht durchdringen. Grad III steht für mittelgradige krankhafte Veränderungen, bei denen der Gelenkrand meist eine geschlossene Randleistenbildung zeigt und die Gelenkfläche Veränderungen auf mehr als 50\% der Fläche aufweist; die möglichen Veränderungen sind die gleichen wie bei Grad II, sind jedoch gröBer und/oder weiter ausgedehnt. Grad IV steht für ein Gelenk mit hochgradigen krankhaften Veränderungen. Die Randleisten der Gelenkränder messen mehr als $3 \mathrm{~mm}$, alle Defekte auf Gelenkfläche und -rand sind kleinflächig ausgebildet. Die poröse Gelenkoberfläche weist großporige Lochdefekte auf und/oder ist eburniert. Gelenke mit Grad V weisen die gleichen Veränderungen auf wie solche mit Grad IV; 
die Defekte sind jedoch größer und flächiger ausgeprägt (meist geschlossene Randleistenbildung und Fläche zu über $50 \%$ betroffen). Grad VI repräsentiert ein total deformiertes und durch degenerative Prozesse verändertes Gelenk. Es liegen Knochenneubildungen oder ausgedehnte Nekrosen an Gelenkrand und -fläche vor.

Gelenkrand und -fläche wurden immer getrennt voneinander betrachtet, der höhere Grad entschied dann über den Gesamtgrad des Gelenkteils. War ein Gelenk vollständig, wurden die Gesamtgrade der jeweiligen Gelenkteile zusammengezählt und durch zwei geteilt. Dies ergibt die Bewertungsziffer des Gelenks (BWZ).

Als pathologisch verändert galt eine Gelenkfläche und/oder ein Gelenkrand ab einem Arthrosegrad von mehr als II (2). Es sei angemerkt, dass im ausführlichen Befundkatalog keine römischen Ziffern für die Arthrosegrade der Gelenkteile verwendet wurden, da diese rechnerisch für das Programm FileMaker Pro ${ }^{\circledast}$ nicht auswertbar gewesen wären. Es finden sich folglich nur arabische Ziffern im vollständigen Befundkatalog.

Unter dem Begriff „Muskeltrauma“ wurden bei der Befunderhebung Enthesiopathien zusammengefasst, die durch Myotendo- bzw. Ligamentopathien im Zuge von muskulärer Überbelastung zu Sehnen- und Bandverknöcherungen geführt haben. Diese Veränderungen stellten sich als proliferativ verknöcherter Bereich dar oder als nekrotisch bedingte Einkerbung.

$\mathrm{Zu}$ Dokumentationszwecken wurde für die Knochen, bei denen es möglich war, ein Untersuchungsblatt zur Erhebung des Gelenkstatus`verwendet (Schultz 1988b), in das die Gradierungen der degenerativen Veränderungen, die sich aus den Untersuchungen ergeben haben, eingetragen wurden. Das war allerdings nur bei zusammenhängenden Gelenkverbänden sinnvoll. Die Gelenke der einzelnen Fundstücke wurden ebenfalls befundet. Im direkten Vergleich miteinander sind auch diese Daten aussagekräftig, dennoch ist es für eine vollständige Beurteilung degenerativer Veränderungen an Gelenkflächen notwendig, alle beteiligten Gelenkkompartimente in befundbarem Zustand betrachten zu können. Nur dann ist eine Gesamtgradierung des Gelenks möglich. Da bei allen drei Populationen überwiegend einzelne Knochen und Knochenfragmente vorlagen, wurde eine Einteilung der einzelnen Gelenkkompartimente in die Grade der degenerativen Veränderungen - wie zuvor beschrieben - durchgeführt.

Die Befundung der Wirbel erfolgte nach der gleichen Methode, wie sie zuvor für die Langknochen beschrieben wurde. Wirbelsäulenspezifische Besonderheiten wurden ebenfalls dokumentiert. Die Einteilung in die sieben verschiedenen Grade von degenerativen Veränderungen kam zusätzlich zur Anwendung. Zur Dokumentation wurde das Befundschema für Wirbelsäulen von Schultz (1988b) genutzt. 


\subsubsection{Frakturen}

Das Fundmaterial wurde auch auf traumatische Ereignisse im Sinne von Frakturen untersucht. Zu beachten war hierbei, dass die meisten Zusammenhangstrennungen einzelner Knochen auf postmortale Ereignisse durch Grabstörungen oder Grabungs- und Bergungsarbeiten zurückzuführen waren. Meistens sind Frakturen, die zu Lebzeiten des Individuums entstanden sind, gegen postmortale Frakturen insofern abzugrenzen, als dass diese häufig Ausheilungsspuren zeigen (Schultz 1988b). Lediglich bei perimortalen oder postmortalen Ereignissen bleiben Spuren der Ausheilung aus. Perimortale Frakturen konnten bei dem vorliegenden Material nicht mit ausreichender Sicherheit gegen postmortale Artefakte abgegrenzt werden. Deutliche intravitale Frakturgeschehen mit Ausheilung waren jedoch an manchen Fundstücken nachweisbar.

\subsubsection{Befundung der Zähne und Zahnhalteapparate}

Für die Dokumentation wurde das Untersuchungsschema für Zähne und Kiefer nach Schultz (1988b) verwendet. Hier wurde der Zustand der Zähne und des Zahnhalteapparates sowie der Kiefergelenke abgefragt (Schultz 1988b). Mittels der Befundung der Zähne können Aussagen über das Sterbealter, die Nahrungszusammensetzung und genetische Muster getätigt werden. Notiert wurde in dem Befundschema, ob ein Zahn erhalten war und in welcher Form - lag er einzeln vor oder in einer Alveole. Leere Alveolen wurden ebenfalls erfasst, an ihnen sind Parodontopathien (Grade 1 bis 5) post mortem noch zu beurteilen. Weiterhin wurden Befunde über Schmelzhypoplasien, Neubildungen in Form von Sekundär- und Tertiärdentin oder Hyperzementose, Abrasionen, Karies und Zahnstein erstellt, in verschiedene Grade und Spezifitätskategorien eingeteilt und dokumentiert. Abrasionen wurden nach Schemata von Szilvássy (1988, nach Miles 1963 und Brothwell 1981, modifiziert) sowie Perizonius und Pot (1981) befundet. Anomalien der Zähne und Kiefer, der Arthrosegrad der Kiefergelenke und Zusatzbefunde wie Spuren einer Stomatitis oder Spuren einer Entzündung der Kieferhöhle konnten hier ebenfalls vermerkt werden.

Auf die Gradierung der Abrasionen wurde bereits zuvor eingegangen, weswegen hier auf eine erneute Erklärung verzichtet wird. Bezüglich der Schmelzhypoplasien sind die Grade 0 bis 5 möglich. Schmelzhypoplasien entstehen u. a. im Zuge von Infektionskrankheiten oder Mangelernährung. Fehlen beispielsweise Kalksalze, kann es zu einer Störung der Verkalkung der Zahnsubstanz kommen; auch ein Proteinmangel wirkt sich negativ auf das Wachstum der Zähne aus (Schultz 1988b). Das Phänomen der Mangelernährung äußert sich als rillen- oder furchenförmige Struktur (Schultz 1988b). Es wurden nur transversale Schmelzhypoplasien auf dem 
Befundblatt aufgenommen. Punktförmige Schmelzhypoplasien im Sinne von Loci minores resistentiae wurden im Beschreibungstext erwähnt.

Neubildungen in Form von Sekundär- bzw. Tertiärdentin wurden immer bei einem Abrasionsgrad von mindestens Grad 4 angegeben, wobei Sekundärdentin zeitlebens physiologisch gebildet wird und Tertiärdentin eine Reaktion auf einen Reiz ist (pathologisch). War unabhängig von Abrasionen eine Neubildung von Sekundär- oder Tertiärdentin zu beobachten, wurde diese ebenfalls vermerkt; Ursachen können hier z. B. ein höheres Lebensalter des Individuums (Sekundärdentin) oder Karies (Reizdentin) gewesen sein. Auf eine Gradierung wurde meist verzichtet, weil man aufgrund der Abrasionen lediglich davon ausgehen konnte, dass sich überhaupt Dentin neu gebildet hat. Bei einigen Zahnfunden mit Abrasionsgrad 2 konnte allerdings bereits durch die Eröffnung der Dentinkanäle von Bildung neuen Dentins ausgegangen werden. Dieses war bei Abrasionen häufig bereits durch makroskopische Begutachtung zu erkennen. Die Unterscheidung zwischen Sekundäroder Tertiärdentin in den Dentintubuli wäre allerdings nur mikroskopisch möglich gewesen. Aufgrund der geringen Aussagekraft dieser Unterscheidung wurde auf eine zusätzliche, mikroskopische Befundung verzichtet. Dentinneubildungen sind entweder makroskopisch (bei offen liegendem Pulpencavum) sichtbar oder röntgenologisch durch eine Verkleinerung des Pulpencavums und des gesamten Wurzeldentins. Der Nachweis von Dentinneubildungen trägt zur Abschätzung des Abnutzungsgrades bei - der beispielsweise durch die Verwendung der Zähne als Werkzeug entstanden sein konnte - und ist hilfreich bei der Sterbealterbestimmung anhand der Zähne. In dieser Arbeit soll im Folgenden jedoch nicht zwischen Sekundär- und Tertiärdentin unterschieden werden. Stattdessen wird das Wort „Dentinneubildungen“ eingeführt, welches beide Arten von Neubildungen umfasst, aber keine Differenzierung vorsieht. Neben Dentinneubildungen wurden auch Hyperzementosen erfasst. Eine Besonderheit ergibt sich für die Erfassung dieser Befunde: War eine Neubildung zu diagnostizieren, deren Grad aber nicht Anzeichen oder Konsequenz eines pathologischen Prozesses war, wurde der Befund als "gesund“ und „krank" gleichzeitig eingestuft, da sonst bei diesen Veränderungen eine falsche künstliche Tendenz zugunsten der „kranken“ oder „gesunden“ Zähne hervorgerufen worden wäre. Diese gleichzeitige Einstufung in "gesund“ und "krank" soll diesen Fehler minimieren, um das Verhältnis zwischen "gesunden“ und „kranken“ Befunden nicht zu verfälschen. Es muss hier ausdrücklich auf diesen Sachverhalt hingewiesen werden, da sonst die im Ergebnisteil folgenden Diagramme nicht sinnvoll zu interpretieren sind, denn nicht jede Veränderung deutet auf etwas Krankhaftes hin. Bei den Befunden der Hyperzementosen und Dentinneubildungen in den Diagrammen ist somit nur der Prozentwert aussagekräftig, nicht aber die 
absoluten Zahlen, da - wie beschrieben - ein Zahn „doppelt“ gezählt werden konnte, wenn beispielsweise eine Dentinneubildung vorlag, diese aber nicht krankhaft war, sondern lediglich dokumentiert werden sollte.

Für kariöse Defekte wurden nach Schultz (1988b) Gradierungen zwischen 1 und 6 vergeben. 1 bezeichnet einen stecknadelkopfgroßen kariösen Defekt, Grad 2 ist sesamkorngroß, 3 ist pfefferkorngroß, 4 ist reiskorngroß, bei Grad 5 ist etwa die Hälfte der Krone zerstört und Grad 6 bezieht sich auf diejenigen Zähne, deren Krone vollständig kariös zerstört ist. Die Gradierungen 5 und 6 finden nur Anwendung bei Molaren.

Zahnstein, welcher regelmäßig an den Zähnen vorkam, wird nach Schultz (1988b) in fünf Grade eingeteilt, welche sich auf „leichtes“ bis „,sehr starkes“ Zahnsteinvorkommen beziehen. Allerdings sei hier erwähnt, dass durch die Grabungs- und Reinigungsarbeiten Zahnstein versehentlich entfernt worden sein könnte. Dies kann nachträglich nicht mehr erkannt werden. Die Angaben enthalten somit möglicherweise einen unvermeidbaren und nicht korrigierbaren Fehler.

Bei der Population aus Rheine gab es die Besonderheit, dass einige Zähne zwar ihrer Zahngruppe zuzuordnen waren, jedoch nicht eindeutig einer Seite oder dem Ober- oder Unterkiefer. Ein Zahn war überhaupt nicht einzuordnen. Dass es hier im Gegensatz zu den anderen Populationen Schwierigkeiten gab, liegt darin begründet, dass das Fundgut in teilweise sehr schlechtem Erhaltungszustand vorlag. Weiterhin war in manchen Fällen nur die Zahnkrone erhalten. Besonders in solchen Fällen war eine Zuordnung der Zähne nicht immer eindeutig möglich, weswegen vor diesen Zähnen zwei Nullen eingefügt wurden, um deutlich zu machen, dass die genaue Zuordnung nicht möglich war. Der Zahn, der überhaupt nicht zuzuordnen war, trägt die Bezeichnung „000“. Jene Zähne, die nur einer Zahngruppe (z. B. Incisivi, Prämolaren etc.) zuzuordnen waren, tragen beispielsweise die Bezeichnung „004“. Das heißt, dieser Zahn war ein erster Prämolar, der jedoch nicht einem der Quadranten zugeteilt werden konnte.

Folgende Buchstaben wurden nach Schultz (1988b) für die Lokalisation von Veränderungen und die Beschreibung des Gebisses gewählt: „K“ für Krone betroffen, „H“ für Zahnhals betroffen, „W" für Wurzel betroffen, „O" für occlusal, „ $\mathrm{M}^{\prime \prime}$ für mesial, „D“ für distal, „ $\mathrm{B}^{\prime \prime}$ für buccal oder labial, „ $\mathrm{L}$ “ für lingual und „ $\mathrm{P}^{\prime}$ für palatinal. Erkrankungen des Parodontiums wurden mit „Po“ für Parodontose, „Pi“ für Parodontitis und "S" für Tasche dokumentiert. Apicale Prozesse konnten per Sichtdiagnose (makroskopisch oder im Röntgenbild) in "G" für Granulom, „A" für Abszess und „Z" für Zyste eingeteilt werden, wobei diese Einteilung nur aufgrund der Größe getroffen werden konnte. Einen Beweis für eine der drei 
apicalen Veränderungen kann nur eine lichtmikroskopische Untersuchung von Weichgewebeerbringen, das beimazeriertem Fund guteben nichtmehrvorhanden ist. Aufgrund dessen wurde in der Arbeit grundsätzlich von einer genauen Einteilung der apicalen Prozesse Abstand genommen. Die Angaben sind also lediglich als Tendenz für die eine oder andere Veränderung anzusehen. Wichtiger ist jedoch die Feststellung, ob apicale Veränderungen - ungeachtet ihrer genauen Ätiologie oder Pathogenese - überhaupt aufgetreten waren. Die apicalen Prozesse können nach Schultz (1988b) in fünf Grade unterteilt werden. Dabei entspricht Grad 1 etwa der Größe eines Sesamkorns, Grad 2 der Größe eines Pfefferkorns, Grad 3 der Größe einer Erbse, Grad 4 der Größe einer Bohne und Grad 5 der Größe einer Kirsche.

Neubildungen können nach Schultz (1988b) generell mit „\#“ für Hyperzementosen oder " " für Sekundärdentin gekennzeichnet werden. Wie bereits beschrieben, wurde aber von dieser genauen Einteilung bei dieser Arbeit Abstand genommen. Schmelzhypoplasien wurden mit „ $\mathrm{U}^{\prime \prime}$ für punktförmige und „ $\mathrm{T}^{\prime \prime}$ für transversale beschrieben. Die Schmelzhypoplasien sind Ausdruck von Mangelernährung bzw. physiologischen Stresssituationen während der Zahnschmelzgenese (Schultz 1988b). Dabei kommt es durch eine Unterentwicklung des Zahnschmelzes zu transversaler Rillen- bzw. Furchenbildung. Anhand der Höhe bzw. der Lage einer Hypoplasie kann in etwa der Zeitpunkt ihrer Entstehung abgelesen werden (Goodman et al. 1988).

Der Zahnstatus wurde ebenfalls mithilfe von Abkürzungen angegeben: „f " steht für eine intravital vollständig geschlossene Alveole, „(f)“ bedeutet, dass eine Alveole intravital noch nicht vollständig verknöchert war, „, $\mathrm{v}^{\prime \prime}$ heißt, dass ein Zahn postmortal verloren wurde, "xx" zeigt an, dass ein Zahn und eine Alveole fehlen bzw. nicht beurteilbar sind (statt „ $x x^{\prime \prime}$ wurde in dieser Arbeit meist eine Lücke gelassen, sprich: Der Zahn oder die Alveole wurden im Befundschema nicht mit aufgenommen; nur bei einem Individuum konnte das „, $\mathrm{xx}$ “ sinnhaft angewandt werden). "_- heißt, dass ein Zahn isoliert vorliegt und die Alveole fehlt, " $\mathrm{d}$ “ bedeutet, dass ein Zahn devital oder intravital abgebrochen war (dieses Zeichen war nur selten anzuwenden, da nicht immer mit Sicherheit eine Devitalität angenommen werden konnte und auch ein intravital abgebrochener Zahn sich nicht unbedingt von einem postmortal abgebrochenen unterscheiden ließ). , $\downarrow$ " ' bedeutet, dass eine Lücke vorliegt, die als Trema oder Diastema zu verstehen ist. „( ( ) heißt, dass ein Zahn noch vollständig in der Alveole befindlich ist und noch nicht durchgebrochen war. Das Zeichen „I I “ wird verwendet, wenn ein Zahn noch im Durchbruch und somit noch nicht in Okklusion stand, sondern noch teilweise in der Alveole befindlich war. Bei fraglichem Vorhandensein der Zahnanlage wurde " $\mathrm{O}^{\prime \prime}$ im Befundschema 
eingegeben. Wenn ein Zahn intravital nicht angelegt war, wurde " $\varnothing^{\prime \prime}$ eingetragen. Bei postmortal abgebrochener Krone und alleinig erhaltener Wurzel wurde das Zeichen " $\mathrm{E}^{\prime \prime}$ verwendet. Wenn ein Zahn oder eine Region nicht bewertbar war, wurde im Befundschema „/" eingetragen. Für Auflagerungen poröser Art wurde „Auf“ im Befundschema vermerkt.

\subsubsection{Krankheiten und ihre vereinfachte Betrachtung im Ergebnisteil}

Da besonders unter dem Oberbegriff „Muskeltrauma“ viele verschiedene Spuren pathologischer Veränderungen zusammengefasst wurden, soll hier kurz erläutert werden, warum sich diese Zusammenfassung anbot. In der Datenbank - und damit auch im detaillierten Ergebnisbereich - wurde jede krankhafte Veränderung einer Krankheit zugeordnet. Für manche Veränderungen war es post mortem nicht mehr möglich, die genaue Ätiologie zu bestimmen, weswegen dann in der Beschreibung des Knochens eine entsprechende Formulierung zu finden ist, wie wahrscheinlich es ist, dass die Zuordnung einer Veränderung zu einer bestimmten Erkrankung richtig vorgenommen wurde. Unter dem im Übersichtsteil der Ergebnisse zu findenden Begriff „Muskeltrauma“ ist eine Anzahl verschiedener möglicher Erkrankungen zu verstehen, die teilweise sehr ähnlich aussehen und gegebenenfalls nur mit weiteren, mikroskopischen Untersuchungen zu verifizieren sind. Folgende krankhafte Veränderungen wurden unter dem Oberbegriff „Muskeltrauma“ zusammengefasst: Enthesiopathien, Muskel-, Sehnen-, Bänderüberbelastungen, Ligamentopathien, Muskelreizungen (durch ständigen oder übermäßigen Zug des Muskels an seiner Ursprungs- oder Ansatzstelle), Myositis ossificans, Myotendopathien, Sehnenverknöcherungen, Zerrungen und Bandverknöcherungen.

Die Erkrankungsbezeichnung „Impressionen tiefer Krampfadern“ ist eine Bezeichnung für die furchenartigen, kleinen Längseinkerbungen an Langknochen der unteren Extremität. Hierbei kann grundsätzlich eine Entzündung einer tiefen Vene nicht ausgeschlossen werden, die möglicherweise differentialdiagnostisch postmortal nicht mehr von Impressionen tiefer Krampfadern zu unterscheiden ist. Es wurde dennoch grundsätzlich die Bezeichnung „Impressionen tiefer Krampfadern“ gewählt.

\subsubsection{Datenbank zur Befunddokumentation und -auswertung}

Nachdem alle Fundstücke gesichtet waren, stellte sich die Aufgabe, die zahlreichen Daten übersichtlich darzustellen und auszuwerten. Alle Daten zu einem Fundstück sollten möglichst auf einer Seite erscheinen. Fotos, Röntgenbilder, Endoskopiebilder, lichtmikroskopische Bilder von histologischen Präparaten, das Skeletdatenblatt, die gesamte Beschreibung des Fundstücks, sämtliche Maße, Alter, Geschlecht, 
Körperseite (bei paarig angelegten Knochen) Erhaltungszustand, erhaltenes Segment eines Knochens bei Fragmenten von Langknochen, Schädeln und Wirbeln, der Zustand "gesund“ oder „krank“, eingetragene Krankheiten sollten berücksichtigt werden und gleichzeitig verfügbar sein.

In Zusammenarbeit mit Julian Görtz entwickelte ich eine computergestützte Methode, die eine praktikable Auswertung der großen Datenmengen ermöglicht.

Wir erstellten eine Datenbank, die auf dem Programm FileMaker Pro ${ }^{\circledR}$ basiert. Während der ersten Anwendungsphase wurden immer wieder neue Features entworfen und eingebaut. Durch ständig neue, verbessernde und vor allem vereinfachende Anpassungen wurde die Datenbank Schritt für Schritt zu einer erheblichen technischen Vereinfachung in Bezug auf die Auswertung der großen Befundmengen. Insgesamt entstand ein Programm, das genau auf die Anforderungen dieser Dissertation zugeschnitten ist.

Die Unterstützung von Julian Görtz bezog sich bei der Entwicklung und Erarbeitung der Datenbank auf technisches, computer- und programmierbezogenes Wissen. Fachliche Anforderungen für die paläopathologische Einschätzung und Befundung der Fundstücke, die Idee einer anwenderfreundlichen Benutzeroberfläche zum Umgang mit den Daten und die auf diese Arbeit zugeschnittenen Bedürfnisse zur Auswertung steuerte ich im gemeinsamen Entwicklungsprozess bei.

Jeder Knochen muss unter anderen Kriterien untersucht werden. Somit unterscheiden sich die Benutzeroberflächen der Datenbank je nachdem, welcher Knochen eingetragen wird. Für Zähne wurde eine völlig andere Oberfläche entwickelt, die das gemeinsame Auflisten der Zähne eines Individuums ermöglicht. Für alle Fundstücke kann bei pathologischen Befunden in einem „Krankheitsfeld“ die entsprechende Diagnose notiert werden. Dieses „Krankheitsfeld“ wurde so konzipiert, dass es ausreichend Raum bietet, um die mitunter zahlreichen Spuren pathologischer Veränderungen an einem Knochen zu dokumentieren.

Die Datenbank bietet weiterhin die Möglichkeit, verschiedene Maße für die Fundstücke aufzunehmen. Das Vorgehen bei der Vermessung der Fundstücke wurden bereits kurz erläutert (Osteometrie nach Bräuer 1988); da sich jedoch zahlreiche Eingabefelder für verschiedene Fundstücke in der Datenbank befinden, soll hier noch einmal vollständig dargestellt werden, wie die Maße zustande kamen, die in den Feldern zu finden sind. Grundsätzlich wurde die Länge und Größe der vollständigen Langknochen, Schulterblätter, Brustbeine, Fersenbeine, Sprungbeine und Rippen dokumentiert und bei unvollständigen Fundstücken gegebenenfalls nach Möglichkeit rekonstruiert. Weiterhin wurde die Breite (breiteste messbare Region im rechten Winkel zur Längsachse) dokumentiert. Oberarmknochen, Steißbeine, Becken, Oberschenkelknochen und Schienbeine wurden detaillierter gemessen. 
Bei Schlüsselbeinen erfolgte zusätzlich zu Länge und Breite noch eine Ermittlung des Umfangs in der Mitte des Knochens. An Oberarmknochen wurde die größte Länge, der frontale und sagittale Durchmesser des Kopfes, die Epicondylenbreite, der Umfang in Schaftmitte und der Umfang des Schaftes über der Tuberositas deltoidea gemessen und dokumentiert. An Steißbeinen wurden Länge, Breite und Durchmesser der Basis des ersten Sakralgelenks gemessen. An Beckenknochen wurde ebenfalls die Länge und Breite dokumentiert und darüber hinaus noch der Durchmesser der Hüftpfanne. An Oberschenkelknochen wurde die größte Länge, der Umfang in Schaftmitte, die Epicondylenbreite, der Collum - Corpus - Winkel, der horizontale und vertikale Durchmesser des Kopfes, der anterior - posterior - Durchmesser und der medial - lateral - Durchmesser (jeweils subtrochlear gemessen) erfasst. An Schienbeinen wurde die größte Länge, die medizinische Länge (Distanz zwischen den Gelenkflächen des Tibiaplateaus und der distalen Tibiagelenkfläche) der Schaftumfang in der Mitte, die größte Breite des proximalen und distalen Gelenks und der Schaftumfang über dem Foramen nutricium tibiae gemessen.

Es wurden zunächst handschriftliche Befundblätter angefertigt, die dann in digitalisierter Form zusätzlich gespeichert wurden und in der Datenbank abrufbereit hinterlegt werden konnten. Die Datenbank, die ich mit Herrn Görtz für die Auswertung dieser Arbeit entwickelt habe, ist ein wichtiger Teil der Arbeit und ihrer methodischen Umsetzung. Alle Befunde wurden in der Datenbank ausgewertet und werden im Teil „Ergebnisse“ gezeigt. Es folgen nun bildliche Ausschnitte aus der Benutzeroberfläche der Datenbank. Die Abbildungen 2 bis 9 zeigen Screenshots der in FileMaker Pro $^{\circledR}$ entwickelten Datenbankoberfläche. $\mathrm{Zu}$ sehen sind Beispiele der verschiedenen Oberflächen, die auf alle individuellen Ansprüche abgestimmt sind.

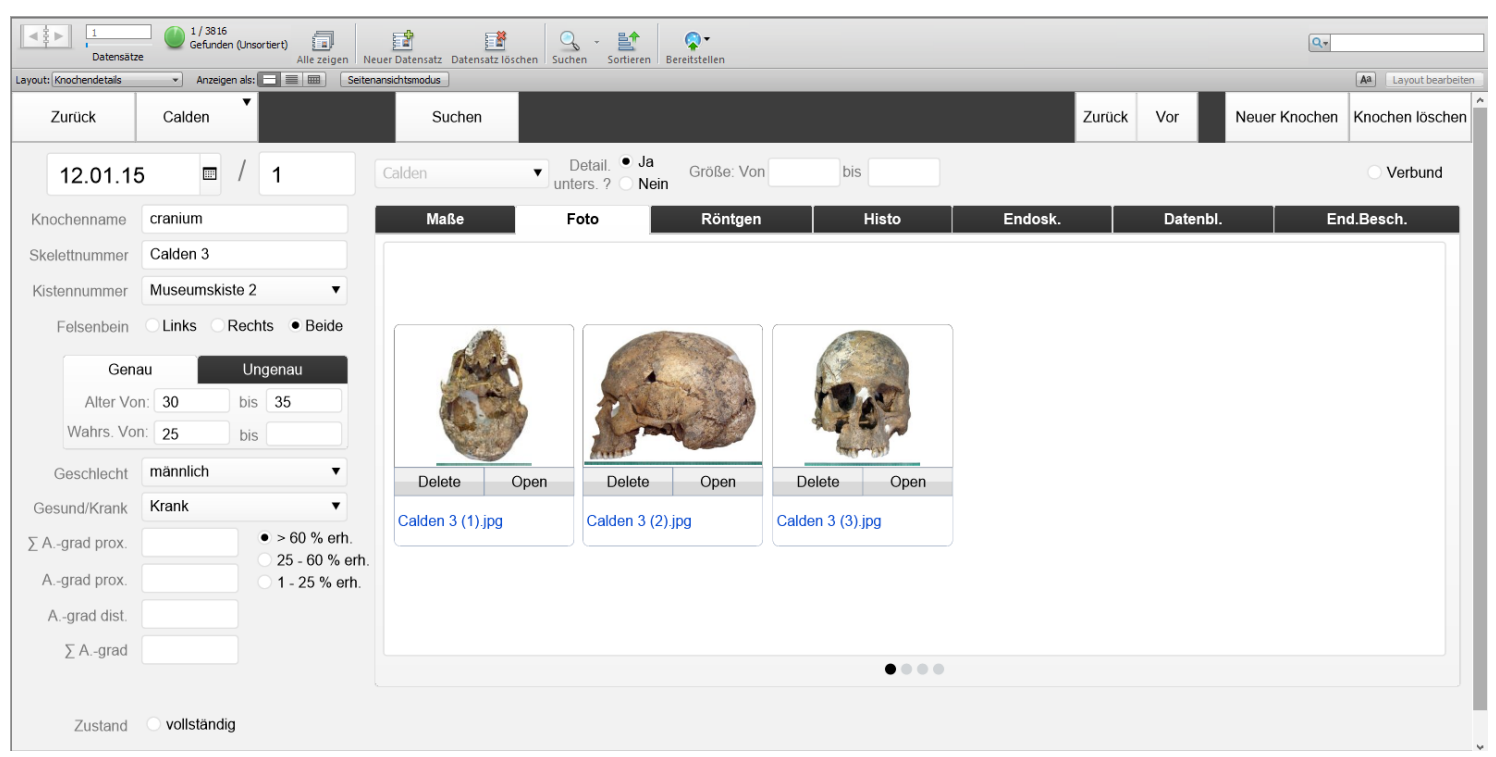

Abb. 2 Screenshot 1 aus FileMaker Pro ${ }^{\circledR}$; Cranien mit Fotografien 


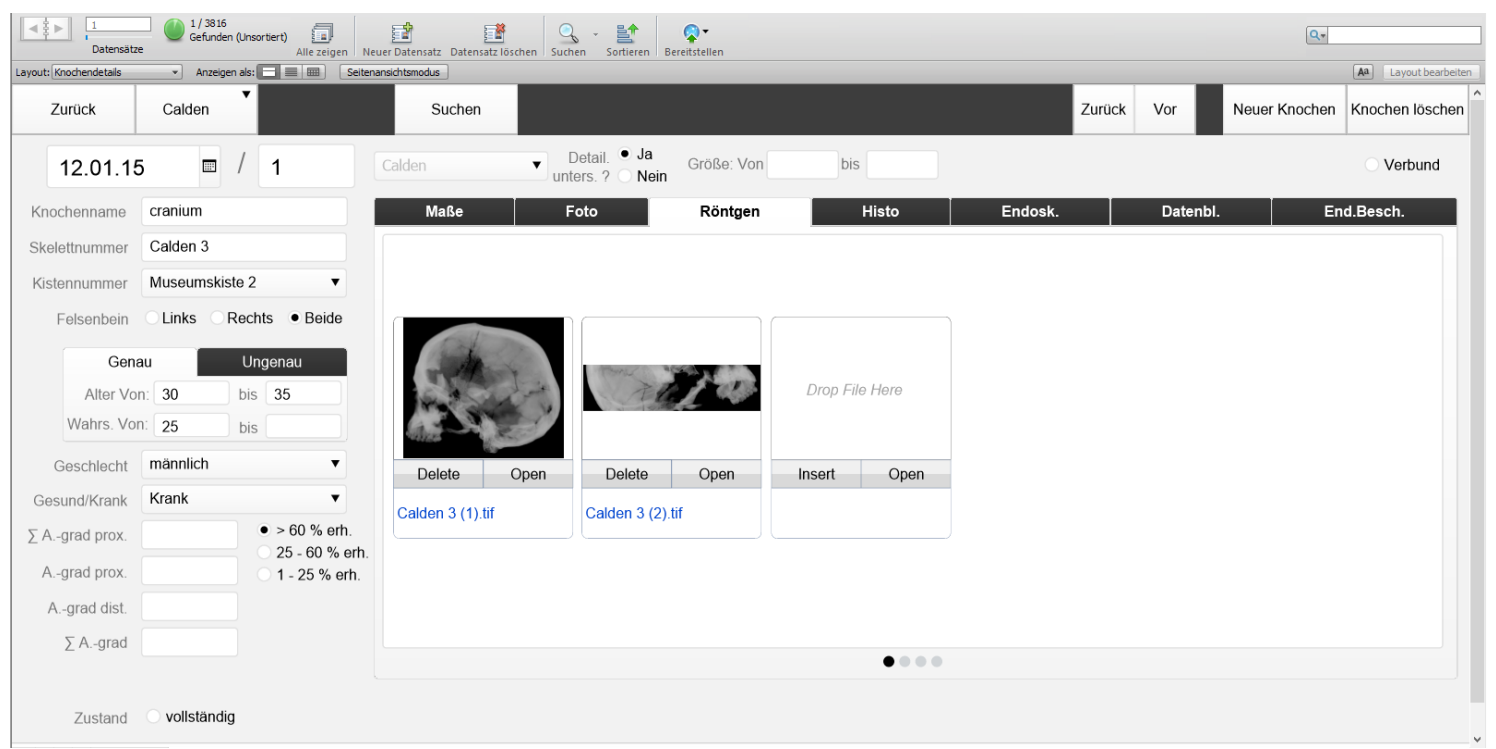

Abb. 3 Screenshot 2 aus FileMaker Pro ${ }^{\circledR} ;$ Cranien mit Röntgenbildern

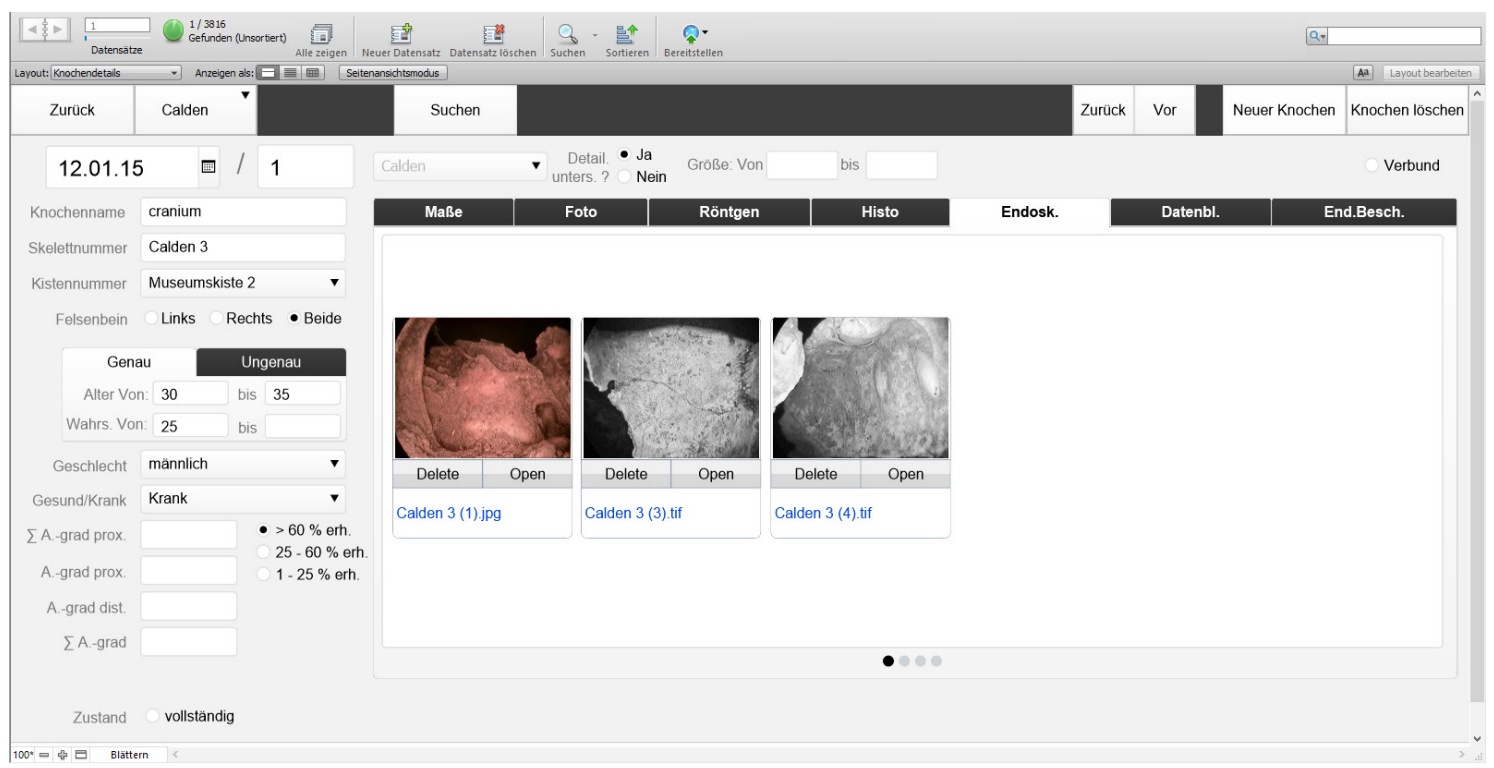

Abb. 4 Screenshot 3 aus FileMaker Pro ${ }^{\circledR}$; Cranien mit Endoskopfotografien 


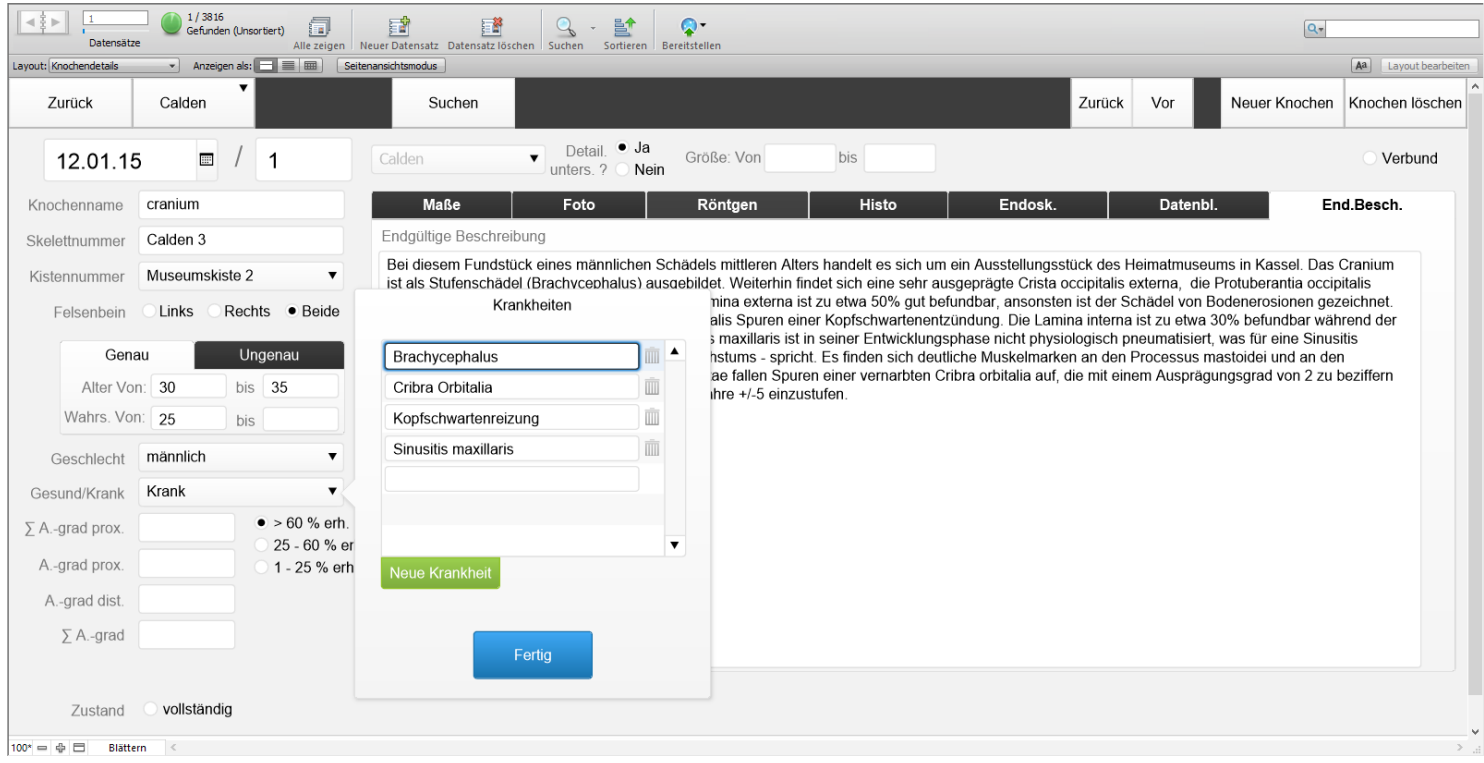

Abb. 5 Screenshot 5 aus FileMaker Pro ${ }^{\circledR}$; Spuren von Krankheiten

Im Hintergrund ist der Menüpunkt „End.Besch."(Endgültige Beschreibung) geöffnet zu sehen, in dem das Fundstück detailliert beschrieben werden konnte.

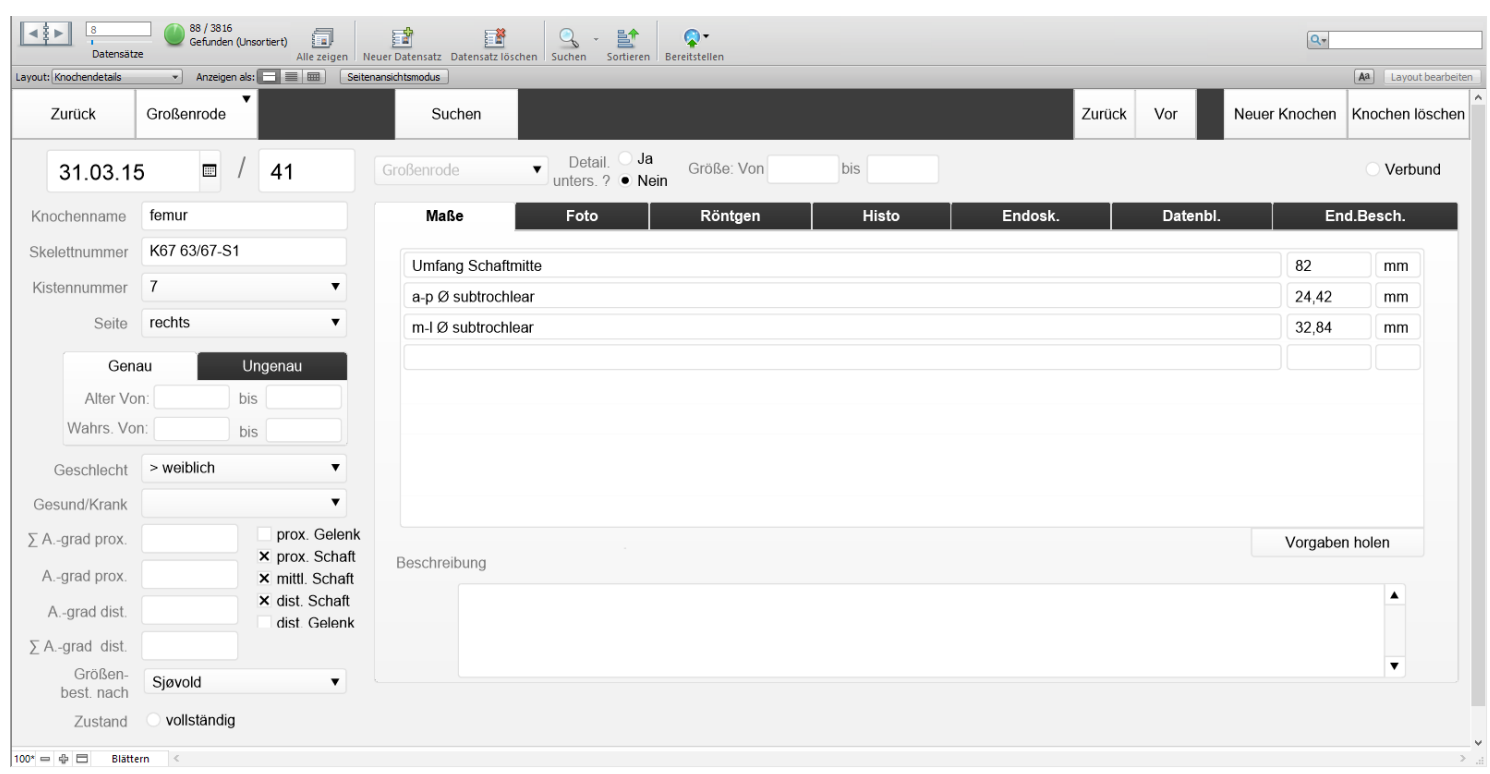

Abb. 6 Screenshot 6 aus FileMaker Pro ${ }^{\circledR}$; Befunde von Langknochen

Die anderen Oberflächen der Menüpunkte von z. B. "Röntgen“ sind analog zu denen von den Cranien. 


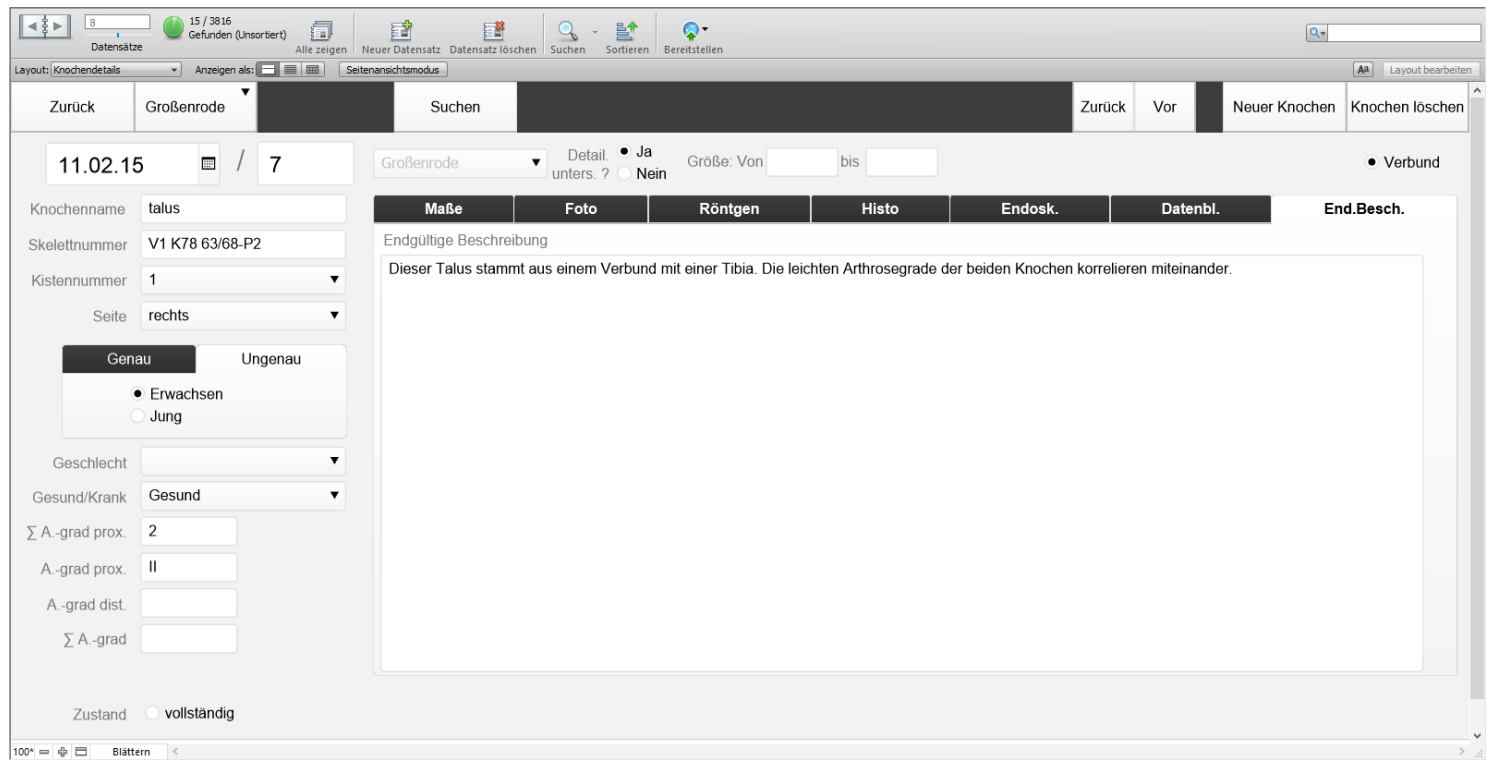

Abb. $7 \quad$ Screenshot 7 aus FileMaker Pro ${ }^{\circledR}$; Arthrosegrad der Gelenke

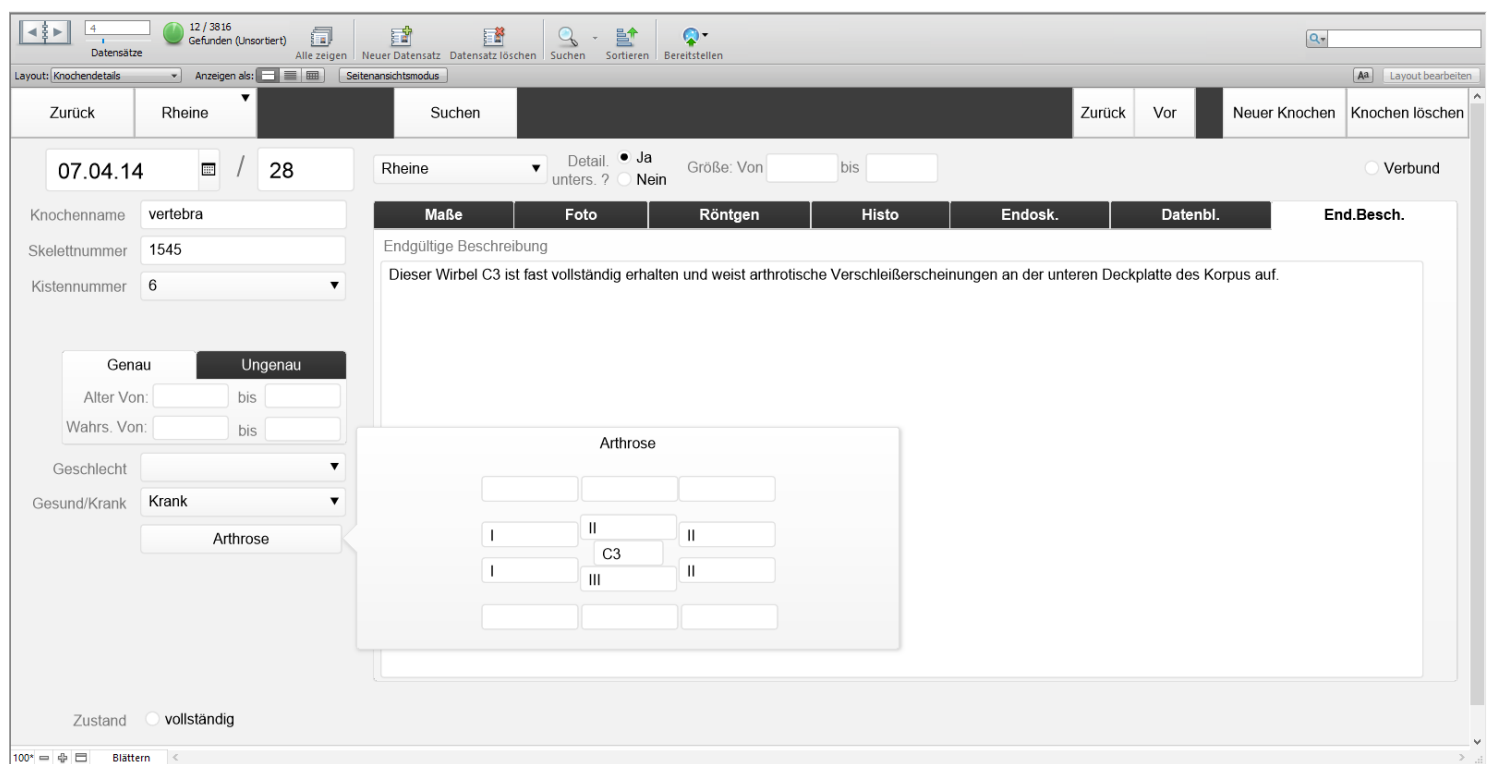

Abb. 8 Screenshot 8 aus FileMaker Pro ${ }^{\circledR}$; Arthrosegrad von Wirbeln 


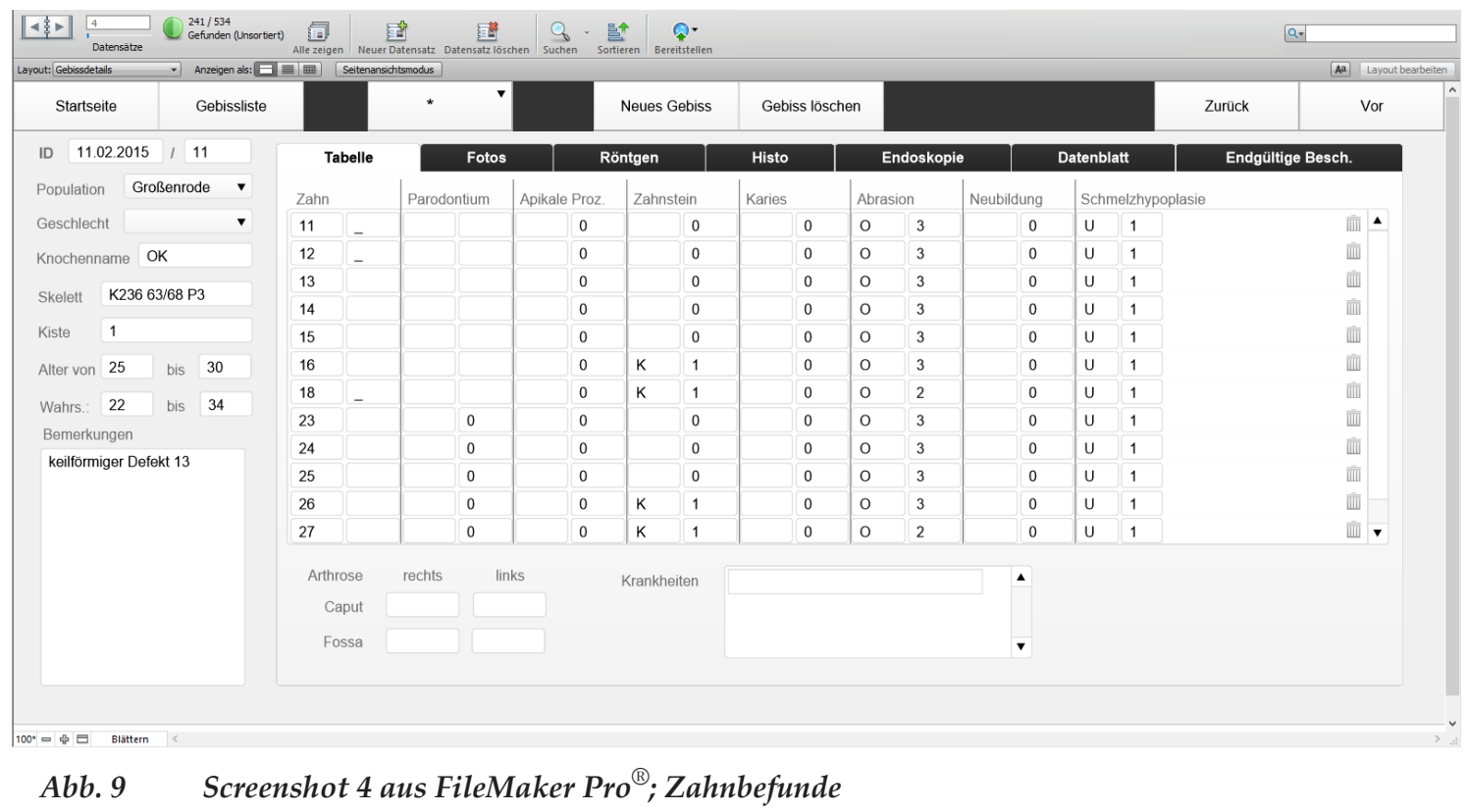

Sämtliche Befundbögen (über 600 Seiten) wurden eingescannt, sie hier alle abzudrucken erscheint jedoch nicht sinnvoll, da sie keinen weiteren Erkenntnisgewinn zulassen würden. Exemplarisch werden im Anhang besondere Befunde vorgestellt. Alle Befundbögen sind handgezeichnet. Aus Gründen der Genauigkeit wurden sie in der Regel nicht erneut digital erstellt. Es sollte an dieser Stelle vermieden werden, dass die zuvor teilweise sehr präzise gezeichneten Auffälligkeiten verfälscht werden.

Für Fundstücke, die einem Verband aus mehreren Knochen zuzuordnen waren, wurde die Zusatzbezeichnung „im Verband“ gewählt, um direkt zu erkennen, dass Fundstücke zusammengehören. Da sie nicht immer in denselben Kisten aufbewahrt und oft erst nach der Registrierung einander zuzuordnen waren, ergibt sich eine in den fortlaufenden Nummern nicht direkt nachvollziehbare Nummerierung. Um es dem Leser zu vereinfachen, Knochenverbände zu finden, wurde die Fundstückbezeichnung „V" als Präfix mit einer Nummer gewählt. So gehören alle „V23“ beispielsweise zu einem Verband.

\subsubsection{Auswertung}

Die Auswertung der Befunde erfolgte mit dem Computerprogramm Filemaker Pro ${ }^{\circledR}$ und LibreOffice Calc ${ }^{\circledR}$; die gesamte Arbeit wurde dann in Adobe InDesign ${ }^{\circledR}$ formatiert. Fotografische Aufnahmen wurden digital mit den Computerprogrammen PhotoScape $^{\circledR}$ und Adobe Photoshop ${ }^{\circledR}$ bearbeitet. Weiterhin wurden die Microsoft ${ }^{\circledR}$ Programme Word ${ }^{\circledR}$ und Paint ${ }^{\circledR}$ verwendet. 


\subsubsection{Material- und Methodenkritik}

Alle angewandten Methoden zur Befunderhebung unterliegen gewissen Rahmenbedingungen und bringen Fehler mit sich. Durch Verwendung verschiedener Herangehensweisen und Techniken wurde stets versucht, die Fehlerhaftigkeit der Befunde sowie Alters- und Geschlechtsbestimmungen zu minimieren. Dennoch weisen alle Methoden Grenzen auf: So kann man z. B. bei der Altersbestimmung eines weiblichen Individuums nicht verlässlich das Becken heranziehen, da durch Geburtsvorgänge ähnliche Spuren von Veränderungen entstehen können, wie sie ebenfalls bei Alterungsprozessen auftreten. Ob das befundete Beckenfundstück also von einem jüngeren Individuum stammte (und bloß viele Geburten erlebt hatte) oder von einem älteren (welches gar keine Geburten erlebt hatte), ist demnach post mortem nicht mehr erkennbar. Ähnliches gilt für die radiologische Bestimmung des Alters von Oberschenkelknochen adulter und seniler Individuen. Hier kann durch mehr oder weniger Beanspruchung ein Knochen deutlich jünger oder älter wirken, als er zum Zeitpunkt des Todes in Wahrheit war. Insgesamt ist eine Altersbestimmung durch Knochenstrukturanalyse eines ausgewachsenen Knochens nur mit Einschränkung vorzunehmen, da diese zu sehr den Veränderungen durch Lebensverhältnisse unterliegt und damit verfälscht sein kann. Die Bewertung der Schädelnähte ist auch keine absolut fehlerfreie Methode, so differieren die Altersdiagnosen manchmal schon bei Bewertung des internen und externen Ossifikationsgrades der Schädelnähte. Gleiches gilt auch für das Becken, an dem die Alterserscheinungen an verschiedenen Stellen unterschiedlich ausgeprägt sein können. Dahingegen ist die Altersbestimmung von subadulten Individuen genauer. Je mehr Informationen über das Individuum bekannt sind und je vollständiger ein Skelet vorliegt, desto genauer kann ein Alter zum Zeitpunkt des Sterbens angegeben werden. Für diese Arbeit lagen aber überwiegend Einzelfundstücke vor. Weiterhin ist festzuhalten, dass die Altersbestimmung auf tabellarischen Nachschlagewerken basiert, die für bestimmte Populationen entworfen wurden und damit nie allgemeingültig sein können. Oft wurden diese Tabellen aufgrund statistischer Auswertungen von Funden und Vergleichen mit rezenten Individuen der heutigen Zeit mit bekanntem Sterbealter entworfen. Hier kommt zum Tragen, dass sich Populationen zu unterschiedlichen Zeiten und an verschiedenen Orten in ihrer Lebensweise und ihrer Physis unterschiedlich entwickelten (z. B. Eveleth und Tanner 1976). Allein das birgt einen möglicherweise nicht vermeidbaren Fehler, der bei allen Altersbestimmungen berücksichtigt werden muss. Viele Angaben des Sterbealters sind hier allenfalls als Näherungen anzusehen, was sowohl an der unzureichenden Genauigkeit der Methodik für neolithische Populationen liegt als auch daran, dass bei der angewandten Methodik das biologische Alter dem chronologischen gleichgesetzt 
wird. Durch grundsätzliche Fehler in der Methodik kann ein Durchschnittsalter einer Population entweder insgesamt zu alt oder zu jung eingestuft werden (Masset 1971).

Für die Geschlechtsbestimmung sind die Methoden ähnlich begrenzt verwendbar, was auch wieder mit der Individualität der Population an sich und mit der Entwicklung der Maßstäbe für die Geschlechtsbestimmung aus statistischen Untersuchungen zusammenhängt. Hierzu gibt es Tabellen, mit deren Hilfe man dann die Bestimmung des Geschlechtes zu objektivieren versucht. Das Objektivieren durch Tabellen, die ein Stück weit auf subjektiven Bewertungskriterien der Befundenden beruhen, ist sicherlich nicht optimal. Weiterhin gelten bei der Geschlechtsbestimmung Kriterien, die für in Studien untersuchte Individuen mit bekanntem Geschlecht erarbeitet wurden. Nun ist fraglich, ob diese Kriterien, die manchmal mit bestimmten Maßen unterstützt werden, für andere Individuen generell gelten. Natürlich wurde versucht, Untersuchungskriterien und -methoden für die Population aus Calden, Rheine und Großenrode angemessen zu modifizieren, doch entscheidet nicht zuletzt der subjektive Blick der Untersucher über definierte Merkmale. Beispielsweise wäre eine sichere Geschlechtsbestimmung nur mithilfe zusätzlicher biochemischer Untersuchungen an sehr gut erhaltenem Knochenmaterial möglich.

Einschränkungen gelten auch für die Befundung der pathologischen Veränderungen: Differentialdiagnostisch sind nicht immer alle Spuren von verschiedenen Erkrankungen voneinander abzugrenzen. So sind beispielsweise Knochenstrukturen aufgrund ihres Erhaltungszustands mitunter nur unzureichend untersuchbar. Auch kann nicht jeder Knochen einer maximal umfangreichen Diagnostik unterzogen werden. Dies bedeutet im Umkehrschluss, dass nach dem bloßen Hinsehen und Betrachten mit einer Lupe ein Verdacht vorliegen muss, bevor der Knochen weitergehend mit teilweise sehr kosten - und arbeitsaufwändigen Mitteln untersucht wird, um den Verdacht zu erhärten oder zu verwerfen. 


\section{Ergebnisse}

Die Befunderhebung erfolgte mit einer ausführlichen Dokumentation. Die Ergebnisse sollen hier dargestellt werden.

Der Struktur des menschlichen Skelets von Kopf bis Fuß folgend, beginnt die Darstellung der Ergebnisse mit den Schädeln. Danach werden die Ergebnisse zu den befundeten Zähnen und Kiefern vorgestellt und anschließend die Befundergebnisse der Postcranien. Weiterhin folgen die Ergebnisse der Alters- und Geschlechtsbestimmung sowie ggf. die Rekonstruktion der Körperhöhe, basierend auf der Länge von Oberschenkelknochen. In den jeweiligen Kategorien werden die Populationen in der Reihenfolge Calden, Rheine und schließlich Großenrode vorgestellt. Allgemeine Erklärungen zu den Darstellungen der Ergebnisse werden im Abschnitt für die Population aus Calden gemacht. Individuell spezifische Erläuterungen zu den Ergebnissen der jeweiligen Populationen sind im entsprechenden Abschnitt für die Populationen aus Calden, Rheine und Großenrode zu finden. Die grundsätzliche Darstellungsweise ist für die drei Populationen grundsätzlich identisch.

Im Ergebnisteil dieser Arbeit werden keine Einzelergebnisse vorgestellt, da diese in ihrer Gesamtheit sehr umfangreich sind, und in dieser Form kaum etwas Wesentliches zur Aussage über den Gesundheitszustand der untersuchten Populationen beitragen. Der Ergebnisteil zeigt die relevanten Resultate der ausgewerteten, gesamten Befunderhebung. Im Anschluss an den Ergebnisteil findet sich eine Aufstellung ausgewählter Fundstücke und Teilskelete, die näher vorgestellt werden sollen. Dort werden diese ausgewählten Ergebnisse und Befunde mit Fotos illustriert und der Erhaltungszustand gegebenenfalls mit Skeletbögen belegt. Weiterhin findet sich dort eine detaillierte Beschreibung der Befunde zu den Skeletfunden und gegebenenfalls die Auswertung lichtmikroskopischer, rasterelektronenmikroskopischer, binokular-lupenmikroskopischer, endoskopischer, röntgenologischer und digitalvolumentomografischer Untersuchungen und Bildgebungen. Es handelt sich um exemplarische Darstellungen besonders auffälliger Befunde, da es im Rahmen dieser Arbeit nicht möglich ist, sämtliche Befunde in derselben Art und Weise zu zeigen. Alle Befunde zu den drei Populationen wurden jedoch stets vollständig und sorgfältig erhoben und finden auch im Anhang in schriftlicher Form Berücksichtigung. Wegen der Fülle des Materials befinden sich die vollständigen Untersuchungsergebnisse als PDF-Dateien auf einer CD. Diese PDF-Dateien wurde aus der für diese Arbeit speziell angelegten Datenbank exportiert. Die in der Datenbank abgespeicherten Ergebnisse können in den PDF-Dateien im Detail, individuell und vollständig eingesehen werden. 


\subsection{Calden}

Zuerst werden die Ergebnisse der Befunderhebung der Population aus Calden vorgestellt.

\section{Mindestindividuenzahl}

Für die cranialen und postcranialen Skeletelemente konnte eine Mindestindividuenzahl von 39 anhand rechter Femora errechnet werden. Errechnet nach Zähnen beträgt die Mindestindividuenzahl 26; der linke untere erste Molar (Zahn 36) hat sich am häufigsten erhalten.

\subsubsection{Cranien}

Insgesamt gibt es zu den Schädelfunden aus Calden 117 Datensätze (angelegt in der Datenbank), in die die Ergebnisse der Schädelbefunderhebung eingetragen wurden.

Das heißt jedoch nicht zwangsläufig, dass die darin enthaltenen Fundstücke von 117 verschiedenen Individuen stammen. Die Zahl ist so zu verstehen, dass es sich um 117 Fundstücke - oder besser gesagt um Datensätze - handelt, die auch mehrere Schädelfundstücke enthalten können. Damit ist eine genaue Individuenzahl aufgrund der Anzahl an Datensätzen allein nicht zu nennen. Werden aber nur die Schläfenbeine einer Seite - oder Fragmente davon - gezählt, so kann man mit dieser Region eines Schädels eine Mindestindividuenzahl errechnen. Die Felsenbeine - oder Fragmente derselben - sind deswegen am häufigsten erhalten, weil sie besonders massive Knochenanteile besitzen, die weniger von Bodenerosionen oder anderen postmortalen Beschädigungen verändert oder zerstört werden. Für die Population aus Calden beträgt die Mindestindividuenzahl 36 - errechnet ausschließlich aufgrund der erhaltenen Felsenbeine oder Felsenbeinfragmente einer Seite. Rechte Felsenbeine haben sich 36-fach erhalten, die linken 34-fach.

Die folgende Grafik (Abb. 10) veranschaulicht, welche Schädelkompartimente sich in welcher Anzahl erhalten haben und ob sie als nicht befundbar - oder wenn befundbar - als "gesund“ oder "krank" diagnostiziert wurden. Die Kompartimente werden für sich betrachtet, während es für diese Auflistung zunächst unerheblich ist, ob mehrere Kompartimente einem Individuum zugeordnet werden konnten oder nicht. Hier ist das bloße Vorhandensein entscheidend. 


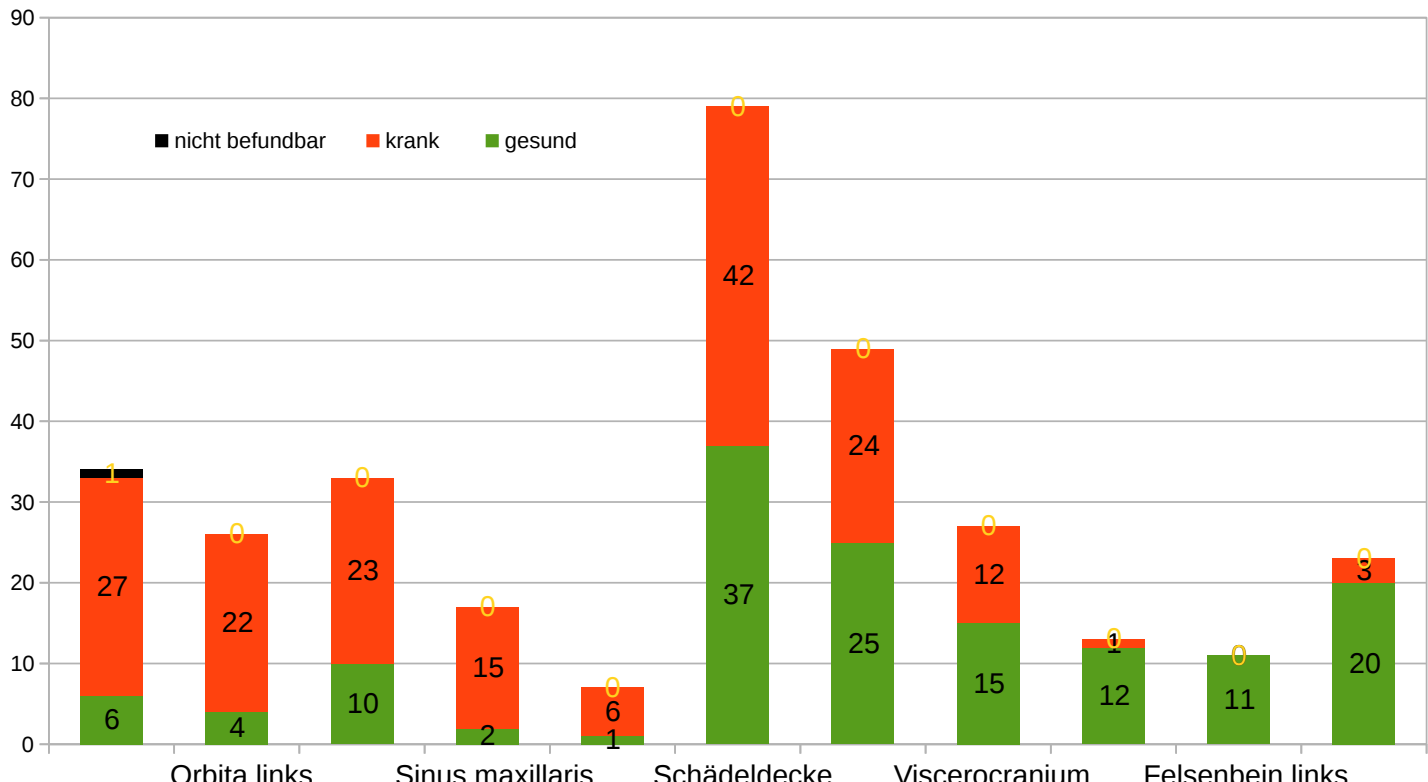

Orbita rechts Sinus frontalis Sinus sphenoidalis Schädelbasis Felsenbein rechts beide Felsenbeine

Abb. $10 \quad$ Verteilung der Schädelfragmente; Calden

Das Balkendiagramm zeigt die absolute Anzahl der erhaltenen Kompartimente mit Berücksichtigung des Befundungszustandes "nicht befundbar", "krank" und, gesund". Die als "krank" bezeichneten Fundstücke weisen Veränderungen auf, die meist als Spuren von Erkrankungen diagnostiziert wurden. Auf der Ordinate befindet sich die Angabe der Gesamtzahl.

Eine genaue Summe der zusammenhängenden Schädelfragmente findet sich in nachfolgender Grafik (Abb. 11). Dort ist aufgeführt, in welcher Menge Fundstücke zu dem Cranium eines Individuums zugeordnet werden konnten, sodass insgesamt 1-25\%, 26-60\% oder mehr als 61\% dem Schädel eines Individuums zuzuordnen waren.

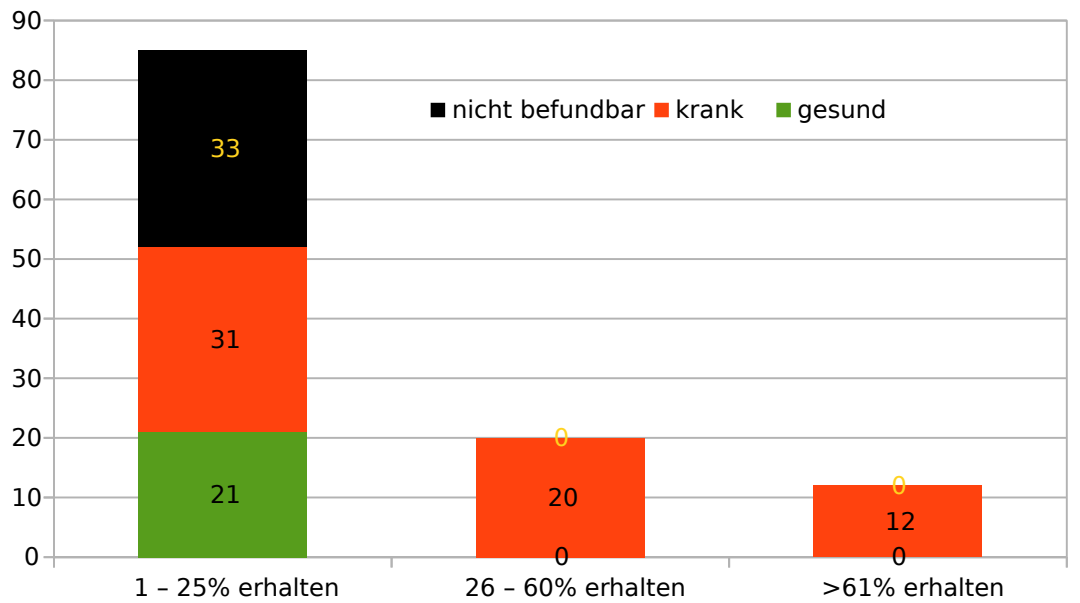

Abb.11 Absolute Anzahl der Erhaltungsmenge je Cranium eines Individuums; Calden

Einteilung in die Kategorien "1-25\%", "26-60\%" und ">61\%". Auf der Ordinate befindet sich die Angabe der Gesamtzahl. 
Alle Fundstücke wurden nach der Befunderhebung in ",nicht befundbare“, „kranke" und "gesunde“ Schädelkompartimente sortiert (Abb. 12). Somit ist auf den ersten Blick ersichtlich, um was für ein Fundstück es sich handelt und was für ein Befund zugrunde liegt. Insgesamt wurden die Datensätze so präzise wie möglich benannt und alle Informationen wurden hinterlegt, sodass anschließend bei der Auswertung alle Fundstücke erfasst werden konnten, die bestimmte Kategorien zum Beispiel "gesund“ oder „krank“ - repräsentieren. Nur so ist es möglich, die gesamte Aussagekraft aller Befunde auszuschöpfen und die verschiedenen Schnittmengen zu berücksichtigen.

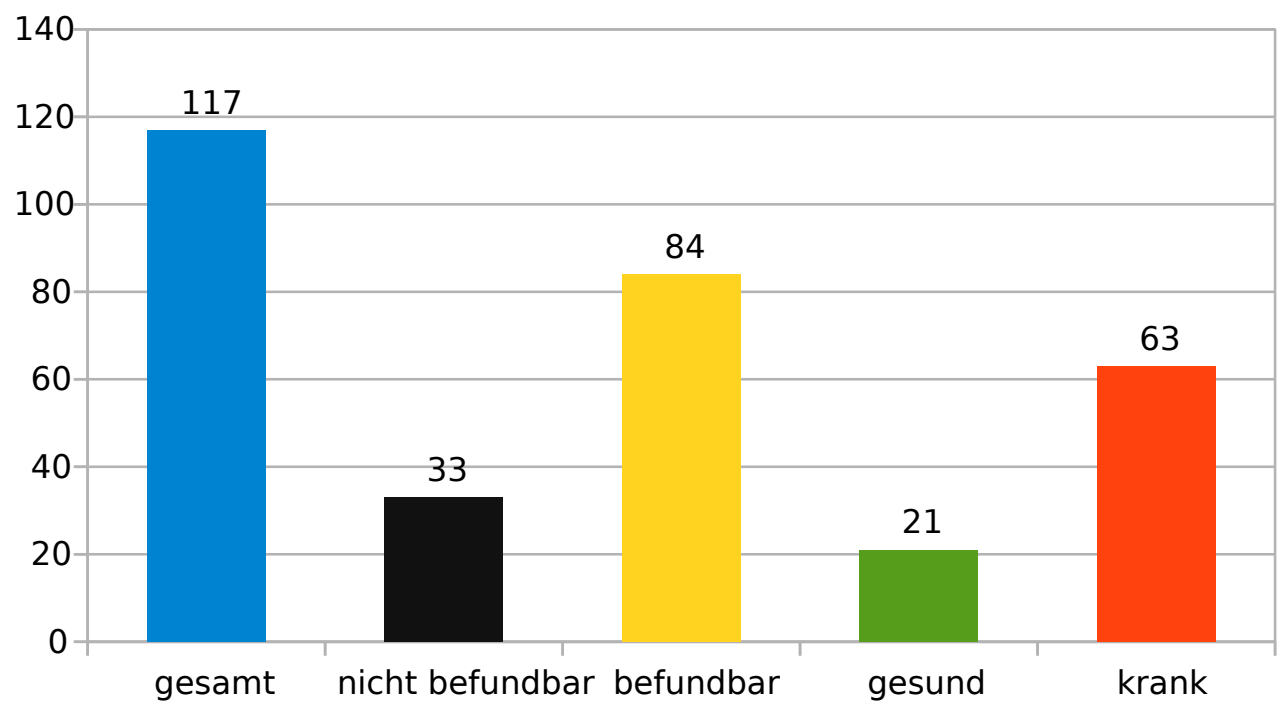

Abb.12 Gesamtheit der Datensätze für die Schädelfunde; Calden

Darstellung in den Kategorien "gesamt", "nicht befundbar", "befundbar", "gesund"und "krank". Dabei ergeben "nicht befundbar" und "befundbar" die Gesamtsumme und "gesund" und "krank" summieren sich zu "befundbar". Auf der Ordinate befindet sich die Angabe der Gesamtzahl.

Nachdem die genannten Kategorisierungen vorgenommen worden waren, wurden die als „krank" befundeten Fundstücke nach der jeweiligen Krankheit eingeteilt (Abb. 13). Bei der großen Anzahl von Fragmenten und Schädelsplittern - die zum Teil auch krankhafte Veränderungen aufwiesen - ist eine vergleichende Aufstellung der Ergebnisse schwierig zu realisieren. Deswegen wurden alle Schädelkompartimente - unabhängig davon, wie viele Fragmente einem bestimmten Individuum zuzuordnen waren - für sich und damit individuell betrachtet. 


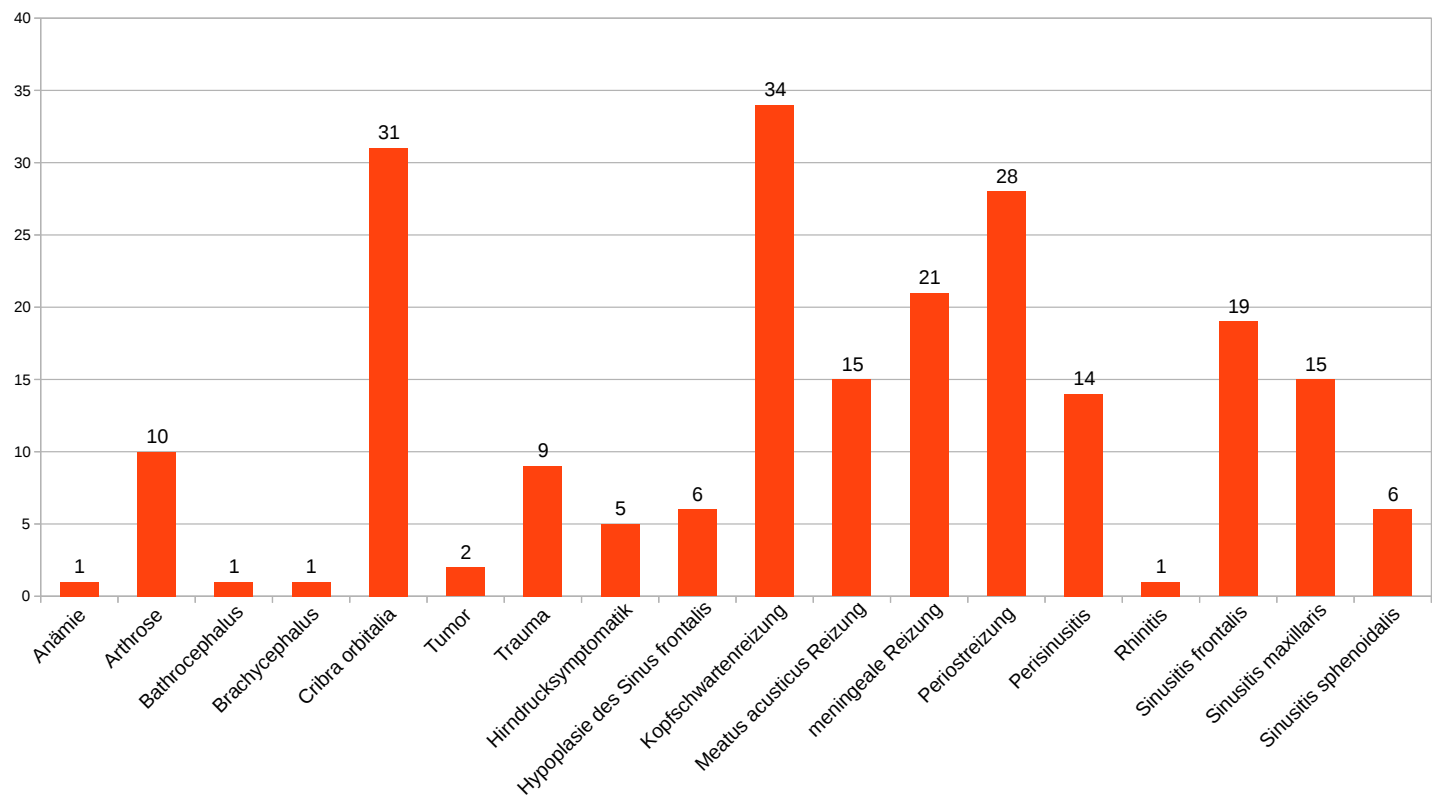

Abb.13 Diagnostizierte Veränderungen an den Schädelfunden; Calden Auf der Ordinate befindet sich die Angabe der Gesamtzahl.

\subsubsection{Zähne}

Dieser Ergebnisteil beinhaltet die Fundstücke aus dem Mund-Kieferbereich der Population aus Calden. Aufgeführt sind die Veränderungen an Kiefern und Zähnen. Sortiert wurden die Ergebnisse der Vergleichbarkeit halber nach Zahngruppen. Wenn Zähne und Kiefer einem Individuum zuzuordnen waren, sind die (Teil-) Gebisse und zugehörige Knochen als zusammengehörig im Ergebnisteil im Anhang dargestellt worden. An dieser Stelle sollen vorerst nur die Gesamtergebnisse gezeigt werden, denn wichtiger und anschaulicher ist die Übersicht über die Gesamtheit der verschiedenen Zahngruppen. Diese ergeben schlussendlich die auswertbaren Ergebnisse. Es folgen verschiedene Diagramme, die den Zustand der Zähne der Individuen möglichst anschaulich beleuchten sollen. Insgesamt wurden für die Population aus Calden 90 Datensätze angelegt, die alle Zähne, den Zahnhalteapparat und die knöchernen Strukturen eines Ober- und Unterkiefers enthalten können. Zusammen enthalten diese 90 Datensätze 838 Zähne bzw. Zahn-Kieferregionen (leere Alveolen mit inbegriffen). 


\subsubsection{Bleibende Zähne}

Abb. 14 zeigt die Anzahl der erhaltenen Zähne und leeren Alveolen des Dauergebisses.

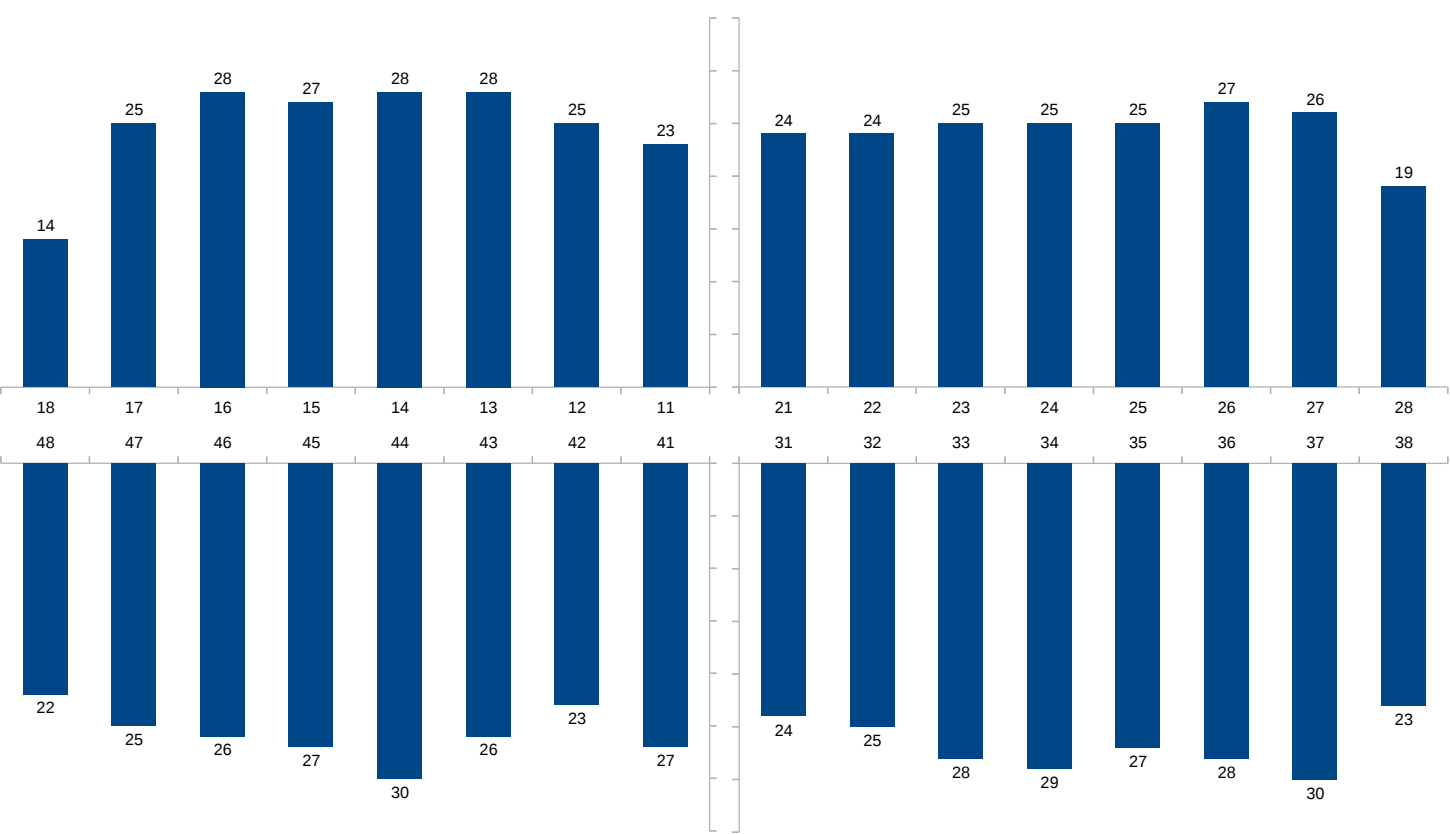

Abb.14 Erhaltene Zähne und leere Alveolen des Dauergebisses; Calden

Die Ansicht ist so gewählt, dass die vier Quadranten sichtbar sind, als würde man das Gebiss von vorn betrachten (übliche Darstellung in der Zahnmedizin). In dieser Abbildung befindet sich oben links (erster Quadrant) der obere rechte Quadrant des Individuums (Zähne 11 bis 18). Über den Säulen befindet sich die Anzahl der jeweiligen Zähne bzw. Kieferregionen. Leere Alveolen postmortal verlorener Zähne wurden in dieses Diagramm mit aufgenommen.

Im Folgenden sollen alle Zahntypen der bleibenden Zähe mit den befundeten Veränderungen vorgestellt werden. Dafür wurden die Zähne in die acht verschiedenen Zahntypen sortiert, nämlich in erste und zweite Incisivi, Canini, erste und zweite Prämolaren und erste, zweite und dritte Molaren. Alle vier Quadranten wurden zusammengezählt, also beispielsweise alle Zähne 12 (gesprochen „eins-zwei“), 22, 32 und 42. Beispiel: Von der Population aus Calden haben sich insgesamt 32 zweite Incisivi erhalten. Diese Zahl entspricht der tatsächlichen Zahnzahl. Die Gesamtanzahl „"n“ bezieht sich auf die Gesamtheit der Befunde der entsprechenden Zahn-Kieferregion - leere Alveolen eingeschlossen. Um das vorherige Beispiel erneut aufzugreifen, handelt es sich bei den zweiten Incisivi um $\mathrm{n}=97$.

58 Zähne wurden intravital verloren. 
Die Diagramme 15 bis 22 zeigen die Veränderungen an den acht Zahngruppen der bleibenden Zähne aller vier Quadranten in den Gebissen der Individuen der Population aus Calden. In der Diagrammbeschriftung ist die Zahngruppe angegeben, um die es sich handelt. „n“ steht für die Gesamtzahl der befundeten Fundstücke (Zähne und leere Alveolen postmortal verlorener Zähne), die „,tatsächliche Zahnzahl“ gibt an, wie viele Zähne der zugrunde liegenden Zahngruppe auch tatsächlich als Zahn vorhanden waren. Aufgeschlüsselt sind die Diagramme alle auf dieselbe Art und Weise nach „gesund“ und „krank“. Über den Säulen sind zwei Zahlen angegeben. Die linke ist die absolute Zahl der Zähne, die eine Veränderung besitzen oder nicht besitzen, die rechte ist die Prozentzahl der Zähne, die - bezogen auf die Gesamtzahl der befundeten Zähne - eine bestimmte Veränderung aufweisen.

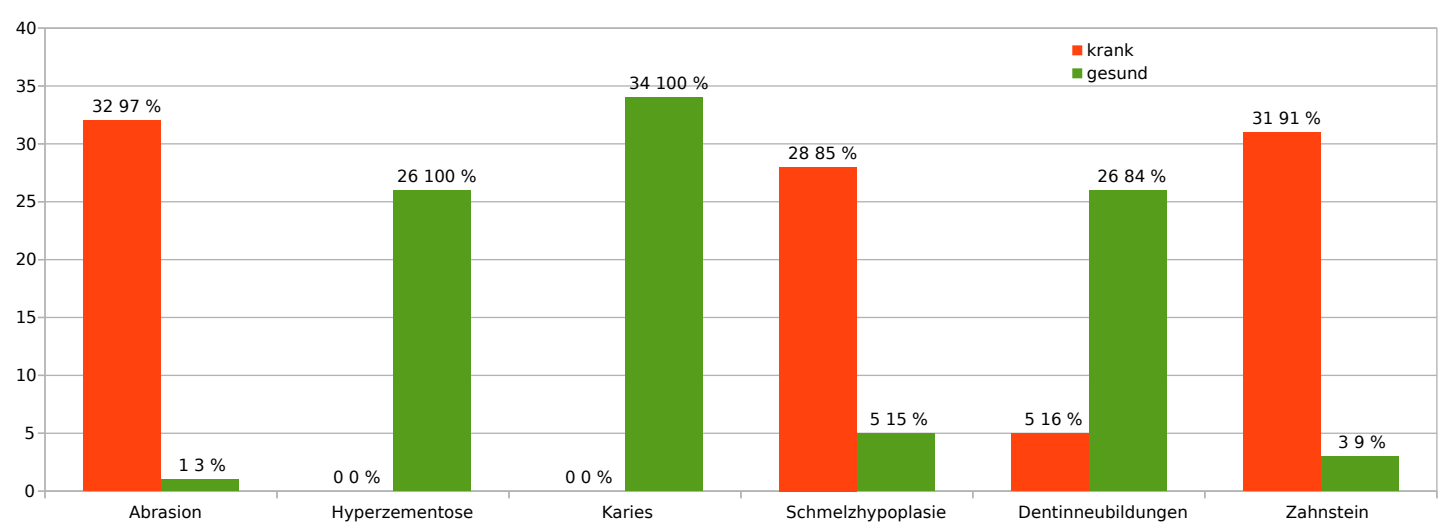

Abb. 15 Veränderungen an allen bleibenden ersten Incisivi; Calden

Alle ersten, bleibenden Incisivi der vier Quadranten, $n=98$, tatsächliche Zahnzahl: 40, auf der Ordinate befindet sich die Angabe der Gesamtzahl, über den Säulen links die absoluten Anzahlen, rechts daneben die Prozentzahlen. "n" umfasst alle Zähne und leere Alveolen, die "tatsächliche Zahnzahl" gibt nur die Zahl der Zähne an, ohne leere Alveolen. 


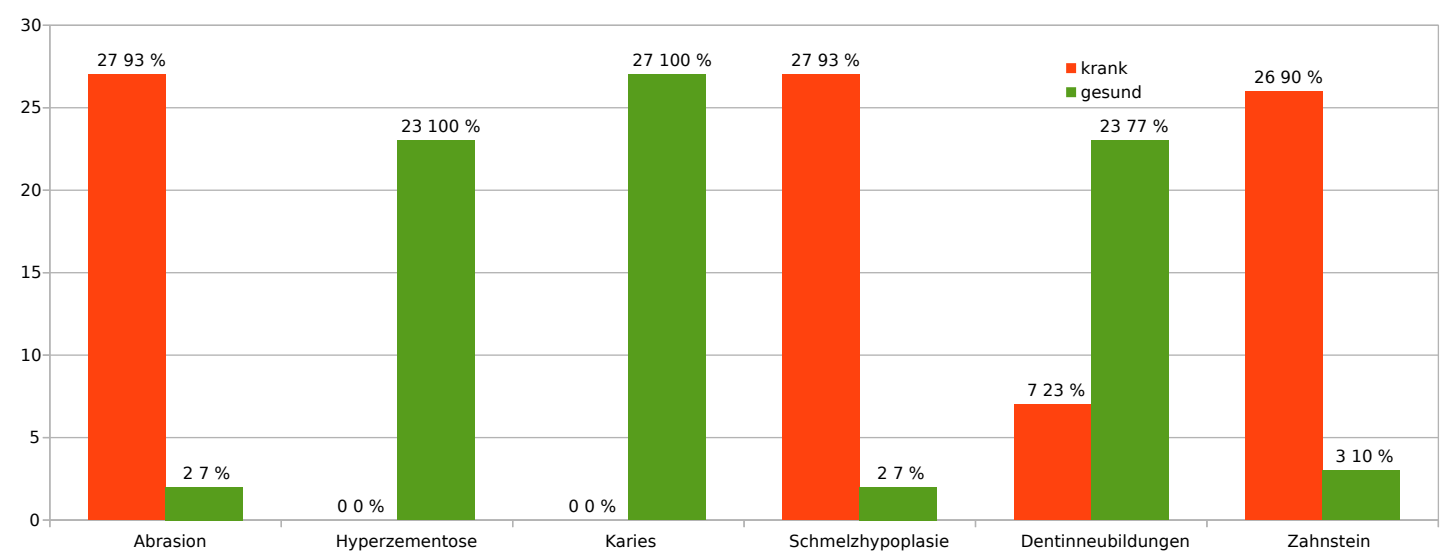

Abb. $16 \quad$ Veränderungen an allen bleibenden zweiten Incisivi; Calden

Alle zweiten, bleibenden Incisivi der vier Quadranten, $n=97$, tatsächliche Zahnzahl: 32, auf der Ordinate befindet sich die Angabe der Gesamtzahl, über den Säulen links die absoluten Anzahlen, rechts daneben die Prozentzahlen. "n" umfasst alle Zähne und leere Alveolen, die "tatsächliche Zahnzahl" gibt nur die Zahl der Zähne an, ohne leere Alveolen.

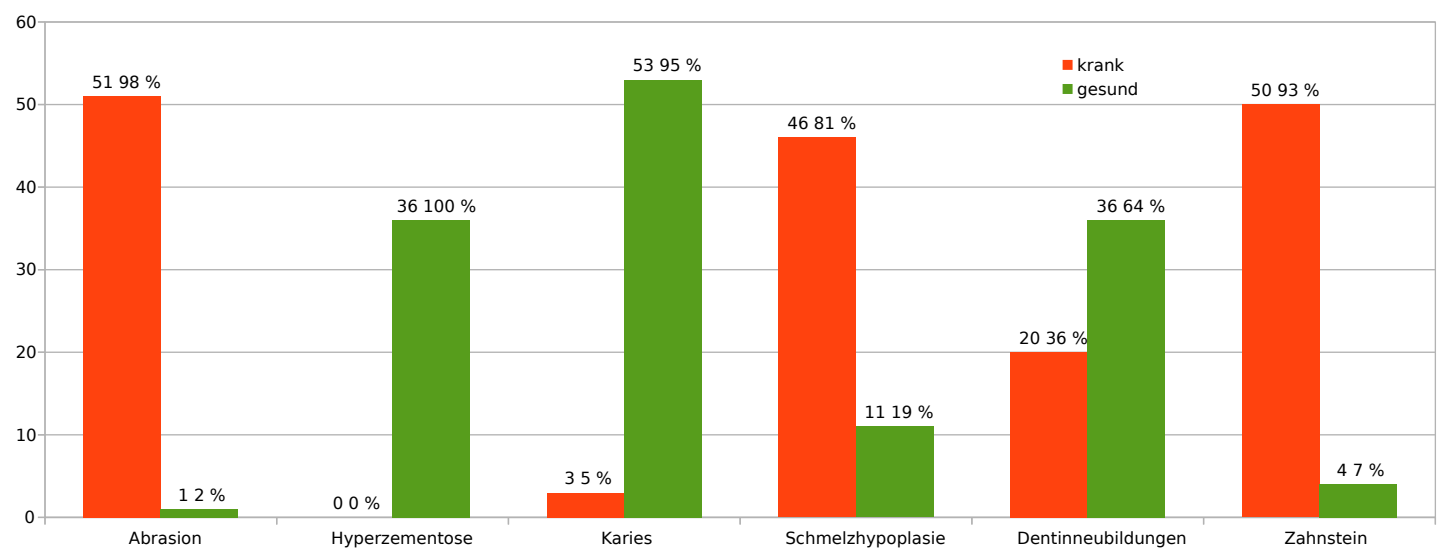

Abb.17 Veränderungen an allen bleibenden Canini; Calden

Alle bleibenden Canini der vier Quadranten, $n=107$, tatsächliche Zahnzahl: 69, auf der Ordinate befindet sich die Angabe der Gesamtzahl, über den Säulen links die absoluten Anzahlen, rechts daneben die Prozentzahlen. "n" umfasst alle Zähne und leere Alveolen, die "tatsächliche Zahnzahl” gibt nur die Zahl der Zähne an, ohne leere Alveolen. 


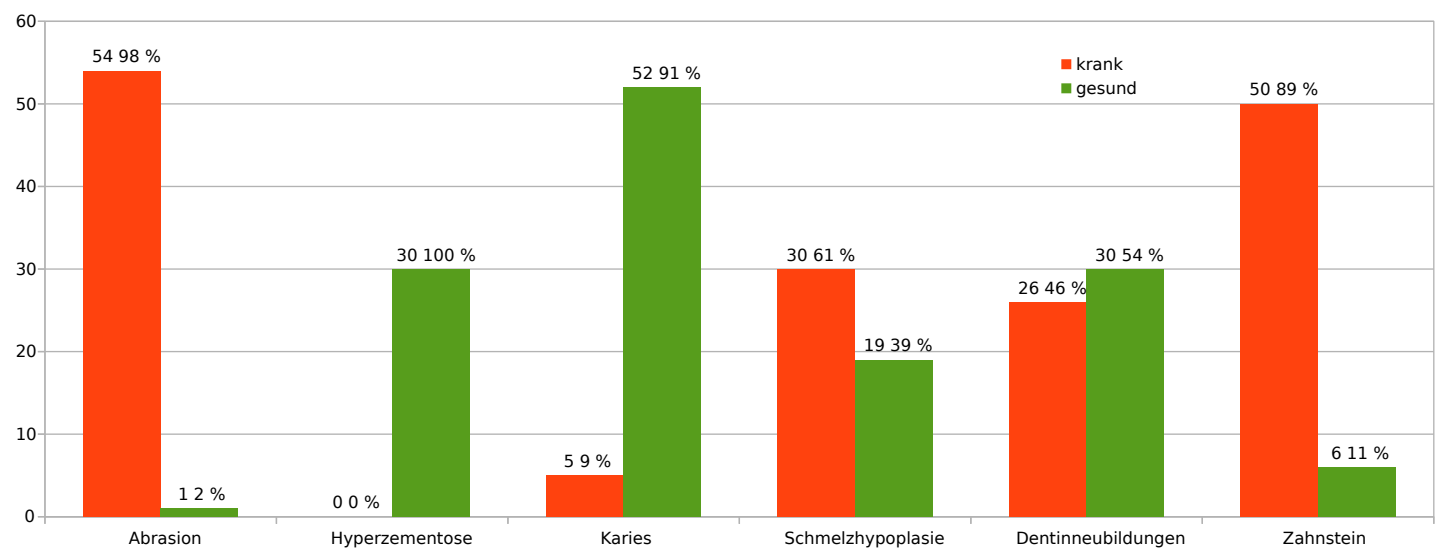

Abb. 18 Veränderungen an allen ersten Prämolaren; Calden

Alle ersten Prämolaren der vier Quadranten, $n=112$, tatsächliche Zahnzahl: 73, auf der Ordinate befindet sich die Angabe der Gesamtzahl, über den Säulen links die absoluten Anzahlen, rechts daneben die Prozentzahlen. "n" umfasst alle Zähne und leere Alveolen, die "tatsächliche Zahnzahl" gibt nur die Zahl der Zähne an, ohne leere Alveolen.

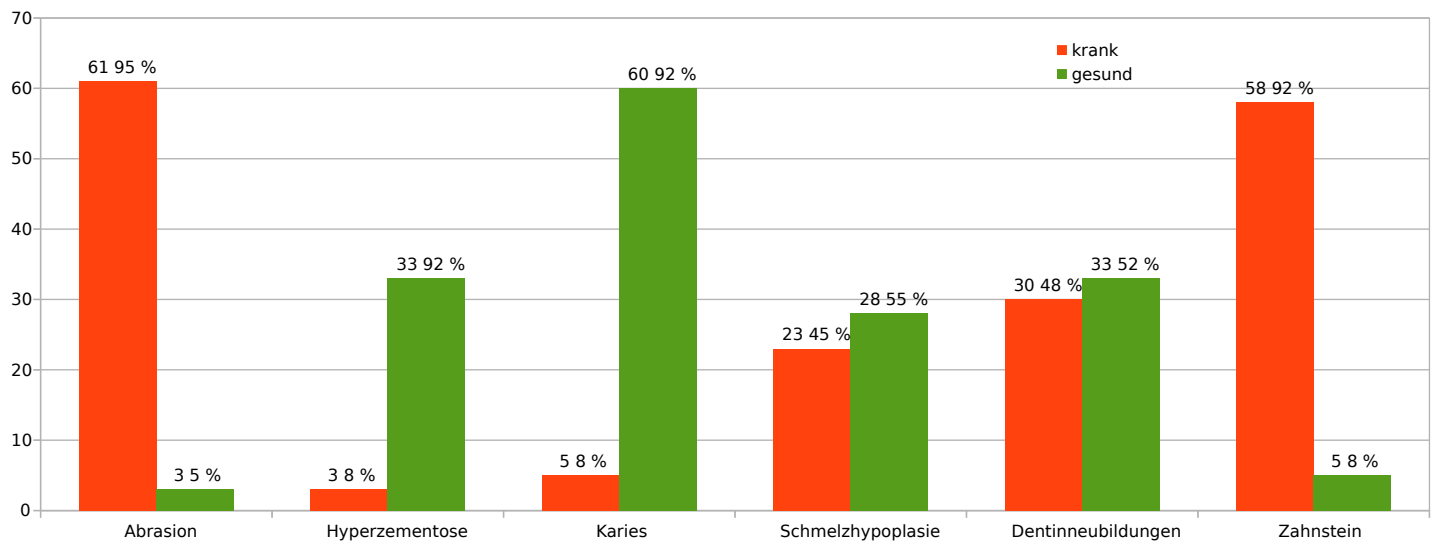

Abb. 19 Veränderungen an allen zweiten Prämolaren; Calden

Alle zweiten Prämolaren der vier Quadranten, $n=106$, tatsächliche Zahnzahl: 76, auf der Ordinate befindet sich die Angabe der Gesamtzahl, über den Säulen links die absoluten Anzahlen, rechts daneben die Prozentzahlen. " $n$ " umfasst alle Zähne und leere Alveolen, die "tatsächliche Zahnzahl" gibt nur die Zahl der Zähne an, ohne leere Alveolen. 


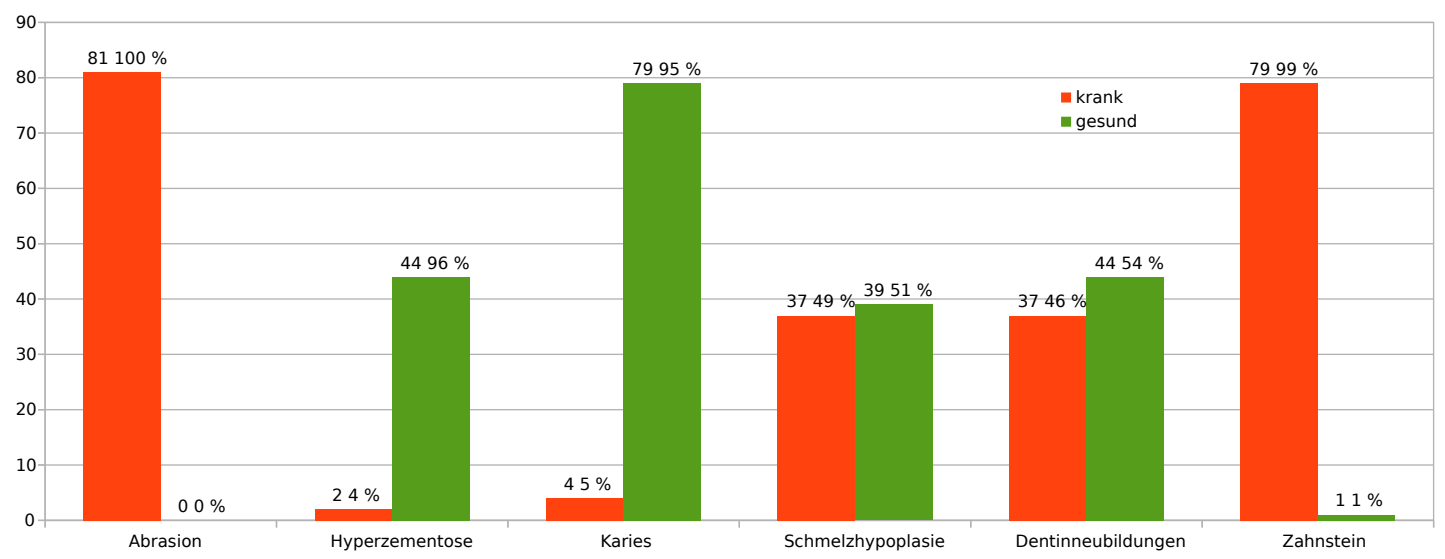

Abb. $20 \quad$ Veränderungen an allen bleibenden ersten Molaren; Calden

Alle ersten, bleibenden Molaren der vier Quadranten, $n=109$, tatsächliche Zahnzahl: 86, auf der Or-dinate befindet sich die Angabe der Gesamtzahl, über den Säulen links die absoluten Anzahlen, rechts daneben die Prozentzahlen. "n" umfasst alle Zähne und leere Alveolen, die "tatsächliche Zahnzahl" gibt nur die Zahl der Zähne an, ohne leere Alveolen.

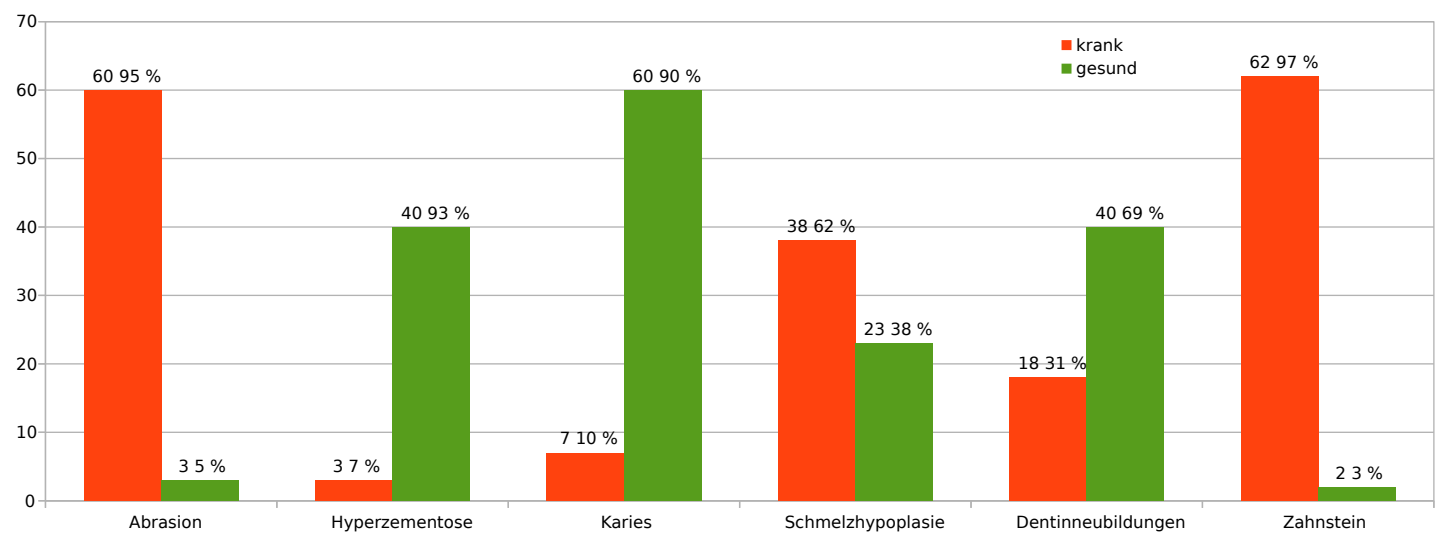

Abb. 21 Veränderungen an allen bleibenden zweiten Molaren; Calden

Alle zweiten, bleibenden Molaren der vier Quadranten, $n=106$, tatsächliche Zahnzahl: 82, auf der Ordinate befindet sich die Angabe der Gesamtzahl, über den Säulen links die absoluten Anzahlen, rechts daneben die Prozentzahlen. " $n$ " umfasst alle Zähne und leere Alveolen, die "tatsächliche Zahnzahl" gibt nur die Zahl der Zähne an, ohne leere Alveolen. 


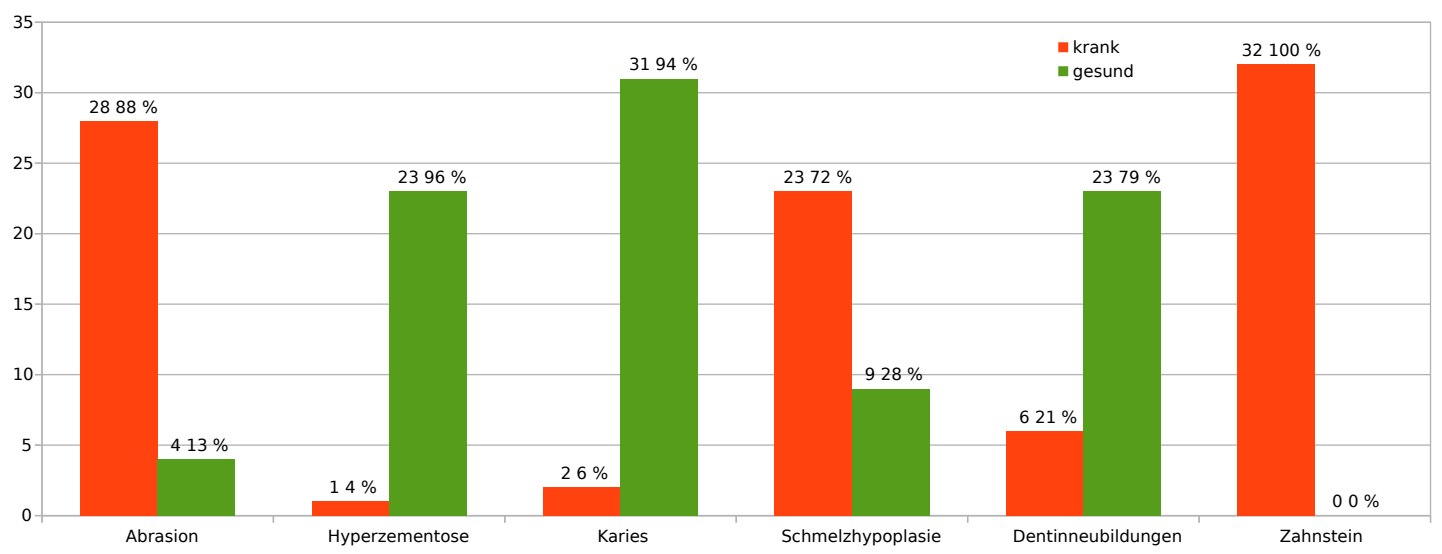

Abb. 22 Veränderungen an allen dritten Molaren; Calden

Alle dritten Molaren der vier Quadranten, $n=78$, tatsächliche Zahnzahl: 38, auf der Ordinate befindet sich die Angabe der Gesamtzahl, über den Säulen links die absoluten Anzahlen, rechts daneben die Prozentzahlen. "n" umfasst alle Zähne und leere Alveolen, die "tatsächliche Zahnzahl" gibt nur die Zahl der Zähne an, ohne leere Alveolen.

Um die verschiedenen Zahntypen und deren Veränderungen eines Quadranten miteinander vergleichen zu können, wurden die folgenden vier Diagramme erstellt (Abbildungen 23 bis 26). Gezeigt werden die Veränderungen an den Zähnen jeweils eines Quadranten. Angegeben ist die absolute Zahnzahl mit den jeweiligen Veränderungen.

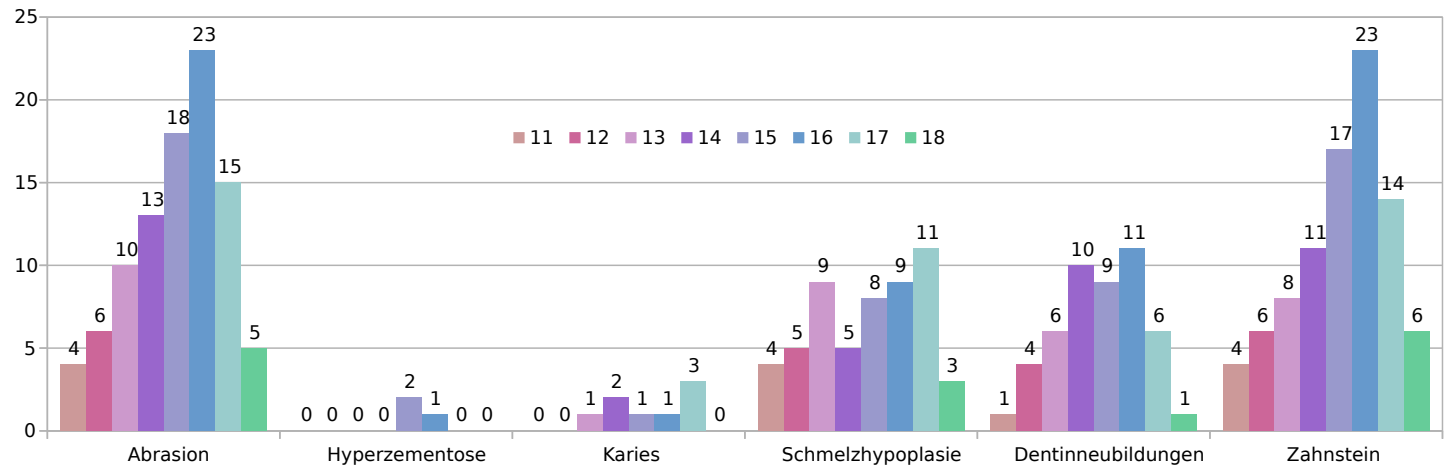

Abb. 23 Veränderungen an allen Zahntypen des 1. Quadranten; Calden

Auf der Ordinate findet sich die Angabe der Gesamtzahl, auf der Abszisse die Veränderungen der Zähne, über den Säulen sind die absoluten Anzahlen angegeben. Die verschiedenen Farben der Säulen entsprechen den Zähnen des ersten Quadranten (Zähne 11-18). 


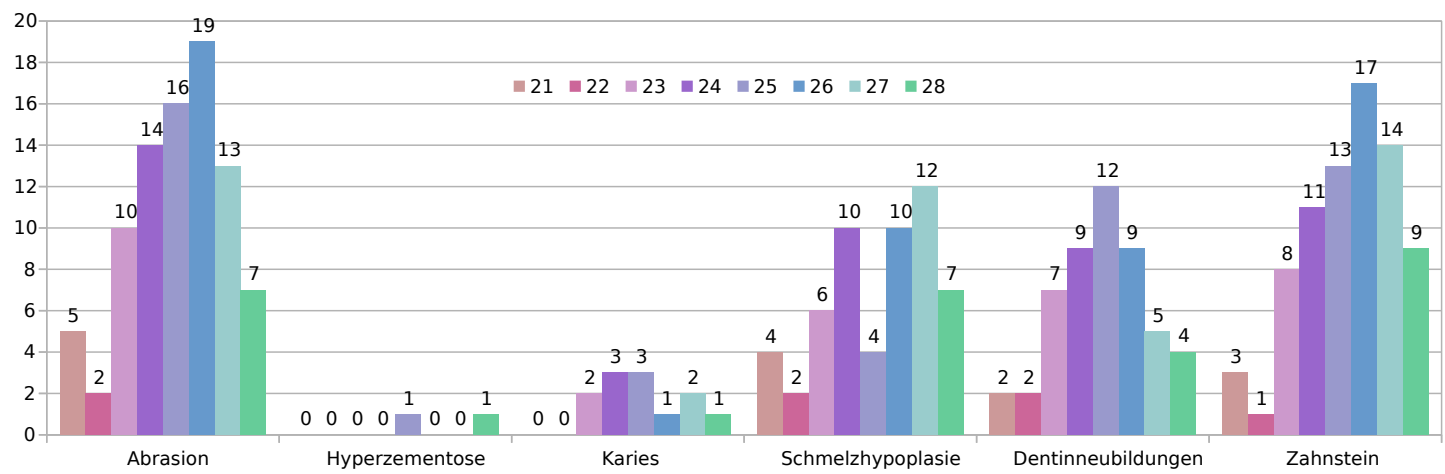

Abb. 24 Veränderungen an allen Zahntypen des 2. Quadranten; Calden

Auf der Ordinate findet sich die Angabe der Gesamtzahl, auf der Abszisse die Veränderungen der Zähne, über den Säulen sind die absoluten Anzahlen angegeben. Die verschiedenen Farben der Säulen entsprechen den Zähnen des zweiten Quadranten (Zähne 21-28).

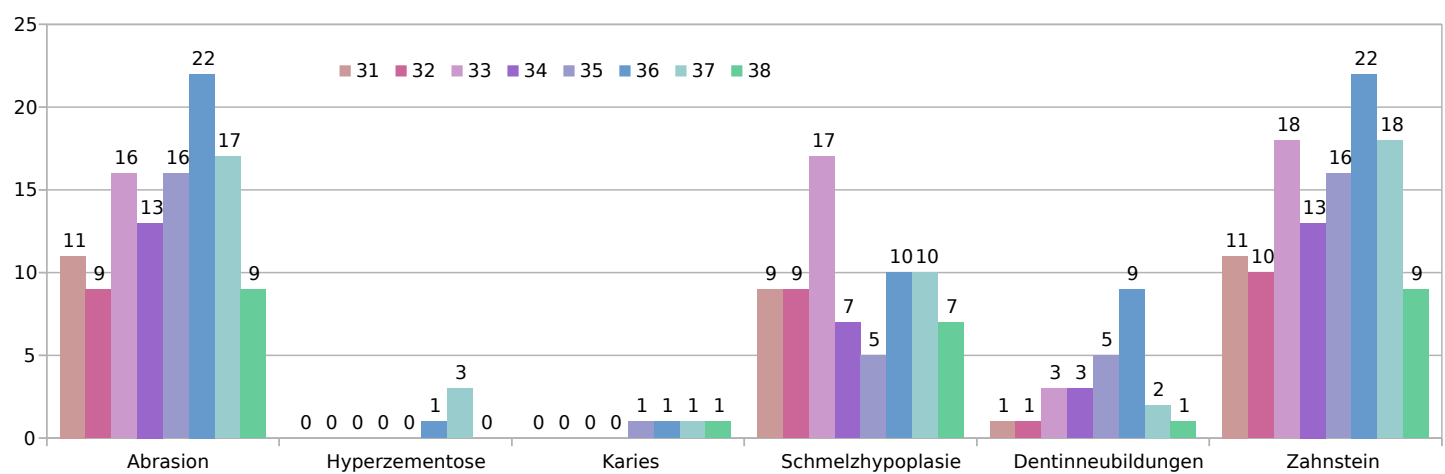

Abb. $25 \quad$ Veränderungen an allen Zahntypen des 3. Quadranten; Calden

Auf der Ordinate findet sich die Angabe der Gesamtzahl, auf der Abszisse die Veränderungen der Zähne, über den Säulen sind die absoluten Anzahlen angegeben. Die verschiedenen Farben der Säulen entsprechen den Zähnen des dritten Quadranten (Zähne 31-38).

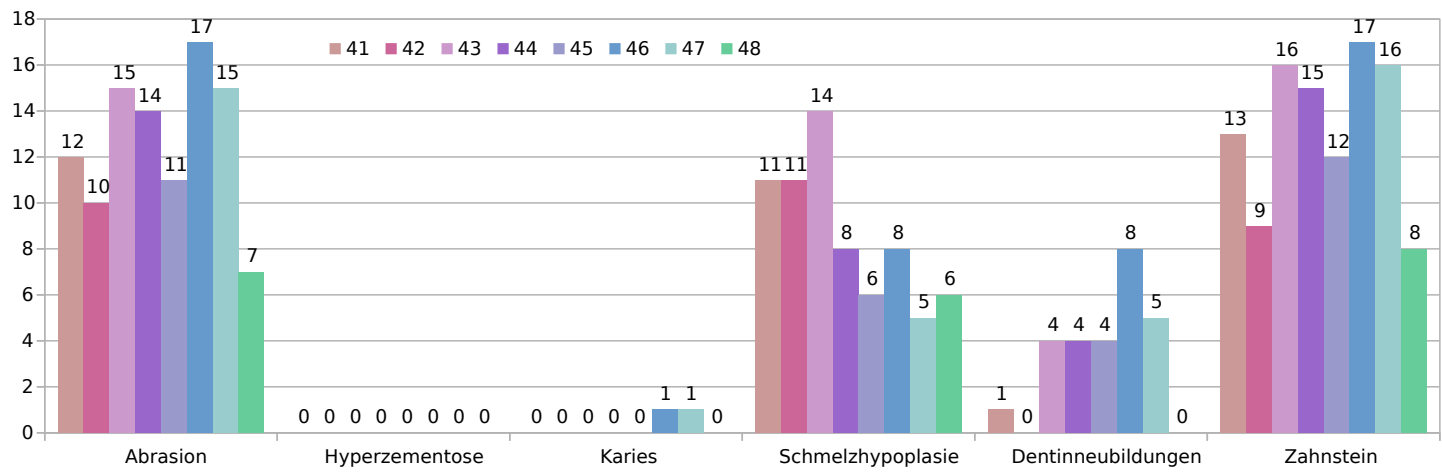

Abb. 26 Veränderungen an allen Zahntypen des 4. Quadranten; Calden

Auf der Ordinate findet sich die Angabe der Gesamtzahl, auf der Abszisse die Veränderungen der Zähne, über den Säulen sind die absoluten Anzahlen angegeben. Die verschiedenen Farben der Säulen entsprechen den Zähnen des vierten Quadranten (Zähne 41-48). 
In dem folgenden Diagramm (Abb. 27) werden ausschließlich die 6-Jahres-Molaren der vier Quadranten dargestellt. Sie geben Aufschluss über Veränderungen an Zähnen im Kindes- und Erwachsenenalter, da sie in der Regel die ersten bleibenden Zähne im Kindergebiss sind.

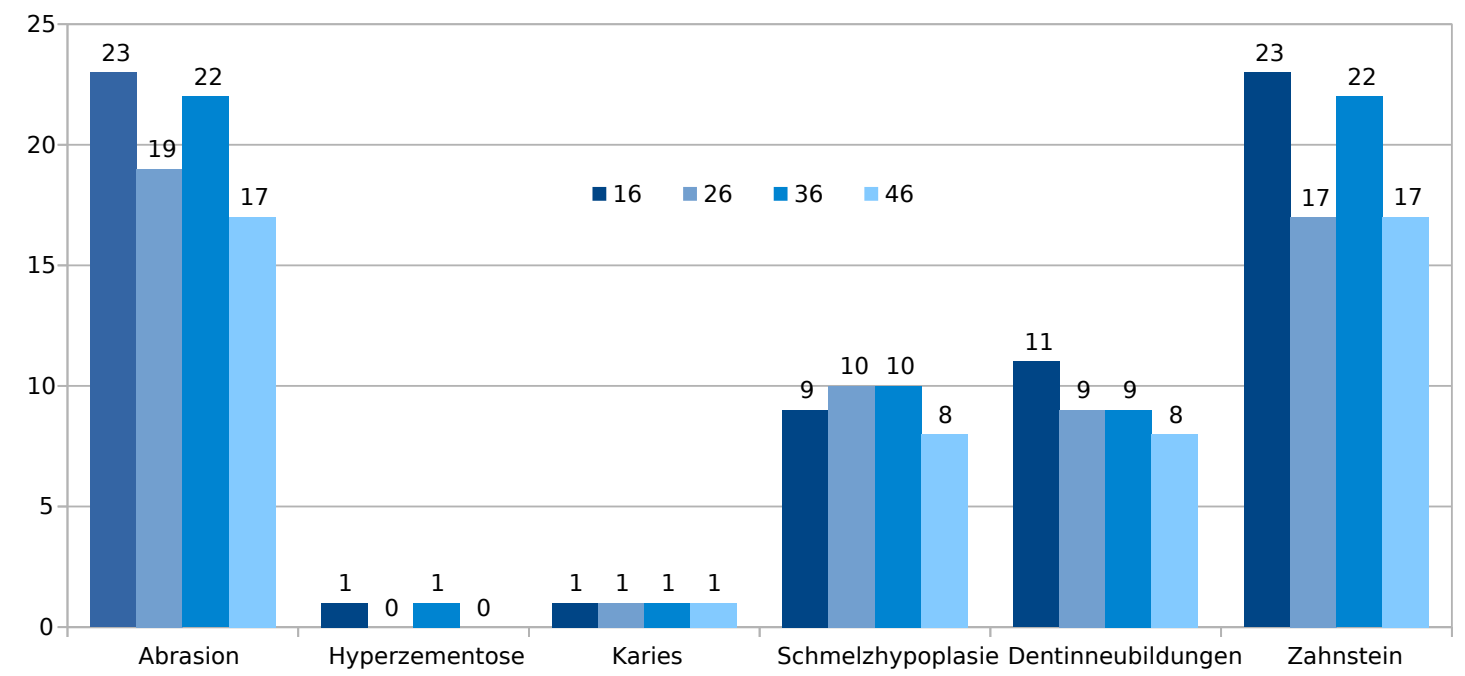

Abb. 27 Die vier Sechs-Jahres-Molaren aller Quadranten im Vergleich; Calden Auf der Ordinate findet sich die Angabe der Gesamtzahl, auf der Abszisse die Veränderungen der Zähne, über den Säulen sind die absoluten Anzahlen angegeben. Die verschiedenen Farben der Säulen entsprechen den Zähnen 16, 26, 36 und 46.

\subsubsection{Milchzähne}

Abb. 28 zeigt die Anzahl der erhaltenen Zähne des Milchgebisses.

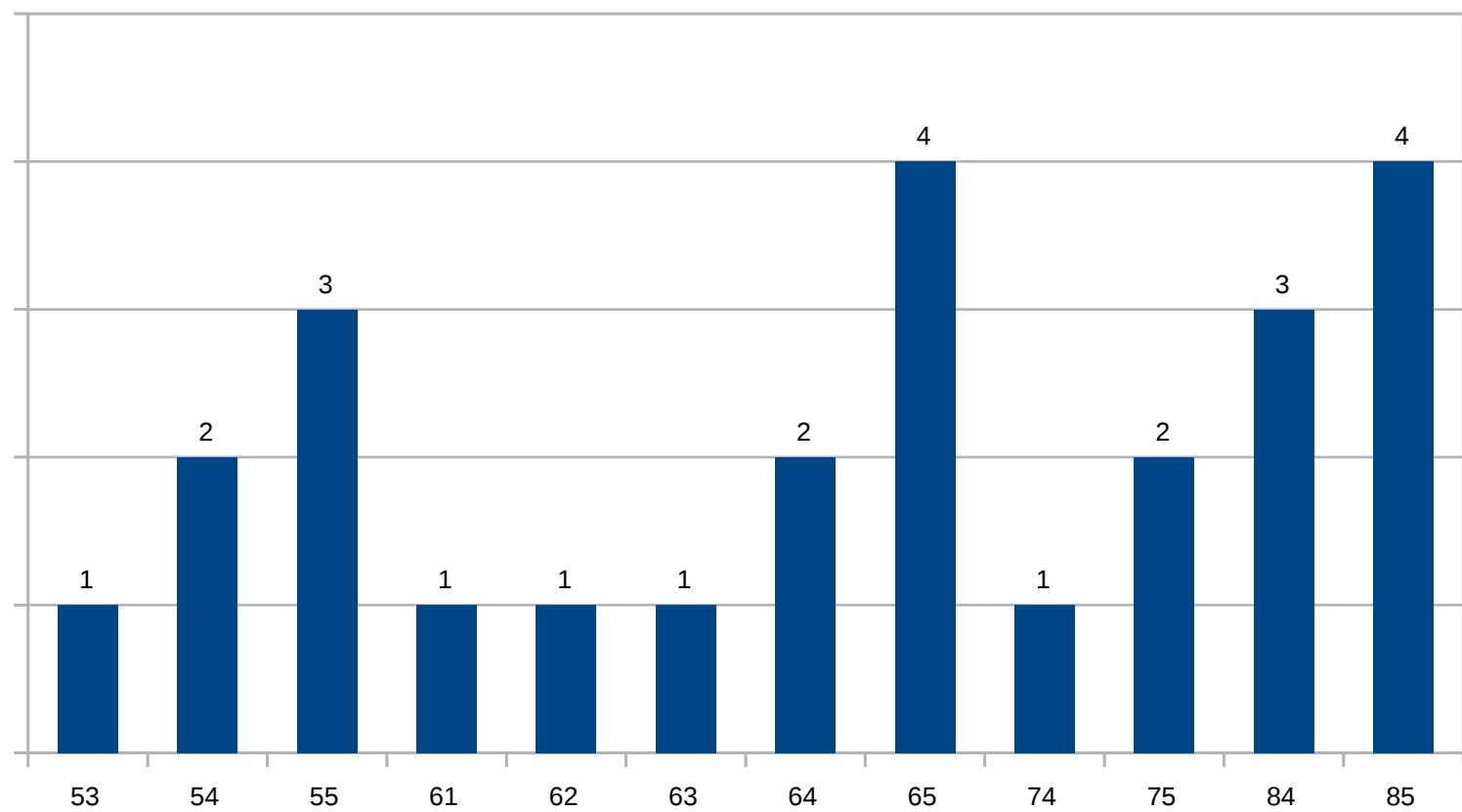

Abb. $28 \quad$ Erhaltene Zähne und leere Alveolen des Milchgebisses; Calden Auf der Abszisse sind die Milchzähne aufgeführt, über den Säulen finden sich die absoluten Anzahlen. 
Die Diagramme 29 und 30 enthalten die Darstellung der Veränderungen an Milchzähnen. „n“ steht für die Gesamtanzahl der Befunde mit der angegebenen Zahngruppe (auch leere Alveolen postmortal verlorener Zähne) und die „tatsächliche Zahnzahl“ gibt an, wie viele Zähne der zugrunde liegenden Zahngruppe tatsächlich vorhanden waren. Die Darstellungsform entspricht der der bleibenden Zähne.

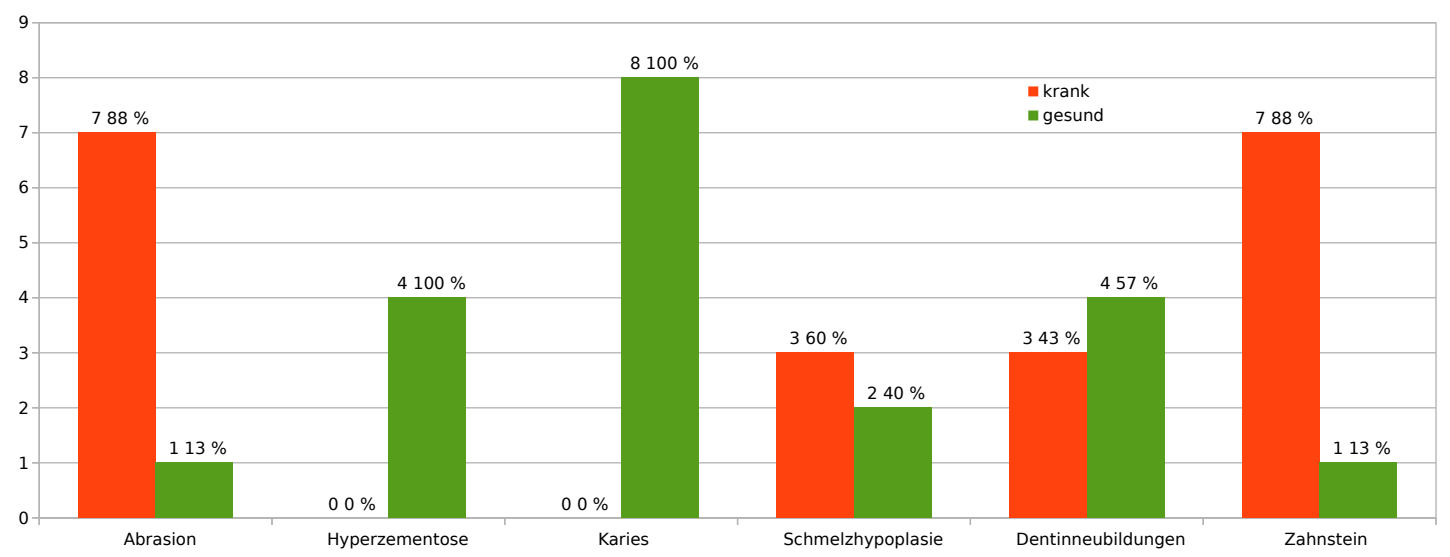

Abb. 29 Veränderungen an allen ersten Milchmolaren; Calden

Alle ersten Milchmolaren der vier Quadranten, $n=8$, tatsächliche Zahnzahl: 8, auf der Ordinate befindet sich die Angabe der Gesamtzahl, über den Säulen links die absoluten Anzahlen, rechts daneben die Prozentzahlen. " $n$ " umfasst alle Zähne und leere Alveolen, die "tatsächliche Zahnzahl" gibt nur die Zahl der Zähne an, ohne leere Alveolen.

Da sich insgesamt nur wenige Milchzähne erhalten haben, wurden sie lediglich nach Zahntypen sortiert dargestellt. Milchincisivi und Milchcanini haben sich aus der Population aus Calden nicht erhalten.

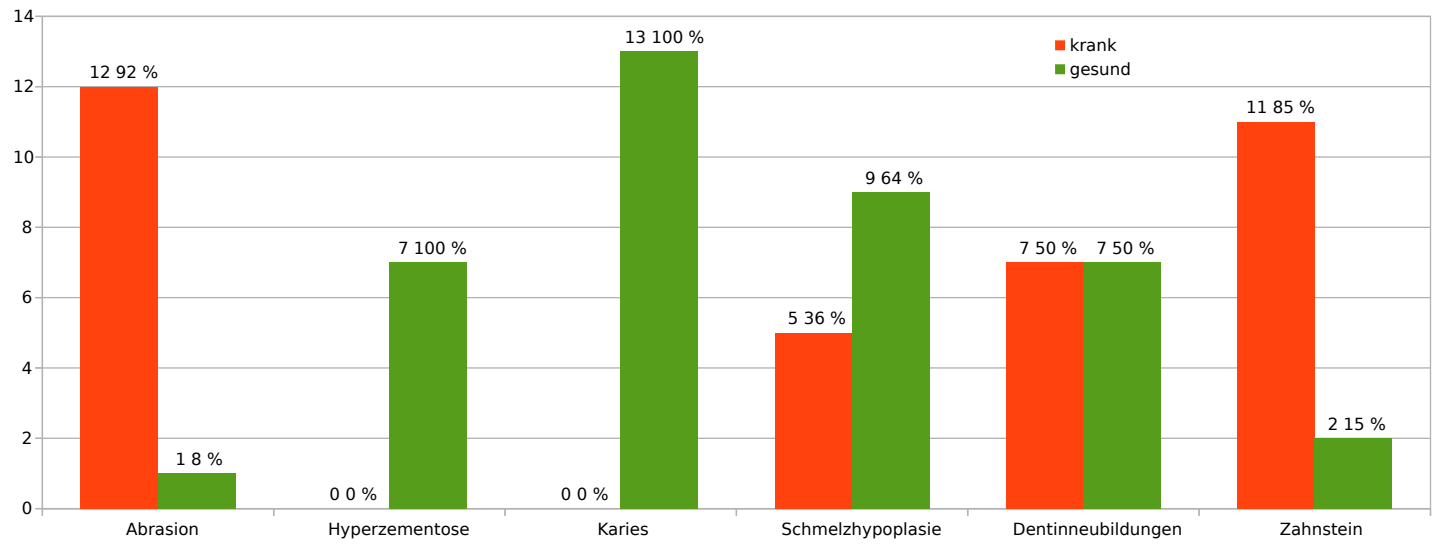

Abb. $30 \quad$ Veränderungen an allen zweiten Milchmolaren; Calden

Alle zweiten Milchmolaren der vier Quadranten, $n=13$, tatsächliche Zahnzahl: 13, auf der Ordinate befindet sich die Angabe der Gesamtzahl, über den Säulen links die absoluten Anzahlen, rechts daneben die Prozentzahlen. "n" umfasst alle Zähne und leere Alveolen, die "tatsächliche Zahnzahl" gibt nur die Zahl der Zähne an, ohne leere Alveolen. 


\subsubsection{Apicale Prozesse und Parodontalveränderungen an Milch- und}

Dauergebissen

Die den Kieferknochen betreffenden krankhaften Veränderungen werden nun gesondert aufgeführt, da sie sowohl das Milchgebiss als auch das bleibende Gebiss betreffen. Weiterhin sind diese Veränderungen zwar mit den Zähnen an sich assoziiert, betreffen aber den Kieferknochen und seine Reaktionen auf entzündliche oder nicht entzündliche Reize.

Die folgenden Diagramme bieten eine Übersicht über die Veränderungen am Kieferknochen. Zuerst werden die apicalen Prozesse aufgeführt.

Die Diagramme 31 und 32 zeigen die Anzahl und die Graduierungen der apicalen Prozesse.

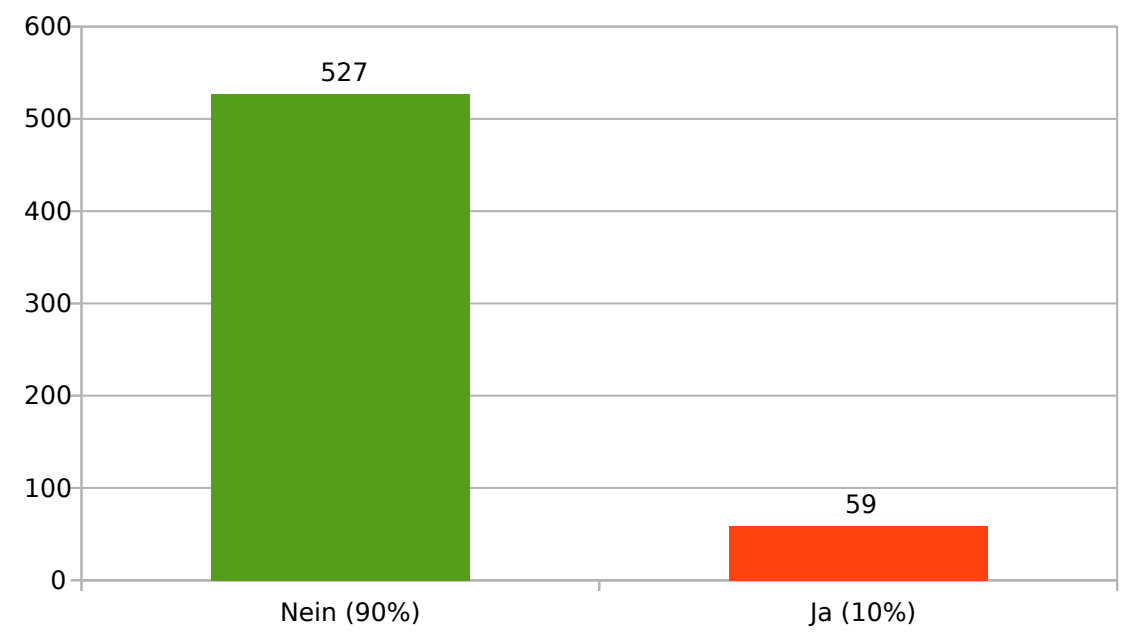

Abb. 31 Diagramm zur Häufigkeit apicaler Prozesse; Calden

"Nein" heißt, dass keine apicalen Prozesse vorlagen, "Ja" bedeutet, dass eine Zahnregion apicale Prozesse aufwies. Es lagen 586 befundbare Zahnregionen vor. Auf der Ordinate befindet sich die Gesamtzahl, über den Säulen sind die absoluten Zahlen der Häufigkeiten aufgeführt, unter den Säulen sind die prozentualen Zahlen in Klammern angegeben. 


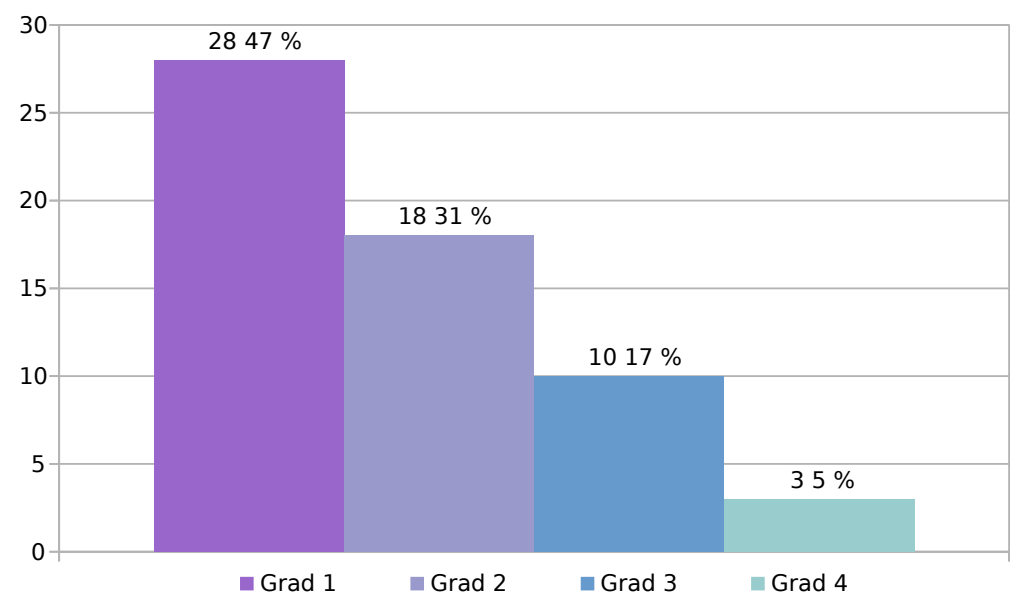

Abb. 32 Graduierung apicaler Prozesse (,JJ"-Anteil aus Diagramm 31); Calden

In dieser Darstellung findet sich die Aufteilung in verschiedene Graduierungen von 1 bis 4 (Abszisse), wobei Grad 1 einer schwachen Ausprägung entspricht und Grad 4 einer starken. Auf der Ordinate befindet sich die Gesamtzahl, über den Säulen sind links die absoluten, rechts die prozentualen Anzahlen angegeben.

Die Diagramme 33 bis 35 stellen die Parodontopathien mit Graduierungen und krankhaften Veränderungen dar.

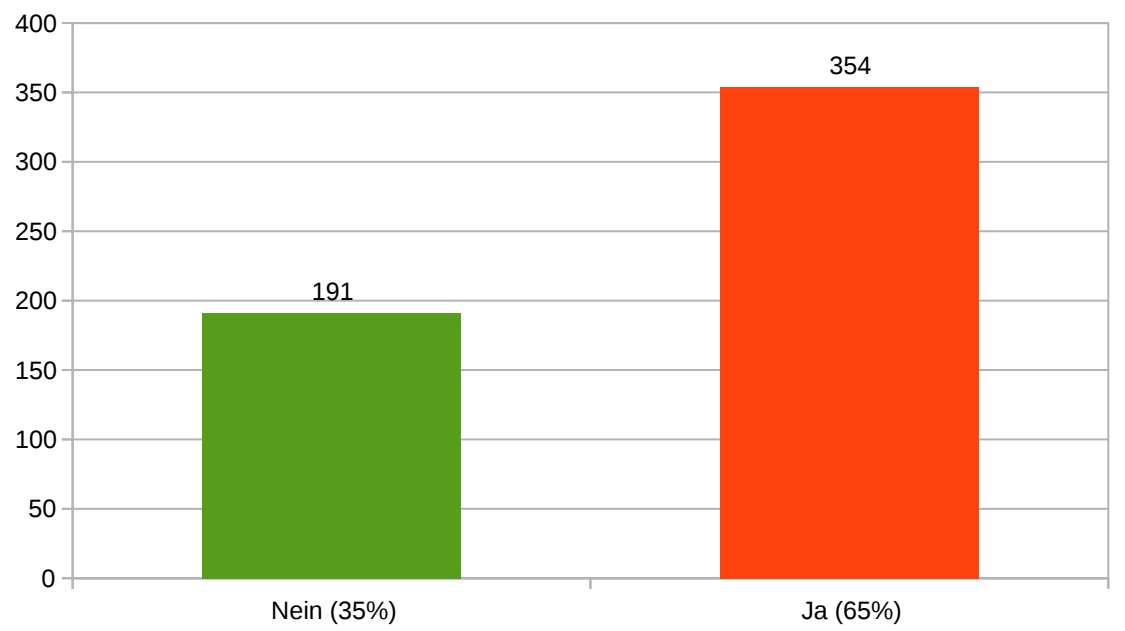

Abb. 33 Diagramm zur Häufigkeit von Parodontopathien; Calden

"Nein" heißt, dass keine Parodontopathien vorlagen, "Ja" bedeutet, dass eine Zahnregion Parodontopathien aufwies. Es lagen 545 befundbare Zahnregionen vor. Auf der Ordinate befindet sich die Gesamtzahl, über den Säulen sind die absoluten Zahlen der Häufigkeiten aufgeführt, unter den Säulen sind die prozentualen Zahlen in Klammern angegeben. 


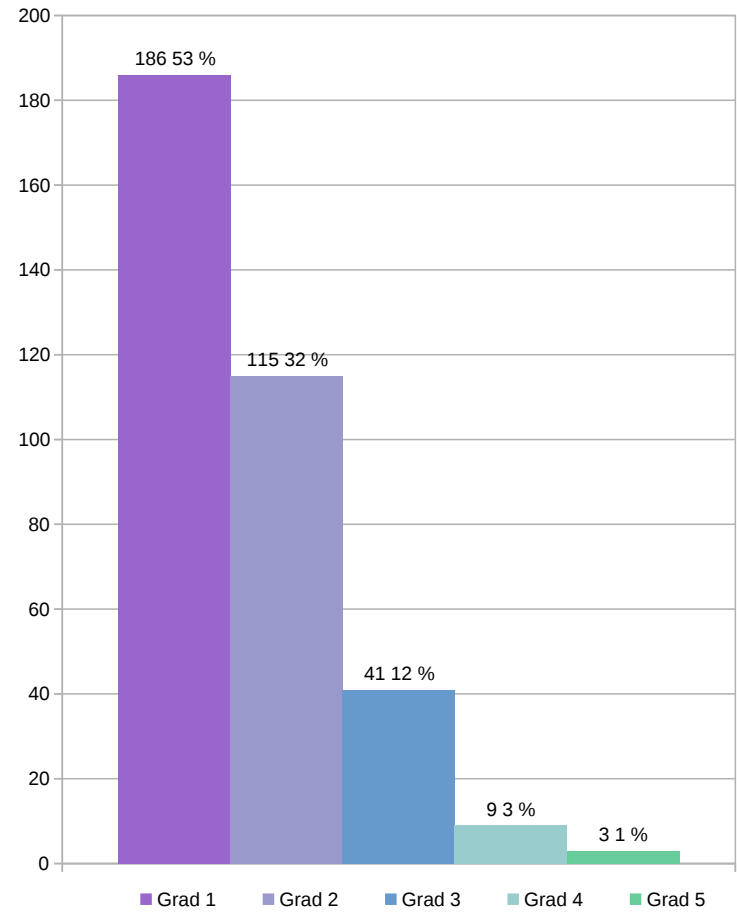

Abb. 34 Graduierung der Parodontopathien (,Ja"-Anteil aus Diagramm 33); Calden

In dieser Darstellung findet sich die Aufteilung in verschiedene Graduierungen von 1 bis 5 (Abszisse), wobei Grad 1 einer schwachen Ausprägung entspricht und Grad 5 der stärksten. Auf der Ordinate befindet sich die Angabe der Gesamtzahl, über den Säulen sind links die absoluten, rechts die prozentualen Anzahlen angegeben.

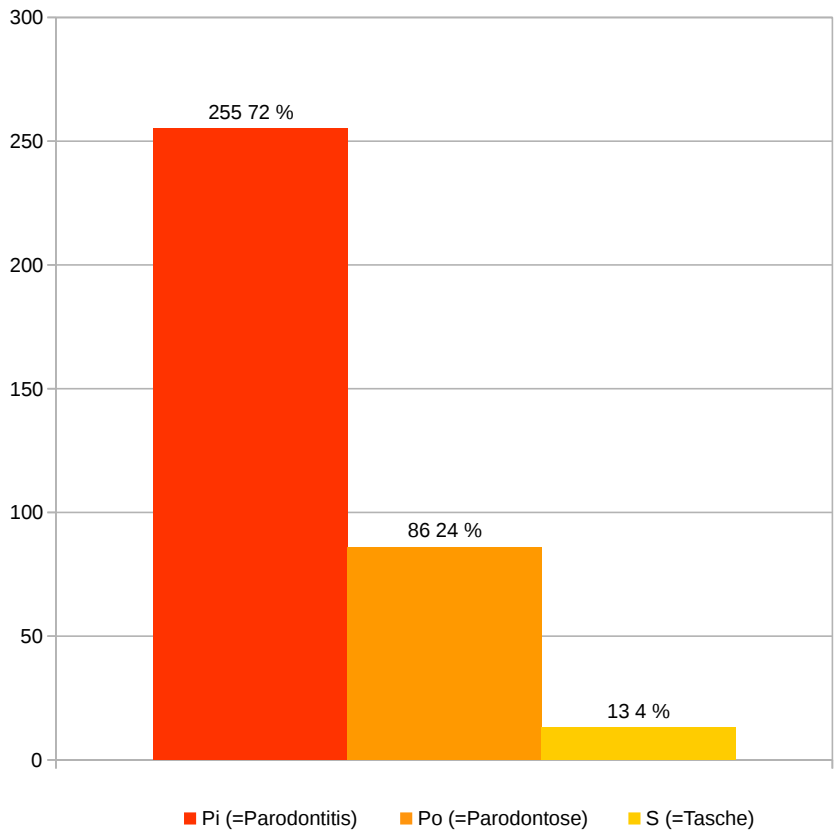

Abb. 35 Darstellung der verschiedenen Parodontopathien; Calden

Dieses Diagramm nimmt Bezug auf den "Ja"-Anteil aus Diagramm 33. Auf der Ordinate befindet sich die Angabe der Gesamtzahl, über den Säulen sind links die absoluten, rechts die prozentualen Anzahlen angegeben. 


\subsubsection{Postcranien}

Die postcranialen Fundstücke der Population aus Calden wurden in insgesamt 2181 Datensätze eingepflegt. Diese Datensätze beinhalten in der Regel ein Skeletsegment, beispielsweise einen Oberschenkelknochen, ein Becken usw. Es kam jedoch vor, dass ganze Konvolute von kleinsten Knochen und Knochensplittern eingepflegt werden mussten. Diese wurden dann ggf. zusammen in einem Datensatz erfasst. Wenn möglich, wurde die Skeletregion ihrer Herkunft mit angegeben. Teilskelete sind im Anhang mit dem Präfix „"V" (steht für Verband) und einer Nummer im Feld „Skeletnummer“ versehen, sodass die verschiedenen Datensätze bei Bedarf sofort zusammen abgerufen werden können. 322 Fundstücke konnten einem Verband zugeordnet werden.

Tabelle 1 gibt einen Überblick über die absolute Anzahl der Fundstücke, die alle entweder als "gesund“, "krank", „befundbar" oder „nicht befundbar" bezeichnet wurden. Die absoluten Gesamtzahlen der Befundkategorien sind ebenfalls aufgeführt. 
Tab. 1

\section{Postcraniale Fundstücke; Calden}

Darstellung der postccranialen Fundstücke nach Einteilung in gesund, krank, befundbar und nicht befundbar (gesund + krank = befundbar; befundbar + nicht befundbar = gesamt). "Knochen der oberen Extremität" umfasst jene Knochen, die - wenn auch in fragmentiertem Zustand - sicher der oberen Extremität zuzuordnen waren. Es handelte sich dabei um Fragmente und Splitter. "Ossa manus" bezieht sich auf jene Fundstücke, die der Hand zugeordnet werden konnten, jedoch nicht einem bestimmten Knochen. Die Bezeichnung "Manus / Pes“ bedeutet, dass das betreffende Fundstück entweder von der Hand oder dem Fuß stammt, aber nicht genauer bestimmt werden konnte. Ähnlich ist die Bezeichnung "Phalanx manus / pedis" zu verstehen; das Fundstück wurde als Phalanx identifiziert, konnte aber nicht einer Phalanx der Hand oder des Fußes zugeordnet werden.

\begin{tabular}{|c|c|c|c|c|c|}
\hline & gesund & krank & befundbar & nicht befundbar & gesamt \\
\hline Vertebra & 162 & 79 & 241 & 59 & 300 \\
\hline Clavicula & 15 & 5 & 20 & 12 & 32 \\
\hline Costa & 121 & 9 & 130 & 238 & 368 \\
\hline Sternum & 1 & 0 & 1 & 2 & 3 \\
\hline Manubrium & 3 & 0 & 3 & 4 & 7 \\
\hline Scapula & 17 & 14 & 31 & 36 & 67 \\
\hline Humerus & 56 & 6 & 62 & 23 & 85 \\
\hline Ulna & 36 & 13 & 49 & 17 & 66 \\
\hline Radius & 42 & 8 & 50 & 12 & 62 \\
\hline Os scaphoideum & 0 & 0 & 0 & 3 & 3 \\
\hline Os lunatum & 0 & 0 & 0 & 1 & 1 \\
\hline Os triquetrum & 0 & 0 & 0 & 1 & 1 \\
\hline Os pisiforme & 0 & 0 & 0 & 1 & 1 \\
\hline Os trapezium & 0 & 0 & 0 & 3 & 3 \\
\hline Os capitatum & 0 & 0 & 0 & 5 & 5 \\
\hline Os hamatum & 1 & 0 & 1 & 3 & 4 \\
\hline Os metacarpale & 12 & 0 & 12 & 10 & 22 \\
\hline Phalanx manus & 5 & 2 & 7 & 11 & 18 \\
\hline Ossa manus & 18 & 0 & 18 & 117 & 135 \\
\hline Knochen der oberen Extremität & 0 & 0 & 0 & 18 & 18 \\
\hline Os sacrum & 16 & 8 & 24 & 13 & 37 \\
\hline Os coxae & 38 & 20 & 58 & 63 & 121 \\
\hline Os femoris & 64 & 51 & 115 & 37 & 152 \\
\hline Patella & 7 & 16 & 23 & 4 & 27 \\
\hline Tibia & 45 & 34 & 79 & 47 & 126 \\
\hline Fibula & 30 & 17 & 47 & 23 & 70 \\
\hline Talus & 34 & 1 & 35 & 5 & 40 \\
\hline Calcaneus & 32 & 1 & 33 & 8 & 41 \\
\hline Os naviculare & 2 & 0 & 2 & 11 & 13 \\
\hline Os cuneiforme & 1 & 0 & 1 & 23 & 24 \\
\hline Os cuboideum & 1 & 0 & 1 & 14 & 15 \\
\hline Os metatarsale & 9 & 2 & 11 & 27 & 38 \\
\hline Phalanx pedis & 1 & 5 & 6 & 8 & 14 \\
\hline Pes & 20 & 0 & 20 & 115 & 135 \\
\hline Manus / Pes & 3 & 0 & 3 & 68 & 71 \\
\hline Knochenklein & 2 & 0 & 2 & 26 & 28 \\
\hline Phalanx manus / pedis & 5 & 3 & 8 & 20 & 28 \\
\hline gesamt & 799 & 294 & 1093 & 1088 & 2181 \\
\hline
\end{tabular}


Nachfolgend werden die langen Extremitätenknochen vorgestellt (Tab. 2). Sie sind in Fünftel ihrer Länge gegliedert, um Erhaltungsmenge und eventuelle Spuren pathologischer Veränderungen direkt vergleichen zu können. Diese Aufteilung in Regionen machte es möglich, die verschiedenartigen Fundstücke - durch Erosion, Bruch oder anderweitig postmortal verändert - auszuwerten. Häufig fehlten Teile von Knochen, sodass nur Fragmente ausgewertet werden konnten, die ohne eine Aufteilung in Regionen nicht miteinander hätten verglichen werden können. 
Tab. 2 Arthrose/Arthritis langer Extremitätenknochen; Calden

Darstellung der absoluten Anzahlen der langen Extremitätenknochen und jeweils befundeter Arthrose oder Arthritis. Die Knochen sind dabei in Fünftel aufgeteilt, um die jeweiligen Fünftel vergleichen zu können. Arthrose und Arthritis sind nur an Gelenken zu finden, weswegen sie nur für die proximalen und distalen Fünftel der Knochen angegeben sind. "re" bedeutet rechter Knochen, "li" linker Knochen, "ind" bedeutet, dass die Seite nicht bestimmbar war. "Vollständig" bedeutet, dass ein Knochen in ganzer Länge vollständig vorhanden war. "ges." steht für Gesamtanzahl, "Arthro/Arthri" für Arthrose und/oder Arthritis.

\begin{tabular}{|c|c|c|c|c|c|c|c|c|}
\hline Ulna & re. & li. & ind. & ges. & $\begin{array}{l}\text { Arthro/Arthri } \\
\text { re. }\end{array}$ & $\begin{array}{l}\text { Arthro/Arthri } \\
\text { li. }\end{array}$ & $\begin{array}{l}\text { Arthro/Arthri } \\
\text { ind. }\end{array}$ & $\begin{array}{l}\text { Arthro/Arthri } \\
\text { ges. }\end{array}$ \\
\hline $1 . / 5$ & 20 & 17 & 0 & 37 & 6 & 1 & 0 & $7(19 \%)$ \\
\hline $2 . / 5$ & 22 & 22 & 0 & 44 & & & & \\
\hline $3 . / 5$ & 16 & 18 & 1 & 35 & & & & \\
\hline $4 . / 5$ & 12 & 21 & 1 & 34 & & & & \\
\hline $5 . / 5$ & 10 & 17 & 1 & 28 & 4 & 1 & 0 & $5(18 \%)$ \\
\hline vollständig & 5 & 3 & 0 & 8 & & & & \\
\hline Radius & re. & li. & ind. & ges. & $\begin{array}{l}\text { Arthro/Arthri } \\
\text { re. }\end{array}$ & $\begin{array}{l}\text { Arthro/Arthri } \\
\text { li. }\end{array}$ & $\begin{array}{l}\text { Arthro/Arthri } \\
\text { ind. }\end{array}$ & $\begin{array}{l}\text { Arthro/Arthri } \\
\text { ges. }\end{array}$ \\
\hline $1 . / 5$ & 18 & 14 & 2 & 34 & 0 & 0 & 0 & $0(0 \%)$ \\
\hline $2 . / 5$ & 20 & 16 & 1 & 37 & & & & \\
\hline $3 . / 5$ & 23 & 13 & 0 & 36 & & & & \\
\hline $4 . / 5$ & 17 & 17 & 1 & 35 & & & & \\
\hline $5 . / 5$ & 13 & 14 & 1 & 28 & 2 & 3 & 0 & $5(18 \%)$ \\
\hline vollständig & 4 & 4 & 0 & 8 & & & & \\
\hline Humerus & re. & li. & ind. & ges. & $\begin{array}{l}\text { Arthro/Arthri } \\
\text { re. }\end{array}$ & $\begin{array}{l}\text { Arthro/Arthri } \\
\text { li. }\end{array}$ & $\begin{array}{l}\text { Arthro/Arthri } \\
\text { ind. }\end{array}$ & $\begin{array}{l}\begin{array}{l}\text { Arthro/Arthri } \\
\text { ges. }\end{array} \\
\end{array}$ \\
\hline $1 . / 5$ & 11 & 20 & 3 & 34 & 1 & 2 & 0 & $3(9 \%)$ \\
\hline $2 . / 5$ & 14 & 24 & 0 & 38 & & & & \\
\hline $3 . / 5$ & 16 & 27 & 4 & 47 & & & & \\
\hline $4 . / 5$ & 16 & 31 & 1 & 48 & & & & \\
\hline $5 . / 5$ & 17 & 29 & 2 & 48 & 0 & 0 & 1 & $1(2 \%)$ \\
\hline vollständig & 0 & 4 & 0 & 4 & & & & \\
\hline Femur & re. & li. & ind. & ges. & $\begin{array}{l}\text { Arthro/Arthri } \\
\text { re. }\end{array}$ & $\begin{array}{l}\text { Arthro/Arthri } \\
\text { li. }\end{array}$ & $\begin{array}{l}\text { Arthro/Arthri } \\
\text { ind. }\end{array}$ & $\begin{array}{l}\begin{array}{l}\text { Arthro/Arthri } \\
\text { ges. }\end{array} \\
\end{array}$ \\
\hline $1 . / 5$ & 34 & 26 & 5 & 65 & 12 & 11 & 0 & $23(35 \%)$ \\
\hline $2 . / 5$ & 39 & 37 & 4 & 80 & & & & \\
\hline $3 . / 5$ & 36 & 32 & 12 & 80 & & & & \\
\hline $4 . / 5$ & 38 & 30 & 5 & 73 & & & & \\
\hline $5 . / 5$ & 37 & 30 & 2 & 69 & 12 & 10 & 0 & $22(32 \%)$ \\
\hline vollständig & 4 & 3 & 0 & 7 & & & & \\
\hline Tibia & re. & li. & ind. & ges. & $\begin{array}{l}\text { Arthro/Arthri } \\
\text { re. }\end{array}$ & $\begin{array}{l}\text { Arthro/Arthri } \\
\text { li. }\end{array}$ & $\begin{array}{l}\text { Arthro/Arthri } \\
\text { ind. }\end{array}$ & $\begin{array}{l}\begin{array}{l}\text { Arthro/Arthri } \\
\text { ges. }\end{array} \\
\end{array}$ \\
\hline $1 . / 5$ & 26 & 24 & 1 & 51 & 4 & 5 & 0 & $9(18 \%)$ \\
\hline $2 . / 5$ & 31 & 33 & 3 & 67 & & & & \\
\hline $3 . / 5$ & 33 & 35 & 9 & 77 & & & & \\
\hline $4 . / 5$ & 28 & 32 & 2 & 62 & & & & \\
\hline $5 . / 5$ & 21 & 25 & 0 & 46 & 3 & 0 & 0 & $3(7 \%)$ \\
\hline vollständig & 6 & 4 & 0 & 10 & & & & \\
\hline Fibula & re. & li. & ind. & ges. & $\begin{array}{l}\text { Arthro/Arthri } \\
\text { re. }\end{array}$ & $\begin{array}{l}\text { Arthro/Arthri } \\
\text { li. } \\
\end{array}$ & $\begin{array}{l}\text { Arthro/Arthri } \\
\text { ind. } \\
\end{array}$ & \begin{tabular}{|l}
$\begin{array}{l}\text { Arthro/Arthri } \\
\text { ges. }\end{array}$ \\
\end{tabular} \\
\hline $1 . / 5$ & 11 & 10 & 1 & 22 & 1 & 1 & 0 & $2(9 \%)$ \\
\hline $2 . / 5$ & 13 & 13 & 3 & 29 & & & & \\
\hline $3 . / 5$ & 17 & 16 & 12 & 45 & & & & \\
\hline $4 . / 5$ & 17 & 23 & 3 & 43 & & & & \\
\hline $5 . / 5$ & 14 & 19 & 1 & 34 & 1 & 3 & 0 & $4(12 \%)$ \\
\hline vollständig & 3 & 2 & 0 & 5 & & & & \\
\hline
\end{tabular}


Ergänzend zu Tabelle 2 können noch folgende geschlechtsspezifische Angaben zu degenerativen Veränderungen von Hüftpfannen gemacht werden: Es lagen von den befundbaren rechten Hüftpfannen vier männliche gesunde, vier weibliche gesunde und zwölf indifferente gesunde vor. Krankhaft verändert waren drei männliche, drei weibliche und drei indifferente. Weiterhin lagen von der linken Seite drei männliche gesunde, fünf weibliche gesunde und sechs indifferente gesunde vor. Krankhaft verändert waren zwei männliche linke, fünf weibliche linke und zwei indifferente linke. Bei den weiblichen Oberschenkelknochen konnten an sechs proximalen und fünf distalen Gelenkflächen Spuren degenerativer Gelenkerkrankungen festgestellt werden sowie an 17 proximalen und zwölf distalen Gelenkflächen männlicher Oberschenkelknochen. Dabei waren vier rechte und zwei linke Oberschenkelköpfe von weiblichen Individuen sowie acht rechte und neun linke von männlichen Individuen. Insgesamt konnten an sieben von 25 Gelenkflächen weiblicher und an 19 von 40 männlicher Femora Spuren degenerativer Gelenkerkrankungen gefunden werden. An folgenden weiteren Skeletelementen konnten geschlechtsspezifische Unterschiede in Bezug auf degenerative Gelenkerkrankungen festgestellt werden: Wirbel von vier weiblichen und acht männlichen Individuen, zwei weibliche Kreuzbeine und vier männliche, vier weibliche Atlantooccipitalgelenke und drei männliche, ein männliches Schlüsselbein, ein männliches Wadenbein. Insgesamt war bei 31 von 185 (17\%) weiblichen Fundstücken eine Arthrose zu finden und bei 50 von 174 (29\%) männlichen. 
Es folgen nun die Ergebnisse der an den Wirbeln der Population aus Calden erhobenen Befunde, die der Vergleichbarkeit halber einheitlich dargestellt wurden (Abb. 36).

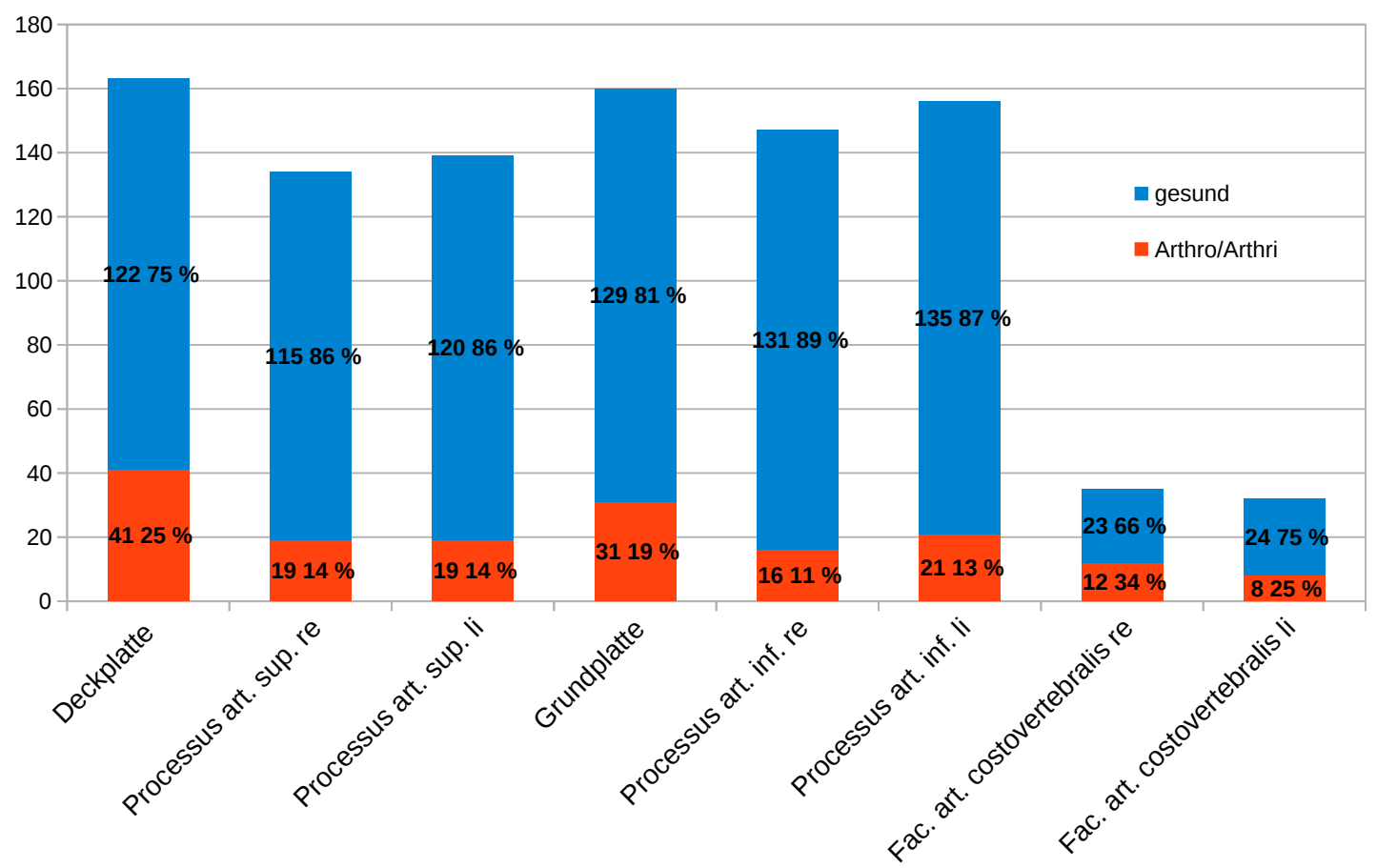

Abb. $36 \quad$ Darstellung der Befunde der Wirbel; Calden

Auf der Abszisse sind die anatomischen Wirbelregionen angegeben. In den Säulen finden sich links die absoluten Anzahlen, rechts die Prozentzahlen in Bezug auf die Gesamtanzahl der befundeten Wirbelregionen und im Sinne von Arthrose undloder Arthritis krankhaft veränderter Wirbelregionen.

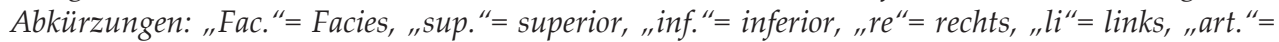
articularis. Die Gesamtzahl der befundeten Bewegungssegmente ist auf der Ordinate angegeben.

Zur vereinfachten Darstellung wird nun noch ein Schema vorgestellt (Abb. 37), aus dem bildlich erkennbar ist, wie oft eine Wirbelregion vorhanden und befundbar war und wie oft diese krankhaft verändert vorlag. Das Diagramm und das Schema der Wirbelauswertung haben sich als hilfreich erwiesen, da das Fundgut häufig unvollständige oder nur teilweise befundbare Wirbel aufwies. Dieses Schema berücksichtigt nicht nur einen Datensatz der Datenbank als „einen Wirbel“, sondern differenziert nun genau nach erhaltenen Regionen aller Wirbel (Bewegungssegmente) unabhängig davon, ob vollständig oder nur teilweise erhalten. Das Schema ist grafisch so entworfen, dass man sich vorstellen kann, man würde von anterior auf einen Brustwirbel schauen. Da nicht die Wirbel an sich verglichen werden, sondern nur die anatomischen Regionen, ist es unerheblich, dass die äußersten Felder nur für Brustwirbel gelten. Alle anderen Wirbel weisen diese Region nicht auf, sodass dort keine Werte eingetragen wurden. Bei Atlas und Axis wurde der Morphologie dieser beiden Wirbel folgend entsprechend verfahren. 


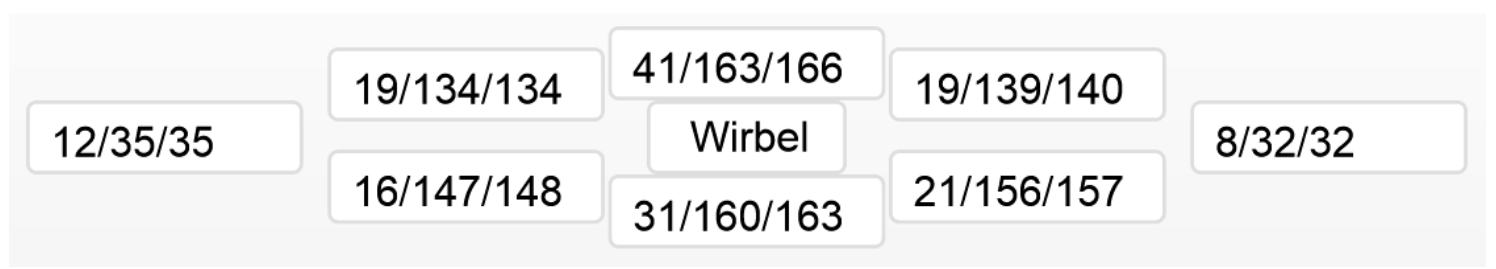

Abb. 37 Anatomisch orientierte Darstellung der Wirbelregionen; Calden

Mittleres oberes Feld: Deckplatte, links daneben das Feld für den Processus articularis superior der rechten Seite, rechts neben der Deckplatte das Feld für den Processus articularis superior der linken Seite. Ganz außen links: Feld für die Gelenkpfanne der Articulatio costovertebralis (Fovea costalis processus transversi) der rechten Seite, rechts ganz außen das Feld für die Gelenkpfanne der Articulatio costovertebralis (Fovea costalis processus transversi) der linken Seite. Mittleres unteres Feld: Grundplatte, daneben links das Feld für die Gelenkflüche am Processus articularis inferior der rechten Seite, neben der Grundplatte rechts das Feld für die Gelenkfläche am Processus articularis inferior der linken Seite. Im oben abgebildeten Gelenkbefundungsschema sind in jedem Zahlenkästchen drei Zahlen aufgeführt. Die erste Zahl (von links) ist die Anzahl der mit Arthrose und/oder Arthritis erkrankten Regionen, die zweite Zahl (von links) ist die Gesamtzahl der jeweils für eine bestimmte Gelenkeinheit befundbaren Flächen. Die dritte Zahl (von links) ist die Gesamtzahl der insgesamt erhaltenen Flächen (befundbar und unbefundbar).

Die nachfolgenden Aufstellungen (Abb. 38 und 39) gehen auf die insgesamt erhaltene Fundgutmenge und die diagnostizierten pathologischen Veränderungen an den Knochen ein. Die Diagramme zeigen eine Aufstellung der Fundstücke, die als "gesund“ oder „krank“ diagnostiziert wurden. Vereinfacht ist es so zu verstehen, dass die Gesamtheit der Fundstücke in „,befundbar“ und „nicht befundbar“ eingeteilt wurde. Von den befundbaren Fundstücken wurden die Knochen ohne krankhafte oder andere Veränderungen in die Gruppe der gesunden eingeteilt, während die Knochen mit Veränderungen krankhafter oder anderer Art in die Gruppe der als krank diagnostizierten Knochen eingeteilt wurde. 


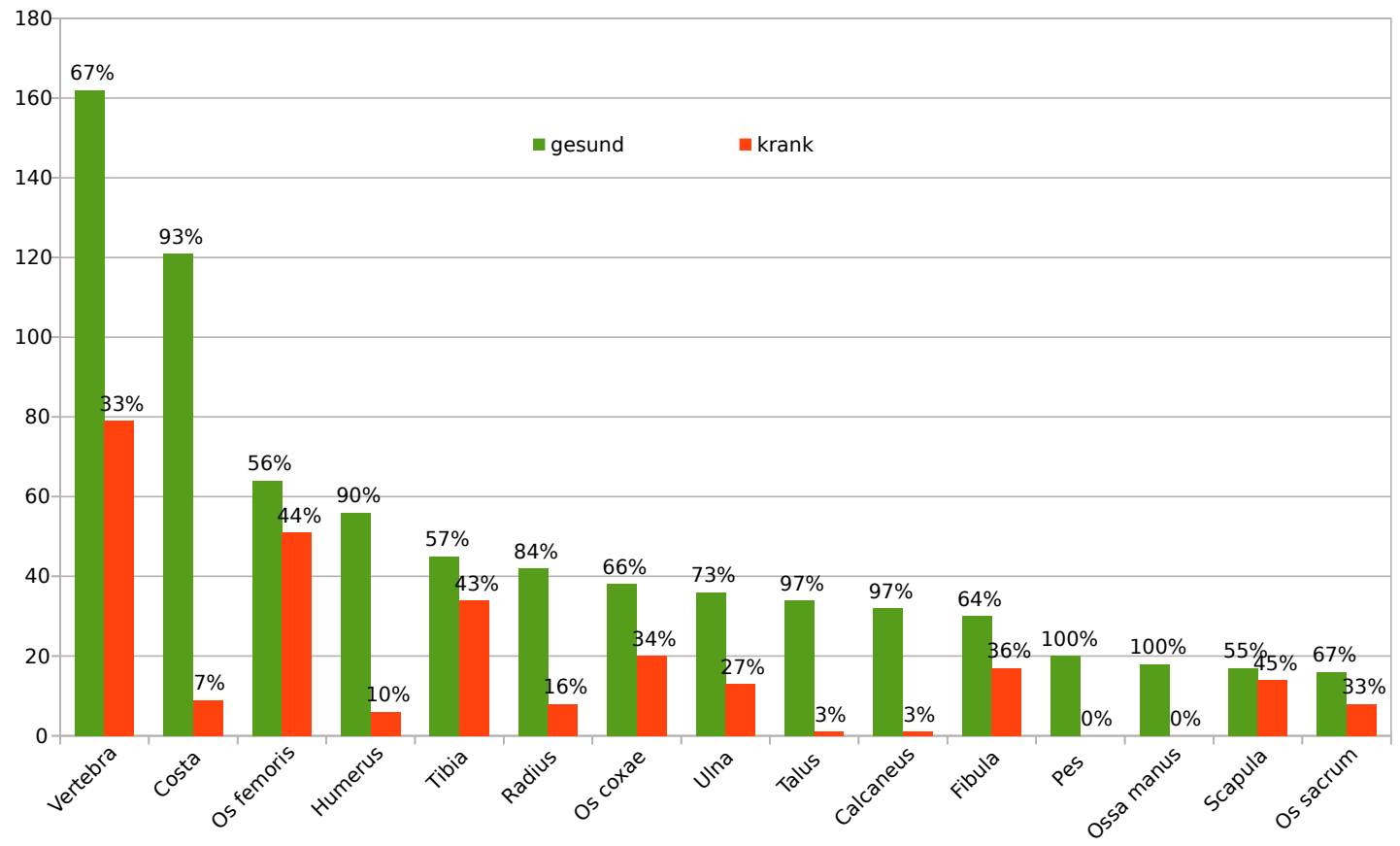

Abb. 38 Befundbare Fundstücke (außer Schädel und den Zähnen) - Teil 1; Calden

In diesem Diagramm sind alle Fundstücke aufgeführt, die befundbar waren. Prozentual werden die als "gesund" und "krank" diagnostizierten Fundstücke aller befundbaren Knochen angegeben. Die absolute Anzahl ist auf der Ordinate festgehalten.

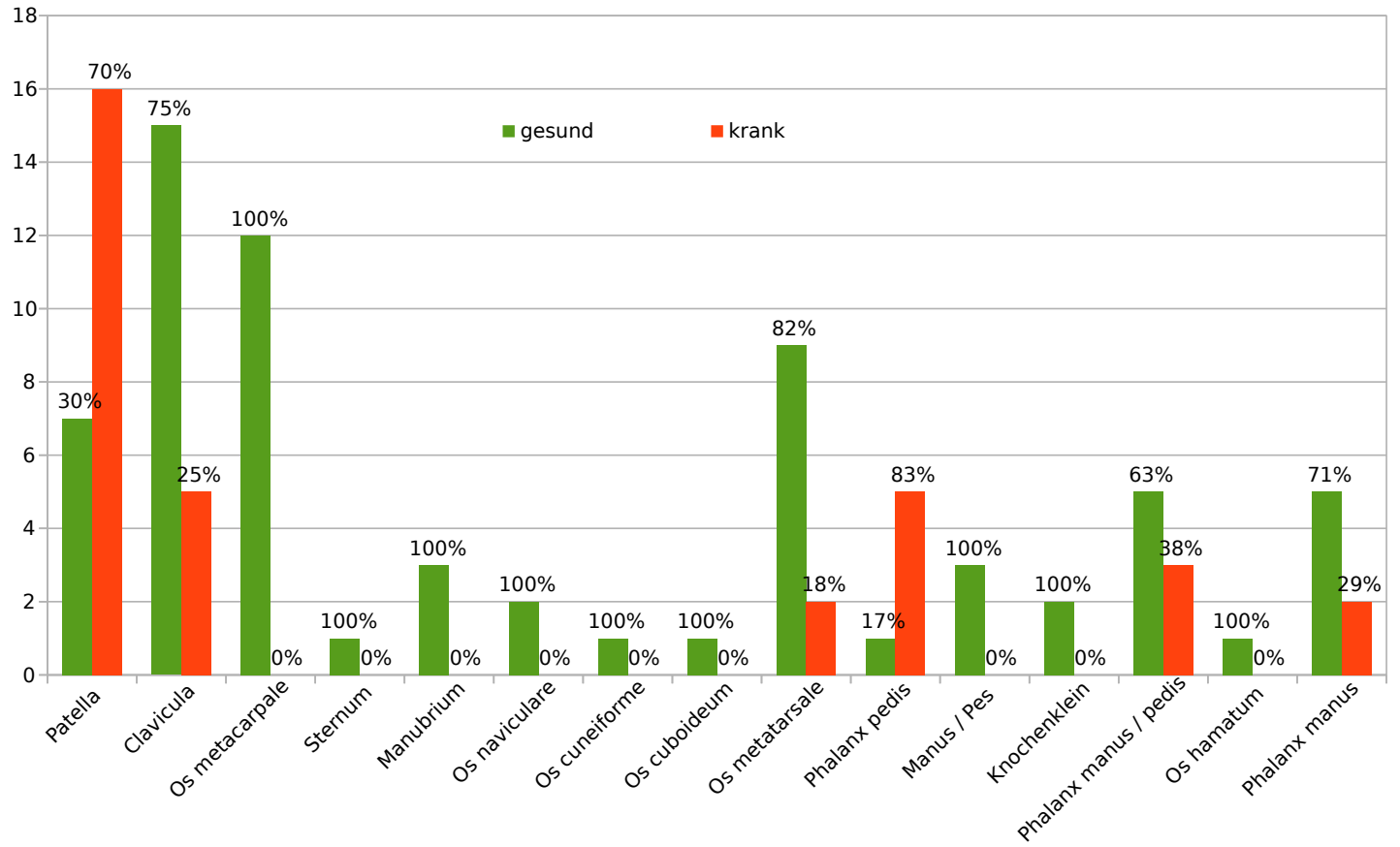

Abb.39 Befundbare Fundstücke (außer Schädel und den Zähnen) - Teil 2; Calden

In diesem Diagramm sind alle Fundstücke aufgeführt, die befundbar waren. Prozentual werden die als "gesund" und "krank" diagnostizierten Fundstücke aller befundbaren Knochen angegeben. Die absolute Anzahl ist auf der Ordinate festgehalten. 
Es folgen nun eine Tabelle (Tab. 3) und Diagramme, die einen Überblick über die an den Fundstücken diagnostizierten Krankheiten geben. Angegeben ist jeweils eine Knochengruppe, bei der die auf der x-Achse aufgeführten Krankheiten zu diagnostizieren waren. Die tabellarische Darstellung bezieht sich auf Veränderungen (krankhafter oder anderer Art) und Fundstücke, die jeweils nur einfach vorkamen. Eine Darstellung dieser Fundstücke in Diagrammen wäre zu unübersichtlich und lässt keinen weiteren Erkenntnisgewinn erwarten, weswegen hier darauf verzichtet wurde. Die Fundstücke, die Spuren unterschiedlicher Krankheiten aufwiesen oder die Veränderungen, die an mehreren verschiedenen Fundstücken diagnostiziert wurden, finden sich in den danach folgenden Diagrammen wieder.

Tab. 3 (Einzelne) Veränderungen an (einzelnen) Knochen; Calden

Die Tabelle zeigt Fundstücke, die nur eine Veränderung aufwiesen. Weiterhin zeigt sie Veränderungen, die nur bei einer Gruppe von Fundstücken nachzuweisen waren. Mit dem Begriff "Schnürfurche" werden Impressionen von Periostgefäßen bezeichnet, die eine furchenartige Impression an darunter gelegenem Knochen hinterlassen

\begin{tabular}{|c|c|c|c|c|c|c|c|c|c|}
\hline & Arthrose & Anämie & Exostose & & \multirow{2}{*}{\begin{tabular}{|r|} 
Fraktur \\
3 \\
\end{tabular}} & \multicolumn{2}{|c|}{$\begin{array}{l}\text { Hocker- } \\
\text { facette }\end{array}$} & \multirow[t]{2}{*}{$\begin{array}{l}\text { Reiter- } \\
\text { facette }\end{array}$} & $\begin{array}{l}\text { Schmor'sche } \\
\text { Knorpel- } \\
\text { knötchen }\end{array}$ \\
\hline Vertebra & & & & & & & & & 1 \\
\hline Os coxae & & & & 1 & & & & & \\
\hline Os femoris & & 22 & & & & & & 1 & \\
\hline Tibia & & & & & & & 2 & & \\
\hline Talus & 1 & & & & & & & & \\
\hline Calcaneus & 1 & & & & & & & & \\
\hline $\begin{array}{l}\text { Os } \\
\text { metatarsale }\end{array}$ & 2 & & & & & & & & \\
\hline $\begin{array}{l}\text { Os phalangis } \\
\text { pedis }\end{array}$ & 5 & & & & & & & & \\
\hline Os phalangis & 2 & & & & & & & & \\
\hline & Schnürfurch & e $\quad$ Osteor & hyten & & ondylolistl & esis & & adylolysi & \\
\hline Os sacrum & & & & & & 1 & & & 1 \\
\hline Patella & & & 4 & & & & & & \\
\hline Tibia & & 1 & & & & & & & \\
\hline
\end{tabular}


Die Diagramme 40 bis 53 zeigen alle verschiedenen pathologischen Befunde an den untersuchten Knochen des Postcraniums der Population aus Calden. Über den Säulen in den Diagrammen finden sich die absoluten Anzahlen der jeweiligen Knochengruppe, die eine oder mehrere der pathologischen Veränderungen aufwiesen.

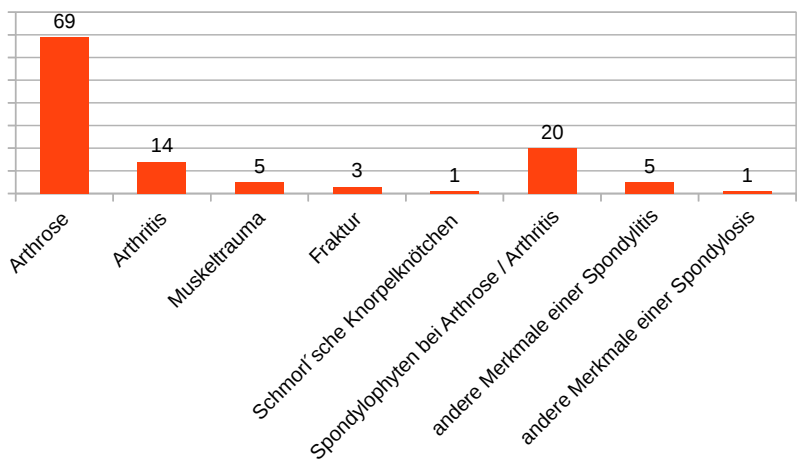

Abb. 40 Veränderungen an Vertebrae (gesamt befundbare: $n=241$ ); Calden

"n" bezieht sich auf alle Regionen. Auf der Abszisse sind die Veränderungen aufgeführt, über den Säulen findet sich die absolute Anzahl.

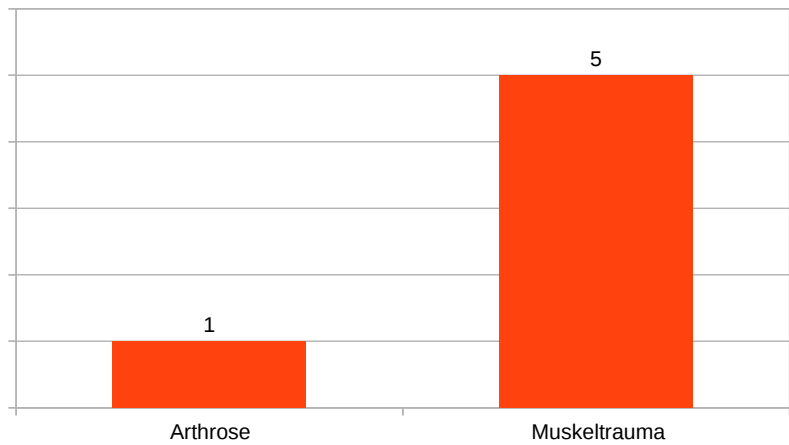

Abb. 41 Veränderungen an Claviculae (gesamt befundbare: $n=20$ ); Calden

Auf der Abszisse sind die Veränderungen aufgeführt, über den Säulen findet sich die absolute Anzahl. In dieser Darstellung wird nicht zwischen rechter und linker Körperseite differenziert.

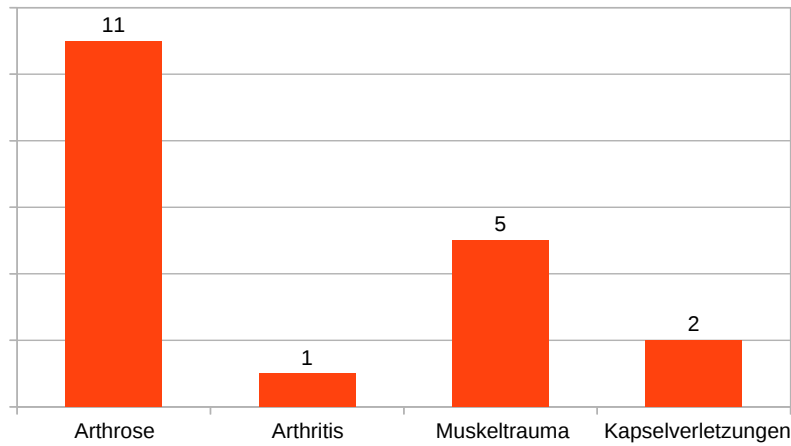

Abb. 42 Veränderungen an Scapulae (gesamt befundbare: $n=31$ ); Calden

Auf der Abszisse sind die Veränderungen aufgeführt, über den Säulen findet sich die absolute Anzahl. In dieser Darstellung wird nicht zwischen rechter und linker Körperseite differenziert. 


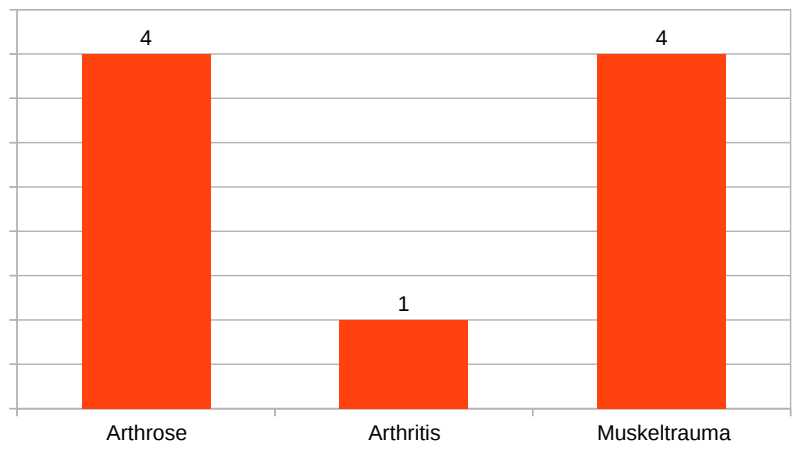

Abb. 43 Veränderungen an Costae (gesamt befundbare: $n=130$ ); Calden

Auf der Abszisse sind die Veränderungen aufgeführt, über den Säulen findet sich die absolute Anzahl. In dieser Darstellung wird nicht zwischen rechter und linker Körperseite differenziert.

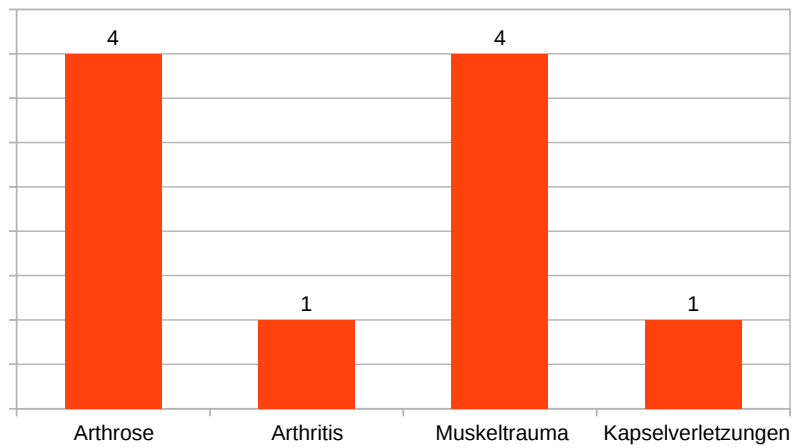

Abb. $44 \quad$ Veränderungen an Humeri (gesamt befundbare: $n=62)$; Calden

Auf der Abszisse sind die Veränderungen aufgeführt, über den Säulen findet sich die absolute Anzahl. In dieser Darstellung wird nicht zwischen rechter und linker Körperseite differenziert.

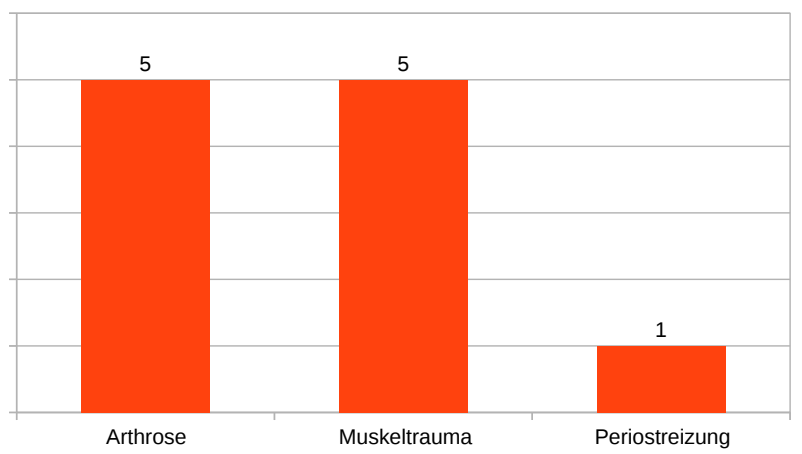

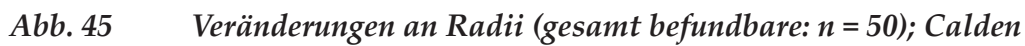

Auf der Abszisse sind die Veränderungen aufgeführt, über den Säulen findet sich die absolute Anzahl. In dieser Darstellung wird nicht zwischen rechter und linker Körperseite differenziert. 


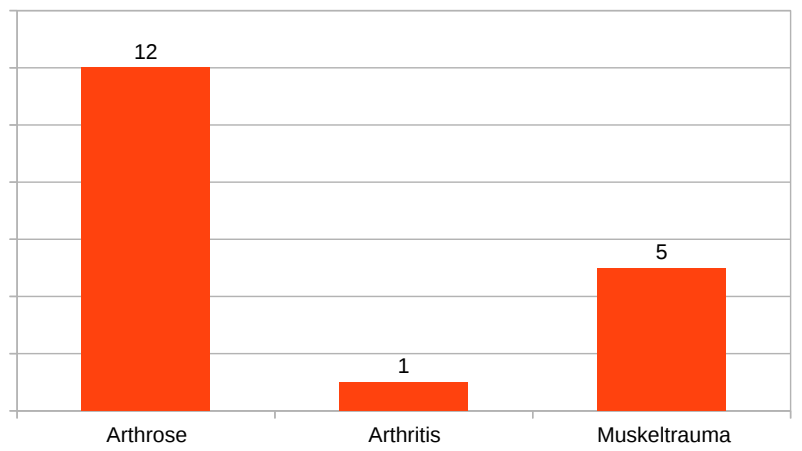

Abb. 46 Veränderungen an Ulnae (gesamt befundbare: $n=49$ ); Calden

Auf der Abszisse sind die Veränderungen aufgeführt, über den Säulen findet sich die absolute Anzahl. In dieser Darstellung wird nicht zwischen rechter und linker Körperseite differenziert.

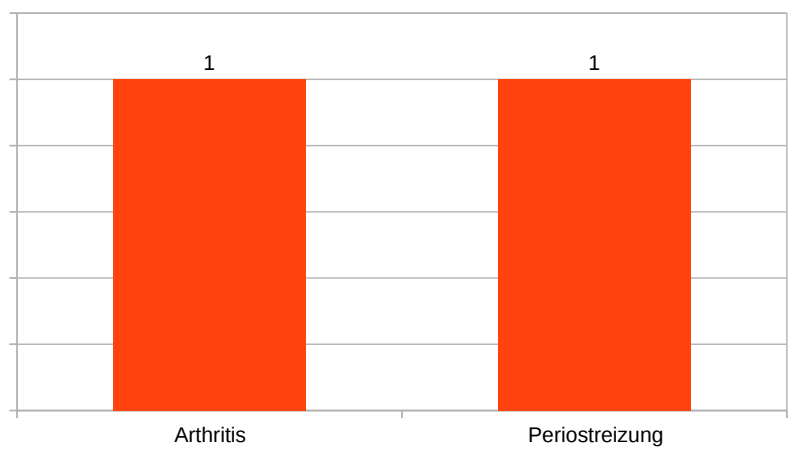

Abb. 47 Veränderungen an Phalanges manus (gesamt befundbare: $n=7$ ); Calden

Alle Phalangen der Hand eingeschlossen; auf der Abszisse sind die Veränderungen aufgeführt, über den Säulen findet sich die absolute Anzahl.

In dieser Darstellung wird nicht zwischen rechter und linker Körperseite differenziert.

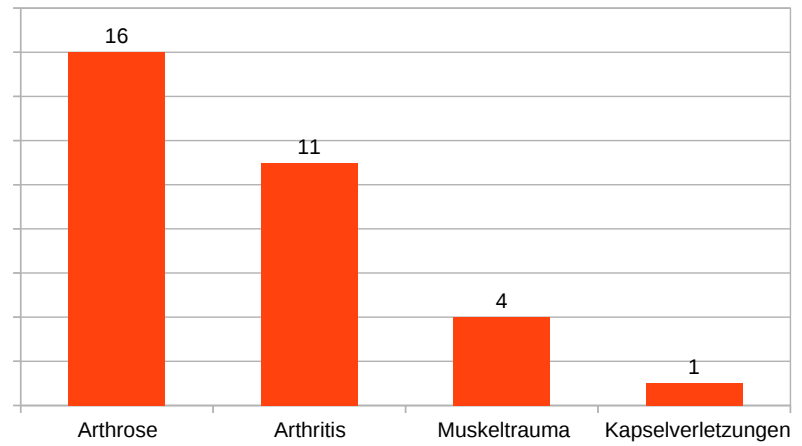

Abb. $48 \quad$ Veränderungen an Ossa coxae (gesamt befundbare: $n=58$ ); Calden

Auf der Abszisse sind die Veränderungen aufgeführt, über den Säulen findet sich die absolute Anzahl. In dieser Darstellung wird nicht zwischen rechter und linker Körperseite differenziert. 


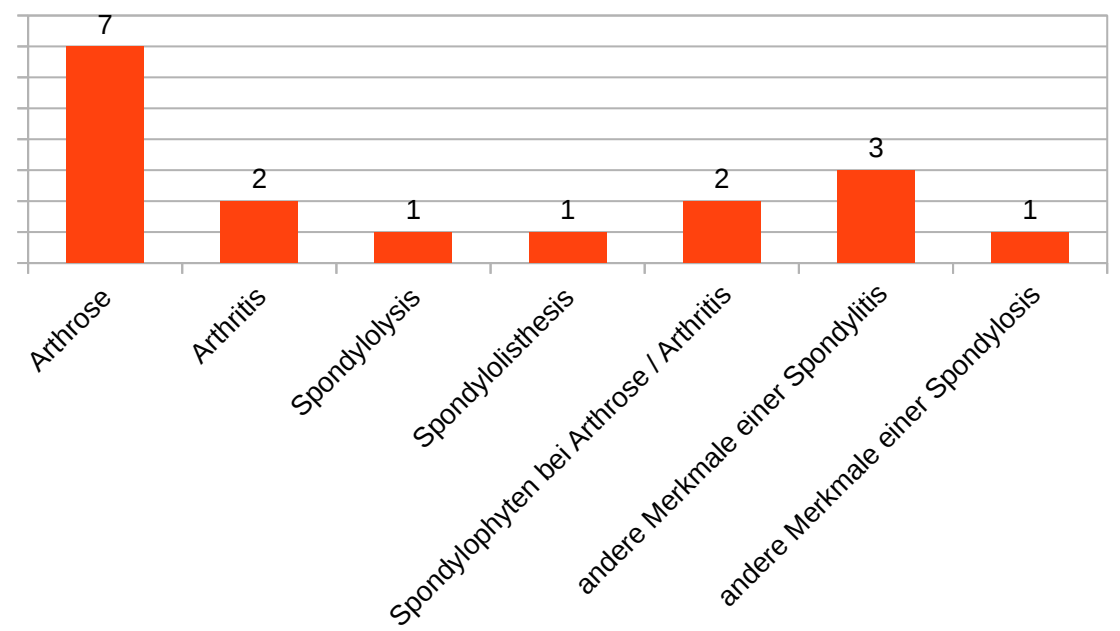

Abb. 49 Veränderungen an Ossa sacra (gesamt befundbare: $n=24) ;$ Calden

Auf der Abszisse sind die Veränderungen aufgeführt, über den Säulen findet sich die absolute Anzahl.

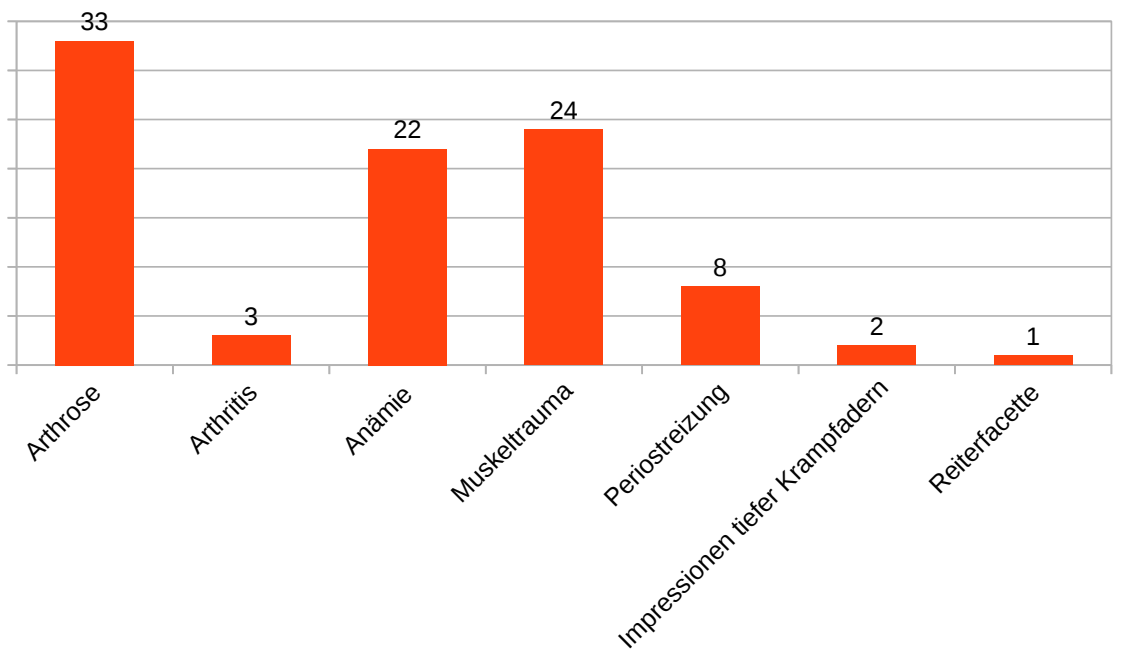

Abb. 50 Veränderungen an Ossa femoris (gesamt befundbare: $n=115$ ); Calden

Auf der Abszisse sind die Veränderungen aufgeführt, über den Säulen findet sich die absolute Anzahl. In dieser Darstellung wird nicht zwischen rechter und linker Körperseite differenziert. 


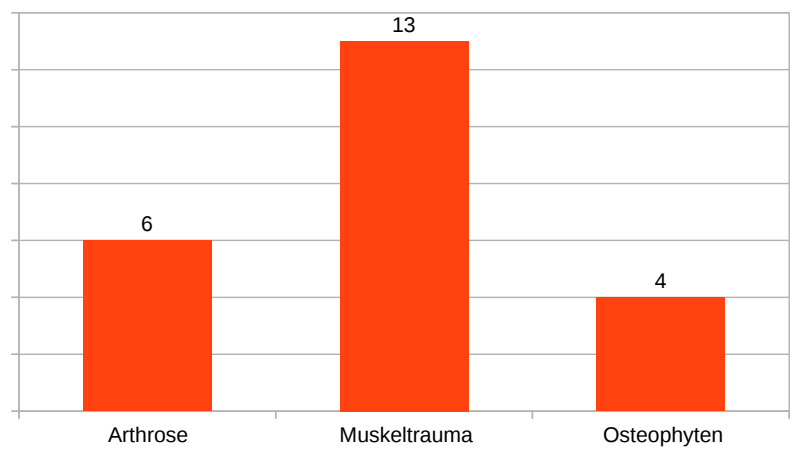

Abb. 51 Veränerungen an Patellae (gesamt befundbare: $n=23$ ); Calden

Auf der Abszisse sind die Veränderungen aufgeführt, über den Säulen findet sich die absolute Anzahl. In dieser Darstellung wird nicht zwischen rechter und linker Körperseite differenziert.
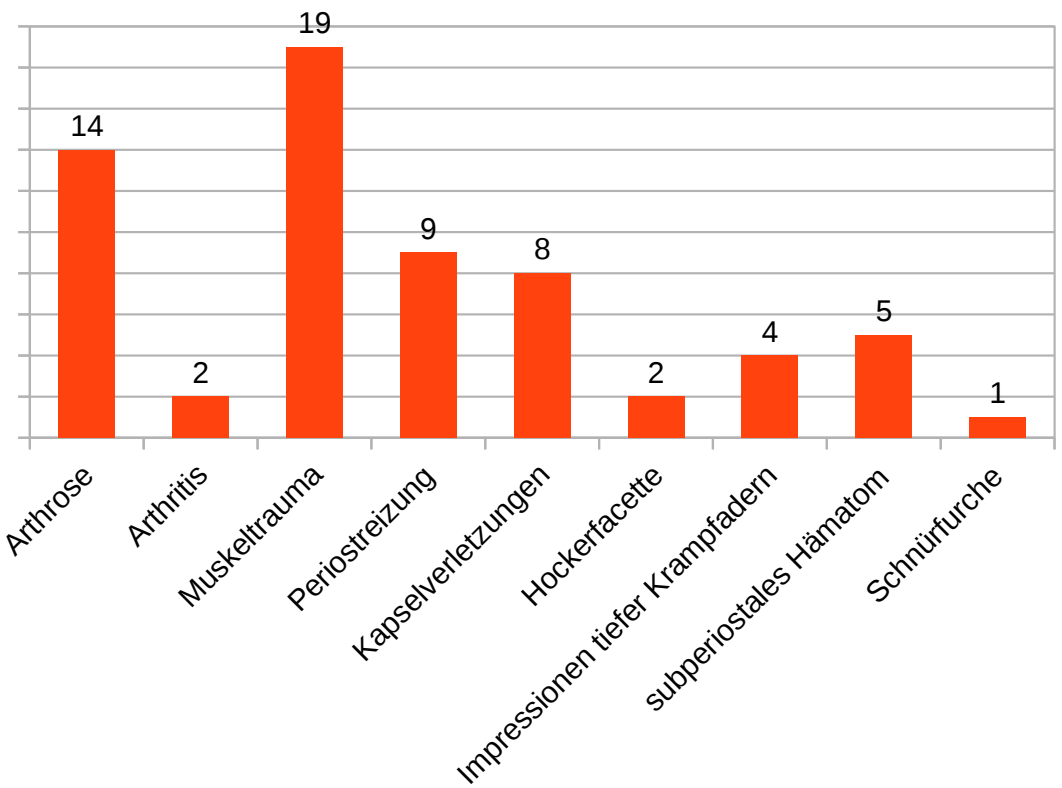

Abb. 52 Veränderungen an Tibiae (gesamt befundbare: $n=79$ ); Calden

Auf der Abszisse sind die Veränderungen aufgeführt, über den Säulen findet sich die absolute Anzahl. Mit dem Begriff "Schnürfurche" werden Impressionen von Periostgefäßen bezeichnet, die eine furchenartige Impression an darunter gelegenem Knochen hinterlassen. In dieser Darstellung wird nicht zwischen rechter und linker Körperseite differenziert. 


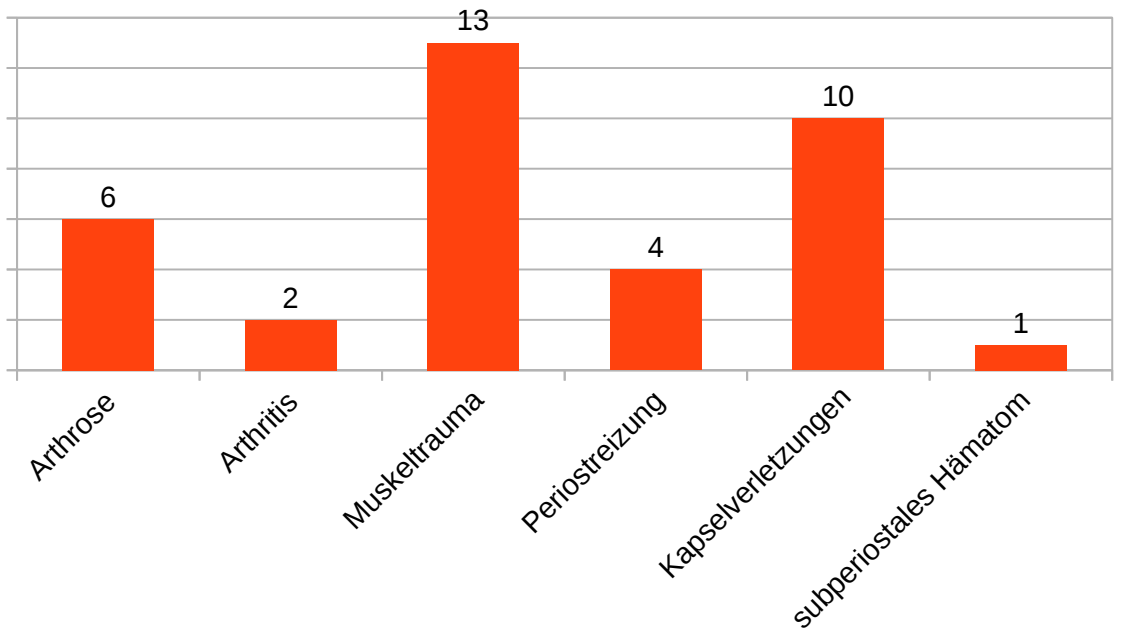

Abb. $53 \quad$ Veränderungen an Fibulae (gesamt befundbare: $n=47) ;$ Calden

Auf der Abszisse sind die Veränderungen aufgeführt, über den Säulen findet sich die absolute Anzahl. In dieser Darstellung wird nicht zwischen rechter und linker Körperseite differenziert.

Im Folgenden werden die verschiedenen Krankheiten in jeweils einem Diagramm dargestellt (Abbildungen 54 bis 63), dem zu entnehmen ist, wie oft die Krankheit bei den auf der x-Achse angegebenen Knochengruppen zu diagnostizieren war. Die Anzahl der Knochen einer Knochengruppe mit der jeweiligen pathologischen Veränderung wird in absoluten Zahlen über den Säulen der Diagramme angegeben.

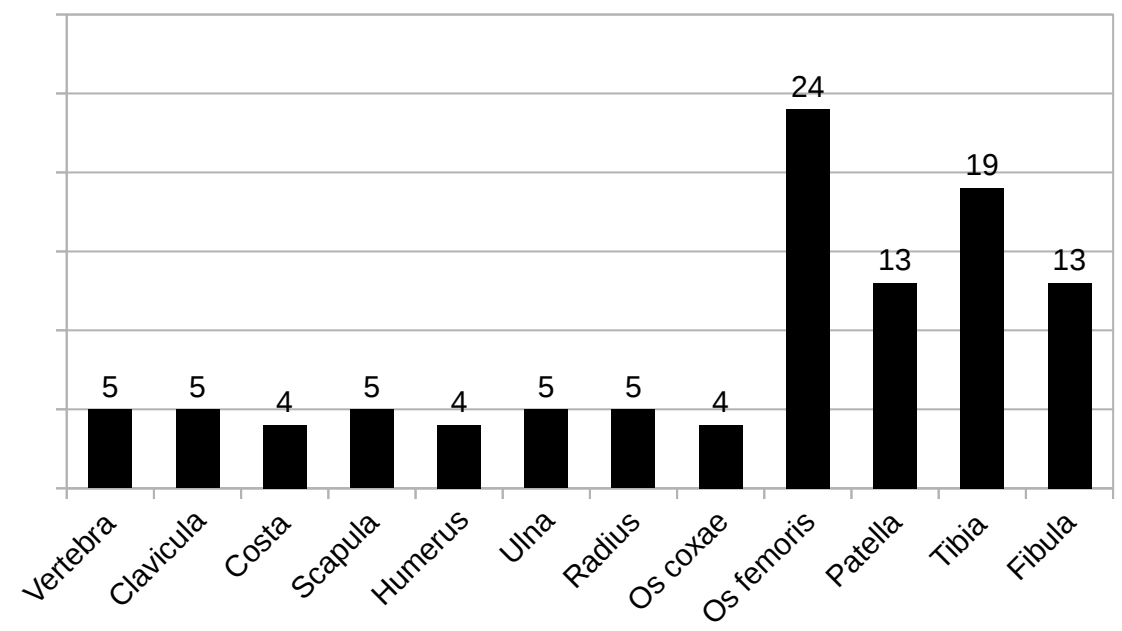

Abb. 54 Muskeltraumta an verschiedenen Skeletelementen; Calden

Auf der Abszisse sind die Knochen aufgeführt, über den Säulen findet sich die absolute Anzahl. 


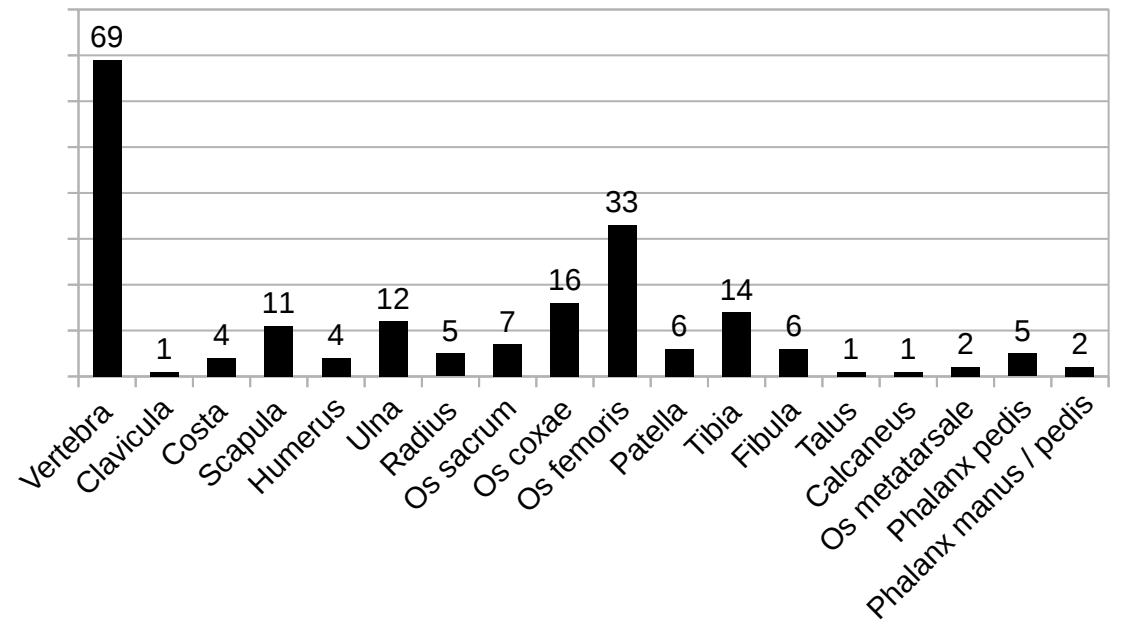

Abb. 55 Arthrose an verschiedenen Skeletelementen; Calden

Als "Phalanx pedis" wurden alle Phalangen des Fußes zusammengefasst, die nicht einem bestimmten Zeh zugeordnet werden konnten. Auf der Abszisse sind die Knochen aufgeführt, über den Säulen findet sich die absolute Anzahl.

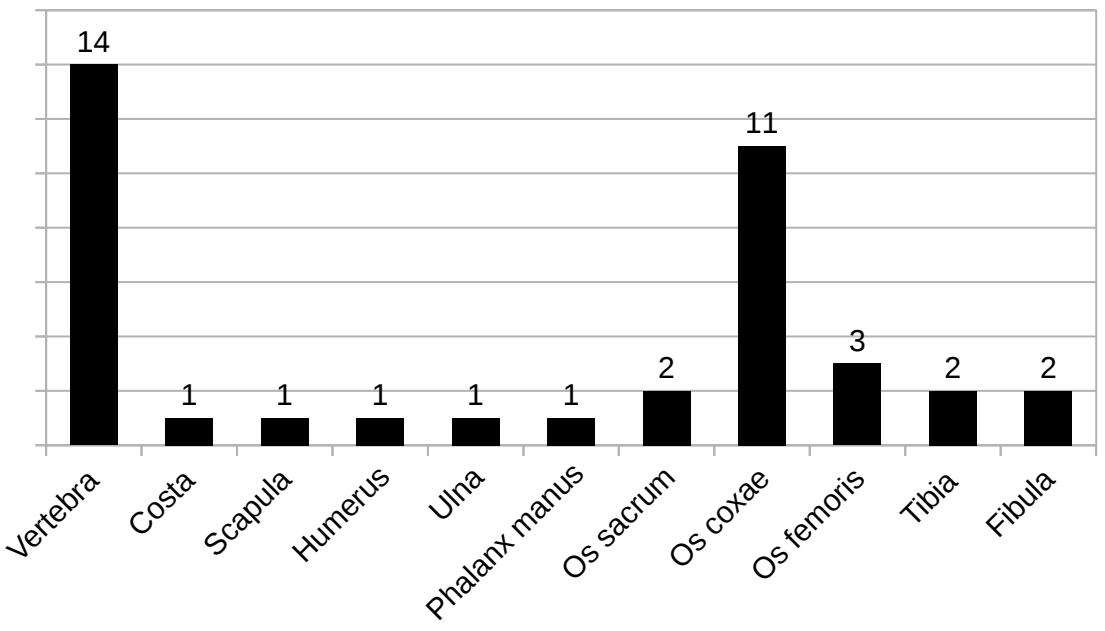

$A b b .56$

Arthritis an verschiedenen Skeletelementen; Calden

Auf der Abszisse sind die Knochen aufgeführt, über den Säulen findet sich die absolute Anzahl. 


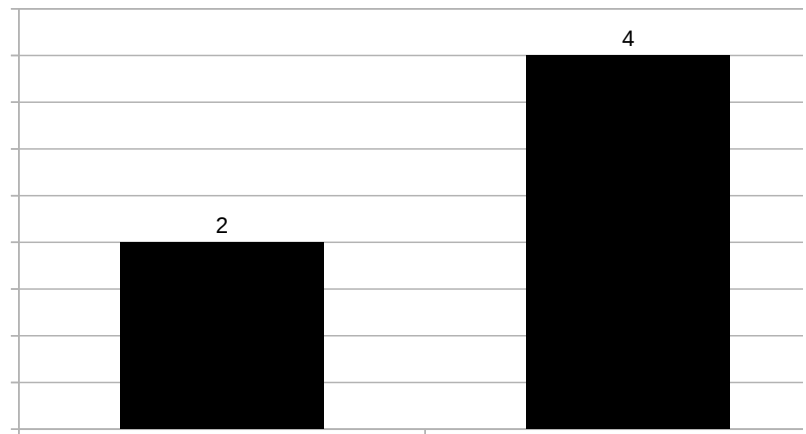

Os femoris

Tibia

Abb.57 Impressionen tiefer Krampfadern; Calden

Auf der Abszisse sind die Knochen aufgeführt, über den Säulen findet sich die absolute Anzahl.

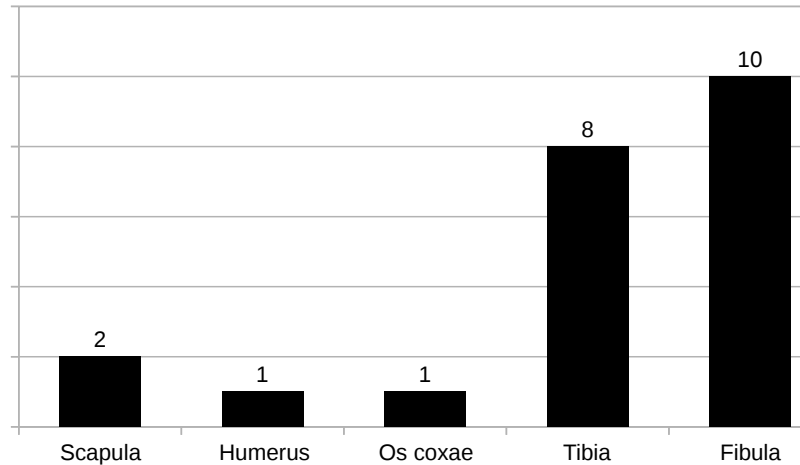

Abb. $58 \quad$ Kapselverletzungen an verschiedenen Skeletelementen; Calden

Auf die Darstellung der genauen Befundregionen der entsprechenden Knochen wird an dieser Stelle verzichtet, um nur die Kernaussage - ob Spuren von Kapselverletzungen festgestellt werden konnten und an welchen Knochen - zu präsentieren. Auf der Abszisse sind die Knochen aufgeführt, über den Säulen findet sich die absolute Anzahl.

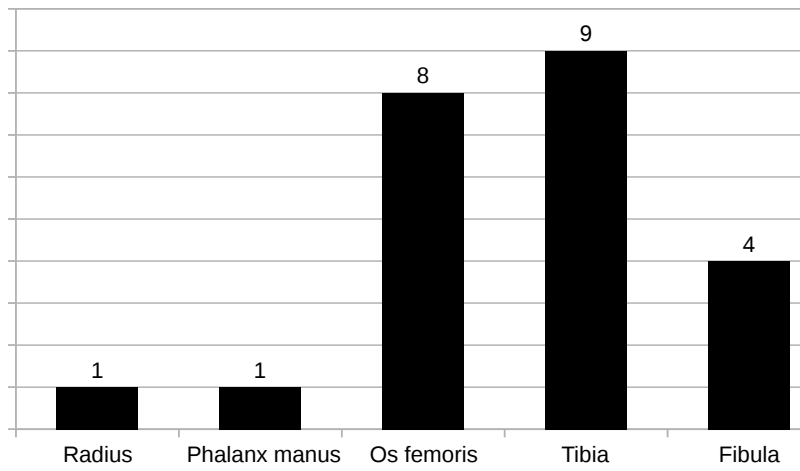

Abb.59 Periostreizungen an verschiedenen Skeletelementen; Calden

Als "Phalanx manus" wurden alle Phalangen der Hand zusammengefasst, die nicht einem Finger zugeordnet werden konnten. An dieser Stelle werden Spuren von Periostreizungen an allen Regionen der Knochen dargestellt, die nicht einer Gelenkdiagenese oder einer Muskelreizung entsprechen. Auf der Abszisse sind die Knochen aufgeführt, über den Säulen findet sich die absolute Anzahl. 


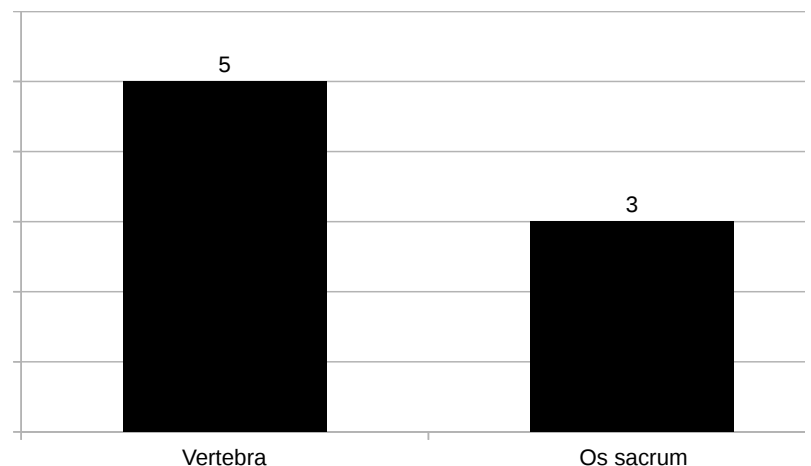

Abb. 60 Spondylitis an Vertebrae und Ossa sacra; Calden

Auf der Abszisse sind die Knochen aufgeführt, über den Säulen findet sich die absolute Anzahl.

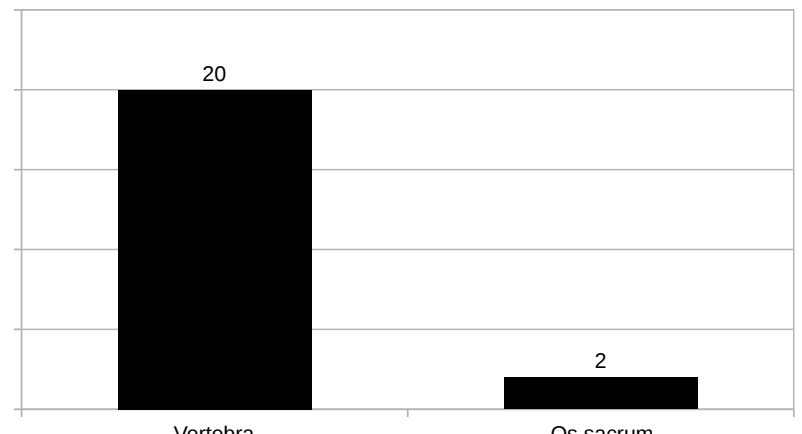

Vertebra

Os sacrum

Abb. $61 \quad$ Spondylophyten an Vertebrae und Ossa sacra; Calden

Auf der Abszisse sind die Knochen aufgeführt, über den Säulen findet sich die absolute Anzahl.

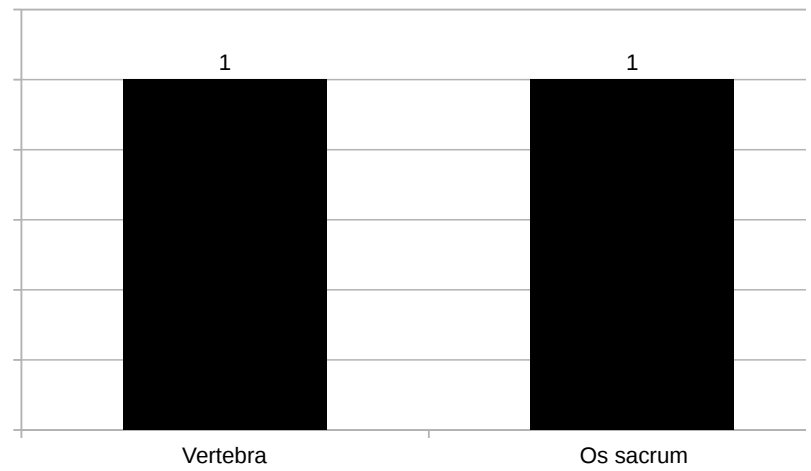

Abb. 62 Spondylosis an Vertebrae und Ossa sacra; Calden

Auf der Abszisse sind die Knochen aufgeführt, über den Säulen findet sich die absolute Anzahl. 


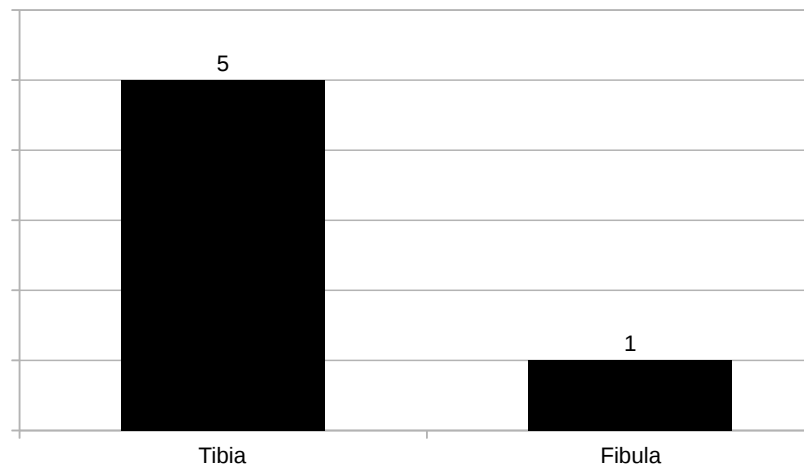

Abb. 63 Subperiostale Hämatome an Tibiae und Fibulae; Calden Auf der Abszisse sind die Knochen aufgeführt, über den Säulen findet sich die absolute Anzahl.

\subsubsection{Ermittlung des Sterbealters}

In den folgenden Diagrammen werden alle Fundstücke aufgeführt, bei denen eine Ermittlung des Sterbealters möglich war. Die Altersbestimmung aller Fundstücke (außer Zähnen) wurde in zwei Chargen gegliedert, da die Darstellung sonst zu unübersichtlich wäre. Die erste Charge gibt die Altersbestimmung in zwei Abstufungen der Altersschätzung an, während sich die zweite Charge auf jene Fundstücke bezieht, bei denen das Alter in einem engeren Rahmen bestimmt werden konnte.

Vergleicht man die fünf Diagramme, so fallen deutliche Gemeinsamkeiten auf. Zahlreiche Fundstücke sind in einen bestimmten Sterbealterbereich einzuordnen. Dieser liegt etwa zwischen 30 und 50 Jahren. Am aussagekräftigsten ist die Bestimmung des Sterbealters jener Fundstücke, die ebenfalls eine Aussage über die Mindestindividuenzahl zulassen. Das sind zum einen die Femora der rechten Seite von denen als Kriterium jeweils mindestens das zweite Fünftel proximal erhalten sein musste - und zum anderen die unteren ersten Molaren der linken Seite. Diese beiden Gruppen der Fundstücke sind jene, die die MIZ der Population aus Calden am verlässlichsten repräsentieren.

Die Diagramme 64 bis 68 zeigen die Altersspannen des ermittelten Sterbealters der untersuchten Fundstücke. Der dicke Balken entspricht der Altersspanne des wahrscheinlichen Sterbealters. Der blaue Strich gibt die maximalen und minimalen Grenzwerte des noch möglichen Sterbealters an. Insgesamt sollen die folgenden Darstellungen dazu dienen, auf den ersten Blick den Altersbereich erkennen zu können, in den die meisten Fundstücke einzuordnen waren. 

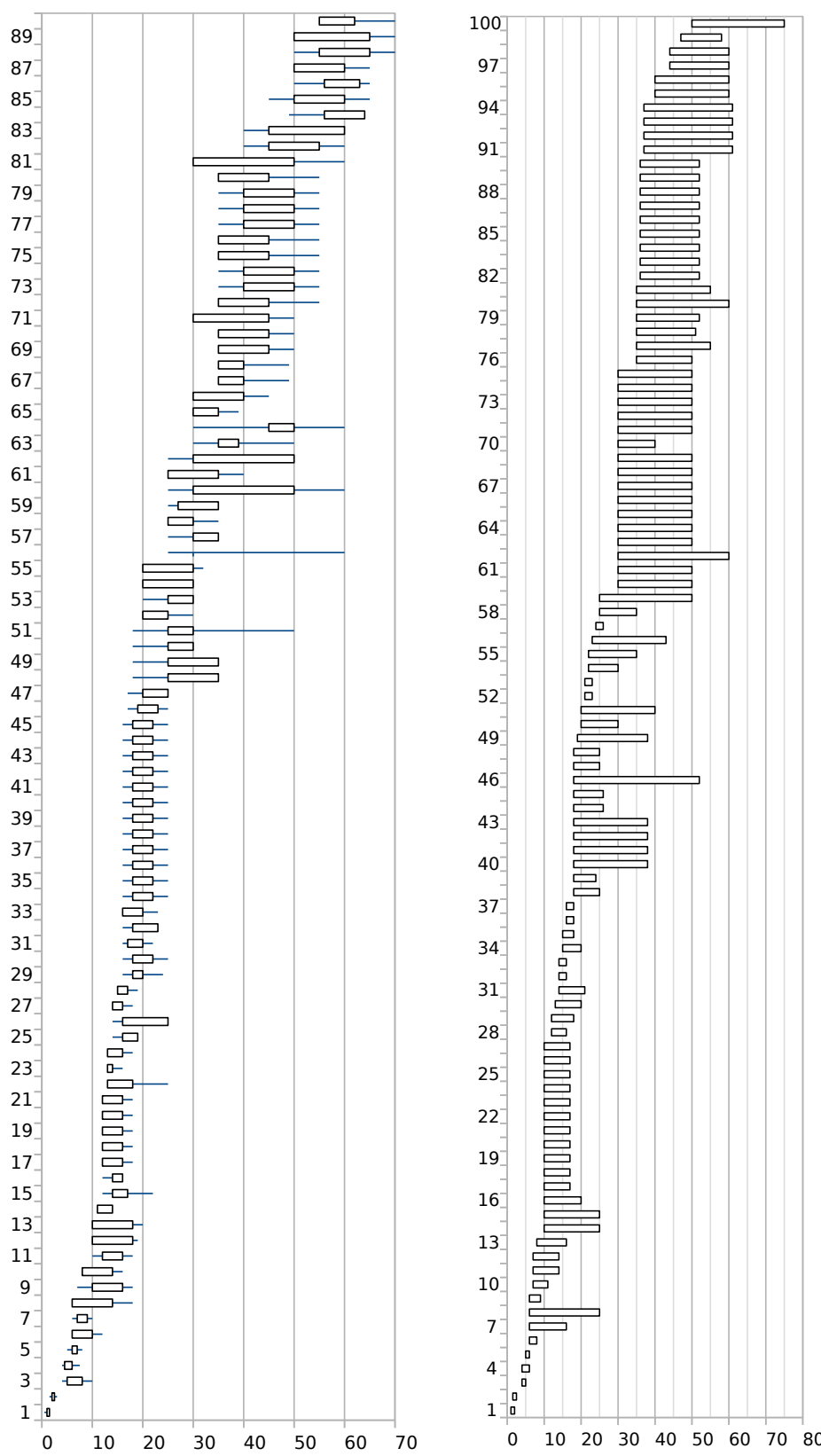

Abb.64 Links: Sterbealterbestimmung aller Fundstücke (außer den Zähnen) Teil 1; Calden

Abb. 65 Rechts: Sterbealterbestimmung aller Fundstücke (außer den Zähnen) Teil 2; Calden

Beschreibung zu den Abbildungen 64 und 65: In Diagramm 64 finden sich die Fundstücke (außer den Zähnen), deren Sterbealter nur in größerem Rahmen bestimmbar war, in Diagramm 65 sind jene Fundstücke (außer den Zähnen) dargestellt, deren Sterbealter genauer eingeordnet werden konnte. Auf der $x$-Achse ist das Sterbealter aufgetragen, auf der $y$-Achse entspricht jede volle Einheit einem Fundstück, für das im Diagramm dann das Sterbealter in einem "Wahrscheinlichkeitsbereich" (Balken und/oder Strich) abzulesen ist. Der blaue Strich steht dabei gegebenenfalls für die noch möglichen maximalen und minimalen Grenzwerte des Sterbealters, der Balken für das wahrscheinliche Sterbealter. 

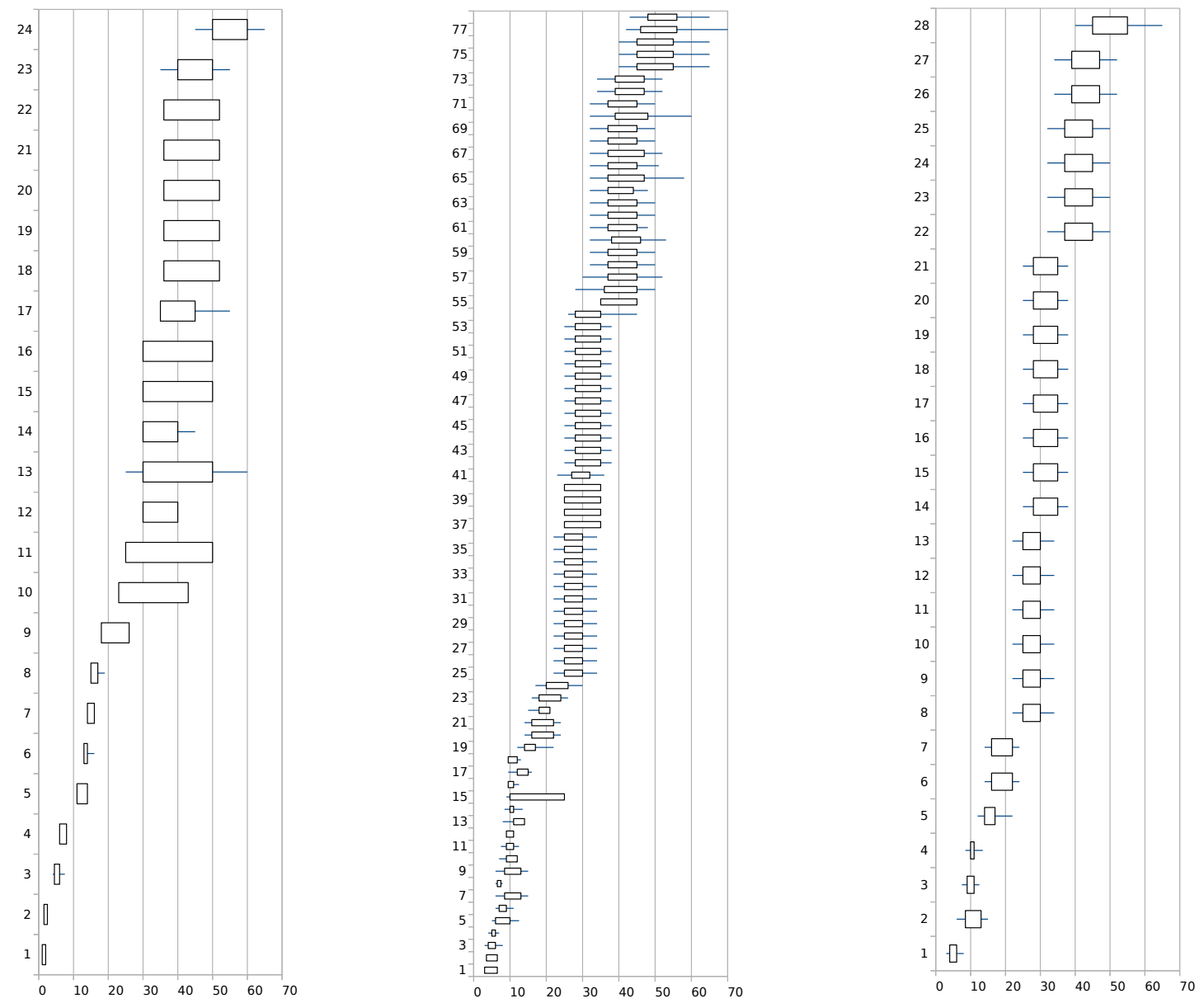

Abb. 66 Links: Sterbealterbestimmung rechter Femora (MIZ); Calden

Abb. 67 Mitte: Sterbealterbestimmung aller Zähne; Calden

Abb. 68 Rechts: Sterbealterbestimmung der Zähne 36 (MIZ); Calden

Legende für die Abbildungen 66-68: Auf der x-Achse ist das Sterbealter aufgetragen, auf der $y$-Achse entspricht jede volle Einheit einem Fundstück, für das im Diagramm dann das Sterbealter in einem "Wahrscheinlichkeitsbereich" (Balken und/oder Strich) abzulesen ist. Der blaue Strich steht dabei gegebenenfalls für die noch möglichen maximalen und minimalen Grenzwerte des Sterbealters, der Balken für das wahrscheinliche Sterbealter.

Bei den meisten Fundstücken war keine genaue Altersbestimmung möglich. Um dennoch einen orientierenden Überblick zu bekommen, wurden Fundstücke wenn möglich in "adult" und „subadult“ eingeordnet. Diese Zuordnung wurde dokumentiert und anschließend ausgewertet (Abb. 69). 


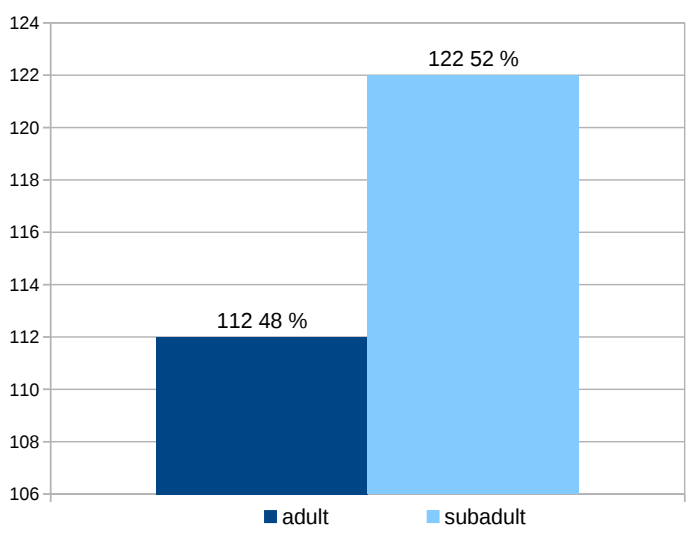

Abb. 69 Alterseinteilung der Fundstücke in ",adult" u. "subadult"; Calden

Einteilung in die zwei großen Altersgruppen aufgrund morphologischer Gesichtspunkte (wenn beispielsweise offene Epiphysen vorlagen, wurde das Fundstück in die Kategorie "subadult" eingeteilt). Über den Säulen sind die absoluten Häufigkeiten links aufgeführt, rechts daneben finden sich jeweils die prozentualen Anteile. Auf der Ordinate befindet sich die Angabe der Gesamtzahl.

\subsubsection{Geschlechtsbestimmung}

Für die Population aus Calden konnten 327 Fundstücke einer Geschlechtsbestimmung unterzogen werden. Oft war es lediglich möglich, die Tendenz anzugeben, dass ein Fundstück eher einem männlichen oder eher einem weiblichen Individuum zuzuordnen war (Abb. 70).

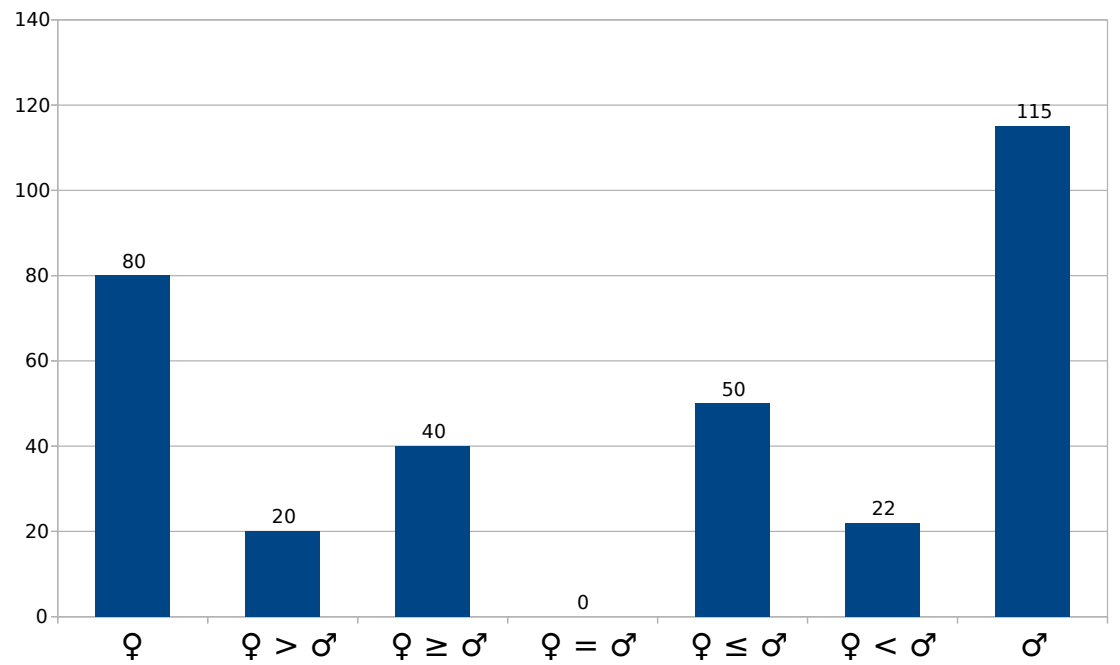

Abb. 70 Geschlechtsverteilung Diagramm 1; Calden

Im Diagramm sind alle Fundstücke erfasst, bei denen eine Geschlechtsbestimmung möglich war ( $n=327$ Fundstücke). Die Einteilung erfolgte in "wahrscheinlich" weiblich (q), "wohl" weiblich (q $>\hat{\jmath})$, "eher" weiblich $(q \geq \hat{0})$, "indifferent" $(q=\hat{\varnothing})$, also keinem Geschlecht zuzuordnen, "eher"

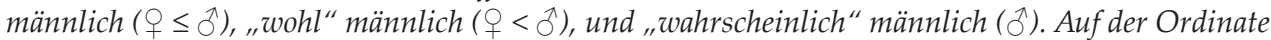
befindet sich die Angabe der Gesamtzahl. 
Nach dem Gesamtüberblick über die Geschlechtsbestimmung aller Fundstücke soll nun ein Diagramm mit der Geschlechtsverteilung bei jenen Femora gezeigt werden (Abb. 71), die für die Bestimmung der Mindestindividuenzahl herangezogen wurden.

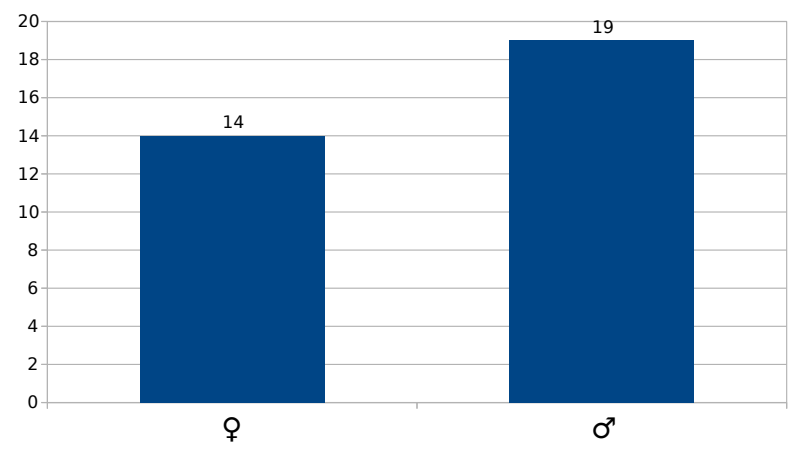

Abb. 71 Geschlechtsverteilung Diagramm 2; Calden

Geschlechtsverteilung der Population aus Calden anhand von rechten Femora (MIZ). Aufgrund der besseren Übersicht wird in dieser Darstellung auf die genauere Darstellung der Geschlechtstendenzen verzichtet. Die Gesamtzahl der für die Bestimmung der MIZ verwendeten rechten Femora beträgt 39, jedoch konnte bei sechs dieser Femora keine Geschlechterzuordnung vorgenommen werden. Auf der Ordinate befindet sich die Angabe der Gesamtzahl.

Die Geschlechtsverteilung ist leicht in Richtung der männlichen Individuen verschoben.

\subsubsection{Rekonstruktion der Körperhöhe}

Wenn möglich wurde eine Körperhöhenrekonstruktion mittels der Länge der Femora berechnet (Abb. 72). Für das Diagramm wurde eine Formel verwendet, die männliche und weibliche Knochen berücksichtigt. Dies bietet den Vorteil, dass nach dieser Formel alle Femora - ungeachtet der Seite und des Geschlechts - mit einbezogen werden können. Weitere Formeln wurden ebenfalls herangezogen, um die Körperhöhe zu berechnen. Eine Tabelle mit den Ergebnissen dieser Berechnungen findet sich am Schluss der Erebnisse der Population aus Calden. 


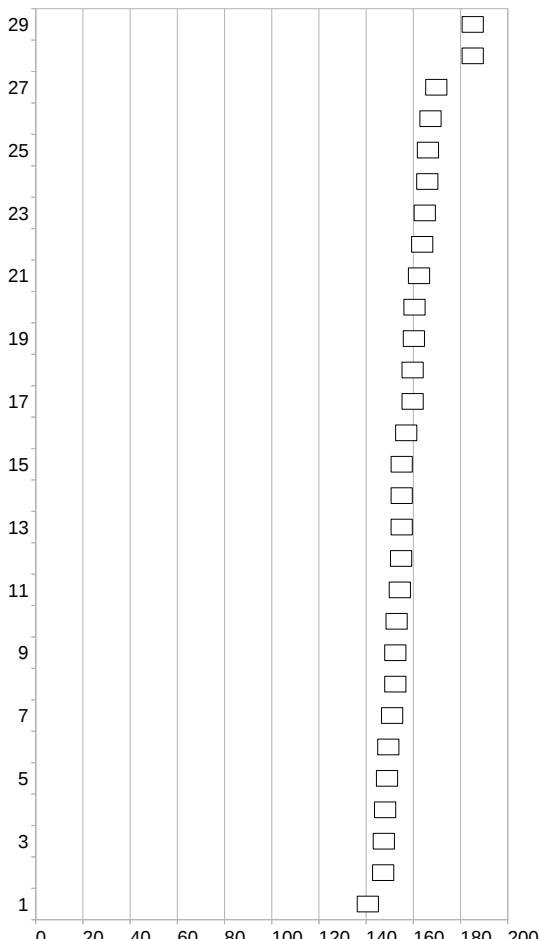

Abb. 72 Femora $(n=29)$ für die Körperhöhenrekonstruktion; Calden

Darstellung der Femora ( $n=29)$, deren Gesamtlängen für die Körperhöhenrekonstruktion verwendet werden konnten. Auf der $x$-Achse ist die Körperhöhe in Zentimetern aufgetragen, auf der $y$-Achse findet sich die Anzahl der Femora. Die Balken geben den Minimal- und Maximalwert der Körperhöhe an.

Danach folgt ein reduzierter Anhang für den Ergebnisteil der Population aus Calden, in dem Tabellen zur Körperhöhenrekonstruktion nach verschiedenen Autoren aufgeführt sind. Die Tabelle 4 bezieht sich auf die verschiedenen Berechnungsformeln für die Rekonstruktion der Körperhöhen mit Längen der Oberschenkelknochen. Angegeben sind jeweils die Größen, die sich nach Anwendung der Formeln berechnen ließen.

Tab. $4 \quad$ Körperhöhenbestimmung anhand von Femora; Calden

Körperhöhenbestimmung berechnet anhand von Formeln verschiedener Autoren, je nach Formel getrennt nach weiblich und männlich.

\begin{tabular}{|l|l|l|r|r|r|l|l|}
\hline $\begin{array}{l}\text { Bezeichnung } \\
\text { des Femur }\end{array}$ & Geschlecht & Seite & Größe & $\begin{array}{l}\text { Ab- } \\
\text { wei- } \\
\text { chung }\end{array}$ & $\begin{array}{l}\text { Mini- } \\
\text { male } \\
\text { Größe }\end{array}$ & $\begin{array}{l}\text { Maxi- } \\
\text { male } \\
\text { Größe }\end{array}$ & Formel nach \\
\hline unter Sk 10 37 & männlich & links & 163,84 & 3,30 & 160,54 & 167,14 & Pearson 1899 \\
\hline unter Sk 10 37 & männlich & links & 166,53 & 4,80 & 161,73 & 171,33 & Breitinger 1938 \\
\hline unter Sk 10 37 & männlich & links & 162,79 & 0,00 & 162,79 & 162,79 & Siegmund 2010 \\
\hline unter Sk 10 37 & männlich & links & 164,04 & 0,00 & 164,04 & 164,04 & Telkkä 1950 \\
\hline unter Sk 10 37 & männlich & links & 163,01 & 3,22 & 159,79 & 166,23 & Raxter 2008 \\
\hline unter Sk 1037 & männlich & links & 164,83 & 4,49 & 160,34 & 169,32 & Sjøvold 1990 \\
\hline unter Sk 10 37 & männlich & links & 164,64 & 4,15 & 160,49 & 168,79 & Cerný/Komenda 1982 \\
\hline
\end{tabular}




\begin{tabular}{|c|c|c|c|c|c|c|c|}
\hline V50 49 & weiblich & rechts & 145,59 & 3,30 & 142,29 & 148,89 & Pearson 1899 \\
\hline V50 49 & weiblich & rechts & 155,8 & 4,10 & 151,7 & 159,9 & Bach 1965 \\
\hline V50 49 & weiblich & rechts & 146,88 & 0,00 & 146,88 & 146,88 & Telkkä 1950 \\
\hline V50 49 & weiblich & rechts & 147,21 & 4,49 & 142,72 & 151,7 & Sjøvold 1990 \\
\hline V50 49 & weiblich & rechts & 144,59 & 4,44 & 140,15 & 149,03 & Cerný/Komenda 1982 \\
\hline V50 50 & weiblich & links & 146,17 & 3,30 & 142,87 & 149,47 & Pearson 1899 \\
\hline V50 50 & weiblich & links & 156,19 & 4,10 & 152,09 & 160,29 & Bach 1965 \\
\hline V50 50 & weiblich & links & 147,42 & 0,00 & 147,42 & 147,42 & Telkkä 1950 \\
\hline V50 50 & weiblich & links & 148,03 & 4,49 & 143,54 & 152,52 & Sjøvold 1990 \\
\hline V50 50 & weiblich & links & 145,51 & 4,51 & 141 & 150,02 & Cerný/Komenda 1982 \\
\hline V46 2 & männlich & rechts & 160,83 & 3,30 & 157,53 & 164,13 & Pearson 1899 \\
\hline V46 2 & männlich & rechts & 163,89 & 4,80 & 159,09 & 168,69 & Breitinger 1938 \\
\hline V46 2 & männlich & rechts & 159,68 & 0,00 & 159,68 & 159,68 & Siegmund 2010 \\
\hline V46 2 & männlich & rechts & 160,68 & 0,00 & 160,68 & 160,68 & Telkkä 1950 \\
\hline V46 2 & männlich & rechts & 159,4 & 3,22 & 156,18 & 162,62 & Raxter 2008 \\
\hline V46 2 & männlich & rechts & 160,49 & 4,49 & 156 & 164,98 & Sjøvold 1990 \\
\hline V46 2 & männlich & rechts & 160,93 & 4,21 & 156,72 & 165,14 & Cerný/Komenda 1982 \\
\hline V6362 & weiblich & rechts & 148,31 & 3,30 & 145,01 & 151,61 & Pearson 1899 \\
\hline V63 62 & weiblich & rechts & 157,63 & 4,10 & 153,53 & 161,73 & Bach 1965 \\
\hline V63 62 & weiblich & rechts & 149,4 & 0,00 & 149,4 & 149,4 & Telkkä 1950 \\
\hline V63 62 & weiblich & rechts & 151,01 & 4,49 & 146,52 & 155,5 & Sjøvold 1990 \\
\hline V63 62 & weiblich & rechts & 148,07 & 4,44 & 143,63 & 152,51 & Cerný/Komenda 1982 \\
\hline V6363 & weiblich & links & 149,28 & 3,30 & 145,98 & 152,58 & Pearson 1899 \\
\hline V63 63 & weiblich & links & 158,29 & 4,10 & 154,19 & 162,39 & Bach 1965 \\
\hline V63 63 & weiblich & links & 150,3 & 0,00 & 150,3 & 150,3 & Telkkä 1950 \\
\hline V63 63 & weiblich & links & 152,36 & 4,49 & 147,87 & 156,85 & Sjøvold 1990 \\
\hline V63 63 & weiblich & links & 149,21 & 4,51 & 144,7 & 153,72 & Cerný/Komenda 1982 \\
\hline 56 & männlich & links & 167,22 & 3,30 & 163,92 & 170,52 & Pearson 1899 \\
\hline 56 & männlich & links & 169,49 & 4,80 & 164,69 & 174,29 & Breitinger 1938 \\
\hline 56 & männlich & links & 166,3 & 0,00 & 166,3 & 166,3 & Siegmund 2010 \\
\hline 56 & männlich & links & 167,82 & 0,00 & 167,82 & 167,82 & Telkkä 1950 \\
\hline 56 & männlich & links & 167,07 & 3,22 & 163,85 & 170,29 & Raxter 2008 \\
\hline 56 & männlich & links & 169,71 & 4,49 & 165,22 & 174,2 & Sjøvold 1990 \\
\hline 56 & männlich & links & 168,82 & 4,15 & 164,67 & 172,97 & Cerný/Komenda 1982 \\
\hline P.Sk.9. 427 & männlich & rechts & 156,51 & 3,30 & 153,21 & 159,81 & Pearson 1899 \\
\hline P.Sk.9. 427 & männlich & rechts & 160,11 & 4,80 & 155,31 & 164,91 & Breitinger 1938 \\
\hline P.Sk.9. 427 & männlich & rechts & 155,2 & 0,00 & 155,2 & 155,2 & Siegmund 2010 \\
\hline P.Sk.9. 427 & männlich & rechts & 155,85 & 0,00 & 155,85 & 155,85 & Telkkä 1950 \\
\hline P.Sk.9. 427 & männlich & rechts & 154,21 & 3,22 & 150,99 & 157,43 & Raxter 2008 \\
\hline P.Sk.9. 427 & männlich & rechts & 154,26 & 4,49 & 149,77 & 158,75 & Sjøvold 1990 \\
\hline P.Sk.9. 427 & männlich & rechts & 155,44 & 4,21 & 151,23 & 159,65 & Cerný/Komenda 1982 \\
\hline
\end{tabular}




\begin{tabular}{|c|c|c|c|c|c|c|c|}
\hline V57 SK9 5420 & männlich & rechts & 164,59 & 3,30 & 161,29 & 167,89 & Pearson 1899 \\
\hline V57 SK9 5420 & männlich & rechts & 167,18 & 4,80 & 162,38 & 171,98 & Breitinger 1938 \\
\hline V57 SK9 5420 & männlich & rechts & 163,57 & 0,00 & 163,57 & 163,57 & Siegmund 2010 \\
\hline V57 SK9 5420 & männlich & rechts & 164,88 & 0,00 & 164,88 & 164,88 & Telkkä 1950 \\
\hline V57 SK9 5420 & männlich & rechts & 163,92 & 3,22 & 160,7 & 167,14 & Raxter 2008 \\
\hline V57 SK9 5420 & männlich & rechts & 165,91 & 4,49 & 161,42 & 170,4 & Sjøvold 1990 \\
\hline V57 SK9 5420 & männlich & rechts & 165,7 & 4,21 & 161,49 & 169,91 & Cerný/Komenda 1982 \\
\hline V57 SK9 554 & männlich & links & 165,53 & 3,30 & 162,23 & 168,83 & Pearson 1899 \\
\hline V57 SK9 554 & männlich & links & 168,01 & 4,80 & 163,21 & 172,81 & Breitinger 1938 \\
\hline V57 SK9 554 & männlich & links & 164,55 & 0,00 & 164,55 & 164,55 & Siegmund 2010 \\
\hline V57 SK9 554 & männlich & links & 165,93 & 0,00 & 165,93 & 165,93 & Telkkä 1950 \\
\hline V57 SK9 554 & männlich & links & 165,04 & 3,22 & 161,82 & 168,26 & Raxter 2008 \\
\hline V57 SK9 554 & männlich & links & 167,27 & 4,49 & 162,78 & 171,76 & Sjøvold 1990 \\
\hline V57 SK9 554 & männlich & links & 166,73 & 4,15 & 162,58 & 170,88 & Cerný/Komenda 1982 \\
\hline 32 E. B-S. 39 & männlich & rechts & 160,27 & 3,30 & 156,97 & 163,57 & Pearson 1899 \\
\hline 32 E. B-S. 39 & männlich & rechts & 163,4 & 4,80 & 158,6 & 168,2 & Breitinger 1938 \\
\hline 32 E. B-S. 39 & männlich & rechts & 159,09 & 0,00 & 159,09 & 159,09 & Siegmund 2010 \\
\hline 32 E. B-S. 39 & männlich & rechts & 160,05 & 0,00 & 160,05 & 160,05 & Telkkä 1950 \\
\hline 32 E. B-S. 39 & männlich & rechts & 158,72 & 3,22 & 155,5 & 161,94 & Raxter 2008 \\
\hline 32 E. B-S. 39 & männlich & rechts & 159,68 & 4,49 & 155,19 & 164,17 & Sjøvold 1990 \\
\hline 32 E. B-S. 39 & männlich & rechts & 160,21 & 4,21 & 156 & 164,42 & Cerný/Komenda 1982 \\
\hline 4038 E. B-S. & männlich & rechts & 162,15 & 3,30 & 158,85 & 165,45 & Pearson 1899 \\
\hline 4038 E. B-S. & männlich & rechts & 165,04 & 4,80 & 160,24 & 169,84 & Breitinger 1938 \\
\hline 4038 E. B-S. & männlich & rechts & 161,04 & 0,00 & 161,04 & 161,04 & Siegmund 2010 \\
\hline 4038 E. B-S. & männlich & rechts & 162,15 & 0,00 & 162,15 & 162,15 & Telkkä 1950 \\
\hline 4038 E. B-S. & männlich & rechts & 160,98 & 3,22 & 157,76 & 164,2 & Raxter 2008 \\
\hline 4038 E. B-S. & männlich & rechts & 162,39 & 4,49 & 157,9 & 166,88 & Sjøvold 1990 \\
\hline 4038 E. B-S. & männlich & rechts & 162,59 & 4,21 & 158,38 & 166,8 & Cerný/Komenda 1982 \\
\hline 34 & weiblich & rechts & 145,78 & 3,30 & 142,48 & 149,08 & Pearson 1899 \\
\hline 34 & weiblich & rechts & 155,93 & 4,10 & 151,83 & 160,03 & Bach 1965 \\
\hline 34 & weiblich & rechts & 147,06 & 0,00 & 147,06 & 147,06 & Telkkä 1950 \\
\hline 34 & weiblich & rechts & 147,48 & 4,49 & 142,99 & 151,97 & Sjøvold 1990 \\
\hline 34 & weiblich & rechts & 144,84 & 4,44 & 140,4 & 149,28 & Cerný/Komenda 1982 \\
\hline 132 & männlich & links & 160,64 & 3,30 & 157,34 & 163,94 & Pearson 1899 \\
\hline 132 & männlich & links & 163,73 & 4,80 & 158,93 & 168,53 & Breitinger 1938 \\
\hline 132 & männlich & links & 159,48 & 0,00 & 159,48 & 159,48 & Siegmund 2010 \\
\hline 132 & männlich & links & 160,47 & 0,00 & 160,47 & 160,47 & Telkkä 1950 \\
\hline 132 & männlich & links & 159,18 & 3,22 & 155,96 & 162,4 & Raxter 2008 \\
\hline 132 & männlich & links & 160,22 & 4,49 & 155,73 & 164,71 & Sjøvold 1990 \\
\hline 132 & männlich & links & 160,68 & 4,15 & 156,53 & 164,83 & Cerný/Komenda 1982 \\
\hline Sk.11. 1910 & männlich & rechts & 163,09 & 3,30 & 159,79 & 166,39 & Pearson 1899 \\
\hline Sk.11. 1910 & männlich & rechts & 165,87 & 4,80 & 161,07 & 170,67 & Breitinger 1938 \\
\hline Sk.11. 1910 & männlich & rechts & 162,01 & 0,00 & 162,01 & 162,01 & Siegmund 2010 \\
\hline
\end{tabular}




\begin{tabular}{|c|c|c|c|c|c|c|c|}
\hline Sk.11. 1910 & männlich & rechts & 163,2 & 0,00 & 163,2 & 163,2 & Telkkä 1950 \\
\hline Sk.11. 1910 & männlich & rechts & 162,11 & 3,22 & 158,89 & 165,33 & Raxter 2008 \\
\hline Sk.11. 1910 & männlich & rechts & 163,74 & 4,49 & 159,25 & 168,23 & Sjøvold 1990 \\
\hline Sk.11. 1910 & männlich & rechts & 163,79 & 4,21 & 159,58 & 168 & Cerný/Komenda 1982 \\
\hline P16+18 723 & männlich & rechts & 156,88 & 3,30 & 153,58 & 160,18 & Pearson 1899 \\
\hline P16+18 723 & männlich & rechts & 160,44 & 4,80 & 155,64 & 165,24 & Breitinger 1938 \\
\hline P16+18 723 & männlich & rechts & 155,59 & 0,00 & 155,59 & 155,59 & Siegmund 2010 \\
\hline P16+18 723 & männlich & rechts & 156,27 & 0,00 & 156,27 & 156,27 & Telkkä 1950 \\
\hline P16+18 723 & männlich & rechts & 154,66 & 3,22 & 151,44 & 157,88 & Raxter 2008 \\
\hline P16+18 723 & männlich & rechts & 154,8 & 4,49 & 150,31 & 159,29 & Sjøvold 1990 \\
\hline P16+18 723 & männlich & rechts & 155,92 & 4,21 & 151,71 & 160,13 & Cerný/Komenda 1982 \\
\hline $\mathrm{V} 21 \mathrm{v}$ & weiblich & links & 152,59 & 3,30 & 149,29 & 155,89 & Pearson 1899 \\
\hline V21 v & weiblich & links & 160,52 & 4,10 & 156,42 & 164,62 & Bach 1965 \\
\hline V21 v & weiblich & links & 153,36 & 0,00 & 153,36 & 153,36 & Telkkä 1950 \\
\hline V21 v & weiblich & links & 156,97 & 4,49 & 152,48 & 161,46 & Sjøvold 1990 \\
\hline $\mathrm{V} 21 \mathrm{v}$ & weiblich & links & 153,13 & 4,51 & 148,62 & 157,64 & Cerný/Komenda 1982 \\
\hline V11 578 Sk.4. & männlich & links & 157,07 & 3,30 & 153,77 & 160,37 & Pearson 1899 \\
\hline V11 578 Sk.4. & männlich & links & 160,6 & 4,80 & 155,8 & 165,4 & Breitinger 1938 \\
\hline V11 578 Sk.4. & männlich & links & 155,78 & 0,00 & 155,78 & 155,78 & Siegmund 2010 \\
\hline V11 578 Sk.4. & männlich & links & 156,48 & 0,00 & 156,48 & 156,48 & Telkkä 1950 \\
\hline V11 578 Sk.4. & männlich & links & 154,89 & 3,22 & 151,67 & 158,11 & Raxter 2008 \\
\hline V11 578 Sk.4. & männlich & links & 155,07 & 4,49 & 150,58 & 159,56 & Sjøvold 1990 \\
\hline V11 578 Sk.4. & männlich & links & 156,27 & 4,15 & 152,12 & 160,42 & Cerný/Komenda 1982 \\
\hline P.Sk.1.24 38 & weiblich & rechts & 147,14 & 3,30 & 143,84 & 150,44 & Pearson 1899 \\
\hline P.Sk.1.24 38 & weiblich & rechts & 156,85 & 4,10 & 152,75 & 160,95 & Bach 1965 \\
\hline P.Sk.1.24 38 & weiblich & rechts & 148,32 & 0,00 & 148,32 & 148,32 & Telkkä 1950 \\
\hline P.Sk.1.24 38 & weiblich & rechts & 149,38 & 4,49 & 144,89 & 153,87 & Sjøvold 1990 \\
\hline P.Sk.1.24 38 & weiblich & rechts & 146,58 & 4,44 & 142,14 & 151,02 & Cerný/Komenda 1982 \\
\hline P.Sk.1. 2657 & & links & 148,84 & 4,49 & 144,35 & 153,33 & Sjøvold 1990 \\
\hline V9 P.Sk1. 2129 & weiblich & rechts & 149,67 & 3,30 & 146,37 & 152,97 & Pearson 1899 \\
\hline V9 P.Sk1. 2129 & weiblich & rechts & 158,55 & 4,10 & 154,45 & 162,65 & Bach 1965 \\
\hline V9 P.Sk1. 2129 & weiblich & rechts & 150,66 & 0,00 & 150,66 & 150,66 & Telkkä 1950 \\
\hline V9 P.Sk1. 2129 & weiblich & rechts & 152,9 & 4,49 & 148,41 & 157,39 & Sjøvold 1990 \\
\hline V9 P.Sk1. 2129 & weiblich & rechts & 149,82 & 4,44 & 145,38 & 154,26 & Cerný/Komenda 1982 \\
\hline V9 P.Sk.1. 2011 & weiblich & links & 149,28 & 3,30 & 145,98 & 152,58 & Pearson 1899 \\
\hline V9 P.Sk.1. 2011 & weiblich & links & 158,29 & 4,10 & 154,19 & 162,39 & Bach 1965 \\
\hline V9 P.Sk.1. 2011 & weiblich & links & 150,3 & 0,00 & 150,3 & 150,3 & Telkkä 1950 \\
\hline V9 P.Sk.1. 2011 & weiblich & links & 152,36 & 4,49 & 147,87 & 156,85 & Sjøvold 1990 \\
\hline V9 P.Sk.1. 2011 & weiblich & links & 149,21 & 4,51 & 144,7 & 153,72 & Cerný/Komenda 1982 \\
\hline $\begin{array}{l}\text { V8 bei Sk7 und } \\
\text { Sch. } 23+251853\end{array}$ & & rechts & 140,71 & 4,49 & 136,22 & 145,2 & Sjøvold 1990 \\
\hline P7 2119 & männlich & rechts & 160,27 & 3,30 & 156,97 & 163,57 & Pearson 1899 \\
\hline P7 2119 & männlich & rechts & 163,4 & 4,80 & 158,6 & 168,2 & Breitinger 1938 \\
\hline
\end{tabular}




\begin{tabular}{|c|c|c|c|c|c|c|c|}
\hline P7 2119 & männlich & rechts & 159,09 & 0,00 & 159,09 & 159,09 & Siegmund 2010 \\
\hline P7 2119 & männlich & rechts & 160,05 & 0,00 & 160,05 & 160,05 & Telkkä 1950 \\
\hline P7 2119 & männlich & rechts & 158,72 & 3,22 & 155,5 & 161,94 & Raxter 2008 \\
\hline P7 2119 & männlich & rechts & 159,68 & 4,49 & 155,19 & 164,17 & Sjøvold 1990 \\
\hline P7 2119 & männlich & rechts & 160,21 & 4,21 & 156 & 164,42 & Cerný/Komenda 1982 \\
\hline P7 2517 & männlich & rechts & 164,78 & 3,30 & 161,48 & 168,08 & Pearson 1899 \\
\hline P7 2517 & männlich & rechts & 167,35 & 4,80 & 162,55 & 172,15 & Breitinger 1938 \\
\hline P7 2517 & männlich & rechts & 163,77 & 0,00 & 163,77 & 163,77 & Siegmund 2010 \\
\hline P7 2517 & männlich & rechts & 165,09 & 0,00 & 165,09 & 165,09 & Telkkä 1950 \\
\hline P7 2517 & männlich & rechts & 164,14 & 3,22 & 160,92 & 167,36 & Raxter 2008 \\
\hline P7 2517 & männlich & rechts & 166,18 & 4,49 & 161,69 & 170,67 & Sjøvold 1990 \\
\hline P7 2517 & männlich & rechts & 165,93 & 4,21 & 161,72 & 170,14 & Cerný/Komenda 1982 \\
\hline 31 & männlich & rechts & 177,94 & 3,30 & 174,64 & 181,24 & Pearson 1899 \\
\hline 31 & männlich & rechts & 178,86 & 4,80 & 174,06 & 183,66 & Breitinger 1938 \\
\hline 31 & männlich & rechts & 177,4 & 0,00 & 177,4 & 177,4 & Siegmund 2010 \\
\hline 31 & männlich & rechts & 179,79 & 0,00 & 179,79 & 179,79 & Telkkä 1950 \\
\hline 31 & männlich & rechts & 179,94 & 3,22 & 176,72 & 183,16 & Raxter 2008 \\
\hline 31 & männlich & rechts & 185,15 & 4,49 & 180,66 & 189,64 & Sjøvold 1990 \\
\hline 31 & männlich & rechts & 182,63 & 4,21 & 178,42 & 186,84 & Cerný/Komenda 1982 \\
\hline 3 & männlich & links & 177,94 & 3,30 & 174,64 & 181,24 & Pearson 1899 \\
\hline 3 & männlich & links & 178,86 & 4,80 & 174,06 & 183,66 & Breitinger 1938 \\
\hline 3 & männlich & links & 177,4 & 0,00 & 177,4 & 177,4 & Siegmund 2010 \\
\hline 3 & männlich & links & 179,79 & 0,00 & 179,79 & 179,79 & Telkkä 1950 \\
\hline 3 & männlich & links & 179,94 & 3,22 & 176,72 & 183,16 & Raxter 2008 \\
\hline 3 & männlich & links & 185,15 & 4,49 & 180,66 & 189,64 & Sjøvold 1990 \\
\hline 3 & männlich & links & 182,63 & 4,21 & 178,42 & 186,84 & Cerný/Komenda 1982 \\
\hline 17 & männlich & links & 157,07 & 3,30 & 153,77 & 160,37 & Pearson 1899 \\
\hline 17 & männlich & links & 160,6 & 4,80 & 155,8 & 165,4 & Breitinger 1938 \\
\hline 17 & männlich & links & 155,78 & 0,00 & 155,78 & 155,78 & Siegmund 2010 \\
\hline 17 & männlich & links & 156,48 & 0,00 & 156,48 & 156,48 & Telkkä 1950 \\
\hline 17 & männlich & links & 154,89 & 3,22 & 151,67 & 158,11 & Raxter 2008 \\
\hline 17 & männlich & links & 155,07 & 4,49 & 150,58 & 159,56 & Sjøvold 1990 \\
\hline 17 & männlich & links & 156,27 & 4,15 & 152,12 & 160,42 & Cerný/Komenda 1982 \\
\hline 24 & männlich & rechts & 157,07 & 3,30 & 153,77 & 160,37 & Pearson 1899 \\
\hline 24 & männlich & rechts & 160,6 & 4,80 & 155,8 & 165,4 & Breitinger 1938 \\
\hline 24 & männlich & rechts & 155,78 & 0,00 & 155,78 & 155,78 & Siegmund 2010 \\
\hline 24 & männlich & rechts & 156,48 & 0,00 & 156,48 & 156,48 & Telkkä 1950 \\
\hline 24 & männlich & rechts & 154,89 & 3,22 & 151,67 & 158,11 & Raxter 2008 \\
\hline 24 & männlich & rechts & 155,07 & 4,49 & 150,58 & 159,56 & Sjøvold 1990 \\
\hline 24 & männlich & rechts & 156,27 & 4,15 & 152,12 & 160,42 & Cerný/Komenda 1982 \\
\hline
\end{tabular}




\subsection{Rheine}

Die hier für die Population aus Rheine präsentierten Ergebnisse entsprechen in der Form ihrer Darstellung den Ergebnissen aus Calden.

\section{Mindestindividuenzahl}

Die Errechnung der Mindestindividuenzahl konnte für die Population aus Rheine anhand der rechten Felsenbeine erfolgen; es haben sich fünf rechte Felsenbeine erhalten. Wird die Mindestindividuenzahl anhand der erhaltenen Zähne errechnet, ergeben sich 23 Individuen. Der Zahn, der sich am häufigsten erhalten hat, ist der obere linke erste Molar (Zahn 26).

\subsubsection{Cranien}

Die Skeletfunde der Population aus Rheine beinhalten 27 Datensätze für die Schädel. Gut erhaltene Schädelfunde gibt es in der Population aus Rheine nicht; alle Schädel liegen in teilweise sehr kleine Fragmente zerbrochen vor. Vermutlich wurde eine größere Menge von Schädelfragmenten bei der Grabung gar nicht geborgen oder ist bereits während der Bodenlagerung aufgrund der Diagenese im Grab zerfallen. Die Vorstellung der Ergebnisse der Schädelbefundung erfolgt in Form der Abbildungen 73 bis 76 .

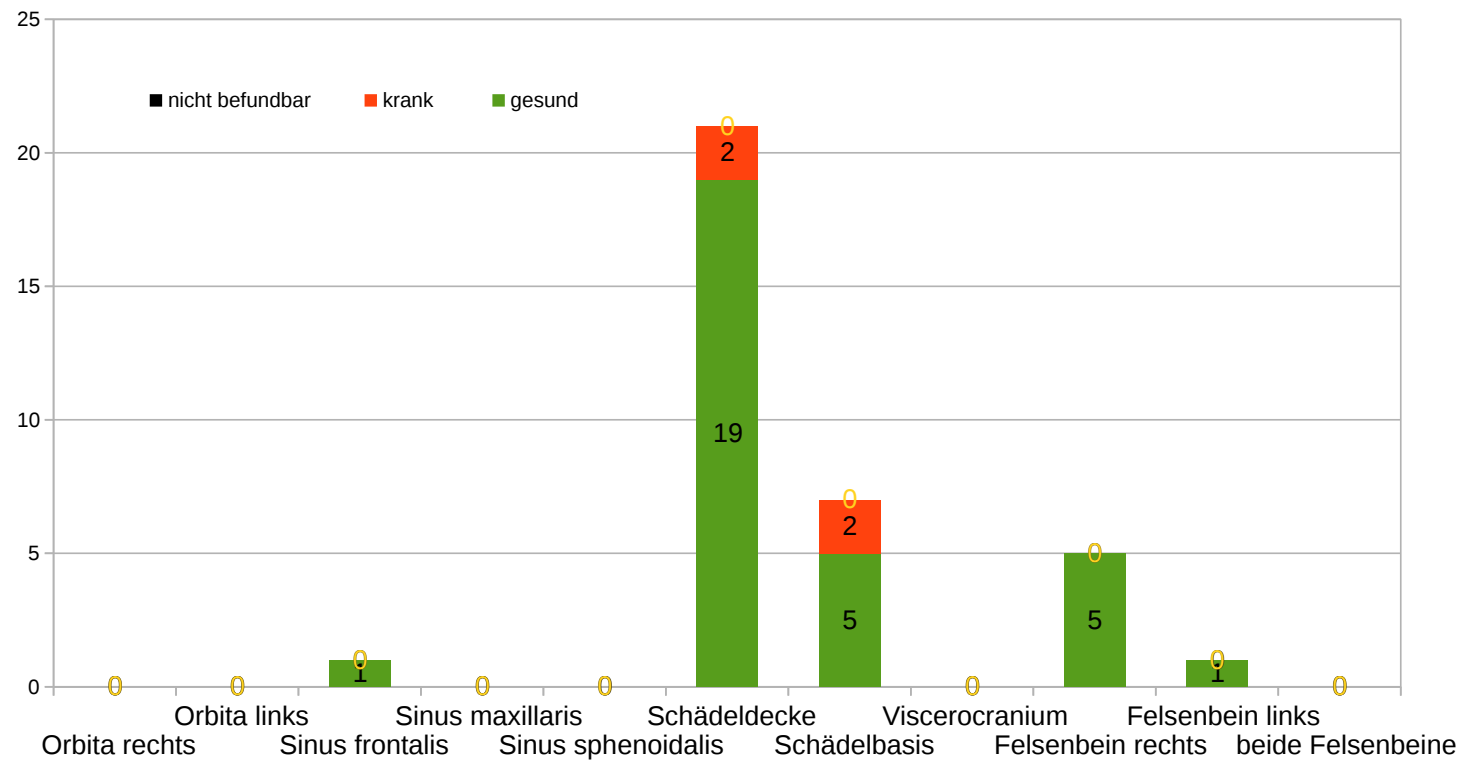

Abb. 73

Verteilung der Schädelfragmente; Rheine

Das Balkendiagramm zeigt die absolute Anzahl der erhaltenen Kompartimente mit Berücksichtigung des Befundungszustandes "nicht befundbar", "krank" und,gesund". Die als "krank" bezeichneten Fundstücke weisen Veränderungen auf, die meist als Spuren von Erkrankungen diagnostiziert wurden. Auf der Ordinate wird die Anzahl der Fragmente angegeben. 


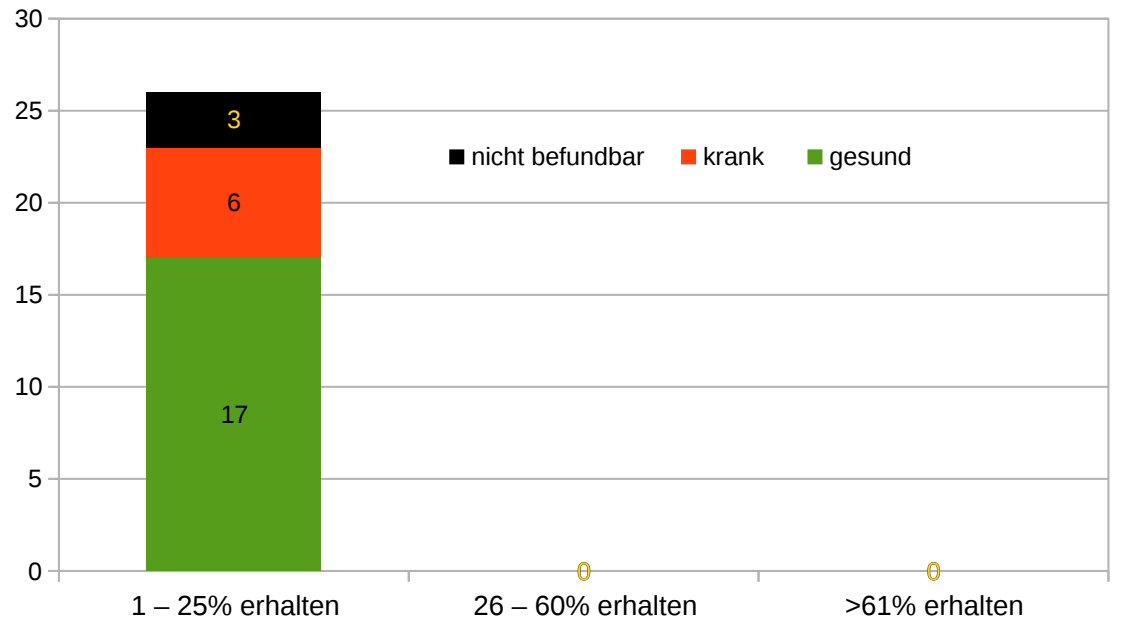

Abb. 74 Absolute Anzahl der Erhaltungsmenge je Cranium eines Individuums; Rheine

Einteilung in die Kategorien "1-25\%", "26-60\%" und "> $>61 \%$ ". Auf der Ordinate befindet sich die Angabe der Gesamtzahl.

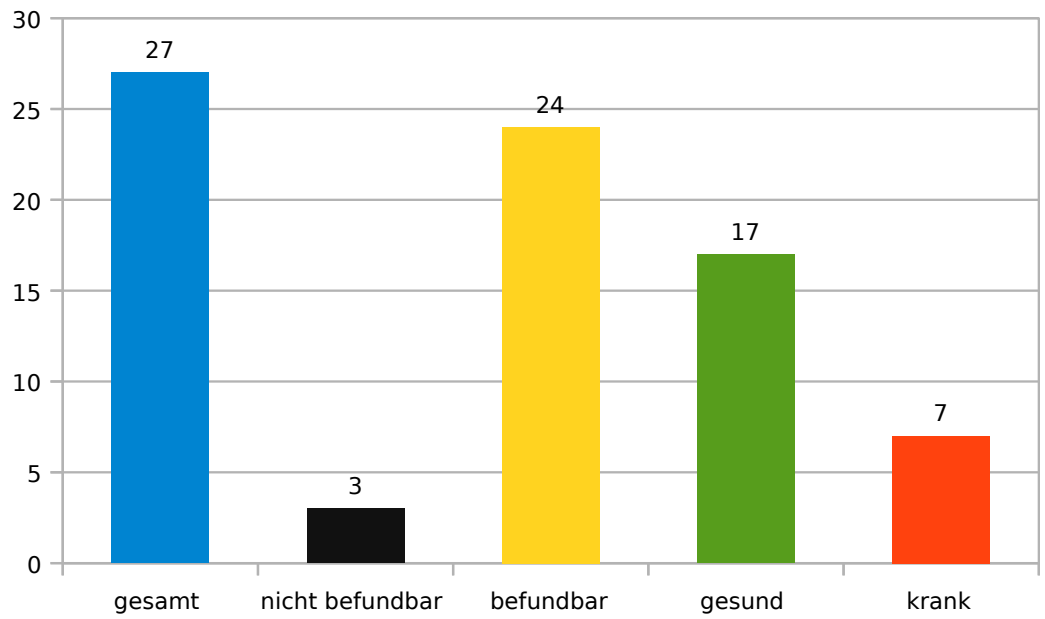

Abb. 75 Gesamtheit der Datensätze für die Schädelfunde; Rheine

Darstellung in den Kategorien "gesamt", "nicht befundbar", "befundbar", "gesund"und "krank". Dabei ergeben "nicht befundbar" und "befundbar" die Gesamtsumme und "gesund" und "krank" summieren sich zu "befundbar". Auf der Ordinate befindet sich die Angabe der Gesamtzahl. 


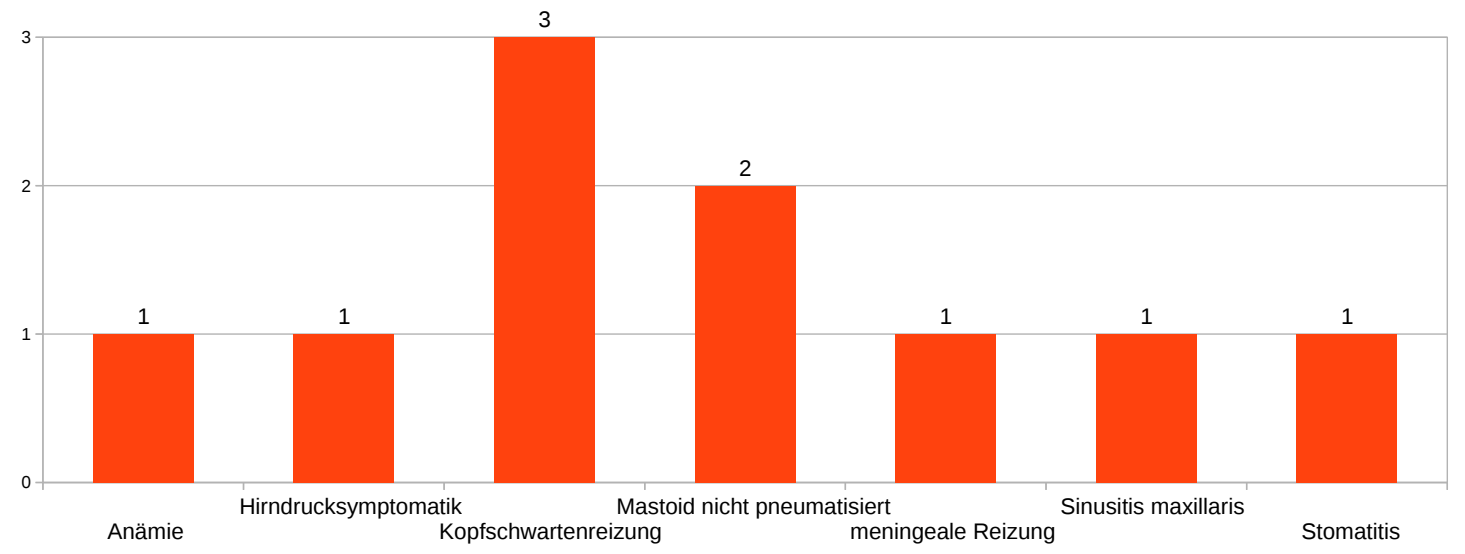

Abb. 76 Diagnostizierte Veränderungen an den Schädelfunden; Rheine Auf der Ordinate befindet sich die Angabe der Gesamtzahl.

\subsubsection{Zähne}

Für die Skeletfunde der Population aus Rheine lässt sich zusammenfassend sagen, dass die Funde aus dem Kieferbereich die größte befundbare Fundgutanzahl boten. Auf die Ergebnisse der Zahn- und Kieferbefundung soll deswegen ein besonderes Augenmerk gelegt werden. Für die Population aus Rheine wurden 203 Datensätze angelegt, die insgesamt 217 Zähne enthalten. Meist lagen die Zähne einzeln und oft auch teilweise stark beschädigt vor. 


\subsubsection{Bleibende Zähne}

Das Diagramm 77 zeigt die erhaltenen Zähne des Dauergebisses, das Diagramm 78 zeigt Zähne, die nicht eindeutig zuzuordnen waren.

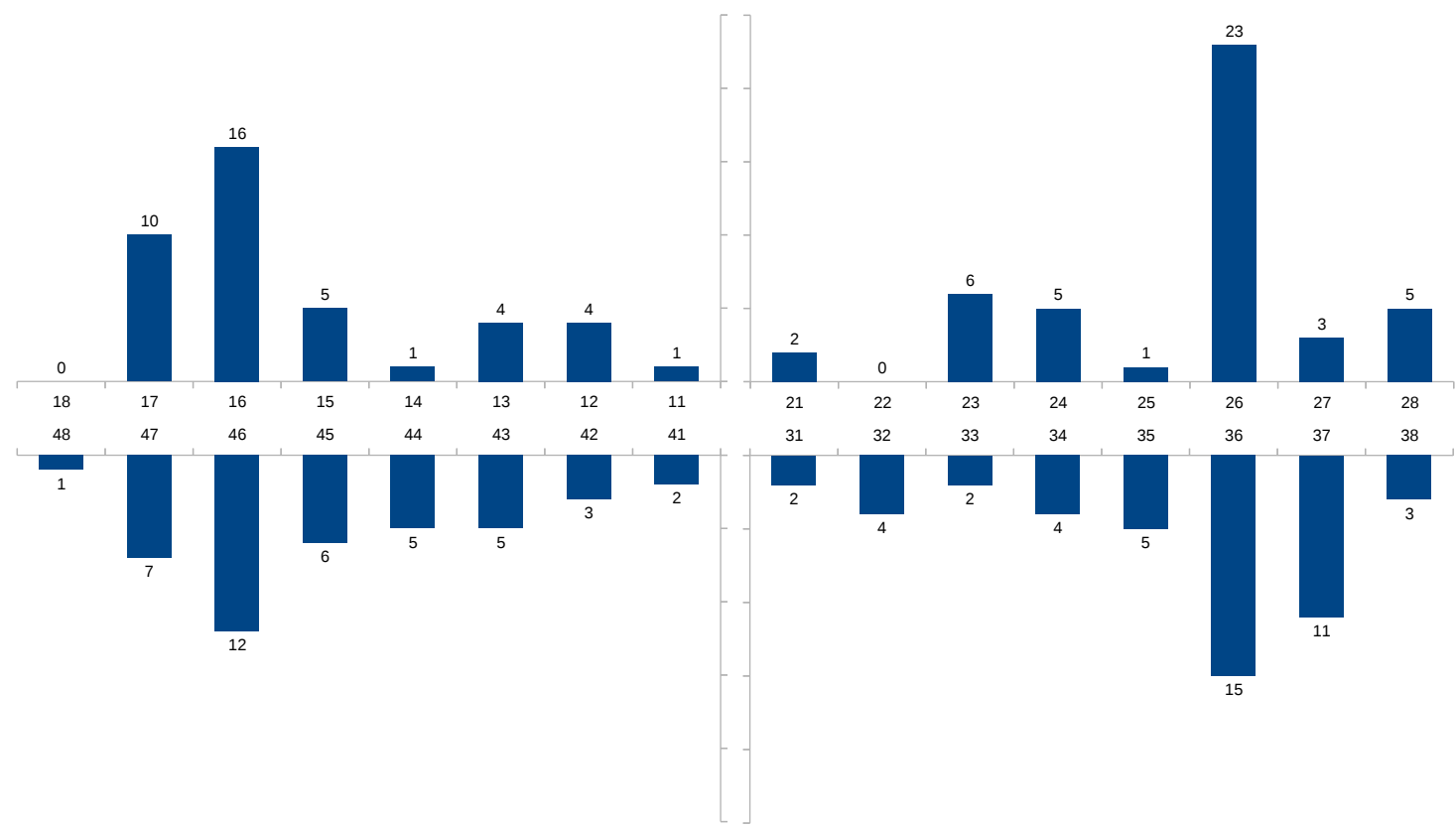

Abb. $77 \quad$ Erhaltene Zähne und leere Alveolen des Dauergebisses; Rheine

Die Ansicht ist so gewählt, dass die vier Quadranten sichtbar sind, als würde man das Gebiss von vorn betrachten (übliche Darstellung in der Zahnmedizin). In dieser Abbildung befindet sich oben links (erster Quadrant) der obere rechte Quadrant des Individuums (Zähne 11 bis 18). Über den Säulen befindet sich die Anzahl der jeweiligen Zähne bzw. Kieferregionen. Leere Alveolen postmortal verlorener Zähne wurden in dieses Diagramm mit aufgenommen.

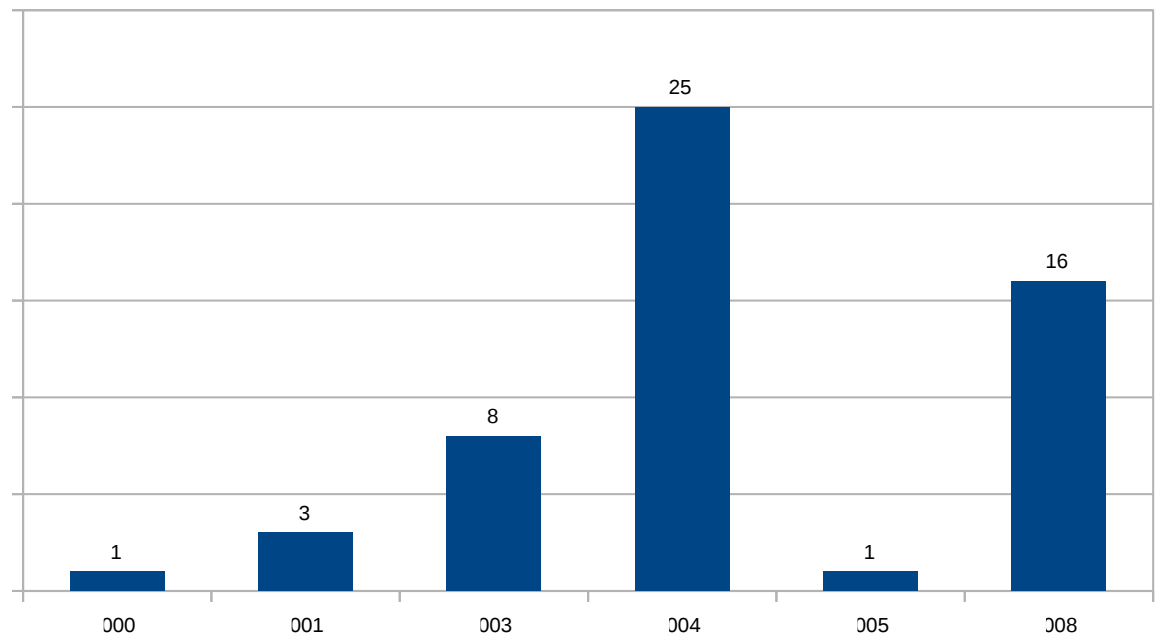

Abb. $78 \quad$ Bleibende Zähne, die nicht bestimmbar waren; Rheine

"000"(bedeutet nicht zuzuordnen), "001"(bedeutet: Als Incisivus zuzuordnen), usw. Diese Nummern wurden für die nicht eindeutig zuzuordnenden Zähne gewählt. Auf der Abszisse sind die Milchzähne aufgeführt, über den Säulen finden sich die absoluten Anzahlen. 
Die Diagramme 79 bis 86 zeigen die Veränderungen an den acht Zahngruppen der bleibenden Zähne aller vier Quadranten im Gebiss der Individuen der Population aus Rheine.

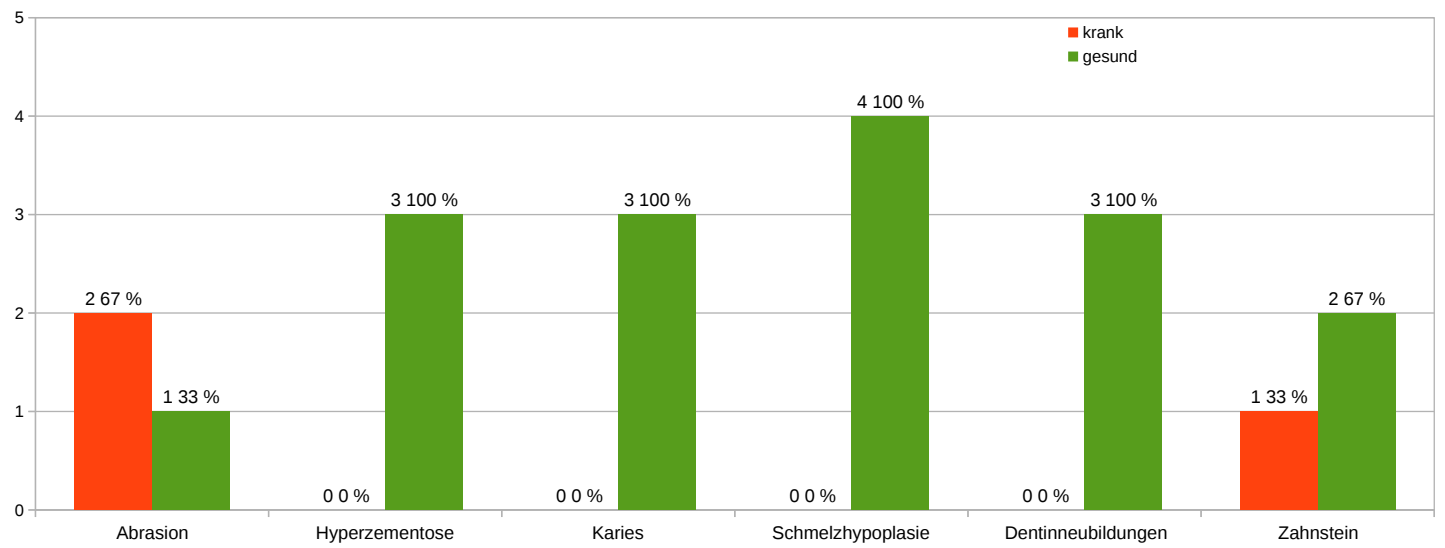

Abb. 79 Veränderungen an allen bleibenden ersten Incisivi; Rheine

Alle ersten, bleibenden Incisivi der vier Quadranten, $n=7$, tatsächliche Zahnzahl: 5, aufder Ordinate befindet sich die Angabe der Gesamtzahl, über den Säulen links die absoluten Anzahlen, rechts daneben die Prozentzahlen. "n" umfasst alle Zähne und leere Alveolen, die "tatsächliche Zahnzahl" gibt nur die Zahl der Zähne an, ohne leere Alveolen.

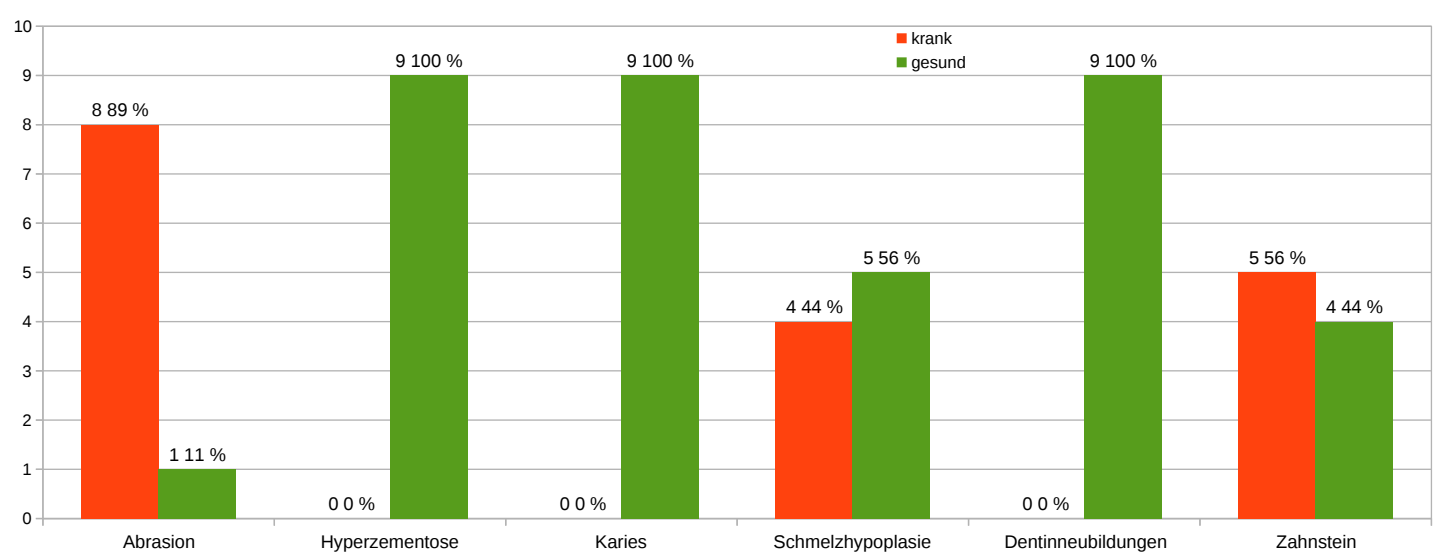

Abb. $80 \quad$ Veränderungen an allen bleibenden zweiten Incisivi; Rheine

Alle zweiten, bleibenden Incisivi der vier Quadranten, $n=11$, tatsächliche Zahnzahl: 9, auf der Ordinate befindet sich die Angabe der Gesamtzahl, über den Säulen links die absoluten Anzahlen, rechts daneben die Prozentzahlen. "n" umfasst alle Zähne und leere Alveolen, die "tatsächliche Zahnzahl" gibt nur die Zahl der Zähne an, ohne leere Alveolen. 


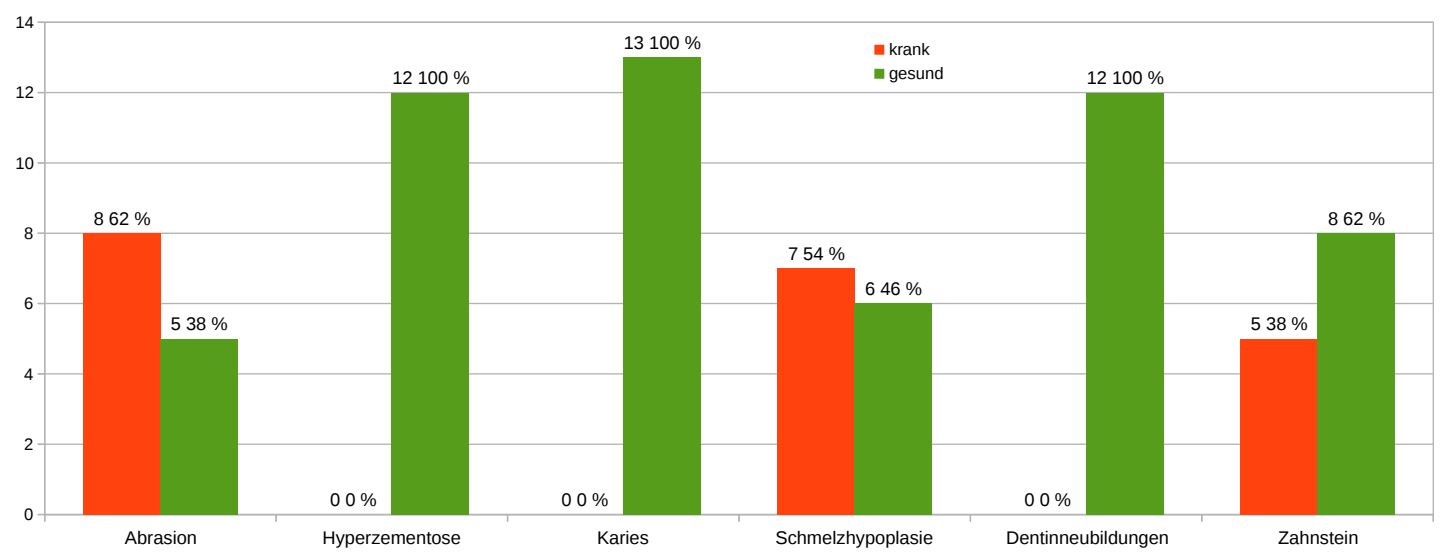

Abb. $81 \quad$ Veränderungen an allen bleibenden Canini; Rheine

Alle bleibenden Canini der vier Quadranten, $n=17$, tatsächliche Zahnzahl: 15, auf der Ordinate befindet sich die Angabe der Gesamtzahl, über den Säulen links die absoluten Anzahlen, rechts daneben die Prozentzahlen. "n" umfasst alle Zähne und leere Alveolen, die "tatsächliche Zahnzahl" gibt nur die Zahl der Zähne an, ohne leere Alveolen.

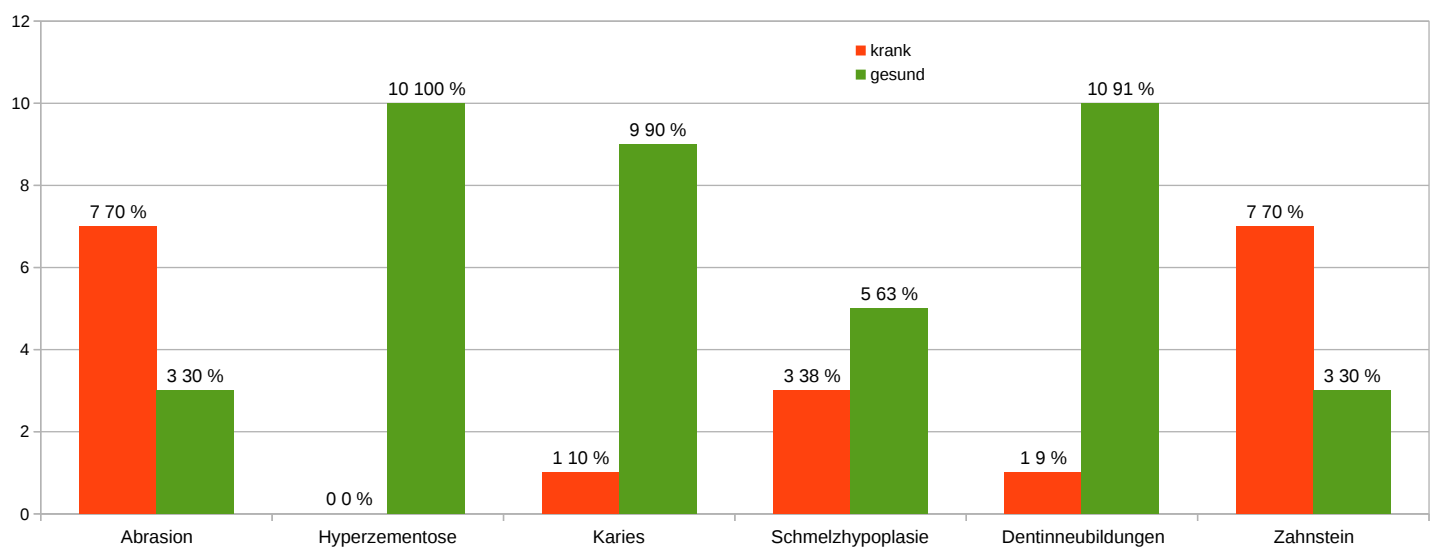

Abb. 82 Veränderungen an allen ersten Prämolaren; Rheine

Alle ersten Prämolaren der vier Quadranten, $n=15$, tatsächliche Zahnzahl: 13, auf der Ordinate befindet sich die Angabe der Gesamtzahl, über den Säulen links die absoluten Anzahlen, rechts daneben die Prozentzahlen. "n“ umfasst alle Zähne und leere Alveolen, die "tatsächliche Zahnzahl" gibt nur die Zahl der Zähne an, ohne leere Alveolen. 


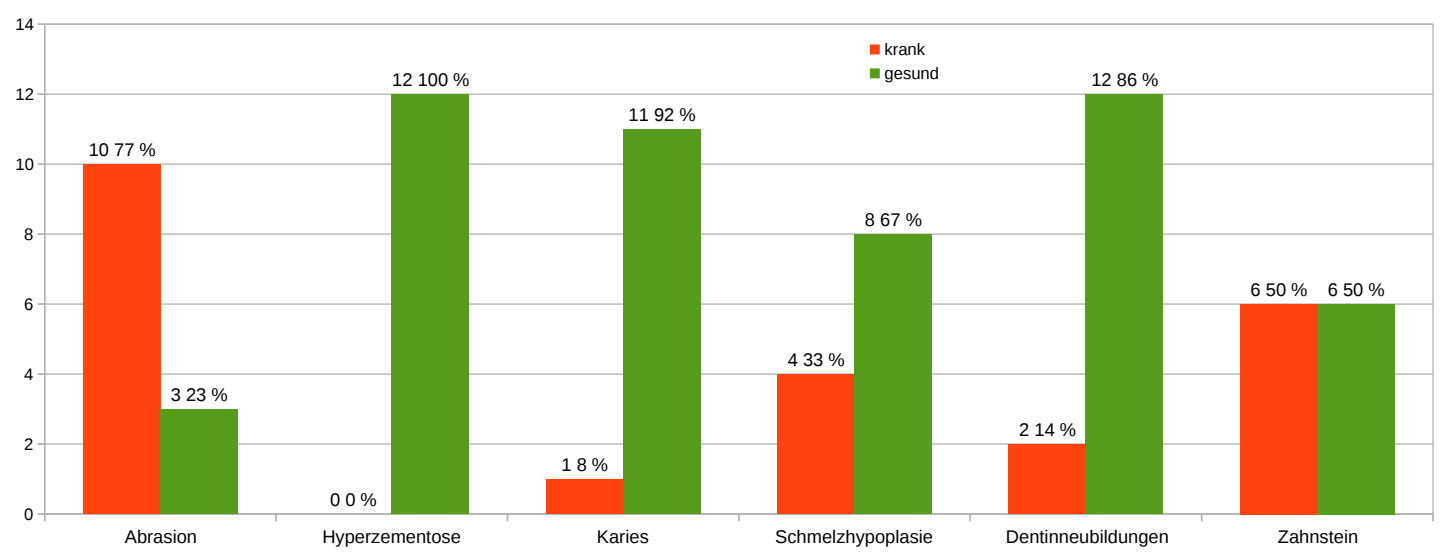

Abb. $83 \quad$ Veränderungen an allen zweiten Prämolaren; Rheine

Alle zweiten Prämolaren der vier Quadranten, $n=17$, tatsächliche Zahnzahl: 16, auf der Ordinate befindet sich die Angabe der Gesamtzahl, über den Säulen links die absoluten Anzahlen, rechts daneben die Prozentzahlen. "n" umfasst alle Zähne und leere Alveolen, die "tatsächliche Zahnzahl" gibt nur die Zahl der Zähne an, ohne leere Alveolen.

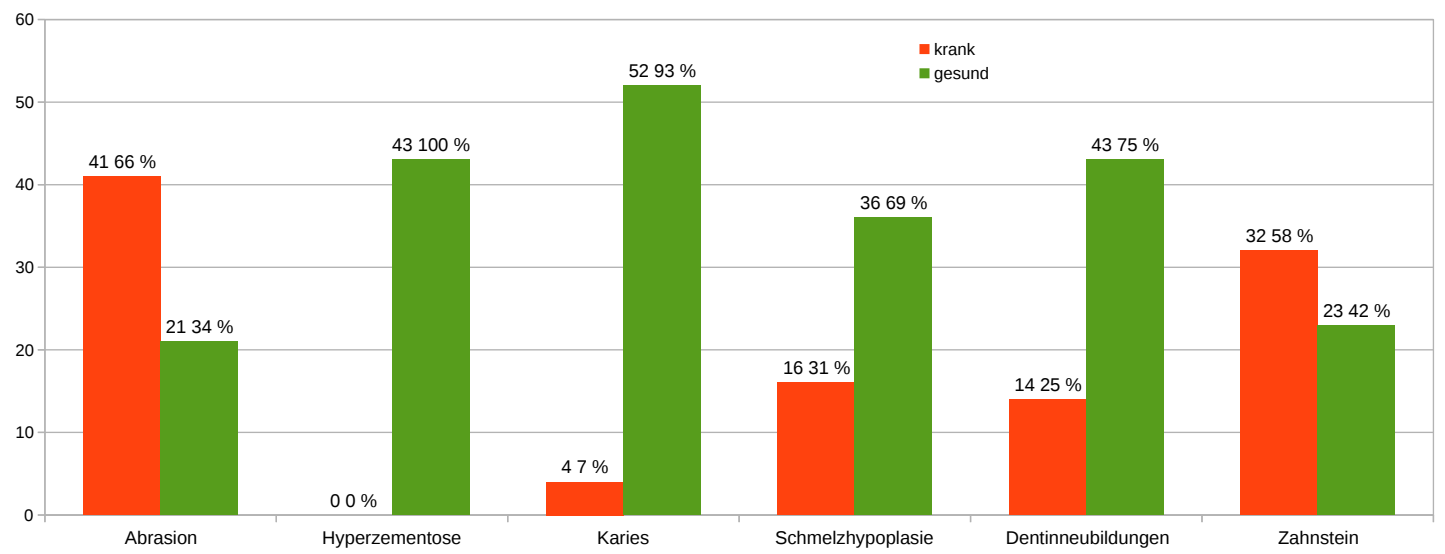

Abb. $84 \quad$ Veränderungen an allen bleibenden ersten Molaren; Rheine

Alle ersten, bleibenden Molaren der vier Quadranten, $n=66$, tatsächliche Zahnzahl: 65, auf der Ordinate befindet sich die Angabe der Gesamtzahl, über den Säulen links die absoluten Anzahlen, rechts daneben die Prozentzahlen. "n" umfasst alle Zähne und leere Alveolen, die "tatsächliche Zahnzahl" gibt nur die Zahl der Zähne an, ohne leere Alveolen. 


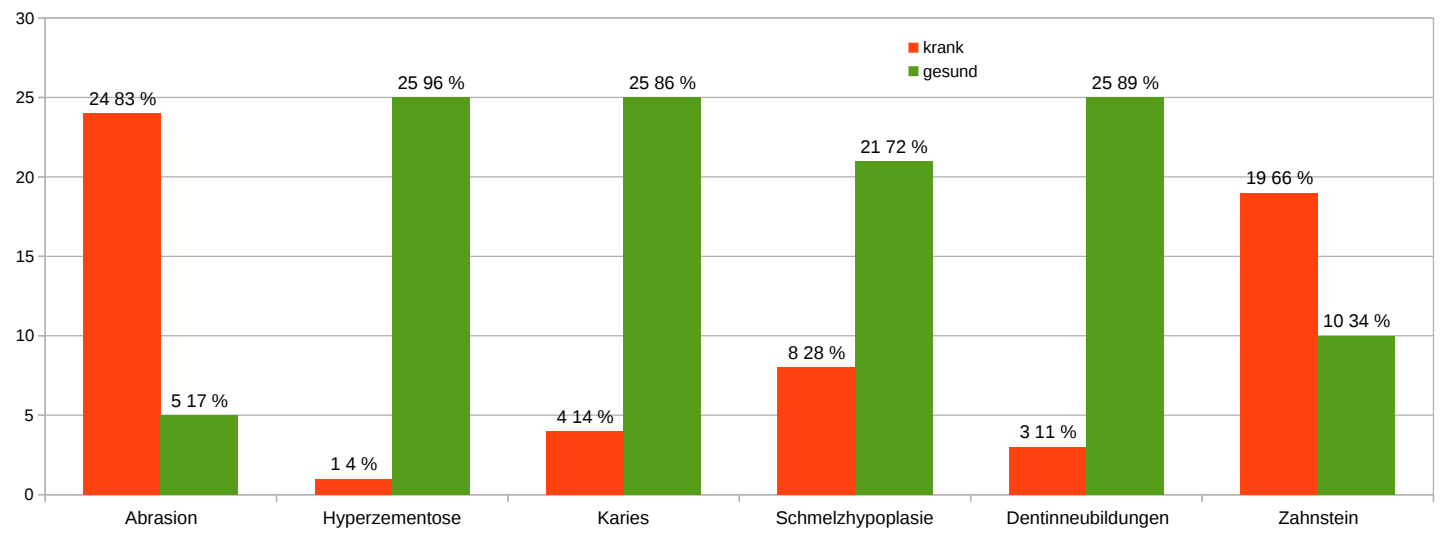

Abb. $85 \quad$ Veränderungen an allen bleibenden zweiten Molaren; Rheine

Alle zweiten, bleibenden Molaren der vier Quadranten, $n=31$, tatsächliche Zahnzahl: 29, aufder Ordinate befindet sich die Angabe der Gesamtzahl, über den Säulen links die absoluten Anzahlen, rechts daneben die Prozentzahlen. "n" umfasst alle Zähne und leere Alveolen, die "tatsächliche Zahnzahl" gibt nur die Zahl der Zähne an, ohne leere Alveolen.

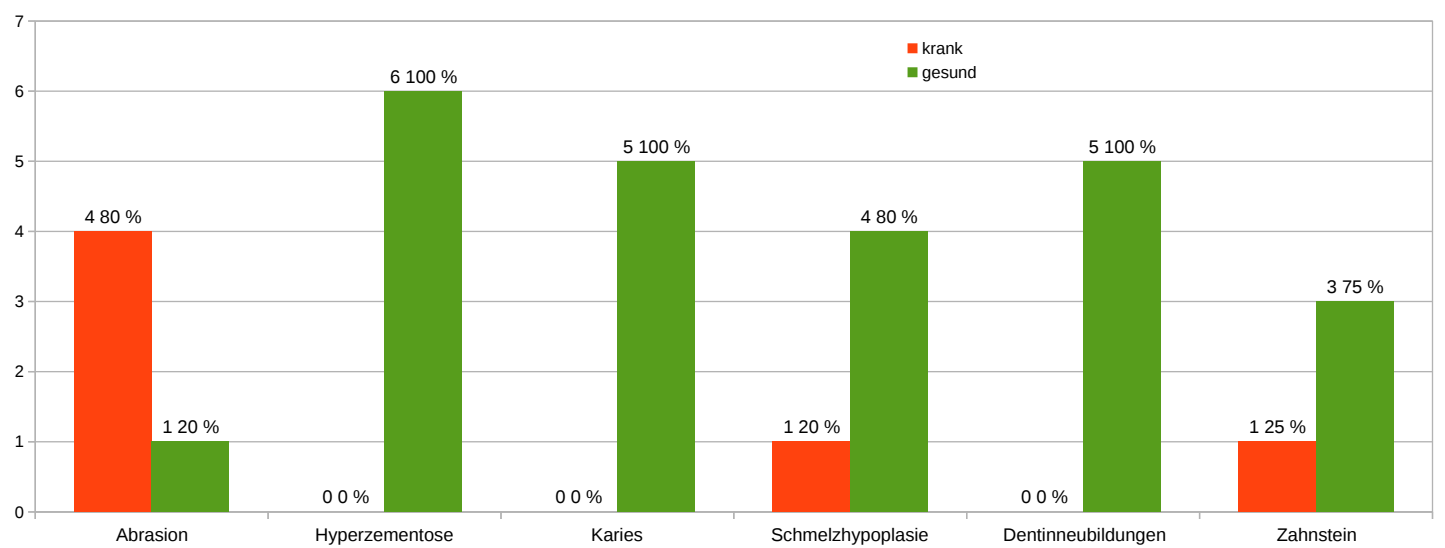

Abb. $86 \quad$ Veränderungen an allen dritten Molaren; Rheine

Alle dritten Molaren der vier Quadranten, $n=9$, tatsächliche Zahnzahl: 6, auf der Ordinate befindet sich die Angabe der Gesamtzahl, über den Säulen links die absoluten Anzahlen, rechts daneben die Prozentzahlen. "n" umfasst alle Zähne und leere Alveolen, die "tatsächliche Zahnzahl" gibt nur die Zahl der Zähne an, ohne leere Alveolen. 
Die Diagramme 87 bis 90 zeigen die Veränderungen an den Zähnen jeweils eines Quadranten.

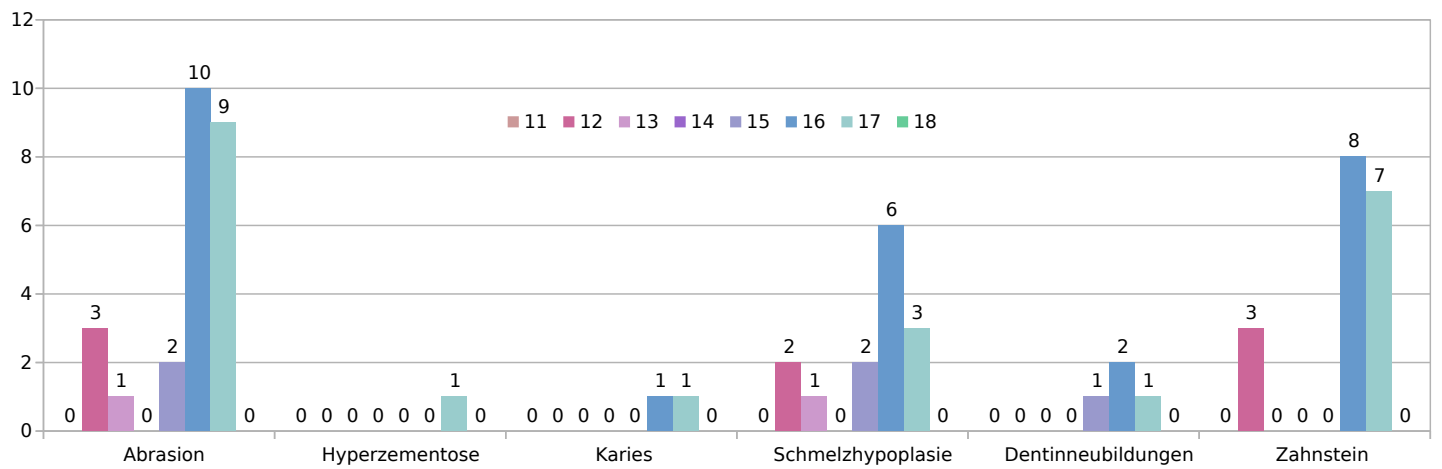

Abb. $87 \quad$ Veränderungen an allen Zahntypen des 1. Quadranten; Rheine

Auf der Ordinate findet sich die Angabe der Gesamtzahl, auf der Abszisse die Veränderungen der Zähne, über den Säulen sind die absoluten Anzahlen angegeben. Die verschiedenen Farben der Säulen entsprechen den Zähnen des ersten Quadranten (Zähne 11-18).

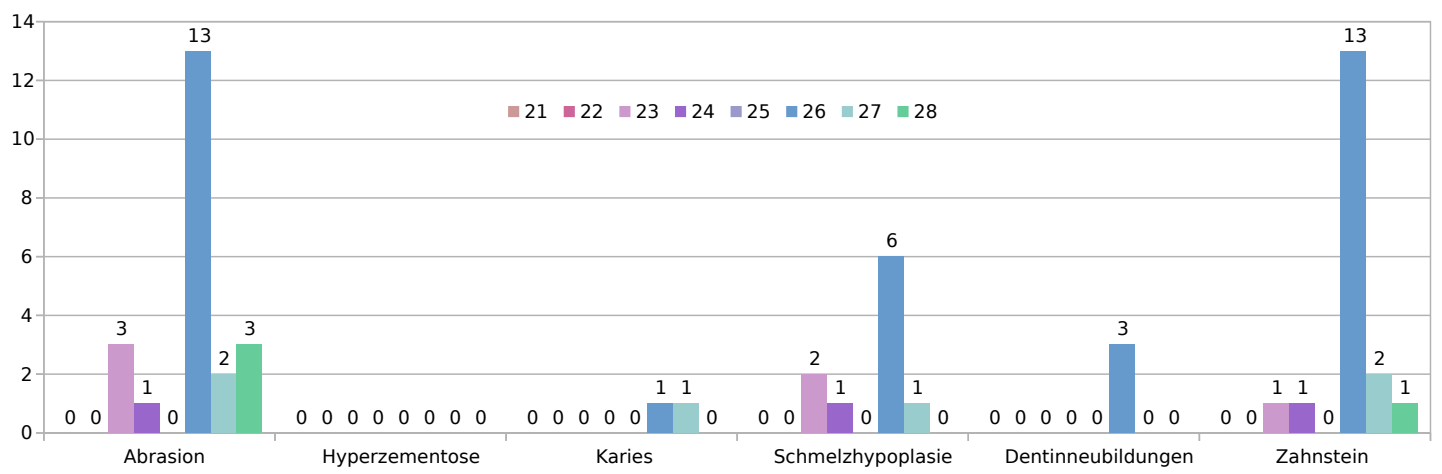

Abb. $88 \quad$ Veränderungen an allen Zahntypen des 2. Quadranten; Rheine

Auf der Ordinate findet sich die Angabe der Gesamtzahl, auf der Abszisse die Veränderungen der Zähne, über den Säulen sind die absoluten Anzahlen angegeben. Die verschiedenen Farben der Säulen entsprechen den Zähnen des zweiten Quadranten (Zähne 21-28).

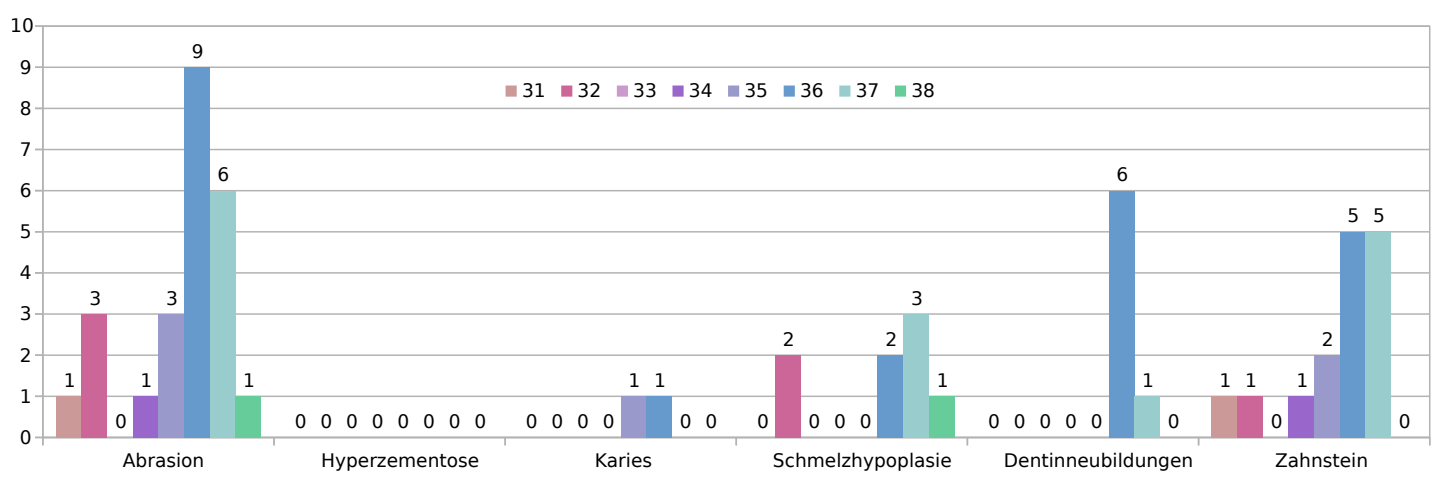

Abb.89 Veränderungen an allen Zahntypen des 3. Quadranten; Rheine

Auf der Ordinate findet sich die Angabe der Gesamtzahl, auf der Abszisse die Veränderungen der Zähne, über den Säulen sind die absoluten Anzahlen angegeben. Die verschiedenen Farben der Säulen entsprechen den Zähnen des dritten Quadranten (Zähne 31-38). 


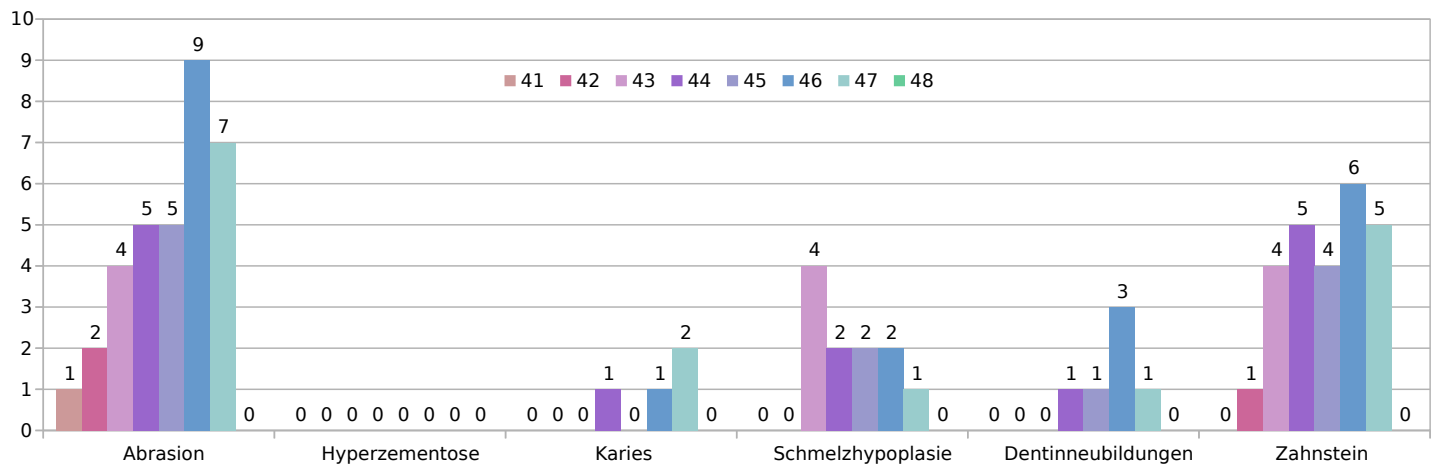

Abb.90 Veränderungen an allen Zahntypen des 4. Quadranten; Rheine

Auf der Ordinate findet sich die Angabe der Gesamtzahl, auf der Abszisse die Veränderungen der Zähne, über den Säulen sind die absoluten Anzahlen angegeben. Die verschiedenen Farben der Säulen entsprechen den Zähnen des vierten Quadranten (Zähne 41-48).

\section{Die Abbildung 91 illustriert die Veränderungen an den Sechsjahresmolaren.}

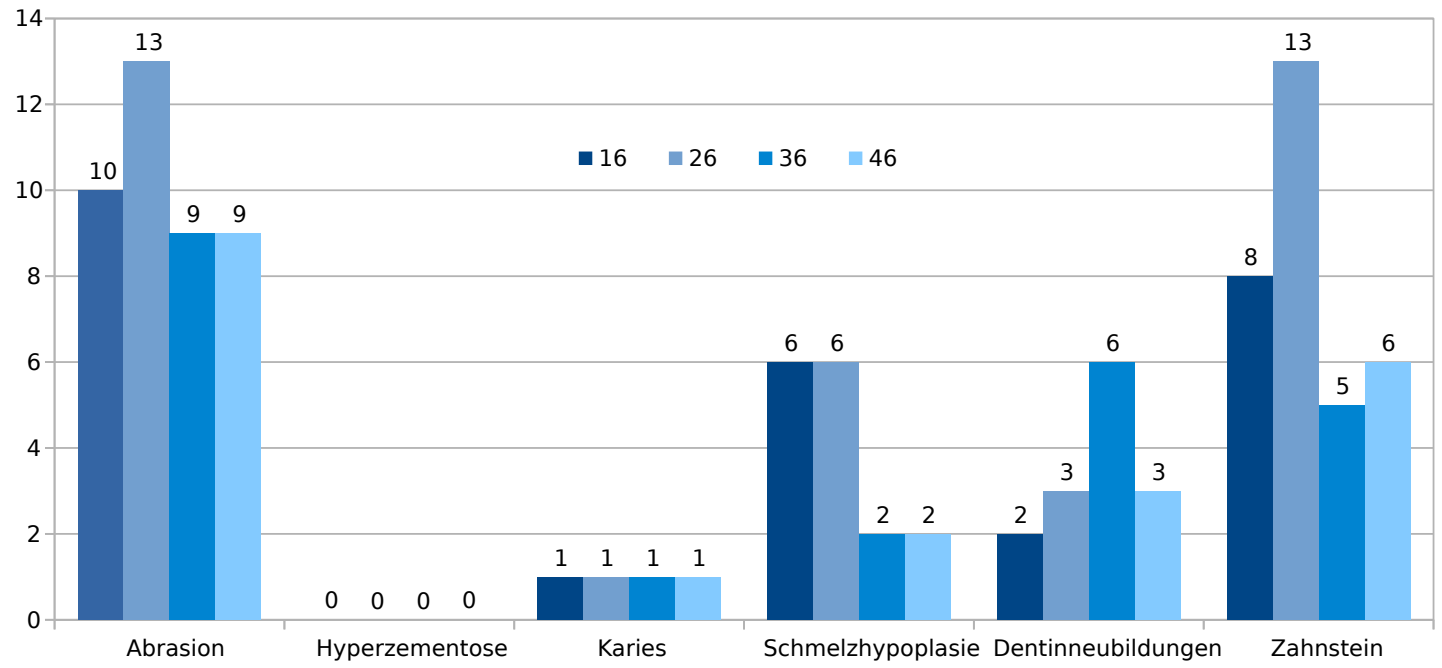

Abb.91 Die vier Sechs-Jahres-Molaren aller Quadranten im Vergleich; Rheine

Auf der Ordinate findet sich die Angabe der Gesamtzahl, auf der Abszisse die Veränderungen der Zähne, über den Säulen sind die absoluten Anzahlen angegeben. Die verschiedenen Farben der Säulen entsprechen den Zähnen 16, 26, 36 und 46. 


\subsubsection{Milchzähne}

In der Population aus Rheine haben sich fünf Milchzähne erhalten (Abb. 92).

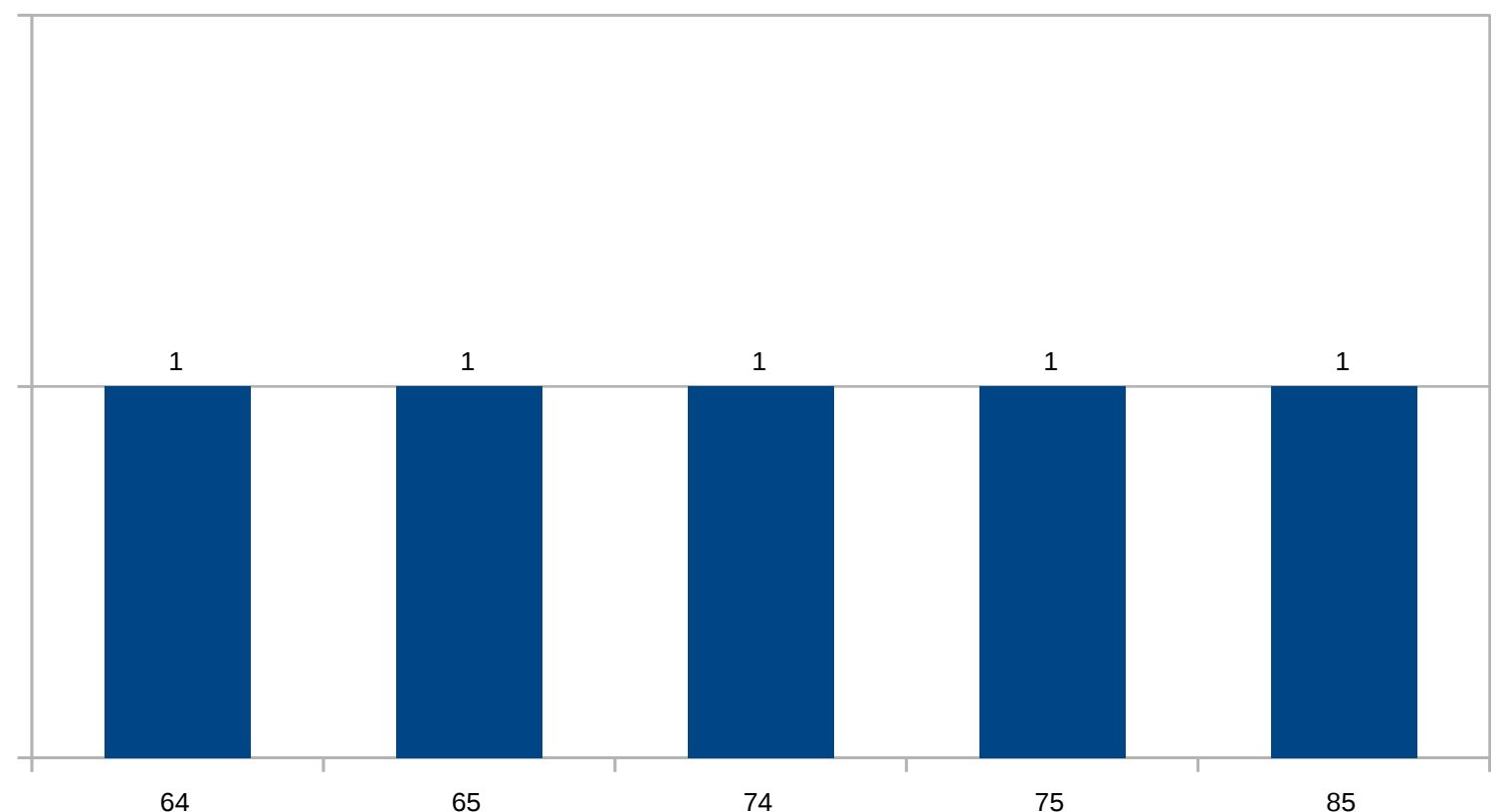

Abb. 92

Erhaltene Zähne und leere Alveolen des Milchgebisses; Rheine

Auf der Abszisse sind die Milchzähne aufgeführt, über den Säulen finden sich die absoluten Anzahlen.

Die Diagramme 93 und 94 zeigen die Veränderungen an den zwei erhaltenen Zahngruppen der Milchzähne.

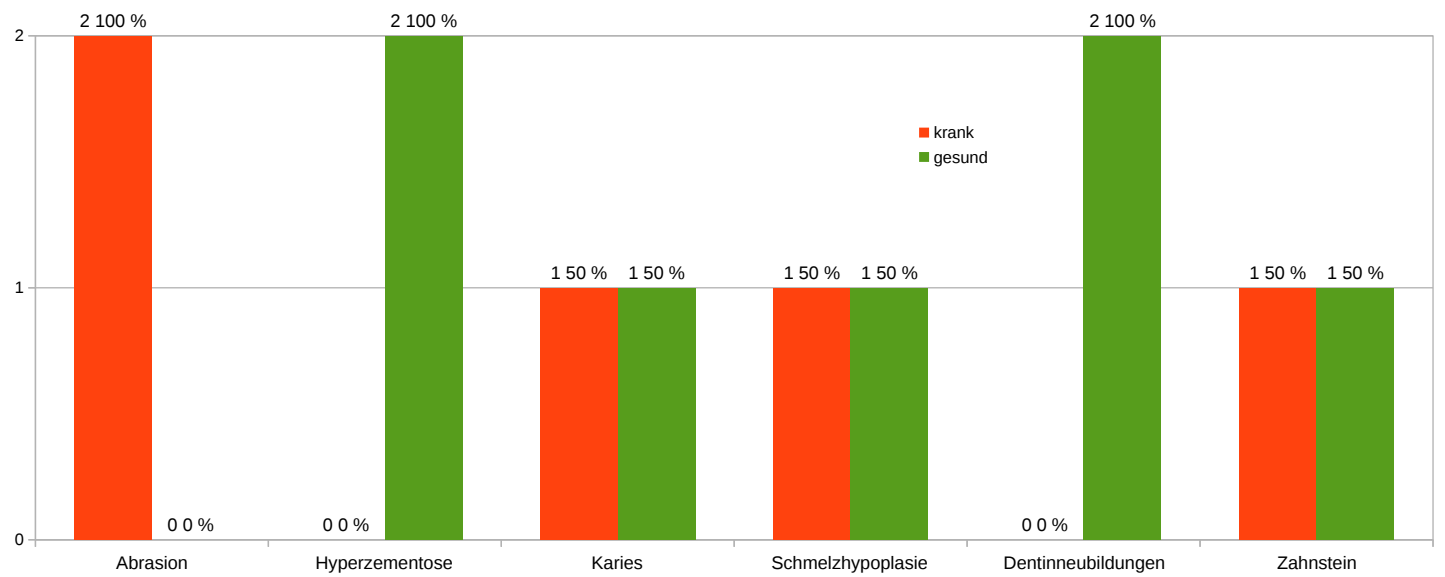

Abb.93 Veränderungen an allen ersten Milchmolaren; Rheine

Alle ersten Milchmolaren der vier Quadranten, $n=2$, tatsächliche Zahnzahl: 2, auf der Ordinate befindet sich die Angabe der Gesamtzahl, über den Säulen links die absoluten Anzahlen, rechts daneben die Prozentzahlen. "n" umfasst alle Zähne und leere Alveolen, die "tatsächliche Zahnzahl" gibt nur die Zahl der Zähne an, ohne leere Alveolen. 


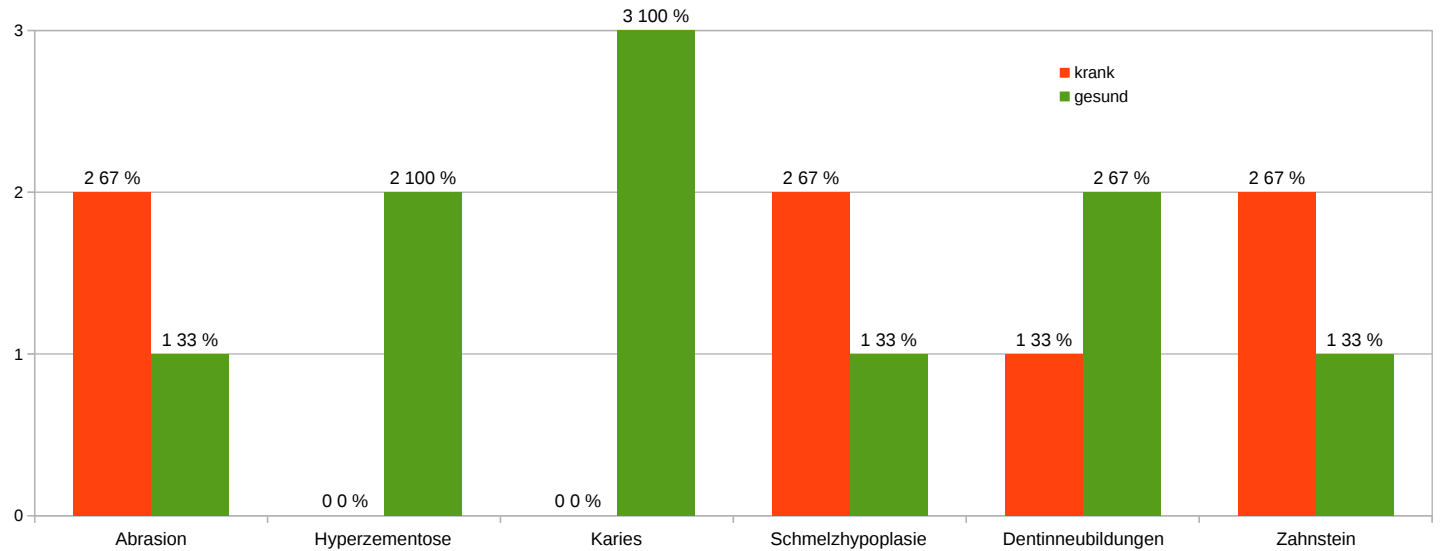

Abb.94 Veränderungen an allen zweiten Milchmolaren; Rheine

Alle zweiten Milchmolaren der vier Quadranten, $n=3$, tatsächliche Zahnzahl: 3, auf der Ordinate befindet sich die Angabe der Gesamtzahl, über den Säulen links die absoluten Anzahlen, rechts daneben die Prozentzahlen. "n" umfasst alle Zähne und leere Alveolen, die "tatsächliche Zahnzahl" gibt nur die Zahl der Zähne an, ohne leere Alveolen.

\subsubsection{Nicht eindeutig zuzuordnende Zähne}

Unter dem Fundgut der Population aus Rheine waren einige Zähne erhalten, die nicht mehr eindeutig zuzuordnen waren. Für diese Fundstücke wurde eine gesonderte Auswertung vorgenommen, um sie von den bestimmbaren Zähnen abzugrenzen. Ein Zahn war gar keiner Position mehr zuzuordnen und alle weiteren nur einer Gruppe (beispielsweise erster Prämolar oder Incisivus). Folgend werden die Befunde dieser unbestimmbaren Zähne in Diagrammen dargestellt (Abbildungen 95 bis 100). Die Darstellungsform erfolgte in bekannter Art und Weise.

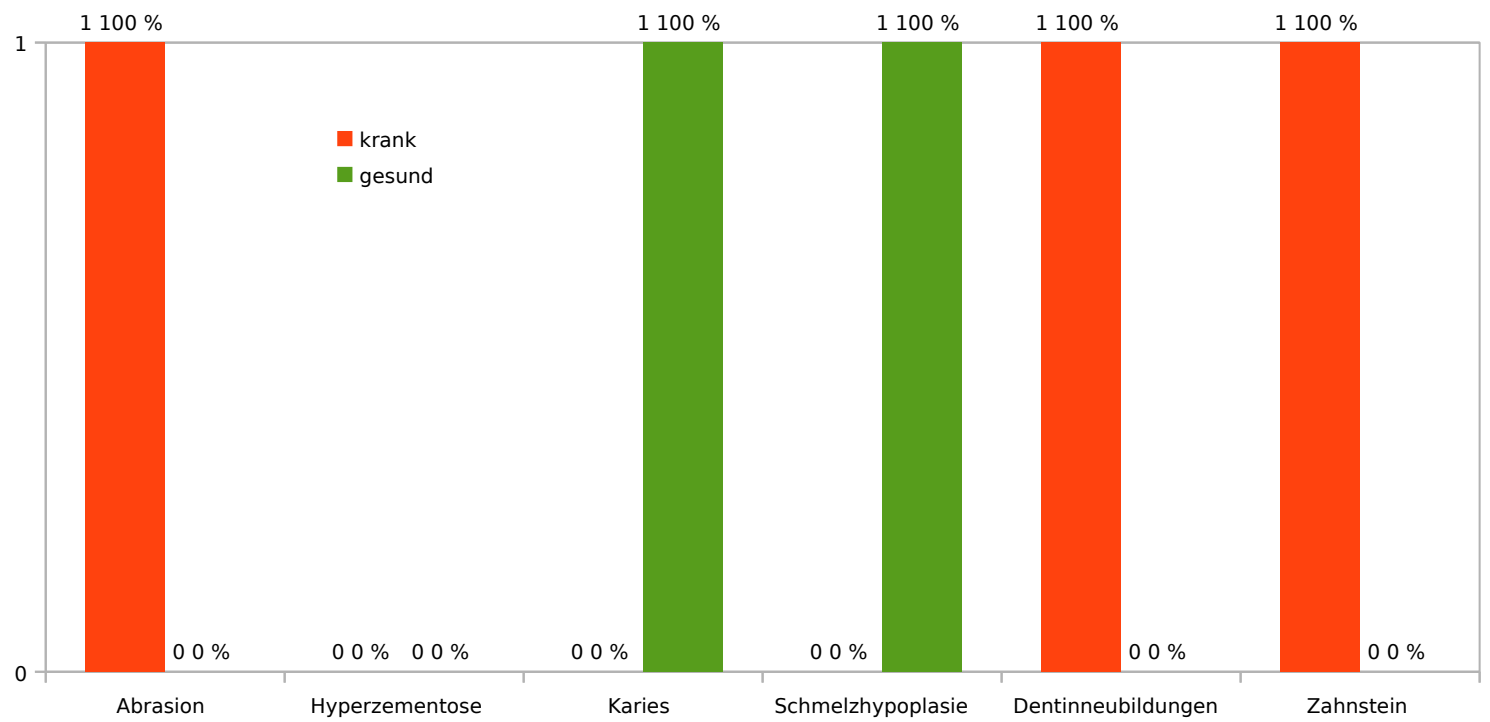

Abb.95 Ein Zahn, der keiner Zahngruppe zuzuordnen war, $n=1$; Rheine

Auf der Ordinate befindet sich die Angabe der Gesamtzahl, über den Säulen links die absoluten Anzahlen, rechts daneben die Prozentzahlen. "n" umfasst alle Zähne. 


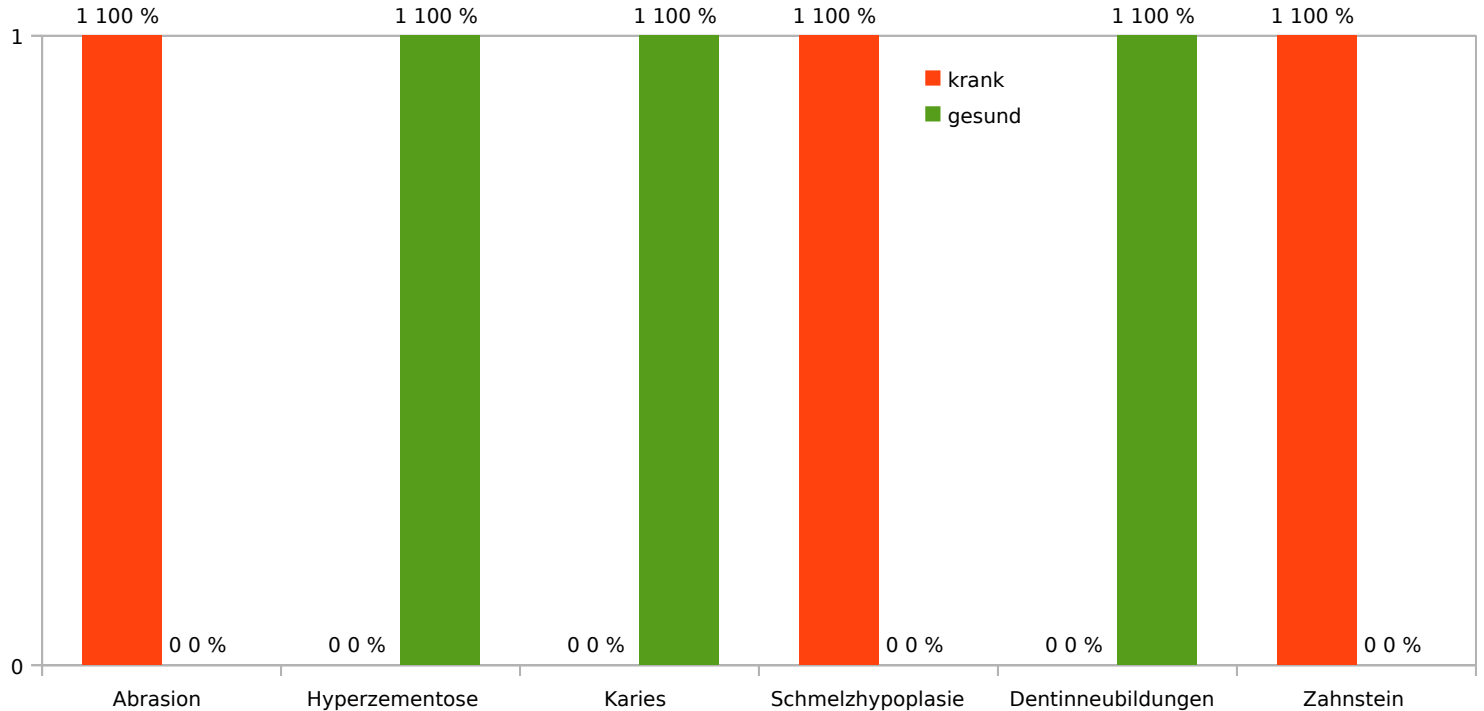

Abb.96 Incisivi, die nicht genau einer Position zuzuordnen waren, $n=3$; Rheine

Auf der Ordinate befindet sich die Angabe der Gesamtzahl, über den Säulen links die absoluten Anzahlen, rechts daneben die Prozentzahlen. "n“ umfasst alle Zähne.

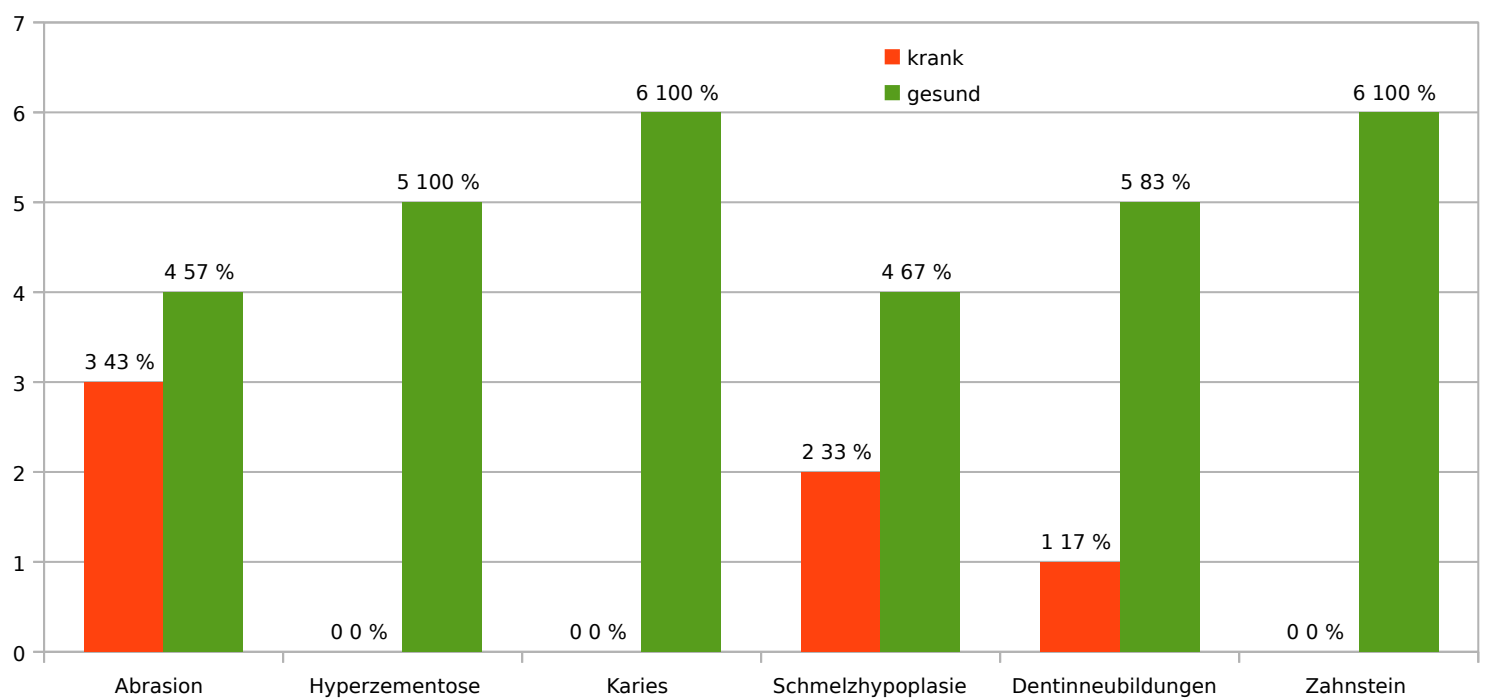

Abb.97 Canini, die einer Zahngruppe nicht genau zuzuordnen waren, $n=8$; Rheine

Auf der Ordinate befindet sich die Angabe der Gesamtzahl, über den Säulen links die absoluten Anzahlen, rechts daneben die Prozentzahlen. "n“ umfasst alle Zähne. 


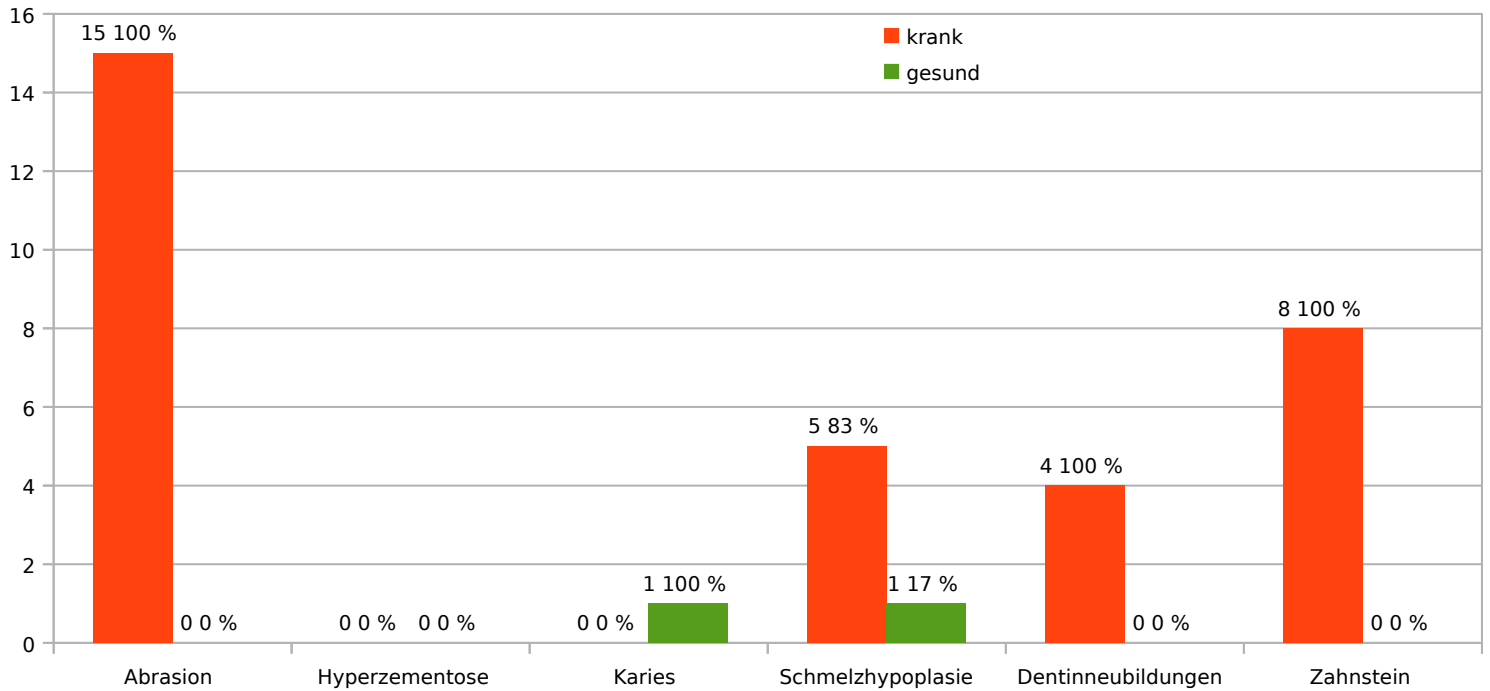

Abb.98 Erste Prämolaren, die nicht genau zugeordnet werden konnten, $n=25$; Rheine

Auf der Ordinate befindet sich die Angabe der Gesamtzahl, über den Säulen links die absoluten Anzahlen, rechts daneben die Prozentzahlen. "n“ umfasst alle Zähne.

$1100 \%$

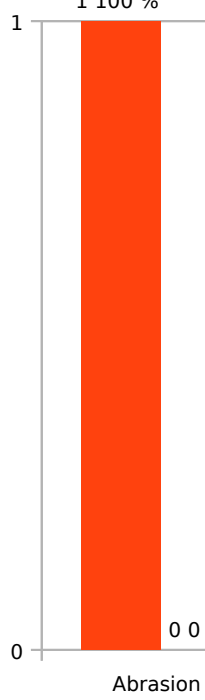

$1100 \%$

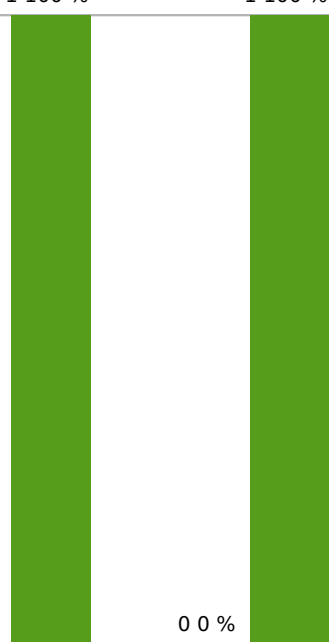

Karies
$1100 \%$

krank
घgesun

gesund

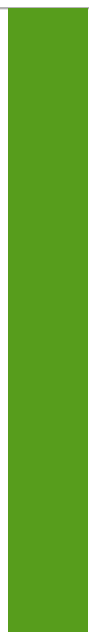

$00 \%$

$00 \% \quad 00 \%$

Schmelzhypoplasie Dentinneubildungen

Zahnstein

Abb.99 Ein zweiter Prämolar, der nicht eindeutig zugeordnet werden konnte, $n=1$; Rheine Auf der Ordinate befindet sich die Angabe der Gesamtzahl, über den Säulen links die absoluten Anzahlen, rechts daneben die Prozentzahlen. "n" umfasst alle Zähne. 


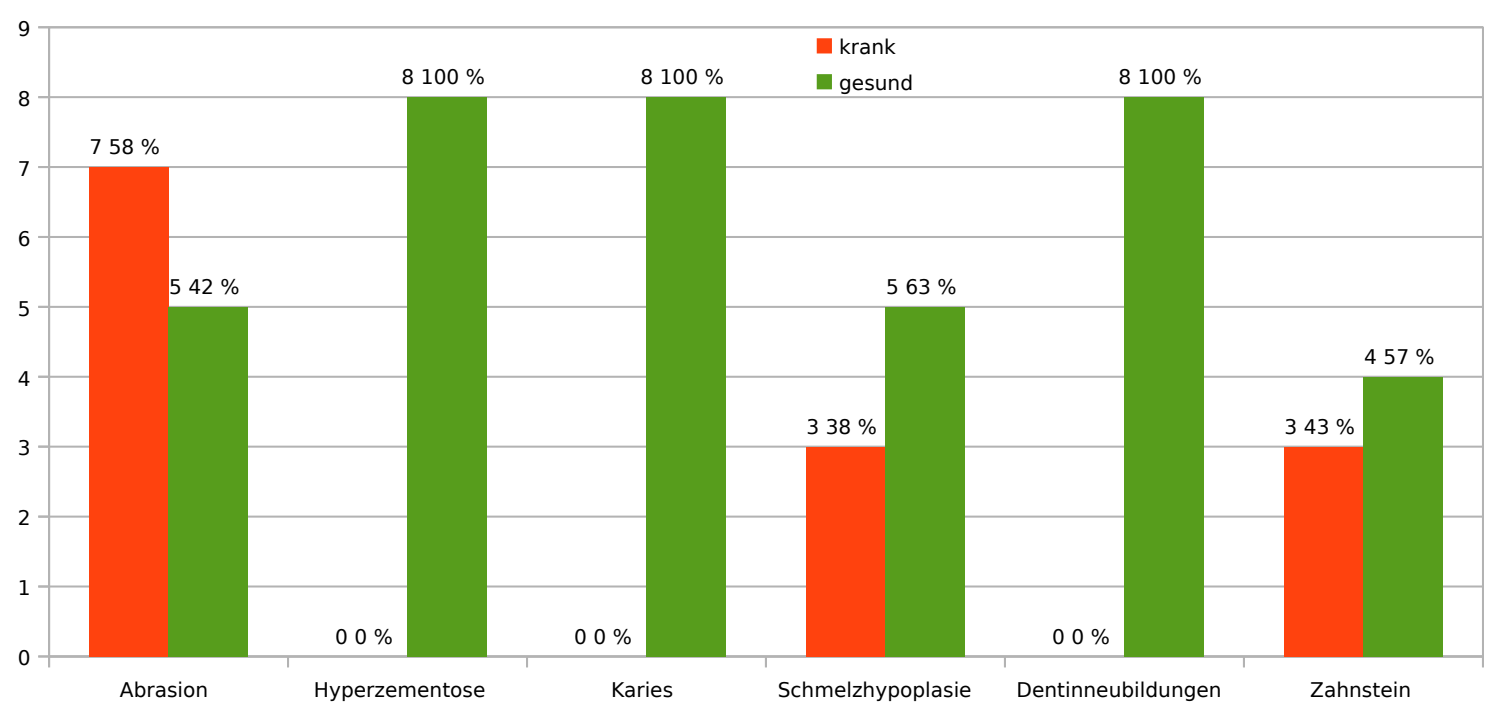

Abb. 100 Dritte Molaren, die nicht genau zuzuordnen waren, $n=16$; Rheine

Auf der Ordinate befindet sich die Angabe der Gesamtzahl, über den Säulen links die absoluten Anzahlen, rechts daneben die Prozentzahlen. "n“ umfasst alle Zähne.

\subsubsection{Apicale Prozesse und Parodontalveränderungen an Milch- und}

\section{Dauergebissen}

Die Diagramme 101 und 102 zeigen die Häufigkeit und die Graduierung der apicalen Prozesse.

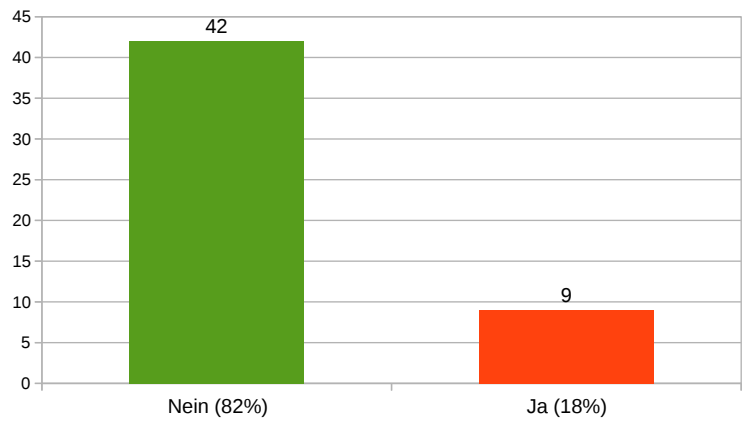

Abb. 101 Diagramm zur Häufigkeit apicaler Prozesse; Rheine

"Nein" heißt, dass keine apicalen Prozesse vorlagen, "Ja" bedeutet, dass eine Zahnregion apicale Prozesse aufwies. Es lagen 51 befundbare Zahnregionen vor. Auf der Ordinate befindet sich die Gesamtzahl, über den Säulen sind die absoluten Zahlen der Häufigkeiten aufgeführt, unter den Säulen sind die prozentualen Zahlen in Klammern angegeben. 


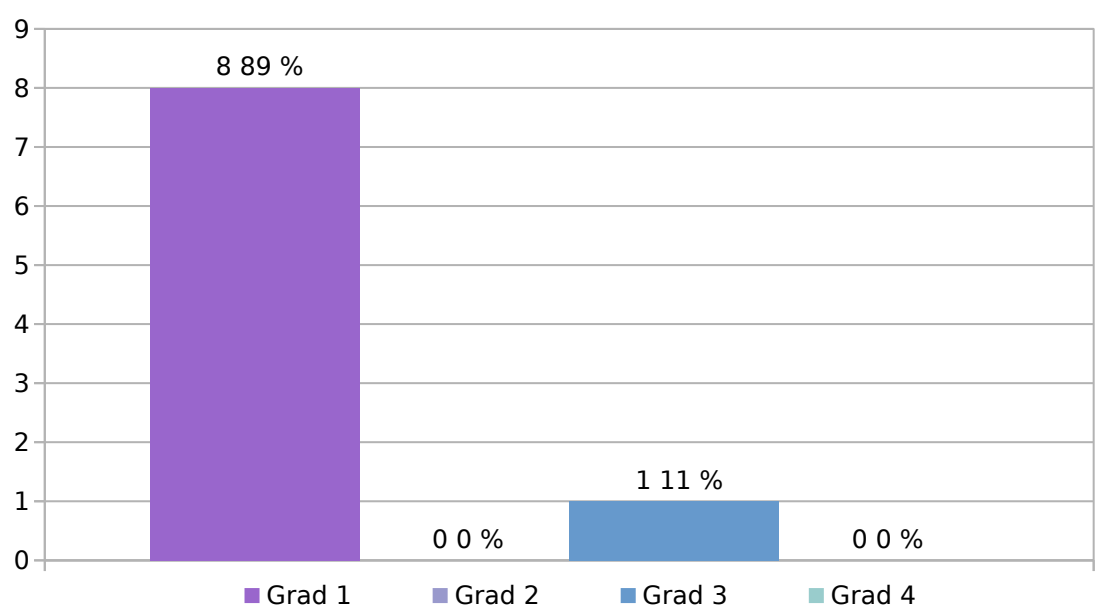

Abb. 102 Graduierung apicaler Prozesse („Ja“-Anteil aus Diagramm 101); Rheine

In dieser Darstellung findet sich die Aufteilung in verschiedene Graduierungen von 1 bis 4 (Abszisse), wobei Grad 1 einer schwachen Ausprägung entspricht und Grad 4 einer starken. Auf der Ordinate befindet sich die Gesamtzahl, über den Säulen sind links die absoluten, rechts die prozentualen Anzahlen angegeben.

\section{Als nächstes werden die Parodontopathien dargestellt. Die Diagramme 103 bis 105 zeigen dabei die Häufigkeit der Parodontopathien mit Graduierung und krankhaf- ter Veränderung.}

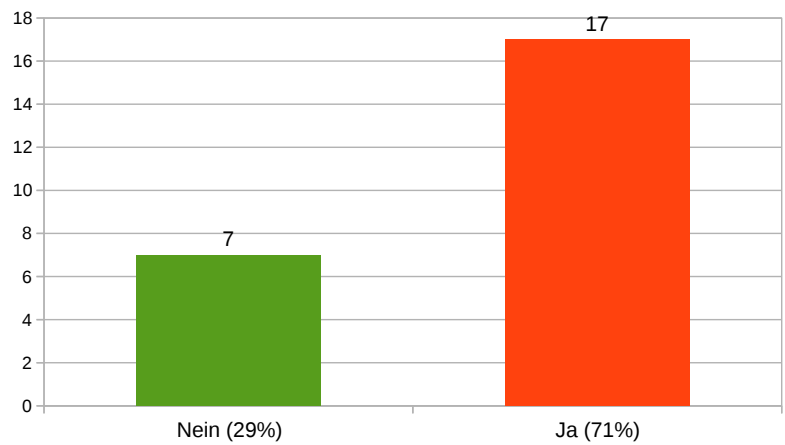

Abb. 103 Diagramm zur Häufigkeit von Parodontopathien; Rheine

"Nein" heißt, dass keine Parodontopathien vorlagen, "Ja" bedeutet, dass eine Zahnregion Parodontopathien aufwies. Es lagen 24 befundbare Zahnregionen vor. Auf der Ordinate befindet sich die Gesamtzahl, über den Säulen sind die absoluten Zahlen der Häufigkeiten aufgeführt, unter den Säulen sind die prozentualen Zahlen in Klammern angegeben. 


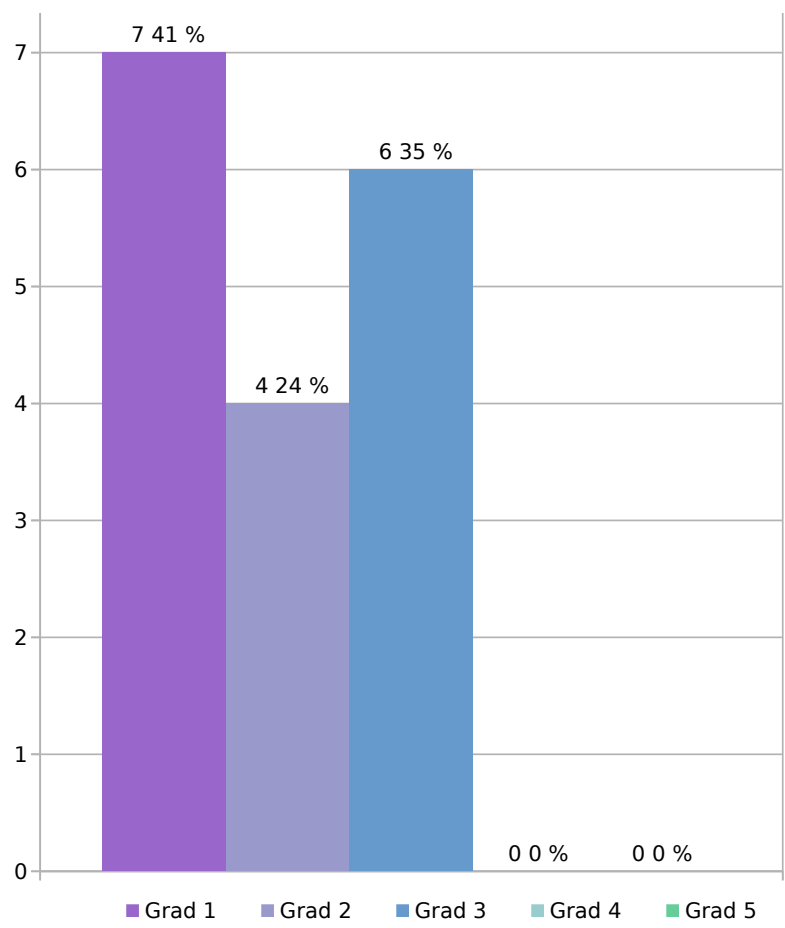

Abb. 104 Graduierung der Parodontopathien (,Ja“-Anteil aus Diagramm 103); Rheine In dieser Darstellung findet sich die Aufteilung in verschiedene Graduierungen von 1 bis 5 (Abszisse), wobei Grad 1 einer schwachen Ausprägung entspricht und Grad 5 der stärksten. Auf der Ordinate befindet sich die Angabe der Gesamtzahl, über den Säulen sind links die absoluten, rechts die prozentualen Anzahlen angegeben.

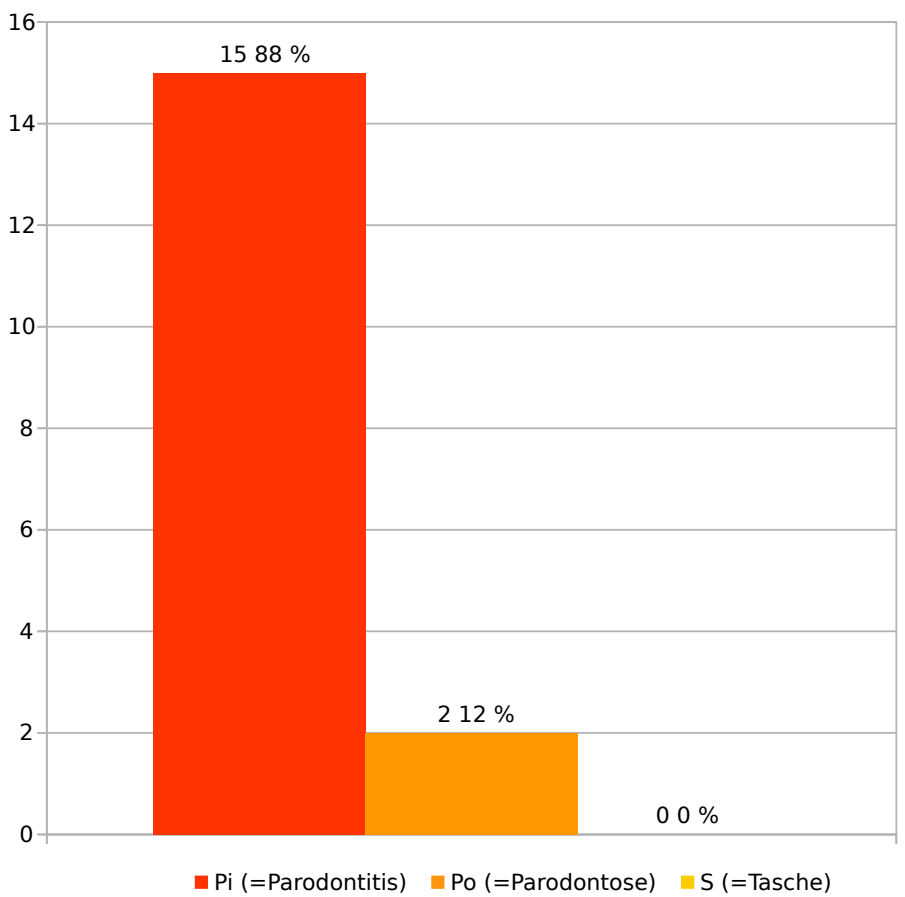

Abb. 105 Darstellung der verschiedenen Parodontopathien; Rheine

Dieses Diagramm nimmt Bezug auf den "Ja"-Anteil aus Diagramm 103. Auf der Ordinate befindet sich die Angabe der Gesamtzahl, über den Säulen sind links die absoluten, rechts die prozentualen Anzahlen angegeben. 


\subsubsection{Postcranien}

Es folgt die Darstellung der Ergebnisse der postcranialen Skeletelemente (Tab. 5).

Die Gestaltung der Tabelle erfolgt nach dem gleichen Prinzip wie die der Population aus Calden.

Tab. 5 Postcraniale Fundstücke; Rheine

Darstellung der postccranialen Fundstücke nach Einteilung in gesund, krank, befundbar und nicht befundbar (gesund + krank= befundbar; befundbar + nicht befundbar=gesamt). Weiterhin finden sich die absoluten Gesamtzahlen der Befundkategorien. „Phalanx manus / pedis“ bedeutet, dass das Fundstück als Phalanx identifiziert, aber nicht einer Phalanx der Hand oder des Fußes zugeordnet werden konnte.

\begin{tabular}{|l|r|r|r|r|r|}
\hline & gesund & krank & befundbar & nicht befundbar & gesamt \\
\hline Vertebra & 3 & 3 & 6 & 6 & 12 \\
\hline Clavicula & 2 & 1 & 3 & 1 & 4 \\
\hline Costa & 8 & 1 & 9 & 0 & 9 \\
\hline Scapula & 3 & 1 & 4 & 0 & 4 \\
\hline Humerus & 0 & 1 & 1 & 4 & 5 \\
\hline Ulna & 2 & 1 & 3 & 1 & 4 \\
\hline Radius & 6 & 0 & 6 & 2 & 8 \\
\hline Os triquetrum & 1 & 0 & 1 & 0 & 1 \\
\hline Os pisiforme & 1 & 0 & 1 & 0 & 1 \\
\hline Os metacarpale & 1 & 0 & 1 & 1 & 2 \\
\hline Phalanx manus & 1 & 0 & 1 & 0 & 1 \\
\hline Os coxae & 1 & 0 & 1 & 1 & 2 \\
\hline Os femoris & 11 & 1 & 12 & 4 & 16 \\
\hline Patella & 0 & 0 & 0 & 1 & 1 \\
\hline Tibia & 1 & 5 & 6 & 3 & 9 \\
\hline Fibula & 4 & 0 & 4 & 1 & 5 \\
\hline Talus & 3 & 0 & 3 & 0 & 3 \\
\hline Calcaneus & 3 & 0 & 3 & 0 & 3 \\
\hline Os naviculare & 0 & 0 & 0 & 2 & 2 \\
\hline Os cuneiforme & 2 & 0 & 2 & 0 & 2 \\
\hline Os metatarsale & 1 & 0 & 1 & 0 & 1 \\
\hline Knochenklein & 4 & 0 & 4 & 36 & 40 \\
\hline Phalanx manus / pedis & 0 & 0 & 0 & 2 & 2 \\
\hline gesamt & 58 & 14 & 72 & 65 & 137 \\
\hline
\end{tabular}

Die den Funden aus der Population aus Rheine zugehörigen Daten wurden in insgesamt 137 Datensätze eingepflegt. Diese Datensätze beinhalten in der Regel ein Skeletsegment, beispielsweise einen Oberschenkelknochen, ein Becken usw. Nur ein Talus und ein Calcaneus konnten demselben Fuß zugeordnet werden; alle anderen Fundstücke lagen unzusammenhängend vor. Da die Population aus Rheine jene Population ist, welche den schlechtesten Erhaltungszustand von allen drei hier untersuchten Populationen aufweist, mussten viele Knochen als Splitter oder als „Knochenklein“ eingetragen werden. Zahlreiche dieser gesammelten 
Knochensplitter wurden gewogen und in der Datenbank als „Knochenklein“ dokumentiert. Zunächst werden Aufstellungen über die Gesamtzahl der einzelnen Knochen sowie über den Nachweis von Arthrose und Arthritis an den langen Extremitätenknochen vorgestellt.

Die Tabelle 6 zeigt die langen Extremitätenknochen nach Knochenabschnitt, Seite und befundeter Arthrose bzw. Arthritis.

Tab. 6 Arthrose/Arthritis langer Extremitätenknochen; Rheine

Darstellung der absoluten Anzahlen der langen Extremitätenknochen und jeweils befundeter Arthrose oder Arthritis. Die Knochen sind dabei in Fünftel aufgeteilt, um die jeweiligen Fünftel vergleichen zu können. Arthrose und Arthritis sind nur an Gelenken zu finden, weswegen sie nur für die proximalen und distalen Fünftel der Knochen angegeben sind. "re" bedeutet rechter Knochen, "li" linker Knochen, "ind" bedeutet, dass die Seite nicht bestimmbar war. "Vollständig" bedeutet, dass ein Knochen in ganzer Länge vollständig vorhanden war. "ges." steht für Gesamtanzahl, "Arthro/Arthri" für Arthrose undloder Arthritis.

\begin{tabular}{|c|c|c|c|c|c|c|c|c|}
\hline Humerus & re. & li. & ind. & ges. & $\begin{array}{l}\text { Arthro/Arthri } \\
\text { re. }\end{array}$ & $\begin{array}{l}\text { Arthro/Arthri } \\
\text { li. }\end{array}$ & $\begin{array}{l}\text { Arthro/Arthri } \\
\text { ind. }\end{array}$ & $\begin{array}{l}\text { Arthro/Arthri } \\
\text { ges. }\end{array}$ \\
\hline $1 . / 5$ & 0 & 0 & 0 & 0 & 0 & 0 & 0 & 0 \\
\hline $2 . / 5$ & 0 & 1 & 0 & 1 & & & & \\
\hline $3 . / 5$ & 1 & 0 & 1 & 2 & & & & \\
\hline $4 . / 5$ & 1 & 0 & 0 & 1 & & & & \\
\hline $5 . / 5$ & 0 & 0 & 1 & 1 & 0 & 0 & 0 & 0 \\
\hline vollständig & 0 & 0 & 0 & 0 & & & & \\
\hline Femur & re. & li. & ind. & ges. & $\begin{array}{l}\text { Arthro/Arthri } \\
\text { re. }\end{array}$ & $\begin{array}{l}\text { Arthro/Arthri } \\
\text { li. }\end{array}$ & $\begin{array}{l}\text { Arthro/Arthri } \\
\text { ind. }\end{array}$ & $\begin{array}{l}\text { Arthro/Arthri } \\
\text { ges. }\end{array}$ \\
\hline $1 . / 5$ & 0 & 0 & 0 & 0 & 0 & 0 & 0 & 0 \\
\hline $2 . / 5$ & 3 & 1 & 0 & 4 & & & & \\
\hline $3 . / 5$ & 4 & 4 & 3 & 11 & & & & \\
\hline $4 . / 5$ & 1 & 0 & 0 & 1 & & & & \\
\hline $5 . / 5$ & 1 & 1 & 0 & 2 & & & & \\
\hline vollständig & 0 & 0 & 0 & 0 & 0 & 0 & 0 & 0 \\
\hline Tibia & re. & li. & ind. & ges. & $\begin{array}{l}\text { Arthro/Arthri } \\
\text { re. }\end{array}$ & $\begin{array}{l}\text { Arthro/Arthri } \\
\text { li. }\end{array}$ & $\begin{array}{l}\text { Arthro/Arthri } \\
\text { ind. }\end{array}$ & $\begin{array}{l}\text { Arthro/Arthri } \\
\text { ges. }\end{array}$ \\
\hline $1 . / 5$ & 1 & 0 & 0 & 1 & 0 & 0 & 0 & 0 \\
\hline $2 . / 5$ & 5 & 2 & 0 & 7 & & & & \\
\hline $3 . / 5$ & 3 & 3 & 1 & 7 & & & & \\
\hline $4 . / 5$ & 0 & 2 & 0 & 2 & & & & \\
\hline $5 . / 5$ & 0 & 1 & 0 & 1 & 0 & 0 & 0 & 0 \\
\hline vollständig & 0 & 0 & 0 & 0 & & & & \\
\hline Fibula & re. & li. & ind. & ges. & $\begin{array}{l}\text { Arthro/Arthri } \\
\text { re. }\end{array}$ & $\begin{array}{l}\text { Arthro/Arthri } \\
\text { li. }\end{array}$ & $\begin{array}{l}\text { Arthro/Arthri } \\
\text { ind. }\end{array}$ & $\begin{array}{l}\text { Arthro/Arthri } \\
\text { ges. }\end{array}$ \\
\hline $1 . / 5$ & 0 & 0 & 0 & 0 & 0 & 0 & 0 & 0 \\
\hline $2 . / 5$ & 0 & 0 & 0 & 0 & & & & \\
\hline $3 . / 5$ & 0 & 1 & 4 & 5 & & & & \\
\hline $4 . / 5$ & 0 & 0 & 0 & 0 & & & & \\
\hline $5 . / 5$ & 0 & 0 & 0 & 0 & & & & \\
\hline vollständig & 0 & 0 & 0 & 0 & 0 & 0 & 0 & 0 \\
\hline
\end{tabular}


Weiterhin folgen nun die Ergebnisse der an den Wirbeln der Population aus Rheine erhobenen Befunde (Abbildungen 106 und 107). Die Ergebnisdarstellung erfolgt in bekannter Form.

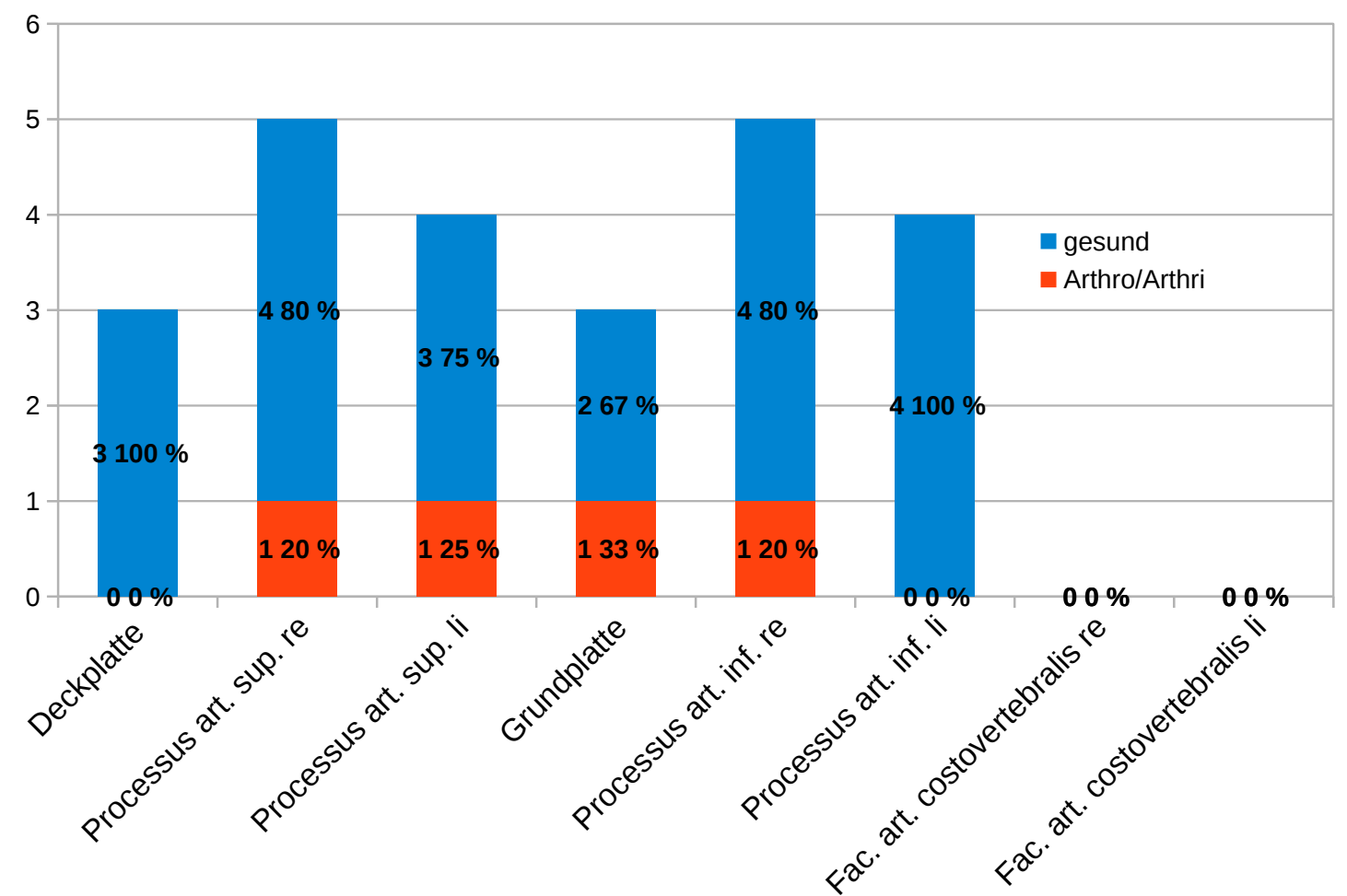

Abb.106 Darstellung der Befunde der Wirbel; Rheine

Auf der Abszisse sind die anatomischen Wirbelregionen angegeben. In den Säulen finden sich links die absoluten Anzahlen, rechts die Prozentzahlen in Bezug auf die Gesamtanzahl der befundeten Wirbelregionen und im Sinne von Arthrose undloder Arthritis krankhaft veränderter Wirbelregionen. Abkürzungen: "Fac."= Facies, „sup."= superior, "inf."= inferior, "re" = rechts, "li"= links, "art."= articularis. Die Gesamtzahl der befundeten Bewegungssegmente ist auf der Ordinate angegeben.

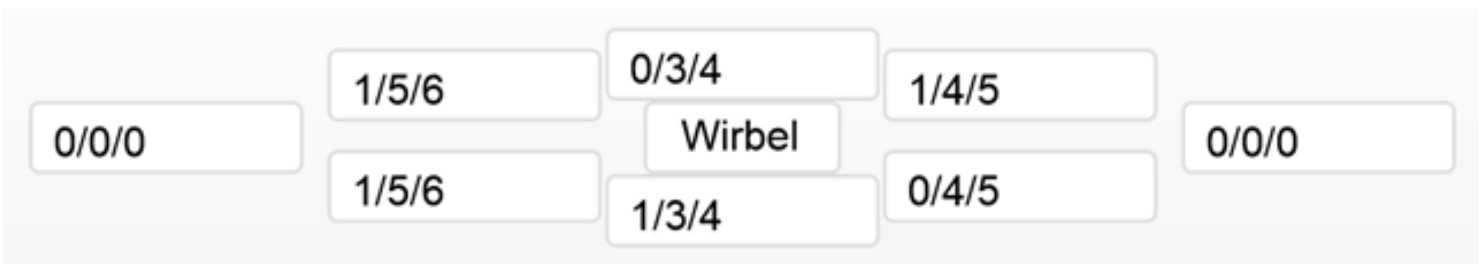

Abb. 107

Anatomisch orientierte Darstellung der Wirbelregionen; Rheine

Mittleres oberes Feld: Deckplatte, links daneben das Feld für den Processus articularis superior der rechten Seite, rechts neben der Deckplatte das Feld für den Processus articularis superior der linken Seite. Ganz außen links: Feld für die Gelenkpfanne der Articulatio costovertebralis (Fovea costalis processus transversi) der rechten Seite, rechts ganz außen das Feld für die Gelenkpfanne der Articulatio costovertebralis (Fovea costalis processus transversi) der linken Seite. Mittleres unteres Feld: Grundplatte, daneben links das Feld für die Gelenkfläche am Processus articularis inferior der rechten Seite, neben der Grundplatte rechts das Feld für die Gelenkfläche am Processus articularis inferior der linken Seite. Im oben abgebildeten Gelenkbefundungsschema sind in jedem Zahlenkästchen drei Zahlen aufgeführt. Die erste Zahl (von links) ist die Anzahl der mit Arthrose und/oder Arthritis erkrankten Regionen, die zweite Zahl (von links) ist die Gesamtzahl der jeweils für eine bestimmte Gelenkeinheit befundbaren Flächen. Die dritte Zahl (von links) ist die Gesamtzahl der insgesamt erhaltenen Flächen (befundbar und unbefundbar). 
Nachfolgend werden die Ergebnisse der Befundung der Postcranien der Population aus Rheine vorgestellt. In den Diagrammen 108 und 109 sind alle Fundstücke aufgeführt, die befundbar waren. Prozentual werden die als „gesund“ und „krank“ diagnostizierten Fundstücke aller befundbaren Knochen angegeben.

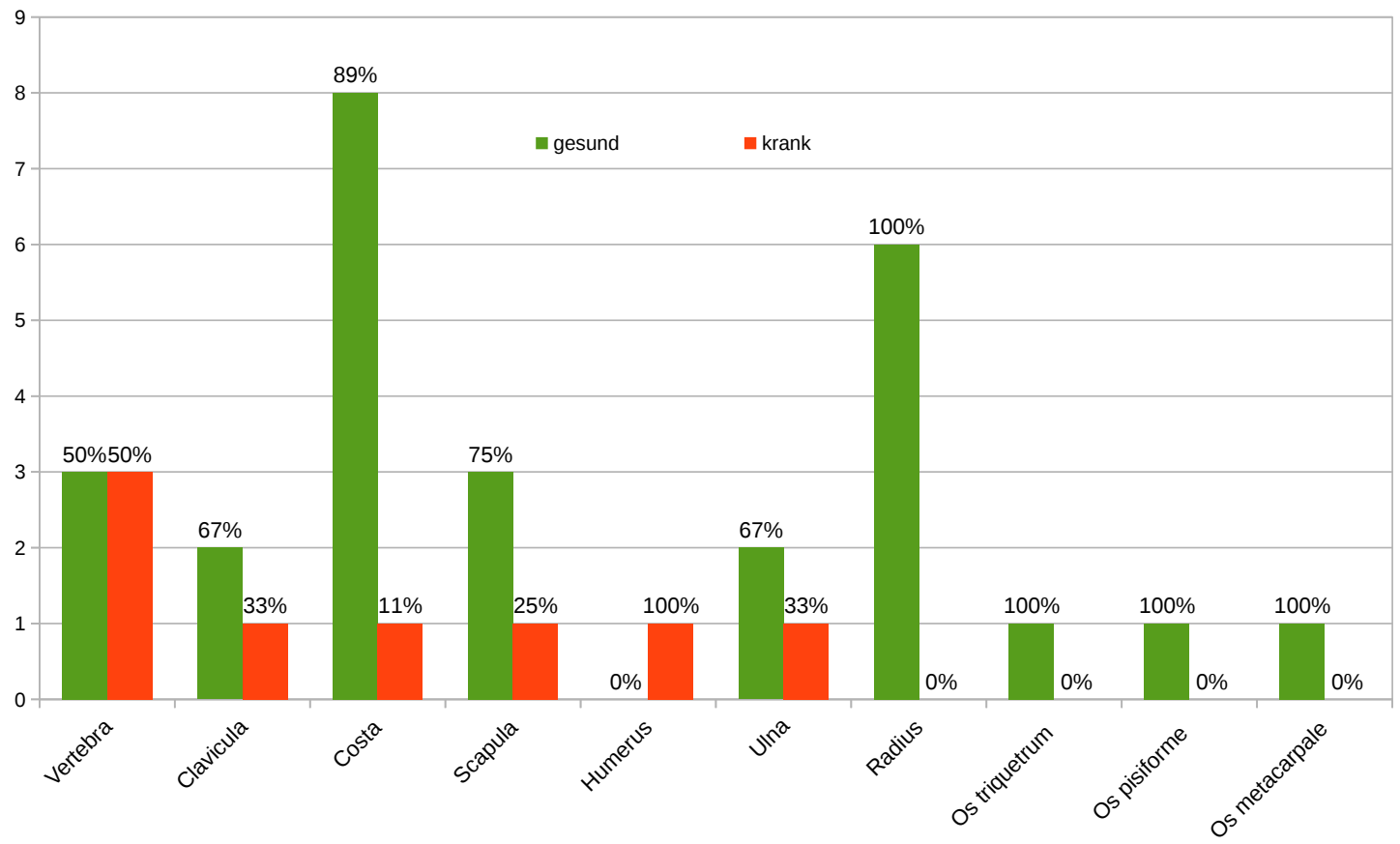

Abb. 108 Befundbare Fundstücke (außer Schädel und den Zähnen) - Teil 1; Rheine

In diesem Diagramm sind alle Fundstücke aufgeführt, die befundbar waren. Prozentual werden die als "gesund" und "krank" diagnostizierten Fundstücke aller befundbaren Knochen angegeben. Die absolute Anzahl ist auf der Ordinate festgehalten.

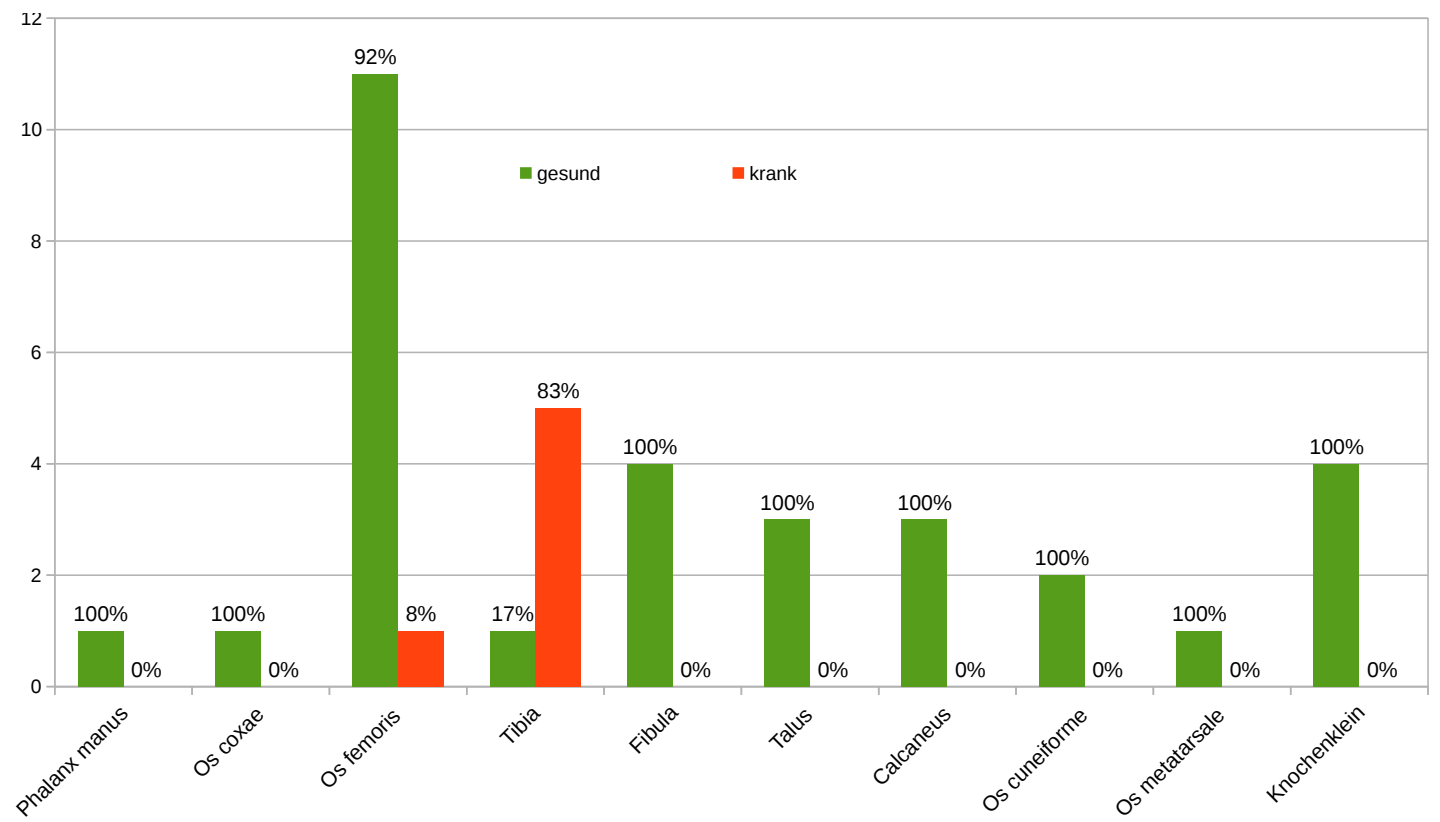

Abb.109 Befundbare Fundstücke (außer Schädel und den Zähnen) - Teil 2; Rheine

In diesem Diagramm sind alle Fundstücke aufgeführt, die befundbar waren. Prozentual werden die als "gesund" und "krank" diagnostizierten Fundstücke aller befundbaren Knochen angegeben. Die absolute Anzahl ist auf der Ordinate festgehalten. 
Es folgt nun Tabelle 7, die einen Überblick über die an den Fundstücken diagnostizierten Krankheiten gibt.

Tab. 7 (Einzelne) Veränderungen an (einzelnen) Knochen; Rheine

Die Tabelle zeigt Fundstücke, die nur eine Veränderung aufwiesen. Weiterhin zeigt sie Veränderungen, die nur bei einer Gruppe von Fundstücken nachzuweisen waren.

\begin{tabular}{|c|c|c|c|c|c|}
\hline & Arthrose & Arthritis & Entzündung tiefer Beinvenen & Muskeltrauma & Periostreizung \\
\hline Vertebra & 2 & 1 & & & \\
\hline Clavicula & & & & 1 & \\
\hline Costa & & & & 1 & \\
\hline Scapula & 1 & & & & \\
\hline Humerus & & & & 2 & \\
\hline Ulna & & & & 2 & \\
\hline Os femoris & & & 1 & & \\
\hline Tibia & & & & 2 & 3 \\
\hline
\end{tabular}

\subsubsection{Ermittlung des Sterbealters}

Das Sterbealter konnte bei der Population aus Rheine für sieben Skeletsegmente (außer den Zähnen) bestimmt werden (Abb. 110). Deutlich aussagekräftiger ist die Altersbestimmung der Zähne (Abbildungen 111 und 112).
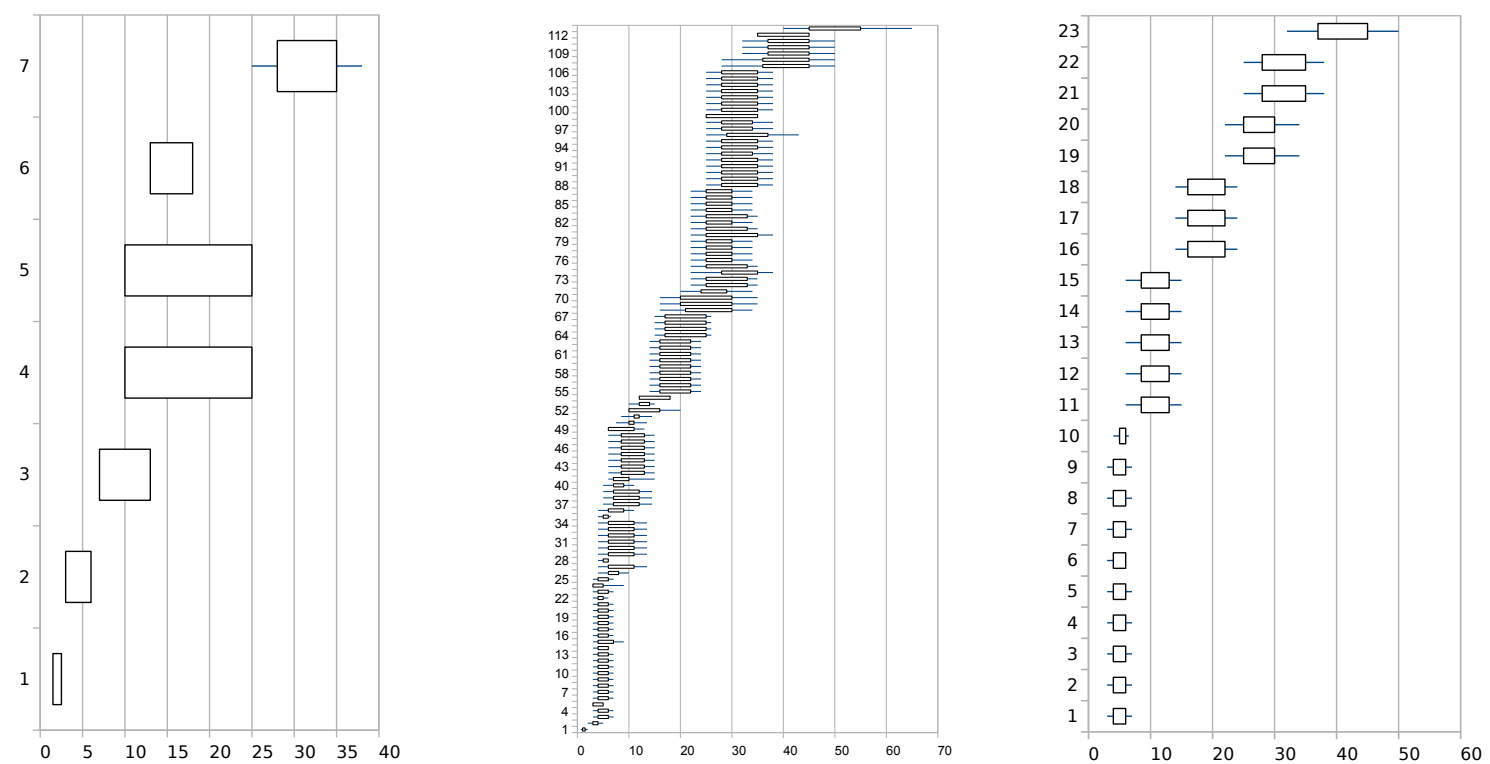

Abb.110 Links: Sterbealterbestimmung anh. aller Fundstücke ohne Zähne; Rheine

Abb.111 Mitte: Sterbealterbestimmung anh. der Zahnfundstücke; Rheine

Abb.112 Rechts: Sterbealterbestimmung anh. von Zähnen der MIZ-Bestimmung; Rheine Legende für die Abbildungen 110-112: Auf der $x$-Achse ist das Sterbealter aufgetragen, auf der $y$-Achse entspricht jede volle Einheit einem Fundstück, für das im Diagramm dann das Sterbealter in einem "Wahrscheinlichkeitsbereich" (Balken undloder Strich) abzulesen ist. Der blaue Strich steht dabei gegebenenfalls für die noch möglichen maximalen und minimalen Grenzwerte des Sterbealters, der Balken für das wahrscheinliche Sterbealter. Links findet sich das Diagramm für alle Fundstücke, außer den Zähnen, mittig ist das Diagramm aller Zähne und rechts das jener Zähne, die für die Mindestindividuenzahl herangezogen wurden (alle Zähne "26“). 
Bei zehn postcranialen Einzelknochen konnte eine Einteilung des Sterbealters nur abschätzungsweise in adult oder subadult erfolgen (Abb. 113).

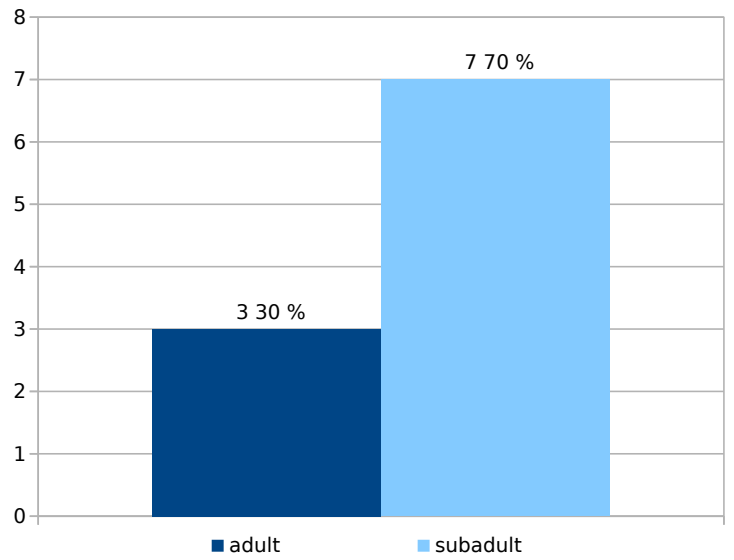

Abb. 113 Alterseinteilung der Fundstücke in "adult" und "subadult"; Rheine

Einteilung in die zwei großen Altersgruppen aufgrund morphologischer Gesichtspunkte (wenn beispielsweise offene Epiphysen vorlagen, wurde das Fundstück in die Kategorie "subadult" eingeteilt). Über den Säulen sind die absoluten Häufigkeiten links aufgeführt, rechts daneben finden sich jeweils die prozentualen Anteile. Auf der Ordinate befindet sich die Angabe der Gesamtzahl.

\subsubsection{Geschlechtsbestimmung}

Für die Population aus Rheine konnten vier Fundstücke einer Geschlechtsbestimmung unterzogen werden (Abb. 114).

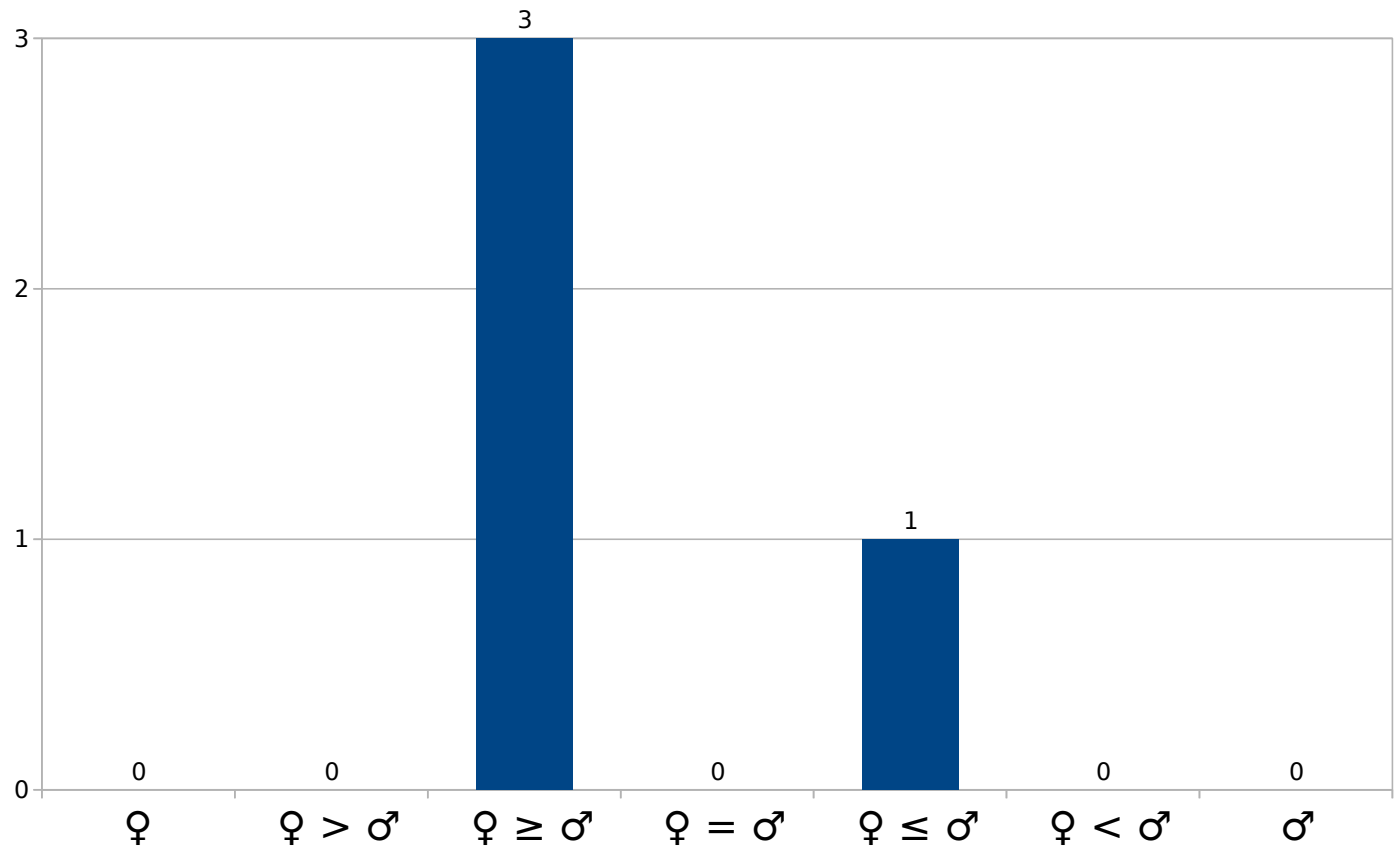

Abb. $114 \quad$ Geschlechtsverteilung; Rheine

Im Diagramm sind alle Fundstücke erfasst, bei denen eine Geschlechtsbestimmung möglich war $(n=4)$. Die Einteilung erfolgte in "wahrscheinlich" weiblich $($ Q $)$, "wohl" weiblich $(Q>0)$, ",eher" weiblich $(q \geq \hat{O})$, "indifferent" $(q=\widehat{\delta})$, also keinem Geschlecht zuzuordnen, "eher" männlich

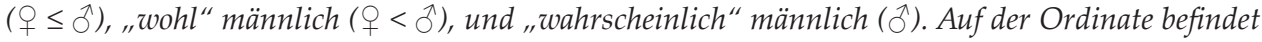
sich die Angabe der Gesamtzahl.

Es fällt auf, dass die Geschlechtsverteilung leicht zugunsten der weiblichen Individuen verteilt ist. 


\subsection{Großenrode}

Obwohl auch die Skeletfunde der Population aus Großenrode in einem stark fragmentierten Zustand vorlagen, war ihr Zustand meist etwas besser im Vergleich zu den Funden aus Rheine. Dennoch gab es eine Vielzahl nicht befundbarer Knochen und Zähne. Das Fundgut enthielt Knochen, die oft zu mehr als 50\% ihrer Gesamtgröße erhalten waren, aber so stark oberflächenerodiert vorlagen, dass oft keine Befundung möglich war.

Anders war die Situation bei den Zähnen, die sich in großer Anzahl und weniger erodiert erhalten haben. Die besten Befundergebnisse konnten - wie auch bei der Population aus Rheine - für Zähne erzielt werden. Alle Ergebnisse werden - wie im Teil 3.1. für Calden bereits beschrieben - nachfolgend dargestellt.

\section{Mindestindividuenzahl}

Die Rekonstruktion der Mindestzahl der Individuen der Population aus Großenrode ließ sich anhand linker Sprungbeine errechnen; es haben sich 23 erhalten. Alternativ wurde die Kalkulation der Mindestanzahl der Individuen mit dem Vorhandensein des Zahns 46 vorgenommen; 43 untere rechte erste Molaren haben sich erhalten. Der Grund für die Diskrepanz zwischen den beiden Berechnungsergebnissen liegt offenbar in dem mangelhaften Erhaltungszustand vieler postcranialer Skeletelemente. Zähne sind in ihrer Struktur stabiler und sind nicht zuletzt aufgrund ihrer Größe besser erhalten und weniger postmortal verändert.

\subsubsection{Cranien}

Unter den Fundstücken aus der Population aus Großenrode befanden sich zahlreiche - in 116 Datensätze der Datenbank eingepflegte - Schädelfragmente. Unter zahlreichen fragmentierten Fundstücken fanden sich einige mittelmäßig bis gut erhaltene Schädelanteile. 
Die Abbildungen 115 bis 118 zeigen die Darsellungen zu den Schädelbefunden in bekannter Art und Weise.

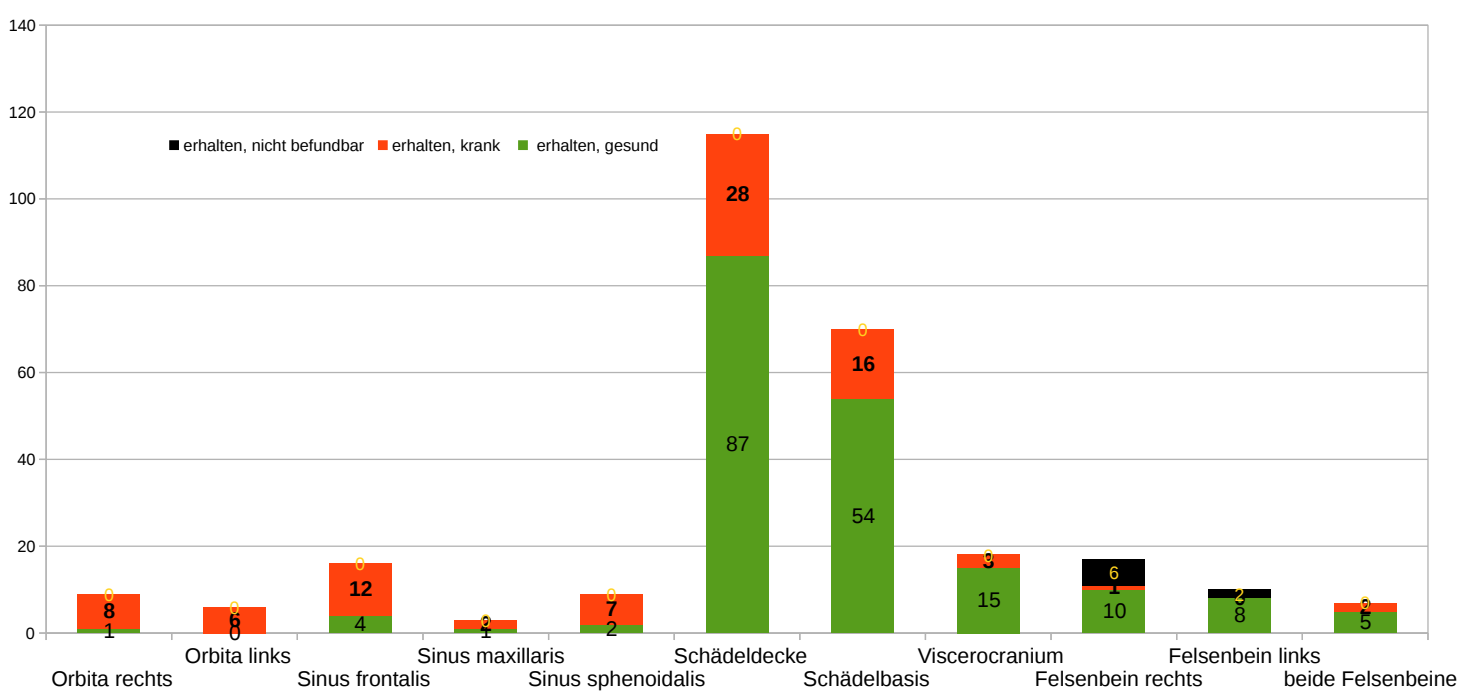

Abb. $115 \quad$ Verteilung der Schädelfragmente; Großenrode

Das Balkendiagramm zeigt die absolute Anzahl der erhaltenen Kompartimente mit Berücksichtigung des Befundungszustandes "nicht befundbar", "krank" und, gesund". Die als "krank" bezeichneten Fundstücke weisen Veränderungen auf, die meist als Spuren von Erkrankungen diagnostiziert wurden. Auf der Ordinate befindet sich die Angabe der Gesamtzahl.

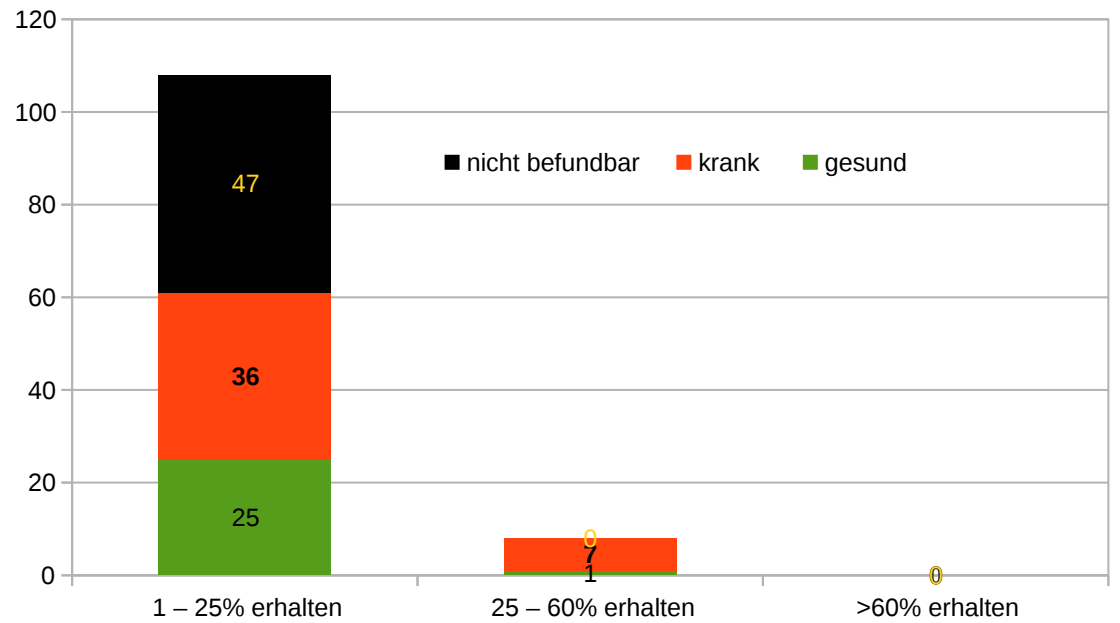

Abb.116 Absolute Zahl der Erhaltungsmenge je Cranium eines Individuums; Großenrode Einteilung in die Kategorien "1-25\%", "26-60\%" und ">61\%". Auf der Ordinate befindet sich die Angabe der Gesamtzahl. 


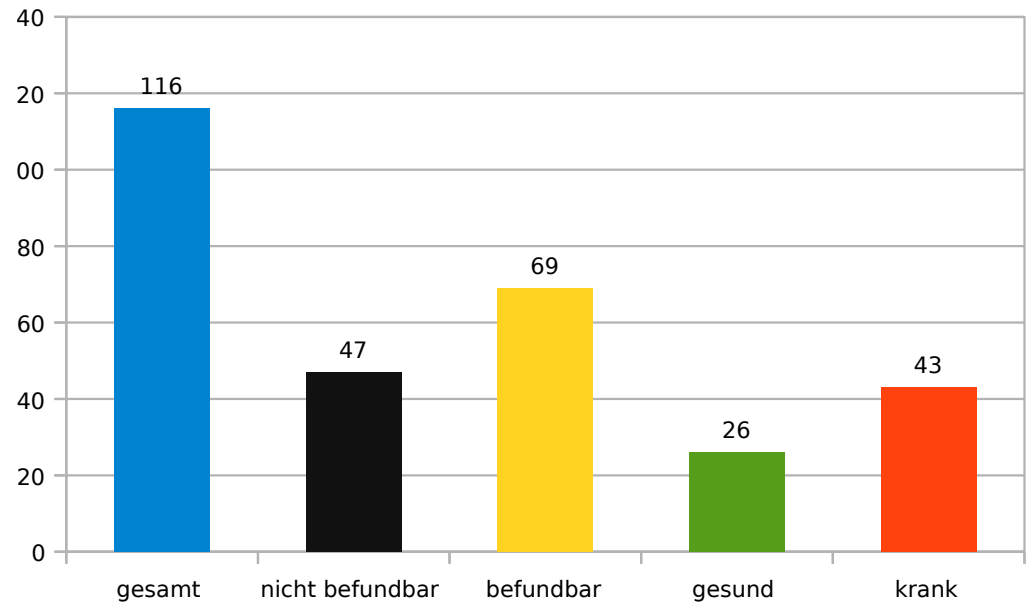

Abb.117 Gesamtheit der Datensätze für die Schädelfunde; Großenrode

Darstellung in den Kategorien "gesamt", "nicht befundbar", "befundbar", "gesund"und "krank". Dabei ergeben "nicht befundbar" und "befundbar" die Gesamtsumme und "gesund" und "krank" summieren sich zu "befundbar". Auf der Ordinate befindet sich die Angabe der Gesamtzahl.

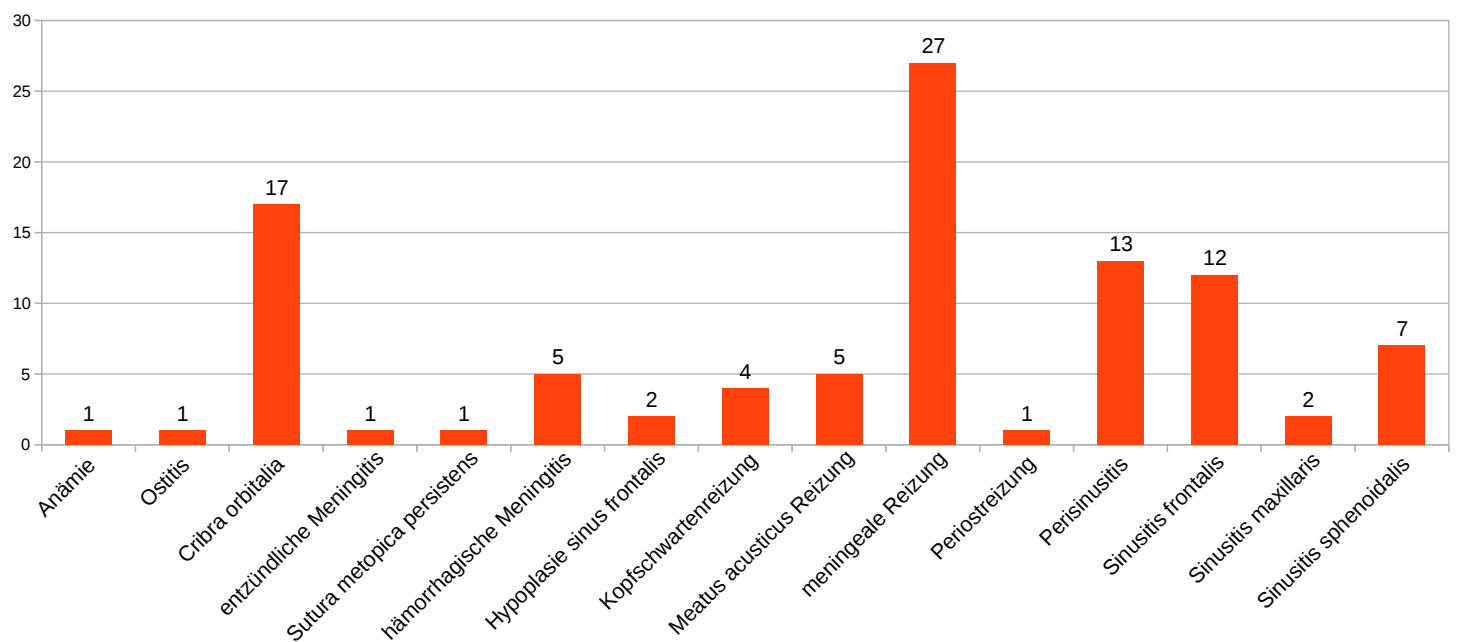

Abb.118 Diagnostizierte Veränderungen an den Schädelfunden; Großenrode Auf der Ordinate befindet sich die Angabe der Gesamtzahl.

\subsubsection{Zähne}

Die von der Population aus Großenrode vorhandenen Zahnfunde haben sich durchweg in besserem Zustand erhalten als die cranialen und postcranialen Fundstücke. Dennoch gab es auch hier einige unbefundbare Fundstücke. Insgesamt wurden 652 Zähne der Population aus Großenrode befundet und die Befunddaten in 241 Datensätze hinterlegt. 


\subsubsection{Bleibende Zähne}

Das folgende Diagramm (Abb. 119) zeigt die Anzahlen der bleibenden Zähne im Dauergebiss.

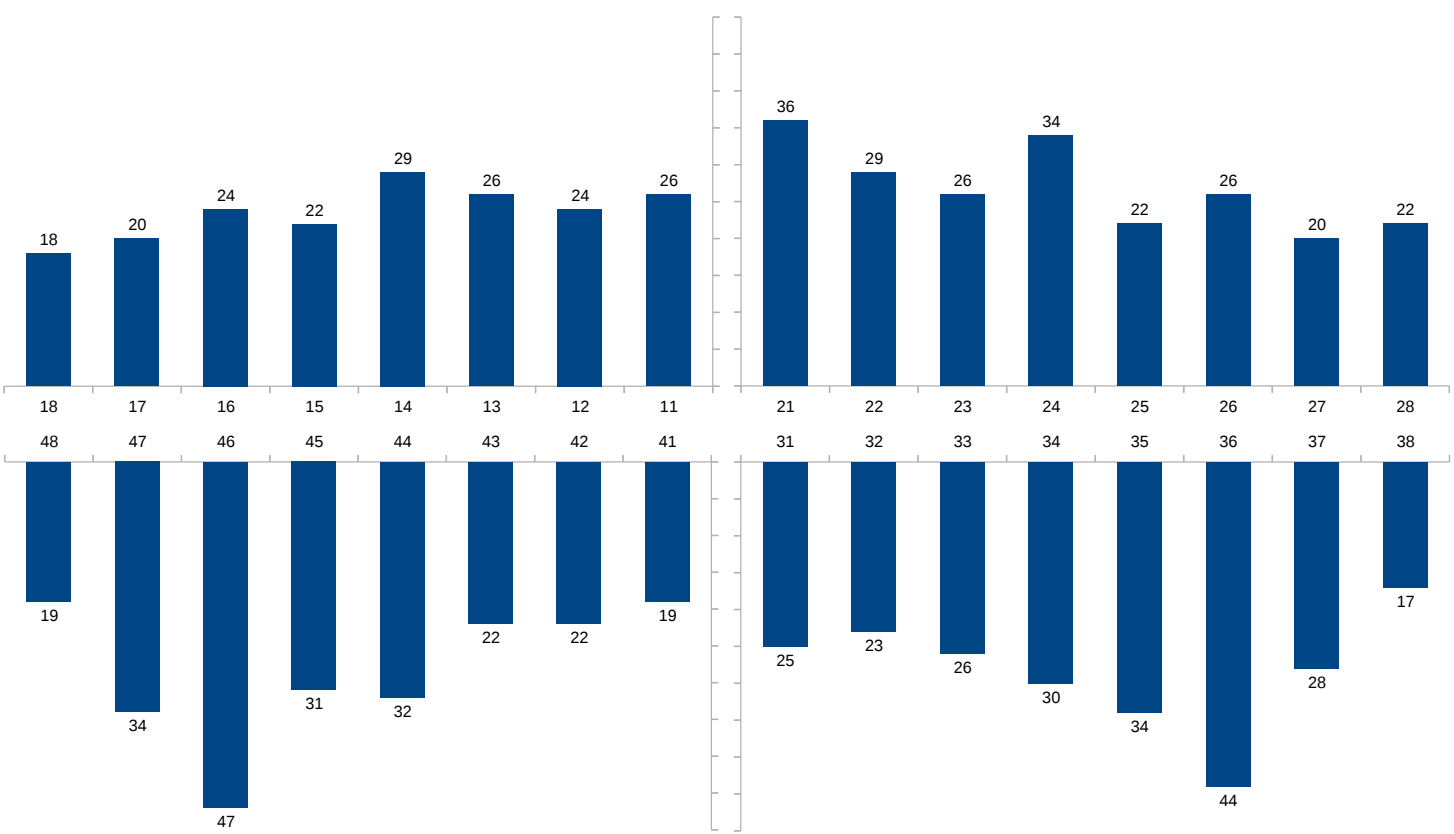

Abb.119 Erhaltene Zähne und leere Alveolen des Dauergebisses; Großenrode

Die Ansicht ist so gewählt, dass die vier Quadranten sichtbar sind, als würde man das Gebiss von vorn betrachten (übliche Darstellung in der Zahnmedizin). In dieser Abbildung befindet sich oben links (erster Quadrant) der obere rechte Quadrant des Individuums (Zähne 11 bis 18). Über den Säulen befindet sich die Anzahl der jeweiligen Zähne bzw. Kieferregionen. Leere Alveolen postmortal verlorener Zähne wurden in dieses Diagramm mit aufgenommen.

Die Diagramme 120 bis 127 zeigen die Veränderungen an den acht Zahngruppen der bleibenden Zähne aller vier Quadranten im Gebiss der Individuen der Population aus Großenrode in bereits für die Population aus Calden beschriebener Art und Weise. 70 Zähne wurden intravital verloren.

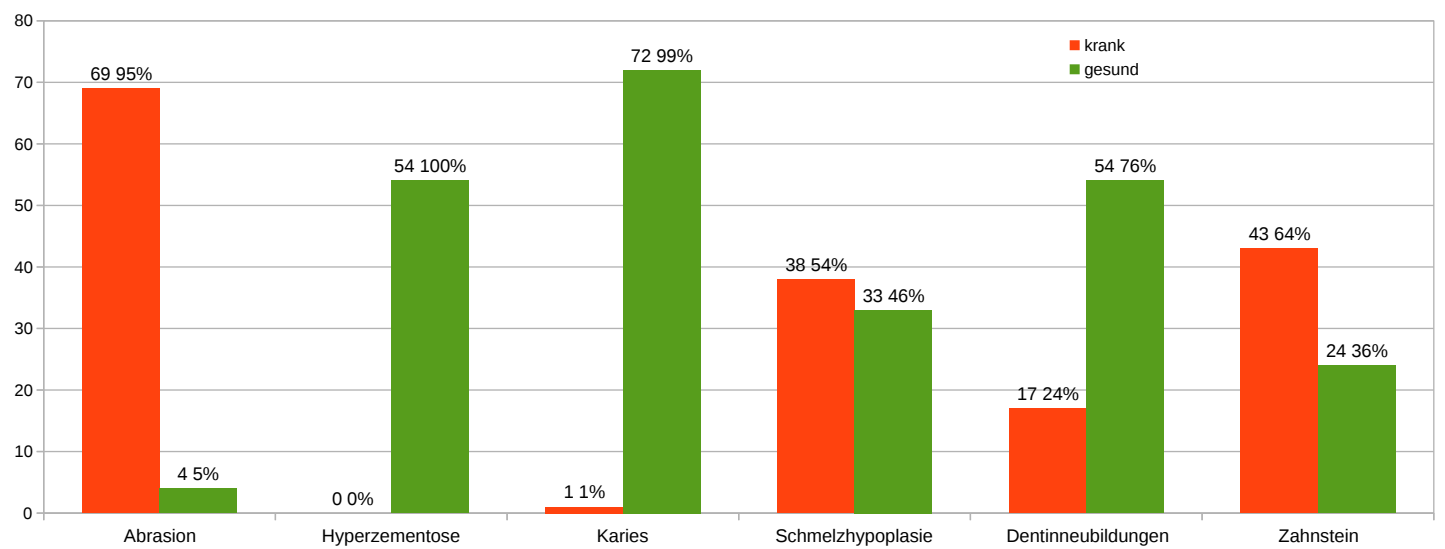

Abb. 120 Veränderungen an allen bleibenden ersten Incisivi; Großenrode

Alle ersten, bleibenden Incisivi der vier Quadranten, $n=106$, tatsächliche Zahnzahl: 74, auf der Ordinate befindet sich die Angabe der Gesamtzahl, über den Säulen links die absoluten Anzahlen, rechts daneben die Prozentzahlen. " $n$ " umfasst alle Zähne und leere Alveolen, die "tatsächliche Zahnzahl" gibt nur die Zahl der Zähne an, ohne leere Alveolen. 


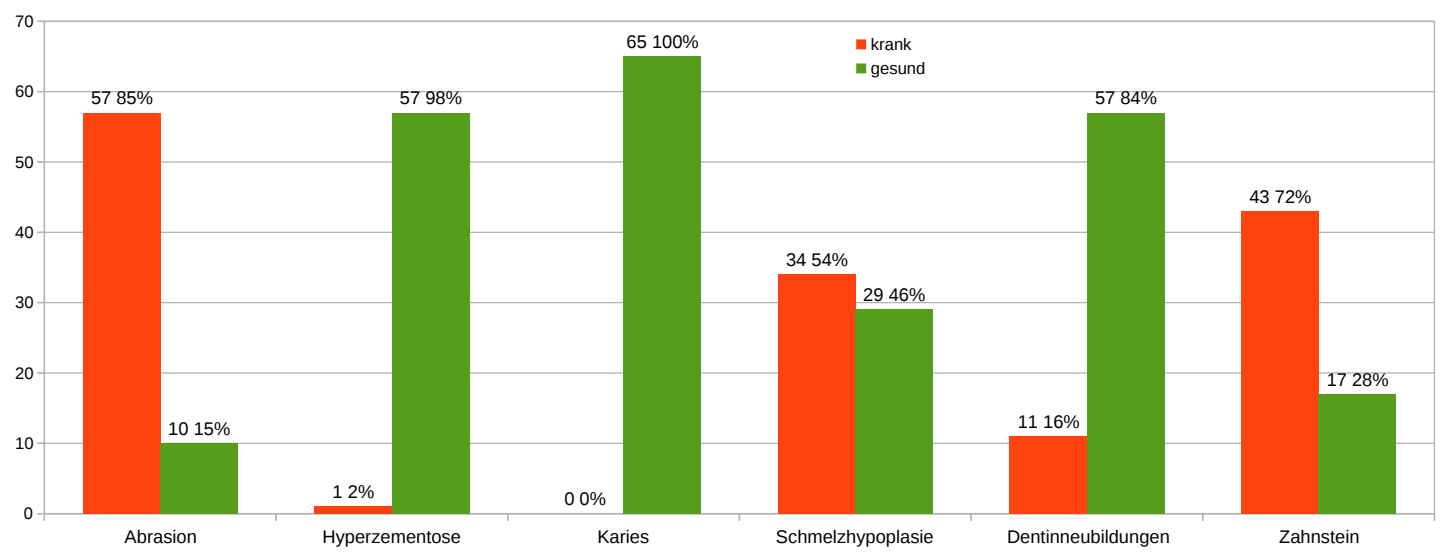

Abb. 121 Veränderungen an allen bleibenden zweiten Incisivi; Großenrode

Alle zweiten, bleibenden Incisivi der vier Quadranten, $n=98$, tatsächliche Zahnzahl: 72, auf der Ordinate befindet sich die Angabe der Gesamtzahl, über den Säulen links die absoluten Anzahlen, rechts daneben die Prozentzahlen. "n" umfasst alle Zähne und leere Alveolen, die "tatsächliche Zahnzahl" gibt nur die Zahl der Zähne an, ohne leere Alveolen.

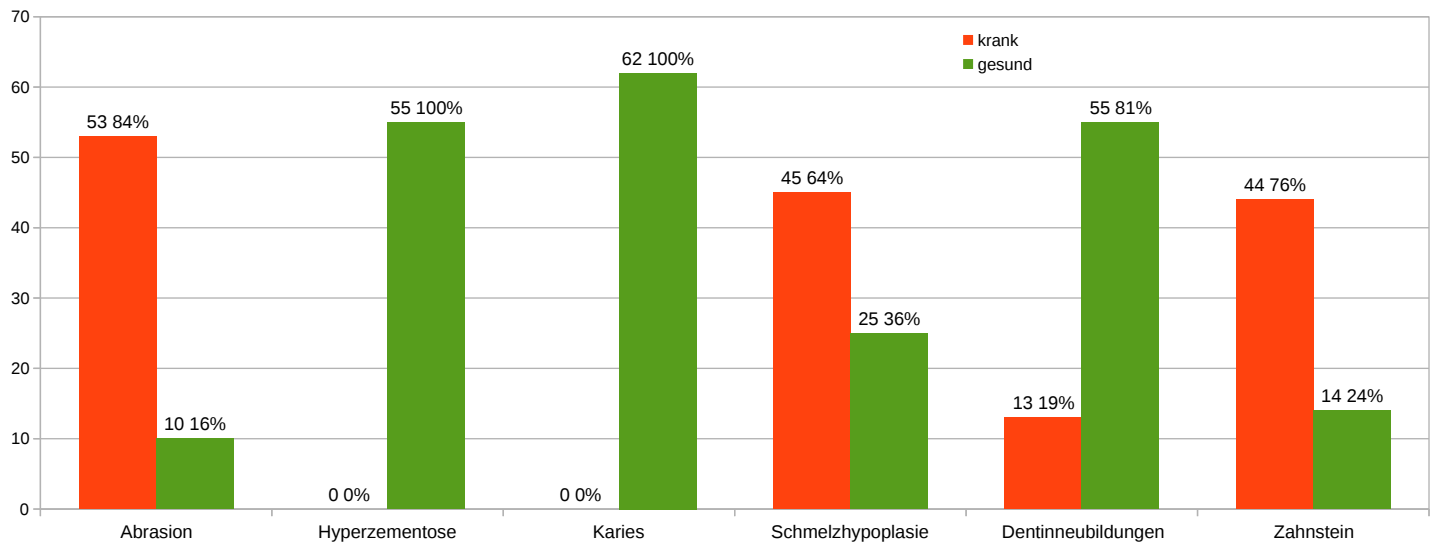

Abb. 122 Veränderungen an allen bleibenden Canini; Großenrode

Alle bleibenden Canini der vier Quadranten, $n=100$, tatsächliche Zahnzahl: 79, auf der Ordinate befindet sich die Angabe der Gesamtzahl, über den Säulen links die absoluten Anzahlen, rechts daneben die Prozentzahlen. "n“ umfasst alle Zähne und leere Alveolen, die "tatsächliche Zahnzahl" gibt nur die Zahl der Zähne an, ohne leere Alveolen. 


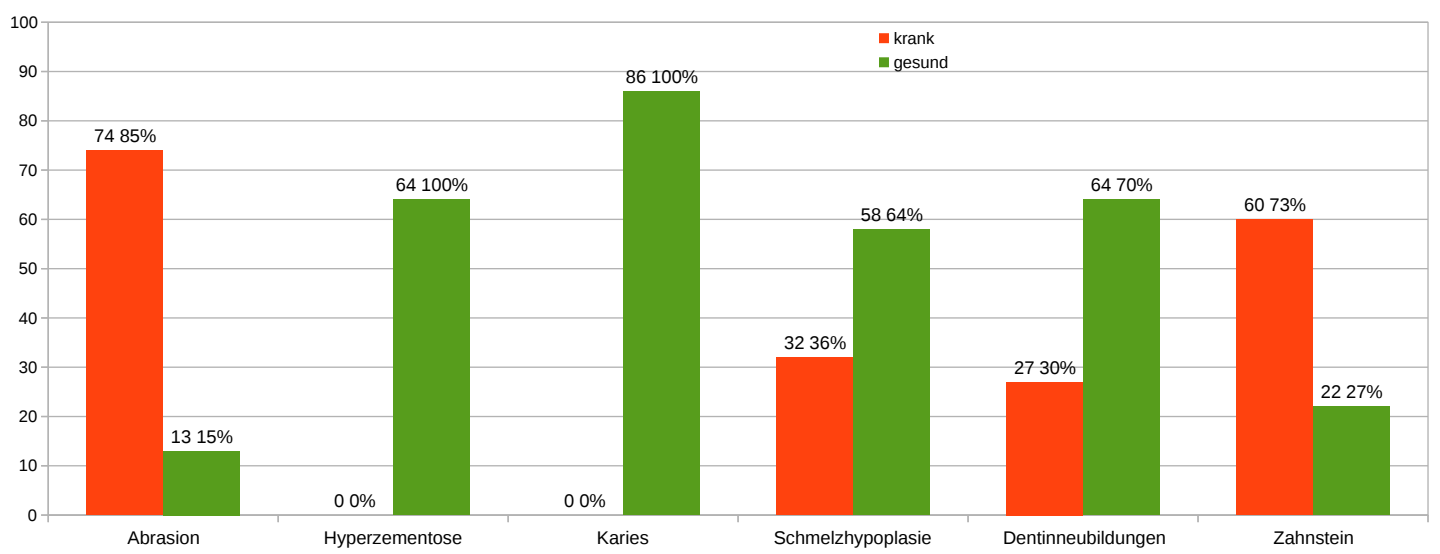

Abb. 123 Veränderungen an allen ersten Prämolaren; Großenrode

Alle ersten Prämolaren der vier Quadranten, $n=125$, tatsächliche Zahnzahl: 105, auf der Ordinate befindet sich die Angabe der Gesamtzahl, über den Säulen links die absoluten Anzahlen, rechts daneben die Prozentzahlen. "n" umfasst alle Zähne und leere Alveolen, die "tatsächliche Zahnzahl" gibt nur die Zahl der Zähne an, ohne leere Alveolen.

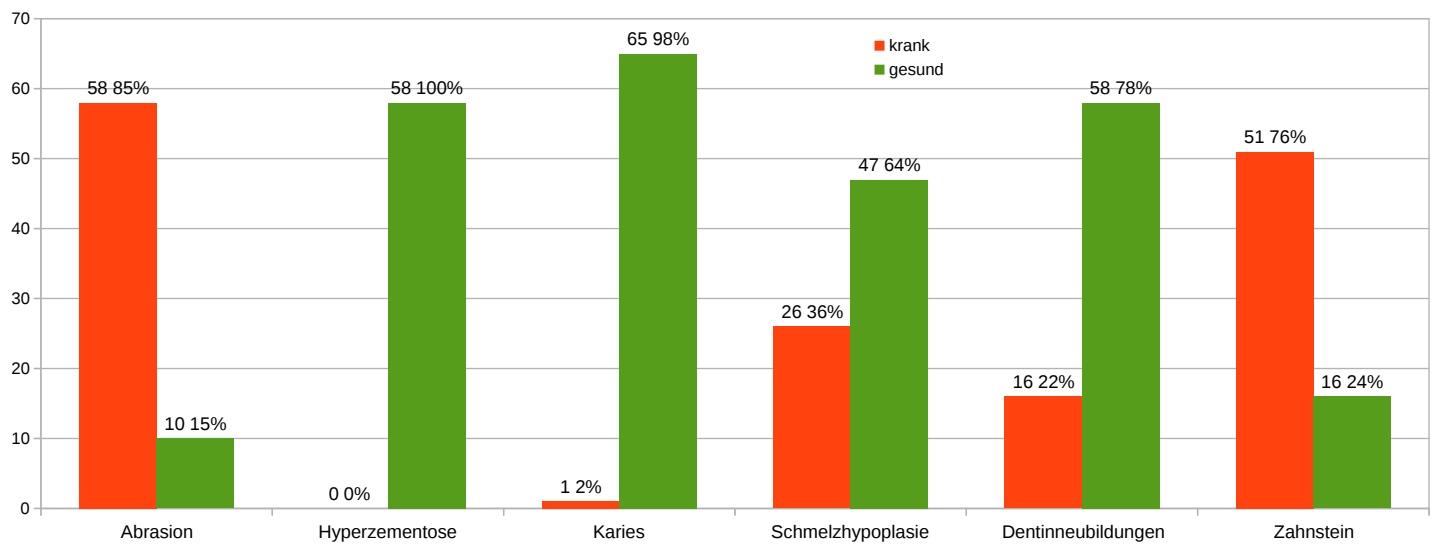

Abb. 124 Veränderungen an allen zweiten Prämolaren; Großenrode

Alle zweiten Prämolaren der vier Quadranten, $n=109$, tatsächliche Zahnzahl: 85, auf der Ordinate befindet sich die Angabe der Gesamtzahl, über den Säulen links die absoluten Anzahlen, rechts daneben die Prozentzahlen. " $n$ " umfasst alle Zähne und leere Alveolen, die "tatsächliche Zahnzahl" gibt nur die Zahl der Zähne an, ohne leere Alveolen. 


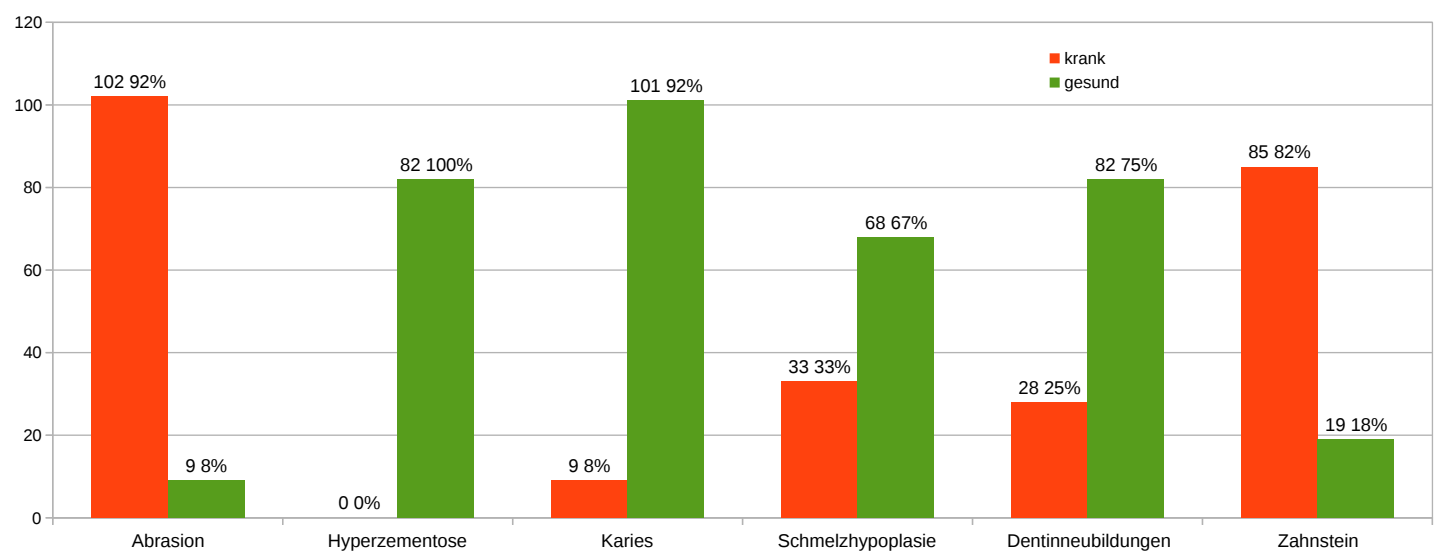

Abb.125 Veränderungen an allen bleibenden ersten Molaren; Großenrode

Alle ersten, bleibenden Molaren der vier Quadranten, $n=141$, tatsächliche Zahnzahl: 117, auf der Ordinate befindet sich die Angabe der Gesamtzahl, über den Säulen links die absoluten Anzahlen, rechts daneben die Prozentzahlen. " $n$ " umfasst alle Zähne und leere Alveolen, die "tatsächliche Zahnzahl" gibt nur die Zahl der Zähne an, ohne leere Alveolen.

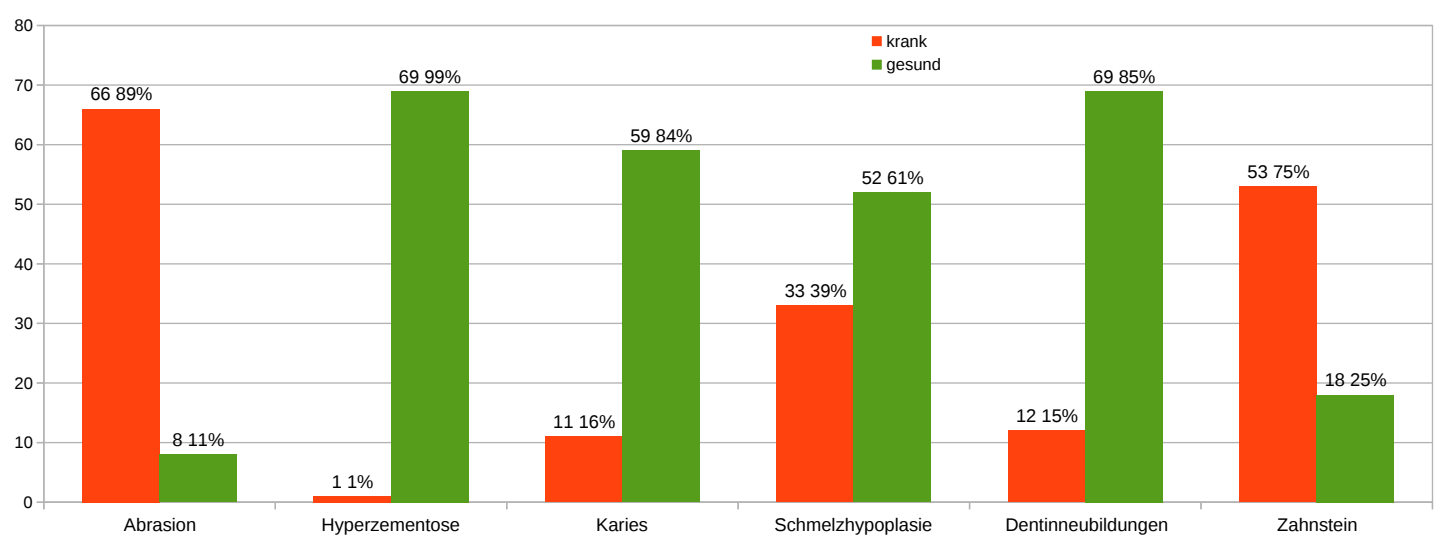

Abb.126 Veränderungen an allen bleibenden zweiten Molaren; Großenrode

Alle zweiten, bleibenden Molaren der vier Quadranten, $n=102$, tatsächliche Zahnzahl: 88, auf der Ordinate befindet sich die Angabe der Gesamtzahl, über den Säulen links die absoluten Anzahlen, rechts daneben die Prozentzahlen. " $n$ " umfasst alle Zähne und leere Alveolen, die "tatsächliche Zahnzahl" gibt nur die Zahl der Zähne an, ohne leere Alveolen. 


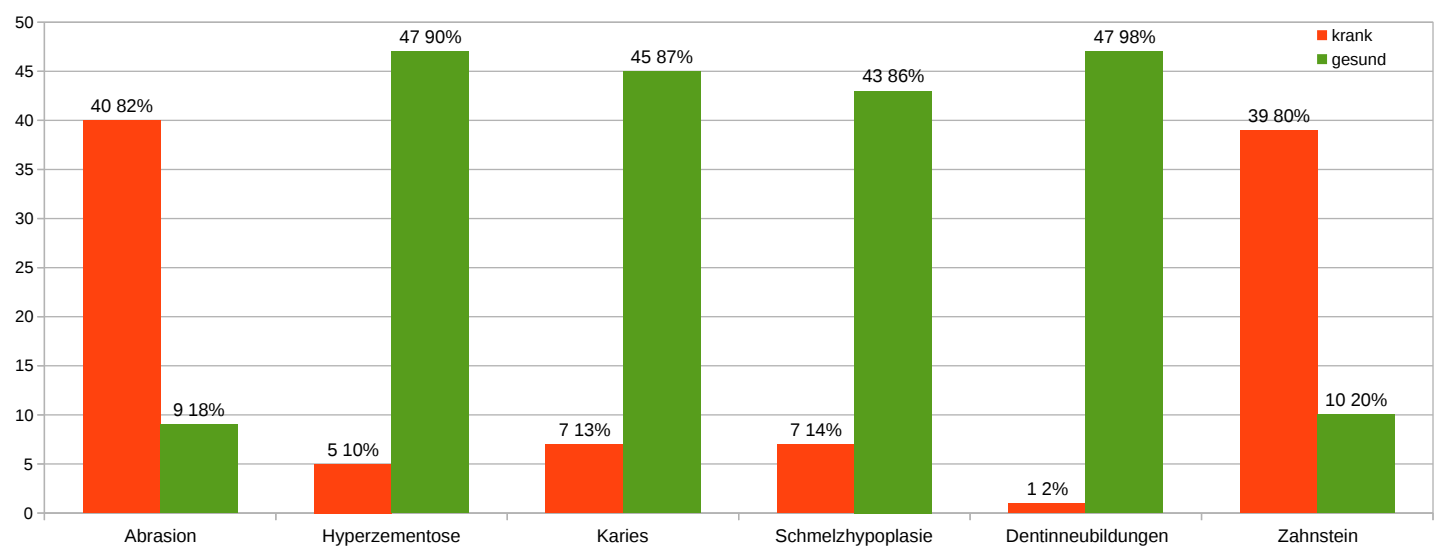

Abb.127 Veränderungen an allen dritten Molaren; Großenrode

Alle dritten Molaren der vier Quadranten, $n=76$, tatsächliche Zahnzahl: 58, auf der Ordinate befindet sich die Angabe der Gesamtzahl, über den Säulen links die absoluten Anzahlen, rechts daneben die Prozentzahlen. "n" umfasst alle Zähne und leere Alveolen, die "tatsächliche Zahnzahl" gibt nur die Zahl der Zähne an, ohne leere Alveolen.

Die Diagramme 128 bis 131 zeigen die Veränderungen an den Zähnen jeweils eines Quadranten in bekannter Form.

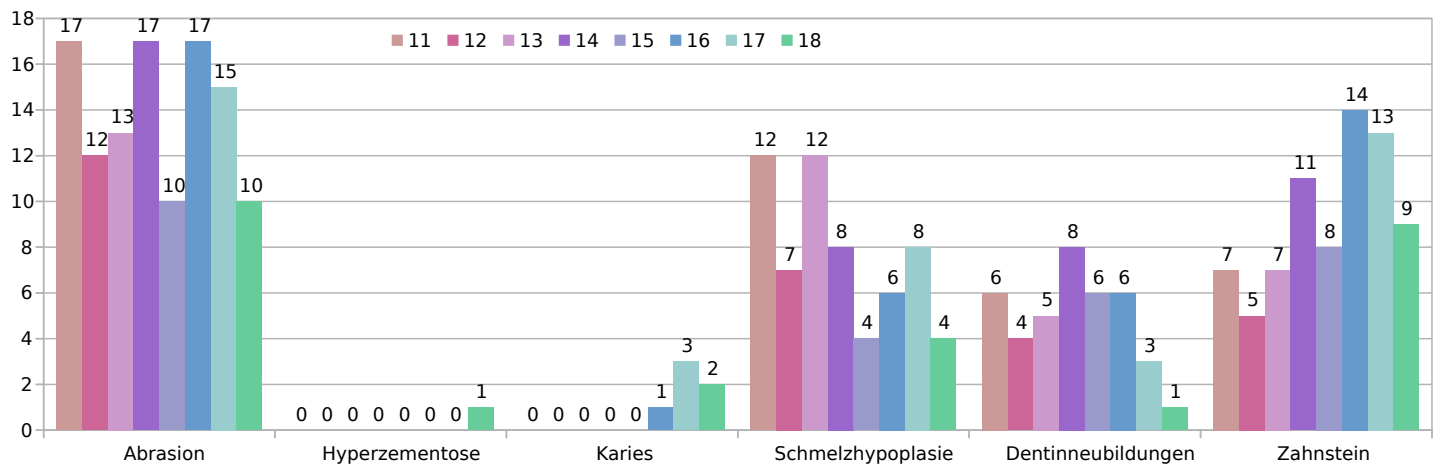

Abb. 128 Veränderungen an allen Zahntypen des 1. Quadranten; Großenrode

Auf der Ordinate findet sich die Angabe der Gesamtzahl, auf der Abszisse die Veränderungen der Zähne, über den Säulen sind die absoluten Anzahlen angegeben. Die verschiedenen Farben der Säulen entsprechen den Zähnen des ersten Quadranten (Zähne 11-18). 


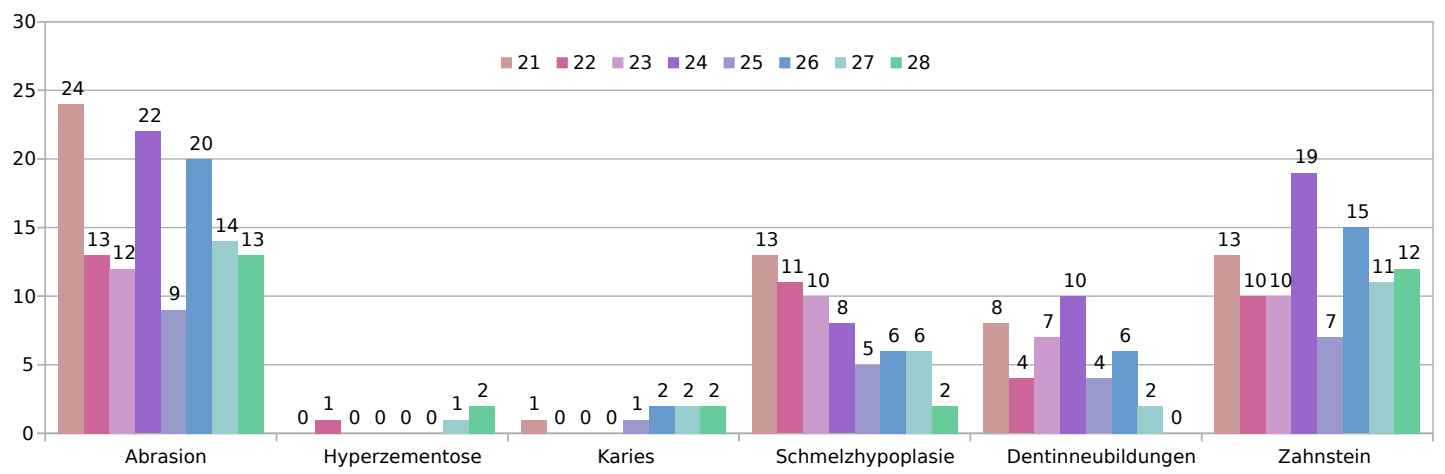

Abb.129 Veränderungen an allen Zahntypen des 2. Quadranten; Großenrode

Auf der Ordinate findet sich die Angabe der Gesamtzahl, auf der Abszisse die Veränderungen der Zähne, über den Säulen sind die absoluten Anzahlen angegeben. Die verschiedenen Farben der Säulen entsprechen den Zähnen des zweiten Quadranten (Zähne 21-28).

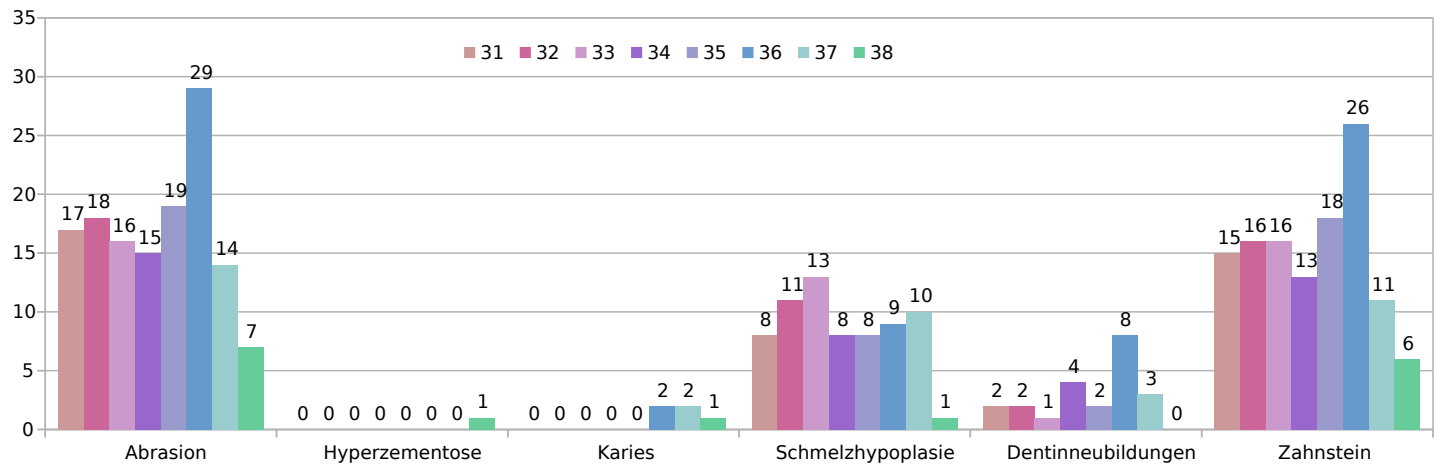

Abb. $130 \quad$ Veränderungen an allen Zahntypen des 3. Quadranten; Großenrode

Auf der Ordinate findet sich die Angabe der Gesamtzahl, auf der Abszisse die Veränderungen der Zähne, über den Säulen sind die absoluten Anzahlen angegeben. Die verschiedenen Farben der Säulen entsprechen den Zähnen des dritten Quadranten (Zähne 31-38).

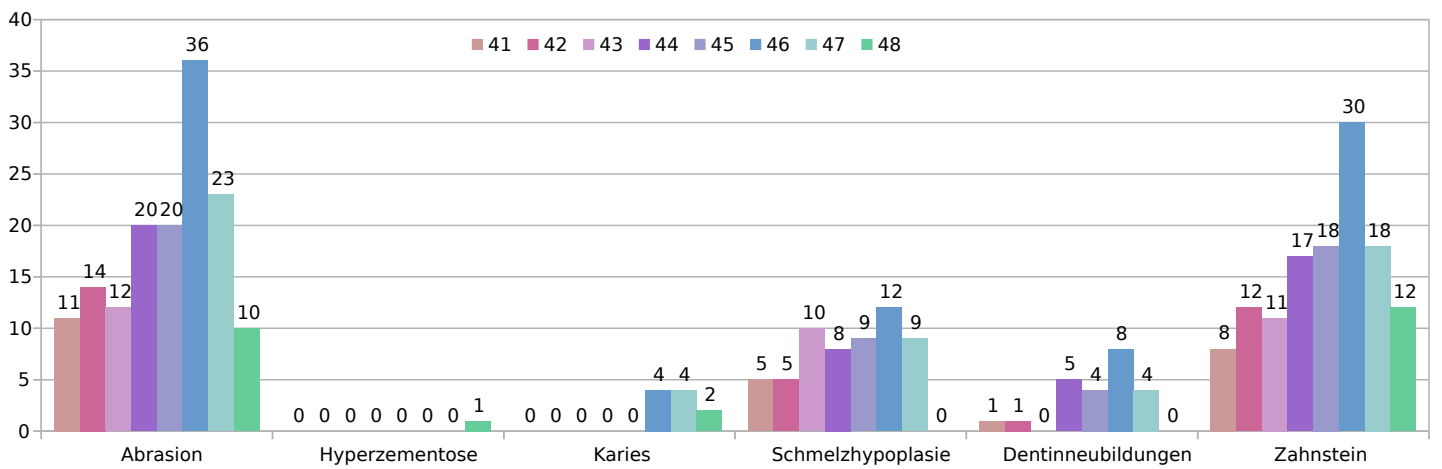

Abb.131 Veränderungen an allen Zahntypen des 4. Quadranten; Großenrode

Auf der Ordinate findet sich die Angabe der Gesamtzahl, auf der Abszisse die Veränderungen der Zähne, über den Säulen sind die absoluten Anzahlen angegeben. Die verschiedenen Farben der Säulen entsprechen den Zähnen des vierten Quadranten (Zähne 41-48). 
Darstellung der 6-Jahres-Molaren der vier Quadranten (Abb. 132).

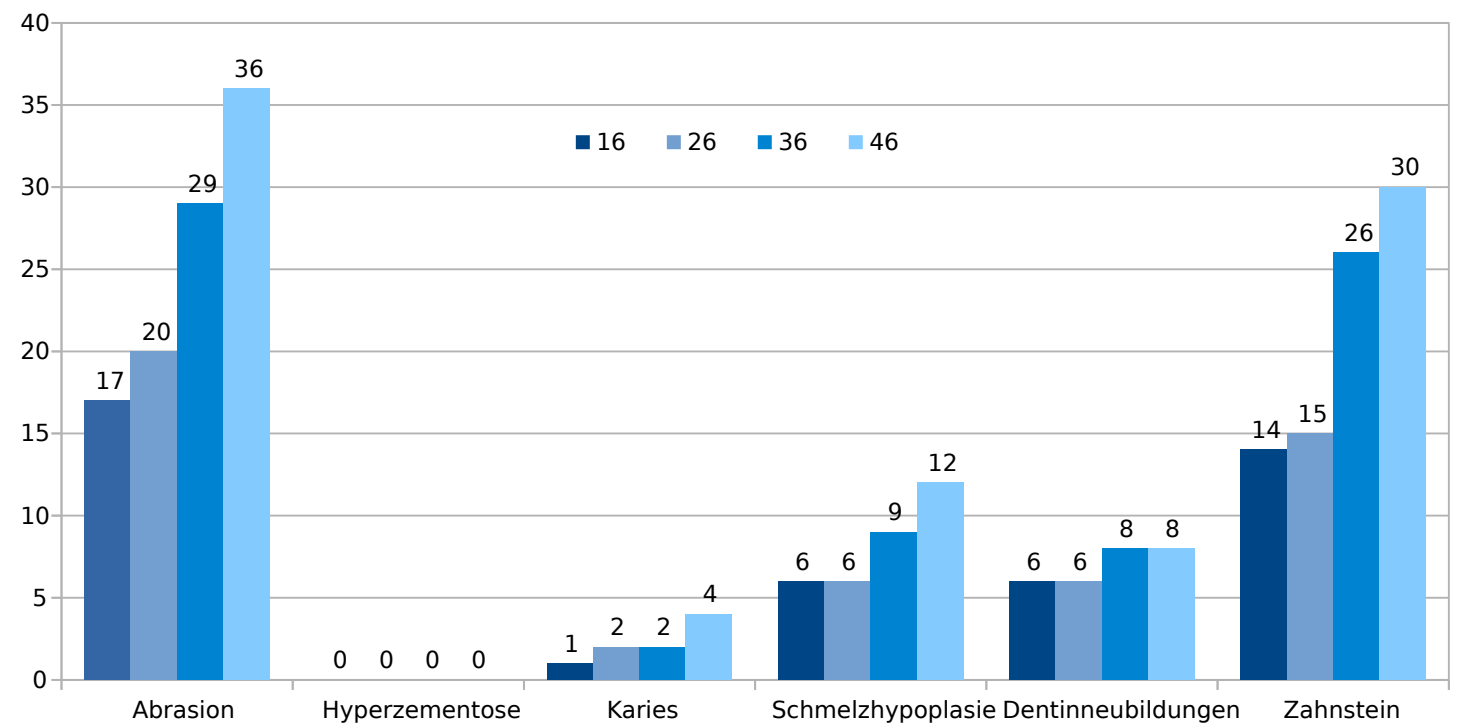

Abb. 132 Die vier Sechs-Jahres-Molaren aller Quadranten im Vergleich; Großenrode Auf der Ordinate findet sich die Angabe der Gesamtzahl, auf der Abszisse die Veränderungen der Zähne, über den Säulen sind die absoluten Anzahlen angegeben. Die verschiedenen Farben der Säulen entsprechen den Zähnen 16, 26, 36 und 46.

\subsubsection{Milchzähne}

In der Population aus Großenrode haben sich 42 Milchzähne erhalten (Abb. 133).

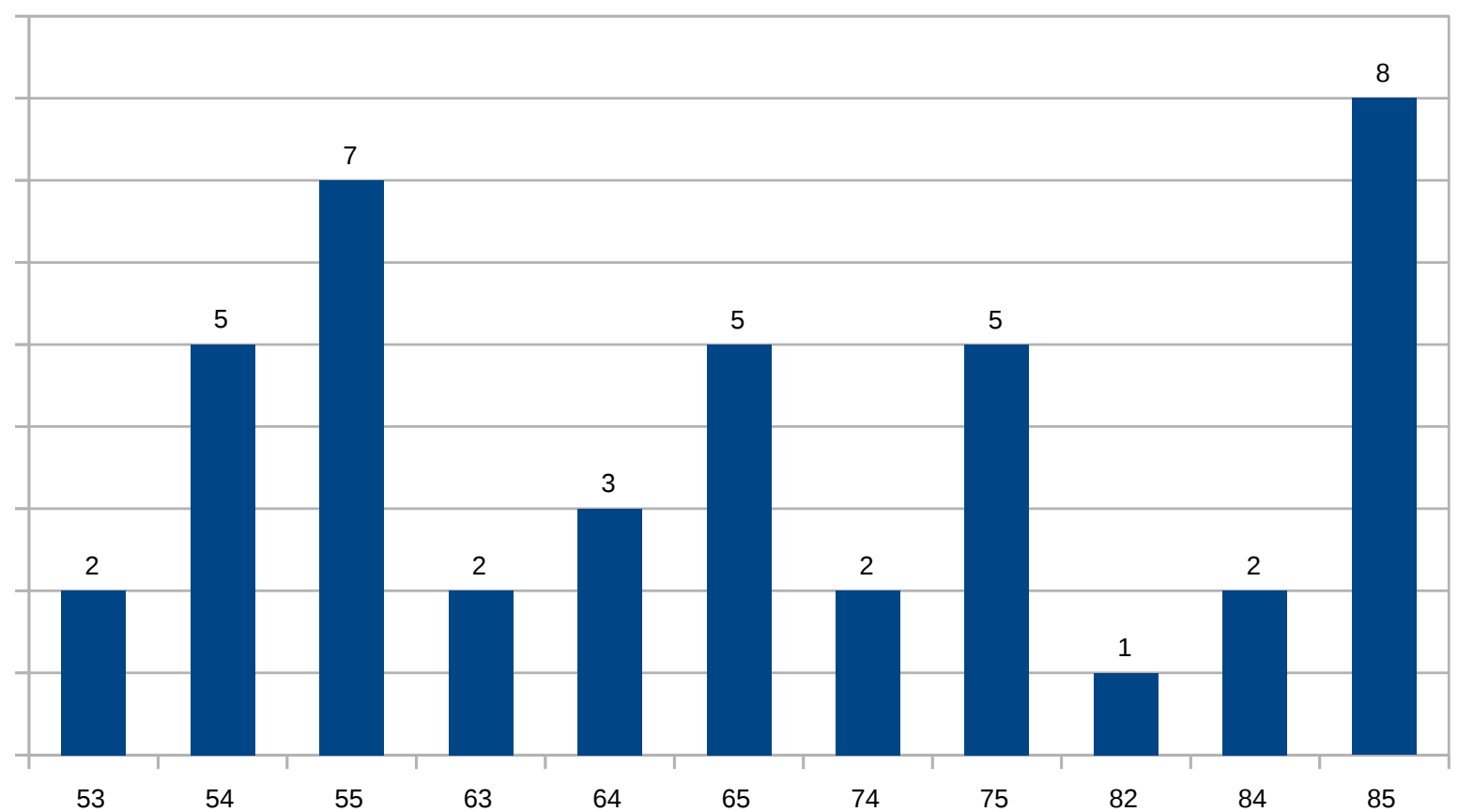

Abb. 133 Erhaltene Zähne und leere Alveolen des Milchgebisses; Großenrode Auf der Abszisse sind die Milchzähne aufgeführt, über den Säulen finden sich die absoluten Anzahlen. 
Die Diagramme 134 bis 137 zeigen die Veränderungen an den erhaltenen Zahngruppen der Milchzähne in bekannter Art und Weise.

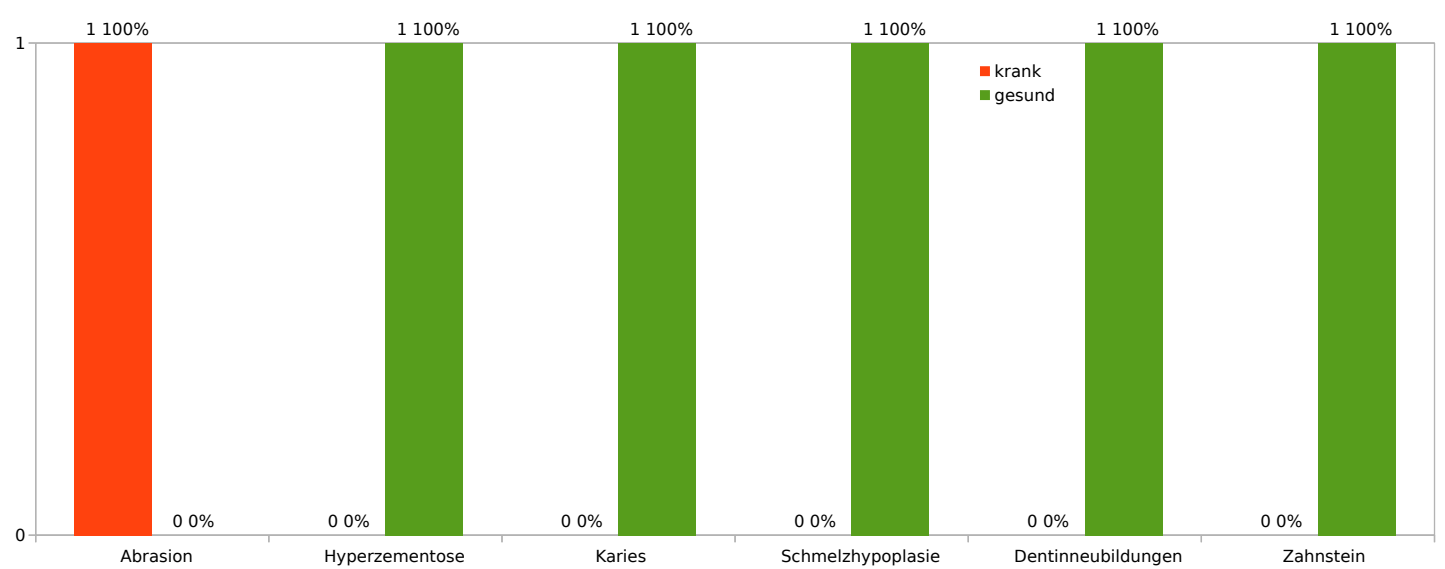

Abb. $134 \quad$ Veränderungen an allen zweiten Milchincisivi; Großenrode

Alle zweiten Milchincisivi der vier Quadranten, $n=1$, tatsächliche Zahnzahl: 1, auf der Ordinate befindet sich die Angabe der Gesamtzahl, über den Säulen links die absoluten Anzahlen, rechts daneben die Prozentzahlen. "n" umfasst alle Zähne und leere Alveolen, die "tatsächliche Zahnzahl" gibt nur die Zahl der Zähne an, ohne leere Alveolen.

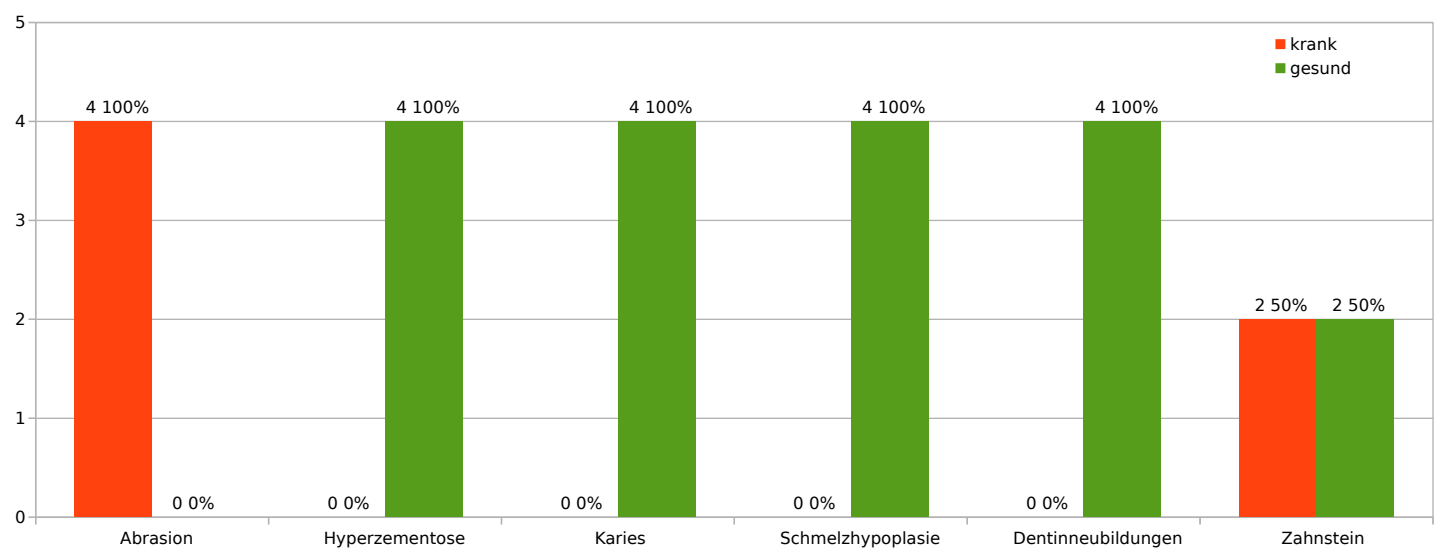

Abb. 135 Veränderungen an allen Milchcanini; Großenrode

Alle Milchcanini der vier Quadranten, $n=4$, tatsächliche Zahnzahl: 4, auf der Ordinate befindet sich die Angabe der Gesamtzahl, über den Säulen links die absoluten Anzahlen, rechts daneben die Prozentzahlen. "n" umfasst alle Zähne und leere Alveolen, die "tatsächliche Zahnzahl" gibt nur die Zahl der Zähne an, ohne leere Alveolen. 


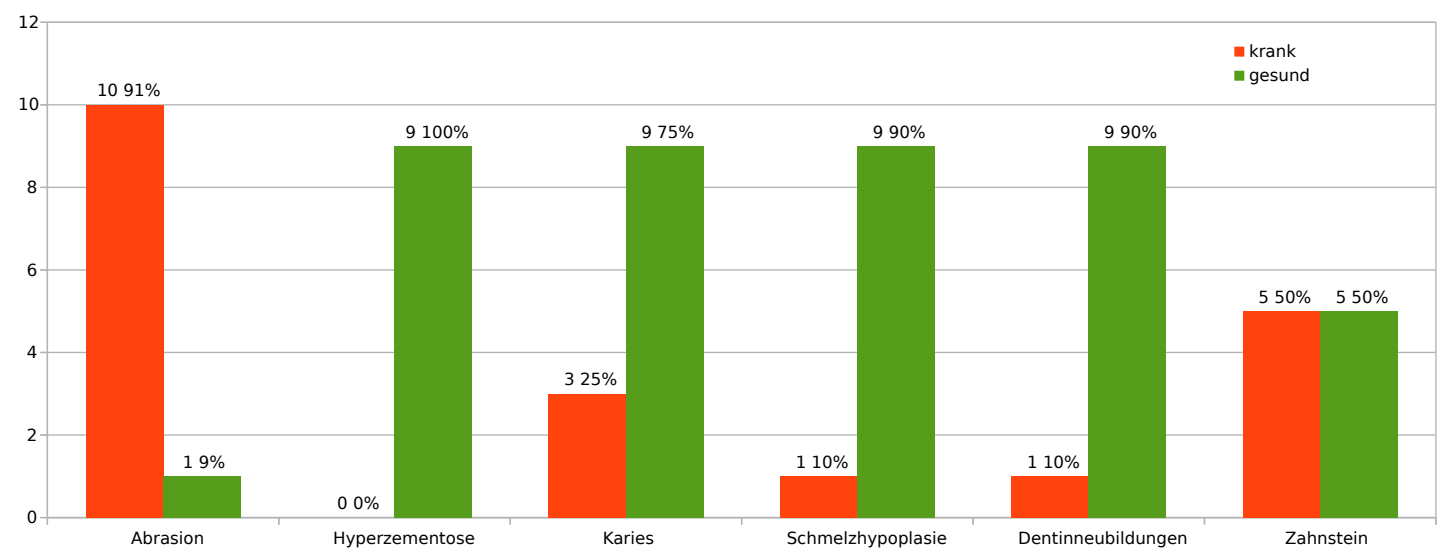

Abb.136 Veränderungen an allen ersten Milchmolaren; Großenrode

Alle ersten Milchmolaren der vier Quadranten, $n=12$, tatsächliche Zahnzahl: 10, auf der Ordinate befindet sich die Angabe der Gesamtzahl, über den Säulen links die absoluten Anzahlen, rechts daneben die Prozentzahlen. "n" umfasst alle Zähne und leere Alveolen, die "tatsächliche Zahnzahl" gibt nur die Zahl der Zähne an, ohne leere Alveolen.

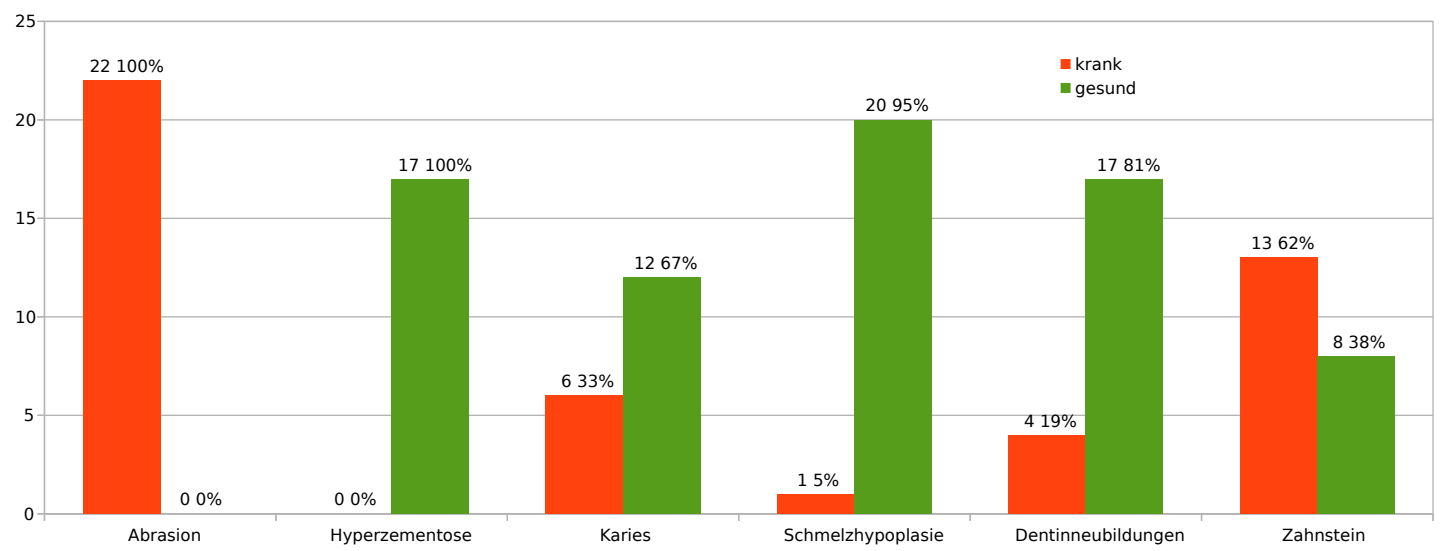

Abb.137 Veränderungen an allen zweiten Milchmolaren; Großenrode

Alle zweiten Milchmolaren der vier Quadranten, $n=25$, tatsächliche Zahnzahl: 23, auf der Ordinate befindet sich die Angabe der Gesamtzahl, über den Säulen links die absoluten Anzahlen, rechts daneben die Prozentzahlen. "n" umfasst alle Zähne und leere Alveolen, die "tatsächliche Zahnzahl" gibt nur die Zahl der Zähne an, ohne leere Alveolen. 


\subsubsection{Apicale Prozesse und Parodontalveränderungen an Milch- und}

Dauergebissen

Die Diagramme 138 und 139 zeigen die Anzahl und die Graduierung der apicalen Prozesse in bekannter Form.

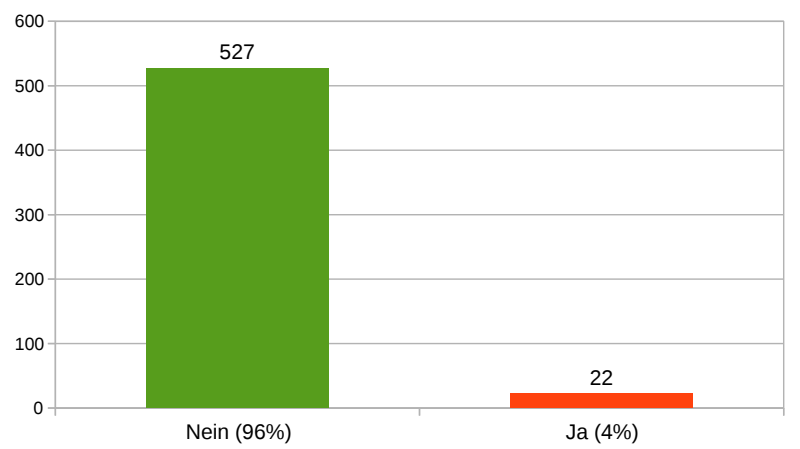

Abb. 138 Diagramm zur Häufigkeit apicaler Prozesse; Großenrode

"Nein" heißt, dass keine apicalen Prozesse vorlagen, "Ja" bedeutet, dass eine Zahnregion apicale Prozesse aufwies. Es lagen 549 befundbare Zahnregionen vor. Auf der Ordinate befindet sich die Gesamtzahl, über den Säulen sind die absoluten Zahlen der Häufigkeiten aufgeführt, unter den Säulen sind die prozentualen Zahlen in Klammern angegeben.

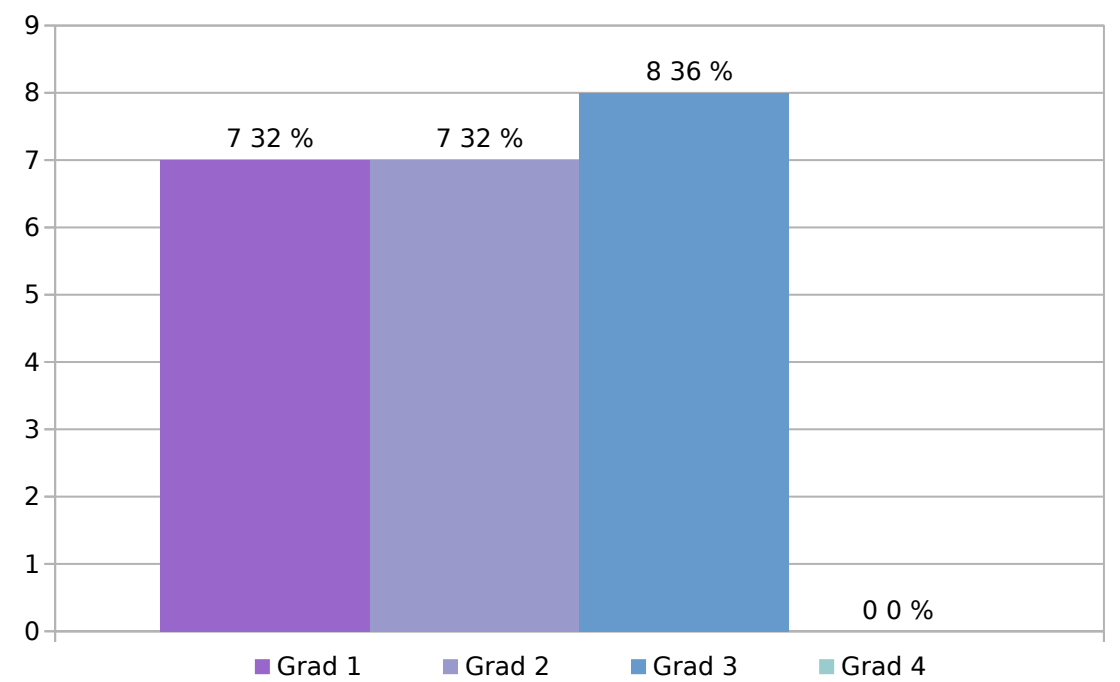

Abb. 139 Graduierung apicaler Prozesse (,Ja“-Anteil aus Diagramm 138); Großenrode

In dieser Darstellung findet sich die Aufteilung in verschiedene Graduierungen von 1 bis 4 (Abszisse), wobei Grad 1 einer schwachen Ausprägung entspricht und Grad 4 einer starken. Auf der Ordinate befindet sich die Gesamtzahl, über den Säulen sind links die absoluten, rechts die prozentualen Anzahlen angegeben. 
Die Diagramme 140 bis 142 zeigen Darstellungen der Parodontopathien mit Graduierung und krankhafter Veränderung in bekannter Form.

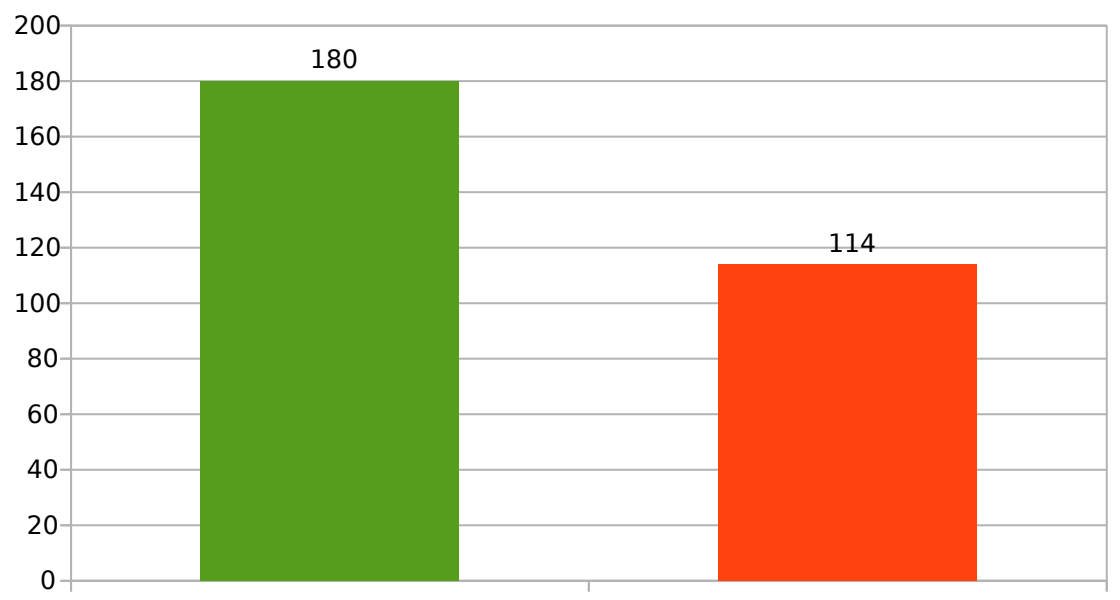

Nein $(61 \%)$

Ja (39\%)

Abb. 140 Diagramm zur Häufigkeit von Parodontopathien; Großenrode

"Nein" heißt, dass keine Parodontopathien vorlagen, "Ja" bedeutet, dass eine Zahnregion Parodontopathien aufwies. Es lagen 294 befundbare Zahnregionen vor. Auf der Ordinate befindet sich die Gesamtzahl, über den Säulen sind die absoluten Zahlen der Häufigkeiten aufgeführt, unter den Säulen sind die prozentualen Zahlen in Klammern angegeben.

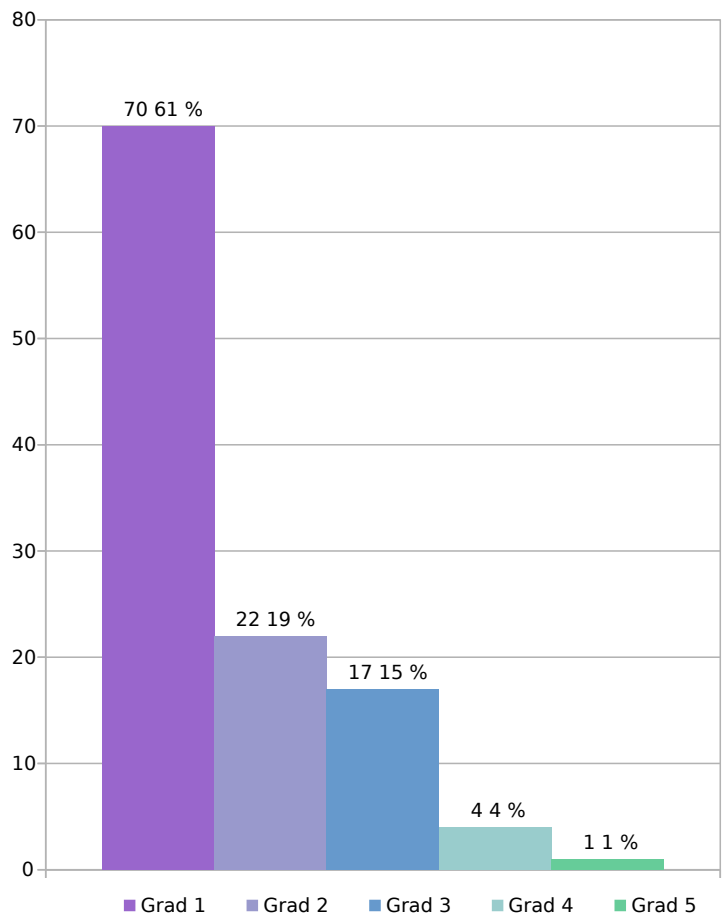

$A b b .141$

Graduierung der Parodontopathien („JJ"-Anteil aus Diagramm 140); Großenrode

In dieser Darstellung findet sich die Aufteilung in verschiedene Graduierungen von 1 bis 5 (Abszisse), wobei Grad 1 einer schwachen Ausprägung entspricht und Grad 5 der stärksten. Auf der Ordinate befindet sich die Angabe der Gesamtzahl, über den Säulen sind links die absoluten, rechts die prozentualen Anzahlen angegeben. 


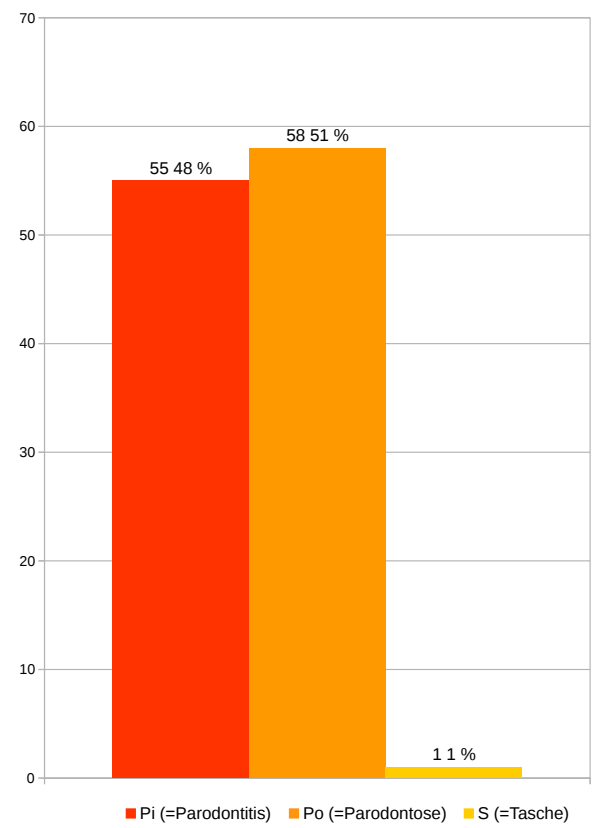

Abb. 142

Darstellung der verschiedenen Parodontopathien; Großenrode

Dieses Diagramm nimmt Bezug auf den "Ja“-Anteil aus Diagramm 140. Auf der Ordinate befindet sich die Angabe der Gesamtzahl, über den Säulen sind links die absoluten, rechts die prozentualen Anzahlen angegeben.

\subsubsection{Postcranien}

Für die Population aus Großenrode wurden 1237 Datensätze angelegt, in denen die postcranialen Fundstücke dokumentiert wurden.

Die nachfolgende Tabelle (Tab. 8) gibt einen Überblick über die absolute Anzahl der Fundstücke, die alle entweder als "gesund“, ,krank", „,befundbar" und „,nicht befundbar" bezeichnet wurden. Weiterhin finden sich die absoluten Gesamtzahlen der Befundkategorien. 
Tab. 8

\section{Postcraniale Fundstücke; Großenrode}

Darstellung der postccranialen Fundstücke nach Einteilung in gesund, krank, befundbar und nicht befundbar (gesund + krank = befundbar; befundbar + nicht befundbar= gesamt). "Knochen der oberen Extremität" umfasst jene Knochen, die - wenn auch in fragmentiertem Zustand - sicher der oberen Extremität zuzuordnen waren. Es handelte sich dabei um Fragmente und Splitter. "Ossa manus" bezieht sich auf jene Fundstücke, die der Hand zugeordnet werden konnten, jedoch nicht einem bestimmten Knochen. Die Bezeichnung "Manus / Pes" bedeutet, dass das betreffende Fundstück entweder von der Hand oder von dem Fuß stammt, aber nicht genauer bestimmt werden konnte. Ähnlich ist die Bezeichnung "Phalanx manus / pedis" zu verstehen; das Fundstück wurde als Phalanx identifiziert, konnte aber nicht einer Phalanx der Hand oder des Fußes zugeordnet werden.

\begin{tabular}{|c|c|c|c|c|c|}
\hline & gesund & krank & befundbar & nicht befundbar & gesamt \\
\hline Vertebra & 156 & 35 & 191 & 10 & 201 \\
\hline Clavicula & 13 & 2 & 15 & 7 & 22 \\
\hline Costa & 5 & 2 & 7 & 5 & 12 \\
\hline Sternum & 1 & 0 & 1 & 1 & 2 \\
\hline Scapula & 28 & 1 & 29 & 21 & 50 \\
\hline Humerus & 34 & 1 & 35 & 54 & 89 \\
\hline Ulna & 22 & 1 & 23 & 33 & 56 \\
\hline Radius & 17 & 0 & 17 & 31 & 48 \\
\hline Os metacarpale & 2 & 0 & 2 & 4 & 6 \\
\hline Phalanx manus & 0 & 0 & 0 & 4 & 4 \\
\hline Ossa manus & 2 & 0 & 2 & 26 & 28 \\
\hline Knochen der oberen Extremität & 0 & 0 & 0 & 1 & 1 \\
\hline Os sacrum & 9 & 1 & 10 & 7 & 17 \\
\hline Os coxae & 20 & 1 & 21 & 18 & 39 \\
\hline Os femoris & 43 & 9 & 52 & 36 & 88 \\
\hline Patella & 14 & 0 & 14 & 8 & 22 \\
\hline Tibia & 47 & 11 & 58 & 31 & 89 \\
\hline Fibula & 11 & 9 & 20 & 14 & 34 \\
\hline Talus & 29 & 0 & 29 & 14 & 43 \\
\hline Calcaneus & 23 & 2 & 25 & 12 & 37 \\
\hline Os naviculare & 1 & 0 & 1 & 0 & 1 \\
\hline Os cuboideum & 2 & 0 & 2 & 0 & 2 \\
\hline Os metatarsale & 4 & 1 & 5 & 13 & 18 \\
\hline Phalanx pedis & 3 & 3 & 6 & 4 & 10 \\
\hline Pes & 1 & 0 & 1 & 37 & 38 \\
\hline Manus / Pes & 1 & 0 & 1 & 3 & 4 \\
\hline Knochenklein & 34 & 0 & 34 & 236 & 270 \\
\hline Phalanx manus / pedis & 1 & 1 & 2 & 4 & 6 \\
\hline gesamt & 523 & 80 & 603 & 634 & 1237 \\
\hline
\end{tabular}

Tabelle 9 zeigt im Folgenden die langen Extremitätenknochen nach Knochenabschnitt, Seite und befundeter Arthrose bzw. Arthritis. 
Tab.9 Arthrose/Arthritis langer Extremitätenknochen; Großenrode

Darstellung der absoluten Anzahlen der langen Extremitätenknochen und jeweils befundeter Arthrose oder Arthritis. Die Knochen sind dabei in Fünftel aufgeteilt, um die jeweiligen Fünftel vergleichen zu können. Arthrose und Arthritis sind nur an Gelenken zu finden, weswegen sie nur für die proximalen und distalen Fünftel der Knochen angegeben sind. "re" bedeutet rechter Knochen, "li“ linker Knochen, "ind" bedeutet, dass die Seite nicht bestimmbar war. "Vollständig" bedeutet, dass ein Knochen in ganzer Länge vollständig vorhanden war. "ges." steht für Gesamtanzahl, "Arthro/Arthri" für Arthrose und/oder Arthritis.

\begin{tabular}{|c|c|c|c|c|c|c|c|c|}
\hline Ulna & re. & li. & ind. & ges. & $\begin{array}{l}\text { Arthro/Arthri } \\
\text { re. }\end{array}$ & $\begin{array}{l}\text { Arthro/Arthri } \\
\text { li. }\end{array}$ & $\begin{array}{l}\text { Arthro/Arthri } \\
\text { ind. }\end{array}$ & $\begin{array}{l}\text { Arthro/Arthri } \\
\text { ges. }\end{array}$ \\
\hline $1 . / 5$ & 19 & 8 & 0 & 27 & 0 & 0 & 0 & $0(0 \%)$ \\
\hline $2 . / 5$ & 26 & 12 & 0 & 38 & & & & \\
\hline $3 . / 5$ & 21 & 12 & 0 & 33 & & & & \\
\hline $4 . / 5$ & 14 & 4 & 0 & 18 & & & & \\
\hline $5 . / 5$ & 7 & 1 & 0 & 8 & 1 & 0 & 0 & $1(13 \%)$ \\
\hline vollständig & 0 & 0 & 0 & 0 & & & & \\
\hline Radius & re. & li. & ind. & ges. & $\begin{array}{l}\text { Arthro/Arthri } \\
\text { re. }\end{array}$ & $\begin{array}{l}\text { Arthro/Arthri } \\
\text { li. }\end{array}$ & $\begin{array}{l}\text { Arthro/Arthri } \\
\text { ind. }\end{array}$ & $\begin{array}{l}\text { Arthro/Arthri } \\
\text { ges. }\end{array}$ \\
\hline $1 . / 5$ & 3 & 6 & 0 & 9 & 0 & 0 & 0 & $0(0 \%)$ \\
\hline $2 . / 5$ & 9 & 11 & 1 & 21 & & & & \\
\hline $3 . / 5$ & 10 & 14 & 3 & 27 & & & & \\
\hline $4 . / 5$ & 9 & 10 & 1 & 20 & & & & \\
\hline $5 . / 5$ & 3 & 4 & 1 & 8 & 0 & 0 & 0 & $0(0 \%)$ \\
\hline vollständig & 0 & 0 & 0 & 0 & & & & \\
\hline Humerus & re. & li. & ind. & ges. & $\begin{array}{l}\text { Arthro/Arthri } \\
\text { re. }\end{array}$ & $\begin{array}{l}\text { Arthro/Arthri } \\
\text { li. }\end{array}$ & $\begin{array}{l}\text { Arthro/Arthri } \\
\text { ind. }\end{array}$ & $\begin{array}{l}\text { Arthro/Arthri } \\
\text { ges. }\end{array}$ \\
\hline $1 . / 5$ & 8 & 9 & 2 & 19 & . & 0 & 0 & $0(0 \%)$ \\
\hline $2 . / 5$ & 19 & 15 & 0 & 34 & & & & \\
\hline $3 . / 5$ & 23 & 18 & 4 & 45 & & & & \\
\hline $4 . / 5$ & 17 & 16 & 2 & 35 & & & & \\
\hline $5 . / 5$ & 12 & 11 & 0 & 23 & 0 & 0 & 0 & $0(0 \%)$ \\
\hline vollständig & 0 & 0 & 0 & 0 & & & & \\
\hline Femur & re. & li. & ind. & ges. & $\begin{array}{l}\text { Arthro/Arthri } \\
\text { re. }\end{array}$ & $\begin{array}{l}\text { Arthro/Arthri } \\
\text { li. }\end{array}$ & $\begin{array}{l}\text { Arthro/Arthri } \\
\text { ind. }\end{array}$ & $\begin{array}{l}\text { Arthro/Arthri } \\
\text { ges. }\end{array}$ \\
\hline $1 . / 5$ & 10 & 10 & 8 & 28 & 0 & 0 & 1 & $1(4 \%)$ \\
\hline $2 . / 5$ & 20 & 22 & 1 & 43 & & & & \\
\hline $3 . / 5$ & 14 & 20 & 3 & 37 & & & & \\
\hline $4 . / 5$ & 11 & 15 & 0 & 26 & & & & \\
\hline $5 . / 5$ & 10 & 17 & 1 & 28 & 1 & 1 & 0 & $2(7 \%)$ \\
\hline vollständig & 0 & 0 & 0 & 0 & & & & \\
\hline Tibia & re. & li. & ind. & ges. & $\begin{array}{l}\text { Arthro/Arthri } \\
\text { re. }\end{array}$ & $\begin{array}{l}\text { Arthro/Arthri } \\
\text { li. }\end{array}$ & $\begin{array}{l}\text { Arthro/Arthri } \\
\text { ind. }\end{array}$ & $\begin{array}{l}\text { Arthro/Arthri } \\
\text { ges. }\end{array}$ \\
\hline $1 . / 5$ & 9 & 15 & 4 & 28 & 0 & 0 & 0 & $0(0 \%)$ \\
\hline $2 . / 5$ & 18 & 14 & 3 & 35 & & & & \\
\hline $3 . / 5$ & 26 & 17 & 1 & 44 & & & & \\
\hline $4 . / 5$ & 21 & 15 & 1 & 37 & & & & \\
\hline $5 . / 5$ & 10 & 13 & 0 & 23 & 0 & 0 & 0 & $0(0 \%)$ \\
\hline vollständig & 0 & 0 & 0 & 0 & & & & \\
\hline Fibula & re. & li. & ind. & ges. & $\begin{array}{l}\text { Arthro/Arthri } \\
\text { re. }\end{array}$ & $\begin{array}{l}\text { Arthro/Arthri } \\
\text { li. }\end{array}$ & $\begin{array}{l}\text { Arthro/Arthri } \\
\text { ind. }\end{array}$ & $\begin{array}{l}\text { Arthro/Arthri } \\
\text { ges. }\end{array}$ \\
\hline $1 . / 5$ & 2 & 3 & 1 & 6 & 0 & 0 & 0 & $0(0 \%)$ \\
\hline $2 . / 5$ & 3 & 7 & 2 & 12 & & & & \\
\hline $3 . / 5$ & 8 & 7 & 4 & 19 & & & & \\
\hline $4 . / 5$ & 8 & 7 & 1 & 16 & & & & \\
\hline $5 . / 5$ & 4 & 4 & 1 & 9 & 0 & 1 & 0 & $1(11 \%)$ \\
\hline vollständig & 0 & 0 & 0 & 0 & & & & \\
\hline
\end{tabular}


Geschlechtsspezifische Unterschiede in Bezug auf degenerative Veränderungen konnten bei drei Fundstücken festgestellt werden: Ein Os coxae eines weiblichen Individuums, ein Os femoris eines weiblichen Individuums und eine Fibula eines männlichen Individuums wiesen Spuren degenerativer Veränderung auf.

Es folgen nun die Ergebnisse der an den Wirbeln der Population aus Großenrode erhobenen Befunde (Abb. 143).

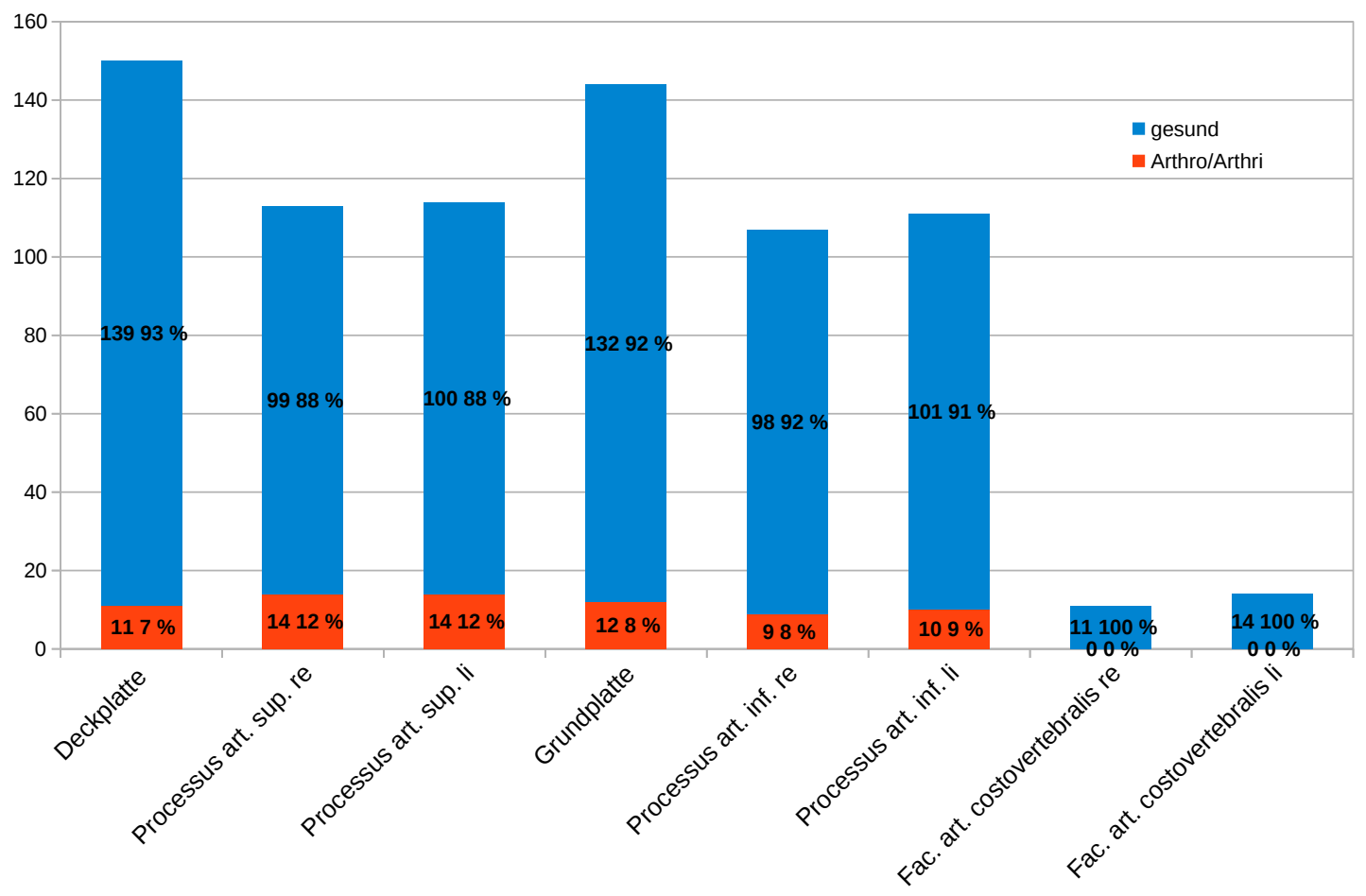

Abb. 143

Darstellung der Befunde der Wirbel; Großenrode

Auf der Abszisse sind die anatomischen Wirbelregionen angegeben. In den Säulen finden sich links die absoluten Anzahlen, rechts die Prozentzahlen in Bezug auf die Gesamtanzahl der befundeten Wirbelregionen und im Sinne von Arthrose und/oder Arthritis krankhaft veränderter Wirbelregionen. Abkürzungen: "Fac."= Facies, "sup."= superior, "inf."= inferior, "re"= rechts, "li"= links, "art."= articularis. Die Gesamtzahl der befundeten Bewegungssegmente ist auf der Ordinate angegeben. 
Zur vereinfachten Darstellung folgt nun noch ein Schema (Abb. 144), aus dem bildlich erkennbar ist, wie oft die jeweiligen Wirbelregionen vorhanden und befundbar waren und wie häufig sie Veränderungen aufwiesen.

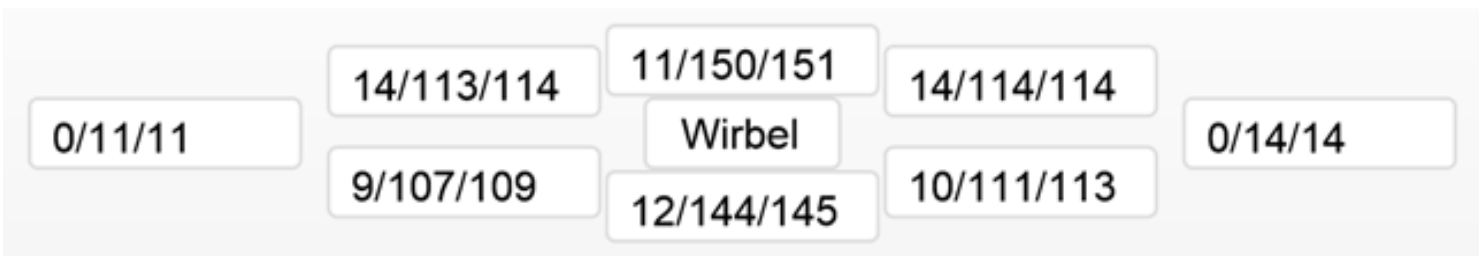

Abb. 144 Anatomisch orientierte Darstellung der Wirbelregionen; Großenrode

Mittleres oberes Feld: Deckplatte, links daneben das Feld für den Processus articularis superior der rechten Seite, rechts neben der Deckplatte das Feld für den Processus articularis superior der linken Seite. Ganz außen links: Feld für die Gelenkpfanne der Articulatio costovertebralis (Fovea costalis processus transversi) der rechten Seite, rechts ganz außen das Feld für die Gelenkpfanne der Articulatio costovertebralis (Fovea costalis processus transversi) der linken Seite. Mittleres unteres Feld: Grundplatte, daneben links das Feld für die Gelenkfläche am Processus articularis inferior der rechten Seite, neben der Grundplatte rechts das Feld für die Gelenkfläche am Processus articularis inferior der linken Seite. Im oben abgebildeten Gelenkbefundungsschema sind in jedem Zahlenkästchen drei Zahlen aufgeführt. Die erste Zahl (von links) ist die Anzahl der mit Arthrose und/oder Arthritis erkrankten Regionen, die zweite Zahl (von links) ist die Gesamtzahl der jeweils für eine bestimmte Gelenkeinheit befundbaren Flächen. Die dritte Zahl (von links) ist die Gesamtzahl der insgesamt erhaltenen Flächen (befundbar und unbefundbar).

Folgend werden die Ergebnisse der Postcranien der Population aus Großenrode in bekannter Form dargestellt (Abb. 145 und 146).

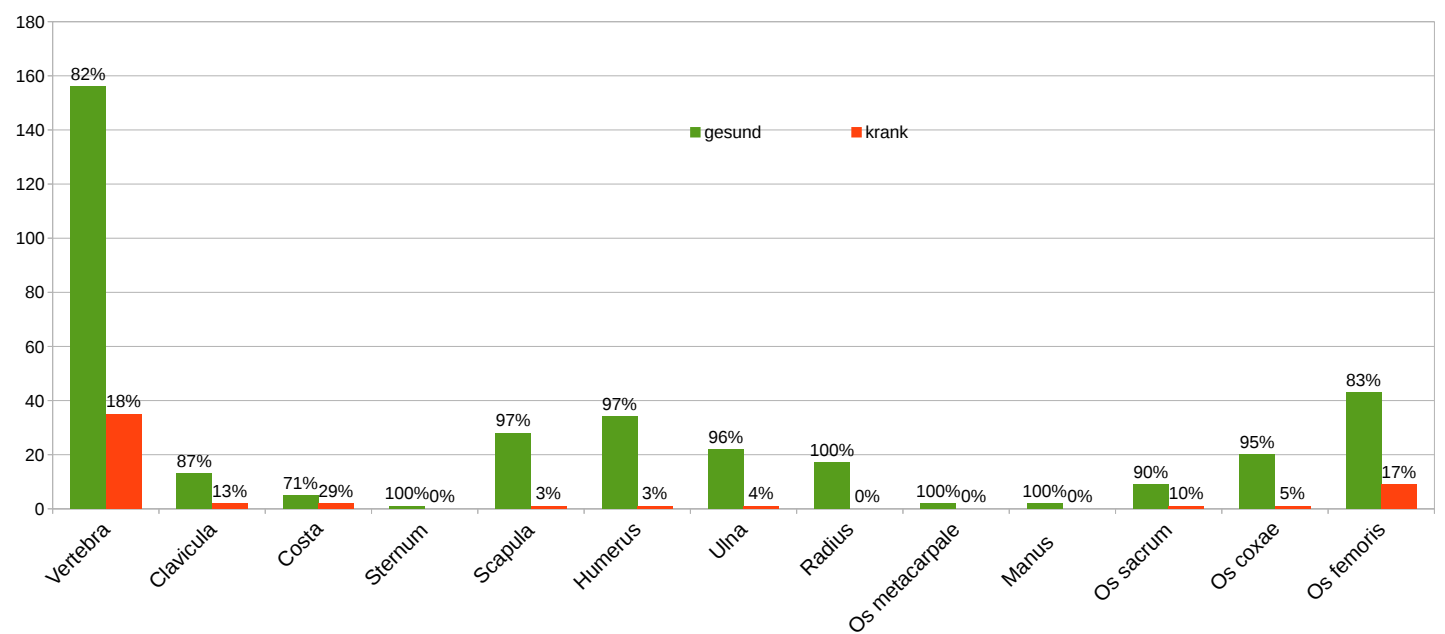

Abb. 145 Befundbare Fundstücke (außer Schädel und den Zähnen) - Teil 1; Großenrode In diesem und dem nachfolgenden Diagramm sind alle Fundstücke aufgeführt, die befundbar waren. Prozentual werden die als "gesund" und "krank" diagnostizierten Fundstücke aller befundbaren Knochen angegeben. Die absolute Zahl ist auf der Ordinate festgehalten. 


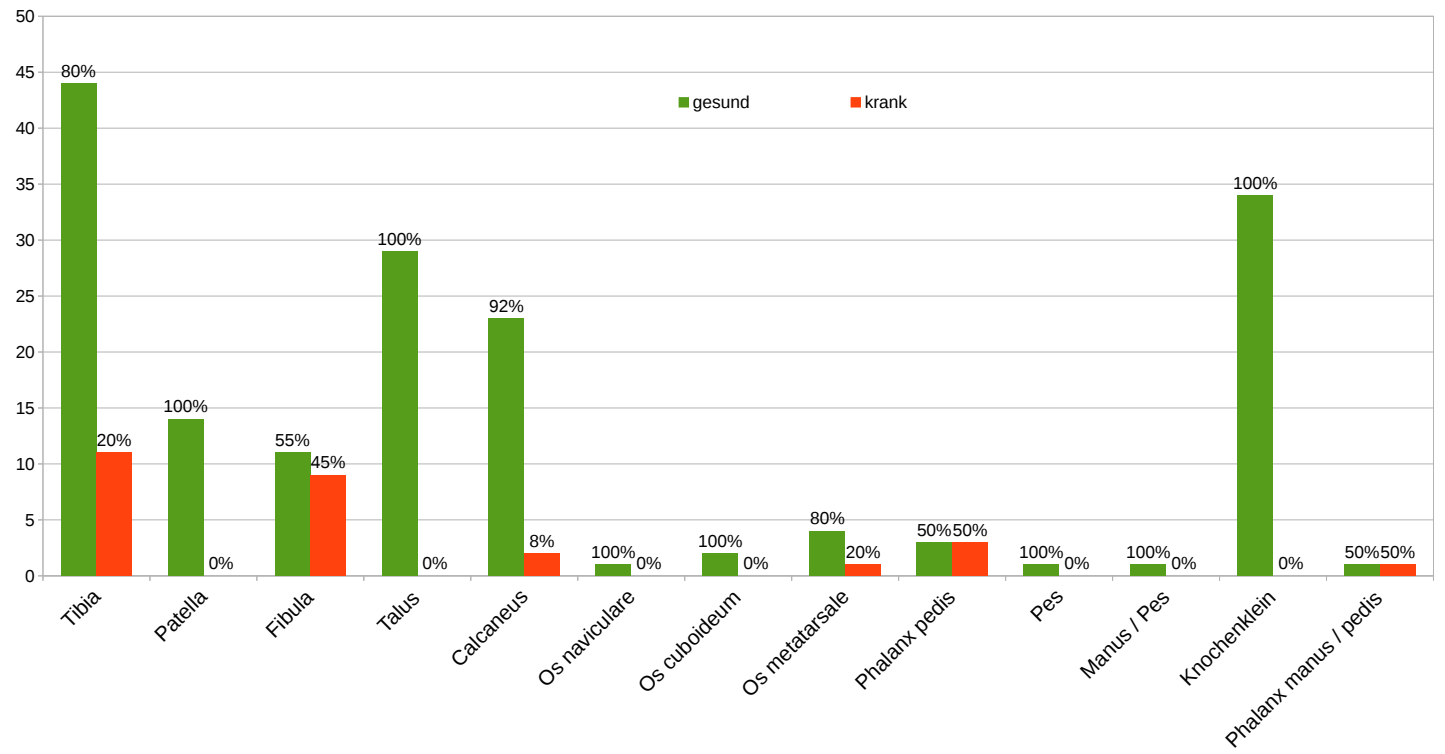

Abb. 146 Befundbare Fundstücke (außer Schädel und den Zähnen) - Teil 2; Großenrode In diesem Diagramm sind alle Fundstücke aufgeführt, die befundbar waren. Prozentual werden die als "gesund" und "krank" diagnostizierten Fundstücke aller befundbaren Knochen angegeben. Die absolute Anzahl ist auf der Ordinate festgehalten.

Es folgt nun eine Tabelle (Tab. 10), die einen Überblick über die an den Fundstücken diagnostizierten Krankheiten geben soll. Angegeben ist jeweils eine Knochengruppe, bei der die angeführten Krankheiten zu diagnostizieren waren. Die tabellarische Darstellung bezieht sich nur auf Krankheiten und Fundstücke, die jeweils einzeln vorkamen. Eine Darstellung in Diagrammen für diese Fundstücke wäre zu unübersichtlich, weswegen hier darauf verzichtet wurde. Die Fundstücke, die mehrere Krankheiten aufwiesen oder die Krankheiten, die an mehreren verschiedenen Fundstücken diagnostiziert wurden, finden sich in den danach folgenden Diagrammen wieder.

Tab.10 (Einzelne) Veränderungen an (einzelnen) Knochen; Großenrode Die Tabelle zeigt Fundstücke, die nur eine Veränderung aufwiesen. Weiterhin zeigt sie Veränderungen, die nur bei einer Gruppe von Fundstücken nachzuweisen waren.

\begin{tabular}{|c|c|c|c|c|}
\hline & Arthrose & Muskeltrauma & Fersensporn & Spondylitis \\
\hline Scapula & 1 & & & \\
\hline Humerus & & 1 & & \\
\hline Ulna & 1 & & & \\
\hline Os coxae & 1 & & & \\
\hline Phalanx manus / pes & 1 & & & \\
\hline Calcaneus & & & 2 & \\
\hline Vertebra & & & & 1 \\
\hline
\end{tabular}


Nachfolgend sind die Krankheiten und Fundstücke einzeln aufgeschlüsselt in Diagrammen dargestellt. Dabei zeigen die Diagramme 147 bis 160 alle verschiedenen pathologischen Befunde an allen befundeten Knochen des Postcraniums der Population aus Großenrode. Über den Säulen der Diagramme finden sich die absoluten Anzahlen der jeweiligen Knochengruppe, die eine oder mehrere der pathologischen Veränderungen aufwiesen.

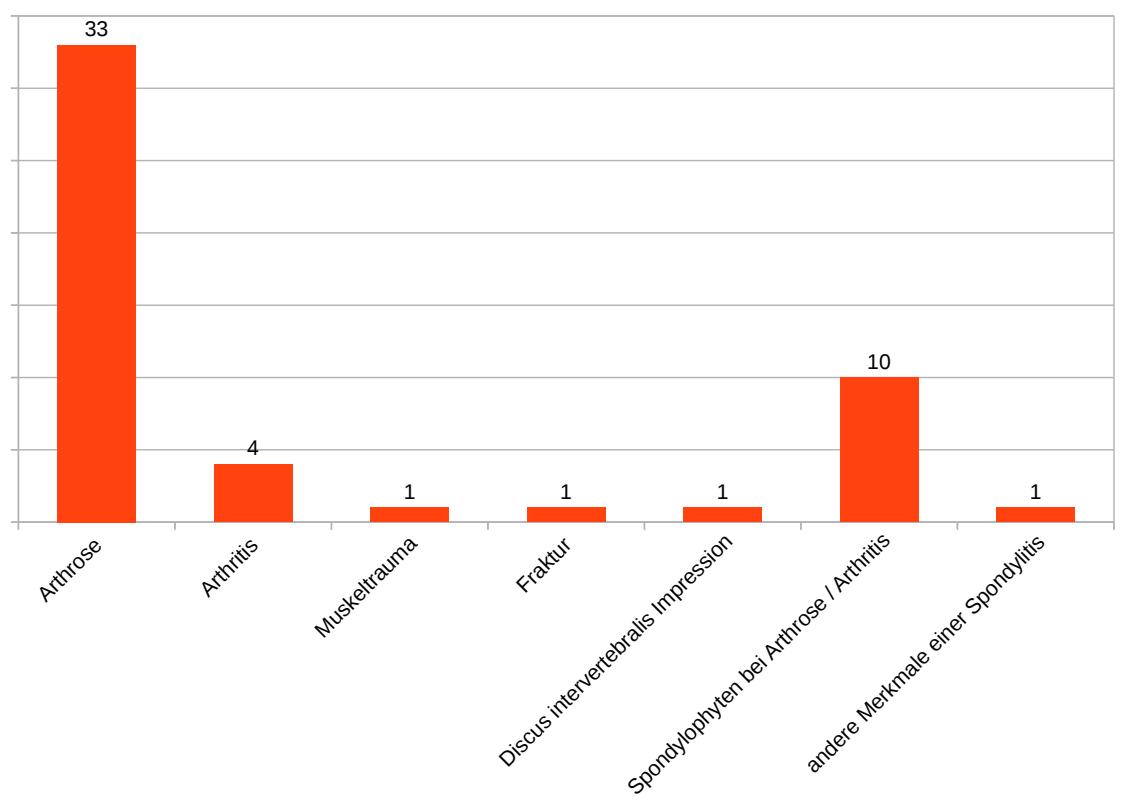

Abb. 147 Veränderungen an Vertebrae (gesamt befundbare: $n=191) ;$ Großenrode "n" bezieht sich auf alle Regionen. Auf der Abszisse sind die Veränderungen aufgeführt, über den Säulen findet sich die absolute Anzahl.

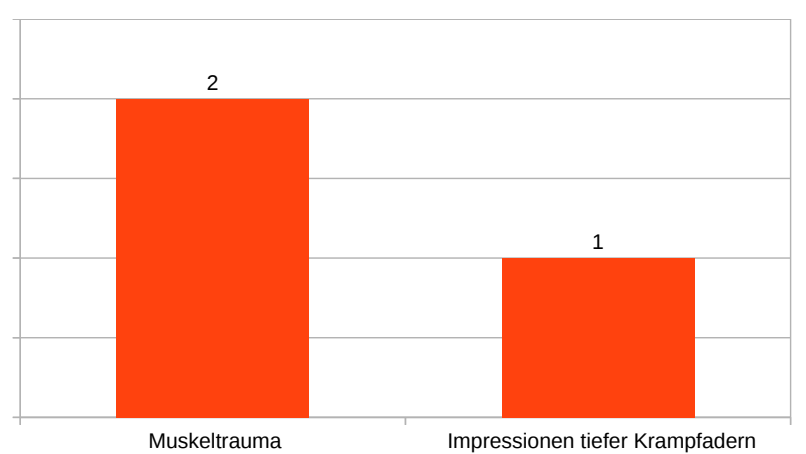

Abb. 148 Veränderungen an Claviculae (gesamt befundbare: $n=15$ ); Großenrode

Aufder Abszisse sind die Veränderungen aufgeführt, über den Säulen findet sich die absolute Anzahl. In dieser Darstellung wird nicht zwischen rechter und linker Körperseite differenziert. 


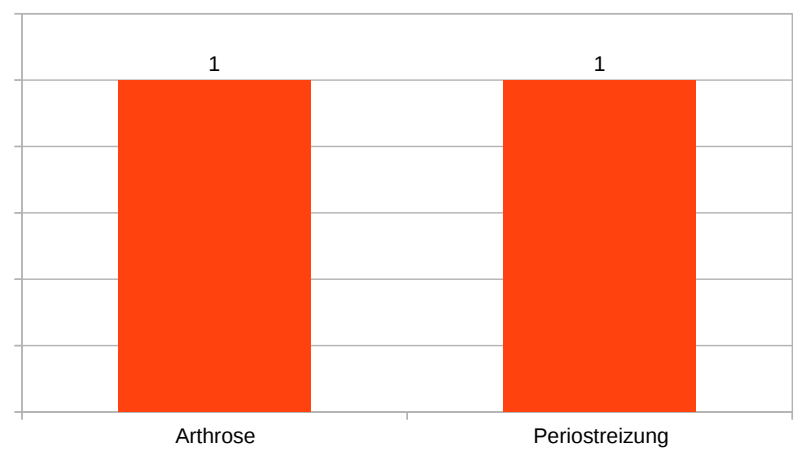

Abb. 149 Veränderungen an Costae (gesamt befundbare: $n=7$ ); Großenrode

Auf der Abszisse sind die Veränderungen aufgeführt, über den Säulen findet sich die absolute Anzahl. In dieser Darstellung wird nicht zwischen rechter und linker Körperseite differenziert.

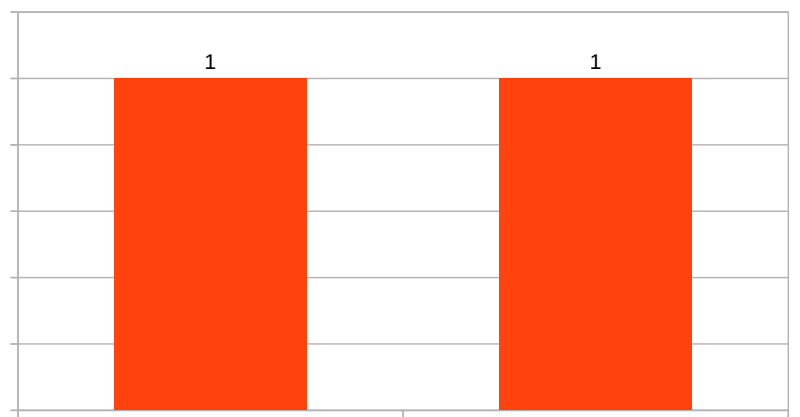

Arthrose

Arthritis

Abb. 150 Veränderungen an Ossa sacra (gesamt befundbare: $n=10) ;$ Großenrode

Aufder Abszisse sind die Veränderungen aufgeführt, über den Säulen findet sich die absolute Anzahl.

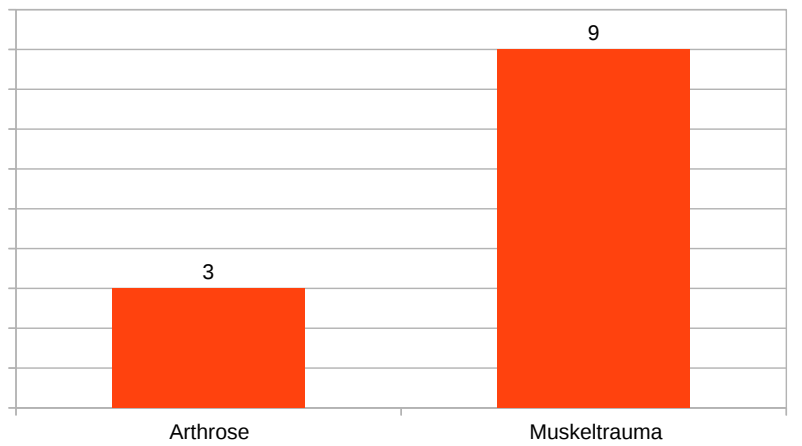

Abb. 151 Veränderungen an Ossa femoris (gesamt befundbare: $n=52$ ); Großenrode

Aufder Abszisse sind die Veränderungen aufgeführt, über den Säulen findet sich die absolute Anzahl. In dieser Darstellung wird nicht zwischen rechter und linker Körperseite differenziert. 


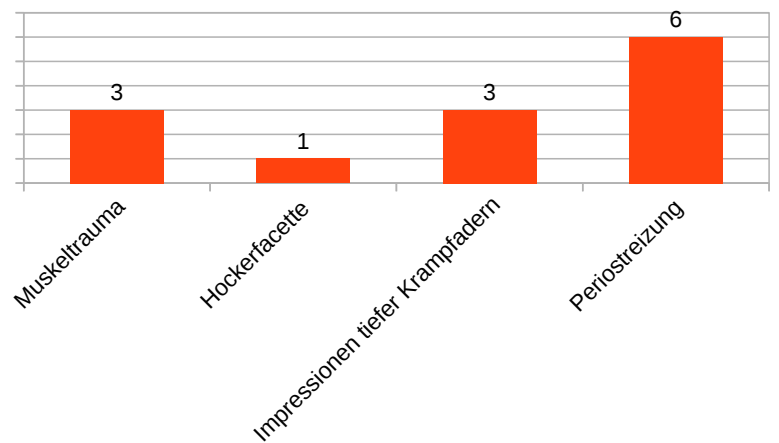

Abb. 152 Veränderungen an Tibiae (gesamt befundbare: $n=58)$; Großenrode

Auf der Abszisse sind die Veränderungen aufgeführt, über den Säulen findet sich die absolute Anzahl. In dieser Darstellung wird nicht zwischen rechter und linker Körperseite differenziert.

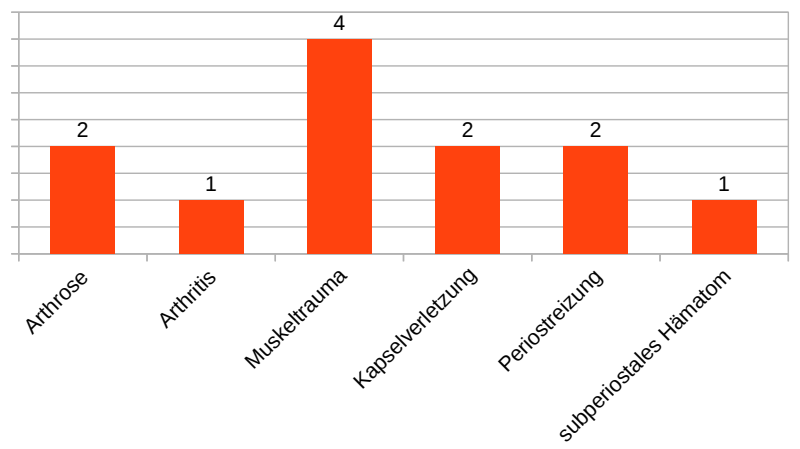

Abb. 153 Veränderungen an Fibulae (gesamt befundbare: $n=20$ ); Großenrode Auf der Abszisse sind die Veränderungen aufgeführt, über den Säulen findet sich die absolute Anzahl. In dieser Darstellung wird nicht zwischen rechter und linker Körperseite differenziert.

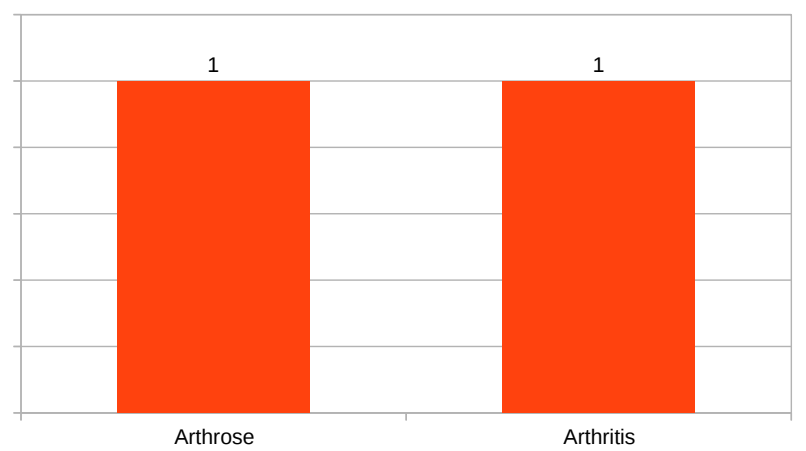

Abb. 154 Veränderungen an Ossa metatarsales (gesamt befundbare: $n=5$ ); Großenrode Aufder Abszisse sind die Veränderungen aufgeführt, über den Säulen findet sich die absolute Anzahl. In dieser Darstellung wird nicht zwischen rechter und linker Körperseite differenziert. 


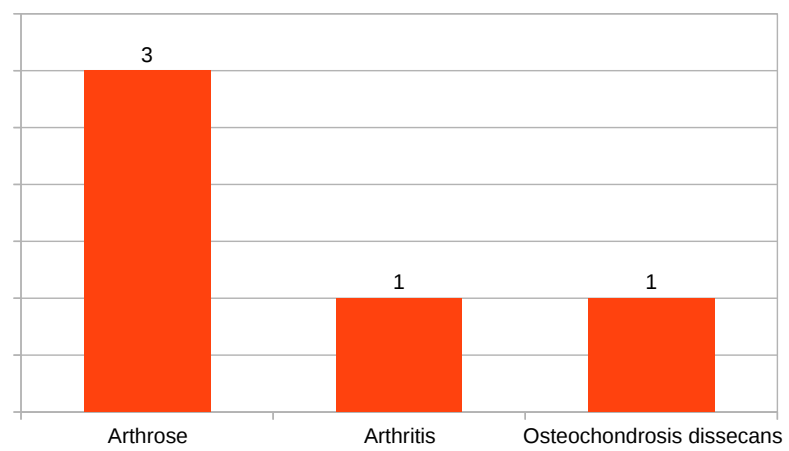

Abb.155 Veränderungen an Phalanges pedis (gesamt befundbare: $n=6$ ); Großenrode

Alle Phalangen des Fußes eingeschlossen. Auf der Abszisse sind die Veränderungen aufgeführt, über den Säulen findet sich die absolute Anzahl.

In dieser Darstellung wird nicht zwischen rechter und linker Körperseite differenziert.

Im Folgenden werden die diagnostizierten Krankheiten in jeweils einem Diagramm dargestellt. Zu entnehmen ist, wie oft die Krankheit bei den auf der x-Achse angegebenen Knochengruppen zu befunden war. Dabei zeigen die Diagramme 156 bis 160 die Aufschlüsslung der Fundstücke, die eine bestimmte Krankheit aufwiesen. Die Anzahl der Knochen einer Knochengruppe mit der jeweiligen pathologischen Veränderung wird in absoluten Zahlen über den Säulen der Diagramme angegeben.

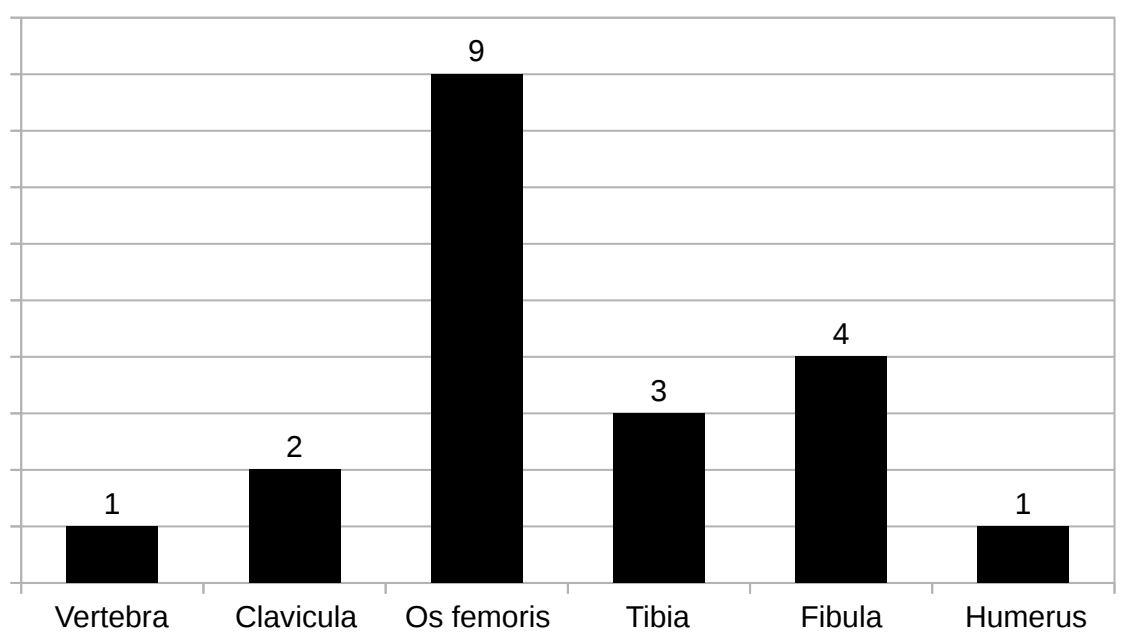

Abb.156 Muskeltraumta an verschiedenen Skeletelementen; Großenrode

Auf der Abszisse sind die Knochen aufgeführt, über den Säulen findet sich die absolute Anzahl. 


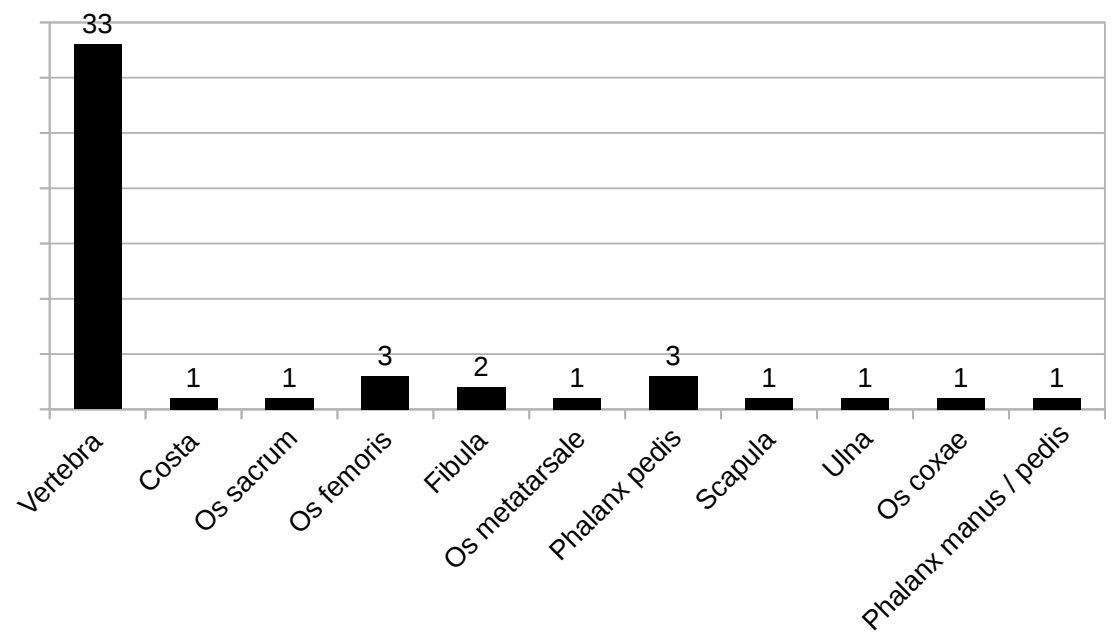

Abb. 157 Arthrose an verschiedenen Skeletelementen; Großenrode Auf der Abszisse sind die Knochen aufgeführt, über den Säulen findet sich die absolute Anzahl.

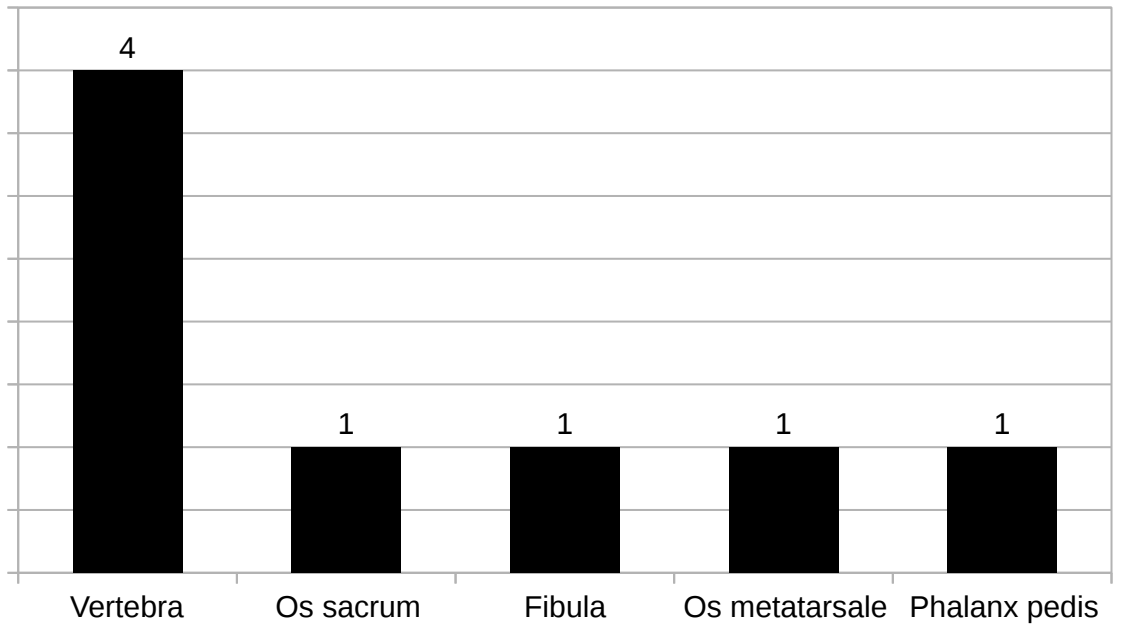

Abb. 158 Arthritis an verschiedenen Skeletelementen; Großenrode

Auf der Abszisse sind die Knochen aufgeführt, über den Säulen findet sich die absolute Anzahl. 


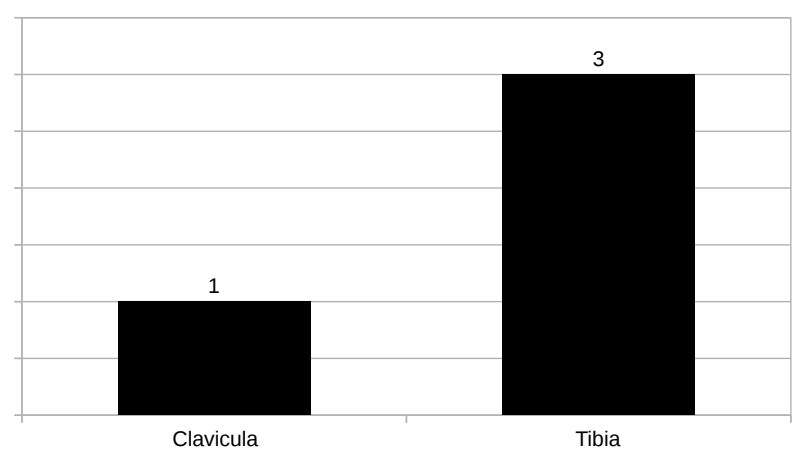

Abb.159 Impressionen tiefer Krampfadern; Großenrode

Auf der Abszisse sind die Knochen aufgeführt, über den Süulen findet sich die absolute Anzahl.

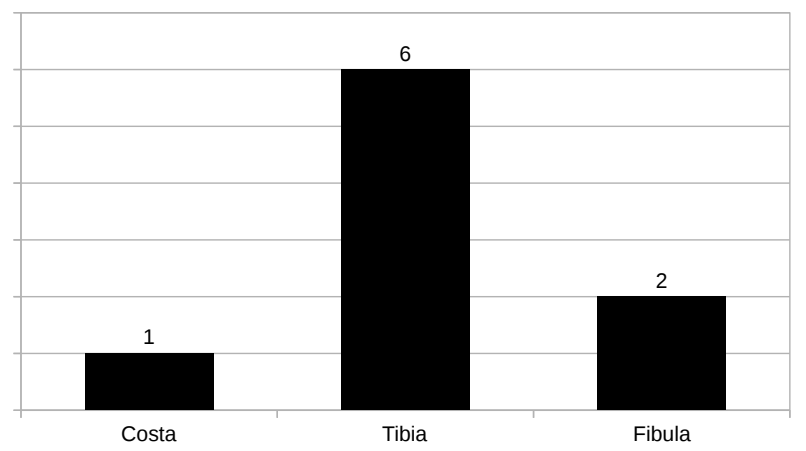

Abb.160 Periostreizungen an verschiedenen Skeletelementen; Großenrode

Auf der Abszisse sind die Knochen aufgeführt, über den Süulen findet sich die absolute Anzahl.

\subsubsection{Ermittlung des Sterbealters}

Bei der Population aus Großenrode konnte eine Bestimmung des Sterbealters bei deutlich mehr Fundstücken erfolgen als bei der Population aus Rheine. Somit sind die Ergebnisse der Altersbestimmung der Population aus Großenrode aussagekräftiger. 
In den Diagrammen 161 bis 164 ist eine Darstellung aller Fundstücke zu sehen, bei denen eine genauere Altersbestimmung möglich war.

Es findet sich ein Diagramm für alle Fundstücke außer den Zähnen, ein Diagramm für linke Femora, ein Diagramm für alle Zähne und ein Diagramm für die Zähne 46 (Mindestindividuenzahl). Anstelle linker Sprungbeine (MIZ) wurden für die Population aus Großenrode linke Femora gewählt. Dies ermöglicht eine bessere Vergleichbarkeit mit den anderen beiden Populationen. Weiterhin ist die Altersbestimmung an Femora besser zu realisieren.
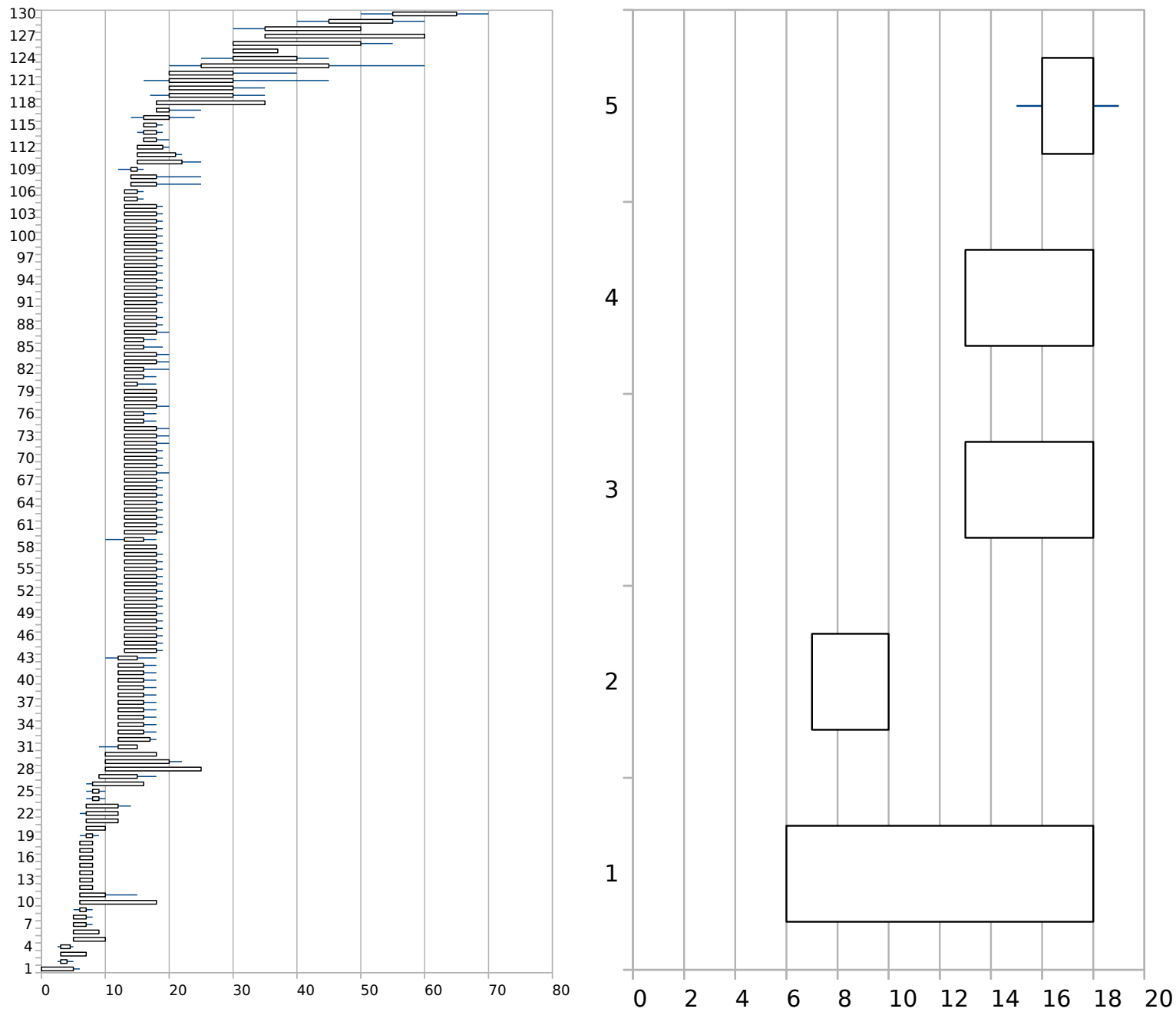

Abb. 161 Links: Sterbealterbestimmung aller Fundstücke (außer den Zähnen); Großenrode

Abb. 162

Rechts: Sterbealterbestimmung linker Femora; Großenrode

Legende zu den Abbildungen 161 und 162: Auf der x-Achse ist das Sterbealter aufgetragen, auf der y-Achse entspricht jede volle Einheit einem Fundstück, für das im Diagramm dann das Sterbealter in einem "Wahrscheinlichkeitsbereich" (Balken und/oder Strich) abzulesen ist. Der blaue Strich steht dabei gegebenenfalls für die noch möglichen maximalen und minimalen Grenzwerte des Sterbealters, der Balken für das wahrscheinliche Sterbealter. 

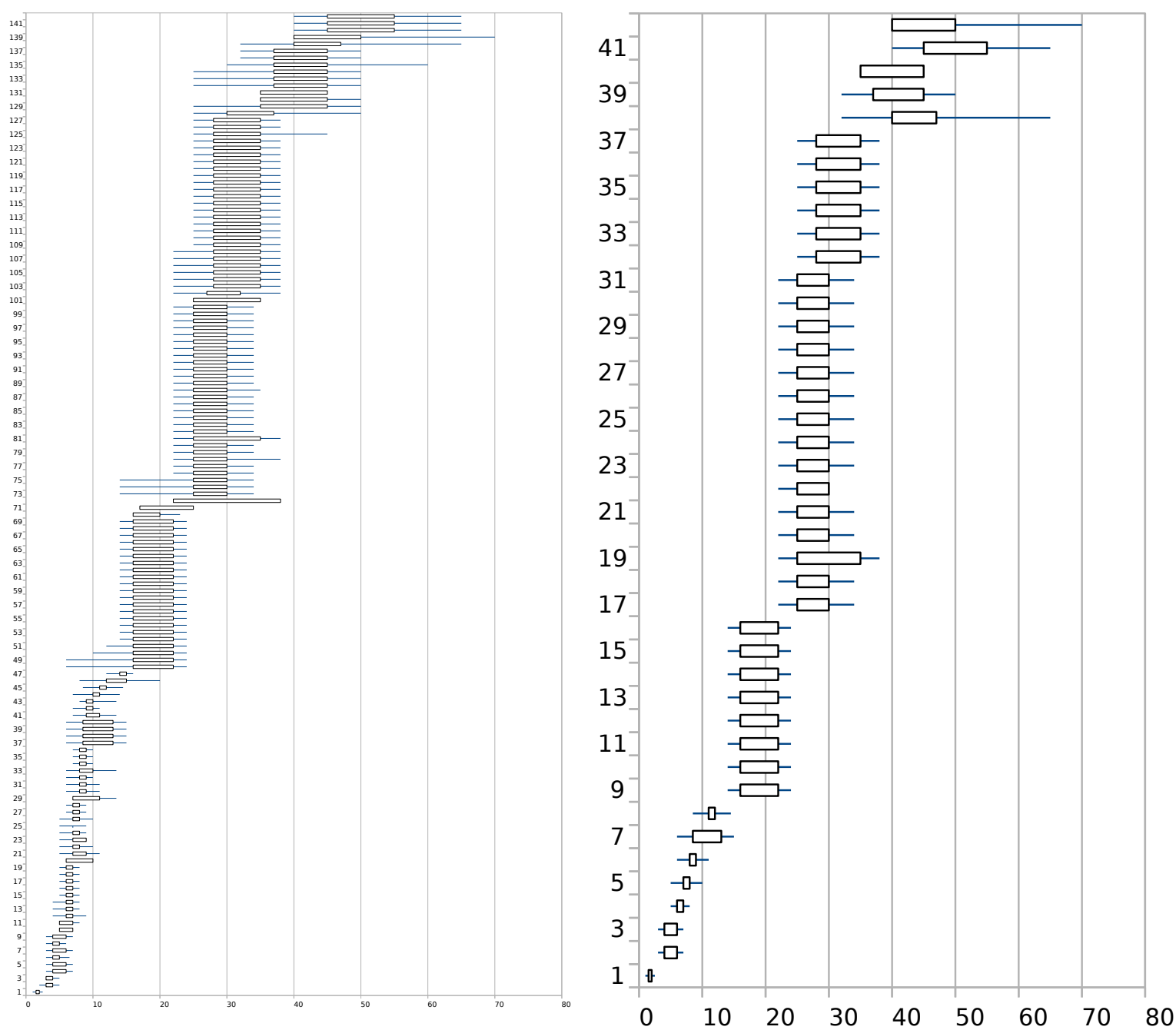

Abb. 163

Links: Sterbealterbestimmung aller Zähne; Großenrode

Abb. 164

Rechts: Sterbealterbestimmung der Zähne 46 (MIZ); Großenrode

Legende zu den Abbildungen 163 und 164: Auf der x-Achse ist das Sterbealter aufgetragen, auf der y-Achse entspricht jede volle Einheit einem Fundstück, für das im Diagramm dann das Sterbealter in einem "Wahrscheinlichkeitsbereich" (Balken und/oder Strich) abzulesen ist. Der blaue Strich steht dabei gegebenenfalls für die noch möglichen maximalen und minimalen Grenzwerte des Sterbealters, der Balken für das wahrscheinliche Sterbealter.

Ein Diagramm zur Einteilung von Fundstücken in die Altersgruppen adult und subadult enthält Abb. 165. Bei diesesn Fundstücken war eine genauere Altersbestimmung nicht möglich. 


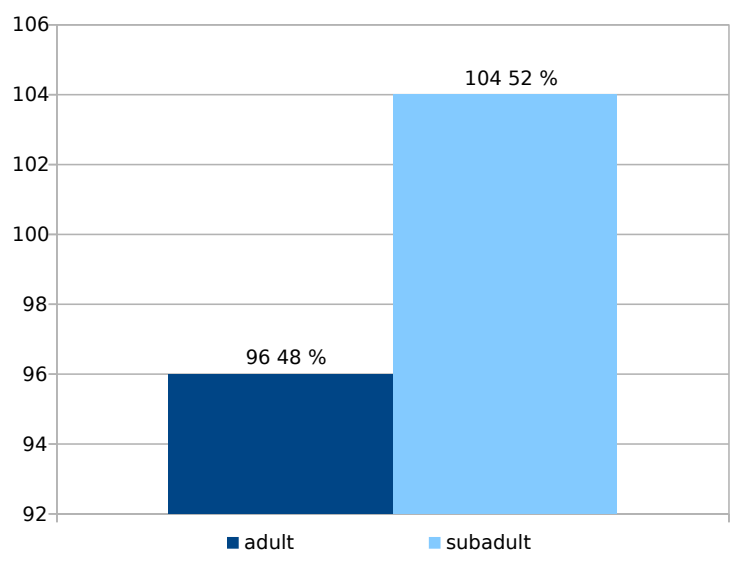

Abb. 165 Alterseinteilung der Fundstïcke in ",adult" u. „subadult"; Großenrode

Einteilung in die zwei großen Altersgruppen aufgrund morphologischer Gesichtspunkte (wenn beispielsweise offene Epiphysen vorlagen, wurde das Fundstück in die Kategorie "subadult" eingeteilt). Über den Säulen sind die absoluten Häufigkeiten links aufgeführt, rechts daneben finden sich jeweils die prozentualen Anteile. Auf der Ordinate befindet sich die Angabe der Gesamtzahl.

\subsubsection{Geschlechtsbestimmung}

Aus der Population aus Großenrode konnten 138 Fundstücke einer Geschlechtsbestimmung unterzogen werden. Oft konnte jedoch nur eine Tendenz angegeben werden (Abb. 166).

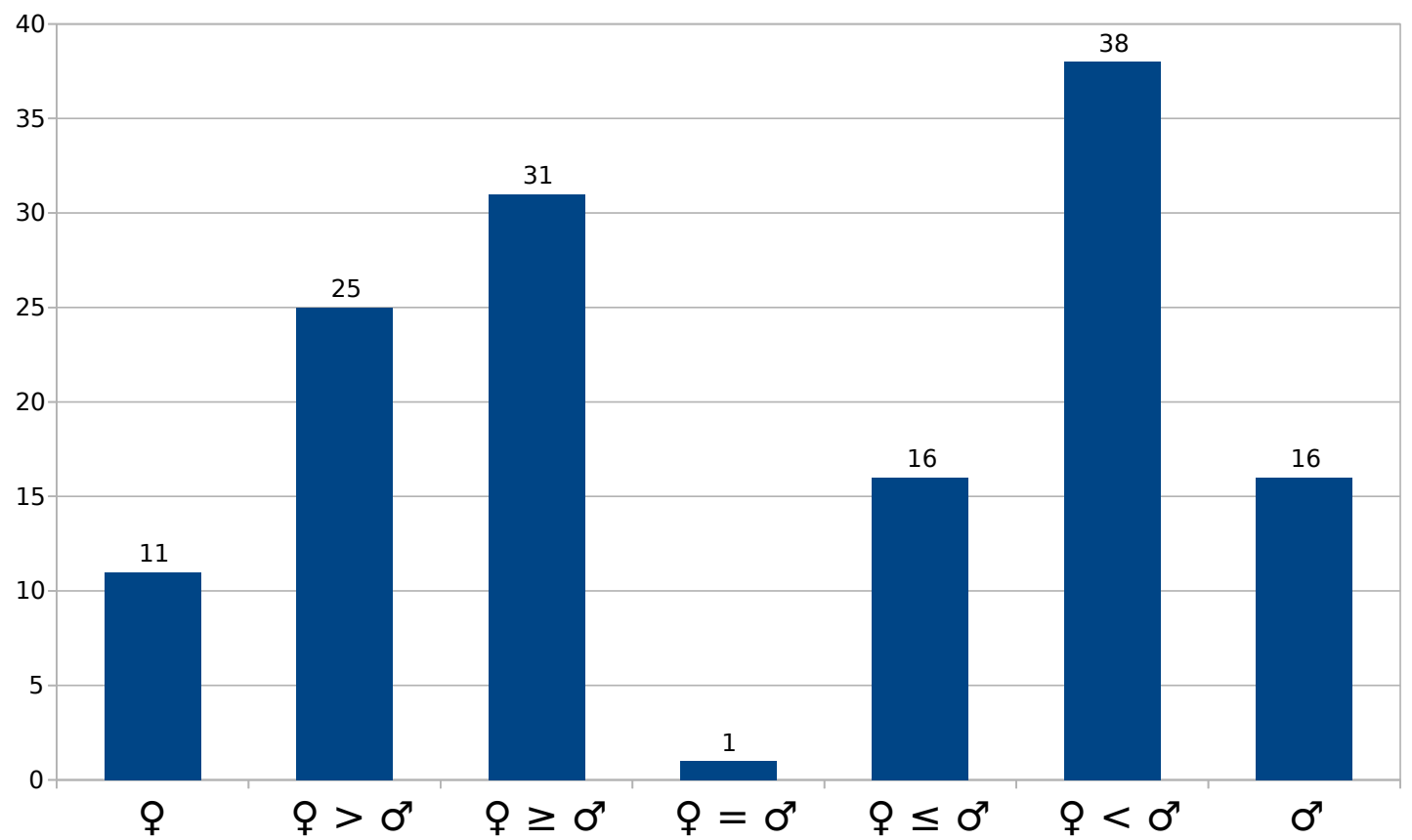

Abb. 166 Geschlechtsverteilung Diagramm 1; Großenrode

Im Diagramm sind alle Fundstücke erfasst, bei denen eine Geschlechtsbestimmung möglich war $(n=138$ Fundstücke). Die Einteilung erfolgte in "wahrscheinlich" weiblich (q), "wohl" weiblich $(q>\hat{O})$, "eher" weiblich $(+\geq \hat{O})$, "indifferent" $(+=\hat{\sigma})$, also keinem Geschlecht zuzuordnen, "eher" männlich $(\varphi \leq \hat{O})$, "wohl" männlich $(\phi<\hat{\dagger})$, und "wahrscheinlich" männlich $(\hat{O})$. Aufder Ordinate befindet sich die Angabe der Gesamtzahl. 
Nach dem großen Überblick über die gesamten Fundstücke soll nun ein Diagramm mit der Geschlechtsverteilung bei jenen Femora gezeigt werden, die für die Bestimmung der Mindestindividuenzahl dienten (Abb. 167).

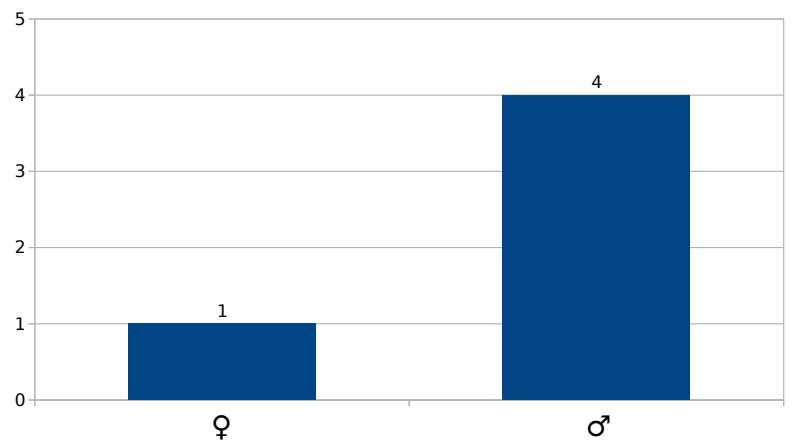

Abb. 167 Geschlechtsverteilung Diagramm 2; Großenrode

Einteilung anhand von linken Sprungbeinen (MIZ). Aufgrund der besseren Übersicht wird in dieser Darstellung auf die genauere Aufschlüsselung der Geschlechtstendenzen verzichtet. Die Gesamtzahl der für die Bestimmung der MIZ verwendeten rechten Tali beträgt fünf. Auf der Ordinate befindet sich die Angabe der Gesamtzahl.

Da insgesamt nur sehr wenige Fundstücke einem Geschlecht zuzuordnen waren, ist die Aussagekraft über die ungleiche Verteilung weiblicher und männlicher Individuen wenig aussagekräftig. 


\subsection{Zusammenfassung der Ergebnisse}

Das Fundgut der Populationen aus Calden, Rheine und Großenrode unterschied sich in einigen Punkten. So variierte der Erhaltungszustand der Fundstücke teils erheblich. Weiterhin unterschieden sich die Böden, in denen die Fundstücke mehrere tausend Jahre lagen; dies zeigte sich durch verschiedene Erosionsspuren an den Fundstücken der drei Populationen. Bei den Populationen aus Rheine und Großenrode waren die meisten Fundstücke derart erodiert, dass eine Befunderhebung nur mit großen Einschränkungen zu erzielen war. Somit ergaben sich für die drei Populationen Ergebnisse, die nicht ohne weiteres vergleichbar sind. Die Zahnfunde gaben zumeist noch die besten vergleichbaren Ergebnisse her. Ihre Substanz hat sich bei allen drei Populationen annähernd vergleichbar erhalten.

Die Mindestindividuenzahl kann anhand der Zähne für die Population aus Calden mit 26 angegeben werden; der Zahn 36 hat sich am häufigsten erhalten. Für die Population aus Rheine kann die MIZ anhand des Zahnes 26 auf 23 Individuen beziffert werden. Für die Population aus Großenrode kann die MIZ mit 43 angegeben werden; der Zahn 46 hat sich am häufigsten erhalten. Anhand von Knochen ist die MIZ für die Population aus Calden mit 39 (rechte Femora) anzugeben, für die Population aus Rheine mit fünf (rechte Felsenbeine), für die Population aus Großenrode mit 23 (linke Sprungbeine).

Bei der Befunderhebung wurden die einzelnen Fundstücke individuell betrachtet; eine Zuordnung zu einem Individuum war meist nicht möglich. Die Skeletelemente wurden in Gruppen ausgewertet (z. B. alle Femora). Vergleiche von einzelnen Individuen konnten nicht aufgestellt werden, da keine größeren Skeletverbände wiederherzustellen waren.

Die meisten Schädel - oder Fragmente davon - wurden in der Population aus Calden beobachtet $(\mathrm{n}=117)$. Der größte Anteil an krankhaften Veränderungen $(54 \%$ aller Schädelfunde) zeigte sich ebenfalls in der Population aus Calden. Absolut waren 63 von 117 Schädelfunden krankhaft verändert. Die Population aus Rheine enthielt 26 Schädelfragmente, von denen sechs (23\%) Spuren krankhafter Veränderungen aufwiesen. Bei der Population aus Großenrode konnten bei 43 von 116 (37\%) Schädelfunden Spuren von krankhaften Veränderungen nachgewiesen werden. Dabei waren bei den Schädelfunden der Population aus Calden Spuren einer Kopfschwartenreizung am häufigsten; sie konnte 34-mal nachgewiesen werden. In der Population aus Rheine waren ebenfalls Kopfschwartenreizungen die am häufigsten aufgetretene pathologische Veränderung; sie konnten dreimal diagnostiziert werden. In der Population aus Großenrode kamen meningeale Reizungen am häufigsten vor: Sie wurden 27-mal nachgewiesen. 
Die Zahnfunde der drei Populationen waren - wie bereits beschrieben - die am besten vergleichbare Fundgruppe; sie wiesen aber auch deutliche Unterschiede auf. So war in der Population aus Calden ein sehr ausgeglichenes Bild bezüglich der Erhaltungsmengen der verschiedenen bleibenden Zähne zu finden, während bei der Population aus Rheine die Fundgutmengen verschiedener Zahngruppen weit auseinander lagen: Der Zahn 22 kam beispielsweise gar nicht vor, während der Zahn - bzw. die regio - 26 sich 23-mal erhalten hat. Bei der Population aus Großenrode zeigte sich eine regelmäßigere Verteilung der verschiedenen erhaltenen Zahngruppen als bei der Population aus Rheine. Die gleichmäßigste Verteilung der Zahngruppen wiesen die Zahnfunde der Population aus Calden auf. Die verschiedenen Zahngruppen der drei Populationen zeigten ein vielfältiges Bild an Veränderungen: Abrasionen (Calden: 96\%, n = 394 von 409, Rheine: 72\%, n = 104 von 144, Großenrode: 88\%, n = 519 von 592) waren bei allen drei Populationen sehr häufig, während Karies selten auftrat (Calden: 6\%, $n=26$ von 422, Rheine: $7 \%, \mathrm{n}=10$ von 137, Großenrode: 5\%, $\mathrm{n}=29$ von 555). Schmelzhypoplasien (Calden: $65 \%, n=252$ von 388, Rheine: 33\%, $n=43$ von 132, Großenrode: 41\%, n = 248 von 603) und Zahnstein (Calden: $94 \%, \mathrm{n}=387$ von 411, Rheine: 56\%, n = 76 von 135, Großenrode: $75 \%, \mathrm{n}=418$ von 558) kamen regelmäßig in unterschiedlichen Ausmaßen vor. Hyperzementosen (Calden: $3 \%, n=9$ von 264, Rheine: $1 \%, n=1$ von 120 , Großenrode: $1 \%, \mathrm{n}=7$ von 493) waren insgesamt bei allen drei Populationen sehr selten zu finden, während Dentinneubildungen (Calden: 36\%, n = 146 von 401, Rheine: 14\%, n = 20 von 139, Großenrode: 21\%, $\mathrm{n}=125$ von 558) gelegentlich vorkamen. Insgesamt fielen bei der Population aus Rheine durchschnittlich die wenigsten Veränderungen an den Zähnen auf. Betrachtet man nur die 6-Jahres-Molaren aller Populationen, so ergibt sich bezüglich der Veränderungen an ihnen ein ähnliches Bild. Apicale Prozesse wurden bei den drei Populationen in unterschiedlicher Häufigkeit gefunden (Calden 10\%, $\mathrm{n}=59$ von 586, Rheine 18\%, n = 9 von 51, Großenrode 4\%, n = 22 von 549), Parodontopathien in der Population aus Calden bei 65\% ( $\mathrm{n}=354$ von 545), in der Population aus Rheine bei $71 \%(\mathrm{n}=17$ von 24$)$ und in der Population aus Großenrode bei 39\% (n=114 von 294) der Fälle. Spuren intravitalen Zahnverlustes konnten bei 58 Zahn-Kieferregionen der Funde der Population aus Calden beobachtet werden, bei der Population aus Großenrode konnten 70 festgestellt werden. Bei der Population aus Rheine waren keine Anhaltspunkte für intravitalen Zahnverlust festzustellen; dazu lagen die Kieferfunde in nicht ausreichend gut erhaltenem Zustand vor.

Bezüglich der am postcranialen Skelet erhobenen Befunde sind vergleichende Aussagen kaum zu treffen. Die in der Arbeit angegebenen absoluten Zahlen krankhafter Veränderungen an den postcranialen Fundstücken sind oft nicht in Prozenten 
anzugeben, da die Erhaltungsmengen derjeniger Fundstücke so stark voneinander abwichen, dass der Vergleich miteinander oder innerhalb der Populationen zu gravierenden Verfälschungen führen würde. Für die Befundung der großen Gelenke der langen Extremitätenknochen konnten prozentuale Werte errechnet werden, da hier nur vergleichbare Fundstücke herangezogen wurden. In der Population aus Calden traten degenerative Gelenkerkrankungen am Oberschenkelknochen am häufigsten auf (proximal in 35\%, $\mathrm{n}=23$, distal in 32\%, $\mathrm{n}=22$ der Fälle). Bezüglich der Population aus Rheine gab es keine Ergebnisse für die entsprechende Knochengruppe, in der Population aus Großenrode traten degenerative Gelenkerkrankungen ebenfalls am häufigsten am Os femoris auf (proximal $4 \%, n=1$, distal 7\%, n =2). Für die Ergebnisse der Befundung degenerativer Erkrankungen der Wirbel schwankten die Häufigkeiten degenerativer Veränderungen je nach Wirbelregion (z. B. Deckplatte oder Processus articularis inferior links) bei der Population aus Calden zwischen $11 \%(n=16$ aus 147$)$ und $34 \%(n=12$ aus 35$)$, bei der Population aus Rheine zwischen $0 \%$ und 33\% ( $n=1$ aus 3 ) und bei der Population aus Großenrode zwischen $0 \%$ und $12 \%(\mathrm{n}=14$ von 113$)$.

Aufgrund der geringen Fallzahl sicher geschlechtsdifferenzierbarer Individuen wurde auf eine Darstellung der prozentualen Verteilung verzichtet; hingegen wurden bei der Diskussion bestimmte geschlechtsspezifische (krankhafte) Veränderungen an den Knochenfunden herausgestellt.

Die größten Häufigkeiten pathologischer Veränderungen fanden sich bei der Population aus Calden an den Kniescheiben $(83 \%, n=5)$, bei der Population aus Rheine am Oberarmknochen $(100 \%, \mathrm{n}=1)$ und bei der Population aus Großenrode an den Phalangen des Fußes $(50 \%, n=3)$.

Die Körperhöhe konnte für 29 Individuen der Population aus Calden anhand der Länge von Femora rekonstruiert werden. Mit eingeschlossen wurden rechte und linke Femora von weiblichen, männlichen und indifferenten Individuen. Bei den anderen zwei Populationen war der Erhaltungszustand der Femora zu mangelhaft für eine Berechnung der Körperhöhe. Frauen aus der Population aus Calden waren mindestens 151,7 cm groß, maximal 162,4 cm. Männer waren mindestens 155,3 cm groß und maximal 183,7 cm. Durchschnittlich waren Frauen 157,6 cm groß und Männer 165,8 cm.

Für die Altersbestimmung konnten bei allen drei Populationen Fundstücke aus den Altersstufen von Infans I bis Senilis gefunden werden. Die individuelle Altersbestimmung anhand der Zähne stellt die einzige Methode dar, die einen demografischen Vergleich zwischen den drei Populationen erlaubt. Dabei lassen sich die meisten Zähne der Populationen aus Calden und Rheine dem adulten Lebensalter 
zuordnen. Ganz ähnlich sieht es mit den Zähnen der Population aus Großenrode aus; auch hier sind die meisten Zähne in der Altersgruppe der Adulten anzutreffen. Allerdings findet sich in der Großenrodener Population auch eine größere Anzahl von Individuen der Altersstufen Infans II und Juvenis.

Für die Geschlechtsbestimmung wurde grundsätzlich jedes Fundstück herangezogen, bei dem ein Geschlecht bestimmbar war. An dieser Stelle werden die Ergebnisse der Geschlechtsbestimmung der Fundstücke verglichen, die auch für die Bestimmung der Mindestindividuenzahl dienten. Für die Population aus Calden ergab die entsprechende Betrachtung der rechten Femora eine Verteilung von 14 Frauen zu 19 Männern. Bei der Population aus Rheine waren insgesamt nur vier Fundstücke verfügbar, die zur Bestimmung des Geschlechts herangezogen werden konnten (drei Frauen und ein Mann). Für die Population aus Großenrode konnten fünf linke Sprungbeine zur Bestimmung des Geschlechts herangezogen werden; die Auswertung ergab eine Frau und vier Männer. Betrachtet man die Geschlechtsverteilung linker Femora, so ergibt diese vier zu eins zugunsten des weiblichen Geschlechts. Die linken Femora wurden statt der linken Tali (MIZ) bereits zur Bestimmung des Alters für die Population aus Großenrode herangezogen, da sie mehr verwertbare Ergebnisse lieferten. Da aber die zur Verfügung stehenden Fundstücke nur in geringer Anzahl für die Bestimmung des Geschlechts herangezogen werden konnten, ist ein direkter Vergleich der Geschlechterverteilung der drei Populationen nur eingeschränkt möglich. 


\section{Diskussion}

\subsection{Fundgut, Befunderhebung und Auswertung}

\subsubsection{Fundgut und Befunderhebung}

Die Befunderhebung für das vorliegende Material stellte sich durchweg als kompliziert und schwierig dar (siehe auch Abbildungen 168-170), wozu u. a. folgende Aspekte beitrugen: Der teilweise sehr schlechte Erhaltungszustand des Fundguts, die unzureichend vorliegenden Informationen über die Grabungsarbeiten, fehlen der Details über die genaue Fundstelle der Knochen in den Gräbern und die Tatsache, dass die zahlreichen Funde offenbar meist als Einzelobjekte bzw. Einzelknochen gelten mussten. Unter diesen Voraussetzungen ergaben sich kaum vergleichbare Ergebnisse. Besonders der häufig mangelhafte Zustand, in dem sich die Knochen erhalten haben, schränkte die Befundbarkeit ein.

Dabei ist für die paläopathologische Befunderhebung problematisch, dass die Unterscheidung zwischen intravitalen und postmortalen Veränderungen an der Knochenoberfläche ein schwieriges Unterfangen ist, wenn sich die Knochensubstanz in schlechtem Zustand erhalten hat (Schultz 1986, 1997).

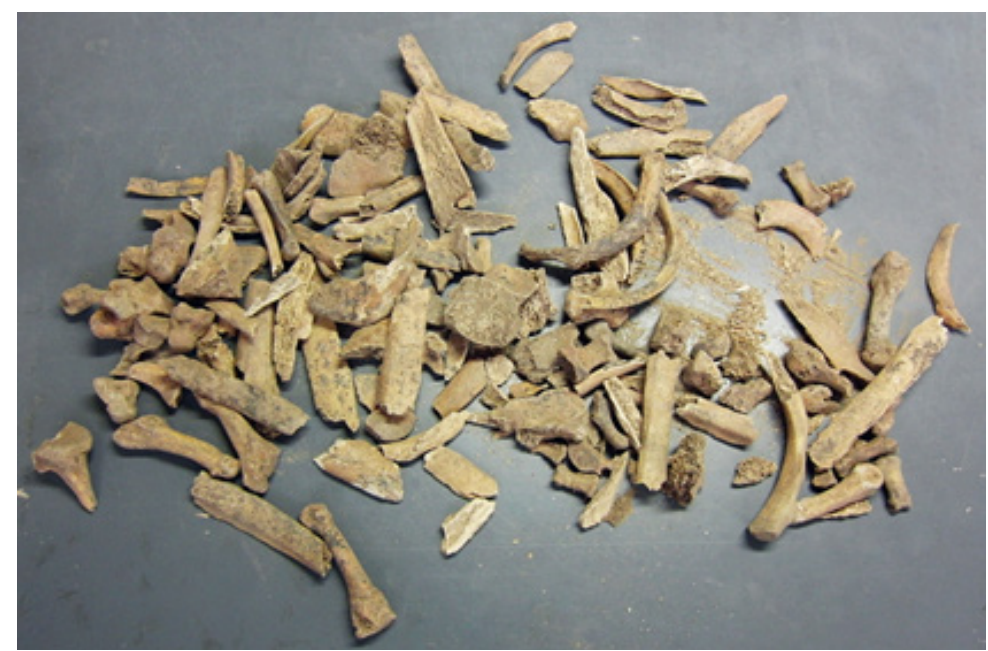

$A b b .168$

Fundgut in Fragmenten (Beispiel) 


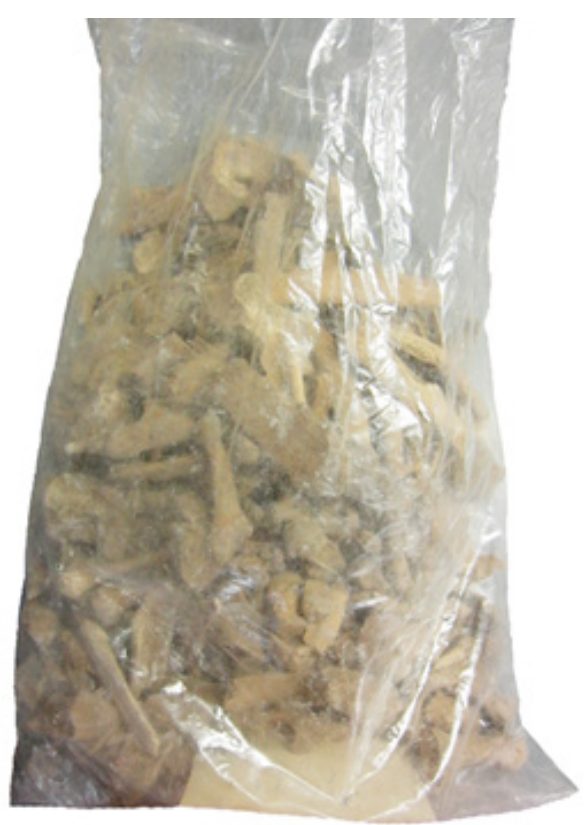

$A b b .169$

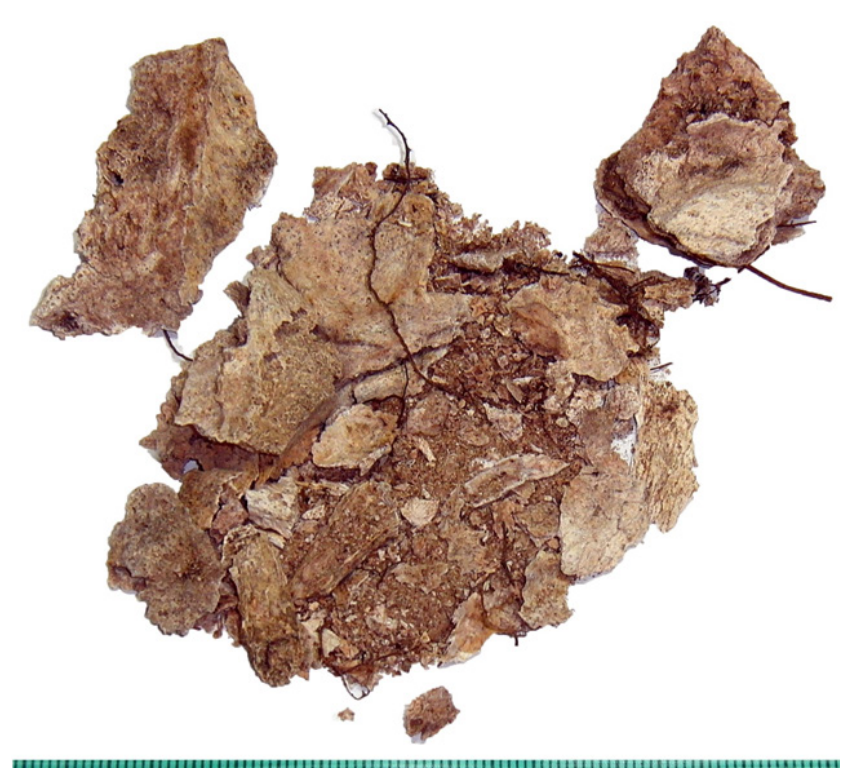

Abb. 170

Fundgut mit Erdmaterialien geborgen (Beispiel)

Raetzel-Fabian (2012a, http://www.jna.uni-kiel.de/index.php/jna/article/view/57/57) beschrieb die Fundsituation im Erdwerk von Calden folgendermaßen:

"In zwei Grabenköpfen wurden auf der Sohle Ensembles aus menschlichen Schädelteilen, Rinderhornzapfen, größeren Tierknochen und Steinen freigelegt. Einzelne kleinere menschliche Skeletteile traten auch in höheren Grabenschichten auf." 
So und ähnlich wurden wahrscheinlich die meisten Fundstücke der drei Populationen vorgefunden und in diesem Zustand geborgen. Es durften dementsprechend keine großen Erwartungen an den Erhaltungszustand gestellt werden.

Die Knochen der Populationen aus Rheine und Großenrode sind sehr brüchig, was wohl mit dem Schwund an Knochenkollagen während der langen Bodenlagerung zu erklären ist (Schultz et al. 2014). Weiterhin fanden sich Spuren von Pflanzenwuchs und Insektenfraß an der Knochenoberfläche, was bei der lichtmikroskopischen Untersuchung häufig als Nebenbefund festgehalten wurde. Auch diese beiden Umstände tragen zum Zerfall der Knochen bei. Außerdem waren Spuren von Pilzfraß nachweisbar, der die Hohlräume einiger der lichtmikroskopisch untersuchten Knochen postmortal verändert hat. Alle genannten Vorgänge und die Bodenlagerung unter erosiven Bedingungen führen zur Degradation des organischen Materials der Knochen; aber auch krankhaft veränderte Knochensubstanz kann unter Umständen schneller zerfallen als gesunde. Dadurch werden die Knochen brüchig und sind selbst mithilfe moderner lichtmikroskopischer Untersuchungsmethoden - zum Teil unter Verwendung von polarisiertem Durchlicht - nicht mehr vollständig befundbar; die Fundstücke könnten jedoch auch durch krankhafte Strukturveränderungen sehr brüchig geworden sein, wobei die dann anschließende Degradation durch Bodenlagerung diese pathologischen Veränderungen kaschiert hat. Spuren von pathologischen Veränderungen könnten also unwiederbringlich verloren gegangen sein; stattdessen haben sich aber möglicherweise „Pseudopathologien“ (Wells 1967) z. B. durch Pilzfraß oder Bodenerosion gebildet. Makroskopisch - und manchmal auch lichtmikroskopisch - sehen solche postmortalen Artefakte häufig wie Spuren pathologischer Veränderungen aus.

\subsubsection{Auswertung}

Da eine alleinige Auswertung mittels eines Tabellenkalkulationsprogramms nicht möglich erschien, wurde eine computergestützte Software in Form einer Datenbank in Filemaker Pro ${ }^{\circledR}$ mit einer speziell programmierten Oberfläche von Julian Görtz und mir entwickelt, um das Material und die erhobenen Befunde zu dokumentieren.

Die wissenschaftliche Arbeit dieser Dissertation bezieht sich also zum einen auf die erhobenen Befunde sowie zum anderen auf die Auswertungs- und Darstellungsmethoden.

Es wurden alle Fundstücke berücksichtigt und im Anhang vollständig sowie im Ergebnisteil in Auszügen dargestellt; prozentuale Angaben zu Ergebnissen wurden stets gerundet. 
Daten sind nur dann für Leser verständlich, wenn sie sinnvoll und anschaulich vorgestellt werden. Dazu gehört die Überlegung, verschiedene Datenschnittmengen zusammenzuführen und gemeinsam darzustellen.

Als Beispiel sei die Altersbestimmung anhand der rechten Femora (Mindestindividuenzahl) für die Population aus Calden erwähnt: Die Datenschnittmenge ergab sich dadurch, dass das Fundstück ein rechtes Femur sein, aus der Population aus Calden stammen und sich in entsprechendem Zustand erhalten haben musste, um einer Altersbestimmung zugeführt werden zu können. Weiterhin musste mindestens das proximale zweite Fünftel erhalten sein. Waren all diese Bedingungen erfüllt, konnten die betreffenden Fundstücke mit in die Datenauswertung der Kategorie „Altersbestimmung rechter Femora (Mindestindividuenzahl)“ aufgenommen werden.

Das vorangegangene Beispiel soll verdeutlichen, wie solche Schnittmengen zustande kommen und warum sie sinnvoll sind. Die Datenbank erlaubt mithilfe der Suchfunktion die genaue Ermittlung von Fundstücken, die bestimmten Kriterien entsprechen mussten. Die Knochenfunde, die alle unterschiedlich waren, aber dennoch unter bestimmten Kriterien einer Gruppe zugeordnet werden konnten, konnten so ausgewertet und verglichen werden. So stellen z. B. alle Femora eine Gruppe dar, sie sind zwar meist an verschiedenen Stellen im Grab geborgen worden, besitzen unterschiedliche Maße, sind möglicherweise nur in Fragmenten erhalten, sind eher einem weiblichen oder männlichen Individuum zuzuordnen und sind möglicherweise in verschiedene Altersstufen einzuordnen, gehören aber alle in eine große Gruppe, nämlich „Femora“.

Mit der Datenbank in Filemaker Pro ${ }^{\circledR}$ ist die Registrierung, Katalogisierung und Suche der Fundstücke zuverlässig möglich. So können Ergebnisse der Befunderhebungen ausgewertet und in Diagrammen und Tabellen anschaulich vorgestellt werden.

\subsection{Altersbestimmung}

Soweit es möglich war, wurden die Fundstücke einer Alters- und Geschlechtsbestimmung unterzogen. Dabei ergab sich dieselbe Schwierigkeit wie bei der Befundung pathologischer Veränderungen: Der Erhaltungszustand und das Vorliegen der Fundstücke als Einzelknochen - meist nicht im anatomischen Verband mit anderen Fundstücken - machte genauere Aussagen schwer oder sogar unmöglich.

Die Ergebnisse der Altersbestimmung sollen nun diskutiert werden.

Für die Population aus Calden wurden fünf Diagramme erstellt, die eine Übersicht über das Sterbealter aller Fundstücken zeigen - so denn eine Sterbealterbestimmung 
möglich war. Dabei schwanken die bestimmten Sterbealter zwischen mindestens etwa 0,5 Jahren bis maximal etwa 75 Jahren. Die extreme Schwankungsbreite bildet häufig das „normale Geschehen“ einer Zivilisation ab, denn auch Kinder sterben oder werden bereits tot geboren. Es genügten wenige Fundstücke $(n=26)$, die einer Altersklasse von Infans I zuzuordnen waren, um dieses Bild zu untermauern. Der Gesamtdurchschnitt des Alters unter Einbeziehung aller Fundstücke beträgt etwa 27 Jahre. Dass der Altersdurchschnitt anscheinend etwas niedrig ist, liegt möglicherweise daran, dass Fundstücke junger Individuen bei unverknöcherten Wachstumsfugen leichter einem Alter zugeordnet werden konnten und dass dann in der Gesamtmenge der befundeten Knochen mehr Knochen junger Individuen bestimmt wurden, als von erwachsenen.

Die nicht verknöcherte Wachstumsfuge eines Knochens kann schon eine orientierende Aussage zum Sterbealter des Individuums zulassen, auch wenn es nur ein sehr kleines Fragment ist (Abb. 171). Denn finden sich keine Anhaltspunkte dafür, dass das Individuum subadult war, kann nicht automatisch auf ein adultes Sterbealter geschlossen werden. Diese Komplikation liegt darin begründet, dass nicht jedes Knochenfragment einen Bereich besitzt, in dem eine Wachstumsfuge sichtbar ist. Gerade bei Knochensplittern ist auch eine Altersbestimmung aufgrund der Größe des Knochens nur schwer möglich, so könnte von einem subadulten Oberarmknochen ein Fragment erhalten sein, an dem die reale Größe nicht zu rekonstruieren ist.

Der genannte Gesamtdurchschnittswert spiegelt daher nur annäherungsweise den tatsächlichen Wert wider. Die Tabelle 11 zeigt, dass die verschiedenen Altersstufen in den drei Populationen repräsentiert sind.

Tab. 11 Übersicht über die Einteilung der Fundstücke in die jeweiligen Altersstufen "Anzahlen Alter min" sind die Angaben über die untere Grenze des bestimmten Alters, "Anzahlen Alter max." die Angaben über die obere Grenze des bestimmbaren Alters. Beispiel für Infans I: 26 Fundstücke waren im Atersbereich Infans I oder älter, sieben waren höchstens Infans I, vielleicht sogar von pränatalen Individuen.

\begin{tabular}{|l|l|l|}
\hline Altersstufe & Anzahlen Alter min. & Anzahlen Alter max. \\
\hline Infans I & 26 & 7 \\
\hline Infans II & 47 & 18 \\
\hline Juvenis & 51 & 43 \\
\hline Frühadultus & 53 & 46 \\
\hline Spätadultus & 71 & 45 \\
\hline Frühmaturus & 14 & 10 \\
\hline Spätmaturus & 7 & 61 \\
\hline Senilis & 0 & 30 \\
\hline
\end{tabular}

In der Population aus Rheine waren zur Altersbestimmung anhand von postcranialen Fundstücken lediglich sieben verfügbar. Davon waren zwei Infans I, eins Infans II, drei Juvenis, und eins Adultus. Es fällt eine Verteilung zugunsten junger 
Individuen ins Auge. Die möglichen Gründe für diese Verteilung wurden bereits oben diskutiert. Bei der Altersbestimmung anhand von Zähnen standen deutlich mehr Fundstücke zur Verfügung, anhand derer eine Altersbestimmung möglich war. An den 113 Zähnen konnte eine Altersverteilung nachgewiesen werden, die im Vergleich zu der aus Calden weiter zugunsten subadulter Individuen verteilt ist. Etwa zwei Sechstel befanden sich im infantilen Altersbereich, etwa ein Sechstel im juvenilen bis frühadulten Altersbereich, etwa zwei Sechstel im adulten und ein letztes Sechstel im maturen Altersbereich. Eine analoge Verteilung ergab auch die Auswertung der Zähne 26 (MIZ). Wird lediglich die Einteilung von Fundstücken in die zwei großen Altersgruppen adult und subadult betrachtet, so ergibt sich eine sehr ähnliche Verteilung wie in der Population aus Calden, nämlich etwas weniger als ein Drittel adult und etwas mehr als zwei Drittel subadult. In der Population aus Calden ist dieses Verhältnis noch weiter in Richtung der subadulten Altersstufen verschoben.

In der Population aus Großenrode haben sich 130 Fundstücke erhalten, die einer Altersbestimmung unterzogen werden konnten. Die Altersbestimmung linker Sprungbeine (MIZ) wurde hier jedoch nicht als vergleichende Betrachtung gewählt, sondern die Altersbestimmung linker Femora. Dies geschah aus zwei Gründen: Zum einen waren nur drei linke Tali einer Altersbestimmung zuzuführen, zum anderen ergab sich durch die Betrachtung linker Femora eine besser vergleichbare Basis zur Population aus Calden, in der rechte Femora betrachtet wurden. Der Vergleich gleicher Knochen birgt den Vorteil, dass ein eventuell auftretender Fehler bei der Bestimmung des Alters anhand von Femora für alle Populationen gleich ist. Außerdem standen in der Population aus Großenrode anstelle von drei linken Sprungbeinen fünf linke Femora für eine Altersbestimmung zur Verfügung.

Die Altersverteilung aller Fundstücke der Population aus Großenrode ist sehr deutlich in Richtung subadulter Altersstufen verschoben: Etwa zwei Zehntel entfallen auf den Altersbereich Infans I und II, knapp sieben Zehntel auf Juvenis und gut ein Zehntel auf die Altersstufen Adultus bis Senilis.

Die Altersbestimmung linker Femora in Großenrode ergab, dass fünf von fünf wahrscheinlich von subadulten Individuen stammten.

Bei Betrachtung dieser Ergebnisse liegt der Verdacht nahe, dass die oben angeführten Gründe für eine derartig ausgeprägte Verschiebung der Altersangaben zugunsten subadulter Individuen der Population aus Großenrode noch mehr zum Tragen kamen.

Wirft man allerdings einen Blick auf die Altersverteilung, die anhand von Zähnen 
angegeben wurde, so zeigt sich ein deutlich ausgeglicheneres Ergebnis: Etwa zwei Sechstel der 142 Zähne wurden in die Altersstufen Infans I und II eingeordnet, ein Sechstel in Juvenis bis Frühadultus, zwei Sechstel in Adultus, und das letzte Sechstel in Maturus. Die Altersverteilung der Zähne 46 (MIZ) ergab ein Fünftel Infans I und II, ein Fünftel Juvenis bis Frühadultus, zwei Fünftel Adultus und ein Fünftel Maturus.

Abschließend bleibt festzustellen, dass die Aussagekraft der Zähne bezüglich einer Altersbestimmung für alle drei Populationen recht realistische Werte ergab, d. h. den erwarteten demografischen Verhältnissen entspricht. Bei der Population aus Calden lagen zu etwa einem Drittel subadulte Skeletfunde vor und zu etwa zwei Dritteln adulte. Das könnte daran liegen, dass sich die Fundstücke im Vergleich zu den anderen beiden Populationen am besten erhalten haben und damit eine genauere Altersbestimmung - im Speziellen bei Fundstücken erwachsener Individuen möglich war. Das würde im Umkehrschluss bedeuten, dass die Ergebnisse der Populationen aus Rheine und Großenrode artifiziell verfälscht sind, da überwiegend Knochenfragmente und -splitter vorlagen und dass, wenn eine Altersbestimmung möglich war, diese häufig nur aufgrund von sichtbaren, erhaltenen Wachstumsanzeichen der Knochen oder anhand der Knochenmaße vorgenommen werden konnte.

Bei der Altersbestimmung der Zähne fällt eine Verfälschung der Werte zunächst nicht auf. War ein Zahn erhalten und befundbar, konnte oft auch das ungefähre Alter angegeben werden, unabhängig davon, ob das Individuum subadult oder adult war. Weiterhin war die Altersbestimmung anhand eines Wechselgebisses sehr verlässlich möglich. Die Schwierigkeiten der Altersbestimmung der anderen Fundstücke galten folglich nur bedingt für die Altersbestimmung der Zähne.

Ein „erwachsener“ Zahn weist andere Alters- und Verschleißerscheinungen auf als ein „nicht erwachsener", weswegen hier recht einfach zwischen eher jungen und eher älteren Zähnen unterschieden werden kann. Weiterhin haben sich bei allen Populationen Zähne im Vergleich zu anderen Skeletanteilen wesentlich besser erhalten, sodass eine höhere Aussagekraft der Altersbestimmung anzunehmen ist. Außerdem sind die Zähne der drei Populationen auf dieselbe Art und Weise befundet worden, was einen vergleichbaren Fehler bei der Befundung erwarten lässt. Dadurch bilden die Zähne gut vergleichbare Objekte. Allerdings gab es auch bei der Befundung der Zähne nicht befundbare Fundstücke. Diese wurden dann als solche im Befund gekennzeichnet und bei den Ergebnissen der Befundung als „nicht befundbar" geführt.

Die genannten Aspekte lassen eine entsprechend verlässliche Vergleichbarkeit 
innerhalb der Populationen, aber auch zwischen den Populationen erwarten.

Es ist anzunehmen, dass sich Kinderskelete bei den drei untersuchten Populationen im Gegensatz zu ausgewachsenen Skeleten weniger gut im Grab erhalten haben (Acsádi und Nemeskéri 1970, Angel 1972). Dies könnte damit zusammenhängen, dass Kinderknochen kleiner sind als die von Erwachsenen und damit leichter durch Bodenerosion beschädigt werden können. Weiterhin ist die Knochenstruktur von Kinderskeleten relativ grazil und - bei Kleinkindern - noch nicht vollständig mineralisiert, was möglicherweise grundsätzlich dazu führen könnte, dass sie leichter zerfällt, als ein vollmineralisierter Erwachsenenknochen. Diese Überlegungen stellen die überwiegend zugunsten nicht erwachsener Individuen tendierende Altersbestimmung weiter infrage. Es scheint, als ob die weiter oben genannte Annahme zuträfe und die gefundenen Knochen tendenziell sicherer einem subadulten Individuum zugeordnet werden könnten - wenn es dafür Anhaltspunkte gab - als einem adulten, wenn eindeutige Nachweise dafür fehlten. Dabei waren jene Fundstücke zahlenmäßig überlegen, die sicher einem subadulten Individuum zuzuordnen waren, denn - wie anfangs erwähnt - kann bei zunächst adult wirkenden Fundstücken oft nicht sicher ein adultes Alter angegeben werden.

Die Bestimmung des Alters zum Zeitpunkt des Todes bei einem mazerierten Skelet ist auch heute in der Forensik noch kompliziert. Versuche, anhand der Konzentrationen von Elementen wie Kalzium, Natrium, Kalium, Magnesium, Eisen, Zink, Mangan, Kupfer oder Blei in Knochen oder Zähnen das Alter zum Todeszeitpunkt rekonstruieren zu können, scheiterten (Kósa et al. 1989).

Die lichtmikroskopische Begutachtung von Knochendünnschliffpräparaten lässt meist eine relativ genaue Altersbestimmung bzw. bessere Altersschätzung mithilfe der histomorphologischen (HML) sowie der histomorphometrischen Methode zu (z. B. Kerley 1965, Kerley und Ubelaker 1978, Nováček 2012, Wolf 1999, Schultz 1986, Schultz und Nováček 2012). In Kombination der beiden Methoden ist eine Altersschätzung teilweise auf fünf bis zehn Jahre möglich. Wallin und Mitarbeiter (1994) kamen anhand der Osteonenstruktur und ihres Umbaus (bone remodelling) an rezenten Femora mit einer Standardabweichung von etwa 13 Jahren und unter Berücksichtigung des Geschlechts zu recht genauen Ergebnissen.

Wie bereits zu Anfang der Arbeit schon einmal erwähnt, kann die Altersbestimmung anhand des Wechselgebisses eines juvenilen Individuums als eine gute Methode der Altersbestimmung angesehen werden. Dies zeigte auch eine Arbeit von Beyer-Olsen und Risnes (1994), bei der Wechselgebisse von 248 infantilen und juvenilen archäologischen Individuen radiologisch und makroskopisch untersucht wurden. Die rein radiologische Methode der Altersbestimmung anhand des 
Wechselgebisses korrelierte stark mit der Methode, die Skelete makroskopisch einer Altersbestimmung zu unterziehen. Der statistische Fehler lag bei 0,33 Jahren und die größten Unterschiede zwischen den beiden Methoden zeigten sich zwischen 12 und 15 Jahren.

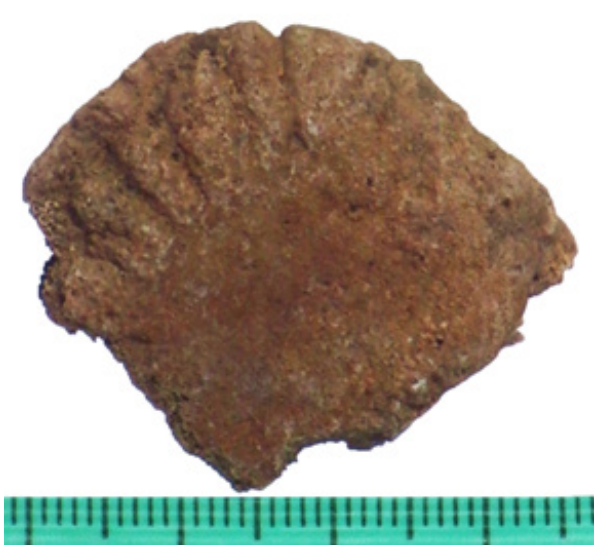

Abb. 171 Wirbelfragment eines jungen Individuums

Dritter oder vierter Brustwirbel eines Kindes im Altersbereich Infans II.

\subsection{Vergleich der Skeletfunde der drei Populationen}

Für diese Arbeit besonders interessant war der Vergleich der verschiedenen Gräber der Populationen aus Calden, Rheine und Großenrode. Im Folgenden sollen die drei Populationen detaillierter beleuchtet, in einen zeitlichen Kontext eingeordnet, Skeletfunde vorgestellt und Ergebnisse verschiedener publizierter Arbeiten mit den drei untersuchten Populationen dieser Dissertation verglichen werden.

\subsubsection{Gräberfeld Calden}

\subsubsection{Galeriegrab Calden I}

Das Galeriegrab Iin Calden-aus dem diein dieser Arbeit untersuchten Knochenfunde stammen - befindet sich südlich der Ortsmitte Caldens nahe zweier Quellen, welche in den Fluss Calde fließen (Raetzel-Fabian 2012b). Nach persönlicher Auskunft von Frau Dr. Irina Görner (Vor- und Frühgeschichtliche Sammlung Museumslandschaft Hessen Kassel) und laut Czarnetzki $(1966,1978)$ fand die Grabung 1948/1949 statt und wurde von Otto Uenze vom Landesamt für Denkmalpflege (Außenstelle Marburg) geleitet. Der Grabeingang ist in südöstliche Richtung orientiert (Raetzel-Fabian 2012b). Es fanden sich zahlreiche Funde in Form von Grabbeigaben und Knochen, wobei der Zerstörungsgrad des Grabes zunächst dazu führte, dass es keine große wissenschaftliche Beachtung fand (Raetzel-Fabian 2012b). Die Störungen - z. B. waren u. a. Wandsteine umgeworfen worden - gehen auf die römische Kaiserzeit und das Mittelalter zurück (Raetzel-Fabian 2012b). Das Grab konnte dennoch rekonstruiert 
werden: Die Außenlänge kann mit ca. 12,6 m, die Breite mit 3 m und die Höhe mit 1-1,5 $\mathrm{m}$ angegeben werden (Raetzel-Fabian 2012b). In den Maßen findet sich bereits die erste Gemeinsamkeit der beiden Galeriegräber Calden I und II (Raetzel-Fabian 2012b).

Teile der Bestattungsschicht waren trotz der massiven Störungen intakt geblieben; trotzdem konnten keine vollständigen Skelete aufgefunden werden (Raetzel-Fabian 2012b). Es wurde rekonstruiert, dass die Bestatteten längs ausgerichtet in gestreckter Rückenlage mit den Füßen dem Eingang entgegengesetzt abgelegt worden waren, wobei es zu Über- und Nebeneinanderlagerungen kam (Raetzel-Fabian $2012 b)$. Aus Grabungsunterlagen geht hervor, dass mindestens 40 Schädel geborgen wurden (Raetzel-Fabian 2012b). Als Czarnetzki (1966) die anthropologische Bearbeitung vornahm, konnte er das Vorhandensein von nur noch 27 Schädeln sicher nachweisen.

Als persönliche Gegenstände wurden den Toten Beigaben, die sie am Körper trugen, mit ins Grab gegeben: Tierzähne, Tierknochen, möglicherweise Kettchen und Kupfergegenstände, Flintklingen und Pfeilbewehrungen - um die wichtigsten zu nennen (Raetzel-Fabian 2012b).

Keramik wurde nur im Eingangsbereich des Grabes gefunden, nicht aber in der Grabkammer selbst, dies haben die beiden Galeriegräber Calden I und II ebenfalls gemeinsam (Raetzel-Fabian 2012b).

Zwei 14C-Untersuchungen an menschlichen Knochen ergaben eine Datierung des Galeriegrabes Calden I in das 34. Jh. v. Chr. (Raetzel-Fabian 2012b). Es ist davon auszugehen, dass dieses Grab etwa von 3400 bis 3200 v. Chr. genutzt wurde, während das Galeriegrab Calden II länger genutzt wurde (Raetzel-Fabian 2012b). Laut Frau Dr. Görner kann das Steingrab I aus Calden der Wartbergkultur zugerechnet werden. Die Zahl der Mindestindividuen konnte in dieser Arbeit für die Population aus Calden (Galeriegrab I) mit 39 angegeben werden, was sich mit den Angaben von Raetzel-Fabian (2012b) und Czarnetzki (1966) grundsätzlich in Deckung bringen lässt (die Ausgräber berichteten über Schäddelreste von mindestens 40 Schädeln, während Czarnetzki Reste von mindestens 30 Schädeln dokumentierte). Es konnten für diese Arbeit zwölf Schädel befundet werden, die eine Erhaltungsmasse von mindestens $61 \%$ besaßen. Weiterhin waren 20 Schädel mit einer Erhaltungsmasse von 26-60\% vorhanden und weitere 85 Schädelfragmente von 1-25\% Erhaltungsmasse.

Die Zahnfunde des Galeriegrabs I der Population aus Calden wurden im Rahmen zweier Dissertationen im zahnärztlichen Institut der Universität Marburg/Lahn 
untersucht. Meyer (1959) fand heraus, dass 11,63\% aller Zähne und 34,15\% der Gebisse kariös waren. In der hier vorgelegten Arbeit konnten andere Häufigkeiten bezüglich des Kariesbefalls der Zähne nachgewiesen werden: $0 \%$ ( $n=0$ von 61 ) der ersten und zweiten Incisivi, 5\% ( $\mathrm{n}=3$ von 56 ) der Canini, 9\% ( $\mathrm{n}=5$ von 57 ) der ersten Prämolaren, $8 \%$ ( $n=5$ von 65$)$ der zweiten Prämolaren, $5 \%(n=4$ von 83$)$ der ersten Molaren, $10 \%$ ( $n=7$ von 67$)$ der zweiten Molaren und $6 \%(n=2$ von 33$)$ der dritten Molaren. Insgesamt ergibt sich damit eine Karieshäufigkeit von $6 \%(n=26$ von 422$)$. Die Differenz zwischen den Werten dieser Arbeit und den Befunden von Ilselott Meyer könnte dadurch zustande gekommen sein, dass in der Zahnmedizin über die Jahre neue Erkenntnisse in Bezug auf die Kariesdiagnostik - insbesondere an archäologischen Funden - gewonnen wurden. So muss nicht jede Verfärbung der Occlusalfläche eine Karies sein. Die Sensibilität für noch gesunde Zähne, die aber verfärbt aussehen, ist in der heutigen Zahnmedizin sicherlich anders als in den 50iger Jahren. Meyer (1959) fand verschiedene apicale Auffälligkeiten, wie Granulome, Zysten und Hyperzementose. Die genannten absoluten Zahlen dazu sind jedoch mit den Ergebnissen dieser Arbeit nicht vergleichbar: In der hier vorgelegten Arbeit wurde jeder Zahn oder jede Zahnregion für sich betrachtet und befundet. Meyer (1959) bezog die Funde von apicalen Auffälligkeiten jedoch auf die vorhandenen Schädel, also auf ganze Gebisse (17\% der Schädel wiesen Erkrankungen der Zahnwurzeln auf, davon fünf Granulome, sechs Zysten und eine umschriebene Ostitis). Ein direkter Vergleich der Ergebnisse ist bei diesen Angaben nicht möglich. Die in der Arbeit von Ilselott Meyer sowie in der hier vorgelegten Arbeit angeführten Ergebnisse zeigen aber dennoch, dass apicale Prozesse vorkamen. Zahnfehlstellungen wurden von Meyer (1959) auch diagnostiziert: Caninushochstand, lückige Protrusion und Totalprotrusion. Solche und ähnliche Fehlstellungen wurden auch für diese Arbeit dokumentiert. Zahnstein und parodontale Veränderungen wurden in der Arbeit von Ilselott Meyer ebenfalls berücksichtigt, wobei die Atrophie des Kieferknochens zwischen den Zähnen offenbar von Ilselott Meyer nicht als Parodontitis im klassischen Sinne verstanden wurde, da das bloße Auftreten meist horizontalen Knochenabbaus ohne vertikale Taschen nicht als Parodontose bezeichnet wurde (Meyer 1959). Schäffer (1959) untersuchte in seiner Dissertation Perikymatien. Bei diesen feinen Linien oder Rillen im Zahnschmelz handelt es sich um Spuren des normalen Schmelzwachstums, die eine Aussage über die Geschwindigkeit des Wachstums des Zahnschmelzes zulassen. Diese feinen Linien sind nicht zu verwechseln mit den transversalen linearen Schmelzhypoplasien. An der buccalen Seite der Zähne fand Schäffer (1959) an Incisivi in 52,1\% der Zähne Perikymatien, an Canini in $62,5 \%$, an Prämolaren in 35,2\%, an Molaren in 35\%. Bei der Befunderhebung für diese Arbeit waren „Perikymatien“ differentialdiagnostisch von Schmelzhypoplasien 
abzugrenzen, wurden jedoch als Normalbefunde nicht dokumentiert.

Bei der Altersbestimmung wurden von Czarnetzki $(1966,1978) 26$ Schädel berücksichtigt; das Durchschnittsalter lag bei 30 Jahren, Infans I war gar nicht vertreten, die meisten lagen im Bereich Adultus. Dieser Sterbealterbereich kann auch für diese Arbeit angegeben werden, wobei ein leichter Ausschlag Richtung Maturus vorherrscht. Tendenziell ist die Altersgliederung dieser Arbeit folglich etwas zugunsten eines höheren Sterbealters verteilt.

Der Schwankungsbereich der anhand von Femora errechneten Körperhöhe beträgt 146-159 cm für weibliche und 159-171 cm für männliche Individuen (Czarnetzki 1966, 1978). Für diese Arbeit wurden mehrere verschiedene Autoren zur Berechnung der Körperhöhe herangezogen: Diese waren Pearson (1899), Breitinger (1938), Telkkä (1950), Bach (1965), Cerný und Komenda (1982), Sjøvold (1990), Raxter et al. (2008) und Siegmund (2010). Für Frauen kann eine Körpergrößenspanne von etwa 153-162 cm (Bach 1965) angegeben werden und für Männer 160-171 cm (Breitinger 1938).

Aufgrund der metrischen Merkmalen gibt Czarnetzki (1978) die Schädel und Extremitätenknochen als durchschnittlich mittelgroß an.

Czarnetzki (1966) machte eine Geschlechtsbestimmung der Fundstücke, die im Falle rechter Femora mit zwölf zu zehn zugunsten der männlichen Individuen verteilt war. Für diese Arbeit wurden u. a. ebenfalls rechte Femora für eine Geschlechtsbestimmung herangezogen (Mindestindividuenzahl). Diese ergab mit 14 zu 19 ebenfalls eine Verteilung zugunsten der männlichen Individuen.

\subsubsection{Galeriegrab Calden II und Erdwerk}

Im Sommer 1976 wurde das jungsteinzeitliche Erdwerk Calden entdeckt (Raetzel-Fabian 2012d). Ein Pilot beobachtete beim Anflug auf den Regionalflughafen Kassel-Calden verschiedene Bewuchsareale auf einem bestellten Feld (Raetzel-Fabian 2012d). Das Erdwerk ist aus einem geschlossenen Doppelgrabensystem aufgebaut, welches insgesamt etwa 14 ha groß ist (Raetzel-Fabian 2012f). Für die Errichtung des Erdwerks war eine große Anzahl von Arbeitskräften nötig, die u. a. Holz von 13000 Bäumen herbeischaffen und für den Bau von Gräben ca. $15000 \mathrm{~m}^{3}$ Erde und Kalk aus- und umgraben mussten (Raetzel-Fabian und Kappel 1991). Dies zeigt, wie viel Aufwand bereits in der Steinzeit betrieben wurde, um derartige Anlagen zu bauen und wie gut die Menschen vernetzt gewesen sein müssen, dass tausende Arbeiter zur Mithilfe gerufen werden konnten.

1969 wurde das Grab II bereits beim Verlegen einer Wasserleitung entdeckt, ohne dass damals weitere Untersuchungen stattfanden, da die Funde einem 
vermeintlichen Hügelgrab zugesprochen wurden (Raetzel-Fabian 2012c). Ein bis dahin unentdeckter Teil des Objekts wurde durch den Bau der Wasserleitung weitgehend zerstört (Pasda 2000). Das Galeriegrab II und das Erdwerk der Population aus Calden befinden sich ca. $1750 \mathrm{~m}$ südwestlich vom Ortskern Calden, wobei Grab II etwa $100 \mathrm{~m}$ südlich, außerhalb des Grabenrings vom Erdwerk liegt (Raetzel-Fabian 2012d). Grabungsarbeiten am Grab II und am Erdwerk erfolgten in den Jahren 1988 bis 1992 (Raetzel-Fabian 2012d).

In chronologischer Reihenfolge seien die relevanten Aktivitäten im Erdwerk aufgelistet: Erbauung ca. 3700/3600 v. Chr. mit anschließender erster Hauptnutzungsphase der Michelsberger / Baalberger Kultur; für die Zeit 3500/3400-3200 v. Chr. waren stellenweise Aktivitäten nachweisbar; 3200-3000 v. Chr. gab es ausgeprägte Aktivitäten in der zweiten Hauptnutzungsphase der älteren Wartbergkultur mit gleichzeitigem Bau von Calden II durch Individuen der älteren Wartbergkultur; um 3000-2000 v. Chr. war die dritte Hauptnutzungsphase durch die ältere und jüngere Einzelgrabkultur und Nutzung von Calden II ebenfalls durch die Einzelgrabkultur (Raetzel-Fabian 2012e). Es folgte die Nutzung von Populationen der Bronzezeit über die Eisenzeit bis hin zum Mittelalter, d. h. bis ins 14. Jh. n. Chr. (Raetzel-Fabian2012e).Radiokarbondatenund dieradiometrischeAltersbestimmung geborgener Keramik halfen bei der Einordnung des Erdwerks in das 37. Jh. v. Chr. (Raetzel-Fabian 2003).

Eine genaue Einordnung der Knochenfunde in eine bestimmte Epoche erscheint eher schwierig, da über tausende von Jahren verschiede Kulturen an ein und demselben Ort gelebt haben. Daher ist auch nicht ganz auszuschließen, dass Gräber weiter genutzt und sogar geräumt wurden, um neuen Platz zu schaffen. Im Erdwerk von Calden fand sich Keramik, die zur Wartbergkultur gezählt wird; allerdings belegen Radiokarbondaten von Tierknochen und Holzkohle der Anlagenzäune einen Konstruktionszeitpunkt des Erdwerks um 3700/3600 v. Chr., also der späten Michelsbergkultur (Raetzel-Fabian 2002).

Die Knochenfunde lagen nicht mehr im anatomischen Verband vor und waren größtenteils fragmentiert (Pasda 2000). Im Folgenden sollen die Ergebnisse der Befunderhebung der Skelete aus dem Steingrab II kurz zusammengefasst werden. Insgesamt konnten aus Grab II 377 craniale, 5005 poscraniale Knochen und 841 Zähne geboren werden (Pasda 2000). Die Gesamtanzahl der gefundenen Knochen aus Grab II ist größer als die der gefundenen Knochen aus Grab I. Für diese Arbeit lagen zur Befunderhebung aus Grab I 838 Zähne vor; für Grab II wird die Zahl der Zähne mit 841 angegeben (Pasda 2000). Die Anzahl der Zähne deckt sich also ziemlich genau - was wohl ein Zufall ist. Denn von den anderen Fundstücken sind aus 
Grab II überwiegend mehr als die doppelte Anzahl des jeweiligen Knochens vorhanden. Die Beobachtung, dass die Altersbestimmung der Individuen anhand von Zähnen (bestimmt nach dem Abrasionsschema von Szilvássy (1988)) in Richtung adulter Altersstufen verschoben ist - im Gegensatz zur Bestimmung des Alters anhand der Schädel, des Zahnzustands der Molaren etc. - machte auch Pasda (2000). Für die Altersbestimmung nach Szilvássy (1988) entsprechen 11,3\% der Individuen Infans oder Juvenis, 46,4\% spät Juvenis und Frühadultus, 29,4\% Adultus, 11,6\% Spätadultus und Frühmaturus, Maturus oder älter 1,4\% (Pasda 2000). Die Bestimmung der Schädel etc. ergab 49,5\% Infans und Juvenis, 17,7\% Spät Juvenis und Frühadultus, 14\% Adultus, 7,8\% Spätadultus und Frühmaturus und 10,9\% Maturus oder älter (Pasda 2000). Bei der Altersbestimmung für Grab I fiel ebenfalls auf, dass die Bestimmung mit dem Abrasionsschema nach Szilvássy (1988) etwas höhere Alterswerte ergibt. Dieser Unterschied war jedoch bei der Population aus Großenrode noch viel deutlicher ausgeprägt.

Die Bestimmung des Geschlechts anhand von Schädeln und Kiefern (ohne Zähne) ergab von den bestimmbaren Fundstücken nach Pasda (2000) 40\% weibliche und 60\% männliche Individuen. Dieses Verhältnis entsprach 62 zu 93 Fundstücken, wobei weitere 222 gar nicht bestimmbar waren (Pasda 2000). Für die hier vorgelegte Arbeit konnte anhand sicherer Methoden ein Geschlechterverhältnis von $43 \%$ ( $n=140$ von 327) weiblichen zu 57\% ( $n=187$ von 327) männlichen Individuen errechnet werden. Anhand von Größenabschätzungen der Fragmente und Kleinknochen kann ein Verhältnis von $42 \%$ ( $n=14$ von 33) Frauen zu 58\% ( $=19$ von 33) Männern angegeben werden. Die beiden genannten Methoden dieser Arbeit liegen also den Werten nach sehr dicht beieinander und ebenfalls recht dicht am Ergebnis der Geschlechtsbestimmung von Grab II (Pasda 2000).

Für Grab II konnte eine MIZ von 107 errechnet werden (Pasda 2000). Für Grab I beträgt die MIZ 39 (Bestimmung anhand rechter Femora). Der angegebene Wert für Grab II wurde anders berechnet als für Grab I: Es wurden jeweils die am häufigsten vorkommenden Knochenfunde einer Altersgruppe addiert. Geht man nach der Methode, die für diese Arbeit verwendet wurde, so ergibt sich für Grab II anhand von Zähnen eine MIZ von 84 und anhand von Schulterblättern und Oberarmknochen eine MIZ von jeweils 65 (diese Knochen waren gleich häufig vorhanden) (Pasda 2000).

$\mathrm{Zu}$ den pathologischen Veränderungen nennt Pasda (2000) sieben Fälle von Cribra orbitalia, neun Fälle von Cribra cranii und dentogene Kieferosteomyelitiden an zwei Oberkiefern und einem Unterkiefer, marginale Parodontopathien an sieben Ober- und Unterkiefern, apicale Prozesse an insgesamt 34 Zähnen bzw. Alveolen, 
eine chronisch-sklerosierende Osteomyelitis sicca Garré an einem Oberkiefer, eine nichtentzündliche Veränderung unbekannter Ätiologie an einem infantilen Schädel und an 48 von 78 Unterkiefern parodontalen Abbau. Weiterhin wurden drei Fälle von Osteoarthritis, ein mögliches Osteosarkom an einem Schädel, Karies an acht Ober- und an 18 Unterkiefern, intravitaler Zahnverlust bei fünf Ober-und zehn Unterkiefern, 25 Ober und 37 Unterkiefer mit Zahnstein (72,8\% der bleibenden Zähne) angegeben (Pasda 2000). Hypoplastische Auffälligkeiten wurden von Pasda (2000) für 15,5\% der bleibenden Zähne beschrieben. Frakturen mit Dislokation kamen bei einem Radius und einer Fibula vor, Frakturen ohne Dislokation bei einer Tibia, einer Fibula, drei Ossa metatarsalia und einer Phalanx pedis (Pasda 2000). Es kamen außerdem ein fibröser Corticalisdefekt an einer Fibula sowie eine Periostitis ossificans an einer Tibia vor (Pasda 2000). Pasda (2000) beschrieb auch Osteoporosen bei zwei Humeri, 17 Vertebrae, einem Femur und drei Ossa coxae. Osteoid-Osteome konnten bei zwei Schädeln und drei Schienbeinen gefunden werden sowie Osteome an vier Ossa pubis, zwei Humeri, einer Tibia, drei Fibulae und einem Radius (Pasda 2000). Aneurismatische Knochenzysten fanden sich bei zwei Ossa metatarsalia, Arthrosis deformans an zwei Humeri, einer Phalanx manus, einem Femur, einem Calcaneus, einem Os metatarsale und einer Phalanx pedis (Pasda 2000). Omarthrosen wurden an drei Scapulae gefunden und Osteoarthritis an einem Femur, einem Humerus, einem Calcaneus und einem Os cuboideum (Pasda 2000). An neun Rippen wurde eine Pleuritis festgestellt (Pasda 2000).Erkrankungen und degenerative Veränderungen der Wirbel wurden an 25 Wirbeln festgestellt sowie Skoliosen an zehn Wirbeln.

\subsubsection{Großsteingrab Rheine}

1983 begann die Untersuchung eines kleinen Hügels am nördlichen Stadtrand von Rheine im Zuge von Inventarisationen archäologischer Denkmäler im Umland; dieser Hügel war bereits seit 1930 als Großsteingrab bekannt (Eckert 1999). Dass es sich um ein Großsteingrab handelte, belegten $u$. a. Hinweise auf eine Tiefstichkeramik (Eckert 1999). Die Erschließung des Großsteingrabes begann im Mai 1983 durch das Anlegen von drei Grabungsschnitten und endete im Juli 1983 (Eckert 1999). Schnitt 1 war zwar von starken, älteren Störungen geprägt, u. a. waren die Tragsteine entnommen worden (Eckert 1999), aber es konnten Trichterbecherkeramiken, Flintgeräte, Knochen und Leichenbrand geborgen werden (Eckert 1999). Der Bereich, den Schnitt 2 abdeckte, ist ebenfalls sehr stark gestört worden und auch hier waren u. a. in jüngerer Zeit alle Tragesteine von ihrem ursprünglichen Platz wegbewegt worden (Eckert 1999). In Schnitt 2 konnten als Folge der Störungen keine weiteren Erkenntnisse gewonnen werden, da auch alles neolithische Material entfernt 
worden war (Eckert 1999). In Schnitt 3 fanden sich ebenfalls Spuren von Störungen, die aber nicht bis in die basalen Schichten reichten, sodass dort eine Bestattungsschicht von 30-50 cm in ungestörtem Zustand geborgen werden konnte (Eckert 1999). Hier fanden sich Gefäßteile, Skeletreste, Feuersteinartefakte und rare Schmuckstücke aus Kupfer, die zu den ältesten Metallfunden im norddeutschen Raum gehören (Eckert 1999). Das Grab war nach Süden ausgerichtet; die Kammerbreite des Grabes wird mit über $2 \mathrm{~m}$ angegeben, die Höhe mit etwa $1 \mathrm{~m}$ (Eckert 1999). Datiert wird das Grab in das Spät-Drouwen bis Spät-Havelte Zeitalter, sodass angenommen werden kann, dass das Grab über 350 Jahre zunächst regelmäßig und weitere 100 Jahre eher selten von Individuen der Trichterbecherkultur genutzt wurde (Eckert 1999). In 14C-Daten entspricht dies einem Zeitraum von 3200 bis 2850 v. Chr. (Bakker 1992). Im Spätneolithikum wurde das Grab noch hin und wieder weiter genutzt, was Teile von Gefäßen aus der Becherkultur belegen (Eckert 1999). Das Grab ist wie die meisten Großsteingräber - zwar auf Sandboden errichtet worden, da aber Kalksteine als Abdichtung der Kammer verwendet wurden, haben sich die Knochen vergleichsweise besser erhalten (Eckert 1999). In Schnitt 3 fanden sich die meisten Skeletteile; u. a. wurden an den menschlichen Überresten Spuren von Erkrankungen der Wirbelsäule sowie Spuren eines Vitamin-C-Mangels festgestellt (Eckert 1999). Es wurde eine Anzahl von zwölf Individuen verschiedener Altersstufen rekonstruiert (Eckert 1999). Weiterhin konnten 250 Fragmente von Leichenbrand gefunden werden, was für trichterbecherzeitliche Brandbestattungen - ähnlich denen von Rheine - entsprechen könnte (Eckert 1999).

Interessant bleibt weiterhin zu erwähnen, dass die für den Bau des Grabes verwendeten Platten aus Dörenther Sandstein bestehen, der in einer Entfernung von mindesten $11 \mathrm{~km}$ Luftlinie abgebaut und bis nach Rheine transportiert worden war (Eckert 1999).

Bezüglich der Befundung der Skeletfunde aus Rheine für die vorgelegte Arbeit konnte der Verdacht auf eine ausgeheilte Kieferfraktur bei einem Fundstück erhärtet werden (Abbildungen 172 und 173). Diese Fraktur wurde bereits bei Voruntersuchungen entdeckt und beschrieben (Eckert 1999). 


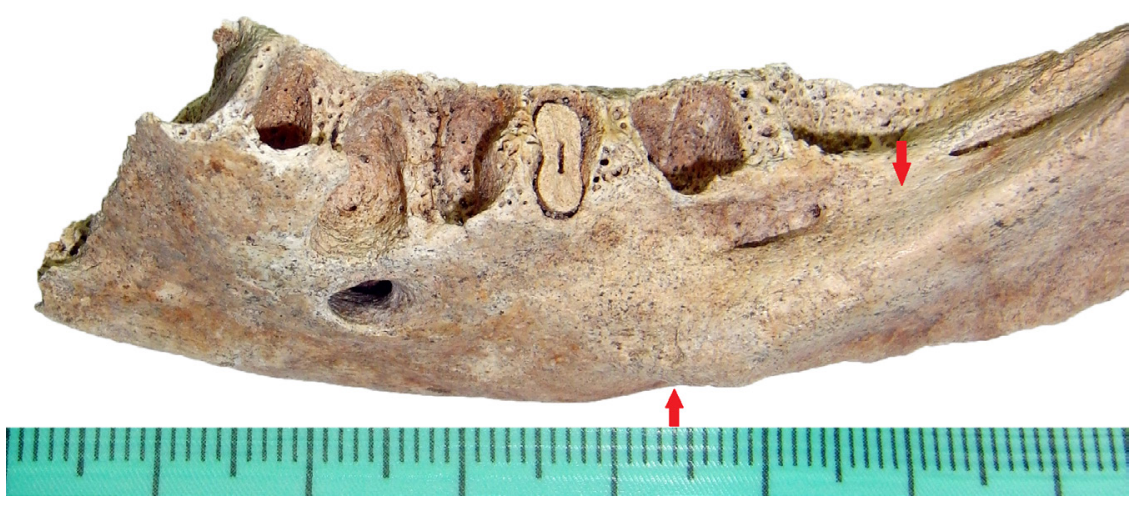

Abb. 172 Verheilte Fraktur eines linken Unterkieferastes (Bild Nr. 1); Rheine Im vorderen Bereich des aufsteigenden Unterkieferastes ist eine längs laufende, verheilte Fraktur zu beobachten (Pfeile).

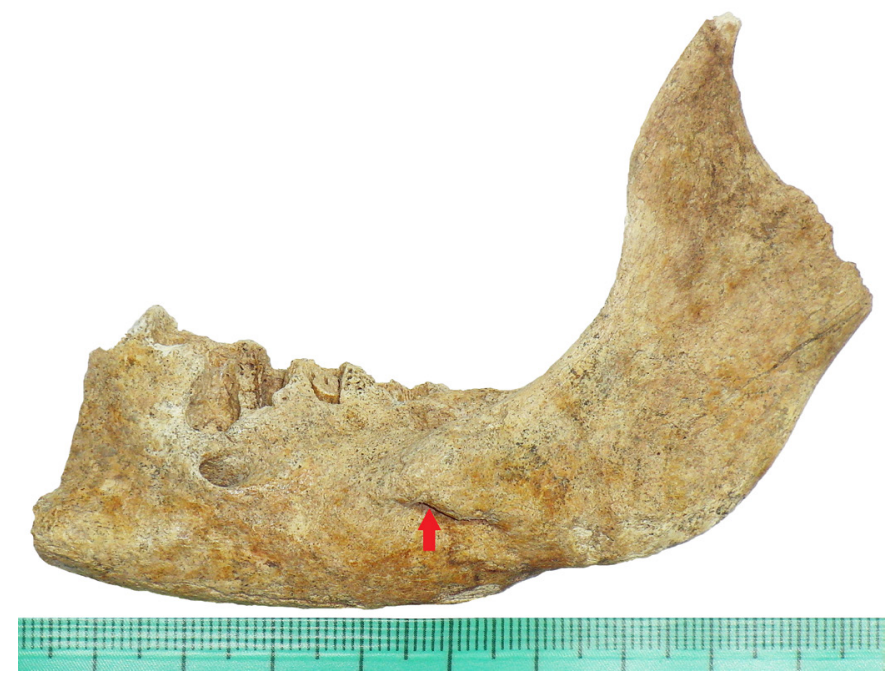

Abb. $173 \quad$ Verheilte Fraktur eines linken Unterkieferastes (Bild Nr. 2); Rheine

In der Ansicht von links oben seitlich ist die Frakturlinie entlang des Verlaufs des linken Unterkieferastes zu sehen (Pfeil).

Die Fundstücke konnten in verschiedene Altersstufen eingeordnet werden: Von Infans I bis Maturus; ein Fundstück könnte möglicherweise sogar auf ein spätmatures oder sogar seniles Alter hinweisen. An verschiedenen Wirbeln konnten degenerative Veränderungen festgestellt werden, wie sie bereits zuvor schon einmal beschrieben wurden (Eckert 1999). Spuren eines möglichen Vitamin-C-Mangels konnten bei der Befunderhebung für diese Arbeit nicht gefunden werden; es wurden solche Befunde jedoch zuvor angegeben (Eckert 1999). Allerdings wurden „Muskeltraumata" an Schlüsselbein und Rippe sowie an Oberarmknochen, Elle und Schienbein diagnostiziert. An einem Oberschen- kelknochenfragment konnten Spuren einer tiefen Beinvenenentzündung in Form von Gefäßimpressionen und porös-wulstiger 
Oberflächenstruktur gefunden werden und die Oberarmgelenkfläche eines Schulterblatts wies Spuren einer Arthrose auf. Außerdem konnte in drei Fällen eine reaktive Knochenbildung nach periostaler Reizung an Schienbeinen diagnostiziert werden. An den Zahnfunden konnten Abrasionen, Hyperzementose, Karies, Schmelzhypoplasien, Dentinneubildungen und Zahnstein gefunden werden. Weiterhin fanden sich Spuren von Stomatitiden, Parodontitiden und apicalen Abszessen. An den befundbaren Schädelfragmenten konnten in einem Fall eine Anämie, eine erhöhte Hirndrucksymptomatik, drei Kopfschwartenreizungen, zwei nicht pneumatisierte Warzenfortsätze, eine meningeale Reizung und eine Sinusitis maxillaris festgestellt werden.

Unter den Fundstücken befanden sich zahlreiche Fragmente, die als Leichenbrand bezeichnet werden können (Abbildungen 174 und 175). Eckert (1999) erwähnte ebenfalls das Vorhandensein von Leichenbrand.

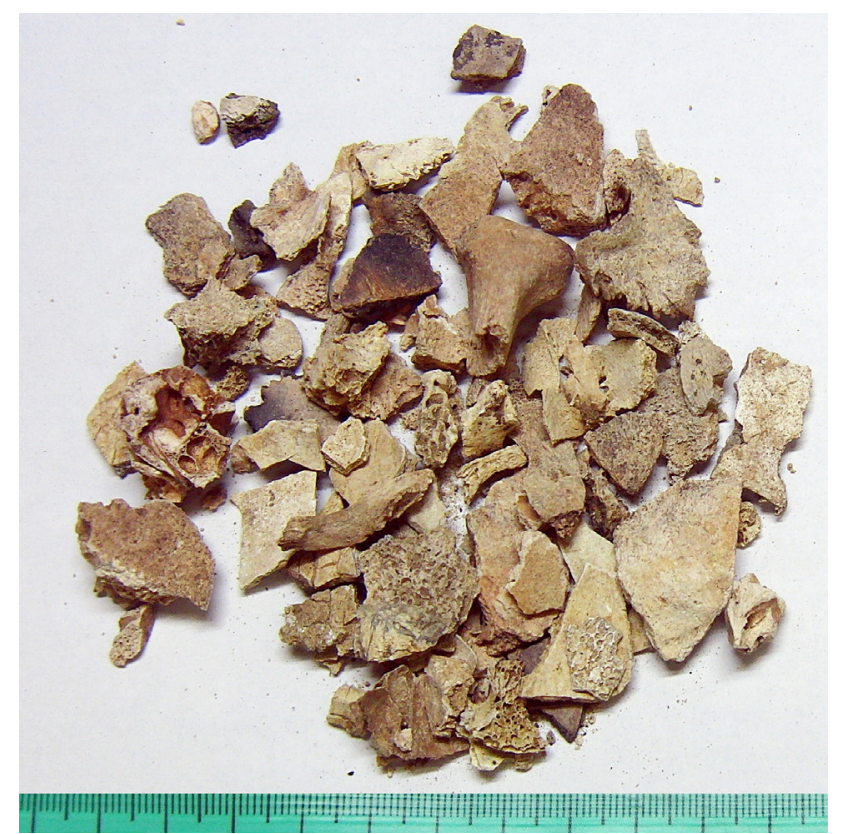

Abb. 174 Durch Feuer verfärbte Knochen der Population aus Rheine (Beispiel 1)

Schädelfragmente, unter denen die dunkel gefärbten zwar möglicherweise leicht verkohlt sind, jedoch noch nicht als Leichenbrand bezeichnet werden können. 


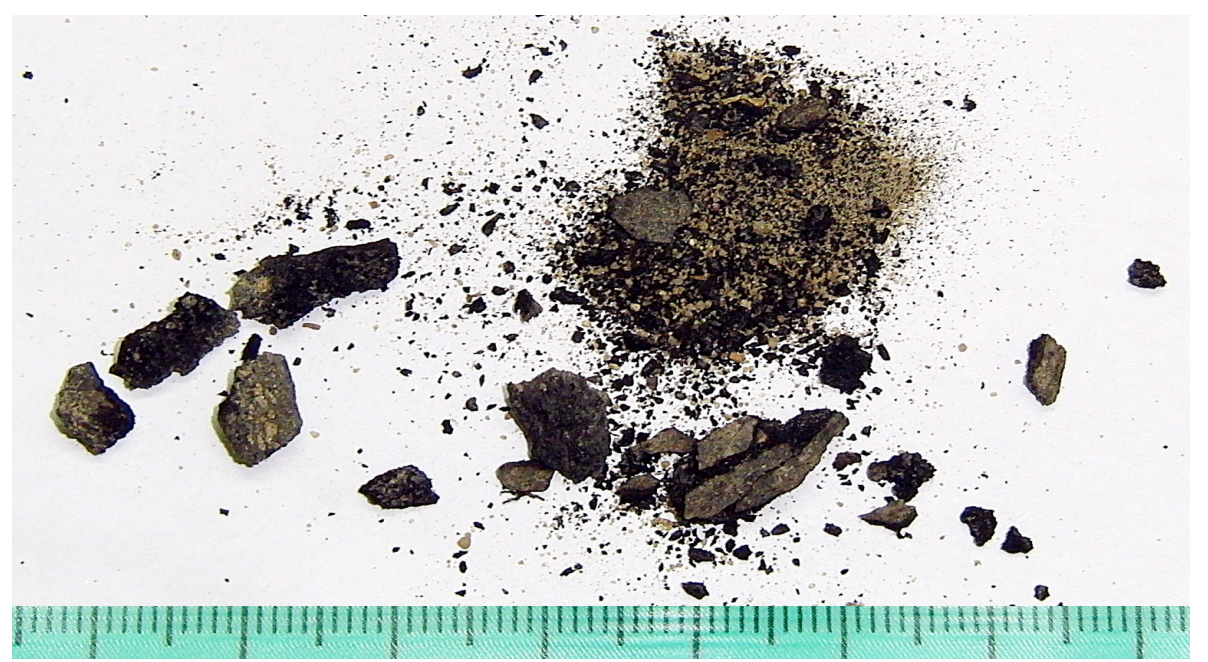

$A b b .175$

Leichenbrand der Population aus Rheine (Beispiel 2)

Fragmente aus Leichenbrand.

\subsubsection{Gräberfeld Großenrode}

Die beiden Gräber Großenrode I und II liegen ca. 13 km südlich von Odagsen, einem Dorf in Südniedersachsen, bei 178 m über Normal Null auf dem Feldberg (Rinne 2003, 2012a). Die Grabanlage I misst eine Fläche von 2,90 m x 9,65 m und ist damit größer als die der Grabanlage II mit 2,65 m x 7 m; Grab I befindet sich 60 m nördlich von Grab II (Rinne 2012b). Das Grab I wurde 1988 ausgegraben und vollständig untersucht, Grab II im Jahre 1989 entdeckt und 1990 in toto untersucht (Rinne 2012a, Rinne 2012b). Eine Datierung von Grab I mithilfe gewonnener 14C-Daten und archäologischen Funden führte zu unklaren Ergebnissen; es ergaben sich zwei Datierungsintervalle, die am wahrscheinlichsten zutreffen: 3310-3230 v. Chr. und 3110-3020 v. Chr. (Rinne 2003, 2012a). Möglich wäre aber auch eine Einordnung bis 2910 v. Chr. (Rinne 2003) bzw. nach 3000 v. Chr. (Rinne 2012a). In Grab II fanden sich deutlichere Hinweise auf eine Datierung in die Wartbergkultur (Rinne 2003, 2012a). Doch Funde an Keramik in Grab II lassen auch eine Einordnung in die Walternienburger Kultur bzw. die jüngste Phase der Tiefstichkeramik zu (Rinne 2012b). Die Datierung von Grab II mithilfe der 14C-Methode an vier Knochen- und zwei Holzkohleproben ergab eine Zeitspanne von etwa 3630-2920 v. Chr. (Rinne 2012b). Möglicherweise ist das Grab II eher der Wartbergkultur zuzuordnen und somit älter als das Grab I, welches eher der Bernburger Kultur zuzuordnen ist (Rinne 2003, 2012a).

Die Bauart der Gräber I und II weist Parallelen und Gemeinsamkeiten auf, so waren beispielsweise die Eingangskonstruktionen in gleicher Art und Weise gestaltet worden (Rinne 2003). Weiterhin liegen die beiden Gräber in direkter Nachbarschaft zueinander; Grab II liegt nur etwa 60 m entfernt von Grab I (Rinne 2012b). 
Grab II weist megalithische und nichtmegalithische Charakteristika auf; so besitzt der im Süden liegende Eingang einen Lochstein, der ein typisches Merkmal westfälischer und hessischer Gräber dieser Art ist (Rinne 2012b). Die Innenmaße der Kammer sind 2,6-2,7 x 7 m, wobei die Ausrichtung NNW-SSO-Richtung ist. In Grab II wurden ebenfalls zahlreiche Tierknochen und -zähne gefunden, denen zum Teil eine symbolische Bedeutung als Jagdtrophäen oder Trachtschmuck zugesprochen werden kann (Rinne 2012b).

Beide Gräber sind in ihrer Struktur über die Jahre verändert worden; so wurden sie offenbar erstmals durch die späthallstatt-/frühlatènezeitliche Siedlungstätigkeit gestört (Rinne 2003). Die jungneolithische Kammer von Grab I wurde weitgehend zerstört, was der schlechte Erhaltungszustand des Pflasters und der Knochenfunde belegen; jüngst war möglicherweise die Landwirtschaft für Störungen verantwortlich (Rinne 2003). Im Laufe der Zeit erfolgten verschiedenste Störungen, sodass sich Knochen nicht mehr in anatomischem Verband befanden oder zu Fragmenten zerbrachen.

Grab II wurde, wie Grab I, durch metallzeitliche Eingriffe gestört und in der Bronze- und frühen Eisenzeit nahezu zerstört; es wurden die Eingangssteine zerschlagen und versenkt und es fand ein großflächiger Eingriff in der Kammer statt (Rinne 2012b). Die Angaben bezüglich des Zeitpunktes der Zerstörungen stützen sich auf eine große Menge erhaltener Keramik, die im Grab II geborgen wurde (Rinne 2012b).

In Grab I konnten persönliche Beigaben - meist in Form von Pfeilbewehrungen aufgefunden werden (Rinne 2003, 2012a). Weiterhin wurden durchbohrte Tierzähne als Beigaben geborgen, die entweder Kleidungsaccessoires oder Schmuck gewesen sein könnten (Rinne 2003, 2012a). Es wurden auch Knochen von anderen Tieren wie Fuchs, Gans und Maulwurf entdeckt, die jedoch wahrscheinlich nicht im Zusammenhang mit dem Grab stehen; Knochenfunde von Hauskatze oder Schaf können allerdings als Speisebeigabe gedeutet werden (Rinne 2003, 2012a).

Es wurden 5700 Skeletfragmente in Grab I gesichert, unter denen sich auch Leichenbrand befand (Rinne 2003, 2012a). Das Fundgut befand sich in sehr stark fragmentiertem Zustand und die Skelete wurden verbandlos vorgefunden (Rinne 2003, 2012a). Es handelte sich um mindestens 15 Individuen, die allen Altersklassen zugeordnet sind und verschiedene pathologische Veränderungen aufweisen: Verheilte Sinusitiden, verheilte Meningitiden, intravitale Zahnverluste, Zahnabrasionen, Karies, Parodontitis, Spuren möglicher Stomatitiden, apicale Abszesse, Arthrose an Wirbeln und einem Großzehgelenk; weiterhin wurden Frakturen an Rippen und einem Wirbel festgestellt (Rinne 2003, 2012a). Die Befunde dieser Arbeit decken sich 
großenteils mit den angeführten Ergebnissen aus Grab I. So reichte die Altersspanne der Individuen aus Grab II ebenfalls von Infans bis Maturus - und sogar noch weiter als für Grab I angegeben - bis Senilis. Die Altersspanne für Grab I wurde von Rinne (2003, 2012a) mit Infans, Juvenis, Adultus bis Maturus angegeben. Die meisten Fundstücke, bei denen man das Alter zum Zeitpunkt des Todes feststellen konnte, lag bei Infans II bzw. Juvenis (Altersangabe ohne Zähne). Dass besonders viele Individuen anscheinend früh gestorben waren, ist aber wohl ein Trugschluss. Man bedenke, dass das Alter der nicht ausgewachsener Knochen deutlich einfacher und zuverlässiger bestimmbar ist, als das der ausgewachsenen (z. B. Szilvássy und Kritscher 1990, Rösing et al. 2005). Ging es um eine möglichst genaue Angabe des Sterbealters, so war dies nur für heranwachsende Individuen möglich. Die Knochen, die sich offensichtlich nicht mehr im Wachstum befanden, konnten folglich nur noch als „erwachsen“, also adult angegeben werden. Eine genauere Angabe war meist nicht möglich. Vergleicht man nun die Ergebnisse dieser Arbeit miteinander - also orientierende Angabe mit adult oder subadult und genauere Angabe in Jahreszahlen - so fällt auf, dass $48 \%$ (n = 96 von 200) der Fundstücke als erwachsen eingestuft werden konnten. Die Anzahl der subadulten mit 52\% ( $n=104$ von 200) war noch sehr hoch. Das liegt darin begründet, dass Knochensplitter, die nicht eindeutig zuzuordnen waren und weiter auch keine Wachstumsregionen wie Wachstumsfugen aufwiesen, trotzdem nicht eindeutig einem erwachsenen Individuum zugeordnet werden konnten. Es konnte ja nicht ausgeschlossen werden, dass der Teil mit Wachstumsfuge fehlt, der eine genauere Altersbestimmung möglich gemacht hätte. Um diese Fehleinschätzung zu vermeiden, wurden nur die Knochenfunde als adult eingestuft, die auch definitiv nur adult sein konnten - wenn also nahezu ausgeschlossen werden konnte, dass keine Wachstumsfugen fehlen. Diese Herangehensweise erlaubt demnach keine genaue Betrachtung des Altersdurchschnitts, weil die subadulten Fundstücke stets leichter erkennbar sind, als adulte. Waren bloß Splitter erhalten, die aber eine Wachstumsregion aufwiesen, wurden sie sofort als subadult gezählt. Betrachtet man das Durchschnittsalter der Zähne - welches entweder aufgrund des Wechselgebisses oder des Abrasionsgrades der Zähne bestimmt wurde - so ist der Altersdurchschnitt nicht mehr so auffällig jung. Hier fallen die meisten Fundstücke in den Bereich Adultus.

Eine deutliche Diskrepanz zwischen den Befunden und Ergebnissen für die beiden Gräber liegt in der Mindestindividuenzahl: Für diese Arbeit konnte eine MIZ von 43 anhand erhaltener rechter unterer 6-Jahres-Molaren angegeben werden. Vergleichsweise schlecht haben sich jedoch die postcranialen Skeletelemente erhalten, denn der am häufigsten erhaltene Knochen war das linke Sprungbein: 23 linke Sprungbeine wurden unter den Fundstücken aus Grab II nachgewiesen und dokumentiert. 
Was die pathologischen Befunde betrifft, so traten bei den Individuen aus Grab II ebenfalls mehrfach Spuren meningealer Reizungen auf. An 27 Schädelfragmenten konnten Spuren meningealer Reaktionen beschrieben werden; in fünf der Fälle mit Spuren einer meningealen Reizung handelte es sich vermutlich um eine überwiegend hämorrhagische Hirnhautreaktion, in einem weiteren Fall wohl eher um eine überwiegend entzündliche Hirnhautreaktion. Weiterhin fanden sich in sieben Fällen Spuren einer Sinusitis sphenoidalis, in zwei Fällen Spuren einer Sinusitis maxillaris und an zwei Schädelfragmenten konnte ein hypoplastischer Sinus frontalis nachgewiesen werden.

Bezüglich der Zahnbefunde können vergleichend folgende Angaben zu den Individuen aus Grab II gemacht werden: 70 intravitale Zahnverluste; Abrasionen bei $95 \%(n=69$ von 73$)$ der ersten Frontzähne, bei 85\% $(n=57$ von 67$)$ der zweiten Frontzähne, bei 84\% (n= 53 von 63) der Eckzähne, bei 85\% ( $n=74$ von 87) der ersten und bei 85\% ( $n=58$ von 68) der zweiten kleinen Backenzähne, bei 92\% ( $n=102$ von 111) der ersten großen Backenzähne, bei $89 \%$ ( $n=66$ von 74$)$ der zweiten großen Backenzähne und bei 82\% ( $=40$ von 49) der Weisheitszähne. Weiterhin konnte Karies bei $1 \%(n=1$ von 73$)$ der ersten Frontzähne, bei $1 \%(n=1$ von 66$)$ der zweiten kleinen Backenzähne, bei $8 \%(n=9$ von 110) der ersten großen Backenzähne, bei $16 \%$ ( $n=11$ von 70 ) der zweiten großen Backenzähne und bei 13\% ( $n=7$ von 52) der Weisheitszähne nachgewiesen werden. Apicale Prozesse wurden ebenfalls beobachtet und zwar bei $4 \%$ aller Zähne bzw. Kieferregionen, also insgesamt bei 22 Zahn-Kieferregionen. Parodontopathien wurden in 39\% der befundeten Zahn-Kieferregionen gefunden (absolut bei 114 Zahn-Kieferregionen). Bei 39 befundbaren Kiefern bzw. Kieferfragmenten waren Spuren von Stomatitiden festzustellen. Weiterhin konnten sechs Zähne gefunden werden, bei denen nur die Kronen - also der Schmelz - erhalten waren. Dies erinnert an zahlreiche Funde der Population aus Rheine: Auch da waren in zahlreichen Fällen nur Kronen erhalten; manchmal fanden sich noch deformierte Dentinreste in der Schmelzkrone. Möglicherweise war hierfür Hitzeeinwirkung verantwortlich, durch die das Zahnbein stärker schrumpfte als der Schmelz. Dabei löste sich das Dentin aus der Schmelzkrone oder platzte möglicherweise sogar regelrecht $\mathrm{ab}$.

Die Ursache für die Deformation des Dentins im Gegensatz zum Schmelz könnte darin begründet sein, dass das Zahnbein einen niedrigeren Mineralanteil (70 Gew.-\%) hat als der fast nur aus mineralischen Stoffen bestehende Zahnschmelz (96-97 Gew.-\%) (Mjør und Fejerskov 1986). Für Hitzeeinwirkung spricht zudem, dass diese einzeln vorliegenden Kronen eher porös wirkten und zudem eine andere Farbe angenommen haben, als andere Zahnfunde. Möglicherweise war jedoch die 
lange Bodenlagerung im sauren Milieu für die Deformationen und farblichen Auffälligkeiten an den Zähnen verantwortlich.

An 33 Wirbeln bzw. Wirbelfragmenten (alle Regionen und Gelenke mit inbegriffen) wurden Spuren von Arthrose festgestellt, bei einem Wirbel sogar eine Fraktur. Knochen des Fußes waren größtenteils nicht befundbar; Veränderungen im Sinne einer Arthrose konnten hier nicht erkannt werden.

\subsection{Zahnstatus}

Bei der Befunderhebung der Zähne und Zahnhalteapparate wurden Zahnerkrankungen und Erkrankungen des Zahnhalteapparates diagnostiziert und dokumentiert. Die Zähne wurden nicht gesondert nach Geschlecht aufgegliedert. Diese Vorgehensweise ist damit zu begründen, dass nur in wenigen Fällen Kriterien zur Geschlechtsbestimmung vorlagen.

Bei einem Gebiss eines Individuums aus der Population aus Calden konnten deutliche Spuren von Putzvorgängen der Zahnzwischenräume - mit einer Sonde z. B. aus Holz oder Knochen - beobachtet werden. Das Vorhandensein von Putzspuren lässt darauf schließen, dass die Individuen - zumindest der Population aus Calden - Fleisch gegessen haben, welches möglicherweise in Faserform in Zahnzwischenräumen hängen blieb, dort Parodontopathien förderte und ggf. mit Sonden als Putzinstrument entfernt wurde.

\subsubsection{Karies}

Zahnkaries gilt heute mit einer Häufigkeit von 95\% in den westlichen Industrieländern als Zivilisationskrankheit; sie kam allerdings bereits bei Individuen prähistorischer Zeit vor (Schultz 1982). Die Häufigkeit mit der Karies heutzutage auftritt kann mit der Aufnahme leicht fermentierbarer Kohlenhydrate in Verbindung gebracht werden; hierzu zählen u. a. kohlenhydratreiche und gezuckerte Nahrungsmittel (Eshed et al. 2006). Ein Beispiel eines archäologischen Zahnfundes mit Karies zeigt die Abb. 176.

Zur Kariesentstehung tragen aber auch in der Nahrung vorhandene Ionenzusammensetzungen metallischer Stoffe wie Eisen, Kupfer und Zink bei; während der Schmelzbildung (Amelogenese) werden sie in das Kristallgitter des Schmelzes eingelagert und zeigen einen kariostatischen Effekt, während andere - dabei ist Nickel hervorzuheben - einen kariogenen bewirken (Schneider 1986).

Das häufigere Auftreten von Karies an den zweiten Molaren im Vergleich zu den ersten in der Population aus Calden ist auffällig. Da die ersten Molaren die Zähne sind, die als erste bleibende Zähne durchbrechen und in der Regel dadurch länger 
als alle anderen Zähne kariogenen Substanzen ausgesetzt sind, würde man aufgrund der längeren Benutzung erwarten, dass eigentlich sie mehr Karies aufweisen.

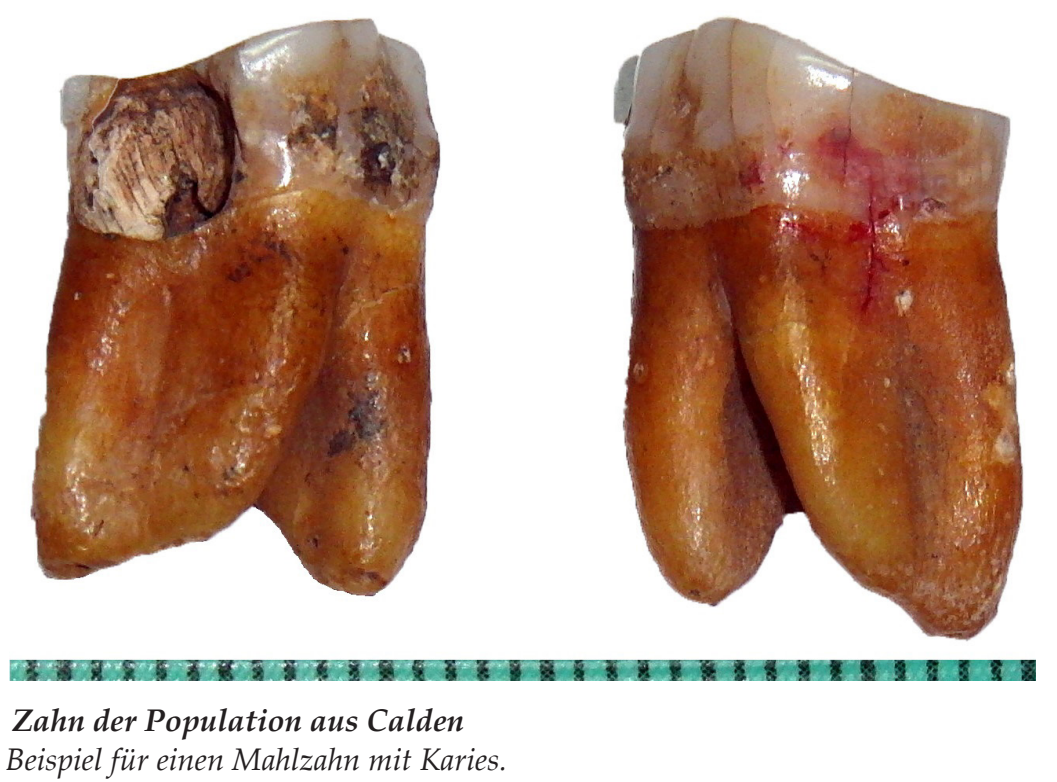

$A b b .176$

Beispiel für einen Mahlzahn mit Karies.

\subsubsection{Apicale Prozesse und Parodontopathien}

$\mathrm{Zu}$ den apicalen Prozessen fiel bei der Auswertung der Ergebnisse auf, dass sie überwiegend durch kariöse Infektionen der Zähne oder starke Abrasionen hervorgerufen wurden, selten aber durch Parodontopathien. Taschenbildungen konnten nur in wenigen Fällen beobachtet werden, obwohl die Häufigkeit von Parodontopathien allgemein im Fundgut der Population aus Calden bei etwa 65\% ( $\mathrm{n}=$ 354 von 545) lag (4\% Taschen; $\mathrm{n}=13$ ), in der Population aus Rheine bei etwa 71\% ( $\mathrm{n}=17$ von 24; keine Taschen) und in der Population aus Großenrode bei etwa 39\% $(\mathrm{n}=114$ von $294 ; 1 \%$ Taschen $(\mathrm{n}=1))$. Es wurden also häufig Parodontopathien diagnostiziert; Taschen fanden sich aber nur selten. Bei den Zahnfunden aus Calden könnte man eine Korrelation von neun apicalen Prozessen mit gleichzeitig diagnostizierten Taschen am selben Zahn annehmen. Insgesamt konnten bei der Population aus Calden 59 von 586 apicale Prozesse diagnostiziert werden (10\%). Für die Population aus Rheine liegt die Häufigkeit von apicalen Prozessen bei neun von 51 (18\%) und für die Population aus Großenrode bei 22 von 547 (4\%). Bei den beiden letzteren Populationen traten keine Taschen in Kombination mit apicalen Prozessen auf.

Dentale Abszesse und ausgeprägte, eitrige Parodontopathien können im Oberkiefer mit Sinusitiden der Kieferhöhle in Verbindung gebracht werden (Schultz et al. 2008), besonders bei den Oberkieferprämolaren und -molaren. Die Häufigkeit der 
Sinusitiden, beispielsweise des Sinus maxillaris war sehr hoch bei den Populationen aus Calden und Großenrode. Für die Population aus Rheine sind dazu keine Aussagen möglich, da die Fundstücke zumeist unbefundbar waren. In der Population aus Calden waren apicale Prozesse nur in $22 \%(n=13$ von 59) der Fälle größer als Grad II. Die Gradierung reicht bis Grad V; dieser wurde aber in keiner der Populationen erreicht. Grad IV wurde in der Population aus Calden in drei Fällen (5\%) festgestellt und trat in den Populationen Rheine und Großenrode gar nicht auf. Diese Zahlen sprechen eindeutig gegen eine generelle Korrelation von Kieferhöhlenentzündungen und apicalen Prozessen. Es müsste schon mindestens ein Grad III erreicht sein, um eine Beteiligung der Kieferhöhle nachzuweisen. Bei den drei Fällen aus Calden mit Gradierung IV handelte es sich um die Regionen der Zähne 16, 18 und 47. Nur die erst genannten Zähne kommen dabei überhaupt infrage, eventuell eine entzündliche Reaktion der Kieferhöhle hervorgerufen zu haben. Die entsprechenden Regionen befanden sich in Heilung, nachdem die Zähne intravital verloren gegangen waren; dabei waren die Alveolen zum Todeszeitpunkt noch nicht verschlossen. Ein mögliches Szenario wäre in diesem Fall, dass tatsächlich eine odontogene Sinusitis maxillaris und ihre Ausbreitung über einige Zeit eine Sepsis hervorgerufen und dann nach wenigen Tagen zum Tode geführt hat. Das würde erklären, warum die Alveolen genau dieser Zähne noch nicht vollständig verschlossen waren.

Schwere, eitrige Parodontopathien kamen in der Population aus Rheine nicht vor. Grad IV und V konnten nicht festgestellt werden. Bei der Population aus Calden gab es drei Fälle (1\%) mit Grad V und neun Fälle (3\%) mit Grad IV. Die anderen 327 (97\%) dokumentierten Fälle von Parodontopathien entsprachen Grad I, II oder III. Vier der Fälle betrafen Prämolaren oder Molaren des Oberkiefers; diese wiesen Grad IV auf. Eine Entzündung der Kieferhöhle aufgrund dieser Parodontopathien wird in diesen Fällen nicht angenommen. Bei der Population aus Großenrode gab es einen Fall mit Grad I (1\%) und vier Fälle mit Grad IV (4\%). Die anderen 95\% ( $n=109$ von 114) repräsentierten Grad III oder weniger. Von diesen betraf nur einer (Grad IV) den Oberkiefer-Seitenzahnbereich. Jedoch konnte hier an dem entsprechenden Oberkieferfragment keine Spur einer Sinusitis maxillaris festgestellt werden.

\subsubsection{Abrasionen}

Zahnabrasionen sind ein multifaktorielles Geschehen. Sie werden durch Zusammensetzung und Konsistenz der Nahrung sowie Kultur, Alter und Geschlecht der Individuen beeinflusst (Eshed et al. 2006). Der zum Teil sehr hohe Grad an Abrasionen (Vergleich Abbildungen 177, 179, 180 und weitere Aufnahmen bei den Befunden im Anhang) und ihre große Häufigkeit könnten folgende Hintergründe haben: Zum einen kann anhand der Zahnfunde angenommen werden, dass die 
Neolithiker aus Calden, Rheine und Großenrode faserreiche Nahrung zu sich genommen haben, zum anderen kann durch Mahlen von Nahrungsbestandteilen (anzunehmen ist in diesem Fall Getreide) ein erhöhter Anteil aus Staub von Mahlsteinen in die Nahrung gelangt sein - wie es bei vor- und frühgeschichtlichen Ackerbauern üblich war. Weiterhin geben einige Fundstücke Hinweise darauf, dass die Zähne auch als Werkzeug verwendet wurden. Dabei wurden Gegenstände immer wieder in ähnlicher Art und Weise zwischen die Zähne genommen, die z. B. als Schneidewerkzeuge für Kornwickel oder als Haltewerkzeug bei der Herstellung von Utensilien genutzt wurden. Bei zahlreichen Zahn-/Kieferfundstücken der Populationen aus Calden, Rheine und Großenrode war eine schräg abradierte Zahnfläche zu beobachten. Das mit den Zähnen bearbeitete Material wurde z. B. für die Herstellung von Körben stets in ähnlichem Winkel angesetzt (Siehe Abb. 178) und hinterließ das beschriebene signifikante Abrasionsmuster (Eshed et al. 2006). Es entstand ein Zahnbogen, in den die Zähne schräg hineinrutschten und einen halbmondförmigen Rand von Schmelz hinterließen, nachdem der Rest der Krone abgeschert worden war (Abbildungen 177 und 180) (vgl. Anderson 1965).

Anderson (1965) beschrieb zudem eine generelle Abhängigkeit bestimmter Abrasionsmustern von Ernährungsgewohnheiten. Dabei gibt Anderson (1965) verschiedene Zeitspannen an, in denen je nach Entwicklungsgrad der Zivilisation verschiedene Abrasionsmuster anzutreffen waren. Frühe Phasen beschreibt er u. a. mit der Nutzung der Zähne als Werkzeug. In späteren Phasen kam es weniger zu Abrasionen der Frontzähne und auch die Seitenzähne zeigten etwas weniger Abrasionsspuren (Anderson 1965). Dennoch ist der Abrasionsgrad der Molaren noch immer als hoch einzustufen, da gemahlenes Getreide einen recht hohen Sandanteil enthielt, was dann zu Abrasionen der Molaren führte (Anderson 1965). Diese Abrasionen waren aber zumeist flach und nicht schräg (Anderson 1965). 


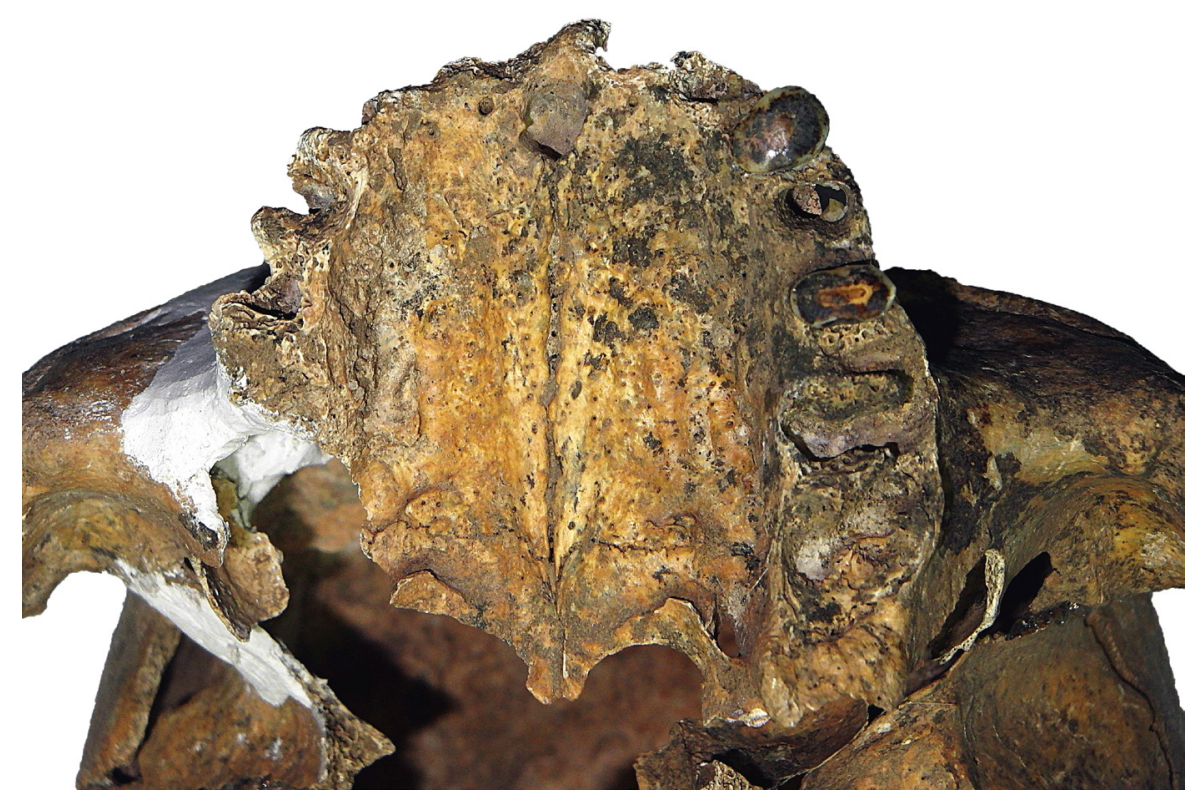

Abb. 177

Beispiel für sehr stark abradierte Zähne (linke Oberkieferseite)

Dieser Oberkiefer der Population aus Calden weist im 2. Quadranten Seitenzähne mit sehr starken Abrasionen bis in die Nähe des Knochenniveaus auf.

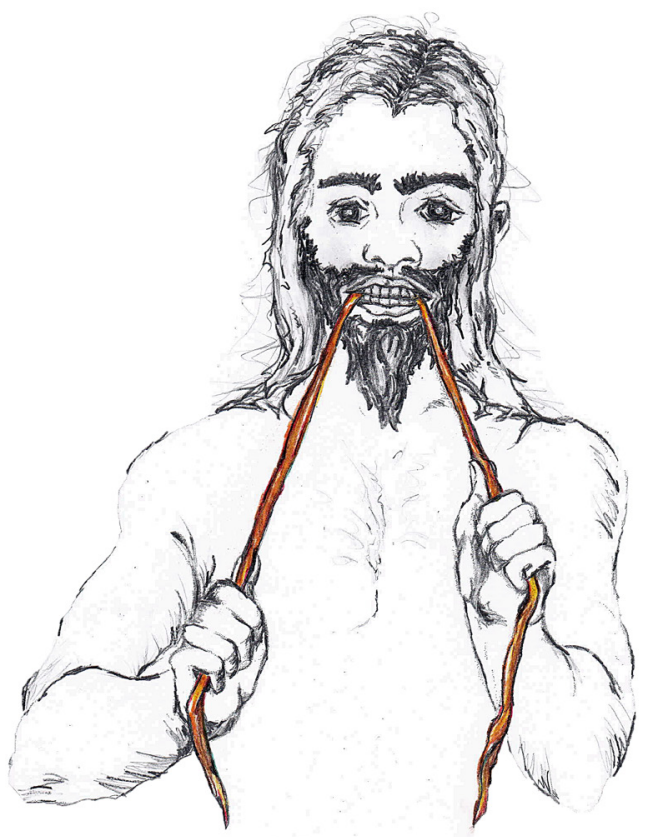

Abb. 178 Beispielzeichnung zur Verwendung der Zähne als Werkzeug Zeichnung freundlicherweise für diese Arbeit erstellt von Andrea Cyris (modifiziert nach Eshed et al. 2006). 

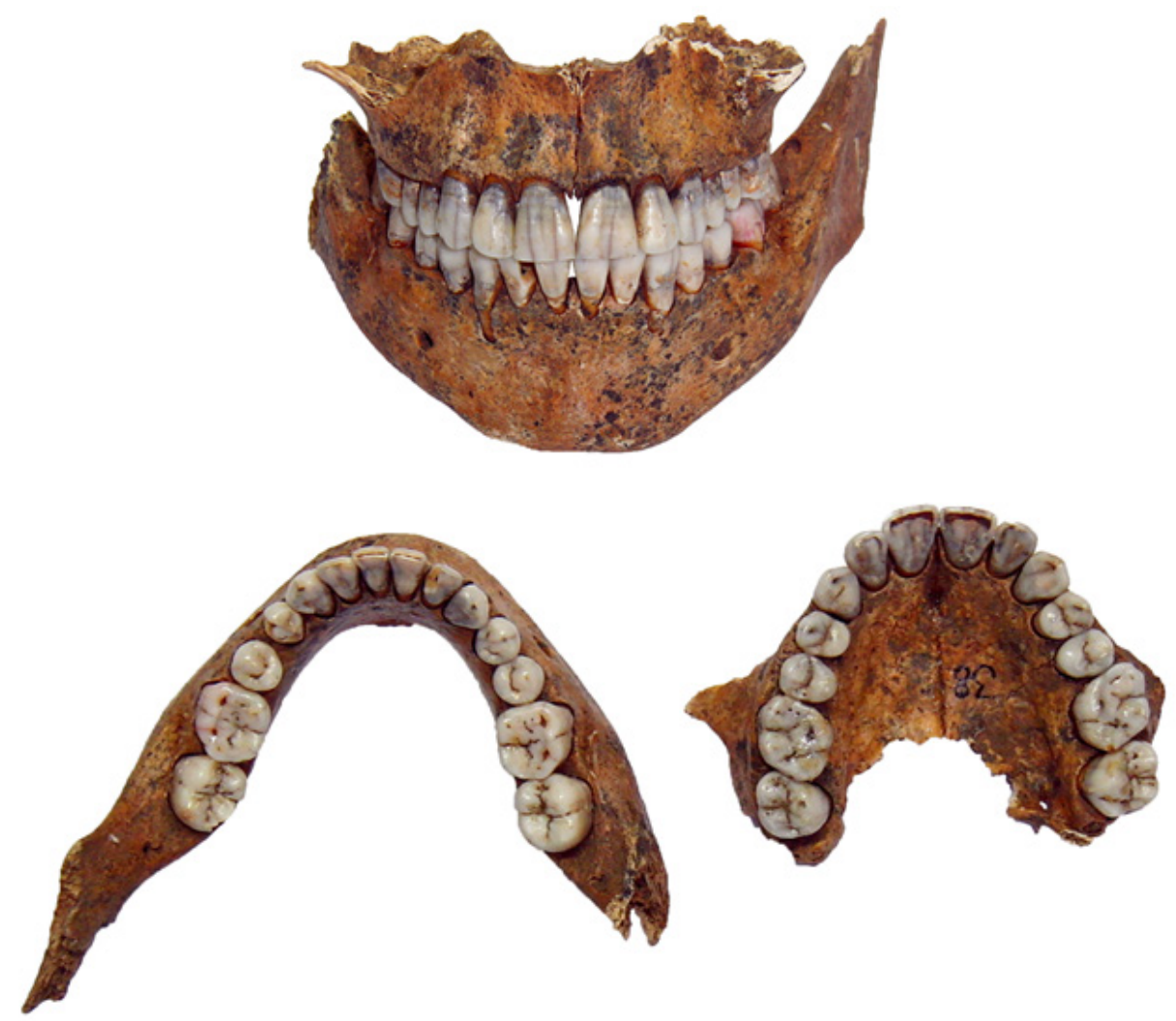

Abb. 179

Kiefer der Population aus Calden (Beispiel 1)

Beispiel für ein recht junges Individuum mit nicht so stark abradiertem Gebiss.
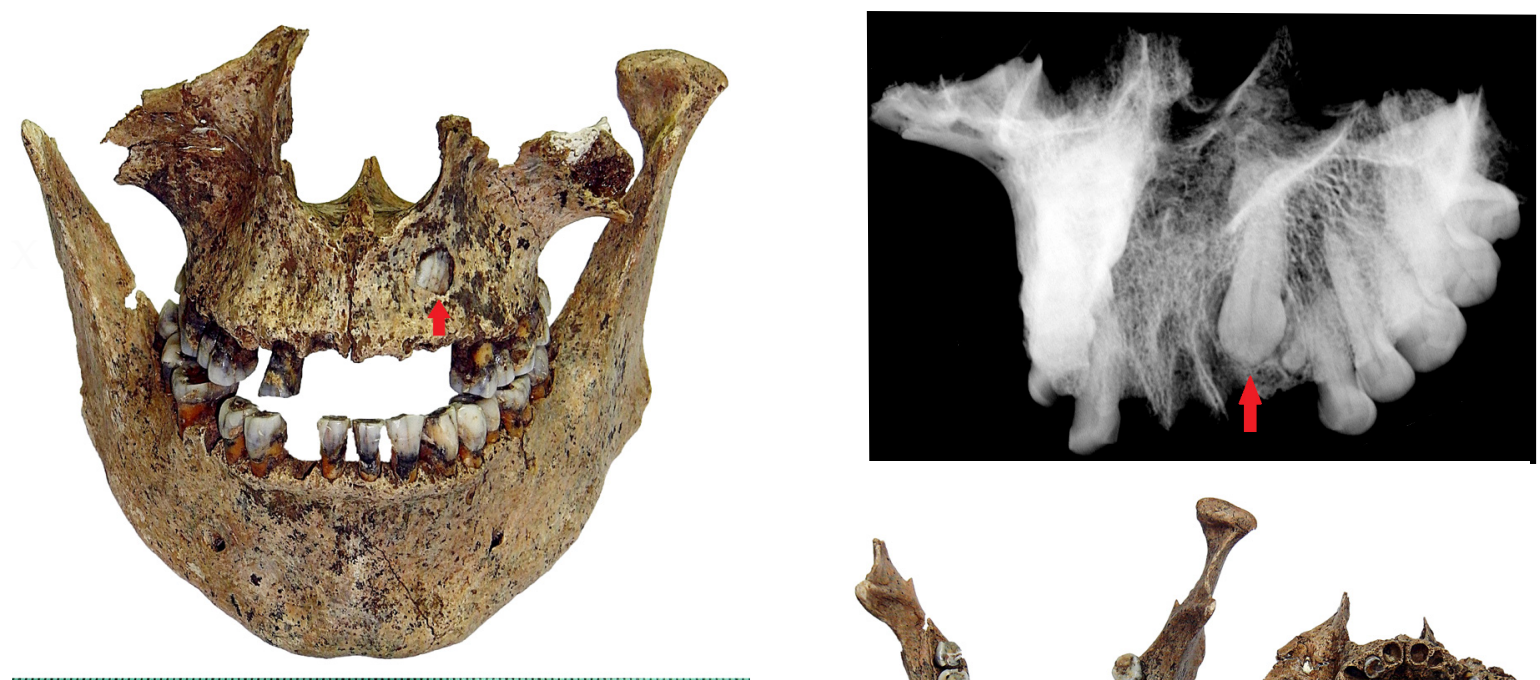

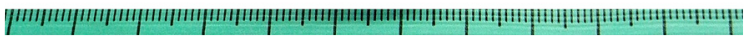

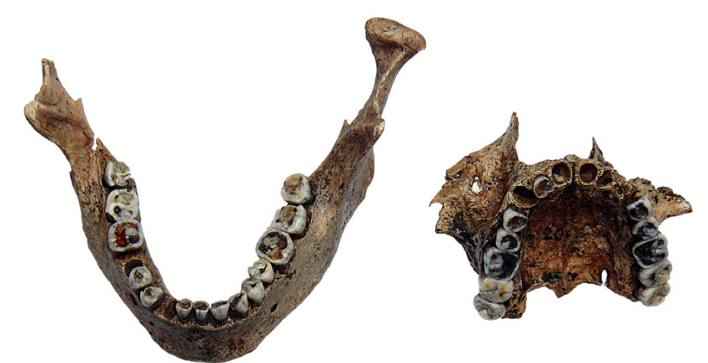

Abb.180 Kiefer der Population aus Calden (Beispiel 2)

Beispiel für ein älteres Individuum mit stärkeren Abrasionsspuren der Zähne nach Nutzung als Werkzeug. Weiterhin fällt ein retinierter und verlagerter linker, oberer Eckzahn auf (Pfeile), der auch im Röntgenbild gut zu sehen ist. Weiterhin sind deutliche parodontale Schäden am Gebiss zu erkennen: Ein horizontaler Knochenabbau von etwa $2 \mathrm{~mm}$. 


\subsection{Sinusitiden}

Bei einigen Kieferhöhlen der Individuen der Populationen aus Calden und Großenrode fanden sich Spuren einer chronischen Sinusitis maxillaris, die sich als plattenförmige Auflagerungen im Sinne von knöchernen Neubildungen darstellten, wie sie auch Schultz (1987) beschrieb. Sinusitiden können starke Schmerzen hervorrufen und sogar durch eine Sepsis zum Tod führen (Schultz et al. 2008).

In der Population aus Calden konnte bei 70\% ( $\mathrm{n}=23$ von 33) der erhaltenen und befundbaren Stirnhöhlen eine Sinusitis frontalis festgestellt werden, bei $88 \%$ $(n=15$ von 17$)$ der Kieferhöhlen eine Sinusitis maxillaris, bei 86\% ( $n=6$ von 7$)$ der Keilbeinhöhlen eine Sinusitis sphenoidalis.

In der Population aus Rheine haben sich keine auswertbaren Fundstücke bezüglich nachweisbarer Veränderungen an Nasennebenhöhlen erhalten.

Die Funde der Population aus Großenrode enthielten Schädelfragmente mit entsprechenden Nasennebenhöhlen. Hier war bei $75 \%$ ( $n=12$ von 16) der Stirnhöhlen eine Sinusitis frontalis festzustellen, bei $67 \%(\mathrm{n}=2$ von 3 ) der Kieferhöhlen eine Sinusitis maxillaris, bei 78\% ( $\mathrm{n}=7$ von 9) der Keilbeinhöhlen eine Sinusitis sphenoidalis. Eine chronische, möglicherweise granulomatöse Rhinitis hatte bei einem Schädel eines Individuums aus Calden eine Periostreizung hervorgerufen, welche im Zuge einer entzündlichen Reaktion charakteristische Spuren am Knochen hinterlassen hat. Die Entzündung breitete sich über die Nasennebenhöhlen aus und führte möglicherweise sogar zu einer Pansinusitis.

Das gehäufte Auftreten von Sinusitiden könnte mit den Lebensverhältnissen der Menschen der hier untersuchten Populationen erklärt werden. Schlechte Atemluft (z. B. durch Stäube und Feuerqualm) wäre deutlich plausibler als dentale Ursachen (Roberts 2007). Diese Aussage konnte in der vorgelegten Arbeit unterstützt werden. Nur in wenigen Fällen konnten dentale Abszesse festgestellt werden, die die Knochenwände durchbrochen hatten. In mindestens einem Fall - der Population aus Calden - konnte jedoch in diesem Zusammenhang von einer odontogenen Sinusitis maxillaris ausgegangen werden.

\section{Meningeale Reaktionen}

Bei der Population aus Calden konnten an 21 von 84 befundbaren Schädelfunden Spuren einer meningealen Reaktion gefunden werden. Das entspricht einer Häufigkeit von 25\%. Bei der Population aus Rheine wurde an einem von 24 Schädelfragmente (4\%) eine meningeale Reizung festgestellt und bei der Population aus Großenrode an 27 von 69 Schädelfunden (39\%). Die Spuren der hier beobachteten Hirnhautreaktionen manifestierten sich z. B. entlang der Rinne des Sinus 
sagittalis superior (vgl. Schultz et al. 2014). Es kommen verschiedene Ursachen für die Entstehung der meningealen Reizungen in der Population aus Calden in Betracht. Als wahrscheinlichste Ätiologie sind bakterielle Entzündungen anzunehmen. In 19 von 21 Fällen war eine meningeale Reizung vergesellschaftet mit einer weiteren Erkrankung: Neun Fälle einer Reizung des Meatus acusticus externus, 13 Fälle eines entzündlich-hämorrhagischen Prozesses der venösen Hirnblutleiter (perisinuöser Prozess), sieben Fälle einer Sinusitis frontalis, neun Fälle einer Cribra orbitalia, zwölf Fälle einer Kopfschwartenreizung bzw. -entzündung, vier Fälle einer Sinusitis maxillaris und einer Sinusitis sphenoidalis. Nun ist es natürlich post mortem schwierig nachzuvollziehen, ob diese Spuren verschiedener Erkrankungen im Kopfbereich kausal miteinander in Verbindung standen, sich gegenseitig hervorriefen oder unabhängig voneinander auftraten. Besonders schwierig ist es dann, wenn sie zeitlich zusammen aufgetreten waren, weil Entzündungen zur gleichen Zeit an verschiedenen Orten auftreten können, ohne miteinander in Verbindung zu stehen. Das Alter eines Entzündungsprozesses ist in manchen Fällen an Spuren des anschließenden Heilungsprozesses - zum Beispiel an Narben - zu erkennen. Der Immunzustand eines solchen Individuums war wahrscheinlich zeitweise - besonders zur Winterszeit - sehr eingeschränkt. Dann konnte der Körper Entzündungsreizen weniger trotzen und wurde in den immunologischen Tiefs möglicherweise tatsächlich an verschiedenen Schädelregionen zur selben Zeit infiziert. Dieses Szenario ist nicht auszuschließen, dennoch ist beim Auftreten bestimmter Konstellationen von Entzündungen im Kopfbereich auch ein kausaler Zusammenhang möglich, der tatsächlich an einigen Fundstücken nachvollziehbar war. So konnten regelrechte Durchbruchspuren einer Entzündung beobachtet werden. Zumeist war der primäre Ursprungsort nicht sicher nachweisbar, wenn auch eine Ausbreitung in die eine oder andere Richtung plausibel schien.

\subsection{Cribra orbitalia}

Cribra orbitalia ist ein Begriff zur Beschreibung einer siebartigen und porösen Oberfläche des Orbitadachs, die als Erweiterung der Diploë und Verdünnung der Lamina externa mit Auftreten kleiner Öffnungen (wie in einem Sieb) verstanden werden kann (z. B. Welcker 1885, 1888, Naveed et al. 2012, Steyn et al. 2016); weiterhin bezeichnet der Begriff Auflagerungen bei Hämorrhagien von beispielsweise Skorbut (ausgelöst durch chronischen Vitamin-C-Mangel) oder Rachitis (ausgelöst durch chronischen Vitamin-D-Mangel). Als Ursachen werden vornehmlich Anämien, aber auch Entzündungen oder Nahrungsmittelmangel angenommen (z. B. El-Najjar et al. 1976, Wapler et al. 2004).

Seit einiger Zeit herrscht Uneinigkeit darüber, ob es vornehmlich Anämien sind, 
die Cribra orbitalia hervorrufen; an 333 nubischen Schädeln konnte mit lichtmikroskopischen Methoden gezeigt werden, dass mindestens 56,5\% der dort gefundenen Cribra orbitalia-Fälle nicht durch anämische Prozesse entstanden sind, vielmehr konnten in 56,5\% der Fälle die Veränderungen auf Entzündungen, Osteoporose oder Pseudopathologien zurückgeführt werden (Wapler et al. 2004). Cribra orbitalia kann neueren Erkenntnissen zufolge als nichtspezifischer Stressindikator von Mangelernährungen oder Infektionskrankheiten angesehen werden (Schultz und Schmidt-Schultz 2014).

Cribra orbitalia ist aber keineswegs das Merkmal einer Erkrankung vergangener Zeiten; auch in der heutigen Zeit ist sie anzutreffen und das zum Teil in ähnlichem Ausmaß oder in manchen Regionen sogar häufiger als bei prähistorischen Populationen (Steyn et al. 2016, vgl. Götz 1988). Vergesellschaftete Begleiterscheinungen einer Cribra orbitalia können unter anderen eine Einengung des Canalis opticus um bis zu $1 \mathrm{~mm}$ sein - was durch die veränderte Struktur von Diploë und Corticalis zu erklären ist - wie auch die Abnahme an Knochendichte des Orbitadachs (Naveed et al. 2012).

Bei der Population aus Calden konnte an 31 Schädelfundstücken ( $\mathrm{n}=27$ von 33; $82 \%$ rechte Orbitadächer und $n=22$ von $26 ; 85 \%$ linke Orbitadächer) eine Cribra orbitalia des Orbitadachs nachgewiesen werden, bei der Population aus Rheine waren jedoch keine Spuren einer Cribra orbitalia zu finden. Bei der Population aus Großenrode konnte an 17 Schädelteilen ( $n=8$ von 9; 89\% rechte Orbitadächer und $\mathrm{n}=6$ von $6 ; 100 \%$ linke Orbitadächer) eine Cribra orbitalia gefunden werden.

Die Betrachtung dieser Werte gibt Hinweise auf Stressmarker, die auf chronische Mangelernährungen und/oder Infektionskrankheiten in den Populationen aus Calden und Großenrode hinweisen.

\subsection{Traumata an den Schädelfunden}

Von der Population aus Calden lagen größere Fragmente von insgesamt sechs Schädeln vor, die möglicherweise verheilte Schädelverletzungen aufwiesen. Bei dem gut erhaltenen Schädel "Calden 30 “ fand sich ziemlich mittig oben auf der Schädeldecke eine erhabene Abflachung. Dieser Bereich wurde möglicherweise durch eine stumpfe Gewalteinwirkung entlang der Körperachse auf die Schädelbasis eingedrückt, jedoch nicht vollständig durchbrochen. Von dem Schädel wurde ein DVT angefertigt, um eine überlagerungsfreie Darstellung der Schädelstrukturen im Schichtbildverfahren (vgl. Herrmann 1988b) zu bekommen. Alle Schädelkompartimente konnten so noch einmal detailliert untersucht und die verschiedenen Schichten des DTV begutachtet werden. Hierbei konnte ein Durchbruch der traumatischen Verletzung 
oben auf der Schädeldecke ausgeschlossen und die differierende Knochendicke in und neben der Frakturzone begutachtet werden. Durch eine rein makroskopische Begutachtung hätten diese Informationen nicht gewonnen werden können.

Die Abbildungen 181 bis 184 zeigen den beschriebenen Befund oben auf der Schädeldecke des Schädels 30 aus Calden. Das Trauma ist abgeheilt, zog aber eine Reizung des Periosts nach sich, was an der leicht erhabenen Knochenneubildung in dem Bereich der Abflachung zu erkennen ist. Dort finden sich die typischen Spuren, die auch eine Kopfschwartenreizung hinterlässt: Leicht poröse Knochenoberfläche und Erhabenheiten. Möglicherweise war durch das Trauma auch eine offene Weichgewebeverletzung entstanden, die eine Eintrittspforte für Krankheitserreger darstellte. Diese Krankheitserreger könnten dann einen entzündlichen Reiz der Knochenhaut hervorgerufen haben. Dieser Befund eines Schädeltraumas zeigt deutlich, wie eng verschiedene Befunde miteinander verwoben sein können. Das vorausgegangene Trauma führte wahrscheinlich zu einer lokalen Entzündung des Periosts, welche zu den zuvor beschriebenen Veränderungen der Knochenoberfläche führte. Im Zuge dieses Prozesses hat sich lokal in der direkten Umgebung des Traumas Knochen als Reaktion auf die Entzündung neu gebildet. Dabei lagerte sich poröser, neu gebildeter Knochen auf die ursprüngliche Knochenoberfläche auf (vgl. auch Schultz 2011a). Die Fraktur sowie auch die lokale periostale Entzündungsreaktion heilten offenbar komplikationslos ab. 

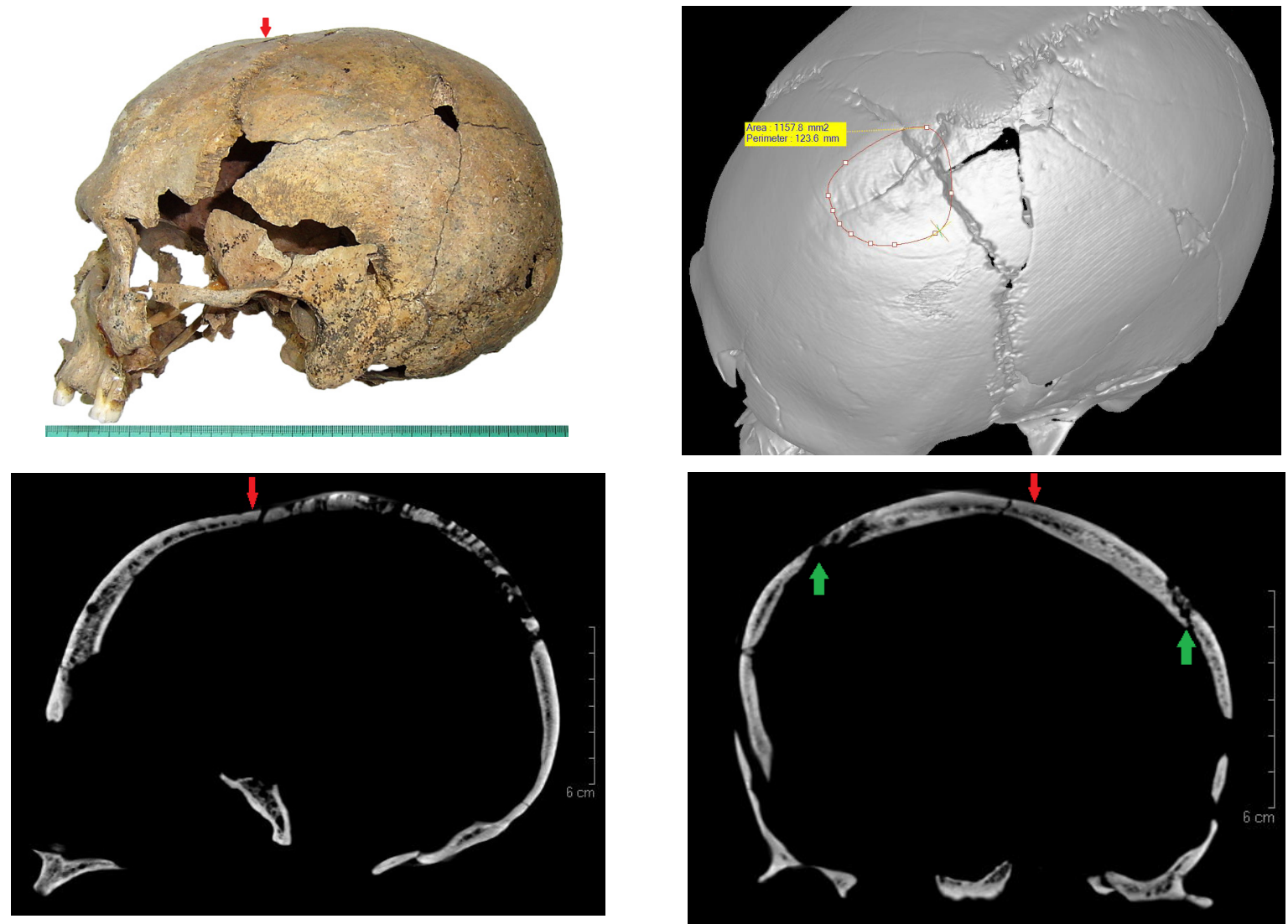

$A b b .181$

Links oben: Übersichtsaufnahme der linken Seite des Craniums "Calden 30" Der Pfeil markiert die Region mit der Abflachung.

Abb. 182 Rechts oben: DVT des Cranium "Calden 30“

Der abgeflachte Bereich wurde eingekreist und gemessen (gelber Kasten im Bild). Die Fläche ist etwa $1150 \mathrm{~mm}^{2}$ groß.

Abb. 183 Links unten: DVT des Cranium "Calden 30" in sagittaler Ansicht Der Pfeil markiert die abgeflachte Stelle.

Abb. 184

Rechts unten: DVT des Cranium "Calden 30" in coronaler Ansicht

Der rote Pfeil markiert die Abflachung, die grünen Pfeile markieren die Sutura coronalis, links neben dem roten Pfeil ist die Sutura sagittalis zu sehen.

Der Schädel 29 der Population aus Calden wies drei verheilte knöcherne Verletzungen auf; davon befand sich eine links am Os frontale, eine rechts am medialen Orbitarand und eine weitere kleine auf der rechten Schädelseite. Die Verletzungen am Knochen sind flächenmäßig allesamt sehr klein. Als Ursachen kommen beispielsweise eine kriegerische Auseinandersetzung oder ein Sturz in Betracht. Aber auch eine Jagdverletzung - verursacht durch Raubtiere - ist denkbar. Die am Knochen sichtbaren Spuren gehen offenbar auf eine Knochenneubildung im Gefolge einer Knochenhautreaktion zurück, die durch umschriebene lokale Weichgewebeverletzung in der betreffenden Region entstanden sein könnten.

Der Schädel C28, der detailliert im Befundkatalog vorgestellt wird, zeigt deutliche Spuren einer Hiebverletzung (Abb. 185). 


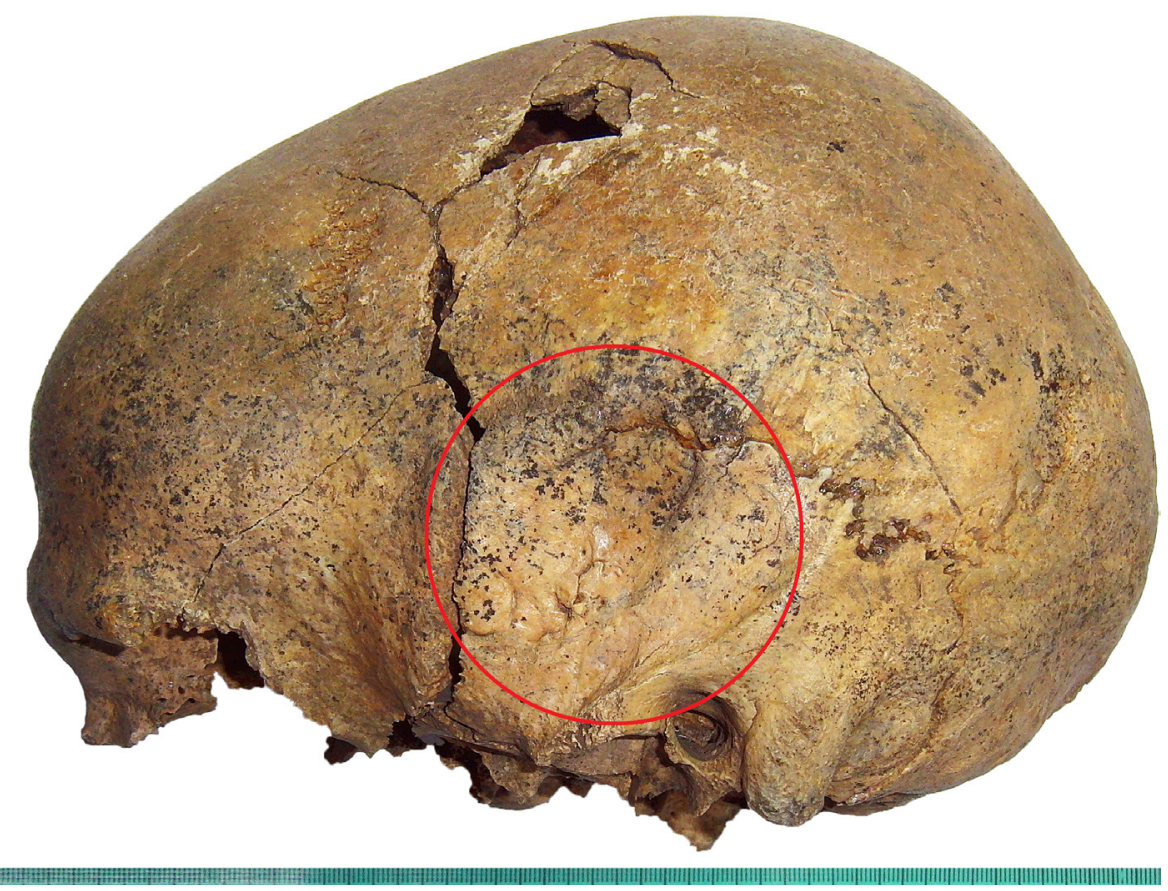

Abb. 185

Trauma am Schädel C28; Calden

Das Cranium 28 weist eine verheilte Fraktur der linken Seite auf (roter Kreis).

Das Individuum überlebte die Attacke. Das ist daran zu erkennen, dass die Fraktur des Schädels eine vernarbte Knochenstruktur im Sinne des Heilungsprozesses an der Schädeldecke aufweist. Vergleicht man dieses Schädeltrauma nach äußerer Gewalteinwirkung mit anderen Hiebverletzungen, z. B. aus der Eisenzeit, so fällt auf, dass das klassische Muster einer Frakturbildung bei C28 nicht mehr erkennbar ist, da die Läsion gut verheilte. Die anzunehmende Größe und das Ausmaß der ursprünglichen Verletzung entsprechen nicht einer Klingenwaffe der Eisenzeit. Klingenwaffen hinterlassen häufig ein signifikantes Muster, nachdem sie den Knochen durchdrungen haben. Bei einer Impressionsfraktur ist der Defekt, beispielsweise bei einer Lochfraktur, häufig so geformt wie es die Form der Waffe vorgibt. Dies gilt prinzipiell auch bei Hiebverletzungen, die mit einer scharfen oder spitzen Waffe ausgeführt wurden (z. B. Murphy und Davis-Kimbal 2015). Der verheilten Verletzung an C28 fehlt ein derartig definiertes Aussehen. Das Aussehen dieser Läsion spricht eher für eine Waffe mit stumpfer, unregelmäßiger Form, wie z. B. eine steinerne Hammeraxt. Die hier vorgestellte Läsion kann auch nicht als eine verheilte Trepanation - also eine chirurgische Eröffnung des Schädeldachs - angesehen werden, wie sie Schultz (1995) an frühbronzezeitlichen Schädeln Nordanatoliens von der Fundstelle İkiztepe beschrieben hat oder wie Schultz et al. (2006) sie an gefundenen Trepanationen Jordanischer Schädelfunde als damals wohl älteste bekannte chirurgische Interventionen an der Schädeldecke bezeichnet haben. Inwiefern nach dem Trauma eine Hirnschädigung bei dem Individuum vorlag, ist post mortem 
schwierig zu sagen. Es ist jedoch keine Seltenheit, dass Individuen mit Kompressionstraumata überleben und die Frakturen gut ausheilen (Weber und Czarnetzki 2001). Die ausgeheilte Region am Schädel 28 wurde bisher stets als eine Fraktur beschrieben. Ob es wirklich eine Fraktur gewesen ist - bei allen typischen Merkmalen, die diese Region aufweist - bleibt nicht endgültig beweisbar. Es sollte daher auch eine andere Ursache für die verheilte Schädeldecke mit in Betracht gezogen werden. So soll z. B. die Heilung einer Langerhans-Zell-Histiozytose - oder eines Eosinophiles Granuloms des Schädels als eine Varietät - ein ähnliches Bild am Schädel hinterlassen, wodurch selbst Fachleute es manchmal kaum von einer heilenden Fraktur unterscheiden können (Steinbok 2015).

Ein Aspekt, der bisher noch nicht angesprochen wurde, ist, dass es sich bei den sechs Schädeln, die verheilte Spuren einer Fraktur aufweisen, bei vieren eher um weibliche Individuen handelt. Einer war keinem Geschlecht zuzuordnen und einer stammt von einem männlichen Individuum. Fibiger (Schulting und Fibiger 2012) erklärte das Phänomen verletzter weiblicher Individuen so, dass sie wahrscheinlich weniger die Aggressoren einer tätlichen Auseinandersetzung waren, sondern mehr die Opfer.

Dass die Verletzungen ausheilten, könnte darauf zurückzuführen sein, dass die Individuen bereits damals über ein ausgeprägtes Sozialverhalten verfügten und dass Kranke und Schwache geschützt und gepflegt wurden. Weiterhin waren möglicherweise bereits Kenntnise über die Heilkunde menschlicher Körper vorhanden. Durch sozialen Zusammenhalt und entsprechende Pflege konnten Individuen nach Verletzungen genesen.

\subsection{Chronische Mittelohrentzündungen}

\subsubsection{Mittelohrentzündungen}

Mittelohrentzündungen haben stets die Tendenz, sich auszubreiten. In schweren Krankheitsverläufen können sie zu Mastoiditiden, Meningitiden und Hirnabszessen führen. Eine Ohrentzündung, die sogar das Os temporale perforierte und ein 9 x 8 mm großes Loch hinterließ, wurde von Slater (1994) an einem mazerierten Schädel beschrieben. Weiterhin können Mittelohrentzündungen zu potentiell tödlichen Meningitiden führen (Bates und Drake-Lee 1988, Schultz und Bátora 2001). Es müssen aber nicht immer fatale Konsequenzen sein, die aus chronischen Ohrentzündungen entstehen. Ein banal erscheinender Aspekt ist beispielsweise, dass Ergüsse im Mittelohr zu schlechterem Hören führen können, was bei Kindern zu einer eingeschränkten Sprachentwicklung und Problemen der kognitiven Entwicklung beitragen kann (Klein 1994). 
Spuren von Mittelohrentzündungen konnten bei der Population aus Calden in 17 Fällen gefunden werden und bei der Population aus Großenrode in sechs. Bei der Population aus Rheine konnten keine diesbezüglichen Krankheitsfälle festgestellt werden. In neun Fällen war die Mittelohrreizung bei der Population aus Calden mit einer meningealen Reizung vergesellschaftet und in sechs Fällen mit einer Perisinusitis der inneren venösen Blutleiter des Schädels. Bei der Population aus Großenrode traten drei Fälle einer Mittelohrreizung mit einer meningealen Reizung auf und in einem Fall mit einer Perisinusitis der venösen Blutleiter des Schädels. Diese Beobachtung lässt die Vermutung zu, dass es sich um Entzündungen mit Ausbreitungstendenz gehandelt hatte. Von welchem Entzündungsherd die verschiedenen Entzündungsgebiete ausgingen, ist nicht mehr nachzuvollziehen, es liegt aber die Vermutung nahe, dass es jeweils primär zu einer Mittelohrentzündung gekommen war.

\subsubsection{Veränderungen am äußeren Gehörgang}

Poröse Veränderungen in der Region des Porus acusticus, also oberhalb des Dachs des äußeren Gehörgangs, waren bei der Population aus Calden fünfmal zu finden, bei der Population aus Großenrode viermal. Ein oberhalb des Porus acusticus externus gelegenes, gereiztes Areal kann für eine Otitis externa sprechen. Die Spuren dieser Erkrankung werden mit häufigem Wasserkontakt in Verbindung gebracht; so findet man sie bei Populationen, die in Wassernähe lebten (Baggieri und di Diacomo 2002).

Es sei am Rande erwähnt, dass die Population aus Calden in der Nähe von Wasser lebte. In Calden befinden sich zwei Quellen, die die Calde speisen. Diese Quellen liegen in der Nähe der Gebiete, die damals von den prähistorischen Individuen bewohnt wurden. Diese örtliche Nähe der Besiedlungen zu Wasser mit allen Otitiden in Verbindung zu bringen, erscheint allerdings etwas abwegig, da nicht davon ausgegangen werden kann, dass Individuen sich häufig im Quellwasser oder in der Calde aufgehalten haben. Dennoch ist dieser Aspekt in Betracht zu ziehen, da vielleicht die eine oder andere Otitis externa tatsächlich durch einen häufigeren Wasserkontakt entstanden war.

\subsubsection{Veränderungen am Warzenfortsatz}

Die Untersuchung inwieweit ein Mastoid pneumatisiert war, wurde entweder mit dem konventionellen Röntgenverfahren vorgenommen oder - wenn das Mastoid bereits durch postmortale Beschädigungen gefenstert war - durch makroskopische Betrachtung der Cellulae mastoideae. 
Eine Hypopneumatisation des Warzenfortsatzes kann primär durch Mangelentwicklung der luftgefüllten Räume im Mastoid im Kindesalter oder sekundär durch Obliteration dieser Räume im späteren Leben - beispielsweise nach Entzündungen - entstehen (Flohr et al. 2009). Ist eine Hypopneumatisation festgestellt worden, wurde anschließend nach der Ursache geforscht. Bei manchen Schädeln ließ sich dann eine Kausalkette rekonstruieren: Eine Otitis media - die bei einem Schädel der Population aus Großenrode festgestellt wurde - war beispielsweise mit entzündeter Schleimhaut Ursprungsort einer Entzündung, die sich über eine Mastoiditis bis in das Schädelinnere ausgebreitet hatte. Erkrankungen des Warzenfortsatzes sind nämlich in der Regel nicht primäre Entzündungen des Mastoids, sondern meist Folge der Ausbreitung einer Otitis media (Kirkpatrick 1913). Durch die Entzündung der Schleimhäute konnte sich ebenfalls der Knochen infizieren (Mastoiditis). In dem Stadium hatte sich die Entzündung bereits ausgebreitet, was ebenfalls an knöchernen Neubildungen in den Cellulae mastoideae erkennbar war. Wanderte dieser Entzündungsprozess weiter durch den Schädelknochen, konnte er zu einer Osteomyelitis führen, die venösen Blutleiter des Schädelinnenraums (Sinus) erreichen und die Entzündung damit weiter streuen und eine Meningitis bzw. Encephalitis auslösen. Spuren einer solchen Hirnhautentzündung waren ebenfalls nachweisbar. Bei entsprechend erhaltenen Spuren der entzündlich pathologisch veränderten Knochenoberfläche konnten diese oder ähnliche Kausalketten in weiteren Fällen vervollständigt werden.

Nicht jede gefundene Spur einer intravitalen Mastoiditis muss jedoch unbedingt mit einem schweren klinischen Verlauf verbunden gewesen sein; bei Skeletfunden sind Interpretationen, wie schwer eine Mastoiditis verlaufen sein mag, nicht mehr zu machen (vgl. Flohr und Schultz 2009).

\subsection{Degenerative Veränderungen an Gelenken}

Es ist vorauszuschicken, dass es bei einer Arthrose nicht nur zu degenerativen, sondern auch zu proliferativen morphologischen Veränderungen kommt. Beide Prozesse hinterlassen am Knochen Spuren, die in der Paläopathologie ausgewertet werden und - in der Regel bei entsprechendem Erhaltungszustand - Rückschlüsse auf den Gesundheitszustand der Gelenke gestatten. Wenn im Folgenden von degenerativen Gelenkveränderungen gesprochen wird, werden die bei einer Arthrose auftretenden proliferativ bedingten Veränderungen mit eingeschlossen.

Ein wesentlicher Teil der Befundungsarbeit war es, degenerative Veränderungen an Gelenken festzustellen. Es soll an dieser Stelle diskutiert werden, inwiefern die im Ergebnisteil vorgestellten Zahlen zu Spuren von Gelenkdegenerationen aussagefähig sind und inwieweit Geschlechtsunterschiede dabei eine Rolle spielen. Bei den 
erkannten Spuren degenerativer Gelenkerkrankungen muss stets mit in Betracht gezogen werden, dass sie nicht ausschließlich durch starke Belastungen entstehen können, sondern auch durch übermäßiges Schonen und wenig körperliche Aktivitäten.

\subsubsection{Befunde zu degenerativen Gelenkerkrankungen}

Aufgrund der Tatsache, dass die Fundstücke in überwiegender Anzahl nicht einem Individuum zuzuordnen waren und somit ein Gelenk nicht im anatomischen Verband bzw. mit dem entsprechenden Gegenstück befundet werden konnte, ist die Aussagekraft der Ergebnisse zu den degenerativen Veränderungen an Teilgelenken eher eingeschränkt. In einem solchen Fall kann keine Bewertungsziffer für ein Gelenk erstellt werden, sondern nur der Arthrosegrad einer Gelenkeinheit bestimmt werden.

Die vorgestellten Ergebnisse der Population aus Calden zeigen dennoch, dass degenerative Veränderungen an Gelenken an verschiedenen Körperabschnitten mit unterschiedlichen Häufigkeiten vorkamen. So lag die Häufigkeit einer Arthrose im Bereich der oberen Extremität an den Schulterblättern (Schultergelenkpfanne) mit $39 \%$ ( $n=11$ von 31 ) und an den Langknochen der oberen Extremität (proximale und distale Grenzflächen an Humerus, Radius und Ulna) mit 0\% bis 19\% ( $n=4-12$ ). Interessant ist hier, dass die Humerusköpfe nur in 9\% ( $n=3$ von 34) der Fälle Spuren einer degenerativen Gelenkkrankheit aufwiesen, während der diesbezügliche Wert an den Scapulae jedoch deutlich höher lag (39\%, $\mathrm{n}=11$ von 31).

Hier fällt die anfänglich beschriebene Problematik ins Auge, dass Aussagen über den Arthrosegrad von Gelenken nur mit eingeschränkter Vollständigkeit zu treffen sind, wenn die Gelenke zur Befundung nicht als Einheit vorliegen. An den unteren Extremitäten waren Spuren einer Arthrose häufiger zu diagnostizieren. Die Hüftpfannen wiesen in $44 \%$ ( $n=18$ von 41 ) der Fälle degenerative bzw. proliferative Veränderungen auf, die Oberschenkelköpfe in 35\% ( $=23$ von 65), die Oberschenkelcondylen in 32\% ( $n=22$ von 69). Bei den Schienbeinen kann eine Häufigkeit für das distale Kniegelenk von $18 \%$ ( $\mathrm{n}=9$ von 51 ) und das proximale Sprunggelenk von $7 \%$ ( $\mathrm{n}=3$ von 46$)$ angegeben werden, bei den Wadenbeinen proximal 9\% (n=2 von 22 ) und distal $12 \%$ ( $n=4$ von 34). Möglicherweise hängen die unterschiedlichen Häufigkeiten mit der Unvollständigkeit der entsprechenden Gelenkeinheiten zusammen. Von arthrosekranken Gelenken wird erst gesprochen, wenn der Arthrosegrad größer als 2 ist (> Grad II). Alle niedrigeren Grade finden keine Berücksichtigung bei der Auswertung der krankhaften Veränderungen. Liegt ein Gelenk vollständig vor, kann beispielsweise der proximale Anteil Grad III aufweisen, während der distale nur mit Grad II ausgeprägt ist; daraus resultiert eine 
Bewertungsziffer von 2.5. Da die Knochen aber meist ohne den andern zugehörigen Gelenkabschnitt vorlagen, kann ein Gesamtgelenkstatus, d. h. eine Bewertungsziffer für ein solches Gelenk nicht errechnet werden. Das könnte erklären, warum deutlich mehr Hüftpfannen eine degenerative Gelenkerkrankung aufzeigten, als Oberschenkelköpfe.

\subsubsection{Geschlechtsunterschiede bei degenerativen Gelenkerkrankungen}

Um Lebensbedingungen von Populationen verstehen $\mathrm{zu}$ können, ist auch die Rekonstruktion und Betrachtung der Arbeitsteilung von weiblichen und männlichen Individuen wichtig. Anhand von Gelenkerkrankungen ist generell eine Rekonstruktion einer geschlechtsabhängigen Arbeitsverteilung möglich, wie Teegen und Schultz (2003) mit Befunden an 34 Individuen aus slawischen Gräberfeldern zeigen konnten. Ein menschliches Skelet kann folglich unter Umständen und u. a. in Korrelation mit archäologischen Daten Auskunft über körperliche Aktivitäten geben, die das Individuum täglich während seines Lebens ausgeführt hat (Hawkey und Merbs 1995). Aufgrund des Erhaltungszustandes der Fundstücke konnte nur für die Population aus Calden diesbezüglich eine nennenswerte Aussage getroffen werden. Für die Population aus Großenrode waren nur drei Fundstücke - die eine Arthrose aufwiesen - einem Geschlecht zuzuordnen. Im Detail waren dies ein Os coxae und ein Os femoris eines weiblichen Individuums und eine Fibula eines männlichen Individuums. Bei einer so geringen Anzahl an entsprechenden Funden kann keine Aussage über die geschlechtsspezifischen Unterschiede der körperlichen Aktivität der Population aus Großenrode getroffen werden. Bei der Population aus Rheine war kein einziges Fundstück mit den entsprechenden Kriterien nachzuweisen.

Für die Population aus Calden ergeben sich folgende, vergleichbare Ergebnisse (Knochen weiblicher Individuen sind immer zuerst genannt): Die Häufigkeit der Arthrose an den Gelenkflächen von Ellen, Schienbeinen, Gelenkflächen von Schulterblättern und Oberarmknochen ließ keine wesentlichen, geschlechtsspezifischen Unterschiede erkennen; hingegen wurden bei Wirbeln in vier zu acht Fällen, bei Kreuzbeinen in zwei zu vier Fällen, bei Hüftpfannen in acht zu fünf Fällen, bei Oberschenkelknochen in sieben (mit sechs proximal und fünf distal) zu 19 Fällen (mit 17 proximal und 12 distal), bei Atlantooccipitalgelenken in vier zu drei Fällen Spuren von Arthrose beobachtet. Weiterhin waren ein männliches Schlüsselbein und ein männliches Wadenbein mit Arthrose zu finden. Bei der Population aus Calden gab es insgesamt 31 von 185 Skeletelemente, die an den Gelenkflächen Spuren einer Arthrose aufwiesen, einem weiblichen Individuum zuzuordnen und befundbar waren und 50 aus 174 von männlichen Individuen. 
Auch wenn für die Population aus Calden eine größere Zahl an befundbaren Skeletfunden vorlag als in den beiden anderen hier untersuchten Populationen, die für die Untersuchung geschlechtsspezifischer Unterschiede von degenerativen Gelenkerkrankungen zur Verfügung standen, so ist dennoch die Aussagekraft als gering einzuschätzen, weil zu wenige Fundstücke überhaupt einem Geschlecht zugeordnet werden konnten. Für den Vergleich von weiblichen und männlichen Femora waren zwar ebenfalls nicht viele, aber dennoch genügend Fundstücke vorhanden, um zumindest eine Annäherung für die Fragestellung zu liefern: Sieben von $25(28 \%)$ Femora weiblicher Individuen wiesen degenerative Gelenkerkrankungen auf und 19 von 40 (48\%) Femora männlicher Individuen. Die Hüftpfannen wiesen mit $47 \%$ ( $n=8$ von 17 ) weiblichen $\mathrm{zu} 42 \%$ ( $\mathrm{n}=5$ von 12 ) männlichen keinen aussagekräftigen geschlechtsspezifischen Unterschied bezüglich degenerativer Gelenkerkrankungen auf. Bringt man die Werte rechter und linker weiblicher und männlicher Hüftpfannen mit den Werten der Femora zusammen, so ergeben sich folgende Ergebnisse: Von den weiblichen Hüftpfannen wiesen drei rechte und fünf linke eine Arthrose auf sowie vier rechte Oberschenkelköpfe und zwei linke. Bei den Hüftpfannen männlicher Individuen wiesen drei rechte und zwei linke eine Arthrose auf sowie acht rechte Oberschenkelköpfe und neun linke. Die Werte kann man nicht ohne weiteres korrelieren, da die verschiedenen Knochen wahrscheinlich nicht einzelnen Individuen zuzuordnen sind. Dennoch ist anhand der vorgestellten Beobachtung die Vermutung zu äußern, dass degenerative Gelenkerkrankungen des gesamten Hüftgelenks bei männlichen Individuen häufiger vorkamen, als bei weiblichen. Dies könnte ein Hinweis auf einen geschlechtsspezifischen Unterschied der Bewegungsgewohnheiten der Individuen sein. Demzufolge gibt es Anhaltspunkte dafür, dass Männer der Population aus Calden ihre unteren Extremitäten stärker beansprucht haben, da sie möglicherweise $u$. a. für die Nahrungsbeschaffung häufig längere Strecken zu Fuß zurücklegen mussten sowie schwerere Lasten zu tragen hatten. Diese Annahme würde die Rolle des Mannes als Jäger und die Rolle der Frau als „Hausfrau“ unterstützen. Dass bei Hüftpfannen insgesamt keine aussagekräftigen, geschlechtsspezifischen Unterschiede gefunden werden konnten, mag ein Zufall sein, da insgesamt nur wenige Hüftpfannen befundbar waren (insgesamt 52 Hüftpfannen, davon 29 rechte und 23 linke).

\subsection{Muskeltraumata}

Die in der vorgelegten Arbeit unter dem Oberbegriff „Muskeltrauma“ zu verstehenden Spuren pathologischer Veränderungen sind Enthesiopathien, die als Band- und Sehnenverknöcherungen an Knochen sichtbar sind und durch muskuläre Überbelastungen im Sinne von Myotendo- bzw. Ligamentopathien entstanden sind. 
Sie wurden unter dem Begriff „Muskeltrauma“ zusammengefasst, weil sie makroskopisch untereinander häufig nicht sicher unterscheidbar waren. Am Rande sei bemerkt, dass sich starke Überbelastungen schneller am Knochen manifestieren, als leichte, deren Manifestation am Knochen mehr Zeit in Anspruch nimmt; aufgrund dieser Tatsache wird die Gesamthäufigkeit von „Muskeltraumata“ unterschätzt (Gresky et al. 2008). Traumata dieser Art hinterlassen bei entsprechender Ausdehnung eine erkennbare Struktur am Knochen in Form knöcherner Neubildungen oder lokaler Nekrosen.

Bei der Population aus Calden waren folgende Knochen von einem „Muskeltrauma“ betroffen: Fünf Wirbel (von insgesamt 241 befundbaren; 2\%), fünf Schlüsselbeine (von insgesamt 20 befundbaren; 25\%), vier Rippen (von insgesamt 130 befundbaren; 3\%), fünf Schulterblätter (von insgesamt 31 befundbaren; 16\%), vier Oberarmknochen (von insgesamt 62 befundbaren; 6\%), fünf Ellen (von insgesamt 49 befundbaren; 10\%), fünf Speichen (von insgesamt 50 befundbaren; 10\%), 24 Oberschenkelknochen (von insgesamt 116 befundbaren; 21\%), 13 Kniescheiben (von 23 befundbaren; 57\%), 19 Schienbeine (von insgesamt 79 befundbaren; 24\%), 13 Wadenbeine (von insgesamt 47 befundbaren; 28\%).

Es fällt auf, dass bei den Knochen der unteren Extremität „Muskeltraumata“ insgesamt häufiger gefunden wurden. Nur die Schlüsselbeine wiesen eine ähnlich hohe Häufigkeit auf.

Das insgesamt häufigere Auftreten von „Muskeltraumata“ an der unteren Extremität könnte ein Hinweis darauf sein, dass die Individuen der Population aus Calden viel zu Fuß unterwegs gewesen sind. Bei der vorangegangenen Betrachtung degenerativer Gelenkerkrankungen konnte ein ähnlicher Schluss gezogen werden.

Für die Population aus Rheine waren bezüglich des Auftretens von „Muskeltraumata“ keine aussagekräftigen Ergebnisse erzielbar, da die Fundstücke in so stark erodiertem Zustand vorlagen, dass eine Oberflächenbefundung meist nicht möglich war.

In der Population aus Großenrode fanden sich an einem Wirbel (von insgesamt 191 befundbaren; 1\%), zwei Schlüsselbeinen (von insgesamt 15 befundbaren; 13\%), einem Oberarmknochen (von insgesamt 35 befundbaren; 3\%), neun Oberschenkelknochen (von insgesamt 52 befundbaren; 17\%), drei Schienbeinen (von insgesamt 58 befundbaren; 5\%) und vier Wadenbeinen (von insgesamt 20 befundbaren; 20\%) Spuren von „Muskeltraumata“.

Diese Werte spiegeln nicht das Ergebnis der Population aus Calden wider. Da die Population aus Großenrode fast ausschließlich in Form von Knochenfragmenten 
vorlag, ist es nicht verwunderlich, dass Spuren pathologischer Veränderungen möglicherweise nicht leicht zu entdecken waren. Weiterhin könnten von den Knochen die relevanten Bereiche gefehlt haben oder erodiert gewesen sein, sodass entsprechende Bereiche mit Spuren von „Muskeltrauma“ der Befundung nicht mehr zur Verfügung standen.

\subsection{Mindestindividuenzahl}

In dieser Arbeit stützen sich viele Aussagen auf die Mindestindividuenzahl, die aber - wie der Name schon aussagt - nur eine Mindestzahl bedeutet. So könnte es sein, dass beispielsweise die 152 Fundstücke, die bei der Population aus Calden Oberschenkelknochen zuzuordnen waren, nicht zu den mindestens vorhandenen 39 Individuen gehörten, sondern zu weiteren. Die Anzahl der tatsächlich vorhandenen Individuen ist nicht anzugeben, doch es darf angenommen werden, dass die Zahl deutlich über der Mindestindividuenzahl liegt. Dies hängt mit der Bestattungsweise in Kollektivgräbern zusammen, bei der augenscheinlich zahlreiche Knochen zerstört wurden oder durch Bodenerosion zerfielen. Weiterhin ist anzunehmen, dass durch landwirtschaftliches Überpflügen der Grabanlagen über Jahrhunderte obere Schichten der Gräber zerstört wurden und dabei auch Fundgut für immer verloren ging. Für die Bestimmung der MIZ wurden Zähne und Knochen herangezogen. Die jeweils größte Zahl wurde dann als MIZ angegeben. Für die Population aus Calden wurde eine MIZ von 39 anhand rechter Femora errechnet, für die Population aus Rheine eine MIZ von 23 anhand von Zähnen 26, für die Population aus Großenrode wurden die MIZ mit 43 anhand der Anzahl des Zahns 46 errechnet.

\subsection{Körperhöhe}

Die Körperhöhe ist ein komplexes Maß am menschlichen Körper und wird von Rösing (1988) als eines der variabelsten und kompliziertesten am Menschen bezeichnet. Die Körperhöhe unterliegt großen Schwankungen, die unter anderem von Alter, Geschlecht, ethnischer Herkunft und vielem mehr abhängt sowie nur dann möglichst genau berechnet werden kann, wenn an einem Skelet viele Messungen durchführbar sind (Rösing 1988). Das Fundgut der für diese Arbeit untersuchten Populationen enthielt keine vollständigen Skelete. Mehrere Maße an verschiedenen Knochen eines Individuums waren nicht zu erheben, lediglich einige Oberschenkelknochen konnten bei entsprechendem Erhaltungszustand vermessen werden. Somit ist die Angabe der Körperhöhe in dieser Arbeit nur eine Näherung. Da jedoch ausschließlich Oberschenkelknochen für die Vermessung zur Verfügung standen, ist der damit einhergehende Fehler für alle gemessenen Femora gleich. Damit sind die rekonstruierten Körperhöhen zumindest untereinander 
näherungsweise vergleichbar, wobei auch innerhalb eines Skelets Schwankungsbreiten verschiedener Knochen auftreten, die - wenn individuell betrachtet - zu abweichenden Körperhöhenrekonstruktionen führen würden (Rösing 1988). Bei der Rekonstruktion von Körperhöhen nach Sjøvold (1990) für die Individuen der Population aus Calden konnten die Gesamtlängen von 29 Oberschenkelknochen verwendet werden. Die berechneten Körperhöhen der Individuen schwankten insgesamt zwischen mindestens 136,2 cm bis maximal 189,6 cm, unabhängig von der Seite und dem Geschlecht; die durchschnittliche Schwankungsbreite liegt zwischen 140,7 cm und 185,2 cm. Der Median liegt bei etwa $155 \mathrm{~cm}$, der Mittelwert bei etwa $158 \mathrm{~cm}$. Für weibliche Individuen kann eine durchschnittliche Spanne der Körpergröße von etwa 153,5-161,7 cm (berechnet nach Bach 1965) angegeben werden und für männliche etwa 161-170,6 cm (berechnet nach Breitinger 1938).

Die kleinen Größen gehen möglicherweise darauf zurück, dass manche Individuen noch nicht vollständig ausgewachsen waren.

Der Erhaltungszustand des Fundgutes der Populationen aus Rheine und Großenrode war so mangelhaft, dass die Längendaten der Oberschenkelknochen nicht messoder rekonstruierbar waren. Zudem fehlten zumeist Teile der Knochen, sodass eine Rekonstruktion der Körperhöhe nicht vorgenommen werden konnte.

\subsection{Periostale Reaktionen}

Bei hämorrhagischer Periostose findet eine Knochenneubildung auf der ursprünglichen, gesunden und damit nicht betroffenen Knochenoberfläche statt, während bei ostitisch oder osteomyelitisch bedingter Periostitis die ursprüngliche Knochenschicht vergleichsweise wenig durch lytische Prozesse verändert wird (Schultz 2011a). Periostale Reaktionen waren bei der Population aus Calden an 23 Fundstücken zu finden: An einem Radius, einem Phalanx manus, acht Femora, neun Tibiae und vier Fibulae. Bei der Population aus Rheine konnten an drei Tibiae periostale Reaktionen festgestellt werden und bei der Population aus Großenrode an neun Fundstücken; diese waren eine Costa, sechs Tibiae und zwei Fibulae.

\subsection{Leichenbrand}

„Leichenbrand“ meint verbrannte Knochen von lebendig oder tot verbrannten Individuen (Herrmann 1988a). Ob sie jeweils lebendig verbrannt wurden oder bereits tot waren, ist aufgrund von Leichenbrandfragmenten allein nicht auszusagen.

Unter den Fundstücken der drei Populationen konnten augenscheinlich durch Hitze deformierte Knochen gefunden werden, bei denen man per definitionem von Leichenbrand sprechen kann (Herrmann 1988a). Diese Knochenfragmente wiesen 
meist klare und signifikante Spuren einer Verbrennung auf. So konnten Fundstücke mit schwarzer, grauer und weißer Farbe dokumentiert werden. Meist waren mehrere Farben an ein und demselben Knochenfragment zu finden. Die Farbgebung schwarz, grau und weiß spricht für eine weniger starke oder stärkere (heißere) Verbrennung, wobei sich der Knochen bei zunehmender Hitze von der Verkohlung (schwarz verfärbt) über grau zu weiß verfärbt. Um Knochen zu kalzinieren, sind Temperaturen von über $800^{\circ} \mathrm{C}$ notwendig, während unter $800^{\circ} \mathrm{C}$ das möglicherweise noch vorhandene organische Material am Knochen nicht vollständig verbrennt (Eckert 1981). Kalzinieren bedeutet, dass unter langer, starker Hitzeeinwirkung die organischen Bestandteile des Knochens vollständig verbrennen (Küchelmann 2009). Um Knochen bis zum Weißwerden zu verbrennen, beziehungsweise zu verglühen, bedarf es eines Holzfeuers, z. B. eines Scheiterhaufens (Eckert 1981), dabei erreicht die Knochenstruktur ein Minimum an Festigkeit und erscheint bei der kritischen Temperatur von $800{ }^{\circ} \mathrm{C}$ kreidig (Herrmann 1988a).

Feuer unterscheiden sich beispielsweise in Größe und Ausbreitungsgeschwindigkeit, aber auch dadurch, ob sie versehentlich oder beabsichtigt entfacht wurden (Eckert 1981). Im Falle der verbrannten und zum Teil verglühten Knochen aus Rheine handelte es sich eher um ein absichtliches Feuer, auf dem Individuen verbrannt wurden. Es wäre zu unwahrscheinlich, dass ein zufälliges Feuer genügend Holz gehabt und ausreichend lange gebrannt hat, um Knochen bis zum Weißwerden zu erhitzen.

\subsection{Postmortale Artefakte am Fundgut}

Zahlreiche Fundstücke aller drei Populationen wiesen postmortale Artefakte auf. Diese können in ihrer Form und Gestalt nicht immer einer genauen Entstehung zugeordnet werden. Manche löchrige Strukturen an der Schädelinnenseite allerdings können vermutlich im Sinne eines Insektenfraßes interpretiert werden (Gladykowska-Rzecycka und Parafiniuk 2001).

Einige makroskopisch sichtbare Veränderungen der Knochenoberfläche entpuppten sich erst bei lichtmikroskopischer Untersuchung von Knochendünnschliffpräparaten der Region als „Pseudopathologien“, wie Wells (1967) sie nannte. Somit erfüllt die mikroskopische Befundung in der Paläopathologie eine sehr wichtige und nicht ersetzbare Aufgabe.

Grundsätzlich können jedoch nicht nur scheinbar intravitale Veränderungen lichtmikroskopisch als postmortale identifiziert werden, sondern auch scheinbar postmortale als intravitale (Schultz 1997, 2001). Intravitale und postmortale Veränderungen der Knochenstruktur können folglich oft nur bei lichtmikroskopischen Untersuchungen erkannt und als solche dann dokumentiert werden. 


\subsection{Rekonstruktion damaliger Lebensbedingungen}

Eine Rekonstruktion der Lebensbedingungen prähistorischer Völker kann nur durch vielfache Erforschung verschiedener Völker der entsprechenden Zeit gelingen. Dabei ist zu berücksichtigen, dass die heute erhaltenen Großsteingräber nur einen Bruchteil der ehemals erbauten darstellen, da nicht zuletzt der Abbau von Findlingen der Gräber zwecks Weiterverwertung in neuerer Zeit viele dieser Grabanlagen unkenntlich machte (Bartelt 2009).

Gute Lebensbedingungen hängen $\mathrm{u}$. a. mit der Güte der zugeführten Nahrungsmittel zusammen (Czermak 2011). Da bei den Populationen aus Calden, Rheine und Großenrode einige Fundstücke mit Spuren anämischer Veränderungen gefunden wurden, kann dies ein Zeichen für zumindest zeitweise vorherrschende Mangelernährung sein. Allerdings können auch Wurmerkrankungen, genetische Eigenschaften oder Infektionserkrankungen diese anämischen Veränderungen verursacht haben. Bezogen auf mögliche Mangelernährungen könnten Jagdausfälle oder schlechte Ernteerträge unmittelbar und mittelbar verantwortlich sein.

Das häufige Auftreten von Reizungen und Entzündungen der Hirnhäute, Mittelohrentzündungen, Warzenfortsatzentzündungen, Entzündungen der Nasennebenhöhlen und auch Anämien sprechen für einen eher schlechteren Gesundheitszustand innerhalb einer Individuengruppe, was Schultz und Bátora (2001) im Rahmen einer Untersuchung an 45 Kinderskeleten aus dem Aunjetitzer Gräberfeld von Jelšovce zeigen konnten.

Neolithische Populationen sind offenbar stark durch ihre Umwelt beeinflusst worden, was anhand der Ernährungsgewohnheiten und der damit einhergehenden Anpassung an äußere Bedingungen rekonstruierbar ist (Schultz 1989). Unter den Mangelerkrankungen manifestieren sich $u$. a. Anämien am Knochen, sodass sie für heutige Forscher noch diagnostizierbar sind (Schultz 1989). Anämien zeigen sich u. a. an platten Schädeldachknochen in Form einer Diploëhypertrophie; dort ist die Lamina interna erhalten, die Lamina externa jedoch abgebaut und die Diploëstruktur wächst nach außen, was eine porös erscheinende äußere Knochenoberfläche hinterlässt (Schultz 1989, 2001, 2003, Schultz und Nováček 2012). Dieses Phänomen konnte bei der Befunderhebung für diese Arbeit in jeweils einem Fall an Schädeln der drei Populationen beobachtet werden.

Die Lebensbedingungen prähistorischer Völker können sicherlich als rau bezeichnet werden. Dennoch ist erstaunlich, dass nicht noch mehr Spuren von Erkrankungen bei den Populationen aus Calden, Rheine und Großenrode gefunden wurden. Zum einen liegt das sicherlich daran, dass die Individuen durchaus ein stabiles und vor 
allem effektives Immunsystem gehabt haben müssen und es ihnen vergleichsweise gut ging; weiterhin denkbar ist, dass bestimmte Pathogene nach Befall gleichzeitig eine Art Schutzschild gegen ähnliche Erreger gebildet und damit das Immunsystem der Individuen in gewisser Weise unterstützt haben (Koch 2008). Außerdem manifestieren sich nicht alle Erkrankungen am Knochen. Die Funde haben sich teilweise auch in zu mangelhaftem Zustand erhalten, alsdass hätte sichergestellt werden können, dass alle pathologischen Veränderungen erfasst wurden.

Es kommen daher mehrere Erklärungen dafür infrage, dass an den Skeletfunden nicht noch mehr Spuren von Erkrankungen gefunden werden konnten.

Infektionskrankheiten waren in Mitteleuropa besonders häufig erst bei spätmittelalterlichen Populationen aufgetreten. Sie gingen möglicherweise auf erhöhte Keimbelastungen zurück, die aufgrund der hygienischen Bedingungen der eng beieinander lebenden Menschen und Tiere auftraten. 


\section{Zusammenfassung}

Ziel dieser Arbeit war es, die spätneolithischen menschlichen Skeletfunde aus Calden, Rheine und Großenrode paläopathologisch zu untersuchen, die Ergebnisse der Befundarbeiten vorzustellen, die Ursachen und Häufigkeiten von diagnostizierten Krankheiten unter Nutzung bereits vorliegender Literatur zu diskutieren, diese in den gesamtgeschichtlichen Kontext einzuordnen und damit die Lebensbedingungen der Steinzeitmenschen der drei Populationen zu rekonstruieren; ein weiterer Aspekt der vorgelegten Arbeit war die Entwicklung einer Datenbank in FileMaker Pro ${ }^{\circledast}$, um die großen Befunddatenmengen zu dokumentieren und auszuwerten.

Diese Arbeit zeigt, dass es lohnenswert ist, bei der Befunderhebung verschiedene diagnostische Techniken anzuwenden, um intravital von postmortal entstandenen Spuren abzugrenzen und Krankheiten verlässlich diagnostizieren zu können. Dies gilt besonders für die - zwar nur bei besonderen Fragestellungen erfolgten - lichtmikroskopischen und rasterelektronenmikroskopischen Untersuchungsmethoden, mit deren Hilfe einige Spuren morphologischer Veränderungen als postmortal identifiziert werden konnten. Die Entstehung anderer morphologischer Spuren konnte mithilfe lichtmikroskopischer Untersuchungen wiederum auf intravital erfolgte Prozesse zurückgeführt werden. Weiterhin zeigte sich die Anfertigung eines DVT bei verschiedenen Schädeln - zwecks des eindeutigen Nachweises von Frakturgeschehen - als sehr nützlich. Nicht in allen Fällen mussten für eine verlässliche Diagnosestellung aufwändige diagnostische Mittel herangezogen werden, um Spuren morphologischer Veränderungen als sicher krankhaft zu diagnostizieren. Neben der makroskopischen Begutachtung wurde eine Lupe als Hilfsmittel verwendet und auch Streiflicht war eine gute Hilfe bei der Oberflächenbefundung der Fundstücke. Konventionelles Röntgen kam häufig und erfolgreich zum Einsatz. Weitere Gerätschaften wie ein binokulares Lupenmikroskop mit Fotoeinrichtung und Datenbank sowie ein analoges und ein digitales Endoskop standen ebenfalls bereit, um Verdachtsdiagnosen zu erhärten oder zu entkräften.

Die Befunde - und ggf. zugehörige Daten (Fotos, Röntgenbilder, etc.) - wurden in die für diese Arbeit programmierte Datenbank (in FileMaker Pro ${ }^{\circledR}$ ) eingegeben. Die Datenbank verfügt über Module zur Auswertung der umfangreichen und sehr verschiedenartigen Informationen, die bei der Befunderhebung an den Fundstücken gewonnen werden konnten. In der Datenbank sind die Befunde nicht nur vollständig einsehbar und übersichtlich abgespeichert, sondern auch so formatiert, dass diese großen Datenvolumina schnell und zielgerichtet abrufbar sind. 
Durch die 14C-Datierungen der Gräber in die Zeiträume 3400 - 3200 v. Chr. (Population aus Calden), 3200 - 2850 v. Chr. (Population aus Rheine) und 3620 - 2910 v. Chr. (Population aus Großenrode) wird eine zeitliche Überschneidung der Nutzung dieser Bestattungsplätze belegt, die örtlich dicht beieinander liegen (etwa zwischen 46 km bzw. 183 km Luftlinie). Daraus ergibt sich eine Vergleichbarkeit dieser spätneolithischen Populationen, die auf ähnliche Lebensbedingungen schließen lässt.

Für die Population aus Calden ist die Mindestindividuenzahl (MIZ) mit 39, für Rheine mit 23 und für Großenrode mit 43 anzugeben. Das mittlere Sterbealter (errechnet anhand des Zahnalters der MIZ) ergibt für die Population aus Calden etwa 28,8 Jahre, für Großenrode knapp 24,6 Jahre und für Rheine 13,9 Jahre (bzw. 18,6 Jahre unter Einbeziehung aller Zahnfunde). Die Geschlechtsbestimmung ergab bei der Population aus Calden 140 Fundstücke weiblicher Individuen und 187 Fundstücke männlicher, bei der Population aus Rheine drei Fundstücke weiblicher Individuen und ein Fundstück eines männlichen und bei der Population aus Großenrode 67 Fundstücke weiblicher Individuen und 70 Fundstücke männlicher.

Für die Population aus Calden war eine Rekonstruktion der Körperhöhe in 29 Fällen möglich. Frauen waren durchschnittlich etwa zwischen 153,5 und 161,7 cm groß und Männer etwa zwischen 161 und 170,6 cm.

Trotz eingeschränkter Bedingungen bezüglich der Befundung pathologischer Veränderungen an den Skeletresten konnten dennoch einige aussagekräftige Ergebnisse generiert werden. $\mathrm{Zu}$ den wesentlichen Aspekten gehört, dass bei den drei Populationen Fundstücke aus allen Altersstufen gefunden wurden. Die für diese Arbeit - bezogen auf die drei Populationen aus Calden, Rheine und Großenrode - errechneten Angaben der Altersstufen können mit den bereits diskutierten Angaben anderer Autoren zu den drei Populationen größtenteils untermauert werden.

Die Knochenfunde wiesen Spuren pathologischer Veränderungen auf. Dies lässt darauf schließen, dass die Individuen der Populationen aus Calden, Rheine und Großenrode Erkrankungen wie Meningitiden, Sinusitiden oder degenerative Gelenkerkrankungen durchlebt hatten. Da die Fundstücke in unterschiedlichen Anzahlen und in verschiedenen Erhaltungszuständen vorlagen, können Vergleiche der Häufigkeiten pathologischer Veränderungen nur mit Einschränkungen getätigt werden. So wurden Spuren krankhafter Prozesse an den Schädelfunden der Populationen aus Calden ( $54 \%, \mathrm{n}=63$ von 117$)$, Rheine $(23 \%, \mathrm{n}=6$ von 26$)$ und Großenrode (37\%, $n=43$ von 116) nachgewiesen. Kopfschwartenreizungen waren in den Populationen aus Calden $(n=34)$ und Rheine $(n=3)$ die am häufigsten beobachteten pathologischen Veränderungen, während in der Population aus Großenrode meningeale Reizungen $(n=27)$ am häufigsten auftraten. In der Population aus Calden kamen 
auch Sinusitiden (19 Fälle mit Sinusitis frontalis, 15 Fälle mit Sinusitis maxillaris und sechs Fälle mit Sinusitis sphenoidalis) vor; Cribra orbitalia wurde - im Sinne von unspezifischen Stressmarkern - in 31 Fällen beobachtet. In der Population aus Rheine konnte jeweils ein Fall von meningealer Reizung und Sinusitis maxillaris gefunden werden. Cribra orbitalia spielte auch in der Population aus Großenrode eine Rolle $(n=17)$ sowie Perisinusitiden $(n=13)$, die möglicherweise mit meningealen Prozessen assoziiert waren. Außerdem wurden zwölf Fälle von Sinusitiden der Stirnhöhle und Spuren von Entzündungen im Bereich des äußeren Gehörgangs und des Mittelohrs ( $n=5)$ bei der Population aus Großenrode gefunden. In der Population aus Calden konnten 15 Fälle von Entzündungen im Bereich des äußeren Gehörgangs und des Mittelohrs festgestellt werden.

Zahnabrasionen wurden häufig und meist auch in vergleichsweise ausgeprägter Intensität nachgewiesen (Calden: 96\% ( $n=394$ von 409), Rheine: $72 \%$ ( $n=104$ von 144), Großenrode: $88 \%(n=519$ von 592)).

Dem Abrasionsmuster der Zähne zufolge haben sich die Individuen $u$. a. von Getreideprodukten ernährt, deren Mahl sandige Bestandteile der Mahlsteine enthielt. Außerdem spricht das Abrasionsmuster dafür, dass vereinzelte Individuen ihre Zähne als Werkzeug genutzt haben. Ein entsprechendes Abrasionsmuster war bei allen für diese Arbeit untersuchten Populationen festzustellen. Außerdem konnten häufig Parodontopathien bei den drei Populationen gefunden werden: In der Population aus Calden bei 65\% der Zahnregionen ( $n=354$ von 545), bei der Population aus Rheine bei 71\% ( $n=17$ von 24) und bei der Population aus Großenrode bei 39\% ( $n=114$ von 294) der Fälle. Vergleichsweise selten konnte Karies an den Zähnen gefunden werden (Calden: 6\% ( $\mathrm{n}=26$ von 422$)$, Rheine: $7 \%$ ( $\mathrm{n}=10$ von 137$)$, Großenrode: 5\% ( $n=29$ von 584)). Die berechneten Häufigkeiten liegen für die drei Populationen dicht beieinander. Dies lässt auf ähnliche Ernährungsgewohnheiten schließen. Offenbar waren mehr tierische Produkte als leicht fermentierbare Kohlenhydrate konsumiert worden. Die Erkenntnis über das eher häufige Auftreten von Parodontopathien und das recht seltene Vorkommen kariöser Läsionen spricht weniger für reine Ackerbauern als vielmehr dafür, dass die Populationen aus Calden, Rheine und Großenrode auch Jäger und Viehzüchter - und damit auch Fleischesser waren.

Interessant zu beobachten ist die vergleichsweise große Häufigkeit unspezifischer Stressmarker in allen drei Populationen, welche die harten Lebensbedingungen belegen und sowohl auf nicht näher bestimmbare Mangelerkrankungen als auch auf Infektionskrankheiten zurückzuführen sind. Als Stressmarker wurden Schmelzhypoplasien an den Zähnen aller drei Populationen nachgewiesen (Calden: 65\% 
( $n=252$ von 388), Rheine: 33\% ( $n=43$ von 132), Großenrode: $41 \%$ ( $n=248$ von 603$)$ ); Cribra orbitalia trat in den Populationen aus Calden und Großenrode ebenfalls vermehrt auf (Calden: 31, Rheine: 0, Großenrode: 17). In einem Fall aus Calden konnte als Ursache der Cribra orbitalia mithilfe einer lichtmikroskopischen Untersuchung sicher Anämie diagnostiziert werden. Poröse Strukturen an prädisponierten Stellen dreier Langknochen aus der Caldener Population deuten ebenfalls einen anämischen Ursprung an. Als Ursache für das Auftreten der Anämie ist möglicherweise an Ernte- oder Wildjagdausfälle zu denken. Spuren anderer Mangelerkrankungen - wie Vitamin C oder -D Mangel - ließen sich mit den hier angewandten Methoden nicht nachweisen.

Die angeführten Spuren von Infektionskrankheiten und Mangelerkrankungen lassen vermuten, dass die Menschen dieser drei Siedlungen der ausgehenden Jungsteinzeit rauen Umweltbedingungen ausgesetzt waren. Siedlungsbedingte unhygienische Verhältnisse könnten zudem zu einer schnelleren Ausbreitung von Infektionen geführt haben.

Degenerative Gelenkerkrankungen in allen drei Populationen weisen auf übermäßige körperliche Aktivitäten hin, die vornehmlich im Bereich von großen Gelenken der unteren Extremität der Männer gefunden werden konnten; dies ist wahrscheinlich in Zusammenhang mit der Jagd und Ackerbau zu bringen. Die gefundenen Spuren degenerativer Veränderungen an den Extremitätengelenken - z. B. am Femur - zeigen, dass an einem menschlichen Skelet post mortem noch Hinweise auf die körperlichen Aktivitäten des Individuums nachgewiesen werden können. An $35 \%$ ( $n=23$ von 65 ) der Femurköpfe und an 32\% ( $n=22$ von 69) der Femurcondylen konnten degenerative Gelenkerkrankungen in der Population aus Calden beobachtet werden. In der Population aus Großenrode waren 4\% ( $\mathrm{n}=1$ von 28) der Femurköpfe und 7\% ( $\mathrm{n}=2$ von 28$)$ der Femurcondylen degenerativ verändert. In der Population aus Rheine waren nur wenige Femora erhalten, an denen eine Befundung durchführbar war. Hier konnten keine degenerativen Erkrankungen festgestellt werden. Weitere Zeichen starker körperlicher Aktivität sind u. a. auch „Muskeltraumata“ (Calden: 96 Fälle, Rheine: Acht Fälle, Großenrode: 20 Fälle).

Beifunde in den Gräbern - wie beispielsweise Teile bzw. Reste von Schmuck oder Trachtzubehör (z. B. Tierzähne) - lassen unter Umständen Rückschlüsse auf bestimmte Bestattungsrituale zu. Es ist bekannt, dass Kollektivgräber - und somit auch die der hier untersuchten Populationen - über viele Jahre hinweg während der Dauer mehrerer Generationen verwendet wurden. Fast immer wurden diese Gräber in späteren Jahrhunderten gestört und ausgeraubt. Dies erklärt den fragmentierten Erhaltungszustand der Skeletfunde. Trotzdem erlauben die erhobenen 
Befunde und die vorgestellten Ergebnisse wesentliche Rückschlüsse auf die Lebensweisen der neolithischen Populationen aus Calden, Rheine und Großenrode: An den Skeletfunden aller drei Populationen waren morphologisch unterschiedliche Spuren von Entzündungskrankheiten und Mangelerkrankungen zu finden. Dies belegt ungünstige Lebensverhältnisse, die für spätneolithische Populationen typisch und zu erwarten sind.

Es ist interessant, dass bei spätmittelalterlichen Populationen Mitteleuropas eine höhere Krankheitsbelastung - namentlich der Infektionskrankheiten - bekannt ist. Dort herrschten möglicherweise Lebensbedingungen mit höherer Keimbelastung. Infektionen konnten - in Populationen der Vor-Antibiotika-Ära - nicht hinreichend therapiert werden. Dies erklärt die teilweise doch sehr deutlich ausgebildeten Entzündungsspuren an den Skeletfunden der Populationen aus Calden, Rheine und Großenrode.

Abschließend ist festzustellen, dass die Individuen der drei Populationen aus Calden, Rheine und Großenrode verschiedene Erkrankungen durchlebt haben, dennoch aber in nennenswerten Zahlen (Calden: Etwa 54\%, Rheine: Etwa 13\%, Großenrode: Etwa 29\%) ein für steinzeitliche Populationen vergleichsweise hohes Alter (Bereich Spätadultus und älter) erreicht haben. Die in allen drei Populationen niedrige Karieshäufigkeit, das Zahnabrasionsschema und die zumindest für Calden nachgewiesenen Fälle degenerativer Gelenkerkrankungen (Extremitätengelenke und Wirbelsäule) sprechen nicht für eine reine Ackerbauernkultur. Vielmehr ist anzunehmen, dass neben Ackerbau vor allem auch Viehzucht bzw. Jagd eine Rolle in der Versorgung dieser spätneolithischen Populationen spielten. Dies lassen Ausprägung und Häufigkeit der Parodontopathien und die Praxis der Zahnreinigung mit einer Sonde vermuten. Für die Population aus Calden ist hervorzuheben, dass sie offenbar in einer unruhigen Zeit lebte: Sechs Fälle von Schädeltraumata, die aber alle überlebt wurden, deuten auf kriegerische Auseinandersetzungen hin. Letzteres spricht für ein ausgeprägtes Sozialverhalten im Sinne einer Pflege der Verletzten und möglicherweise auch für gewisse Grundkenntnisse der Heilkunde. Die Todesursache der in den Kollektivgräbern Bestatteten konnte in keiner der drei Populationen festgestellt werden. 


\section{Ausblick}

Die vorgelegte Arbeit liefert mit der paläopathologisch-anthropologischen Untersuchung menschlicher Skeletfunde (weit über 10.000 Knochenfragmente), die insgesamt mindestens 105 Individuen zuzuordnen sind und drei Kollektivgräbern entstammen, einen Beitrag zum Verständnis der Lebensbedingungen spätneolithischer Populationen Zentraleuropas. Besonderes Augenmerk lag bei der Begutachtung der Knochenfunde auf den Spuren pathologischer Veränderungen. Diese an Knochen nachgewiesenen Spuren repräsentieren im Sinne einer biohistorischen Urkunde die Lebensbedingungen einer neolithischen Population. Mangelzustände, entzündlich bedingte und degenerative Erkrankungen sowie Verletzungen von kriegerischen Auseinandersetzungen manifestierten sich häufig morphologisch an erhaltenen Skeletfunden, sodass hier von biohistorischen Urkunden gesprochen werden kann. Die hier vorgestellten Ergebnisse sowie die diskutierten Zusammenhänge und Unterschiede zwischen den Populationen aus Calden, Rheine und Großenrode - auch unter Einbeziehung bereits publizierter Arbeiten hierzu - stellen einen weiteren Mosaikstein für das heutige Verständnis des Neolithikums dar. Die Erforschung des neolithischen Zeitalters gestaltet sich aus paläopathologischer und anthropologischer Sicht meist als schwierig, da häufig nur kleinere Skeletfragmente und kleinste Knochenreste geborgen werden. Zudem ist zu berücksichtigen, dass einst sehr viel mehr Großsteingräber erbaut wurden, als heute noch erhalten sind. Dies hängt vor allem damit zusammen, dass das damalige Baumaterial (die Findlinge) in neuerer Zeit häufig auch als Baumaterial, z. B. für den Straßenbau, Verwendung fand. Auf diese Weise sind wertvolle Quellen unwiederbringlich verloren gegangen. Umso bedeutender sind die Funde der Populationen aus Calden, Rheine und Großenrode, die der Wartberg- und Trichterbecherkultur zuzuordnen sind. Die hier erarbeiteten Erkenntnisse stellen seltene Informationen über unsere Vorgeschichte dar und können als Basis weiterer Forschungsarbeiten angesehen werden.

Ein weiterer, wesentlicher Teil dieser Arbeit war die Erarbeitung eines Konzepts zur Dokumentation komplexer Daten. Diese Daten werden hier nach Auswertung mit einer in FileMaker Pro ${ }^{\circledR}$ programmierten Datenbank umfassend vorgestellt. Mit dieser Datenbank wurde - neben ausführlichen handschriftlichen und zeichnerischen Aufzeichnungen - die gesamte Befunddokumentation realisiert. Die entwickelte Datenbank hat Vorbildfunktion und kann für zukünftige Arbeiten im Rahmen einer Dokumentation und Auswertung von Befunden herangezogen werden. 


\section{Literaturverzeichnis}

Acsádi G, Nemeskéri J: History of human life span and mortality. Akadémiai Kiadó, Budapest 1970

Anderson JE (1965): Human skeletons of Tehuacán. Science 148, 496-497

Angel JL (1972): History of human life span and mortality. By Gy. Acsádi and J. Nemeskéri. Translated by K. Balas. 346 pp. Akadémiai Kiadó, Budapest. 1970. \$10.00. Am J Phys Anthropol 36, 300-302

Bach H (1965): Zur Berechnung der Körperhöhe aus den langen Gliedmaßenknochen weiblicher Skelette. Anthropol Anz 29, 12-21

Baggieri G, di Diacomo M: Three cases of exostosis of the auditory canal probably due to aquatic activity. 14. European Meeting of the Paleopathology Association. Coimbra, 28.-31. August 2002. Departamento de Antropologia da Universidade de Coimbra. (https://paleopathologyassociation.wildapricot.org/resources/Documents/European \%20PPA\%20Pr ograms/2002\%2014th\%20European\%20PPA\%20Coimbra\%20August\%2028$31 \% 202002 \% 20$ small.pdf)

Bakker JA: The Dutch Hunebedden: Megalithic Tombs of the Funnel Beaker Culture. Band Archaeological Series 2; International Monographs in Prehistory; Ann Arbor, Michigan 1992

Bartelt U (2009): Eigene Bauweise - Großsteingräber im westlichen Niedersachsen. Archäol Dtschl 4 , 26-29

Bates GJ, Drake-Lee AB (1988): Meningitis complicating acute otitis media. Br Med $\mathrm{J}$ (Clin Res Ed) 296,532

Beyer-Olsen EMS, Risnes S (1994): Radiographic analysis of dental development used in age determination of infant and juvenile skulls from a medieval archaeological site in Norway. Int J Osteoarchaeol $\underline{4}$, 299-303

Bräuer G: Osteometrie. In: Knußmann R (Hrsg.): Anthropologie. Handbuch der vergleichenden Biologie des Menschen. Wesen und Methoden der Anthropologie. Band 1; Fischer Verlag, Stuttgart-New York 1988, 160-231

Breitinger E (1938): Zur Berechnung der Körperhöhe aus den langen Gliedmaßenknochen. Anthropol Anz 14, 249-274

Broca MP: Sur le volume et la forme du cerveau suivant les individus et suivant les races. Typographie Hennuyer, Paris 1861

Brothwell DR: Digging up bones. 2. Auflage; London 1972 
Brothwell DR: Digging up bones. The Excavation, Treatment and Study of Human Skeletal Remains. 3. Auflage; Cornell University Press, New York 1981

Černý M, Komenda S: Sexual Diagnosis by the Measurements of Humerus and Femur. In: Klementa J (Hrsg.): Sborník prací pedagogické fakulty Univerzity Palackého v Olomouci. Státní pedagogické nakladatelství, Olomouc 1980, 147-167

Černý M, Komenda S: Reconstruction of body height based on humerus and femur lengths (material from Czech lands); in: IInd Anthropological Congress of Aleš Hrdlička: proceedings of the IInd Anthropological Congress dedicated to Dr. Aleš Hrdlička, held in Prague and Humpolec, September 3-7, 1979 = II. antropologický kongres Aleše Hrdličky; 1982, 475479

Czarnetzki A: Die menschlichen Skelettreste aus vier neolithischen Steinkisten Hessens und Niedersachsens. Rer. nat. Diss. Tübingen 1966

Czarnetzki A: Vier neolithische Steinkistenpopulationen aus Hessen und Niedersachsen. In: Schwabedissen H (Hrsg.): Die Anfänge des Neolithikums vom Orient bis Nordeuropa. Teil VIII b Anthropologie, Band 2; Böhlau, Köln/Wien 1978, 228-230

Czermak AM: Soziale Stratifizierung im frühen Mittelalter. Text.PhDThesis. Rer. nat. Diss. München 2011

Eckert J: Das Großsteingrab in Rheine: Expedition in die Vergangenheit. Ausstellungskatalog. Rheine 1999, 96-105

Eckert WG (1981): The medicolegal and forensic aspects of fires. Am J Forensic Med Pathol $\underline{4}(2), 347-357$

El-Najjar MY, Ryan DJ, Turner CG, Lozoff B (1976): The etiology and porotic hyperostosis among the prehistoric and historic Anasazi Indians of Southwestern United States. Am J Phys Anthropol 44, 477-487

Eshed V, Gopher A, Hershkovitz I (2006): Tooth wear and dental pathology at the advent of agriculture: New evidence form the levant. Am J Phys Anthropol 130, 145-159

Eveleth PB, Tanner JM: Worldwide variation in human growth. (International Biological Programme 8); Cambridge University Press, Cambridge-New York 1976

Ferembach D, Schwidetzky I, Stloukal M (1979): Empfehlungen für die Alters- und Geschlechtsdiagnose am Skelett. Homo 30, 1-32 
Flohr S, Schultz M (2009): Mastoiditis-Paleopathological evidence of a rarely reported disease. Am J Phys Anthropol 138, 266-273

Flohr S, Kierdorf U, Schultz M (2009): Differential diagnosis of mastoid hypocellularity in human skeletal remains. Am J Phys Anthropol 140, 442453

Gladykowska-Rzeczycka JJ, Parafiniuk M (2001): Atypical cranial vault and cervical vertebrae lesions caused by insects. J Paleopathol $\underline{13}, 75-78$

Goodman AH, Thomas RB, Swedlund AC, Armelagos GJ (1988): Biocultural perspectives on stress in prehistoric, historical and contemporary population research. Yearb Phys Anthropol 31, 169-202

Götz W: Histologische Untersuchungen an Cribra orbitalia. Ein Beitrag zur Paläopathologie des Orbitadaches. Med. Diss. Göttingen 1988

Gresky J, Wu XH, Wagner M, Schmidt-Schultz T, Schultz M (2008): Alltagsstress in Liushui: Krankheitsbilder des Bewegungsapparates im bronzezeitlichen Westchina. Eurasia Antiq 14, 167-191

Grupe G, Christiansen K, Schröder I, Wittwer-Backofen U: Anthropologie: Ein einführendes Lehrbuch. Springer-Verlag, Berlin Heidelberg 2005

Hawkey DE, Merbs CF (1995): Activity-induced musculoskeletal stress markers (MSM) and subsistence strategy changes among ancient Hudson Bay Eskimos. Int J Osteoarchaeol $\underline{5}, 324-338$

Herrmann B: Behandlung von Leichenbrand. In: Knußmann R (Hrsg.): Anthropologie. Handbuch der vergleichenden Biologie des Menschen. Wesen und Methoden der Anthropologie. Band 1; Fischer Verlag, StuttgartNew York 1988a, 576-585

Herrmann B: Röntgenologische Methoden. In: Knußmann R (Hrsg.): Anthropologie. Handbuch der vergleichenden Biologie des Menschen. Wesen und Methoden der Anthropologie. Band 1; Fischer Verlag, StuttgartNew York 1988b, 684-698

Kerley ER (1965): The microscopic determination of age in human bone. Am J Phys Anthropol 23, 149-163

Kerley ER, Ubelaker DH (1978): Revisions in the microscopic method of estimating age at death in human cortical bone. Am J Phys Anthropol 49, 545-546

Kirkpatrick S (1913): Mastoiditis. South Med J $\underline{6}$, 673-676

Klein JO (1994): Otitis media. Clin Infect Dis $\underline{19}$ 823-832 
Koch AL (2008): Stone age diseases and modern AIDS. Virol J $\underline{5}, 93$

Kósa F, Virágos Kis E, Rengeil B (1989): Altersbedingte Veränderungen des Gehaltes menschlicher Knochen an anorganischen Substanzen. Acta Biol 35 , 191-198

Küchelmann HC: Untersuchung von Knochenfunden aus Emstek, Kreis Cloppenburg. Archäozoologie • Taphonomie • Worked Bone, Bremen 2009; https://www.knochenarbeit.de/wp/wpcontent/uploads/2018/12/Emstek.pdf

Martin R: Lehrbuch der Anthropologie. 2. Auflage; Gustav Fischer, Jena 1928

Masset C (1971): Erreurs systématiques dans la détermination de l'âge par les sutures crâniennes. Bull Mém Société Anthropol Paris $\underline{7}$, 85-105

McKern TW, Stewart TD: Skeletal age changes in young American males. Analysis from the standpoint of age identification. Defense Technical Information Center, Fort Belvoir, VA 1957

Meyer I: Untersuchungen der Kiefer und Zähne aus dem Steinkistengrab (Jungsteinzeit) bei Calden (Nordhessen). Med. dent. Diss. Marburg 1959

Miles AEW: The dentition in the assessment of individual age in skeletal material. In: Brothwell DR (Hrsg.): Dental Anthropology. Pergamon 1963, 191-209

Mjør IA, Fejerskov O: Human oral embryology and histology. Munksgaard, Copenhagen 1986

Murphy EM, Davis-Kimbal J (2015): Iron age weapon trauma from the Chowhougou cemetery complex, western China. J Paleopathol $\underline{13}$, 27-34

Naveed H, Abed SF, Davagnanam I, Uddin JM, Adds PJ (2012): Lessons from the past: Cribra orbitalia, an orbital roof pathology. Orbit 31, 394-399

Nemeskéri J, Harsányi L, Acsádi G (1960): Methoden zur Diagnose des Lebensalters von Skelettfunden. Anthropol Anz 24, 70-95

Nováček J: Möglichkeiten und Grenzen der mikroskopischen Leichenbranduntersuchung. Rer. nat. Diss. Hildesheim 2012

Novotný V: Diskriminanzanalyse der Geschlechtsmerkmale auf dem Os coxae beim Menschen. XIII Czechoslovakian Anthropological Congress, Brno 1975

Novotný V: Revision of sex diagnosis in some fossil hominids according to the pelvis; Universitas Carolina Pragensis 1982 
Olivier G: Pratique Anthropologique. vigot freres, Paris 1960

Pasda K: Die Menschenreste aus dem Galeriegrab Calden II. In: Raetzel-Fabian D (Hrsg.): Calden. Erdwerk und Bestattungsplätze des Jungneolithikums. Architektur - Ritual - Chronologie. Band 70; Dr. Rudolf Habelt GmbH, Bonn 2000, 315-353

Pearson K (1899): IV. Mathematical contributions to the theory of evolution. - V. On the reconstruction of the stature of prehistoric races. Phil Trans R Soc Lond A $\underline{192}$, 169-244

Pearson K, Bell J: A study of the long bones of the English skeleton. London Cambridge University Press, Cambridge 1919

Perizonius WRK, Pot TJ (1981): Diachronic dental research on human skeletal remains excavated in the Netherlands. I. Dorestad's Cemetery on 'the Heul'. Ber Van Rilksdienst Voor Het Oudh Bodemonderz Jaargang 31, 369413

Pettener D, Brasili Gualandi P (1979): La funzione discriminante nella diagnosi del sesso in base ai caratteri metrici dei femore. Antropol Contemp 59-68

Phenice TW (1969): A newly developed visual method of sexing the os pubis. Am J Phys Anthropol 30, 297-301

Purcell MW: Sex differences in the femur and acetabulum: Biomechanical analysis with forensic significance. Master's thesis. Texas State University 2013

Raetzel-Fabian D, Kappel I: Erdwerk und Megalithgrab bei Calden: Mittelpunkt einer Region vor 5000 Jahren. Die Ergebnisse der Ausgrabungen 1988-1990 bei Calden, Kreis Kassel. (Archäologische Denkmäler in Hessen 91); Wiesbaden 1991

Raetzel-Fabian D (2002): Absolute chronology and cultural development of the neolithic Wartberg Culture in Germany. J Neolit Archaeol http://www.jna.uni-kiel.de/index.php/jna/article/view/82

Raetzel-Fabian D (2003): Eine neue Parallele zu den Einbauten im spätmichelsbergzeitlichen Erdwerk von Calden, Kr. Kassel? J Neolit Archaeol http://www.jna.uni-kiel.de/index.php/jna/article/view/3

Raetzel-Fabian D (2012a): Das Erdwerk (2) - Funde, Chronologie, Nutzung. J Neolit Archaeol http://www.jna.uni-kiel.de/index.php/jna/article/view/57/57 
Raetzel-Fabian D (2012b): Das Galeriegrab Calden I. J Neolit Archaeol http://www.jna.uni-kiel.de/index.php/jna/article/view/59/59

Raetzel-Fabian D (2012c): Das Galeriegrab Calden II. J Neolit Archaeol http://www.jna.uni-kiel.de/index.php/jna/article/view/61/61

Raetzel-Fabian D (2012d): Einführung. J Neolit Archaeol http://www.jna.uni-kiel.de/index.php/jna/article/view/53/54

Raetzel-Fabian D (2012e): Rekonstruktion einer rituellen Landschaft. J Neolit Archaeol

http://www.jna.uni-kiel.de/index.php/jna/article/view/64/65

Raetzel-Fabian D (2012f): Das Erdwerk (1) - Befunde. J Neolit Archaeol http://www.jna.uni-kiel.de/index.php/jna/article/view/55/55

Raxter MH, Ruff CB, Azab A, Erfan M, Soliman M, El-Sawaf A (2008): Stature estimation in ancient Egyptians: a new technique based on anatomical reconstruction of stature. Am J Phys Anthropol 136, 147-155

Rinne C: Odagsen und Großenrode, Ldkr. Northeim, Jungsteinzeitliche Kollektivgräber im südlichen Leinetal. In: Assendorp JJ, Cosack E, Eckert J, Geschwinde M (Hrsg.): Beiträge zur Archäologie in Niedersachsen. Band 5; Verlag Marie Leidorf GmbH, Rahden/Westfalen 2003, 83-87

Rinne C (2012a): Das Kollektivgrab Großenrode I. J Neolit Archaeol http://www.jna.uni-kiel.de/index.php/jna/article/view/75/76

Rinne C (2012b): Das Kollektivgrab Großenrode II. J Neolit Archaeol http://www.jna.uni-kiel.de/index.php/jna/article/view/76/77

Roberts CA (2007): A bioarcheological study of maxillary sinusitis. Am J Phys Anthropol 133, 792-807

Rösing FW (1977): Methoden der Aussagemöglichkeiten der anthropologischen Leichenbrandbearbeitung. Archäol und Naturwissenschaften 1, 53-80

Rösing FW: Körperhöhenrekonstruktion aus Skelettmaßen. In: Knußmann R (Hrsg.): Anthropologie. Handbuch der vergleichenden Biologie des Menschen. Wesen und Methoden der Anthropologie. Band 1; Fischer Verlag, Stuttgart-New York 1988, 586-599

Rösing FW, Graw M, Marré B, Ritz-Timme S, Rothschild MA, Rötzscher K, Schmeling A, Schröder I, Geserick G (2005): Empfehlungen für die forensische Geschlechts- und Altersdiagnose am Skelett. Anthropol Anz $\underline{63}$, 221-232 
Schäffer W: Oberflächenhistologische Untersuchungen an Zähnen von Steinkistenschädeln aus dem Grabfund von Calden (Nordhessen). Med. dent. Diss. Marburg 1959

Schneider KN (1986): Dental caries, enamel composition, and subsistence among prehistoric Amerindians of Ohio. Am J Phys Anthropol 71, 95-102

Schour I, Massler M (1941): The development of the human dentition. J Am Dent Assoc 1153-1160

Schulting R, Fibiger L: Sticks, Stones, and Broken Bones. Neolithic Violence in a European Perspective. Oxford University Press, Oxford 2012

Schultz M: Umwelt und Krankheit des vor- und frühgeschichtlichen Menschen. In: Wendt H, Loacker N (Hrsg.): Kindlers Enzyklopädie. Der Mensch. Band 2; Kindler Verlag, München/Zürich 1982

Schultz M: Die mikroskopische Untersuchung prähistorischer Skeletfunde: Anwendung und Aussagemöglichkeiten der differentialdiagnostischen Untersuchung in der Paläopathologie. Band 1; Amt für Museen und Archäologie BL, Liestal, Schweiz 1986

Schultz M: Spuren unspezifischer Entzündungen an prähistorischen und historischen Schädeln: ein Beitrag zur Paläopathologie. Med. Habil.-Schr. Göttingen 1987

Schultz M: Methoden der Licht- und Elektronenmikroskopie. In: Knußmann R (Hrsg.): Anthropologie. Handbuch der vergleichenden Biologie des Menschen. Wesen und Methoden der Anthropologie. Band 1; Fischer Verlag, Stuttgart-New York 1988a, 698-730

Schultz M: Paläopathologische Diagnostik. In: Knußmann R (Hrsg.): Anthropologie. Handbuch der vergleichenden Biologie des Menschen. Wesen und Methoden der Anthropologie. Band 1; Fischer Verlag, StuttgartNew York 1988b, 480-496

Schultz M (1989): Zur Morbidität neolithischer Populationen. Ein Beitrag zur Paläopathologie. Homo 40, 81-98

Schultz M: Leben, Krankheit und Tod - Skeletfunde als Spiegel der Lebensbedingungen. In: Jockenhövel A, Kubach W (Hrsg.): Bronzezeit in Deutschland. Theiss Verlag, Stuttgart 1994, 15-17 
Schultz M: Neuere Ergebnisse zur vor- und frühgeschichtlichen Schädeltrepanation: Die frühbronzezeitlichen Schädel von İkiztepe. In: Saternus K-S, Bonte W (Hrsg.): Forensische Osteologie - Anthropologie, Biomechanik, Klinik, Archäologie. Festschrift für Steffen Berg. SchmidtRömhild Verlag, Lübeck 1995, 109-130.

Schultz M: Microscopic investigation of excavated skeletal remains: a contribution to paleopathology and forensic medicine. In: Haglund WD, Sorg $\mathrm{MH}$ (Hrsg.): Forensic taphonomy. The postmortem fate of human remains. CRC Press, Boca Raton, USA 1997, 201-222

Schultz M: Bronze Age man; in: Gods and heroes of the bronze age : Europe at the time of Ulysses; hrsg. v. Council of Europe. Art Exhibition Copenhagen D; Copenhagen: National Museum of Denmark; London: Thames and Hudson, Copenhagen; London 1998, 73-78

Schultz M (2001a): Paleohistopathology of bone: A new approach to the study of ancient diseases. Am J Phys Anthropol 116, 106-147

Schultz M: Light microscopic analysis in skeletal paleopathology; in: Identification of Pathological Conditions in Human Skeletal Remains; 2003, 73-107

Schultz M: Light microscopic analysis of pathologically changed macerated bones. In: Crowder C, Stout S (Hrsg.): Bone Histology. An Anthropological Perspective. CRC Press, Bota Raton/New York/London 2011a

Schultz M: Paläobiographik. In: Jüttemann G (Hrsg.): Biographische Diagnostik. Pabst Science Publ, Lengerich; Berlin; Bremen; Viernheim; Wien [u.a.] 2011b, 222-236

Schultz M, Drommer R: Möglichkeiten der Präparatherstellung aus dem Gesichtsschädelbereich für die makroskopische und mikroskopische Untersuchung unter Verwendung neuer Kunststofftechniken. In: Hoppe W (Hrsg.): Experimentelle Mund-Kiefer-Gesichtschirurgie. Mikrochirurgische Eingriffe. Thieme, Stuttgart 1983, 95-97

Schultz M, Schmidt-Schultz TH (1999): Ätiologie und Epidemiologie der Krankheiten des Kindesalters in der Bronzezeit. Beitr Z Archäozool U Prähist Anthr 2,7

Schultz M, Bátora J: Zum Gesundheitszustand der frühbronzezeitlichen Population des Gräberfeldes von Jelšovce, Südwestslowakei; in: Mensch und Umwelt während des Neolithikums und der Frühbronzezeit in Mitteleuropa. Ergebnisse interdisziplinärer Zusammenarbeit zwischen Archäologie, Klimatologie, Biologie und Medizin. Wien, 9.-12.November 1995; Leidorf, Rahden/Westf 2001b, 307-315 
Schultz M, Nováček J: Ergebnisse der lichtmikroskopischen Untersuchung an den menschlichen Skeletresten aus dem Tumulus auf dem İlyastepe. In: Pirson F, Japp S, Kelp U, Stappmanns V, Teegen W-R, Wirsching A (Hrsg.): Der Tumulus auf dem İlyastepe und die pergamenischen Grabhügel. Istanbuler Mitteilungen (des Deutschen Archäologischen Instituts). Band 61; Ernst Wasmuth Verlag, Istanbul 2012, 165-181

Schultz M, Schmidt-Schultz TH: The role of deficiency diseases in infancy and childhood of Bronze Age populations. In: Milano L (Hrsg.): Paleonutrition and Food Practices in the Ancient Near East. Towards a Multidisciplinary Approach. S.A.R.G.O.N. Editrice e Libreria, Padova 2014, 25-39

Schultz M, Schmidt-Schultz TH, Gresky J, Kreutz K, Berner M (2006): Morbidity and mortality in the late PPNB populations from Basta and Ba'ja (Jordan). Archaeopress (BAR Int. Ser. 1603), 82-99

Schultz M, Parzinger H, Posdnjakov DV, Chikisheva TA, Schmidt-Schultz TH (2007): Oldest known case of metastasizing prostate carcinoma diagnosed in the skeleton of a 2,700-year-old Scythian king from Arzhan (Siberia, Russia). Int J Cancer 121, 2591-2595

Schultz M, Timme U, Hilgers R, Schmidt-Schultz TH: Die Krankheiten der Kinder des Grasshopper Pueblos (Arizona). Ergebnisse paläopathologischbioarchäologischer Untersuchungen. In: Piek J, Terberger T (Hrsg.): Verletzungen und Krankheitsspuren an historischen und prähistorischen Skelettresten. Marie Leidorf Verlag, Rahden/Westfalen 2008, 137-160

Schultz M, Oplesch E, Nováček J: Die Michelsberger Hockerbestattung von Regensburg-Burgweinting - Archäologie und Anthropologie. In: Husty L, Irlinger W, Pechtl J (Hrsg.): „...und es hat doch was gebracht!“ Festschrift für Karl Schmotz zum 65. Geburtstag. Internationale Archäologie. Studia Honorari a. Marie Leidorf GmbH, Rahden/Westfalen 2014, 121-144

Schwörer I: Die Skelettentwicklung des Menschen. Lehrtafel. Thieme, Stuttgart 1975

Siegmund F: Die Körpergrösse der Menschen in der Ur- und Frühgeschichte Mitteleuropas und ein Vergleich ihrer anthropologischen Schätzmethoden. Books on Demand GmbH, Norderstedt 2010

Sjøvold T: Geschlechtsdiagnose am Skelett. In: Knußmann R (Hrsg.): Anthropologie. Handbuch der vergleichenden Biologie des Menschen. Wesen und Methoden der Anthropologie. Band 1; Fischer Verlag, StuttgartNew York 1988, 444-480 
Sjøvold T (1990): Estimation of stature from long bones utilizing the line of organic correlation. Hum Evol $\underline{5}, 431-447$

Slater CP (1994): A temporal bone lesion in a modern subject to explain a defect in the Kabwe skull. Int J Osteoarchaeol 4, 371-375

Steel FLD (1966): Further observations on the osteometric discriminant function. The human clavicle. Am J Phys Anthropol 25, 319-323

Steele DG (1976): The estimation of sex on the basis of the talus and calcaneus. Am J Phys Anthropol 45, 581-588

Steinbok P (2015): Healing calvarial eosinophilic granuloma or healing skull fracture? Childs Nerv Syst $\underline{31}$, 1175-1176

Stewart TD: Identification by the skeletal structures. In: Camps FE (Hrsg.): Gradwohl's legal medicine. John Wrights \& Sons, Bristol 1968

Steyn M, Voeller S, Botha D, Ross AH (2016): Cribra orbitalia: Prevalence in contemporary populations. Clin Anat $\underline{29}, 823-830$

Stloukal M, Hanáková H (1978): Die Länge der Längsknocken altslawischer Bevölkerungen unter besonderer Berücksichtigung von Wachstumsfragen. Homo $\underline{29}$, 53-69

Strádaloá V (1975): Sex differences and sex determination on the sacrum. Anthropol 1962- 13, 237-244

Szilvássy J: Altersdiagnose am Skelett. In: Knußmann R (Hrsg.): Anthropologie. Handbuch der vergleichenden Biologie des Menschen. Wesen und Methoden der Anthropologie. Band 1; Fischer Verlag, Stuttgart-New York 1988, 421-443

Szilvássy J, Kritscher H (1990): Bestimmung des individuellen Lebensalters beim Menschen mit Hilfe der Spongiosastruktur der Langknochen. Ann Naturhist Mus Wien 91, 145-154

Teegen W-R, Schultz M (2003): Geschlechtsabhängige Arbeitsverteilung in slawischen Gräberfeldern nach Aussage der Gelenkerkrankungen. Leipz Online-Beitr Zur Ur- Frühgesch Archäol 41-48

Telkkä A (1950): On the prediction of human stature from the long bones. Acta Anat (Basel) $\underline{9}, 103-117$ 
Ubelaker DH: Human skeletal remains: excavation, analysis, interpretation. Aldine Pub. Co., Chicago 1978

Vallois HV (1937): La durée de la vie chez l'homme fossile. L'Anthrop 47, 499-532

von Hagens G (1978): Preserving human, animal or plant specimens - by impregnation with a polymerisable plastic material without affecting outline. Patent DE2710147(A1)-1978-09-14

(https://worldwide.espacenet.com/publicationDetails/biblio?II=10\&ND=3\&adjacen $\mathrm{t}=$ true\&locale $=$ en_EP\&FT $=\mathrm{D} \&$ date $=19780914 \& C C=\mathrm{DE} \& N R=2710147 \mathrm{~A} 1 \& \mathrm{KC}=\mathrm{A} 1 \#)$

von Hagens G, von Hagens C (1984): Method for the improved utilisation of plastics in the preservation of biological preparations. Patent DE3232756(A1)-1984-03-08

(https://worldwide.espacenet.com/publicationDetails/biblio?II=7\&ND=3\&adjacent $=$ true $\&$ locale $=$ en_EP\&FT $=$ D\&date $=19840308 \& C C=D E \& N R=3232756 A 1 \& K C=A 1 \#$ )

Wallin JA, Tkocz I, Kristensen G (1994): Microscopic age determination of human skeletons including an unknown but calculable variable. Int J Osteoarchaeol $\underline{4}, 353-362$

Wapler U, Crubézy E, Schultz M (2004): Is cribra orbitalia synonymous with anemia? Analysis and interpretation of cranial pathology in Sudan. Am J Phys Anthropol 123, 333-339

Weber J, Czarnetzki A (2001): Neurotraumatological aspects of depressed skull fracture in antiquity with special reference to skulls from central Europe in the early medieval period. J Paleopathol $\underline{13}$, 35-40

Welcker H: Die Abstammung der Bevölkerung von Socotra. In: Kietrich R (Hrsg.): Verhandl. d. 5. deutschen Geographentages zu Hamburg. Dietrich Reimer Verlag, Berlin 1885, 92-94

Welcker H (1888): Cribra orbitalia, ein ethnologisch-diagnostisches Merkmal am Schädel mehrerer Menschenrassen. Arch Anthropol 17, 1-18

Wells C: Pseudopathology. In: Brothwell DR, Sandison AT (Hrsg.): Diseases in antiquity. Charles C Thomas, Springfield 1967, 5-19

Wolf M: Ergebnisse makro- und mikroskopischer Untersuchungen an den römischen Brandgräbern von Rheinzabern (Rheinland-Pfalz); in: Beiträge zur Paläopathologie 3; Cuvillier Verlag, Göttingen 1999, 1-171 


\section{Anhang}

Im ersten Teil des Anhangs sollen einzelne Fundstücke vorgestellt werden. Beispielhaft werden Befunde gezeigt und mit Fotografien, Röntgenbildern, Endoskopbildern, Mikroskopbildern und Elektronenmikroskopbildern dargestellt. Der vollständige Befundkatalog befindet sich als Teil dieser Arbeit auf einer CD. 


\subsection{Befund 1: Cranium 3 der Population aus Calden}

Knochenname: Cranium

Skeletnummer: $\quad$ Calden 3

Kistennummer: $\quad$ Museumskiste 2

Alter: $\quad(25) 30-35$ J.

Geschlecht:

Erhaltungszustand: gut

Gesund/krank: krank

- Cribra Orbitalia beidseitig

- Kopfschwartenreizung

- Sinusitis maxillaris beidseitig

Besonderheiten:

- Bathrocephalus

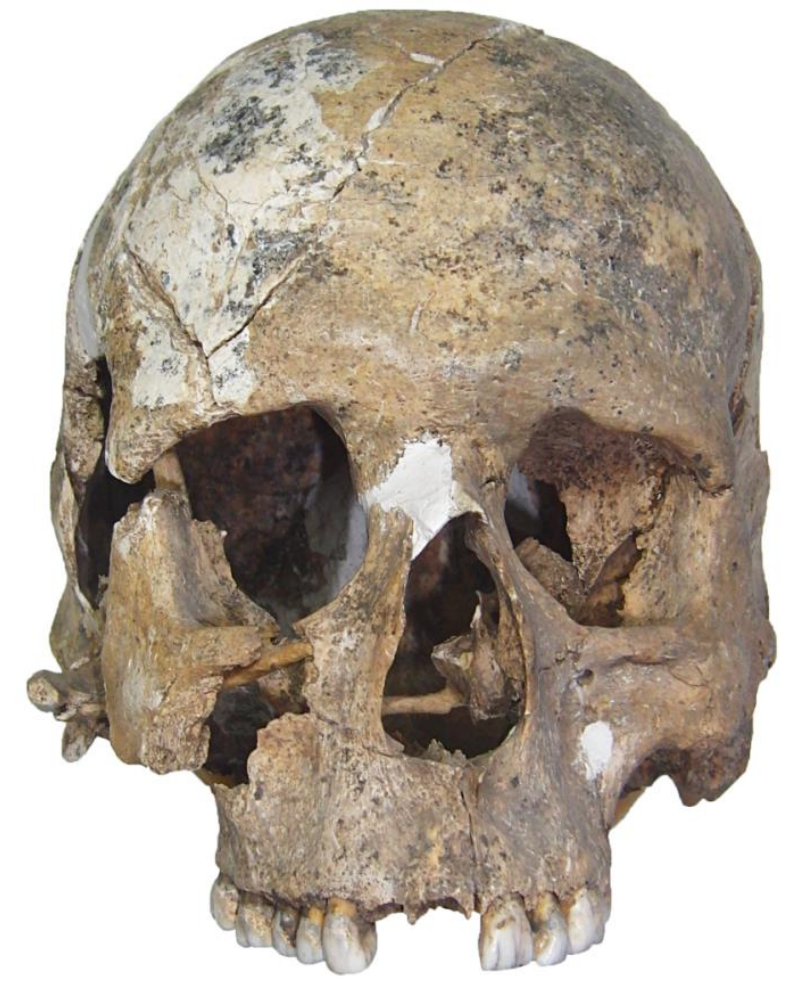

Gesamtbeschreibung:

Bei diesem Schädel eines männlichen Individuums mittleren Alters handelt es sich um ein Ausstellungsstück des Heimatmuseums in Kassel. Das Cranium ist als Stufenschädel (Bathrocephalus) ausgebildet. Weiterhin findet sich eine Protuberantia occipitalis externa, die leichte Ähnlichkeiten mit einer Crista occipitalis externa zeigt. Die Lamina externa ist zu etwa 50\% gut erhalten; ansonsten ist der Schädel von Bodenerosionen gezeichnet. Es finden sich auf den Ossa parietalia und der Squama occipitalis Spuren einer Kopfschwartenentzündung. Die Lamina interna ist zu etwa 30\% befundbar während alles weitere wegen Erosionen unbefundbar ist. Der Sinus maxillaris ist in seiner Entwicklungsphase nicht physiologisch pneumatisiert, was für eine Sinusitis maxillaris im Kindesalter - also während des Wachstums - spricht. Es finden sich deutliche Muskelmarken an den Processus mastoidei und an den Processus zygomatici. An den Dächern der Orbitae fallen Spuren einer vernarbten Cribra orbitalia auf, die mit einem Ausprägungsgrad von $2 \mathrm{zu}$ beziffern sind. Das Alter des Individuums ist auf etwa 30 Jahre +/- 5 einzustufen. 


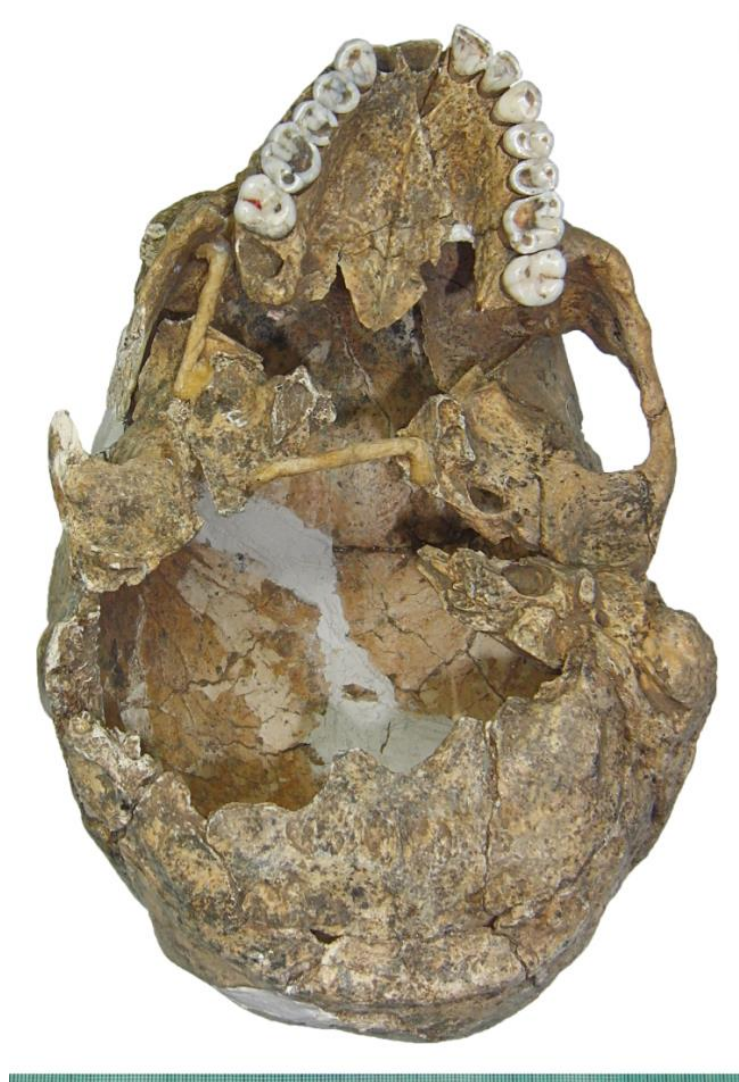

Abb. 2

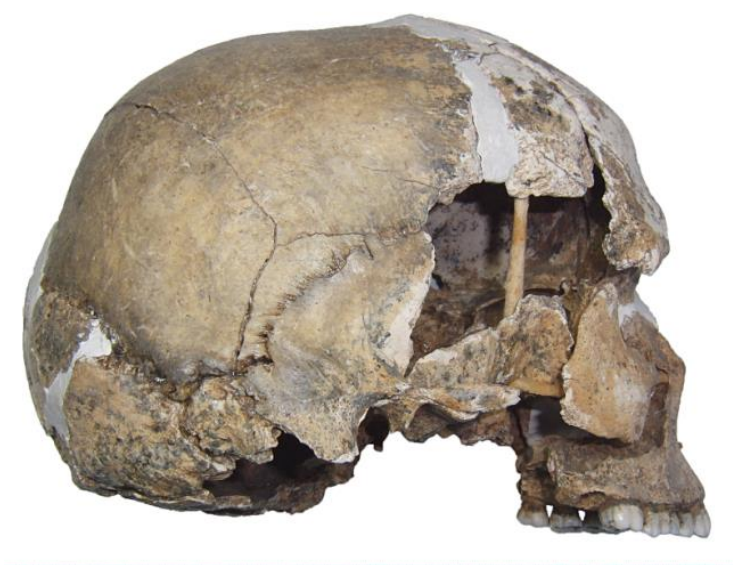

Abb. 4

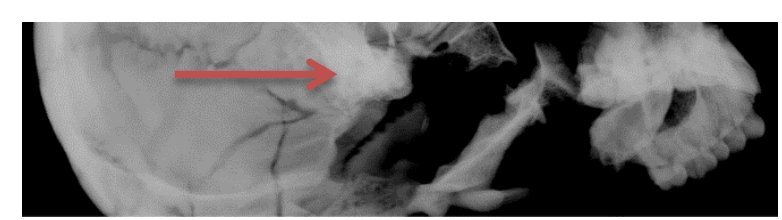

Abb. 6

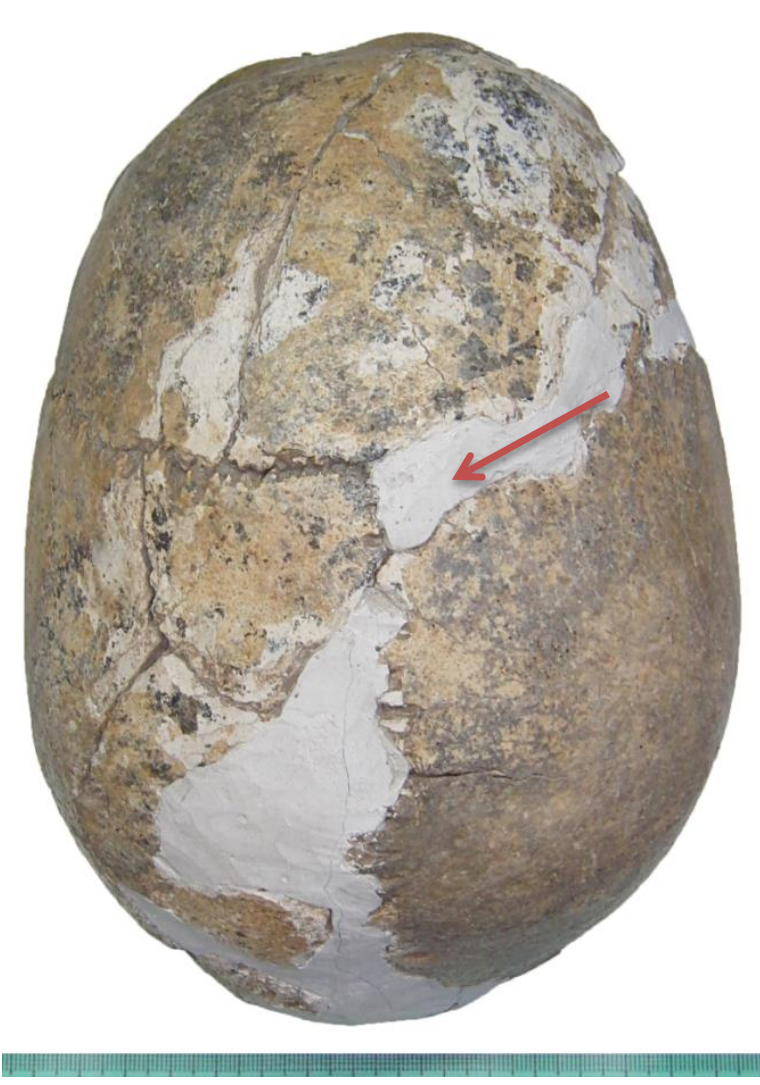

$A b b .3$

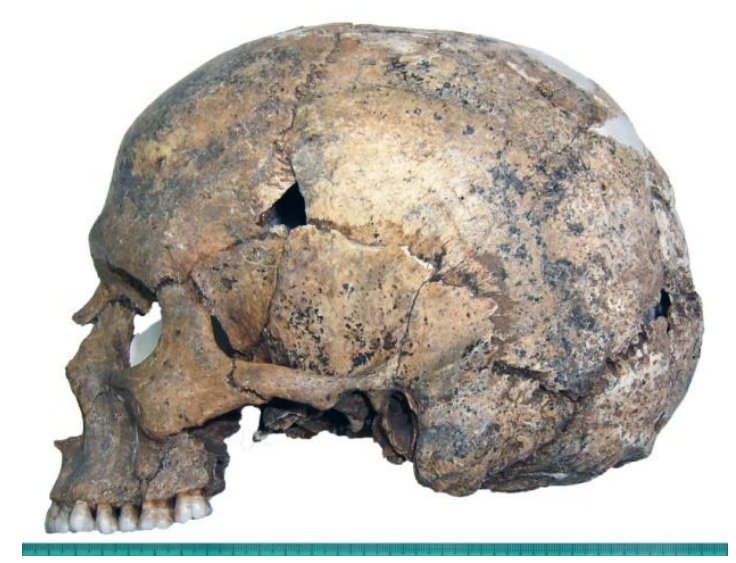

Abb. 5

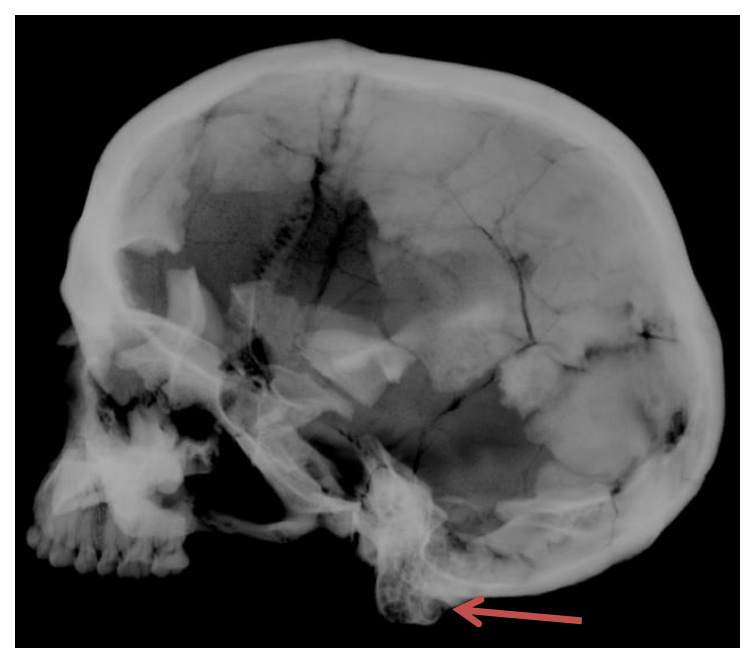

Abb. 7 


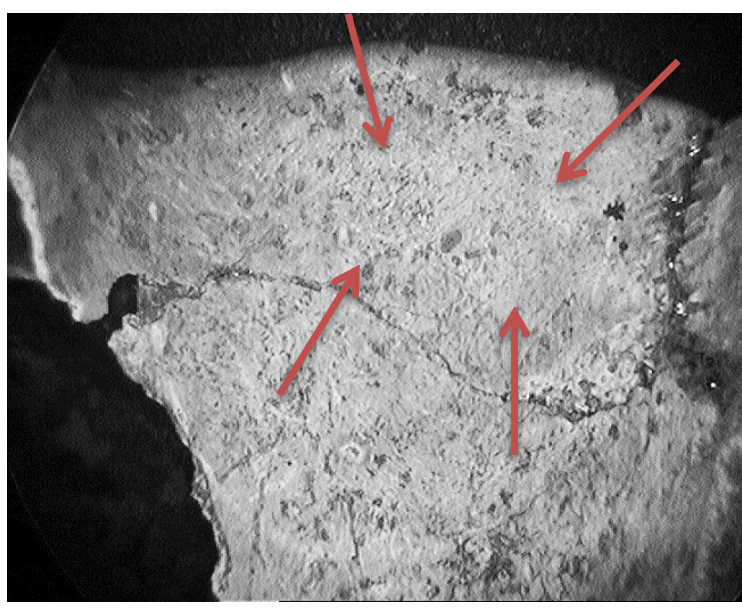

Abb. 8

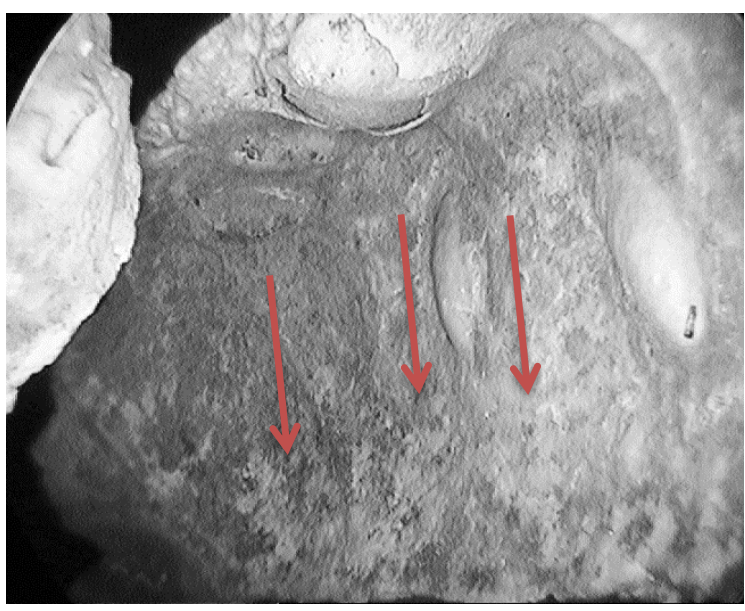

Abb. 9

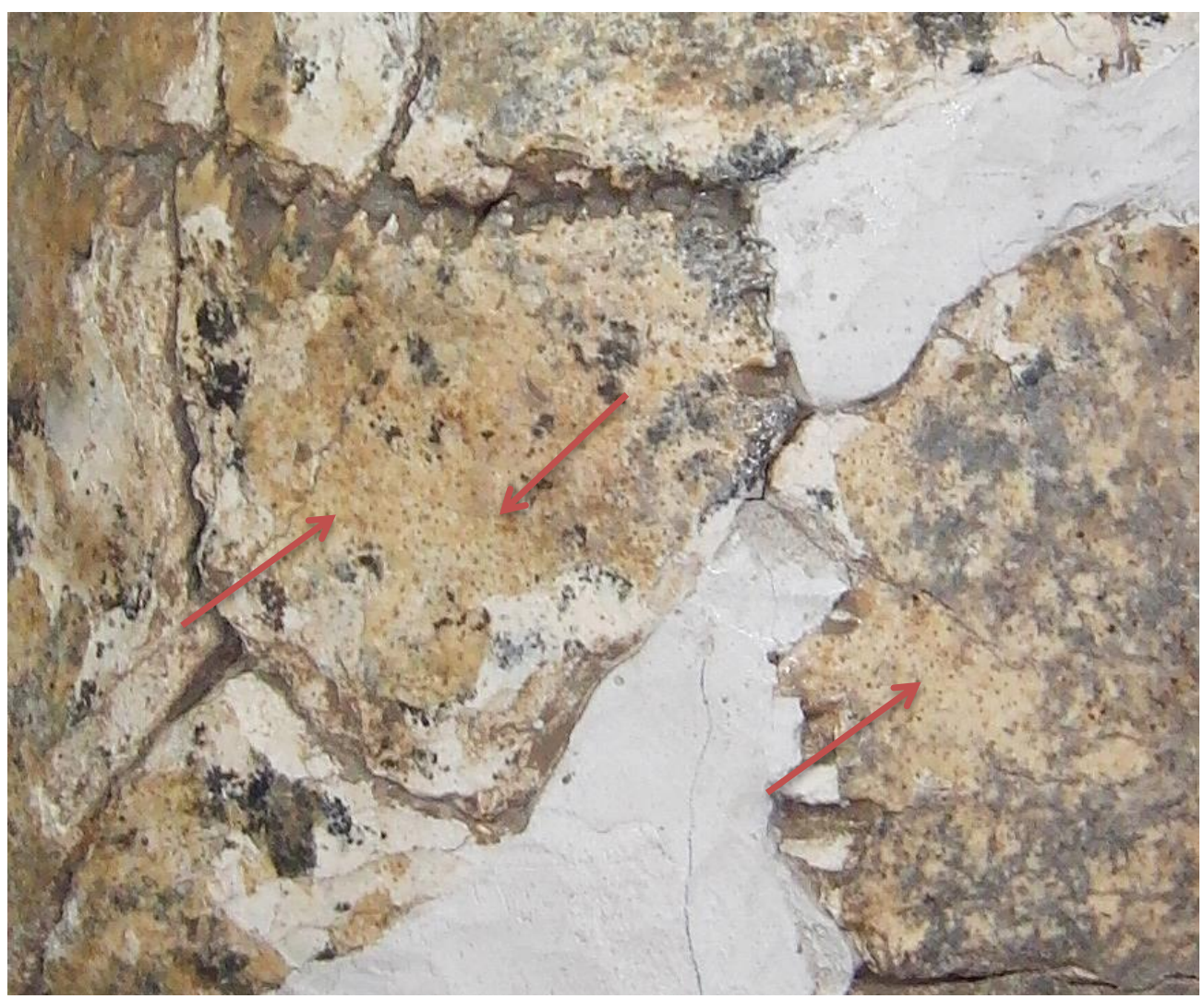

Abb. 10

\section{Abbildungen:}

1. Foto des Schädels von anterior. Es sind Fremdkörper - wie Gips und Holzstäbchen - zu sehen, die zum Erhalt des Schädels in dieser Form beitragen sollen. Gips und Holzstäbchen sind von anderen Personen an den Schädel angebracht worden.

2. Abbildung des Schädels in axialer Richtung von caudal. Es sind Reparaturmaterialien (von anderen Personen angebracht) zu sehen, die den Schädel stabilisieren. 
3. Axiale Aufnahme von cranial, zu sehen ist die Schädeldecke. Lücken durch postmortale Brüche der Knochenstruktur wurden mit hellem Gips aufgefüllt. Der Pfeil deutet auf die Spuren einer Kopfschwartenreizung.

4. Eine sagittale Aufnahme von rechts.

5. Sagittale Abbildung von links.

6. Ausschnitt - Röntgenaufnahme der rechten Seite des Schädels. Der Pfeil deutet auf das Mastoid der rechten Seite. Auf den ersten Blick schien es nur eingeschränkt pneumatisiert zu sein, durch Kontraständerungen mit dem Bildprogramm des Röntgengerätes erwies sich dies jedoch als falsch, da eine Überlagerung mit der Felsenbeinpyramide vorliegt. Nach längerer Untersuchung konnte somit eine Pneumatisierung festgestellt werden. Weiterhin konnten apicale Prozesse an den Zähnen der linken Seite röntgenologisch ausgeschlossen werden.

7. Röntgenaufnahme der linken Seite des Schädels. Es imponiert das pneumatisierte Mastoid der linken Seite, welches durch den Pfeil markiert ist. Die Zähne der linken Seite zeigten auf dieser Aufnahme keine Auffälligkeiten.

8. Endoskopaufnahme des linken Orbitadachs. Die Pfeile grenzen den Bereich $a b$, in dem eine leichte bis mittelschwere Cribra orbitalia nachweisbar war. Aufgrund des höheren Kontrastes wurde auf eine farbige Abbildung verzichtet und stattdessen ein Graustufenbild angefertigt.

9. Endoskopaufnahme der rechten Kieferhöhle. Die Pfeile deuten auf die Spuren einer leichten, bereits verheilten Sinusitis maxillaris. Zu erkennen sind die leicht erhabenen Knochenstrukturen durch den Hell - Dunkel Kontrast, die sich im Zuge des Entzündungsprozesses reaktiv gebildet haben. Zur besseren Darstellung wurde eine Farbauflösung des Bildes in Graustufen gewählt.

10. Nahaufnahme von Abbildung 3. Es sind die Spuren der verheilten Kopfschwartenreizung zu erkennen. Die Pfeile markieren beispielhaft einige Bereiche, in denen die knöchernen Veränderungen gut sichtbar sind. 


\subsection{Befund 2: Cranium 28 der Population aus Calden}

Knochenname: Cranium

Skeletnummer: $\quad$ Calden 28

Kistennummer: $\quad 5271289$

Alter:

(50) $55-65 \mathrm{~J}$.

Geschlecht:

$\uparrow \geq 0$

Erhaltungszustand: gut

Gesund/krank: krank

- Reizung des

Meatus acusticus ext.

- Cribra orbitalia (verheilt/vernarbt)

- meningeale Reizung

- Periostreizung

- Fraktur durch Trauma

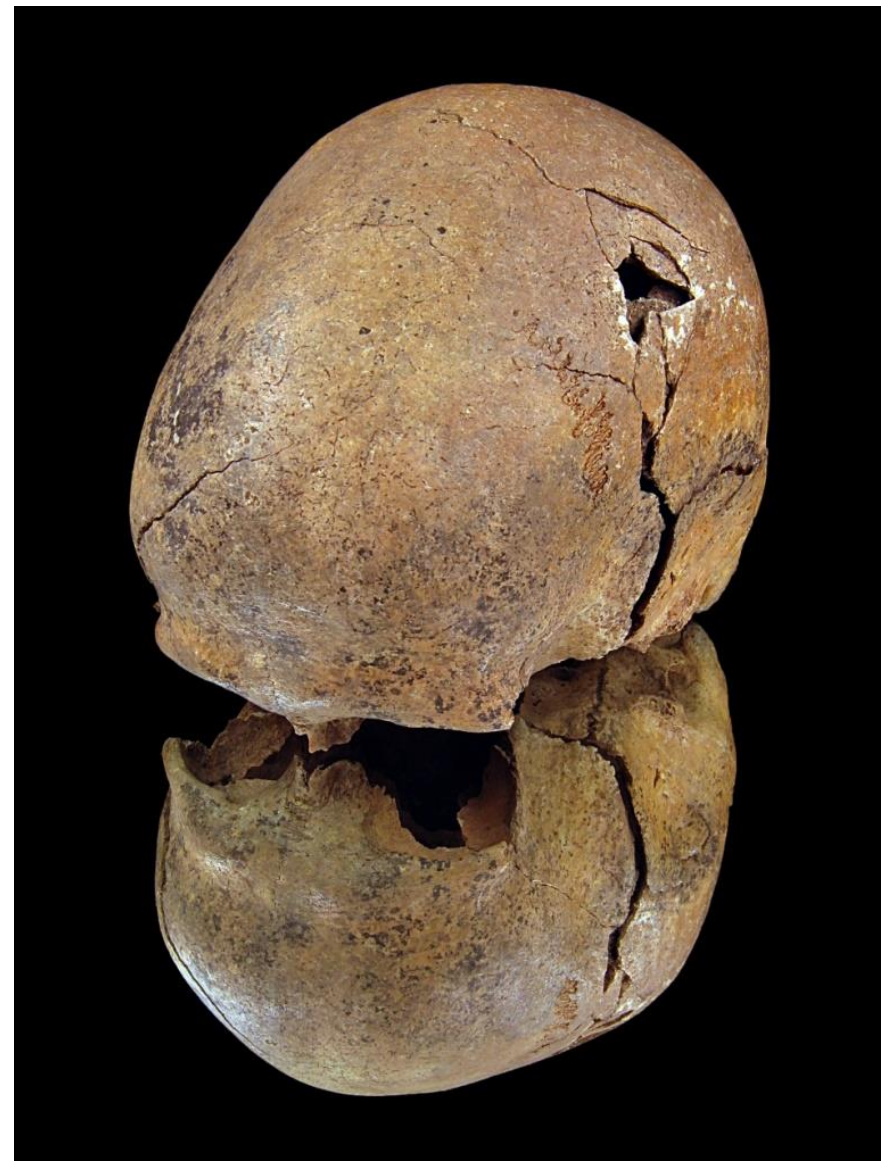

$A b b .1$
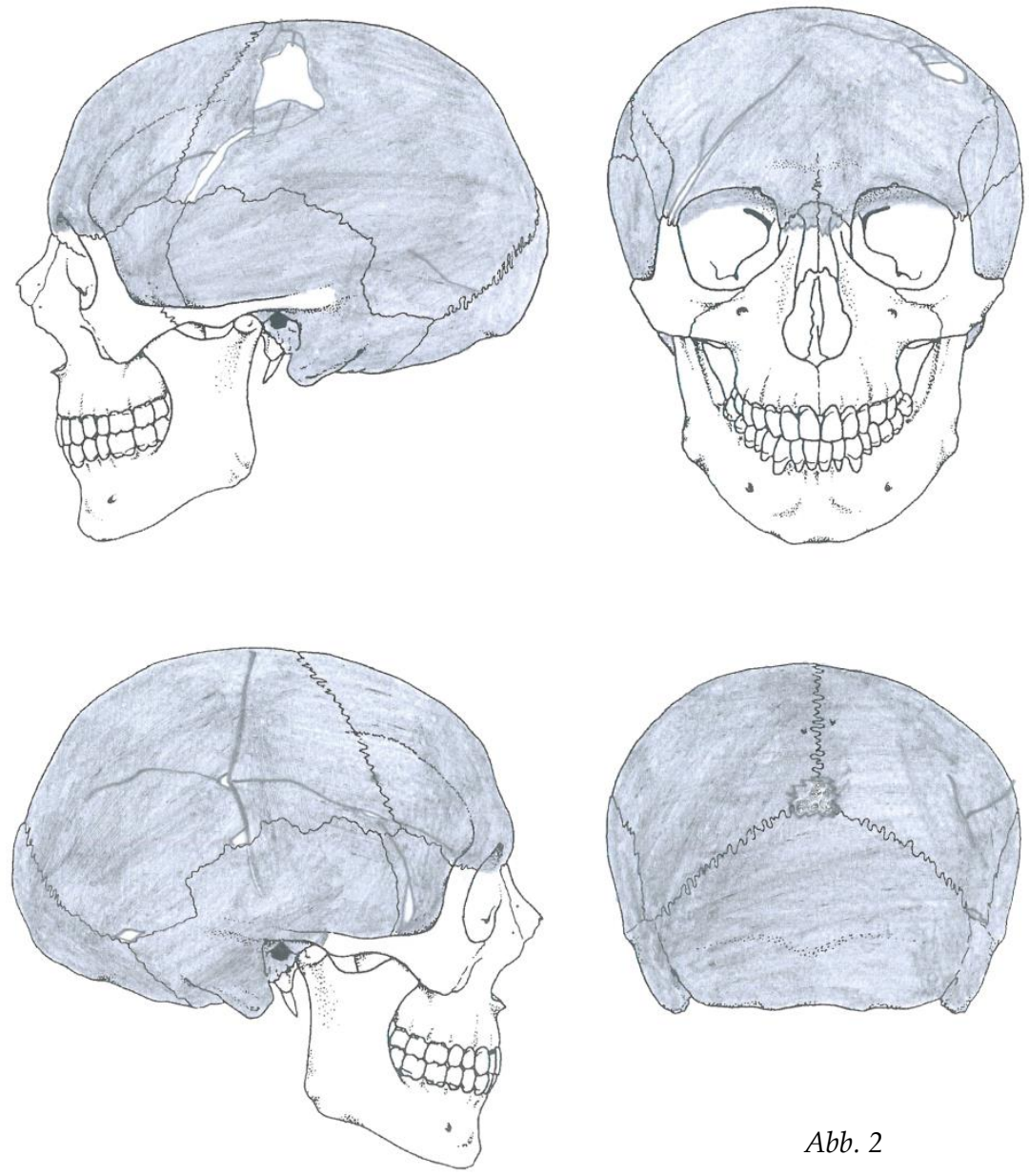

Abb. 2 


\section{Beschreibung:}

Dieses Cranium weist gut erhaltene Laminae interna und externa auf. Die Lamina externa ist sehr glatt, dennoch fallen hier der rechte und linke Margo supraorbitalis durch eine poröse Oberfläche ins Auge. Weiterhin zeigt sich ein Schaltknochen an typischer Stelle, nämlich am Übergang von der Sutura sagittalis zur Sutura lambdoidea. An den Orbitadächern sind Spuren einer leichten, vernarbten Cribra orbitalia erkennbar und der Meatus acusticus externus ist mit porösen Auflagerungen gesäumt. Diese Veränderungen sprechen für eine periostale Reizung, die im Sinne einer Otitis externa interpretiert werden könnten. Etwas Außergewöhnliches stellt die verheilte und vernarbte, traumatisch bedingte Verletzung des linken Os parietale et temporale dar. Das Einwirken äußerer Gewalt hat eine Fraktur des Schädeldachs verursacht, wobei die Schädeldecke möglicherweise nicht vollständig durchdrungen wurde. Im rechten Os parietale fällt ebenfalls eine kleine vernarbte Verletzung des Schädelknochens ins Auge. Eine mögliche Situation der Entstehung der Verletzungen könnte wie folgt ausgesehen haben: Ein Angreifer schlug mit einem kleinen, eher stumpfen und schweren Gegenstand - vermutlich einer kleinen Axt oder Ähnlichem - von hinten an die linke Kopfseite seines Opfers. Das Opfer fällt nach rechts um und schlägt mit der rechten Seite des Kopfes auf eine Erhöhung am Boden auf. Dieser zweite Stoß verursachte das kleinere Trauma an der rechten Schädelseite. Dass das Individuum dabei nicht sein Leben verlor, ist damit zu belegen, dass die Verletzungen eindeutig abgeheilt waren.

Weiterhin sind auf der Lamina interna beider Ossa parietalia im parasinuösen Bereich plattenförmige Auflagerungen $\mathrm{zu}$ beobachten, die offenbar auf eine meningeale Reizung (wohl eine Entzündung) zurückgehen dürften. Diese sind im vorderen Drittel derselben unmittelbar neben der verknöcherten Sutura sagittalis lokalisiert.

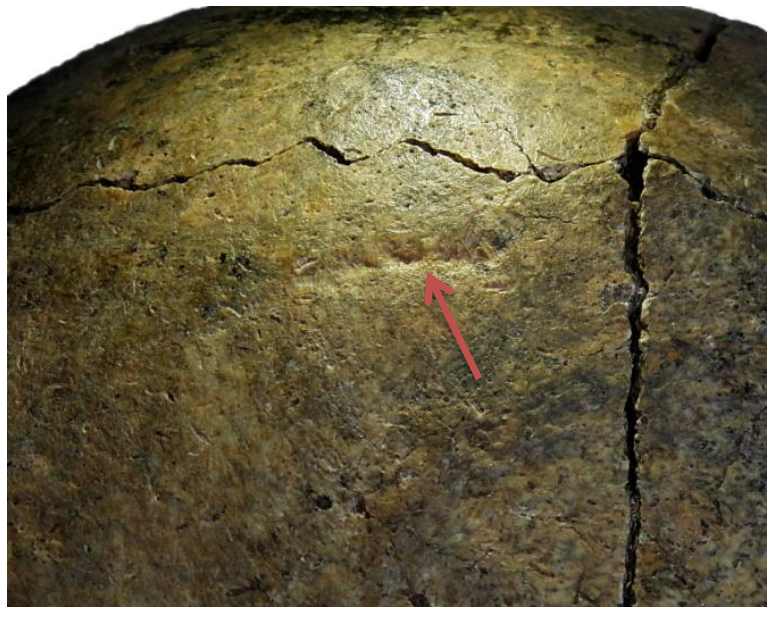

Abb. 3

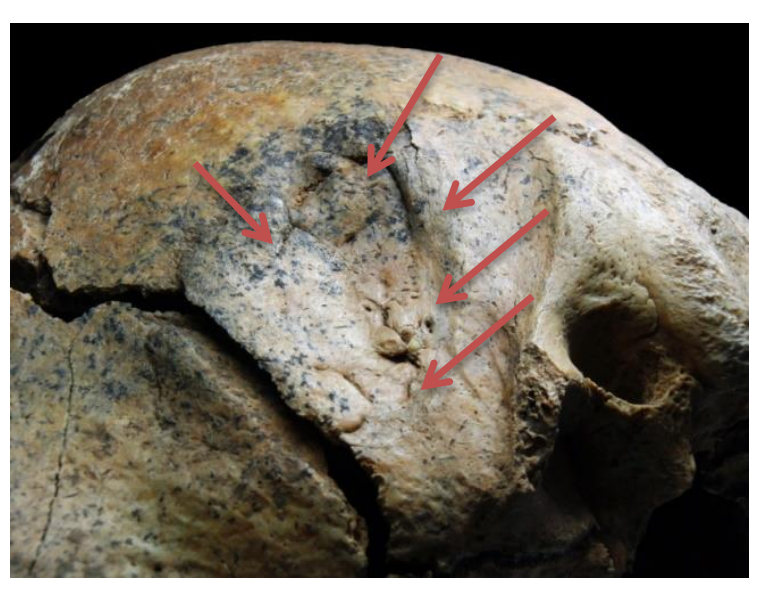

Abb. 4 


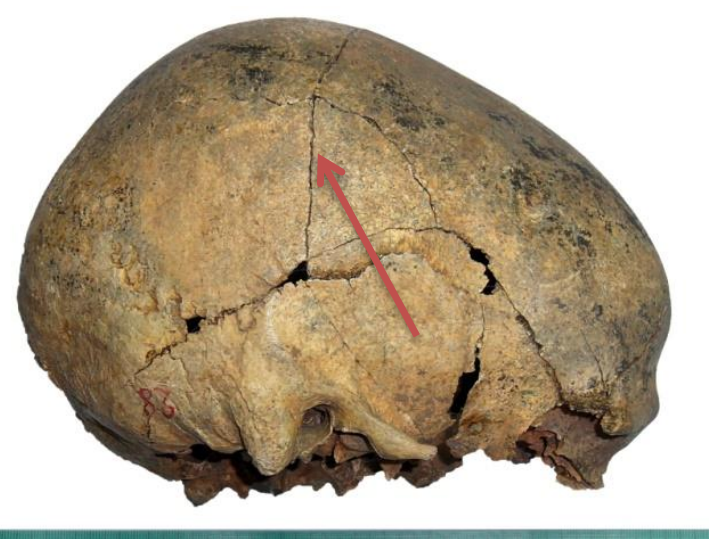

$A b b .5$

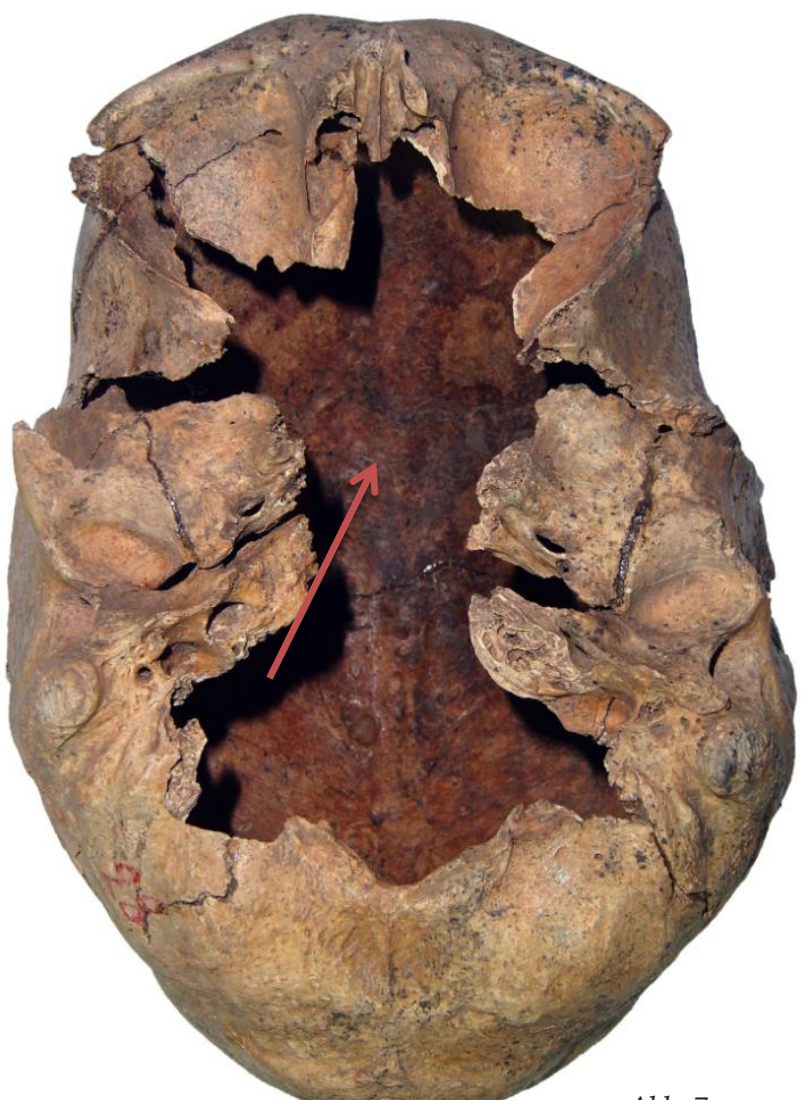

$A b b .7$

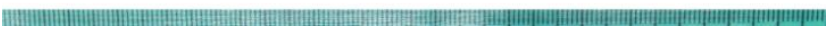

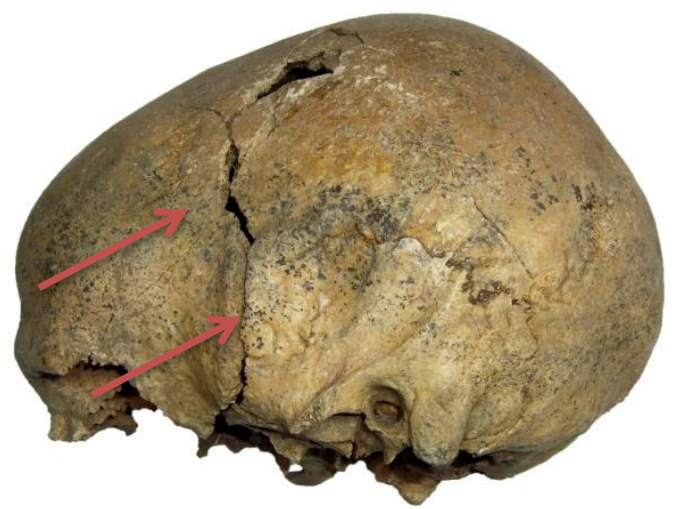

Abb. 6

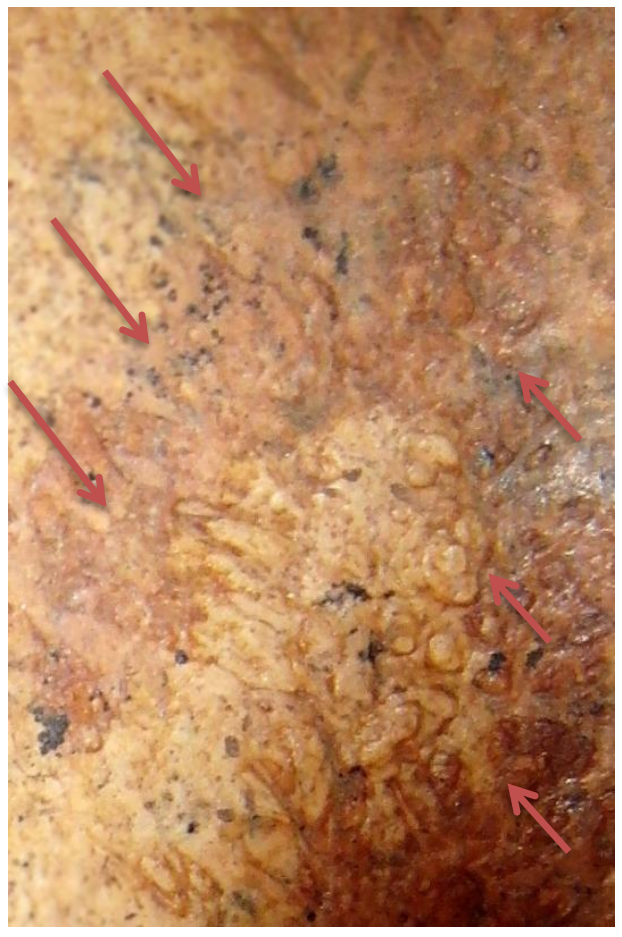

$A b b .8$

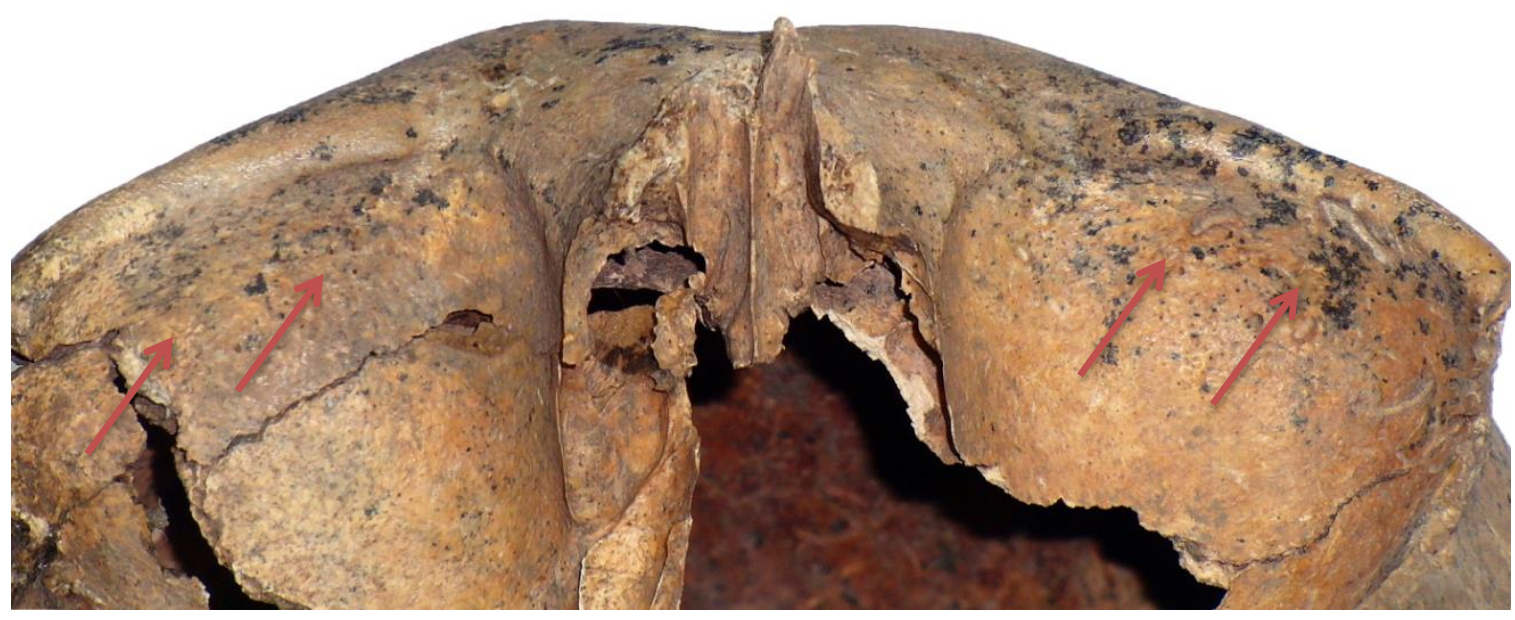

Abb. 9 


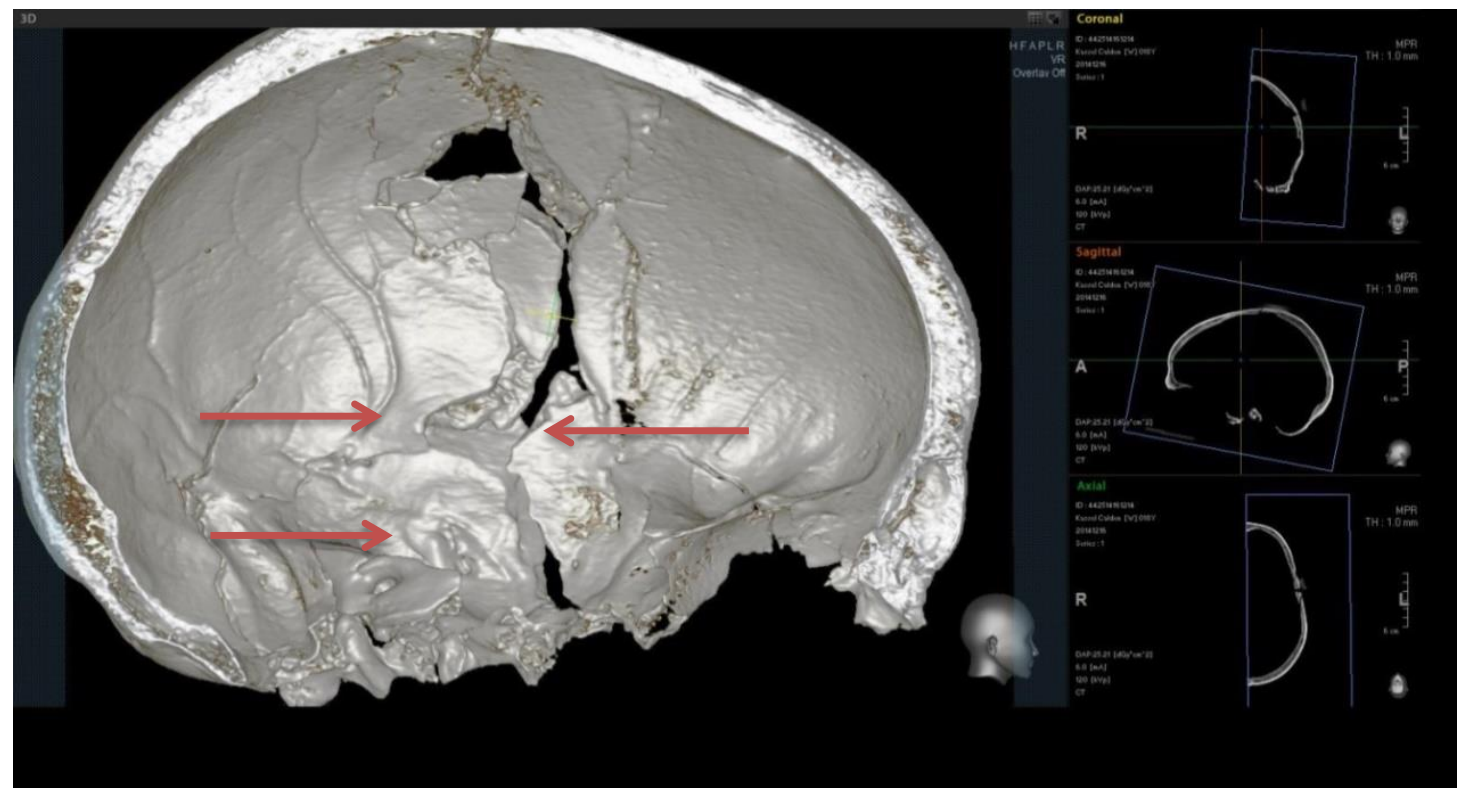

Abb. 10
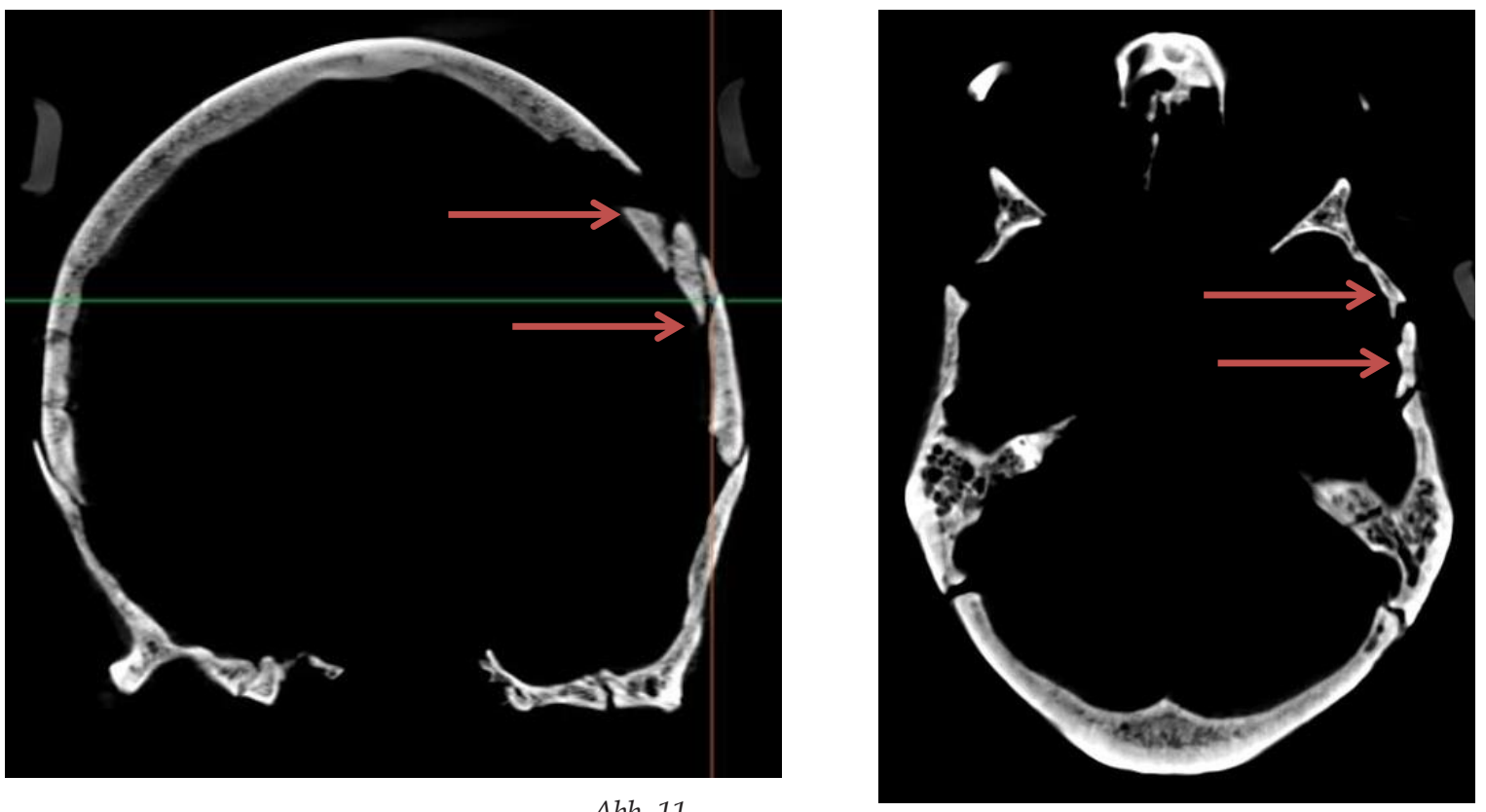

Abb. 11

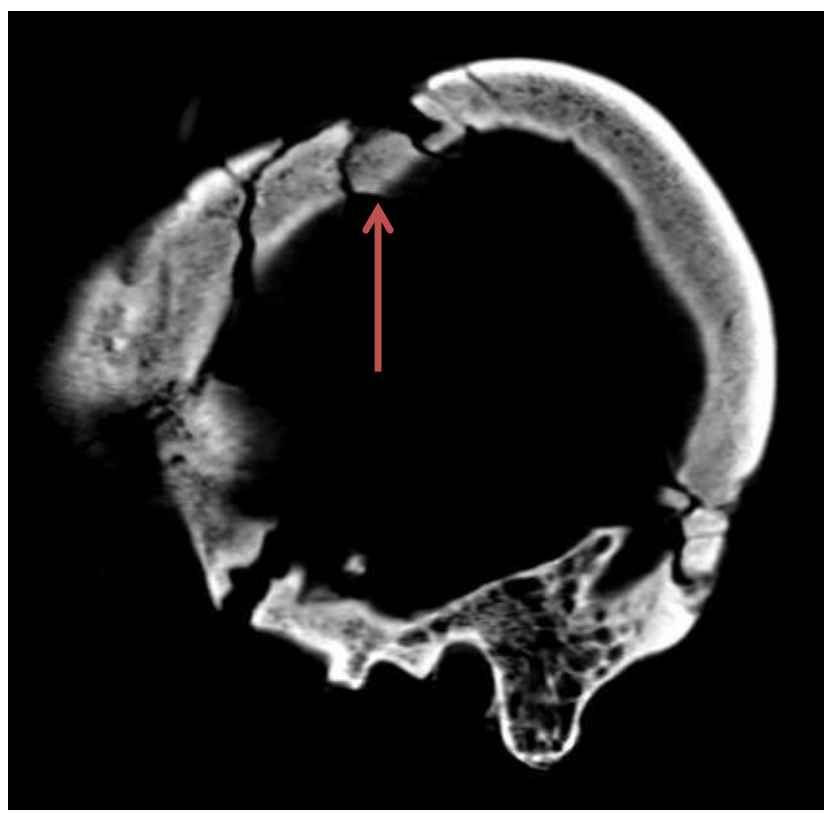

Abb. 12 
Abbildungen:

1. Übersichtsfoto des Schädels auf einem Spiegel.

2. Schemazeichnung des Schädels. Sie skizziert die Erhaltungsmenge des Craniums.

3. Foto von der rechten Schädelseite. Deutlich erkennbar ist die linienförmige Impression als Folge der Fraktur der Compacta des rechten Os parietale (Pfeil).

4. Aufnahme von links, es ist die vernarbte Fraktur am linken Os temporale zu sehen. Sie ist durch einen Pfeil markiert.

5. Nahaufnahme von Abb. 3. Der Pfeil zeigt auf die kleine vernarbte Struktur am rechten Os parietale.

6. Hier ist die vernarbte Fraktur am linken Os temporale in der Nahaufnahme von Abb. 4. zu sehen. Die Pfeile markieren die Grenzen der vernarbten Frakturlinien.

7. Axiale Aufnahme von caudal, der Pfeil zeigt auf die Region, in der die stärksten Vernarbungen nach Abheilung der meningealen Reizung zu sehen sind.

8. Detailaufnahme von Abb. 7. Die Pfeile begrenzen den Bereich der vernarbten Knochenstrukturen am Inneren der Schädelkalotte.

9. Aufnahme der beiden Orbitadächer. Die Pfeile deuten auf die vernarbten Spuren der Cribra orbitalia.

10. Aufnahme mit einem Digitalen Volumentomografen (DVT) in Schichttechnik. Die Abbildung erlaubt die Sicht von endocranial auf die Innenseite der linken Schädelhälfte (computergestützte Zusammenrechnung der Daten für diese sagittale Masseanzeige [technische Größe]). Der Schädelknochen wurde durch die Fraktur möglicherweise nicht durchtrennt, sondern nach innen eingedrückt (Frakturbereich durch Pfeile begrenzt).

11. Sichtbare, bereits verheilte Fraktur linksseitig. Die Pfeile zeigen den Bereich der Fraktur an. Weitere postmortale Frakturen erschweren die Identifikation der echten, intravitalen Fraktur in dieser Coronalebene der DVT Aufnahme.

12. Axiale Aufnahme mit dem DVT; zu sehen ist die nach endocranial gerichtete Fraktur (Pfeile); der Schädelknochen ist nach innen eingedrückt.

13. DVT in sagittaler Schicht mit Sicht von endocranial auf die Innenseite der linken Schädelhälfte. Der Pfeil zeigt auf die vernarbten Strukturen der Fraktur. 


\subsection{Befund 3: Oberkiefer 25 der Population aus Calden}

\begin{tabular}{|c|c|c|c|c|c|c|c|c|c|c|c|}
\hline Ok & & 25. & 2012 / 1 & & & & & 712 & & & \\
\hline Geschlecht: & indiffe & & & & & Stom & & & Caput & & \\
\hline Zahn & Status & Parodontium & Apikale Prozesse & & Ihnstein & Karies & $\mathrm{Ab}$ & asion & Neubildung & Schm & zhypoplasie \\
\hline 12 & v & & & & & & & & & & \\
\hline 16 & & & 0 & $\mathrm{~K}$ & 1 & 0 & 0 & 2 & 0 & & \\
\hline 22 & $v$ & & & & & & & & & & \\
\hline 23 & & 0 & 0 & $\mathrm{~K}$ & 1 & 0 & 0 & 1 & 0 & $T$ & \\
\hline 24 & & 0 & 0 & $\mathrm{~K}$ & 1 & 0 & 0 & 1 & 0 & U & \\
\hline 25 & $v$ & 0 & & & & & & & & & \\
\hline 26 & & 0 & 0 & $\mathrm{~K}$ & 1 & 0 & 0 & 2 & 0 & $\mathrm{~T}$ & \\
\hline
\end{tabular}

Beschreibung: Dieser Oberkiefer befand sich zum Todeszeitpunkt noch im Wachstum. Dies ist unter anderem daran festzumachen, dass das Wurzelwachstum des Zahnes 27 noch nicht abgeschlossen war. In regio 22 ist ein Wurzelrest eines Milchzahns verblieben. Weiterhin weist das Fundstück Spuren einer Sinusitis maxillaris und eine Stomatitis auf.

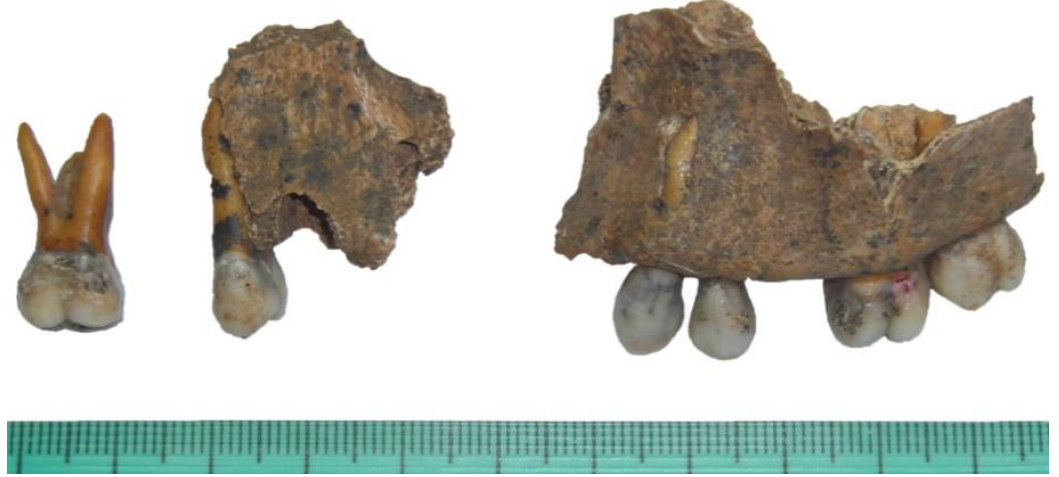

$A b b .1$

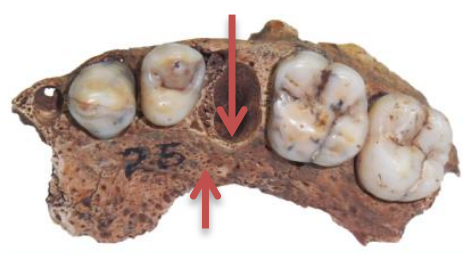

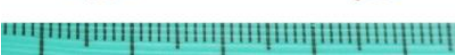

$A b b .2$

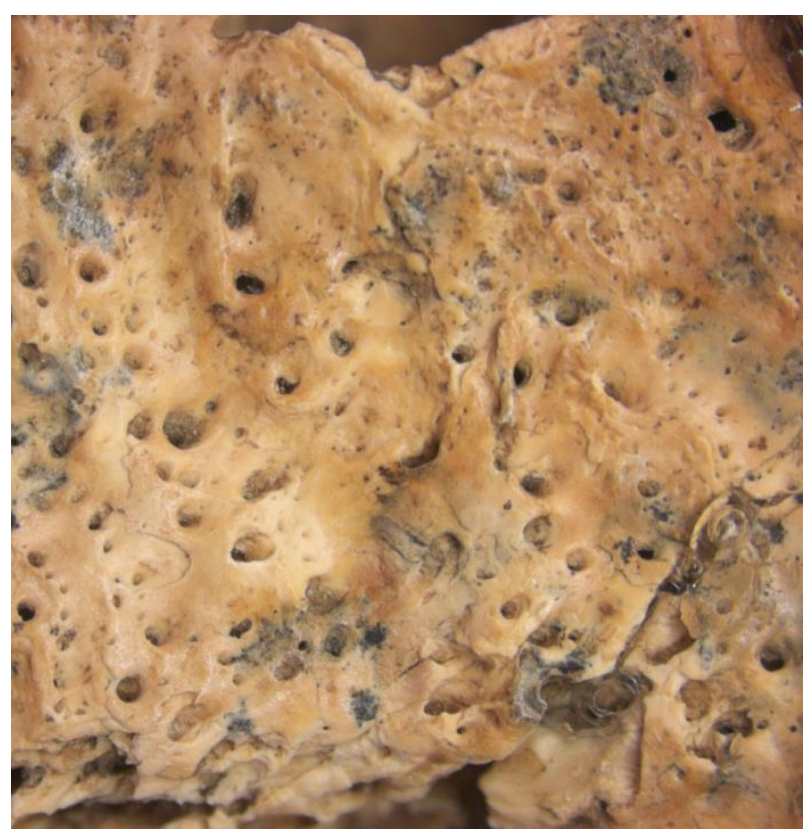

Abb. 3 


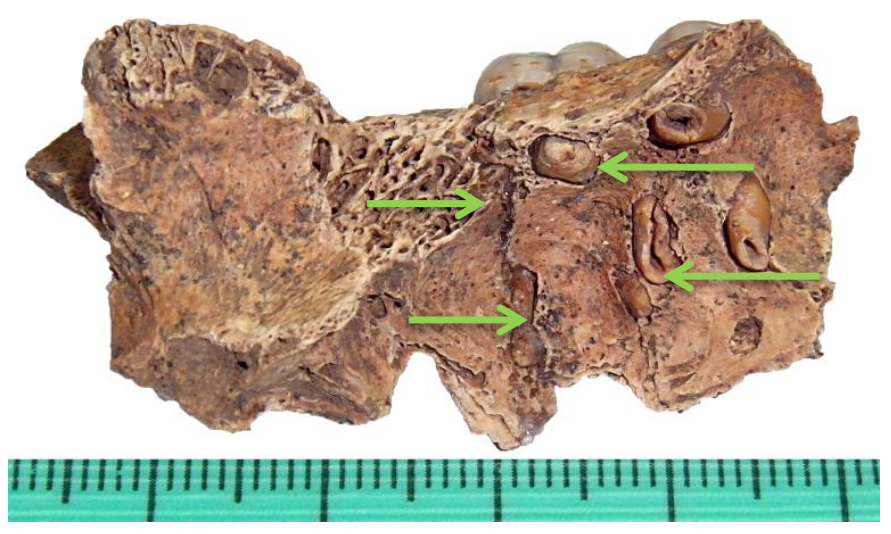

$A b b .4$

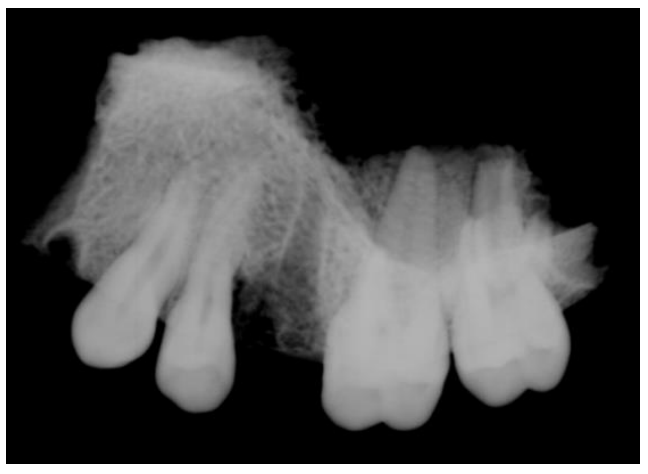

Abb. 5

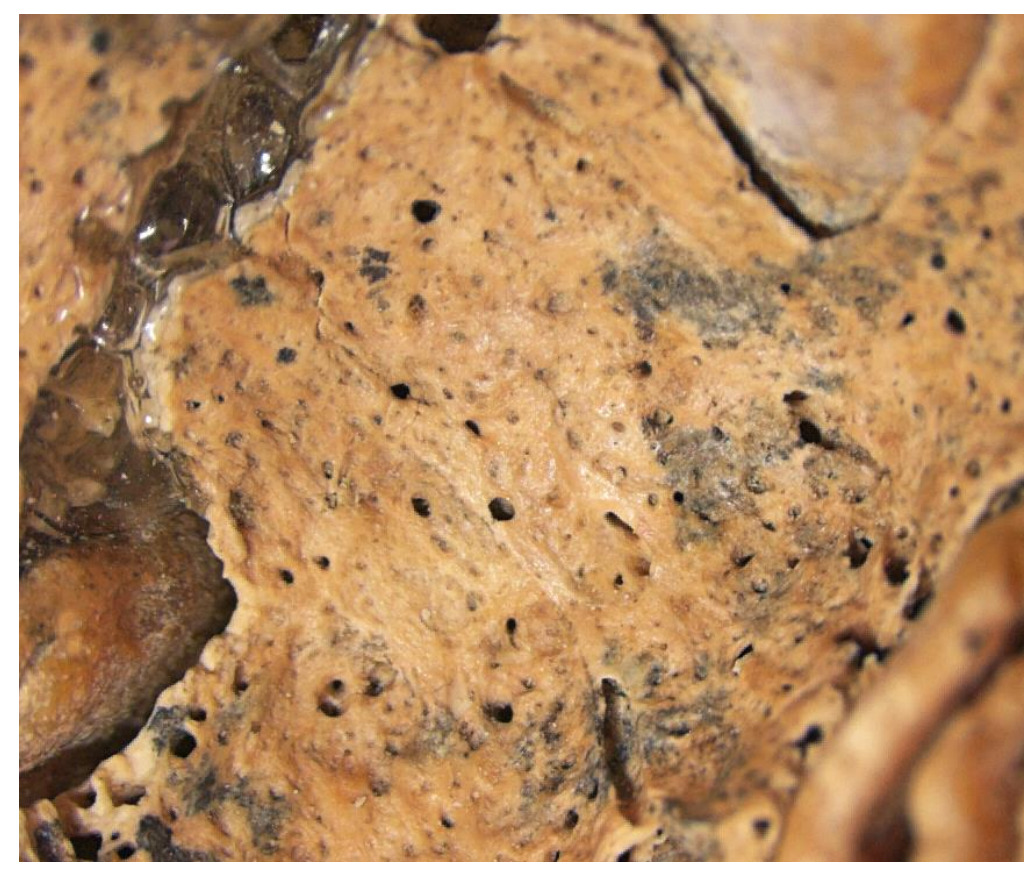

$A b b .6$

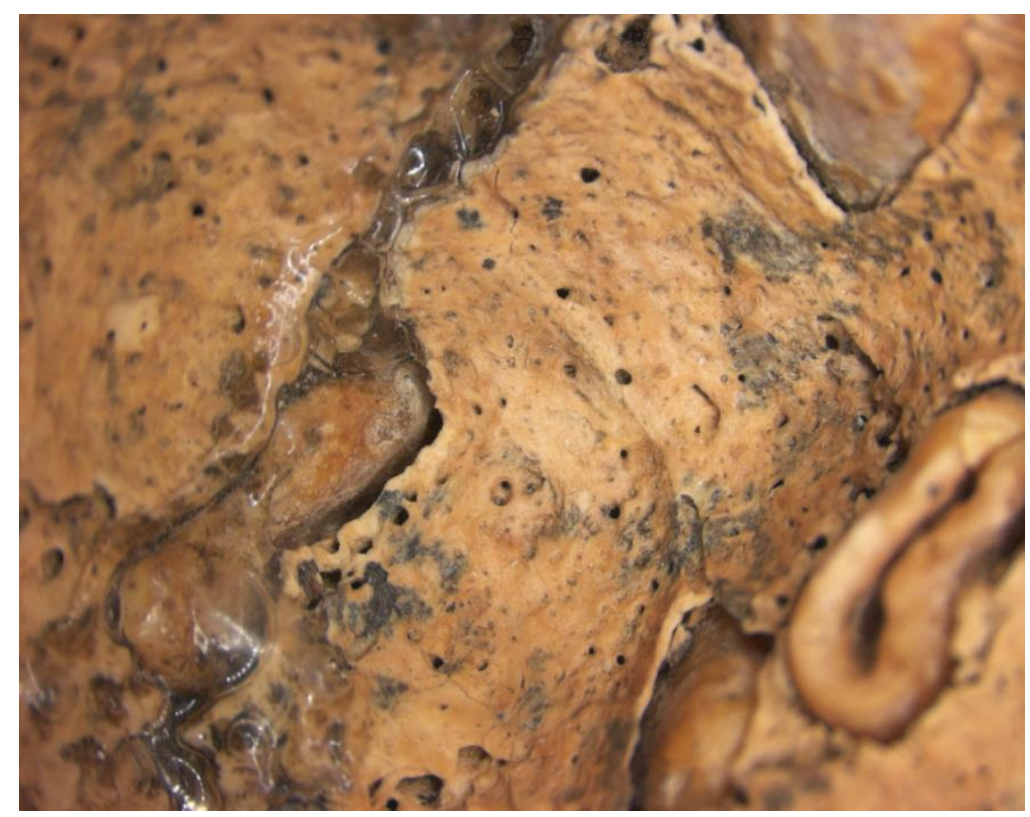

Abb. 7 


\section{Abbildungen:}

1. Übersichtsaufnahme der erhaltenen Fundstücke.

2. Abbildung des Fragments aus dem Molarenbereich. Die Pfeile zeigen auf den Bereich der Detailaufnahme Abb. 3. Bereits in der Übersichtsaufnahme ist die Stomatitis am knöchernen Gaumen zu erkennen.

3. Binokular- Detailaufnahme von Abb. 2. Die porösen Spuren der Stomatitis sind hier im Streiflicht deutlich zu erkennen.

4. Sicht auf die Kieferhöhle des linken Oberkiefers; zu erkennen ist das nicht abgeschlossene Wurzelwachstum des Zahnes 27. Die Wurzeln von 26 und 27 sind infolge von Erosionen postmortal freigelegt und durch den beschädigten Kieferhöhlenboden sichtbar. Die Pfeile deuten auf den Bereich der Detailaufnahmen (Abbildungen 5 und 6).

5. Diagnostische Röntgenaufnahme des großen Oberkieferfragments; im Falle der Zähne 23 und 24 war ein apicaler Prozess auszuschließen. Das Röntgenbild zeigt keine pathologischen Veränderungen der abgebildeten Strukturen.

6. Binokular- Aufnahme mit vergrößerten Teilausschnitten der Abb. 4; hier sind die im Knochen manifestierten Spuren einer leichten Sinusitis maxillaris $\mathrm{zu}$ sehen, die durch poröse, bläschenförmige Auftreibungen in der Oberfläche auffallen. Es wurden mehrere Fragmente zusammengeklebt, die Klebenaht ist zu sehen. Die Belichtung erfolgte unter Streiflicht.

7. Aufnahme mit dem Binokular: Der Ausschnitt aus Abb. 4 wird hier in einem anderen Winkel gezeigt. Belichtung erfolgte ebenfalls unter Streiflicht. 


\subsection{Befund 4: Ober- und Unterkiefer 32/18 der Population aus Calden}

\begin{tabular}{|c|c|c|c|c|c|c|c|c|c|c|c|c|c|}
\hline \multirow{3}{*}{$\begin{array}{l}\text { OK; UK } \\
\text { Population: } \\
\text { Geschlecht: }\end{array}$} & \multicolumn{5}{|c|}{$30.10 .2012 / 1$} & \multicolumn{8}{|c|}{5271289} \\
\hline & \multirow{2}{*}{\multicolumn{2}{|c|}{$\begin{array}{l}\text { Calden } \\
\text { weiblich }\end{array}$}} & \multicolumn{2}{|c|}{ Skelett: } & \multirow[t]{3}{*}{1832} & \multirow{3}{*}{\multicolumn{2}{|c|}{ Krankheiten: }} & \multirow{3}{*}{\multicolumn{3}{|c|}{$\begin{array}{l}\text { Sinusitis maxillaris } \\
\text { Stomatitis } \\
\text { Periostreizung } \\
\text { Vorbiss OK } \\
\text { Muskelreizung } \\
\text { Anomalie }\end{array}$}} & \multirow{3}{*}{$\begin{array}{l}\text { Arthrose } \\
\text { Caput } \\
\text { Fossa }\end{array}$} & \multirow[t]{2}{*}{ rechts } & \multirow[t]{3}{*}{ links } \\
\hline & & & & & & & & & & & & & \\
\hline Alter: & \multicolumn{3}{|c|}{ (40) $45-55(65)$} & & & & & & & & & & \\
\hline Zahn & Status & & rodontium & \multicolumn{2}{|c|}{ Apikale Prozesse } & \multicolumn{2}{|c|}{ Zahnstein } & Karies & \multicolumn{2}{|c|}{ Abrasion } & Neubildung & \multicolumn{2}{|c|}{ Schmelzhypoplasi } \\
\hline 11 & $f$ & & & & & & & & & & & & \\
\hline 12 & (f) & & & & & & & & & & & & \\
\hline 13 & $v$ & & & & 0 & & & & & & & & \\
\hline 14 & (f) & & & G & 1 & & & & & & & & \\
\hline 15 & (f) & & & & & & & & & & & & \\
\hline 16 & & $\mathrm{Pi}$ & 3 & & 0 & K & 1 & 0 & 0 & 6 & * & & 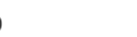 \\
\hline 17 & $\mathrm{v}$ & $\mathrm{Pi}$ & 4 & & & & & & & & & & \\
\hline 18 & $\mathrm{v}$ & $\mathrm{Pi}$ & 4 & & & & & & & & & & \\
\hline 21 & $\mathrm{v}$ & & & & 0 & & & & & & & & \\
\hline 22 & $v$ & & & & 0 & & & & & & & & \\
\hline 23 & $\mathrm{v}$ & & & z & 1 & & & & & & & & \\
\hline 24 & $f$ & & & & & & & & & & & & \\
\hline 25 & $v$ & & & & 0 & & & & & & & & \\
\hline 26 & & Po & 3 & & 0 & $\mathrm{~K}$ & 1 & 0 & 0 & 6 & * & & \\
\hline 27 & & Po & 3 & & 0 & $\hat{\mathrm{k}}$ & 1 & 0 & 0 & 5 & * & $T$ & \\
\hline 28 & & Po & 3 & & 0 & $\mathrm{k}$ & 1 & 0 & & 0 & 0 & u & \\
\hline 31 & & Po & 2 & & 0 & $\mathrm{k}$ & 2 & 0 & 0 & 5 & * & u & \\
\hline 32 & & Po & 2 & & 0 & $\mathrm{~K}$ & 1 & 0 & 0 & 5 & * & u & \\
\hline 33 & & Po & 2 & & 0 & K & 1 & 0 & 0 & 6 & * & $T$ & \\
\hline 34 & & & & & 0 & & & & & & & & \\
\hline 35 & & & & & 0 & K & 1 & 0 & 0 & 5 & * & & \\
\hline 36 & $\mathrm{v}$ & & & & & & & & & & & & \\
\hline 37 & $\mathrm{v}$ & & & & & & & & & & & & \\
\hline 38 & $\varnothing$ & & & & & & & & & & & & \\
\hline 41 & & & & & 0 & $\mathrm{~K}$ & 1 & 0 & 0 & 5 & * & u & \\
\hline 42 & $v$ & & & & & & & & & & & & \\
\hline 43 & & Po & 2 & & 0 & K & 1 & 0 & 0 & 6 & * & & 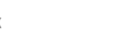 \\
\hline 44 & & Po & 3 & & 0 & K & 1 & 0 & 0 & 5 & * & & \\
\hline 45 & & Po & 3 & & 0 & $\mathrm{k}$ & 1 & 0 & 0 & 5 & * & & \\
\hline 46 & & Po & 3 & & 0 & $\mathrm{k}$ & 1 & 0 & 0 & 5 & * & & 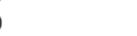 \\
\hline 47 & & Po & 3 & & 0 & $\mathrm{~K}$ & 1 & 0 & 0 & 5 & $*$ & & \\
\hline 48 & $\varnothing$ & & & & & & & & & & & & \\
\hline
\end{tabular}

Beschreibung: Die beiden Fundstücke OK 32 und UK 18 gehören wahrscheinlich zusammen. Möglicherweise hat ein Vorbiss des Oberkiefers vorgelegen; somit wären die beiden Fundstücke miteinander kombinierbar. Für die Zusammengehörigkeit spricht weiterhin, dass die Oberkieferweisheitszähne durchgebrochen, aber die Unterkieferweisheitszähne nicht angelegt waren. Der erhaltene 28 hat offenkundig keinen Antagonisten gehabt, da jegliche Abrasion fehlt. Trotz des Überbisses kam es wohl nicht zum Kontakt zu den zweiten Molaren des Unterkiefers, da der Weisheitszahn etwas verlagert stand. Auffällig am Gesamtbild der beiden Fundstücke sind die zahlreichen Anomalien: Der Unterkiefer wirkt, als wäre er auf der linken Seite länger gewachsen. Dies könnte dann dazu geführt haben, dass die Zähne das vorliegende Abrasionsmuster zeigen und die Neigung der Molaren und Prämolaren nach rechts hin weist. Es ist definitiv festzustellen, dass die Zähne nicht entsprechend ihrer physiologischen Zahnachse gewachsen waren, sondern mit einer Achsabweichung nach rechts. Da anscheinend die Oberkiefer Sechser Kontakt mit den Unterkiefer Fünfern hatten, ergaben sich diese beachtenswerten Abrasions- und Attritionsmuster. Weiterhin waren auch einige Zähne intravital ausgefallen und die Frontzähne beider Kiefer nicht physiologisch angeordnet; sie sind teilweise gedreht und im Falle des 
Oberkiefers nach distal geneigt. Zusätzlich stand der rechte Unterkieferalveolarfortsatz im Molaren - und Prämolarenbereich etwas höher.

Die apicalen Prozesse betreffend kann nicht mit Sicherheit ausgesagt werden, welche Art von Prozess intravital vorlag. Dies ist aufgrund von röntgenologisch sichtbaren, apicalen Aufhellungen allein nicht möglich.

Im rechten Sinus maxillaris ist ein streifiges Impressionsmuster erkennbar, was für eine verheilte Sinusitis maxillaris spricht. Im linken Sinus zeigen sich poröse Auflagerungen, was ein Hinweis für einen aktiven Prozess einer Sinusitis maxillaris ist. Weiterhin ist eine Streifung im Sinne einer Reizung der Außenseite des aufsteigenden Unterkieferastes erkennbar, welche möglicherweise muskulär bedingt ist.

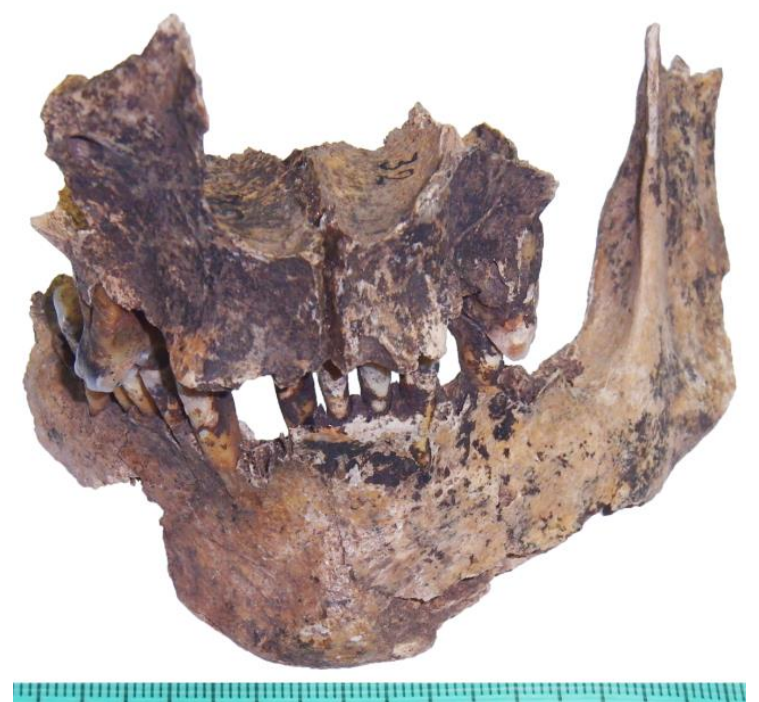

$A b b .1$

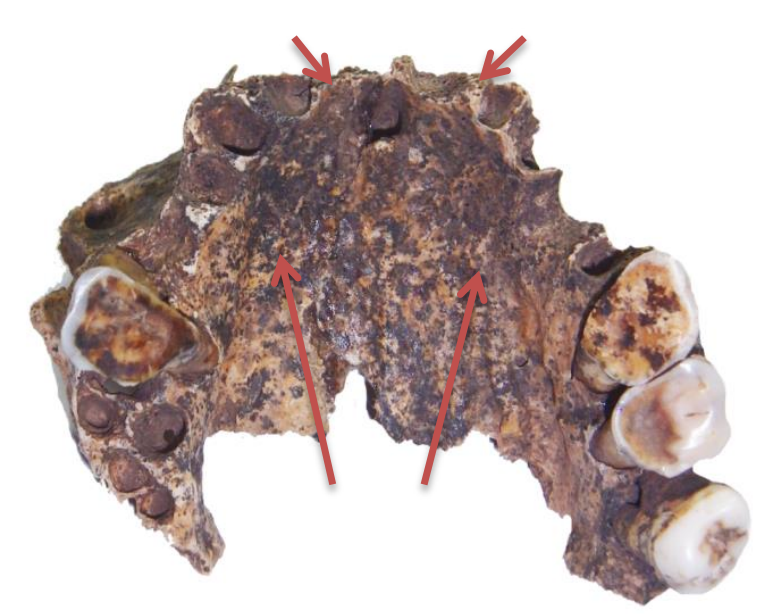

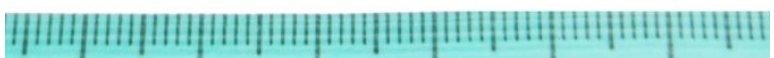

Abb. 2

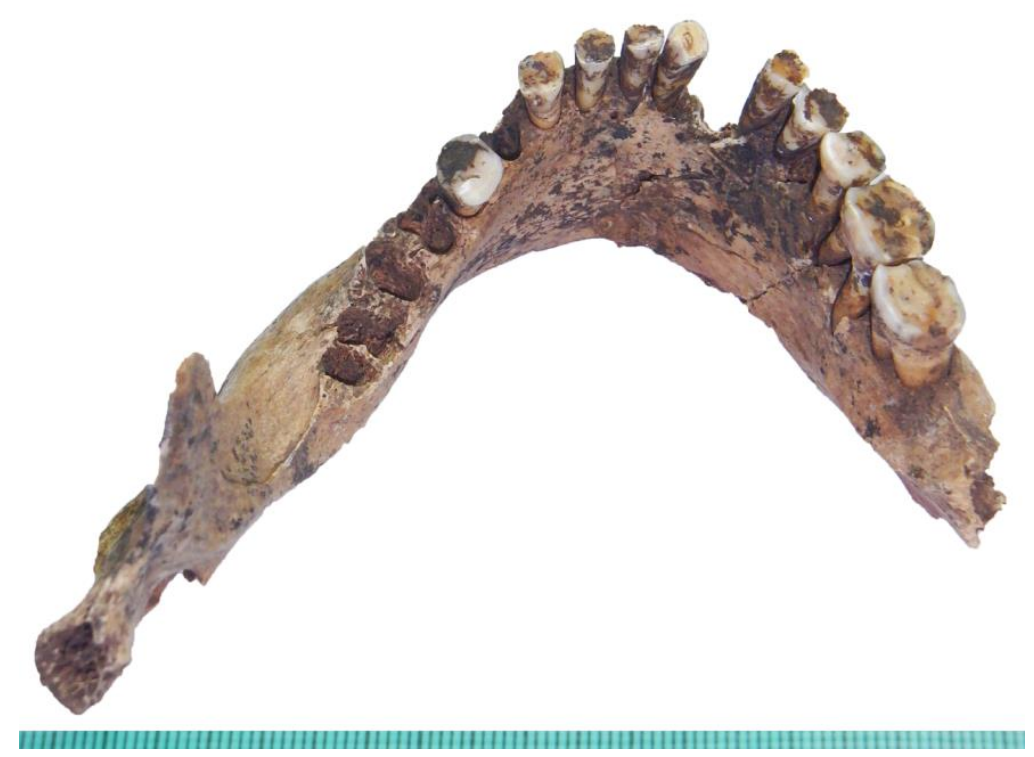

Abb. 3 


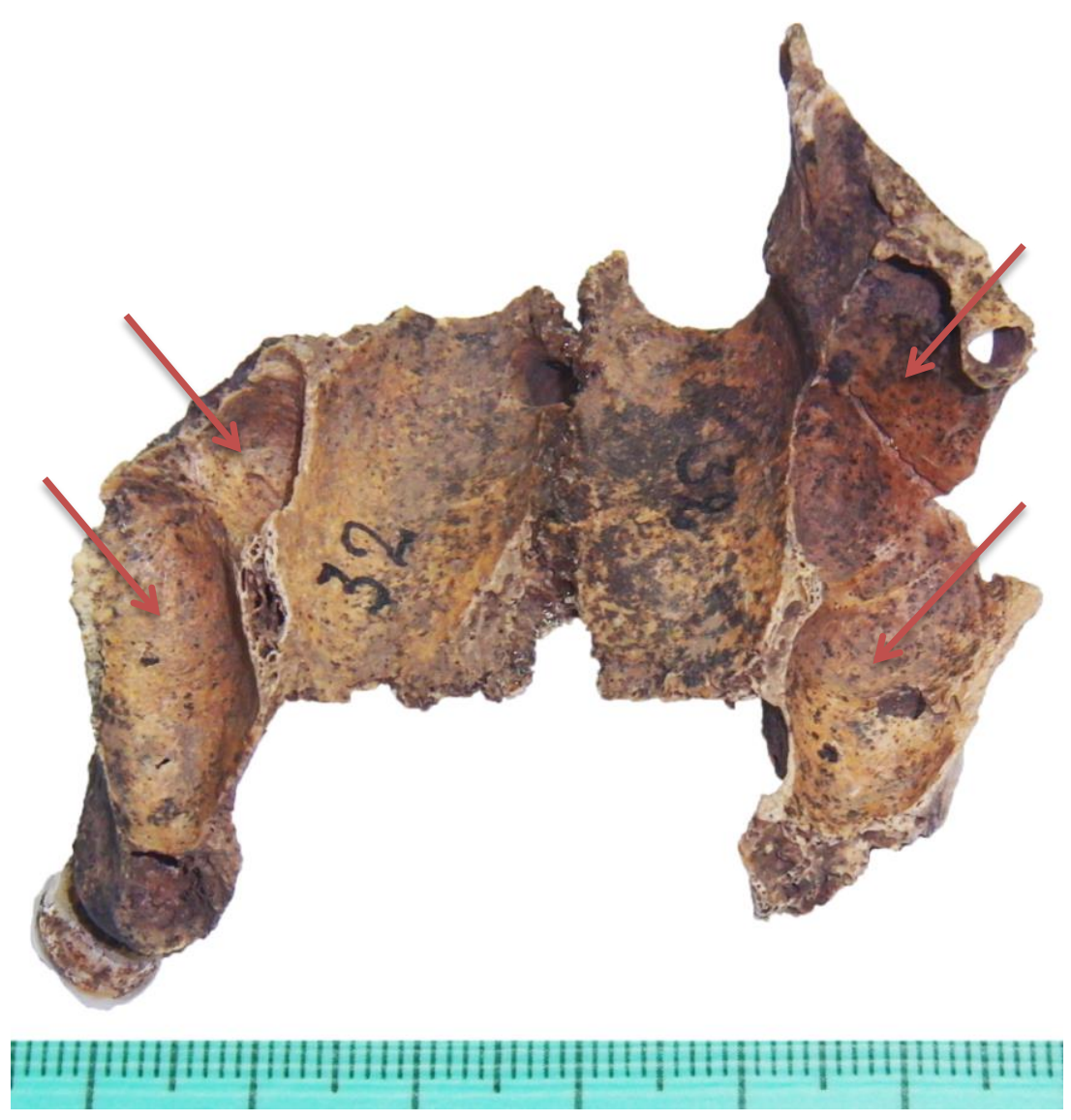

Abb. 4

\section{Abbildungen:}

1. Übersichtsaufnahme der beiden Kiefer übereinander.

2. Abbildung des Oberkiefers. Zu sehen sind die erhaltenen Restzähne und der knöcherne Gaumen. Die kurzen Pfeile deuten auf die Stellungsanomalie der Oberkieferfrontzähne hin, die langen Pfeile zeigen beispielhaft auf die Spuren der Stomatitis.

3. Foto des Unterkiefers mit Sicht auf die Occlusalflächen.

4. Abbildung des Oberkiefers von cranial; zu sehen sind der knöcherne Gaumen von cranial aus betrachtet und die Kammern der Kieferhöhlen rechts und links. Die Pfeile zeigen beispielhaft die Spuren der leichten Sinusitis maxillaris. 


\subsection{Befund 5: Oberkiefer 27 der Population aus Calden}

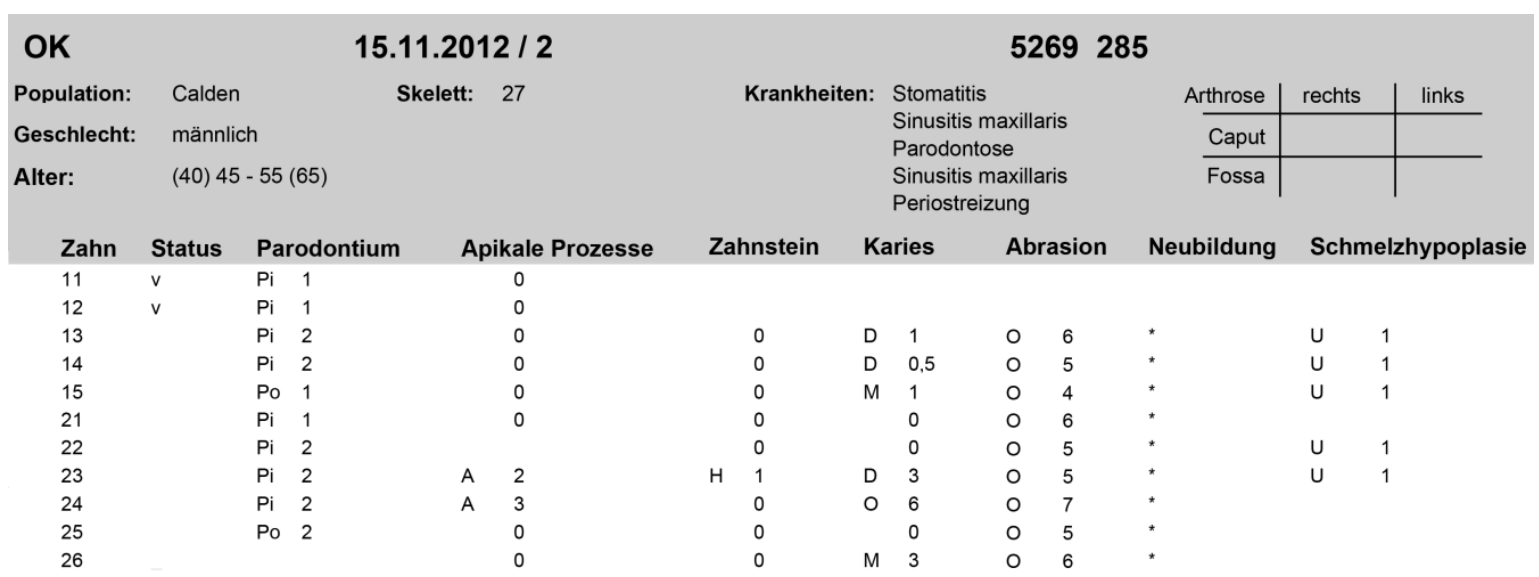

Beschreibung: Dieses Fundstück ist ein Teil eines Oberkiefers. Zusätzlich erhalten ist ein Fragment des linken Os zygomaticum mit einem Teil des Orbitabodens der linken Seite. Im Alveolarfortsatz haben sich insgesamt acht Zähne erhalten; ein Molar lag einzeln vor und war nicht in eine Alveole zurückzuführen, da diese zu stark erodiert war. Drei weitere Zähne sind nachweislich erst postmortal ausgefallen. Bei den verbliebenen handelt es sich um sehr stark attritierte und abradierte Zähne, die z.T. apicale Prozesse aufwiesen. Weiterhin war an einigen Zähnen Karies nachzuweisen. Auffällig war weiterhin eine plattenförmige Auflagerung im linken Sinus maxillaris im oberen Teil; teilweise war der Orbitaboden von unten mit betroffen. Hierbei handelt es sich um Spuren einer Sinusitis maxillaris. Anzeichen einer Kieferhöhlenentzündung waren auch im rechten Sinus maxillaris zu finden. Die Spuren der Sinusitis in der linken Kieferhöhle haben eine Ausdehnung von etwa $5 \mathrm{~mm}$ x $9 \mathrm{~mm}$. Am harten Gaumen sind darüber hinaus noch Spuren einer Stomatitis zu erkennen.

Eine weitere Auffälligkeit bot das Os zygomaticum der linken Seite von facial gesehen: Direkt unterhalb des Foramen zygomaticofaciale liegt eine knöcherne Auftreibung von $19 \mathrm{~mm} \times 8,5 \mathrm{~mm} \times 2 \mathrm{~mm}$. Es könnte sich um ein knöchernes Trauma mit anschließendem Entzündungsprozess gehandelt haben.

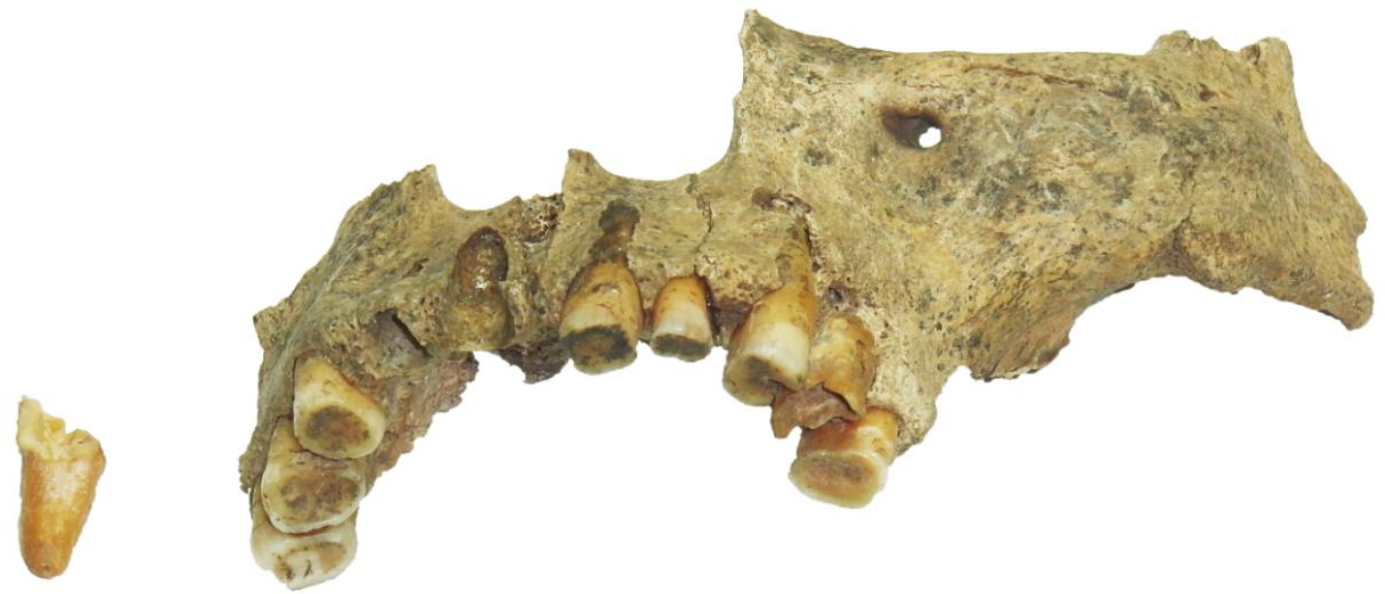




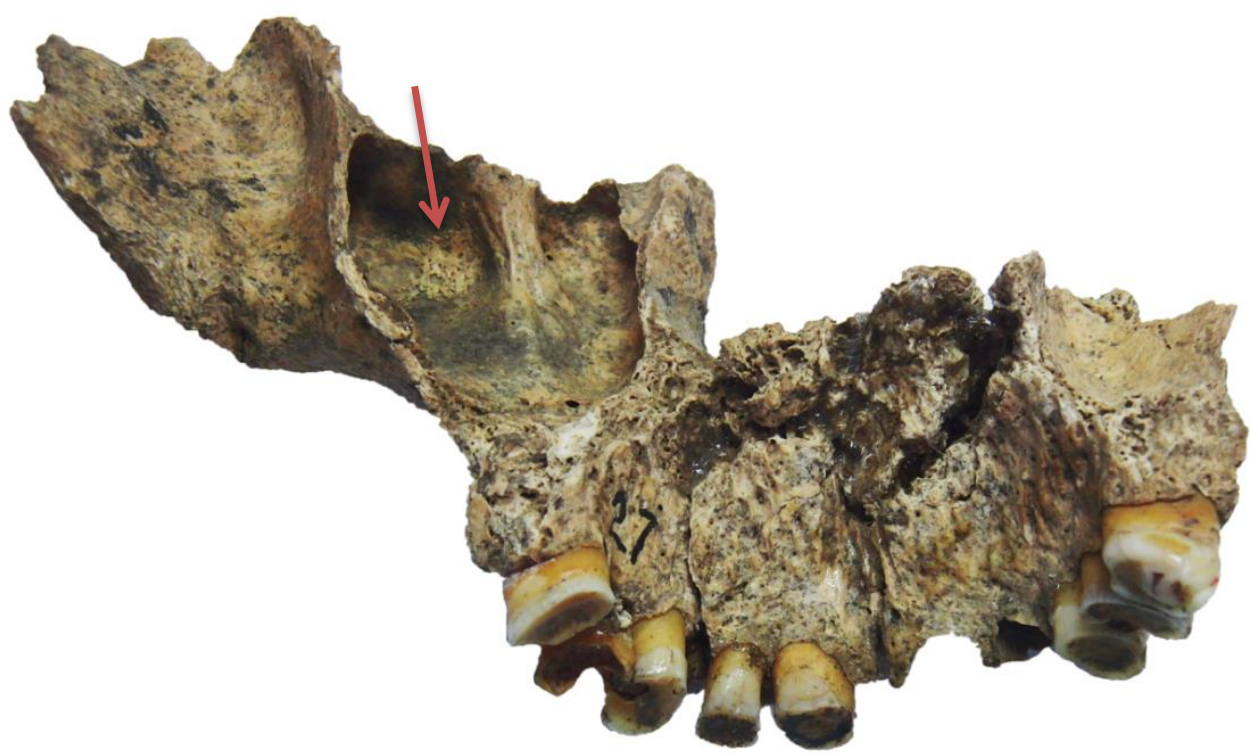

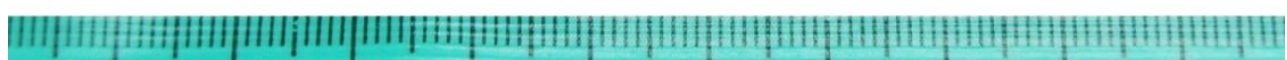

$A b b .2$
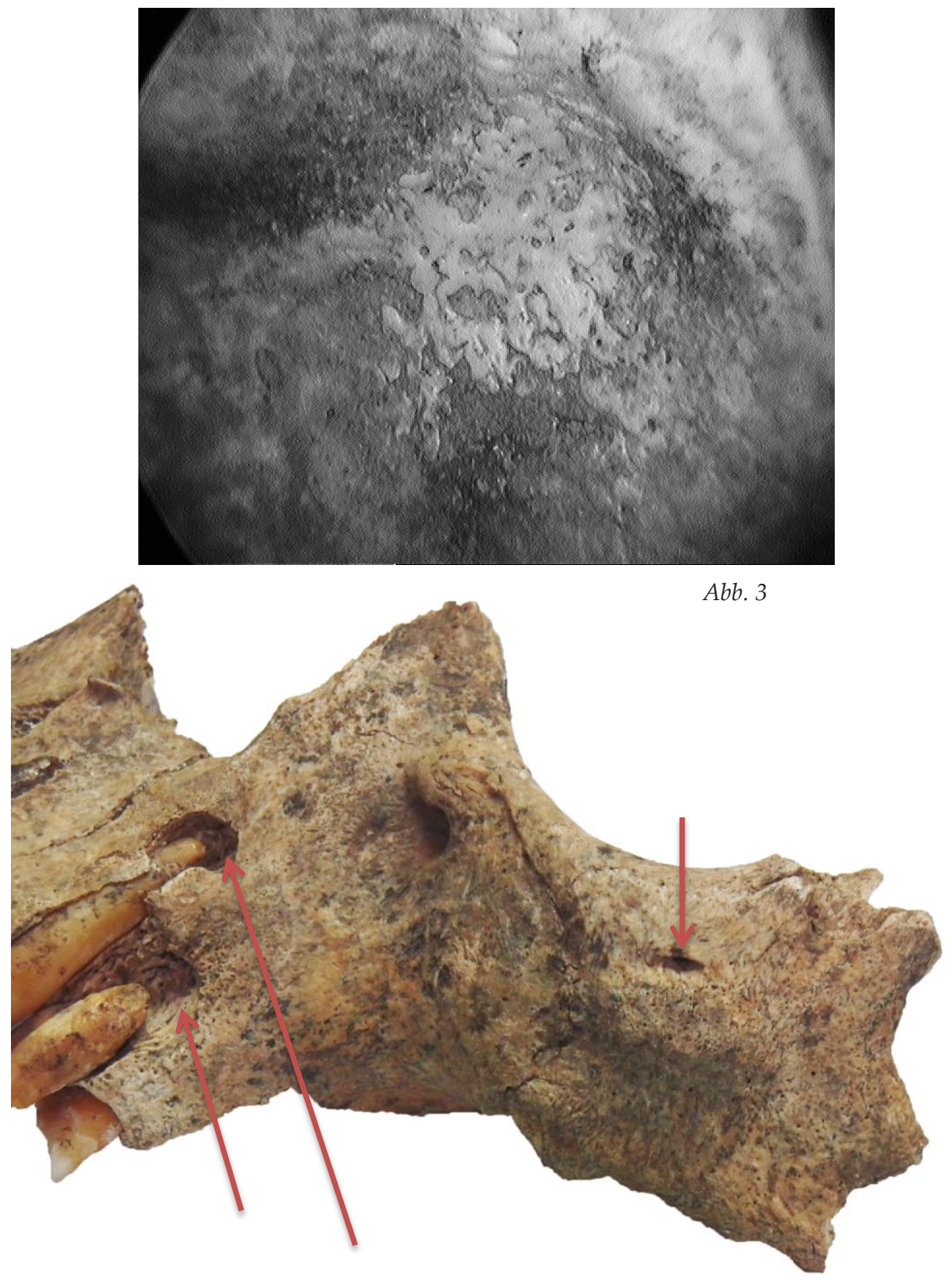

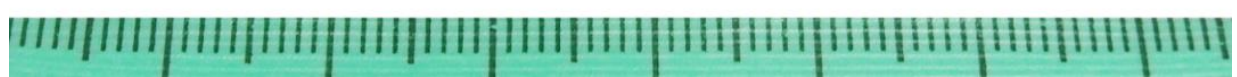



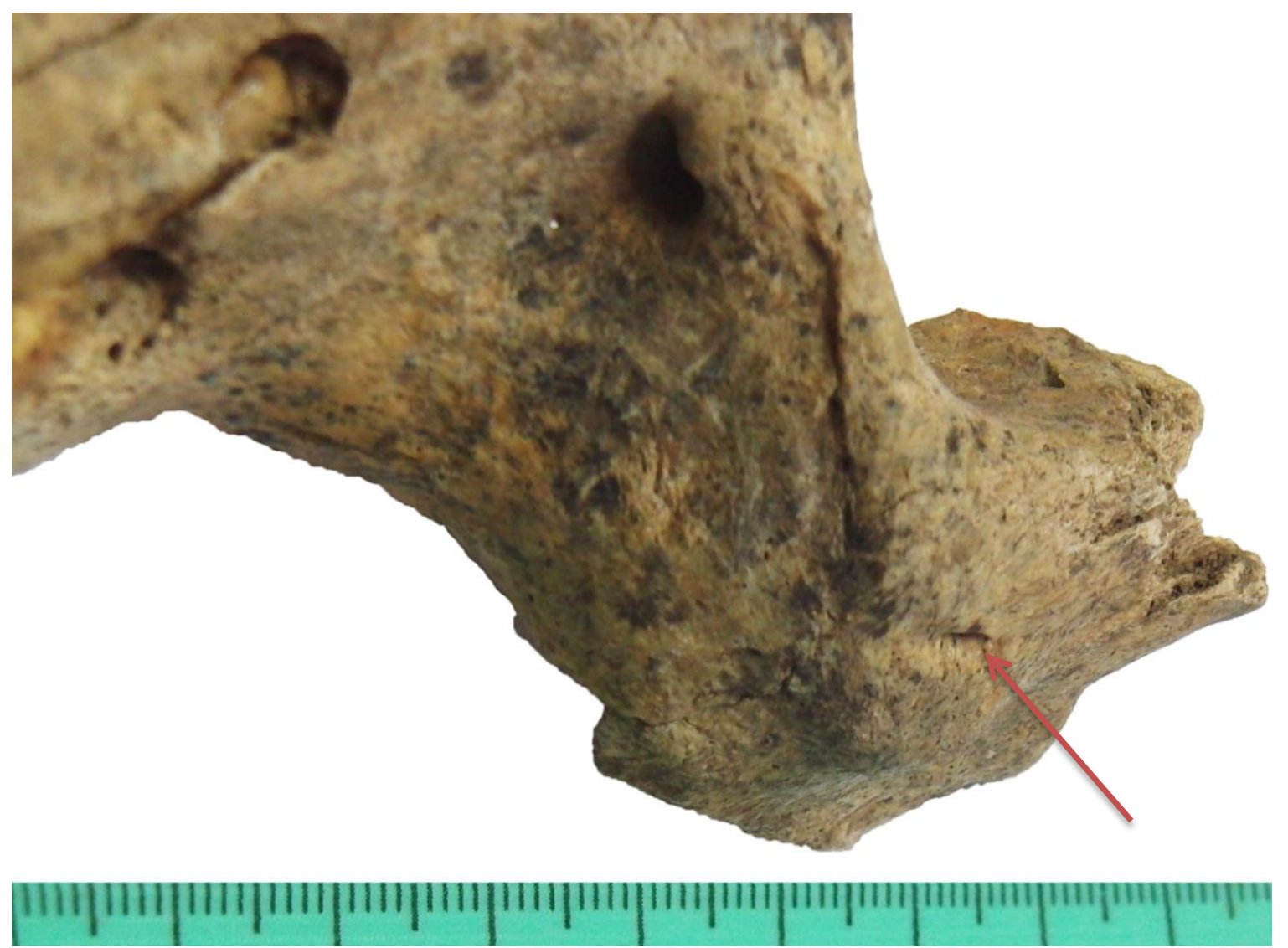

Abb. 5

Abbildungen:

1. Abbildung des Oberkiefers von anterior- caudal- links. Die Abrasionen und Attritionen an den Zähnen fallen auf.

2. Foto des Oberkiefers von posterior mit Blick in die linke Kieferhöhle. Der Pfeil zeigt auf den durch die Sinusitis maxillaris veränderten Bereich. An dieser Stelle ist eine deutliche Knochenummodellierung zu sehen.

3. Detailaufnahme mit dem Endoskop des Bereichs aus Abb. 2.

4. Großaufnahme der linken Seite des Fundstücks. Der lange Pfeil deutet auf einen offenen apicalen Prozess des Zahns 23 hin. Der mittlere Pfeil markiert einen offenen apicalen Prozess des Zahnes 24 und der kurze Pfeil zeigt auf eine kleine knöcherne Einkerbung am Os zygomaticum der linken Seite. Darunter ist eine poröse Auftreibung der Knochensubstanz zu erkennen.

5. Abbildung der kleinen knöchernen Einkerbung aus einer anderen Perspektive. Der Pfeil zeigt auf den Bereich. Es könnte sich um eine entzündete Verletzung nach einem Trauma gehandelt haben. 


\subsection{Befund 6: Oberkiefer 23 der Population aus Calden}

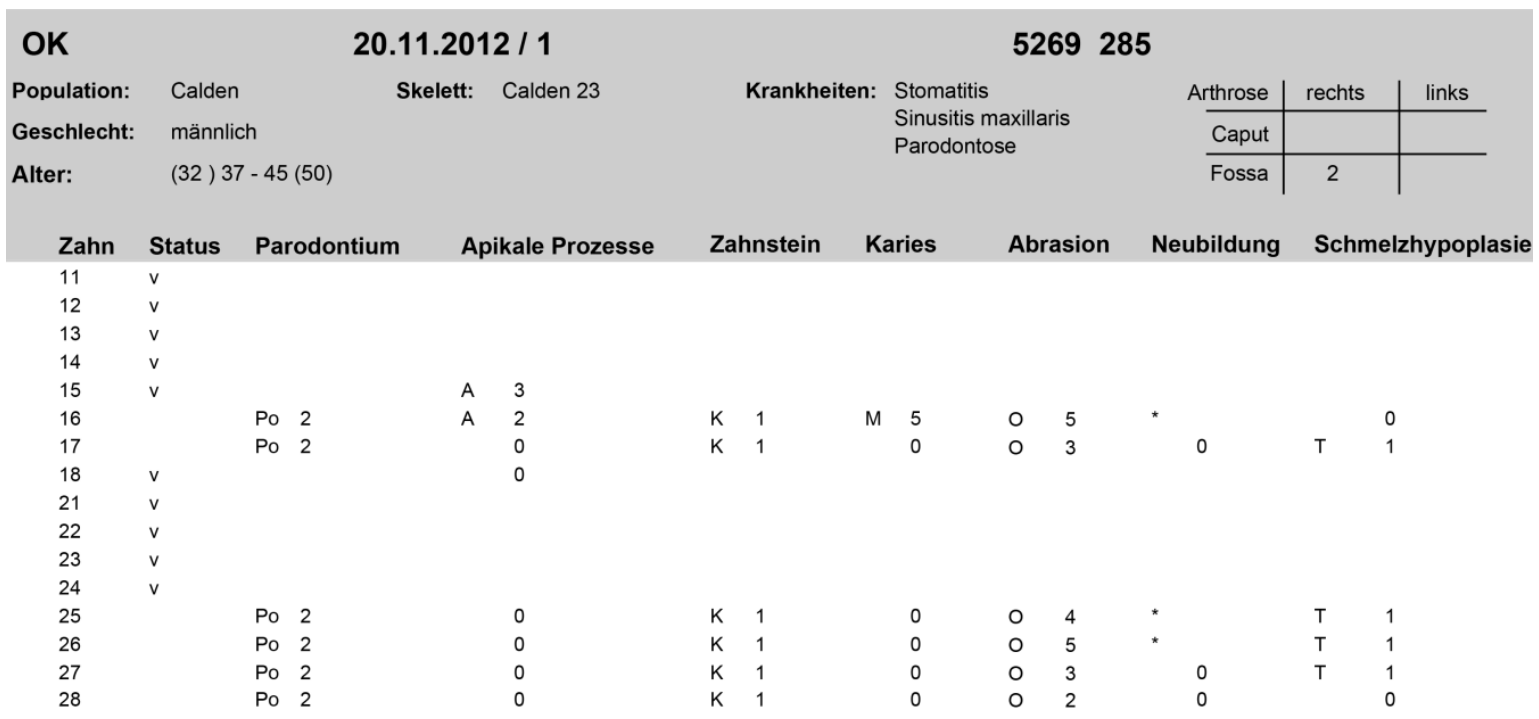

Beschreibung: Bei diesem Oberkiefer fällt ein dreiwurzliger 14 ins Auge. Weiterhin weist das Fundstück eine nicht vollständig pneumatisierte Kieferhöhle auf, die wohl aus einer in jungen Jahren aufgetretenen, aber später verheilten Sinusitis maxillaris resultiert.

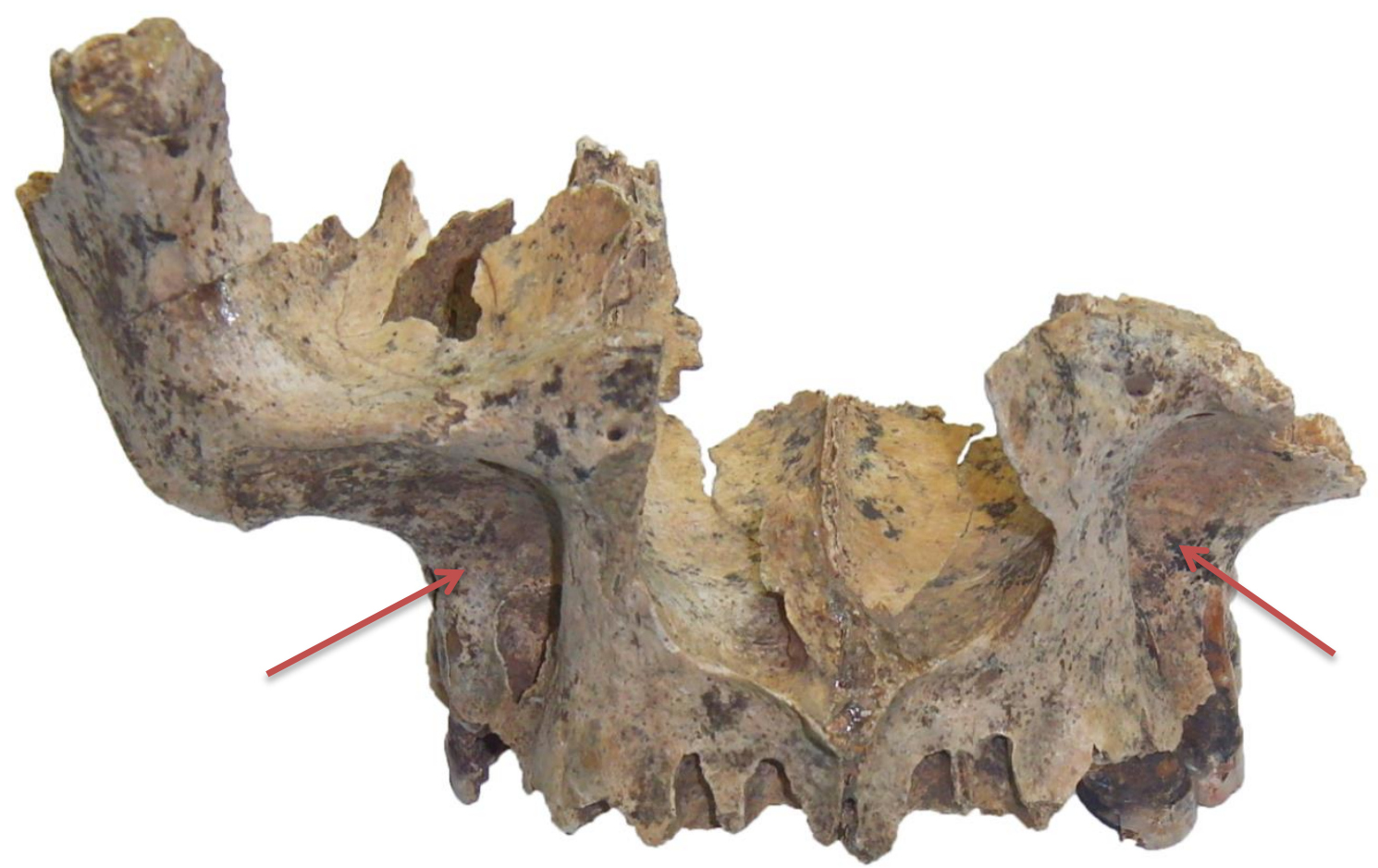




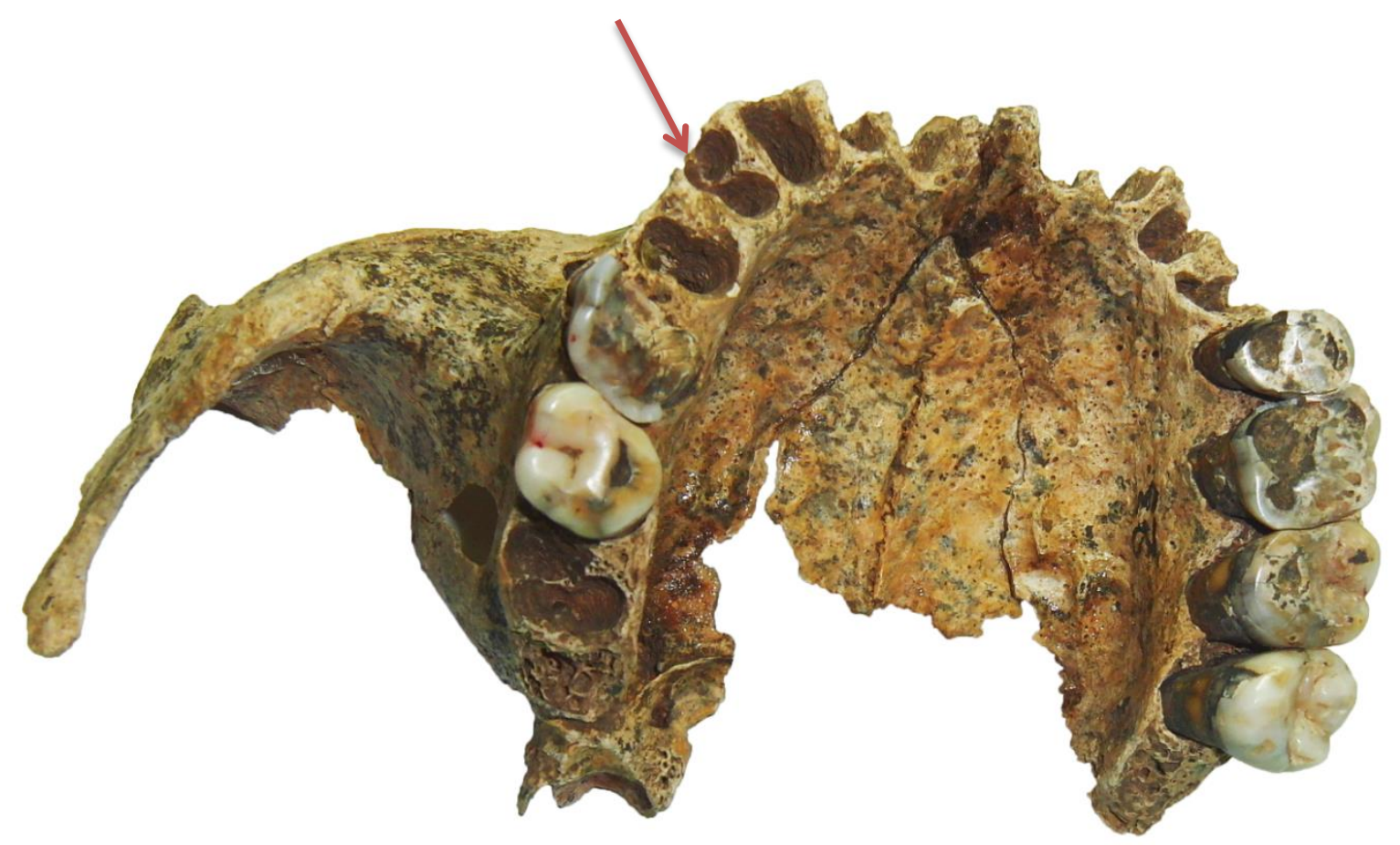

"

Abb. 2

\section{Abbildungen:}

1. Abbildung des Oberkiefers von anterior. Es fallen die deutlichen Einziehungen der anterioren und lateralen Wand des Sinus maxillaris rechts und links auf (Pfeile).

2. Foto des Oberkiefers von caudal. $\mathrm{Zu}$ erkennen sind die scheinbar verlängerten Zahnhälse. Dieses Phänomen ist durch eine Parodontose entstanden. Weiterhin sind die Spuren einer Stomatitis am knöchernen Gaumen zu erkennen. Der Pfeil deutet auf die Alveole des Zahns 14; erkennbar sind drei Wurzelfächer, was beweist, dass der Zahn 14 drei Wurzeln hatte. 


\subsection{Befund 7: Unterkiefer 3 der Population aus Calden}

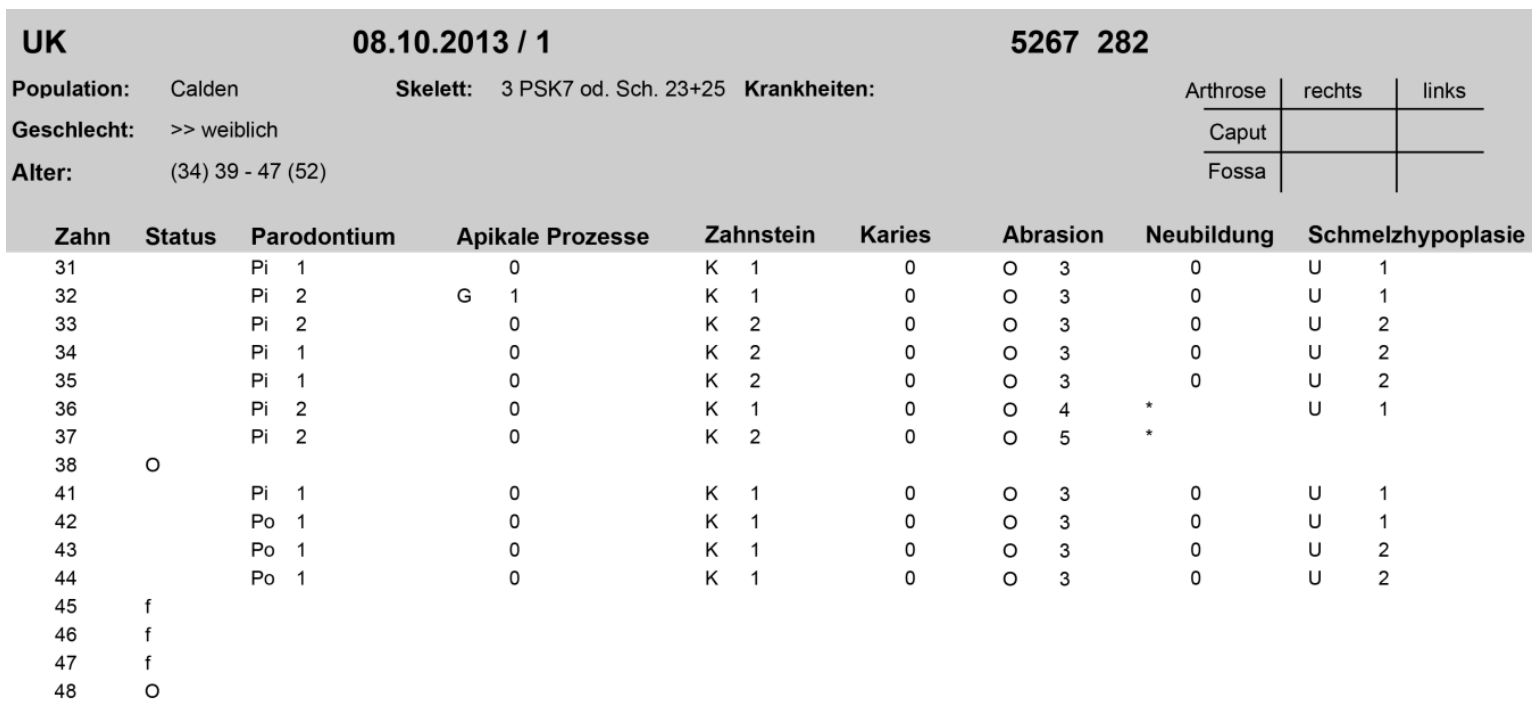

Beschreibung: Bei diesem Unterkiefer handelt es sich um ein Ausstellungsstück des Landesmuseums Hessen in Kassel. Das Fundstück ist wahrscheinlich einem weiblichen Individuum zuzuordnen. Auffällig ist, dass die Zähne des 4. Quadranten ab dem 45 intravital ausgefallen waren und die Alveolen vollständig verschlossen sind. Der Zahnverlust kann diskutiert werden: Möglich ist, dass die rechte Seite des Kauapparats als Werkzeug verwendet wurde und die Zähne dadurch nicht physiologisch belastet wurden, was dann zum vorzeitigen Zahnverlust führte. Da der Oberkiefer nicht vorhanden ist, ist diese Theorie nicht belegbar. Auszuschließen ist an dieser Stelle auch nicht, dass ein knöchernes Trauma vorgelegen hatte, welches z. B. durch eine äußere Gewalteinwirkung auf den rechten Bereich des Kopfes entstanden sein könnte.

Insgesamt befindet sich das Fundstück in gutem Erhaltungszustand.

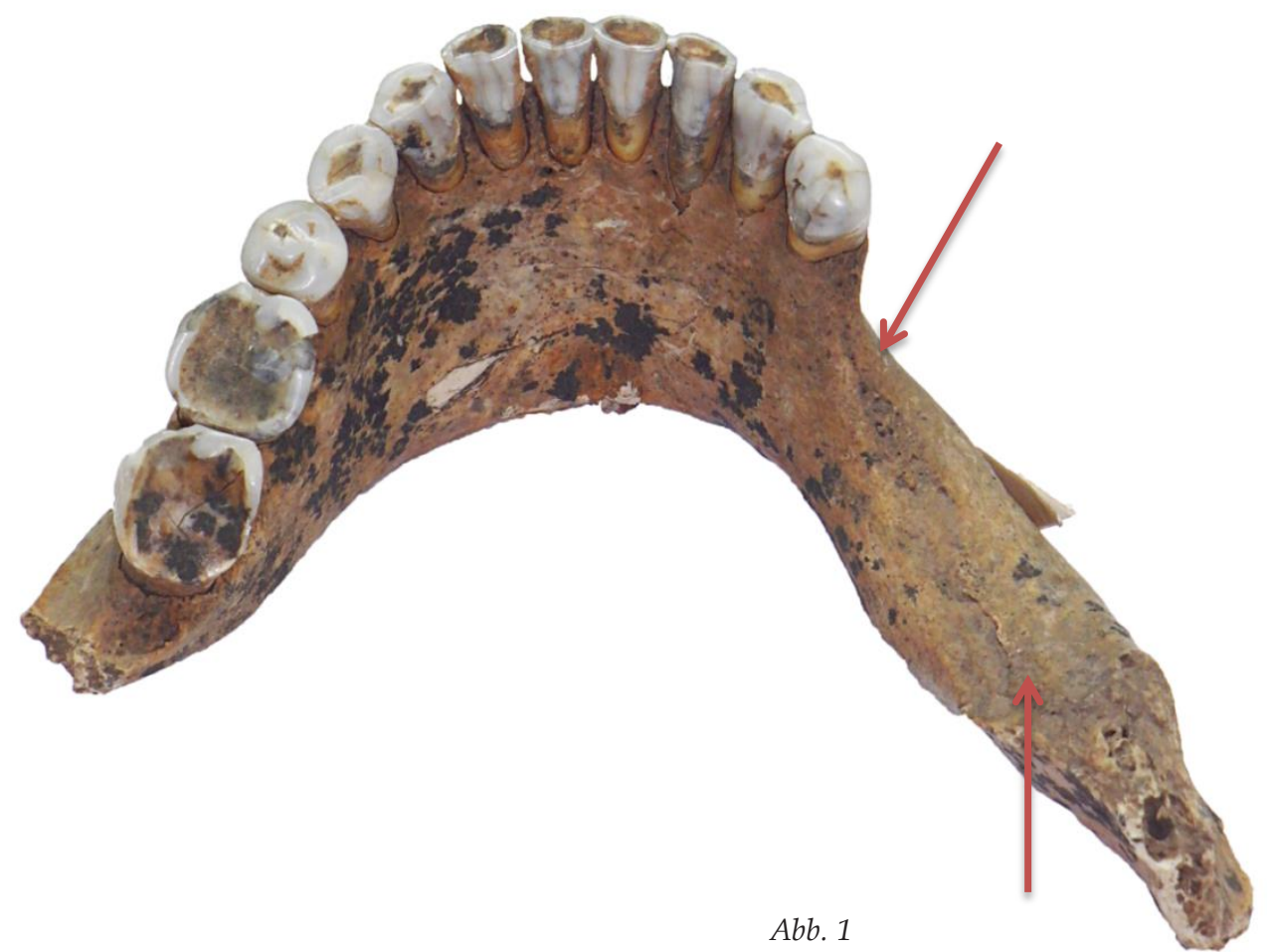




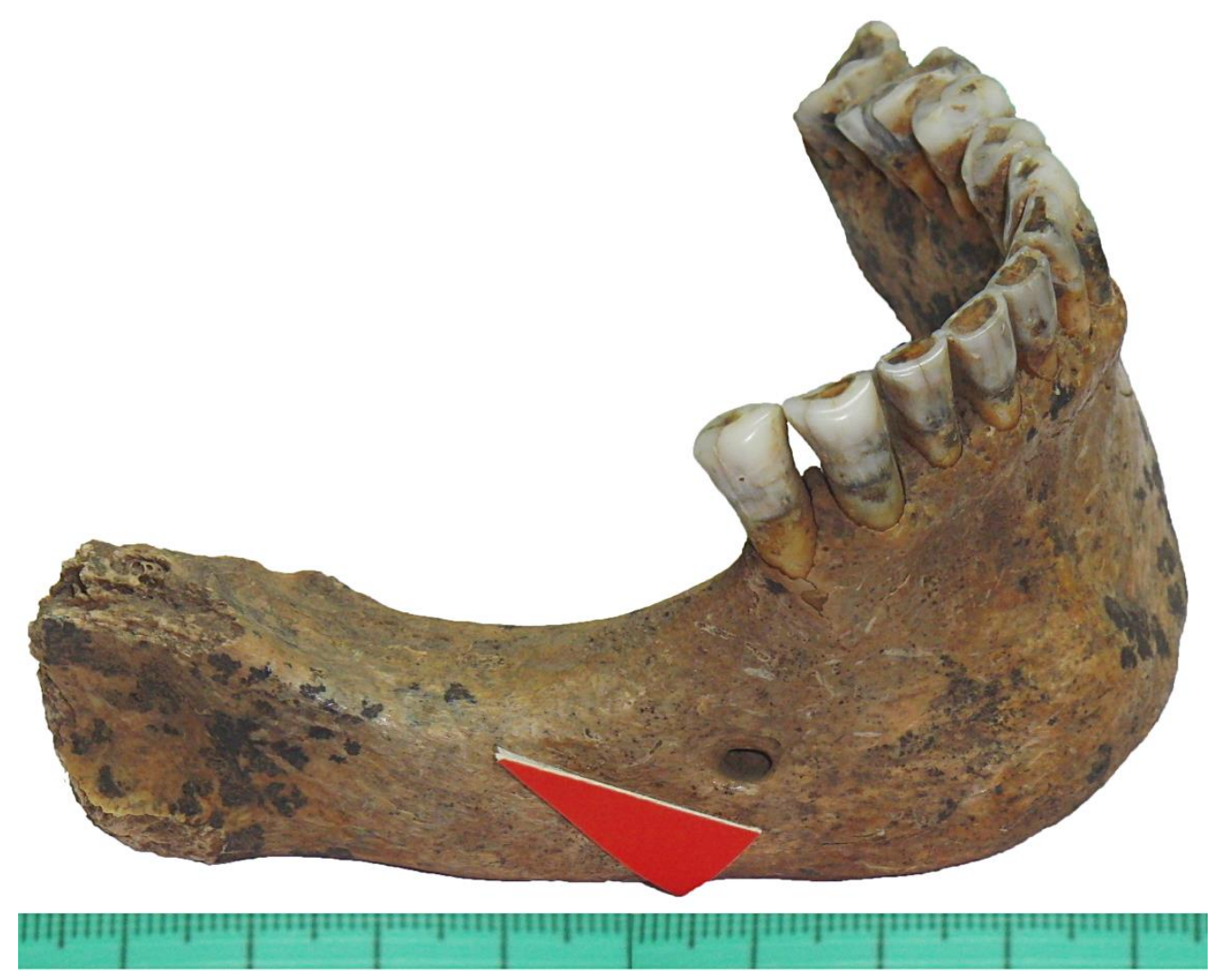

$A b b .2$

\section{Abbildungen:}

1. Abbildung des Unterkiefers von posterior. Die Pfeile markieren den Beriech im 4. Quadranten, in dem die Zähne 45, 46 und 47 intravital ausgefallen waren.

2. Der 4. Quadrant wurde von den Ausstellern des Museums mit einem roten Pfeil markiert, da hier alle Zähne ab 45 intravital ausgefallen waren. 


\subsection{Befund 8: Teilskelet 11 der Population aus Calden}

Knochenname: Teilskelet

Skeletnummer: $\quad$ Calden V11

Kistennummer: 269

Alter:

(35) 40 - 50 (55) J.

Geschlecht:

$\hat{0}$

Erhaltungszustand: gut

Gesund/krank: krank

Gesamtbeschreibung:

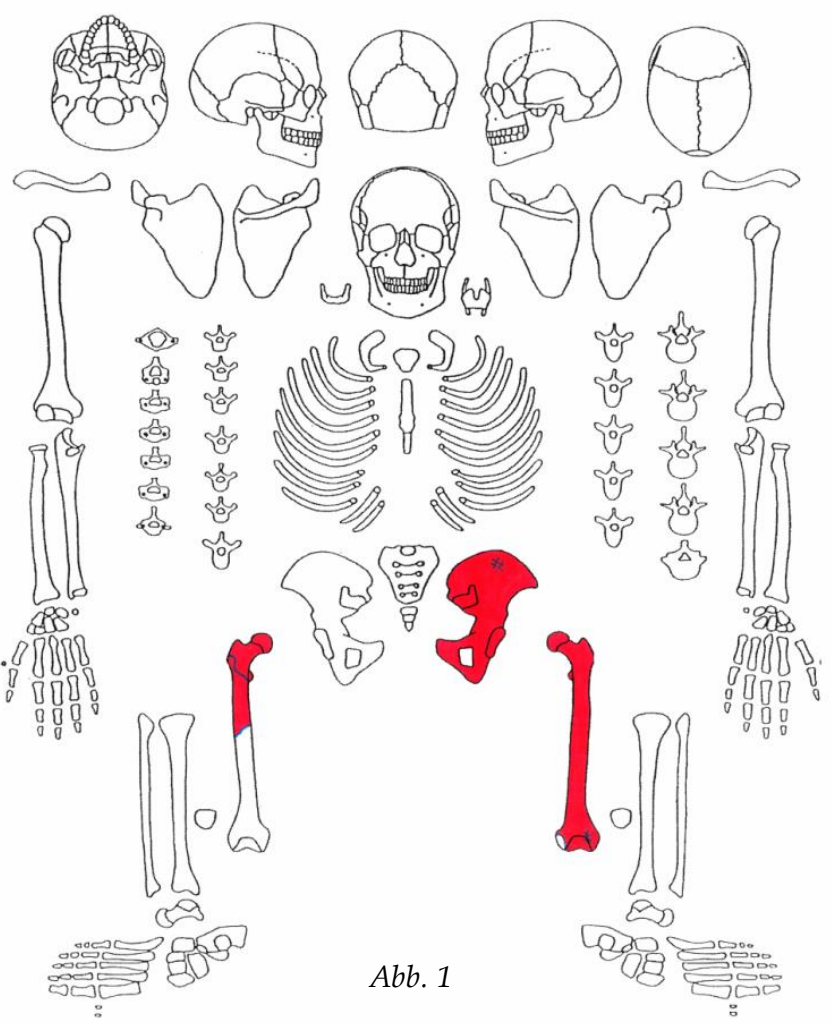

Dieses Teilskelet besteht aus dem linken und rechten Os femoris und dem linken Teil des Os coxae.

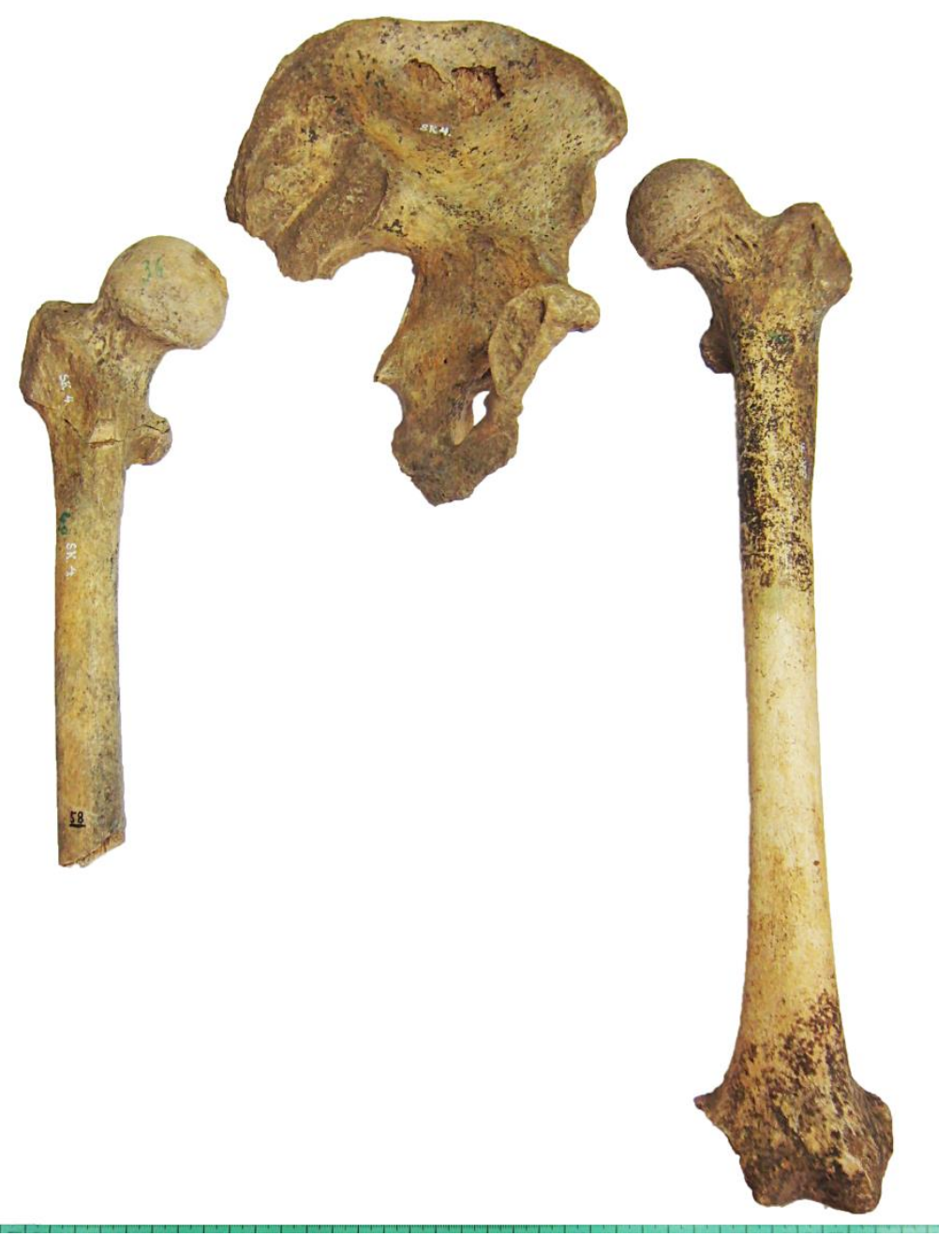


Befunde der einzelnen Skeletelemente

Knochenname: Os coxae

Skeletnummer: $\quad$ SK.4

Erhaltungszustand: gut

Gesund/krank: $\quad$ krank

- Arthrose Grad IV, gesamt 4

- Arthritis

- Periostreizung

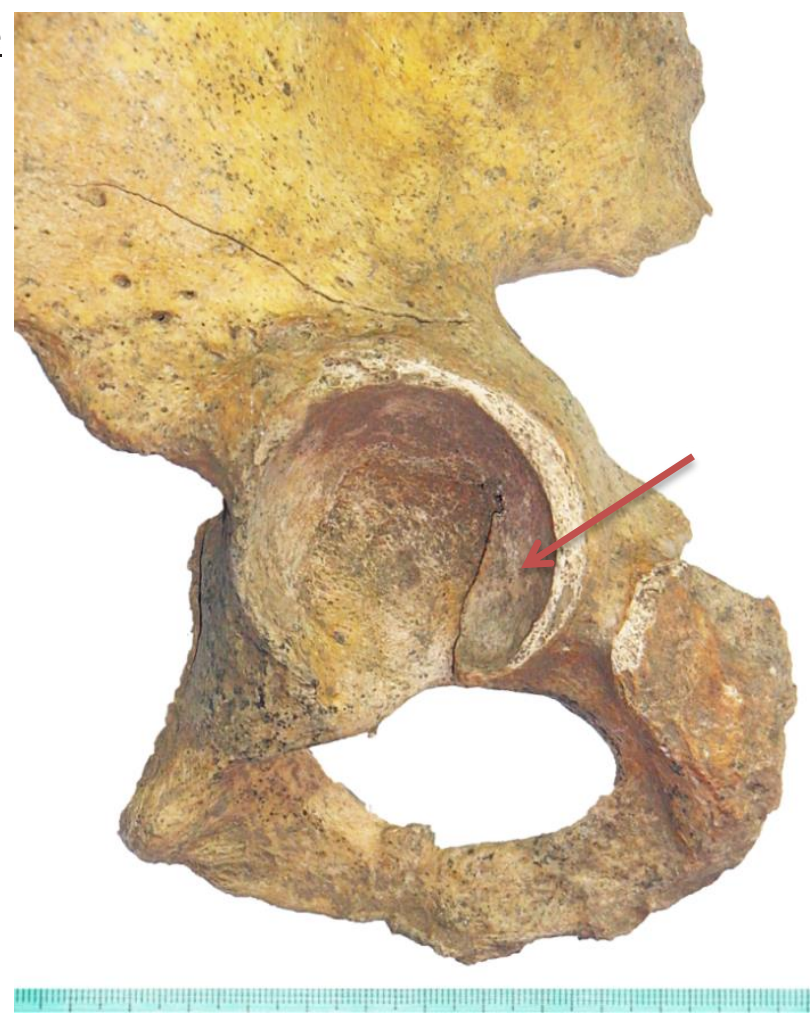

$A b b .3$

Beschreibung des Fundstücks: Das linke Os coxae weist Spuren gelenkverschleißender Prozesse und Spuren periostaler Reizungen durch Muskelzug auf. Die Arthrose, welche in den entzündlichen Prozess einer Arthritis übergegangen ist, wurde mit Grad IV bewertet.

Knochenname: Os femoris rechts

Skeletnummer: $\quad$ SK.4

Erhaltungszustand: gut

Gesund/krank: krank

- Arthrose Grad III

Beschreibung des Fundstücks: Das rechte Os femoris weist eine deutliche Linea aspera (M. adductor longus) auf. Sie prägt den Schaft, der insgesamt aber eher grazil ist; dennoch sprechen einige Details für ein männliches Individuum. Weitere Muskelmarken der Mm. gluteus minimus, gastrocnemius, vastus lateralis, obturatorius inferior, piriformis et iliopsoas sind zu erkennen. Sie sind allerdings nicht so deutlich ausgeprägt, wie die Linea aspera. Es fehlt die distale Hälfte des Knochens und der posteriore Teil des Trochanter major. Insgesamt ist der Knochen wenig durch postmortale Oberflächenerosionen verändert worden. 
Knochenname: Os femoris links

Skeletnummer: $\quad$ SK.4

Erhaltungszustand: gut

Gesund/krank: krank

- Arthrose proximal Grad IV, gesamt 4

- Arthrose distal Grad II

- Arthritis

- Spuren einer tiefen Venenentzündung

- Periostreizung

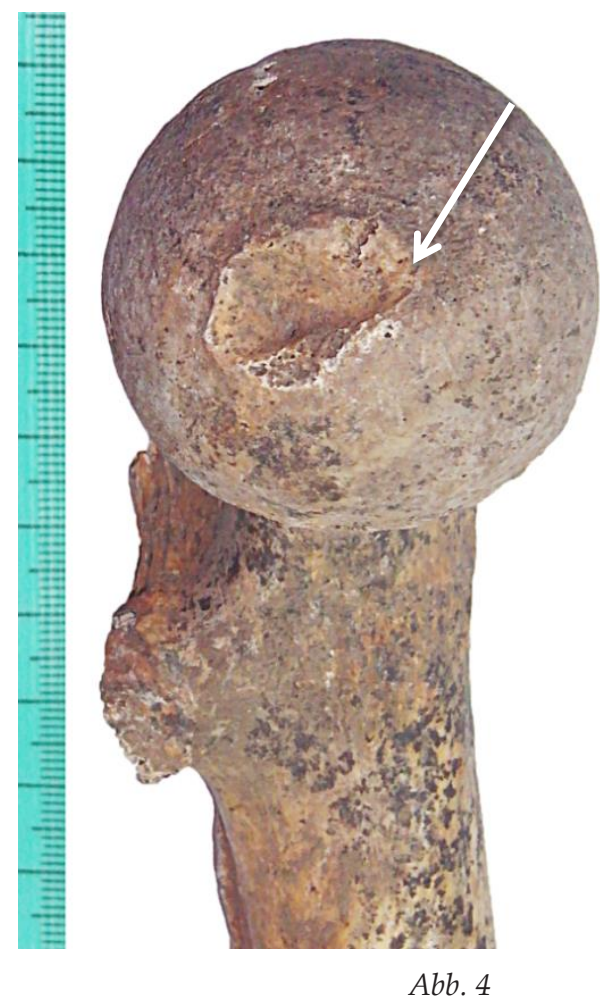

Beschreibung des Fundstücks: Das linke Os femoris ist gut erhalten, Bodenerosionen sind makroskopisch kaum vorhanden. Die distale Gelenkfläche ist nur teilweise befundbar, die proximale dagegen besser, wobei nicht die ganze Fläche erhalten ist. Auch bei diesem Fundstück fällt die markante Linea aspera ins Auge. Es finden sich die gleichen Muskelmarken wie am rechten Os femoris. Es fällt eine 45 x 22 mm große Fläche im unteren Drittel des Knochens anterior auf. Hierbei handelt es sich wahrscheinlich um muskulär bedingte Periostreizungen. Weiterhin finden sich Gefäßimpressionen, die als Spuren einer tiefen Venenentzündung im proximalen Drittel des Knochens interpretiert wurden.

Abbildungen:

1. Skeletbefundbogen über den Erhaltungszustand: "rot" entspricht den erhaltenen Knochen, „blau“ entspricht einem Knochendefekt im Sinne eines postmortalen Artefakts.

2. Alle erhaltenen Skeletelemente des Teilskelets.

3. Bei dem erhaltenen linken Teil des Os coxae deutet der rote Pfeil auf die Veränderungen hin, die durch die gelenkverschleißenden Prozesse im Sinne einer Arthrose und Arthritis hervorgerufen wurden.

4. Linkes Os femoris; der Pfeil deutet auf die gelenkverschleißenden Veränderungen durch Arthrose und Arthritis hin, welche besonders an der Fovea capitis femoris vorhanden sind. 


\subsection{Befund 9: Teilskelet 12 der Population aus Calden}

Knochenname: Teilskelet

Skeletnummer: Calden V12

Kistennummer: 269

Alter:

$40-60 \mathrm{~J}$.

Geschlecht:

๙

Erhaltungszustand: gut

Gesund/krank: krank

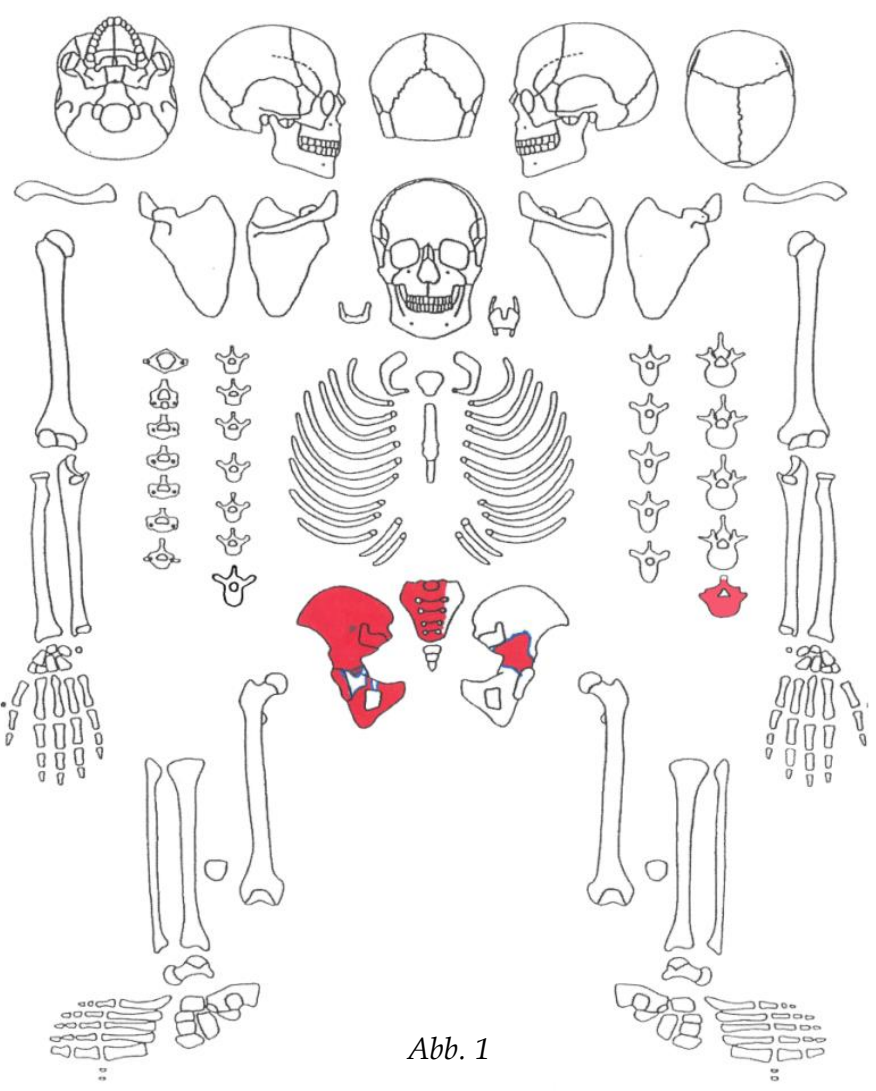

Gesamtbeschreibung:

Vier Knochen repräsentieren dieses Teilskelet. Es haben sich Fragmente des Beckens, des Steißbeins und eines Wirbels aus dem lumbalen Bereich erhalten.

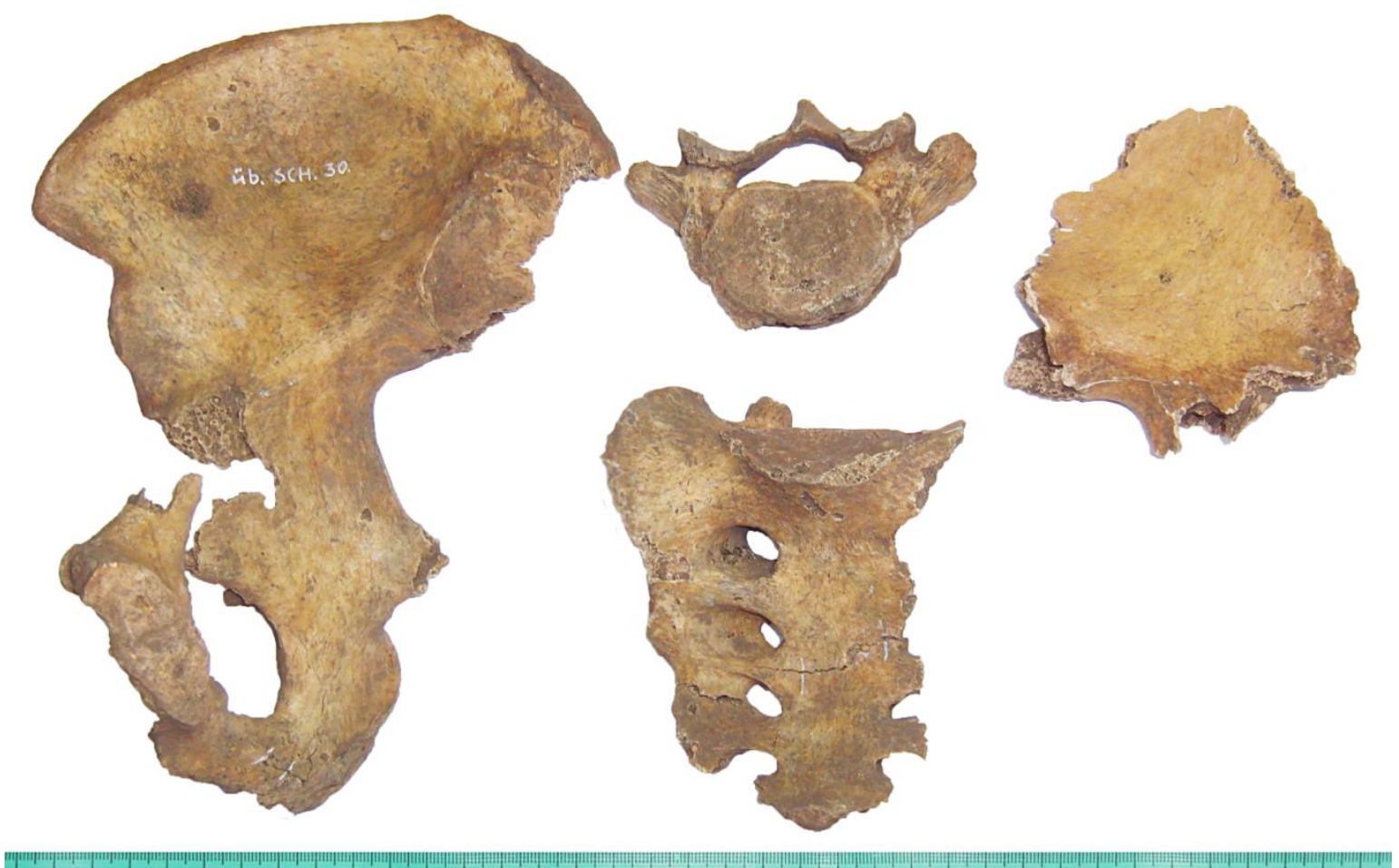


Befunde der einzelnen Skeletelemente

Knochenname: Vertebra

Skeletnummer: üb. SCH.30

Erhaltungszustand: gut

Gesund/krank: krank

- Arthrose

- Spondylophyten

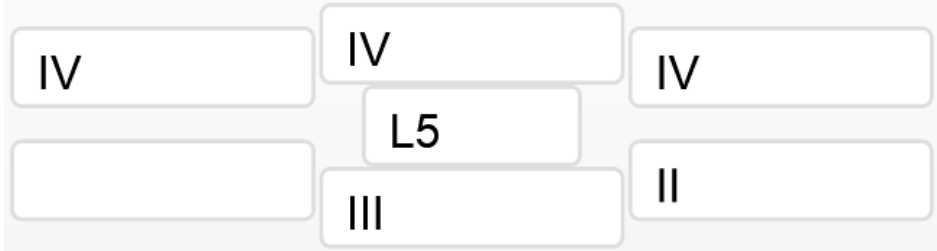

$A b b .3$
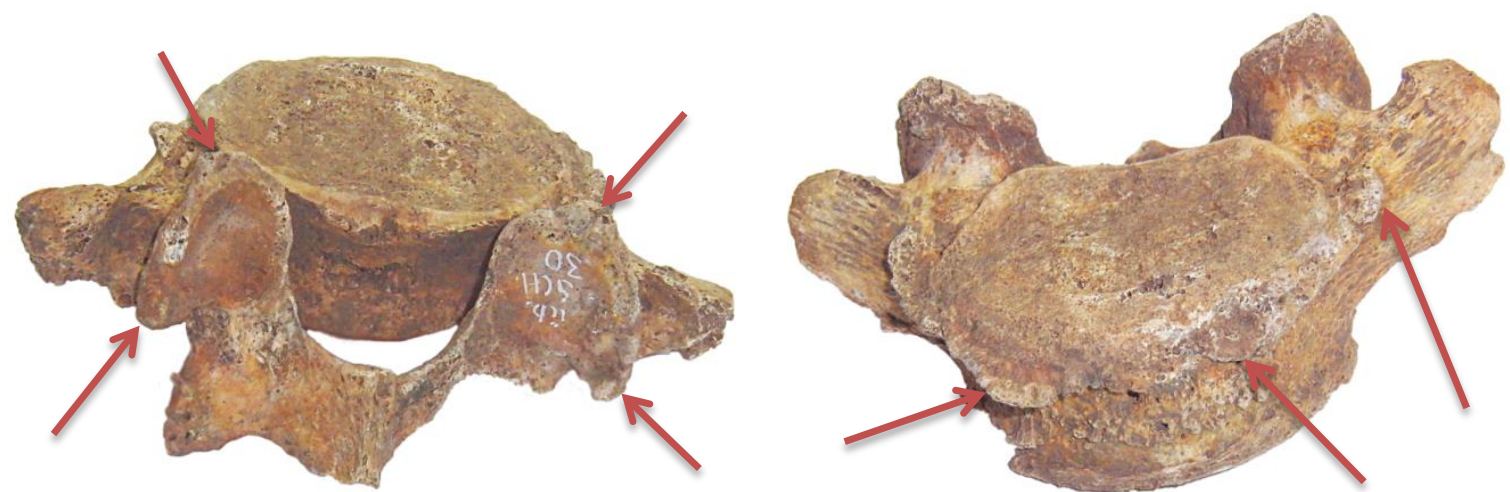

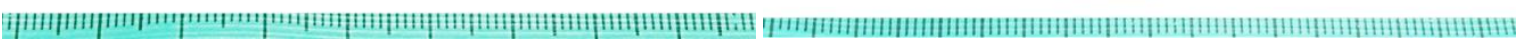

Beschreibung: Der Lendenwirbel L5 des Verbands weist besonders auf der oberen Deckplatte des Korpus, aber auch auf der unteren Spondylophyten auf. Diese messen bis $\mathrm{zu} 5,3 \mathrm{~mm}$ und sind eher rechtsseitig $\mathrm{zu}$ finden. Auffällige Verschleißspuren zeigen sich auch an den Costovertebralgelenken, besonders am rechten, welches am oberen Rand eburniert ist. Weiterhin weisen die Ränder Spondylophyten auf, die als reaktionäre Knochenneubildungen im Zuge von starken körperlichen Belastungen und Überbelastungen entstanden sind. Es haben sich der linke Processus articularis inferior und der Processus spinosus erhalten. 
Knochenname: Os sacrum

Skeletnummer: $\quad$ üb. SCH. 30

Erhaltungszustand: gut

Gesund/krank: krank

- Arthrose S1 Grad III, gesamt 3

- Processus articularis rechts Grad I

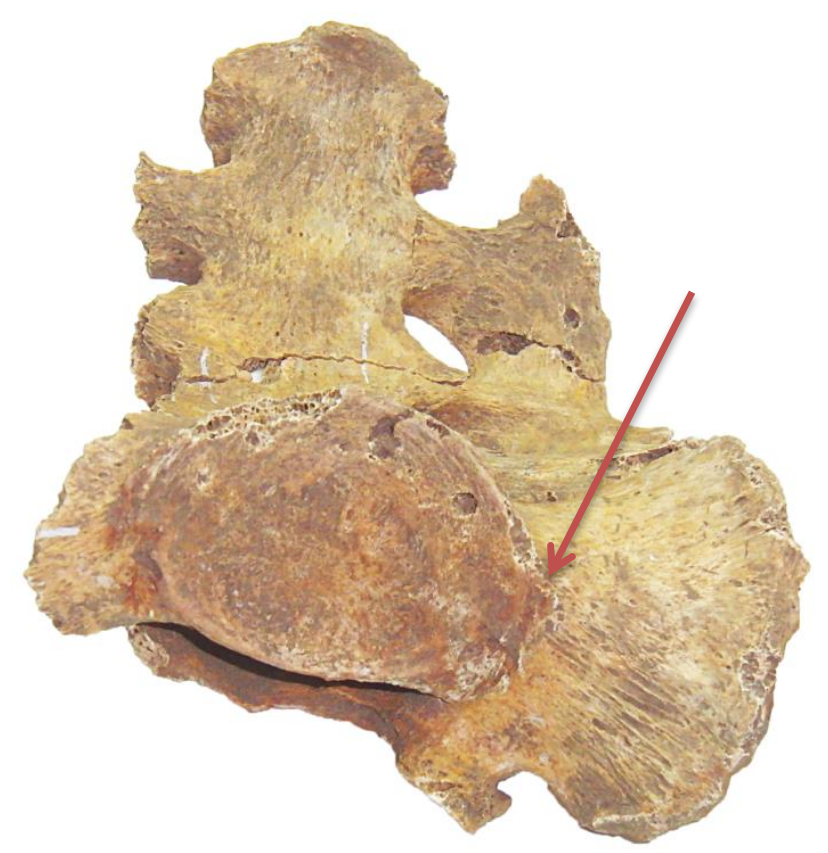

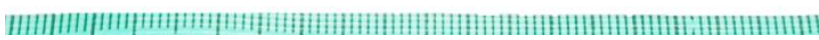
$A b b .6$

Beschreibung des Fundstücks: Das Os sacrum des Verbands liegt nicht vollständig vor, es fehlt das linke Drittel. Das erste Sakralgelenk und der rechte Processus articularis superior sind befundbar. Dem lumbalen Wirbel L5 entsprechend, ist die Basis ossis sacri durch Arthrose geschädigt.

Knochenname: Os coxae

Skeletnummer: $\quad$ üb. SCH. 30

Erhaltungszustand: gut

Gesund/krank: gesund

- Arthrose des Acetabulums Grad II

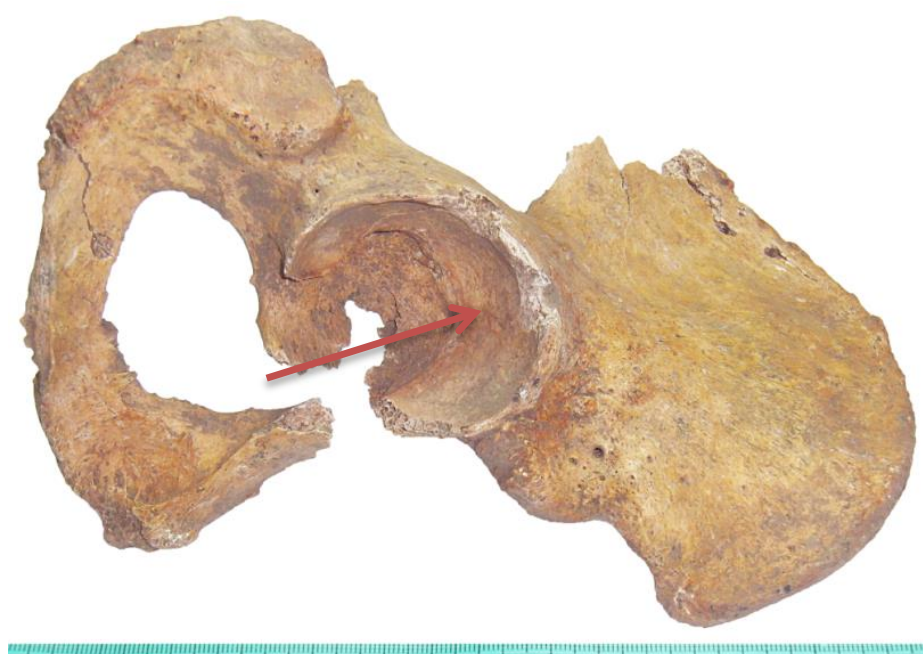

$A b b .7$

Beschreibung des Fundstücks: Das Becken des Verbands besteht aus einem fast vollständigen und einem fragmentierten und unvollständigen linken Teil. Muskelmarken fallen deutlich am Ramus ossis ischii ins Auge, wo Spuren von Muskelreizungen in Form von kleinen Exostosen zu finden sind. 
Abbildungen:

1. Skeletbefundbogen über den Erhaltungszustand: "rot" entspricht den erhaltenen Knochen, „blau“ entspricht einem Knochendefekt im Sinne eines postmortalen Artefakts.

2. Abbildung aller erhaltenen Skeletelemente.

3. Wirbelbefundschema, welches die Arthrosegrade der Gelenkfortsätze und der Deck- und Grundplatte angibt. Ansicht von anterior.

4. Foto des Wirbels L5 von posterior; deutlich $\mathrm{zu}$ sehen sind die Spondylophyten am rechten und linken Processus articularis superior (siehe Pfeile).

5. Hier ist der Wirbel L5 von anterior abgebildet. Die Pfeile deuten auf die deutlich sichtbaren Spondylophyten an der oberen Deckplatte des Wirbels.

6. Das Os sacrum ist von cranial- anterior fotografiert worden. Der Blick auf die Basis ossis sacri ist gegeben und der deutlich arthrotisch veränderte Rand des ersten Sakralgelenks fällt ins Auge.

7. Die letzte Abbildung zeigt den rechten Teil des Beckens um $90^{\circ} \mathrm{im}$ Uhrzeigersinn gedreht von caudal- lateral. Der direkte Blick in die Gelenkpfanne ist somit gegeben. Das Acetabulum zeigt nur geringe Spuren einer Arthrose (Pfeil). 


\subsection{Befund 10: Teilskelet 14 der Population aus Calden}

Knochenname: Teilskelet

Skeletnummer: Calden V14

Kistennummer: $\quad 719$

Alter: $\quad$ adult

Geschlecht:

/

Erhaltungszustand: gut

Gesund/krank: krank

Gesamtbeschreibung:
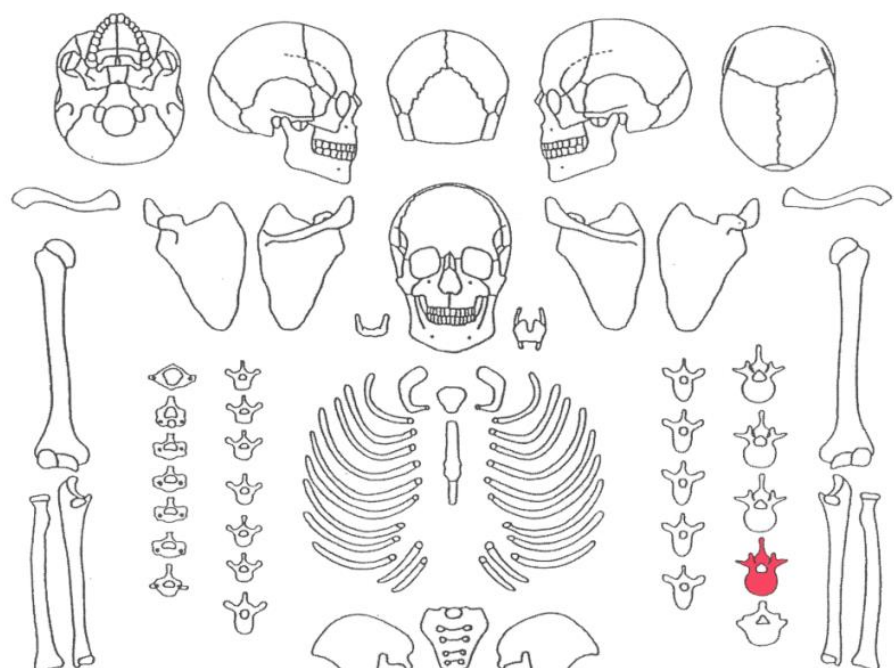

$$
\text { \& }
$$
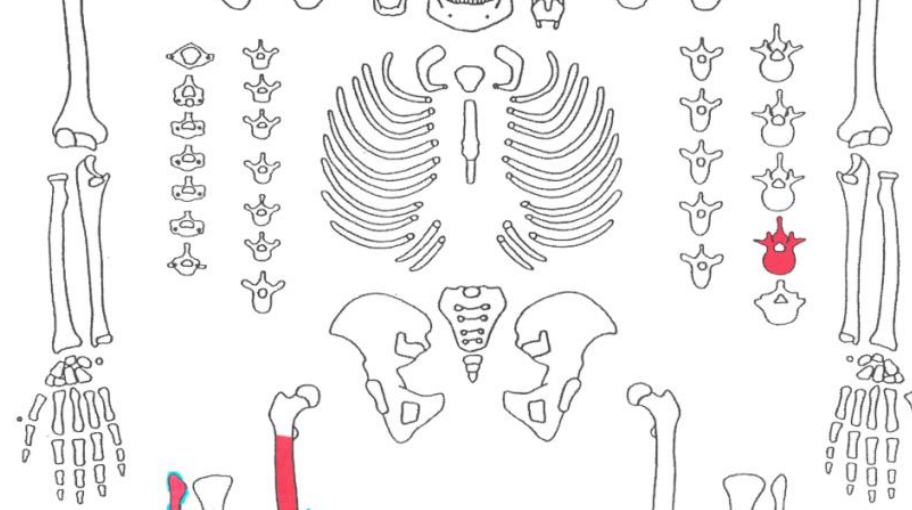

)ै
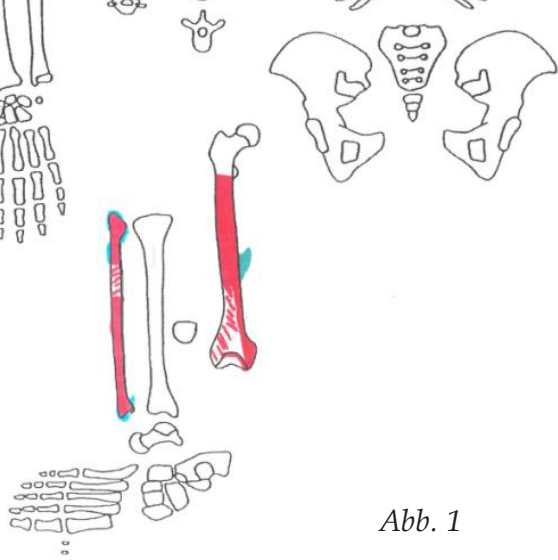

Abb. 1

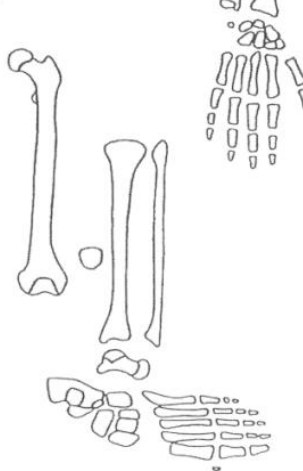

Dieses Teilskelet setzt sich aus einem lumbalen Wirbel, einem rechten Oberschenkelknochen und einem rechten Wadenbein zusammen. Dass diese Knochen $\mathrm{zu}$ einem Verband gehören, stützt sich $\mathrm{u}$. a. darauf, dass die Skeletsegmente miteinander vergleichbare Spuren von traumatischen Ereignissen aufweisen. So sind möglicherweise die Verletzungen bei ein und demselben Ereignis entstanden. Dieses könnte ein Sprung oder Sturz aus größerer Höhe gewesen sein, bei dem der Boden eher als vom Individuum erwartet erreicht wurde und es mit den Fußspitzen zuerst landete. Eventuell könnte ein solcher Sturz in eine verdeckte Grube geschehen sein oder ein Sprung von einem Baum, der unkontrolliert verlief. Das Verletzungs- bzw. Verheilungsmuster der drei Skeletsegmente lässt auf dasselbe Ereignis schließen, das dem Schaden zugrunde gelegen hat. Zweifelsohne hat das Individuum diesen Sturz überlebt, da die Verletzungen zu Folgeerkrankungen geführt haben oder mit entsprechenden Umbauvorgängen vergesellschaftet verheilt sind.

Befunde der einzelnen Skeletelemente

Knochenname: Vertebra

Skeletnummer: $\quad$ P16+18 10

Erhaltungszustand: gut

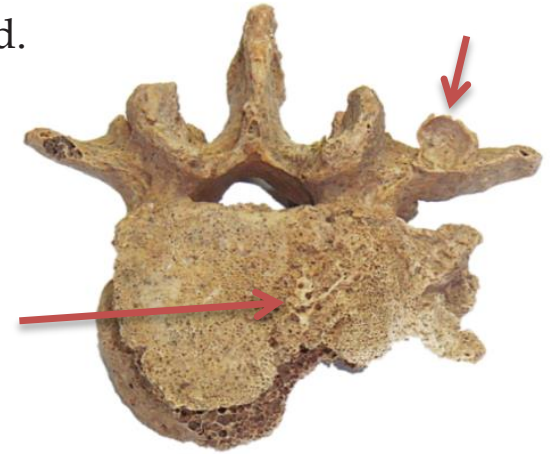


Gesund/krank: $\quad$ krank

- Arthritis

- Arthrose

- Zystenbildung

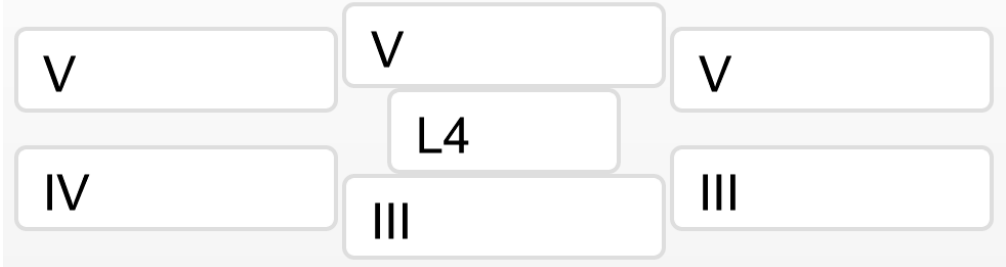

$A b b .3$

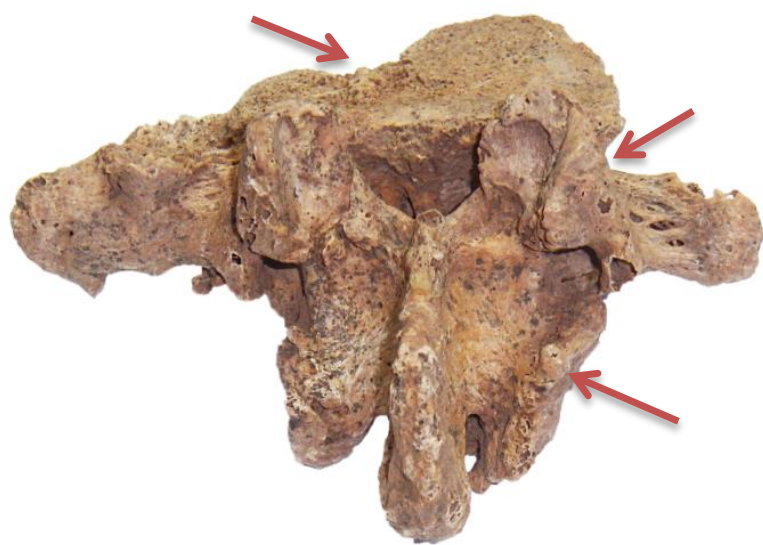

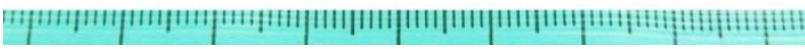

$A b b .4$

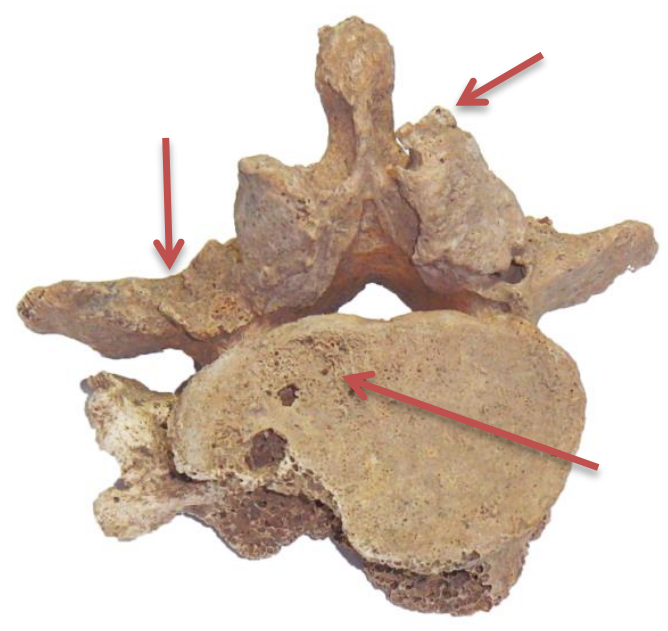

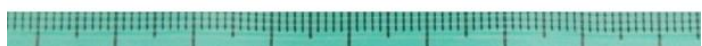

$A b b .5$

Beschreibung: Bei diesem Wirbel L4 kam es auf der rechten Seite des Corpus zum knöchernen Einbruch durch körperliche Überbelastung: der vorherige Wirbel glitt nach rechts über den Corpus; dadurch kam es zur Bildung von Zysten an den lateralen Wirbelfortsätzen.

Knochenname: Os femoris rechts

Skeletnummer: $\quad 3226$

Erhaltungszustand: gut

Gesund/krank: krank

- Myositis ossficans

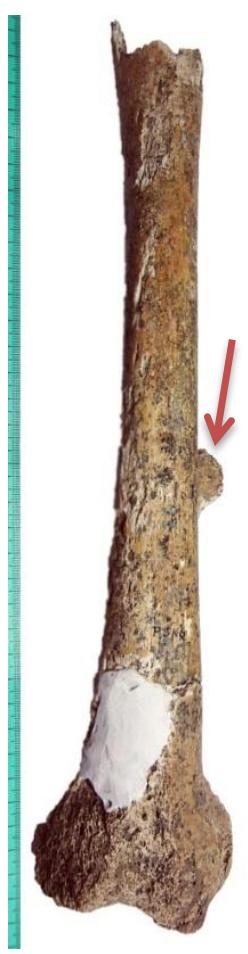

$A b b .6$

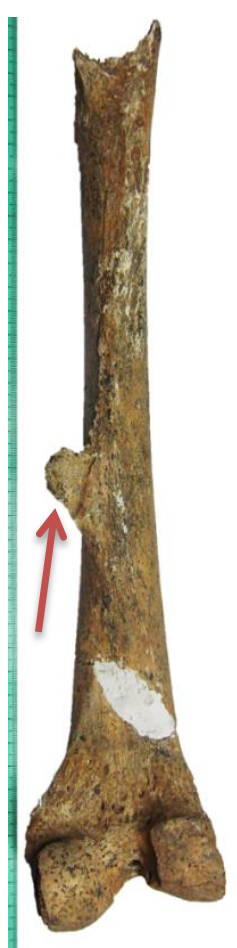

$A b b .7$

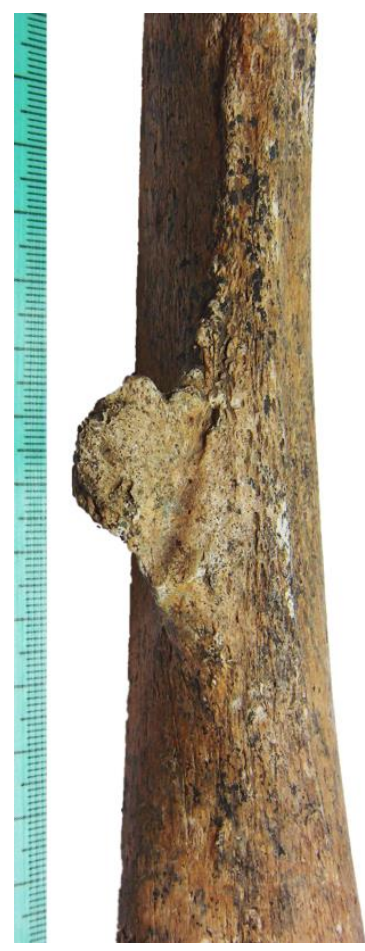

$A b b .8$ 
Beschreibung des Fundstücks: Dieses Os femoris der rechten Seite weist eine deutliche Myositis ossificans auf. Diese ragte bis in den Muskel (M. vastus) und misst etwa $17 \mathrm{~mm}$ medial - lateral und $38 \mathrm{~mm}$ proximal - distal. Das Periost ist an einigen Stellen angehoben, was zu einer furchigen Struktur geführt hat (Gefäßimpressionen durch Druckatrophie). Diese Stelle weist zwei Ränder auf, der eine konkav, der andere konvex; somit lag die Gefäßimpression in zwei Schichten vor und führte auch randständig zu Knochenneubildungen.

Knochenname: Fibula rechts

Skeletnummer: $\quad$ P16+18 10

Erhaltungszustand: gut

Gesund/krank: krank

- Arthritis

- Kapselriss
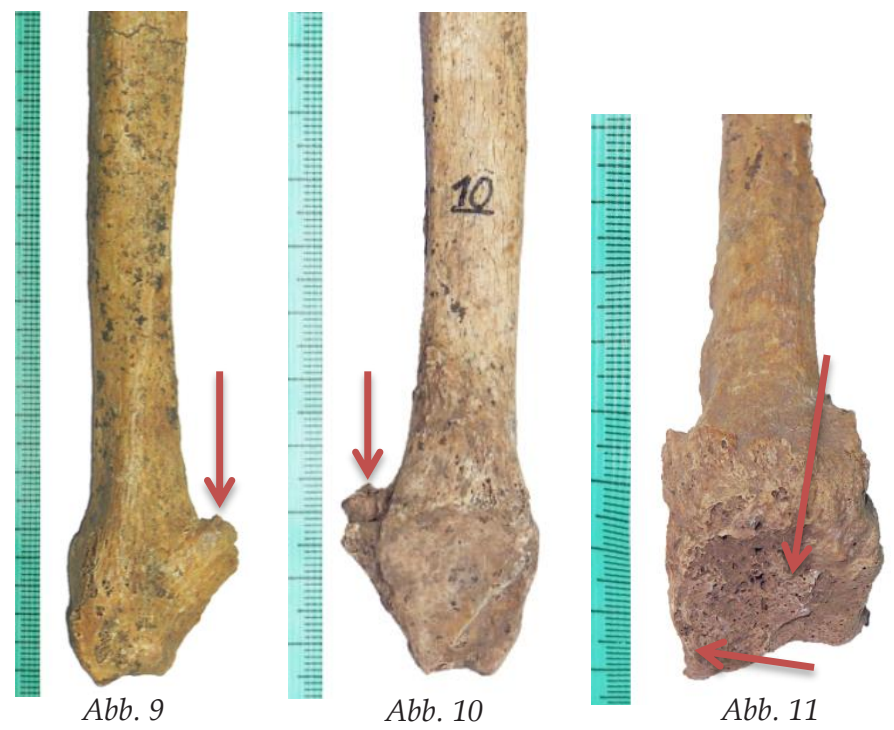

Beschreibung des Fundstücks: Diese Fibula weist pathologische Veränderungen nach einem traumatischen Ereignis auf. Der Ablauf des Ereignisses könnte wie folgt ausgesehen haben: Das Individuum sprang aus größerer Höhe und landete zu früh mit dem noch ausgestreckten Fuß bzw. der Fußspitze. Dabei ist der Talus keilförmig in die Articulatio talo - cruralis vorgeschoben worden und die Kapsel der Fibula an dieser Stelle gerissen. Weiterhin ergab sich eine starke Zerrung der $\mathrm{Mm}$. fibularis brevis und soleus. Außerdem kam es zu einem Kapselriss am Articulatio geniculatum mit einem später resultierenden seitlichen Auswuchs und einer Arthritis an der Facies articularis malleoli lateralis. Der Gelenkverschleiß resultierte aus der gerissenen Kapsel, die dem Gelenk keinen ausreichenden Halt mehr geben konnte.

Abbildungen:

1. Skeletbefundbogen über den Erhaltungszustand: "rot" entspricht den erhaltenen Knochen, „türkis“ entspricht einer intravitalen, knöchernen Veränderung.

2. Der Wirbel L4 ist von cranial- anterior abgebildet. Der lange Pfeil markiert die knöchernen Veränderungen, die durch den traumatisch bedingten arthrotisch- und arthritisch geprägten Gelenkverschleiß entstanden sind. 
Der kurze Pfeil deutet auf die Knochenaushöhlung, die durch eine Zyste entstanden ist.

3. Wirbelbefundschema, welches die Arthrosegrade der Gelenkfortsätze und der Deck- und Grundplatte angibt. Ansicht von vorne.

4. Abbildung des Wirbels L4 von posterior- rechts. Der lange Pfeil zeigt auf die obere Deckplatte des Korpus, die durch das Trauma und die anschließende Arthrose und Arthritis intravital pathologisch knöchern umgebaut wurde. Der mittellange Pfeil deutet auf die wulstige arthrotische Veränderung des rechten Processus articularis superior. Der kurze Pfeil deutet auf den arthrotisch bedingten Randwulst des rechten Processus articularis inferior.

5. Abbildung des Wirbels L4 von distal- anterior. Der lange Pfeil zeigt auf die leichte arthrotisch- arthritisch bedingte Veränderung der unteren Deckplatte des Corpus. Der mittellange Pfeil deutet auf die knöcherne Aushöhlung, die durch eine Zyste bedingt sein könnte. Der kurze Pfeil deutet auf den arthrotisch bedingten Randwulst des Processus articularis inferior.

6. Foto des Os femoris der rechten Seite, aufgenommen von anterior. Deutlich $\mathrm{zu}$ sehen ist die Myositis ossificans, die durch den Pfeil markiert wird. Weiter distal fällt eine helle, nichtknöcherne Substanz an dem Knochen auf. Es handelt sich hierbei um Gips, mit dem ein Defekt an der Knochensubstanz ausgeglichen wurde; er wurde von anderen Personen angebracht.

7. Abbildung des Os femoris von distal. Der Pfeil zeigt auf die Myositis ossificans. Der helle Bereich des Knochens weiter distal ist eine Füllung mit Gips, die einen knöchernen Defekt der Knochensubstanz ausgleicht. Der Gips wurde von anderen Personen angebracht.

8. Nahaufnahme von Abb. 6. Hier ist die Myositis ossificans sehr deutlich hervorgehoben.

9. Foto der rechten Fibula von lateral. Der Pfeil deutet auf die knöcherne Struktur, die nach einem Kapselriss im Zuge der Heilung gebildet wurde.

10. Abbildung der Fibula von medial. Der Pfeil zeigt auf die verknöcherte Struktur im Sinne einer Reparatur - Neubildung nach dem Kapselriss des Tibio- Fibulargelenks.

11. Foto der Facies articularis malleoli lateralis von proximal- distal. Die Pfeile markieren die Dimension der arthritischen Veränderungen an der Gelenkfläche. 


\subsection{Befund 11: Teilskelet 33 der Population aus Calden}

Knochenname: Teilskelet

Skeletnummer: $\quad$ Calden V33

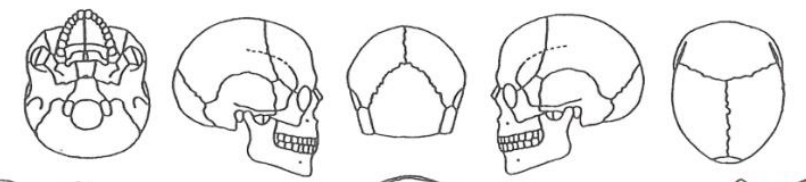

Kistennummer: $\quad 277$

Alter: $\quad$ adult

Geschlecht:

/

Erhaltungszustand: gut

Gesund/krank: krank

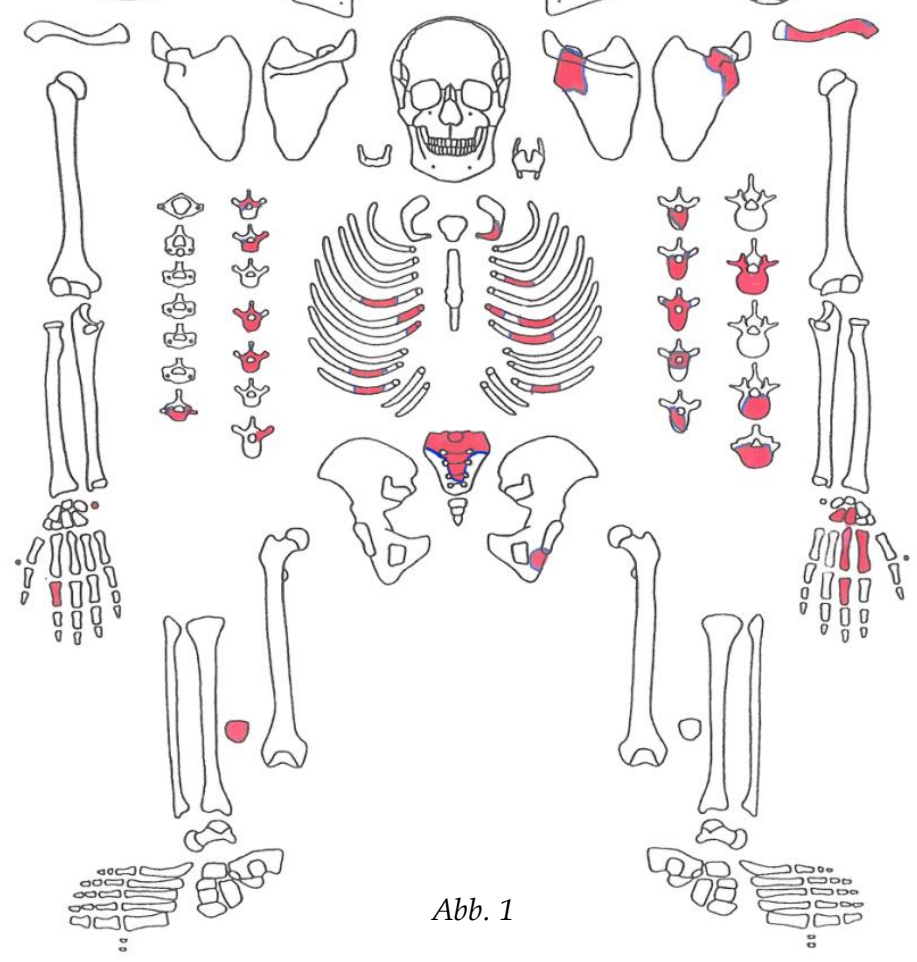

Gesamtbeschreibung:

Bei diesem Teilskelet handelt es sich um 14 in Fragmenten erhaltene Wirbel, zwei kleine Teile des Steißbeins, ein Fragment eines Schulterblattes, den Großteil des linken Schlüsselbeins, Fragmente von Rippen, ein Teil eines Beckens, mehrere Fingerknochen und eine Kniescheibe.

Befunde der einzelnen Skeletelemente

Knochenname: 14 Vertebrae

Skeletnummer: „kleine Tüte“

Erhaltungszustand: gut

Gesund/krank: nicht zu befunden

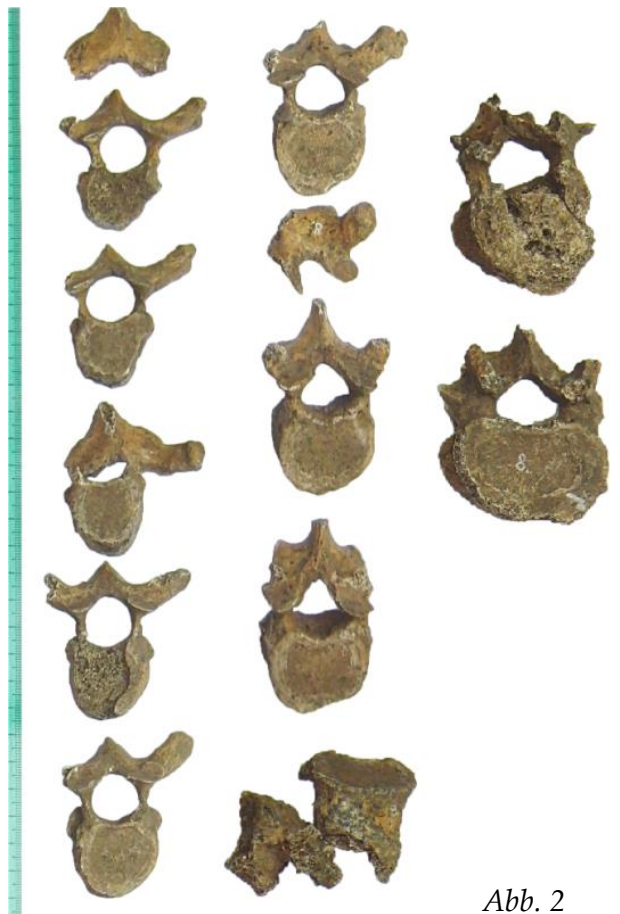


Beschreibung der Fundstücke: Es haben sich Fragmente der Wirbel C7, Th1, Th2, Th4, Th5, Th7, Th8, bis Th12, L2 L4 und L5 erhalten.

Knochenname: Os sacrum

Skeletnummer: $\quad$ kleine Tüte

Erhaltungszustand: gut

Gesund/krank: gesund

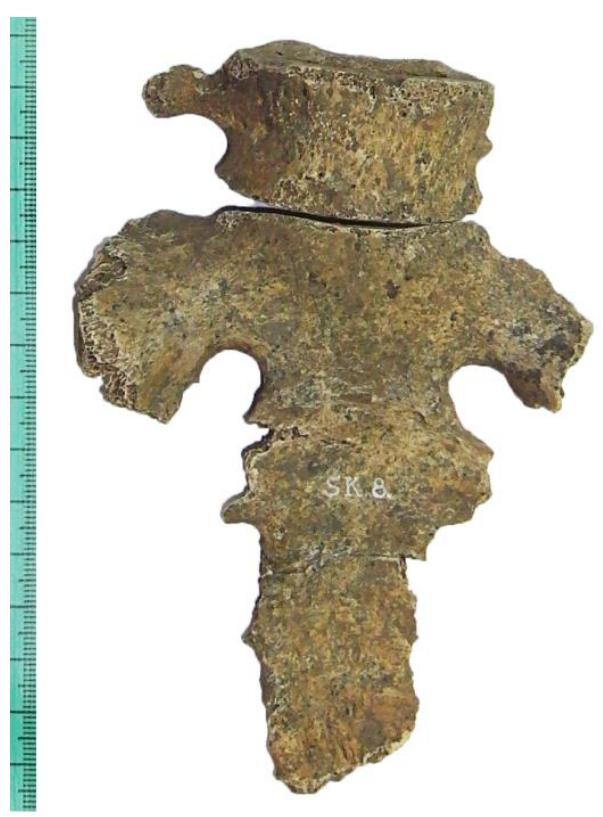

$A b b .3$

Beschreibung der Fundstücke: Von diesem Os sacrum sind zwei kleine Fragmente des cranialen Bereichs erhalten.

Knochenname: Scapula

Skeletnummer: $\quad$ kleine Tüte

Erhaltungszustand: mittel

Gesund/krank: gesund

- $\quad$ Arthrose Grad II

Beschreibung des Fundstücks: Ein Scapulafragment mit Cavitas glenoidalis. 
Knochenname: Clavicula

Skeletnummer: $\quad$ Sk. 11.

Erhaltungszustand: gut

Gesund/krank: krank

- Periostreizung durch überstrapazierenden Muskelzug

Beschreibung des Fundstücks: Bei dieser Clavicula findet sich ein starker Muskelansatz am Tuberculum conoideum des M. deltoideus.

Knochenname: 10 Costae

Skeletnummer: $\quad$ kleine Tüte

Erhaltungszustand: mittel

Gesund/krank: gesund

Beschreibung der Fundstücke: Es sind zehn Rippenfragmente erhalten, diese sind teilweise ihrer Lokalisation zuzuordnen. So sind Teilfragmente der 4. linken, der 5. rechten, der 6. linken und rechten, der 7. rechten und linken, der 9. rechten, der 10. linken und rechten Rippe erhalten.

Knochenname: Os coxae links

Skeletnummer: $\quad$ kleine Tüte

Erhaltungszustand: mittel

Gesund/krank: nicht befundbar

Beschreibung des Fundstücks: Es ist nur ein kleines Fragment des rechten Teils des Beckens erhalten, es stammt vom Os ischii. 
Knochenname: 7 Handknochen

Skeletnummer: $\quad$ kleine Tüte

Erhaltungszustand: gut

Gesund/krank: nicht befundbar

Beschreibung der Fundstücke: Es sind sieben Handknochen erhalten. Es handelt sich um das linke Os capitatum, das linke Os hamatum, das linke Os metacarpale, ein Os phalangis proximalis 3 der linken Seite, ein rechtes Os pisiforme und zwei Ossa metacarpi 2 und 3 der linken Seite.

Knochenname: Patella rechts

Skeletnummer: $\quad$ kleine Tüte

Erhaltungszustand: gut

Gesund/krank: krank

- Sehnenverknöcherung

- Arthrose Grad IV

Beschreibung des Fundstücks: Die rechte Kniescheibe ist gut erhalten. Sie zeigt deutliche Spuren einer Arthrose und Verknöcherungen der Patellarsehne.

Abbildungen:

1. Skeletbefundbogen über den Erhaltungszustand: "rot" entspricht den erhaltenen Knochen, „blau“ entspricht einem Knochendefekt im Sinne eines postmortalen Artefakts.

2. Foto der Wirbel C7, Th1, Th2, Th4, Th5, Th7, bis Th12, L2 und L4.

3. Abbildung des Steißbeins und des Wirbels L5 auf dem ersten Sakralgelenk des Os sacrum. 


\subsection{Befund 12: Teilskelet 39 der Population aus Calden}

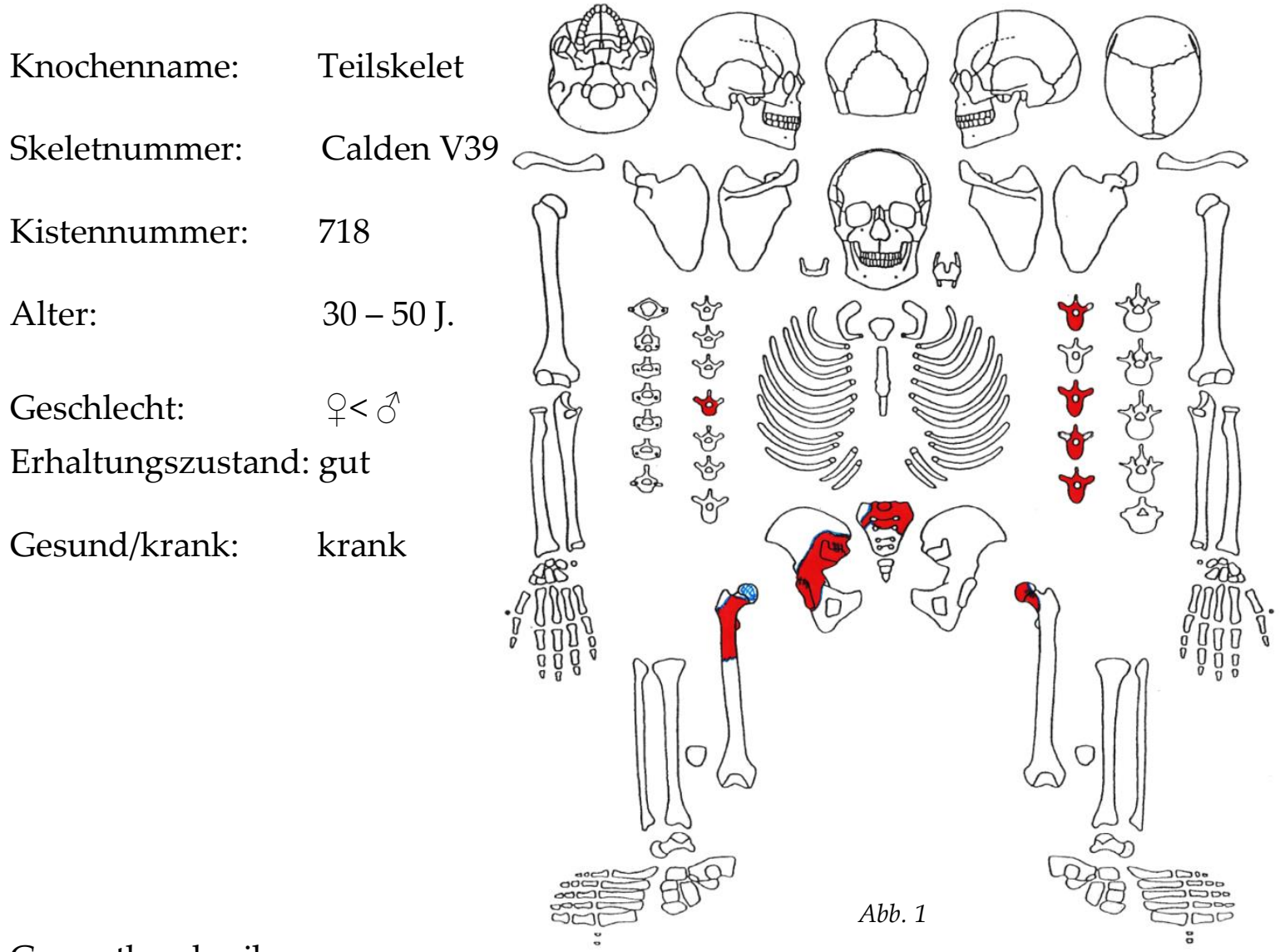

Gesamtbeschreibung:

Dieses Teilskelet setzt sich aus fünf Wirbeln, einem Fragment des Steißbeines, einem Fragment des rechten Teils des Beckens und aus jeweils einem Fragment des rechten und linken Oberschenkelknochens zusammen.

Befunde der einzelnen Skeletelemente

Knochenname: 5 Vertebrae

Erhaltungszustand: gut

Gesund/krank: krank

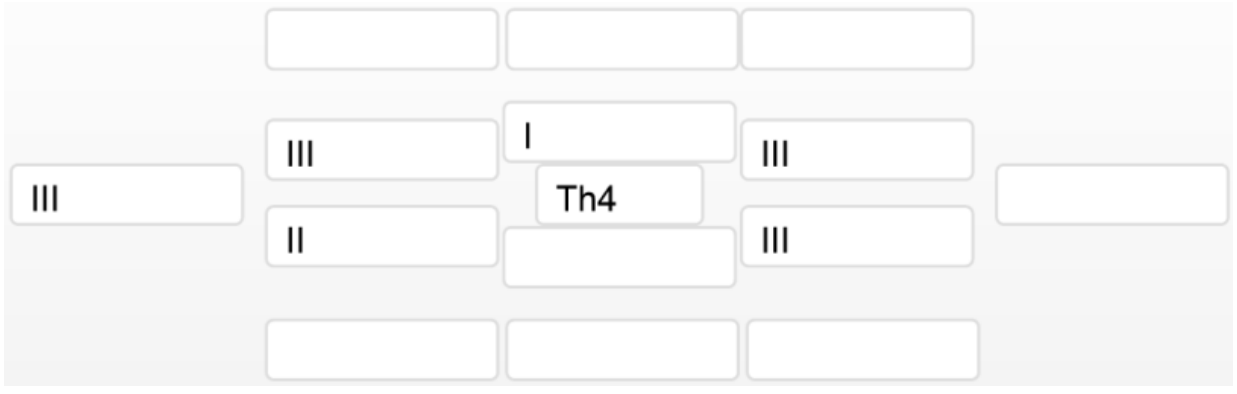

Abb. 2

Beschreibung des Fundstücks: Es handelt sich hier wohl um einen Wirbel Th4, wobei die Zuordnung nicht eindeutig möglich war. Es zeigen sich deutliche Verschleißerscheinungen am Costovertebralgelenk. 


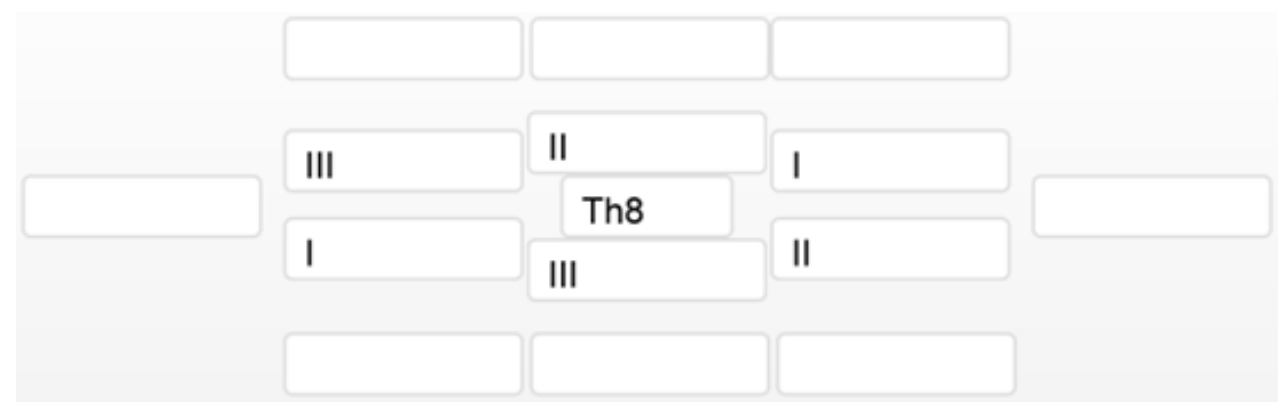

$A b b .3$

Beschreibung des Fundstücks: Dieser Wirbel ist wohl ein thorakaler der Nummer 8. Die Zuordnung ist jedoch nicht eindeutig. Es zeigen sich Spuren einer Spondylitis an der Unterseite des Wirbelcorpus.

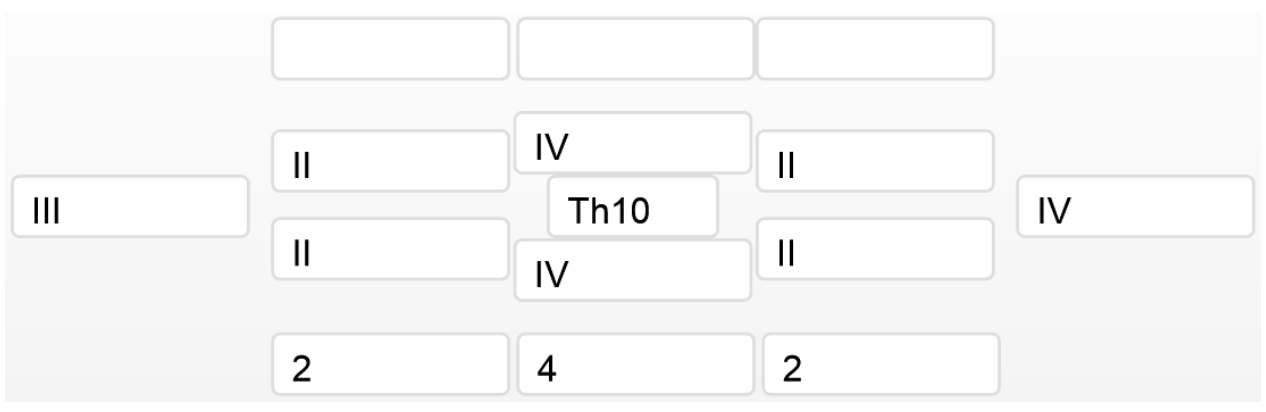

$A b b .4$

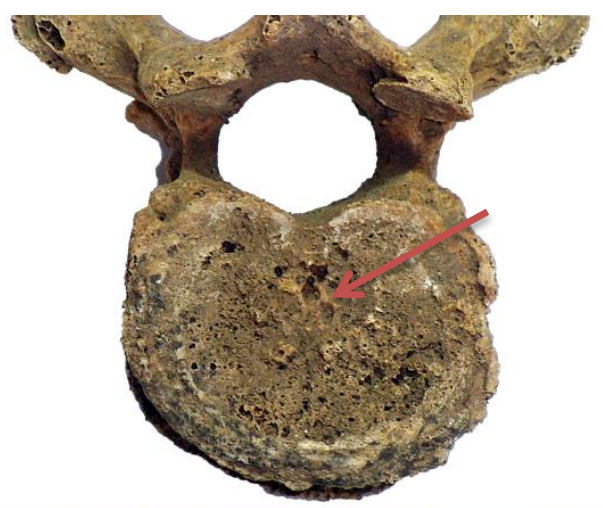

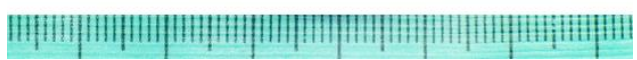
$A b b .5$

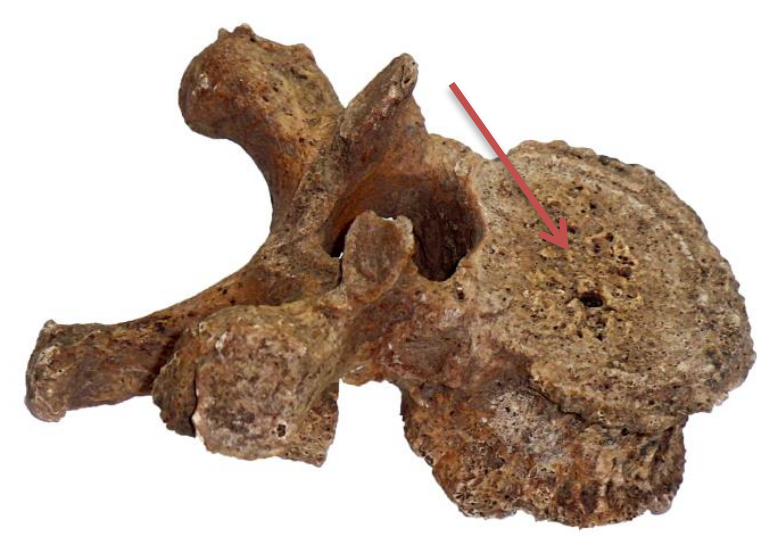

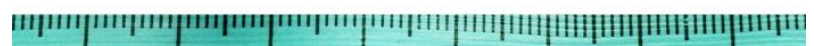

$A b b .6$

Beschreibung des Fundstücks: Dieser 10. thorakale Wirbel zeigt deutliche Verschleißspuren, auch am Costovertebralgelenk. Der Wirbel weit am Corpus Spondylophyten bis etwa $4 \mathrm{~mm}$ Breite auf. 


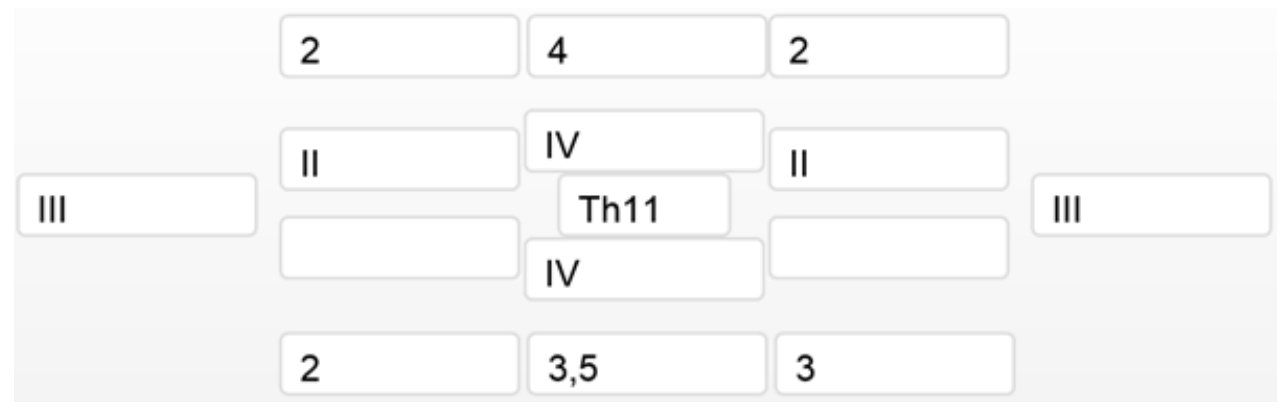

Abb. 7

Beschreibung des Fundstücks: Dieser 11. thorakale Wirbel weist Spondylophyten bis $8 \mathrm{~mm}$ unten und $6 \mathrm{~mm}$ oben am Corpus auf. Weiterhin ist eine Spondylitis oben und unten zu diagnostizieren.

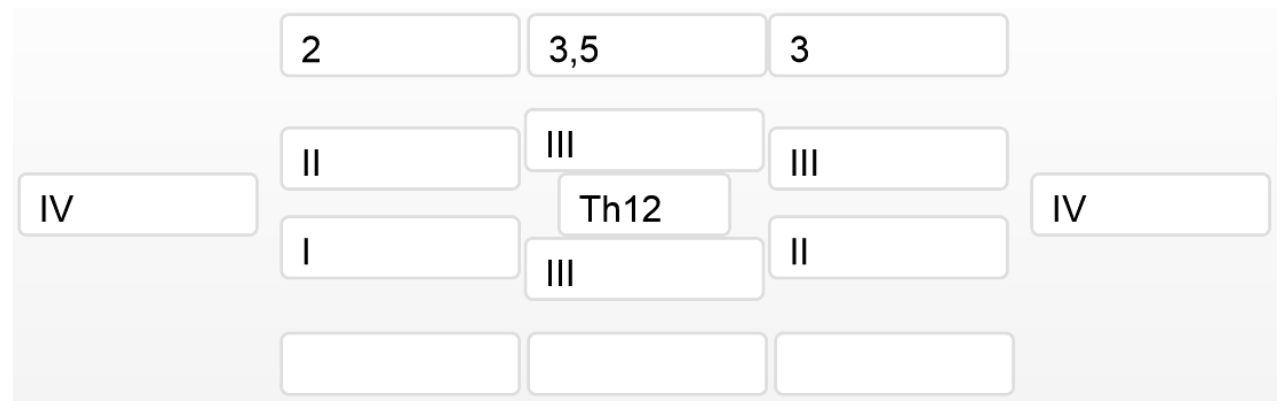

Abb. 8

Beschreibung des Fundstücks: Dieser zwölfte thorakale Wirbel zeigt deutliche Verschleißspuren an den Costovertebralgelenken. Weiterhin fallen Spondylophyten bis etwa $5 \mathrm{~mm}$ oben und $4 \mathrm{~mm}$ unten ins Auge.

Knochenname: Os sacrum

Erhaltungszustand: gut

Gesund/krank: krank

- Spondylitis

- Spondylolisthesis

- Spondylolysis

- Spondylosis

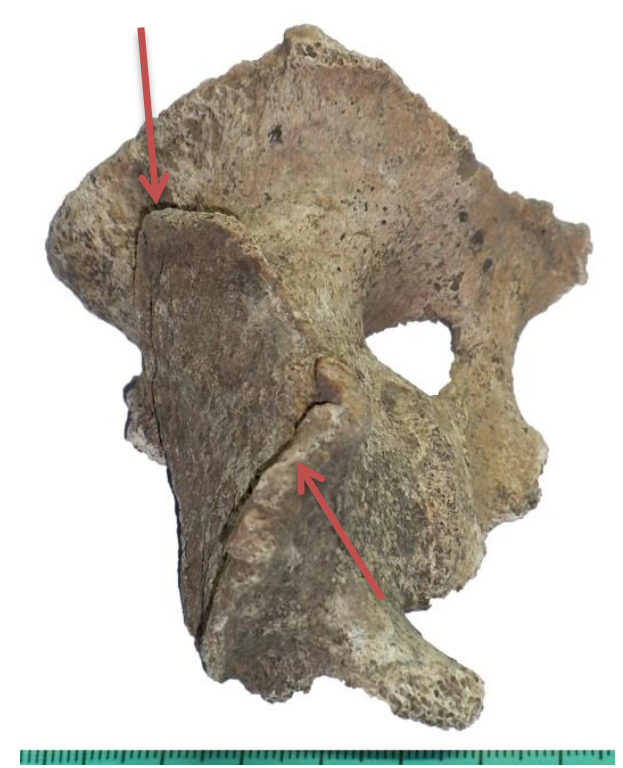




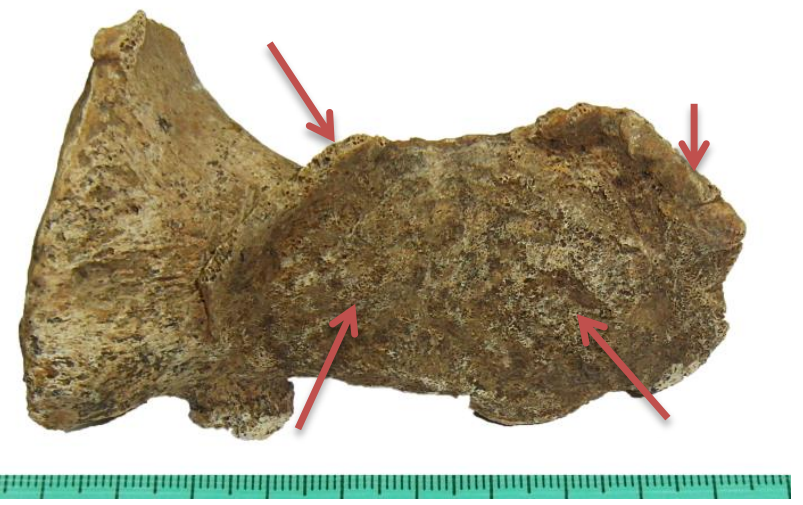

Abb. 10

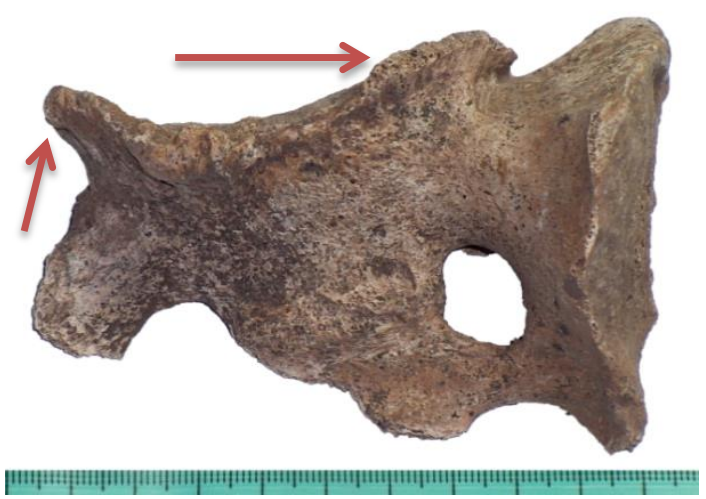

Abb. 11

Beschreibung des Fundstücks: An diesem Os sacrum finden sich massive Knochenneubildungen, hervorgerufen durch eine starke Spondylosis. Im Rahmen der entzündlichen Reaktion haben sich Spondylophyten gebildet, die v.a. rechts ausgebildet sind.

Es kam intravital wohl zu einem leichten Frakturgeschehen und zwar zu einer Kompressionsfraktur auf der rechten Seite mit anschließenden reaktiven Auswachsungen. In der Mitte gab es dann einen Bandscheibenprolaps, Breite etwa $20 \mathrm{~mm}$. Hier kam es zu Wirbelgleiten als Spondylolisthesis. Bei der Spondylolysis am Lendenwirbel entstand eine symmetrische, laterale Bogenspalte. Als proliferierende Neubildung bildete sich im subadulten Alter ein Wulst.

Knochenname: Os coxae rechts

Erhaltungszustand: gut

Gesund/krank: $\quad$ krank

- $\quad$ Arthrose Grad III

- Arthritis Grad III

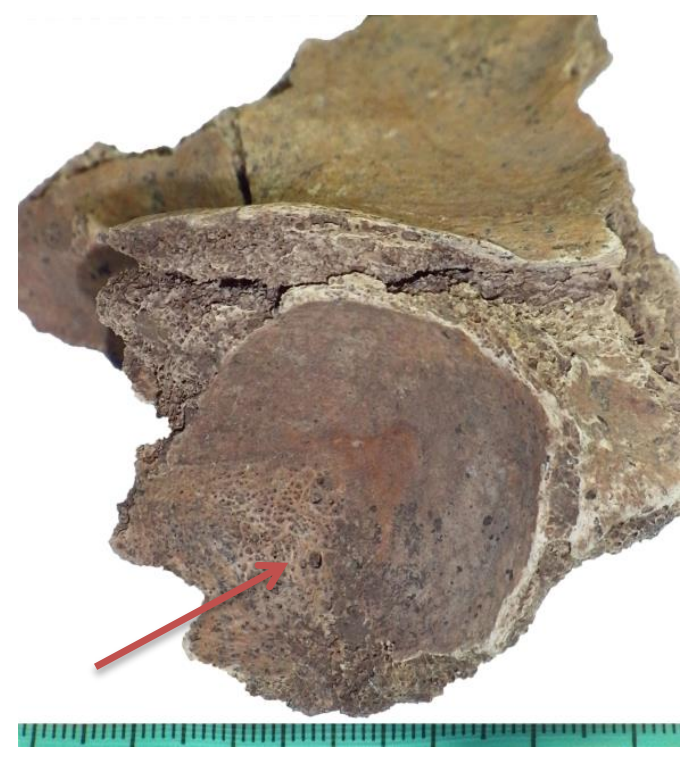

Abb. 12

Beschreibung des Fundstücks: Fragment eines Beckens, etwa ein Drittel hat sich erhalten. Das Acetabulum weist entzündliche und degenerative Veränderungen arthrotischer und arthritischer Art auf; der Rand ist erodiert. 
Knochenname: Os femoris rechts

Erhaltungszustand: gut

Gesund/krank: gesund

- Arthrose Grad II, gesamt Grad 2

Abb. 13

Beschreibung des Fundstücks: Von diesem Os femoris sind zwei proximale Fragmente erhalten, der Arthrosegrad korreliert mit dem Acetabulum des Beckens.

Knochenname: Os femoris links

Erhaltungszustand: mittel

Gesund/krank: gesund

- Arthrose Grad II

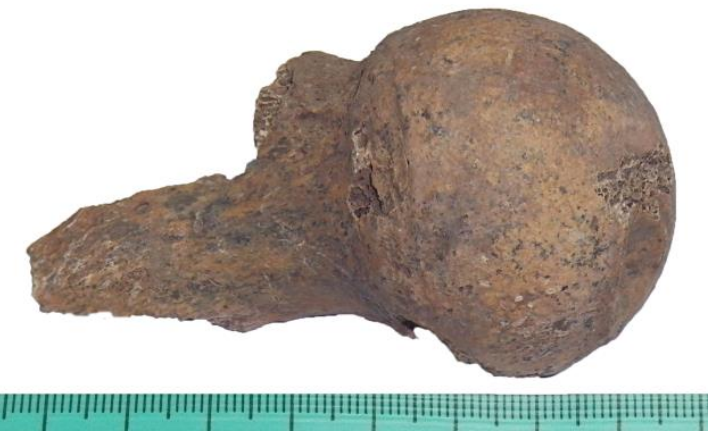

$A b b .14$

Beschreibung des Fundstücks: Von diesem Os femoris hat sich das proximale Gelenk und ein kleiner Teil des Schaftes erhalten.

Abbildungen:

1. Skeletbefundbogen über den Erhaltungszustand: "rot" entspricht den erhaltenen Knochen, „blau“ entspricht einem Knochendefekt im Sinne eines postmortalen Artefakts.

2. Wirbelbefundschema für den Wirbel TH4, welches die Arthrosegrade der Gelenkfortsätze und der Deck- und Grundplatte angibt. Ansicht von anterior.

3. Wirbelbefundschema für den Wirbel TH8, welches die Arthrosegrade der Gelenkfortsätze und der Deck- und Grundplatte angibt. Ansicht von anterior. 
4. Wirbelbefundschema für den Wirbel TH10, welches die Arthrosegrade der Gelenkfortsätze und der Deck- und Grundplatte angibt. Weiterhin werden die Gesamtarthrosegrade in arabischen Zahlen über bzw. unter dem Feld angegeben. Ansicht von anterior.

5. Das Foto zeigt den zehnten thorakalen Wirbel in axialer Richtung von caudal. Der Pfeil markiert die Spuren des arthrotischen Prozesses an der untern Deckplatte.

6. Die obere Deckplatte des Wirbels Th10 ist abgebildet. Der Pfeil markiert die Spuren des gelenkverschleißenden Prozesses. Auch hier handelte es sich um eine Arthrose.

7. Wirbelbefundschema für den Wirbel TH11, welches die Arthrosegrade der Gelenkfortsätze und der Deck- und Grundplatte angibt. Weiterhin werden die Gesamtarthrosegrade in arabischen Zahlen über bzw. unter dem Feld angegeben. Ansicht von anterior.

8. Wirbelbefundschema für den Wirbel TH12, welches die Arthrosegrade der Gelenkfortsätze und der Deck- und Grundplatte angibt. Weiterhin werden die Gesamtarthrosegrade in arabischen Zahlen über bzw. unter dem Feld angegeben. Ansicht von anterior.

9. Abbildung des Steißbeins von anterior - links. Markiert sind die deutlich erkennbaren Randwulste an der Basis ossis sacri, die infolge eines traumatischen Ereignisses im Sinne einer reaktionären Knochenneubildung entstanden sind.

10. An diesem Bild des Os sacrum sind die Randwulste deutlich erkennbar. Der ebenfalls durch das traumatische Ereignis entstandene arthrotischarthritische Prozess ist in Form der knöchernen Veränderungen erkennbar.

11. Das Os sacrum ist hier von anterior abgebildet. Deutlich sichtbar ist der massive Randwulst an der Basis ossis sacri.

12. Abbildung des rechten Teils des Os coxae. Im Acetabulum finden sich Spuren der knöchernen Reaktion auf einen arthritischen und arthrotischen Prozess.

13. Dieses Foto zeigt die beiden erhaltenen Fragmente des rechten Os femoris.

14. Foto des erhaltenen Teils des linken Os femoris. 
8.13 Befund 13: Teilskelet 46 der Population aus Calden

$\begin{array}{ll}\text { Knochenname: } & \text { Teilskelet } \\ \text { Skeletnummer: } & \text { Calden V46 }\end{array}$

Kistennummer: $\quad 273 ; 718$

Alter:

Geschlecht:

Erhaltungszustand: gut

Gesund/krank: krank

Gesamtbeschreibung: adult

○

Von diesem Individuum haben sich vier in Zusammenhang zu bringen waren.

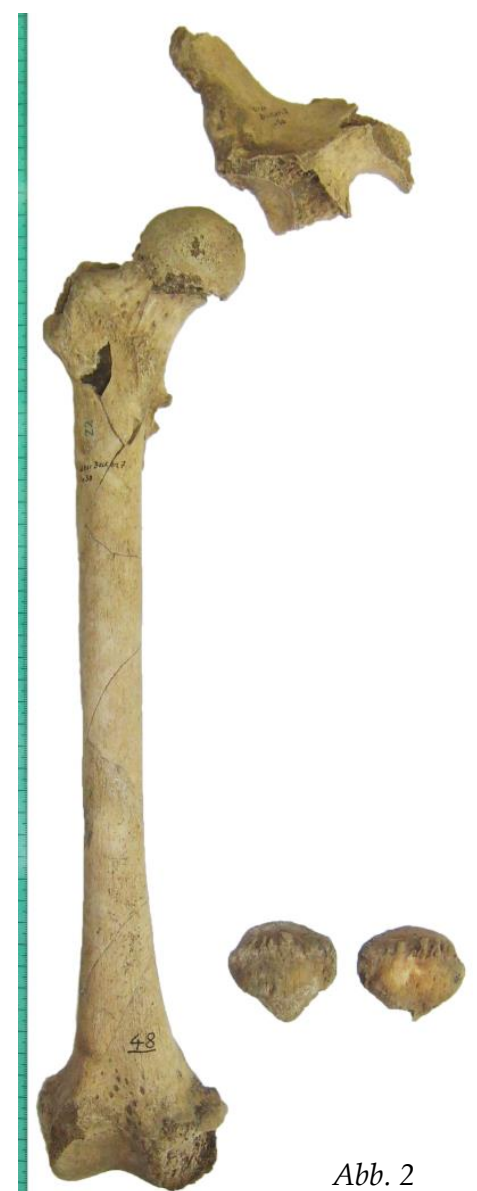

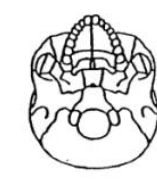
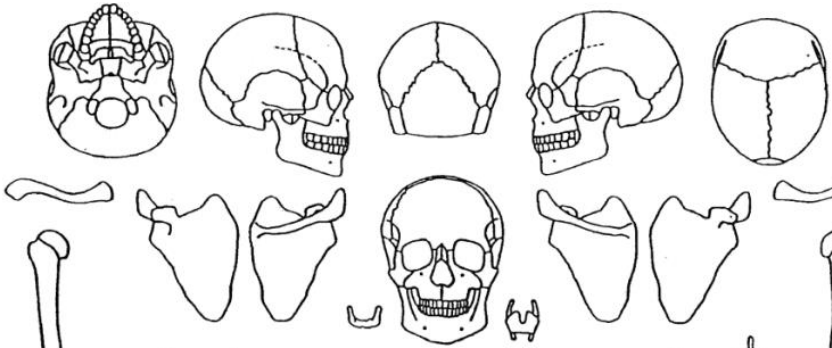

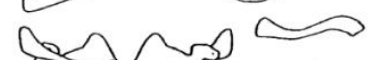
$\operatorname{tg}$
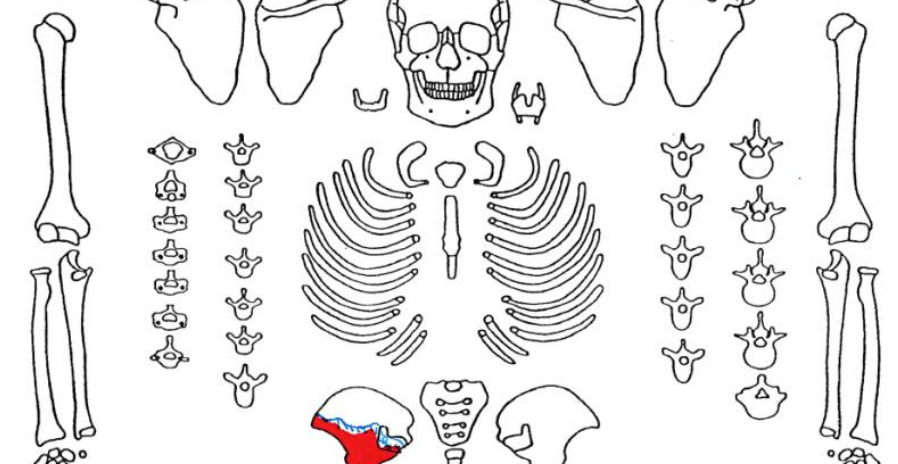

息

且

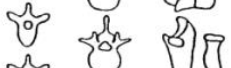

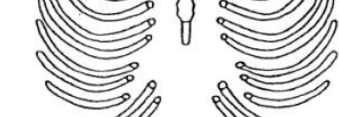

ช

कृ जols
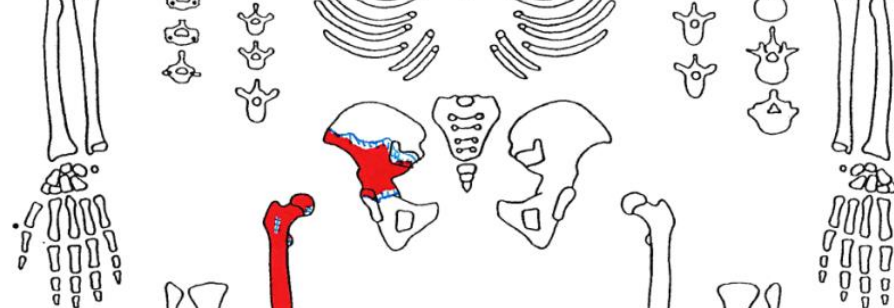

के

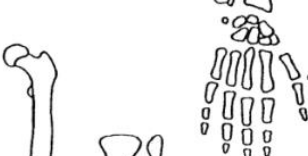

Abb. 1

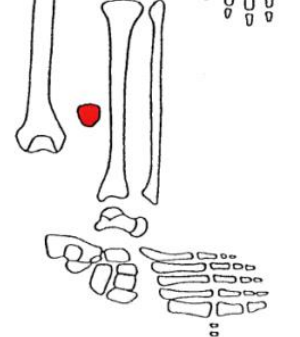


Befunde der einzelnen Skeletelemente

Knochenname: Os coxae rechts

Skeletnummer: $\quad$ über Becken 7+30

Erhaltungszustand: gut

Gesund/krank: krank

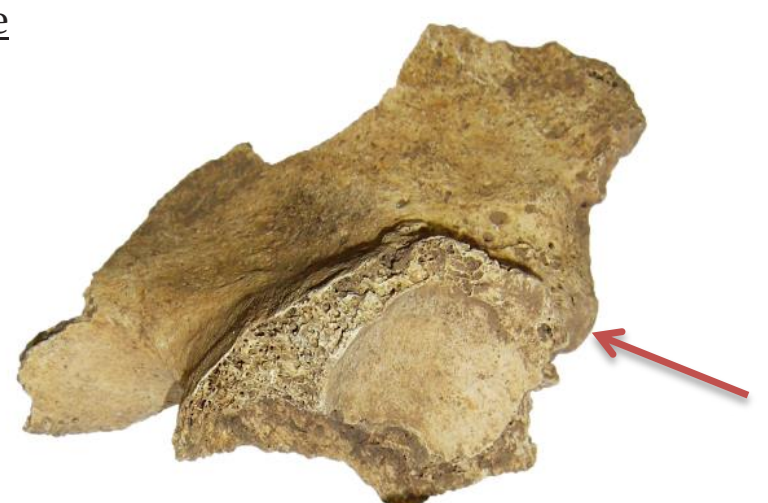

- Arthrose Grad III, gesamt 3

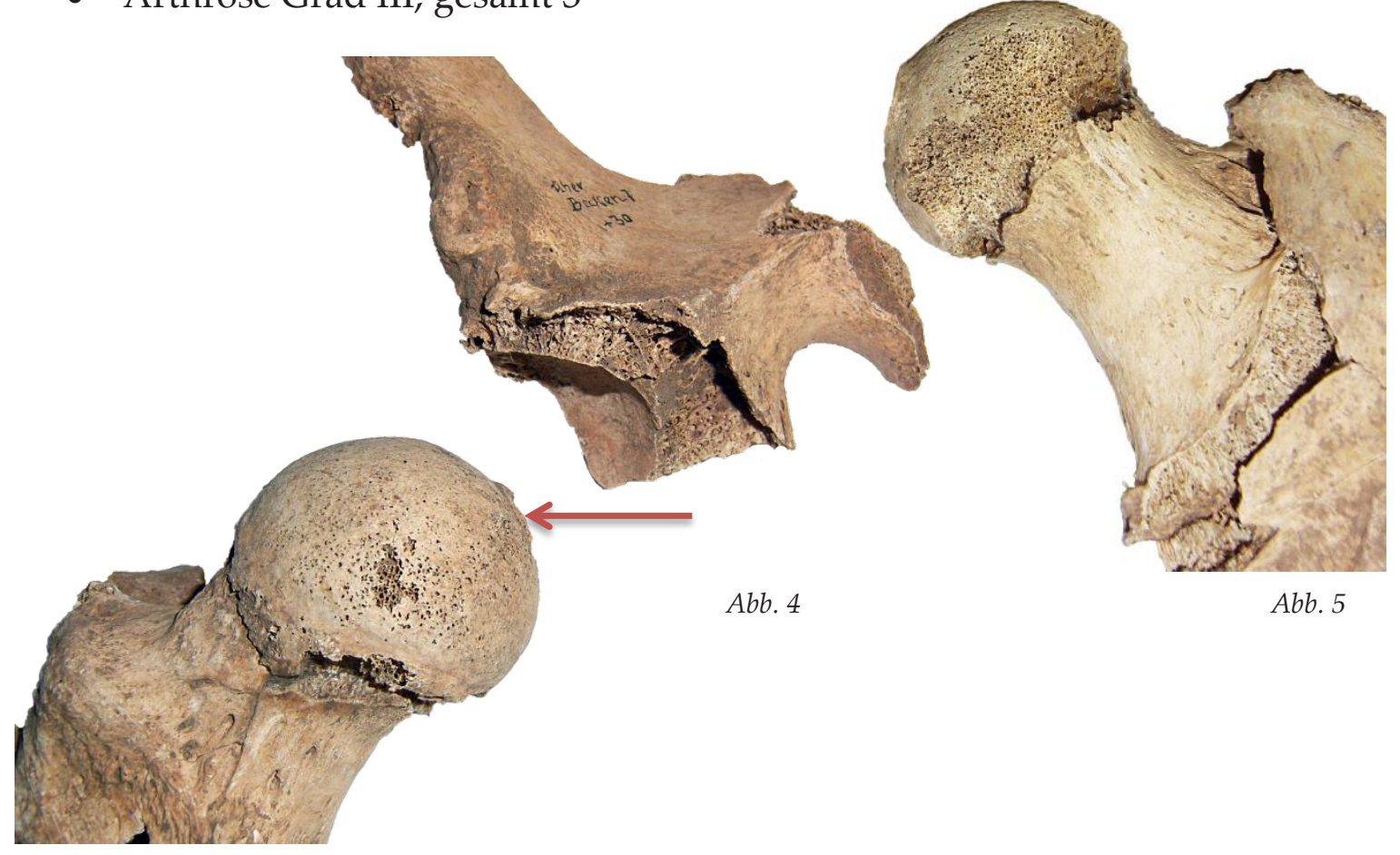

Beschreibung des Fundstücks: Das erhaltene Fragment des rechten Os coxae ist etwa faustgroß; das Acetabulum weist deutliche Spuren einer Arthrose auf, die mit denen am Caput ossis femoris korrelieren. 
Knochenname: Os femoris rechts

Skeletnummer: $\quad 2$

Erhaltungszustand: gut

Gesund/krank: krank

- Arthrose proximal Grad II, gesamt 3

- Arthrose Condylen Grad III

- Arthrose Facies patellaris III, gesamt 3
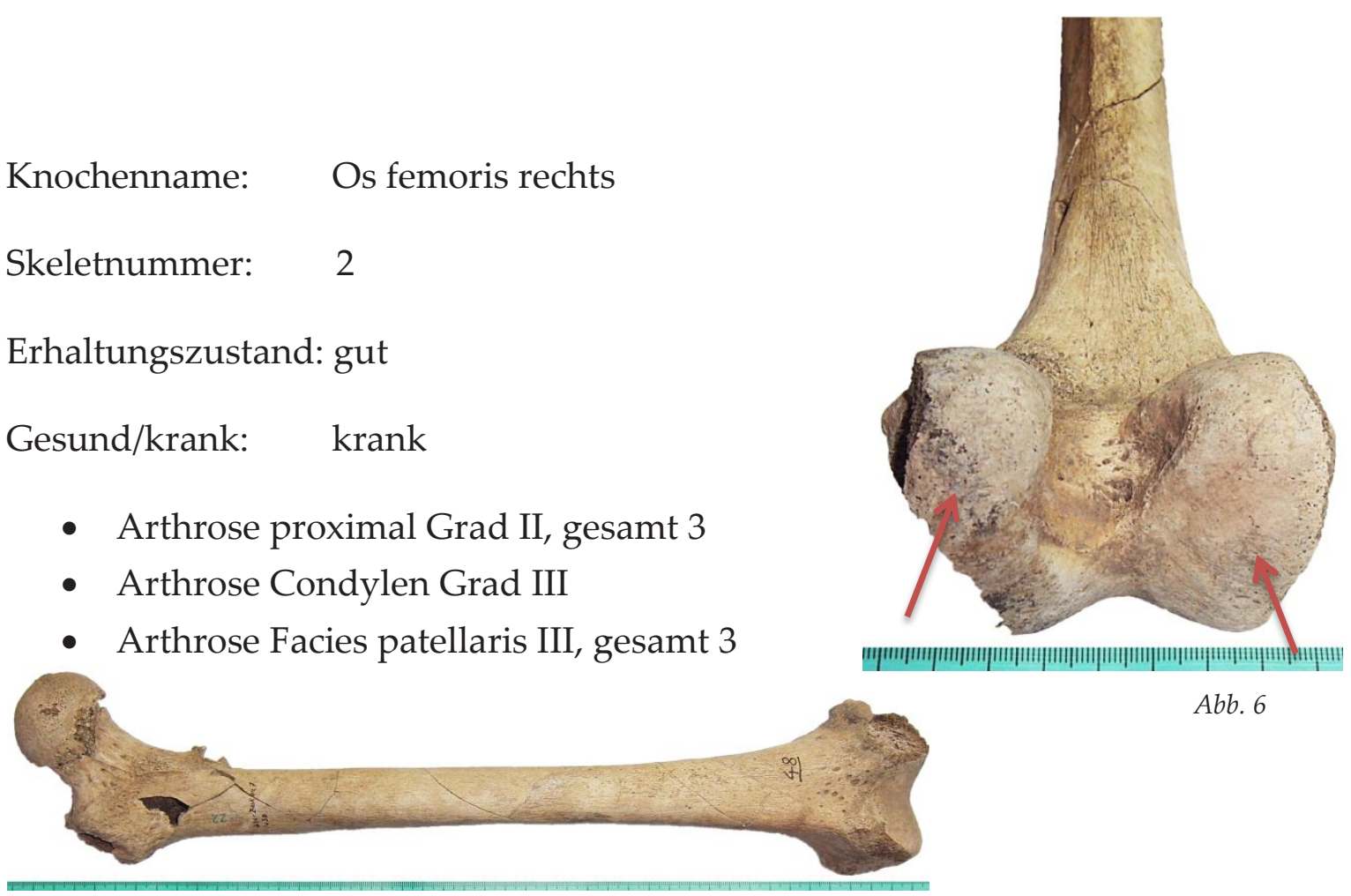

$A b b .6$

$A b b .7$

Beschreibung des Fundstücks: Das Os femoris entstammt wohl einem muskulösen Individuum. Dies lässt sich an der massiven Ausprägung zahlreicher Ansätzen bzw. Ursprüngen folgender Muskeln festmachen: M. gluteus maximus, $M$. adductor magnus, M. gastrocnemius und M. vastus medialis. Weiterhin ist die Linea aspera sehr prominent ausgebildet und auch der Trochanter major fällt durch seine Größe auf. Die Fovea capitis femoris weist einen wulstigen Rand auf, der Zeichen eines arthrotischen Gelenkverschleißes ist. Die Condylen weisen ebenfalls arthrotische Verschleißerscheinungen auf. Diese sind so ausgeprägt, dass wahrscheinlich stellenweise der Meniskus und der Gelenkknorpel beschädigt waren.

Knochenname: Patella rechts

Erhaltungszustand: gut

Gesund/krank: krank

- Sehnenverknöcherung der Patellarsehne

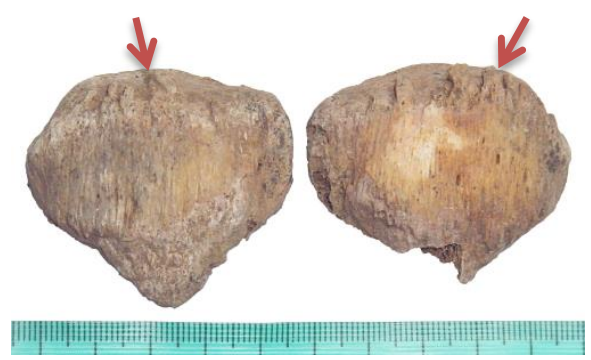

Abb. 8

- Arthrose Grad III, gesamt 3 
Beschreibung des Fundstücks: Die Kniescheibe ist postmortal durch Bodenerosion etwas beschädigt. Die Spuren der arthrotischen Veränderungen korrelieren mit der Facies patellaris des Os femoris.

Knochenname: Patella links

Erhaltungszustand: gut

Gesund/krank: krank

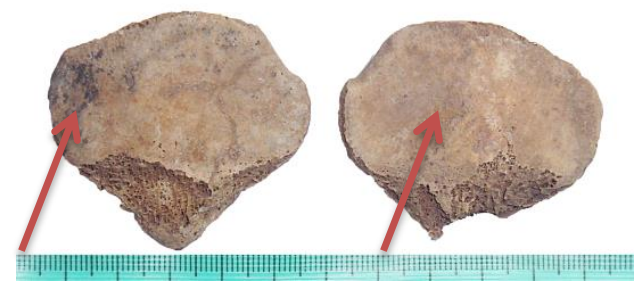

Abb. 9

- Sehnenverknöcherung der Patellarsehne

- Arthrose Grad III

Beschreibung des Fundstücks: Die Knochensubstanz ist durch Bodenerosionen etwas beschädigt worden.

Abbildungen:

1. Skeletbefundbogen über den Erhaltungszustand: "rot" entspricht den erhaltenen Knochen, „blau“ entspricht einem Knochendefekt im Sinne eines postmortalen Artefakts.

2. Diese Abbildung zeigt die erhaltenen Fundstücke von anterior.

3. Hier sind die Fundtücke von posterior abgebildet.

4. Das Foto zeigt eine Nahaufnahme von Abb. 2. Der Pfeil markiert den deutlich sichtbaren Knochenwulst, der sich durch die Arthrose an der Fovea capitis femoris gebildet hat.

5. Nahaufnahme von Abb. 3. Der Pfeil markiert die knöchernen Veränderungen, die sich in der Hüftpfanne durch Arthrose gebildet haben.

6. Nahaufnahme der Condylen des Oberschenkelknochens von posterior. Die Pfeile markieren die Regionen des Condylus, an denen die größten Ausprägungen der Arthrose zu erkennen sind.

7. Dieses Foto zeigt das nahezu vollständig erhaltene Os femoris mit den durch Bodenerosionen hervorgerufenen postmortalen Schäden.

8. Abbildung der rechten und linken Kniescheibe von anterior. Im Bild links ist die rechte Patella zu erkennen. Die Pfeile deuten auf die Spuren der stellenweise verknöcherten Patellarsehne hin.

9. Hier sind links die rechte und rechts die linke Kniescheibe von posterior abgebildet. Auf der Facies articularis beider Kniescheiben sind Spuren einer Arthrose zu erkennen, auf welche die Pfeile deuten. 


\subsection{Befund 14: Teilskelet 50 der Population aus Calden}

Knochenname: Teilskelet

Skeletnummer: Calden V50

Kistennummer: $\quad 273,718$

Alter:

(35) $40-50$ (55) J.

Geschlecht:

Erhaltungszustand: gut

Gesund/krank: krank
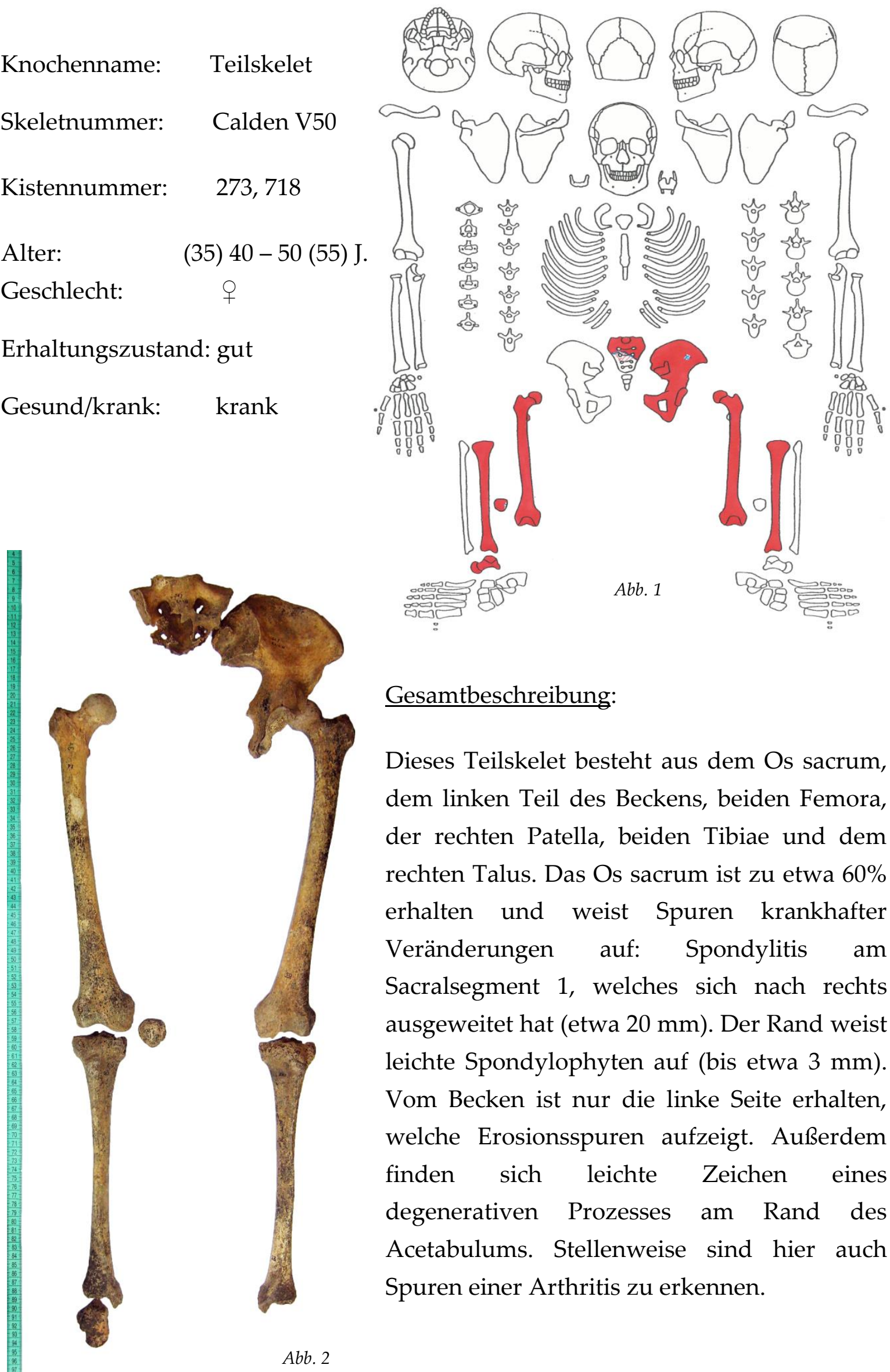

Gesamtbeschreibung:

Dieses Teilskelet besteht aus dem Os sacrum, dem linken Teil des Beckens, beiden Femora, der rechten Patella, beiden Tibiae und dem rechten Talus. Das Os sacrum ist zu etwa 60\% erhalten und weist Spuren krankhafter Veränderungen auf: Spondylitis am Sacralsegment 1, welches sich nach rechts ausgeweitet hat (etwa $20 \mathrm{~mm}$ ). Der Rand weist leichte Spondylophyten auf (bis etwa $3 \mathrm{~mm}$ ). Vom Becken ist nur die linke Seite erhalten, welche Erosionsspuren aufzeigt. Außerdem finden sich leichte Zeichen eines degenerativen Prozesses am Rand des Acetabulums. Stellenweise sind hier auch Spuren einer Arthritis zu erkennen. 
Das linke Os femoris ist zu etwa 99\% gut erhalten. Hüftkopf und -pfanne sind arthrotisch ähnlich verändert. Das rechte Os femoris ist ebenfalls gut erhalten und weist eine Auffälligkeit im unteren Drittel (43 mm x $12 \mathrm{~mm}$ x $6 \mathrm{~mm}$ ) auf. Es handelt sich dabei um eine Verknöcherung im Sinne einer Ligamentopathie, die aus einer Zerrung des M. vastus lateralis stammt. Die sichtbaren Muskelmarken der Femora stammen von M. vastus medialis, M. adductor magnus, M. plantaris, M. gluteus maximus und die Linea aspera. Die rechte Patella weist im Vergleich zu anderen Patellae der Population kaum Sehnenverknöcherungen auf. An der Innenseite ist eine Arthrose mit Grad II ausgeprägt. Die linke Tibia zeigt in Schaftmitte einen verknöcherten Bereich, der durch ein subperiostales Hämatom (21 mm x $10 \mathrm{~mm}$ ) entstanden sein könnte. Dieses entstand womöglich durch "einen Tritt ans Schienbein". Weiterhin zeigt sich eine leichte Streifung der Oberfläche im mittleren Schaftbereich. Die linke Tibia ist nur sehr wenig durch Erosionsspuren gezeichnet und hat sich zu etwa 99\% sehr gut erhalten. Die rechte Tibia hat sich ebenfalls zu etwa 99\% erhalten und weist lediglich leichte Erosionsspuren am proximalen Gelenk auf. Der rechte Talus ist zu etwa 98\% erhalten und weist insgesamt einen Arthrosegrad von II auf.

\section{Befunde der einzelnen Skeletelemente}

Knochenname: Os sacrum

Skeletnummer: $\quad$ SK7

Erhaltungszustand: gut

Gesund/krank: krank

- Arthrose Processus articularis superior rechts Grad IV

- Arthrose Processus articularis links Grad III

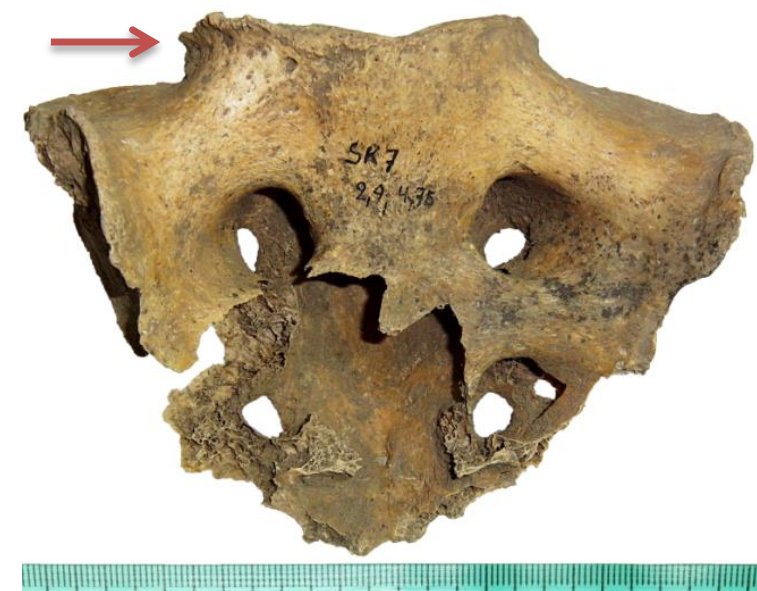

$A b b .3$

- Arthrose 1. Sakralgelenk Grad III

- Spondylitis

- Spondylophyten 


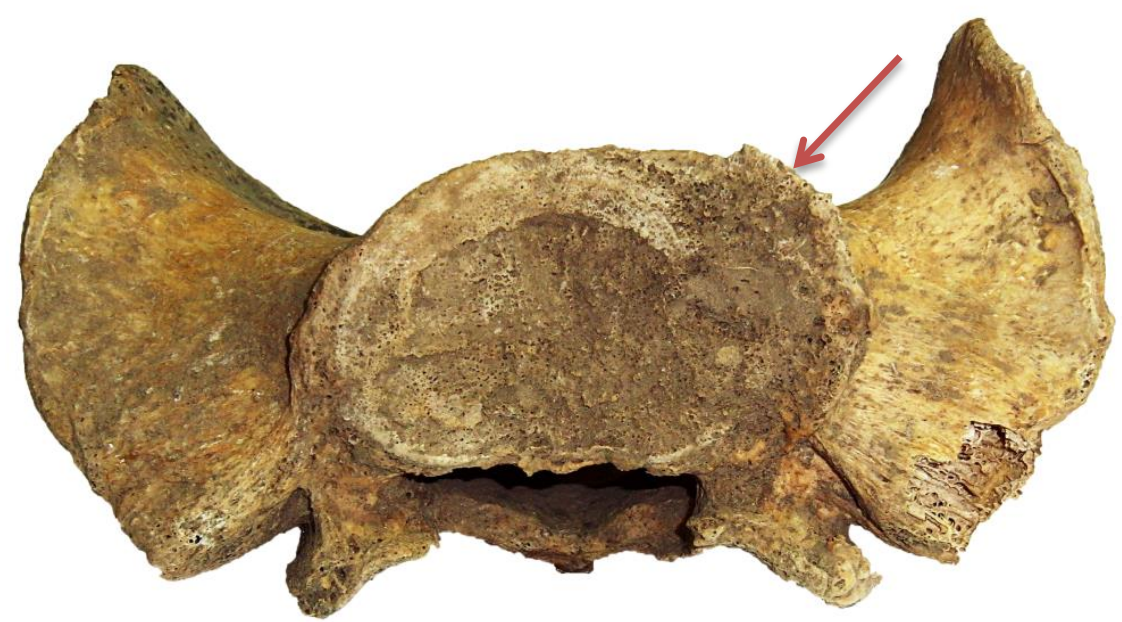

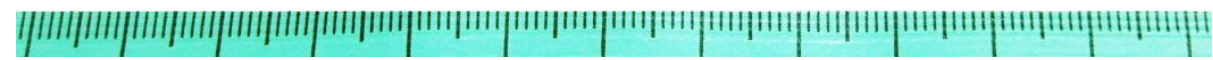

$A b b .4$

Beschreibung des Fundstücks: Das Os sacrum ist insgesamt gut erhalten. Eine deutliche Arthrose an den Processus articulares superiores ist $\mathrm{zu}$ erkennen, weiterhin fällt der deutliche Rand des ersten Sakralgelenks auf.

Knochenname: $\quad$ Os coxae links

Skeletnummer: $\quad$ SK7

Erhaltungszustand: gut

Gesund/krank: krank

- Arthrose linkes Acetabulum Grad II, gesamt 2,5

- Arthritis linkes Acetabulum im Randbereich Grad I

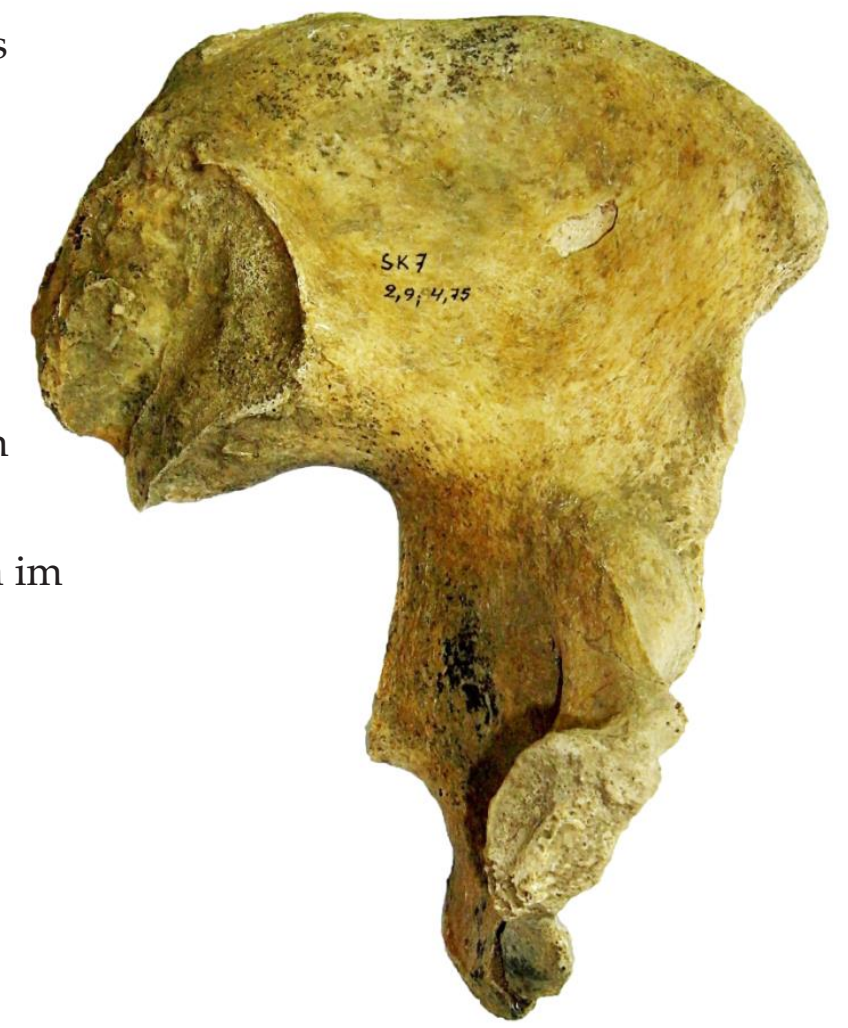

Beschreibung des Fundstücks: Dieser linke Teil des Beckens ist gut erhalten. Die Arthrose in der Hüftpfanne korreliert nicht vollständig mit der am Gelenkkopf des linken Oberschenkelknochens. 
Knochenname: Os femoris rechts

Skeletnummer: $\quad 49$

Erhaltungszustand: gut

Gesund/krank: krank

- Arthrose proximales Gelenk Grad III

- Arthrose distales Gelenk Grad III, gesamt 2,5

- Enthesiopathie

- Periostreizung durch Muskelzug

- Zerrung

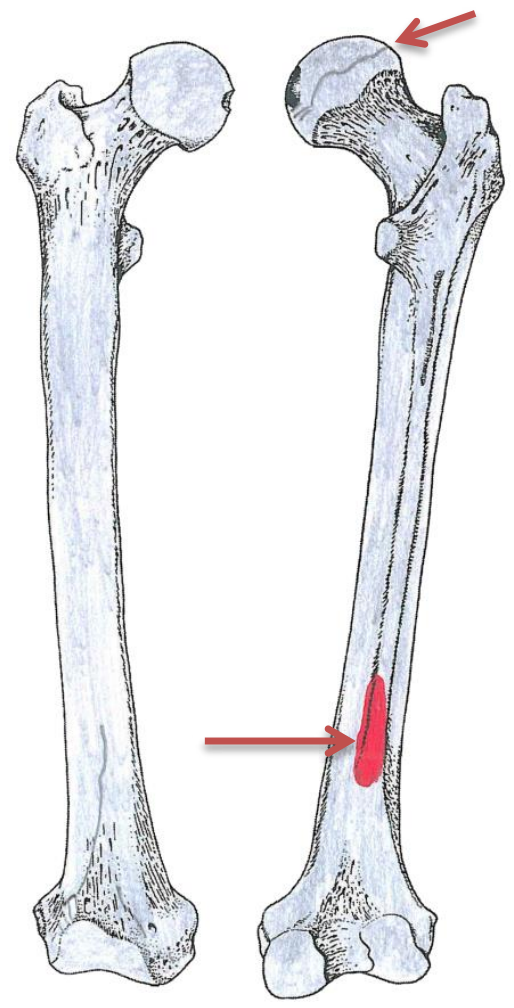

Abb. 6

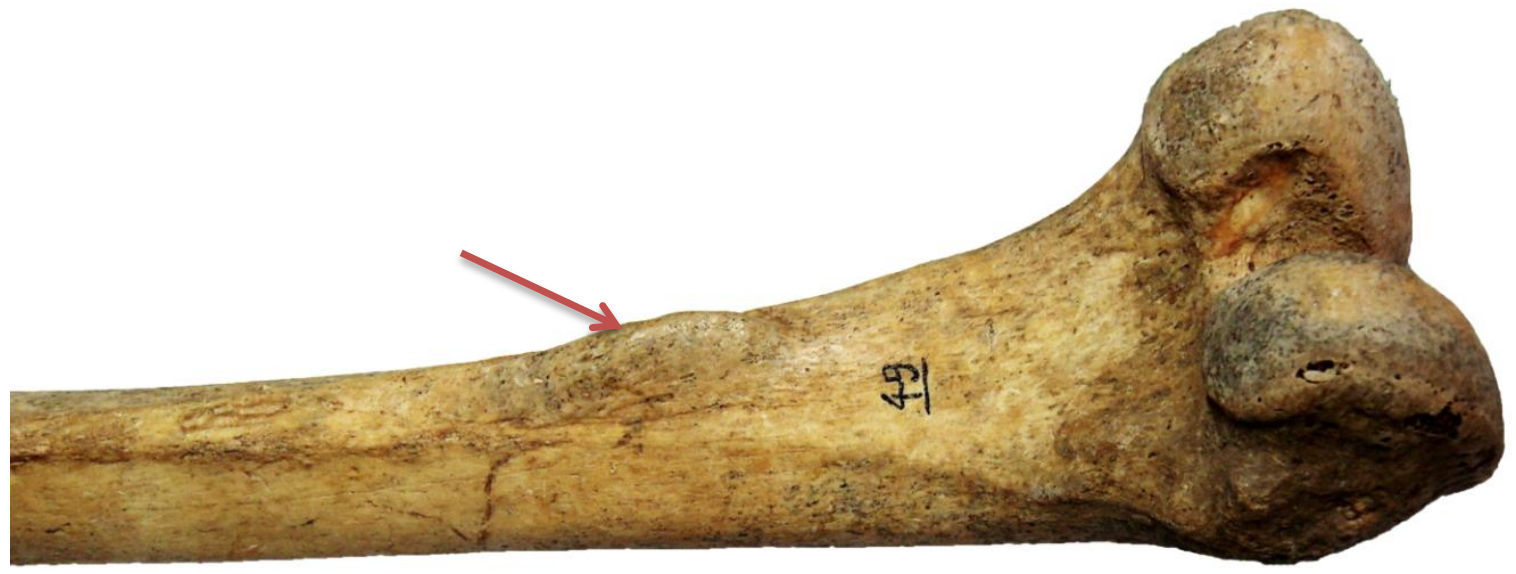

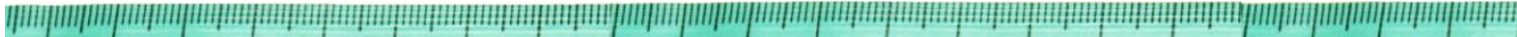

Abb. 7

Beschreibung des Fundstücks: Der rechte Oberschenkelknochen ist gut erhalten. Die zahlreichen pathologischen Veränderungen lassen alle auf eine sehr starke Belastung schließen. Das Individuum hat demzufolge körperlich sehr starke Arbeit geleistet. 


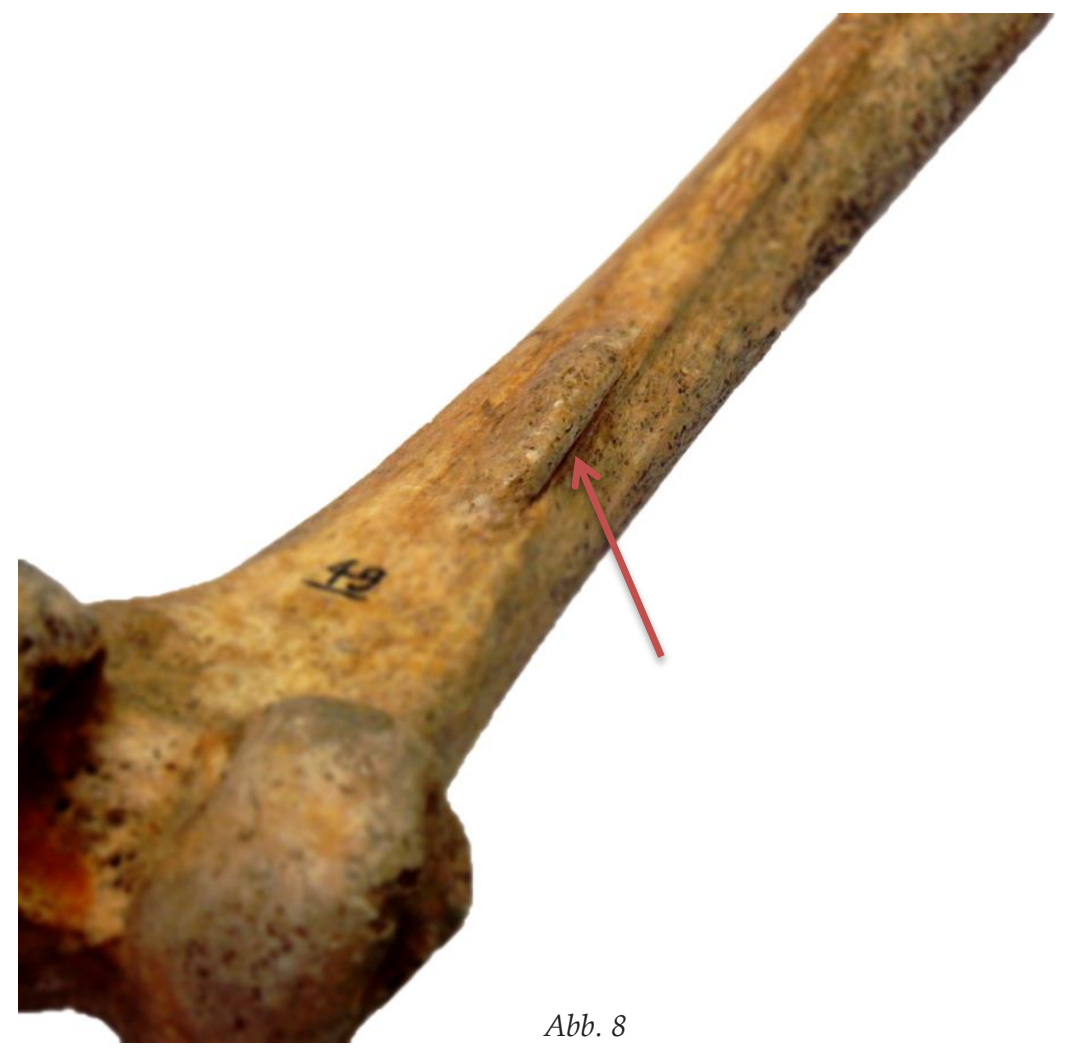

Knochenname: Os femoris links

Skeletnummer: $\quad 50$

Erhaltungszustand: gut

Gesund/krank: krank

- Arthritis am Rand des Caput femoris Grad I

- Arthrose proximales Gelenk Grad III, gesamt 2,5

- Arthrose distales Gelenk Grad III, gesamt 2,5
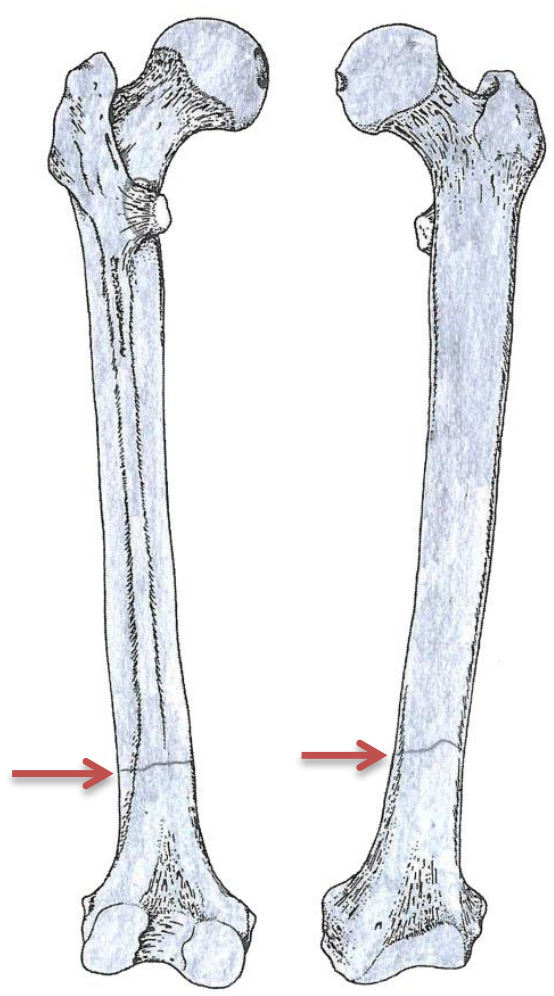

Abb. 9

Beschreibung des Fundstücks: Das gut erhaltene Os femoris der linken Seite zeigt sowie auch das rechte Os femoris - deutliche Spuren starker körperlicher Belastungen. Die Arthrosegrade des proximalen und distalen Gelenks korrelieren nicht vollständig mit den Gelenkpartnern. 
Knochenname: Tibia rechts

Skeletnummer: $\quad 21$

Erhaltungszustand: gut

Gesund/krank: krank

- Arthrose proximal Grad II, gesamt 2,5

- Arthrose distal Grad II, gesamt 2

Beschreibung des Fundstücks: Die rechte Tibia ist gut erhalten. Sie zeigt einen leicht arthrotisch bedingten Gelenkverschleiß.

Knochenname: Tibia links

Skeletnummer: $\quad 22$

Erhaltungszustand: gut

Gesund/krank: krank

- Periostreizung

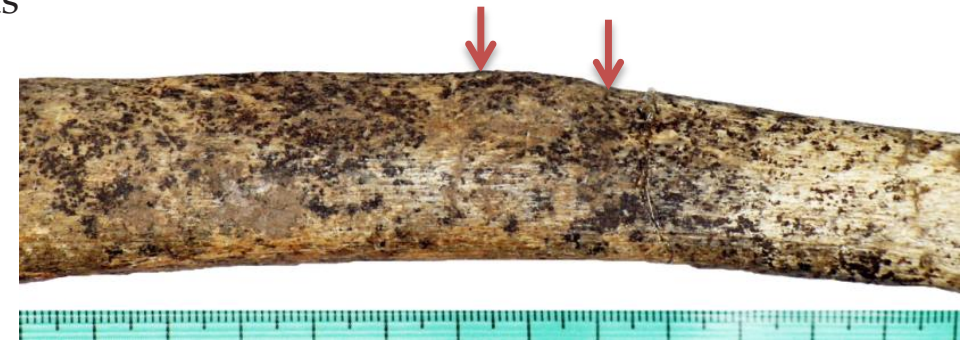

Abb. 10

- subperiostales Hämatom

- Arthrose proximal Grad II, gesamt 2,5

- Arthrose distal Grad II

Beschreibung des Fundstücks: Die linke Tibia ist gut erhalten. Sie weist ein subperiostales Hämatom auf sowie eine Periostreizung, die sich mit einer streifigen Oberfläche zeigt.

Knochenname: Patella rechts

Skeletnummer: /

Erhaltungszustand: gut

Gesund/krank: gesund

Beschreibung des Fundstücks: Die rechte Patella weist an der Außenseite nur sehr klein ausgeprägte Osteophyten im Sinne einer leichten Sehnenverknöcherung (Patellarsehne) auf. An der Innenseite sind leichte arthrotische Gelenkflächenveränderungen festzustellen (Arthrose Grad II). 
Knochenname: Talus rechts

Skeletnummer: /

Erhaltungszustand: gut

Gesund/krank: krank

- $\quad$ Arthrose proximal Grad II, gesamt 2

Beschreibung des Fundstücks: Der rechte Talus ist gut erhalten. Die leichten Spuren einer Arthrose am proximalen Gelenk korrelieren mit denen des distalen Gelenks der rechten Tibia.

Abbildungen:

1. Skeletbefundbogen über den Erhaltungszustand: "rot“ entspricht den erhaltenen Knochen, „blau“ entspricht einem Knochendefekt im Sinne eines postmortalen Artefakts.

2. Dieses Foto zeigt das erhaltene Teilskelet.

3. Abbildung des Os sacrum von anterior. Der Pfeil markiert den Bereich des Spondylophyten.

4. Foto des Os sacrum von cranial. Zu sehen sind Spuren einer Spondylitis am ersten Sakralsegment. Der Pfeil zeigt auf den besonders stark veränderten Bereich der Basis ossis sacri.

5. Foto des Os coxae links von medial.

6. In dem Schema für Oberschenkelknochen ist die Enthesiopathie (langer Pfeil) des rechten Femurs rot eingezeichnet. Der kurze Pfeil markiert eine postmortale Frakturlinie (im Schema grau eingezeichnet) durch das Caput ossis femoris.

7. Das Foto zeigt die Enthesiopathie am linken Os femoris. Der verknöcherte Bereich wird durch den Pfeil angezeigt.

8. Die Abbildung zeigt die Enthesiopathie (Pfeil) des rechten Oberschenkelknochens von distal.

9. Schema für Oberschenkelknochen. In Grau eingezeichnet ist das linke Os femoris. Postmortal ist es distal durchgebrochen und wurde geklebt. Die Klebefuge ist grau eingezeichnet (Pfeile).

10. Abbildung der Tibia. Es ist die Verknöcherung nach subperiostalem Hämatom zu erkennen. Die Pfeile begrenzen den Bereich. 


\subsection{Befund 15: Teilskelet 57 der Population aus Calden}

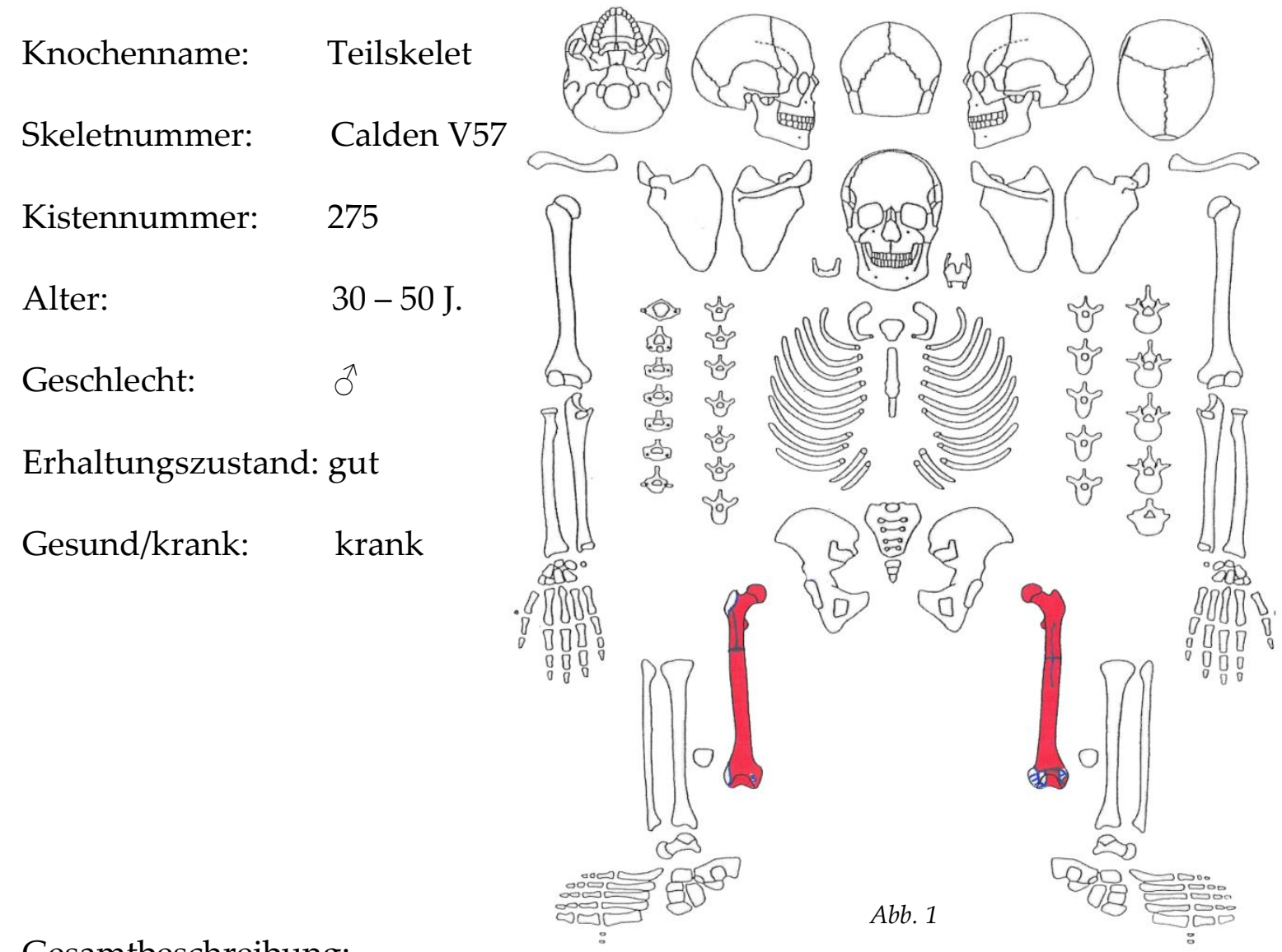

Gesamtbeschreibung:

Von diesem Individuum liegen beide Oberschenkelknochen in gutem Erhaltungszustand vor.

Befunde der einzelnen Skeletelemente

Knochenname: Os femoris rechts

Skeletnummer: $\quad$ SK9 5420

Erhaltungszustand: gut

Gesund/krank: krank

- Arthrose proximal Grad III

- Arthrose distal Grad III

Beschreibung des Fundstücks: Bei diesem Os femoris und auch bei dem der linken Seite hat sich durch einen arthrotisch bedingten Gelenkverschleiß eine Auswalzung (Randwulst) im Randbereich des Caput femoris gebildet.

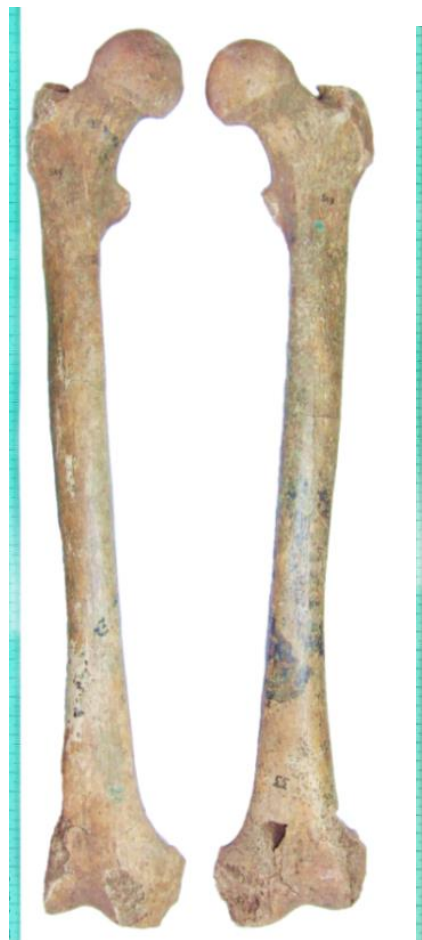

Abb. 2

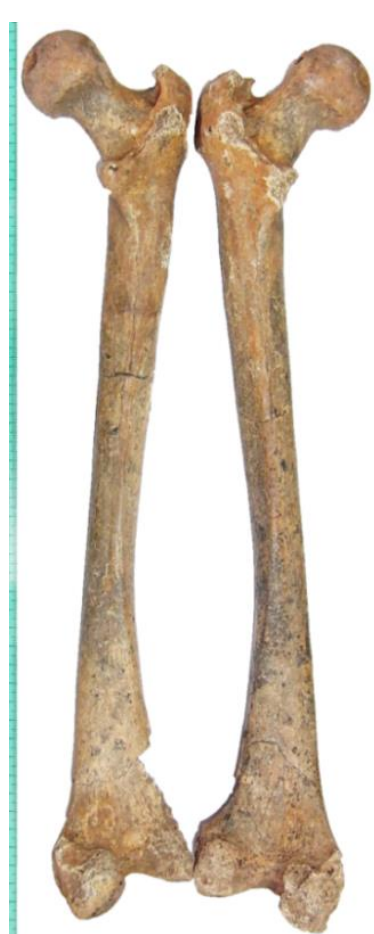

Abb. 3 
Knochenname: Os femoris links

Skeletnummer: $\quad$ SK9 554

Erhaltungszustand: gut

Gesund/krank: krank

- Arthrose proximal Grad III

- Arthrose distal Grad III

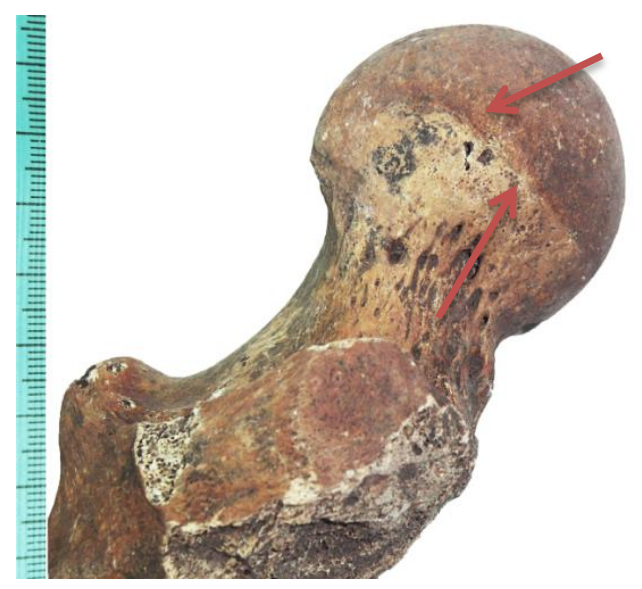

Abb. 4

Beschreibung des Fundstücks: Wie bei dem Os femoris der rechten Seite, hat sich auch hier eine Auswalzung am Rand des Caput femoris gebildet, welche auf die Arthrose des Gelenks zurückzuführen ist.

Abbildungen:

1. Skeletbefundbogen über den Erhaltungszustand: "rot" entspricht den erhaltenen Knochen, „blau“ entspricht einem Knochendefekt im Sinne eines postmortalen Artefakts.

2. Beide Oberschenkelknochen sind hier nebeneinander von anterior abgebildet. Links im Bild ist der rechte zu sehen.

3. Hier sind beide Oberschenkelknochen von posterior abgebildet. Links im Bild ist der rechte zu erkennen.

4. Das linke Os femoris ist hier von seitlich oben fotografiert worden. Im Vordergrund erkennt man den Trochanter major, links im Hintergrund den Trochanter minor und zentral- oben das Caput femoris. Die Pfeile markieren die Wulstbildung (Arthrose). 


\subsection{Befund 16: Teilskelet 63 der Population aus Calden}

Knochenname: Teilskelet

Skeletnummer: $\quad$ Calden V63

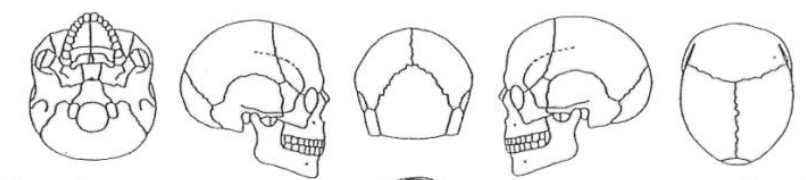

Kistennummer: $\quad 270$

Alter:

$35-45(55) \mathrm{J}$.

Geschlecht:

$$
\text { }
$$

Erhaltungszustand: gut

Gesund/krank: krank

Gesamtbeschreibung:
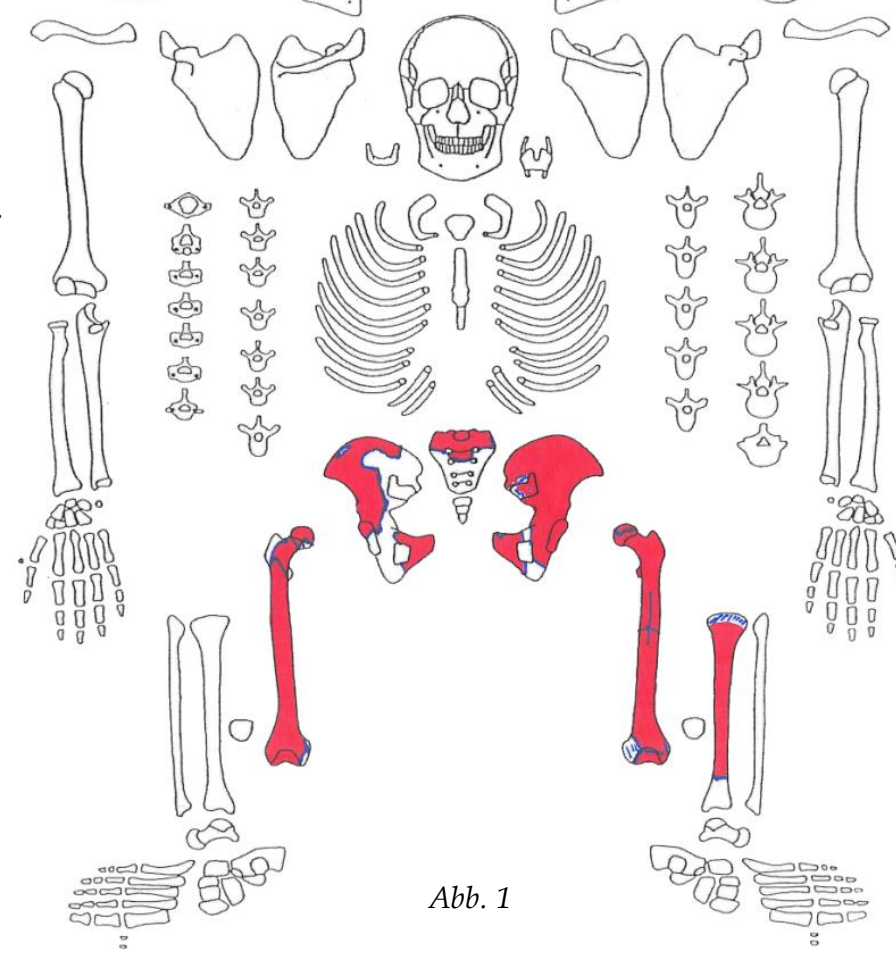

Abb. 1

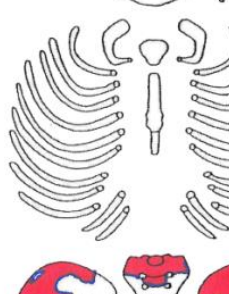

Dies ist ein Teilskelet aus Fragmenten des Beckens, des Steißbeins, beiden Oberschenkelknochen und des linken Schienbeins. Alle Knochen und Knochenfragmente sind in gutem Erhaltungszustand und wenig erodiert; es sind lediglich kleinere Knochenteile abfrakturiert. Über das Alter dieses Individuums lässt sich sehr kontrovers diskutieren. Es ist festzuhalten, dass die Knochenoberflächen der Symphyse des Beckens zwar auf den ersten Blick recht jung wirken, jedoch ein Trauma aufweisen. Dies äußert sich in Form von Löchern, die auf der Innenseite der knöchernen Symphysen lokalisiert sind. Da dies wahrscheinlich ein weibliches Individuum ist, könnte das traumatische Ereignis auf eine Geburt zurückzuführen sein, was $\mathrm{zu}$ der Arthrose an den Oberschenkelköpfen passen würde. Weiterhin zeigt die Facies auricularis Spuren, die man auf einen Geburtsvorgang zurückführen kann. Die Verschleißspuren am Becken könnten durch Geburtsvorgänge entstanden sein und sind nicht unbedingt altersbedingt. Eine noch leicht angedeutete Epiphysenfuge ist an den Femora zu erkennen, was ebenfalls für ein nicht so fortgeschrittenes Alter sprechen würde. Das Os sacrum weist eher die Merkmale eines Menschen im mittleren Alter auf. Aufgrund der divergierenden Altersspuren der Fundstücke ist eine exakte Altersbestimmung folglich sehr schwierig. 
Befunde der einzelnen Skeletelemente

Knochenname: Os sacrum

Skeletnummer: $\quad 4$

Erhaltungszustand: gut

Gesund/krank: gesund

Beschreibung des Fundstücks: Das Os sacrum ist in gutem Zustand erhalten.

Knochenname: Os coxae

Skeletnummer: $\quad$ SK5

Erhaltungszustand: gut

Gesund/krank: krank

- Arthrose Acetabulum rechts Grad III, gesamt Grad 3

- Arthrose Acetabulum links Grad III, gesamt Grad 3

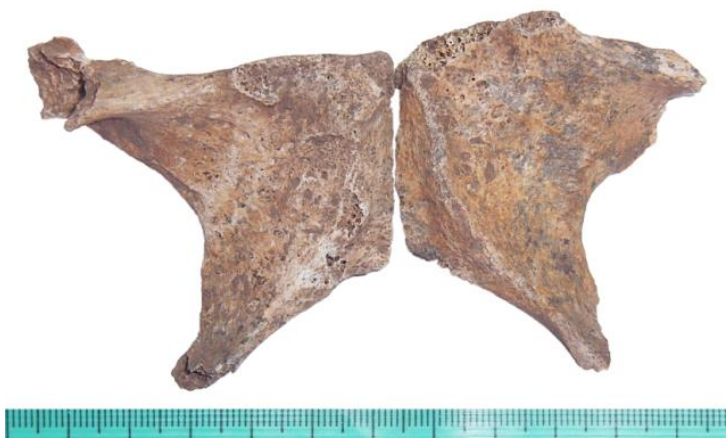

$A b b .2$

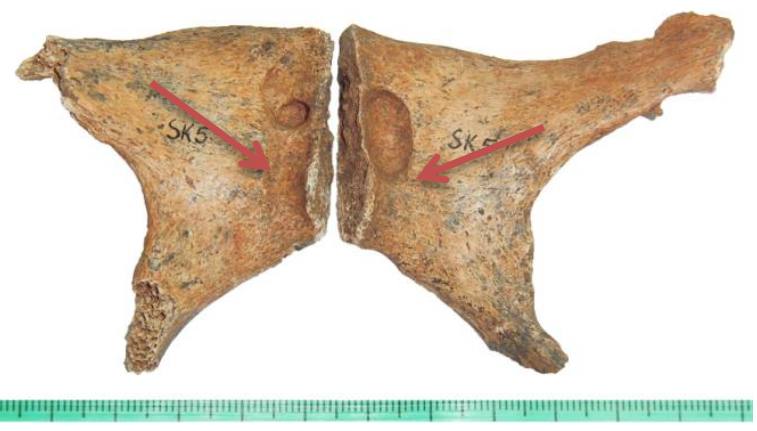

Abb. 3

Beschreibung der Fundstücke: Das Becken ist insgesamt gut erhalten. Beide Gelenkpfannen weisen eine Arthrose auf, welche möglicherweise auf eine Schwangerschaft zurückzuführen ist.

Knochenname: Os femoris rechts

Skeletnummer: $\quad 62$

Erhaltungszustand: gut

Gesund/krank: krank

- Arthrose proximal Grad III, gesamt Grad 3

Beschreibung des Fundstücks: Dieser Oberschenkelknochen ist insgesamt gut erhalten. Es zeigen sich Spuren einer Arthrose am Gelenkkopf, die mit denen in der Gelenkpfanne des Beckens korrelieren. 
Knochenname: $\quad$ Os femoris links

Skeletnummer: $\quad 63$

Erhaltungszustand: gut

Gesund/krank: krank

- Arthrose proximal Grad III, gesamt Grad 3

- Arthrose distal Grad III, gesamt Grad 3

Beschreibung des Fundstücks: Der Oberschenkelknochen ist in Form und Struktur gut erhalten. Er weist am Gelenkkopf die zu der Gelenkpfanne des Beckens passenden Verschleißspuren auf.

Knochenname: Tibia links

Skeletnummer: $\quad 28$

Erhaltungszustand: gut

Gesund/krank: Krank

- Periostreizung

- Arthrose Grad II

Beschreibung des Fundstücks: Die Tibia weist eine leichte Längsstreifung in der Oberfläche auf, die für eine Periostreizung im Sinne eines übermäßigen Muskelzuges spricht.

Abbildungen:

1. Skeletbefundbogen über den Erhaltungszustand: "rot" entspricht den erhaltenen Knochen, „blau“ entspricht einem Knochendefekt im Sinne eines postmortalen Artefakts.

2. Abbildung von zwei Fragmenten des Beckens. Es handelt sich um Fragmente der Symphyse. Aufnahme von anterior.

3. Aufnahme von posterior. Zu sehen sind Fragmente des rechten und linken Os pubis. 


\subsection{Lichtmikroskopischer Befund 1 der Population aus Calden}

Bei der lichtmikroskopischen Untersuchung der Dünnschliffe dieses Knochens konnten mehrere Befunde erhoben werden. Zum einen konnte nachgewiesen werden, dass es sich hierbei um einen menschlichen Knochen handelt, zum anderen, dass es wahrscheinlich eine Tibia ist. Die lichtmikroskopischen Bilder sind stellenweise wie durch Nebel bedeckt. Das Kollagen des Knochens ist noch erhalten, es finden sich jedoch zahlreiche Spuren von Pilzfraß; dieser fällt durch Pilzfraßtunnel auf. Der Pilz hat den Knochen postmortal degradiert, was zu zahlreichen und teilweise flächendeckenden Artefakten geführt hat. Dennoch erhielten sich einige Knochenschichten in gutem Zustand, sodass kleine und große Haverssysteme erkennbar waren. Die Gesamtstruktur des Knochens ist beweisend für einen menschlichen Knochen.

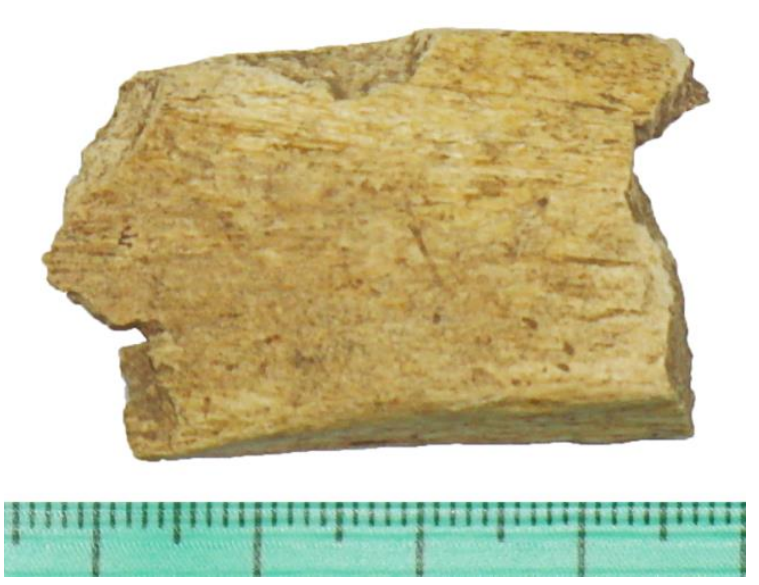

Abb. 1: Makroskopische Abbildung des Fundstücks von der Außenseite.

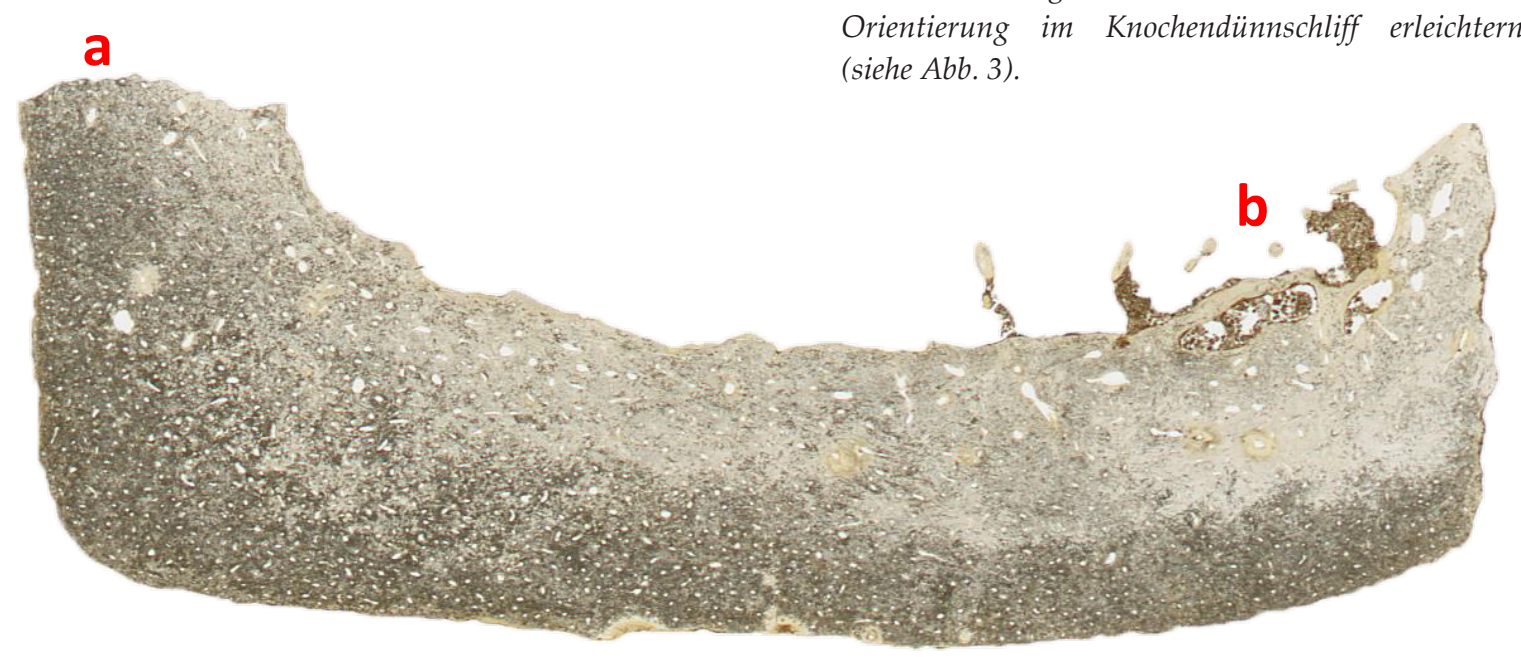

Abb. 3: Eingescannter Dünnschliff. Die Buchstaben sollen die Orientierung für den Knochendünnschliff erleichtern (siehe Abb. 2). Unten im Bild befindet sich Compacta, oben Spongiosa. 


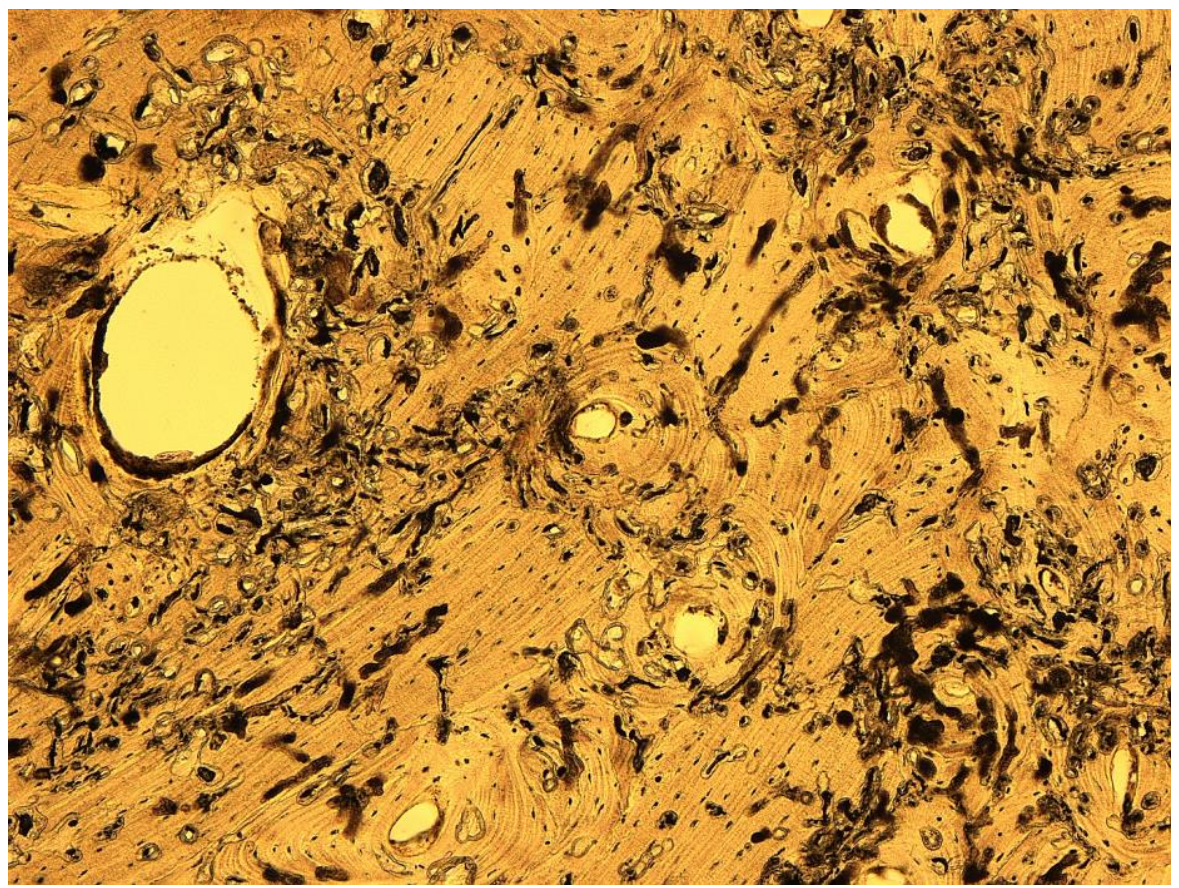

Abb. 4: Dünnschliffdicke 50 m, Vergrößerung 100x; innere Generallamelle im einfachen Durchlicht.

Wie in den Abb. 4 und $5 \mathrm{zu}$ sehen ist, liegt die innere Generallamelle in Resten erhalten vor, was zunächst auf ein Sterbealter von maximal 30 Jahren, mindestens aber wohl 25 Jahren schließen lässt. Eine äußere Generallamelle ist hier nicht zu erkennen, was erst einmal in Konflikt mit der vorläufigen Sterbealterbestimmung steht. Die Knochenoberfläche weist weder Streifungen noch Gefäßimpressionen auf.

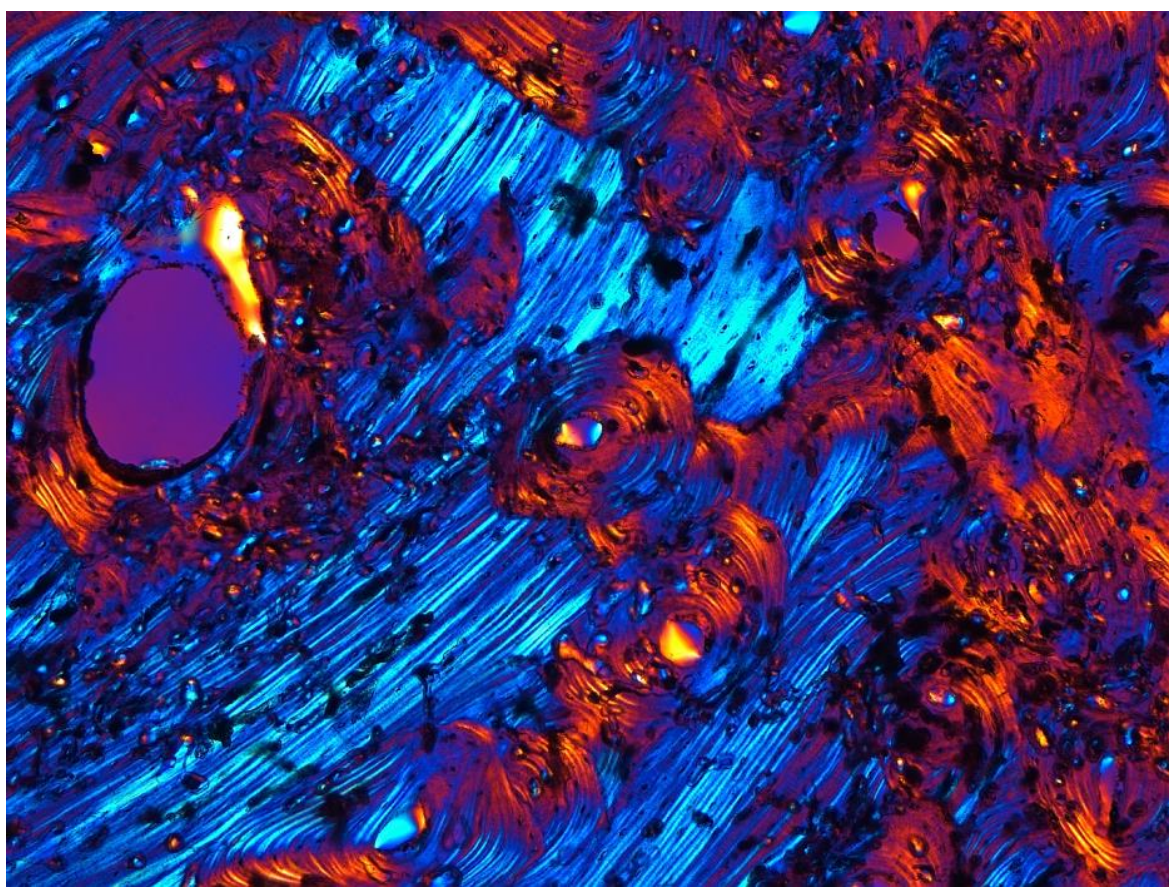

Abb. 5: Dünnschliffdicke $50 \mu m$, Vergrößerung 100x; innere Generallamelle im polarisierten Durchlicht unter Verwendung eines Hilfsobjektes Rot 1. Ordnung (Quarz) als Kompensator. 


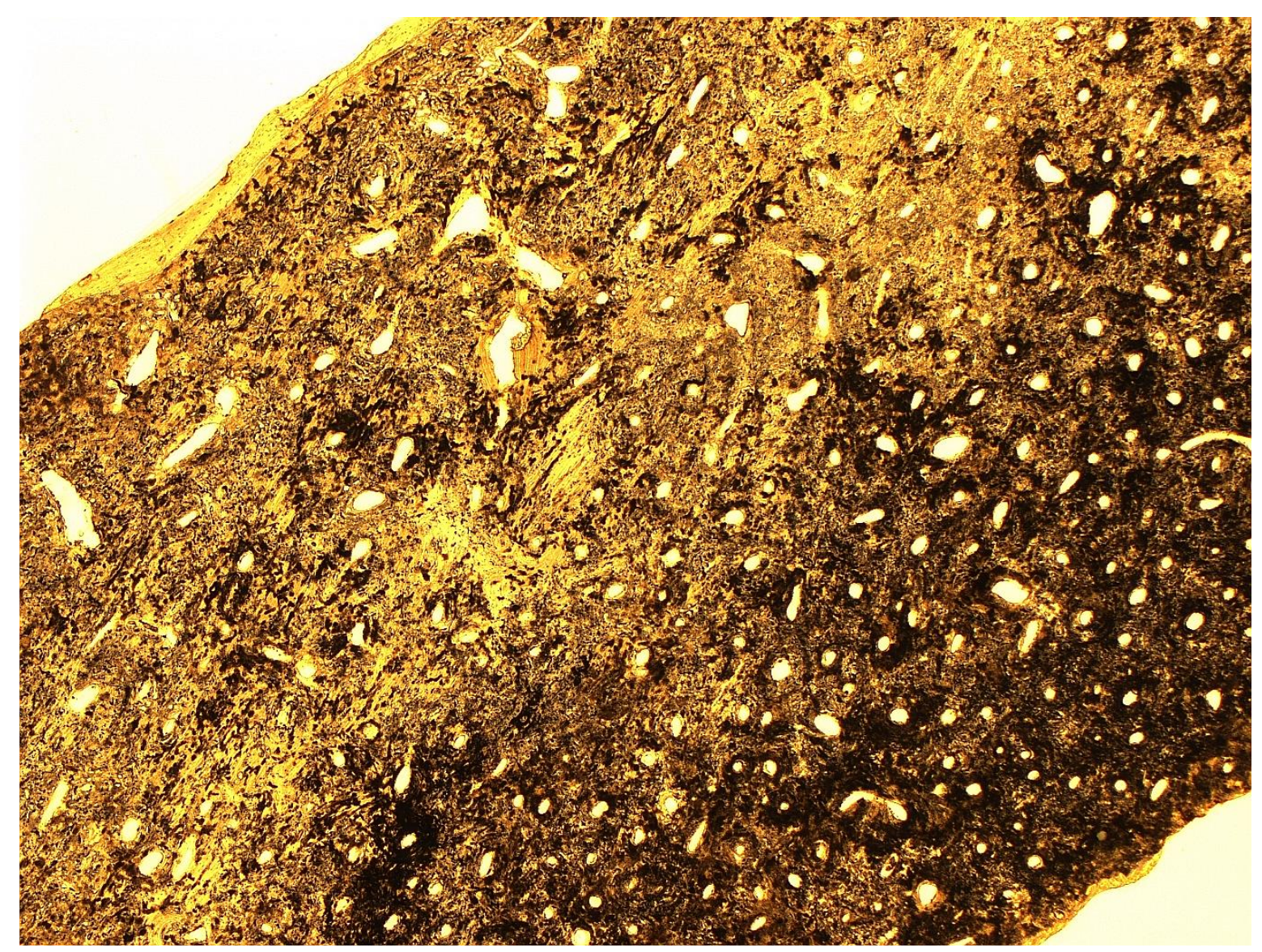

Abb. 6: Dünnschliffdicke $50 \mu m$, Vergrößerung 25x; äußere und innere Generallamelle im einfachen Durchlicht.

Hier ist eine äußere und innere Generallamelle zu erkennen (Abb. 6). Aufgrund des Vorhandenseins der äußeren Generallamelle ist es nun möglich, das Sterbealter des Individuums auf maximal $40 \mathrm{zu}$ bestimmen; aufgrund des Vorhandenseins der inneren Generallamelle kann das Alter auf maximal 30 genauer beziffert werden. Das Individuum war demnach im Altersbereich Adultus. 


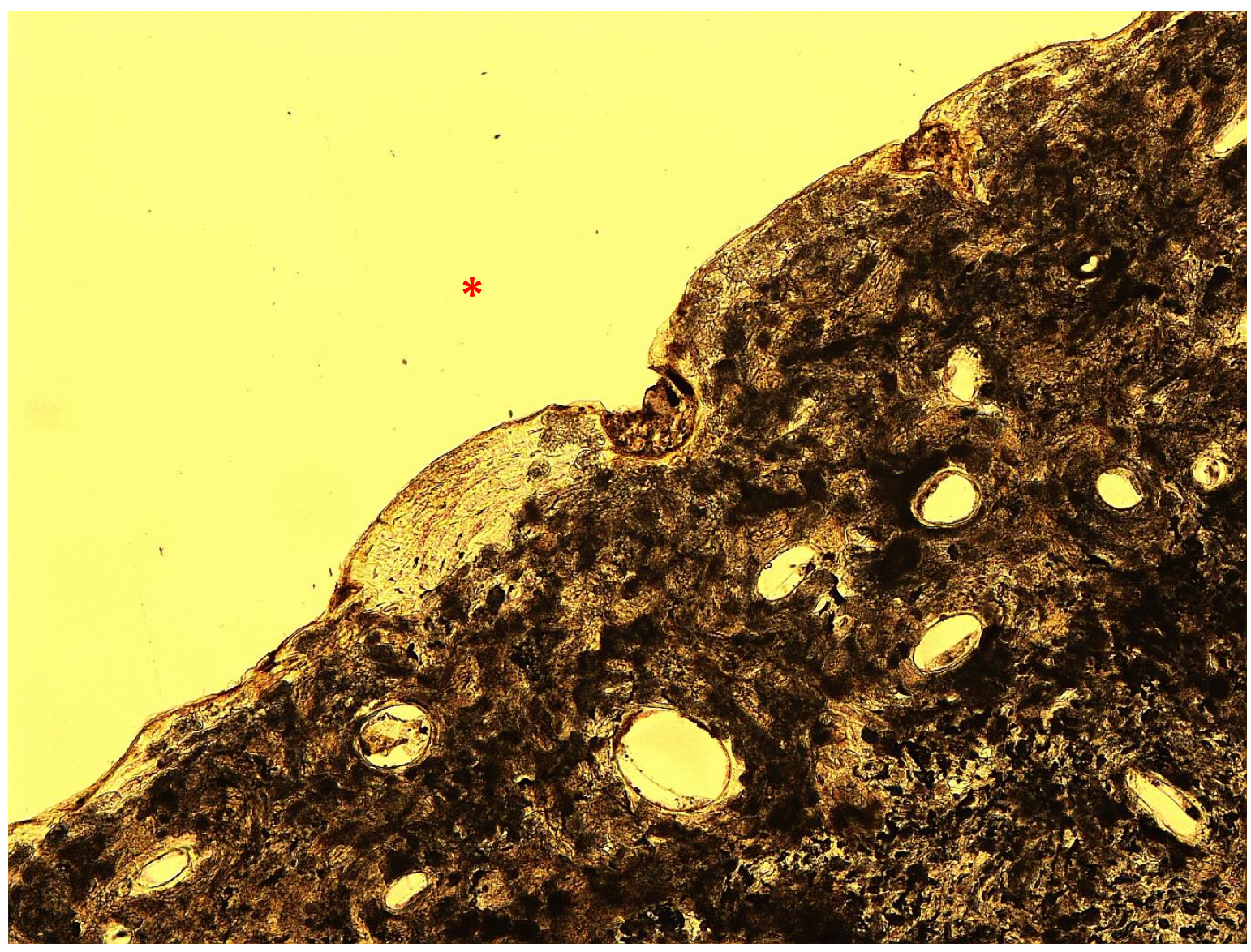

Abb. 7: Dünnschliffdicke $50 \mu m$, Vergrößerung 100x; Periostreaktion in Gefäßnähe $\left(^{*}\right)$ im einfachen Durchlicht.

In Abb. 7 erkennt man eine leichte Gefäßaffektion, der eine Periostreaktion folgte. Aufgrund dieser Beobachtung ist eine Hypervaskularisierung im Periostbereich anzunehmen. Gut $\mathrm{zu}$ erkennen sind der Abdruck des Gefäßes und Aufmauerungen ober- und unterhalb der Gefäßimpression.

Die Tatsache, dass Tangentiallamellen vorliegen, spricht für einen funktionell unbelasteten Knochenabschnitt. Es existiert ein größeres Areal, welches offenbar nicht belastet wurde. Folglich sind Spuren einer Inaktivitätsathrophie erkennbar, die durch Nichtbenutzen des Knochens entstanden sind. Die beschriebenen Gefäßimpressionen könnten von Krankheiten wie Syphilis, Lepra oder einer Entzündung der tiefen Beinvenen herrühren. Differentialdiagnostisch wäre auch eine Osteomyelitis denkbar. Jede der genannten Krankheiten könnten dazu geführt haben, dass der Knochen folglich funktionell nicht optimal genutzt werden konnte. Es handelt sich jedoch nur um Mutmaßungen, beweisen lässt sich der Verdacht einer bestimmten Erkrankung nicht. 


\subsection{Lichtmikroskopischer Befund 2 der Population aus Calden}

Bei der lichtmikroskopischen Untersuchung dieses Fundstücks fiel eine deutlich ausgeprägte Diagenese des Knochens auf. Sichtbar waren eine Tangentiallamelle sowie eine äußere und innere Generallamelle (Abb. 5). Ein frühadultes Alter kann somit angenommen werden.

Der größte Teil der Probe ist nicht befundbar, da zu stark degeneriert. Der Erhaltungszustand kann am dickeren Ende des Schnittes von außen nach innen betrachtet als besser bezeichnet werden.

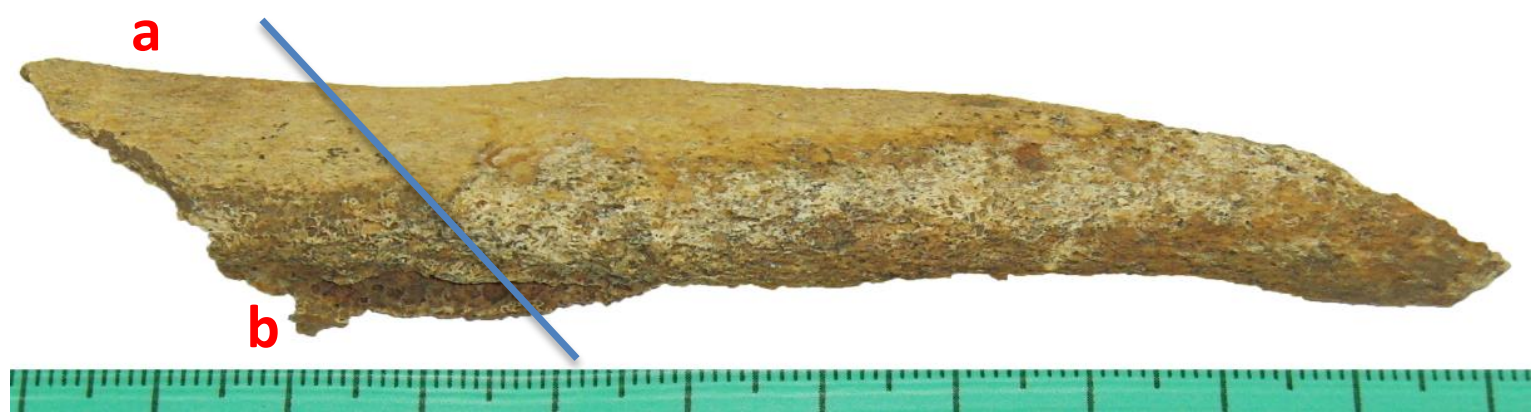

Abb. 1: Makroskopische Abbildung des Fundstücks mit Sicht auf die Außenseite. Mit der blauen Linie ist die Schnittebene eingezeichnet. Die Buchstaben sollen die Orientierung am Knochendünnschliff erleichtern (siehe Abb. 3).

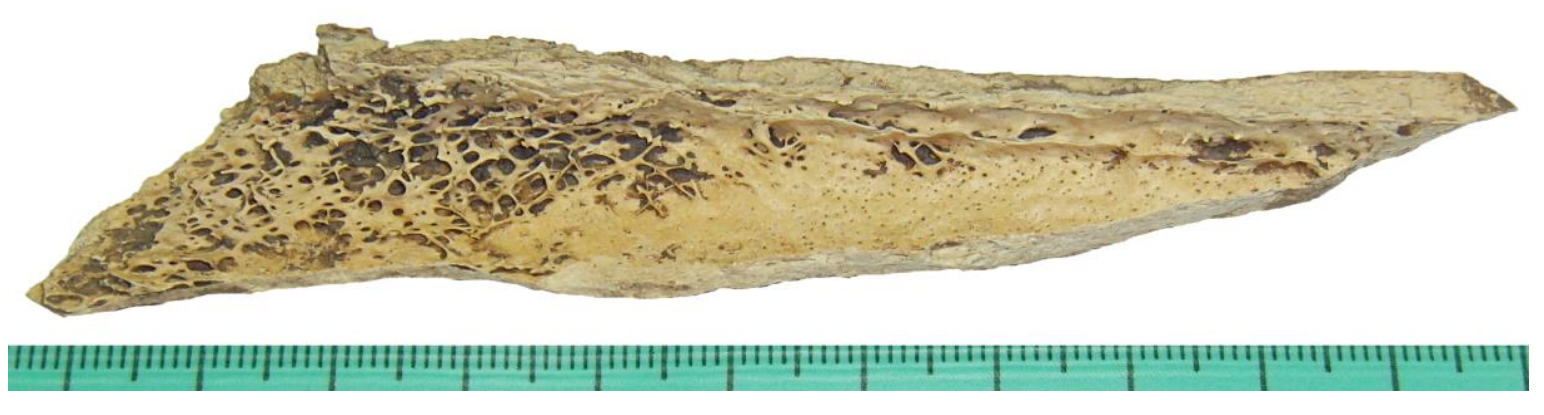

Abb. 2: Makroskopische Abbildung des Fundstücks mit Sicht auf die Innenseite.

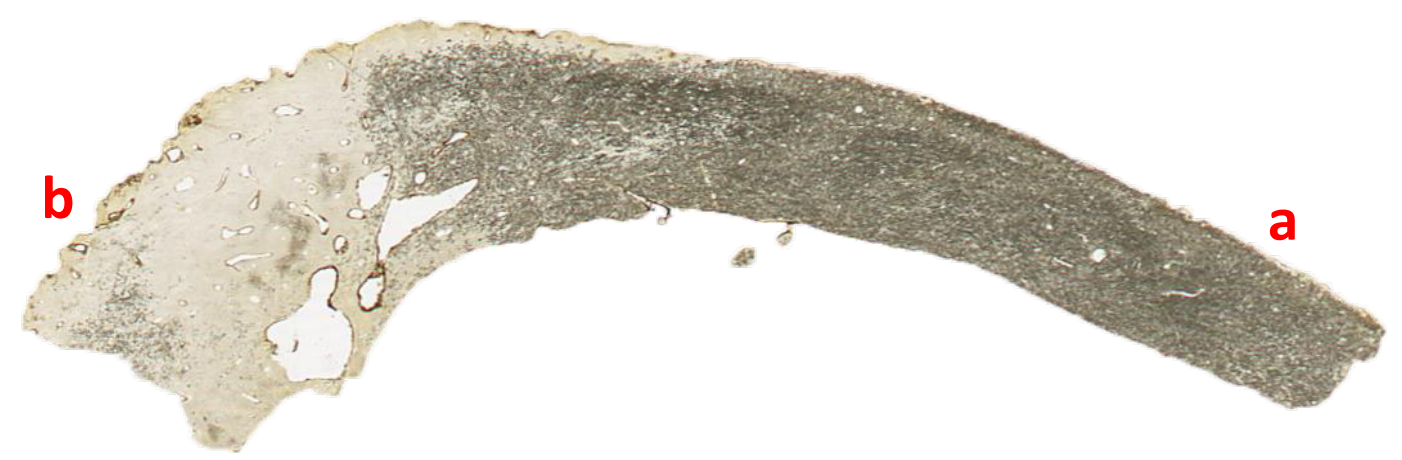

Abb. 3: Eingescannter Dünnschliff. Die Buchstaben sollen die Orientierung am Knochendünnschliff erleichtern (Vgl. Abb. 1). Oben im Bild befindet sich Compacta, unten Spongiosa. 


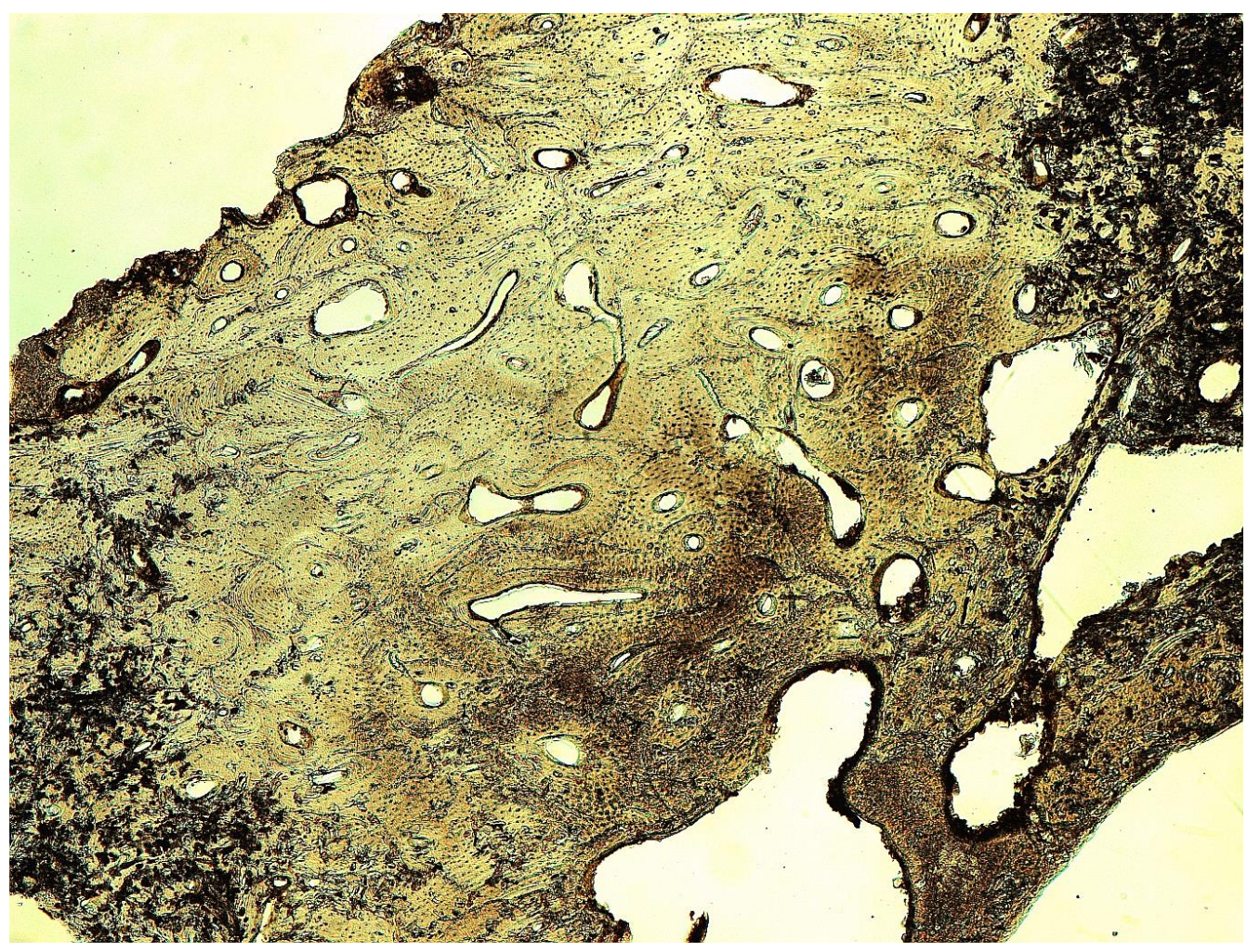

Abb. 4: Dünnschliffdicke $70 \mu m$, Vergrößerung 25x; deutlich degenerierte Knochenstruktur im einfachen Durchlicht.

Auf Abb. 4 sind besonders im Randbereich die postmortal degenerativ veränderten Bereiche zu erkennen. Auf Abb. 5 ist die äußere Generallamelle zu sehen.

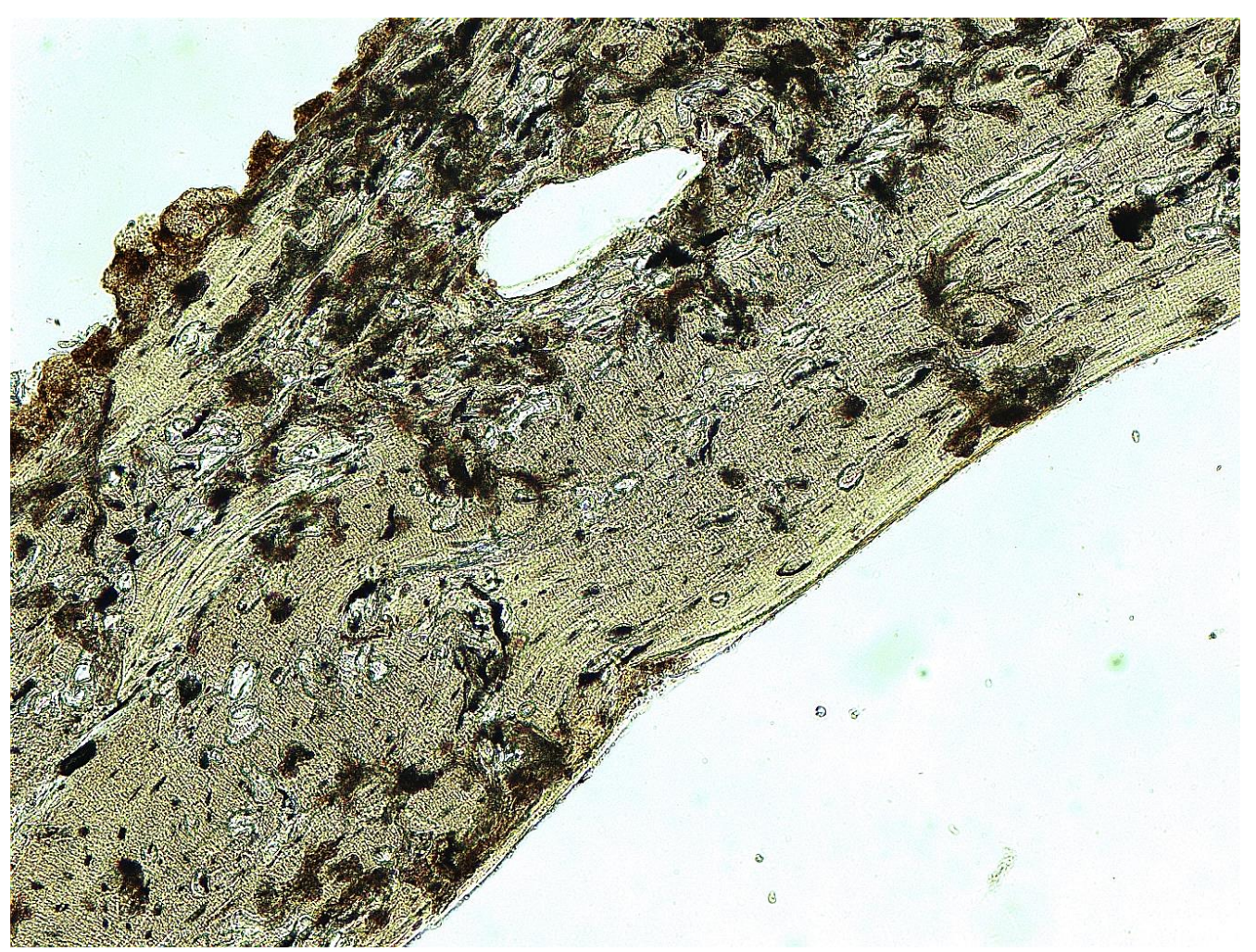

Abb. 5: Dünnschliffdicke $70 \mu m$, Vergrößerung 100x; innere Generallamelle im einfachen Durchlicht. 


\subsection{Lichtmikroskopischer Befund 3 der Population aus Calden}

Die Fragestellung für die lichtmikroskopische Untersuchung bezog sich auf eine makroskopisch sichtbare Streifung in der äußeren Knochenstruktur am proximalen Schaft dieser rechten Fibula. Auffällig sind die zahlreich vorhandenen Spuren von Pilzfraß, der sich im Bild als dunkle Struktur darstellt.

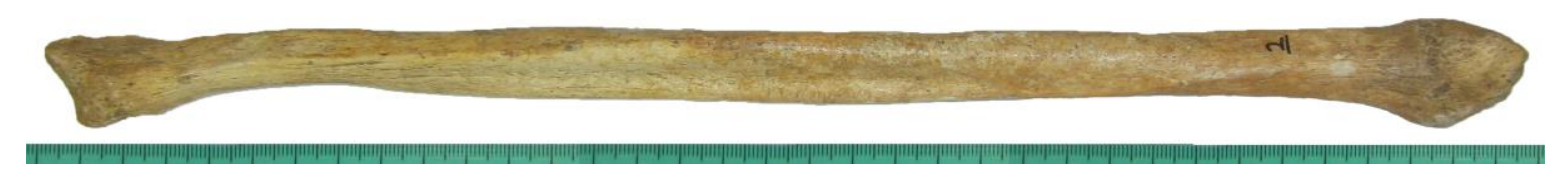

Abb. 1: Makroskopische Aufnahme der Fibula in voller Länge; rechts im Bild befindet sich der distale Anteil des Knochens.

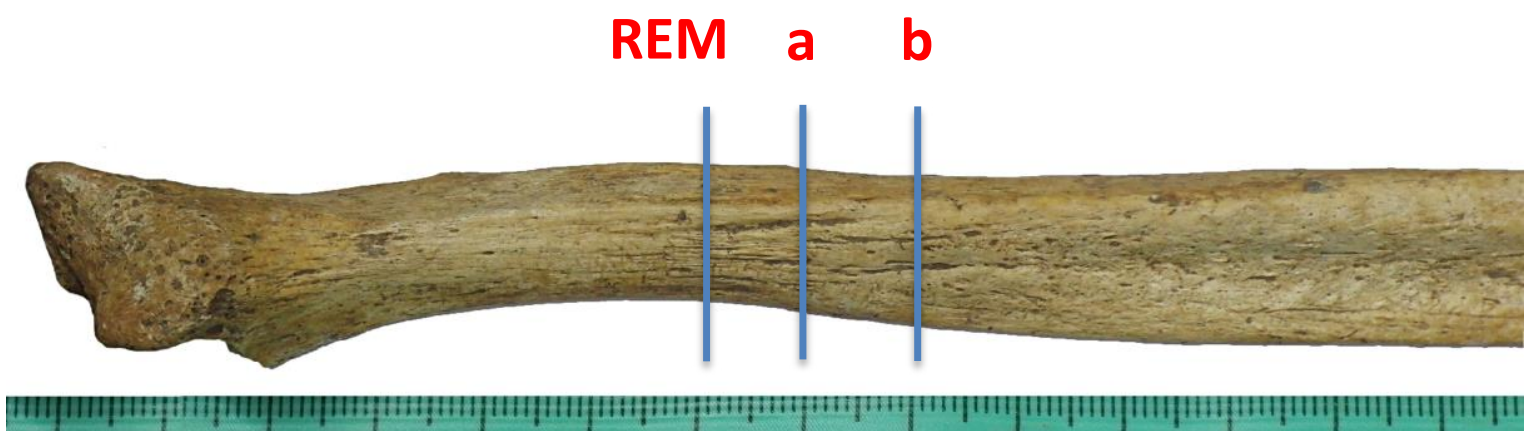

Abb. 2: Nahaufnahme des proximalen Schaftanteils mit eingezeichneten Schliffebenen.

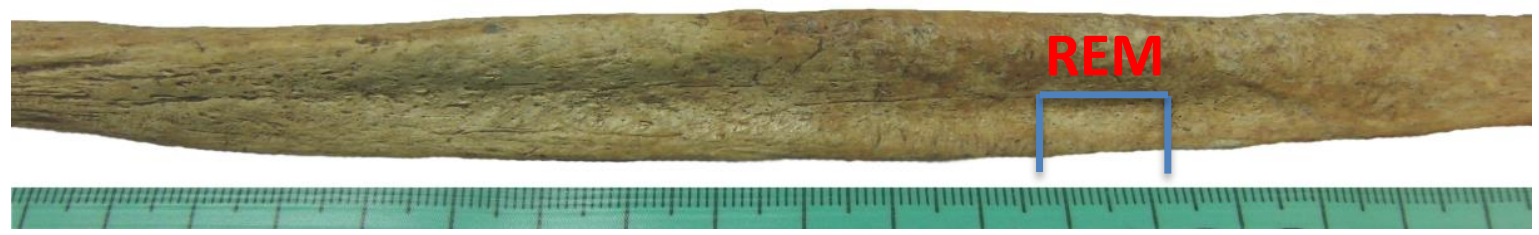

Abb. 3: Nahaufnahme des mittleren Schaftanteils mit eingezeichnetem Bereich der Probeentnahme für die REMUntersuchung.

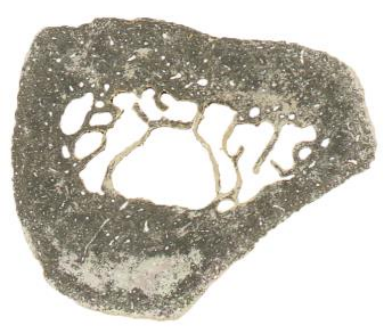

Abb. 4:

Eingescannter

Dünnschliff der

Schliffebene a ( Vgl.

Abb. 2).

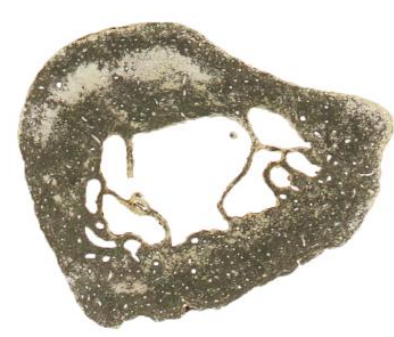

Abb. 5:

Eingescannter

Dünnschliff der

Schliffebene b (Vgl.

Abb. 2). 
Auf den Abbildungen 6-8 ist deutlicher Pilzfraß am Fundstück zu erkennen. Der Pilz konnte sich post mortem im Knochengewebe ausbreiten.

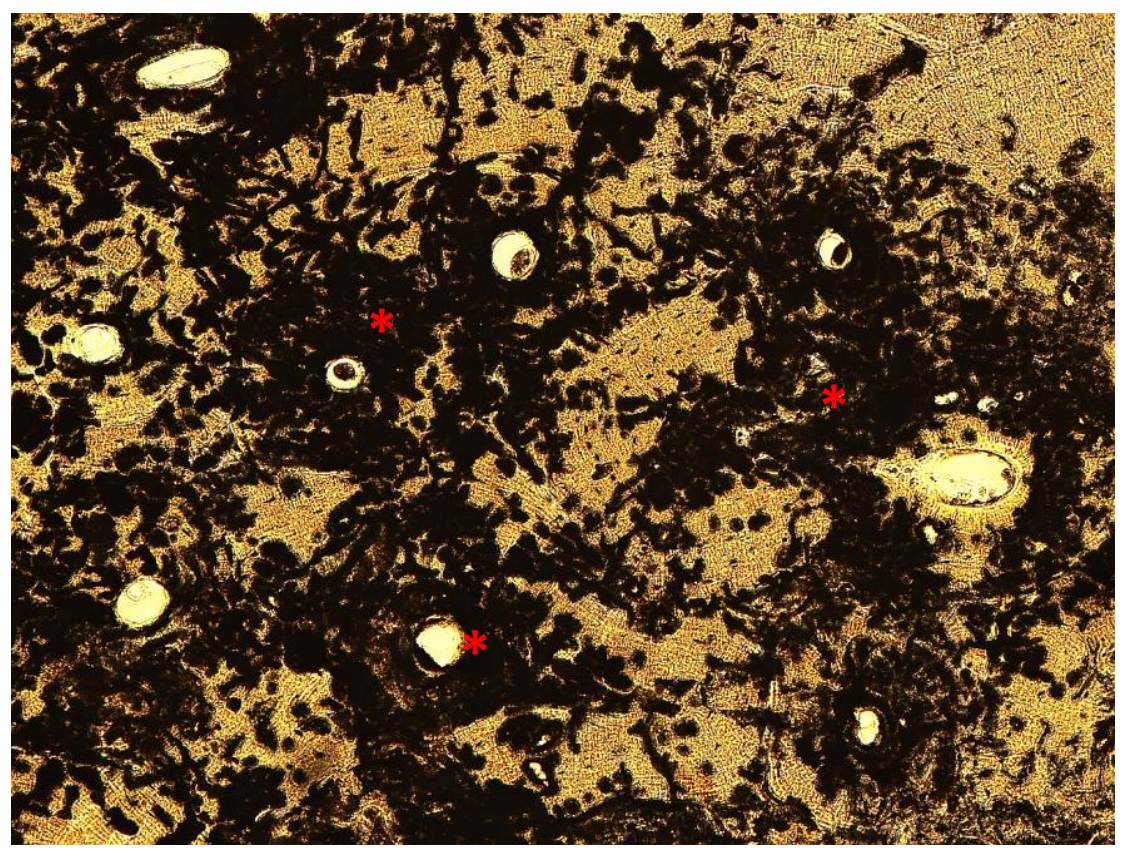

Abb. 6: Dünnschliffdicke $70 \mu \mathrm{m}$, Vergrößerung 100x; Pilzfraß in den dunklen Bereichen (*) im einfachen Durchlicht.

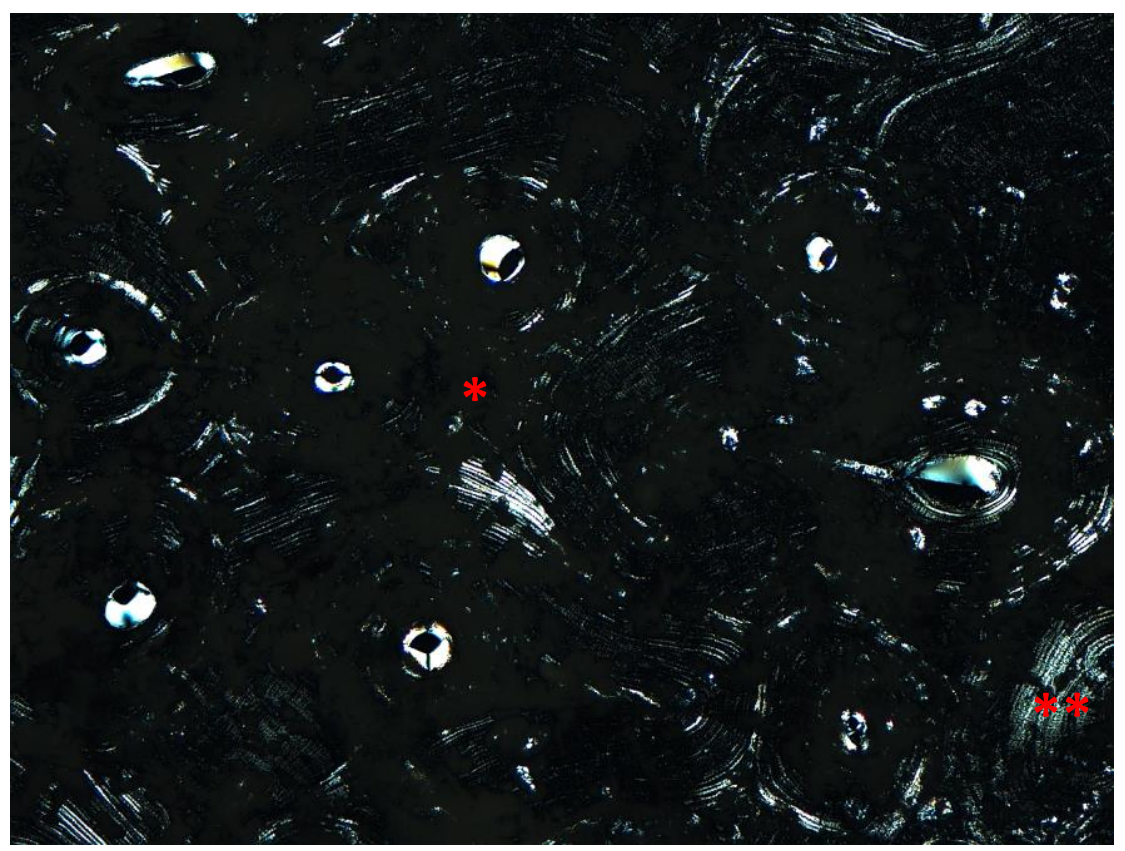

Abb. 7: Dünnschliffdicke $70 \mu \mathrm{m}$, Vergrößerung 100x, Aufnahme mit polarisiertem Durchlicht; Pilzfraß (*) und kaum noch kollagene Strukturen (hellere Bereiche; ${ }^{* *}$ ). 


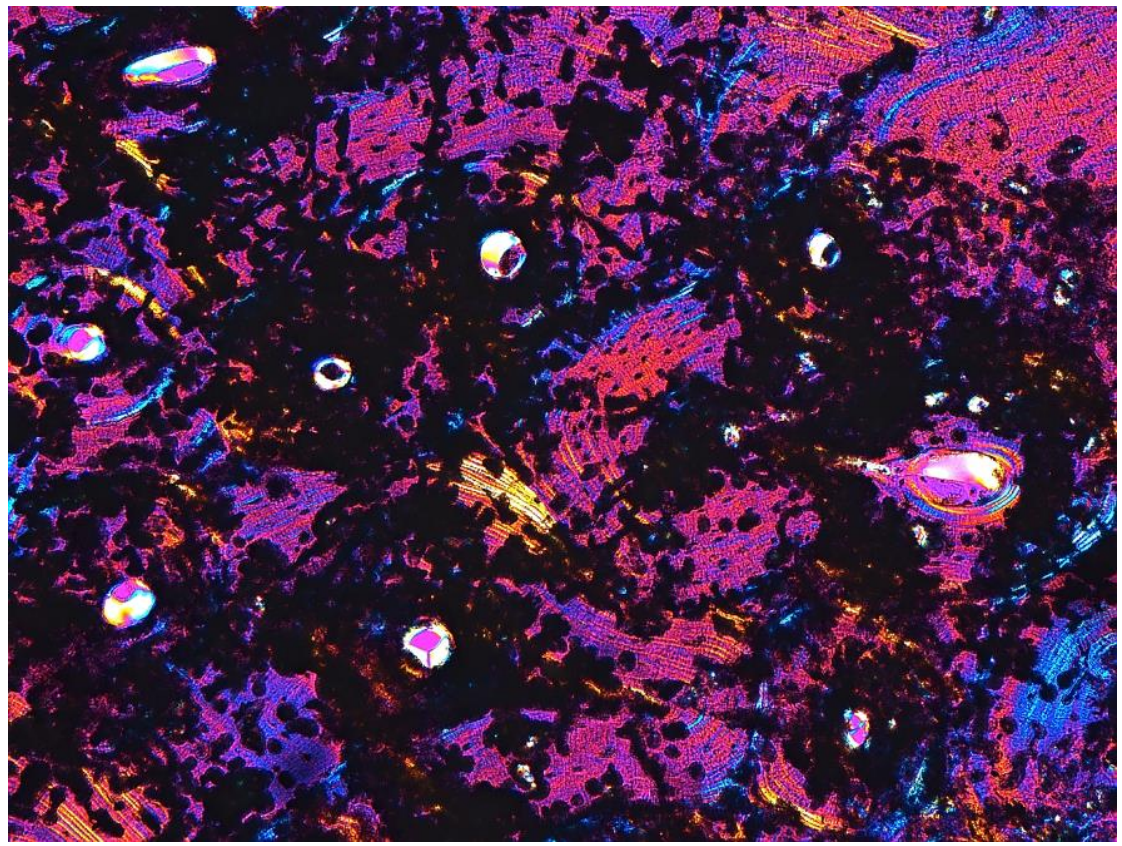

Abb. 8: Dünnschliffdicke $70 \mu m$, Vergrößerung 100x; Pilzfraß (dunkle Bereiche) im polarisierten Durchlicht unter Verwendung eines Hilfsobjektes Rot 1. Ordnung (Quarz) als Kompensator.

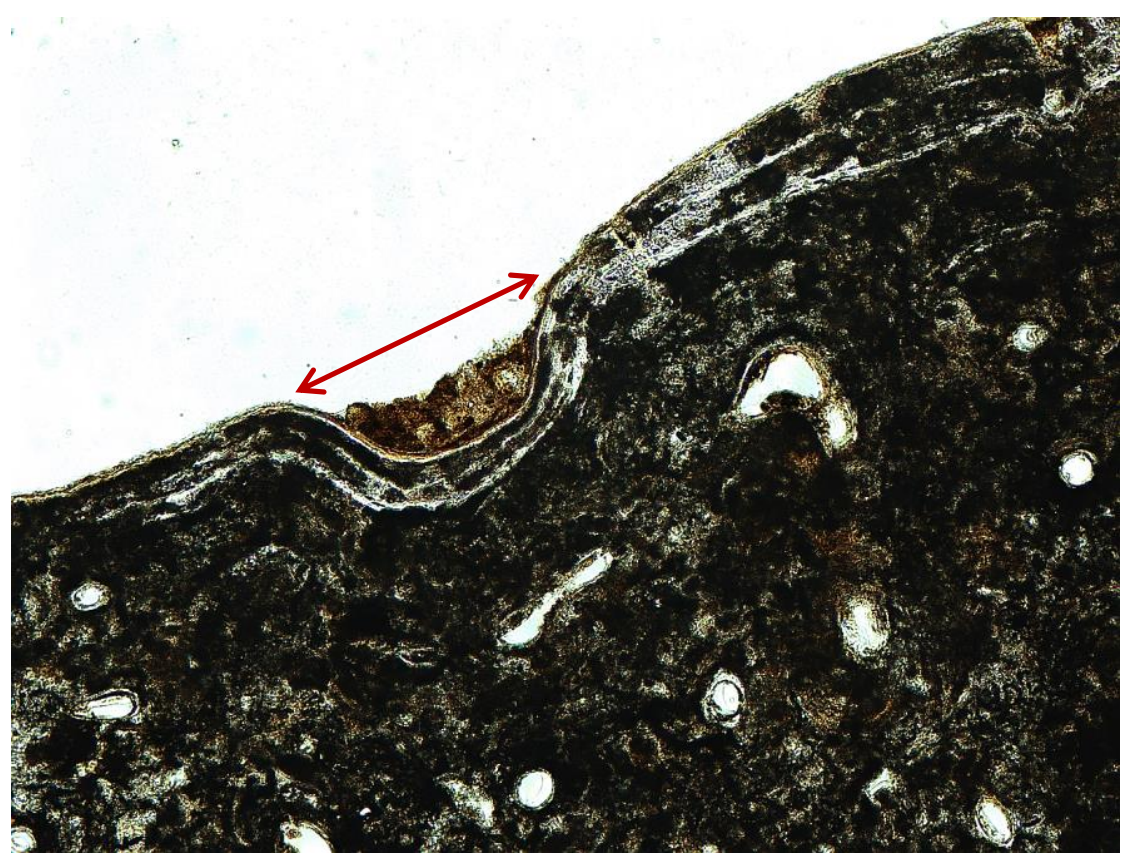

Abb. 9: Dünnschliffdicke $70 \mu m$, Vergrößerung 100x; Gefäß (Doppelpfeil) im einfachen Durchlicht.

Auch wenn die meisten der makroskopisch als möglicherweise intravitale Streifung identifizierten Strukturen lichtmikroskopisch als postmortale Erosionsspuren identifiziert werden konnten, ist in diesem Ausschnitt (Abb. 9) eine deutliche intravitale Gefäßimpression durch eine im Periostbereich entstandene Hypervaskularisierung $\mathrm{zu}$ sehen. Abb. 10 zeigt einen nicht eindeutigen Befund: Auffällig ist eine Mulde, die durch ein Gefäß entstanden sein 
könnte. Die typischen Aufmauerungen rechts und links davon fehlen jedoch. Trotzdem könnte es zu einer Periostreizung gekommen sein, die eine reaktive Knochenummodellierung im Sinne der Mulde hervorrief. Postmortal könnte dieser Bereich dann zusätzlich verändert worden sein.

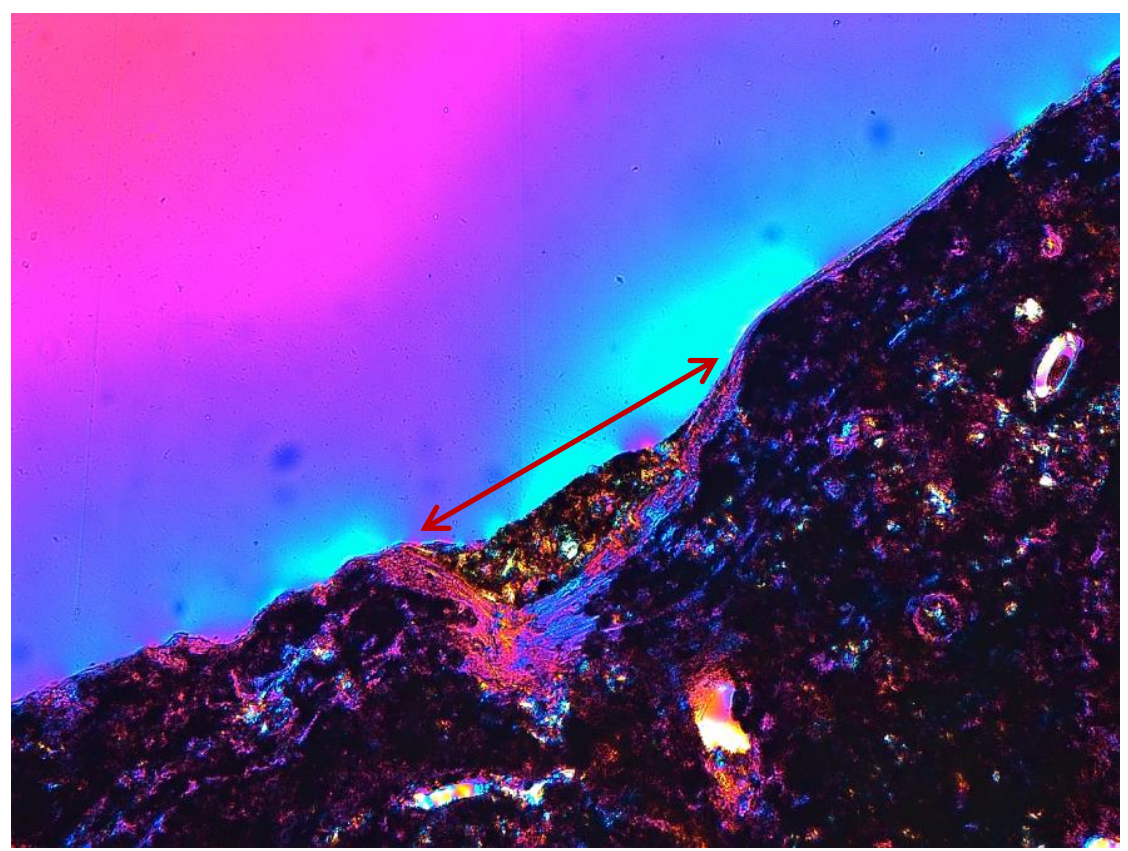

Abb. 10: Dünnschliffdicke $70 \mu \mathrm{m}$, Vergrößerung 100x; fragliches Gefäß (Doppelpfeil) im polarisierten Durchlicht unter Verwendung eines Hilfsobjektes Rot 1. Ordnung (Quarz) als Kompensator.

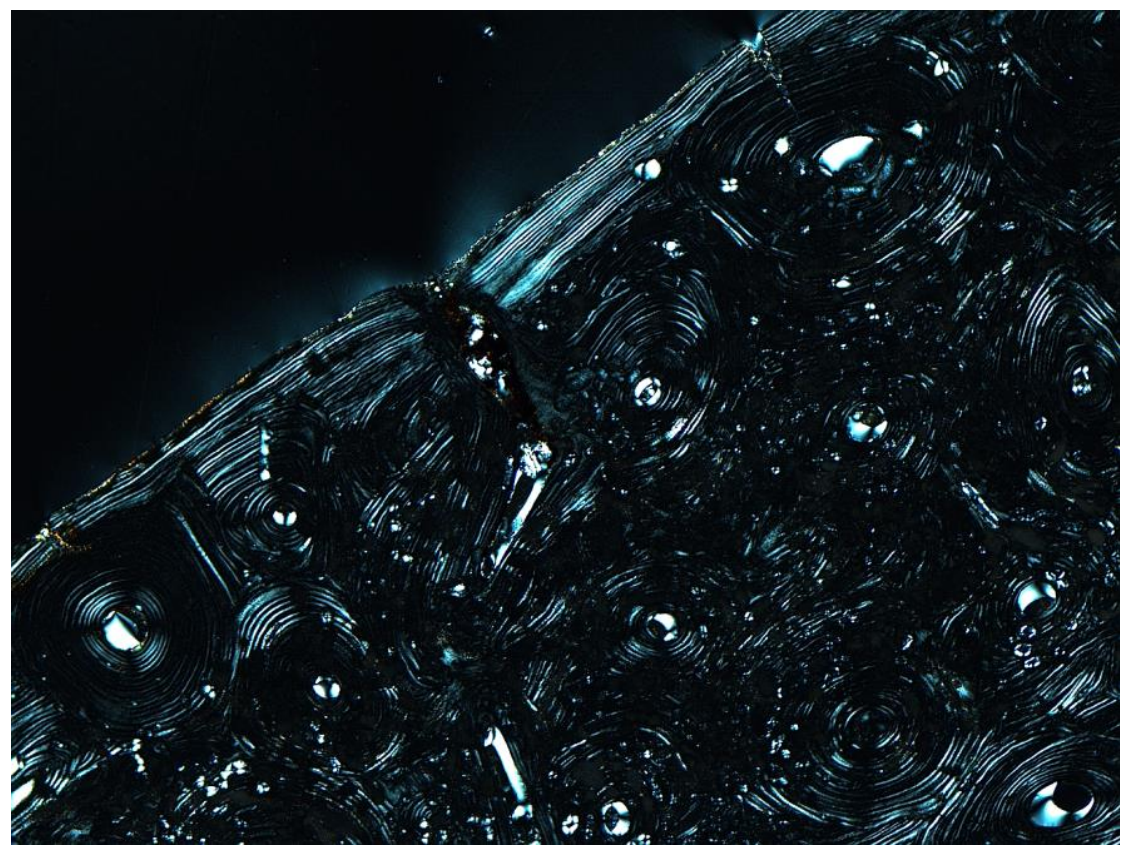

Abb. 11: Dünnschliffdicke $50 \mu m$, Vergrößerung 100x; äußere Generallamelle im polarisierten Durchlicht.

In Abb. 11 ist die äußere Generallamelle deutlich zu erkennen. Das Vorhandensein derselben spricht für ein adultes Sterbealter von maximal 40 Jahren. 


\subsection{Lichtmikroskopischer Befund 4 der Population aus Calden}

Bei diesem Präparat handelt es sich um eine Fibula eines jungen Individuums. Die Knochendünnschliffe sind rechtwinklig zur Länge des Röhrenknochens angefertigt worden. Die makroskopischen Dimensionen deuten auf ein Sterbealter im Bereich von Infans I hin. Die histologischen Merkmale beziffern das Sterbealter auf Infans I b, bzw. noch genauer auf mindestens 3, wahrscheinlich 4 bis 5 und maximal 6 Jahre.

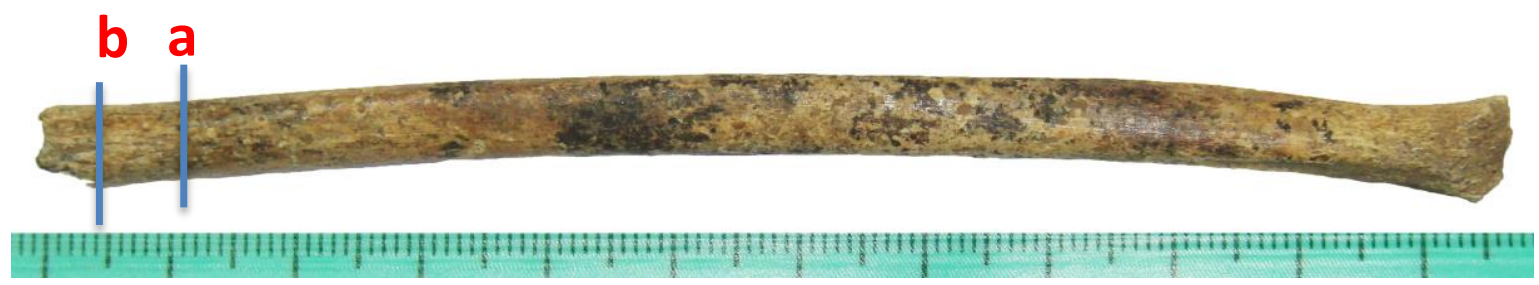

Abb. 1: Makroskopische Abbildung der frühkindlichen Fibula von posterior. Rechts im Bild findet sich die distale Epiphyse. Die blauen Linien markieren die zwei verschiedenen Schnittebenen.

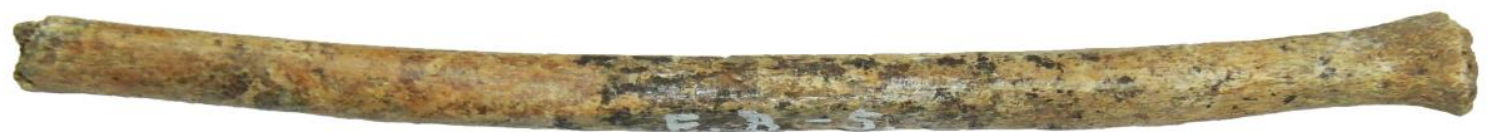

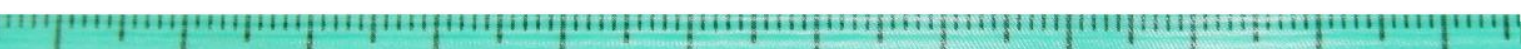

Abb.2: Makroskopische Abbildung der frühkindlichen Fibula von anterior. Rechts im Bild findet sich die distale Epiphyse.

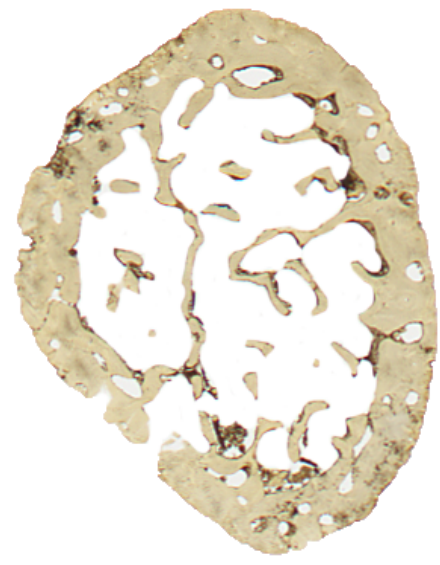

Abb. 3: Eingescannter Dünnschliff aus der Schnittebene a (Vgl. Abb. 1).

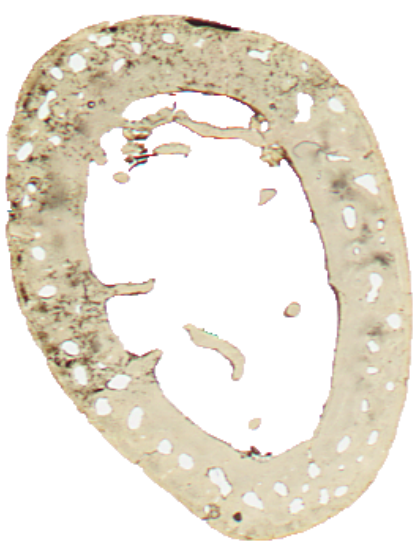

Abb. 4: Eingescannter Dünnschliff aus der Schnittebene b (Vgl. Abb. 1). 
In Abb. 5 sind noch keine Haverssysteme erkennbar, lediglich Resorptionshöhlen sind sichtbar. Deutlich ist Spongiosa im Inneren des Knochens zu sehen, was eine Anämie zum Zeitpunkt des Todes vermuten lässt.

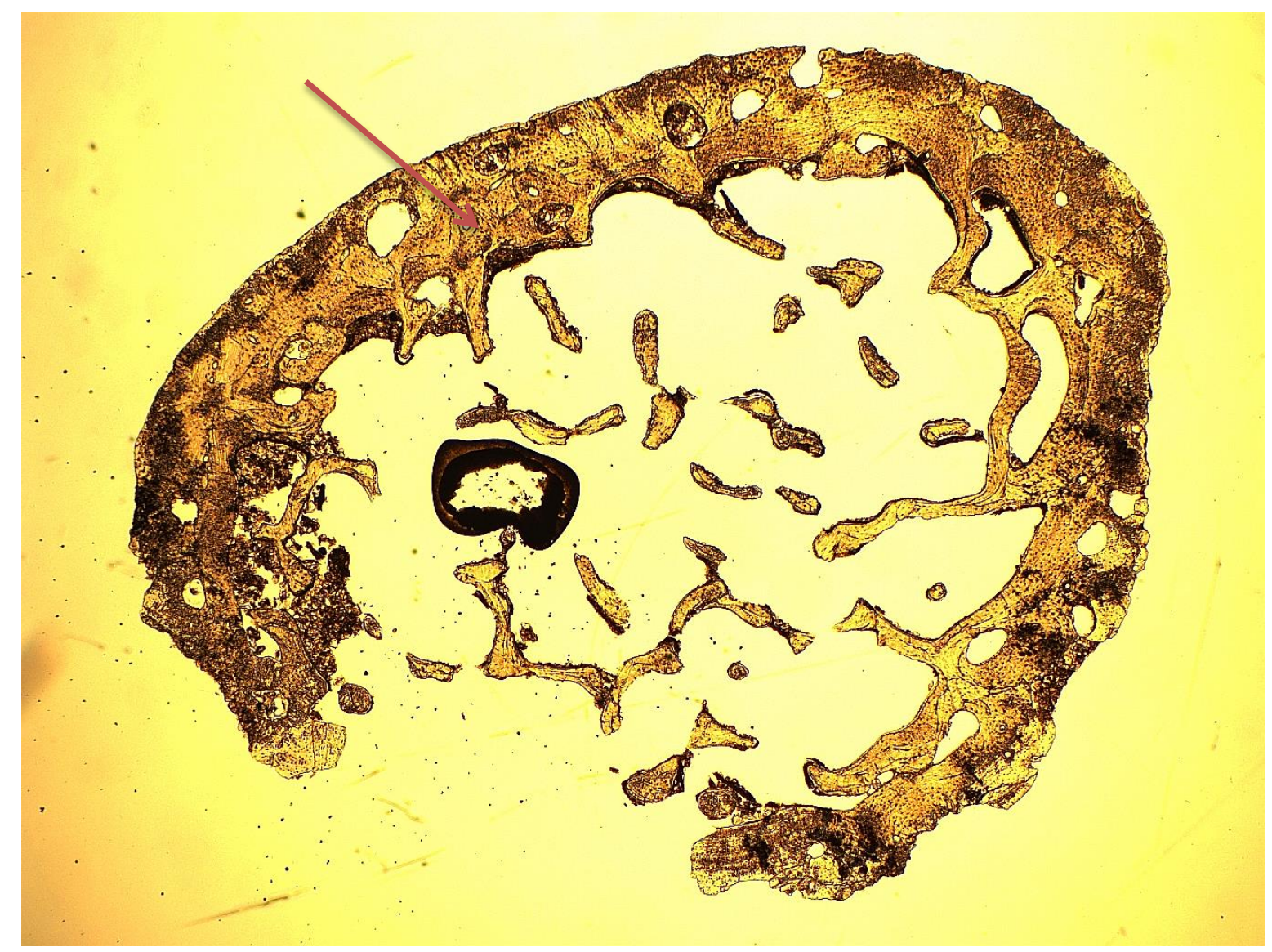

Abb. 5: Dünnschliffdicke $50 \mu m$, Vergrößerung 16x; Resorptionshöhlen (roter Pfeil) im einfachen Durchlicht.

Das Fundstück ist durchsetzt mit Sandkristallen und anderen Fremdkörpern, die in den Abbildungen 6 - 8 als bunte Objekte neben der Knochenstruktur auffallen. 


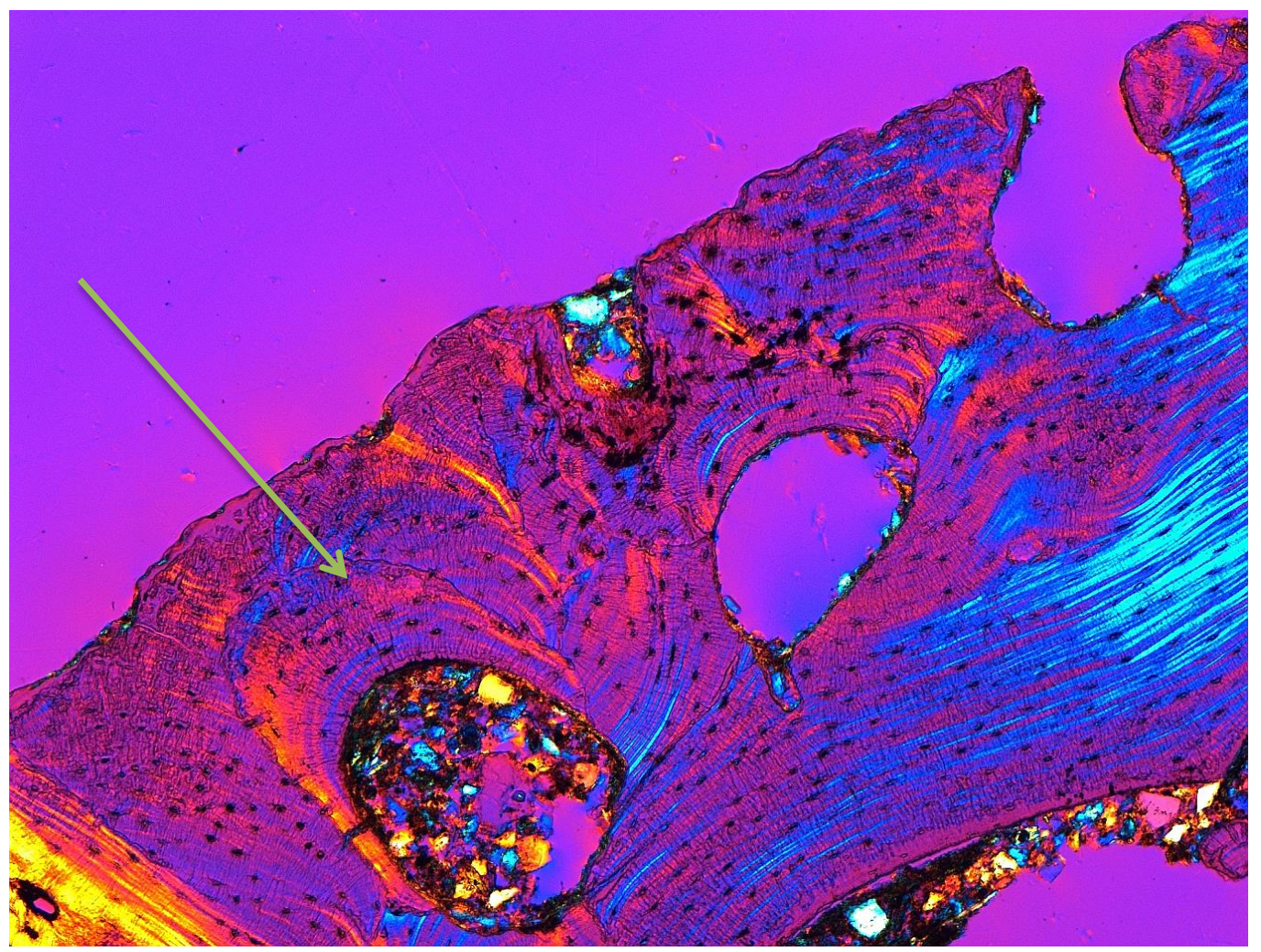

Abb. 6: Dünnschliffdicke $50 \mu$ m, Vergrößerung 100x; Knochenstruktur mit postmortal eingelagerten Fremdkörpern (grüner Pfeil) im polarisierten Durchlicht unter Verwendung eines Hilfsobjektes Rot 1. Ordnung (Quarz) als Kompensator.

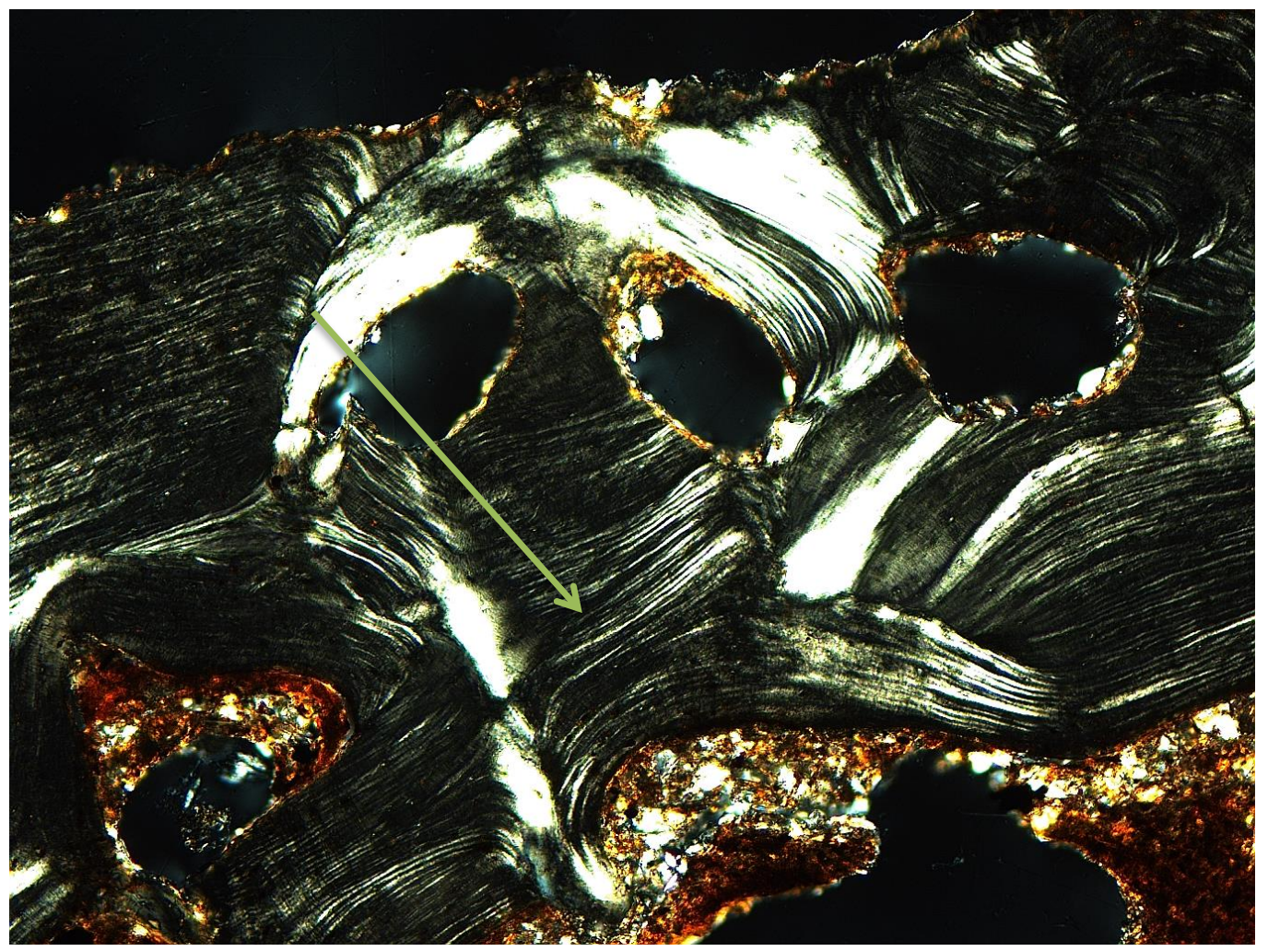

Abb. 7: Dünnschliffdicke 50 m, Vergrößerung 100x; Sandkristalle und Fremdkörper (grüner Pfeil) als bunte Strukturen inmitten des Knochengewebes im polarisierten Durchlicht. 


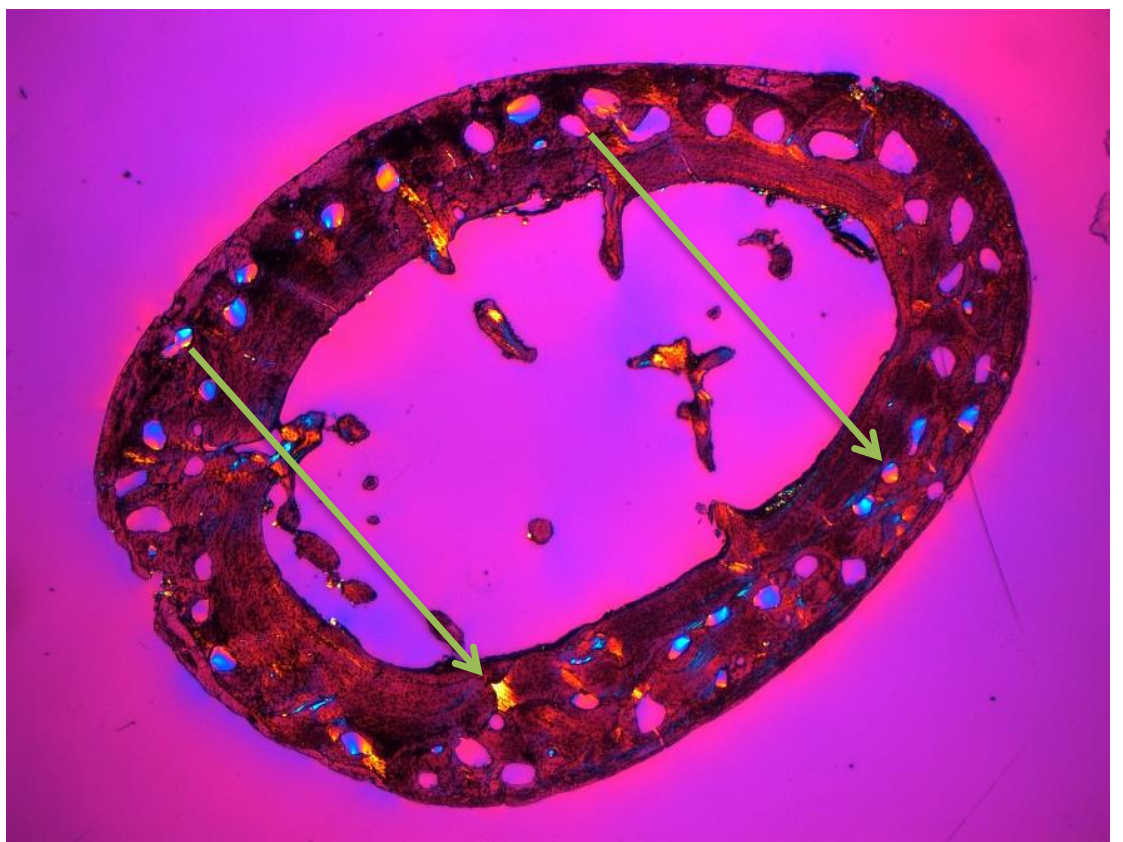

Abb. 8: Dünnschliffdicke $50 \mu \mathrm{m}$, Vergrößerung 16x; Knochenstruktur mit Sandkristallen (grüne Pfeile) im polarisierten Durchlicht unter Verwendung eines Hilfsobjektes Rot 1. Ordnung (Quarz) als Kompensator.

Der Knochen ist so klein, dass ein ganzer Querschnitt für die Aufnahmen darstellbar war (Abbildungen 5 und 8)

Im Bild dieses dickeren Dünnschliffs (Abb. 9) sind bereits Haverssysteme erkennbar. Das grenzt den Rahmen des Sterbealters ein.

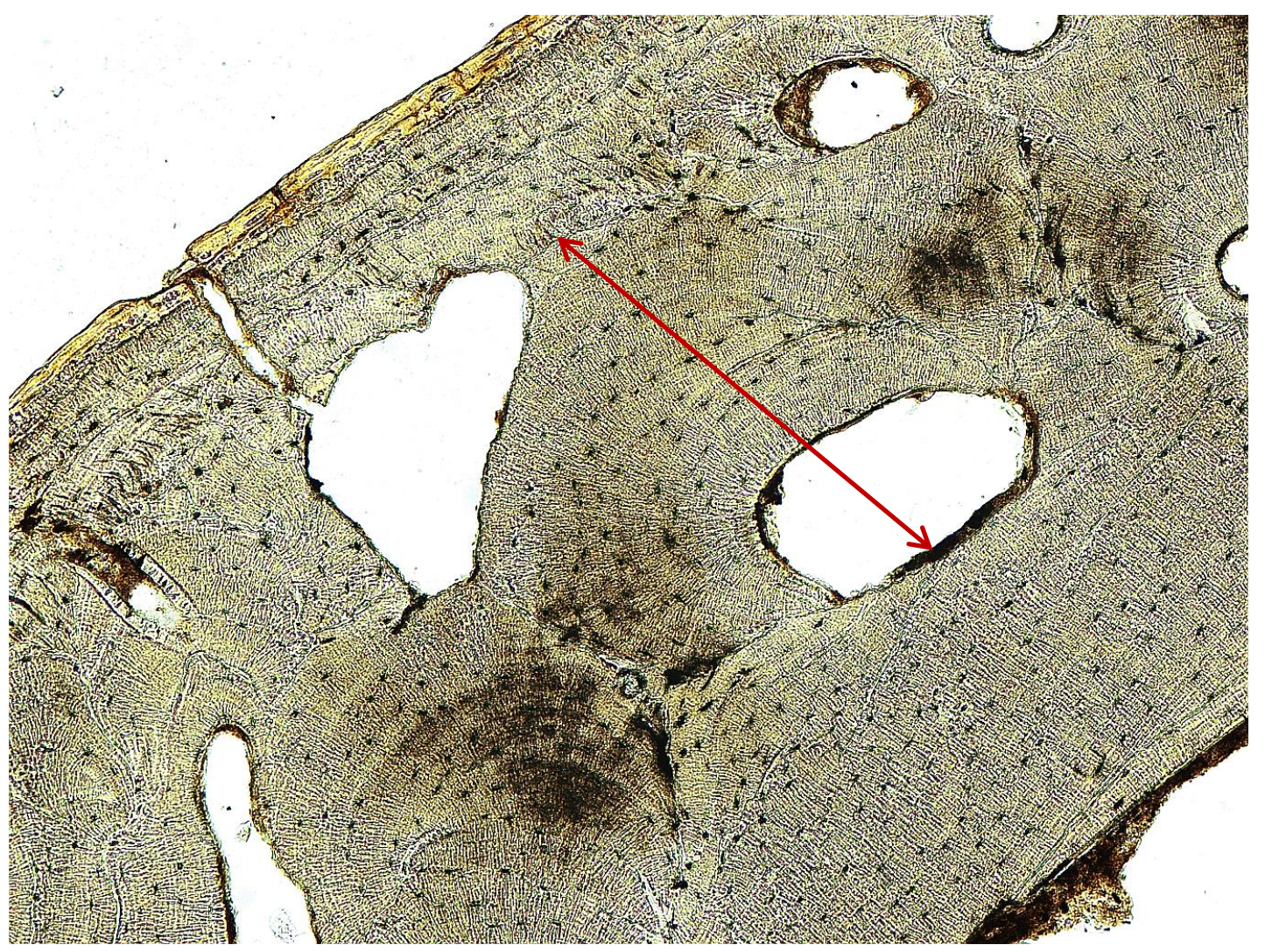

Abb. 9: Dünnschliffdicke $70 \mu \mathrm{m}$, Vergrößerung 100x; Haverssysteme (roter Doppelpfeil) im einfachen Durchlicht. 


\subsection{Lichtmikroskopischer Befund 5 der Population aus Calden}

Die Schädeldecke dieses linken Os parietale ist bis zu $11 \mathrm{~mm}$ dick. Mikroskopisch sind keine pathologischen Veränderungen an der Lamina interna oder -externa zu erkennen. Die Diploë zeigt eine normale Struktur. Einzig leichte Erosionen sind an der Lamina interna und -externa auszumachen. Das Sterbealter kann auf 20 bis 40 (55) Jahre beziffert werden.

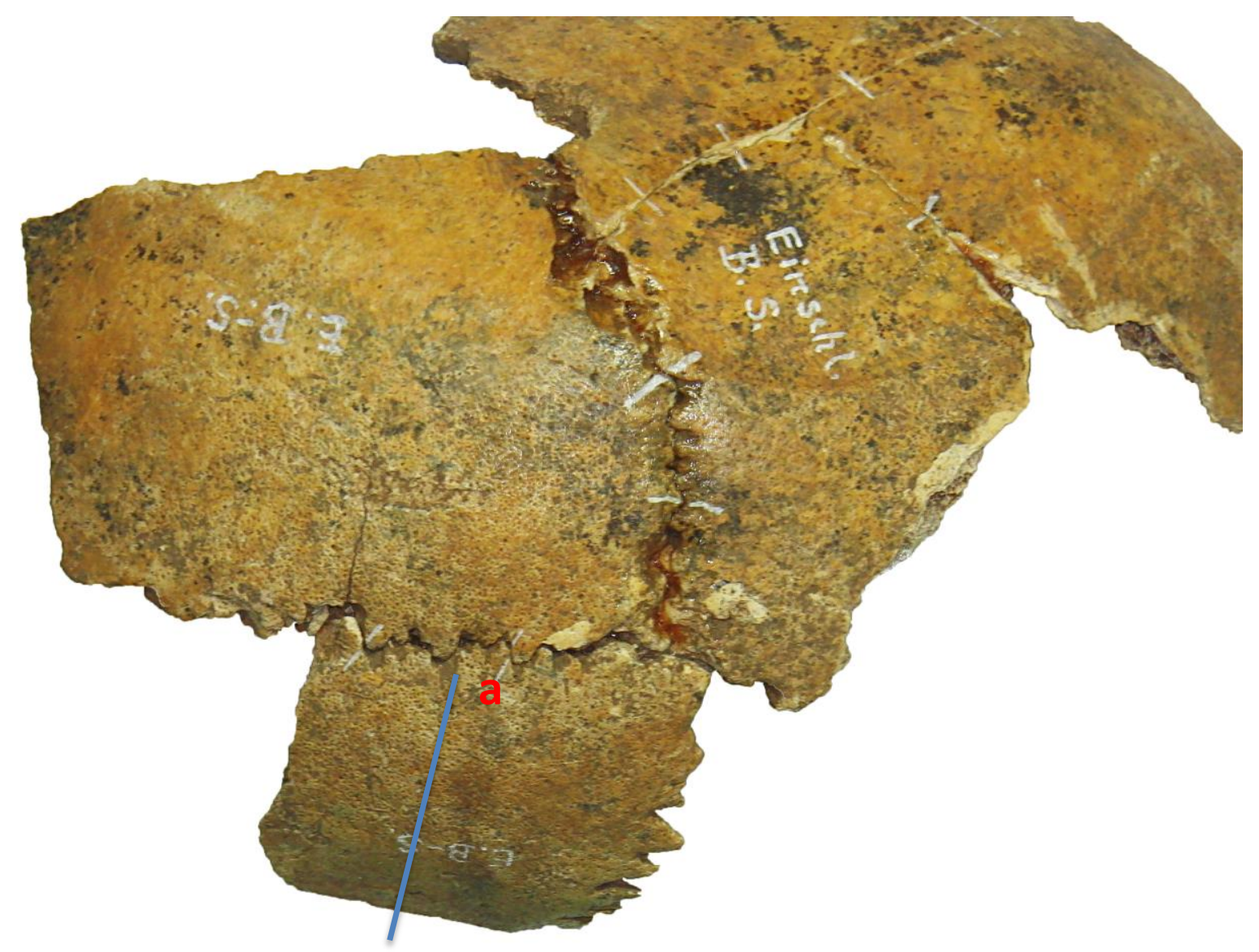

Abb. 1: Makroskopische Aufnahme des untersuchten Fundstücks mit in blau eingezeichneter Schnittebene des Dünnschliffs. ", $a$ " dient der Orientierung für Abb.2.

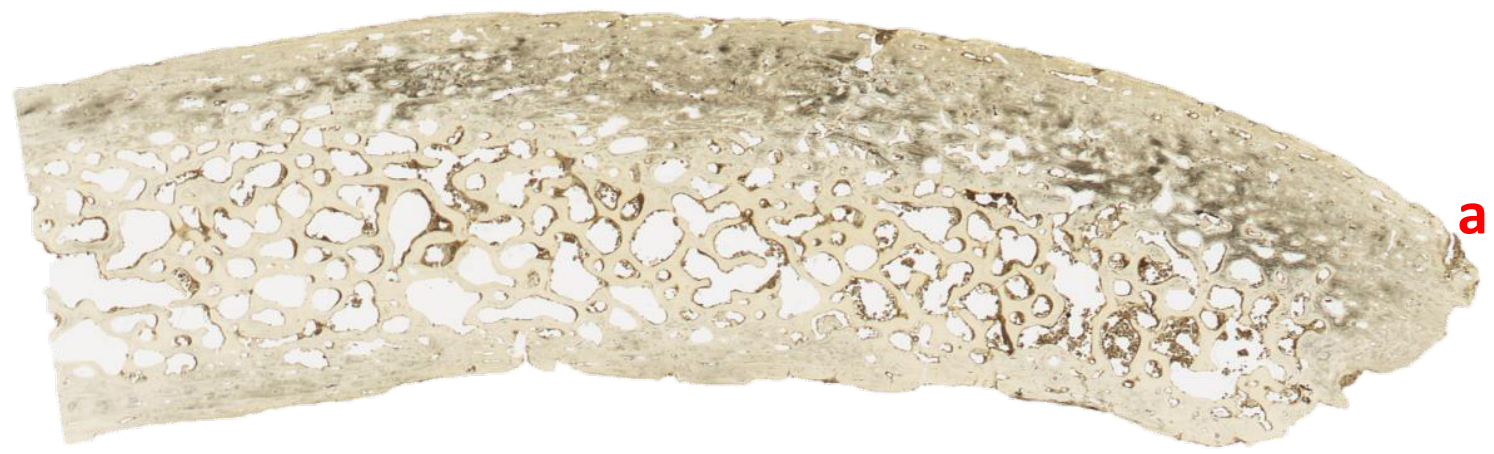

Abb. 2: Aufnahme des eingescannten Dünnschliffs. "a“ ist ein Orientierungspunkt (vgl. Abb. 1). 


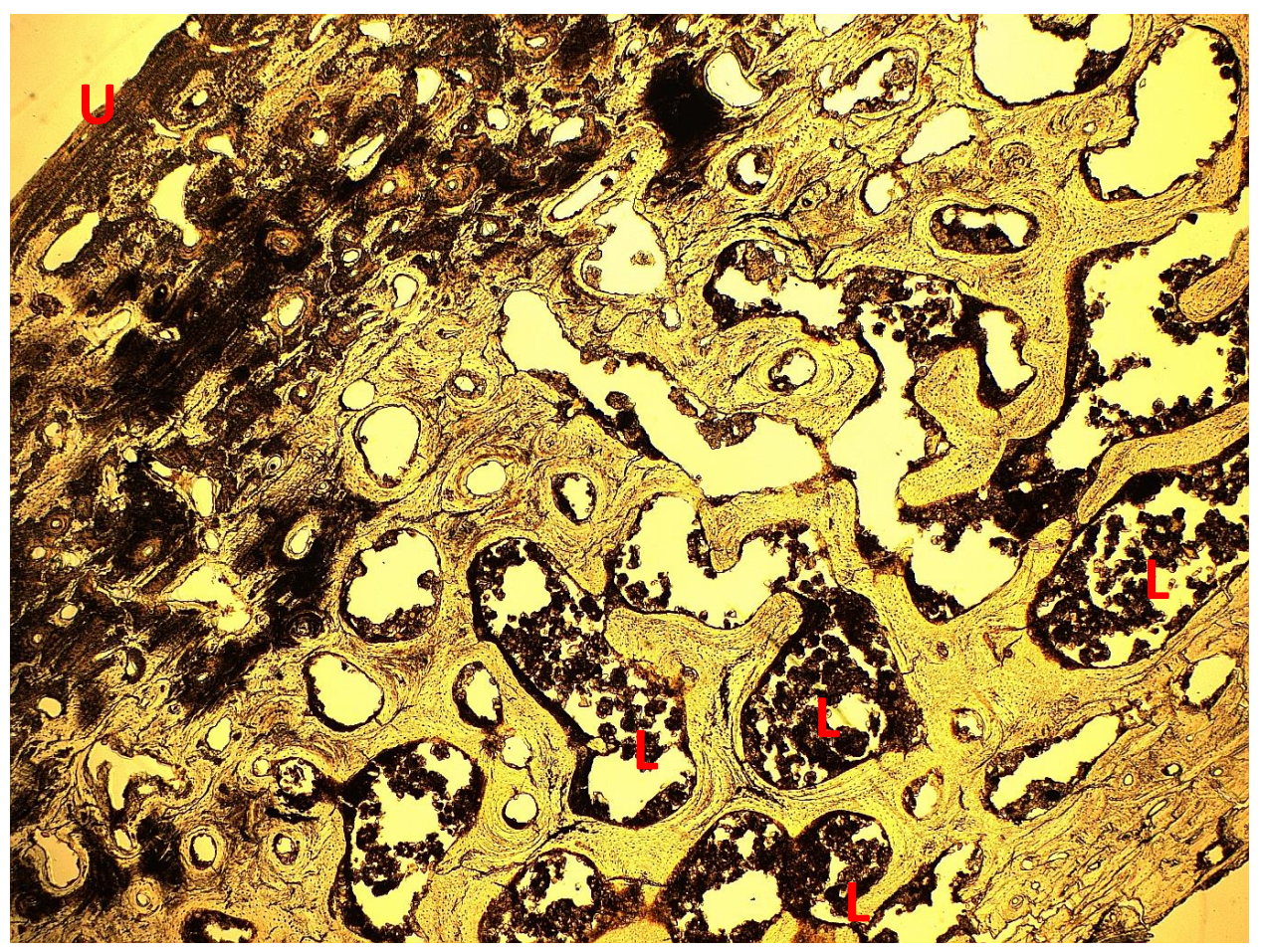

Abb. 3: Dünnschliffdicke $50 \mu m$ Vergrößerung 16x, Aufnahme im einfachen Durchlicht; Buchstabenverzeichnis: U: Lamina externa; L: Diploë mit eingelagerten biologischen Materialien.

Das Fundstück weist eine deutlich erkennbare Lamina externa auf, die teilweise erodiert ist (Abb. 4). Weiterhin zeigt sich eine normale Diploëstruktur, die zum Teil mit biologischen Materialien gefüllt ist (Abb. 3). Außerdem fallen Spuren von Pilzfraß auf.

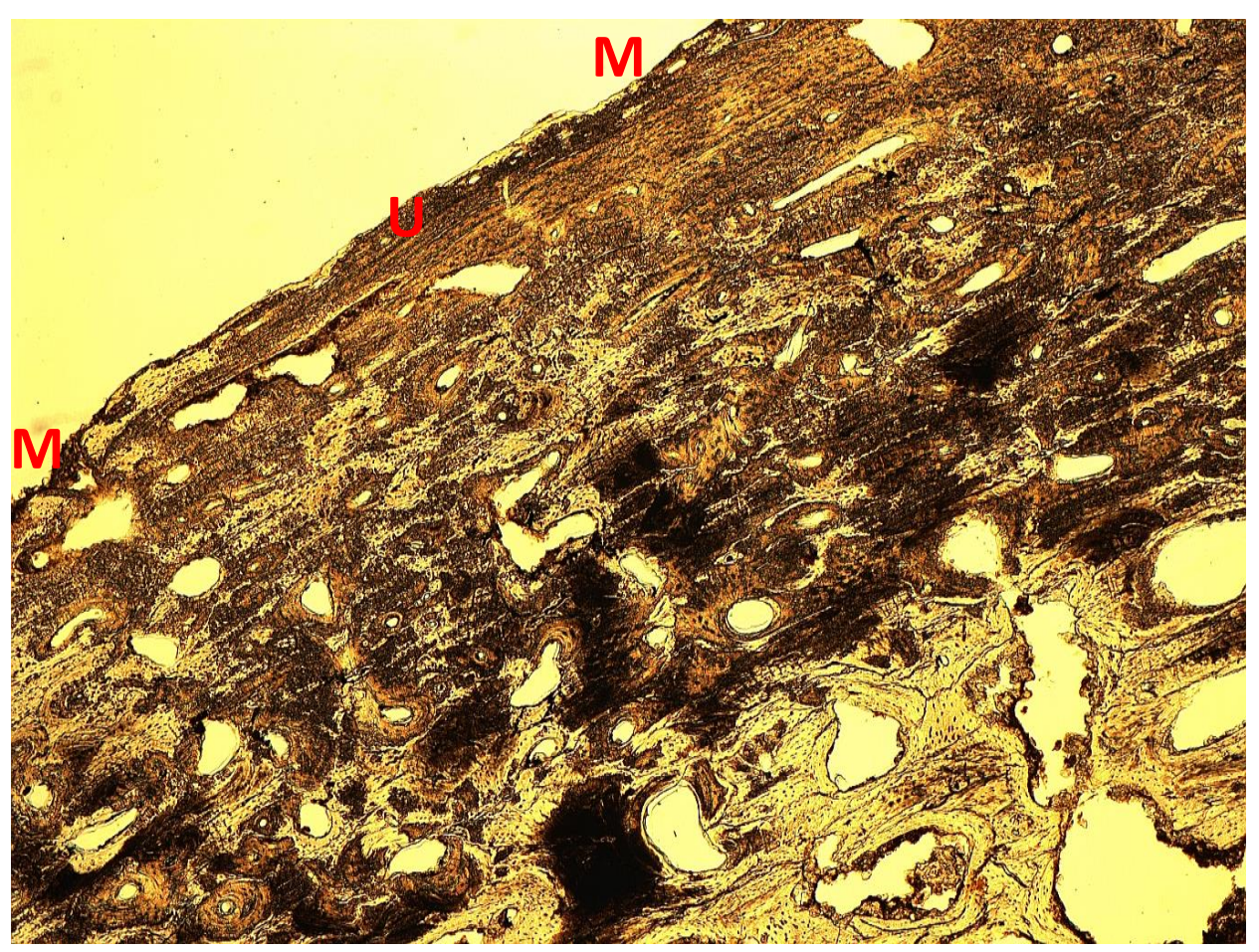

Abb. 4: Dünnschliffdicke $50 \mu m$, Vergrößerung 25x, Aufnahme im einfachen Durchlicht; Buchstabenverzeichnis: $U$ : Lamina externa mit Erosionen (M). 


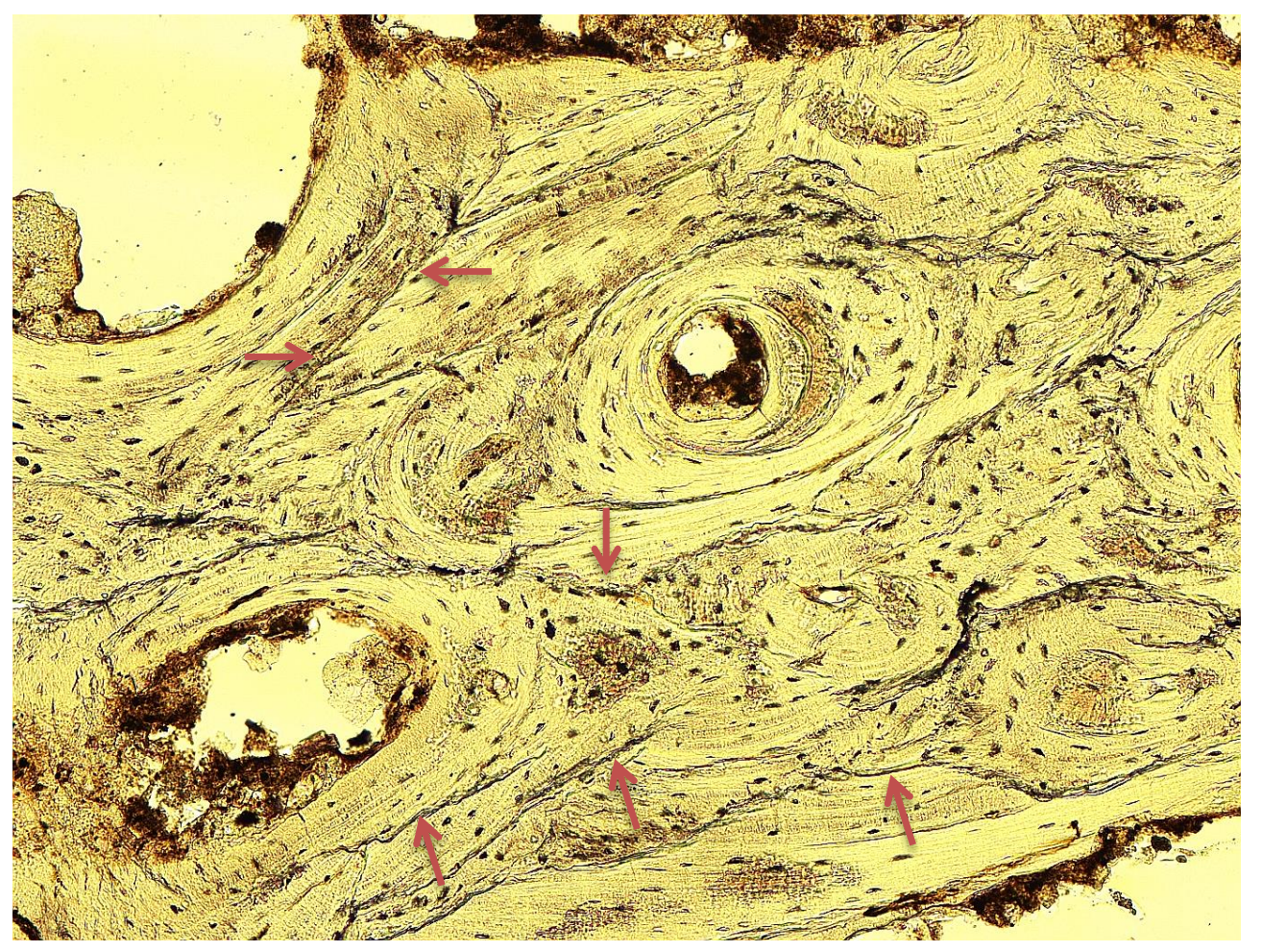

Abb. 5: Dünnschliffdicke $50 \mu m$, Vergrößerung 100x, Aufnahme im einfachen Durchlicht; die Pfeile zeigen beispielhaft die (Mikro-) Risse in der Knochenstruktur.

Die Knochenstruktur weist Mikrorisse auf, die sich entlang der Kittlinien befinden (Abb. 5). Sie sind durch den hohen Bodendruck im Grabbereich entstanden. Im gesamten Präparat sind Auswirkungen dieses Bodendrucks zu finden (Abb. 6).

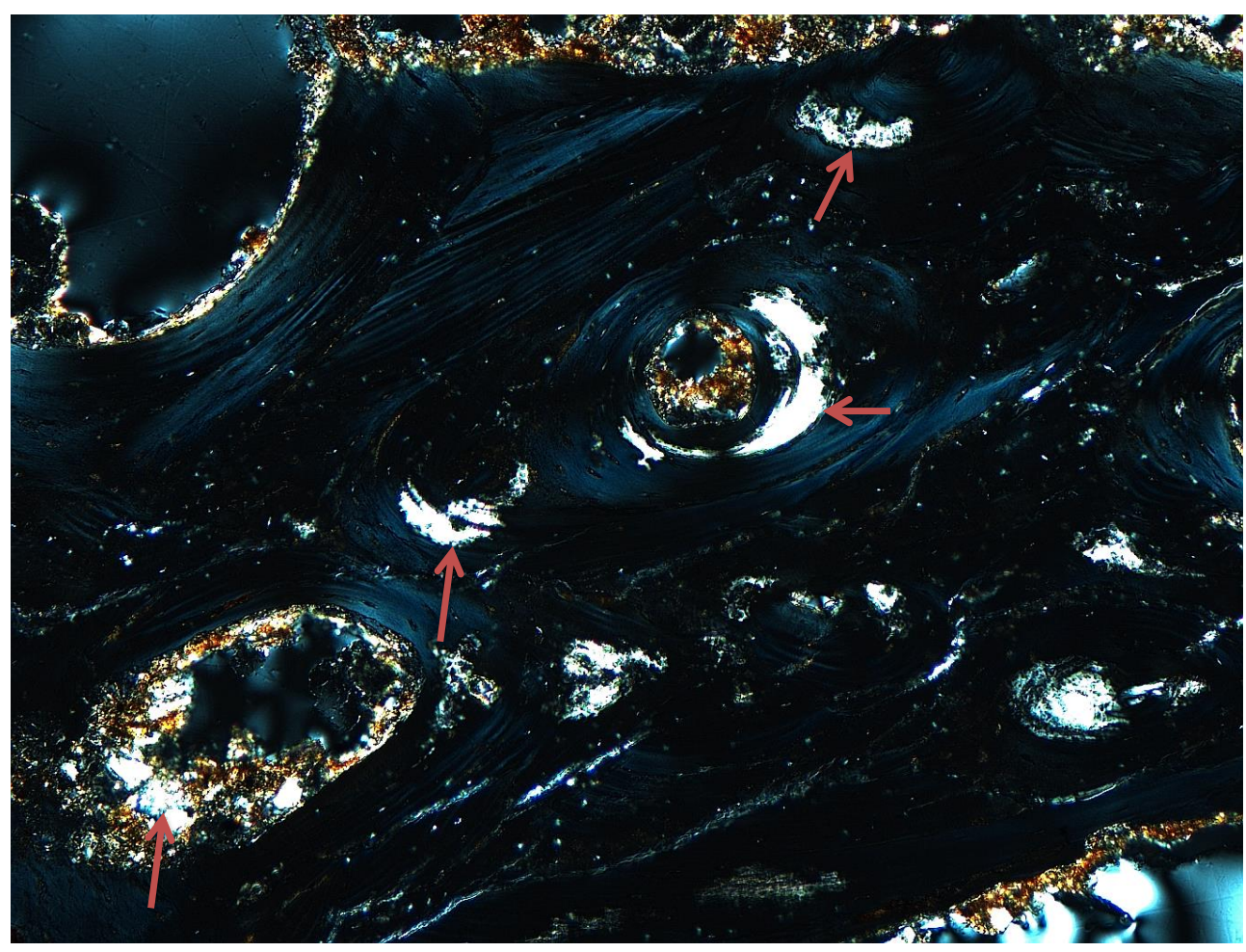

Abb. 6: Dünnschliffdicke $50 \mu \mathrm{m}$, Vergrößerung 100x, Aufnahme mit polarisiertem Durchlicht; die Pfeile zeigen auf die im Polarisationslicht hellblau erscheinenden Spuren der postmortalen Degradation. 


\subsection{Lichtmikroskopischer Befund 6 der Population aus Calden}

Der Knochendünnschliff dieses Fundstücks stammt von demselben Schädel wie Probe 5 (8.21). Die makroskopischen Aufnahmen wurden hier so gewählt, dass die Schnittebene (Abb. 2) dieses Dünnschliffs deutlich wird. Für weitere Ansichten siehe Probe 5.

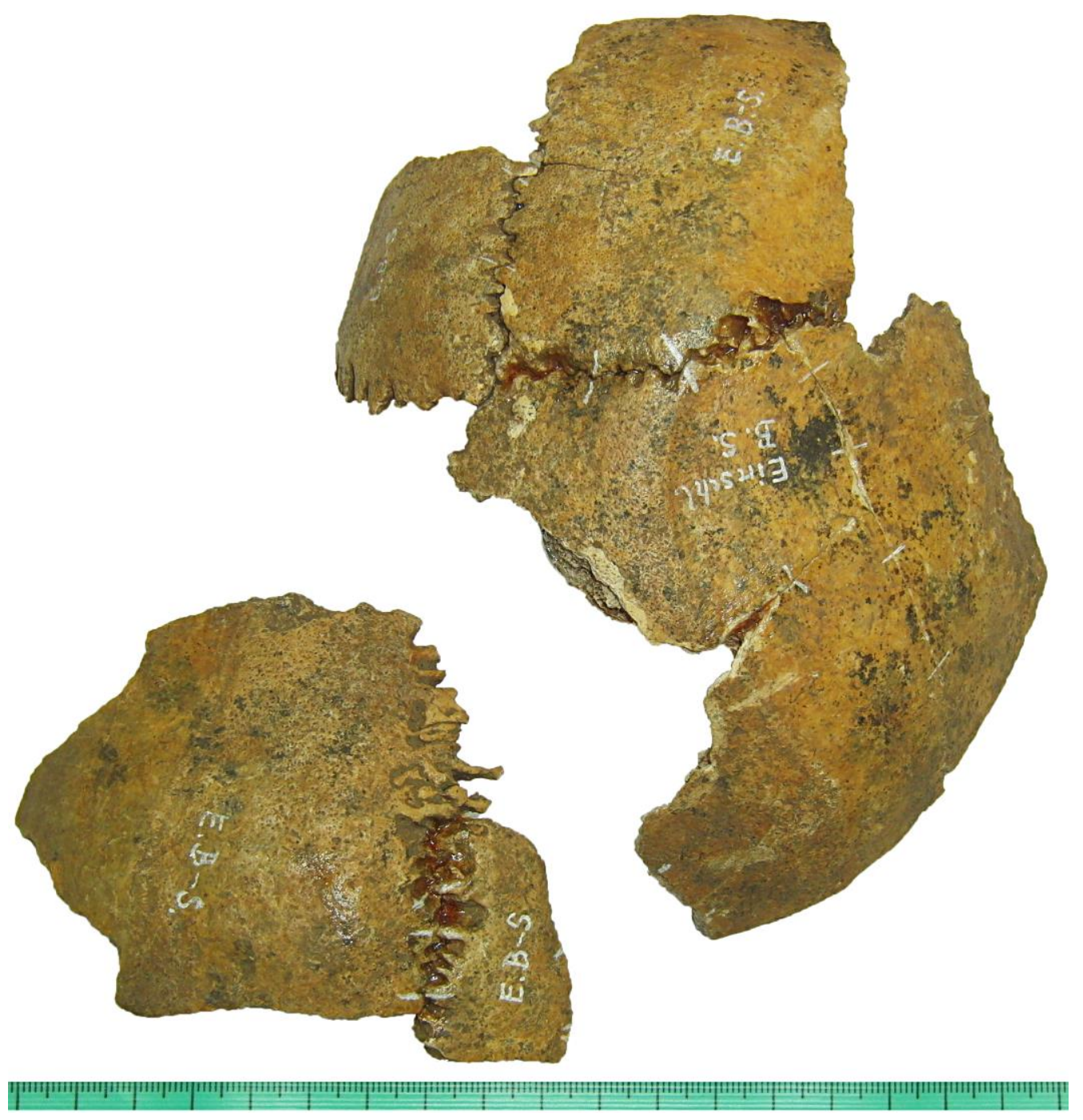

Abb. 1: Makroskopische Aufnahme der erhaltenen Schädelkompartimente von außen.

Bei der makroskopischen Betrachtung des Schliffs fällt auf, dass die Schädeldecke stellenweise sehr dick ausgeprägt war (bis $11 \mathrm{~mm}$ Dicke). Diese dicke Schädeldecke geht in einen Bereich über, in dem sie wieder normal dick erscheint. Dort ist die Diploë physiologisch und dünn ausgeprägt. Im dicken Bereich der Diploë konnte bei der lichtmikroskopischen Untersuchung eine Anämie vermutet werden, die aber offenbar bis zum Todeszeitpunkt ausgeheilt war. Differentialdiagnostisch wäre ein alter, verheilter, entzündlicher Prozess denkbar. Nicht in Frage kommen Skorbut oder Rachitis als Ursprung der ausgesprochen dicken Diploë. 


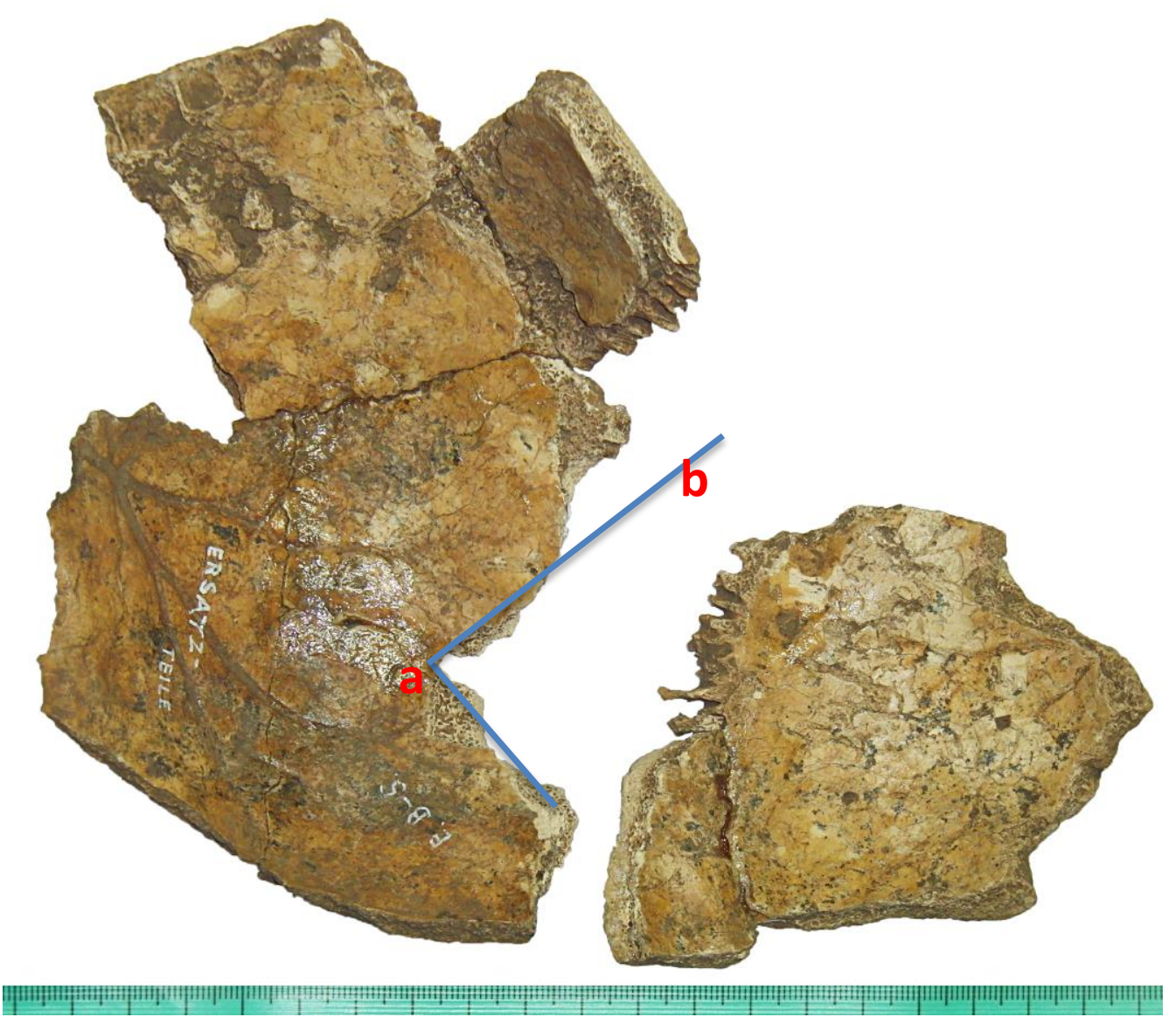

Abb. 2: Makroskopische Aufnahme der erhaltenen Schädelkompartimente von innen. Die blauen Linien markieren den ausgesägten Bereich, die Buchstaben die Schnittebene für den Dünnschliff.

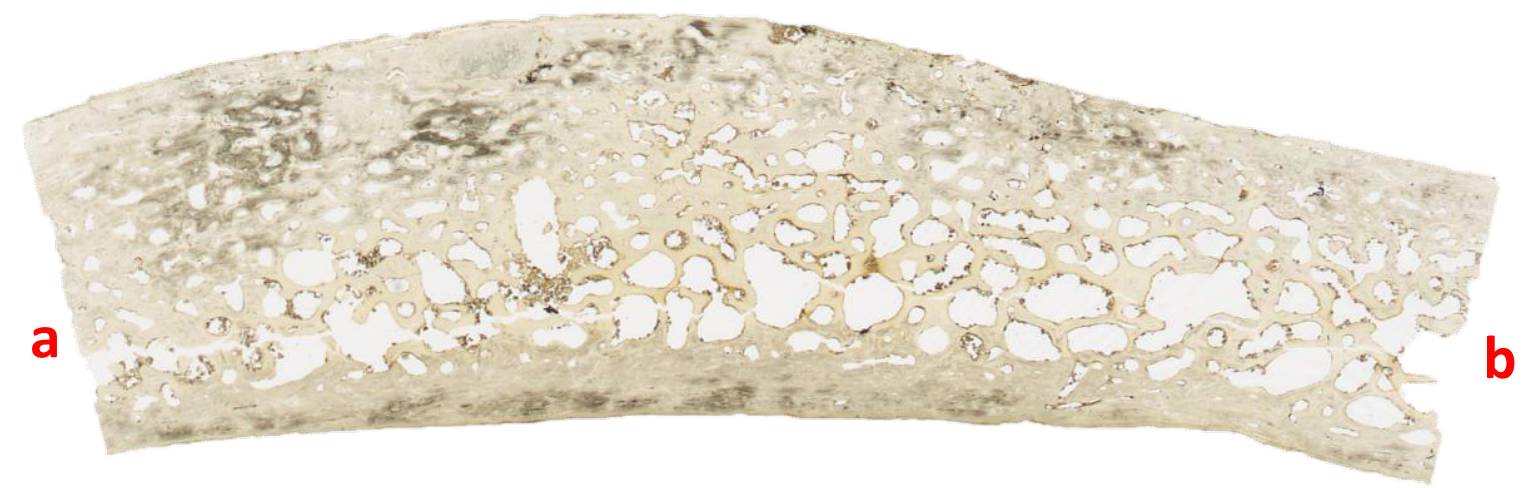

Abb. 3: Eingescannter Dünnschliff mit Buchstabenmarkierung zur Orientierung der Schnittebene im Vergleich zu der makroskopischen Aufnahme(Abb. 2). Oben im Bild befindet sich die Lamina externa.

Die Lamina interna (Abb. 14) dieses Schädeldaches ist lichtmikroskopisch betrachtet ohne pathologischen Befund. Die Lamina externa ist sehr dick ausgeprägt (Abb. 4), auch in den Arealen, in denen die Gesamtdicke der Schädeldecke dünner ist als die maximal gemessenen $11 \mathrm{~mm}$. Im lichtmikroskopischen Bild sind Zerfallshöhlen zu erkennen, die am Rand sichtlich versintert sind. Manche dieser Höhlen sind jedoch keine Zerfallshöhlen, sondern 
Resorptionshöhlen im Sinne des physiologischen Knochenremodellings mit Knochenresorption und -apposition (Abb. 6). Postmortale, „unechte“ Zerfallshöhlen könnten dadurch entstanden sein, dass Gefäßhöhlen durch Sand und andere im Boden vorhandene, erosive Stoffe postmortal abgerieben wurden. Dieses Phänomen zeigt sich im lichtmikroskopischen Bild mit typischen Merkmalen in Form von einer "Sägezahnstruktur", die den Innenrand ursprünglich physiologischer Höhlen im Knochen säumt (Abb. 6 und 7). Hier wurde postmortal Knochenmaterial durch erosive Stoffe im Boden abgeraspelt.

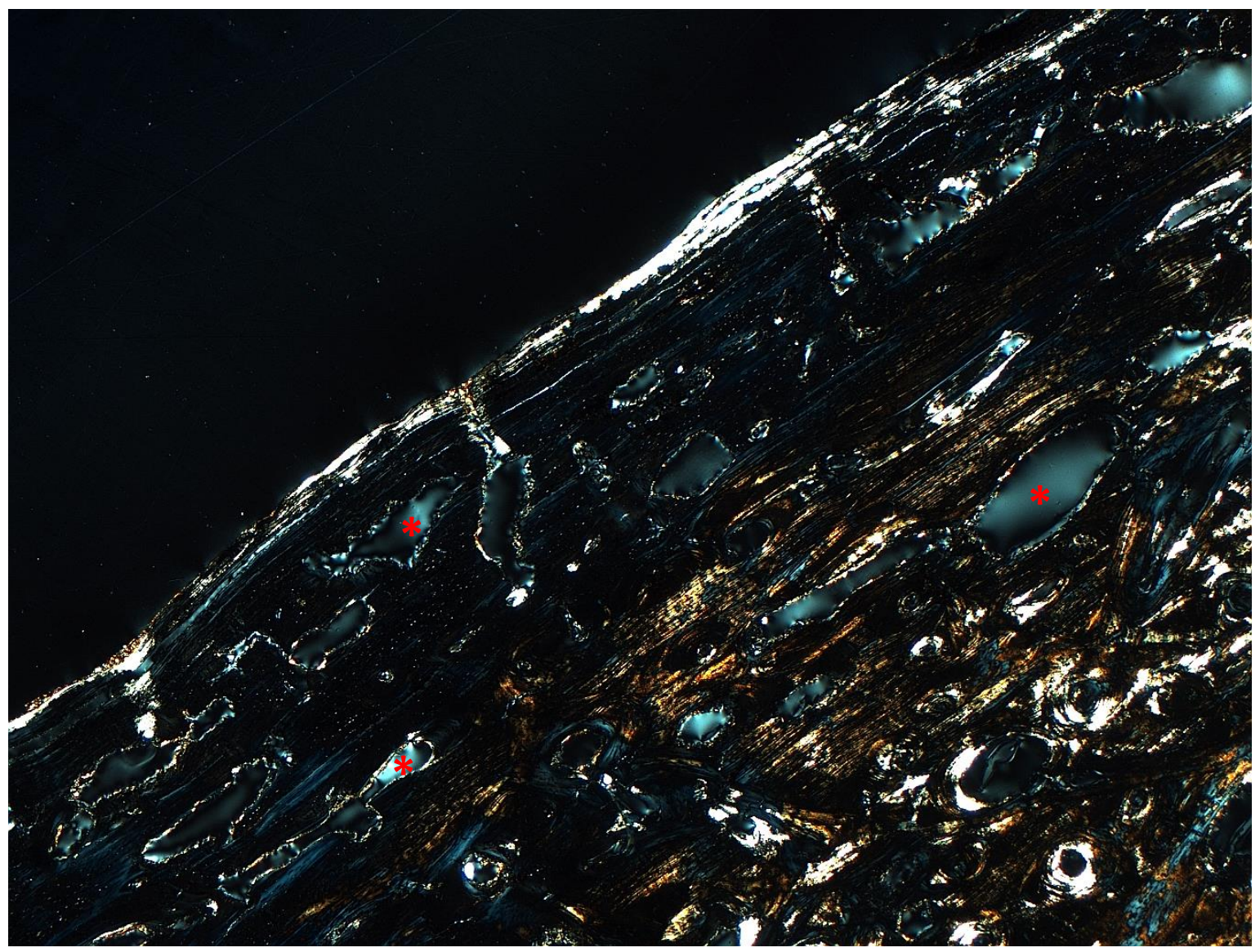

Abb. 4: Dünnschliffdicke $50 \mu \mathrm{m}$, Vergrößerung 25x; Lamina externa im polarisierten Durchlicht. Die physiologischen Knochenhöhlen sind innen durch Sandkristalle postmortal abgewetzt worden. Einige Kristalle lagerten sich am Rand der Höhlen ab und erscheinen im polarisierten Licht sehr hell. Das * markiert beispielhaft drei dieser Höhlen.

In Abb. 4 fallen die weißlichen, hell reflektierenden Randsäume der „echten“ und postmortalen Resorptionshöhlen auf. Hier haben sich postmortal kleine Kristalle im Sinne von kleinsten Sandkörnern abgelagert, die für die Erosionen verantwortlich waren. Sie brechen das Licht so, dass sie sich hell und weißlich darstellen. Doch nicht nur Sand hat die Resorptionshöhlen beschädigt, sondern auch Pilzfraß, der sich von in Kochen befindlichen Stoffen ernährt. Beispielhaft zeigen die Abbildungen 10 bis 13 (aufgenommen mit verschiedenen Belichtungen) einen sogenannten Pilzfraßtunnel, der mit Pflanzenwurzeln und Luft gefüllt ist; dadurch wirkt er sehr dunkel im lichtmikroskopischen Bild. 


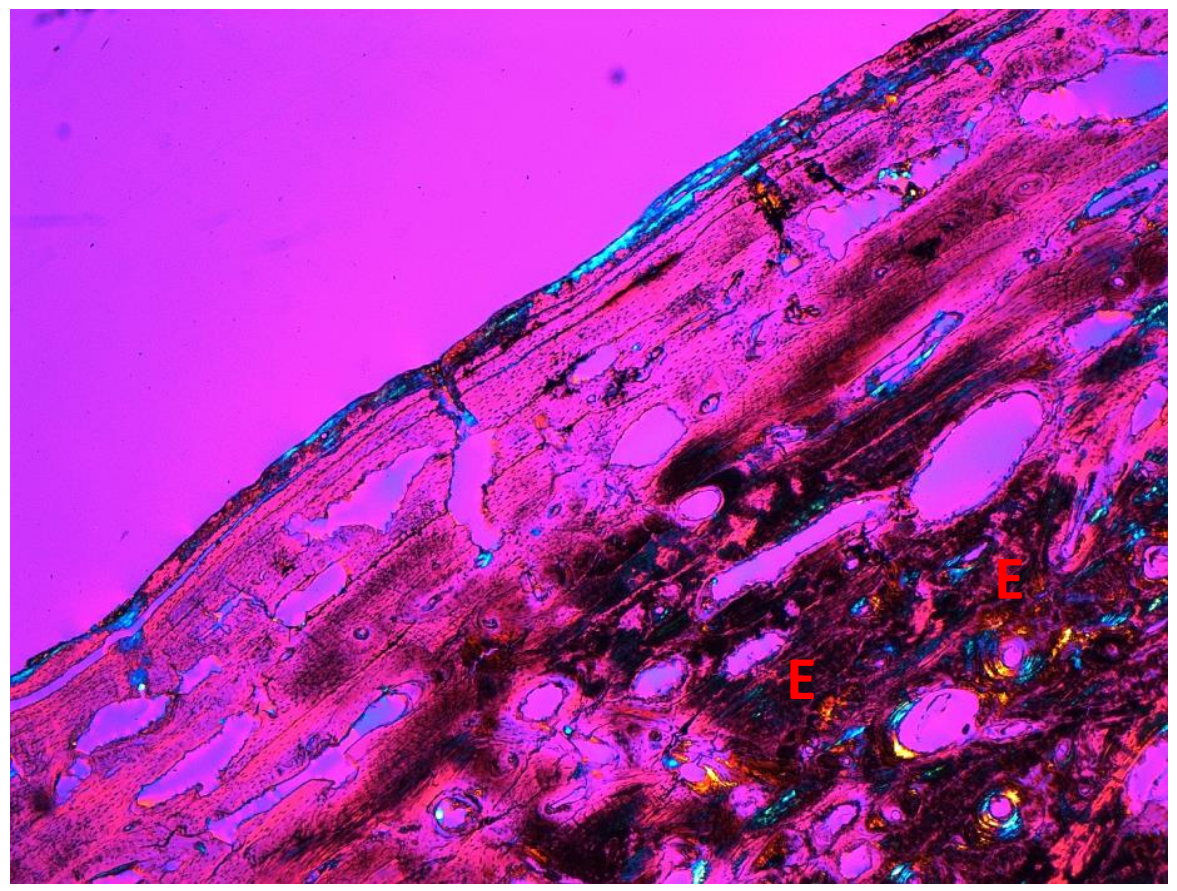

Abb. 5 Dünnschliffdicke $50 \mu \mathrm{m}$, Vergrößerung 25x; Bei der Aufnahme mit polarisiertem Durchlicht unter Verwendung eines Hilfsobjektes Rot 1. Ordnung (Quarz) als Kompensator zeigen sich durch Pilzfraß degradierte Gebiete dunkel (E).

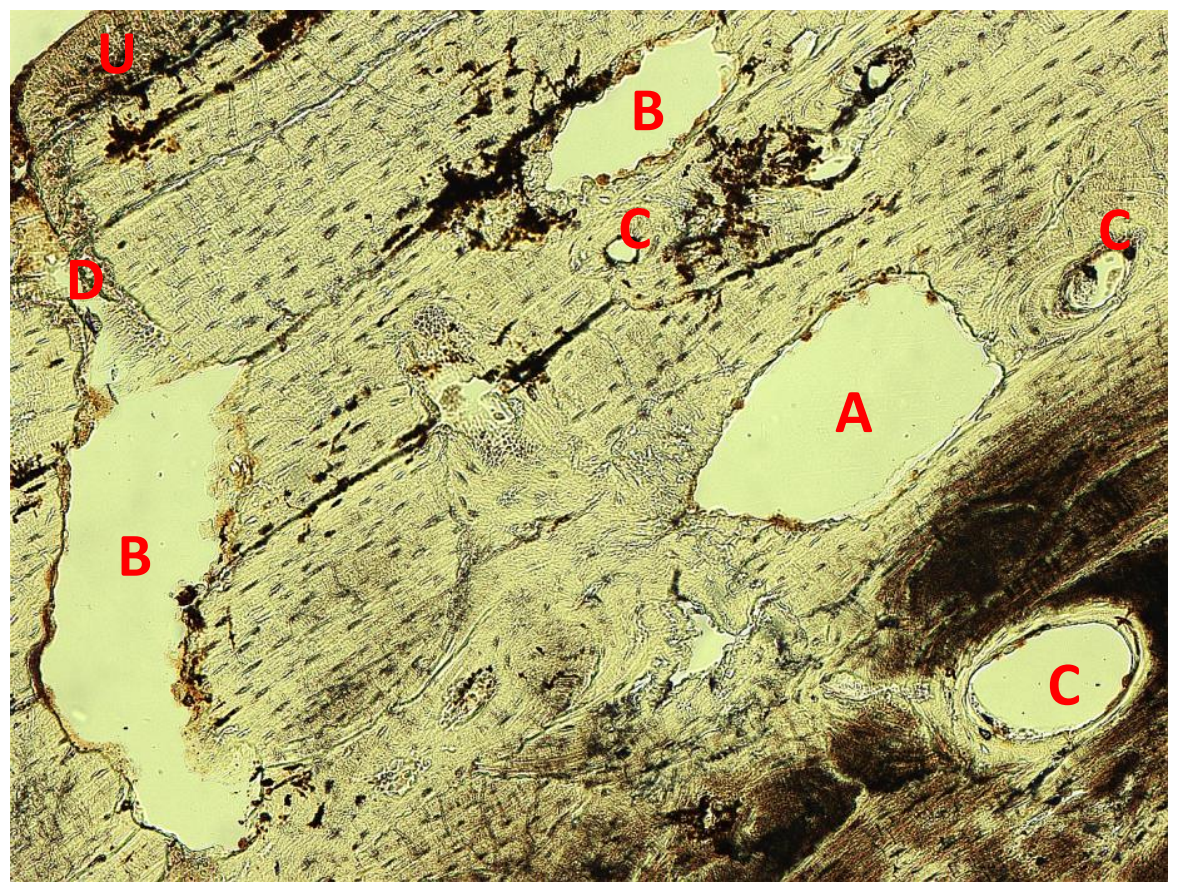

Abb. 6: Dünnschliffdicke $50 \mu m$, Vergrößerung 100x; Lamina externa im einfachen Durchlicht mit Graufilter. Buchstabenlegende: A: "echte", intravitale Resorptionslakune mit "Sägezahnstruktur", B: postmortale, "unechte" Resorptionslakune, C: Blutgefäß, D: kleiner Tunnel in der Lamina externa (U); es könnte sich um eine Pflanzenwurzel gehandelt haben, die hier im Knochen verankert war. Dieser Tunnel führt bis in eine der postmortalen Resorptionslakunen darunter.

In Abb. 6 sind mehrere „echte“ und „unechte“ Resorptionshöhlen zu erkennen. 


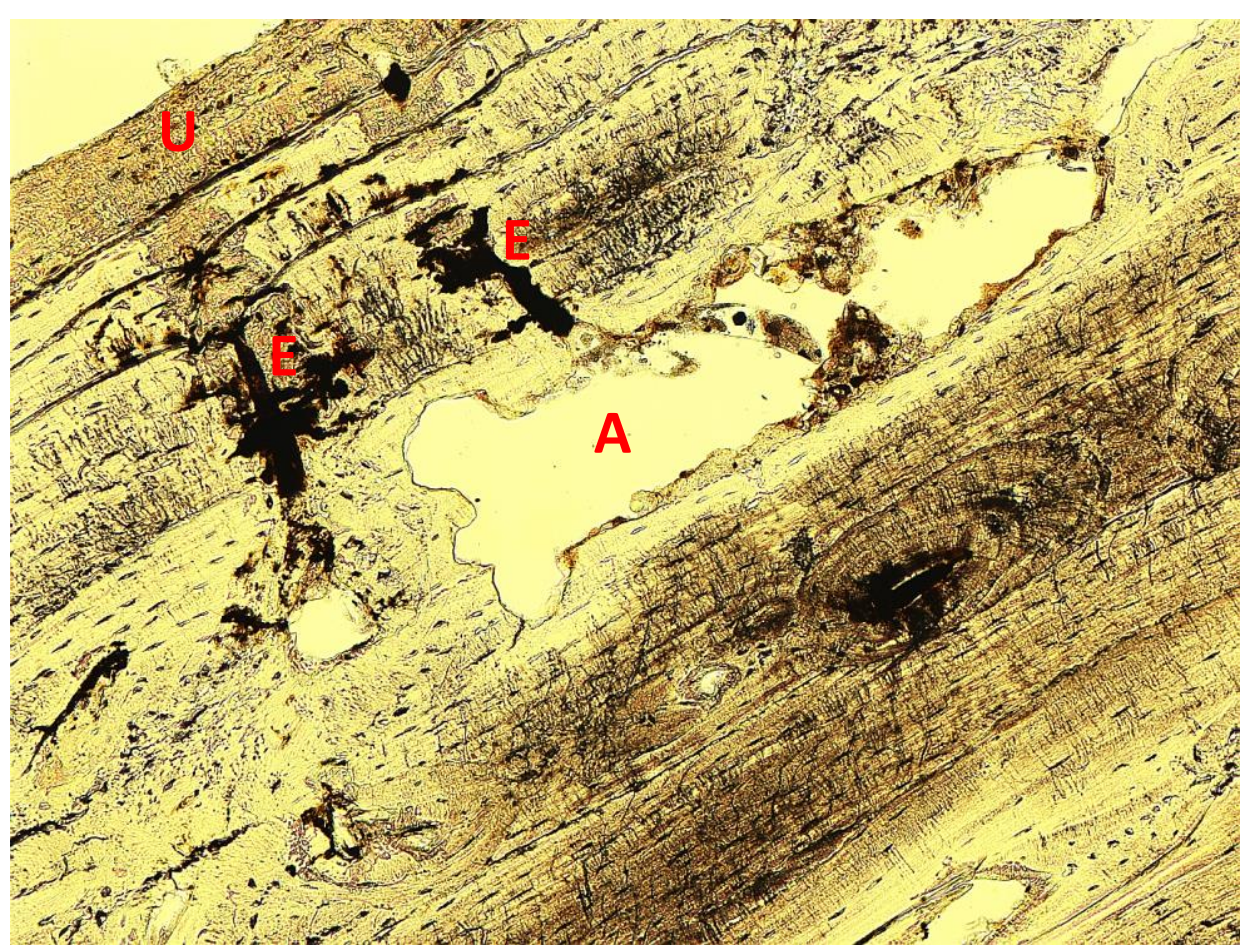

Abb. 7: Dünnschliffdicke $50 \mu \mathrm{m}$, Vergrößerung 100x, Aufnahme im einfachen Durchlicht; Buchstabenverzeichnis: A: intravitale Resorptionslakune (= Howshipsche Lakune), welche postmortal erosiv verändert wurde („Sägezahnstruktur“), U: Lamina externa, E: Pilzfraßtunnel.

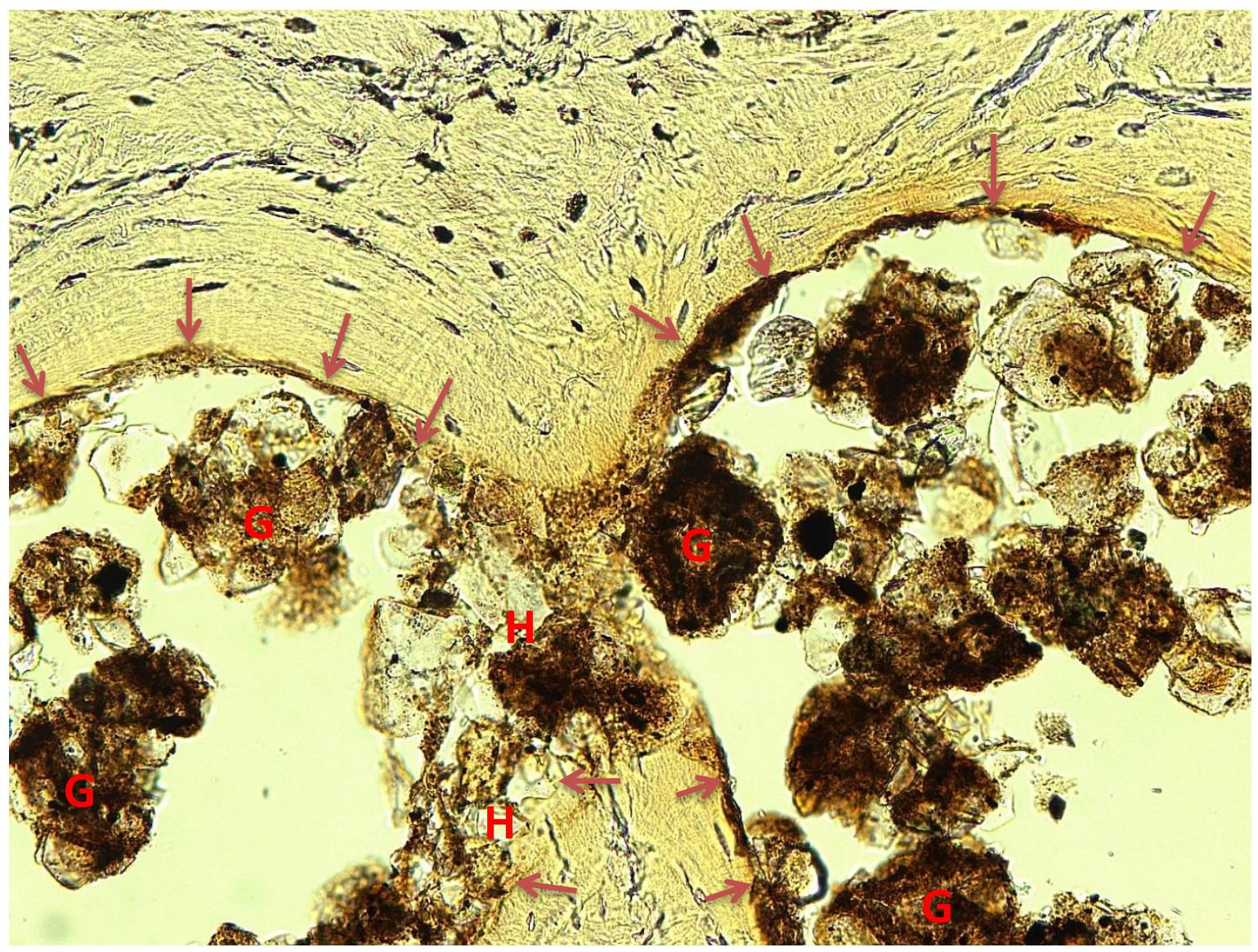

Abb. 8: Dünnschliffdicke $50 \mu m$, Vergrößerung 200x, Aufnahme im einfachen Durchlicht; die Pfeile markieren die Begrenzung des Lumens der Diploë. Buchstabenverzeichnis: G: Sand und organisches Material, die in der Diploë eingelagert sind und postmortal die knöcherne Begrenzung der Diploë erosiv beschädigten $(H)$. 


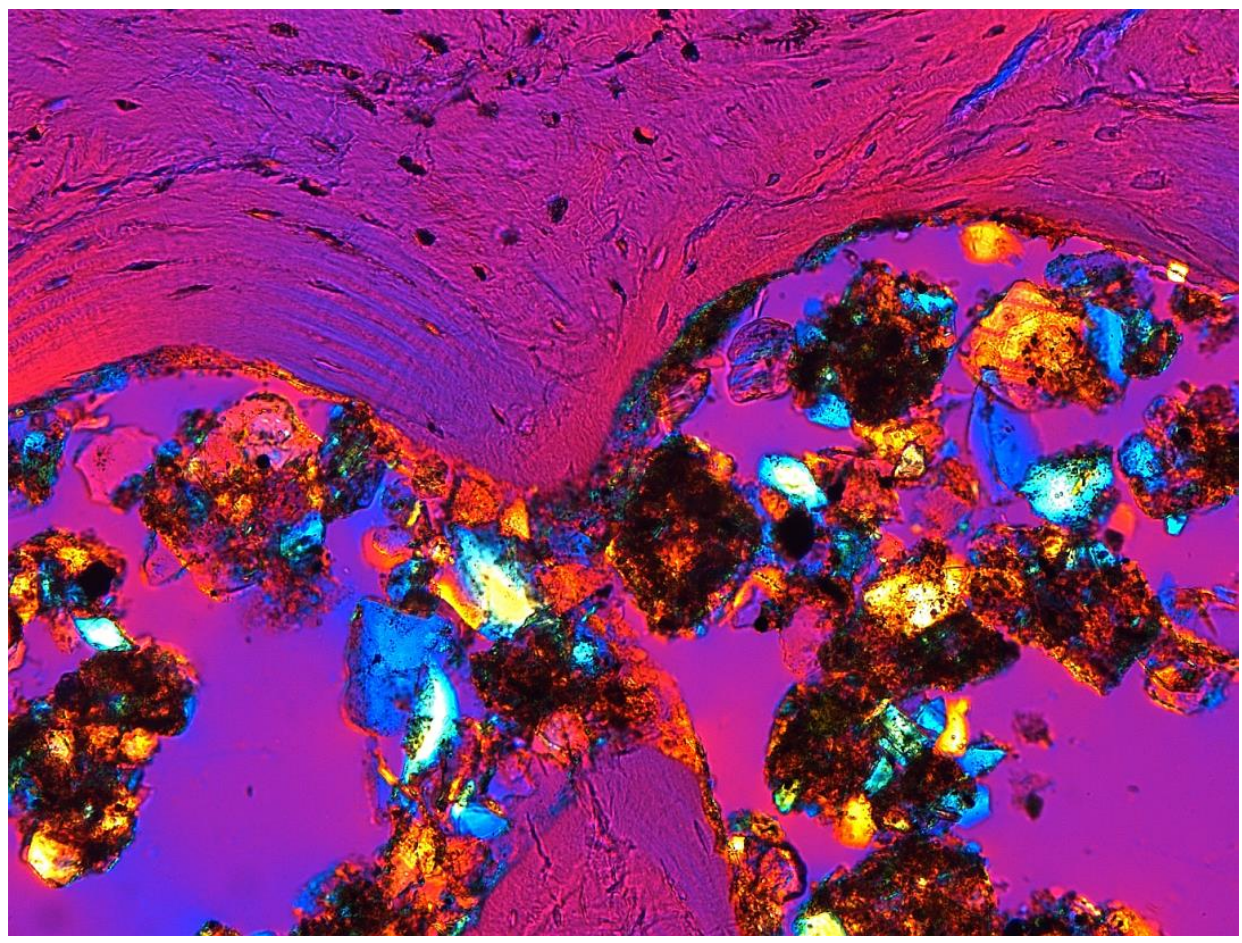

Abb. 9: Dünnschliffdicke $50 \mu m$, Vergrößerung 200x; Sandkristalle (Vgl. Abb. 8) im polarisierten Durchlicht unter Verwendung eines Hilfsobjektes Rot 1. Ordnung (Quarz) als Kompensator.

Auf den Abbildungen 8 und 9 ist zu erkennen, wie sich Sand und organisches Material in die Diploë eingelagert haben. Diese führten zu einer postmortalen Diagenese. Eine intravitale Veränderung scheint unwahrscheinlich. Die Diploë ist dünn und physiologisch ausgebildet.

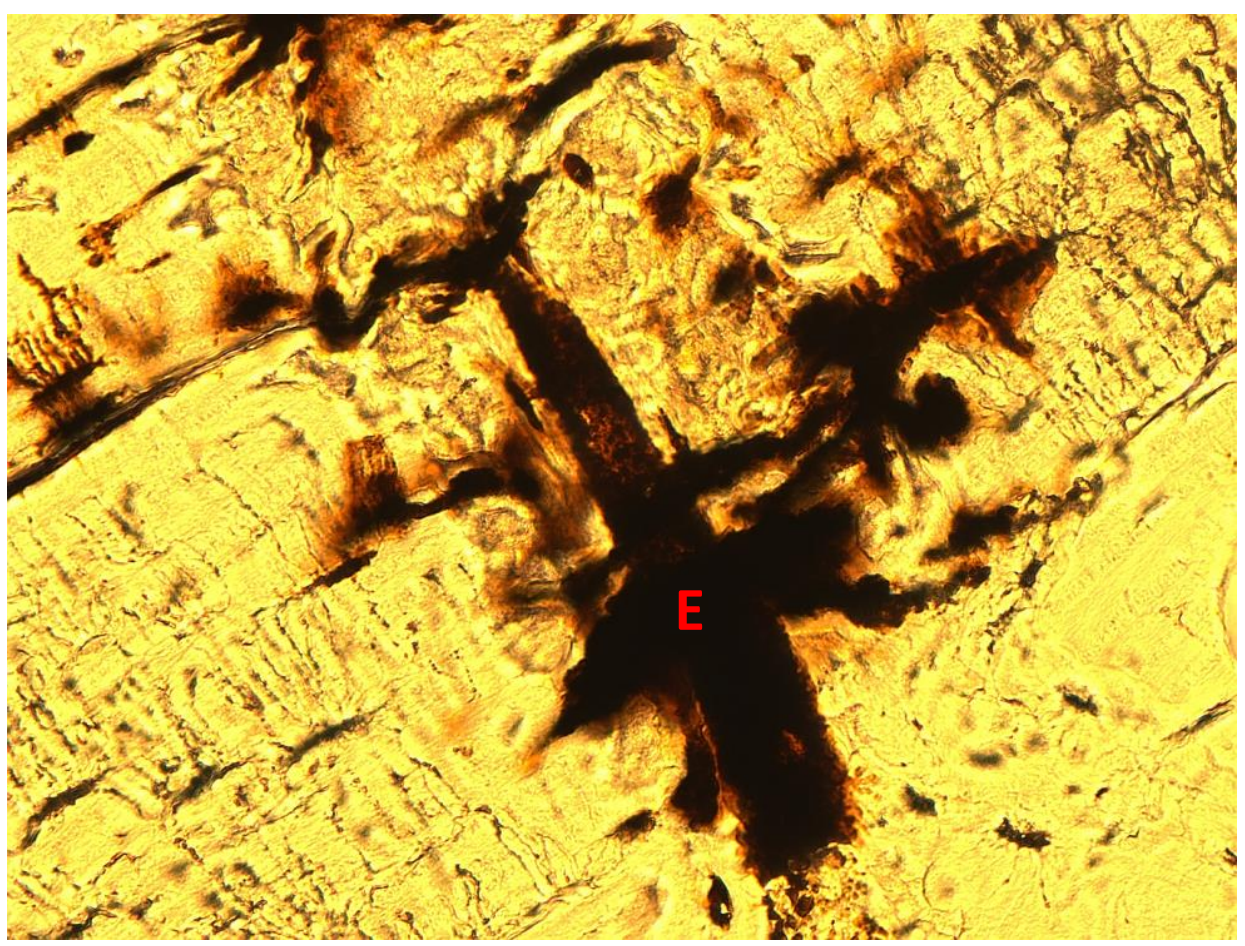

Abb. 10: Dünnschliffdicke $50 \mu \mathrm{m}$, Vergrößerung 400x, Aufnahme im einfachen Durchlicht; Abbildung eines Pilzfraßtunnels (E) in hoher Vergrößerung. Im Inneren finden sich Reste biologischen Materials (dunkel). 


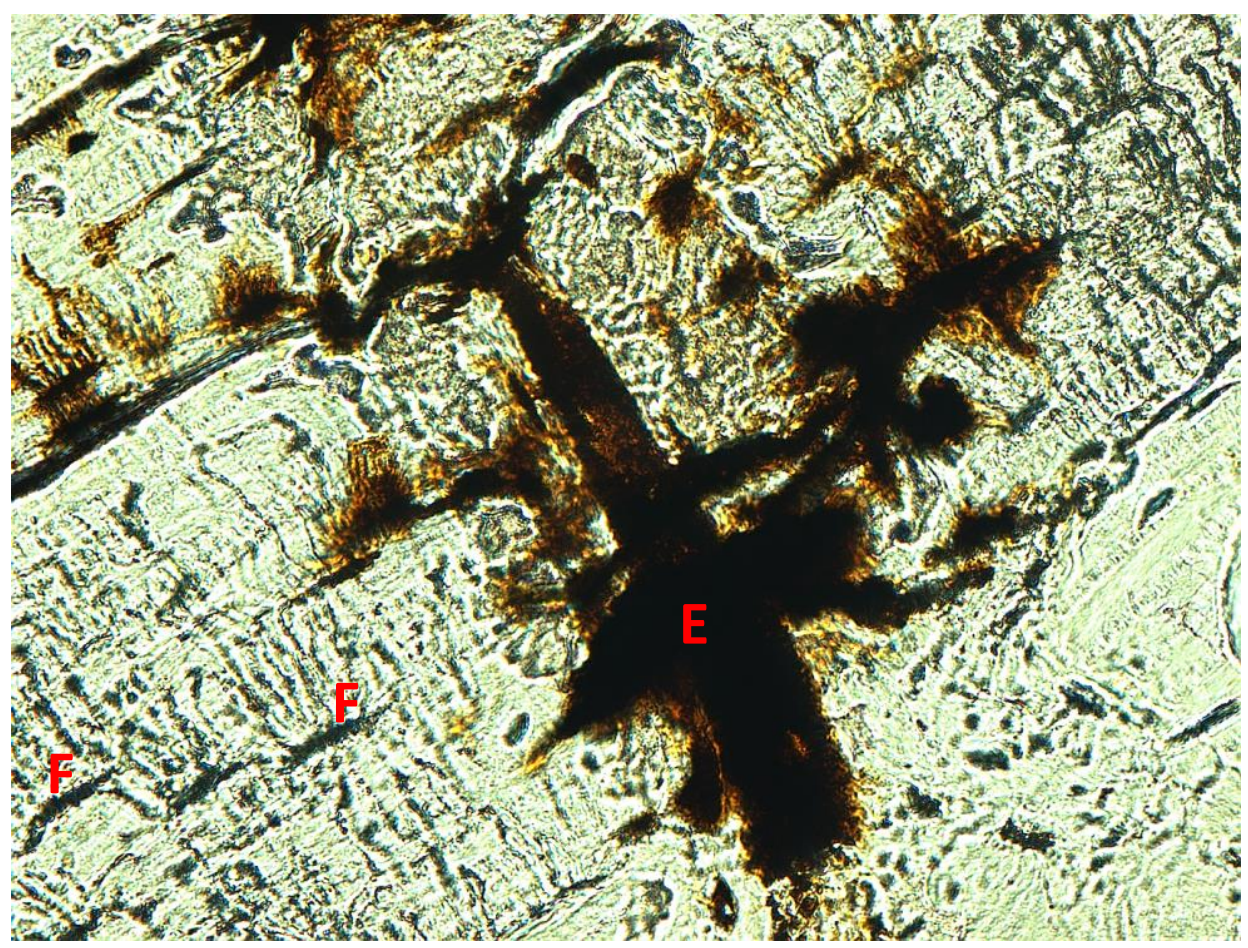

Abb. 11: Dünnschliffdicke $50 \mu m$, Vergrößerung 400x; Lamina externa aufgenommen im einfachen Durchlicht mit Graufilter. Buchstabenverzeichnis: E: Pilzfraßtunnel, F: Osteozytenlakunen.

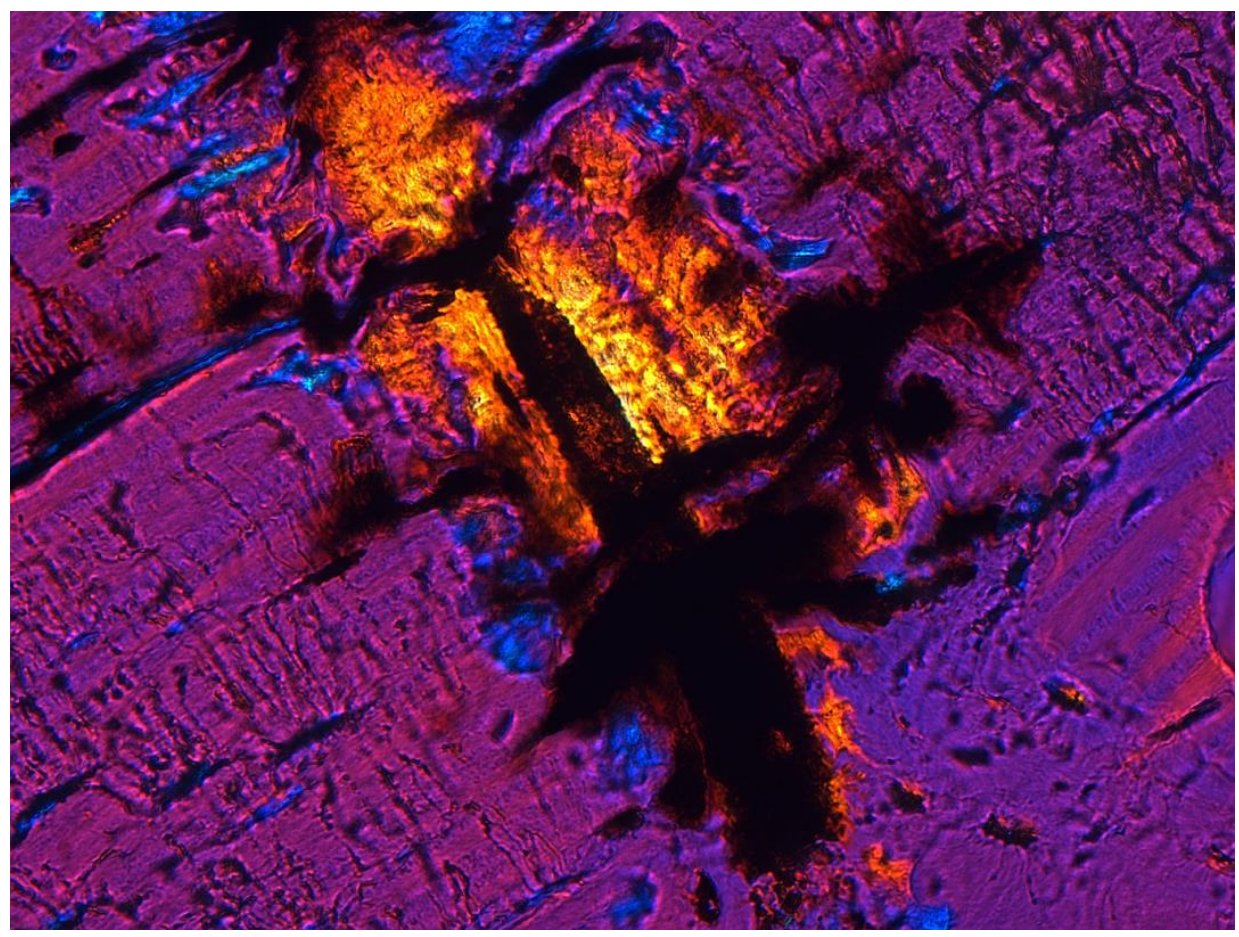

Abb. 12: Dünnschliffdicke $50 \mu \mathrm{m}$, Vergrößerung 400x; Pilzfraßtunnel (schwarzer Bereich) im polarisierten Durchlicht unter Verwendung eines Hilfsobjektes Rot 1. Ordnung (Quarz) als Kompensator.

Die Abbildungen 9 bis 12 zeigen den Pilzfraßtunnel in polarisiertem Licht. Die Belichtung wurde durch das Zuschalten einer Frontlinse beeinflusst (Abb. 12). Die 
Frontlinse erzeugt ein stärker belichtetes Bild auf Kosten eines schwächeren Kontrastes.

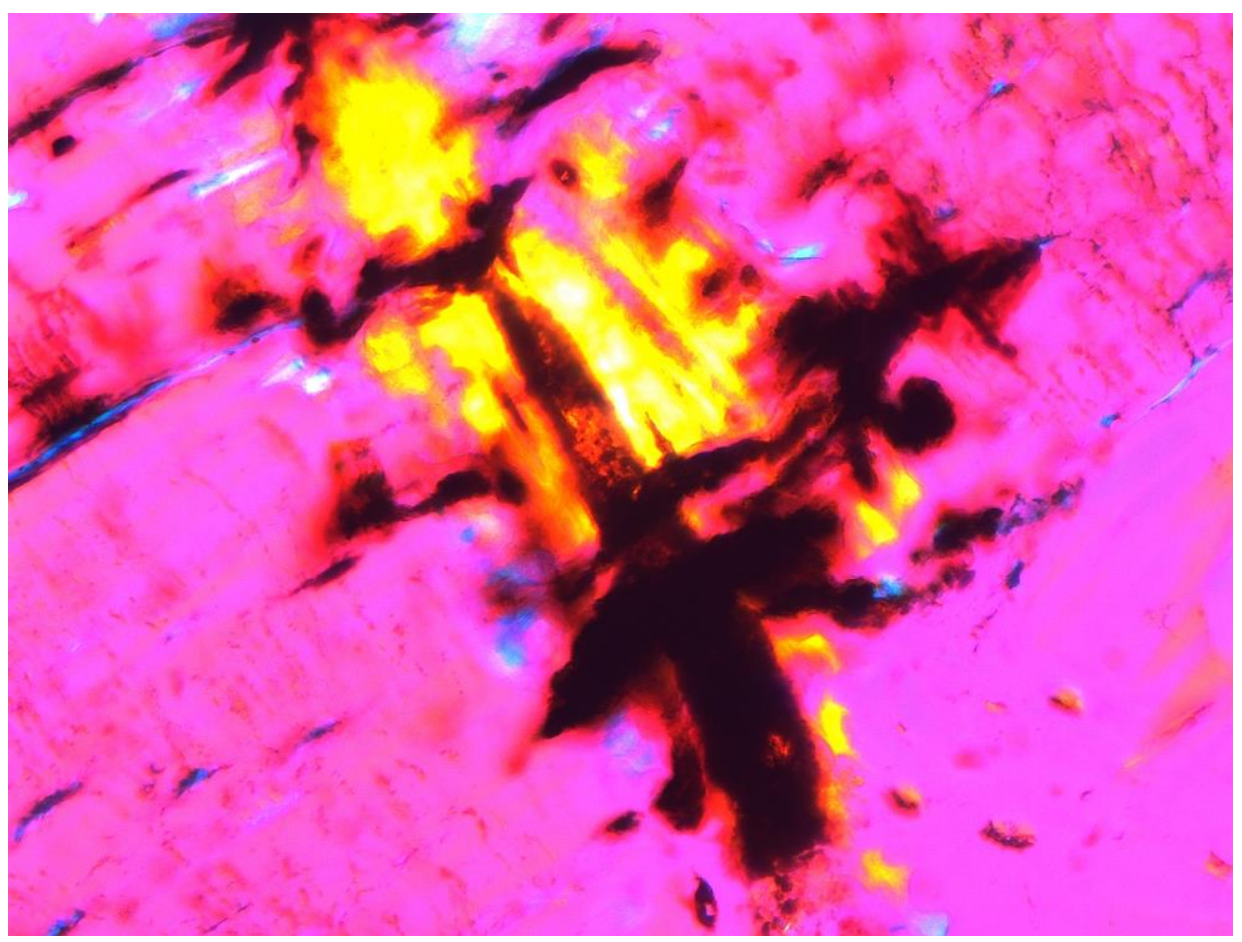

Abb. 13: Dünnschliffdicke $50 \mu m$, Vergrößerung 400x; Lamina externa im polarisierten Durchlicht mit Frontlinse unter Verwendung eines Hilfsobjektes Rot 1. Ordnung (Quarz) als Kompensator.

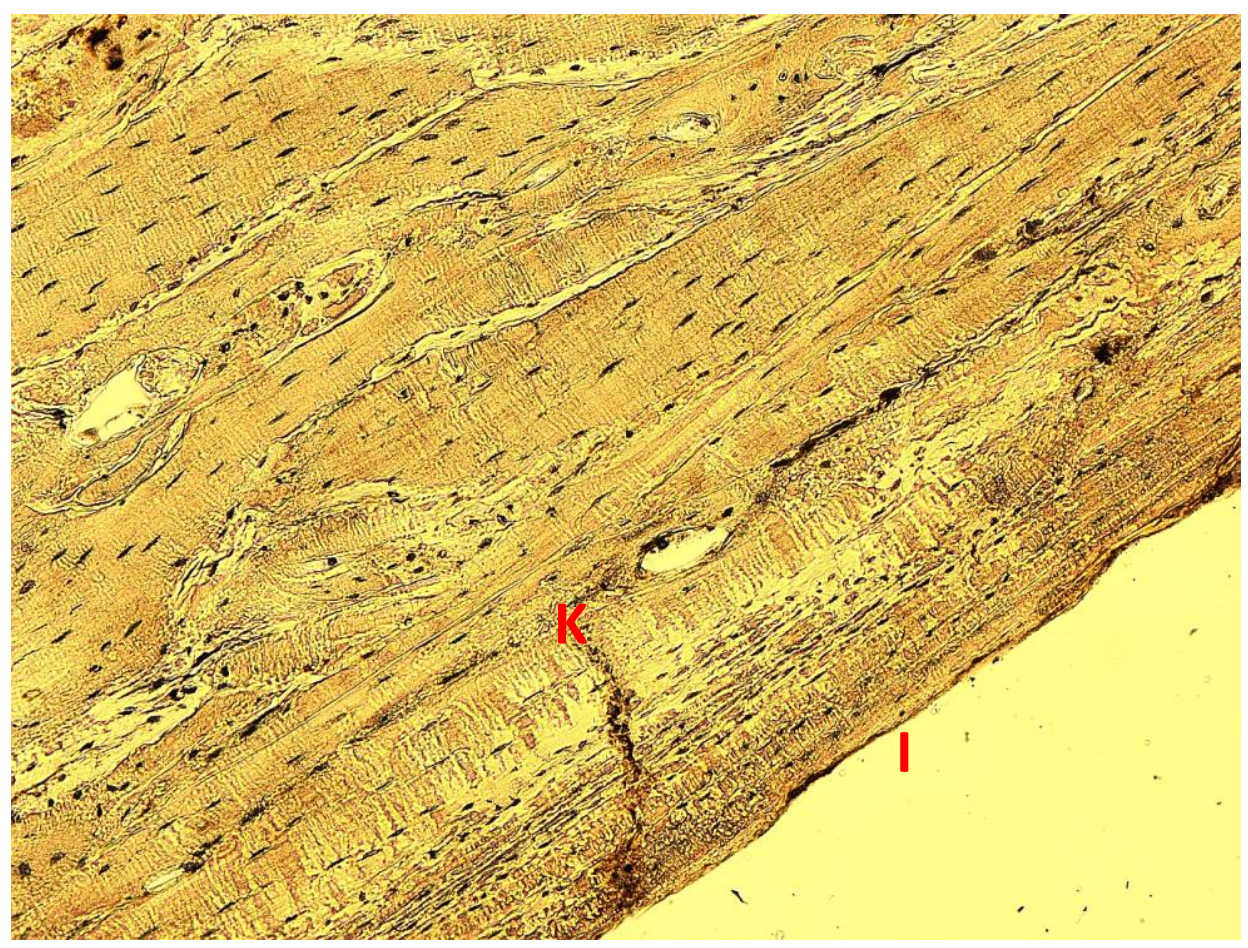

Abb. 14: Dünnschliffdicke $50 \mu m$, Vergrößerung 100x, Aufnahme im einfachen Durchlicht; Buchstabenverzeichnis: I: Lamina interna, K: Riss in der Knochenstruktur. Dieser ist ein Zeichen postmortaler Degradation.

In Abb. 14 ist die Lamina interna gut zu erkennen; es ist keine intravitale, pathologische Veränderung festzustellen. Zu sehen sind die postmortalen Schäden 
durch Bodenerosion und -druck. Auch in den Abbildungen 15 und 16 sind keine Unregelmäßigkeiten der Lamina interna im polarisierten Durchlicht zu erkennen.

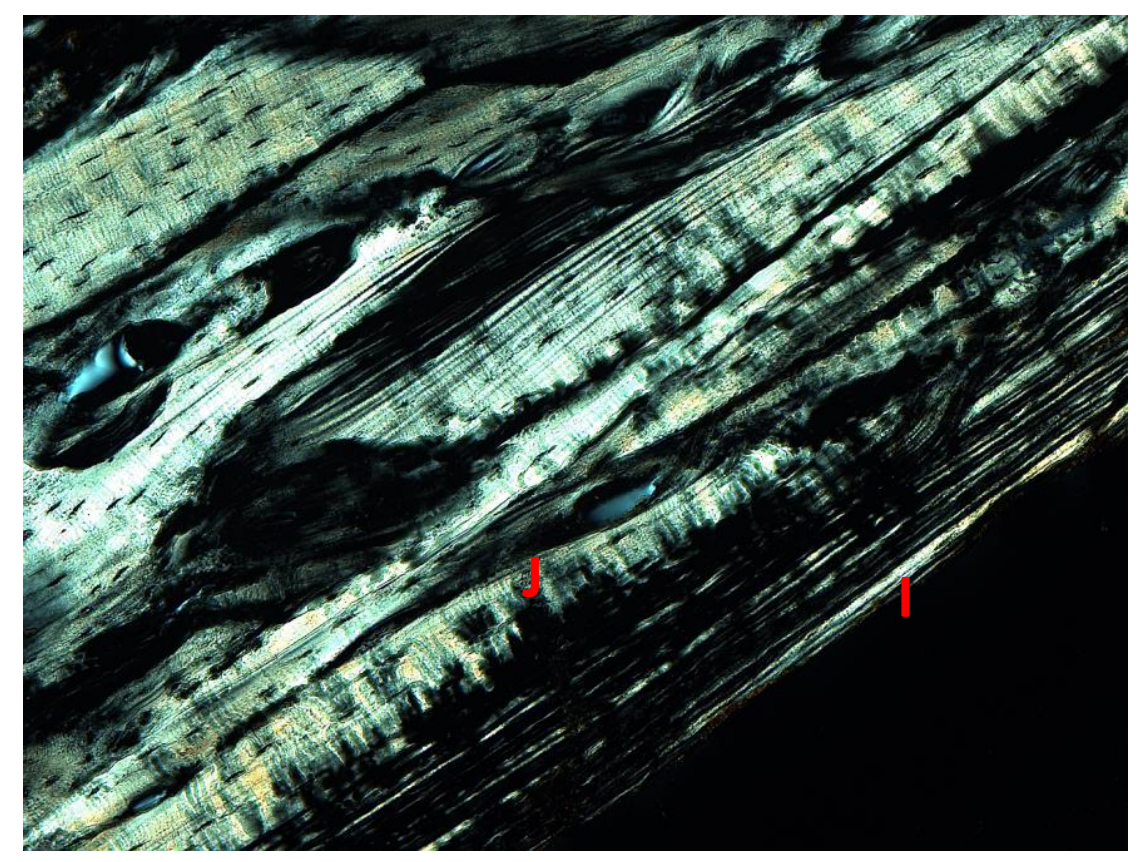

Abb. 15: Dünnschliffdicke $50 \mu \mathrm{m}$, Vergrößerung 100x; Lamina interna im polarisierten Durchlicht; Buchstabenverzeichnis: I: Lamina interna, J: zapfenförmige Degradation.

Im Detail sind in Abb. 15 und 16 die zapfenförmigen Diageneseerscheinungen der Lamina interna zu erkennen. Bodenstoffe und Sandkristalle sind in die Knochenstruktur eingedrungen und haben diese Struktur durch Erosion des Kollagens hervorgerufen.

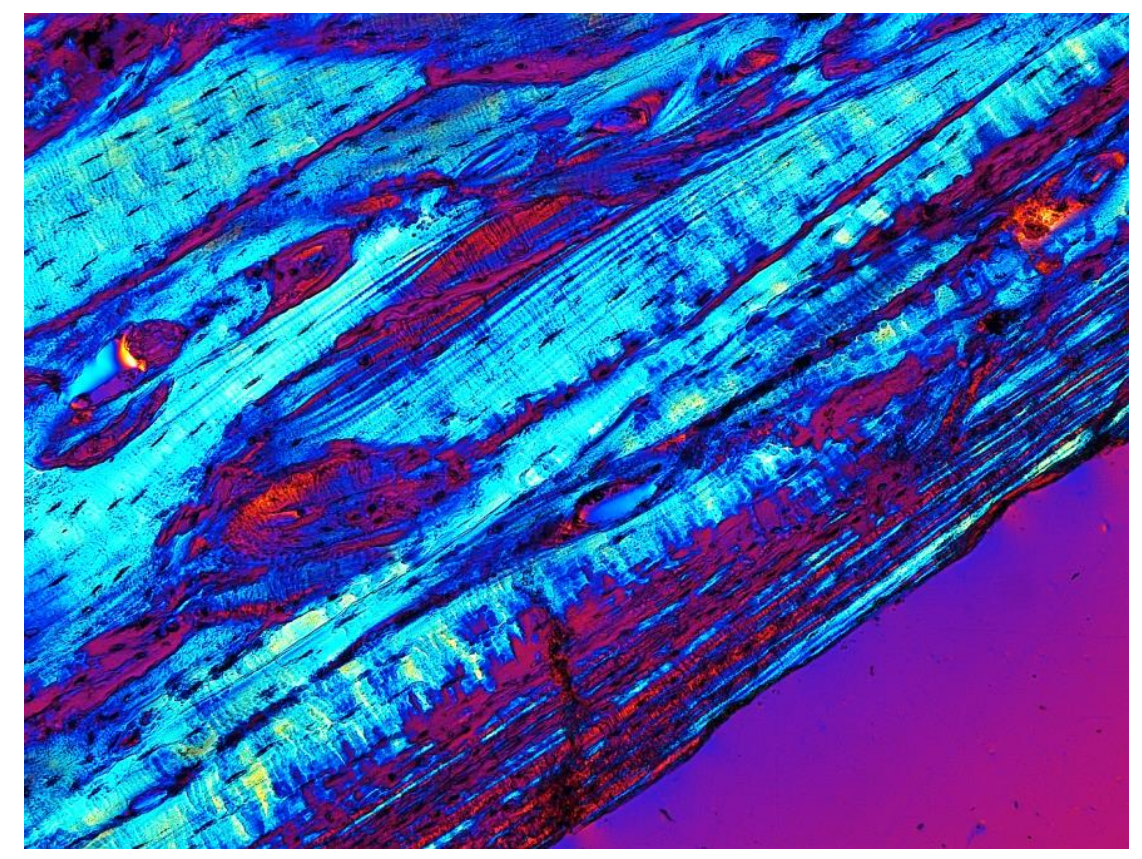

Abb. 16: Dünnschliffdicke $50 \mu m$, Vergrößerung 100x; Lamina interna mit Zapfenstruktur (Vgl. Abb. 15) im polarisierten Durchlicht unter Verwendung eines Hilfsobjektes Rot 1. Ordnung (Quarz) als Kompensator. 


\subsection{Lichtmikroskopischer Befund 7 der Population aus Calden}

Dieser Knochendünnschliff entstammt dem lateralen Condylus eines linken Os femoris. Makroskopisch waren eine Frakturlinie und ein im Bruchspalt „versinterter" Bereich erkennbar. Die Fragestellung zu diesem Fundstück bezieht sich auf den Ursprung der Fraktur, nämlich ob es sich um eine postmortale oder intravitale handelt. Es wurden insgesamt vier Dünnschliffe aus zwei verschiedenen Bereichen des Fundstücks angefertigt (8.23 und 8.24). In den zwei Präparaten aus dem ersten Bereich waren keine Hinweise auf osteologische Neubildungen zu finden. Auch ein osteoklastischer Knochenabbau war nicht nachzuweisen.

Der Dünnschliff entstammt demselben Fundstück wie die Probe 8 (Vgl. 8.24) aus Calden.

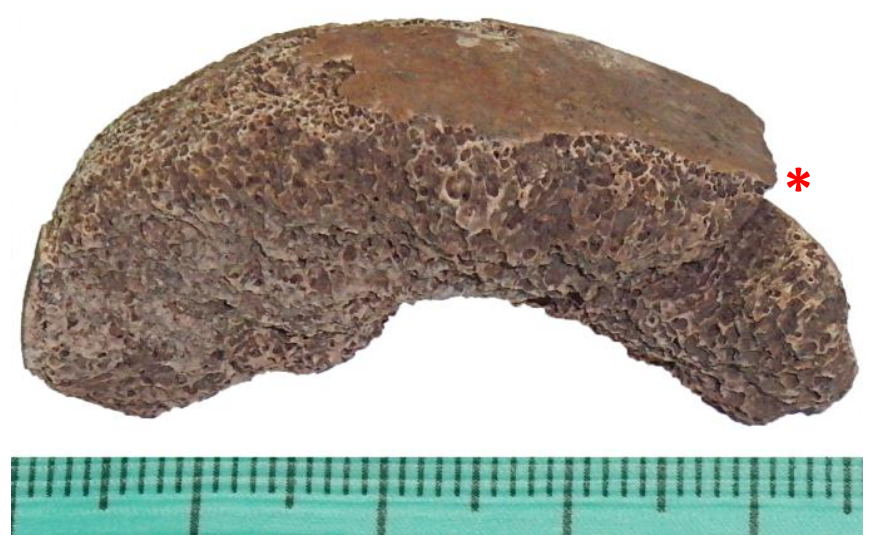

Abb. 1: Fotografie des Condylus von medial; oben im Bild befindet sich die Gelenkfläche, rechts im Bild ist anterior. Der Frakturspalt ist markiert ${ }^{*}$ ).

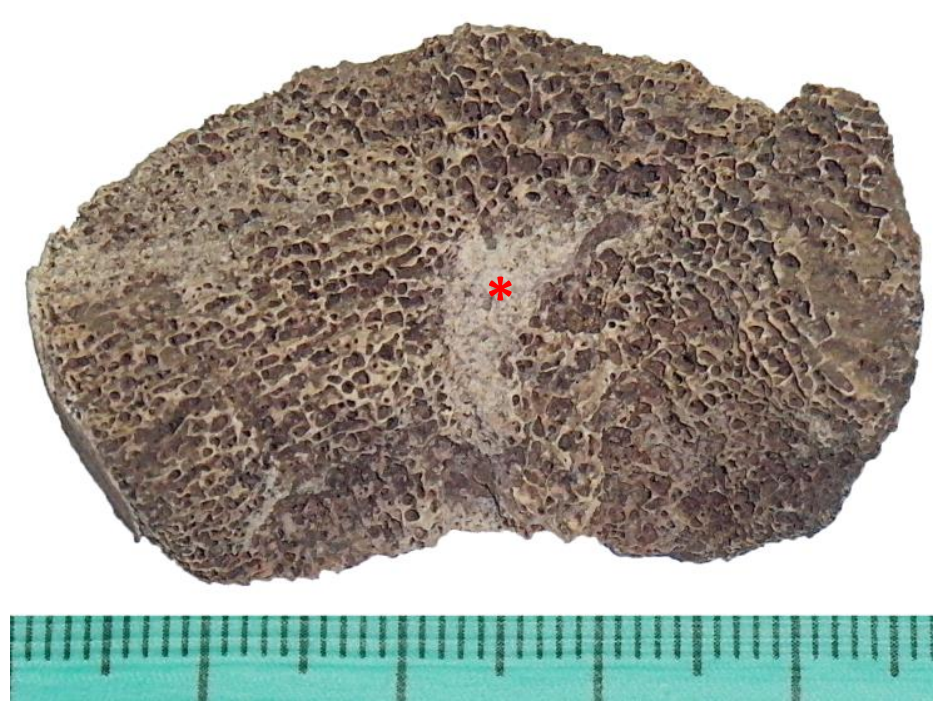

Abbildung 2: Fotografie des Condylus von cranial; zu sehen ist der "Versinterungsbereich", in dem die Spongiosastruktur zusammengestaucht ist $\left(^{*}\right)$. Rechts im Bild ist anterior. 


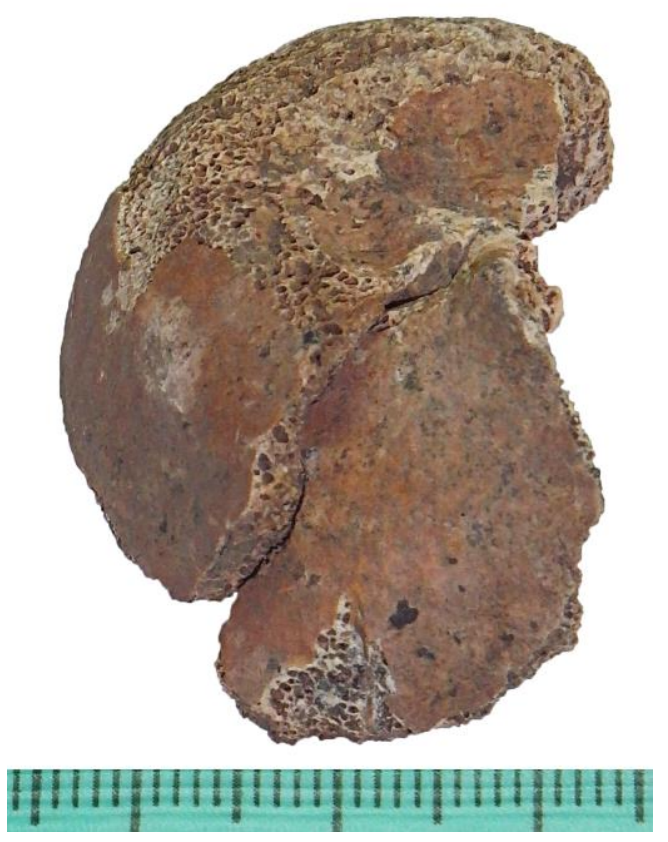

Abb. 3: Fotografie von lateral - anterior; oben befindet sich die laterale Seite des Condylus.

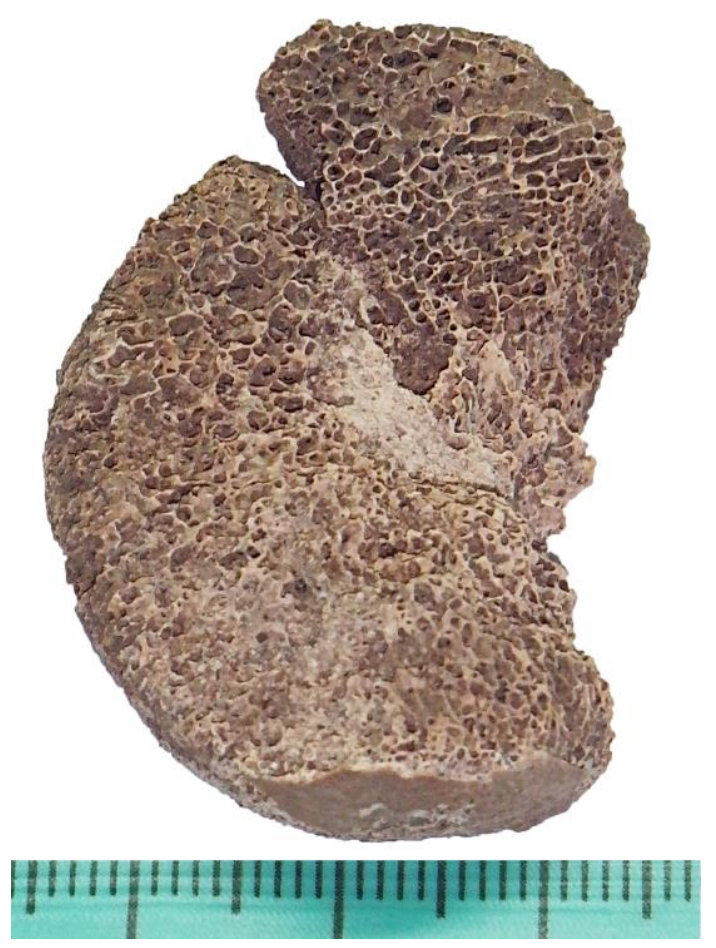

Abb. 5: Fotografie von medial - cranial; oben befindet sich die mediale, abfrakturierte Seite des Condylus.

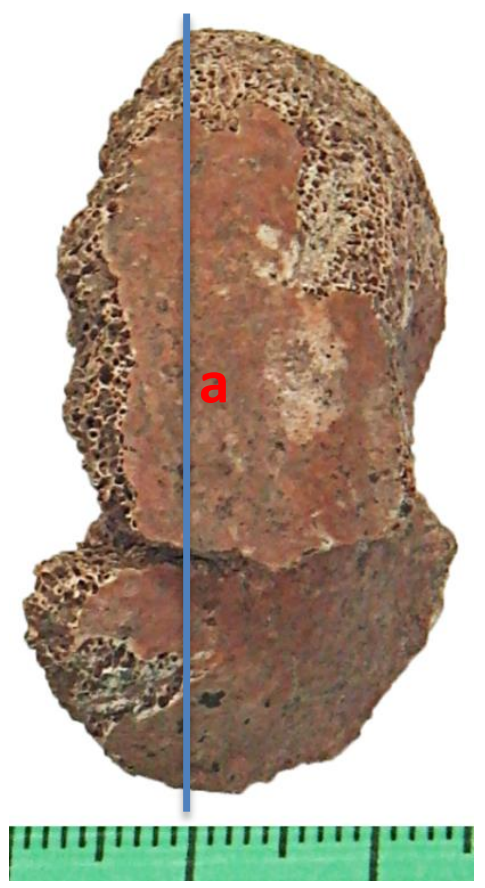

Abb. 4: Abbildung des Fundstücks mit in blau eingezeichneter Schnittebene; rechts im Bild ist lateral. Buchstabe a markiert den Bereich oberhalb des Frakturspalts, (Vgl. Abb. 9).

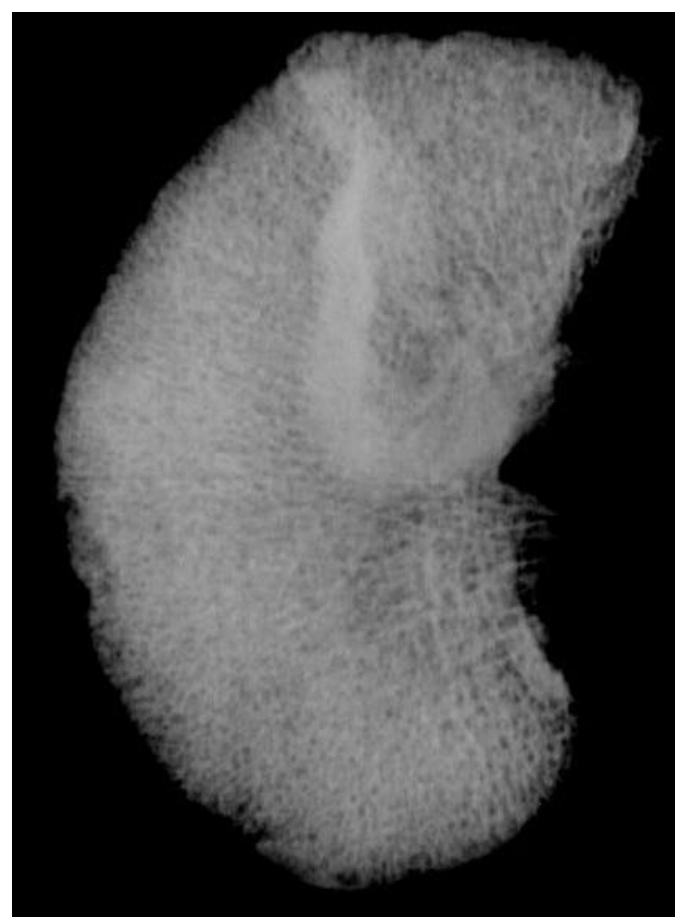

Abb. 6: Röntgenaufnahme in ungefährer Position von Abb. 5. 


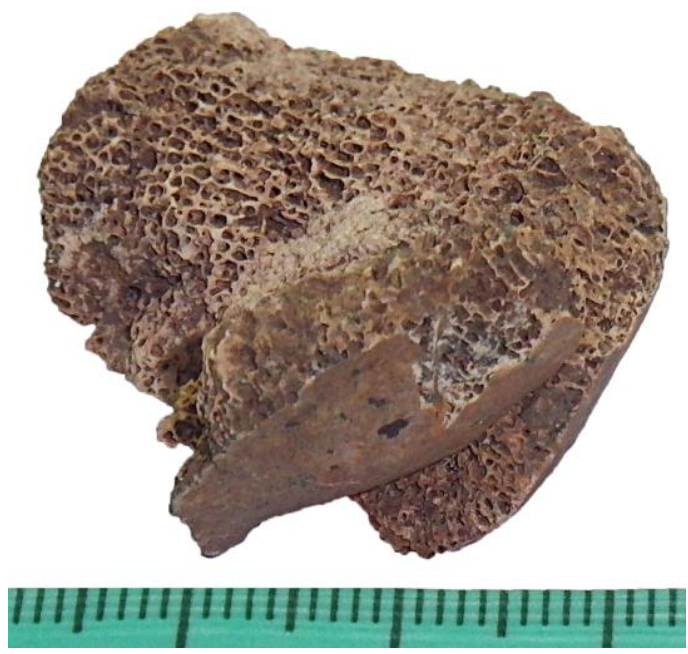

Abb. 7: Fotografie von anterior; rechts im Bild befindet sich die Gelenkfläche, oben der mediale Bereich des lateralen Condylus.

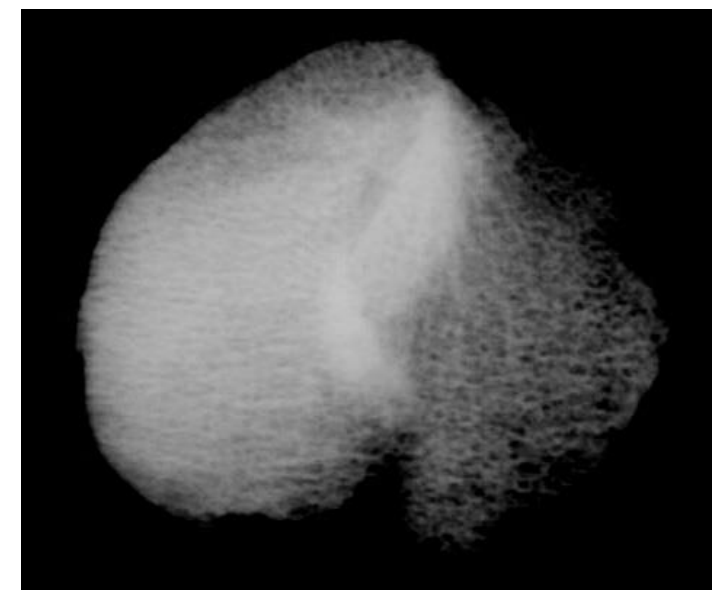

Abb. 8: Röntgenaufnahme in ungefährer Position von $A b b .7$.

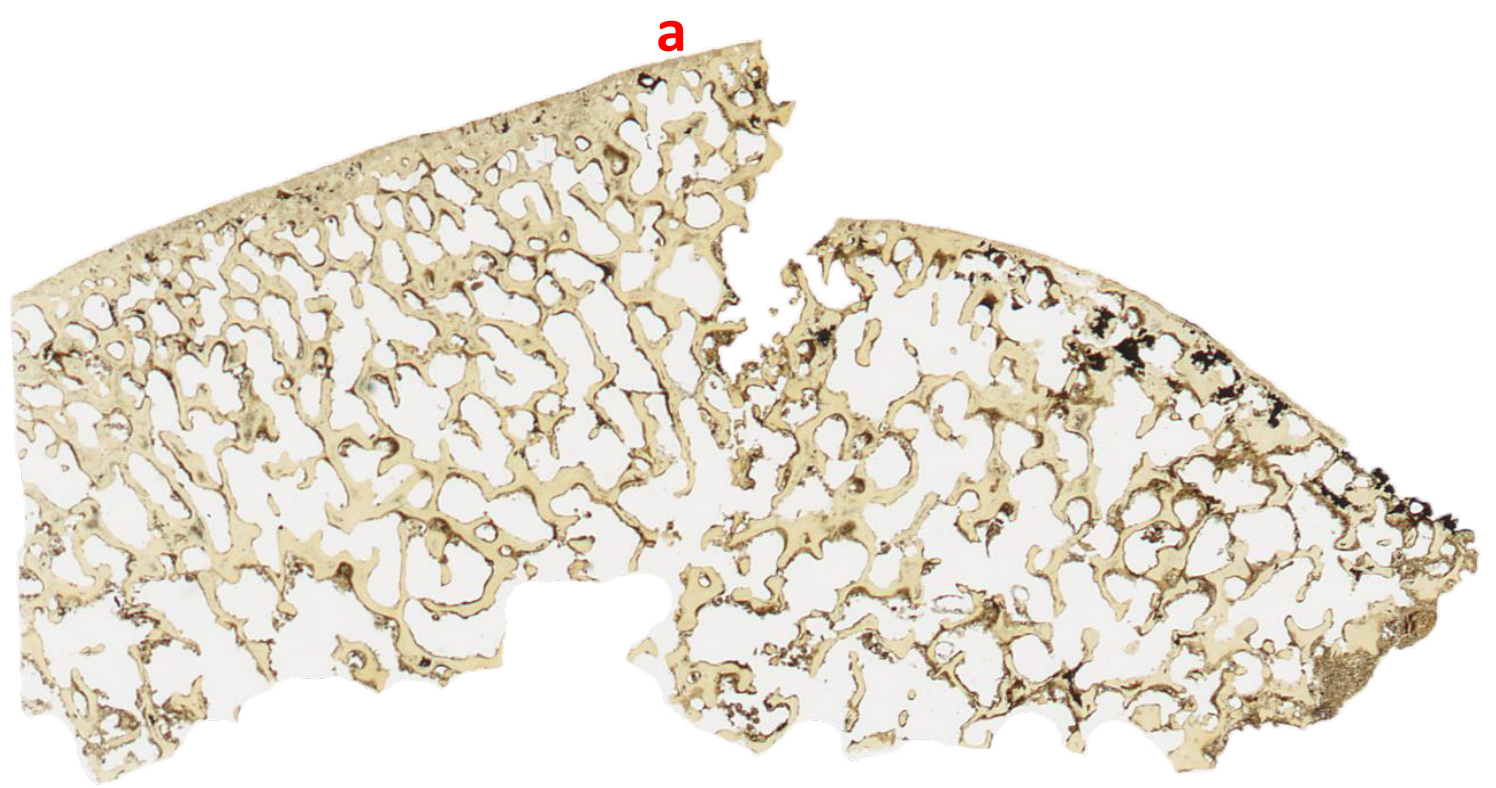

Abb. 9: Eingescannter Dünnschliff; Buchstabe a markiert zur Orientierung die Gelenkfläche wie in der makroskopischen Aufnahme (Abb. 3).

In den Abbildungen 10 und 11 ist mineralisierter Gelenkknorpel im Bereich der Gelenkfläche sichtbar. Diese Schicht ist intravital erhalten gewesen, was für einen geringen Gelenkverschleiß spricht. 


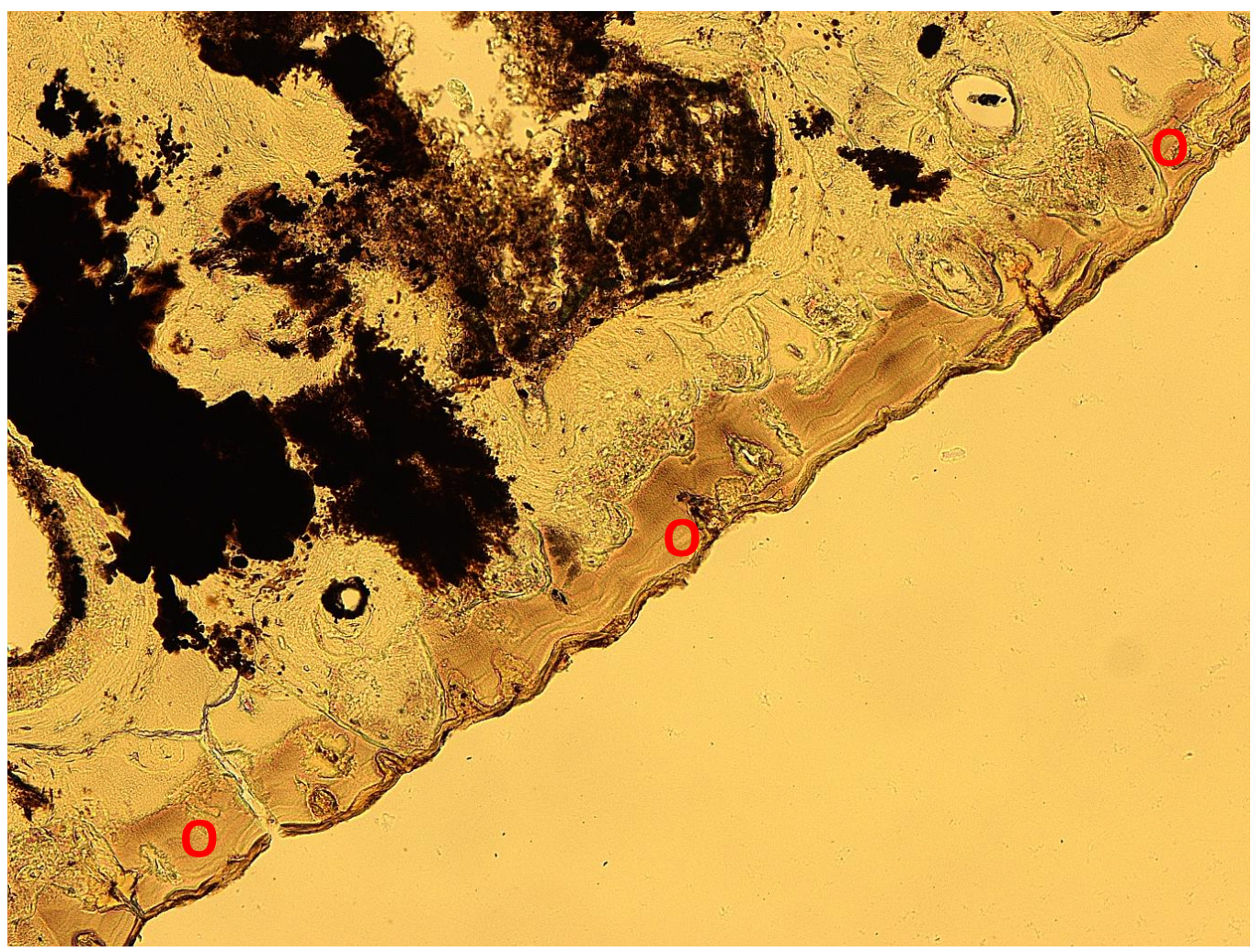

Abb. 10: Dünnschliffdicke $50 \mu m$, Vergrößerung 100x, Aufnahme im einfachen Durchlicht; Buchstabenverzeichnis: O: mineralisierter Gelenkknorpel.

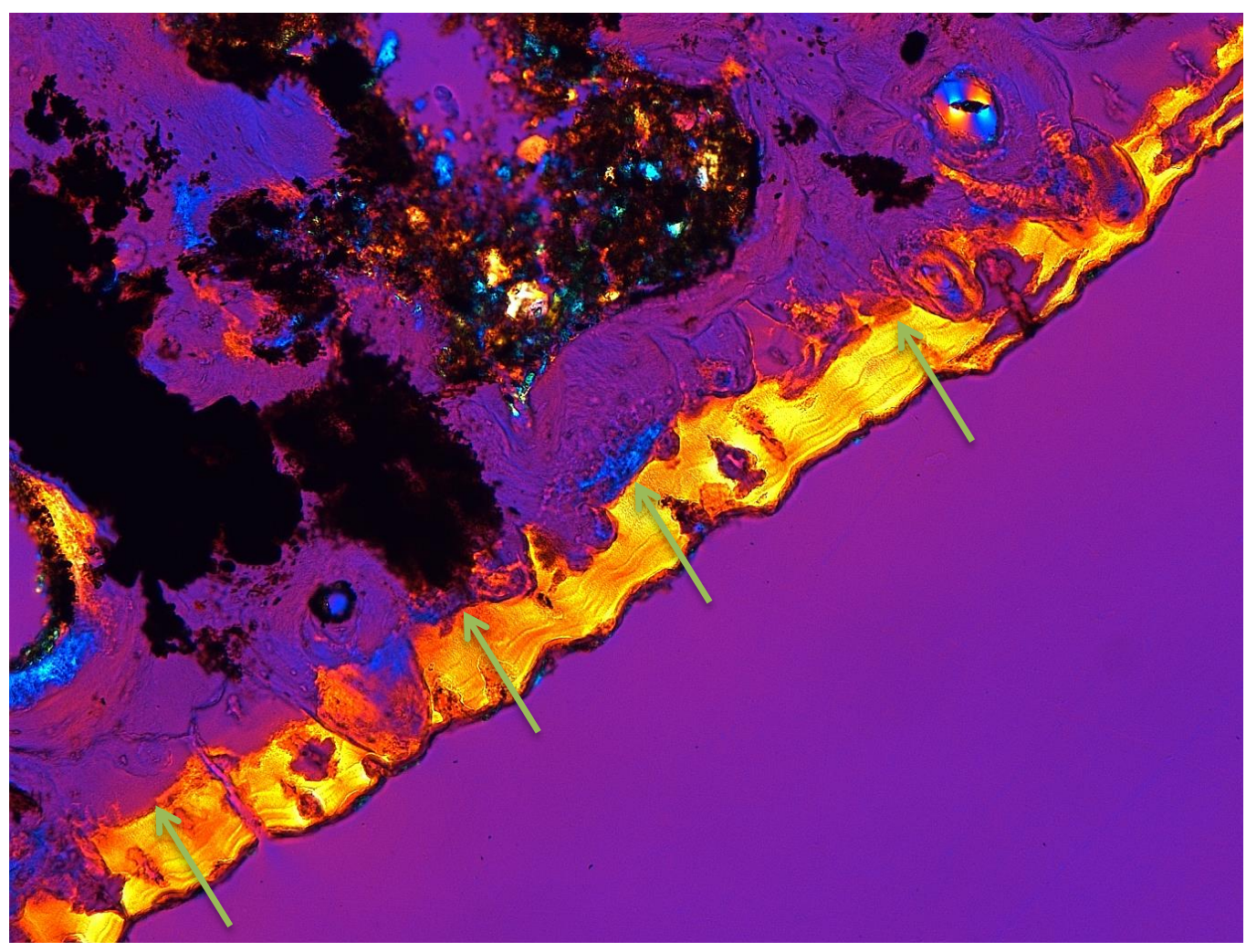

Abb. 11: Dünnschliffdicke $50 \mu m$, Vergrößerung 100x, Aufnahme im polarisierten Durchlicht unter Verwendung eines Hilfsobjektes Rot 1. Ordnung (Quarz) als Kompensator; die Zone, in der der mineralisierte Gelenkknorpel aufliegt, ist hier durch Pfeile markiert. 
In Abb. 12 ist der Frakturspalt gut erkennbar. Innerhalb desselben sind die Spongiosabälkchen zerbrochen und gegeneinander verschoben, was $\mathrm{zu}$ der postmortalen „Versinterung“ der beiden Frakturhälften führte.

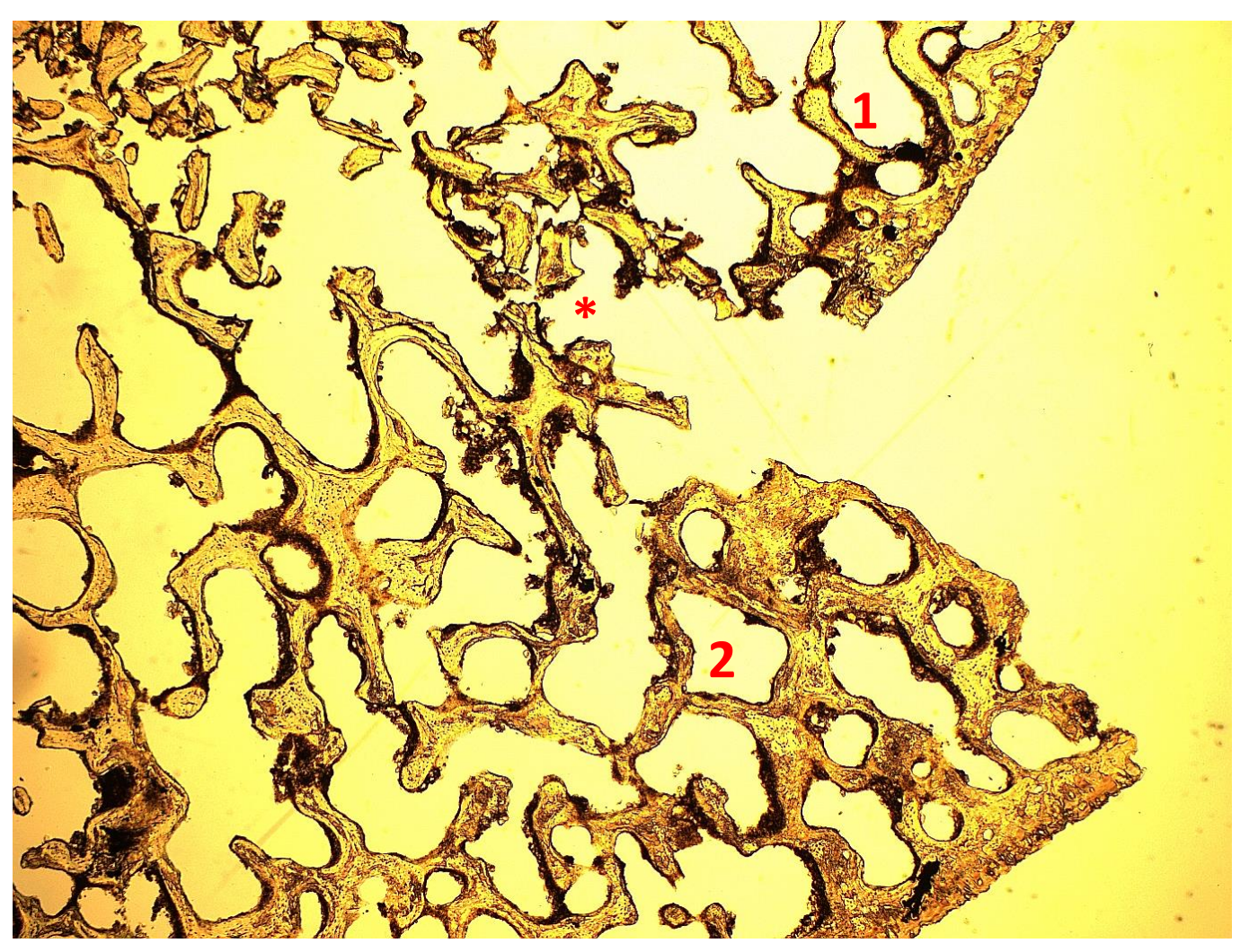

Abb. 12: Dünnschliffdicke $50 \mu \mathrm{m}$, Vergrößerung 16x, Aufnahme im einfachen Durchlicht; deutlich sichtbarer

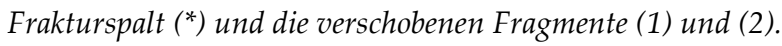

Aufgrund der lichtmikroskopischen Untersuchung konnte festgestellt werden, dass die Fraktur entstanden ist, nachdem der Knochen schon länger unter der Erde gelegen hatte. Die lange Bodenlagerung trug dazu bei, dass die Knochensubstanz nicht mehr lebend-frisch war, weswegen die Knochenstruktur brüchiger wurde. Diese postmortale Fraktur führte zu der "Versinterung“ der Knochensubstanz (Spongiosa) mit den Sandkristallen. Die „Versinterung“ hielt die beiden durch die Fraktur getrennten Gelenkteile in Disposition zusammen (Abb. 12), was an den unterschiedlichen Richtungsverläufen der Spongiosa und an den makroskopischen Aufnahmen nachzuvollziehen ist.

Die Abbildungen 13 und 14 zeigen zerbrochene Spongiosa. In Abb. 13 ist oben und unten jeweils intakte Spongiosastruktur erkennbar, während mittig der Bereich mit "versinterten“ Spongiosabruchteilen zu sehen ist. Abb. 14 zeigt eine Nahaufnahme zerbrochener Spongiosa. Deutlich wird hier, dass die Spongiosa postmortal zerbrochen ist. 


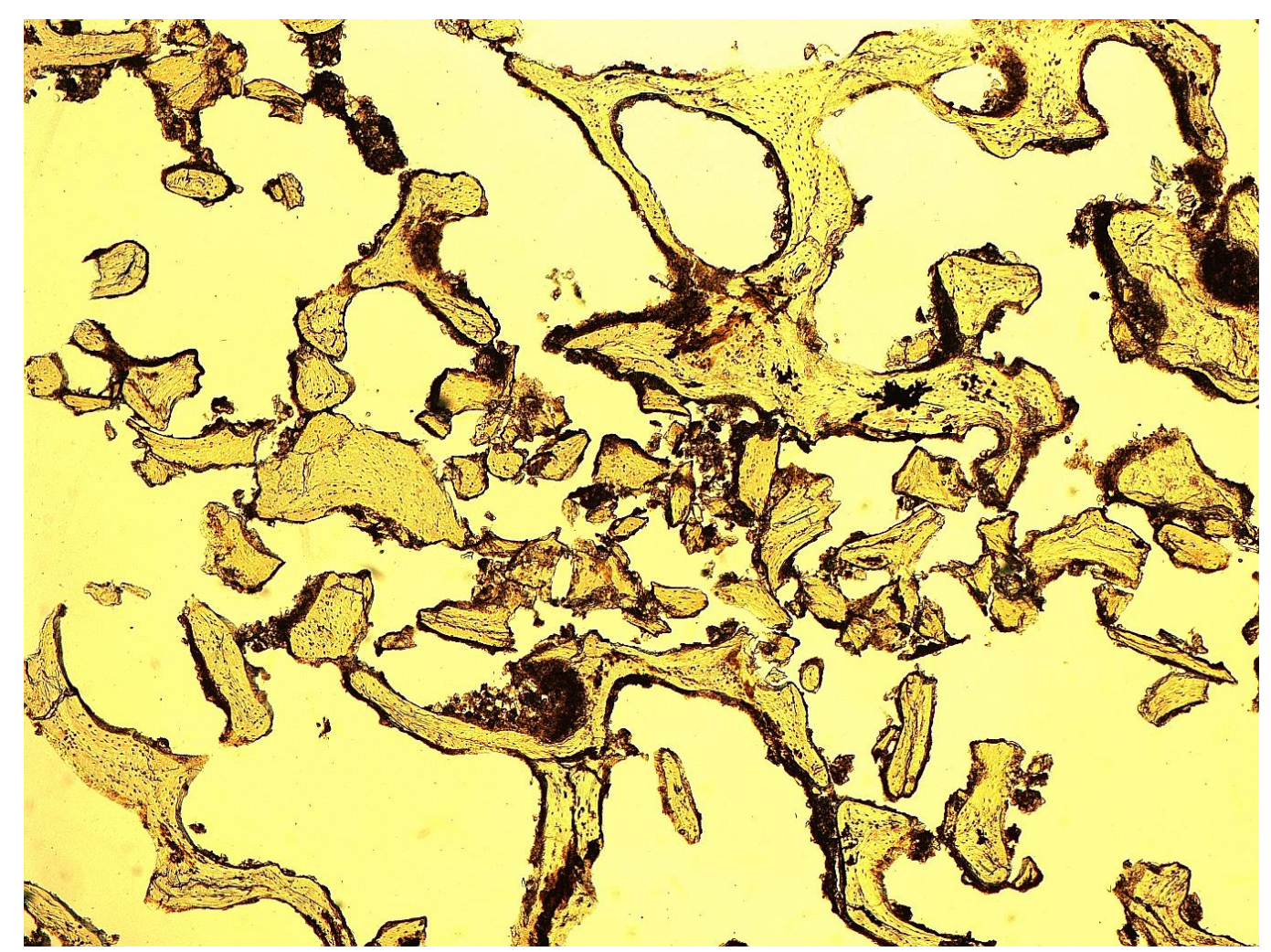

Abb. 13: Dünnschliffdicke $50 \mu m$, Vergrößerung 25x, Aufnahme im einfachen Durchlicht; intakte Spongiosa oben und unten im Bild, mittig der Bereich "versinterter" Spongiosafragmente.

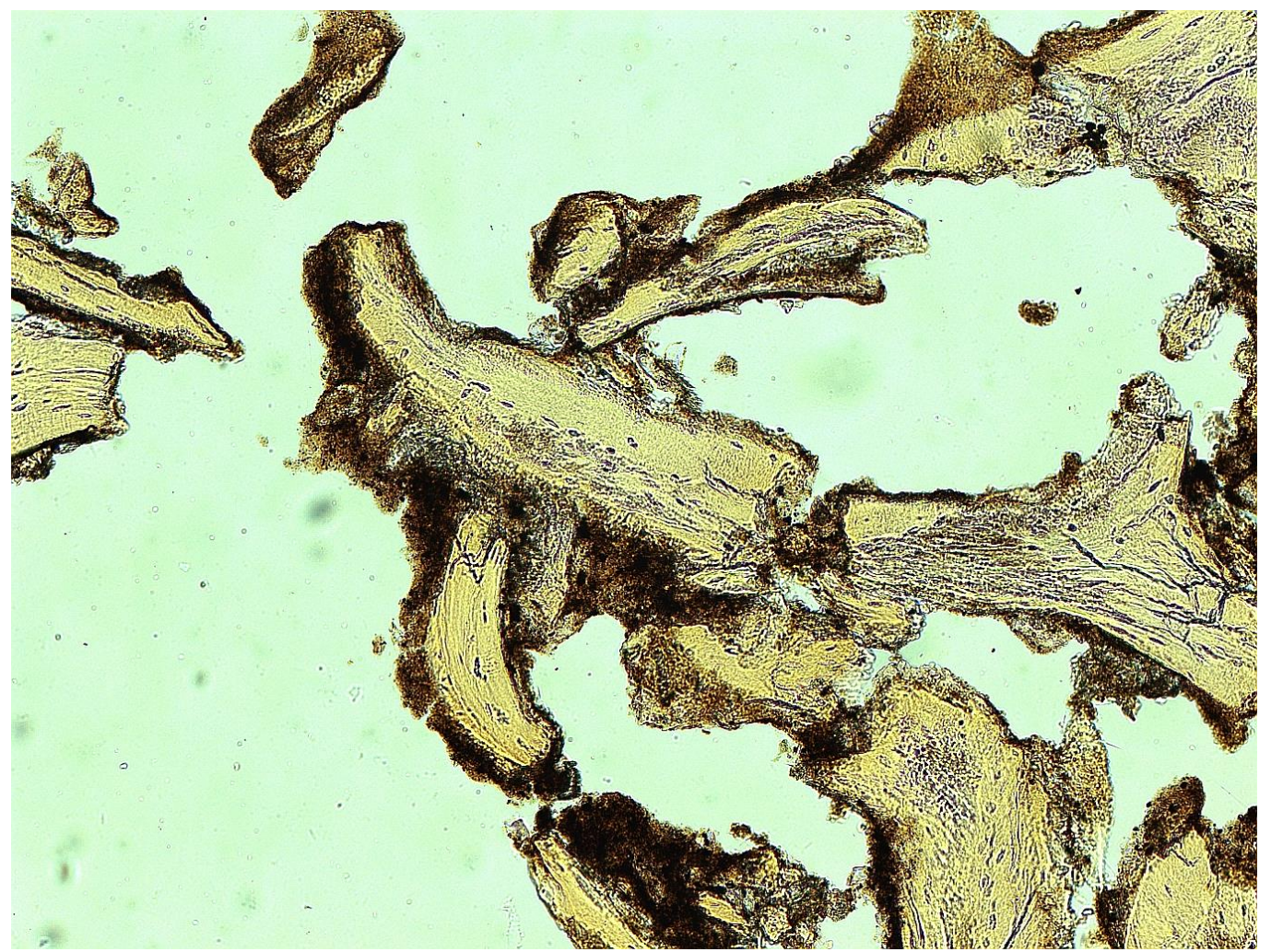

Abb. 14: Dünnschliffdicke $50 \mu m$, Vergrößerung 100x; Aufnahme im einfachen Durchlicht mit Graufilter; zu sehen sind frakturierte Spongiosabälkchen. 


\subsection{Lichtmikroskopischer Befund 8 der Population aus Calden}

Die Proben 7 und 8 entstammen demselben Fundstück. Weitere makroskopische und röntgenologische Aufnahmen finden sich in der Beschreibung des Fundstücks 7 (Vgl. 8.23).

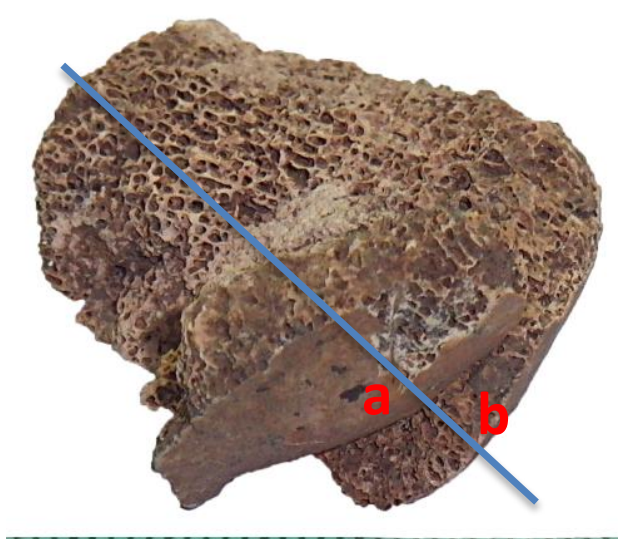

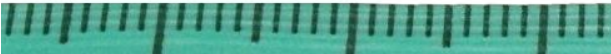

Abb. 1: makroskopische Aufnahme des Fundstücks. Rechts im Bild befindet sich die Gelenkflüche des Condylus und oben im Bild der mediale Bereich. In Blau ist die Schnittebene des Dünnschliffs eingezeichnet, die Buchstaben der Orientierung bei der Betrachtung des eingescannten Dünnschliffs (Abb. 2).

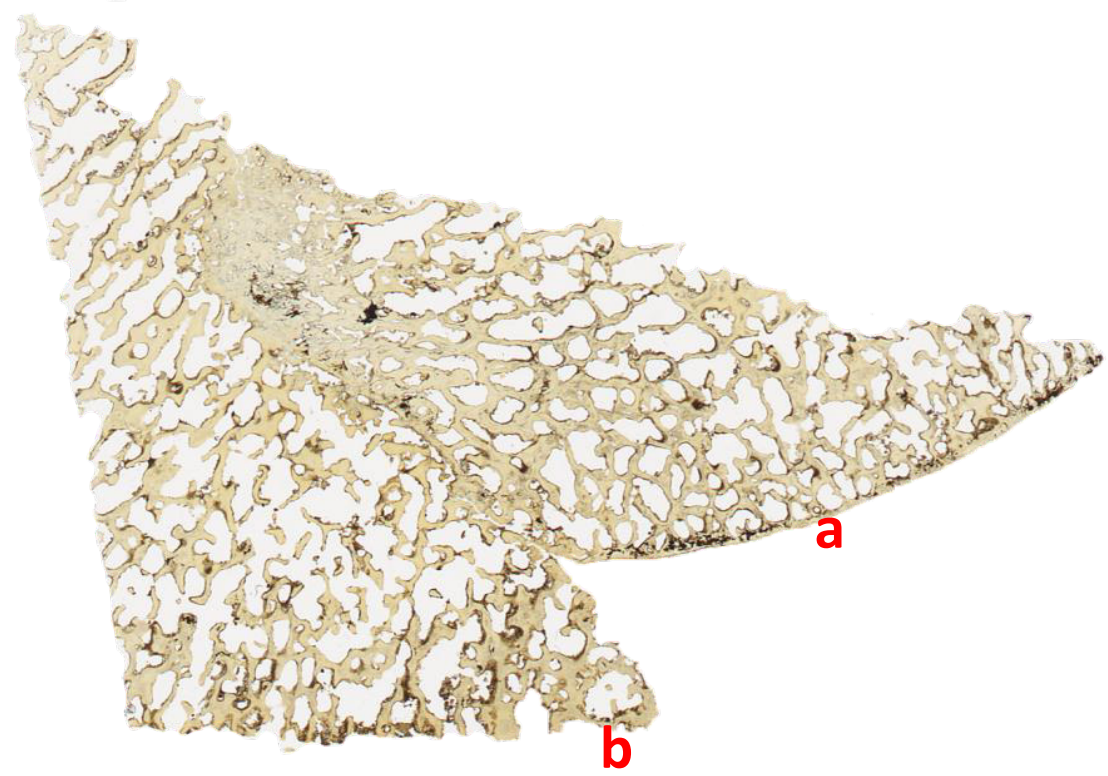

Abb. 2: Eingescannter Dünnschliff mit Buchstabenbezeichnungen als Orientierungshilfen (Vgl. Abb. 1).

Die Schnittebene dieses Knochendünnschliffs verläuft durch den „versinterten“ Bereich des Frakturspalts (Abbildungen 2 - 4). Aufgrund des schlechten Erhaltungszustandes der Mikrostruktur, kann nicht vollständig ausgeschlossen werden, dass Spuren einer intravitalen Veränderung durch postmortale (diagenetische) Einflüsse verändert wurden. Allerdings fehlen Anzeichen der Ausheilung eines eventuell intravitalen Frakturgeschehens. Es sind keine lichtmikroskopisch sichtbaren Knochenstrukturen erhalten, die die Annahme stützen, dass es sich um eine intravitale Fraktur handelte. In Abb. 3 ist $\mathrm{zu}$ 
erkennen, wie die Knochenbälkchen der beiden durch die Fraktur getrennten Teile in verschiedene Richtungen weisen.

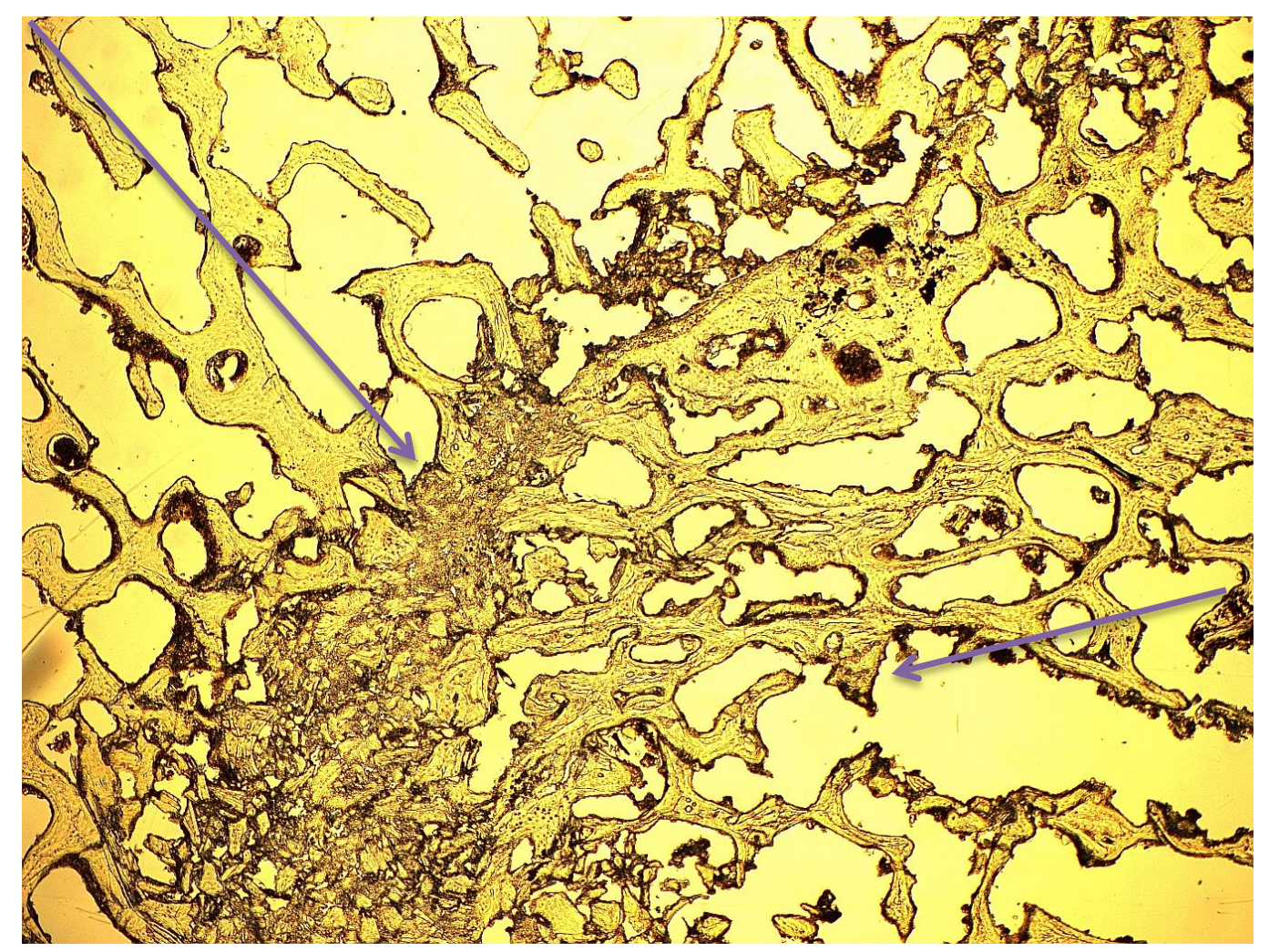

Abb. 3: Dünnschliffdicke $50 \mu m$, Vergrößerung 16x, Aufnahme im einfachen Durchlicht; die Pfeile deuten die verschiedenen Richtungen der Knochenbälkchen der Spongiosa der beiden Frakturkompartimente an.

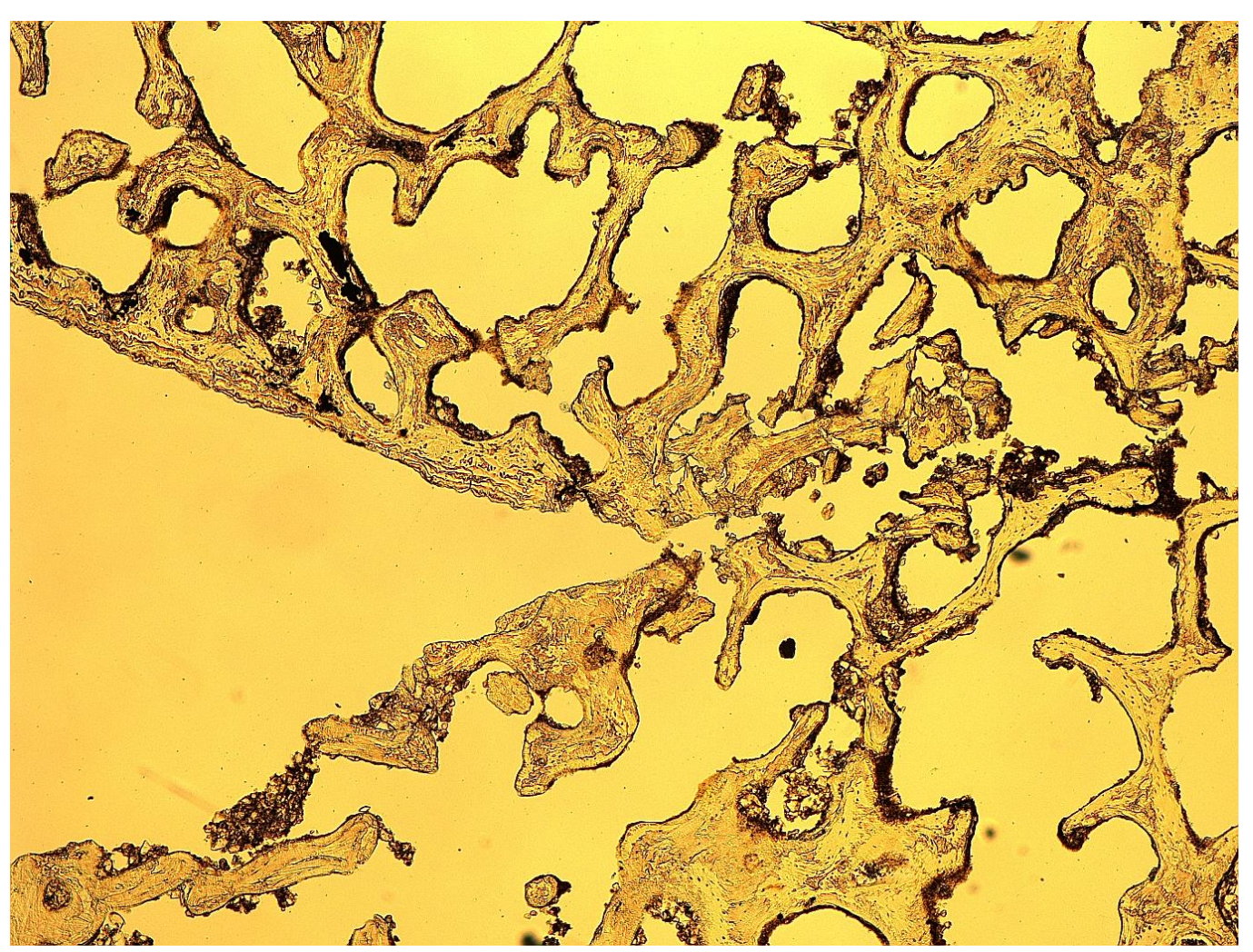

Abb. 4: Dünnschliffdicke $50 \mu m$, Vergrößerung 25x, Aufnahme im einfachen Durchlicht; v-förmige Frakturspaltöffnung. 
Die durch das Frakturgeschehen entstandenen „Knochenschredder" werden durch die postmortal eingelagerten Sinter gehalten. In den Abbildungen 5 und 6 ist gut erhaltene Spongiosa neben dem entstandenen Knochenschredder zu sehen.

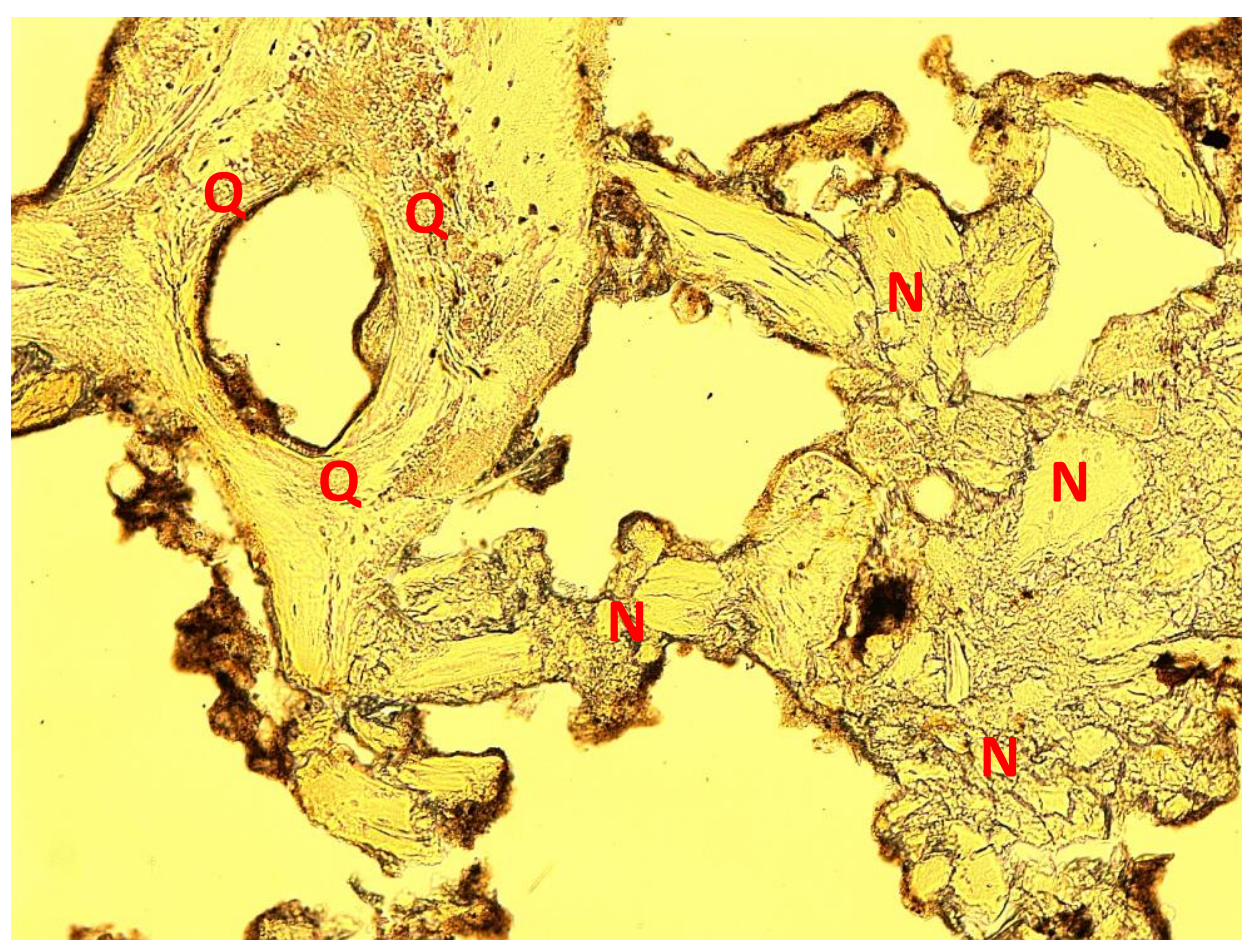

Abb. 5: Dünnschliffdicke $50 \mu \mathrm{m}$, Vergrößerung 100x, Aufnahme im einfachen Durchlicht; Buchstabenverzeichnis: Q: gut erhaltene Spongiosastruktur, nicht vom Frakturgeschehen betroffen. N: "Knochenschredder" (vom Frakturgeschehen zerstörte Spongiosa).

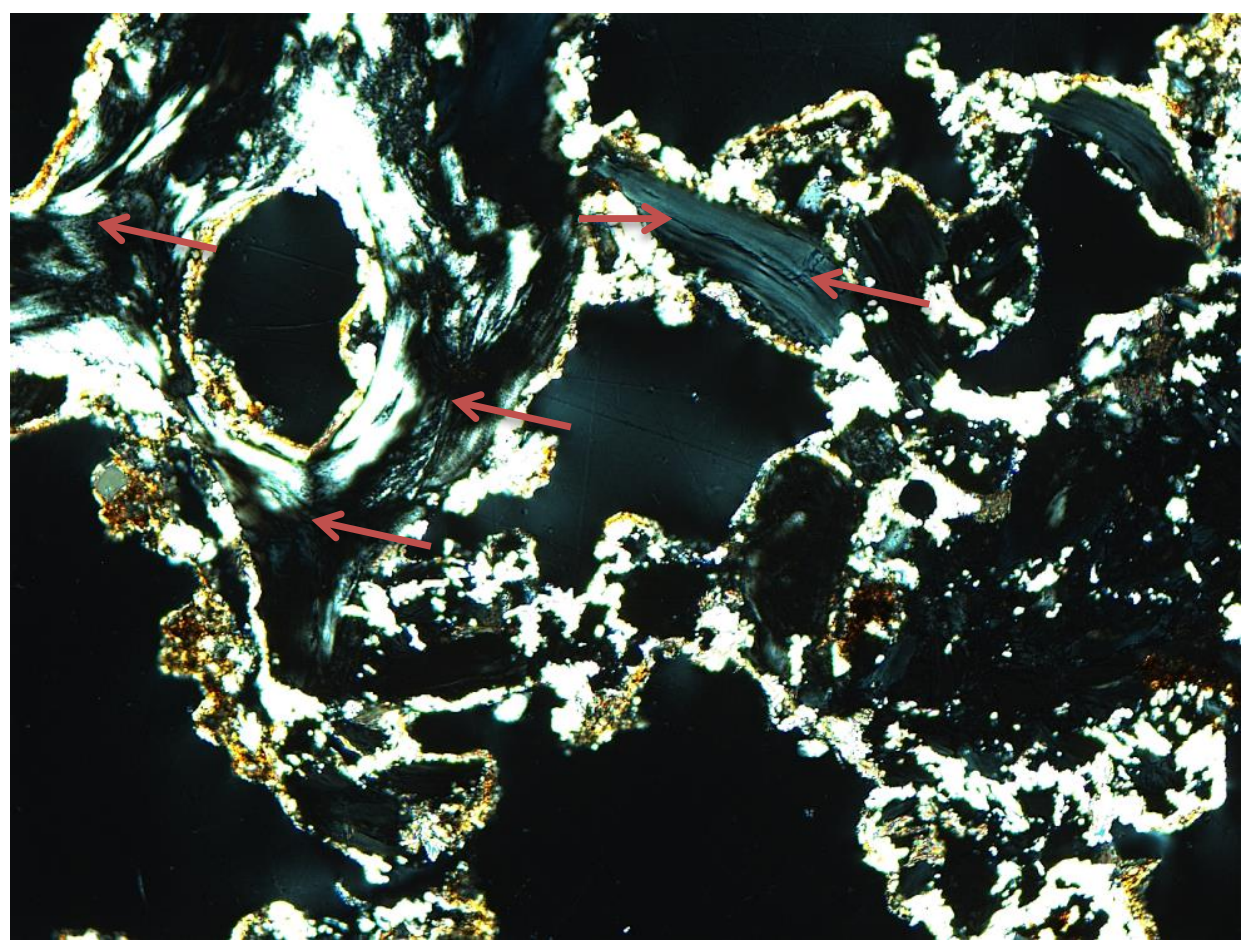

Abb. 6: Dünnschliffdicke $50 \mu m$, Vergrößerung 100x; eine absichtlich überbelichtete Aufnahme im polarisierten Durchlicht, welche die Kollagenstruktur in den Knochenbälkchen der erhaltenen und frakturierten Spongiosastruktur sichtbar macht (Pfeile). 
Zerbrochene Spongiosastruktur mit eingelagerten Sandkristallen ist in Abb. $7 \mathrm{zu}$ sehen.

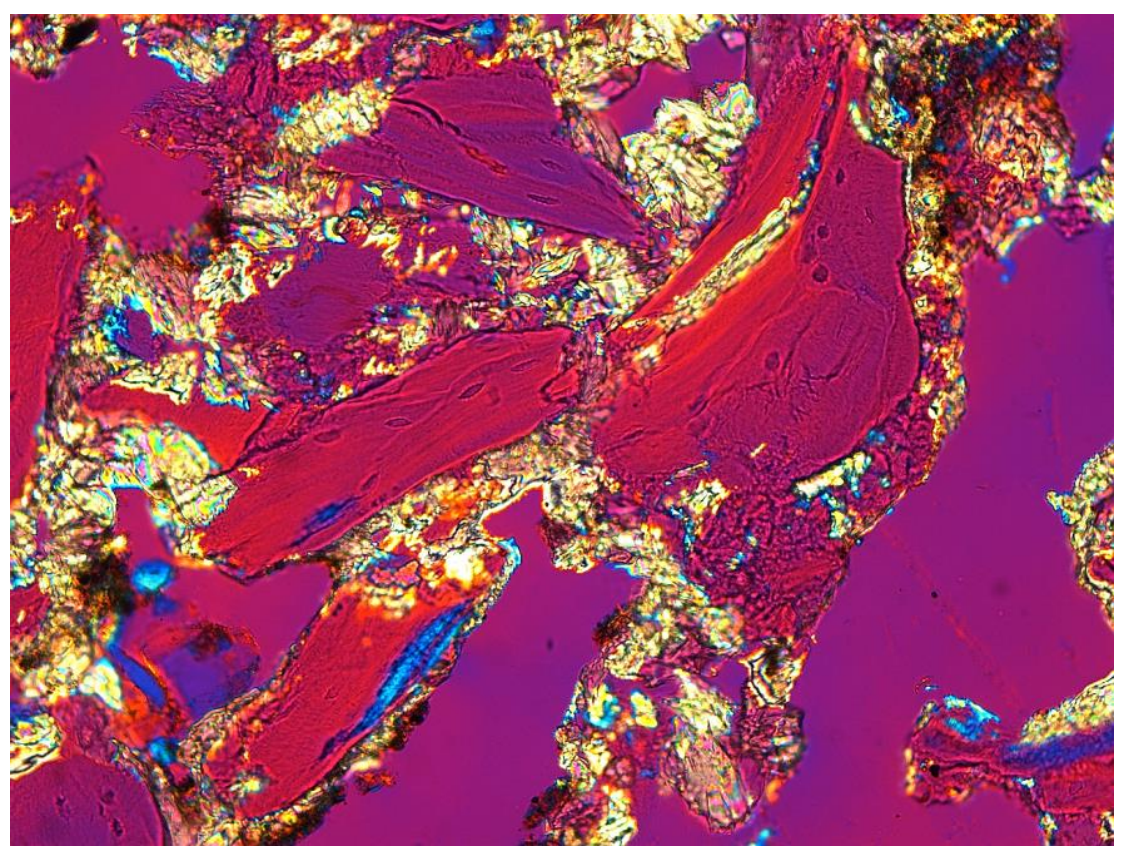

Abb. 7: Dünnschliffdicke $50 \mu m$, Vergrößerung 200x; zerbrochene Spongiosastruktur im polarisierten Durchlicht unter Verwendung eines Hilfsobjektes Rot 1. Ordnung (Quarz) als Kompensator.

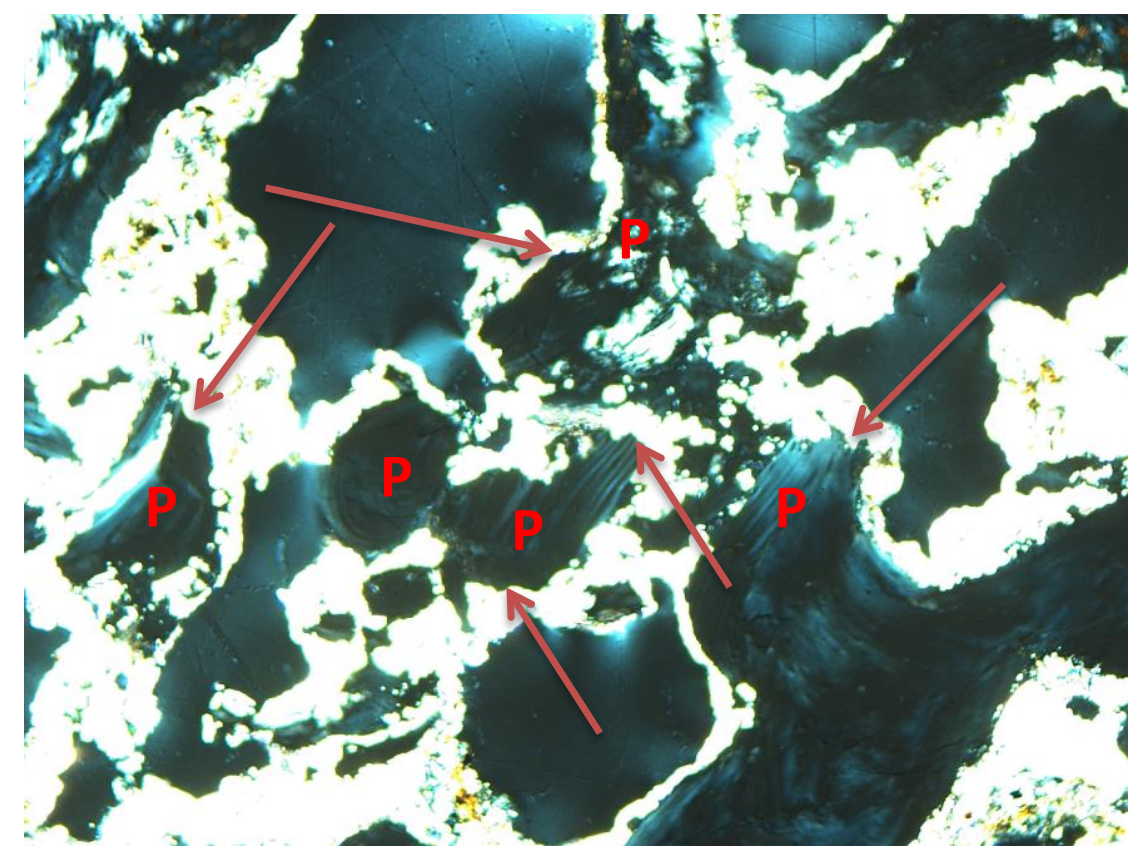

Abb. 8: Dünnschliffdicke $50 \mu \mathrm{m}$, Vergrößerung 100x, Aufnahme im polarisierten Durchlicht; Buchstabenverzeichnis: P: frakturierte Spongiosabälkchen. Die Pfeile zeigen die Bruchkanten. Deutlich wird, dass diese gedanklich nicht zusammenzufügen sind, was für eine deutliche Verschiebung der Frakturteile untereinander spricht.

Abb. 8 zeigt noch einmal die Kollagenstruktur und ihren Verlauf neben dem überbelichteten Sinter. Die Richtungen der Kollagenfasern der sehr kleinen Spongiosafragmente sind so unterschiedlich, dass die Teile nicht so zusammengehört haben können, wie sie am Ende nach der Fraktur zu liegen 
kamen. In Abb. 9 ist der Sinter neben erhaltener Kollagenstruktur im polarisierten Durchlicht gut zu erkennen.

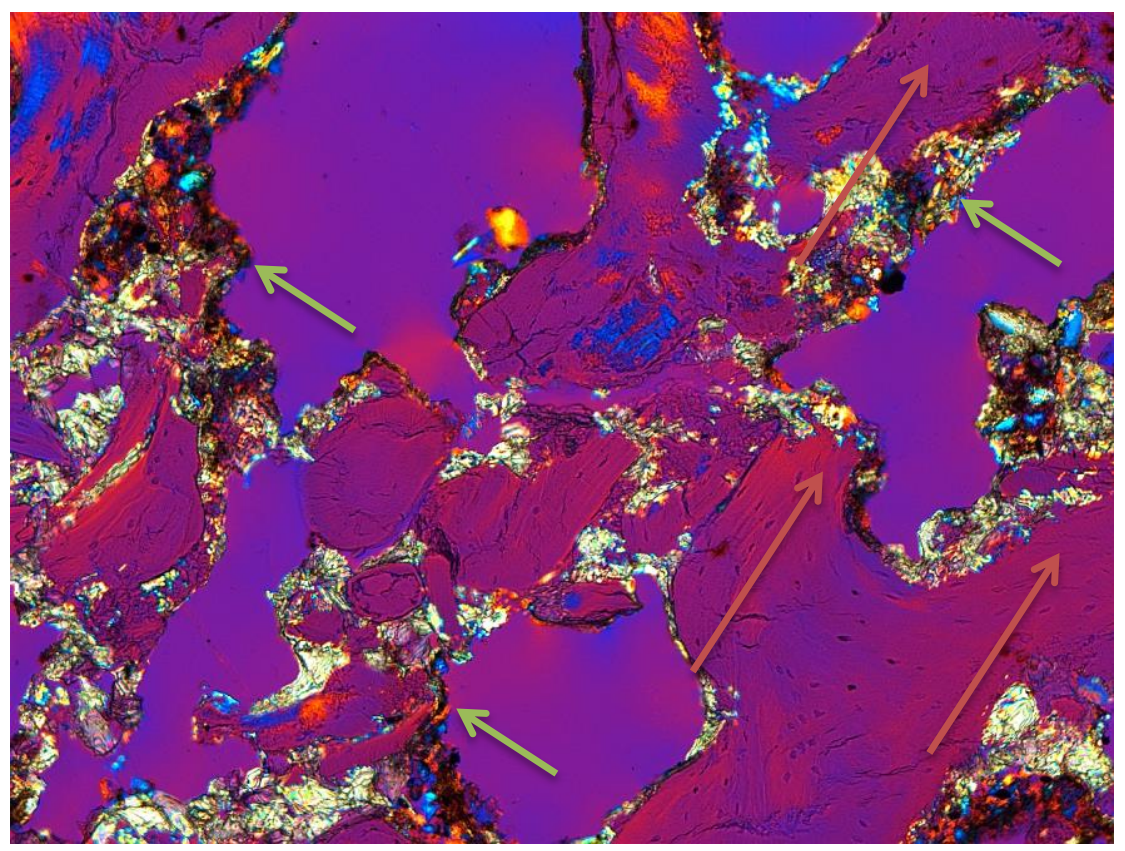

Abb. 9: Dünnschliffdicke $50 \mu$ m, Vergrößerung 100x, Aufnahme im polarisierten Durchlicht unter Verwendung eines Hilfsobjektes Rot 1. Ordnung (Quarz) als Kompensator; Kollagenstruktur (lange rote Pfeile) und Sinter (kurze grüne Pfeile) sind deutlich zu erkennen.

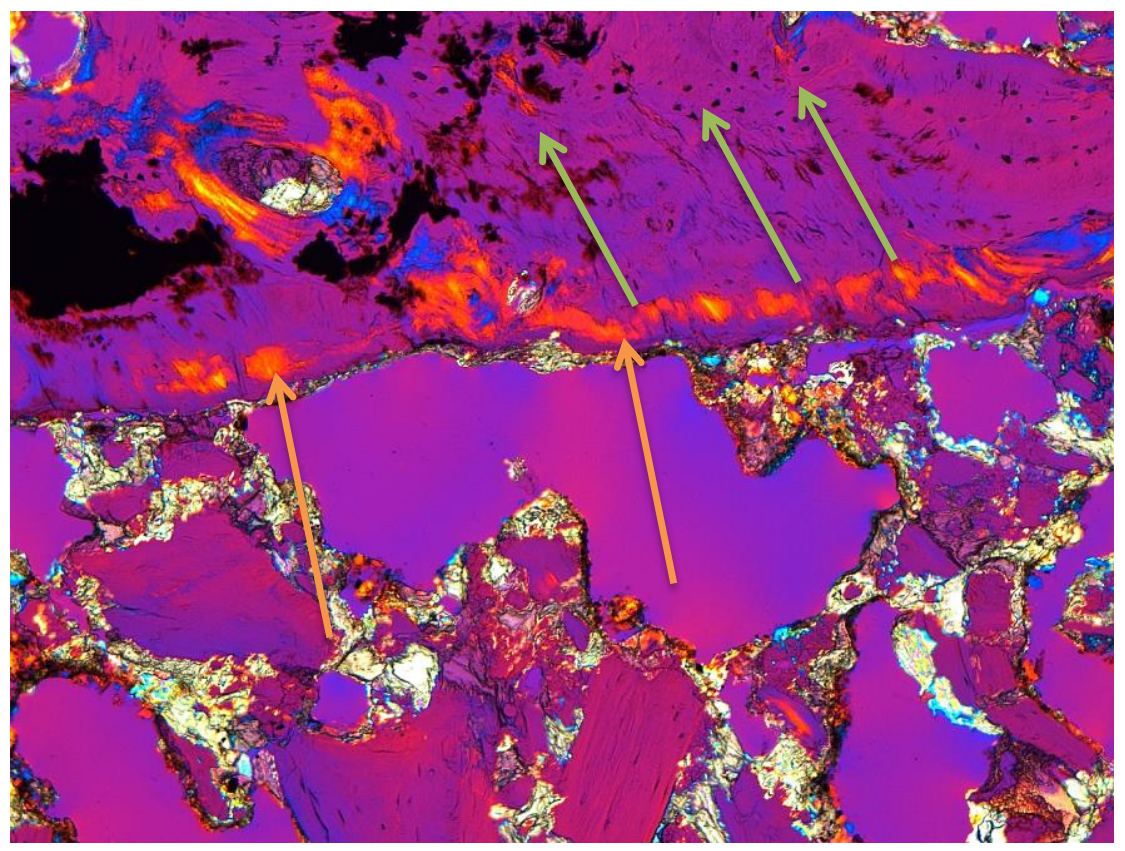

Abb. 10: Dünnschliffdicke $50 \mu$ m, Vergrößerung 100x, Aufnahme im polarisierten Durchlicht unter Verwendung eines Hilfsobjektes Rot 1. Ordnung (Quarz) als Kompensator; die orangefarbenen Pfeile markieren beispielhaft den Bereich eines Bandansatzes. Die grünen Pfeile deuten den Kollagenfaserverlauf der Ansatzfläche an, der mikroskopisch deutlich nachzuvollziehen ist.

Ein kleines Fragment mit Compacta ist bei dem Frakturgeschehen in den Bruchspalt hinein gedrückt worden (Abb. 12). Dieses Fragment ist hier zu erkennen, weil die Außenfläche durch eine knorpelähnliche Struktur auffiel und 
die darüber in der Compacta liegenden Kollagenfasern in Zugrichtung ausgerichtet waren, was für den Ansatzbereich eines Bandes spricht (Abb. 10). Somit kann das Fragment nicht vom Inneren des Condylus stammen, sondern muss hineingedrückt worden sein. Da das Präparat vom lateralen Condylus stammt, könnte es sich um ein Kollateralband oder die Kapsel des Kniegelenkes gehandelt haben, die in dem gezeigten Knochenfragment ansetzte.

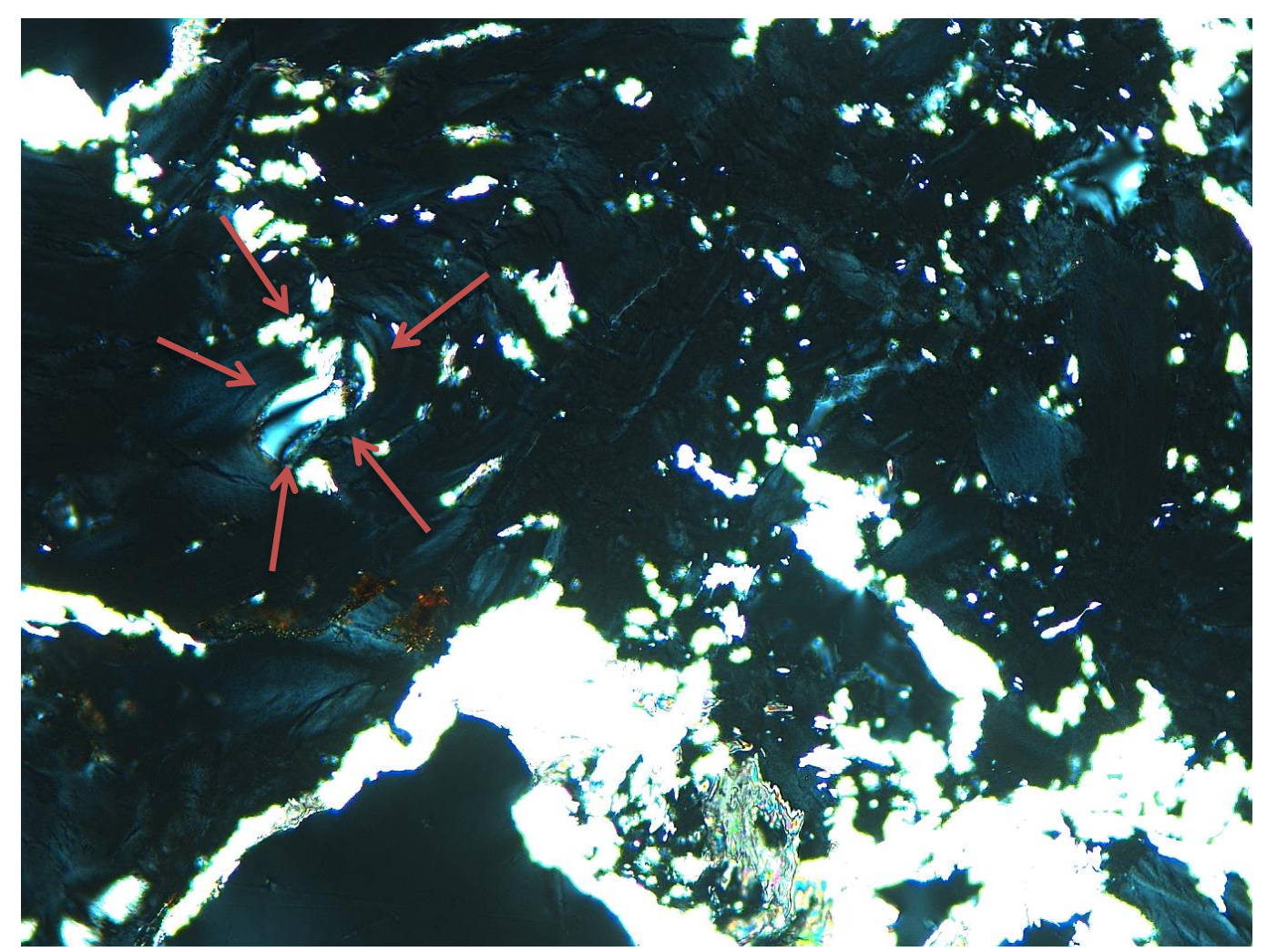

Abb. 11: Dünnschliffdicke $50 \mu m$, Vergrößerung 200x, Aufnahme im polarisierten Durchlicht; Überbelichtetes Bild, was die Kollagenstrukturen zeigt. Die weißlich erscheinenden Gebiete sind Sandkristalle im Versinterungsbereich. Die Pfeile zeigen den Umriss eines spongiösen Bereiches, der vor der Fraktur einmal fast rund ausgeprägt war. Durch die Fraktur ist die Struktur gebrochen und die beiden Halbkreise aneinander vorbei geschoben worden, was das Ausmaß der Fraktur verdeutlicht.

Die Abb. 11 zeigt die verschobene Spongiosa nach der Fraktur; besonders deutlich erkennbar ist hier auch die Kollagenstruktur; durch die Überbelichtung des Bildes wird sie sehr schön dargestellt. In Abb. 12 wird deutlich, dass die ursprünglich intakte Spongiosa durch den Frakturhergang zerbrochen und verschoben wurde. 


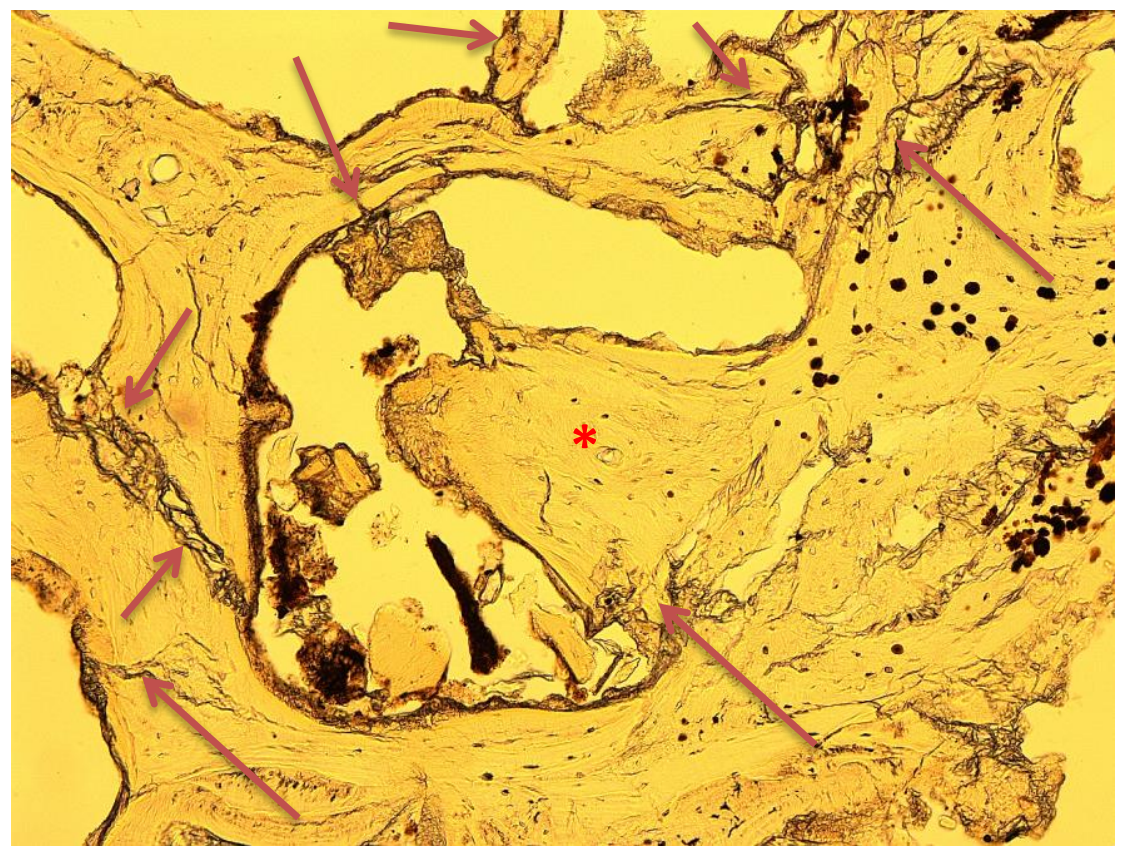

Abb. 12: Dünnschliffdicke $50 \mu \mathrm{m}$, Vergrößerung 100x, Aufnahme im einfachen Durchlicht; die Fraktur hat die Spongiosa im und um den Bruchspalt herum deutlich in ihrer Struktur verschoben. Die Abbildung zeigt eine ehemals runde Spongiosastruktur, in welche dieser zapfenförmige Spongiosabalken (*) hineingedrückt wurde. So kann die Spongiosa intravital vor der Fraktur nicht geformt gewesen sein. Die Pfeile zeigen beispielhaft mehrere Frakturbereiche.

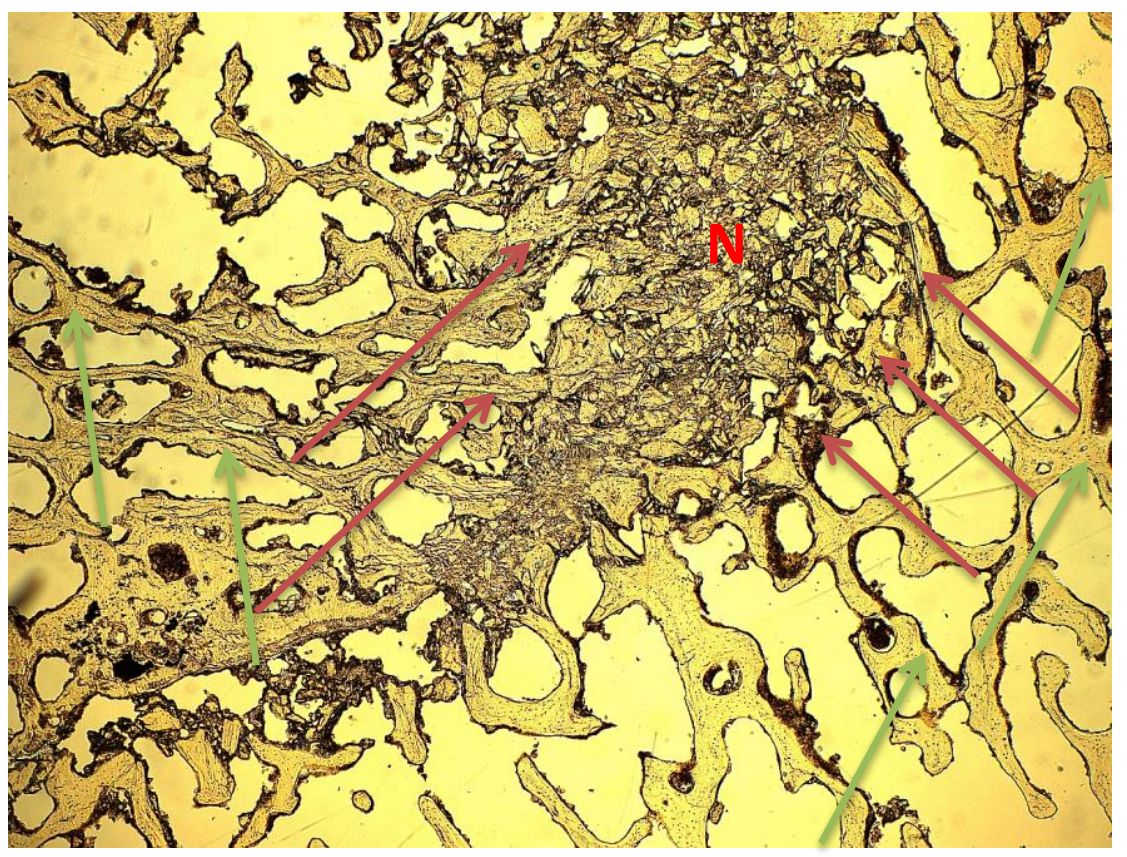

Abb. 13: Dünnschliffdicke $50 \mu m$, Vergrößerung 16x, Aufnahme im einfachen Durchlicht; die grünen Pfeile markieren die unversehrte Spongiosa, die roten die durch das Frakturgeschehen bereits tangierte Spongiosa. Buchstabenverzeichnis: N: Knochenschredder.

In Abb. 13 wird deutlich gezeigt, wo Bereiche zerbrochener Spongiosa zu liegen gekommen sind und wo sich noch intakte Spongiosabälkchen befinden.

Abb. 14 lässt den Sinter neben der zum Teil zerbrochenen Spongiosastruktur im polarisierten Durchlicht deutlich zur Geltung kommen. Postmortal eingebrachtes Material ist in dieser Abbildung sicher von Spongiosa abzugrenzen. 


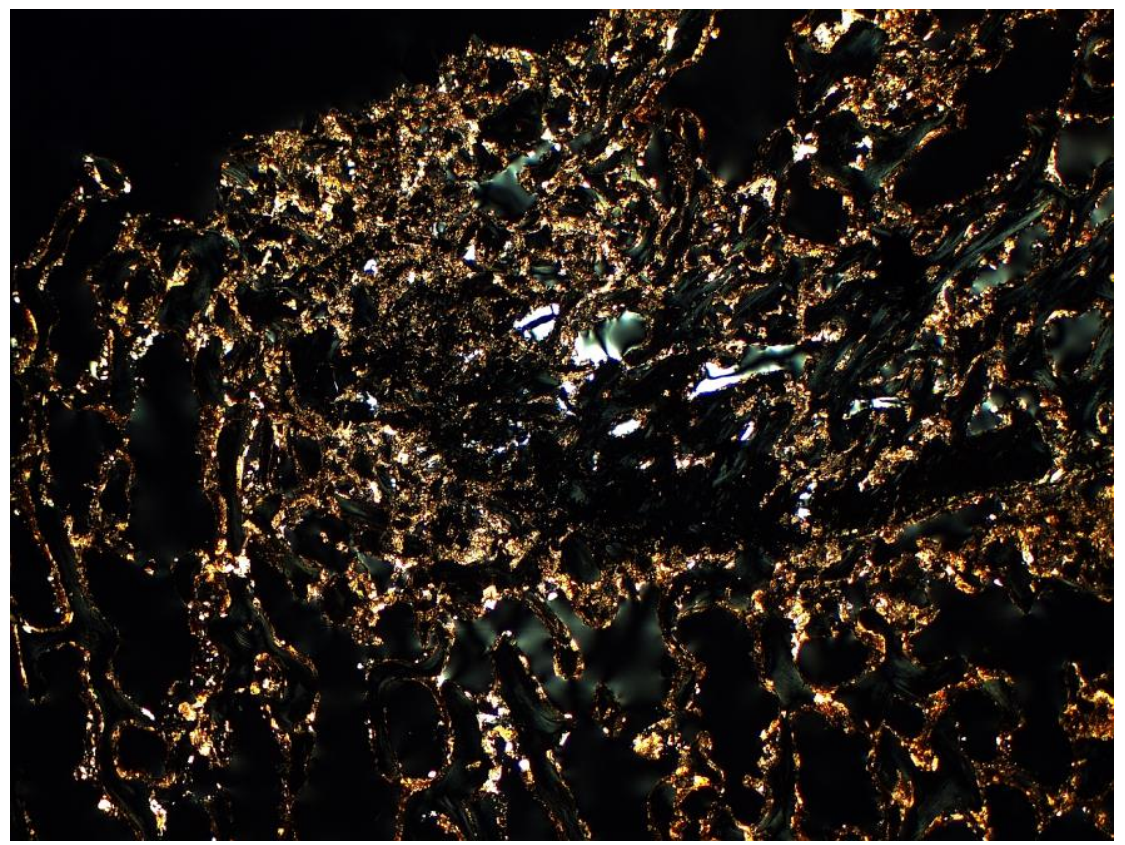

Abb. 14: Dünnschliffdicke $70 \mu m$, Vergrößerung 16x; diese Aufnahme im polarisierten Durchlicht verdeutlicht die Versinterungsstruktur. Alle hellen Bereiche entstanden durch Lichtbrechung von Sandkristallen. Diese sind weit verteilt und mit dunklen Bereichen vermischt. Bei den dunklen Bereichen handelt es sich um Knochenstrukturen.

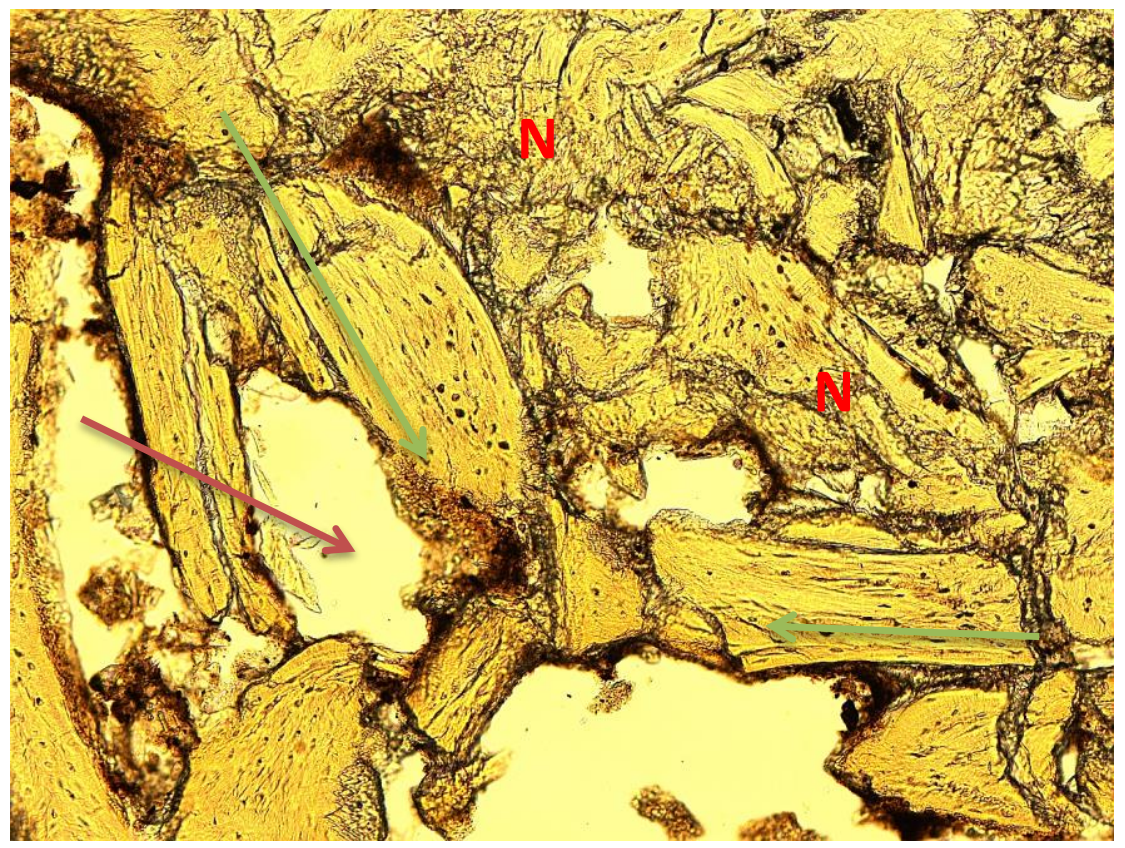

Abb. 15: Dünnschliffdicke $70 \mu m$, Vergrößerung 100x, Aufnahme im einfachen Durchlicht; durch starken axialen Druck (Pfeilrichtung rot) sind die Spongiosabälkchen längs geplatzt (Pfeilrichtung grün) und haben die "Crashzone" mit Knochenschredder (N) produziert.

Es sind auch in Abb. 15 mit deutlicherer Sicht auf die Frakturzone keine Spuren intravitaler Aktivität im Sinne von osteoklastischer oder osteoblastischer Knochenumbaumaßnahmen zu erkennen. Damit ist eine intravitale Fraktur eher auszuschließen. 


\subsection{Lichtmikroskopischer Befund 9 der Population aus Calden}

Dieses Präparat entstammt dem Dach einer linken Orbita eines Schädels der Population aus Calden. Die lichtmikroskopische Untersuchung sollte klären, aufgrund welcher krankhaften Genese die makroskopisch sichtbare Cribra orbitalia entstanden ist. Bei der lichtmikroskopischen Untersuchung konnte eine Cribra orbitalia anämischen Typus nachgewiesen werden.

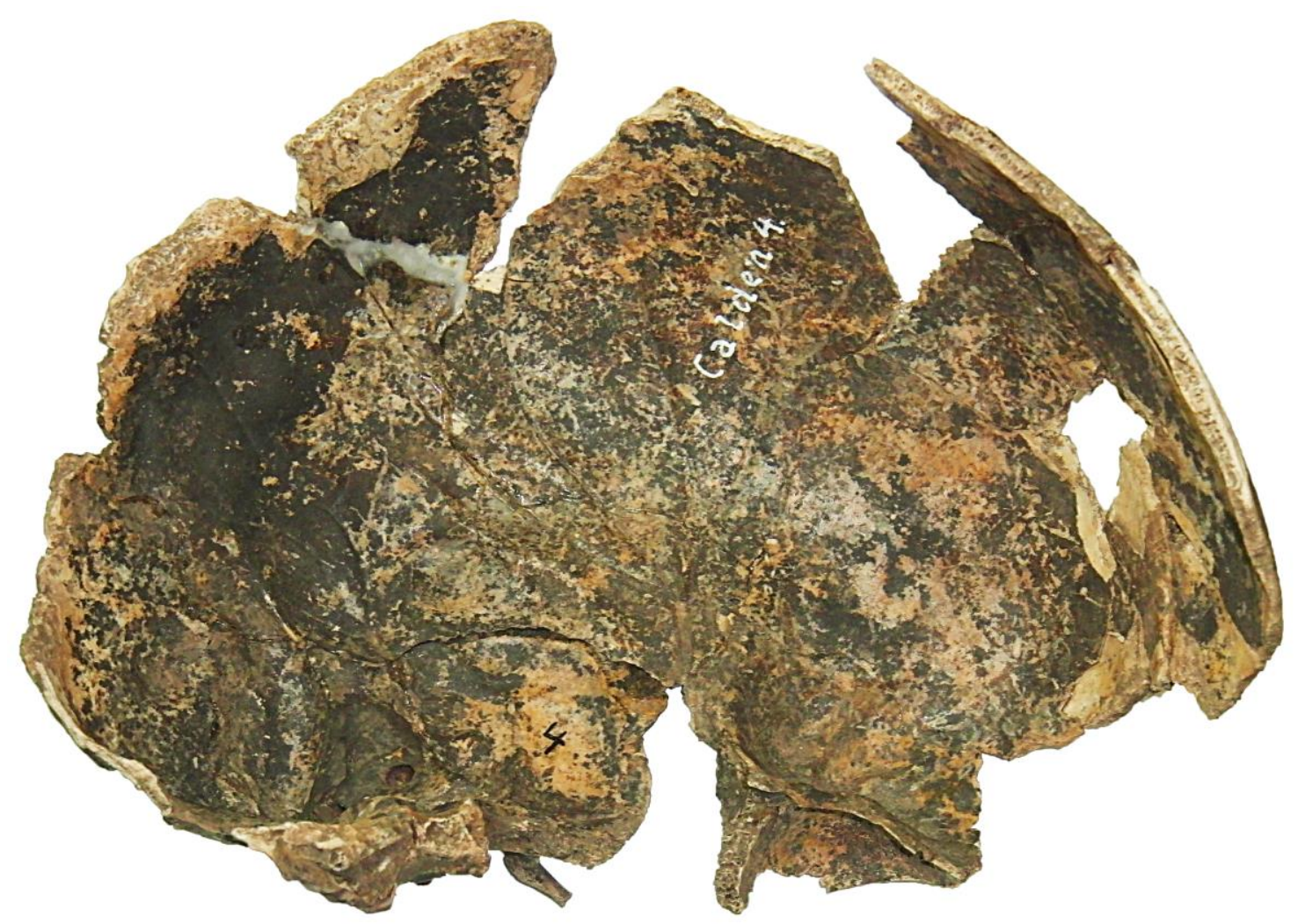

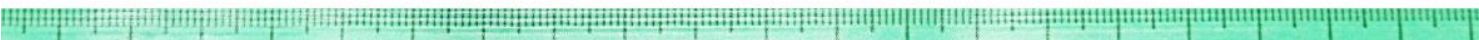

Abb. 1: Aufnahme von rechts auf die linke Innenseite des Schädels.

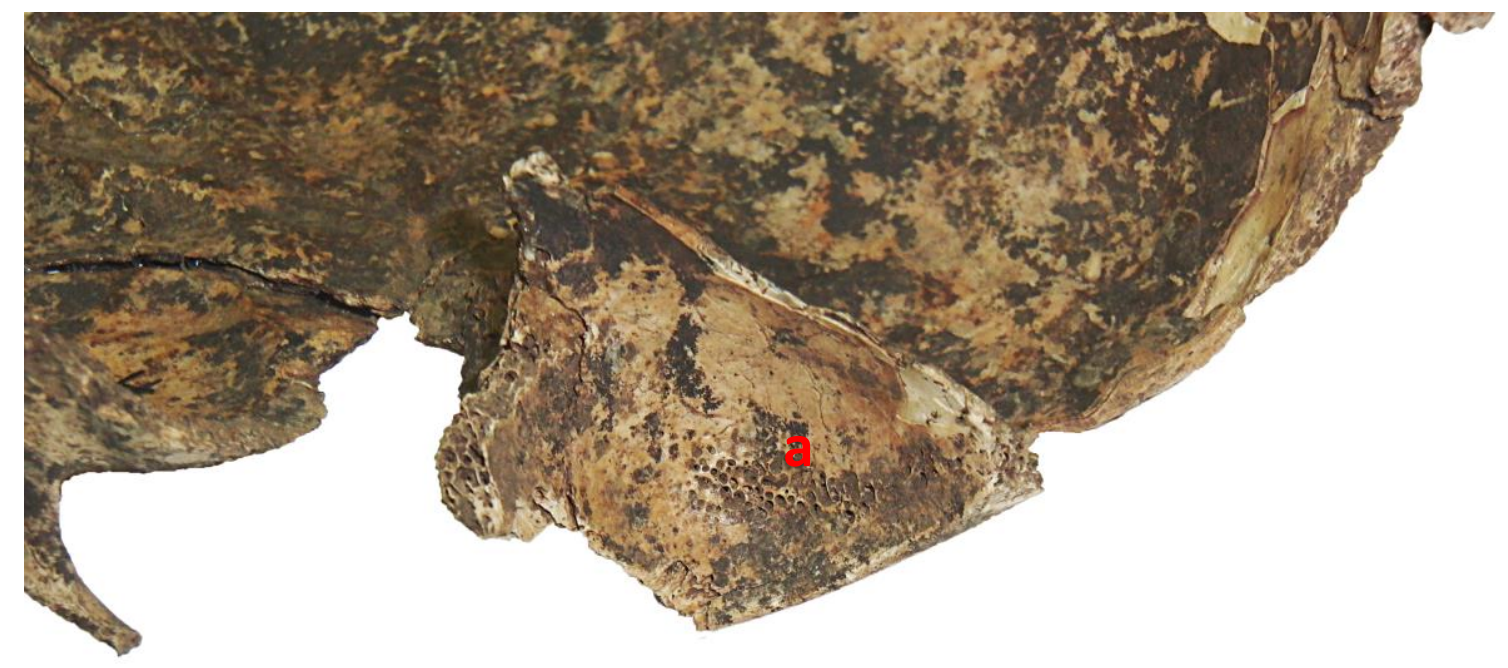

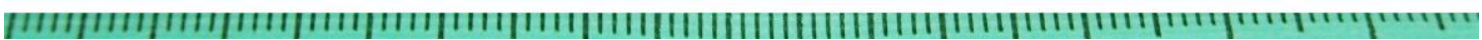

Abb. 2: Nahaufnahme und makroskopische Ansicht der Cribra orbitalia des linken Orbitadaches (a). 


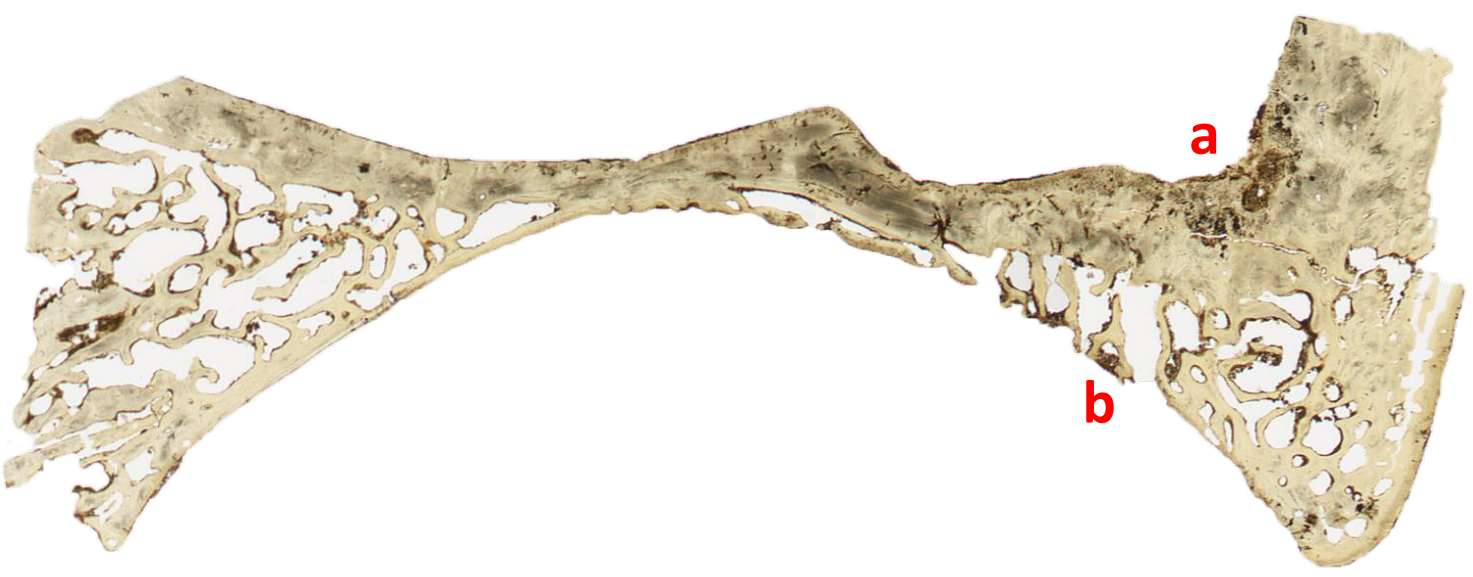

Abb. 3: eingescannter Dünnschliff. Buchstabenverzeichnis: a: vordere Schädelgrube, b: poröse Cribra orbitalia.

Dieser Knochendünnschliff zeigt das Dach einer linken Orbita.

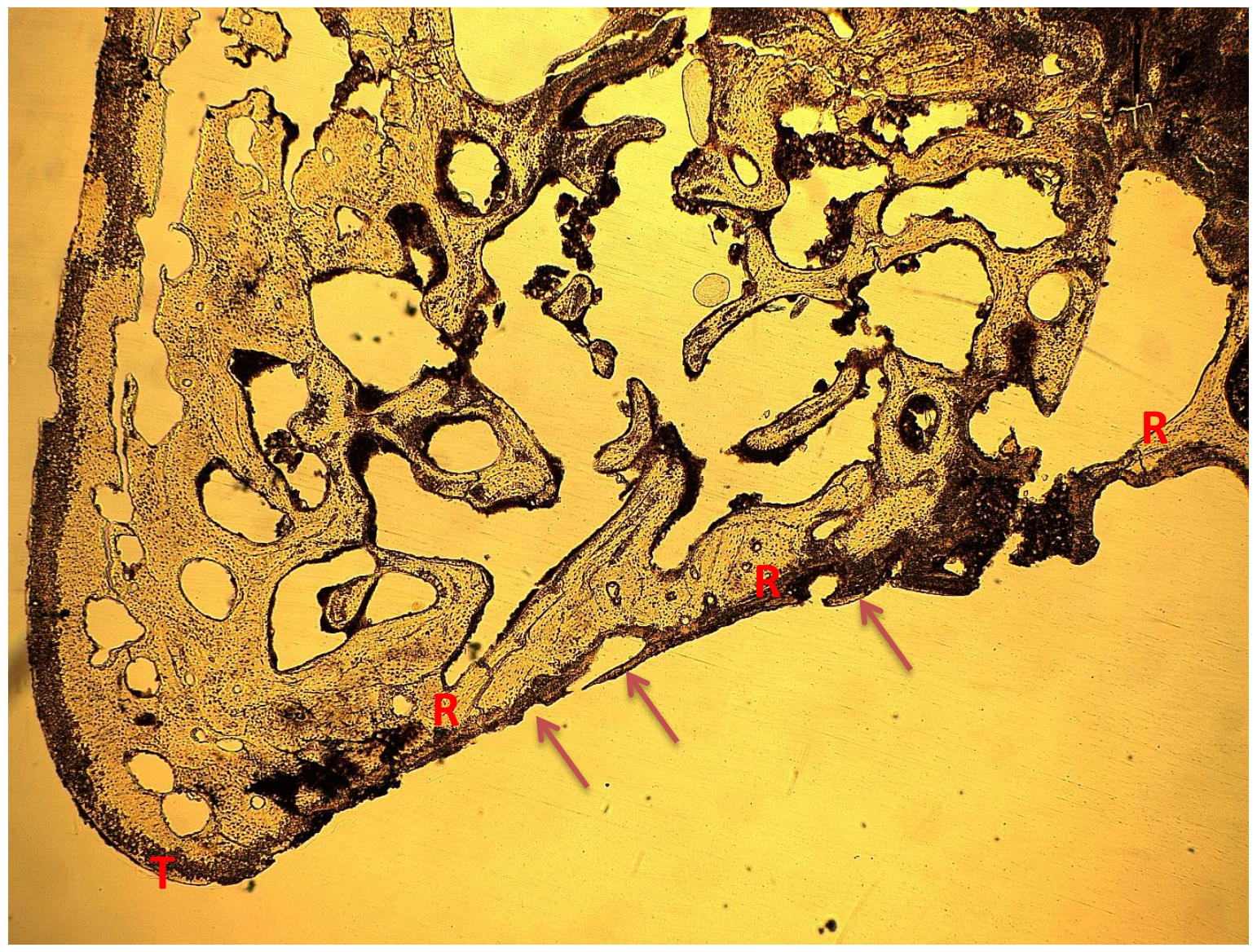

Abb. 4: Dünnschliffdicke $50 \mu \mathrm{m}$, Vergrößerung 16x, Aufnahme im einfachen Durchlicht; Buchstabenverzeichnis: T: Margo supraorbitalis, R: Orbitadach. Die Pfeile markieren die in 16x-Vergrößerung sichtbare Spuren der Cribra orbitalia.

Das Fundstück ist postmortal geringfügig degradiert, es finden sich Spuren von Erdmaterial in den Hohlräumen des Präparats (Abb. 5). 


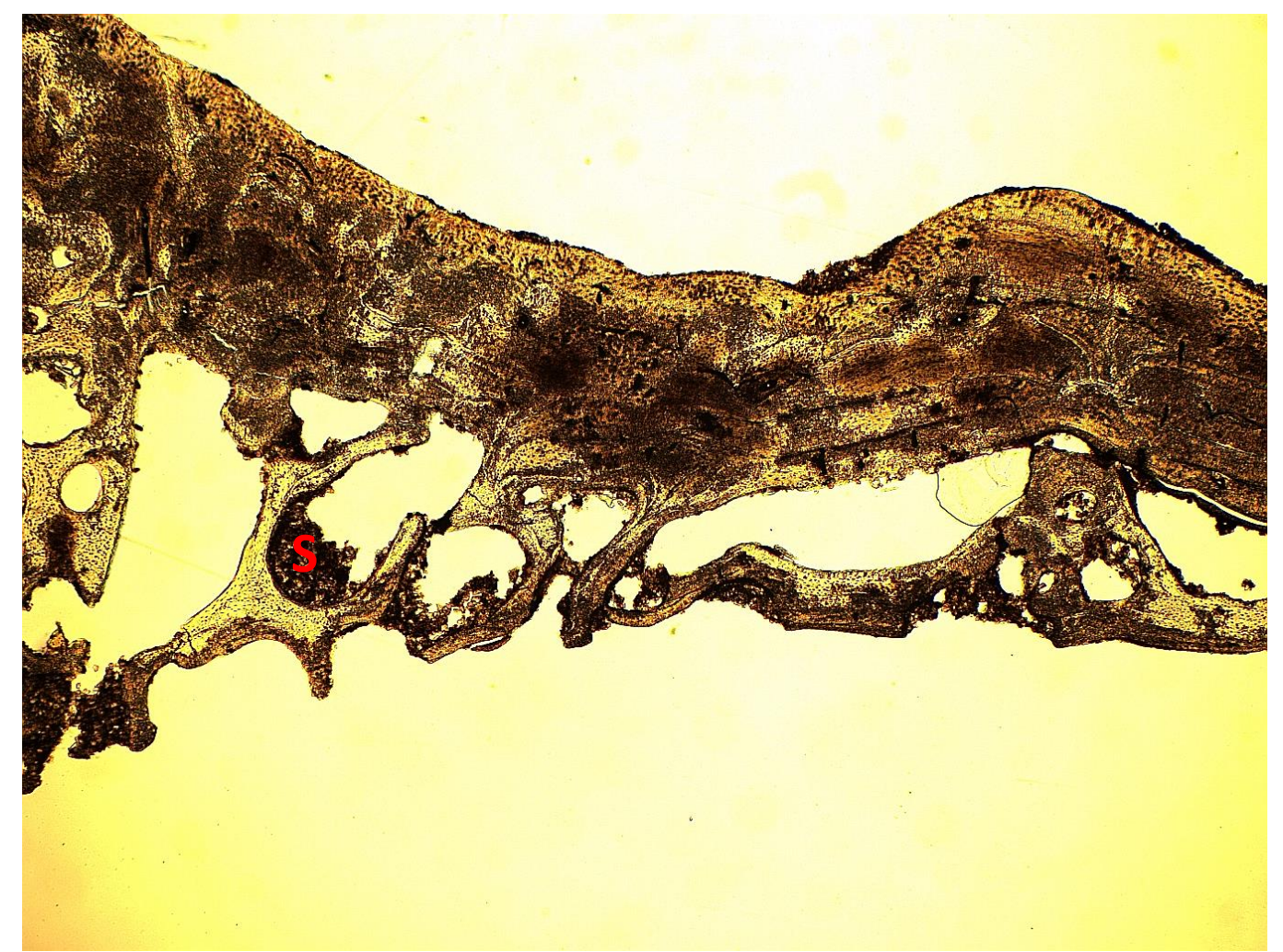

Abb. 5: Dünnschliffdicke $50 \mu m$, Vergrößerung 16x, Aufnahme im einfachen Durchlicht; Buchstabenverzeichnis: S: in Hohlräume eingelagertes Erdmaterial.

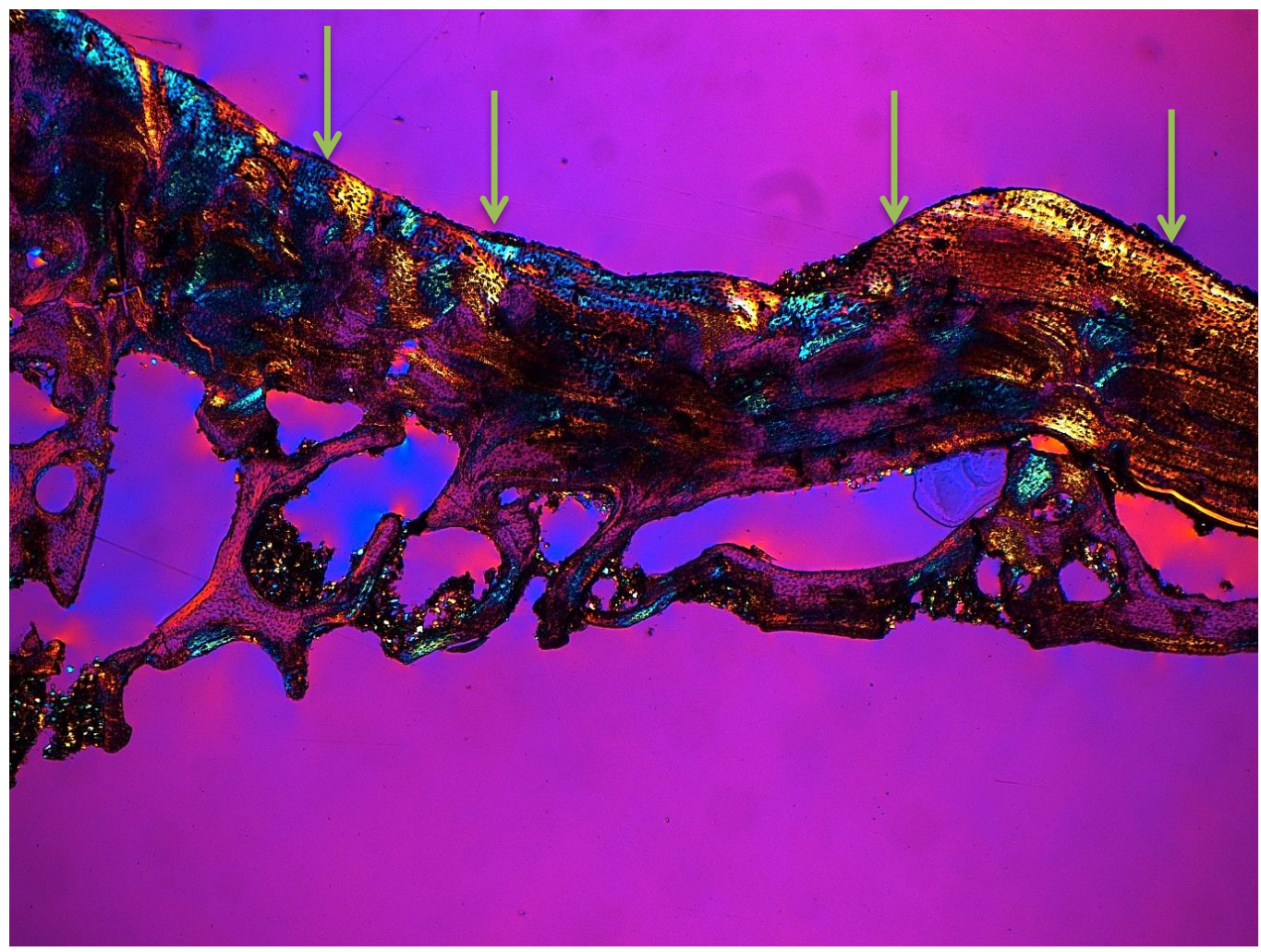

Abb. 6: Dünnschliffdicke $50 \mu m$, Vergrößerung 16x, Aufnahme im polarisierten Durchlicht unter Verwendung eines Hilfsobjektes Rot 1. Ordnung (Quarz) als Kompensator; die vordere Schädelgrube (im Bild oben, siehe grüne Pfeile) ist nicht affektiert. Sie weist keine pathologischen Veränderungen auf. 


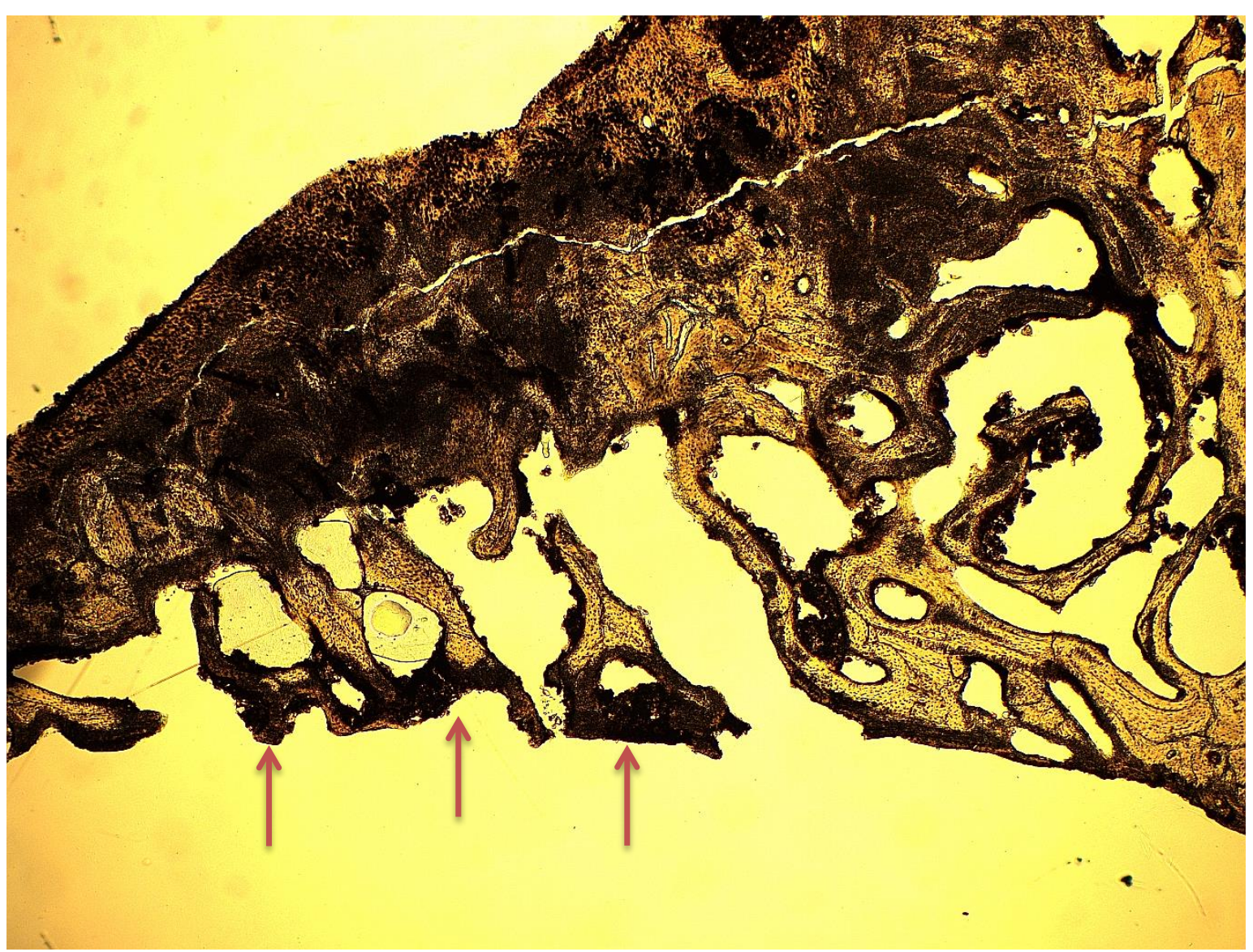

Abb. 7: Dünnschliffdicke $70 \mu m$, Vergrößerung 16x, Aufnahme im einfachen Durchlicht; die Pfeile zeigen beispielhaft die poröse Struktur des Orbitadaches.

Besonders in diesem dickeren Präparat $(70 \mu \mathrm{m})$ sind deutliche anämische Strukturen festzustellen. Die Cribra orbitalia war zum Zeitpunkt des Todes bereits verheilt, dennoch sind hier deutliche Spuren erhalten, die eine durchlebte Anämie beweisen. Die makroskopisch sehr poröse Oberfläche des Orbitadaches ist hier im mikroskopischen Bild deutlich zu erkennen. 


\subsection{Lichtmikroskopischer Befund der Population aus Rheine}

Von diesem Os zygomaticum wurden vier Dünnschliffe aus zwei verschiedenen Schliffebenen angefertigt. Es war makroskopisch eine poröse Oberfläche auf der Außenseite des Jochbeins zu sehen, die lichtmikroskopisch untersucht werden sollte. Auch auf der Innenseite fanden sich auffällige Erhabenheiten, die wie entzündlich veränderte Knochenstruktur aussahen.
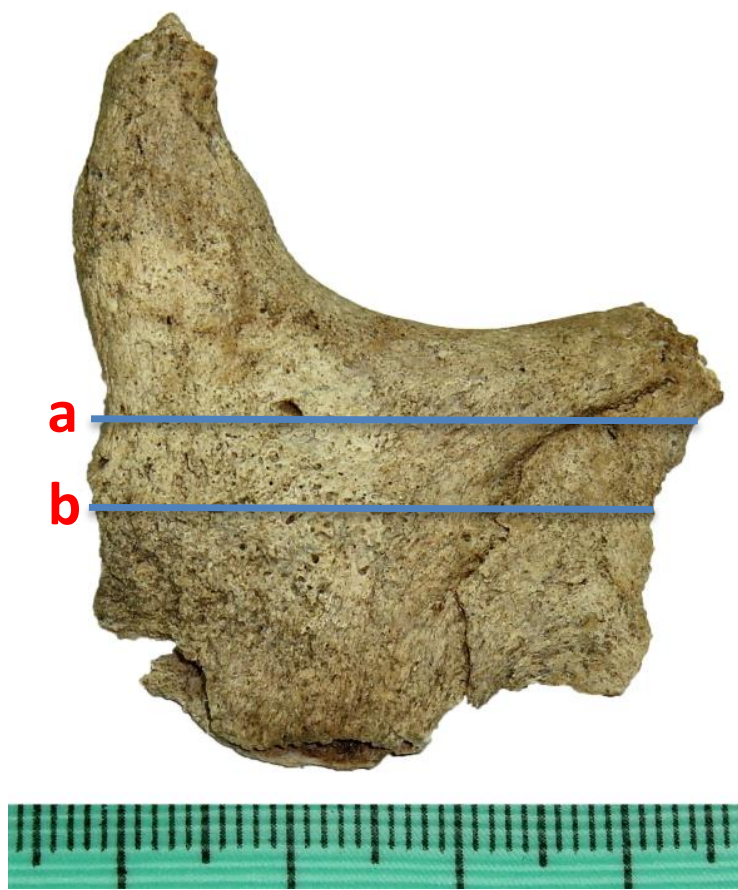

Abb. 1: Makroskopische Aufnahme des rechten Os zygomaticum. Die zwei verschiedenen Schnittebenen sind mit blauen Linien gekennzeichnet.

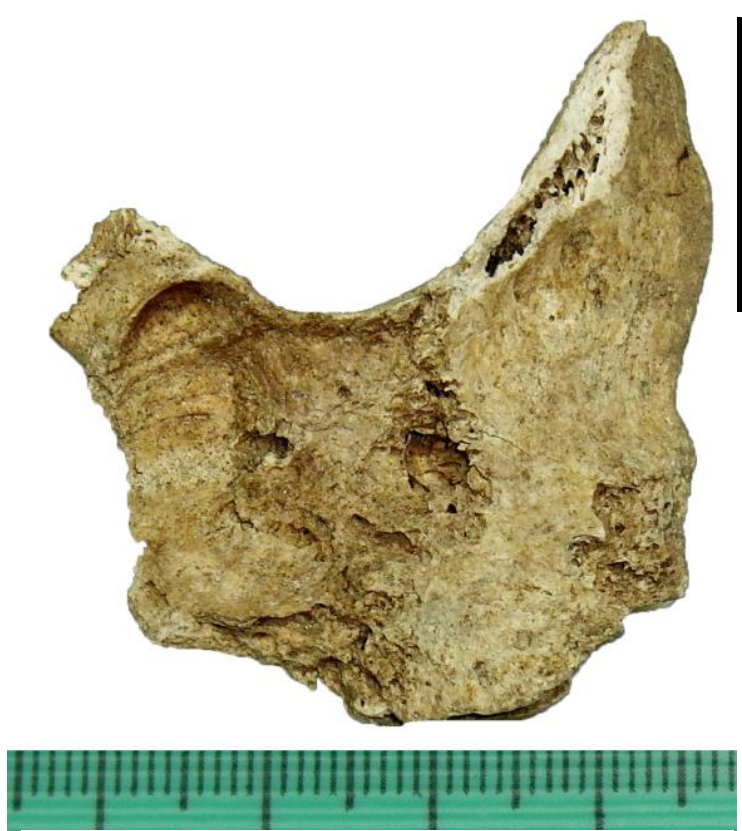

Abb. 3: Os zygomaticum, Ansicht von Innen.

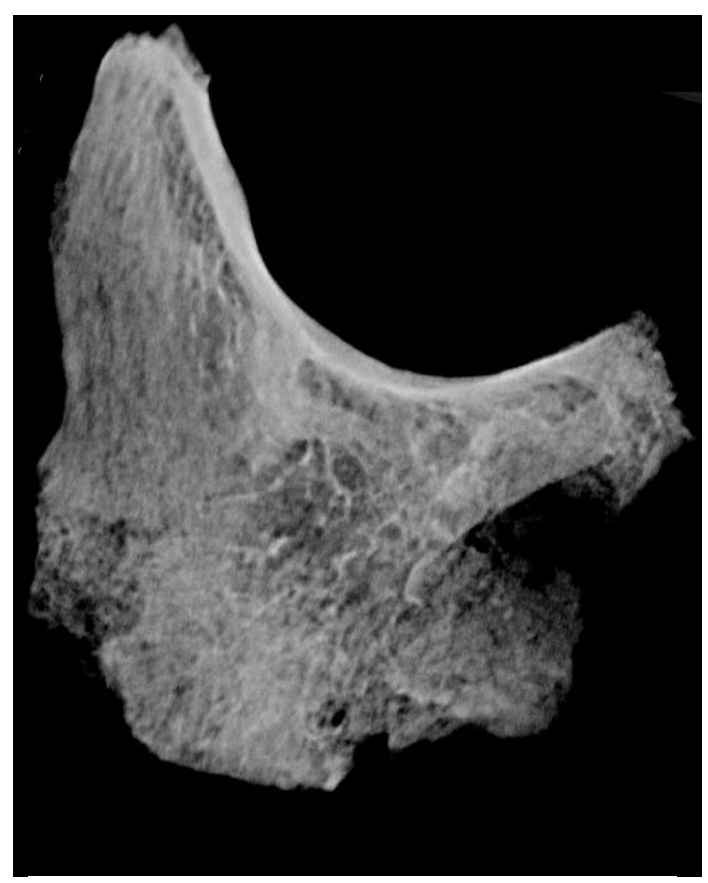

Abb. 2: Röntgenaufnahme in der gleichen Position wie in Abb. 1.

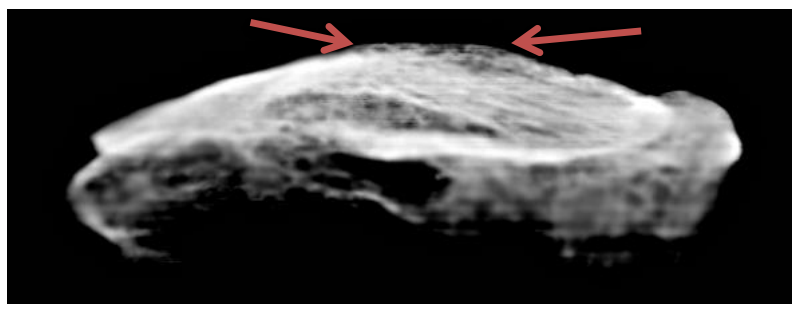

Abb. 4: Röntgenaufnahme des Os zygomaticum in cranial - distaler Richtung. Oben im Bild befindet sich die auffällige Knochenauflagerung, die als erhabene Struktur (Pfeile) zu sehen ist. Hier ist poröser Faserknochen aufgelagert, was sich bei der lichtmikroskopischen Untersuchung nachweisen ließ. 


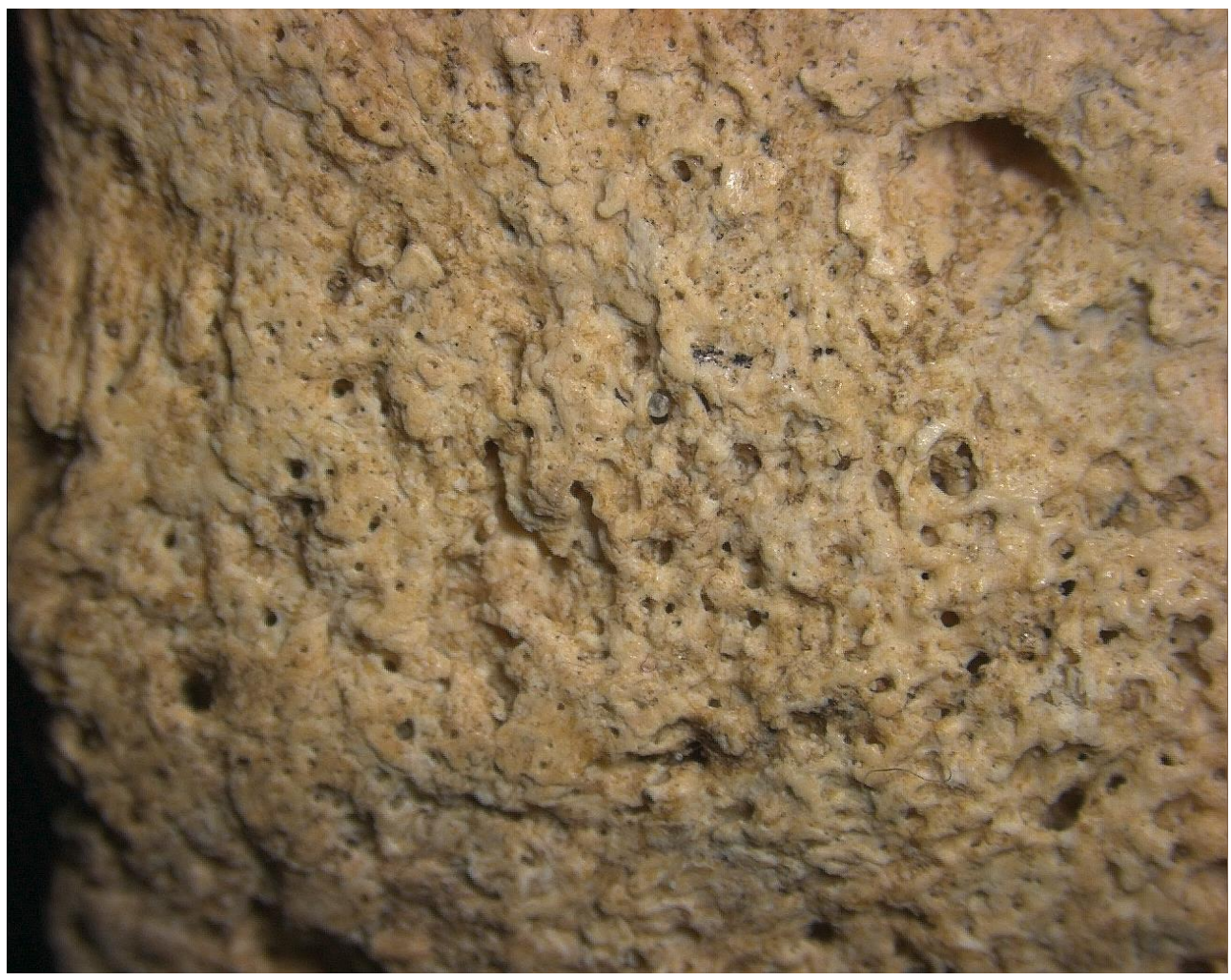

Abb. 5: Poröse Knochenneubildungen auf der äußeren Seite des Fundstücks.

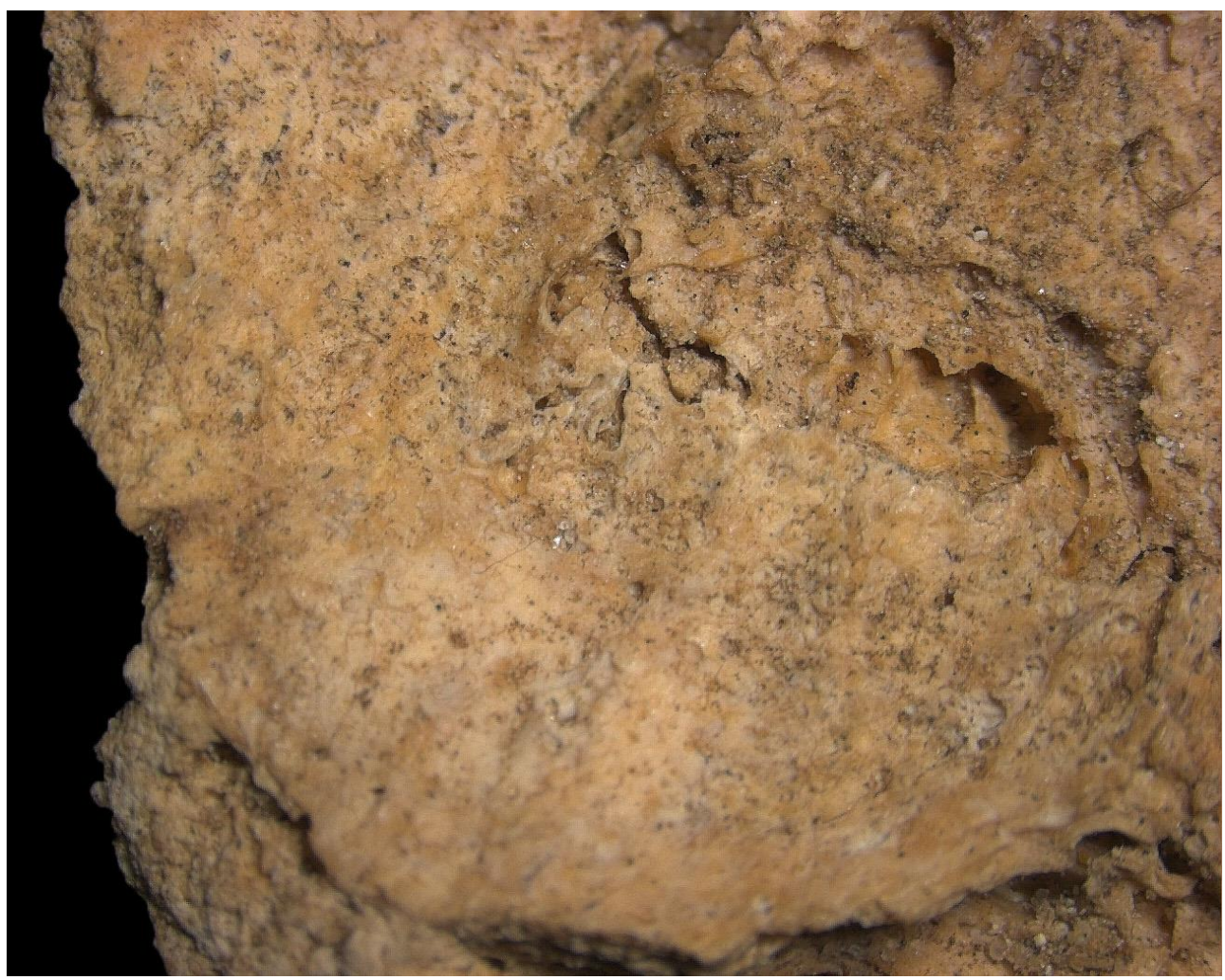

Abb. 6: Makroskopisch sichtbare Veränderungen auf der Innenseite des Os zygomaticum. Bei der lichtmikroskopischen Untersuchung konnten diese Veränderungen als postmortale Artefakte identifiziert werden. 


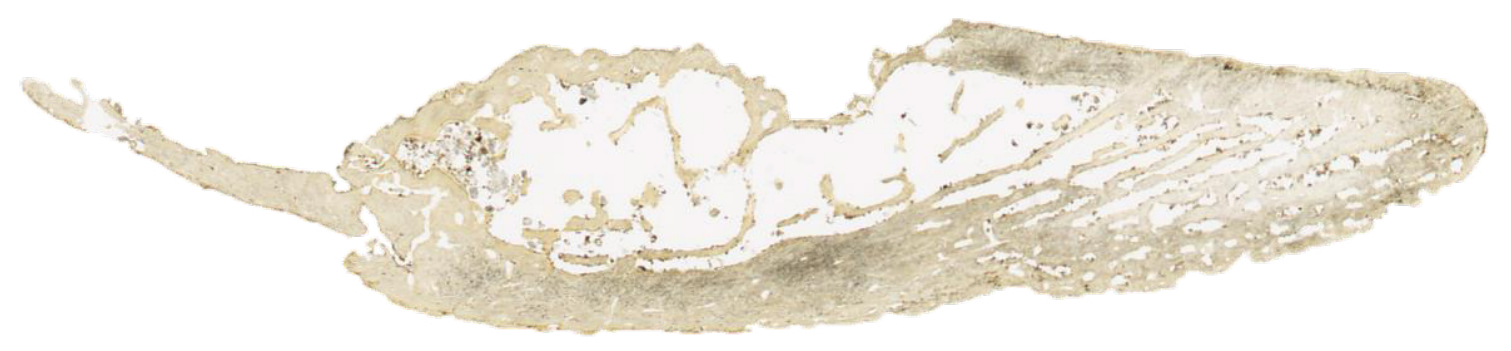

Abb. 7: Eingescannter Dünnschliff der Schnittebene "a" (Vgl. Abb. 1). Oben im Bild befindet sich die Innenseite des Fundstücks.

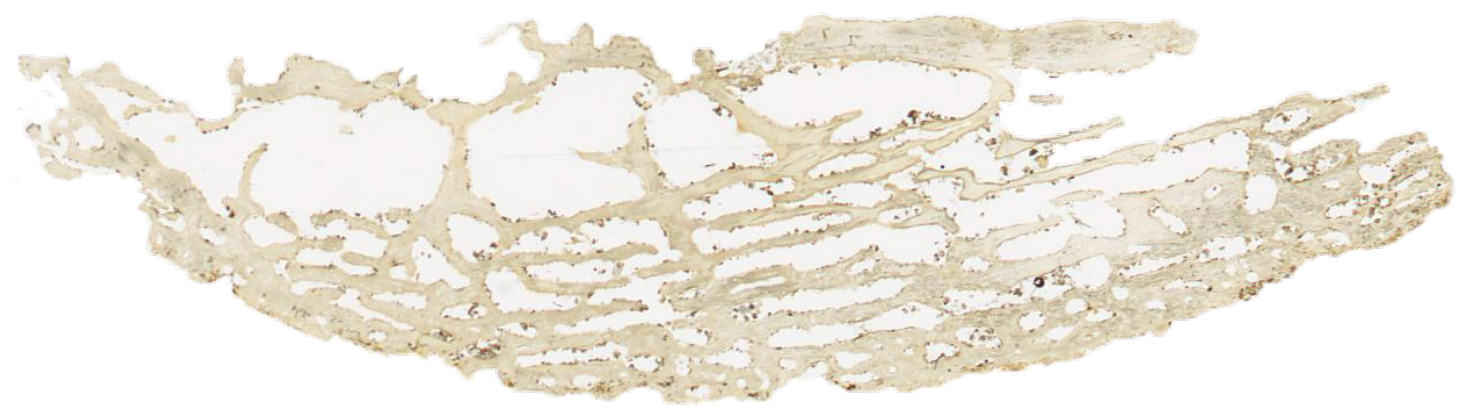

Abb. 8: Eingescannter Dünnschliff der Schnittebene " $b^{\prime}$ (Vgl. Abb. 1). Oben im Bild befindet sich die Innenseite des Fundstücks.

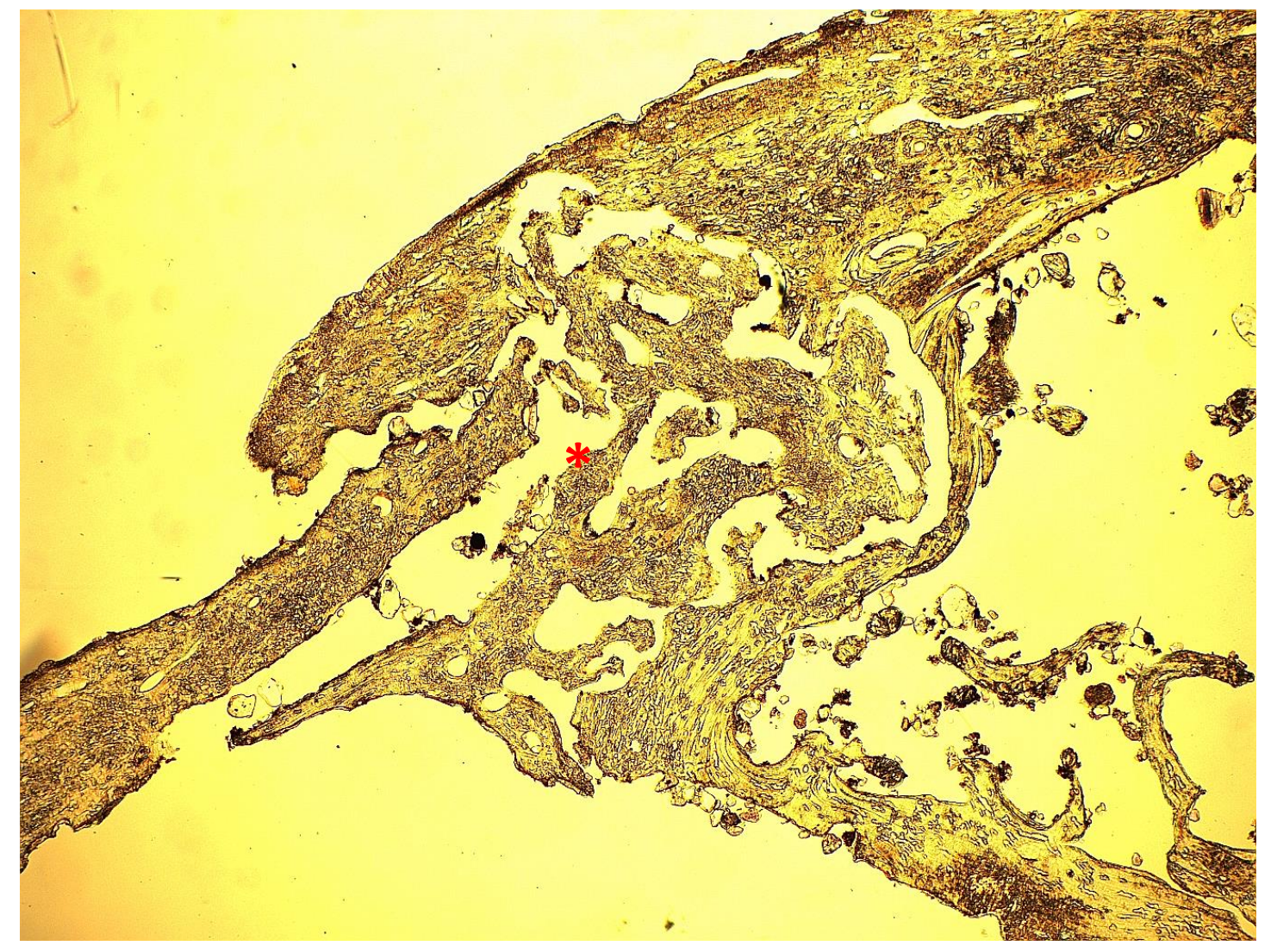

Abb. 9: Dünnschliffdicke $50 \mu m$, Vergrößerung 16x, Aufnahme im einfachen Durchlicht; Schnitt durch die Sutura zygomaticomaxillaris $\left(^{*}\right)$.

In Abb. 9 ist die Nahtstruktur der Sutura zygomaticomaxillaris zu erkennen. 
Die porösen Strukturen auf der Knochenoberfläche sind in den Abbildungen 10 bis 15 gut zu erkennen. Aufgrund des schlechten Erhaltungszustandes, der bei der mikroskopischen Untersuchung auffiel, ist eine genaue Diagnose nicht zu stellen. Fest steht jedoch, dass hier eine periostale Reizung der Knochenoberfläche stattgefunden hatte, die intravital zu porös erscheinenden Knochenneubildungen geführt hatte. Diese wurden durch Bodenerosionen postmortal verändert.

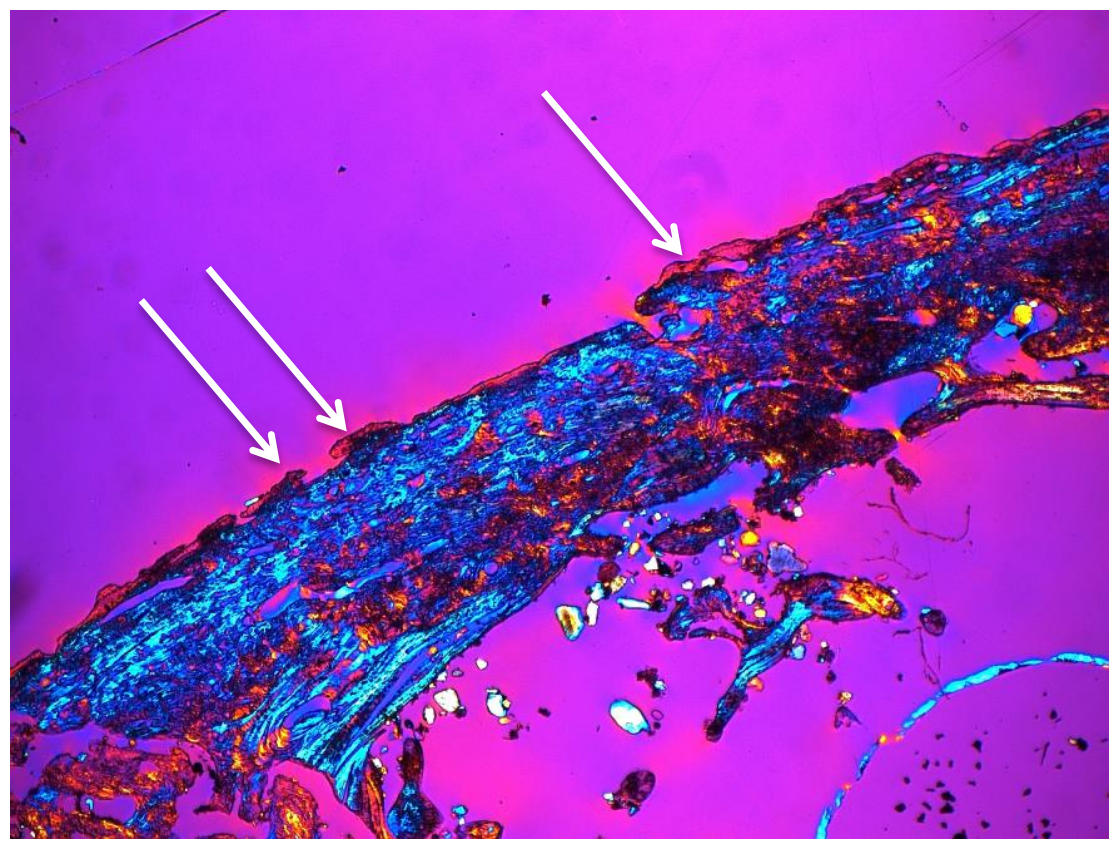

Abb. 10: Dünnschliffdicke $50 \mu m$, Vergrößerung 16x, Aufnahme im polarisierten Durchlicht unter Verwendung eines Hilfsobjektes Rot 1. Ordnung (Quarz) als Kompensator; deutliche, poröse Strukturen auf der äußeren Oberfläche des Os zygomaticum (Pfeile).

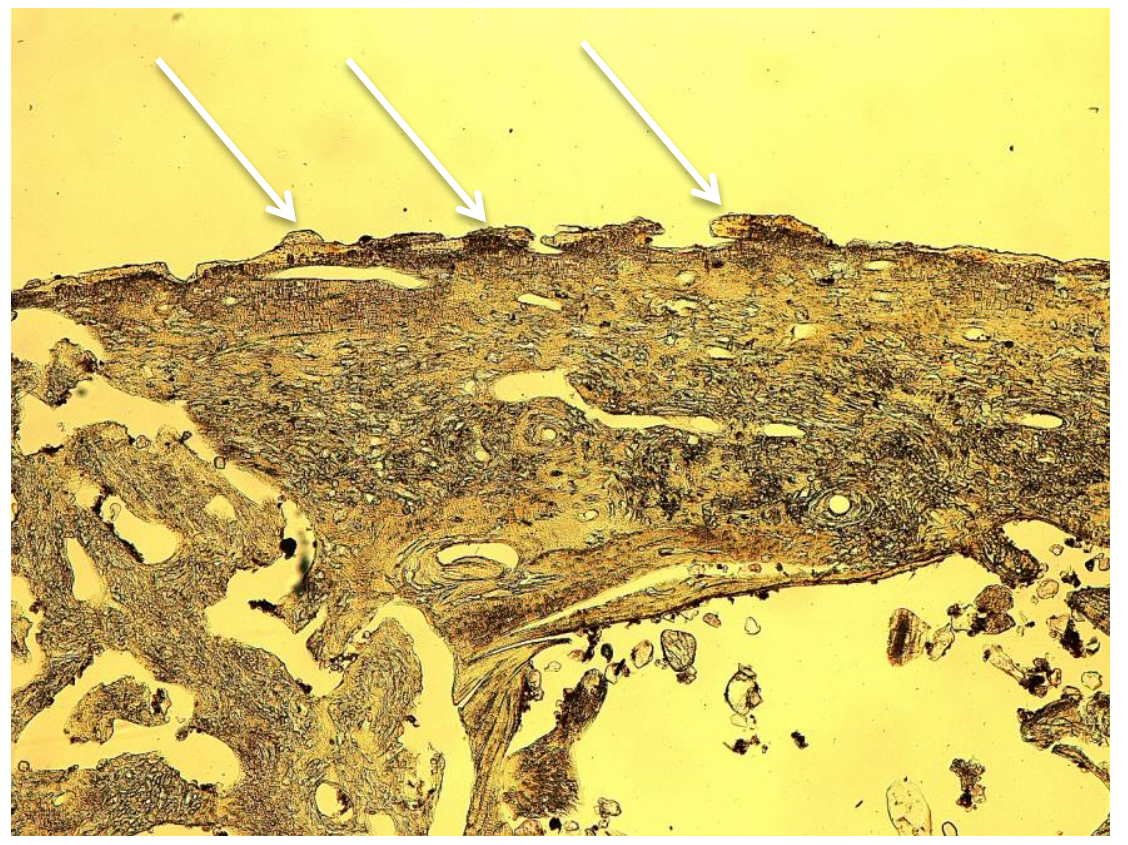

Abb. 11: Dünnschliffdicke $50 \mu m$, Vergrößerung 25x, Aufnahme im einfachen Durchlicht; vergrößerte Aufnahme der Strukturen der porösen Knochenneubildungen (Pfeile). 


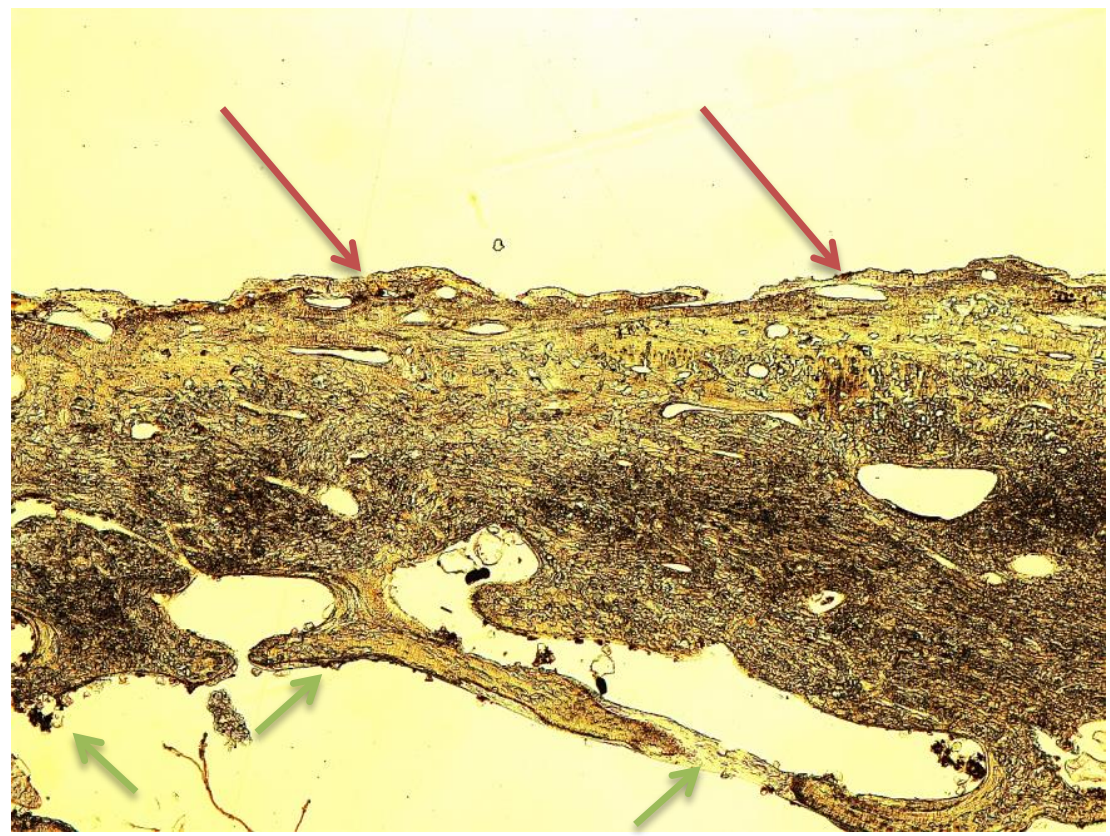

Abb. 12: Dünnschliffdicke $50 \mu m$, Vergrößerung 25x, Aufnahme im einfachen Durchlicht; außen finden sich deutliche Spuren der intravitalen Auflagerungen (rote Pfeile). Innen sind Spuren postmortaler Degradation zu erkennen. Es handelt sich um postmortale, poröse Defekte (grüne Pfeile).

In Abb. 12 ist ein Ausschnitt der postmortalen Artefakte vom Inneren des Jochbeins dargestellt. Diese Veränderungen sind hier deutlich als nicht intravital zu identifizieren.

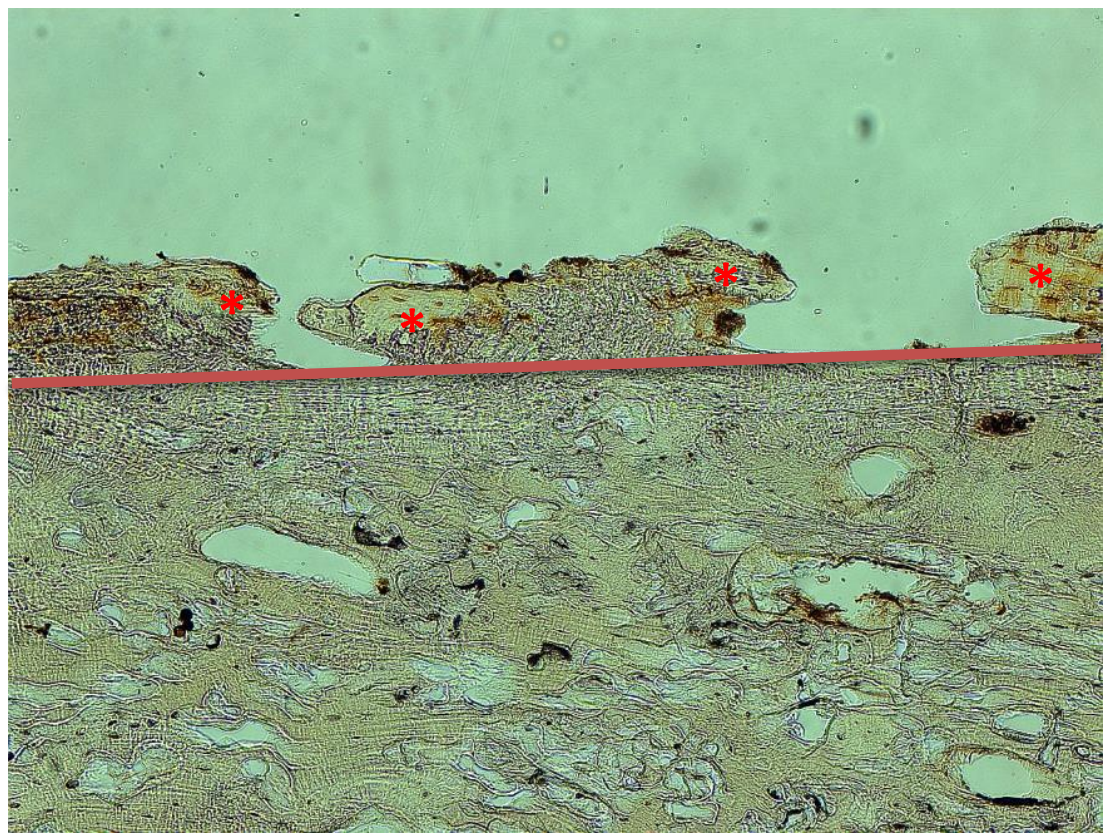

Abb. 13: Dünnschliffdicke $50 \mu \mathrm{m}$, Vergrößerung 100x, Aufnahme im einfachen Durchlicht mit Graufilter; Nahaufnahme der Auflagerungen (*). Ursprüngliche, gesunde Knochenlinie (rote Linie).

Abb. 13 zeigt den ursprünglichen Verlauf der Compacta. Durch den entzündlichen Prozess, der eine Reizung des Periosts hervorgerufen hat, haben sich plattenartige Neubildungen auf der ursprünglichen Compacta gebildet. 


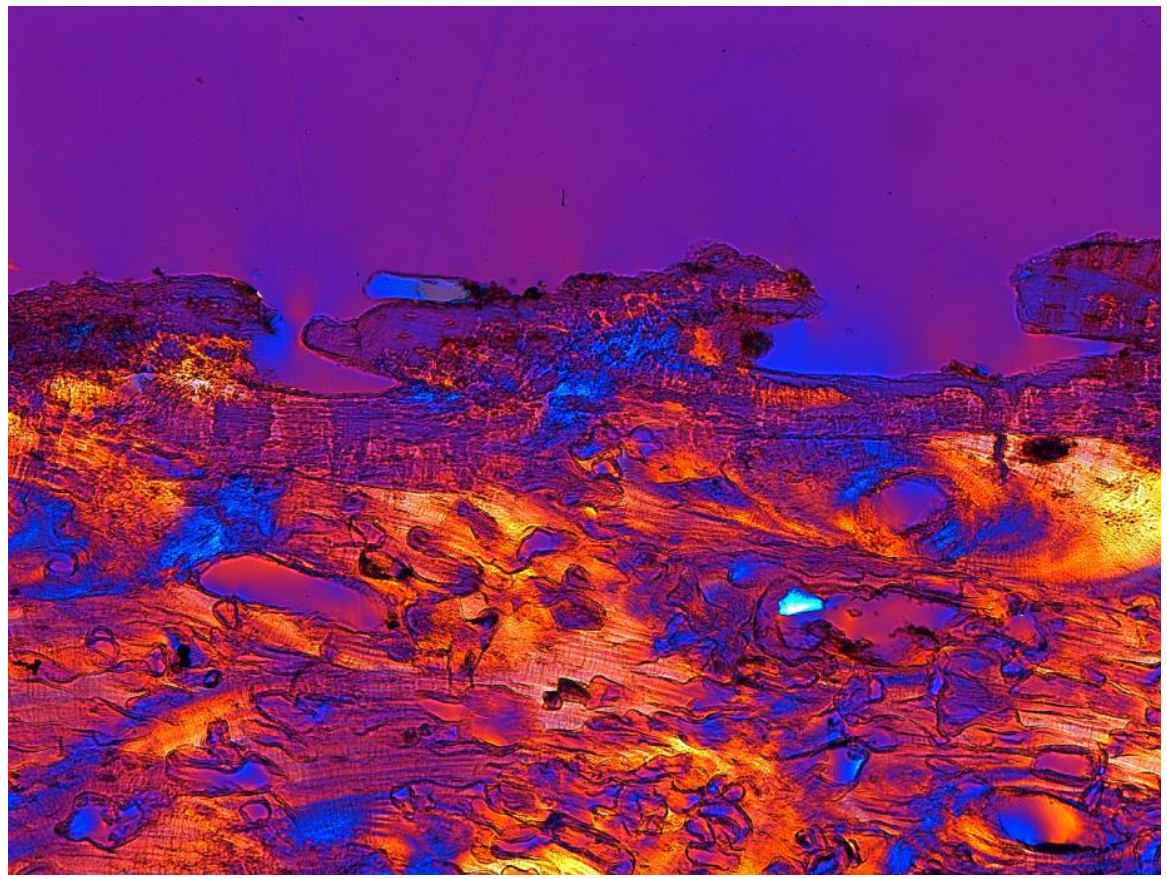

Abb. 14: Dünnschliffdicke $50 \mu m$, Vergrößerung 100x, Aufnahme im polarisierten Durchlicht unter Verwendung eines Hilfsobjektes Rot 1. Ordnung (Quarz) als Kompensator; der Mangel an Kollagen in der aufgelagerten Knochenstruktur lässt auf Faserknochen schließen, der nicht integriert ist.

Die Abbildungen 14 und 15 zeigen die plattenartigen Neubildungen auf der Knochenoberfläche in polarisiertem Licht. Die aufgelagerten Strukturen weisen weniger Kollagen auf, als der gesunde, darunter liegende Knochen. Daraus lässt sich ableiten, dass die Neubildungen nicht in die ursprüngliche Knochenstruktur integriert waren.

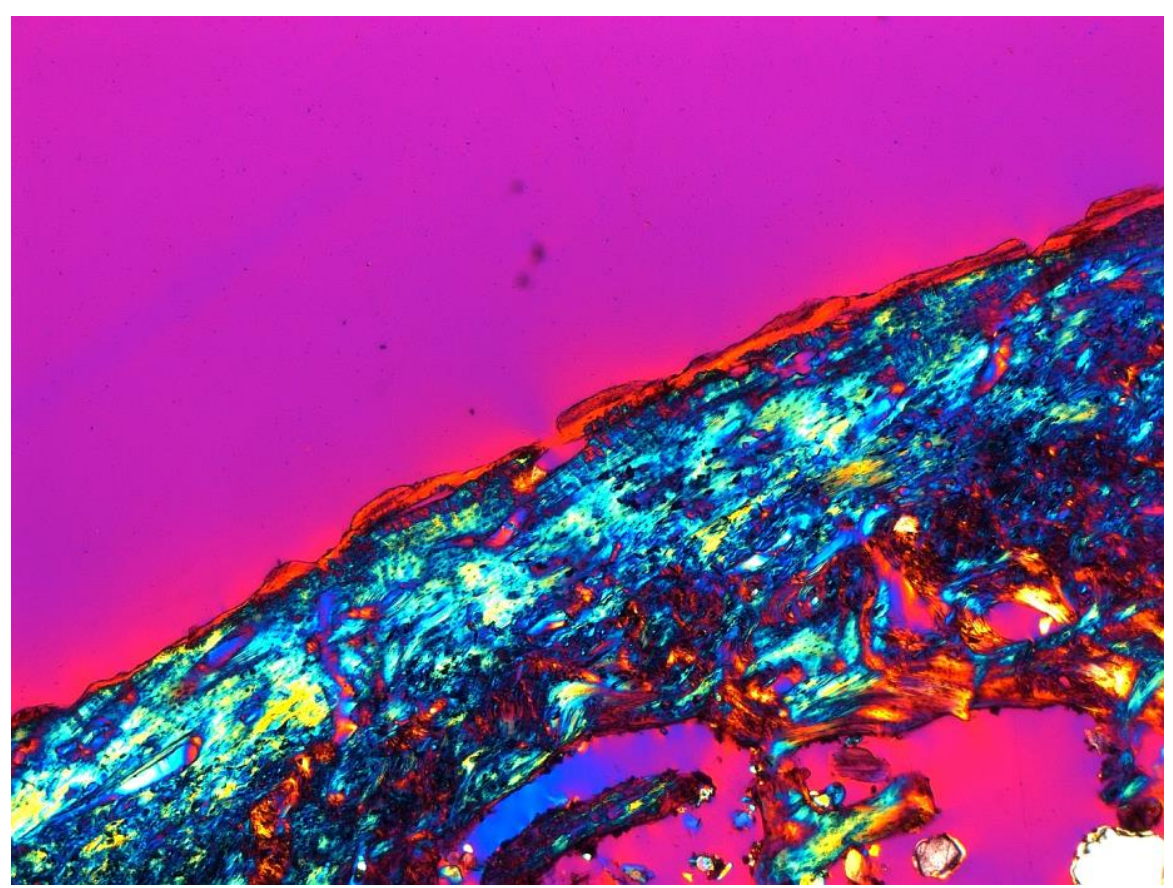

Abb. 15: Dünnschliffdicke $70 \mu m$, Vergrößerung 25x, Aufnahme im polarisierten Durchlicht unter Verwendung eines Hilfsobjektes Rot 1. Ordnung (Quarz) als Kompensator; hier deutlich erkennbar: Kollagenarmes Knochengewebe im Bereich der Auflagerungen. Kollagenreiche Strukturen werden hier blau dargestellt, kollagenarme in rot. 


\subsection{Lichtmikroskopischer Befund 1 der Population aus Großenrode}

Diese Knochendünnschliffe entstammen dem rechten und linken Os parietale (im Folgenden als „Pariet“ abgekürzt) des Schädels eines erwachsenen Individuums der Population aus Großenrode. Das Sterbealter kann lichtmikroskopisch auf 40 bis 70 Jahre beziffert werden. Makroskopisch fallen deutliche Erhebungen auf der Lamina interna auf, welche lichtmikroskopisch untersucht wurden. Aus zwei verschiedenen Regionen jedes Scheitelbeins wurden Knochenproben entnommen und Dünnschliffe angefertigt.

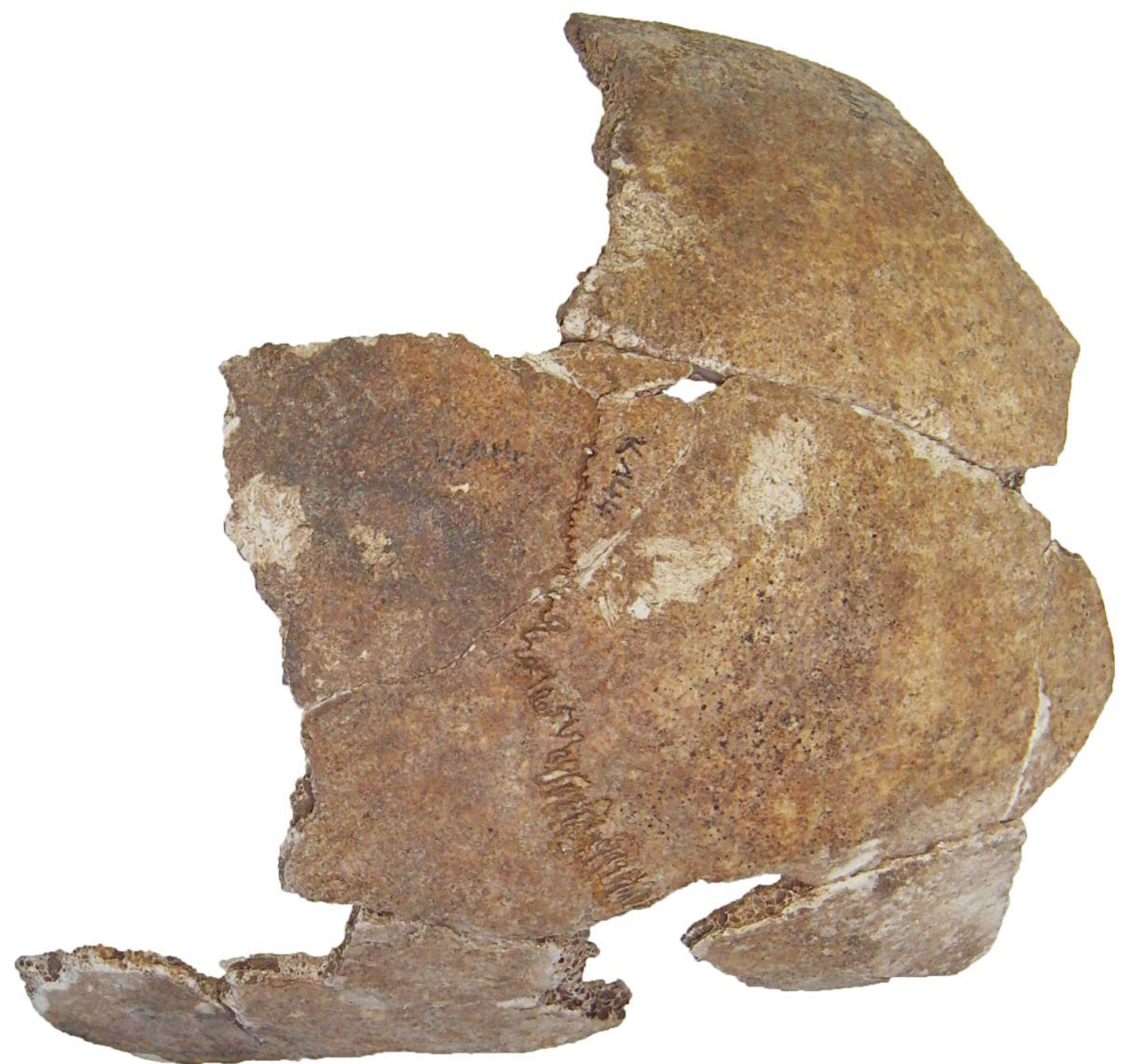

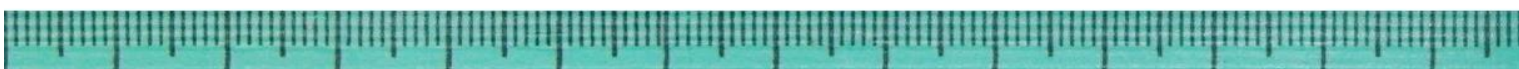

Abb. 1: Makroskopische Abbildung des untersuchten Schädelkompartiments. Unten im Bild befindet sich das rechte Os parietale, oben das linke. Rechts im Bild ist das Os frontale zu finden. 


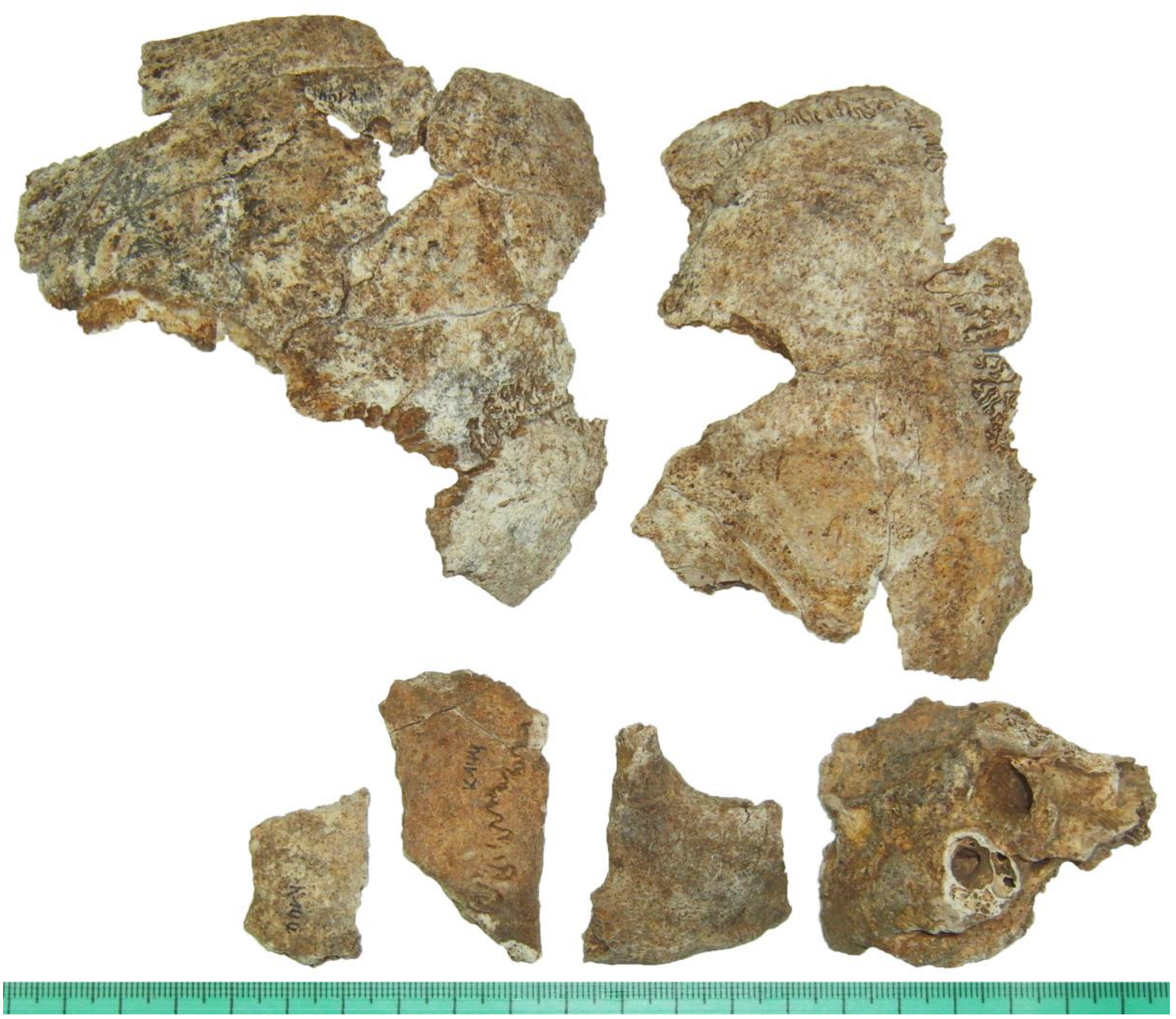

Abb. 2: Abbildung weiterer erhaltener Schädelkompartimente.

Bei den im Folgenden gezeigten Auflagerungen handelt es sich möglicherweise um Knochenneubildungen im Sinne reaktiver Periostreaktionen nach einem Entzündungsreiz. Die Vertiefungen wurden als Gefäßimpressionen identifiziert; sie sind durch die Hypervaskularisierung im Entzündungsgebiet gebildet worden.

Die Abbildungen 8 bis 26 zeigen beispielhaft Ausschnitte der Befunde der lichtmikroskopischen Untersuchung. 


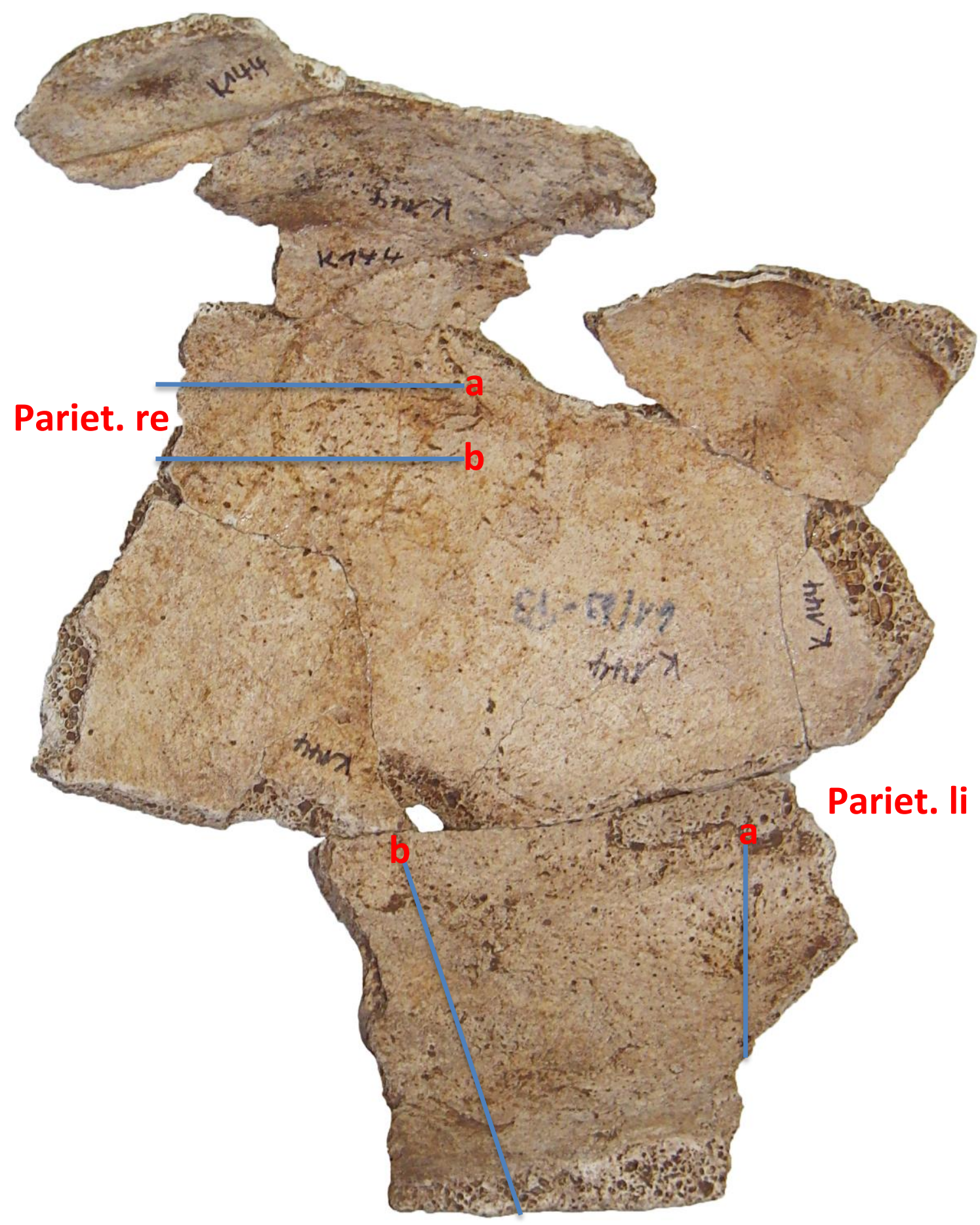

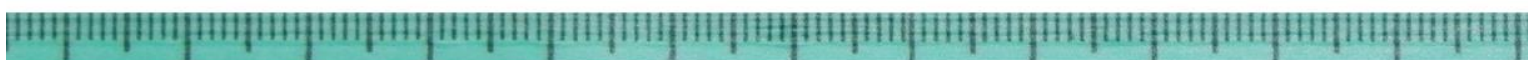

Abb. 3: Aufnahme des untersuchten Schädelkompartiments mit Ansicht auf die Innenseite. Eingezeichnet sind die verschiedenen Schnittebenen. 


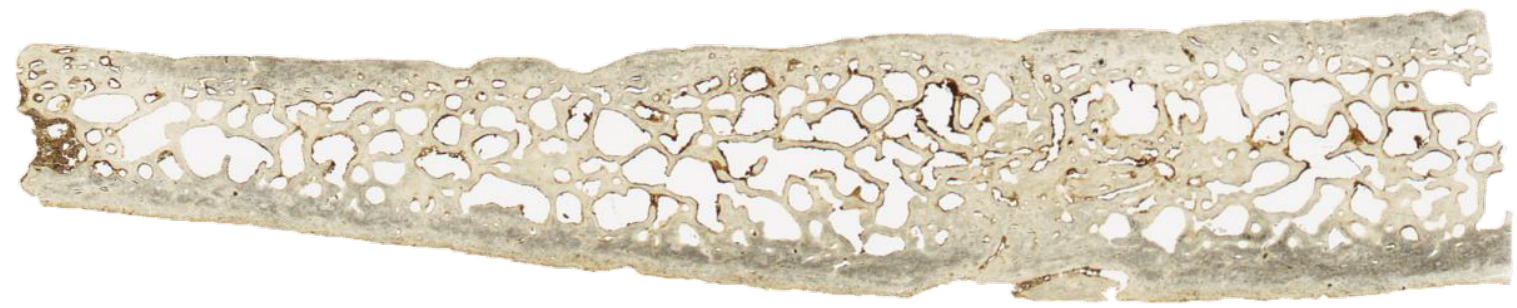

Abb. 4: Eingescannter Dünnschliff Pariet. re a. Oben im Bild befindet sich die Lamina interna.

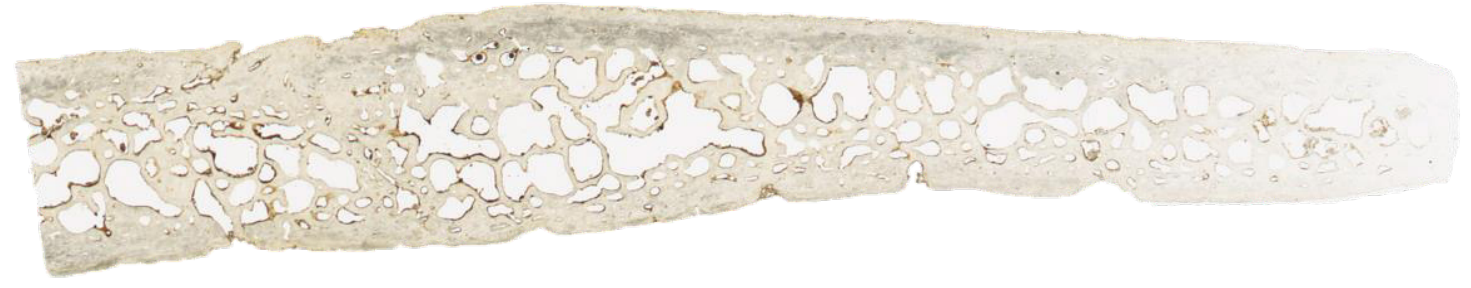

Abb. 5: Eingescannter Dünnschliff Pariet. re b. Oben im Bild befindet sich die Lamina externa.

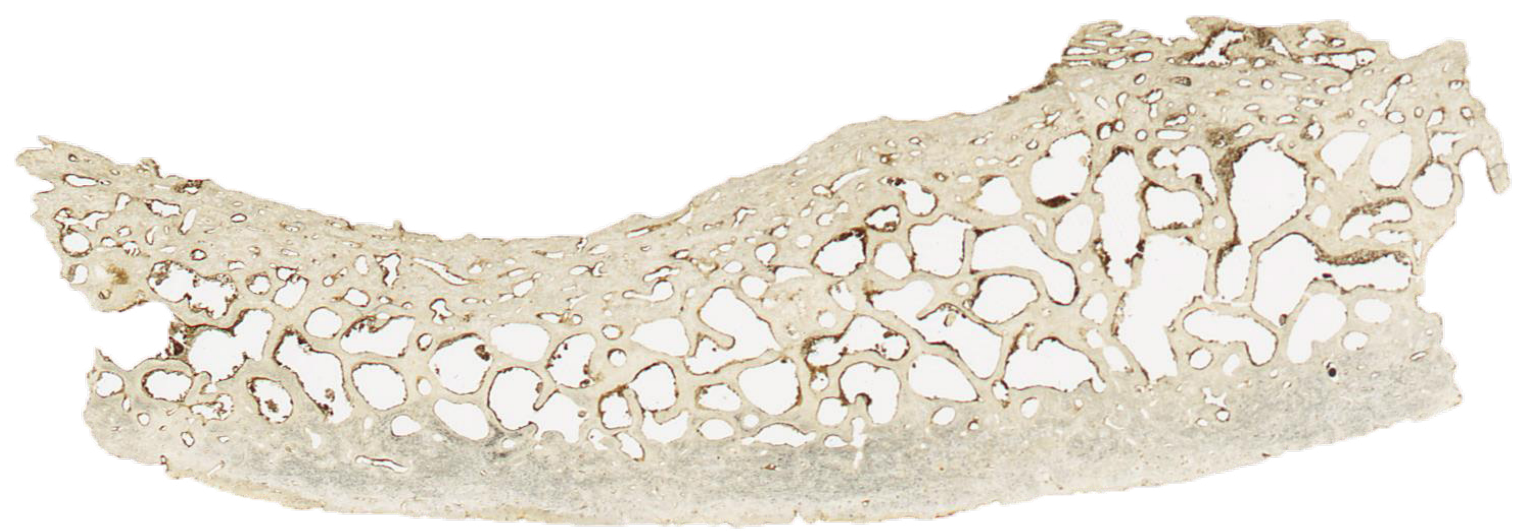

Abb. 6: Eingescannter Dünnschliff Pariet. li a. Oben im Bild befindet sich die Lamina interna.

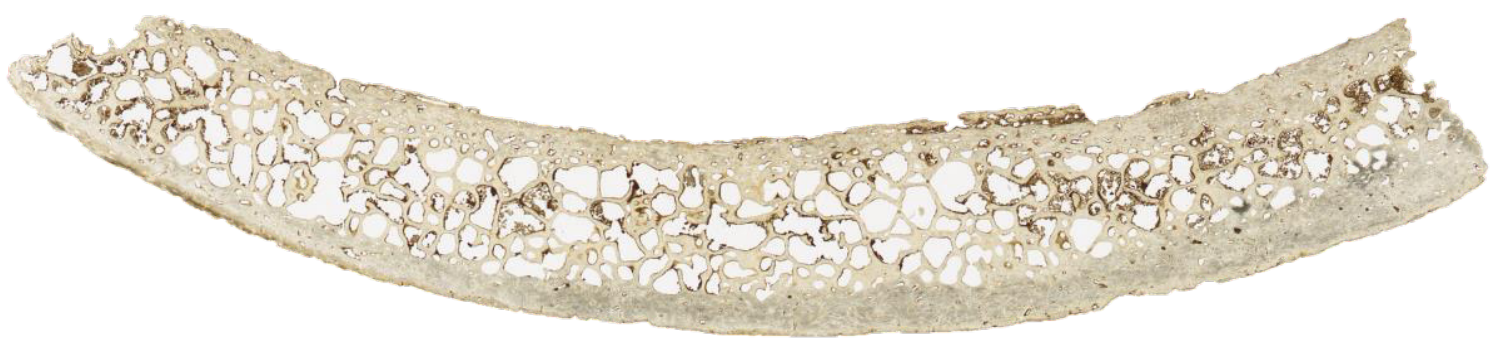

Abb. 7: Eingescannter Dünnschliff Pariet. li b. Oben im Bild befindet sich die Lamina interna. Es handelt sich hierbei um einen großen Dünnschliff.

In Abb. 8 kann man auf einen Gefäßbogen in der untersuchten Region schließen. Es handelt sich dabei um eine alte Affektion; der untersuchte Bereich zeigt eine deutlich vernarbte Struktur. Aufgrund des mangelnden Kollagengehaltes (durch Degradation) ist diese Affektion nicht genau differenzierbar; es könnte sich jedoch 
um eine meningeale Reizung gehandelt haben. Zugrunde lag nachweislich eine ostitische Reaktion mit anschließender Periostitis.

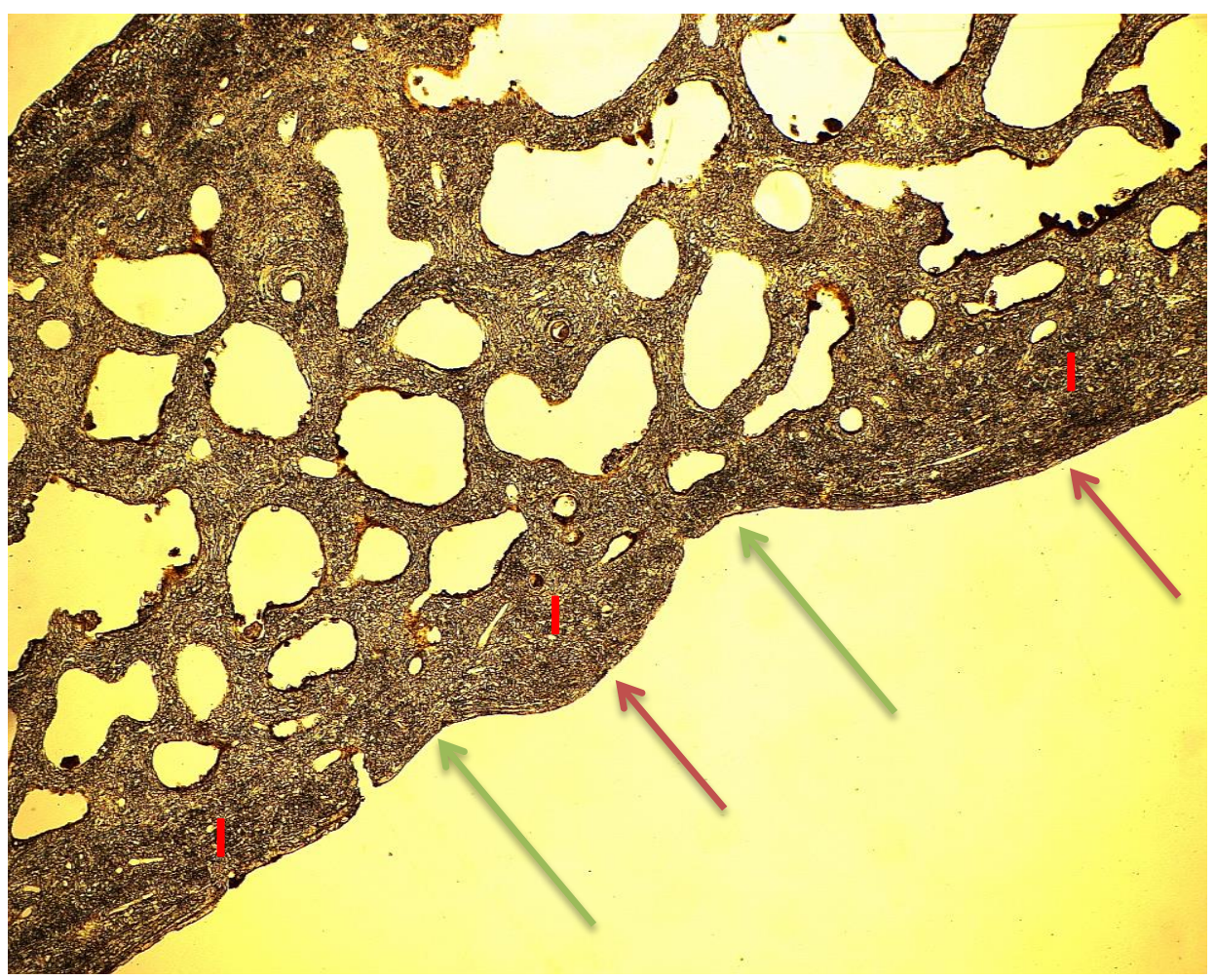

Abb. 8: Dünnschliffdicke $50 \mu m$, Vergrößerung 16x, Aufnahme im einfachen Durchlicht; die Pfeile deuten auf die deutlich erkennbaren Anhebungen (rot) und Absenkungen (grün) in der Knochenstruktur der Lamina interna (I).

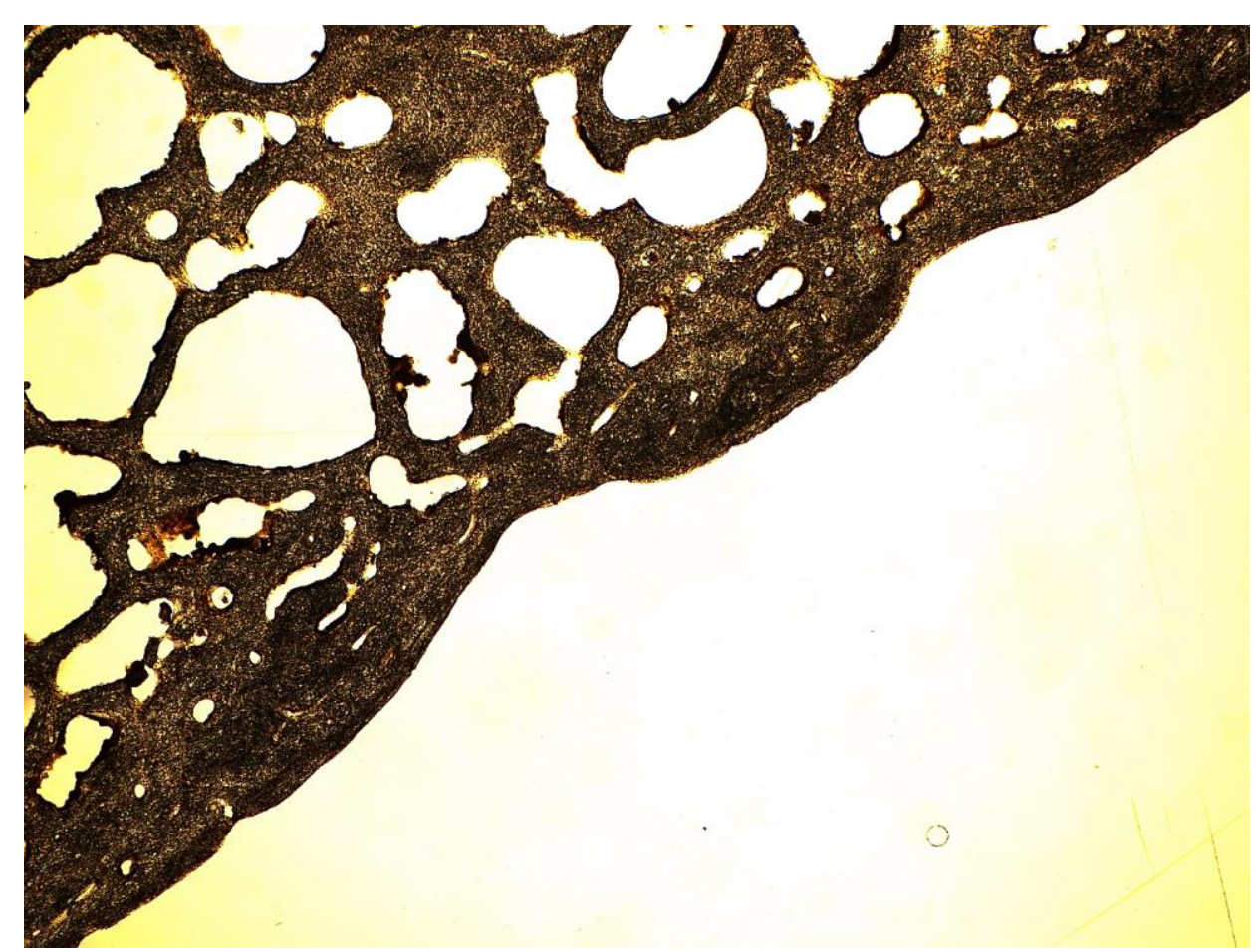

Abb. 9: Dünnschliffdicke $70 \mu \mathrm{m}$, Vergrößerung 16x, Aufnahme im einfachen Durchlicht; analoge Struktur zu der in Abb. 8. 
In Abb. 9 ist eine deutliche Auflagerung auf der Lamina interna zu erkennen. Es handelt sich um eine sehr gut organisierte Knochenneubildung, die sich kaum von der ursprünglichen, gesunden Struktur abhebt, was allerdings auch mit dem mangelnden Erhalt von Kollagen zusammenhängt.

Die folgenden Präparate stammen vom linken Os parietale:

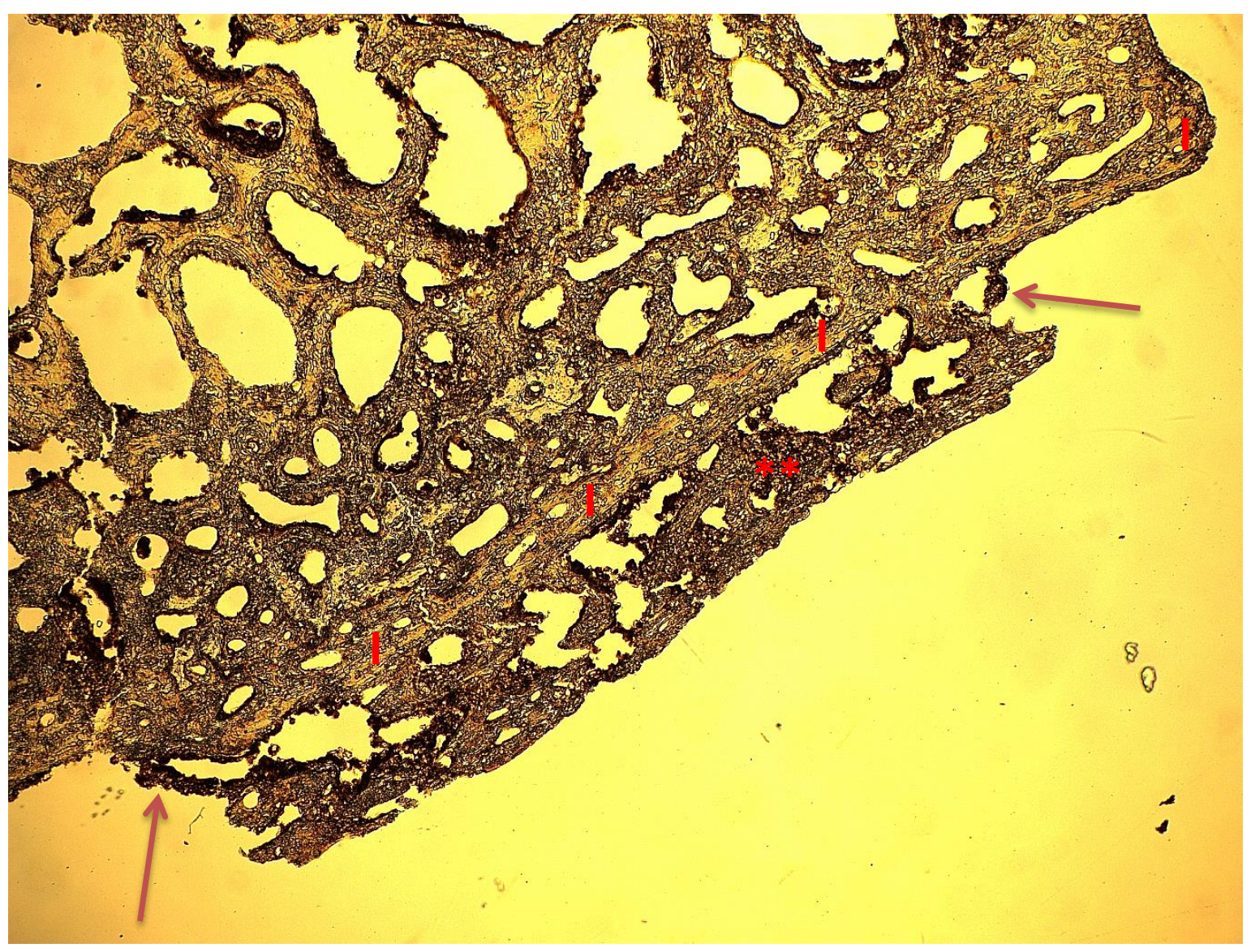

Abb. 10: Dünnschliffdicke $50 \mu m$, Vergrößerung 16x, Aufnahme im einfachen Durchlicht; die Reste der Auflagerung auf der Lamina interna (I) sind durch die Pfeile begrenzend markiert. Zeichenverzeichnis: I: gesunde und ursprüngliche Knochenstruktur der Lamina interna, **: krankhafte Knochenneubildung als Auflagerung auf der Lamina interna.

Abb. 10 zeigt eine große Auflagerung (im Sinne einer Knochenneubildung), die nicht so gut integriert ist, wie die vorangegangenen. Deutlich erkennbar ist der Unterschied zwischen Knochenneubildung und ursprünglicher Knochensubstanz.

In Abb. 11 ist eine verheilte Auflagerung zu sehen, die eventuell mit jener von Abb.8 in Zusammenhang zu bringen ist. Sie ist demnach ebenfalls verheilt und gut integriert.

Aufgrund der Erkenntnisse nach der lichtmikroskopischen Untersuchung, kann festgehalten werden, dass es sich wohl um zwei verschiedene Krankheitszustände gehandelt hat, die auch zeitlich auseinander lagen. 


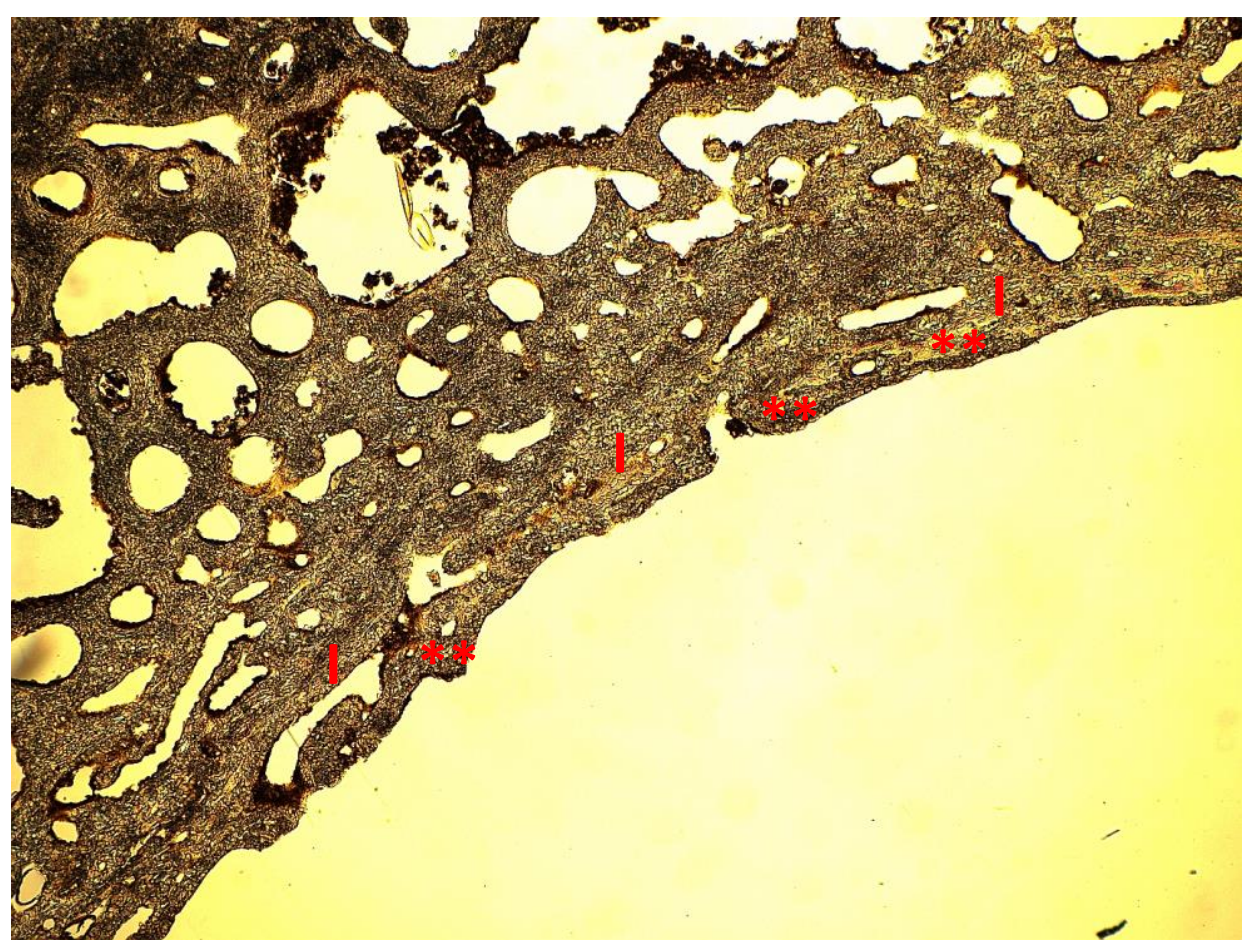

Abb. 11: Dünnschliffdicke $50 \mu m$, Vergrößerung 16x, Aufnahme im einfachen Durchlicht; Lamina interna mit verheilten Spuren eines Reizzustandes. Es finden sich integrierte, plattenförmige Auflagerungen ${ }^{* *}$ ) aufder Lamina interna (I).

Die Auflagerung in Abb. 12 weist eine poröse Struktur auf. Es handelte sich intravital noch um Faserknochen, der im lichtmikroskopischen Bild aufgrund des Fehlens von Kollagen in den Resten der Auflagerung zu identifizieren ist.

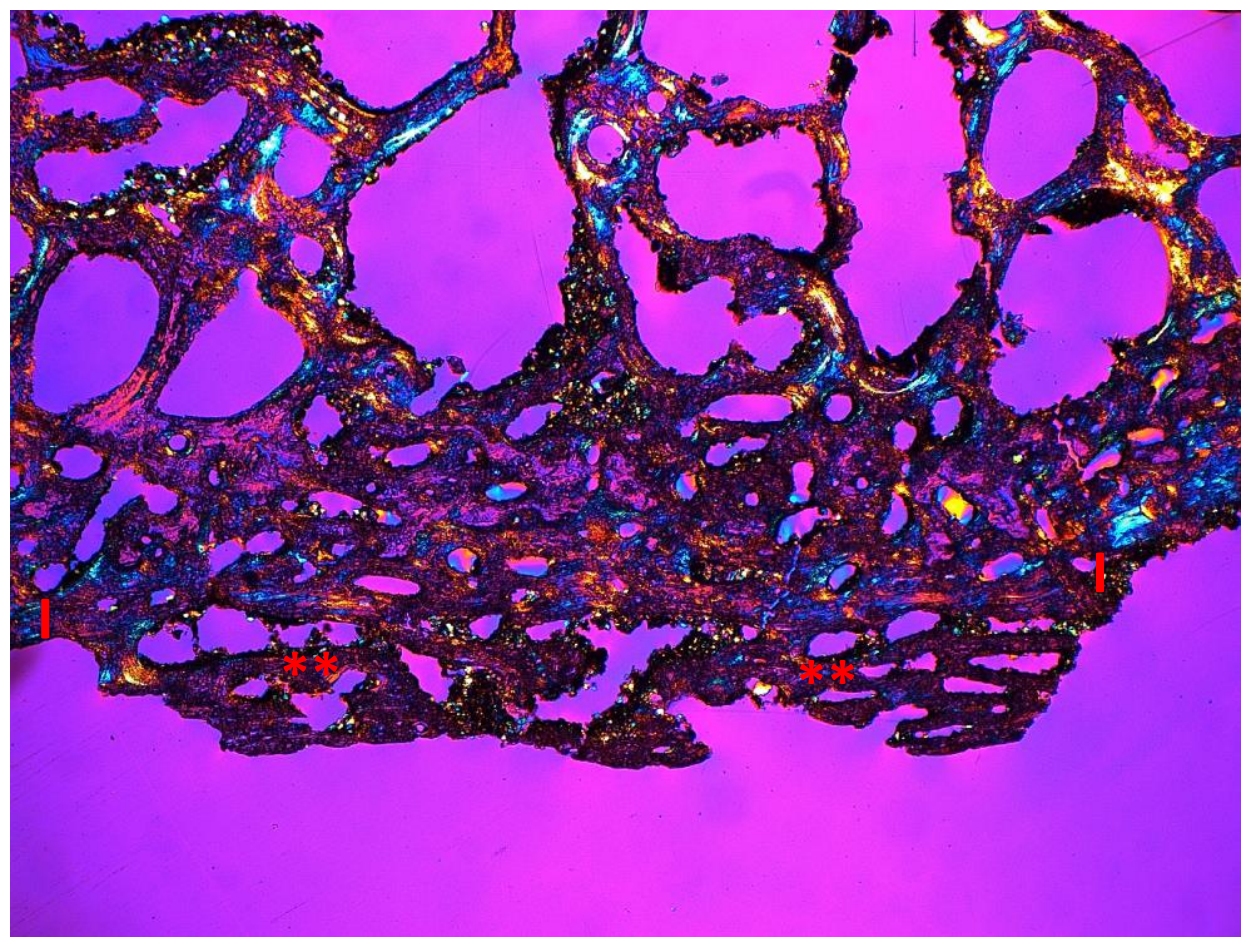

Abb. 12: Dünnschliffdicke $70 \mu \mathrm{m}$, Vergrößerung 16x, Aufnahme im polarisierten Durchlicht unter Verwendung eines Hilfsobjektes Rot 1. Ordnung (Quarz) als Kompensator; Auflagerung (**) auf der Lamina interna (I). Es sind kaum kollagene Strukturen in der Knochenneubildung auszumachen. Kollagen ist in dieser Aufnahme als bläulich - türkis zu identifizieren. 
Die darunter liegende, gesunde Lamina interna weist unregelmäßig geformte, eher kleinere Lochdefekte auf, die an intravitale Resorptionslakunen erinnern. Der gesamte Knochen ist in schlechtem Erhaltungszustand.

Großer Schliff:

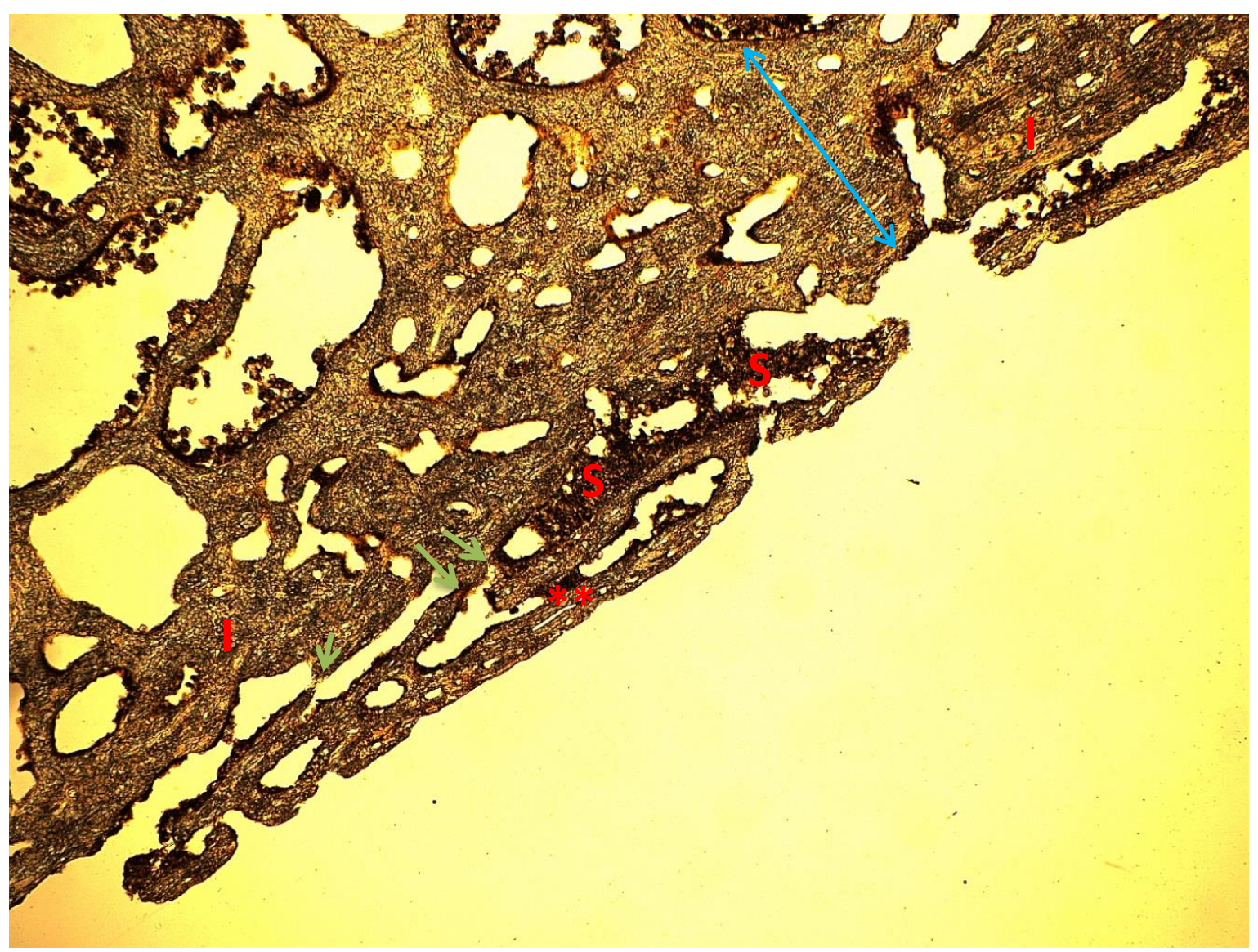

Abb. 13: Dünnschliffdicke $50 \mu m$, Vergrößerung 16x, Aufnahme im einfachen Durchlicht; deutlich erkennbar ist die sehr massige Lamina interna (blauer Pfeil). Das Bild zeigt eine große poröse Knochenplatte (**), die der Lamina interna (I) aufgelagert ist. Sie ist nicht integriert; der Spalt zwischen Lamina interna und Platte ist bis auf kleine Brückenverbindungen (grüne Pfeile) durchgängig. Zwischen Platte und Lamina interna hat sich biologisches Material (S) gesammelt.

In Abb. 13 sind poröse Knochenplatten erkennbar, die über breitbasige Stiele der krankheitsbedingt veränderten Lamina interna aufsitzen. Die Lamina interna ist durch zahlreiche, überwiegend kleinere Resorptionshöhlen verändert; die angrenzenden Trabekel der Diploë sind verklumpt und bilden inselartige Strukturen, die in die ursprüngliche, nicht krankhaft veränderte Diploë hineinreichen. Offenbar handelt es sich bei den Auflagerungen um reaktive Knochenneubildungen nach einem Entzündungsprozess, der von den Hirnhäuten ausgehend die Lamina interna beeinflusst hat. Die Platten sind nicht in die Lamina interna integriert, es gibt nur kleine Brücken. 
In Abb. 14 sind die Laminae interna sowie externa erkennbar.

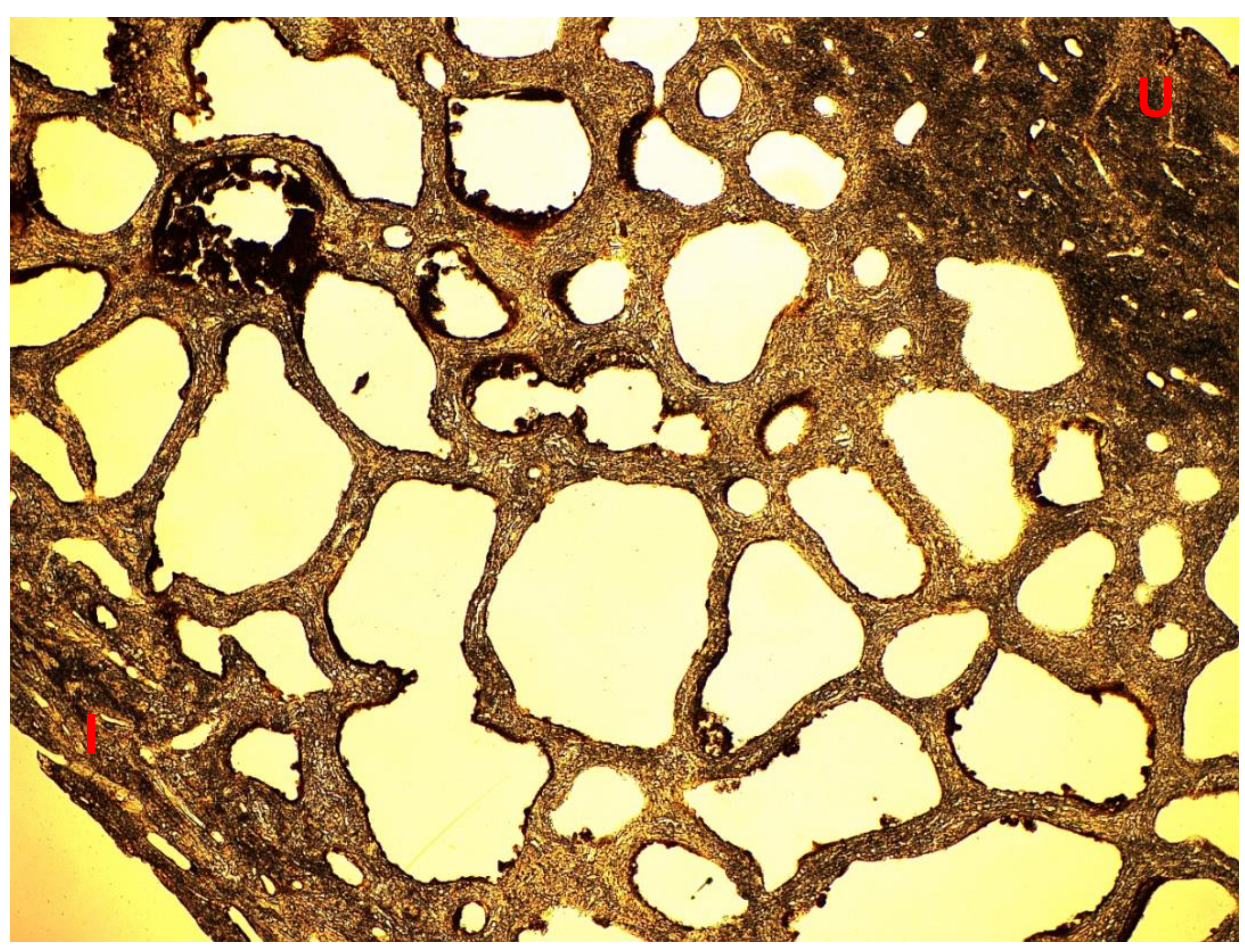

Abb. 14: Dünnschliffdicke $50 \mu m$, Vergrößerung 16x, Aufnahme im einfachen Durchlicht; in diesem Ausschnitt sind die Lamina interna (I) und die Lamina externa (U) getroffen. Die Lamina externa weist keine pathologischen Veränderungen auf. Die Lamina interna ist in diesem Ausschnitt normal dick ausgeprägt.

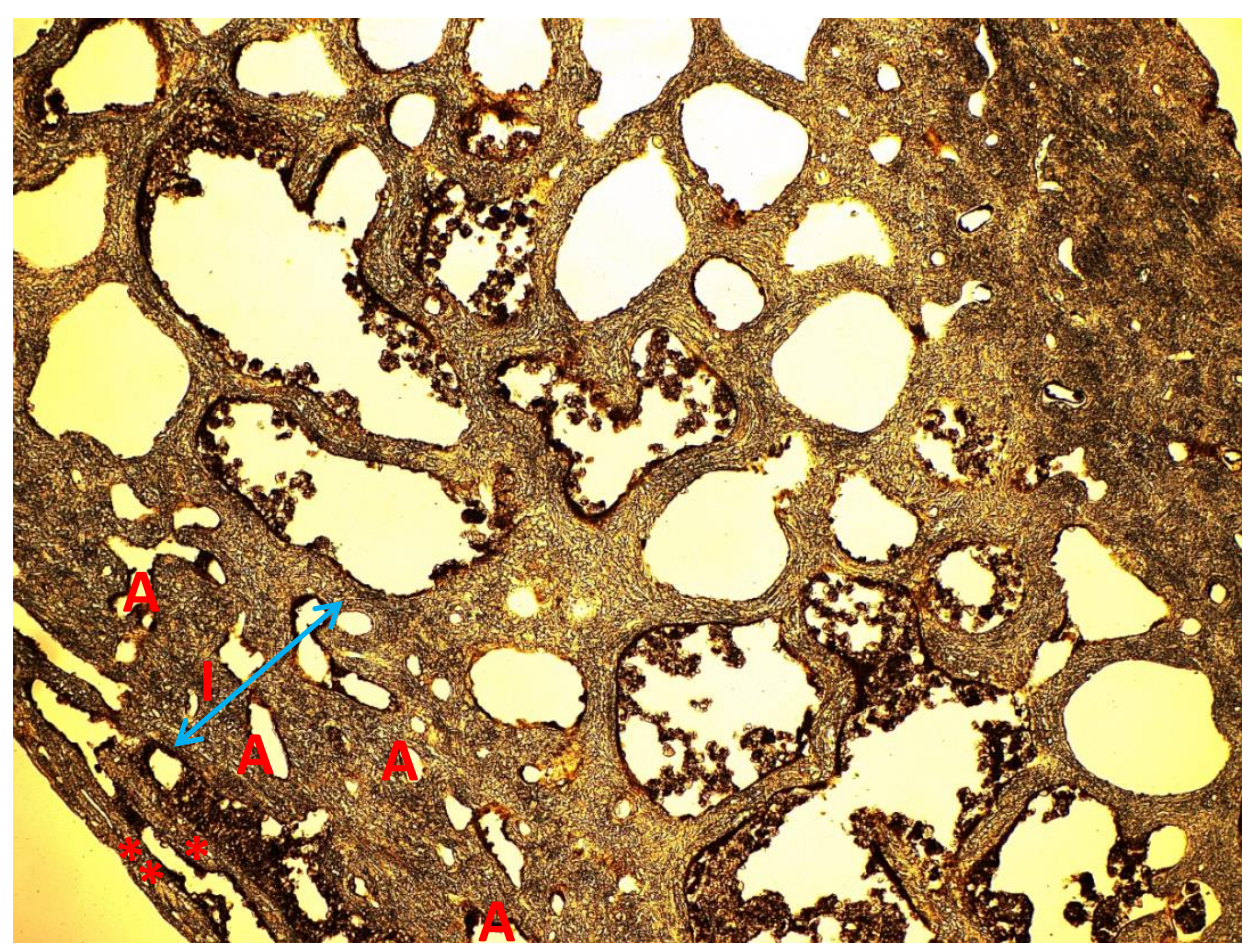

Abb. 15: Dünnschliffdicke $50 \mu m$, Vergrößerung 16x, Aufnahme im einfachen Durchlicht; in dieser Aufnahme fällt die deutlich verdickte Lamina interna (I) auf. Ihre Breite zeigt der blaue Pfeil an. Auf der Lamina interna liegt die pathologische Auflagerung (*: länger zurück liegende Entzündung;*: jüngere Entzündung). Innerhalb der Lamina interna finden sich zahlreiche Resorptionshöhlen $(A)$. 
Die Lamina interna ist im Bereich der plattenförmigen Knochenneubildungen stark verdickt (Abb. 15). Der Prozess ragte hier weit in den Diploëraum hinein. Die Resorptionshöhlen in der Lamina interna und die Platten sprechen eindeutig für einen entzündlichen Reiz. Eine epidurale Blutung kann als Ursache ausgeschlossen werden.

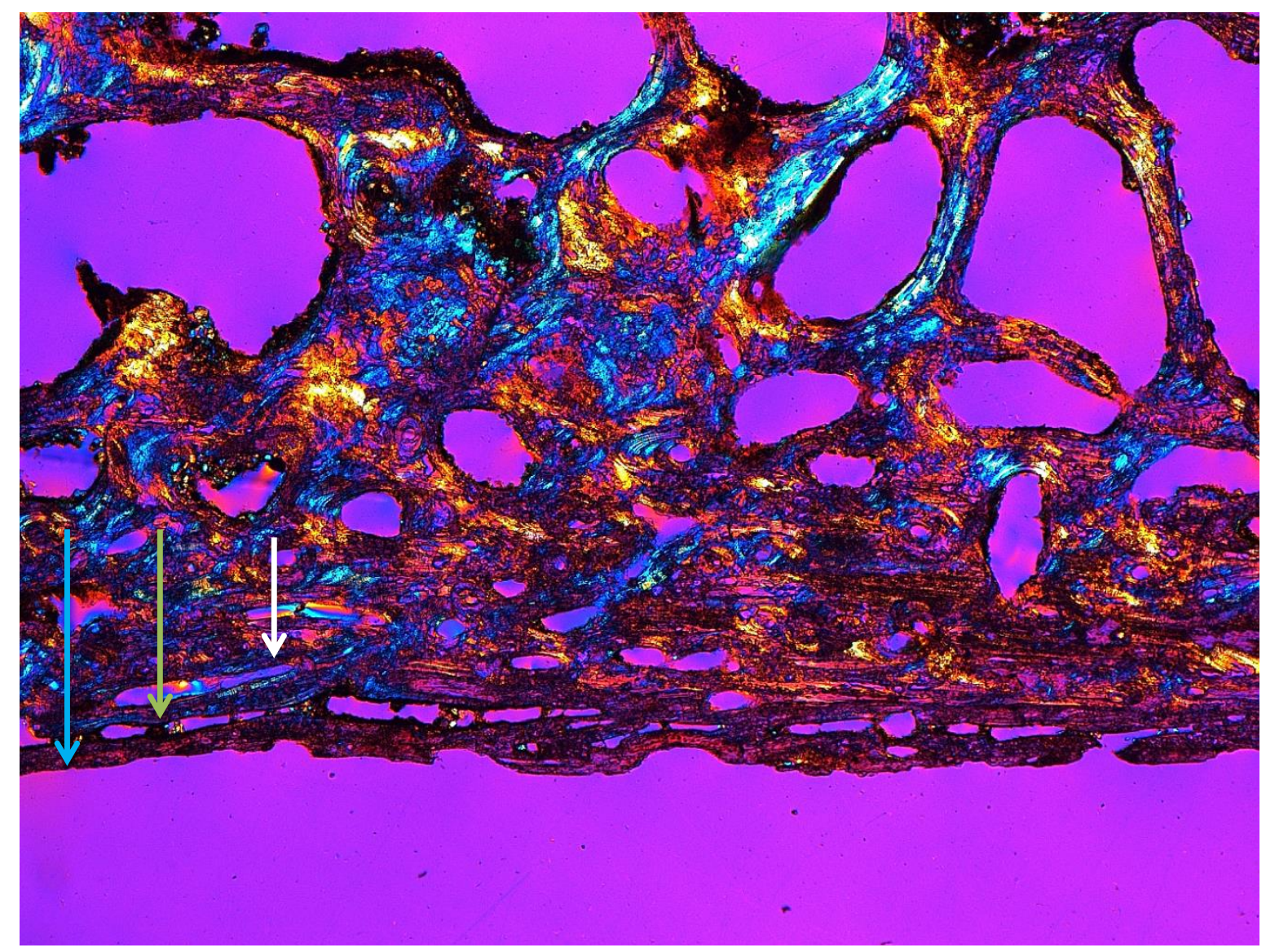

Abb. 16: Dünnschliffdicke $50 \mu m$, Vergrößerung 25x, Aufnahme im polarisierten Durchlicht unter Verwendung eines Hilfsobjektes Rot 1. Ordnung (Quarz) als Kompensator; Abbildung mit den verschiedenen Schichten im Sinne der plattenförmigen Knochenneubildungen. Der Prozess der Neubildung ist ein- bis zweimal unterbrochen worden, sodass sich mindestens 2, aber maximal 3 verschiedene Knochenlagen neu gebildet haben. Die verschiedenfarbigen Pfeile deuten die möglichen Abgrenzungen der Schichten an.

Nach Begutachtung der Lamina interna mit den aufgelagerten Platten, waren zwei bis drei Schichten verschieden alter Knochenneubildungen $\mathrm{zu}$ finden (Abb. 16). Diese Beobachtung legt den Verdacht nahe, dass es sich um einen länger andauernden Entzündungsprozess gehandelt hatte, der in Schüben abgelaufen war. Weiterhin denkbar wäre, dass es sich bei den neueren Schichten um Rezidive ein und desselben Prozesses handelt. Dass mindestens zwei verschiedene Entzündungsprozesse an der Lamina interna dieses Schädels abgelaufen waren, wurde bereits durch vorherige Abbildungen gezeigt. Die in Abb. 16 erkennbare Dreischichtigkeit unterstützt diese These; möglicherweise liefen die älteren Prozesse an den verschiedenen Lokalisationen gleichzeitig ab und die jüngeren 
Entzündungsprozesse ebenfalls gleichzeitig. Dies ist nicht eindeutig belegbar, da die Knochenstrukturen lichtmikroskopisch zwar als verschieden alt, aber nicht auf einen genauen Zeitpunkt eines oder mehrerer Prozesse datiert werden können.

Abb. 17 zeigt physiologische Resorptionshöhlen in der Knochenstruktur, die aber postmortal durch Bodenstoffe degeneriert wurden.

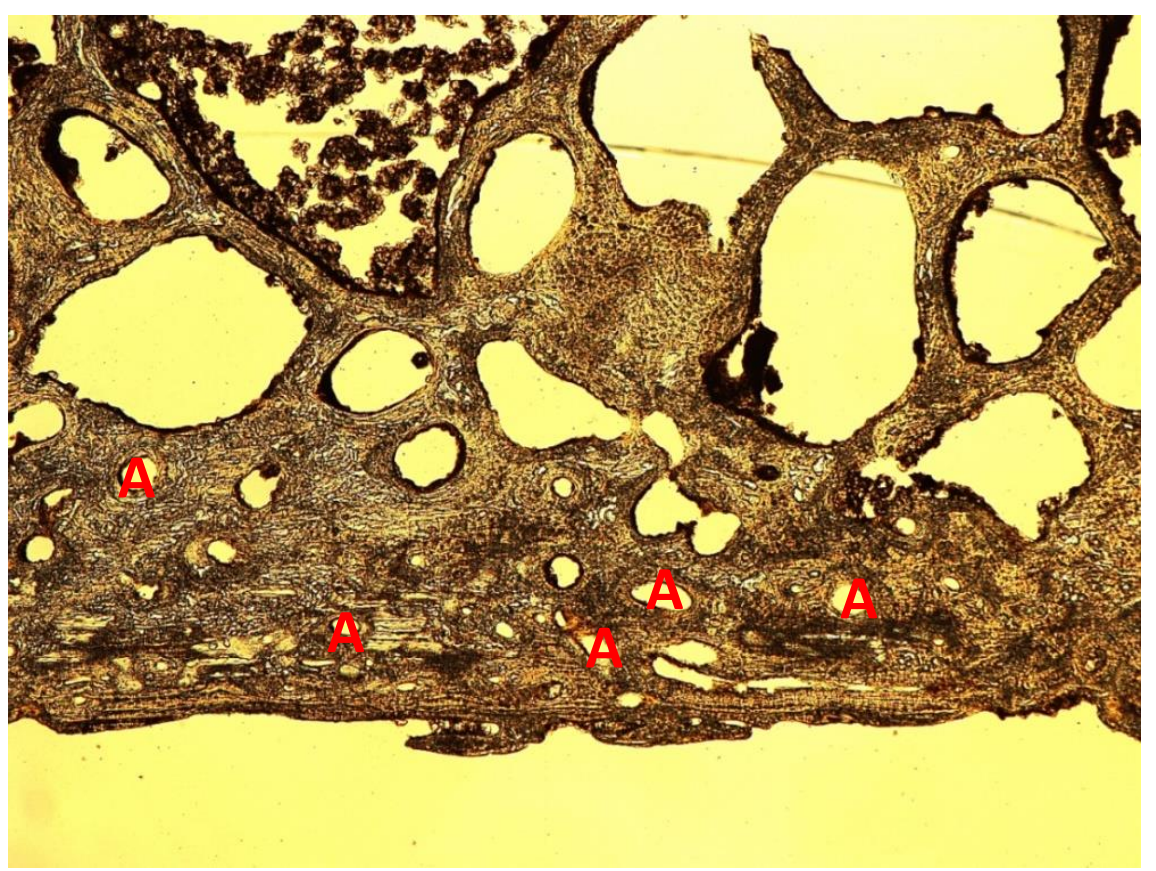

Abb. 17: Dünnschliffdicke $50 \mu m$, Vergrößerung, 25x, Aufnahme im einfachen Durchlicht; die Resorptionshöhlen (A) sind durch postmortale Diagenese verändert worden.

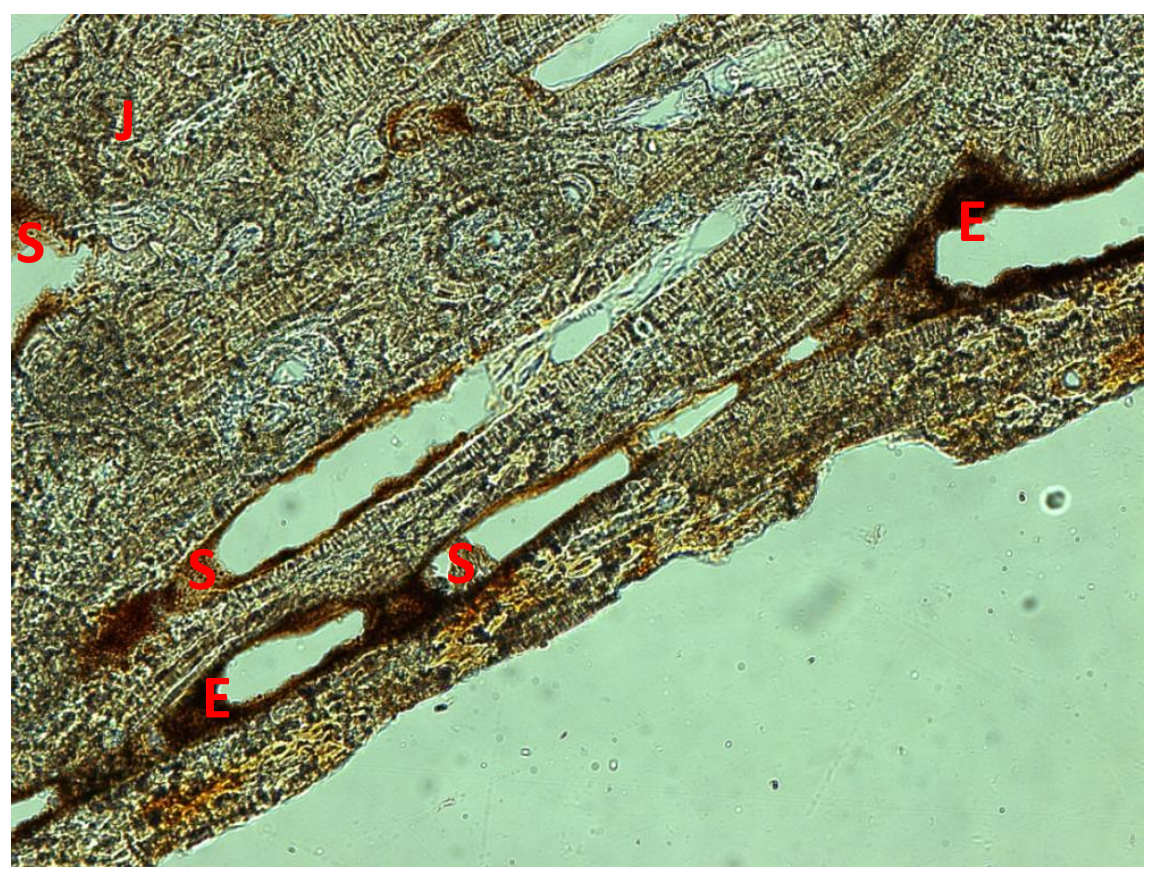

Abb. 18: Dünnschliffdicke $50 \mu m$, Vergrößerung 100x Aufnahme im einfachen Durchlicht mit Graufilter; der gesamte Knochen ist stark durch Bodenerosionen degradiert. Die dunklen Bereiche sind Pilzfraßspuren (E) und Ablagerungen biologischer Erdmaterialien (S). Oben links im Bild findet sich ein Bereich besonders starker Degradation der Knochenstruktur (J). 
Die Abbildungen 18 bis 22 zeigen unter verschiedener Belichtung die teilweise stark ausgeprägten Degradationsspuren an der Knochenoberfläche.

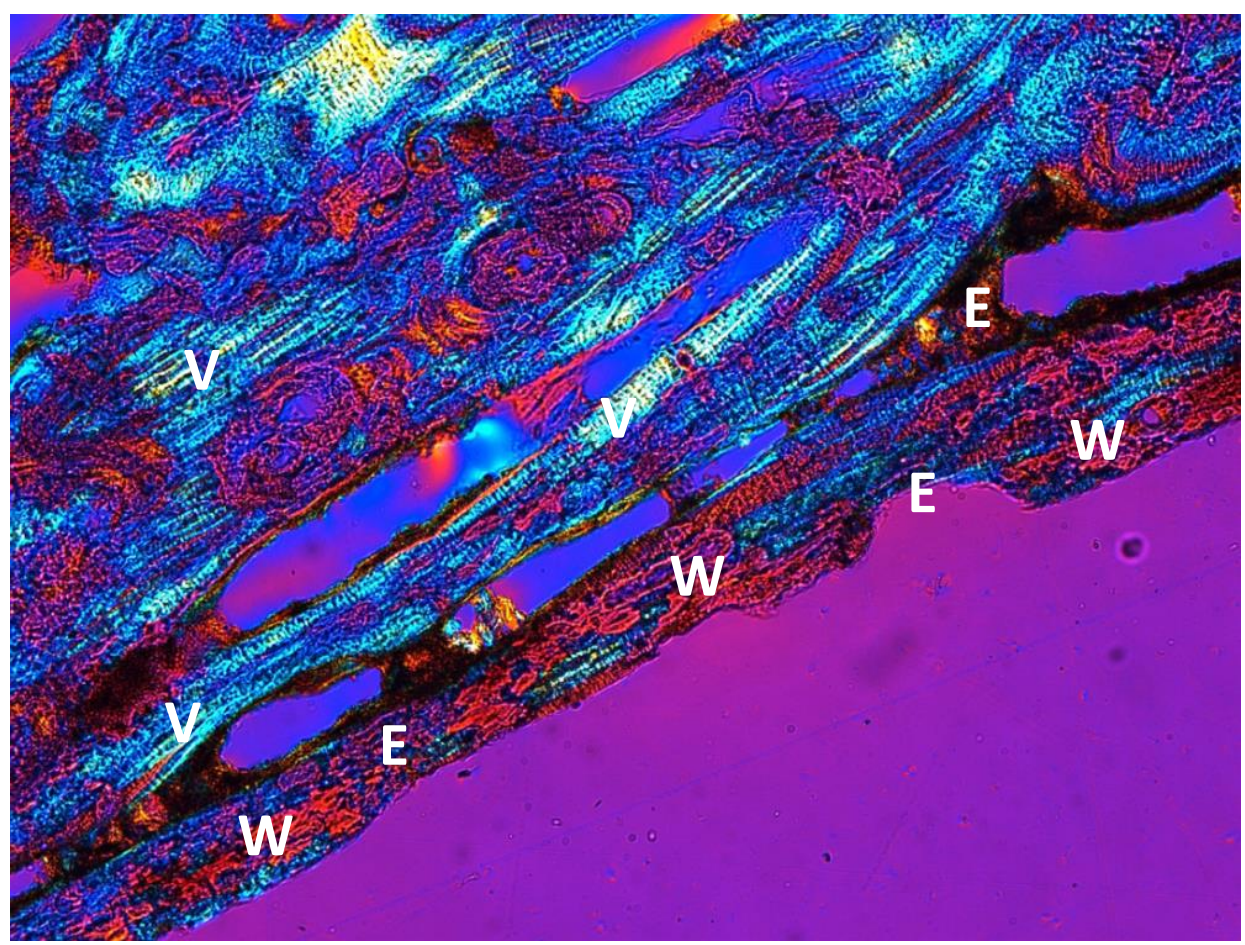

Abb. 19: Dünnschliffdicke $50 \mu m$, Vergrößerung 100x, Aufnahme im polarisierten Durchlicht unter Verwendung eines Hilfsobjektes Rot 1. Ordnung (Quarz) als Kompensator; die äußeren Schichten der Knochenneubildungen sind kollagenärmer $(W)$ als die inneren. Dieses Phänomen ist durch die starke Degradation durch Bodenerosion und Pilzfraß (E) zu erklären. Im Bild sieht man die kollagenreichen Strukturen bläulich - hell (V).

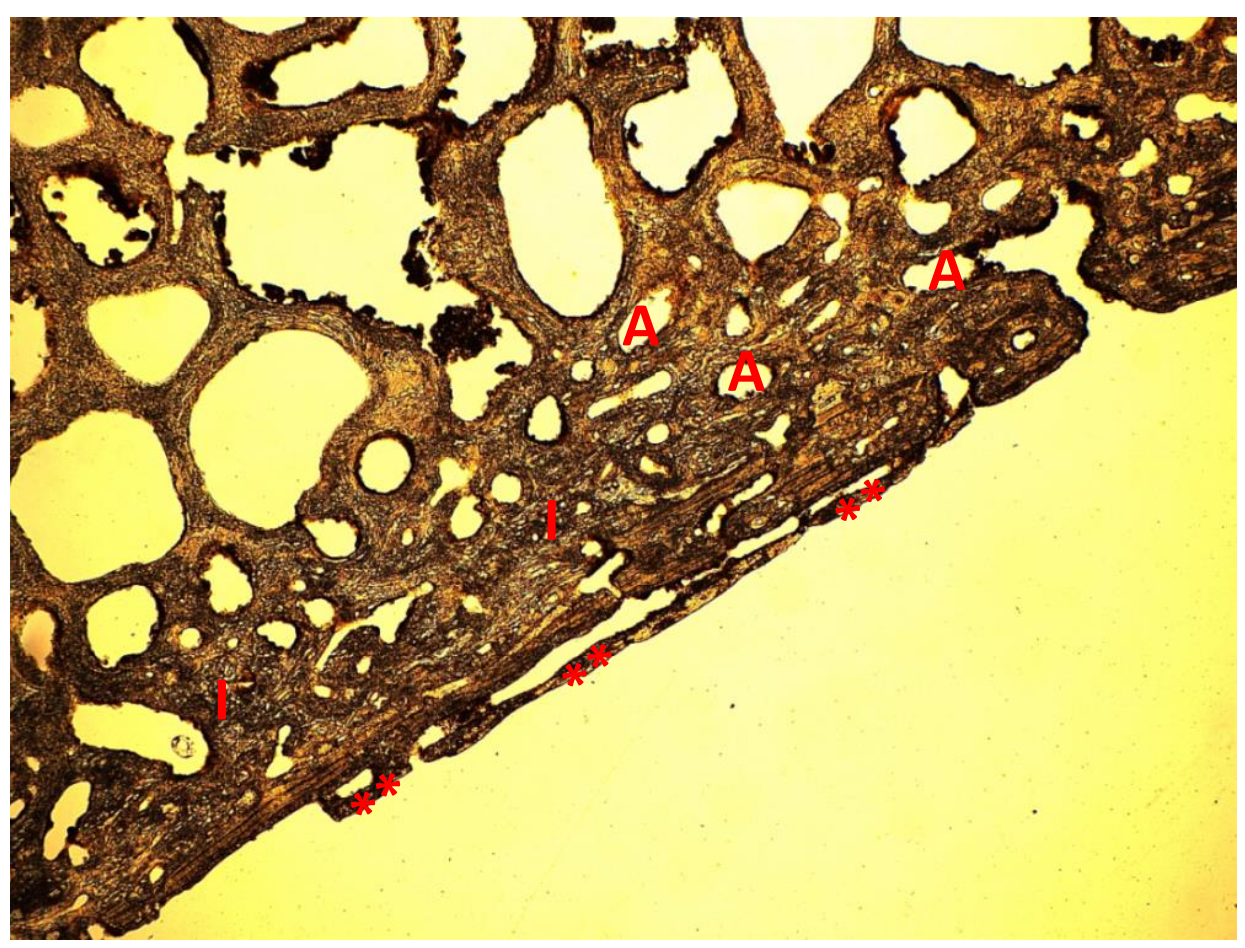

Abb. 20: Dünnschliffdicke $70 \mu m$, Vergrößerung 16x, Aufnahme im einfachen Durchlicht; es fällt auf, wie sehr die Resorptionslakunen (A) die Diploë geschädigt haben. Auf der Lamina interna (I) finden sich Knochenplatten (**) aufgelagert. Diese wurden durch postmortale diagenetische Prozesse überdeckt, in ihrer Struktur beschädigt und damit verfremdet. 


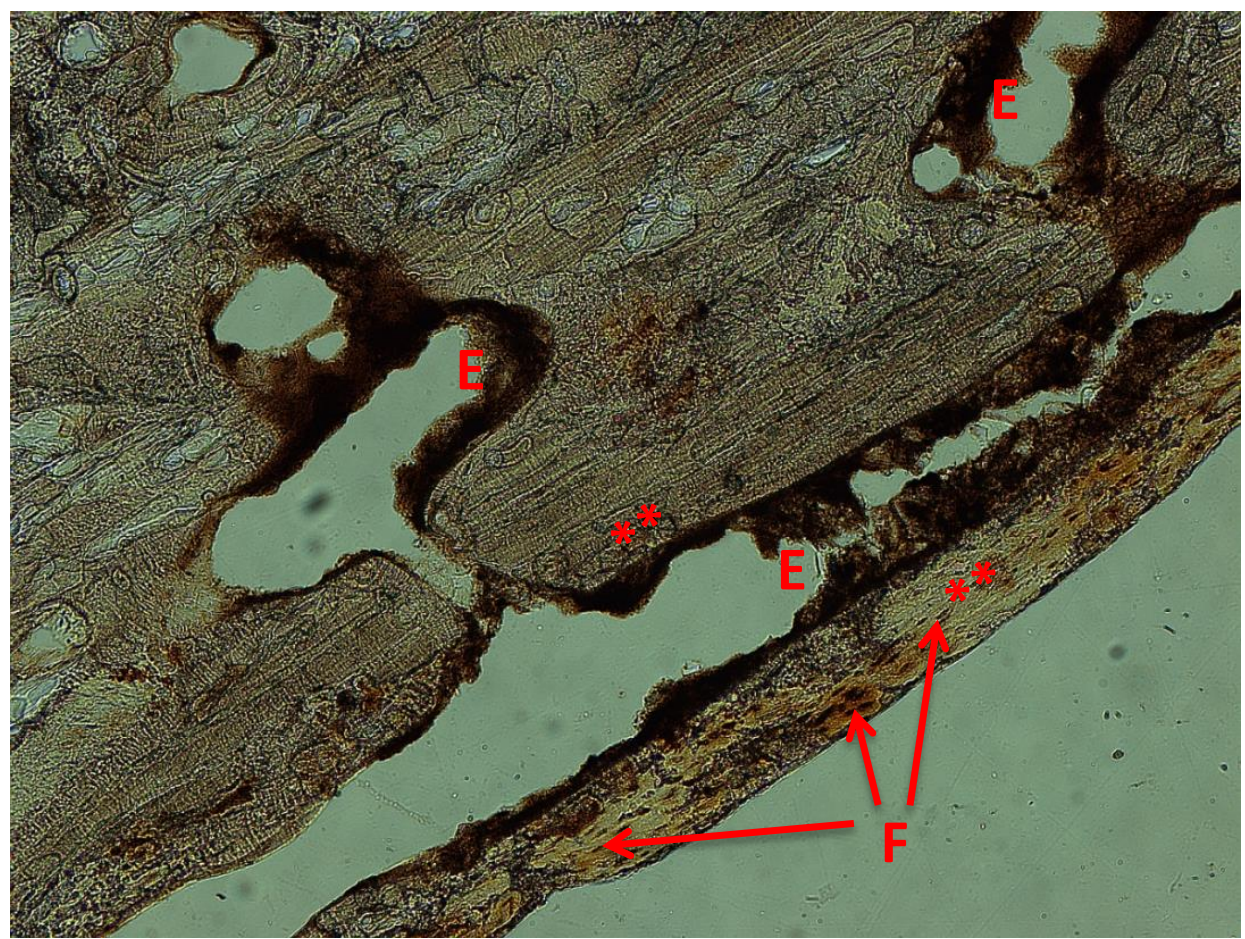

Abb. 21: Dünnschliffdicke $70 \mu m$, Vergrößerung 100x, Aufnahme im einfachen Durchlicht mit Graufilter; die Knochenplatten (**) bestehen aus Lamellenknochen, was in dieser Ansicht trotz schlechten Erhaltungszustandes des Fundstücks gut belegbar ist: Es finden sich Osteozytenlakunen (F). Pilzfraßtunnel (E) sind hier diagonal im Bild zu erkennen.

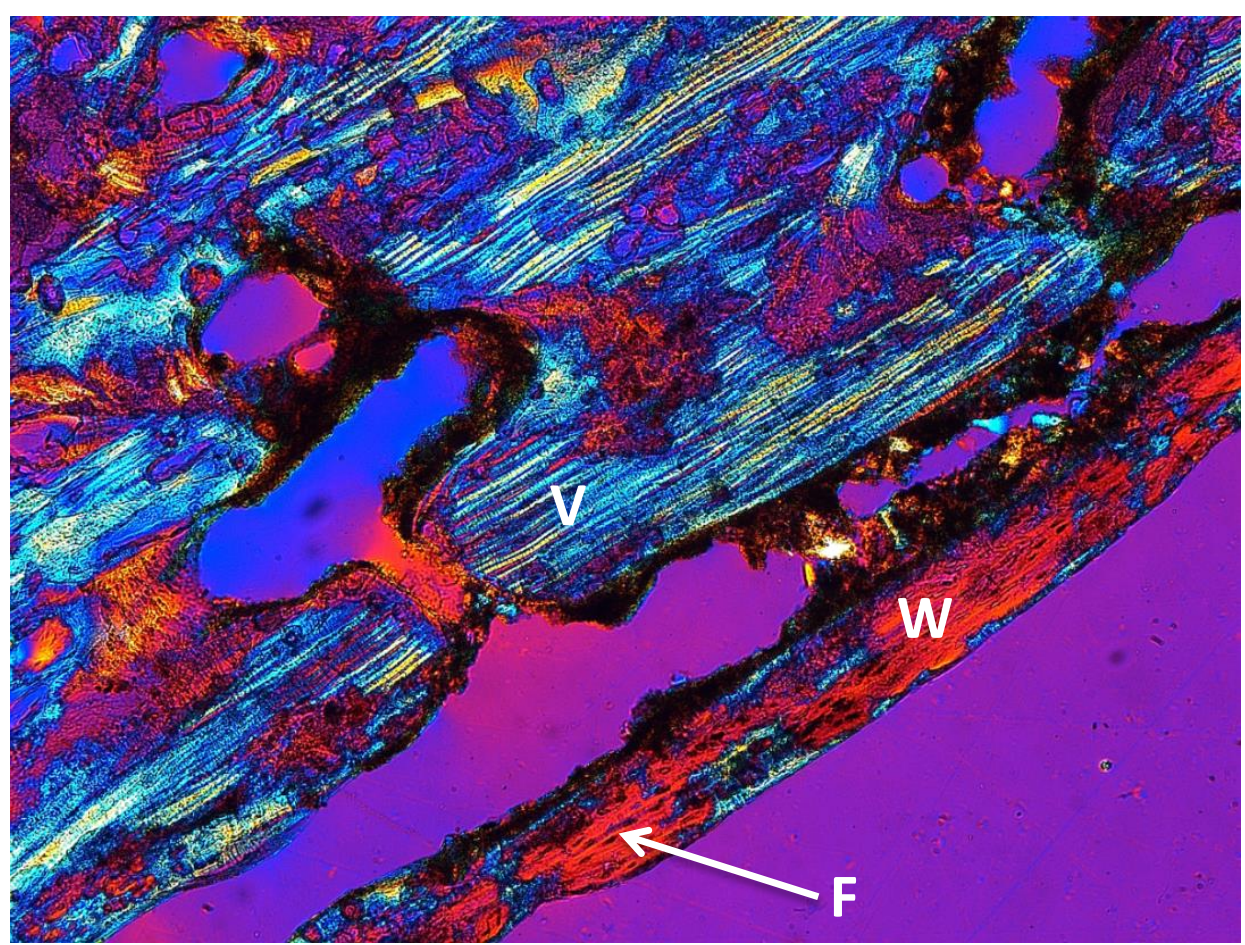

Abb. 22: Dünnschliffdicke $70 \mu m$, Vergrößerung 100x, Aufnahme im polarisierten Durchlicht unter Verwendung eines Hilfsobjektes Rot 1. Ordnung (Quarz) als Kompensator; deutlich wird in dieser Abbildung, dass der Knochen postmortal stark degeneriert wurde, was durch erodierte Strukturen (kollagenarme Bereiche $(W)$ ) erkennbar ist. Nur in tieferen Bereichen sind noch kollagene Strukturen (V) zu finden. In dem Bereich, in dem Osteozytenhöhlen (F) zu finden sind, fehlt es an Kollagenstrukturen. Trotzdem ist hier auf Lamellenknochen und nicht auf Faserknochen zu schließen, da das Kollagen lediglich postmortal erosiv entfernt wurde. 
Die Degradation ist soweit fortgeschritten, dass sich in der Knochenstruktur Tunnelsysteme und Gänge gebildet haben (Abbildungen 23 und 24).

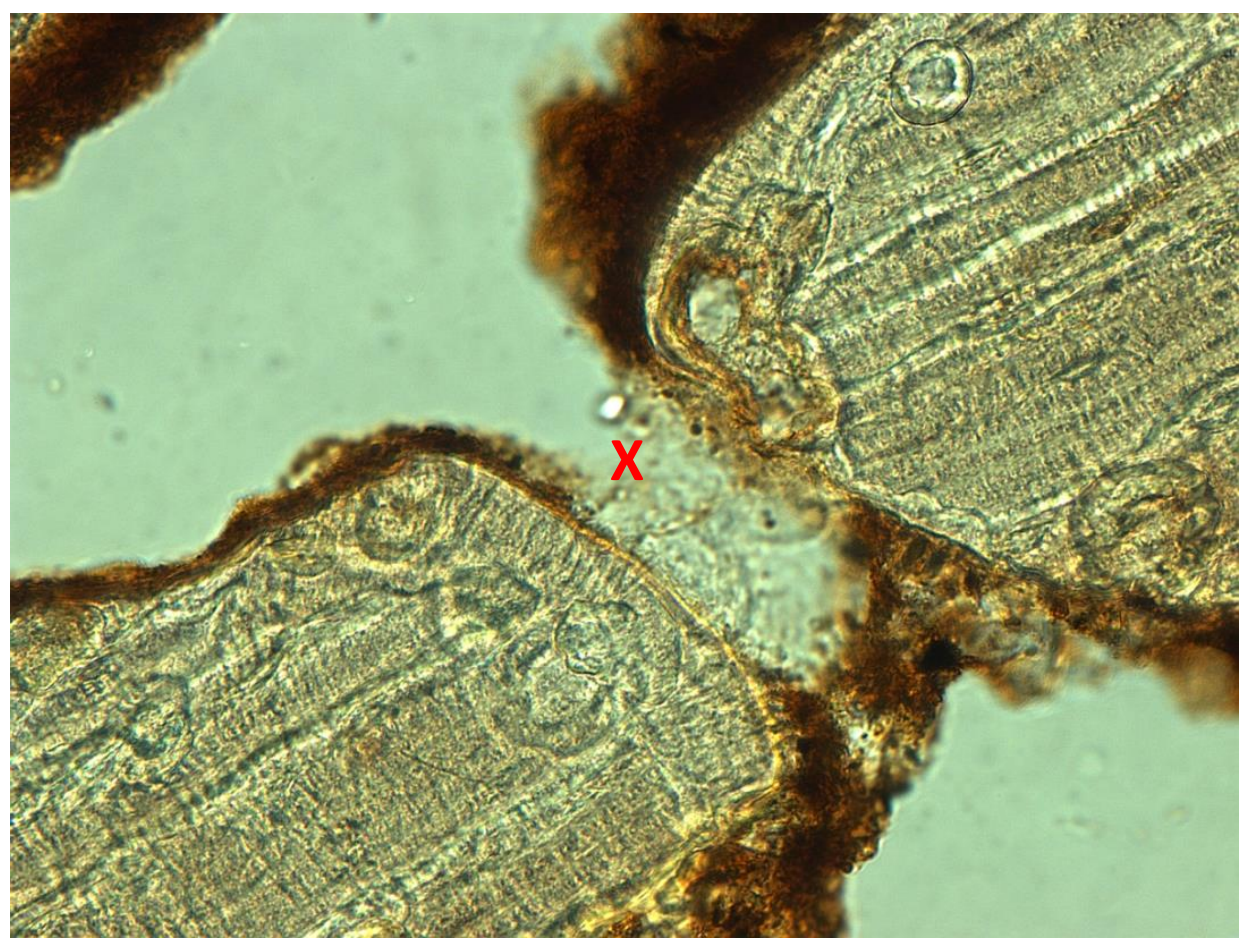

Abb. 23: Dünnschliffdicke $70 \mu \mathrm{m}$, Vergrößerung 400x; Aufnahme im einfachen Durchlicht mit starker Vergrößerung und Graufilter sieht man einen vermeintlich intravitalen, abgerundeten kleinen Tunnel $(X)$ in der durchgängigen Knochenstruktur.

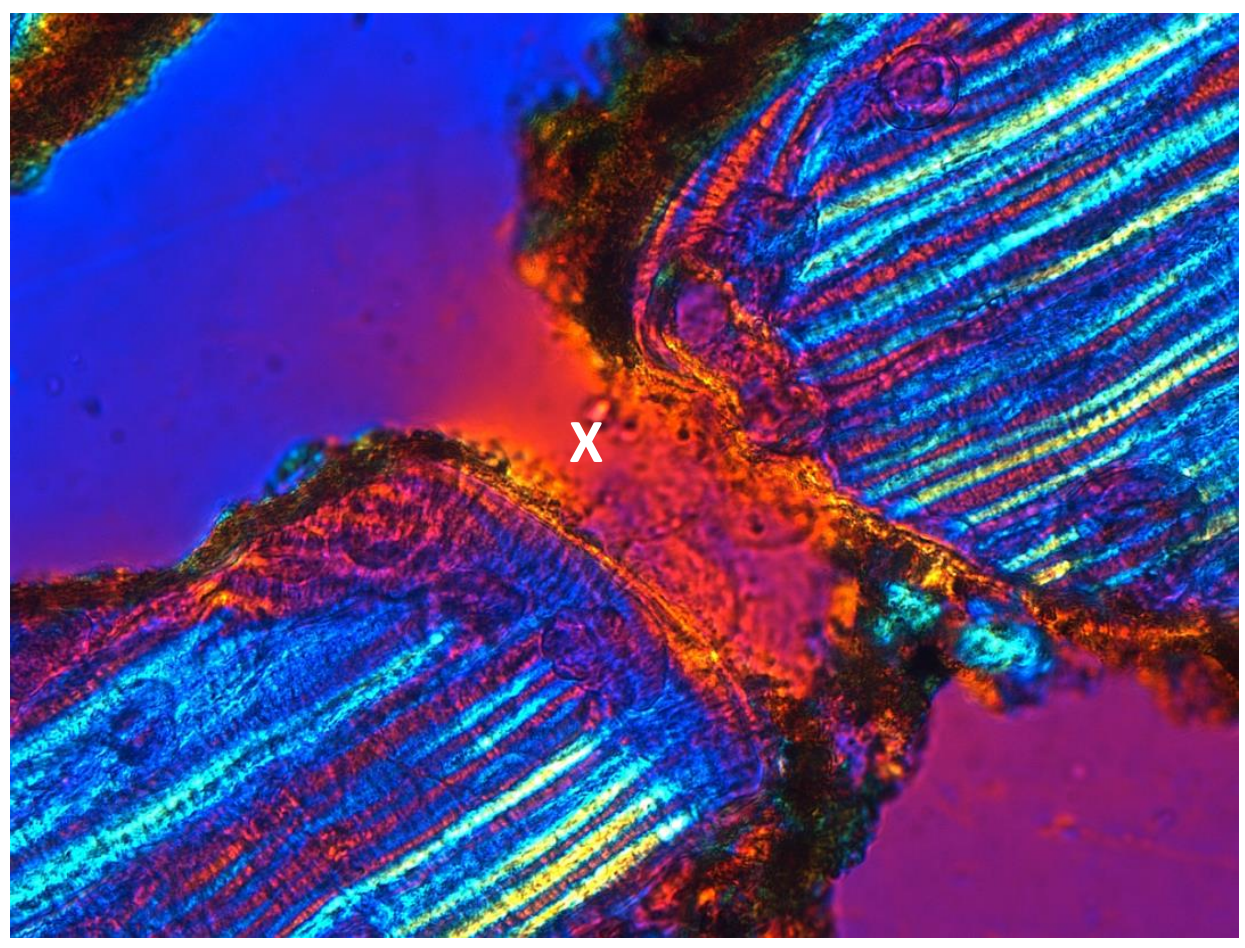

Abb. 24: Dünnschliffdicke $70 \mu m$, Vergrößerung 400x, Aufnahme im polarisierten Durchlicht unter Verwendung eines Hilfsobjektes Rot 1. Ordnung (Quarz) als Kompensator; im polarisierten Licht deutlich sichtbar: Unterbrechung der Kollagenfasern nach postmortaler Degradation. Durch den Bruchspalt (vermeintlich intravitaler Kanal (X)) sind biologische Materialien weiter in die Knochensubstanz gelangt. 
Der Erhaltungszustand der Fundstücke kann als mittelmäßig bis schlecht bezeichnet werden. Dennoch konnten aussagekräftige Befunde $\mathrm{zu}$ den intravitalen, plattenförmigen Auflagerungen erhoben werden.

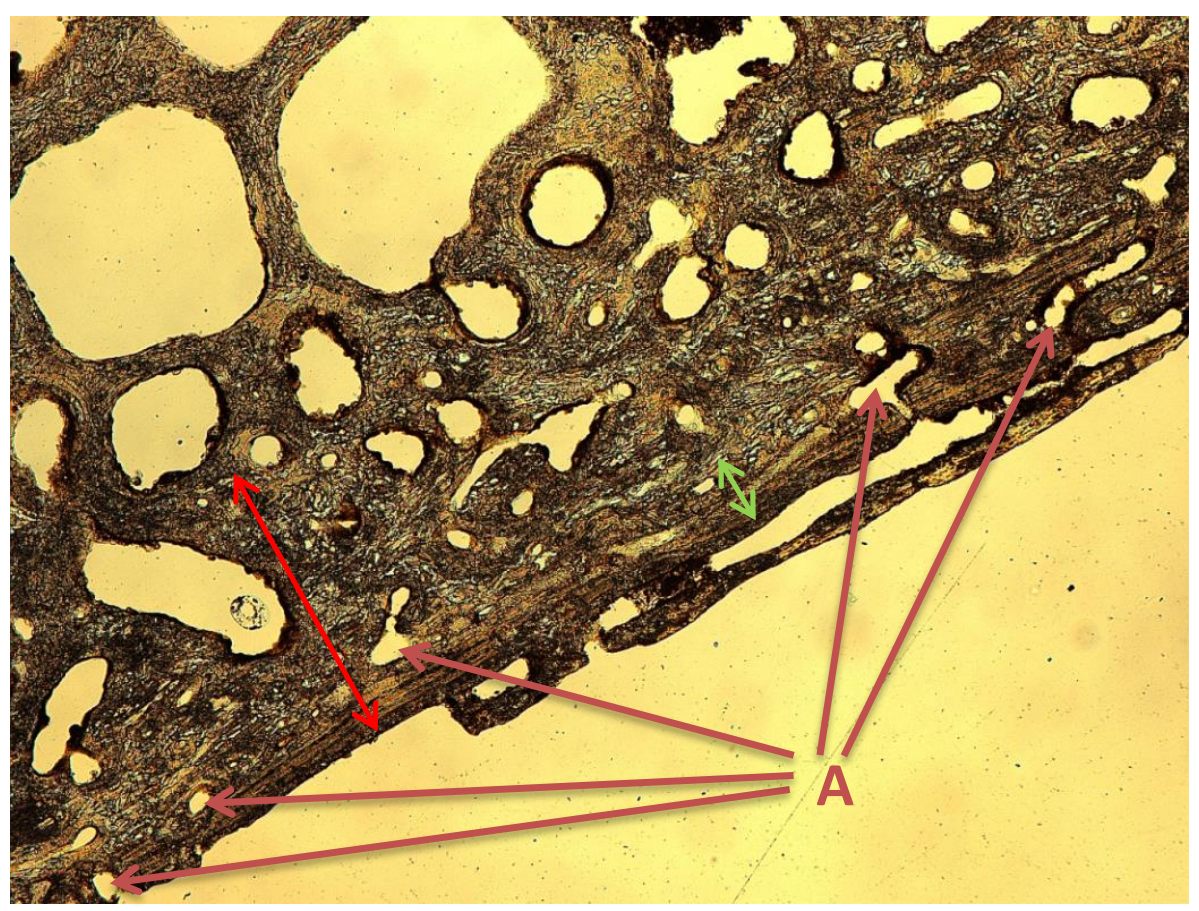

Abb. 25: Dünnschliffdicke $70 \mu m$, Vergrößerung 25x, Aufnahme im einfachen Durchlicht; im gesamten Bereich der verdickten Lamina interna lockern Resorptionshöhlen (A) die gesamte Struktur auf. In der Breite des roten Doppelpfeils ist die Knochenstruktur durch den Entzündungsprozess verändert und verdickt. In der Breite des grünen Doppelpfeils sollte die Lamina interna durchgängig und kontinuierlich ohne Auflockerung von Resorptionslakunen verlaufen.

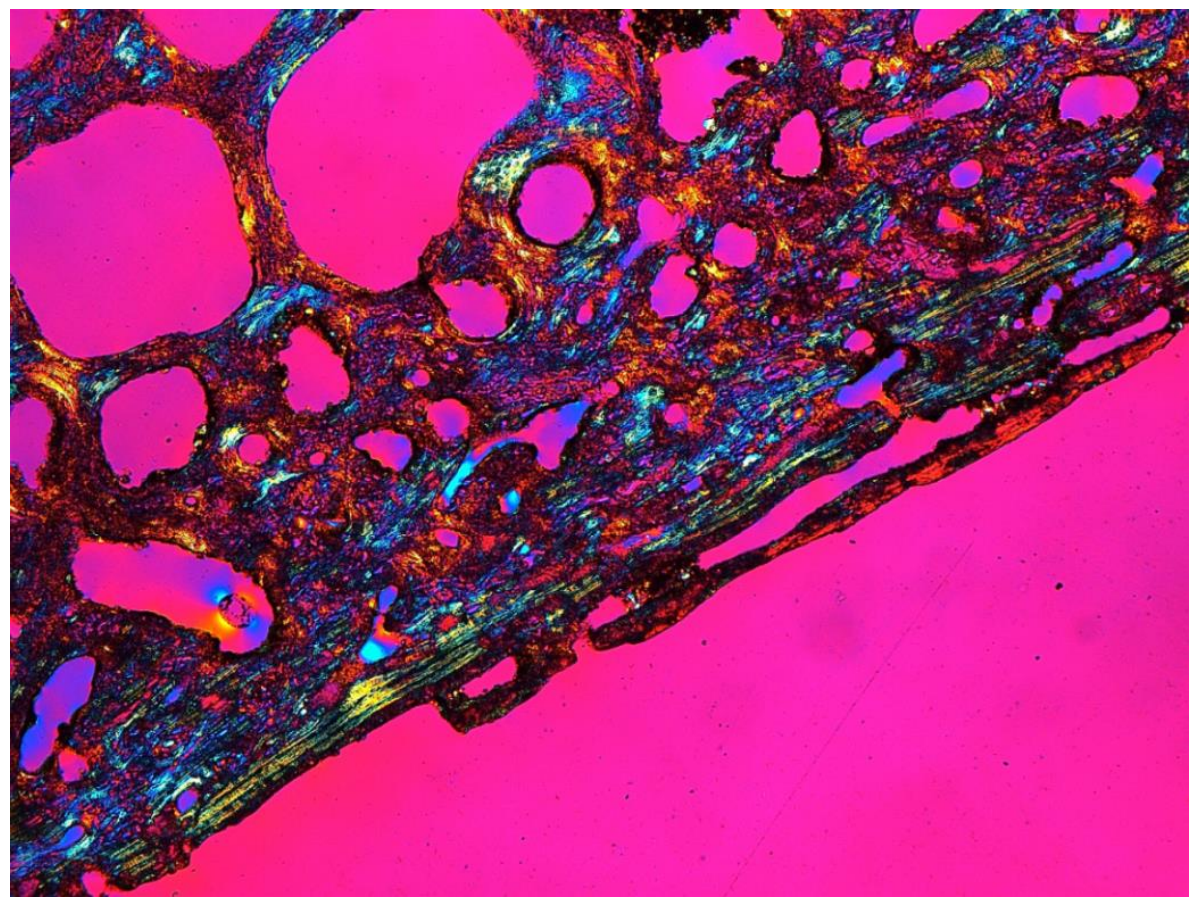

Abb. 26: Dünnschliffdicke $70 \mu m$, Vergrößerung 25x, Aufnahme im polarisierten Durchlicht unter Verwendung eines Hilfsobjektes Rot 1. Ordnung (Quarz) als Kompensator; mit dieser Vergrößerung ist im Bereich der Knochenplatten nicht zwischen Lamellen- und Faserknochen zu unterscheiden. 


\subsection{Lichtmikroskopischer Befund 2 der Population aus Großenrode}

Von den Fundstücken dieses Craniums wurden Knochendünnschliffe aus dem Os temporale angefertigt, um makroskopisch sichtbare, plattenförmige Auflagerungen auf der Lamina interna lichtmikroskopisch zu untersuchen. Zunächst wurde die Squama ossis temporalis mit einem Binokular untersucht und anschließend geröntgt, um so bereits erste Informationen über die Entstehung der Auflagerungen zu gewinnen. Die lichtmikroskopische Untersuchung sollte dann die bereits erhobenen Verdachtsdiagnosen erhärten und beweisende Bilder liefern.

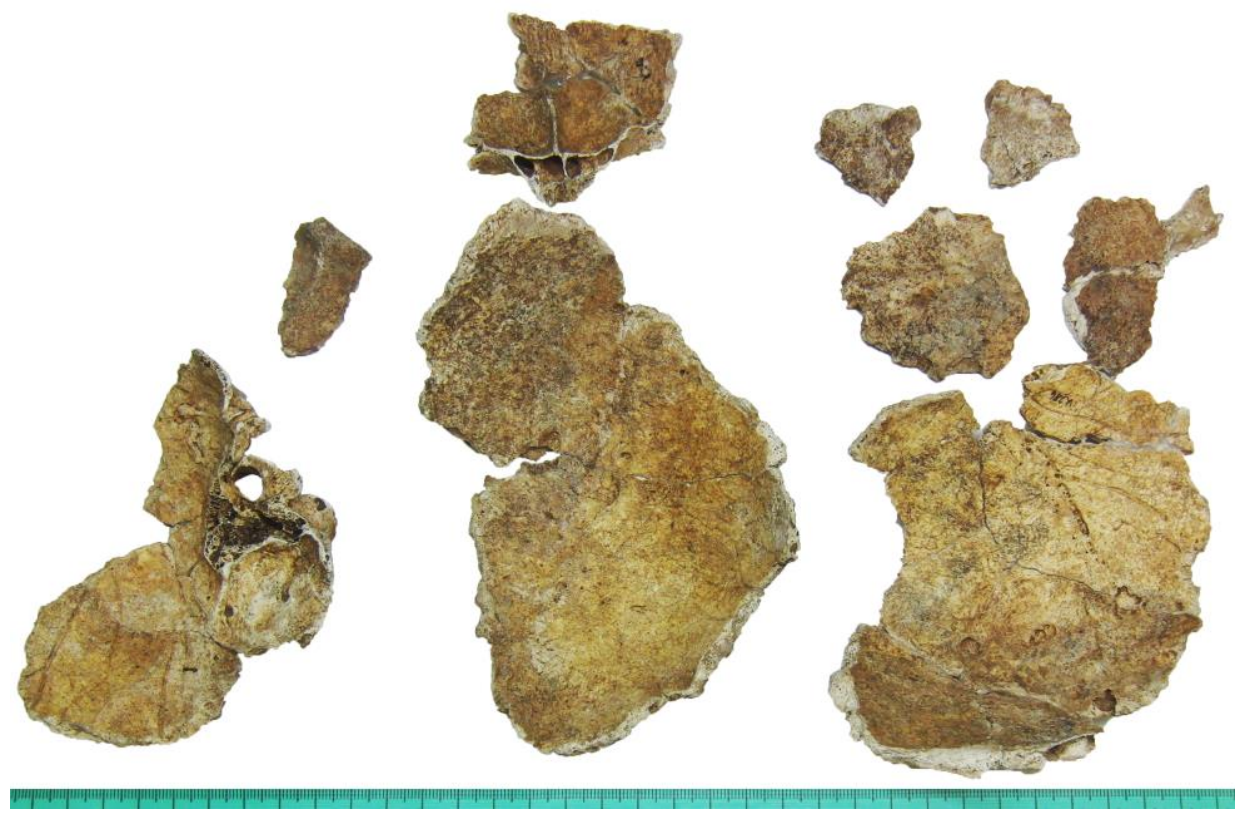

Abb. 1: Gesamtübersicht über die erhaltenen Fundstücke des Craniums.

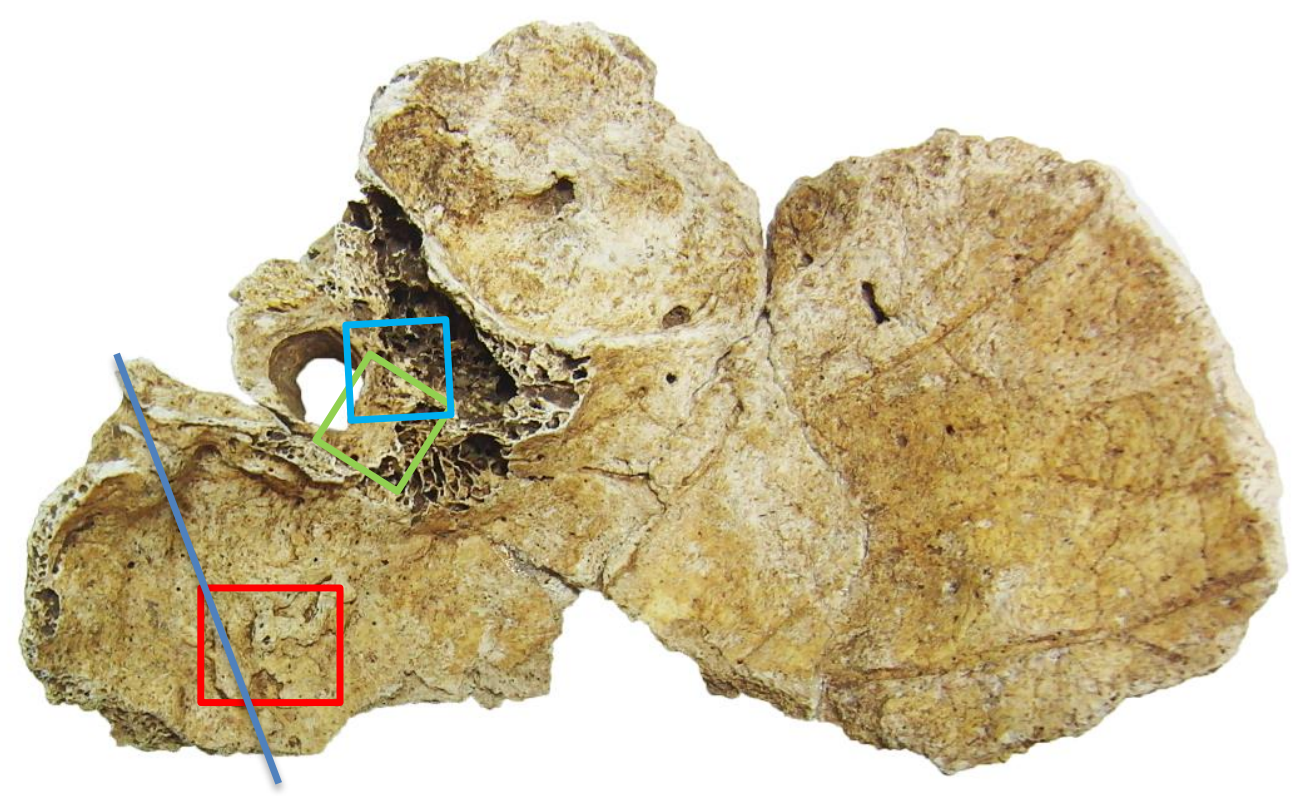

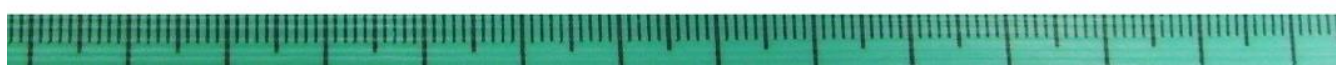

Abb. 2: Aufnahme mit Squama ossis temporalis links. Die blaue Linie markiert die Schnittebene der beiden Dünnschliffe für die lichtmikroskopische Untersuchung. Die roten Kästen rahmen den Bereich der Binokular-Detailaufnahmen (rot: Abb. 4, grün: Abb. 5 und blau: Abb. 6) ein. Die blaue Linie markiert die Schnittebene für den Dünnschliff (Abb. 10). 


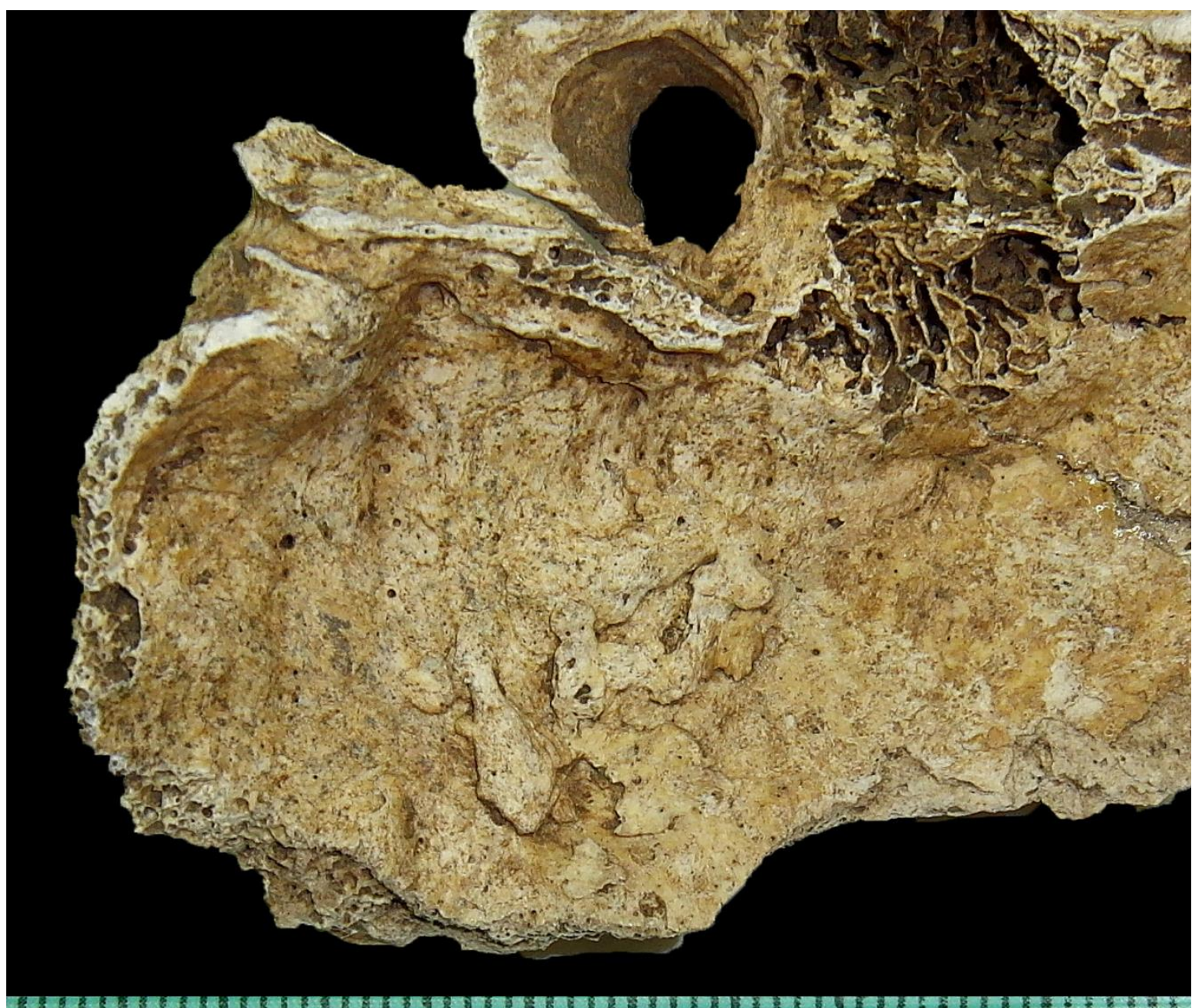

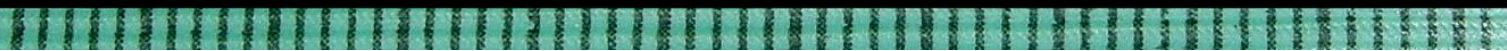

Abb. 3: Kontrastreichere, vergrößerte Aufnahme der linken Squama ossis temporalis (Vgl. Abb. 2).

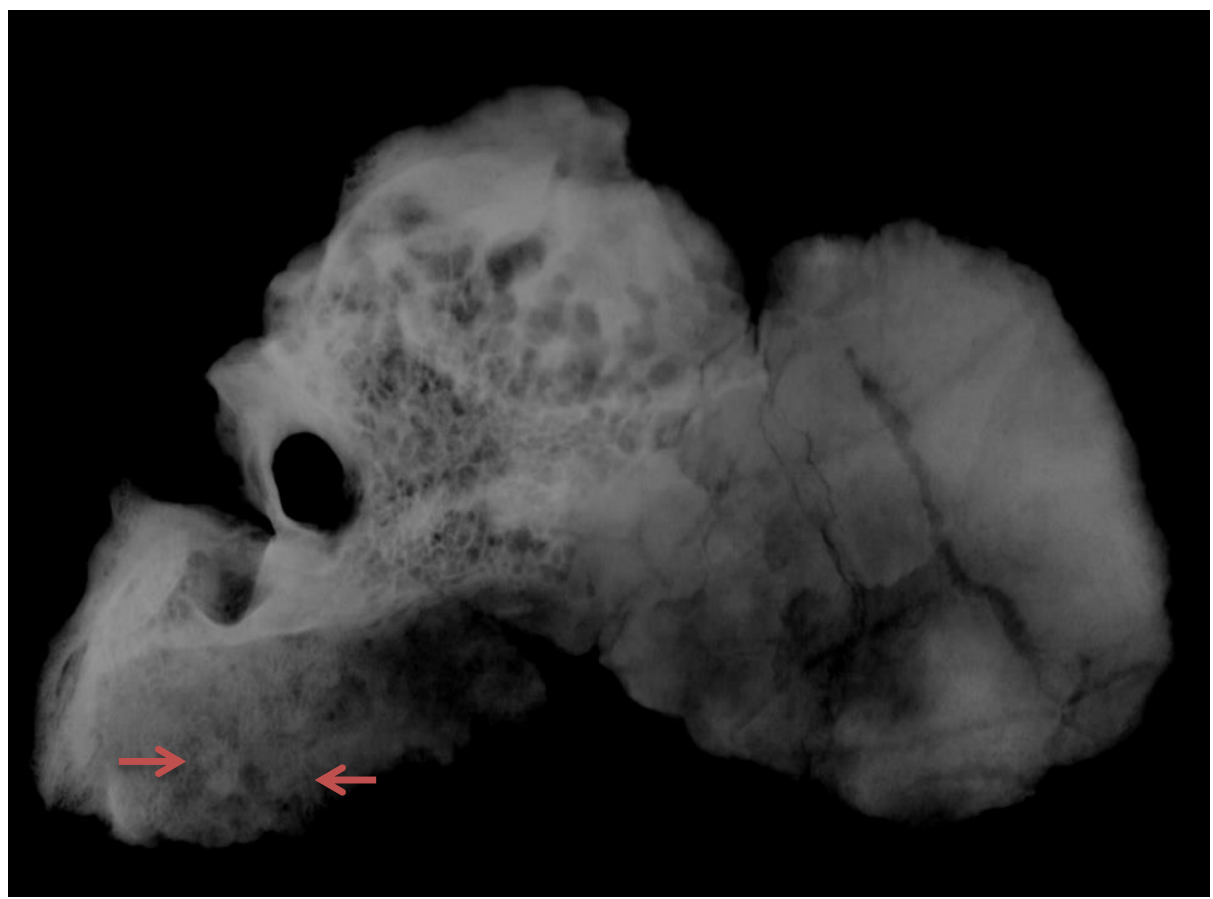

Abb. 4: Röntgenaufnahme der Squama ossis temporalis der linken Seite. Die plattenförmigen Auflagerungen sind im Röntgenbild zu erkennen (Pfeile). Positionierung der Aufnahme wie in Abb. 2. 


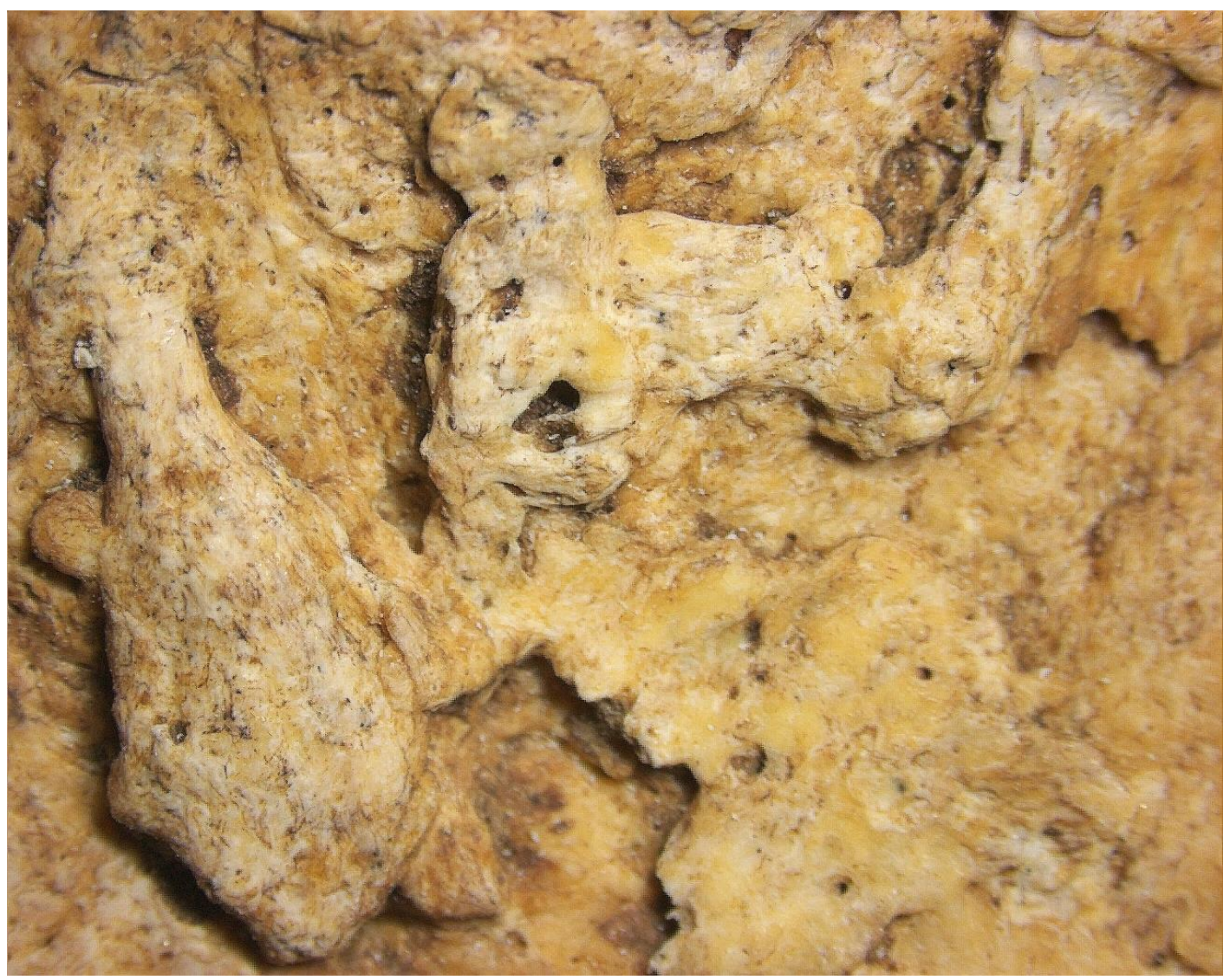

Abb. 5: Detailaufnahme mit einem binokularen Lupenmikroskop. Ausschnitt siehe Abb. 2, roter Kasten.

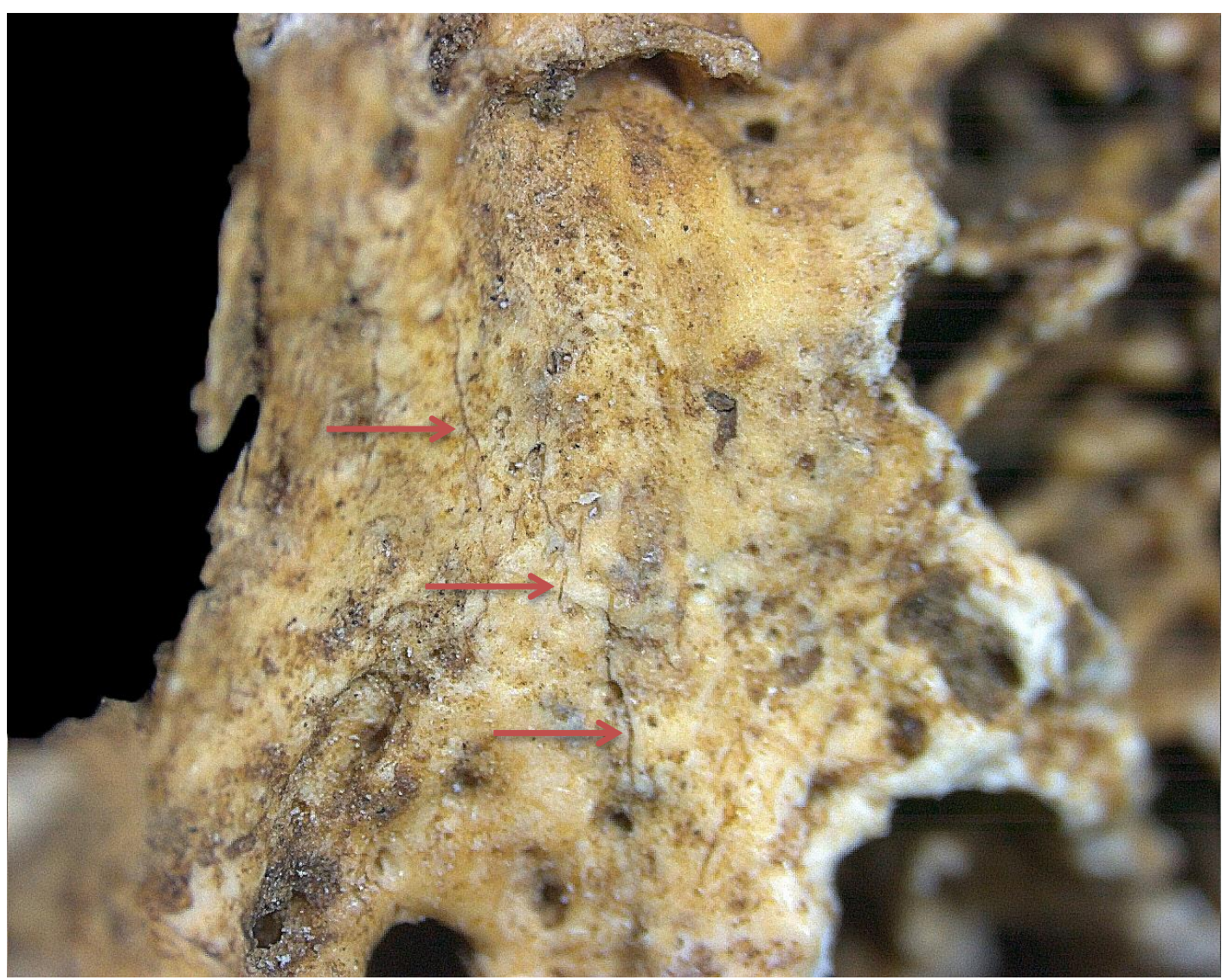

Abb. 6: Detailaufnahme mit einem binokularen Lupenmikroskop. Ausschnitt siehe Abb.2, grüner Kasten. Die roten Pfeile markieren kleine plattenförmige Auflagerungen am Eingang vom Porus acusticus externus. 


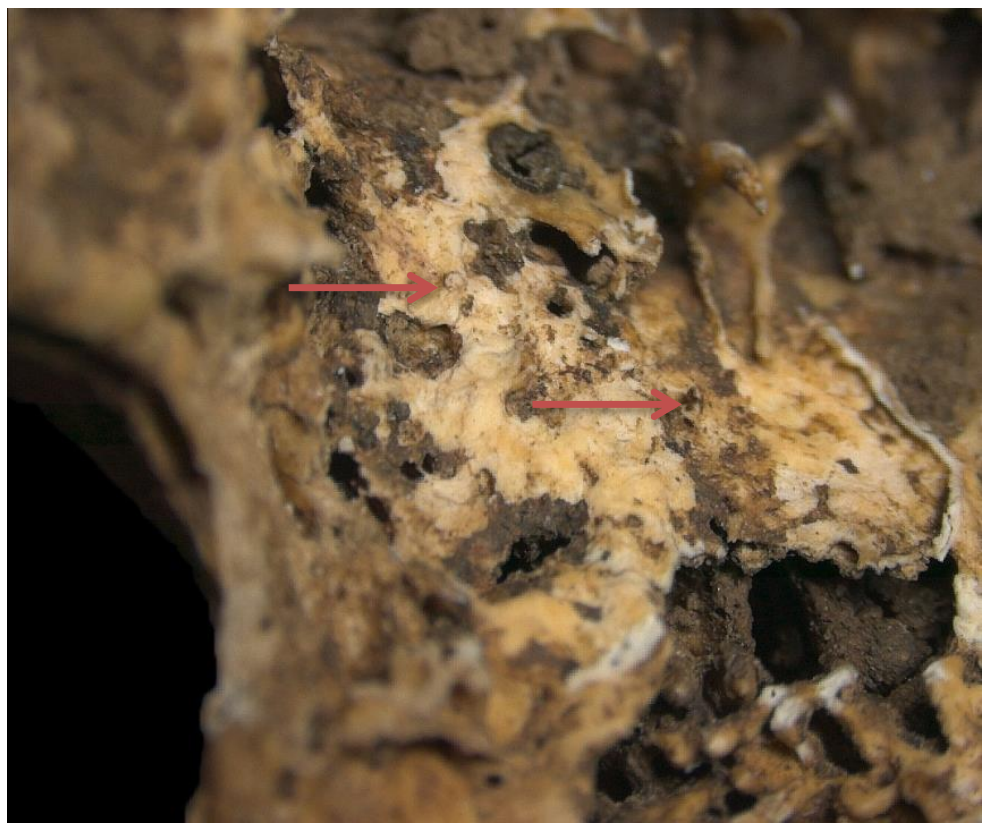

Abb. 7: Detailaufnahme aus Abb. 2; blauer Kasten, die Pfeile zeigen beispielhaft Bereiche mit porösen Auflagerungen.

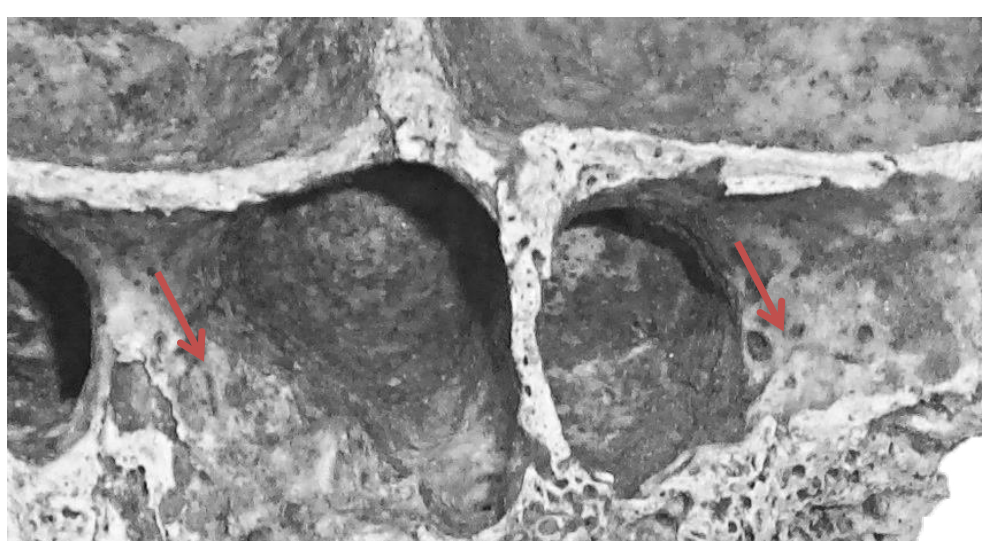

Abb. 8: Nahaufnahme der rechten und linken Stirnhöhle mit Spuren einer verheilten Sinusitis frontalis (Pfeile).
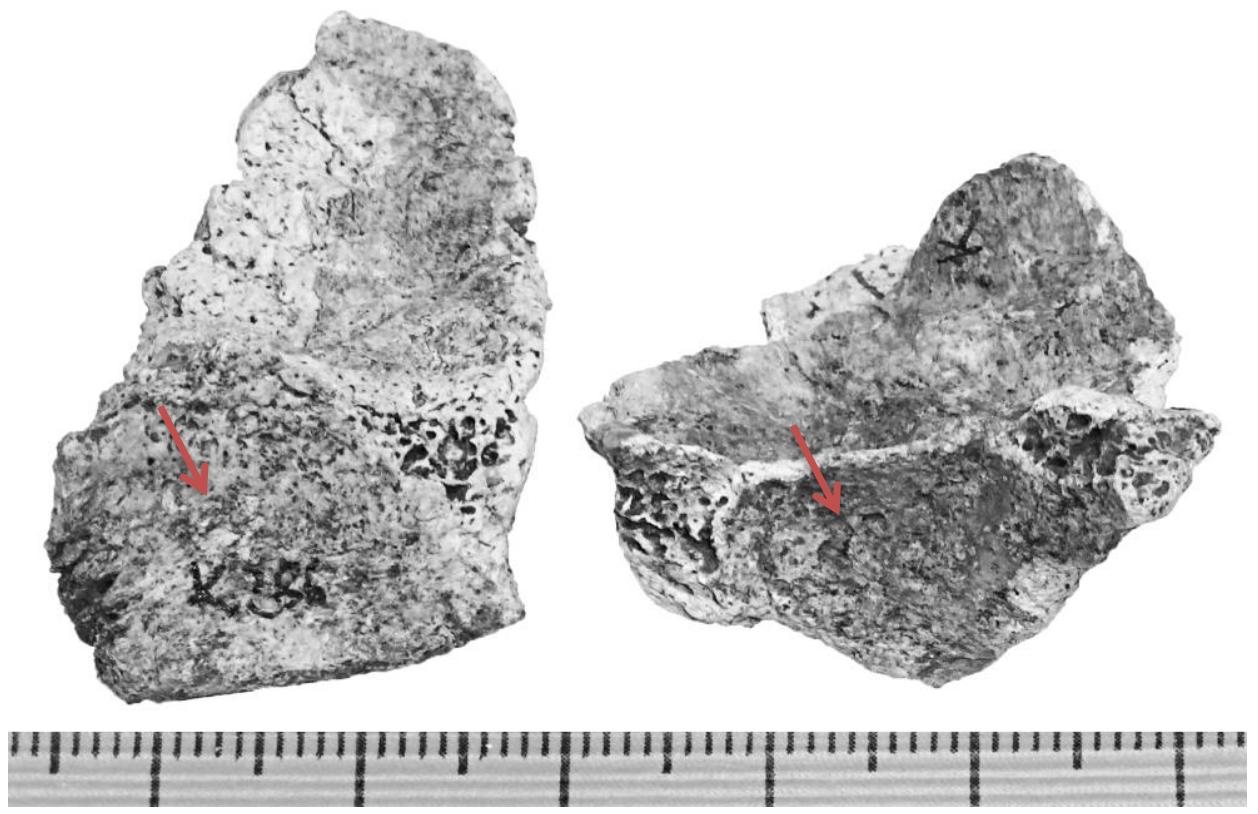

Abb. 9: Fragmente der Orbitadächer rechts und links mit porösen Spuren einer Cribra orbitalia (Pfeile). 


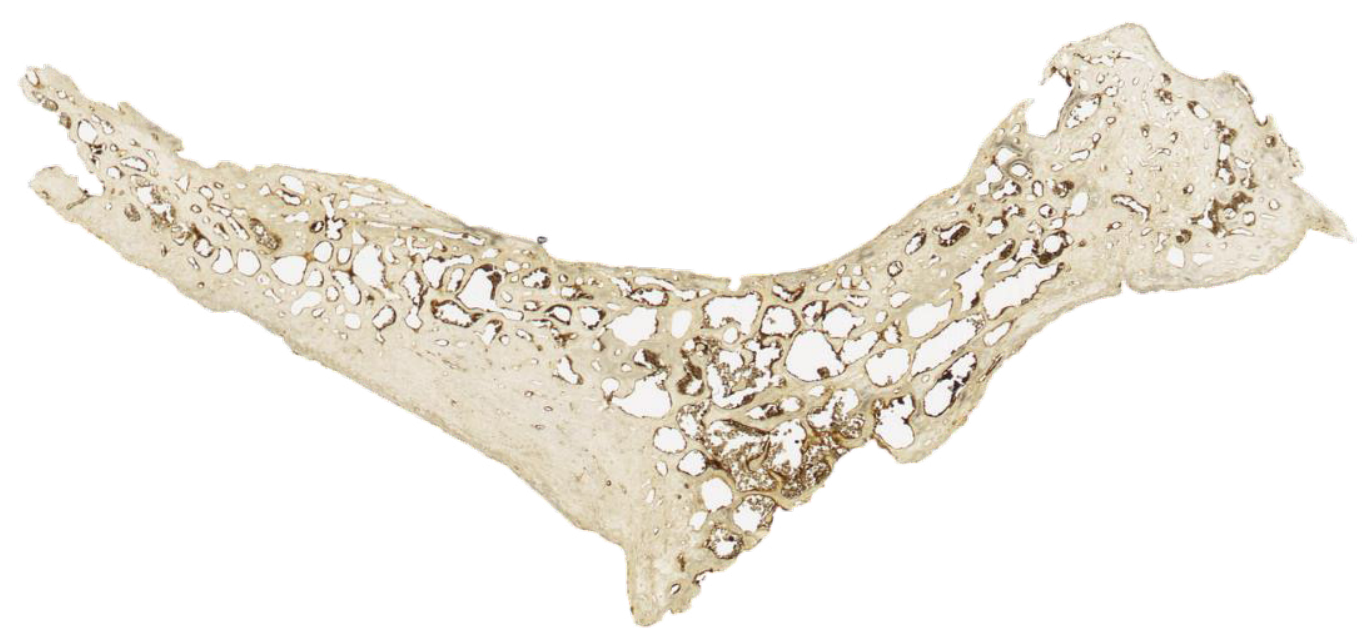

Abb. 10: Eingescannter Dünnschliff aus der Schnittebene (Vgl. Abb. 2). Oben im Bild befindet sich die Lamina interna.

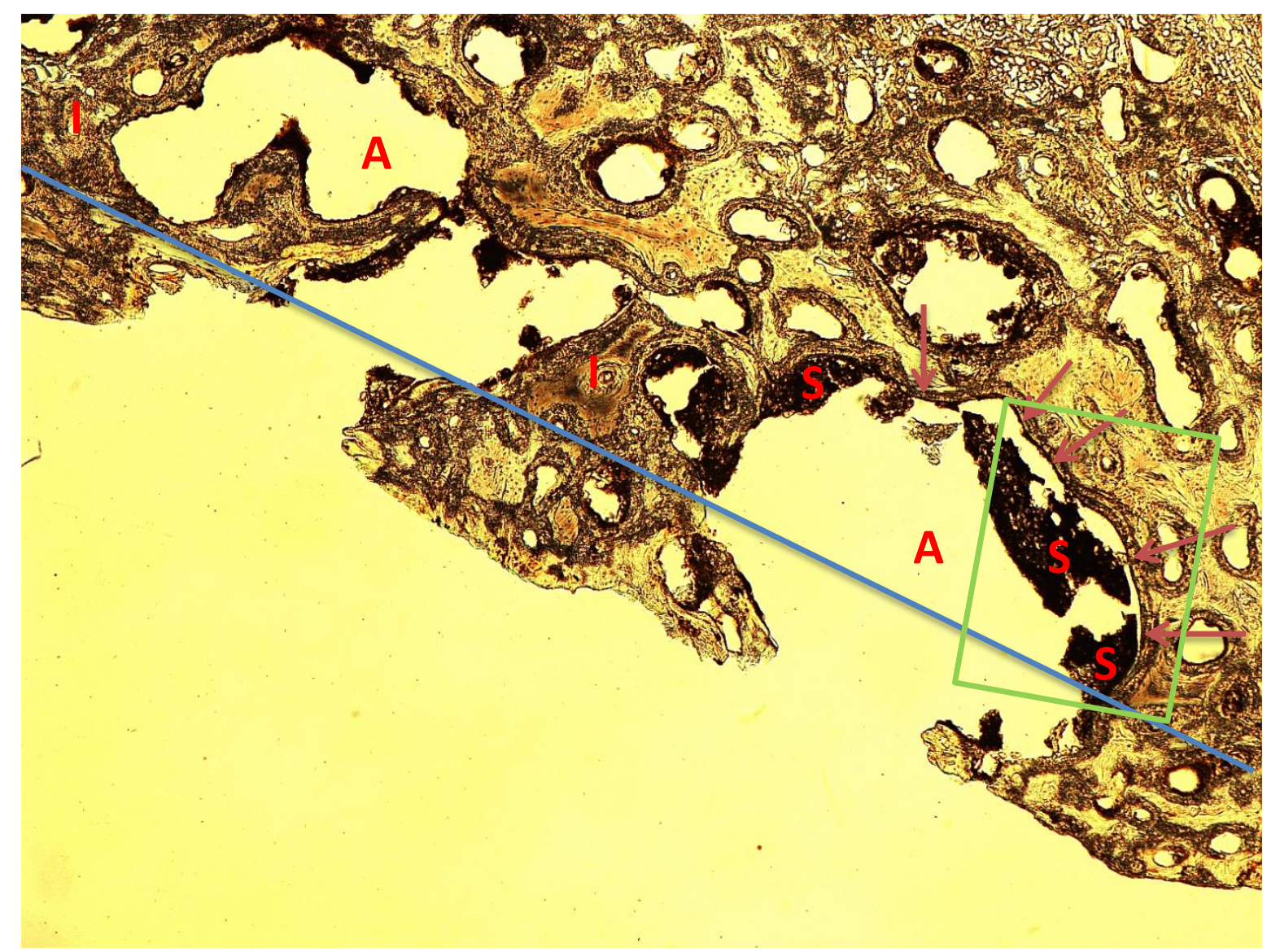

Abb. 11: Dünnschliffdicke $50 \mu m$, Vergrößerung 25x, Aufnahme im einfachen Durchlicht; Detailansicht der Lamina interna squama ossis temporalis (I). Die Pfeile deuten auf die kollagenfaserreich aufgebaute Wandbegrenzung der großen Resorptionshöhle, welche sich zwischen zwei plattenförmigen Neubildungen befindet. In den intravital gebildeten Resorptionslakunen (A) befindet sich abgelagertes biologisches Material (S). Die blaue Linie zeigt den ursprünglichen und physiologischen Verlauf der Lamina interna. Der grüne Rahmen markiert den Bereich einer Detailaufnahme, siehe Abb. 12.

Die lichtmikroskopische Untersuchung ermöglichte es, den Beweis für ein intravitales, entzündliches Geschehen am Os temporale zu liefern. Die in Abb. 11 markierte Resorptionshöhle ragt weit in den Diploëraum hinein. 
Die Knochenneubildungen sind also weit in die Lamina interna hineingelangt (Vgl. Abb. 12).

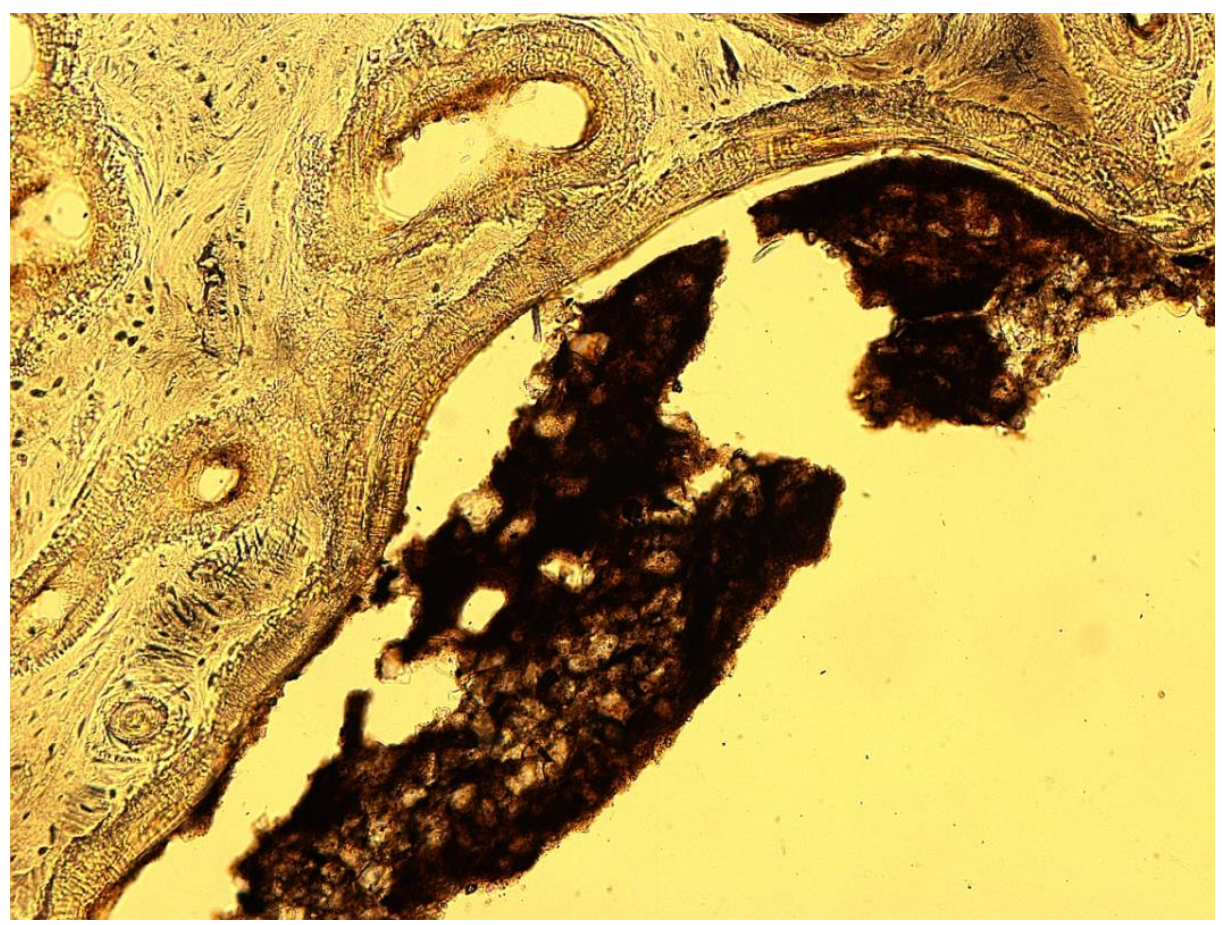

Abb. 12: Dünnschliffdicke $50 \mu m$, Vergrößerung 100x, Aufnahme im einfachen Durchlicht; Detailabbildung (grüner Rahmen) aus Abb. 11. Darstellung der Resorptionslakune nach $90^{\circ}$ Drehung gegen den Uhrzeigersinn. Zu sehen ist die Wand der Resorptionshöhle, die sekundär im Zuge der Knochenreaktion aufgemauert wurde.

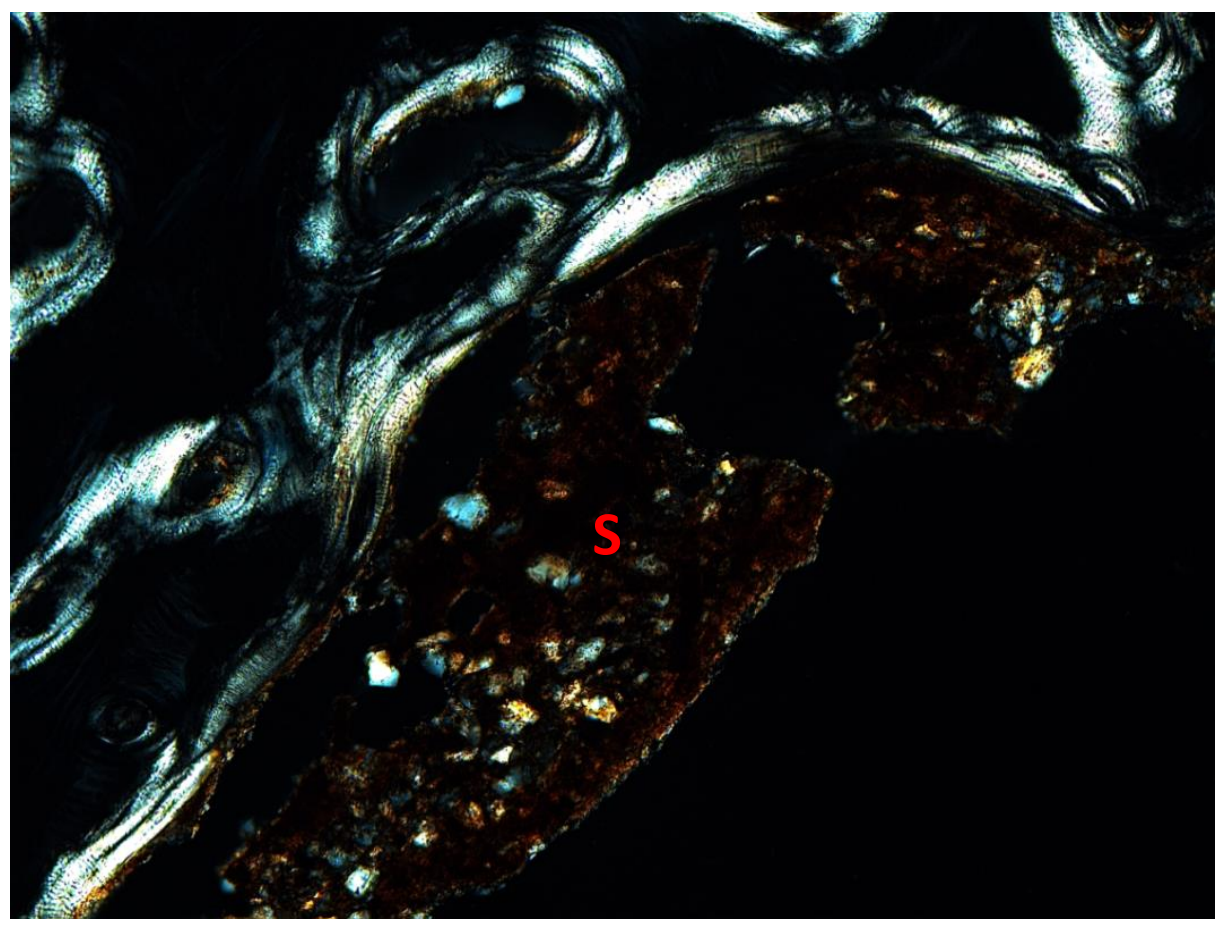

Abb. 13: Dünnschliffdicke $50 \mu m$, Vergrößerung 100x, Aufnahme im polarisierten Durchlicht; die Kollagenfasern sind auch hier deutlich degradiert und diffus zerfallen, was im polarisierten Licht deutlich zu erkennen ist. Kollagenfasern werden in dieser Darstellung hell gezeigt und andere Strukturen dunkel. Ebenfalls hell funkelnd abgebildet werden Sandkristalle im postmortal abgelagerten biologischen Material (S). Dabei fällt auf, dass die hellen Kollagenfasern durch dunkle Bereiche unterbrochen werden, was zu der "Auffaserung" im Bild führt. Die einzelnen Kollagenfibrillen sind nach der Degradation nicht mehr so gut zu sehen. 


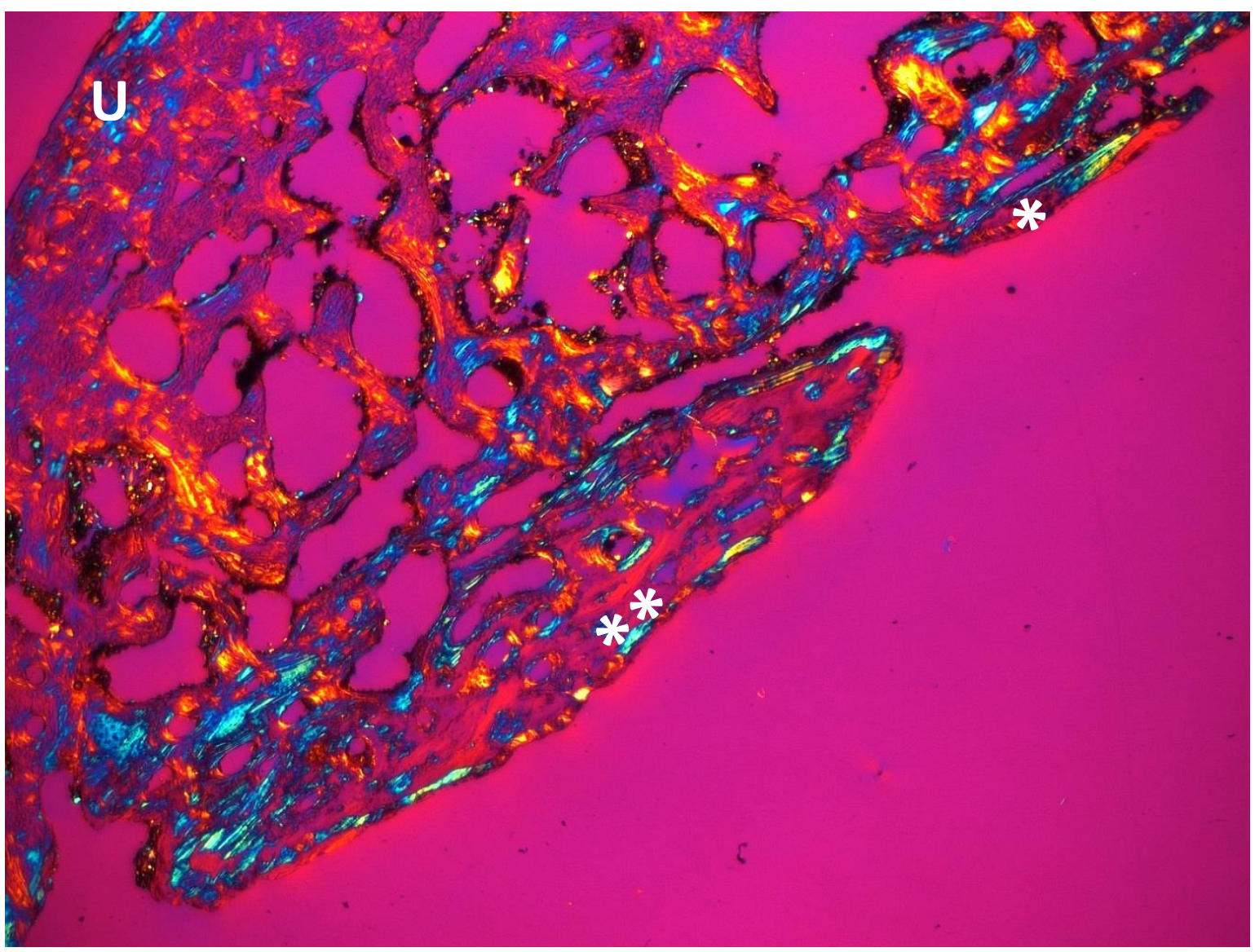

Abb. 14: Dünnschliffdicke $50 \mu \mathrm{m}$, Vergrößerung 16x, Aufnahme im polarisierten Durchlicht unter Verwendung eines Hilfsobjektes Rot 1. Ordnung (Quarz) als Kompensator; diese Abbildung zeigt eine große plattenförmige Auflagerung $\left.{ }^{* *}\right)$ und eine kleinere $\left(^{*}\right)$. Auch zu sehen ist die Lamina externa $(U)$.

Die intravital gebildeten, plattenförmigen Auflagerungen heben sich deutlich von der Lamina interna ab. Ein unterhöhlter Bereich verdeutlicht, dass die Platten gestielt durch einzelne schmale oder breite Stege mit der Lamina interna verbunden sind (Abbildungen 14 und 15).

Bei der lichtmikroskopischen Untersuchung konnte ein entzündlicher Ursprung der Neubildungen erkannt werden, der charakteristische Eigenschaften zeigt: Das Niveau der Lamina interna wurde durch die Knochenneubildungen überschritten, stellenweise aber auch durch Resorptionsvorgänge unterschritten (Abbildungen 11, 14 und 15). 


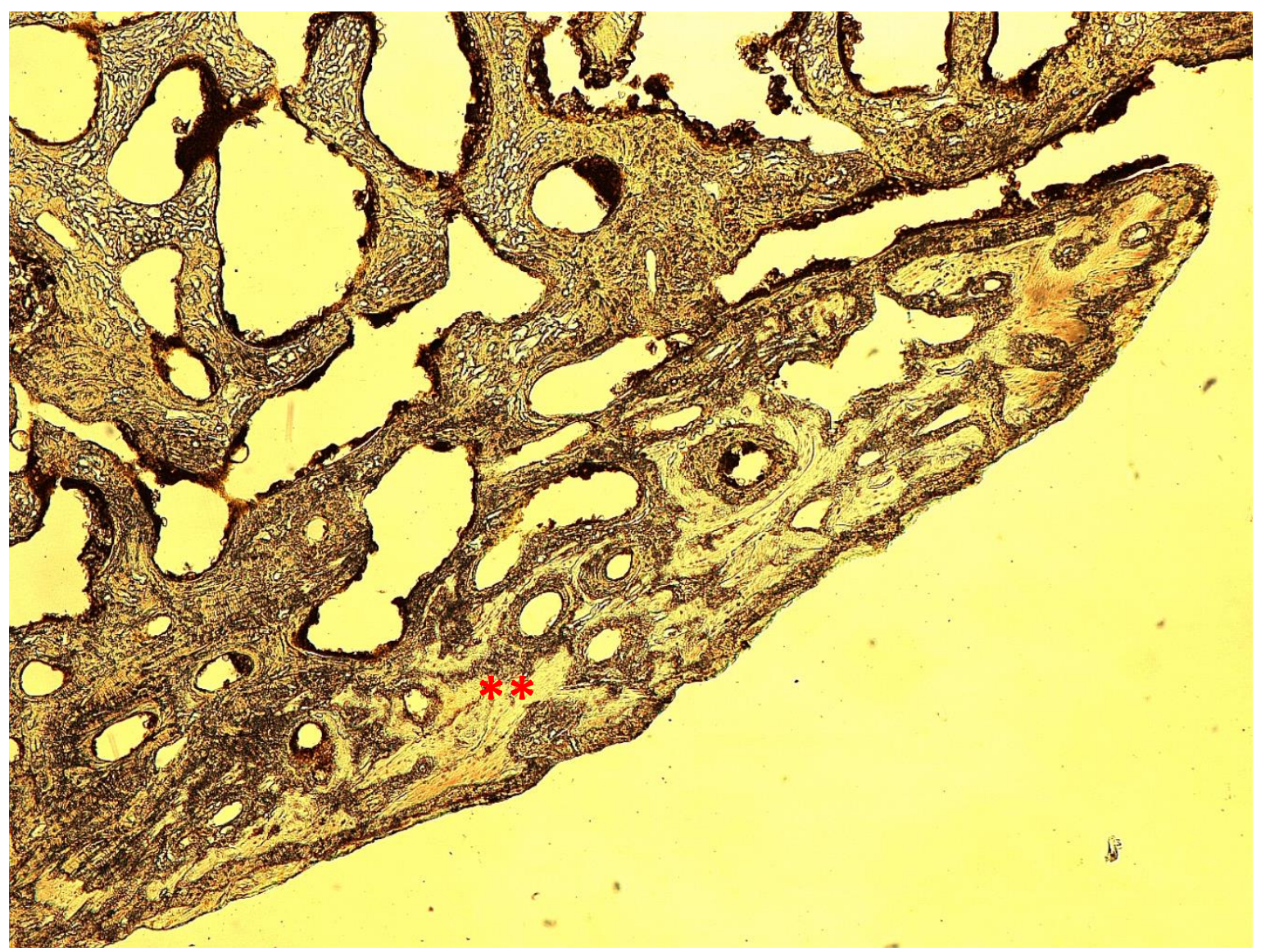

Abb. 15: Dünnschliffdicke $50 \mu m$, Vergrößerung 25x, Aufnahme im einfachen Durchlicht; zu sehen ist eine große Knochenplatte (**) im Sinne einer Neubildung nach entzündlichem Reiz.

Die untersuchten plattenförmigen Auflagerungen waren lichtmikroskopisch eindeutig als intravitale Spuren eines entzündlichen Reizes zu identifizieren. Als mögliche Ursache dieses entzündlichen Reizes kommt eine Meningitis in Frage. Weiterhin kann auch eine Otitis media zu einer solchen entzündlichen Reaktion mit Beteiligung des Mastoids und letztendlich auch der Lamina interna des Schädeldaches führen. Dieses Szenario erscheint durchaus denkbar, zumal sowohl am Porus acusticus externus als auch in den Cellulae mastoides kleinere Auflagerungen im Sinne von Knochenneubildungen nachzuweisen waren (Bereiche des Mittel- oder Innenohrs waren leider nicht erhalten). Diese wurden mit einem binokularen Lupenmikroskop fotografisch festgehalten und würden die Theorie einer "Infektionskette“ stützen, bei der sich eine Entzündung vom Ort ihrer Entstehung weiter verbreitet hat. Der Ursprung der Entzündung ist nicht eindeutig zu bestimmen, denkbar wäre allerdings eine Otitis media. Die Präparate weisen Spuren von abgelagertem Erdmaterial auf, welches sich während der langen Bodenlagerung in den Hohlräumen des Knochens gesammelt hat (Abbildungen 11, 12 und 13). 


\subsection{REM-Befund 1 der Population aus Calden (Vgl. 7.19)}

Dieses Präparat stammt aus dem mittleren Schaft einer Fibula. Analog zu diesem REM-Präparat wurden Dünnschliffe angefertigt (Vgl. 8.19), um der Fragestellung nachzugehen, ob die deutlichen Streifen in der Knochenoberflächenstruktur intravitalen Ursprungs sind und damit z. B. Zeichen einer früheren Reizung der Knochenhaut sein könnten.

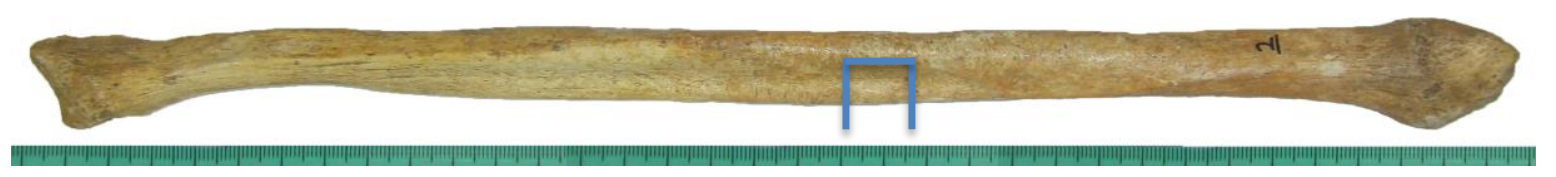

Abb. 1: Foto des Fundstücks in ganzer Länge. Der blaue Rahmen markiert die Entnahmestelle der Knochenprobe für die rasterelektronenmikroskopische Untersuchung.

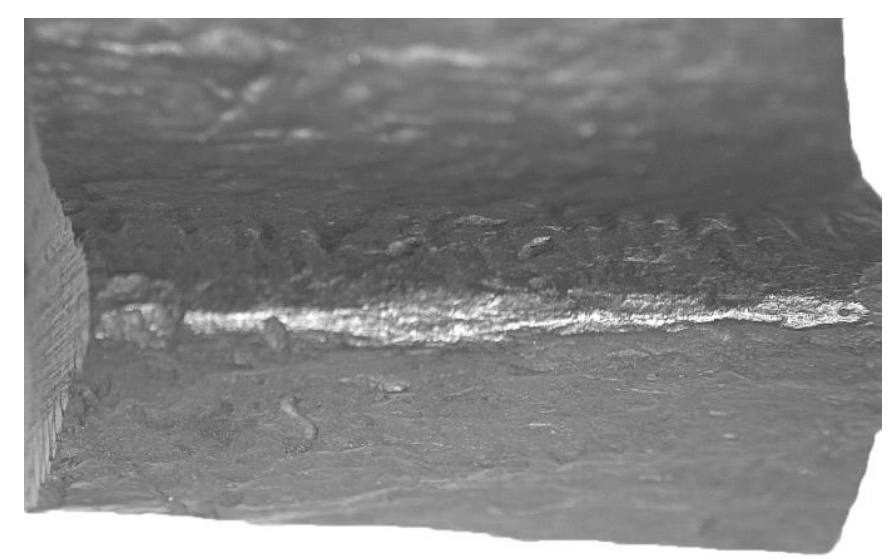

Abb. 2: Aufnahme des Fundstücks mit dem Binokular. Zu erkennen sind mit dieser Vergrößerung die Furchen und Strukturen der Oberfläche.

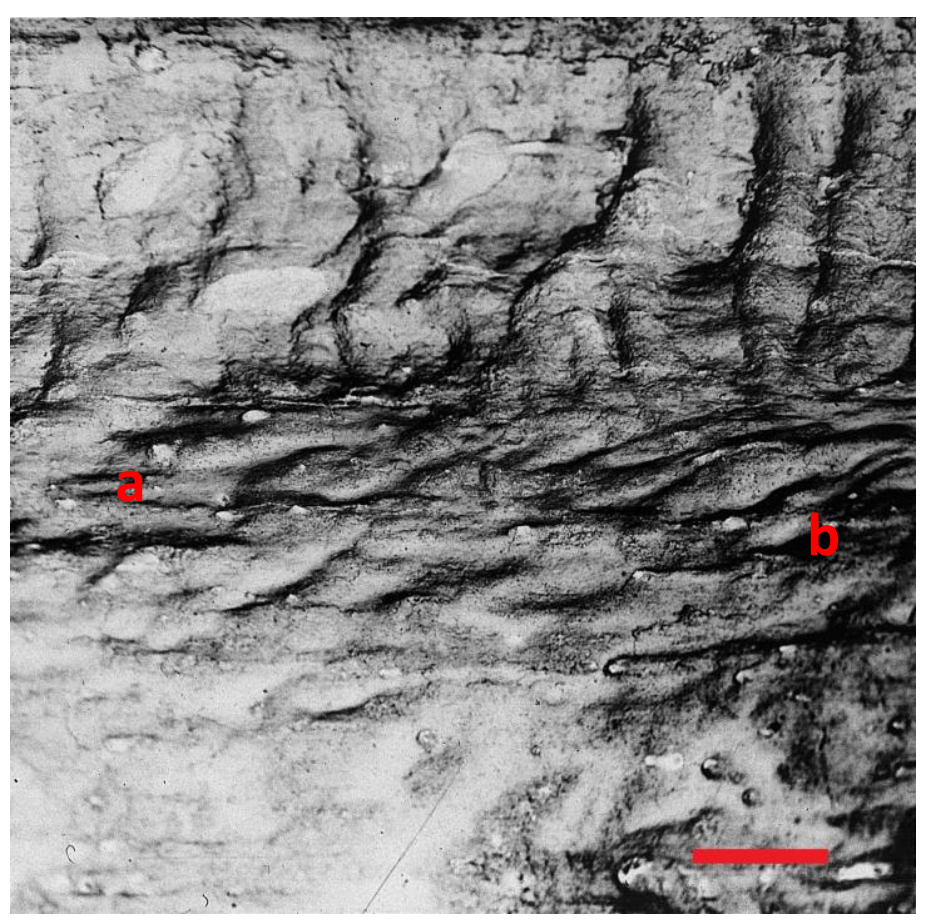

Abb. 3: Aufnahme bei $15 \mathrm{kV}$, Entfernung zum Objekt $18 \mathrm{~mm}$, Vergrößerung 15x, Maß ist $1 \mathrm{~mm}$ (roter Balken unten rechts). Am Boden der Rinne könnte die Oberfläche wenig verändert und damit noch original sein. Die Buchstaben " $a$ " und "b" markieren den Verlauf der Rinne, die in der Verbindungslinie zwischen den beiden Buchstaben verläuft. 
Die streifenförmigen Veränderungen stellten sich als postmortale Artefakte heraus. Unabhängig von der Fragestellung konnten einige Strukturen erkannt werden, die in den Abbildungen 3 bis 8 gezeigt und in der Abbildungsunterschrift erklärt werden.

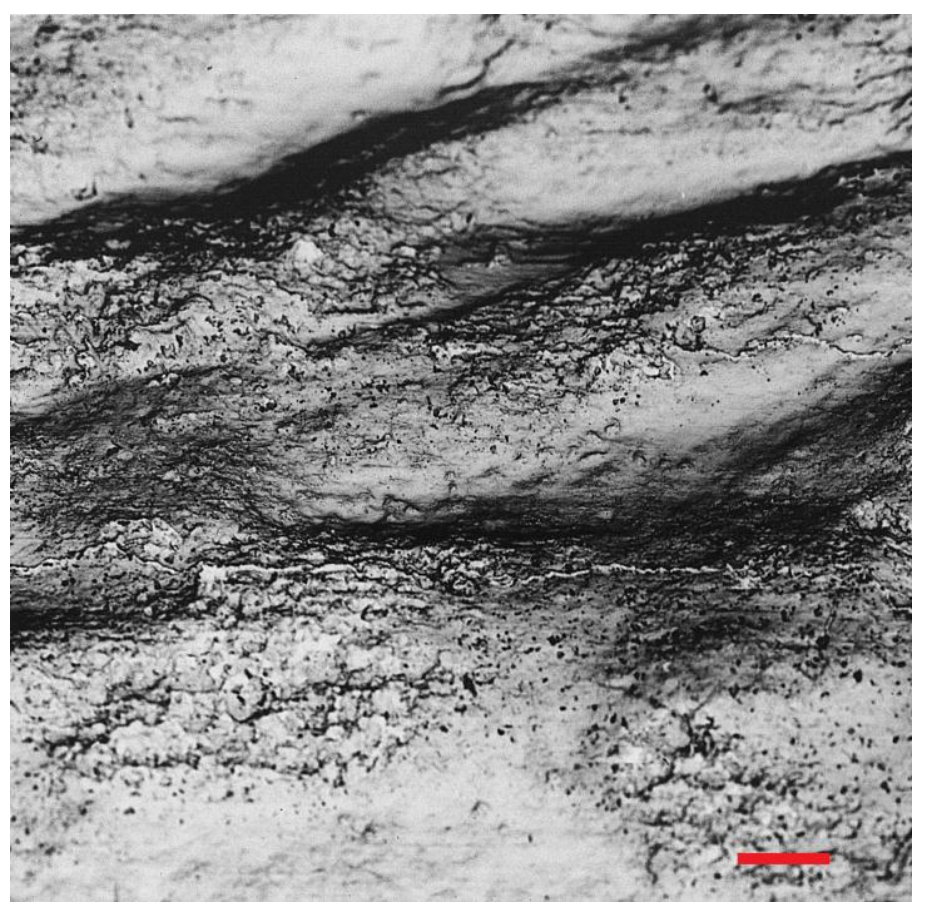

Abb. 4: Aufnahme bei 15 kV, Entfernung zum Objekt 18 mm, Vergrößerung 100x, Maß ist $100 \mu \mathrm{m}$ (roter Balken unten rechts). Sklerosierte Rinne, postmortal nur leicht verändert. Leichte Degeneration durch Bodenerosionen, aber die originale Oberfläche ist trotz der Sklerosierung erhalten.

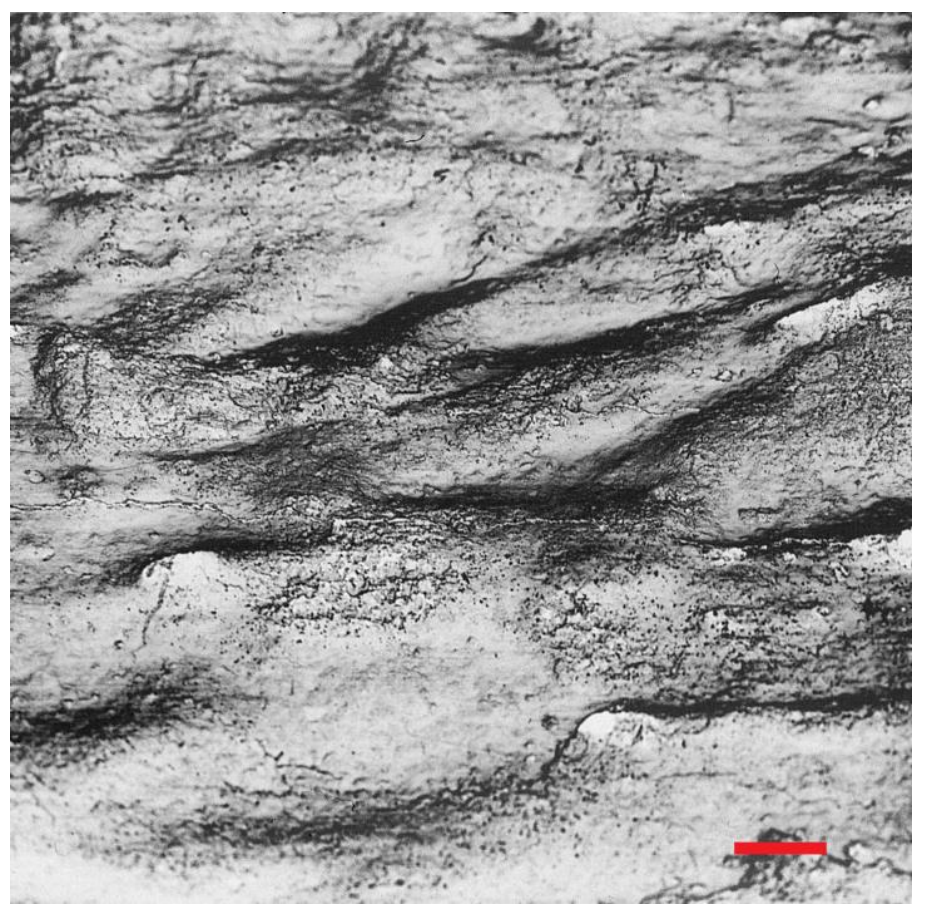

Abb. 5: Aufnahme bei $15 \mathrm{kV}$, Entfernung zum Objekt $18 \mathrm{~mm}$, Vergrößerung 50x, Maß ist $200 \mu \mathrm{m}$ (roter Balken unten rechts). Nahaufnahme der Streifung. Sharpey'sche Fasern gehen in die Tiefe, es ist kein Blutgefäß, sondern ein Muskelansatz. 


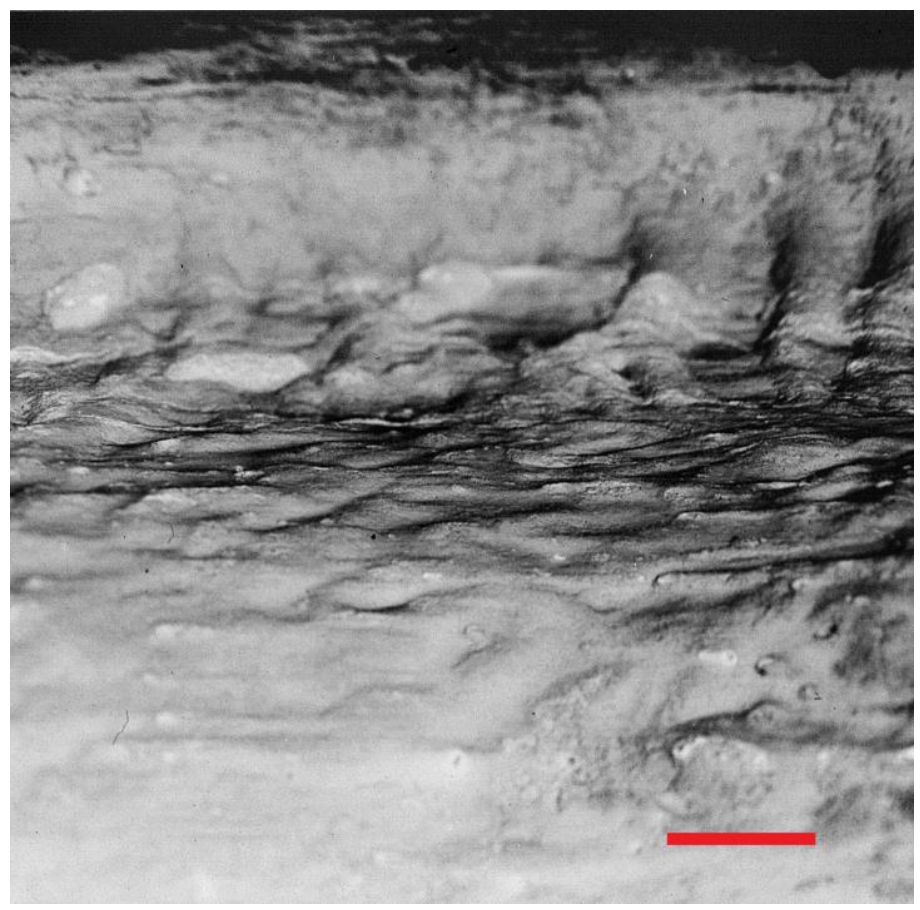

Abb. 6: Aufnahme bei $15 \mathrm{kV}$, Entfernung zum Objekt $12 \mathrm{~mm}$, Vergrößerung 16x, Maß ist $1 \mathrm{~mm}$ (roter Balken unten rechts). Übersichtsaufnahme über die Rinne. Ansatz von Band-oder Sehnenfasern. Diese sind durch Aussprengungen bedingt, die in Folge einer Überbelastung entstanden sind. Dadurch entstand eine Grube, die der am Costoclaviculargelenk ähnelt.

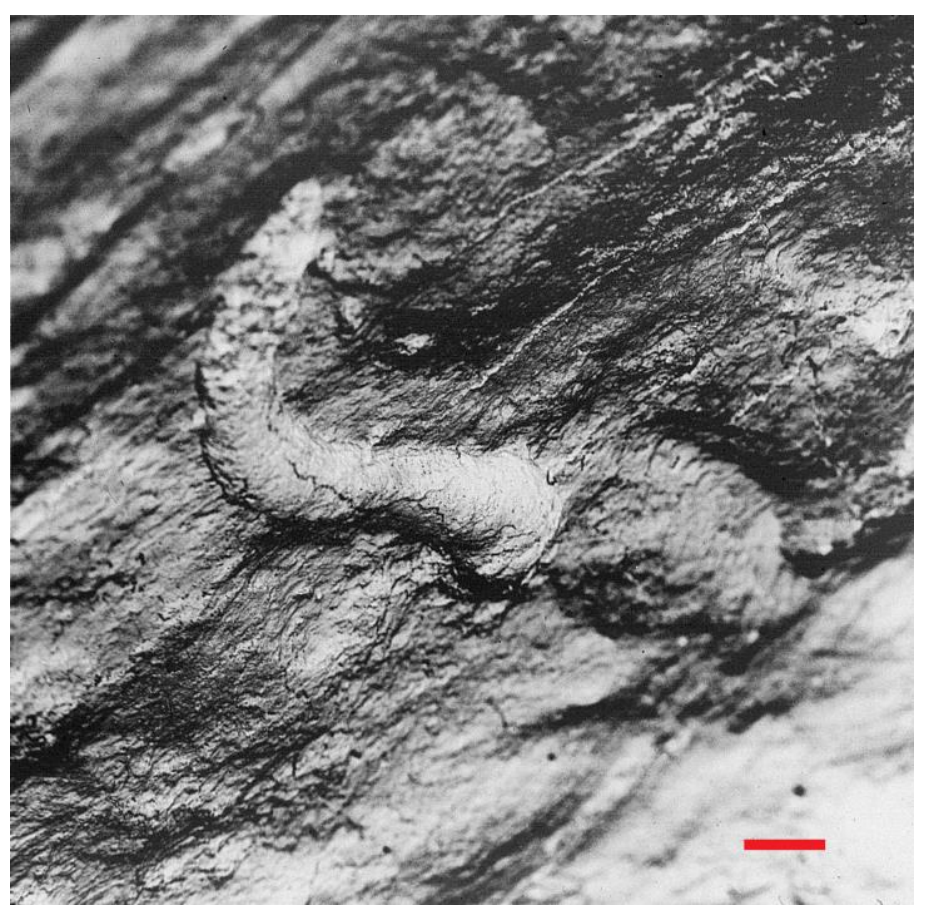

Abb. 7: Aufnahme bei $15 \mathrm{kV}$, Entfernung zum Objekt 9 mm, Vergrößerung 45x, Maß ist $200 \mu \mathrm{m}$ (roter Balken unten rechts). Nahaufnahme einer Wurzelimpression; es finden sich auch postmortale Schleifspuren. Der Knochen ist durch Bodenmaterial abgewetzt worden. Die Beschädigungen an den unterschiedlichen Präparatentnahmestellen ähneln sich deutlich. In der Rinne hat sich allerdings originale Knochensubstanz erhalten, da sie in der Rinne anscheinend Schutz vor der Schleiferosion hatte. Die Knochenoberfläche kann deswegen als original identifiziert werden, weil sonst auch dort die gleichen Schleifspuren zu entdecken sein müssten. 


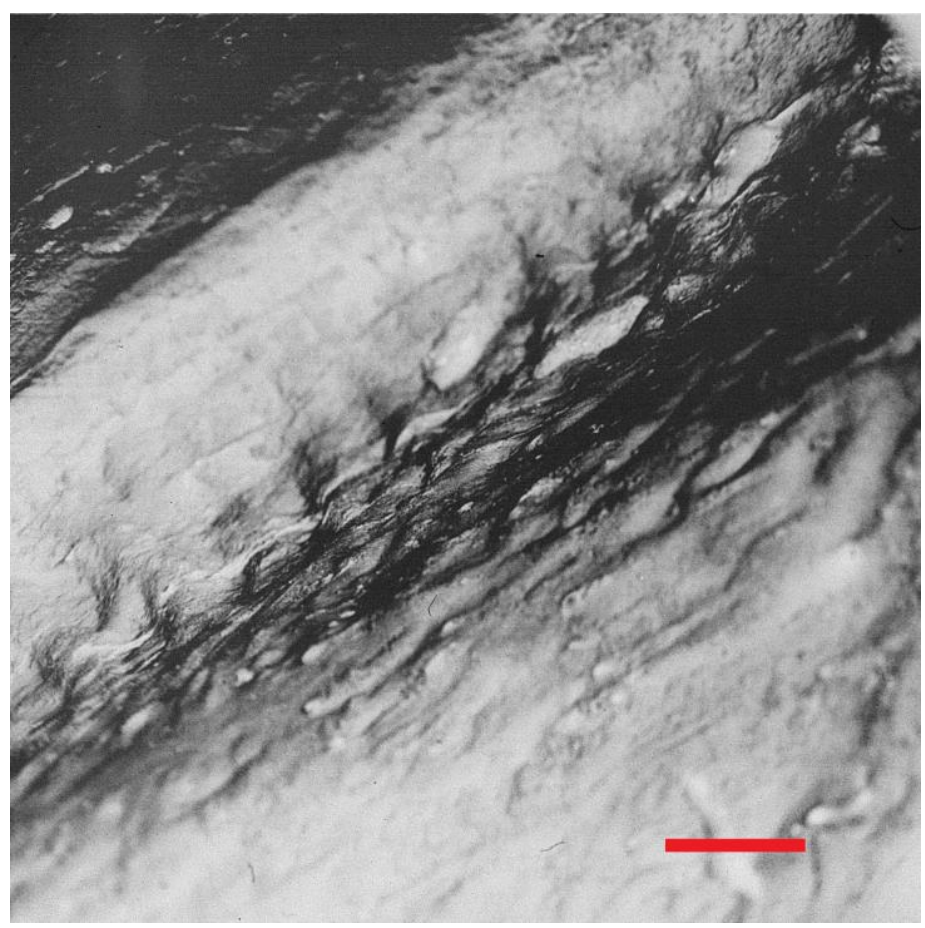

Abb. 8: Aufnahme bei $15 \mathrm{kV}$, Entfernung zum Objekt $11 \mathrm{~mm}$, Vergrößerung 15x, Maß ist $1 \mathrm{~mm}$ (roter Balken unten rechts). Rinne in weiterer Übersichtsaufnahme. Zu erkennen sind die deutlichen, jedoch postmortalen Veränderungen der Knochenoberfläche.

Bei der rasterelektronenmikroskopischen Untersuchung konnten die Befunde der lichtmikroskopischen Untersuchungen bestätigt werden, dass alle Veränderungen der Knochenoberfläche postmortalen Ursprungs sind. Sie sind durch Bodenerosionen entstanden, als der Knochen den Witterungsbedingungen und der Bodenerosion ausgesetzt war. 


\subsection{REM-Befund 2 der Population aus Calden (Vgl. 7.19)}

Das Präparat für die REM-Untersuchung entstammt dem proximalen Schaft einer Fibula der linken Seite. Aus der gleichen Region wurden mehrere Knochendünnschliffe und eine weitere Rasterelektronenmikroskopprobe angefertigt. Die Fragestellung für die Untersuchungen bezog sich auf eine makroskopisch sichtbare Streifung, die am Schaft im proximalen Teil des Knochens festzustellen war.

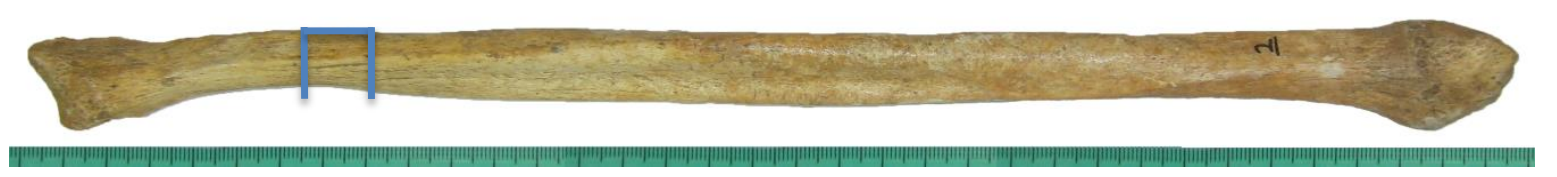

Abb. 1: Foto des Fundstücks in ganzer Länge. Der blaue Rahmen markiert die Entnahmestelle der Knochenprobe für die rasterelektronenmikroskopische Untersuchung.

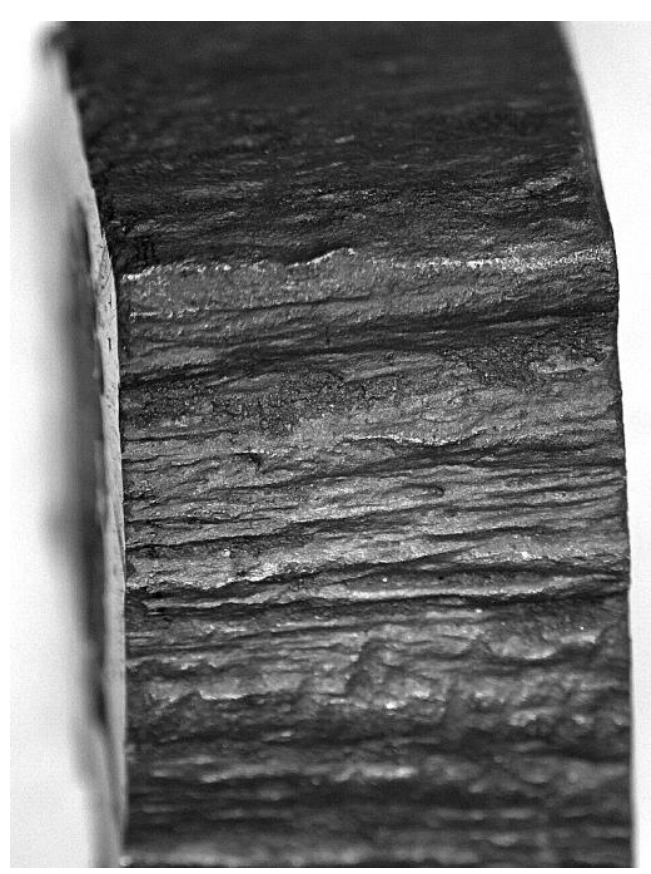

Abb. 2: Übersichtsaufnehme des Präparates mit dem binokularen Lupenmikroskop. Gezeigt ist die lange, flache Seite der Fibula.

Im Rasterelektronenmikroskopbild ist eine postmortale Freilegung der Kollagenfasern durch Erosion zu erkennen. Diese Beobachtung konnte bereits bei vorangegangenen lupenmikroskopischen Untersuchungen gemacht werden. Auffällig erschienen freigelegte Gefäßtunnel, die „fransig“ gebrochen waren. Sie wurden ebenfalls durch postmortale Bodenerosionen freigelegt. In der oberen Knochenstruktur finden sich kleine Risse, die durch den Bodendruck entstanden sein könnten.

Die Abbildungen 3 bis 8 zeigen die auffälligen Knochenstrukturen und Nebenbefunde. Die Erklärungen $\mathrm{zu}$ den Bildern finden sich in der Bildunterschrift. 
Der Verdacht, dass die gezeigten Veränderungen intravitalen und möglicherweise pathologischen Ursprungs sind, konnte bei der rasterelektronenmikroskopischen Untersuchung nicht bestätigt werden.

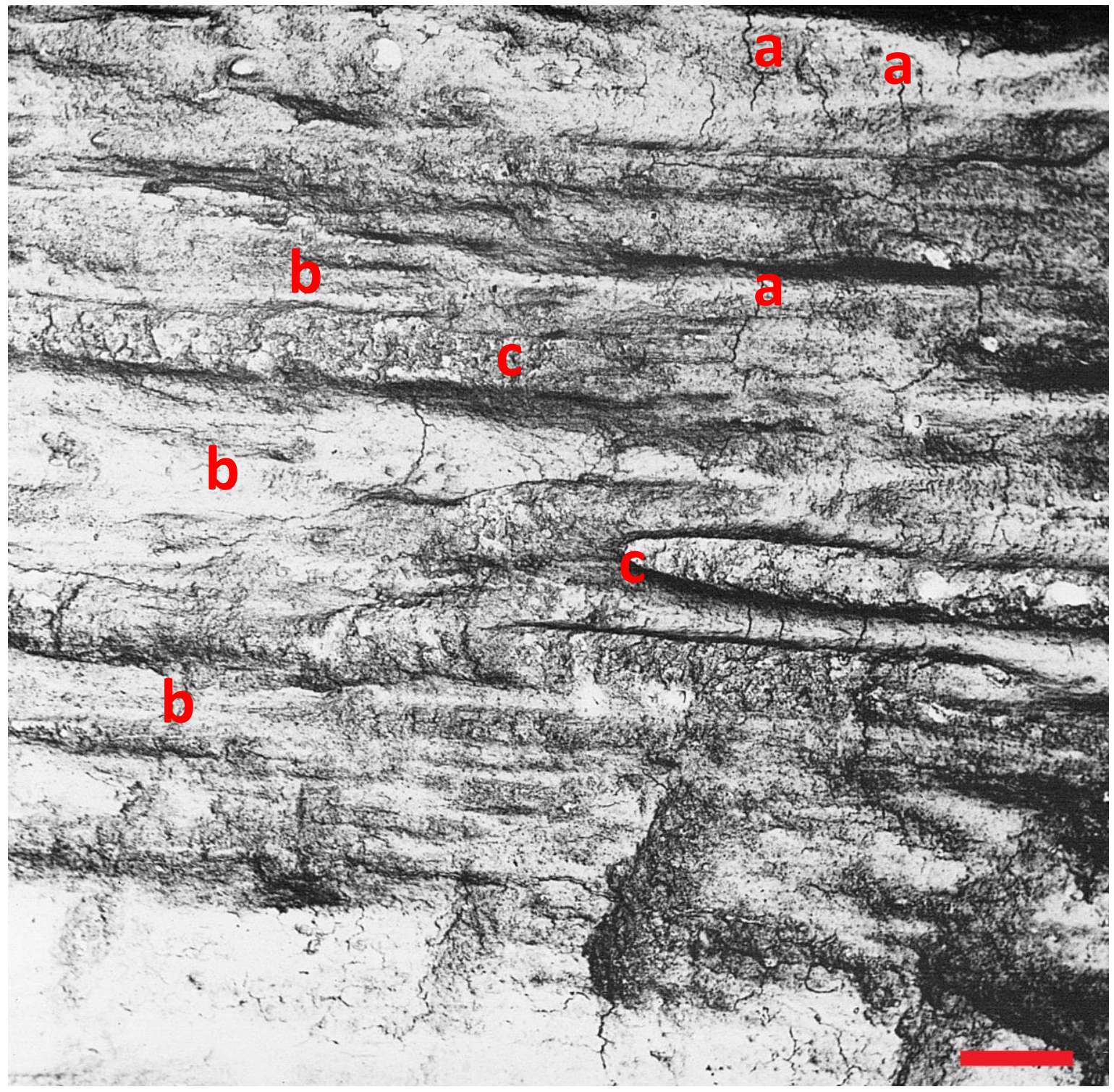

Abb. 3: Aufnahme bei $15 \mathrm{kV}$, Entfernung zum Objekt 26 mm, Vergrößerung 20x, Maß ist $500 \mu \mathrm{m}$ (roter Balken unten rechts). Aufsicht auf das zerklüftet und "fransig" aussehende Erosionsmuster der Fibula. "a" markiert die Mikrorisse in der Knochenstruktur. Die Buchstaben "b" deuten auf die freigelegten Gefäßbette. "c" zeigt beispielhaft die "fransigen" Formen der freigelegten Kollagenstruktur als „Wände“ der Gefäßkanäle.

In Abb. 3 ist ein unregelmäßiger, aufgetriebener Bereich zu sehen, der wohl postmortal durch Bodendruck und Pflanzenwurzeln verändert wurde. 


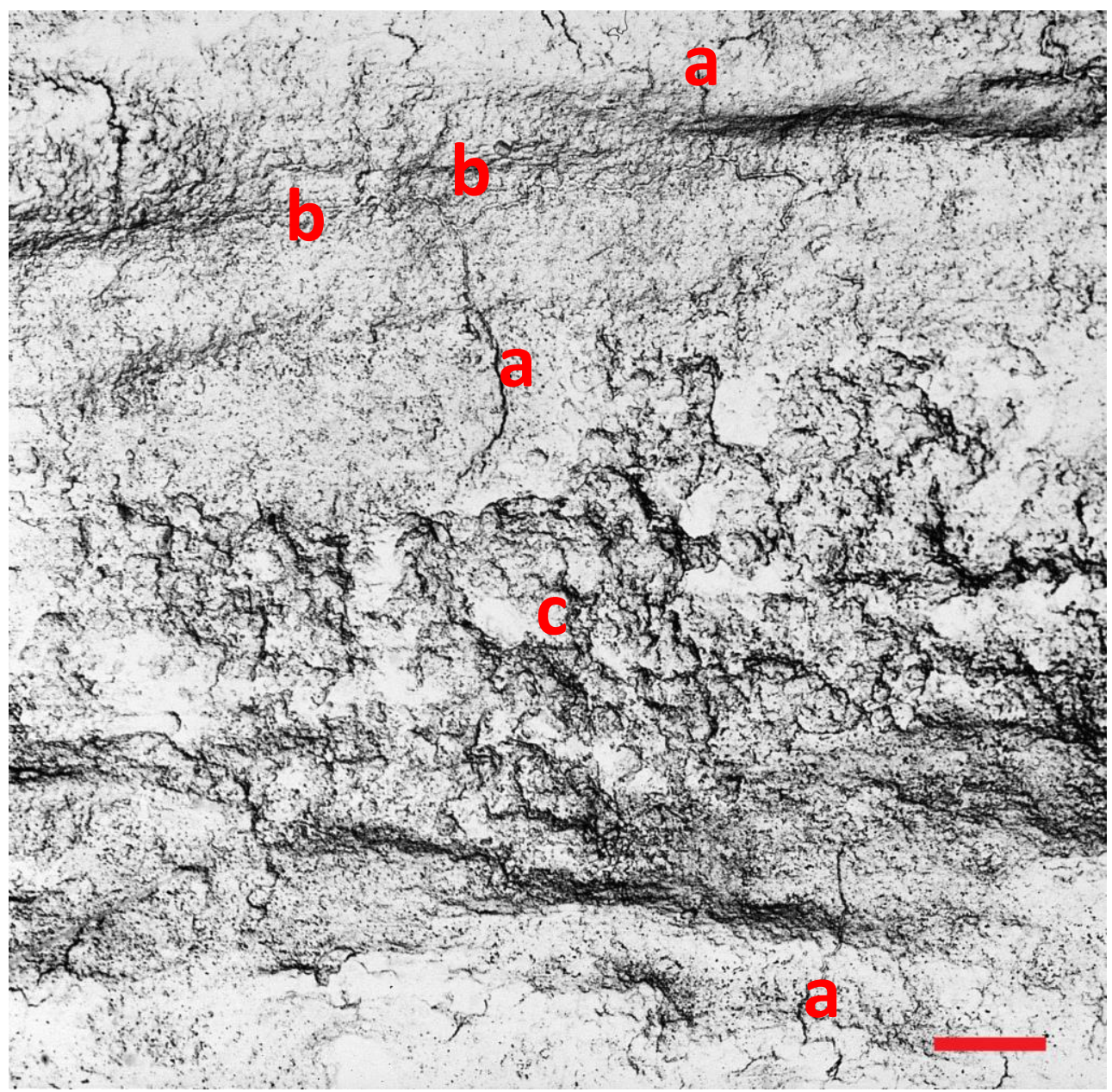

Abb. 4: Aufnahme bei 15 kV, Entfernung zum Objekt 21 mm, Vergrößerung 50x, Maß ist $200 \mu \mathrm{m}$ (roter Balken unten rechts). "a" deutet auf Mikrorisse in der Knochenstruktur hin. "b" zeigt vermutliche Spuren einer Pflanzenwurzel, die Schäden in der Kollagenstruktur des Knochens hervorgerufen hat. „c" markiert den Bereich von erosiver, postmortaler Oberflächenzerstörung.

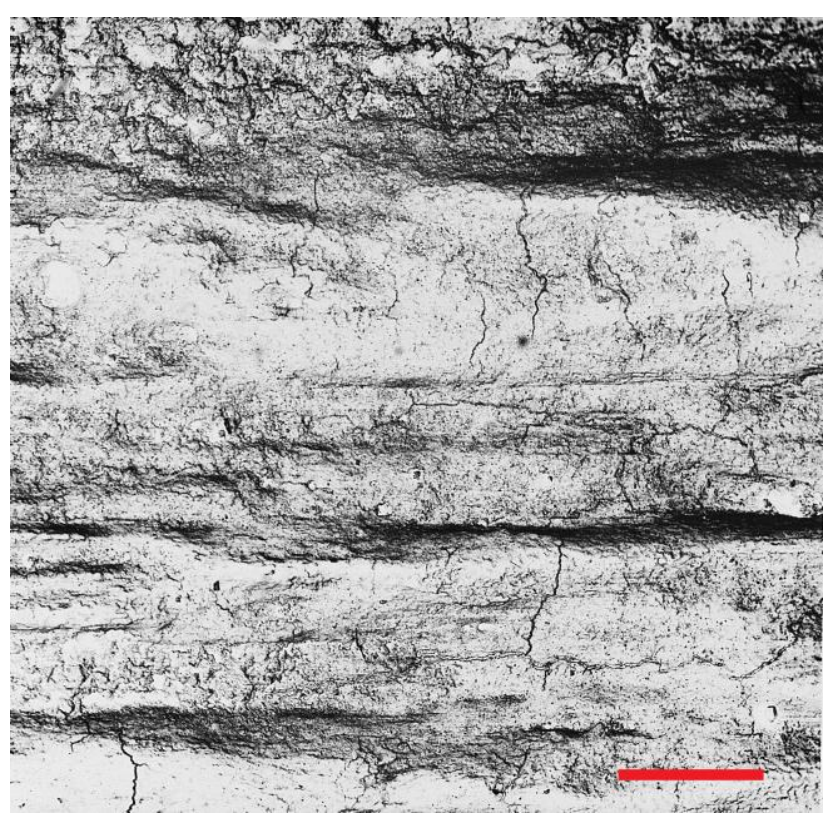

Abb. 5: Aufnahme bei $15 \mathrm{kV}$, Entfernung zum Objekt 22 mm, Vergrößerung 35x, Maß ist $500 \mu \mathrm{m}$ (roter Balken unten rechts). 
In Abb. 6 sind zwei Volkmann'sche Kanäle und eine Übersicht über die Streifung zu sehen. Es lässt sich jedoch kein Beweis für ein intravitales Geschehen finden. Alle gefundenen und untersuchten Streifenstrukturen stammen wahrscheinlich von postmortaler Erosion.

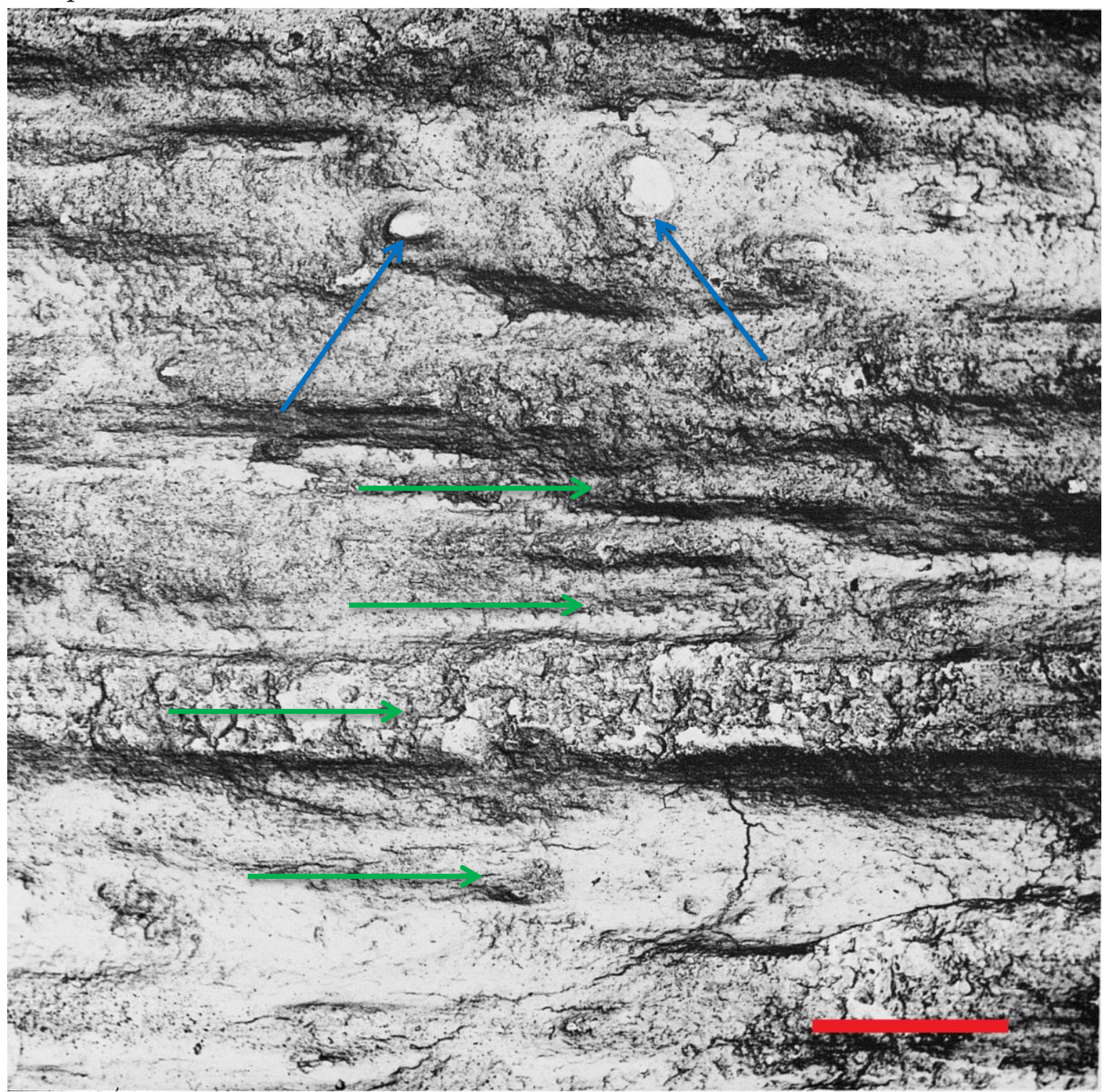

Abb. 6: Aufnahme bei $15 \mathrm{kV}$, Entfernung zum Objekt 22 mm, Vergrößerung 35x, Maß ist 500 m (roter Balken unten rechts). In dieser Aufnahme ist die Streifung sehr gut zu erkennen, die bereits makroskopisch auffiel (grüne Pfeile). Zwei senkrecht in die Knochenstruktur eintretende Volkmann'sche Knochenkanäle sind mit den blauen Pfeilen markiert. 
Zwei Gefäßkanäle sind hier längs getroffen (Abb. 7). Durch Erosion sind diese postmortal offen gelegt worden.

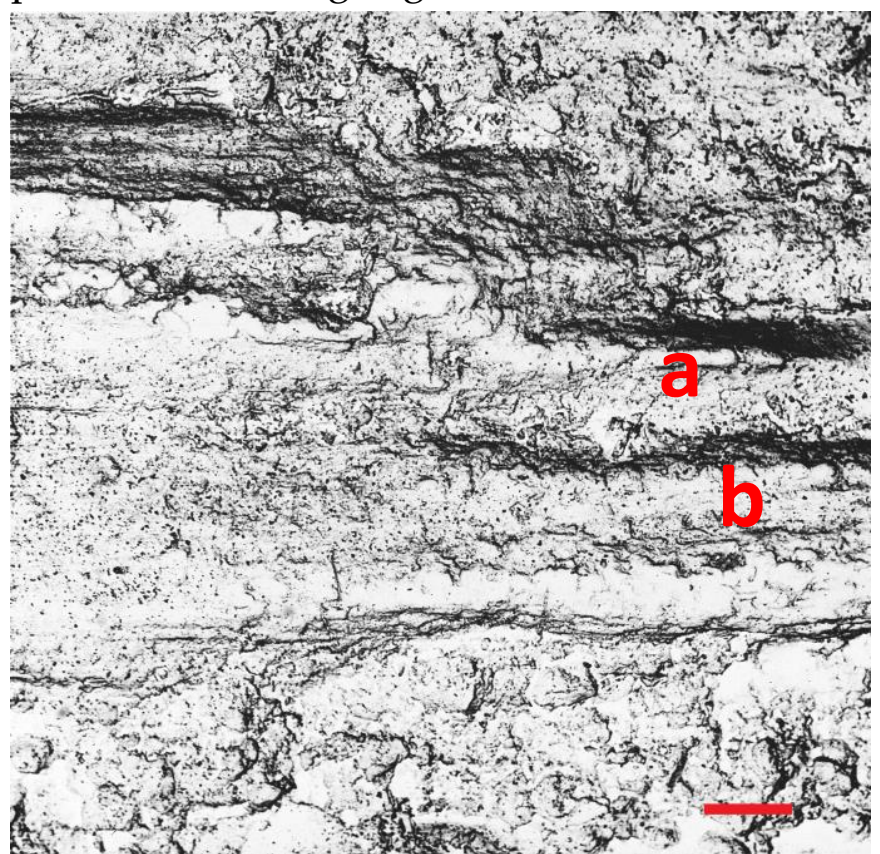

Abb. 7: Aufnahme bei $15 \mathrm{kV}$, Entfernung zum Objekt 22 mm, Vergrößerung, 100x; Maß ist $100 \mu \mathrm{m}$ (roter Balken unten rechts). "a" zeigt den Verlauf eines Gefäßes, "b" zeigt ein anderes Gefäß.

Abb. 8 zeigt einen quer getroffenen Gefäßkanal.

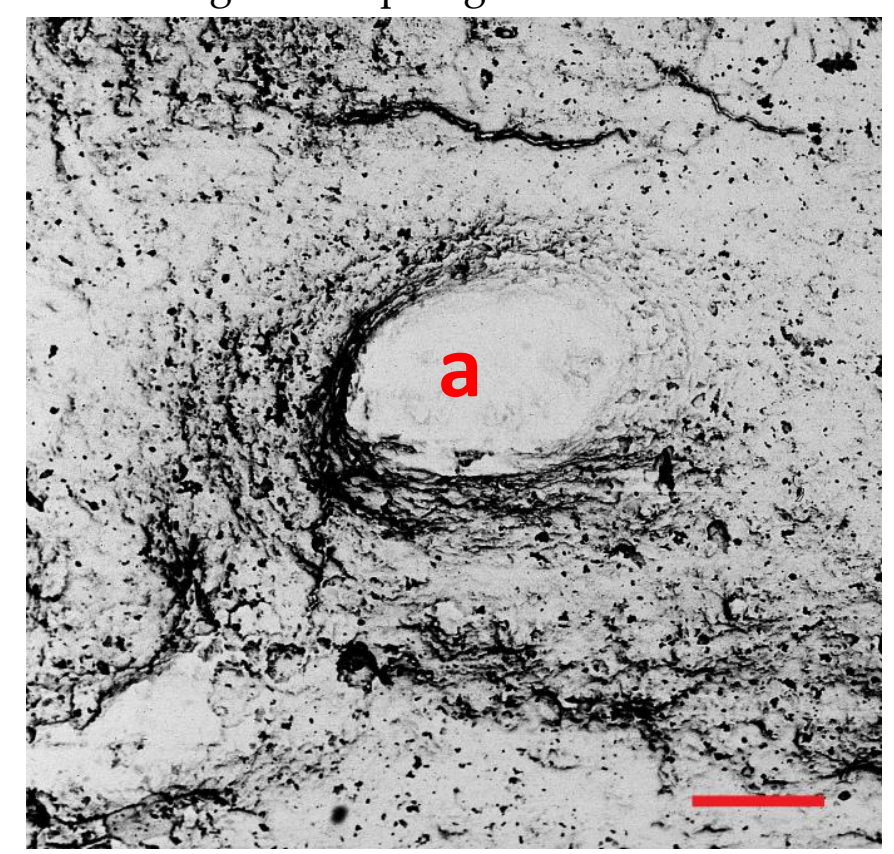

Abb. 8: Aufnahme bei $15 \mathrm{kV}$, Entfernung zum Objekt $22 \mathrm{~mm}$, Vergrößerung 300x; Maß ist 50 m (roter Balken unten rechts). Bei dieser Aufnahme wurde ein Gefäßkanal quer getroffen (a). 


\section{Danksagung}

Ich möchte mich bei Herrn Prof. Dr. med. Dr. phil. nat. Michael Schultz, Leiter der Arbeitsgruppe Paläopathologie am Zentrum Anatomie der Georg-August-Universität Göttingen, für die Vergabe des Themas und das Anvertrauen der Skeletfunde der drei Populationen, seine Unterstützung beim Erlernen der paläopathologischen Methodik und die motivierende Betreuung bedanken.

Herrn Michael Brandt, Zentrum Anatomie der Georg-August-Universität Göttingen, möchte ich für die Unterstützung beim Anfertigen der Knochenschliffe für licht- und rasterelektronenmikroskopische Untersuchungen danken.

Weiterer Dank geht an Frau Ingrid Hettwer-Steeger, die die Proben für die REM-Untersuchung freundlicherweise bedampft hat.

Ich bedanke mich bei der Arbeitsgruppe Paläopathologie am Zentrum Anatomie der Georg-August-Universität Göttingen für eine abwechslungsreiche Zusammenarbeit.

Für die Anfertigung der DVT und die Bereitstellung des Gerätes für diese Arbeit danke ich Herrn Klenke und Frau Degenhardt aus der Abteilung Zahn-, Mund- und Kieferheilkunde der Universitätsmedizin Göttingen.

Meinem sehr guten Freund Julian Görtz aus Lingen möchte ich ausdrücklich für seine wertvollen Ideen danken, die er für die Auswertung meiner Ergebnisse in die Tat umsetzte und es möglich machte, die große Menge an Daten auszuwerten. Herr Görtz ist Maschinenbauingenieur und entwickelte für meine Dissertation eigens eine unterstützende Softwareprogrammierung in FileMaker Pro ${ }^{\circledR}$, die für mich das Auswerten aller Daten ermöglichte! Seine unermüdliche Motivation, tatkräftige Unterstützung und vor allem unendliche Geduld weiß ich sehr zu schätzen. Außerdem half mir Herr Görtz bei der Formatierung der Arbeit in dem Computerprogramm Adobe InDesign ${ }^{\circledR}$, damit Abbildungen, Tabellen und Text in hoher Auflösung und in gutem Verhältnis zueinander dargestellt werden konnten. Auch dafür möchte ich ihm ganz herzlich danken.

Dank geht auch an Frau Dr. Irina Görner (Vor- und Frühgeschichtliche Sammlung Museumslandschaft Hessen Kassel). Sie beantwortete mir Fragen zum Fundgut der Population aus Calden.

Meiner Freundin, Miriam Seidel, möchte ich dafür danken, dass sie beim Korrekturlesen eine große Hilfe war.

Zu guter Letzt möchte ich meinen Eltern für das mehrfache Korrekturlesen der vorgelegten Arbeit danken sowie meiner Mutter für das Anfertigen einer Zeichnung. 
Bezeichn:: Cranium

\section{Kiste:}

Skelet: Calden 3

Population: Calden

Felsenbein: Beide

Erhaltung: $>60 \%$ erh.

$25-60 \%$ erh.

$1-25 \%$ erh.
Ges./Kr.: Krank

Krankh.: Cribra Orbitalia

Sinusitis maxillaris

Kopfschwartenreizung

Bathrocephalus

\section{Maß}

Orbita re / li

Schädeldecke / Schädelbasis

Sinus frontalis

Sinus maxillaris

Viscerocranium

\section{Beschreibung:}

Bei diesem Fundstück eines männlichen Schädels mittleren Alters handelt es sich um ein Ausstellungsstück des Heimatmuseums in Kassel. Das Cranium ist als

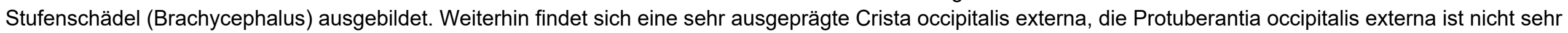

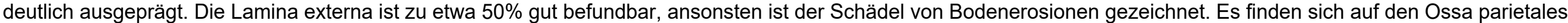

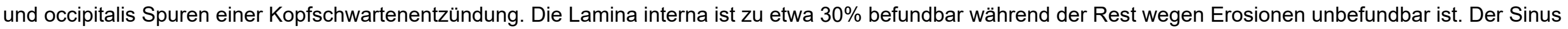

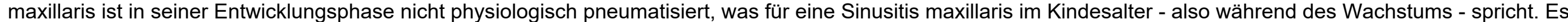

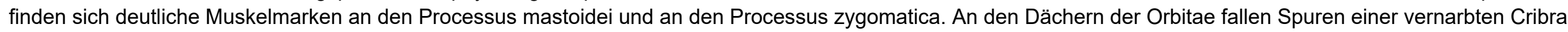
orbitalia auf, die mit einem Ausprägungsgrad von 2 zu beziffern sind. Das Alter des Individuums ist auf etwa 30 Jahre $+/-5$ einzustufen. 
Bezeichn.: Cranium

Kiste:

Skelet: $\quad$ Calden 30

Population: Calden

Felsenbein: Beide

Erhaltung: $\bullet 60 \%$ erh

$25-60 \%$ erh.

$1-25 \%$ erh.
Verband: $\quad \square$ Verband

Alter: $25-30$ (35)

\section{Geschlecht: ¿}

\section{Arthrose:}

Ges./Kr.: Krank

Krankh.: Cribra Orbitalia

Fraktur

Kopfschwartenreizung

Sinusitis frontalis

Sinusitis maxillaris

Sinusitis sphenoidalis

Stomatitis

\begin{tabular}{l|l|l} 
Maß & Wert & Einheit \\
\hline Orbita re / li & 2 & 2 \\
Schädeldecke / Schädelbasis & 2 & 1 \\
Sinus frontalis & 2 & \\
Sinus maxillaris & 2 & \\
Sinus sphenoidalis & 2 & \\
Viscerocranium & 2 &
\end{tabular}

\section{Beschreibung:}

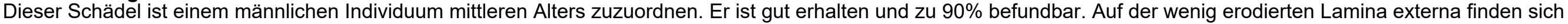

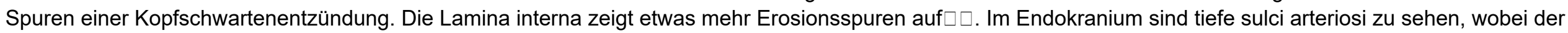

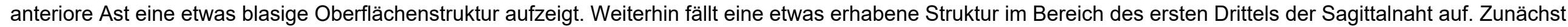

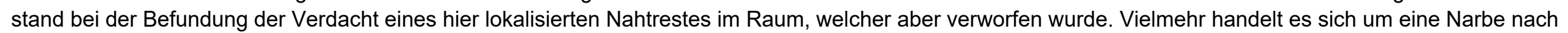

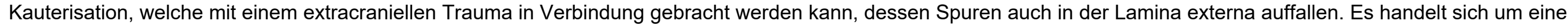

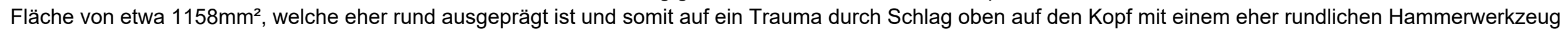

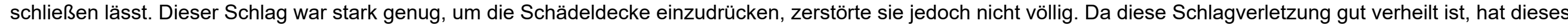

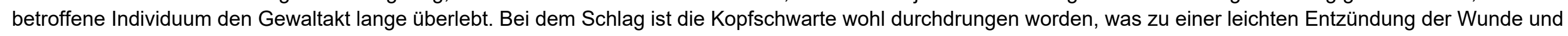
damit der Kopfschwarte geführt hat. Die Entzündung wanderte dann unter der Galea aponeurotica aus und hinterließ die nun vernarbten Strukturen der

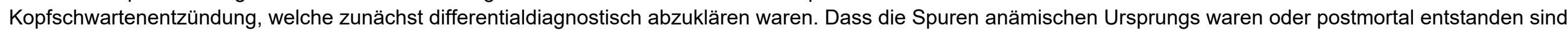

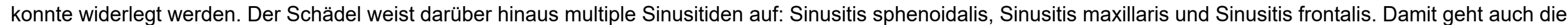

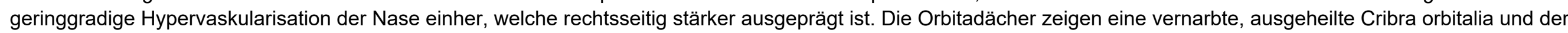
Gaumen weist Spuren einer Stomatitis auf. 
Kiste:

Skelet: Museumskiste

Population: Calden

Felsenbein: Beide

Erhaltung: $>60 \%$ erh

- $25-60 \%$ erh.

$1-25 \%$ erh.
Ges./Kr.: Krank

Krankh.: meningeale Reizung

Perisinusitis

meatus acusticus Reizung

Sinusitis frontalis

Bathrocephalus

\begin{tabular}{l|l|l} 
Maß & Wert & Einheit \\
\hline Orbita re / li & 1 & 1 \\
Schädeldecke / Schädelbasis & 2 & 2 \\
Sinus frontalis & 2 & \\
& &
\end{tabular}

\section{Beschreibung:}

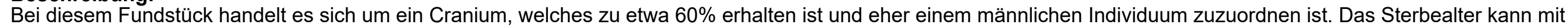

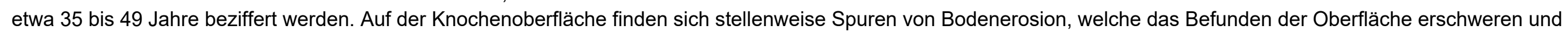

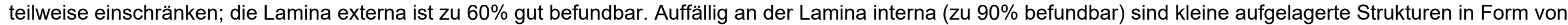

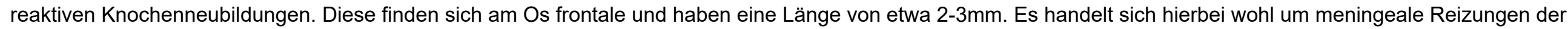
Knochenoberfläche. Weiterhin sind kleine plattenförmige Auflagerungen im Bereich der Sinus transversus zu finden. Auf der rechten Seite sind die kleinen Knochenneubildungen unterhalb des Sinus transversus und auf der linken Seite auf der Leitstrucktur des Sinus transversus zu finden, wobei links besagte

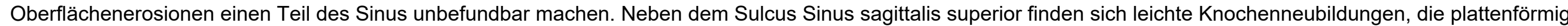

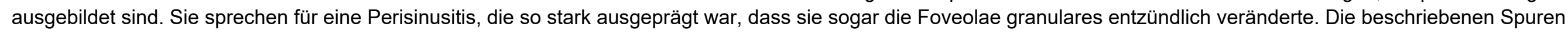

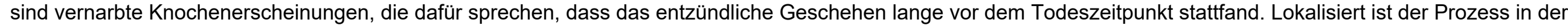

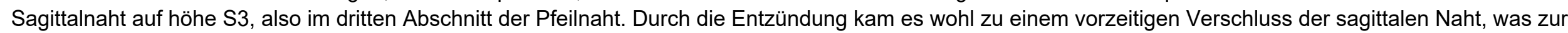

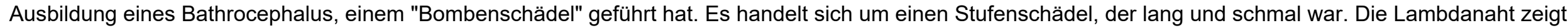
Verknöcherungszeichen zu einem verspäteten Zeitpunkt, was zu der Schädelform beitrug.

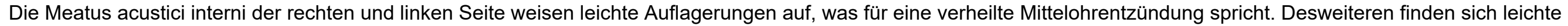
Auflagerungen im Sinus frontalis, was auch hier für einen vorangegangenen entzündlichen Prozess spricht. 


\section{Kiste: \\ Skelet:}

Population: Calden

Felsenbein: Beide

Erhaltung: $>60 \%$ erh.

$25-60 \%$ erh.

$1-25 \%$ erh.
Ges./Kr.: Krank

Krankh.: Kopfschwartenreizung

Cribra Orbitalia

Sinusitis sphenoidalis

Sinusitis maxillaris

Sinusitis frontalis

\begin{tabular}{l|l|l} 
Maß & Wert & Einheit \\
\hline Orbita re / li & 2 & 2 \\
Schädeldecke / Schädelbasis & 2 & 1 \\
Sinus frontalis & 2 & \\
Sinus maxillaris & 2 & \\
Sinus sphenoidalis & 2 & \\
Viscerocranium & 1 &
\end{tabular}

\section{Beschreibung:}

Das vorliegende Fundstück ist ein Bathrocephalus eines zwischen 35 und 55 Jahre alten, männlichen Individuums. Es ist auch der Oberkiefer erhalten, womit der

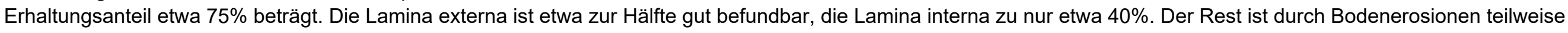

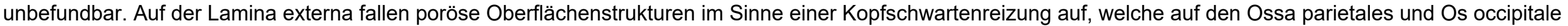

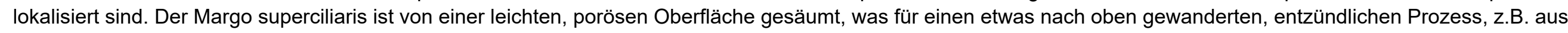

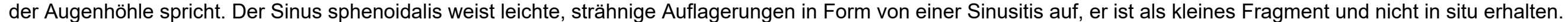

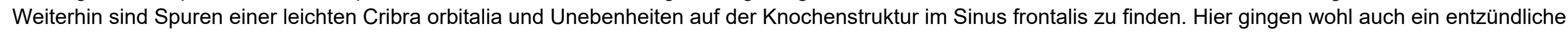

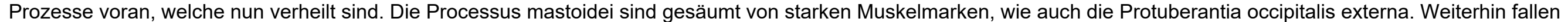
im Sinus maxillaris Spuren einer Sinusitis maxillaris auf. 
Kiste:

Cranium

Skelet: Calden 19

Population: Calden

Felsenbein: Beide

Erhaltung: $\bullet 60 \%$ erh.

$25-60 \%$ erh.

$1-25 \%$ erh.
Ges./Kr.: Krank

Krankh.: Kopfschwartenreizung

Sinusitis frontalis

meatus acusticus Reizung

\section{Maß}

Orbita re / li

Schädeldecke / Schädelbasis

Sinus frontalis

Sinus maxillaris

Viscerocranium

\section{Geschlecht: $q \geq 0$}

Arthrose:

\begin{tabular}{|l|l} 
Wert & Einheit \\
1 & 1 \\
2 & 1 \\
2 & \\
1 & \\
1 &
\end{tabular}

\section{Beschreibung:}

Dieses Cranium ist zu etwa $75 \%$ erhalten und eher einem weiblichen Individuum zuzuordnen. Das Alter kann auf etwa 35 bis 49 Jahre angegeben werden. Die

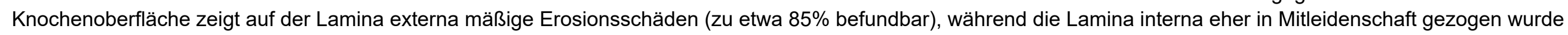

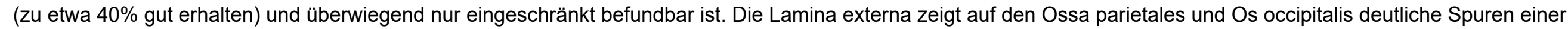

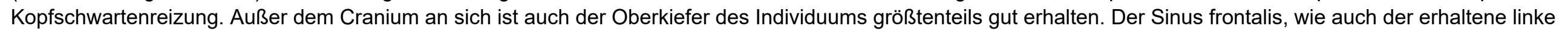
Meatus acusticus internus weisen leichte Auflagerungen auf, was für einen verheilten entzündlichen Prozess spricht. 
Bezeichn.: Cranium

\section{Kiste:}

Skelet: Calden 13

Population: Calden

Felsenbein: Beide

Erhaltung: $>60 \%$ erh.

$25-60 \%$ erh.

$1-25 \%$ erh.
Ges./Kr.: Krank

Krankh.: Sinusitis frontalis

Kopfschwartenreizung

\section{Verband \\ Alter: (25) 27 - 35}

Geschlecht: $\delta$

Arthrose:

\section{Maß}

Orbita re / li

Schädeldecke / Schädelbasis

Sinus frontalis

\section{Beschreibung:}

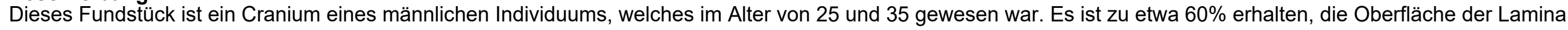

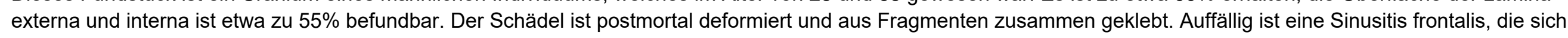

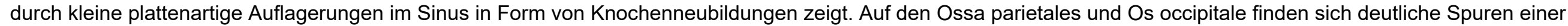
Kopfschwartenentzündung.

Der Schädel weist ausgeprägte Muskelmarken an den Processus mastoidei auf. 


$\begin{array}{lllll}\text { Bezeichn.: } & \text { Cranium } & \text { Verband: } \square \text { Verband } & \text { Ges./Kr.: Gesund } & \text { Maß } \\ \text { Kiste: } & 8505718 & \text { Alter: } & \text { Gert } & \text { Einheit } \\ \text { Skelet: } \quad \text { aus Tüte } & \text { Arthrose: } & & \text { Sinus sphenoidalis } \\ \text { Population: } & \text { Calden } & & 1 \\ \text { Felsenbein: } & \text { Rechts } & & \\ \text { Erhaltung: } & >60 \% \text { erh. } & & \\ & 25-60 \% \text { erh. } & & \\ & 1-25 \% \text { erh. } & & \end{array}$

\section{Beschreibung:}

Hier sind mehrere Fragmente eines. Ein Fragment stammt aus dem Os sphenoidale der rechten Seite, ein weiteres stammt ebenfalls vom Os sphenoidale und ein anderes von der Schädelkalotte. Die Fragmente weisen keine Auffälligkeiten auf. 


\section{Bezeichn.: Cranium \\ Kiste: $\quad 5271288$}

Skelet: $\quad$ Schädel 22 Knochenklein

Population: Calden

Felsenbein:

Erhaltung: $>60 \%$ erh

$$
25-60 \% \text { erh. }
$$

- 1 - $25 \%$ erh.
Ges./Kr.: Krank

Krankh.: Sinusitis sphenoidalis

\section{Maß}

Sinus sphenoidalis

\section{Geschlecht:}

Arthrose:

\section{Beschreibung:}

Ein Fragment des Sinus sphenoidalis, welches leichte strähnige Auflagerungen aufweist. Es sind noch weitere kleine Schädelsplitter erhalten. 


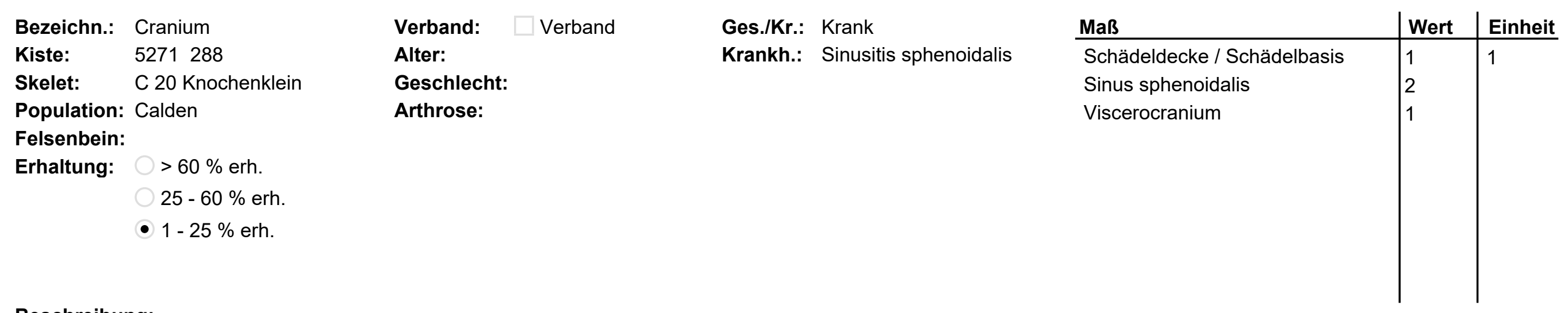

\section{Beschreibung:}

Schädelfragmente, unter anderen Os zygomaticum der rechten Seite, Os occipitale mit dem rechten Articulatio atlanto occipitalis, Basis des Os sphenoidale rechts mit ala minor und Sinus sphenoidalis, welcher leichte Auflagerungen in Form von plattenförmigen Knochenneubildungen aufweist. 


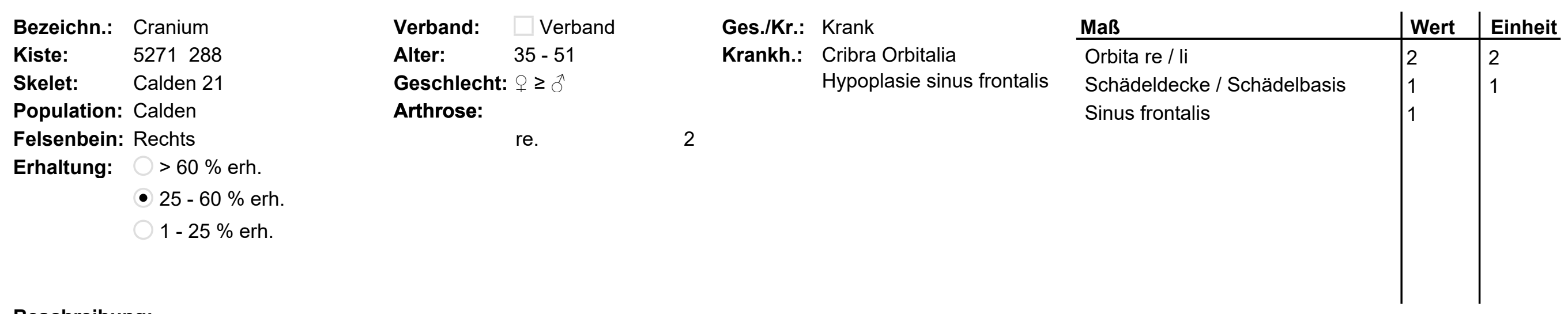

\section{Beschreibung:}

Ein in recht guter Konstitution erhaltener Schädel, die Lamina interna allerdings zeigt erosionsbedingte Beschädigungen. Die Lamina externa ist teilweise erodiert und die Form des Schädels eher länglich.

Die Orbitadächer weisen eine Cribra orbitalia mit Grad 2 auf. Der Sinus frontalis ist hypoplastisch, der Meatus acusticus externus der rechten Seite ist erhalten, zeigt jedoch keine krankhaften Auffälligkeiten. Das rechte Os mastoideum ist erhalten, ist recht klein und physiologisch pneumatisiert.

Weiterhin erhalten ist die rechte Fossa mandibularis. 


\section{Kiste: \\ 5271288 \\ Skelet: Calden 20}

Population: Calden

Felsenbein: Beide

Erhaltung: $>60 \%$ erh

- $25-60 \%$ erh.

$1-25 \%$ erh.
Ges./Kr.: Krank

Krankh.: Cribra Orbitalia

Kopfschwartenreizung

Sinusitis frontalis

meningeale Reizung

Perisinusitis

Arthrose

\section{Maß}

Orbita re / li

Schädeldecke / Schädelbasis

Sinus frontalis

Viscerocranium

\section{Beschreibung:}

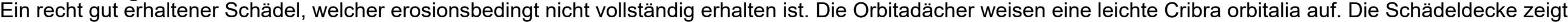

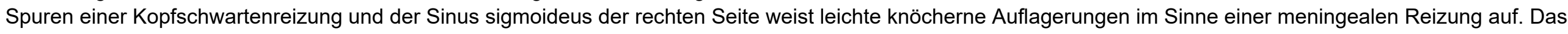
rechte Os mastoideum fällt mit stärkeren Muskelansätzen auf als das linke. Die Lamina interna im Bereich der Ossa parietales ist gespickt mit plattenförmigen

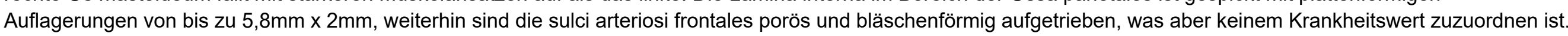
Die beiden erhaltenen Meatus acusticus internus sind nicht krankhaft verändert. Erhalten sind auch die fossae mandibulae rechts und links. 


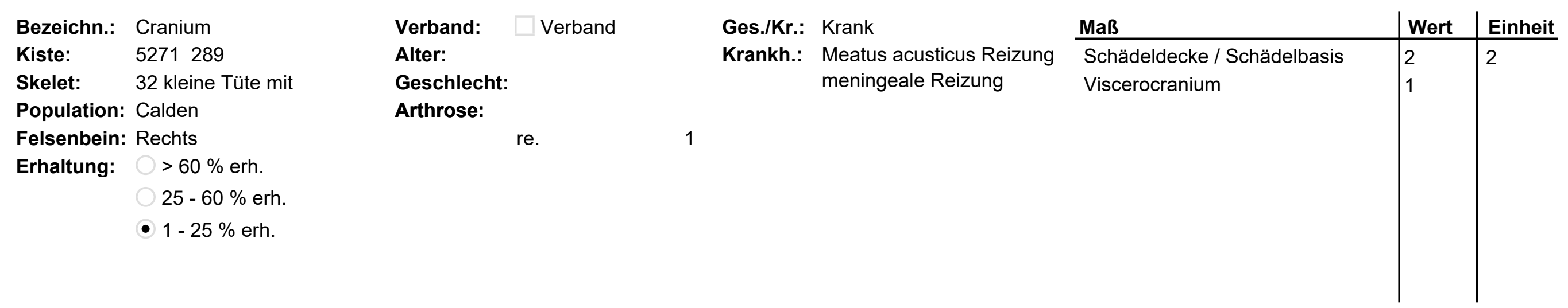

\section{Beschreibung:}

Fragmente eines Schädels mit Teilen aus dem Bereich der Schädelbasis und -decke: unter anderen ein Fragment aus der Fossa cranii media ganz weit rostral mit Auflagerungen und porösem kleinen Loch,eines stammt aus dem rechten Os zygomaticum, eines von der Schädelbasis mit einem Teil des foramen magnum und ein weiteres mit Articulatio atlanto-occipitalis. Ein Teil des Os temporale mit porösem Porus acusticus externus rechts. 


\section{Bezeichn: Cranium \\ Kiste: $\quad 5271289$ \\ Skelet: 18}

Population: Calden

Felsenbein:

Erhaltung: $>60 \%$ erh

$25-60 \%$ erh.

- $1-25 \%$ erh.
Verband: $\square$ Verband

\section{Alter:}

Geschlecht:

\section{Arthrose:}

Ges./Kr.: Gesund

\section{Maß}

Schädeldecke / Schädelbasis

\section{Beschreibung:}

Dies sind 5 Schädeldeckenfragmente, das Größte ist vom Os parietale. 
Bezeichn.: Cranium

Kiste: $\quad 5271289$

Skelet: $\quad 25$ Knochenklein mit OK

Population: Calden

Felsenbein: Rechts

Erhaltung: $>60 \%$ erh.

$25-60 \%$ erh.

- $1-25 \%$ erh.

\section{Ges./Kr.: Krank \\ Krankh.: Meatus acusticus Reizung \\ $\square$ Verband \\ Alter:}

Geschlecht:

Arthrose:

\section{Beschreibung:}

Hier ist ein kleiner Teil der Felsenbeinpyramide erhalten: der Margo superior partis petrosae mit einsehbarem Porus acusticus internus Auf dem kleinen Fragment finden sich etwa 6,5mm vom Porus entfernt kleine knöcherne Auflagerungen. 


\section{Bezeichn.: Cranium \\ Kiste: \\ 5271289}

Skelet: Knochenklein 25

Population: Calden

Felsenbein:

Erhaltung: $>60 \%$ erh

$$
25-60 \% \text { erh. }
$$

- 1 - $25 \%$ erh.
Verband: $\quad \square$ Verband

\section{Alter:}

Geschlecht:

\section{Arthrose:}

Maß

Schädeldecke / Schädelbasis

Wert $\quad$ Einheit

\section{Beschreibung:}

Schädelsplitter. 
Bezeichn:: Cranium

\section{Kiste:}

5271289

Skelet: $\quad$ Fragmente in kleiner Tüte

Population: Calden

Felsenbein: Rechts

Erhaltung: $>60 \%$ erh

$25-60 \%$ erh.

- $1-25 \%$ erh.
Ges./Kr.: Krank

Krankh.: Sinusitis sphenoidalis

\section{Maß}

Schädeldecke / Schädelbasis

Sinus sphenoidalis

Viscerocranium

\section{Geschlecht: $+>ð$}

Arthrose:

1

\begin{tabular}{|l|l} 
Wert & Einheit \\
1 & 1 \\
2 & \\
&
\end{tabular}

\section{Beschreibung:}

Hier liegen Fragmente vom Os temporale, Os sphenoidale, Os zygomaticum, ein Caput mandibulae und drei Fragmente einer Schädeldecke vor. Das Fragment des Os sphenoidale weist deutliche poröse Strukturen auf. Die Fossa mandibulae und das Caput könnten evtl. zusammen gehören. Gelenkverschleiß unauffällig, das Caput ist sehr klein, also eher weiblich. Der Porus acusticus externus weist keine Auffälligkeiten auf. 


\section{Bezeichn.: Cranium \\ Kiste: \\ 5273291}

Skelet: Knochenklein und $106 \mathrm{~g}$

Population: Calden

Felsenbein:

Erhaltung: $>60 \%$ erh

$$
25-60 \% \text { erh. }
$$

- $1-25 \%$ erh.

\section{Beschreibung:}

Kleinste Schädelfragmente.

\section{Verband: $\quad$ Verband}

\section{Alter:}

Geschlecht:

Arthrose:
Maß

Schädeldecke / Schädelbasis

Wert $\quad$ Einheit

1

1




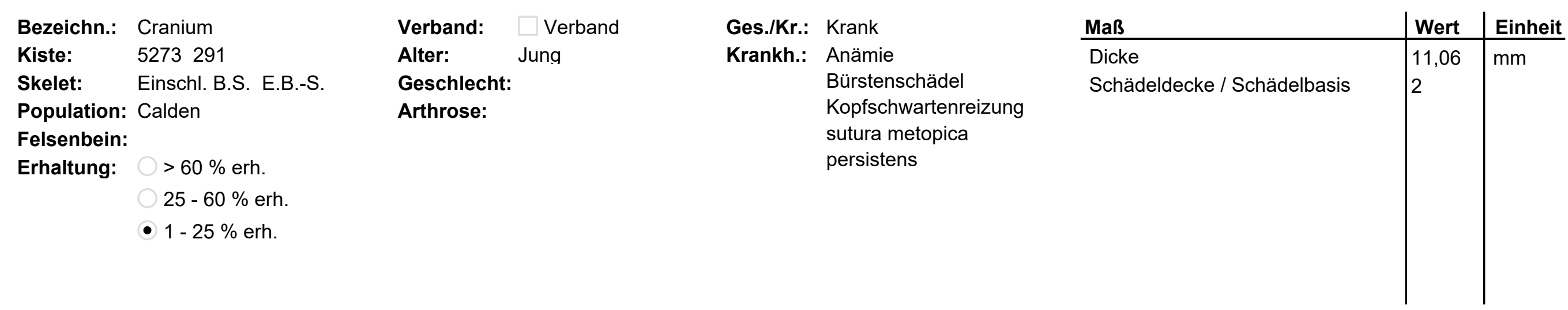

\section{Beschreibung:}

Bei diesem Fundstück handelt es sich um ein teilweise erhaltenes Cranium. Der Schädel weist einige Besonderheiten auf, so liegt eine stellenweise stark aufgequollene Lamina externa vor. Weiterhin ist die Schädeldecke bis $11 \mathrm{~mm}$ dick. Diese Beobachtungen lassen auf eine Anämie schließen. Außerdem ist besonders, dass hier eine Sutura metopica vorliegt. Die Ansatzfläche der Mm. temporales ist deutliche ausgeprägt. 


\section{Bezeichn.: Cranium \\ Kiste: \\ 5273291 \\ Skelet: Ersatzteile}

Population: Calden

Felsenbein:

Erhaltung: $>60 \%$ erh

$$
25-60 \% \text { erh. }
$$

- 1 - $25 \%$ erh.

\section{Verband \\ Ges./Kr.: Gesund}

\section{Alter:}

Geschlecht:

Arthrose:

\section{Beschreibung:}

Ein kleines Schädelfragment mit leichten Gefäßimpressionen auf der Lamina interna. 


\section{Bezeichn.: Cranium \\ Kiste: \\ 5273291 \\ Skelet: Ersatzteile}

Population: Calden

Felsenbein:

Erhaltung: $>60 \%$ erh

$25-60 \%$ erh.

- 1 - $25 \%$ erh.
Ges./Kr.: Krank

Krankh.: meningeale Reizung

Perisinusitis

\section{Maß}

Schädeldecke / Schädelbasis

\section{Geschlecht:}

Arthrose:

\section{Beschreibung:}

Teil des Os occipitale mit leichten Auflagerungen beim Sinus transversus. 


\section{Bezeichn.: Cranium \\ Kiste: \\ 5273291 \\ Skelet: Ersatzteile}

Population: Calden

Felsenbein:

Erhaltung: $>60 \%$ erh.

$$
25-60 \% \text { erh. }
$$

- 1 - $25 \%$ erh.

\section{Beschreibung:}

Kleines Schädelfragment Os parietale rechts unten in der Nähe des Os occipitale. 
Bezeichn:: Cranium

Kiste:

5272290

Skelet:

33

Population: Calden

Felsenbein: Beide

Erhaltung: $>60 \%$ erh

- $25-60 \%$ erh.

$1-25 \%$ erh.
Ges./Kr.: Krank

Krankh.: Kopfschwartenreizung

meningeale Reizung

Hirndrucksymptomatik

\section{Maß}

Schädeldecke / Schädelbasis

Wert $\quad$ Einheit

Geschlecht: $\delta$

Arthrose:

\section{9 - 38}

2

2

\section{Beschreibung:}

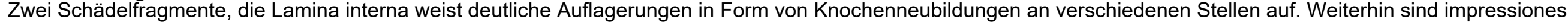

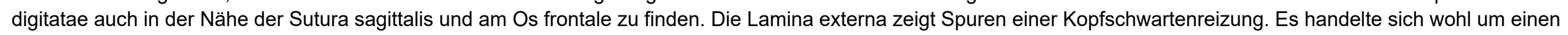
recht massiven Schädel, der postmortal in der Mitte gebrochen ist. Die Oberfläche ist zum Teil stark erodiert, zum Teil aber auch gut erhalten. 


$\begin{array}{lllll}\text { Bezeichn.: } & \text { Cranium } & \text { Verband: } & \square \text { Verband } & \text { Ges./Kr.: } \\ \text { Kiste: } & 5272290 & \text { Alter: } & 37-61 & \text { Krank } \\ \text { Skelet: } & 34 & \text { Geschlecht: } & \text { Krankh.: } & \text { Cribra Orbitalia } \\ \text { Population: } & \text { Calden } & \text { Arthrose: } & & \text { Sinusitis frontalis } \\ \text { Felsenbein: } & \text { Beide } & \text { re. } & 3 & \text { Kopfschwartenreizung } \\ \text { Erhaltung: } & >60 \% \text { erh. } & \text { li. } & 3 & \text { Arthrose } \\ & & & & \\ & & & & \\ & & & & \end{array}$

\begin{tabular}{l|l|l} 
Maß & Wert & Einheit \\
\hline Orbita re / li & 2 & 2 \\
Schädeldecke / Schädelbasis & 2 & 1 \\
Sinus frontalis & 2 & \\
& &
\end{tabular}

\section{Beschreibung:}

Bei diesem Schädel imponiert die Formstruktur mit einer recht langgezogenen Stirn. Insgesamt ist der Schädel recht schmal. Die Lamina externa weist Spuren einer Kopfschwartenreizung auf. Insgesamt ist die Oberfläche des Schädels stark erodiert. Die beiden erhaltenen Orbitadächer weisen eine Cribra orbitalia auf und der Sinus frontalis eine Sinusitis. Es sind die fossae mandibulae erhalten. 
Bezeichn.: Cranium

\section{Kiste:}

5272290

Skelet:

38

Population: Calden

Felsenbein: Beide

Erhaltung: $>60 \%$ erh

- $25-60 \%$ erh.

$1-25 \%$ erh.

\section{Maß}

Orbita re / li

Schädeldecke / Schädelbasis

Sinus frontalis

Sinus maxillaris

Viscerocranium
Ges./Kr.: Krank

Krankh.: Cribra Orbitalia

Kopfschwartenreizung

Sinusitis maxillaris

Stomatitis

\begin{tabular}{|l|l} 
Wert & Einheit \\
\hline & 2
\end{tabular}

Geschlecht:

\section{Arthrose:}

2

\section{Beschreibung:}

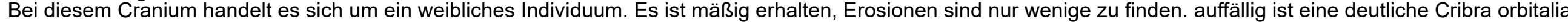

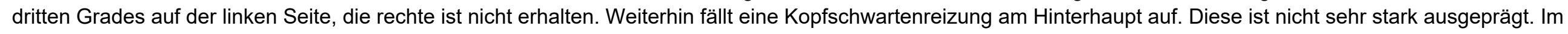
Inneren des Schädels sind Impressiones digitatae auch am Os frontale und an den Ossa parietales Richtung Sutura sagittalis festzustellen, was für eine erhöhte

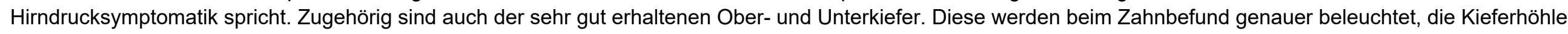
weist eine Sinusitis auf. 
Bezeichn:: Cranium

Kiste: 5272290

Skelet: 29

Population: Calden

Felsenbein: Beide

Erhaltung: $>60 \%$ erh

$25-60 \%$ erh.

$1-25 \%$ erh.
Ges./Kr.: Krank

Krankh.: Kopfschwartenreizung

Cribra Orbitalia

Fraktur

Stomatitis

Sinusitis maxillaris

Sinusitis frontalis

Hirndruckssvmntomatik

\section{Maß}

Orbita re / li

Schädeldecke / Schädelbasis

Sinus frontalis

Sinus maxillaris

Viscerocranium

\begin{tabular}{l|l} 
Wert & Einheit \\
2 & 2 \\
2 & 2 \\
2 & \\
2 & \\
2 &
\end{tabular}

\section{Beschreibung:}

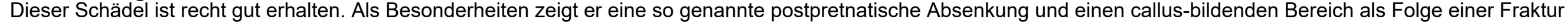

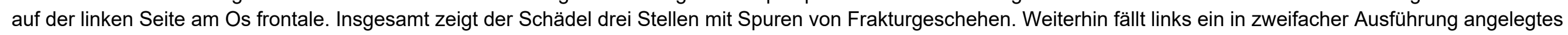

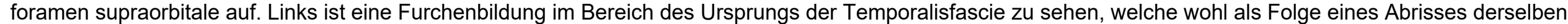

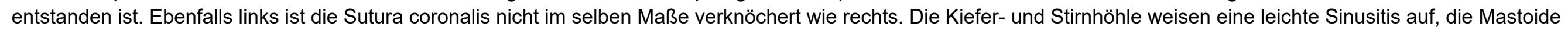

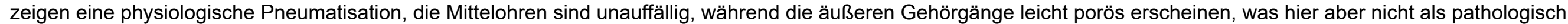

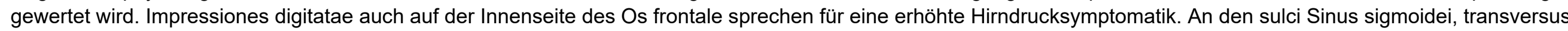

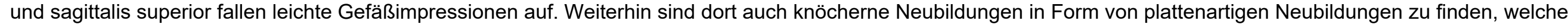
für eine Reizung der Hirnhaut sprechen. 


\section{Bezeichn: Cranium}

\section{Kiste:}

5274292

Skelet: $\quad$ A6 Calden 35 und 36

Population: Calden

Felsenbein: Links

Erhaltung: $>60 \%$ erh.

$$
25-60 \% \text { erh. }
$$

- 1 - $25 \%$ erh
Ges./Kr.: Krank

Krankh.: Meatus acusticus Reizung

Kopfschwartenreizung

meningeale Reizung

Perisinusitis

\begin{tabular}{l|l|l} 
Maß & Wert & Einheit \\
\hline Schädeldecke / Schädelbasis & 2 & 2 \\
& &
\end{tabular}

\section{Beschreibung:}

Hierbei handelt es sich um drei Schädelfragmente, das eine enthält ein junges Os mastoideum der linken Seite, im Meatus acusticus internus finden sich leichte Auflagerungen. Die beiden anderen Fragmente weisen Spuren einer Kopfschwartenreizung auf. Der Sinus sigmoideus zeigt verheilte Spuren einer meningealen Reaktion. Über dem Porus acusticus externus zeigt sich eine leicht poröse Struktur. 


\begin{tabular}{|c|c|c|c|c|c|c|c|c|}
\hline Bezeichn.: & Cranium & Verband: & $\square$ Verband & Ges./Kr.: & Krank & Maß & Wert & Einheit \\
\hline Kiste: & 5274292 & Alter: & Erwachsen & Krankh.: & Kopfschwartenreizung & Schädeldecke / Schädelbasis & 2 & 2 \\
\hline Skelet: & B5 & Geschlecht: & & & Fraktur & & & \\
\hline Population: & Calden & Arthrose: & & & meningeale Reizung & & & \\
\hline Felsenbein: & Rechts & & & & Perisinusitis & & & \\
\hline Erhaltung: & $>60 \%$ erh. & & & & & & & \\
\hline & $25-60 \%$ erh. & & & & & & & \\
\hline & - $1-25 \%$ erh. & & & & & & & \\
\hline
\end{tabular}

\section{Beschreibung:}

Hier liegen vier Schädelfragmente vor, drei des Os parietale und ein größeres Os occipitale. Das Fragment des Os temporale weist am Mastoid Unregelmäßigkeiten auf, die auf eine verheilte Fraktur schließen lassen könnten. Es findet sich hier eine Einbuchtung, die rund herum wie durch Knochenneubildung zugewachsen erscheint. Die Lamina interna der Fragmente weist keine weiteren Besonderheiten auf und das Mastoid ist physiologisch pneumatisiert. Der Gehörgang weist ebenfalls keine Besonderheiten auf. Um den Sinus sigmoideus zeigen sich plattenförmige Knochenneubildungen, welche auf einen perisinuösen Prozess schließen lassen. 


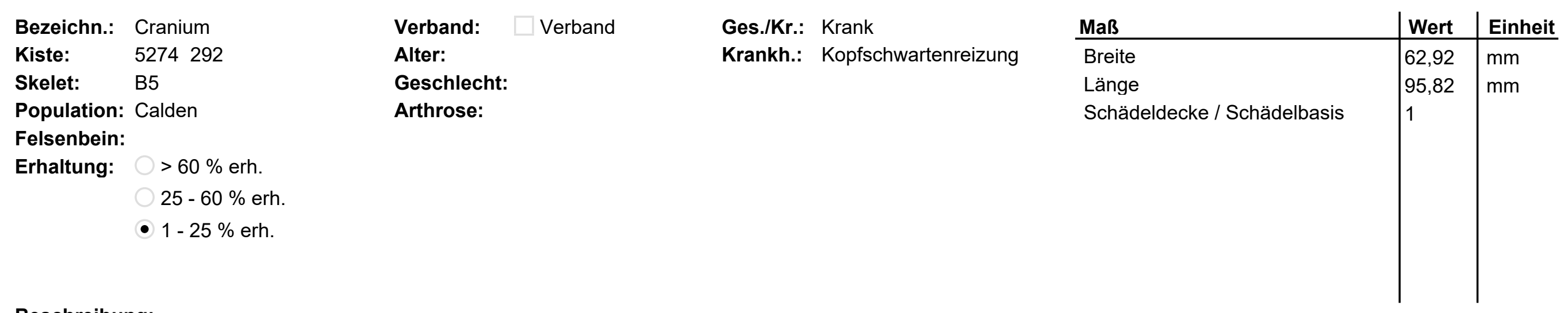

\section{Beschreibung:}

Dieses Fragment eines Os parietale der rechten Seite weist Porositäten auf. Es handelt sich um Spuren einer Kopfschwartenentzündung. Die Lamina interna ist unauffällig. 


\section{Bezeichn: Cranium \\ Kiste: $\quad 5274292$ \\ Skelet: B5}

Population: Calden

Felsenbein:

Erhaltung: $>60 \%$ erh

$$
25-60 \% \text { erh. }
$$

- 1 - $25 \%$ erh.
Ges./Kr.: Krank

Krankh.: Periostreizung

\section{Beschreibung:}

Sieben befundbare und noch weitere kleinere Splitter eines Craniums. Auffällig sind plattenförmige Auflagerungen auf der Lamina externa. Hier sind wohl Knochenneubildungen im Zuge einer Periostreizung entstanden. 
Bezeichn:: Cranium

\section{Kiste:}

5273291

Skelet: Calden 39 5273-11

Population: Calden

Felsenbein: Rechts

Erhaltung: $>60 \%$ erh.

$25-60 \%$ erh.

- $1-25 \%$ erh.
Ges./Kr.: Krank

Krankh.: meningeale Reizung

meatus acusticus Reizung

Perisinusitis

\section{Beschreibung:}

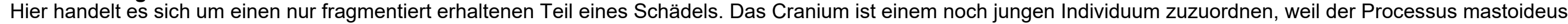

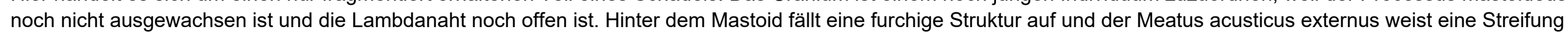

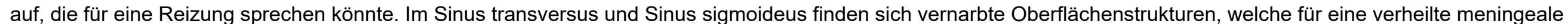
Reizung in den Sinus sprechen könnten. 


$\begin{array}{lll}\text { Bezeichn.: } & \text { Cranium } & \text { Verband: } \square \text { Verband } \\ \text { Kiste: } & 8505720 & \text { Alter: Jung } \\ \text { Skelet: } & 1.2 & \text { Geschlecht: } \\ \text { Population: } & \text { Calden } & \text { Arthrose: } \\ \text { Felsenbein: } & \\ \text { Erhaltung: } & >60 \% \text { erh. } & \\ & 25-60 \% \text { erh. } & \\ & & 1-25 \% \text { erh. }\end{array}$

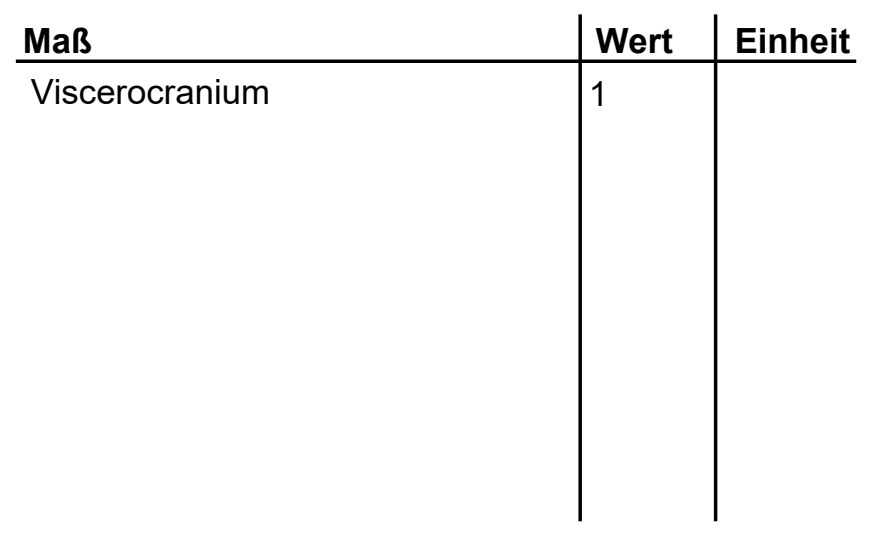

Beschreibung:

Ein Os zygomaticum mit scheinbar nicht verknöcherten Schädelnähten. 


\section{Bezeichn.: Cranium \\ Kiste: $\quad 8505720$ \\ Skelet: $\quad 1.2$}

Population: Calden

Felsenbein:

Erhaltung: $>60 \%$ erh

$25-60 \%$ erh.

- 1 - $25 \%$ erh.

\section{Beschreibung:}

Ein Teil der Schädeldecke, wohl Os parietale.

\section{Verband: $\quad$ Verband}

\section{Alter:}

Geschlecht:

Arthrose:
Maß

Breite

Länge

Schädeldecke / Schädelbasis

\begin{tabular}{|l|l} 
Wert & Einheit \\
\hline 43 & $\mathrm{~mm}$
\end{tabular}

$61,96 \mathrm{~mm}$

1 


$\begin{array}{llllll}\text { Bezeichn.: } & \text { Cranium } & \text { Verband: } \square \text { Verband } & \text { Ges./Kr.: Krank } & \text { Maß } & \text { Einheit } \\ \text { Kiste: } & 8505720 & \text { Alter: } & \text { Krankh.: Kopfschwartenreizung } & \text { Schädeldecke / Schädelbasis } \\ \text { Skelet: } & \text { einzeln } 1.1 & \text { Arthrose: } & & 2 \\ \text { Population: } & \text { Calden } & & & \\ \text { Felsenbein: } & & & \\ \text { Erhaltung: } & >60 \% \text { erh. } & & \\ & 25-60 \% \text { erh. } & & \\ & 1-25 \% \text { erh. } & & \end{array}$

\section{Beschreibung:}

Ein kleines Fragment, welches Spuren einer Kopfschwartenreizung und eine Dicke bis etwa 8,66mm aufweist. Der Struktur zur Folge handelt es sich wahrscheinlich um ein Fragment eines Os parietale. 


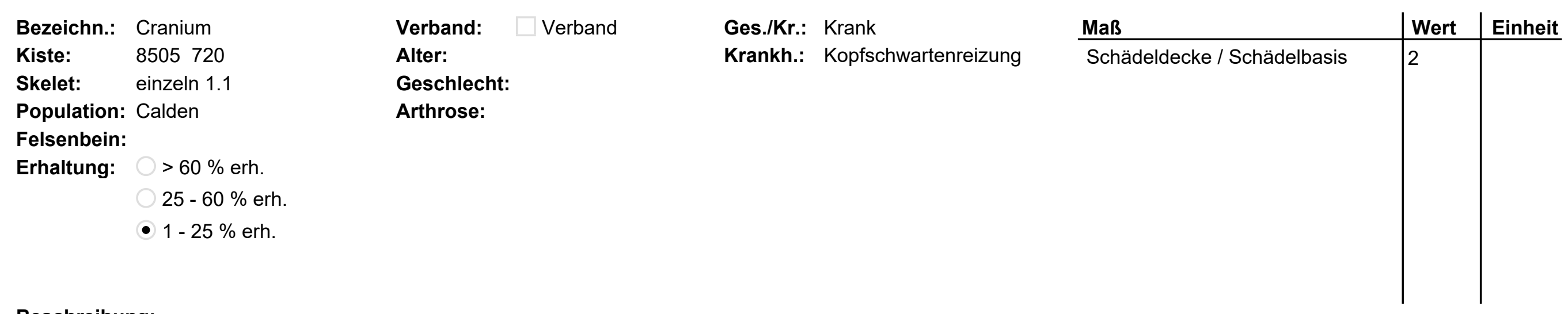

\section{Beschreibung:}

Bei diesem Fragment eines Schädels handelt es sich wohl um ein Fragment eines Os parietale mit deutlichen Spuren einer Kopfschwartenreizung. Weiterhin misst das Fragment bis zu etwa $8,6 \mathrm{~mm}$ Dicke. 


\section{Bezeichn:: Cranium \\ Kiste: \\ 8505720 \\ Skelet: einzeln 1.1}

Population: Calden

Felsenbein:

Erhaltung: $>60 \%$ erh

$$
25-60 \% \text { erh. }
$$

- 1 - $25 \%$ erh.

\section{Verband: \\ Verband \\ Ges./Kr.: Gesund}

\section{Alter:}

Geschlecht:

\section{Arthrose:}

\section{Beschreibung:}

Hierbei handelt es sich um ein Fragment eines Craniums. Die Lokalisation ist allerdings nicht genau festzustellen 

Bezeichn.: Cranium
Skelet: einzeln 1.1
Population: Calden
Felsenbein:
Erhaltung: $>60 \%$ erh
$25-60 \%$ erh.
- 1 - $25 \%$ erh.

Verband:

Verband

\section{Alter:}

Maß

Schädeldecke / Schädelbasis Wert $\quad$ Einheit

Geschlecht:

Arthrose:

\section{Beschreibung:}

Ein einzelnes kleines Fragment eines Craniums. Nicht weiter zuzuordnen. 


\section{Bezeichn:: Cranium \\ Kiste: \\ 8505720 \\ Skelet: einzeln 1.1}

Population: Calden

Felsenbein:

Erhaltung: $>60 \%$ erh

$25-60 \%$ erh.

- $1-25 \%$ erh.
Ges./Kr.: Krank

Krankh.: Kopfschwartenreizung
Maß

Schädeldecke / Schädelbasis

\section{Geschlecht:}

\section{Arthrose:}

\section{Beschreibung:}

Bei diesem kleinen Fragment eines Craniums liegt eine Kopfschwartenreizung vor. 


\section{Bezeichn.: Cranium \\ Kiste: $\quad 8505720$ \\ Skelet: einzeln}

Population: Calden

Felsenbein:

Erhaltung: $>60 \%$ erh

$25-60 \%$ erh.

- $1-25 \%$ erh.
Verband: $\quad$ Verband

\section{Alter:}

Geschlecht:

Arthrose:

\section{Beschreibung:}

Ein kleines Schädelfragment. 


\begin{tabular}{|c|c|c|c|c|c|c|c|}
\hline Bezeichn.: & Cranium & Verband: & $\square$ Verband & Ges./Kr.: Krank & Maß & Wert & Einheit \\
\hline Kiste: & 8505720 & Alter: & & Krankh.: Cribra Orbitalia & Orbita re / li & 2 & \\
\hline Skelet: & 1.3 & Geschlecht: & & & Schädeldecke / Schädelbasis & 1 & \\
\hline Population: & Calden & Arthrose: & & & & & \\
\hline Felsenbein: & & & & & & & \\
\hline Erhaltung: & $>60 \%$ erh. & & & & & & \\
\hline & $25-60 \%$ erh. & & & & & & \\
\hline & - $1-25 \%$ erh. & & & & & & \\
\hline
\end{tabular}

\section{Beschreibung:}

Von diesem Cranium sind lediglich zwei kleine Fragmente erhalten geblieben. Bei dem größeren handelt es sich um einen Teil eines rechten Os frontale. Auch das Orbitadach ist zur Hälfte erhalten. Dieses weist eine Cribra orbitalia Grad 1 auf. Das zweite Fragment stammt wohl von dem linken Teil des Os frontale. Es ist ein ganz kleiner Teil des Margo supraorbitale und ein kleiner Teil des Orbitadaches erhalten. Beide Fragmente wirken sehr massiv, weiterhin ist bei dem linken Fragment ein sehr gut ausgeprägte Glabella. Deswegen gibt es eine Tendenz, diese Fundstücke als eher männlich einzuordnen. 


\section{Bezeichn.: Cranium \\ Kiste: $\quad 8505720$ \\ Skelet: $\quad 1.3$}

Population: Calden

Felsenbein:

Erhaltung: $>60 \%$ erh.

$25-60 \%$ erh.

- 1 - $25 \%$ erh.
Verband: $\quad$ Verband

\section{Alter:}

Geschlecht:

Arthrose:

\section{Maß}

Breite

Länge

Schädeldecke / Schädelbasis

Wert $\quad$ Einheit

$33 \quad \mathrm{~mm}$

$45 \quad \mathrm{~mm}$

\section{Beschreibung:}

Von diesem Cranium ist nur ein kleines Fragment der Schädeldecke erhalten. Es misst etwa $45 \mathrm{~mm}$ x 33mm. Woher es stammt bleibt ungeklärt. 


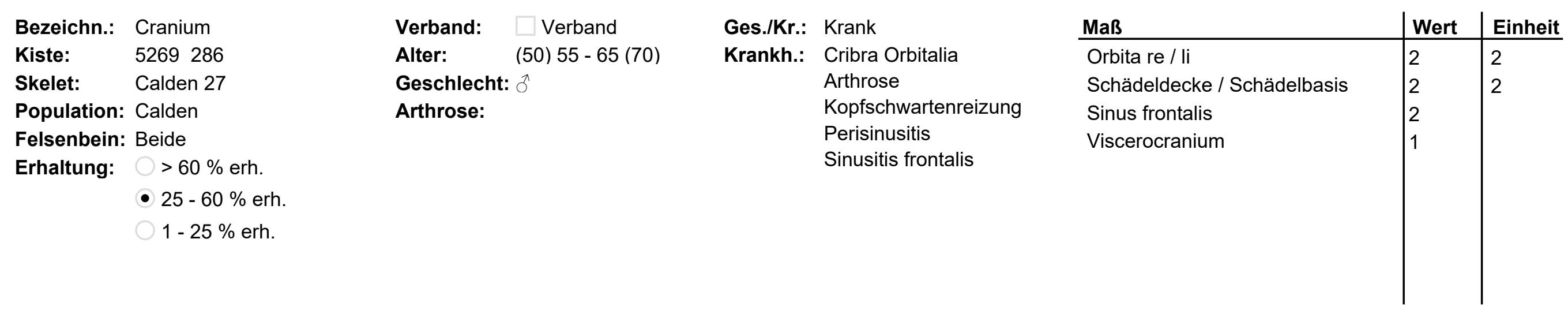

\section{Beschreibung:}

Dieses Fundstück ist ein Craniums, welches überwiegend gut erhalten ist. Ein Os interparietale und die in der Orbita lokalisierten Foramina supraorbitales sind hier individuelle Varietäten. Es handelt sich um einen recht großen Schädel.

Der Schädel weist eine Cribra orbitalia mit Grad 2 und eine auffällig massive Schädeldecke auf. Weiterhin fallen punktförmige Auflagerungen auf dem Os parietale (5,4mm) auf und der Arcus superciliaris hat eine poröse Oberfläche. Der Sinus transversus zeigt eine strähnige Oberflächenstruktur, die rostralen Sulci arteriosi sind bläschenförmig aufgetrieben, insgesamt ist aber die Lamina interna nicht suffizient zu beurteilen, weil die Oberfläche teilweise erodiert ist. Eine Arthrose der Fossae mandibulares ist mit Grad 3 zu beurteilen. Der linke Porus acusticus internus ist nicht eindeutig zu befunden, wirkt jedoch gesund. Die Porus acustici externi weisen soweit keine erkennbaren Auffälligkeiten auf. Deutliche Muskelmarken sind erkennbar an den Ansatzstellen der Mm. temporales, sternocleidomastoidei und an der Protuberantia occipitalis externa. 


\section{Kiste:}

ranium

Skelet:

5269286

Population: Calden

Felsenbein: Beide

Erhaltung: $>60 \%$ erh.

- $25-60 \%$ erh.

$1-25 \%$ erh.
Verband: $\square$ Verband

\section{Alter: $\quad 18-38$}

\section{Geschlecht: 우}

\section{Arthrose:}

Ges./Kr.: Krank

Krankh.: Kopfschwartenreizung

Sinusitis maxillaris

Stomatitis

Cribra Orbitalia

Sinusitis sphenoidalis

meatus acusticus Reizung

meninceale Reizınn

\begin{tabular}{l|l|l} 
Maß & Wert & Einheit \\
\hline Orbita re / li & 2 & 2 \\
Schädeldecke / Schädelbasis & 2 & 2 \\
Sinus frontalis & 1 & \\
Sinus maxillaris & 2 & \\
Sinus sphenoidalis & 2 & \\
Viscerocranium & 2 &
\end{tabular}

\section{Beschreibung:}

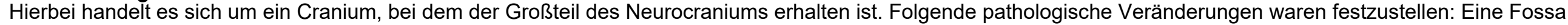

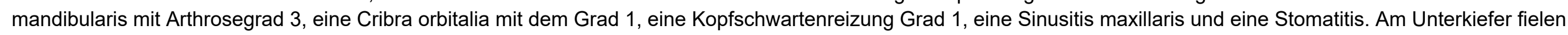

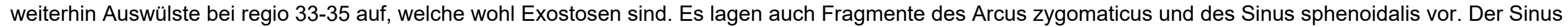
sphenoidalis weist innen eine poröse Oberfläche auf, welche auf eine leichte Sinusitis sphenoidalis schließen lässt. Der Meatus acusticus internuns weist leichte

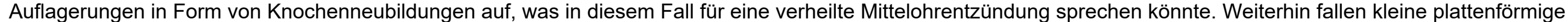

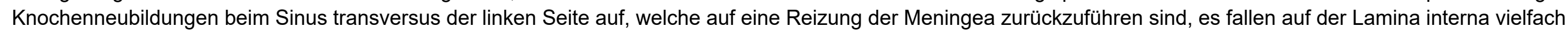

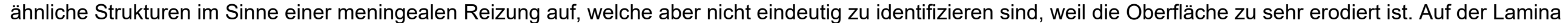
interna fällt weiterhin ins Auge, dass der rostrale Sulcus arteriosus bläschenförmig aufgetrieben ist. Dies ist auf der rechten und linken Seite der Fall. 
Bezeichn:

\section{Kiste:}

Cranium

Skelet: $\quad$ Calden 26

Population: Calden

Felsenbein: Beide

Erhaltung: $>60 \%$ erh.

$25-60 \%$ erh.

$1-25 \%$ erh.
Ges./Kr.: Krank

Krankh.: Kopfschwartenreizung

Cribra Orbitalia

Sinusitis frontalis

Hypoplasie sinus frontalis

\section{Maß}

Orbita re / li

Schädeldecke / Schädelbasis

Sinus frontalis

Sinus maxillaris

Viscerocranium

\section{Beschreibung:}

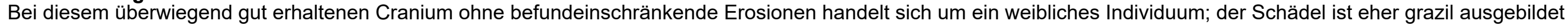
und weist keine besonders ausgeprägten Muskelmarken auf.

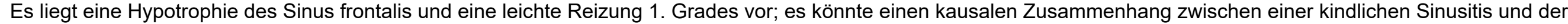
Sinushypotrophie geben. Es finden sich weiterhin Auflagerungen auf dem Os occipitale und Os parietale der linken und rechten Seite, welche auf eine

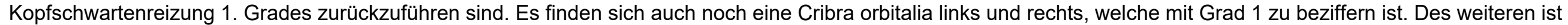

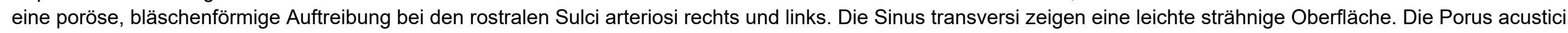
interni und externi sind beidseitig jeweils unauffällig. Auch alle Strukturen der knöchernen Nase sind o.B. Die Processus mastoidei sind ebenfalls o.B. 
Bezeichn:: Cranium

\section{Kiste:} 5267283

Skelet:

Population: Calden

Felsenbein: Rechts

Erhaltung: $>60 \%$ erh

- $25-60 \%$ erh.

$1-25 \%$ erh.
Verband: $\quad$ Verband

\section{Alter: $\quad 50-75$}

Geschlecht:

Arthrose:
Ges./Kr.: Krank

Krankh.: Cribra Orbitalia

Sinusitis frontalis

Kopfschwartenreizung

meningeale Reizung

Arthrose

Perisinusitis

\section{Maß}

\section{Orbita re / li}

Schädeldecke / Schädelbasis

Sinus frontalis

\section{Beschreibung:}

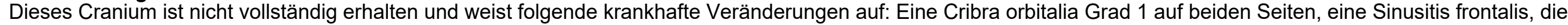

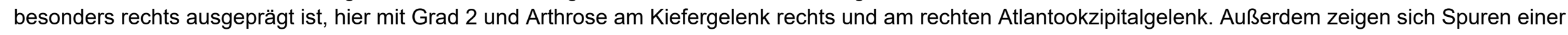

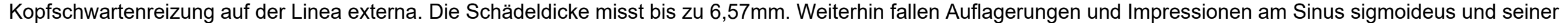
Umgebung auf. 


\begin{tabular}{|c|c|c|c|c|c|c|c|c|}
\hline Bezeichn.: & Cranium & Verband: & $\square$ Verband & Ges./Kr.: & Krank & Maß & Wert & Einheit \\
\hline Kiste: & 5267283 & Alter: & $25-35$ & Krankh.: & Sinusitis maxillaris & Schädeldecke / Schädelbasis & 1 & 1 \\
\hline Skelet: & C5 & Geschlecht & $: q \leq \hat{O}$ & & Stomatitis & Sinus maxillaris & 2 & \\
\hline Population: & Calden & Arthrose: & & & & Viscerocranium & 2 & \\
\hline Felsenbein: & Links & & & & & & & \\
\hline Erhaltung: & $>60 \%$ erh. & & & & & & & \\
\hline & $25-60 \%$ erh. & & & & & & & \\
\hline & - $1-25 \%$ erh. & & & & & & & \\
\hline
\end{tabular}

\section{Beschreibung:}

Mehrere Schädelfragmente, eines davon ein größeres Fragment des Os maxillare mit einer leicht ausgeprägten Sinusitis maxillaris und einer Stomatitis palatina. Erhalten sind weiterhin das linke Os mastoideum, welches physiologisch pneumatisiert ist und weitere kleinere Fragmente erhalten. 
Bezeichn:: Cranium

\section{Kiste:}

5270287

Skelet:

17

Population: Calden

Felsenbein: Beide

Erhaltung: $>60 \%$ erh

$25-60 \%$ erh.

$1-25 \%$ erh.

\section{Verband: $\quad$ Verband}

\section{Alter:}

(40) 45 - 55 (60)

Geschlecht: $q>0$

\section{Arthrose:}

re.

li.
Ges./Kr.: Krank

Krankh.: Arthrose

dentogener Prozess

Sinusitis maxillaris

Stomatitis

meningeale Reizung

Sinusitis frontalis

Konfschwartenreizınn
Maß

Orbita re / I

Schädeldecke / Schädelbasis

Sinus frontalis

Sinus maxillaris

Viscerocranium

\begin{tabular}{|l|l} 
Wert & Einheit \\
1 & 1 \\
2 & 1 \\
2 & \\
2 \\
2
\end{tabular}

\section{Beschreibung:}

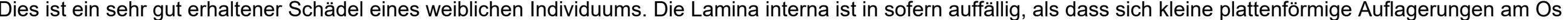

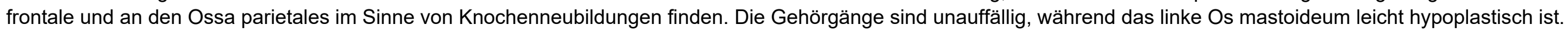

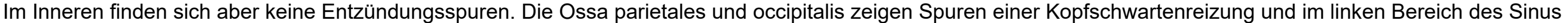
frontalis finden sich Spuren einer Sinusitis, welche durch kleine plattenförmige Knochenneubildungen auffallen. Die sulci arteriosi anteriores rechts und links sind

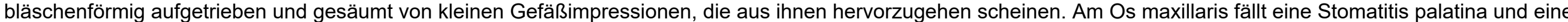

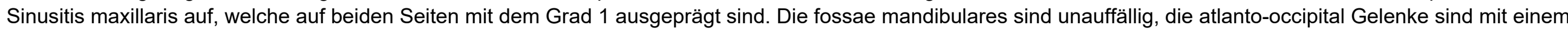
Arthrosegrad 2 zu beziffern. Weiterhin fällt auf, dass das linke foramen supraorbitale eher eine fissura supraorbitale darstellt. 
Bezeichn:: Cranium

\section{Kiste:}

5270287

Skelet:

31

Population: Calden

Felsenbein: Rechts

Erhaltung: $>60 \%$ erh

- $25-60 \%$ erh.

$1-25 \%$ erh.
Ges./Kr.: Krank

Krankh.: Hypoplasie Sinus frontalis Cribra Orbitalia

Stomatitis

Kopfschwartenreizung

Tumor

Rhinitis

\section{Maß}

Orbita re / li

Schädeldecke / Schädelbasis

Sinus frontalis

Viscerocranium

\section{Beschreibung:}

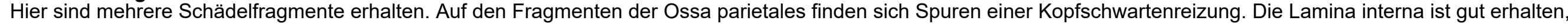

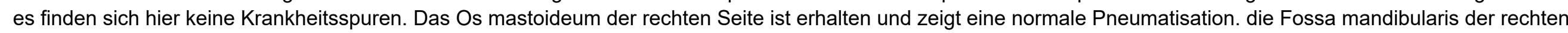
Seite ist erhalten und ist ebenfalls unauffällig, so ist auch der Gehörgang ohne Befund.

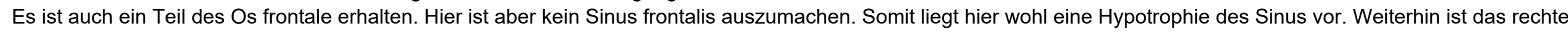
Orbitadach erhalten, welches eine Cribra orbitalia 2. Grades aufweist. In der knöchernen Nasenhöhle finden sich kleine riffelige Spuren eines nun vernarbten

Entzündungsgeschehens. Ein Schädelfragment weist eine tumoröse Auftreibung auf der Oberfläche auf. 


\section{Bezeichn.: Cranium \\ Kiste: \\ 5267283 \\ Skelet: $\quad$ Calden 6}

Population: Calden

Felsenbein: Beide

Erhaltung: $>60 \%$ erh

- $25-60 \%$ erh.

$1-25 \%$ erh.

\section{Verband: $\quad$ Verband}

\section{Alter: \\ (50) $56-63(65)$}

Geschlecht: 0

Arthrose:

re.
Ges./Kr.: Krank

Krankh.: Kopfschwartenreizung

Sinusitis frontalis

meningeale Reizung

Cribra Orbitalia

Arthrose
Maß

Orbita re / li

Schädeldecke / Schädelbasis

Sinus frontalis

\section{Beschreibung:}

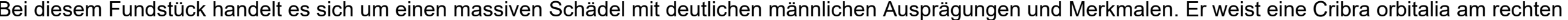

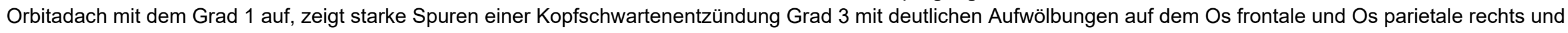

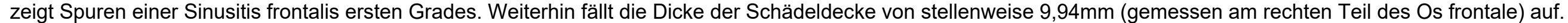

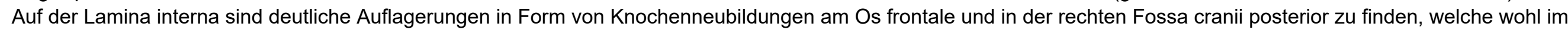
Sinne einer meningealen Reizung gedeutet werden können. 


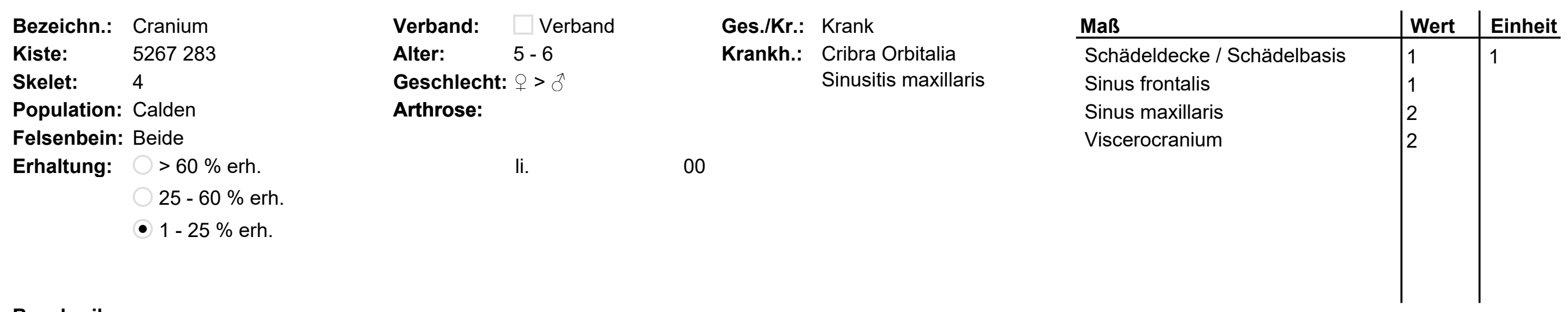

\section{Beschreibung:}

Ein Cranium eines jungen Individuums, die Schädelbasis der rechten Seite ist nicht erhalten. Es sind zwei Fragmente des Oberkiefers beider Seiten erhalten. Insgesamt ist der Erhaltungszustand des craniums mäßig - die Oberfläche ist stellenweise stark erodiert, insgesamt ist der Schädel nur in einzelnen Fragmenten unvollständig vorhanden. Es fällt zunächst die noch nicht verknöcherte Sutura frontalis auf. Weiterhin ist das Mastoid der linken Seite altersbedingt noch nicht vollständig pneumatisiert und noch nicht ausgewachsen. Das Cranium weist eine Cribra orbitalia zweiten Grades am linken Orbitadach auf - das rechte ist nicht erhalten. Die auffällig zahlreichen impressiones digitatae, die auch am Os frontale und in der Nähe der Sutura sagittalis auffallen, sind wohl nur altersbedingt so stark ausgeprägt. Beide Seiten des Porus acusticus externus sind erhalten und weisen keine Auffälligkeiten auf. Auch die Porus acusticus interni sind erhalten und ohne Befund. Beide Oberkieferfragmente weisen Spuren einer Sinusitis maxillaris auf. Die Altersdiagnose wurde aufgrund der Sutura frontalis erhoben, die zum Zeitpunkt des Todes noch nicht geschlossen war. 


\begin{tabular}{|c|c|c|c|c|c|c|c|}
\hline Bezeichn.: & Cranium & Verband: & $\square$ Verband & Ges./Kr.: Gesund & Maß & Wert & Einheit \\
\hline Kiste: & 5267283 & Alter: & & & Schädeldecke / Schädelbasis & 1 & 1 \\
\hline Skelet: & 4 mit in der Tüte & Geschlecht: & & & & & \\
\hline Population: & Calden & Arthrose: & & & & & \\
\hline Felsenbein: & & & re. & 2 & & & \\
\hline Erhaltung: & $>60 \%$ erh. & & & & & & \\
\hline & $25-60 \%$ erh. & & & & & & \\
\hline & - $1-25 \%$ erh. & & & & & & \\
\hline
\end{tabular}

\section{Beschreibung:}

Ein Fragment eines craniums, mit clivus und kleinem Teil des Os occipitale. Außerdem ist das rechte articularis atlanto-occipitalis erhalten. 

Bezeichn.: Cranium
Skelet: letzte Tüte
Population: Calden

Verband:

Verband

\section{Alter:}

\section{Geschlecht:}

\section{Arthrose:}

\begin{tabular}{l|l|l} 
Maß & Wert & Einheit \\
\hline Breite & 29,63 & $\mathrm{~mm}$ \\
Länge & 47,68 & $\mathrm{~mm}$ \\
Schädeldecke / Schädelbasis & 1 & \\
& & \\
& &
\end{tabular}

\section{Beschreibung:}

Kleines Fragment der Schädeldecke, es weist starke Erosionsspuren auf. 


\begin{tabular}{|c|c|c|c|c|c|}
\hline Bezeichn.: & Cranium & Verband: $\quad \square$ Verband & Maß & Wert & Einheit \\
\hline Kiste: & 5242266 & Alter: & Breite & 43,85 & $\mathrm{~mm}$ \\
\hline Skelet: & letzte Tüte & Geschlecht: & Länge & 40,52 & $\mathrm{~mm}$ \\
\hline Population: & Calden & Arthrose: & Schädeldecke / Schädelbasis & 1 & 1 \\
\hline Felsenbein: & & & & & \\
\hline Erhaltung: & $>60 \%$ erh. & & & & \\
\hline & $25-60 \%$ erh. & & & & \\
\hline & • $1-25 \%$ erh. & & & & \\
\hline
\end{tabular}

\section{Beschreibung:}

Fragment eines Os temporale mit pneumatisiertem Anteil in der Nähe des Processus mastoideus und einem Teil des Porus acusticus externus 


\section{Bezeichn.: Cranium \\ Kiste: \\ 5242266}

Skelet: $\quad$ E.B.S. letzte Tüte

Population: Calden

Felsenbein:

Erhaltung: $>60 \%$ erh

$25-60 \%$ erh.

- $1-25 \%$ erh.

\section{Verband: $\quad$ Verband}

\section{Alter:}

Geschlecht:

Arthrose:
Maß

Breite

Länge

2

\section{Beschreibung:}

Fragment aus der Schädelbasis mit Gelenkfläche des articularis atlanto-occipitalis. 
Bezeichn:: Cranium

\section{Kiste:}

5267282

Skelet:

2.

Population: Calden

Felsenbein: Beide

Erhaltung: $>60 \%$ erh.

- $25-60 \%$ erh.

$1-25 \%$ erh.
Ges./Kr.: Krank

Krankh.: Cribra Orbitalia

Sinusitis frontalis

Hirndrucksymptomatik

Hypoplasie sinus frontalis

sutura metopica

persistens

\section{Maß}

\section{Orbita re / li}

Schädeldecke / Schädelbasis

Sinus frontalis

Viscerocranium

\section{Beschreibung:}

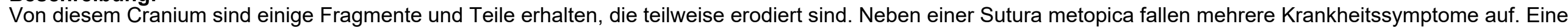

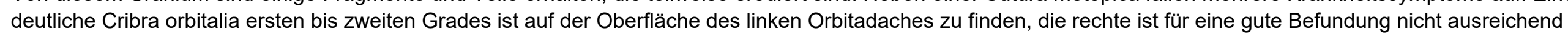

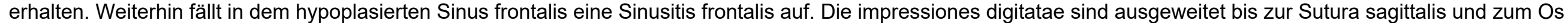

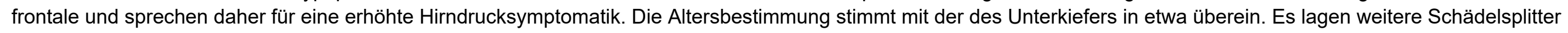
vor. 


\section{Bezeichn.: Cranium \\ Kiste: $\quad 5267282$ \\ Skelet: 2}

Population: Calden

Felsenbein:

Erhaltung: $>60 \%$ erh

$25-60 \%$ erh.

- 1 - $25 \%$ erh.
Verband: $\square$ Verband

\section{Alter:}

Geschlecht:

Arthrose:

\section{Beschreibung:}

Fragmente von Schädelbasis und -decke, sowie Os zygomaticum. 


\section{Bezeichn.: Cranium \\ Kiste: $\quad 5267282$ \\ Skelet: Zettel}

Population: Calden

Felsenbein:

Erhaltung: $>60 \%$ erh

$25-60 \%$ erh.

- $1-25 \%$ erh.
Verband: $\quad$ Verband

\section{Alter:}

Geschlecht:

Arthrose:

\section{Beschreibung:}

Fragment des Os occipitale links mit Articulatio atlanto-occipitalis. 


\section{Bezeichn.: Cranium \\ Kiste: \\ 5267282 \\ Skelet: Zettel Nr1}

Population: Calden

Felsenbein:

Erhaltung: $>60 \%$ erh

$$
25-60 \% \text { erh. }
$$

- 1 - $25 \%$ erh.

\section{Verband: $\quad$ Verband}

\section{Alter:}

Geschlecht: $q \leq \hat{0}$

Arthrose:

\section{Ges./Kr.: Gesund}

\section{Beschreibung:}

Durch Naht verbundene Teile des Os sphenoidale und Os temporale mit der Fossa mandibularis der rechten Seite. Es handelt sich bei der Verbindungsstelle um die Sutura spheno-temporalis. 


\section{Bezeichn.: Cranium \\ Kiste: $\quad 5267282$ \\ Skelet: Zettel Nr1}

Population: Calden

Felsenbein:

Erhaltung: $>60 \%$ erh. $25-60 \%$ erh.

- $1-25 \%$ erh.

\section{Ges./Kr.: Krank \\ Krankh.: meningeale Reizung \\ Verband \\ Alter:}

Geschlecht: $q \leq \AA$

Arthrose:

\section{Beschreibung:}

Fragment eines Os sphenoidale der linken Seite mit kleinere Auflagerungen und Porositäten. 


\section{Bezeichn.: Cranium \\ Kiste: $\quad 5267282$ \\ Skelet: Zettel}

Population: Calden

Felsenbein:

Erhaltung: $>60 \%$ erh $25-60 \%$ erh.

- 1 - $25 \%$ erh.
Verband: $\quad$ Verband

\section{Alter:}

Geschlecht:

Arthrose:

Ges./Kr.: Krank

Krankh.: Arthrose

\section{Beschreibung:}

Dies ist ein Fragment der Fossa mandibularis der rechten Seite. 


\section{Bezeichn.: Cranium \\ Kiste: $\quad 5267282$ \\ Skelet: Zettel}

Population: Calden

Felsenbein:

Erhaltung: $>60 \%$ erh

$$
25-60 \% \text { erh. }
$$

- $1-25 \%$ erh.
Ges./Kr.: Krank

Krankh.: Sinusitis maxillaris

\section{Maß}

Sinus maxillaris

\section{Geschlecht:}

\section{Arthrose:}

2

\section{Beschreibung:}

Dies ist ein Fragment des Os maxillaris der linken Seite. Dieses weist eine Sinusitis maxillaris auf, die mit einem Grad 1 zu bewerten ist. 


\section{Bezeichn.: Cranium \\ Kiste: $\quad 5267282$ \\ Skelet: Zettel}

Population: Calden

Felsenbein:

Erhaltung: $>60 \%$ erh $25-60 \%$ erh.

- $1-25 \%$ erh.
Verband: $\quad$ Verband

\section{Alter:}

Geschlecht:

Arthrose:
Ges./Kr.: Krank

Krankh.: Arthrose

\section{Beschreibung:}

Ein Fragment des Os occipitale mit linkem Articulatio atlanto-occipitalis mit Arthrosegrad 3. 
Bezeichn.: Cranium

\section{Kiste:}

5267282

Skelet: Zettel Nr1

Population: Calden

Felsenbein: Rechts

Erhaltung: $>60 \%$ erh.

$25-60 \%$ erh.

- $1-25 \%$ erh.

\section{Verband: $\quad$ Verband}

\section{Alter:}

Geschlecht:

Arthrose:

\section{Ges./Kr.: Gesund}

\section{Beschreibung:}

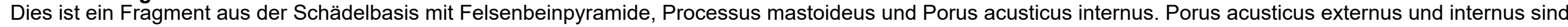
unauffällig. 


\section{Bezeichn.: Cranium \\ Kiste: $\quad 5267282$ \\ Skelet: Zettel}

Population: Calden

Felsenbein:

Erhaltung: $>60 \%$ erh

$25-60 \%$ erh.

- $1-25 \%$ erh.
Ges./Kr.: Krank
Alter: Krankh.: Cribra Orbitalia

\section{Geschlecht:}

Arthrose:

\section{Beschreibung:}

Dieses Schädelfragment ist ein Orbitadach der linken Seite, es weist eine Cribra orbitalia auf. 


\section{Bezeichn.: Cranium \\ Kiste: \\ 5267282 \\ Skelet: Zettel $\mathrm{Nr} 1$}

Population: Calden

Felsenbein:

Erhaltung: $>60 \%$ erh

$$
25-60 \% \text { erh. }
$$

- 1 - $25 \%$ erh.
Verband: $\quad$ Verband

\section{Alter:}

Ges./Kr.: Gesund

\section{Geschlecht:}

Arthrose:

\section{Maß}

Schädeldecke / Schädelbasis

Wert $\quad$ Einheit

\section{Beschreibung:}

Dies sind Bruchstücke eines Schädels, eines davon ist von einem Os occipitale der linken Seite. 


\section{Bezeichn.: Cranium \\ Kiste: \\ 5267282 \\ Skelet: Zettel Nr1}

Population: Calden

Felsenbein:

Erhaltung: $>60 \%$ erh

$$
25-60 \% \text { erh. }
$$

- 1 - $25 \%$ erh
Verband: $\square$ Verband

\section{Alter:}

Ges./Kr.: Gesund

\section{Geschlecht:}

Arthrose:

\section{Beschreibung:}

Dies ist ein Teil eines Os zygomaticum der rechten Seite mit einem kleinen Teil des Orbitabodens. 


\section{Bezeichn.: Cranium \\ Kiste: $\quad 5267282$ \\ Skelet: einzeln}

Population: Calden

Felsenbein:

Erhaltung: $>60 \%$ erh $25-60 \%$ erh.

- $1-25 \%$ erh.

\section{Beschreibung:}

Fragment des dorsum sallae.
Verband: $\square$ Verband

\section{Alter:}

Geschlecht:

Arthrose: 


\section{Bezeichn:: Cranium \\ Kiste: $\quad 5267282$ \\ Skelet: OK 1.}

Population: Calden

Felsenbein:

Erhaltung: $>60 \%$ erh.

$25-60 \%$ erh.

- 1 - $25 \%$ erh.
Verband: $\square$ Verband

Alter: (18) 25 - 35

Geschlecht: $q \leq \AA$

Arthrose:

\section{Beschreibung:}

Kleinste Schädelsplitter. 


\section{Bezeichn.: Cranium \\ Kiste: \\ 5267282 \\ Skelet: Calden 1}

Population: Calden

Felsenbein:

Erhaltung:

$$
\begin{aligned}
& 25-60 \% \text { erh. } \\
& 1-25 \% \text { erh. }
\end{aligned}
$$

Ges./Kr.: Krank

Krankh.: Cribra Orbitalia

Kopfschwartenreizung

\section{Beschreibung:}

Dieses Fundstück ist ein Cranium eines eher weiblichen Individuums. Das Alter wird mit wahrscheinlich 30 bis 35 Jahren angenommen. Diese Annahme stützt sich auf die Beobachtung, dass die Lamina interna der Kranznaht synostosiert ist, aber die Lamina externa der selbigen noch nicht vollständig. Da aber die inneren Schädelnähte später schließen, muss ein Alter über 30 Jahre angenommen werden. Das Cranium weist eine leichte Cribra orbitalia auf der rechten Seite auf, weiterhin finden sich Spuren einer leichten Kopfschwartenreizung auf den Ossa parietales. Darüber hinaus ist festzustellen, dass die intrakranielle Oberfläche stark erodiert ist. 


\section{Bezeichn.: Cranium \\ Kiste: $\quad 5273291$ \\ Skelet: Zettel}

Population: Calden

Felsenbein: Links

Erhaltung: $>60 \%$ erh

$25-60 \%$ erh.

- 1 - $25 \%$ erh.
Verband: $\quad$ Verband

\section{Alter:}

Geschlecht:

Arthrose:

\section{Beschreibung:}

Hier ist ein Os mastoideum mit Teil des Gehörganges erhalten. 


\section{Bezeichn.: Cranium \\ Kiste: $\quad 5273291$ \\ Skelet: Zettel}

Population: Calden

Felsenbein: Links

Erhaltung: $>60 \%$ erh

$$
25-60 \% \text { erh. }
$$

- $1-25 \%$ erh.
Verband: $\square$ Verband

\section{Alter:}

Ges./Kr.: Gesund

Geschlecht: $q>\lambda$

Arthrose:

\section{Beschreibung:}

Hier ist ein Os mastoideum mit Teil des Gehörganges erhalten. 


\section{Bezeichn.: Cranium \\ Kiste: $\quad 5273291$ \\ Skelet: Zettel}

Population: Calden

Felsenbein: Rechts

Erhaltung: $>60 \%$ erh.

$25-60 \%$ erh.

- 1 - $25 \%$ erh.
Verband: $\square$ Verband

\section{Alter:}

Geschlecht: $q \leq \curvearrowright$

Arthrose:

re.

\section{Beschreibung:}

Hier ist ein Os temporale mit Teil des Gehörganges erhalten. 


\section{Bezeichn.: Cranium \\ Kiste: $\quad 5273291$ \\ Skelet: Zettel}

Population: Calden

Felsenbein: Links

Erhaltung: $>60 \%$ erh

$$
25-60 \% \text { erh. }
$$

- $1-25 \%$ erh.
Verband: $\square$ Verband

\section{Alter:}

Ges./Kr.: Gesund

Geschlecht: $q>\lambda$

Arthrose:

\section{Beschreibung:}

Hier ist ein Os mastoideum mit Teil des Gehörganges erhalten. 


\section{Bezeichn.: Cranium

Kiste: $\quad 5273291$ \\ Skelet: Zettel}

Population: Calden

Felsenbein: Links

Erhaltung: $>60 \%$ erh

$25-60 \%$ erh.

- $1-25 \%$ erh.

\section{Ges./Kr.: Krank \\ Krankh.: Arthrose \\ Verband \\ Alter:}

Geschlecht: $q \leq \lambda$

Arthrose:

\section{Beschreibung:}

Hier ist ein Fragment eines Os temporale erhalten, welches eine Fossa mandibularis enthält, die eine Arthrose hat, weiterhin ist das Os mastoideum erhalten. 


\section{Bezeichn.: Cranium

Kiste: $\quad 5273291$ \\ Skelet: Zettel}

Population: Calden

Felsenbein: Links

Erhaltung: $>60 \%$ erh.

$$
25-60 \% \text { erh. }
$$

- 1 - $25 \%$ erh.
Verband: $\square$ Verband

\section{Alter:}

Geschlecht: $+>\widehat{\sigma}$

Arthrose:

\section{Beschreibung:}

Hier ist ein Os mastoideum mit Teil des Gehörganges erhalten. 


$\begin{array}{lll}\text { Bezeichn.: } & \text { Cranium } & \text { Verband: } \square \text { Verband } \\ \text { Kiste: } & 5273291 & \text { Alter: } \\ \text { Skelet: } & \text { Fragmente bei } 13 & \text { Geschlecht: } \\ \text { Population: } & \text { Calden } & \text { Arthrose: } \\ \text { Felsenbein: } & & \\ \text { Erhaltung: } & >60 \% \text { erh. } & \\ & 25-60 \% \text { erh. } & \\ & \bullet 1-25 \% \text { erh. } & \end{array}$

\section{Beschreibung:}

Hier sind diverse kleine Schädelfragmente erhalten. Sie zeigen keine pathologischen Auffälligkeiten. 


\section{Bezeichn.: Cranium \\ Kiste: \\ 5273291}

Skelet: Ersatzteile Fragmente

Population: Calden

Felsenbein:

Erhaltung: $>60 \%$ erh

$25-60 \%$ erh.

- 1 - $25 \%$ erh.
Verband: $\quad \square$ Verband

\section{Alter:}

Geschlecht:

\section{Arthrose:}

\section{Beschreibung:}

Fragmente eines Schädels, welche weder befundbar, noch zuzuordnen waren. 


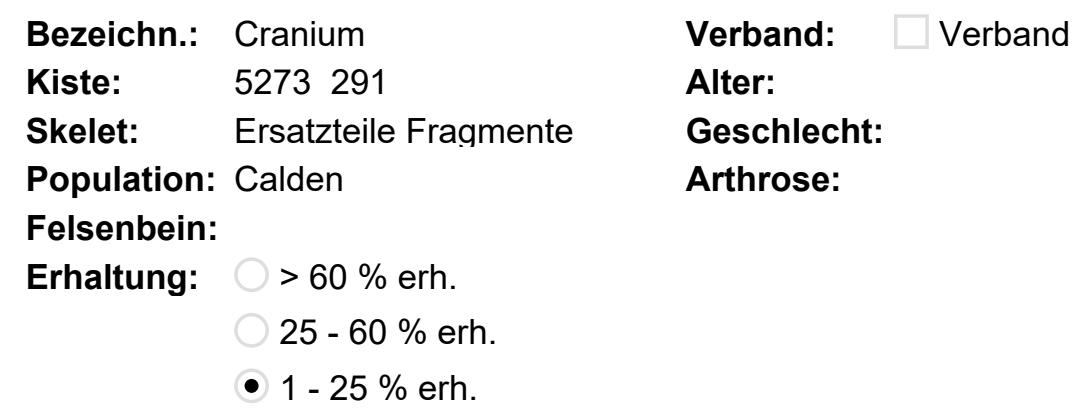

\section{Beschreibung:}

Fragmente eines Schädels, welche weder befundbar, noch zuzuordnen waren. 


\section{Bezeichn.: Cranium \\ Kiste: \\ 5273291}

Skelet: Ersatzteile Fragmente

Population: Calden

Felsenbein:

Erhaltung: $>60 \%$ erh

$25-60 \%$ erh.

- 1 - $25 \%$ erh.
Verband: $\quad \square$ Verband

\section{Alter:}

Geschlecht:

\section{Arthrose:}

\section{Beschreibung:}

Fragmente eines Schädels, welche weder befundbar, noch zuzuordnen waren 


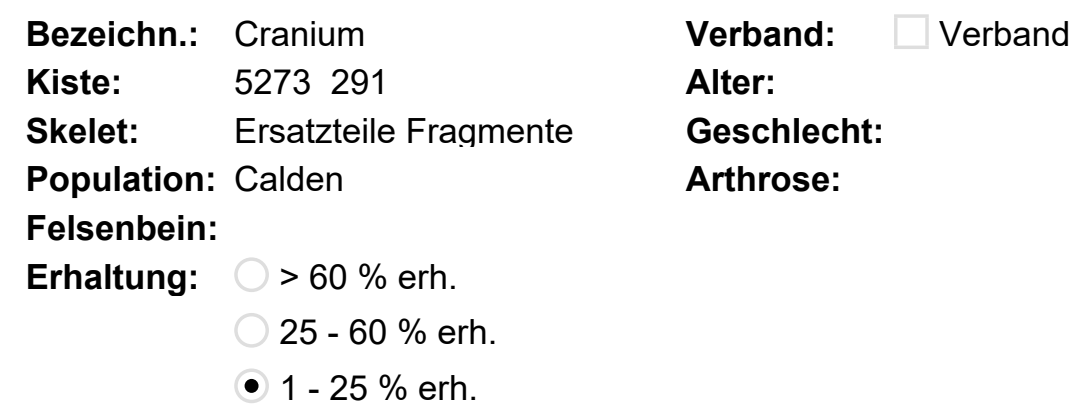

\section{Beschreibung:}

Fragmente eines Schädels, welche weder befundbar, noch zuzuordnen waren. 


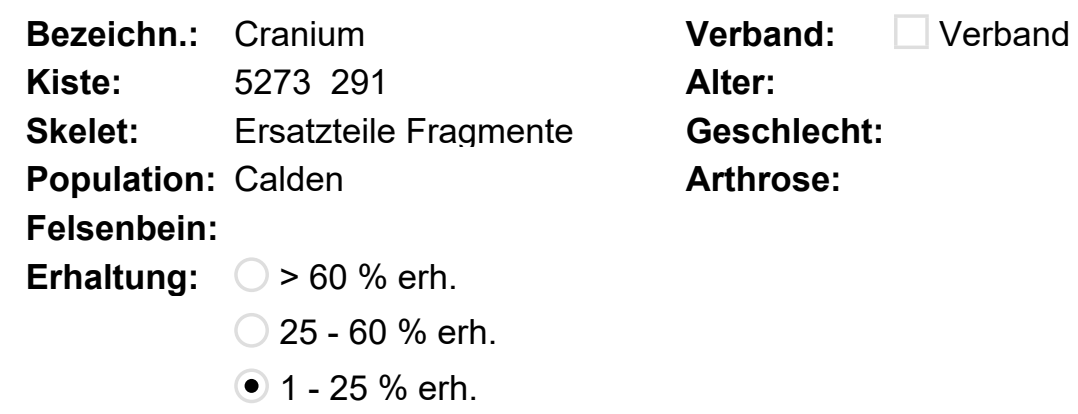

\section{Beschreibung:}

Fragmente eines Schädels, welche weder befundbar, noch zuzuordnen waren. 


\section{Bezeichn.: Cranium \\ Kiste: \\ 5273291}

Skelet: Ersatzteile Fragmente

Population: Calden

Felsenbein:

Erhaltung: $>60 \%$ erh

$25-60 \%$ erh.

- 1 - $25 \%$ erh.
Verband: $\quad \square$ Verband

\section{Alter:}

Geschlecht:

\section{Arthrose:}

\section{Beschreibung:}

Fragmente eines Schädels, welche weder befundbar, noch zuzuordnen waren. 


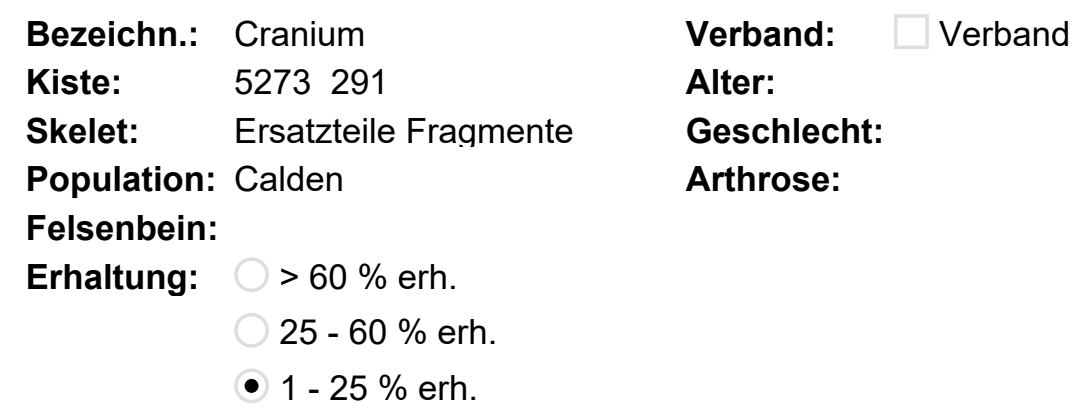

\section{Beschreibung:}

Fragmente eines Schädels, welche weder befundbar, noch zuzuordnen waren. 


\section{Bezeichn.: Cranium \\ Kiste: \\ 5273291}

Skelet: Ersatzteile Fragmente

Population: Calden

Felsenbein:

Erhaltung: $>60 \%$ erh

$$
25-60 \% \text { erh. }
$$

- 1 - $25 \%$ erh

\section{Beschreibung:}

Fragmente eines Schädels, welche weder befundbar, noch zuzuordnen waren

\section{Verband}

\section{Alter:}

Geschlecht:

\section{Arthrose:}

Maß

Schädeldecke / Schädelbasis

1

(




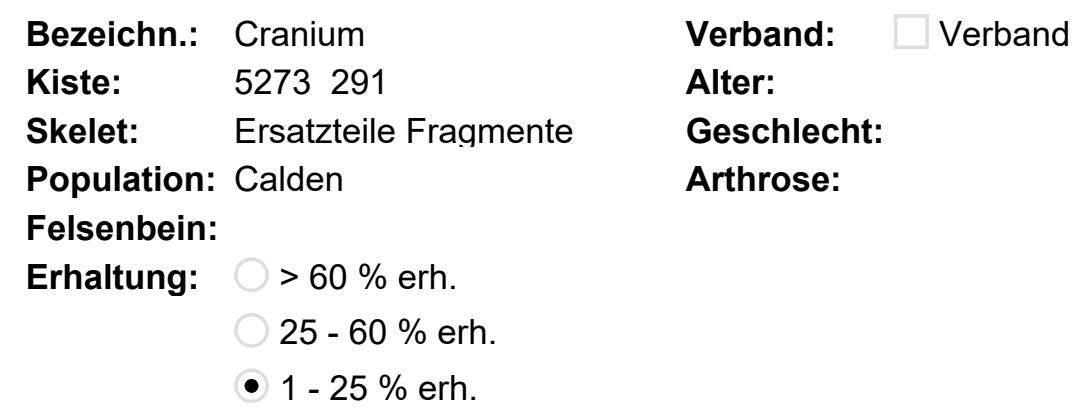

\section{Beschreibung:}

Fragmente eines Schädels, welche weder befundbar, noch zuzuordnen waren. 


\section{Bezeichn.: Cranium \\ Kiste: \\ 5273291}

Skelet: Ersatzteile Fragmente

Population: Calden

Felsenbein:

Erhaltung: $>60 \%$ erh

$25-60 \%$ erh.

- 1 - $25 \%$ erh.
Verband: $\quad \square$ Verband

\section{Alter:}

Geschlecht:

\section{Arthrose:}

\section{Beschreibung:}

Fragmente eines Schädels, welche weder befundbar, noch zuzuordnen waren. 


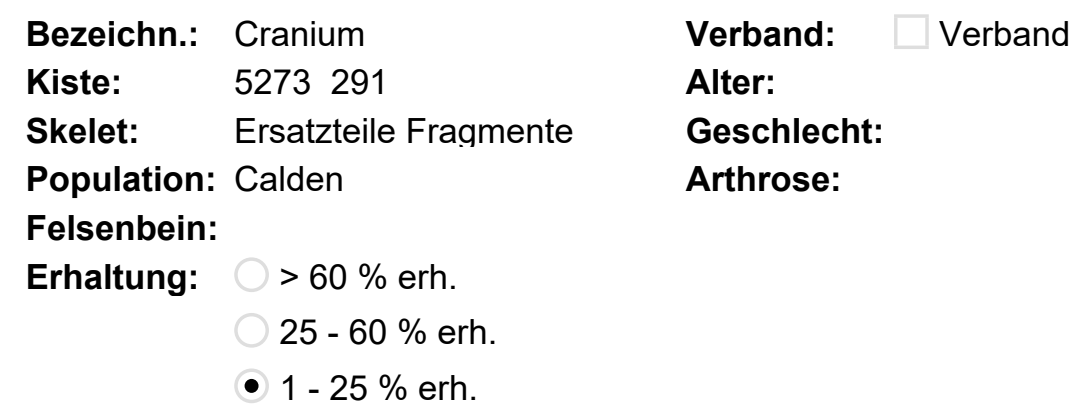

\section{Beschreibung:}

Fragmente eines Schädels, welche weder befundbar, noch zuzuordnen waren. 
$\begin{array}{ll}\text { Bezeichn.: } & \text { Cranium } \\ \text { Kiste: } & 5273291 \\ \text { Skelet: } & 2519 \text { mit }\end{array}$

Skelet: $\quad 2519$ mit Sch.20

Population: Calden

Felsenbein:

Erhaltung: $>60 \%$ erh

$$
25-60 \% \text { erh. }
$$

- $1-25 \%$ erh.

\section{Verband: $\quad$ Verband}

\section{Alter:}

Geschlecht:

\section{Arthrose:}

\section{Beschreibung:}

Hier sind wenige kleine Splitter in Form von Schädelfragmenten vorhanden. Diese sind sehr klein und ohne Befund.

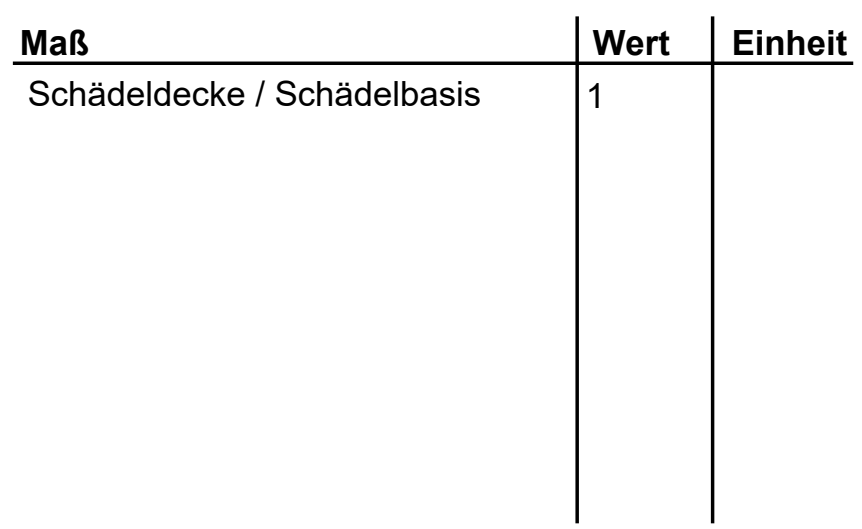




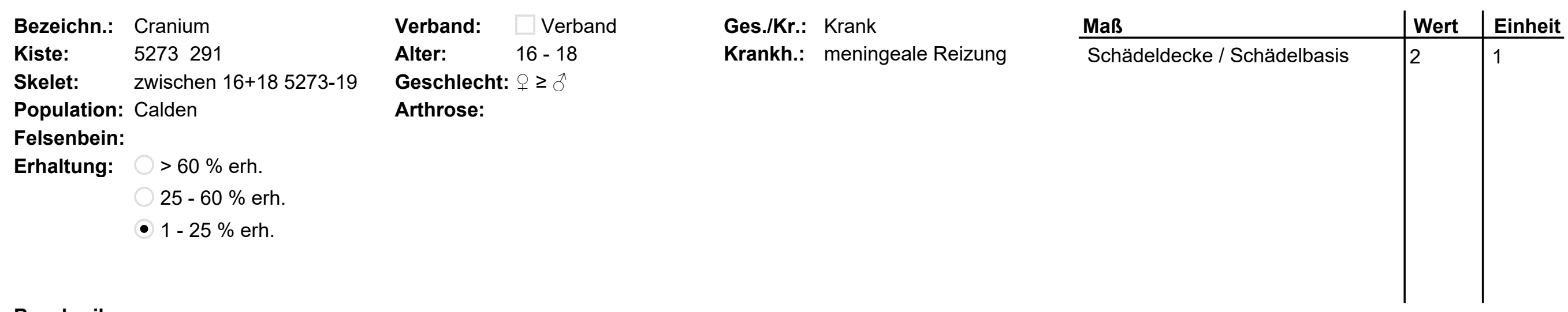

\section{Beschreibung:}

Es handelt sich hier um ein Fragment des Os occipitale. Es ist recht grazil, dünn und die Schädelnähte sind noch nicht geschlossen. Weiterhin gehört noch ein kleineres Fragment der Schädelkalotte dazu, wo sich auf der Lamina interna leichte plattenförmige Auflagerungen im Sinne einer meningealen Reizung finden. Außerdem ist noch ein kleines Fragment der Schädelbasis erhalten mit einem Articulatio atlanto-occipitalis der linken Seite. 


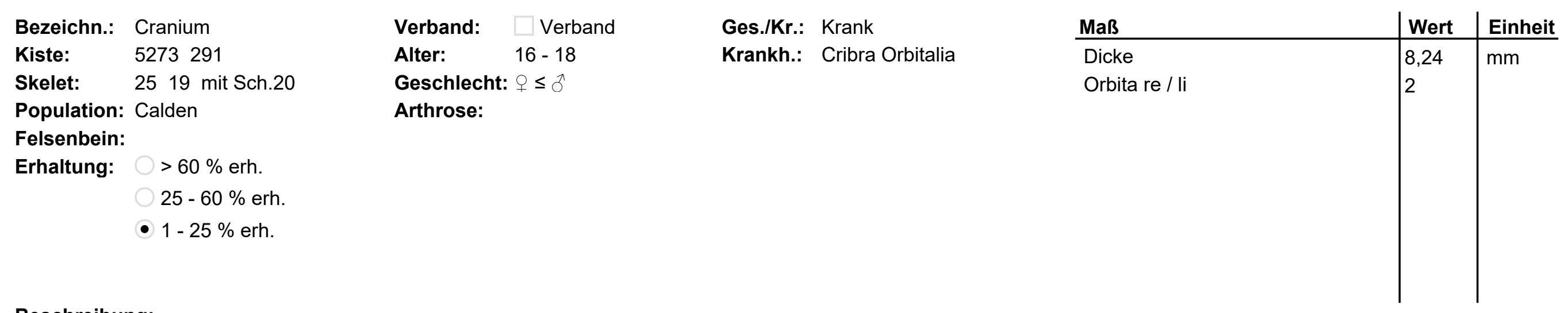

\section{Beschreibung:}

Dies ist ein Fragment des Os frontale, welches sehr massiv ist (8,3mm). Das Fundstück schließt Teile der Schädelregionen Margo supraorbitalis, foramen supraorbitale und pars orbitale ein. An einem rechten Fragment des Os frontale fallen im Orbitadach Spuren einer Cribra orbitalia auf. 
Bezeichn:: Cranium

\section{Kiste:}

5273291

Skelet: $\quad$ Schädel 105273 ? Calden

Population: Calden

Felsenbein: Links

Erhaltung: $>60 \%$ erh

- $25-60 \%$ erh.

$1-25 \%$ erh.
Verband: $\quad$ Verband

\section{Alter: $\quad 18-38$}

Geschlecht: $q \geq \hat{\sigma}$

\section{Arthrose:}

Ges./Kr.: Krank

Krankh.: Cribra Orbitalia

meatus acusticus Reizung

Periostreizung

meningeale Reizung

Hirndrucksymptomatik

Hypoplasie sinus frontalis

Sinısitis maxillaris

\section{Maß}

Dicke

Orbita re / li

Schädeldecke / Schädelbasis

Sinus frontalis

Sinus maxillaris

Viscerocranium

\begin{tabular}{|l|l} 
Wert & Einheit \\
5,1 & $\mathrm{~mm}$ \\
2 & 2 \\
2 & 2 \\
2 & \\
2 & \\
1 &
\end{tabular}

\section{Beschreibung:}

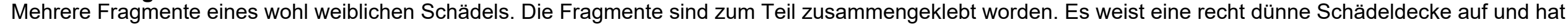

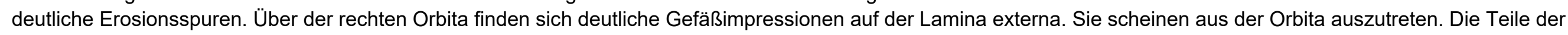

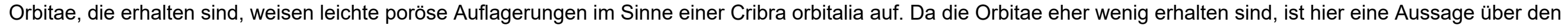

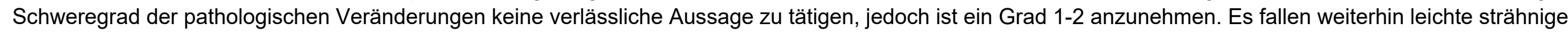

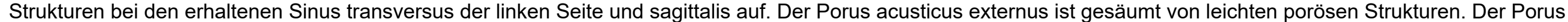

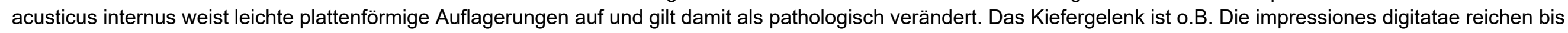

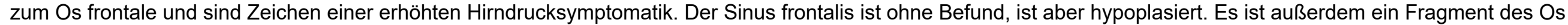

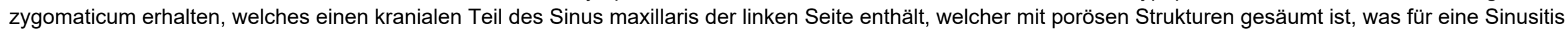
maxillaris spricht. Diese ist wohl mit einem Grad 3 zu bewerten. 


\begin{tabular}{|c|c|c|c|c|c|c|c|}
\hline Bezeichn.: & Cranium & Verband: & $\square$ Verband & Ges./Kr.: Gesund & Maß & Wert & Einheit \\
\hline Kiste: & 5273291 & Alter: & $12-18$ & & Dicke & 3,22 & $\mathrm{~mm}$ \\
\hline Skelet: & Calden 10 (Schädel 10) 2. & Geschlecht: & & & Schädeldecke / Schädelbasis & 1 & \\
\hline Population: & Calden & Arthrose: & & & & & \\
\hline Felsenbein: & & & & & & & \\
\hline Erhaltung: & $>60 \%$ erh. & & & & & & \\
\hline & $25-60 \%$ erh. & & & & & & \\
\hline & - $1-25 \%$ erh. & & & & & & \\
\hline
\end{tabular}

\section{Beschreibung:}

Ein Fragment eines rechten Os parietale mit beteiligten Schädelnähten der Lambdanaht, der Sutura sagittalis und der Sutura squamosa. Die Nähte sind nicht geschlossen gewesen. Impressiones digitatae sind bis zur Sutura sagittalis zu finden, was entweder für einen noch nicht ausgewachsenen Schädel oder eine erhöhte Hirndrucksymptomatik spricht, aufgrund der Konstitution ist hier ein junges Alter anzunehmen. 


\begin{tabular}{|c|c|c|c|c|c|c|c|}
\hline Bezeichn.: & Cranium & Verband: & $\square$ Verband & Ges./Kr.: Gesund & Maß & Wert & Einheit \\
\hline Kiste: & 5273291 & Alter: & & & Schädeldecke / Schädelbasis & 1 & 1 \\
\hline Skelet: & V71 Schädel $85273 ?$ & Geschlecht: & & & & & \\
\hline Population: & Calden & Arthrose: & & & & & \\
\hline Felsenbein: & Rechts & & re. & 1 & & & \\
\hline Erhaltung: & $>60 \%$ erh. & & & & & & \\
\hline & $25-60 \%$ erh. & & & & & & \\
\hline & - $1-25 \%$ erh. & & & & & & \\
\hline
\end{tabular}

\section{Beschreibung:}

Ein zusammenhängendes Fragment mit Teilen der Ossa parietale, occipitale und temporale. Es finden sich starke Muskelmarken am Processus mastoideus. Das rechte Kiefergelenk ist erhalten. 


\section{Bezeichn: Cranium \\ Kiste: $\quad 5273291$ \\ Skelet: 18}

Population: Calden

Felsenbein:

Erhaltung: $>60 \%$ erh

$25-60 \%$ erh.

- $1-25 \%$ erh.
Verband: $\quad$ Verband

\section{Alter:}

Geschlecht:

Arthrose:

\section{Beschreibung:}

Schädelsplitter. 


\begin{tabular}{|c|c|c|c|c|c|c|c|}
\hline Bezeichn.: & Cranium & Verband: & Verband & Ges./Kr.: Krank & Maß & Wert & Einheit \\
\hline Kiste: & 5273291 & Alter: & & Krankh.: Cribra Orbitalia & Orbita re / li & 2 & \\
\hline Skelet: & Ersatzteile 15 & Geschlecht: & & & Schädeldecke / Schädelbasis & 2 & \\
\hline Population: & Calden & Arthrose: & & & Sinus frontalis & 2 & \\
\hline Felsenbein: & & & & & & & \\
\hline Erhaltung: & $>60 \%$ erh. & & & & & & \\
\hline & $25-60 \%$ erh. & & & & & & \\
\hline & - $1-25 \%$ erh. & & & & & & \\
\hline
\end{tabular}

\section{Beschreibung:}

Mehrere Fragmente eines Schädels, es sind unter anderen Teile von Os frontale mit Orbita erhalten. Das Orbitadach weist eine mit Cribra orbitalia mit Grad 1 auf, das Os frontale hat von innen impressiones digitatae. Ein Fragment enthält einen Teil vom Sinus frontalis mit leichter poröser Oberfläche, die auf eine Sinusitis frontalis 1. Grades schließen lässt. 


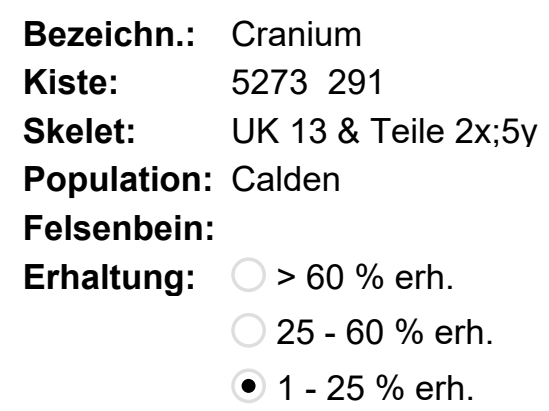

Skelet: UK 13 \& Teile 2x;5y

Population: Calden

Felsenbein:

Erhaltung: $>60 \%$ erh

$$
25-60 \% \text { erh. }
$$

- $1-25 \%$ erh.

\section{Geschlecht: $q \leq \delta$}

\section{Arthrose:}

\section{Beschreibung:}

Hier sind Splitter eines Schädels erhalten. Sie zeigen größtenteils starke Erosionsspuren. 


\section{Bezeichn.: Cranium}

\section{Kiste:}

5273291

Skelet: $\quad$ UK 13 \& Teile 2x;5y

Population: Calden

Felsenbein:

Erhaltung: $>60 \%$ erh $25-60 \%$ erh.

- 1 - $25 \%$ erh.
Verband: $\quad \square$ Verband

\section{Alter:}

Geschlecht:

Arthrose:

\section{Beschreibung:}

Ein Teil der Schädelbasis mit foramen magnum und clivus. 


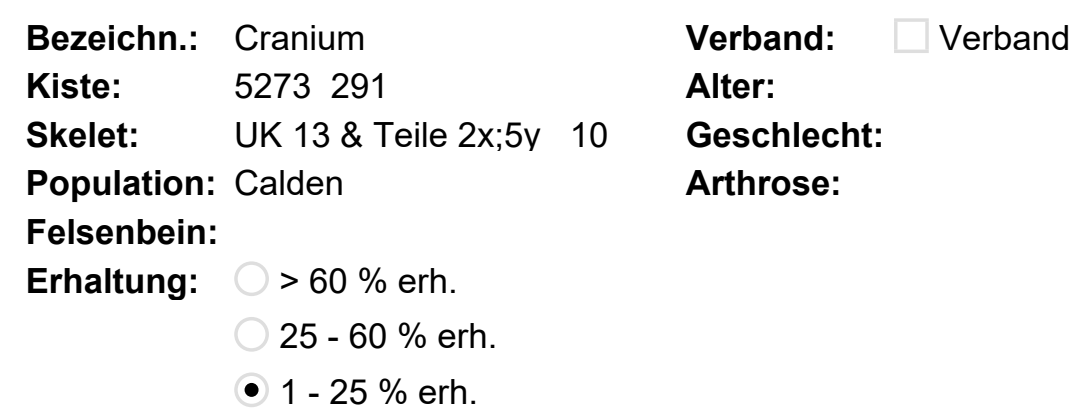

\section{Beschreibung:}

Ein Schädelfragment mit Margo supraorbitalis und Teil der Orbita. 


$\begin{array}{lll}\text { Bezeichn.: } & \text { Cranium } & \text { Verband: } \square \text { Verband } \\ \text { Kiste: } & 5273291 & \text { Alter: Jung } \\ \text { Skelet: } & \text { UK 13 \& Teile 2x;5y } & \text { Geschlecht: } \\ \text { Population: } & \text { Calden } & \text { Arthrose: } \\ \text { Felsenbein: } & & \\ \text { Erhaltung: } & >60 \% \text { erh. } & \\ & 25-60 \% \text { erh. } & \\ & \bullet 1-25 \% \text { erh. } & \end{array}$

\section{Beschreibung:}

Ein Fragment der Schädelbasis eines jungen Individuums. 


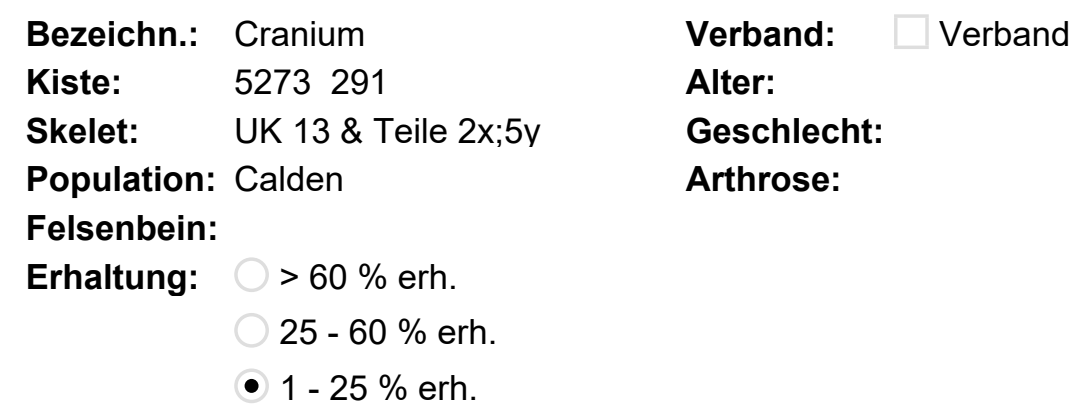

Skelet: $\quad$ UK 13 \& Teile 2x;5y

\section{Geschlecht:}

Population: Calden

Arthrose:

Felsenbein:

Erhaltung: $>60 \%$ erh$$
25-60 \% \text { erh. }
$$

- $1-25 \%$ erh.

\section{Beschreibung:}

Ein Fragment einer rechten lateralen Orbita rechts. 


\begin{tabular}{|c|c|c|c|c|c|c|c|}
\hline Bezeichn.: & Cranium & Verband: & Verband & Ges./Kr.: Krank & Maß & Wert & Einheit \\
\hline Kiste: & 5273291 & Alter: & & Krankh.: Sinusitis maxillaris & Sinus maxillaris & 2 & \\
\hline Skelet: & UK 13 \& Teile 2x;5y 5273 & Geschlecht: & & & & & \\
\hline Population: & Calden & Arthrose: & & & & & \\
\hline Felsenbein: & & & & & & & \\
\hline Erhaltung: & $>60 \%$ erh. & & & & & & \\
\hline & $25-60 \%$ erh. & & & & & & \\
\hline & - $1-25 \%$ erh. & & & & & & \\
\hline
\end{tabular}

\section{Beschreibung:}

Dies ist ein Fragment einer linken Kieferhöhle mit Spuren einer Sinusitis maxillaris, welche recht deutlich mit Grad 2-3 ausgeprägt ist. 


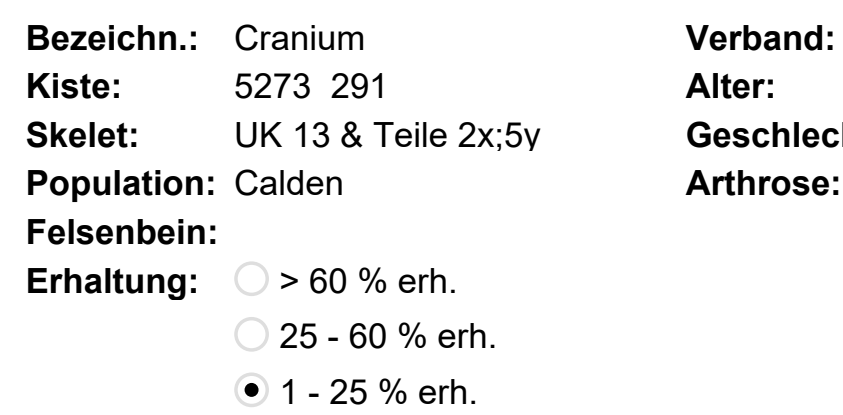

\section{Beschreibung:}

Ein Fragment der linken Schädelbasis eines jungen Individuums. Es enthält sella turcica und das foramen jugulare. 


\begin{tabular}{|c|c|c|c|c|c|c|c|c|}
\hline Bezeichn.: & Cranium & Verband: & Verband & Ges./Kr.: & Krank & Maß & Wert & Einheit \\
\hline Kiste: & 5271289 & Alter: & & Krankh.: & Kopfschwartenreizung & Schädeldecke / Schädelbasis & 2 & 2 \\
\hline Skelet: & 25 & Geschlecht: & & & Perisinusitis & & & \\
\hline Population: & Calden & Arthrose: & & & meningeale Reizung & & & \\
\hline Felsenbein: & & & & & & & & \\
\hline Erhaltung: & $>60 \%$ erh. & & & & & & & \\
\hline & $25-60 \%$ erh. & & & & & & & \\
\hline
\end{tabular}

\section{Beschreibung:}

Hier sind zwei größere Fragmente eines craniums und zwei weitere kleinere Splitter erhalten. Bei den größeren Fragmenten handelt es sich um ein Teil des Os parietale und einen Teil eines Os temporale der linken Seite. Unter dem Sinus sigmoideus der linken Seite finden sich kleine Impressionen (12mm x 1,8mm). Auf der Lamina externa fallen poröse Spuren einer Kopfschwartenreizung ins Auge. 
Bezeichn:: Cranium

Kiste:

5271289

Skelet:

32

Population: Calden

Felsenbein: Links

Erhaltung: $>60 \%$ erh

$25-60 \%$ erh.

$1-25 \%$ erh.
Ges./Kr.: Krank

Krankh.: Kopfschwartenreizung

Cribra Orbitalia

meningeale Reizung

Hypoplasie sinus frontalis

meatus acusticus Reizung

\section{Maß}

Orbita re / li

Schädeldecke / Schädelbasis

Sinus frontalis

\section{Beschreibung:}

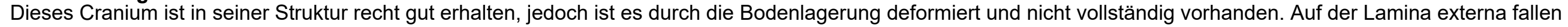

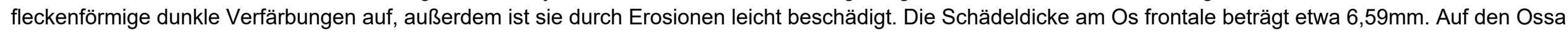

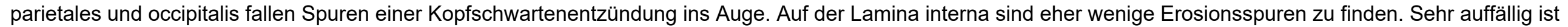

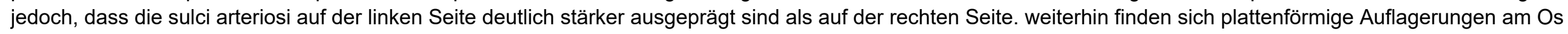

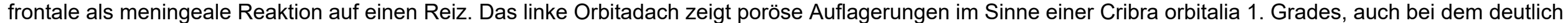

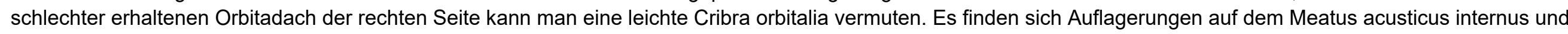
der Sinus frontalis ist stark hypoplasiert. 


\begin{tabular}{|c|c|c|c|c|c|c|c|}
\hline Bezeichn.: & Cranium & Verband: $\quad \square$ Verband & Ges./Kr.: & Krank & Maß & Wert & Einheit \\
\hline Kiste: & 5269285 & Alter: & Krankh.: & Cribra Orbitalia & Orbita re / li & 2 & 2 \\
\hline Skelet: & Calden 14 & Geschlecht: $\stackrel{+}{>} \hat{0}$ & & Kopfschwartenreizung & Schädeldecke / Schädelbasis & 2 & 2 \\
\hline Population: & Calden & Arthrose: & & Sinusitis maxillaris & Sinus frontalis & 1 & \\
\hline Felsenbein: & Beide & & & meatus acusticus Reizung & Sinus maxillaris & 2 & \\
\hline Erhaltung: & $\begin{array}{l}>60 \% \text { erh. } \\
25-60 \% \text { erh. } \\
1-25 \% \text { erh. }\end{array}$ & & & $\begin{array}{l}\text { Fraktur } \\
\text { dentogener Prozess } \\
\text { Stomatitis }\end{array}$ & Viscerocranium & 2 & \\
\hline
\end{tabular}

\section{Beschreibung:}

Bei diesem Fundstück handelt es sich wahrscheinlich um ein weibliches Individuum. Der Schädel ist recht stark erodiert, dennoch ist der Großteil des Neurocraniums erhalten. Die Schädelnähte sind teilweise von innen, aber nicht von außen geschlossen. Da die Oberfläche so erodiert ist, lässt sie keine vollständige Befundung zu. Im Meatus acusticus internus sind kleine poröse Auflagerungen zu sehen, eine leichte Kopfschwartenreizung ist an der Lamina externa zu verzeichnen, sowie eine leichte Cribra orbitalia an den Orbitadächern. Das Endokranium weist einige foveolae granulares auf. Am Viscerocranium fällt bei der Außenfläche des Os zygomaticum eine verheilte Verletzung auf. Weiterhin ist der Oberkiefer von krankhaften Veränderungen förmlich gesäumt. Ein Granulom, welches Zugang ins Vestibulum hatte ist am Zahn 14 zu erkennen. Eine Stomatitis am harten Gaumen, eine generalisierte Parodontitis und eine entzündlich veränderte apertura piriformis sind weitere Befunde, sowie eine bilaterale Sinusitis maxillaris. 


\section{Kiste:}

Cranium

Skelet:

5269285

Population: Calden

Felsenbein: Beide

Erhaltung: $>60 \%$ erh

$25-60 \%$ erh.

$1-25 \%$ erh.
Ges./Kr.: Krank

Krankh.: Kopfschwartenreizung

Cribra Orbitalia

Sinusitis frontalis

Sinusitis maxillaris
Maß

Orbita re / li

Schädeldecke / Schädelbasis

Sinus frontalis

Sinus maxillaris

Viscerocranium

\begin{tabular}{|l|l} 
Wert & Einheit \\
\hline 2 & \\
2 & 1 \\
2 & \\
2 \\
2
\end{tabular}

\section{Beschreibung:}

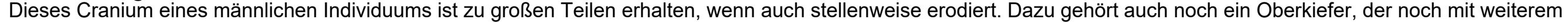

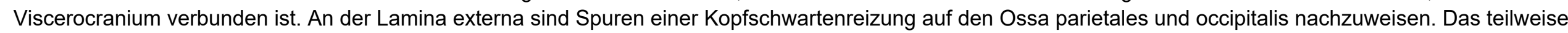

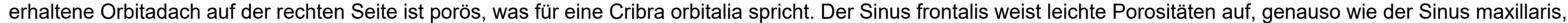

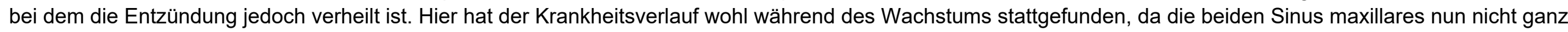

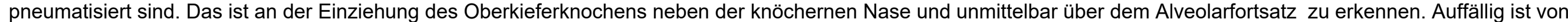
außen betrachtet eine $15 \mathrm{~mm} \times 10 \mathrm{~mm}$ große Einziehung zwischen foramen magnum und Linea nuchalis. Hierbei könnte es sich um einen muskulären Reiz der Nackenmuskulatur gehandelt habe, der zu der Einziehung geführt hat.

Das Alter des Individuums ist nicht klar zu bestimmen, da hier mehrere Merkmale nicht miteinander korrelieren. 
Kiste:

Cranium

Skelet: $\quad$ Calden

Population: Calden

Felsenbein: Beide

Erhaltung: $>60 \%$ erh

$25-60 \%$ erh.

1 - $25 \%$ erh.
Verband: $\quad$ Verband

\section{Alter: $\quad 35-45(50)$}

Geschlecht: +

Arthrose:

re.

li.
Ges./Kr.: Krank

Krankh.: Meatus acusticus Reizung

Tumor

Sinusitis maxillaris

Stomatitis

Arthrose

Parodontitis

Konfschwartenreizınn
Maß

Orbita re / li

Schädeldecke / Schädelbasis

Sinus frontalis

Sinus maxillaris

Viscerocranium

\begin{tabular}{|l|l} 
Wert & Einheit \\
\hline 2 & 2 \\
2 & 2 \\
2 & \\
2 \\
2
\end{tabular}

\section{Beschreibung:}

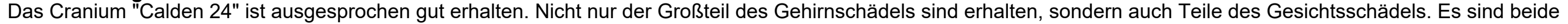

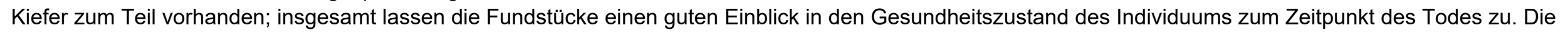

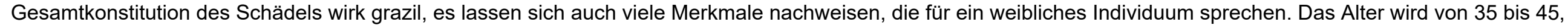

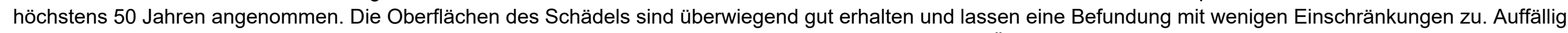

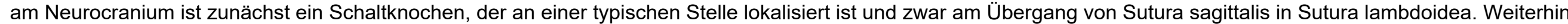

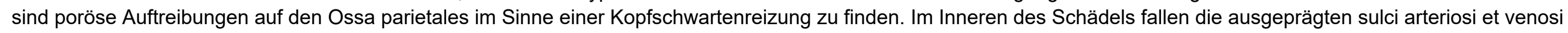
ins Auge, welche sich weit über die Ossa temporales und parietales erstrecken. Der befundbare rechte Porus acusticus internus weist leichte plattenförmige

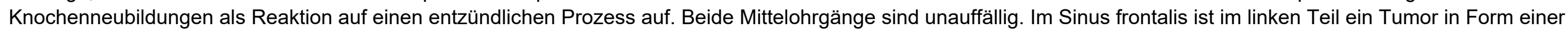

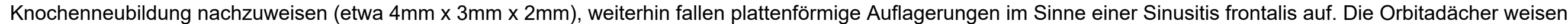

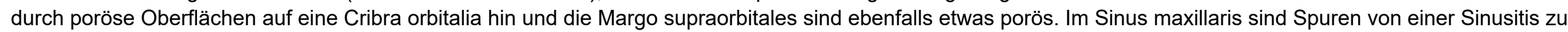
finden, welche allerdings im rechten Sinus eher den Eindruck machen, als seien sie mittlerweile verheilt gewesen. Ein recht stark aufgetriebener und von kleinen

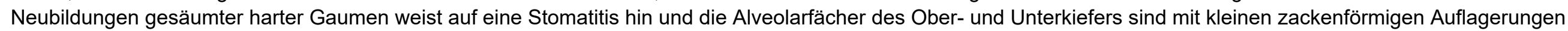

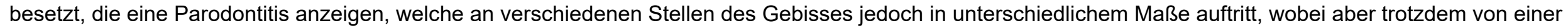
generalisierten Parodontitis gesprochen werden darf. Die Atlantookzipitalgelenke fallen mit leichten Abnutzungsspuren ins Auge. 


\section{Kiste:}

ranium

Skelet:

5268284

Population: Calden

Felsenbein: Beide

Erhaltung: $>60 \%$ erh

- $25-60 \%$ erh.

$1-25 \%$ erh.

\section{Ges./Kr.: Krank}

Krankh.: Kopfschwartenreizung

Hirndrucksymptomatik

meatus acusticus Reizung

\section{Maß}

Orbita re / li

Schädeldecke / Schädelbasis

Viscerocranium

\section{Geschlecht: \\ Arthrose: \\ (18) $25-30$

$+$ \\ Alter:}

\section{Beschreibung:}

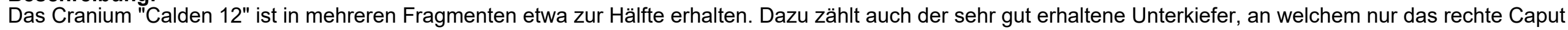

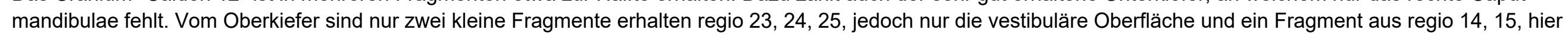

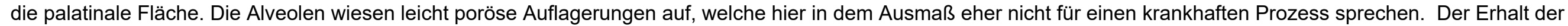

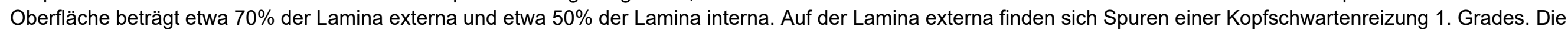

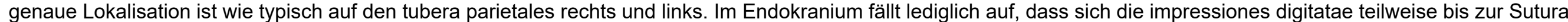

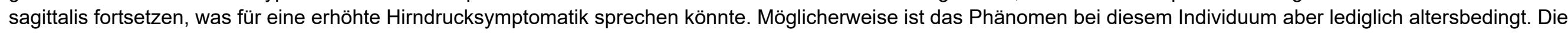

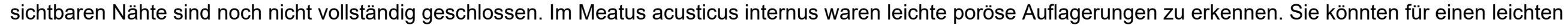
Entzündungsprozess sprechen. 


\begin{tabular}{|c|c|c|c|c|c|c|c|c|}
\hline Bezeichn.: & Cranium & Verband: & $\square$ Verband & Ges./Kr.: & Krank & Maß & Wert & Einheit \\
\hline Kiste: & 5268284 & Alter: & $50-60(65)$ & Krankh.: & Kopfschwartenreizung & Orbita re / li & 2 & 2 \\
\hline Skelet: & Calden 11 & Geschlecht: & : $0^{\lambda}$ & & Cribra Orbitalia & Schädeldecke / Schädelbasis & 2 & 1 \\
\hline Population: & Calden & Arthrose: & & & Periostreizung & Sinus frontalis & 1 & \\
\hline Felsenbein: & Rechts & & & & & & & \\
\hline Erhaltung: & $>60 \%$ erh. & & & & & & & \\
\hline & - $25-60 \%$ erh. & & & & & & & \\
\hline & $1-25 \%$ erh. & & & & & & & \\
\hline
\end{tabular}

\section{Beschreibung:}

Das Fundstück "Calden 11" ist das Cranium eines männlichen Individuums. Es macht einen sehr massiven Eindruck, zumal die Suturen bereits geschlossen sind. Durch die lange Bodenlagerung ist die Schädelform etwas deformiert. Die laminae externa und interna sind zu etwa 90\% erhalten und befundbar. Die Lamina externa weist eine poröse Oberfläche auf im Sinne einer verheilten Kopfschwartenentzündung oder einer Kopfschwartenreizung. Sie befinden sich auf den tubera parietales. Weiterhin sind an diesen Stellen etwa 20 schmale Einkerbungen (bis 1,55mm x 10mm) zu sehen. Auf dem Margo supraorbitalis rechts und links finden sich poröse Oberflächenbereiche von jeweils etwa $44 \mathrm{~mm} \times 20 \mathrm{~mm}$. Die Dächer der Orbitae sind ebenfalls porös, wobei die rechte eher einem Grad 2 einer gegebenen Cribra orbitalia entspricht und die linke eher Grad 1. Im Endokranium fallen sehr große sulci arteriosi / venosi auf, die eine Breite von bis zu 5,3mm und eine Tiefe von $2 \mathrm{~mm}$ erreichen. 


\section{Bezeichn.: Cranium \\ Kiste: \\ 5268284 \\ Skelet: Calden 9}

Population: Calden

Felsenbein:

Erhaltung:

$>60 \%$ erh

$25-60 \%$ erh.

- 1 - $25 \%$ erh

\section{Verband: $\quad$ Verband}

\section{Alter: $\quad 50-65(70)$}

Geschlecht: 0

\section{Arthrose:}

Ges./Kr.: Gesund

\section{Maß}

\section{Dicke}

Schädeldecke / Schädelbasis

Sinus frontalis

\begin{tabular}{l|l} 
Wert & Einheit \\
\hline 7,41 & $\mathrm{~mm}$ \\
1 & \\
& \\
&
\end{tabular}

\section{Beschreibung:}

Bei diesem Cranium ist die Kranznaht rückstandslos verschlossen und die Schädeldecke misst bis zu 7,41mm Dicke.

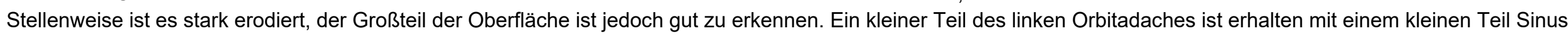

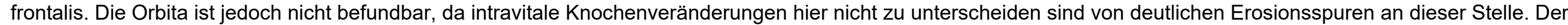
Sinus allerdings ist befundbar und weist keine ersichtlichen krankhaften Veränderungen auf. 
Bezeichn:: Cranium

Kiste: 5268284

Skelet: C7

Population: Calden

Felsenbein: Links

Erhaltung: $>60 \%$ erh

- $25-60 \%$ erh.

$1-25 \%$ erh.
Verband: $\quad$ Verband

Alter: $\quad 55-62$ (70)

\section{Geschlecht:}

\section{Arthrose:}

Ges./Kr.: Krank

Krankh.: Cribra Orbitalia

meatus acusticus Reizung

Periostreizung

Stomatitis

Kopfschwartenreizung

meningeale Reizung

Perisinusitis

\begin{tabular}{l|l|l} 
Maß & Wert & Einheit \\
\hline Dicke & 7,18 & $\mathrm{~mm}$ \\
Orbita re / li & 2 & 2 \\
Schädeldecke / Schädelbasis & 2 & 2 \\
Sinus frontalis & 2 & \\
Viscerocranium & 2 &
\end{tabular}

\section{Beschreibung:}

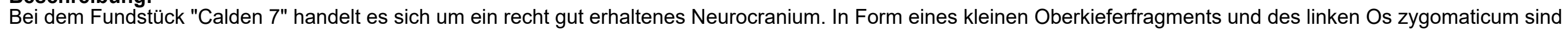

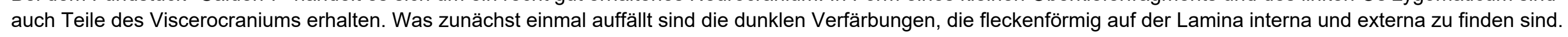
Die Oberflächen derselben sind zu etwa $60 \%$ gut erhalten, sodass bedingt Oberflächenveränderungen befundbar sind. Etwa $40 \%$ sind durch Bodenerosion und

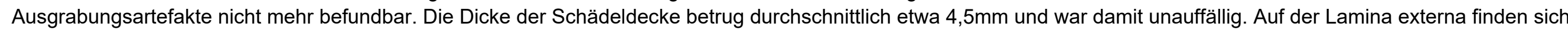

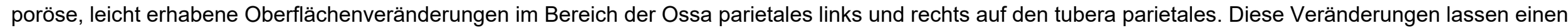

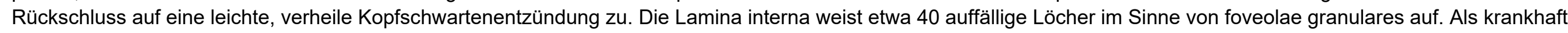

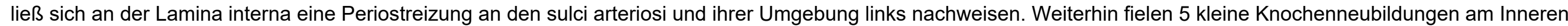

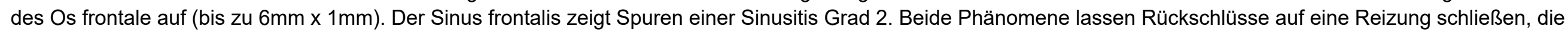

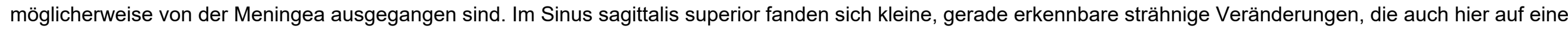

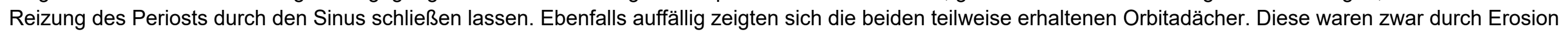

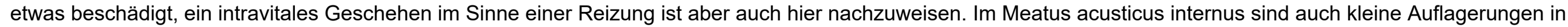

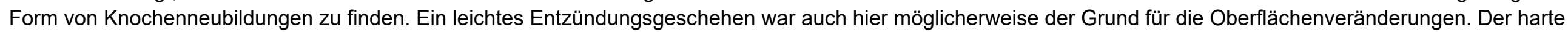

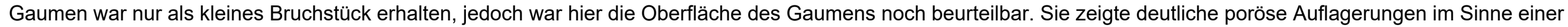
Stomatitis, die als Grad 2 ausgeprägt war. 


\section{Kiste: \\ Skelet: $\quad 5271289$}

Population: Calden

Felsenbein: Links

Erhaltung: $>60 \%$ erh.

- $25-60 \%$ erh.

$1-25 \%$ erh.
Ges./Kr.: Krank

Krankh.: Sinusitis frontalis

Cribra Orbitalia

Kopfschwartenreizung

Fraktur

meatus acusticus Reizung

\section{Maß}

Dicke

Orbita re / li

Schädeldecke / Schädelbasis

Sinus frontalis

\section{Beschreibung:}

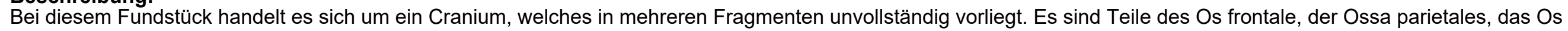

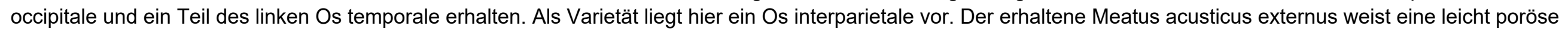

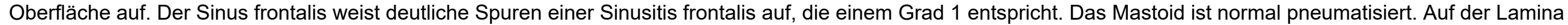

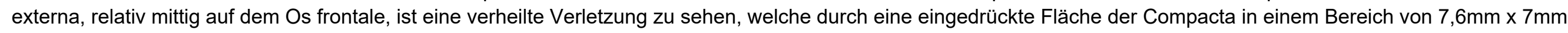

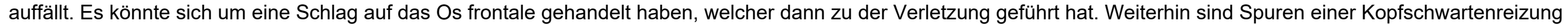

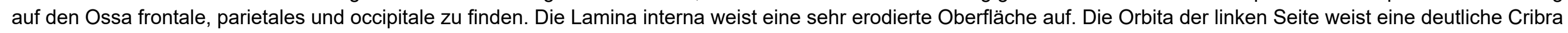

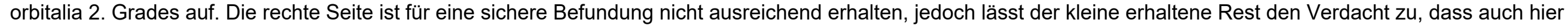
eine Cribra orbitalia vorlag. Die Schädeldicke beträgt 7,4mm. 
Bezeichn:

Kiste:

Skelet:

Population: Calden

Felsenbein: Beide

Erhaltung: $>60 \%$ erh

- $25-60 \%$ erh.

$1-25 \%$ erh.
Ges./Kr.: Krank

Krankh.: meningeale Reizung

Fraktur

Periostreizung

meatus acusticus

externus Reizung

Cribra Orbitalia

\begin{tabular}{l|l|l} 
Maß & Wert & Einheit \\
\hline Orbita re / li & 2 & 2 \\
Schädeldecke / Schädelbasis & 2 & 2 \\
Sinus frontalis & 1 & \\
& &
\end{tabular}

\section{Beschreibung:}

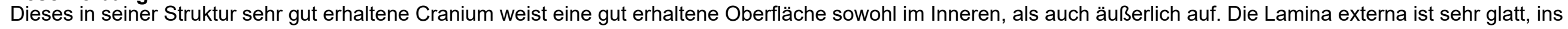

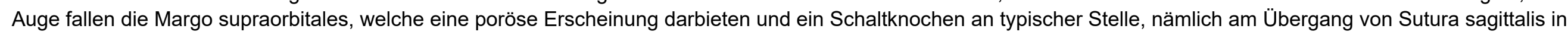

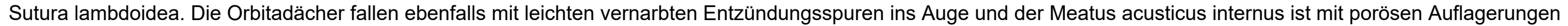

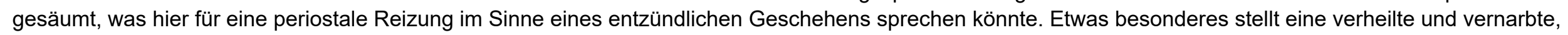

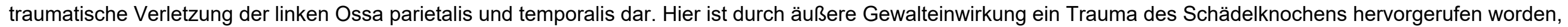

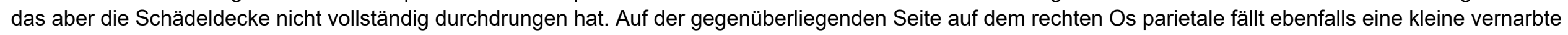

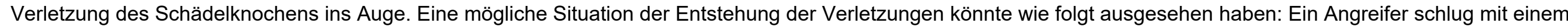

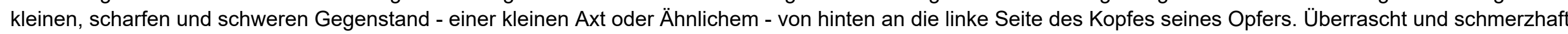

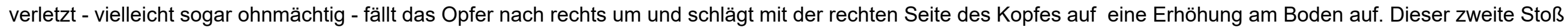

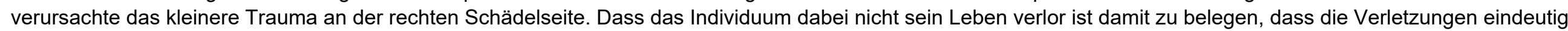

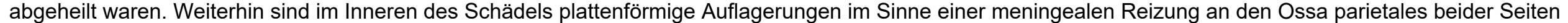
parasinuös zu erkennen. Diese sind im vorderen Drittel derselben unmittelbar neben der verknöcherten Sutura sagittalis lokalisiert. 


\begin{tabular}{|c|c|c|c|c|c|c|c|c|}
\hline Bezeichn.: & Cranium & Verband: & $\square$ Verband & Ges./Kr.: & Krank & Maß & Wert & Einheit \\
\hline Kiste: & 8505721 & Alter: & Jung & Krankh.: & meningeale Reizung & Schädeldecke / Schädelbasis & 1 & 2 \\
\hline Skelet: & Kiste 13 Calden 2,5;2,75 & Geschlecht: & $: \stackrel{p}{ } \geq \hat{\sigma}$ & & Perisinusitis & & & \\
\hline Population: & Calden & Arthrose: & & & & & & \\
\hline Felsenbein: & & & & & & & & \\
\hline Erhaltung: & $>60 \%$ erh. & & & & & & & \\
\hline & $25-60 \%$ erh. & & & & & & & \\
\hline & - $1-25 \%$ erh. & & & & & & & \\
\hline
\end{tabular}

\section{Beschreibung:}

Bei diesem Fundstück handelt es sich Fragmente eines Schädels. Es ist das fast vollständig erhaltene Os occipitale und ein kleines Fragment des Os parietale, das noch über die offene Schädelnaht Sutura lambdoidea verbunden ist. Das Fundstück wirkt sehr grazil und damit eher weiblich. Die Protuberantia occipitalis externa ist ebenfalls einem weiblichen Individuum entsprechend fast gar nicht ausgeprägt. Auf der Oberfläche der Sinus transversus finden sich leichte strähnige Auflagerungen im Sinne einer meningealen Reizung. Diese Reizung ist auf eine Perisinusitis zurück zu führen.

Die Sutura lambdoidea ist wie bereits beschrieben nicht geschlossen gewesen. 


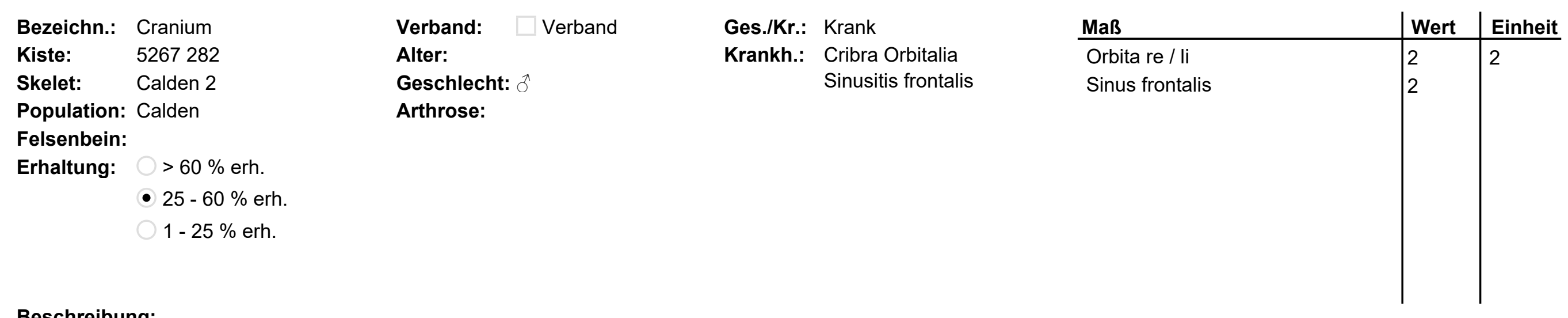

\section{Beschreibung:}

Beide Orbitadächer weisen eine Cribra Orbitalia auf, wobei die linke Orbita deutliche Gefäßimpressionen aufweist. Die spricht für einen entzündlichen Prozess, der sich bis in den Sinus frontalis fortsetzte, wo die Knochenoberfläche auch Entzündungsspuren im Sinne einer Sinusitis frontalis zeigt. 


\section{Bezeichn.: Cranium \\ Kiste: $\quad 8505720$ \\ Skelet: $\quad 1.1$}

Population: Calden

Felsenbein:

Erhaltung: $>60 \%$ erh

$25-60 \%$ erh.

- 1 - $25 \%$ erh.

\section{Beschreibung:}

Kleine Schädelsplitter.
Verband: $\quad$ Verband

\section{Alter:}

Geschlecht:

Arthrose:
Maß

Schädeldecke / Schädelbasis

Wert $\quad$ Einheit

1

1




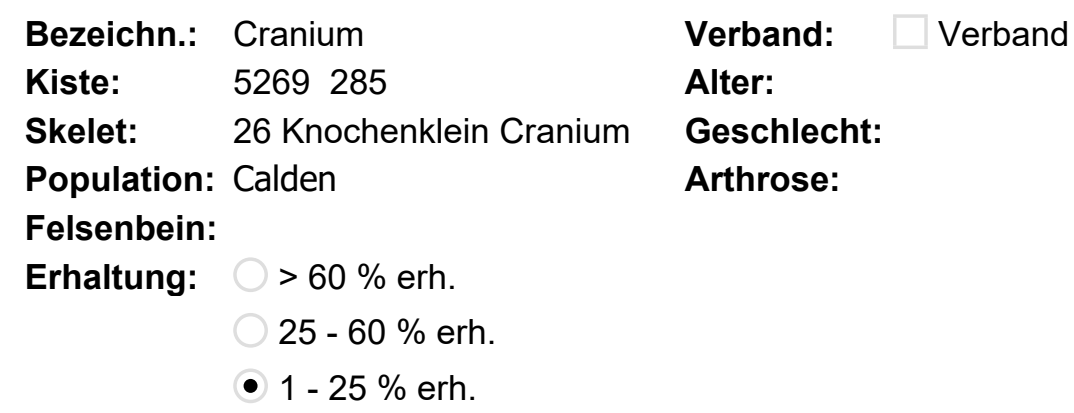

Kiste: $\quad 5269285$

Geschlecht:

Population: Calden

Arthrose:

Felsenbein:

Erhaltung: $>60 \%$ erh

$25-60 \%$ erh.

- 1 - $25 \%$ erh.

\section{Beschreibung:}

26 Splitter vom Schädel, unter anderem Os frontale. Es waren keine Pathologien nachzuweisen. 


\section{Bezeichn: Cranium \\ Kiste: $\quad 5270287$ \\ Skelet: $\quad 31$}

Population: Calden

Felsenbein:

Erhaltung: $>60 \%$ erh

$25-60 \%$ erh.

- 1 - $25 \%$ erh.
Verband: $\quad$ Verband

\section{Alter:}

Geschlecht: $q>\AA$

\section{Arthrose:}

\section{Beschreibung:}

Ein Schädelfragment, welches vom Os sphenoidale stammt. 


\section{Bezeichn.: Vertebra}

Kiste: Museumskiste 3

Skelet:

Population: Calden

\section{Verband: $\quad$ Verband Ges./Kr.: Krank}

Alter: Krankh.: Bandverknöcherungen

\section{Geschlecht:}

Arthrose:

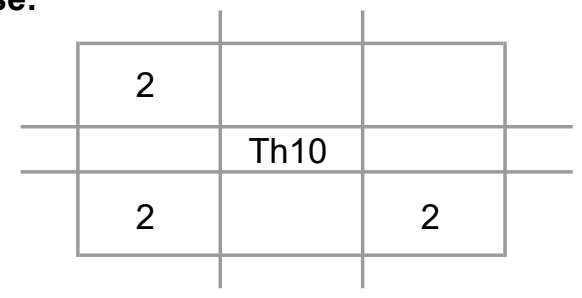

\section{Beschreibung:}

Verknöcherungen des Ligamentum an allen Wirbeln. Es kann davon ausgegangen werden, dass die Wirbel zusammengehörig sind. 
Bezeichn.: Vertebra

Kiste: Museumskiste 3

Skelet:

Population: Calden
Verband: $\quad \square$ Verband

Ges./Kr.: Gesund

\section{Geschlecht:}

Arthrose:

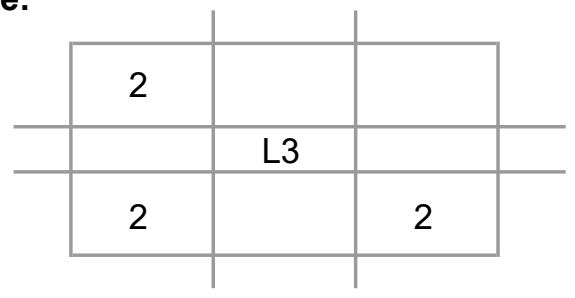

\section{Beschreibung:}


Bezeichn.: Vertebra

Kiste: Museumskiste 3

Skelet:

Population: Calden
Verband: $\quad \square$ Verband

Ges./Kr.: Gesund

\section{Geschlecht:}

Arthrose:

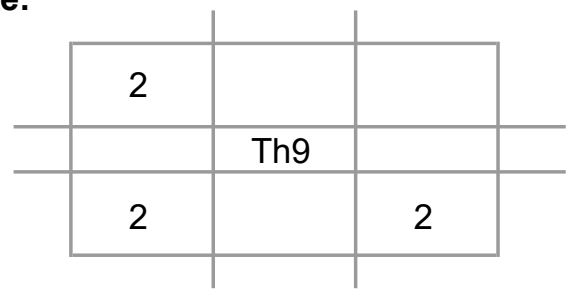

\section{Beschreibung:}


Bezeichn.: Vertebra

Kiste: Museumskiste 3

Skelet:

Population: Calden
Verband: $\quad \square$ Verband

Alter:

Ges./Kr.: Gesund

\section{Geschlecht:}

Arthrose:

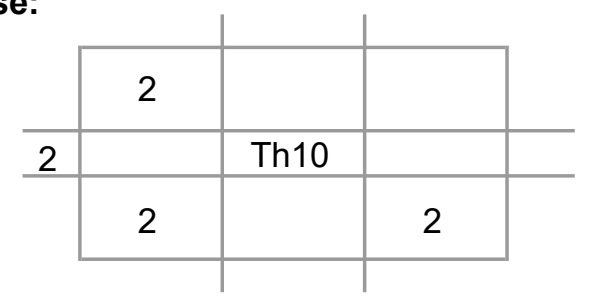

\section{Beschreibung:}


Bezeichn.: Vertebra

Kiste: Museumskiste 3

Skelet:

Population: Calden
Verband: $\quad \square$ Verband

Alter:

Ges./Kr.: Gesund

\section{Geschlecht:}

Arthrose:

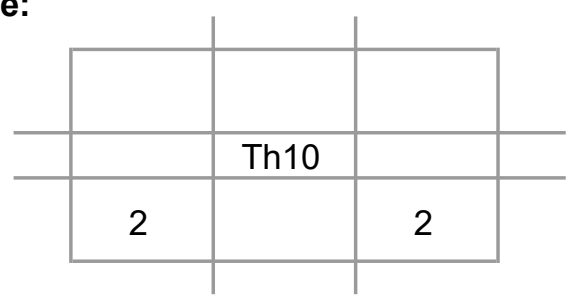

\section{Beschreibung:}


Bezeichn.: Vertebra

Kiste: Museumskiste 3

Skelet:

Population: Calden

\section{Verband: $\quad$ Verband Ges./Kr.: Krank}

Alter: Krankh.: Arthrose

\section{Geschlecht:}

Arthrose:

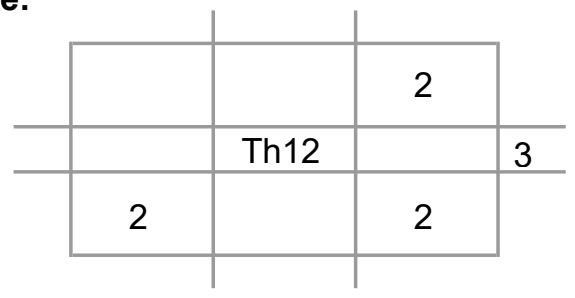

\section{Beschreibung:}

Arthrose am Articulatio Costo vertebralis. 
Bezeichn.: Vertebra

Kiste: Museumskiste 3

Skelet:

Population: Calden
Verband: $\quad \square$ Verband

Alter:

Ges./Kr.: Gesund

\section{Geschlecht:}

Arthrose:

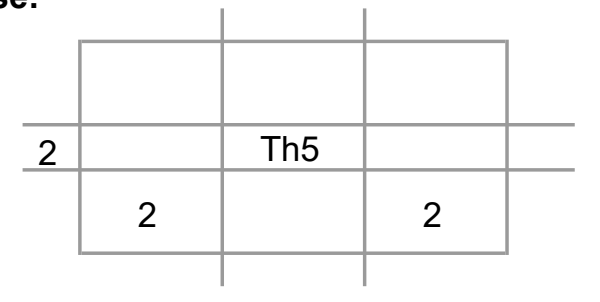

\section{Beschreibung:}


Bezeichn.: Vertebra

Kiste: Museumskiste 3

Skelet:

Population: Calden
Verband: $\quad \square$ Verband

Ges./Kr.: Gesund

\section{Geschlecht:}

Arthrose:

\begin{tabular}{|c|c|c|}
\hline 2 & & 2 \\
\hline & Th9 & \\
\hline 2 & & 2 \\
\hline
\end{tabular}

\section{Beschreibung:}




\section{Bezeichn.: Vertebra \\ Kiste: $\quad 8505718$ \\ Skelet: aus Tüte}

Population: Calden
Verband: $\quad$ Verband

\section{Alter: Jung}

Geschlecht:

Arthrose:

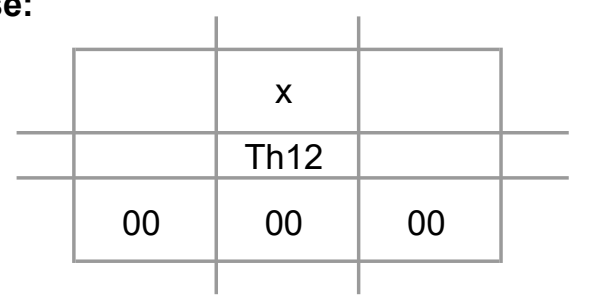

\section{Beschreibung:}

Dies ist ein junger Wirbel Th12, der zum Teil starke Erosionsspuren zeigt. 


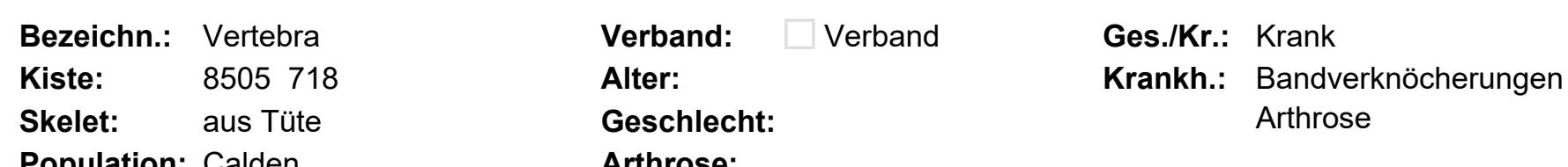

Population: Calden

Arthrose:

\begin{tabular}{|c|c|c|}
\hline 1 & & 1 \\
\hline & Th & \\
\hline 2 & & 3 \\
\hline
\end{tabular}

\section{Beschreibung:}

Dieser Wirbel stammt aus dem mittleren thorakalen Bereich und weist Bandverknöcherungen am Processus spinosus auf. 


\section{Bezeichn.: Vertebra \\ Kiste: 8505718 \\ Skelet: aus Tüte}

Population: Calden
Verband: $\quad$ Verband

\section{Alter: Jung}

Geschlecht:

Arthrose:

\begin{tabular}{|l|l|l|}
\cline { 2 - 3 } \multicolumn{1}{c|}{00} & 00 & 00 \\
\hline & Th & \\
\hline 00 & 00 & 00 \\
\hline
\end{tabular}

\section{Beschreibung:}

Dieser Wirbel aus dem thorakalen Bereich ist jung und weist keine weiteren Auffälligkeiten auf. 


\section{Bezeichn.: Vertebra \\ Kiste: 8505718 \\ Skelet: aus Tüte}

Population: Calden
Verband: $\quad$ Verband

\section{Alter: Jung}

Geschlecht:

Arthrose:

\begin{tabular}{|l|l|l|}
\cline { 2 - 3 } \multicolumn{1}{c|}{00} & 00 & 00 \\
\hline & Th & \\
\hline 00 & 00 & 00 \\
\hline
\end{tabular}

\section{Beschreibung:}

Dieser Wirbel aus dem thorakalen Bereich ist jung und weist keine weiteren Auffälligkeiten auf. 
Bezeichn.: Vertebra

Kiste: $\quad 8505718$

Skelet: aus Tüte

Population: Calden
Verband: $\quad \square$ Verband

\section{Alter:}

Geschlecht:

Arthrose:

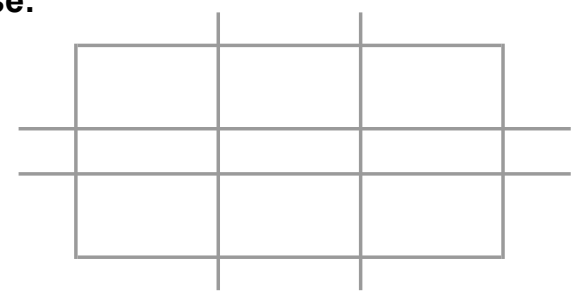

\section{Beschreibung:}

Hier ist nur ein kleines Fragment eines Wirbels erhalten, welches nicht zugeordnet werden kann. 
Bezeichn.: Vertebra

Kiste: $\quad 8505718$

Skelet: aus Tüte

Population: Calden
Verband: $\quad \square$ Verband

\section{Alter:}

Geschlecht:

Arthrose:

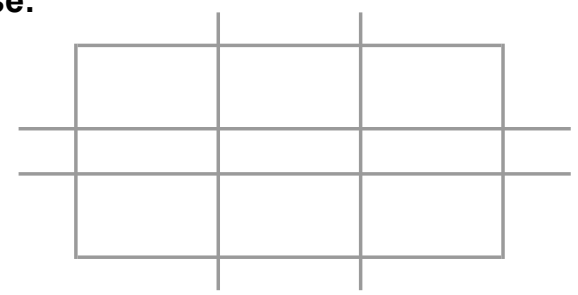

\section{Beschreibung:}

Hier ist nur ein kleines Fragment eines Wirbels erhalten, welches nicht zugeordnet werden kann. 
Bezeichn.: Vertebra

Kiste: $\quad 8505718$

Skelet: aus Tüte

Population: Calden
Verband: $\quad \square$ Verband

\section{Alter:}

Geschlecht:

Arthrose:

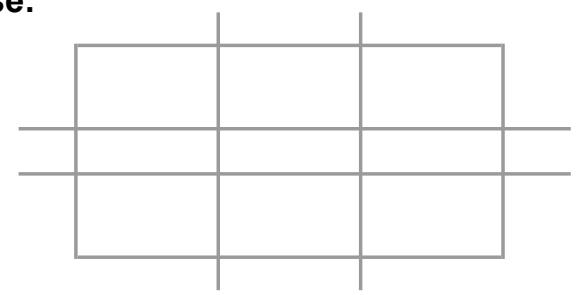

\section{Beschreibung:}

Hier ist nur ein kleines Fragment eines Wirbels erhalten, welches nicht zugeordnet werden kann. 
Bezeichn.: Vertebra

Kiste: $\quad 8505718$

Skelet: aus Tüte

Population: Calden
Verband: $\quad \square$ Verband

\section{Alter:}

Geschlecht:

Arthrose:

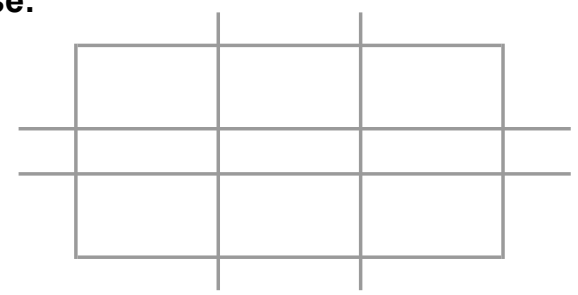

\section{Beschreibung:}

Hier ist nur ein kleines Fragment eines Wirbels erhalten, welches nicht zugeordnet werden kann. 
Bezeichn.: Vertebra

Kiste: $\quad 8505718$

Skelet: aus Tüte

Population: Calden
Verband: $\quad \square$ Verband

\section{Alter:}

Geschlecht:

Arthrose:

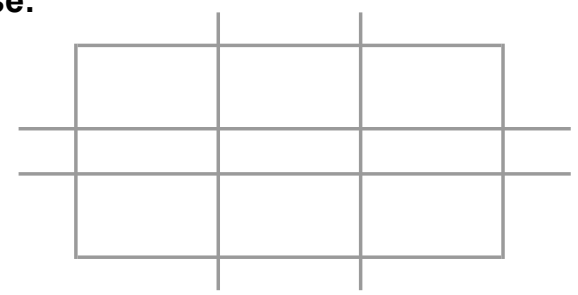

\section{Beschreibung:}

Hier ist nur ein kleines Fragment eines Wirbels erhalten, welches nicht zugeordnet werden kann. 
Bezeichn.: Vertebra

Kiste: $\quad 8505718$

Skelet: aus Tüte

Population: Calden
Verband: $\quad \square$ Verband

\section{Alter:}

Geschlecht:

Arthrose:

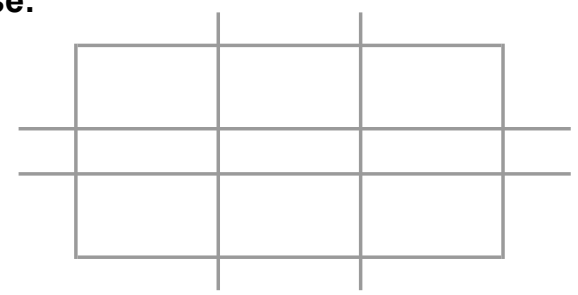

\section{Beschreibung:}

Hier ist nur ein kleines Fragment eines Wirbels erhalten, welches nicht zugeordnet werden kann. 
Bezeichn.: Vertebra

Kiste: $\quad 8505718$

Skelet: aus Tüte

Population: Calden
Verband: $\quad \square$ Verband

\section{Alter:}

Geschlecht:

Arthrose:

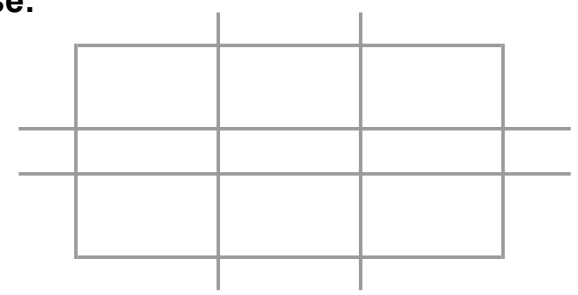

\section{Beschreibung:}

Hier ist nur ein kleines Fragment eines Wirbels erhalten, welches nicht zugeordnet werden kann. 
Bezeichn.: Vertebra

Kiste: $\quad 8505718$

Skelet: aus Tüte

Population: Calden
Verband: $\quad \square$ Verband

\section{Alter:}

Geschlecht:

Arthrose:

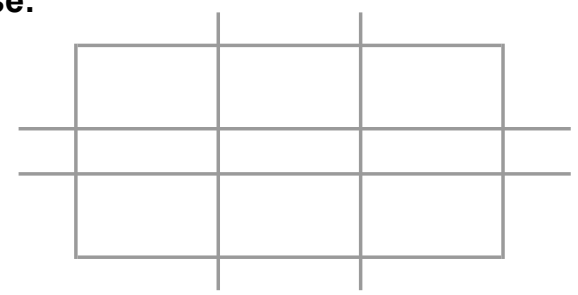

\section{Beschreibung:}

Hier ist nur ein kleines Fragment eines Wirbels erhalten, welches nicht zugeordnet werden kann. 
Bezeichn.: Vertebra

\section{Kiste:}

8505718

V66 aus Tüte

Population: Calden
Verband: $\quad \square$ Verband

Ges./Kr.: Gesund

\section{Geschlecht:}

Arthrose:

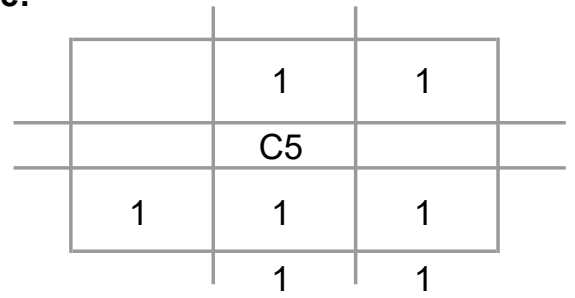

\section{Beschreibung:}

Dieser Wirbel C5 weist physiologische Gelenkflächen auf. 
Bezeichn.: Vertebra

\section{Kiste:}

8505718

V66 aus Tüte

Population: Calden
Verband: $\quad \square$ Verband

Ges./Kr.: Gesund

\section{Geschlecht:}

Arthrose:

\begin{tabular}{l|c|c|}
\multicolumn{1}{l|}{} & 1 & 1 \\
\cline { 2 - 3 } & 1 & 1 \\
\hline & C6 & \\
\hline & 1 & 1 \\
\hline
\end{tabular}

\section{Beschreibung:}

Dieser Wirbel C6 weist physiologische Gelenkflächen auf. 
Bezeichn:: Vertebra

Kiste: $\quad 8505718$

Skelet: aus Tüte

Population: Calden
Verband: $\quad$ Verband

\section{Alter:}

Ges./Kr.: Krank

Geschlecht:

Arthrose:
Krankh.: Arthrose

\begin{tabular}{|c|c|c|}
\cline { 2 - 4 } \multicolumn{1}{c|}{} & \multicolumn{1}{c|}{} \\
\hline & 4 & 2 \\
\hline 2 & 1 & 2 \\
\hline
\end{tabular}

\section{Beschreibung:}

Dieser Atlas weist Gelenkflächen mit arthrotischen Veränderungen auf. 
Bezeichn:: Vertebra

Kiste: $\quad 8505718$

Skelet: aus Tüte

Population: Calden
Verband: $\square$ Verband

Ges./Kr.: Gesund

\section{Geschlecht:}

Arthrose:

\begin{tabular}{|c|c|c|}
\cline { 2 - 3 } \multicolumn{1}{c|}{} & \multicolumn{1}{c|}{} & \multicolumn{1}{c}{} \\
\hline & 2 & 2 \\
\hline 2 & 1 & 2 \\
\hline
\end{tabular}

\section{Beschreibung:}

Dieser Atlas weist physiologische Gelenkflächen auf. 
Bezeichn:: Vertebra

Kiste: $\quad 8505718$

Skelet: aus Tüte

Population: Calden
Verband: $\square$ Verband

Ges./Kr.: Gesund

\section{Geschlecht:}

Arthrose:

\begin{tabular}{|c|c|c|}
\cline { 2 - 3 } \multicolumn{1}{c||}{2} & 1 & 2 \\
\hline 2 & 1 & 1 \\
\hline
\end{tabular}

\section{Beschreibung:}

Dieser Atlas weist physiologische Gelenkflächen auf. 
Bezeichn:: Vertebra

Kiste: $\quad 8505718$

Skelet: $\quad$ V67 aus Tüte

Population: Calden

\section{Verband: $\quad$ Verband Ges./Kr.: Krank}

Alter: Krankh.: Arthrose

\section{Geschlecht:}

Arthrose:

\begin{tabular}{|c|c|c|}
\cline { 2 - 4 } \multicolumn{1}{l||}{2} & 2 & 2 \\
\hline & Th3 & \\
\hline 4 & 2 & 4 \\
\hline
\end{tabular}

\section{Beschreibung:}

Dieser Wirbel Th3 weist deutliche Verschleißerscheinungen am linken Processus articularis inferior auf, welcher eburniert ist und am rechten, welcher ebenfalls arthrotisch geschädigt ist. 
Bezeichn.: Vertebra

\section{Kiste:}

8505718

V67 aus Tüte

Population: Calden
Verband: $\quad \square$ Verband

Ges./Kr.: Gesund

\section{Alter:}

\section{Geschlecht:}

Arthrose:

\begin{tabular}{|c|c|c|}
\cline { 2 - 3 } \multicolumn{1}{c|}{} & \multicolumn{1}{c|}{} \\
\hline 2 & 2 & 2 \\
\hline & Axis & \\
\hline & 2 & 2 \\
\hline
\end{tabular}

\section{Beschreibung:}

Dieser Axis weist physiologische Gelenkflächen auf. 
Bezeichn.: Vertebra

Verband: $\quad \square$ Verband

Ges./Kr.: Krank

\section{Kiste: $\quad 5274292$}

\section{Alter:}

Krankh.: Arthritis

Skelet: $\quad 5274 \mathrm{~A}$

\section{Geschlecht:}

Arthritis

Population: Calden

\begin{tabular}{c|c|c|c|c}
\multicolumn{1}{c|}{} & \multicolumn{2}{c}{} & \multicolumn{2}{c}{} \\
\cline { 2 - 4 } \multicolumn{1}{c|}{2} & 4 & 2 & \\
\hline 3 & & Th7 & & 2 \\
\hline & 5 & 5 & 5 & \\
\cline { 2 - 4 } & & & \multicolumn{2}{c}{}
\end{tabular}

\section{Beschreibung:}

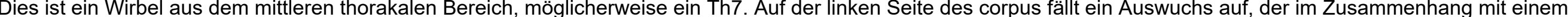
verschleißenden Prozess entstanden ist. Dazu kommt noch ein sehr auffälliger Spondylophyt an der Unterseite des corpus. 


\section{Bezeichn.: Vertebra \\ Kiste: $\quad 5274292$ \\ Skelet: $\quad 5274 \mathrm{~A}$}

Population: Calden
Verband: $\quad$ Verband

Ges./Kr.: Gesund

\section{Alter:}

Geschlecht:

Arthrose:

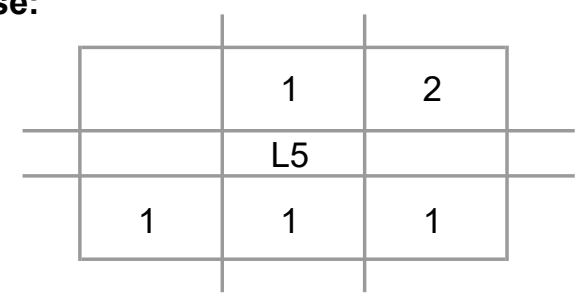

\section{Beschreibung:}

Dieser Wirbel ist aus dem unteren lumbalen Bereich, wohl ein L5. 


\section{Bezeichn: Vertebra \\ Kiste: $\quad 5274292$ \\ Skelet: $\quad 5274 \mathrm{~A}$}

Population: Calden

\section{Verband: $\square$ Verband Ges./Kr.: Gesund}

\section{Alter: $\quad 18-25$}

Geschlecht:

Arthrose:

\begin{tabular}{|l|l|l|}
\hline \multicolumn{1}{c||}{00} & 00 & 00 \\
\hline & C6 & \\
\hline 00 & 00 & 00 \\
\hline
\end{tabular}

\section{Beschreibung:}

Dies ist ein Wirbel aus dem unteren cervikalen Bereich. Er ist einem jungen Individuum zuzuordnen, da die Gelenkflächen nicht verknöchert sind. 


\section{Bezeichn: Vertebra \\ Kiste: $\quad 5274292$ \\ Skelet: $\quad 5274 \mathrm{~A}$}

Population: Calden

\section{Verband: $\quad$ Verband \\ Ges./Kr.: Krank

Alter: Krankh.: Arthrose \\ Geschlecht: \\ Arthritis}

Arthrose:

\begin{tabular}{l|c|c|c|}
\cline { 2 - 4 } \multicolumn{1}{c|}{} & 4 & 1 & 5 \\
\hline & & C5 & \\
\hline 2 & 4 & 2 \\
\hline
\end{tabular}

\section{Beschreibung:}

Dies ist ein cervikaler Wirbel, wohl ein C5. Er weist eine Arthritis an der Unterseite des corpus auf und zeigt ebenfalls an der Unterseite eine Gelenkerweiterung durch arthrotischen Prozess nach rechts. Der Processus articularis superior der linken Seite ist eburniert. 
Bezeichn.: Vertebra

Kiste: $\quad 5242266$

Skelet:

Population: Calden
Verband: $\quad \square$ Verband

\section{Alter:}

Geschlecht:

Arthrose:

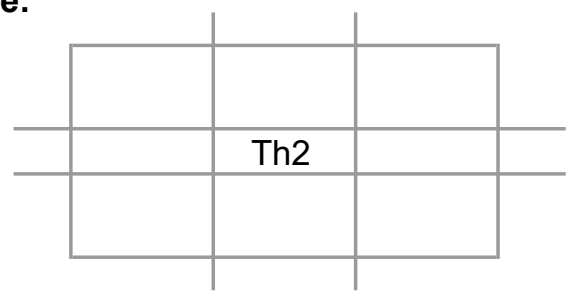

Beschreibung:

Ein Fragment. 
Bezeichn.: Vertebra

Kiste: $\quad 8505720$

Skelet: $\quad 1.0$

Population: Calden
Verband: $\quad \square$ Verband

Ges./Kr.: Gesund

\section{Geschlecht:}

Arthrose:

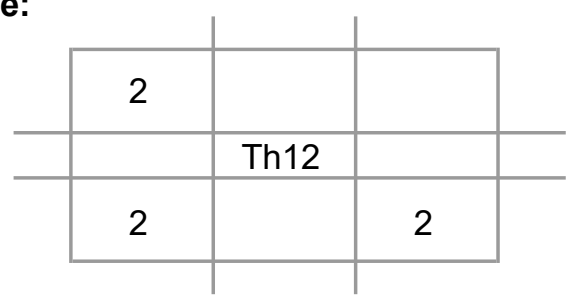

\section{Beschreibung:}

Frakturiert erhalten, ohne Wirbelbogen. 


\section{Bezeichn: Vertebra \\ Kiste: $\quad 8505720$ \\ Skelet: $\quad 1.0$}

Population: Calden

\section{Verband: $\square$ Verband Ges./Kr.: Krank

Alter: Krankh.: Arthrose \\ Geschlecht: $q \leq \hat{0}$ Arthritis}

Arthrose:

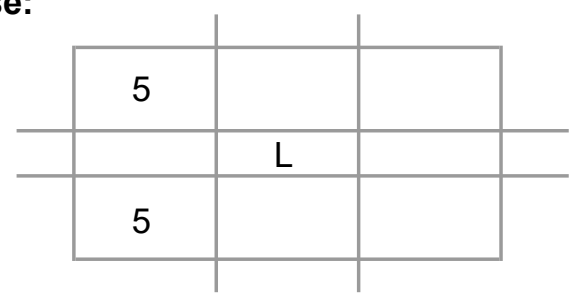

\section{Beschreibung:}

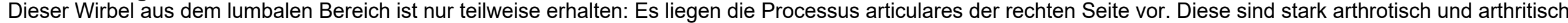
verändert. Weiterhin wirkt das Wirbelfragment sehr massiv. 
Bezeichn.: Vertebra

Kiste: $\quad 8505720$

Skelet: $\quad 1.0$

Population: Calden
Verband: $\quad \square$ Verband

\section{Alter:}

Geschlecht:

Arthrose:

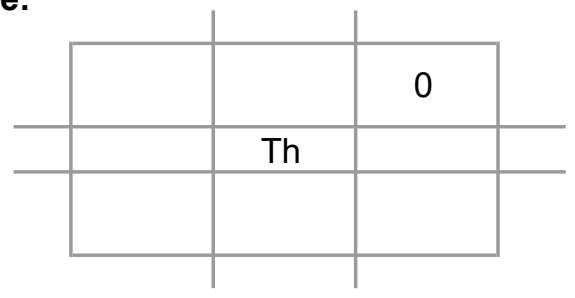

\section{Beschreibung:}


Bezeichn.: Vertebra

Kiste: $\quad 8505720$

Skelet: $\quad 1.0$

Population: Calden
Verband: $\square$ Verband

Ges./Kr.: Gesund

\section{Alter:}

Geschlecht:

Arthrose:

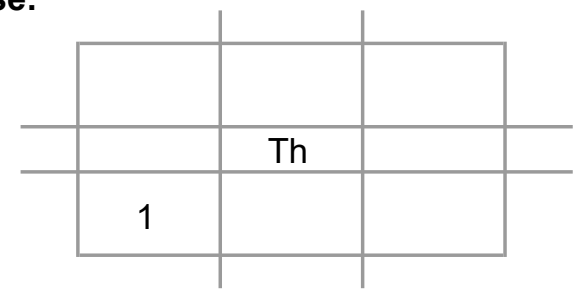

\section{Beschreibung:}

Wirbelfragment des Processus spinosus aus mittlerem thorakalen Bereich. 
Bezeichn.: Vertebra

Kiste: $\quad 8505720$

Skelet: $\quad 1.0$

Population: Calden
Verband: $\quad \square$ Verband

\section{Alter:}

Geschlecht:

Arthrose:

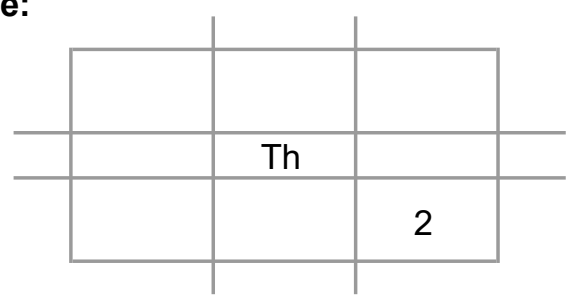

\section{Beschreibung:}


Bezeichn.: Vertebra

Kiste: $\quad 8505720$

Skelet: $\quad 1.0$

Population: Calden
Verband: $\quad \square$ Verband

Alter:

Geschlecht:

Arthrose:

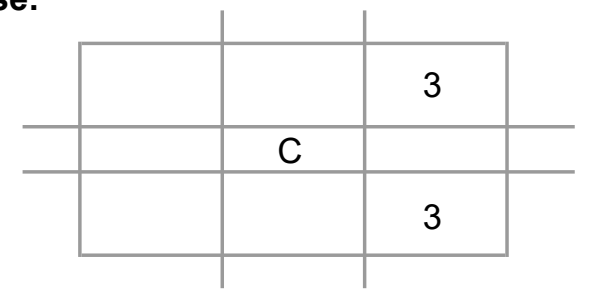

Ges./Kr.: Krank

Krankh.: Arthrose

\section{Beschreibung:}


Bezeichn.: Vertebra

Kiste: $\quad 8505720$

Skelet: $\quad 1.0$

Population: Calden
Verband: $\quad \square$ Verband

\section{Alter:}

Geschlecht:

Arthrose:

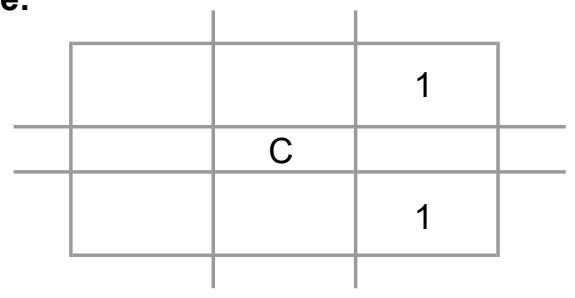

\section{Beschreibung:}




\section{Bezeichn.: Vertebra \\ Kiste: $\quad 8505720$ \\ Skelet: $\quad 1.0$}

Population: Calden

\section{Verband: $\quad \square$ Verband \\ Alter: Jung \\ Geschlecht:}

Arthrose:

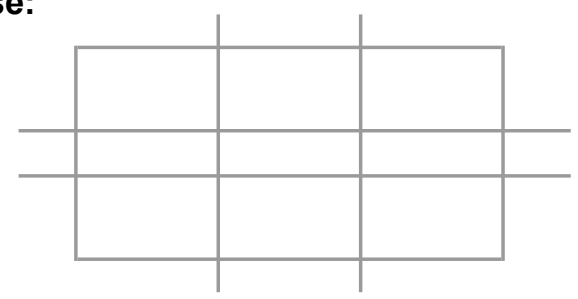

Maß

Breite

Länge

\begin{tabular}{l|l} 
Wert & Einheit \\
\hline 19,57 & $\mathrm{~mm}$
\end{tabular}

9,82

$\mathrm{mm}$

\section{Beschreibung:}

Dies ist der corpus eines sehr jungen Wirbels. Es konnte keine genaue Lokalisation festgestellt werden. 
Bezeichn.: Vertebra

Kiste: $\quad 8505720$

Skelet: $\quad 1.0$

Population: Calden
Verband: $\quad \square$ Verband $\quad$ Ges./Kr.: Gesund

\section{Alter: Jung}

Geschlecht:

Arthrose:

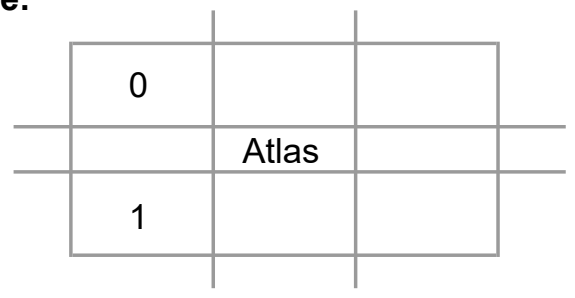

\section{Beschreibung:}

Ein Atlas eines jungen Individuums. 
Bezeichn.: Vertebra

Kiste: $\quad 8505720$

Skelet: $\quad 1.0$

Population: Calden
Verband: $\quad \square$ Verband

\section{Alter:}

Geschlecht:

Arthrose:

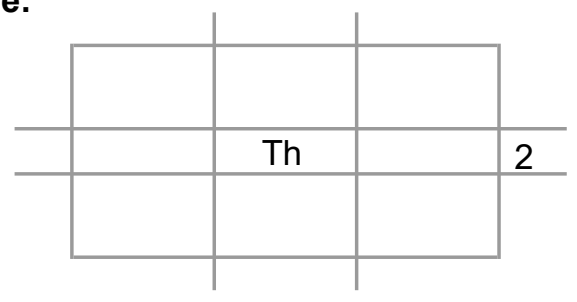

\section{Beschreibung:}


Bezeichn.: Vertebra

Kiste: $\quad 8505720$

Skelet: $\quad 1.0$

Population: Calden
Verband: $\quad$ Verband

\section{Alter:}

Geschlecht:

Arthrose:

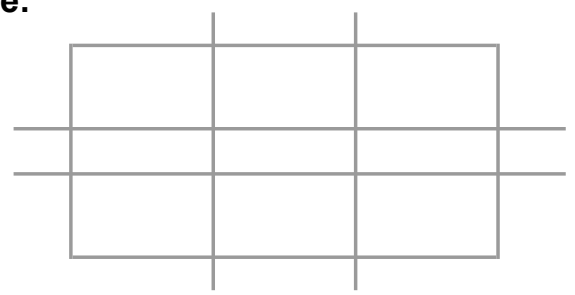

\section{Beschreibung:}


Bezeichn.: Vertebra

Kiste: $\quad 8505720$

Skelet: $\quad 1.2$

Population: Calden
Verband: $\quad \square$ Verband

\section{Alter:}

Geschlecht:

Arthrose:

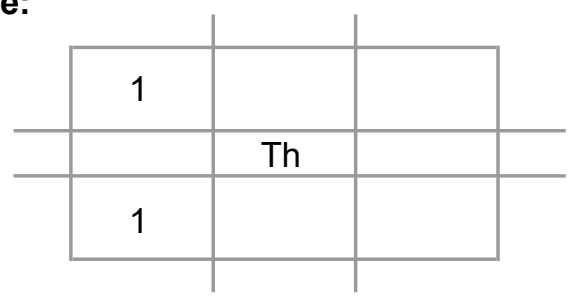

\section{Beschreibung:}


Bezeichn.: Vertebra

Kiste: $\quad 8505720$

Skelet: $\quad 1.2$

Population: Calden
Verband: $\quad \square$ Verband

\section{Alter:}

Geschlecht:

Arthrose:

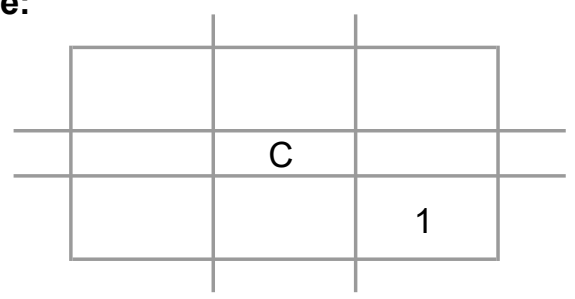

\section{Beschreibung:}


Bezeichn.: Vertebra

Kiste: $\quad 8505720$

Skelet: $\quad 1.2$

Population: Calden
Verband: $\square$ Verband

Alter:

Ges./Kr.: Gesund

\section{Geschlecht:}

Arthrose:

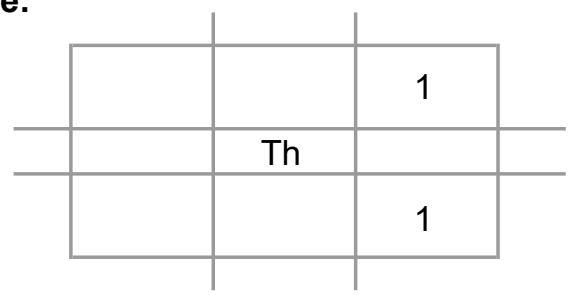

Beschreibung:

Ohne corpus erhalten. 
Bezeichn.: Vertebra

Kiste: $\quad 8505720$

Skelet: $\quad 1.2$

Population: Calden
Verband: $\quad \square$ Verband

Alter:

\section{Geschlecht:}

Arthrose:

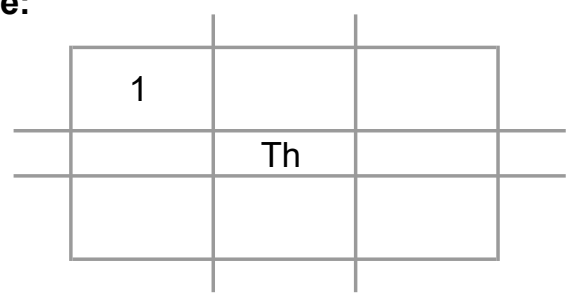

Beschreibung:

Ohne corpus erhalten. 
Bezeichn.: Vertebra

Kiste: $\quad 8505720$

Skelet: $\quad 1.2$

Population: Calden
Verband: $\quad \square$ Verband

\section{Alter:}

Geschlecht:

Arthrose:

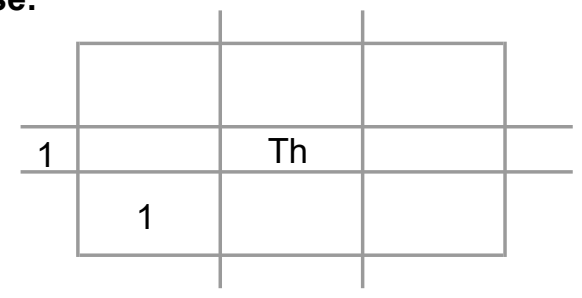

\section{Beschreibung:}


Bezeichn:: Vertebra

Kiste: $\quad 8505720$

Skelet: $\quad 1.2$

Population: Calden
Verband: $\quad \square$ Verband

\section{Alter:}

Geschlecht:

Arthrose:
Ges./Kr.: Krank

Krankh.: Arthritis

Arthrose

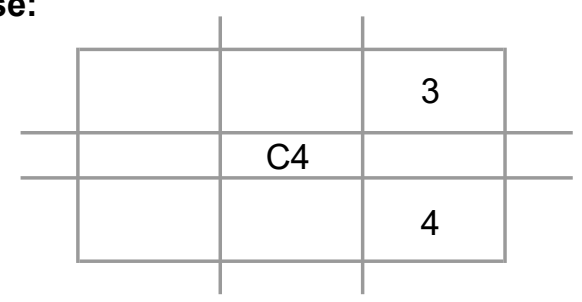

\section{Beschreibung:}

Der untere Gelenkfortsatz der linken Seite ist etwas eburniert. 
Bezeichn.: Vertebra

Kiste: $\quad 8505720$

Skelet: $\quad 1.2$

Population: Calden
Verband: $\quad \square$ Verband

Ges./Kr.: Gesund

\section{Geschlecht:}

Arthrose:

\begin{tabular}{|c|c|}
\hline 2 & 1 \\
\hline & $\mathrm{C} 7$ \\
\hline & 1 \\
\hline
\end{tabular}

\section{Beschreibung:}


Bezeichn.: Vertebra

Kiste: $\quad 8505720$

Skelet: $\quad 1.2$

Population: Calden
Verband: $\quad$ Verband

Alter:

Geschlecht:

Arthrose:
Ges./Kr.: Krank

Krankh.: Arthrose

Spondylophyten

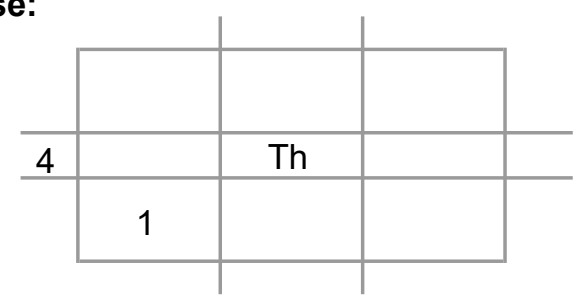

\section{Beschreibung:}

Ein Wirbel aus dem oberen thorakale Bereich, beim rechten Processus lateralis fallen hier kleine Spondylophyten auf. 
Bezeichn.: Vertebra

Kiste: $\quad 8505720$

Skelet: $\quad 1.2$

Population: Calden
Verband: $\quad \square$ Verband

Alter:

Geschlecht:

Arthrose:

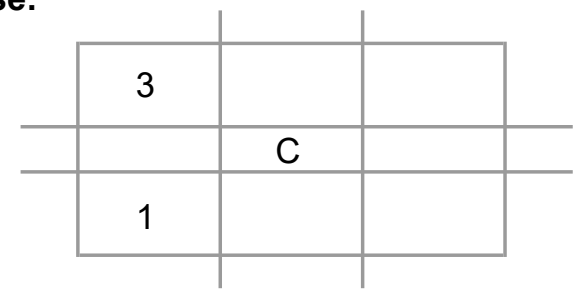

Ges./Kr.: Krank

Krankh.: Arthrose

\section{Beschreibung:}


Bezeichn.: Vertebra

Kiste: $\quad 8505720$

Skelet: $\quad 1.2$

Population: Calden
Verband: $\quad \square$ Verband

Ges./Kr.: Gesund

\section{Geschlecht:}

Arthrose:

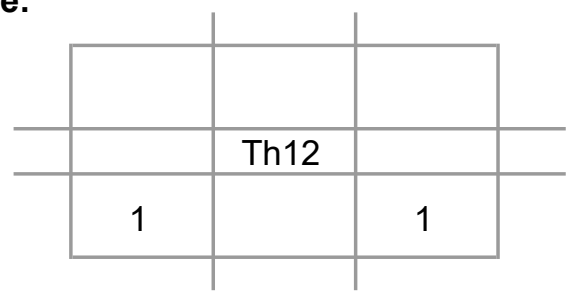

\section{Beschreibung:}


Bezeichn.: Vertebra

Kiste: 8505720

Skelet: $\quad 1.2$

Population: Calden
Verband: $\quad \square$ Verband

Alter:

Ges./Kr.: Gesund

\section{Geschlecht:}

Arthrose:

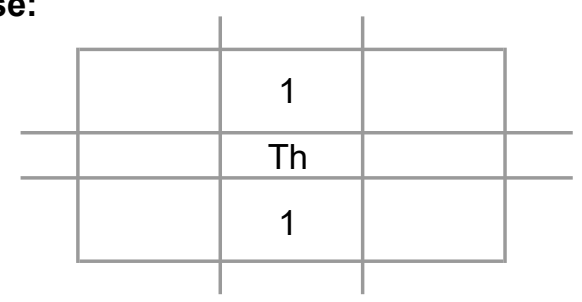

Beschreibung:

Hier ist nur ein Fragment des corpus erhalten 
Bezeichn.: Vertebra

Kiste: $\quad 8505720$

Skelet: einzeln 1.1

Population: Calden
Verband: $\square$ Verband

\section{Alter:}

Geschlecht:

Arthrose:
Ges./Kr.: Krank

Krankh.: Spondylitis

Spondylophyten

\begin{tabular}{|c|c|c|c|c|}
\hline & 2 & 3 & 2 & \\
\hline \multirow[t]{2}{*}{2} & & Th10 & & 2 \\
\hline & 3 & 4 & 3 & \\
\hline
\end{tabular}

\section{Beschreibung:}

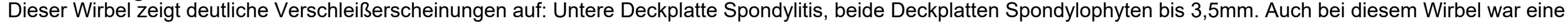
Zuordnung nicht eindeutig zu machen. 
Bezeichn.: Vertebra

Kiste: $\quad 8505720$

Skelet: einzeln 1.1

Population: Calden
Verband: $\square$ Verband

Ges./Kr.: Gesund

\section{Geschlecht:}

Arthrose:

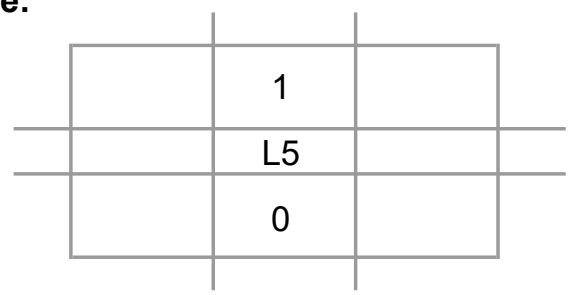

\section{Beschreibung:}


Bezeichn.: Vertebra

Kiste: 8505720

Skelet: einzeln 1.1

Population: Calden
Verband: Verband

\section{Alter:}

\section{Geschlecht:}

Arthrose:

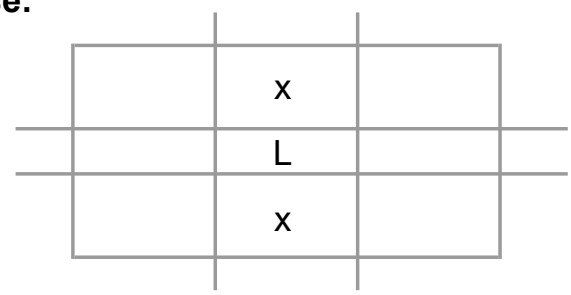

Beschreibung:

Sehr erodiert. 


\section{Bezeichn.: Vertebra \\ Kiste: \\ 8505720 \\ Skelet: \\ einzeln 1.1}

Population: Calden

\section{Verband: $\quad$ Verband}

\section{Alter:}

Geschlecht:

Arthrose:

\section{Ges./Kr.: Gesund}

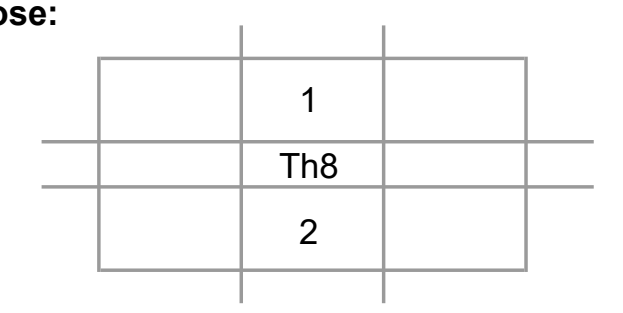

\section{Beschreibung:}

Bei diesem Vertebra ist nicht mehr als ein Teil des corpus erhalten, auf der unteren Deckplatte findet sich ein Loch. Dieses misst etwa 6,5mm x 4mm. Es ist an dieser Stelle eine intravitale Entstehung nicht auszuschließen. Durch starke Erosion des Randes des Defektes ist nicht eindeutig festzustellen, ob möglicherweise eine Spondylitis diesen Defekt verursachte, der aussieht wie eine lokalisierte Knochenatrophie. Die Deckplatten weisen allerdings eher wenige Spuren eines verschleißenden Prozesses auf. 


\section{Bezeichn: Vertebra \\ Kiste: \\ 8505720 \\ einzeln 1.1}

Population: Calden

\section{Verband: $\quad$ Verband Ges./Kr. Gesund}

\section{Alter: Jung}

Geschlecht:

Arthrose:

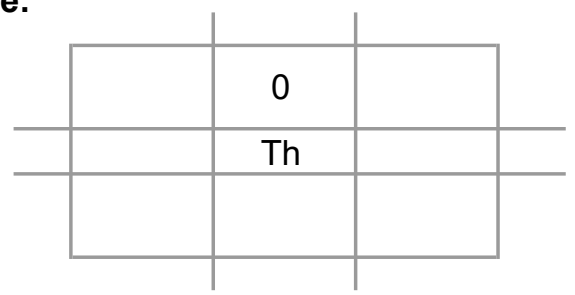

\section{Beschreibung:}

Ein Fragment eines thorakalen Wirbels, wovon nur die obere Deckplatte erhalten ist. Diese ist diagnostisch unauffällig. Die Oberflächenstruktur lässt zu, dass man hier über ein subadultes Alter diskutieren darf. 
Bezeichn:: Vertebra

Kiste: $\quad 8505720$

Skelet: $\quad 1.1$

Population: Calden
Verband: $\quad$ Verband

Alter:

Ges./Kr.: Krank

\section{Geschlecht:}

Arthrose:

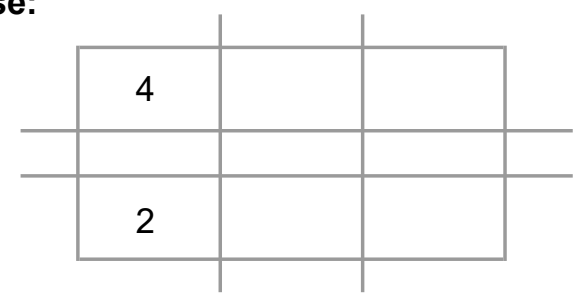

\section{Beschreibung:}

Hier sind die rechten Processus articulares erhalten. 
Bezeichn.: Vertebra

Kiste: $\quad 8505720$

Skelet: $\quad 1.3$

Population: Calden
Verband: $\square$ Verband

Ges./Kr.: Gesund

\section{Alter:}

Geschlecht:

Arthrose:

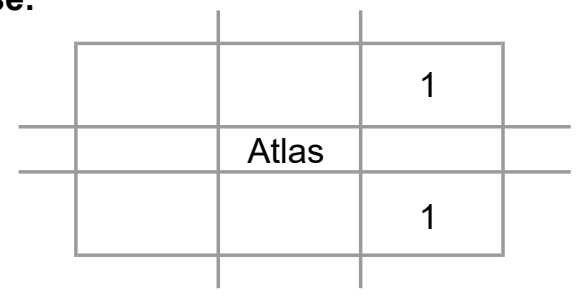

\section{Beschreibung:}

Ein Fragment eines Atlas, welches etwa zu etwa $40 \%$ erhalten ist. 
Bezeichn.: Vertebra

Kiste: $\quad 8505720$

Skelet: $\quad 1.3$

Population: Calden
Verband: $\quad \square$ Verband

Alter:

Geschlecht:

Arthrose:

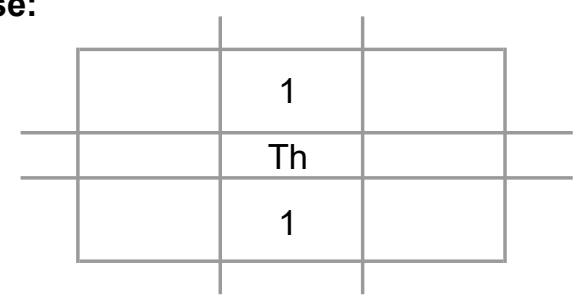

\section{Beschreibung:}

Nur der corpus ist hier erhalten. 
Bezeichn:: Vertebra

Kiste: $\quad 8505720$

Skelet: $\quad 1.3$

Population: Calden

\section{Verband: $\quad$ Verband Ges./Kr.: Krank}

Alter: Krankh.: Arthrose

\section{Geschlecht:}

Arthrose:

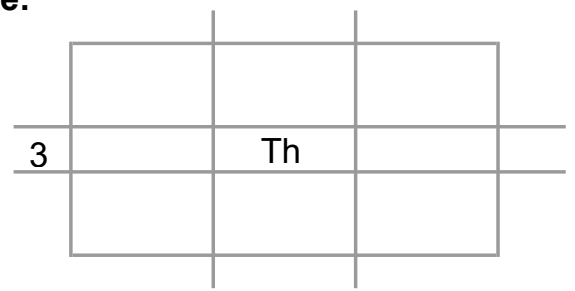

\section{Beschreibung:}

Bei diesem Fragment handelt es sich um einen rechten Querfortsatz eines thorakalen Wirbels. 
Bezeichn.: Vertebra

Kiste: $\quad 5249270$

Skelet: Zettel

Population: Calden
Verband: Verband

\section{Alter:}

Geschlecht:

Arthrose:

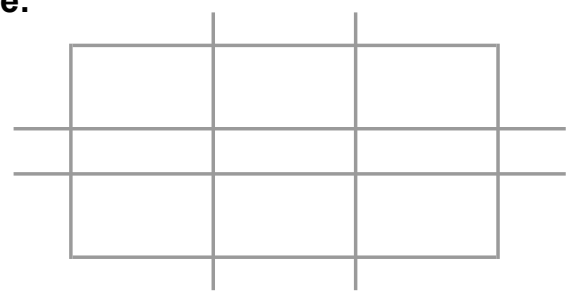

\section{Beschreibung:}


Bezeichn.: Vertebra

Kiste: $\quad 5255273$

Skelet: Zettel

Population: Calden
Verband: Verband Ges./Kr.: Krank

Alter: Krankh.: Spondylitis

\section{Geschlecht:}

Arthrose:

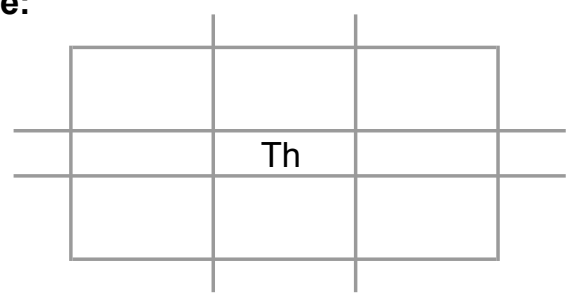

\section{Beschreibung:}


Bezeichn.: Vertebra

Kiste: $\quad 5267283$

Skelet: $\quad$ bei Schädel 5 in der Tüte

Population: Calden

\section{Verband: $\quad$ Verband Ges./Kr.: Gesund}

\section{Alter:}

Geschlecht: $q<\lesssim$

Arthrose:

\begin{tabular}{|c|c|c|}
\cline { 2 - 3 } \multicolumn{1}{c|}{} & & \multicolumn{1}{c|}{} \\
\hline 2 & & 2 \\
\hline 2 & 2 & 2 \\
\hline
\end{tabular}

\section{Beschreibung:}

Bei diesem Fundstück handelt es sich um einen vollständig erhaltenen Atlas eines wahrscheinlich männlichen Individuums. 


\section{Bezeichn: Vertebra \\ Kiste: $\quad 5242266$ \\ Skelet: 3. Tüte}

Population: Calden

\section{Verband: $\square$ Verband Ges./Kr.: Gesund}

\section{Alter: Jung}

\section{Geschlecht:}

Arthrose:

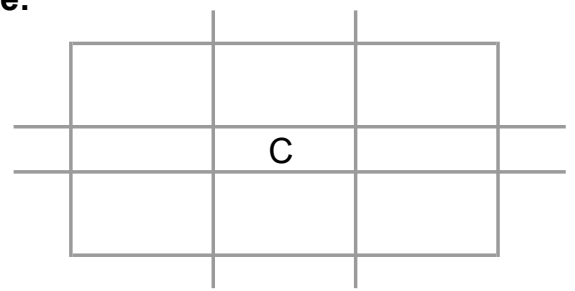

\section{Beschreibung:}

Hier ist ein cervikaler Wirbel eines jungen Individuums erhalten. 
Bezeichn.: Vertebra

\section{Kiste:}

5242266

Skelet: $\quad$ aus Tüte 1

Population: Calden

\section{Verband: $\quad$ Gerband $\quad$ Ges.: Gesund}

\section{Alter:}

Geschlecht:

Arthrose:

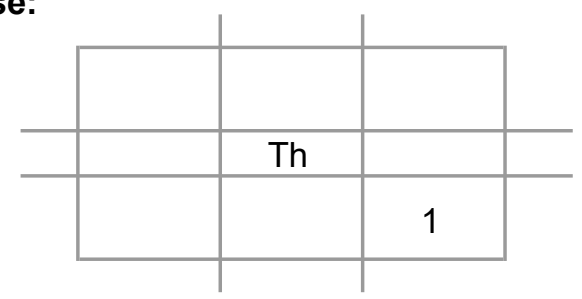

\section{Beschreibung:}

Von diesem thorakalen Wirbel aus dem thorakalen Bereich ist nur der Processus articularis superior der linken Seite erhalten. Die Gelenkfläche weist keinerlei Verschleißerscheinungen auf. 
Bezeichn.: Vertebra

Kiste:

5242266

Skelet: aus Tüte 1

Population: Calden

\section{Verband: $\square$ Verband Ges./Kr.: Gesund}

\section{Alter:}

Geschlecht:

Arthrose:

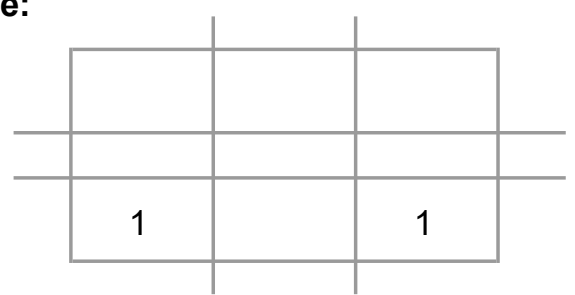

Beschreibung:

von diesem aus dem oberen Drittel der thorakalen Wirbelsäule stammenden Wirbel sind nur die Processus articulares inferiores und Processus spinosi zum Teil erhalten 
Bezeichn.: Vertebra

Kiste:

5242266

aus Tüte 1

Skelet:

Calden
Verband: $\quad$ Verband

Ges./Kr.: Gesund

\section{Alter:}

Geschlecht:

Arthrose:

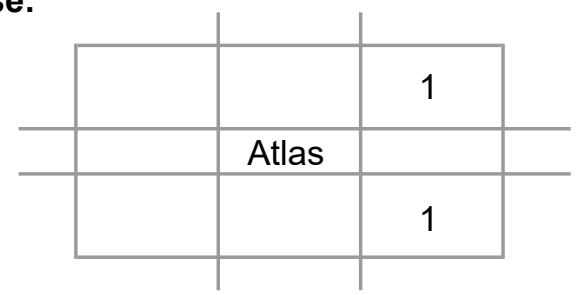

\section{Beschreibung:}

Es ist von diesem Atlas nur die linke Seite zum Teil erhalten. 
Bezeichn.: Vertebra

Kiste:

5242266

Skelet: aus Tüte 1

Population: Calden

\section{Verband: $\square$ Verband Ges./Kr.: Gesund}

\section{Alter:}

Geschlecht:

Arthrose:

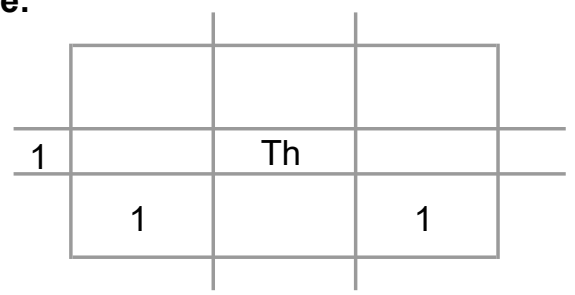

\section{Beschreibung:}

Von diesem mittig thorakal gelegenen Wirbel sind die Processus articulares inferiores, ein Teil des Processus spinosus und ein Teil des Processus transversus. 
Bezeichn.: Vertebra

Kiste:

5242266

$\begin{array}{ll}\text { Skelet: } & \text { aus Tüte } 1 \\ \text { Population: } & \text { Calden }\end{array}$
Verband: $\quad$ Verband

Ges./Kr.: Gesund

\section{Alter:}

Geschlecht:

Arthrose:

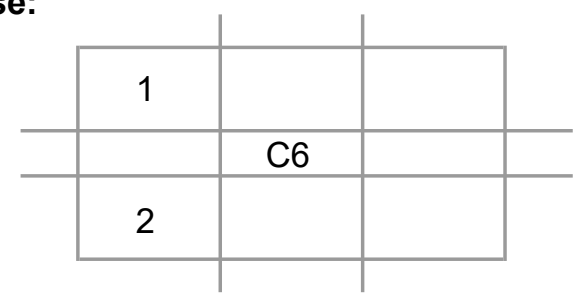

\section{Beschreibung:}

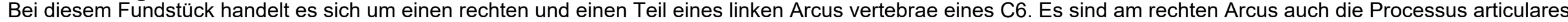
superior und inferior erhalten. 
Bezeichn.: Vertebra

Kiste:

5242266

aus Tüte 1

Population: Calden
Verband: $\quad \square$ Verband

Ges./Kr.: Gesund

\section{Alter:}

Geschlecht:

Arthrose:

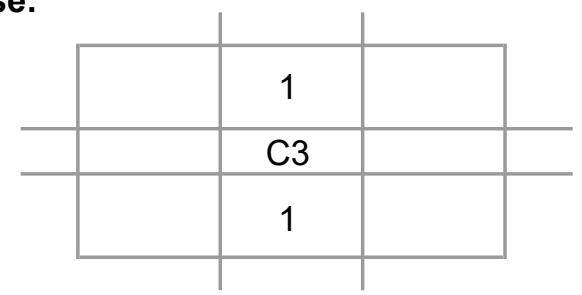

\section{Beschreibung:}

Hier ist nur der corpus und ein Teil des linken Arcus vertebrae erhalten 
Bezeichn.: Vertebra

Kiste:

5242266

Skelet: aus Tüte 1

Population: Calden
Verband: $\square$ Verband

Ges./Kr.: Gesund

\section{Alter:}

Geschlecht:

Arthrose:

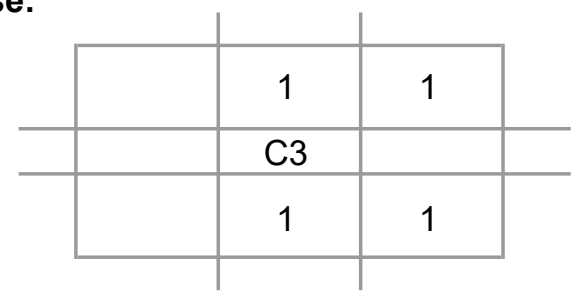

\section{Beschreibung:}

Ein Fragment eines Wirbels C3 mit linkem Arcus vertebrae und Processus articulares superior und inferior. 
Bezeichn.: Vertebra

Verband: $\quad$ Verband

Ges./Kr.: Gesund

Kiste: $\quad 5242266$

Skelet: aus Tüte 1

\section{Alter:}

\section{Geschlecht:}

Population: Calden

Arthrose:

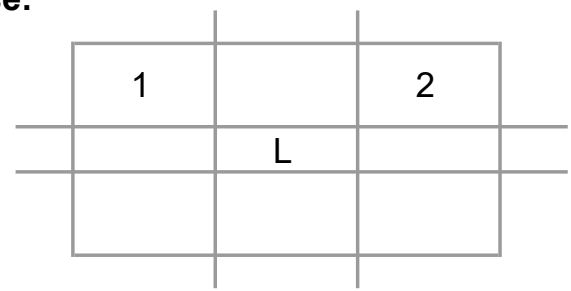

\section{Beschreibung:}

Fragmente eines linken und rechten Processus articularis superior und den anliegenden Processus articulares superiores eines lumbalen Wirbels. Das rechte Fragment enthält auch einen kleinen Teil der oberen Deckplatte und einen Processus articularis inferior, es besteht aus zwei Einzelfragmenten. 
Bezeichn.: Vertebra

Kiste:

5242266

$\begin{array}{ll}\text { Skelet: } & \text { aus Tüte } 1 \\ \text { Population: } & \text { Calden }\end{array}$
Verband: $\square$ Verband

Ges./Kr.: Gesund

\section{Alter:}

Geschlecht:

Arthrose:

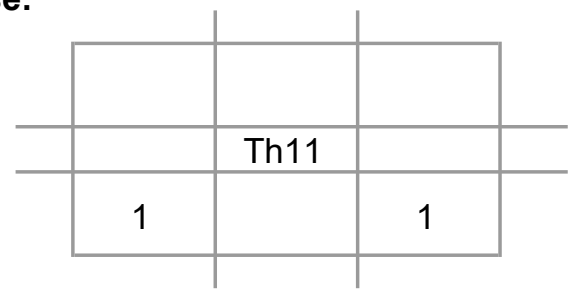

\section{Beschreibung:}

Es ist teilweise die Lamina Arcus vertebrae dieses Th11 erhalten. 


\section{Bezeichn: Vertebra \\ Kiste: $\quad 5242266$ \\ Skelet: aus Tüte 1}

Population: Calden
Verband: $\quad$ Verband

\section{Alter: Jung}

Geschlecht:

Arthrose:

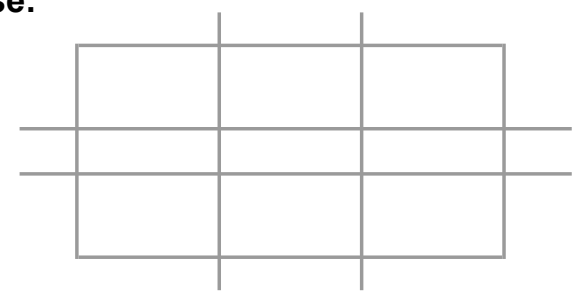

\section{Beschreibung:}

Es handelt sich hier um zwei kindliche Wirbel aus dem mittleren thorakalen Bereich. Sie weisen Erosionsspuren auf. 


\section{Bezeichn: Vertebra \\ Kiste: $\quad 5242266$ \\ Skelet: aus Tüte 1}

Population: Calden
Verband: $\quad$ Verband

\section{Alter: Jung}

Geschlecht:

Arthrose:

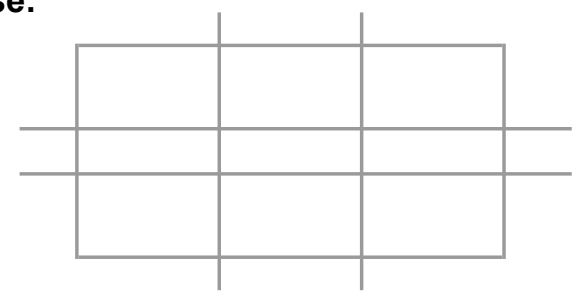

\section{Beschreibung:}

Es handelt sich hier um zwei kindliche Wirbel aus dem mittleren thorakalen Bereich. Sie weisen Erosionsspuren auf. 
Bezeichn:: Vertebra

Kiste: 5242266

Skelet: aus Tüte 1

Population: Calden
Verband: $\quad$ Verband

\section{Alter:}

\section{Geschlecht:}

Arthrose:
Ges./Kr.: Krank

Krankh.: Arthrose

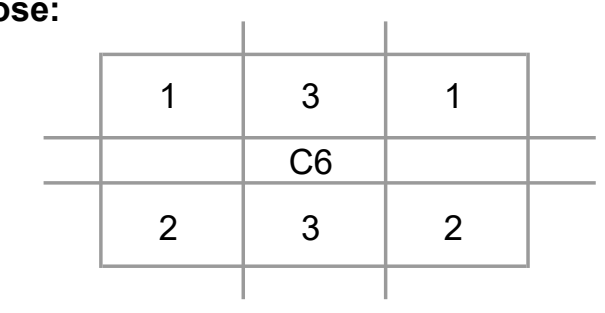

\section{Beschreibung:}

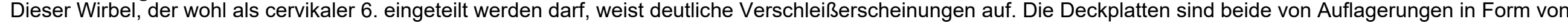

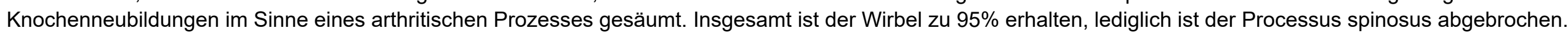


Bezeichn: Vertebra

Kiste:

5242266

Skelet: aus Tüte 1

Population: Calden

\section{Verband: $\quad$ Verband Ges./Kr.: Gesund}

\section{Alter: Jung}

Geschlecht:

Arthrose:

\begin{tabular}{|c|c|c|}
\cline { 2 - 3 } \multicolumn{1}{c||}{} & \multicolumn{1}{c|}{} & \multicolumn{1}{c}{} \\
\hline 0 & 00 & 0 \\
\hline & Th8 & \\
\hline 0 & 00 & 0 \\
\hline
\end{tabular}

\section{Beschreibung:}

Dies ist ein Wirbel aus dem mittleren thorakalen Bereich. Das Fundstück stammt von einem jungen Individuum, da hier die Deckplatten noch nicht vollständig verknöchert sind. 
$\begin{array}{ll}\text { Bezeichn.: } & \text { Vertebra } \\ \text { Kiste: } & 5242266 \\ \text { Skelet: } & \text { aus Tüte } 1\end{array}$

$\begin{array}{ll}\text { Skelet: } & \text { aus Tüte } \\ \text { Population: } & \text { Calden }\end{array}$

\section{Verband: $\quad$ Verband Ges./Kr.: Gesund}

\section{Alter:}

Geschlecht: $q>\AA$

Arthrose:

\begin{tabular}{c|c|c|c|c}
\cline { 2 - 4 } \multicolumn{1}{c|}{0} & 0 & 0 & \\
\hline 0 & & Th11 & & 0 \\
\hline & 1 & 0 & 0 & \\
\cline { 2 - 4 } & 1 & &
\end{tabular}

\section{Beschreibung:}

Dieser 11. thorakale Wirbel ist fast vollständig (98\%) erhalten und weist nur wenige Erosionsspuren auf. Es fallen keine weiteren Verschleißerscheinungen ins Auge. 
Bezeichn: Vertebr

Kiste:

5242266

Skelet:

V52 aus Tüte 1

Population: Calden

\section{Verband:}

\section{Alter:}

Ges./Kr.: Gesund

\section{Jung}

\section{Geschlecht:}

\section{Arthrose:}

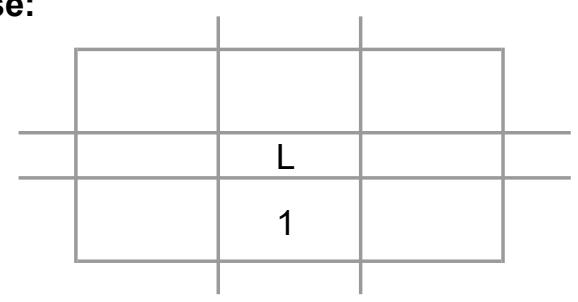

\section{Beschreibung:}

Dieser Verband aus 17 Wirbeln weist keine auffälligen Verschleißerscheinungen auf. Vielmehr wirken die überwiegend recht gut erhaltenen Wirbel ohne viel Erosionsspuren eher jung. Die Verknöcherung ist allem Anschein nach noch nicht allzu lange vor dem Zeitpunkt des Todes geschehen. Hin und wieder fehlten bei den Fundstücken einzelne Segmente, wie Gelenkfortsätze oder der Wirbelbogen. Der Größe nach - besonders der lumbalen Wirbel - ist dies eher ein weibliches Individuum gewesen. Es wird ein Zusammenhang zwischen allen gz1 angenommen, zumindest aber zwischen Os sacrum und diesem L5. Ein Zusammenhang für die gesamte Wirbelsäule darf aber angenommen werden, weil die Wirbel sich alle sehr ähnlich sehen und auch die Alterserscheinung miteinander übereinstimmen. Das Os sacrum ist zu 95\% erhalten, es fehlt lediglich der apex ossis sacri. Aufgrund der Form und Größe kann man sagen, dass es sich hier um ein männliches Individuum handelt. Es finden sich keine auffälligen Verschleißerscheinungen. Es dürfte sich um ein im Alter noch nicht sehr fortgeschrittenes Individuum handeln. 
Bezeichn.: Vertebra

Kiste:

5242266

aus Tüte 1

Population: Calden
Verband: $\quad$ Verband

Ges./Kr.: Gesund

Jung

Geschlecht:

Arthrose:

\begin{tabular}{|l|l|l|}
\multicolumn{1}{c||}{} & \multicolumn{1}{c|}{} \\
\hline 0 & 0 & 0 \\
\hline & $\mathrm{L}$ & \\
\hline & 0 & 0 \\
\hline
\end{tabular}

\section{Beschreibung:}

Hier sind 95\% eines Wirbels eines jungen Individuums erhalten. 
Bezeichn.: Vertebra

Kiste: $\quad 5242266$

Skelet: aus Tüte 1

Population: Calden
Verband: $\quad \square$ Verband

Alter: Erwachsen

Geschlecht:

Arthrose:

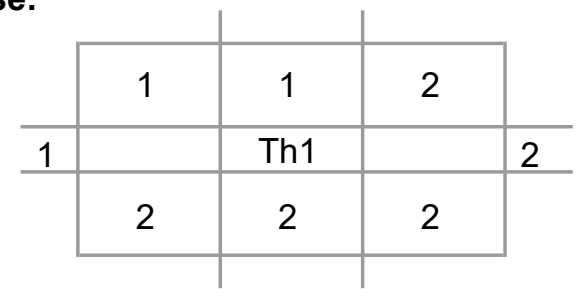

\section{Beschreibung:}

Dieser Wirbel ist vollständig und in gutem Erhaltungszustand erhalten. 
Bezeichn.: Vertebra

Kiste: 5242266

Skelet: aus Tüte 1

Population: Calden
Verband: $\quad$ Verband

Alter: Erwachsen

Geschlecht: $\delta$

Arthrose:

\begin{tabular}{|c|c|c|}
\cline { 2 - 3 } \multicolumn{1}{c|}{2} & 2 & 2 \\
\hline & C4 & \\
\hline 2 & 2 & 2 \\
\hline
\end{tabular}

Beschreibung:

Vollständig erhalten 


\begin{tabular}{|c|c|c|c|c|c|}
\hline \multirow{4}{*}{$\begin{array}{l}\text { Bezeichn.: } \\
\text { Kiste: } \\
\text { Skelet: } \\
\text { Population: }\end{array}$} & \multirow{4}{*}{$\begin{array}{l}\text { Vertebra } \\
5242266 \\
\text { V52 aus Tüte } 1 \\
\text { Calden }\end{array}$} & \multirow{4}{*}{$\begin{array}{l}\text { Verband: } \\
\text { Alter: } \\
\text { Geschlecht } \\
\text { Arthrose: }\end{array}$} & \multirow{2}{*}{\multicolumn{2}{|c|}{$\begin{array}{l}\square \text { Verband } \\
\text { Jung }\end{array}$}} & \\
\hline & & & & & \\
\hline & & & & & \\
\hline & & & & & \\
\hline & & & 1 & 1 & 1 \\
\hline & & & & C4 & \\
\hline & & & 1 & 1 & 1 \\
\hline
\end{tabular}

\section{Beschreibung:}

Dieser Verband aus 17 Wirbeln weist keine auffälligen Verschleißerscheinungen auf. Vielmehr wirken die überwiegend recht gut erhaltenen Wirbel ohne viel Erosionsspuren eher jung. Die Verknöcherung ist allem Anschein nach noch nicht allzu lange vor dem Zeitpunkt des Todes geschehen. Hin und wieder fehlten bei den Fundstücken einzelne Segmente, wie Gelenkfortsätze oder der Wirbelbogen. Der Größe nach - besonders der lumbalen Wirbel - ist dies eher ein weibliches Individuum gewesen. Es wird ein Zusammenhang zwischen allen gz1 angenommen, zumindest aber zwischen Os sacrum und diesem L5. Ein Zusammenhang für die gesamte Wirbelsäule darf aber angenommen werden, weil die Wirbel sich alle sehr ähnlich sehen und auch die Alterserscheinung miteinander übereinstimmen. Das Os sacrum ist zu 95\% erhalten, es fehlt lediglich der apex ossis sacri. Aufgrund der Form und Größe kann man sagen, dass es sich hier um ein männliches Individuum handelt. Es finden sich keine auffälligen Verschleißerscheinungen. Es dürfte sich um ein im Alter noch nicht sehr fortgeschrittenes Individuum handeln. 
Bezeichn.: Vertebra

\section{Kiste:}

5242266

Skelet: $\quad$ V52 aus Tüte 1

Population: Calden
Verband: $\quad$ Verband

\section{Alter:}

Geschlecht:

Arthrose:

\begin{tabular}{|c|c|c|}
\hline 1 & 1 & 1 \\
\hline & C6 & \\
\hline 1 & 1 & 1 \\
\hline
\end{tabular}

\section{Beschreibung:}

Ein Wirbel aus einem Verband. 
Bezeichn.: Vertebra

\section{Kiste:}

5242266

Skelet: $\quad$ V52 aus Tüte 1

Population: Calden
Verband: $\quad$ Verband

\section{Alter:}

Geschlecht:

Arthrose:

\begin{tabular}{|c|c|c|c|}
\hline & 1 & 0 & 2 \\
\hline \multirow[t]{3}{*}{2} & & Th1 & \\
\hline & 1 & 0 & 2 \\
\hline & 1 & 0 & 1.5 \\
\hline
\end{tabular}

\section{Beschreibung:}

Ein Wirbel aus einem Verband. 
Bezeichn.: Vertebra

Kiste: 5242266

Skelet: $\quad$ V52 aus Tüte 1

Population: Calden
Verband: $\quad$ Verband

\section{Alter:}

\section{Geschlecht:}

Arthrose:

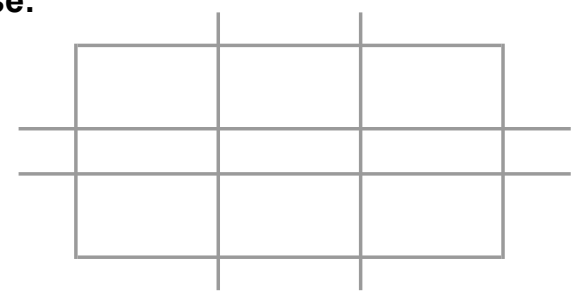

\section{Beschreibung:}

Ein kleines Wirbelfragment, welches zum Verband gehört. 
Bezeichn.: Vertebra

\section{Kiste:}

5242266

Skelet: $\quad$ V52 aus Tüte 1

Population: Calden
Verband: Verband

Ges./Kr.: Gesund

\section{Alter:}

Geschlecht:

Arthrose:

\begin{tabular}{l|c|c|c|c}
\multicolumn{1}{c|}{1} & 0 & 1.5 & \multicolumn{1}{c}{} \\
\cline { 2 - 4 } \multicolumn{1}{l|}{1} & 0 & 1 & \\
\hline 2 & & Th2 & & 2 \\
\hline & 1 & 1 & 1 & \\
\cline { 2 - 4 } & 1 & 0.5 & \multicolumn{2}{c}{}
\end{tabular}

\section{Beschreibung:}

Ein Wirbel aus einem Verband. 
Bezeichn.: Vertebra

\section{Kiste:}

5242266

Skelet: $\quad$ V52 aus Tüte 1

Population: Calden
Verband: $\quad$ Verband

\section{Alter:}

Geschlecht:

Arthrose:

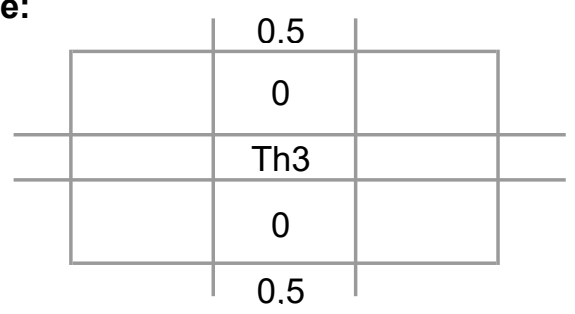

\section{Beschreibung:}

Ein Wirbel aus einem Verband. 
Bezeichn.: Vertebra

\section{Kiste:}

5242266

Skelet: $\quad$ V52 aus Tüte 1

Population: Calden
Verband: $\quad$ Verband

\section{Alter:}

Geschlecht:

Arthrose:

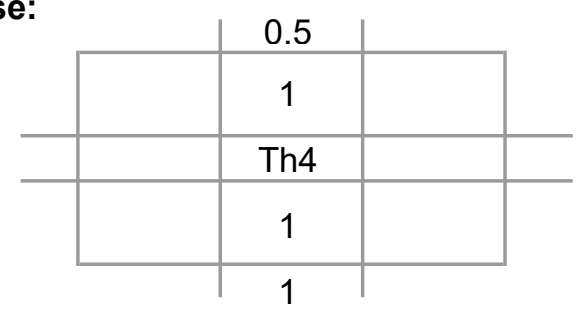

\section{Beschreibung:}

Ein Wirbel aus einem Verband. 
Bezeichn.: Vertebra

\section{Kiste:}

5242266

Skelet: $\quad$ V52 aus Tüte 1

Population: Calden
Verband: Verband

\section{Alter:}

Geschlecht:

Arthrose:

\begin{tabular}{|c|c|c|c|}
\hline & & 1 & \\
\hline & 1 & 1 & 1 \\
\hline \multirow[t]{2}{*}{1} & & Th5 & \\
\hline & 1 & 1 & 1 \\
\hline
\end{tabular}

\section{Beschreibung:}

Ein Wirbel aus einem Verband. 
Bezeichn.: Vertebra

\section{Kiste:}

5242266

Skelet: $\quad$ V52 aus Tüte 1

Population: Calden
Verband: Verband

\section{Alter:}

Geschlecht:

Arthrose:

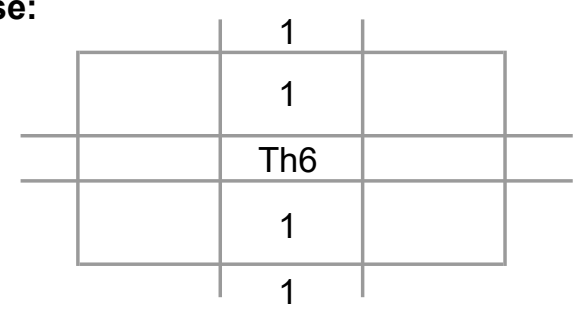

\section{Beschreibung:}

Ein Wirbel aus einem Verband. 
Bezeichn.: Vertebra

\section{Kiste:}

5242266

Skelet: $\quad$ V52 aus Tüte 1

Population: Calden
Verband: $\quad$ Verband

\section{Alter:}

\section{Geschlecht:}

Arthrose:

\begin{tabular}{|c|c|c|c|c|}
\hline & \multirow[b]{2}{*}{1} & 1 & \multicolumn{2}{|c|}{ ? } \\
\hline & & 1 & 1 & \\
\hline 1 & & Th7 & & 1 \\
\hline & 1 & 1 & 1 & \\
\hline & 1 & 1 & 1 & \\
\hline
\end{tabular}

Beschreibung:

Wirbel aus Verband. 
Bezeichn.: Vertebra

\section{Kiste:}

5242266

Skelet: $\quad$ V52 aus Tüte 1

Population: Calden
Verband:

Verband

Ges./Kr.: Gesund

\section{Alter:}

Geschlecht:

Arthrose:

\begin{tabular}{l|c|c|c|}
\multicolumn{1}{c|}{1} & 1 & 1 \\
\cline { 2 - 3 } & 1 & 1 & 1 \\
\hline & & Th8 & \\
\hline 1 & 1 & 1 \\
\hline 1 & 1 & 1
\end{tabular}

Beschreibung:

Wirbel aus Verband. 
Bezeichn.: Vertebra

\section{Kiste:}

5242266

Skelet: $\quad$ V52 aus Tüte 1

Population: Calden
Verband:

Verband

Ges./Kr.: Gesund

\section{Alter:}

Geschlecht:

Arthrose:

\begin{tabular}{l|c|c|c|}
\multicolumn{1}{c|}{1} & 1 & 1 \\
\cline { 2 - 4 } \multicolumn{1}{c|}{1} & 1 & 1 \\
\hline 1 & & Th9 & \\
\hline & 1 & 1 & 1 \\
\hline
\end{tabular}

Beschreibung:

Wirbel aus Verband. 
Bezeichn.: Vertebra

\section{Kiste:}

5242266

Skelet: $\quad$ V52 aus Tüte 1

Population: Calden
Verband:

Verband

Ges./Kr.: Gesund

\section{Alter:}

Geschlecht:

Arthrose:

\begin{tabular}{l|c|c|c|}
\multicolumn{1}{c|}{1} & 1 & 1 \\
\cline { 2 - 4 } & 1 & 1 & 1 \\
\hline & & Th10 & \\
\hline 1 & 1 & 1 \\
\hline
\end{tabular}

Beschreibung:

Wirbel aus Verband. 
Bezeichn.: Vertebra

\section{Kiste:}

5242266

Skelet: $\quad$ V52 aus Tüte 1

Population: Calden
Verband: $\quad$ Verband

\section{Alter:}

\section{Geschlecht:}

Arthrose:

\begin{tabular}{|c|c|c|}
\cline { 2 - 3 } \multicolumn{1}{c|}{} & \multicolumn{1}{c|}{} \\
\hline 1 & 1 & 1 \\
\hline 1 & 1 & 1 \\
\hline 1 & 1 & \multicolumn{1}{|c}{} \\
\hline
\end{tabular}

Beschreibung:

Wirbel aus Verband. 
Bezeichn.: Vertebra

\section{Kiste:}

5242266

Skelet: $\quad$ V52 aus Tüte 1

Population: Calden
Verband: $\quad$ Verband

\section{Alter:}

Geschlecht:

Arthrose:

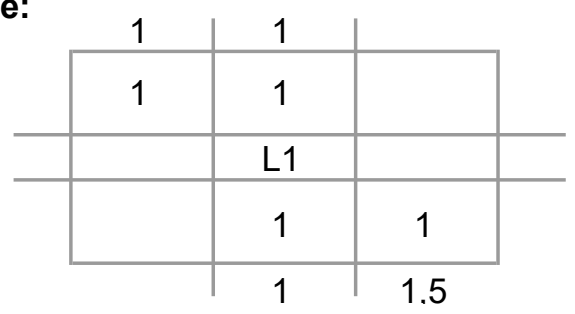

Beschreibung:

Wirbel aus Verband. 
Bezeichn.: Vertebra

\section{Kiste:}

5242266

Skelet: $\quad$ V52 aus Tüte 1

Population: Calden
Verband: $\quad$ Verband

Ges./Kr.: Gesund

\section{Alter:}

Geschlecht:

Arthrose:

\begin{tabular}{|c|c|c|}
\hline & 1 & 1.5 \\
\hline 2 & 1 & 2 \\
\hline & L2 & \\
\hline 2 & 2 & 1 \\
\hline
\end{tabular}

Beschreibung:

Wirbel aus Verband. 


$\begin{array}{llll}\text { Bezeichn.: } & \text { Vertebra } & \text { Verband: } \square \text { Verband } \\ \text { Kiste: } & 8505718 & \text { Alter: } & 7-14 \\ \text { Skelet: } & \text { aus Kiste } & \text { Geschlecht: }\end{array}$

Population: Calden Arthrose:

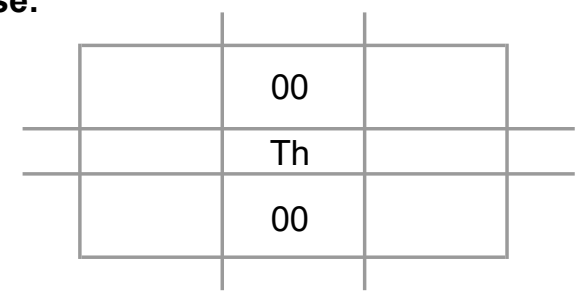

\section{Beschreibung:}

Ein caudaler Brustwirbel, der einem jungen Individuum zuzuordnen ist. 
$\begin{array}{ll}\text { Bezeichn.: } & \text { Vertebra } \\ \text { Kiste: } & 8505718 \\ \text { Skelet: } & \text { aus Kiste }\end{array}$

Skelet: aus Kistation: Calden
Verband: $\quad$ Verband

\section{Alter: $\quad 7-14$}

Geschlecht:

Arthrose:

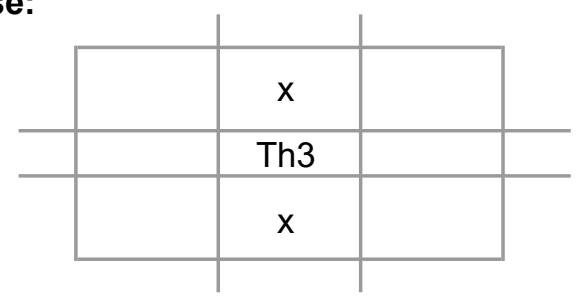

\section{Beschreibung:}

Hier sind der corpus und der linke Wirbelbogen erhalten. 
Bezeichn:: Vertebra

Kiste: $\quad 8505718$

Skelet: $\quad$ aus Kiste

Population: Calden

\section{Verband: $\quad$ Verband Ges./Kr.: Krank}

Alter: $15-18 \quad$ Krankh.: Fraktur

\section{Geschlecht:}

Arthrose:

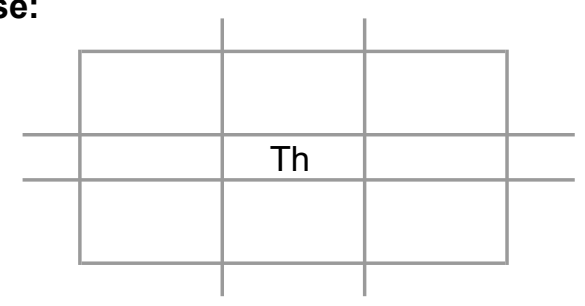

\section{Beschreibung:}

Es handelt sich hier um einen caudalen Brustwirbel oder einen Lendenwirbel. Das Fragment ist gezeichnet von einer Wachstumsirritation durch traumatisierende Einwirkung. Dies zeigt sich am Rand des corpus des Wirbels. 
$\begin{array}{ll}\text { Bezeichn.: } & \text { Vertebra } \\ \text { Kiste: } & 8505718 \\ \text { Skelet: } & \text { aus Kiste }\end{array}$

Skelet: aus Kiste

\section{Verband: $\quad$ Verband Ges./Kr: Gesund}

\section{Alter:}

Geschlecht:

Arthrose:

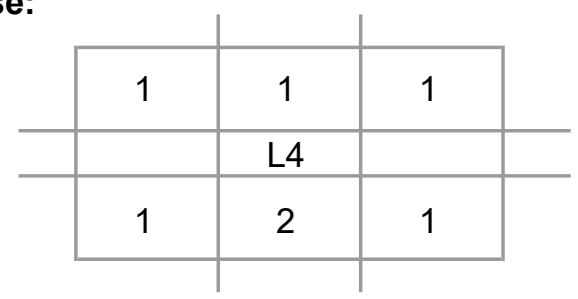

\section{Beschreibung:}

Bei diesem lumbalen Wirbel ist der linke Teil des corpus weggebrochen, außerdem könnte es zu kleinen Einbrüchen zwischen diesem und dem darunter liegenden Wirbel gekommen sein. 
Bezeichn.: Vertebra

Kiste: $\quad 8505718$

Skelet: aus Kiste

Population: Calden
Verband: $\quad \square$ Verband

Ges./Kr.: Gesund

Geschlecht:

Arthrose:

\begin{tabular}{c|c|c|c|c}
\multicolumn{1}{c|}{2} & \multicolumn{2}{c}{} \\
\cline { 2 - 4 } \multicolumn{1}{c|}{2} & 1 & 2 & \\
\hline 2 & & Th12 & & 2 \\
\hline & 1 & 1 & 1 & \\
\cline { 2 - 4 } & & & \multicolumn{2}{c}{}
\end{tabular}

\section{Beschreibung:}

Dieser zwölfte Brustwirbel ist vollständig erhalten. 
$\begin{array}{ll}\text { Bezeichn.: } & \text { Vertebra } \\ \text { Kiste: } & 8505718 \\ \text { Skelet: } & \text { aus Kiste }\end{array}$

Population: Calden

\section{Verband: $\quad$ Verband Ges./Kr.: Krank}

Alter: Krankh.: Spondylophyten

\section{Geschlecht:}

Arthrose:

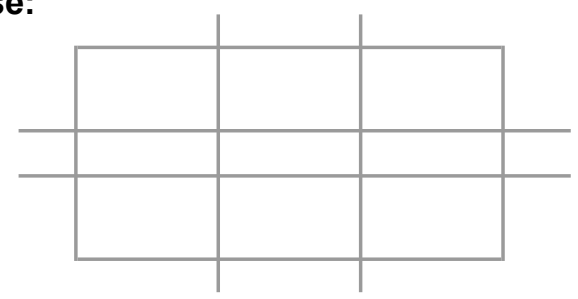

\section{Beschreibung:}

Bei diesem Wirbel sind nur etwa $90 \%$ des corpus erhalten. Die Oberseite weist einen Spondylophyt auf (16mm x 5,5mm). Die Unterseite ist wegen Oberflächenerosion nicht befundbar. Eine genaue Zuordnung war nicht möglich. 
Bezeichn:: Vertebra

Kiste: $\quad 8505718$

Skelet: $\quad$ V39

Population: Calden

\author{
Verband: $\quad \square$ Verband \\ Alter: $\quad 30-50$
}

Geschlecht: $\circ<\hat{0}$

Arthrose:
Ges./Kr.: Krank

Krankh.: Arthrose

Spondylitis

Spondylophyten

\begin{tabular}{c|c|c|c|c}
\cline { 2 - 4 } \multicolumn{1}{c|}{2} & 4 & 2 & \\
\hline 3 & & Th10 & & 4 \\
\hline & 2 & 4 & 2 & \\
\cline { 2 - 4 } 2 & 4 & 2 &
\end{tabular}

\section{Beschreibung:}

Dieser 10. thorakale Wirbel zeigt deutliche Verschleißerscheinungen, auch am Costo - vertebral Gelenk. Der Wirbel hat regelmäßig am Corpus Spondylophyten bis 4,2mm Breite. 
Bezeichn:: Vertebra

Kiste: $\quad 8505718$

Skelet: V39

Population: Calden

\author{
Verband: $\quad \square$ Verband \\ Alter: $\quad 30-50$
}

Geschlecht: $q<\hat{0}$

Arthrose:

\begin{tabular}{c|c|c|c|c}
\multicolumn{1}{c|}{2} & 4 & 2 & \multicolumn{1}{c}{2} \\
\cline { 2 - 4 } \multicolumn{1}{l|}{2} & 4 & 2 & \\
\hline 3 & & Th11 & & 3 \\
\hline & & 4 & & \\
\cline { 2 - 4 } & & 3.5 & 3 & \multicolumn{1}{c}{3}
\end{tabular}

Ges./Kr.: Krank

Krankh.: Arthrose

Spondylophyten

\section{Beschreibung:}

Dieser 11. thorakale Wirbel weist Spondylophyten bis $8 \mathrm{~mm}$ unten und $6 \mathrm{~mm}$ oben am Corpus auf. Weiterhin ist eine Spondylitis oben und unten zu diagnostizieren. 


\section{Bezeichn: Vertebra \\ Kiste: $\quad 8505718$ \\ Skelet: V39}

Population: Calden
Verband: $\quad \square$ Verband
Alter: $\quad 30-50$
Geschlecht: $q<\hat{0}$
Ges./Kr.: Krank
Krankh.: Arthrose
Spondylophyten

Arthrose:

\begin{tabular}{|c|c|c|c|c|}
\hline & 2 & 3.5 & 3 & \\
\hline & 2 & 3 & 3 & \\
\hline 4 & & Th12 & & 4 \\
\hline & 1 & 3 & 2 & \\
\hline
\end{tabular}

\section{Beschreibung:}

Dieser zwölfte thorakale Wirbel zeigt deutliche Verschleißerscheinungen an den Costo-vertebral Gelenken auf. Weiterhin fallen Spondylophyten bis 5,2mm oben und 4,2mm unten ins Auge. 


\section{Bezeichn: Vertebra \\ Kiste: $\quad 8505718$ \\ Skelet: V39}

Population: Calden

\section{Verband: $\quad$ Verband Ges./Kr.: Krank}

Alter: Krankh.: Arthrose

\section{Geschlecht:}

Arthrose:

\begin{tabular}{|c|c|c|}
\cline { 2 - 3 } \multicolumn{1}{c|}{3} & 2 & 1 \\
\hline & Th8 & \\
\hline 1 & 3 & 2 \\
\hline
\end{tabular}

\section{Beschreibung:}

Dieser Wirbel ist wohl ein thorakaler der Nummer 8. Die Zuordnung ist jedoch nicht eindeutig. Es zeigen sich Spuren einer Spondylitis an der Unterseite des Wirbelcorpus. 


\section{Bezeichn: Vertebra \\ Kiste: $\quad 8505718$ \\ Skelet: V39}

Population: Calden

\section{Verband: $\quad$ Verband Ges./Kr.: Krank}

Alter: Krankh.: Arthrose

\section{Geschlecht:}

Arthrose:

\begin{tabular}{c|c|c|c|}
\multicolumn{1}{c|}{3} & \multicolumn{1}{c|}{} \\
\cline { 2 - 4 } \multicolumn{1}{c|}{3} & 1 & 3 \\
\hline 3 & & Th4 & \\
\hline & 2 & & 3 \\
\cline { 2 - 3 }
\end{tabular}

\section{Beschreibung:}

Es handelt sich hier wohl um einen Wirbel Th4, wobei die Zuordnung nicht eindeutig möglich war. Es zeigen sich deutliche Verschleißerscheinungen am Costo - vertebral Gelenk. 
Bezeichn.: Vertebra

Kiste: $\quad 5252271$

Skelet: V38

Population: Calden
Verband: $\quad$ Verband

\section{Alter:}

Geschlecht: ${ }^{\pi}$

Arthrose:

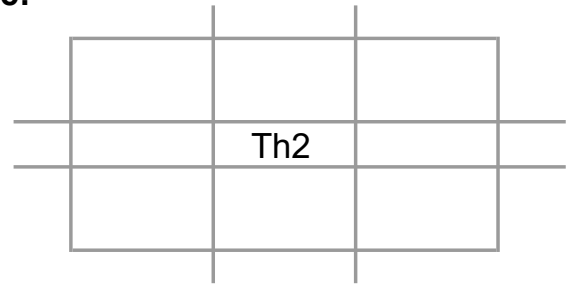

Beschreibung:

Wirbel aus Verband. 
Bezeichn:: Vertebra

Kiste: $\quad 5252271$

Skelet: V38

Population: Calden

\section{Verband: $\quad$ Verband Ges./Kr.: Krank}

Alter: Krankh.: Spondylophyten

\section{Geschlecht:}

Arthrose:

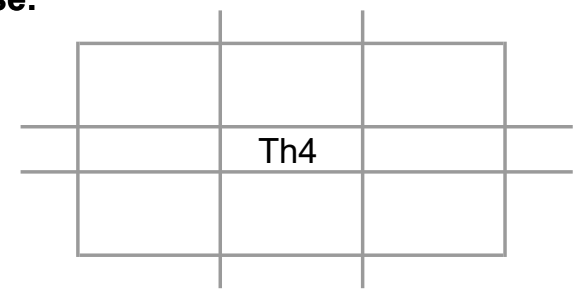

\section{Beschreibung:}

Dieser thorakale Wirbel weist Verschleißerscheinungen auf: Neubildungen am Rand im Sinne von Spondylophyten. 
Bezeichn.: Vertebra

Kiste: $\quad 5252271$

Skelet: V38

Population: Calden
Verband: $\square$ Verband

\section{Alter:}

Geschlecht:

Arthrose:

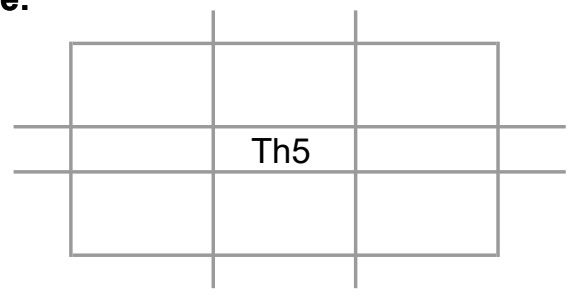

Beschreibung:

Wirbel aus Verband. 
Bezeichn.: Vertebra

Kiste: $\quad 5252271$

Skelet: V38

Population: Calden
Verband: $\square$ Verband

\section{Alter:}

Geschlecht:

Arthrose:

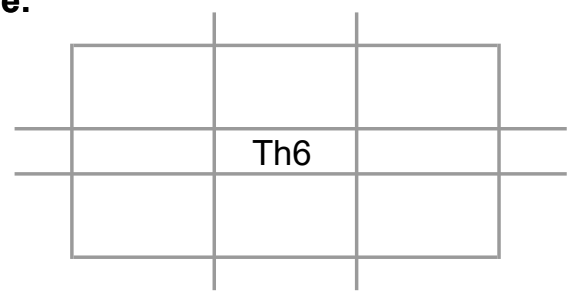

Beschreibung:

Wirbel aus Verband. 
Bezeichn.: Vertebra

Kiste: $\quad 5252271$

Skelet: V38

Population: Calden
Verband: $\square$ Verband

\section{Alter:}

Geschlecht:

Arthrose:

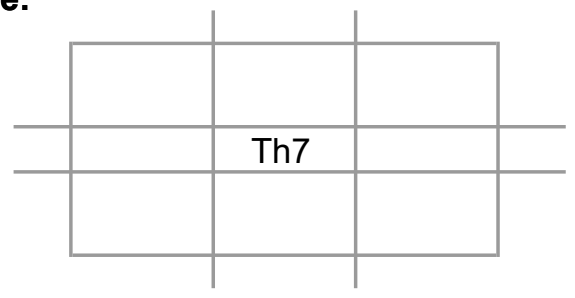

Beschreibung:

Wirbel aus Verband. 
Bezeichn.: Vertebra

Kiste: $\quad 5252271$

Skelet: V38

Population: Calden
Verband: $\quad$ Verband

\section{Alter:}

Geschlecht:
Ges./Kr.: Krank

Krankh.: Arthritis

Arthrose

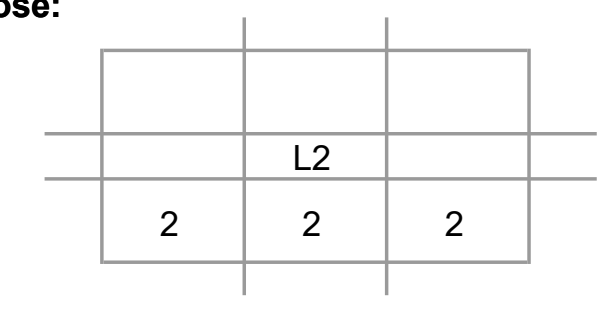

\section{Beschreibung:}

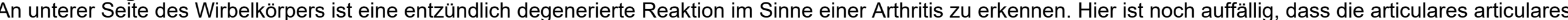
inferiores ungleichmäßig hoch liegen. 
Bezeichn.: Vertebra

Kiste: $\quad 5252271$

Skelet: V38

Population: Calden
Verband: $\quad$ Verband

Alter:

Geschlecht:

Arthrose:

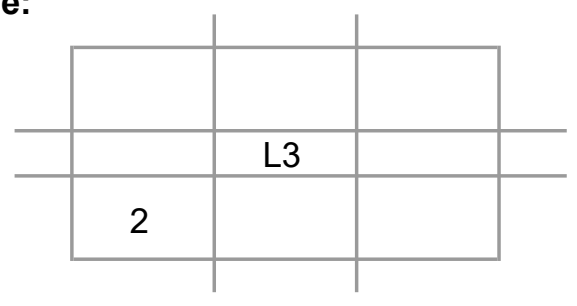

Beschreibung:

Wirbel aus Verband. 
Bezeichn:: Vertebra

Kiste: $\quad 5252271$

Skelet: V38

Population: Calden

\section{Verband: $\quad$ Verband Ges./Kr.: Krank}

Alter: Krankh.: Arthrose

Geschlecht:

Arthritis

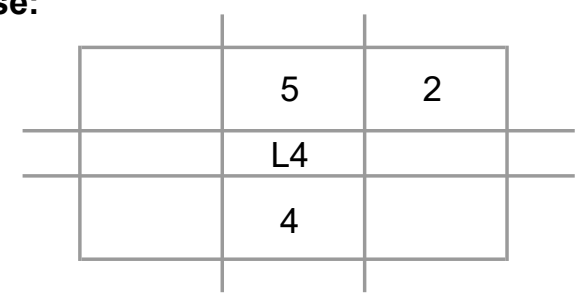

\section{Beschreibung:}

Dieser Wirbel weist folgende Verschleißerscheinungen auf: Die obere Wirbelkörperfläche weist Neubildungen am Rand auf und untere Seite ist konkav geformt. 
Bezeichn.: Vertebra

Kiste: $\quad 5252271$

Skelet: V38

Population: Calden
Verband: $\square$ Verband

\section{Alter:}

Ges./Kr.: Krank

\section{Geschlecht:}

Arthrose:

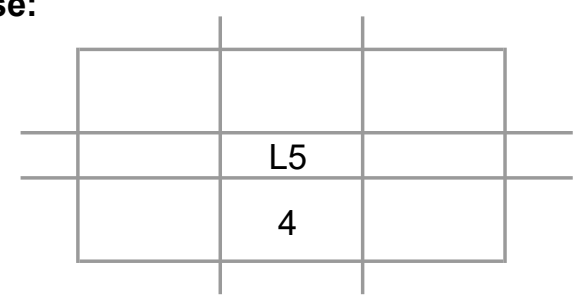

\section{Beschreibung:}

Wirbel aus Verband. 


\section{Bezeichn: Vertebra \\ Kiste: $\quad 5243267$ \\ Skelet: Zettel}

Population: Calden
Verband: Verband

\section{Alter:}

Geschlecht:

Arthrose:

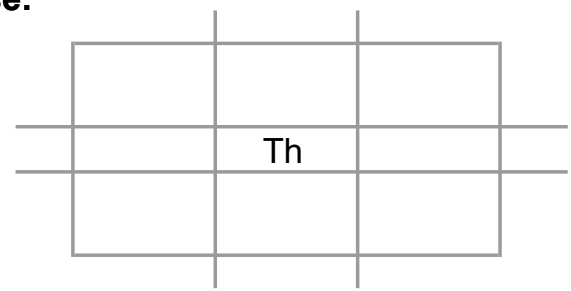

\section{Beschreibung:}

Ein thorakaler Wirbel aus dem mittleren Bereich. 
Bezeichn.: Vertebra

Kiste: 5243267

Skelet: Zettel

Population: Calden
Verband: Verband

\section{Alter:}

Geschlecht:

Arthrose:

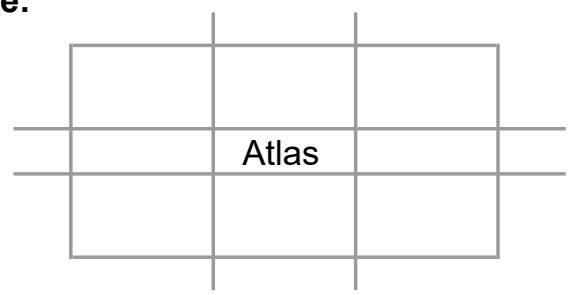

\section{Beschreibung:}


Bezeichn.: Vertebra

Kiste: 5243267

Skelet: Zettel

Population: Calden
Verband: Verband

\section{Alter:}

Geschlecht:

Arthrose:

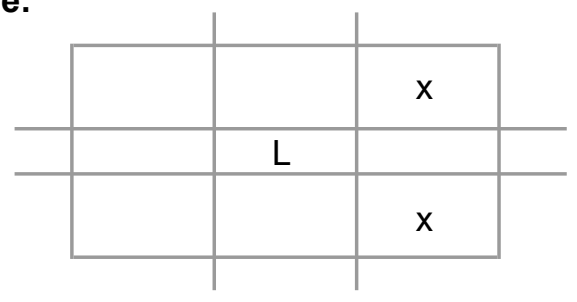

\section{Beschreibung:}


Bezeichn.: Vertebra

Verband: $\quad \square$ Verband

Ges./Kr.: Krank

Kiste: $\quad 5243267$

\section{Alter:}

Geschlecht:

\section{Arthrose:}

\begin{tabular}{l|c|c|c|}
\cline { 2 - 3 } & 1 & 3 & 1 \\
\hline & & L1 & \\
\hline 1 & 0 & 1 \\
\hline
\end{tabular}

\section{Beschreibung:}

Bei diesem Fundstück handelt es sich um einen lumbalen Wirbel der Nummer 1. Das Alter dieses Individuums ist wohl noch nicht so hoch gewesen, da die

Verschleißerscheinungen sehr gering sind. Auffällig ist jedoch eine etwas eingedrückte Deckplatte oben. Hier könnte während des Wachstums eine Überbelastung statt gefunden haben, die zu der sichtbaren Fraktur der oberen Deckplatte geführt hat. Diese Überbelastung könnte durch eine harte Landung auf den Füßen nach einem Sprung zustande gekommen sein. dabei wurde der discus intervertebralis verschoben und drückte sich mit dem Kern in den Wirbelkörper, was eine sichtbare Impression hinterließ. Durch die Vorwärtsverlagerung des Th12 ist dann ein Abrutschen nach anterior geschehen, welches diese Fraktur hinterließ. 
Bezeichn.: Vertebra

Kiste: $\quad 5256274$

Skelet: V34 8.

Population: Calden
Verband: $\quad \square$ Verband

\section{Alter:}

Geschlecht:

Arthrose:

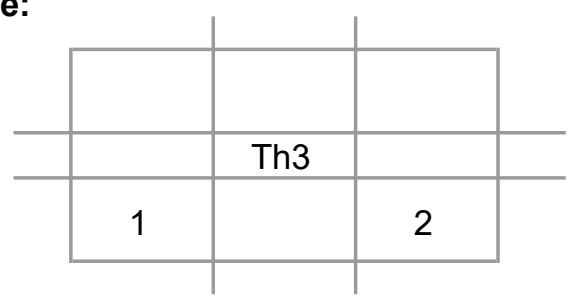

\section{Beschreibung:}


Bezeichn.: Vertebra

Kiste: $\quad 5256274$

Skelet: V34 8.

Population: Calden
Verband: $\quad \square$ Verband

\section{Alter:}

Geschlecht:

Arthrose:

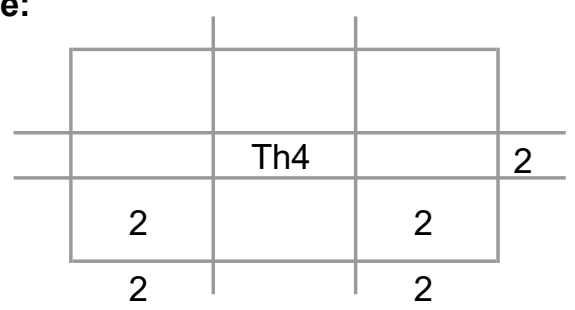

\section{Beschreibung:}


Bezeichn:: Vertebra

Kiste: $\quad 5256274$

Skelet: V34 8.

Population: Calden
Verband: $\quad$ Verband

Ges./Kr.: Gesund

\section{Alter:}

Geschlecht:

Arthrose:

\begin{tabular}{|c|c|c|c|}
\hline 2 & & 2 & \\
\hline 2 & & 2 & \\
\hline & Th5 & & 2 \\
\hline 2 & 1 & 2 & \\
\hline 2 & 1 & 2 & \\
\hline
\end{tabular}

\section{Beschreibung:}


Bezeichn:: Vertebra

Kiste: $\quad 5256274$

Skelet: V34 8.

Population: Calden
Verband: $\quad \square$ Verband

Ges./Kr.: Gesund

\section{Geschlecht:}

Arthrose:

\begin{tabular}{l|c|c|c|c}
\multicolumn{1}{c|}{2} & 1 & 2 & \multicolumn{1}{c}{ e: } \\
\cline { 2 - 4 } & 2 & 1 & 2 & \\
\hline & & Th6 & & 1 \\
\hline 2 & 1 & 2 & \\
\cline { 1 - 3 } 2 & 1 & 1.5 &
\end{tabular}

\section{Beschreibung:}


Bezeichn.: Vertebra

Kiste: $\quad 5256274$

Skelet: V34 8.

Population: Calden
Verband: Verband

\section{Alter:}

Geschlecht:

Arthrose:

\begin{tabular}{l|c|c|c}
\multicolumn{1}{l|}{} & 1 & 1.5 & \multicolumn{1}{c}{} \\
\cline { 2 - 3 } & 1 & 1 & \\
\hline & Th7 & & 2 \\
\hline & 1 & 2 & \\
\hline & & 1.5 &
\end{tabular}

\section{Beschreibung:}


Bezeichn:: Vertebra

Kiste: $\quad 5256274$

Skelet: V34 8.

Population: Calden
Verband: $\quad \square$ Verband

Ges./Kr.: Gesund

\section{Geschlecht:}

Arthrose:

\begin{tabular}{|c|c|c|c|}
\hline & & 1.5 & \\
\hline 1 & & 1 & \\
\hline & Th8 & & 2 \\
\hline 2 & 1 & 2 & \\
\hline 2 & 1 & 2 & \\
\hline
\end{tabular}

\section{Beschreibung:}


Bezeichn.: Vertebra

Kiste: $\quad 5256274$

Skelet: V34 8.

Population: Calden
Verband: $\square$ Verband

Ges./Kr.: Gesund

\section{Alter:}

Geschlecht:

Arthrose:

\begin{tabular}{l|c|c|c|c}
\multicolumn{1}{l|}{2} & 1 & 2 & \multicolumn{1}{c}{} \\
\cline { 2 - 4 } \multicolumn{2}{c|}{2} & 1 & 2 & \\
\hline & & Th9 & & 2 \\
\hline 2 & 2 & 2 & \\
& 2 & 1.5 & 2 &
\end{tabular}

\section{Beschreibung:}


Bezeichn.: Vertebra

Kiste: $\quad 5256274$

Skelet: V34 8.

Population: Calden
Verband: $\quad$ Verband

Ges./Kr.: Gesund

\section{Alter:}

Geschlecht:

Arthrose:

\begin{tabular}{l|c|c|c|c}
\multicolumn{1}{c|}{2} & 1.5 & 2 & \multicolumn{1}{c}{} \\
\cline { 2 - 4 } & 2 & 1 & 2 & \\
\hline & & Th10 & & 2 \\
\hline 2 & 2 & 2 & \\
& 2 & 1.5 & 2 &
\end{tabular}

\section{Beschreibung:}


Bezeichn.: Vertebra

Kiste: $\quad 5256274$

Skelet: V34 8.

Population: Calden
Verband: $\quad$ Verband

Ges./Kr.: Gesund

\section{Alter:}

Geschlecht:

Arthrose:

\begin{tabular}{l|c|c|c|}
\cline { 2 - 3 } \multicolumn{1}{l|}{2} & 1.5 & 2 \\
\hline & 2 & 1 & 2 \\
\hline & & Th11 & \\
\hline 2 & 1 & 2 \\
\hline 2 & 1 & 2
\end{tabular}

\section{Beschreibung:}


Bezeichn.: Vertebra

Kiste: $\quad 5256274$

Skelet: V34 8.

Population: Calden
Verband: $\square$ Verband

Ges./Kr.: Krank

\section{Alter:}

Krankh.: Arthrose

\section{Geschlecht:}

Arthrose:

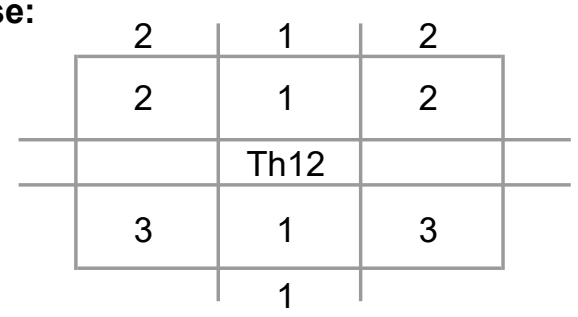

\section{Beschreibung:}


Bezeichn.: Vertebra

Kiste: $\quad 5256274$

Skelet: V34 8.

Population: Calden

\section{Verband: $\quad$ Verband Ges./Kr.: Krank}

Alter: Krankh.: Arthrose

\section{Geschlecht:}

Arthrose:

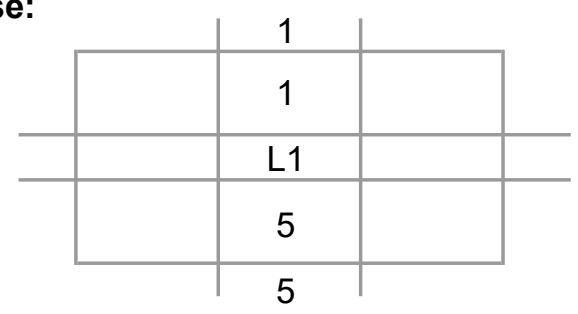

\section{Beschreibung:}




\section{Bezeichn: Vertebra \\ Kiste: \\ 5256274 \\ Skelet: \\ V34 8.}

Population: Calden
Verband: $\square$ Verband

\section{Alter:}

Geschlecht:

Arthrose:
Ges./Kr.: Krank

Krankh.: Arthrose

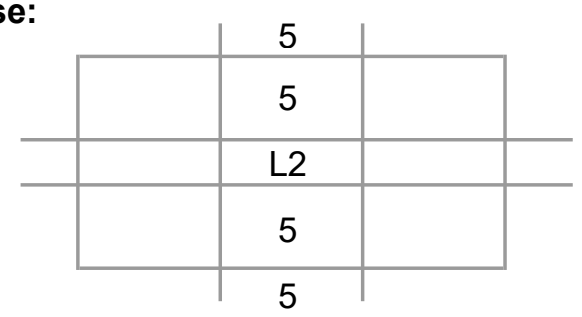

\section{Beschreibung:}

Dieser Verband aus 14 Wirbeln und einem kleinen Fragment des Os sacrum ist zum Teil recht gut, teilweise jedoch nur fragmentiert und erodiert erhalten. Auffällig sind die Wirbel L1 und L2, weil hier die Wirbel synostesiert sind. Dies muss durch eine zuvor erlittene Fraktur im Sinne einer axialen Überbelastung geschehen sein, zum Beispiel bei einem Sprung auf einen harten Boden. Die Lokalisation der Fraktur und der zusammengewachsenen Stelle ist typisch bei Überbelastungen. Die Wirbelkörper sind in einem Winkel von etwa $80^{\circ}$ nach anterior zusammengesintert. Da leider einige Teile der Wirbel fehlen, ist nicht klar, wie die Deckplatten beschaffen waren. An den anderen Wirbelkörpern sind keine Auffälligkeiten zu verzeichnen.

Es können auch Th12, L1, L2 zusammengesintert sein. Möglicherweise sind es 3 Fragmente, bzw.

eher L1, L2, L3 
Bezeichn.: Vertebra

Kiste: $\quad 5256274$

Skelet: V34 8.

Population: Calden

\section{Verband: $\quad$ Verband Ges./Kr.: Krank}

Alter: Krankh.: Arthrose

\section{Geschlecht:}

Arthrose:

\begin{tabular}{|c|c|c|}
\cline { 2 - 3 } \multicolumn{1}{c|}{} & 5 & \\
\hline 3 & 5 & \\
\hline & L3 & \\
\hline 1 & 1 & 1 \\
\hline 1.5 & 1.5 & 1.5
\end{tabular}

\section{Beschreibung:}


Bezeichn:: Vertebra

Kiste: $\quad 5256274$

Skelet: V34 8.

Population: Calden
Verband: $\quad$ Verband

Ges./Kr.: Gesund

\section{Alter:}

Geschlecht:

Arthrose:

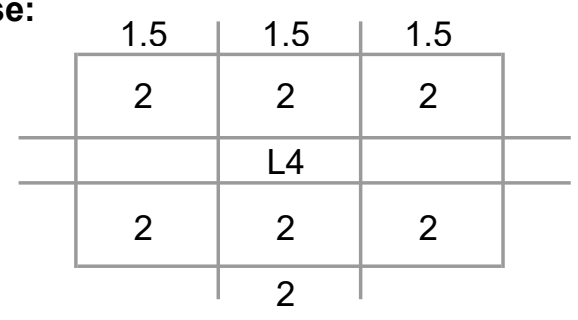

\section{Beschreibung:}


Bezeichn.: Vertebra

Kiste: $\quad 5256274$

Skelet: $\quad$ V34 8.

Population: Calden
Verband: Verband

\section{Alter:}

Geschlecht:

Arthrose:

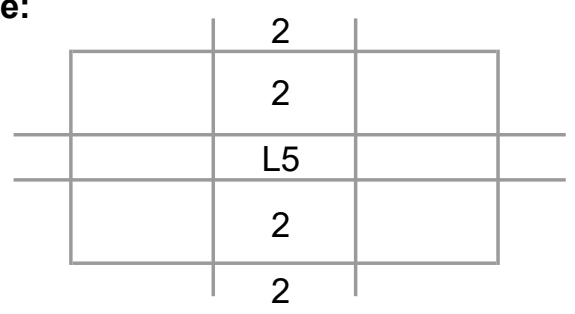

\section{Beschreibung:}


Bezeichn.: Vertebra

Kiste: 5273291

Skelet: V71 Schädel 8

Population: Calden
Verband: $\quad \square$ Verband

Ges./Kr.: Gesund

\section{Geschlecht:}

Arthrose:

\begin{tabular}{|c|c|c|}
\cline { 2 - 3 } \multicolumn{1}{c|}{} & & \multicolumn{1}{c|}{} \\
\hline 1 & & 1 \\
\hline 1 & 1 & 1 \\
\hline 1 & 1 & 1
\end{tabular}

\section{Beschreibung:}


Bezeichn.: Vertebra

Kiste: 5273291

Skelet: V71 Schädel 8

Population: Calden
Verband: $\square$ Verband

Ges./Kr.: Gesund

\section{Alter:}

Geschlecht:

Arthrose:

\begin{tabular}{l|c|c|c|}
\multicolumn{1}{c|}{1} & 1 & 1 \\
\cline { 2 - 4 } & 1 & 1 & 1 \\
\hline & & Axis & \\
\hline 1 & 1 & 1 \\
\hline
\end{tabular}

\section{Beschreibung:}

Wirbel aus Verband. 
Bezeichn.: Vertebra

Kiste: 5273291

Skelet: V71 Schädel 8

Population: Calden
Verband: $\quad \square$ Verband

Ges./Kr.: Gesund

\section{Geschlecht:}

Arthrose:

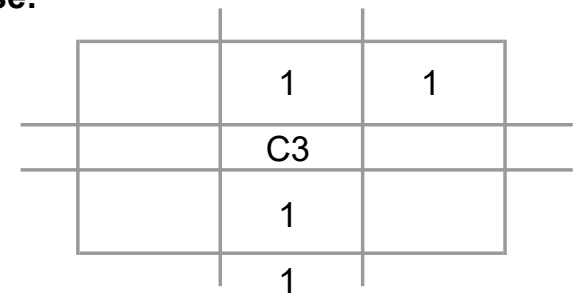

\section{Beschreibung:}

Wirbel aus Verband. 
Bezeichn.: Vertebra

Kiste: 5273291

Skelet: V71 Schädel 8

Population: Calden
Verband: $\square$ Verband

Ges./Kr.: Gesund

\section{Alter:}

Geschlecht:

Arthrose:

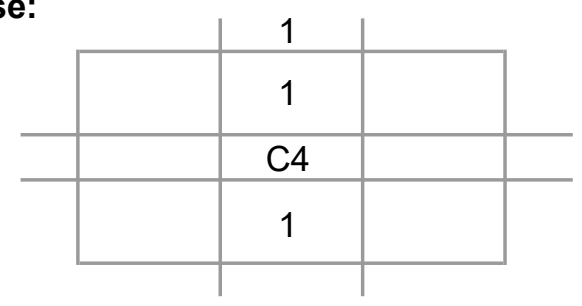

\section{Beschreibung:}

Wirbel aus Verband. 
Bezeichn.: Vertebra

Kiste: 5273291

Skelet: V71 Schädel 8

Population: Calden
Verband: $\quad$ Verband

Ges./Kr.: Gesund

\section{Geschlecht:}

Arthrose:

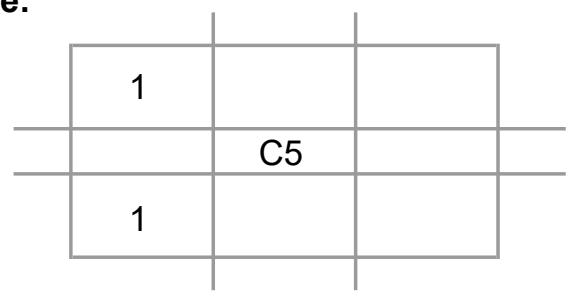

\section{Beschreibung:}

Wirbel aus Verband. 
Bezeichn.: Vertebra

Kiste: 5273291

Skelet: V71 Schädel 8

Population: Calden
Verband: $\quad$ Verband

\section{Alter:}

Geschlecht:

Arthrose:

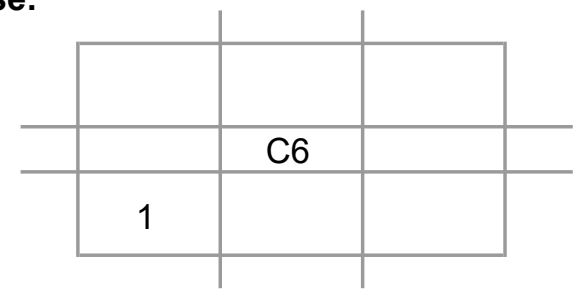

Beschreibung:

Wirbel aus Verband. 
Bezeichn.: Vertebra

Kiste: 5273291

Skelet: Ersatzteile 15

Population: Calden
Verband: $\quad$ Verband

\section{Alter:}

Ges./Kr.: Krank

\section{Geschlecht:}

Arthrose:

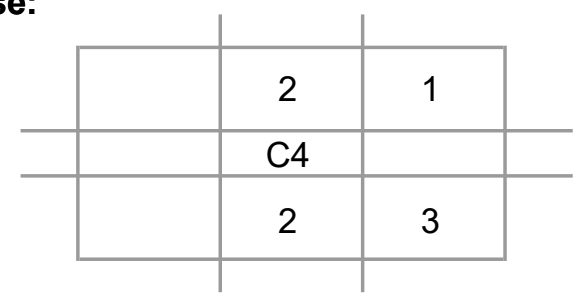

\section{Beschreibung:}


Bezeichn:: Vertebra

Kiste: $\quad 5273291$

Skelet: UK 13 \& Teile 2x;5y

Population: Calden
Verband: $\square$ Verband

\section{Alter:}

Geschlecht:

Arthrose:

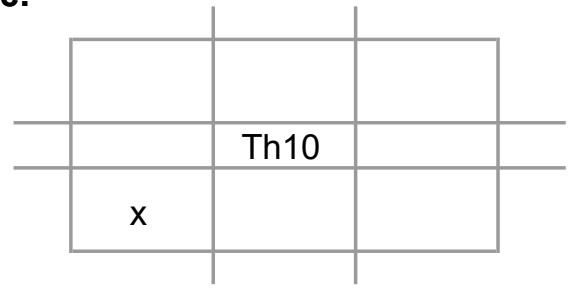

\section{Beschreibung:}


Bezeichn.: Vertebra

Kiste: $\quad 5261277$

Skelet: $\quad$ V33 kleine Tüte

Population: Calden
Verband: Verband

Alter: Erwachsen

\section{Geschlecht:}

Arthrose:

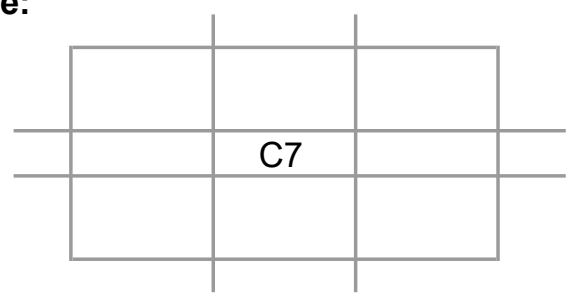

Beschreibung:

Wirbel aus Verband. 
Bezeichn: Vertebra

\section{Kiste: $\quad 5261277$}

Skelet: $\quad$ V33 kleine Tüte

Population: Calden
Verband: Verband

Alter: Erwachsen

\section{Geschlecht:}

Arthrose:

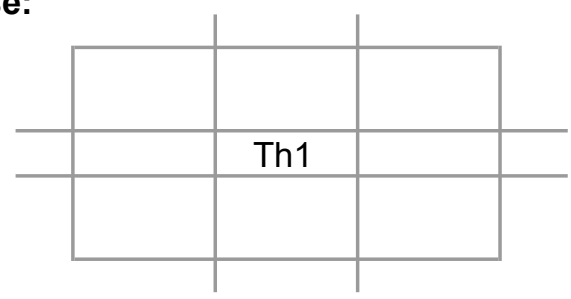

Beschreibung:

Wirbel aus Verband. 
Bezeichn.: Vertebra

Kiste: $\quad 5261277$

Skelet: V33 kleine Tüte

Population: Calden
Verband: $\quad$ Verband

Alter: Erwachsen

\section{Geschlecht:}

Arthrose:

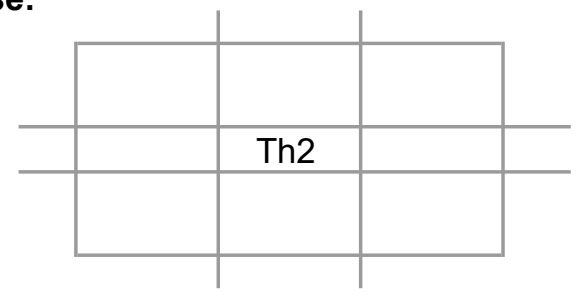

\section{Beschreibung:}

Wirbel aus Verband. 
Bezeichn.: Vertebra

Kiste: $\quad 5261277$

Skelet: V33 kleine Tüte

Population: Calden
Verband: $\quad$ Verband

Alter: Erwachsen

\section{Geschlecht:}

Arthrose:

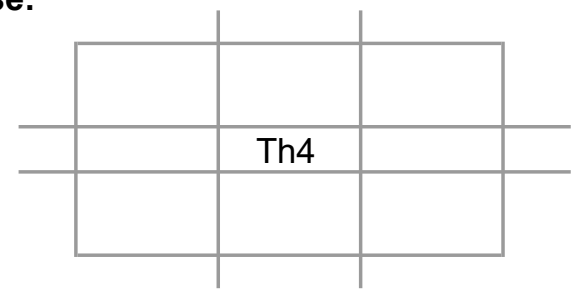

\section{Beschreibung:}

Wirbel aus Verband. 
Bezeichn.: Vertebra

Kiste: $\quad 5261277$

Skelet: V33 kleine Tüte

Population: Calden
Verband: $\quad$ Verband

Alter: Erwachsen

\section{Geschlecht:}

Arthrose:

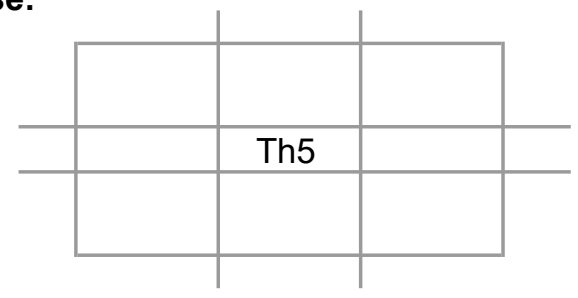

\section{Beschreibung:}

Wirbel aus Verband. 
Bezeichn: Vertebra

\section{Kiste: $\quad 5261277$}

Skelet: $\quad$ V33 kleine Tüte

Population: Calden
Verband: Verband

Alter: Erwachsen

\section{Geschlecht:}

Arthrose:

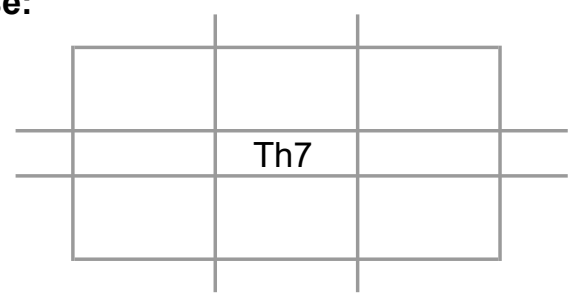

Beschreibung:

Wirbel aus Verband. 
Bezeichn.: Vertebra

Kiste: $\quad 5261277$

Skelet: V33 kleine Tüte

Population: Calden
Verband: $\quad$ Verband

Alter: Erwachsen

\section{Geschlecht:}

Arthrose:

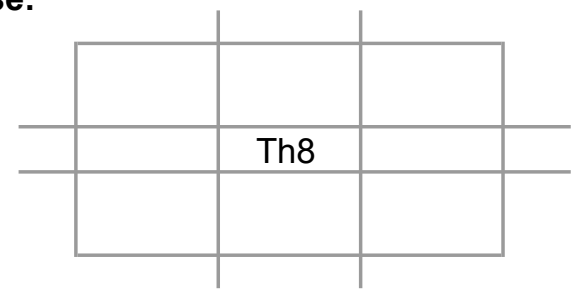

\section{Beschreibung:}

Wirbel aus Verband. 
Bezeichn: Vertebra

\section{Kiste: $\quad 5261277$}

Skelet: $\quad$ V33 kleine Tüte

Population: Calden
Verband: Verband

Alter: Erwachsen

\section{Geschlecht:}

Arthrose:

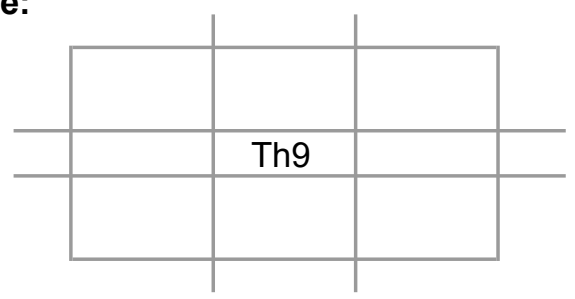

Beschreibung:

Wirbel aus Verband. 
Bezeichn: Vertebra

\section{Kiste: $\quad 5261277$}

Skelet: $\quad$ V33 kleine Tüte

Population: Calden
Verband: Verband

Alter: Erwachsen

\section{Geschlecht:}

Arthrose:

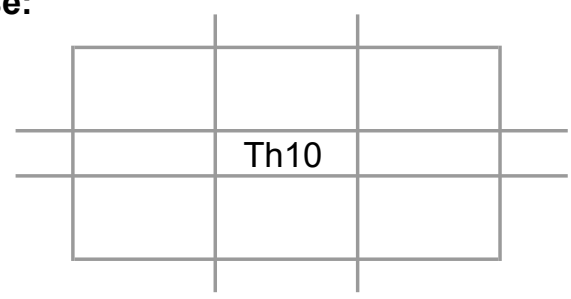

Beschreibung:

Wirbel aus Verband. 
Bezeichn: Vertebra

\section{Kiste: $\quad 5261277$}

Skelet: $\quad$ V33 kleine Tüte

Population: Calden
Verband: Verband

Alter: Erwachsen

\section{Geschlecht:}

Arthrose:

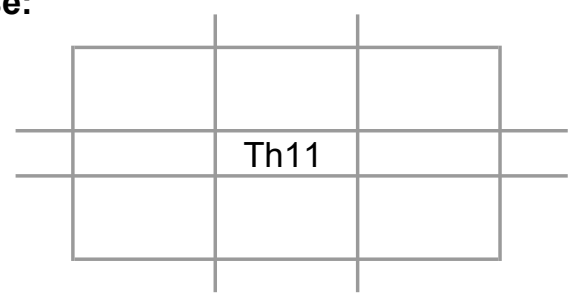

Beschreibung:

Wirbel aus Verband. 
Bezeichn: Vertebra

\section{Kiste: $\quad 5261277$}

Skelet: $\quad$ V33 kleine Tüte

Population: Calden
Verband: Verband

Alter: Erwachsen

\section{Geschlecht:}

Arthrose:

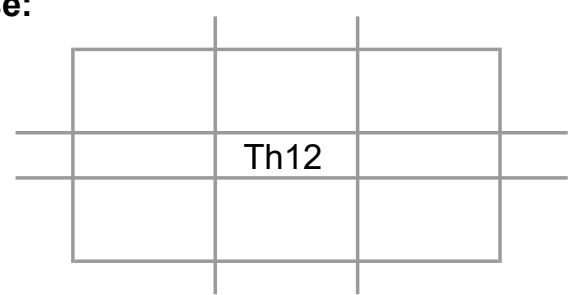

Beschreibung:

Wirbel aus Verband. 
Bezeichn.: Vertebra

Kiste: $\quad 5261277$

Skelet: V33 kleine Tüte

Population: Calden
Verband: $\quad$ Verband

Alter: Erwachsen

\section{Geschlecht:}

Arthrose:

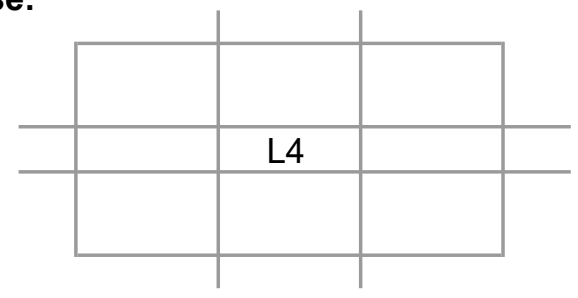

Beschreibung:

Wirbel aus Verband. 
Bezeichn.: Vertebra

Kiste: $\quad 5261277$

Skelet: V33 kleine Tüte

Population: Calden
Verband: $\quad$ Verband

Alter: Erwachsen

\section{Geschlecht:}

Arthrose:

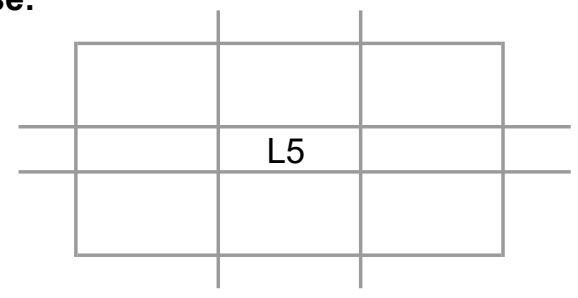

Beschreibung:

Wirbel aus Verband. 
Bezeichn:: Vertebra

\section{Kiste:}

5261277

Skelet: kleine Tüte

Population: Calden
Verband: Verband

\section{Alter:}

Geschlecht:

Arthrose:

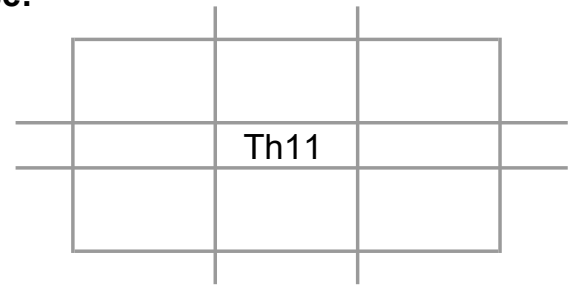

Beschreibung:

Wirbel aus Verband. 

Bezeichn.: Vertebra
Verband: $\quad$ Verband
Ges./Kr.: Krank
Kiste: $\quad 5261277$
Alter: Erwachsen
Skelet: mittlere Tüte unter SCH. 8
Geschlecht: $q \leq 0$
Krankh.: Arthrose

Population: Calden

Arthrose:

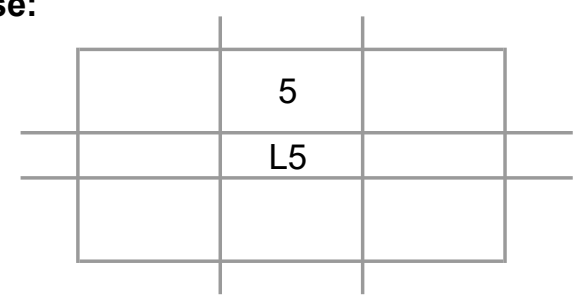

\section{Beschreibung:}

Hier liegt eine obere Deckplatte und ein Teil des corpus eines L5 vor. Die obere Deckplatte weist Spondylophyten auf. Sie sind bis $13,7 \mathrm{~mm}$ lang und säumen den gesamten Teil der Deckplatte. Die Oberfläche ist eher unauffällig. 
Bezeichn.: Vertebra

Verband: $\square$ Verband

Ges./Kr.: Gesund

\section{Kiste: $\quad 5261277$}

Skelet: $\quad$ V6 mittlere Tüte

Population: Calden

\section{Alter: Jung}

\section{Geschlecht:}

Arthrose:

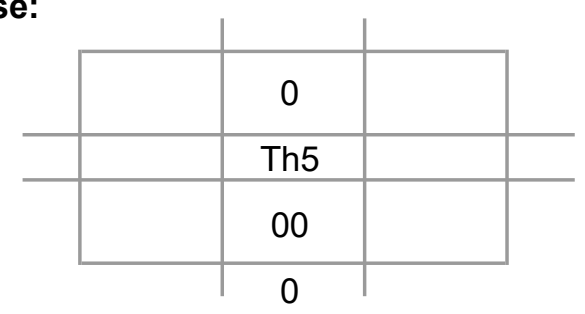

\section{Beschreibung:}

Bei diesen Wirbeln von Th5 bis L5 (es fehlt L7) liegt ein Verband vor, der von einem Individuum stammt, welches noch recht jung war. Es liegen auf den Unterseite aller Wirbel typische Zeichen einer frischen noch nicht ganz vollständigen Verknöcherung vor. Alle Wirbelteile, die erhalten waren weisen fast keine Erosionsspuren auf, lediglich sind bei manchen die Arcus vertebrae abfrakturiert. 
Bezeichn.: Vertebra

Kiste: $\quad 5261277$

Skelet: $\quad$ V6 mittlere Tüte

Population: Calden
Verband: $\square$ Verband Ges./Kr.: Gesund

\section{Alter: Jung}

Geschlecht:

Arthrose:

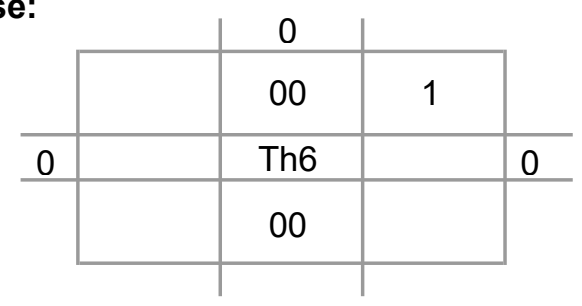

Beschreibung:

Wirbel aus Verband. 
Bezeichn.: Vertebra

Kiste: $\quad 5261277$

Skelet: $\quad$ V6 mittlere Tüte

Population: Calden
Verband: $\quad$ Verband

\section{Alter: Jung}

Geschlecht:

Arthrose:

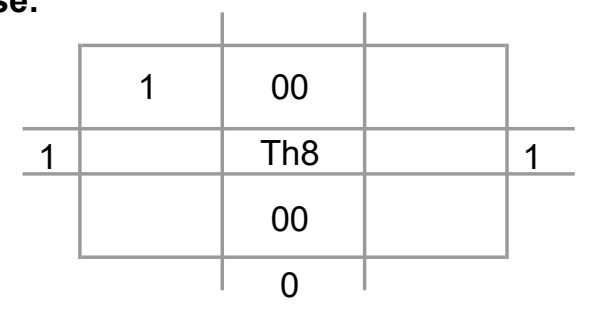

Beschreibung:

Wirbel aus Verband. 
Bezeichn.: Vertebra

Kiste: $\quad 5261277$

Skelet: $\quad$ V6 mittlere Tüte

Population: Calden
Verband: $\square$ Verband Ges./Kr.: Gesund

\section{Alter: Jung}

Geschlecht:

Arthrose:

\begin{tabular}{l|c|c|c}
\multicolumn{1}{l|}{} & 0 & \multicolumn{2}{c}{} \\
\cline { 2 - 3 } & 00 & 0 & \\
\hline & Th9 & & 1 \\
\hline & 00 & & \\
& 0 & \multicolumn{2}{c}{}
\end{tabular}

Beschreibung:

Wirbel aus Verband. 
Bezeichn.: Vertebra

Kiste: $\quad 5261277$

Skelet: $\quad$ V6 mittlere Tüte

Population: Calden
Verband: $\quad$ Verband Ges./Kr.: Gesund

\section{Alter: Jung}

Geschlecht:

Arthrose:

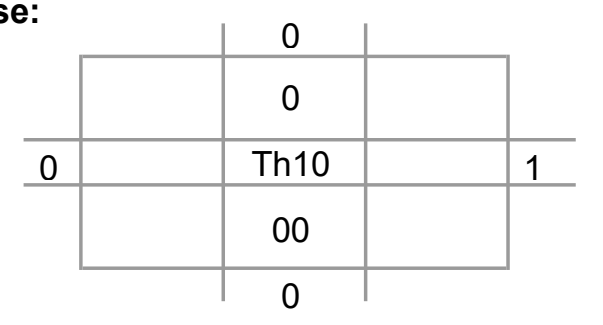

Beschreibung:

Wirbel aus Verband. 
Bezeichn.: Vertebra

Kiste: $\quad 5261277$

Skelet: $\quad$ V6 mittlere Tüte

Population: Calden
Verband: $\square$ Verband Ges./Kr.: Gesund

\section{Alter: Jung}

Geschlecht:

Arthrose:

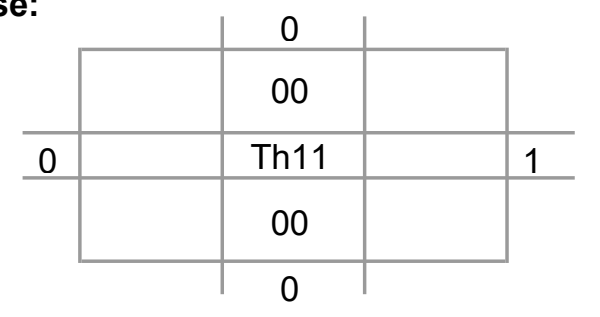

Beschreibung:

Wirbel aus Verband. 
Bezeichn.: Vertebra

Kiste: $\quad 5261277$

Skelet: $\quad$ V6 mittlere Tüte

Population: Calden
Verband: $\square$ Verband Ges./Kr.: Gesund

\section{Alter: Jung}

Geschlecht:

Arthrose:

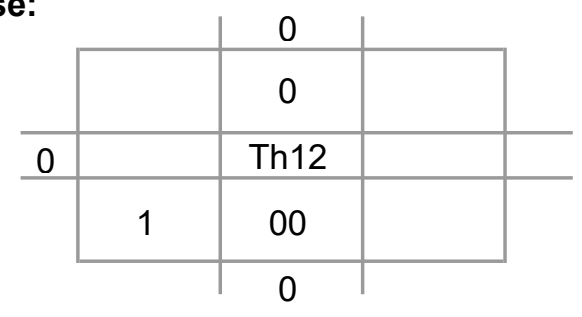

\section{Beschreibung:}

Ein Wirbel aus einem Verband. 
Bezeichn.: Vertebra

Kiste: $\quad 5261277$

Skelet: $\quad$ V6 mittlere Tüte

Population: Calden
Verband: Verband Ges./Kr.: Gesund

\section{Alter: Jung}

Geschlecht:

Arthrose:

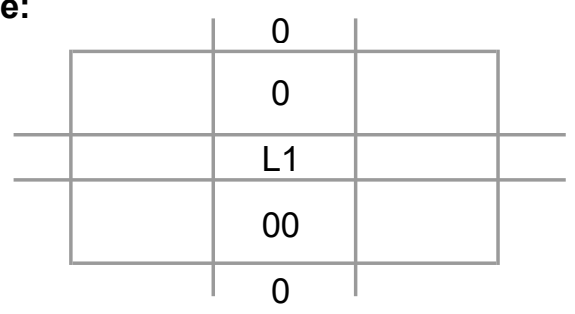

\section{Beschreibung:}

Wirbel aus Verband. 
Bezeichn.: Vertebra

Kiste: $\quad 5261277$

Skelet: $\quad$ V6 mittlere Tüte

Population: Calden
Verband: $\square$ Verband Ges./Kr.: Gesund

\section{Alter: Jung}

Geschlecht:

Arthrose:

\begin{tabular}{l|c|c|}
\multicolumn{1}{c|}{} & 0 & \multicolumn{1}{c}{} \\
\cline { 2 - 4 } \multicolumn{1}{c|}{1} & 0 & 1 \\
\hline & L2 & \\
\hline 1 & 00 & 1 \\
\hline & 0 & \multicolumn{1}{c}{}
\end{tabular}

Beschreibung:

Wirbel aus Verband. 
Bezeichn.: Vertebra

Kiste: $\quad 5261277$

Skelet: $\quad$ V6 mittlere Tüte

Population: Calden
Verband: $\square$ Verband Ges./Kr.: Gesund

\section{Alter: Jung}

Geschlecht:

Arthrose:

\begin{tabular}{l|c|c|}
\multicolumn{1}{c|}{} & 0 & \multicolumn{1}{c}{} \\
\cline { 2 - 4 } \multicolumn{1}{c|}{1} & 0 & 1 \\
\hline & L3 & \\
\hline 1 & 00 & 1 \\
\hline & 0 & \multicolumn{1}{c}{}
\end{tabular}

Beschreibung:

Wirbel aus Verband. 
Bezeichn.: Vertebra

Kiste: $\quad 5261277$

Skelet: $\quad$ V6 mittlere Tüte

Population: Calden
Verband: $\square$ Verband Ges./Kr.: Gesund

\section{Alter: Jung}

Geschlecht:

Arthrose:

\begin{tabular}{l|c|c|}
\multicolumn{1}{c|}{} & 0 & \multicolumn{1}{c}{} \\
\cline { 2 - 4 } \multicolumn{1}{c|}{1} & 0 & 1 \\
\hline & $\mathrm{L} 4$ & \\
\hline 1 & 00 & 1 \\
\hline & 0 & \multicolumn{1}{c}{}
\end{tabular}

Beschreibung:

Wirbel aus Verband. 
Bezeichn.: Vertebra

Kiste: $\quad 5261277$

Skelet: $\quad$ V6 mittlere Tüte

Population: Calden
Verband: $\square$ Verband Ges./Kr.: Gesund

\section{Alter: Jung}

Geschlecht:

Arthrose:

\begin{tabular}{|c|c|c|}
\hline & 0 & \\
\hline 1 & 0 & 1 \\
\hline & L5 & \\
\hline 1 & 00 & 1 \\
\hline
\end{tabular}

Beschreibung:

Wirbel aus Verband. 
Bezeichn.: Vertebra

Kiste: $\quad 5261277$

Skelet: unter $\mathrm{ScCH} .8+3$

Population: Calden
Verband: $\square$ Verband

\section{Alter:}

Geschlecht:

Arthrose:
Ges./Kr.: Krank

Krankh.: Arthrose

\section{Spondylosis}

Spondylophyten

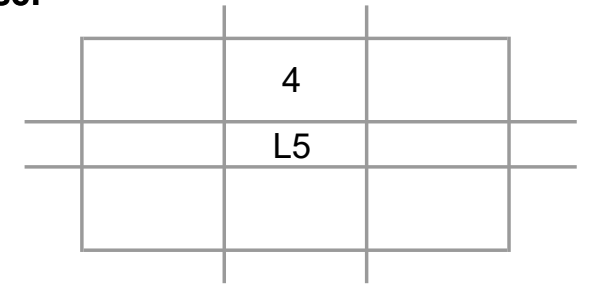

Beschreibung:

Dieser Wirbel weist starke Spondylophyten auf, die im Zuge eines verschleißenden Prozesses gebildet worden sein könnten. 
Bezeichn.: Vertebra

Kiste: $\quad 52651-3279$

Skelet: V28 unter $\mathrm{SCH} .32$.

Population: Calden

\section{Verband: $\quad$ Verband Ges./Kr.: Krank}

Alter: Krankh.: Arthrose

\section{Geschlecht: $q$}

Arthrose:

\begin{tabular}{|c|c|}
\hline 2 & 2 \\
\hline & Th11 \\
\hline 2 & 3 \\
\hline 2 & 3 \\
\hline
\end{tabular}

\section{Beschreibung:}


Bezeichn:: Vertebra

Kiste: $\quad 52651-3279$

Skelet: V28 unter $\mathrm{SCH} .32$.

Population: Calden
Verband: $\square$ Verband

Ges./Kr.: Gesund

\section{Alter:}

Geschlecht: $q$

Arthrose:

\begin{tabular}{|c|c|l|}
\hline \multicolumn{1}{c|}{2} & 3 & \multicolumn{1}{l}{} \\
\hline 1 & 2 & \\
\hline & Th12 & \\
\hline 2 & 2 & \\
\hline 2 & 2 & \multicolumn{1}{c}{} \\
\hline
\end{tabular}

\section{Beschreibung:}


Bezeichn.: Vertebra

Kiste: $\quad 52651-3279$

Skelet: V28 unter $\mathrm{SCH} .32$.

Population: Calden
Verband: $\quad \square$ Verband

\section{Alter:}

Geschlecht: +

Arthrose:

\begin{tabular}{|c|c|c|}
\hline \multicolumn{1}{c|}{2} & 2 & \multicolumn{1}{l|}{} \\
\hline 2 & 2 & \\
\hline & $\mathrm{L} 1$ & \\
\hline 2 & 3 & \\
\hline & 4 & \multicolumn{1}{|}{} \\
\hline
\end{tabular}

Ges./Kr.: Krank

Krankh.: Spondylophyten

Arthrose

\section{Beschreibung:}


Bezeichn.: Vertebra

Kiste: $\quad 52651-3279$

Skelet: V28 unter $\mathrm{SCH} .32$.

Population: Calden
Verband: $\quad \square$ Verband

\section{Alter:}

Geschlecht:

Arthrose:

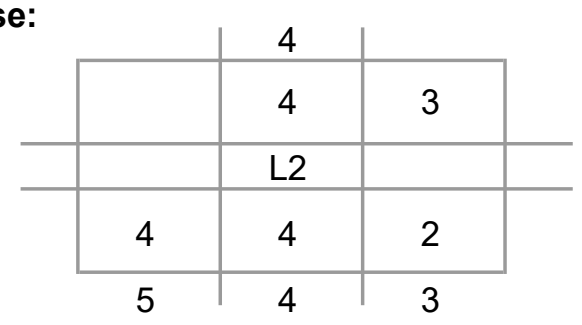

Ges./Kr.: Krank

Krankh.: Arthrose

Spondylophyten

\section{Beschreibung:}


Bezeichn.: Vertebra

Kiste: $\quad 52651-3279$

Skelet: V28 unter $\mathrm{SCH} .32$.

Population: Calden
Verband: $\square$ Verband

Alter:

Ges./Kr.: Krank

\section{Geschlecht:}

Arthrose:

\begin{tabular}{|c|c|c|}
\hline 5 & 4 & 3 \\
\hline 5 & 4 & 3 \\
\hline & L3 & \\
\hline 4 & 4 & \\
\hline 4 & 4 & \\
\hline
\end{tabular}

\section{Beschreibung:}


Bezeichn.: Vertebra

Kiste: $\quad 52651-3279$

Skelet: V28 unter $\mathrm{SCH} .32$.

Population: Calden
Verband: $\quad$ Verband

Alter:

Geschlecht: +

Arthrose:

\begin{tabular}{|c|c|c|}
\hline 4 & 4 & \\
\hline 4 & 4 & 3 \\
\hline & L4 & \\
\hline 3 & 4 & 2 \\
\hline 3 & 4 & 3 \\
\hline
\end{tabular}

Ges./Kr.: Krank

Krankh.: Arthritis

Spondylophyten

Spondylitis

Arthrose

\section{Beschreibung:}


Bezeichn.: Vertebra

Kiste: $\quad 52651-3279$

Skelet: V28 unter $\mathrm{SCH} .32$.

Population: Calden
Verband: $\quad$ Verband

Alter:

Geschlecht: 우

Arthrose:

\begin{tabular}{|c|c|c|}
\hline 3 & 4 & 3 \\
\hline 3 & 4 & 3 \\
\hline & L5 & \\
\hline 4 & 1 & 4 \\
\hline 4 & 1 & 4 \\
\hline
\end{tabular}

Ges./Kr.: Krank

Krankh.: Arthrose

Arthritis

Spondylitis

Spondylophyten

\section{Beschreibung:}


Bezeichn.: Vertebra

Kiste: $\quad 5245269$

Skelet: gesammelt

Population: Calden
Verband: Verband

\section{Alter:}

Geschlecht:

Arthrose:

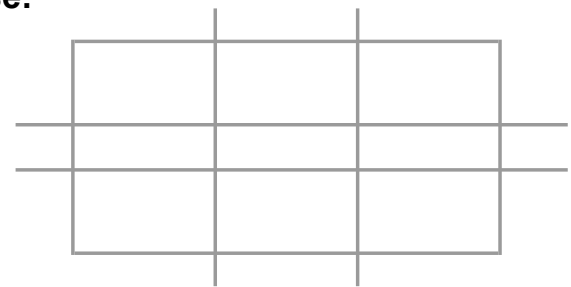

\section{Beschreibung:}

Ein kleines Fragment eines Wirbels. 
Bezeichn:: Vertebra

\section{Kiste:}

5263278

Skelet: V20 gesammelt

Population: Calden

\section{Verband: $\square$ Verband \\ Ges./Kr.: Krank \\ Krankh.: Arthrose \\ Geschlecht: Arthritis}

Arthrose:

\begin{tabular}{l|c|c|}
\cline { 2 - 3 } \multicolumn{1}{c|}{} & \multicolumn{1}{c|}{} \\
\hline 1 & 3 & 1 \\
\hline 3 & 2 & 5 \\
\hline 2.5 & 2 & 5
\end{tabular}

\section{Beschreibung:}

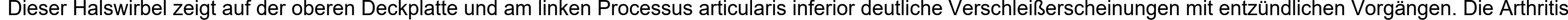
am linken Processus articularis inferior passen zu Wirbel Th1. 
Bezeichn:: Vertebra

Kiste:

5263278

Skelet: $\quad$ V20 gesammelt

Population: Calden
Verband: $\square$ Verband

\section{Alter:}

Geschlecht:

Arthrose:

\begin{tabular}{c|c|c|c|c}
\multicolumn{1}{c|}{2.5} & 2 & 5 \\
\cline { 2 - 4 } & 2 & 2 & 5 & \\
\hline 3 & & Th1 & & 2 \\
\hline & 2 & 2 & 2 & \\
\cline { 2 - 4 } & 2 & & \multicolumn{2}{c}{2}
\end{tabular}

Ges./Kr.: Krank

Krankh.: Arthrose

Arthritis

\section{Beschreibung:}

Dieser erste thorakale Wirbel weist deutliche Verschleißerscheinung am linken Processus articularis superior auf, welche zu dem Wirbel C7 passen. 
Bezeichn.: Vertebra

\section{Kiste:}

8505719

Skelet: gesammelt

Population: Calden
Verband: $\square$ Verband

Ges./Kr.: Gesund

\section{Geschlecht:}

\section{Arthrose:}

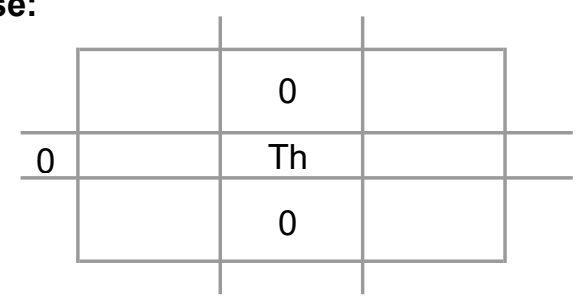

\section{Beschreibung:}

Corpus und linker Bogen erhalten. 
Bezeichn:: Vertebra

Kiste:

8505719

Skelet: gesammelt

Population: Calden
Verband: $\square$ Verband

\section{Alter:}

Geschlecht:

Geschlech
Ges./Kr.: Krank

Krankh.: Schmor'sche

Knorpelknötchen

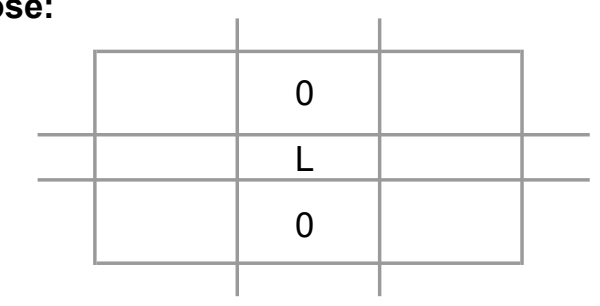

Beschreibung:

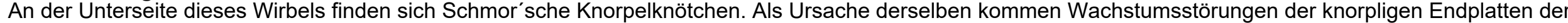
Wirbelkörper und/oder Traumen der Endplatten in Frage. 
Bezeichn.: Vertebra

Kiste: $\quad 8505719$

Skelet: gesammelt

Population: Calden
Verband: $\quad$ Verband

\section{Alter:}

Geschlecht:

Arthrose:

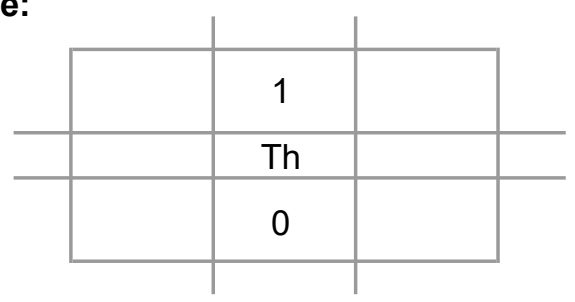

\section{Beschreibung:}


Bezeichn.: Vertebra

Kiste: $\quad 8505719$

Skelet: gesammelt

Population: Calden
Verband: $\quad$ Verband

\section{Alter:}

Geschlecht:

Arthrose:

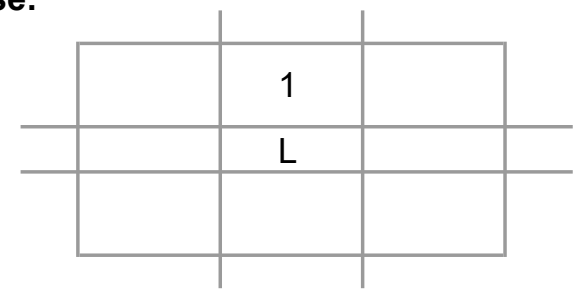

\section{Beschreibung:}


Bezeichn.: Vertebra

Kiste: $\quad 8505719$

Skelet: gesammelt

Population: Calden
Verband: $\quad \square$ Verband

Ges./Kr.: Gesund

\section{Geschlecht:}

Arthrose:

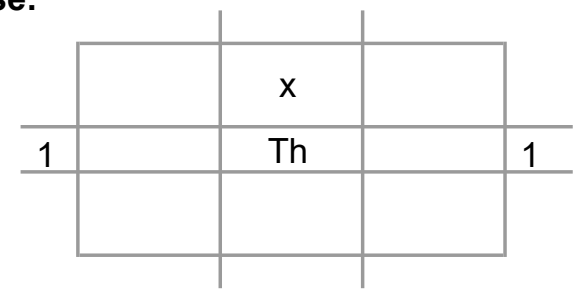

\section{Beschreibung:}


Bezeichn.: Vertebra

Kiste: $\quad 8505719$

Skelet: gesammelt

Population: Calden
Verband: $\quad$ Verband

\section{Alter:}

Geschlecht:

Arthrose:

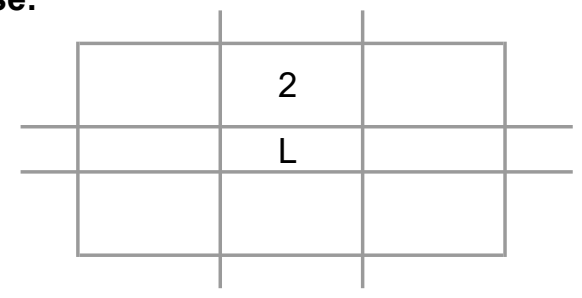

\section{Beschreibung:}


Bezeichn.: Vertebra

Kiste: $\quad 8505719$

Skelet: gesammelt

Population: Calden
Verband: $\quad$ Verband

\section{Alter:}

Geschlecht:

Arthrose:

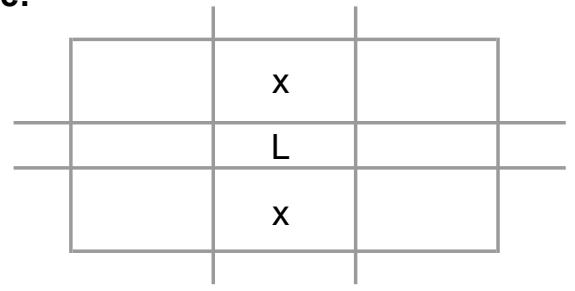

\section{Beschreibung:}


Bezeichn.: Vertebra

Kiste: $\quad 8505719$

Skelet: gesammelt

Population: Calden
Verband: $\quad$ Verband

Alter:

Ges./Kr.: Krank

\section{Geschlecht:}

Arthrose:

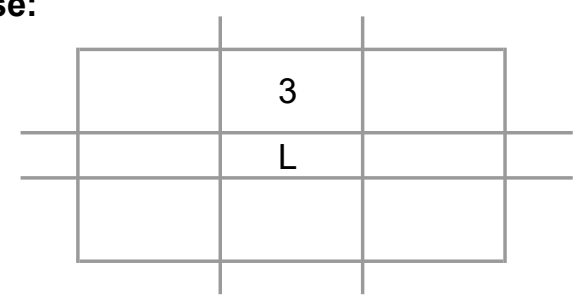

\section{Beschreibung:}




$\begin{array}{llll}\text { Bezeichn.: } & \text { Vertebra } & \text { Verband: } \square \text { Verband } & \text { Ges./Kr.: Krank } \\ \text { Kiste: } & 8505719 & \text { Alter: Jung } & \text { Krankh.: Überbelastung } \\ \text { Skelet: } & \text { gesammelt } & \text { Geschlecht: } & \end{array}$

Skelet: gesammelt

Geschlecht:

Population: Calden

Arthrose:

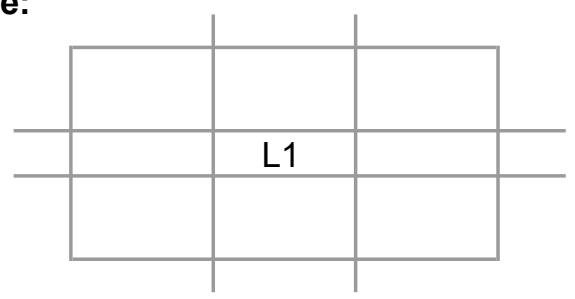

\section{Beschreibung:}

Bei diesem Fundstück eines lumbalen Wirbels L1 fällt eine zusätzliche Gelenkfläche Costo - vertebralis auf. Es handelt sich um eine Lendenrippe oder einen thorakalen Wirbel mit lumbalen Gelenkfacetten. Bei einem Alter von unter 20 Jahren hatte das Individuum recht schwere körperliche Arbeit verrichtet: Der Wirbelkörper ist nach ventral abgeflacht, was definitiv gegen eine Anämie spricht, die man auf den ersten Blick hätte vermuten können. Es müssen gehäuft Oberkörperbeugungen durchgeführt worden sein. Dadurch entstand ein Bandscheibenprolaps und die Knochenverdrängung (Druck) führte zu der Abflachung. 
Bezeichn.: Vertebra

Kiste: $\quad 8505719$

Skelet: gesammelt

Population: Calden
Verband: $\quad$ Verband

\section{Alter:}

Geschlecht:

Arthrose:

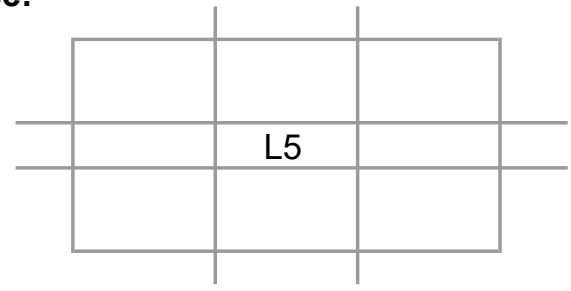

\section{Beschreibung:}


Bezeichn.: Vertebra

Kiste: $\quad 8505719$

Skelet: gesammelt

Population: Calden
Verband: $\quad$ Verband

\section{Alter:}

Geschlecht:

Arthrose:

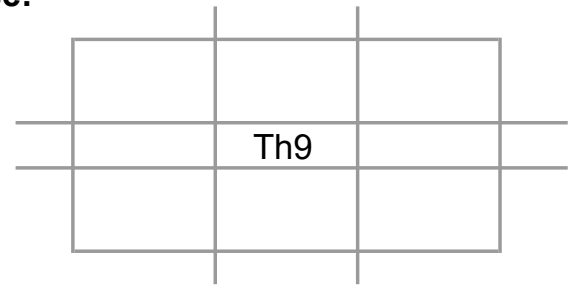

\section{Beschreibung:}


Bezeichn.: Vertebra

Kiste: $\quad 8505719$

Skelet: gesammelt

Population: Calden
Verband: $\quad$ Verband

\section{Alter:}

Geschlecht:

Arthrose:

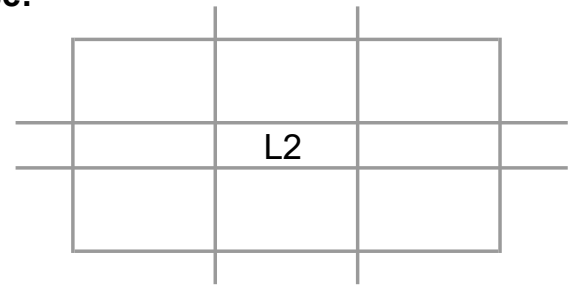

\section{Beschreibung:}


Bezeichn.: Vertebra

Kiste: $\quad 8505719$

Skelet: gesammelt

Population: Calden
Verband: $\quad$ Verband

\section{Alter:}

Geschlecht:

Arthrose:

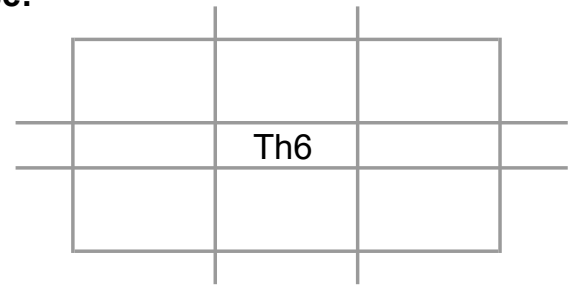

\section{Beschreibung:}


Bezeichn.: Vertebra

Kiste: $\quad 8505719$

Skelet: gesammelt

Population: Calden
Verband: $\quad$ Verband

\section{Alter:}

Geschlecht:

Arthrose:

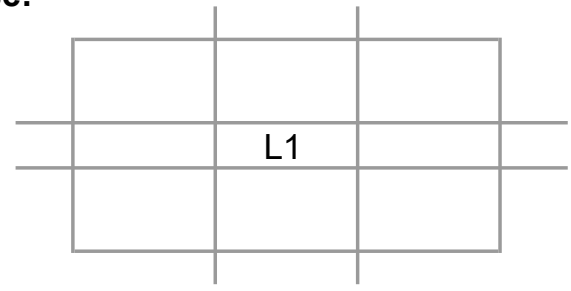

\section{Beschreibung:}


Bezeichn.: Vertebra

Kiste: $\quad 8505719$

Skelet: gesammelt

Population: Calden
Verband: $\quad$ Verband

\section{Alter:}

Geschlecht:

Arthrose:

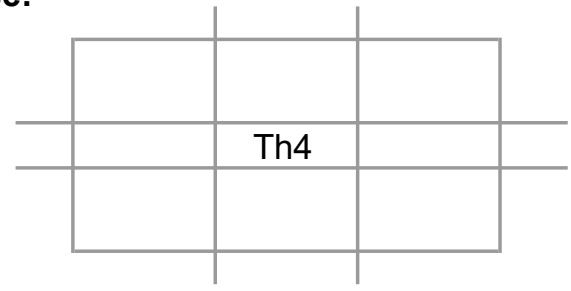

\section{Beschreibung:}


Bezeichn.: Vertebra

Kiste: $\quad 8505719$

Skelet: gesammelt

Population: Calden
Verband: $\quad$ Verband

\section{Alter:}

Geschlecht:

Arthrose:

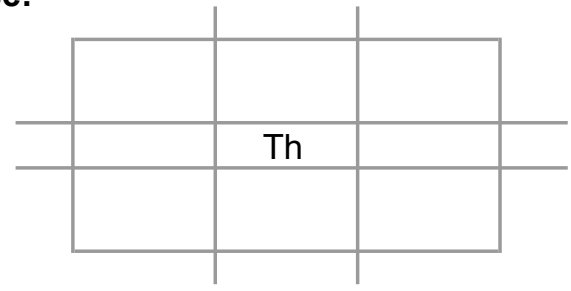

\section{Beschreibung:}


Bezeichn.: Vertebra

Kiste: $\quad 8505719$

Skelet: gesammelt

Population: Calden
Verband: $\quad$ Verband

\section{Alter:}

Geschlecht:

Arthrose:

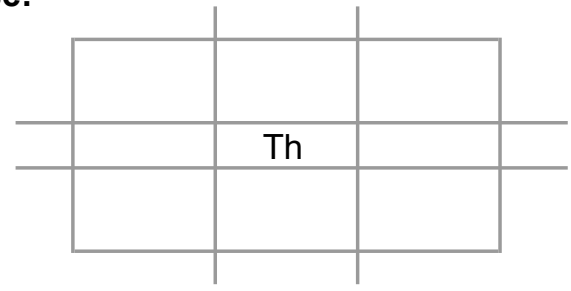

\section{Beschreibung:}


Bezeichn.: Vertebra

Kiste: $\quad 8505719$

Skelet: gesammelt

Population: Calden
Verband: $\quad$ Verband

\section{Alter:}

Geschlecht:

Arthrose:

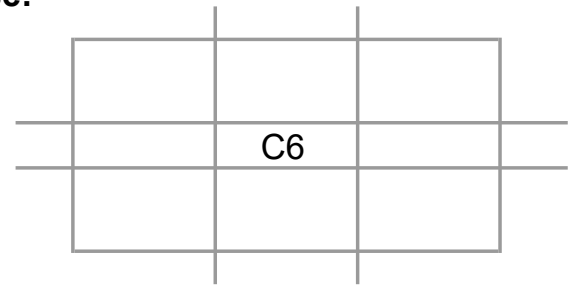

\section{Beschreibung:}


Bezeichn.: Vertebra

Kiste: $\quad 8505719$

Skelet: gesammelt

Population: Calden
Verband: $\quad$ Verband

\section{Alter:}

\section{Geschlecht:}

Arthrose:

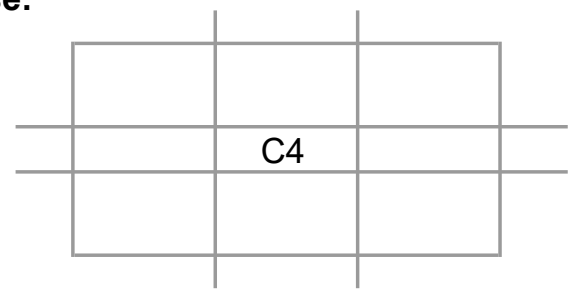

\section{Beschreibung:}

Ein Fragment eines cervikalen Wirbels. 
Bezeichn:: Vertebra

Kiste: $\quad 8505719$

Skelet: gesammelt

Population: Calden
Verband: $\quad$ Verband

\section{Alter: Jung}

\section{Geschlecht:}

Arthrose:

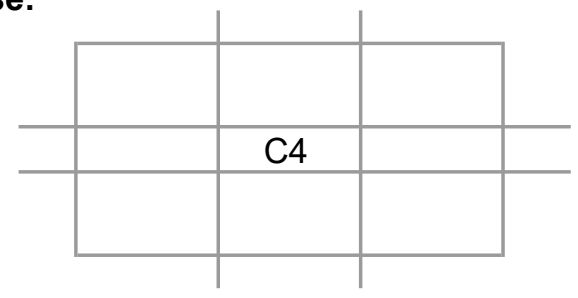

\section{Beschreibung:}

Ein corpus eines jungen Wirbels. 
Bezeichn.: Vertebra

Kiste:

8505719

Skelet: $\quad$ V73 Wirbelbogen

Population: Calden

\section{Verband: $\quad$ Verband Ges./Kr.: Gesund}

\section{Alter: $\quad 21-23$}

Geschlecht:

Arthrose:

\begin{tabular}{|c|c|c|}
\cline { 2 - 3 } \multicolumn{1}{c|}{} & & \\
\hline 0 & 0 & \\
\hline & Th12 & \\
\hline 0 & 0 & 0 \\
\hline 0 & 0 & 0
\end{tabular}

\section{Beschreibung:}

Dieser Wirbel zeigt die seltene anatomische Struktur einer Lendenrippe. Eine Verwandtschaft könnte vorliegen mit dem folgenden Wirbel. 
Bezeichn.: Vertebra

\section{Kiste:}

8505719

Skelet: $\quad$ V73 Wirbelbogen

Population: Calden

\section{Verband: $\quad$ Verband Ges./Kr.: Gesund}

\section{Alter: $21-23$}

Geschlecht:

Arthrose:

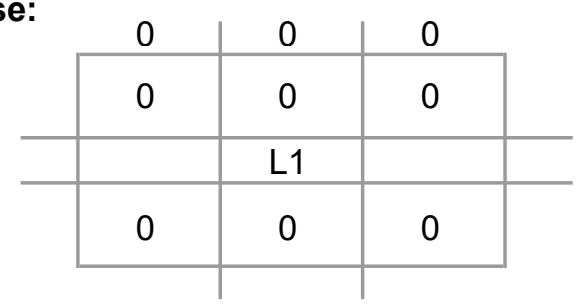

\section{Beschreibung:}

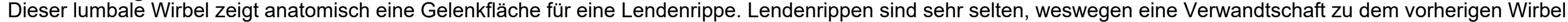
angenommen werden kann. 
Bezeichn.: Vertebra

Kiste: $\quad 5245269$

Skelet: gesammelt

Population: Calden
Verband:

Verband

Ges./Kr.: Gesund

\section{Alter:}

Geschlecht:

Arthrose:

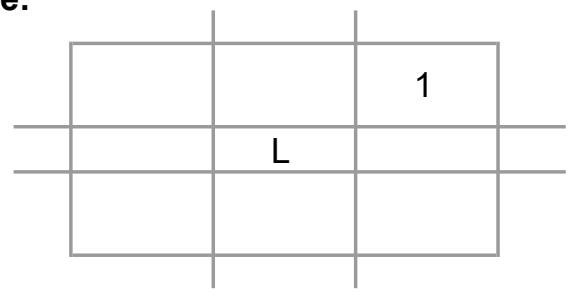

Beschreibung:

Ein Wirbelfragment. 


\section{Bezeichn: Vertebra \\ Kiste: $\quad 5245269$ \\ Skelet: gesammelt}

Population: Calden
Verband: $\quad \square$ Verband

\section{Alter:}

Geschlecht:

Arthrose:

\begin{tabular}{|c|c|c|}
\hline 1 & & 1 \\
\hline & L2 & \\
\hline 2 & & 1 \\
\hline
\end{tabular}

\section{Beschreibung:}

Hier ist ein posteriores Teil erhalten 
Bezeichn.: Vertebra

Kiste: $\quad 5245269$

Skelet: gesammelt

Population: Calden

\section{Verband: $\quad$ Verband Ges./Kr.: Krank}

Alter: Krankh.: Arthrose

\section{Geschlecht:}

Arthrose:

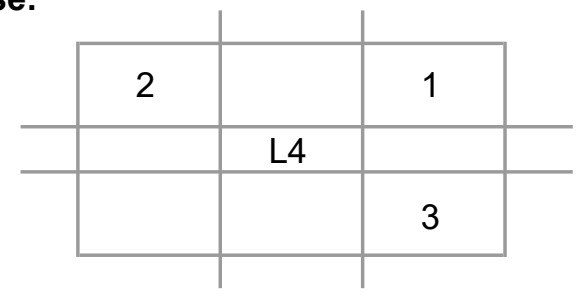

\section{Beschreibung:}

Wirbel mit kleiner Einbuchtung auf der rechten Seite des Bogens. 
Bezeichn.: Vertebra

Kiste: $\quad 8505719$

Skelet: Wirbelzettel

Population: Calden
Verband: $\square$ Verband

\section{Alter:}

Ges./Kr.: Krank

\section{Geschlecht:}

Arthrose:

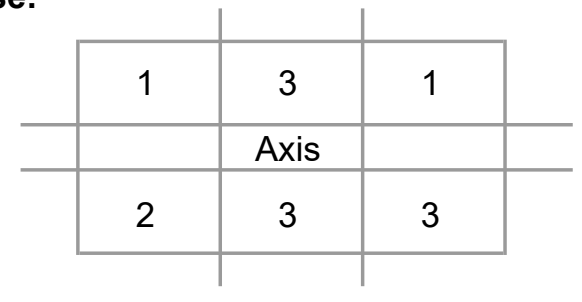

Beschreibung:

Ein vollständiger Atlas. 
Bezeichn.: Vertebra

\section{Kiste:}

8505719

wirbelzettel

Population: Calden
Verband: $\square$ Verband

Ges./Kr.: Gesund

\section{Geschlecht:}

Arthrose:

\begin{tabular}{|c|c|c|}
\hline 0 & 0 & 0 \\
\hline & Atlas & \\
\hline 1 & & 1 \\
\hline
\end{tabular}

\section{Beschreibung:}

Ein nahezu vollständiger Atlas. 
Bezeichn.: Vertebra

Kiste: $\quad 8505719$

Skelet: Wirbelzettel

Population: Calden
Verband: $\square$ Verband

\section{Alter:}

Ges./Kr.: Krank

\section{Geschlecht:}

Arthrose:

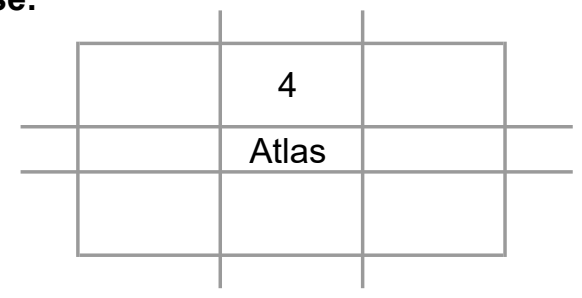

Beschreibung:

Ein Fragment eines Atlas. 
Bezeichn.: Vertebra

Kiste: $\quad 8505719$

Skelet: wirbelzettel

Population: Calden
Verband: $\square$ Verband

Ges./Kr.: Gesund

\section{Geschlecht:}

Arthrose:

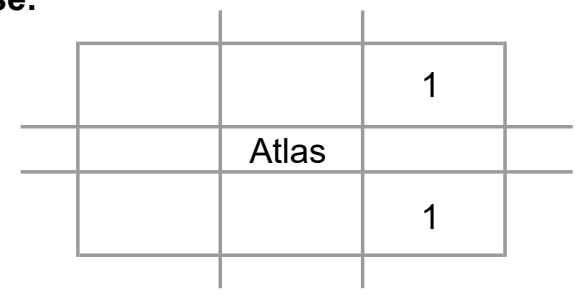

\section{Beschreibung:}

Ein Atlasfragment. 


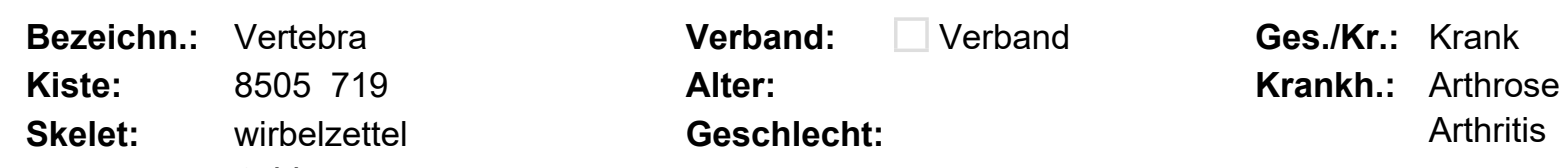

Population: Calden

Arthrose:

\begin{tabular}{|c|c|c|}
\cline { 2 - 3 } \multicolumn{1}{l|}{} & \multicolumn{1}{c|}{} \\
\hline 1 & 3 & 6 \\
\hline 1 & 3 & 2 \\
\hline
\end{tabular}

\section{Beschreibung:}

Bei diesem Wirbel lag eine starke Überbelastung der linken Seite vor, was zu einer starken Arthritis des linken Processus articularis superius führte, wodurch rechts keine Abnutzungserscheinungen entstanden. 
Bezeichn:: Vertebra

Kiste: $\quad 8505719$

Skelet: wirbelzettel

Population: Calden
Verband: $\square$ Verband

\section{Alter:}

Ges./Kr.: Krank

\section{Geschlecht:}

Arthrose:

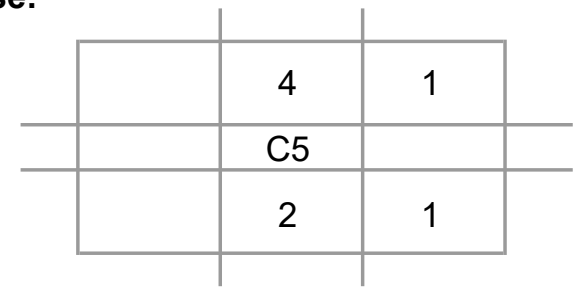

Beschreibung:

Ein linkes Wirbelfragment. 
Bezeichn.: Vertebra

Kiste: $\quad 8505719$

Skelet: Wirbelzettel

Population: Calden
Verband: $\quad$ Verband

Alter:

Ges./Kr.: Krank

\section{Geschlecht:}

Arthrose:

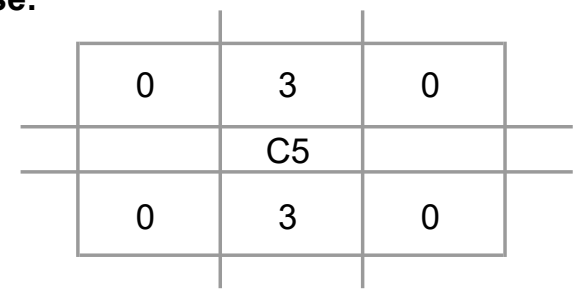

Beschreibung:

Ein vollständiger Wirbel. 
Bezeichn.: Vertebra

\section{Kiste:}

8505719

Wirbelzettel

Population: Calden
Verband: $\quad$ Verband

\section{Alter:}

\section{Geschlecht:}

Arthrose:

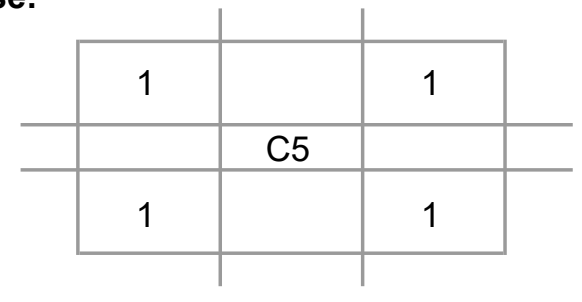

Beschreibung:

Ein Wirbelfragment. 
Bezeichn.: Vertebra

Kiste: $\quad 8505719$

Skelet: Wirbelzettel

Population: Calden
Verband: $\quad$ Verband

Alter:

Ges./Kr.: Krank

\section{Geschlecht:}

Arthrose:

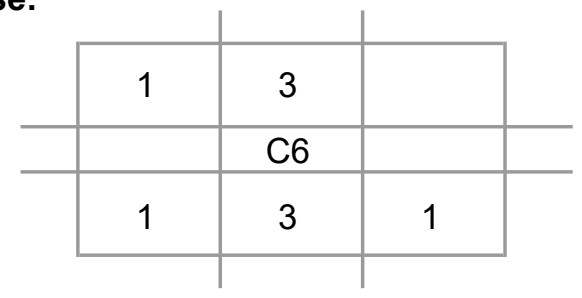

\section{Beschreibung:}

Ein fast vollständiger Wirbel. 
Bezeichn.: Vertebra

Kiste: $\quad 8505719$

Skelet: wirbelzettel

Population: Calden
Verband: $\quad \square$ Verband

Alter:

Ges./Kr.: Krank

\section{Geschlecht:}

Arthrose:

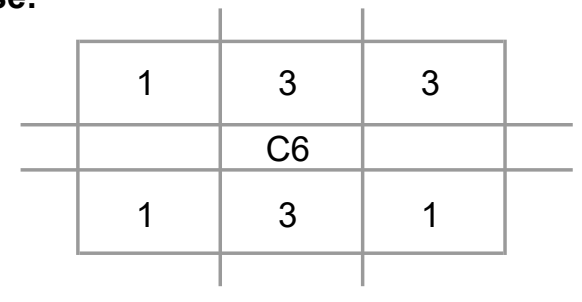

Beschreibung:

Ein vollständiger Wirbel. 
Bezeichn:: Vertebra

Kiste: $\quad 8505719$

Skelet: wirbelzettel

Population: Calden
Verband: $\quad$ Verband

\section{Alter:}

Ges./Kr.: Krank

\section{Geschlecht:}

Arthrose:

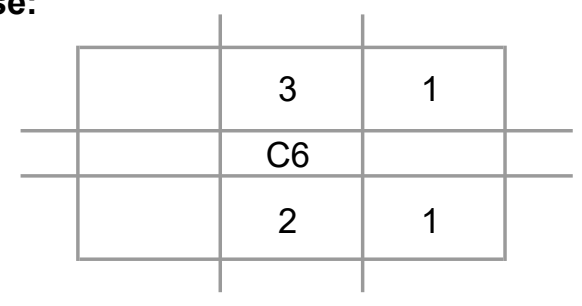

Beschreibung:

Fragment. 
Bezeichn.: Vertebra

Kiste: $\quad 8505719$

Skelet: wirbelzettel

Population: Calden
Verband: $\quad \square$ Verband

\section{Alter:}

Ges./Kr.: Krank

\section{Geschlecht:}

Arthrose:

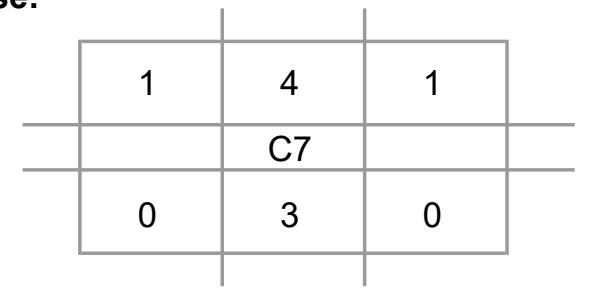

Beschreibung:

Ein vollständiger Wirbel. 
Bezeichn.: Vertebra

Kiste: $\quad 8505719$

Skelet: wirbelzettel

Population: Calden
Verband: $\square$ Verband

\section{Alter:}

Ges./Kr.: Krank

\section{Geschlecht:}

Arthrose:

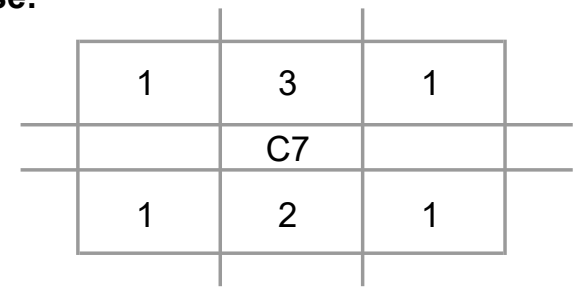

Beschreibung:

Ein vollständiger Wirbel. 
Bezeichn:: Vertebra

Kiste: $\quad 8505719$

Skelet: Wirbelzettel 2

Population: Calden
Verband: $\square$ Verband

\section{Alter:}

Ges./Kr.: Krank

Geschlecht:

Arthrose:

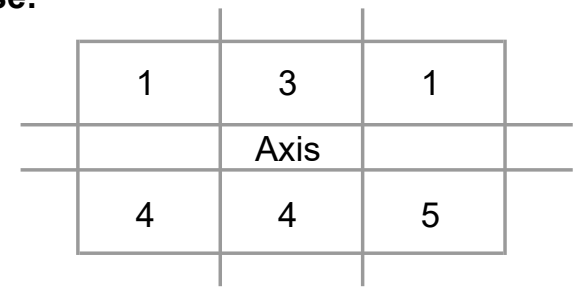

\section{Beschreibung:}

Die Processus articulares superiores sind leicht, die inferiores stark eburniert. 
Bezeichn.: Vertebra

Kiste: $\quad 8505719$

Skelet: Wirbelzettel 2

Population: Calden
Verband: $\square$ Verband

\section{Alter:}

Ges./Kr.: Krank

\section{Geschlecht:}

Arthrose:

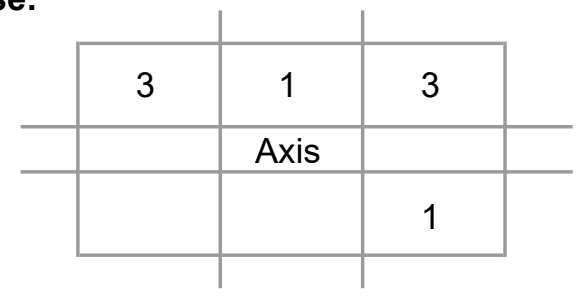

Beschreibung:

Fragment. 
Bezeichn:: Vertebra

Kiste: $\quad 8505719$

Skelet: Wirbelzettel 2

Population: Calden

\section{Verband: $\quad$ Verband Ges./Kr.: Krank}

Alter: Krankh.: Arthrose

\section{Geschlecht:}

Arthrose:

\begin{tabular}{l|c|c|c|}
\cline { 2 - 4 } \multicolumn{1}{c|}{} & \multicolumn{1}{c|}{} & \multicolumn{1}{c}{} \\
\hline 1 & 4 & 1 \\
\hline 1 & 1 & 1 \\
\hline
\end{tabular}

\section{Beschreibung:}

Die Processus articulares superiores dieses Wirbels sind leicht eburniert. 
Bezeichn.: Vertebra

Kiste: $\quad 8505719$

Skelet: Wirbelzettel 2

Population: Calden
Verband: $\square$ Verband

Ges./Kr.: Gesund

\section{Alter:}

Geschlecht:

Arthrose:

\begin{tabular}{|c|c|c|}
\hline 1 & 1 & 1 \\
\hline & Axis & \\
\hline 1 & 2 & 1 \\
\hline
\end{tabular}

\section{Beschreibung:}

Ein vollständiger Wirbel. 
Bezeichn.: Vertebra

\section{Kiste:}

8505719

Wirbelzettel 2

Population: Calden
Verband: $\quad \square$ Verband

Ges./Kr.: Gesund

\section{Alter:}

Geschlecht:

Arthrose:

\begin{tabular}{l|c|c|c|}
\cline { 2 - 4 } \multicolumn{1}{c|}{} & 1 & 2 \\
\hline & & Axis & \\
\hline 1 & 2 & 1 \\
\hline
\end{tabular}

\section{Beschreibung:}

Der Processus articularis superior ist leicht eburniert. 
Bezeichn:: Vertebra

Kiste: $\quad 8505719$

Skelet: Wirbelzettel 2

Population: Calden
Verband: $\square$ Verband

Alter:

Ges./Kr.: Krank

\section{Geschlecht:}

Arthrose:

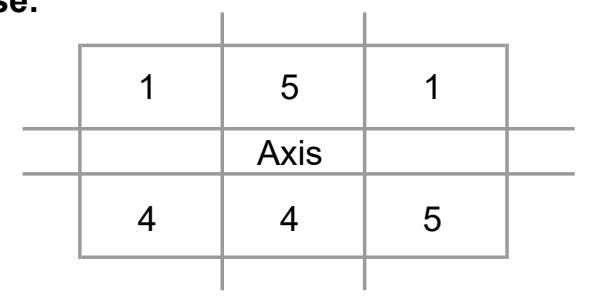

\section{Beschreibung:}

Die Gelenkflächen dieses Wirbels sind teilweise eburniert. 
Bezeichn.: Vertebra

Kiste: $\quad 8505719$

Skelet: Wirbelzettel 2

Population: Calden
Verband: $\quad \square$ Verband

Ges./Kr.: Gesund

\section{Geschlecht:}

Arthrose:

\begin{tabular}{|c|c|c|}
\hline 1 & 1 & 1 \\
\hline & $\mathrm{L}$ & \\
\hline & 1 & 1 \\
\hline
\end{tabular}

\section{Beschreibung:}

Wirbelfragment. 
Bezeichn:: Vertebra

\section{Kiste:}

8505719

Skelet:

V14 mit Fibula und Femur

Population: Calden

\section{Verband: $\quad \square$ Verband \\ Alter: Erwachsen}

Geschlecht:

Arthrose:
Ges./Kr.: Krank

Krankh.: Arthrose

\section{Zystenbildung}

Arthritis

\begin{tabular}{|c|c|c|}
\cline { 2 - 3 } \multicolumn{1}{c||}{5} & 5 & 5 \\
\hline 4 & 3 & 3 \\
\hline
\end{tabular}

\section{Beschreibung:}

Dieser Wirbel liegt im Verband mit einer Fibula vor. Bei diesem Wirbel L4 kam es auf der rechten Seite des Corpus zum knöchernen Einbruch durch körperliche

Überbelastung: der vorherige Wirbel glitt nach rechts über den Corpus, damit kam es zur Bildung von Zysten an den lateralen Wirbelfortsätzen. 
Bezeichn.: Vertebra

Kiste: $\quad 8505719$

Skelet: Wirbelzettel 2

Population: Calden
Verband: $\quad \square$ Verband

Alter:

Ges./Kr.: Krank

\section{Geschlecht:}

Arthrose:

\begin{tabular}{|c|c|c|}
\cline { 2 - 4 } \multicolumn{1}{c||}{3} & 2 & 3 \\
\hline 2 & 1 & 2 \\
\hline
\end{tabular}

Beschreibung:

Ein vollständiger Wirbel. 
Bezeichn.: Vertebra

Kiste: $\quad 8505719$

Skelet: Wirbelzettel 2

Population: Calden
Verband: $\quad$ Verband

Alter:

\section{Geschlecht:}

Arthrose:

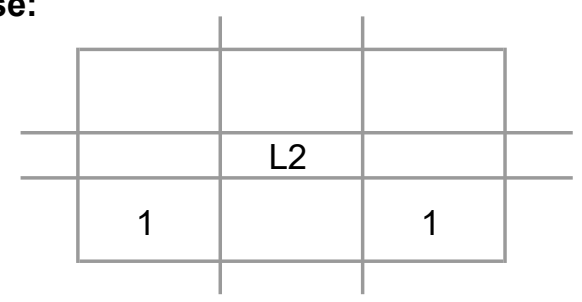

\section{Beschreibung:}

Wirbelfragment. 
Bezeichn.: Vertebra

Kiste: $\quad 8505719$

Skelet: Wirbelzettel 2

Population: Calden
Verband: $\quad$ Verband

Ges./Kr.: Gesund

\section{Alter:}

Geschlecht:

Arthrose:

\begin{tabular}{|c|c|c|}
\hline 1 & & 1 \\
\hline & L1 & \\
\hline 1 & 1 & 1 \\
\hline
\end{tabular}

Beschreibung:

Ein Wirbelfragment. 
Bezeichn.: Vertebra

Kiste: $\quad 8505719$

Skelet: Wirbelzettel 2

Population: Calden
Verband: $\quad \square$ Verband

Ges./Kr.: Gesund

\section{Geschlecht:}

Arthrose:

\begin{tabular}{|c|c|c|}
\hline 1 & 1 & 1 \\
\hline & L1 & \\
\hline 1 & 1 & 1 \\
\hline
\end{tabular}

\section{Beschreibung:}

Dieser Wirbel ist vollständig. 
Bezeichn.: Vertebra

Kiste: $\quad 8505719$

Skelet: Wirbelzettel 3

Population: Calden
Verband: $\quad \square$ Verband

\section{Alter:}

Ges./Kr.: Krank

\section{Geschlecht:}

Arthrose:

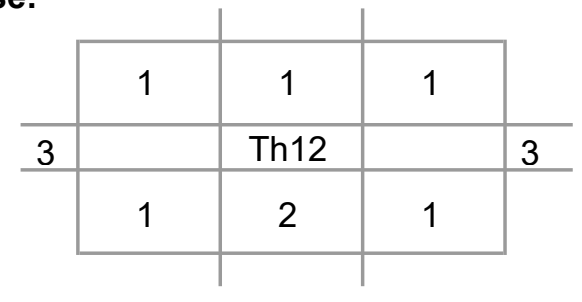

\section{Beschreibung:}

Ein vollständiger Wirbel. 
Bezeichn.: Vertebra

Kiste: $\quad 8505719$

Skelet: Wirbelzettel 3

Population: Calden
Verband: $\quad$ Verband

Ges./Kr.: Gesund

\section{Alter:}

Geschlecht:

Arthrose:

\begin{tabular}{|c|c|c|}
\hline 1 & & 1 \\
\hline & Th11 & \\
\hline 1 & 1 & 1 \\
\hline
\end{tabular}

Beschreibung:

Ein Wirbelfragment. 
Bezeichn.: Vertebra

Kiste: $\quad 8505719$

Skelet: Wirbelzettel 3

Population: Calden
Verband: $\square$ Verband

Ges./Kr.: Gesund

\section{Geschlecht:}

Arthrose:

\begin{tabular}{|c|c|c|}
\hline 1 & 1 & 1 \\
\hline & Th11 & \\
\hline 1 & 1 & 2 \\
\hline
\end{tabular}

\section{Beschreibung:}

Ein vollständiger Wirbel. 
Bezeichn.: Vertebra

Kiste: $\quad 8505719$

Skelet: Wirbelzettel 3

Population: Calden
Verband: $\quad$ Verband

Ges./Kr.: Gesund

\section{Geschlecht:}

Arthrose:

\begin{tabular}{|c|c|c|}
\hline 1 & 1 & 1 \\
\hline & Th11 & \\
\hline 1 & 1 & 1 \\
\hline
\end{tabular}

\section{Beschreibung:}

Ein vollständiger Wirbel. 
Bezeichn.: Vertebra

Kiste: $\quad 8505719$

Skelet: Wirbelzettel 3

Population: Calden
Verband: $\square$ Verband

Ges./Kr.: Gesund

\section{Geschlecht:}

Arthrose:

\begin{tabular}{|c|c|c|}
\hline 1 & 1 & 1 \\
\hline & Th11 & \\
\hline 1 & 1 & 1 \\
\hline
\end{tabular}

\section{Beschreibung:}

Ein vollständiger Wirbel. 
Bezeichn:: Vertebra

Kiste: $\quad 8505719$

Skelet: Wirbelzettel 3

Population: Calden

\section{Verband: $\quad$ Verband Ges./Kr.: Krank}

Alter: Krankh.: Arthrose

\section{Geschlecht:}

Arthrose:

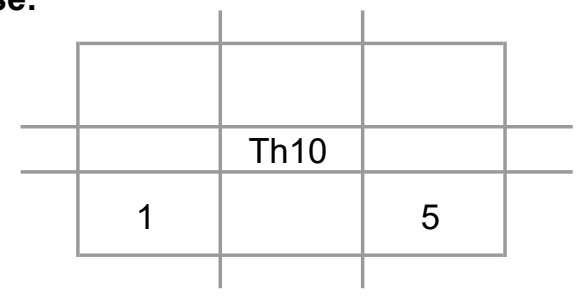

\section{Beschreibung:}

Ein Wirbelfragment mit eburnierter Gelenkfläche. 
Bezeichn.: Vertebra

Kiste: $\quad 8505719$

Skelet: Wirbelzettel 3

Population: Calden
Verband: $\square$ Verband

Ges./Kr.: Gesund

\section{Alter:}

Geschlecht:

Arthrose:

\begin{tabular}{|c|c|c|}
\hline 1 & 1 & 1 \\
\hline & Th10 & \\
\hline 1 & 2 & 2 \\
\hline
\end{tabular}

Beschreibung:

Ein vollständiger Wirbel. 
Bezeichn.: Vertebra

Kiste: $\quad 8505719$

Skelet: Wirbelzettel 3

Population: Calden
Verband: $\square$ Verband

Ges./Kr.: Gesund

\section{Geschlecht:}

Arthrose:

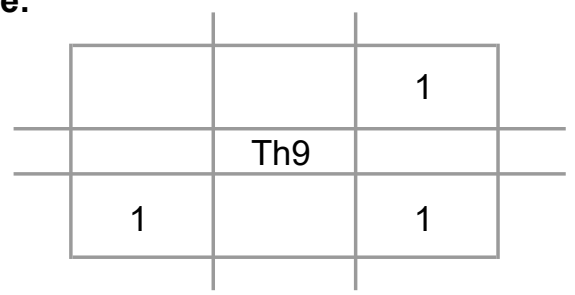

\section{Beschreibung:}

Wirbelfragment. 
Bezeichn.: Vertebra

Kiste: $\quad 8505719$

Skelet: Wirbelzettel 3

Population: Calden
Verband: $\square$ Verband

Ges./Kr.: Gesund

\section{Geschlecht:}

Arthrose:

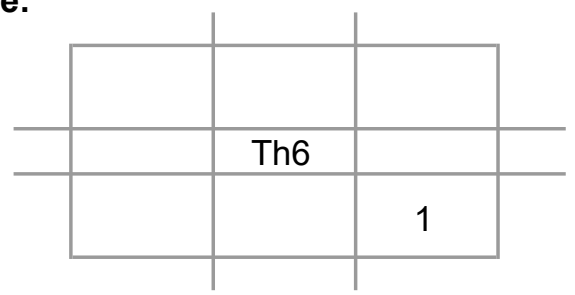

\section{Beschreibung:}

Wirbelfragment. 
Bezeichn:: Vertebra

Kiste: $\quad 8505719$

Skelet: Wirbelzettel 3

Population: Calden
Verband: $\quad$ Verband

Alter:

Ges./Kr.: Krank

\section{Geschlecht:}

Arthrose:

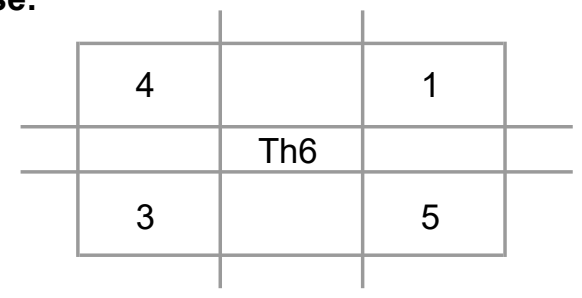

\section{Beschreibung:}

Wirbelfragment. 
Bezeichn.: Vertebra

Kiste: $\quad 8505719$

Skelet: Wirbelzettel 3

Population: Calden
Verband: $\square$ Verband

Ges./Kr.: Gesund

\section{Geschlecht:}

Arthrose:

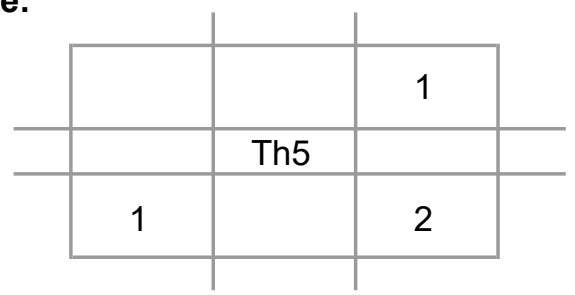

\section{Beschreibung:}

Wirbelfragment. 
Bezeichn.: Vertebra

Kiste: $\quad 8505719$

Skelet: Wirbelzettel 3

Population: Calden
Verband: $\quad \square$ Verband

Ges./Kr.: Gesund

\section{Alter:}

Geschlecht:

Arthrose:

\begin{tabular}{|c|c|c|}
\hline 2 & 1 & \\
\hline & Th4 & \\
\hline 1 & 1 & 1 \\
\hline
\end{tabular}

\section{Beschreibung:}

Wirbelfragment. 
Bezeichn.: Vertebra

Kiste: $\quad 8505719$

Skelet: Wirbelzettel 3

Population: Calden
Verband: $\square$ Verband

Ges./Kr.: Gesund

\section{Geschlecht:}

Arthrose:

\begin{tabular}{|c|c|c|}
\hline 1 & & 1 \\
\hline & Th4 & \\
\hline 1 & & 1 \\
\hline
\end{tabular}

\section{Beschreibung:}

Wirbelfragment. 
Bezeichn.: Vertebra

Kiste: $\quad 8505719$

Skelet: Wirbelzettel 3

Population: Calden
Verband: $\square$ Verband

Ges./Kr.: Gesund

\section{Geschlecht:}

Arthrose:

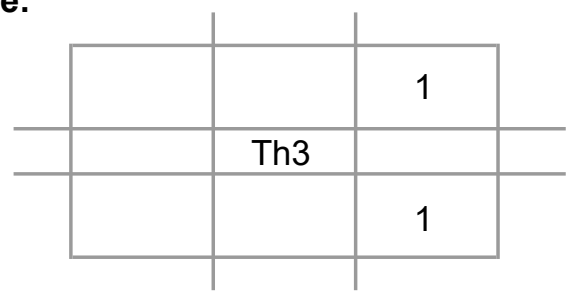

\section{Beschreibung:}

Wirbelfragment. 
Bezeichn.: Vertebra

Kiste: $\quad 8505719$

Skelet: Wirbelzettel 3

Population: Calden
Verband: $\square$ Verband

Ges./Kr.: Gesund

\section{Alter:}

Geschlecht:

Arthrose:

\begin{tabular}{|c|c|c|}
\hline 1 & 1 & 1 \\
\hline & Th3 & \\
\hline 1 & 1 & 1 \\
\hline
\end{tabular}

\section{Beschreibung:}

Ein vollständiger Wirbel. 


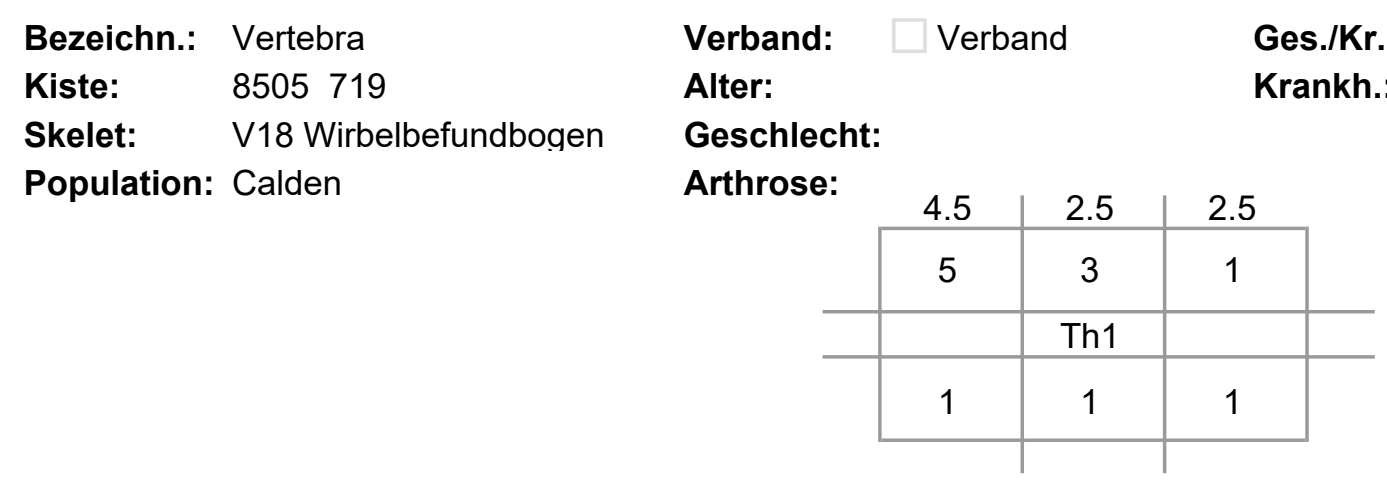

\section{Beschreibung:}

Ein thorakaler Wirbel 1, der eburnierte Oberflächen zeigt. 
Bezeichn:: Vertebra

Kiste: $\quad 8505719$

Skelet: V18 Wirbelbefundbogen

Population: Calden
Verband: $\quad$ Verband

Alter:

Ges./Kr.: Krank

\section{Geschlecht:}

Arthrose:

\begin{tabular}{|c|c|c|}
\hline 1.5 & 3 & 1.5 \\
\hline 2 & 4 & 2 \\
\hline & C7 & \\
\hline 4 & 2 & 4 \\
\hline 4.5 & 2.5 & 2.5 \\
\hline
\end{tabular}

\section{Beschreibung:}

Wirbel aus Verband. 
Bezeichn:: Vertebra

Kiste: $\quad 8505719$

Skelet: $\quad$ V18 Wirbelbefundbogen

Population: Calden
Verband: $\quad$ Verband

Alter:

Ges./Kr.: Krank

Geschlecht:

Arthrose:

\begin{tabular}{c|c|c|}
\multicolumn{1}{c|}{} & \multicolumn{1}{c|}{} \\
\cline { 2 - 4 } \multicolumn{1}{c|}{1} & 5 & 1 \\
\hline 1 & 2 & 1 \\
\hline 1.5 & 3 & 1.5
\end{tabular}

Beschreibung:

Wirbel aus Verband. 
Bezeichn.: Vertebra

Kiste:

8505719

Skelet: V19 Wirbelbogen

Population: Calden
Verband: Verband

\section{Alter:}

Geschlecht:

Arthrose:

\begin{tabular}{l|c|c|c|}
1 & 1.5 & 1 \\
\hline 1 & 2 & 1 \\
\hline & & Th6 & \\
\hline 1 & 2 & 1 \\
\hline
\end{tabular}

\section{Beschreibung:}

Wirbel aus Verband. 
Bezeichn.: Vertebra

\section{Kiste:}

8505719

Skelet: V19 Wirbelbogen

Population: Calden
Verband: Verband

\section{Alter:}

Geschlecht:

Arthrose:

\begin{tabular}{|c|c|c|}
\hline 1 & 1 & 1 \\
\hline 1 & 1 & 1 \\
\hline & Th5 & \\
\hline 1 & 1 & 1 \\
\hline 1 & 1.5 & 1 \\
\hline
\end{tabular}

Beschreibung:

Wirbel aus Verband. 
Bezeichn.: Vertebra

\section{Kiste:}

8505719

Skelet: V19 Wirbelbogen

Population: Calden
Verband: Verband

\section{Alter:}

Geschlecht:

Arthrose:

\begin{tabular}{l|c|c|c|}
\multicolumn{1}{c|}{1} & 2 & 1 \\
\cline { 2 - 3 } & 1 & 1 & 1 \\
\hline & & Th4 & \\
\hline 1 & 1 & 1 \\
\hline 1 & 1 & 1
\end{tabular}

Beschreibung:

Wirbel aus Verband. 
Bezeichn:: Vertebra

Kiste: $\quad 8505719$

Skelet: $\quad$ V19 Wirbelbogen

Population: Calden
Verband: $\square$ Verband

Alter:

Ges./Kr.: Krank

\section{Geschlecht:}

Arthrose:

\begin{tabular}{|c|c|c|}
\hline 1 & 2.5 & 1 \\
\hline 1 & 3 & 1 \\
\hline & Th3 & \\
\hline 1 & 3 & 1 \\
\hline 1 & 2 & 1 \\
\hline
\end{tabular}

Beschreibung:

Wirbel aus Verband. 
Bezeichn.: Vertebra

\section{Kiste:}

8505719

Skelet: $\quad$ V19 Wirbelbogen

Population: Calden
Verband: Verband

\section{Alter:}

Geschlecht:

Arthrose:

\begin{tabular}{|c|c|c|}
\cline { 2 - 3 } \multicolumn{1}{c|}{} & \multicolumn{1}{c|}{} \\
\hline 1 & 2 & 3 \\
\hline 1 & 2 & 1 \\
\hline 1 & 1.5 & 1
\end{tabular}

Beschreibung:

Wirbel aus Verband. 
Bezeichn.: Vertebra

\section{Kiste:}

8505719

Skelet: $\quad$ V19 Wirbelbogen

Population: Calden
Verband: Verband

Ges./Kr.: Gesund

Geschlecht:

Arthrose:

\begin{tabular}{|c|c|c|}
\hline 1 & 1.5 & 1 \\
\hline 1 & 1 & 1 \\
\hline & Th2 & \\
\hline 1 & 2 & 1 \\
\hline 1 & 2.5 & 1 \\
\hline
\end{tabular}

Beschreibung:

Wirbel aus Verband. 
Bezeichn.: Vertebra

\section{Kiste:}

8505719

Wirbelsammelzettel

$\begin{array}{ll}\text { Skelet: Wirbelsam } & \text { Calden }\end{array}$

\section{Beschreibung:}

Ein kleines Fragment.
Verband: Verband

\section{Alter:}

Geschlecht:

Arthrose:

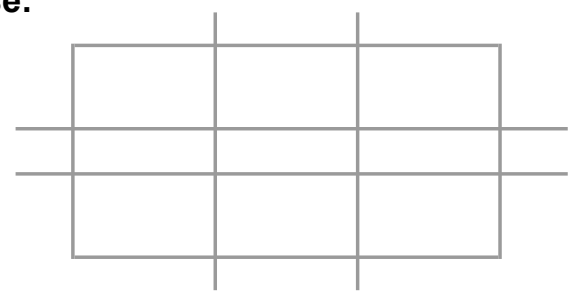


Bezeichn.: Vertebra

\section{Kiste:}

8505719

Skelet: Wirbelsammelzettel

Population: Calden
Verband: $\quad$ Verband

\section{Alter:}

Ges./Kr.: Krank

Geschlecht:

Arthrose:

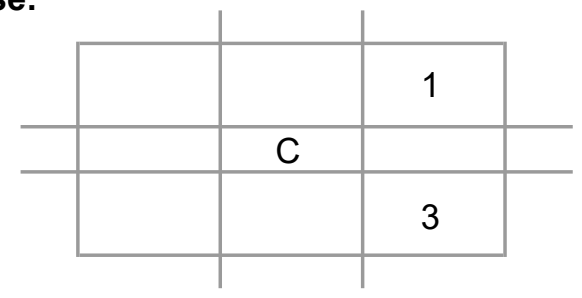

\section{Beschreibung:}

Ein Fragment aus dem Bereich C 3-7. 
Bezeichn.: Vertebra

\section{Kiste:}

8505719

Skelet: Wirbelsammelzettel

Population: Calden
Verband: $\quad$ Verband

\section{Alter:}

Geschlecht:

Arthrose:

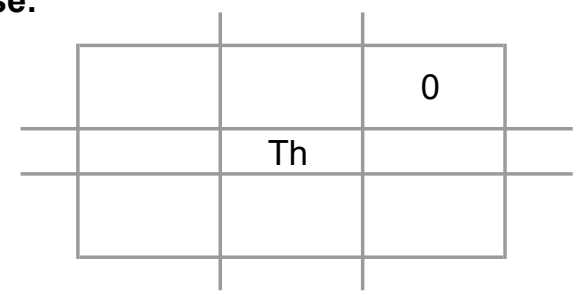

\section{Beschreibung:}

Wirbelfragment. 
Bezeichn.: Vertebra

\section{Kiste:}

8505719

Skelet: Wirbelsammelzettel

Population: Calden
Verband: $\square$ Verband

\section{Alter: $8-16$}

Geschlecht:

Arthrose:

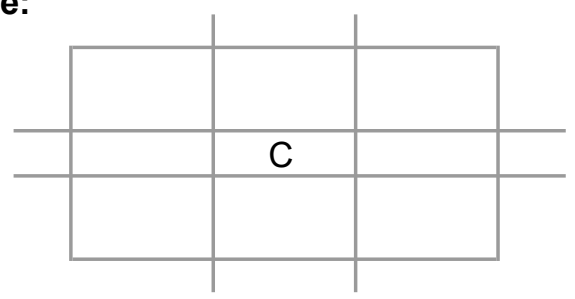

\section{Beschreibung:}

Ein Fragment eines Wirbels eines jungen Individuums. 
Bezeichn.: Vertebra

\section{Kiste:}

8505719

Wirbelsammelzettel

Polet: Population: Calden
Verband:

Verband

Ges./Kr.: Gesund

\section{Alter:}

Geschlecht:

Arthrose:

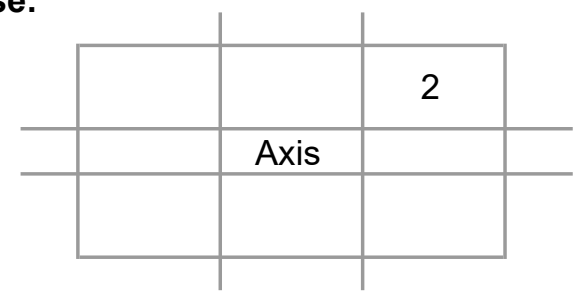

\section{Beschreibung:}

Wirbelfragment. 
Bezeichn.: Vertebra

\section{Kiste:}

8505719

Wirbelsammelzettel

Population: Calden
Verband: $\square$ Verband

Ges./Kr.: Gesund

\section{Geschlecht:}

\section{Arthrose:}

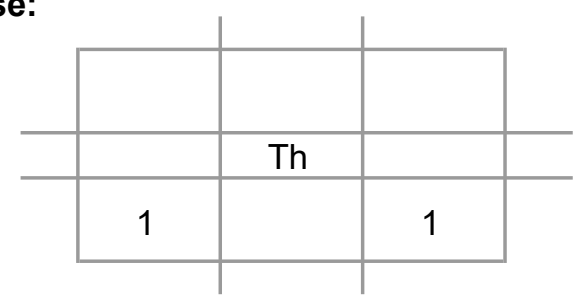

\section{Beschreibung:}

Wirbelfragment. 
Bezeichn.: Vertebra

\section{Kiste:}

8505719

Wirbelsammelzettel

Population: Calden
Verband: $\quad$ Verband

\section{Alter:}

Geschlecht:

Arthrose:

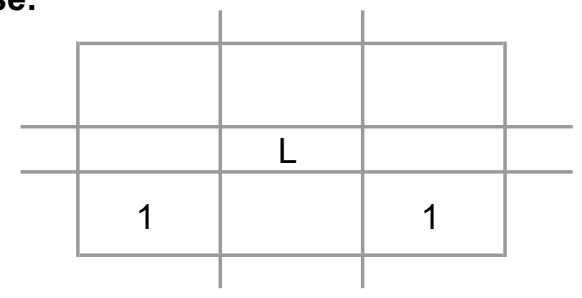

\section{Beschreibung:}

Wirbelfragment. 
Bezeichn.: Vertebra

\section{Kiste:}

8505719

Wirbelsammelzettel

Population: Calden
Verband: Verband

\section{Alter:}

Geschlecht:

Arthrose:

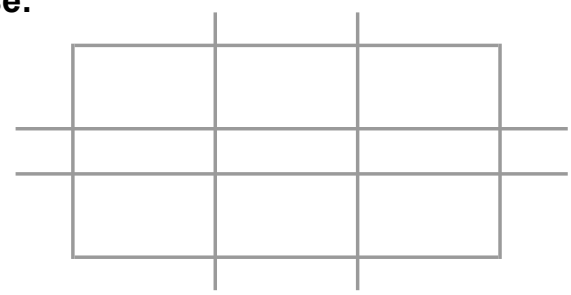

Beschreibung:

Ein sehr stark erodiertes Fragment. 
Bezeichn.: Vertebra

Kiste:

8505719

Skelet: Wirbelsammelzettel

Population: Calden

\section{Verband: $\quad$ Verband}

\section{Alter:}

Ges./Kr.: Krank

Geschlecht:

Arthrose:

\section{Krankh.: Bandverknöcherungen}

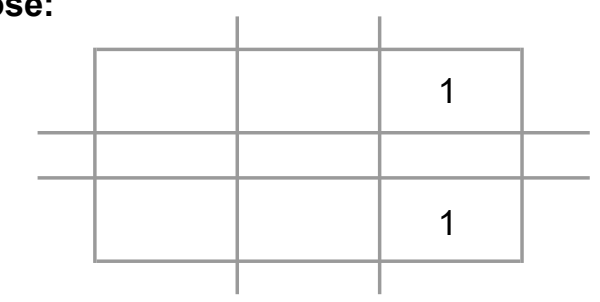

\section{Beschreibung:}

Ein nur seitlich erhaltenes Fragment eines Wirbels, welcher eine leichte Bandverknöcherung des Ligamentum flavum aufweist. 
Bezeichn.: Vertebra

\section{Kiste:}

8505719

Wirbelsammelzettel

Polet: Population: Calden
Verband: $\quad \square$ Verband

Alter:

Geschlecht:

Arthrose:

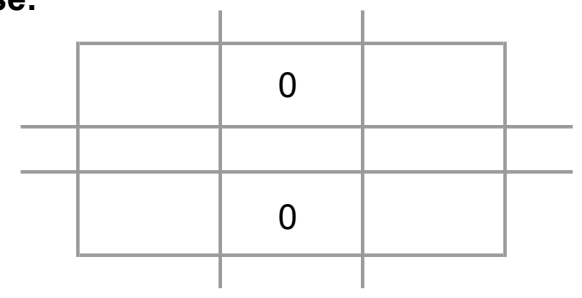

\section{Beschreibung:}

Wirbelfragment. 
Bezeichn.: Vertebra

\section{Kiste:}

8505719

Wirbelsammelzettel

Population: Calden
Verband: $\square$ Verband

Ges./Kr.: Gesund

\section{Geschlecht:}

Arthrose:

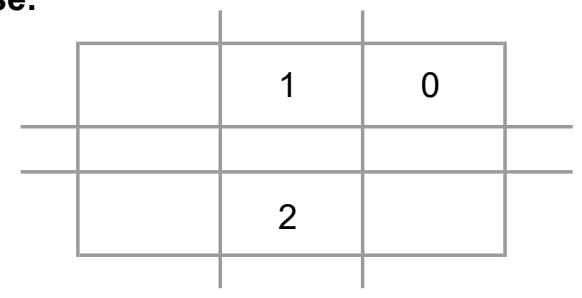

\section{Beschreibung:}

Wirbelfragment. 
Bezeichn.: Vertebra

\section{Kiste:}

8505719

Wirbelsammelzettel

Population: Calden
Verband: $\quad \square$ Verband

Alter:

Geschlecht:

Arthrose:

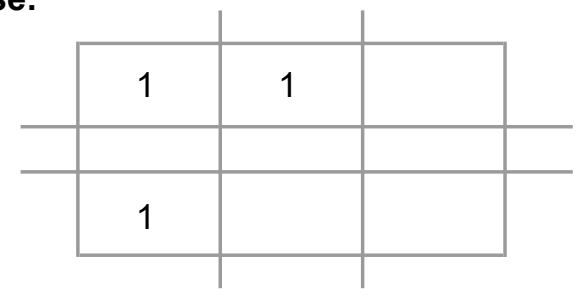

\section{Beschreibung:}

Wirbelfragment. 
Bezeichn.: Vertebra

\section{Kiste:}

8505719

Skelet: Extremitätenfragemente

Population: Calden
Verband: Verband

\section{Alter:}

Geschlecht:

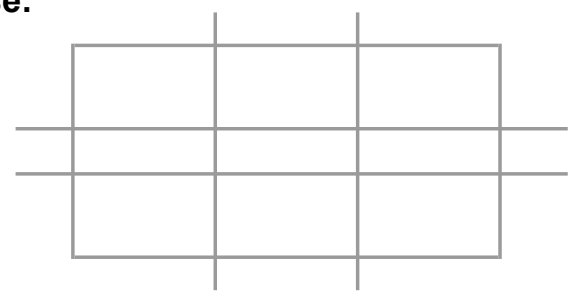

\section{Beschreibung:}

Ein kleines Fragment des Processus articularis superius. 
Bezeichn.: Vertebra

Kiste: $\quad 8505719$

Skelet: Vertebra Fragment

Population: Calden
Verband: Verband

\section{Alter:}

Geschlecht:

Arthrose:

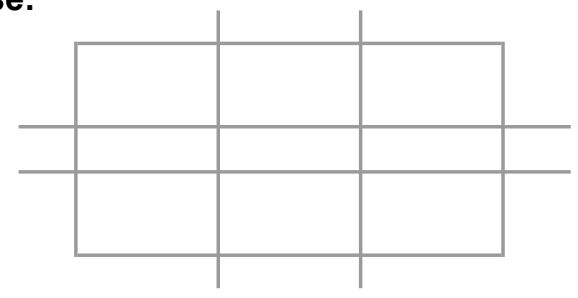

Beschreibung:

Ein kleines Fragment. 
Bezeichn: Vertebra

Verband: $\quad \square$ Verband

Ges./Kr.: Krank

Kiste: $\quad 5245269$

Skelet: $\quad$ V12 üb. SCH.30

Alter: Erwachsen

Krankh.: Arthrose

Population: Calden

\section{Geschlecht: ${ }^{\lambda}$}

Spondylophyten

\begin{tabular}{|c|c|c|}
\cline { 2 - 3 } \multicolumn{1}{c|}{} & \multicolumn{1}{c|}{} \\
\hline 4 & 4 & 4 \\
\hline & L5 & \\
\hline & 3 & 2 \\
\hline
\end{tabular}

\section{Beschreibung:}

Der Lendenwirbel L5 des Verbands weist besonders auf der oberen Deckplatte des Corpus, aber auch auf der unteren Spondylophyten auf. Diese messen bis zu 5,3mm und sind eher rechtsseitig zu finden. Auffällige Verschleißerscheinungen zeigen sich auch an den Costo - vertebralen Gelenken, besonders am rechten, welches am oberen Rand auffällig eburniert ist. Weiterhin weisen die Ränder Spondylophyten auf, die als Knochenneubildungen im Zuge von starken körperlichen Belastungen und

Überbelastungen reaktionär entstanden sind. Es sind der linke Processus articularis inferior und der Processus spinosus erhalten. 
Bezeichn.: Vertebra

\section{Kiste:}

5254272

Skelet: ohne Bezeichnung

Population: Calden
Verband: $\square$ Verband

Ges./Kr.: Gesund

\section{Geschlecht:}

Arthrose:

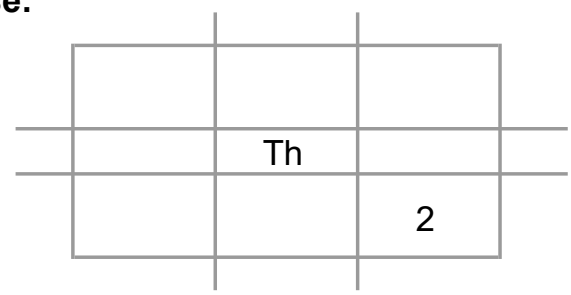

\section{Beschreibung:}

Fragment mit Teil des Processus spinosus, kein Körper erhalten. 
Bezeichn.: Vertebra

\section{Kiste:}

5254272

Skelet: ohne Bezeichnung

Population: Calden
Verband: Verband

\section{Alter:}

Geschlecht:

Arthrose:

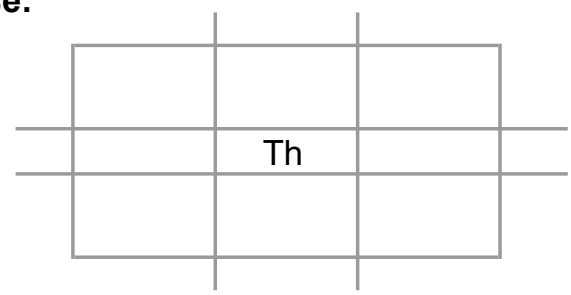

\section{Beschreibung:}

Ein sehr kleines Fragment. 
Bezeichn.: Vertebra

Kiste: $\quad 5259276$

Skelet: $\quad$ aus Tüte mit Becken und

Population: Calden

\section{Verband: $\quad$ Verband Ges./Kr.: Gesund}

\section{Alter:}

Geschlecht:

Arthrose:

\begin{tabular}{l|c|c|c}
\multicolumn{1}{c|}{} & \multicolumn{1}{c}{} \\
\cline { 2 - 4 } \multicolumn{1}{l|}{0} & 0 & 0 \\
\hline 1 & & Th10 & \\
\hline & 1 & & 1 \\
\cline { 2 - 4 } & & & \multicolumn{1}{c}{}
\end{tabular}

\section{Beschreibung:}

Dieser Wirbel stammt aus dem mittleren bis unteren thorakalen Bereich. Es sind die untere Deckplatte und der komplette corpus nicht erhalten. Der Wirbel wirkt farblich sehr hell. 
Bezeichn:: Vertebra

Kiste: $\quad 5259276$

Skelet: $\quad$ V4 aus Tüte mit Becken

Population: Calden

\section{Verband: $\square$ Verband Ges./Kr.: Krank}

Alter: $20-30$ (32) Krankh.: Arthrose

Geschlecht:

Arthrose:

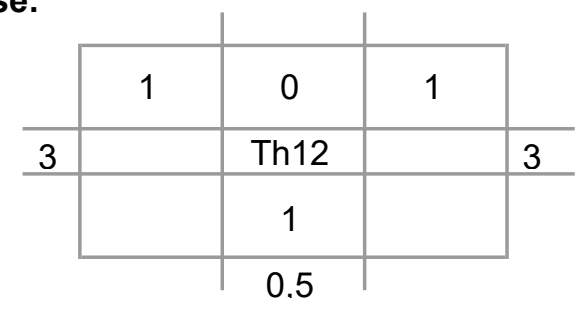

\section{Beschreibung:}

Hier sind zwei Wirbel eines Verbands erhalten, die von einem Individuum stammen. 
Bezeichn.: Vertebra

Kiste: $\quad 5259276$

Skelet: $\quad$ V4 aus Tüte mit Becken

Population: Calden
Verband: $\quad$ Verband

Ges./Kr.: Gesund

Geschlecht:

Arthrose:

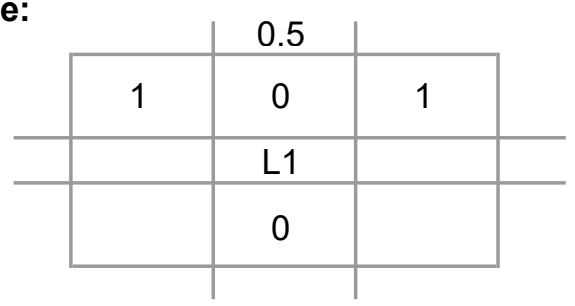

\section{Beschreibung:}

Wirbel aus Verband. 


\section{Bezeichn.: Vertebra \\ Kiste: $\quad 8505721$ \\ Skelet: Kiste 12}

Population: Calden

\section{Verband: $\quad$ Verband \\ Ges./Kr.: Gesund}

\section{Alter:}

Geschlecht:

Arthrose:

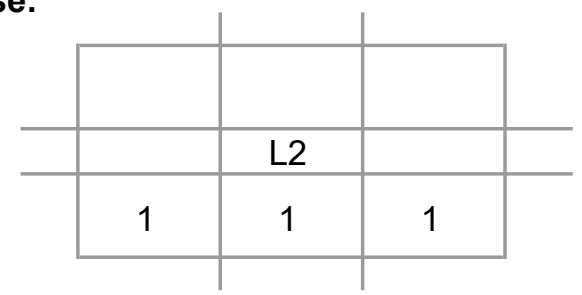

\section{Beschreibung:}

Es ist nur die untere Deckplatte zum Teil erhalten und die unteren Gelenkfortsätze. Es handelt sich um einen Wirbel des oberen lumbalen Bereichs. 


\section{Bezeichn: Vertebra \\ Kiste: $\quad 8505721$ \\ Skelet: Kiste 5}

Population: Calden

\section{Verband: $\quad$ Verband \\ Ges./Kr.: Gesund}

\section{Alter:}

Geschlecht: $q>\lambda$

Arthrose:

\begin{tabular}{|c|c|c|}
\cline { 2 - 3 } \multicolumn{1}{c||}{} & \multicolumn{1}{c|}{} \\
\hline 1 & 2 & 1 \\
\hline 2 & 1 & 1 \\
\hline
\end{tabular}

\section{Beschreibung:}

Dies ist ein fast vollständig erhaltener Axis, der einen eher grazilen Eindruck macht, weswegen ein weibliches Individuum angenommen wird. 


\section{Bezeichn.: Vertebra \\ Kiste: \\ 8505721 \\ Kiste 5}

Skelet: Kopulation: Calden

\section{Verband: $\quad$ Verband \\ Ges./Kr.: Gesund}

Alter: $\quad 16-20$ (23)

Geschlecht:

Arthrose:

\begin{tabular}{|c|c|c|c|c|}
\hline & 0 & 0 & 0 & \\
\hline \multirow[t]{2}{*}{00} & & Th & & 00 \\
\hline & 0 & 0 & 0 & \\
\hline
\end{tabular}

\section{Beschreibung:}

Hier liegt ein fast vollständig erhaltener thorakaler Wirbel vor, der noch nicht verknöcherte laterale Gelenkfortsätze aufweist. 


\begin{tabular}{|c|c|c|c|c|}
\hline $\begin{array}{l}\text { Bezeichn.: } \\
\text { Kiste: } \\
\text { Skelet: }\end{array}$ & $\begin{array}{l}\text { Vertebra } \\
8505721 \\
\text { aus großer Kiste }\end{array}$ & $\begin{array}{l}\text { Verband: } \\
\text { Alter: } \\
\text { Geschlecht: }\end{array}$ & Verband & $\begin{array}{ll}\text { Ges./Kr.: } & \text { Krank } \\
\text { Krankh.: } & \text { Spondylophyten } \\
& \text { Arthrose }\end{array}$ \\
\hline
\end{tabular}

Population: Calden

Arthrose:

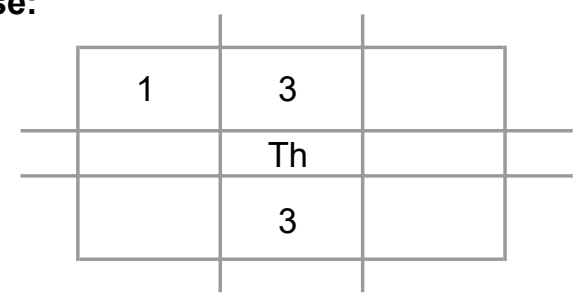

\section{Beschreibung:}

Dieses Wirbelfragment eines corpus stammt aus dem mittleren bis lumbalen Bereich. Es fallen lediglich leichte Spondylophyten an den anterioren Flächen der Deckplatten ins Auge. 
Bezeichn.: Vertebra

Kiste: $\quad 8505721$

Skelet: aus großer Kiste

Population: Calden
Verband: $\square$ Verband

\section{Alter:}

Geschlecht:

Arthrose:
Ges./Kr.: Krank

Krankh.: Bandverknöcherungen

Arthrose

\begin{tabular}{l|c|c|c|c}
\cline { 2 - 4 } \multicolumn{1}{c|}{} & 3 & 2 & 3 & \\
\hline 3 & & Th & & 3 \\
\hline & 2 & 1 & 2 & \\
\cline { 2 - 4 } & & & \multicolumn{2}{c}{}
\end{tabular}

\section{Beschreibung:}

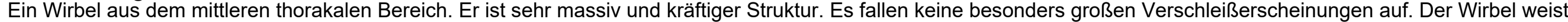
leichte Bandverknöcherungen an der Lamina Arcus vertebrae auf. 
Bezeichn:: Vertebra

\section{Kiste: $\quad 8505721$}

Skelet: aus großer Kiste

Population: Calden

\section{Verband: $\quad$ Verband Ges./Kr: Gesund}

\section{Alter: Jung}

Geschlecht:

Arthrose:

\begin{tabular}{|c|c|c|c|c|}
\hline & 0 & 0 & 0 & \\
\hline \multirow[t]{2}{*}{0} & & Th 6 & & 0 \\
\hline & 0 & 0 & 0 & \\
\hline
\end{tabular}

\section{Beschreibung:}

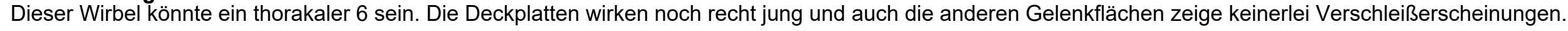


Verband: $\quad$ Verband

\section{Alter:}

Geschlecht: $q \leq \hat{0}$

Skelet: V2 aus großer Kiste

Population: Calden

Arthrose:

\begin{tabular}{|c|c|c|}
\hline 2.5 & 4 & 2.5 \\
\hline 3 & 4 & 3 \\
\hline & L1 & \\
\hline 3 & 5 & 3 \\
\hline
\end{tabular}

Ges./Kr.: Krank

Krankh.: Arthrose

Arthritis

Fraktur

Spondylophyten

\section{Beschreibung:}

Dieser letzte thorakale Wirbel weist einen sehr breiten Rand an der oberen Deckplatte auf. Weiterhin sieht es so aus, als sei der Wirbelkörper nach vorne eingebrochen. Die obere Deckplatte zeigt allerdings keine starken Verschleißerscheinungen. An der Fovea costalis superior ist eine sehr starke Arthritis zu erkennen. Der Wirbelkörper weist deutliche Spondylophyten auf und auch der erste lumbale Wirbel hat starke Spondylophyten an der unteren Deckplatte und einige an der obere Deckplatte. Die untere Deckplatte weist eine leichte Arthritis auf. Die beiden Wirbel gehören zusammen, es könnte sich nach dieser Begutachtung zufolge um ein traumatisches Ereignis gehandelt haben, bei dem sich die Zwischenwirbelscheibe der Wirbel Th11 und Th12 stark verdichtet und dann den Wirbel Th12 zusammengestaucht hat. Interessanterweise zeigen die Deckplatten der beiden Wirbel keine Zeichen traumatischer Ereignisse, außer den Spuren des beschriebenen Absackens. 
Verband: $\quad \square$ Verband

Ges./Kr.: Krank

Kiste: $\quad 8505721$

Skelet: $\quad$ V2 aus großer Kiste

\section{Alter:}

Krankh.: Arthritis

Population: Calden

\section{Geschlecht: $q \leq \delta$}

Arthrose:

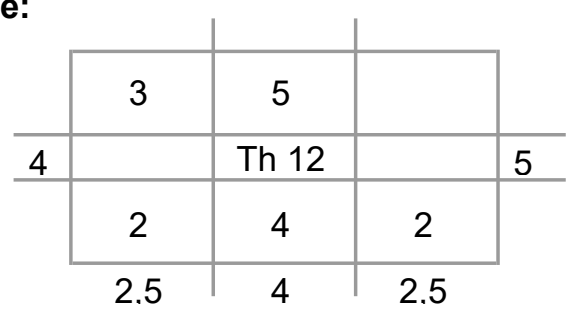

Arthrose

Arthritis

Spondylophyten

\section{Beschreibung:}

Dieser letzte thorakale Wirbel weist einen sehr breiten Rand an der oberen Deckplatte auf. Weiterhin sieht es so aus, als sei der Wirbelkörper nach vorne eingebrochen. Die obere Deckplatte zeigt allerdings keine starken Verschleißerscheinungen. An der Fovea costalis superior ist eine sehr starke Arthritis zu erkennen. Der Wirbelkörper weist deutliche Spondylophyten auf und auch der erste lumbale Wirbel hat starke Spondylophyten an der unteren Deckplatte und einige an der obere Deckplatte. Die untere Deckplatte weist eine leichte Arthritis auf. Die beiden Wirbel gehören zusammen, es könnte sich nach dieser Begutachtung zufolge um ein traumatisches Ereignis gehandelt haben, bei dem sich die Zwischenwirbelscheibe der Wirbel Th11 und Th12 stark verdichtet und dann den Wirbel Th12 zusammengestaucht hat. Interessanterweise zeigen die Deckplatten der beiden Wirbel keine Zeichen traumatischer Ereignisse, außer den Spuren des beschriebenen Absackens. 


\section{Bezeichn: Vertebra \\ Kiste: 5243267 \\ Skelet: V 37}

Population: Calden
Verband: $\quad$ Verband

Alter: (16) 18 - 22 (25)

Geschlecht:

Arthrose:

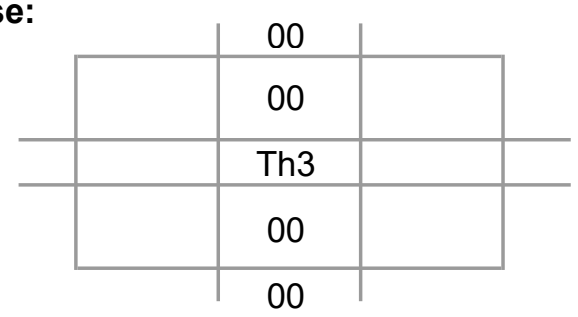

\section{Beschreibung:}




\section{Bezeichn: Vertebra \\ Kiste: 5243267 \\ Skelet: V 37}

Population: Calden
Verband: $\quad$ Verband

Alter: (16) 18 - 22 (25)

Geschlecht:

Arthrose:

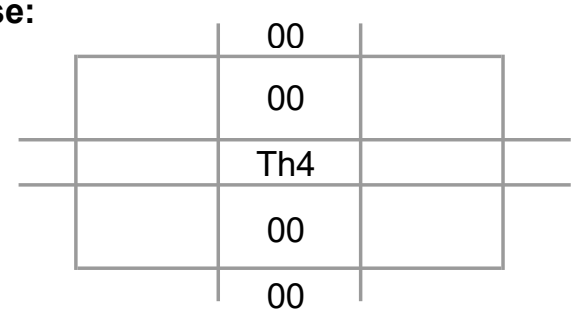

\section{Beschreibung:}




\section{Bezeichn: Vertebra \\ Kiste: 5243267 \\ Skelet: V 37}

Population: Calden
Verband: $\square$ Verband

Alter: (16) 18 - 22 (25)

Geschlecht:

Arthrose:

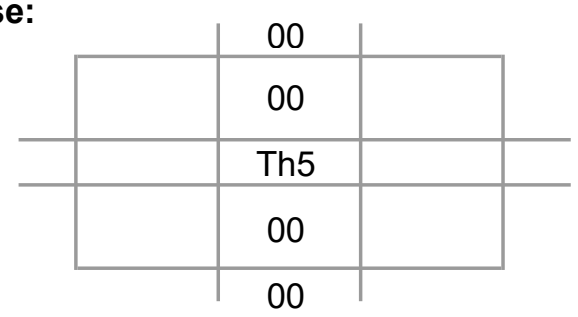

\section{Beschreibung:}




\section{Bezeichn: Vertebra \\ Kiste: 5243267 \\ Skelet: V 37}

Population: Calden
Verband: $\square$ Verband

Alter: (16) 18 - 22 (25)

Geschlecht:

Arthrose:

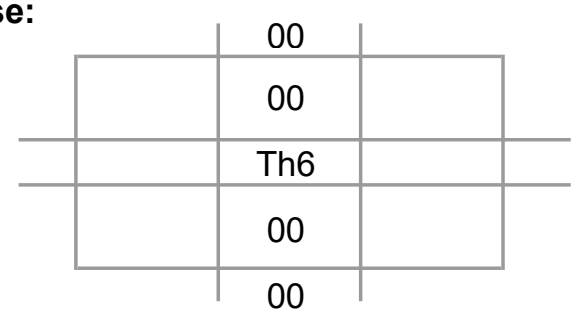

\section{Beschreibung:}




\section{Bezeichn: Vertebra \\ Kiste: 5243267 \\ Skelet: V 37}

Population: Calden
Verband: $\quad$ Verband

Alter: (16) 18 - 22 (25)

Geschlecht:

Arthrose:

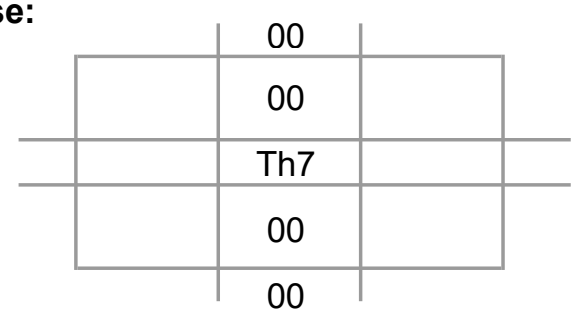

\section{Beschreibung:}




\section{Bezeichn: Vertebra \\ Kiste: 5243267 \\ Skelet: V 37}

Population: Calden
Verband: $\quad$ Verband

Alter: (16) 18 - 22 (25)

Geschlecht:

Arthrose:

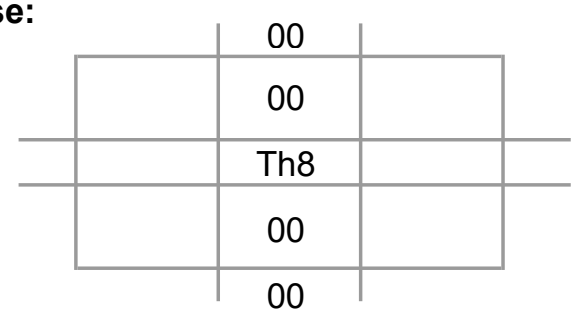

\section{Beschreibung:}




\section{Bezeichn: Vertebra \\ Kiste: 5243267 \\ Skelet: V 37}

Population: Calden
Verband: $\quad$ Verband

Alter: (16) 18 - 22 (25)

Geschlecht:

Arthrose:

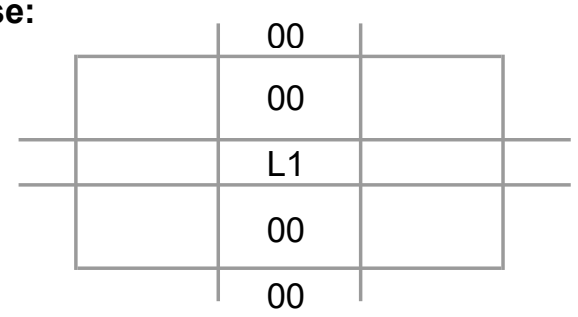

\section{Beschreibung:}




\section{Bezeichn: Vertebra \\ Kiste: 5243267 \\ Skelet: V 37}

Population: Calden
Verband: $\quad$ Verband

Alter: (16) 18 - 22 (25)

Geschlecht:

Arthrose:

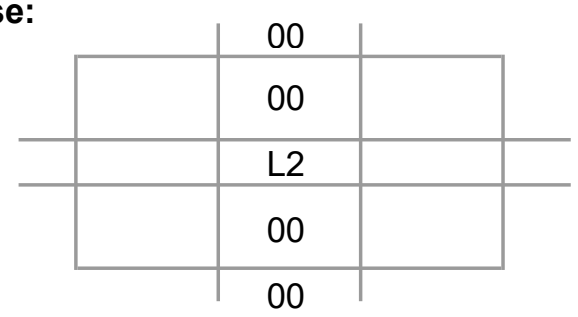

\section{Beschreibung:}




\section{Bezeichn: Vertebra \\ Kiste: 5243267 \\ Skelet: V 37}

Population: Calden
Verband: $\quad$ Verband

Alter: (16) 18 - 22 (25)

Geschlecht:

Arthrose:

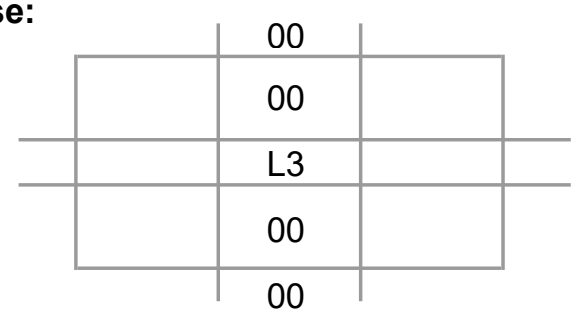

\section{Beschreibung:}




\section{Bezeichn: Vertebra \\ Kiste: 5243267 \\ Skelet: V 37}

Population: Calden
Verband: $\quad$ Verband

Alter: (16) 18 - 22 (25)

Geschlecht:

Arthrose:

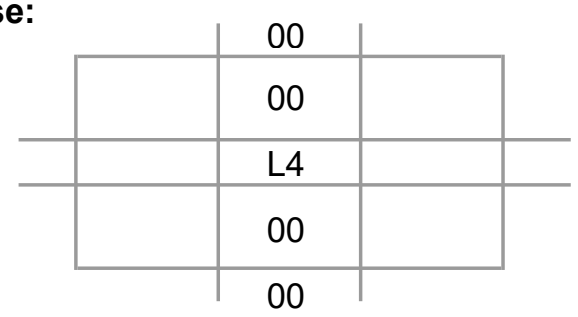

\section{Beschreibung:}




\section{Bezeichn: Vertebra \\ Kiste: 5243267 \\ Skelet: $\vee 37$}

Population: Calden
Verband: $\quad$ Verband

Alter: (16) 18 - 22 (25)

Geschlecht:

Arthrose:

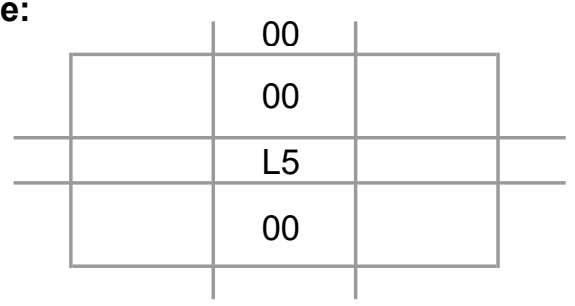

\section{Beschreibung:}


Bezeichn.: Vertebra

Kiste: $\quad 5261277$

Skelet: V33 kleine Tüte

Population: Calden
Verband: $\quad$ Verband

Alter: Erwachsen

\section{Geschlecht:}

Arthrose:

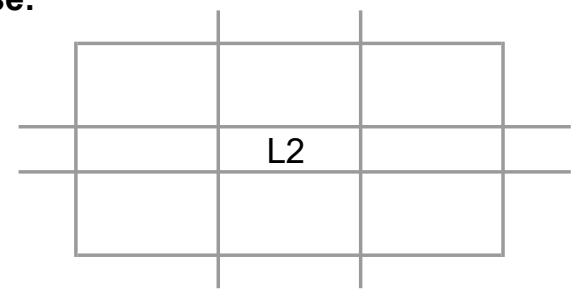

Beschreibung:

Wirbel aus Verband. 


\section{Bezeichn.: Costa}

\section{Kiste: \\ Museumskiste 3}

Skelet: ohne

Population: Calden

Seite:

n. def.

\section{Verband: $\quad$ Verband}

\section{Alter:}

Geschlecht:

Arthrose:

\section{Beschreibung:}

Es handelt sich um ein sternales Fragment, welches etwa 1/7 der gesamten Rippe ausmacht. 
Bezeichn.: Costa

Kiste: Museumskiste 3

Skelet: ohne

Population: Calden

Seite:

links
Verband: $\square$ Verband

\section{Alter:}

Geschlecht:

Arthrose:

\section{Beschreibung:}

Hierbei handelt es sich um eine 3. Rippe der linken Seite. 
Bezeichn.: Costa

Kiste: Museumskiste 3

Skelet: ohne

Population: Calden

Seite:

rechts
Verband: $\quad$ Verband

\section{Alter:}

Geschlecht:

Arthrose:

\section{Beschreibung:}

Dies ist eine 3. Rippe der rechten Seite. 
Bezeichn.: Costa

Kiste: $\quad 8505718$

Skelet: aus Tüte

Population: Calden

\section{Beschreibung:}

Dies ist ein Rippenfragment.
Verband:

Verband

\section{Alter:}

Geschlecht:

Arthrose:
Ges./Kr.: Gesund

\section{Ges./Kr.: Gesund}


Bezeichn.: Costa

Kiste: $\quad 8505718$

Skelet: aus Tüte

Population: Calden

Seite:

rechts
Verband: $\quad \square$ Verband

\section{Alter:}

Geschlecht:

Arthrose:

\section{Beschreibung:}

Dies ist ein Rippenfragment. 
Bezeichn.: Costa

Kiste: $\quad 8505718$

Skelet: aus Tüte

Population: Calden

\section{Beschreibung:}

Eine Rippe eines jungen Individuums.
Verband:

\section{Alter:}

Ges./Kr.: Gesund

Geschlecht:

Arthrose: 
Bezeichn.: Costa

Kiste: $\quad 8505718$

Skelet: aus Tüte

Population: Calden

\section{Beschreibung:}

Ein Rippenfragment.
Verband:

Verband

\section{Alter:}

Geschlecht:

Arthrose:
Ges./Kr.: Gesund

\section{Ges./Kr: : Gesund}




\section{Bezeichn.: Costa}

Kiste: 8505718

Skelet: aus Tüte

Population: Calden

Seite:

rechts

\section{Verband: $\quad$ Verband}

\section{Alter:}

Geschlecht: $q \leq \lambda$

Arthrose:

\section{Beschreibung:}

Rippe eines älteren Individuums, es handelt sich wohl um die 9. der rechten Seite. 
Bezeichn.: Costa

Kiste: $\quad 8505718$

Skelet: aus Tüte

Population: Calden

Seite:

links
Verband: $\quad \square$ Verband

Ges./Kr.: Gesund

\section{Alter:}

Geschlecht: $q \leq \hat{\sigma}$

Arthrose:

\section{Beschreibung:}

Ein Fragment einer linken Rippe von der etwa 30\% erhalten sind. Sie ist sehr massiv. 
Bezeichn.: Costa

Kiste: $\quad 8505718$

Skelet: aus Tüte

Population: Calden

Seite:

rechts
Verband: $\quad$ Verband

\section{Alter: Jung}

Geschlecht:

Arthrose:

\section{Beschreibung:}

Mittiges Fragment einer jungen Rippe der rechten Seite. Es sind etwa 50\% der gesamten Rippe erhalten. 
Bezeichn.: Costa

Kiste: $\quad 8505718$

Skelet: aus Tüte

Population: Calden

\section{Beschreibung:}

Ein Rippenfragment.
Verband:

Verband

\section{Alter:}

Geschlecht:

Arthrose:
Ges./Kr.: Gesund

\section{Ges./Kr: Gesund}




\section{Bezeichn.: Costa}

Kiste: 8505718

Skelet: aus Tüte

Population: Calden

Seite:

links
Verband: $\square$ Verband

\section{Alter:}

Geschlecht: $q \leq \hat{O}$

Arthrose:

\section{Beschreibung:}

Wohl 9. Rippe links, es sind etwa 50\% aus der Mitte erhalten. 
Bezeichn.: Costa

Kiste: $\quad 8505718$

Skelet: aus Tüte

Population: Calden

Seite:

links
Verband:

Verband

\section{Alter:}

Geschlecht:

Arthrose:
Ges./Kr.: Gesund

\section{Beschreibung:}

Rippenfragment, etwa $30 \%$ erhalten. 
Bezeichn.: Costa

Kiste: $\quad 8505718$

Skelet: aus Tüte

Population: Calden

\section{Beschreibung:}

Ein Fragment einer jungen Rippe.
Verband:

Verband

Alter:

Ges./Kr.: Gesund

\section{Geschlecht:}

Arthrose: 
Bezeichn.: Costa

Kiste: $\quad 8505718$

Skelet: aus Tüte

Population: Calden

\section{Beschreibung:}

Fragment einer Rippe.
Verband: $\square$ Verband

\section{Alter:}

Geschlecht:

Arthrose:
Ges./Kr.: Gesund 
Bezeichn.: Costa

Kiste: $\quad 8505718$

Skelet: aus Tüte

Population: Calden

\section{Beschreibung:}

Fragment einer Rippe.
Verband: $\square$ Verband

\section{Alter:}

Geschlecht:

Arthrose:
Ges./Kr.: Gesund 
Bezeichn.: Costa

Kiste: $\quad 8505718$

Skelet: aus Tüte

Population: Calden

\section{Beschreibung:}

Fragment einer Rippe.
Verband: $\quad$ Verband

\section{Alter:}

Geschlecht:

Arthrose:
Ges./Kr.: Gesund 
Bezeichn.: Costa

Kiste: $\quad 8505718$

Skelet: aus Tüte

Population: Calden

\section{Beschreibung:}

Fragment einer Rippe.
Verband: $\quad$ Verband

\section{Alter:}

Geschlecht:

Arthrose:
Ges./Kr.: Gesund 
Bezeichn.: Costa

Kiste: $\quad 8505718$

Skelet: aus Tüte

Population: Calden

\section{Beschreibung:}

Fragment einer Rippe.
Verband: $\square$ Verband

\section{Alter:}

Geschlecht:

Arthrose:
Ges./Kr.: Gesund 
Bezeichn.: Costa

Kiste: $\quad 8505718$

Skelet: aus Tüte

Population: Calden

\section{Beschreibung:}

Fragment einer Rippe.
Verband: $\square$ Verband

\section{Alter:}

Geschlecht:

Arthrose:
Ges./Kr.: Gesund 
Bezeichn.: Costa

Kiste: $\quad 8505718$

Skelet: aus Tüte

Population: Calden

\section{Beschreibung:}

Fragment einer Rippe.
Verband: $\square$ Verband

\section{Alter:}

Geschlecht:

Arthrose:
Ges./Kr.: Gesund 
Bezeichn.: Costa

Kiste: $\quad 8505718$

Skelet: aus Tüte

Population: Calden

\section{Beschreibung:}

Fragment einer Rippe.
Verband: $\square$ Verband

\section{Alter:}

Geschlecht:

Arthrose:
Ges./Kr.: Gesund 
Bezeichn.: Costa

Kiste: $\quad 8505718$

Skelet: aus Tüte

Population: Calden

\section{Beschreibung:}

Fragment einer Rippe.
Verband: $\square$ Verband

\section{Alter:}

Geschlecht:

Arthrose:
Ges./Kr.: Gesund 
Bezeichn.: Costa

Kiste: $\quad 8505718$

Skelet: aus Tüte

Population: Calden

Seite:
Verband:

Verband

\section{Alter:}

Geschlecht:

Arthrose:

Ges./Kr.: Gesund

\section{Beschreibung:}

Fragment einer Rippe, welches etwa 40\% der gesamten Rippe ausmacht. 


\section{Bezeichn.: Costa}

Kiste: 8505718

Skelet: aus Tüte

Population: Calden

Seite:
Verband:

Verband

\section{Alter:}

Geschlecht:

Arthrose:
Ges./Kr.: Gesund

\section{Beschreibung:}

Rippenfragment, welches die Hälfte der Rippe ausmacht. 
Bezeichn.: Costa

Kiste: $\quad 8505720$

Skelet: $\quad 1.2$

Population: Calden
Verband:

\section{Alter:}

Geschlecht:

Arthrose:
Ges./Kr.: Gesund

\section{Beschreibung:}

Fragment. 
Bezeichn.: Costa

Kiste: $\quad 8505720$

Skelet: $\quad 1.2$

Population: Calden
Verband:

\section{Alter:}

Geschlecht:

Arthrose:
Ges./Kr.: Gesund

\section{Beschreibung:}

Fragment. 
Bezeichn.: Costa

Kiste: $\quad 8505720$

Skelet: $\quad 1.2$

Population: Calden
Verband:

\section{Alter:}

Geschlecht:

Arthrose:
Ges./Kr.: Gesund

\section{Beschreibung:}

Fragment. 
Bezeichn.: Costa

Kiste: $\quad 8505720$

Skelet: $\quad 1.2$

Population: Calden
Verband:

\section{Alter:}

Geschlecht:

Arthrose:
Ges./Kr.: Gesund

\section{Beschreibung:}

Fragment. 
Bezeichn.: Costa

Kiste: $\quad 8505720$

Skelet: $\quad 1.2$

Population: Calden
Verband:

\section{Alter:}

Geschlecht:

Arthrose:
Ges./Kr.: Gesund

\section{Beschreibung:}

Fragment. 
Bezeichn.: Costa

Kiste: $\quad 8505720$

Skelet: $\quad 1.0$

Population: Calden

Verband: $\quad$ Verband

\section{Alter:}

Geschlecht:

Arthrose:

\section{Beschreibung:}

Fragment. 
Bezeichn.: Costa

Kiste: $\quad 8505720$

Skelet: $\quad 1.0$

Population: Calden

Verband: $\quad$ Verband

\section{Alter:}

Geschlecht:

Arthrose:

\section{Beschreibung:}

Fragment. 
Bezeichn.: Costa

Kiste: $\quad 8505720$

Skelet: $\quad 1.0$

Population: Calden

Verband: $\quad$ Verband

\section{Alter:}

Geschlecht:

Arthrose:

\section{Beschreibung:}

Fragment. 
Bezeichn.: Costa

Kiste: $\quad 8505720$

Skelet: $\quad 1.0$

Population: Calden

Verband: $\quad$ Verband

\section{Alter:}

Geschlecht:

Arthrose:

\section{Beschreibung:}

Fragment. 
Bezeichn.: Costa

Kiste: $\quad 8505720$

Skelet: $\quad 1.0$

Population: Calden

Verband: $\quad$ Verband

\section{Alter:}

Geschlecht:

Arthrose:

\section{Beschreibung:}

Fragment. 
Bezeichn.: Costa

Kiste: $\quad 8505720$

Skelet: $\quad 1.0$

Population: Calden

Verband: $\quad$ Verband

\section{Alter:}

Geschlecht:

Arthrose:

\section{Beschreibung:}

Fragment. 
Bezeichn.: Costa

Kiste: $\quad 8505720$

Skelet: $\quad 1.0$

Population: Calden

Verband: $\quad$ Verband

\section{Alter:}

Geschlecht:

Arthrose:

\section{Beschreibung:}

Fragment. 
Bezeichn.: Costa

Kiste: $\quad 8505720$

Skelet: $\quad 1.0$

Population: Calden

Verband: $\quad$ Verband

\section{Alter:}

Geschlecht:

Arthrose:

\section{Beschreibung:}

Fragment. 
Bezeichn.: Costa

Kiste: $\quad 8505720$

Skelet: $\quad 1.0$

Population: Calden

Verband: $\quad$ Verband

\section{Alter:}

Geschlecht:

Arthrose:

\section{Beschreibung:}

Fragment. 
Bezeichn.: Costa

Kiste: $\quad 8505720$

Skelet: $\quad 1.0$

Population: Calden

Verband: $\quad$ Verband

\section{Alter:}

Geschlecht:

Arthrose:

\section{Beschreibung:}

Fragment. 
Bezeichn.: Costa

Kiste: $\quad 8505720$

Skelet: $\quad 1.0$

Population: Calden

Verband: $\quad$ Verband

\section{Alter:}

Geschlecht:

Arthrose:

\section{Beschreibung:}

Fragment. 
Bezeichn.: Costa

Kiste: $\quad 8505720$

Skelet: $\quad 1.0$

Population: Calden

Verband: $\quad$ Verband

\section{Alter:}

Geschlecht:

Arthrose:

\section{Beschreibung:}

Fragment. 
Bezeichn.: Costa

Kiste: $\quad 8505720$

Skelet: $\quad 1.0$

Population: Calden

Verband: $\quad$ Verband

\section{Alter:}

Geschlecht:

Arthrose:

\section{Beschreibung:}

Fragment. 
Bezeichn.: Costa

Kiste: $\quad 8505720$

Skelet: $\quad 1.0$

Population: Calden

Verband: $\quad$ Verband

\section{Alter:}

Geschlecht:

Arthrose:

\section{Beschreibung:}

Fragment. 
Bezeichn.: Costa

Kiste: $\quad 8505720$

Skelet: $\quad 1.0$

Population: Calden

Verband: $\quad$ Verband

\section{Alter:}

Geschlecht:

Arthrose:

\section{Beschreibung:}

Fragment. 
Bezeichn.: Costa

Kiste: $\quad 8505720$

Skelet: $\quad 1.0$

Population: Calden

Verband: $\quad$ Verband

\section{Alter:}

Geschlecht:

Arthrose:

\section{Beschreibung:}

Fragment. 
Bezeichn.: Costa

Kiste: $\quad 8505720$

Skelet: $\quad 1.0$

Population: Calden

Verband: $\quad$ Verband

\section{Alter:}

Geschlecht:

Arthrose:

\section{Beschreibung:}

Fragment. 
Bezeichn.: Costa

Kiste: $\quad 5271289$

Skelet: $\quad 1.2$

Population: Calden

Verband: $\quad$ Verband

\section{Alter:}

Geschlecht:

Arthrose:

\section{Beschreibung:}

Fragment. 
Bezeichn.: Costa

Kiste: $\quad 8505720$

Skelet: $\quad 1.2$

Population: Calden

Seite:
Verband: $\quad$ Verband

Alter:

\section{Geschlecht:}

Arthrose:
Ges./Kr.: Krank

Krankh.: Arthrose

\section{Beschreibung:}

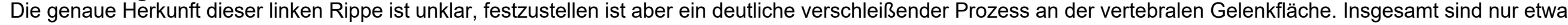
$40 \%$ der vertebralen Seite der Rippe erhalten. 
Bezeichn.: Costa

Kiste: $\quad 8505720$

Skelet: $\quad 1.2$

Population: Calden

Seite:

rechts
Verband:

Verband

\section{Alter:}

\section{Geschlecht:}

Arthrose:

Ges./Kr.: Gesund

\section{Ges.Kr: Gesund}




\begin{tabular}{|c|c|c|c|c|c|}
\hline Bezeichn.: & Costa & Verband: $\quad \square$ Verband & Maß & Wert & Einheit \\
\hline Kiste: & 8505720 & Alter: & Breite & 24,5 & $\mathrm{~mm}$ \\
\hline Skelet: & einzeln 1.1 & Geschlecht: & Länge & 50 & $\mathrm{~mm}$ \\
\hline $\begin{array}{l}\text { Population: } \\
\text { Seite: }\end{array}$ & $\begin{array}{l}\text { Calden } \\
\text { rechts }\end{array}$ & Arthrose: & & & \\
\hline
\end{tabular}

Beschreibung:

es liegt nur ein sternales Ende einer rechten, sehr massiven Rippe vor, welche ein reifes alter erreicht hat. Die Breite dieser Rippe aus dem Bereich 5 bis 8 ist $24,5 \mathrm{~mm}$ breit. 
Bezeichn.: Costa

Kiste: $\quad 8505720$

Skelet: einzeln 1.1

Population: Calden

Seite:

links
Verband: $\quad$ Verband

\section{Alter:}

Geschlecht:

Arthrose:
Ges./Kr.: Gesund

\section{Maß}

Breite

Länge

Wert $\quad$ Einheit

$13,78 \mathrm{~mm}$

130

$\mathrm{mm}$

\section{Beschreibung:}

Eine 11. Rippe eines nicht ausgewachsenen Individuums. Die Epiphysen sind nicht geschlossen. Das Fundstück ist vollständig erhalten. 
Bezeichn.: Costa

Kiste: $\quad 8505720$

Skelet: einzeln

Population: Calden

Seite: rechts
Verband: $\quad \square$ Verband

Ges./Kr.: Gesund

\section{Alter:}

Geschlecht:

Arthrose:

\section{Beschreibung:}

Hierbei handelt es sich um ein Fragment einer ersten Rippe rechts. Es ist nur etwa das proximale Viertel erhalten. 
Bezeichn.: Costa

Kiste: 8505720

Skelet: einzeln 1.1

Population: Calden

Seite:

links

\section{Verband: $\quad$ Verband}

Ges./Kr.: Gesund

\section{Alter:}

Geschlecht:

Arthrose:

\section{Beschreibung:}

Hierbei handelt es sich um eine erste Rippe der rechten Seite. Es ist nur ein mittig bis proximales Fragment erhalten. 
Bezeichn.: Costa

Kiste: $\quad 8505720$

Skelet: $\quad 1.3$

Population: Calden

Verband: $\quad$ Verband

\section{Alter:}

Geschlecht:

Arthrose:

\section{Beschreibung:}

Fragment. 
Bezeichn.: Costa

Kiste: $\quad 8505720$

Skelet: $\quad 1.3$

Population: Calden

Verband: $\quad$ Verband

\section{Alter:}

Geschlecht:

Arthrose:

\section{Beschreibung:}

Fragment. 
Bezeichn.: Costa

Kiste: $\quad 8505720$

Skelet: $\quad 1.3$

Population: Calden

Verband: $\quad$ Verband

\section{Alter:}

Geschlecht:

Arthrose:

\section{Beschreibung:}

Fragment. 
Bezeichn.: Costa

Kiste: $\quad 8505720$

Skelet: $\quad 1.3$

Population: Calden

Verband: $\quad$ Verband

\section{Alter:}

Geschlecht:

Arthrose:

\section{Beschreibung:}

Fragment. 
Bezeichn.: Costa

Kiste: $\quad 8505720$

Skelet: $\quad 1.3$

Population: Calden

Verband: $\quad$ Verband

\section{Alter:}

Geschlecht:

Arthrose:

\section{Beschreibung:}

Fragment. 
Bezeichn.: Costa

Kiste: $\quad 8505720$

Skelet: $\quad 1.3$

Population: Calden

Verband: $\quad$ Verband

\section{Alter:}

Geschlecht:

Arthrose:

\section{Beschreibung:}

Fragment. 
Bezeichn.: Costa

Kiste: $\quad 8505720$

Skelet: $\quad 1.3$

Population: Calden

Verband: $\quad$ Verband

\section{Alter:}

Geschlecht:

Arthrose:

\section{Beschreibung:}

Fragment. 
Bezeichn.: Costa

Kiste: $\quad 8505720$

Skelet: $\quad 1.3$

Population: Calden

Verband: $\quad$ Verband

\section{Alter:}

Geschlecht:

Arthrose:

\section{Beschreibung:}

Fragment. 
Bezeichn.: Costa

Kiste: $\quad 8505720$

Skelet: $\quad 1.3$

Population: Calden

Verband: $\quad$ Verband

\section{Alter:}

Geschlecht:

Arthrose:

\section{Beschreibung:}

Fragment. 
Bezeichn.: Costa

Kiste: $\quad 8505720$

Skelet: $\quad 1.3$

Population: Calden

Verband: $\quad$ Verband

\section{Alter:}

Geschlecht:

Arthrose:

\section{Beschreibung:}

Fragment. 
Bezeichn.: Costa

Kiste: $\quad 8505720$

Skelet: $\quad 1.3$

Population: Calden

Verband: $\quad$ Verband

\section{Alter:}

Geschlecht:

Arthrose:

\section{Beschreibung:}

Fragment. 
Bezeichn.: Costa

Kiste: $\quad 8505720$

Skelet: $\quad 1.3$

Population: Calden

Verband: $\quad$ Verband

\section{Alter:}

Geschlecht:

Arthrose:

\section{Beschreibung:}

Fragment. 
Bezeichn.: Costa

Kiste: $\quad 8505720$

Skelet: $\quad 1.3$

Population: Calden

Verband: $\quad$ Verband

\section{Alter:}

Geschlecht:

Arthrose:

\section{Beschreibung:}

Fragment. 
Bezeichn.: Costa

Kiste: $\quad 8505720$

Skelet: $\quad 1.3$

Population: Calden

Verband: $\quad$ Verband

\section{Alter:}

Geschlecht:

Arthrose:

\section{Beschreibung:}

Fragment. 
Bezeichn.: Costa

Kiste: $\quad 8505720$

Skelet: $\quad 1.3$

Population: Calden

Verband: $\quad$ Verband

\section{Alter:}

Geschlecht:

Arthrose:

\section{Beschreibung:}

Fragment. 
Bezeichn.: Costa

Kiste: $\quad 8505720$

Skelet: $\quad 1.3$

Population: Calden

Verband: $\quad$ Verband

\section{Alter:}

Geschlecht:

Arthrose:

\section{Beschreibung:}

Fragment. 
Bezeichn.: Costa

Kiste: $\quad 8505720$

Skelet: $\quad 1.3$

Population: Calden

Verband: $\quad$ Verband

\section{Alter:}

Geschlecht:

Arthrose:

\section{Beschreibung:}

Fragment. 
Bezeichn.: Costa

Kiste: $\quad 8505720$

Skelet: $\quad 1.3$

Population: Calden

Verband: $\quad$ Verband

\section{Alter:}

Geschlecht:

Arthrose:

\section{Beschreibung:}

Fragment. 
Bezeichn.: Costa

Kiste: $\quad 8505720$

Skelet: $\quad 1.3$

Population: Calden

Verband: $\quad$ Verband

\section{Alter:}

Geschlecht:

Arthrose:

\section{Beschreibung:}

Fragment. 
Bezeichn.: Costa

Kiste: $\quad 8505720$

Skelet: $\quad 1.3$

Population: Calden

Verband: $\quad$ Verband

\section{Alter:}

Geschlecht:

Arthrose:

\section{Beschreibung:}

Fragment. 
Bezeichn.: Costa

Kiste: $\quad 8505720$

Skelet: $\quad 1.3$

Population: Calden

Verband: $\quad$ Verband

\section{Alter:}

Geschlecht:

Arthrose:

\section{Beschreibung:}

Fragment. 
Bezeichn.: Costa

Kiste: $\quad 8505720$

Skelet: $\quad 1.3$

Population: Calden

Verband: $\quad$ Verband

\section{Alter:}

Geschlecht:

Arthrose:

\section{Beschreibung:}

Fragment. 
Bezeichn.: Costa

Kiste: $\quad 8505720$

Skelet: $\quad 1.3$

Population: Calden

Verband: $\quad$ Verband

\section{Alter:}

Geschlecht:

Arthrose:

\section{Beschreibung:}

Fragment. 
Bezeichn.: Costa

Kiste: $\quad 8505720$

Skelet: $\quad 1.3$

Population: Calden

Verband: $\quad$ Verband

\section{Alter:}

Geschlecht:

Arthrose:

\section{Beschreibung:}

Fragment. 
Bezeichn.: Costa

Kiste: $\quad 8505720$

Skelet: $\quad 1.3$

Population: Calden

Verband: $\quad$ Verband

\section{Alter:}

Geschlecht:

Arthrose:

\section{Beschreibung:}

Fragment. 
Bezeichn.: Costa

Kiste: $\quad 8505720$

Skelet: $\quad 1.3$

Population: Calden

Verband: $\quad$ Verband

\section{Alter:}

Geschlecht:

Arthrose:

\section{Beschreibung:}

Fragment. 
Bezeichn.: Costa

Kiste: $\quad 8505720$

Skelet: $\quad 1.3$

Population: Calden

Verband: $\quad$ Verband

\section{Alter:}

Geschlecht:

Arthrose:

\section{Beschreibung:}

Fragment. 
Bezeichn.: Costa

Kiste: $\quad 8505720$

Skelet: $\quad 1.3$

Population: Calden

Verband: $\quad$ Verband

\section{Alter:}

Geschlecht:

Arthrose:

\section{Beschreibung:}

Fragment. 
Bezeichn.: Costa

Kiste: $\quad 8505720$

Skelet: $\quad 1.3$

Population: Calden

Verband: $\quad$ Verband

\section{Alter:}

Geschlecht:

Arthrose:

\section{Beschreibung:}

Fragment. 
Bezeichn.: Costa

Kiste: $\quad 8505720$

Skelet: $\quad 1.3$

Population: Calden

Verband: $\quad$ Verband

\section{Alter:}

Geschlecht:

Arthrose:

\section{Beschreibung:}

Fragment. 
Bezeichn.: Costa

Kiste: $\quad 8505720$

Skelet: $\quad 1.3$

Population: Calden

Verband: $\quad$ Verband

\section{Alter:}

Geschlecht:

Arthrose:

\section{Beschreibung:}

Fragment. 
Bezeichn.: Costa

Kiste: $\quad 8505720$

Skelet: $\quad 1.3$

Population: Calden

Verband: $\quad$ Verband

\section{Alter:}

Geschlecht:

Arthrose:

\section{Beschreibung:}

Fragment. 
Bezeichn.: Costa

Kiste: $\quad 8505720$

Skelet: $\quad 1.3$

Population: Calden

Verband: $\quad$ Verband

\section{Alter:}

Geschlecht:

Arthrose:

\section{Beschreibung:}

Fragment. 
Bezeichn.: Costa

Kiste: $\quad 8505720$

Skelet: $\quad 1.3$

Population: Calden

Verband: $\quad$ Verband

\section{Alter:}

Geschlecht:

Arthrose:

\section{Beschreibung:}

Fragment. 
Bezeichn.: Costa

Kiste: $\quad 8505720$

Skelet: $\quad 1.3$

Population: Calden

Verband: $\quad$ Verband

\section{Alter:}

Geschlecht:

Arthrose:

\section{Beschreibung:}

Fragment. 
Bezeichn.: Costa

Kiste: $\quad 8505720$

Skelet: $\quad 1.3$

Population: Calden

Verband: $\quad$ Verband

\section{Alter:}

Geschlecht:

Arthrose:

\section{Beschreibung:}

Fragment. 
Bezeichn.: Costa

Kiste: $\quad 8505720$

Skelet: $\quad 1.3$

Population: Calden

Verband: $\quad$ Verband

\section{Alter:}

Geschlecht:

Arthrose:

\section{Beschreibung:}

Fragment. 
Bezeichn.: Costa

Kiste: $\quad 8505720$

Skelet: $\quad 1.3$

Population: Calden

Verband: $\quad$ Verband

\section{Alter:}

Geschlecht:

Arthrose:

\section{Beschreibung:}

Fragment. 
Bezeichn.: Costa

Kiste: $\quad 8505720$

Skelet: $\quad 1.3$

Population: Calden

Verband: $\quad$ Verband

\section{Alter:}

Geschlecht:

Arthrose:

\section{Beschreibung:}

Fragment. 
Bezeichn.: Costa

Kiste: $\quad 8505720$

Skelet: $\quad 1.3$

Population: Calden

Verband: $\quad$ Verband

\section{Alter:}

Geschlecht:

Arthrose:

\section{Beschreibung:}

Fragment. 
Bezeichn.: Costa

Kiste: $\quad 8505720$

Skelet: $\quad 1.3$

Verband: $\quad$ Verband

Population: Calden

\section{Alter:}

Geschlecht:

Arthrose:

\section{Beschreibung:}


Bezeichn.: Costa

Kiste: $\quad 8505720$

Skelet: $\quad 1.3$

Population: Calden

Verband: $\quad$ Verband

\section{Alter:}

Geschlecht:

Arthrose:

\section{Beschreibung:}

Fragment. 
Bezeichn.: Costa

Kiste: $\quad 8505720$

Skelet: $\quad 1.3$

Population: Calden

Verband: $\quad$ Verband

\section{Alter:}

Geschlecht:

Arthrose:

\section{Beschreibung:}

Fragment. 
Bezeichn.: Costa

Kiste: $\quad 8505720$

Skelet: $\quad 1.3$

Population: Calden

Verband: $\quad$ Verband

\section{Alter:}

Geschlecht:

Arthrose:

\section{Beschreibung:}

Fragment. 
Bezeichn.: Costa

Kiste: $\quad 8505720$

Skelet: $\quad 1.3$

Population: Calden

Verband: $\quad$ Verband

\section{Alter:}

Geschlecht:

Arthrose:

\section{Beschreibung:}

Fragment. 
Bezeichn.: Costa

Kiste: $\quad 8505720$

Skelet: $\quad 1.3$

Population: Calden

Verband: $\quad$ Verband

\section{Alter:}

Geschlecht:

Arthrose:

\section{Beschreibung:}

Fragment. 
Bezeichn.: Costa

Kiste: $\quad 8505720$

Skelet: $\quad 1.3$

Population: Calden

Verband: $\quad$ Verband

\section{Alter:}

Geschlecht:

Arthrose:

\section{Beschreibung:}

Fragment. 
Bezeichn.: Costa

Kiste: $\quad 8505720$

Skelet: $\quad 1.3$

Population: Calden

Verband: $\quad$ Verband

\section{Alter:}

Geschlecht:

Arthrose:

\section{Beschreibung:}

Fragment. 
Bezeichn.: Costa

Kiste: $\quad 8505720$

Skelet: $\quad 1.3$

Population: Calden

Verband: $\quad$ Verband

\section{Alter:}

Geschlecht:

Arthrose:

\section{Beschreibung:}

Fragment. 
Bezeichn.: Costa

Kiste: $\quad 8505720$

Skelet: $\quad 1.3$

Population: Calden

Verband: $\quad$ Verband

\section{Alter:}

Geschlecht:

Arthrose:

\section{Beschreibung:}

Fragment. 
Bezeichn.: Costa

Kiste: $\quad 8505720$

Skelet: $\quad 1.3$

Population: Calden

Verband: $\quad$ Verband

\section{Alter:}

Geschlecht:

Arthrose:

\section{Beschreibung:}

Fragment. 
Bezeichn.: Costa

Kiste: $\quad 8505720$

Skelet: $\quad 1.3$

Population: Calden

Verband: $\quad$ Verband

\section{Alter:}

Geschlecht:

Arthrose:

\section{Beschreibung:}

Fragment. 
Bezeichn.: Costa

Kiste: $\quad 8505720$

Skelet: $\quad 1.3$

Population: Calden

Verband: $\quad$ Verband

\section{Alter:}

Geschlecht:

Arthrose:

\section{Beschreibung:}

Fragment. 
Bezeichn.: Costa

Kiste: $\quad 8505720$

Skelet: $\quad 1.3$

Population: Calden

Verband: $\quad$ Verband

\section{Alter:}

Geschlecht:

Arthrose:

\section{Beschreibung:}

Fragment. 
Bezeichn.: Costa

Kiste: $\quad 8505720$

Skelet: $\quad 1.3$

Population: Calden

Verband: $\quad$ Verband

\section{Alter:}

Geschlecht:

Arthrose:

\section{Beschreibung:}

Fragment. 
Bezeichn.: Costa

Kiste: $\quad 8505720$

Skelet: $\quad 1.3$

Population: Calden

Verband: $\quad$ Verband

\section{Alter:}

Geschlecht:

Arthrose:

\section{Beschreibung:}

Fragment. 
Bezeichn.: Costa

Kiste: $\quad 8505720$

Skelet: $\quad 1.3$

Population: Calden

Verband: $\quad$ Verband

\section{Alter:}

Geschlecht:

Arthrose:

\section{Beschreibung:}

Fragment. 
Bezeichn.: Costa

Kiste: $\quad 8505720$

Skelet: $\quad 1.3$

Population: Calden

Verband: $\quad$ Verband

\section{Alter:}

Geschlecht:

Arthrose:

\section{Beschreibung:}

Fragment. 
Bezeichn.: Costa

Kiste: $\quad 8505720$

Skelet: $\quad 1.3$

Population: Calden

Verband: $\quad$ Verband

\section{Alter:}

Geschlecht:

Arthrose:

\section{Beschreibung:}

Fragment. 
Bezeichn.: Costa

Kiste: $\quad 8505720$

Skelet: $\quad 1.3$

Population: Calden

Verband: $\quad$ Verband

\section{Alter:}

Geschlecht:

Arthrose:

\section{Beschreibung:}

Fragment. 
Bezeichn.: Costa

Kiste: $\quad 8505720$

Skelet: $\quad 1.3$

Population: Calden

Verband: $\quad$ Verband

\section{Alter:}

Geschlecht:

Arthrose:

\section{Beschreibung:}

Fragment. 
Bezeichn.: Costa

Kiste: $\quad 8505720$

Skelet: $\quad 1.3$

Population: Calden

Verband: $\quad$ Verband

\section{Alter:}

Geschlecht:

Arthrose:

\section{Beschreibung:}

Fragment. 
Bezeichn.: Costa

Kiste: $\quad 8505720$

Skelet: $\quad 1.3$

Population: Calden

Verband: $\quad$ Verband

\section{Alter:}

Geschlecht:

Arthrose:

\section{Beschreibung:}

Fragment. 
Bezeichn.: Costa

Kiste: $\quad 8505720$

Skelet: $\quad 1.3$

Population: Calden

Verband: $\quad$ Verband

\section{Alter:}

Geschlecht:

Arthrose:

\section{Beschreibung:}

Fragment. 
Bezeichn.: Costa

Kiste: $\quad 8505720$

Skelet: $\quad 1.3$

Population: Calden

Verband: $\quad$ Verband

\section{Alter:}

Geschlecht:

Arthrose:

\section{Beschreibung:}

Fragment. 
Bezeichn.: Costa

Kiste: $\quad 8505720$

Skelet: $\quad 1.3$

Population: Calden

Verband: $\quad$ Verband

\section{Alter:}

Geschlecht:

Arthrose:

\section{Beschreibung:}

Fragment. 
Bezeichn.: Costa

Kiste: $\quad 8505720$

Skelet: $\quad 1.3$

Population: Calden

Verband: $\quad$ Verband

\section{Alter:}

Geschlecht:

Arthrose:

\section{Beschreibung:}

Fragment. 
Bezeichn.: Costa

Kiste: $\quad 8505720$

Skelet: $\quad 1.3$

Population: Calden

Verband: $\quad$ Verband

\section{Alter:}

Geschlecht:

Arthrose:

\section{Beschreibung:}

Fragment. 
Bezeichn.: Costa

Kiste: $\quad 8505720$

Skelet: $\quad 1.3$

Population: Calden

Verband: $\quad$ Verband

\section{Alter:}

Geschlecht:

Arthrose:

\section{Beschreibung:}

Fragment. 
Bezeichn.: Costa

Kiste: $\quad 8505720$

Skelet: $\quad 1.3$

Population: Calden

Verband: $\quad$ Verband

\section{Alter:}

Geschlecht:

Arthrose:

\section{Beschreibung:}

Fragment. 
Bezeichn.: Costa

Kiste: $\quad 8505720$

Skelet: $\quad 1.3$

Population: Calden

Verband: $\quad$ Verband

\section{Alter:}

Geschlecht:

Arthrose:

\section{Beschreibung:}

Fragment. 
Bezeichn.: Costa

Kiste: $\quad 8505720$

Skelet: $\quad 1.3$

Population: Calden

Verband: $\quad$ Verband

\section{Alter:}

Geschlecht:

Arthrose:

\section{Beschreibung:}

Fragment. 
Bezeichn.: Costa

Kiste: $\quad 8505720$

Skelet: $\quad 1.3$

Population: Calden
Verband: Verband

\section{Alter:}

Geschlecht:

Arthrose:

\section{Beschreibung:}


Bezeichn.: Costa

Kiste: $\quad 8505720$

Skelet: $\quad 1.3$

Population: Calden

Verband: $\quad$ Verband

\section{Alter:}

Geschlecht:

Arthrose:

\section{Beschreibung:}

Fragment. 
Bezeichn.: Costa

Kiste: $\quad 8505720$

Skelet: $\quad 1.3$

Population: Calden

Verband: $\quad$ Verband

\section{Alter:}

Geschlecht:

Arthrose:

\section{Beschreibung:}

Fragment. 
Bezeichn.: Costa

Kiste: $\quad 8505720$

Skelet: $\quad 1.3$

Population: Calden

Verband: $\quad$ Verband

\section{Alter:}

Geschlecht:

Arthrose:

\section{Beschreibung:}

Fragment. 
Bezeichn.: Costa

Kiste: $\quad 8505720$

Skelet: $\quad 1.3$

Population: Calden

Verband: $\quad$ Verband

\section{Alter:}

Geschlecht:

Arthrose:

\section{Beschreibung:}

Fragment. 
Bezeichn.: Costa

Kiste: $\quad 8505720$

Skelet: $\quad 1.3$

Population: Calden

Verband: $\quad$ Verband

\section{Alter:}

Geschlecht:

Arthrose:

\section{Beschreibung:}

Fragment. 
Bezeichn.: Costa

Kiste: $\quad 8505720$

Skelet: $\quad 1.3$

Population: Calden

Verband: $\quad$ Verband

\section{Alter:}

Geschlecht:

Arthrose:

\section{Beschreibung:}

Fragment. 
Bezeichn.: Costa

Kiste: $\quad 8505720$

Skelet: $\quad 1.3$

Population: Calden

Seite: rechts
Verband: Verband

\section{Alter:}

Geschlecht:

Arthrose:

\section{Beschreibung:}

Dies ist eine rechte erste Rippe. Es handelt sich um ein Fragment, welches nur gelenknah erhalten ist. 


$\begin{array}{lll}\text { Bezeichn.: } & \text { Costa } & \text { Verband: } \square \text { Verband } \\ \text { Kiste: } & 8505720 & \text { Alter: Jung } \\ \text { Skelet: } & 1.3 & \text { Geschlecht: } \\ \text { Population: } & \text { Calden } & \text { Arthrose: } \\ \text { Seite: } & \text { links } & \end{array}$

\section{Beschreibung:}

Hierbei handelt es sich um eine eine junge sehr kleine erste Rippe der linken Körperseite. Sie ist nur gelenknah erhalten. 


\section{Bezeichn.: Costa \\ Kiste: $\quad 8505720$ \\ Skelet: $\quad 1.3$}

Population: Calden
Verband: $\quad$ Verband

\section{Alter: Jung}

Geschlecht:

Arthrose:

\section{Beschreibung:}

Hierbei handelt es sich um eine Rippe, die noch nicht ausgewachsen war, es ist nur ein sternales Fragment erhalten. 
Bezeichn.: Costa

Kiste: $\quad 8505720$

Skelet: $\quad 1.3$

Population: Calden
Verband: $\quad$ Verband

\section{Alter:}

\section{Geschlecht:}

Arthrose:

\section{Beschreibung:}

Dieses nicht genauer zuzuordnende Rippenfragment weist leichte punktförmige Auflagerungen auf. Diese sind etwa $1 \mathrm{~mm} \times 1 \mathrm{~mm}$ groß. Eventuell handelt es sich lediglich um Muskelmarken der Zwischenrippenmuskulatur. 


\section{Bezeichn.: Costa \\ Kiste: 8505720 \\ Skelet: $\quad 1.3$}

Population: Calden
Verband: $\quad$ Verband

\section{Alter: Jung}

Geschlecht:

Arthrose:

\section{Beschreibung:}

Dies ist eine nicht vollständig ausgewachsene erste Rippe der rechten Seite. Die Epiphysen weisen noch so eben erkennbare Spuren des Wachstums auf. 
Bezeichn.: Costa

Kiste: $\quad 8505720$

Skelet: $\quad 1.3$

Population: Calden

Seite:

rechts
Verband: $\square$ Verband

Alter:

\section{Geschlecht:}

Arthrose:
Ges./Kr.: Krank

Krankh.: Arthrose

\section{Beschreibung:}

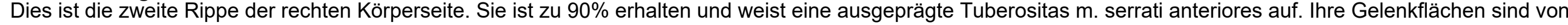
deutlichen Verschleißerscheinungen gezeichnet. 
Bezeichn:: Costa

Kiste: $\quad 8505720$

Skelet: $\quad 1.3$

Population: Calden

Seite:

rechts
Verband: $\square$ Verband

\section{Alter:}

Geschlecht:

Arthrose:
Ges./Kr.: Gesund

\section{Beschreibung:}

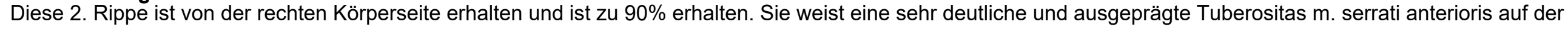
cranialen äußeren Oberfläche auf. Diese Erhabenheit misst etwa $25 \mathrm{~mm}$ x 12mm x 4mm. Die Gesamtansatzstelle zieht sich allerdings noch weiter fort. 
Bezeichn.: Costa

Kiste: $\quad 8505720$

Skelet: $\quad 1.3$

Population: Calden

Seite:
Verband: $\quad$ Verband

\section{Alter:}

\section{Geschlecht:}

Arthrose:
Ges./Kr.: Gesund

\section{Beschreibung:}

Hierbei handelt es sich um die 10. Rippe der rechten Seite. Es ist etwa ein Drittel des sternalen Teils erhalten. 
Bezeichn.: Costa

Kiste: 8505720

Skelet: $\quad 1.3$

Population: Calden

Seite:

rechts
Verband:

\section{Alter:}

Geschlecht:

Arthrose:
Ges./Kr.: Gesund

\section{Beschreibung:}

Dies ist das vertebrale Fragment einer 2. rechten Rippe. Es ist etwa 40\% erhalten. Die Rippe weist deutliche Muskelmarken der Zwischenrippenmuskulatur auf. 
Bezeichn.: Costa

Kiste: $\quad 8505720$

Verband: $\quad \square$ Verband

Skelet: $\quad 1.3 \quad$ Geschlecht:

Population: Calden Arthrose:

Seite: links

\section{Beschreibung:}

Dieses Fragment einer linken 8. Rippe ist als sternale Hälfte erhalten. Die Rippe weist einige kleinere Auflagerungen auf: Sowohl auf der Außenfläche, als auch auf der Innenfläche sind kleine punkt- bis zylinderartige Auflagerungen einer Größe bis $7 \mathrm{~mm}$ auf. Das Individuum hat wohl ein mittleres adultes Alter erreicht. 


\begin{tabular}{|c|c|c|c|c|c|}
\hline Bezeichn.: & Costa & Verband: $\quad \square$ Verband & Maß & Wert & Einheit \\
\hline $\begin{array}{l}\text { Kiste: } \\
\text { Skelet: } \\
\text { Population: } \\
\text { Seite: }\end{array}$ & $\begin{array}{l}8505720 \\
1.3 \\
\text { Calden } \\
\text { links }\end{array}$ & $\begin{array}{l}\text { Alter: Jung } \\
\text { Geschlecht: } \\
\text { Arthrose: }\end{array}$ & Breite & 78,22 & $\mathrm{~mm}$ \\
\hline
\end{tabular}

\section{Beschreibung:}

Hierbei handelt es sich um eine erste Rippe der linken Seite. Sie erscheint noch recht jung zu sein, auch wenn die Epiphysen bereits geschlossen sind. Muskelmarken sind einem noch jüngeren Individuum entsprechend nicht auffällig ausgeprägt. 


$\begin{array}{lll}\text { Bezeichn:: } & \text { Costa } & \text { Verband: } \square \text { Verband } \\ \text { Kiste: } & 8505720 & \text { Alter: } \\ \text { Skelet: } & 1.3 & \text { Geschlecht: } \\ \text { Population: } & \text { Calden } & \text { Arthrose: } \\ \text { Seite: } & \text { links } & \end{array}$

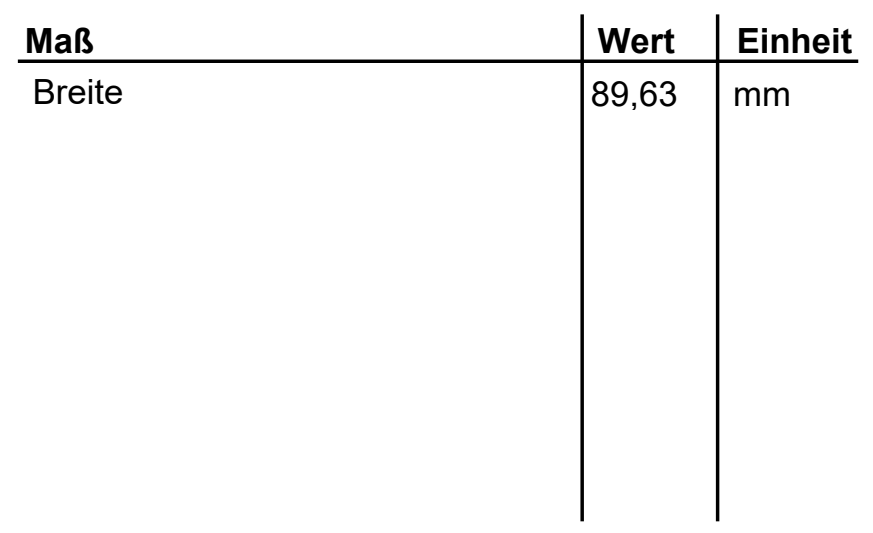

\section{Beschreibung:}

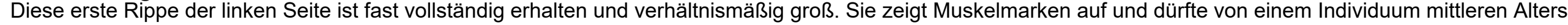
stammen. 


$\begin{array}{lll}\text { Bezeichn:: } & \text { Costa } & \text { Verband: } \square \text { Verband } \\ \text { Kiste: } & 8505720 & \text { Alter: } \\ \text { Skelet: } & 1.3 & \text { Geschlecht: } \\ \text { Population: } & \text { Calden } & \text { Arthrose: } \\ \text { Seite: } & \text { rechts } & \end{array}$

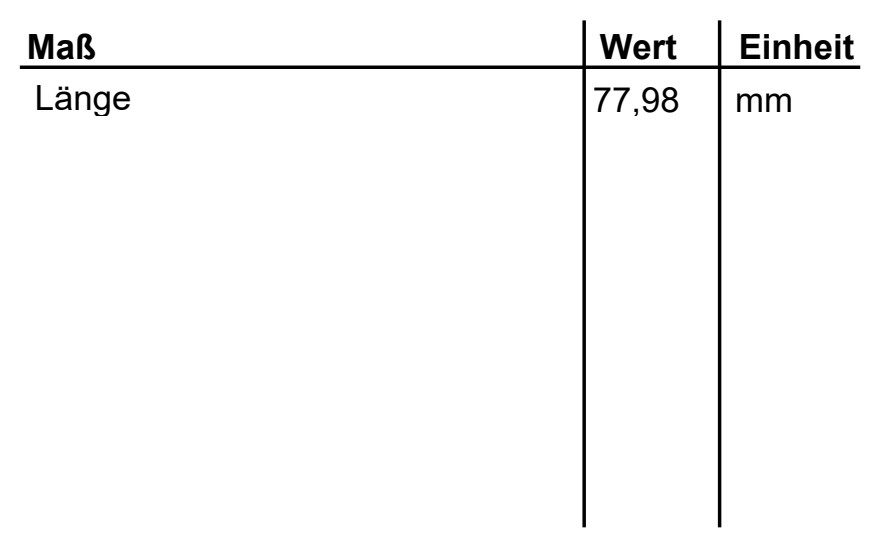

\section{Beschreibung:}

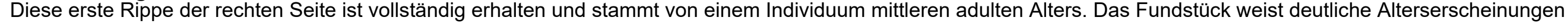
auf, so sind deutliche Muskelmarken und eine teilweise verknöcherte Syndesmose zu finden. 
Bezeichn.: Costa

Kiste: $\quad 8505720$

Skelet: $\quad 1.3$

Population: Calden

Seite:

Verband: $\quad$ Verband

\section{Alter:}

Geschlecht:

Arthrose:

\section{Beschreibung:}

Diese 7. Rippe der rechten Seite ist etwa zur Hälfte erhalten. 
Bezeichn.: Costa

Kiste: $\quad 8505720$

Skelet: $\quad 1.3$

Population: Calden

Seite:

rechts
Verband: Verband

\section{Alter:}

Geschlecht:

Arthrose:

\section{Beschreibung:}

Diese 10. Rippe der rechten Seite ist fast vollständig erhalten. 
Bezeichn.: Costa

Kiste: $\quad 8505720$

Skelet: $\quad 1.3$

Population: Calden

Seite:

rechts
Verband: $\square$ Verband

Alter: Erwachsen

Geschlecht:

Arthrose:

西

\section{Ges./Kr.: Gesund}

li.

\section{Beschreibung:}

Diese 9. Rippe der rechten Seite ist vollständig erhalten und stammt wohl von einem adulten Individuum mittleren Alters. 
Bezeichn.: Costa

Kiste: $\quad 8505720$

Skelet: $\quad 1.3$

Population: Calden

Seite:
Verband: $\square$ Verband

Alter: Erwachsen

Geschlecht:

Arthrose:

Ges./Kr.: Krank

Krankh.: Arthrose

\section{Beschreibung:}

Dies ist wahrscheinlich eine 8. Rippe der linken Seite. Sie ist sehr gut und vollständig erhalten. Sie weist ein mittleres adultes Alter auf. 
Bezeichn.: Costa

Kiste: $\quad 8505720$

Skelet: $\quad 1.3$

Population: Calden

Seite:

rechts
Verband: $\square$ Verband

Alter:

\section{Geschlecht:}

Arthrose:
Ges./Kr.: Krank

Krankh.: Arthrose

\section{Beschreibung:}

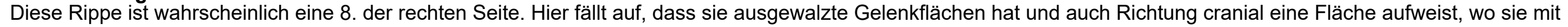
dem Querfortsatz des darüber liegenden Wirbels Kontakt gehabt haben muss. 
Bezeichn.: Costa

Kiste: $\quad 5249270$

Skelet: Zettel

Population: Calden

Seite:

n. def.

Verband: $\quad$ Verband

\section{Alter:}

Geschlecht:

Arthrose:

\section{Beschreibung:}

Fragment. 
Bezeichn.: Costa

Kiste: $\quad 5255273$

Skelet: Zettel

Population: Calden

\section{Beschreibung:}

Fragment.
Verband:

Verband

\section{Alter:}

Geschlecht:

Arthrose:
Ges./Kr.: Gesund 
Bezeichn.: Costa

Kiste: $\quad 5255273$

Skelet: Zettel

Population: Calden

\section{Beschreibung:}

Fragment.
Verband:

Verband

\section{Alter:}

Geschlecht:

Arthrose:
Ges./Kr.: Gesund 
Bezeichn.: Costa

Kiste: $\quad 5255273$

Skelet: Zettel

Population: Calden

Beschreibung:

Fragment.
Verband: Verband

\section{Alter:}

Geschlecht:

Arthrose: 
Bezeichn.: Costa

Kiste: $\quad 5255273$

Skelet: Zettel

Population: Calden

Beschreibung:

Fragment.
Verband: Verband

\section{Alter:}

Geschlecht:

Arthrose: 
Bezeichn.: Costa

Kiste: $\quad 5255273$

Skelet: Zettel

Population: Calden

Beschreibung:

Fragment.
Verband: Verband

\section{Alter:}

Geschlecht:

Arthrose: 
Bezeichn.: Costa

Kiste: $\quad 5242266$

Skelet: 3. Tüte

Population: Calden

\section{Beschreibung:}

Fragment.
Verband: $\quad$ Verband

\section{Alter:}

Geschlecht:

Arthrose: 
Bezeichn.: Costa

Kiste: $\quad 5242266$

Skelet: 3. Tüte

Population: Calden

\section{Beschreibung:}

Fragment.
Verband: $\quad$ Verband

\section{Alter:}

Geschlecht:

Arthrose: 
Bezeichn.: Costa

Kiste: $\quad 5242266$

Skelet: 3. Tüte

Population: Calden

\section{Beschreibung:}

Fragment.
Verband: $\square$ Verband

\section{Alter:}

Geschlecht:

Arthrose: 
Bezeichn.: Costa

Kiste: $\quad 5242266$

Skelet: 3. Tüte

Population: Calden

\section{Beschreibung:}

Fragment.
Verband: $\quad$ Verband

\section{Alter:}

Geschlecht:

Arthrose: 
Bezeichn.: Costa

Kiste: $\quad 5242266$

Skelet: 3. Tüte

Population: Calden

\section{Beschreibung:}

Fragment.
Verband: $\quad$ Verband

\section{Alter:}

Geschlecht:

Arthrose: 
Bezeichn.: Costa

Kiste: $\quad 5242266$

Skelet: 3. Tüte

Population: Calden

\section{Beschreibung:}

Fragment.
Verband: $\quad$ Verband

\section{Alter:}

Geschlecht:

Arthrose: 
Bezeichn.: Costa

Kiste: $\quad 5242266$

Skelet: 3. Tüte

Population: Calden

\section{Beschreibung:}

Fragment.
Verband: $\quad$ Verband

\section{Alter:}

Geschlecht:

Arthrose: 
Bezeichn.: Costa

Kiste: $\quad 5242266$

Skelet: 3. Tüte

Population: Calden

\section{Beschreibung:}

Fragment.
Verband: $\quad$ Verband

\section{Alter:}

Geschlecht:

Arthrose: 
Bezeichn.: Costa

Kiste: $\quad 5242266$

Skelet: 3. Tüte

Population: Calden

\section{Beschreibung:}

Fragment.
Verband: $\quad$ Verband

\section{Alter:}

Geschlecht:

Arthrose: 
Bezeichn.: Costa

Kiste: $\quad 5242266$

Skelet: 3. Tüte

Population: Calden

\section{Beschreibung:}

Fragment.
Verband: $\quad$ Verband

\section{Alter:}

Geschlecht:

Arthrose: 
Bezeichn.: Costa

Kiste: $\quad 5242266$

Skelet: 3. Tüte

Population: Calden

\section{Beschreibung:}

Fragment.
Verband: $\quad$ Verband

\section{Alter:}

Geschlecht:

Arthrose: 
Bezeichn.: Costa

Kiste: $\quad 5242266$

Skelet: 3. Tüte

Population: Calden

\section{Beschreibung:}

Fragment.
Verband: $\quad$ Verband

\section{Alter:}

Geschlecht:

Arthrose: 
Bezeichn.: Costa

Kiste: $\quad 5242266$

Skelet: 3. Tüte

Population: Calden

\section{Beschreibung:}

Fragment.
Verband: $\square$ Verband

\section{Alter:}

Geschlecht:

Arthrose: 
Bezeichn.: Costa

Kiste: $\quad 5242266$

Skelet: 3. Tüte

Population: Calden

\section{Beschreibung:}

Fragment.
Verband: $\quad$ Verband

\section{Alter:}

Geschlecht:

Arthrose: 
Bezeichn.: Costa

Kiste: $\quad 5242266$

Skelet: 3. Tüte

Population: Calden

\section{Beschreibung:}

Fragment.
Verband: $\quad$ Verband

\section{Alter:}

Geschlecht:

Arthrose: 
Bezeichn.: Costa

Kiste: $\quad 5242266$

Skelet: 3. Tüte

Population: Calden

\section{Beschreibung:}

Fragment.
Verband: $\quad$ Verband

\section{Alter:}

Geschlecht:

Arthrose: 
Bezeichn.: Costa

Kiste: $\quad 5242266$

Skelet: 3. Tüte

Population: Calden

\section{Beschreibung:}

Fragment.
Verband: $\quad$ Verband

\section{Alter:}

Geschlecht:

Arthrose: 
Bezeichn.: Costa

Kiste: $\quad 5242266$

Skelet: 3. Tüte

Population: Calden

\section{Beschreibung:}

Fragment.
Verband: $\square$ Verband

\section{Alter:}

Geschlecht:

Arthrose: 
Bezeichn.: Costa

Kiste: $\quad 5242266$

Skelet: 3. Tüte

Population: Calden

\section{Beschreibung:}

Fragment.
Verband: $\quad$ Verband

\section{Alter:}

Geschlecht:

Arthrose: 
Bezeichn.: Costa

Kiste: $\quad 5242266$

Skelet: 3. Tüte

Population: Calden

\section{Beschreibung:}

Fragment.
Verband: $\quad$ Verband

\section{Alter:}

Geschlecht:

Arthrose: 
Bezeichn.: Costa

Kiste: $\quad 5242266$

Skelet: 3. Tüte

Population: Calden

\section{Beschreibung:}

Fragment.
Verband: $\quad$ Verband

\section{Alter:}

Geschlecht:

Arthrose: 
Bezeichn.: Costa

Kiste: $\quad 5242266$

Skelet: 3. Tüte

Population: Calden

\section{Beschreibung:}

Fragment.
Verband: $\quad$ Verband

\section{Alter:}

Geschlecht:

Arthrose: 
Bezeichn.: Costa

Kiste: $\quad 5242266$

Skelet: 3. Tüte

Population: Calden

\section{Beschreibung:}

Fragment.
Verband: $\square$ Verband

\section{Alter:}

Geschlecht:

Arthrose: 
Bezeichn.: Costa

Kiste: $\quad 5242266$

Skelet: 3. Tüte

Population: Calden

\section{Beschreibung:}

Fragment.
Verband: $\quad$ Verband

\section{Alter:}

Geschlecht:

Arthrose: 
Bezeichn.: Costa

Kiste: $\quad 5242266$

Skelet: 3. Tüte

Population: Calden

\section{Beschreibung:}

Fragment.
Verband: $\quad$ Verband

\section{Alter:}

Geschlecht:

Arthrose: 
Bezeichn.: Costa

Kiste: $\quad 5242266$

Skelet: 3. Tüte

Population: Calden

\section{Beschreibung:}

Fragment.
Verband: $\quad$ Verband

\section{Alter:}

Geschlecht:

Arthrose: 
Bezeichn.: Costa

Kiste: $\quad 5242266$

Skelet: 3. Tüte

Population: Calden

\section{Beschreibung:}

Fragment.
Verband: $\square$ Verband

\section{Alter:}

Geschlecht:

Arthrose: 
Bezeichn.: Costa

Kiste: $\quad 5242266$

Skelet: 3. Tüte

Population: Calden

\section{Beschreibung:}

Fragment.
Verband: $\quad$ Verband

\section{Alter:}

Geschlecht:

Arthrose: 
Bezeichn.: Costa

Kiste: $\quad 5242266$

Skelet: 3. Tüte

Population: Calden

\section{Beschreibung:}

Fragment.
Verband: $\quad$ Verband

\section{Alter:}

Geschlecht:

Arthrose: 
Bezeichn.: Costa

Kiste: $\quad 5242266$

Skelet: 3. Tüte

Population: Calden

\section{Beschreibung:}

Fragment.
Verband: $\square$ Verband

\section{Alter:}

Geschlecht:

Arthrose: 
Bezeichn.: Costa

Kiste: $\quad 5242266$

Skelet: 3. Tüte

Population: Calden

\section{Beschreibung:}

Fragment.
Verband: $\square$ Verband

\section{Alter:}

Geschlecht:

Arthrose: 
Bezeichn.: Costa

Kiste: $\quad 5242266$

Skelet: 3. Tüte

Population: Calden

\section{Beschreibung:}

Fragment.
Verband: $\quad$ Verband

\section{Alter:}

Geschlecht:

Arthrose: 
Bezeichn.: Costa

Kiste: $\quad 5242266$

Skelet: 3. Tüte

Population: Calden

\section{Beschreibung:}

Fragment.
Verband: $\quad$ Verband

\section{Alter:}

Geschlecht:

Arthrose: 
Bezeichn.: Costa

Kiste: $\quad 5242266$

Skelet: 3. Tüte

Population: Calden

\section{Beschreibung:}

Fragment.
Verband: $\square$ Verband

\section{Alter:}

Geschlecht:

Arthrose: 
Bezeichn.: Costa

Kiste: $\quad 5242266$

Skelet: 3. Tüte

Population: Calden

\section{Beschreibung:}

Fragment.
Verband: $\square$ Verband

\section{Alter:}

Geschlecht:

Arthrose: 
Bezeichn.: Costa

Kiste: $\quad 5242266$

Skelet: 3. Tüte

Population: Calden

\section{Beschreibung:}

Fragment.
Verband: $\square$ Verband

\section{Alter:}

Geschlecht:

Arthrose: 
Bezeichn.: Costa

Kiste: $\quad 5242266$

Skelet: 3. Tüte

Population: Calden

\section{Beschreibung:}

Fragment.
Verband: $\quad$ Verband

\section{Alter:}

Geschlecht:

Arthrose: 
Bezeichn.: Costa

Kiste: $\quad 5242266$

Skelet: 3. Tüte

Population: Calden

\section{Beschreibung:}

Fragment.
Verband: $\square$ Verband

\section{Alter:}

Geschlecht:

Arthrose: 
Bezeichn.: Costa

Kiste: $\quad 5242266$

Skelet: 3. Tüte

Population: Calden

\section{Beschreibung:}

Fragment.
Verband: $\square$ Verband

\section{Alter:}

Geschlecht:

Arthrose: 
Bezeichn.: Costa

Kiste: $\quad 5242266$

Skelet: 3. Tüte

Population: Calden

\section{Beschreibung:}

Fragment.
Verband: $\square$ Verband

\section{Alter:}

Geschlecht:

Arthrose: 
Bezeichn.: Costa

Kiste: $\quad 5242266$

Skelet: 3. Tüte

Population: Calden

\section{Beschreibung:}

Fragment.
Verband: $\square$ Verband

\section{Alter:}

Geschlecht:

Arthrose: 
Bezeichn.: Costa

Kiste: $\quad 5242266$

Skelet: 3. Tüte

Population: Calden

\section{Beschreibung:}

Fragment.
Verband: $\square$ Verband

\section{Alter:}

Geschlecht:

Arthrose: 
Bezeichn.: Costa

Kiste: $\quad 5242266$

Skelet: 3. Tüte

Population: Calden

\section{Beschreibung:}

Fragment.
Verband: $\quad$ Verband

\section{Alter:}

Geschlecht:

Arthrose: 
Bezeichn.: Costa

Kiste: $\quad 5242266$

Skelet: 3. Tüte

Population: Calden

\section{Beschreibung:}

Fragment.
Verband: $\square$ Verband

\section{Alter:}

Geschlecht:

Arthrose: 
Bezeichn.: Costa

Kiste: $\quad 5242266$

Skelet: 3. Tüte

Population: Calden

\section{Beschreibung:}

Fragment.
Verband: $\square$ Verband

\section{Alter:}

Geschlecht:

Arthrose: 
Bezeichn.: Costa

Kiste: $\quad 5242266$

Skelet: 3. Tüte

Population: Calden

\section{Beschreibung:}

Fragment.
Verband: $\quad$ Verband

\section{Alter:}

Geschlecht:

Arthrose: 
Bezeichn.: Costa

Kiste: $\quad 5242266$

Skelet: 3. Tüte

Population: Calden

\section{Beschreibung:}

Fragment.
Verband: $\square$ Verband

\section{Alter:}

Geschlecht:

Arthrose: 
Bezeichn.: Costa

Kiste: $\quad 5242266$

Skelet: 3. Tüte

Population: Calden

\section{Beschreibung:}

Fragment.
Verband: $\quad$ Verband

\section{Alter:}

Geschlecht:

Arthrose: 


\section{Bezeichn.: Costa}

Kiste: $\quad 8505718$

Skelet: aus Kiste

Population: Calden

Seite:

links
Verband: $\quad \square$ Verband

\section{Alter:}

Geschlecht:

Arthrose:
Ges./Kr.: Krank

Krankh.: Myotendopathie

\section{Beschreibung:}

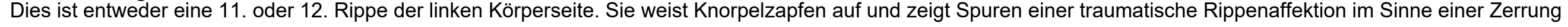
der Zwischenrippenmuskulatur also einer Myotendopathie. 
Bezeichn.: Costa

Kiste: 8505718

Skelet: aus Kiste

Population: Calden

Seite:

rechts
Verband: $\square$ Verband

Alter: (4) 5 - 8 (10)

Geschlecht:

Arthrose:
Beschreibung:

Eine junge Rippe. 


\section{Bezeichn.: Costa}

Kiste: $\quad 8505718$

Skelet: aus Kiste

Population: Calden

Seite:

links
Ges./Kr.: Krank

\section{Krankh.: Muskelreizung \\ Verband \\ Alter:}

Geschlecht:

Arthrose:

\section{Beschreibung:}

Diese 6. Rippe der linken Seite ist fast vollständig erhalten und weist eine leichte Reizung der intercostalen Muskulatur auf. 
Bezeichn.: Costa

Kiste: $\quad 5252271$

Skelet: Zettel

Population: Calden

Seite:

rechts

Verband: $\quad$ Verband

\section{Alter:}

Geschlecht:

Arthrose:

\section{Beschreibung:}

Rippenfragment. 
Bezeichn.: Costa

Kiste: $\quad 5252271$

Skelet: Zettel

Population: Calden

Seite: rechts

\section{Beschreibung:}

Rippenfragment
Verband: $\quad$ Verband

Alter: (30) 45 - 50 (60)

Geschlecht:

Arthrose: 
Bezeichn.: Costa

Kiste: $\quad 5243267$

Skelet: Zettel

Population: Calden

Seite:

links
Verband: Verband

\section{Alter:}

Geschlecht:

Arthrose:

\section{Beschreibung:}

Rippenfragment. 
Bezeichn.: Costa

Kiste: $\quad 5243267$

Skelet: Zettel

Population: Calden

Seite: rechts

\section{Beschreibung:}

Rippenfragment einer jungen Rippe.
Verband: Verband

\section{Alter: Jung}

Geschlecht:

Arthrose: 
Bezeichn.: Costa

Kiste: $\quad 5243267$

Skelet: Zettel

Population: Calden

\section{Beschreibung:}

Rippenfragment.
Verband: $\quad$ Verband

\section{Alter:}

Geschlecht:

Arthrose: 
Bezeichn.: Costa

Kiste: $\quad 5243267$

Skelet: Zettel

Population: Calden

\section{Beschreibung:}

Rippenfragment.
Verband: $\quad \square$ Verband

\section{Alter:}

Geschlecht:

Arthrose: 
Bezeichn.: Costa

Kiste: $\quad 5243267$

Skelet: Zettel

Population: Calden

\section{Beschreibung:}

Rippenfragment.
Verband: $\square$ Verband

\section{Alter:}

Geschlecht:

Arthrose: 
Bezeichn.: Costa

Kiste: $\quad 5243267$

Skelet: Zettel

Population: Calden

\section{Beschreibung:}

Rippenfragment.
Verband: $\quad$ Verband

\section{Alter:}

Geschlecht:

Arthrose: 
Bezeichn.: Costa

Kiste: $\quad 5243267$

Skelet: Zettel

Population: Calden

\section{Beschreibung:}

Rippenfragment.
Verband: $\quad$ Verband

\section{Alter:}

Geschlecht:

Arthrose: 
Bezeichn.: Costa

Kiste: $\quad 5243267$

Skelet: V72 Zettel

Population: Calden
Verband: Verband

\section{Alter:}

Geschlecht:

Arthrose:

\section{Beschreibung:}

Rippenfragment eines Verbands. 
Bezeichn.: Costa

Kiste: $\quad 5243267$

Skelet: V72 Zettel

Population: Calden

Seite:

n. def.
Verband: $\quad \square$ Verband

\section{Alter: Jung}

Geschlecht:

Arthrose:

\section{Beschreibung:}

Rippenfragment eines jungen Individuums aus einem Verband. 
Bezeichn.: Costa

Kiste: 5256274

Skelet: V32 Sk.8.

Population: Calden

Seite:

links
Verband: $\quad \square$ Verband

Alter:

Geschlecht:

Arthrose:
Ges./Kr.: Krank

Krankh.: Muskelreizung

\section{Beschreibung:}

Eine 7. Rippe der linken Seite. Sie weist auf der Innenseite leichte knöcherne Auflagerungen in Form von Neubildungen auf. 
Bezeichn.: Costa

Kiste: $\quad 5256274$

Skelet: V32 Sk8

Population: Calden

Seite:

rechts
Verband: $\quad \square$ Verband

\section{Alter:}

Geschlecht:

Arthrose:

\section{Beschreibung:}

$$
\text { 1. Rippe. }
$$


Bezeichn.: Costa

Kiste: $\quad 5256274$

Skelet: V32 Sk8

Population: Calden

Seite:

rechts
Verband: $\quad \square$ Verband

\section{Alter:}

Geschlecht:

Arthrose:

\section{Beschreibung:}

2. Rippe. 
Bezeichn.: Costa

Kiste: $\quad 5256274$

Skelet: V32 Sk8

Population: Calden

Seite:

rechts
Verband: $\quad \square$ Verband

\section{Alter:}

Geschlecht:

Arthrose:

\section{Beschreibung:}

3. Rippe.
Ges./Kr.: Gesund

\section{Ges.Kr: Gesund}


Bezeichn.: Costa

Kiste: $\quad 5256274$

Skelet: V32 Sk8

Population: Calden

Seite:

links
Verband:

Verband

\section{Alter:}

Geschlecht:

Arthrose:

\section{Beschreibung:}

3. Rippe. 
Bezeichn.: Costa

Kiste: $\quad 5256274$

Skelet: V32 Sk8

Population: Calden

Seite:

rechts
Verband: $\quad \square$ Verband

\section{Alter:}

Geschlecht:

Arthrose:

\section{Beschreibung:}

$$
\text { 4. Rippe. }
$$


Bezeichn.: Costa

Kiste: $\quad 5256274$

Skelet: V32 Sk8

Population: Calden

Seite:

links
Verband:

Verband

\section{Alter:}

Geschlecht:

Arthrose:

\section{Beschreibung:}

$$
\text { 4. Rippe. }
$$


Bezeichn.: Costa

Kiste: $\quad 5256274$

Skelet: V32 Sk8

Population: Calden

Seite:

rechts
Verband:

Verband

\section{Alter:}

Geschlecht:

Arthrose:

\section{Beschreibung:}

5. Rippe.
Ges./Kr.: Gesund

\section{Ges/Kr: Gesund}


Bezeichn.: Costa

Kiste: $\quad 5256274$

Skelet: V32 Sk8

Population: Calden

Seite:

links
Verband:

Verband

\section{Alter:}

Geschlecht:

Arthrose:

\section{Beschreibung:}

5. Rippe. 
Bezeichn.: Costa

Kiste: $\quad 5256274$

Skelet: V32 Sk8

Population: Calden

Seite:

rechts
Verband:

Verband

\section{Alter:}

Geschlecht:

Arthrose:

\section{Beschreibung:}

6. Rippe. 
Bezeichn.: Costa

Kiste: $\quad 5256274$

Skelet: V32 Sk8

Population: Calden

Seite:

links
Verband:

Verband

\section{Alter:}

Geschlecht:

Arthrose:

\section{Beschreibung:}

6. Rippe. 
Bezeichn.: Costa

Kiste: $\quad 5256274$

Skelet: V32 Sk8

Population: Calden

Seite:

links
Verband:

Verband

\section{Alter:}

Geschlecht:

Arthrose:

\section{Beschreibung:}

7. Rippe. 
Bezeichn.: Costa

Kiste: $\quad 5256274$

Skelet: V32 Sk8

Population: Calden

Seite:

rechts
Verband:

Verband

\section{Alter:}

Geschlecht:

Arthrose:

\section{Beschreibung:}

8. Rippe.
Ges./Kr.: Gesund

\section{Ges./Kr.: Gesund}


Bezeichn.: Costa

Kiste: $\quad 5256274$

Skelet: V32 Sk8

Population: Calden

Seite:

links
Verband: $\square$ Verband

\section{Alter:}

Geschlecht:

Arthrose:

\section{Beschreibung:}

8. Rippe.
Ges./Kr.: Gesund

\section{Ges.Kr: Gesund}


Bezeichn.: Costa

Kiste: $\quad 5256274$

Skelet: V32 Sk8

Population: Calden

Seite:

rechts
Verband:

Verband

\section{Alter:}

Geschlecht:

Arthrose:

\section{Beschreibung:}

10. Rippe. 
Bezeichn.: Costa

Kiste: $\quad 5256274$

Skelet: V32 Sk8

Population: Calden

Seite:

rechts
Verband:

Verband

\section{Alter:}

Geschlecht:

Arthrose:

\section{Beschreibung:}

11. Rippe. 
Bezeichn.: Costa

Kiste: $\quad 5256274$

Skelet: V32 Sk8

Population: Calden

Seite:

links
Verband: $\square$ Verband

\section{Alter:}

Geschlecht:

Arthrose:

\section{Beschreibung:}

Ein Rippenfragment der linken Seite.
Ges./Kr.: Gesund

\section{Ges.Kr: Gesund}


Bezeichn.: Costa

Kiste: $\quad 5273291$

Skelet: V71 Schädel 8

Population: Calden

Seite: rechts

\section{Beschreibung:}

Ein vertebrales Fragment einer Rippe.
Verband: $\quad$ Verband

\section{Alter:}

Geschlecht:

Arthrose:
Ges./Kr.: Gesund 
Bezeichn.: Costa

Kiste: $\quad 5273291$

Skelet: V71 Schädel 8

Population: Calden

Seite:

links
Verband: $\quad \square$ Verband

\section{Alter:}

Geschlecht:

Arthrose:

\section{Beschreibung:}

Ein vertebrales Fragment einer Rippe. 
Bezeichn.: Costa

Kiste: $\quad 5261277$

Skelet: $\quad$ V33 kleine Tüte

Population: Calden

Seite:

links
Verband: $\square$ Verband

Alter: Erwachsen

Geschlecht:

Arthrose:

\section{Beschreibung:}

Ein vertebrales Fragment einer Rippe. 
Bezeichn.: Costa

Kiste: $\quad 5261277$

Skelet: V33 kleine Tüte

Population: Calden

Seite:

links
Verband: $\quad$ Verband

Alter: Erwachsen

Geschlecht:

Arthrose:

\section{Beschreibung:}

$$
\text { 4. Rippe. }
$$


Bezeichn.: Costa

Kiste: $\quad 5261277$

Skelet: V33 kleine Tüte

Population: Calden

Seite: rechts

\section{Beschreibung:}

5. Rippe.
Verband: $\quad \square$ Verband

Alter: Erwachsen

Geschlecht:

Arthrose:

Ges./Kr.: Gesund 
Bezeichn.: Costa

Kiste: $\quad 5261277$

Skelet: V33 kleine Tüte

Population: Calden

Seite: rechts

\section{Beschreibung:}

6. Rippe.
Verband: $\quad \square$ Verband

Alter: Erwachsen

Geschlecht:

Arthrose:

Ges./Kr.: Gesund 
Bezeichn.: Costa

Kiste: $\quad 5261277$

Skelet: V33 kleine Tüte

Population: Calden

Seite:

links
Verband: $\quad$ Verband

Alter: Erwachsen

Geschlecht:

Arthrose:

\section{Beschreibung:}

6. Rippe. 
Bezeichn.: Costa

Kiste: $\quad 5261277$

Skelet: $\quad$ V33 kleine Tüte

Population: Calden

Seite:

rechts
Verband: $\quad$ Verband

Alter: Erwachsen

Geschlecht:

Arthrose:

\section{Beschreibung:}

7. Rippe. 
Bezeichn.: Costa

Kiste: $\quad 5261277$

Skelet: $\quad$ V33 kleine Tüte

Population: Calden

Seite:

links
Verband: $\quad$ Verband

Alter: Erwachsen

Geschlecht:

Arthrose:

\section{Beschreibung:}

7. Rippe. 
Bezeichn.: Costa

Kiste: $\quad 5261277$

Skelet: V33 kleine Tüte

Population: Calden

Seite: rechts

\section{Beschreibung:}

9. Rippe.
Verband: $\quad \square$ Verband

Alter: Erwachsen

Geschlecht:

Arthrose:

Ges./Kr.: Gesund 
Bezeichn.: Costa

Kiste: $\quad 5261277$

Skelet: $\quad$ V33 kleine Tüte

Population: Calden

Seite:

rechts
Verband: $\quad$ Verband

Alter: Erwachsen

Geschlecht:

Arthrose:

\section{Beschreibung:}

10. Rippe. 
Bezeichn.: Costa

Kiste: $\quad 5261277$

Skelet: V33 kleine Tüte

Population: Calden

Seite:

links
Verband: $\quad$ Verband

Alter: Erwachsen

Geschlecht:

Arthrose:

\section{Beschreibung:}

10. Rippe. 
Bezeichn.: Costa

Kiste: $\quad 5261277$

Skelet: Zettel

Population: Calden

Seite: rechts

\section{Beschreibung:}

5. Rippe.
Verband: $\quad$ Verband

Alter: 4 - 5

Geschlecht:

Arthrose: 
Bezeichn.: Costa

Kiste: $\quad 5261277$

Skelet: Zettel

Population: Calden

Seite: n. def.

\section{Beschreibung:}

Rippenfragment.
Verband: $\quad \square$ Verband

\section{Alter:}

Geschlecht:

Arthrose: 
Bezeichn.: Costa

Kiste: $\quad 52651-3279$

Skelet: Zettel

Population: Calden

Seite:

links
Verband: Verband

\section{Alter:}

Geschlecht:

Arthrose:

\section{Beschreibung:}

Ein Fragment einer ersten Rippe. 
Bezeichn.: Costa

Kiste: $\quad 5245269$

Skelet: gesammelt

Population: Calden

Seite: rechts
Verband: Verband

\section{Alter:}

Geschlecht: $q \leq \AA$

Arthrose:

\section{Beschreibung:}

Wohl eine 8. Rippe der rechten Seite. Sie ist recht massiv. 
Bezeichn.: Costa

Kiste: $\quad 5245269$

Skelet: gesammelt

Population: Calden

Seite:

links

Verband: $\quad$ Verband

\title{
Alter:
}

Geschlecht:

Arthrose:

\author{
Beschreibung: \\ Eine 11. Rippe der linken Seite.
}


Bezeichn.: Costa

Kiste: $\quad 5245269$

Skelet: gesammelt

Population: Calden

\section{Beschreibung:}

Ein Fragment.
Verband: $\quad$ Verband

\section{Alter:}

Geschlecht:

Arthrose: 
Bezeichn.: Costa

Kiste: $\quad 5245269$

Skelet: gesammelt

Population: Calden

\section{Beschreibung:}

Ein Fragment.
Verband: $\quad$ Verband

\section{Alter:}

Geschlecht:

Arthrose: 
Bezeichn.: Costa

Kiste: $\quad 5245269$

Skelet: gesammelt

Population: Calden

Seite:

rechts
Verband: Verband

\section{Alter:}

Geschlecht:

Arthrose:

\section{Beschreibung:}

Ein Fragment einer rechten Rippe aus dem mittleren Bereich. 
Bezeichn.: Costa

Kiste: $\quad 5245269$

Skelet: gesammelt

Population: Calden
Verband: Verband

\section{Alter:}

Geschlecht:

Arthrose:

\section{Beschreibung:}

Rippenfragment. 
Bezeichn.: Costa

Kiste: $\quad 5245269$

Skelet: gesammelt

Population: Calden

Seite:

rechts

Verband: $\quad$ Verband

\section{Alter:}

Geschlecht:

Arthrose:

\section{Beschreibung:}

Wohl einer 4. Rippe der rechten Seite. 
Bezeichn.: Costa

Kiste: $\quad 5245269$

Skelet: gesammelt

Population: Calden

Seite:

rechts
Verband: Verband

\section{Alter:}

Geschlecht:

Arthrose:

\section{Beschreibung:}

Wohl eine 8. Rippe der rechten Seite, sie ist als Fragment erhalten. 
Bezeichn.: Costa

Kiste: $\quad 5245269$

Skelet: gesammelt

Population: Calden

Beschreibung:

Ein Rippenfragment.
Verband: Verband

\section{Alter:}

Geschlecht:

Arthrose: 
Bezeichn.: Costa

Kiste: $\quad 5245269$

Skelet: gesammelt

Population: Calden

Seite:

links

Verband: $\quad$ Verband

\section{Alter:}

Geschlecht:

Arthrose:

\section{Beschreibung:}

Wohl eine 4. Rippe der linken Seite. 


\section{Bezeichn.: Costa}

Kiste:

8505719

Skelet: Steinkammergrab 1

Population: Calden

Seite:

links
Verband: Verband

Alter: $\quad 30-50$

Geschlecht:

Arthrose:

\section{Beschreibung:}

Wohle eine erste Rippe der rechten Seite. 


\section{Bezeichn.: Costa}

Kiste:

8505719

Skelet: Steinkammergrab 1

Population: Calden

Seite:

links
Verband:

Verband

Alter:

Geschlecht:

Arthrose:

\section{Beschreibung:}

Eine 8. Rippe der linken Seite. 
Bezeichn.: Costa

Kiste:

8505719

Skelet: Steinkammergrab 1

Population: Calden

Seite:

rechts
Verband: $\quad$ Verband

Alter:

Geschlecht:

Arthrose:

\section{Beschreibung:}

Eine 7. Rippe der rechten Seite. 


\section{Bezeichn.: Costa}

Kiste:

8505719

steinkammergrab 1

Skelet:

Population: Calden

Seite:

rechts
Verband: Verband

\section{Alter:}

Geschlecht:

Arthrose:

\section{Beschreibung:}

Eine erste Rippe der rechten Seite. 
Bezeichn.: Costa

Kiste:

8505719

Skelet: steinkammergrab 1

Population: Calden

Seite:

rechts
Verband: $\quad$ Verband

\section{Alter:}

Geschlecht:

Arthrose:

\section{Beschreibung:}

Eine 2 Rippe der rechten Seite. 


\section{Bezeichn.: Costa}

Kiste:

8505719

Skelet: Steinkammergrab 1

Population: Calden

Seite:

links
Verband: $\quad$ Verband

\section{Alter:}

Geschlecht:

Arthrose:

\section{Beschreibung:}

Wohl eine 2. Rippe der linken Seite. 
Bezeichn.: Costa

Kiste: $\quad 8505719$

Skelet: Steinkammergrab 1

Population: Calden

Seite:

links
Verband: Verband

\section{Alter:}

Geschlecht:

Arthrose:

\section{Beschreibung:}

Wohl eine 6. Rippe der linken Seite. 
Bezeichn.: Costa

Kiste: $\quad 8505719$

Skelet: Steinkammergrab 1

Population: Calden

Seite: rechts

\section{Beschreibung:}

Wohl eine 3. Rippe der rechten Seite.
Verband: Verband

\section{Alter:}

Geschlecht:

Arthrose: 


\section{Bezeichn: Costa}

\section{Kiste:}

8505719

steinkammergrab 1

Skelet:

Population: Calden

Seite:

rechts
Verband: $\square$ Verband

Alter: Jung

Geschlecht:

Arthrose:

\section{Beschreibung:}

Eine erste Rippe eines jungen Individuums. 


\section{Bezeichn: Costa}

\section{Kiste:}

8505719

Skelet: $\quad$ steinkammergrab 1

Population: Calden

Seite:

links
Verband: Verband

\section{Alter:}

Geschlecht:

Arthrose:

\section{Beschreibung:}

Wohl eine zweite Rippe der linken Seite. 
Bezeichn.: Costa

Kiste: $\quad 5244268$

Skelet: Nr.8

Population: Calden

Seite:

rechts
Verband: $\quad \square$ Verband

Alter:

Geschlecht:

Arthrose:

\section{Beschreibung:}

Ein Rippenfragment einer Rippe der rechten Seite. 


\section{Bezeichn: Costa}

\section{Kiste:}

5254272

Skelet: $\quad$ Teil einer Rippe

Population: Calden

Seite:
Verband: $\square$ Verband

Alter: $\quad 30-50$ (60)

Geschlecht:

Arthrose:
Maß

Breite

Länge

\section{Beschreibung:}

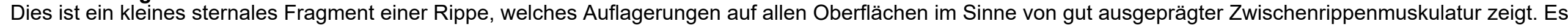

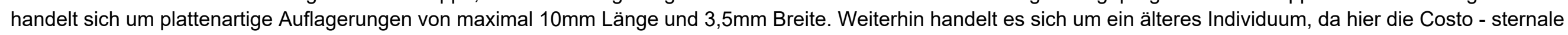
Syndesmose schon Verknöcherungen aufweist. 
Bezeichn.: Costa

Kiste: $\quad 5254272$

Skelet: ohne Bezeichnung

Population: Calden

Seite: rechts

\section{Beschreibung:}

Ein kleines Rippenfragment.
Verband: $\quad$ Verband

\section{Alter:}

Geschlecht:

Arthrose:
Maß

Wert $\mid$ Einheit

$22,64 \mathrm{~mm}$


Bezeichn.: Costa

Kiste: $\quad 5254272$

Skelet: ohne Bezeichnung

Population: Calden

Seite:

links
Verband:

Verband

\section{Alter:}

Geschlecht:

Arthrose:
Ges./Kr.: Gesund

Maß

Länge

\begin{tabular}{|l|l} 
Wert & Einheit
\end{tabular}

$59,78 \mathrm{~mm}$

\section{Beschreibung:}

Eine 6. Rippe der linken Seite. 
Bezeichn.: Costa

Kiste: $\quad 5254272$

Skelet: ohne Bezeichnung

Population: Calden

Seite:
Verband: $\square$ Verband

\section{Alter:}

Geschlecht:

Arthrose:
Ges./Kr.: Gesund

Maß

Länge

Wert $\quad$ Einheit

$54,62 \mathrm{~mm}$

Beschreibung:

Ein Rippenfragment einer linken Seite. 
Bezeichn.: Costa

Kiste: $\quad 5254272$

Skelet: ohne Bezeichnung

Population: Calden

Seite: n. def.
Verband: Verband

\section{Alter:}

Geschlecht:

Arthrose:

\section{Beschreibung:}

Dieses Fragment weist minimale Auflagerungen im Sinne einer normal beanspruchten Zwischenrippenmuskulatur auf. 


\section{Bezeichn: Costa}

\section{Kiste:}

5254272

Skelet: ohne Bezeichnung

Population: Calden

Seite:

\section{Verband:}

\section{Alter:}

Verband

Geschlecht: Erwachsen

Arthrose:
Ges./Kr.: Gesund

\section{Maß}

Breite

Länge

Wert $\quad$ Einheit

$22,23 \mathrm{~mm}$

76,51

$\mathrm{mm}$

\section{Beschreibung:}

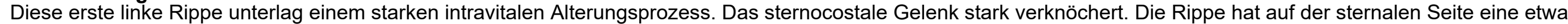
$25 \mathrm{~mm}$ tiefe Einbuchtung. An dieser Stelle ist der Knorpel zwischen erster Rippe und dem Sternum altersbedingt verknöchert. 


\section{Bezeichn.: Costa \\ Kiste: $\quad 5259276$ \\ Skelet: in Tüte}

Population: Calden
Verband: Verband

Ges./Kr.: Gesund

\section{Alter:}

Geschlecht:

Arthrose:

\section{Beschreibung:}

Hier ist ein Fragment einer Rippe erhalten. Es handelt sich um ein wirbelsäulennahes Fragment. 


\section{Bezeichn: Costa \\ Kiste: 5259276 \\ Skelet: in Tüte}

Population: Calden

Seite:

links
Verband:

Verband

\section{Alter:}

Geschlecht:

Arthrose:
Ges./Kr.: Gesund

\section{Beschreibung:}

Rippe mit Caput und kleinem Teil des corpus erhalten. 
Bezeichn.: Costa

Kiste: $\quad 5259276$

Skelet: in Tüte

Population: Calden

Seite: rechts

\section{Beschreibung:}

Rippe mit Caput und kleinem Teil des corpus erhalten.
Verband: $\quad$ Verband

\section{Alter:}

Geschlecht:

Arthrose:
Ges./Kr.: Gesund 


\section{Bezeichn.: Costa \\ Kiste: $\quad 5259276$ \\ Skelet: in Tüte}

Population: Calden

Seite:

links

\section{Verband:}

Verband

\section{Alter:}

Geschlecht:

Arthrose:
Ges./Kr.: Gesund

\section{Beschreibung:}

Rippe mit Caput und kleinem Teil des corpus erhalten. 


\section{Bezeichn.: Costa \\ Kiste: $\quad 5259276$ \\ Skelet: in Tüte}

Population: Calden

Seite:

links
Verband:

Verband

\section{Alter:}

Geschlecht:

Arthrose:
Ges./Kr.: Gesund

\section{Beschreibung:}

Rippe mit Caput und kleinem Teil des corpus erhalten 
Bezeichn.: Costa

Kiste: 8505721

Skelet: Zettel Kiste 1

Population: Calden

Seite:

links
Verband: $\square$ Verband

\section{Alter:}

Geschlecht:

Arthrose:

\section{Beschreibung:}

Die 9. Rippe der linken Seite.
Ges./Kr.: Gesund

\section{Ges/Kr: Gesund}


Bezeichn.: Costa

Kiste: 8505721

Skelet: Zettel Kiste 1

Population: Calden

Seite:

rechts
Verband: $\quad \square$ Verband

\section{Alter:}

Geschlecht:

Arthrose:

\section{Beschreibung:}

Die dritte Rippe der rechten Seite. 
Bezeichn.: Costa

Kiste: 8505721

Skelet: Zettel Kiste 1

Population: Calden

Seite:

links
Verband: $\square$ Verband

\section{Alter:}

Geschlecht:

Arthrose:

\section{Beschreibung:}

Die 5. Rippe der linken Seite. 
Bezeichn.: Costa

Kiste: $\quad 8505721$

Skelet: Zettel Kiste 1

Population: Calden

Seite:

links
Verband: $\square$ Verband

\section{Alter:}

Geschlecht:

Arthrose:
Beschreibung:

Linke dritte Rippe. 
Bezeichn.: Costa

Kiste: $\quad 8505721$

Skelet: Zettel Kiste 1

Population: Calden

Seite:

rechts
Verband: $\quad \square$ Verband

\section{Alter:}

Geschlecht:

Arthrose:
Beschreibung:

10. Rippe rechts. 
Bezeichn.: Costa

Kiste: $\quad 8505721$

Skelet: Zettel Kiste 1

Population: Calden

Seite:

links
Verband: $\square$ Verband

\section{Alter:}

Geschlecht:

Arthrose:

\section{Beschreibung:}

11. Rippe links. 
Bezeichn.: Costa

Kiste: $\quad 8505721$

Skelet: Zettel Kiste 1

Population: Calden

Seite:

links
Verband: $\square$ Verband

\section{Alter:}

Geschlecht:

Arthrose:

\section{Beschreibung:}

5. Rippe links. 
Bezeichn.: Costa

Kiste: 8505721

Skelet: Zettel Kiste 1

Population: Calden

Seite:

links
Verband: $\square$ Verband

\section{Alter:}

Geschlecht:

Arthrose:

\section{Beschreibung:}

9. Rippe links. 
Bezeichn.: Costa

Kiste: $\quad 8505721$

Skelet: Zettel Kiste 1

Population: Calden

Seite:

rechts
Verband: $\quad \square$ Verband

\section{Alter:}

Geschlecht:

Arthrose:

\section{Beschreibung: \\ 7.}

Ges./Kr.: Gesund 
Bezeichn.: Costa

Kiste: $\quad 8505721$

Skelet: Zettel Kiste 1

Population: Calden

Seite:

links
Verband:

Verband

\section{Alter: \\ Geschlecht:}

Arthrose:

\section{Beschreibung:}

$$
8 .
$$


Bezeichn.: Costa

Kiste: $\quad 8505721$

Skelet: Zettel Kiste 1

Population: Calden

Seite:

rechts
Verband: $\quad \square$ Verband

\section{Alter:}

Geschlecht:

Arthrose:

\section{Beschreibung:}

10. 
Bezeichn.: Costa

Kiste: $\quad 8505721$

Skelet: Zettel Kiste 1

Population: Calden

Seite:

links
Verband:

Verband

\section{Alter: \\ Geschlecht:}

Arthrose:

\section{Beschreibung:}

10. 
Bezeichn.: Costa

Kiste: $\quad 8505721$

Skelet: Zettel Kiste 1

Population: Calden

Seite:

links
Verband:

Verband

\section{Alter: \\ Geschlecht:}

Arthrose:

\section{Beschreibung:}


Bezeichn.: Costa

Kiste: $\quad 8505721$

Skelet: Zettel Kiste 1

Population: Calden

Seite:

links
Verband:

Verband

\section{Alter: \\ Geschlecht:}

Arthrose:

\section{Beschreibung: \\ 7.}

Ges./Kr.: Gesund 
Bezeichn.: Costa

Kiste: $\quad 8505721$

Skelet: Zettel Kiste 1

Population: Calden

Seite:

rechts
Verband: $\quad \square$ Verband

\section{Alter:}

Geschlecht:

Arthrose:

\section{Beschreibung:}

12. 
Bezeichn.: Costa

Kiste: $\quad 8505721$

Skelet: Zettel Kiste 1

Population: Calden

Seite:

links
Verband:

Verband

\section{Alter: \\ Geschlecht:}

Arthrose:

\section{Beschreibung:}

$$
8 .
$$


Bezeichn.: Costa

Kiste: $\quad 8505721$

Skelet: Zettel Kiste 1

Population: Calden

Seite:

links
Verband:

Verband

\section{Alter: \\ Geschlecht:}

Arthrose:

\section{Beschreibung:}

$$
8 .
$$


Bezeichn.: Costa

Kiste: $\quad 8505721$

Skelet: Zettel Kiste 1

Population: Calden

Seite:

links
Verband:

Verband

\section{Alter: \\ Geschlecht:}

Arthrose:

\section{Beschreibung: \\ 7.}

Ges./Kr.: Gesund 
Bezeichn.: Costa

Kiste: 8505721

Skelet: Zettel Kiste 1

Population: Calden

Seite:

rechts
Verband: $\quad \square$ Verband

\section{Alter:}

Geschlecht:

Arthrose:

\section{Beschreibung:}

\section{1.}


Bezeichn.: Costa

Kiste: $\quad 8505721$

Skelet: Zettel Kiste 1

Population: Calden

Seite:

links
Verband:

Verband

\section{Alter: \\ Geschlecht:}

Arthrose:

\section{Beschreibung: \\ 1.}


Bezeichn.: Costa

Kiste: $\quad 8505721$

Skelet: Zettel Kiste 1

Population: Calden

Seite:

links
Verband:

Verband

\section{Alter: \\ Geschlecht:}

Arthrose:

\section{Beschreibung:}


Bezeichn.: Costa

Kiste: $\quad 8505721$

Skelet: Zettel Kiste 1

Population: Calden

Seite:

links
Verband:

Verband

\section{Alter: \\ Geschlecht:}

Arthrose:

\section{Beschreibung:}

$$
8 .
$$


Bezeichn.: Costa

Kiste: $\quad 8505721$

Skelet: Zettel Kiste 1

Population: Calden

Seite:

rechts
Verband: $\quad \square$ Verband

\section{Alter:}

Geschlecht:

Arthrose:

\section{Beschreibung:}


Bezeichn.: Costa

Kiste: $\quad 8505721$

Skelet: Zettel Kiste 1

Population: Calden

Seite:

rechts
Verband: $\quad \square$ Verband

\section{Alter:}

Geschlecht:

Arthrose:

\section{Beschreibung:}

$$
6 .
$$


Bezeichn.: Costa

Kiste: $\quad 8505721$

Skelet: Zettel Kiste 1

Population: Calden

Seite:

links
Verband:

Verband

\section{Alter: \\ Geschlecht:}

Arthrose:

\section{Beschreibung:}

\section{1.}


Bezeichn.: Costa

Kiste: $\quad 8505721$

Skelet: Zettel Kiste 1

Population: Calden

Seite:

rechts
Verband: $\quad \square$ Verband

\section{Alter:}

Geschlecht:

Arthrose:

\section{Beschreibung:}

$$
6 .
$$


Bezeichn.: Costa

Kiste: $\quad 8505721$

Skelet: Zettel Kiste 1

Population: Calden

Seite:

links
Verband:

Verband

\section{Alter: \\ Geschlecht:}

Arthrose:

\section{Beschreibung:}

$$
8 .
$$


Bezeichn.: Costa

Kiste: $\quad 8505721$

Skelet: Zettel Kiste 1

Population: Calden

Seite:

rechts
Verband: $\quad \square$ Verband

\section{Alter:}

Geschlecht:

Arthrose:

\section{Beschreibung: \\ 7.}

Ges./Kr.: Gesund 
Bezeichn.: Costa

Kiste: $\quad 8505721$

Skelet: Zettel Kiste 1

Population: Calden

Seite:

rechts
Verband: $\quad \square$ Verband

\section{Alter:}

Geschlecht:

Arthrose:

\section{Beschreibung:}


Bezeichn.: Costa

Kiste: $\quad 8505721$

Skelet: Zettel Kiste 1

Population: Calden

Seite:

links
Verband:

Verband

\section{Alter: \\ Geschlecht:}

Arthrose:

\section{Beschreibung:}


Bezeichn.: Costa

Kiste: $\quad 8505721$

Skelet: Zettel Kiste 1

Population: Calden

Seite:

links
Verband:

Verband

\section{Alter: \\ Geschlecht:}

Arthrose:

\section{Beschreibung:}


Bezeichn.: Costa

Kiste: $\quad 8505721$

Skelet: Zettel Kiste 1

Population: Calden

Seite:

rechts
Verband: $\quad \square$ Verband

\section{Alter:}

Geschlecht:

Arthrose:

\section{Beschreibung:}


Bezeichn.: Costa

Kiste: $\quad 8505721$

Skelet: Kiste 1 Rippenfragmente

Population: Calden
Verband: Verband

\section{Alter:}

Geschlecht:

Arthrose:

\section{Beschreibung:}

Ein Fragment. 
Bezeichn.: Costa

Kiste: $\quad 8505721$

Skelet: Kiste 1 Rippenfragmente

Population: Calden
Verband: Verband

\section{Alter:}

Geschlecht:

Arthrose:

\section{Beschreibung:}

Ein Fragment. 
Bezeichn.: Costa

Kiste: $\quad 8505721$

Skelet: Kiste 1 Rippenfragmente

Population: Calden
Verband: Verband

\section{Alter:}

Geschlecht:

Arthrose:

\section{Beschreibung:}

Ein Fragment. 
Bezeichn.: Costa

Kiste: $\quad 8505721$

Skelet: Kiste 1 Rippenfragmente

Population: Calden
Verband: Verband

\section{Alter:}

Geschlecht:

Arthrose:

\section{Beschreibung:}

Ein Fragment. 
Bezeichn.: Costa

Kiste: $\quad 8505721$

Skelet: Kiste 1 Rippenfragmente

Population: Calden

Verband:

Verband

Alter:

Geschlecht:

Arthrose:

\section{Beschreibung:}

Ein Fragment. 
Bezeichn.: Costa

Kiste: $\quad 8505721$

Skelet: Kiste 1 Rippenfragmente

Population: Calden
Verband: Verband

\section{Alter:}

Geschlecht:

Arthrose:

\section{Beschreibung:}

Ein Fragment. 
Bezeichn.: Costa

Kiste: $\quad 8505721$

Skelet: Kiste 1 Rippenfragmente

Population: Calden
Verband: Verband

\section{Alter:}

Geschlecht:

Arthrose:

\section{Beschreibung:}

Ein Fragment. 
Bezeichn.: Costa

Kiste: $\quad 8505721$

Skelet: Kiste 1 Rippenfragmente

Population: Calden
Verband: Verband

\section{Alter:}

Geschlecht:

Arthrose:

\section{Beschreibung:}

Ein Fragment. 
Bezeichn.: Costa

Kiste: $\quad 8505721$

Skelet: Kiste 1 Rippenfragmente

Population: Calden
Verband: Verband

\section{Alter:}

Geschlecht:

Arthrose:

\section{Beschreibung:}

Ein Fragment. 
Bezeichn.: Costa

Kiste: $\quad 8505721$

Skelet: Kiste 1 Rippenfragmente

Population: Calden
Verband: Verband

\section{Alter:}

Geschlecht:

Arthrose:

\section{Beschreibung:}

Ein Fragment. 
Bezeichn.: Costa

Kiste: $\quad 8505721$

Skelet: Kiste 1 Rippenfragmente

Population: Calden
Verband: Verband

\section{Alter:}

Geschlecht:

Arthrose:

\section{Beschreibung:}

Ein Fragment. 
Bezeichn.: Costa

Kiste: $\quad 8505721$

Skelet: Kiste 1 Rippenfragmente

Population: Calden
Verband: Verband

\section{Alter:}

Geschlecht:

Arthrose:

\section{Beschreibung:}

Ein Fragment. 
Bezeichn.: Costa

Kiste: $\quad 8505721$

Skelet: Kiste 1 Rippenfragmente

Population: Calden
Verband: Verband

\section{Alter:}

Geschlecht:

Arthrose:

\section{Beschreibung:}

Ein Fragment. 
Bezeichn.: Costa

Kiste: $\quad 8505721$

Skelet: Kiste 1 Rippenfragmente

Population: Calden
Verband: Verband

\section{Alter:}

Geschlecht:

Arthrose:

\section{Beschreibung:}

Ein Fragment. 
Bezeichn.: Costa

Kiste: $\quad 8505721$

Skelet: Kiste 1 Rippenfragmente

Population: Calden
Verband: Verband

\section{Alter:}

Geschlecht:

Arthrose:

\section{Beschreibung:}

Ein Fragment. 
Bezeichn.: Costa

Kiste: $\quad 8505721$

Skelet: Kiste 1 Rippenfragmente

Population: Calden
Verband: Verband

\section{Alter:}

Geschlecht:

Arthrose:

\section{Beschreibung:}

Ein Fragment. 
Bezeichn.: Costa

Kiste: $\quad 8505721$

Skelet: Kiste 1 Rippenfragmente

Population: Calden
Verband: Verband

\section{Alter:}

Geschlecht:

Arthrose:

\section{Beschreibung:}

Ein Fragment. 
Bezeichn.: Costa

Kiste: $\quad 8505721$

Skelet: Kiste 1 Rippenfragmente

Population: Calden
Verband: Verband

\section{Alter:}

Geschlecht:

Arthrose:

\section{Beschreibung:}

Ein Fragment. 
Bezeichn.: Costa

Kiste: $\quad 8505721$

Skelet: Kiste 1 Rippenfragmente

Population: Calden
Verband: Verband

\section{Alter:}

Geschlecht:

Arthrose:

\section{Beschreibung:}

Ein Fragment. 
Bezeichn.: Costa

Kiste: $\quad 8505721$

Skelet: Kiste 1 Rippenfragmente

Population: Calden
Verband: Verband

\section{Alter:}

Geschlecht:

Arthrose:

\section{Beschreibung:}

Ein Fragment. 
Bezeichn.: Costa

Kiste: $\quad 8505721$

Skelet: Kiste 1 Rippenfragmente

Population: Calden
Verband: Verband

\section{Alter:}

Geschlecht:

Arthrose:

\section{Beschreibung:}

Ein Fragment. 
Bezeichn.: Costa

Kiste: $\quad 8505721$

Skelet: Kiste 1 Rippenfragmente

Population: Calden
Verband: Verband

\section{Alter:}

Geschlecht:

Arthrose:

\section{Beschreibung:}

Ein Fragment. 
Bezeichn.: Costa

Kiste: $\quad 8505721$

Skelet: Kiste 1 Rippenfragmente

Population: Calden
Verband: Verband

\section{Alter:}

Geschlecht:

Arthrose:

\section{Beschreibung:}

Ein Fragment. 
Bezeichn.: Costa

Kiste: $\quad 8505721$

Skelet: Kiste 1 Rippenfragmente

Population: Calden
Verband: Verband

\section{Alter:}

Geschlecht:

Arthrose:

\section{Beschreibung:}

Ein Fragment. 
Bezeichn.: Costa

Kiste: $\quad 8505721$

Skelet: Kiste 1 Rippenfragmente

Population: Calden
Verband: Verband

\section{Alter:}

Geschlecht:

Arthrose:

\section{Beschreibung:}

Ein Fragment. 
Bezeichn.: Costa

Kiste: $\quad 8505721$

Skelet: Kiste 1 Rippenfragmente

Population: Calden
Verband: Verband

\section{Alter:}

Geschlecht:

Arthrose:

\section{Beschreibung:}

Ein Fragment. 
Bezeichn.: Costa

Kiste: $\quad 8505721$

Skelet: Kiste 1 Rippenfragmente

Population: Calden
Verband: Verband

\section{Alter:}

Geschlecht:

Arthrose:

\section{Beschreibung:}

Ein Fragment. 
Bezeichn.: Costa

Kiste: $\quad 8505721$

Skelet: Kiste 1 Rippenfragmente

Population: Calden
Verband: Verband

\section{Alter:}

Geschlecht:

Arthrose:

\section{Beschreibung:}

Ein Fragment. 
Bezeichn.: Costa

Kiste: $\quad 8505721$

Skelet: Kiste 1 Rippenfragmente

Population: Calden
Verband: Verband

\section{Alter:}

Geschlecht:

Arthrose:

\section{Beschreibung:}

Ein Fragment. 
Bezeichn.: Costa

Kiste: $\quad 8505721$

Skelet: Kiste 1 Rippenfragmente

Population: Calden
Verband: Verband

\section{Alter:}

Geschlecht:

Arthrose:

\section{Beschreibung:}

Ein Fragment. 
Bezeichn.: Costa

Kiste: $\quad 8505721$

Skelet: Kiste 1 Rippenfragmente

Population: Calden
Verband: Verband

\section{Alter:}

Geschlecht:

Arthrose:

\section{Beschreibung:}

Ein Fragment. 
Bezeichn.: Costa

Kiste: $\quad 8505721$

Skelet: Kiste 1 Rippenfragmente

Population: Calden
Verband: Verband

\section{Alter:}

Geschlecht:

Arthrose:

\section{Beschreibung:}

Ein Fragment. 
Bezeichn.: Costa

Kiste: $\quad 8505721$

Skelet: Kiste 1 Rippenfragmente

Population: Calden
Verband: Verband

\section{Alter:}

Geschlecht:

Arthrose:

\section{Beschreibung:}

Ein Fragment. 
Bezeichn.: Costa

Kiste: $\quad 8505721$

Skelet: Kiste 1 Rippenfragmente

Population: Calden
Verband: Verband

\section{Alter:}

Geschlecht:

Arthrose:

\section{Beschreibung:}

Ein Fragment. 
Bezeichn.: Costa

Kiste: $\quad 8505721$

Skelet: Kiste 1 Rippenfragmente

Population: Calden
Verband: Verband

\section{Alter:}

Geschlecht:

Arthrose:

\section{Beschreibung:}

Ein Fragment. 
Bezeichn.: Costa

Kiste: $\quad 8505721$

Skelet: Kiste 1 Rippenfragmente

Population: Calden
Verband: Verband

\section{Alter:}

Geschlecht:

Arthrose:

\section{Beschreibung:}

Ein Fragment. 
Bezeichn.: Costa

Kiste: $\quad 8505721$

Skelet: Kiste 1 Rippenfragmente

Population: Calden
Verband: Verband

\section{Alter:}

Geschlecht:

Arthrose:

\section{Beschreibung:}

Ein Fragment. 
Bezeichn.: Costa

Kiste: $\quad 8505721$

Skelet: Kiste 1 Rippenfragmente

Population: Calden
Verband: Verband

\section{Alter:}

Geschlecht:

Arthrose:

\section{Beschreibung:}

Ein Fragment. 
Bezeichn.: Costa

Kiste: $\quad 8505721$

Skelet: Kiste 12

Population: Calden

Seite:

links
Verband: $\quad \square$ Verband

Alter:

\section{Geschlecht:}

Arthrose:
Ges./Kr.: Krank

Krankh.: Muskelreizung

\section{Beschreibung:}

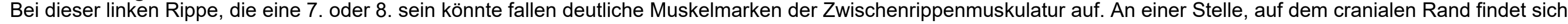
eine durch Muskelzug hervorgerufene Erhabenheit. Sie misst $17 \mathrm{~mm} \times 5 \mathrm{~mm} \times 1,5 \mathrm{~mm}$. 
Bezeichn.: Costa

Kiste: $\quad 8505721$

Skelet: Kiste 12

Population: Calden

Seite:

rechts

Verband: $\quad$ Verband

\section{Alter:}

Geschlecht:

Arthrose:

\section{Beschreibung:}

Ein sternales Fragment. 
Bezeichn.: Costa

Kiste: $\quad 8505721$

Skelet: Kiste 12

Population: Calden

Seite:

links

Verband: $\quad \square$ Verband

\section{Alter:}

Geschlecht:

Arthrose:

\section{Beschreibung:}

Ein mittleres Fragment. 
Bezeichn.: Costa

Kiste: $\quad 8505721$

Skelet: Kiste 12

Population: Calden

Seite:

rechts

Verband: $\quad$ Verband

\section{Alter:}

Geschlecht:

Arthrose:

\section{Beschreibung:}

Ein sternales Fragment. 
Bezeichn.: Costa

Kiste: $\quad 8505721$

Skelet: Kiste 12

Population: Calden

Seite:

rechts

\section{Beschreibung:}

Ein vertebrales Fragment
Verband: $\quad \square$ Verband

\section{Alter:}

Geschlecht:

Arthrose:

\section{Ges./Kr.: Gesund}


Bezeichn.: Costa

Kiste: $\quad 8505721$

Skelet: Kiste 12

Population: Calden

Seite:

rechts

Verband: $\quad$ Verband

\section{Alter:}

Geschlecht:

Arthrose:

\section{Beschreibung:}

Ein sternales Fragment. 
Bezeichn.: Costa

Kiste: $\quad 8505721$

Skelet: Kiste 12

Population: Calden

Seite:

links

Verband: $\quad \square$ Verband

\section{Alter:}

Geschlecht:

Arthrose:

\section{Beschreibung:}

Ein sternales Fragment. 
Bezeichn.: Costa

Kiste: $\quad 8505721$

Skelet: Kiste 5

Population: Calden

Seite:

rechts
Verband: $\square$ Verband

Alter:

\section{Geschlecht:}

Arthrose:
Ges./Kr.: Krank

Krankh.: Arthritis

\section{Beschreibung:}

Dieses Fragment ist eine rechte Rippe. Es handelt sich um ein vertebral erhaltenes Fragment. Hier fällt am costovertebralen Gelenk eine leichte Arthritis auf. Ansonsten ist das Fragment eher unauffällig. 
Bezeichn.: Costa

Kiste: $\quad 8505721$

Skelet: aus großer Kiste

Population: Calden

Seite:

rechts

\section{Beschreibung:}

Ein mittiges Fragment.
Verband: $\quad \square$ Verband

\section{Alter:}

Geschlecht:

Arthrose: 


$\begin{array}{lll}\text { Bezeichn.: } & \text { Costa } & \text { Verband: } \square \text { Verband } \\ \text { Kiste: } & 8505721 & \text { Alter: Jung } \\ \text { Skelet: } & \text { aus großer Kiste } & \text { Geschlecht: } \\ \text { Population: } & \text { Calden } & \text { Arthrose: }\end{array}$

\section{Beschreibung:}

Ein vertebrales Fragment einer jungen Rippe. 
Bezeichn.: Costa

Kiste: $\quad 8505721$

Skelet: aus großer Kiste

Population: Calden

Seite:

links
Verband:

Verband

\section{Alter:}

Geschlecht:

Arthrose:
Ges./Kr.: Gesund
Beschreibung:

Ein vertebrales Fragment. 
Bezeichn.: Costa

Kiste: $\quad 8505721$

Skelet: aus großer Kiste

Population: Calden
Verband: Verband

\section{Alter:}

Geschlecht:

Arthrose:

\section{Beschreibung:}

Ein Rippenfragment. 
Bezeichn.: Costa

Kiste: $\quad 8505721$

Skelet: aus großer Kiste

Population: Calden

Seite:

rechts

\section{Beschreibung:}

Ein sternales Fragment.
Verband: $\quad$ Verband

\section{Alter:}

Geschlecht:

Arthrose:
Ges./Kr.: Gesund

\section{Ges./Kr: : Gesund}




\section{Bezeichn: Costa}

Kiste:

8505720

Skelet: $\quad 13$ Rippenfragmente 1.1

Population: Calden
Verband:

Alter:

Geschlecht:

Arthrose:

\section{Beschreibung:}

13 Rippenfragmente. Es fielen keine Auffälligkeiten auf. 
Bezeichn.: Costa

Kiste: $\quad 5245269$

Skelet: 8 Rippenfragmente

Population: Calden
Verband: Verband

Alter:

Geschlecht:

Arthrose:

Beschreibung:

Hier sind acht kleine Rippenfragmente erhalten. 
Bezeichn:: Manubrium

Kiste: 5242266

Skelet: V56 sternum 3. Tüte

Population: Calden
Verband: $\quad$ Verband

Alter: Jung

Geschlecht:

Arthrose:
Maß

Breite

Länge

\begin{tabular}{|l|l} 
Wert & Einheit \\
\hline 46 & $\mathrm{~mm}$
\end{tabular}

prox. $\quad 1$

dist. 1

\section{Beschreibung:}

Hier ist ein manubrium erhalten, welches aufgrund seiner Konstitution und Größe einem jungen Individuum zuzuordnen ist. 
Bezeichn.: Manubrium

Kiste: $\quad 5242266$

Skelet: 3. Tüte

Population: Calden
Verband: $\quad$ Verband

Alter: Erwachsen

Geschlecht:

Arthrose:

prox

dist.
Ges./Kr.: Gesund

Maß

Breite

Länge \begin{tabular}{|l|l} 
Wert & Einheit \\
\hline 60 & $\mathrm{~mm}$
\end{tabular}

\begin{tabular}{l|l}
60 & $\mathrm{~mm}$
\end{tabular}

$53 \mathrm{~mm}$

\section{Beschreibung:}

Hier ist ein manubrium erhalten. 
Bezeichn.: Manubrium

Kiste: $\quad 5242266$

Skelet: 3. Tüte

Population: Calden
Verband: $\square$ Verband

Alter: Erwachsen

Geschlecht:

Arthrose:

prox.

dist.
Ges./Kr.: Gesund

Maß

Breite

Länge

\begin{tabular}{|l|l} 
Wert & Einheit \\
\hline 56 & $\mathrm{~mm}$
\end{tabular}

2

2

\section{Beschreibung:}

Dies ist ein manubrium eines wohl ausgewachsenen Individuums. 
$\begin{array}{ll}\text { Bezeichn.: } & \text { Manubrium } \\ \text { Kiste: } & 8505719 \\ \text { Skelet: } & \text { gesammelt }\end{array}$

Pkelet: gesamm

\section{Verband: $\quad \square$ Verband}

Alter: $\quad 40-60$

Geschlecht:

Arthrose:

\section{Maß}

Breite

Länge \begin{tabular}{|l|l} 
Wert & Einheit \\
\hline 53
\end{tabular}

$53 \quad \mathrm{~mm}$

47

\section{Beschreibung:}

Dieses manubrium ist seitlich etwas verknöchert, was für ein Individuum im fortgeschrittenen Alter spricht. 
$\begin{array}{ll}\text { Bezeichn.: } & \text { Manubrium } \\ \text { Kiste: } & 8505719 \\ \text { Skelet: } & \text { gesammelt }\end{array}$

Population: Calden
Verband:

Alter:

Verband

(14) $16-25$

Geschlecht:

Arthrose:
Maß

Breite

Länge
Wert $\quad$ Einheit

\begin{tabular}{ll|l}
58,6 & $\mathrm{~mm}$
\end{tabular}

$53,62 \mathrm{~mm}$

\section{Beschreibung:}

Dieses manubrium ist einem recht jungen Individuum zuzuordnen. 


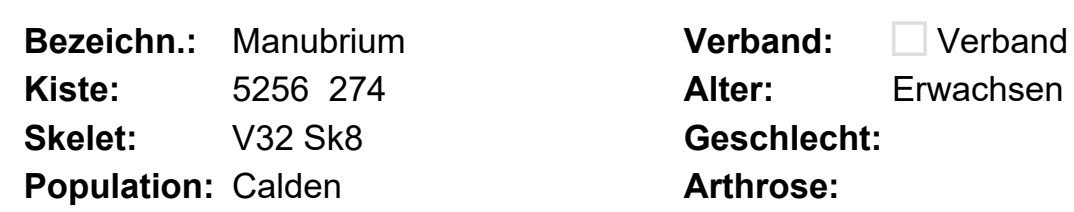

Arthrose:

\section{Beschreibung:}

Hier ist ein manubrium erhalten, welches wohl einem erwachsenen Individuum zuzuordnen ist. 


\begin{abstract}
Bezeichn.: Manubrium
Kiste: $\quad 8505718$

Skelet: aus Tüte
\end{abstract}

Population: Calden
Verband: $\square$ Verband

\section{Alter:}

Geschlecht:

Arthrose:
Ges./Kr.: Gesund

\section{Maß}

Breite

Wert $\quad$ Einheit

$60,75 \mathrm{~mm}$

\section{Beschreibung:}

Hier ist ein Fragment eines manubrium sterni erhalten. 
Bezeichn:: Sternum

Kiste: $\quad 5242266$

Skelet: $\quad$ V56 manubrium 3. Tüte

Population: Calden
Verband: $\quad$ Verband

Alter: Jung

Geschlecht:

Arthrose:
Maß

Breite

Länge \begin{tabular}{|l|l} 
Wert & Einheit \\
\hline 37 &
\end{tabular}

$37 \quad \mathrm{~mm}$

$82 \mathrm{~mm}$

\section{Beschreibung:}

Ein sternum aus einem Verband. 
Bezeichn:: Sternum

Kiste: $\quad 5256274$

Skelet: V32 Sk8

Population: Calden

Seite: n. def.

\section{Beschreibung:}

Sternum aus Verband.
Verband: Verband

\section{Alter:}

Geschlecht:

Arthrose: 


\section{Bezeichn.: Sternum \\ Kiste: $\quad 5259276$ \\ Skelet: PSK10}

Population: Calden

Seite:

n. def.

\section{Verband: $\square$ Verband}

\section{Alter:}

Geschlecht:

Arthrose:
Ges./Kr.: Gesund

\begin{tabular}{l|l|l} 
Maß & Wert & Einheit \\
\hline Breite & 42,24 & $\mathrm{~mm}$ \\
Länge & 96,83 & $\mathrm{~mm}$ \\
& & \\
& & \\
& &
\end{tabular}

\section{Beschreibung:}

Hierbei handelt es sich um eine anschauliche Variation im Sinne eines Loches in der Mitte des Sternums. 


\section{Bezeichn.: Clavicula}

Kiste: $\quad$ Museumskiste 3

Skelet: $\quad$ P2

Population: Calden

Seite:

links
Verband: $\square$ Verband

Alter: Erwachsen

Geschlecht:

Arthrose:

prox.
Ges./Kr.: Gesund

\section{Maß}

gr. Länge

Umfang Schaftmitte \begin{tabular}{|l|l} 
Wert & Einheit \\
130 & $\mathrm{~mm}$
\end{tabular}

$\mathrm{mm}$

$40 \quad \mathrm{~mm}$

\section{Beschreibung:}

Diese Clavicula ist in fast vollständigem Zustand und nur wenig erodiert. 


\section{Bezeichn.: Clavicula}

Kiste: Museumskiste 3

Skelet: $\quad$ P2

Population: Calden

Seite:

links
Verband: $\square$ Verband

Alter: Erwachsen

Geschlecht:

Arthrose:
Ges./Kr.: Gesund

prox.
Maß

Umfang Schaftmitte
Wert 1 Einheit

\begin{tabular}{ll|l}
42 & $\mathrm{~mm}$
\end{tabular}

\section{Beschreibung:}

Ein sternales Fragment einer Clavicula, etwa zu 50\% erhalten. 


\section{Bezeichn:: Clavicula \\ Kiste: $\quad 5256274$ \\ Skelet: Sk.8.}

Population: Calden

Seite:

links
Verband: Verband

\section{Alter:}

Geschlecht: +

Arthrose:
Ges./Kr.: Gesund

gr. Länge

Umfang Schaftmitte \begin{tabular}{|l|l} 
Wert & Einheit \\
\hline 130 & $\mathrm{~mm}$
\end{tabular}

$\mathrm{mm}$

$39 \mathrm{~mm}$

\section{Beschreibung:}

Eine sehr grazile Clavicula der linken Körperseite. 


\section{Bezeichn: Clavicula \\ Kiste: $\quad 8505720$ \\ Skelet: $\quad 1.0$}

Population: Calden

Seite:

\section{Verband:}

\section{Alter:}

Ges./Kr.: Gesund

Geschlecht:

Arthrose:

\section{Maß}

Umfang Schaftmitte
Einheit

$\mathrm{mm}$

\section{Beschreibung:}

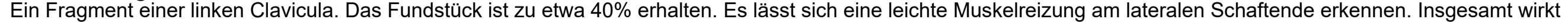
dieses eher lateral erhaltene Fundstück noch nicht ausgewachsen. Die Epiphysen fehlen. 


$\begin{array}{lll}\text { Bezeichn.: } & \text { Clavicula } & \text { Verband: } \square \text { Verband } \\ \text { Kiste: } & 8505720 & \text { Alter: Jung } \\ \text { Skelet: } & 1.2 & \text { Geschlecht: } \\ \text { Population: } & \text { Calden } & \text { Arthrose: } \\ \text { Seite: } & \text { rechts } & \end{array}$

\begin{tabular}{l|l|l} 
Maß & Wert & Einheit \\
\hline Umfang Schaftmitte & 27 & $\mathrm{~mm}$ \\
& & \\
& &
\end{tabular}

\section{Beschreibung:}

Diese rechte Clavicula ist zu etwa $60 \%$ erhalten, aber eher die sternale Seite. Es handelt sich um ein junges Individuum. 


\section{Bezeichn:: Clavicula \\ Kiste: 8505720 \\ Skelet: $\quad 1.2$}

Population: Calden

Seite:

rechts

\section{Verband: $\quad$ Verband}

Alter: Jung

Geschlecht:

Arthrose:

\section{Maß}

gr. Länge

Umfang Schaftmitte
Wert $\quad$ Einheit

$94,32 \mathrm{~mm}$

23

\section{Beschreibung:}

Diese rechte Clavicula stammt von einem jungen Individuum. Sie ist gut erhalten und weist wenig Erosion auf. 


\begin{tabular}{|c|c|c|c|c|c|}
\hline Bezeichn.: & Clavicula & Verband: $\quad \square$ Verband & Maß & Wert & Einheit \\
\hline Kiste: & 8505720 & Alter: Jung & gr. Länge & 93,5 & $\mathrm{~mm}$ \\
\hline Skelet: & 1.2 & Geschlecht: & Umfang Schaftmitte & 23 & $\mathrm{~mm}$ \\
\hline $\begin{array}{l}\text { Population: } \\
\text { Seite: }\end{array}$ & $\begin{array}{l}\text { Calden } \\
\text { links }\end{array}$ & Arthrose: & & & \\
\hline
\end{tabular}

\section{Beschreibung:}

Bei dieser linken, in voller Länge erhaltenen Clavicula handelt es sich um ein nicht ausgewachsenes Individuum. Allerdings ist die Oberfläche recht stark erodiert. 


$\begin{array}{llll}\text { Bezeichn.: } & \text { Clavicula } & \text { Verband: } & \square \text { Verband } \\ \text { Kiste: } & 8505720 & \text { Alter: } & \text { Erwachsen } \\ \text { Skelet: } & 1.2 & \text { Geschlecht: } & \\ \text { Population: } & \text { Calden } & \text { Arthrose: } & \end{array}$

Arthrose:

\section{Beschreibung:}

Von dieser linken Clavicula ist nur ein Teil des Schaftes erhalten. 


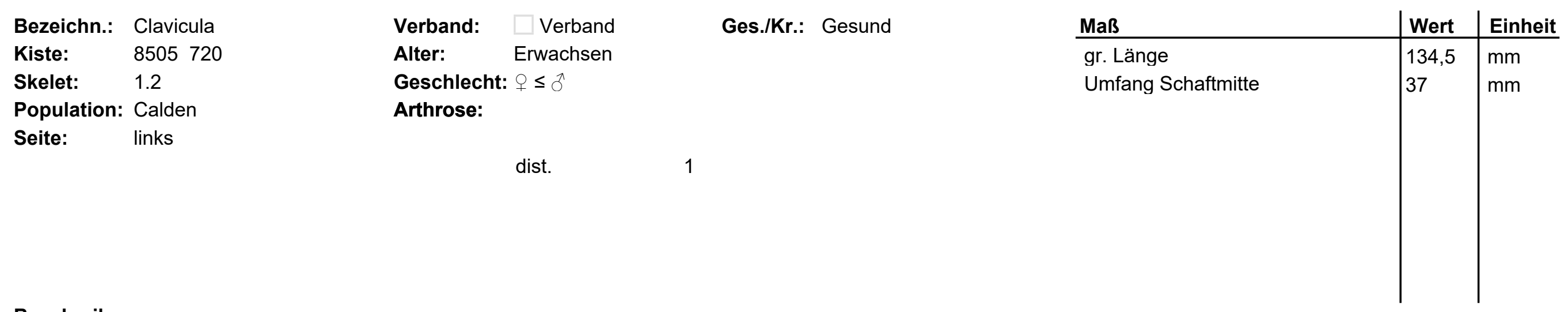

\section{Beschreibung:}

Diese linke Clavicula macht einen soliden Eindruck und weist auch ausgeprägte Muskelmarken auf. Allerdings ist nur die Facies articularis acromialis erhalten. Diese ist eher unauffällig. 


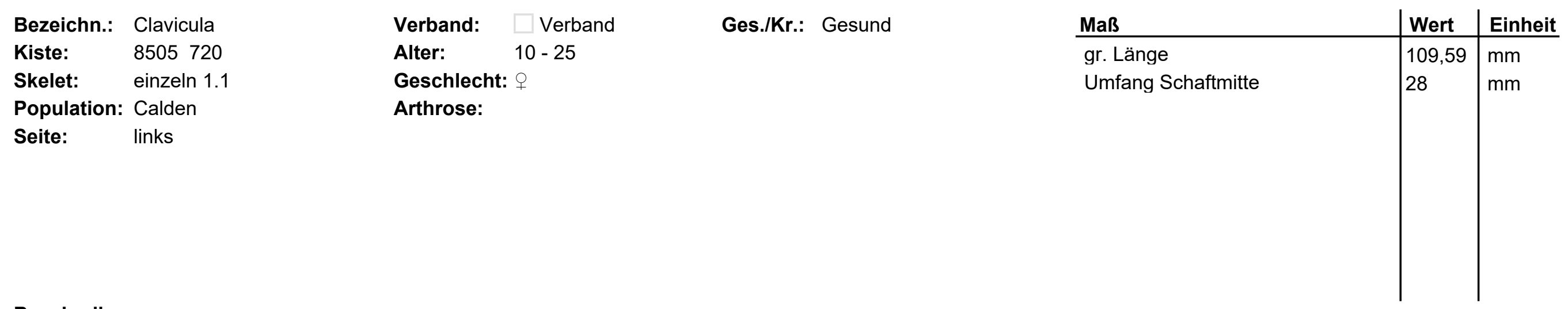

\section{Beschreibung:}

Dies ist eine auffällig kleine Clavicula, der linken Seite. Es zeigt sich, dass die Epiphysen nicht verknöchert sind. Es handelt sich also um ein junges Individuum. 


$\begin{array}{llll}\text { Bezeichn.: } & \text { Clavicula } & \text { Verband: } & \square \text { Verband } \\ \text { Kiste: } & 8505720 & \text { Alter: } & \text { Erwachsen } \\ \text { Skelet: } & \text { einzeln } 1.1 & \text { Geschlecht: } & \\ \text { Population: } & \text { Calden } & \text { Arthrose: } & \end{array}$

Arthrose:

\section{Beschreibung:}

Ein mediales Fragment. 


\section{Bezeichn: Clavicula \\ Kiste: $\quad 8505720$ \\ Skelet: $\quad 1.3$}

Population: Calden
Verband: $\square$ Verband

Alter: Jung

Geschlecht:

Arthrose:

\section{Beschreibung:}

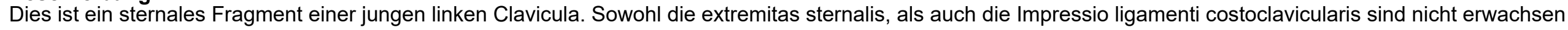
ausgebildet. 


\begin{tabular}{|c|c|c|c|c|c|c|c|c|}
\hline Bezeichn.: & Clavicula & Verband: & $\square$ Verband & Ges./Kr.: & Krank & Maß & Wert & Einheit \\
\hline Kiste: & 8505720 & Alter: & Erwachsen & Krankh.: & Myotendopathie & Umfang Schaftmitte & 37 & $\mathrm{~mm}$ \\
\hline Skelet: & 1.3 & Geschlecht: & & & & & & \\
\hline Population: & Calden & Arthrose: & & & & & & \\
\hline Seite: & links & & prox. & & & & & \\
\hline
\end{tabular}

\section{Beschreibung:}

Hierbei handelt es sich um ein sternales Fragment einer linken Scapula. Es weist eine sehr starke Impressio ligamenti costoclavicularis auf, die etwas ausgehöhlt ist und wie eine Myotendopathie aussieht. Die extremitas sternalis wirkt gesund. 


\section{Bezeichn: Clavicula \\ Kiste: $\quad 8505720$ \\ Skelet: $\quad 1.3$}

Population: Calden

Seite:

links

\section{Verband: $\quad$ Verband}

\section{Alter:}

Geschlecht:

Arthrose:

\section{Beschreibung:}

Hier ist ein eher laterales Fragment einer linken Scapula erhalten. es fehlt aber die laterale Synchondrose. 


$\begin{array}{llll}\text { Bezeichn.: } & \text { Clavicula } & \text { Verband: } & \square \text { Verband } \\ \text { Kiste: } & 8505720 & \text { Alter: } & 10-25 \\ \text { Skelet: } & 1.3 & \text { Geschlecht: } \\ \text { Population: } & \text { Calden } & \text { Arthrose: }\end{array}$

\section{Beschreibung:}

Hier ist ein kleines laterales Fragment einer rechten Scapula erhalten, welche nicht ausgewachsen war. 
Bezeichn:: Clavicula

Kiste: $\quad 8505720$

Skelet: $\quad 1.3$

Population: Calden

Seite: rechts
Verband: $\square$ Verband

Alter: Erwachsen

Geschlecht:

Arthrose:

Ges./Kr.: Gesund

\section{Beschreibung:}

Bei diesem Fragment handelt es sich um eine rechte Clavicula, die zu etwa $70 \%$ sternal erhalten ist. 


\section{Bezeichn.: Clavicula \\ Kiste: $\quad 8505720$ \\ Skelet: $\quad 1.3$}

Population: Calden

Seite:

links
Verband: $\quad$ Verband

\section{Alter:}

Geschlecht:

Arthrose:

\section{Beschreibung:}

Fragment aus dem Schaft einer linken Clavicula. 


\section{Bezeichn.: Clavicula}

Kiste: $\quad 5255273$

Skelet: V58 Scapulae und

Population: Calden

Seite:

links
Verband: $\quad$ Verband

Alter: Erwachsen

Geschlecht: +

Arthrose:

prox.

dist.
Ges./Kr.: Gesund

Maß

Länge

Wert $\quad$ Einheit

$129,5 \mathrm{~mm}$

\section{Beschreibung:}

Eine Clavicula aus einem Verband. 


\section{Bezeichn:: Clavicula \\ Kiste: $\quad 5257+58275$ \\ Skelet: Zettel}

Population: Calden

Seite:

links

\section{Beschreibung:}

Eine sehr grazile, junge Clavicula.
Verband: $\quad$ Verband $\quad$ Ges./Kr.: Gesund

Alter: $\quad 10-20$

Geschlecht: ㅇ

Arthrose: 


\section{Bezeichn: Clavicula \\ Kiste: $\quad 5242266$ \\ Skelet: 3. Tüte}

Population: Calden

Seite:

links
Verband: Verband

\section{Alter:}

Geschlecht:

Arthrose:

\section{Beschreibung:}

Eine recht stark erodierte Clavicula. 


\section{Bezeichn: Clavicula \\ Kiste: 5242266 \\ Skelet: 3. Tüte}

Population: Calden
Verband: Verband

\section{Alter:}

Geschlecht:

Arthrose:

\section{Beschreibung:}

Ein Fragment einer Clavicula in schlechtem Erhaltungszustand. 


\section{Bezeichn.: Clavicula \\ Kiste: $\quad 5242266$ \\ Skelet: 3. Tüte}

Population: Calden

\section{Beschreibung:}

Eine junge Clavicula.
Verband: $\square$ Verband

Alter: $\quad 12-16$

Geschlecht:

Arthrose: 


$\begin{array}{ll}\text { Bezeichn.: } & \text { Clavicula } \\ \text { Kiste: } & 8505718 \\ \text { Skelet: } & \text { aus Kiste } \\ \text { Population: } & \text { Calden } \\ \text { Seite: } & \text { rechts }\end{array}$

Verband: $\square$ Verband

Alter: Erwachsen

Geschlecht: $q \leq \lambda$

Arthrose:
Ges./Kr.: Krank

Krankh.: Arthrose

Myotendopathie
Maß

gr. Länge

Umfang Schaftmitte

\begin{tabular}{|l|l} 
Wert & Einheit \\
\hline 75,35 & $\mathrm{~mm}$
\end{tabular}

50

\section{Beschreibung:}

Diese rechte Clavicula ist kräftig ausgebildet und zeigt Spuren einer Myotendopathie und Arthrose an den Gelenkflächen. 
$\begin{array}{ll}\text { Bezeichn.: } & \text { Clavicula } \\ \text { Kiste: } & 8505718 \\ \text { Skelet: } & \text { aus Kiste }\end{array}$

Population: Calden

Seite:

rechts
Ges./Kr.: Krank

Krankh.: Myotendopathie

\section{Maß}

Umfang Schaftmitte
Wert $\quad$ Einheit

\section{Geschlecht:}

Arthrose:

\section{Beschreibung:}

Diese Clavicula weist eine Myotendopathie in Grubenform auf, die durch eine Überreizung des Ligamentum costoclaviculare hervorgerufen wurde. 
Bezeichn.: Clavicula

Kiste: 5256274

Skelet: V32 Sk8

Population: Calden

Seite:

links
Verband: $\quad$ Verband

Alter: Erwachsen

Geschlecht:

Arthrose:

\section{Beschreibung:}

Vollständig erhalten. 


\section{Bezeichn:: Clavicula \\ Kiste: $\quad 5245269$ \\ Skelet: Sk2}

Population: Calden

Seite:

links
Verband:

Verband

\section{Alter:}

Geschlecht:

Arthrose:

\section{Beschreibung:}

Eine gut erhaltene Clavicula, es fehlt der sternale Teil. 


\section{Bezeichn:: Clavicula \\ Kiste: \\ 5254272 \\ Skelet: $\quad$ P7}

Population: Calden

Seite:
Verband: $\quad$ Verband

Ges./Kr.: Gesund

\section{Alter:}

Geschlecht: ${ }^{\pi}$

Arthrose:

\begin{tabular}{l|l|l} 
Maß & Wert & Einheit \\
\hline gr. Länge & 160 & $\mathrm{~mm}$ \\
Umfang Schaftmitte & 42 & $\mathrm{~mm}$ \\
& & \\
& & \\
& &
\end{tabular}

\section{Beschreibung:}

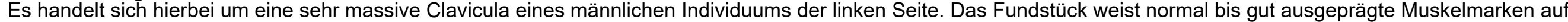
und hat keinen ersichtlichen Gelenkverschleiß. 


\section{Bezeichn.: Clavicula \\ Kiste: $\quad 8505721$ \\ Skelet: Kiste 9}

Population: Calden

Seite:

links

\section{Verband:}

\section{Alter:}

Ges./Kr.: Gesund

Geschlecht:

Arthrose:

\begin{tabular}{l|l|l} 
Maß & Wert & Einheit \\
\hline gr. Länge & 86 & $\mathrm{~mm}$ \\
Umfang Schaftmitte & 23 & $\mathrm{~mm}$ \\
& & \\
& & \\
& &
\end{tabular}

\section{Beschreibung:}

Diese linke Clavicula ist noch nicht ausgewachsen. 


\section{Bezeichn:: Clavicula \\ Kiste: $\quad 8505721$ \\ Skelet: Kiste 11}

Population: Calden

Seite:
Verband: $\quad \square$ Verband

Alter: Erwachsen

Geschlecht: $q<\hat{0}$

Arthrose:
Ges./Kr.: Krank

Krankh.: Myotendopathie

\section{Maß}

gr. Länge

Umfang Schaftmitte

\begin{tabular}{|l|l} 
Wert & Einheit \\
\hline 143 & mm
\end{tabular}

$\mathrm{mm}$

prox. $\quad 1$

dist. 1

\section{Beschreibung:}

Diese Clavicula ist sehr groß und deswegen eher männlich und weist wenige Muskelmarken auf. Verschleißerscheinungen fallen an diesem Fundstück nicht auf. Sie zeigt aber eine sehr deutliche Impressio ligamenti costoclavicularis mit recht tiefer Aushöhlung. 
Bezeichn.: Clavicula

Kiste: $\quad 8505721$

Skelet: aus großer Kiste

Population: Calden

Seite: rechts
Verband: $\square$ Verband

Alter: (17) $20-25$

Geschlecht:

Arthrose:

\section{Beschreibung:}

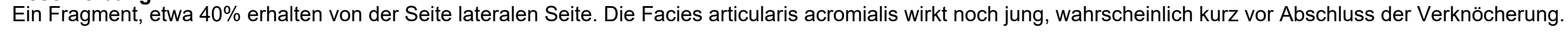




\section{Bezeichn.: Clavicula}

Kiste: $\quad 5261277$

Skelet: $\quad$ V33 Sk.11. kleine Tüte

Population: Calden

Seite:

links
Verband: $\quad$ Verband

Alter: Erwachsen

\section{Geschlecht:}

Arthrose:
Ges./Kr.: Krank

Krankh.: Muskelreizung

\section{Beschreibung:}

Bei dieser Clavicula findet sich ein starker Muskelansatz am Tuberculum conoideum des M. deltoideus. 


\section{Bezeichn.: Clavicula}

\section{Kiste: $\quad 5271289$}

Skelet: $\quad$ Fragmente in kleiner Tüte

Population: Calden

Seite:

Erhaltung:
Verband: $\square$ Verband

Alter: Erwachsen

Geschlecht: $q \leq \AA$

Arthrose:

prox.

dist.

Ges./Kr.: Gesund

\section{Beschreibung:}

Hier ist nur ein sternales Drittel einer linken Clavicula erhalten. 


\section{Bezeichn.: Scapula}

Kiste: Museumskiste 3

Skelet: P2

Population: Calden

Seite: rechts
Verband: $\quad$ Verband

\section{Alter:}

Geschlecht: $q \geq \AA$

Arthrose:

\section{Ges./Kr.: Gesund}

\section{Beschreibung:}

Dieses kleine Fragment einer Scapula ist sehr grazil und nur zu etwa 1/5 erhalten. Die Cavitas glenoidalis ist zu etwa 1/5 erhalten, es fallen nur leichte Verschleißerscheinungen ins Auge 


\section{Bezeichn.: Scapula}

Kiste: Museumskiste 3

Skelet: $\quad$ P2

Population: Calden

Seite: rechts
Verband: $\quad$ Verband

\section{Alter:}

Geschlecht:

Arthrose:

Ges./Kr.: Gesund

\section{Beschreibung:}

Hier sind zwei zusammen gefügte Fragmente einer Scapula in gutem Zustand erhalten. Insgesamt etwa 2/3. 


\section{Bezeichn.: Scapula}

Kiste: Museumskiste 3

Skelet: P2

Population: Calden

Seite: rechts

\section{Beschreibung:}

Diese Scapula ist zu 2/3 gut erhalten.
Verband: $\square$ Verband

Ges./Kr.: Gesund

\section{Alter:}

Geschlecht: $q \leq \hat{0}$

Arthrose: 


\section{Bezeichn.: Scapula}

Kiste: $\quad$ Museumskiste 3

Skelet: ohne

Population: Calden

Seite:

links
Verband: $\quad \square$ Verband

\section{Alter:}

Geschlecht:

Arthrose:

\section{Beschreibung:}

Hier ist der Margo lateralis zum Teil als Fragment einer linken Scapula erhalten. 


\section{Bezeichn.: Scapula}

Kiste: Museumskiste 3

Skelet: $\quad$ P2

Population: Calden

Seite:

rechts
Verband: $\quad \square$ Verband

Ges./Kr.: Gesund

\section{Alter:}

Geschlecht:

Arthrose:

\section{Beschreibung:}

Von dieser Scapula sind zwei Fragmente erhalten, was in etwa 20\% der gesamten Scapula ausmacht. 


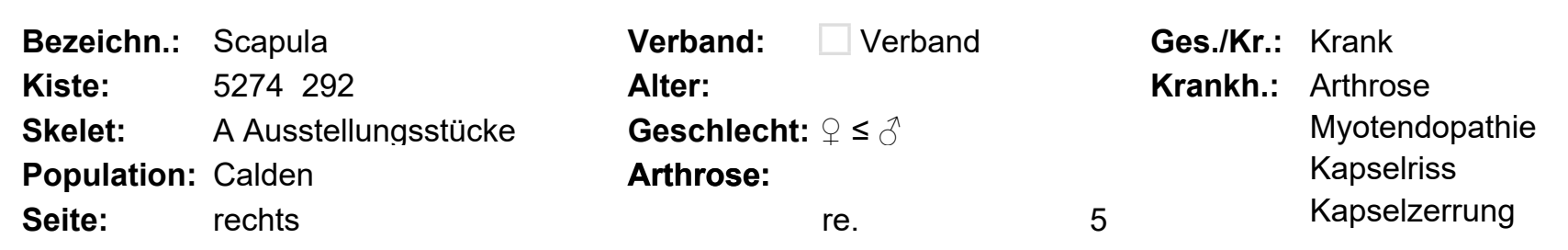

\section{Beschreibung:}

Diese Scapula ist zu etwa 70\% erhalten. Dazu gehört die Cavitas glenoidalis und ein Teil des Margo lateralis. Es liegt eine Arthrose der Cavitas glenoidalis vor, die als recht schwerwiegend eingestuft werden muss. Durch anschließende Schonung der Schulter entstand dann nach Wiederbewegung eine Überlastung der Kapsel, die eine Zerrung erfuhr. Das ist als kleine Ausrisse geprägt gewesen, die deutlich am Knochen als kleine Ausrissstellen und Neuverknöcherungen nachzuweisen sind. Eine Myotendopathie durch den M. quadriceps Caput longum ist ebenfalls an der Scapula zu erkennen. 
Bezeichn.: Scapula

Kiste: 5274292

Skelet: $\quad$ A Ausstellungsstücke

Population: Calden

Seite:
Verband: $\square$ Verband

Alter:

Geschlecht: $q>\hat{\sigma}$

Arthrose:
Ges./Kr.: Gesund

\section{Beschreibung:}

Ein Fragment einer grazilen Scapula der linken Seite. An dem Fragment beteiligt sind Cavitas glenoidalis und Margo lateralis. 
Bezeichn.: Scapula

Kiste: $\quad 8505720$

Skelet: $\quad 1.0$

Population: Calden

Seite:

rechts
Verband: Verband

\section{Alter:}

Geschlecht:

Arthrose:

\section{Beschreibung:}

Fragment der Cavitas glenoidalis der rechten Körperseite. Es handelt sich um ein sehr kleines Fragment 
Bezeichn.: Scapula

Kiste: $\quad 8505720$

Skelet: $\quad 1.0$

Population: Calden

Seite:

rechts

Verband: $\quad$ Verband

\section{Alter:}

Geschlecht:

Arthrose:

\section{Beschreibung:}

Fragment des Processus coracoideus. 
Bezeichn.: Scapula

Kiste: $\quad 8505720$

Skelet: $\quad 1.0$

Population: Calden

Seite:

links
Verband: Verband

\section{Alter:}

Geschlecht:

Arthrose:

\section{Beschreibung:}

Fragment des Processus coracoideus. 


\section{Bezeichn.: Scapula}

Kiste: $\quad 8505720$

Skelet: $\quad 1.0$

Population: Calden

Seite:
Verband: $\square$ Verband

Alter:

Geschlecht:

Arthrose:

\section{Beschreibung:}

Von dieser Scapula ist nur ein Fragment des Acromions erhalten. 


\section{Bezeichn.: Scapula}

Kiste: $\quad 8505720$

Skelet: $\quad 1.2$

Population: Calden

Seite:

rechts
Verband: $\quad$ Verband

Alter: Jung

Geschlecht:

Arthrose:

\section{Beschreibung:}

Hier ist nur ein kleines Fragment mit Processus coracoideus und einem kleinen Teil der Facies glenoidalis erhalten. Das Individuum ist anscheinend nicht ausgewachsen gewesen, da sowohl die Facies glenoidalis, als auch der Processus coracoideus noch eine geöffnete Epiphysenfuge aufweisen. 
Bezeichn.: Scapula

Kiste: $\quad 8505720$

Skelet: $\quad 1.2$

Population: Calden

Seite: rechts

\section{Beschreibung:}

Ein Fragment, es ist nur ein dünner Teil der Fläche erhalten.

\section{Verband: $\quad \square$ Verband}

\section{Alter:}

Geschlecht:

Arthrose: 
Bezeichn.: Scapula

Kiste: $\quad 8505720$

Skelet: $\quad 1.2$

Population: Calden

Seite:

links
Verband: $\quad$ Verband

\section{Alter:}

Geschlecht:

Arthrose:

\section{Beschreibung:}

Hier ist nur das Acromion der Scapula erhalten. 
Bezeichn.: Scapula

Kiste: $\quad 8505720$

Skelet: einzeln 1.1

Population: Calden

Seite:

links

Verband: $\quad \square$ Verband

\section{Alter:}

Geschlecht:

Arthrose:

\section{Beschreibung:}

Ein Fragment. 


\section{Bezeichn.: Scapula}

Kiste: $\quad 8505720$

Skelet: $\quad 1.3$

Population: Calden

Seite: rechts
Verband: $\quad$ Verband

Alter:

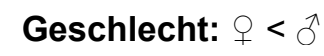

Arthrose:
Ges./Kr.: Krank

Krankh.: Arthrose

\section{Beschreibung:}

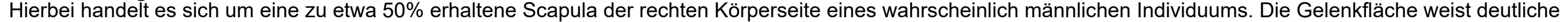
Verschleißerscheinungen auf. 


\section{Bezeichn.: Scapula \\ Kiste: $\quad 8505720$ \\ Skelet: $\quad 1.3$}

Population: Calden
Verband: $\quad$ Verband

\section{Alter:}

Geschlecht:

Arthrose:

\begin{tabular}{l|l} 
Wert & Einheit \\
\hline 139 & $\mathrm{~mm}$
\end{tabular}

\section{Beschreibung:}

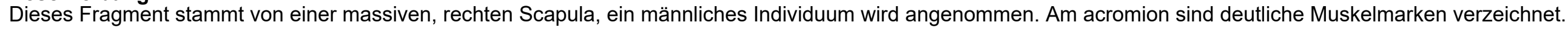




$\begin{array}{lll}\text { Bezeichn.: } & \text { Scapula } & \text { Verband: } \square \text { Verband } \\ \text { Kiste: } & 8505720 & \text { Alter: Jung } \\ \text { Skelet: } & 1.3 & \text { Geschlecht: } \\ \text { Population: } & \text { Calden } & \text { Arthrose: } \\ \text { Seite: } & \text { links } & \end{array}$

\section{Beschreibung:}

Dieses Fundstück ist eine linke Scapula, die nur teilweise erhalten ist. Sie ist noch nicht ausgewachsen gewesen; die Epiphysehnfugen sind noch nicht geschlossen, auch nicht die es Processus coracoideus. 
Bezeichn:: Scapula

Kiste: $\quad 8505720$

Skelet: $\quad 1.3$

Population: Calden

Seite:

links
Verband: $\quad$ Verband

\section{Alter:}

Geschlecht:

Arthrose:

\section{Beschreibung:}

Dieses Fundstück stammt von einer linken Scapula. Es ist auch ein kleiner Teil der Cavitas glenoidalis erhalten. 
Bezeichn.: Scapula

Kiste: $\quad 8505720$

Skelet: $\quad 1.3$

Population: Calden

Seite:

links
Verband: $\quad$ Verband

\section{Alter:}

Geschlecht:

Arthrose:

\section{Beschreibung:}

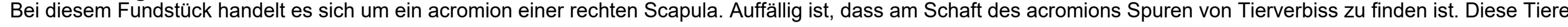
müssten in dem Fall das gesamte acromion abgetrennt haben, um derartige Bissspuren zu hinterlassen. 
Bezeichn:: Scapula

Kiste: $\quad 8505720$

Skelet: $\quad 1.3$

Population: Calden

Seite:

links
Verband: $\quad$ Verband

Alter:

Geschlecht: $q \geq 0$

Arthrose:

\section{Beschreibung:}

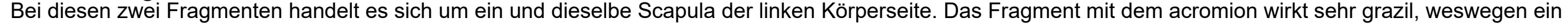
weibliches Individuum angenommen werden kann. 
Bezeichn.: Scapula

Kiste: $\quad 8505720$

Skelet: $\quad 1.3$

Population: Calden

Seite:

links
Verband: Verband

\section{Alter:}

Geschlecht:

Arthrose:

\section{Beschreibung:}

Fragment einer linken Scapula. 
Bezeichn.: Scapula

Kiste: $\quad 8505720$

Skelet: $\quad 1.3$

Population: Calden

Seite:

links
Verband: Verband

\section{Alter:}

Geschlecht:

Arthrose:

\section{Beschreibung:}

Fragment einer linken Scapula. 


$\begin{array}{lll}\text { Bezeichn.: } & \text { Scapula } & \text { Verband: } \square \text { Verband } \\ \text { Kiste: } & 8505720 & \text { Alter: Jung } \\ \text { Skelet: } & 1.3 & \text { Geschlecht: } \\ \text { Population: } & \text { Calden } & \text { Arthrose: } \\ \text { Seite: } & \text { links } & \end{array}$

Dieses Fragment einer linken Scapula stammt von einem nicht ausgewachsenen Individuum. Die Epiphysen sind noch nicht geschlossen. 
Bezeichn.: Scapula

Kiste: $\quad 8505720$

Skelet: $\quad 1.3$

Population: Calden

Seite:

links
Verband: $\square$ Verband

\section{Alter:}

Geschlecht:

Arthrose:

\section{Beschreibung:}

Dieses Fragment stammt von einer linken Scapula und beinhaltet den Schaft des acromions. Ansonsten ist nichts weiter erhalten. 
Bezeichn.: Scapula

Kiste: $\quad 5249270$

Skelet: Zettel

Population: Calden

Seite: rechts

\section{Beschreibung:}

Ein Fragment.
Verband: $\quad$ Verband

Alter:

Geschlecht: $\rho>\hat{\sigma}$

Arthrose:
Ges./Kr.: Krank

Krankh.: Arthrose 
Bezeichn.: Scapula

Kiste: $\quad 5255273$

Skelet: V58 Scapulae

Population: Calden

Seite: rechts

\section{Beschreibung:}

Ein im Verband zuzuordnendes Fundstück.
Verband: $\quad \square$ Verband

Alter:

Geschlecht: +

Arthrose: 
Bezeichn.: Scapula

Kiste: $\quad 5255273$

Skelet: unter SK7

Population: Calden

Seite:

links

\section{Beschreibung:}

Ein Fragment eines Acromions.
Verband: Verband

\section{Alter:}

Geschlecht:

Arthrose: 
Bezeichn.: Scapula

Kiste: $\quad 5257+58275$

Skelet: Sk.9.

Population: Calden

Verband: $\quad$ Verband

\section{Alter:}

Geschlecht:

Arthrose:

\section{Beschreibung:}

Ein Fragment. 
Bezeichn.: Scapula

Kiste: $\quad 5257+58275$

Skelet: SK.9.

Population: Calden

Verband: $\quad$ Verband

\section{Alter:}

Geschlecht:

Arthrose:

\section{Beschreibung:}

Scapulafragmente. 
Bezeichn.: Scapula

Kiste: $\quad 5255273$

Skelet: V58 Scapulae

Population: Calden

Seite:

links
Verband: $\quad$ Verband

Alter:

Geschlecht: +

Arthrose:
Ges./Kr.: Krank

Krankh.: Arthrose

\section{Beschreibung:}

Ein im Verband einzuordnendes Fundstück. 


\section{Bezeichn.: Scapula \\ Kiste: 5242266 \\ Skelet: 3. Tüte}

Population: Calden

Seite:

rechts
Verband: $\square$ Verband

\section{Alter:}

Geschlecht:

Arthrose:

\section{Beschreibung:}

Dies ist ein Fragment einer Scapula, welches mit dem Processus coracoideus erhalten ist. Dieser weist starke Muskelreizungen in Form von Zerrungen auf. Weiterhin ist ein kleines Stück des Gelenks erhalten. 


\section{Bezeichn: Scapula \\ Kiste: 5242266 \\ Skelet: $\quad 3$. Tüte}

Population: Calden

Seite:

links
Verband: $\square$ Verband

\section{Alter:}

Geschlecht:

Arthrose:
Ges./Kr.: Gesund

\section{Beschreibung:}

Ein Scapulafragment mit Gelenkfläche und frakturiertem Processus coracoideus und Teil des Acromions. 


\section{Bezeichn.: Scapula \\ Kiste: $\quad 5242266$ \\ Skelet: 3. Tüte}

Population: Calden

Seite:

rechts

\section{Verband: $\quad$ Verband \\ Ges./Kr.: Krank \\ Alter: Krankh.: Muskelreizung \\ Geschlecht: Zerrung}

Arthrose:

\section{Beschreibung:}

Dies ist das Fragment einer Scapula, die nur in Form des Acromions erhalten ist. Es weist starke Muskelreizungen in Form von Zerrungen auf. 


\section{Bezeichn: Scapula \\ Kiste: $\quad 5242266$ \\ Skelet: $\quad 3$. Tüte}

Population: Calden

Seite:

links
Verband: Verband

\section{Alter:}

Geschlecht:

Arthrose:

\section{Beschreibung:}

Ein Fragment mit Processus acromialis, kleinem Teil der Gelenkfläche und frakturiertem Margo lateralis. 


\section{Bezeichn.: Scapula \\ Kiste: $\quad 5242266$ \\ Skelet: 3. Tüte}

Population: Calden

Seite: rechts
Verband: $\square$ Verband

\section{Alter:}

Geschlecht:

Arthrose:
Ges./Kr.: Krank

Krankh.: Arthrose

\section{Beschreibung:}

Fragment mit etwa $60 \%$ der Gelenkfläche, die eindeutige Spuren von Arthrose aufweist. Ein kleiner Teil des Processus coracoideus und Margo lateralis sind ebenfalls erhalten. 
Bezeichn.: Scapula

Kiste: $\quad 5242266$

Skelet: 3. Tüte

Population: Calden

Seite: rechts
Verband: Verband

\section{Alter:}

Geschlecht:

Arthrose:

\section{Beschreibung:}

Scapulafragment mit Processus coracoideus und Cavitas glenoidalis. 


\section{Bezeichn: Scapula \\ Kiste: $\quad 5242266$ \\ Skelet: 3. Tüte}

Population: Calden

Seite:

links
Verband: Verband

\section{Alter:}

Geschlecht:

Arthrose:

\section{Beschreibung:}

Fragment einer Scapula mit Margo lateralis und der angrenzenden Fläche. 
Bezeichn:: Scapula

Kiste: $\quad 5242266$

Skelet: 3. Tüte

Population: Calden

\section{Beschreibung:}

Ein Scapulafragment.
Verband: Verband

\section{Alter:}

Geschlecht:

Arthrose: 
Bezeichn.: Scapula

Kiste: $\quad 5242266$

Skelet: 3. Tüte

Population: Calden

\section{Beschreibung:}

Ein Scapulafragment.
Verband: Verband

\section{Alter:}

Geschlecht:

Arthrose: 
Bezeichn:: Scapula

Kiste: $\quad 5242266$

Skelet: 3. Tüte

Population: Calden

\section{Beschreibung:}

Ein Scapulafragment.
Verband: Verband

\section{Alter:}

Geschlecht:

Arthrose: 
Bezeichn:: Scapula

Kiste: $\quad 5242266$

Skelet: 3. Tüte

Population: Calden

\section{Beschreibung:}

Ein Scapulafragment.
Verband: Verband

\section{Alter:}

Geschlecht:

Arthrose: 
Bezeichn.: Scapula

Kiste: $\quad 5242266$

Skelet: 3. Tüte

Population: Calden

\section{Beschreibung:}

Ein Scapulafragment.
Verband: Verband

\section{Alter:}

Geschlecht:

Arthrose: 
Bezeichn.: Scapula

Kiste: $\quad 5242266$

Skelet: 3. Tüte

Population: Calden

\section{Beschreibung:}

Ein Scapulafragment.
Verband: Verband

\section{Alter:}

Geschlecht:

Arthrose: 
Bezeichn.: Scapula

Kiste: $\quad 8505718$

Skelet: aus Kiste

Population: Calden

Seite:

rechts
Verband:

\section{Alter:}

Ges./Kr.: Gesund

Geschlecht:

Arthrose:

\section{Beschreibung:}

Ein Fragment mit Teil der Spina scapulae, welche nicht ganz verknöchert ist. 
Bezeichn.: Scapula

Kiste: $\quad 5252271$

Skelet: $\quad 34$

Population: Calden
Verband: $\square$ Verband

\section{Alter:}

Geschlecht:

Arthrose:

\section{Beschreibung:}

Mehrere Scapulafragmente. 


\section{Bezeichn.: Scapula \\ Kiste: 5256274 \\ Skelet: P.SK.8}

Population: Calden

Seite: rechts
Verband: $\square$ Verband

\section{Alter:}

Geschlecht:

Arthrose:
Ges./Kr.: Krank

Krankh.: Arthrose

\section{Beschreibung:}

Ein Scapulafragment mit Cavitas glenoidalis und Margo lateralis, es weist leichte poröse Auftreibung unterhalb des Gelenks 


\section{Bezeichn.: Scapula \\ Kiste: $\quad 5256274$ \\ Skelet: Zettel}

Population: Calden

Seite:

links
Verband: $\quad$ Verband

Alter:

Geschlecht:

Arthrose:
Ges./Kr.: Krank

Krankh.: Arthrose

\section{Beschreibung:}

Ein Scapulafragment mit Cavitas glenoidalis und Margo lateralis. 
Bezeichn.: Scapula

Kiste: $\quad 5261277$

Skelet: Zettel

Population: Calden

Seite:

links

Verband: Verband

\section{Alter:}

Geschlecht:

Arthrose:

\section{Beschreibung:}

Ein Fragment. 
Bezeichn.: Scapula

Kiste: 5261277

Skelet: $\quad$ V33 kleine Tüte

Population: Calden

Seite:

links

\section{Beschreibung:}

Ein Scapulafragment mit Cavitas glenoidalis.
Verband: $\quad \square$ Verband

Alter: Erwachsen

Geschlecht:

Arthrose: 
Bezeichn.: Scapula

Kiste: $\quad 5261277$

Skelet: unter $\mathrm{SCH} .8+3$

Population: Calden

Seite:

rechts

\section{Beschreibung:}

Ein Scapulafragment.
Verband: Verband

\section{Alter:}

Geschlecht:

Arthrose: 
Bezeichn.: Scapula

Kiste: $\quad 52651-3279$

Skelet: Zettel

Population: Calden

Seite:

links

\section{Beschreibung:}

Ein Fragment mit Cavitas glenoidalis.
Verband: $\quad$ Verband

\section{Alter:}

Geschlecht:

Arthrose:
Ges./Kr.: Krank

Krankh.: Arthrose 


\section{Bezeichn.: Scapula \\ Kiste: $\quad 5263278$ \\ Skelet: $\quad \mathrm{P} 16+18$}

Population: Calden

Seite: rechts
Verband: $\square$ Verband

\section{Alter:}

Geschlecht:

Arthrose:
Ges./Kr.: Krank

Krankh.: Arthrose

\section{Beschreibung:}

Ein Scapulafragment der rechten Seite, es enthält die Cavitas glenoidalis und einen Teil des Margo lateralis. 
Bezeichn.: Scapula

Kiste: $\quad 5263278$

Skelet: P.SK8.

Population: Calden

Seite:

rechts

\section{Beschreibung:}

Ein Scapulafragment.
Verband: Verband

\section{Alter:}

Geschlecht:

Arthrose: 
Bezeichn.: Scapula

Kiste: $\quad 5245269$

Skelet: gesammelt

Population: Calden

Seite:

rechts

Verband: $\quad$ Verband

\title{
Alter:
}

Geschlecht:

Arthrose:

\author{
Beschreibung: \\ Ein Fragment mit Margo medialis.
}




\section{Bezeichn: Scapula \\ Kiste: $\quad 5245269$ \\ Skelet: $\quad$ Sk2}

Population: Calden

Seite:
Verband: $\square$ Verband

\section{Alter:}

Geschlecht:

Arthrose:

\section{Beschreibung:}

Ein Fragment einer Scapula, bei dem die Cavitas glenoidalis erhalten ist. 


\section{Bezeichn.: Scapula}

Kiste: $\quad 8505719$

Skelet: unter Schädel 23

Population: Calden

Seite: rechts
Verband: $\quad$ Verband

Alter: Erwachsen

Geschlecht:

Arthrose:

Ges./Kr.: Gesund

\section{Beschreibung:}

Ein Scapulafragment, bei dem das acromion erhalten ist. Dieses zeigt deutliche Muskelmarken. 


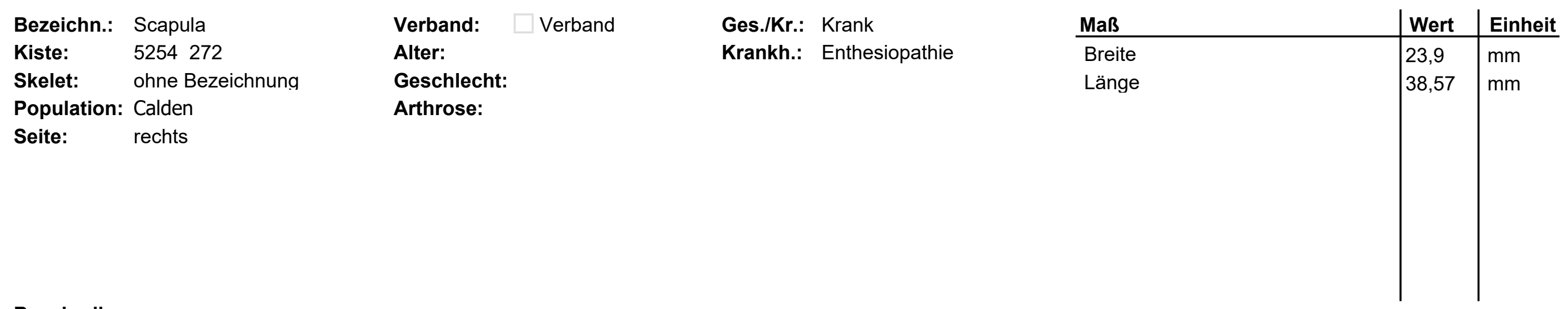

\section{Beschreibung:}

Es ist nur ein kleines Fragment erhalten, welches unterhalb des Tuberculum infraglenoidale herausgebrochen ist. Es weist einen deutlichen Muskelansatz auf, bei dem es möglicherweise zu einer leichten Enthesiopathie geführt hat (12,4mm x 10,67mm x 2,81mm). 
Bezeichn.: Scapula

Kiste: $\quad 5254272$

Skelet: bei Sk7 ev. Sch.23+25

Population: Calden

Seite: links
Ges./Kr.: Krank

Krankh.: Enthesiopathie

\section{Maß}

Breite

Länge

\section{Alter:}

Arthrose:

\section{Beschreibung:}

Ein Scapulafragment der linken Seite mit gut ausgeprägten Muskelmarken des M. latissimus dorsi mit leichter Enthesiopathie an der Ansatzstelle. 


\section{Bezeichn.: Scapula \\ Kiste: $\quad 5266280$ \\ Skelet: $\quad 3,45 ; 3,75$}

Population: Calden

Seite: rechts
Verband: $\quad \square$ Verband

Alter:

Geschlecht: $q \leq \AA$

Arthrose:

Ges./Kr.: Gesund

\section{Beschreibung:}

Diese Scapula weist eine Impression im rechten Drittel mittig auf. weiterhin hat sie dunkle Verfärbungen und mehrere $2 \mathrm{~mm}$ tiefe Löcher (intravital) und Wurzel / Wurm Impressionen. 


\section{Bezeichn: Scapula \\ Kiste: $\quad 5266280$ \\ Skelet: $\quad 4 ; 4$}

Population: Calden

Seite:

links
Verband: $\quad$ Verband

\section{Alter:}

Geschlecht:

Arthrose:
Ges./Kr.: Gesund

resund

\section{Beschreibung:}

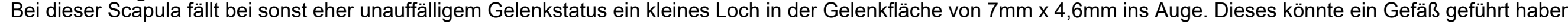

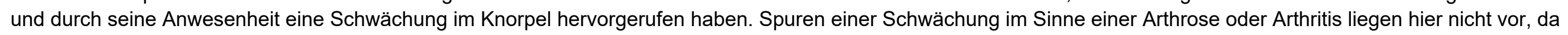
es wohl noch nicht zu einem stark verschleißenden Prozess gekommen war. 
Bezeichn.: Scapula

Kiste: $\quad 5259276$

Skelet: gesammelt

Population: Calden

Seite:

rechts

Verband: Verband

\section{Alter:}

Geschlecht:

Arthrose:

\section{Beschreibung:}

Ein kleines Fragment einer Scapula. 


\section{Bezeichn.: Scapula \\ Kiste: $\quad 5259276$ \\ Skelet: P.Sk.9.}

Population: Calden

Seite:
Verband: $\quad$ Verband

\section{Alter:}

Geschlecht: $q<\hat{0}$

Arthrose:
Ges./Kr.: Krank

Krankh.: Arthrose

Arthritis

\section{Beschreibung:}

Dieses Fragment einer linken Scapula fällt wegen einer starken Arthrose, welche hier mit einer Arthritis vergesellschaftet ist, ins Auge. Es finden sich sogar zwei kleine Löcher (bis zu $5 \mathrm{~mm} \times 3,7 \mathrm{~mm}$ ) in der Gelenkfläche, die im Zuge des verschleißenden Bewegungsprozesses entstanden sind. Das Fundstück wirkt insgesamt recht massiv und zeigt einige Muskelmarken. Diese Merkmale deuten eher auf ein männliches Individuum hin. 
Bezeichn.: Scapula

Kiste: 5259276

Skelet: Fragment

Population: Calden

Seite:

rechts
Verband: Verband

\section{Alter:}

Geschlecht:

Arthrose:

\section{Beschreibung:}

Ein kleines Fragment mit Margo lateralis und Teil von der Cavitas glenoidalis, die Scapula wirkt recht grazil. 
Bezeichn.: Scapula

Kiste: $\quad 8505721$

Skelet: Kiste ohne Bezeichnung

Population: Calden

Seite: rechts
Verband: $\quad \square$ Verband

Alter:

Geschlecht: $q \geq 0$

Arthrose:

Ges./Kr.: Gesund

re.

2

\section{Beschreibung:}

Hier sind insgesamt 8 Fragmente einer rechten Scapula erhalten, auch ein kleines Fragment von der Cavitas glenoidalis ist erhalten. 
Bezeichn.: Scapula

Kiste:

8505721

Skelet: aus großer Kiste

Population: Calden

Seite:
Verband: $\square$ Verband

Alter:

Geschlecht: $q<\hat{0}$

Arthrose:

\section{Ges./Kr.: Gesund}

\section{Beschreibung:}

Von dieser Scapula ist nur der Processus coracoideus und ein kleiner Teil des Ansatzes des Processus acromialis erhalten. Die Cavitas glenoidalis ist recht groß ausgeprägt, zeigt aber keine besonderen Verschleißerscheinungen. 


\section{Bezeichn: Scapula \\ Kiste: $\quad 5243267$ \\ Skelet: V 37}

Population: Calden

Seite:

links
Verband: $\quad$ Verband

\section{Alter: Jung}

Geschlecht:

Arthrose:

\section{Beschreibung:}

Dies ist eine Scapula der linken Seite, es ist nur ein Fragment der Cavitas glenoidalis erhalten, ihre Epiphyse war noch nicht verknöchert. 
Bezeichn.: Obere Extremität

Kiste: $\quad 5249270$

Skelet: Zettel

Population: Calden
Verband: Verband

\section{Alter:}

Geschlecht:

Arthrose:

\section{Beschreibung:}


Bezeichn.: Obere Extremität

Kiste: $\quad 5249270$

Skelet: Zettel

Population: Calden
Verband: Verband

\section{Alter:}

Geschlecht:

Arthrose:

\section{Beschreibung:}


Bezeichn.: Obere Extremität

Kiste: $\quad 5249270$

Skelet: Zettel

Population: Calden
Verband: Verband

\section{Alter:}

Geschlecht:

Arthrose:

\section{Beschreibung:}


Bezeichn.: Obere Extremität Kiste: 5242266

Knochenklein

Skelet: Knoche
Population: Calden

\section{Beschreibung:}

Verband: Verband

\section{Alter:}

Geschlecht:

Arthrose: 
Bezeichn.: Obere Extremität Kiste: 5242266

Knochenklein

Skelet: Knoche
Population: Calden

\section{Beschreibung:}

Verband: Verband

\section{Alter:}

Geschlecht:

Arthrose: 
Bezeichn.: Obere Extremität Kiste: 5242266

Knochenklein

Skelet: Knochentation: Calden

\section{Beschreibung:}

Verband: Verband

\section{Alter:}

Geschlecht:

Arthrose: 
Bezeichn.: Obere Extremität Kiste: 5242266

Knochenklein

Skelet: Knochentation: Calden

\section{Beschreibung:}

Verband: Verband

\section{Alter:}

Geschlecht:

Arthrose: 
Bezeichn.: Obere Extremität Kiste: 5242266

Knochenklein

Skelet: Knoche
Population: Calden

\section{Beschreibung:}

Verband: Verband

\section{Alter:}

Geschlecht:

Arthrose: 
Bezeichn.: Obere Extremität Kiste: 5242266

Knochenklein

Skelet: Knochentation: Calden

\section{Beschreibung:}

Verband: Verband

\section{Alter:}

Geschlecht:

Arthrose: 
Bezeichn.: Obere Extremität

Kiste: 5242266

Skelet: Splitter

Population: Calden
Verband: Verband

\section{Alter:}

Geschlecht:

Arthrose:

\section{Beschreibung:}


Bezeichn.: Obere Extremität Kiste: 5242266

Knochenklein

Skelet: Knoche
Population: Calden

\section{Beschreibung:}

Verband: Verband

\section{Alter:}

Geschlecht:

Arthrose: 
Bezeichn.: Obere Extremität Kiste: 5242266

Knochenklein

Skelet: Knochentation: Calden

\section{Beschreibung:}

Verband: Verband

\section{Alter:}

Geschlecht:

Arthrose: 
Bezeichn.: Obere Extremität Kiste: 5242266

Knochenklein

Skelet: Knoche
Population: Calden

\section{Beschreibung:}

Verband: Verband

\section{Alter:}

Geschlecht:

Arthrose: 
Bezeichn.: Obere Extremität Kiste: 5242266

Knochenklein

Skelet: Knochentation: Calden

\section{Beschreibung:}

Verband: Verband

\section{Alter:}

Geschlecht:

Arthrose: 
Bezeichn.: Obere Extremität Kiste: 5242266

Knochenklein

Skelet: Knoche
Population: Calden

\section{Beschreibung:}

Verband: Verband

\section{Alter:}

Geschlecht:

Arthrose: 
Bezeichn.: Obere Extremität Kiste: 5242266

Knochenklein

Skelet: Knoche
Population: Calden

\section{Beschreibung:}

Verband: Verband

\section{Alter:}

Geschlecht:

Arthrose: 
Bezeichn.: Obere Extremität Kiste: 5242266

Knochenklein

Skelet: Knochentation: Calden

\section{Beschreibung:}

Verband: Verband

\section{Alter:}

Geschlecht:

Arthrose: 
Bezeichn.: Obere Extremität Kiste: 5242266

Knochenklein

Skelet: Knoche
Population: Calden

\section{Beschreibung:}

Verband: Verband

\section{Alter:}

Geschlecht:

Arthrose: 


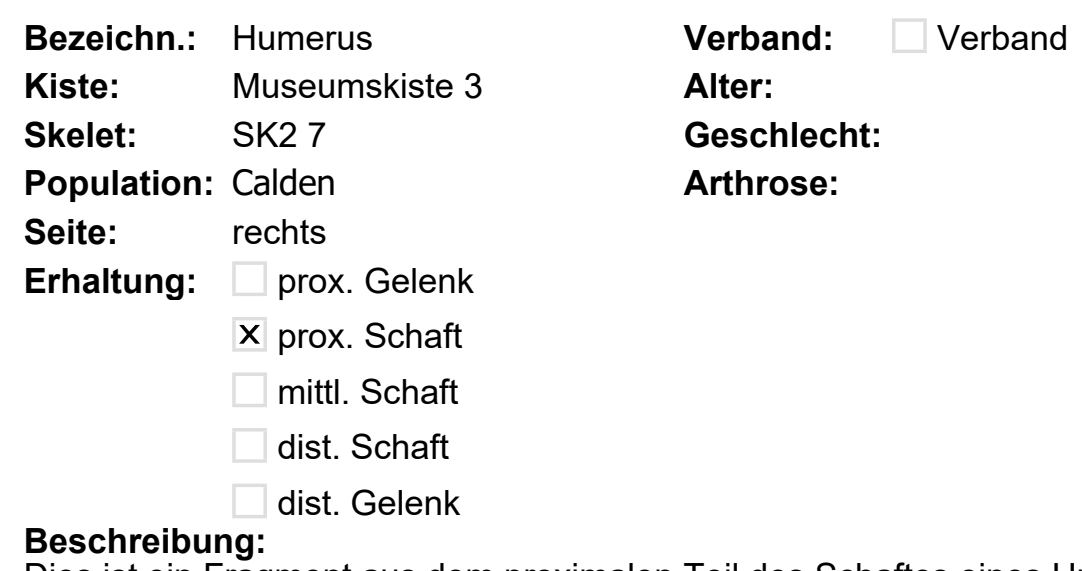

Dies ist ein Fragment aus dem proximalen Teil des Schaftes eines Humerus. es ist etwa 1/3 des Schaftes in erodiertem Zustand erhalten. 


$\begin{array}{ll}\text { Bezeichn.: } & \text { Humerus } \\ \text { Kiste: } & 8505718 \\ \text { Skelet: } & \text { aus Tüte } \\ \text { Population: } & \text { Calden } \\ \text { Seite: } & \text { links } \\ \text { Erhaltung: } & \square \text { prox. Gelenk } \\ & \square \text { prox. Schaft } \\ & \square \text { mittl. Schaft } \\ & \square \text { dist. Schaft } \\ & \mathbf{X} \text { dist. Gelenk }\end{array}$

Verband: $\quad \square$ Verband

Alter:

Geschlecht: $q \geq 0$

Ein Fragment eines grazilen Humerus, es handelt sich um das Fragment des distalen Gelenks. 
Bezeichn.: Humerus

Kiste: $\quad 8505718$

Skelet: aus Tüte

Population: Calden

Seite: n. def.

Erhaltung: $\mathbf{X}$ prox. Gelenk prox. Schaft mittl. Schaft dist. Schaft dist. Gelenk

\section{Beschreibung:}

Ein Fragment eines Caput humeri.
Verband: Verband

\section{Alter:}

Geschlecht:

Arthrose: 

Bezeichn.: Humerus
Kiste: $\quad 8505718$
Skelet: aus Tüte
Population: Calden
Seite: links
Erhaltung: $\mathbf{X}$ prox. Gelenk
prox. Schaft
mittl. Schaft
dist. Schaft
dist. Gelenk

Beschreibung:

Es ist hier ein Caput humeri erhalten.
Verband: $\quad$ Verband

Alter: Erwachsen

Geschlecht:

Arthrose:

prox.
Ges./Kr.: Gesund

\section{Maß}

Caput frontaler $\varnothing$

Caput, sagittaler $\varnothing$ 


\section{Bezeichn.: Humerus \\ Kiste: 5243267 \\ Skelet: 25}

Population: Calden

Seite: rechts

Erhaltung: $\mathbf{X}$ prox. Gelenk

$X$ prox. Schaft

$\mathbf{X}$ mittl. Schaft

$\mathbf{X}$ dist. Schaft

$X$ dist. Gelenk

Beschreibung:

Ein fast vollständiges Os humeri eines jungen Individuums.

Geschlecht:

Arthrose:
Ges./Kr.: Gesund

$$
\begin{array}{ll}
\text { Alter: } & \text { (5) 6-7 (8) }
\end{array}
$$

\begin{tabular}{l|l|l} 
Maß & Wert & Einheit \\
\hline Caput frontaler $\varnothing$ & 27,3 & $\mathrm{~mm}$ \\
Caput, sagittaler $\varnothing$ & 23,1 & $\mathrm{~mm}$ \\
Epicondylenbreite & 32 & $\mathrm{~mm}$ \\
gr. Länge & 165 & $\mathrm{~mm}$ \\
Umfang Schaftmitte & 43 & $\mathrm{~mm}$ \\
Umfang ü. Tub. deltoidea & 45 & $\mathrm{~mm}$
\end{tabular}




$\begin{array}{lll}\text { Bezeichn.: } & \text { Humerus } & \text { Verband: } \square \text { Verband } \\ \text { Kiste: } & 5256274 & \text { Alter: Jung } \\ \text { Skelet: } & \text { P.SK.8. } 3939 & \text { Geschlecht: } \\ \text { Population: } & \text { Calden } & \text { Arthrose: } \\ \text { Seite: } & \text { rechts } & \\ \text { Erhaltung: } & \square \text { prox. Gelenk } & \\ & \text { X prox. Schaft } & \\ & \text { X mittl. Schaft } & \\ & \square \text { dist. Schaft } & \\ & \square \text { dist. Gelenk }\end{array}$

\section{Ein Fragment des rechten Humerus eines jungen Individuums.}



Bezeichn.: Humerus
Kiste: $\quad 8505720$
Skelet: einzeln
Population: Calden
Seite: links
Erhaltung: $\square$ prox. Gelenk
prox. Schaft
mittl. Schaft
$\mathbf{X}$ dist. Schaft
$\mathbf{X}$ dist. Gelenk

\section{Beschreibung:}

Verband: $\square$ Verband
Alter: Jung
Geschlecht:
Arthrose:

Ges./Kr.: Gesund

Maß

Epicondylenbreite

Umfang Schaftmitte

Von diesem jungen Humerus ist nur ein distales Fragment erhalten, von dem das distale Gelenk fehlt. 

Bezeichn.: Humerus
Kiste: $\quad 8505720$
Skelet: $\quad 1.3$
Population: Calden
Seite: links
Erhaltung: X prox. Gelenk
prox. Schaft
mittl. Schaft
dist. Schaft
dist. Gelenk

Beschreibung:

Verband: $\square$ Verband

Alter: Erwachsen

Geschlecht:

Arthrose:

prox.

2

Hier ist nur ein Fragment eines Caput humeri erhalten. Wahrscheinlich handelt es sich um die linke Körperseite. 


\section{Bezeichn: Humerus \\ Kiste: $\quad 5249270$ \\ Skelet: Zettel}

Population: Calden

\section{Erhaltung:}

prox. Gelenk

prox. Schaft

$X$ mittl. Schaft

dist. Schaft

dist. Gelenk

Beschreibung:

Ein Fragment.
Verband: Verband

\section{Alter:}

Geschlecht:

Arthrose: 


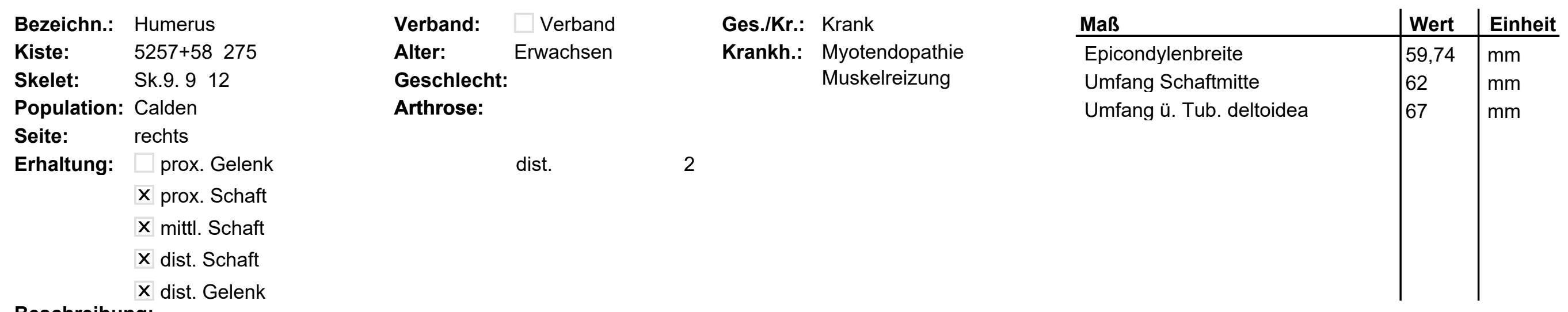

Beschreibung:

Bei diesem Humerus fällt eine Myotendopathie ins Auge. Auslöser dafür könnte der M. latissimus dorsi und der M. bicipes brachii Caput longum gewesen sein. 


\begin{tabular}{|c|c|}
\hline & \\
\hline ezeichn.: & Humerus \\
\hline Kiste: & $5257+58 \quad 275$ \\
\hline Skelet: & SK9 83 \\
\hline Population: & Calden \\
\hline Seite: & rechts \\
\hline Erhaltung: & $\square$ prox. Gelenk \\
\hline & X prox. Schaft \\
\hline & X mittl. Schaft \\
\hline & $\mathbf{X}$ dist. Schaft \\
\hline & $\mathbf{X}$ dist. Gelenk \\
\hline
\end{tabular}

Verband: $\square$ Verband

Alter: Erwachsen

\section{Geschlecht:}

Arthrose:

dist.
Ges./Kr.: Gesund

\section{Maß}

Epicondylenbreite

Umfang Schaftmitte

Umfang ü. Tub. deltoidea \begin{tabular}{|l|l} 
Wert & Einheit \\
\hline 56,07 & $\mathrm{~mm}$
\end{tabular}

$61 \quad \mathrm{~mm}$

70

Im Bereich der Ansatzstellen der m. deltoideus und pectoralis major sind starke und definierte Muskelmarken zu erkennen. 


\section{Bezeichn:: Humerus \\ Kiste: $\quad 5255273$ \\ Skelet: $\quad 1019$}

Population: Calden

Seite: links

Erhaltung: $\mathbf{X}$ prox. Gelenk

$X$ prox. Schaft

$X$ mittl. Schaft

$\mathbf{X}$ dist. Schaft

$\mathbf{X}$ dist. Gelenk

Beschreibung:

Ein fast vollständiges Os humeri.
Verband: $\square$ Verband

\section{Alter: Erwachsen}

Geschlecht:

Arthrose:

prox.

dist.

2

2
Ges./Kr.: Gesund

Maß

Caput frontaler $\varnothing$

Caput, sagittaler $\varnothing$

Epicondylenbreite

gr. Länge

Umfang Schaftmitte

Umfang ü. Tub. deltoidea

\begin{tabular}{|l|l} 
Wert & Einheit \\
40,82 & $\mathrm{~mm}$
\end{tabular}

47

60,51

311

$\mathrm{mm}$

$\mathrm{mm}$

70 


$\begin{array}{ll}\text { Bezeichn.: } & \text { Humerus } \\ \text { Kiste: } & 5255273 \\ \text { Skelet: } & 6 \text { ?ob7 } 33 \\ \text { Population: } & \text { Calden } \\ \text { Seite: } & \text { links } \\ \text { Erhaltung: } & \square \text { prox. Gelenk } \\ & \text { X prox. Schaft } \\ & \text { X mittl. Schaft } \\ & \text { X dist. Schaft } \\ & \text { X dist. Gelenk }\end{array}$

Verband: $\quad$ Verband

Alter: Erwachsen

\section{Geschlecht:}

Arthrose:

dist.

\begin{tabular}{l|l|l} 
Maß & Wert & Einheit \\
\hline Epicondylenbreite & 61 & $\mathrm{~mm}$ \\
gr. Länge & 290 & $\mathrm{~mm}$ \\
Umfang Schaftmitte & 70 & $\mathrm{~mm}$ \\
Umfang ü. Tub. deltoidea & 75 & $\mathrm{~mm}$ \\
& & \\
& &
\end{tabular}

An diese Humerus sind folgende Muskelmarken gut ausgeprägt: M. deltoideus, M. teres major und M. latissimus dorsi. 


\section{Bezeichn.: Humerus \\ Kiste: $\quad 5255273$ \\ Skelet: 5 Zettel}

Population: Calden

Seite: links

Erhaltung: $\square$ prox. Gelenk

$\mathbf{X}$ prox. Schaft

$X$ mittl. Schaft

dist. Schaft dist. Gelenk

\section{Beschreibung:}

Ein mittleres Fragment eines Os humeri, es ist sehr groß.

\section{Verband: $\quad$ Verband}

\section{Alter:}

Geschlecht: ${ }^{\lambda}$

Arthrose:

\section{Maß}

Umfang Schaftmitte

Umfang ü. Tub. deltoidea \begin{tabular}{|l|l} 
Wert & Einheit \\
75 &
\end{tabular}

\begin{tabular}{l|l}
75 & $\mathrm{~mm}$
\end{tabular}


Bezeichn.: Humerus

Kiste: $\quad 5255273$

Skelet: 12

Population: Calden

Seite: n. def.

Erhaltung: $\mathbf{X}$ prox. Gelenk prox. Schaft mittl. Schaft dist. Schaft dist. Gelenk

Beschreibung:

Caput humeri Fragment.
Verband: $\quad$ Verband

Alter: Erwachsen

Geschlecht:

Arthrose: 
Bezeichn.: Humerus

Kiste: $\quad 5257+58275$

Skelet:

Population: Calden

Erhaltung: $\square$ prox. Gelenk prox. Schaft X mittl. Schaft dist. Schaft dist. Gelenk

\section{Beschreibung:}

Ein kleines Fragment.
Verband: $\quad$ Verband

\section{Alter:}

Geschlecht:

Arthrose: 


\section{Bezeichn.: Humerus \\ Kiste: 5242266 \\ Skelet: E. B-S. 3}

Population: Calden

Verband:

Verband

\section{Alter:}

Ges./Kr.: Gesund

Geschlecht:

Arthrose:

\section{Erhaltung: $\square$ prox. Gelenk \\ prox. Schaft \\ mittl. Schaft \\ dist. Schaft $X$ dist. Gelenk}

Beschreibung:

Ein distales Fragment eines jungen Os humeri. 


\section{Bezeichn.: Humerus \\ Kiste: $\quad 5242266$ \\ Skelet: 3. Tüte}

Population: Calden

Seite: links

Erhaltung: $\square$ prox. Gelenk

$X$ prox. Schaft

$X$ mittl. Schaft

$\mathbf{X}$ dist. Schaft

X dist. Gelenk

\section{Beschreibung:}

Dieser Humerus ist sehr massiv und weist deutliche Muskelmarken auf.
Verband: $\square$ Verband

\section{Alter: Erwachsen}

\section{Geschlecht:}

\section{Arthrose:}

$$
\text { dist. }
$$

Ges./Kr.: Gesund

Maß

Epicondylenbreite

gr. Länge

Umfang Schaftmitte

Umfang ü. Tub. deltoidea

\begin{tabular}{|l|l} 
Wert & Einheit \\
\hline 62 & $\mathrm{~mm}$
\end{tabular}

$75 \quad \mathrm{~mm}$

$85 \mathrm{~mm}$




$\begin{array}{ll}\text { Bezeichn.: } & \text { Humerus } \\ \text { Kiste: } & 5242266 \\ \text { Skelet: } & \text { letzte Tüte } \\ \text { Population: } & \text { Calden } \\ \begin{array}{ll}\text { Seite: } & \text { links } \\ \text { Erhaltung: } & \text { X prox. Gelenk } \\ & \square \text { prox. Schaft } \\ & \square \text { mittl. Schaft } \\ & \square \text { dist. Schaft } \\ & \square \text { dist. Gelenk }\end{array}\end{array}$

Ges./Kr.: Gesund

Von diesem linken Humerus, der noch jung war, ist nur ein Fragment des Caput humeri erhalten. 

Bezeichn.: Humerus
Kiste: $\quad 5242266$
Skelet: letzte Tüte
Population: Calden
Seite: n. def.
Erhaltung: $\mathbf{X}$ prox. Gelenk
prox. Schaft
mittl. Schaft
dist. Schaft
dist. Gelenk
Beschreibung:

Hier ist nur das Fragment eines Caput humeri erhalten.
Verband: $\quad$ Verband

Alter: Erwachsen

Geschlecht:

Arthrose:

prox. 


\section{Bezeichn.: Humerus \\ Kiste: $\quad 8505718$ \\ Skelet: aus Kiste \\ Population: Calden \\ Seite: links \\ Erhaltung: $\square$ prox. Gelenk prox. Schaft mittl. Schaft dist. Schaft $X$ dist. Gelenk \\ Beschreibung:}

Ein junges Os humeri.
Verband: $\square$ Verband

Alter: $\quad 6-10(12)$

Geschlecht:

Arthrose: 

Bezeichn.: Humerus
Kiste: $\quad 8505718$
Skelet: aus Kiste
Population: Calden
Seite: rechts
Erhaltung: $\quad X$ prox. Gelenk
prox. Schaft
mittl. Schaft
dist. Schaft dist. Gelenk
Beschreibung:

Fragment eines jungen Humerus.
Verband: $\quad$ Verband $\quad$ Ges./Kr.: Gesund

Alter: Jung

Geschlecht:

Arthrose: 

Bezeichn.: Humerus
Kiste: $\quad 8505718$
Skelet: aus Kiste
Seite: rechts
Erhaltung: $\square$ prox. Gelenk
$X$ prox. Schaft
$X$ mittl. Schaft
dist. Schaft
dist. Gelenk
Beschreibung:

Verband:

Verband

Ges./Kr.: Gesund

Alter:

Maß

Geschlecht: $\delta$

Arthrose:

gr. Länge

Umfang Schaftmitte

Umfang ü. Tub. deltoidea

\begin{tabular}{|l|l} 
Wert & Einheit \\
\hline 157 & $\mathrm{~mm}$
\end{tabular}

Dies ist ein Schaftfragment eines äußerst massiven Humerus mit Canidenverbiss und sehr stark ausgeprägte Tuberositas deltoidea. 

Bezeichn.: Humerus
Kiste: $\quad 8505718$
Skelet: aus Kiste
Population: Calden
Seite: links
Erhaltung: $\square$ prox. Gelenk
prox. Schaft
$X$ mittl. Schaft
$\mathbf{X}$ dist. Schaft
$\mathbf{X}$ dist. Gelenk
Beschreibung:

\section{Verband: $\square$ Verband \\ Alter: Erwachsen \\ Geschlecht:}

Arthrose:

Ges./Kr.: Gesund

Maß

Umfang Schaftmitte

Umfang ü. Tub. deltoidea

Distales Fragment mit nur einem kleinen Rest des Gelenks und mittigem Teil des Schaftes in zwei Fragmenten. 


\begin{tabular}{|c|c|c|c|c|}
\hline $\begin{array}{l}\text { Bezeichn.: } \\
\text { Kiste. }\end{array}$ & $\begin{array}{l}\text { Humerus } \\
8505718\end{array}$ & $\begin{array}{l}\text { Verband: } \\
\text { Alter: }\end{array}$ & $\begin{array}{l}\square \text { Verband } \\
\text { Erwachsen }\end{array}$ & \\
\hline $\begin{array}{l}\text { Kiste: } \\
\text { Skelet: }\end{array}$ & $\begin{array}{l}8505718 \\
\text { aus Kiste }\end{array}$ & $\begin{array}{l}\text { Alter: } \\
\text { Geschlecht: }\end{array}$ & & \\
\hline Population: & Calden & Arthrose: & & \\
\hline Seite: & links & & & \\
\hline Erhaltung: & $\square$ prox. Gelenk & & dist. & 1 \\
\hline & $\square$ prox. Schaft & & & \\
\hline & $\square$ mittl. Schaft & & & \\
\hline & $\square$ dist. Schaft & & & \\
\hline 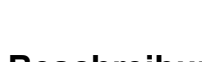 & X dist. Gelenk & & & \\
\hline
\end{tabular}

\begin{tabular}{l|l|l} 
Maß & Wert & Einheit \\
\hline Epicondylenbreite & 64 & $\mathrm{~mm}$ \\
& & \\
& &
\end{tabular}

Distales Gelenk, also nur die trochlea erhalten, Fläche fast vollständig vorhanden. 


\section{Bezeichn:: Humerus}

Kiste: $\quad 5252271$

Skelet: $\quad 102$ Sk6 (?) Bericht

Population: Calden

Seite: rechts

Erhaltung: $\mathbf{X}$ prox. Gelenk

$X$ prox. Schaft

$X$ mittl. Schaft

$\mathbf{X}$ dist. Schaft

$\mathbf{X}$ dist. Gelenk

Beschreibung:
Verband: $\square$ Verband

Alter: Erwachsen

Geschlecht:

Arthrose:

prox.

dist.
Ges./Kr.: Gesund

2 

Bezeichn.: Humerus

Kiste: $\quad 5252271$
Skelet: 11 bei Sk.6.
Population: Calden
Seite: rechts
Erhaltung: $\mathbf{X}$ prox. Gelenk
$X$ prox. Schaft
$X$ mittl. Schaft
$\mathbf{X}$ dist. Schaft
$X$ dist. Gelenk

Beschreibung:

Ein sehr gut erhaltenes Fundstück.
Verband: $\square$ Verband

Alter: (40) 45 - 60

Geschlecht: $q$

Arthrose:

prox.

dist.
Ges./Kr.: Krank

Krankh.: Arthrose
Maß

Caput frontaler $\varnothing$

Caput, sagittaler $\varnothing$

Epicondylenbreite

gr. Länge \begin{tabular}{l|l|l} 
Wert & Einheit \\
\hline 37,6 & $\mathrm{~mm}$
\end{tabular}

$53,63 \mathrm{~mm}$

$283 \mathrm{~mm}$ 

Bezeichn.: Humerus
Kiste: $\quad 5243267$
Skelet: 2. Tüte aus Calden
Population: Calden
Seite: links
Erhaltung: $\square$ prox. Gelenk
X prox. Schaft
mittl. Schaft
dist. Schaft
dist. Gelenk

Verband: $\quad \square$ Verband

\section{Alter:}

Geschlecht:

Beschreibung:

Ein proximales Fragment eines linken Os humeri. 


\section{Bezeichn.: Humerus \\ Kiste: $\quad 5243267$ \\ Skelet: 2. Tüte aus Calden \\ Population: Calden \\ Seite: rechts \\ Erhaltung: $\square$ prox. Gelenk \\ prox. Schaft \\ mittl. Schaft \\ dist. Schaft \\ $X$ dist. Gelenk \\ Beschreibung:}

Ein distales Fragment.
Verband: $\square$ Verband

Alter: Erwachsen

Geschlecht:

Arthrose:

dist. 


$\begin{array}{ll}\text { Bezeichn.: } & \text { Humerus } \\ \text { Kiste: } & 5243267 \\ \text { Skelet: } & \text { P.Sk.1.14 } \\ \text { Population: } & \text { Calden } \\ \text { Seite: } & \text { links } \\ \begin{array}{ll}\text { Erhaltung: } & \square \text { prox. Gelenk } \\ & \square \text { prox. Schaft } \\ & \text { X mittl. Schaft } \\ & \text { X dist. Schaft } \\ & \square \text { dist. Gelenk }\end{array} \\ \text { Beschreibung: }\end{array}$

Verband: $\quad \square$ Verband

Alter:

Geschlecht:

Arthrose:

Ein stark erodiertes Fragment. 

Bezeichn.: Humerus
Kiste: $\quad 5243267$
Skelet: P.Sk.1.15
Population: Calden
Seite: links
Erhaltung: $\square$ prox. Gelenk
prox. Schaft
$X$ mittl. Schaft
$\mathbf{X}$ dist. Schaft
dist. Gelenk

Verband: $\quad \square$ Verband

\section{Alter:}

\section{Beschreibung:}

Geschlecht:

Arthrose:

Ein Fragment aus dem distalen Teil eines linken Humerus. 


$\begin{array}{ll}\text { Bezeichn.: } & \text { Humerus } \\ \text { Kiste: } & 5243267 \\ \text { Skelet: } & \text { P.Sk.1. } \\ \text { Population: } & \text { Calden } \\ \text { Seite: } & \text { links } \\ \text { Erhaltung: } & \square \text { prox. Gelenk } \\ & \square \text { prox. Schaft } \\ & \square \text { mittl. Schaft } \\ & \text { X dist. Schaft } \\ & \mathbf{X} \text { dist. Gelenk }\end{array}$

Verband: $\quad \square$ Verband

Alter:

Geschlecht:

Beschreibung:
Dieses Fundstück liegt in schlechtem Erhaltungszustand vor. 


\section{Bezeichn:: Humerus \\ Kiste: $\quad 5243267$ \\ Skelet: $\quad 227$}

Population: Calden

Seite: rechts

Erhaltung: $\square$ prox. Gelenk

prox. Schaft

mittl. Schaft

$\mathbf{X}$ dist. Schaft

$\mathbf{X}$ dist. Gelenk

\section{Beschreibung:}

Ein Humerus, der eine sehr dicke Compacta aufweist. Das Fundstück ist nur als distales Fragment erhalten.
Verband: $\quad$ Verband

Alter: Erwachsen

\section{Geschlecht: $q \leq 0$}

Arthrose:
Ges./Kr.: Gesund

dist.

\begin{tabular}{l|l|l} 
Maß & Wert & Einheit \\
\hline Epicondylenbreite & 54,37 & $\mathrm{~mm}$ \\
Umfang Schaftmitte & 61 & $\mathrm{~mm}$ \\
& & \\
& &
\end{tabular}


$\begin{array}{ll}\text { Bezeichn.: } & \text { Humerus } \\ \text { Kiste: } & 5243267 \\ \text { Skelet: } & \text { P.Sk.1.219 }\end{array}$

Population: Calden

Erhaltung: $\square$ prox. Gelenk

prox. Schaft

$X$ mittl. Schaft

$\mathbf{X}$ dist. Schaft

$\mathbf{X}$ dist. Gelenk

Beschreibung:

Dieser Humerus ist nur proximal erhalten und weist deutliche Muskelmarken auf.

\section{Geschlecht:}

Arthrose:
Ges./Kr.: Krank

Krankh.: Arthrose

$58,58 \mathrm{~mm}$




\begin{tabular}{|c|c|c|c|c|c|c|c|}
\hline \multirow{3}{*}{$\begin{array}{l}\text { Bezeichn.: } \\
\text { Kiste: } \\
\text { Skelet: }\end{array}$} & Humerus & Verband: & $\square$ Verband & Ges./Kr.: Gesund & Maß & Wert & Einheit \\
\hline & 5243267 & Alter: & Erwachsen & & Epicondylenbreite & 62 & $\mathrm{~mm}$ \\
\hline & 165 Sk.1. & Geschlecht: & & & Umfang Schaftmitte & 70 & $\mathrm{~mm}$ \\
\hline Population: & Calden & Arthrose: & & & & & \\
\hline Seite: & rechts & & & & & & \\
\hline Erhaltung: & $\square$ prox. Gelenk & & dist. & 2 & & & \\
\hline & $\square$ prox. Schaft & & & & & & \\
\hline & $\mathbf{X}$ mittl. Schaft & & & & & & \\
\hline & $\mathbf{X}$ dist. Schaft & & & & & & \\
\hline & X dist. Gelenk & & & & & & \\
\hline
\end{tabular}

\section{Beschreibung:}

Dies ist ein Fragment eines Humerus, welcher nur distal erhalten ist. Es handelt sich um einen massiven Knochen, der gut erhalten ist. Das Fundstück weist eine dicke Kompakt auf. 


\section{Bezeichn.: Humerus \\ Kiste: $\quad 5243267$ \\ Skelet: V36 30}

Population: Calden

Seite: rechts

Erhaltung: $\mathbf{X}$ prox. Gelenk

$X$ prox. Schaft

$X$ mittl. Schaft

$\mathbf{X}$ dist. Schaft

X dist. Gelenk

\section{Beschreibung:}

Bei diesem Os femoris fällt eine sehr erhabene Tuberositas deltoidea ins Auge.
Verband: $\quad$ Verband

\section{Alter: Erwachsen}

Ges./Kr.: Gesund

Geschlecht:

prox.

dist.

2

$\sum$ dist.

2

$\sum$ dist.

\begin{tabular}{l|l|l} 
Maß & Wert & Einheit \\
\hline Caput frontaler $\varnothing$ & 43,6 & $\mathrm{~mm}$ \\
Caput, sagittaler $\varnothing$ & 45,5 & $\mathrm{~mm}$ \\
Epicondylenbreite & 60,6 & $\mathrm{~mm}$ \\
gr. Länge & 318 & $\mathrm{~mm}$ \\
Umfang Schaftmitte & 66 & $\mathrm{~mm}$ \\
Umfang ü. Tub. deltoidea & 79 & $\mathrm{~mm}$
\end{tabular}




\begin{tabular}{|c|c|c|c|c|c|c|c|c|}
\hline Bezeichn.: & Humerus & Verband: & $\square$ Verband & Ges./Kr.: & Krank & Maß & Wert & Einheit \\
\hline Kiste: & 5243267 & Alter: & Erwachsen & Krankh.: & Arthrose & Caput frontaler $\varnothing$ & 46,37 & $\mathrm{~mm}$ \\
\hline Skelet: & V36 P.Sk.1. & Geschlecht: & & & Arthritis & Caput, sagittaler $\varnothing$ & 41 & $\mathrm{~mm}$ \\
\hline Population: & Calden & Arthrose: & & & Muskelreizung & Epicondylenbreite & 57 & $\mathrm{~mm}$ \\
\hline Seite: & links & & prox. & 3 & Kapselzerrung & gr. Länge & 319 & $\mathrm{~mm}$ \\
\hline Erhaltung: & X prox. Gelenk & & dist. & 2 & & Umfang Schaftmitte & 73 & $\mathrm{~mm}$ \\
\hline & X prox. Schaft & & $\sum$ dist. & 2,5 & & Umfang ü. Tub. deltoidea & 77 & $\mathrm{~mm}$ \\
\hline & X mittl. Schaft & & & & & & & \\
\hline & $\mathbf{X}$ dist. Schaft & & & & & & & \\
\hline & X dist. Gelenk & & & & & & & \\
\hline
\end{tabular}

\section{Beschreibung:}

Bei diesem Humerus fallen insgesamt deutliche Muskelmarken auf. Eine Reizung des Periosts ist zu erkennen bei der Ansatzstelle des M. latissimus dorsi. Unterhalb des Caput humeri sind Spuren eines nekrotischen Prozesses zu finden im Sinne einer Kapselzerrung. 


\section{Bezeichn:: Humerus \\ Kiste: $\quad 5243267$ \\ Skelet: $\quad 2329$}

Population: Calden

Seite: links

Erhaltung: $\mathbf{X}$ prox. Gelenk

$X$ prox. Schaft

$\mathbf{X}$ mittl. Schaft

$\mathbf{X}$ dist. Schaft

$\mathbf{X}$ dist. Gelenk

Beschreibung:

Im der Fossa olecrani dieses Humerus finden sich Spuren eines leicht nekrotischen Prozesses.

\section{Verband: $\quad$ Verband \\ Ges./Kr.: Gesund}

\section{Alter: Erwachsen}

Geschlecht:

Arthrose:

prox. $\quad 2$

$$
\text { dist. }
$$

2

\begin{tabular}{l|l|l} 
Maß & Wert & Einheit \\
\hline Caput frontaler $\varnothing$ & 40,36 & $\mathrm{~mm}$ \\
Caput, sagittaler $\varnothing$ & 38,21 & $\mathrm{~mm}$ \\
Epicondylenbreite & 53,11 & $\mathrm{~mm}$ \\
gr. Länge & 277 & $\mathrm{~mm}$ \\
Umfang Schaftmitte & 64 & $\mathrm{~mm}$ \\
Umfang ü. Tub. deltoidea & 68 & $\mathrm{~mm}$
\end{tabular}


$\begin{array}{ll}\text { Bezeichn.: } & \text { Humerus } \\ \text { Kiste: } & 5243267 \\ \text { Skelet: } & \text { PSK1 36 }\end{array}$

Population: Calden

Seite: rechts

Erhaltung: $\square$ prox. Gelenk

$X$ prox. Schaft

$X$ mittl. Schaft

$\mathbf{X}$ dist. Schaft

$\mathbf{X}$ dist. Gelenk

Beschreibung:

Ein schlecht erhaltenes Fragment eines Os humeri.
Verband: $\square$ Verband

Alter: Erwachsen

\section{Geschlecht:}

Arthrose:

dist.
Maß

Epicondylenbreite

Umfang Schaftmitte

Umfang ü. Tub. deltoidea \begin{tabular}{|l|l} 
Wert & Einheit \\
\hline 58,51 & $\mathrm{~mm}$
\end{tabular}

$\mathrm{mm}$



Bezeichn.: Humerus
Kiste: $\quad 5243267$
Skelet: P.Sk.1.13
Population: Calden
Seite: links
Erhaltung: $\square$ prox. Gelenk
$\mathbf{X}$ prox. Schaft
$X$ mittl. Schaft
dist. Schaft
dist. Gelenk
Beschreibung:

Ein Fragment aus dem proximalen Schaft eines linken Humerus.
Verband: $\quad \square$ Verband

\section{Alter:}

Geschlecht:

Arthrose:

\section{Maß}

Umfang Schaftmitte

Umfang ü. Tub. deltoidea

\begin{tabular}{|l|l} 
Wert & Einheit \\
64 & $\mathrm{~mm}$
\end{tabular}

$\mathrm{mm}$ 


\begin{tabular}{lll|l|l} 
Bezeichn.: & Humerus & Verband: $\square$ Verband & Maß & Umfang Schaftmitte \\
Kiste: & 5243267 & Alter: & Geschlecht: & Umfang ü. Tub. deltoidea \\
Skelet: & P.Sk.1. 28 & Arthrose: & mm \\
Population: & Calden & & mm \\
Seite: & links & & 70 \\
Erhaltung: & $\square$ prox. Gelenk & & \\
& $\mathbf{X}$ prox. Schaft & & \\
& $\mathbf{X}$ mittl. Schaft & & \\
& $\mathbf{X}$ dist. Schaft & & \\
& $\square$ dist. Gelenk & &
\end{tabular}

\section{Beschreibung:}

Dieser Humerus befindet sich in sehr schlechtem Erhaltungszustand. Er ist nur als Fragment erhalten und weist eine gut ausgeprägte Tuberositas deltoidea auf. Auffällig ist weiterhin Tierverbiss am Schaft. 


\section{Bezeichn.: Humerus \\ Kiste: $\quad 5256274$ \\ Skelet: P.SK.8}

Population: Calden

Seite: rechts

Erhaltung: $\mathbf{X}$ prox. Gelenk prox. Schaft mittl. Schaft dist. Schaft dist. Gelenk

Beschreibung:

Ein Caput humeri.
Verband: Verband

\section{Alter:}

Geschlecht:

Arthrose: 


\section{Bezeichn:: Humerus \\ Kiste: $\quad 5256274$ \\ Skelet: $\quad 4025$}

Population: Calden

Seite: links

Erhaltung: $\square$ prox. Gelenk

prox. Schaft

$X$ mittl. Schaft

$\mathbf{X}$ dist. Schaft

X dist. Gelenk

\section{Beschreibung:}

Dieses Fundstück stammt aus dem distalen Teil eines Os humeri.
Ges./Kr.: Gesund

Alter: Erwachsen

Geschlecht: $q \leq \AA$

Arthrose:

\begin{tabular}{l|l|l} 
Maß & Wert & Einheit \\
\hline Epicondylenbreite & 59,93 & $\mathrm{~mm}$ \\
Umfang Schaftmitte & 69 & $\mathrm{~mm}$ \\
& & \\
& & \\
& &
\end{tabular}



Bezeichn.: Humerus
Kiste: $\quad 5256274$
Skelet: Sk8
Population: Calden
Seite: links
Erhaltung: $\square$ prox. Gelenk
$X$ prox. Schaft
$X$ mittl. Schaft
$\mathbf{X}$ dist. Schaft
dist. Gelenk

\section{Beschreibung:}

Ein Schaftfragment eines Humerus der linken Seite.
Ges./Kr.: Gesund

\section{Maß}

Umfang ü. Tub. deltoidea

Geschlecht:

Arthrose:

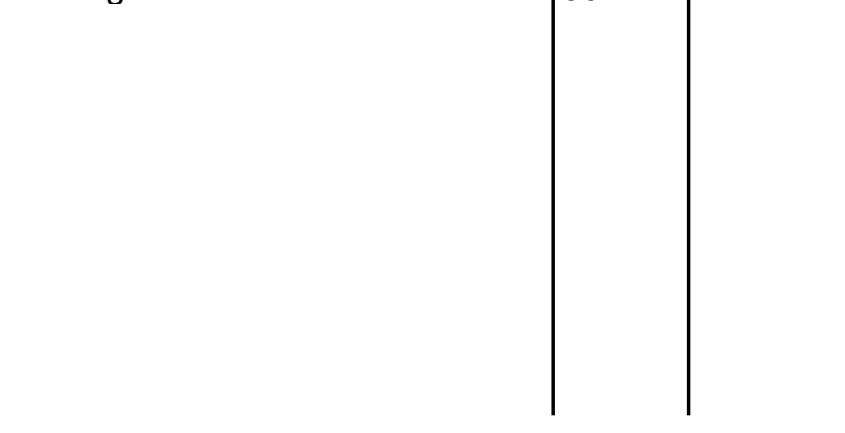



Bezeichn.: Humerus
Kiste: $\quad 5261277$
Population: Calden
Seite: links
Erhaltung: $\mathbf{X}$ prox. Gelenk
$X$ prox. Schaft
$X$ mittl. Schaft
$\mathbf{X}$ dist. Schaft
X dist. Gelenk

Skelet: $\quad$ Sk.1134 SCH. 8. 2734

\section{Beschreibung:}

\section{Verband: \\ Verband \\ Ges./Kr.: Gesund}

Alter:

(18) 25 - 30 (50)

Geschlecht: ${ }^{\lambda}$

Arthrose:

prox. $\quad 2$

dist.

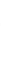

\section{Maß}

Caput frontaler $\varnothing$

Caput, sagittaler $\varnothing$

Epicondylenbreite

gr. Länge

Umfang Schaftmitte

Umfang ü. Tub. deltoidea

\begin{tabular}{|l|l} 
Wert & Einheit \\
44,73 & $\mathrm{~mm}$
\end{tabular}

49,16

$59,5 \quad \mathrm{~mm}$

$\mathrm{mm}$

$315 \mathrm{~mm}$

\begin{tabular}{l|l}
72 & $\mathrm{~mm}$ \\
77 & $\mathrm{~mm}$
\end{tabular}

Dieser Humerus weist deutliche Muskelmarken, besonders eine gut ausgeprägte Tuberositas deltoidea auf. 

Bezeichn.: Humerus
Kiste: $\quad 5261277$
Skelet: über Sk.11+SCH.820 32
Population: Calden
Seite: links
Erhaltung: X prox. Gelenk
$X$ prox. Schaft
$X$ mittl. Schaft
$\mathbf{X}$ dist. Schaft
$X$ dist. Gelenk

Beschreibung:

Ein fast vollstăndiges Os humeri.
Verband: $\square$ Verband

Alter: (25) $30-50$

Ges./Kr.: Gesund

Geschlecht: $9>0$

Arthrose:

prox.

dist.

\begin{tabular}{l|l|l} 
Maß & Wert & Einheit \\
\hline Caput frontaler $\varnothing$ & 38,82 & $\mathrm{~mm}$ \\
Caput, sagittaler $\varnothing$ & 41,66 & $\mathrm{~mm}$ \\
Epicondylenbreite & 58,5 & $\mathrm{~mm}$ \\
gr. Länge & 303 & $\mathrm{~mm}$ \\
Umfang Schaftmitte & 69 & $\mathrm{~mm}$ \\
Umfang ü. Tub. deltoidea & 70 & $\mathrm{~mm}$
\end{tabular}




\author{
Bezeichn.: Humerus \\ Kiste: $\quad 52651-3279$ \\ Skelet: Zettel \\ Population: Calden \\ Erhaltung: \\ prox. Gelenk \\ prox. Schaft \\ $X$ mittl. Schaft \\ dist. Schaft \\ dist. Gelenk \\ Beschreibung: \\ Ein Fragment.
}

Verband: $\quad \square$ Verband

\section{Alter:}

Geschlecht:

Arthrose: 


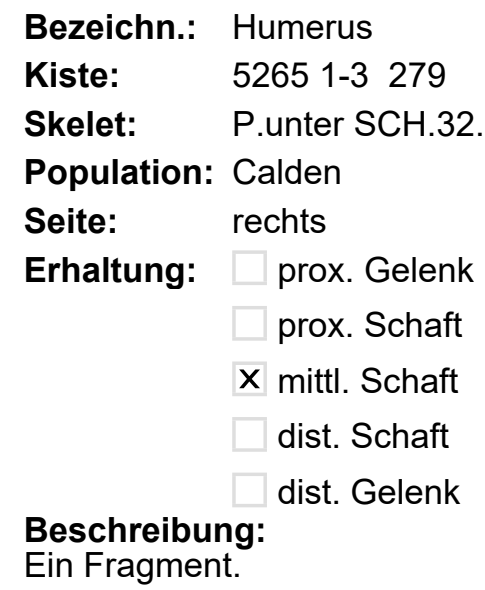

Verband: $\square$ Verband

\section{Alter: $\quad 6-25$}

Geschlecht:

Arthrose: 

Bezeichn.: Humerus
Kiste: $\quad 52651-3279$
Skelet: P.unter $\mathrm{SCH} .32$
Population: Calden
Seite: links
Erhaltung: $\square$ prox. Gelenk
X prox. Schaft
$X$ mittl. Schaft
$\mathbf{X}$ dist. Schaft
X dist. Gelenk

\section{Beschreibung:}

Dieses Fundstück ist erodiert und zu etwa 3/4 an Länge erhalten.
Verband: $\quad$ Verband

\section{Alter: Erwachsen}

\section{Geschlecht:}

Arthrose: 


\section{Bezeichn:: Humerus \\ Kiste: $\quad 5256274$ \\ Skelet: Zettel}

Population: Calden

Seite: rechts

Erhaltung: $\square$ prox. Gelenk

prox. Schaft

mittl. Schaft

dist. Schaft

X dist. Gelenk

Beschreibung:

Ein Condylus eines jungen Os humeri.
Verband: Verband

Alter: Jung

Geschlecht:

Arthrose: 

Bezeichn.: Humerus
Kiste: $\quad 5263278$
Skelet: $\quad$ P16+18 3636
Population: Calden
Seite: links
Erhaltung: $\mathbf{X}$ prox. Gelenk
$X$ prox. Schaft
$X$ mittl. Schaft
$\mathbf{X}$ dist. Schaft
$\mathbf{X}$ dist. Gelenk
Beschreibung:

Verband:

Verband

Alter:

$18-25$

Geschlecht:

Ein fast vollständiges Os humeri eines jungen Individuums.
Ges./Kr.: Gesund

Maß

Epicondylenbreite

gr. Länge

Umfang Schaftmitte

Umfang ü. Tub. deltoidea

\begin{tabular}{l|l} 
Wert & Einheit \\
\hline 49 & $\mathrm{~mm}$
\end{tabular}

$270 \mathrm{~mm}$

$57 \mathrm{~mm}$

$63 \mathrm{~mm}$




\section{Bezeichn.: Humerus \\ Kiste: $\quad 5263278$}

Skelet: $\quad \mathrm{P} 16+18 \quad 37 \quad 16$

Population: Calden

Seite: links

Erhaltung: $\mathbf{X}$ prox. Gelenk

$\mathbf{X}$ prox. Schaft

$X$ mittl. Schaft

$\mathbf{X}$ dist. Schaft

$\mathbf{X}$ dist. Gelenk

Beschreibung:

Ein vollständiges Os humeri mit nur kleiner Muskelmarke bei den Mm. brachialis und brachiomedialis. Der Knochen ist recht grazil.
Verband: $\square$ Verband

\section{Alter: Erwachsen}

Ges./Kr.: Gesund

\section{Geschlecht: +}

Arthrose:

$\begin{array}{ll}\text { prox. } & 2 \\ \text { dist. } & 1\end{array}$

\begin{tabular}{l|l|l} 
Maß & Wert & Einheit \\
\hline Caput frontaler $\varnothing$ & 34,7 & $\mathrm{~mm}$ \\
Caput, sagittaler $\varnothing$ & 38 & $\mathrm{~mm}$ \\
Epicondylenbreite & 56 & $\mathrm{~mm}$ \\
gr. Länge & 261 & $\mathrm{~mm}$ \\
Umfang Schaftmitte & 67 & $\mathrm{~mm}$ \\
Umfang ü. Tub. deltoidea & 68 & $\mathrm{~mm}$
\end{tabular}



Bezeichn:: Humerus
Kiste:
5263278
Skelet: bei SCH. 26+27 15-2041
Population: Calden
Seite: rechts
Erhaltung: $\mathbf{X}$ prox. Gelenk
$X$ prox. Schaft
mittl. Schaft
dist. Schaft
dist. Gelenk
Beschreibung:

Verband:

\section{Alter:}

Ges./Kr.: Gesund

Geschlecht:

Arthrose:

Ein proximales Fragment eines jungen Os humeri. 


\begin{tabular}{|c|c|c|c|c|c|c|c|}
\hline Bezeichn.: & Humerus & Verband: & $\square$ Verband & Ges./Kr.: Gesund & Maß & Wert & Einheit \\
\hline Kiste: & 5263278 & Alter: & & & Caput frontaler $\varnothing$ & 37 & $\mathrm{~mm}$ \\
\hline Skelet: & parallel 23+24 3118 & Geschlecht: & $\phi>\lambda \hat{~}$ & & Caput, sagittaler $\varnothing$ & 38,3 & $\mathrm{~mm}$ \\
\hline Population: & Calden & Arthrose: & & & Epicondylenbreite & 53,5 & $\mathrm{~mm}$ \\
\hline Seite: & links & & prox. & 2 & gr. Länge & 262 & $\mathrm{~mm}$ \\
\hline Erhaltung: & X prox. Gelenk & & dist. & 1 & Umfang Schaftmitte & 63 & $\mathrm{~mm}$ \\
\hline & X prox. Schaft & & & & Umfang ü. Tub. deltoidea & 64 & $\mathrm{~mm}$ \\
\hline & $\mathbf{X}$ mittl. Schaft & & & & & & \\
\hline & $\mathbf{X}$ dist. Schaft & & & & & & \\
\hline & X dist. Gelenk & & & & & & \\
\hline
\end{tabular}

\section{Beschreibung:}

Ein vollständiges Os humeri. Es weist eine gut ausgeprägte Tuberositas deltoidea auf, wobei es sich um einen recht grazilen Knochen handelt. Das Fundstück ist sehr gut erhalten. 


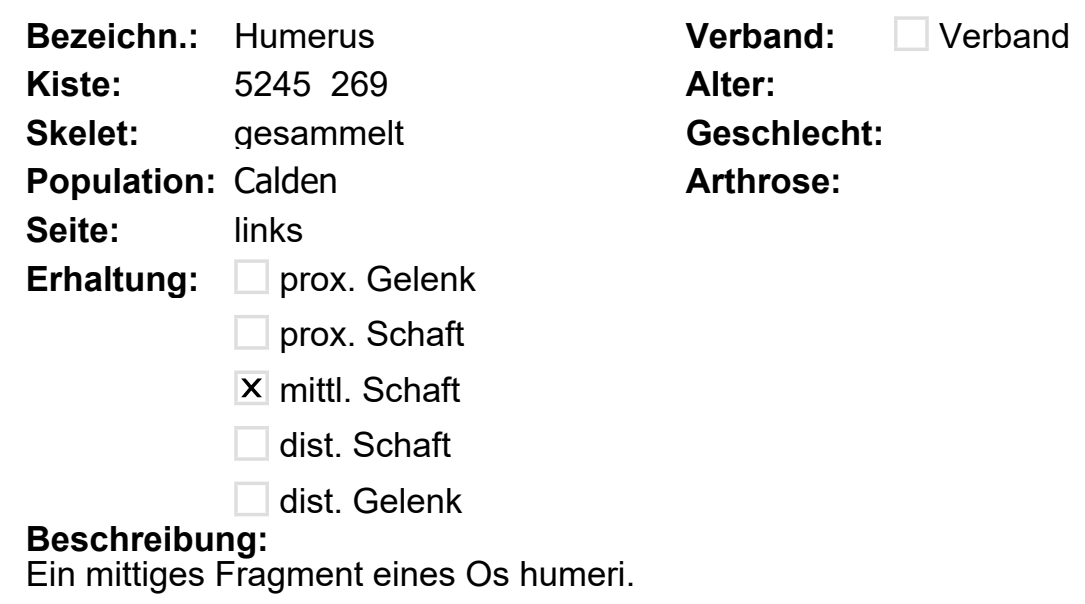




$\begin{array}{ll}\text { Bezeichn.: } & \text { Humerus } \\ \text { Kiste: } & 8505719 \\ \text { Skelet: } & \text { Steinkammer } 1 \\ \text { Population: } & \text { Calden } \\ \begin{array}{ll}\text { Seite: } & \text { links } \\ \text { Erhaltung: } & \square \text { prox. Gelenk } \\ & \text { X prox. Schaft } \\ & \square \text { mittl. Schaft } \\ & \square \text { dist. Schaft } \\ & \square \text { dist. Gelenk }\end{array}\end{array}$

Verband: $\quad$ Verband

Alter:

Ges./Kr.: Gesund

\section{Geschlecht: $q>{ }^{\lambda}$}

Arthrose:

Ein proximales Fragment aus dem Schaft mit schlecht erhaltener Oberfläche, es ist grazil. 


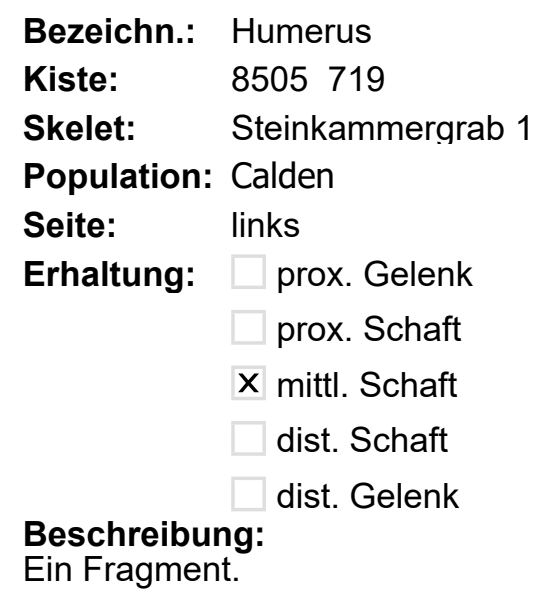

Skelet: Steinkammergrab 1

Population: Calden

Seite: links

Erhaltung: $\square$ prox. Gelenk

prox. Schaft

$X$ mittl. Schaft

dist. Schaft

dist. Gelenk

Beschreibung:

Ein Fragment.

Verband: $\quad$ Verband

\section{Alter:}

Ges./Kr.: Gesund

\section{Geschlecht:}

Arthrose:

\section{Maß}

Umfang Schaftmitte

\begin{tabular}{|l|l}
72 & $\mathrm{~mm}$ \\
&
\end{tabular}



Bezeichn.: Humerus
Kiste: $\quad 8505719$
Skelet: P2 3311
Population: Calden
Seite: rechts
Erhaltung: $\square$ prox. Gelenk
prox. Schaft
mittl. Schaft
$X$ dist. Schaft
X dist. Gelenk
Beschreibung:

$\begin{array}{ll}\text { Verband: } \square \text { Verband } & \text { Ges./Kr.: Krank } \\ \text { Alter: } & \text { Krankh.: Enthesiopathie }\end{array}$

\begin{tabular}{l|l|l} 
Maß & Wert & Einheit \\
\hline Epicondylenbreite & 61,09 & $\mathrm{~mm}$ \\
& & \\
& &
\end{tabular}

Geschlecht:

Arthrose:

Dieses Os humeri weist eine Enthesiopathie im distalen Schaft auf. 


\section{Bezeichn.: Humerus \\ Kiste: \\ 8505719 \\ Skelet: Zettel}

Population: Calden

Seite: rechts

Erhaltung: $\square$ prox. Gelenk

prox. Schaft

mittl. Schaft

$\mathbf{X}$ dist. Schaft

$\mathbf{X}$ dist. Gelenk

\section{Beschreibung:}

Bei diesem distale Fragment eines Oberarmknochens sind die Muskelmarken mittelmäßig ausgeprägt

\section{Verband: $\quad$ Verband}

\section{Alter:}

Geschlecht:

Arthrose:

\begin{tabular}{l|l|l} 
Maß & Wert & Einheit \\
\hline Epicondylenbreite & 64,67 & $\mathrm{~mm}$ \\
Umfang Schaftmitte & 71 & $\mathrm{~mm}$ \\
& & \\
& & \\
& &
\end{tabular}




$\begin{array}{ll}\text { Bezeichn.: } & \text { Humerus } \\ \text { Kiste: } & 8505719 \\ \text { Skelet: } & \text { Extremitätenfragemer } \\ \text { Population: } & \text { Calden } \\ \text { Seite: } & \text { rechts } \\ \text { Erhaltung: } & \square \text { prox. Gelenk } \\ & \text { X prox. Schaft } \\ & \mathbf{X} \text { mittl. Schaft } \\ & \square \text { dist. Schaft } \\ & \square \text { dist. Gelenk }\end{array}$

Verband: $\quad$ Verband

Alter:

Geschlecht:

Arthrose:

\section{Maß}

Umfang Schaftmitte

Umfang ü. Tub. deltoidea \begin{tabular}{|l|l} 
Wert & Einheit \\
\hline 63 & mm
\end{tabular}

$63 \quad \mathrm{~mm}$

$67 \quad \mathrm{~mm}$

Dieses mittlere Fragment ist stark erodiert. 


\section{Bezeichn.: Humerus \\ Kiste: $\quad 8505719$ \\ Skelet: Zettel}

Population: Calden

Seite: rechts

Erhaltung: $\square$ prox. Gelenk

prox. Schaft

$X$ mittl. Schaft

dist. Schaft

dist. Gelenk

\section{Beschreibung:}

Ein Fragment aus der Mitte des Schaftes.
Verband: $\quad$ Verband

\section{Alter:}

Geschlecht:

Arthrose:
Maß

Umfang Schaftmitte \begin{tabular}{|l|l} 
Wert & Einheit \\
\hline
\end{tabular}

\begin{tabular}{l|l}
69 & $\mathrm{~mm}$
\end{tabular}




\section{Bezeichn:: Humerus \\ Kiste: $\quad 8505719$ \\ Skelet: Zettel}

Population: Calden

Seite: links

Erhaltung: $\square$ prox. Gelenk prox. Schaft

mittl. Schaft

$X$ dist. Schaft

X dist. Gelenk

Beschreibung:

Ein distales Fragment.
Verband: $\square$ Verband

\section{Alter:}

Geschlecht:

Arthrose:
Ges./Kr.: Gesund

Maß

Epicondylenbreite

Wert $\quad$ Einheit

$62,25 \mathrm{~mm}$



Bezeichn.: Humerus
Kiste: $\quad 8505719$
Skelet: Zettel
Population: Calden
Seite: links
Erhaltung: $\square$ prox. Gelenk
prox. Schaft
mittl. Schaft
$\mathbf{X}$ dist. Schaft
$X$ dist. Gelenk
Beschreibung:

Ein distales Fragment.
Verband: $\quad$ Verband

\section{Alter:}

Geschlecht:

Arthrose:
Maß

Epicondylenbreite

Einheit

\begin{tabular}{ll|l}
62 & $\mathrm{~mm}$
\end{tabular}




\section{Bezeichn:: Humerus \\ Kiste: $\quad 8505719$ \\ Skelet: Zettel}

Population: Calden

Seite: links

Erhaltung: $\mathbf{X}$ prox. Gelenk

prox. Schaft

mittl. Schaft

dist. Schaft

dist. Gelenk

Beschreibung:

Hier ist ein Teil des Caput humeri erhalten.
Verband: $\quad$ Verband

Ges./Kr.: Gesund

\section{Alter:}

Geschlecht:

Arthrose:

prox. 

Bezeichn.: Humerus
Kiste:
8505719
Skelet: parallel Sch. $23+24$
Population: Calden
Seite: links
Erhaltung: $\mathbf{X}$ prox. Gelenk
$X$ prox. Schaft
mittl. Schaft
dist. Schaft
dist. Gelenk

Beschreibung:

Ein proximales Fragment eines Os humeri.
Verband: $\square$ Verband

Alter:

Ges./Kr.: Gesund

Geschlecht: $q$

Arthrose:

prox.

\begin{tabular}{l|l|l} 
Maß & Wert & Einheit \\
\hline Caput frontaler $\varnothing$ & 37,92 & $\mathrm{~mm}$ \\
Caput, sagittaler $\varnothing$ & 34,83 & $\mathrm{~mm}$ \\
Umfang ü. Tub. deltoidea & 70 & $\mathrm{~mm}$ \\
& & \\
& & \\
& &
\end{tabular}




\section{Bezeichn.: Humerus \\ Kiste: $\quad 8505719$ \\ Skelet: Zettel}

Population: Calden

Seite: links

Erhaltung: $\mathbf{X}$ prox. Gelenk

$X$ prox. Schaft

mittl. Schaft

dist. Schaft

dist. Gelenk

\section{Beschreibung:}

Ein Fragment eines sehr massiven Os humeri.
Verband: $\square$ Verband

\section{Alter:}

Ges./Kr.: Gesund

Geschlecht:

Arthrose:

prox.

\begin{tabular}{l|l|l} 
Maß & Wert & Einheit \\
\hline Caput frontaler $\varnothing$ & 48,52 & $\mathrm{~mm}$ \\
Caput, sagittaler $\varnothing$ & 46,14 & $\mathrm{~mm}$ \\
Umfang ü. Tub. deltoidea & 79 & $\mathrm{~mm}$ \\
& & \\
& &
\end{tabular}




$\begin{array}{lll}\text { Bezeichn.: } & \text { Humerus } & \text { Verband: } \square \text { Verband } \\ \text { Kiste: } & 8505719 & \text { Alter: } \\ \text { Skelet: } & \text { SCH. } 28+25 . & \text { Geschlecht: } \\ \text { Population: } & \text { Calden } & \text { Arthrose: } \\ \text { Seite: } & \text { rechts } & \\ \text { Erhaltung: } & \square \text { prox. Gelenk } & \\ & X \text { prox. Schaft } & \\ & \square \text { mittl. Schaft } & \\ & \square \text { dist. Schaft } & \\ & \square \text { dist. Gelenk }\end{array}$

\begin{tabular}{l|l|l} 
Maß & Wert & Einheit \\
\hline Umfang ü. Tub. deltoidea & 71 & $\mathrm{~mm}$ \\
& & \\
& &
\end{tabular}

Dieser Humerus weist deutliche Gefäßimpression $(55 \mathrm{~mm}$ x 2,6mm) in der Oberfläche auf. 


\section{Bezeichn.: Humerus \\ Kiste: $\quad 8505719$ \\ Skelet: Zettel}

Population: Calden

Seite: links

Erhaltung: $\square$ prox. Gelenk

X prox. Schaft

$X$ mittl. Schaft

dist. Schaft

dist. Gelenk

\section{Beschreibung:}

Ein Fragment aus dem proximalen Schaft eines Os humeri.
Ges./Kr.: Gesund

\section{Alter:}

\section{Geschlecht:}

Arthrose:

dist.

2

\begin{tabular}{l|l|l} 
Maß & Wert & Einheit \\
\hline Umfang Schaftmitte & 66 & $\mathrm{~mm}$ \\
Umfang ü. Tub. deltoidea & 75 & $\mathrm{~mm}$ \\
& & \\
& &
\end{tabular}




\begin{tabular}{|c|c|c|c|c|c|c|}
\hline Bezeichn.: & Humerus & Verband: $\quad \square$ Verband & Ges./Kr.: Gesund & Maß & Wert & Einheit \\
\hline Kiste: & 5254272 & Alter: & & Caput, sagittaler $\varnothing$ & 45 & $\mathrm{~mm}$ \\
\hline Skelet: & PSK 7 od. Sch. $23+2513$ & Geschlecht: $\widehat{\jmath}$ & & Umfang Schaftmitte & 81 & $\mathrm{~mm}$ \\
\hline Population: & Calden & Arthrose: & & Umfang ü. Tub. deltoidea & 87 & $\mathrm{~mm}$ \\
\hline Seite: & rechts & & & & & \\
\hline Erhaltung: & X prox. Gelenk & & & & & \\
\hline & X prox. Schaft & & & & & \\
\hline & X mittl. Schaft & & & & & \\
\hline & $\square$ dist. Schaft & & & & & \\
\hline & $\square$ dist. Gelenk & & & & & \\
\hline
\end{tabular}

\section{Beschreibung:}

Bei diesem Os femoris handelt es sich um ein männliches Individuum. Das Fundstück ist bedingt befundbar, da das Caput humeri erodiert ist und der distale Teil des Knochens fehlt. Die Tuberositas deltoidea ist sehr kräftig ausgebildet und auch die anderen Muskelansätze weisen auf eine starke körperliche Arbeit hin. 


$\begin{array}{ll}\text { Bezeichn.: } & \text { Humerus } \\ \text { Kiste: } & 5266280 \\ \text { Skelet: } & 14 \\ \text { Population: } & \text { Calden } \\ \text { Seite: } \quad & \text { rechts } \\ \text { Erhaltung: } & \square \text { prox. Gelenk } \\ & \square \text { prox. Schaft } \\ & \square \text { mittl. Schaft } \\ & \mathbf{X} \text { dist. Schaft } \\ & \mathbf{X} \text { dist. Gelenk }\end{array}$

Verband: $\quad \square$ Verband Ges./Kr.: Gesund

Alter: Jung

Geschlecht:

Arthrose:

\begin{tabular}{l|l|l} 
Maß & Wert & Einheit \\
\hline Epicondylenbreite & 40,11 & $\mathrm{~mm}$ \\
gr. Länge & 119,11 & $\mathrm{~mm}$ \\
& & \\
& & \\
& &
\end{tabular}

Dieses Os humeri eines jungen Individuums weist dunkle Flecken und eine erodierte Oberfläche auf. Die Epikondylen sind erodiert. 


\begin{tabular}{|c|c|c|c|c|c|c|}
\hline \multirow{2}{*}{$\begin{array}{l}\text { Bezeichn.: } \\
\text { Kiste: }\end{array}$} & Humerus & \multirow{2}{*}{$\begin{array}{l}\text { Verband: } \square \text { Verband } \\
\text { Alter: }\end{array}$} & Ges./Kr.: Gesund & Maß & Wert & Einheit \\
\hline & 5266280 & & & gr. Länge & 170 & $\mathrm{~mm}$ \\
\hline Skelet: & 35 & Geschlecht: & & Umfang Schaftmitte & 75 & $\mathrm{~mm}$ \\
\hline Population: & Calden & Arthrose: & & & & \\
\hline Seite: & links & & & & & \\
\hline Erhaltung: & $\square$ prox. Gelenk & & & & & \\
\hline & $\square$ prox. Schaft & & & & & \\
\hline & $\square$ mittl. Schaft & & & & & \\
\hline & $\mathbf{X}$ dist. Schaft & & & & & \\
\hline & $\square$ dist. Gelenk & & & & & \\
\hline
\end{tabular}

\section{Beschreibung:}

Bei diesem Os humeri fallen dunkle Verfärbungen bei sonst glatter Oberfläche auf. Der Margo medialis ist gut ausgeprägt. Insgesamt liegen wenige und nur leichte Erosionsspuren vor. 


\begin{tabular}{|c|c|c|c|c|c|c|}
\hline Bezeichn.: & Humerus & $\square$ Verband & Ges./Kr.: Gesund & Maß & Wert & Einheit \\
\hline Kiste: & 5266280 & Alter: & & Epicondylenbreite & 62,81 & $\mathrm{~mm}$ \\
\hline Skelet: & 8 & Geschlecht: & & gr. Länge & 109 & $\mathrm{~mm}$ \\
\hline Population: & Calden & Arthrose: & & Umfang Schaftmitte & 75 & $\mathrm{~mm}$ \\
\hline Seite: & rechts & & & & & \\
\hline Erhaltung: & $\square$ prox. Gelenk & dist. & 2 & & & \\
\hline & $\square$ prox. Schaft & & & & & \\
\hline & $\square$ mittl. Schaft & & & & & \\
\hline & $\mathbf{X}$ dist. Schaft & & & & & \\
\hline & X dist. Gelenk & & & & & \\
\hline
\end{tabular}

\section{Beschreibung:}

Bei diesem Humerus ist der Margo lateralis gut ausgeprägt. Es finden sich kleine Auflagerungen am lateralen Rand der Fossa olecrani. Außerdem liegen kleine Erosionsdefekte vor, ansonsten ist aber die Oberfläche gut beurteilbar. 


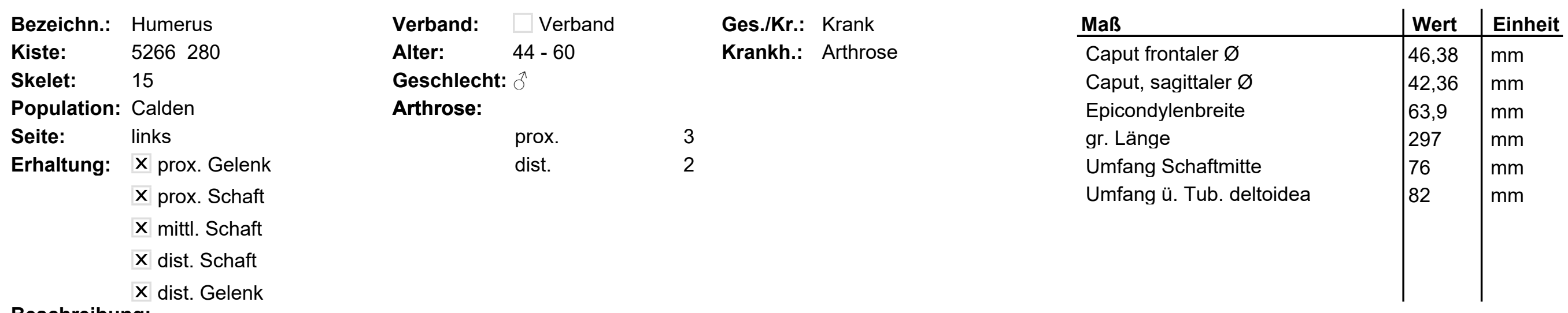

\section{Beschreibung:}

Dies ist ein sehr robuster Humerus mit deutlichen Muskelmarken an den Ansatzstellen der m. deltoideus, latissimus dorsi, teres major, pectoralis major und triceps brachii. Weiterhin fanden sich auf der Oberfläche einige Artefakte im Sinne von Wurzelimpressionen. 


\section{Bezeichn.: Humerus \\ Kiste: $\quad 5266280$ \\ Skelet: 32}

Population: Calden

Seite: links

Erhaltung: $\square$ prox. Gelenk prox. Schaft

mittl. Schaft

$X$ dist. Schaft

X dist. Gelenk

Beschreibung:

Ein distales Fragment.
Verband: $\quad$ Verband

\section{Alter:}

\section{Geschlecht:}

Arthrose:

dist.

\begin{tabular}{l|l|l} 
Maß & Wert & Einheit \\
\hline Epicondylenbreite & 60,51 & $\mathrm{~mm}$ \\
gr. Länge & 111 & $\mathrm{~mm}$ \\
Umfang Schaftmitte & 75 & $\mathrm{~mm}$ \\
& & \\
& &
\end{tabular}




\section{Bezeichn.: Humerus \\ Kiste: $\quad 5266280$ \\ Skelet: 6}

Population: Calden

Seite: rechts

Erhaltung: $\square$ prox. Gelenk

prox. Schaft

mittl. Schaft

$\mathbf{X}$ dist. Schaft

$X$ dist. Gelenk

Beschreibung:

Ein erodiertes Fragment eines Os humeri.
Verband: $\square$ Verband

\section{Alter:}

Geschlecht:

Arthrose:

Maß

Epicondylenbreite

gr. Länge

Umfang Schaftmitte
Wert $\quad$ Einheit

$60,91 \mathrm{~mm}$

$155 \mathrm{~mm}$

70 


\section{Bezeichn: Humerus \\ Kiste: $\quad 5266280$ \\ Skelet: 24}

Population: Calden

Seite: links

Erhaltung: $\square$ prox. Gelenk

prox. Schaft

mittl. Schaft

$\mathbf{X}$ dist. Schaft

$\mathbf{X}$ dist. Gelenk

Beschreibung:

Ein recht graziles Os humeri.
Verband: $\quad$ Verband

\section{Alter:}

Geschlecht:

Arthrose:

dist.

\begin{tabular}{l|l|l} 
Maß & Wert & Einheit \\
\hline Epicondylenbreite & 53,08 & $\mathrm{~mm}$ \\
gr. Länge & 105,89 & $\mathrm{~mm}$ \\
Umfang Schaftmitte & 62 & $\mathrm{~mm}$ \\
& & \\
& &
\end{tabular}




\section{Bezeichn.: Humerus \\ Kiste: $\quad 5266280$ \\ Skelet: $\quad 34$}

Population: Calden

Seite: links

Erhaltung: $\square$ prox. Gelenk

X prox. Schaft

$X$ mittl. Schaft

X dist. Schaft

dist. Gelenk

\section{Ges./Kr.: Gesund}

\section{Alter:}

\section{Geschlecht:}

Arthrose:

\begin{tabular}{l|l|l} 
Maß & Wert & Einheit \\
\hline gr. Länge & 190 & $\mathrm{~mm}$ \\
Umfang Schaftmitte & 67 & $\mathrm{~mm}$ \\
Umfang ü. Tub. deltoidea & 68 & $\mathrm{~mm}$ \\
& & \\
& &
\end{tabular}

\section{Beschreibung:}

Hier liegt ein Fragment eines Humerus vor. Es finden sich leichte dunkle Verfärbungen und erosionsbedingte leichte Risse fallen ins Auge. 


\section{Bezeichn.: Humerus \\ Kiste: $\quad 5266280$ \\ Skelet: 21}

Population: Calden

Seite: links

Erhaltung: $\mathbf{X}$ prox. Gelenk

$X$ prox. Schaft

$X$ mittl. Schaft

$X$ dist. Schaft

$X$ dist. Gelenk

\section{Verband: \\ Verband \\ Ges./Kr.: Gesund}

\section{Alter:}

$44-60$

Geschlecht:

Arthrose:

\section{prox.}

dist.

\begin{tabular}{l|l|l} 
Maß & Wert & Einheit \\
\hline Caput frontaler $\varnothing$ & 42,5 & $\mathrm{~mm}$ \\
Caput, sagittaler $\varnothing$ & 44,39 & $\mathrm{~mm}$ \\
Epicondylenbreite & 58,67 & $\mathrm{~mm}$ \\
gr. Länge & 330 & $\mathrm{~mm}$ \\
Umfang Schaftmitte & 68 & $\mathrm{~mm}$ \\
Umfang ü. Tub. deltoidea & 72 & $\mathrm{~mm}$
\end{tabular}

\section{Beschreibung:}

Dieser Humerus hat starke Muskelmarken bei den Ansatzstellen der m. latissimus dorsi, bzw. biceps brachii und recht stark des deltoideus. Die Oberfläche ist recht gut erhalten, in der Mitte bis distal sind leicht dunkle Verfärbungen zu finden. 
$\begin{array}{ll}\text { Bezeichn.: } & \text { Humerus } \\ \text { Kiste: } & 5259276 \\ \text { Skelet: } & \text { V5 } 1730\end{array}$

Population: Calden

Seite: links

Erhaltung: $\square$ prox. Gelenk prox. Schaft

mittl. Schaft

$X$ dist. Schaft

X dist. Gelenk

Beschreibung:

Ein distales Fragment.
Verband: $\quad$ Verband

\section{Alter:}

Geschlecht:

Arthrose:

dist.

2

\begin{tabular}{l|l|l} 
Maß & Wert & Einheit \\
\hline Epicondylenbreite & 56 & $\mathrm{~mm}$ \\
gr. Länge & 116,25 & $\mathrm{~mm}$ \\
& & \\
& & \\
& &
\end{tabular}




\section{Bezeichn:: Humerus \\ Kiste: $\quad 5259276$ \\ Skelet: $\quad 1929$}

Population: Calden

Seite: links

Erhaltung: $\square$ prox. Gelenk prox. Schaft

$X$ mittl. Schaft

$\mathbf{X}$ dist. Schaft X dist. Gelenk
Verband: $\quad$ Verband

\section{Alter:}

Geschlecht:

Arthrose:
Ges./Kr.: Gesund

Maß

Epicondylenbreite

gr. Länge

Umfang Schaftmitte \begin{tabular}{|l|l} 
Wert & Einheit
\end{tabular}

$56,29 \mathrm{~mm}$

$186 \mathrm{~mm}$

62

\section{Beschreibung:}

dist.

2

Distales Fragment eines linken Humerus. Es ist etwa die Hälfte erhalten und durch eine gut erhaltene Oberfläche befundbar. 


$\begin{array}{ll}\text { Bezeichn.: } & \text { Humerus } \\ \text { Kiste: } & 5259276 \\ \text { Skelet: } & \text { V5 } 1838 \\ \text { Population: } & \text { Calden } \\ \text { Seite: } & \text { links } \\ \text { Erhaltung: } & \text { X prox. Gelenk } \\ & \text { X prox. Schaft } \\ & \text { X mittl. Schaft } \\ & \text { X dist. Schaft } \\ & \text { X dist. Gelenk }\end{array}$

\section{Verband: $\quad \square$ Verband \\ Alter: $\quad 15-20$ \\ Geschlecht:}

Arthrose:

prox.

1
Ges./Kr.: Gesund

\section{Maß}

Caput frontaler $\varnothing$

Caput, sagittaler $\varnothing$

Umfang Schaftmitte

Umfang ü. Tub. deltoidea

\begin{tabular}{|l|l} 
Wert & Einheit \\
45,66 & $\mathrm{~mm}$ \\
40 & $\mathrm{~mm}$ \\
63 & $\mathrm{~mm}$ \\
68 & $\mathrm{~mm}$
\end{tabular}

Bei diesem linken Humerus könnte es sich noch um ein jüngeres Individuum handeln. Die Spongiosastruktur am Caput humeri ist sehr stark durch Bodenerosion und die Ausgrabung zerstört worden, ein Hinweis ist aber, dass eine Furche im Bereich des Ansatzes des M. deltoideus zu sehen ist (38mm x 5,5mm x $2 \mathrm{~mm})$. Alternativ kann es sich hierbei auch um eine Myotendopathie im Sinne einer Überlastung des M. deltoideus handeln. Weiterhin ist der M. coracobrachialis mit seiner Ansatzfläche gut ausgeprägt gewesen. 


$\begin{array}{lll}\text { Bezeichn.: } & \text { Humerus } & \text { Verband: } \square \text { Verband } \\ \text { Kiste: } & 8505721 & \text { Alter: Jung } \\ \text { Skelet: } & \text { aus großer Kiste } & \text { Geschlecht: } \\ \text { Population: } & \text { Calden } & \text { Arthrose: } \\ \text { Seite: } & \text { rechts } & \\ \text { Erhaltung: } & \square \text { prox. Gelenk } & \\ & \square \text { prox. Schaft } & \\ & \mathbf{X} \text { mittl. Schaft } & \\ & \mathbf{X} \text { dist. Schaft } & \\ & \square \text { dist. Gelenk }\end{array}$

Ein distaler Teil eines Schaftes eines Humerus von einem jungen Individuum. 

Bezeichn.: Humerus
Kiste: $\quad 8505721$
Skelet: aus großer Kiste
Population: Calden
Seite: rechts
Erhaltung: $\square$ prox. Gelenk
prox. Schaft
$X$ mittl. Schaft
$\mathbf{X}$ dist. Schaft
$\mathbf{X}$ dist. Gelenk
Beschreibung:

Distal mit Gelenk erhalten, 2/3 sind vorhanden.
Verband: $\square$ Verband

Alter:

Ges./Kr.: Gesund

Geschlecht: +

Arthrose:

dist.

2

\begin{tabular}{l|l|l} 
Maß & Wert & Einheit \\
\hline Epicondylenbreite & 61,45 & $\mathrm{~mm}$ \\
Umfang Schaftmitte & 68 & $\mathrm{~mm}$ \\
& & \\
& &
\end{tabular}




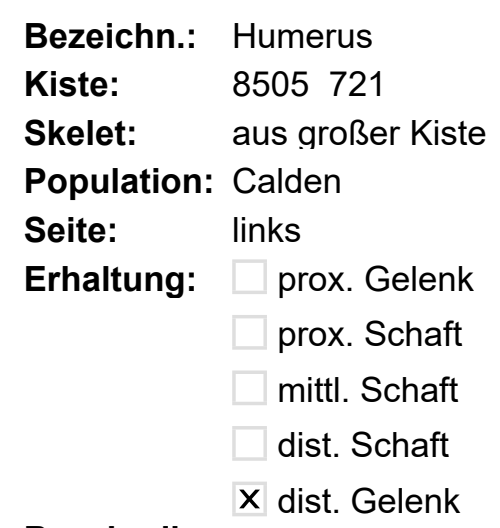

Verband: $\quad$ Verband Ges./Kr.: Gesund

\section{Alter:}

\section{Maß}

Epicondylenbreite

Geschlecht: $\delta$

Arthrose:

\begin{tabular}{|l|l} 
Wert & Einheit \\
\hline
\end{tabular}

\begin{tabular}{l|l}
65 & $\mathrm{~mm}$
\end{tabular}

\section{Beschreibung:}

Dieser Humerus weist einen auffällig groß ausgeprägten Epikondylus medialis auf. Insgesamt wirkt der Knochen sehr massiv. 


\begin{tabular}{|c|c|c|c|c|c|c|c|}
\hline \multirow{3}{*}{$\begin{array}{l}\text { Bezeichn.: } \\
\text { Kiste: } \\
\text { Skelet: }\end{array}$} & Humerus & Verband: & $\square$ Verband & Ges./Kr.: Gesund & $\mathrm{Maß}$ & Wert & Einheit \\
\hline & 8505721 & Alter: & (16) $17-20(22)$ & & Epicondylenbreite & 49,5 & $\mathrm{~mm}$ \\
\hline & aus großer Kiste & Geschlecht: & ㅇ $>\hat{0}$ & & Umfang Schaftmitte & 48 & $\mathrm{~mm}$ \\
\hline Population: & Calden & Arthrose: & & & & & \\
\hline Seite: & links & & & & & & \\
\hline Erhaltung: & $\square$ prox. Gelenk & & dist. & 00 & & & \\
\hline & $\square$ prox. Schaft & & & & & & \\
\hline & $\square$ mittl. Schaft & & & & & & \\
\hline & $\mathbf{X}$ dist. Schaft & & & & & & \\
\hline & X dist. Gelenk & & & & & & \\
\hline
\end{tabular}

\section{Beschreibung:}

Dieses distale Fragment eines linken Humerus weist zwar eine geschlossene Epiphysenfuge auf, wirkt aber dennoch recht jung, als sei die Epiphysenfuge soeben geschlossen. 

Bezeichn.: Ulna
Kiste: Museumskiste 3
$\begin{array}{ll}\text { Skelet: P2 } & \text { Population: } \\ \text { Calden }\end{array}$
Seite: links
Erhaltung: $\square$ prox. Gelenk
$X$ prox. Schaft
$X$ mittl. Schaft
$\mathbf{X}$ dist. Schaft
$\square$ dist. Gelenk

Verband: $\square$ Verband

Ges./Kr.: Gesund

Alter:

Geschlecht: $q \leq \hat{0}$

Beschreibung:

Diese Ulna ist nur als Fragment aus dem Schaft erhalten. Das Fragment macht etwa 3/4 des Schaftes aus. 


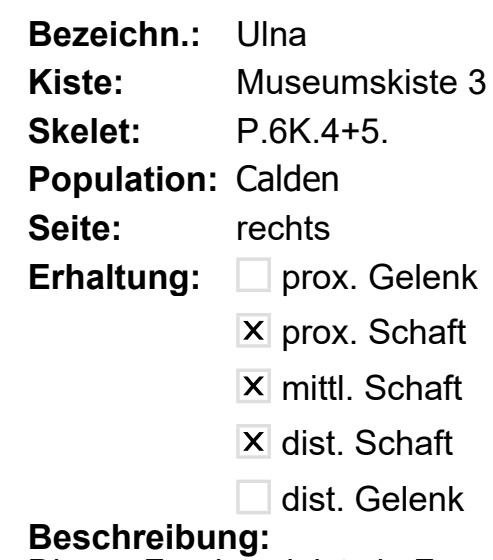

Dieses Fundstück ist ein Fragment aus dem Schaft einer Ulna. Es macht etwa 2/3 des gesamten Knochens aus. Die Oberfläche ist stark erodiert und nur bedingt befundbar. 

Bezeichn.: Ulna
Kiste: $\quad 8505718$
Skelet: aus Tüte
Population: Calden
Seite: rechts
Erhaltung: $\square$ prox. Gelenk
prox. Schaft
$X$ mittl. Schaft
dist. Schaft dist. Gelenk
Beschreibung:

Fragment aus dem Schaft einer Ulna.
Verband: $\quad \square$ Verband

\section{Alter:}

Geschlecht:

Arthrose: 


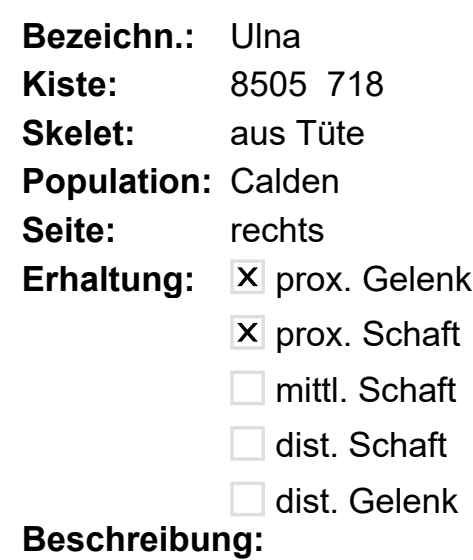

Verband: $\square$ Verband Ges./Kr.: Gesund

Alter: Jung

Geschlecht:

Arthrose:

Dieses Fragment stammt aus dem proximalen Segment einer Ulna, welche noch nicht ausgewachsen war. Die Epiphyse ist nicht erhalten. 

Bezeichn.: Ulna
Kiste: $\quad 8505718$
Skelet: aus Tüte
Population: Calden
Seite: rechts
Erhaltung: $\mathbf{X}$ prox. Gelenk
$X$ prox. Schaft
mittl. Schaft
dist. Schaft
dist. Gelenk
Beschreibung:

Ein proximales Fragment.
Verband: $\square$ Verband

\section{Alter:}

\section{Geschlecht:}

Arthrose:

prox. 


$$
\begin{array}{ll}
\text { Bezeichn.: } & \text { Ulna } \\
\text { Kiste: } & 8505720 \\
\text { Skelet: } & 1.0 \\
\text { Population: } & \text { Calden } \\
\text { Seite: } & \text { links } \\
\text { Erhaltung: } & \square \text { prox. Gelenk } \\
& \square \text { prox. Schaft } \\
& \square \text { mittl. Schaft } \\
& \mathbf{X} \text { dist. Schaft } \\
& \mathbf{X} \text { dist. Gelenk }
\end{array}
$$

Verband:

Verband

Ges./Kr.: Gesund

Maß

Breite Epiphyse distal

Wert $\quad$ Einheit

Geschlecht:

Beschreibung:

Ein Fragment aus dem distalen Teil des Schaftes einer linken Ulna. Der Knochen ist einem jungen Individuum zuzuordnen. 


$\begin{array}{ll}\text { Bezeichn.: } & \text { Ulna } \\ \text { Kiste: } & 8505720 \\ \text { Skelet: } & 1.2 \\ \text { Population: } & \text { Calden } \\ \text { Erhaltung: } & \square \text { prox. Gelenk } \\ & \square \text { prox. Schaft } \\ & \square \text { mittl. Schaft } \\ & \mathbf{X} \text { dist. Schaft } \\ & \mathbf{X} \text { dist. Gelenk } \\ & \\ \text { Beschreibung: } \\ \text { Ein distales Fragment. }\end{array}$

Ein distales Fragment.
Verband: $\quad \square$ Verband

Ges./Kr.: Gesund

\section{Alter:}

Geschlecht:

Arthrose:

dist. 

Bezeichn.: Ulna
Kiste: $\quad 8505720$
$\begin{array}{ll}\text { Skelet: } & 1.2 \\ \text { Population: } & \text { Calden }\end{array}$
Seite: links
Erhaltung: $\mathbf{X}$ prox. Gelenk
$X$ prox. Schaft
mittl. Schaft
dist. Schaft dist. Gelenk

Verband: $\quad$ Verband

Alter: Jung

Beschreibung:

Ein proximales Fragment eines nicht ausgewachsenen Knochens. 

Bezeichn.: Ulna
Kiste:
8505720
Skelet: einzeln 1.1
Population: Calden
Seite: links
Erhaltung: $\mathbf{X}$ prox. Gelenk
$X$ prox. Schaft
$X$ mittl. Schaft
$\mathbf{X}$ dist. Schaft
dist. Gelenk
Beschreibung:

Ein Schaft einer jungen Ulna.
Verband: Verband Ges./Kr.: Gesund

Maß

Wert $\quad$ Einheit

Alter: Jung

Geschlecht:

Arthrose:

106

$\mathrm{mm}$



Bezeichn.: Ulna
Kiste:
8505720
einzeln 1.1
Pkelet:
Seite: rechts
Erhaltung: $\mathbf{X}$ prox. Gelenk
X prox. Schaft
mittl. Schaft
dist. Schaft
dist. Gelenk

\section{Beschreibung:}

Ein proximales Fragment einer rechten Ulna. Das Gelenk weist Verschleißerscheinungen auf.
Verband: $\square$ Verband

Ges./Kr.: Gesund

\section{Alter:}

Geschlecht:

Arthrose:

prox

2 

Bezeichn.: Ulna
Kiste: $\quad 8505720$
Skelet: $\quad 1.3$
Population: Calden
Seite: rechts
Erhaltung: $\square$ prox. Gelenk
prox. Schaft
mittl. Schaft
$\mathbf{X}$ dist. Schaft
$\mathbf{X}$ dist. Gelenk
Beschreibung:

Dies ist ein distales Fragment einer Ulna. Die Gelenkfläche weist deutliche Verschleißerscheinungen auf.
Ges./Kr.: Krank

Krankh.: Arthrose

\section{Alter: \\ Geschlecht:}

Arthrose:
3

dist. 3



Bezeichn.: Ulna
Kiste:
5255273
Population: Calden
Seite: rechts
Erhaltung: $\mathbf{X}$ prox. Gelenk
$X$ prox. Schaft
X mittl. Schaft
dist. Schaft
dist. Gelenk

Verband: $\square$ Verband

Ges./Kr.: Krank

Skelet: $\quad$ V60 13 über Becken $7+$

\section{Alter:}

Krankh.: Arthrose

Geschlecht:

Arthrose:

\section{Beschreibung:}

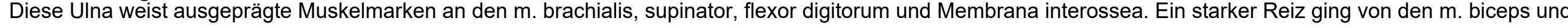
supinator aus, was stellenweise zu Neubildungen geführt hat. 


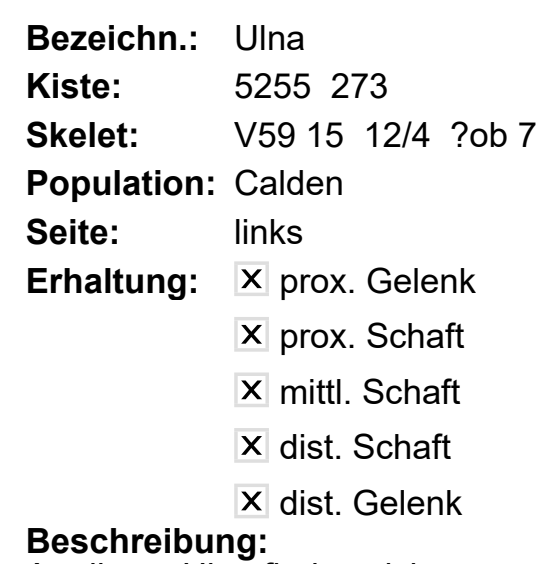

Population: Calden

Seite: links

Erhaltung: X prox. Gelenk

$X$ prox. Schaft

$X$ mittl. Schaft

$\mathbf{X}$ dist. Schaft

X dist. Gelenk

Beschreibung:

Geschlecht:

Arthrose:

An dieser Ulna finden sich ausgeprägte Muskelmarken der m. pronator teres, bicipes brachii, brachialis und eine deutliche Linea interossea.

$\begin{array}{ll}\text { prox. } & 2 \\ & 25\end{array}$




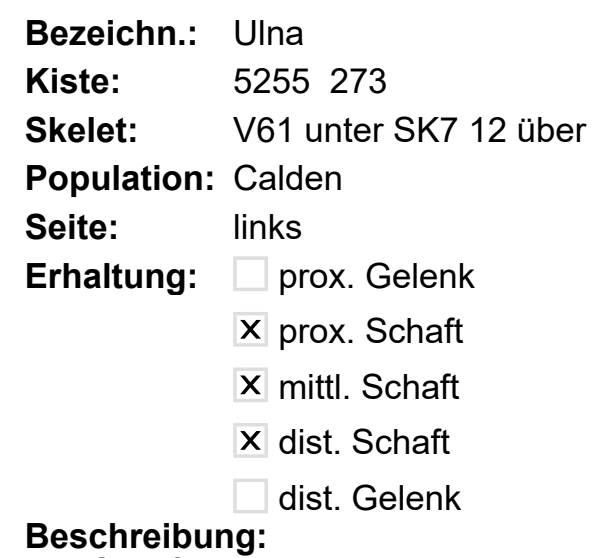

Der Schaft einer linken UIna.

Verband: $\quad$ Verband

Ges./Kr.: Gesund

\section{Alter:}

Geschlecht:

Arthrose: 

Bezeichn.: Ulna
Kiste: $\quad 5255273$
Skelet: V62 12
Population: Calden
Seite: rechts
Erhaltung: $\mathbf{X}$ prox. Gelenk
$X$ prox. Schaft
mittl. Schaft
dist. Schaft
dist. Gelenk
Beschreibung:

Ein proximales Fragment.
Verband: $\quad$ Verband

\section{Alter:}

Geschlecht:

Arthrose:

prox. 

Bezeichn.: Ulna
Kiste: $\quad 5257+58275$
Skelet: SK.9. 8
Population: Calden
Seite: rechts
Erhaltung: $\mathbf{X}$ prox. Gelenk
$X$ prox. Schaft
mittl. Schaft
dist. Schaft
dist. Gelenk
Beschreibung:

Ein proximales Fragment.
Verband: $\square$ Verband

\section{Alter:}

Geschlecht:

Arthrose:

prox. 

Bezeichn.: Ulna
Kiste:
5242266
Skelet: E. B-S.
Population: Calden
Seite: rechts
Erhaltung: $\square$ prox. Gelenk
X prox. Schaft
$X$ mittl. Schaft
X dist. Schaft
dist. Gelenk
Beschreibung:

Etwa 50\% einer jungen Ulna.
Verband: $\quad$ Verband Ges./Kr.: Gesund

\section{Alter: Jung}

Geschlecht:

Arthrose: 
Bezeichn.: Ulna

Kiste:

5242266

Verband:

Verband

\section{Alter:}

Ges./Kr.: Gesund

Skelet: $\quad$ E.B.-S 7 3. Tüte

Population: Calden

Seite: rechts

Erhaltung: $\mathbf{X}$ prox. Gelenk

$X$ prox. Schaft

X mittl. Schaft

$\mathbf{X}$ dist. Schaft

X dist. Gelenk

Beschreibung:

Diese Ulna weist einen gut ausgeprägten Ansatz des M. brachialis auf. 

Bezeichn.: Ulna
Kiste:
5242266
Skelet: $\quad$ E. B-S. 1
Population: Calden
Seite: links
Erhaltung: $\mathbf{X}$ prox. Gelenk
X prox. Schaft
mittl. Schaft
dist. Schaft
dist. Gelenk
Beschreibung:

Ein proximales Fragment.
Verband: $\quad \square$ Verband

\section{Alter:}

Geschlecht:

Arthrose:

prox. 

Bezeichn.: Ulna
Kiste:
5242266
Skelet: E. B-S.
Population: Calden
Seite: links
Erhaltung: $\mathbf{X}$ prox. Gelenk
X prox. Schaft
mittl. Schaft
dist. Schaft
dist. Gelenk
Beschreibung:

Ein proximales Fragment.
Verband: $\quad$ Verband

\section{Alter:}

Geschlecht:

Arthrose:

prox. 


\section{Bezeichn.: Ulna \\ Kiste: $\quad 5242266$ \\ Skelet: $\quad$ E. B-S. 11 \\ Population: Calden \\ Seite: links \\ Erhaltung: $\square$ prox. Gelenk prox. Schaft \\ mittl. Schaft $\mathbf{X}$ dist. Schaft $X$ dist. Gelenk \\ Beschreibung:}

Ein distales Fragment.
Verband: $\quad$ Verband

\section{Alter:}

Geschlecht:

Arthrose:
Ges./Kr.: Gesund 


\author{
Bezeichn.: Ulna \\ Kiste: $\quad 5242266$ \\ Skelet: $\quad$ E. B-S. 10 \\ Verband: $\quad$ Verband \\ Skelet: E. B-S. 10 \\ Alter: \\ Seite: rechts \\ Erhaltung: $\square$ prox. Gelenk \\ prox. Schaft \\ $X$ mittl. Schaft \\ dist. Schaft \\ dist. Gelenk \\ Beschreibung: \\ Ein stark frakturiertes Fundstück aus einer Ulna.
}



Bezeichn.: Ulna
Kiste:
5242266
Skelet: $\quad$ E. B-S. 8
Population: Calden
Seite: rechts
Erhaltung: $\mathbf{X}$ prox. Gelenk
$X$ prox. Schaft
mittl. Schaft
dist. Schaft
dist. Gelenk
Beschreibung:

Ein proximales Fragment.
Verband: $\square$ Verband

\section{Alter:}

Geschlecht:

Arthrose:

prox. 

Bezeichn.: Ulna
Kiste: $\quad 5242266$
Skelet: E. B-S.
Population: Calden
Seite: rechts
Erhaltung: $\mathbf{X}$ prox. Gelenk
$X$ prox. Schaft
mittl. Schaft
dist. Schaft dist. Gelenk
Beschreibung:

Ein proximales Fragment.
Verband: $\quad$ Verband

\section{Alter:}

Geschlecht:

Arthrose:

prox.
Ges./Kr.: Krank

Krankh.: Arthrose 
Bezeichn.: Ulna

Kiste: $\quad 5242266$

Skelet: E. B-S.

Population: Calden

Seite: rechts

Erhaltung: $\square$ prox. Gelenk prox. Schaft

$X$ mittl. Schaft dist. Schaft dist. Gelenk

\section{Beschreibung:}

Ein Fragment aus dem Schaft einer Ulna
Verband: $\quad$ Verband

\section{Alter:}

\section{Geschlecht:}

Arthrose: 


\section{Bezeichn.: Ulna \\ Kiste: \\ 5242266 \\ Skelet: E. B-S. 4 \\ Population: Calden \\ Seite: links \\ Erhaltung: $\square$ prox. Gelenk prox. Schaft \\ mittl. Schaft $\mathbf{X}$ dist. Schaft $X$ dist. Gelenk \\ Beschreibung:}

Ein distales Fragment.
Verband: $\square$ Verband

\section{Alter:}

Geschlecht:

Arthrose: 


\section{Bezeichn.: Ulna \\ Kiste: \\ 5242266 \\ Skelet: E. B-S. 6}

Population: Calden

Seite: rechts

Erhaltung: $\mathbf{X}$ prox. Gelenk

$X$ prox. Schaft

mittl. Schaft

dist. Schaft dist. Gelenk
Verband: $\square$ Verband

\section{Alter:}

Geschlecht:

Arthrose:

prox.

\section{Beschreibung:}

Von dieser Ulna ist nur ein proximales Fragment erhalten. Der Ansatz des M. brachialis ist gut ausgeprägt. 

Bezeichn.: Ulna
Kiste:
5242266
Skelet: $\quad$ E. B-S. 9
Population: Calden
Seite: links
Erhaltung: $\mathbf{X}$ prox. Gelenk
$X$ prox. Schaft
mittl. Schaft
dist. Schaft
dist. Gelenk
Beschreibung:

Ein proximales Fragment.
Verband: $\quad$ Verband

\section{Alter:}

Geschlecht:

Arthrose:

prox. 

Bezeichn.: Ulna
Kiste: $\quad 8505718$
Skelet: V42
Population: Calden
Seite: rechts
Erhaltung: $\mathbf{X}$ prox. Gelenk
$X$ prox. Schaft
$X$ mittl. Schaft
X dist. Schaft
$\square$ dist. Gelenk

Verband: $\quad \square$ Verband

Beschreibung:

Ein Verband aus Ulna und Radius. Sehr stark erodierte Fragmente. 


\section{Bezeichn.: Ulna \\ Kiste: $\quad 8505718$ \\ Skelet: aus Kiste \\ Population: Calden \\ Seite: links \\ Erhaltung: $\square$ prox. Gelenk prox. Schaft \\ mittl. Schaft \\ $X$ dist. Schaft $X$ dist. Gelenk \\ Beschreibung:}

Ein distales Fragment.
Verband: $\quad \square$ Verband

\section{Alter:}

\section{Geschlecht:}

Arthrose:
Ges./Kr.: Gesund

Ges.Kr:: Gesund 

Bezeichn.: Ulna
Kiste: $\quad 8505718$
Skelet: aus Kiste
Population: Calden
Seite: links
Erhaltung: $\square$ prox. Gelenk
prox. Schaft
$X$ mittl. Schaft
X dist. Schaft
$\square$ dist. Gelenk

Verband: $\quad \square$ Verband

\section{Alter:}

Geschlecht:

\section{Beschreibung:}

Ein distales Fragment einer Ulna ohne Gelenkflächen. Die Ansatzstelle der Membrana interossea ist deutlich geprägt. 

Bezeichn.: Ulna
Kiste: $\quad 8505718$
Skelet: aus Kiste
Population: Calden
Seite: rechts
Erhaltung: $\square$ prox. Gelenk prox. Schaft $X$ mittl. Schaft $\mathbf{X}$ dist. Schaft $X$ dist. Gelenk

Verband: $\quad \square$ Verband

\section{Alter:}

Geschlecht:

Beschreibung:

Ein distales, gespaltenes Fragment einer rechten Ulna 


\begin{tabular}{|c|c|c|c|c|c|c|c|c|}
\hline Bezeichn.: & Ulna & Verband: & $\square$ Verband & Ges./Kr.: & Krank & Maß & Wert & Einheit \\
\hline Kiste: & 5252271 & Alter: & & Krankh.: & Enthesiopathie & Länge & 242 & $\mathrm{~mm}$ \\
\hline Skelet: & PSK6 26 & Geschlecht: & $q>\hat{O}$ & & Arthrose & & & \\
\hline Population: & Calden & Arthrose: & & & & & & \\
\hline Seite: & links & & prox. & & & & & \\
\hline Erhaltung: & X prox. Gelenk & & dist. & & & & & \\
\hline & X prox. Schaft & & & & & & & \\
\hline & X mittl. Schaft & & & & & & & \\
\hline & $\mathbf{X}$ dist. Schaft & & & & & & & \\
\hline & X dist. Gelenk & & & & & & & \\
\hline
\end{tabular}

\section{Beschreibung:}

Bei dieser Ulna liegt eine Enthesiopathie bei der Ansatzstelle der m. digitorus profundus, extensor pollicis longus, extensor indicus und der Membrana interossea vor. 


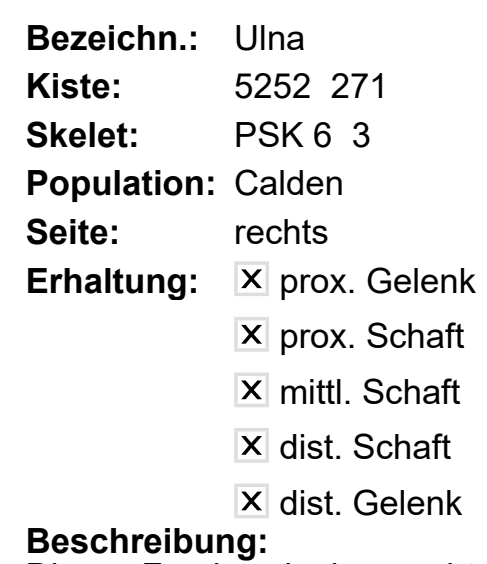

Beschreibung:

Verband: $\quad \square$ Verband

Alter:

Geschlecht: $\curvearrowright$

Arthrose:

prox.

dist.
Ges./Kr.: Krank

Krankh.: Arthrose

Myotendopathie

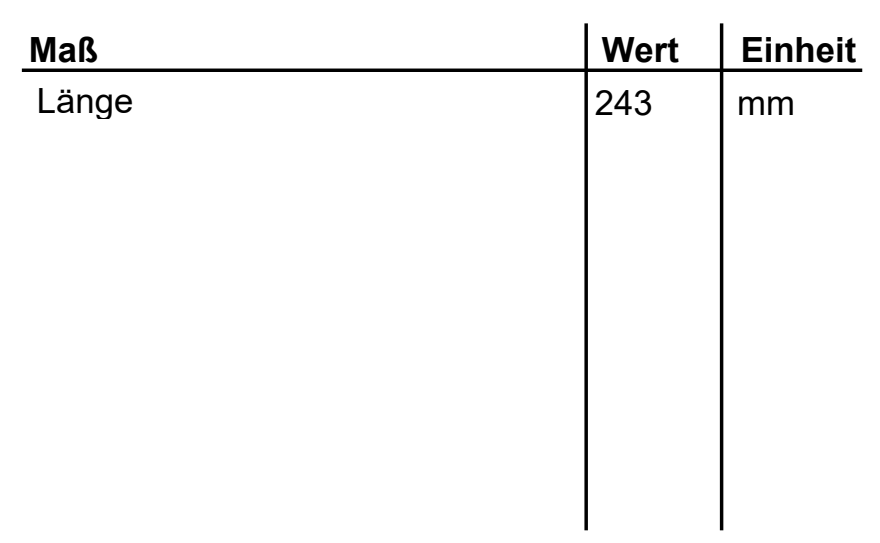

Dieses Fundstück einer rechten Ulna weist deutliche Muskelmarken auf, an der Ansatzstelle der Membrana interossea findet sich eine leichte Myotendopathie. 

Bezeichn:: Ulna
Kiste:
5243267
Skelet: leeres Feld
X prox. Gelenk
$X$ prox. Schaft
$X$ mittl. Schaft
$\mathbf{X}$ dist. Schaft
X dist. Gelenk

\section{Beschreibung:}

Verband:

Verband

\section{Alter:}

Ges./Kr.: Krank

\section{Geschlecht:}

Arthrose:

\section{prox.}

dist.

3

Dieses Fundstück einer rechten Ulna weist deutliche Muskelmarken auf. 

Bezeichn.: Ulna
Kiste: $\quad 5243267$
Skelet: Zettel
Population: Calden
Seite: links
Erhaltung: $\square$ prox. Gelenk
$X$ prox. Schaft
$X$ mittl. Schaft
$\mathbf{X}$ dist. Schaft
$\square$ dist. Gelenk

Verband: Verband

Alter: $\quad 13-20$

Beschreibung:

Ein Fragment einer jungen Ulna.

\section{Geschlecht:}

Arthrose: 


\begin{tabular}{|c|c|}
\hline & \\
\hline Bezeichn.: & Ulna \\
\hline Kiste: & 5243267 \\
\hline Skelet: & P.Sk.1. \\
\hline Population: & Calden \\
\hline Seite: & rechts \\
\hline Erhaltung: & X prox. Gelenk \\
\hline & $\mathbf{X}$ prox. Schaft \\
\hline & $\square$ mittl. Schaft \\
\hline & $\square$ dist. Schaft \\
\hline & $\square$ dist. Gelenk \\
\hline
\end{tabular}

Ein proximales Ulnafragment.
Verband: $\quad$ Verband

\section{Alter:}

Geschlecht:

Arthrose:

prox. 


$\begin{array}{ll}\text { Bezeichn.: } & \text { Ulna } \\ \text { Kiste: } & 5243267 \\ \text { Skelet: } & \text { P.Sk.1. } \\ \text { Population: } & \text { Calden } \\ \begin{array}{ll}\text { Seite: } & \text { links } \\ \text { Erhaltung: } & \text { X prox. Gelenk } \\ & \text { X prox. Schaft } \\ & \text { X mittl. Schaft } \\ & \text { X dist. Schaft } \\ & \square \text { dist. Gelenk }\end{array} \\ \text { Beschreibung: }\end{array}$

Verband: $\quad \square$ Verband

Alter:

Geschlecht:

Arthrose:

Dieses stark erodierte Fragment einer linken Ulna weist deutliche Muskelmarken auf. 


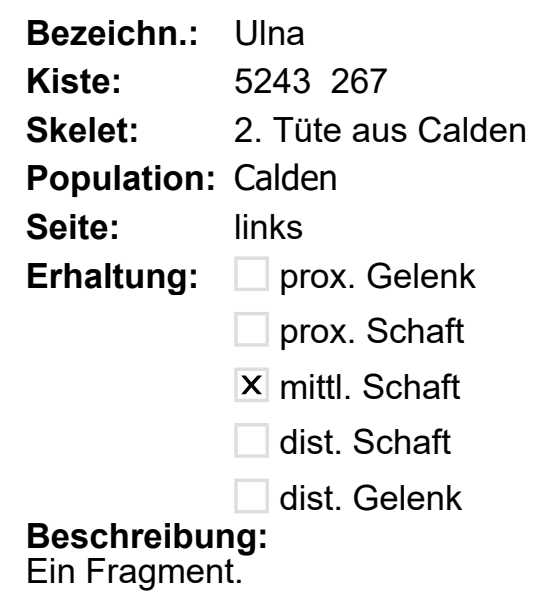

Skelet: 2. Tüte aus Calden

Population: Calden

Seite: links

Erhaltung: $\square$ prox. Gelenk prox. Schaft $X$ mittl. Schaft dist. Schaft dist. Gelenk

Beschreibung:

Ein Fragment.

Verband: Verband

\section{Alter:}

Geschlecht:

Arthrose: 

Bezeichn.: Ulna
Kiste: $\quad 5243267$
Skelet: 2. Tüte aus Calden
Population: Calden
Seite: links
Erhaltung: $\mathbf{X}$ prox. Gelenk
$X$ prox. Schaft
$X$ mittl. Schaft
X dist. Schaft
dist. Gelenk

Verband: $\quad \square$ Verband

\section{Alter:}

Geschlecht:

Beschreibung:

Ein Fragment einer Ulna, welches erodiert ist. 

Bezeichn.: Ulna
Kiste: $\quad 5243267$
Skelet: Sk. 1
Population: Calden
Seite: rechts
Erhaltung: $\mathbf{X}$ prox. Gelenk
$X$ prox. Schaft
$X$ mittl. Schaft
dist. Schaft
dist. Gelenk
Beschreibung:

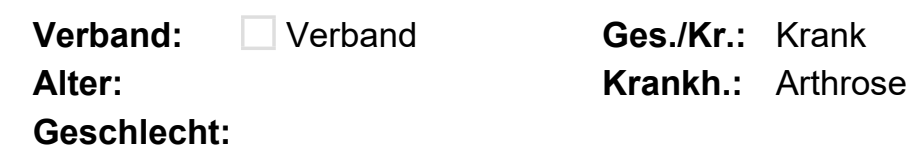

Es handelt sich hier um eine Ulna mit deutlich definierten Muskelmarken. Das Fundstück stammt aus dem proximalen Teil. 
Bezeichn.: Ulna

Kiste: $\quad 5243267$

Skelet: P.Sk.1.

Population: Calden

Seite: rechts

Erhaltung: $\square$ prox. Gelenk

prox. Schaft

mittl. Schaft

$\mathbf{X}$ dist. Schaft

$X$ dist. Gelenk

Beschreibung:

Ein distales Fragment einer Ulna der rechten Seite.
Verband: $\square$ Verband

\section{Alter:}

Geschlecht:

Arthrose:

dist.
Ges./Kr.: Krank

Krankh.: Arthrose 


$\begin{array}{ll}\text { Bezeichn.: } & \text { Ulna } \\ \text { Kiste: } & 5243267 \\ \text { Skelet: } & \text { Zettel } \\ \text { Population: } & \text { Calden } \\ \text { Seite: } & \text { links } \\ \text { Erhaltung: } & \square \text { prox. Gelenk } \\ & \square \text { prox. Schaft } \\ & \square \text { mittl. Schaft } \\ & \mathbf{X} \text { dist. Schaft } \\ & \mathbf{X} \text { dist. Gelenk }\end{array}$

Verband: $\quad \square$ Verband

Alter:

Geschlecht: $ㅇ$

Ein distales Fragment einer kleinen und grazilen Ulna der linken Seite. 

Bezeichn.: Ulna
Kiste: $\quad 5243267$
Skelet: Zettel
Population: Calden
Seite: links
Erhaltung: $\square$ prox. Gelenk
$X$ prox. Schaft
$X$ mittl. Schaft
dist. Schaft
dist. Gelenk

Verband: $\quad \square$ Verband

\section{Alter:}

Geschlecht:

Beschreibung:

Ein Fragment aus dem Schaft einer Ulna.

\section{Arthrose:}



Bezeichn.: Ulna
Kiste: $\quad 5243267$
Skelet: P.Sk.1. keine B
Population: Calden
Seite: rechts
Erhaltung: $\mathbf{X}$ prox. Gelenk
prox. Schaft
mittl. Schaft
dist. Schaft dist. Gelenk

Beschreibung:

Ein proximales Fragment einer Ulna.
Verband: Verband

\section{Alter:}

Ges./Kr.: Krank

Geschlecht:

Arthrose:

prox

3 


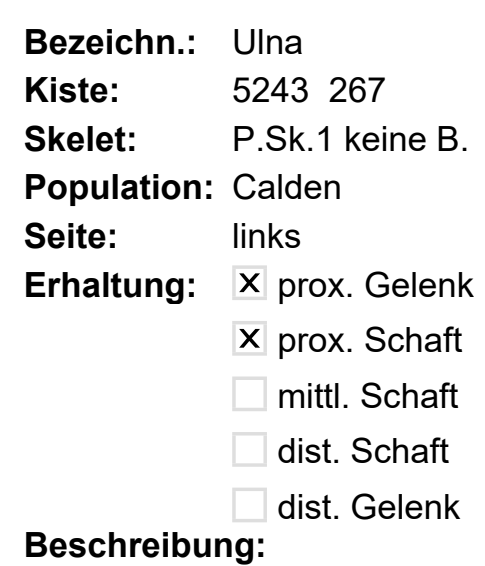

Diese Ulna ist nur proximal erhalten und weist eine Reizung am Ansatz des M. brachialis auf. 


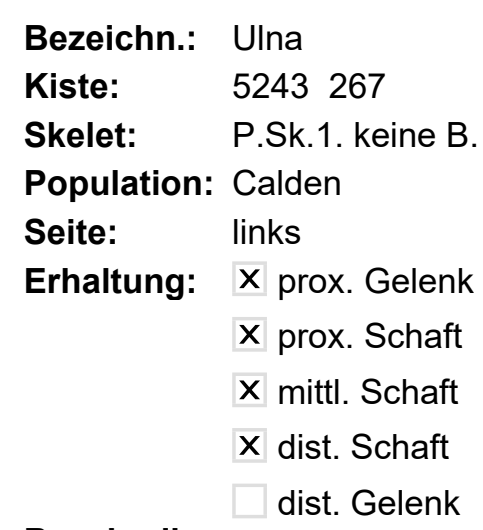

Verband: $\quad$ Verband

\section{Alter:}

Geschlecht:

Arthrose:

prox.

\section{Beschreibung:}

Eine Ulna, die recht gut erhalten ist, distal ist etwas abfrakturiert. Es finden sich mittelmäßige Muskelmarken. 


\section{Bezeichn.: Ulna \\ Kiste: $\quad 5261277$ \\ Skelet: Zettel \\ Population: Calden \\ Seite: links \\ Erhaltung: $\square$ prox. Gelenk prox. Schaft mittl. Schaft $X$ dist. Schaft $X$ dist. Gelenk \\ Beschreibung:}

Ein distales Fragment.
Verband: $\quad \square$ Verband

\section{Alter:}

Geschlecht:

Arthrose: 


$$
\begin{array}{ll}
\text { Bezeichn.: } & \text { Ulna } \\
\text { Kiste: } & 5261277 \\
\text { Skelet: } & \text { Sk.11. zu SCH.8. } \\
\text { Population: } & \text { Calden } \\
\begin{array}{ll}
\text { Seite: } & \text { links } \\
\text { Erhaltung: } & \text { X prox. Gelenk } \\
& \text { X prox. Schaft } \\
& \text { X mittl. Schaft } \\
& \text { X dist. Schaft } \\
& \square \text { dist. Gelenk }
\end{array} \\
\text { Beschreibung: }
\end{array}
$$

\section{Beschreibung:}$$
\text { Verband: } \quad \square \text { Verband }
$$$$
\text { Ges./Kr.: Gesund }
$$

Eine recht gut erhaltene Ulna, distal abfrakturiert. 
Bezeichn.: Ulna

Kiste: $\quad 5257+58275$

Skelet: V26 SK9 16

Population: Calden

Seite: rechts

Erhaltung: $\mathbf{X}$ prox. Gelenk

$X$ prox. Schaft

$X$ mittl. Schaft

$\mathbf{X}$ dist. Schaft

X dist. Gelenk

Beschreibung:

Eine vollständige Ulna.
Verband: $\quad \square$ Verband

\section{Alter:}

Ges./Kr.: Krank

Geschlecht:

Arthrose:

prox.

dist.

2

3
Maß

Länge

\begin{tabular}{l|l} 
Wert & Einheit \\
\hline 233 & $\mathrm{~mm}$
\end{tabular}




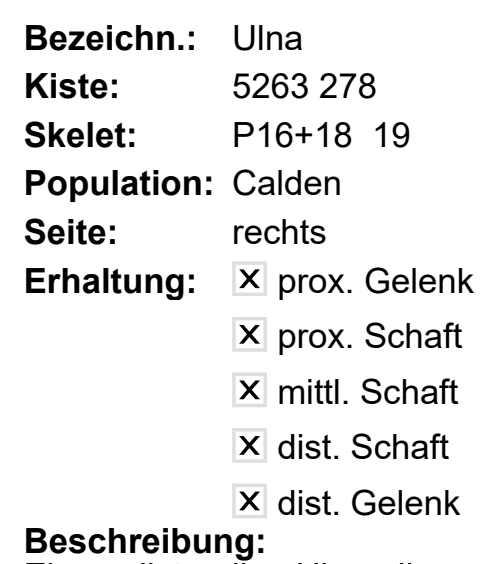

Population: Calden

Seite: rechts

Erhaltung: $\mathbf{X}$ prox. Gelenk

$X$ prox. Schaft

$X$ mittl. Schaft

$\mathbf{X}$ dist. Schaft

$\mathbf{X}$ dist. Gelenk

Beschreibung:

Verband:

\section{Alter:}

Geschlecht:

Arthrose:

Eine vollständige Ulna, die muskuläre Reizungen aufweist, die sich in Form von reaktioneller Knochenneubildungen äußern.
Ges./Kr.: Krank

Krankh.: Arthrose

\section{Arthritis}

Muskelreizung

prox. 2

dist. $\quad 3$

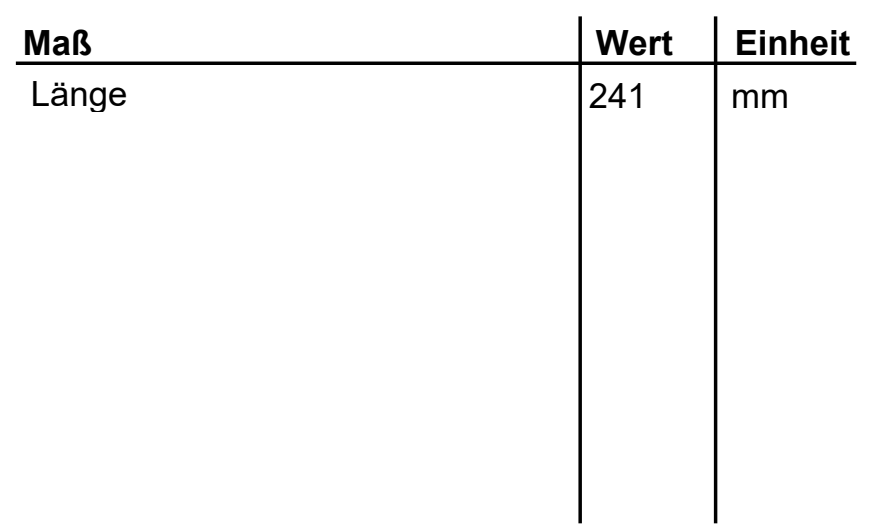


Bezeichn.: Ulna

Kiste:

5263278

Skelet: V24 P16+18

Population: Calden

Seite: rechts

Erhaltung: $\mathbf{X}$ prox. Gelenk

$X$ prox. Schaft

$X$ mittl. Schaft

dist. Schaft

dist. Gelenk
Verband: $\quad \square$ Verband

Alter:

\section{Geschlecht:}

Arthrose:

prox.

\section{Beschreibung:}

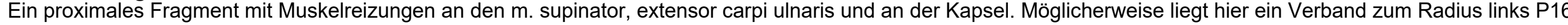
+18 vor. 
Bezeichn.: Ulna

Kiste:

5263278

Skelet: $\quad$ parallel Sch. $23+2410$

Population: Calden

Seite: links

Erhaltung: $\mathbf{X}$ prox. Gelenk

X prox. Schaft

X mittl. Schaft

dist. Schaft

dist. Gelenk

Beschreibung:

Ein proximales Fragment.
Verband: $\square$ Verband

\section{Alter:}

Geschlecht: $q>\hat{\sigma}$

Arthrose:

prox. 


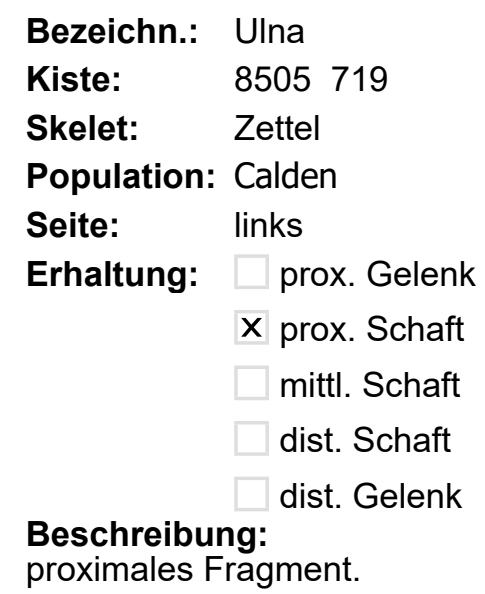

Verband

\section{Alter:}

Geschlecht:

Arthrose: 


$\begin{array}{ll}\text { Bezeichn.: } & \text { Ulna } \\ \text { Kiste: } & 8505719 \\ \text { Skelet: } & \text { Zettel } \\ \text { Population: } & \text { Calden } \\ \begin{array}{ll}\text { Seite: } & \text { links } \\ \text { Erhaltung: } & \text { X prox. Gelenk } \\ & \square \text { prox. Schaft } \\ & \square \text { mittl. Schaft } \\ & \square \text { dist. Schaft } \\ & \square \text { dist. Gelenk }\end{array} \\ \text { Beschreibung: }\end{array}$

Verband: $\quad \square$ Verband

Alter:

Geschlecht:

Arthrose:

Dieses Fragment stammt aus dem proximalen Teil einer Ulna. 

Bezeichn.: Ulna
Kiste: $\quad 8505719$
Skelet: Zettel
Population: Calden
Seite:
links
Erhaltung: $\square$ prox. Gelenk
X prox. Schaft
mittl. Schaft
dist. Schaft
dist. Gelenk
Beschreibung:

Ein proximales Fragment.
Verband: $\square$ Verband

\section{Alter:}

Geschlecht:

Arthrose: 

Bezeichn.: Ulna
Kiste:
8505719
Skelet:
Population: Calden
Seite: rechts
Erhaltung: $\square$ prox. Gelenk
X prox. Schaft
mittl. Schaft
dist. Schaft
dist. Gelenk

Verband:

Verband

Alter:

Geschlecht:

Beschreibung:

Ein proximales Fragment mit ausgeprägten Muskelmarken. 

Bezeichn.: UIna
Kiste:
5245269
Skelet: bei Becken SK.4.
Population: Calden
Seite: rechts
Erhaltung: $\square$ prox. Gelenk
prox. Schaft
mittl. Schaft
$\mathbf{X}$ dist. Schaft
$\mathbf{X}$ dist. Gelenk
Beschreibung:

Verband: $\square$ Verband

Alter:

Ges./Kr.: Gesund

Geschlecht: $q>\Uparrow$

Arthrose:

Diese Ulna ist eher grazil und es ist nur die distale Hälfte erhalten. 
Bezeichn.: Ulna

Kiste:

5259276

Skelet: PSK10 20

Population: Calden

Seite: links

Erhaltung: $\mathbf{X}$ prox. Gelenk

$X$ prox. Schaft

$X$ mittl. Schaft

$\mathbf{X}$ dist. Schaft

X dist. Gelenk

\section{Beschreibung:}

Diese Ulna ist vollständig erhalten. Sie wurde aus zwei Fragmenten wieder zusammengeklebt.

\section{Verband: \\ Verband \\ Ges./Kr.: Gesund}

\section{Alter:}

Geschlecht:

Arthrose:

\section{prox}

dist.

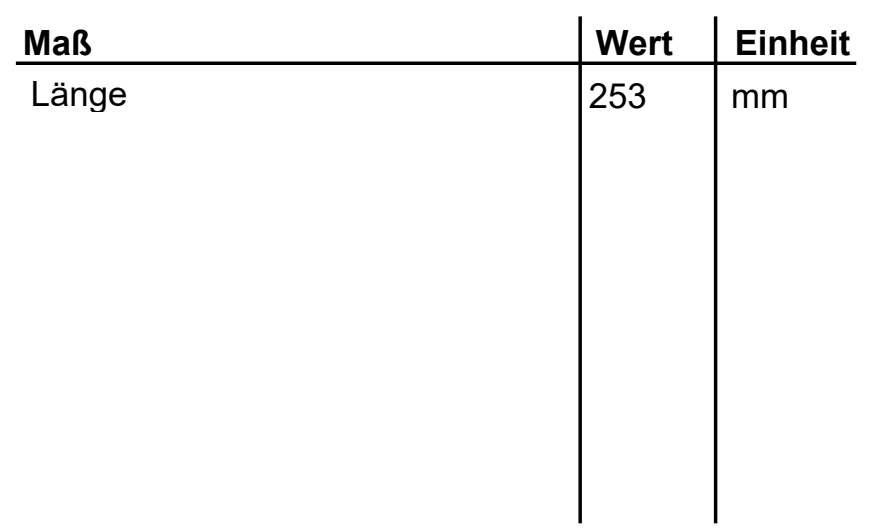



Bezeichn.: Ulna
Kiste: $\quad 5259276$
Skelet: PSK4 18
Population: Calden
Seite: links
Erhaltung: $\mathbf{X}$ prox. Gelenk
$X$ prox. Schaft
$X$ mittl. Schaft
X dist. Schaft
$\mathbf{X}$ dist. Gelenk

Beschreibung:

Diese Ulna der linken Seite ist vollständig erhalten.
Verband: $\quad$ Verband $\quad$ Ges./Kr.: Gesund

\section{Alter:}

Maß

Geschlecht:

Arthrose:

prox.

dist.

$277 \quad \mathrm{~mm}$


Bezeichn.: Ulna

Kiste: $\quad 8505721$

Skelet: Kiste 5

Population: Calden

Seite: links

Erhaltung: $\square$ prox. Gelenk

prox. Schaft

mittl. Schaft

$\mathbf{X}$ dist. Schaft

$\mathbf{X}$ dist. Gelenk
Verband: $\quad$ Verband

\section{Alter:}

Geschlecht:

Arthrose:
Ges./Kr.: Gesund

\section{Beschreibung:}

Dieses Fundstück ist ein distales Fragment einer eher männlichen Ulna. Sie weist recht starke Muskelmarken auf. Ihr äußeres Erscheinungsbild ist von Erosionen geprägt, weswegen ihre Konstitution nicht mehr so gut ist. Die Gelenkfläche ist wegen Erosion nicht zu beurteilen. 


$\begin{array}{ll}\text { Bezeichn.: } & \text { Ulna } \\ \text { Kiste: } & 8505721 \\ \text { Skelet: } & \text { Kiste } 5 \\ \text { Population: } & \text { Calden } \\ \text { Seite: } & \text { links } \\ \text { Erhaltung: } & \square \text { prox. Gelenk } \\ & \square \text { prox. Schaft } \\ & \text { X mittl. Schaft } \\ & \square \text { dist. Schaft } \\ & \square \text { dist. Gelenk }\end{array}$

Verband: $\quad$ Verband

Ges./Kr.: Gesund

Beschreibung:

Ein kleines Fragment aus dem Schaft einer linken Ulna. 

Bezeichn.: Ulna
Kiste:
8505721
Skelet: aus großer Kiste
Population: Calden
Seite: links
Erhaltung: $\mathbf{X}$ prox. Gelenk
$X$ prox. Schaft
$X$ mittl. Schaft
dist. Schaft
dist. Gelenk

Verband:

Verband

Ges./Kr.: Gesund

Beschreibung:

Alter:

Geschlecht: $q<\lambda$

Arthrose:

Von dieser linken Ulna ist etwa die proximale Hälfte erhalten. Sie wirkt sehr massiv. 


$\begin{array}{ll}\text { Bezeichn.: } & \text { Ulna } \\ \text { Kiste: } & 8505721 \\ \text { Skelet: } & \text { aus großer Kiste } \\ \text { Population: } & \text { Calden } \\ \begin{array}{ll}\text { Seite: } & \text { rechts } \\ \text { Erhaltung: } & \mathbf{X} \text { prox. Gelenk } \\ & \mathbf{X} \text { prox. Schaft } \\ & \mathbf{X} \text { mittl. Schaft } \\ & \square \text { dist. Schaft } \\ & \square \text { dist. Gelenk }\end{array} \\ \text { Beschreibung: }\end{array}$

Verband: $\square$ Verband

\section{Alter:}

Geschlecht:

Arthrose:

prox.

Hierbei handelt es sich um ein teilweise erodiertes Fragment einer Ulna der rechten Seite. Sie ist etwa zu 60\% proximal erhalten. 
Bezeichn.: Ulna

Kiste: $\quad 5257+58275$

Skelet: $\quad 17$

Population: Calden

Seite: links

Erhaltung: $\square$ prox. Gelenk prox. Schaft mittl. Schaft $\mathbf{X}$ dist. Schaft X dist. Gelenk

Beschreibung:

Ein distales Fragment.
Verband: $\quad \square$ Verband

\section{Alter:}

Geschlecht:

Arthrose:

dist. 


\section{Bezeichn.: Ulna \\ Kiste: 8505721 \\ Skelet: Kiste 9}

Population: Calden

\section{Erhaltung:} prox. Gelenk prox. Schaft $X$ mittl. Schaft dist. Schaft dist. Gelenk

\section{Beschreibung:}

Ein Fragment aus dem Schaft eines jungen Knochens.

\section{Verband: \\ Alter:}

Ges./Kr.: Gesund

Geschlecht:

Arthrose: 


$\begin{array}{ll}\text { Bezeichn.: } & \text { Radius } \\ \text { Kiste: } & \text { Museumskiste } 3 \\ \text { Skelet: } & \text { P2 } \\ \text { Population: } & \text { Calden } \\ \begin{array}{ll}\text { Seite: } & \text { links } \\ \text { Erhaltung: } & \mathbf{X} \text { prox. Gelenk } \\ & \mathbf{X} \text { prox. Schaft } \\ & \mathbf{X} \text { mittl. Schaft } \\ & \mathbf{X} \text { dist. Schaft } \\ & \mathbf{X} \text { dist. Gelenk }\end{array} \\ \text { Beschreibung: }\end{array}$

Verband: $\square$ Verband

Alter:

Ges./Kr.: Gesund

Geschlecht: $q \geq \hat{0}$

Arthrose:

Beschreibung:

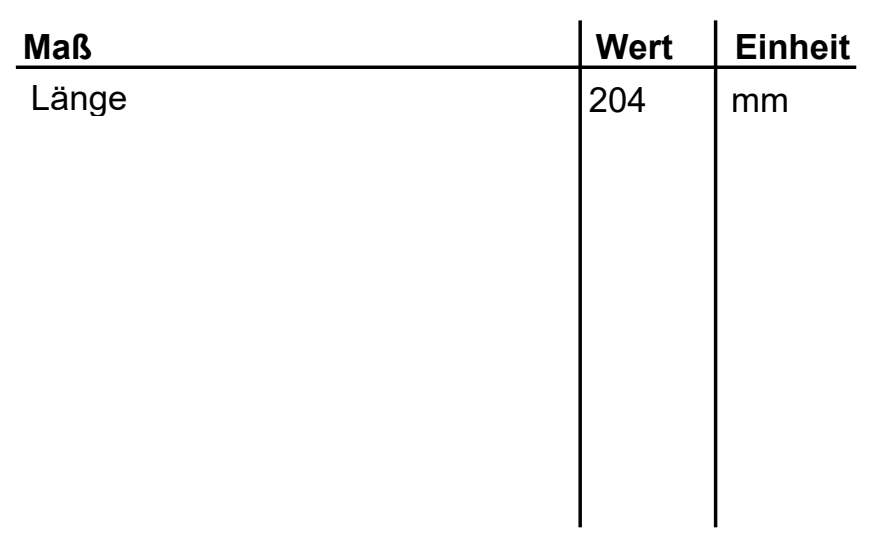

Dieses Fundstück ist fast vollständig erhalten und weist nur distal Erosionsspuren auf. 
Verband:

Verband

Ges./Kr.: Gesund
Bezeichn.: Radius
Kiste: Museumskiste 3
Skelet: P2
Population: Calden
Seite: links
Erhaltung: $\square$ prox. Gelenk
$X$ prox. Schaft
$X$ mittl. Schaft
$\mathbf{X}$ dist. Schaft dist. Gelenk

Beschreibung

Hier ist nur ein Fragment aus dem Schaft erhalten, es ist etwa die Hälfte des Knochens erhalten. 


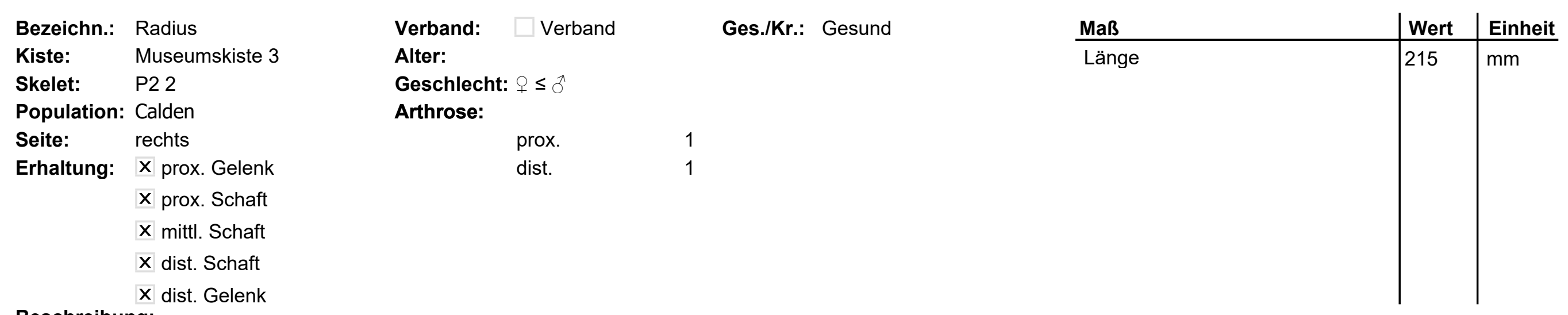

Dieser Radius ist fast vollständig erhalten, weist an der Membrana interossea antebrachii, dem M. pronator teres und dem M. supinator deutliche Muskelmarken auf. 


$\begin{array}{ll}\text { Bezeichn.: } & \text { Radius } \\ \text { Kiste: } & 8505718 \\ \text { Skelet: } & \text { aus Tüte } \\ \text { Population: } & \text { Calden } \\ \text { Seite: } & \text { rechts } \\ \text { Erhaltung: } & \square \text { prox. Gelenk } \\ & \square \text { prox. Schaft } \\ & \mathbf{X} \text { mittl. Schaft } \\ & \square \text { dist. Schaft } \\ & \square \text { dist. Gelenk }\end{array}$

Verband: $\square$ Verband

Alter:

Geschlecht: $q<\hat{\jmath}$

Arthrose:

\section{Beschreibung:}

Dies ist das Fragment aus dem Schaft eines massiven Radius. 

Bezeichn.: Radius
Kiste: $\quad 8505718$
Skelet: aus Tüte
Population: Calden
Seite:
links
Erhaltung: $\square$ prox. Gelenk
prox. Schaft
$X$ mittl. Schaft
dist. Schaft dist. Gelenk

\section{Beschreibung:}

Fragment aus dem Schaft eines Radius.
Verband: $\quad$ Verband

\section{Alter:}

Geschlecht:

Arthrose:
Ges./Kr.: Gesund 

Bezeichn.: Radius
Kiste: $\quad 8505718$
Skelet: aus Tüte
Population: Calden
Seite: rechts
Erhaltung: $\square$ prox. Gelenk
$X$ prox. Schaft
$X$ mittl. Schaft
X dist. Schaft
$\square$ dist. Gelenk
Beschreibung:

Verband: $\square$ Verband

Ges./Kr.: Krank

Alter:

Krankh.: Muskelreizung

Geschlecht: $q<\hat{0}$

Fragment des Schaftes eines massiven Radius, welcher starke Muskelmarken aufweist. 


$\begin{array}{lll}\text { Bezeichn.: } & \text { Radius } & \text { Verband: } \\ \text { Kiste: } & 8505718 & \text { Alter: } \\ \text { Skelet: } & \text { aus Tüte } & \text { Geschlecht: } \\ \text { Population: } & \text { Calden } & \text { Arthrose: } \\ \text { Seite: } & \text { rechts } & \\ \text { Erhaltung: } & \square \text { prox. Gelenk } & \\ & \square \text { prox. Schaft } & \\ & \text { X mittl. Schaft } & \\ & \square \text { dist. Schaft } & \\ & \\ \text { Beschreibung: } & \text { dist. Gelenk } & \\ \text { Ein Fragment aus dem Schaft eines Radius; stark erodiert. }\end{array}$




$\begin{array}{ll}\text { Bezeichn.: } & \text { Radius } \\ \text { Kiste: } & 8505720 \\ \text { Skelet: } & 1.0 \\ \text { Population: } & \text { Calden } \\ \begin{array}{ll}\text { Seite: } & \text { rechts } \\ \text { Erhaltung: } & \square \text { prox. Gelenk } \\ & \square \text { prox. Schaft } \\ & \square \text { mittl. Schaft } \\ & \mathbf{X} \text { dist. Schaft } \\ & \square \text { dist. Gelenk }\end{array} \\ \text { Beschreibung: }\end{array}$

\section{Verband: \\ Verband}

\section{Alter:} Jung

Geschlecht:

Arthrose:

Hier handelt es sich um einen Radius der rechten Seite eines jungen Individuums. Er ist nur distal erhalten. 


\section{Bezeichn: Radius \\ Kiste: $\quad 8505720$ \\ Skelet: $\quad 1.2$}

Population: Calden

\section{Erhaltung:}

prox. Gelenk

prox. Schaft

mittl. Schaft

$\mathbf{X}$ dist. Schaft

X dist. Gelenk

Beschreibung:

Ein distales Fragment eines Radius.
Verband: $\square$ Verband

Ges./Kr.: Gesund

\section{Alter:}

Geschlecht: $q \leq \curvearrowright$

Arthrose: 

Bezeichn.: Radius
Kiste: $\quad 8505720$
Skelet: $\quad 1.3$
Population: Calden
Seite: links
Erhaltung: $\square$ prox. Gelenk
prox. Schaft
mittl. Schaft
$\mathbf{X}$ dist. Schaft
$\mathbf{X}$ dist. Gelenk
Beschreibung:

Verband:

Verband

Ges./Kr.: Gesund

Maß

Breite Epiphyse distal

\begin{tabular}{|l|l} 
Wert & Einheit \\
\hline
\end{tabular}

Alter: Jung

Geschlecht:

Arthrose:

Hierbei handelt es sich um ein Fragment eines nicht ausgewachsenen Radius der linken Seite. Er wirkt bereit sehr massiv. 


\section{Bezeichn:: Radius \\ Kiste: \\ 8505720}

Skelet:

Population: Calden

Seite: rechts

Erhaltung: $\square$ prox. Gelenk

prox. Schaft

mittl. Schaft

$\mathbf{X}$ dist. Schaft

X dist. Gelenk

\section{Beschreibung:}

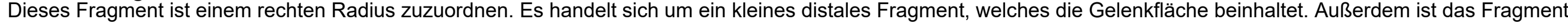
recht grazil.

\section{Verband: $\square$ Verband}

\section{Alter:}

Geschlecht: $q>\hat{\sigma}$

Arthrose:
Ges./Kr.: Gesund 


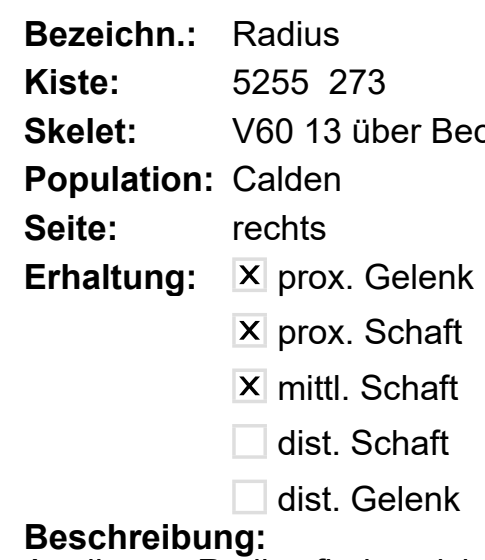

An diesem Radius finden sich ausgeprägte Muskelmarken an den m. brachialis, supinator, flexor digitorum und an Membrana interossea. 


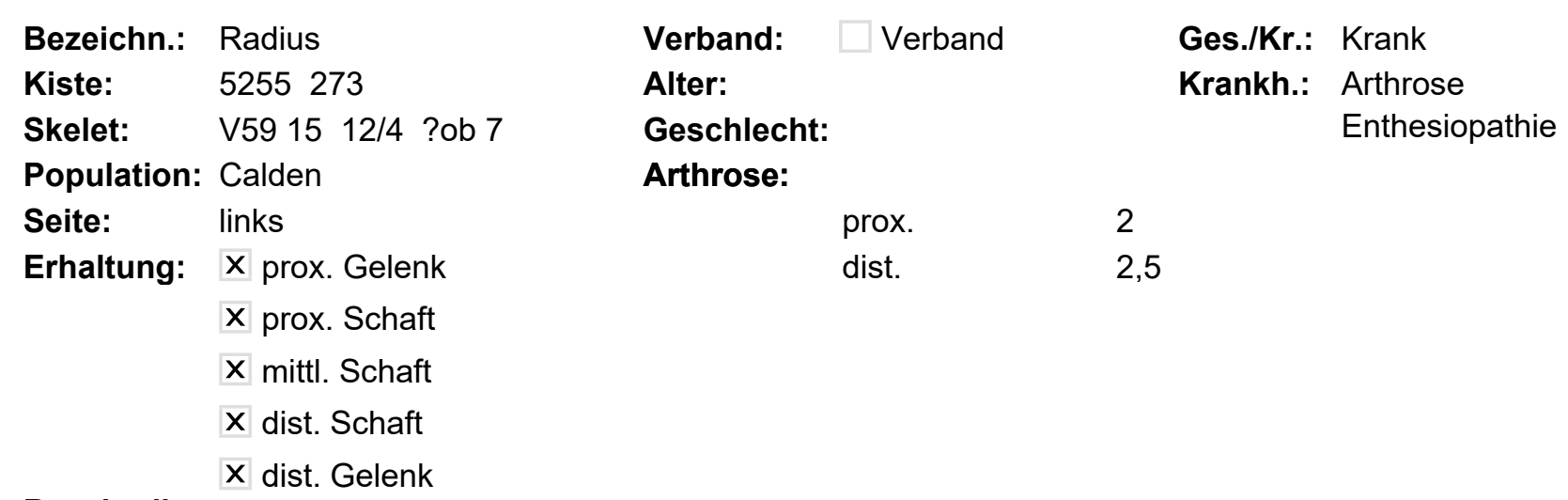

Verband: $\quad \square$ Verband

Alter:

Geschlecht:

Arthrose:

Population: Calden

Seite: links

Erhaltung: $\mathbf{X}$ prox. Gelenk

$X$ prox. Schaft

$X$ mittl. Schaft

$\mathbf{X}$ dist. Schaft

X dist. Gelenk

Ges./Kr.: Krank

Krankh.: Arthrose

Enthesiopathie

\section{Beschreibung:}

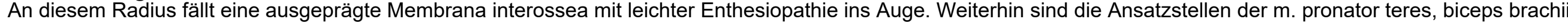
und brachialis (mit leichter Enthesiopathie) gut ausgeprägt. 


$\begin{array}{ll}\text { Bezeichn.: } & \text { Radius } \\ \text { Kiste: } & 5255273 \\ \text { Skelet: } & \text { V61 unter SK7 } 12 \\ \text { Population: } & \text { Calden } \\ \text { Seite: } & \text { links } \\ \text { Erhaltung: } & \mathbf{X} \text { prox. Gelenk } \\ & \text { X prox. Schaft } \\ & \text { X mittl. Schaft } \\ & \mathbf{X} \text { dist. Schaft } \\ & \mathbf{X} \text { dist. Gelenk }\end{array}$

Verband: $\square$ Verband Ges./Kr.: Krank

Alter:

Geschlecht:

Arthrose:

prox.

dist.
Maß

Krankh.: Arthrose

Enthesiopathie

Dieser Radius weist einen gut ausgeprägten Ansatz des M. brachialis mit leichter Enthesiopathie auf. 


\section{Bezeichn.: Radius \\ Kiste: $\quad 5255273$ \\ Skelet: V62 12}

Population: Calden

Seite: rechts

Erhaltung: X prox. Gelenk

$X$ prox. Schaft

$X$ mittl. Schaft

$\mathbf{X}$ dist. Schaft

$\mathbf{X}$ dist. Gelenk

Beschreibung:

Ein vollständiges Fundstück.
Verband: $\quad \square$ Verband

\section{Alter:}

Ges./Kr.: Krank

Geschlecht:

Arthrose:

prox.

dist.

1,5

2,5

\section{Maß}

Länge

Wert 1 Einheit

$224 \mathrm{~mm}$


Bezeichn.: Radius

Kiste: $\quad 5257+58275$

Skelet: $\quad 16$

Population: Calden

Seite: links

Erhaltung: $\square$ prox. Gelenk

prox. Schaft

mittl. Schaft

$\mathbf{X}$ dist. Schaft

$X$ dist. Gelenk

Beschreibung:

Ein distales Fragment eines Os radii.
Verband: $\square$ Verband

\section{Alter:}

Geschlecht:

Arthrose:

dist. 

Bezeichn.: Radius
Kiste:
5242266
Skelet:
Population: Calden
Seite:
links
Erhaltung: $\mathbf{X}$ prox. Gelenk
$X$ prox. Schaft
mittl. Schaft
dist. Schaft
dist. Gelenk

Beschreibung:

Ein proximales Fragment eins Os radii.
Verband: $\quad \square$ Verband

Ges./Kr.: Gesund

\section{Alter:}

Geschlecht:

Arthrose:

prox. 


\section{Bezeichn.: Radius \\ Kiste: 5242266 \\ Skelet: E.B-S. 8 \\ Population: Calden \\ Seite: links \\ Erhaltung: $\square$ prox. Gelenk \\ prox. Schaft \\ mittl. Schaft \\ $\mathbf{X}$ dist. Schaft \\ $X$ dist. Gelenk}

Beschreibung:

Ein distales Fragment eines Os radii.
Verband: $\quad \square$ Verband

\section{Alter:}

Geschlecht:

Arthrose:

dist. 

Radius
Kiste:
5242266
Skelet: $\quad$ E.B-S. 10
Population: Calden
Seite: links
Erhaltung: $\mathbf{X}$ prox. Gelenk
$X$ prox. Schaft
mittl. Schaft
dist. Schaft
dist. Gelenk

Beschreibung:

Ein proximales Fragment eines Os radii.
Verband: $\quad \square$ Verband

\section{Alter:}

Geschlecht:

Arthrose:

prox. 


$\begin{array}{ll}\text { Bezeichn.: } & \text { Radius } \\ \text { Kiste: } & 5242266 \\ \text { Skelet: } & \text { E.B-S. } 7 \\ \text { Population: } & \text { Calden } \\ \text { Seite: } & \text { rechts } \\ \text { Erhaltung: } & \square \text { prox. Gelenk } \\ & \square \text { prox. Schaft } \\ & \square \text { mittl. Schaft } \\ & \text { X dist. Schaft } \\ & \quad \mathbf{X} \text { dist. Gelenk } \\ \text { Beschreibung: } \\ \text { Ein distales Fragment. }\end{array}$

Ein distales Fragment.
Verband: $\square$ Verband

Alter:

\section{Geschlecht:}

Arthrose:

dist. 
$\begin{array}{ll}\text { Bezeichn.: } & \text { Radius } \\ \text { Kiste: } & 5242\end{array}$

Skelet: $\quad$ PSK7 ad. Sch. $23+25$

Population: Calden

Seite: links

Erhaltung: $\square$ prox. Gelenk

prox. Schaft

mittl. Schaft

$\mathbf{X}$ dist. Schaft

$X$ dist. Gelenk

Beschreibung:

Ein distales Fragment.
Verband: $\quad$ Verband

\section{Alter:}

Geschlecht:

Arthrose:

dist. 


\section{Bezeichn.: Radius \\ Kiste: $\quad 5242266$ \\ Skelet: $\quad$ E.B.-S 7 3. Tüte \\ Population: Calden \\ Seite: rechts \\ Erhaltung: $\mathbf{X}$ prox. Gelenk \\ $\mathbf{X}$ prox. Schaft \\ $X$ mittl. Schaft \\ $\mathbf{X}$ dist. Schaft \\ $X$ dist. Gelenk \\ Beschreibung:}

Verband: $\square$ Verband

Ges./Kr.: Gesund

Alter:

Maß

Wert $\quad$ Einheit

Geschlecht: $\hat{\delta}$

Arthrose:

prox. 2

dist. 2

Dieser rechte Radius ist zu 98\% erhalten und hat einen gut ausgeprägten Ansatz des M. brachialis. 


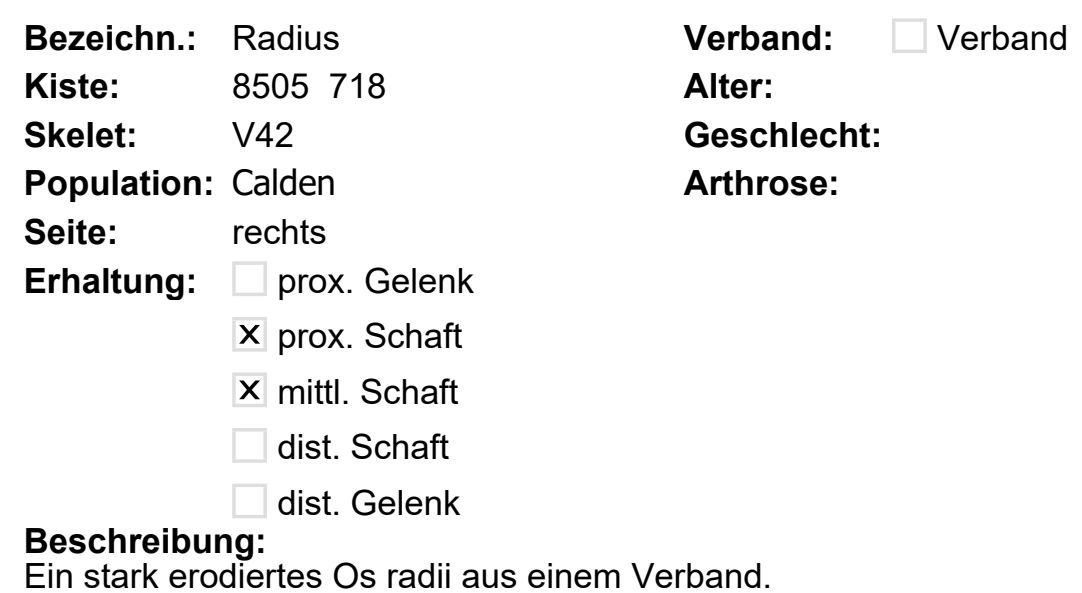

Ein stark erodiertes Os radii aus einem Verband. 

Bezeichn.: Radius
Kiste: $\quad 8505718$
Skelet: aus Kiste
Population: Calden
Seite: rechts
Erhaltung: $\mathbf{X}$ prox. Gelenk
$X$ prox. Schaft
mittl. Schaft
dist. Schaft
dist. Gelenk

\section{Beschreibung:}

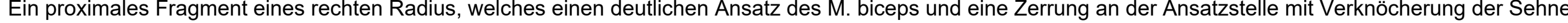
aufweist.

\section{Verband: $\quad \square$ Verband \\ Ges./Kr.: Krank

Alter: Krankh.: Zerrung

\section{Geschlecht:}

Arthrose:

prox.

1 


$\begin{array}{ll}\text { Bezeichn.: } & \text { Radius } \\ \text { Kiste: } & 8505718 \\ \text { Skelet: } & \text { aus Kiste } \\ \text { Population: } & \text { Calden } \\ \text { Seite: } & \text { rechts } \\ \text { Erhaltung: } & \mathbf{X} \text { prox. Gelenk } \\ & \mathbf{X} \text { prox. Schaft } \\ & \square \text { mittl. Schaft } \\ & \square \text { dist. Schaft } \\ & \square \text { dist. Gelenk }\end{array}$

Verband: $\square$ Verband

Alter:

Geschlecht: $q<\hat{\jmath}$

Arthrose:

prox.

1

Dies ist das proximales Fragment eines rechten Radius, bei dem der Ansatz des M. biceps weggebrochen ist. Dennoch wirkt die Ansatzfläche kräftig ausgebildet. 


\section{Bezeichn.: Radius \\ Kiste: $\quad 5252271$ \\ Skelet: $\quad 2$ PSK 6}

Population: Calden

Seite: rechts

Erhaltung: $\mathbf{X}$ prox. Gelenk

$X$ prox. Schaft

$X$ mittl. Schaft

$\mathbf{X}$ dist. Schaft

$\mathbf{X}$ dist. Gelenk

Beschreibung:

Das Fundstück ist ein Radius, der gut ausgeprägte Muskelmarken aufweist.
Verband: Verband Ges./Kr.: Gesund

\section{Alter:}

Geschlecht:

Arthrose:

\section{prox}

dist.
Maß

Länge

Wert $\quad$ Einheit

$243 \quad \mathrm{~mm}$


$\begin{array}{ll}\text { Bezeichn.: } & \text { Radius } \\ \text { Kiste: } & 5252\end{array}$

5252271

Skelet: $\quad$ PSK6 17

Population: Calden

Seite: rechts

Erhaltung: $\square$ prox. Gelenk

$X$ prox. Schaft

$X$ mittl. Schaft

$\mathbf{X}$ dist. Schaft

$X$ dist. Gelenk

\section{Beschreibung:}

Ein gut erhaltenes Fragment eines echten Os radii.
Verband: $\quad \square$ Verband

Ges./Kr.: Gesund

\section{Alter:}

Geschlecht: $\delta$

Arthrose: 


\section{Bezeichn.: Radius \\ Kiste: 5252271 \\ Skelet: $\quad$ PSK 649 \\ Population: Calden \\ Seite: rechts \\ Erhaltung: $\mathbf{X}$ prox. Gelenk \\ $X$ prox. Schaft \\ $X$ mittl. Schaft \\ dist. Schaft dist. Gelenk \\ Beschreibung:}

Dieser Radius ist proximal bis mittig erhalten.
Verband: $\quad \square$ Verband

Alter:

Geschlecht: $q<0$

Arthrose:

prox. 


\section{Bezeichn.: Radius \\ Kiste: 5252271 \\ Skelet: $\quad 3$ PSK6}

Population: Calden

Seite: rechts

Erhaltung: $\square$ prox. Gelenk

prox. Schaft

mittl. Schaft

$\mathbf{X}$ dist. Schaft

$X$ dist. Gelenk

\section{Beschreibung:}

Dieses Fragment ist einem distalen Os radii zuzuordnen.
Verband: $\quad \square$ Verband

\section{Alter:}

Geschlecht: $q \geq \hat{0}$

Arthrose: 

Bezeichn.: Radius
Kiste: $\quad 5252271$
Skelet: $\quad$ SK(6)? 510
Population: Calden
Seite: rechts
Erhaltung: $\mathbf{X}$ prox. Gelenk
X prox. Schaft
$X$ mittl. Schaft
dist. Schaft
dist. Gelenk

\section{Beschreibung:}

Ein graziles Fragment eines rechten Os radii. Der Knochen ist eher grazil.
Verband: $\square$ Verband

\section{Alter:}

Geschlecht: $q \geq \hat{0}$

Arthrose:

prox. 

Bezeichn.: Radius
Kiste: $\quad 5243267$
Skelet: Zettel
Population: Calden
Seite: links
Erhaltung: $\square$ prox. Gelenk
prox. Schaft
mittl. Schaft
X dist. Schaft
dist. Gelenk

Beschreibung:

Ein Fragment eines Radius distal links.
Verband: Verband

\section{Alter:}

Geschlecht:

Arthrose: 

Bezeichn.: Radius
Kiste: $\quad 5243267$
Skelet: Zettel
Population: Calden
Seite: links
Erhaltung: $\square$ prox. Gelenk prox. Schaft
mittl. Schaft
X dist. Schaft dist. Gelenk
Beschreibung:

Fragment distal links.
Verband: $\quad \square$ Verband

\section{Alter:}

Geschlecht:

Arthrose: 
$\begin{array}{ll}\text { Bezeichn.: } & \text { Radius } \\ \text { Kiste: } & 5243267\end{array}$

Skelet: P.Sk.1.

Population: Calden

Seite: rechts

Erhaltung: $\mathbf{X}$ prox. Gelenk

$X$ prox. Schaft

mittl. Schaft

dist. Schaft dist. Gelenk

\section{Ges./Kr.: Gesund}

\section{Alter:}

Geschlecht:

Arthrose:

prox.

2

\section{Beschreibung:}

Hierbei handelt es sich um ein proximales Fragment eines rechten Radius, der von ausgeprägten Muskelmarken gesäumt ist. Außerdem finden sich hier Grabungsartefakte. 

Bezeichn.: Radius
Kiste: $\quad 5243267$
Skelet: 2. Tüte aus Calden
Population: Calden
Seite: links
Erhaltung: $\mathbf{X}$ prox. Gelenk
X prox. Schaft
$X$ mittl. Schaft
X dist. Schaft
dist. Gelenk

\section{Beschreibung:}

Ein Fragment eines linken Os radii, welches eher grazil ist.
Verband: $\quad \square$ Verband

Ges./Kr.: Gesund

\section{Alter:}

Geschlecht: $q>\hat{\jmath}$

Arthrose:

prox. 


\section{Bezeichn: Radius \\ Kiste: $\quad 5243267$ \\ Skelet: P.Sk.1.}

Population: Calden

Seite: links

Erhaltung: $\mathbf{X}$ prox. Gelenk

$X$ prox. Schaft

$X$ mittl. Schaft

dist. Schaft

dist. Gelenk

\section{Beschreibung:}

Ein Fragment eines linken Os radii
Verband: $\quad$ Verband

Ges./Kr.: Gesund

\section{Alter:}

Geschlecht:

Arthrose:

prox. 


\section{Bezeichn.: Radius \\ Kiste: $\quad 5243267$ \\ Skelet: 2. Tüte aus Calden \\ Population: Calden \\ Seite: rechts \\ Erhaltung: $\square$ prox. Gelenk \\ prox. Schaft \\ mittl. Schaft \\ $\mathbf{X}$ dist. Schaft \\ $\mathbf{X}$ dist. Gelenk \\ Beschreibung:}

Ein distales Fragment.
Verband: $\square$ Verband

\section{Alter:}

\section{Geschlecht:}

Arthrose:

dist. 

Bezeichn.: Radius
Kiste: $\quad 5243267$
Skelet: 2. Tüte aus Calden
Population: Calden
Seite: links
Erhaltung: $\square$ prox. Gelenk
$X$ prox. Schaft
$X$ mittl. Schaft
$\mathbf{X}$ dist. Schaft
$\mathbf{X}$ dist. Gelenk

Verband: $\square$ Verband

Ges./Kr.: Krank

Alter:

Krankh.: Periostreizung

Geschlecht:

Beschreibung:

Ein Fragment eines linken Os radii, es ist proximal nicht erhalten. Auf der Oberfläche finden sich leicht streifige Spuren einer Periostreizung. 

Bezeichn.: Radius
Kiste: $\quad 5243267$
Skelet: 2. Tüte aus Calden
Population: Calden
Seite: rechts
Erhaltung: $\square$ prox. Gelenk
prox. Schaft
$X$ mittl. Schaft
dist. Schaft
dist. Gelenk

Verband: $\quad \square$ Verband

\section{Alter:}

Geschlecht:

Beschreibung:

Dieses mittige Fragment eines rechten Radius weist Grabungsartefakte auf. 


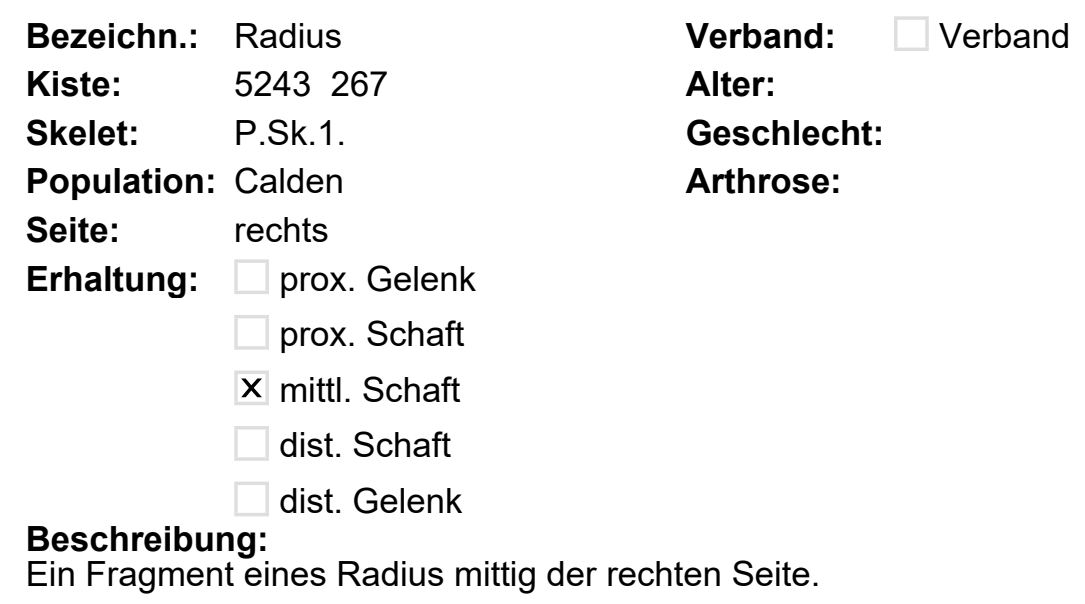



Bezeichn:: Radius
Kiste: $\quad 5243267$
Skelet: P.Sk.1.
Population: Calden
Seite: rechts
Erhaltung: $\square$ prox. Gelenk
prox. Schaft
$X$ mittl. Schaft
dist. Schaft
dist. Gelenk
Beschreibung:
Ein mittiges Radiusfragment. 


\section{Bezeichn: Radius \\ Kiste: $\quad 5243267$ \\ Skelet: Zettel}

Population: Calden

Seite: rechts

Erhaltung: $\square$ prox. Gelenk

prox. Schaft

$X$ mittl. Schaft

dist. Schaft

dist. Gelenk

Beschreibung:

Ein mittiges Fragment.
Verband: Verband

\section{Alter:}

Geschlecht:

Arthrose: 


\section{Bezeichn.: Radius \\ Kiste: $\quad 5243267$ \\ Skelet: keine Beschriftung \\ Population: Calden \\ Seite: links \\ Erhaltung: $\mathbf{X}$ prox. Gelenk \\ X prox. Schaft \\ $X$ mittl. Schaft \\ dist. Schaft \\ dist. Gelenk \\ Beschreibung:}

Verband: $\quad$ Verband

Ges./Kr.: Gesund

\section{Alter:}

Geschlecht:

Arthrose:

prox 

Bezeichn.: Radius
Kiste: $\quad 5243267$
Skelet: Zettel
Population: Calden
Seite: links
Erhaltung: $\mathbf{X}$ prox. Gelenk
$X$ prox. Schaft
mittl. Schaft
dist. Schaft
dist. Gelenk

\section{Beschreibung:}

Ein proximales Fragment in recht gutem Erhaltungszustand.
Verband: $\square$ Verband

Ges./Kr.: Gesund

\section{Alter:}

Geschlecht:

Arthrose:

prox. 


\section{Bezeichn.: Radius \\ Kiste: $\quad 5261277$ \\ Skelet: Zettel}

Population: Calden

Erhaltung: $\quad \mathbf{X}$ prox Gelenk

prox. Schaft

mittl. Schaft

dist. Schaft

dist. Gelenk

\section{Beschreibung:}

Ein Fragment der proximalen Gelenkfläche eines Radius. Die Seite blieb leider unbestimmbar.
Verband: $\quad$ Verband

Ges./Kr.: Gesund

\section{Alter:}

Geschlecht:

Arthrose:

prox.

1 

Bezeichn:: Radius
Kiste:
5261277
Skelet: $\quad$ über Sk.11+SCH.8.
Population: Calden
Seite:
links
Erhaltung: prox. Gelenk
$X$ prox. Schaft
$X$ mittl. Schaft
$\mathbf{X}$ dist. Schaft
$\mathbf{X}$ dist. Gelenk

Beschreibung:

Ein fast vollständiges Fragment eines linken Os radii.
Verband: $\quad$ Verband

\section{Alter:}

Geschlecht:

dist. 

Bezeichn.: Radius
Kiste: $\quad 52651-3279$
Skelet: Zettel
Population: Calden
Seite: rechts
Erhaltung: $\square$ prox. Gelenk
prox. Schaft
$X$ mittl. Schaft
X dist. Schaft
dist. Gelenk
Beschreibung:

Ein distales Fragment eines Os radii.
Verband: $\quad \square$ Verband

\section{Alter:}

Geschlecht:

Arthrose: 


\section{Bezeichn.: Radius}

Kiste: $\quad 5257+58275$

Skelet: V26 SK9 17

Population: Calden

Seite: rechts

Erhaltung: $\mathbf{X}$ prox. Gelenk

$X$ prox. Schaft

$X$ mittl. Schaft

$\mathbf{X}$ dist. Schaft

X dist. Gelenk

Beschreibung:

Ein vollständiges Os radii der rechten Seite.
Verband: $\square$ Verband

\section{Alter:}

Ges./Kr.: Gesund

Geschlecht:

Arthrose:

prox.

dist.

2

2
Maß

Länge

\begin{tabular}{l|l} 
Wert & Einheit \\
\hline 215 & $\mathrm{~mm}$
\end{tabular}




\section{Bezeichn.: Radius \\ Kiste: $\quad 5263278$ \\ Skelet: Zettel}

Population: Calden

Seite: rechts

Erhaltung: $\square$ prox. Gelenk

$X$ prox. Schaft

$X$ mittl. Schaft

X dist. Schaft

dist. Gelenk

\section{Beschreibung:}

Dieses Fragment eines rechten Os radii ist nach medial konkav gekrümmt.
Verband: $\quad \square$ Verband

\section{Alter:}

Geschlecht:

Arthrose: 


\section{Bezeichn.: Radius \\ Kiste: $\quad 5263278$ \\ Skelet: V24 P16+18 \\ Erhaltung: $\square$ prox. Gelenk \\ $X$ prox. Schaft \\ $X$ mittl. Schaft \\ X dist. Schaft \\ X dist. Gelenk \\ Beschreibung:}

Verband: $\quad \square$ Verband

Ges./Kr.: Krank

\section{Alter:}

Geschlecht:

Arthrose:

dist.

Ein Fragment, bei dem lediglich das proximale Teile des Radius fehlt. Der Knochen ist stark belastet worden, so zeigt er an m. brachio-radialis, pronator teres, biceps brachii und abductor pollicis longus muskuläre Reize. 

Bezeichn.: Radius
Kiste: $\quad 8505719$
Skelet: Zettel
Population: Calden
Seite: rechts
Erhaltung: $\mathbf{X}$ prox. Gelenk
$X$ prox. Schaft
mittl. Schaft
dist. Schaft
dist. Gelenk

Beschreibung:

Ein proximales Fragment eines Os radii.
Verband: $\quad \square$ Verband

\section{Alter:}

Geschlecht:

Arthrose:

prox.

1 


\section{Bezeichn.: Radius \\ Kiste: \\ 8505719 \\ Skelet: Zettel}

Population: Calden

Seite:

links

Erhaltung: $\square$ prox. Gelenk

prox. Schaft

mittl. Schaft

X dist. Schaft

X dist. Gelenk

Beschreibung:

Ein Fragment aus dem distalen Teil des Schaftes eines Radius.
Verband: Verband

\section{Alter:}

Geschlecht:
Arthrose:

dist.

Ges./Kr.: Gesund 


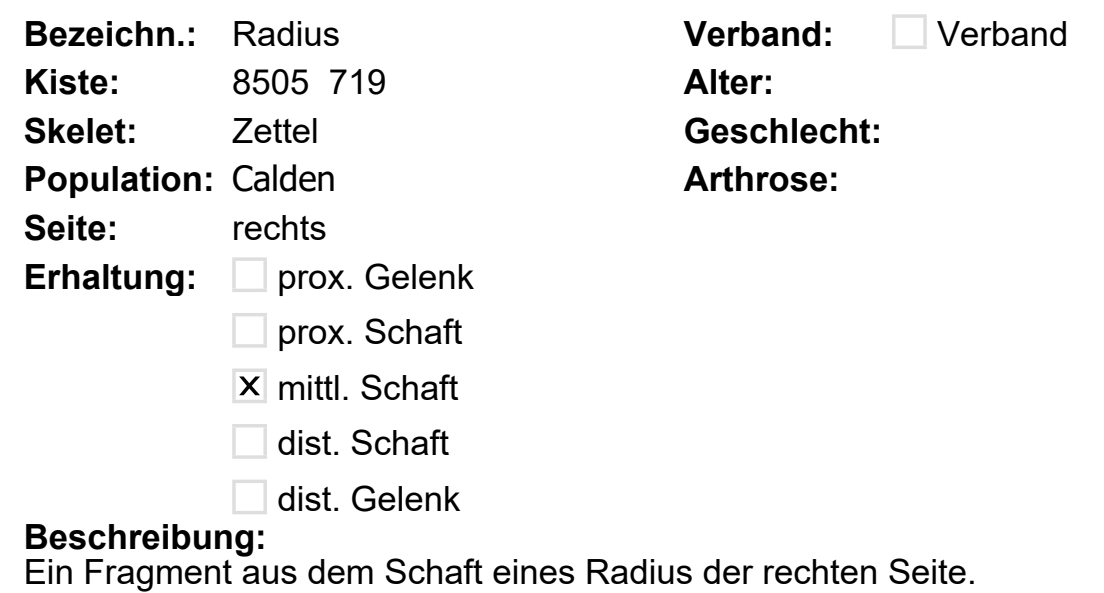

Ein Fragment aus dem Schaft eines Radius der rechten Seite. 


\begin{tabular}{|c|c|c|c|c|c|c|c|}
\hline Bezeichn.: & Radius & Verband: & $\square$ Verband & Ges./Kr.: Gesund & Maß & Wert & Einheit \\
\hline Kiste: & 5245269 & Alter: & & & Länge & 225 & $\mathrm{~mm}$ \\
\hline Skelet: & Sk4 18 & Geschlecht: & & & & & \\
\hline Population: & Calden & Arthrose: & & & & & \\
\hline Seite: & links & & prox. & 2 & & & \\
\hline Erhaltung: & X prox. Gelenk & & dist. & 2 & & & \\
\hline & X prox. Schaft & & & & & & \\
\hline & X mittl. Schaft & & & & & & \\
\hline & $\mathbf{X}$ dist. Schaft & & & & & & \\
\hline & X dist. Gelenk & & & & & & \\
\hline
\end{tabular}

\section{Beschreibung:}

Dieser linke Radius ist kräftig, wenn auch recht klein und vollständig erhalten ohne auffällige Defekte. Lediglich sind flechtenförmige, dunkle Verfärbungen zu finden. Es fallen mehrere Muskelmarken auf: Membrana interossea, Ansatz des M. brachioradialis, Ansatz M. biceps brachii (mit leichter Zerrung) und M. pronator teres, welcher so stark ausgeprägt ist, dass hier von einer starken Muskelreizung gesprochen werden darf. 


\section{Bezeichn.: Radius \\ Kiste: 5254272 \\ Skelet: V8}

Population: Calden

Erhaltung: $\mathbf{X}$ prox. Gelenk

$\mathbf{X}$ prox. Schaft

mittl. Schaft

dist. Schaft dist. Gelenk

\section{Beschreibung:}

Ein proximales Fragment eines jungen Radius, welches Erosionsspuren zeigt.$$
\text { Jung }
$$

Geschlecht:

Arthrose:

\section{Verband:

$$
\text { Verband }
$$ \\ Ges./Kr.: Gesund}

\section{Maß}

Breite Epiphyse distal

Länge

\begin{tabular}{|l|l} 
Wert & Einheit \\
12,5 & $\mathrm{~mm}$ \\
53 & $\mathrm{~mm}$ \\
&
\end{tabular}




\begin{tabular}{|c|c|}
\hline Bezeichn.: & Radius \\
\hline Kiste: & 5266281 \\
\hline Skelet: & 3 \\
\hline Population: & Calden \\
\hline Seite: & links \\
\hline Erhaltung: & X prox. Gelenk \\
\hline & X prox. Schaft \\
\hline & $\mathbf{X}$ mittl. Schaft \\
\hline & $\mathbf{X}$ dist. Schaft \\
\hline & $\mathbf{X}$ dist. Gelenk \\
\hline
\end{tabular}

Verband: $\quad \square$ Verband $\quad$ Ges./Kr.: Gesund

Alter:

Geschlecht:

Arthrose:

prox.

dist.
Maß

Länge

US

\begin{tabular}{|l|l} 
Wert & Einheit \\
\hline 228 & $\mathrm{~mm}$
\end{tabular}

Hier liegt ein vollständiger Radius vor, die Membrana interossea ist gut ausgeprägte. 

Bezeichn:: Radius
Kiste: $\quad 5266280$
Skelet: 5
Population: Calden
Seite: rechts
Erhaltung: $\square$ prox. Gelenk
prox. Schaft
mittl. Schaft
$\mathbf{X}$ dist. Schaft
X dist. Gelenk
Beschreibung:

$\begin{array}{ll}\text { Verband: } \quad \square \text { Verband } & \text { Ges./Kr.: Krank } \\ \text { Alter: } & \text { Krankh.: Arthrose }\end{array}$

\begin{tabular}{l|l|l} 
Maß & Wert & Einheit \\
\hline Länge & 179 & $\mathrm{~mm}$ \\
US & 46 & $\mathrm{~mm}$ \\
& & \\
& &
\end{tabular}

Geschlecht:

Arthrose:

Ein Fragment eines rechten Os radii, die Oberfläche ist glatte, es finden sich nur leichte Erosion und nur wenig Verfärbung. 


\begin{tabular}{|c|c|c|c|c|c|c|c|}
\hline Bezeichn.: & Radius & Verband: & $\square$ Verband & Ges./Kr.: Gesund & Maß & Wert & Einheit \\
\hline Kiste: & 5266280 & Alter: & & & Länge & 222 & $\mathrm{~mm}$ \\
\hline Skelet: & 3 & Geschlecht: & & & & & \\
\hline Population: & Calden & Arthrose: & & & & & \\
\hline Seite: & rechts & & prox. & 1 & & & \\
\hline Erhaltung: & X prox. Gelenk & & dist. & 2 & & & \\
\hline & X prox. Schaft & & & & & & \\
\hline & X mittl. Schaft & & & & & & \\
\hline & $\mathbf{X}$ dist. Schaft & & & & & & \\
\hline & X dist. Gelenk & & & & & & \\
\hline
\end{tabular}

\section{Beschreibung:}

Bei diesem Radius liegt ein gut ausgeprägter Margo interosseus und auch sonst gut erkennbare Muskelmarken vor. Es fällt ein kleinerer Einschnitt distal auf der posterioren Seite auf, der aussieht wie ein Sägeschnitt. Die Oberfläche ist recht glatte und gut erhaltene. Allerdings finden sich ein paar Verfärbungen und ein paar Wurm/Wurzellöcher, die besonders mittig ins Auge fallen. 


$\begin{array}{ll}\text { Bezeichn.: } & \text { Radius } \\ \text { Kiste: } & 5266281 \\ \text { Skelet: } & 1 \\ \text { Population: } & \text { Calden } \\ \text { Seite: } & \text { rechts } \\ \text { Erhaltung: } & \mathbf{X} \text { prox. Gelenk } \\ & \text { X prox. Schaft } \\ & \mathbf{X} \text { mittl. Schaft } \\ & \mathbf{X} \text { dist. Schaft } \\ & \mathbf{X} \text { dist. Gelenk }\end{array}$

Verband: $\quad \square$ Verband $\quad$ Ges./Kr.: Gesund

Alter:

Geschlecht:

Arthrose:

prox. $\quad 1$

Bei diesem Radius liegt eine ausgeprägte Linea interossea vor. Ansonsten sind keine auffälligen Muskelmarken zu erkennen. 


$\begin{array}{ll}\text { Bezeichn.: } & \text { Radius } \\ \text { Kiste: } & 8505721 \\ \text { Skelet: } & \text { aus großer Kiste } \\ \text { Population: } & \text { Calden } \\ \begin{array}{ll}\text { Seite: } & \text { rechts } \\ \text { Erhaltung: } & \mathbf{X} \text { prox. Gelenk } \\ & \mathbf{X} \text { prox. Schaft } \\ & \square \text { mittl. Schaft } \\ & \square \text { dist. Schaft } \\ & \square \text { dist. Gelenk }\end{array}\end{array}$

Verband: $\square$ Verband

Alter:

Geschlecht: +

Arthrose:

prox.

Bei diesem Fundstück handelt es sich um ein Fragment eines rechten Radius, es sind etwa 40\% proximal erhalten. Es wirkt recht grazil. 


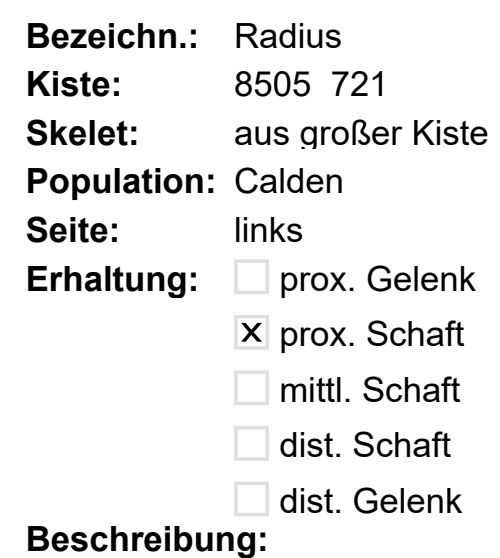

Hier ist ein proximales Fragment aus dem Schaft eines linken Radius erhalten. 


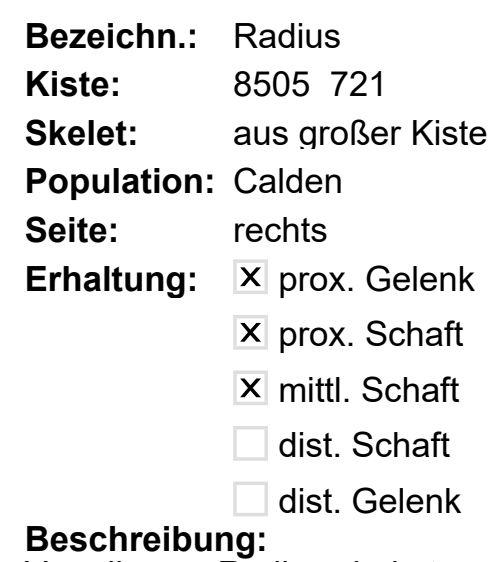

Von diesem Radius sind etwa 40\% proximal erhalten. Das Caput radii ist teilweise erodiert. 

Bezeichn:: Radius
Kiste: $\quad 5243267$
Skelet: 2. Tüte aus Calden
Population: Calden
Seite: rechts
Erhaltung: $\mathbf{X}$ prox. Gelenk
prox. Schaft
mittl. Schaft
dist. Schaft
dist. Gelenk
Beschreibung:

Ein Os radii rechts proximal.
Verband: $\quad \square$ Verband

\section{Alter:}

Geschlecht:

Arthrose:

prox. 
Bezeichn.: Os Lunatum

Kiste: $\quad 8505718$

Skelet: aus 2. Kiste

Population: Calden

Seite:

links
Verband: Verband

\section{Alter:}

Geschlecht:

Arthrose:

\section{Beschreibung:}


Bezeichn.: Os Pisiforme

Kiste: $\quad 5261277$

Skelet: $\quad$ V33 kleine Tüte

Population: Calden

Seite:

rechts
Verband: Verband

Alter: Erwachsen

\section{Geschlecht:}

Arthrose:

\section{Beschreibung:}

Os pisiforme aus einem Verband. 
Bezeichn.: Os Capitatum

Kiste: $\quad 8505718$

Skelet: aus 2. Kiste

Population: Calden

Seite:

rechts
Verband: Verband

\section{Alter:}

Geschlecht:

Arthrose:

\section{Beschreibung:}


Bezeichn.: Os Capitatum

Kiste: $\quad 5256274$

Skelet: Zettel

Population: Calden

Seite:

links
Verband: Verband

\section{Alter:}

Geschlecht:

Arthrose:

\section{Beschreibung:}


Bezeichn.: Os Capitatum

Kiste: $\quad 5261277$

Skelet: $\quad$ V33 kleine Tüte

Population: Calden

Seite:

links
Verband: Verband

Alter: Erwachsen

\section{Geschlecht:}

Arthrose:

\section{Beschreibung:}

Ein Os capitatum aus einem Verband. 
Bezeichn.: Os Capitatum

Kiste: $\quad 8505719$

Skelet: Zettel

Population: Calden

Seite:

links
Verband: Verband

\section{Alter:}

Geschlecht:

Arthrose:

\section{Beschreibung:}


Bezeichn.: Os Capitatum

Kiste: $\quad 5245269$

Skelet: gesammelt

Population: Calden

Seite:

rechts
Verband: Verband

\section{Alter:}

Geschlecht:

Arthrose:

\section{Beschreibung:}


Bezeichn:: Os Hamatum

Kiste: $\quad 5266281$

Skelet: $\quad$ V65 aus Tüte 4

Population: Calden

Seite:

rechts
Verband: $\quad$ Verband

\section{Alter:}

Geschlecht:

Arthrose:

\section{Beschreibung:}

Ein Os hamatum 1. 
Bezeichn.: Os Hamatum

Kiste: $\quad 8505718$

Skelet: aus 2. Kiste

Population: Calden

Seite:

rechts
Verband: Verband

\section{Alter:}

Geschlecht:

Arthrose:

\section{Beschreibung:}


Bezeichn.: Os Hamatum

Kiste: $\quad 8505718$

Skelet: aus 2. Kiste

Population: Calden

Seite:

links
Verband: Verband

\section{Alter:}

Geschlecht:

Arthrose:

\section{Beschreibung:}


Bezeichn.: Os Hamatum

Kiste: $\quad 5261277$

Skelet: $\quad$ V33 kleine Tüte

Population: Calden

Seite:

links
Verband: $\square$ Verband

Alter: Erwachsen

Geschlecht:

Arthrose:

\section{Beschreibung:}

Os hamatum aus einem Verband. 
Bezeichn.: Os Scaphoideum

Kiste: $\quad 8505718$

Skelet: aus 2. Kiste

Population: Calden

Seite:

links
Verband: Verband

\section{Alter:}

Geschlecht:

Arthrose:

\section{Beschreibung:}


Bezeichn.: Os Scaphoideum Kiste: 8505718

aus 2. Kiste

Skelet:

Population: Calden

Seite:

rechts
Verband: Verband

\section{Alter:}

Geschlecht:

Arthrose:

\section{Beschreibung:}


Bezeichn.: Os Scaphoideum Kiste: 8505718

aus 2. Kiste

Skelet:

Population: Calden

Seite:

rechts
Verband: Verband

\section{Alter:}

Geschlecht:

Arthrose:

\section{Beschreibung:}


Bezeichn.: Os Triquetrum

Kiste: $\quad 5267282$

Skelet: einzeln

Population: Calden

Seite:

links

Verband: $\quad$ Verband

\section{Alter:}

Geschlecht:

Arthrose:

\section{Beschreibung:}


Bezeichn.: Os Trapezium

Kiste: $\quad 5243267$

Skelet: Zettel

Population: Calden

Seite:

rechts

Verband: Verband

\section{Alter:}

Geschlecht:

Arthrose:

\section{Beschreibung:}


Bezeichn.: Os Trapezium

Kiste: $\quad 5256274$

Skelet: Zettel

Population: Calden

Seite:

links

Verband: Verband

\section{Alter:}

Geschlecht:

Arthrose:

\section{Beschreibung:}


Bezeichn.: Os Trapezium

Kiste: $\quad 52651-3279$

Skelet: Zettel

Population: Calden

Seite:

links

Verband: Verband

Alter:

Geschlecht:

Arthrose:

\section{Beschreibung:}


Bezeichn.: Os Metacarpale

Kiste: $\quad 5243267$

Skelet: Zettel

Population: Calden

Seite:

links

Verband: Verband

\section{Alter:}

Geschlecht:

Arthrose:

\section{Beschreibung:}


Bezeichn.: Os Metacarpale

Kiste:

5272290

Skelet:

Verband:

Verband

Alter:

Ges./Kr.: Gesund

Population: Calden

Arthrose:

\section{Beschreibung:}

Ein Os metacarpale eines jungen Individuums. 
Bezeichn.: Os Metacarpale

Kiste:

5266281

V65 aus Tüte 4

Polet:

Seite:

rechts
Verband: $\quad$ Verband

\section{Alter:}

Geschlecht:

Arthrose:

\section{Beschreibung:}

Ein Os metacarpale 1 der rechten Seite. 
Bezeichn.: Os Metacarpale

Kiste:

5266281

V65 aus Tüte 4

Skelet:

Seite:

rechts
Verband:

Verband

\section{Alter: \\ Geschlecht:}

Arthrose:

\section{Beschreibung:}

Os metacarpale 2 rechts. 
Bezeichn.: Os Metacarpale

Kiste:

5266281

V65 aus Tüte 4

Skelet:

Seite:

rechts
Verband: $\quad$ Verband

\section{Alter:}

Geschlecht:

Arthrose:

\section{Beschreibung:}

Os metacarpale 3 rechts. 
Bezeichn.: Os Metacarpale

Kiste:

5266281

V65 aus Tüte 4

Skelet:

Seite:

rechts
Verband: $\quad$ Verband

\section{Alter:}

Geschlecht:

Arthrose:

\section{Beschreibung:}

Os metacarpale 4 rechts. 
Bezeichn.: Os Metacarpale

Kiste:

5266281

V65 aus Tüte 4

Skelet:

Seite:

rechts
Verband:

Verband

\section{Alter: \\ Geschlecht:}

Arthrose:

\section{Beschreibung:}

Os metacarpale 5 rechts. 
Bezeichn.: Os Metacarpale

Kiste:

5266281

V65 aus Tüte 4

Skelet:

Seite:

links
Verband:

Verband

\section{Alter: \\ Geschlecht:}

Arthrose:

\section{Beschreibung:}

Os metacarpale 1 links. 
Bezeichn.: Os Metacarpale

Kiste:

5266281

V65 aus Tüte 4

Skelet:

Seite:

rechts
Verband: $\quad$ Verband

\section{Alter:}

Geschlecht:

Arthrose:
Beschreibung:

Ein Os metacarpale 5. 
Bezeichn.: Os Metacarpale

Kiste:

5267283

bei Calden 6

Population: Calden

Seite:

rechts
Verband:

\section{Alter:}

Ges./Kr.: Gesund

Geschlecht:

Arthrose:

\section{Beschreibung:}

Ein Os metacarpale 4 eines jungen Individuums. 
Bezeichn.: Os Metacarpale

Kiste: $\quad 5243267$

Skelet: P.Sk.1.

Population: Calden

Seite: rechts

\section{Beschreibung:}

Verband: Verband

Alter:

Geschlecht:

Arthrose: 
Bezeichn:: Os Metacarpale

\section{Kiste:} 5243267

P.Sk.1.

Skelet: Population: Calden

Seite: rechts

\section{Beschreibung:}

Verband: Verband

Ges./Kr.: Gesund

\section{Alter:}

Geschlecht:

Arthrose: 
Bezeichn.: Os Metacarpale

Kiste:

5256274

Skelet: Zettel

Population: Calden

Seite:

links
Verband: Verband

\section{Alter:}

Geschlecht:

Arthrose:

\section{Beschreibung:}

Ein Os metacarpale 1 der linken Seite. 
Bezeichn.: Os Metacarpale

Kiste:

5256274

Zettel

Population: Calden

Seite:

rechts
Verband: Verband

\section{Alter:}

Geschlecht:

Arthrose:

Beschreibung:

Ein Os metacarpale 4 der rechten Seite. 
Bezeichn.: Os Metacarpale

Kiste:

5256274

Zettel

Population: Calden

Seite:

rechts
Verband: Verband

\section{Alter:}

Geschlecht:

Arthrose:

\section{Beschreibung:}

Ein Os metacarpale 5 der rechten Seite. 
Bezeichn.: Os Metacarpale

Kiste:

5261277

Skelet: $\quad$ V33 kleine Tüte

Population: Calden

Seite:

links
Verband: Verband

Alter: Erwachsen

Geschlecht:

Arthrose:

Beschreibung:

Ein Os metacarpale 2 der linken Seite. 
Bezeichn.: Os Metacarpale

Kiste:

5261277

Skelet: $\quad$ V30 kleine Tüte

Population: Calden

Seite:

links

Verband: Verband

\section{Alter:}

Geschlecht:

Arthrose:

\section{Beschreibung:}

Ein Os metacarpale 3 der linken Seite. 
Bezeichn:: Os Metacarpale

Kiste:

5245269

gesammelt

Skelet:

Population: Calden

Seite:

rechts
Verband: Verband

\section{Alter:}

Geschlecht:

Arthrose:

\section{Beschreibung:}

Ein Os metacarpale 1 der rechten Seite. 
Bezeichn.: Os Metacarpale

Kiste:

5245269

bei Becken 4 .

Pkelet:

Seite:

links
Verband:

Verband

\section{Alter:}

Geschlecht:

Arthrose:

\section{Beschreibung:}

Ein Os metacarpale 2 der linken Seite. 


\begin{tabular}{|c|c|c|c|c|c|c|}
\hline Bezeichn.: & Os Metacarpale & Verband: $\quad \square$ Verband & Ges./Kr.: Gesund & Maß & Wert & Einheit \\
\hline Kiste: & 8505721 & Alter: & & Länge & 47,15 & $\mathrm{~mm}$ \\
\hline Skelet: & Kiste 12 & Geschlecht: & & & & \\
\hline Population: & Calden & Arthrose: & & & & \\
\hline Seite: & links & & & & & \\
\hline
\end{tabular}

\section{Beschreibung:}

Dieses erste Os metacarpale der rechten Seite ist zu 100\% erhalten und nicht erodiert. Es weist deutliche Muskelreizungen auf, was für eine Rechtshändigkeit und starke Beanspruchung sprechen dürfte. 
Bezeichn.: Os Metacarpale

Kiste:

5256274

Zettel

Population: Calden

Seite:

links
Verband: Verband

\section{Alter:}

Geschlecht:

Arthrose:
Beschreibung:

Ein Os metacarpale 4 der linken Seite. 
Bezeichn.: Os Metacarpale

Kiste:

5245269

bei Becken Sk.4.

Pkelet: Calden

Seite:

links
Verband: Verband

\section{Alter:}

Geschlecht:

Arthrose:

\section{Beschreibung:}

Ein Os metacarpale 3 der linken Seite. 
Bezeichn.: Os Sacrum

Kiste: $\quad 8505720$

Skelet: $\quad 1.0$

Population: Calden

Seite:
Verband:

Verband

Ges./Kr.: Gesund

Alter:

Geschlecht:

Arthrose:

proc. art. sup. li. 1

\section{Beschreibung:}

Dieses Fundstück ist ein Fragment des Processus articularis superior eines Os sacrum. 


\section{Bezeichn. \\ Kiste: \\ 8505720 \\ Skelet: $\quad 1.2$}

Population: Calden
Verband:

Verband

\section{Alter:}

Geschlecht:

Arthrose:

\section{Beschreibung:}

Nur ein kleines Fragment der Crista sacralis mediana 
Bezeichn.: Os Sacrum

Kiste: $\quad 8505720$

Skelet:

Population: Calden
Verband: $\quad$ Verband

\section{Alter:}

Geschlecht:

Arthrose:

\section{Beschreibung:}

Dieses Fundstück ist ein Fragment eines Os sacrum. 


\section{Bezeichn.: Os Sacrum \\ Kiste: \\ 5249270 \\ Skelet: \\ V63 4}

Population: Calden
Verband: $\square$ Verband

\section{Alter: $\quad 35-45$ (50)}

Geschlecht: 우

Arthrose:
Ges./Kr.: Gesund

\section{Maß}

Breite

S1 \begin{tabular}{|l|l} 
Wert & Einheit
\end{tabular}

50,94

\section{Beschreibung:}

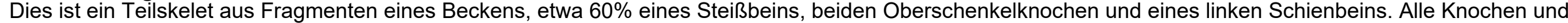
Knochenfragmente sind in gutem Erhaltungszustand und wenig erodiert, es sind lediglich wenige kleine Knochenteile abfrakturiert. Die Tibia weist eine leichte

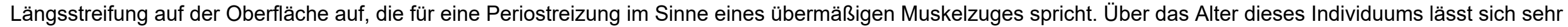

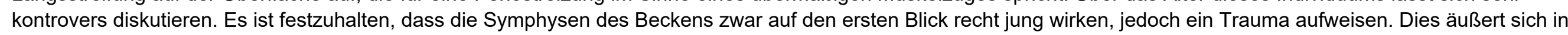

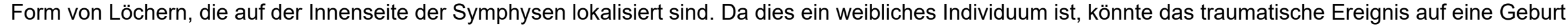

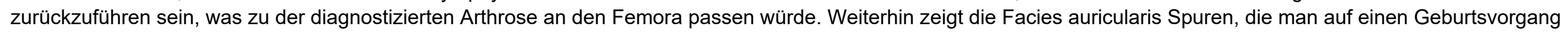

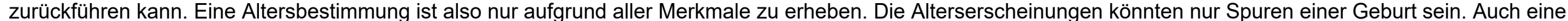

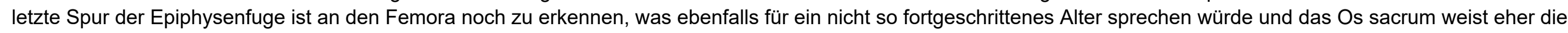
Gesamterscheinung eines Menschen im mittleren Alter auf. 


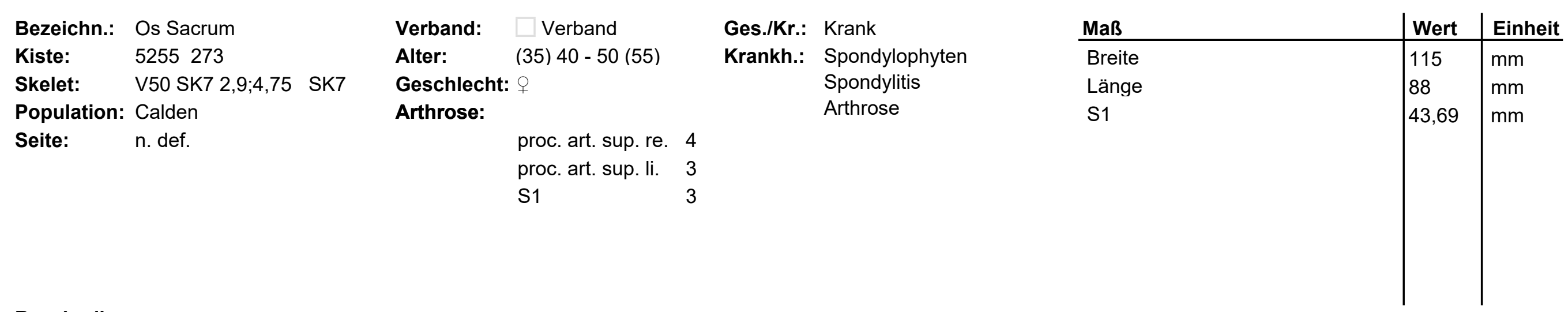

\section{Beschreibung:}

Dieser Verband besteht aus einem Os sacrum, dem linken Teil des Beckens, beiden Femora, der rechten Patella, beiden Tibiae und dem rechten Talus. Das Os sacrum ist zu etwa 60\% erhalten und weist Spuren von krankhaften Veränderungen auf: Spondylitis am Sacralsegment 1, welches sich nach rechts ausgeweitet hat (etwa 20mm). Der Rand weist leichte Spondylophyten auf (bis 3,3mm). Vom Becken ist nur die linke Seite erhalten, welche jedoch Erosionsspuren aufzeigt. Außerdem finden sich leichte Zeichen eines entzündlichen Prozesses am Rand des Acetabulums. Hier ist der verschleißende arthrotische Prozess in einen entzündlichen arthritischen Prozess übergegangen. Das linke Os femoris ist zu etwa 99\% gut erhalten und zeigt die zum Becken passende Arthrose, bzw. leichte Arthritis. Das rechte Os femoris ist ebenfalls gut erhalten und weist eine Auffälligkeit im unteren Drittel $(43 \mathrm{~mm} \times 12 \mathrm{~mm} \times 6 \mathrm{~mm})$ auf. Es handelt sich dabei um eine Verknöcherung im Sinne einer Ligamentopathie, die aus einer Zerrung des M. vastus lateralis stammt. Die sichtbaren Muskelmarken der Femora sind ausgeprägt, auch wenn sie eher grazil sind: M. vastus medialis, M. adductor magnus und M. plantaris distal und proximal der M. gluteus maximus und die Linea aspera. Die rechte Patella weist im Vergleich zu anderen Patellae der Population kaum Bandverknöcherungen auf. Auch die auf der Innenseite typische Arthrose ist nur mit Grad 2 ausgeprägt und damit eher unauffällig. Die linke Tibia zeigt in Schaftmitte ein subperiostales Hämatom $(21 \mathrm{~mm} \times 10 \mathrm{~mm})$, welches wahrscheinlich durch "einen Tritt ans Schienbein" entstanden ist. Die linke Tibia ist nur sehr wenig durch Erosionsspuren gezeichnet und zu etwa $99 \%$ sehr gut erhalten. Die rechte Tibia ist ebenfalls zu etwa 99\% erhalten, weist lediglich leichte Erosionsspuren am proximalen Gelenk auf. Der rechte Talus ist zu etwa 98\% erhalten und weist insgesamt einen unauffälligen Arthrosegrad von 2 auf. 
$\begin{array}{ll}\text { Bezeichn.: } & \text { Os Sacrum } \\ \text { Kiste: } & 5242266 \\ \text { Skelet: } & \text { E.B.-S 3. Tüte }\end{array}$

Population: Calden

\section{Verband:}

\section{Alter:}

Verband

12 - 16 (18)

Geschlecht:

Arthrose:
Ges./Kr.: Krank

Krankh.: Arthrose

\section{Maß}

Breite

Iliosacralgelenk anterior-

Iliosacralgelenk medial-latera

\begin{tabular}{|l|l} 
Wert & Einheit \\
110 & $\mathrm{~mm}$ \\
31 & $\mathrm{~mm}$ \\
46 & $\mathrm{~mm}$
\end{tabular}

\section{Beschreibung:}

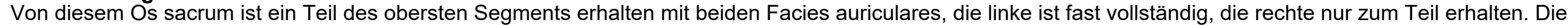
Gesamtkonstitution des Fundstücks spricht eher für ein junges Individuum. Das rechte Bogengelenk weist kleine plattenförmige Auflagerungen in Form von

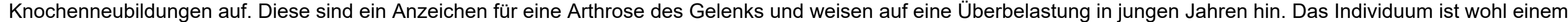
jungen Individuum zuzuordnen, was von der Größe und Konstitution des Fundstücks abzuleiten ist. 


\section{Bezeichn.: Os Sacrum \\ Kiste: \\ 5242266 \\ Skelet: 3. Tüte}

Population: Calden

\section{Verband: \\ Alter: \\ Verband \\ 12 - $16(18)$ \\ Geschlecht:}

Arthrose:
Ges./Kr.: Gesund

\section{Maß}

Breite

\begin{tabular}{|l|l}
\hline 104 & $\mathrm{~mm}$ \\
& \\
&
\end{tabular}

\section{Beschreibung:}

Dieses Fragment enthält die rechte Seite und einen Teil der Mitte von S1. Insgesamt ist es ein eher kleines Fundstück, welches unter Bodenerosionen gelitten hat. Die Konstitution des Os sacrum entspricht einem jungen Individuum. 


\section{Bezeichn.: Os Sacrum \\ Kiste: \\ 5242266 \\ Skelet: 3 . Tüte}

Population: Calden
Verband: $\quad \square$ Verband

Alter:

Geschlecht:

Arthrose:
Maß

Breite

Länge
Wert $\quad$ Einheit

$\begin{array}{ll}53 & \mathrm{~mm}\end{array}$

$56 \mathrm{~mm}$

\section{Beschreibung:}

Hier ist nur ein Fragment erhalten, es stammt aus der frontalen Fläche mit lineae transversae. 


\begin{abstract}
Bezeichn.: Os Sacrum
Kiste:

5242266

Skelet: $\quad 3$. Tüte
\end{abstract}

Population: Calden
Verband: $\quad$ Verband

Alter:

Geschlecht:

Arthrose:
Maß

Breite

Länge
Wert $\quad$ Einheit

$56 \mathrm{~mm}$

$57 \quad \mathrm{~mm}$

\section{Beschreibung:}

Fragment aus der hinteren Fläche mit Teil von Crista sacralis medialis. 


\section{Bezeichn.: Os Sacrum \\ Kiste: $\quad 5242266$ \\ Skelet: 3. Tüte}

Population: Calden
Verband: Verband

\section{Alter:}

Geschlecht:

Arthrose:

\section{Beschreibung:}

Hier ist nur ein kleines Fragment erhalten. 


\section{Bezeichn.: Os Sacrum \\ Kiste: \\ 5242266 \\ Skelet: \\ V52 E. B-S.}

Population: Calden
Verband: $\square$ Verband

\section{Alter: (16) $18-23$}

Geschlecht: $\lesssim$

Arthrose:
Ges./Kr.: Gesund

\begin{tabular}{l|l|l} 
Maß & Wert & Einheit \\
\hline Breite & 116 & $\mathrm{~mm}$ \\
Länge & 130 & $\mathrm{~mm}$ \\
S1 & 50 & $\mathrm{~mm}$ \\
& & \\
& & \\
& &
\end{tabular}

\section{Beschreibung:}

Dieser Verband aus 17 Wirbeln weist keine auffälligen Verschleißerscheinungen auf. Vielmehr wirken die überwiegend recht gut erhaltenen Wirbel eher jung. Die Verknöcherung ist allem Anschein nach noch nicht allzu lange vor dem Zeitpunkt des Todes geschehen. Hin und wieder fehlten bei den Fundstücken einzelne Segmente, wie Gelenkfortsätze oder der Wirbelbogen. Es wir ein Zusammenhang zwischen allen "gz1" angenommen, zumindest aber zwischen Os sacrum und diesem L5. Ein Zusammenhang für die gesamte Wirbelsäule darf aber angenommen werden, weil die Wirbel sich alle sehr ähnlich sehen und auch die Alterserscheinung miteinander übereinstimmen. Das Os sacrum ist zu 95\% erhalten, es fehlt lediglich der apex ossis sacri. Aufgrund der Form und Größe kann man sagen, dass es sich hier um ein männliches Individuum handelt. Es finden sich keine auffälligen Verschleißerscheinungen. 


\section{Bezeichn.: Os Sacrum \\ Kiste: $\quad 5242266$ \\ Skelet: E. B-S.}

Population: Calden
Verband: $\square$ Verband

\section{Alter:}

Geschlecht:

Arthrose:

\section{Beschreibung:}

Hier ist nur ein Fragment von der Crista sacralis mediana und medialis erhalten. 


\section{Bezeichn: Os Sacrum \\ Kiste: \\ 5242266 \\ Skelet:}

Population: Calden
Verband: $\quad \square$ Verband

Ges./Kr.: Gesund

\section{Alter:}

Geschlecht: $q<\circlearrowright$

Arthrose:

\section{Beschreibung:}

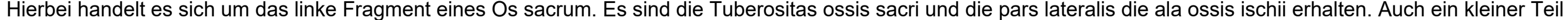
der Basis ossis sacri ist erhalten. Es weist eher männliche Merkmale auf. 


\begin{abstract}
Bezeichn.: Os Sacrum
Kiste:

5242266

Skelet: letzte Tüte
\end{abstract}

Population: Calden

Beschreibung:

Ein kleines Fragment.
Verband: $\quad$ Verband

\section{Alter:}

Geschlecht:

Arthrose:
Maß

Breite

Länge
Wert $\quad$ Einheit

20,39 $\mathrm{mm}$

42,25 


\section{Bezeichn.: Os Sacrum \\ Kiste: $\quad 8505718$ \\ Skelet: aus Kiste}

Population: Calden

Seite:

links

\section{Verband: $\quad \square$ Verband}

\section{Ges./Kr.: Gesund}

\section{Alter:}

Geschlecht: + 인

Arthrose:

\section{Beschreibung:}

Dieses Os sacrum ist nur in Form eines kleinen Fragmentes erhalten. Das Fragment macht einen grazilen Eindruck. 
$\begin{array}{ll}\text { Bezeichn:: } & \text { Os Sacrum } \\ \text { Kiste: } & 8505718 \\ \text { Skelet: } & \text { aus 2. Kiste }\end{array}$

Population: Calden

Seite:

links

\section{Verband: $\quad$ Verband}

Ges./Kr.: Gesund

\section{Alter:}

Geschlecht: $q$

Arthrose:

\section{Beschreibung:}

Dieses Os sacrum ist nur in Form eines Fragmentes erhalten. Das Fragment macht einen grazilen Eindruck. 


\section{Bezeichn: Os Sacrum \\ Kiste: \\ 8505718 \\ Skelet: \\ V39}

Population: Calden

\section{Verband: $\quad \square$ Verband \\ Alter: $\quad 30-50$ \\ Geschlecht: $q<\delta$ \\ Arthrose:}

Ges./Kr.: Krank

Krankh.: Spondylitis

Spondylosis

Spondylolisthesis

Spondylolysis

\section{Maß}

Breite S1

\begin{tabular}{|l|l} 
Wert & Einheit \\
\hline 74,33 & $\mathrm{~mm}$ \\
&
\end{tabular}

proc. art. sup. li.

5

\section{Beschreibung:}

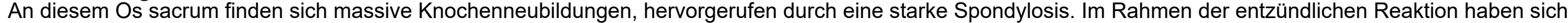
Spondylophyten gebildet, die v.a. rechts ausgebildet sind.

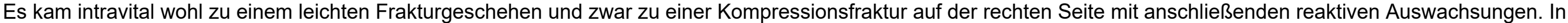

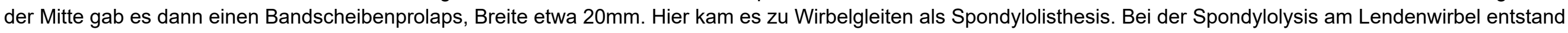
eine symmetrische laterale Bogenspalte. Als proliferierende Neubildung bildete sich im subadulten Alter eine Wulst. 


$\begin{array}{ll}\text { Kiste: } & 5252271 \\ \text { Skelet: } & \text { SK } 6\end{array}$

Skelet: SK 6

Population: Calden

Seite:
Verband: $\square$ Verband

\section{Alter: Erwachsen}

Geschlecht: $\delta$

Arthrose:

Ges./Kr.: Krank

Krankh.: Arthrose

Arthritis

proc. art. sup. re. 1

proc. art. sup. li. 4

s1

\section{Beschreibung:}

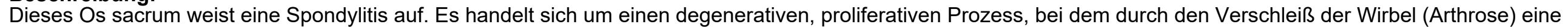

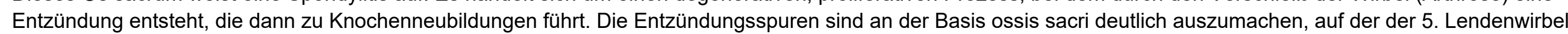

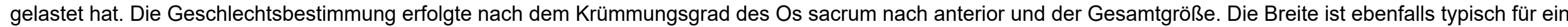

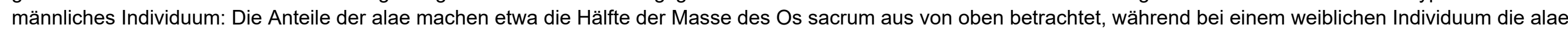

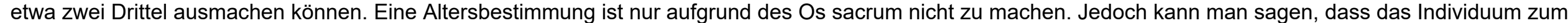

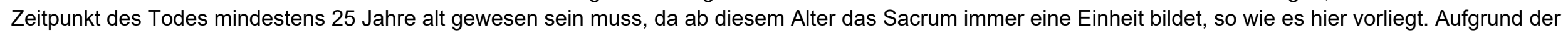
Verschleißerscheinungen der Basis ossis sacri ist jedoch ein Alter weit über 25 Jahren anzunehmen. 


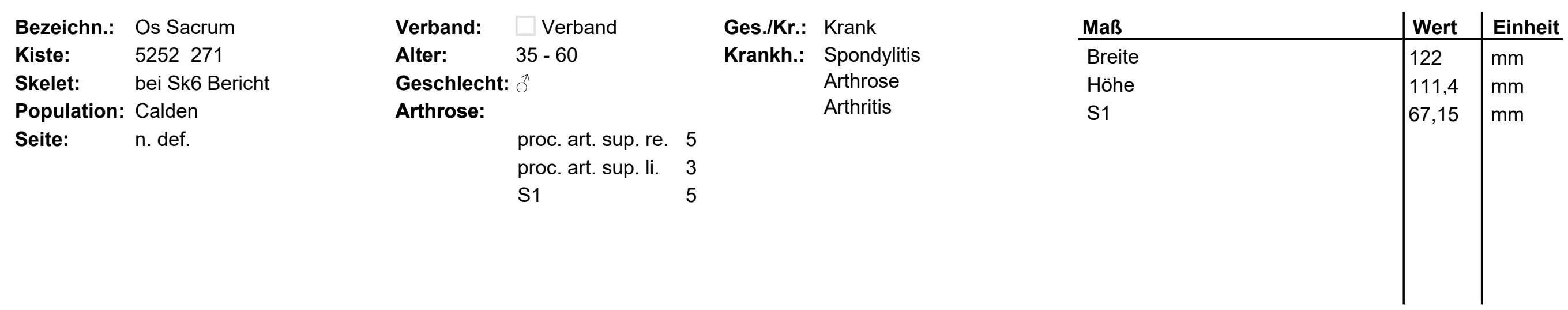

\section{Beschreibung:}

Bei diesem Fundstück handelt es sich um ein Os sacrum, welches eine Spondylitis und Arthrose aufweist, die allen Anschein nach in eine Arthritis übergegangen ist. Die Deckplatte von S1 ist schon recht stark deformiert. Die Processus articulates superiores weisen nur geringe Verschleißerscheinungen im Sinne einer Arthrose mit Grad 2 auf. Rechtsseitig fällt hier noch eine weitere Gelenkfläche ins Auge, die über dem Processus articularis superior positioniert ist. Es wirkt so, als hätte ein großer Processus transversus dort Platz gefunden. Die Gelenkfläche ist hier eher wulstig ausgeprägt und entspricht einem Grad 5. Auf der linken Seite ist ebenfalls so eine Fläche zu erkennen, die wohl Kontakt mit einem Processus transversus hatte, diese ist allerdings unauffällig. 


\section{Bezeichn.: Os Sacrum \\ Kiste: $\quad 5252271$ \\ Skelet: V36 30}

Population: Calden
Verband: $\square$ Verband

Ges./Kr.: Gesund

Geschlecht: $\hat{0}$

Arthrose:

\section{Beschreibung:}

Hier sind zwei Fragmente eines Os sacrum erhalten. Sie liegen im Verband mit Wirbeln vor. 


\section{Bezeichn: Os Sacrum \\ Kiste: \\ 5243267 \\ Zettel}

Population: Calden

Seite:
Verband: $\quad$ Verband

\section{Alter:}

Geschlecht:

Arthrose:

\section{Beschreibung:}

Hier sind drei Fragmente eines Os sacrum erhalten. Es sind der linke obere, der rechte Teil und noch ein weiteres Fragment des rechten Teils erhalten. 


\section{Bezeichn: Os Sacrum \\ Kiste: \\ 5243267}

$\begin{array}{ll}\text { Skelet: P.Sk.1. } & \text { Population: } \\ \text { Calden }\end{array}$

Seite:
Verband: Verband

\section{Alter:}

Geschlecht:

Arthrose:

\section{Beschreibung:}

Hier ist ein kleines Teil eines Os sacrum erhalten. Es stammt vom kranialen Bereich. 


\section{Bezeichn.: Os Sacrum \\ Kiste: $\quad 5243267$ \\ Skelet: P.Sk.1.}

Population: Calden
Verband: $\quad$ Verband

\section{Alter:}

Geschlecht:

Arthrose:

\section{Beschreibung:}

Hier ist ein kleiner Teil aus dem rechten Bereich eines Os sacrum erhalten 


\section{Bezeichn: Os Sacrum \\ Kiste: \\ 5256274 \\ Skelet: SK.8.}

Population: Calden
Verband: $\quad$ Verband

\section{Alter:}

Geschlecht: $\uparrow \leq \curvearrowright$

Arthrose:

proc. art. sup. re. 2

proc. art. sup. li. 2

S1

\section{Beschreibung:}

Ein fast vollständiges Os sacrum.
Ges./Kr.: Gesund

Maß

Breite

Länge

S1 \begin{tabular}{|l|l} 
Wert & Einheit \\
52 &
\end{tabular}

$110 \mathrm{~mm}$

$46 \quad \mathrm{~mm}$




$\begin{array}{llll}\text { Bezeichn.: } & \text { Os Sacrum } & \text { Verband: } \square \text { Verband } & \text { Ges./Kr.: Gesund } \\ \text { Kiste: } & 5261277 & \text { Alter: } & \text { Erwachsen } \\ \text { Skelet: } & \text { V33 kleine Tüte } & \text { Geschlecht: } & \\ \text { Population: } & \text { Calden } & \text { Arthrose: } & \end{array}$

Population: Calden Arthrose:

\section{Beschreibung:}

Von diesem Os sacrum sind zwei kleine Fragmente des kranialen Bereichs erhalten. 


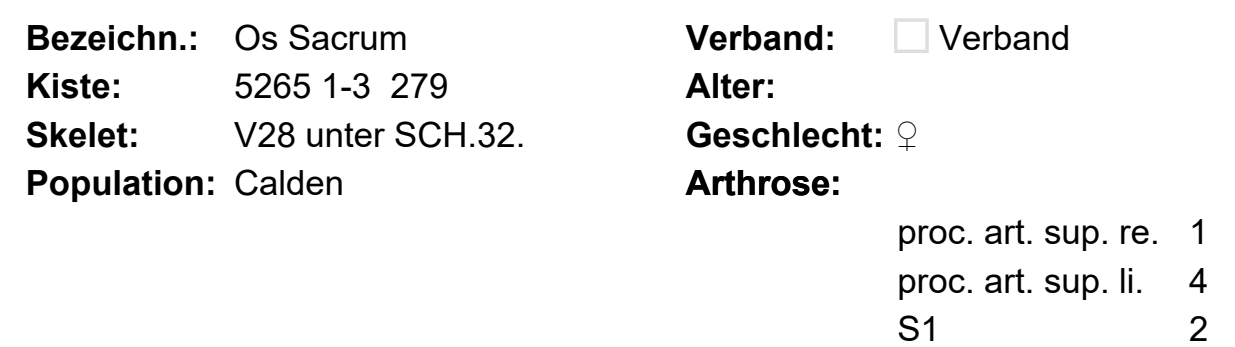

\section{Beschreibung:}

Von diesem Os sacrum ist S1 erhalten, es weist eburnierte Processus articulares auf, was für einen fortgeschrittenen Gelenkverschleiß des lliosakralgelenks spricht. 
Bezeichn:: Os Sacrum

Kiste: $\quad 5263278$

Skelet: V25 verschiedene

Population: Calden
Verband: $\quad \square$ Verband

Alter:

Geschlecht: $ڤ$

Arthrose:
Ges./Kr.: Krank

Krankh.: Arthrose

Spondylophyten

\begin{tabular}{l|l|l} 
Maß & Wert & Einheit \\
\hline Breite & 110 & $\mathrm{~mm}$ \\
S1 & 55 & $\mathrm{~mm}$ \\
& & \\
& & \\
& &
\end{tabular}

\section{Beschreibung:}

Dieses Os sacrum gehört zum Verband mit einem Becken. Die Deckplatte mit kleinen Spondylophyten bis 5mm x 20mm weist auf einen Gelenkverschleiß hin. 


\section{Bezeichn.: Os Sacrum \\ Kiste: \\ 5263278 \\ P7 3,5;3,5}

Skelet:
Verband: $\square$ Verband

Alter: $\quad 12-16(18)$

Geschlecht:

Arthrose:

\section{Beschreibung:}

Ein Fragment eines Os sacrum, welches eher links erhalten ist. S1 fehlt, die anderen Segmente sind teilweise erhalten. Insgesamt ist das Os sacrum noch nicht ausgewachsen gewesen. 
$\begin{array}{ll}\text { Bezeichn.: } & \text { Os Sacrum } \\ \text { Kiste: } & 8505719 \\ \text { Skelet: } & \text { gesammelt }\end{array}$

Population: Calden
Verband: Verband

\section{Alter:}

Geschlecht:

Arthrose:

\section{Beschreibung:}

Dieses Os sacrum ist nur teilweise erhalten. 


\section{Bezeichn.: Os Sacrum \\ Kiste: \\ 8505719 \\ gesammelt}

Population: Calden
Verband:

\section{Alter:}

$\checkmark$ Verband

$12-16(18)$

Geschlecht:

Arthrose:

\section{Beschreibung:}

Ein zur Hälfte erhaltenes Os sacrum. Es ist nicht ausgewachsen gewesen. 
$\begin{array}{ll}\text { Bezeichn.: } & \text { Os Sacrum } \\ \text { Kiste: } & 5245269 \\ \text { Skelet: } & \text { gesammelt }\end{array}$

Population: Calden

Seite:
Verband: Verband

\section{Alter:}

Geschlecht:

Arthrose:

\section{Beschreibung:}

Ein kleines Fragment eines Os sacrum. Es stammt vom kranialen Anteil des Os sacrum. 


\section{Bezeichn.: Os Sacrum \\ Kiste: $\quad 8505719$ \\ Skelet: Sk4.3.}

Population: Calden

\section{Verband:}

Verband

Ges./Kr.: Gesund

\section{Alter:}

Geschlecht:

Arthrose:

\section{Beschreibung:}

Fragment des Os sacrum, welches links noch teilweise mit halben foramina sacralia anteriores erhalten ist. 
Bezeichn.: Os Sacrum

Kiste: $\quad 8505719$

Skelet: gesammelt

Population: Calden
Verband: Verband

\section{Alter:}

Geschlecht:

Arthrose:

\section{Beschreibung:}

Ein Fragment. 


$\begin{array}{lll}\text { Bezeichn.: } & \text { Os Sacrum } & \text { Verband: } \square \text { Verband } \\ \text { Kiste: } & 8505719 & \text { Alter: } 12-16(18) \\ \text { Skelet: } & \text { gesammelt } & \text { Geschlecht: } \\ \text { Population: } & \text { Calden } & \text { Arthrose: }\end{array}$

Population: Calden Arthrose:

\section{Beschreibung:}

Ein teilweise erhaltenes S2 - Segment. Es ist nicht ausgewachsen. 
$\begin{array}{ll}\text { Bezeichn.: } & \text { Os Sacrum } \\ \text { Kiste: } & 5245269 \\ \text { Skelet: } & \text { V12 üb. SCH. } 30\end{array}$

Population: Calden
Verband: $\quad$ Verband

Alter: Erwachsen

\section{Geschlecht:}

Arthrose:
Ges./Kr.: Krank

Krankh.: Arthrose

\begin{tabular}{l|l|l} 
Maß & Wert & Einheit \\
\hline Breite & 108 & $\mathrm{~mm}$ \\
Länge & 124 & $\mathrm{~mm}$ \\
S1 & 43 & $\mathrm{~mm}$ \\
& & \\
& &
\end{tabular}

\section{Beschreibung:}

Das Os sacrum des Verbands liegt nicht vollständig vor, es fehlt das linke Drittel. Es lässt jedoch Befunde von S1 und des rechten Processus articularis superior zu. Dieses ist mit 1 zu bewerten. Dem lumbalen Wirbel L5 entsprechend ist die Basis ossis sacri durch Arthrose geschädigt. Es handelt sich um Grad 3. Das Os sacrum zeigt männliche Merkmale. 


\section{Bezeichn: Os Sacrum \\ Kiste: $\quad 5243267$ \\ Skelet: $\quad \mathrm{V} 37$}

Population: Calden
Verband: $\quad$ Verband

Alter: (16) 18 - 22 (25)

Geschlecht:

Arthrose:

\section{Beschreibung:}

Dies ist ein Verband aus Wirbeln und dem S1 des Os sacrum. 


\begin{tabular}{|c|c|c|c|}
\hline Bezeichn.: & Os Sacrum & Verband: & Verband \\
\hline Kiste: & 5259276 & Alter: & $35-55$ \\
\hline Skelet: & V3 PSK10 & Geschlech & $\hat{0}$ \\
\hline Population: & Calden & Arthrose: & \\
\hline Seite: & rechts & & $\begin{array}{l}\text { proc. art. sup. re. } \\
\text { proc. art. sup. li. } \\
\text { S1 }\end{array}$ \\
\hline
\end{tabular}

\section{Beschreibung:}

Es liegt ein fast vollständiger rechter Teil eines Beckens vor, es weist im Acetabulum arthrotisch - arthritische Veränderungen im Sinne eines Gelenkverschleißes auf, weiterhin findet sich eine Gefäßöffnung im Acetabulum in der Gelenkfläche, die wohl zu einer leichten Knorpelschwächung geführt hat. Dazu gehört ein linkes Becken, bei dem der Ramus ossis ischii und die rami ossis pubis fehlen. Es misst $200 \mathrm{~mm} \times 140 \mathrm{~mm}$ und das Acetabulum misst $53 \mathrm{~mm}$ Durchmesser. Es ist darauf hinzuweisen, dass das linke Beckenteil etwas erodiert ist und deswegen an Größe abgenommen hat. Gelenkverschleiß ist hier im gleichen Maße festzustellen, wie auf der Gegenseite. Zu diesen beiden Beckenteilen gehört ein Os sacrum, welches fast vollständig erhalten ist. Beurteilt man alle Merkmale, so handelt es sich wohl um ein männliches Individuum. Das Os sacrum misst $120 \mathrm{~mm} \times 110 \mathrm{~mm}$. An Gelenkverschleiß ist hier außer ein gut belastetes Sakralgelenk 1 nichts zu verzeichnen. Es ist anzunehmen, dass das linke Os femoris $37 \mathrm{zu}$ diesem Verband dazugehörig ist. 


\begin{tabular}{|c|c|c|c|c|c|c|c|}
\hline Bezeichn.: & Os Coxae & Verband: & $\square$ Verband & Ges./Kr.: Krank & Maß & Wert & Einheit \\
\hline Kiste: & 8505718 & Alter: & & Krankh.: Arthrose & Breite & 60 & $\mathrm{~mm}$ \\
\hline Skelet: & aus Tüte & Geschlecht: & & & Länge & 102,17 & $\mathrm{~mm}$ \\
\hline Population: & Calden & Arthrose: & & & & & \\
\hline Seite: & rechts & & re. & & & & \\
\hline
\end{tabular}

\section{Beschreibung:}

Dieses Fundstück ist ein Fragment eines Beckens der rechten Seite. Es ist unter anderem ein Teil des Acetabulum erhalten, welches einen Arthrosegrad von 5 aufweist, da der Rand sehr starke Auswüchse bis $5 \mathrm{~mm}$ Breite zeigt. Die Fläche ist weniger arthrotisch verändert. 


\begin{tabular}{|c|c|c|c|c|c|c|}
\hline Bezeichn.: & Os Coxae & $\square$ Verband & Ges./Kr.: Gesund & Maß & Wert & Einheit \\
\hline Kiste: & 8505718 & Alter: $\quad$ Jung & & Breite & 45 & $\mathrm{~mm}$ \\
\hline Skelet: & aus Tüte & Geschlecht: & & Länge & 65,5 & $\mathrm{~mm}$ \\
\hline Population: & Calden & Arthrose: & & & & \\
\hline Seite: & links & & & & & \\
\hline
\end{tabular}

\section{Beschreibung:}

Dies ist ein Fragment eines jungen Beckens der linken Seite. Es ist ein Teil des Acetabulum und ein Teil des Ramus ischiadicum inferior erhalten. Die Gelenkfläche des Acetabulum ist nicht endgültig verknöchert. 


$\begin{array}{ll}\text { Bezeichn.: } & \text { Os Coxae } \\ \text { Kiste: } & 8505718 \\ \text { Skelet: } & \text { aus Tüte } \\ \text { Population: } & \text { Calden } \\ \text { Seite: } & \text { rechts }\end{array}$

Verband: $\quad$ Verband

\section{Alter:}

Geschlecht:

Arthrose:

Dies ist ein kleines Fragment eines rechten Beckenteils mit einem kleinen Teil des Acetabulum. 


$\begin{array}{ll}\text { Bezeichn.: } & \text { Os Coxae } \\ \text { Kiste: } & 8505718 \\ \text { Skelet: } & \text { aus Tüte } \\ \text { Population: } & \text { Calden } \\ \text { Seite: } & \text { links }\end{array}$

Verband: $\quad \square$ Verband

\section{Alter:}

Geschlecht:

Arthrose:
Ges./Kr.: Gesund

Maß

Breite

Länge Wert 1 Einheit

$33 \quad \mathrm{~mm}$

\section{Beschreibung:}

Hier ist das Fragment eines linken Sitzbeinhöckers erhalten. 


\section{Bezeichn.: Os Coxae \\ Kiste: \\ 5243267 \\ Skelet: unter SK.1}

Population: Calden

Seite:

links

\section{erband:}

Verband

Alter:

Jung

Geschlecht:

Arthrose:
Ges./Kr.: Gesund

Breite

Länge
Wert $\mid$ Einheit

$86,68 \mathrm{~mm}$

90,94

$\mathrm{mm}$

\section{Beschreibung:}

Dies ist ein vollständig erhaltenes linkes Becken eines Kindes. 


\section{Bezeichn.: Os Coxae \\ Kiste: $\quad 5266281$ \\ Skelet: Tüte 3}

Population: Calden

Seite:

rechts
Verband: $\square$ Verband

Alter: $\quad 30-50$

Geschlecht: $q<\pi$

Arthrose:

\section{Beschreibung:}

Von diesem Becken ist die rechte Symphyse erhalten.

Ges./Kr.: Gesund

\section{Maß}

Länge

Wert $\quad$ Einheit

$38,44 \mathrm{~mm}$




\section{Bezeichn: Os Coxae \\ Kiste: $\quad 8505720$ \\ Skelet: $\quad 1.2$}

Population: Calden
Verband: $\square$ Verband

\section{Alter:}

Geschlecht:

Arthrose:

\section{Beschreibung:}

Dies ist ein kleines Fragment einer Crista iliaca eines Beckens. 


\section{Bezeichn:: Os Coxae \\ Kiste: $\quad 8505720$ \\ Skelet: $\quad 1.2$}

Population: Calden

Seite:

rechts
Verband: $\quad$ Verband

Alter: $\quad 22-30$

Geschlecht: $q \leq \lambda$

Arthrose:

\section{Beschreibung:}

Eine Symphyse der rechten Seite, die stark erodiert ist. 
Bezeichn:: Os Coxae

Kiste: $\quad 8505720$

Skelet: einzelnes Fragment 1.1

Population: Calden

Seite:

\section{Verband: $\quad$ Verband}

\section{Alter:}

Geschlecht:

Arthrose:

\section{Beschreibung:}

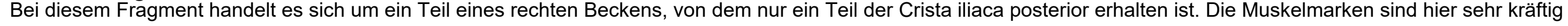
definiert ausgebildet. 


$\begin{array}{lll}\text { Bezeichn.: } & \text { Os Coxae } & \text { Verband: } \square \text { Verband } \\ \text { Kiste: } & 8505720 & \text { Alter: } \\ \text { Skelet: } & 1.3 & \text { Geschlecht: } \\ \text { Population: } & \text { Calden } & \text { Arthrose: } \\ \text { Seite: } & \text { rechts } & \end{array}$

\section{Beschreibung:}

Dieses Fragment ist der Sitzbeinhöcker eines rechten Beckens. 
Bezeichn.: Os Coxae

Kiste: $\quad 8505720$

Skelet: $\quad 1.3$

Population: Calden

Seite: rechts
Verband:

\section{Alter:}

Geschlecht:

Arthrose:
Ges./Kr.: Gesund

\section{Beschreibung:}

Ein Fragment aus dem rechten Becken. Es ist dem Os ilium zuzuordnen und enthält auch einen kleinen Teil des acetabulums. 


\section{Bezeichn: Os Coxae \\ Kiste: $\quad 8505720$}

Skelet: $\quad 1.3$

Population: Calden

Seite:
Verband: $\quad$ Verband

\section{Alter:}

Geschlecht:

Arthrose:

\section{Beschreibung:}

Ein Fragment eins rechten Beckens mit einem kleinen teil des acetabulums, welches aber unbefundbar ist. Das Fragment stammt aus dem Os ilium. 
Bezeichn.: Os Coxae

Kiste: $\quad 8505720$

Skelet: $\quad 1.3$

Population: Calden
Verband: Verband

\section{Alter:}

Geschlecht:

Arthrose:

Beschreibung:

Fragment der Crista iliaca. 


\section{Bezeichn: Os Coxae \\ Kiste: $\quad 8505720$ \\ Skelet: $\quad 1.3$}

Population: Calden
Verband: $\square$ Verband

Alter: $\quad 20-25(30)$

Geschlecht: $q<\hat{0}$

Arthrose:

\section{Beschreibung:}

Dies ist eine linke Symphyse. Sie macht einen sehr massiven und eher männlichen Eindruck, auch bei Rekonstruktion des angulus symphysialis findet diese These Unterstützung. Sie macht einen recht jungen Eindruck. 
Bezeichn.: Os Coxae

Kiste: $\quad 5249270$

Skelet: "bei Becken 4"

Population: Calden

Seite:

rechts
Verband: $\square$ Verband

Alter: (25) 30 (60)

Geschlecht:

Arthrose:

\section{Beschreibung:}

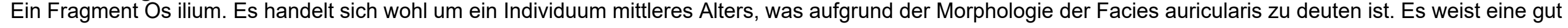
ausgeprägte Muskelmarke an der Crista iliaca auf. 
Bezeichn:: Os Coxae

Kiste: $\quad 5249270$

Skelet: gesammelt

Population: Calden
Verband: Verband

\section{Alter:}

Geschlecht:

Arthrose:

\section{Beschreibung:}

Ein Beckenfragment. 


\section{Bezeichn: Os Coxae \\ Kiste: \\ 5249270 \\ Skelet: \\ V63 4 SK.5}

Population: Calden
Verband: Verband

Alter: $\quad 35$ - 45 (55)

Geschlecht: $q$

Arthrose: $\Sigma$ re

$$
\text { re. }
$$

Ges./Kr.: Krank

Krankh.: Arthrose

\section{Beschreibung:}

Dies ist ein Teilskelet aus Fragmenten eines Beckens, etwa 60\% eines Steißbeins, beiden Oberschenkelknochen und eines linken Schienbeins. Alle Knochen und Knochenfragmente sind in gutem Erhaltungszustand und wenig erodiert, es sind lediglich wenige kleine Knochenteile abfrakturiert. Die Tibia weist eine leichte

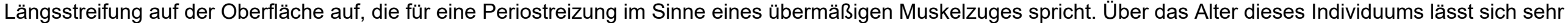

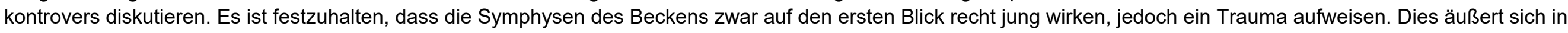
Form von Löchern, die auf der Innenseite der Symphysen lokalisiert sind. Da dies ein weibliches Individuum ist, könnte das traumatische Ereignis auf eine Geburt

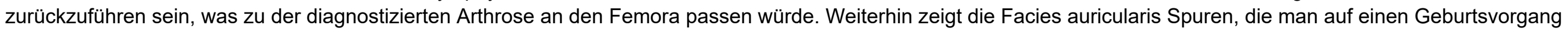

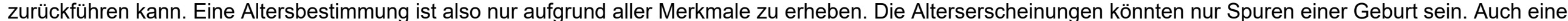

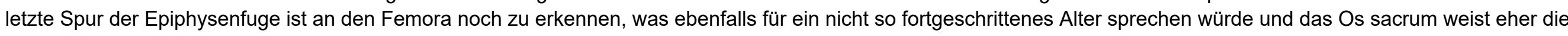
Gesamterscheinung eines Menschen im mittleren Alter auf. 
Bezeichn:: Os Coxae

Kiste:

5255273

Skelet:

V50 SK7 2,9;4,75 SK7

Population: Calden

Seite:
Verband: $\square$ Verband

\section{Alter: \\ (35) 40 - 50 (55)}

Geschlecht: $q$

Arthrose:
Ges./Kr.: Krank

Krankh.: Arthrose

Arthritis
2

\section{Beschreibung:}

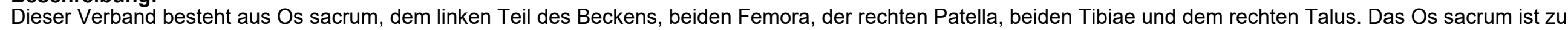

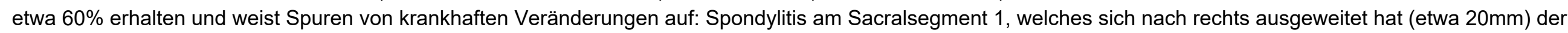

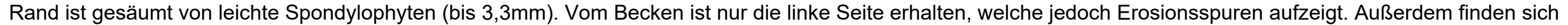

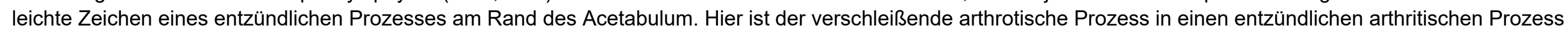

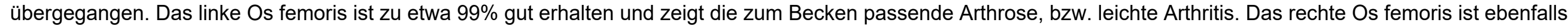

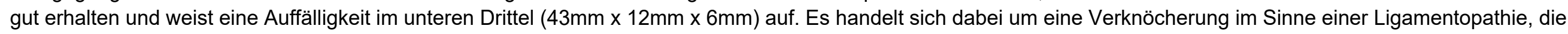

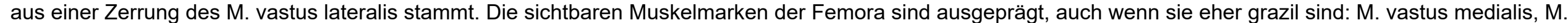

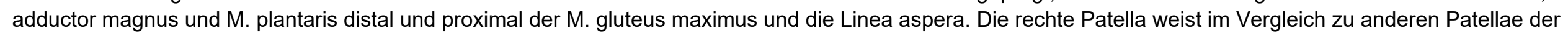

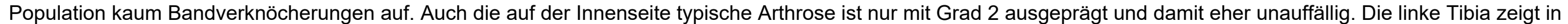

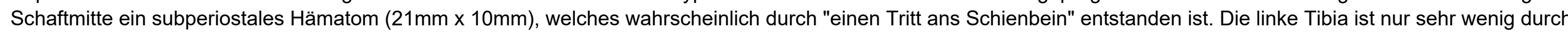

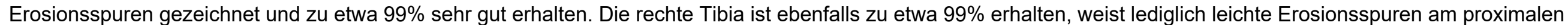
Gelenk auf. Der rechte Talus ist zu etwa 98\% erhalten und weist insgesamt einen unauffälligen Arthrosegrad von 2 auf. 


\section{Bezeichn: Os Coxae \\ Kiste: $\quad 5255273$ \\ Skelet: $\quad$ V46 über Becken 7+30 \\ Population: Calden}

Seite: rechts
Verband: $\quad$ Verband

Alter:

Geschlecht: $\lesssim$

Arthrose:
Ges./Kr.: Krank

Krankh.: Arthrose

\author{
Beschreibung: \\ Ein faustgroßes Beckenfragment, welches nur teilweise erhalten ist und arthrotische Veränderungen zeigt.
}




$\begin{array}{lll}\text { Bezeichn.: } & \text { Os Coxae } & \text { Verband: } \square \text { Verband } \\ \text { Kiste: } & 5267283 & \text { Alter: } \\ \text { Skelet: } & \text { bei Calden } 6 & \text { Geschlecht: } \\ \text { Population: } & \text { Calden } & \text { Arthrose: } \\ \text { Seite: } & \text { rechts } & \end{array}$

\section{Beschreibung:}

Ein kleines Fragment mit einem Teil der Incisura ischiadica major und einem Teil der Facies auricularis. 
Bezeichn:: Os Coxae

Kiste: $\quad 5242266$

Skelet: 3. Tüte

Population: Calden

\section{Beschreibung:}

Ein Beckenfragment.
Verband: Verband

\section{Alter:}

Geschlecht:

Arthrose: 
Bezeichn.: Os Coxae

Kiste: $\quad 5242266$

Skelet: 3. Tüte

Population: Calden

\section{Beschreibung:}

Ein Beckenfragment.
Verband: Verband

\section{Alter:}

Geschlecht:

Arthrose: 
Bezeichn:: Os Coxae

Kiste: $\quad 5242266$

Skelet: 3. Tüte

Population: Calden

\section{Beschreibung:}

Ein Beckenfragment.
Verband: Verband

\section{Alter:}

Geschlecht:

Arthrose: 
Bezeichn:: Os Coxae

Kiste: $\quad 5242266$

Skelet: 3. Tüte

Population: Calden

\section{Beschreibung:}

Ein Beckenfragment.
Verband: Verband

\section{Alter:}

Geschlecht:

Arthrose: 


\section{Bezeichn: Os Coxae \\ Kiste: $\quad 5242266$ \\ Skelet: E. B-S.}

Population: Calden

Seite: rechts
Verband: $\quad$ Verband

\section{Alter:}

Geschlecht: +

Arthrose:
Ges./Kr.: Gesund

Maß

Acetabulum

Breite

Länge \begin{tabular}{|l|l} 
Wert & Einheit
\end{tabular}

43,82 $\mathrm{mm}$

$146 \mathrm{~mm}$

$190 \mathrm{~mm}$

\section{Beschreibung:}

re. 2

Hierbei handelt es sich um ein fast vollständig erhaltenes rechtes Becken. Es wird ein weibliches Individuum angenommen. Es sind keine besonderen Verschleißerscheinungen zu erkennen. 


\section{Bezeichn: Os Coxae \\ Kiste: $\quad 5242266$ \\ Skelet: E. B-S.}

Population: Calden

Seite: rechts

\section{Verband: $\quad$ Verband Ges./Kr: Gesund}

\section{Alter:}

Geschlecht:

Arthrose:

\section{Beschreibung:}

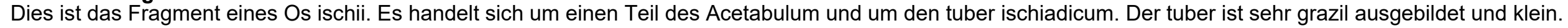




\section{Bezeichn: Os Coxae \\ Kiste: $\quad 5242266$ \\ Skelet: E. B-S.}

Population: Calden

Seite: rechts
Verband: $\quad$ Verband

\section{Alter:}

Geschlecht: $q \leq \lambda$

Arthrose:

\section{Beschreibung:}

Es handelt sich um das Fragment eines Teils des Os ischii. Es hat einen Teil der Incisura ischiadica major. Diese wirkt sehr grazil und weist männliche Merkmale auf. 


\section{Bezeichn: Os Coxae \\ Kiste: $\quad 5242266$ \\ Skelet: $\quad$ E. B-S.}

Population: Calden

Seite: rechts
Verband: $\quad$ Verband

Alter:

Geschlecht:

Arthrose:
Ges./Kr.: Gesund

\section{Beschreibung:}

Hierbei handelt es sich um das Fragment eines acetabulums der rechten Seite. Es weist nur leichte Verschleißerscheinungen auf. 


\section{Bezeichn: Os Coxae \\ Kiste: $\quad 5242266$ \\ Skelet: $\quad$ E. B-S.}

Population: Calden

Seite: rechts
Verband: Verband Ges./Kr.: Gesund

Alter: $\quad 18-25$

Geschlecht:

Arthrose:

\section{Beschreibung:}

Bei diese Fundstück handelt es sich um die Symphyse eines rechten Beckens. Es weist die Merkmale eines jüngeren Individuums auf. 
Bezeichn.: Os Coxae

Kiste: $\quad 5242266$

Skelet: $\quad$ E.B-S. letzte Tüte

Population: Calden

Seite: rechts

\section{Beschreibung:}

Dies ist ein Fragment eines rechten Acetabulum.
Verband: $\square$ Verband

\section{Alter:}

Geschlecht:

Arthrose:
Ges./Kr.: Gesund

Maß

Breite

Länge

1 


$\begin{array}{lll}\text { Bezeichn.: } & \text { Os Coxae } & \text { Verband: } \square \text { Verband } \\ \text { Kiste: } & 5242266 & \text { Alter: Jung } \\ \text { Skelet: } & \text { E.B-S. letzte Tüte } & \text { Geschlecht: } \\ \text { Population: } & \text { Calden } & \text { Arthrose: } \\ \text { Seite: } & \text { links } & \end{array}$

\begin{tabular}{l|l|l} 
Maß & Wert & Einheit \\
\hline Breite & 36 & $\mathrm{~mm}$ \\
Länge & 64,46 & $\mathrm{~mm}$ \\
& & \\
& &
\end{tabular}

\section{Beschreibung:}

Dies ist das Fragment eines linken Beckens mit einem Teil der Crista iliaca und einem kleinem Teil der Facies auricularis. 


$\begin{array}{llll}\text { Bezeichn.: } & \text { Os Coxae } & \text { Verband: } \square \text { Verband } \\ \text { Kiste: } & 5242266 & \text { Alter: } & \text { (16) 18-20 (24) } \\ \text { Skelet: } & \text { E.B-S. letzte Tüte } & \text { Geschlecht: } \\ \text { Population: } & \text { Calden } & \text { Arthrose: }\end{array}$

Population:

Arthrose:

$\mathrm{mm}$

Seite:

links

\section{Beschreibung:}

Fragment eines Beckens, bei dem die Crista iliaca nicht verknöchert ist. 


\section{Bezeichn.: Os Coxae \\ Kiste: $\quad 8505718$ \\ Skelet: aus Kiste}

Population: Calden

Seite:

rechts
Verband: $\square$ Verband

Alter: $\quad 24-26$

Geschlecht: $\delta$

Arthrose:

\section{Beschreibung:}

Von diesem Becken ist nur die rechte Seite der Symphyse und ein Teil des angulus symphysialis erhalten. 
$\begin{array}{ll}\text { Bezeichn.: } & \text { Os Coxae } \\ \text { Kiste: } & 8505718 \\ \text { Skelet: } & \text { aus 2. Kiste }\end{array}$

Population: Calden

Seite:

links
Verband: $\quad$ Verband

Alter: Jung

Geschlecht: +

Arthrose:

\section{Beschreibung:}

Fragment eines linken Beckens mit einem Teil der Facies auricularis. 


\section{Bezeichn.: Os Coxae \\ Kiste: \\ 8505718 \\ Skelet: aus 2. Kiste}

Population: Calden

Seite: rechts

\section{Verband:}

Verband

\section{Alter:}

Geschlecht: 우

Arthrose:

\section{Ges./Kr.: Gesund}

\section{Beschreibung:}

Dieses rechte Becken ist als Fragment erhalten: Ein Teil des Os pubis mit Ramus superior ossis pubis und Sitzbeinhöcker und kleinem Teil des Acetabulum. 
Bezeichn.: Os Coxae

Kiste: $\quad 8505718$

Skelet: $\quad$ V39

Population: Calden

Seite: rechts
Verband: $\quad$ Verband

Alter: $\quad 30-50$

Geschlecht: $+\leq \widehat{0}$

Arthrose:
Ges./Kr.: Krank

\section{Krankh.: Arthrose}

Arthritis

\section{Beschreibung:}

Fragment eines Beckens, etwa ein Drittel ist erhalten. Das Acetabulum weist entzündliche und degenerative Veränderungen arthrotischer und arthritischer Art auf. Der Rand ist erodiert. 


\section{Bezeichn: Os Coxae \\ Kiste: $\quad 5252271$ \\ Skelet: $\quad \mathrm{Sk} 6$}

Population: Calden

Seite: rechts

\section{Beschreibung:}

Rechter Teil eines Beckens.
Verband: $\square$ Verband

Alter: $\quad 30-60$

Geschlecht: $\hat{\delta}$

Arthrose:

$158 \mathrm{~mm}$


Bezeichn.: Os Coxae

Kiste: 5243267

Skelet: Sk. 1

Population: Calden

Seite: rechts

\section{Beschreibung:}

Rechter Teil eines Beckens.
Verband: Verband

\section{Alter:}

Geschlecht:

Arthrose: 
Bezeichn.: Os Coxae

Kiste: $\quad 5243267$

Skelet: Sk. 1

Population: Calden

Seite:

links

Verband: $\quad \square$ Verband

\section{Alter:}

Geschlecht:

Arthrose:

\section{Beschreibung:}

Ein Beckenfragment. 


\section{Bezeichn.: Os Coxae \\ Kiste: 5243267}

Skelet: gesammelt

Population: Calden

Seite:

links
Verband: Verband

\section{Alter:}

Geschlecht:

Arthrose:

\section{Beschreibung:}

Ein Beckenfragment mit Teil der Symphyse. 


\section{Bezeichn: Os Coxae \\ Kiste: 5243267 \\ Skelet: Sk. 1}

Population: Calden
Verband: Verband

\section{Alter:}

Geschlecht:

Arthrose:

\section{Beschreibung:}

Ein Beckenfragment mit einem Fragment des tuber ischiadicum. 


\section{Bezeichn.: Os Coxae \\ Kiste: 5243267 \\ Skelet: P.Sk.1.}

Population: Calden
Verband: Verband

\section{Alter:}

Geschlecht:

Arthrose:

\section{Beschreibung:}

Dieses Fragment stammt von der regio Facies auricularis. 


\section{Bezeichn: Os Coxae \\ Kiste: $\quad 5243267$}

Skelet: gesammelt

Population: Calden

Seite:

links
Verband: Verband

\section{Alter:}

Geschlecht:

Arthrose:

\section{Beschreibung:}

Fragment der Incisura ischiadica. 


\section{Bezeichn: Os Coxae \\ Kiste: $\quad 5243267$ \\ Skelet: P.Sk.1.}

Population: Calden

Seite:

n. def.
Verband: Verband

\section{Alter:}

Geschlecht:

Arthrose:

\section{Beschreibung:}

Ein Beckenfragment mit Facies auricularis. 


$\begin{array}{lll}\text { Bezeichn.: } & \text { Os Coxae } & \text { Verband: } \square \text { Verband } \\ \text { Kiste: } & 5243267 & \text { Alter: } \\ \text { Skelet: } & \text { P.Sk.1. } & \text { Geschlecht: } \\ \text { Population: } & \text { Calden } & \text { Arthrose: } \\ \text { Seite: } & \text { rechts } & \end{array}$

\section{Beschreibung:}

Fragment des rechte Beckens mit Acetabulum. 


\section{Bezeichn:: Os Coxae \\ Kiste: $\quad 5243267$ \\ Skelet: Sk. 1}

Population: Calden

Seite: rechts
Verband: $\quad$ Verband

\section{Alter:}

Geschlecht:

Arthrose:
Ges./Kr.: Krank

Krankh.: Arthrose

\section{Beschreibung:}

Dies ist ein Fragment eines rechten Becken mit Acetabulum, welches arthrotische Veränderungen aufweist. 


$\begin{array}{lll}\text { Bezeichn.: } & \text { Os Coxae } & \text { Verband: } \square \text { Verband } \\ \text { Kiste: } & 5243267 & \text { Alter: } \\ \text { Skelet: } & \text { gesammelt } & \text { Geschlecht: } \\ \text { Population: } & \text { Calden } & \text { Arthrose: } \\ \text { Seite: } & \text { rechts } & \end{array}$

\section{Beschreibung:}

Ein Fragment eines rechten Beckens mit Linea arcuata. 


$\begin{array}{lll}\text { Bezeichn.: } & \text { Os Coxae } & \text { Verband: } \square \text { Verband } \\ \text { Kiste: } & 5243267 & \text { Alter: } \\ \text { Skelet: } & \text { gesammelt } & \text { Geschlecht: } \\ \text { Population: } & \text { Calden } & \text { Arthrose: } \\ \text { Seite: } & \text { rechts } & \end{array}$

\section{Beschreibung:}

Ein Beckenfragment der rechten Seite mit Linea arcuata. 


\section{Bezeichn: Os Coxae \\ Kiste: $\quad 5243267$ \\ Skelet: Sk. 1}

Population: Calden

Seite: rechts

\section{Beschreibung:}

Ein Beckenfragment aus regio Linea arcuata.
Verband: Verband

\section{Alter:}

Geschlecht:

Arthrose: 


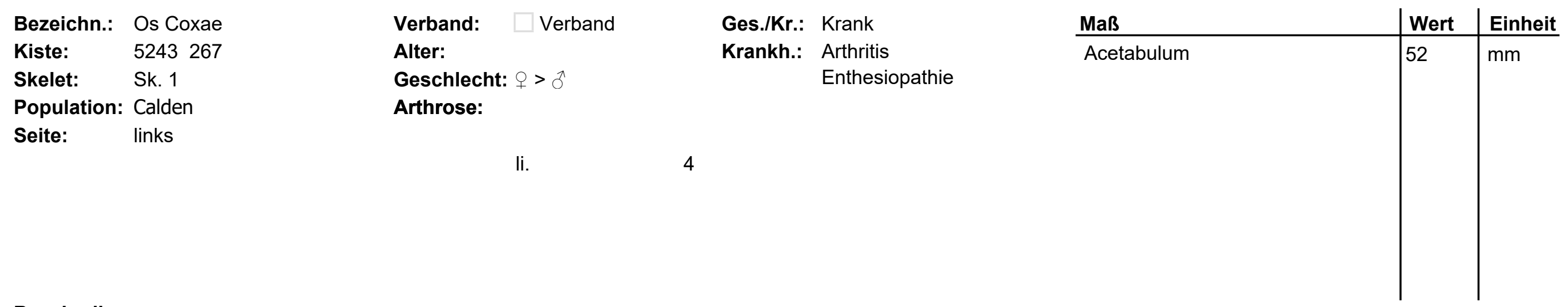

\section{Beschreibung:}

An diesem Becken finden sich arthritische Veränderungen an der Facies auricularis. Am tuber ischiadicum sind enthesiopathische Veränderungen von übermäßigem Muskelzug zu sehen. 


\section{Bezeichn:: Os Coxae \\ Kiste: $\quad 5243267$ \\ Skelet: Sk. 1}

Population: Calden

Seite: rechts

\section{Beschreibung:}

Ein Beckenfragment mit Crista iliaca und Acetabulum.

\section{Alter: \\ Geschlecht:}

Arthrose:
Ges./Kr.: Krank

Krankh.: Arthritis 


\section{Bezeichn.: Os Coxae \\ Kiste: $\quad 5243267$}

Skelet: gesammelt

Population: Calden

Seite:

links
Verband: $\quad \square$ Verband

Alter:

Geschlecht: $\rho>\hat{\sigma}$

Arthrose:

\author{
Beschreibung: \\ Ein Beckenfragment mit Incisura ischiadica.
}




\section{Bezeichn: Os Coxae \\ Kiste: $\quad 5252271$ \\ Skelet: $\quad$ SK 6}

Population: Calden

Seite: rechts

\section{Beschreibung:}

Ein Beckenfragment mit tuber ischiadicum und Acetabulum.
Verband: $\square$ Verband

\section{Alter:}

Geschlecht:

Arthrose:

Ges./Kr.: Gesund 


\section{Bezeichn:: Os Coxae \\ Kiste: $\quad 5252271$}

Skelet: gesammelt

Population: Calden

Seite:

rechts
Verband: $\quad$ Verband

Ges./Kr.: Gesund

\section{Alter:}

Geschlecht:

Arthrose:

\section{Beschreibung:}

Beckenfragment mit einem Teil des Os pubis, Ramus superior ossis pubis und Symphyse. 


$\begin{array}{lll}\text { Bezeichn.: } & \text { Os Coxae } & \text { Verband: } \square \text { Verband } \\ \text { Kiste: } & 5243267 & \text { Alter: } \\ \text { Skelet: } & \text { P.Sk.1. } & \text { Geschlecht: } \\ \text { Population: } & \text { Calden } & \text { Arthrose: } \\ \text { Seite: } & \text { links } & \end{array}$

\section{Beschreibung:}

Ein Beckenfragment mit einem Teil der Crista iliaca. 


\section{Bezeichn.: Os Coxae \\ Kiste: $\quad 5243267$ \\ Skelet: Zettel}

Population: Calden
Verband: Verband

\section{Alter:}

Geschlecht:

Arthrose:

\section{Beschreibung:}

Zwei Beckenfragmente, welche zusammen gehören. 


\section{Bezeichn.: Os Coxae \\ Kiste: $\quad 5243267$ \\ Skelet: Zettel}

Population: Calden
Verband: Verband

\section{Alter:}

Geschlecht:

Arthrose:

\section{Beschreibung:}

Fragment eines Acetabulum. 


\section{Bezeichn: Os Coxae \\ Kiste: $\quad 5243267$ \\ Skelet: Zettel}

Population: Calden

Seite:

links
Verband: Verband

\section{Alter:}

Geschlecht:

Arthrose:

\section{Beschreibung:}

Fragment der Incisura ischiadica media. 
Bezeichn.: Os Coxae

Kiste: 5243267

Skelet: P.Sk.1.

Population: Calden

Seite:

n. def.

Verband: Verband

\section{Alter:}

Geschlecht:

Arthrose:

\section{Beschreibung:}

Fragment Acetabulum 


\section{Bezeichn: Os Coxae \\ Kiste: $\quad 5243267$ \\ Skelet: Zettel}

Population: Calden

Seite:

links

Verband: Verband

\section{Alter:}

Geschlecht:

Arthrose:

\section{Beschreibung:}

Ein Fragment eines linken Beckens. 


\section{Bezeichn: Os Coxae \\ Kiste: 5256274 \\ Skelet: $\quad$ Sk.8.}

Population: Calden

Seite:

links
Verband: $\square$ Verband

Alter: $\quad 35-50$

Geschlecht: $q \geq 0$

Arthrose:

\section{Beschreibung:}

Hier sind 3 Fragmente eines Beckens erhalten: Symphyse, Sitzbeinhöcker und Os ilium mit kleinem Teil Acetabulum. Die Gesamterscheinung ist sehr grazil. 
Bezeichn.: Os Coxae

\section{Kiste:}

5273291

Skelet: V71 Schädel 8

Population: Calden

Seite:

links
Verband: $\square$ Verband

Alter: $22-35$

Geschlecht:

Arthrose:

\section{Beschreibung:}

Linke Symphyse eines Beckens. 


\section{Os Coxae

Kiste: $\quad 5261277$ \\ Skelet: Zettel}

Population: Calden
Verband: Verband

\section{Alter:}

Geschlecht:

Arthrose:

\section{Beschreibung:}

Fragment eines Beckens. 


\section{Bezeichn.: Os Coxae \\ Kiste: $\quad 5261277$ \\ Skelet: Zettel}

Population: Calden

Seite:

rechts

Verband: $\quad$ Verband

\section{Alter:}

Geschlecht:

Arthrose:

\section{Beschreibung:}

Rechte Symphyse eines Beckens. 


\section{Bezeichn.: Os Coxae \\ Kiste: $\quad 5261277$ \\ Skelet: Zettel}

Population: Calden

Seite: n. def.

\section{Beschreibung:}

Fragment eines Beckens.
Verband: Verband

\section{Alter:}

Geschlecht:

Arthrose: 


\section{Bezeichn: Os Coxae \\ Kiste: $\quad 5261277$ \\ Skelet: Zettel}

Population: Calden
Verband: Verband

\section{Alter:}

Geschlecht:

Arthrose:

\section{Beschreibung:}

Fragment eines Beckens mit einem Teil des Acetabulum. 


\section{Bezeichn.: Os Coxae \\ Kiste: $\quad 5261277$ \\ Skelet: ohne Bezeichnung}

Population: Calden
Verband: $\quad \square$ Verband

Alter:

Geschlecht: $\hat{\sigma}$

Arthrose:
Ges./Kr.: Krank

Krankh.: Arthrose

\section{Beschreibung:}

Mehrere Fragmente eines Beckens rechts und links. Es sind etwa 60\% des gesamten Beckens erhalten. Bei den Acetabula liegt links eine Arthrose Grad 2 vor, rechts Grad 3. 


$\begin{array}{llll}\text { Bezeichn.: } & \text { Os Coxae } & \text { Verband: } & \square \text { Verband } \\ \text { Kiste: } & 5261277 & \text { Alter: } & \text { Erwachsen } \\ \text { Skelet: } & \text { V33 kleine Tüte } & \text { Geschlecht: } \\ \text { Population: } & \text { Calden } & \text { Arthrose: }\end{array}$

\section{Beschreibung:}

Ein kleines Beckenfragment. 


\begin{tabular}{|c|c|c|c|c|c|c|}
\hline Bezeichn.: & Os Coxae & Verband: $\quad \square$ Verband & Ges./Kr.: Gesund & Maß & Wert & Einheit \\
\hline $\begin{array}{l}\text { Kiste: } \\
\text { Skelet: } \\
\text { Population: } \\
\text { Seite: }\end{array}$ & $\begin{array}{l}52651-3279 \\
\text { unter SCH.32 } \\
\text { Calden } \\
\text { rechts }\end{array}$ & $\begin{array}{l}\text { Alter: } \\
\text { Geschlecht: } q \leq \AA \\
\text { Arthrose: }\end{array}$ & & Acetabulum & 60 & $\mathrm{~mm}$ \\
\hline
\end{tabular}

\section{Beschreibung:}

Es handelt sich hier um ein rechtes Becken, welches sehr unvollständig erhalten ist. Es sind mehrere kleinere Fragmente vorhanden, unter anderem mit vollständigen Acetabulum. 
Bezeichn.: Os Coxae

Kiste: $\quad 5261277$

Skelet: unter $\mathrm{SCH} .8+3$

Population: Calden

Seite:
Verband: $\square$ Verband

Alter:

Ges./Kr.: Krank

Geschlecht: $q$

Arthrose:
Maß

Acetabulum

\begin{tabular}{|l|l} 
Wert & Einheit \\
\hline 50 & $\mathrm{~mm}$ \\
&
\end{tabular}

Beschreibung:

li.

4

Von diesem linken Becken ist etwa 1/3 erhalten. Das Acetabulum weist einen Arthrosegrad 4 auf. 


\section{Bezeichn: Os Coxae \\ Kiste: \\ 5261277 \\ SK2}

Population: Calden
Verband: Verband

\section{Alter:}

Geschlecht:

Arthrose:

Ges./Kr.: Gesund

\section{Beschreibung:}

Zwei Fragmente eines Beckens rechts und links, wobei das rechte Acetabulum erhalten ist. 
Bezeichn:: Os Coxae

Kiste:

5265 1-3 279

Skelet:

V28 unter $\mathrm{SCH} .32$

Population: Calden

Seite:

\section{Verband: $\quad$ Verband \\ Alter: \\ (17) 19 - 23 (25) \\ Geschlecht: ㅇ \\ Arthrose:}

Ges./Kr.: Krank

Krankh.: Arthrose

Arthritis
Maß

Acetabulum

51

$\mathrm{mm}$

\section{Beschreibung:}

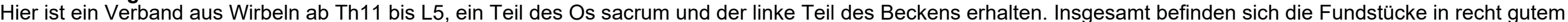

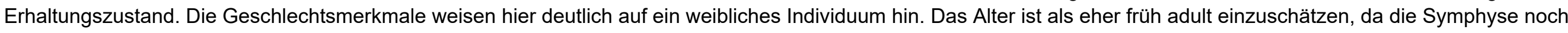
sehr jung wirkt und auch das erste Segment des Os sacrum noch nicht definitiv verwachsen war. Allerdings weisen die Wirbel L4 und L5 arthritische

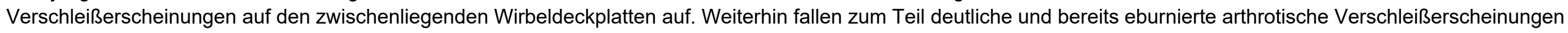
an den Processus articulares superiores und/oder inferiores der Wirbel L3, L4, L5 und am Os sacrum auf. Außerdem sind die Wirbel teils mehr teils weniger mit

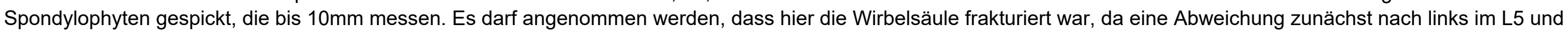

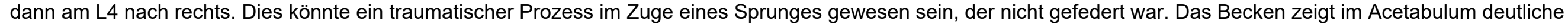
arthrotische bis leichte arthritische Verschleißerscheinungen.

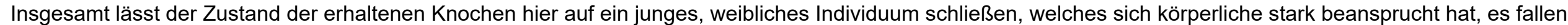
besonders die Verschleißerscheinungen im lumbalen Bereich ins Auge und die leichte Arthrose am Hüftgelenk. Besondere Muskelmarker fallen jedoch nicht auf. 


\section{Bezeichn.: Os Coxae \\ Kiste: $\quad 52651-3279$ \\ Skelet: Zettel}

Population: Calden
Verband: Verband

\section{Alter:}

Geschlecht:

Arthrose:

\section{Beschreibung:}

Hier ist ein Beckenfragment des Ramus inferior erhalten. 


\section{Bezeichn.: Os Coxae \\ Kiste: $\quad 5263278$ \\ Skelet: P.SK.8.}

Population: Calden

Seite:

rechts
Verband: $\square$ Verband

Alter:

Geschlecht: $q>\hat{0}$

Arthrose:
Ges./Kr.: Krank

Krankh.: Arthritis

Arthrose

\section{Beschreibung:}

Ein Beckenfragment, es ist ein kleiner Teil des Acetabulum erhalten, etwa 10\%, dieser Teil weilst deutliche arthritische und arthrotische Verschleißerscheinungen auf. 


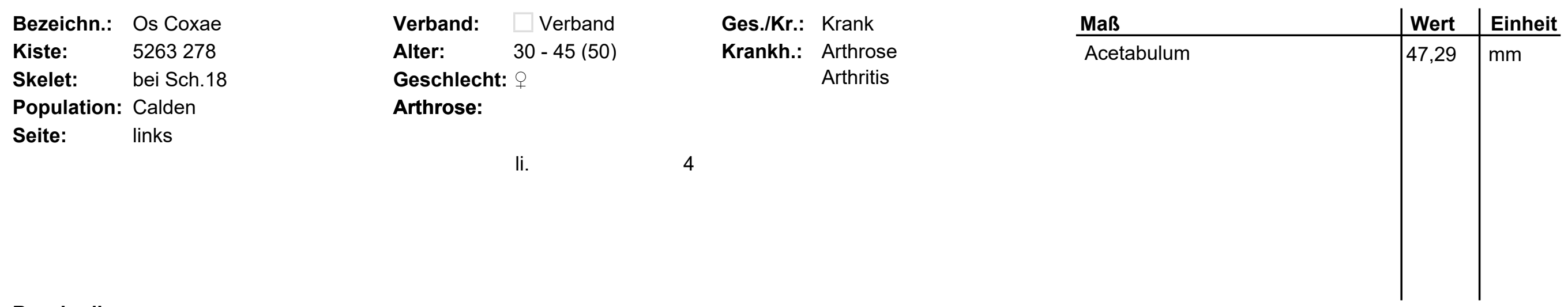

\section{Beschreibung:}

Hier ist ein Großteil eines linken Beckens mit Acetabulum erhalten. Insgesamt liegen etwa 85\% des linken Beckens vor. Das Acetabulum weist deutliche arthritische und arthrotische Verschleißerscheinungen mit Grad 4 auf. Weiterhin fallen deutliche Muskelmarken des M. gluteus maximus ins Auge. Die Crista iliaca weist eine sehr deutliche S- Form auf. 


\section{Bezeichn: Os Coxae \\ Kiste: $\quad 5263278$ \\ Skelet: $\quad \mathrm{P} 16+18$}

Population: Calden

Seite:

links

Verband: Verband

\section{Alter:}

Geschlecht: +

Arthrose:

\section{Beschreibung:}

Ein Beckenfragment. 


\section{Bezeichn.: Os Coxae \\ Kiste: $\quad 5263278$ \\ Skelet: $\quad 16+18$}

Population: Calden

Seite:
Verband: $\square$ Verband

Alter:

Geschlecht: $\delta$

Arthrose:

\section{Maß}

Acetabulum

\begin{tabular}{l|l} 
Wert & Einheit \\
\hline 61 & $\mathrm{~mm}$
\end{tabular}

\section{Beschreibung:}

Hier sind etw 35\% des linken Beckens erhalten, das Acetabulum liegt zu 70\% vor. 
Bezeichn:: Os Coxae

Kiste: $\quad 5263278$

Skelet: V25 verschiedene

Population: Calden
Verband: $\square$ Verband

Ges./Kr.: Gesund

Alter:

Geschlecht: $q \leq \curvearrowright$

Arthrose:

\section{Beschreibung:}

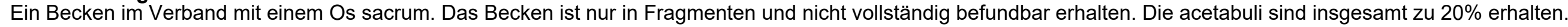




$\begin{array}{lll}\text { Bezeichn.: } & \text { Os Coxae } & \text { Verband: } \square \text { Verband } \\ \text { Kiste: } & 5245269 & \text { Alter: } \\ \text { Skelet: } & \text { gesammelt } & \text { Geschlecht: } \\ \text { Population: } & \text { Calden } & \text { Arthrose: } \\ \text { Seite: } & \text { links } & \end{array}$

\section{Beschreibung:}

Beckenfragment mit Incisura ischiadica major. 
Bezeichn.: Os Coxae

Kiste: $\quad 5245269$

Skelet: gesammelt

Population: Calden

Seite:

links
Verband: $\quad \square$ Verband

\section{Alter:}

Geschlecht:

Arthrose:

\section{Beschreibung:}

Ein Beckenfragment aus dem Os ilii. 
Bezeichn:: Os Coxae

Kiste: $\quad 5245269$

Skelet: gesammelt

Population: Calden

Seite:

links

Verband: $\quad$ Verband

\section{Alter:}

Geschlecht:

Arthrose:

\section{Beschreibung:}

Beckenfragment mit Crista iliaca. 


\section{Bezeichn.: Os Coxae \\ Kiste: $\quad 5249270$}

Skelet: gesammelt

Population: Calden
Verband: Verband

\section{Alter:}

Geschlecht:

Arthrose:

\section{Beschreibung:}

Beckenfragment wohl aus dem Os ilii. 


\section{Bezeichn: Os Coxae \\ Kiste: $\quad 5245269$ \\ Skelet: Sk2}

Population: Calden

Seite: rechts
Verband: Verband

\section{Alter:}

Geschlecht:

Arthrose:

\section{Beschreibung:}

Kleines Beckenfragment mit anteriorem Teil der Crista iliaca. 


\section{Bezeichn: Os Coxae \\ Kiste: $\quad 5245269$ \\ Skelet: Sk2}

Population: Calden

Seite:
Verband: Verband

\section{Alter:}

Geschlecht:

Arthrose:

\section{Beschreibung:}

Ein Fragment des Os ilii mit Facies auricularis und Tuberositas iliaca. 
Bezeichn.: Os Coxae

Kiste: $\quad 5245269$

Skelet: $\quad$ Sk2

Population: Calden

Seite:

links
Verband: Verband

\section{Alter:}

Geschlecht:

Arthrose:

\section{Beschreibung:}

Beckenfragment mit Crista iliaca. 


\section{Bezeichn:: Os Coxae \\ Kiste: $\quad 5245269$ \\ Skelet: SK2}

Population: Calden
Verband: Verband

\section{Alter:}

Geschlecht:

Arthrose:

\section{Beschreibung:}

Beckenfragment mit Acetabulum. 


\section{Bezeichn: Os Coxae \\ Kiste: $\quad 8505719$ \\ Skelet: $\quad \mathrm{Sk} 3$}

Population: Calden

Seite:

rechts

\section{Verband: $\quad$ Verband Ges./Kr.: Krank}

Alter: Krankh.: Sehnenverknöcherung

\section{Geschlecht:}

Arthrose:

\section{Beschreibung:}

Beckenfragmente, Os ischii soweit vollständig erhalten, an der Crista iliaca eine kleine Muskelreizung, wo eine Exostose bzw. eine Sehnenverknöcherung durch starken Reiz stattgefunden hat. 
Bezeichn.: Os Coxae

Kiste: $\quad 8505719$

Skelet: Sk.3.

Population: Calden

Seite:

rechts
Verband: Verband

\section{Alter:}

Geschlecht:

Arthrose:

\section{Beschreibung:}

Beckenfragment Os ischii. 
$\begin{array}{ll}\text { Bezeichn.: } & \text { Os Coxae } \\ \text { Kiste: } & 8505719 \\ \text { Skelet: } & \text { gesammelt }\end{array}$

Population: Calden
Verband: Verband

\section{Alter:}

Geschlecht: $\delta$

Arthrose:

\section{Beschreibung:}

Beckenfragment mit Incisura ischiadica major und Teil von Acetabulum und tuber ischiadicum. 
Bezeichn:: Os Coxae

Kiste: $\quad 8505719$

Skelet: gesammelt

Population: Calden
Verband: Verband

\section{Alter:}

Geschlecht:

Arthrose:

\section{Beschreibung:}

Beckenfragment Os ischii. 


\section{Bezeichn.: Os Coxae \\ Kiste: $\quad 8505719$}

Skelet: gesammelt

Population: Calden

Seite:

links
Verband: $\square$ Verband

\section{Alter:}

Geschlecht:

Arthrose:

\section{Beschreibung:}

Beckenfragment mit gut erkennbaren Muskelansätzen, das Fragment ist mit einem Teil der Symphyse und kleinem Teil des Ramus superior ossis pubis erhalten. 


$\begin{array}{lll}\text { Bezeichn.: } & \text { Os Coxae } & \text { Verband: } \square \text { Verband } \\ \text { Kiste: } & 8505719 & \text { Alter: } \\ \text { Skelet: } & \text { Wirbelsammelzettel } & \text { Geschlecht: } \\ \text { Population: } & \text { Calden } & \text { Arthrose: } \\ \text { Seite: } & \text { links } & \end{array}$

\section{Beschreibung:}

Beckenfragment mit Ramus superior ossis pubis der linken Seite und mit Teil des Acetabulum. 


$\begin{array}{lll}\text { Bezeichn.: } & \text { Os Coxae } & \text { Verband: } \square \text { Verband } \\ \text { Kiste: } & 8505719 & \text { Alter: Jung } \\ \text { Skelet: } & \text { Wirbelsammelzettel } & \text { Geschlecht: } \\ \text { Population: } & \text { Calden } & \text { Arthrose: } \\ \text { Seite: } & \text { links } & \end{array}$

\section{Beschreibung:}

Ein Fragment eins Beckens der linken Seite, es handelt sich um ein junges Individuum. 


$\begin{array}{lll}\text { Bezeichn.: } & \text { Os Coxae } & \text { Verband: } \square \text { Verband } \\ \text { Kiste: } & 8505719 & \text { Alter: } \\ \text { Skelet: } & \text { Extremitätenfragemente } & \text { Geschlecht: } \\ \text { Population: } & \text { Calden } & \text { Arthrose: } \\ \text { Seite: } & \text { links } & \end{array}$

\section{Beschreibung:}

Ein linkes Beckenfragment mit Crista iliaca. 


$\begin{array}{llll}\text { Bezeichn.: } & \text { Os Coxae } & \text { Verband: } \square \text { Verband } & \text { Ges./Kr.: Gesund } \\ \text { Kiste: } & 8505719 & \text { Alter: } & 20-30 \\ \text { Skelet: } & \text { Extremitätenfragemente } & \text { Geschlecht: } & \\ \text { Population: } & \text { Calden } & \text { Arthrose: } & \\ \text { Seite: } & \text { links } & \end{array}$

\section{Beschreibung:}

Beckenfragment mit Symphyse der linken Seite. 
Bezeichn.: Os Coxae

Kiste: 8505719

Skelet: Fragment

Population: Calden
Verband: Verband

\section{Alter:}

Geschlecht:

Arthrose:

Beschreibung:

Wohl Symphyse eines Beckens. 


\section{Bezeichn:: Os Coxae}

Kiste: $\quad 8505719$

Skelet:

Population: Calden

Seite:

links

\section{Beschreibung:}

Beckenfragment links mit Acetabulum.
Verband: $\quad$ Verband

\section{Alter:}

Geschlecht:

Arthrose: 
Bezeichn.: Os Coxae

Kiste: 8505719

Skelet: Zettel

Population: Calden

Seite: rechts

\section{Beschreibung:}

Beckenfragment mit Symphyse.
Verband: $\quad \square$ Verband

Alter: (16) 18 - 22 (25)

Geschlecht:

Arthrose: 


\section{Bezeichn.: Os Coxae \\ Kiste: $\quad 8505719$}

Skelet: gesammelt

Population: Calden

Seite:
Verband: $\quad$ Verband

\section{Alter:}

Geschlecht:

Arthrose:

\section{Beschreibung:}

Dies ist ein Fragment eines Beckens mit einem Teil vom Acetabulum und tuber ischiadicum. Es weist gute Muskelmarken auf. 


$\begin{array}{lll}\text { Bezeichn.: } & \text { Os Coxae } & \text { Verband: } \square \text { Verband } \\ \text { Kiste: } & 8505719 & \text { Alter: } \\ \text { Skelet: } & \text { gesammelt } & \text { Geschlecht: } \\ \text { Population: } & \text { Calden } & \text { Arthrose: } \\ \text { Seite: } & \text { links } & \end{array}$

\section{Beschreibung:}

Fragment eines linken Beckens mit tuber ischiadicum. 


$\begin{array}{lll}\text { Bezeichn.: } & \text { Os Coxae } & \text { Verband: } \square \text { Verband } \\ \text { Kiste: } & 8505719 & \text { Alter: } \\ \text { Skelet: } & \text { gesammelt } & \text { Geschlecht: } \\ \text { Population: } & \text { Calden } & \text { Arthrose: } \\ \text { Seite: } & \text { links } & \end{array}$

\section{Beschreibung:}

Fragment eines Beckens mit Incisura ischiadica major. 
$\begin{array}{ll}\text { Bezeichn.: } & \text { Os Coxae } \\ \text { Kiste: } & 8505719 \\ \text { Skelet: } & \text { gesammelt }\end{array}$

Population: Calden
Verband: Verband

\section{Alter:}

Geschlecht:

Arthrose:

\section{Beschreibung:}

Beckenfragment mit Teil von Acetabulum. Die Linea arcuata weist mittlere Muskelmarken auf. 


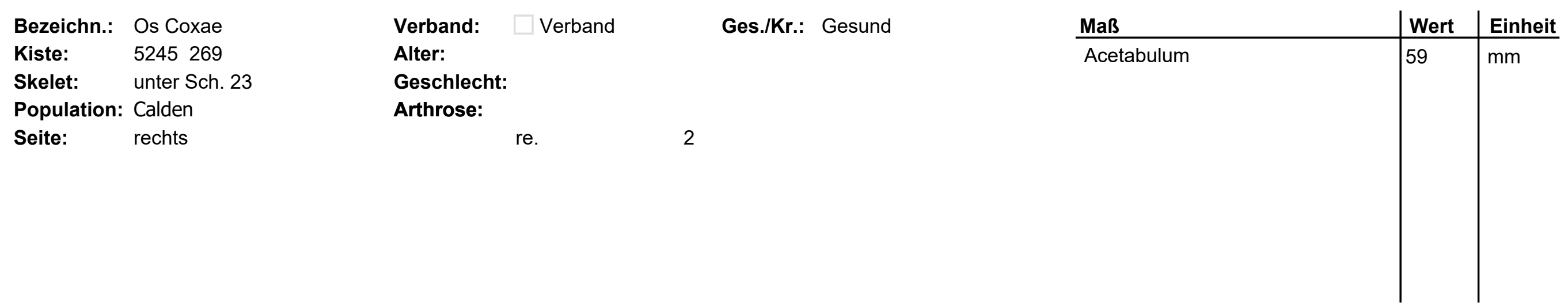

\section{Beschreibung:}

Das Acetabulum (vollständig) dieses Fundstücks ist ausgesprochen groß und weist einen großen Durchmesser auf. Es sind etwa $90 \%$ des rechten Beckens erhalten. 


\section{Bezeichn: Os Coxae \\ Kiste: \\ 5245269 \\ Skelet: V12 üb. SCH. 30}

Population: Calden
Verband: $\quad$ Verband

Alter: $\quad 40-60$

Geschlecht: $\delta$

Arthrose:
Ges./Kr.: Gesund

\section{Maß}

Acetabulum

Breite

Länge

\begin{tabular}{|l|l} 
Wert & Einheit \\
\hline 56,28 & $\mathrm{~mm}$
\end{tabular}

160

208

$\mathrm{mm}$

\section{Beschreibung:}

Das Becken des Verbands besteht aus einem fast vollständigen und einem fragmentierten und unvollständigen linken Teil. Muskelmarken fallen deutlich am Ramus ossis ischii ins Auge, wo Spuren von Muskelreizungen in Form von kleinen Exostosen zu finden sind. Die Geschlechtsbestimmung fältt für das Individuum nicht ganz klar aus, ergibt aber unter Berücksichtigung aller gegebenen Merkmale ein eher männliches Individuum. 
$\begin{array}{ll}\text { Bezeichn.: } & \text { Os Coxae } \\ \text { Kiste: } & 5245269 \\ \text { Skelet: } & \text { V11 SK4. }\end{array}$

Population: Calden

Seite:

links
Verband: $\quad$ Verband

Alter: (35) 40 - 50 (55)

Geschlecht: $\widehat{\jmath}$

Arthrose:
Ges./Kr.: Krank

Krankh.: Arthrose

Arthritis

Exostose

Kapselzerrung

Muskelreizung

Zerrung

\begin{tabular}{l|l|l} 
Maß & Wert & Einheit \\
\hline Breite & 157 & $\mathrm{~mm}$ \\
Länge & 202 & $\mathrm{~mm}$ \\
& & \\
& &
\end{tabular}

\section{Beschreibung:}

Ein zu 95\% erhaltenes linkes Os coxae. 


\section{Bezeichn: Os Coxae \\ Kiste: \\ 5254272 \\ Skelet: $\quad$ P7}

Population: Calden

Seite:
Verband: $\quad$ Verband

\section{Alter:}

Geschlecht:

Arthrose:
Ges./Kr.: Krank

Krankh.: Arthritis

\section{Maß}

Breite

Länge

\begin{tabular}{l|l} 
Wert & Einheit \\
\hline 53 & $\mathrm{~mm}$ \\
74 & $\mathrm{~mm}$ \\
& \\
&
\end{tabular}

\section{Beschreibung:}

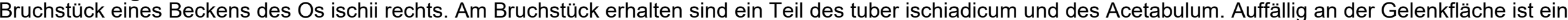

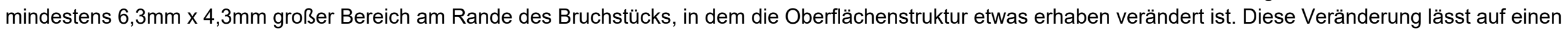
gelenkverschleißenden Vorgang im Sinne einer leichten Arthritis schließen. 


\section{Bezeichn: Os Coxae \\ Kiste: \\ 5254272 \\ Skelet: \\ P7}

Population: Calden

Seite:
Verband:

Alter:

Verband 13 - 18 (25)

Geschlecht: $\delta$

Arthrose:
Ges./Kr.: Gesund

\section{Maß}

Breite

133

$\mathrm{mm}$

\section{Beschreibung:}

Ein junges, männliches Becken ( $80 \%$ erhalten), von dem nur das Os ilium und kleinere Teile der Ossa ischii und pubis vorhanden sind. die Crista iliaca ist noch nicht verschlossen gewesen zum Zeitpunkt des Todes. Die Oberfläche ist teilweise erodiert. Gut zu bewerten war das Acetabulum, welches auf der Gelenkfläche ein 5,8mm $\mathrm{x}$ $6,6 \mathrm{~mm}$ großes Loch aufweist, welches nicht verschleißbedingt entstanden ist. Es handelt sich wohl um ein foramen nutricium. 


\section{Bezeichn.: Os Coxae \\ Kiste: \\ 5259276 \\ Skelet: V3 PSK10}

Population: Calden

\section{Verband: Verband \\ Alter: $\quad 35-55$ \\ Geschlecht: $0 \hat{~}$}

Arthrose:
Ges./Kr.: Krank

Krankh.: Arthrose

Arthritis
Maß

Acetabulum

Breite

Länge

\begin{tabular}{|l|l} 
Wert & Einheit \\
\hline 53 & $\mathrm{~mm}$ \\
159 & $\mathrm{~mm}$ \\
220 & $\mathrm{~mm}$ \\
& \\
&
\end{tabular}

\section{Beschreibung:}

Es liegt ein fast vollständiger rechter Teil eines Beckens vor, es weist im Acetabulum arthrotisch - arthritische Veränderungen im Sinne eines Gelenkverschleißes auf, weiterhin findet sich eine Gefäßöffnung im Acetabulum in der Gelenkfläche, die wohl zu einer leichten Knorpelschwächung geführt hat. Dazu gehört ein linkes Becken, bei dem der Ramus ossis ischii und die rami ossis pubis fehlen. Es misst $200 \mathrm{~mm} \times 140 \mathrm{~mm}$ und das Acetabulum misst $53 \mathrm{~mm}$ Durchmesser. Es ist darauf hinzuweisen, dass das linke Beckenteil etwas erodiert ist und deswegen an Größe abgenommen hat. Gelenkverschleiß ist hier im gleichen Maße festzustellen, wie auf der Gegenseite. Zu diesen beiden Beckenteilen gehört ein Os sacrum, welches fast vollständig erhalten ist. Beurteilt man alle Merkmale, so handelt es sich wohl um ein männliches Individuum. Das Os sacrum misst $120 \mathrm{~mm} \times 110 \mathrm{~mm}$. An Gelenkverschleiß ist hier außer ein gut belastetes Sakralgelenk 1 nichts zu verzeichnen. 


\section{Bezeichn.: Os Coxae \\ Kiste: $\quad 5259276$ \\ Skelet: $\quad 405117$}

Population: Calden

Seite:

links

\section{Verband: $\quad \square$ Verband \\ Alter: Jung \\ Geschlecht:}

Arthrose:

Ein Fragment des linken Beckens eines jungen Individuums. 


$\begin{array}{llll}\text { Bezeichn.: } & \text { Os Coxae } & \text { Verband: } \square \text { Verband } \\ \text { Kiste: } & 5259276 & \text { Alter: } & 18-24 \\ \text { Skelet: } & \text { PSK10 } & \text { Geschlecht: } \\ \text { Population: } & \text { Calden } & \text { Arthrose: } \\ \text { Seite: } & \text { links } & \end{array}$

\section{Beschreibung:}

Hier ist nur ein Fragment der linken Symphyse erhalten. Sie ist einem jungen Individuum zuzuordnen. 


\section{Bezeichn: Os Coxae \\ Kiste: 5259276 \\ Skelet: SK10}

Population: Calden

\section{Verband:}

Alter:

Verband

(30) 35 - 39 (50)

Geschlecht: $q \geq 0$

Arthrose:
Ges./Kr.: Gesund

\section{Maß}

Acetabulum
Wert 1 Einheit

\begin{tabular}{ll|l}
46 & $\mathrm{~mm}$
\end{tabular}

\section{Beschreibung:}

Dieses beidseitig erhaltene Becken liegt in Form von 5 Fragmenten vor. Es weist an der Symphyse Alterserscheinungen auf und die Gesamtkonstitution entspricht einem weiblichen Individuum. 
$\begin{array}{ll}\text { Bezeichn.: } & \text { Os Coxae } \\ \text { Kiste: } & 8505721 \\ \text { Skelet: } & \text { Kiste } 12\end{array}$

Population: Calden

Seite:

links
Verband: $\quad$ Verband

\section{Alter:}

Geschlecht:

Arthrose:

\section{Beschreibung:}

Ein posteriores kleines Fragment der Crista iliaca nahe der Facies auricularis. 
$\begin{array}{ll}\text { Bezeichn.: } & \text { Os Coxae } \\ \text { Kiste: } & 8505721 \\ \text { Skelet: } & \text { Kiste } 12\end{array}$

Population: Calden

Seite:
Verband: $\square$ Verband

Ges./Kr.: Gesund

\section{Geschlecht:}

Arthrose:

\section{Beschreibung:}

Dies ist ein posteriores kleines Fragment der Crista iliaca nahe der Facies auricularis. 
Bezeichn.: Os Coxae

Kiste: $\quad 8505721$

Skelet: aus großer Kiste

Population: Calden

Seite: rechts
Verband: $\square$ Verband

Ges./Kr.: Gesund

\section{Alter:}

Geschlecht:

Arthrose:

\section{Beschreibung:}

Ein posteriores Fragment eines rechten Beckens mit Teil der Crista iliaca und Teil des acetabulums. 


\section{Bezeichn: Os Coxae \\ Kiste: $\quad 5249270$ \\ Skelet: Zettel}

Population: Calden

Seite:
Verband: $\square$ Verband

\section{Alter:}

Geschlecht:

Arthrose:
Ges./Kr.: Krank

Krankh.: Arthrose

Arthritis

\section{Beschreibung:}

Das Acetabulum dieses Beckens weist ein kleines Loch in der Gelenkfläche auf. Hierbei könnte es sich um ein foramen nutricium handeln. Problematisch werden diese foramina dann, wenn sie eine Schwächung des Gelenkknorpels an der Stelle der Lokalisation hervorrufen. Dieses Acetabulum zeigt einen Arthrosegrad 4, der in eine Arthritis über geht. 


\section{Bezeichn.: Os Coxae \\ Kiste: $\quad 5242266$ \\ Skelet: letzte Tüte}

Population: Calden

Seite:

rechts
Verband: $\quad$ Verband

Alter:

Geschlecht:

Arthrose:
Maß

Breite

Länge
Wert 1 Einheit

$\begin{array}{ll}32 & \mathrm{~mm}\end{array}$

\section{Beschreibung:}

Fragment aus der Nähe der Symphyse eines rechten Beckens. 


\section{Bezeichn.: Os Coxae \\ Kiste: \\ 8505718 \\ Skelet: aus Kiste}

Population: Calden

Seite:

links
Verband: Verband

\section{Alter:}

Geschlecht:

Arthrose:
Maß

Breite

Länge \begin{tabular}{l|l} 
Wert & Einheit
\end{tabular}

$40 \mathrm{~mm}$

$63 \mathrm{~mm}$

\section{Beschreibung:}

Fragment mit kleinem Teil der Crista iliaca und Facies auricularis. 


\section{Bezeichn.: Os Coxae \\ Kiste: \\ 8505718 \\ Skelet: aus Kiste}

Population: Calden

Seite:

n. def.
Verband: $\square$ Verband

\section{Alter:}

Geschlecht:

Arthrose:

\begin{tabular}{l|l|l} 
Maß & Wert & Einheit \\
\hline Breite & 28 & $\mathrm{~mm}$ \\
Länge & 63 & $\mathrm{~mm}$ \\
& & \\
& &
\end{tabular}

\section{Beschreibung:}

Ein kleines Fragment mit einem Teil des Acetabulum.

Ges./Kr.: Gesund 


\section{Bezeichn.: Os Coxae \\ Kiste: \\ 8505718 \\ Skelet: aus Kiste}

Population: Calden

Seite:

links
Verband: Verband

\section{Alter:}

Geschlecht:

Arthrose:
Maß

Breite

Länge
Wert $\quad$ Einheit

$32 \quad \mathrm{~mm}$

$56 \mathrm{~mm}$

\section{Beschreibung:}

Fragment des linken Beckens mit Teil des Acetabulum bei Sitzbeinhöcker 


\section{Bezeichn:: Os Coxae \\ Kiste: \\ 5243267 \\ Skelet: Zettel}

Population: Calden

Seite:

links

\section{Verband: $\quad$ Verband}

\section{Alter:}

Geschlecht:

Arthrose:
Ges./Kr.: Krank

Krankh.: Arthrose
Maß

Acetabulum

Wert 1 Einheit

$47,71 \mathrm{~mm}$

\section{Beschreibung:}

Ein Beckenfragment mit Acetabulum, welches arthrotische Veränderungen zeigt. 


\section{Bezeichn.: Os Coxae \\ Kiste: $\quad 52651-3279$ \\ Skelet: unter $\mathrm{SCH} .32$}

Population: Calden
Verband: $\quad$ Verband

Alter: Erwachsen

Geschlecht: $q<{ }^{\lambda}$

Arthrose:
Ges./Kr.: Krank

Krankh.: Arthrose

\section{Maß}

Acetabulum
Wert $\quad$ Einheit

$55,45 \mathrm{~mm}$

li.

\section{Beschreibung:}

Hier sind fünf Fragmente eines Beckens erhalten. Es ist das linke Acetabulum vollständig erhalten, das rechte nur als ein kleiner Teil. Insgesamt sind 10\% des gesamten Beckens erhalten. 


\section{Bezeichn.: Femur}

Kiste: Museumskiste 3

Skelet: $\quad$ P2 33

Population: Calden

\section{Erhaltung:} prox. Gelenk prox. Schaft

$X$ mittl. Schaft

$\mathbf{X}$ dist. Schaft X dist. Gelenk
Verband: $\quad$ Verband

Alter: Erwachsen

Geschlecht: $q \geq{ }^{\lambda}$

Arthrose:
Ges./Kr.: Gesund

\section{Maß}

Epicondylenbreite

Umfang Schaftmitte

\begin{tabular}{|l|l} 
Wert & Einheit \\
78,37 & $\mathrm{~mm}$
\end{tabular}

dist.

\section{Beschreibung:}

Dieses Fundstück ist ein Fragment eines Os femoris, welches zu 3/4 distal erhalten ist. Die Linea aspera zeichnet sich deutlich am Schaft ab. 


\section{Bezeichn.: Femur \\ Kiste: Museumskiste 3 \\ Skelet: V69 P2 \\ Population: Calden \\ Seite: links \\ Erhaltung: $\square$ prox. Gelenk \\ prox. Schaft \\ mittl. Schaft \\ dist. Schaft \\ X dist. Gelenk \\ Beschreibung:}

Verband: $\quad$ Verband

\section{Alter:}

Geschlecht:

Arthrose:

Dieses Fundstück ist ein Fragment des linken lateralen Condylus eines Os femoris. 
Bezeichn.: Femur

Kiste: $\quad 8505718$

Skelet: aus Tüte

Population: Calden

Seite: rechts

Erhaltung: $\square$ prox. Gelenk

prox. Schaft

mittl. Schaft

$\mathbf{X}$ dist. Schaft dist. Gelenk
Ges./Kr.: Krank

Krankh.: Muskelreizung

Enthesiopathie

\section{Beschreibung:}

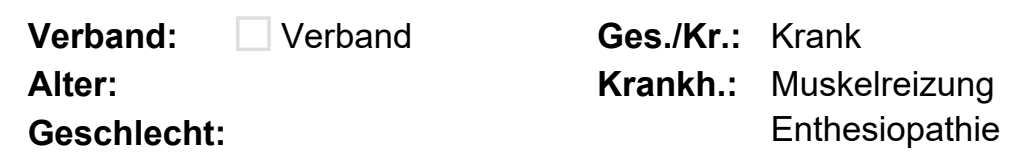

Arthrose:

nt ist wohl ein $\mathrm{Fe}$ 


$\begin{array}{ll}\text { Bezeichn.: } & \text { Femur } \\ \text { Kiste: } & 8505718 \\ \text { Skelet: } & \text { aus Tüte } \\ \text { Population: } & \text { Calden } \\ \text { Seite: } & \text { links } \\ \text { Erhaltung: } & \square \text { prox. Gelenk } \\ & \square \text { prox. Schaft } \\ & \square \text { mittl. Schaft } \\ & \square \text { dist. Schaft } \\ & \mathbf{X} \text { dist. Gelenk }\end{array}$

Verband: $\quad \square$ Verband

Alter:

Geschlecht:

Arthrose:

Ein kleines Fragment des Condylus eines linken Os femoris. 


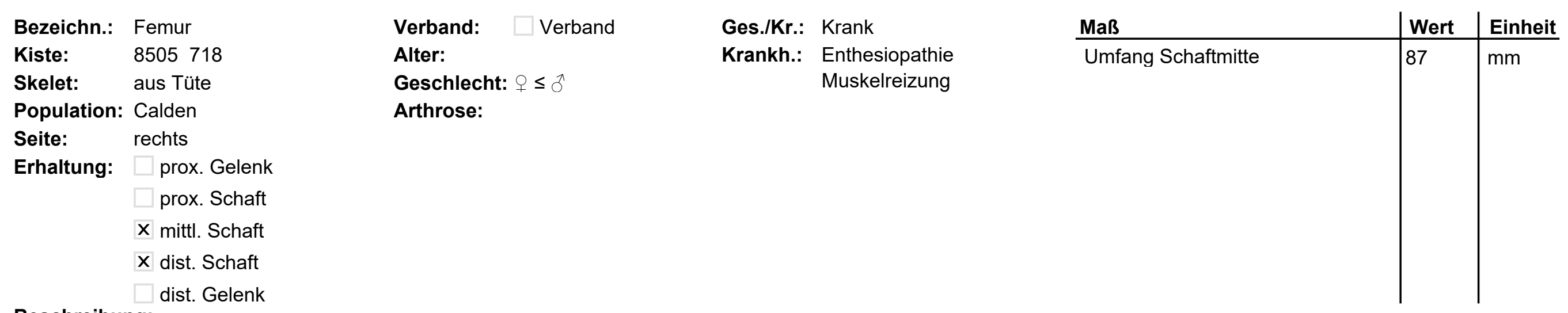

\section{Beschreibung:}

Dies ist ein Teil aus dem Schaft eines sehr massiven Os femoris der rechten Seite. Die sehr stark ausgeprägte Linea aspera weist eine Enthesiopathie auf, welche durch Muskelreizung entstanden ist. 


\section{Bezeichn.: Femur \\ Kiste: $\quad 8505718$ \\ Skelet: aus Tüte \\ Population: Calden \\ Seite: \\ links \\ Erhaltung: $\square$ prox. Gelenk \\ prox. Schaft \\ mittl. Schaft \\ $\mathbf{X}$ dist. Schaft \\ $X$ dist. Gelenk \\ Beschreibung: \\ Ein kleines Fragment.}

Verband: Verband

\section{Alter:}

Geschlecht:

Arthrose: 


$\begin{array}{lll}\text { Bezeichn.: } & \text { Femur } & \text { Verband: } \square \text { Verband } \\ \text { Kiste: } & 8505718 & \text { Alter: } \\ \text { Skelet: } & \text { aus Tüte } & \text { Geschlecht: } \\ \text { Population: } & \text { Calden } & \text { Arthrose: } \\ \text { Seite: } & \text { rechts } & \\ \text { Erhaltung: } & \square \text { prox. Gelenk } & \\ & \square \text { prox. Schaft } & \\ & \square \text { mittl. Schaft } & \\ & \mathbf{X} \text { dist. Schaft } & \\ & \square \text { dist. Gelenk }\end{array}$

Hier ist die distale Epiphyse des Os femoris eines jungen Individuums erhalten. 

Bezeichn.: Femur
Kiste:
5266281 Tüte 2
$3,75 x ; 5,5 y$
Skelet: $3,75 x, 5,5$
Seite:
links
Erhaltung: $\mathbf{X}$ prox. Gelenk
prox. Schaft
mittl. Schaft
dist. Schaft
dist. Gelenk

\section{Beschreibung:}

Verband: $\square$ Verband

Alter: Erwachsen

Geschlecht:

Ges./Kr.: Krank

Krankh.: arthrose

Arthrose:

prox.

2,5

\begin{tabular}{l|l|l} 
Maß & Wert & Einheit \\
\hline Caput, horizontaler $\varnothing$ & 46,4 & $\mathrm{~mm}$ \\
Caput, vertikaler $\varnothing$ & 46,7 & $\mathrm{~mm}$ \\
& & \\
& &
\end{tabular}

Hier ist ein Caput femoris erhalten, welches mittelmäßige Verschleißerscheinungen aufweist. 


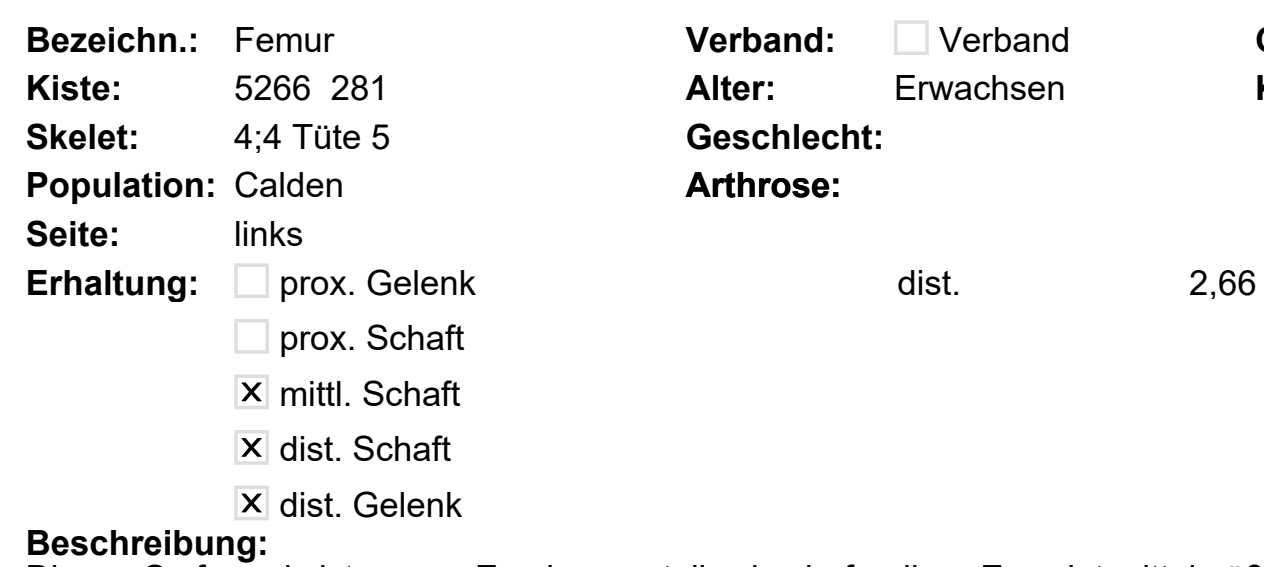

Ges./Kr.: Krank

Krankh.: Arthrose

2,66

Dieses Os femoris ist wegen Erosion nur teilweise befundbar. Es zeigt mittelmäßige Verschleißerscheinungen im Sinne von arthrotischen Prozessen. 

Bezeichn:: Femur
Kiste: $\quad 8505720$
Skelet: $\quad 1.2$
Population: Calden
Seite:
links
Erhaltung: $\square$ prox. Gelenk
prox. Schaft
mittl. Schaft
dist. Schaft
X dist. Gelenk

Beschreibung:

Fragment eines Condylus lateralis eines linken Femurs.
Verband: $\quad$ Verband

\section{Alter:}

Geschlecht:

Arthrose:

dist.

2 
Bezeichn:: Femur

Kiste: $\quad 8505720$

Skelet: $\quad 1.0$

Population: Calden

Seite: rechts

Erhaltung: $\square$ prox. Gelenk

prox. Schaft

mittl. Schaft

dist. Schaft

X dist. Gelenk
Verband: $\quad$ Verband

Alter: Erwachsen

\section{Geschlecht:}

Arthrose:

Ges./Kr.: Krank

Krankh.: Arthrose

Arthritis

\section{Beschreibung:}

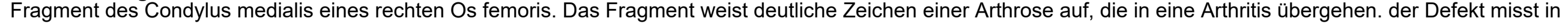

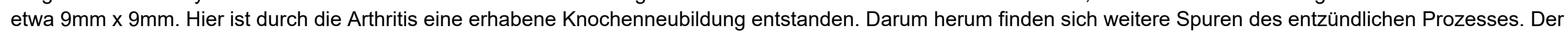
Rand des Fragmentes fällt durch seine außerordentliche Breite von bis zu 5,3mm auf. 

Bezeichn.: Femur
Kiste: $\quad 8505720$
Skelet: $\quad 1.0$
Population: Calden
Seite: links
Erhaltung: $\square$ prox. Gelenk
prox. Schaft
mittl. Schaft
dist. Schaft
X dist. Gelenk

Verband: $\quad$ Verband

Ges./Kr.: Gesund

Alter:

Geschlecht:

\section{Beschreibung:}

Hierbei handelt es sich um den lateralen Teil des Condylus eines linken Femurs. Auffällig ist, dass eine Bruchlinie durch die Spongiosa führt und ein gesamter Teil des Condylus abgesunken und stabil versintert ist. Histologisch konnte festgestellt werden, dass die Fraktur sehr wahrscheinlich postmortal stattgefunden hatte. 

Bezeichn:: Femur
Kiste: $\quad 8505720$
Skelet: einzeln
Population: Calden
Seite: rechts
Erhaltung: $\square$ prox. Gelenk
prox. Schaft
mittl. Schaft
$\mathbf{X}$ dist. Schaft
dist. Gelenk

\section{Beschreibung:}

Dies ist ein distales Fragment eines Femurs ohne weitere Auffälligkeiten.

\section{Verband: $\quad$ Verband}

\section{Alter:}

Geschlecht:

Arthrose:

Ges./Kr.: Gesund 

Bezeichn:: Femur
Kiste: $\quad 8505720$
Skelet: $\quad$ einzeln 1.1
Population: Calden

\section{Erhaltung: $\square$ prox. Gelenk \\ prox. Schaft \\ $X$ mittl. Schaft \\ dist. Schaft \\ dist. Gelenk}

\section{Alter: Jung \\ Geschlecht:}

Verband: $\quad$ Verband

Arthrose:

Beschreibung:

Ein Fragment eines Os femoris eines jungen Individuums. 

Bezeichn.: Femur
Kiste:
8505720
Population: Calden
Seite: links
Erhaltung: $\square$ prox. Gelenk
$X$ prox. Schaft
mittl. Schaft
dist. Schaft
dist. Gelenk

Verband

Ges./Kr.: Krank

\section{Alter:}

Krankh.: Myotendopathie

\section{Geschlecht:}

Periostreizung

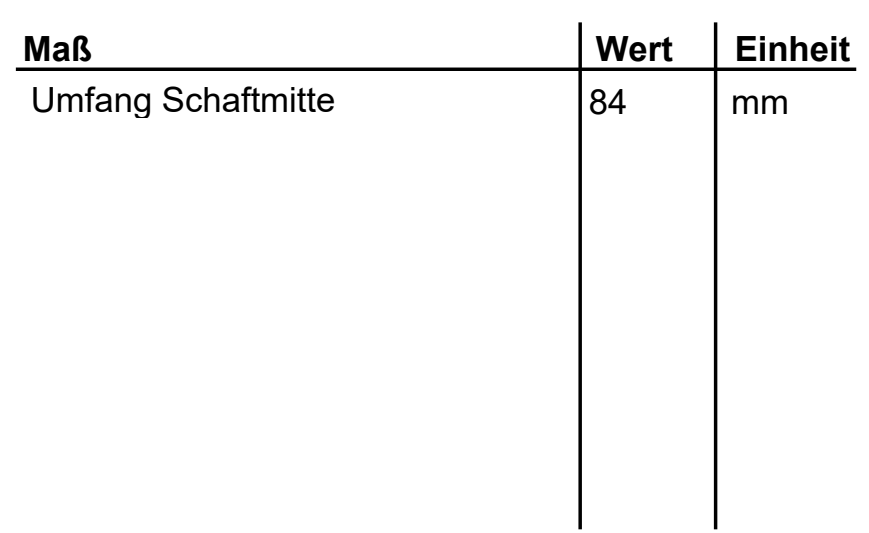

Arthrose:

\section{Beschreibung:}

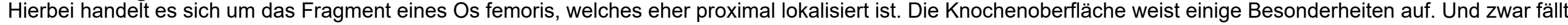

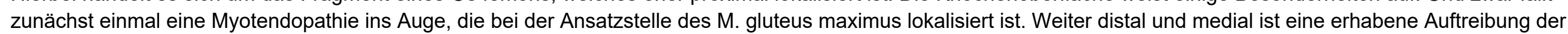
Oberfläche im Sinne einer Periostreizung zu sehen. Da das Fragment so klein ist, sind keine weiterführenden Untersuchungen möglich. 

Bezeichn.: Femur
Kiste: $\quad 8505720$
Skelet: einzeln 1.1
Population: Calden
prox. Gelenk
prox. Schaft
mittl. Schaft
dist. Schaft
dist. Gelenk

Verband: $\quad \square$ Verband

Ges./Kr.: Krank

Alter:

Krankh.: Periostreizung

Geschlecht:

\section{Beschreibung:}

Ein recht kleines Fragment eines Femurs. Es fällt eine kleine Porosität der Oberfläche im Sinne einer Periostreizung ins Auge. Da diese Stelle aber an einer Bruchkante lokalisiert ist, sind keine näheren Untersuchungen möglich. 
Bezeichn.: Femur

Kiste: $\quad 8505720$

Skelet: einzeln 1.1

Population: Calden

prox. Gelenk

prox. Schaft

mittl. Schaft

dist. Schaft

dist. Gelenk

Beschreibung:

Ein kleines Fragment.
Verband: Verband

\section{Alter:}

Geschlecht:

Arthrose: 
Bezeichn.: Femur

Kiste: $\quad 8505720$

Skelet: einzeln 1.1

Population: Calden

Seite: links

Erhaltung: $\square$ prox. Gelenk

prox. Schaft

mittl. Schaft

dist. Schaft

X dist. Gelenk
Verband: $\quad$ Verband

Alter: Erwachsen

\section{Geschlecht:}

Arthrose:
Ges./Kr.: Krank

Krankh.: Arthritis

\section{Beschreibung:}

Bei diesem Fundstück handelt es sich um ein Fragment des Condylus medialis eines linken Os femoris. Hier ist ein deutlicher verschleißender Prozess im Sinne einer Arthritis zu erkennen. 
Bezeichn.: Femu

Kiste: 5255273

Skelet:

V50 49

Population: Calden

Seite: rechts

Erhaltung: $\mathbf{X}$ prox. Gelenk

$X$ prox. Schaft

$X$ mittl. Schaft

$\mathbf{X}$ dist. Schaft

X dist. Gelenk
Ges./Kr.: Krank

Krankh.: Arthrose

Muskelreizung

Zerrung

Enthesiopathie

Ligamentopathie

Körperhöhe nach Sjøvold: 142,7 - 151,7cm

\begin{tabular}{l|l|l} 
Maß & Wert & Einheit \\
\hline a-p $\varnothing$ subtrochlear & 23,89 & $\mathrm{~mm}$ \\
Caput, horizontaler $\varnothing$ & 38,64 & $\mathrm{~mm}$ \\
Caput, vertikaler $\varnothing$ & 38,47 & $\mathrm{~mm}$ \\
Collum-Corpus-Winkel & 120 & $\circ$ \\
Epicondylenbreite & 70,89 & $\mathrm{~mm}$ \\
gr. Länge & 374 & $\mathrm{~mm}$ \\
m-I $\varnothing$ subtrochlear & 32,13 & $\mathrm{~mm}$ \\
Umfang Schaftmitte & 77 & $\mathrm{~mm}$ \\
& &
\end{tabular}

Beschreibung:

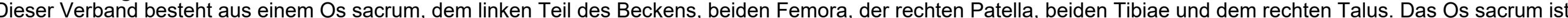

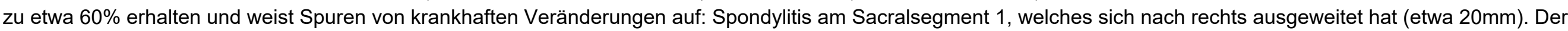

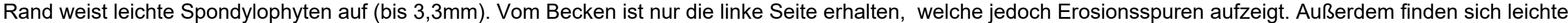
Zeichen eines entzündlichen Prozesses am Rand des Acetabulums. Hier ist der verschleißende arthrotische Prozess in einen entzündlichen arthritischen Prozess

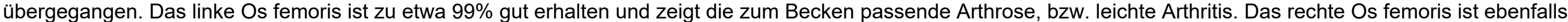
gut erhalten und weist eine Auffälligkeit im unteren Drittel (43mm x 12mm x $6 \mathrm{~mm}$ ) auf. Es handelt sich dabei um eine knöcherne Neubildung im Sinne einer

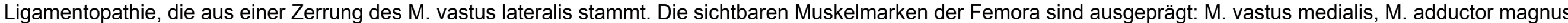

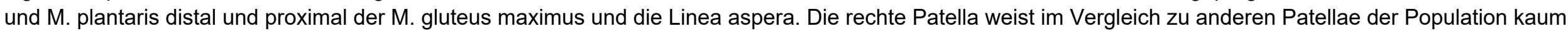

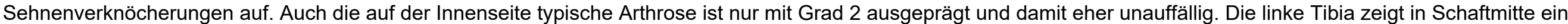

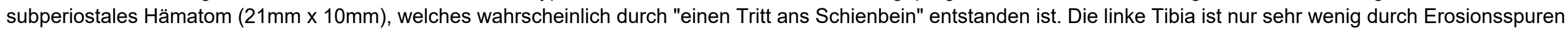

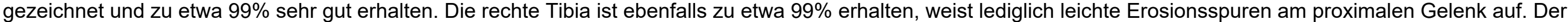
rechte Talus ist zu etwa $98 \%$ erhalten und weist insgesamt einen unauffälligen Arthrosegrad von 2 auf. 
Bezeichn.: Femur

Kiste:

5255273

Skelet: V50 50

Population: Calden

Seite: links

Erhaltung: $\mathbf{X}$ prox. Gelenk

$X$ prox. Schaft

$X$ mittl. Schaft

$\mathbf{X}$ dist. Schaft

X dist. Gelenk
Ges./Kr.: Krank

Krankh.: Arthrose

Arthritis

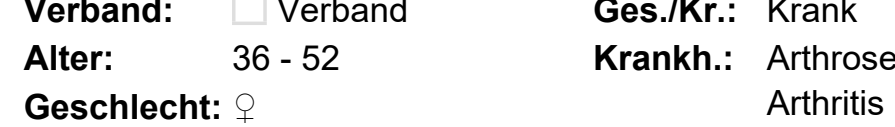

Geschlecht:

Arthrose:

$$
\text { prox. }
$$

dist.

3

Körperhöhe nach Sjøvold: 143,5 - 152,5 cm

\begin{tabular}{l|l|l} 
Maß & Wert & Einheit \\
\hline a-p $\varnothing$ subtrochlear & 23,12 & $\mathrm{~mm}$ \\
Caput, horizontaler $\varnothing$ & 38,13 & $\mathrm{~mm}$ \\
Caput, vertikaler $\varnothing$ & 38,3 & $\mathrm{~mm}$ \\
Collum-Corpus-Winkel & 120 & $\circ$ \\
Epicondylenbreite & 69,17 & $\mathrm{~mm}$ \\
gr. Länge & 377 & $\mathrm{~mm}$ \\
m-I $\varnothing$ subtrochlear & 31,2 & $\mathrm{~mm}$ \\
Umfang Schaftmitte & 77 & $\mathrm{~mm}$
\end{tabular}

\section{Beschreibung:}

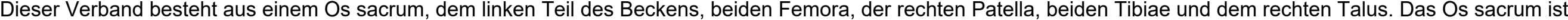

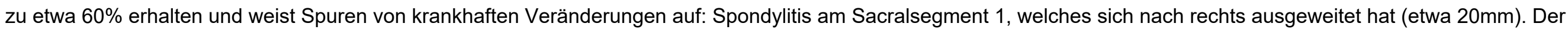

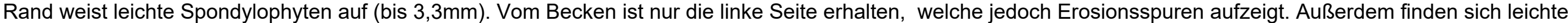
Zeichen eines entzündlichen Prozesses am Rand des Acetabulums. Hier ist der verschleißende arthrotische Prozess in einen entzündlichen arthritischen Prozess

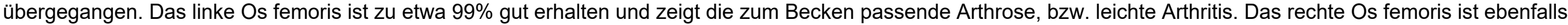
gut erhalten und weist eine Auffälligkeit im unteren Drittel (43mm x 12mm x $6 \mathrm{~mm}$ ) auf. Es handelt sich dabei um eine knöcherne Neubildung im Sinne einer

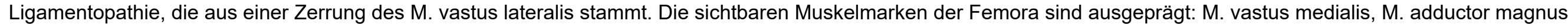

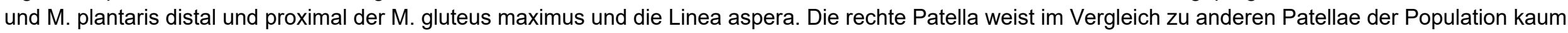

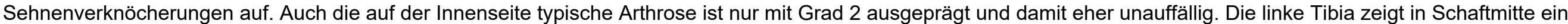

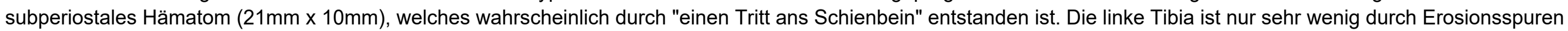

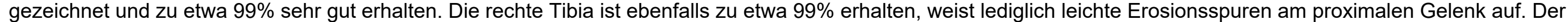
rechte Talus ist zu etwa $98 \%$ erhalten und weist insgesamt einen unauffälligen Arthrosegrad von 2 auf. 


\section{Bezeichn.: Femur \\ Kiste: $\quad 5249270$ \\ Skelet: Zettel}

Population: Calden

Seite: rechts

Erhaltung: $\square$ prox. Gelenk

$X$ prox. Schaft

$X$ mittl. Schaft

$\mathbf{X}$ dist. Schaft

dist. Gelenk

\section{Beschreibung:}

Bei diesem Fragment eines Os femoris fallen Bissspuren von Rudentieren auf.

\section{Alter:}

Geschlecht: $q>\hat{0}$

Arthrose:
Verband: $\quad$ Verband 


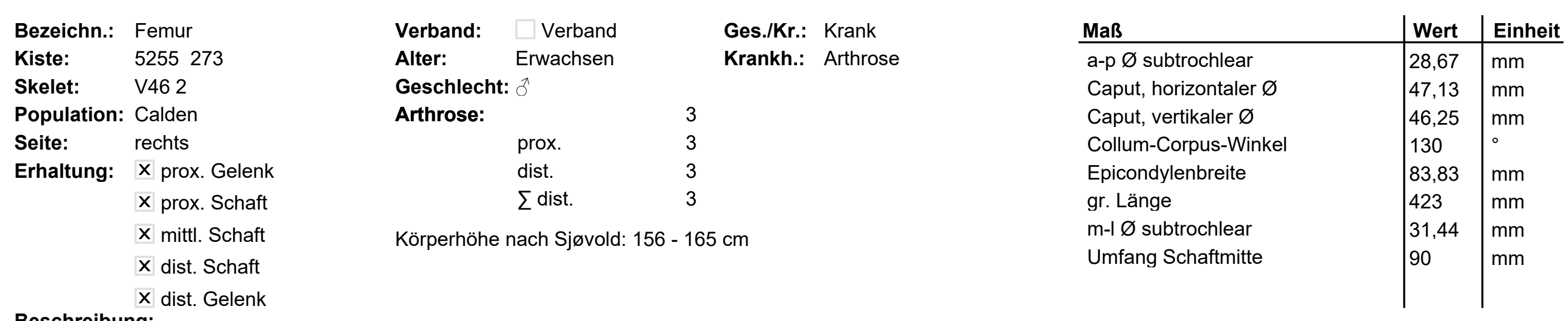

Dies ist ein Verband aus einem Beckenfragment rechts, rechtem Os femoris und beiden Patellae. Das Os femoris ist fast vollständig erhalten, nur stellenweise ist es erodiert und weist folgende Muskelmarken auf: Eine stark ausgeprägte Linea aspera, Ansatz des M. gluteus maximus, ein massiver Trochanter major, M. adductor magnus, M. gastrocnemius und eine ausgeprägte Ansatzstelle des M. vastus medialis. Die Fovea capitis femoris hat einen Rand, welcher über 4mm misst und auch die Condylen weisen eindeutige Verschleißspuren auf. Stellenweise wird der Gelenkknorpel schon verschlissen gewesen sein. 
Bezeichn:: Femur

\section{Kiste: $\quad 5249270$}

Skelet: V63 62

Population: Calden

Seite: rechts

Erhaltung: $\mathbf{X}$ prox. Gelenk

$X$ prox. Schaft

$X$ mittl. Schaft

$\mathbf{X}$ dist. Schaft

X dist. Gelenk
Ges./Kr.: Krank

Krankh.: Arthrose

Alter: $\quad 35-45$ (55) Krankh.: Arthrose

\section{Geschlecht: $ᄋ$}

Arthrose:

prox.

3

Körperhöhe nach Sjøvold: 146,5 - 155,5 cm

\section{Maß}

Caput, horizontaler $\varnothing$

Caput, vertikaler $\varnothing$

Collum-Corpus-Winkel

Epicondylenbreite

gr. Länge

Umfang Schaftmitte

\begin{tabular}{|l|l} 
Wert & Einheit \\
\hline 39 & $\mathrm{~mm}$
\end{tabular}

36,13

57,2

388

80

\section{Beschreibung:}

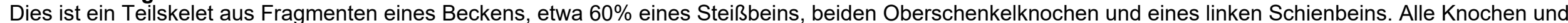
Knochenfragmente sind in gutem Erhaltungszustand und wenig erodiert, es sind lediglich wenige kleine Knochenteile abfrakturiert. Die Tibia weist eine leichte

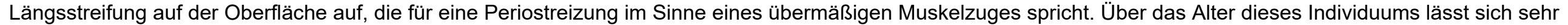

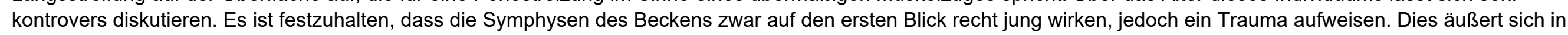

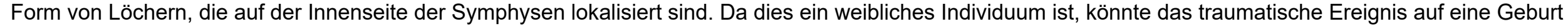

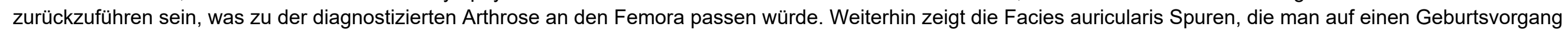

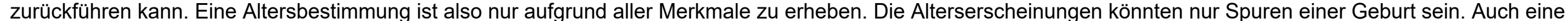

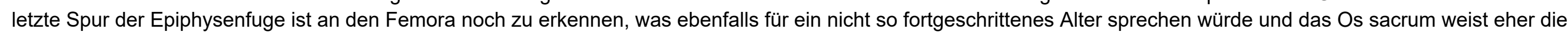
Gesamterscheinung eines Menschen im mittleren Alter auf. 
Bezeichn.: Femur

\section{Kiste:} 5249270

Skelet:

Population: Calden

Seite: links

Erhaltung: $\mathbf{X}$ prox. Gelenk

$X$ prox. Schaft

$X$ mittl. Schaft

$\mathbf{X}$ dist. Schaft

X dist. Gelenk
Ges./Kr.: Krank

Krankh.: Arthrose

Alter: $\quad 35-45$ (55) Krankh.: Arthrose

Geschlecht: $q$

\section{Arthrose:}

\section{prox.}

dist.

3

3

Körperhöhe nach Sjøvold: 147,9 - 156,9 cm

\begin{tabular}{l|l|l} 
Maß & Wert & Einheit \\
\hline a-p $\varnothing$ subtrochlear & 25,7 & $\mathrm{~mm}$ \\
Caput, horizontaler $\varnothing$ & 40 & $\mathrm{~mm}$ \\
Caput, vertikaler $\varnothing$ & 39 & $\mathrm{~mm}$ \\
Collum-Corpus-Winkel & 122 & $\circ$ \\
Epicondylenbreite & 56,45 & $\mathrm{~mm}$ \\
gr. Länge & 393 & $\mathrm{~mm}$ \\
m-I $\varnothing$ subtrochlear & 32,7 & $\mathrm{~mm}$ \\
Umfang Schaftmitte & 80 & $\mathrm{~mm}$
\end{tabular}

\section{Beschreibung:}

Dies ist ein Teilskelet aus Fragmenten eines Beckens, etwa 60\% eines Steißbeins, beiden Oberschenkelknochen und eines linken Schienbeins. Alle Knochen und Knochenfragmente sind in gutem Erhaltungszustand und wenig erodiert, es sind lediglich wenige kleine Knochenteile abfrakturiert. Die Tibia weist eine leichte

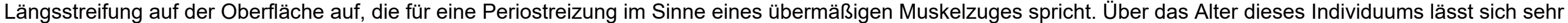

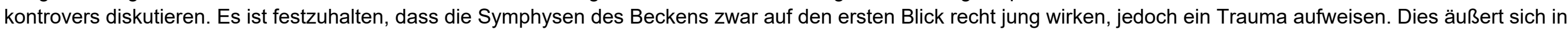
Form von Löchern, die auf der Innenseite der Symphysen lokalisiert sind. Da dies ein weibliches Individuum ist, könnte das traumatische Ereignis auf eine Geburt

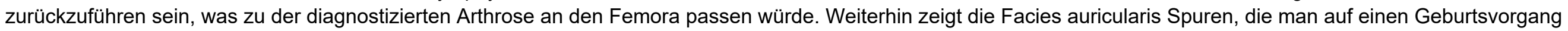

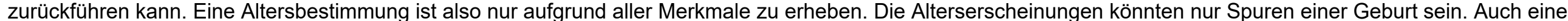

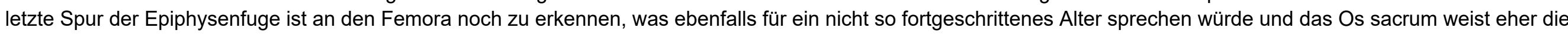
Gesamterscheinung eines Menschen im mittleren Alter auf. 


\section{Bezeichn.: Femur \\ Kiste: $\quad 5249270$ \\ Skelet: $\quad 56$ \\ Population: Calden \\ Seite: links \\ Erhaltung: $\mathbf{X}$ prox. Gelenk \\ $X$ prox. Schaft \\ $X$ mittl. Schaft \\ $\mathbf{X}$ dist. Schaft \\ $X$ dist. Gelenk}

Beschreibung:

Dieses Os femoris ist sehr massiv.
Verband: $\quad$ Verband Ges./Kr.: Krank

Alter: $\quad 30-50 \quad$ Krankh.: Arthrose

\section{Geschlecht: $\delta$}

Arthrose:

$\begin{array}{ll}\text { prox. } & 3 \\ \text { dist. } & 4\end{array}$

Körperhöhe nach Sjøvold: 165,2 - 174,2 cm
Maß

a-p $\varnothing$ subtrochlear

Caput, horizontaler $\varnothing$

Caput, vertikaler $\varnothing$

Collum-Corpus-Winkel

Epicondylenbreite

gr. Länge

$\mathrm{m}-\mathrm{\varnothing}$ subtrochlear

Umfang Schaftmitte

\begin{tabular}{|l|l} 
Wert & Einheit \\
\hline 32,2 & $\mathrm{~mm}$ \\
48 & $\mathrm{~mm}$ \\
52,08 & $\mathrm{~mm}$ \\
126 & $\circ$ \\
77,16 & $\mathrm{~mm}$ \\
457 & $\mathrm{~mm}$ \\
38,26 & $\mathrm{~mm}$ \\
105 & $\mathrm{~mm}$
\end{tabular}




\section{Bezeichn.: Femur}

\section{Kiste:}

$5257+58275$

Skelet: $\quad$ P.Sk.9. 427

Population: Calden

Seite: rechts

Erhaltung: $\mathbf{X}$ prox. Gelenk

X prox. Schaft

$X$ mittl. Schaft

$\mathbf{X}$ dist. Schaft

dist. Gelenk
Ges./Kr.: Krank

Krankh.: Arthrose
Maß

a-p $\varnothing$ subtrochlear

Caput, horizontaler $\varnothing$

Caput, vertikaler $\varnothing$

Collum-Corpus-Winkel

gr. Länge

m-I Ø subtrochlear

Umfang Schaftmitte

\begin{tabular}{|l|l} 
Wert & Einheit \\
\hline 27,63 & $\mathrm{~mm}$
\end{tabular}

$49,23 \mathrm{~mm}$

$49,23 \mathrm{~mm}$

128

$400 \mathrm{~mm}$

$36,72 \mathrm{~mm}$

$88 \mathrm{~mm}$

\section{Beschreibung:}

Körperhöhe nach Sjøvold: 149,8 - 158,8 cm

88

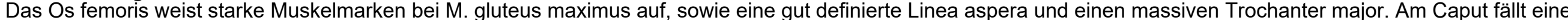

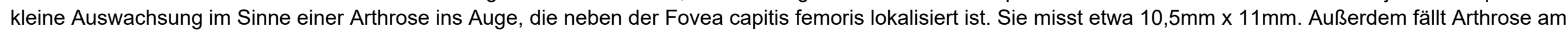
oberen Rand des Caput auf. 


\section{Bezeichn.: Femur \\ Kiste: $\quad 5257+58275$ \\ Skelet: P.Sk.9. 39 \\ Population: Calden \\ Seite: links \\ Erhaltung: $\mathbf{X}$ prox. Gelenk \\ $X$ prox. Schaft \\ $\mathbf{X}$ mittl. Schaft \\ dist. Schaft \\ dist. Gelenk \\ Beschreibung:}

Verband: $\square$ Verband Ges./Kr.: Krank

Alter: $\quad 35-52 \quad$ Krankh.: Arthrose

\section{Geschlecht:}

Arthrose:

prox.

3

\begin{tabular}{l|l|l} 
Maß & Wert & Einheit \\
\hline a-p $\varnothing$ subtrochlear & 25,7 & $\mathrm{~mm}$ \\
Caput, horizontaler $\varnothing$ & 46,55 & $\mathrm{~mm}$ \\
Caput, vertikaler $\varnothing$ & 45,58 & $\mathrm{~mm}$ \\
Collum-Corpus-Winkel & 132 & $\circ$ \\
gr. Länge & 323 & $\mathrm{~mm}$ \\
m-I $\varnothing$ subtrochlear & 37,8 & $\mathrm{~mm}$ \\
Umfang Schaftmitte & 86 & $\mathrm{~mm}$
\end{tabular}

Bei diesem Os femoris ist eine gut ausgeprägte Ansatzstelle des M. gluteus maximus zu erkennen. 
Bezeichn:: Femur

\section{Kiste: $\quad 5257+58275$}

Skelet: $\quad 67$ über Becken 9

Population: Calden

Seite: links

Erhaltung: $\square$ prox. Gelenk

prox. Schaft

$X$ mittl. Schaft

$\mathbf{X}$ dist. Schaft

X dist. Gelenk

Beschreibung:

Ein mittleres bis distales Fragment.
Verband: $\quad$ Verband

Alter: Erwachsen

\section{Geschlecht:}

Arthrose:
Ges./Kr.: Gesund

Maß

Epicondylenbreite

Umfang Schaftmitte \begin{tabular}{|c|c} 
Wert & Einheit \\
79,51 & mm
\end{tabular}

$79,51 \mathrm{~mm}$

87 


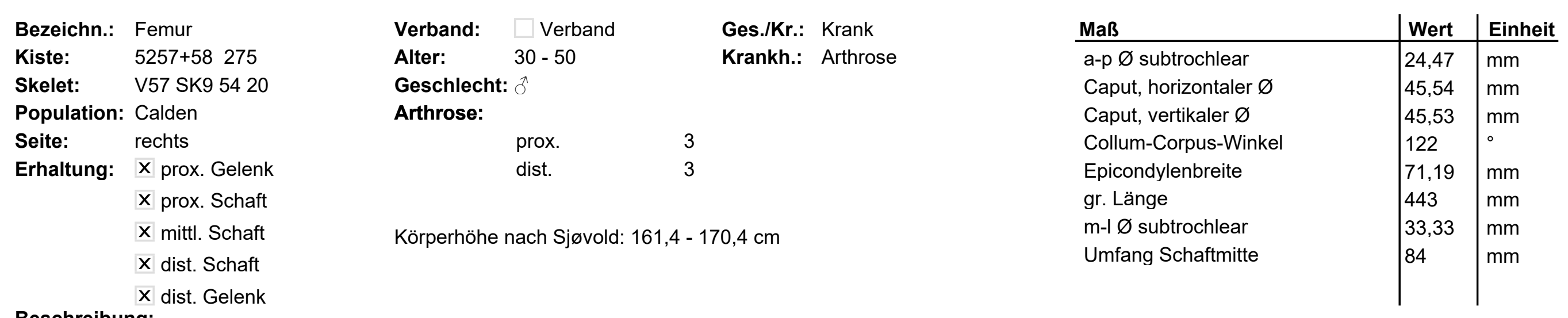

\section{Beschreibung:}

Auffällig ist bei beiden Femora, dass am oberen Rand eine Auswalzung des Gelenkrandes stattgefunden hat. Hier ist als Furche ausgeprägt eine Arthrose sehr glatt abgeschliffen. 


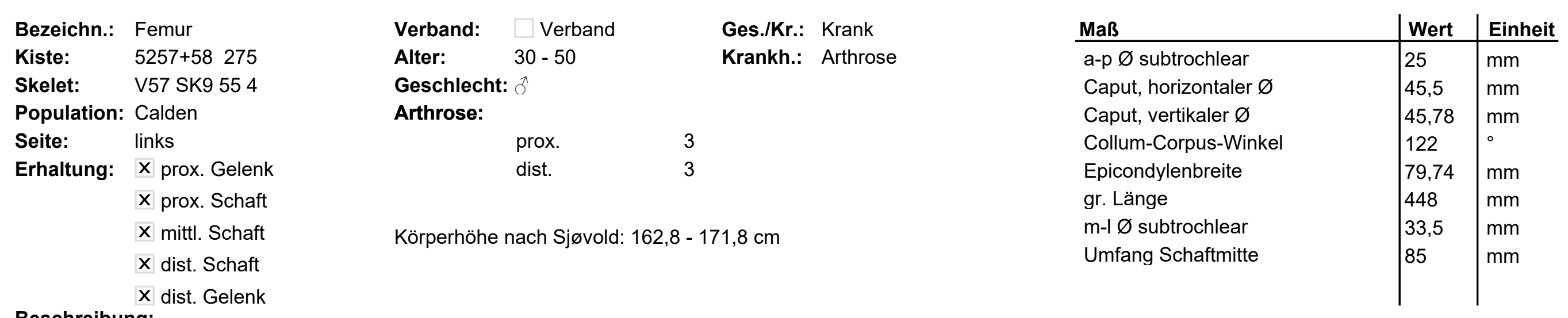

\section{Beschreibung:}

Auffällig ist bei beiden Femora, dass am oberen Rand eine Auswalzung des Gelenkrandes stattgefunden hat. Hier ist als Furche ausgeprägt eine Arthrose sehr glatt abgeschliffen. 


$\begin{array}{ll}\text { Bezeichn.: } & \text { Femur } \\ \text { Kiste: } & 5255273 \\ \text { Skelet: } & \text { Zettel } \\ \text { Population: } & \text { Calden } \\ \text { Seite: } & \text { links } \\ \text { Erhaltung: } & \square \text { prox. Gelenk } \\ & \square \text { prox. Schaft } \\ & \square \text { mittl. Schaft } \\ & \square \text { dist. Schaft } \\ & \mathbf{X} \text { dist. Gelenk }\end{array}$

Verband: $\quad \square$ Verband

Alter:

Geschlecht:

Ein Fragment des medialen Condylus eines linken Os femoris. 

Bezeichn.: Femur
Kiste: $\quad 5255273$
Skelet: Zettel
Population: Calden
Seite: links
Erhaltung: $\square$ prox. Gelenk
prox. Schaft
mittl. Schaft
dist. Schaft
$\mathbf{X}$ dist. Gelenk

Verband: $\quad \square$ Verband

\section{Alter:}

Beschreibung:

Ein Fragment eines linken Os femoris, es handelt sich um ein Teil des lateralen Condylus. 


\section{Bezeichn.: Femur}

\section{Kiste:}

$5257+58275$

Skelet: P.SK.9. 37505

Population: Calden

Seite: rechts

Erhaltung: $\mathbf{X}$ prox. Gelenk

$X$ prox. Schaft

$X$ mittl. Schaft

dist. Schaft

dist. Gelenk

\section{Beschreibung:}

Ein Fragment eines rechten Os femoris, welches sehr grazil wirkt.

\section{Ges./Kr.: Gesund}

\section{Alter:}

Geschlecht:

Arthrose:

\section{Maß}

a-p $\varnothing$ subtrochlear

Collum-Corpus-Winkel

m-I Ø subtrochlear

Umfang Schaftmitte \begin{tabular}{|l|l} 
Wert & Einheit \\
\hline 23,85 & $\mathrm{~mm}$
\end{tabular}

23,85 $\mathrm{mm}$

122

$32,19 \mathrm{~mm}$

$79 \mathrm{~mm}$



Bezeichn.: Femur
Kiste: $\quad 5257+58275$
Skelet: P.SK.9. 39505
Population: Calden

\section{Erhaltung: $\square$ prox. Gelenk \\ prox. Schaft \\ mittl. Schaft \\ $\mathbf{X}$ dist. Schaft \\ dist. Gelenk}

Verband: $\quad$ Verband

\section{Alter:}

Geschlecht:

Arthrose:

Beschreibung:

Ein distales Fragment eines Os femoris. 


\section{Bezeichn.: Femur}

\section{Kiste:}

$5257+58275$

Skelet: $\quad 53$ unter SCH.33+SK.9.

Population: Calden

Seite: rechts

Erhaltung: prox. Gelenk

$X$ prox. Schaft

$X$ mittl. Schaft

$X$ dist. Schaft

dist. Gelenk
Ges./Kr.: Krank

Krankh.: Muskelreizung
Maß

a-p $\varnothing$ subtrochlear

$\mathrm{m}-\mathrm{\varnothing} \varnothing$ subtrochlear

Umfang Schaftmitte

\begin{tabular}{l|l} 
Wert & Einheit \\
\hline 27 & $\mathrm{~mm}$ \\
35,45 & $\mathrm{~mm}$ \\
93 & $\mathrm{~mm}$ \\
&
\end{tabular}

\section{Beschreibung:}

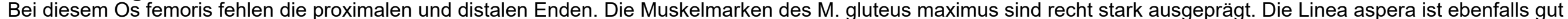

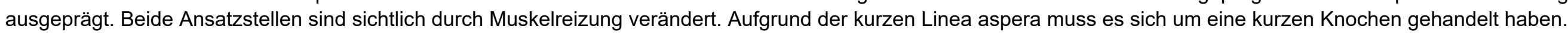




\section{Bezeichn:: Femur \\ Kiste: $\quad 5242266$ \\ Skelet: $\quad 32$ E. B-S. 39 \\ Population: Calden \\ Seite: rechts \\ Erhaltung: $\mathbf{X}$ prox. Gelenk \\ $X$ prox. Schaft \\ $X$ mittl. Schaft \\ X dist. Schaft \\ dist. Gelenk \\ Beschreibung:}

Ein proximal erhaltenes Os femoris.

\section{Verband: $\square$ Verband Ges./Kr.: Krank}

Alter: (25) $30-50$ (60) Krankh.: Arthrose

\section{Geschlecht: $\precsim$}

\section{Arthrose:}

prox.

Körperhöhe nach Sjøvold: 155,2 - 164,2 cm

\section{Maß}

a-p $\varnothing$ subtrochlear

Caput, horizontaler $\varnothing$

Caput, vertikaler $\varnothing$

Collum-Corpus-Winkel

gr. Länge

m-l Ø subtrochlear

Umfang Schaftmitte

\begin{tabular}{|l|l} 
Wert & Einheit \\
\hline 26,18 & $\mathrm{~mm}$
\end{tabular}

\begin{tabular}{l|l}
44,25 & $\mathrm{~mm}$ \\
45,5 & $\mathrm{~mm}$
\end{tabular}

$45,5 \mathrm{~mm}$

135

$420 \quad \mathrm{~mm}$

$35,7 \quad \mathrm{~mm}$

$93 \mathrm{~mm}$




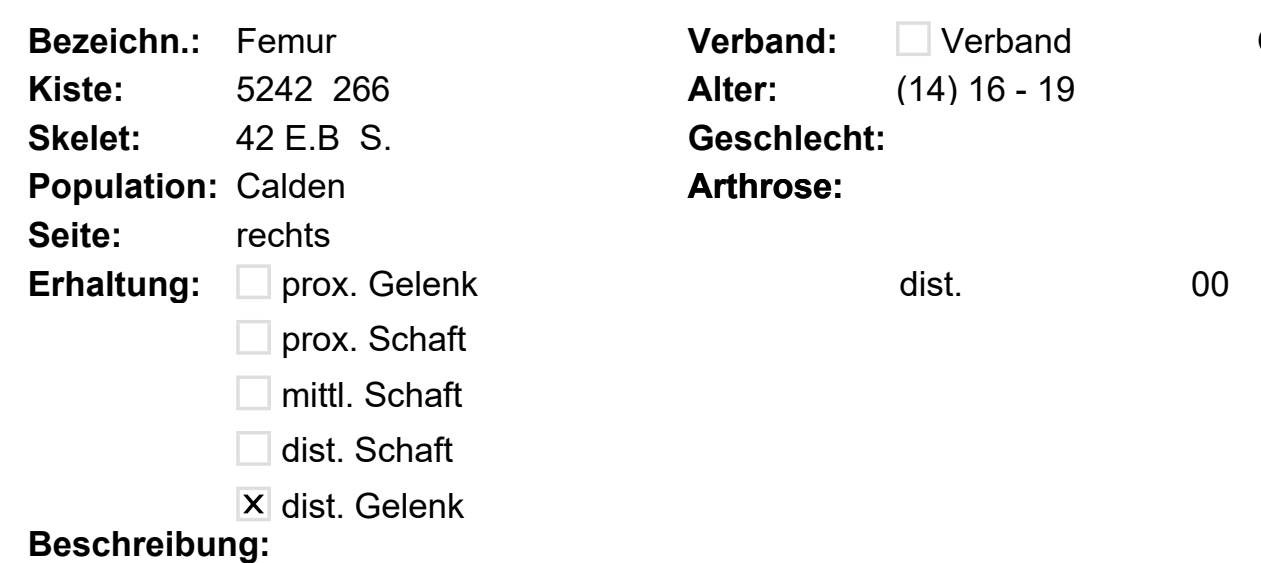

Es handelt sich hier um die distale rechte Epiphyse eines juvenilen Os femoris. 

Bezeichn.: Femur
Kiste: $\quad 5242266$
Skelet: 402
Population: Calden
Seite: links
Erhaltung: $\square$ prox. Gelenk
prox. Schaft
$X$ mittl. Schaft
$\mathbf{X}$ dist. Schaft
$\mathbf{X}$ dist. Gelenk

Verband: $\quad \square$ Verband

\section{Alter:}

Beschreibung:

Ein sehr stark erodiertes Schaftfragment eines linken Os femoris. 


\begin{tabular}{|c|c|c|c|c|}
\hline \multirow{10}{*}{$\begin{array}{l}\text { Bezeichn.: } \\
\text { Kiste: } \\
\text { Skelet: } \\
\text { Population: } \\
\text { Seite: } \\
\text { Erhaltung: }\end{array}$} & Femur & \multirow{3}{*}{$\begin{array}{l}\text { Verband: } \\
\text { Alter: } \\
\text { Geschlecht }\end{array}$} & \multirow{2}{*}{$\begin{array}{l}\square \text { Verband } \\
\text { Erwachsen }\end{array}$} & Ges./Kr. \\
\hline & 5242266 & & & Krankh \\
\hline & 4038 E. B-S. & & $\hat{0}$ & \\
\hline & Calden & Arthrose: & & \\
\hline & rechts & & & \\
\hline & $\square$ prox. Gelenk & & dist. & \\
\hline & $\mathbf{X}$ prox. Schaft & & & \\
\hline & $\mathbf{X}$ mittl. Schaft & Körperhöh€ & nach Sjøvold: & $166,9 \mathrm{~cm}$ \\
\hline & $\mathbf{X}$ dist. Schaft & & & \\
\hline & X dist. Gelenk & & & \\
\hline
\end{tabular}

\begin{tabular}{l|l|l} 
Maß & Wert & Einheit \\
\hline gr. Länge & 430 & $\mathrm{~mm}$ \\
Umfang Schaftmitte & 87 & $\mathrm{~mm}$ \\
& & \\
& &
\end{tabular}

Dieses Fundstück eines rechten Os femoris weist eine stark ausgeprägte Linea aspera auf. 


\section{Bezeichn.: Femur \\ Kiste: $\quad 5242266$ \\ Skelet: $\quad 4142$}

Population: Calden

Seite: links

Erhaltung: $\square$ prox. Gelenk

$X$ prox. Schaft

mittl. Schaft

dist. Schaft

dist. Gelenk

\section{Beschreibung:}

\section{Verband: $\quad$ Verband}

\section{Alter:}

Geschlecht: $\delta$

Arthrose:

\section{Ges./Kr.: Gesund}

\section{Maß}

Collum-Corpus-Winkel

Umfang Schaftmitte \begin{tabular}{|l|l} 
Wert & Einheit \\
\hline 125 & $\circ$
\end{tabular}

Es handelt sich um ein massives Os femoris, welches nur teilweise erhalten ist. Es weist deutliche Muskelmarken auf. 


\section{Bezeichn.: Femur \\ Kiste: $\quad 5242266$ \\ Skelet: $\quad$ E. B-S.}

Population: Calden

Seite: links

Erhaltung: $\square$ prox. Gelenk

prox. Schaft

mittl. Schaft

$\mathbf{X}$ dist. Schaft

$\mathbf{X}$ dist. Gelenk

\section{Beschreibung:}

Es handelt sich hier um das Fragment eines jungen Os femoris.

\section{Geschlecht:}

Arthrose:

$\begin{array}{ll}70 & \mathrm{~mm} \\ & \end{array}$



Bezeichn.: Femur
Kiste: $\quad 8505718$
Skelet: aus Kiste, ohne Bez.
Population: Calden
Seite: rechts
Erhaltung: $\mathbf{X}$ prox. Gelenk
$X$ prox. Schaft
X mittl. Schaft
dist. Schaft
dist. Gelenk
Beschreibung:

Verband: $\quad \square$ Verband

Alter: $6-8$

Ges./Kr.: Gesund

Geschlecht:

Arthrose:

Ein proximales Fragment eines jungen Os femoris.

\begin{tabular}{l|l|l} 
Maß & Wert & Einheit \\
\hline & & \\
a-p $\varnothing$ subtrochlear & 18,52 & $\mathrm{~mm}$ \\
Collum-Corpus-Winkel & 130 & $\circ$ \\
gr. Länge & 235 & $\mathrm{~mm}$ \\
m-I $\varnothing$ subtrochlear & 21,25 & $\mathrm{~mm}$ \\
Umfang Schaftmitte & 55 & $\mathrm{~mm}$ \\
& &
\end{tabular}



Bezeichn.: Femur
Kiste: $\quad 8505718$
Skelet: aus Kiste
Population: Calden
Seite: links
Erhaltung: $\mathbf{X}$ prox. Gelenk
$X$ prox. Schaft
mittl. Schaft
dist. Schaft
dist. Gelenk
Beschreibung:

Verband:

\section{Alter:}

Ges./Kr.: Gesund

Ein proximales Fragment eines jungen Os femoris. 

Bezeichn.: Femur
Kiste: $\quad 8505718$
Skelet: $\quad$ V40 aus Kiste
Seite: rechts
Erhaltung: $\square$ prox. Gelenk
prox. Schaft
mittl. Schaft
dist. Schaft
$\mathbf{X}$ dist. Gelenk
Beschreibung:

Verband:

Alter:

Ges./Kr.: Gesund

Geschlecht:

Arthrose:

Von diesem Os femoris ist nur ein distales $1 / 5$ erhalten. 

Bezeichn.: Femur
Kiste:
8505718
aus Kiste
Skelet:
Calden
Seite: rechts
Erhaltung: X prox. Gelenk
prox. Schaft
mittl. Schaft
dist. Schaft
dist. Gelenk

Verband:

Verband

Alter:

Ges./Kr.: Gesund

Geschlecht:

Beschreibung:

Hier ist nur ein Caput femoris zu $70 \%$ erhalten. 
Bezeichn.: Femur

Kiste: $\quad 8505718$

Skelet: aus Kiste

Population: Calden

Seite: rechts

prox. Gelenk

prox. Schaft

mittl. Schaft

dist. Schaft

dist. Gelenk
Verband: $\square$ Verband

\section{Alter:}

Geschlecht:

Arthrose:

\section{Beschreibung:}

Hier ist ein kleines Fragment des Condylus eines rechten Os femoris erhalten. Das Fragment wirkt eher grazil. 
Bezeichn.: Femur

Kiste: $\quad 8505718$

Skelet: aus Kiste

Population: Calden

Seite: rechts

Erhaltung: $\square$ prox. Gelenk

prox. Schaft

mittl. Schaft

dist. Schaft

$X$ dist. Gelenk

\section{Ges./Kr.: Krank \\ Krankh.: Arthrose \\ Erwachsen}

Verband

Geschlecht:

Arthrose:

\section{Beschreibung:}

Dies ist ein Fragment des Condylus femoris. Das Fragment ist zur Hälfte mit etwas erhabenen Anhebungen gesäumt, welche im Sinne einer Arthrose 3. Grades zu interpretieren sind. 

Bezeichn.: Femur
Kiste: $\quad 8505718$
Skelet: $\quad$ V40 aus Kiste
Population: Calden
Seite: links
Erhaltung: $\square$ prox. Gelenk
prox. Schaft
X mittl. Schaft
dist. Schaft
dist. Gelenk

\section{Beschreibung:}

Ein Fragment eines jungen Os femoris.
Verband: $\quad$ Verband Ges./Kr.: Gesund

Maß

Umfang Schaftmitte

\section{Geschlecht:}

Arthrose: 

Bezeichn.: Femur
Kiste: $\quad 8505718$
Skelet: aus 2. Kiste
Population: Calden
Seite: n. def.
Erhaltung: $\square$ prox. Gelenk prox. Schaft
mittl. Schaft
X dist. Schaft
dist. Gelenk

Verband: $\quad \square$ Verband

\section{Alter:}

Geschlecht:

\section{Beschreibung:}

Ein Fragment aus dem distalen Teil eines Os femoris nicht bestimmbarer Seite. 

Bezeichn.: Femur
Kiste: $\quad 8505718$
Skelet: V39
Population: Calden
Seite: rechts
Erhaltung: $\mathbf{X}$ prox. Gelenk
X prox. Schaft
mittl. Schaft
dist. Schaft
dist. Gelenk

\section{Verband: $\square$ Verband \\ Alter: $\quad 30-50$ \\ Geschlecht: $q<\hat{\jmath}$ \\ Arthrose:}

prox.

2
Ges./Kr.: Gesund

\section{Maß}

a-p $\varnothing$ subtrochlear

Caput, vertikaler $\varnothing$

Collum-Corpus-Winkel

m-I $\varnothing$ subtrochlear

Umfang Schaftmitte

\begin{tabular}{|l|l} 
Wert & Einheit \\
27,81 & $\mathrm{~mm}$
\end{tabular}

48

130

33,41

93

\section{Beschreibung:}

Von diesem Os femoris sind zwei proximale Fragmente erhalten, wobei das eine etwa 50\% des Caput femoris ausmacht. 

Bezeichn.: Femur
Kiste: $\quad 8505718$
Skelet: V39
Population: Calden
Seite: links
Erhaltung: $\mathbf{X}$ prox. Gelenk
$X$ prox. Schaft
mittl. Schaft
dist. Schaft
dist. Gelenk

Beschreibung:

Verband: $\quad \square$ Verband
Alter: $\quad 30-50$
Geschlecht: $q<\widehat{\emptyset}$
Arthrose:

prox.
Ges./Kr.: Gesund

\begin{tabular}{l|l|l} 
Maß & Wert & Einheit \\
\hline Caput, horizontaler $\varnothing$ & 47 & $\mathrm{~mm}$ \\
Caput, vertikaler $\varnothing$ & 48 & $\mathrm{~mm}$ \\
& & \\
& &
\end{tabular}

Von diesem Os femoris sind das proximale Gelenk und ein kleiner Teil des Schaftes erhalten. 


\section{Bezeichn:: Femur \\ Kiste: $\quad 5252271$ \\ Skelet: $\quad 34$}

Population: Calden

Seite: rechts

Erhaltung: $\mathbf{X}$ prox. Gelenk

$X$ prox. Schaft

$\mathbf{x}$ mittl. Schaft

$\mathbf{X}$ dist. Schaft

X dist. Gelenk

Beschreibung:

Ein Fragment eines grazilen Os femoris. Die Begutachtung wurde durch Bodenerosionen eingeschränkt.

\section{Verband: \\ Verband \\ Ges./Kr.: Krank \\ Alter: (45) 50 - 60 (65) \\ Krankh.: Arthrose}

\section{Geschlecht:}

prox. $\quad 3$

Körperhöhe nach Sjøvold: 143 - 152 cm

\begin{tabular}{l|l|l} 
Maß & Wert & Einheit \\
\hline a-p $\varnothing$ subtrochlear & 24,35 & $\mathrm{~mm}$ \\
Caput, horizontaler $\varnothing$ & 38,7 & $\mathrm{~mm}$ \\
Caput, vertikaler $\varnothing$ & 40,4 & $\mathrm{~mm}$ \\
Collum-Corpus-Winkel & 126 & $\circ$ \\
Epicondylenbreite & 58,5 & $\mathrm{~mm}$ \\
gr. Länge & 375 & $\mathrm{~mm}$ \\
m-I $\varnothing$ subtrochlear & 32,65 & $\mathrm{~mm}$ \\
Umfang Schaftmitte & 82 & $\mathrm{~mm}$
\end{tabular}




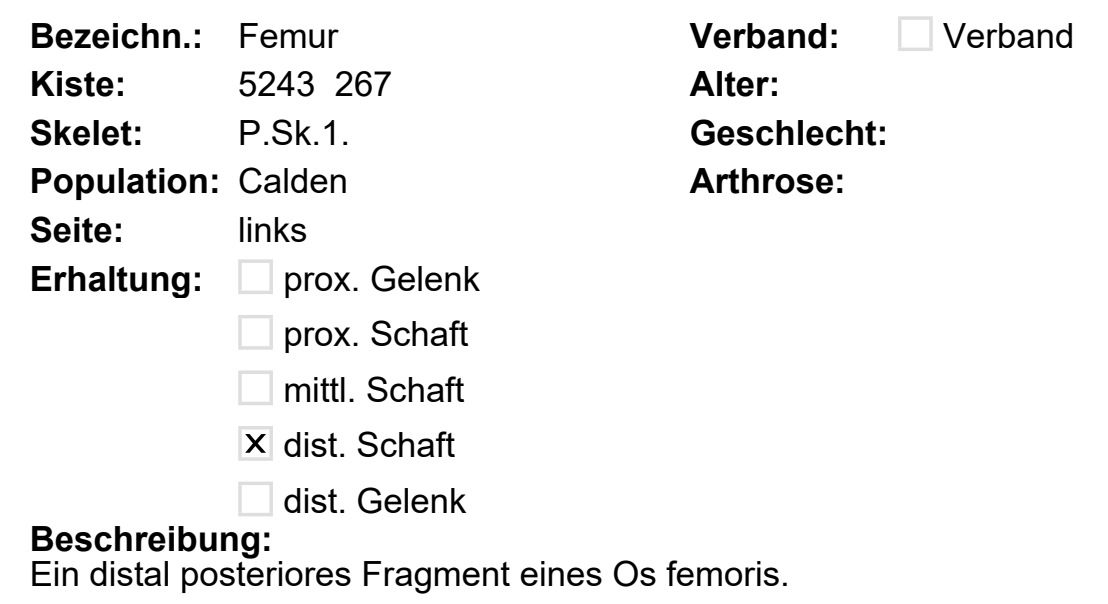




\section{Bezeichn.: Femur \\ Kiste: 5252271 \\ Skelet: Zettel}

Population: Calden

Erhaltung: $\mathbf{X}$ prox. Gelenk

prox. Schaft

mittl. Schaft

dist. Schaft

dist. Gelenk

Beschreibung:

Hier ist lediglich ein kleiner Teil des Caput erhalten.
Verband: $\quad \square$ Verband

\section{Alter:}

Geschlecht:

Arthrose:

prox. 


\section{Bezeichn.: Femur \\ Kiste: $\quad 5252271$ \\ Skelet: Zettel}

Population: Calden

Seite: rechts

Erhaltung: $\square$ prox. Gelenk

$X$ prox. Schaft

mittl. Schaft

dist. Schaft dist. Gelenk

\section{Beschreibung:}

Dies ist ein Fragment eines proximalen Femurs mit Linea aspera. Die Tuberositas glutea ist gut ausgeprägt.

\section{Verband: $\quad$ Verband Ges./Kr: Gesund}

\section{Alter:}

Geschlecht:

Arthrose: 


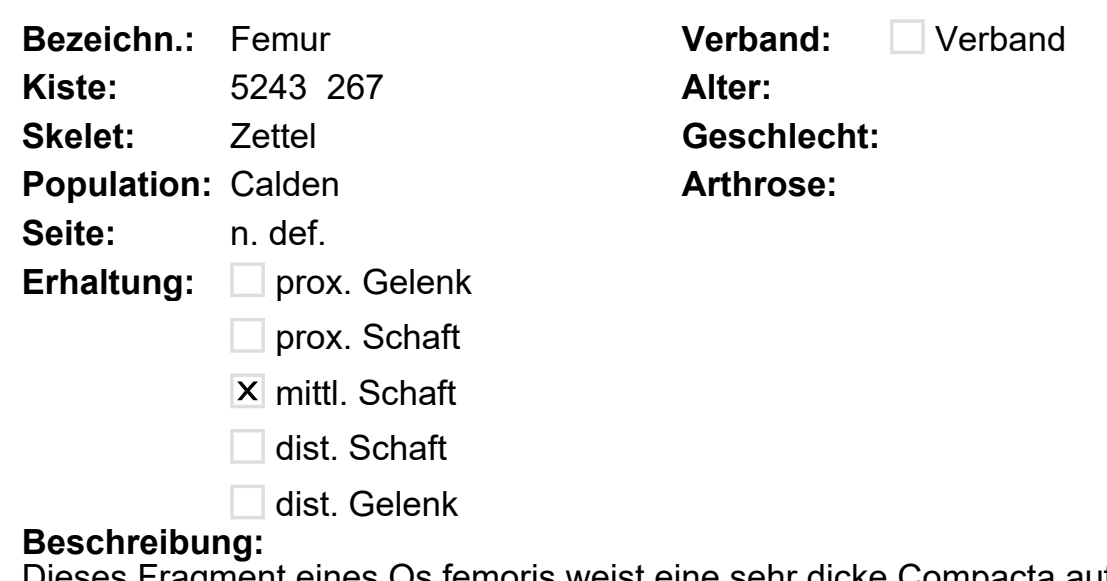

Dieses Fragment eines Os femoris weist eine sehr dicke Compacta auf. 
Bezeichn.: Femur

Kiste: 5243267

Skelet: PSK1

Population: Calden

Seite: n. def.

Erhaltung: $\square$ prox. Gelenk prox. Schaft

$X$ mittl. Schaft dist. Schaft dist. Gelenk

Beschreibung:

Fragment.
Verband: $\quad$ Verband

\section{Alter:}

Geschlecht:

Arthrose: 

Bezeichn.: Femur
Kiste: 5243267
Skelet: P.Sk.1. 20
Population: Calden
Seite: $\quad n$. def.
Erhaltung: $\square$ prox. Gelenk
prox. Schaft
$X$ mittl. Schaft
dist. Schaft
dist. Gelenk

Verband: $\square$ Verband

Ges./Kr.: Krank

Alter:

Krankh.: Periostreizung

Geschlecht:

\section{Beschreibung:}

Dieses Fundstück ist nicht eindeutig einem Os femoris zuzuordnen. Das Fragment weist einige Auflagerungen auf seiner Oberfläche auf. Diese sind bei diesem Erhaltungszustand allerdings nicht genauer zu diagnostizieren. Es könnte sich jedoch um eine periostale Reizung handeln. 

Bezeichn.: Femur
Kiste: $\quad 5243267$
Skelet: Zettel
Population:

\section{Erhaltung: $\square$ prox. Gelenk \\ $X$ prox. Schaft \\ mittl. Schaft \\ dist. Schaft \\ dist. Gelenk}

Verband: $\square$ Verband

Ges./Kr.: Krank

Alter:

Geschlecht:

Krankh.: Muskelreizung

Arthrose:

\section{Beschreibung:}

Dieses Fragment eines Os femoris weist deutliche Muskelmarken und eine Streifung der Oberfläche auf, die jedoch bei gegebenen nicht guten Erhaltungszustand nicht zu verifizieren ist. Es handelt sich aber möglicherweise um eine muskuläre Reizung. 

Bezeichn.: Femur
Kiste: $\quad 5243267$
Skelet: Zettel
Population:
Seite: n. def.
Erhaltung: $\square$ prox. Gelenk
prox. Schaft
$X$ mittl. Schaft
dist. Schaft
dist. Gelenk

Verband: $\quad \square$ Verband

Ges./Kr.: Krank

\section{Alter:}

Krankh.: Periostreizung

Geschlecht:

Muskelreizung

\section{Beschreibung:}

Dieses Fragment aus dem Schaft eines Os femoris weist eine oberflächliche Streifung auf, die möglicherweise auf eine muskuläre Periostreizung zurückzuführen ist. 


\section{Bezeichn: Femur \\ Kiste: $\quad 5243267$ \\ Skelet: Zettel}

Population: Calden

Seite: $\quad$ n. def.

Erhaltung: $\square$ prox. Gelenk

$X$ prox. Schaft

mittl. Schaft

dist. Schaft dist. Gelenk

\section{Beschreibung:}

Dies ist ein kleines Fragment.
Verband: Verband

Ges./Kr.: Gesund

\section{Alter:}

Geschlecht:

Arthrose: 


\section{Bezeichn.: Femur \\ Kiste: $\quad 5243267$ \\ Skelet: Zettel \\ Population: Calden \\ Seite: rechts \\ Erhaltung: $\square$ prox. Gelenk \\ prox. Schaft \\ mittl. Schaft \\ dist. Schaft \\ $X$ dist. Gelenk}

Verband: $\quad \square$ Verband

\section{Alter:}

Beschreibung:

Dies ist ein Fragment eines Condylus lateralis eines rechten Os femoris. 


\section{Bezeichn.: Femur \\ Kiste: $\quad 5243267$ \\ Skelet: Zettel}

Population: Calden

Erhaltung: X prox. Gelenk

prox. Schaft

mittl. Schaft

dist. Schaft

dist. Gelenk

Beschreibung:

Dies ist die proximale Femurepiphyse eines junge Individuums.
Ges./Kr.: Gesund

Maß

Caput, vertikaler $\varnothing$

Geschlecht:

Arthrose:

$30,6 \quad \mathrm{~mm}$




\section{Bezeichn.: Femur \\ Kiste: $\quad 5243267$ \\ Skelet: V72, Z. \\ Population: Calden \\ Seite: rechts \\ Erhaltung: $\square$ prox. Gelenk \\ $X$ prox. Schaft \\ $X$ mittl. Schaft \\ $\mathbf{X}$ dist. Schaft \\ $X$ dist. Gelenk \\ Beschreibung:}

Ein junges Os femoris aus einem Verband.
Verband: $\square$ Verband

Alter: $\quad 1,5-2,5$

Geschlecht:

Arthrose:
Maß

gr. Länge

\begin{tabular}{l|l|l} 
Wert & Einheit \\
\hline 148 & $\mathrm{~mm}$
\end{tabular}




$\begin{array}{ll}\text { Bezeichn.: } & \text { Femur } \\ \text { Kiste: } & 5243267 \\ \text { Skelet: } & \text { P.Sk.1. } 24 \\ \text { Population: } & \text { Calden } \\ \text { Seite: } & \text { links } \\ \text { Erhaltung: } & \square \text { prox. Gelenk } \\ & \square \text { prox. Schaft } \\ & \text { X mittl. Schaft } \\ & \square \text { dist. Schaft } \\ & \square \text { dist. Gelenk }\end{array}$

Verband: $\quad \square$ Verband

Alter:

Geschlecht:

Dies ist ein ziemlich rundes Fragment aus dem Schaft eines linken Os femoris. 


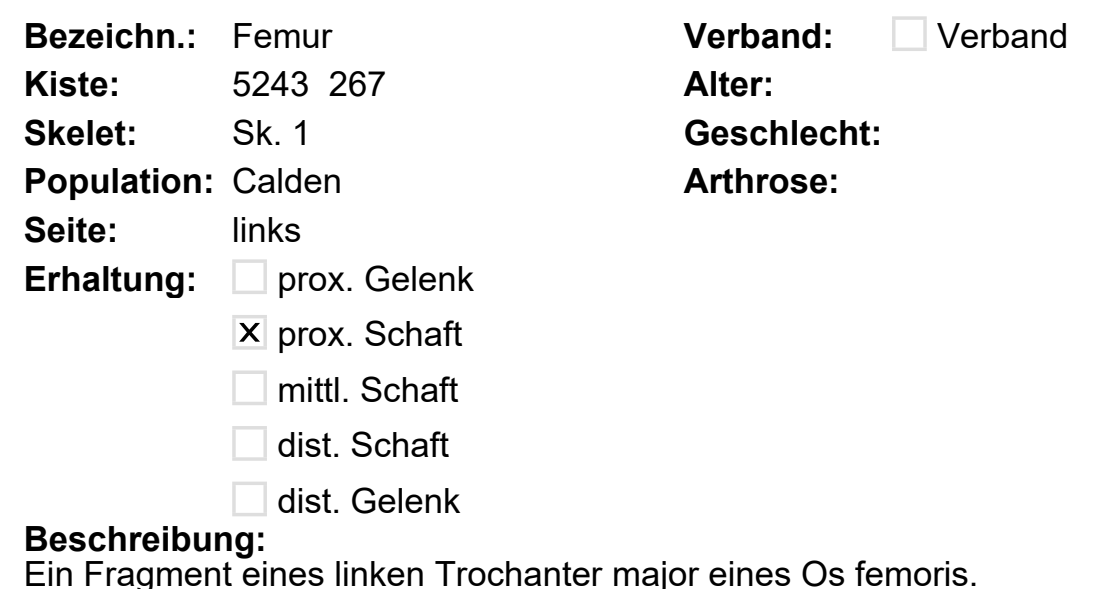

Ein Fragment eines linken Trochanter major eines Os femoris. 


\section{Bezeichn.: Femur \\ Kiste: $\quad 5243267$ \\ $\begin{array}{ll}\text { Skelet: Zettel } & \\ \text { Population: } & \text { Calden }\end{array}$ \\ Erhaltung: $\quad \mathbf{X}$ prox. Gelenk \\ prox. Schaft \\ mittl. Schaft \\ dist. Schaft \\ dist. Gelenk \\ Beschreibung:}

Verband: $\quad$ Verband

\section{Alter:}

Geschlecht:

Dies ist ein stark erodiertes Fragment eines Caput femoris. 
Bezeichn:: Femur

Kiste: $\quad 5243267$

Skelet: $\quad 6 . \operatorname{Sch} 166$

Population: Calden

Seite: links

Erhaltung: $\square$ prox. Gelenk

prox. Schaft

mittl. Schaft

X dist. Schaft

dist. Gelenk
Ges./Kr.: Krank

Krankh.: Periostreizung

Erwachsen

\section{Geschlecht:}

Arthrose:

dist.

2

\begin{tabular}{l|l|l} 
Maß & Wert & Einheit \\
\hline Epicondylenbreite & 72,5 & $\mathrm{~mm}$ \\
Umfang Schaftmitte & 75 & $\mathrm{~mm}$ \\
& & \\
& & \\
& &
\end{tabular}

\section{Beschreibung:}

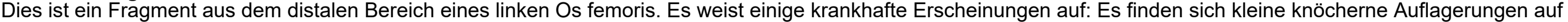
der Knochenoberfläche, welche als Periostreizung zu interpretieren sind. Weiterhin ist der Ansatz des M. biceps gastrocnemius gut ausgeprägt. 

Bezeichn.: Femur
Kiste: $\quad 5256274$
Seite: rechts
Erhaltung: $\mathbf{X}$ prox. Gelenk
$X$ prox. Schaft
$X$ mittl. Schaft
$\mathbf{X}$ dist. Schaft
$\mathbf{X}$ dist. Gelenk
Beschreibung:

Verband:

Verband

Ges./Kr.: Krank

Alter: (4) $4,5-6(7,5)$

Krankh.: Anämie

Skelet: V35 über Sx.8 3,75;4,2 1 Geschlecht:

Population: Calden Arthrose:

\begin{tabular}{l|l|l} 
Maß & Wert & Einheit \\
\hline a-p $\varnothing$ subtrochlear & 14,9 & $\mathrm{~mm}$ \\
Caput, horizontaler $\varnothing$ & 24,05 & $\mathrm{~mm}$ \\
Caput, vertikaler $\varnothing$ & 23,95 & $\mathrm{~mm}$ \\
Epicondylenbreite & 44 & $\mathrm{~mm}$ \\
gr. Länge & 222 & $\mathrm{~mm}$ \\
m-l $\varnothing$ subtrochlear & 18,87 & $\mathrm{~mm}$ \\
Umfang Schaftmitte & 47 & $\mathrm{~mm}$
\end{tabular}

Dieses recht vollständige Femur weist eine Krümmung nach medial auf. Es findet sich weiterhin eine Porosität unter dem Caput femoris. Bei dieser Porosität an dieser genannten Stelle könnte es sich um eine Anämieerscheinung handeln. 


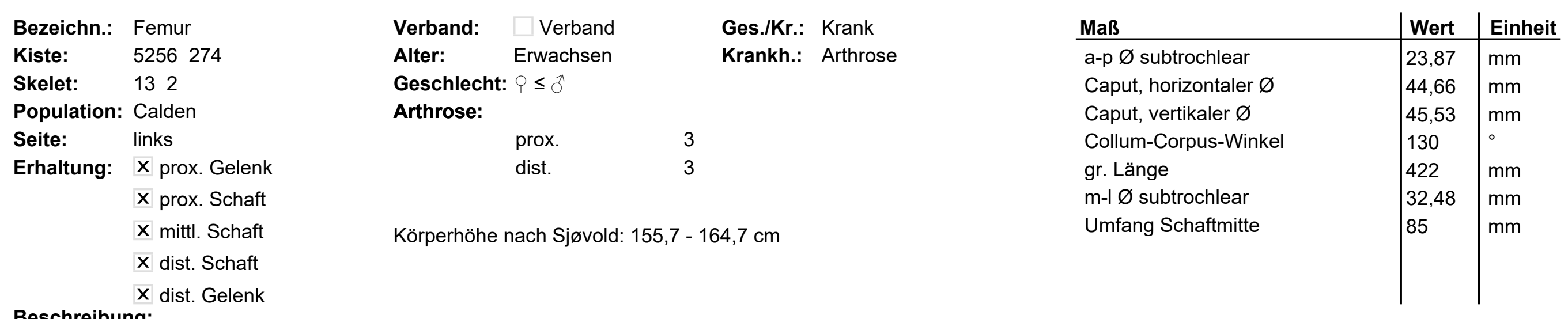

\section{Beschreibung:}

Dieses Fundstück eines Os femoris der linken Seite ist fast vollständig. Es weist arthrotische Gelenkabnutzungen auf. Das Caput femoris ist so stark erodiert, dass es nicht befundbar ist. 

Bezeichn.: Femur
Kiste: $\quad 5261277$
Population: Calden
Seite: rechts
Erhaltung: $\mathbf{X}$ prox. Gelenk
$X$ prox. Schaft
$X$ mittl. Schaft
X dist. Schaft
$\square$ dist. Gelenk

\section{Beschreibung:}

Skelet: $\quad$ Sk.1134 SCH. 8. 1245

Bei diesem Femur fällt eine deutliche ausgeprägte Tuberositas glutea auf.

\section{Ges./Kr.: Gesund}

\section{Alter: $\quad 30-40$}

Geschlecht: $+\leq \delta^{\lambda}$

\section{Arthrose:}

Maß

a-p $\varnothing$ subtrochlear

Caput, horizontaler $\varnothing$

Caput, vertikaler $\varnothing$

Collum-Corpus-Winkel

m-I $\varnothing$ subtrochlear

Umfang Schaftmitte

\begin{tabular}{l|l|l} 
Wert & Einheit \\
\hline 27,23 & $\mathrm{~mm}$
\end{tabular}

$42,75 \mathrm{~mm}$

$44,66 \mathrm{~mm}$

126

35,81 


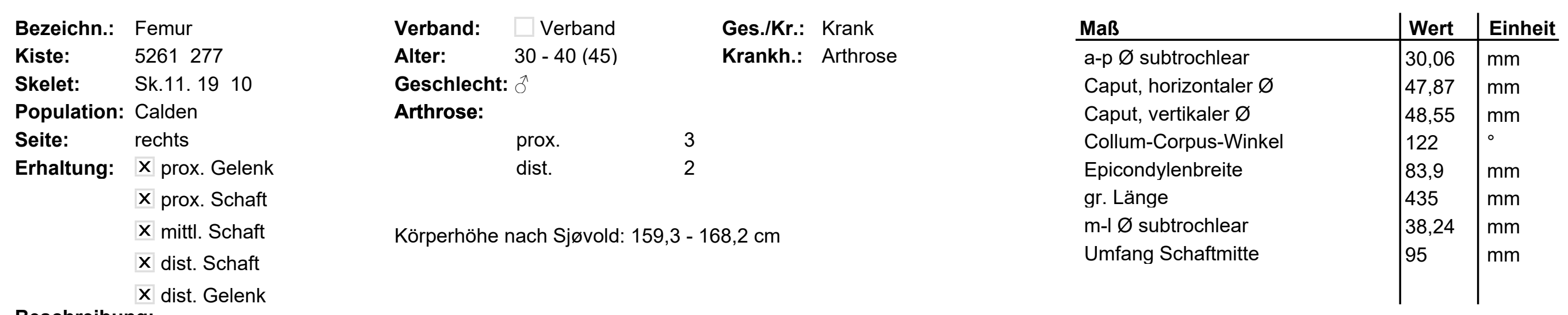

\section{Beschreibung:}

Diese Os femoris weist deutliche Muskelmarken auf: m. gastrocnemius, pectineus, vastus medialis und gluteus maximus. Die Linea aspera, und die Kapsel sind gezerrt. 
Bezeichn.: Femu

Kiste: $\quad 5261277$

Skelet: Zettel

Population: Calden

Seite: links

Erhaltung: $\square$ prox. Gelenk

X prox. Schaft

mittl. Schaft

dist. Schaft

dist. Gelenk

Beschreibung:

Fragment.
Verband: $\quad \square$ Verband

\section{Alter:}

Geschlecht:

Arthrose: 


\section{Bezeichn: Femur \\ Kiste: $\quad 5261277$ \\ Skelet: Zettel}

Population: Calden

\section{Erhaltung:}

prox. Gelenk

prox. Schaft

X mittl. Schaft

dist. Schaft

dist. Gelenk

Beschreibung:

Ein sehr stark erodiertes kleines Fragment.
Verband: $\quad \square$ Verband

\section{Alter:}

Geschlecht:

Arthrose: 

Bezeichn.: Femur
Kiste: 5261277
Skelet: Zettel
Population: Calden
Seite: links
Erhaltung: $\begin{aligned} \square \text { prox. Gelenk } \\ \quad \mathbf{X} \text { prox. Schaft }\end{aligned}$
mittl. Schaft
dist. Schaft
dist. Gelenk

Verband: $\quad \square$ Verband

Ges./Kr.: Gesund

\section{Alter:}

Geschlecht:

Arthrose:

Beschreibung:

Ein Fragment eines Trochanter major eines linken Os femoris 


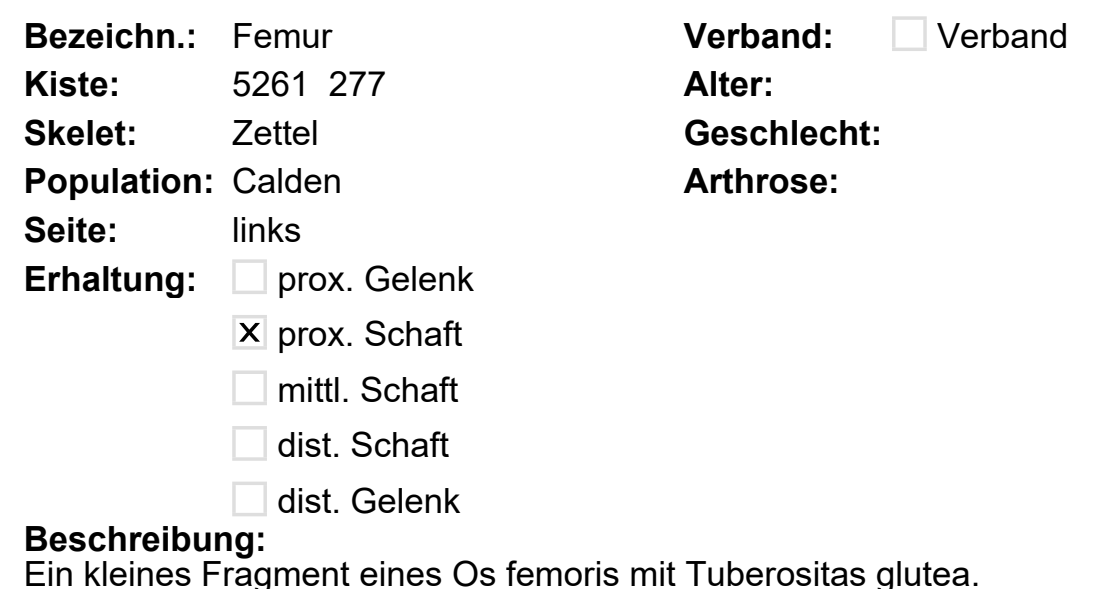

Ein kleines Fragment eines Os femoris mit Tuberositas glutea. 


$\begin{array}{lll}\text { Bezeichn.: } & \text { Femur } & \text { Verband: } \\ \text { Kiste: } & 5261277 & \text { Alter: } \\ \text { Skelet: } & \text { Zettel } & \text { Geschlecht: } \\ \text { Population: } & \text { Calden } & \text { Arthrose: } \\ \text { Seite: } & \text { links } & \\ \text { Erhaltung: } & \square \text { prox. Gelenk } \\ & \square \text { prox. Schaft } & \\ & \square \text { mittl. Schaft } \\ & \mathbf{X} \text { dist. Schaft } & \\ & \square \text { dist. Gelenk }\end{array}$




\section{Bezeichn.: Femur \\ Kiste: $\quad 5261277$ \\ Skelet: 13 \\ Population: Calden \\ Seite: links \\ Erhaltung: X prox. Gelenk \\ prox. Schaft \\ mittl. Schaft \\ dist. Schaft \\ dist. Gelenk \\ Beschreibung:}

Ein kleines Fragment von Kopf und Hals eines linken Os femoris.
Verband: $\quad$ Verband

Alter: Erwachsen

\section{Geschlecht:}

Arthrose:

prox. 

Bezeichn.: Femur
Kiste: $\quad 5261277$
Skelet: SKEL.11 115
Population: Calden
Seite: links
Erhaltung: $\square$ prox. Gelenk
X prox. Schaft
$X$ mittl. Schaft
$\mathbf{X}$ dist. Schaft
dist. Gelenk

\section{Beschreibung:}

Verband:

Verband

\section{Alter:}

Ges./Kr.: Gesund

\section{Geschlecht:}

Ein Fragment aus dem Schaft eines linken Os femoris. Die Linea aspera ist deutlich ausgeprägt. 

Bezeichn.: Femur
Kiste: $\quad 5261277$
Skelet: unter $\mathrm{SCH} .8+3$
Population: Calden
Seite: $\quad$ n. def.
Erhaltung: $\mathbf{X}$ prox. Gelenk prox. Schaft
mittl. Schaft
dist. Schaft dist. Gelenk

Verband:

Verband

Alter:

$6-16$

Geschlecht:

Beschreibung:

Eine proximale Epiphyse eines jungen Os femoris.

Arthrose:

\begin{tabular}{|l|l} 
& \\
& \\
&
\end{tabular}


Bezeichn.: Femur

Kiste: $\quad 52651-3279$

Skelet: unter $\mathrm{SCH} .32$.

Population: Calden

Erhaltung: $\mathbf{X}$ prox. Gelenk

prox. Schaft

mittl. Schaft

dist. Schaft

dist. Gelenk

Beschreibung:

Ein Fragment eines Caput femoris.
Verband: $\quad \square$ Verband

\section{Alter:}

Geschlecht: 우

Arthrose: 


$\begin{array}{lll}\text { Bezeichn.: } & \text { Femur } & \text { Verband: } \square \text { Verband } \\ \text { Kiste: } & 52651-3279 & \text { Alter: } \\ \text { Skelet: } & \text { Zettel } & \text { Geschlecht: } \\ \text { Population: } & \text { Calden } & \text { Arthrose: } \\ \text { Seite: } & \text { rechts } & \\ \text { Erhaltung: } & \square \text { prox. Gelenk } \\ & \square \text { prox. Schaft } & \\ & \text { X mittl. Schaft } & \\ & \square \text { dist. Schaft } & \\ & \text { dist. Gelenk }\end{array}$




\author{
Bezeichn.: Femur \\ Kiste: $\quad 52651-3279$ \\ Skelet: Zettel \\ Verband: $\quad$ Verband \\ Population: Calden \\ Seite: n. def. \\ Erhaltung: $\square$ prox. Gelenk \\ prox. Schaft \\ $X$ mittl. Schaft \\ dist. Schaft \\ dist. Gelenk \\ Beschreibung: \\ Ein Fragment aus dem Schaft eines Os femoris. \\ Alter: \\ Geschlecht: \\ Arthrose:
}




\author{
Bezeichn.: Femur \\ Kiste: $\quad 52651-3279$ \\ Skelet: Zettel \\ Verband: $\quad$ Verband \\ Population: Calden \\ Seite: n. def. \\ Erhaltung: $\square$ prox. Gelenk \\ prox. Schaft \\ $X$ mittl. Schaft \\ dist. Schaft \\ dist. Gelenk \\ Beschreibung: \\ Ein Fragment aus dem Schaft eines Os femoris. \\ Alter: \\ Geschlecht: \\ Arthrose:
}




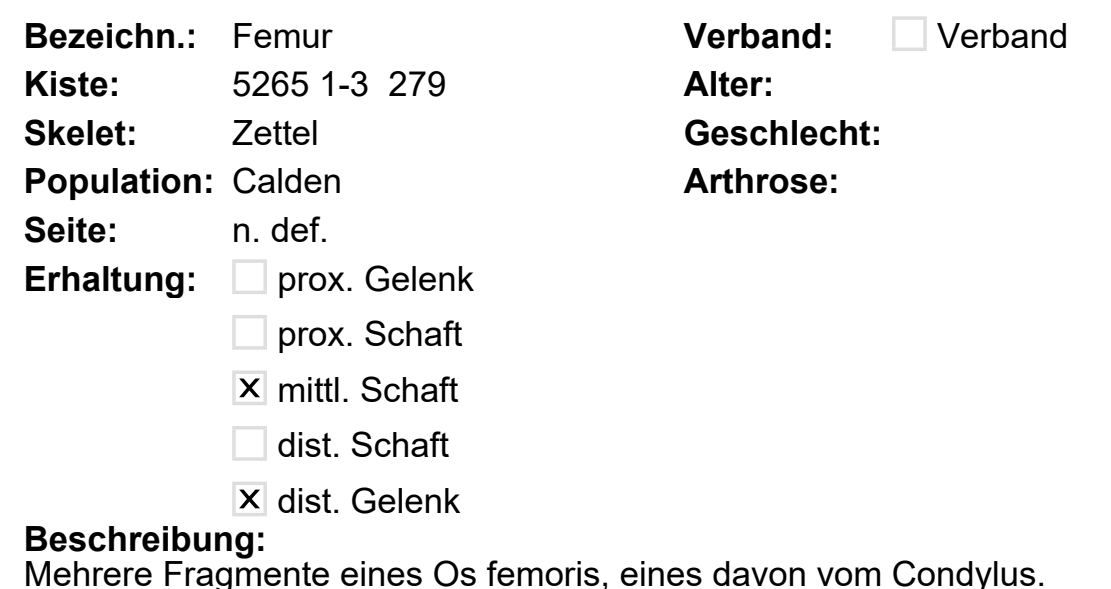

Mehrere Fragmente eines Os femoris, eines davon vom Condylus. 
Bezeichn:: Femur

Kiste: $\quad 52651-3279$

Skelet: Zettel

Population: Calden

Seite: links

Erhaltung: $\square$ prox. Gelenk

prox. Schaft

mittl. Schaft

dist. Schaft

X dist. Gelenk

Beschreibung:

Ein Fragment des medialen Condylus eines linken Os femoris.

Ges./Kr.: Krank

Krankh.: Arthrose 

Bezeichn.: Femur
Kiste: $\quad 52651-3279$
Skelet: Zettel
Population: Calden
Seite: n. def.
Erhaltung: $\square$ prox. Gelenk
$X$ prox. Schaft
mittl. Schaft
dist. Schaft
dist. Gelenk
Beschreibung:

Ein Fragment mit starken Muskelansätzen.
Verband:

Verband

Alter: Jung

Geschlecht:

Ges./Kr.: Gesund

Arthrose: 


\section{Bezeichn.: Femur \\ Kiste: $\quad 52651-3279$ \\ Skelet: Zettel \\ Population: Calden \\ Erhaltung: $\square$ prox. Gelenk \\ $X$ prox. Schaft \\ $X$ mittl. Schaft \\ X dist. Schaft \\ dist. Gelenk \\ Beschreibung:}

Mehrere Splitter eines Os femoris.
Verband: $\quad \square$ Verband

\section{Alter:}

Geschlecht:

Arthrose: 

Bezeichn.: Femur
Kiste: $\quad 52651-3279$
Skelet: Zettel
Population: Calden
Seite: links
Erhaltung: $\square$ prox. Gelenk
prox. Schaft
mittl. Schaft
$\mathbf{X}$ dist. Schaft
dist. Gelenk

\section{Beschreibung:}

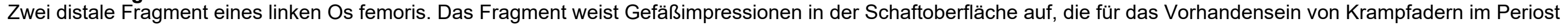
sprechen. 


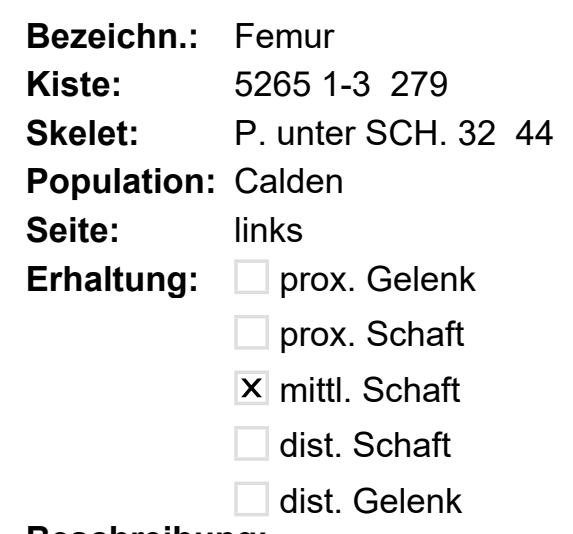

Seite: links

Erhaltung: $\square$ prox. Gelenk

prox. Schaft

$X$ mittl. Schaft

dist. Schaft

dist. Gelenk

Ges./Kr.: Krank Alter: Krankh.: Muskelreizung

\section{Geschlecht: ${ }^{\lambda}$}

Arthrose:

\section{Beschreibung:}

Ein mittleres Fragment aus einem linken Os femoris. die Linea aspera zeigt Spuren von Muskelüberreizungen, insgesamt ist das Fragment sehr massiv. 

Bezeichn.: Femur
Kiste:
5263278
Skelet: $\quad \mathrm{P} 16+18856$
Population: Calden
Seite: links
Erhaltung: $\square$ prox. Gelenk
$X$ prox. Schaft
$X$ mittl. Schaft
$\mathbf{X}$ dist. Schaft
X dist. Gelenk
Beschreibung:

Verband:

\section{Alter:}

Verband

\section{Geschlecht:}

Arthrose:

Ges./Kr.: Gesund

Es handelt sich hier um das Os femoris der linken Seite eines jungen Individuums.

\begin{tabular}{l|l|l} 
Maß & Wert & Einheit \\
\hline a-p $\varnothing$ subtrochlear & 27,82 & $\mathrm{~mm}$ \\
gr. Länge & 380 & $\mathrm{~mm}$ \\
m-l $\varnothing$ subtrochlear & 30,25 & $\mathrm{~mm}$ \\
Umfang Schaftmitte & 75 & $\mathrm{~mm}$ \\
& & \\
& &
\end{tabular}




\section{Bezeichn: Femu \\ Kiste: $\quad 5263278$ \\ Skelet: Zettel}

Population: Calden

Seite: rechts

Erhaltung: $\square$ prox. Gelenk

prox. Schaft

mittl. Schaft

dist. Schaft

$\mathbf{X}$ dist. Gelenk
Ges./Kr.: Krank

Krankh.: Arthrose

\section{Beschreibung:}

Alter: Krankh.: Arthrose

Hier ist nur ein Fragment des lateralen Condylus erhalten. Das Fragment weist Spuren von dem gelenkverschleißenden Prozess einer Arthrose auf. Die Konstitution des Knochens spricht für ein graziles Individuum, welches wohl weiblich war. 
Bezeichn.: Femur

\section{Kiste:}

5263278

Skelet:

P16+18 723

Population: Calden

Seite: rechts

Erhaltung: $\mathbf{X}$ prox. Gelenk

$X$ prox. Schaft

$X$ mittl. Schaft

$\mathbf{X}$ dist. Schaft

X dist. Gelenk
Ges./Kr.: Krank

Krankh.: Arthrose

Enthesiopathie

Reiterfacette
Maß

a-p $\varnothing$ subtrochlear

Caput, horizontaler $\varnothing$

Caput, vertikaler $\varnothing$

Collum-Corpus-Winkel

Epicondylenbreite

gr. Länge

m-I $\varnothing$ subtrochlear

Umfang Schaftmitte

\begin{tabular}{|l|l} 
Wert & Einheit \\
\hline 29 & $\mathrm{~mm}$ \\
44 & $\mathrm{~mm}$ \\
46 & $\mathrm{~mm}$ \\
130 & $\circ$ \\
79 & $\mathrm{~mm}$ \\
402 & $\mathrm{~mm}$ \\
33,23 & $\mathrm{~mm}$ \\
92 & $\mathrm{~mm}$
\end{tabular}

\section{Beschreibung:}

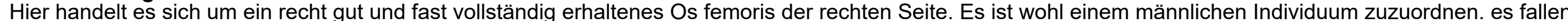

Muskelmarken der Muskeln gluteus maximus und vastus lateralis ins Auge, die gereizt sind und eine leichte Enthesiopathie bilden. An den Ansätzen ist die

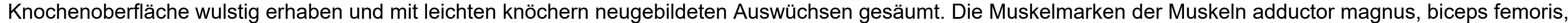

adductor brevis, gluteus minimus und medius, vastus lateralis und gastrocnemius fallen als gut ausgeprägt auf.

Als eine so genannte Reiterfacette fällt hier eine Vergrößerung der Kopffläche auf. Diese ist nahe des Collums im ventro - proximalen Bereich. 

Bezeichn.: Femur
Kiste: $\quad 5263278$
Skelet: $\quad \mathrm{P} 16+18951$
Population: Calden
Seite: rechts
Erhaltung: $\mathbf{X}$ prox. Gelenk
$X$ prox. Schaft
$X$ mittl. Schaft
X dist. Schaft
dist. Gelenk

\section{Beschreibung:}

Dieses Os femoris der rechten Seite weist normal ausgeprägte Muskelmarken auf.

Verband: $\quad$ Verband

Alter: Erwachsen

Geschlecht: $q>\hat{\sigma}$

Arthrose:

prox.

3
Ges./Kr.: Krank

Krankh.: Arthrose

\begin{tabular}{l|l|l} 
Maß & Wert & Einheit \\
\hline a-p $\varnothing$ subtrochlear & 24,48 & $\mathrm{~mm}$ \\
Caput, horizontaler $\varnothing$ & 41,57 & $\mathrm{~mm}$ \\
Caput, vertikaler $\varnothing$ & 41,3 & $\mathrm{~mm}$ \\
Collum-Corpus-Winkel & 130 & $\circ$ \\
m-I $\varnothing$ subtrochlear & 32,39 & $\mathrm{~mm}$ \\
Umfang Schaftmitte & 80 & $\mathrm{~mm}$
\end{tabular}




\section{Bezeichn.: Femur \\ Kiste: 5263278 \\ Skelet: $\quad 14$ \\ Population: Calden \\ Seite: rechts \\ Erhaltung: $\square$ prox. Gelenk \\ prox. Schaft \\ mittl. Schaft \\ $\mathbf{X}$ dist. Schaft \\ $X$ dist. Gelenk}

Beschreibung:

Ein distal erhaltenes Os femoris im sehr erodierten Zustand.
Verband: $\square$ Verband

\section{Alter:}

Geschlecht: +

Arthrose:
Maß

Epicondylenbreite

\begin{tabular}{|l|l} 
Wert & Einheit
\end{tabular}

\begin{tabular}{ll|l}
70 & $\mathrm{~mm}$
\end{tabular}




\section{Bezeichn.: Femur \\ Kiste: $\quad 5263278$ \\ Skelet: $\quad$ V21 v}

Population: Calden

Seite: links

Erhaltung: $\mathbf{X}$ prox. Gelenk

$X$ prox. Schaft

$X$ mittl. Schaft

X dist. Schaft

dist. Gelenk

\section{Beschreibung:}

Verband: $\square$ Verband

\section{Alter: Erwachsen}

\section{Geschlecht: $O$}

Arthrose:

prox.

\section{2}

Körperhöhe nach Sjøvold: 152,5 - 161,5 cm
Maß

a-p $\varnothing$ subtrochlear

Caput, horizontaler $\varnothing$

Caput, vertikaler $\varnothing$

Collum-Corpus-Winkel

gr. Länge

m-I $\varnothing$ subtrochlear

Umfang Schaftmitte

\begin{tabular}{|l|l} 
Wert & Einheit \\
\hline 2635 & $\mathrm{~mm}$
\end{tabular}

37

$37,3 \mathrm{~mm}$

$\mathrm{mm}$

130

$410 \mathrm{~mm}$

$33 \quad \mathrm{~mm}$

$80 \quad \mathrm{~mm}$

Dieses Os femoris weist eine sehr gut ausgeprägte Linea aspera auf. 

Bezeichn.: Femur
Kiste:
5263278
Skelet: V21 viele
Population: Calden
Seite: rechts
Erhaltung: $\square$ prox. Gelenk
prox. Schaft
mittl. Schaft
$\mathbf{X}$ dist. Schaft
$X$ dist. Gelenk

Beschreibung:

Ein sehr stark erodiertes rechtes Os femoris.
Verband: $\quad$ Verband

\section{Alter:}

Ges./Kr.: Gesund

Geschlecht: $q \geq 0$

Arthrose: 

Bezeichn.: Femur
Kiste:
8505719
Skelet: $\quad 49 \mathrm{~T}$. Extremitäten
Population: Calden
Seite: rechts
Erhaltung: $\square$ prox. Gelenk
$X$ prox. Schaft
$X$ mittl. Schaft
$\mathbf{X}$ dist. Schaft
dist. Gelenk
Beschreibung:

Verband: $\quad \square$ Verband

Alter:

Ges./Kr.: Gesund

Geschlecht: $+>>\hat{0}$

Von diesem Os femoris der rechten Seite ist nur der Schaft erhalten.

\begin{tabular}{l|l|l} 
Maß & Wert & Einheit \\
\hline a-p $\varnothing$ subtrochlear & 26,8 & $\mathrm{~mm}$ \\
gr. Länge & 364 & $\mathrm{~mm}$ \\
m-I $\varnothing$ subtrochlear & 36,59 & $\mathrm{~mm}$ \\
Umfang Schaftmitte & 87 & $\mathrm{~mm}$ \\
& &
\end{tabular}




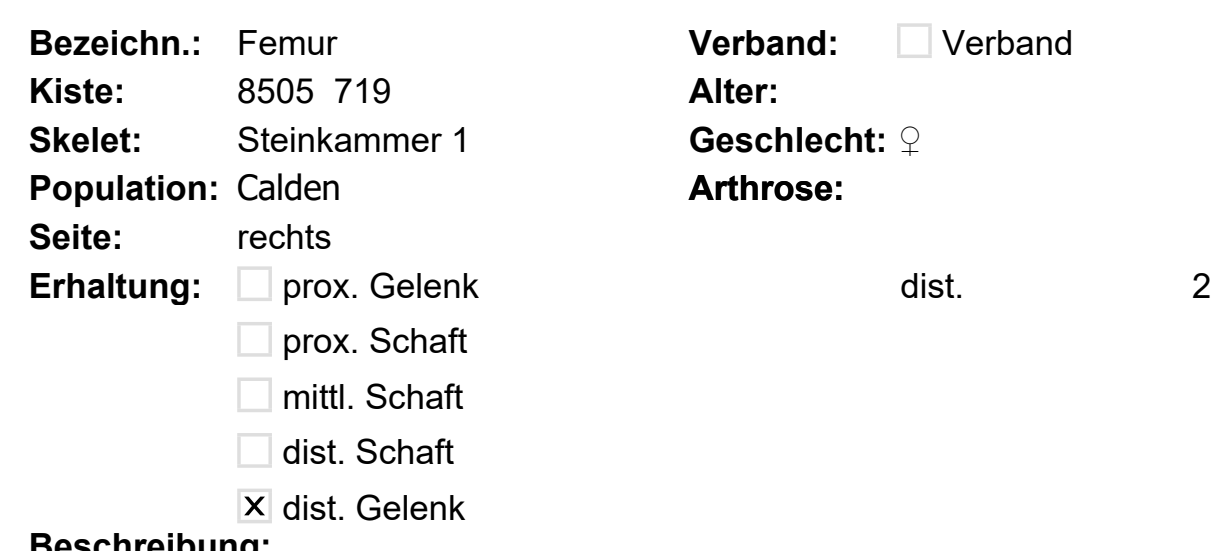

Von diesem rechten Os femoris ist nur ein erodierter distaler Teil erhalten. 


\section{Bezeichn.: Femur \\ Kiste: $\quad 8505719$ \\ Skelet: Steinkammer 1 \\ Population: Calden

$$
\begin{aligned}
& \text { prox. Gelenk } \\
& \text { prox. Schaft } \\
& \text { mittl. Schaft } \\
& \text { dist. Schaft }
\end{aligned}
$$ \\ dist. Gelenk}

Verband: $\quad$ Verband

\section{Alter:}

Geschlecht:

\section{Arthrose:}

Beschreibung:

Hierbei handelt es sich um kleine Knochensplitter. 


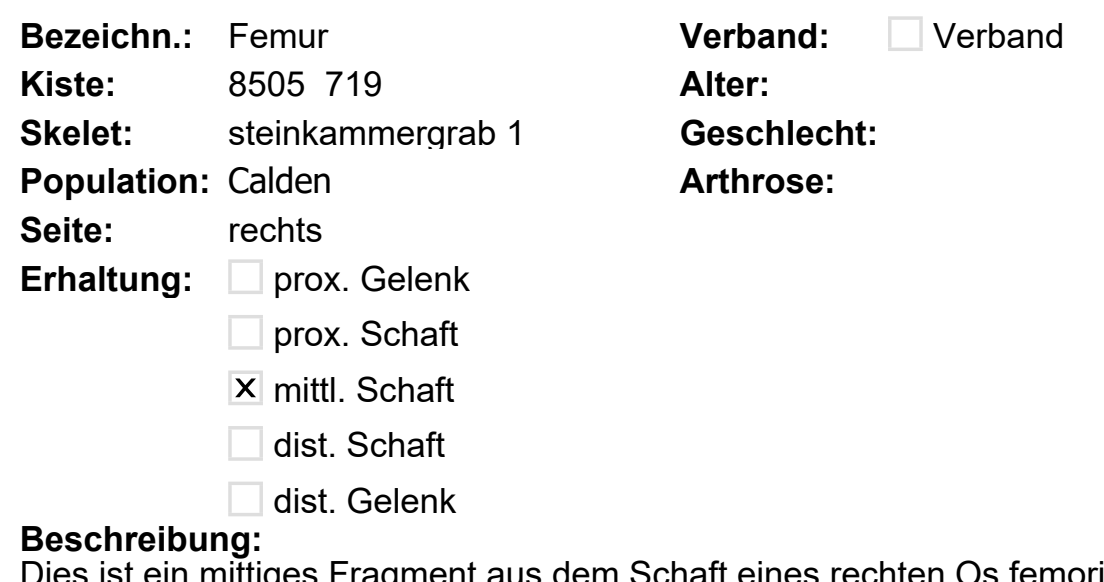

Dies ist ein mittiges Fragment aus dem Schaft eines rechten Os femoris. 

Bezeichn.: Femur
Kiste:
8505719
Skelet: $\quad$ steinkammergrab 1
Population: Calden
Seite: links
Erhaltung: $\mathbf{X}$ prox. Gelenk
X prox. Schaft
mittl. Schaft
dist. Schaft
dist. Gelenk
Beschreibung:

\section{Verband:}

Alter:

Ges./Kr.: Gesund

Ein proximales Fragment eines jungen Os femoris. 


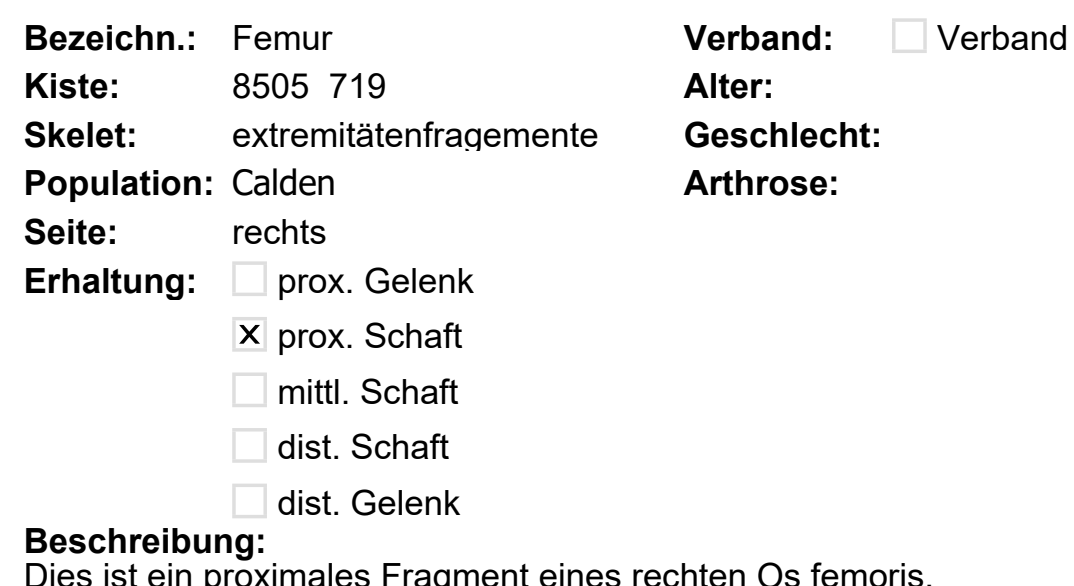

Dies ist ein proximales Fragment eines rechten Os femoris. 


$\begin{array}{lll}\text { Bezeichn.: } & \text { Femur } & \text { Verband: } \square \text { Verband } \\ \text { Kiste: } & 8505719 & \text { Alter: Jung } \\ \text { Skelet: } & \text { Zettel } & \text { Geschlecht: } \\ \text { Population: } & \text { Calden } & \text { Arthrose: } \\ \text { Seite: } & \text { links } & \\ \text { Erhaltung: } & \text { X prox. Gelenk } & \\ & \square \text { prox. Schaft } & \\ & \square \text { mittl. Schaft } & \\ & \square \text { dist. Schaft } & \\ & \square \text { dist. Gelenk }\end{array}$

Hier ist die proximale Epiphyse eines jungen Os femoris erhalten. 
Bezeichn.: Femur

Kiste: $\quad 8505719$

Skelet: Zettel

Population: Calden

Seite: rechts

Erhaltung: $\square$ prox. Gelenk

prox. Schaft

mittl. Schaft

dist. Schaft

X dist. Gelenk

Beschreibung:

Ein Teil des Condylus lateralis eines rechten Os femoris.
Verband: $\quad$ Verband

\section{Alter:}

Geschlecht:

Arthrose:
Ges./Kr.: Krank

Krankh.: Arthrose 


\section{Bezeichn:: Femur \\ Kiste: $\quad 8505719$ \\ Skelet: Zettel}

Population: Calden

Seite: links

Erhaltung: $\square$ prox. Gelenk

prox. Schaft

mittl. Schaft

dist. Schaft X dist. Gelenk

Beschreibung:

Ein Teil des Condylus lateralis eines linken Os femoris.
Verband: $\quad$ Verband

\section{Alter:}

Geschlecht:

Arthrose:
Ges./Kr.: Krank

Krankh.: Arthrose 
Bezeichn.: Femur

Kiste: $\quad 8505719$

Skelet: Zettel

Population: Calden

Seite: rechts

Erhaltung: $\square$ prox. Gelenk

prox. Schaft

mittl. Schaft

dist. Schaft

X dist. Gelenk

Beschreibung:

Ein Teil des Condylus medialis eines rechten Os femoris.
Verband: $\quad$ Verband

Alter:

Geschlecht:

Arthrose:

dist.

4
Ges./Kr.: Krank

Krankh.: Arthrose 


\section{Bezeichn.: Femur \\ Kiste: $\quad 8505719$ \\ Skelet: Zettel}

Population: Calden

Seite: links

Erhaltung: $\square$ prox. Gelenk prox. Schaft

mittl. Schaft

dist. Schaft X dist. Gelenk

Beschreibung:

Ein Teil des Condylus lateralis eines linken Os femoris.
Verband: $\quad \square$ Verband

Ges./Kr.: Gesund

\section{Alter:}

Geschlecht:

Arthrose:

dist. 
Bezeichn:: Femur

\section{Kiste:}

8505719

Skelet:

V14 3226

Population: Calden

Seite: rechts

Erhaltung: $\square$ prox. Gelenk

$X$ prox. Schaft

$X$ mittl. Schaft

$\mathbf{X}$ dist. Schaft

$\mathbf{X}$ dist. Gelenk
Verband: $\quad$ Verband

\section{Alter: Erwachsen}

Geschlecht:

Arthrose:
Ges./Kr.: Krank

Krankh.: Myositis ossificans
Maß

Epicondylenbreite

Umfang Schaftmitte

\section{Einheit}

$\mathrm{mm}$

$\mathrm{mm}$

\section{Beschreibung:}

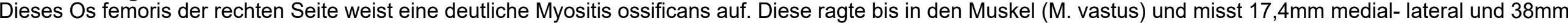

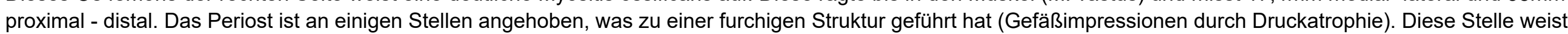
zwei Ränder auf, einer konkav, der andere konvex, somit lag die Gefäßimpression in zwei Schichten vor und führte auch randständig zu Knochenneubildungen. 

Bezeichn.: Femur
Kiste: $\quad 5245269$
Skelet: V13 Sk2
Seite: links
Erhaltung: $\mathbf{X}$ prox. Gelenk
$X$ prox. Schaft
mittl. Schaft
dist. Schaft
dist. Gelenk
Population: Calden
Verband: $\quad$ Verband
Alter: Erwachsen
Geschlecht: $\lambda$

Arthrose:

\section{Ges./Kr.: Gesund}

\section{Maß}

Caput, horizontaler $\varnothing$

Caput, vertikaler $\varnothing$

2

\section{Beschreibung:}

Dieses Os femoris ist lediglich proximal erhalten. Es sind Hals und Gelenkkopf in gutem Zustand, unterhalb des Trochanter major ist der Rest weggebrochen. Der Trochanter major ist gut ausgebildet. Insgesamt wirkt der Knochen sehr massiv. 


\begin{tabular}{|c|c|c|c|c|c|c|c|}
\hline Bezeichn.: & Femur & Verband: & $\square$ Verband & Ges./Kr.: Gesund & Maß & Wert & Einheit \\
\hline Kiste: & 5245269 & Alter: & Erwachsen & & Caput, horizontaler $\varnothing$ & 40 & $\mathrm{~mm}$ \\
\hline Skelet: & V13 Sk2 & Geschlecht: & & & Caput, vertikaler $\varnothing$ & 45,81 & $\mathrm{~mm}$ \\
\hline Population: & Calden & Arthrose: & & & & & \\
\hline Seite: & rechts & & prox. & 1 & & & \\
\hline Erhaltung: & X prox. Gelenk & & & & & & \\
\hline & X prox. Schaft & & & & & & \\
\hline & $\square$ mittl. Schaft & & & & & & \\
\hline & $\square$ dist. Schaft & & & & & & \\
\hline & $\square$ dist. Gelenk & & & & & & \\
\hline
\end{tabular}

\section{Beschreibung:}

Bei diesem Fundstück handelt es sich um ein rechtes Os femoris. Es ist lediglich ein Teil des Caput und des Halses erhalten. Die sichtbaren Muskelmarken sind so ausgeprägt, wie bei dem linken Os femoris. Das Caput war nur zu unter $10 \%$ befundbar. 


$\begin{array}{lll}\text { Bezeichn.: } & \text { Femur } & \text { Verband: } \\ \text { Kiste: } & 8505719 & \text { Alter: } \\ \text { Skelet: } & \text { Sk3 } & \text { Geschlecht: } \\ \text { Population: } & \text { Calden } & \text { Arthrose: } \\ \text { Seite: } & \text { rechts } & \\ \text { Erhaltung: } & \mathbf{X} \text { prox. Gelenk } & \\ & \square \text { prox. Schaft } \\ & \square \text { mittl. Schaft } \\ & \square \text { dist. Schaft } \\ & \square \text { dist. Gelenk }\end{array}$

Ein Caput femoris, welches zur Hälfte erhalten ist. 
Bezeichn.: Femur

\section{Kiste: $\quad 5244268$}

Skelet: $\quad$ P.Sk.12714

Population: Calden

Seite: links

Erhaltung: $\mathbf{X}$ prox. Gelenk

$X$ prox. Schaft

$X$ mittl. Schaft

dist. Schaft

dist. Gelenk
Verband: $\square$ Verband

\section{Alter: $\quad 18-26$}

Geschlecht: $q$

Arthrose:

prox.
Ges./Kr.: Gesund

\begin{tabular}{l|l|l} 
Maß & Wert & Einheit \\
\hline a-p $\varnothing$ subtrochlear & 23,69 & $\mathrm{~mm}$ \\
Caput, horizontaler $\varnothing$ & 37,2 & $\mathrm{~mm}$ \\
Caput, vertikaler $\varnothing$ & 38,69 & $\mathrm{~mm}$ \\
Collum-Corpus-Winkel & 122,5 & $\circ$ \\
gr. Länge & 207 & $\mathrm{~mm}$ \\
m-I $\varnothing$ subtrochlear & 31,56 & $\mathrm{~mm}$ \\
Umfang Schaftmitte & 78 & $\mathrm{~mm}$
\end{tabular}

\section{Beschreibung:}

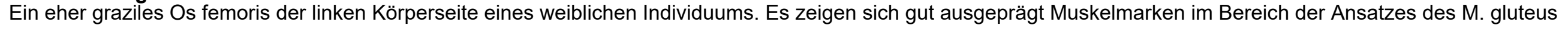
maximus und ein durch M. vastus lateralis hervorgerufener Trochanter tertius. Die Oberfläche ist überwiegend gut erhalten, weiterhin ist eine frisch verknöcherte Epiphysenfuge im Röntgenbild zu erkennen. Über dem Trochanter minor findet sich eine 17,5mm x 11mm x 2,5mm große, erhabene Anhebung in Form einer Knochenneubildung, welche wohl durch eine Reizung der Muskeln piriformis und obturatorius inferior hervorgerufen worden sind. 

Bezeichn.: Femur
Kiste: $\quad 5244268$
Skelet: $\quad 3142$
Population: Calden
links
Erhaltung: $\mathbf{X}$ prox. Gelenk
prox. Schaft
mittl. Schaft
dist. Schaft
dist. Gelenk
Beschreibung:
Verband:
Alter: Jung
Geschlecht:

Arthrose:

Ges./Kr.: Gesund

Maß

Caput, horizontaler $\varnothing$

Caput, vertikaler $\varnothing$

Ein proximales Fragment eines jungen Os femoris. 
Bezeichn.: Femur

Kiste:

Population: Calden

Seite: rechts

Erhaltung: $\mathbf{X}$ prox. Gelenk

$X$ prox. Schaft

$X$ mittl. Schaft

dist. Schaft

dist. Gelenk

\section{Ges./Kr.: Krank}

\section{Alter:} (35) 40 - 50 (55)

Geschlecht:

\section{Arthrose:}

prox.

Krankh.: Arthrose

\section{Maß}

a-p $\varnothing$ subtrochlear

Caput, horizontaler $\varnothing$

Caput, vertikaler $\varnothing$

Collum-Corpus-Winkel

$\mathrm{m}-\mathrm{I} \varnothing$ subtrochlear

Umfang Schaftmitte

\begin{tabular}{|l|l} 
Wert & Einheit \\
25 & $\mathrm{~mm}$ \\
45,56 & $\mathrm{~mm}$ \\
46 & $\mathrm{~mm}$ \\
128 & $\circ$ \\
32,7 & $\mathrm{~mm}$ \\
89 & $\mathrm{~mm}$
\end{tabular}

\section{Beschreibung:}

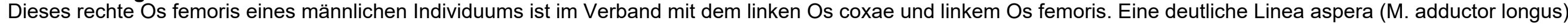

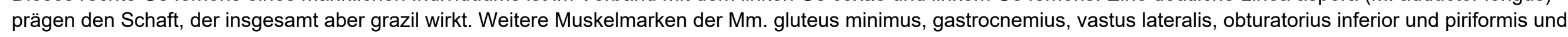

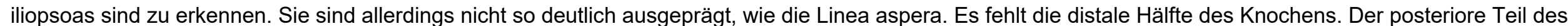
Trochanter major fehlt, Oberflächenerosionen sind wenig vorhanden und das proximale Gelenk ist gut zu beurteilen.

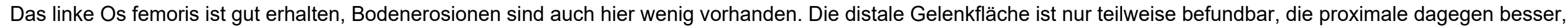

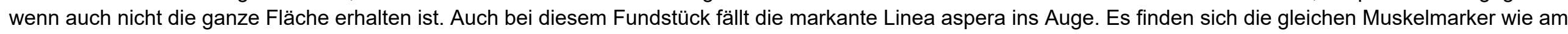

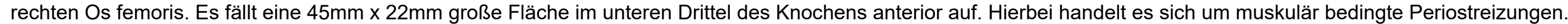
Weiterhin finden sich Spuren von Entzündungen tiefer Krampfadern im proximalen Drittel des Knochens.

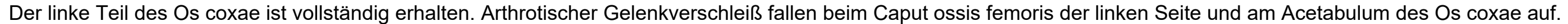

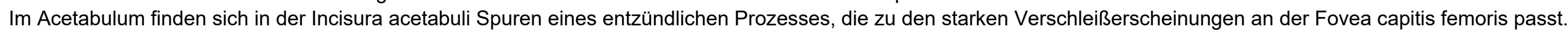

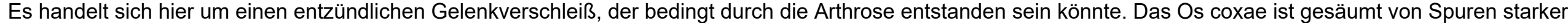

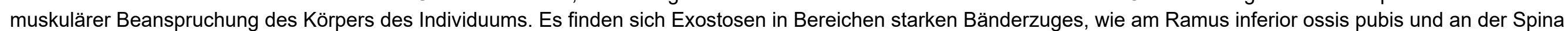
ischiadica. Auch Spina - und Tuberositas iliaca weisen deutliche Muskelmarken auf. 
Bezeichn.: Femur

Kiste: $\quad 5245269$

Skelet: V11578 Sk.4.

Population: Calden

Seite: links

Erhaltung: $\mathbf{X}$ prox. Gelenk

$X$ prox. Schaft

$X$ mittl. Schaft

$\mathbf{X}$ dist. Schaft

X dist. Gelenk

Beschreibung:

Ein Os femoris aus einem Verband.
Verband: $\quad$ Verband Ges./Kr.: Krank

Alter: (35) 40 - 50 (55)

Geschlecht: $ð$

Arthrose:

prox.

dist.

Körperhöhe nach Sjøvold: 150,6 - 159,6 cm
Maß

a-p $\varnothing$ subtrochlear

Caput, horizontaler $\varnothing$

Caput, vertikaler $\varnothing$

Collum-Corpus-Winkel

gr. Länge

m- Ø subtrochlear

Umfang Schaftmitte

\begin{tabular}{|l|l} 
Wert & Einheit \\
26 & $\mathrm{~mm}$ \\
44 & $\mathrm{~mm}$ \\
43 & $\mathrm{~mm}$ \\
128 & $\circ$ \\
403 & $\mathrm{~mm}$ \\
32,5 & $\mathrm{~mm}$ \\
89 & $\mathrm{~mm}$
\end{tabular}


Bezeichn.: Femur

\section{Kiste:}

5244268

Skelet:

\section{P.Sk.1.24 38}

Population: Calden

Seite: rechts

Erhaltung: $\square$ prox. Gelenk

$X$ prox. Schaft

$\mathbf{X}$ mittl. Schaft

$\mathbf{X}$ dist. Schaft

X dist. Gelenk
Verband: $\quad$ Verband

\section{Alter: $\quad 14-16$}

Geschlecht: $q$

\section{Arthrose:}

dist.

Körperhöhe nach Sjøvold: 144,9 - 153,9 cm

\begin{tabular}{l|l} 
Wert & Einheit \\
\hline 23 & $\mathrm{~mm}$ \\
71 & $\mathrm{~mm}$ \\
382 & $\mathrm{~mm}$ \\
29,52 & $\mathrm{~mm}$ \\
80 & $\mathrm{~mm}$
\end{tabular}

\section{Beschreibung:}

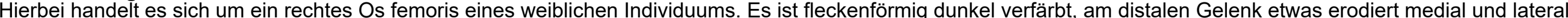

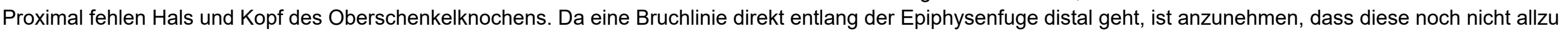

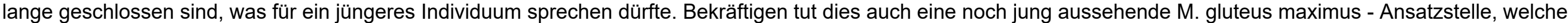
noch nicht wie bei älteren Individuen richtig ausgeprägt, sondern eher nur leicht porös erhaben ist. 

Bezeichn.: Femur
Kiste: $\quad 5244268$
Skelet: P.Sk.1.61
Population: Calden
Seite: rechts
Erhaltung: $\square$ prox. Gelenk
prox. Schaft
mittl. Schaft
$\mathbf{X}$ dist. Schaft dist. Gelenk

Verband:

Verband

Alter:

Ges./Kr.: Krank

\section{Beschreibung:}

Ein mittleres Fragment aus einem rechten Os femoris. 


\begin{tabular}{|c|c|c|c|c|c|c|}
\hline Bezeichn.: & Femur & $\square$ Verband & Ges./Kr.: Gesund & Maß & Wert & Einheit \\
\hline Kiste: & 5244268 & Alter: & & a-p $\varnothing$ subtrochlear & 22,83 & $\mathrm{~mm}$ \\
\hline Skelet: & P.Sk.1. 2939 & Geschlecht: $q$ & & gr. Länge & 249 & $\mathrm{~mm}$ \\
\hline Population: & Calden & Arthrose: & & m-I Ø subtrochlear & 32,89 & $\mathrm{~mm}$ \\
\hline Seite: & links & & & Umfang Schaftmitte & 76 & $\mathrm{~mm}$ \\
\hline Erhaltung: & $\square$ prox. Gelenk & & & & & \\
\hline & $\mathbf{X}$ prox. Schaft & & & & & \\
\hline & X mittl. Schaft & & & & & \\
\hline & $\square$ dist. Schaft & & & & & \\
\hline & $\square$ dist. Gelenk & & & & & \\
\hline
\end{tabular}

\section{Beschreibung:}

Bei diesem kleinen und grazilen Os femoris fällt ein außergewöhnlich flacher Schaft subtrochlear auf. Weiterhin weist das Os femoris fleckenförmige Verfärbungen auf und hat Erosionsspuren. Außerdem ist nur ein Teil des Schaftes erhalten. Recht deutliche Muskelmarken des M. gluteus und M. vastus zeichnen den Schaft. 


\begin{tabular}{|c|c|c|c|c|c|c|c|}
\hline Bezeichn.: & Femur & Verband: $\quad \square$ Verband & Ges./Kr.: & Krank & Maß & Wert & Einheit \\
\hline Kiste: & 5244268 & Alter: & Krankh.: & Periostreizung & a-p $\varnothing$ subtrochlear & 27,36 & $\mathrm{~mm}$ \\
\hline Skelet: & P.Sk.1 60 & Geschlecht: $q \leq \widehat{\partial}$ & & Muskelreizung & gr. Länge & 227 & $\mathrm{~mm}$ \\
\hline Population: & Calden & Arthrose: & & & m-I Ø subtrochlear & 33 & $\mathrm{~mm}$ \\
\hline Seite: & links & & & & Umfang Schaftmitte & 92 & $\mathrm{~mm}$ \\
\hline Erhaltung: & $\square$ prox. Gelenk & & & & & & \\
\hline & $\mathbf{X}$ prox. Schaft & & & & & & \\
\hline & $\mathbf{X}$ mittl. Schaft & & & & & & \\
\hline & $\square$ dist. Schaft & & & & & & \\
\hline & $\square$ dist. Gelenk & & & & & & \\
\hline
\end{tabular}

\section{Beschreibung:}

Ein Fragment eines linken Os femoris aus dem Schaft. Der Knochen wirkt eher massiv, deswegen wird die Geschlechtsbestimmung mit eher männlich angegeben. Das Fundstück ist recht stark erodiert, es ist weniger als die Hälfte der Oberfläche befundbar. 

Bezeichn.: Femur

Kiste: 5244268
Skelet: P.Sk.13o 54
Population: Calden
Seite: links
Erhaltung: $\square$ prox. Gelenk
$X$ prox. Schaft
$X$ mittl. Schaft
$\mathbf{X}$ dist. Schaft
dist. Gelenk

Verband: $\square$ Verband

\section{Alter:}

Ges./Kr.: Krank

Krankh.: Muskelreizung

Enthesiopathie

\section{Maß}

a-p $\varnothing$ subtrochlear

gr. Länge

m-l Ø subtrochlear

Umfang Schaftmitte

\begin{tabular}{|l|l} 
Wert & Einheit \\
\hline 31,6 & $\mathrm{~mm}$
\end{tabular}

Arthrose:

305

36,83

90

\section{Beschreibung:}

Es handelt sich um ein sehr stark erodiertes linkes Os femoris, es fällt durch gut ausgeprägte Muskelmarken wie der Linea aspera und M. gluteus maximus auf. Unterhalb des Trochanter minimus fällt eine Muskelreizung in Form einer Enthesiopathie ins Auge. Der Größe nach und wegen der gut ausgeprägten Muskelmarken handelt es sich eher um ein männliches Individuum. 


$\begin{array}{ll}\text { Bezeichn.: } & \text { Femur } \\ \text { Kiste: } & 5244268 \\ \text { Skelet: } & \text { P.Sk.1. } 2548 \\ \text { Population: } & \text { Calden } \\ \begin{array}{ll}\text { Seite: } & \text { rechts } \\ \text { Erhaltung: } & \square \text { prox. Gelenk } \\ & \text { X prox. Schaft } \\ & \text { X mittl. Schaft } \\ & \text { X dist. Schaft } \\ & \square \text { dist. Gelenk }\end{array} \\ \text { Beschreibung: }\end{array}$

Verband: $\quad$ Verband

Ges./Kr.: Gesund

Alter:

Maß gr. Länge

Umfang Schaftmitte

\begin{tabular}{|l|l} 
Wert & Einheit \\
\hline 232 & $\mathrm{~mm}$
\end{tabular}

Es handelt sich um ein äußerst massives Fragment aus dem Schaft eines rechten Os femoris. Das Fragment weist deutliche Muskelmarken auf. 


\begin{tabular}{|c|c|c|c|c|c|c|}
\hline Bezeichn.: & Femur & $\square$ Verband & Ges./Kr.: Gesund & Maß & Wert & Einheit \\
\hline Kiste: & 5244268 & Alter: & & a-p $\varnothing$ subtrochlear & 22,82 & $\mathrm{~mm}$ \\
\hline Skelet: & V10 P.Sk.123 28 & Geschlecht: & & Caput, horizontaler $\varnothing$ & 39,77 & $\mathrm{~mm}$ \\
\hline Population: & Calden & Arthrose: & & Caput, vertikaler $\varnothing$ & 44,17 & $\mathrm{~mm}$ \\
\hline Seite: & rechts & & & Collum-Corpus-Winkel & 119 & \\
\hline Erhaltung: & X prox. Gelenk & & & m-I Ø subtrochlear & 37 & $\mathrm{~mm}$ \\
\hline & $\mathbf{X}$ prox. Schaft & & & Umfang Schaftmitte & 87 & $\mathrm{~mm}$ \\
\hline & $\mathbf{X}$ mittl. Schaft & & & & & \\
\hline & $\square$ dist. Schaft & & & & & \\
\hline & $\square$ dist. Gelenk & & & & & \\
\hline
\end{tabular}

Beide Femora weisen außergewöhnliche Maße subtrochlear auf. Sie sind sehr massiv und erodiert. Das rechte Os femoris weist nur Reste des Caput femoris auf. 


\begin{tabular}{|c|c|c|c|c|c|c|}
\hline Bezeichn.: & Femur & $\square$ Verband & Ges./Kr.: Gesund & Maß & Wert & Einheit \\
\hline Kiste: & 5244268 & Alter: $\quad 25-35(40)$ & & a-p $\varnothing$ subtrochlear & 26,67 & $\mathrm{~mm}$ \\
\hline Skelet: & V10 P.Sk.1. 28 & Geschlecht: & & $\mathrm{m}-\mathrm{l} \varnothing$ subtrochlear & 36,32 & $\mathrm{~mm}$ \\
\hline Population: & Calden & Arthrose: & & & & \\
\hline Seite: & links & & & & & \\
\hline Erhaltung: & $\square$ prox. Gelenk & & & & & \\
\hline & X prox. Schaft & & & & & \\
\hline & $\square$ mittl. Schaft & & & & & \\
\hline & $\square$ dist. Schaft & & & & & \\
\hline & $\square$ dist. Gelenk & & & & & \\
\hline
\end{tabular}

Beide Femora weisen außergewöhnliche Maße subtrochlear auf. Sie sind sehr massiv und erodiert. Das rechte Os femoris weist nur Reste des Caput femoris auf. 


$\begin{array}{lll}\text { Bezeichn.: } & \text { Femur } & \text { Verband: } \\ \text { Kiste: } & 5244268 & \text { Alter: } \\ \text { Skelet: } & \text { P.Sk.1. } 2657 & \text { Geschlecht: } \\ \text { Population: } & \text { Calden } & \text { Arthrose: } \\ \text { Seite: } & \text { links } & \\ \text { Erhaltung: } & \square \text { prox. Gelenk } & \\ & \text { X prox. Schaft } & \\ & \text { X mittl. Schaft } & \\ & \text { X dist. Schaft } & \text { Körperhöhe nach Sjøvold: } 144,4-153,3 \mathrm{~cm} \\ & \square \text { dist. Gelenk } & \\ & \end{array}$

\begin{tabular}{l|l|l} 
Maß & Wert & Einheit \\
\hline a-p Ø subtrochlear & 27,52 & $\mathrm{~mm}$ \\
gr. Länge & 380 & $\mathrm{~mm}$ \\
m-l $\varnothing$ subtrochlear & 32,16 & $\mathrm{~mm}$ \\
Umfang Schaftmitte & 86 & $\mathrm{~mm}$
\end{tabular}

Beschreibung:

Dieses Fundstück ist zu etwa 50\% auf der Oberfläche erodiert, es fehlen proximaler und distaler Teil. 

Bezeichn.: Femur
Kiste: $\quad 5244268$
Skelet: $\quad$ V9 P.Sk1. 2129
Population: Calden
Seite: rechts
Erhaltung: $\mathbf{X}$ prox. Gelenk
$\mathbf{X}$ prox. Schaft
$X$ mittl. Schaft
$X$ dist. Schaft
$\mathbf{X}$ dist. Gelenk

Verband: $\quad$ Verband

Ges./Kr.: Gesund

\section{Alter: $\quad 18-26$}

\section{Geschlecht: $ᄋ$}

Arthrose:

prox.

2

dist.

2

Körperhöhe nach Sjøvold: 148,4 - 157,4 cm

\section{Maß}

a-p $\varnothing$ subtrochlear

Caput, horizontaler $\varnothing$

Caput, vertikaler $\varnothing$

Collum-Corpus-Winkel

Epicondylenbreite

gr. Länge

m-I $\varnothing$ subtrochlear

Umfang Schaftmitte

\begin{tabular}{l|l}
23,7 & $\mathrm{~mm}$ \\
39,6 & $\mathrm{~mm}$
\end{tabular}

$39,6 \mathrm{~mm}$

\section{Beschreibung:}

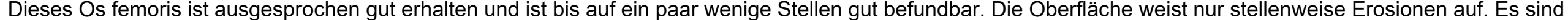

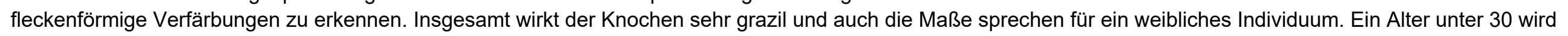
angenommen, da die Epiphysenfugen noch nicht lange geschlossen sind laut Röntgenbefund.

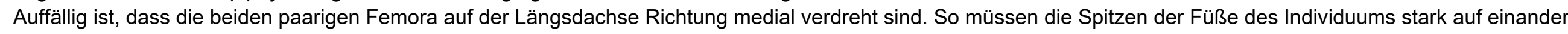
gezeigt haben. 


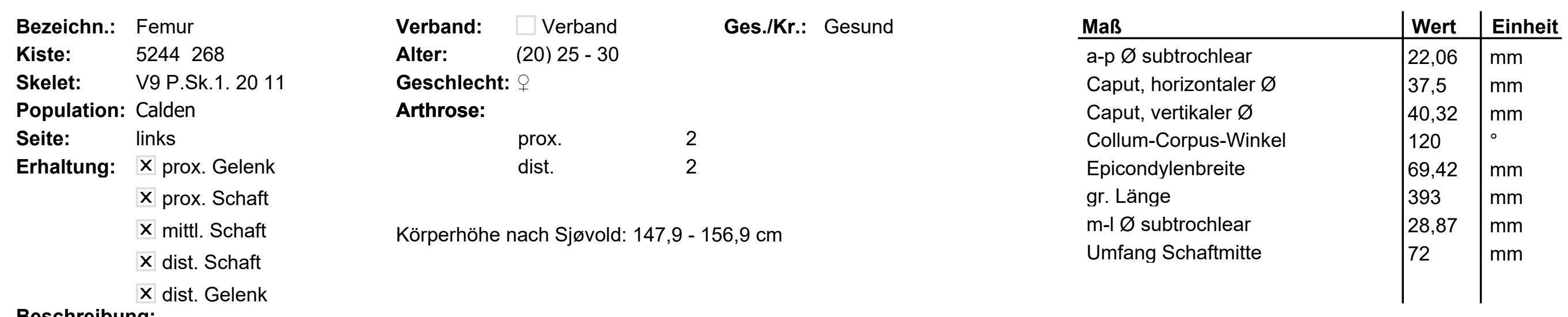

\section{Beschreibung:}

Dieses linke Os femoris weist etwas mehr Erosionsspuren auf, als das recht, ist aber dennoch insgesamt gut erhalten. Auch hier fällt die Achsabweichung in der vertikalen Ebene auf. 


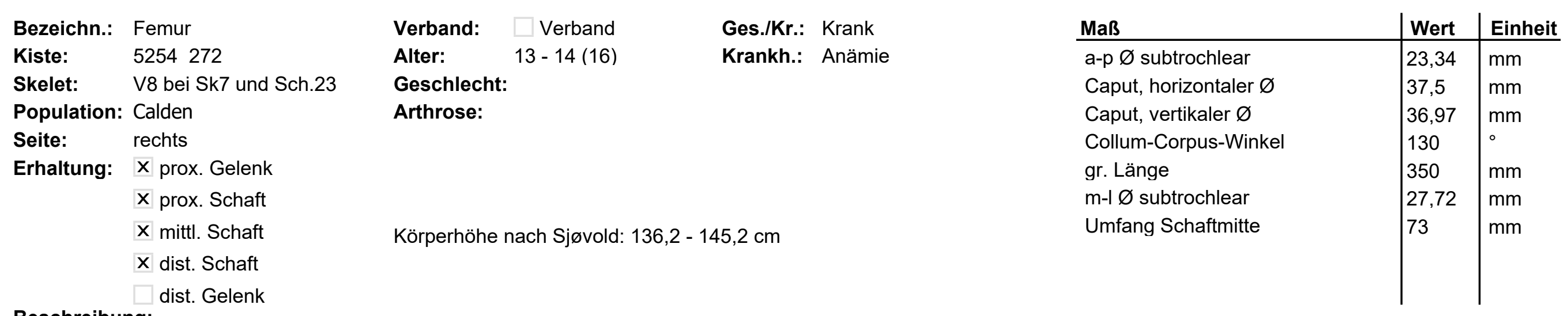

\section{Beschreibung:}

Ein junges Os femoris, bei dem der distale Teil fehlt und dessen Oberfläche gut erhalten ist. Es ist gesäumt von fleckenförmigen dunklen Verfärbungen und hat Porositäten unter der Epiphyse. 

Bezeichn.: Femur
Kiste:
Skelet: P7 P.Sk.7 16
Seite: links
Erhaltung: $\square$ prox. Gelenk
$X$ prox. Schaft
$X$ mittl. Schaft
$\mathbf{X}$ dist. Schaft
dist. Gelenk

Verband:

Verband

Ges./Kr.: Gesund

\section{Alter:}

Maß

a-p Ø subtrochlear

Collum-Corpus-Winkel

m-I Ø subtrochlear

Umfang Schaftmitte

\section{Geschlecht:}

\begin{tabular}{|l|l} 
Wert & Einheit \\
\hline 28,14 & $\mathrm{~mm}$
\end{tabular}

\section{Beschreibung:}

Das Fundstück ist ein Os femoris der linken Seite, welches nicht gut erhalten ist. Es ist nur die Metaphyse erhalten und diese ist z.T. erodiert. Das Os femoris weist eine dicke Kortikalis auf, wirkt sehr massiv und hat stellenweise fleckenförmige dunkle Verfärbungen. 
Bezeichn:: Femur

\section{Kiste:}

5254272

Skelet:

P7 2119

Population: Calden

Seite: rechts

Erhaltung: $\mathbf{X}$ prox. Gelenk

$X$ prox. Schaft

$X$ mittl. Schaft

$\mathbf{X}$ dist. Schaft

X dist. Gelenk
Ges./Kr.: Krank

Krankh.: Arthrose

Enthesiopathie
Maß

a-p $\varnothing$ subtrochlear

Caput, horizontaler $\varnothing$

Caput, vertikaler $\varnothing$

Collum-Corpus-Winkel

Epicondylenbreite

gr. Länge

m-I $\varnothing$ subtrochlear

Umfang Schaftmitte

\begin{tabular}{|l|l} 
Wert & Einheit \\
36,1 & $\mathrm{~mm}$ \\
45,48 & $\mathrm{~mm}$ \\
45,6 & $\mathrm{~mm}$ \\
120 & $\circ$ \\
80,4 & $\mathrm{~mm}$ \\
420 & $\mathrm{~mm}$ \\
32,72 & $\mathrm{~mm}$ \\
86 & $\mathrm{~mm}$
\end{tabular}

\section{Beschreibung:}

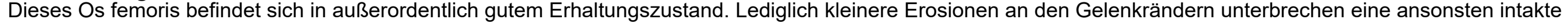

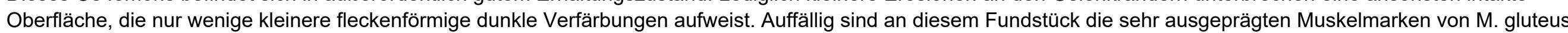

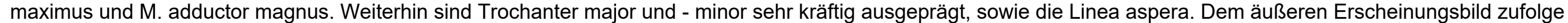

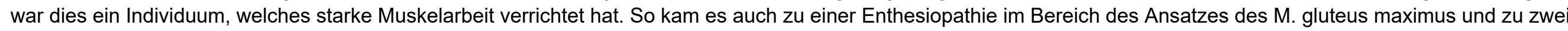
kleinen Krampfaderspuren im Periost, welche bis etwa $1 \mathrm{~mm}$ breit waren. 

Bezeichn.: Femur
Kiste: $\quad 5254272$
Skelet: P7 2517
Population: Calden
Seite: rechts
Erhaltung: $\mathbf{X}$ prox. Gelenk
$\mathbf{X}$ prox. Schaft
$X$ mittl. Schaft
$\mathbf{X}$ dist. Schaft
$\mathbf{X}$ dist. Gelenk

Verband:

Verband

Ges./Kr.: Krank

Alter: $\quad 36-52 \quad$ Krankh.: Arthrose

Geschlecht: ${ }^{\lambda}$

Krankh.: Arthrose

\section{Arthrose:}

dist.

3

Körperhöhe nach Sjøvold: 161,7 - 170,7 cm

\begin{tabular}{l|l|l} 
Maß & Wert & Einheit \\
\hline a-p $\varnothing$ subtrochlear & 28,29 & $\mathrm{~mm}$ \\
Caput, horizontaler $\varnothing$ & 42,69 & $\mathrm{~mm}$ \\
Caput, vertikaler $\varnothing$ & 46,1 & $\mathrm{~mm}$ \\
Collum-Corpus-Winkel & 120 & $\circ$ \\
Epicondylenbreite & 81,83 & $\mathrm{~mm}$ \\
gr. Länge & 444 & $\mathrm{~mm}$ \\
m-I $\varnothing$ subtrochlear & 33,4 & $\mathrm{~mm}$ \\
Umfang Schaftmitte & 92 & $\mathrm{~mm}$
\end{tabular}

\section{Beschreibung:}

Das Fundstück ist ein recht massives Os femoris eines männlichen Individuums. Das proximale Gelenk ist so stark erodiert, dass es keine Befundung zulässt. Auch das distale Gelenk ist teilweise erodiert, die Gesamtoberfläche blieb jedoch größtenteils gut erhalten. Die Muskelmarken sind bei diesem Os femoris eher unauffällig. 


$\begin{array}{ll}\text { Bezeichn.: } & \text { Femur } \\ \text { Kiste: } & 5266280 \\ \text { Skelet: } & 10 \\ \text { Population: } & \text { Calden } \\ \begin{array}{ll}\text { Seite: } & \text { links } \\ \text { Erhaltung: } & \mathbf{X} \text { prox. Gelenk } \\ & \text { X prox. Schaft } \\ & \mathbf{X} \text { mittl. Schaft } \\ & \mathbf{X} \text { dist. Schaft } \\ & \square \text { dist. Gelenk }\end{array} \\ \text { Beschreibung: }\end{array}$

\section{Verband: $\quad \square$ Verband \\ Ges./Kr.: Krank}

Alter: $\quad 47-58$

Geschlecht: $\hat{\sigma}$

Arthrose:

prox.

3

Krankh.: Arthrose

Maß

a-p $\varnothing$ subtrochlear

Caput, horizontaler $\varnothing$

Caput, vertikaler $\varnothing$

Collum-Corpus-Winkel

gr. Länge

m-I Ø subtrochlear

Umfang Schaftmitte
Wert 1 Einheit

$26,16 \mathrm{~mm}$

43,52 $\mathrm{mm}$

$44 \mathrm{~mm}$

139

387

33,56

90

An diesem Femur liegt eine muskuläre Reizung der Linea aspera vor, die als Reaktion kleine Knochenneubildungen hervorgebracht hat. 


$\begin{array}{ll}\text { Bezeichn.: } & \text { Femur } \\ \text { Kiste: } & 5266281 \\ \text { Skelet: } & 41 \\ \text { Population: } & \text { Calden } \\ \text { Seite: } & \text { links } \\ \text { Erhaltung: } & \square \text { prox. Gelenk } \\ & \text { X prox. Schaft } \\ & \square \text { mittl. Schaft } \\ & \square \text { dist. Schaft } \\ & \square \text { dist. Gelenk }\end{array}$

Verband: $\quad$ Verband

Alter: Erwachsen

Geschlecht: $q \leq \AA$

Arthrose:
Ges./Kr.: Gesund

Maß

a-p Ø subtrochlear

$\mathrm{m}-\mathrm{I} \varnothing$ subtrochlear

Umfang Schaftmitte

\begin{tabular}{|l|l} 
Wert & Einheit \\
\hline 32,6 & $\mathrm{~mm}$ \\
42,67 & $\mathrm{~mm}$ \\
98 & $\mathrm{~mm}$ \\
& \\
& \\
\end{tabular}

Hier liegt ein sehr massives Os femoris der linken Körperseite vor mit sehr auffällig massiver compacta und einer ausgeprägten Linea aspera. 


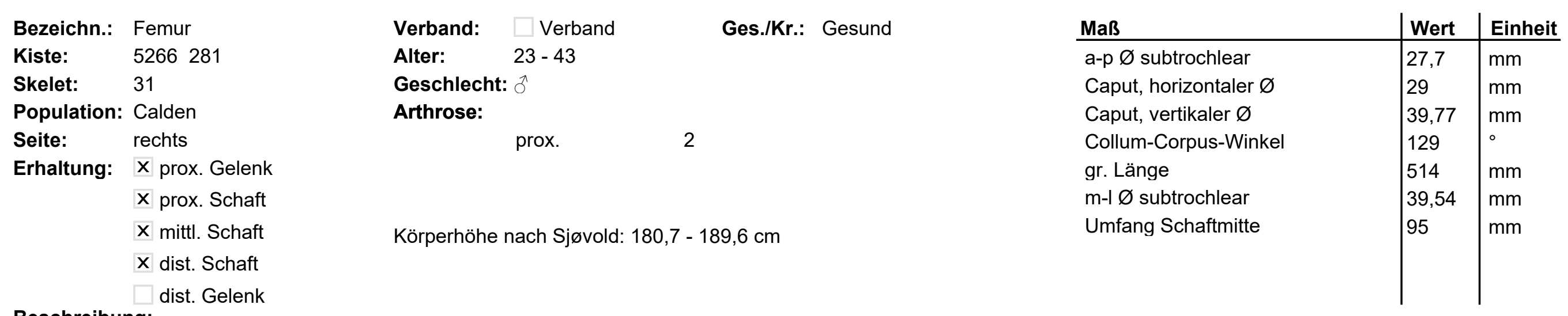

\section{Beschreibung:}

Bei diesem Os femoris der rechten Körperseite sind keine deutlich ausgeprägten Muskelmarken zu verzeichnen mit Ausnahme einer gut ausgeprägten Linea aspera in der Mitte des Fundstücks. Das Caput femoris ist etwa zu 50\% erhalten. Insgesamt wirkt dieses Os femoris sehr massiv. 
Bezeichn:: Femur

Kiste: $\quad 5266281$

Skelet: 7

Population: Calden

Seite: links

Erhaltung: $\square$ prox. Gelenk

$X$ prox. Schaft

$X$ mittl. Schaft

$\mathbf{X}$ dist. Schaft

X dist. Gelenk
Verband: $\square$ Verband

Alter: Erwachsen

Geschlecht: $q \leq ð$

Arthrose:
Ges./Kr.: Gesund

dist.

\begin{tabular}{l|l|l} 
Maß & Wert & Einheit \\
\hline a-p $\varnothing$ subtrochlear & 29,39 & $\mathrm{~mm}$ \\
Epicondylenbreite & 73,39 & $\mathrm{~mm}$ \\
gr. Länge & 435 & $\mathrm{~mm}$ \\
$\mathrm{~m}-\mathrm{I} \varnothing$ subtrochlear & 31,22 & $\mathrm{~mm}$ \\
Umfang Schaftmitte & 83 & $\mathrm{~mm}$
\end{tabular}

\section{Beschreibung:}

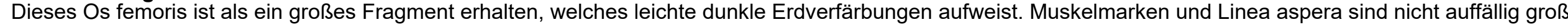
ausgeprägt. Die wenig poröse Oberfläche zeigt Wurzelimpressionen und Wurmlöcher. 


\section{Bezeichn.: Femur \\ Kiste: 5266280 \\ Skelet: $\quad 3$ \\ Population: Calden \\ Seite: links \\ Erhaltung: $\mathbf{X}$ prox. Gelenk \\ $X$ prox. Schaft \\ $X$ mittl. Schaft \\ $\mathbf{X}$ dist. Schaft \\ $X$ dist. Gelenk \\ Beschreibung:}

Ges./Kr.: Gesund

\begin{tabular}{l|l|l} 
Maß & Wert & Einheit \\
\hline a-p $\varnothing$ subtrochlear & 27,21 & $\mathrm{~mm}$ \\
Caput, horizontaler $\varnothing$ & 45,81 & $\mathrm{~mm}$ \\
Caput, vertikaler $\varnothing$ & 44,35 & $\mathrm{~mm}$ \\
Collum-Corpus-Winkel & 122 & $\circ$ \\
Epicondylenbreite & 80,66 & $\mathrm{~mm}$ \\
gr. Länge & 440 & $\mathrm{~mm}$ \\
m-l $\varnothing$ subtrochlear & 33,54 & $\mathrm{~mm}$ \\
Umfang Schaftmitte & 92 & $\mathrm{~mm}$
\end{tabular}

Dieses fast vollständige Os femoris ist in teilweise recht gutem und teilweise erodierten Zustand erhalten. Es weist nur mäßige Muskelmarken auf, es fallen Wurzelimpressionen und Wurmlöcher auf. 


$\begin{array}{ll}\text { Bezeichn.: } & \text { Femur } \\ \text { Kiste: } & 5266281 \\ \text { Skelet: } & 35 \\ \text { Population: } & \text { Calden } \\ \text { Seite: } & \text { rechts } \\ \text { Erhaltung: } & \square \text { prox. Gelenk } \\ & \square \text { prox. Schaft } \\ & \square \text { mittl. Schaft } \\ & \mathbf{X} \text { dist. Schaft } \\ & \mathbf{X} \text { dist. Gelenk }\end{array}$

Verband: $\quad$ Verband

Alter: Erwachsen

\section{Geschlecht: $\delta$}

Arthrose:

\section{Ges./Kr.: Gesund}

\section{Maß}

Epicondylenbreite

Wert $\quad$ Einheit

Dieses Os femoris der rechten Seite ist nur als distales Fragment erhalten. Es weist dunkle Verfärbungen und kleinere Risse in der Oberfläche auf. 


\begin{tabular}{|c|c|c|c|c|c|c|c|}
\hline Bezeichn.: & Femur & Verband: & $\square$ Verband & Ges./Kr.: Gesund & Maß & Wert & Einheit \\
\hline Kiste: & 5266281 & Alter: & Erwachsen & & a-p $\varnothing$ subtrochlear & 27,45 & $\mathrm{~mm}$ \\
\hline Skelet: & 6 & Geschlecht: & & & Epicondylenbreite & 85,47 & $\mathrm{~mm}$ \\
\hline Population: & Calden & Arthrose: & & & m-I $\varnothing$ subtrochlear & 36,51 & $\mathrm{~mm}$ \\
\hline Seite: & links & & & & Umfang Schaftmitte & 90 & $\mathrm{~mm}$ \\
\hline Erhaltung: & $\square$ prox. Gelenk & & dist. & 2 & & & \\
\hline & X prox. Schaft & & & & & & \\
\hline & X mittl. Schaft & & & & & & \\
\hline & $\mathbf{X}$ dist. Schaft & & & & & & \\
\hline & X dist. Gelenk & & & & & & \\
\hline
\end{tabular}

\section{Beschreibung:}

Dieses Os femoris weist eine starke Linea aspera auf, welche etwas durch Muskelzug gereizt ist. Anterio - medial sind Verfärbungen von der langen Lagerung in der Erde zu sehen. Die Oberfläche ist teilweise porös, aber größtenteils gut beurteilbar. Es finden sich starke Muskelmarken an der Ansatzfläche des M. gluteus maximus. 
Bezeichn.: Femur

Kiste: $\quad 5266280$

Skelet: 17

Population: Calden

Seite: links

Erhaltung: $\mathbf{X}$ prox. Gelenk

$X$ prox. Schaft

$X$ mittl. Schaft

$\mathbf{X}$ dist. Schaft dist. Gelenk

\section{Ges./Kr.: Krank \\ Krankh.: Arthrose \\ Verband: Verband \\ Alter: $\quad 18-52$}

Geschlecht: 0

Arthrose:

prox.

3

Körperhöhe nach Sjøvold: 150,6 - 159,6 cm

\begin{tabular}{l|l|l} 
Maß & Wert & Einheit \\
\hline a-p $\varnothing$ subtrochlear & 28,82 & $\mathrm{~mm}$ \\
Caput, horizontaler $\varnothing$ & 47,82 & $\mathrm{~mm}$ \\
Caput, vertikaler $\varnothing$ & 48,85 & $\mathrm{~mm}$ \\
Collum-Corpus-Winkel & 120 & $\circ$ \\
gr. Länge & 403 & $\mathrm{~mm}$ \\
m-I $\varnothing$ subtrochlear & 38,41 & $\mathrm{~mm}$ \\
Umfang Schaftmitte & 105 & $\mathrm{~mm}$
\end{tabular}

\section{Beschreibung:}

Der Schaft dieses Femurs weist eine Krümmung nach lateral auf, weiterhin ist der Knochen sehr massiv. Die Fläche des Caput femoris weist eine leichte

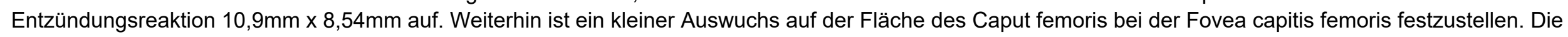
Oberfläche weist anterior dunkle Verfärbungen auf. 

Bezeichn:: Femur
Kiste: $\quad 5266281$
Skelet: 24
Population: Calden
Seite: rechts
Erhaltung: $\mathbf{X}$ prox. Gelenk
$X$ prox. Schaft
$X$ mittl. Schaft
X dist. Schaft dist. Gelenk

Verband: $\square$ Verband

Alter: $\quad 36-52$

Geschlecht: $+\leq \widehat{\diamond}$

Arthrose:

prox. 2

Körperhöhe nach Sjøvold: 153,8 - 162,8 cm
$\mathrm{Maß}$

a-p $\varnothing$ subtrochlear

Caput, horizontaler $\varnothing$

Caput, vertikaler $\varnothing$

gr. Länge

m-I $\varnothing$ subtrochlear

Umfang Schaftmitte

\begin{tabular}{|l|l} 
Wert & Einheit \\
\hline 25,93 & $\mathrm{~mm}$
\end{tabular}

43,45

$43,45 \mathrm{~mm}$

$44,15 \mathrm{~mm}$

$415 \mathrm{~mm}$

$37,68 \mathrm{~mm}$

90

\section{Beschreibung:}

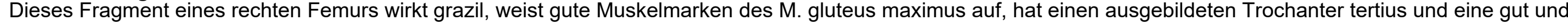

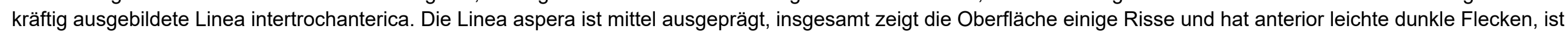
bei dünner Compacta aber recht gut erhalten. 


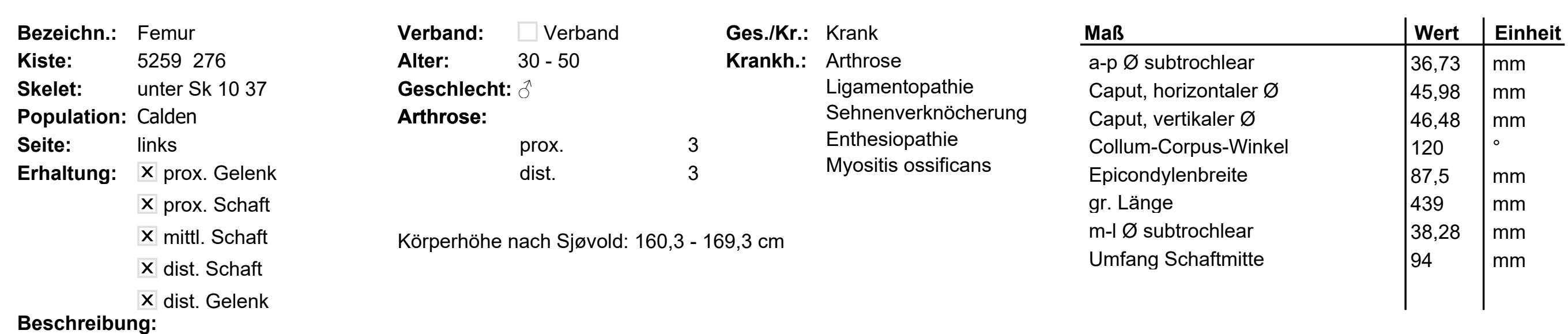

Dieses Os femoris, was wohl einem männlichen Individuum zuzuordnen ist, weist mehrere Besonderheiten auf. Sofort erkennbar ist die sehr deutliche Ligamentopathie im unteren Drittel des Knochens ( $51 \mathrm{~mm}$ x 16mm x 7,5mm). Zu dieser Knochenneubildung wird vermutlich ein Abriss der Sehne des dort ansetzenden Muskels, des M. vastus lateralis, geführt haben. Die Sehne ist dann nach Abriss im distalen Ansatzbereich verknöchert. Weiterhin ist das Os femoris nach medial in der vertikalen Achse eingedreht. Es weist deutliche Spuren einer Arthrose auf und wirkt insgesamt solide und massiv. 


$\begin{array}{ll}\text { Bezeichn.: } & \text { Femur } \\ \text { Kiste: } & 5259276 \\ \text { Skelet: } & \text { unter Becken } 10 \\ \text { Population: } & \text { Calden } \\ \text { Seite: } & \text { rechts } \\ \text { Erhaltung: } & \mathbf{X} \text { prox. Gelenk } \\ & \mathbf{X} \text { prox. Schaft } \\ & \mathbf{X} \text { mittl. Schaft } \\ & \mathbf{X} \text { dist. Schaft } \\ & \mathbf{X} \text { dist. Gelenk }\end{array}$

Verband: $\quad \square$ Verband

Alter: $\quad 15-17(19)$

Ges./Kr.: Gesund

Geschlecht: 0

Arthrose:

prox.

00

\begin{tabular}{l|l|l} 
Maß & Wert & Einheit \\
\hline a-p $\varnothing$ subtrochlear & 27 & $\mathrm{~mm}$ \\
Caput, horizontaler $\varnothing$ & 44,8 & $\mathrm{~mm}$ \\
Caput, vertikaler $\varnothing$ & 45,5 & $\mathrm{~mm}$ \\
Collum-Corpus-Winkel & 136 & $\circ$ \\
gr. Länge & 406 & $\mathrm{~mm}$ \\
m-I $\varnothing$ subtrochlear & 34,4 & $\mathrm{~mm}$ \\
Umfang Schaftmitte & 86 & $\mathrm{~mm}$
\end{tabular}

Bei diesem recht gut erhaltenen Os femoris eines jungen Individuums liegen leichte Erosionen vor und es fehlt die distale Epiphyse. 

Bezeichn.: Femur
Kiste: $\quad 5259276$
Skelet: $\quad$ unter Sk10 3655
Population: Calden
Seite: rechts
Erhaltung: X prox. Gelenk
$X$ prox. Schaft
$X$ mittl. Schaft
$\mathbf{X}$ dist. Schaft
$X$ dist. Gelenk

Beschreibung:

Ein fast vollständiges Os femoris.
Verband: $\quad \square$ Verband Ges./Kr.: Gesund

Alter: $\quad 11-14$

\section{Geschlecht:}

Arthrose:

Maß

a-p $\varnothing$ subtrochlear

Caput, horizontaler $\varnothing$

Caput, vertikaler $\varnothing$

Collum-Corpus-Winkel

Epicondylenbreite

gr. Länge

m-I $\varnothing$ subtrochlear

Umfang Schaftmitte

\begin{tabular}{|l|l} 
Wert & Einheit \\
\hline 20,25 & $\mathrm{~mm}$
\end{tabular}

$29,25 \mathrm{~mm}$

$26 \quad \mathrm{~mm}$

130

50

328

25,4

69

$\mathrm{mm}$


Bezeichn:: Femur

Kiste: $\quad 5259276$

Skelet: $\quad$ SK10(?) 6559

Population: Calden

Seite: links

Erhaltung: $\mathbf{X}$ prox. Gelenk

X prox. Schaft

mittl. Schaft

dist. Schaft

dist. Gelenk
Verband: $\square$ Verband

Alter: $\quad 20-40$

Geschlecht: $\delta$

Arthrose:
Ges./Kr.: Gesund

\begin{tabular}{l|l|l} 
Maß & Wert & Einheit \\
\hline a-p $\varnothing$ subtrochlear & 29 & $\mathrm{~mm}$ \\
Caput, horizontaler $\varnothing$ & 43,3 & $\mathrm{~mm}$ \\
Caput, vertikaler $\varnothing$ & 42,49 & $\mathrm{~mm}$ \\
Collum-Corpus-Winkel & 121 & $\circ$ \\
m-I $\varnothing$ subtrochlear & 37,86 & $\mathrm{~mm}$
\end{tabular}

\section{Beschreibung:}

Ein Fragment eines recht massiven, linken Os femoris. Das Fragment weist im Bereich des M. gluteus - Ansatzes gut ausgeprägte Muskelmarken auf. 

Bezeichn.: Femur
Kiste: $\quad 5259276$
Skelet: $\quad$ PSK10 "auf Becken 10"
Population: Calden
Seite: rechts
Erhaltung: $\mathbf{X}$ prox. Gelenk
$X$ prox. Schaft
$X$ mittl. Schaft
$\mathbf{X}$ dist. Schaft
$X$ dist. Gelenk

Beschreibung:

Ein fast vollstăndiges Os femoris.
Verband: $\quad \square$ Verband Ges./Kr.: Gesund

\section{Alter: $\quad 1$ - 2}

Geschlecht:

Arthrose:

Maß

a-p $\varnothing$ subtrochlear

Caput, horizontaler $\varnothing$

Caput, vertikaler $\varnothing$

Epicondylenbreite

gr. Länge

m-I Ø subtrochlear

Umfang Schaftmitte

\begin{tabular}{|l|l} 
Wert & Einheit \\
\hline 14,53 & $\mathrm{~mm}$
\end{tabular}

$19,88 \mathrm{~mm}$

$20,79 \mathrm{~mm}$

$42,36 \mathrm{~mm}$

$134 \mathrm{~mm}$

$17,35 \mathrm{~mm}$

42,2 $\mathrm{mm}$ 


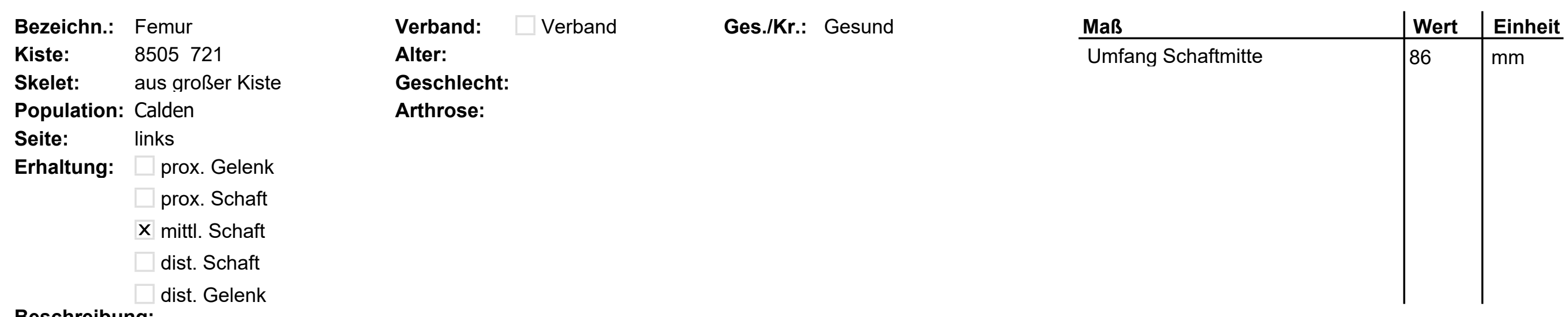

\section{Beschreibung:}

Bei diesem Fragment aus dem Schaft eines linken Femurs fällt eine kurze Linea aspera ins Auge, was für einen eher kurzen Knochen spricht und damit auch eher für einen kleinen Menschen. 

Bezeichn.: Femur
Kiste:
8505721
aus großer Kiste
Population: Calden
Seite: rechts
Erhaltung: $\mathbf{X}$ prox. Gelenk
$X$ prox. Schaft
mittl. Schaft
dist. Schaft
dist. Gelenk

\section{Beschreibung:}

Verband:

\section{Alter:}

Verband

Geschlecht

Proximales Fragment eines Os femoris jungen Alters.

$19,33 \mathrm{~mm}$

$35,76 \mathrm{~mm}$

$25,03 \mathrm{~mm}$

$66 \mathrm{~mm}$




\section{Bezeichn.: Femur \\ Kiste: $\quad 8505721$ \\ Seite: links \\ Erhaltung: $\square$ prox. Gelenk \\ prox. Schaft \\ $X$ mittl. Schaft \\ $\mathbf{X}$ dist. Schaft dist. Gelenk \\ Beschreibung:}

Verband: $\quad$ Verband

Ges./Kr.: Gesund

Alter:

Skelet: aus großer Kiste Geschlecht: $q \leq \lambda$

Population: Calden Arthrose:

Hierbei handelt es sich um ein mittig distales Fragment aus dem Schaft eines linken Femurs, der recht massiv und kräftig ausgebildet ist und eine gut definierte Linea aspera aufweist. 


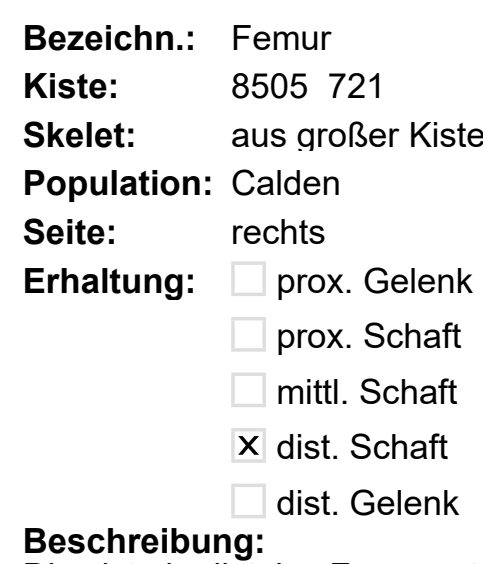

Verband: $\quad$ Verband

Alter:

Ges./Kr.: Gesund

\section{Geschlecht:}

Arthrose:

Dies ist ein distales Fragment aus dem Schaft eines recht grazilen, rechten Femurs. 

Bezeichn.: Femur
Kiste: $\quad 8505721$
Skelet: aus großer Kiste
Population: Calden
Seite: links
Erhaltung: $\square$ prox. Gelenk
X prox. Schaft
$X$ mittl. Schaft
$\mathbf{X}$ dist. Schaft
dist. Gelenk
Beschreibung:

\section{Verband: $\quad \square$ Verband \\ Alter: Jung \\ Geschlecht:}

Arthrose:

Ein Fragment eines linken Os femoris eines jungen Individuums.
Ges./Kr.: Gesund

Maß

a-p $\varnothing$ subtrochlear

m-I Ø subtrochlear

Umfang Schaftmitte 
Bezeichn.: Femur

Kiste: $\quad 5242266$

Skelet: V1 E.B-S.

Population: Calden

Seite: rechts

Erhaltung: $\square$ prox. Gelenk

X prox. Schaft

mittl. Schaft

dist. Schaft

dist. Gelenk

\section{Beschreibung:}

Ein Fragment eines jungen Os femoris, es ist lediglich ein proximaler Teil erhalten.

\section{Verband: $\quad \square$ Verband Ges./Kr.: Gesund}

\section{Alter: Jung}

\section{Geschlecht:}

Arthrose: 

Bezeichn.: Femur
Kiste: $\quad 5252271$
Skelet: $\quad 11$ bei Sk.6.
Population: Calden

\section{Erhaltung: $\square$ prox. Gelenk prox. Schaft $X$ mittl. Schaft dist. Schaft dist. Gelenk}

Verband: $\quad \square$ Verband

\section{Alter:}

Geschlecht:

Arthrose:

Beschreibung:

Ein Fragment eines Os femoris. 
Bezeichn.: Patella

Kiste: $\quad 8505718$

Skelet: aus Tüte

Population: Calden

Seite:

links
Verband: $\quad \square$ Verband

Alter:

\section{Geschlecht:}

Arthrose:
Ges./Kr.: Krank

Krankh.: Sehnenverknöcherung

fac. art.

\section{Beschreibung:}

Bei dieser linken Patella finden sich auf der Außenfläche Sehnenverknöcherungen mittleren Grades, was für eine starke Beanspruchung der Muskulatur im Bereich des Oberschenkels spricht. Auf der Innenseite sind nur leichte Spuren einer Arthrose zu finden. 


\section{Bezeichn: Patella \\ Kiste: $\quad 8505720$ \\ Skelet: $\quad 1.0$}

Population: Calden
Verband: Verband

\section{Alter:}

Geschlecht:

Arthrose:

\section{Beschreibung:}

Sehr stark erodiertes und nicht befundbares Fundstück. 
Bezeichn.: Patella

Kiste: 8505720

Skelet: einzeln 1.1

Population: Calden

Seite:

links
Verband: $\quad \square$ Verband

Alter:

Geschlecht:

Arthrose:
Ges./Kr.: Krank

Krankh.: Sehnenverknöcherung

\section{Maß}

Breite

Länge

Wert $\mid$ Einheit

$48,47 \mathrm{~mm}$

40,9

$\mathrm{mm}$

\section{Beschreibung:}

Diese gut erhaltene Patella weist eine deutliche Verknöcherung der Pattelasehne auf. Die Gelenkflächen zeigen eine sichtbare Verschleißerscheinung. 
Bezeichn.: Patella

Kiste: $\quad 8505718$

Skelet: aus 2. Kiste

Population: Calden

Seite:

rechts
Verband: $\quad \square$ Verband

Alter:

Geschlecht:

Arthrose:
Ges./Kr.: Krank

Krankh.: Osteophyten

Sehnenverknöcherung

fac. art.

\section{Beschreibung:}

Die Außenfläche dieser Patella ist durch Sehnenzerrungen sehr stark mit Osteophyten verknöchert, diese messen bis zu $17 \mathrm{~mm}$ auf einer Länge von bis zu $37 \mathrm{~mm}$. 
Bezeichn.: Patella

Kiste: $\quad 8505718$

Skelet: $\quad$ V45 aus 2. Kiste

Population: Calden

Seite:
Verband: $\square$ Verband

Alter:

Geschlecht:

Arthrose:
Ges./Kr.: Krank

Krankh.: Osteophyten

Sehnenverknöcherung

fac. art.

\section{Beschreibung:}

Diese Patella weist außen Sehnenverknöcherungen auf und beide Patellae gehören zusammen. Die Osteophyten messen bis zu $6 \mathrm{~mm}$. 
Bezeichn.: Patella

Kiste: $\quad 8505718$

Skelet: V45 aus 2. Kiste

Population: Calden

Seite: rechts
Verband: $\square$ Verband

Alter:

Geschlecht:

Arthrose:
Ges./Kr.: Krank

\section{Krankh.: Osteophyten}

Sehnenverknöcherung

fac. art.

\section{Beschreibung:}

Diese Patella weist außen Sehnenverknöcherungen auf und beide Patellae gehören zusammen. Die Osteophyten messen bis zu $6 \mathrm{~mm}$. 
Bezeichn.: Patella

Kiste: 8505718

Skelet: $\quad$ V46 mit Femur 2. Kiste

Population: Calden

Seite: rechts
Verband: $\square$ Verband

\section{Alter:}

Geschlecht:

\section{Arthrose:}

Ges./Kr.: Krank

Krankh.: Arthrose

Sehnenverknöcherung

\section{Beschreibung:}

Dies ist ein Verband aus einem rechten Beckenfragment, rechtem Os femoris und beiden Patellae. Das Os femoris ist stellenweise recht stark erodiert und weist folgende Muskelmarken auf: eine starke Linea aspera, Ansatz des M. gluteus maximus, ein massiver Trochanter major, M. adductor magnus, M. gastrocnemius und eine ausgeprägte Ansatzstelle des M. vastus medialis. Die Fovea capitis femoris hat einen Rand , welcher über $4 \mathrm{~mm}$ misst und auch die Condylen weisen eindeutige Verschleißspuren auf. Stellenweise wird der Gelenkknorpel schon verschlissen gewesen sein. Die linke Patella hat auf der Außenfläche starke Sehnenverknöcherungen. Die Osteophyten messen bis zu 7,5mm. Die rechte Patella weist ebenfalls starke Sehnenverknöcherungen auf. 
Bezeichn.: Patella

Kiste: $\quad 8505718$

Skelet: $\quad$ V46 mit Femur 2. Kiste

Population: Calden

Seite:
Verband: $\quad$ Verband

\section{Alter:}

Geschlecht:

Arthrose:
Ges./Kr.: Krank

Krankh.: Sehnenverknöcherung

Arthrose

\section{Beschreibung:}

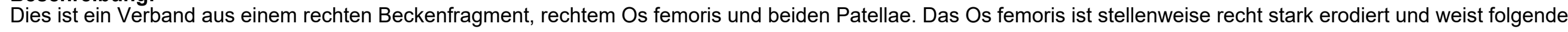

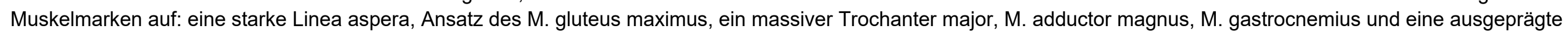

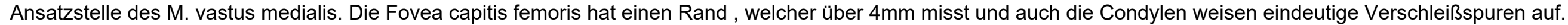

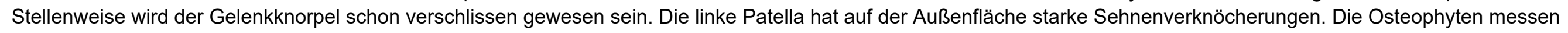
bis zu 7,5mm. Die rechte Patella weist ebenfalls starke Sehnenverknöcherungen auf. 
Bezeichn.: Patella

Kiste: $\quad 8505718$

Skelet: $\quad$ V47 aus 2. Kiste

Population: Calden

Seite: rechts
Verband: $\quad \square$ Verband

Alter:

\section{Geschlecht:}

Arthrose:
Ges./Kr.: Krank

Krankh.: Sehnenverknöcherung

fac. art.

\section{Beschreibung:}

Diese beiden Patellae sind demselben Individuum zuzuordnen. Sie zeigen beide mäßige Sehnenverknöcherungen und auf der Gelenkfläche eine nur mit leichtem Grad ausgeprägte Arthrose. 
Bezeichn.: Patella

Kiste: $\quad 8505718$

Skelet: $\quad$ V47 aus 2. Kiste

Population: Calden

Seite:
Verband: $\square$ Verband

Alter:

Geschlecht:

Arthrose:
Ges./Kr.: Krank

Krankh.: Sehnenverknöcherung

fac. art.

\section{Beschreibung:}

Diese beiden Patellae sind demselben Individuum zuzuordnen. Sie zeigen beide mäßige Sehnenverknöcherungen und auf der Gelenkfläche eine nur mit leichtem Grad ausgeprägte Arthrose. 
Bezeichn.: Patella

Kiste: $\quad 8505718$

Skelet: aus 2. Kiste

Population: Calden

Seite:

links

\section{Verband:}

Verband

\section{Alter:}

Geschlecht:

Arthrose:
Ges./Kr.: Gesund

fac. art.

\section{Beschreibung:}

Diese Patella ist durch Bodenerosionen auf der Innenseite nur teilweise befundbar und außen gar nicht. 
Bezeichn.: Patella

Kiste: $\quad 8505718$

Skelet: aus 2. Kiste

Population: Calden

Seite:

links

\section{Verband:}

Verband

\section{Geschlecht:}

Arthrose:

\section{Ges./Kr.: Gesund}

r.: Gesund

fac. art.

\section{Beschreibung:}

Die Innenseite dieser Patella war befundbar, wies aber nur eine leichte Arthrose auf. Die Außenseite zeigte leichte Sehnenverknöcherungen. 
Bezeichn.: Patella

Kiste: $\quad 8505718$

Skelet: aus 2. Kiste

Population: Calden

Seite:

links
Verband: $\quad \square$ Verband

Alter:

\section{Geschlecht:}

Arthrose:
Ges./Kr.: Krank

Krankh.: Sehnenverknöcherung

fac. art.

\section{Beschreibung:}

Die Innenseite dieser Patella war befundbar, wies aber nur eine leichte Arthrose auf. Die Außenseite zeigte mäßige Sehnenverknöcherungen. 
Bezeichn.: Patella

Kiste: $\quad 8505718$

Skelet: aus 2. Kiste

Population: Calden

Seite:

links

\section{Verband:}

Verband

\section{Alter:}

Geschlecht:

Arthrose:
Ges./Kr.: Gesund

\section{Beschreibung:}

Die Innenseite dieser Patella war befundbar, wies aber nur eine leichte Arthrose auf. Die Außenseite zeigte leichte Sehnenverknöcherungen. 
Bezeichn.: Patella

Kiste: $\quad 8505718$

Skelet: aus 2. Kiste

Population: Calden

Seite:

links

\section{Verband:}

Verband

\section{Alter:}

Geschlecht:

Arthrose:
Ges./Kr.: Gesund

\section{Beschreibung:}

Die Innenseite dieser Patella war befundbar, wies aber nur eine leichte Arthrose auf. Die Außenseite zeigte sehr leichte Sehnenverknöcherungen. 
Bezeichn.: Patella

Kiste: $\quad 8505718$

Skelet: aus 2. Kiste

Population: Calden

Seite:

links
Verband: $\quad \square$ Verband

Alter:

\section{Geschlecht:}

Arthrose:
Ges./Kr.: Krank

Krankh.: Arthrose

fac. art.

\section{Beschreibung:}

Bei dieser Patella fällt eine Arthrose auf der Innenseite auf, welche gut befundbar war. Die Außenseite zeigt kaum Spuren einer Sehenverknöcherung. 
Bezeichn.: Patella

Kiste: $\quad 8505718$

Skelet: aus 2. Kiste

Population: Calden

Seite:

rechts
Verband: $\quad \square$ Verband

Alter:

Geschlecht:

Arthrose:
Ges./Kr.: Krank

Krankh.: Arthrose

Sehnenverknöcherung

fac. art.

\section{Beschreibung:}

Auf der Innenseite dieser Patella finden sich Spuren einer Arthrose, wobei die Gelenkfläche nur zum Teil befundbar war. Die Außenseite zeigt mittelmäßig ausgeprägte Sehnenverknöcherungen. 
Bezeichn:: Patella

Kiste:

Skelet: V50 aus 2. Kiste

Population: Calden

Seite:

\section{Verband: \\ Alter:}

Geschlecht:

Arthrose:

fac. art.

\section{Beschreibung:}

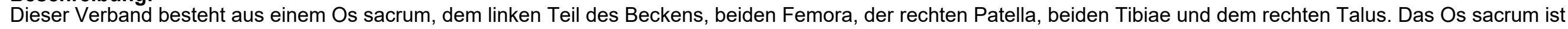

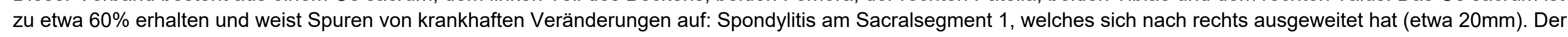

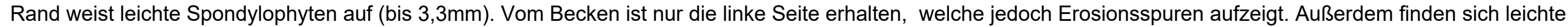

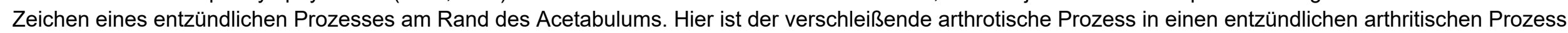

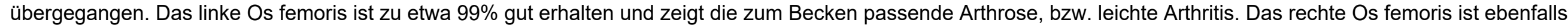

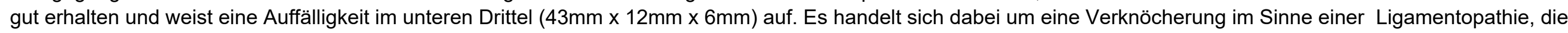

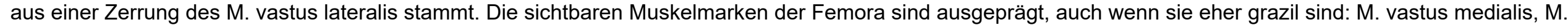

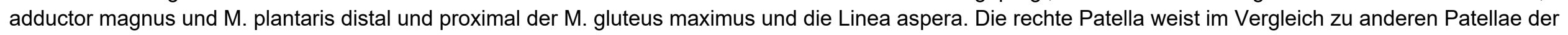

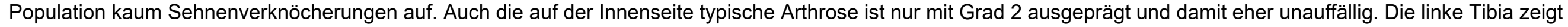

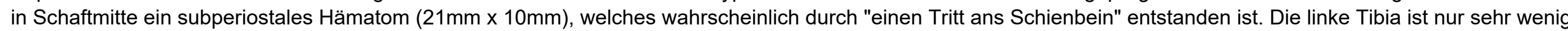

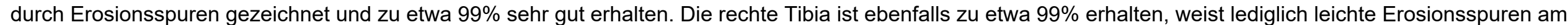
proximalen Gelenk auf. Der rechte Talus ist zu etwa 98\% erhalten und weist insgesamt einen unauffälligen Arthrosegrad von 2 auf. 
Bezeichn.: Patella

Kiste: $\quad 8505718$

Skelet: $\quad$ aus 2. Kiste

Population: Calden

Seite:

rechts

\section{Verband:}

Verband

\section{Alter:}

Geschlecht:

Arthrose:
Ges./Kr.: Gesund

\section{Ges./Kr: Gesund}

fac. art.

\section{Beschreibung:}

Bei dieser Patella ist die Innenseite gut befundbar, die Außenseite zeigt kaum Sehnenverknöcherungen. 
Bezeichn.: Patella

Kiste: $\quad 8505718$

Skelet: aus 2. Kiste

Population: Calden

Seite:

rechts
Verband: $\square$ Verband

Alter:

\section{Geschlecht:}

Arthrose:
Ges./Kr.: Krank

Krankh.: Arthrose

fac. art.

\section{Beschreibung:}

Diese Patella ist auf der Innenseite teilweise befundbar. Sie weist eine Arthrose auf der Gelenkfläche auf, außen sind aber kaum Spuren einer Sehnenreizung auszumachen. 


\section{Bezeichn.: Patella \\ Kiste: $\quad 5243267$ \\ Skelet: P.Sk.1.}

Population: Calden

Seite:

links
Verband: $\square$ Verband

Alter:

Geschlecht:

Arthrose:
Ges./Kr.: Krank

Krankh.: Sehnenverknöcherung

fac. art.

\section{Beschreibung:}

Auf der Außenfläche der Patella finden sich sehr starke Verknöcherungen, welche durch Reizung der Sehne (Lig. Patellae und M. quadriceps femoris tendo) hervorgerufen wurden. 
Bezeichn.: Patella

Kiste: 5243267

Skelet: Zettel

Population: Calden

Seite:

links

Verband: $\quad$ Verband

\section{Alter:}

Geschlecht:

Arthrose:

\section{Beschreibung:}

Diese Patella ist fast vollständig. 
Bezeichn.: Patella

Kiste: 5243267

Skelet: P.Sk.1.

Population: Calden

Seite:

rechts

Verband: $\quad$ Verband

\title{
Alter:
}

Geschlecht:

Arthrose:

\author{
Beschreibung: \\ Diese Patella ist fast vollständig.
}


Bezeichn.: Patella

Kiste: 5261277

Skelet: $\quad$ V33 kleine Tüte

Population: Calden

Seite:

rechts
Verband: $\quad \square$ Verband

Alter: Erwachsen

Geschlecht:

Arthrose:
Ges./Kr.: Krank

Krankh.: Arthrose

Sehnenverknöcherung

fac. art.

\section{Beschreibung:}

Diese Patella hat starke Auswüchse auf der Außenfläche durch starke Sehnenreizung. Die Gelenkfläche der Innenseite ist eburniert. 
Bezeichn.: Patella

Kiste: $\quad 8505719$

Skelet: steinkammergrab 1

Population: Calden

Seite: rechts

\section{Beschreibung:}

Verband: $\quad \square$ Verband

\section{Alter:}

Geschlecht:

Arthrose:

fac. art.
Ges./Kr.: Krank

Krankh.: Arthrose 
Bezeichn.: Patella

Kiste: $\quad 8505719$

Skelet: Steinkammergrab 1

Population: Calden

Seite: rechts

\section{Beschreibung:}

Verband: $\quad$ Verband

\section{Alter:}

Geschlecht:

Arthrose:

fac. art.

Ges./Kr.: Gesund 
$\begin{array}{ll}\text { Bezeichn.: Patella } \\ \text { Kiste: } & 8505 \\ \end{array}$

Kiste: $\quad 8505721$

Skelet: Kiste 5

Population: Calden

Seite:

links
Verband: $\quad \square$ Verband

\section{Alter:}

Geschlecht:

Arthrose:

\section{Beschreibung:}

Diese linke Patella ist sehr stark erodiert und lässt keine weitere Befundung zu. 


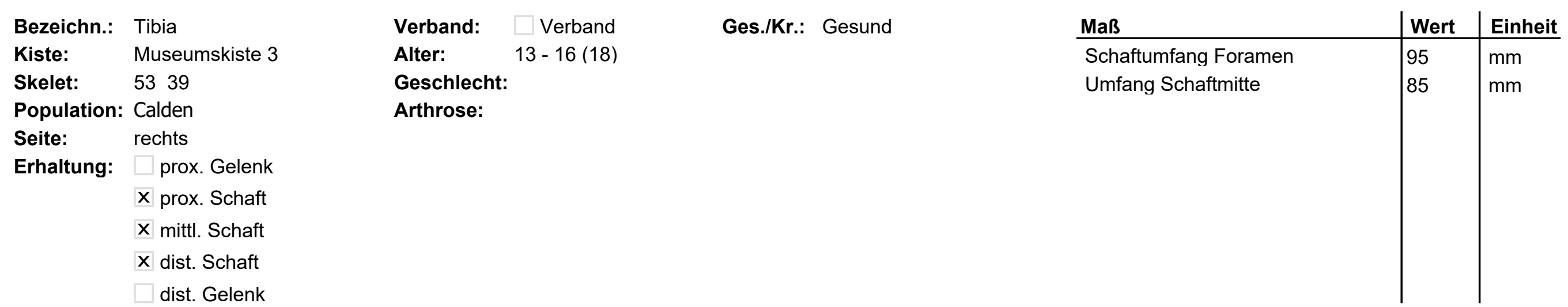

\section{Beschreibung:}

Ein Fragment einer jungen Tibia. Die Ansatzstelle ist wie für dieses Alter typisch als kleine Furche ausgeprägt. Weiterhin waren die Epiphysenfugen nicht verschlossen. 

Bezeichn: Tibia
Kiste:
Museumskiste 3
Skelet: $\quad 47$ P.SCH. 25-30.
Population: Calden
Seite: rechts
Erhaltung: $\square$ prox. Gelenk
$X$ prox. Schaft
$X$ mittl. Schaft
$\mathbf{X}$ dist. Schaft
dist. Gelenk

Verband:

Verband

\section{Alter:}

Geschlecht:

Arthrose:

Beschreibung

Hier sind etwa 2/3 des Schaftes einer Tibia erhalten. Das Fundstück ist stark erodiert.

\begin{tabular}{|l|l} 
Wert & Einheit \\
\hline 87 & $\mathrm{~mm}$ \\
& $\mathrm{~mm}$ \\
&
\end{tabular}



Bezeichn.: Tibia
Kiste: Museumskiste 3
Skelet: $\quad$ P2 38
Population: Calden
Seite: links
Erhaltung: $\square$ prox. Gelenk
$X$ prox. Schaft
$X$ mittl. Schaft
$\mathbf{X}$ dist. Schaft
$\square$ dist. Gelenk

Verband: $\quad \square$ Verband

\section{Alter:}

Geschlecht:

\section{Beschreibung:}

Bei dieser Tibia sind das proximale und distale Ende nicht erhalten. Der Knochen ist weiterhin sehr stark erodiert. 


\section{Bezeichn.: Tibia \\ Kiste: Museumskiste 3 \\ Skelet: 56 \\ Pkelet: 56 \\ Erhaltung: $\square$ prox. Gelenk \\ $X$ prox. Schaft \\ $X$ mittl. Schaft \\ $\mathbf{X}$ dist. Schaft \\ dist. Gelenk \\ Beschreibung:}

Verband: $\quad$ Verband

\section{Alter:}

Geschlecht:

Arthrose:

Dies ist ein stark erodiertes Fragment aus dem Schaft einer Tibia. Es ist etwa die Hälfte des gesamten Knochens erhalten. 

Bezeichn.: Tibia
Kiste: Museumskiste 3
Skelet: $\quad$ P2 52
Population: Calden
Seite: rechts
Erhaltung: $\square$ prox. Gelenk
$X$ prox. Schaft
$\mathbf{X}$ mittl. Schaft
$\mathbf{X}$ dist. Schaft
$\square$ dist. Gelenk

Verband: $\quad \square$ Verband

\section{Alter:}

Geschlecht:

\section{Beschreibung:}

Arthrose:

Dieses Fragment einer Tibia ist sehr stark erodiert, es sind etwa 2/3 des gesamten Knochens erhalten. Distal und posterior sind Teile abfrakturiert. 


\section{Bezeichn.: Tibia \\ Kiste: Museumskiste 3 \\ Skelet: $\quad$ V69 P2(?) \\ Population: Calden \\ Seite: links \\ Erhaltung: X prox. Gelenk \\ prox. Schaft \\ mittl. Schaft \\ dist. Schaft \\ dist. Gelenk \\ Beschreibung:}

Verband: $\quad \square$ Verband

\section{Alter:}

Geschlecht: $q \geq 0$

Dieses Fragment einer Tibia ist stark erodiert und nur als Fragment erhalten. Das Os femoris P2 und diese Tibia sind wohl aus einem Verband. Die Tibia ist sehr grazil. Es ist etwa $1 / 5$ des gesamten Knochens erhalten. 


$\begin{array}{ll}\text { Bezeichn.: } & \text { Tibia } \\ \text { Kiste: } & \text { Museumskiste } 3 \\ \text { Skelet: } & \text { P2(?) } \\ \text { Population: } & \text { Calden } \\ \begin{array}{ll}\text { Seite: } & \text { links } \\ \text { Erhaltung: } & \square \text { prox. Gelenk } \\ & \square \text { prox. Schaft } \\ & \quad \text { mittl. Schaft } \\ & \square \text { dist. Schaft } \\ & \square \text { dist. Gelenk }\end{array}\end{array}$

Verband: $\quad \square$ Verband

Alter:

Geschlecht:

Dies ist ein Fragment aus dem Schaft einer Tibia. Das Fragment macht etwa 1/7 des gesamten Knochens aus. Es ist sehr stark erodiert und nicht gut erhalten. 


$\begin{array}{ll}\text { Bezeichn.: } & \text { Tibia } \\ \text { Kiste: } & 8505718 \\ \text { Skelet: } & \text { aus Tüte } \\ \text { Population: } & \text { Calden } \\ \begin{array}{ll}\text { Seite: } & \text { rechts } \\ \text { Erhaltung: } & \mathbf{X} \text { prox. Gelenk } \\ & \square \text { prox. Schaft } \\ & \square \text { mittl. Schaft } \\ & \square \text { dist. Schaft } \\ & \square \text { dist. Gelenk }\end{array}\end{array}$

Verband: $\quad \square$ Verband

Alter:

Geschlecht:

Arthrose:

Ein Fragment des lateralen Tibiaplateaus einer rechten Tibia. 

Bezeichn.: Tibia
Kiste:
8505718
$\begin{array}{ll}\text { Skelet: } & \text { aus Tüte } \\ \text { Population: Calden }\end{array}$
Seite: rechts
Erhaltung: $\square$ prox. Gelenk
$X$ prox. Schaft
$X$ mittl. Schaft
dist. Schaft
dist. Gelenk
Beschreibung:

Verband:

\section{Alter:}

Ein Fragment aus dem Schaft einer Tibia, es ist stark erodiert.
Verband

\section{Maß}

Schaftumfang Foramen

Umfang Schaftmitte \begin{tabular}{|l|l} 
Wert & Einheit \\
\hline
\end{tabular}

Geschlecht:

Arthrose:

\begin{tabular}{|l|l}
98 & $\mathrm{~mm}$ \\
85 & $\mathrm{~mm}$ \\
&
\end{tabular}




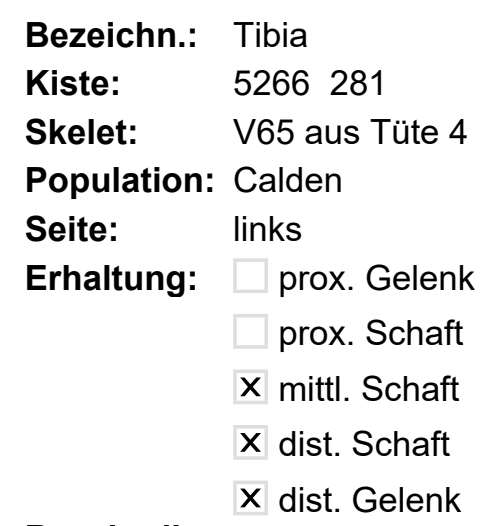

Skelet: $\quad$ V65 aus Tüte 4

Population: Calden

Seite: links

Erhaltung: $\square$ prox. Gelenk

prox. Schaft

$X$ mittl. Schaft

X dist. Schaft

X dist. Gelenk

Beschreibung:

Verband: $\square$ Verband

\section{Alter:}

Ges./Kr.: Gesund

Geschlecht:

Arthrose:
Maß

gr. Breite dist. Gelenk

Umfang Schaftmitte

\begin{tabular}{|l|l} 
Wert & Einheit \\
\hline 52,43 & $\mathrm{~mm}$
\end{tabular}

dist.

Von dieser Tibia ist ein distales Fragment erhalten. 


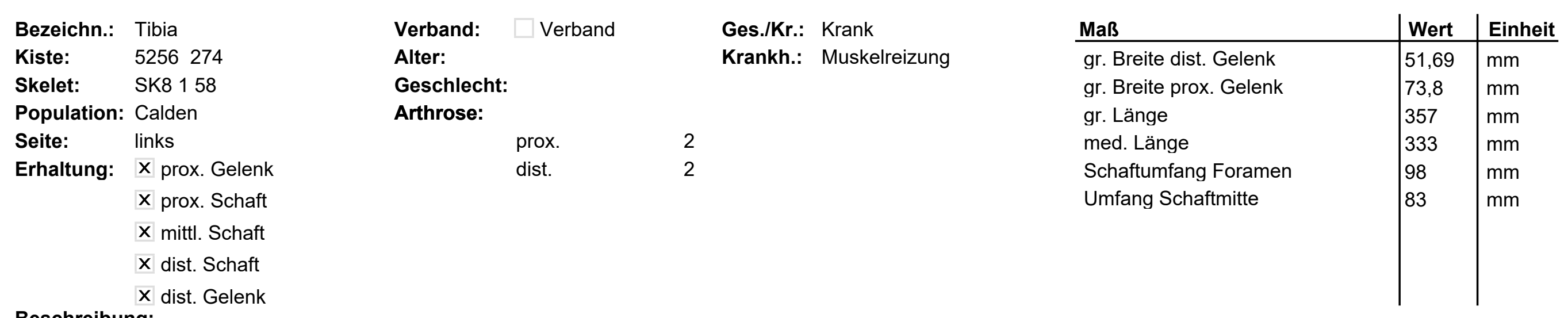

\section{Beschreibung:}

Eine fast vollständig erhaltene Tibia der linken Seite, welche wenige Erosionsspuren aufweist und in gutem Zustand ist. Auf der medialen Seite finden sich leichte Streifungen in der Oberfläche, welche wohl für eine muskuläre Reizung sprechen. 


\section{Bezeichn.: Tibia \\ Kiste: $\quad 5256274$ \\ Skelet: $\quad$ zu Sk.8. üb.SCH.30 \\ Population: Calden \\ Seite: rechts \\ Erhaltung: $\square$ prox. Gelenk \\ prox. Schaft \\ $X$ mittl. Schaft \\ $\mathbf{X}$ dist. Schaft \\ X dist. Gelenk \\ Beschreibung:}

Dieses Fragment stammt aus dem distalen Teil einer rechten Tibia. Es fällt eine leichte Hockerfacette am distalen Gelenk auf.

\section{Verband: $\square$ Verband Ges./Kr.: Krank}

\section{Geschlecht:}

Arthrose:

dist.

2
Alter: Krankh.: Hockerfacette 

Bezeichn.: Tibia
Kiste:
5259276
Skelet: tibiaplateau
Population: Calden
Seite: links
Erhaltung: X prox. Gelenk
prox. Schaft
mittl. Schaft
dist. Schaft
dist. Gelenk

Verband:

Verband

Alter:

\section{Beschreibung:}

Dies ist der laterale Teil eines Tibiaplateaus einer linken Tibia.
Ges./Kr.: Gesund

\section{Geschlecht:}

Arthrose:

prox 


\section{Bezeichn.: Tibia \\ Kiste: $\quad 8505720$ \\ Skelet: einzeln \\ Population: Calden \\ Seite: links \\ Erhaltung: $\square$ prox. Gelenk \\ $X$ prox. Schaft \\ mittl. Schaft \\ dist. Schaft \\ dist. Gelenk \\ Beschreibung:}

Verband: $\quad \square$ Verband

Ges./Kr.: Krank

Alter:

Krankh.: Myotendopathie

\section{Geschlecht:}

Ein von proximal - posterior - medial stammendes Fragment eines Tibiaschaftes der linken Seite. Es findet sich an der Ansatzstelle des M. soleus eine Myotendopathie, die in der Grube porös aufgetrieben ist und einen porösen und wulstigen Rand aufweist. 
Bezeichn.: Tibia

\section{Kiste: $\quad 5255273$}

Skelet: V50 22

Population: Calden

Seite: links

Erhaltung: $\mathbf{X}$ prox. Gelenk

$X$ prox. Schaft

$X$ mittl. Schaft

$\mathbf{X}$ dist. Schaft

X dist. Gelenk
Ges./Kr.: Krank

Krankh.: Periostreizung

subperiostales Hämatom

Arthrose $\square$ Verband

Geschlecht: 9

Arthrose:

prox.

dist.

\begin{tabular}{l|l|l} 
Maß & Wert & Einheit \\
\hline gr. Breite dist. Gelenk & 42,44 & $\mathrm{~mm}$ \\
gr. Breite prox. Gelenk & 64 & $\mathrm{~mm}$ \\
gr. Länge & 309 & $\mathrm{~mm}$ \\
med. Länge & 285 & $\mathrm{~mm}$ \\
Schaftumfang Foramen & 82 & $\mathrm{~mm}$ \\
Umfang Schaftmitte & 71 & $\mathrm{~mm}$
\end{tabular}

\section{Beschreibung:}

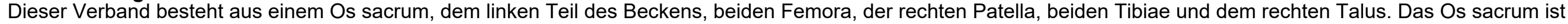

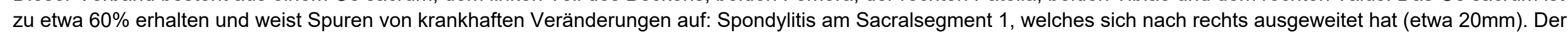

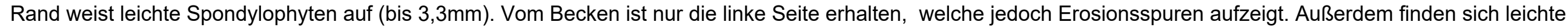

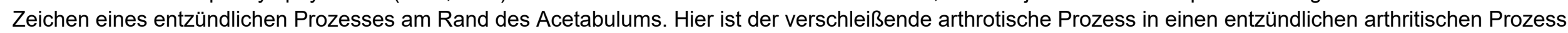

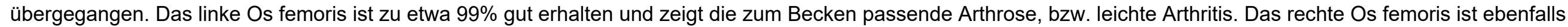

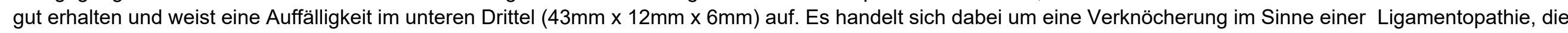

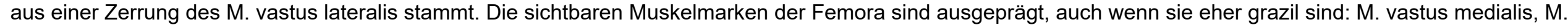

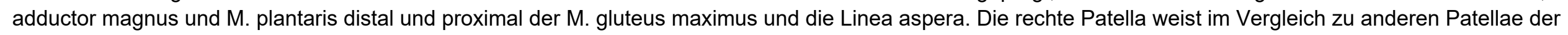

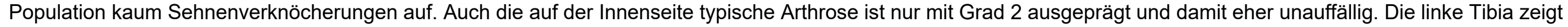

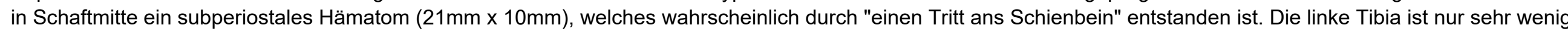

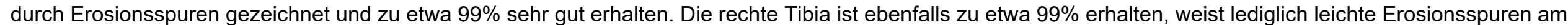
proximalen Gelenk auf. Der rechte Talus ist zu etwa 98\% erhalten und weist insgesamt einen unauffälligen Arthrosegrad von 2 auf. 
Bezeichn.: Tibia

\section{Kiste: $\quad 5255273$}

Skelet: V50 21

Population: Calden

Seite: rechts

Erhaltung: $\mathbf{X}$ prox. Gelenk $X$ prox. Schaft

$X$ mittl. Schaft

$\mathbf{X}$ dist. Schaft

X dist. Gelenk
Ges./Kr.: Krank

Krankh.: Arthrose
Verband: $\quad \square$ Verband

Alter: $\quad 36-52$

Geschlecht: +

Arthrose:

$\begin{array}{ll}\text { prox. } & 2 \\ \text { dist. } & 2 \\ \sum \text { dist. } & 2\end{array}$

\begin{tabular}{l|l|l} 
Maß & Wert & Einheit \\
\hline gr. Breite dist. Gelenk & 42,25 & $\mathrm{~mm}$ \\
gr. Breite prox. Gelenk & 62,4 & $\mathrm{~mm}$ \\
gr. Länge & 310 & $\mathrm{~mm}$ \\
med. Länge & 288 & $\mathrm{~mm}$ \\
Schaftumfang Foramen & 82 & $\mathrm{~mm}$ \\
Umfang Schaftmitte & 72 & $\mathrm{~mm}$
\end{tabular}

\section{Beschreibung:}

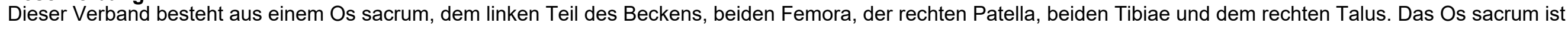

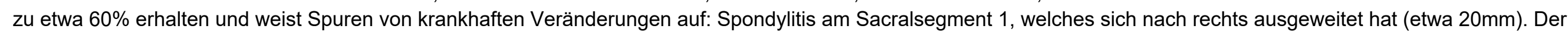

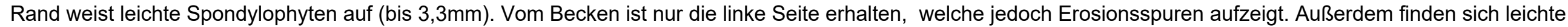

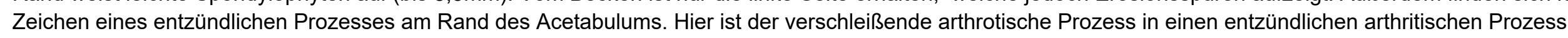

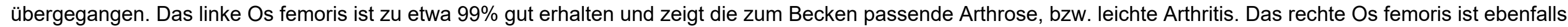

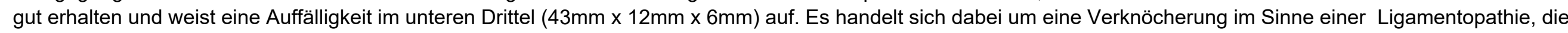

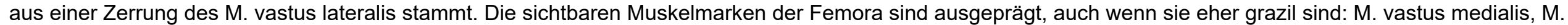

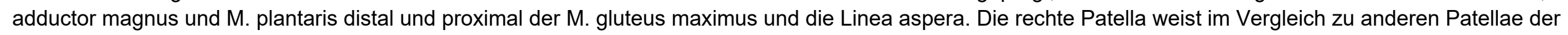

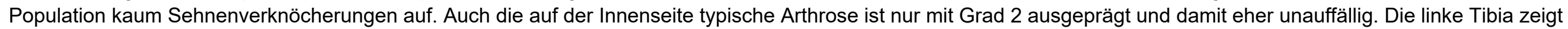

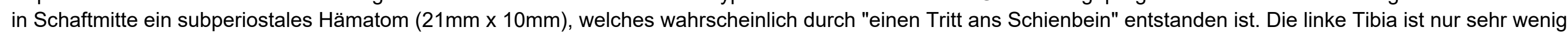

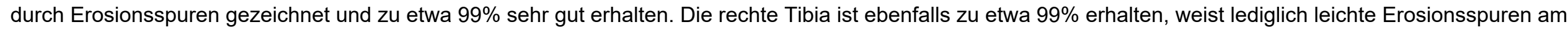
proximalen Gelenk auf. Der rechte Talus ist zu etwa $98 \%$ erhalten und weist insgesamt einen unauffälligen Arthrosegrad von 2 auf. 
Bezeichn.: Tibia

\section{Kiste: $\quad 5249270$}

Skelet: V63 28

Population: Calden

Seite: links

Erhaltung: $\mathbf{X}$ prox. Gelenk

$X$ prox. Schaft

$X$ mittl. Schaft

X dist. Schaft dist. Gelenk
Verband: $\quad \square$ Verband

Alter: $\quad 35-45$ (55)

\section{Geschlecht:}

Arthrose:

prox.
Ges./Kr.: Krank

Krankh.: Periostreizung
Maß

gr. Breite prox. Gelenk

Schaftumfang Foramen

Umfang Schaftmitte

\begin{tabular}{|l|l} 
Wert & Einheit \\
61,87 & $\mathrm{~mm}$ \\
75 & $\mathrm{~mm}$ \\
73 & $\mathrm{~mm}$
\end{tabular}

\section{Beschreibung:}

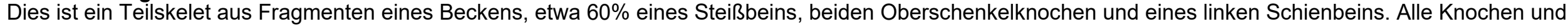
Knochenfragmente sind in gutem Erhaltungszustand und wenig erodiert, es sind lediglich wenige kleine Knochenteile abfrakturiert. Die Tibia weist eine leichte

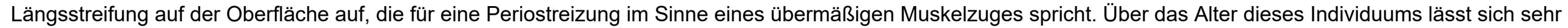

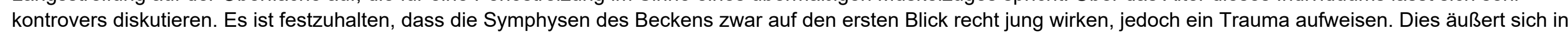

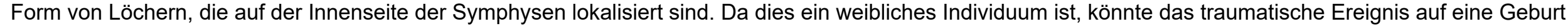

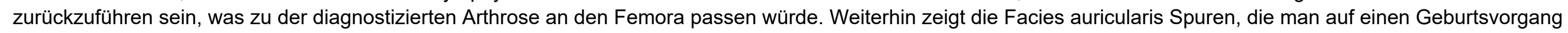

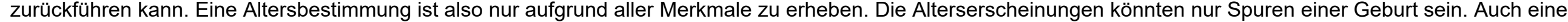

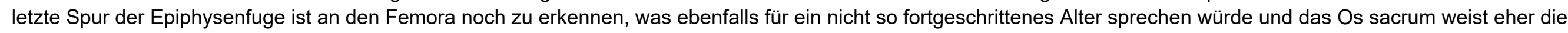
Gesamterscheinung eines Menschen im mittleren Alter auf. 


\section{Bezeichn.: Tibia \\ Kiste: 5249270 \\ Skelet: Zettel}

Population: Calden

\section{Erhaltung:}

prox. Gelenk

prox. Schaft

$X$ mittl. Schaft dist. Schaft dist. Gelenk

Beschreibung:

Ein Tibiafragment.
Verband: Verband

\section{Alter:}

\section{Geschlecht:}

Arthrose: 


\section{Bezeichn.: Tibia \\ Kiste: 5249270 \\ Skelet: Zettel}

Population: Calden

\section{Erhaltung:}

prox. Gelenk

prox. Schaft

$X$ mittl. Schaft dist. Schaft dist. Gelenk

Beschreibung:

Ein Tibiafragment.
Verband: Verband

\section{Alter:}

\section{Geschlecht:}

Arthrose: 


\section{Bezeichn.: Tibia \\ Kiste: 5249270 \\ Skelet: Zettel}

Population: Calden

\section{Erhaltung:}

prox. Gelenk

prox. Schaft

$X$ mittl. Schaft dist. Schaft dist. Gelenk

Beschreibung:

Ein Tibiafragment.
Verband: Verband

\section{Alter:}

\section{Geschlecht:}

Arthrose: 


\section{Bezeichn.: Tibia \\ Kiste: 5249270 \\ Skelet: Zettel}

Population: Calden

\section{Erhaltung:}

prox. Gelenk

prox. Schaft

$X$ mittl. Schaft dist. Schaft dist. Gelenk

Beschreibung:

Ein Tibiafragment.
Verband: Verband

\section{Alter:}

\section{Geschlecht:}

Arthrose: 

Bezeichn.: Tibia
Kiste: $\quad 5255273$
Skelet: $\quad 15$ PSK4+5
Population: Calden
Seite:
links
Erhaltung: $\mathbf{X}$ prox. Gelenk
prox. Schaft
mittl. Schaft
dist. Schaft
dist. Gelenk
Beschreibung:
Ein laterales Tibiaplateau.

\section{Geschlecht:}

Arthrose: 

Bezeichn.: Tibia
Kiste: $\quad 5257+58275$
Skelet: $\quad 3554$ P9
Population: Calden
Seite: links
Erhaltung: $\square$ prox. Gelenk
$X$ prox. Schaft
$X$ mittl. Schaft
dist. Schaft dist. Gelenk
Beschreibung:

Ein stark erodiertes Fundstück.
Verband: $\square$ Verband

\section{Alter:}

Geschlecht:

Arthrose:
Ges./Kr.: Gesund

\section{Maß}

Schaftumfang Foramen

Umfang Schaftmitte
Wert 1 Einheit

$97 \quad \mathrm{~mm}$

$82 \mathrm{~mm}$




$\begin{array}{ll}\text { Bezeichn.: } & \text { Tibia } \\ \text { Kiste: } & 5242266 \\ \text { Skelet: } & \text { E. B-S. } 62 \\ \text { Population: } & \text { Calden } \\ \begin{array}{ll}\text { Seite: } & \text { rechts } \\ \text { Erhaltung: } & \text { X prox. Gelenk } \\ & \text { X prox. Schaft } \\ & \square \text { mittl. Schaft } \\ & \square \text { dist. Schaft } \\ & \square \text { dist. Gelenk }\end{array} \\ \text { Beschreibung: }\end{array}$

\section{Verband: $\quad$ Verband}

\section{Alter:}

Geschlecht: 우

Arthrose:

prox.

2

Dieses proximale Fragment einer rechten Tibia ist sehr stark erodiert und lässt damit keine weitergehenden Befunde zu. 

Bezeichn.: Tibia
Kiste: $\quad 5242266$
Skelet: 225
Population: Calden
Seite: rechts
Erhaltung: $\mathbf{X}$ prox. Gelenk
$X$ prox. Schaft
mittl. Schaft
dist. Schaft dist. Gelenk

Beschreibung:

Ein proximales Fragment.
Verband: $\quad \square$ Verband

Alter:

Ges./Kr.: Gesund

Geschlecht: +

Arthrose:

prox.

\begin{tabular}{l|l|l} 
Maß & Wert & Einheit \\
\hline gr. Breite prox. Gelenk & 66,3 & $\mathrm{~mm}$ \\
Schaftumfang Foramen & 90 & $\mathrm{~mm}$ \\
& & \\
& & \\
& &
\end{tabular}




\section{Bezeichn: Tibia \\ Kiste: 5242266 \\ Skelet: 21}

Population: Calden

Erhaltung: $\quad \mathbf{X}$ prox. Gelenk

$X$ prox. Schaft

$\mathbf{X}$ mittl. Schaft

dist. Schaft dist. Gelenk

\section{Beschreibung:}

Ein proximales Tibiafragment, welches gut erhalten ist.
Verband: $\square$ Verband

\section{Alter:}

Ges./Kr.: Gesund

Geschlecht: $q$

Arthrose:

prox.

\begin{tabular}{l|l|l} 
Maß & Wert & Einheit \\
\hline gr. Breite prox. Gelenk & 67,49 & $\mathrm{~mm}$ \\
Schaftumfang Foramen & 80 & $\mathrm{~mm}$ \\
Umfang Schaftmitte & 78 & $\mathrm{~mm}$ \\
& & \\
& &
\end{tabular}



Bezeichn.: Tibia
Kiste:
5242266
Skelet: $\quad 33$ EB-S. 4
Population: Calden
Seite: rechts
Erhaltung: $\mathbf{X}$ prox. Gelenk
$\mathbf{X}$ prox. Schaft
mittl. Schaft
dist. Schaft
dist. Gelenk

Beschreibung:

$\begin{array}{ll}\text { Verband: } \square \text { Verband } & \text { Ges./Kr.: Krank } \\ \text { Alter: } & \text { Krankh.: Arthrose }\end{array}$

Geschlecht: $\curvearrowright$

Arthrose:

prox.

3

\begin{tabular}{l|l|l} 
Maß & Wert & Einheit \\
\hline gr. Breite prox. Gelenk & 77,94 & $\mathrm{~mm}$ \\
Schaftumfang Foramen & 94 & $\mathrm{~mm}$ \\
Umfang Schaftmitte & 93 & $\mathrm{~mm}$ \\
& & \\
& &
\end{tabular}

Ein proximales Fragment, welches eine Arthrose am Rand des Tibiaplateaus aufweist. 


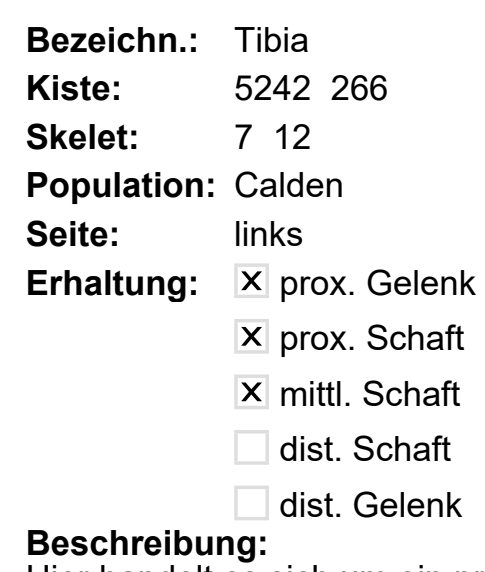

\section{Beschreibung:}

Verband: $\quad \square$ Verband

\section{Alter:}

Geschlecht: 우

Arthrose:

prox.
Ges./Kr.: Krank

Krankh.: Arthrose

Schnürfurche
Maß

gr. Breite prox. Gelenk

Schaftumfang Foramen

Umfang Schaftmitte

\begin{tabular}{|l|l} 
Wert & Einheit \\
666,9 & $\mathrm{~mm}$ \\
78 & $\mathrm{~mm}$ \\
75 & $\mathrm{~mm}$
\end{tabular}

Hier handelt es sich um ein proximales Fragment einer linken Tibia, welches am Schaft eine leichte Schnürfurche aufweist $(13,5 \mathrm{~mm} \times 0,8 \mathrm{~mm})$ 


\section{Bezeichn.: Tibia \\ Kiste: $\quad 5242266$ \\ Skelet: 2010}

Population: Calden

Seite: links

Erhaltung: $\square$ prox. Gelenk prox. Schaft

$X$ mittl. Schaft

$\mathbf{X}$ dist. Schaft

$\mathbf{X}$ dist. Gelenk

Beschreibung:

Ein distales Tibiafragment.
Verband: $\square$ Verband

\section{Alter:}

Ges./Kr.: Gesund

Geschlecht: $q$

Arthrose:
Maß

Umfang Schaftmitte

\begin{tabular}{|l|l} 
Wert & Einheit
\end{tabular}

dist. 


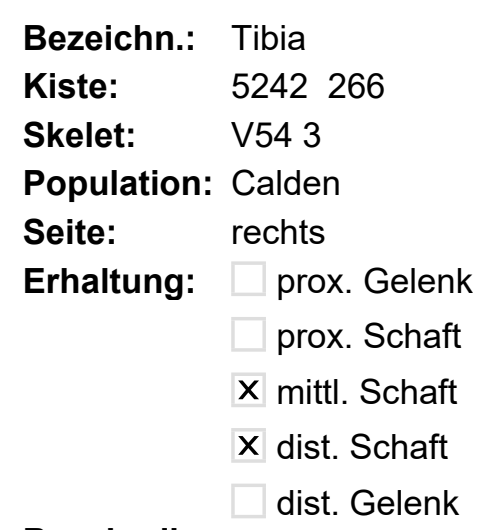

Diese Tibiae gehören wohl zusammen.

Verband: $\square$ Verband

Alter:

Ges./Kr.: Gesund

\section{Geschlecht: $q>0$}

Arthrose: 


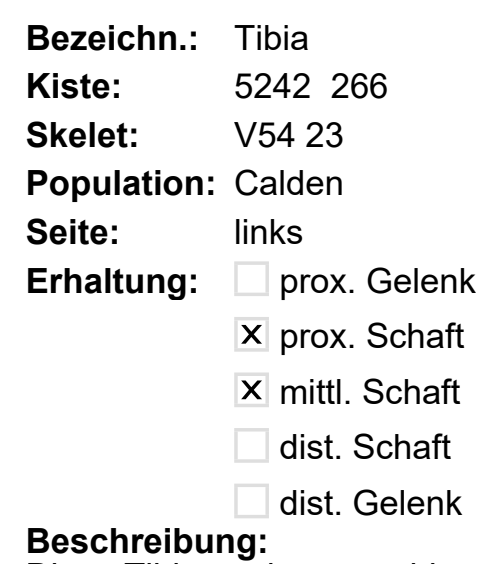

Diese Tibiae gehören wohl zusammen.

Verband: $\square$ Verband

\section{Alter:}

Geschlecht: $q>\hat{\sigma}$

Arthrose:

\section{Ges./Kr.: Gesund}

\section{Maß}

Schaftumfang Foramen

Umfang Schaftmitte
Wert $\quad$ Einheit

$91 \quad \mathrm{~mm}$



Bezeichn.: Tibia
Kiste: $\quad 5242266$
Skelet: $\quad 1110$
Population: Calden

\section{Verband: \\ Alter:}

Verband

Geschlecht: 0

Arthrose:

Ges./Kr.: Krank

Krankh.: subperiostales Hämatom

Periostreizung

Muskelreizung

Maß

Schaftumfang Foramen

Umfang Schaftmitte

\section{Beschreibung:}

Diese Tibia hat eine ausgeprägte Linea aspera und die leicht strähnige Oberflächengestaltung an der Vorderkante der Lateralfläche spricht für einen Stessmarker, der muskulär bedingt war. 


\section{Bezeichn.: Tibia \\ Kiste: \\ 5242266 \\ Skelet: $\quad$ Einschlag B.S. 38 \\ Population: Calden \\ Seite: links \\ Erhaltung: $\mathbf{X}$ prox. Gelenk \\ $\mathbf{X}$ prox. Schaft \\ $X$ mittl. Schaft \\ $\mathbf{X}$ dist. Schaft \\ $X$ dist. Gelenk \\ Beschreibung:}

Eine sehr gut erhaltene Tibia, die im Ganzen vorhanden ist.

\section{Ges./Kr.: Gesund}

\section{Alter:}

Geschlecht: $q \leq \hat{\jmath}$

Arthrose:

$$
\text { prox. }
$$

dist.

\section{Maß}

gr. Breite dist. Gelenk

gr. Breite prox. Gelenk

gr. Länge

med. Länge

Schaftumfang Foramen

Umfang Schaftmitte \begin{tabular}{|l|l} 
Wert & Einheit \\
\hline 46,76 & $\mathrm{~mm}$
\end{tabular}

$70,14 \mathrm{~mm}$

$350 \mathrm{~mm}$

$323 \mathrm{~mm}$

$96 \mathrm{~mm}$

$\mathrm{mm}$



Bezeichn.: Tibia
Kiste:
5242266
Skelet: E.B-S. 13
Population: Calden
Seite: rechts
Erhaltung: $\square$ prox. Gelenk
$X$ prox. Schaft
$X$ mittl. Schaft
X dist. Schaft
$\mathbf{X}$ dist. Gelenk

\section{Beschreibung:}

\section{Verband:}

\section{Alter:}

Verband

Dieses Fundstück ist eine Tibia eines jungen Individuums.

\section{Maß}

gr. Breite dist. Gelenk

gr. Länge

Schaftumfang Foramen

Umfang Schaftmitte 

Bezeichn.: Tibia
Kiste: $\quad 5242266$
Skelet: 3. Tüte
Population: Calden
Seite: links
Erhaltung: $\square$ prox. Gelenk
prox. Schaft
mittl. Schaft
dist. Schaft
$\mathbf{X}$ dist. Gelenk
Beschreibung:

Verband:

Verband

Alter: Jung

Ges./Kr.: Gesund

Maß

gr. Breite dist. Gelenk

\begin{tabular}{|l|l} 
Wert & Einheit \\
\hline 48 & mm
\end{tabular}

Geschlecht:

Arthrose:

Von dieser Tibia eines jungen Individuums ist nur die distale Epiphyse vorhanden. 

Bezeichn.: Tibia
Kiste: $\quad 5242266$
Skelet: 3. Tüte
Population: Calden
Seite: rechts
Erhaltung: $\square$ prox. Gelenk
prox. Schaft
mittl. Schaft
X dist. Schaft
$X$ dist. Gelenk
Beschreibung:

Verband: $\quad \square$ Verband

\section{Alter:}

Geschlecht:

Hier ist ein kleines distales Fragment erhalten, die Gelenkfläche ist größtenteils nicht erhalten.

\section{Arthrose:}



Bezeichn.: Tibia
Kiste: $\quad 5242266$
Skelet: 3. Tüte
Population: Calden
Seite: links
Erhaltung: $\square$ prox. Gelenk
prox. Schaft
mittl. Schaft
dist. Schaft $X$ dist. Gelenk

Beschreibung:

Hier ist nur die distale Epiphyse erhalten.
Verband: $\quad \square$ Verband

\section{Alter:}

Geschlecht:

Arthrose:
Maß

gr. Breite dist. Gelenk

Wert $\mid$ Einheit

\begin{tabular}{l|l}
47,7 & $\mathrm{~mm}$
\end{tabular}




\section{Bezeichn: Tibia \\ Kiste: $\quad 5242266$ \\ Skelet: $\quad 642$}

Population: Calden

Seite: rechts

Erhaltung: $\square$ prox. Gelenk prox. Schaft

$X$ mittl. Schaft dist. Schaft dist. Gelenk

\section{Beschreibung:}

Ein Fragment.
Verband: Verband

\section{Alter:}

Geschlecht:

Arthrose: 


\author{
Bezeichn: Tibia \\ Kiste: $\quad 5242266$ \\ Skelet: E. B-S. 14 \\ Population: Calden \\ Seite: \\ links \\ Erhaltung: prox. Gelenk \\ prox. Schaft \\ $X$ mittl. Schaft \\ dist. Schaft \\ dist. Gelenk \\ Beschreibung: \\ Ein Fragment.
}

Verband: Verband

\section{Alter:}

Geschlecht:

Arthrose: 

Bezeichn.: Tibia
Kiste: $\quad 8505718$
aus Kiste
Population: Calden
Seite: rechts
Erhaltung: $\square$ prox. Gelenk
prox. Schaft
mittl. Schaft
dist. Schaft
$\mathbf{X}$ dist. Gelenk

\section{Verband:}

Alter:

Geschlecht:

Beschreibung:

Hier ist die distale Epiphyse einer jungen Tibia erhalten.
Verband

Arthrose:

$39,5 \mathrm{~mm}$

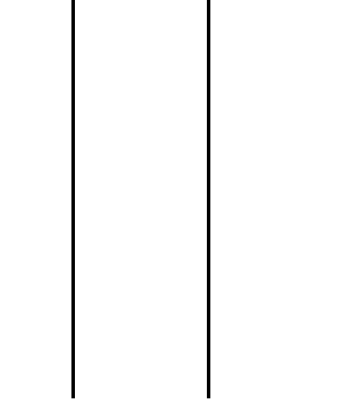



Bezeichn.: Tibia
Kiste: $\quad 8505718$
Skelet: aus Kiste
Population: Calden
Seite: links
Erhaltung: X prox. Gelenk
$X$ prox. Schaft
$X$ mittl. Schaft
$\mathbf{X}$ dist. Schaft
$X$ dist. Gelenk

Beschreibung:

Eine Metaphyse einer jungen Tibia.
Verband: $\square$ Verband

Alter: $\quad(0,5) 1-1,5$

Geschlecht:

Arthrose:

Ges./Kr.: Gesund

Maß

gr. Länge

Schaftumfang Foramen

Umfang Schaftmitte

\begin{tabular}{|l|l} 
Wert & Einheit \\
98 & $\mathrm{~mm}$ \\
40 & $\mathrm{~mm}$ \\
38 & $\mathrm{~mm}$ \\
& \\
&
\end{tabular}



Bezeichn.: Tibia
Kiste:
8505718
Population: Calden
Seite: links
Erhaltung: $\square$ prox. Gelenk
prox. Schaft
mittl. Schaft
$X$ dist. Schaft
$\mathbf{X}$ dist. Gelenk

Verband:

Verband

Ges./Kr.: Krank

Alter:

Krankh.: Zerrung

Kapselzerrung

Geschlecht:

Kapselriss

Arthrose:

Arthritis

\section{Beschreibung:}

Von dieser Fibula ist nur das distale Gelenk mit etwas Schaft erhalten. Am tibio - fibular - Gelenk finden sich bläschenförmige Auflagerungen. Hier gab es augenscheinlich eine Zerrung, die zum Beispiel durch einen Sprung mit anschließender harter Landung ausgelöst worden sein könnte. Dabei hat sich dann der Talus keilförmig zwischen Tibia und Fibula nach oben gedrückt, was dann zu Kapselzerrung bzw. bisweilen auch zu einem Kapselriss führen kann. Hier führte das traumatische Ereignis jedenfalls zu einer entzündlichen Reaktion. Von der Tibia ist auch nur ein distales Fragment mit Gelenk erhalten. 

Bezeichn.: Tibia
Kiste: $\quad 8505718$
Skelet: aus Kiste
Population: Calden
Seite: links
Erhaltung: $\square$ prox. Gelenk
prox. Schaft
mittl. Schaft
X dist. Schaft
$X$ dist. Gelenk

\section{Verband:}

Verband

Ges./Kr.: Gesund

\section{Alter:}

Geschlecht:

Arthrose:

dist.

\section{Beschreibung:}

Von dieser Tibia ist nur das distale Drittel mit einem Teil der Gelenkfläche erhalten. 

Bezeichn.: Tibia
Kiste:
8505718
Skelet: aus Kiste
Population: Calden
Seite: rechts
Erhaltung: $\square$ prox. Gelenk
prox. Schaft
$X$ mittl. Schaft
dist. Schaft dist. Gelenk
Beschreibung:

Ein Fragment aus dem Schaft.
Verband: $\square$ Verband

\section{Alter:}

Geschlecht:

Arthrose:
Ges./Kr.: Gesund

Maß

gr. Länge

Umfang Schaftmitte

\begin{tabular}{l|l} 
Wert & Einheit \\
\hline 146 & $\mathrm{~mm}$
\end{tabular}

$90 \quad \mathrm{~mm}$



Bezeichn.: Tibia
Kiste:
8505718
Skelet: aus Kiste
Population: Calden
Seite: rechts
Erhaltung: $\mathbf{X}$ prox. Gelenk
$X$ prox. Schaft
mittl. Schaft
dist. Schaft
dist. Gelenk
Beschreibung:

Verband:

Verband

Ges./Kr.: Krank

\section{Alter:}

Krankh.: Arthrose

Geschlecht:

Arthrose:

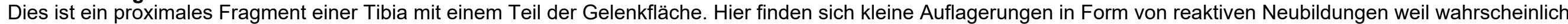

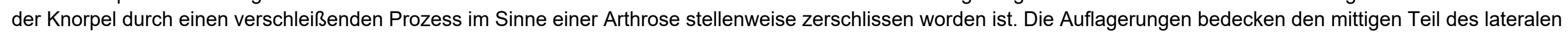
Plateaus zu mehr als 50\%, deswegen Grad 3 für die Fläche. 

Bezeichn.: Tibia
Kiste: $\quad 8505718$
Skelet: aus Kiste
Population: Calden
Seite: rechts
Erhaltung: $\square$ prox. Gelenk
$X$ prox. Schaft
mittl. Schaft
dist. Schaft
dist. Gelenk

Verband:

Verband

Alter:

Geschlecht:

Beschreibung:

Ein kleines Tibiafragment mit Tuberositas Tibiae. 


\section{Bezeichn:: Tibia \\ Kiste: $\quad 8505718$ \\ Skelet: aus 2. Kiste \\ Population: Calden \\ Seite: links \\ Erhaltung: $\square$ prox. Gelenk \\ prox. Schaft \\ mittl. Schaft \\ dist. Schaft X dist. Gelenk \\ Beschreibung:}

Eine distale Epiphyse eines jungen Individuums.

\section{Verband: \\ Verband \\ Ges./Kr.: Gesund}

Geschlecht:

Arthrose:
Maß

gr. Breite dist. Gelenk

\begin{tabular}{|l|l} 
Wert & Einheit \\
\hline 40 &
\end{tabular}

dist. 

Bezeichn.: Tibia
Kiste:
8505718
aus 2. Kiste
Population: Calden
Seite: rechts
Erhaltung: $\mathbf{X}$ prox. Gelenk
prox. Schaft
mittl. Schaft
dist. Schaft dist. Gelenk

\section{Verband:}

\section{Alter:}

Beschreibung:

Eine proximale Epiphyse eines jungen Individuums.
Verband

Geschlecht:

Ges./Kr.: Gesund

\section{Maß}

gr. Breite prox. Gelenk

Wert $\quad$ Einheit

Arthrose:

prox.

0 

Bezeichn.: Tibia
Kiste:
8505718
aus 2. Kiste
Population: Calden
Seite: links
Erhaltung: X prox. Gelenk
prox. Schaft
mittl. Schaft
dist. Schaft dist. Gelenk

\section{Verband:}

Alter:

Geschlecht:

Beschreibung:

Eine proximale Epiphyse eines jungen Individuums.
Verband

\section{Ges./Kr.: Gesund}

Maß

gr. Breite prox. Gelenk

\begin{tabular}{|l|l} 
Wert & Einheit
\end{tabular}

Arthrose:

prox.

0 

Bezeichn.: Tibia
Kiste:
8505718
Skelet: aus 2. Kiste
Population: Calden
Seite: rechts
Erhaltung: $\mathbf{X}$ prox. Gelenk
prox. Schaft
mittl. Schaft
dist. Schaft
dist. Gelenk
Beschreibung:

Verband:

\section{Alter:}

Geschlecht:

Ein mediales Tibiaplateau einer rechten Tibia.
Verband

Ges./Kr.: Gesund

Arthrose:

prox. 

Bezeichn.: Tibia
Kiste: $\quad 5252271$
Skelet: unter 62
Population: Calden
Seite: rechts
Erhaltung: $\square$ prox. Gelenk
$X$ prox. Schaft
$X$ mittl. Schaft
$\mathbf{X}$ dist. Schaft
$\square$ dist. Gelenk

Verband: $\quad \square$ Verband

\section{Alter:}

Geschlecht:

Beschreibung:

Ein Tibiafragment aus dem Schaft in schlechtem Erhaltungszustand. 


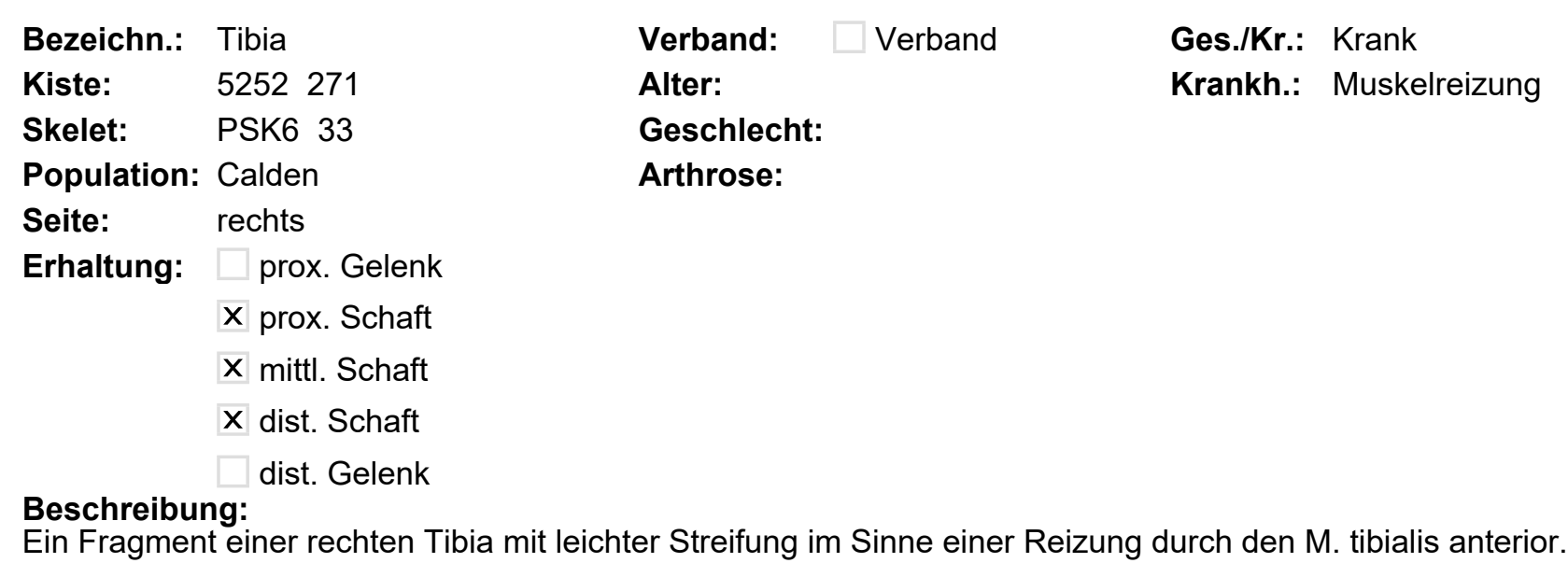

Ein Fragment einer rechten Tibia mit leichter Streifung im Sinne einer Reizung durch den M. tibialis anterior. 


\section{Bezeichn.: Tibia \\ Kiste: $\quad 5252271$ \\ Skelet: Zettel}

Population: Calden

Seite: n. def.

Erhaltung: $\square$ prox. Gelenk

prox. Schaft

$X$ mittl. Schaft

dist. Schaft

dist. Gelenk

\section{Beschreibung:}

Zwei Fragmente, die nicht genau einer Seite zuzuordnen waren.
Verband: $\quad \square$ Verband

\section{Alter:}

Geschlecht:

Arthrose:

\section{Ges./Kr.: Gesund}



Bezeichn.: Tibia
Kiste: 5243267
Skelet: SK.1.
Population: Calden
Seite: rechts
Erhaltung: $\square$ prox. Gelenk
prox. Schaft
mittl. Schaft
X dist. Schaft
$X$ dist. Gelenk

\section{Beschreibung:}

Verband: $\square$ Verband

Alter:

Geschlecht:

Arthrose:
Ges./Kr.: Krank

Krankh.: Muskelreizung

Dies ist ein Fragment des distalen Teils einer rechten Tibia. Auf der posterioren Fläche findet sich eine Streifung im Sinn einer Muskelreizung. 


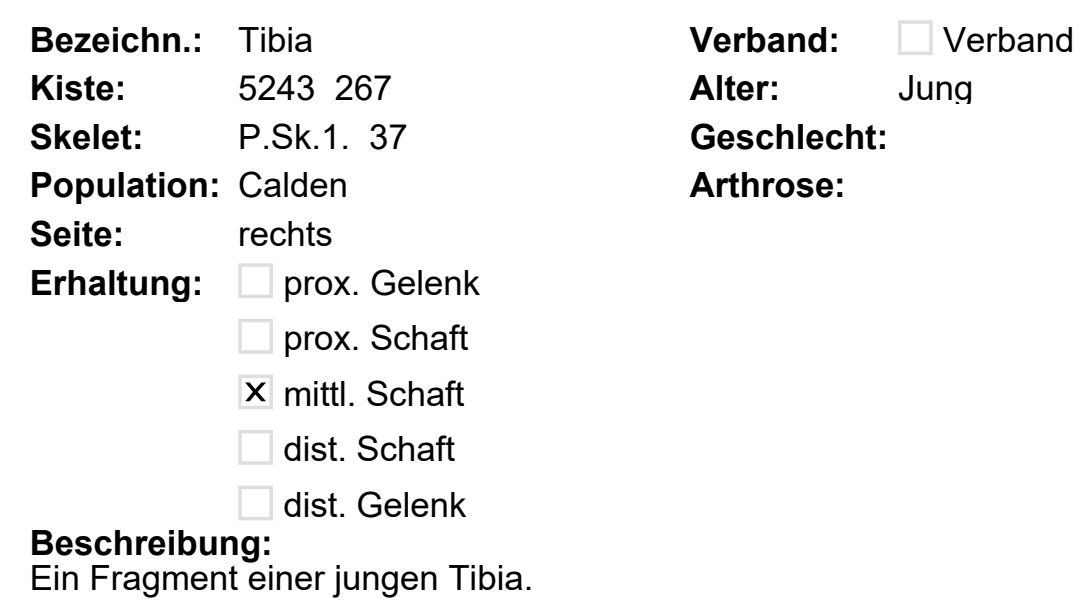




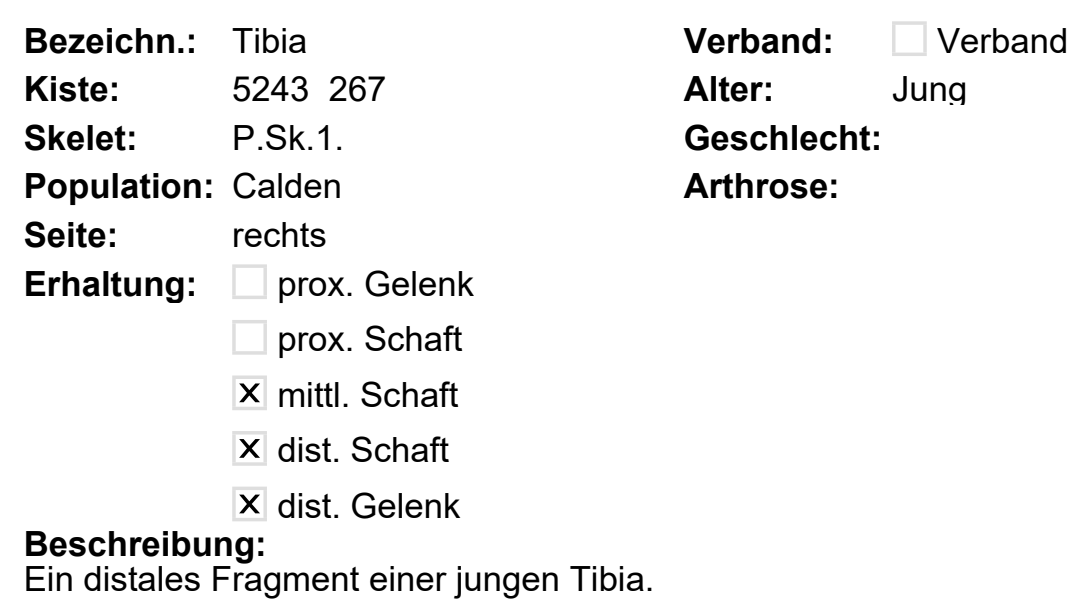



Bezeichn.: Tibia
Kiste: $\quad 5243267$
Skelet: $\quad 31$
Population: Calden
Seite: n. def.
Erhaltung: $\square$ prox. Gelenk prox. Schaft
mittl. Schaft
X dist. Schaft
dist. Gelenk

Verband:

Verband

Beschreibung:

\section{Alter:}

Geschlecht:

Arthrose:

Ein distales Tibiafragment. Es ist sehr stark erodiert. 

Bezeichn.: Tibia
Kiste: $\quad 5243267$
Skelet: Zettel
Population: Calden
Seite: links
Erhaltung: $\square$ prox. Gelenk
prox. Schaft
mittl. Schaft
X dist. Schaft
$\square$ dist. Gelenk
Beschreibung:

Verband: $\quad \square$ Verband

\section{Alter:}

Ein distales Tibiafragment. Es ist sehr stark erodiert. 


$\begin{array}{ll}\text { Bezeichn.: } & \text { Tibia } \\ \text { Kiste: } & 5243267 \\ \text { Skelet: } & \text { Zettel } \\ \text { Population: } & \text { Calden } \\ \text { Seite: } & \text { links } \\ \begin{array}{ll}\text { Erhaltung: } & \text { X prox. Gelenk } \\ & \square \text { prox. Schaft } \\ & \square \text { mittl. Schaft } \\ & \square \text { dist. Schaft } \\ & \square \text { dist. Gelenk } \\ \text { Beschreibung: } \\ \text { Ein Tibiaplateau medial. }\end{array}\end{array}$

Verband: $\quad$ Verband

Alter:

Geschlecht:

Arthrose:

prox.

3 

Bezeichn.: Tibia
Kiste: $\quad 5243267$
Skelet: P.Sk.1.
Population: Calden
Seite: rechts
Erhaltung: $\square$ prox. Gelenk
prox. Schaft
mittl. Schaft
dist. Schaft
$\mathbf{X}$ dist. Gelenk

Beschreibung:

Tibiafragment mit Facies articularis.

\section{Geschlecht:}

Arthrose: 


\section{Bezeichn.: Tibia \\ Kiste: $\quad 5243267$ \\ Skelet: Zettel \\ Population: Calden \\ Seite: links \\ Erhaltung: $\square$ prox. Gelenk \\ $\mathbf{X}$ prox. Schaft \\ mittl. Schaft \\ dist. Schaft \\ dist. Gelenk}

Verband: $\quad$ Verband

\section{Alter:}

Geschlecht:

Beschreibung:

Ein Fragment aus dem proximalen Bereich einer Tibia mit Tuberositas Tibiae. 

Bezeichn.: Tibia
Kiste: $\quad 5243267$
Skelet: Zettel
Population: Calden
Seite: links
Erhaltung: $X$ prox. Gelenk
prox. Schaft
mittl. Schaft
dist. Schaft dist. Gelenk
Beschreibung

Ein laterales Tibiaplateau einer linken Tibia.

Verband: Verband

Ges./Kr.: Gesund

\section{Alter:}

Geschlecht:

Arthrose:

prox 


\section{Bezeichn.: Tibia \\ Kiste: $\quad 5243267$ \\ Skelet: Zettel \\ Population: Calden \\ Seite: links \\ Erhaltung: $\square$ prox. Gelenk \\ $X$ prox. Schaft \\ mittl. Schaft \\ dist. Schaft \\ dist. Gelenk \\ Beschreibung:}

Verband: $\quad$ Verband

Alter: Jung

\section{Geschlecht:}

Arthrose:

Ein Fragment einer proximalen Tibia der linken Seite. Der Knochen war wohl noch jung und noch nicht ausgewachsen. 

Bezeichn.: Tibia
Kiste: $\quad 5243267$
Skelet: P.Sk.1.27
Population: Calden
Seite: links
Erhaltung: $\square$ prox. Gelenk
prox. Schaft
$X$ mittl. Schaft
dist. Schaft
dist. Gelenk

Beschreibung:

Diese Tibia ist eher schlecht erhalten.

Verband: $\quad \square$ Verband

\section{Alter:}

Geschlecht:

Arthrose: 


\author{
Bezeichn: Tibia \\ Kiste: 5243267 \\ Skelet: Zettel \\ Population: Calden \\ Seite: rechts \\ Erhaltung: X prox. Gelenk \\ prox. Schaft \\ mittl. Schaft \\ dist. Schaft \\ dist. Gelenk \\ Beschreibung: \\ Ein laterales Tibiaplateau.
}

Verband: Verband

\section{Alter:}

Geschlecht:

Arthrose:

prox. 


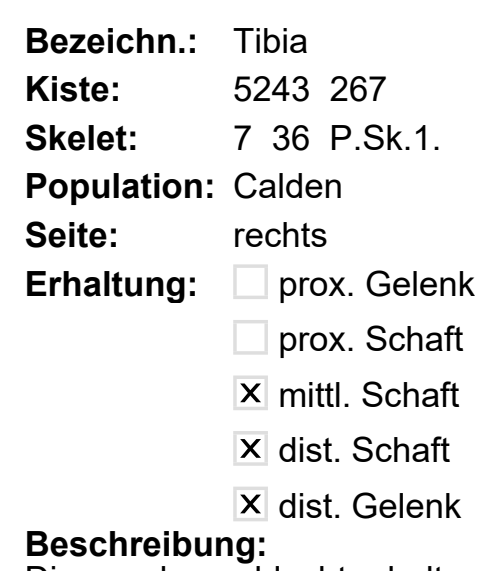

$\begin{array}{ll}\text { Seite: } & \text { rechts }\end{array}$

Erhaltung: $\square$ prox. Gelenk

prox. Schaft

$X$ mittl. Schaft

$\mathbf{X}$ dist. Schaft

X dist. Gelenk

\section{Beschreibung:}

Verband: $\quad \square$ Verband

\section{Alter:}

Geschlecht:

Arthrose:
Ges./Kr.: Krank

Krankh.: Arthrose
Maß

Schaftumfang Foramen

Umfang Schaftmitte \begin{tabular}{|l|l} 
Wert & Einheit \\
\hline 97 & mm
\end{tabular}

$97 \quad \mathrm{~mm}$

$82 \quad \mathrm{~mm}$

Dieses eher schlecht erhaltene Fundstück einer Tibia weist eine auffällige Krümmung nach medial auf. 


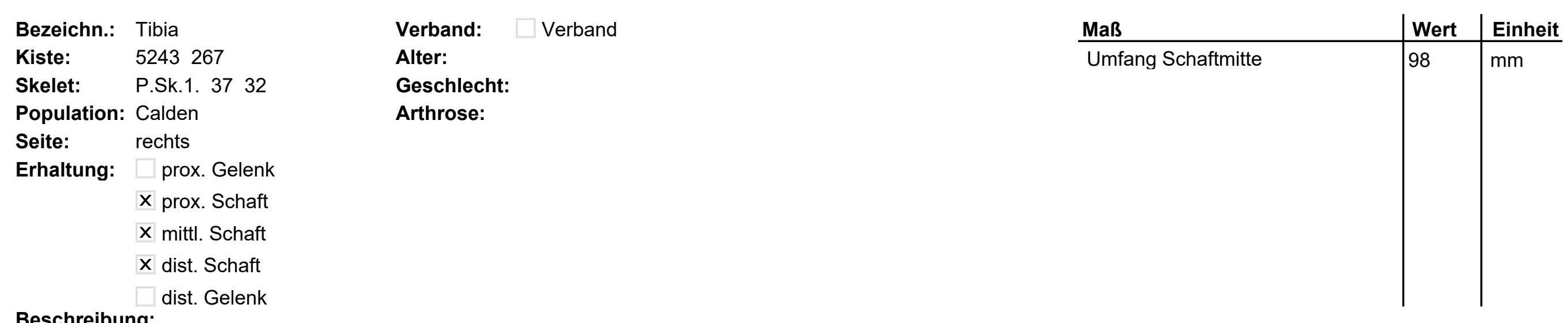

Diese Tibia befindet sich in schlechtem Erhaltungszustand, es ist nur als Fragment erhalten. Es findet sich eine ausgeprägte Membrana interossea, außerdem fällt auf, dass der Knochen nach ventral gebogen ist. 

Bezeichn.: Tibia
Kiste: $\quad 5243267$
Skelet: P.Sk.1. 26
Population: Calden
Seite: links
Erhaltung: X prox. Gelenk
prox. Schaft
mittl. Schaft
dist. Schaft dist. Gelenk
Beschreibung:

Ein Tibiaplateau einer linken Tibia.
Verband: $\quad$ Verband

\section{Alter:}

Geschlecht:

Arthrose:

prox.

3
Ges./Kr.: Krank

Krankh.: Arthrose 


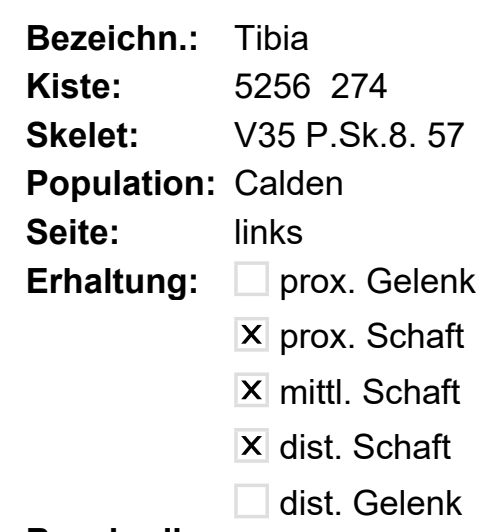

Population: Calden

Seite: links

Erhaltung: $\square$ prox. Gelenk

$X$ prox. Schaft

$X$ mittl. Schaft

$\mathbf{X}$ dist. Schaft

$\square$ dist. Gelenk

\section{Geschlecht:}

\section{Arthrose:}

\section{Beschreibung:}

Ein Tibia im Verband mit einem rechten Os femoris eines Individuums im Altersbereich Infans II. 


\section{Bezeichn.: Tibia \\ Kiste: $\quad 5256274$ \\ Skelet: V32 Sk8 \\ Population: Calden \\ Seite: rechts \\ Erhaltung: $\square$ prox. Gelenk prox. Schaft \\ $X$ mittl. Schaft \\ $\mathbf{X}$ dist. Schaft $X$ dist. Gelenk \\ Beschreibung:}

Eine rechte Tibia im Verband.
Verband: $\square$ Verband

\section{Alter:}

Geschlecht:

Arthrose:

dist.
Ges./Kr.: Krank

Krankh.: Arthrose 


\begin{tabular}{|c|c|c|c|c|}
\hline Bezeichn.: & Tibia & Verband: & $\square$ Verband & \\
\hline Kiste: & $5256 \quad 274$ & Alter: & & \\
\hline Skelet: & V32 Sk8 & Geschlecht: & & \\
\hline Population: & Calden & Arthrose: & & \\
\hline Seite: & links & & prox. & 2 \\
\hline Erhaltung: & $\mathbf{X}$ prox. Gelenk & & dist. & 2 \\
\hline & X prox. Schaft & & & \\
\hline & X mittl. Schaft & & & \\
\hline & $\mathbf{X}$ dist. Schaft & & & \\
\hline & $\mathbf{X}$ dist. Gelenk & & & \\
\hline
\end{tabular}

Eine linke Tibia, die in einem Stück vollständig erhalten ist; sie liegt im Verband vor. 

Bezeichn.: Tibia
Kiste:
5261277
Skel.11. 5136
Skelet: Skel.11.
Seite: links
Erhaltung: $\square$ prox. Gelenk
prox. Schaft
$X$ mittl. Schaft
$\mathbf{X}$ dist. Schaft
$X$ dist. Gelenk

Beschreibung:

Ein distales Fragment einer linken Tibia.
Verband: $\quad \square$ Verband

Alter:

Ges./Kr.: Gesund

\section{Geschlecht: $q>0$}

Arthrose:

\begin{tabular}{l|l|l} 
Maß & Wert & Einheit \\
\hline Schaftumfang Foramen & 10 & $\mathrm{~mm}$ \\
Umfang Schaftmitte & 85 & $\mathrm{~mm}$ \\
& & \\
& &
\end{tabular}




\section{Bezeichn.: Tibia \\ Kiste: $\quad 5261277$ \\ Skelet: Zettel \\ Population: Calden \\ Seite: links \\ Erhaltung: $\mathbf{X}$ prox. Gelenk \\ prox. Schaft \\ mittl. Schaft \\ dist. Schaft \\ dist. Gelenk \\ Beschreibung}

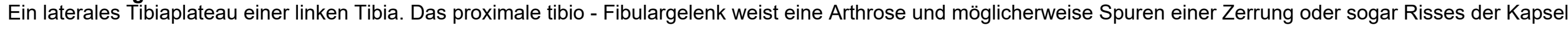
auf.

\section{Alter:}

Geschlecht:

Arthrose:

prox.
Ges./Kr.: Krank

Krankh.: Arthrose

Kapselriss

Kapselzerrung 

Bezeichn.: Tibia
Kiste: $\quad 5261277$
Skelet: $\quad$ über Sk.11+SCH.8. 5025
Population: Calden
Seite: rechts
Erhaltung: $\mathbf{X}$ prox. Gelenk
$X$ prox. Schaft
$X$ mittl. Schaft
$X$ dist. Schaft
X dist. Gelenk

Beschreibung:

\begin{abstract}
Verband: $\square$ Verband
Alter: Erwachsen
\end{abstract}

Ges./Kr.: Gesund

Geschlecht: $q>\delta$

Arthrose:

$$
\text { prox. }
$$

dist.

1
Eine recht scharfkantige, eher grazile Tibia, die einen deutlich ausgeprägten Margo anterior aufweist.

\begin{tabular}{l|l|l} 
Maß & Wert & Einheit \\
\hline gr. Breite dist. Gelenk & 47 & $\mathrm{~mm}$ \\
gr. Breite prox. Gelenk & 65 & $\mathrm{~mm}$ \\
gr. Länge & 317 & $\mathrm{~mm}$ \\
med. Länge & 295 & $\mathrm{~mm}$ \\
Schaftumfang Foramen & 85 & $\mathrm{~mm}$ \\
Umfang Schaftmitte & 81 & $\mathrm{~mm}$
\end{tabular}




\section{Bezeichn.: Tibia \\ Kiste: $\quad 52651-3279$ \\ $\begin{array}{ll}\text { Skelet: Zettel } & \\ \text { Population: } & \text { Calden }\end{array}$ \\ Erhaltung: prox. Gelenk \\ prox. Schaft \\ $X$ mittl. Schaft \\ dist. Schaft \\ dist. Gelenk \\ Beschreibung:}

Verband: $\quad \square$ Verband

\section{Alter:}

Geschlecht:

Ein kleines Fragment. Die genaue Zuordnung war nicht möglich. 


\author{
Bezeichn.: Tibia \\ Kiste: $\quad 52651-3279$ \\ Skelet: Zettel \\ Population: Calden \\ Erhaltung: \\ prox. Gelenk \\ prox. Schaft \\ $X$ mittl. Schaft \\ dist. Schaft \\ dist. Gelenk

\section{Beschreibung:} \\ Ein Fragment.
}

Verband: $\quad \square$ Verband

\section{Alter:}

Geschlecht:

Arthrose: 

Bezeichn.: Tibia
Kiste: $\quad 5261277$
Skelet: Zettel
Population: Calden
Seite:
links
Erhaltung: $\square$ prox. Gelenk prox. Schaft
mittl. Schaft
$X$ dist. Schaft
$X$ dist. Gelenk
Beschreibung:
Ein distales Tibiafragment.

Verband: Verband

\section{Alter:}

Geschlecht:

Arthrose: 

Bezeichn.: Tibia
Kiste: $\quad 5261277$
Skelet: unter SCH.8+3 14
Population: Calden
Seite: links
Erhaltung: $\square$ prox. Gelenk
$X$ prox. Schaft
$X$ mittl. Schaft
X dist. Schaft
$\square$ dist. Gelenk
Beschreibung:

Verband:

Verband

Ges./Kr.: Krank

Alter:

Krankh.: Periostreizung

\begin{tabular}{l} 
Maß \\
\hline Schaftumfang Foramen \\
Umfang Schaftmitte
\end{tabular}

Wert $\quad$ Einheit

Geschlecht:

Arthrose:

Diese gut erhaltene Tibia ist stark dunkel verfärbt. Sie weist eine Streifung auf der Knochenoberfläche auf. 


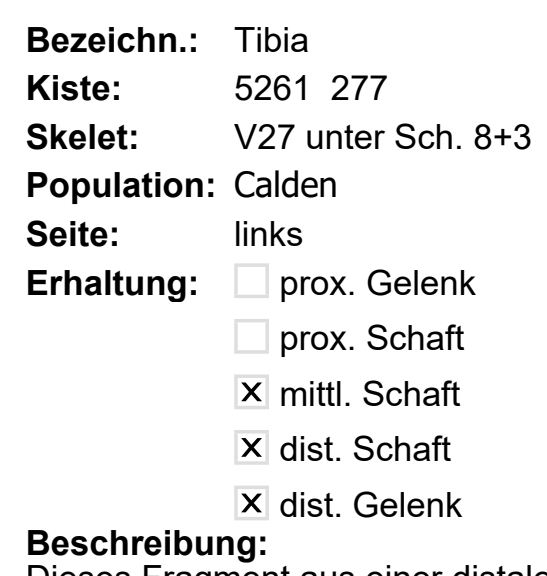

Skelet: V27 unter Sch. 8+3

Population: Calden

Seite: links

Erhaltung: $\square$ prox. Gelenk prox. Schaft

$X$ mittl. Schaft

$\mathbf{X}$ dist. Schaft

$X$ dist. Gelenk

\section{Beschreibung:}

Verband:

Verband

Ges./Kr.: Gesund

Alter:

Geschlecht:

Arthrose:

Dieses Fragment aus einer distalen Tibia gehört wohl zum Verband mit zwei tali. 

Bezeichn.: Tibia
Kiste: $\quad 52651-3279$
$\begin{array}{ll}\text { Skelet: Zettel } & \\ \text { Population: } & \text { Calden }\end{array}$
Seite: links
Erhaltung: $\square$ prox. Gelenk
$X$ prox. Schaft
mittl. Schaft
dist. Schaft
dist. Gelenk

Verband: $\quad \square$ Verband

Alter: Jung

Geschlecht:

Beschreibung:

Ein proximales Fragment einer nicht ausgewachsenen Tibia. 

Bezeichn.: Tibia
Kiste:
5263278
Skelet: P16+18 63
Population: Calden
Seite: links
Erhaltung: $\square$ prox. Gelenk
$X$ prox. Schaft
$X$ mittl. Schaft
$\mathbf{X}$ dist. Schaft
$X$ dist. Gelenk

\section{Verband: $\quad \square$ Verband \\ Alter: $\quad 7-11$ \\ Geschlecht:}

Ges./Kr.: Gesund

Maß

\section{Arthrose:}

gr. Breite dist. Gelenk

gr. Länge

Schaftumfang Foramen

Umfang Schaftmitte

\begin{tabular}{|l|l} 
Wert & Einheit \\
\hline 23,5 & $\mathrm{~mm}$
\end{tabular}

Beschreibung:

Ein fast vollständig erhaltenes Os Tibiae. Es ist einem jungen Individuum zuzuordnen, die Epiphysen waren nicht verknöchert. 

Bezeichn.: Tibia
Kiste:
5263278
Skelet: $\quad$ P16+18 556 .
Population: Calden
Seite: links
Erhaltung: $\mathbf{X}$ prox. Gelenk
$X$ prox. Schaft
mittl. Schaft
$\mathbf{X}$ dist. Schaft
X dist. Gelenk

Verband:

Verband

Ges./Kr.: Krank

\section{Alter:}

Geschlecht: $q \leq \hat{0}$

Arthrose:

Krankh.: Arthrose

\section{Arthritis}

Impressionen tiefer

Krampfadern

prox.

3

dist.

Zerrung

\begin{tabular}{l|l|l} 
Maß & Wert & Einheit \\
\hline gr. Breite dist. Gelenk & 53,16 & $\mathrm{~mm}$ \\
gr. Breite prox. Gelenk & 75,31 & $\mathrm{~mm}$ \\
gr. Länge & 325 & $\mathrm{~mm}$ \\
med. Länge & 297 & $\mathrm{~mm}$ \\
Schaftumfang Foramen & 97 & $\mathrm{~mm}$ \\
Umfang Schaftmitte & 90 & $\mathrm{~mm}$
\end{tabular}

\section{Beschreibung:}

Bei dieser in ganzer Länge erhaltenen Tibia waren die Gelenkflächen größtenteils befundbar, der Rest war durch Erosionen zerstört. Eine Arthrose, die in eine Arthritis übergegangen ist ist zu sehen. Weiterhin fallen deutliche Muskelmarken am M. soleus (Zerrung) auf. Die Tibia ist massiv und weist eine leichte Krümmung nach medial auf. 

Bezeichn.: Tibia
Kiste: $\quad 5263278$
Skelet: V22 45
Population: Calden
Seite: rechts
Erhaltung: $\square$ prox. Gelenk
$X$ prox. Schaft
$X$ mittl. Schaft
X dist. Schaft

$$
\square \text { dist. Gelenk }
$$

\section{Beschreibung:}

Verband: $\square$ Verband

\section{Alter:}

Geschlecht:

Arthrose:

Ein Verband aus zwei stark erodierten Tibiafragmenten.

$81 \quad \mathrm{~mm}$



Bezeichn.: Tibia
Kiste: $\quad 5263278$
Skelet: V22 43
Population: Calden
Seite: links
Erhaltung: $\square$ prox. Gelenk
$X$ prox. Schaft
$X$ mittl. Schaft
$\mathbf{X}$ dist. Schaft
$\square$ dist. Gelenk

Verband: $\square$ Verband

\section{Alter:}

Geschlecht:

Arthrose:

Beschreibung:

Ein Verband aus zwei stark erodierten Tibiafragmenten. 


\begin{tabular}{|c|c|c|c|c|c|c|c|c|c|}
\hline Bezeichn.: & Tibia & Verband: & $\square$ Verband & & Ges./Kr.: & Krank & Maß & Wert & Einheit \\
\hline Kiste: & 5263278 & Alter: & & & Krankh.: & subperiostales Hämatom & gr. Breite dist. Gelenk & 48,56 & $\mathrm{~mm}$ \\
\hline Skelet: & 4629 & Geschlecht: & & & & Impressionen tiefer & gr. Länge & 332 & $\mathrm{~mm}$ \\
\hline Population: & Calden & Arthrose: & & & & Krampfadern & med. Länge & 307 & $\mathrm{~mm}$ \\
\hline Seite: & links & & prox. & 2 & & Kapselzerrung & Schaftumfang Foramen & 92 & $\mathrm{~mm}$ \\
\hline Erhaltung: & $\mathbf{X}$ prox. Gelenk & & dist. & 2 & & & Umfang Schaftmitte & 83 & $\mathrm{~mm}$ \\
\hline & $\mathbf{X}$ prox. Schaft & & & & & & & & \\
\hline & $\mathbf{X}$ mittl. Schaft & & & & & & & & \\
\hline & $\mathbf{X}$ dist. Schaft & & & & & & & & \\
\hline & X dist. Gelenk & & & & & & & & \\
\hline
\end{tabular}

\section{Beschreibung:}

Bei dieser in einem Stück fast vollständig befundbaren Tibia waren die Gelenkflächen größtenteils befundbar. Am Margo anterior fällt ein subperiostales Hämatom (17mm x $4 \mathrm{~mm}$ ) auf, weiterhin sind tiefe Krampfadern auf lateraler Facette des Fundstücks zu finden. Die Syndesmosis tibio - fibularis weist eine deutliche Kapselzerrung auf. 
Bezeichn.: Tibia

Kiste: $\quad 5263278$

Skelet: $\quad$ V23 Tibia Fibula 48

Population: Calden

Seite: rechts

Erhaltung: $\square$ prox. Gelenk

$X$ prox. Schaft

$X$ mittl. Schaft

$\mathbf{X}$ dist. Schaft

X dist. Gelenk
Verband: $\square$ Verband

\section{Alter:}

Geschlecht:

Arthrose:

dist.
Ges./Kr.: Krank

Krankh.: Periostreizung

Muskelreizung

Kapselzerrung

Bandverknöcherungen

\section{Maß}

gr. Breite dist. Gelenk

Schaftumfang Foramen

Umfang Schaftmitte

\begin{tabular}{|l|l} 
Wert & Einheit \\
48,37 & $\mathrm{~mm}$ \\
92 & $\mathrm{~mm}$ \\
83 & $\mathrm{~mm}$
\end{tabular}

\section{Beschreibung:}

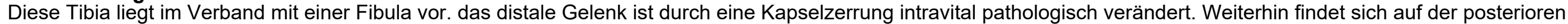
Fläche der Tibia eine streifige, furchige Struktur in der Knochenoberfläche, was für eine muskulär bedingte Periostreizung spricht. 
Bezeichn.: Tibia

Kiste: $\quad 5263278$

Skelet: $\quad$ unter $\mathrm{ScCH}$. 28+25. 4040 Geschlecht:

Population: Calden

Seite: links

Erhaltung: $\square$ prox. Gelenk

$X$ prox. Schaft

$\mathbf{X}$ mittl. Schaft

$\mathbf{X}$ dist. Schaft

dist. Gelenk
Ges./Kr.: Krank

Krankh.: Periostreizung

\section{Maß}

Schaftumfang Foramen

Umfang Schaftmitte

\begin{tabular}{|l|l} 
Wert & Einheit \\
91 & $\mathrm{~mm}$ \\
83 & $\mathrm{~mm}$ \\
&
\end{tabular}

\section{Beschreibung:}

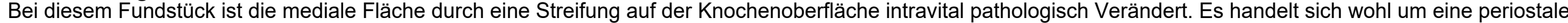

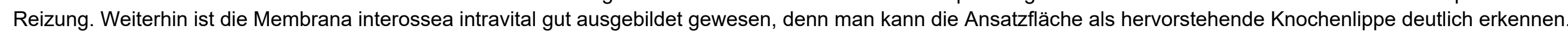



Bezeichn.: Tibia
Kiste: $\quad 5263278$
Skelet: V21 viele
Population: Calden
Seite: rechts
Erhaltung: $\mathbf{X}$ prox. Gelenk
$X$ prox. Schaft
mittl. Schaft
dist. Schaft dist. Gelenk

\section{Beschreibung:}

Ein proximales, erodiertes Tibiafragment.
Verband: $\quad \square$ Verband

\section{Alter:}

\section{Geschlecht:}

Arthrose:

\section{Maß}

gr. Breite prox. Gelenk

\begin{tabular}{|l|l} 
Wert & Einheit
\end{tabular}

\begin{tabular}{|l|l}
65 & $\mathrm{~mm}$ \\
&
\end{tabular}




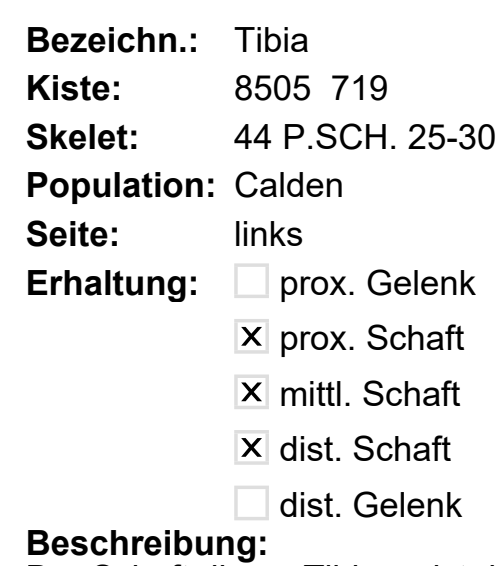

Seite: links

Erhaltung: $\square$ prox. Gelenk

$X$ prox. Schaft

$X$ mittl. Schaft

$\mathbf{X}$ dist. Schaft dist. Gelenk

Beschreibung:

\section{Geschlecht:}

Der Schaft dieser Tibia weist deutliche Bissspuren auf. 


\section{Bezeichn.: Tibia \\ Kiste: $\quad 8505719$ \\ Skelet: Steinkammer 1 \\ Population: Calden \\ Seite: rechts \\ Erhaltung: $\mathbf{X}$ prox. Gelenk \\ $X$ prox. Schaft \\ mittl. Schaft \\ dist. Schaft \\ dist. Gelenk \\ Beschreibung:}

Ein proximales Tibiafragment.
Verband: $\square$ Verband

\section{Alter:}

Geschlecht:

Arthrose:

\section{Maß}

gr. Breite prox. Gelenk

\begin{tabular}{|l|l} 
Wert & Einheit
\end{tabular}

\begin{tabular}{|l|l}
68 & $\mathrm{~mm}$ \\
&
\end{tabular}




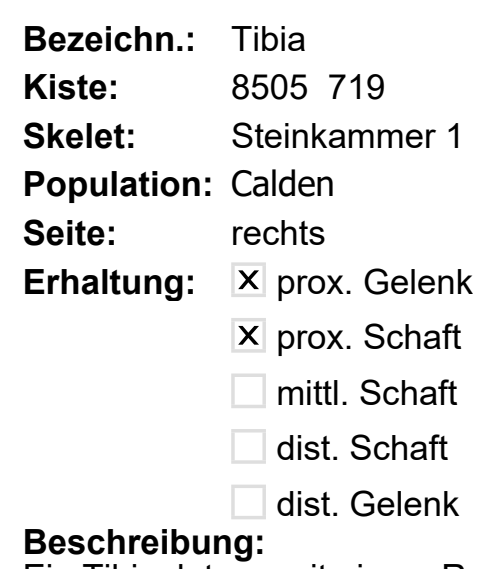

Population: Calden

Seite: rechts

Erhaltung: $\mathbf{X}$ prox. Gelenk

X prox. Schaft

mittl. Schaft

dist. Schaft

dist. Gelenk

\section{Beschreibung:}

Verband: $\quad \square$ Verband

\section{Alter:}

Geschlecht: $\uparrow \leq ð$

Arthrose:

prox.
Ges./Kr.: Krank

Krankh.: Zerrung

Enthesiopathie
Maß

gr. Breite prox. Gelenk

Ein Tibiaplateau mit einem Rest des proximalen Schaftes. Die mediale Plateaufläche ist stark erodiert und damit ist die Gelenkfläche etwa zu 50\% befundbar. Die

Tuberositas Tibiae weist eine leichte Enthesiopathie durch muskuläre Zerrung auf. das Fundstück ist insgesamt sehr massiv. 


\section{Bezeichn.: Tibia \\ Kiste: $\quad 8505719$ \\ Population: Calden \\ Seite: rechts \\ Erhaltung: $\square$ prox. Gelenk \\ prox. Schaft \\ $X$ mittl. Schaft \\ dist. Schaft \\ dist. Gelenk \\ Beschreibung:}

Skelet: über Kiefer 3 zwischen 23 Geschlecht:

Ein Fragment aus dem Schaft.
Verband: $\quad$ Verband

\section{Alter:}

Maß

Umfang Schaftmitte

Arthrose: 

Bezeichn.: Tibia
Skelet: zwischen $23+2530 \mathrm{~cm}$
Seite: links
Erhaltung: $\square$ prox. Gelenk
$X$ prox. Schaft
$X$ mittl. Schaft
dist. Schaft
$\square$ dist. Gelenk

Verband:

Verband

Ges./Kr.: Gesund

\section{Maß}

Alter: Jung

Geschlecht:

Schaftumfang Foramen

Umfang Schaftmitte

\begin{tabular}{l|l} 
Wert & Einheit \\
\hline 82 & $\mathrm{~mm}$ \\
86 & $\mathrm{~mm}$ \\
& \\
&
\end{tabular}

Arthrose:

\section{Beschreibung:}

Bei diesem Fundstück handelt es sich wohl um die Tibia eines nicht ausgewachsenen Individuums. Es weist eine ausgeprägte Tuberositas Tibiae und Membrana interossea auf. Der Knochen erscheint etwas porös, die Oberfläche ist aber nicht pathologisch verändert. Für das Alter typisch findet sich die Ausfurchung bei der Ansatzstelle des M. soleus. 

Bezeichn.: Tibia
Kiste:
8505719
Skelet: steinkammergrab 1
Population: Calden
Seite:
links
Erhaltung: $\square$ prox. Gelenk
$X$ prox. Schaft
mittl. Schaft
dist. Schaft
dist. Gelenk

\section{Beschreibung:}

Ein Fragment einer jungen Tibia.
Verband: Verband

Alter: $\quad 6-14(18)$

\section{Geschlecht:}

Arthrose: 


\section{Bezeichn.: Tibia \\ Kiste: \\ 8505719 \\ Skelet: extremitätenfragemente \\ Population: Calden \\ prox. Gelenk \\ prox. Schaft \\ mittl. Schaft \\ dist. Schaft \\ dist. Gelenk}

Beschreibung:

Splitter von Tibia.
Verband: Verband

\section{Alter:}

Geschlecht:

Arthrose: 


\author{
Bezeichn.: Tibia \\ Kiste: \\ 8505719 \\ Population: Calden \\ Seite: \\ links \\ Erhaltung: $\square$ prox. Gelenk \\ mittl. Schaft \\ $\mathbf{X}$ dist. Schaft \\ $X$ dist. Gelenk \\ Beschreibung: \\ Ein distales Fragment.
}

Skelet: extremitätenfragemente
Verband: $\quad$ Verband

\section{Alter:}

Geschlecht:

Arthrose:
Ges./Kr.: Gesund 


\author{
Bezeichn.: Tibia \\ Kiste: \\ 8505719 \\ Population: Calden \\ Seite: \\ links \\ Erhaltung: $\square$ prox. Gelenk \\ mittl. Schaft \\ $\mathbf{X}$ dist. Schaft \\ $X$ dist. Gelenk \\ Beschreibung: \\ Ein distales Fragment.
}

Skelet: extremitätenfragemente
Verband: $\quad$ Verband

\section{Alter:}

Geschlecht:

Arthrose:

Ges./Kr.: Gesund 


\section{Bezeichn.: Tibia \\ Kiste: $\quad 8505719$ \\ Skelet: extremitätenfragemente \\ Population: Calden \\ Erhaltung: prox. Gelenk \\ X prox. Schaft \\ mittl. Schaft \\ dist. Schaft dist. Gelenk}

Verband: $\quad \square$ Verband

Alter:

Geschlecht:

Arthrose:

Beschreibung:

Ein Splitter aus dem proximalen Anteil einer Tibia. 


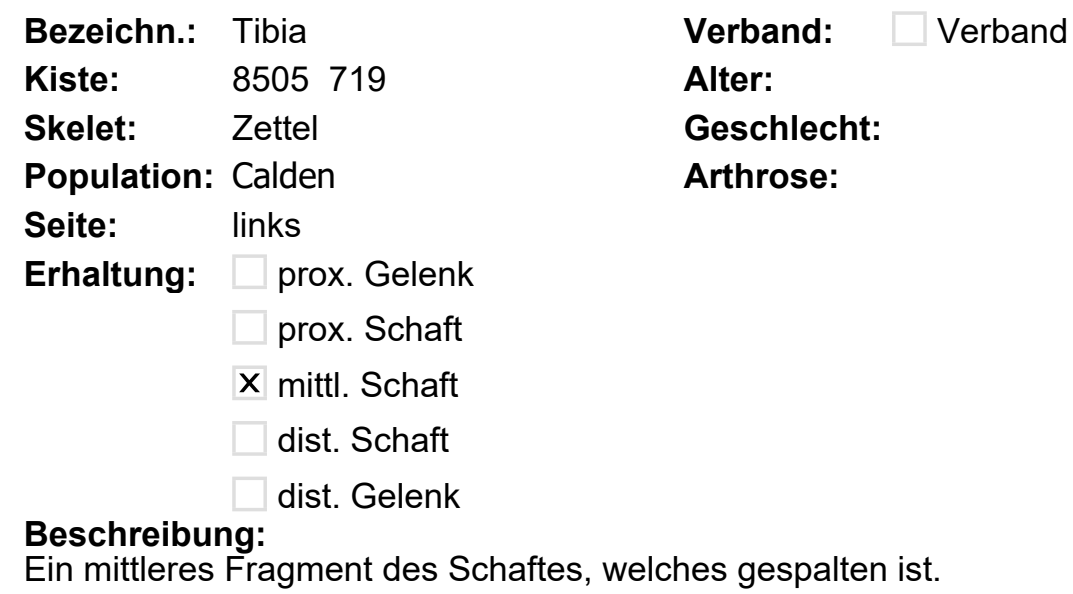

Population: Calden

Arthrose:

Seite: links

Erhaltung: $\square$ prox. Gelenk

prox. Schaft

$X$ mittl. Schaft

dist. Schaft dist. Gelenk

Beschreibung:

Ein mittleres Fragment des Schaftes, welches gespalten ist. 

Bezeichn.: Tibia
Kiste: $\quad 8505719$
Skelet: Zettel
Population: Calden
Seite: links
Erhaltung: $\square$ prox. Gelenk
prox. Schaft
$X$ mittl. Schaft
dist. Schaft
dist. Gelenk

\section{Beschreibung:}

Verband: $\square$ Verband

Alter: Jung

Geschlecht:

Arthrose:

Ein Fragment aus dem Schaft. Es handelt sich wohl um eine junge Tibia.

\begin{tabular}{l|l}
59 & $\mathrm{~mm}$
\end{tabular}



Bezeichn.: Tibia
Kiste: $\quad 5245269$
Population: Calden
Seite: rechts
Erhaltung: $\mathbf{X}$ prox. Gelenk
X prox. Schaft
mittl. Schaft
dist. Schaft
dist. Gelenk

Verband: $\square$ Verband

\section{Alter:}

Geschlecht: $\widehat{\partial}$

Arthrose:

prox.
Ges./Kr.: Krank

Krankh.: Enthesiopathie

\section{Maß}

gr. Breite prox. Gelenk

2

\section{Beschreibung:}

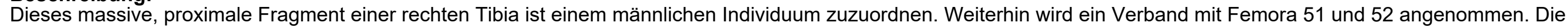

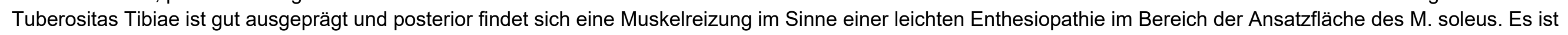
nur ein Teil des proximalen Drittels der Tibia erhalten. 

Bezeichn.: Tibia
Kiste:
5245269
Skelet: Sk.4.17
Population: Calden
Erhaltung: $\quad \mathbf{x}$ prox. Gelenk
$X$ prox. Schaft
$X$ mittl. Schaft
$\mathbf{X}$ dist. Schaft
dist. Gelenk

Verband:

Verband

Ges./Kr.: Krank

Alter:

Geschlecht:

Arthrose:

Krankh.: subperiostales Hämatom

Enthesiopathie

Impressionen tiefer

Krampfadern

\begin{tabular}{l|l|l} 
Maß & Wert & Einheit \\
\hline gr. Länge & 310 & $\mathrm{~mm}$ \\
Schaftumfang Foramen & 100 & $\mathrm{~mm}$ \\
Umfang Schaftmitte & 90 & $\mathrm{~mm}$ \\
& & \\
& &
\end{tabular}

\section{Beschreibung:}

Diese linke Tibia zeigt Erosionsspuren an der Oberfläche. Weiterhin fehlt der mediale Teil des Plateaus und das distale Gelenk. Etwa mittig fällt eine Erhabenheit von $20 \mathrm{~mm}$ x $9 \mathrm{~mm}$ ins Auge, bei der es sich um ein subperiostales Hämatom im Sinne eines "Trittes gegen das Schienbein" handeln dürfte. Im Bereich des Ansatzes des M. soleus findet sich eine leichte Enthesiopathie durch starke und stetige Muskelbeanspruchung (44mm x 8,8mm). Außerdem fallen zwei Impressionen ins Auge im mittigen anterioren Bereich, bei denen es sich um tiefe Krampfadern handeln könnte. 


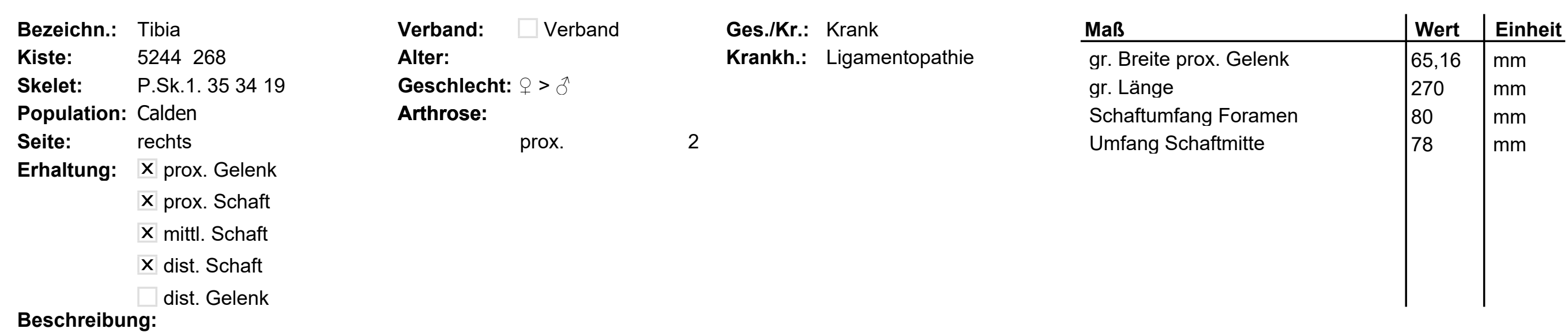

Diese grazile linke Tibia ist proximale anterior stark erodiert, weist eine leichte Ligamentopathie $(50 \mathrm{~mm} \times 6,9 \mathrm{~mm} \times 1,2 \mathrm{~mm})$ im Bereich des M. soleus auf und entspricht eher einem weiblichen Individuum. 

Bezeichn.: Tibia
Kiste:
5244268
Skelet: P.Sk.1.3943
Population: Calden
Erhaltung: X prox. Gelenk
$X$ prox. Schaft
mittl. Schaft
dist. Schaft
dist. Gelenk

Verband:

Verband

Ges./Kr.: Krank

Alter:

Krankh.: Muskelreizung

Geschlecht: $q$

Arthrose:

prox.

2

\section{Beschreibung:}

Dieses Fundstück ist ein proximales, stark erodiertes Fragment einer rechten Tibia, welches ein graziles Erscheinungsbild darbietet, was für ein weibliches Individuum sprechen dürfte. Der Gelenkverschleiß ist nicht eindeutig festzustellen, da auch Teile der Gelenkflächen erodiert sind. Im Bereich des M. tibialis posterior fällt eine Muskelreizung auf. 

Bezeichn.: Tibia
Kiste: $\quad 5244268$
Skelet: P.Sk.13318
Population: Calden
Seite: links
Erhaltung: $\square$ prox. Gelenk
$X$ prox. Schaft
$X$ mittl. Schaft
$\mathbf{X}$ dist. Schaft
$\square$ dist. Gelenk
Beschreibung:

Verband:

Verband

Ges./Kr.: Gesund

\section{Alter:}

Maß

gr. Länge

Schaftumfang Foramen

Umfang Schaftmitte

\begin{tabular}{|l|l} 
Wert & Einheit \\
\hline 200 & $\mathrm{~mm}$
\end{tabular}

Arthrose:

$\mathrm{mm}$

Diese linke Tibia ist stark erodiert, recht massiv und weist deutliche Muskelmarken an der Ansatzstelle der Membrana interossea auf. 
Bezeichn.: Tibia

Kiste:

5244268

Skelet:

P.Sk.1 3838

Population: Calden

Seite: rechts

Erhaltung: $\mathbf{X}$ prox. Gelenk

$X$ prox. Schaft

$X$ mittl. Schaft

$\mathbf{X}$ dist. Schaft

dist. Gelenk
Ges./Kr.: Krank

Krankh.: Ligamentopathie

\section{Alter:}

\section{Geschlecht:}

Arthrose:

prox.

$x$

\begin{tabular}{l|l|l} 
Maß & Wert & Einheit \\
\hline gr. Breite prox. Gelenk & 73,5 & $\mathrm{~mm}$ \\
gr. Länge & 270 & $\mathrm{~mm}$ \\
Schaftumfang Foramen & 100 & $\mathrm{~mm}$ \\
Umfang Schaftmitte & 85 & $\mathrm{~mm}$ \\
& & \\
& &
\end{tabular}

\section{Beschreibung:}

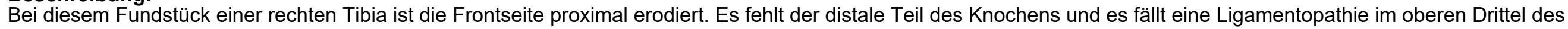

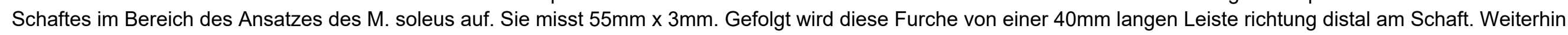

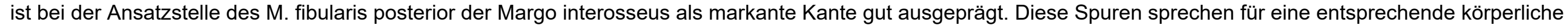
Beanspruchung. Ansonsten weist das Fundstück fleckenförmige, dunkle Verfärbungen und die Oberfläche stellenweise Erosionsspuren auf. 

Bezeichn.: Tibia
Kiste:
5254272
Skelet: ohne Bezeichnung
Population: Calden
Seite: rechts
Erhaltung: $\square$ prox. Gelenk
$X$ prox. Schaft
X mittl. Schaft
dist. Schaft
dist. Gelenk

Verband:

Verband

Alter: $\quad 10-18(20)$

Ges./Kr.: Gesund

Geschlecht:

Arthrose:

\section{Beschreibung:}

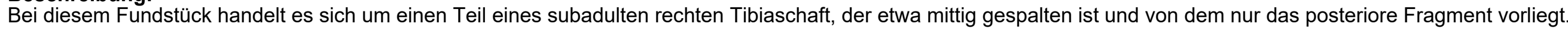

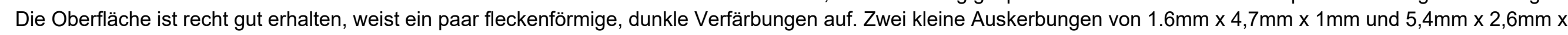

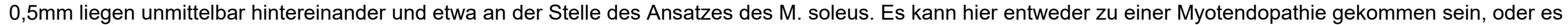

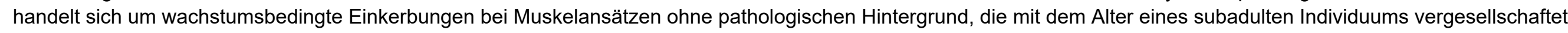
sind. 


\section{Bezeichn.: Tibia}

\section{Kiste:}

5254272

Skelet: $\quad$ über Kiefer Zwischen Sch

Population: Calden

Seite: rechts

Erhaltung: X prox. Gelenk

prox. Schaft

mittl. Schaft

dist. Schaft

dist. Gelenk

\section{Verband: $\quad$ Verband}

\section{Alter:}

Geschlecht:

Arthrose:

\section{Ges./Kr.: Gesund}

prox

\section{Beschreibung:}

Es handelt sich um ein Bruchstück einer rechten Tibia und zwar um das laterale Tibiaplateau mit einem kleinen Abriss des Schaftes lateral. 


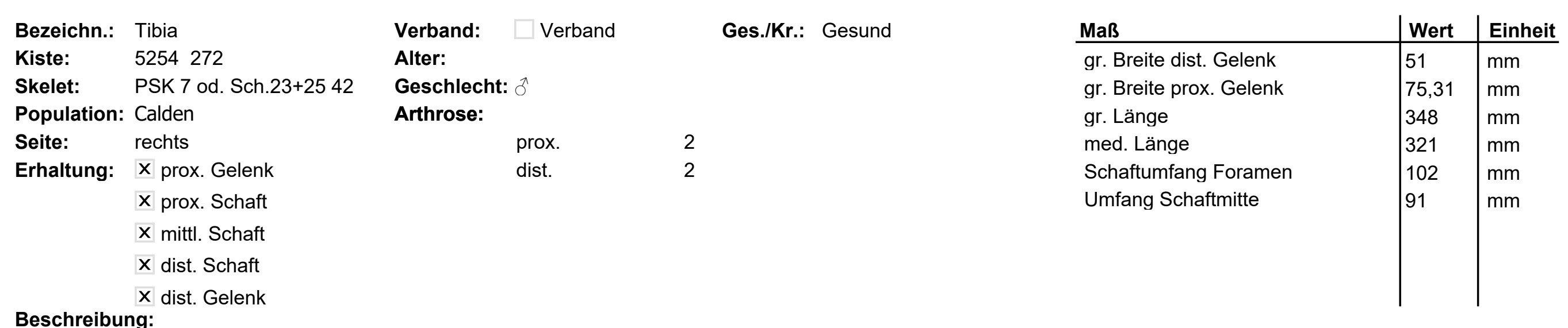

Eine Tibia mit Grabungsartefakt im Sinne einer zerstörten Tuberositas Tibiae. Die Oberfläche ist sonst größtenteils befundbar. Guter Erhaltungszustand. 
Bezeichn.: Tibia

Kiste: 5254272

Skelet:

PSK 7 od. Sch.23+25 41

Population: Calden

Seite: links

Erhaltung: $\mathbf{X}$ prox. Gelenk

$X$ prox. Schaft

$X$ mittl. Schaft

$X$ dist. Schaft

X dist. Gelenk
Ges./Kr.: Krank

Krankh.: Hockerfacette subperiostales Hämatom Periostreizung

\section{Alter:}

\section{Geschlecht:}

\section{Arthrose:}

prox.

dist.
Maß

gr. Breite dist. Gelenk

gr. Breite prox. Gelenk

gr. Länge

med. Länge

Schaftumfang Foramen

Umfang Schaftmitte

\begin{tabular}{|l|l} 
Wert & Einheit \\
50 & $\mathrm{~mm}$ \\
66 & $\mathrm{~mm}$ \\
328 & $\mathrm{~mm}$ \\
300 & $\mathrm{~mm}$ \\
85 & $\mathrm{~mm}$ \\
81 & $\mathrm{~mm}$
\end{tabular}

\section{Beschreibung:}

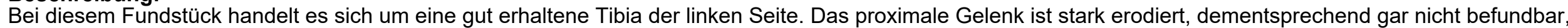

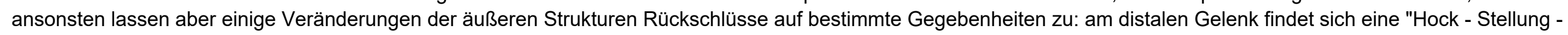

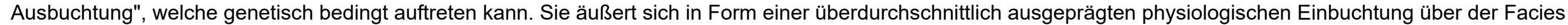

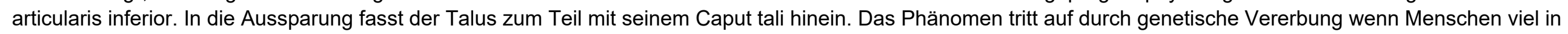
hockender Stellung gearbeitet haben. Bei dieser Körperstellung kommt man dem Boden näher je stärker die beschriebene Ausbuchtung ausgeprägt ist.

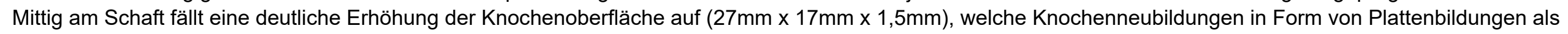

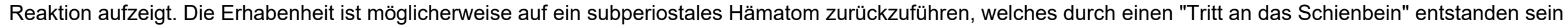

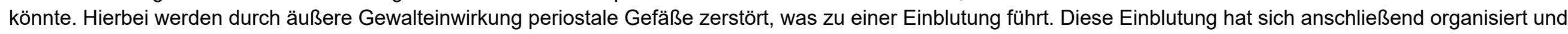

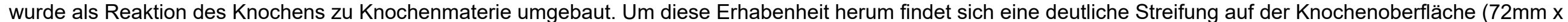

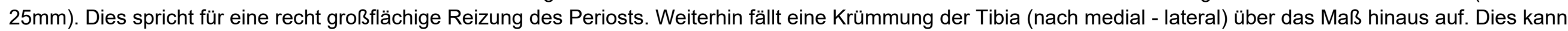

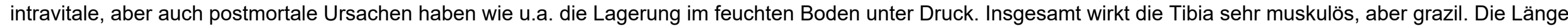
spricht eher für ein weibliches Individuum, die Breite des distalen Gelenkes eher für ein männliches. 

Bezeichn.: Tibia
Kiste: $\quad 5266281$
$\begin{array}{ll}\text { Skelet: } & 30 \\ \text { Population: } & \text { Calden }\end{array}$
Seite:
links
Erhaltung: $\square$ prox. Gelenk
$X$ prox. Schaft
$X$ mittl. Schaft
$\mathbf{X}$ dist. Schaft
dist. Gelenk

Verband: $\quad \square$ Verband

\section{Alter:}

Maß

\section{gr. Länge}

Schaftumfang Foramen

Umfang Schaftmitte

\begin{tabular}{|l|l} 
Wert & Einheit \\
\hline 276 & $\mathrm{~mm}$
\end{tabular}

Geschlecht:

\section{Beschreibung:}

Arthrose:

$\mathrm{mm}$

Die Oberfläche dieser Tibia ist rissig und eingedrückt, Teile der compacta blättern ab, das Fundstück ist nur sehr eingeschränkt befundbar. 


\section{Bezeichn.: Tibia \\ Kiste: $\quad 5266280$ \\ Skelet: 26}

Population: Calden

Seite: rechts

Erhaltung: $\mathbf{X}$ prox. Gelenk

$X$ prox. Schaft

$\mathbf{X}$ mittl. Schaft

$\mathbf{X}$ dist. Schaft

$X$ dist. Gelenk

\section{Beschreibung:}

Ein sehr gut erhaltenes Fundstück, bis auf kleinere postmortale Risse fallen hier keine Veränderungen auf.

\section{Verband: \\ Verband \\ Ges./Kr.: Gesund}

\section{Alter:}

Geschlecht:

Arthrose:

\section{prox.}

dist.

1
Maß

gr. Breite dist. Gelenk

gr. Breite prox. Gelenk

gr. Länge

med. Länge

Schaftumfang Foramen

Umfang Schaftmitte \begin{tabular}{|l|l} 
Wert & Einheit \\
\hline 52,87 & $\mathrm{~mm}$
\end{tabular}

$74,74 \mathrm{~mm}$

$332 \mathrm{~mm}$

$310 \mathrm{~mm}$

$95 \mathrm{~mm}$

$83 \mathrm{~mm}$


Bezeichn.: Tibia

\section{Kiste: $\quad 5266280$}

Skelet: 13

Population: Calden

Seite: links

Erhaltung: $\mathbf{X}$ prox. Gelenk

$X$ prox. Schaft

$X$ mittl. Schaft

$\mathbf{X}$ dist. Schaft

X dist. Gelenk
Ges./Kr.: Krank

Krankh.: Kapselzerrung

Myotendopathie

Kapselriss

Periostreizung

Enthesiopathie

Muskelreizung

\section{Maß}

gr. Breite dist. Gelenk

gr. Breite prox. Gelenk

gr. Länge

med. Länge

Schaftumfang Foramen

Umfang Schaftmitte

\section{Einheit}

$\mathrm{mm}$

$\mathrm{mm}$

385

122

103

$\mathrm{mm}$

$\mathrm{mm}$

\section{Beschreibung:}

Bei diesem Fundstück einer linken Tibia lag eine leichte Myotendopathie bei der Ansatzstelle des M. soleus vor. Weiterhin ist die symphysis tibio - fibularis distalis

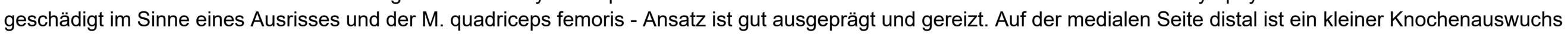

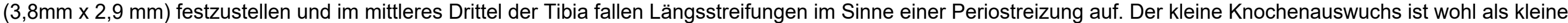
Enthesiopathie zu werten, der durch Muskelreiz zustande gekommen ist. 


\begin{tabular}{|c|c|c|c|c|c|c|c|}
\hline Bezeichn.: & Tibia & Verband: & $\square$ Verband & Ges./Kr.: Gesund & Maß & Wert & Einheit \\
\hline Kiste: & 5266281 & Alter: & & & gr. Breite dist. Gelenk & 49,35 & $\mathrm{~mm}$ \\
\hline Skelet: & 47 & Geschlecht: & & & gr. Länge & 211 & $\mathrm{~mm}$ \\
\hline Population: & Calden & Arthrose: & & & Umfang Schaftmitte & 68 & $\mathrm{~mm}$ \\
\hline Seite: & rechts & & & & & & \\
\hline Erhaltung: & $\square$ prox. Gelenk & & dist. & 1 & & & \\
\hline & $\square$ prox. Schaft & & & & & & \\
\hline & $X$ mittl. Schaft & & & & & & \\
\hline & $\mathbf{X}$ dist. Schaft & & & & & & \\
\hline & X dist. Gelenk & & & & & & \\
\hline
\end{tabular}

\section{Beschreibung:}

Dieses Fundstück weist besonders im proximalen Bereich starke Erosionen auf. Weiterhin sind dunkle Bodenverfärbungen festzustellen, sowie kleine postmortale Risse in der compacta und Impressionen. 

Bezeichn.: Tibia
Kiste: 5266280
$\begin{array}{ll}\text { Skelet: } 9 & 9 \\ \text { Population: } & \text { Calden }\end{array}$
Seite: links
Erhaltung: $\mathbf{X}$ prox. Gelenk
$X$ prox. Schaft
mittl. Schaft
dist. Schaft
dist. Gelenk

Verband: $\quad \square$ Verband

Ges./Kr.: Gesund

\section{Alter:}

Geschlecht:

Arthrose:

\section{Beschreibung:}

Dieses proximale Fragment einer linken Tibia weist lateral leichte, dunkle Verfärbungen auf, ansonsten ist die Oberfläche recht gut erhalten und die compacta sehr massiv.

Es fällt ein gut ausgeprägter Margo interosseus ins Auge. Auf dem Margo medialis findet sich eine Erhebung von $1 \mathrm{~mm}$ Höhe im Sinne einer Muskelmarke. 
Bezeichn.: Tibia

Kiste: $\quad 5266280$

Skelet: $\quad 3,8 x ; 5,5 y ;+1046$

Population: Calden

Seite: rechts

Erhaltung: $\mathbf{X}$ prox. Gelenk

$X$ prox. Schaft

$X$ mittl. Schaft

$\mathbf{X}$ dist. Schaft

$\mathbf{X}$ dist. Gelenk

\section{Beschreibung:}

Diese Tibia ist vollständig erhalten und weist nur wenig Erosionsspuren auf.

\section{Verband: $\quad$ Verband}

\section{Alter:}

Geschlecht: $\delta$

Arthrose:

\section{prox.}

dist.

2
Maß

gr. Breite dist. Gelenk

gr. Breite prox. Gelenk

gr. Länge

med. Länge

Schaftumfang Foramen

Umfang Schaftmitte

\begin{tabular}{|l|l} 
Wert & Einheit \\
56,13 & $\mathrm{~mm}$
\end{tabular}

$82,11 \mathrm{~mm}$

$376 \quad \mathrm{~mm}$

$340 \quad \mathrm{~mm}$

$100 \mathrm{~mm}$



Bezeichn.: Tibia
Kiste: $\quad 5266281$
Skelet: V7 28
Population: Calden
Seite: rechts
Erhaltung: $\mathbf{X}$ prox. Gelenk
$X$ prox. Schaft
$X$ mittl. Schaft
$X$ dist. Schaft
$\mathbf{X}$ dist. Gelenk

Verband

Verband

Ges./Kr.: Krank

\section{Alter:}

Geschlecht:

Arthrose:

\begin{tabular}{l|l|l} 
Maß & Wert & Einheit \\
\hline gr. Breite dist. Gelenk & 47,99 & $\mathrm{~mm}$ \\
gr. Breite prox. Gelenk & 67,15 & $\mathrm{~mm}$ \\
gr. Länge & 318 & $\mathrm{~mm}$ \\
med. Länge & 285 & $\mathrm{~mm}$ \\
Schaftumfang Foramen & 83 & $\mathrm{~mm}$ \\
Umfang Schaftmitte & 68 & $\mathrm{~mm}$
\end{tabular}

\section{Beschreibung:}

Dieses Fundstück einer rechten Tibia gehört paarig zusammen. Die proximalen und distalen Enden sind leicht bis mittel erodiert. Die Beiden paarigen Fundstücke unterscheiden sich in ihrem Gewicht und farblich, ansonsten passen sie gut zusammen. Es findet sich eine Impression am distalen Drittel, es handelt sich wohl um eine Gefäßimpression. Es fallen folgende gut sichtbare Muskelmarken der Ansatzflächen ins Auge: m. soleus, Membrana interossea, (möglicherweise extensor hallucis longus). 


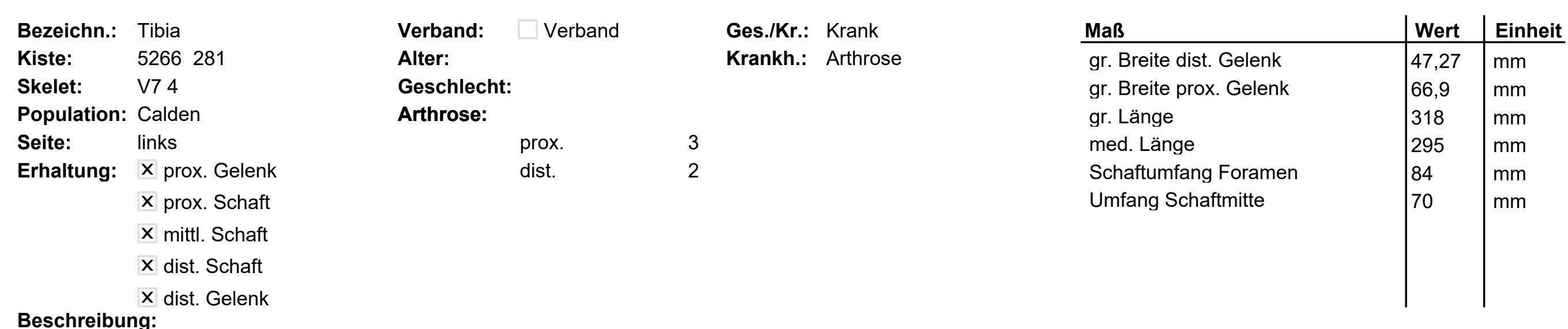

Auf diesem Fundstück einer linken Tibia finden sich kleine Riefen (Erosion), proximal ist das Fundstück etwas erodiert. Bei der Schaftmitte findet sich ein etwa $1 \mathrm{~mm}$ tiefes Loch (postmortal). Sichtbare Muskelmarken wie bei der paarigen rechten Seite: m. soleus, Membrana interossea, evtl. extensor hallucis longus. 


\author{
Bezeichn.: Tibia \\ Kiste: $\quad 5259276$ \\ Verband: $\quad$ Verband \\ Skelet: gesammelt \\ Alter: \\ Population: Calden \\ Geschlecht: \\ Seite: links \\ Erhaltung: $\mathbf{X}$ prox. Gelenk \\ prox. Schaft \\ mittl. Schaft \\ dist. Schaft \\ dist. Gelenk \\ Beschreibung: \\ Hier ist nur ein Fragment eines Tibiaplateaus erhalten.
}




$\begin{array}{lll}\text { Bezeichn.: } & \text { Tibia } & \text { Verband: } \square \text { Verband } \\ \text { Kiste: } & 8505721 & \text { Alter: } \\ \text { Skelet: } & \text { Kiste } 5 & \text { Geschlecht: } \\ \text { Population: } & \text { Calden } & \text { Arthrose: } \\ \text { Seite: } & \text { rechts } & \\ \text { Erhaltung: } & \mathbf{X} \text { prox. Gelenk } & \\ & \square \text { prox. Schaft } & \\ & \square \text { mittl. Schaft } & \\ & \square \text { dist. Schaft } & \\ & \square \text { dist. Gelenk }\end{array}$

\section{Beschreibung:}

Dies ist das laterale Tibiaplateau einer rechten Tibia. Das Fragment ist so stark erodiert, dass keine weiteren Befunde möglich sind. 


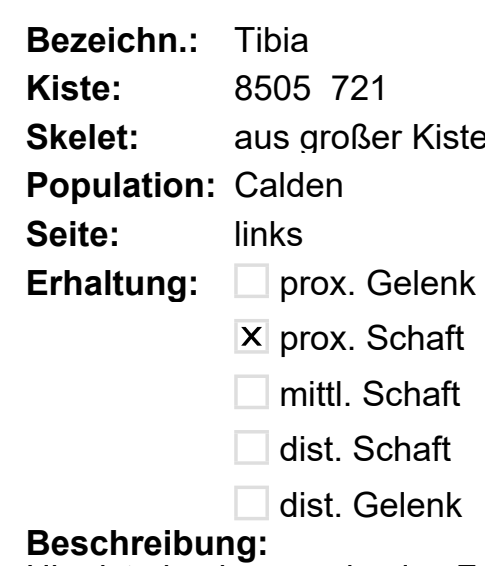

Population: Calden

Seite: links

Erhaltung: $\square$ prox. Gelenk

$X$ prox. Schaft

mittl. Schaft

dist. Schaft

dist. Gelenk

Beschreibung:

Skelet: aus großer Kiste Geschlecht:

Arthrose:

Hier ist ein eher proximales Fragment des Schaftes einer linken Tibia erhalten. Die Ansatzstelle des M. soleus ist gut ausgeprägt. 

Bezeichn.: Tibia
Kiste:
8505721
Skelet: aus großer Kiste
Population: Calden
Seite: rechts
Erhaltung: $\square$ prox. Gelenk prox. Schaft
mittl. Schaft
$\mathbf{X}$ dist. Schaft $X$ dist. Gelenk

Beschreibung:

Ein distales Fragment.
Verband: $\quad$ Verband

\section{Alter:}

Ges./Kr.: Gesund

\section{Geschlecht:}

Arthrose:
Maß

gr. Breite dist. Gelenk

Wert $\quad$ Einheit

$44,79 \mathrm{~mm}$


Bezeichn.: Tibia

\section{Kiste:}

850572

Skelet: aus großer Kiste

Population: Calden

Seite: rechts

Erhaltung: $\mathbf{X}$ prox. Gelenk

$X$ prox. Schaft

$X$ mittl. Schaft

$\mathbf{X}$ dist. Schaft

X dist. Gelenk
Ges./Kr.: Krank

Krankh.: Arthrose

Periostreizung
Maß

gr. Breite dist. Gelenk

gr. Breite prox. Gelenk

gr. Länge

med. Länge

Schaftumfang Foramen

Umfang Schaftmitte

\begin{tabular}{|l|l} 
Wert & Einheit \\
\hline 55,11 & $\mathrm{~mm}$
\end{tabular}

$81 \quad \mathrm{~mm}$

350

11,8

102

102

dist. 2,5

\section{Beschreibung:}

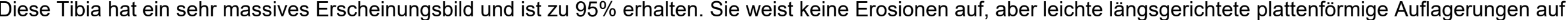

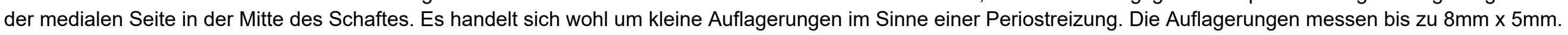

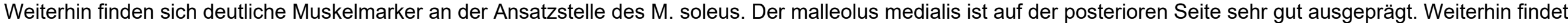
sich ein recht großer Rand am proximalen tibio - fibular - Gelenk. Er misst bis 5,79mm. 

Bezeichn.: Tibia
Kiste:
Skelet: aus großer Kiste
Population: Calden
Seite: rechts
Erhaltung: $\square$ prox. Gelenk
prox. Schaft
$X$ mittl. Schaft
dist. Schaft
dist. Gelenk

Verband:

Verband

Ges./Kr.: Gesund

Alter:

Geschlecht:

Beschreibung:

Ein Fragment aus dem Schaft einer Tibia. Es handelt sich um die mediale Seite. 


\begin{tabular}{|c|c|c|c|}
\hline $\begin{array}{l}\text { Bezeichn.: } \\
\text { Kiste: } \\
\text { Skelet: } \\
\text { Population: } \\
\text { Seite: } \\
\text { Erhaltung: }\end{array}$ & $\begin{array}{l}\text { Tibia } \\
8505721 \\
\text { aus großer Kiste } \\
\text { Calden } \\
\text { rechts } \\
\square \text { prox. Gelenk } \\
\square \text { prox. Schaft } \\
\text { X mittl. Schaft } \\
\square \text { dist. Schaft } \\
\square \text { dist. Gelenk }\end{array}$ & $\begin{array}{l}\text { Verband: } \\
\text { Alter: } \\
\text { Geschlecht: } \\
\text { Arthrose: }\end{array}$ & $\begin{array}{l}\square \text { Verband } \\
\text { Jung }\end{array}$ \\
\hline
\end{tabular}

Ein Fragment aus dem Schaft einer nicht ausgewachsenen Tibia. 

Bezeichn.: Tibia
Kiste:
5242266
Skelet: V1 E.B-S.
Population: Calden
Seite: rechts
Erhaltung: $\square$ prox. Gelenk
$\mathbf{X}$ prox. Schaft
$X$ mittl. Schaft
X dist. Schaft dist. Gelenk
Beschreibung:

Ein Fragment aus dem Schaft einer jungen Tibia der rechten Seite.

\section{Verband: \\ Ges./Kr.: Gesund}

Alter:

Geschlecht:

Arthrose: 


$\begin{array}{ll}\text { Bezeichn.: } & \text { Fibula } \\ \text { Kiste: } & \text { Museumskiste 3 } \\ \text { Skelet: } & \text { P2(?) } \\ \text { Population: } & \text { Calden } \\ \begin{array}{ll}\text { Seite: } & \text { rechts } \\ \text { Erhaltung: } & \square \text { prox. Gelenk } \\ & \square \text { prox. Schaft } \\ & \text { X mittl. Schaft } \\ & \square \text { dist. Schaft } \\ & \square \text { dist. Gelenk }\end{array}\end{array}$

Verband: $\quad$ Verband

Ges./Kr.: Gesund

Dieses Fragment aus dem Schaft einer Fibula ist stark erodiert, massiv und zu etwa 1/5 erhalten. 


$\begin{array}{ll}\text { Bezeichn.: } & \text { Fibula } \\ \text { Kiste: } & 8505718 \\ \text { Skelet: } & \text { aus Tüte } \\ \text { Population: } & \text { Calden } \\ \text { Seite: } & \text { links } \\ \text { Erhaltung: } & \square \text { prox. Gelenk } \\ & \square \text { prox. Schaft } \\ & \mathbf{X} \text { mittl. Schaft } \\ & \square \text { dist. Schaft } \\ & \square \text { dist. Gelenk }\end{array}$

Verband: $\square$ Verband

Alter:

Geschlecht: $\rho>\hat{\sigma}$

Arthrose:

\section{Beschreibung:}

Dies ist ein stark erodiertes Fragment aus dem Schaft einer Fibula. 

Bezeichn.: Fibula
Kiste: $\quad 5263278$
Skelet: $\quad \mathrm{P} 16+18$
Population: Calden
Seite: links
Erhaltung: $\mathbf{X}$ prox. Gelenk
$X$ prox. Schaft
$X$ mittl. Schaft
$X$ dist. Schaft
dist. Gelenk

\section{Beschreibung:}

Ein Fragment einer jungen Fibula.
Verband: $\quad$ Verband Ges./Kr.: Gesund

\section{Alter: Jung}

Geschlecht:

Arthrose: 

Bezeichn.: Fibula
Kiste: $\quad 5266281$
Skelet: $\quad 3,8 x ; 5,5 y ;+10$ Tüte 1
Population: Calden
Seite: rechts
Erhaltung: X prox. Gelenk
$X$ prox. Schaft
$X$ mittl. Schaft
$\mathbf{X}$ dist. Schaft
X dist. Gelenk
Beschreibung:

Eine vollständige Fibula.
Verband: $\quad$ Verband

Alter: Erwachsen

Ges./Kr.: Gesund

Geschlecht:

Arthrose: 
Bezeichn: Fibula

Kiste: $\quad 5266281$

Skelet: $\quad$ V65 aus Tüte 4

Population: Calden

Seite: rechts

Erhaltung: $\square$ prox. Gelenk

prox. Schaft

mittl. Schaft

$\mathbf{X}$ dist. Schaft

$\mathbf{X}$ dist. Gelenk

Beschreibung:

Von dieser Fibula ist ein distales Fragment erhalten.
Verband: $\quad$ Verband

\section{Alter:}

Geschlecht:

Arthrose:
Ges./Kr.: Gesund 
Bezeichn.: Fibula

Kiste: $\quad 5266281$

Skelet: $\quad$ V65 aus Tüte 4

Population: Calden

Seite: links

Erhaltung:

prox. Gelenk

prox. Schaft

mittl. Schaft

$\mathbf{X}$ dist. Schaft

$\mathbf{X}$ dist. Gelenk

Beschreibung:

Von dieser Fibula ist ein distales Fragment erhalten.
Verband: $\quad$ Verband

\section{Alter:}

Geschlecht:

dist. 

Bezeichn.: Fibula
Kiste: $\quad 5256274$
Skelet: Sk8 11
Population: Calden
Seite: rechts
Erhaltung: $\mathbf{X}$ prox. Gelenk
$X$ prox. Schaft
$X$ mittl. Schaft
$\mathbf{X}$ dist. Schaft
$X$ dist. Gelenk

Beschreibung:

Eine rechte Fibula.
Verband: $\square$ Verband

\section{Alter:}

Geschlecht:

Arthrose:
Ges./Kr.: Gesund

Maß

Länge

Wert $\quad$ Einheit

$350 \mathrm{~mm}$



Bezeichn.: Fibula
Kiste: $\quad 8505720$
Skelet: einzeln 1.1
Population: Calden

\section{Erhaltung: $\square$ prox. Gelenk prox. Schaft $X$ mittl. Schaft dist. Schaft dist. Gelenk}

Verband: $\quad$ Verband

\section{Alter:}

Geschlecht:

Arthrose:
Beschreibung:

Fibulafragment mit Bissspuren. 
Bezeichn.: Fibula

Kiste: $\quad 8505720$

Skelet: einzeln 1.1

Population: Calden

\section{Erhaltung:}

prox. Gelenk

prox. Schaft

$X$ mittl. Schaft

dist. Schaft

dist. Gelenk

Beschreibung:

Fibulafragment.
Verband: Verband

\section{Alter:}

Geschlecht:

Arthrose: 


\section{Bezeichn.: Fibula \\ Kiste: $\quad 5249270$ \\ Skelet: Zettel}

Population: Calden

Erhaltung: prox. Gelenk prox. Schaft $X$ mittl. Schaft dist. Schaft dist. Gelenk

\section{Beschreibung:}

Fibulafragment.
Verband: $\square$ Verband

\section{Alter:}

\section{Geschlecht:}

Arthrose: 


\section{Bezeichn.: Fibula \\ Kiste: $\quad 5249270$ \\ Skelet: Zettel}

Population: Calden

Erhaltung: prox. Gelenk prox. Schaft $X$ mittl. Schaft dist. Schaft dist. Gelenk

\section{Beschreibung:}

Fibulafragment.
Verband: $\square$ Verband

\section{Alter:}

\section{Geschlecht:}

Arthrose: 


\section{Bezeichn.: Fibula \\ Kiste: $\quad 5249270$ \\ Skelet: Zettel}

Population: Calden

Erhaltung: prox. Gelenk prox. Schaft $X$ mittl. Schaft dist. Schaft dist. Gelenk

\section{Beschreibung:}

Fibulafragment.
Verband: $\square$ Verband

\section{Alter:}

\section{Geschlecht:}

Arthrose: 

Bezeichn.: Fibula
Kiste: $\quad 5255273$
Skelet: SK7 5
Population: Calden
Seite:
links
Erhaltung: prox. Gelenk
$X$ prox. Schaft
$X$ mittl. Schaft
$\mathbf{X}$ dist. Schaft
X dist. Gelenk
Beschreibung:

Ein großes distales Fragment.
Verband: Verband

\section{Alter:}

Geschlecht:

Arthrose: 


\section{Bezeichn.: Fibula \\ Kiste: $\quad 5257+58275$ \\ Skelet: SK.9. 9 \\ Population: Calden \\ Erhaltung: $\quad \mathbf{X}$ prox. Gelenk \\ $X$ prox. Schaft \\ mittl. Schaft \\ dist. Schaft \\ dist. Gelenk \\ Beschreibung:}

Fibulafragment.
Verband: $\quad$ Verband

Ges./Kr.: Gesund

\section{Alter:}

Geschlecht:

Arthrose:

prox. 


\section{Bezeichn.: Fibula \\ Kiste: $\quad 5257+58275$ \\ Skelet: $\quad$ über Becken 9 . \\ Population: Calden \\ Erhaltung: $\square$ prox. Gelenk $X$ prox. Schaft $X$ mittl. Schaft $\mathbf{X}$ dist. Schaft dist. Gelenk \\ Beschreibung:}

Fibulafragment.
Verband: $\quad$ Verband

Ges./Kr.: Gesund

\section{Alter:}

Geschlecht:

Arthrose: 
Bezeichn.: Fibula

Kiste: $\quad 5257+58275$

Skelet: 7

Population: Calden

Seite: links

Erhaltung: $\square$ prox. Gelenk prox. Schaft

mittl. Schaft

$\mathbf{X}$ dist. Schaft

$X$ dist. Gelenk

\section{Beschreibung:}

Fibulafragment.
Verband:

Verband

\section{Alter:}

Geschlecht:

Arthrose:

dist. 


\section{Bezeichn.: Fibula}

\section{Kiste:}

$5257+58275$

Skelet:

unter 2K.Obersch.SK.9. 8

Population: Calden

Seite: links

Erhaltung: $\mathbf{X}$ prox. Gelenk

$X$ prox. Schaft

$X$ mittl. Schaft

$\mathbf{X}$ dist. Schaft

$\mathbf{X}$ dist. Gelenk

Beschreibung:

Eine vollständige Fibula der linken Seite.
Verband: $\quad$ Verband

\section{Alter:}

Ges./Kr.: Gesund

Geschlecht:

Arthrose:

prox.

dist.
Maß

Länge

Wert $\quad$ Einheit

$327 \quad \mathrm{~mm}$




\begin{tabular}{|c|c|c|c|c|c|c|c|}
\hline Bezeichn.: & Fibula & Verband: & $\square$ Verband & Ges./Kr.: Krank & Maß & Wert & Einheit \\
\hline Kiste: & 5242266 & Alter: & Jung & Krankh.: Anämie & Länge & 125 & $\mathrm{~mm}$ \\
\hline Skelet: & E. B-S. & Geschlecht: & & & & & \\
\hline Population: & Calden & Arthrose: & & & & & \\
\hline Seite: & links & & & & & & \\
\hline Erhaltung: & $\square$ prox. Gelenk & & & & & & \\
\hline & X prox. Schaft & & & & & & \\
\hline & X mittl. Schaft & & & & & & \\
\hline & $\mathbf{X}$ dist. Schaft & & & & & & \\
\hline & X dist. Gelenk & & & & & & \\
\hline
\end{tabular}

\section{Beschreibung:}

Ein distales Fragment einer jungen Fibula. Das Fundstück wurde histologisch untersucht. Es war eine durchlebte Anämie nachzuweisen. Weiterhin war das Sterbealter auf Infans Ib beziffert werden. 


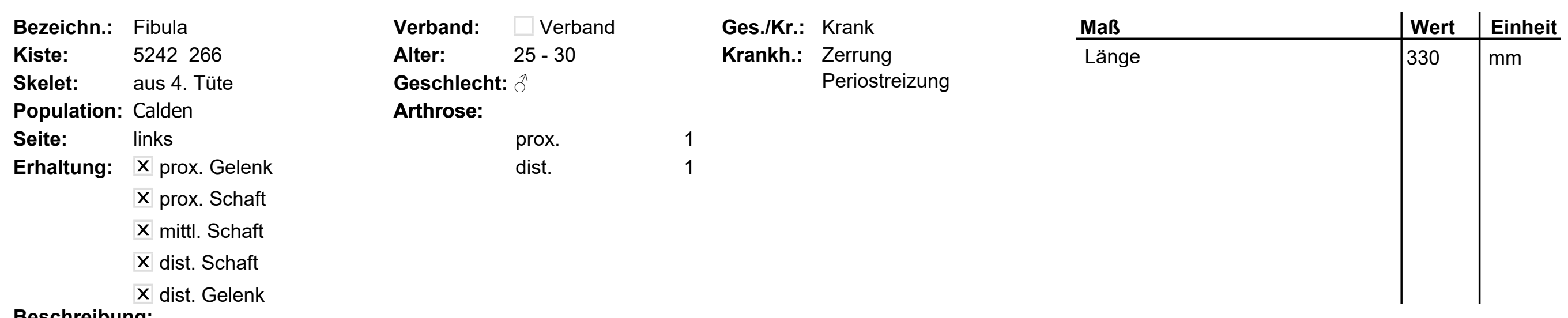

Bei dieser Fibula fällt eine Reizung des Periosts am Schaft im proximales Drittel ins Auge. Es kam zu aufgelagerten Knochenneubildungen wahrscheinlich als entzündlicher Prozess. Weiter proximal ist die Knochenoberfläche streifig aufgetrieben auch im Sinne der Periostreizung. Das Geschehen spielte sich im Ansatzbereich der Membrana interossea ab, die möglicherweise hier durch eine Überbelastung im Sinne einer Zerrung zu der genanten Periostreizung geführt hat. 

Bezeichn.: Fibula

Kiste: $\quad 5242266$
Skelet: $\quad 3$. Tüte
Population: Calden
Seite: links
Erhaltung: $\square$ prox. Gelenk
prox. Schaft
mittl. Schaft
X dist. Schaft
dist. Gelenk

Verband: $\square$ Verband
Alter:

Geschlecht: $\hat{\sigma}$
Ges./Kr.: Krank

\section{Krankh.: Zerrung}

Periostreizung

\section{Beschreibung:}

Dieses Fundstück ist ein Teil aus dem Schaft einer linken Fibula. Sie weist eine Reizung der Membrana interossea und eine Zerrung mit anschließender Verknöcherung im distalen Bereich bei der Ansatzstelle des M. flexor hallucis longus auf. 
Bezeichn.: Fibula

Kiste: $\quad 5242266$

Skelet: 3. Tüte

Population: Calden

Seite: links

Erhaltung: $\square$ prox. Gelenk prox. Schaft

mittl. Schaft

$\mathbf{X}$ dist. Schaft

$X$ dist. Gelenk

\section{Beschreibung:}

Fibulafragment.
Verband: $\square$ Verband

\section{Alter:}

Geschlecht:

Arthrose:
Ges./Kr.: Gesund

Maß

Länge

\begin{tabular}{l|l|l} 
Wert & Einheit \\
\hline 55 & $\mathrm{~mm}$
\end{tabular}


Bezeichn.: Fibula

Kiste: $\quad 5242266$

Skelet: Fragmente

Population: Calden

Erhaltung: $\square$ prox. Gelenk

prox. Schaft

$X$ mittl. Schaft

dist. Schaft

dist. Gelenk

Beschreibung:

Hier sind Fibulafragmente erhalten.
Verband: Verband

\section{Alter:}

Geschlecht:

Arthrose: 
Bezeichn.: Fibula

Kiste: $\quad 5242266$

Skelet: Fragmente

Population: Calden

Erhaltung: $\square$ prox. Gelenk

prox. Schaft

$X$ mittl. Schaft

dist. Schaft

dist. Gelenk

Beschreibung:

Hier sind Fibulafragmente erhalten.
Verband: Verband

\section{Alter:}

Geschlecht:

Arthrose: 
Bezeichn.: Fibula

Kiste: $\quad 5242266$

Skelet: Fragmente

Population: Calden

Erhaltung: $\square$ prox. Gelenk

prox. Schaft

$X$ mittl. Schaft

dist. Schaft

dist. Gelenk

Beschreibung:

Hier sind Fibulafragmente erhalten.
Verband: Verband

\section{Alter:}

Geschlecht:

Arthrose: 
Bezeichn.: Fibula

Kiste: $\quad 5242266$

Skelet: Fragmente

Population: Calden

Erhaltung: $\square$ prox. Gelenk

prox. Schaft

$X$ mittl. Schaft

dist. Schaft

dist. Gelenk

Beschreibung:

Hier sind Fibulafragmente erhalten.
Verband: Verband

\section{Alter:}

Geschlecht:

Arthrose: 
Bezeichn.: Fibula

Kiste: $\quad 8505718$

Skelet: aus Kiste

Population: Calden

Seite: rechts

Erhaltung: $\square$ prox. Gelenk

prox. Schaft

mittl. Schaft

$\mathbf{X}$ dist. Schaft

$X$ dist. Gelenk
Verband: $\quad$ Verband

Alter: $\quad 20-30$ (30)

Geschlecht: $\delta$

\section{Arthrose:}

Ges./Kr.: Krank

Krankh.: Zerrung

\section{Beschreibung:}

Diese Fibula ist nur distal erhalten und hat eine Zerrung im Bereich des M. flexor hallucis longus. Außerdem fällt ein starker Bluterguss von etwa 53mm Länge auf. 


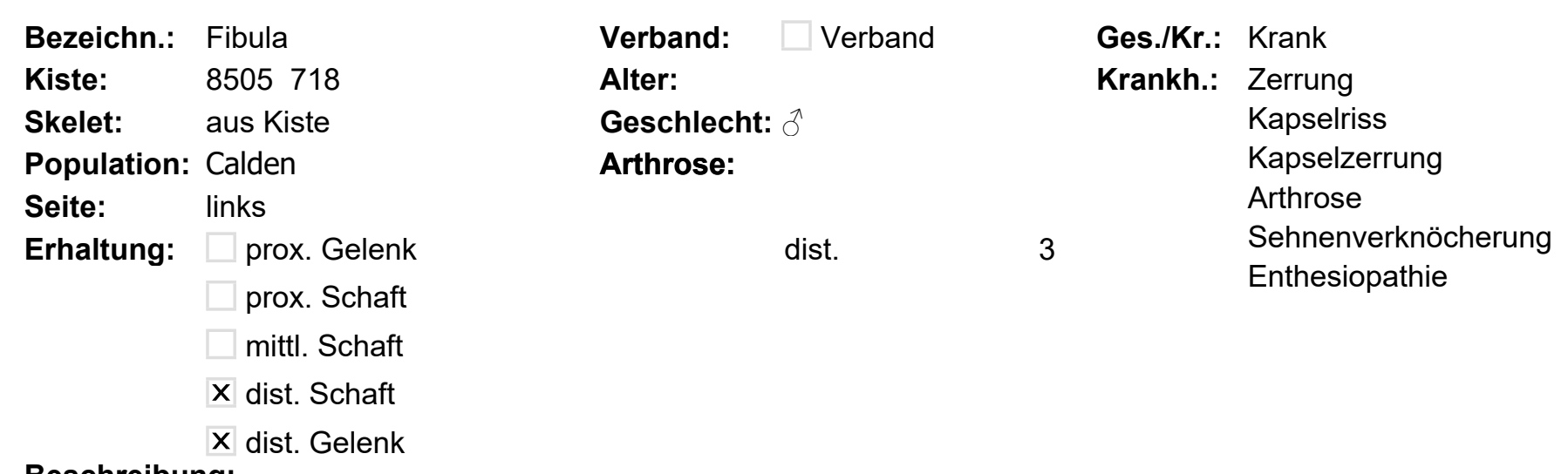

\section{Beschreibung:}

Bei diesem Fundstück handelt es sich um ein distales Fragment einer Fibula. Das Ligamentum tibio - fibularis distalis ist gezerrt worden. Dieser Prozess ist traumatisch verlaufen. Weiterhin ist das Ligamentum collaterale laterale in der Fossa malleoli laterale gezerrt. Die Verknöcherungen der Sehne messen bis zu $46 \mathrm{~mm} \times 12 \mathrm{~mm} \times 10 \mathrm{~mm}$. 

Bezeichn.: Fibula
Kiste: $\quad 8505718$
Skelet: aus Kiste
Seite: links
Erhaltung: $\mathbf{X}$ prox. Gelenk
$\mathbf{X}$ prox. Schaft
$X$ mittl. Schaft
dist. Schaft
dist. Gelenk

Verband:

Verband

Ges./Kr.: Gesund

Alter:

\section{Geschlecht:}

\section{Beschreibung:}

Von dieser Fibula ist nur ein proximales Fragment erhalten, welches etwa die Hälfte der gesamten Fibula ausmacht. Sie ist durch Grabungsartefakte und Canidenverbiss postmortal verändert. Sie weist eine leichte Reizung im Bereich des M. soleus auf. 
Bezeichn.: Fibula

Kiste: $\quad 8505718$

Skelet: Calden 2,6;2,25

Population: Calden

Seite: rechts

Erhaltung: $\mathbf{X}$ prox. Gelenk

$X$ prox. Schaft

$X$ mittl. Schaft

$\mathbf{X}$ dist. Schaft

X dist. Gelenk

\section{Beschreibung:}

Dieses Fundstück einer rechten Fibula ist sehr massiv.
Verband: $\square$ Verband

\section{Alter:}

Ges./Kr.: Gesund

Geschlecht:

Arthrose:

\section{Maß}

Länge

Wert $\quad$ Einheit

\begin{tabular}{l|l}
350 & $\mathrm{~mm}$
\end{tabular}


Bezeichn.: Fibula

Kiste: $\quad 8505718$

Skelet: Calden 3,$75 ; 3,4$

Population: Calden

Seite: rechts

Erhaltung: $\mathbf{X}$ prox. Gelenk

$X$ prox. Schaft

$X$ mittl. Schaft

$\mathbf{X}$ dist. Schaft

X dist. Gelenk

Beschreibung:

Drei Fragmente.
Verband: $\square$ Verband

\section{Alter:}

Ges./Kr.: Gesund

\section{Geschlecht:}

Arthrose:

prox.

dist.

2
Maß

Länge

\begin{tabular}{l|l} 
Wert & Einheit \\
\hline 325 & $\mathrm{~mm}$
\end{tabular}


Bezeichn.: Fibula

Kiste:

8505718

Skelet: $\quad$ V41 aus Kiste

Population: Calden

Seite: links

Erhaltung:

prox. Gelenk

prox. Schaft

mittl. Schaft

$\mathbf{X}$ dist. Schaft

$X$ dist. Gelenk
Verband: $\square$ Verband

\section{Alter:}

Geschlecht:

Arthrose:

dist.
Ges./Kr.: Krank

Krankh.: Arthrose

Myotendopathie

Kapselzerrung

\section{Beschreibung:}

Von dieser Fibula ist nur das distale Gelenk mit etwas Schaft erhalten. Am Tibio - fibular - Gelenk finden sich bläschenförmige Auflagerungen. Hier gab es augenscheinlich eine Zerrung, die zum Beispiel durch einen Sprung mit anschließender harter Landung ausgelöst worden sein könnte. Dabei hat sich dann der Talus keilförmig zwischen Tibia und Fibula nach oben gedrückt, was dann zu Kapselzerrung bzw. bisweilen auch zu einem Kapselriss führen kann. Hier führte das traumatische Ereignis jedenfalls zu einer entzündlichen Reaktion. Von der Tibia ist auch nur ein distales Fragment mit Gelenk erhalten. 
Bezeichn.: Fibula

Kiste: $\quad 8505718$

Skelet: aus Kiste

Population: Calden

Seite: links

Erhaltung: $\square$ prox. Gelenk prox. Schaft

mittl. Schaft

$\mathbf{X}$ dist. Schaft

$\mathbf{X}$ dist. Gelenk

Beschreibung:

Ein distales Fragment.
Verband: $\quad \square$ Verband

Alter:

Geschlecht: $\widehat{\partial}$

Arthrose:

Ges./Kr.: Gesund 
Bezeichn.: Fibula

Kiste: $\quad 5267282$

Skelet: 2.

Population: Calden

Seite: rechts

Erhaltung: $\mathbf{X}$ prox. Gelenk

prox. Schaft

mittl. Schaft

dist. Schaft

dist. Gelenk
Ges./Kr.: Krank

Krankh.: Arthrose

Myotendopathie
Alter:

Geschlecht:

Arthrose:

prox.

\section{Beschreibung:}

Bei dieser Fibula liegt eine leichte Myotendopathie bei der Ansatzstelle des Ligamentum tibio - fibularis proximalis vor. 
Bezeichn.: Fibula

Kiste: $\quad 5243267$

Skelet: P.Sk.1.

Population: Calden

Seite: rechts

Erhaltung: $\square$ prox. Gelenk prox. Schaft

mittl. Schaft

$\mathbf{X}$ dist. Schaft

$X$ dist. Gelenk

Beschreibung:

Ein distales Fibulafragment.
Verband: $\quad \square$ Verband

\section{Alter:}

Geschlecht:

Arthrose:

dist.
Ges./Kr.: Krank

Krankh.: Arthrose 
Bezeichn: Fibula

Kiste: 5243267

Skelet: P.Sk.1.

Population: Calden

Seite: n. def.

Erhaltung: $\square$ prox. Gelenk

prox. Schaft

$X$ mittl. Schaft

dist. Schaft

dist. Gelenk
Ges./Kr.: Krank

Krankh.: Periostreizung

Muskelreizung

\section{Beschreibung:}

Verband: $\quad \square$ Verband

\section{Alter:}

Geschlecht:

Arthrose:

Dieses Fundstück weist auf seiner Oberfläche streifenförmige Knochenneubildungen auf. 
Bezeichn.: Fibula

Kiste: 5243267

Skelet: Zettel

Population: Calden

Seite: links

Erhaltung: $\square$ prox. Gelenk prox. Schaft

mittl. Schaft dist. Schaft X dist. Gelenk

Beschreibung:

Ein distales Fibulafragment.
Verband: $\quad \square$ Verband

\section{Alter:}

\section{Geschlecht:}

Arthrose:

dist. 
Bezeichn.: Fibula

Kiste: 5243267

Skelet: Zettel

Population: Calden

Seite: links

Erhaltung: $\square$ prox. Gelenk

prox. Schaft

$X$ mittl. Schaft

dist. Schaft

dist. Gelenk

Beschreibung:

Ein mittiges Fibulafragment in schlechtem Erhaltungszustand.
Verband: $\quad \square$ Verband

\section{Alter:}

Geschlecht:

Arthrose: 

Bezeichn:: Fibula
Kiste: $\quad 5256274$
Skelet: Sk.11
Population: Calden
Seite: links
Erhaltung: $\mathbf{X}$ prox. Gelenk
$X$ prox. Schaft
$X$ mittl. Schaft
X dist. Schaft
dist. Gelenk
Beschreibung:

Verband: $\square$ Verband

\section{Alter:}

Geschlecht:

Arthrose:

prox.

Diese Fibula weist eine Krümmung nach anterior - media lauf. Diese Krümmung könnte durch starken Zug des M. soleus hervorgerufen worden sein. 
Bezeichn.: Fibula

Kiste: $\quad 5256274$

Skelet: bei SCH 27 im Verbund

Population: Calden

Seite: n. def.

Erhaltung: $\square$ prox. Gelenk

$X$ prox. Schaft

$X$ mittl. Schaft

$\mathbf{X}$ dist. Schaft

dist. Gelenk

Beschreibung:

Ein Fibulafragment mit deutlichen Muskelmarken besonders im Bereich der Membrana interossea.
Verband: $\quad$ Verband

\section{Alter:}

Geschlecht:

Arthrose: 
Bezeichn.: Fibula

Kiste: 5256274

Skelet: Zettel

Population: Calden

Seite: rechts

Erhaltung: $\square$ prox. Gelenk

$X$ prox. Schaft

$X$ mittl. Schaft

$\mathbf{X}$ dist. Schaft

dist. Gelenk

Beschreibung:

Ein mittiges Fibulafragment.
Verband: $\quad \square$ Verband

\section{Alter:}

Geschlecht:

Arthrose: 
Bezeichn.: Fibula

Kiste: 5256274

Skelet: V32 Sk8

Population: Calden

Seite: rechts

Erhaltung: $\square$ prox. Gelenk prox. Schaft

$X$ mittl. Schaft

$\mathbf{X}$ dist. Schaft

$\mathbf{X}$ dist. Gelenk

Beschreibung:

Ein distales Fibulafragment.
Verband: $\square$ Verband

\section{Alter:}

\section{Geschlecht:}

Arthrose:

dist. 

Bezeichn.: Fibula
Kiste:
5256274
Skelet: $\quad$ V32 Sk8
Population: Calden
Seite: links
Erhaltung: $\mathbf{X}$ prox. Gelenk
$X$ prox. Schaft
$x$ mittl. Schaft
$\mathbf{X}$ dist. Schaft
$X$ dist. Gelenk
Beschreibung:

Eine recht gut erhaltene Fibula in fast vollständiger Erhaltungsmenge.
Verband: $\quad$ Verband

\section{Alter:}

Ges./Kr.: Gesund

Geschlecht:

Arthrose:

prox.

dist.

2

2 


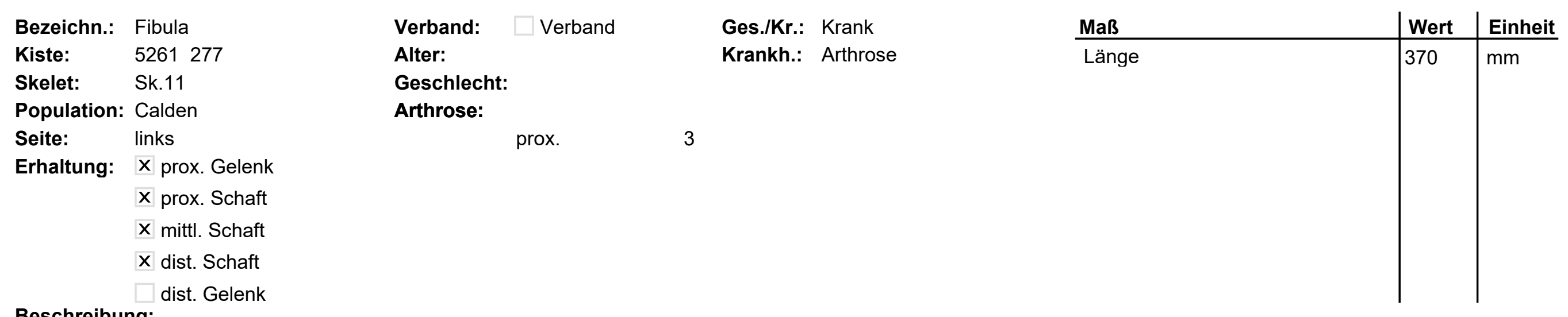

\section{Beschreibung:}

Diese Fibula ist recht stark nach medial gebogen. Sie weist eine starke Membrana interossea mit mittigen Exostosen auf. Am Gelenk findet sich eine Grubenbildung, die durch Muskelüberreizung des M. soleus proximalis hervorgerufen worden sein könnte. 


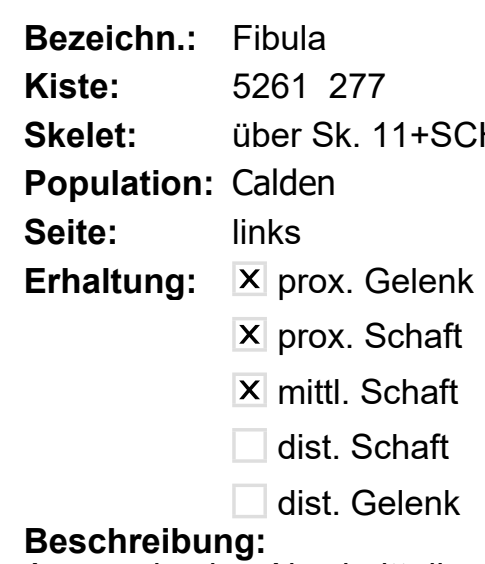

Am proximalen Abschnitt dieser Fibula liegt eine leichte Periostanhebung. Diese könnte als subperiostales Hämatom entstanden sein. 

Bezeichn.: Fibula
Kiste:
5261277
Skelet: ohne Bezeichnung
Population: Calden
Seite:
links
Erhaltung: $\square$ prox. Gelenk
X prox. Schaft
$X$ mittl. Schaft
X dist. Schaft
dist. Gelenk
Beschreibung:

Schaft einer linken Fibula.
Verband: $\square$ Verband

\section{Alter:}

Geschlecht:

Arthrose: 


\section{Bezeichn.: Fibula \\ Kiste: $\quad 5261277$ \\ Skelet: unter $\mathrm{SCH} .8+3$ \\ Population: Calden \\ Seite: \\ links \\ Erhaltung: $\square$ prox. Gelenk \\ prox. Schaft \\ $X$ mittl. Schaft \\ $\mathbf{X}$ dist. Schaft \\ $X$ dist. Gelenk \\ Beschreibung:}

Diese Fibula ist nur distal erhalten.
Verband: Verband

\section{Alter:}

Geschlecht:

Arthrose: 


\section{Bezeichn.: Fibula \\ Kiste: $\quad 5261277$ \\ Skelet: unter $\mathrm{SCH} .8+3$ \\ Population: Calden \\ Seite: rechts \\ Erhaltung: $\square$ prox. Gelenk \\ X prox. Schaft \\ $X$ mittl. Schaft \\ $\mathbf{X}$ dist. Schaft dist. Gelenk \\ Beschreibung:}

Verband: $\quad$ Verband

Ges./Kr.: Gesund

\section{Alter:}

Geschlecht:

Arthrose:

Diese Fibula weist eine Biegung nach distal auf. Weiterhin Fällt ein starker Ansatz der Membrana interossea auf. 
Bezeichn.: Fibula

Kiste: $\quad 5263278$

Skelet: Zettel P16+18

Population: Calden

Seite: links

Erhaltung: $\square$ prox. Gelenk

prox. Schaft

$X$ mittl. Schaft

$\mathbf{X}$ dist. Schaft

X dist. Gelenk
Verband: $\quad$ Verband

\section{Alter:}

Geschlecht:

Arthrose:
Ges./Kr.: Krank

Krankh.: Arthrose

Enthesiopathie

Kapselzerrung

\section{Beschreibung:}

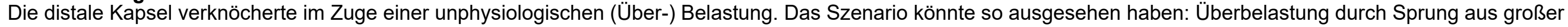

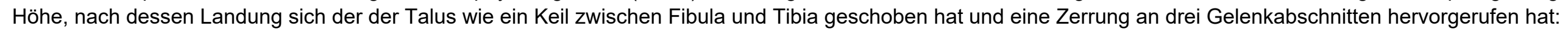

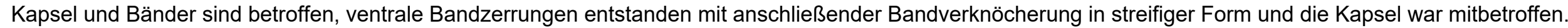


Bezeichn.: Fibula

Kiste: $\quad 5263278$

Skelet:

Population: Calden

Erhaltung: prox. Gelenk prox. Schaft

mittl. Schaft

$\mathbf{X}$ dist. Schaft

$\mathbf{X}$ dist. Gelenk

Beschreibung:

Bei dieser Fibula liegen leichte Verknöcherungen an der Syndesmosis tibio - fibularis vor.

\section{Alter: \\ Geschlecht:}

Arthrose:
Ges./Kr.: Krank

Krankh.: Kapselzerrung 
Bezeichn:: Fibula

Kiste: $\quad 5263278$

Skelet: $\quad$ V23 Tibia Fibula 48

Population: Calden

Seite: rechts

Erhaltung: $\square$ prox. Gelenk

prox. Schaft

$X$ mittl. Schaft

$\mathbf{X}$ dist. Schaft

X dist. Gelenk
Verband: $\quad$ Verband

Alter:

Geschlecht:

Arthrose:
Ges./Kr.: Krank

Krankh.: Kapselzerrung

Bandverknöcherungen
2

\section{Beschreibung:}

Diese Fibula liegt im Verband mit einer Tibia vor. Sie weisen eine deutliche Sehnenverknöcherung des Articulatio Tibio - fibularis auf, die nach einer Kapselzerrung entstanden ist. 
Bezeichn.: Fibula

Kiste: $\quad 5245269$

Skelet: 6

Population: Calden

Seite: links

Erhaltung: $\square$ prox. Gelenk

prox. Schaft

$X$ mittl. Schaft

dist. Schaft

dist. Gelenk

Beschreibung:

Bei diesem mittigen Fibulafragment ist der Margo interosseus gut ausgeprägt.
Verband: $\quad$ Verband

\section{Alter:}

Geschlecht:

Arthrose: 
Bezeichn.: Fibula

Kiste: 8505719

Skelet: Steinkammer 1

Population: Calden

Seite: rechts

Erhaltung: $\square$ prox. Gelenk

prox. Schaft

$X$ mittl. Schaft

dist. Schaft

dist. Gelenk

\section{Beschreibung:}

Ein Fragment aus dem Schaft einer Fibula, welches schlecht erhalten ist.
Verband: $\quad$ Verband

\section{Alter:}

Geschlecht:

Arthrose: 
Bezeichn.: Fibula

Kiste: $\quad 8505719$

Skelet: Steinkammer 1

Population: Calden

Seite: rechts

Erhaltung: $\square$ prox. Gelenk

prox. Schaft

$X$ mittl. Schaft

dist. Schaft

dist. Gelenk

Beschreibung:

ein mittiges Fibulafragment ohne Auffälligkeiten.
Verband: $\quad \square$ Verband

\section{Alter:}

Geschlecht:

Arthrose:

Ges./Kr.: Gesund 


$\begin{array}{lll}\text { Bezeichn.: } & \text { Fibula } & \text { Verband: } \square \text { Verband } \\ \text { Kiste: } & 8505719 & \text { Alter: } \\ \text { Skelet: } & \text { Steinkammer } 1 & \text { Geschlecht: } \\ \text { Population: } & \text { Calden } & \text { Arthrose: } \\ \text { Seite: } & \text { links } & \\ \text { Erhaltung: } & \square \text { prox. Gelenk } & \\ & \text { X prox. Schaft } & \\ & \square \text { mittl. Schaft } & \\ & \square \text { dist. Schaft } & \\ & \square \text { dist. Gelenk }\end{array}$

Dieses Fragment aus dem proximalen Schaft einer jungen Fibula ist in erodiertem Zustand erhalten. 
Bezeichn.: Fibula

Kiste: $\quad 8505719$

Skelet: Steinkammergrab 1

Population: Calden

Seite: links

Erhaltung: $\square$ prox. Gelenk

prox. Schaft

mittl. Schaft

$\mathbf{X}$ dist. Schaft

$\mathbf{X}$ dist. Gelenk

Beschreibung:

Ein distales Fragment einer Fibula.
Verband: $\quad$ Verband

\section{Alter:}

Geschlecht:

Arthrose:
Ges./Kr.: Gesund 
Bezeichn.: Fibula

Kiste: $\quad 8505719$

Skelet: Steinkammergrab 1

Population: Calden

Seite: rechts

Erhaltung: $\square$ prox. Gelenk

$X$ prox. Schaft

mittl. Schaft

dist. Schaft

dist. Gelenk

Beschreibung:

Ein proximales Fragment.
Verband: $\square$ Verband

\section{Alter:}

Geschlecht:

Arthrose: 
Bezeichn.: Fibula

Kiste:

8505719

Skelet: steinkammergrab 1

Population: Calden

Seite:

links

Erhaltung: $\square$ prox. Gelenk

prox. Schaft

mittl. Schaft

X dist. Schaft

dist. Gelenk

Beschreibung:

Ein distales Fragment.
Verband: $\quad \square$ Verband

\section{Alter:}

Geschlecht:

Arthrose: 
Bezeichn.: Fibula

Kiste: $\quad 8505719$

Skelet: Steinkammergrab 1

Population: Calden

Seite:

links

Erhaltung: $\square$ prox. Gelenk prox. Schaft

mittl. Schaft

X dist. Schaft dist. Gelenk

Beschreibung:

Ein distales Fragment.
Verband: $\quad \square$ Verband

\section{Alter:}

Geschlecht:

Arthrose: 
Bezeichn.: Fibula

Kiste: $\quad 8505719$

Skelet: $\quad$ steinkammergrab 1

Population: Calden

Seite: rechts

Erhaltung: $\square$ prox. Gelenk

prox. Schaft

mittl. Schaft

$\mathbf{X}$ dist. Schaft

X dist. Gelenk
Verband: $\quad \square$ Verband

Alter:

Geschlecht:

Arthrose:
Ges./Kr.: Krank

Krankh.: Kapselzerrung

Kapselriss

Arthritis

\section{Beschreibung:}

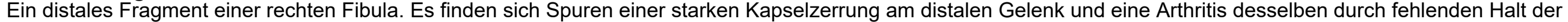
Kapsel, die auch teilweise eingerissen war. 
Bezeichn.: Fibula

Kiste: $\quad 8505719$

Skelet: Steinkammergrab 1

Population: Calden

Seite: links

Erhaltung: $\square$ prox. Gelenk

prox. Schaft

mittl. Schaft

$\mathbf{X}$ dist. Schaft

X dist. Gelenk

Beschreibung:

Ein distales Fragment einer Fibula.
Verband: $\quad$ Verband

\section{Alter:}

Geschlecht:

Arthrose:
Ges./Kr.: Gesund dist. 
Bezeichn.: Fibula

Kiste:

8505719

Verband:

Verband

\section{Alter:}

Ges./Kr.: Gesund

Skelet: steinkammergrab 1

Population: Calden

Seite: rechts

Erhaltung: $\mathbf{X}$ prox. Gelenk

$\mathbf{X}$ prox. Schaft

mittl. Schaft

dist. Schaft

dist. Gelenk

Beschreibung:

Ein proximales Fragment einer sehr massiven rechten Fibula. 
Bezeichn.: Fibula

Kiste:

8505719

Skelet: Extremitätenfragemente

Population: Calden

Seite: rechts

Erhaltung: $\square$ prox. Gelenk

prox. Schaft

mittl. Schaft

X dist. Schaft

dist. Gelenk

Beschreibung:

Ein Fragment aus dem distalen Schaft.
Verband: $\quad \square$ Verband

\section{Alter:}

Geschlecht:

Arthrose: 


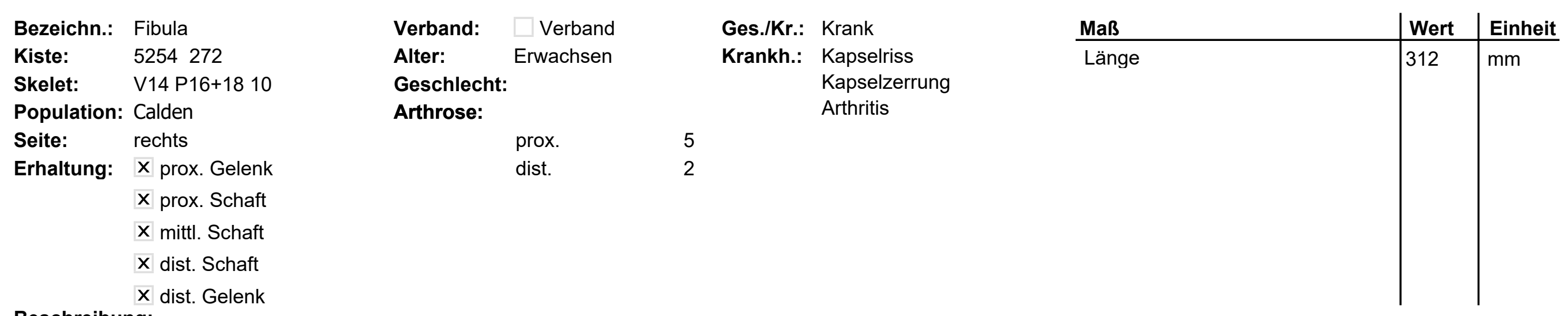

\section{Beschreibung:}

Diese Fibula weist pathologische Veränderungen nach einem traumatischen Ereignisses auf. Der Ablauf des Ereignissen könnte wie folgt ausgesehen haben: Das Individuum sprang aus größerer Höhe und landete zu früh mit dem noch ausgestreckten Fuß, bzw. der Fußspitze. Dabei ist der Talus keilförmig in das Articulatio talo - cruralis vorgeschoben worden und die Kapsel der Fibula an dieser Stelle gerissen. Weiterhin ergab sich eine starke Zerrung der Muskeln Fibularis brevis und Soleus. Außerdem kam es zu einem Kapselriss am Articulatio geniculatum mit einem später resultierenden seitlichen Auswuchs und einer Arthritis an der Facies articularis malleoli lateralis. Der Gelenkverschleiß resultierte aus der gerissenen Kapsel, die dem Gelenk keinen ausreichenden Halt mehr geben konnte. 


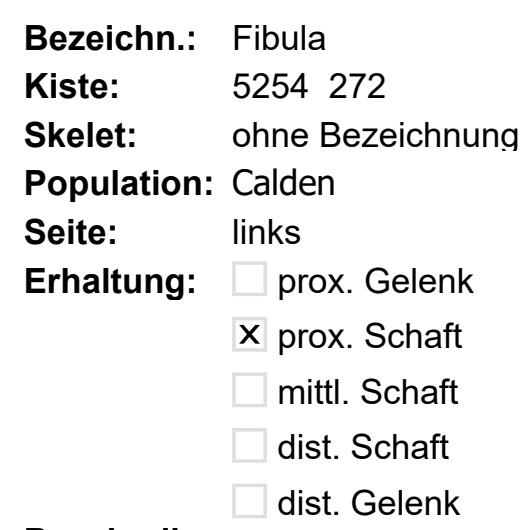

Verband: $\quad \square$ Verband

Alter:

Geschlecht:

Arthrose:

Ein Fragment aus dem proximalen Drittel. 
Bezeichn:: Fibula

\section{Kiste: $\quad 5254272$}

Skelet: $\quad$ P7

Population: Calden

Seite: rechts

Erhaltung: $\square$ prox. Gelenk

$X$ prox. Schaft

$X$ mittl. Schaft

$\mathbf{X}$ dist. Schaft

$\mathbf{X}$ dist. Gelenk

\section{Beschreibung:}

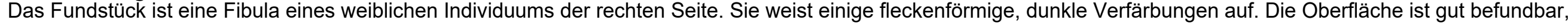

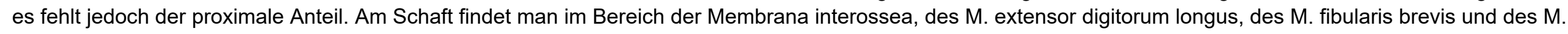
extensor hallucis longus kleine Knochenneubildungen (maximal 7,8mm x 2,2mm) im Sinne einer leichten Reizung des Periostes. 
Bezeichn.: Fibula

Kiste: $\quad 5254272$

Skelet: bei Sk7 o. Sch.23+25

Population: Calden

Seite: rechts

Erhaltung: $\square$ prox. Gelenk

$X$ prox. Schaft

$X$ mittl. Schaft

$\mathbf{X}$ dist. Schaft

$X$ dist. Gelenk

\section{Beschreibung:}

Das Fundstück ist eine männliche Fibula, welche am distalen Gelenk erodiert ist. Das proximale Gelenk fehlt. Ansonsten weist das Fundstück eine gut befundbare

Oberfläche auf. Im Bereich der Muskeln fibularis longus und fibularis brevis zeigen sich kleine Knochenneubildungen im Sinne einer leichten Zerrung der Muskulatur. Die Neubildungen messen höchstens $5 \mathrm{~mm} \times 1,8 \mathrm{~mm}$. 

Bezeichn.: Fibula
Kiste:
5266281
Skelet: parallel Sch. 23
Population: Calden
Seite: rechts
Erhaltung: $\mathbf{X}$ prox. Gelenk
$\mathbf{X}$ prox. Schaft
$X$ mittl. Schaft
dist. Schaft
dist. Gelenk
Beschreibung:

Verband:

Verband

Ges./Kr.: Gesund

\section{Alter:}

Maß

Länge Wert 1 Einheit

Geschlecht:

Arthrose:

Diese Fibula weist definierte Muskelmarken auf. 


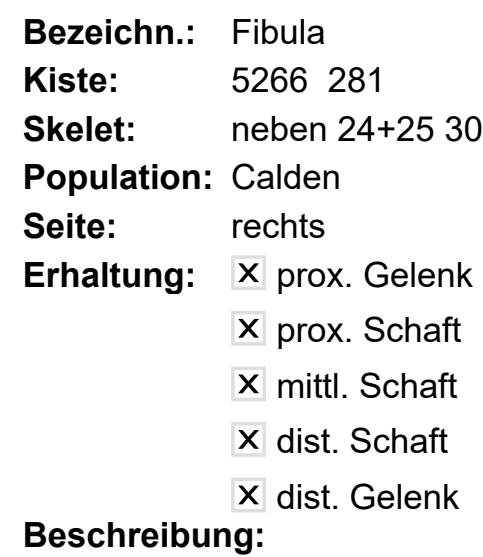

Eine vollständige Fibula.
Verband: $\quad$ Verband

\section{Alter:}

Ges./Kr.: Gesund

Geschlecht:

Arthrose: 
Bezeichn.: Fibula

Kiste: 5259276

Skelet: aus Tüte

Population: Calden

Seite:

links

Erhaltung: $\square$ prox. Gelenk prox. Schaft

mittl. Schaft

$\mathbf{X}$ dist. Schaft dist. Gelenk

Beschreibung:

Ein distales Fragment.
Verband: Verband

\section{Alter:}

Geschlecht:

Arthrose: 
Bezeichn.: Fibula

Kiste: $\quad 8505721$

Skelet: aus großer Kiste

Population: Calden

Seite: rechts

Erhaltung: $\square$ prox. Gelenk prox. Schaft

$X$ mittl. Schaft dist. Schaft dist. Gelenk

Beschreibung:

Fragment aus dem Schaft.
Verband: $\quad \square$ Verband

\section{Alter:}

Geschlecht:

Arthrose:
Ges./Kr.: Gesund

Ges.Kr: Gesund 


\section{Bezeichn.: Talus}

Kiste: $\quad 8505718$

Skelet: $\quad$ V68 aus Tüte

Population: Calden

Seite:

links

\section{Verband: $\quad$ Verband}

\section{Alter:}

Geschlecht: $q$

Arthrose:
Ges./Kr.: Gesund

\section{Maß}

Breite

Länge

\begin{tabular}{|l|l} 
Wert & Einheit \\
\hline
\end{tabular}

$38 \quad \mathrm{~mm}$

$\mathrm{mm}$

\section{Beschreibung:}

Dies ist ein sehr graziler Talus der linken Seite. Er gehört wohl zum Talus der rechten Seite. 


\section{Bezeichn.: Talus}

Kiste: $\quad 8505718$

Skelet: $\quad$ V68 aus Tüte

Population: Calden

Seite:

rechts

\section{Verband: $\quad$ Verband}

\section{Alter:}

Geschlecht: 우

Arthrose:

\begin{tabular}{l|l|l} 
Maß & Wert & Einheit \\
\hline Breite & 37,14 & $\mathrm{~mm}$ \\
Länge & 51 & $\mathrm{~mm}$ \\
& & \\
& & \\
& &
\end{tabular}

\section{Beschreibung:}

Dies ist ein sehr graziler Talus der rechten Seite. Er gehört wohl zum Talus der linken Seite. 
Bezeichn:: Talus

Kiste: $\quad 5272290$

Skelet: bei Cranium 34

Population: Calden

Seite:

links
Verband: $\square$ Verband

Alter:

Geschlecht: 우

Arthrose:
Maß

Breite

Länge
Wert 1 Einheit

$34,55 \mathrm{~mm}$

$46,72 \mathrm{~mm}$

\section{Beschreibung:}

Ein recht kleiner Talus mit Erosionsspuren. 
Bezeichn.: Talus

Kiste: $\quad 5272290$

Skelet: bei Cranium 34

Population: Calden

Seite:

rechts
Ges./Kr.: Gesund

\section{Alter:}

Geschlecht: $q \leq \lambda$

Arthrose:
Beschreibung:

Hier ist nur ein Fragment erhalten. 
Bezeichn:: Talus

Kiste: $\quad 5266281$ Tüte 2

Skelet: $\quad 3,75 x ; 5,5 y$;

Population: Calden

Seite:
Verband: $\square$ Verband

Alter:

Geschlecht:

Arthrose:
Ges./Kr.: Krank

Krankh.: Arthrose

\section{Beschreibung:}

Dieser linke Talus zeigt am Gelenkrand deutliche Verschleißerscheinungen. 
Bezeichn.: Talus

Kiste: $\quad 5266281$

Skelet: $\quad$ V65 aus Tüte 4

Population: Calden

Seite: rechts
Verband: $\quad$ Verband

\section{Alter:}

Geschlecht:

Arthrose:

\section{Beschreibung:}

Zusammen passende tali, was an einer Besonderheit der Gelenkflächen zu erkennen ist. 
Bezeichn:: Talus

Kiste: $\quad 5266281$

Skelet: $\quad$ V65 aus Tüte 4

Population: Calden

Seite:

links
Verband: $\square$ Verband

\section{Alter:}

\section{Geschlecht:}

Arthrose:

\section{Beschreibung:}

Zusammen passende tali, was an einer Besonderheit der Gelenkflächen zu erkennen ist. 
Bezeichn.: Talus

Kiste: $\quad 5242266$

Skelet: 3. Tüte

Population: Calden

Seite: rechts

\section{Beschreibung:}

Ein sehr stark erodiertes Fundstück.
Verband: $\square$ Verband

\section{Alter:}

Geschlecht:

Arthrose:
Maß

Länge

\begin{tabular}{|l|l} 
Wert & Einheit \\
\hline 58 & $\mathrm{~mm}$ \\
&
\end{tabular}


Bezeichn.: Talus

Kiste: $\quad 5242266$

Skelet: $\quad 3$. Tüte

Population: Calden

Seite: rechts

\section{Beschreibung:}

Ein sehr stark erodiertes Fundstück.
Verband: $\quad$ Verband

\section{Alter:}

Geschlecht: $ㅇ$

Arthrose:
Maß

Länge

\begin{tabular}{|l|l} 
Wert & Einheit \\
\hline 47 & $\mathrm{~mm}$ \\
&
\end{tabular}


Bezeichn.: Talus

Kiste: $\quad 5242266$

Skelet: $\quad 3$. Tüte

Population: Calden

Seite:

links
Ges./Kr.: Gesund

\section{Alter:}

Geschlecht: $q \leq \lambda$

Arthrose:

\section{Beschreibung:}

Von diesem Talus sind nur $60 \%$ erhalten. 
Bezeichn.: Talus

Kiste: $\quad 5242266$

Skelet: 3. Tüte

Population: Calden

Seite:

links

Verband: $\quad$ Verband

\section{Alter:}

Geschlecht: $q \leq \lambda$

Arthrose:

\section{Beschreibung:}




\section{Bezeichn.: Talus \\ Kiste: $\quad 5242266$ \\ Skelet: 3 . Tüte}

Population: Calden

Seite:

links
Verband: $\square$ Verband

\section{Alter:}

Geschlecht: ${ }^{\lambda}$

Arthrose:
Ges./Kr.: Gesund

\section{Maß}

Länge

\begin{tabular}{|l|l} 
Wert & Einheit \\
\hline 49 & $\mathrm{~mm}$ \\
&
\end{tabular}

\section{Beschreibung:}

Hier sind etwa $90 \%$ eines Talus erhalten. 
Bezeichn.: Talus

\section{Kiste: $\quad 5242266$}

Skelet: 3 . Tüte

Population: Calden

Seite:

\section{Verband: $\quad$ Verband}

\section{Alter:}

Geschlecht: $\delta$

Arthrose:
Ges./Kr.: Gesund

\section{Maß}

Länge

\begin{tabular}{l|l}
58 & $\mathrm{~mm}$
\end{tabular}

prox.

2

dist.

\section{Beschreibung:}

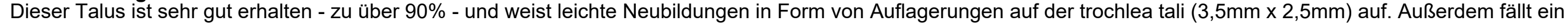

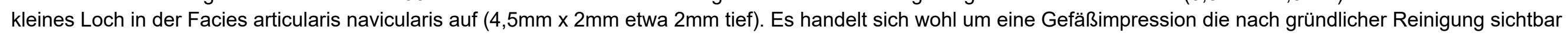

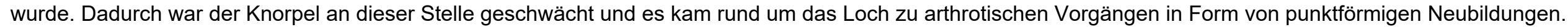


Bezeichn.: Talus

Kiste: $\quad 5242266$

Skelet: $\quad$ V55 Calcaneus 3. Tüte

Population: Calden

Seite:

links
Verband: $\quad$ Verband

\section{Alter:}

Ges./Kr.: Gesund

Geschlecht:

Arthrose:

\section{Beschreibung:}

Dieser Talus ist erodiert, aber zu 90\% erhalten. Er gehört wohl mit dem Calcaneus zusammen. 


\section{Bezeichn.: Talus}

\section{Kiste:}

8505718

Skelet: $\quad$ V43 aus 2. Kiste

Population: Calden

Seite:
Verband: $\quad$ Verband

Alter:

Geschlecht: 우

Arthrose:

\section{Beschreibung:}

Dieser Talus gehört wohl zu dem Calcaneus. 


\section{Bezeichn.: Talus}

Kiste: $\quad 8505718$

Skelet: V53 aus 2. Kiste

Population: Calden

Seite: rechts
Verband: Verband

Alter:

Geschlecht: $q \leq \lesssim$

Arthrose:

$$
\text { prox. }
$$

dist.
Ges./Kr.: Gesund

Maß

Länge

\begin{tabular}{|l|l} 
Wert & Einheit \\
\hline 51 & $\mathrm{~mm}$ \\
&
\end{tabular}

\section{Beschreibung:}

Ein sehr gut erhaltener Talus, welcher zu dem Calcaneus gehört. 


\section{Bezeichn.: Talus}

\section{Kiste:}

8505718

Skelet: $\quad$ V48 aus 2. Kiste

Population: Calden

Seite: rechts
Verband: Verband

\section{Alter:}

Ges./Kr.: Gesund

Geschlecht:

Arthrose:
Maß

Länge

\begin{tabular}{|l|l} 
Wert & Einheit
\end{tabular}

$57 \quad \mathrm{~mm}$

\section{Beschreibung:}

Dieser Talus ist zu 95\% erhalten und gehört zu dem anderen. 


\section{Bezeichn.: Talus}

\section{Kiste:}

8505718

Skelet: $\quad$ V48 aus 2. Kiste

Population: Calden

Seite:
Verband: $\square$ Verband

\section{Alter:}

Ges./Kr.: Gesund

Geschlecht:

Arthrose:

\section{Beschreibung:}

Dieser Talus ist zu 85\% erhalten und gehört zu dem anderen. 


\section{Bezeichn: Talus}

Kiste:

8505718

Skelet: aus 2. Kiste

Population: Calden

Seite:
Verband: $\quad$ Verband

Alter:

Geschlecht: $ᄋ$

Arthrose:

\section{Beschreibung:}

Dieser Talus ist recht grazil, er ist zu $80 \%$ erhalten. 


\section{Bezeichn.: Talus}

\section{Kiste:}

8505718

Skelet: $\quad$ aus 2. Kiste

Population: Calden

Seite:
Verband: $\square$ Verband

Alter:

Geschlecht: $\hat{\delta}$

Arthrose:
Ges./Kr.: Gesund

\section{Maß}

Länge

\begin{tabular}{|l|l}
55,7 & $\mathrm{~mm}$ \\
& \\
&
\end{tabular}

\section{Beschreibung:}

Dieser Talus ist massiv, gut erhalten (95\%) und weist kaum Erosion auf. 


\section{Bezeichn.: Talus}

\section{Kiste:}

8505718

Skelet: $\quad$ V49 aus 2. Kiste

Population: Calden

Seite:
Verband: $\quad$ Verband

\section{Alter:}

Ges./Kr.: Gesund

Geschlecht: $q$

Arthrose:
Maß

Länge

\section{Beschreibung:}

Dieser Talus ist sehr grazil, es sind $90 \%$ erhalten. 


\section{Bezeichn.: Talus}

\section{Kiste:}

8505718

Skelet: $\quad$ V49 aus 2. Kiste

Population: Calden

Seite:

links
Verband: $\quad$ Verband

\section{Alter:}

Geschlecht: $q$

Arthrose:
Ges./Kr.: Gesund

prox

\section{Maß}

Länge

Wert $\quad$ Einheit

dist.

\section{Beschreibung:}

Dieser Talus ist gut erhalten zu 95\% und ist grazil. 


\section{Bezeichn:: Talus}

\section{Kiste:}

8505718

Skelet: $\quad$ V50 Femora Tibiae 2.

Population: Calden

Seite:

rechts
Verband: $\square$ Verband

Alter:

Geschlecht: $q$

Arthrose:

\section{Maß}

Länge

Wert 1 Einheit

\section{Beschreibung:}

Im Verband, zu 98\% erhalten und grazil. 
Bezeichn.: Talus

Kiste: $\quad 8505718$

Skelet: aus 2. Kiste

Population: Calden

Seite:

links
Verband: $\quad$ Verband

\section{Alter:}

Geschlecht: $\hat{\delta}$

Arthrose:
Ges./Kr.: Gesund

\section{Maß}

Länge

\begin{tabular}{|l|l} 
Wert & Einheit \\
\hline 57 & $\mathrm{~mm}$ \\
& \\
&
\end{tabular}

\section{Beschreibung:}

Dieser Talus ist zu 98\% erhalten. 


\section{Bezeichn.: Talus}

Kiste:

8505718

Skelet: $\quad$ V51 aus 2. Kiste Population: Calden

Seite: links

\section{Verband: $\quad$ Verband}

\section{Alter:}

Geschlecht: $\hat{\jmath}$

Arthrose:
Ges./Kr.: Gesund

\section{Maß}

Länge \begin{tabular}{|l|l} 
Wert & Einheit
\end{tabular}

$57 \quad \mathrm{~mm}$

\section{Beschreibung:}

Dieser Talus ist zu 98\% erhalten und weist leichte dunkle Verfärbungen auf. Sie gehören zusammen. 


\section{Bezeichn.: Talus}

Kiste:

Skelet: $\quad$ V51 aus 2. Kiste Population: Calden

Seite:
8505718

\section{Verband: $\quad$ Verband}

\section{Alter:}

Geschlecht: $\hat{\jmath}$

Arthrose:
Ges./Kr.: Gesund

\section{Beschreibung:}

Dieser Talus ist zu 98\% erhalten und weist leichte dunkle Verfärbungen auf. Sie gehören zusammen. 
Bezeichn.: Talus

Kiste: $\quad 8505718$

Skelet: aus 2. Kiste

Population: Calden

Seite: rechts

\section{Beschreibung:}

Dieser Talus ist zu 98\% erhalten.
Verband: $\square$ Verband

Alter:

Ges./Kr.: Gesund

Geschlecht: $\hat{\sigma}$

Arthrose:

prox.

dist.
Maß

Länge

Wert $\mid$ Einheit

$54,5 \mathrm{~mm}$


Bezeichn.: Talus

Kiste: $\quad 8505718$

Skelet: aus 2. Kiste

Population: Calden

Seite:

rechts

Verband: $\quad$ Verband

\section{Alter:}

Geschlecht: ${ }^{\lambda}$

Arthrose:

\section{Beschreibung:}

Ein sehr stark erodiertes Fundstück. 


\section{Bezeichn.: Talus}

\section{Kiste:}

8505718

Skelet: $\quad$ aus 2. Kiste

Population: Calden

Seite:
Verband: $\square$ Verband

Alter:

Geschlecht: ${ }^{\lambda}$

Arthrose:

\section{Beschreibung:}

Dieser Talus ist zu 98\% erhalten und weist leichte Erosionsspuren auf. 


\section{Bezeichn.: Talus}

\section{Kiste:}

8505718

Skelet: aus 2. Kiste

Population: Calden

Seite:
Verband: $\square$ Verband

Alter:

Geschlecht: $\delta$

Arthrose:

\section{Beschreibung:}

Sehr gut erhaltener Talus, etwa 98\%. Er ist sehr massiv. 


\section{Bezeichn.: Talus \\ Kiste: $\quad 5256274$ \\ Skelet: Zettel}

Population: Calden

Seite:

links
Ges./Kr.: Gesund

Alter:

Geschlecht:

Arthrose:

\begin{tabular}{l|l|l} 
Maß & Wert & Einheit \\
\hline Breite & 48 & $\mathrm{~mm}$ \\
Länge & 55,63 & $\mathrm{~mm}$ \\
& & \\
& & \\
& &
\end{tabular}

\section{Beschreibung:}




\section{Bezeichn.: Talus \\ Kiste: $\quad 5256274$ \\ Skelet: Zettel}

Population: Calden

Seite:

links
Ges./Kr.: Gesund

Alter:

Geschlecht:

Arthrose:

\begin{tabular}{l|l|l} 
Maß & Wert & Einheit \\
\hline Breite & 43 & $\mathrm{~mm}$ \\
Länge & 61 & $\mathrm{~mm}$ \\
& & \\
& &
\end{tabular}

\section{Beschreibung:}


Bezeichn:: Talus

Kiste: $\quad 5256274$

Skelet: V32 Sk8

Population: Calden

Seite: rechts

\section{Beschreibung:}

Ein Talus aus einem Verband.
Verband: $\quad$ Verband

\section{Alter:}

Geschlecht:

Arthrose:

\begin{tabular}{l|l|l} 
Maß & Wert & Einheit \\
\hline Breite & 46,55 & $\mathrm{~mm}$ \\
Länge & 55,64 & $\mathrm{~mm}$ \\
& & \\
& & \\
& &
\end{tabular}


Bezeichn.: Talus

Kiste: $\quad 5261277$

Skelet: unter $\mathrm{ScCH} .8+3$

Population: Calden

Seite: rechts

\section{Beschreibung:}

Verband: $\quad \square$ Verband

Ges./Kr.: Gesund

\section{Alter:}

Geschlecht:

Arthrose: 


$\begin{array}{lll}\text { Bezeichn.: } & \text { Talus } & \text { Verband: } \square \text { Verband } \\ \text { Kiste: } & 5261277 & \text { Alter: } \\ \text { Skelet: } & \text { V27 ohne Bezeichnung } & \text { Geschlecht: } \\ \text { Population: } & \text { Calden } & \text { Arthrose: } \\ \text { Seite: } & \text { rechts } & \end{array}$

\section{Beschreibung:}

Ist im Verband mit Tibia und anderem Talus der linken Seite. 
Bezeichn.: Talus

Kiste:

Skelet: $\quad$ V27 ohne Bezeichnung

Population: Calden

Seite: links
Verband:

\section{Alter:}

Geschlecht:

Arthrose:

Ges./Kr.: Gesund

\author{
Beschreibung: \\ Ist im Verband mit Tibia und anderem Talus der rechten Seite.
}


Bezeichn.: Talus

Kiste: $\quad 8505719$

Skelet: Zettel

Population: Calden

Seite:

rechts
Verband: $\quad$ Verband

\section{Alter:}

Geschlecht:

Arthrose:
Ges./Kr.: Gesund

\section{Ges.Kr:: Gesund}

\section{Beschreibung:}


Bezeichn:: Talus

Kiste: $\quad 8505719$

Skelet: V15 Zettel

Population: Calden

Seite:

rechts
Verband: $\quad$ Verband

\section{Alter:}

Geschlecht:

Arthrose:

\section{Beschreibung:}

Talus aus Verband. 
Bezeichn.: Talus

Kiste: $\quad 8505719$

Skelet: V16 Zettel

Population: Calden

Seite:

links
Ges./Kr.: Gesund

\section{Alter:}

Geschlecht:

Arthrose:

\section{Beschreibung:}

Talus aus Verband. 
Bezeichn.: Talus

Kiste: 5243267

Skelet: P.Sk.1.

Population: Calden

Seite: rechts

\section{Beschreibung:}

Verband: $\quad \square$ Verband

Ges./Kr.: Gesund

\section{Alter:}

Geschlecht:

Arthrose: 
Bezeichn.: Calcaneus

Kiste: $\quad 8505718$

Skelet: aus Tüte

Population: Calden

Seite:

links
Verband: $\square$ Verband

\section{Alter:}

Geschlecht:

Arthrose:

\section{Beschreibung:}

Hier ist nur ein kleines proximales Fragment erhalten. 

Bezeichn.: Calcaneus
Kiste:
8505718
Skelet: aus Tüte
Population: Calden
Seite:
rechts

Verband: $\quad$ Verband

\section{Alter:}

Geschlecht: $\delta$

Arthrose:

43,58

$\mathrm{mm}$

2

\section{Beschreibung:}

Ein sehr massives und fast vollständiges Fundstück eines Calcaneus. 
Bezeichn.: Calcaneus

Kiste: $\quad 5266281$ Tüte 2

Skelet: $\quad 3,75 x ; 5,5 y$;

Population: Calden

Seite:
Verband: $\quad$ Verband

Alter:

Geschlecht:

Arthrose:

\section{Beschreibung:}

Ein rechter Calcaneus in gutem Erhaltungszustand. 
Bezeichn.: Calcaneus

\section{Kiste:}

5266281

Skelet: $\quad$ V65 aus Tüte 4

Population: Calden

Seite:

Calden
Verband:

Verband

\section{Alter:}

Geschlecht:

Arthrose:

\section{Ges./Kr.: Gesund}

\section{Beschreibung:}

Ein rechter Calcaneus in gutem Erhaltungszustand. 
Bezeichn.: Calcaneus

\section{Kiste:}

5266281

Skelet: $\quad$ V65 aus Tüte 4

Population: Calden

Seite:

links
Verband: $\square$ Verband

\section{Alter:}

Geschlecht:

Arthrose:

\section{Beschreibung:}

Von diesem Calcaneus ist 1/3 der Gesamtoberfläche abfrakturiert. 
Bezeichn:: Calcaneus

Kiste: $\quad 8505720$

Skelet: $\quad 1.2$

Population: Calden

Seite: rechts
Verband:

Verband

\section{Alter:}

Geschlecht:

Arthrose:

\section{Ges./Kr.: Gesund}

\section{Beschreibung:}

in zur Hälfte erhaltener Calcaneus der rechten Seite. 


\begin{tabular}{|c|c|c|c|c|c|c|c|}
\hline Bezeichn.: & Calcaneus & Verband: & $\square$ Verband & Ges./Kr.: Gesund & Maß & Wert & Einheit \\
\hline Kiste: & 8505720 & Alter: & & & Breite & 43,81 & $\mathrm{~mm}$ \\
\hline Skelet: & einzeln 1.1 & Geschlech & & & Länge & 82,15 & $\mathrm{~mm}$ \\
\hline Population: & Calden & Arthrose: & & & & & \\
\hline Seite: & rechts & & prox. & & & & \\
\hline & & & dist. & & & & \\
\hline
\end{tabular}

\section{Beschreibung:}

An der Ferse, also am Ansatzort der Achillessehne findet sich eine Enthesiopathie in Form einer Verknöcherung der Ansatzstelle. Das Fragment ist zu etwa 50\% erhalten da von innen ausgehöhlt. 
Bezeichn.: Calcaneus

\section{Kiste:}

8505720

Skelet: einzeln 1.1

Population: Calden

Seite:
Verband: $\quad \square$ Verband

\section{Alter:}

Geschlecht: $ð$

Arthrose:
Ges./Kr.: Gesund

\section{Maß}

Breite

Länge

Wert $\quad$ Einheit

42,28 $\mathrm{mm}$

84,9

$\mathrm{mm}$

\section{Beschreibung:}

Ein linker Calcaneus mit einer Enthesiopathie an der Ansatzfläche der Achillessehne. Das Fundstück ist zu etwa 98\% erhalten. 


\section{Bezeichn.: Calcaneus \\ Kiste: \\ 8505720 \\ Skelet: einzeln}

Population: Calden

Seite:

links
Verband: $\quad$ Verband

\section{Alter:}

Geschlecht:

Arthrose:
Maß

Breite

Länge
Ges./Kr.: Gesund

dist.

\section{Beschreibung:}

Ein zu 99\% erhaltener Calcaneus der linken Seite. 


$\begin{array}{lll}\text { Bezeichn.: } & \text { Calcaneus } & \text { Verband: } \square \text { Verband } \\ \text { Kiste: } & 8505720 & \text { Alter: } \\ \text { Skelet: } & \text { einzeln } 1.1 & \text { Geschlecht: } \\ \text { Population: } & \text { Calden } & \text { Arthrose: } \\ \text { Seite: } & \text { links } & \end{array}$

\author{
Beschreibung: \\ Bei diesem Fundstück handelt es sich um einen nicht gut erhaltenen und stark erodierten Calcaneus der linken Seite. Er ist nur zu etwa $70 \%$ erhalten, besonders die \\ Oberfläche ist stark zerstört.
}


Bezeichn.: Calcaneus

Kiste: $\quad 8505720$

Skelet: einzeln 1.1

Population: Calden

Seite:

rechts
Verband: $\square$ Verband Ges./Kr. Gesund

\section{Alter: Jung}

Geschlecht:

Arthrose:

\section{Beschreibung:}

Dies ist ein junger Calcaneus, bei dem die Epiphysen nicht verschlossen sind. 
Bezeichn.: Calcaneus

Kiste: $\quad 5255273$

Skelet: $\quad$ SK7

Population: Calden

Seite:

links
Verband:

Verband

\section{Alter:}

Geschlecht:

Arthrose:

\section{Beschreibung:}

Ein graziler Calcaneus in gutem Erhaltungszustand. 


\section{Bezeichn.: Calcaneus \\ Kiste: $\quad 5242266$ \\ Skelet: 3. Tüte}

Population: Calden
Verband: Verband

\section{Alter:}

Geschlecht:

Arthrose:

\section{Beschreibung:}

Ein posterior erhaltenes Fragment eines Calcaneus. 
Bezeichn.: Calcaneus

Kiste:

5242266

Skelet: 3 . Tüte

Population: Calden

Seite:

links
Verband: $\square$ Verband

Alter:

Geschlecht: ${ }^{\pi}$

Arthrose:

\section{Beschreibung:}

Dieser Calcaneus ist sehr massiv. 


\section{Bezeichn: Calcaneus \\ Kiste: $\quad 5242266$ \\ Skelet: 3 . Tüte}

Population: Calden

Seite:

\section{Verband: $\quad$ Verband}

\section{Alter:}

Geschlecht:

Arthrose:
Ges./Kr.: Gesund

\section{Maß}

Länge

Wert $\quad$ Einheit

\begin{tabular}{l|l}
63 & $\mathrm{~mm}$
\end{tabular}

\section{Beschreibung:}

Hier sind etwa $70 \%$ des Calcaneus erhalten, die cuboidale Gelenkfläche ist erodiert. 
Bezeichn.: Calcaneus

Kiste:

5242266

Skelet: $\quad$ V55 Talus 3. Tüte

Population: Calden

Seite:
Verband: $\quad$ Verband

Alter:

Geschlecht: $q$

Arthrose:

\section{Beschreibung:}

Ein recht stark erodierter Calcaneus aus einem Verband mit einem Talus. 
Bezeichn.: Calcaneus

Kiste: $\quad 8505718$

Skelet: aus Kiste

Population: Calden

Seite:

rechts
Verband:

\section{Alter:}

Ges./Kr.: Gesund

\section{Geschlecht:}

Arthrose:

\section{Beschreibung:}

Ein junger Calcaneus. 
Bezeichn.: Calcaneus

Kiste:

8505718

Skelet: aus Kiste

Population: Calden

Seite:

links

\section{Verband:}

\section{Alter:}

Geschlecht:

Arthrose:
Ges./Kr.: Gesund

\section{Maß}

Länge

\begin{tabular}{|l|l} 
Wert & Einheit \\
\hline 73 & $\mathrm{~mm}$ \\
&
\end{tabular}

\section{Beschreibung:}

Ein vollständig erhaltener sehr massiver Calcaneus der linken Körperseite. 
Bezeichn.: Calcaneus

Kiste: $\quad 8505718$

Skelet: aus Kiste

Population: Calden

Seite:

links
Verband: Verband

\section{Alter:}

Geschlecht: 우

Arthrose:

\section{Beschreibung:}

Ein recht stark erodierter Calcaneus. 
Bezeichn.: Calcaneus

\section{Kiste:}

8505718

Skelet: aus 2. Kiste

Population: Calden

Seite:

links
Verband: $\square$ Verband

Alter:

Geschlecht: +

Arthrose:
Ges./Kr.: Gesund

Maß

Länge

Einheit

\begin{tabular}{l|l}
65 & $\mathrm{~mm}$
\end{tabular}

\section{Beschreibung:}

Ein stark erodierter Calcaneus.
1 
Bezeichn.: Calcaneus

\section{Kiste:}

8505718

Skelet: aus 2. Kiste

Population: Calden

Seite:

links
Verband: $\square$ Verband

Alter:

Geschlecht: ${ }^{\pi}$

Arthrose:

\section{Beschreibung:}

Dieser Calcaneus ist zur Hälfte zerstört. 
Bezeichn.: Calcaneus

\section{Kiste:}

8505718

aus 2. Kiste

Skelet:
Verband: $\square$ Verband

Alter:

Geschlecht: ${ }^{\pi}$

Arthrose:

\begin{tabular}{l|l}
69 & $\mathrm{~mm}$
\end{tabular}

\section{Beschreibung:}

Dieser Calcaneus ist zu 98\% erhalten. 


\begin{abstract}
Bezeichn.: Calcaneus
Kiste:

8505718

Skelet: aus 2. Kiste
\end{abstract}

Population: Calden

\section{Verband: $\quad$ Verband}

Alter:

Geschlecht: $\delta$

Arthrose:

\section{Beschreibung:}

Die Oberfläche dieses Calcaneus ist zu 1/3 erodiert, auch an den Gelenkflächen. 
Bezeichn.: Calcaneus

Kiste:

8505718

Skelet: $\quad$ V43 aus 2. Kiste

Population: Calden

Seite: rechts
Verband: $\quad$ Verband

\section{Alter:}

Geschlecht: $q$

Arthrose:
Ges./Kr.: Gesund

\section{Maß}

Länge

Wert 1 Einheit

\begin{tabular}{l|l}
65 & $\mathrm{~mm}$
\end{tabular}

\section{Beschreibung:}

Hier sind $40 \%$ des proximalen Knochens erhalten. Er liegt im Verband vor. 


\section{Bezeichn.: Calcaneus \\ Kiste: $\quad 8505718$}

Skelet: $\quad$ V53 aus 2. Kiste

Population: Calden

Seite: rechts

\section{Beschreibung:}

Ein gut erhaltener Calcaneus aus einem Verband.
Verband: $\square$ Verband

\section{Alter:}

Ges./Kr.: Gesund

Geschlecht: $q \leq \AA$

Arthrose:

$$
\text { prox. }
$$

\section{Maß}

Länge Wert $\mid$ Einheit

$65 \quad \mathrm{~mm}$


Bezeichn.: Calcaneus

Kiste:

8505718

Skelet: aus 2. Kiste

Population: Calden

Seite: rechts
Verband: $\square$ Verband

Alter:

Geschlecht: $ð$

Arthrose:

Ges./Kr.: Gesund

prox.

\section{Beschreibung:}

Ein kleines Fragment mit Gelenkfläche Facies articularis talaris media. 
Bezeichn.: Calcaneus

Kiste:

8505718

Skelet: $\quad$ V44 aus 2. Kiste

Population: Calden

Seite:

rechts
Verband: $\square$ Verband

\section{Alter:}

Geschlecht: $\delta$

Arthrose:
Ges./Kr.: Gesund

Maß

Länge

\begin{tabular}{|l|l} 
Wert & Einheit
\end{tabular}

\begin{tabular}{l|l}
86 & $\mathrm{~mm}$
\end{tabular}

Beschreibung:

$\mathrm{Zu} 70 \%$ erhalten. prox.

dist. 
Bezeichn.: Calcaneus

Kiste:

8505718

Skelet: $\quad$ V44 aus 2. Kiste

Population: Calden

Seite:

links
Verband: $\square$ Verband

\section{Alter:}

Geschlecht:

Arthrose:
Ges./Kr.: Gesund

Maß

Länge

Einheit

$\mathrm{mm}$

Beschreibung:

Zu 85\% erhalten. 
Bezeichn.: Calcaneus

Kiste: $\quad 5256274$

Skelet: Sk8

Population: Calden

Seite:

rechts
Verband: $\square$ Verband

\section{Alter:}

Geschlecht:

Arthrose:

prox.

dist.
Ges./Kr.: Gesund

Maß

Breite

Länge

2

\section{Beschreibung:}

Ein gut erhaltener Calcaneus. 
Bezeichn.: Calcaneus

Kiste: $\quad 5256274$

Skelet: Sk8

Population: Calden

Seite:

links
Verband: $\square$ Verband

\section{Alter:}

Geschlecht:

Arthrose:
Ges./Kr.: Gesund
Maß

Breite

Länge

\begin{tabular}{l|l} 
Wert & Einheit \\
40,24 & $\mathrm{~mm}$
\end{tabular}

2

dist.

\section{Beschreibung:}

Ein gut erhaltener Calcaneus aus einem Verband. 
Bezeichn.: Calcaneus

Kiste: $\quad 5261277$

Skelet: Zettel

Population: Calden

Seite:

links
Verband: Verband

\section{Alter:}

Geschlecht:

Arthrose:

\section{Beschreibung:}

Ein Fragment. 


\section{Bezeichn.: Calcaneus \\ Kiste: $\quad 5263278$ \\ Skelet: Zettel}

Population: Calden

Seite: rechts

\section{Beschreibung:}

Ein Calcaneus, von dem rechtsseitig Knochenteile abfrakturiert sind.

Ges./Kr.: Krank

Krankh.: Arthrose 
Bezeichn.: Calcaneus

Kiste: $\quad 5263278$

Skelet: bei SCH. 27. im Verb.

Population: Calden

Seite:

links

\section{Beschreibung:}

Ein gut erhaltener Calcaneus.
Verband: $\quad \square$ Verband

Ges./Kr.: Gesund

\section{Alter:}

Geschlecht:

Arthrose:

\section{prox}

dist. 
Bezeichn:: Calcaneus

Kiste: $\quad 5263278$

Skelet: über Sk. 11+SCH.8

Population: Calden

Seite: rechts

\section{Beschreibung:}

ein gut erhaltener Calcaneus.
Verband: $\quad \square$ Verband

\section{Alter:}

Geschlecht:

Arthrose:

\section{prox}

dist.
Ges./Kr.: Gesund

2 
Bezeichn.: Calcaneus

Kiste: $\quad 8505719$

Skelet: Zettel

Population: Calden

Seite:

links
Verband: Verband

\section{Alter:}

Geschlecht:

Arthrose:

\section{Beschreibung:}

Ein mäßig erhaltener Calcaneus. 


$\begin{array}{lll}\text { Bezeichn.: } & \text { Calcaneus } & \text { Verband: } \square \text { Verband } \\ \text { Kiste: } & 8505719 & \text { Alter: } \\ \text { Skelet: } & \text { V15 Zettel } & \text { Geschlecht: } \\ \text { Population: } & \text { Calden } & \text { Arthrose: } \\ \text { Seite: } & \text { links } & \end{array}$

\section{Beschreibung:}

Ein nicht gut erhaltener Calcaneus aus einem Verband. 


$\begin{array}{lll}\text { Bezeichn.: } & \text { Calcaneus } & \text { Verband: } \square \text { Verband } \\ \text { Kiste: } & 8505719 & \text { Alter: } \\ \text { Skelet: } & \text { V16 Zettel } & \text { Geschlecht: } \\ \text { Population: } & \text { Calden } & \text { Arthrose: } \\ \text { Seite: } & \text { links } & \end{array}$

\section{Beschreibung:}

Dieser nicht gut erhaltene Calcaneus liegt im Verband vor. 
Bezeichn:: Calcaneus

Kiste: $\quad 8505719$

Skelet: Zettel

Population: Calden

Seite:

links

\section{Beschreibung:}

Ein gut erhaltener Calcaneus.
Verband: $\square$ Verband

Ges./Kr.: Gesund

\section{Alter:}

Geschlecht:

Arthrose:

\section{prox.}

dist.
1 
Bezeichn.: Calcaneus

\section{Kiste:}

8505721

Skelet: aus großer Kiste lose

Population: Calden

Seite:

\section{Verband:}

\section{Alter:}

Geschlecht:

Arthrose:

\section{Ges./Kr.: Gesund}

prox. 2

\section{Beschreibung:}

Dieser Calcaneus ist recht gut erhalten, ist aber ausgehöhlt und weist ein Loch auf der lateralen Seite auf. Der Knochen wirkt eher massiv und daher ist er eher männlich. 
Bezeichn.: Calcaneus

\section{Kiste:}

8505721

Skelet: aus großer Kiste lose

Population: Calden

Seite:

rechts
Verband:

Verband

\section{Alter:}

\section{Geschlecht:}

Arthrose:

\section{Ges./Kr.: Gesund}

\section{Beschreibung:}

Dieser rechte Calcaneus ist zu etwa 30\% proximal erhalten, der Rest ist abfrakturiert. 
Bezeichn.: Calcaneus

\section{Kiste:}

8505721

Skelet: aus großer Kiste lose

Population: Calden

Seite:

\section{Verband: $\quad$ Verband}

\section{Alter:}

Geschlecht:

Arthrose:

\section{Beschreibung:}

Dieser rechte Calcaneus ist zu etwa 60\% erhalten und weist starke Erosionsspuren auf. 
Bezeichn:: Os Cuboideum

\section{Kiste:}

5266281

V65 aus Tüte 4

Pkelet:

Seite:

rechts
Verband: $\quad$ Verband

\section{Alter:}

Geschlecht:

Arthrose:

\section{Beschreibung:}

Ein Os cuboideum aus einem Verband. 
Bezeichn.: Os Cuboideum

Kiste:

8505718

aus Kiste

Skelet: Population: Calden

Seite:

links

Verband: Verband

\section{Alter:}

Geschlecht:

Arthrose:

\section{Beschreibung:}


Bezeichn.: Os Cuboideum

Kiste:

8505718

aus 2. Kiste

Population: Calden

Seite:

rechts
Verband: Verband

\section{Alter:}

Geschlecht:

Arthrose:

\section{Beschreibung:}


Bezeichn.: Os Cuboideum

Kiste:

8505718

aus 2. Kiste

Population: Calden

Seite:

rechts
Verband: Verband

\section{Alter:}

Geschlecht:

Arthrose:

\section{Beschreibung:}


Bezeichn.: Os Cuboideum

Kiste:

8505718

aus 2. Kiste

Population: Calden

Seite:

rechts
Verband: Verband

\section{Alter:}

Geschlecht:

Arthrose:

\section{Beschreibung:}


Bezeichn.: Os Cuboideum

Kiste:

8505718

aus 2. Kiste

Population: Calden

Seite:

rechts
Verband: Verband

\section{Alter:}

Geschlecht:

Arthrose:

\section{Beschreibung:}


Bezeichn.: Os Cuboideum

Kiste:

8505718

aus 2. Kiste

Population: Calden

Seite:

rechts
Verband: Verband

\section{Alter:}

Geschlecht:

Arthrose:

\section{Beschreibung:}


Bezeichn.: Os Cuboideum

Kiste:

8505718

aus 2. Kiste

Pkelet: Population: Calden

Seite:

links

Verband: Verband

\section{Alter:}

Geschlecht:

Arthrose:

\section{Beschreibung:}


Bezeichn.: Os Cuboideum

Kiste:

8505718

aus 2. Kiste

Pkelet: Population: Calden

Seite:

links

Verband: Verband

\section{Alter:}

Geschlecht:

Arthrose:

\section{Beschreibung:}


Bezeichn.: Os Cuboideum

Kiste:

8505718

aus 2. Kiste

Pkelet: Population: Calden

Seite:

links

Verband: Verband

\section{Alter:}

Geschlecht:

Arthrose:

\section{Beschreibung:}


Bezeichn.: Os Cuboideum

Kiste:

8505718

aus 2. Kiste

Pkelet: Population: Calden

Seite:

links

Verband: Verband

\section{Alter:}

Geschlecht:

Arthrose:

\section{Beschreibung:}


Bezeichn.: Os Cuboideum

Kiste:

8505718

aus 2. Kiste

Pkelet: Population: Calden

Seite:

links

Verband: Verband

\section{Alter:}

Geschlecht:

Arthrose:

\section{Beschreibung:}


Bezeichn.: Os Cuboideum

Kiste:

5243267

$\begin{array}{ll}\text { Skelet: } & \text { P.Sk.1. } \\ \text { Population: } & \text { Calden }\end{array}$

Seite: links

\section{Beschreibung:}

Geschlecht:

Arthrose: 
Bezeichn.: Os Cuboideum

Kiste:

5256274

$\begin{array}{ll}\text { Skelet: Zettel } & \\ \text { Population: } & \text { Calden }\end{array}$

Seite: links

\section{Beschreibung:}

Geschlecht:

Arthrose: 
Bezeichn.: Os Cuboideum

Kiste:

5256274

Zettel

Population: Calden

Seite:

rechts

Verband: Verband

\section{Alter:}

Geschlecht:

Arthrose:

\section{Beschreibung:}


Bezeichn.: Os Cuneiforme

Kiste:

5266281

V65 aus Tüte 4

Skelet: V65 aus
Population: Calden

Seite:

links
Verband:

Verband

\section{Alter:}

Geschlecht:

Arthrose:

\section{Beschreibung:}

Ein Os cuneiforme 1. 
Bezeichn.: Os Cuneiforme

Kiste: $\quad 8505718$

Skelet: aus 2. Kiste

Population: Calden

Seite:

links

Verband: $\quad$ Verband

\section{Alter:}

Geschlecht:

Arthrose:

\section{Beschreibung:}


Bezeichn.: Os Cuneiforme

Kiste: $\quad 8505718$

Skelet: aus 2. Kiste

Population: Calden

Seite:

rechts

Verband: Verband

\section{Alter:}

Geschlecht:

Arthrose:

\section{Beschreibung:}


Bezeichn.: Os Cuneiforme

Kiste: $\quad 8505718$

Skelet: aus 2. Kiste

Population: Calden

Seite:

rechts

Verband: Verband

\section{Alter:}

Geschlecht:

Arthrose:

\section{Beschreibung:}


Bezeichn.: Os Cuneiforme

Kiste: $\quad 8505718$

Skelet: aus 2. Kiste

Population: Calden

Seite:

rechts

Verband: Verband

\section{Alter:}

Geschlecht:

Arthrose:

\section{Beschreibung:}


Bezeichn.: Os Cuneiforme

Kiste: $\quad 8505718$

Skelet: aus 2. Kiste

Population: Calden

Seite:

rechts

Verband: Verband

\section{Alter:}

Geschlecht:

Arthrose:

\section{Beschreibung:}


Bezeichn.: Os Cuneiforme

Kiste: $\quad 8505718$

Skelet: aus 2. Kiste

Population: Calden

Seite:

rechts

Verband: Verband

\section{Alter:}

Geschlecht:

Arthrose:

\section{Beschreibung:}


Bezeichn.: Os Cuneiforme

Kiste: $\quad 8505718$

Skelet: aus 2. Kiste

Population: Calden

Seite:

links

Verband: $\quad$ Verband

\section{Alter:}

Geschlecht:

Arthrose:

\section{Beschreibung:}


Bezeichn.: Os Cuneiforme

Kiste: $\quad 5256274$

Skelet: Zettel

Population: Calden

Seite:

links

Verband: $\quad$ Verband

\section{Alter:}

Geschlecht:

Arthrose:

\section{Beschreibung:}


Bezeichn.: Os Cuneiforme

Kiste: $\quad 8505719$

Skelet: Zettel

Population: Calden

Seite: rechts

\section{Beschreibung:}

Ein Os cuneiforme laterale.
Verband: $\quad$ Verband

\section{Alter:}

Geschlecht:

Arthrose: 
Bezeichn.: Os Cuneiforme

Kiste: $\quad 8505719$

Skelet: Zettel

Population: Calden

Seite:

links
Verband: $\quad$ Verband

\section{Alter:}

Geschlecht:

Arthrose:

\section{Beschreibung:}

Ein Os cuneiforme laterale. 
Bezeichn.: Os Cuneiforme

Kiste: 5256274

Skelet: Zettel

Population: Calden

Seite: rechts

\section{Beschreibung:}

Ein Os cuneiforme intermediale.
Verband: Verband

\section{Alter:}

Geschlecht:

Arthrose: 
Bezeichn.: Os Cuneiforme

Kiste: 5256274

Skelet: Zettel

Population: Calden

Seite: rechts

\section{Beschreibung:}

Ein Os cuneiforme laterale.
Verband: $\quad \square$ Verband

\section{Alter:}

Geschlecht:

Arthrose: 
Bezeichn.: Os Cuneiforme

Kiste: $\quad 8505718$

Skelet: aus 2. Kiste

Population: Calden

Seite:

rechts

Verband: $\quad$ Verband

\section{Alter:}

Geschlecht:

Arthrose:

\section{Beschreibung:}

Ein Os cuneiforme mediale. 
Bezeichn.: Os Cuneiforme

Kiste: $\quad 8505718$

Skelet: aus 2. Kiste

Population: Calden

Seite:

rechts

Verband: Verband

\section{Alter:}

Geschlecht:

Arthrose:

\section{Beschreibung:}


Bezeichn.: Os Cuneiforme

Kiste: $\quad 8505718$

Skelet: aus 2. Kiste

Population: Calden

Seite:

rechts

Verband: $\quad$ Verband

\section{Alter:}

Geschlecht:

Arthrose:

\section{Beschreibung:}

Ein Os cuneiforme mediale. 
Bezeichn.: Os Cuneiforme

Kiste: $\quad 8505718$

Skelet: aus 2. Kiste

Population: Calden

Seite:

rechts

Verband: $\quad$ Verband

\section{Alter:}

Geschlecht:

Arthrose:

\section{Beschreibung:}

Ein Os cuneiforme mediale. 
Bezeichn.: Os Cuneiforme

Kiste: $\quad 8505718$

Skelet: aus 2. Kiste

Population: Calden

Seite:

rechts

Verband: $\quad$ Verband

\section{Alter:}

Geschlecht:

Arthrose:

\section{Beschreibung:}

Ein Os cuneiforme mediale. 
Bezeichn.: Os Cuneiforme

Kiste: $\quad 8505718$

Skelet: aus 2. Kiste

Population: Calden

Seite:

rechts

Verband: $\quad$ Verband

\section{Alter:}

Geschlecht:

Arthrose:

\section{Beschreibung:}

Ein Os cuneiforme mediale. 
Bezeichn.: Os Cuneiforme

Kiste: $\quad 8505718$

Skelet: aus 2. Kiste

Population: Calden

Seite:

rechts
Verband: $\quad$ Verband

\section{Alter:}

Geschlecht:

Arthrose:

\section{Beschreibung:}

Ein Os cuneiforme mediale. 
Bezeichn.: Os Cuneiforme

Kiste: $\quad 8505718$

Skelet: aus 2. Kiste

Population: Calden

Seite:

links
Verband: $\square$ Verband

\section{Alter:}

Geschlecht:

Arthrose:

\section{Beschreibung:}

Ein Os cuneiforme mediale. 
Bezeichn.: Os Cuneiforme

Kiste: $\quad 8505718$

Skelet: aus 2. Kiste

Population: Calden

Seite:

links
Verband: Verband

\section{Alter:}

Geschlecht:

Arthrose:

\section{Beschreibung:}

Ein Os cuneiforme mediale. 
Bezeichn.: Os Cuneiforme

Kiste: $\quad 8505718$

Skelet: aus 2. Kiste

Population: Calden

Seite:

links
Verband: $\square$ Verband

\section{Alter:}

Geschlecht:

Arthrose:

\section{Beschreibung:}

Ein Os cuneiforme mediale. 
Bezeichn.: Os Cuneiforme

Kiste: 5256274

Skelet: Zettel

Population: Calden

Seite: rechts

\section{Beschreibung:}

Ein Os cuneiforme mediale.
Verband: $\quad \square$ Verband

\section{Alter:}

Geschlecht:

Arthrose: 
Bezeichn.: Os Naviculare

Kiste:

8505718

aus 2. Kiste

Population: Calden

Seite:

rechts
Verband: Verband

\section{Alter:}

Geschlecht:

Arthrose:

\section{Beschreibung:}


Bezeichn.: Os Naviculare

Kiste:

8505718

aus 2. Kiste

Population: Calden

Seite:

rechts
Verband: Verband

\section{Alter:}

Geschlecht:

Arthrose:

\section{Beschreibung:}


Bezeichn.: Os Naviculare

Kiste:

8505718

aus 2. Kiste

Population: Calden

Seite:

rechts
Verband: Verband

\section{Alter:}

Geschlecht:

Arthrose:

\section{Beschreibung:}


Bezeichn.: Os Naviculare

Kiste: $\quad 8505718$

Skelet: aus 2. Kiste

Population: Calden

Seite:

links
Verband: Verband

\section{Alter:}

Geschlecht:

Arthrose:

\section{Beschreibung:}


Bezeichn.: Os Naviculare

Kiste: $\quad 8505718$

Skelet: aus 2. Kiste

Population: Calden

Seite:

links
Verband: Verband

\section{Alter:}

Geschlecht:

Arthrose:

\section{Beschreibung:}


Bezeichn.: Os Naviculare

Kiste: $\quad 8505718$

Skelet: aus 2. Kiste

Population: Calden

Seite:

links
Verband: Verband

\section{Alter:}

Geschlecht:

Arthrose:

\section{Beschreibung:}


Bezeichn.: Os Naviculare

Kiste: $\quad 8505718$

Skelet: aus 2. Kiste

Population: Calden

Seite:

links
Verband: Verband

\section{Alter:}

Geschlecht:

Arthrose:

\section{Beschreibung:}


Bezeichn.: Os Naviculare

Kiste: $\quad 5256274$

Skelet: Zettel

Population: Calden

Seite:

links

Verband: $\quad$ Verband

\section{Alter:}

Geschlecht:

Arthrose:

\section{Beschreibung:}


Bezeichn.: Os Naviculare

Kiste: $\quad 5256274$

Skelet: Zettel

Population: Calden

Seite:

rechts
Verband: Verband

\section{Alter:}

Geschlecht:

Arthrose:

\section{Beschreibung:}


Bezeichn:: Os Naviculare

Kiste: 5256274

Skelet: V32 Sk8

Population: Calden

Seite:
Verband:

Verband

\section{Alter: \\ Geschlecht:}

Arthrose:

\section{Beschreibung:}

Os naviculare aus einem Verband. 
Bezeichn.: Os Naviculare

Kiste:

5263278

P.SCH. 25-30

Population: Calden

Seite:

links
Ges./Kr.: Gesund

\section{Alter:}

Geschlecht:

Arthrose:

\section{Beschreibung:}


Bezeichn:: Os Naviculare

Kiste:

8505719

gesammelt

Pkelet: 1 ation: Calden

Seite:

rechts

Verband: Verband

\section{Alter:}

Geschlecht:

Arthrose:

\section{Beschreibung:}


Bezeichn.: Os Naviculare

Kiste:

8505719

Zettel

Skelet: Zettel

Seite: rechts

\section{Beschreibung:}

Geschlecht:

Arthrose: 
Bezeichn:: Os Metatarsale

\section{Kiste:}

5256274

Skelet: Zettel

Population: Calden

Seite:

links
Verband: Verband

\section{Alter:}

Geschlecht:

Arthrose:

\section{Beschreibung:}

Ein Os metatarsale 1 der linken Seite. 
Bezeichn:: Os Metatarsale

Kiste: Museumskiste 3

Skelet: ohne

Population: Calden

Seite: rechts
Verband: $\square$ Verband

Alter:

Geschlecht: $q<\lambda$

Arthrose:

$$
\text { prox. }
$$

Ges./Kr.: Gesund

\section{Maß}

Länge

\begin{tabular}{l|l} 
Wert & Einheit
\end{tabular}

$66,88 \mathrm{~mm}$

\section{Beschreibung:}

Ein fast vollständiges Os metatarsale 1 der rechten Seite. 
Bezeichn:: Os Metatarsale

\section{Kiste:}

5266281

V65 aus Tüte 4

Skelet:

Seite:

rechts
Verband: $\quad$ Verband

\section{Alter:}

Geschlecht:

Arthrose:

\section{Beschreibung:}

Ein Os metatarsale 1 der rechten Seite. 
Bezeichn:: Os Metatarsale

\section{Kiste: $\quad 5266281$}

Skelet: $\quad$ V65 aus Tüte 4

Population: Calden

Seite:

rechts
Verband: $\quad$ Verband

\section{Alter:}

Geschlecht:

Arthrose:

\section{Beschreibung:}

Ein Os metatarsale 2. 
Bezeichn:: Os Metatarsale

\section{Kiste: $\quad 5266281$}

Skelet: $\quad$ V65 aus Tüte 4

Population: Calden

Seite: rechts

\section{Beschreibung:}

Ein Os metatarsale 3.
Verband: $\quad \square$ Verband

\section{Alter:}

Geschlecht:

Arthrose:
Ges./Kr.: Gesund

Ein 
Bezeichn:: Os Metatarsale

\section{Kiste: $\quad 5266281$}

Skelet: $\quad$ V65 aus Tüte 4

Population: Calden

Seite:

rechts
Verband: $\quad$ Verband

\section{Alter:}

Geschlecht:

Arthrose:

\section{Beschreibung:}

Ein Os metatarsale 5. 
Bezeichn:: Os Metatarsale

Kiste: 5243267

$\begin{array}{ll}\text { Skelet: } & \text { P.Sk.1. } \\ \text { Population: } & \text { Calden }\end{array}$

Seite: links

\section{Beschreibung:}

Verband: $\quad$ Verband

Ges./Kr.: Gesund

\section{Alter:}

Geschlecht:

Arthrose: 
Bezeichn:: Os Metatarsale

Kiste: $\quad 5243267$

Skelet: Zettel

Population: Calden

Seite:

rechts

Verband: $\quad$ Verband

\section{Alter:}

Geschlecht:

Arthrose:

\section{Beschreibung:}

Ein Os metatarsale 2 der rechten Seite. 
Bezeichn:: Os Metatarsale

Kiste: $\quad 5256274$

Skelet: Zettel Nr1

Population: Calden

Seite: rechts
Verband: $\quad$ Verband

Alter:

Geschlecht:

Arthrose:
Ges./Kr.: Krank

Krankh.: Arthrose

\author{
Beschreibung: \\ Bei diesem Os metatarsale 1 fallen leichte Auflagerungen auf der Oberfläche ins Auge.
}


Bezeichn:: Os Metatarsale

Kiste:

5256274

Skelet: Zettel

Population: Calden

Seite:

rechts
Verband: $\quad$ Verband

\section{Alter:}

Geschlecht:

Arthrose:

Ges./Kr.: Gesund

\section{Beschreibung:}

Ein Os metatarsale 1 der rechten Seite. 
Bezeichn:: Os Metatarsale

\section{Kiste:}

5256274

Skelet: Zettel

Population: Calden

Seite:

links
Verband: Verband

\section{Alter:}

Geschlecht:

Arthrose:

\section{Beschreibung:}

Ein Os metatarsale 3 der linken Seite. 
Bezeichn:: Os Metatarsale

\section{Kiste:}

5256274

Skelet: Zettel

Population: Calden

Seite:

links
Verband: Verband

\section{Alter:}

Geschlecht:

Arthrose:

\section{Beschreibung:}

Ein Os metatarsale 2 der linken Seite. 
Bezeichn:: Os Metatarsale

Kiste:

5256274

Skelet: Zettel

Population: Calden

Seite:
Verband: $\square$ Verband

Alter:

\section{Geschlecht:}

Arthrose:

\section{Ges./Kr.: Gesund}

$\begin{array}{ll}\text { prox. } & 1 \\ \text { dist. } & 1\end{array}$

\section{Beschreibung:}

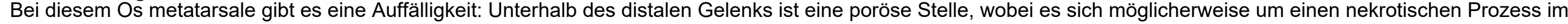
Sinne eines Kapselrisses handeln könnte. 
Bezeichn:: Os Metatarsale

\section{Kiste:}

5256274

Skelet: Zettel

Population: Calden

Seite:

links
Verband: Verband

\section{Alter:}

Geschlecht:

Arthrose:

\section{Beschreibung:}

Ein Os metatarsale 2 der linken Seite. 
Bezeichn:: Os Metatarsale

\section{Kiste:}

5261277

Skelet: Zettel

Population: Calden

Seite:

rechts
Verband: Verband

\section{Alter:}

Geschlecht:

Arthrose:

\section{Beschreibung:}

Ein Os metatarsale 3 der rechten Seite. 
Bezeichn:: Os Metatarsale

Kiste: $\quad 5261277$

Skelet: Zettel

Population: Calden

Seite:

links
Verband: $\quad$ Verband

\section{Alter:}

Geschlecht:

Arthrose:

\section{Beschreibung:}

Ein Os metatarsale 1 der linken Seite. 
Bezeichn:: Os Metatarsale

\section{Kiste:}

5261277

Skelet: Zettel

Population: Calden

Seite:

rechts
Verband: $\square$ Verband

\section{Alter:}

Geschlecht:

Arthrose:

\section{Beschreibung:}

Ein Os metatarsale 2 der rechten Seite. 
Bezeichn.: Os Metatarsale

Kiste:

8505719

Steinkammergrab 1

Pkelet:

Seite: rechts

\section{Beschreibung:}

Ein Os metatarsale 5 der rechten Seite.
Verband: Verband

\section{Alter:}

Geschlecht:

Arthrose: 
Bezeichn:: Os Metatarsale

\section{Kiste:}

8505719

Skelet: extremitätenfragemente

Population: Calden

Seite:

Verband: $\quad \square$ Verband

Alter:

Geschlecht:

Arthrose:

\section{Beschreibung:}

Ein Os metatarsale 1 der rechten Seite. 
Bezeichn:: Os Metatarsale

Kiste:

8505719

Zettel

Skelet: Zettel

Seite: rechts

\section{Beschreibung:}

Ein Os metatarsale 1 der rechten Seite.
Verband: $\quad$ Verband

\section{Alter:}

Geschlecht:

Arthrose: 
Bezeichn:: Os Metatarsale

Kiste:

8505719

Skelet: Zettel

Population: Calden

Seite:

links
Verband: $\quad \square$ Verband

\section{Alter:}

Geschlecht:

Arthrose:

\section{Beschreibung:}

Ein Os metatarsale 1 der linken Seite. 
Bezeichn.: Os Metatarsale

Kiste:

8505719

Skelet: Zettel

Population: Calden

Seite:

links
Verband: $\square$ Verband

\section{Alter:}

Geschlecht:

Arthrose:

\section{Beschreibung:}

Ein Os metatarsale 1 der linken Seite. 
Bezeichn:: Os Metatarsale

Kiste:

8505719

Zettel

Skelet: Zettel

Seite: rechts

\section{Beschreibung:}

Ein Os metatarsale 4 der rechten Seite.
Verband: $\square$ Verband

\section{Alter:}

Geschlecht:

Arthrose: 
Bezeichn:: Os Metatarsale

Kiste:

8505719

Zettel

Skelet: Zettel

Seite: rechts

\section{Beschreibung:}

Ein Os metatarsale 2 der rechten Seite.
Verband: $\quad$ Verband

\section{Alter:}

Geschlecht:

Arthrose: 
Bezeichn:: Os Metatarsale

Kiste:

8505719

Zettel

Skelet: Zettel

Seite: rechts

\section{Beschreibung:}

Ein Os metatarsale 2 der rechten Seite.
Verband: $\quad$ Verband

\section{Alter:}

Geschlecht:

Arthrose: 
Bezeichn.: Os Metatarsale

Kiste: $\quad 8505719$

Skelet: Zettel

Population: Calden

Verband: $\quad$ Verband

\section{Alter:}

Geschlecht:

Arthrose:

\section{Beschreibung:}


Bezeichn:: Os Metatarsale

Kiste:

8505719

Zettel

Skelet: Zettel

Seite: rechts

\section{Beschreibung:}

Ein Os metatarsale 2 der rechten Seite.
Verband: $\quad$ Verband

\section{Alter:}

Geschlecht:

Arthrose: 


$\begin{array}{llll}\text { Bezeichn.: } & \text { Os Metatarsale } & \text { Verband: } & \square \text { Verband } \\ \text { Kiste: } & 8505719 & \text { Alter: } & 14-16(18) \\ \text { Skelet: } & \text { Zettel } & \text { Geschlecht: } \\ \text { Population: } & \text { Calden } & \text { Arthrose: }\end{array}$

\section{Beschreibung:}

Ein Os metatarsale 5 der rechten Seite, es fehlt die Epiphyse, was für ein junges Individuum spricht. 
Bezeichn:: Os Metatarsale

Kiste:

8505719

$\begin{array}{ll}\text { Skelet: } & \text { Zettel } \\ \text { Population: } & \text { Calden }\end{array}$

Population: Calden

\section{Beschreibung:}

Ein Os metatarsale 2.
Verband: $\quad$ Verband

\section{Alter:}

Geschlecht:

Arthrose: 
Bezeichn:: Os Metatarsale

Kiste:

8505719

$\begin{array}{ll}\text { Skelet: } & \text { Zettel } \\ \text { Population: } & \text { Calden }\end{array}$

Population: Calden
Verband: $\quad \square$ Verband

\section{Alter:}

Geschlecht:

Arthrose:

\section{Beschreibung:}

Ein Os metatarsale 3. 
Bezeichn:: Os Metatarsale

Kiste:

8505719

$\begin{array}{ll}\text { Skelet: } & \text { Zettel } \\ \text { Population: } & \text { Calden }\end{array}$

Seite: links

\section{Beschreibung:}

Ein Os metatarsale 5 der linken Seite.
Verband: $\quad$ Verband

\section{Alter:}

Geschlecht:

Arthrose: 
Bezeichn:: Os Metatarsale

Kiste:

8505719

Zettel

Skelet: Zettel

Seite: rechts

\section{Beschreibung:}

Ein Os metatarsale 2 der rechten Seite.
Verband: $\quad$ Verband

\section{Alter:}

Geschlecht:

Arthrose: 
Bezeichn:: Os Metatarsale

Kiste:

8505719

Zettel

Skelet: Zettel

Seite: rechts

\section{Beschreibung:}

Ein Os metatarsale 3 der rechten Seite.
Verband: $\quad$ Verband

\section{Alter:}

Geschlecht:

Arthrose: 
Bezeichn:: Os Metatarsale

Kiste:

8505719

Zettel

Skelet: Zettel

Seite: rechts

\section{Beschreibung:}

Ein Os metatarsale 4 der rechten Seite.
Verband: $\square$ Verband

\section{Alter:}

Geschlecht:

Arthrose: 
Bezeichn:: Os Metatarsale

Kiste:

8505719

Zettel

Skelet: Zettel

Seite: rechts

\section{Beschreibung:}

Ein Os metatarsale 3 der rechten Seite.
Verband: $\quad$ Verband

\section{Alter:}

Geschlecht:

Arthrose: 
Bezeichn:: Os Metatarsale

\section{Kiste: $\quad 5271289$}

Skelet: Kiste 9

Population: Calden

Seite:
Verband: $\square$ Verband

\section{Alter:}

Geschlecht:

Arthrose:

\section{Beschreibung:}

Dies ist ein proximales Fragment eines Os metatarsale 3 links. 
Bezeichn:: Os Metatarsale

Kiste:

8505721

Skelet: aus großer Kiste

Population: Calden

Seite:

links
Verband: $\square$ Verband

Alter:

Geschlecht:

Arthrose:

\section{Beschreibung:}

Ein Os metatarsale 2 der linken Seite. Es ist vollständig erhalten. 
Bezeichn:: Os Metatarsale

\section{Kiste:}

5256274

Skelet: Zettel

Population: Calden

Seite:

links
Verband: Verband

\section{Alter:}

Geschlecht:

Arthrose:

\section{Beschreibung:}

Ein Os metatarsale 4 der linken Seite. 
Bezeichn.: Knochenklein

Kiste: $\quad 8505720$

Skelet: $\quad$ Spliter 1.1

Population: Calden
Verband: $\quad$ Verband

\section{Alter: Jung}

Geschlecht:

Arthrose:

\section{Beschreibung:}

Kleinste Fragmente, teilweise sind Splitter von nicht geschlossenen Epiphysen erhalten, was für das vorliegen junger Individuen spricht. 
Bezeichn.: Knochenklein

Kiste: Museumskiste 3

Skelet: ohne

Population: Calden
Verband: Verband

\section{Alter:}

Geschlecht:

Arthrose:

\section{Beschreibung:}

Bei diesen Knochenfragmenten fanden sich Fragmente von Wirbeln und Schulterblatt. Es sind $50 \mathrm{~g}$. 
Bezeichn.: Knochenklein

Kiste: $\quad 8505718$

Skelet: aus Tüte

Population: Calden

Seite:

rechts

Verband: $\quad$ Verband

\section{Alter:}

Geschlecht:

Arthrose:

\section{Beschreibung:}

113g Knochensplitter. 
Bezeichn.: Knochenklein

Kiste: $\quad 5273291$

Skelet: $\quad 5273 / 2$ Knochensplitter

Population: Calden
Verband: Verband

\section{Alter:}

Geschlecht:

Arthrose:

\section{Beschreibung:}

Knochensplitter Cranium und andere. 
Bezeichn.: Knochenklein

Kiste: $\quad 8505720$

Skelet: $\quad 1.0$ Knochenklein

Population: Calden
Verband: Verband

\section{Alter:}

Geschlecht:

Arthrose:

\section{Beschreibung:}

89g Knochensplitter. 
Bezeichn.: Knochenklein

Kiste:

5271289

Skelet: Knochenklein

Population: Calden

Seite:

n. def.
Verband: $\quad \square$ Verband

Ges./Kr.: Gesund

\section{Alter:}

Geschlecht:

Arthrose:

\section{Beschreibung:}

103g Knochenklein von Cranium, Costa und weitere, die nicht zuzuordnen waren. 
Bezeichn.: Knochenklein

Kiste: $\quad 5267282$

Skelet: Knochenklein 31g

Population: Calden
Verband: $\square$ Verband

\section{Alter:}

Geschlecht:

Arthrose:

\section{Beschreibung:}

31g Schädelsplitter. 
Bezeichn.: Knochenklein

Kiste:

5272290

Cranium 38 Knochenklein

$\begin{array}{ll}\text { Skelet: } & \text { Cranium } \\ \text { Population: } & \text { Calden }\end{array}$

\section{Beschreibung:}

38 kleinste Schädelfragmente.
Verband: $\quad$ Verband

Alter:

Geschlecht:

Arthrose: 
Bezeichn.: Knochenklein

Kiste: $\quad 8505720$

Skelet: $\quad 1.287 \mathrm{~g}$ Knochenklein

Population: Calden
Verband: Verband

\section{Alter:}

Geschlecht:

Arthrose:

\section{Beschreibung:}

87g Knochenklein 
Bezeichn.: Knochenklein

Kiste: $\quad 8505720$

Skelet: $\quad 1.1$

Population: Calden

\section{Verband: $\quad$ Verband}

Alter:

Geschlecht:

Arthrose:

\section{Beschreibung:}

Bei diesen drei Splittern handelt es sich möglicherweise um Fragmente, welche durch Leichenbrand verändert wurden. Sie sind weder sicher einem menschlichen Individum, noch einer Körperregion zuzuordnen. 
Bezeichn.: Knochenklein

Kiste: $\quad 8505720$

Skelet: $\quad 1.390 \mathrm{~g}$ Knochenklein

Population: Calden
Verband: Verband

\section{Alter:}

Geschlecht:

Arthrose:

\section{Beschreibung:}

Kleinste Knochensplitter. 


$\begin{array}{lll}\text { Bezeichn.: } & \text { Knochenklein } & \text { Verband: } \square \text { Verband } \\ \text { Kiste: } & 5249270 & \text { Alter: } \\ \text { Skelet: } & \text { Zettel } & \text { Geschlecht: } \\ \text { Population: } & \text { Calden } & \text { Arthrose: }\end{array}$

\section{Beschreibung:}

Kleine Knochensplitter, welche nicht zuzuordnen sind. 
Bezeichn.: Knochenklein

Kiste: $\quad 5242266$

Skelet: $\quad 8 \mathrm{~g}$ Knochenklein letzte

Population: Calden
Verband: Verband

\section{Alter:}

Geschlecht:

Arthrose:

\section{Beschreibung:}

$8 \mathrm{~g}$ Knochensplitter. 
Bezeichn.: Knochenklein

Kiste: $\quad 5245269$

Skelet: 2 Knochensplitter

Population: Calden
Verband: Verband

Alter:

Geschlecht:

Arthrose:

\section{Beschreibung:}

Zwei kleine Knochensplitter. 
Bezeichn.: Knochenklein

Kiste: $\quad 5245269$

Skelet: 12 weiteres Knochenklein

Population: Calden
Verband: Verband

\section{Alter:}

Geschlecht:

Arthrose:

\section{Beschreibung:}

Kleine Knochensplitter. 
Bezeichn.: Knochenklein

Kiste: 5263278

Skelet: gesammelt

Population: Calden
Verband: Verband

\section{Alter:}

Geschlecht:

Arthrose:

\section{Beschreibung:}

Kleinste Knochensplitter. 
Bezeichn.: Knochenklein

Kiste:

8505719

Skelet: $\quad 8$ Vertebra Fragmente

Population: Calden
Verband: $\square$ Verband

\section{Alter:}

Geschlecht:

Arthrose:

\section{Beschreibung:}

Acht Fragmente von Wirbeln, die nicht befundbar und nicht weiter zuzuordnen sind. 
Bezeichn.: Knochenklein

Kiste:

8505719

gesammelt

$\begin{array}{ll}\text { Skelet: gesamm } & \\ \text { Population: } & \text { Calden }\end{array}$
Verband: $\square$ Verband

\section{Alter:}

Geschlecht:

Arthrose:

\section{Beschreibung:}

Kleine Knochensplitter. 
Bezeichn.: Knochenklein

Kiste: $\quad 8505719$

Skelet: kleines Fragment

Population: Calden
Verband: $\square$ Verband

\section{Alter:}

Geschlecht:

Arthrose:

\section{Beschreibung:}

Ein kleiner und nicht zuzuordnender Knochensplitter. 
Bezeichn.: Knochenklein

Kiste:

8505719

Skelet: 26 Knochenklein

Population: Calden
Verband: Verband

\section{Alter:}

Geschlecht:

Arthrose:

\section{Beschreibung:}

Hier sind 26 kleinste Knochensplitter erhalten, welche nicht weiter zuzuordnen waren. 
Bezeichn.: Knochenklein

Kiste: 8505719

Skelet: $\quad 18$ Knochenklein

Population: Calden
Verband: Verband

\section{Alter:}

Geschlecht:

Arthrose:

\section{Beschreibung:}

Hier sind 18 kleinste Knochenfragmente erhalten, welche nicht zuzuordnen waren. 
Bezeichn.: Knochenklein

Kiste: $\quad 8505719$

Skelet: 27 Rippenfragmente

Population: Calden
Verband: Verband

\section{Alter:}

Geschlecht:

Arthrose:

\section{Beschreibung:}

Hier sind 27 kleine Rippenfragmente erhalten. 
Bezeichn.: Knochenklein

Kiste: $\quad 5245269$

Skelet: Fragment "bei Becken

Population: Calden
Verband: Verband

\section{Alter:}

Geschlecht:

Arthrose:

\section{Beschreibung:}


Bezeichn.: Knochenklein

Kiste: $\quad 5245269$

Skelet: $\quad 7$ Knochenklein

Population: Calden
Verband: $\square$ Verband

Alter:

Geschlecht:

Arthrose:

\section{Beschreibung:}

7 nicht zu identifizierende Knochensplitter. 
Bezeichn.: Knochenklein

\section{Kiste: $\quad 5259276$}

Skelet: Knochenklein $274 \mathrm{~g}$

Population: Calden
Verband: Verband

\section{Alter:}

Geschlecht:

Arthrose:

\section{Beschreibung:}

274g Splitter von Rippen, Langknochen und Wirbeln. 
Bezeichn.: Knochenklein

Kiste:

8505721

Kiste 1 Knochenklein 13g

$\begin{array}{ll}\text { Skelet: } & \text { Kiste } 1 \\ \text { Population: Calden }\end{array}$
Verband: $\quad \square$ Verband

Alter:

Geschlecht:

Arthrose:

\section{Beschreibung:}

13g Knochenklein 
Bezeichn.: Knochenklein

Kiste: $\quad 8505721$

Skelet: 7 Knochenfragmente,

Population: Calden
Verband: Verband

\section{Alter:}

Geschlecht:

Arthrose:

\section{Beschreibung:}

7 kleinste Knochenfragmente, 152g. 
Bezeichn.: Knochenklein

Kiste: $\quad 5249270$

Skelet: Zettel

Population: Calden
Verband: $\quad$ Verband

Alter:

Geschlecht:

Arthrose:

\section{Beschreibung:}

Ein Fragment eines Knochens der unteren Extremität. Die genauere Zuordnung ist aufgrund der Größe des Fragments und des Zerstörungsgrades des Knochens nicht möglich. 
Bezeichn.: Manus

Kiste: $\quad 8505720$

Skelet: $\quad 1.0$

Population: Calden
Verband: $\quad$ Verband

\section{Alter: Jung}

Geschlecht:

Arthrose:

\section{Beschreibung:}

Ein junges Os metacarpale. 
Bezeichn.: Manus

Kiste: $\quad 8505720$

Skelet: $\quad 1.0$

Population: Calden
Verband: Verband

\section{Alter:}

Geschlecht:

Arthrose:

\section{Beschreibung:}

Ein Handknochen. 
Bezeichn.: Manus

Kiste: $\quad 8505720$

Skelet: $\quad 1.0$

Population: Calden
Verband: Verband

\section{Alter:}

Geschlecht:

Arthrose:

\section{Beschreibung:}

Ein Handknochen. 
Bezeichn.: Manus

Kiste: $\quad 8505720$

Skelet: $\quad 1.0$

Population: Calden
Verband: Verband

\section{Alter:}

Geschlecht:

Arthrose:

\section{Beschreibung:}

Ein Handknochen. 
Bezeichn.: Manus

Kiste: $\quad 8505720$

Skelet: $\quad 1.0$

Population: Calden
Verband: Verband

\section{Alter:}

Geschlecht:

Arthrose:

\section{Beschreibung:}

Ein Handknochen. 
Bezeichn.: Manus

Kiste: $\quad 8505720$

Skelet: $\quad 1.0$

Population: Calden
Verband: Verband

\section{Alter:}

Geschlecht:

Arthrose:

\section{Beschreibung:}

Ein Handknochen. 
Bezeichn.: Manus

Kiste: $\quad 8505720$

Skelet: $\quad 1.0$

Population: Calden
Verband: Verband

\section{Alter:}

Geschlecht:

Arthrose:

\section{Beschreibung:}

Ein Handknochen. 
Bezeichn.: Manus

Kiste: $\quad 8505720$

Skelet: $\quad 1.0$

Population: Calden
Verband: Verband

\section{Alter:}

Geschlecht:

Arthrose:

\section{Beschreibung:}

Ein Handknochen. 
Bezeichn.: Manus

Kiste: $\quad 8505720$

Skelet: $\quad 1.0$

Population: Calden
Verband: Verband

\section{Alter:}

Geschlecht:

Arthrose:

\section{Beschreibung:}

Ein Handknochen. 
Bezeichn.: Manus

Kiste: $\quad 8505720$

Skelet: $\quad 1.0$

Population: Calden
Verband: Verband

\section{Alter:}

Geschlecht:

Arthrose:

\section{Beschreibung:}

Ein Handknochen. 
Bezeichn.: Manus

Kiste: $\quad 8505720$

Skelet: $\quad 1.0$

Population: Calden
Verband: Verband

\section{Alter:}

Geschlecht:

Arthrose:

\section{Beschreibung:}

Ein Handknochen. 
Bezeichn.: Manus

Kiste: $\quad 8505720$

Skelet: $\quad 1.0$

Population: Calden
Verband: Verband

\section{Alter:}

Geschlecht:

Arthrose:

\section{Beschreibung:}

Ein Handknochen. 
Bezeichn.: Manus

Kiste: $\quad 8505720$

Skelet: $\quad 1.0$

Population: Calden
Verband: Verband

\section{Alter:}

Geschlecht:

Arthrose:

\section{Beschreibung:}

Ein Handknochen. 
Bezeichn.: Manus

Kiste: $\quad 8505720$

Skelet: $\quad 1.0$

Population: Calden
Verband: Verband

\section{Alter:}

Geschlecht:

Arthrose:

\section{Beschreibung:}

Ein Handknochen. 
Bezeichn.: Manus

Kiste: $\quad 8505720$

Skelet: $\quad 1.0$

Population: Calden
Verband: Verband

\section{Alter:}

Geschlecht:

Arthrose:

\section{Beschreibung:}

Ein Handknochen. 
Bezeichn.: Manus

Kiste: $\quad 8505720$

Skelet: $\quad 1.0$

Population: Calden
Verband: Verband

\section{Alter:}

Geschlecht:

Arthrose:

\section{Beschreibung:}

Ein Handknochen. 
Bezeichn.: Manus

Kiste: $\quad 8505720$

Skelet: $\quad 1.0$

Population: Calden
Verband: Verband

\section{Alter:}

Geschlecht:

Arthrose:

\section{Beschreibung:}

Ein Handknochen. 
Bezeichn.: Manus

Kiste: $\quad 8505720$

Skelet: $\quad 1.0$

Population: Calden
Verband: Verband

\section{Alter:}

Geschlecht:

Arthrose:

\section{Beschreibung:}

Ein Handknochen. 
Bezeichn.: Manus

Kiste: $\quad 8505720$

Skelet: $\quad 1.0$

Population: Calden
Verband: Verband

\section{Alter:}

Geschlecht:

Arthrose:

\section{Beschreibung:}

Ein Handknochen. 
Bezeichn.: Manus

Kiste: $\quad 8505720$

Skelet: $\quad 1.0$

Population: Calden
Verband: Verband

\section{Alter:}

Geschlecht:

Arthrose:

\section{Beschreibung:}

Ein Handknochen. 
Bezeichn.: Manus

Kiste: $\quad 8505720$

Skelet: $\quad 1.0$

Population: Calden
Verband: Verband

\section{Alter:}

Geschlecht:

Arthrose:

\section{Beschreibung:}

Ein Handknochen. 
Bezeichn.: Manus

Kiste: $\quad 8505720$

Skelet: $\quad 1.0$

Population: Calden
Verband: Verband

\section{Alter:}

Geschlecht:

Arthrose:

\section{Beschreibung:}

Ein Handknochen. 
Bezeichn.: Manus

Kiste: $\quad 8505720$

Skelet: $\quad 1.0$

Population: Calden
Verband: Verband

\section{Alter:}

Geschlecht:

Arthrose:

\section{Beschreibung:}

Ein Handknochen. 
Bezeichn.: Manus

Kiste: $\quad 8505720$

Skelet: $\quad 1.0$

Population: Calden
Verband: Verband

\section{Alter:}

Geschlecht:

Arthrose:

\section{Beschreibung:}

Ein Handknochen. 
Bezeichn.: Manus

Kiste: $\quad 8505720$

Skelet: $\quad 1.0$

Population: Calden
Verband: Verband

\section{Alter:}

Geschlecht:

Arthrose:

\section{Beschreibung:}

Ein Handknochen. 
Bezeichn.: Manus

Kiste: $\quad 8505720$

Skelet: $\quad 1.0$

Population: Calden
Verband: Verband

\section{Alter:}

Geschlecht:

Arthrose:

\section{Beschreibung:}

Ein Handknochen. 
Bezeichn.: Manus

Kiste: $\quad 8505720$

Skelet: $\quad 1.0$

Population: Calden
Verband: Verband

\section{Alter:}

Geschlecht:

Arthrose:

\section{Beschreibung:}

Ein Handknochen. 
Bezeichn.: Manus

Kiste: $\quad 8505720$

Skelet: $\quad 1.0$

Population: Calden
Verband: Verband

\section{Alter:}

Geschlecht:

Arthrose:

\section{Beschreibung:}

Ein Handknochen. 
Bezeichn.: Manus

Kiste: $\quad 8505720$

Skelet: $\quad 1.0$

Population: Calden
Verband: Verband

\section{Alter:}

Geschlecht:

Arthrose:

\section{Beschreibung:}

Ein Handknochen. 
Bezeichn.: Manus

Kiste: $\quad 8505720$

Skelet: $\quad 1.0$

Population: Calden
Verband: Verband

\section{Alter:}

Geschlecht:

Arthrose:

\section{Beschreibung:}

Ein Handknochen. 
Bezeichn.: Manus

Kiste: $\quad 8505720$

Skelet: $\quad 1.0$

Population: Calden
Verband: Verband

\section{Alter:}

Geschlecht:

Arthrose:

\section{Beschreibung:}

Ein Handknochen. 
Bezeichn.: Manus

Kiste: $\quad 8505720$

Skelet: $\quad 1.0$

Population: Calden
Verband: Verband

\section{Alter:}

Geschlecht:

Arthrose:

\section{Beschreibung:}

Ein Handknochen. 
Bezeichn.: Manus

Kiste: $\quad 8505720$

Skelet: $\quad 1.0$

Population: Calden
Verband: Verband

\section{Alter:}

Geschlecht:

Arthrose:

\section{Beschreibung:}

Ein Handknochen. 
Bezeichn.: Manus

Kiste: $\quad 8505720$

Skelet: $\quad 1.0$

Population: Calden
Verband: Verband

\section{Alter:}

Geschlecht:

Arthrose:

\section{Beschreibung:}

Ein Handknochen. 
Bezeichn.: Manus

Kiste: $\quad 8505720$

Skelet: $\quad 1.0$

Population: Calden
Verband: Verband

\section{Alter:}

Geschlecht:

Arthrose:

\section{Beschreibung:}

Ein Handknochen. 
Bezeichn.: Manus

Kiste: $\quad 8505720$

Skelet: $\quad 1.0$

Population: Calden
Verband: Verband

\section{Alter:}

Geschlecht:

Arthrose:

\section{Beschreibung:}

Ein Handknochen. 
Bezeichn.: Manus

Kiste: $\quad 8505720$

Skelet: $\quad 1.0$

Population: Calden
Verband: Verband

\section{Alter:}

Geschlecht:

Arthrose:

\section{Beschreibung:}

Ein Handknochen. 
Bezeichn.: Manus

Kiste: $\quad 8505720$

Skelet: $\quad 1.0$

Population: Calden
Verband: Verband

\section{Alter:}

Geschlecht:

Arthrose:

\section{Beschreibung:}

Ein Handknochen. 
Bezeichn.: Manus

Kiste: $\quad 8505720$

Skelet: $\quad 1.0$

Population: Calden
Verband: Verband

\section{Alter:}

Geschlecht:

Arthrose:

\section{Beschreibung:}

Ein Handknochen. 
Bezeichn.: Manus

Kiste: $\quad 8505720$

Skelet: $\quad 1.0$

Population: Calden
Verband: Verband

\section{Alter:}

Geschlecht:

Arthrose:

\section{Beschreibung:}

Ein Handknochen. 
Bezeichn.: Manus

Kiste: $\quad 8505720$

Skelet: $\quad 1.0$

Population: Calden
Verband: Verband

\section{Alter:}

Geschlecht:

Arthrose:

\section{Beschreibung:}

Ein Handknochen. 
Bezeichn.: Manus

Kiste: $\quad 8505720$

Skelet: $\quad 1.0$

Population: Calden
Verband: Verband

\section{Alter:}

Geschlecht:

Arthrose:

\section{Beschreibung:}

Ein Handknochen. 
Bezeichn.: Manus

Kiste: $\quad 8505720$

Skelet: $\quad 1.0$

Population: Calden
Verband: Verband

\section{Alter:}

Geschlecht:

Arthrose:

\section{Beschreibung:}

Ein Handknochen. 
Bezeichn.: Manus

Kiste: $\quad 8505720$

Skelet: $\quad 1.0$

Population: Calden
Verband: Verband

\section{Alter:}

Geschlecht:

Arthrose:

\section{Beschreibung:}

Ein Handknochen. 
Bezeichn.: Manus

Kiste: $\quad 8505720$

Skelet: $\quad 1.0$

Population: Calden
Verband: Verband

\section{Alter:}

Geschlecht:

Arthrose:

\section{Beschreibung:}

Ein Handknochen. 
Bezeichn.: Manus

Kiste: $\quad 8505720$

Skelet: $\quad 1.0$

Population: Calden
Verband: Verband

\section{Alter:}

Geschlecht:

Arthrose:

\section{Beschreibung:}

Ein Handknochen. 
Bezeichn.: Manus

Kiste: $\quad 8505720$

Skelet: $\quad 1.0$

Population: Calden
Verband: Verband

\section{Alter:}

Geschlecht:

Arthrose:

\section{Beschreibung:}

Ein Handknochen. 
Bezeichn.: Manus

Kiste: $\quad 8505720$

Skelet: $\quad 1.0$

Population: Calden
Verband: Verband

\section{Alter:}

Geschlecht:

Arthrose:

\section{Beschreibung:}

Ein Handknochen. 
Bezeichn.: Manus

Kiste: $\quad 8505720$

Skelet: $\quad 1.0$

Population: Calden
Verband: Verband

\section{Alter:}

Geschlecht:

Arthrose:

\section{Beschreibung:}

Ein Handknochen. 
Bezeichn.: Manus

Kiste: $\quad 8505720$

Skelet: $\quad 1.0$

Population: Calden
Verband: Verband

\section{Alter:}

Geschlecht:

Arthrose:

\section{Beschreibung:}

Ein Handknochen. 
Bezeichn.: Manus

Kiste: $\quad 8505720$

Skelet: $\quad 1.0$

Population: Calden
Verband: Verband

\section{Alter:}

Geschlecht:

Arthrose:

\section{Beschreibung:}

Ein Handknochen. 
Bezeichn.: Manus

Kiste: $\quad 8505720$

Skelet: $\quad 1.0$

Population: Calden
Verband: Verband

\section{Alter:}

Geschlecht:

Arthrose:

\section{Beschreibung:}

Ein Handknochen. 
Bezeichn.: Manus

Kiste: $\quad 8505720$

Skelet: $\quad 1.0$

Population: Calden
Verband: Verband

\section{Alter:}

Geschlecht:

Arthrose:

\section{Beschreibung:}

Ein Handknochen. 
Bezeichn.: Manus

Kiste: $\quad 8505720$

Skelet: $\quad 1.0$

Population: Calden
Verband: Verband

\section{Alter:}

Geschlecht:

Arthrose:

\section{Beschreibung:}

Ein Handknochen. 
Bezeichn.: Manus

Kiste: $\quad 8505720$

Skelet: $\quad 1.0$

Population: Calden
Verband: Verband

\section{Alter:}

Geschlecht:

Arthrose:

\section{Beschreibung:}

Ein Handknochen. 
Bezeichn.: Manus

Kiste: $\quad 8505720$

Skelet: $\quad 1.0$

Population: Calden
Verband: Verband

\section{Alter:}

Geschlecht:

Arthrose:

\section{Beschreibung:}

Ein Handknochen. 
Bezeichn.: Manus

Kiste: $\quad 8505720$

Skelet: $\quad 1.0$

Population: Calden
Verband: Verband

\section{Alter:}

Geschlecht:

Arthrose:

\section{Beschreibung:}

Ein Handknochen. 
Bezeichn.: Manus

Kiste: $\quad 8505720$

Skelet: $\quad 1.0$

Population: Calden
Verband: Verband

\section{Alter:}

Geschlecht:

Arthrose:

\section{Beschreibung:}

Ein Handknochen. 
Bezeichn.: Manus

Kiste: $\quad 8505720$

Skelet: $\quad 1.0$

Population: Calden
Verband: Verband

\section{Alter:}

Geschlecht:

Arthrose:

\section{Beschreibung:}

Ein Handknochen. 
Bezeichn.: Manus

Kiste: $\quad 8505720$

Skelet: $\quad 1.0$

Population: Calden
Verband: Verband

\section{Alter:}

Geschlecht:

Arthrose:

\section{Beschreibung:}

Ein Handknochen. 
Bezeichn.: Manus

Kiste: $\quad 8505720$

Skelet: $\quad 1.0$

Population: Calden
Verband: Verband

\section{Alter:}

Geschlecht:

Arthrose:

\section{Beschreibung:}

Ein Handknochen. 
Bezeichn.: Manus

Kiste: $\quad 8505720$

Skelet: $\quad 1.2$

Population: Calden
Verband: Verband

\section{Alter:}

Geschlecht:

Arthrose:

\section{Beschreibung:}

Ein Handknochen. 
Bezeichn.: Manus

Kiste: $\quad 8505720$

Skelet: $\quad 1.2$

Population: Calden
Verband: Verband

\section{Alter:}

Geschlecht:

Arthrose:

\section{Beschreibung:}

Ein Handknochen. 
Bezeichn.: Manus

Kiste: $\quad 8505720$

Skelet: $\quad 1.2$

Population: Calden
Verband: Verband

\section{Alter:}

Geschlecht:

Arthrose:

\section{Beschreibung:}

Ein Handknochen. 
Bezeichn.: Manus

Kiste: $\quad 8505720$

Skelet: $\quad 1.2$

Population: Calden
Verband: Verband

\section{Alter:}

Geschlecht:

Arthrose:

\section{Beschreibung:}

Ein Handknochen. 
Bezeichn.: Manus

Kiste: $\quad 8505720$

Skelet: $\quad 1.2$

Population: Calden
Verband: Verband

\section{Alter:}

Geschlecht:

Arthrose:

\section{Beschreibung:}

Ein Handknochen. 
Bezeichn.: Manus

Kiste: $\quad 8505720$

Skelet: $\quad 1.2$

Population: Calden
Verband: Verband

\section{Alter:}

Geschlecht:

Arthrose:

\section{Beschreibung:}

Ein Handknochen. 
Bezeichn.: Manus

Kiste: $\quad 8505720$

Skelet: $\quad 1.2$

Population: Calden
Verband: Verband

\section{Alter:}

Geschlecht:

Arthrose:

\section{Beschreibung:}

Ein Handknochen. 
Bezeichn.: Manus

Kiste: $\quad 8505720$

Skelet: $\quad 1.2$

Population: Calden
Verband: Verband

\section{Alter:}

Geschlecht:

Arthrose:

\section{Beschreibung:}

Ein Handknochen. 
Bezeichn.: Manus

Kiste: $\quad 8505720$

Skelet: $\quad 1.2$

Population: Calden
Verband: Verband

\section{Alter:}

Geschlecht:

Arthrose:

\section{Beschreibung:}

Ein Handknochen. 
Bezeichn.: Manus

Kiste: $\quad 8505720$

Skelet: $\quad 1.2$

Population: Calden
Verband: Verband

\section{Alter:}

Geschlecht:

Arthrose:

\section{Beschreibung:}

Ein Handknochen. 
Bezeichn.: Manus

Kiste: $\quad 8505720$

Skelet: $\quad 1.2$

Population: Calden
Verband: Verband

\section{Alter:}

Geschlecht:

Arthrose:

\section{Beschreibung:}

Ein Handknochen. 
Bezeichn.: Manus

Kiste: $\quad 8505720$

Skelet: $\quad 1.2$

Population: Calden
Verband: Verband

\section{Alter:}

Geschlecht:

Arthrose:

\section{Beschreibung:}

Ein Handknochen. 
Bezeichn.: Manus

Kiste: $\quad 8505720$

Skelet: $\quad 1.2$

Population: Calden
Verband: Verband

\section{Alter:}

Geschlecht:

Arthrose:

\section{Beschreibung:}

Ein Handknochen. 
Bezeichn.: Manus

Kiste: $\quad 8505720$

Skelet: $\quad 1.2$

Population: Calden
Verband: Verband

\section{Alter:}

Geschlecht:

Arthrose:

\section{Beschreibung:}

Ein Handknochen. 
Bezeichn.: Manus

Kiste: $\quad 8505720$

Skelet: $\quad 1.2$

Population: Calden
Verband: Verband

\section{Alter:}

Geschlecht:

Arthrose:

\section{Beschreibung:}

Ein Handknochen. 
Bezeichn.: Manus

Kiste: $\quad 8505720$

Skelet: $\quad 1.2$

Population: Calden
Verband: Verband

\section{Alter:}

Geschlecht:

Arthrose:

\section{Beschreibung:}

Ein Handknochen. 
Bezeichn.: Manus

Kiste: $\quad 8505720$

Skelet: $\quad 1.2$

Population: Calden
Verband: Verband

\section{Alter:}

Geschlecht:

Arthrose:

\section{Beschreibung:}

Ein Handknochen. 
Bezeichn.: Manus

Kiste: $\quad 8505720$

Skelet: $\quad 1.2$

Population: Calden
Verband: Verband

\section{Alter:}

Geschlecht:

Arthrose:

\section{Beschreibung:}

Ein Handknochen. 
Bezeichn.: Manus

Kiste: $\quad 8505720$

Skelet: $\quad 1.2$

Population: Calden
Verband: Verband

\section{Alter:}

Geschlecht:

Arthrose:

\section{Beschreibung:}

Ein Handknochen. 
Bezeichn.: Manus

Kiste: $\quad 8505720$

Skelet: $\quad 1.2$

Population: Calden
Verband: Verband

\section{Alter:}

Geschlecht:

Arthrose:

\section{Beschreibung:}

Ein Handknochen. 
Bezeichn.: Manus

Kiste: $\quad 8505720$

Skelet: $\quad 1.2$

Population: Calden
Verband: Verband

\section{Alter:}

Geschlecht:

Arthrose:

\section{Beschreibung:}

Ein Handknochen. 
Bezeichn.: Manus

Kiste: $\quad 8505720$

Skelet: $\quad 1.2$

Population: Calden
Verband: Verband

\section{Alter:}

Geschlecht:

Arthrose:

\section{Beschreibung:}

Ein Handknochen. 
Bezeichn.: Manus

Kiste: $\quad 8505720$

Skelet: $\quad 1.2$

Population: Calden
Verband: Verband

\section{Alter:}

Geschlecht:

Arthrose:

\section{Beschreibung:}

Ein Handknochen. 


$\begin{array}{lll}\text { Bezeichn.: } & \text { Manus } & \text { Verband: } \square \text { Verband } \\ \text { Kiste: } & 8505720 & \text { Alter: Jung } \\ \text { Skelet: } & 1.0 & \text { Geschlecht: } \\ \text { Population: } & \text { Calden } & \text { Arthrose: }\end{array}$

\section{Beschreibung:}

Ein Os metacarpale eines jungen Individuums. 


$\begin{array}{lll}\text { Bezeichn.: } & \text { Manus } & \text { Verband: } \square \text { Verband } \\ \text { Kiste: } & 8505720 & \text { Alter: Jung } \\ \text { Skelet: } & 1.0 & \text { Geschlecht: } \\ \text { Population: } & \text { Calden } & \text { Arthrose: }\end{array}$

\section{Beschreibung:}

Ein Os phalangis eines jungen Individuums. 


$\begin{array}{lll}\text { Bezeichn.: } & \text { Manus } & \text { Verband: } \square \text { Verband } \\ \text { Kiste: } & 8505720 & \text { Alter: Jung } \\ \text { Skelet: } & 1.2 & \text { Geschlecht: } \\ \text { Population: } & \text { Calden } & \text { Arthrose: }\end{array}$

\section{Beschreibung:}

Ein Os metacarpale eines jungen Individuums. 


\section{Bezeichn: Manus}

Kiste: $\quad 8505718$

Skelet: aus Tüte

Population: Calden

Seite:

links
Verband: $\square$ Verband

\section{Alter:}

Geschlecht:

Arthrose:

\section{Beschreibung:}

Ein Os capitatum, welches gut erhalten ist. 
Bezeichn.: Manus

Kiste: $\quad 8505718$

Skelet: aus Tüte

Population: Calden

\section{Beschreibung:}

Os phalangis proximalis.
Verband:

Verband

\section{Alter:}

Geschlecht:

Arthrose:
Ges./Kr.: Gesund 
Bezeichn.: Manus

Kiste: $\quad 8505718$

Skelet: aus Tüte

Population: Calden

\section{Beschreibung:}

Os phalangis proximalis.
Verband:

Verband

\section{Alter:}

Geschlecht:

Arthrose:
Ges./Kr.: Gesund 
Bezeichn.: Manus

Kiste: 8505718

Skelet: aus Tüte

Population: Calden

\section{Beschreibung:}

Os metacarpale.
Verband: Verband

\section{Alter:}

Geschlecht:

Arthrose:
Ges./Kr.: Gesund 
Bezeichn.: Manus

Kiste: $\quad 8505718$

Skelet: $\quad$ aus Tüte

Population: Calden
Verband:

\section{Alter:}

Ges./Kr.: Gesund

Geschlecht:

Arthrose:

\section{Beschreibung:}

Os metacarpale eines jungen Individuums. Die distale Epiphysenfuge ist nicht verschlossen gewesen. 
Bezeichn.: Manus

Kiste: $\quad 8505718$

Skelet: aus Tüte

Population: Calden

\section{Beschreibung:}

Os metacarpale.
Verband: Verband

\section{Alter:}

Geschlecht:

Arthrose:
Ges./Kr.: Gesund 
Bezeichn.: Manus

Kiste: $\quad 8505718$

Skelet: aus Tüte

Population: Calden

\section{Beschreibung:}

Os metacarpale.
Verband: Verband

\section{Alter:}

Geschlecht:

Arthrose:
Ges./Kr.: Gesund 
Bezeichn.: Manus

Kiste: $\quad 8505718$

Skelet: aus Tüte

Population: Calden

\section{Beschreibung:}

Os metacarpale.
Verband: Verband

\section{Alter:}

Geschlecht:

Arthrose:
Ges./Kr.: Gesund 
Bezeichn.: Manus

Kiste: $\quad 8505718$

Skelet: aus Tüte

Population: Calden

\section{Beschreibung:}

Os metacarpale.
Verband: Verband

\section{Alter:}

Geschlecht:

Arthrose:
Ges./Kr.: Gesund 
Bezeichn.: Manus

Kiste: 8505718

Skelet: aus Tüte

Population: Calden

\section{Beschreibung:}

Os metacarpale.
Verband: Verband

\section{Alter:}

Geschlecht:

Arthrose:
Ges./Kr.: Gesund 
Bezeichn.: Manus

Kiste: $\quad 8505718$

Skelet: aus Tüte

Population: Calden

\section{Beschreibung:}

Os metacarpale.
Verband: Verband

\section{Alter:}

Geschlecht:

Arthrose:
Ges./Kr.: Gesund 
Bezeichn.: Manus

Kiste: 8505718

Skelet: aus Tüte

Population: Calden

\section{Beschreibung:}

Os metacarpale.
Verband: Verband

\section{Alter:}

Geschlecht:

Arthrose:
Ges./Kr.: Gesund 
Bezeichn.: Manus

Kiste: $\quad 8505718$

Skelet: aus Tüte

Population: Calden

\section{Beschreibung:}

Os metacarpale.
Verband: Verband

\section{Alter:}

Geschlecht:

Arthrose:
Ges./Kr.: Gesund 
Bezeichn.: Manus

Kiste: 8505718

Skelet: aus Tüte

Population: Calden

\section{Beschreibung:}

Os metacarpale.
Verband: Verband

\section{Alter:}

Geschlecht:

Arthrose:
Ges./Kr.: Gesund 
Bezeichn.: Manus

Kiste: $\quad 8505718$

Skelet: aus Tüte

Population: Calden

\section{Beschreibung:}

Os metacarpale.
Verband: Verband

\section{Alter:}

Geschlecht:

Arthrose:
Ges./Kr.: Gesund 
Bezeichn.: Manus

Kiste: $\quad 8505718$

Skelet: aus Tüte

Population: Calden

\section{Beschreibung:}

Os metacarpale.
Verband: Verband

\section{Alter:}

Geschlecht:

Arthrose:
Ges./Kr.: Gesund 
Bezeichn.: Manus

Kiste: $\quad 8505718$

Skelet: aus Tüte

Population: Calden

\section{Beschreibung:}

Os metacarpale.
Verband: Verband

\section{Alter:}

Geschlecht:

Arthrose:
Ges./Kr.: Gesund 


\section{Bezeichn.: Manus}

Kiste: $\quad 8505718$

Skelet: aus Tüte

Population: Calden

Seite:

rechts
Ges./Kr.: Gesund

Maß

Wert 1 Einheit

Alter: Jung

Geschlecht:

Arthrose:

\section{Beschreibung:}

Os metacarpale 1 der rechten Seite eines jüngeren Individuums. Es ist der vollständige Knochen erhalten mit Epiphyse. 
Bezeichn.: Manus

Kiste: $\quad 5242266$

Skelet: 3. Tüte

Population: Calden

\section{Beschreibung:}

Handknochen.
Verband: Verband

\section{Alter:}

Geschlecht:

Arthrose: 


\section{Bezeichn.: Manus \\ Kiste: $\quad 5242266$ \\ Skelet: 3. Tüte}

Population: Calden
Verband: Verband

\section{Alter:}

Geschlecht:

Arthrose:

\section{Beschreibung:}

Handknochen. 
Bezeichn.: Manus

Kiste: $\quad 5242266$

Skelet: 3. Tüte

Population: Calden

\section{Beschreibung:}

Handknochen.
Verband: Verband

\section{Alter:}

Geschlecht:

Arthrose: 
Bezeichn.: Manus

Kiste: $\quad 5242266$

Skelet: 3. Tüte

Population: Calden

\section{Beschreibung:}

Handknochen.
Verband: Verband

\section{Alter:}

Geschlecht:

Arthrose: 
Bezeichn.: Manus

Kiste: $\quad 5242266$

Skelet: 3. Tüte

Population: Calden

\section{Beschreibung:}

Handknochen.
Verband: $\quad$ Verband

\section{Alter:}

Geschlecht:

Arthrose: 
Bezeichn.: Manus

Kiste: $\quad 5242266$

Skelet: 3. Tüte

Population: Calden

\section{Beschreibung:}

Handknochen.
Verband: $\square$ Verband

\section{Alter:}

Geschlecht:

Arthrose: 
Bezeichn.: Manus

Kiste: $\quad 5242266$

Skelet: 3. Tüte

Population: Calden

\section{Beschreibung:}

Handknochen.
Verband: $\square$ Verband

\section{Alter:}

Geschlecht:

Arthrose: 
Bezeichn.: Manus

Kiste: $\quad 5242266$

Skelet: 3. Tüte

Population: Calden

\section{Beschreibung:}

Handknochen.
Verband: $\square$ Verband

\section{Alter:}

Geschlecht:

Arthrose: 
Bezeichn.: Manus

Kiste: $\quad 5242266$

Skelet: 3. Tüte

Population: Calden

\section{Beschreibung:}

Handknochen.
Verband: $\square$ Verband

\section{Alter:}

Geschlecht:

Arthrose: 
Bezeichn.: Manus

Kiste: $\quad 5242266$

Skelet: 3. Tüte

Population: Calden

\section{Beschreibung:}

Handknochen.
Verband: $\square$ Verband

\section{Alter:}

Geschlecht:

Arthrose: 


\section{Bezeichn: \\ Kiste: $\quad 5242266$ \\ Skelet: 3. Tüte}

Population: Calden
Verband: Verband

\section{Alter:}

Geschlecht:

Arthrose:

\section{Beschreibung:}

Handknochen. 
Bezeichn.: Manus

Kiste: $\quad 5242266$

Skelet: 3. Tüte

Population: Calden

\section{Beschreibung:}

Handknochen.
Verband: Verband

\section{Alter:}

Geschlecht:

Arthrose: 
Bezeichn.: Manus

Kiste: $\quad 5242266$

Skelet: 3. Tüte

Population: Calden

\section{Beschreibung:}

Handknochen.
Verband: $\square$ Verband

\section{Alter:}

Geschlecht:

Arthrose: 


\section{Bezeichn.: Manus \\ Kiste: $\quad 5242266$ \\ Skelet: 3. Tüte}

Population: Calden
Verband: Verband

\section{Alter:}

Geschlecht:

Arthrose:

\section{Beschreibung:}

Handknochen. 
Bezeichn.: Manus

Kiste: $\quad 5242266$

Skelet: 3. Tüte

Population: Calden

\section{Beschreibung:}

Handknochen.
Verband: Verband

\section{Alter:}

Geschlecht:

Arthrose: 


\section{Bezeichn: \\ Kiste: $\quad 5242266$ \\ Skelet: 3. Tüte}

Population: Calden
Verband: Verband

\section{Alter:}

Geschlecht:

Arthrose:

\section{Beschreibung:}

Handknochen. 


\section{Bezeichn. \\ Kiste: $\quad 5242266$ \\ Skelet: 3. Tüte}

Population: Calden
Verband: Verband

\section{Alter:}

Geschlecht:

Arthrose:

\section{Beschreibung:}

Handknochen. 
Bezeichn.: Manus

Kiste: $\quad 5242266$

Skelet: 3. Tüte

Population: Calden

\section{Beschreibung:}

Handknochen.
Verband: Verband

\section{Alter:}

Geschlecht:

Arthrose: 
Bezeichn.: Manus

Kiste: $\quad 5242266$

Skelet: 3. Tüte

Population: Calden

\section{Beschreibung:}

Handknochen.
Verband: $\square$ Verband

\section{Alter:}

Geschlecht:

Arthrose: 
Bezeichn.: Manus

Kiste: $\quad 5242266$

Skelet: 3. Tüte

Population: Calden

\section{Beschreibung:}

Handknochen.
Verband: $\quad$ Verband

Alter: $\quad 10-17$

Geschlecht:

Arthrose: 
Bezeichn.: Manus

Kiste: $\quad 5242266$

Skelet: 3. Tüte

Population: Calden

\section{Beschreibung:}

Handknochen.
Verband: $\quad$ Verband

\section{Alter: $\quad 10-17$}

Geschlecht:

Arthrose: 
Bezeichn.: Manus

Kiste: $\quad 5242266$

Skelet: 3. Tüte

Population: Calden

\section{Beschreibung:}

Handknochen.
Verband: $\quad$ Verband

Alter: $\quad 10-17$

Geschlecht:

Arthrose: 
Bezeichn.: Manus

Kiste: $\quad 5242266$

Skelet: 3. Tüte

Population: Calden

\section{Beschreibung:}

Handknochen.
Verband: $\quad$ Verband

Alter: $\quad 10-17$

Geschlecht:

Arthrose: 
Bezeichn.: Manus

Kiste: $\quad 5242266$

Skelet: 3. Tüte

Population: Calden

\section{Beschreibung:}

Handknochen.
Verband: $\quad$ Verband

Alter: $\quad 10-17$

Geschlecht:

Arthrose: 
Bezeichn.: Manus

Kiste: $\quad 5242266$

Skelet: 3. Tüte

Population: Calden

\section{Beschreibung:}

Handknochen.
Verband: $\quad$ Verband

Alter: $\quad 10-17$

Geschlecht:

Arthrose: 
Bezeichn.: Manus

Kiste: $\quad 5242266$

Skelet: 3. Tüte

Population: Calden

\section{Beschreibung:}

Handknochen.
Verband: $\quad$ Verband

Alter: $\quad 10-17$

Geschlecht:

Arthrose: 
Bezeichn.: Manus

Kiste: $\quad 5242266$

Skelet: 3. Tüte

Population: Calden

\section{Beschreibung:}

Handknochen.
Verband: $\quad$ Verband

\section{Alter: $\quad 10-17$}

Geschlecht:

Arthrose: 
Bezeichn.: Manus

Kiste: $\quad 5242266$

Skelet: 3. Tüte

Population: Calden

\section{Beschreibung:}

Handknochen.
Verband: $\quad$ Verband

\section{Alter: $\quad 10-17$}

Geschlecht:

Arthrose: 
Bezeichn.: Manus

Kiste: $\quad 5242266$

Skelet: 3. Tüte

Population: Calden

\section{Beschreibung:}

Handknochen.
Verband: $\quad$ Verband

Alter: $\quad 10-17$

Geschlecht:

Arthrose: 
Bezeichn.: Manus

Kiste: $\quad 5242266$

Skelet: 3. Tüte

Population: Calden

\section{Beschreibung:}

Handknochen.
Verband: $\quad$ Verband

Alter: $\quad 10-17$

Geschlecht:

Arthrose: 


$\begin{array}{lll}\text { Bezeichn.: } & \text { Manus / Pes } & \text { Verband: } \square \text { Verband } \\ \text { Kiste: } & 8505720 & \text { Alter: } \\ \text { Skelet: } & 1.0 & \text { Geschlecht: } \\ \text { Population: } & \text { Calden } & \text { Arthrose: }\end{array}$

\section{Beschreibung:}

Zum Teil fragmentierte Knochen von Hand und Fuß. 


$\begin{array}{lll}\text { Bezeichn.: } & \text { Manus / Pes } & \text { Verband: } \square \text { Verband } \\ \text { Kiste: } & 8505720 & \text { Alter: } \\ \text { Skelet: } & 1.0 & \text { Geschlecht: } \\ \text { Population: } & \text { Calden } & \text { Arthrose: }\end{array}$

\section{Beschreibung:}

Zum Teil fragmentierte Knochen von Hand und Fuß. 


\section{Bezeichn: Manus / Pes \\ Kiste: $\quad 8505720$ \\ Skelet: $\quad 1.0$}

Population: Calden
Verband: Verband

\section{Alter:}

Geschlecht:

Arthrose:

\section{Beschreibung:}

Zum Teil fragmentierte Knochen von Hand und Fuß. 


\section{Bezeichn: Manus / Pes \\ Kiste: $\quad 8505720$ \\ Skelet: $\quad 1.0$}

Population: Calden
Verband: Verband

\section{Alter:}

Geschlecht:

Arthrose:

\section{Beschreibung:}

Zum Teil fragmentierte Knochen von Hand und Fuß. 
Bezeichn.: Manus / Pes

Kiste: $\quad 8505720$

Skelet: $\quad 1.0$

Population: Calden
Verband: Verband

\section{Alter:}

Geschlecht:

Arthrose:

\section{Beschreibung:}

Zum Teil fragmentierte Knochen von Hand und Fuß. 


\section{Bezeichn: Manus / Pes \\ Kiste: $\quad 8505720$ \\ Skelet: $\quad 1.0$}

Population: Calden
Verband: Verband

\section{Alter:}

Geschlecht:

Arthrose:

\section{Beschreibung:}

Zum Teil fragmentierte Knochen von Hand und Fuß. 


$\begin{array}{lll}\text { Bezeichn.: } & \text { Manus / Pes } & \text { Verband: } \square \text { Verband } \\ \text { Kiste: } & 8505720 & \text { Alter: } \\ \text { Skelet: } & 1.0 & \text { Geschlecht: } \\ \text { Population: } & \text { Calden } & \text { Arthrose: }\end{array}$

\section{Beschreibung:}

Zum Teil fragmentierte Knochen von Hand und Fuß. 


$\begin{array}{lll}\text { Bezeichn.: } & \text { Manus / Pes } & \text { Verband: } \square \text { Verband } \\ \text { Kiste: } & 8505720 & \text { Alter: } \\ \text { Skelet: } & 1.0 & \text { Geschlecht: } \\ \text { Population: } & \text { Calden } & \text { Arthrose: }\end{array}$

\section{Beschreibung:}

Zum Teil fragmentierte Knochen von Hand und Fuß. 


\section{Bezeichn: Manus / Pes \\ Kiste: $\quad 8505720$ \\ Skelet: $\quad 1.0$}

Population: Calden
Verband: Verband

\section{Alter:}

Geschlecht:

Arthrose:

\section{Beschreibung:}

Zum Teil fragmentierte Knochen von Hand und Fuß. 


$\begin{array}{lll}\text { Bezeichn.: } & \text { Manus / Pes } & \text { Verband: } \square \text { Verband } \\ \text { Kiste: } & 8505720 & \text { Alter: } \\ \text { Skelet: } & 1.0 & \text { Geschlecht: } \\ \text { Population: } & \text { Calden } & \text { Arthrose: }\end{array}$

\section{Beschreibung:}

Zum Teil fragmentierte Knochen von Hand und Fuß. 


$\begin{array}{lll}\text { Bezeichn.: } & \text { Manus / Pes } & \text { Verband: } \square \text { Verband } \\ \text { Kiste: } & 8505720 & \text { Alter: } \\ \text { Skelet: } & 1.0 & \text { Geschlecht: } \\ \text { Population: } & \text { Calden } & \text { Arthrose: }\end{array}$

\section{Beschreibung:}

Zum Teil fragmentierte Knochen von Hand und Fuß. 


$\begin{array}{lll}\text { Bezeichn.: } & \text { Manus / Pes } & \text { Verband: } \square \text { Verband } \\ \text { Kiste: } & 8505720 & \text { Alter: } \\ \text { Skelet: } & 1.0 & \text { Geschlecht: } \\ \text { Population: } & \text { Calden } & \text { Arthrose: }\end{array}$

\section{Beschreibung:}

Zum Teil fragmentierte Knochen von Hand und Fuß. 


\section{Bezeichn: Manus / Pes \\ Kiste: $\quad 8505720$ \\ Skelet: $\quad 1.0$}

Population: Calden
Verband: Verband

\section{Alter:}

Geschlecht:

Arthrose:

\section{Beschreibung:}

Zum Teil fragmentierte Knochen von Hand und Fuß. 


\section{Bezeichn: Manus / Pes \\ Kiste: $\quad 8505720$ \\ Skelet: $\quad 1.0$}

Population: Calden
Verband: Verband

\section{Alter:}

Geschlecht:

Arthrose:

\section{Beschreibung:}

Zum Teil fragmentierte Knochen von Hand und Fuß. 


\section{Bezeichn: Manus / Pes \\ Kiste: $\quad 8505720$ \\ Skelet: $\quad 1.0$}

Population: Calden
Verband: Verband

\section{Alter:}

Geschlecht:

Arthrose:

\section{Beschreibung:}

Zum Teil fragmentierte Knochen von Hand und Fuß. 


\section{Bezeichn: Manus / Pes \\ Kiste: $\quad 8505720$ \\ Skelet: $\quad 1.0$}

Population: Calden
Verband: Verband

\section{Alter:}

Geschlecht:

Arthrose:

\section{Beschreibung:}

Zum Teil fragmentierte Knochen von Hand und Fuß. 


$\begin{array}{lll}\text { Bezeichn.: } & \text { Manus / Pes } & \text { Verband: } \square \text { Verband } \\ \text { Kiste: } & 8505720 & \text { Alter: } \\ \text { Skelet: } & 1.0 & \text { Geschlecht: } \\ \text { Population: } & \text { Calden } & \text { Arthrose: }\end{array}$

\section{Beschreibung:}

Zum Teil fragmentierte Knochen von Hand und Fuß. 


$\begin{array}{lll}\text { Bezeichn.: } & \text { Manus / Pes } & \text { Verband: } \square \text { Verband } \\ \text { Kiste: } & 8505720 & \text { Alter: } \\ \text { Skelet: } & 1.0 & \text { Geschlecht: } \\ \text { Population: } & \text { Calden } & \text { Arthrose: }\end{array}$

\section{Beschreibung:}

Zum Teil fragmentierte Knochen von Hand und Fuß. 


\section{Bezeichn: Manus / Pes \\ Kiste: $\quad 8505720$ \\ Skelet: $\quad 1.0$}

Population: Calden
Verband: Verband

\section{Alter:}

Geschlecht:

Arthrose:

\section{Beschreibung:}

Zum Teil fragmentierte Knochen von Hand und Fuß. 


$\begin{array}{lll}\text { Bezeichn.: } & \text { Manus / Pes } & \text { Verband: } \square \text { Verband } \\ \text { Kiste: } & 8505720 & \text { Alter: } \\ \text { Skelet: } & 1.0 & \text { Geschlecht: } \\ \text { Population: } & \text { Calden } & \text { Arthrose: }\end{array}$

\section{Beschreibung:}

Zum Teil fragmentierte Knochen von Hand und Fuß. 


\section{Bezeichn: Manus / Pes \\ Kiste: $\quad 8505720$ \\ Skelet: $\quad 1.0$}

Population: Calden
Verband: Verband

\section{Alter:}

Geschlecht:

Arthrose:

\section{Beschreibung:}

Zum Teil fragmentierte Knochen von Hand und Fuß. 


$\begin{array}{lll}\text { Bezeichn.: } & \text { Manus / Pes } & \text { Verband: } \square \text { Verband } \\ \text { Kiste: } & 8505720 & \text { Alter: } \\ \text { Skelet: } & 1.0 & \text { Geschlecht: } \\ \text { Population: } & \text { Calden } & \text { Arthrose: }\end{array}$

\section{Beschreibung:}

Zum Teil fragmentierte Knochen von Hand und Fuß. 


\section{Bezeichn: Manus / Pes \\ Kiste: $\quad 8505720$ \\ Skelet: $\quad 1.0$}

Population: Calden
Verband: Verband

\section{Alter:}

Geschlecht:

Arthrose:

\section{Beschreibung:}

Zum Teil fragmentierte Knochen von Hand und Fuß. 


\section{Bezeichn: Manus / Pes \\ Kiste: $\quad 8505720$ \\ Skelet: $\quad 1.0$}

Population: Calden
Verband: Verband

\section{Alter:}

Geschlecht:

Arthrose:

\section{Beschreibung:}

Zum Teil fragmentierte Knochen von Hand und Fuß. 


\section{Bezeichn: Manus / Pes \\ Kiste: $\quad 8505720$ \\ Skelet: $\quad 1.0$}

Population: Calden
Verband: Verband

\section{Alter:}

Geschlecht:

Arthrose:

\section{Beschreibung:}

Zum Teil fragmentierte Knochen von Hand und Fuß. 


\section{Bezeichn: Manus / Pes \\ Kiste: $\quad 8505720$ \\ Skelet: $\quad 1.0$}

Population: Calden
Verband: Verband

\section{Alter:}

Geschlecht:

Arthrose:

\section{Beschreibung:}

Zum Teil fragmentierte Knochen von Hand und Fuß. 


$\begin{array}{lll}\text { Bezeichn.: } & \text { Manus / Pes } & \text { Verband: } \square \text { Verband } \\ \text { Kiste: } & 8505720 & \text { Alter: } \\ \text { Skelet: } & 1.0 & \text { Geschlecht: } \\ \text { Population: } & \text { Calden } & \text { Arthrose: }\end{array}$

\section{Beschreibung:}

Zum Teil fragmentierte Knochen von Hand und Fuß. 


$\begin{array}{lll}\text { Bezeichn.: } & \text { Manus / Pes } & \text { Verband: } \square \text { Verband } \\ \text { Kiste: } & 8505720 & \text { Alter: } \\ \text { Skelet: } & 1.0 & \text { Geschlecht: } \\ \text { Population: } & \text { Calden } & \text { Arthrose: }\end{array}$

\section{Beschreibung:}

Zum Teil fragmentierte Knochen von Hand und Fuß. 


\section{Bezeichn: Manus / Pes \\ Kiste: $\quad 8505720$ \\ Skelet: $\quad 1.0$}

Population: Calden
Verband: Verband

\section{Alter:}

Geschlecht:

Arthrose:

\section{Beschreibung:}

Zum Teil fragmentierte Knochen von Hand und Fuß. 


\section{Bezeichn: Manus / Pes \\ Kiste: $\quad 8505720$ \\ Skelet: $\quad 1.0$}

Population: Calden
Verband: Verband

\section{Alter:}

Geschlecht:

Arthrose:

\section{Beschreibung:}

Zum Teil fragmentierte Knochen von Hand und Fuß. 


\section{Bezeichn: Manus / Pes \\ Kiste: $\quad 8505720$ \\ Skelet: $\quad 1.0$}

Population: Calden
Verband: Verband

\section{Alter:}

Geschlecht:

Arthrose:

\section{Beschreibung:}

Zum Teil fragmentierte Knochen von Hand und Fuß. 


\section{Bezeichn: Manus / Pes \\ Kiste: $\quad 8505720$ \\ Skelet: $\quad 1.0$}

Population: Calden
Verband: Verband

\section{Alter:}

Geschlecht:

Arthrose:

\section{Beschreibung:}

Zum Teil fragmentierte Knochen von Hand und Fuß. 


\section{Bezeichn: Manus / Pes \\ Kiste: $\quad 8505720$ \\ Skelet: $\quad 1.0$}

Population: Calden
Verband: Verband

\section{Alter:}

Geschlecht:

Arthrose:

\section{Beschreibung:}

Zum Teil fragmentierte Knochen von Hand und Fuß. 


\section{Bezeichn: Manus / Pes \\ Kiste: $\quad 8505720$ \\ Skelet: $\quad 1.0$}

Population: Calden
Verband: Verband

\section{Alter:}

Geschlecht:

Arthrose:

\section{Beschreibung:}

Zum Teil fragmentierte Knochen von Hand und Fuß. 


\section{Bezeichn: Manus / Pes \\ Kiste: $\quad 8505720$ \\ Skelet: $\quad 1.0$}

Population: Calden
Verband: Verband

\section{Alter:}

Geschlecht:

Arthrose:

\section{Beschreibung:}

Zum Teil fragmentierte Knochen von Hand und Fuß. 


\section{Bezeichn: Manus / Pes \\ Kiste: $\quad 8505720$ \\ Skelet: $\quad 1.0$}

Population: Calden
Verband: Verband

\section{Alter:}

Geschlecht:

Arthrose:

\section{Beschreibung:}

Zum Teil fragmentierte Knochen von Hand und Fuß. 


\section{Bezeichn: Manus / Pes \\ Kiste: $\quad 8505720$ \\ Skelet: $\quad 1.0$}

Population: Calden
Verband: Verband

\section{Alter:}

Geschlecht:

Arthrose:

\section{Beschreibung:}

Zum Teil fragmentierte Knochen von Hand und Fuß. 


$\begin{array}{lll}\text { Bezeichn.: } & \text { Manus / Pes } & \text { Verband: } \square \text { Verband } \\ \text { Kiste: } & 8505720 & \text { Alter: } \\ \text { Skelet: } & 1.0 & \text { Geschlecht: } \\ \text { Population: } & \text { Calden } & \text { Arthrose: }\end{array}$

\section{Beschreibung:}

Zum Teil fragmentierte Knochen von Hand und Fuß. 


\section{Bezeichn: Manus / Pes \\ Kiste: $\quad 8505720$ \\ Skelet: $\quad 1.0$}

Population: Calden
Verband: Verband

\section{Alter:}

Geschlecht:

Arthrose:

\section{Beschreibung:}

Zum Teil fragmentierte Knochen von Hand und Fuß. 
Bezeichn.: Manus / Pes

Kiste: $\quad 8505720$

Skelet: $\quad 1.0$

Population: Calden
Verband: Verband

\section{Alter:}

Geschlecht:

Arthrose:

\section{Beschreibung:}

Zum Teil fragmentierte Knochen von Hand und Fuß. 


\section{Bezeichn: Manus / Pes \\ Kiste: $\quad 8505720$ \\ Skelet: $\quad 1.0$}

Population: Calden
Verband: Verband

\section{Alter:}

Geschlecht:

Arthrose:

\section{Beschreibung:}

Zum Teil fragmentierte Knochen von Hand und Fuß. 


$\begin{array}{lll}\text { Bezeichn.: } & \text { Manus / Pes } & \text { Verband: } \square \text { Verband } \\ \text { Kiste: } & 8505720 & \text { Alter: } \\ \text { Skelet: } & 1.0 & \text { Geschlecht: } \\ \text { Population: } & \text { Calden } & \text { Arthrose: }\end{array}$

\section{Beschreibung:}

Zum Teil fragmentierte Knochen von Hand und Fuß. 


$\begin{array}{lll}\text { Bezeichn.: } & \text { Manus / Pes } & \text { Verband: } \square \text { Verband } \\ \text { Kiste: } & 8505720 & \text { Alter: } \\ \text { Skelet: } & 1.0 & \text { Geschlecht: } \\ \text { Population: } & \text { Calden } & \text { Arthrose: }\end{array}$

\section{Beschreibung:}

Zum Teil fragmentierte Knochen von Hand und Fuß. 


\section{Bezeichn: Manus / Pes \\ Kiste: $\quad 8505720$ \\ Skelet: $\quad 1.0$}

Population: Calden
Verband: Verband

\section{Alter:}

Geschlecht:

Arthrose:

\section{Beschreibung:}

Zum Teil fragmentierte Knochen von Hand und Fuß. 
Bezeichn.: Manus / Pes

Kiste: $\quad 8505720$

Skelet: $\quad 1.0$

Population: Calden
Verband: Verband

\section{Alter:}

Geschlecht:

Arthrose:

\section{Beschreibung:}

Zum Teil fragmentierte Knochen von Hand und Fuß. 


\section{Bezeichn: Manus / Pes \\ Kiste: $\quad 8505720$ \\ Skelet: $\quad 1.0$}

Population: Calden
Verband: Verband

\section{Alter:}

Geschlecht:

Arthrose:

\section{Beschreibung:}

Zum Teil fragmentierte Knochen von Hand und Fuß. 


$\begin{array}{lll}\text { Bezeichn.: } & \text { Manus / Pes } & \text { Verband: } \square \text { Verband } \\ \text { Kiste: } & 8505720 & \text { Alter: } \\ \text { Skelet: } & 1.0 & \text { Geschlecht: } \\ \text { Population: } & \text { Calden } & \text { Arthrose: }\end{array}$

\section{Beschreibung:}

Zum Teil fragmentierte Knochen von Hand und Fuß. 


\section{Bezeichn: Manus / Pes \\ Kiste: $\quad 8505720$ \\ Skelet: $\quad 1.0$}

Population: Calden
Verband: Verband

\section{Alter:}

Geschlecht:

Arthrose:

\section{Beschreibung:}

Zum Teil fragmentierte Knochen von Hand und Fuß. 


\section{Bezeichn: Manus / Pes \\ Kiste: $\quad 8505720$ \\ Skelet: $\quad 1.0$}

Population: Calden
Verband: Verband

\section{Alter:}

Geschlecht:

Arthrose:

\section{Beschreibung:}

Zum Teil fragmentierte Knochen von Hand und Fuß. 


\section{Bezeichn: Manus / Pes \\ Kiste: $\quad 8505720$ \\ Skelet: $\quad 1.0$}

Population: Calden
Verband: Verband

\section{Alter:}

Geschlecht:

Arthrose:

\section{Beschreibung:}

Zum Teil fragmentierte Knochen von Hand und Fuß. 


\section{Bezeichn: Manus / Pes \\ Kiste: $\quad 8505720$ \\ Skelet: $\quad 1.0$}

Population: Calden
Verband: Verband

\section{Alter:}

Geschlecht:

Arthrose:

\section{Beschreibung:}

Zum Teil fragmentierte Knochen von Hand und Fuß. 


\section{Bezeichn: Manus / Pes \\ Kiste: $\quad 8505720$ \\ Skelet: $\quad 1.0$}

Population: Calden
Verband: Verband

\section{Alter:}

Geschlecht:

Arthrose:

\section{Beschreibung:}

Zum Teil fragmentierte Knochen von Hand und Fuß. 


\section{Bezeichn: Manus / Pes \\ Kiste: $\quad 8505720$ \\ Skelet: $\quad 1.0$}

Population: Calden
Verband: Verband

\section{Alter:}

Geschlecht:

Arthrose:

\section{Beschreibung:}

Zum Teil fragmentierte Knochen von Hand und Fuß. 


\section{Bezeichn: Manus / Pes \\ Kiste: $\quad 8505720$ \\ Skelet: $\quad 1.0$}

Population: Calden
Verband: Verband

\section{Alter:}

Geschlecht:

Arthrose:

\section{Beschreibung:}

Zum Teil fragmentierte Knochen von Hand und Fuß. 


\section{Bezeichn: Manus / Pes \\ Kiste: $\quad 8505720$ \\ Skelet: $\quad 1.0$}

Population: Calden
Verband: Verband

\section{Alter:}

Geschlecht:

Arthrose:

\section{Beschreibung:}

Zum Teil fragmentierte Knochen von Hand und Fuß. 


$\begin{array}{lll}\text { Bezeichn.: } & \text { Manus / Pes } & \text { Verband: } \square \text { Verband } \\ \text { Kiste: } & 8505720 & \text { Alter: } \\ \text { Skelet: } & 1.2 & \text { Geschlecht: } \\ \text { Population: } & \text { Calden } & \text { Arthrose: }\end{array}$

\section{Beschreibung:}

Zum Teil fragmentierte Knochen von Hand und Fuß. 


$\begin{array}{lll}\text { Bezeichn.: } & \text { Manus / Pes } & \text { Verband: } \square \text { Verband } \\ \text { Kiste: } & 8505720 & \text { Alter: } \\ \text { Skelet: } & 1.2 & \text { Geschlecht: } \\ \text { Population: } & \text { Calden } & \text { Arthrose: }\end{array}$

\section{Beschreibung:}

Zum Teil fragmentierte Knochen von Hand und Fuß. 


$\begin{array}{lll}\text { Bezeichn.: } & \text { Manus / Pes } & \text { Verband: } \square \text { Verband } \\ \text { Kiste: } & 8505720 & \text { Alter: } \\ \text { Skelet: } & 1.2 & \text { Geschlecht: } \\ \text { Population: } & \text { Calden } & \text { Arthrose: }\end{array}$

\section{Beschreibung:}

Zum Teil fragmentierte Knochen von Hand und Fuß. 


$\begin{array}{lll}\text { Bezeichn.: } & \text { Manus / Pes } & \text { Verband: } \square \text { Verband } \\ \text { Kiste: } & 8505720 & \text { Alter: } \\ \text { Skelet: } & 1.2 & \text { Geschlecht: } \\ \text { Population: } & \text { Calden } & \text { Arthrose: }\end{array}$

\section{Beschreibung:}

Zum Teil fragmentierte Knochen von Hand und Fuß. 
Bezeichn.: Manus / Pes

Kiste: $\quad 8505720$

Skelet: $\quad 1.2$

Population: Calden
Verband: Verband

\section{Alter:}

Geschlecht:

Arthrose:

\section{Beschreibung:}

Zum Teil fragmentierte Knochen von Hand und Fuß. 


$\begin{array}{lll}\text { Bezeichn.: } & \text { Manus / Pes } & \text { Verband: } \square \text { Verband } \\ \text { Kiste: } & 8505720 & \text { Alter: } \\ \text { Skelet: } & 1.2 & \text { Geschlecht: } \\ \text { Population: } & \text { Calden } & \text { Arthrose: }\end{array}$

\section{Beschreibung:}

Zum Teil fragmentierte Knochen von Hand und Fuß. 


$\begin{array}{lll}\text { Bezeichn.: } & \text { Manus / Pes } & \text { Verband: } \square \text { Verband } \\ \text { Kiste: } & 8505720 & \text { Alter: } \\ \text { Skelet: } & 1.2 & \text { Geschlecht: } \\ \text { Population: } & \text { Calden } & \text { Arthrose: }\end{array}$

\section{Beschreibung:}

Zum Teil fragmentierte Knochen von Hand und Fuß. 


$\begin{array}{lll}\text { Bezeichn.: } & \text { Manus / Pes } & \text { Verband: } \square \text { Verband } \\ \text { Kiste: } & 8505720 & \text { Alter: } \\ \text { Skelet: } & 1.2 & \text { Geschlecht: } \\ \text { Population: } & \text { Calden } & \text { Arthrose: }\end{array}$

\section{Beschreibung:}

Zum Teil fragmentierte Knochen von Hand und Fuß. 


$\begin{array}{lll}\text { Bezeichn.: } & \text { Manus / Pes } & \text { Verband: } \square \text { Verband } \\ \text { Kiste: } & 8505720 & \text { Alter: } \\ \text { Skelet: } & 1.2 & \text { Geschlecht: } \\ \text { Population: } & \text { Calden } & \text { Arthrose: }\end{array}$

\section{Beschreibung:}

Zum Teil fragmentierte Knochen von Hand und Fuß. 
Bezeichn.: Manus / Pes

Kiste: $\quad 8505720$

Skelet: $\quad 1.2$

Population: Calden
Verband: Verband

\section{Alter:}

Geschlecht:

Arthrose:

\section{Beschreibung:}

Zum Teil fragmentierte Knochen von Hand und Fuß. 


$\begin{array}{lll}\text { Bezeichn.: } & \text { Manus / Pes } & \text { Verband: } \square \text { Verband } \\ \text { Kiste: } & 8505720 & \text { Alter: Jung } \\ \text { Skelet: } & 1.2 & \text { Geschlecht: } \\ \text { Population: } & \text { Calden } & \text { Arthrose: }\end{array}$

\section{Beschreibung:}

Ein Os phalangis eines jungen Individuums. 
Bezeichn.: Manus / Pes

Kiste: 8505721

Skelet: Kiste 5

Population: Calden
Verband:

Verband

\section{Alter:}

Geschlecht:

Arthrose:
Ges./Kr.: Gesund

\section{Beschreibung:}

Os phalangis. 
Bezeichn.: Manus / Pes

Kiste: $\quad 8505721$

Skelet: Kiste 5

Population: Calden

\section{Beschreibung:}

Os phalangis.

Os phala
Verband:

Verband

\section{Alter:}

Geschlecht:

Arthrose:
Ges./Kr.: Gesund 


\section{Bezeichn.: Manus / Pes \\ Kiste: \\ 8505721}

$\begin{array}{ll}\text { Skelet: } & \text { Kiste } 9 \\ \text { Population: } & \text { Calden }\end{array}$

Population: Calden

\section{Beschreibung:}

Ein Fragment eines Os phalangis.
Verband:

Verband

\section{Alter:}

Geschlecht:

Arthrose: 


\section{Bezeichn: Manus / Pes \\ Kiste: $\quad 8505720$ \\ Skelet: $\quad 1.1$}

Population: Calden
Verband: Verband

\section{Alter:}

Geschlecht:

Arthrose:

\section{Beschreibung:}

Es handelt sich hier um mehrere Fragmente und Splitter von Hand- und Fußknochen. 
Bezeichn.: Manus Und Pes

Kiste: $\quad 8505720$

Skelet: $\quad 1.0$

Population: Calden
Verband: Verband

\section{Alter:}

Geschlecht:

Arthrose:

\section{Beschreibung:}

Viele zum Teil fragmentierte Knochen von Hand und Fuß. 
Bezeichn: Pes

Kiste: $\quad 8505720$

Skelet: $\quad 1.0$

Population: Calden
Verband:

\section{Alter:}

Geschlecht:

Arthrose:

Ges./Kr.: Gesund

\section{Beschreibung:}

Ein Os metatarsale eines jungen Individuums. 
Bezeichn: Pes

Verband: $\quad$ Verband

Kiste: $\quad 8505720$

Skelet: $\quad 1.0$

\section{Alter:}

Geschlecht:

Population: Calden

Arthrose:

Beschreibung:

Ein Fußknochen. 
Bezeichn: Pes

Verband: $\quad$ Verband

Kiste: $\quad 8505720$

Skelet: $\quad 1.0$

\section{Alter:}

Geschlecht:

Population: Calden

Arthrose:

Beschreibung:

Ein Fußknochen. 
Bezeichn: Pes

Verband: $\square$ Verband

Kiste: $\quad 8505720$

Skelet: $\quad 1.0$

\section{Alter:}

Geschlecht:

Population: Calden

Arthrose:

Beschreibung:

Ein Fußknochen. 
Bezeichn: Pes

Verband: $\quad$ Verband

Kiste: $\quad 8505720$

Skelet: $\quad 1.0$

\section{Alter:}

Geschlecht:

Population: Calden

Arthrose:

Beschreibung:

Ein Fußknochen. 
Bezeichn: Pes

Verband: $\square$ Verband

Kiste: $\quad 8505720$

Skelet: $\quad 1.0$

\section{Alter:}

Geschlecht:

Population: Calden

Arthrose:

Beschreibung:

Ein Fußknochen. 
Bezeichn: Pes

Verband: $\square$ Verband

Kiste: $\quad 8505720$

Skelet: $\quad 1.0$

\section{Alter:}

Geschlecht:

Population: Calden

Arthrose:

Beschreibung:

Ein Fußknochen. 
Bezeichn: Pes

Verband: $\square$ Verband

Kiste: 8505720

Skelet: $\quad 1.0$

\section{Alter:}

Geschlecht:

Population: Calden

Arthrose:

Beschreibung:

Ein Fußknochen. 
Bezeichn: Pes

Verband: $\square$ Verband

Kiste: 8505720

Skelet: $\quad 1.0$

Alter:

Geschlecht:

Population: Calden

Arthrose:

Beschreibung:

Ein Fußknochen. 
Bezeichn: Pes

Verband: $\square$ Verband

Kiste: $\quad 8505720$

Skelet: $\quad 1.0$

\section{Alter:}

Geschlecht:

Population: Calden

Arthrose:

Beschreibung:

Ein Fußknochen. 
Bezeichn: Pes

Verband: $\square$ Verband

Kiste: $\quad 8505720$

Skelet: $\quad 1.0$

\section{Alter:}

Geschlecht:

Population: Calden

Arthrose:

Beschreibung:

Ein Fußknochen. 
Bezeichn: Pes

Verband: $\quad$ Verband

Kiste: $\quad 8505720$

Skelet: $\quad 1.0$

\section{Alter:}

Geschlecht:

Population: Calden

Arthrose:

Beschreibung:

Ein Fußknochen. 
Bezeichn: Pes

Verband: $\quad$ Verband

Kiste: $\quad 8505720$

Skelet: $\quad 1.0$

\section{Alter:}

Geschlecht:

Population: Calden

Arthrose:

Beschreibung:

Ein Fußknochen. 
Bezeichn: Pes

Verband: $\square$ Verband

Kiste: 8505720

Skelet: $\quad 1.0$

Alter:

Geschlecht:

Population: Calden

Arthrose:

Beschreibung:

Ein Fußknochen. 
Bezeichn: Pes

Verband: $\quad$ Verband

Kiste: $\quad 8505720$

Skelet: $\quad 1.0$

\section{Alter:}

Geschlecht:

Population: Calden

Arthrose:

Beschreibung:

Ein Fußknochen. 
Bezeichn: Pes

Verband: $\quad$ Verband

Kiste: $\quad 8505720$

Skelet: $\quad 1.0$

\section{Alter:}

Geschlecht:

Population: Calden

Arthrose:

Beschreibung:

Ein Fußknochen. 
Bezeichn: Pes

Verband: $\quad$ Verband

Kiste: $\quad 8505720$

Skelet: $\quad 1.0$

\section{Alter:}

Geschlecht:

Population: Calden

Arthrose:

Beschreibung:

Ein Fußknochen. 
Bezeichn: Pes

Verband: $\square$ Verband

Kiste: $\quad 8505720$

Skelet: $\quad 1.0$

\section{Alter:}

Geschlecht:

Population: Calden

Arthrose:

Beschreibung:

Ein Fußknochen. 
Bezeichn: Pes

Verband: $\square$ Verband

Kiste: 8505720

Skelet: $\quad 1.0$

Alter:

Geschlecht:

Population: Calden

Arthrose:

Beschreibung:

Ein Fußknochen. 
Bezeichn: Pes

Verband: $\square$ Verband

Kiste: $\quad 8505720$

Skelet: $\quad 1.0$

\section{Alter:}

Geschlecht:

Population: Calden

Arthrose:

Beschreibung:

Ein Fußknochen. 
Bezeichn: Pes

Verband: $\square$ Verband

Kiste: $\quad 8505720$

Skelet: $\quad 1.0$

\section{Alter:}

Geschlecht:

Population: Calden

Arthrose:

Beschreibung:

Ein Fußknochen. 
Bezeichn: Pes

Verband: $\square$ Verband

Kiste: $\quad 8505720$

Skelet: $\quad 1.0$

\section{Alter:}

Geschlecht:

Population: Calden

Arthrose:

Beschreibung:

Ein Fußknochen. 
Bezeichn: Pes

Verband: $\quad$ Verband

Kiste: $\quad 8505720$

Skelet: $\quad 1.0$

\section{Alter:}

Geschlecht:

Population: Calden

Arthrose:

Beschreibung:

Ein Fußknochen. 
Bezeichn: Pes

Verband: $\square$ Verband

Kiste: 8505720

Skelet: $\quad 1.0$

Alter:

Geschlecht:

Population: Calden

Arthrose:

Beschreibung:

Ein Fußknochen. 
Bezeichn: Pes

Verband: $\quad$ Verband

Kiste: $\quad 8505720$

Skelet: $\quad 1.0$

\section{Alter:}

Geschlecht:

Population: Calden

Arthrose:

Beschreibung:

Ein Fußknochen. 
Bezeichn: Pes

Verband: $\square$ Verband

Kiste: $\quad 8505720$

Skelet: $\quad 1.0$

\section{Alter:}

Geschlecht:

Population: Calden

Arthrose:

Beschreibung:

Ein Fußknochen. 
Bezeichn: Pes

Verband: $\square$ Verband

Kiste: $\quad 8505720$

Skelet: $\quad 1.0$

\section{Alter:}

Geschlecht:

Population: Calden

Arthrose:

Beschreibung:

Ein Fußknochen. 
Bezeichn: Pes

Verband: $\square$ Verband

Kiste: $\quad 8505720$

Skelet: $\quad 1.0$

\section{Alter:}

Geschlecht:

Population: Calden

Arthrose:

Beschreibung:

Ein Fußknochen. 
Bezeichn: Pes

Verband: $\square$ Verband

Kiste: 8505720

Skelet: $\quad 1.0$

Alter:

Geschlecht:

Population: Calden

Arthrose:

Beschreibung:

Ein Fußknochen. 
Bezeichn: Pes

Verband: $\quad$ Verband

Kiste: $\quad 8505720$

Skelet: $\quad 1.0$

\section{Alter:}

Geschlecht:

Population: Calden

Arthrose:

Beschreibung:

Ein Fußknochen. 
Bezeichn: Pes

Verband: $\square$ Verband

Kiste: $\quad 8505720$

Skelet: $\quad 1.0$

\section{Alter:}

Geschlecht:

Population: Calden

Arthrose:

Beschreibung:

Ein Fußknochen. 
Bezeichn: Pes

Verband: $\quad$ Verband

Kiste: $\quad 8505720$

Skelet: $\quad 1.0$

\section{Alter:}

Geschlecht:

Population: Calden

Arthrose:

Beschreibung:

Ein Fußknochen. 
Bezeichn: Pes

Verband: $\quad$ Verband

Kiste: $\quad 8505720$

Skelet: $\quad 1.0$

\section{Alter:}

Geschlecht:

Population: Calden

Arthrose:

Beschreibung:

Ein Fußknochen. 
Bezeichn: Pes

Verband: $\square$ Verband

Kiste: $\quad 8505720$

Skelet: $\quad 1.0$

\section{Alter:}

Geschlecht:

Population: Calden

Arthrose:

Beschreibung:

Ein Fußknochen. 
Bezeichn: Pes

Verband: $\quad$ Verband

Kiste: $\quad 8505720$

Skelet: $\quad 1.0$

\section{Alter:}

Geschlecht:

Population: Calden

Arthrose:

Beschreibung:

Ein Fußknochen. 
Bezeichn: Pes

Verband: $\square$ Verband

Kiste: 8505720

Skelet: $\quad 1.0$

Alter:

Geschlecht:

Population: Calden

Arthrose:

Beschreibung:

Ein Fußknochen. 
Bezeichn: Pes

Verband: $\square$ Verband

Kiste: 8505720

Skelet: $\quad 1.0$

Alter:

Geschlecht:

Population: Calden

Arthrose:

Beschreibung:

Ein Fußknochen. 
Bezeichn: Pes

Verband: $\square$ Verband

Kiste: 8505720

Skelet: $\quad 1.0$

\section{Alter:}

Geschlecht:

Population: Calden

Arthrose:

Beschreibung:

Ein Fußknochen. 
Bezeichn: Pes

Verband: $\square$ Verband

Kiste: $\quad 8505720$

Skelet: $\quad 1.0$

\section{Alter:}

Geschlecht:

Population: Calden

Arthrose:

Beschreibung:

Ein Fußknochen. 
Bezeichn: Pes

Verband: $\square$ Verband

Kiste: 8505720

Skelet: $\quad 1.0$

Alter:

Geschlecht:

Population: Calden

Arthrose:

Beschreibung:

Ein Fußknochen. 
Bezeichn: Pes

Verband: $\square$ Verband

Kiste: 8505720

Skelet: $\quad 1.0$

Alter:

Geschlecht:

Population: Calden

Arthrose:

Beschreibung:

Ein Fußknochen. 
Bezeichn: Pes

Verband: $\square$ Verband

Kiste: 8505720

Skelet: $\quad 1.0$

Alter:

Geschlecht:

Population: Calden

Arthrose:

Beschreibung:

Ein Fußknochen. 
Bezeichn: Pes

Verband: $\quad$ Verband

Kiste: $\quad 8505720$

Skelet: $\quad 1.0$

\section{Alter:}

Geschlecht:

Population: Calden

Arthrose:

Beschreibung:

Ein Fußknochen. 
Bezeichn: Pes

Verband: $\square$ Verband

Kiste: $\quad 8505720$

Skelet: $\quad 1.0$

\section{Alter:}

Geschlecht:

Population: Calden

Arthrose:

Beschreibung:

Ein Fußknochen. 
Bezeichn: Pes

Verband: $\quad$ Verband

Kiste: $\quad 8505720$

Skelet: $\quad 1.0$

\section{Alter:}

Geschlecht:

Population: Calden

Arthrose:

Beschreibung:

Ein Fußknochen. 
Bezeichn: Pes

Verband: $\quad$ Verband

Kiste: $\quad 8505720$

Skelet: $\quad 1.2$

\section{Alter:}

Geschlecht:

Population: Calden

Arthrose:

Beschreibung:

Ein Fußknochen. 
Bezeichn: Pes

Verband: $\quad$ Verband

Kiste: $\quad 8505720$

Skelet: $\quad 1.2$

\section{Alter:}

Geschlecht:

Population: Calden

Arthrose:

Beschreibung:

Ein Fußknochen. 
Bezeichn: Pes

Verband: $\quad$ Verband

Kiste: $\quad 8505720$

Skelet: $\quad 1.2$

\section{Alter:}

Geschlecht:

Population: Calden

Arthrose:

Beschreibung:

Ein Fußknochen. 
Bezeichn: Pes

Verband: $\quad$ Verband

Kiste: 8505720

Skelet: $\quad 1.2$

\section{Alter:}

Geschlecht:

Population: Calden

Arthrose:

Beschreibung:

Ein Fußknochen. 
Bezeichn: Pes

Verband: $\quad$ Verband

Kiste: $\quad 8505720$

Skelet: $\quad 1.2$

\section{Alter:}

Geschlecht:

Population: Calden

Arthrose:

Beschreibung:

Ein Fußknochen. 
Bezeichn: Pes

Verband: $\quad$ Verband

Kiste: 8505720

Skelet: $\quad 1.2$

\section{Alter:}

Geschlecht:

Population: Calden

Arthrose:

Beschreibung:

Ein Fußknochen. 
Bezeichn: Pes

Verband: $\quad$ Verband

Kiste: 8505720

Skelet: $\quad 1.2$

\section{Alter:}

Geschlecht:

Population: Calden

Arthrose:

Beschreibung:

Ein Fußknochen. 
Bezeichn: Pes

Verband: $\quad$ Verband

Kiste: 8505720

Skelet: $\quad 1.2$

\section{Alter:}

Geschlecht:

Population: Calden

Arthrose:

Beschreibung:

Ein Fußknochen. 
Bezeichn: Pes

Verband: $\quad$ Verband

Kiste: 8505720

Skelet: $\quad 1.2$

\section{Alter:}

Geschlecht:

Population: Calden

Arthrose:

Beschreibung:

Ein Fußknochen. 
Bezeichn: Pes

Verband: $\quad$ Verband

Kiste: 8505720

Skelet: $\quad 1.2$

\section{Alter:}

Geschlecht:

Population: Calden

Arthrose:

Beschreibung:

Ein Fußknochen. 
Bezeichn: Pes

Verband: $\quad$ Verband

Kiste: 8505720

Skelet: $\quad 1.2$

\section{Alter:}

Geschlecht:

Population: Calden

Arthrose:

Beschreibung:

Ein Fußknochen. 
Bezeichn: Pes

Verband: $\quad$ Verband

Kiste: $\quad 8505720$

Skelet: $\quad 1.2$

\section{Alter:}

Geschlecht:

Population: Calden

Arthrose:

Beschreibung:

Ein Fußknochen. 
Bezeichn: Pes

Verband: $\quad$ Verband

Kiste: 8505720

Skelet: $\quad 1.2$

\section{Alter:}

Geschlecht:

Population: Calden

Arthrose:

Beschreibung:

Ein Fußknochen. 
Bezeichn: Pes

Verband: $\quad$ Verband

Kiste: 8505720

Skelet: $\quad 1.2$

\section{Alter:}

Geschlecht:

Population: Calden

Arthrose:

Beschreibung:

Ein Fußknochen. 
Bezeichn: Pes

Verband: $\quad$ Verband

Kiste: 8505720

Skelet: $\quad 1.2$

\section{Alter:}

Geschlecht:

Population: Calden

Arthrose:

Beschreibung:

Ein Fußknochen. 
Bezeichn: Pes

Verband: $\quad$ Verband

Kiste: 8505720

Skelet: $\quad 1.2$

\section{Alter:}

Geschlecht:

Population: Calden

Arthrose:

Beschreibung:

Ein Fußknochen. 
Bezeichn: Pes

Verband: $\quad$ Verband

Kiste: 8505720

Skelet: $\quad 1.2$

\section{Alter:}

Geschlecht:

Population: Calden

Arthrose:

Beschreibung:

Ein Fußknochen. 
Bezeichn: Pes

Verband: $\quad$ Verband

Kiste: 8505720

Skelet: $\quad 1.2$

\section{Alter:}

Geschlecht:

Population: Calden

Arthrose:

Beschreibung:

Ein Fußknochen. 
Bezeichn: Pes

Verband: $\quad$ Verband

Kiste: 8505720

Skelet: $\quad 1.2$

\section{Alter:}

Geschlecht:

Population: Calden

Arthrose:

Beschreibung:

Ein Fußknochen. 
Bezeichn: Pes

Verband: $\quad$ Verband

Kiste: 8505720

Skelet: $\quad 1.2$

\section{Alter:}

Geschlecht:

Population: Calden

Arthrose:

Beschreibung:

Ein Fußknochen. 
Bezeichn: Pes

Verband: $\quad$ Verband

Kiste: 8505720

Skelet: $\quad 1.2$

\section{Alter:}

Geschlecht:

Population: Calden

Arthrose:

Beschreibung:

Ein Fußknochen. 
Bezeichn: Pes

Verband: $\quad$ Verband

Kiste: $\quad 8505720$

Skelet: $\quad 1.2$

\section{Alter:}

Geschlecht:

Population: Calden

Arthrose:

Beschreibung:

Ein Fußknochen. 
Bezeichn: Pes

Verband: $\quad$ Verband

Kiste: 8505720

Skelet: $\quad 1.2$

\section{Alter:}

Geschlecht:

Population: Calden

Arthrose:

Beschreibung:

Ein Fußknochen. 
Bezeichn: Pes

Verband: $\quad$ Verband

Kiste: 8505720

Skelet: $\quad 1.2$

\section{Alter:}

Geschlecht:

Population: Calden

Arthrose:

Beschreibung:

Ein Fußknochen. 
Bezeichn: Pes

Verband: $\quad$ Verband

Kiste: 8505720

Skelet: $\quad 1.2$

\section{Alter:}

Geschlecht:

Population: Calden

Arthrose:

Beschreibung:

Ein Fußknochen. 
Bezeichn: Pes

Verband: $\quad$ Verband

Kiste: 8505720

Skelet: $\quad 1.2$

\section{Alter:}

Geschlecht:

Population: Calden

Arthrose:

Beschreibung:

Ein Fußknochen. 
Bezeichn: Pes

Verband: $\quad$ Verband

Kiste: 8505720

Skelet: $\quad 1.2$

\section{Alter:}

Geschlecht:

Population: Calden

Arthrose:

Beschreibung:

Ein Fußknochen. 
Bezeichn: Pes

Verband: $\quad$ Verband

Kiste: 8505720

Skelet: $\quad 1.2$

\section{Alter:}

Geschlecht:

Population: Calden

Arthrose:

Beschreibung:

Ein Fußknochen. 
Bezeichn: Pes

Verband: $\quad$ Verband

Kiste: 8505720

Skelet: $\quad 1.2$

\section{Alter:}

Geschlecht:

Population: Calden

Arthrose:

Beschreibung:

Ein Fußknochen. 
Bezeichn: Pes

Verband: $\quad$ Verband

Kiste: 8505720

Skelet: $\quad 1.2$

\section{Alter:}

Geschlecht:

Population: Calden

Arthrose:

Beschreibung:

Ein Fußknochen. 
Bezeichn: Pes

Verband: $\quad$ Verband

Kiste: 8505720

Skelet: $\quad 1.2$

\section{Alter:}

Geschlecht:

Population: Calden

Arthrose:

Beschreibung:

Ein Fußknochen. 
Bezeichn: Pes

Verband: $\quad$ Verband

Kiste: $\quad 8505720$

Skelet: $\quad 1.2$

\section{Alter:}

Geschlecht:

Population: Calden

Arthrose:

Beschreibung:

Ein Fußknochen. 
Bezeichn: Pes

Verband: $\quad$ Verband

Kiste: 8505720

Skelet: $\quad 1.2$

\section{Alter:}

Geschlecht:

Population: Calden

Arthrose:

Beschreibung:

Ein Fußknochen. 
Bezeichn: Pes

Verband: $\quad$ Verband

Kiste: 8505720

Skelet: $\quad 1.2$

\section{Alter:}

Geschlecht:

Population: Calden

Arthrose:

Beschreibung:

Ein Fußknochen. 
Bezeichn: Pes

Verband: $\quad$ Verband

Kiste: 8505720

Skelet: $\quad 1.2$

\section{Alter:}

Geschlecht:

Population: Calden

Arthrose:

Beschreibung:

Ein Fußknochen. 
Bezeichn: Pes

Verband: $\quad$ Verband

Kiste: 8505720

Skelet: $\quad 1.2$

\section{Alter:}

Geschlecht:

Population: Calden

Arthrose:

Beschreibung:

Ein Fußknochen. 
Bezeichn: Pes

Verband: $\quad$ Verband

Kiste: 8505720

Skelet: $\quad 1.2$

\section{Alter:}

Geschlecht:

Population: Calden

Arthrose:

Beschreibung:

Ein Fußknochen. 
Bezeichn: Pes

Verband: $\quad$ Verband

Kiste: 8505720

Skelet: $\quad 1.2$

\section{Alter:}

Geschlecht:

Population: Calden

Arthrose:

Beschreibung:

Ein Fußknochen. 
Bezeichn: Pes

Verband: $\quad$ Verband

Kiste: 8505720

Skelet: $\quad 1.2$

\section{Alter:}

Geschlecht:

Population: Calden

Arthrose:

Beschreibung:

Ein Fußknochen. 
Bezeichn: Pes

Verband: $\quad$ Verband

Kiste: 8505720

Skelet: $\quad 1.2$

\section{Alter:}

Geschlecht:

Population: Calden

Arthrose:

Beschreibung:

Ein Fußknochen. 
Bezeichn: Pes

Verband: $\quad$ Verband

Kiste: $\quad 8505720$

Skelet: $\quad 1.2$

\section{Alter:}

Geschlecht:

Population: Calden

Arthrose:

Beschreibung:

Ein Fußknochen. 
Bezeichn: Pes

Verband: $\quad$ Verband

Kiste: 8505720

Skelet: $\quad 1.2$

\section{Alter:}

Geschlecht:

Population: Calden

Arthrose:

Beschreibung:

Ein Fußknochen. 
Bezeichn.: Pes

Kiste: $\quad 8505721$

Skelet: Kiste 5

Population: Calden

Seite: rechts

\section{Beschreibung:}

Ein Os metatarsale 1 der rechten Seite.
Verband: $\quad$ Verband

Ges./Kr.: Gesund

\section{Alter:}

Geschlecht:

Arthrose:

\section{prox}

dist.
2 


\section{Bezeichn.: Pes \\ Kiste: $\quad 8505721$ \\ Skelet: Kiste 5}

Population: Calden

\section{Beschreibung:}

Ein Fragment eines Os metatarsale.
Verband:

Verband

\section{Alter:}

Geschlecht:

Arthrose:
Ges./Kr.: Gesund 
Bezeichn.: Pes

Kiste: 8505721

Skelet: Kiste 5

Population: Calden

\section{Beschreibung:}

Os metatarsale.
Verband: $\quad$ Verband

Ges./Kr.: Gesund

\section{Alter:}

Geschlecht:

Arthrose: 
Bezeichn.: Pes

Kiste: $\quad 8505720$

Skelet: $\quad$ Fußgelenk 1.1

Population: Calden
Verband: Verband

\section{Alter:}

Geschlecht:

Arthrose:

\section{Beschreibung:}

Ein Knochen aus dem Fußgelenk. 
Bezeichn.: Pes

Kiste: $\quad 8505720$

Skelet: $\quad$ Fußgelenk 1.1

Population: Calden
Verband: Verband

\section{Alter:}

Geschlecht:

Arthrose:

\section{Beschreibung:}

Ein Knochen aus dem Fußgelenk. 
Bezeichn.: Pes

Kiste: $\quad 8505718$

Skelet: aus Tüte

Population: Calden

Seite: rechts

\section{Beschreibung:}

Ein Os cuneiforme intermediale.
Verband: $\quad \square$ Verband

\section{Alter:}

Geschlecht:

Arthrose:
Ges./Kr.: Gesund 
Bezeichn.: Pes

Kiste: $\quad 8505718$

Skelet: aus Tüte

Population: Calden

Seite:

links
Verband:

Verband

\section{Alter:}

Geschlecht:

Arthrose:

\section{Beschreibung:}

Ein Os cuboideum.
Ges./Kr.: Gesund

\section{Ges/Kr: Gesund}


Bezeichn.: Pes

Kiste: $\quad 8505718$

Skelet: aus Tüte

Population: Calden

Seite:

links
Verband:

Verband

\section{Alter:}

Geschlecht:

Arthrose:

\section{Beschreibung:}

Os naviculare. 
Bezeichn.: Pes

Kiste: $\quad 8505718$

Skelet: aus Tüte

Population: Calden

Seite:

links
Verband:

Verband

\section{Alter:}

Geschlecht:

Arthrose:

\section{Beschreibung:}

Os cuneiforme mediale. 
Bezeichn:: Pes

Kiste: $\quad 8505718$

Skelet: aus Tüte

Population: Calden
Verband:

\section{Alter:}

Geschlecht:

Arthrose:
Ges./Kr.: Gesund

\section{Beschreibung:}

Os phalangis. 
Bezeichn:: Pes

Kiste: $\quad 8505718$

Skelet: aus Tüte

Population: Calden
Verband:

\section{Alter:}

Geschlecht:

Arthrose:
Ges./Kr.: Gesund

\section{Beschreibung:}

Os phalangis. 
Bezeichn:: Pes

Skelet: aus Tüte

Population: Calden
Kiste: $\quad 8505718$
Verband:

\section{Alter:}

Geschlecht:

Arthrose:
Ges./Kr.: Gesund

\section{Beschreibung:}

Os metatarsale. 
Bezeichn:: Pes

Kiste: $\quad 8505718$

Skelet: aus Tüte

Population: Calden
Verband:

\section{Alter:}

Geschlecht:

Arthrose:
Ges./Kr.: Gesund

\section{Beschreibung:}

Os metatarsale. 
Bezeichn:: Pes

Skelet: aus Tüte

Population: Calden
Kiste: $\quad 8505718$
Verband:

\section{Alter:}

Geschlecht:

Arthrose:
Ges./Kr.: Gesund

\section{Beschreibung:}

Os metatarsale. 
Bezeichn:: Pes

Kiste: $\quad 8505718$

Skelet: aus Tüte

Population: Calden
Verband:

\section{Alter:}

Geschlecht:

Arthrose:
Ges./Kr.: Gesund

\section{Beschreibung:}

Os metatarsale. 
Bezeichn:: Pes

Kiste: $\quad 8505718$

Skelet: aus Tüte

Population: Calden
Verband:

\section{Alter:}

Geschlecht:

Arthrose:
Ges./Kr.: Gesund

\section{Beschreibung:}

Os metatarsale. 
Bezeichn:: Pes

Kiste: $\quad 8505718$

Skelet: aus Tüte

Population: Calden
Verband:

\section{Alter:}

Geschlecht:

Arthrose:
Ges./Kr.: Gesund

\section{Beschreibung:}

Os metatarsale. 
Bezeichn:: Pes

Kiste: $\quad 8505718$

Skelet: aus Tüte

Population: Calden
Verband:

\section{Alter:}

Geschlecht:

Arthrose:
Ges./Kr.: Gesund

\section{Beschreibung:}

Os metatarsale. 
Bezeichn:: Pes

Kiste: $\quad 8505718$

Skelet: aus Tüte

Population: Calden
Verband:

\section{Alter:}

Geschlecht:

Arthrose:
Ges./Kr.: Gesund

\section{Beschreibung:}

Os metatarsale. 
Bezeichn:: Pes

Kiste: $\quad 8505718$

Skelet: aus Tüte

Population: Calden
Verband:

\section{Alter:}

Geschlecht:

Arthrose:
Ges./Kr.: Gesund

\section{Beschreibung:}

Os metatarsale. 
Bezeichn:: Pes

Kiste: $\quad 8505718$

Skelet: aus Tüte

Population: Calden
Verband:

\section{Alter:}

Geschlecht:

Arthrose:
Ges./Kr.: Gesund

\section{Beschreibung:}

Os metatarsale. 
Bezeichn.: Pes

Kiste: $\quad 5254272$

Skelet: $\quad 3$. Tüte

Population: Calden
Verband: Verband

\section{Alter:}

Geschlecht:

Arthrose:

\section{Beschreibung:}

Ein Knochen aus dem Bereich des Fußes. 
Bezeichn.: Pes

Kiste: $\quad 5242266$

Skelet: 3. Tüte

Population: Calden

Beschreibung:

Ein Fußknochen.
Verband: Verband

\section{Alter:}

Geschlecht:

Arthrose: 
Bezeichn.: Pes

Kiste: $\quad 5242266$

Skelet: 3. Tüte

Population: Calden

Beschreibung:

Ein Fußknochen.
Verband: Verband

\section{Alter:}

Geschlecht:

Arthrose: 
Bezeichn.: Pes

Kiste: $\quad 5242266$

Skelet: 3. Tüte

Population: Calden

Beschreibung:

Ein Fußknochen.
Verband: Verband

\section{Alter:}

Geschlecht:

Arthrose: 
Bezeichn.: Pes

Kiste: $\quad 5242266$

Skelet: 3. Tüte

Population: Calden

Beschreibung:

Ein Fußknochen.
Verband: Verband

\section{Alter:}

Geschlecht:

Arthrose: 
Bezeichn.: Pes

Kiste: 5242266

Skelet: 3. Tüte

Population: Calden

Beschreibung:

Ein Fußknochen.
Verband: Verband

\section{Alter:}

Geschlecht:

Arthrose: 
Bezeichn.: Pes

Kiste: $\quad 5242266$

Skelet: 3. Tüte

Population: Calden

Beschreibung:

Ein Fußknochen.
Verband: Verband

\section{Alter:}

Geschlecht:

Arthrose: 
Bezeichn.: Pes

Kiste: $\quad 5242266$

Skelet: 3. Tüte

Population: Calden

Beschreibung:

Ein Fußknochen.
Verband: Verband

\section{Alter:}

Geschlecht:

Arthrose: 
Bezeichn.: Pes

Kiste: $\quad 5242266$

Skelet: 3. Tüte

Population: Calden

Beschreibung:

Ein Fußknochen.
Verband: Verband

\section{Alter:}

Geschlecht:

Arthrose: 
Bezeichn.: Pes

Kiste: $\quad 5242266$

Skelet: 3. Tüte

Population: Calden

Beschreibung:

Ein Fußknochen.
Verband: Verband

\section{Alter:}

Geschlecht:

Arthrose: 
Bezeichn.: Pes

Kiste: $\quad 5242266$

Skelet: 3. Tüte

Population: Calden

Beschreibung:

Ein Fußknochen.
Verband: Verband

\section{Alter:}

Geschlecht:

Arthrose: 
Bezeichn.: Pes

Kiste: $\quad 5242266$

Skelet: 3. Tüte

Population: Calden

Beschreibung:

Ein Fußknochen.
Verband: Verband

\section{Alter:}

Geschlecht:

Arthrose: 
Bezeichn.: Pes

Kiste: $\quad 5242266$

Skelet: 3. Tüte

Population: Calden

Beschreibung:

Ein Fußknochen.
Verband: Verband

\section{Alter:}

Geschlecht:

Arthrose: 
Bezeichn.: Pes

Kiste: $\quad 5242266$

Skelet: 3. Tüte

Population: Calden

Beschreibung:

Ein Fußknochen.
Verband: Verband

\section{Alter:}

Geschlecht:

Arthrose: 
Bezeichn.: Pes

Kiste: $\quad 5242266$

Skelet: 3. Tüte

Population: Calden

Beschreibung:

Ein Fußknochen.
Verband: Verband

\section{Alter:}

Geschlecht:

Arthrose: 
Bezeichn.: Pes

Kiste: $\quad 5242266$

Skelet: 3. Tüte

Population: Calden

Beschreibung:

Ein Fußknochen.
Verband: Verband

\section{Alter:}

Geschlecht:

Arthrose: 
Bezeichn.: Pes

Kiste: $\quad 5242266$

Skelet: 3. Tüte

Population: Calden

Beschreibung:

Ein Fußknochen.
Verband: Verband

\section{Alter:}

Geschlecht:

Arthrose: 
Bezeichn.: Pes

Kiste: $\quad 5242266$

Skelet: 3. Tüte

Population: Calden

Beschreibung:

Ein Fußknochen.
Verband: Verband

\section{Alter:}

Geschlecht:

Arthrose: 
Bezeichn.: Pes

Kiste: $\quad 5242266$

Skelet: 3. Tüte

Population: Calden

Beschreibung:

Ein Fußknochen.
Verband: Verband

\section{Alter:}

Geschlecht:

Arthrose: 
Bezeichn.: Pes

Kiste: 5242266

Skelet: 3. Tüte

Population: Calden

Beschreibung:

Ein Fußknochen.
Verband: Verband

\section{Alter:}

Geschlecht:

Arthrose: 
Bezeichn.: Pes

Kiste: $\quad 5242266$

Skelet: 3. Tüte

Population: Calden

Beschreibung:

Ein Fußknochen.
Verband: Verband

\section{Alter:}

Geschlecht:

Arthrose: 
Bezeichn.: Pes

Kiste: $\quad 5242266$

Skelet: 3. Tüte

Population: Calden

Beschreibung:

Ein Fußknochen.
Verband: Verband

\section{Alter:}

Geschlecht:

Arthrose: 
Bezeichn.: Pes

Kiste: $\quad 5242266$

Skelet: 3. Tüte

Population: Calden

Beschreibung:

Ein Fußknochen.
Verband: Verband

\section{Alter:}

Geschlecht:

Arthrose: 
Bezeichn.: Pes

Kiste: $\quad 5242266$

Skelet: 3. Tüte

Population: Calden

Beschreibung:

Ein Fußknochen.
Verband: Verband

\section{Alter:}

Geschlecht:

Arthrose: 
Bezeichn.: Pes

Kiste: $\quad 5242266$

Skelet: 3. Tüte

Population: Calden

Beschreibung:

Ein Fußknochen.
Verband: Verband

\section{Alter:}

Geschlecht:

Arthrose: 
Bezeichn.: Pes

Kiste: $\quad 5242266$

Skelet: 3. Tüte

Population: Calden

Beschreibung:

Ein Fußknochen.
Verband: Verband

\section{Alter:}

Geschlecht:

Arthrose: 
Bezeichn.: Pes

Kiste: $\quad 5242266$

Skelet: 3. Tüte

Population: Calden

Beschreibung:

Ein Fußknochen.
Verband: Verband

\section{Alter:}

Geschlecht:

Arthrose: 
Bezeichn.: Phalanx

Verband: $\quad$ Verband

Kiste: $\quad 8505718$

Alter:

Skelet: aus 2. Kiste

Geschlecht:

Population: Calden

Arthrose:

\section{Beschreibung:}

Ein Os phalangis 1 proximal. Die Seite ist nicht bestimmbar. 
Bezeichn.: Phalanx

Kiste: 5272290

Skelet:

Population: Calden

\section{Beschreibung:}

Ein junges Os phalangis.
Verband: $\square$ Verband

Alter: Jung

Geschlecht:

Arthrose:
Ges./Kr.: Gesund 
Bezeichn.: Phalanx

Kiste: $\quad 5272290$

Skelet:

Population: Calden
Verband:

\section{Alter:}

Geschlecht:

Arthrose:
Ges./Kr.: Gesund
Verband Jung

\section{Beschreibung:}

Ein Os phalangis eines jungen Individuums. 
Bezeichn.: Phalanx

Kiste: $\quad 5274292$

Skelet: B3

Population: Calden

\section{Beschreibung:}

Os phalangis medialis.
Verband:

Verband

\section{Alter:}

Geschlecht:

Arthrose:
Ges./Kr.: Gesund

\section{Ges.Kr: Gesund}


Bezeichn.: Phalanx

Kiste: $\quad 5274292$

Skelet: B3

Population: Calden

\section{Beschreibung:}

Os phalangis distalis.
Verband:

Verband

\section{Alter:}

Geschlecht:

Arthrose:
Ges./Kr.: Gesund

\section{Ges.Kr: Gesund}




$\begin{array}{lll}\text { Bezeichn.: } & \text { Phalanx } & \text { Verband: } \square \text { Verband } \\ \text { Kiste: } & 5267283 & \text { Alter: } \\ \text { Skelet: } & \text { bei Calden } 6 & \text { Geschlecht: } \\ \text { Population: } & \text { Calden } & \text { Arthrose: }\end{array}$

\section{Beschreibung:}

Ein Os phalangis, welches nicht genauer zuzuordnen war. 
Bezeichn.: Phalanx

\section{Kiste:}

5267283

Skelet: bei Calden 6

Population: Calden

Verband: $\quad$ Verband

\section{Alter:}

Geschlecht:

Arthrose:

\section{Beschreibung:}

Nicht genauer zuzuordnen. 
Bezeichn.: Phalanx

\section{Kiste:}

8505718

Skelet: aus 2. Kiste

Population: Calden

Seite:

n. def.
Verband: Verband

\section{Alter:}

Geschlecht:

Arthrose:

\section{Beschreibung:}

Ein Os phalangis proximalis 1 . 
Bezeichn.: Phalanx

Kiste:

5243267

Skelet: Zettel

Population: Calden
Verband:

Verband

\section{Alter:}

Geschlecht:

Arthrose:

\section{Beschreibung:}

Ein Os phalangis proximalis. 
Bezeichn.: Phalanx

Kiste: $\quad 5243267$

Skelet: Zettel

Population: Calden

Verband: $\quad$ Verband

\section{Alter:}

Geschlecht:

Arthrose:

\section{Beschreibung:}

Ein Os phalangis proximalis 1 . 
Bezeichn.: Phalanx

Kiste: 5243267

Skelet: Zettel

Population: Calden

\section{Beschreibung:}

Ein Os phalangis medialis.
Verband: Verband

\section{Alter:}

Geschlecht:

Arthrose: 
Bezeichn.: Phalanx

Kiste: $\quad 5256274$

Skelet: Zettel

Population: Calden

\section{Beschreibung:}

Ein Os phalangis medialis.
Verband: Verband

\section{Alter:}

Geschlecht:

Arthrose: 


$\begin{array}{lll}\text { Bezeichn.: } & \text { Phalanx } & \text { Verband: } \square \text { Verband } \\ \text { Kiste: } & 5261277 & \text { Alter: } \\ \text { Skelet: } & \text { V30 kleine Tüte } & \text { Geschlecht: } \\ \text { Population: } & \text { Calden } & \text { Arthrose: } \\ \text { Seite: } & \text { rechts } & \end{array}$

\section{Beschreibung:}

Ein Os phalangis proximalis manus 2 der rechten Seite. 
Bezeichn:: Phalanx

Kiste: $\quad 8505719$

Skelet: Zettel

Population: Calden

Seite:

links

Verband: $\quad \square$ Verband

\section{Alter:}

Geschlecht:

Arthrose:

\section{Beschreibung:}

Ein Os phalangis proximalis 1 . 
Bezeichn.: Phalanx

Kiste: $\quad 8505719$

Skelet: Zettel

Population: Calden

\section{Beschreibung:}

Ein Os phalangis medialis.
Verband: Verband

\section{Alter:}

Geschlecht:

Arthrose: 
Bezeichn.: Phalanx

Kiste: $\quad 8505719$

Skelet: Zettel

Population: Calden

Seite: rechts

\section{Beschreibung:}

Ein Os phalangis proximalis 1
Verband: Verband

\section{Alter:}

Geschlecht:

Arthrose: 
Bezeichn: Phalanx

Kiste: $\quad 8505719$

Skelet: Zettel

Population: Calden
Verband: $\quad$ Verband

\section{Alter:}

Geschlecht:

Arthrose:

Ges./Kr.: Krank

Krankh.:

dist.

\section{Beschreibung:}

Ein Os phalangis, welches distal eine leichte Arthritis aufweist. 
Bezeichn.: Phalanx

Kiste: $\quad 8505719$

Skelet: Zettel

Population: Calden

Seite:

links
Verband: Verband

\section{Alter:}

Geschlecht:

Arthrose:

\section{Beschreibung:}

Ein Os phalangis distalis 1 . 
Bezeichn:: Phalanx

Kiste: $\quad 8505719$

Skelet: Zettel

Population: Calden

Seite:

links

Verband: $\quad \square$ Verband

\section{Alter:}

Geschlecht:

Arthrose:

\section{Beschreibung:}

Ein Os phalangis 1. 
Bezeichn:: Phalanx

Kiste: $\quad 8505719$

Skelet: Zettel

Population: Calden

Seite:

links

Verband: $\quad \square$ Verband

\section{Alter:}

Geschlecht:

Arthrose:

\section{Beschreibung:}

Ein Os phalangis 4. 
Bezeichn:: Phalanx

Kiste: $\quad 8505719$

Skelet: Zettel

Population: Calden

Seite:

links

Verband: $\quad \square$ Verband

\section{Alter:}

Geschlecht:

Arthrose:

\section{Beschreibung:}

Ein Os phalangis proximalis 3 . 
Bezeichn:: Phalanx

Kiste: $\quad 8505719$

Skelet: Zettel

Population: Calden

Seite:

links

Verband: $\quad \square$ Verband

\section{Alter:}

Geschlecht:

Arthrose:

\section{Beschreibung:}

Ein Os phalangis proximalis 3 . 
Bezeichn.: Phalanx

Kiste: $\quad 5245269$

Skelet: gesammelt

Population: Calden

Seite:

links

Verband: $\square$ Verband

\title{
Alter:
}

Geschlecht:

Arthrose:

\author{
Beschreibung: \\ Ein Os phalangis proximalis 2 .
}


Bezeichn.: Phalanx

Kiste: $\quad 5245269$

Skelet: gesammelt

Population: Calden

Seite:

links

Verband: $\square$ Verband

\title{
Alter:
}

Geschlecht:

Arthrose:

\author{
Beschreibung: \\ Ein Os phalangis proximalis 2 .
}


Bezeichn.: Phalanx

Kiste: $\quad 5245269$

Skelet: gesammelt

Population: Calden

Verband: $\quad$ Verband

Alter:

Geschlecht:

Arthrose:

\author{
Beschreibung: \\ Ein Os phalangis distalis.
}


Bezeichn.: Phalanx

Verband: $\quad$ Verband

Kiste:

5245269

Alter:

Skelet: gesammelt

\section{Geschlecht:}

Population: Calden

Arthrose:

\section{Beschreibung:}

Ein Os phalangis, welches nicht genauer einzuordnen war. 


\section{Bezeichn.: Phalanx \\ Kiste: $\quad 5243267$ \\ Skelet: P.Sk.1.}

Population: Calden

Seite:

links
Verband: $\square$ Verband

Alter:

Geschlecht:

Arthrose:

Ges./Kr.: Krank

Krankh.: Arthrose

\section{Beschreibung:}

Ein Os phalangis proximalis 2 der linken Seite. 


\section{Bezeichn: Phalanx \\ Kiste: $\quad 5243267$ \\ Skelet: P.Sk.1.}

Population: Calden

Seite:

rechts
Verband: Verband

\section{Alter:}

Geschlecht:

Arthrose:

\section{Beschreibung:}

Ein Os phalangis proximalis 1 der rechten Seite. 
Bezeichn.: Phalanx Manus

Kiste:

5266281

Skelet: $\quad$ V65 aus Tüte 4

Population: Calden

Seite:

rechts

\section{Verband: $\quad$ Verband}

\section{Ges./Kr.: Gesund}

\section{Alter:}

Geschlecht:

Arthrose:

\section{Beschreibung:}

Dieses Os phalangis 1 proximal der rechten Seite hat ein kleines Loch in der Gelenkfläche. Dies ist sicherlich als foramen nutricium anzusehen und kann zu Arthrose führen, weil die Gelenkfläche an dieser Stelle geschwächt ist. 
Bezeichn.: Phalanx Manus

Kiste:

5266281

V65 aus Tüte 4

Population: Calden

Seite:

rechts

Verband: $\quad$ Verband

Alter:

Geschlecht:

Arthrose:

\section{Beschreibung:}

Os phalangis der rechten Seite 2 proximal. 
Bezeichn.: Phalanx Manus

Kiste:

5266281

V65 aus Tüte 4

Population: Calden

Seite: rechts

\section{Beschreibung:}

Os phalangis der rechten Seite 3 proximal.
Verband: Verband

\section{Alter:}

Geschlecht:

Arthrose: 
Bezeichn.: Phalanx Manus

Kiste:

5266281

Skelet: $\quad$ V65 aus Tüte 4

Population: Calden

Seite:

rechts

\section{Beschreibung:}

Os phalangis 4 proximal.

Os phala
Verband: $\quad$ Verband

\section{Alter:}

Geschlecht:

Arthrose:
Ges./Kr.: Gesund 
Bezeichn.: Phalanx Manus

Kiste:

5266281

Skelet: $\quad$ V65 aus Tüte 4

Population: Calden

Seite:

rechts

\section{Beschreibung: \\ Os phalangis 3 medialis.}

Verband: $\square$ Verband

Ges./Kr.: Gesund

\section{Alter:}

Geschlecht:

Arthrose: 
Bezeichn.: Phalanx Manus

Kiste: 5266281

Skelet: $\quad$ V65 aus Tüte 4

Population: Calden

Seite:

links
Verband:

Verband

\section{Alter: \\ Geschlecht:}

Arthrose:

\section{Beschreibung:}

Ein Os phalangis 1 proximalis.
Ges./Kr.: Gesund

\section{Ges/Kr: Gesund}


Bezeichn.: Phalanx Manus

Kiste: $\quad 8505720$

Skelet: $\quad 1.0$

Population: Calden

Seite:
Verband: $\square$ Verband

Alter:

Geschlecht:

Arthrose:
Ges./Kr.: Krank

Krankh.: Arthritis

\section{Beschreibung:}

An diesem Os phalangis distalis 1 einer Hand zeigen sich deutliche Verschleiß- und Alterserscheinungen. 
Bezeichn.: Phalanx Manus

Kiste: $\quad 5256274$

Skelet: zettel Nr1

Population: Calden

Seite:

rechts
Verband: $\quad$ Verband

Ges./Kr.: Krank

Alter:

Arthrose:

\section{Beschreibung:}

Bei diesem Os phalangis proximalis 1 fallen leichte Auflagerungen auf der Oberfläche ins Auge. 
Bezeichn.: Phalanx Manus

\section{Kiste: $\quad 5256274$}

Skelet: Zettel

Population: Calden

Seite:

links
Verband: $\square$ Verband

\section{Alter:}

Geschlecht:

Arthrose:

\section{Beschreibung:}

Ein Os phalangis medialis 3 einer Hand. 
Bezeichn.: Phalanx Manus

\section{Kiste: $\quad 5256274$}

Skelet: Zettel

Population: Calden

Seite:

links
Verband: Verband

\section{Alter:}

Geschlecht:

Arthrose:

\section{Beschreibung:}

Ein Os phalangis proximalis manus 4 links. 
Bezeichn.: Phalanx Manus

\section{Kiste: $\quad 5256274$}

Skelet: Zettel

Population: Calden

Seite: rechts

\section{Beschreibung:}

ein Os phalangis proximalis manus 4 rechts.
Verband: $\quad$ Verband

\section{Alter:}

Geschlecht:

Arthrose: 
Bezeichn.: Phalanx Manus

Kiste:

5256274

Skelet: Zettel

Population: Calden

Seite:

links
Verband: Verband

\section{Alter:}

Geschlecht:

Arthrose:

\section{Beschreibung:}

Ein Os phalangis proximalis manus 4 der linken Seite. 
Bezeichn.: Phalanx Manus

Kiste:

5256274

Skelet: Zettel

Population: Calden

Seite:

links
Verband: Verband

\section{Alter:}

Geschlecht:

Arthrose:

\section{Beschreibung:}

Ein Os phalangis medialis manus 3 der linken Seite. 
Bezeichn.: Phalanx Manus

\section{Kiste: $\quad 5261277$}

Skelet: $\quad$ V33 kleine Tüte

Population: Calden

Seite:

links
Verband: $\quad$ Verband

Alter: Erwachsen

Geschlecht:

Arthrose:

\section{Beschreibung:}

Ein Os phalangis proximalis manus 3 der linken Seite. 
Bezeichn.: Phalanx Manus

Kiste: $\quad 8505719$

Skelet: Zettel

Population: Calden

Seite:

links
Verband: Verband

\section{Alter:}

Geschlecht:

Arthrose:

\section{Beschreibung:}

Ein Os phalangis medialis 2 einer Hand. 
Bezeichn.: Phalanx Manus

Kiste: $\quad 8505719$

Skelet: Zettel

Population: Calden

Seite:

links
Verband: Verband

\section{Alter:}

Geschlecht:

Arthrose:

\section{Beschreibung:}

Ei Os phalangis medialis 2 einer Hand. 
Bezeichn.: Phalanx Manus

\section{Kiste: $\quad 8505721$}

Skelet: Kiste 12

Population: Calden

\section{Beschreibung:}

Ein Os phalangis einer Hand.
Verband:

Verband

\section{Alter:}

Geschlecht:

Arthrose:
Ges./Kr.: Gesund 
Bezeichn.: Phalanx Manus

Kiste: $\quad 52651$ 1-3 279

Skelet: Zettel

Population: Calden
Verband: Verband

\section{Alter:}

Geschlecht:

Arthrose:

\section{Beschreibung:}

Ein Os phalangis proximalis einer Hand. 
Bezeichn.: Phalanx Pedis

Kiste: $\quad 8505720$

Skelet: $\quad 1.0$

Population: Calden

Seite:
Verband: $\quad$ Verband

Alter:

Geschlecht:

Arthrose:
Ges./Kr.: Krank

Krankh.: Arthrose

\section{Beschreibung:}

Es finden sich Verschleißerscheinungen an diesem linken ersten Os phalangis distalis eines linken Fußes. 
Bezeichn.: Phalanx Pedis

Kiste: $\quad 8505720$

Skelet: $\quad 1.0$

Population: Calden

Seite: rechts
Verband: $\quad$ Verband

\section{Alter:}

Geschlecht:

Arthrose:
Ges./Kr.: Krank

Krankh.: Arthrose

\section{Beschreibung:}

Dieses erste Os phalangis distalis eines rechten Fußes weist Verschleißerscheinungen auf. 
Bezeichn.: Phalanx Pedis

Kiste: $\quad 8505720$

Skelet: $\quad 1.0$

Population: Calden

Seite:
Verband: $\quad$ Verband

Alter:

Geschlecht:

Arthrose:

Ges./Kr.: Krank

Krankh.: Arthrose

prox.

3

\section{Beschreibung:}

Dieses erste Os phalangis distalis eines linken Fußes weist deutliche Verschleißerscheinungen auf. 
Bezeichn:: Phalanx Pedis

Kiste: $\quad 8505720$

Skelet: V641.0

Population: Calden

Seite: rechts
Verband: $\quad$ Verband

Alter:

Geschlecht:

Arthrose:
Ges./Kr.: Krank

Krankh.: Arthrose

\section{Beschreibung:}

Es zeigen sich deutliche Verschleißerscheinungen an diesem ersten Os phalangis distalis eines rechten Fußes. 
Bezeichn.: Phalanx Pedis

Kiste:

8505720

Skelet: V64 1.0

Population: Calden

Seite:

links
Verband: $\quad$ Verband

Alter:

Geschlecht:

Arthrose:
Ges./Kr.: Krank

Krankh.: Arthrose

\section{Beschreibung:}

Es zeigen sich deutliche Verschleißerscheinungen an diesem ersten Os phalangis distalis eines rechten Fußes. 
Bezeichn.: Phalanx Pedis

Kiste:

5256274

Skelet: Zettel

Population: Calden

Seite:

rechts
Verband: $\quad$ Verband

\section{Alter:}

Geschlecht:

Arthrose:

\section{Beschreibung:}

Ein Os phalangis proximalis 2 der rechten Seite. 
Bezeichn.: Phalanx Pedis

\section{Kiste:}

5256274

Skelet: Zettel

Population: Calden

Seite:

rechts

Verband: $\quad$ Verband

Alter:

Geschlecht:

Arthrose:

\section{Beschreibung:}

Ein Os phalangis proximalis 1 eines Fußes. 
Bezeichn.: Phalanx Pedis

Kiste:

5256274

Skelet: Zettel

Population: Calden

Seite:

n. def.
Verband: Verband

\section{Alter:}

Geschlecht:

Arthrose:

\section{Beschreibung:}

Ein Os phalangis distalis pedis 1, weiter Zuordnung nicht möglich. 
Bezeichn.: Phalanx Pedis

\section{Kiste:} 5273291

Ersatzteile 15

Pkelet: Ersatzlation: Calden

Seite:

links
Verband: Verband

\section{Alter:}

Geschlecht:

Arthrose:

\section{Beschreibung:}

Ein Os phalangis proximalis pedis 2 der linken Seite. 
Bezeichn.: Phalanx Pedis

Kiste: 5261277

Skelet: Zettel

Population: Calden

Seite:

n. def.

Verband: $\quad$ Verband

\section{Alter:}

Geschlecht:

Arthrose:

\section{Beschreibung:}

Ein Os phalangis proximalis pedis 1 . 
Bezeichn.: Phalanx Pedis

Kiste:

5261277

Skelet: Zettel

Population: Calden

Verband: $\quad$ Verband

\section{Alter:}

Geschlecht:

Arthrose:

\section{Beschreibung:}

Ein Os phalangis proximalis pedis 1 . 
Bezeichn.: Phalanx Pedis

Kiste:

8505719

Skelet: Zettel

Population: Calden
Verband: Verband

\section{Alter:}

Geschlecht:

Arthrose:

\section{Beschreibung:}

Ein Os phalangis medialis eines Fußes. 
Bezeichn.: Phalanx Pedis

Kiste:

8505719

Skelet: Zettel

Population: Calden

Seite:

rechts
Verband: $\quad$ Verband

\section{Alter:}

Geschlecht:

Arthrose:

\section{Beschreibung:}

Os phalangis proximalis 1 eines Fußes. Es fällt auf, weil es sehr grazil ist. 
Bezeichn:: Phalanx Pedis

Kiste: 5266281

Skelet: $\quad$ V65 aus Tüte 4

Population: Calden

Seite:

links
Verband:

Verband

\section{Alter:}

Geschlecht:

Arthrose:

\section{Beschreibung:}

Ein Os phalangis 1 proximalis. 


\section{Detailbericht aller Funde für die Population Calden}

\section{OK; UK}

Population:

Geschlecht:

Alter:

weiblich

(32) 37 - 45 (50)

\subsubsection{3/1}

Skelett: $16 /$ unter LK Hand von Sk.11

\section{6}

Krankheiten: Sinusitis maxillaris

Parodontitis

Stomatitis

Arthrose

Exostosen

Elongation

\begin{tabular}{c|c|c} 
Arthrose & rechts & links \\
\hline Caput & & 2 \\
\hline Fossa & 3 & 3
\end{tabular}

Beschreibung: Hier sind ein Ober- und Unterkiefer recht gut, aber zum Teil erodiert erhalten. Die beiden Fundstücke sind dem Cranium 16 zuzuordnen. An Zahn 27 fällt eine Elongation ins Auge. Weiterhin sind eine leichte Sinusitis maxillaris, eine Stomatitis und Exostosesn in regio 33 bis 35 festzustellen. In regio 31 und 32 ist aufgrund der Erosionsschäden und der postmortalen Fraktur nicht mehr nachweisbar, ob noch Zähne vorhanden waren und in welchem Zustand das Parodont ist.

\begin{tabular}{|c|c|c|c|c|c|c|c|c|c|c|c|c|}
\hline \multirow{2}{*}{$\begin{array}{l}\text { Zahn } \\
25\end{array}$} & \multirow[t]{2}{*}{ Status } & \multicolumn{2}{|c|}{ Parodontium } & \multicolumn{2}{|c|}{ Apikale Prozesse } & \multicolumn{2}{|c|}{ Zahnstein } & \multirow{2}{*}{$\begin{array}{c}\text { Karies } \\
0\end{array}$} & \multicolumn{2}{|c|}{ Abrasion } & \multirow{2}{*}{$\begin{array}{l}\text { Neubildung } \\
\text { * }\end{array}$} & \multirow{2}{*}{$\begin{array}{c}\text { Schmelzhypoplasie } \\
0\end{array}$} \\
\hline & & $\mathrm{Pi}$ & 2 & & 0 & $\mathrm{~K}$ & 1 & & 0 & 3 & & \\
\hline 26 & & $\mathrm{Pi}$ & 2 & G & 1 & $\mathrm{~K}$ & 1 & 0 & 0 & 5 & * & \\
\hline 27 & $\varnothing$ & & & & & & & & & & & \\
\hline 28 & $\varnothing$ & & & & & & & & & & & \\
\hline 31 & $\mathrm{v}$ & & & & & & & & & & & \\
\hline 32 & (f) & & & & & & & & & & & \\
\hline 33 & $\mathrm{v}$ & $\mathrm{Pi}$ & 3 & & & & & & & & & \\
\hline 34 & $f$ & & & & & & & & & & & \\
\hline 35 & v & $\mathrm{Pi}$ & 3 & & 0 & & & & & & & \\
\hline
\end{tabular}




$f$
$f$
$\varnothing$
$v$




\section{OK}

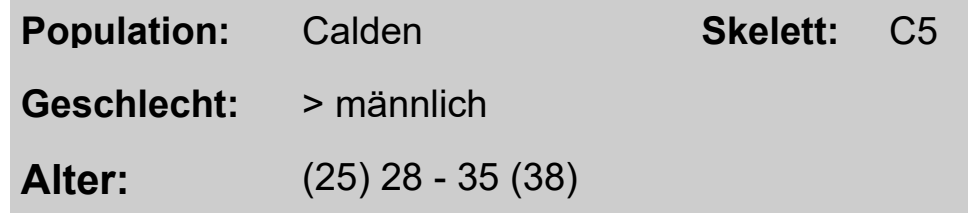

Beschreibung: Dieser Oberkiefer gehört zum Cranium C5, weist eine Stomatitis 2. Grades und eine leichte Sinusitis maxillaris auf. Das Fundstück befindet sich in recht gutem Erhaltungszustand, wenn auch einige Zähne postmortal ausgefallen sind und der Gaumen nicht vollständig erhalten ist.

\begin{tabular}{|c|c|c|c|c|c|c|c|c|c|}
\hline Zahn & Status & Parodontium & Apikale Prozesse & Zahnstein & Karies & & Ision & Neubildung & Schmelzhypoplasie \\
\hline 11 & $\mathrm{v}$ & $\mathrm{Pi} \quad 1$ & & & & & & & \\
\hline 12 & & $\mathrm{Pi} \quad 1$ & 0 & 1 & 0 & $\mathrm{O}$ & 4 & * & $\mathrm{T}$ \\
\hline 13 & $\mathrm{v}$ & $\mathrm{Pi} \quad 1$ & & & & & & & \\
\hline 14 & v & $\mathrm{Pi} \quad 1$ & & & & & & & \\
\hline 15 & & $\mathrm{Pi} \quad 1$ & 0 & 1 & 0 & $\mathrm{O}$ & 4 & * & 0 \\
\hline 16 & & $\mathrm{Pi} \quad 1$ & 0 & 1 & 0 & 0 & 4 & * & 0 \\
\hline 17 & & $\mathrm{Pi} 1$ & 0 & 1 & 0 & 0 & 3 & * & $\mathrm{U}$ \\
\hline 18 & & $\mathrm{Pi} \quad 1$ & 0 & 1 & 0 & & 0 & 0 & 0 \\
\hline 21 & $\mathrm{v}$ & $\mathrm{Pi} 1$ & & & & & & & \\
\hline 22 & v & $\mathrm{Pi} \quad 1$ & & & & & & & \\
\hline 23 & $\mathrm{v}$ & $\mathrm{Pi} \quad 1$ & & & & & & & \\
\hline
\end{tabular}

5267283

Krankheiten: Stomatitis

Sinusitis maxillaris

\begin{tabular}{c|c|c} 
Arthrose & rechts & links \\
\hline Caput & & \\
\hline Fossa & & 1
\end{tabular}




$\begin{array}{llll}0 & 0 & 4 & * \\ 0 & 0 & 4 & * \\ 0 & 0 & 4 & * \\ 0 & 0 & 3 & * \\ 0 & & 0 & \end{array}$

U 1 


\section{UK}
Population: Calden
Geschlecht: >> weiblich
Alter:
(34) $39-47(52)$

\section{$08.10 .2013 / 1$}

Skelett: 3 PSK7 od. Sch. $23+25$ Krankheiten:

\section{2}

\begin{tabular}{c|l|l} 
Arthrose & rechts & links \\
\hline Caput & & \\
\hline Fossa & &
\end{tabular}

Beschreibung: Bei diesem Unterkiefer handelt es sich um ein Ausstellungsstück des Landesmuseums Hessen in Kassel. Es handelt sich wahrscheinlich um ein weibliches Individuum. Auffällig ist, dass die Zähne des 4. Quadranten ab dem 45 intravital ausgefallen waren und die Alveolen vollständig verschlossen sind. Der Zahnverlust kann diskutiert werden: Möglich ist, dass die rechte Seite des Kauapparates als Werkzeug verwendet wurde und die Zähne dadurch unphysiologisch belastet wurden, was dann zum vorzeitigen Zahnverlust führte. Da der Oberkiefer nicht vorhanden ist, ist diese Theorie nicht belegbar. Auszuschließen ist an dieser Stelle auch nicht, dass ein knöchernes Trauma vorgelegen hatte. Insgesamt befindet sich das Fundstück in gutem Erhaltungszustand.

\begin{tabular}{|c|c|c|c|c|c|c|c|c|c|c|c|c|c|}
\hline \multirow{2}{*}{$\begin{array}{l}\text { Zahn } \\
31\end{array}$} & \multirow[t]{2}{*}{ Status } & \multicolumn{2}{|c|}{ Parodontium } & \multicolumn{2}{|c|}{ Apikale Prozesse } & \multicolumn{2}{|c|}{ Zahnstein } & \multirow{2}{*}{$\begin{array}{c}\text { Karies } \\
0\end{array}$} & \multicolumn{2}{|c|}{ Abrasion } & \multirow{2}{*}{$\begin{array}{c}\text { Neubildung } \\
0\end{array}$} & \multicolumn{2}{|c|}{ Schmelzhypoplasie } \\
\hline & & $\mathrm{Pi}$ & 1 & & 0 & $\mathrm{~K}$ & 1 & & $\mathrm{O}$ & 3 & & $U$ & 1 \\
\hline 32 & & $\mathrm{Pi}$ & 2 & $G$ & 1 & $\mathrm{~K}$ & 1 & 0 & $\mathrm{O}$ & 3 & 0 & $U$ & 1 \\
\hline 33 & & $\mathrm{Pi}$ & 2 & & 0 & $\mathrm{~K}$ & 2 & 0 & $\mathrm{O}$ & 3 & 0 & $U$ & 2 \\
\hline 34 & & $\mathrm{Pi}$ & 1 & & 0 & $\mathrm{~K}$ & 2 & 0 & $\mathrm{O}$ & 3 & 0 & $U$ & 2 \\
\hline 35 & & $\mathrm{Pi}$ & 1 & & 0 & $\mathrm{~K}$ & 2 & 0 & $\mathrm{O}$ & 3 & 0 & $U$ & 2 \\
\hline 36 & & $\mathrm{Pi}$ & 2 & & 0 & $\mathrm{~K}$ & 1 & 0 & 0 & 4 & * & $U$ & 1 \\
\hline 37 & & $\mathrm{Pi}$ & 2 & & 0 & $\mathrm{~K}$ & 2 & 0 & 0 & 5 & * & & \\
\hline 38 & 0 & & & & & & & & & & & & \\
\hline 41 & & $\mathrm{Pi}$ & 1 & & 0 & $\mathrm{~K}$ & 1 & 0 & 0 & 3 & 0 & $U$ & 1 \\
\hline 42 & & Po & 1 & & 0 & $\mathrm{~K}$ & 1 & 0 & 0 & 3 & 0 & $U$ & 1 \\
\hline 43 & & Po & 1 & & 0 & $\mathrm{~K}$ & 1 & 0 & 0 & 3 & 0 & $U$ & 2 \\
\hline
\end{tabular}




\section{UK}

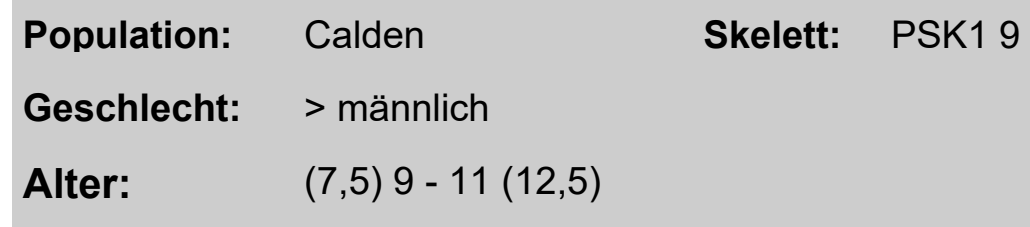

Beschreibung: Ein gut erhaltener, eher männlichen Unterkiefer im Wechselgebiss im Alter von etwa 10 Jahren. Die Anlagen der Weisheitszähne ist laut Röntgenbefund wahrscheinlich.

\begin{tabular}{|c|c|c|c|c|c|c|c|c|c|}
\hline Zahn & Status & Parodontium & Apikale Prozesse & Zahnstein & Karies & $\mathrm{Ab}$ & asion & Neubildung & Schmelzhypoplasie \\
\hline 31 & & 0 & 0 & K 2 & 0 & $\mathrm{O}$ & 1 & 0 & $\mathrm{~T}$ \\
\hline 32 & & 0 & 0 & K 1 & 0 & & 0 & 0 & $\mathrm{~T}$ \\
\hline 33 & II & 0 & 0 & $\begin{array}{ll}\mathrm{K} & 1\end{array}$ & 0 & & & 0 & $\mathrm{~T}$ \\
\hline 34 & II & 0 & 0 & & & & & & \\
\hline 36 & & 0 & 0 & $\mathrm{~K}$ & 0 & 0 & 1 & 0 & $\mathrm{~T}$ \\
\hline 37 & ( ) & 0 & 0 & & & & & & \\
\hline 38 & $\mathrm{O}$ & & & & & & & & \\
\hline 41 & & 0 & 0 & $\mathrm{~K}$ & 0 & $\mathrm{O}$ & 1 & 0 & $\mathrm{~T}$ \\
\hline 42 & & 0 & 0 & 0 & 0 & & 0 & 0 & $\mathrm{~T}$ \\
\hline 43 & ( ) & 0 & 0 & & & & & & $\mathrm{~T}$ \\
\hline 44 & 11 & 0 & 0 & 0 & 0 & & & 0 & $U$ \\
\hline
\end{tabular}




\begin{tabular}{|c|c|c|c|c|c|c|c|c|c|c|}
\hline 46 & 0 & 0 & $\mathrm{~K}$ & 1 & 0 & 0 & 1 & 0 & $\mathrm{~T}$ & 1 \\
\hline 47 & 0 & 0 & & & & & & & & \\
\hline 48 & & & & & & & & & & \\
\hline 75 & 0 & 0 & & 0 & 0 & 0 & 4 & * & & 0 \\
\hline 85 & 0 & 0 & & 0 & 0 & O & 4 & * & & 0 \\
\hline
\end{tabular}




\section{OK}

\section{Population: Calden}

Geschlecht:

Alter:

$$
9,5-11(12,5)
$$

\subsubsection{3/1}

Skelett: 2. OK Schädel 2

\section{2}

Krankheiten:

\begin{tabular}{c|l|l} 
Arthrose & rechts & links \\
\hline Caput & & \\
\hline Fossa & &
\end{tabular}

Beschreibung: Bei diesem Fundstück handelt es sich um Oberkiefer, der nur frakturiert und teilweise erhalten ist. Das Alter beträgt etwa 10 Jahre, somit befand sich der Kiefer zum Zeitpunkt des Todes im Wechselgebiss. Es fällt eine Hyperzementose an der mesiobuccalen Wurzel des 16 ins Auge. Weiterhin ist festzuhalten, dass die Zahnmorphologie, die sehr individuell sein kann, mit der eines anderen Individuums sehr ähnlich ist. Es handelt sich um die hier vorliegenden 7er, welche den 7ern und 8ern des Oberkiefers 1 vom 08.10.2013 sehr ähnlich sehen. Es darf an dieser Stelle also ein verwandtschaftlicher Zusammenhang der beiden genannten Individuen angenommen werden. Zu einem Schädel sind die hier vorliegenden Fundstücke allerdings nicht zuzuordnen.

\begin{tabular}{|c|c|c|c|c|c|c|c|c|c|c|c|}
\hline Zahn & Status & Parodontium & Apikale Prozesse & \multicolumn{2}{|c|}{ Zahnstein } & Karies & \multicolumn{2}{|c|}{ Abrasion } & Neubildung & \multicolumn{2}{|c|}{ Schmelzhypoplasie } \\
\hline 13 & II & & & & 0 & 0 & & & & $\mathrm{~T}$ & 3 \\
\hline 14 & ( ) & & & & & & & & & & \\
\hline 15 & ( ) & & & & & & & & & & \\
\hline 16 & & 0 & 0 & $\mathrm{~K}$ & 1 & 0 & 0 & 1 & $\#$ & $\mathrm{~T}$ & 1 \\
\hline 17 & 11 & & & & 0 & 0 & & & & $\mathrm{~T}$ & 1 \\
\hline 24 & II & 0 & & & 0 & 0 & & & & $\mathrm{~T}$ & 3 \\
\hline 25 & () & & & & & & & & & & \\
\hline 26 & & 0 & 0 & $\mathrm{~K}$ & 1 & 0 & $\mathrm{O}$ & 1 & & $\mathrm{~T}$ & 1 \\
\hline 27 & 11 & & & & & 0 & & & & $u$ & 2 \\
\hline 54 & & 0 & 0 & $\mathrm{~K}$ & 1 & 0 & $\mathrm{O}$ & 5 & * & & 0 \\
\hline 55 & & 0 & 0 & $\mathrm{~K}$ & 1 & 0 & $\mathrm{O}$ & 2 & & & 0 \\
\hline
\end{tabular}




\section{UK}

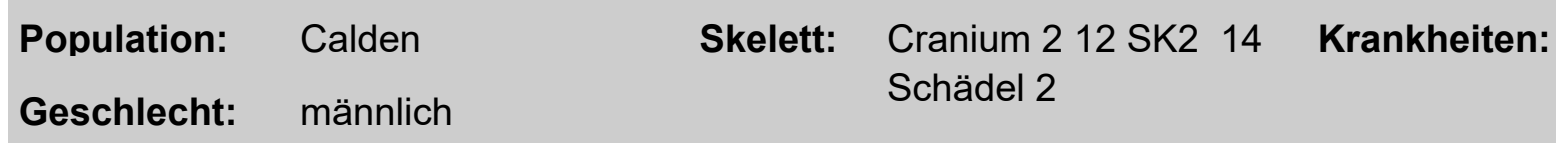

Beschreibung: Dieser männliche Unterkiefer ist zum Teil erhalten. Apical fällt in regio 45 und 47 ein leichter beginnender Prozess ins Auge. Das tatsächliche Vorhandensein bleibt allerdings fraglich. Das Alter ist auf etwa 16 bis 17 Jahre zum Zeitpunkt des Todes zu beziffern.

\begin{tabular}{|c|c|c|c|c|c|c|c|c|}
\hline Zahn & Status & Parodontium & Apikale Prozesse & Zahnstein & Karies & Abrasion & Neubildung & Schmelzhypoplasie \\
\hline 31 & $\mathrm{v}$ & 0 & 0 & & & & & \\
\hline 32 & $v$ & 0 & 0 & & & & & \\
\hline 33 & $v$ & 0 & 0 & & & & & \\
\hline 34 & v & 0 & 0 & & & & & \\
\hline 41 & $v$ & 0 & 0 & & & & & \\
\hline 42 & $\mathrm{v}$ & 0 & 0 & & & & & \\
\hline 43 & $v$ & 0 & 0 & & & & & \\
\hline 44 & $v$ & 0 & 0 & & & & & \\
\hline 45 & $\mathrm{v}$ & 0 & G & & & & & \\
\hline 46 & & Po 1 & 0 & $\mathrm{~K}$ & 0 & $\mathrm{O}$ & 0 & 0 \\
\hline 47 & $\mathrm{v}$ & Po 1 & G & & & & & \\
\hline
\end{tabular}




\section{UK}

\section{Population: Calden}

Geschlecht: männlich

Alter: $\quad(32) 37-45(50)$

\subsubsection{3 / 1}

Skelett: 11 Calden Einschlag Boleg
5242266

Krankheiten:

\begin{tabular}{c|c|c} 
Arthrose & rechts & links \\
\hline Caput & & 2 \\
\hline Fossa & &
\end{tabular}

Beschreibung: Bei diesem Fundstück handelt es sich um einen zum Teil erhaltenen und männlichen Unterkiefer.

\begin{tabular}{|c|c|c|c|c|c|c|c|c|}
\hline Zahn & Status & Parodontium & Apikale Prozesse & Zahnstein & Karies & Abrasion & Neubildung & Schmelzhypoplasie \\
\hline 31 & v & 0 & 0 & & & & & \\
\hline 32 & $v$ & 0 & 0 & & & & & \\
\hline 33 & & 0 & 0 & K 1 & 0 & $\mathrm{O}$ & * & $U$ \\
\hline 34 & & 0 & 0 & K 1 & 0 & 0 & * & 0 \\
\hline 35 & v & 0 & 0 & & & & & \\
\hline 36 & & 0 & 0 & $\mathrm{~K}$ & 0 & $\mathrm{O}$ & * & 0 \\
\hline 37 & & 0 & 0 & $\mathrm{~K}$ & 0 & $\mathrm{O}$ & * & 0 \\
\hline 38 & & 0 & 0 & $\mathrm{~K}$ & 0 & 0 & 0 & 0 \\
\hline 41 & $v$ & & & & & & & \\
\hline 42 & $v$ & & & & & & & \\
\hline
\end{tabular}




\section{OK}

Population: Calden

Geschlecht: > weiblich

Alter:

(32) 38 - 46 (53)

Beschreibung: Hier ist ein Teil eines eher weiblichen Oberkiefers erhalten. Er weist eine Stomatitis auf.

\section{6}

Skelett: ohne genaue Lage Krankheiten: Stomatitis

\begin{tabular}{c|l|l} 
Arthrose & rechts & links \\
\hline Caput & & \\
\hline Fossa & &
\end{tabular}

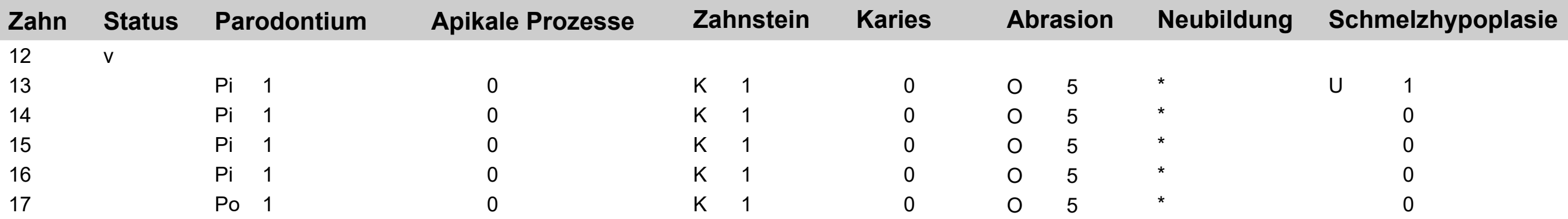




\section{OK}

$\begin{array}{lll}\text { Population: Calden } & \text { Skelett: OK } 4 \\ \text { Geschlecht: } & >\text { weiblich } & \end{array}$

\subsubsection{3/3}

\section{3}

Krankheiten: Sinusitis maxillaris
(6) 7 - $9(11)$
Alter:

Beschreibung: Hier sind zwei Teile eines Oberkiefers im Wechselgebiss erhalten. Das Alter ist und 10 anzunehmen. Der Oberkiefer gehört wohl zu Cranium 4. Es fällt eine mittelschwere Sinusitis maxillaris links und rechts 2. Grades auf.

\begin{tabular}{|c|c|c|c|c|c|c|c|c|c|c|}
\hline Zahn & Status & Parodontium & Apikale Prozesse & & instein & Karies & & sion & Neubildung & Schmelzhypoplasie \\
\hline 12 & () & & & & & & & & & \\
\hline 16 & & 0 & 0 & $\mathrm{~K}$ & 1 & 0 & 0 & 1 & 0 & $\mathrm{~T}$ \\
\hline 17 & () & & & & & & & & & \\
\hline 26 & & 0 & 0 & K & 1 & 0 & 0 & 1 & 0 & $\mathrm{~T}$ \\
\hline 27 & ( ) & & & & & & & & & \\
\hline 53 & v & $\begin{array}{ll}\mathrm{Pi} & 1\end{array}$ & & & & & & & & \\
\hline 54 & & Po 1 & 0 & $\mathrm{~K}$ & 1 & 0 & O & 5 & * & \\
\hline 55 & & 0 & 0 & $\mathrm{~K}$ & 1 & 0 & 0 & 4 & * & $U$ \\
\hline 64 & & Po 1 & 0 & $\mathrm{~K}$ & 1 & 0 & O & 5 & * & $U$ \\
\hline 65 & & Po 1 & 0 & $\mathrm{~K}$ & 1 & 0 & 0 & 4 & * & $U$ \\
\hline
\end{tabular}




\section{OK}

Population: Calden

Geschlecht:

Alter:

(32) $37-45$ (48)

\subsubsection{3/2}

Skelett: lag in Tüte von Cranium Krankheiten: Sinusitis maxillaris 26

5269286

Beschreibung: Hier ist ein Teil eines Oberkiefers erhalten. Das Fragment weist eine Sinusitis maxillaris Grad 1 auf.

$\begin{array}{lllcccccc}\text { Zahn } & \text { Status } & \text { Parodontium } & \text { Apikale Prozesse } & \text { Zahnstein } & \text { Karies } & \text { Abrasion } & \text { Neubildung } & \text { Schmelzhypoplasie } \\ 26 & \text { (f) } & \mathrm{Pi} 3 & & & & & \\ 27 & (\mathrm{f}) & \mathrm{Pi} 3 & 0 & \mathrm{~K} 1 & 0 & \mathrm{O} & 3 & * \\ 28 & & \mathrm{Pi} 2 & & & & \end{array}$




\section{OK}

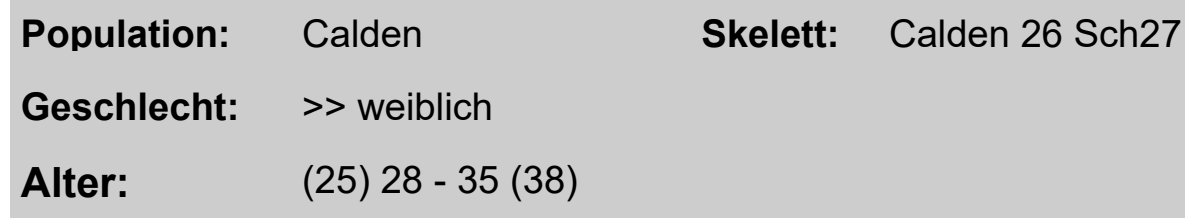

Skelett: Calden 26 Sch27

\subsubsection{3/1}

\section{6}

Beschreibung: Dies ist ein eher weiblicher Oberkiefer, der in recht gutem Erhaltungszustand ist. Er weist eine Stomatitis, sowie eine beidseitige Sinusitis maxillaris auf. In regio 16-18 ist die sehr dünne Knochenlamelle zum Vestibulum und auf der oralen Seite erodiert. Ansonsten sind die wesentlichen Strukturen erhalten, wenn auch einige Zähne fehlend sind.

\begin{tabular}{|c|c|c|c|c|c|c|c|c|}
\hline Zahn & Status & Parodontium & Apikale Prozesse & Zahnstein & Karies & Abrasion & Neubildung & Schmelzhypoplasie \\
\hline 11 & $\mathrm{v}$ & $\mathrm{Pi} \quad 2$ & 0 & & & & & \\
\hline 12 & $\mathrm{v}$ & $\mathrm{Pi} \quad 2$ & 0 & & & & & \\
\hline 13 & & $\mathrm{Pi} \quad 2$ & 0 & $\mathrm{~K}$ & 0 & $\mathrm{O}$ & * & $U$ \\
\hline 14 & & $\mathrm{Pi} \quad 2$ & 0 & $\begin{array}{ll}\mathrm{K} & 1\end{array}$ & 0 & $\mathrm{O}$ & * & \\
\hline 15 & & $\mathrm{Pi} \quad 2$ & 0 & $\mathrm{~K}$ & 0 & O & * & \\
\hline 16 & (f) & S 2 & $G$ & & & & & \\
\hline 17 & (f) & $\mathrm{Pi} \quad 4$ & $G$ & & & & & \\
\hline 18 & (f) & S 2 & G & & & & & \\
\hline 21 & $\mathrm{v}$ & $\mathrm{Pi} \quad 2$ & 0 & & & & & \\
\hline 22 & $\mathrm{v}$ & $\mathrm{Pi} \quad 2$ & 0 & & & & & \\
\hline 23 & $\mathrm{v}$ & $\mathrm{Pi} \quad 2$ & 0 & & & & & \\
\hline
\end{tabular}




$\begin{array}{llll}0 & 0 & 5 \\ 0 & 0 & 5 \\ 0 & 0 & 4\end{array}$ *

O 1

O 3

K 1

O 1

(n)

* 1

U $\quad 1$ 


\section{UK}

\section{Population: Calden}

Geschlecht: männlich

Alter: $\quad(25) 28-35(38)$

Beschreibung: Bei diesem Unterkiefer fält ein sehr prominentes Kinn ins Auge.

\section{1}

Skelett: 1 Calden 4,1;4,0 nähe Krankheiten: Parodontitis Schädel 41

\begin{tabular}{c|c|c} 
Arthrose & rechts & links \\
\hline Caput & 2 & 2 \\
\hline Fossa & &
\end{tabular}

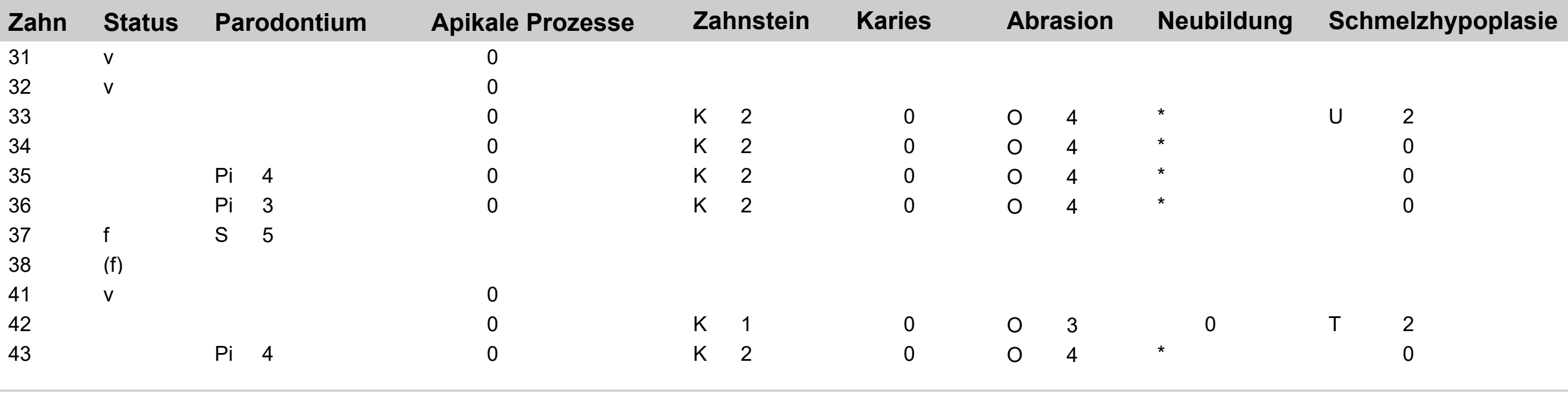


$46 \quad \mathrm{Pi} 5$

A 1 


\section{UK}

Population: Calden

Geschlecht: indifferent

Alter:

(25) 28 - 35 (38)

Beschreibung: Hier fällt auf, dass die Schmelzhypoplasie nur am linken 8er ausgeprägt ist.

\section{3-3 291}

Krankheiten:

\begin{tabular}{c|c|c} 
Arthrose & rechts & links \\
\hline Caput & 2 & 2 \\
\hline Fossa & &
\end{tabular}

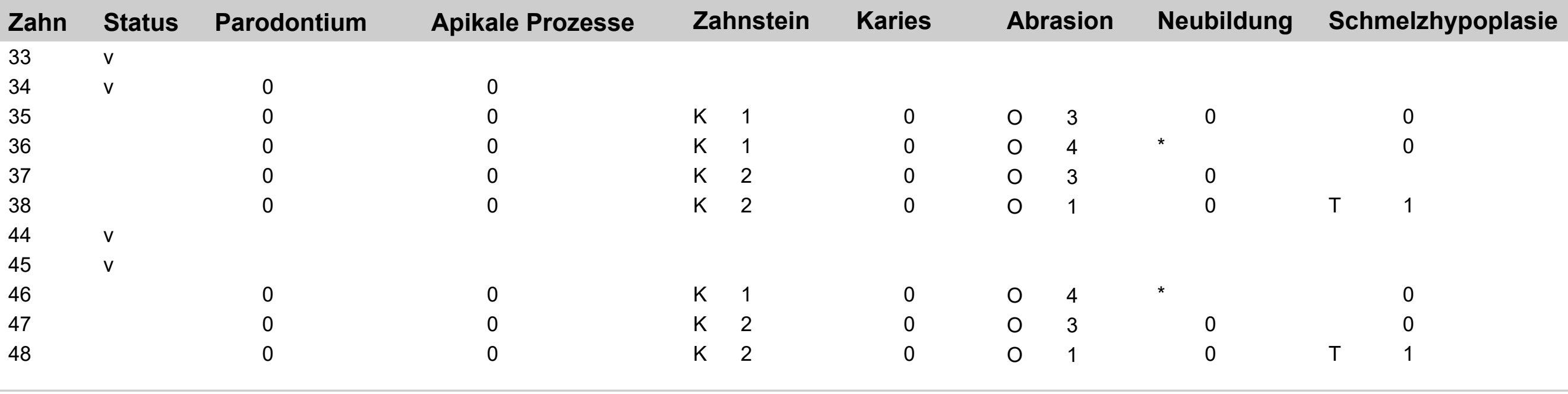




\section{Zähne}

Population:

Geschlecht: indifferent

Alter:

$25-35$

\section{Beschreibung:}

\subsubsection{3 / 3}

Skelett: Ersatzteile

Krankheiten:

\section{3-9 291}

\begin{tabular}{c|l|l} 
Arthrose & rechts & links \\
\hline Caput & & \\
\hline Fossa & &
\end{tabular}

\begin{tabular}{|c|c|c|c|c|c|c|c|c|}
\hline Zahn & Status & Parodontium & Apikale Prozesse & Zahnstein & Karies & Abrasion & Neubildung & Schmelzhypoplasie \\
\hline 11 & & & & $\mathrm{~K}$ & 0 & $\mathrm{O}$ & 0 & $\mathrm{~T}$ \\
\hline 41 & & & 0 & $\begin{array}{ll}\mathrm{K} & 1\end{array}$ & 0 & 0 & 0 & $\mathrm{~T}$ \\
\hline
\end{tabular}




\section{UK}

Population: Calden

Geschlecht: weiblich

Alter:

(34) 39 - 47 (52)

\section{Beschreibung:}

\subsubsection{3 / 1}

Skelett: Calden 2,85;4,65

Krankheiten: Parodontitis

\section{3-15 291}

\begin{tabular}{c|c|c} 
Arthrose & rechts & links \\
\hline Caput & 2 & 2 \\
\hline Fossa & &
\end{tabular}

\begin{tabular}{|c|c|c|c|c|c|c|c|c|}
\hline Zahn & Status & Parodontium & Apikale Prozesse & Zahnstein & Karies & Abrasion & Neubildung & Schmelzhypoplasie \\
\hline 31 & (f) & & & & & & & \\
\hline 32 & $\mathrm{v}$ & & 0 & & & & & \\
\hline 33 & $\mathrm{v}$ & & 0 & & & & & \\
\hline 34 & $\mathrm{v}$ & & G & & & & & \\
\hline 35 & $\mathrm{v}$ & & $G$ & & & & & \\
\hline 36 & $\mathrm{v}$ & S 3 & $A$ & & & & & \\
\hline 37 & $\mathrm{v}$ & S 2 & $G$ & & & & & \\
\hline 38 & $\mathrm{v}$ & S 2 & G & & & & & \\
\hline 41 & v & & 0 & & & & & \\
\hline 42 & $\mathrm{v}$ & & 0 & & & & & \\
\hline 43 & & & G & & & & & \\
\hline
\end{tabular}


45

46

48

$\begin{array}{ll}\text { Po } & 2 \\ S & 2\end{array}$

G

1
0

$\begin{array}{llll} & v & S & 2\end{array}$

G 1
K 1

O 5 


\section{Splitter}

Population:

Calden

Geschlecht:

Alter:

(9) $10-25$

\subsubsection{3 / 2}

Skelett: Zettel
5273291

Krankheiten:

\begin{tabular}{c|c|c} 
Arthrose & rechts & links \\
\hline Caput & 00 & \\
\hline Fossa & &
\end{tabular}

Beschreibung: Hier sind mehrere Fragmente und Splitter erhalten, die nicht genau zu diagnostizieren waren. 


\section{Zähne}

Population:

Calden

Geschlecht:

Alter:

(25) 28 - 35 (38)

\subsubsection{3/ 3}

Skelett: Tüte 5

\section{3-5 291}

Krankheiten:

\begin{tabular}{c|l|l} 
Arthrose & rechts & links \\
\hline Caput & & \\
\hline Fossa & &
\end{tabular}

Beschreibung: Hier fallen außergewöhnlich hohe Abnutzungserscheinungen des linken oberen 5ers auf, möglicherweise wurde der Zahn als Werkzeug genutzt oder es lag eine Anomalie vor. Denn der Unterkiefermolar zeigt kaum Abrasion oder Attrition.

\begin{tabular}{|c|c|c|c|c|c|c|c|c|c|}
\hline Zahn & Status & Parodontium & Apikale Prozesse & Zahnstein & Karies & & ision & Neubildung & Schmelzhypoplasie \\
\hline 25 & & & 0 & $\mathrm{~K}$ & 0 & $\mathrm{O}$ & 6 & * & \\
\hline 33 & & & 0 & $\mathrm{~K}$ & 0 & $\mathrm{O}$ & 1 & 0 & $\mathrm{~T}$ \\
\hline 37 & & & 0 & $\mathrm{~K}$ & 0 & $\mathrm{O}$ & 1 & 0 & $\mathrm{~T}$ \\
\hline 45 & & & G & $\begin{array}{ll}\mathrm{K} & 1\end{array}$ & 0 & 0 & 2 & 0 & $\mathrm{~T}$ \\
\hline
\end{tabular}




\section{UK}

Population: Calden

Geschlecht: weiblich

Alter:

(14) 16 - 22 (24)

\section{Beschreibung:}

\subsubsection{3 / 4}

Skelett: Calden über Schä.31 165 Tüte 6

Krankheiten:

\section{3-6 291}

\begin{tabular}{c|l|l} 
Arthrose & rechts & links \\
\hline Caput & & \\
\hline Fossa & &
\end{tabular}

$\begin{array}{llcccccc}\text { Zahn } & \text { Status } & \text { Parodontium } & \text { Apikale Prozesse } & \text { Zahnstein } & \text { Karies } & \text { Abrasion } & \text { Neubildung } \\ 32 & \mathrm{v} & 0 & 0 & & & & \\ 33 & \mathrm{v} & 0 & 0 & & & \\ 34 & \mathrm{v} & 0 & 0 & \mathrm{~K} \quad 1 & 0 & 0 & 2 \\ 35 & \mathrm{v} & 0 & 0 & & & 0 \\ 36 & & 0 & 0 & 0 & & & \end{array}$




\section{Zähne}

Population:

Calden

Geschlecht:

Alter:

$25-35$

\section{Beschreibung:}

\subsubsection{3 / 5}

Skelett: Schädel 8

Krankheiten:

\section{1}

\begin{tabular}{c|c|c} 
Arthrose & rechts & links \\
\hline Caput & & \\
\hline Fossa & 1 &
\end{tabular}

$\begin{array}{llllcccc}\text { Zahn Status } & \text { Parodontium } & \text { Apikale Prozesse } & \text { Zahnstein } & \text { Karies } & \text { Abrasion } & \text { Neubildung Schmelzhypoplasie } \\ 13 & & \mathrm{~K} 1 & 0 & \mathrm{O} & 3 & 0 \\ 21 & & \mathrm{~K} 1 & 0 & \mathrm{O} & 1 & 0\end{array}$




\section{UK}

Population: Calden

Geschlecht: männlich

Alter:

(22) 25 - $30(34)$

Beschreibung: Bei diesem Unterkiefer liegt ein ausgeprägter M. massetericus - Ansatz vor.

\section{3-14 291}

\begin{tabular}{c|c|c} 
Arthrose & rechts & links \\
\hline Caput & & $\mathrm{x}$ \\
\hline Fossa & &
\end{tabular}

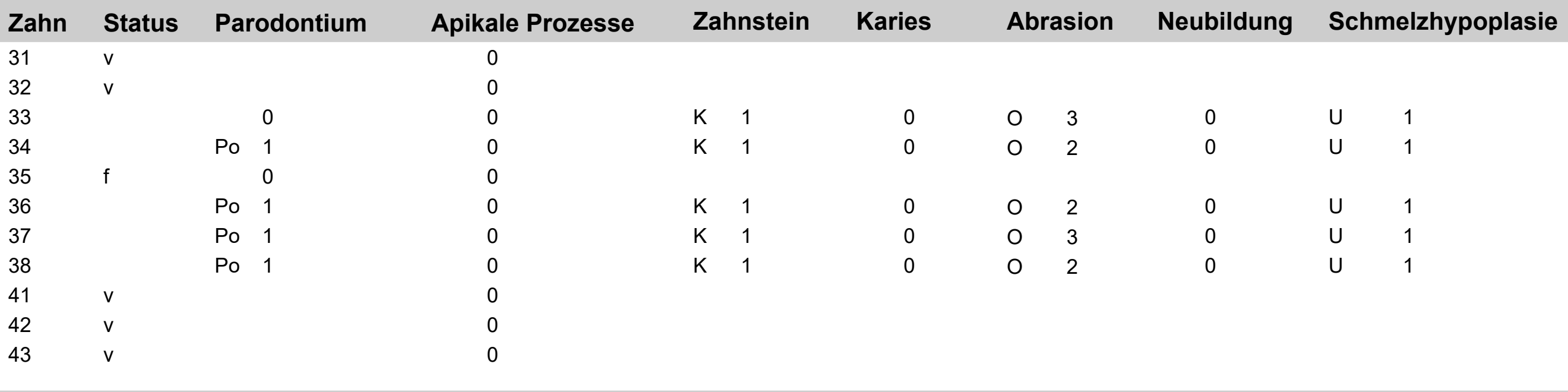




\section{UK}

\section{Population: Calden}

Geschlecht: männlich

Alter:

(32) $37-45(50)$

Beschreibung: Bei diesem Unterkiefer liegt ein ausgeprägter M. massetericus - Ansatz vor.

\section{1}

Skelett: 2 bei Sk. $8+9$ Lage unsicher 5273-16
Krankheiten: Parodontitis Arthrose

\begin{tabular}{c|c|c} 
Arthrose & rechts & links \\
\hline Caput & & 3 \\
\hline Fossa & &
\end{tabular}

\begin{tabular}{|c|c|c|c|c|c|c|c|c|}
\hline Zahn & Status & Parodontium & Apikale Prozesse & Zahnstein & Karies & Abrasion & Neubildung & Schmelzhypoplasie \\
\hline 31 & & $\mathrm{Pi} \quad 2$ & 0 & $\begin{array}{ll}\mathrm{K} & 1\end{array}$ & 0 & $\mathrm{O}$ & 0 & $U$ \\
\hline 32 & & $\mathrm{Pi} 2$ & 0 & $\begin{array}{ll}\mathrm{K} & 1\end{array}$ & 0 & $\mathrm{O}$ & 0 & $U$ \\
\hline 33 & & $\mathrm{Pi} \quad 2$ & 0 & $\begin{array}{ll}\mathrm{K} & 1\end{array}$ & 0 & $\mathrm{O}$ & 0 & $U$ \\
\hline 34 & & $\mathrm{Pi} 2$ & 0 & $\begin{array}{ll}\mathrm{K} & 1\end{array}$ & 0 & $\mathrm{O}$ & 0 & $U$ \\
\hline 35 & & $\mathrm{Pi} \quad 2$ & 0 & $\begin{array}{ll}\mathrm{K} & 1\end{array}$ & 0 & $\mathrm{O}$ & * & $U$ \\
\hline 36 & (f) & S 3 & G & & & & & \\
\hline 37 & & $\mathrm{Pi} \quad 2$ & $G$ & $\mathrm{~K}$ & M 2 & $\mathrm{O}$ & \# & $U$ \\
\hline 38 & & $\mathrm{Pi} \quad 2$ & 0 & $\mathrm{~K}$ & 0 & $\mathrm{O}$ & * & $U$ \\
\hline 41 & & $\mathrm{Pi} \quad 2$ & 0 & $\begin{array}{ll}\mathrm{K} & 1\end{array}$ & 0 & 0 & 0 & $U$ \\
\hline 42 & & $\mathrm{Pi} \quad 2$ & 0 & $\mathrm{~K}$ & 0 & 0 & 0 & $U$ \\
\hline 43 & & $\mathrm{Pi} \quad 2$ & 0 & $\begin{array}{ll}\mathrm{K} & 1\end{array}$ & 0 & 0 & 0 & $U$ \\
\hline
\end{tabular}




\section{UK}

Population: Calden

Geschlecht: weiblich

Alter:

(22) 25 - 30 (34)

\section{Beschreibung:}

\subsubsection{3 / 1}

Skelett: Sk2 12 Tüte 12 5273-12 Krankheiten:

\section{1}

\begin{tabular}{c|c|c} 
Arthrose & rechts & links \\
\hline Caput & & 2 \\
\hline Fossa & &
\end{tabular}

\begin{tabular}{|c|c|c|c|c|c|c|c|c|c|}
\hline Zahn & Status & Parodontium & Apikale Prozesse & Zahnstein & Karies & & asion & Neubildung & Schmelzhypoplasie \\
\hline 36 & & 0 & 0 & $\mathrm{~K}$ & 0 & $\mathrm{O}$ & 3 & 0 & $\mathrm{~T}$ \\
\hline 37 & $\mathrm{v}$ & 0 & 0 & & & & & & \\
\hline 38 & & 0 & 0 & $\mathrm{~K}$ & 0 & 0 & 1 & 0 & $\mathrm{~T}$ \\
\hline
\end{tabular}




\section{OK}

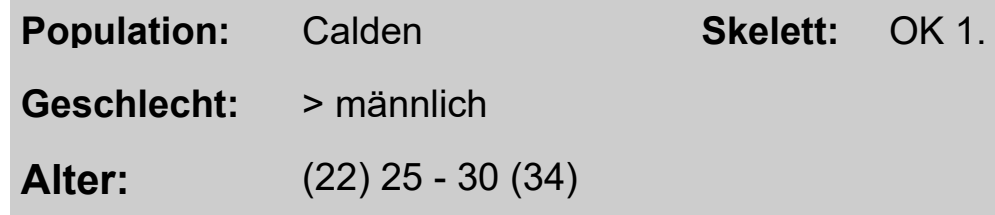

Beschreibung: Dieser Oberkiefer ist in recht gutem Erhaltungszustand und weist einen kleinen Prozess an der Wurzel des 21 auf. Weiterhin fällt eine Hyperzementose an 28 ins Auge, die recht nah im Halsbereich des Zahnes lokalisiert ist. Die Zähne 7 und 8 zeigen eine große Ähnlichkeit zu dem 7er des OK2 (09.10.13/1).

\begin{tabular}{|c|c|c|c|c|c|c|c|c|}
\hline Zahn & Status & Parodontium & Apikale Prozesse & Zahnstein & Karies & Abrasion & Neubildung & Schmelzhypoplasie \\
\hline 11 & $\mathrm{v}$ & $\mathrm{Pi} \quad 1$ & 0 & & & & & \\
\hline 12 & $\mathrm{v}$ & $\begin{array}{ll}\mathrm{Pi} & 1\end{array}$ & 0 & & & & & \\
\hline 13 & $\mathrm{v}$ & $\mathrm{Pi} \quad 1$ & 0 & & & & & \\
\hline 14 & $\mathrm{v}$ & $\mathrm{Pi} \quad 1$ & 0 & & & & & \\
\hline 15 & & $\mathrm{Pi} \quad 1$ & 0 & $\mathrm{~K}$ & 0 & $\mathrm{O}$ & 0 & $\mathrm{~T}$ \\
\hline 17 & & & 0 & $\mathrm{~K}$ & 0 & 0 & 0 & $\mathrm{~T}$ \\
\hline 21 & $\mathrm{v}$ & $\mathrm{Pi} \quad 1$ & G & & & & & \\
\hline 22 & v & $\mathrm{Pi} 1$ & 0 & & & & & \\
\hline 23 & v & $\begin{array}{ll}\mathrm{Pi} & 1\end{array}$ & 0 & & & & & \\
\hline 24 & & $\mathrm{Pi} 1$ & 0 & $\mathrm{~K}$ & 0 & $\mathrm{O}$ & 0 & $\mathrm{~T}$ \\
\hline 25 & & 0 & 0 & $\mathrm{~K}$ & 0 & 0 & 0 & $\mathrm{~T}$ \\
\hline
\end{tabular}




$\begin{array}{ll}0 & 0 \\ 0 & 0 \\ 0 & \end{array}$

0

\#
0

T 1 


\section{Zahn}

Population:

Calden

Geschlecht: indifferent

Alter:

(8) $11-14$

\section{Beschreibung:}

\subsubsection{3/1}

Skelett: Zettel

Krankheiten:

\begin{tabular}{c|l|l} 
Arthrose & rechts & links \\
\hline Caput & & \\
\hline Fossa & &
\end{tabular}

Zahnstein

Karies

K 1

5273-13291
15 


\section{Zahn}

Population:

Calden

Geschlecht:

Alter:

$25-35$

\section{Beschreibung:}

\subsubsection{3/1}

Skelett: Zettel

Krankheiten:

\section{Zahn Status Parodontium}

Apikale Prozesse

12
Zahnstein

K 1

\begin{tabular}{c|l|l} 
Arthrose & rechts & links \\
\hline Caput & & \\
\hline Fossa & &
\end{tabular}

\section{3-13 291}

\section{Karies}

Abrasion

Neubildung

0

Schmelzhypoplasie 


\section{Zahn}

Population:

Calden

Geschlecht:

Alter:

(7) $9-12$

Beschreibung: Ein gesplittertes Fundstück.

\section{3-13 291}

\begin{tabular}{c|l|l} 
Arthrose & rechts & links \\
\hline Caput & & \\
\hline Fossa & &
\end{tabular}

\section{Zahn Status Parodontium Apikale Prozesse}

41
Krankheiten:

Skelett: Zettel

Krankheiten: 


\section{OK}

$\begin{array}{lll}\text { Population: Calden } & \text { Skelett: } 0416 \\ \text { Geschlecht: } & & \end{array}$

Alter: $\quad$ (32) $37-45(50)$

\subsubsection{3 /}

Skelett: 0416

\section{9}

Krankheiten: Abszess

\section{Stomatitis}

Sinusitis maxillaris

ductus nasolacrimalis gereizt

\begin{tabular}{c|l|l} 
Arthrose & rechts & links \\
\hline Caput & & \\
\hline Fossa & &
\end{tabular}

Beschreibung: Bei diesem Oberkiefer fällt ein Prozessgeschehen auf. Es wird sich wohl um einen Abszess im linken Alveolarfortsatz 3. Grades gehandelt haben, der zur Kieferhöhle durchgebrochen sein könnte. Durch den Reiz bedingt kam es zur Sinusitis maxillaris und daraufhin zu einer Reizung des ductus nasolacrimalis. Weiterhin fällt eine Stomatitis am harten Gaumen auf und zwischen 15 und 16 findet sich eine $1 \mathrm{~mm}$ breite Furche, die wohl durch permanentes Reizen mit einem Stück Holz entstanden sein könnte. Damit könnte sich das Individuum die Zahnzwischenräume gereinigt haben.

\begin{tabular}{|c|c|c|c|c|c|c|c|c|}
\hline Zahn & Status & Parodontium & Apikale Prozesse & Zahnstein & Karies & Abrasion & Neubildung & Schmelzhypoplasie \\
\hline 14 & & Po 2 & 0 & 0 & 0 & $\mathrm{O}$ & * & $x$ \\
\hline 15 & & Po 2 & 0 & $\mathrm{~K}$ & 0 & $\mathrm{O}$ & * & 0 \\
\hline 16 & & Po 2 & G & $\mathrm{K}$ & 0 & $\mathrm{O}$ & * & 0 \\
\hline 17 & & Po 2 & 0 & $\mathrm{~K}$ & $\mathrm{D}$ & 0 & * & 0 \\
\hline 18 & & Po 2 & 0 & $\mathrm{~K}$ & 0 & $\mathrm{O}$ & 0 & 0 \\
\hline 22 & v & Po 2 & & & & & & \\
\hline 23 & & Po 2 & 0 & 0 & 0 & $\mathrm{O}$ & * & 0 \\
\hline 24 & & Po 2 & G & 0 & 2 & $\mathrm{O}$ & * & 0 \\
\hline 25 & & Po 2 & G & 0 & 3 & 0 & * & 0 \\
\hline
\end{tabular}




\section{UK; OK}

Population:

Calden

Geschlecht: männlich

Alter:

(14) 16 - 22 (24)

\subsubsection{3 / 1}

Skelett: $\quad$ UK 13 \& Teile 2x;5y 5273-17

\section{1}

Krankheiten: Sinusitis maxillaris

\begin{tabular}{c|l|l} 
Arthrose & rechts & links \\
\hline Caput & & \\
\hline Fossa & &
\end{tabular}

Beschreibung: Hier ist ein recht massiver Unterkiefer und ein Oberkiefer erhalten. Es ist fraglich, ob der Oberkiefer hier zu selben Individuum gehört. Er weist deutliche Zeichen einer starken Sinusitis maxillaris der linken Kieferhöhle auf.

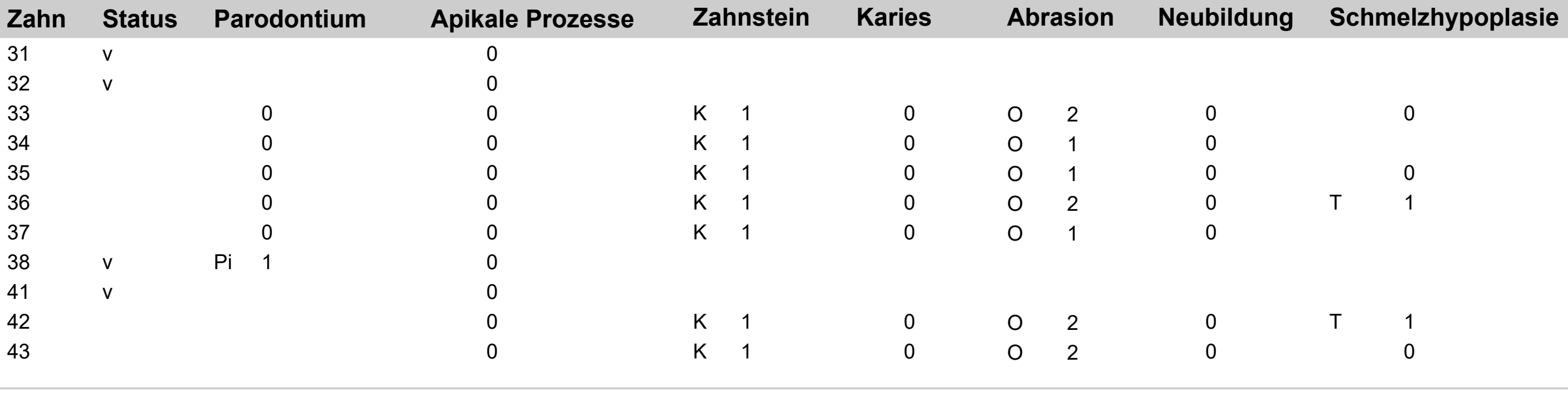




\begin{tabular}{|c|c|c|c|c|c|c|c|c|c|c|}
\hline 44 & & 0 & 0 & $\mathrm{~K}$ & 1 & 0 & 0 & 1 & 0 & \\
\hline 45 & & 0 & 0 & $\mathrm{~K}$ & 1 & 0 & $\mathrm{O}$ & 1 & 0 & \\
\hline 46 & & 0 & 0 & $\mathrm{~K}$ & 1 & 0 & 0 & 2 & 0 & $\mathrm{~T}$ \\
\hline 47 & & 0 & 0 & $\mathrm{~K}$ & 1 & 0 & 0 & 1 & 0 & $\mathrm{~T}$ \\
\hline 48 & $\mathrm{Pi}$ & 1 & 0 & $\mathrm{~K}$ & 1 & & & & & \\
\hline
\end{tabular}




\section{UK}

Population: Calden

Geschlecht: männlich

Alter:

(32) 37 - 44 (48)

\subsubsection{3 / 1}

Skelett: Ersatzteile 15 5273-9 Krankheiten:

\section{1}

\begin{tabular}{c|l|l} 
Arthrose & rechts & links \\
\hline Caput & & \\
\hline Fossa & &
\end{tabular}

\section{Beschreibung:}

\begin{tabular}{|c|c|c|c|c|c|c|c|c|c|c|c|}
\hline Zahn & Status & Parodontium & Apikale Prozesse & \multicolumn{2}{|c|}{ Zahnstein } & Karies & \multicolumn{2}{|c|}{ Abrasion } & Neubildung & \multicolumn{2}{|c|}{ Schmelzhypoplasie } \\
\hline 11 & & & 0 & $\mathrm{~K}$ & 1 & 0 & $\mathrm{O}$ & 1 & 0 & $\mathrm{~T}$ & 1 \\
\hline 43 & $\mathrm{v}$ & & & & & & & & & & \\
\hline 44 & & 0 & 0 & $\mathrm{~K}$ & 1 & 0 & 0 & 4 & * & $\mathrm{T}$ & 1 \\
\hline 45 & & 0 & 0 & $\mathrm{~K}$ & 1 & 0 & $\mathrm{O}$ & 4 & * & $\mathrm{T}$ & 1 \\
\hline 46 & & 0 & 0 & $\mathrm{~K}$ & 1 & 0 & 0 & 5 & * & $\mathrm{T}$ & 1 \\
\hline 47 & v & 0 & 0 & & & & & & & & \\
\hline 48 & & 0 & 0 & $\mathrm{~K}$ & 1 & 0 & $\mathrm{O}$ & 2 & 0 & $\mathrm{~T}$ & 1 \\
\hline
\end{tabular}




\section{OK}

\section{Population: Calden}

Geschlecht: > weiblich
Alter:
(32) $37-47(58)$

\subsubsection{3/1}

Skelett: 18 Tüte 14 5273-18
5273

Krankheiten: Sinusitis maxillaris Stomatitis

\begin{tabular}{c|l|l} 
Arthrose & rechts & links \\
\hline Caput & & \\
\hline Fossa & &
\end{tabular}

Beschreibung: Dieser Oberkiefer weist eine bilaterale Sinusitis maxillaris auf und eine Stomatitis im fortgeschrittenen Stadiums. Weiterhin fällt ein offener Prozess des Zahnes 23 auf. Hier war die Entzündung am apex bis durch die vestibuläre Knochenkortikalis hindurch gedrungen. Auffällig ist weiterhin, dass offenbar nicht Karies der Grund für die Entstehung des apicalen Prozesses gewesen war, bzw. dies nach der sehr starken Abrasion nicht mehr nachzuweisen ist. Allerdings kann auch die auffällig starke Abrasion Grund für eine irreversible Pulpitis gewesen sein, die dann folglich zu dem apicalen Prozess geführt hat.

\begin{tabular}{|c|c|c|c|c|c|c|c|c|}
\hline Zahn & Status & Parodontium & Apikale Prozesse & Zahnstein & Karies & Abrasion & Neubildung & Schmelzhypoplasie \\
\hline 11 & $\mathrm{v}$ & $\mathrm{Pi} \quad 1$ & 0 & & & & & \\
\hline 12 & & $\mathrm{Pi} 1$ & 0 & $\mathrm{~K}$ & 0 & $\mathrm{O}$ & * & 0 \\
\hline 13 & & $\mathrm{Pi} \quad 1$ & 0 & $\begin{array}{ll}\mathrm{K} & 1\end{array}$ & 0 & $\mathrm{O}$ & * & 0 \\
\hline 14 & (f) & $\mathrm{Pi} \quad 2$ & 0 & & & & & \\
\hline 15 & $\mathrm{v}$ & $\mathrm{Pi} \quad 2$ & 0 & & & & & \\
\hline 16 & & $\mathrm{Pi} \quad 2$ & 0 & $\mathrm{~K}$ & 0 & $\mathrm{O}$ & * & 0 \\
\hline 17 & & $\mathrm{Pi} \quad 2$ & 0 & $\mathrm{~K}$ & $0 \quad 1$ & $\mathrm{O}$ & * & 0 \\
\hline 21 & (f) & & 0 & & & & & \\
\hline 22 & $\mathrm{v}$ & & 0 & & & & & \\
\hline 23 & & $\mathrm{Pi} \quad 1$ & G & $\mathrm{K}$ & 0 & 0 & * & 0 \\
\hline 24 & & $\mathrm{Pi} \quad 1$ & 0 & $\mathrm{~K}$ & 0 & $\mathrm{O}$ & * & 0 \\
\hline
\end{tabular}


$\mathrm{Pi} \quad 1$

$\mathrm{Pi} 2$

$\mathrm{Pi} 3$

Pi 3

$\begin{array}{ll}\mathrm{K} & 1 \\ \mathrm{~K} & 1 \\ \mathrm{~K} & 1 \\ \mathrm{~K} & 2\end{array}$

$\begin{array}{lll}0 & 0 & 6 \\ 0 & 0 & 5 \\ 0 & 0 & 5 \\ 0 & 0 & 5\end{array}$




\section{UK}

Population: Calden

Geschlecht: > männlich

Alter:

(25) 28 - 35 (38)

\section{Beschreibung:}

\subsubsection{3 / 3}

Skelett: 2519 mit SCH.20 geborgen 5273-19

Krankheiten:

\begin{tabular}{c|c|c} 
Arthrose & rechts & links \\
\hline Caput & & 1 \\
\hline Fossa & &
\end{tabular}

\begin{tabular}{|c|c|c|c|c|c|c|c|c|c|c|c|}
\hline Zahn & Status & Parodontium & Apikale Prozesse & \multicolumn{2}{|c|}{ Zahnstein } & Karies & \multicolumn{2}{|c|}{ Abrasion } & \multirow{2}{*}{$\begin{array}{c}\text { Neubildung } \\
0\end{array}$} & \multicolumn{2}{|c|}{ Schmelzhypoplasie } \\
\hline 31 & & 0 & & K & 1 & 0 & $\mathrm{O}$ & 2 & & $U$ & 1 \\
\hline 32 & & 0 & 0 & $\mathrm{~K}$ & 1 & 0 & $\mathrm{O}$ & 2 & 0 & $U$ & 1 \\
\hline 33 & & 0 & 0 & K & 2 & 0 & $\mathrm{O}$ & 2 & 0 & $U$ & 1 \\
\hline 34 & & 0 & 0 & $\mathrm{~K}$ & 1 & 0 & $\mathrm{O}$ & 3 & 0 & $U$ & 1 \\
\hline 35 & & 0 & 0 & K & 1 & 0 & $\mathrm{O}$ & 3 & 0 & $U$ & 1 \\
\hline 36 & & 0 & 0 & $\mathrm{~K}$ & 1 & 0 & $\mathrm{O}$ & 4 & * & $U$ & 1 \\
\hline 37 & & 0 & 0 & $\mathrm{~K}$ & 1 & 0 & $\mathrm{O}$ & 3 & 0 & $U$ & 1 \\
\hline 38 & & 0 & 0 & $\mathrm{~K}$ & 1 & 0 & 0 & 3 & 0 & $U$ & 1 \\
\hline 41 & & 0 & 0 & $\mathrm{~K}$ & 2 & 0 & 0 & 2 & 0 & $U$ & 1 \\
\hline 42 & & 0 & 0 & $\mathrm{~K}$ & 1 & 0 & 0 & 2 & 0 & $U$ & 1 \\
\hline 43 & & 0 & 0 & $\mathrm{~K}$ & 1 & 0 & 0 & 2 & 0 & $U$ & 1 \\
\hline
\end{tabular}




\section{OK}

Population: Calden

Geschlecht: > weiblich

Alter:

(22) 25 - 30 (34)

\section{Beschreibung:}

\subsubsection{3 / 1}

Skelett: 31 Cranium 315270 e Krankheiten: Stomatitis

\section{7}

\begin{tabular}{c|l|l} 
Arthrose & rechts & links \\
\hline Caput & & \\
\hline Fossa & &
\end{tabular}

\begin{tabular}{|c|c|c|c|c|c|c|c|c|}
\hline Zahn & Status & Parodontium & Apikale Prozesse & Zahnstein & Karies & Abrasion & Neubildung & Schmelzhypoplasie \\
\hline 12 & v & & & & & & & \\
\hline 13 & $\mathrm{v}$ & $\mathrm{Pi} \quad 2$ & & & & & & \\
\hline 14 & & $\mathrm{Pi} \quad 2$ & & $\mathrm{~K}$ & 0 & $\mathrm{O}$ & 1 & $U$ \\
\hline 15 & & $\mathrm{Pi} \quad 2$ & & $\mathrm{~K}$ & 0 & $\mathrm{O}$ & 1 & $\mathrm{~T}$ \\
\hline 16 & & $\mathrm{Pi} \quad 2$ & & $\mathrm{~K}$ & 0 & $\mathrm{O}$ & 1 & $U$ \\
\hline
\end{tabular}




\section{OK}

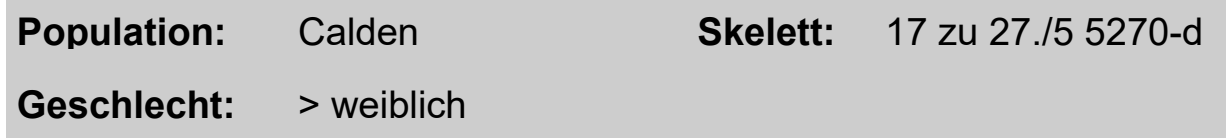

Population: Calden Skelett: 17 zu 27./5 5270-d

\subsubsection{3/1}

Beschreibung: Bei diesem Oberkiefer fallen die recht großen Abrasionsgrade auf. 27 ist bis an den Zahnhals abradiert und durch Karies zerstört. Dies hat zu einem apicalen Prozess geführt. Auch 26 und 21 fallen wegen apicaler Prozesse ins Auge, wobei 26 wohl intravital ausgefallen ist. An 17 ist eine kleine, tropfenförmige Schmelzhyperplasie festzustellen. An 15 ist eine erbsengroße Hyperzementose zu sehen. 14 weist apical einen offenen Prozess auf.

\section{7}

\author{
Krankheiten: Stomatitis \\ dentogener Prozess \\ Sinusitis maxillaris
}

\begin{tabular}{|c|c|c|c|c|c|c|c|c|c|c|c|c|c|}
\hline \multirow{2}{*}{$\begin{array}{l}\text { Zahn } \\
11\end{array}$} & \multirow[t]{2}{*}{ Status } & \multicolumn{2}{|c|}{ Parodontium } & \multicolumn{2}{|c|}{ Apikale Prozesse } & Zahnstein & \multicolumn{2}{|c|}{ Karies } & \multicolumn{2}{|c|}{ Abrasion } & Neubildung & \multicolumn{2}{|c|}{ Schmelzhypoplasie } \\
\hline & & $\mathrm{Pi}$ & 2 & & & 0 & & 0 & $\mathrm{O}$ & 4 & * & $\mathrm{T}$ & 2 \\
\hline 12 & $\mathrm{v}$ & $\mathrm{Pi}$ & 2 & & & & & & & & & & \\
\hline 13 & v & $\mathrm{Pi}$ & 2 & & & & & & & & & & \\
\hline 14 & (f) & $\mathrm{Pi}$ & 4 & & & & & & & & & & \\
\hline 15 & & $\mathrm{Pi}$ & 2 & & & 0 & & 0 & $\mathrm{O}$ & 3 & $\#$ & & 0 \\
\hline 16 & v & $\mathrm{Pi}$ & 3 & & & & & & & & & & \\
\hline 17 & & $S$ & 1 & & 0 & 0 & $\mathrm{H}$ & 2 & 0 & 4 & & $U$ & 1 \\
\hline 18 & v & $S$ & 3 & & & & & & & & & & \\
\hline 21 & & $\mathrm{Pi}$ & 2 & G & 1 & 0 & & 0 & $\mathrm{O}$ & 4 & * & $\mathrm{T}$ & 2 \\
\hline 22 & v & $\mathrm{Pi}$ & 2 & & & & & & & & & & \\
\hline 23 & & $\mathrm{Pi}$ & 2 & & 0 & $\mathrm{~K}$ & $\mathrm{H}$ & 1 & 0 & 5 & * & & 0 \\
\hline
\end{tabular}




$\begin{array}{llll} & 0 & K & 2 \\ & 0 & K & 2 \\ G & 3 & & \\ G & 3 & & \end{array}$

$\begin{array}{ll} & 0 \\ \mathrm{H} & 2 \\ & \\ \mathrm{~K} & 6\end{array}$

0
2
6

$\begin{array}{lll}0 & 5 & \text { * } \\ 0 & 5\end{array}$

U 1 


\section{OK; UK}

Population:

Calden

Geschlecht: weiblich

Alter:

(32) 37 - 47 (52)

\subsubsection{3 / 1}

Skelett: $\quad$ 16/ unter LK Hand von Sk.11

5269286

Beschreibung: Bei diesen Fundstücken fällt ein möglicherweise bereits elongierter 27 auf, was bedeuten könnte, dass der Antagonist ausgefallen war. In regio 33-35 finden sich Auswülste am Unterkiefer und im Oberkiefer neben einer Stomatitis eine Sinusitis maxillaris.

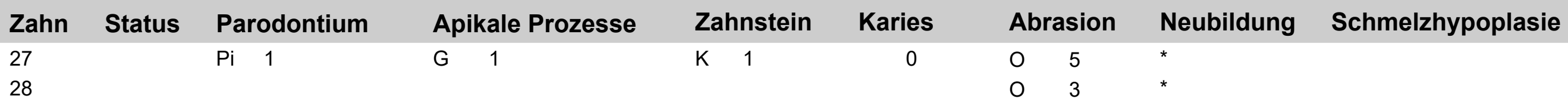




\section{Zähne}

Population:

Calden

Geschlecht: indifferent

Alter:

(4) 5 - $6(7)$

\subsubsection{2/ 2}

Skelett: bei Calden 12

\section{4}

Krankheiten:

\begin{tabular}{c|l|l} 
Arthrose & rechts & links \\
\hline Caput & & \\
\hline Fossa & &
\end{tabular}

Beschreibung: Diese fünf bleibenden Zähne sind noch nicht durchgebrochen und befinden sich noch im Kieferknochen. Aufgrund dieser Tatsache ist ein Altersbereich ziemlich genau anzugeben.

$\begin{array}{lllllll}\text { Zahn } & \text { Status } & \text { Parodontium } & \text { Apikale Prozesse } & \text { Zahnstein Karies } & \text { Abrasion Neubildung Schmelzhypoplasie } \\ 11 & \text { ( ) } & & & \\ 17 & \text { ( ) } & & & \\ 21 & \text { () } & & & \\ 22 & \text { () } & & \\ 27 & \text { ( ) } & \end{array}$




\section{UK; Ok}

Population:

Geschlecht:

Calden

Alter:

(25) 28 - 35 (38)

\subsubsection{2 / 1}

Skelett: Calden 24 UK22 und

Ok 3,$4 ; 4,35$

\section{5}

Beschreibung: Hier liegen ein Ober- und ein Unterkiefer vor, die in recht gutem Erhaltungszustand sind. Es fällt eine generalisierte Parodontitis auf. Weiterhin sind die Molaren des Unterkiefers intravital ausgefallen. An 15 und 25 fällt eine Zementhyperplasie auf, sowie eine auffällig sigmoid - förmig gekrümmte Wurzel. Die beiden Kiefer gehören wohl zu dem

\begin{tabular}{|c|c|c|c|c|c|c|c|c|c|}
\hline Zahn & Status & Parodontium & Apikale Prozesse & Zahnstein & Karies & Abı & asion & Neubildung & Schmelzhypoplasie \\
\hline 11 & $\mathrm{v}$ & $\mathrm{Pi} \quad 1$ & 0 & & & & & & \\
\hline 12 & v & $\mathrm{Pi} \quad 1$ & 0 & & & & & & \\
\hline 13 & & $\mathrm{Pi} \quad 1$ & 0 & K & 0 & 0 & 4 & * & 1 \\
\hline 14 & & $\mathrm{Pi} \quad 2$ & 0 & $\mathrm{~K}$ & 0 & $\mathrm{O}$ & 4 & * & 0 \\
\hline 15 & & $\mathrm{Pi} \quad 2$ & 0 & $\mathrm{~K}$ & 0 & $\mathrm{O}$ & 4 & \# & 1 \\
\hline 16 & & $\mathrm{Pi} \quad 2$ & 0 & $\mathrm{~K}$ & 0 & $\mathrm{O}$ & 4 & * & 1 \\
\hline 17 & & $\mathrm{Pi} \quad 2$ & 0 & $\mathrm{~K}$ & 0 & $\mathrm{O}$ & 3 & * & 1 \\
\hline 18 & v & $\mathrm{Pi} \quad 2$ & 0 & & & & & & \\
\hline 21 & $v$ & $\mathrm{Pi} \quad 1$ & 0 & & & & & & \\
\hline 22 & $\mathrm{v}$ & $\mathrm{Pi} \quad 1$ & 0 & & & & & & \\
\hline 23 & & $\begin{array}{ll}\mathrm{Pi} & 1\end{array}$ & 0 & $\mathrm{~K}$ & 0 & 0 & 4 & * & 1 \\
\hline
\end{tabular}




\begin{tabular}{|c|c|c|c|c|c|c|c|c|c|c|c|c|}
\hline 24 & & $\mathrm{Pi}$ & 2 & 0 & $\mathrm{~K}$ & 1 & $D$ & 2 & 0 & 4 & * & $\mathrm{T}$ \\
\hline 25 & & $\mathrm{Pi}$ & 2 & 0 & $\mathrm{~K}$ & 1 & $\mathrm{M}$ & 1 & 0 & 4 & $\#$ & $\mathrm{~T}$ \\
\hline 26 & & $\mathrm{Pi}$ & 2 & 0 & $\mathrm{~K}$ & 1 & & 0 & 0 & 3 & * & $\mathrm{T}$ \\
\hline 27 & & $\mathrm{Pi}$ & 2 & 0 & $\mathrm{~K}$ & 1 & & 0 & & & & $\mathrm{~T}$ \\
\hline 28 & $\mathrm{v}$ & $\mathrm{Pi}$ & 2 & 0 & & & & & & & & \\
\hline 31 & & $\mathrm{Pi}$ & 4 & 0 & $\mathrm{~K}$ & 1 & & 0 & 0 & 2 & 0 & $\mathrm{~T}$ \\
\hline 32 & $\mathrm{v}$ & $\mathrm{Pi}$ & 3 & 0 & & & & & & & & \\
\hline 33 & $x x$ & & & & & & & & & & & \\
\hline 34 & $x x$ & & & & & & & & & & & \\
\hline 35 & $\mathrm{v}$ & $\mathrm{Pi}$ & 3 & & & & & & & & & \\
\hline 36 & $f$ & & & & & & & & & & & \\
\hline 37 & $f$ & & & & & & & & & & & \\
\hline 38 & $\mathrm{O}$ & & & & & & & & & & & \\
\hline 41 & $\mathrm{v}$ & & & 0 & & & & & & & & \\
\hline 42 & $v$ & & & 0 & & & & & & & & \\
\hline 43 & & $\mathrm{Pi}$ & 2 & 0 & $\mathrm{~K}$ & 1 & & 0 & 0 & 2 & 0 & $U$ \\
\hline 44 & & $\mathrm{Pi}$ & 2 & 0 & $\mathrm{~K}$ & 1 & & 0 & $\mathrm{O}$ & 3 & * & \\
\hline 45 & & Po & 2 & 0 & $\mathrm{~K}$ & 1 & & 0 & 0 & 4 & * & \\
\hline 46 & $f$ & & & & & & & & & & & \\
\hline 47 & $f$ & & & & & & & & & & & \\
\hline 48 & 0 & & & & & & & & & & & \\
\hline
\end{tabular}




\section{Ok}

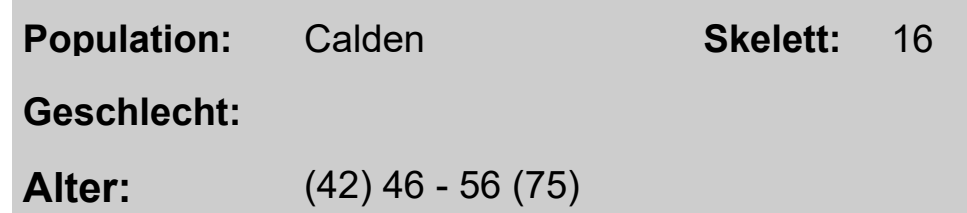
Alter:
(42) $46-56(75)$

\section{9}

Krankheiten: Stomatitis

Sinusitis maxillaris

Beschreibung: Dies ist ein in zwei Fragmenten erhaltener Oberkiefer, der rechtsseitig eine Sinusitis maxillaris aufweist. Weiterhin wurde in diesem Zusammenhang der ductus nasolacrimalis gereizt. An 14 und 16 liegt eine Hyperzementose an der vestibulären Wurzel vor. An 15, 16, 17, 24 und 25 liegt ein apicaler Prozess vor. Hierbei handelt es sich aber teilweise um Verdachtsdiagnosen, die nur teilweise am Röntgen oder anderweitig bewiesen werden können. An 16 kann nach Sichtdiagnose aufgrund der Struktur des Prozesses auch bereits eine Zyste ausgebildet gewesen sein. Hierbei handelt es sich dann wohl um eine radikuläre Zyste.

\begin{tabular}{|c|c|c|c|c|c|c|c|c|c|}
\hline Zahn & Status & Parodontium & Apikale Prozesse & Zahnstein & Karies & $\mathrm{Ab}$ & Ision & Neubildung & Schmelzhypoplasie \\
\hline 13 & $\mathrm{v}$ & & & & & & & & \\
\hline 14 & & $\mathrm{Pi} \quad 2$ & 0 & $\mathrm{H}$ & 0 & $\mathrm{O}$ & 6 & * & \\
\hline 15 & & $\mathrm{Pi} 2$ & G & $\begin{array}{ll}\mathrm{H} & 1\end{array}$ & 0 & $\mathrm{O}$ & 5 & * & \\
\hline 16 & & $\mathrm{Pi} 2$ & G & $\mathrm{H} \quad 1$ & 0 & $\mathrm{O}$ & 5 & * & \\
\hline 17 & & Po 2 & $\mathrm{G}$ & $\begin{array}{ll}\mathrm{K} & 1\end{array}$ & 0 & $\mathrm{O}$ & 5 & * & $U$ \\
\hline 18 & & Po 2 & & K 1 & 0 & $\mathrm{O}$ & 3 & * & $\mathrm{T}$ \\
\hline 22 & $v$ & & & & & & & & \\
\hline 23 & & $\mathrm{Pi} \quad 1$ & 0 & $\mathrm{H} \quad 1$ & 0 & $\mathrm{O}$ & 6 & * & \\
\hline 24 & & $\mathrm{Pi} \quad 1$ & G & $\mathrm{H} \quad 1$ & 0 & $\mathrm{O}$ & 6 & * & \\
\hline 25 & & $\mathrm{Pi} \quad 1$ & $G$ & $\mathrm{H} \quad 1$ & 0 & $\mathrm{O}$ & 7 & * & \\
\hline
\end{tabular}




\section{OK}

$\begin{array}{lll}\text { Population: Calden } & \text { Skelett: Calden } 23 \\ \text { Geschlecht: männlich } & \end{array}$

Alter: $\quad(32) 37-45(50)$

\subsubsection{2/ 1}

Skelett: Calden 23

\section{5}

Krankheiten: Stomatitis

Sinusitis maxillaris

Parodontose

\begin{tabular}{c|c|c} 
Arthrose & rechts & links \\
\hline Caput & & \\
\hline Fossa & 2 &
\end{tabular}

Beschreibung: Bei diesem Oberkiefer fällt ein dreiwurzliger 14 ins Auge. Weiterhin weist das Fundstück eine nicht vollständig pneumatisierte Kieferhöhle auf, die wohl aus einer in jungen Jahren aufgetretenen, aber später verheilten Sinusitis maxillaris resultiert.

\begin{tabular}{|c|c|c|c|c|c|c|c|c|}
\hline Zahn & Status & Parodontium & Apikale Prozesse & Zahnstein & Karies & Abrasion & Neubildung & Schmelzhypoplasie \\
\hline 11 & $\mathrm{v}$ & & & & & & & \\
\hline 12 & $\mathrm{v}$ & & & & & & & \\
\hline 13 & $\mathrm{v}$ & & & & & & & \\
\hline 14 & $\mathrm{v}$ & & & & & & & \\
\hline 15 & $\mathrm{v}$ & & A & & & & & \\
\hline 16 & & Po 2 & A & $\mathrm{K}$ & M 5 & 0 & * & 0 \\
\hline 17 & & Po 2 & 0 & $\mathrm{~K}$ & 0 & 0 & 0 & $\mathrm{~T}$ \\
\hline 18 & $v$ & & 0 & & & & & \\
\hline 21 & $\mathrm{v}$ & & & & & & & \\
\hline 22 & $\mathrm{v}$ & & & & & & & \\
\hline 23 & $\mathrm{v}$ & & & & & & & \\
\hline
\end{tabular}


$24 \quad \mathrm{v}$

25

Po 2

Po 2

Po 2

Po 2

0
0
0
0

$\begin{array}{ll}\mathrm{K} & 1 \\ \mathrm{~K} & 1 \\ \mathrm{~K} & 1 \\ \mathrm{~K} & 1\end{array}$

$\begin{array}{lll}0 & 0 & 4 \\ 0 & 0 & 5 \\ 0 & 0 & 3 \\ 0 & 0 & 2\end{array}$

$\begin{array}{ll}\mathrm{T} & 1 \\ \mathrm{~T} & 1 \\ \mathrm{~T} & 1 \\ & 0\end{array}$




\section{OK}

Population: Calden

Geschlecht: > weiblich

Alter:

(43) 48 - 56 (65)

Beschreibung: Bei diesem Oberkiefer fällt eine beidseitige Sinusitis maxillaris ins Auge.

\subsubsection{2/1}

Skelett: Calden 14

\section{5}

Krankheiten: Stomatitis

Sinusitis maxillaris

\begin{tabular}{c|c|c} 
Arthrose & rechts & links \\
\hline Caput & & \\
\hline Fossa & & 2
\end{tabular}

\begin{tabular}{|c|c|c|c|c|c|c|c|c|}
\hline Zahn & Status & Parodontium & Apikale Prozesse & Zahnstein & Karies & Abrasion & Neubildung & Schmelzhypoplasie \\
\hline 11 & $\mathrm{v}$ & $\mathrm{Pi} \quad 2$ & & & & & & \\
\hline 12 & v & $\mathrm{Pi} \quad 2$ & & & & & & \\
\hline 13 & $\mathrm{v}$ & $\mathrm{Pi} \quad 2$ & & & & & & \\
\hline 14 & & $\mathrm{Pi} \quad 2$ & $A$ & $\mathrm{~K}$ & O 6 & $\mathrm{O}$ & * & $x$ \\
\hline 15 & v & $\mathrm{Pi} \quad 2$ & & & & & & \\
\hline 16 & v & & & & & & & \\
\hline 21 & $\mathrm{v}$ & $\mathrm{Pi} \quad 2$ & & & & & & \\
\hline 22 & $\mathrm{v}$ & $\mathrm{Pi} 2$ & & & & & & \\
\hline 23 & $\mathrm{v}$ & $\mathrm{Pi} \quad 2$ & & & & & & \\
\hline 24 & v & $\mathrm{Pi} \quad 2$ & & & & & & \\
\hline 25 & v & $\mathrm{Pi} \quad 2$ & & & & & & \\
\hline
\end{tabular}




\section{OK}

Population: Calden

Geschlecht:

Alter:

(17) 20 - 26 (30)

\subsubsection{2 / 1}

Skelett: Zahn und Splitter

\section{5}

Krankheiten: Sinusitis maxillaris

\begin{tabular}{c|l|l} 
Arthrose & rechts & links \\
\hline Caput & & \\
\hline Fossa & &
\end{tabular}

Beschreibung: Dieser 27 ist mit einem Fragment des Alveolarknochens erhalten. Erhalten ist auch ein Fragment des Sinus maxillaris der rechten Seite, der Spuren einer Sinusitis aufweist, die noch in einem akuten Stadium war.

$\begin{array}{lllclclcc}\text { Zahn } & \text { Status } & \text { Parodontium } & \text { Apikale Prozesse } & \text { Zahnstein } & \text { Karies } & \text { Abrasion } & \text { Neubildung } & \text { Schmelzhypoplasie } \\ 27 & \text { Po } 2 & 0 & \text { K } 1 & \text { O } & 1 & 1\end{array}$




\section{OK}

$\begin{array}{lll}\text { Population: } & \text { Calden } & \text { Skelett: } 27 \\ \text { Geschlecht: } & \text { männlich } & \end{array}$

\subsubsection{2 / 2}

Skelett: 27

\section{5}

Krankheiten: Stomatitis

Sinusitis maxillaris

Parodontose

Sinusitis maxillaris

Periostreizung

\begin{tabular}{c|l|l} 
Arthrose & rechts & links \\
\hline Caput & & \\
\hline Fossa & &
\end{tabular}

Beschreibung: Dieses Fundstück ist ein Teil eines Oberkiefers. Zusätzlich erhalten ist ein Fragment des linken Os zygomaticum mit einem Teil des Orbitabodens der linken Seite. Im Alveolarfortsatz haben sich insgesamt acht Zähne erhalten; ein Molar lag einzeln vor und war nicht in eine Alveole zurückzuführen, da diese zu stark erodiert war. Drei weitere Zähne sind nachweislich erst postmortal ausgefallen. Bei den verbliebenen handelt es sich um sehr stark attritierte und abradierte Zähne, die z.T. apicale Prozesse aufwiesen. Weiterhin war an einigen Zähnen Karies nachzuweisen. Auffällig war weiterhin eine plattenförmige Auflagerung im linken Sinus maxillaris im oberen Teil; teilweise war der Orbitaboden von unten mit betroffen. Hierbei handelt es sich um Spuren einer Sinusitis maxillaris. Anzeichen einer Kieferhöhlenentzündung waren auch im rechten Sinus maxillaris zu finden. Die Spuren der Sinusitis in der linken Kieferhöhle haben eine Ausdehnung von etwa $5 \mathrm{~mm} \times 9 \mathrm{~mm}$. Am harten Gaumen sind darüber hinaus noch Spuren einer Stomatitis zu erkennen.

Eine weitere Auffälligkeit bot das Os zygomaticum der linken Seite von facial gesehen: Direkt unterhalb des Foramen zygomaticofaciale liegt eine knöcherne Auftreibung von $19 \mathrm{~mm}$ x 8,5 mm x $2 \mathrm{~mm}$. Es könnte sich um ein knöchernes Trauma mit

\begin{tabular}{|c|c|c|c|c|c|c|c|c|}
\hline Zahn & Status & Parodontium & Apikale Prozesse & Zahnstein & Karies & Abrasion & Neubildung & Schmelzhypoplasie \\
\hline 11 & v & $\mathrm{Pi} \quad 1$ & 0 & & & & & \\
\hline 12 & $\mathrm{v}$ & $\mathrm{Pi} \quad 1$ & 0 & & & & & \\
\hline 13 & & $\mathrm{Pi} \quad 2$ & 0 & 0 & $\mathrm{D}$ & 0 & * & $U$ \\
\hline 14 & & $\mathrm{Pi} \quad 2$ & 0 & 0 & 0,5 & $\mathrm{O}$ & * & $U$ \\
\hline 15 & & Po 1 & 0 & 0 & $\mathrm{M}$ & $\mathrm{O}$ & * & $U$ \\
\hline 21 & & $\mathrm{Pi} \quad 1$ & 0 & 0 & 0 & $\mathrm{O}$ & * & \\
\hline 22 & & $\mathrm{Pi} \quad 2$ & & 0 & 0 & 0 & * & $U$ \\
\hline 23 & & $\mathrm{Pi} \quad 2$ & $A$ & $\mathrm{H}$ & $D$ & $\mathrm{O}$ & * & $U$ \\
\hline 24 & & $\mathrm{Pi} \quad 2$ & $A$ & 0 & $\mathrm{O}$ & $\mathrm{O}$ & * & \\
\hline 25 & & Po 2 & 0 & 0 & 0 & O & * & \\
\hline 26 & & & 0 & 0 & M 3 & 0 & * & \\
\hline
\end{tabular}




\section{Ok}

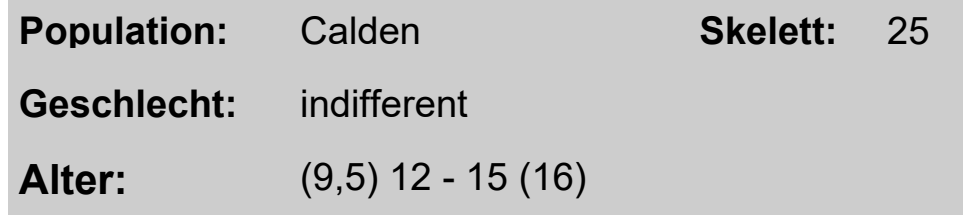
das Fundstück Spuren einer Sinusitis maxillaris und eine Stomatitis auf.

\section{9}

Krankheiten: Sinusitis maxillaris Stomatitis

\begin{tabular}{c|l|l} 
Arthrose & rechts & links \\
\hline Caput & & \\
\hline Fossa & &
\end{tabular}

\begin{abstract}
Beschreibung: Dieser Oberkiefer befand sich zum Todeszeitpunkt noch im Wachstum. Dies ist unter anderem daran festzumachen, dass das
Wurzelwachstum des Zahnes 27 noch nicht abgeschlossen war. In regio 22 ist ein Wurzelrest eines Milchzahns verblieben. Weiterhin weist
Beschreibung: Dieser Oberkiefer befand sich zum Todeszeitpunkt noch im Wachstum. Dies ist unter anderem daran festzumachen, dass das
Wurzelwachstum des Zahnes 27 noch nicht abgeschlossen war. In regio 22 ist ein Wurzelrest eines Milchzahns verblieben. Weiterhin weist
\end{abstract} da funduck Spuen

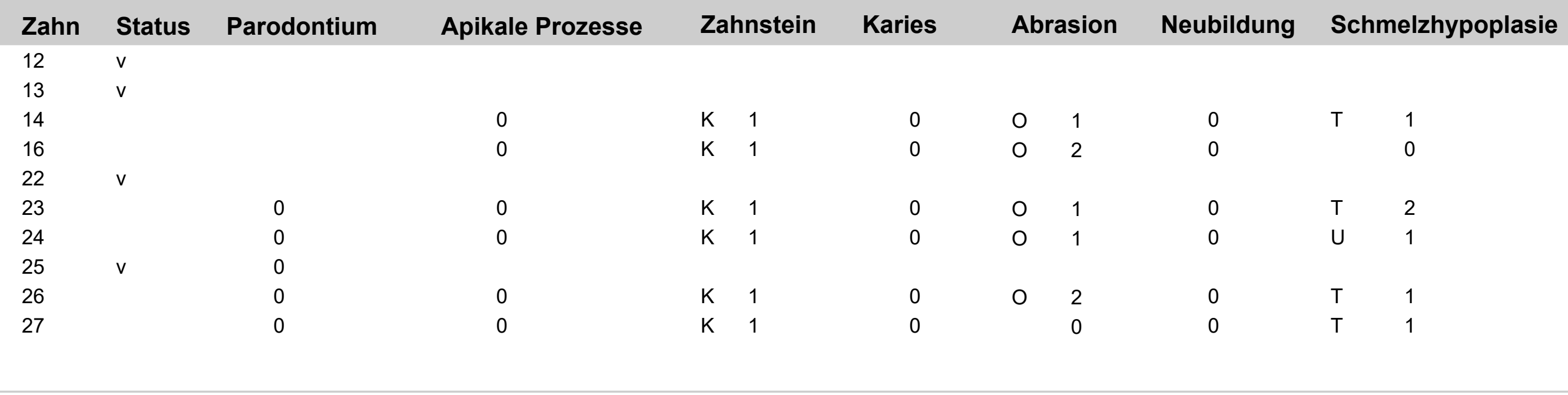




\section{Zahn}

Population: Calden

Geschlecht:

Alter:

$9-11$

\section{Beschreibung:}

\section{Zahn \\ Status Parodontium \\ Apikale Prozesse}

84

\subsubsection{2 / 1}

Skelett: 25

Krankheiten:

5271289

\begin{tabular}{c|l|l} 
Arthrose & rechts & links \\
\hline Caput & & \\
\hline Fossa & &
\end{tabular}

Zahnstein

0

Parodontium

Karies

0

0

Abrasion

0

Schmelzhypoplasie $\mathrm{T} 1$
Neubildung

o 3 


\section{Zähne}

Population:

Calden

Geschlecht:

Alter:

(32) $37-45(50)$

\section{Beschreibung:}

\section{Zahn Status Parodontium Apikale Prozesse}

36

46

\subsubsection{2 / 2}

Skelett: 25

Krankheiten:

\begin{tabular}{c|l|l} 
Arthrose & rechts & links \\
\hline Caput & & \\
\hline Fossa & &
\end{tabular}

5271289

$\begin{array}{lllll}0 & \mathrm{~K} & 2 & & 0 \\ 0 & \mathrm{~K} & 2 & \mathrm{D} & 4\end{array}$

Abrasion Neubildung Schmelzhypoplasie

O 5

\section{\#} 0 


\section{OK; UK}

Population:

Geschlecht:

Calden

Alter:

(40) 45 - 55 (65)

\subsubsection{2 / 1}

Skelett: 1832

\section{9}

Krankheiten: Sinusitis maxillaris

Stomatitis

Periostreizung

Vorbiss OK

Muskelreizung

Anomalie

Beschreibung: Die beiden Fundstücke OK 32 und UK 18 gehören wahrscheinlich zusammen. Möglicherweise hat ein Vorbiss des Oberkiefers vorgelegen, da auf diese Weise die beiden Fundstücke miteinander kombinierbar sind. Für die Zusammengehörigkeit spricht weiterhin, dass die Oberkiefer - Weisheitszähne durchgebrochen, aber die Unterkiefer - Weisheitszähne nicht angelegt waren. Der erhaltene 28 hat offenkundig keinen Antagonisten gehabt, da jegliche Abrasion fehlt. Trotz des Überbisses kam es wohl nicht zum Kontakt zu den zweiten Molaren des Unterkiefers, da der Weisheitszahn etwas verlagert stand. Auffällig am Gesamtbild der beiden Fundstücke sind die zahlreichen Anomalien: Der Unterkiefer wirkt, als wäre er auf der linken Seite länger gewachsen, was dann dazu geführt haben könnte, dass die Zähne das vorliegende Abrasionsmuster zeigen und die Neigung der Molaren und Prämolaren nach rechts hin weist. Es ist definitiv festzustellen, dass die Zähne nicht gerade in den Alveolen aufgehängt waren, sondern mit einer Achsabweichung nach rechts. Da anscheinend die Oberkiefer Sechser Kontakt mit den Unterkiefer Fünfern hatten, ergaben sich diese abstrusen Abrasions- und Attritionsmuster. Es waren auch einige Zähne intravial ausgefallen und die Frontzähne beider Kiefer waren nicht physiologisch angeordnet, sondern teilweise gedreht und im Falle des Oberkiefers nach

\begin{tabular}{|c|c|c|c|c|c|}
\hline Zahn & Status & \multicolumn{2}{|c|}{ Parodontium } & \multicolumn{2}{|c|}{ Apika } \\
\hline 11 & $f$ & & & & \\
\hline 12 & (f) & & & & \\
\hline 13 & v & & & & \\
\hline 14 & (f) & & & $G$ & \\
\hline 15 & (f) & & & & \\
\hline 16 & & $\mathrm{Pi}$ & 3 & & \\
\hline 17 & v & $\mathrm{Pi}$ & 4 & & \\
\hline 18 & v & $\mathrm{Pi}$ & 4 & & \\
\hline 21 & v & & & & \\
\hline 22 & v & & & & \\
\hline 23 & v & & & Z & \\
\hline
\end{tabular}




$\begin{array}{llll}24 & f & & \\ 25 & v & \text { Po } 3 \\ 26 & & \text { Po } 3 \\ 27 & & \text { Po } 3 \\ 28 & & \text { Po } 2 \\ 31 & & \text { Po } 2 \\ 32 & & \text { Po } 2 \\ 33 & & & \\ 34 & & & \\ 35 & & & \\ 36 & v & & \\ 37 & v & & \\ 38 & \varnothing & \text { Po } 2 \\ 41 & & \text { Po } 3 \\ 42 & v & 3 \\ 43 & & \text { Po } 3 \\ 44 & & & \\ 45 & & & \\ 46 & & & \\ 47 & & & \\ 48 & \varnothing & \end{array}$

$$
\begin{array}{ll}
\mathrm{K} & 1 \\
\mathrm{~K} & 1 \\
\mathrm{~K} & 1 \\
\mathrm{~K} & 2 \\
\mathrm{~K} & 1 \\
\mathrm{~K} & 1 \\
& \\
\mathrm{~K} & 1
\end{array}
$$

0
0
0
0
0
0

$\begin{array}{ll}0 & 6 \\ 0 & 5\end{array}$

0

O 5

O 5

Po 2

Po 3

Po 3

Po 3

$\begin{array}{ll}\text { K } & 1 \\ \text { K } & 1 \\ \text { K } & 1 \\ \text { K } & 1 \\ \text { K } & 1 \\ \text { K } & 1\end{array}$

$\begin{array}{llll}0 & 0 & 5 & \text { * } \\ 0 & 0 & 6 & \text { * } \\ 0 & 0 & 5 & \text { * } \\ 0 & 0 & 5 & \text { * } \\ 0 & 0 & 5 & \text { * } \\ 0 & 0 & 5 & \end{array}$

$\begin{array}{ll}\text { U } & 1\end{array}$

0

0

$\mathrm{x}$
0
0
0
0




\section{UK}

Population: Calden

Geschlecht: > männlich

Alter:

(22) 25 - 30 (34)

\subsubsection{2/ 1}

Skelett: 18

Krankheiten:

\section{9}

\begin{tabular}{c|l|l} 
Arthrose & rechts & links \\
\hline Caput & & \\
\hline Fossa & &
\end{tabular}

\section{Beschreibung:}

\begin{tabular}{|c|c|c|c|c|c|c|c|c|c|c|}
\hline Zahn & Status & Parodontium & Apikale Prozesse & Zahnstein & Karies & $A b$ & sion & Neubildung & & elzhypoplasie \\
\hline 33 & & Po 1 & 0 & $\mathrm{~K}$ & 0 & 0 & 1 & 0 & $U$ & 2 \\
\hline 34 & & Po 1 & 0 & $\mathrm{~K}$ & 0 & $\mathrm{O}$ & 1 & 0 & $U$ & 1 \\
\hline 35 & & Po 1 & 0 & $\mathrm{~K}$ & 0 & $\mathrm{O}$ & 2 & 0 & & 0 \\
\hline 36 & & Po 1 & 0 & $\mathrm{~K}$ & 0 & $\mathrm{O}$ & 3 & 0 & $U$ & 1 \\
\hline 37 & v & & & & & & & & & \\
\hline 41 & v & Po 1 & & & & & & & & \\
\hline 42 & v & Po 1 & & & & & & & & \\
\hline 43 & & & 0 & $\mathrm{~K}$ & 0 & $\mathrm{O}$ & 1 & 0 & $U$ & 2 \\
\hline 44 & & & 0 & $\mathrm{~K}$ & 0 & 0 & 1 & 0 & U & 1 \\
\hline 47 & & & & K 1 & 0 & 0 & 2 & 0 & & 0 \\
\hline
\end{tabular}




\section{UK}

Population: Calden

Geschlecht: > weiblich

Alter:

(22) 25 - 30 (34)

\section{Beschreibung:}

\subsubsection{2/1}

Skelett: Sch.1219

\section{4}

Krankheiten: Arthrose

\begin{tabular}{c|c|c} 
Arthrose & rechts & links \\
\hline Caput & & 3 \\
\hline Fossa & 1 &
\end{tabular}

\begin{tabular}{|c|c|c|c|c|c|c|c|c|c|}
\hline Zahn & Status & Parodontium & Apikale Prozesse & Zahnstein & Karies & $\mathrm{Ab}$ & sion & Neubildung & Schmelzhypoplasie \\
\hline 17 & & & 0 & $\mathrm{~K}$ & 0 & $\mathrm{O}$ & 1 & 0 & 0 \\
\hline 31 & & 0 & 0 & $\begin{array}{ll}\mathrm{K} & 1\end{array}$ & 0 & $\mathrm{O}$ & 2 & 0 & $\mathrm{~T}$ \\
\hline 32 & & 0 & 0 & $\begin{array}{ll}\mathrm{K} & 1\end{array}$ & 0 & $\mathrm{O}$ & 2 & 0 & $\mathrm{~T}$ \\
\hline 33 & & 0 & 0 & $\mathrm{~K}$ & 0 & $\mathrm{O}$ & 1 & 0 & $\mathrm{~T}$ \\
\hline 34 & & 0 & 0 & $\mathrm{~K}$ & 0 & 0 & 1 & 0 & $\mathrm{~T}$ \\
\hline 35 & & 0 & 0 & $\mathrm{~K}$ & 0 & $\mathrm{O}$ & 1 & 0 & $\mathrm{~T}$ \\
\hline 36 & & Po 1 & 0 & $\mathrm{~K}$ & 0 & $\mathrm{O}$ & 3 & 0 & 0 \\
\hline 37 & & 0 & 0 & $\mathrm{~K}$ & 0 & $\mathrm{O}$ & 1 & 0 & 0 \\
\hline 38 & $\varnothing$ & & & & & & & & \\
\hline 41 & & 0 & 0 & $\mathrm{~K}$ & 0 & 0 & 2 & 0 & $\mathrm{~T}$ \\
\hline 42 & & 0 & 0 & $\begin{array}{ll}\mathrm{K} & 1\end{array}$ & 0 & 0 & 2 & 0 & $\mathrm{~T}$ \\
\hline
\end{tabular}


43

45

46

47

48

0
0
0
Po 1
0

$\varnothing$

$\begin{array}{ll}\mathrm{K} & 1 \\ \mathrm{~K} & 1 \\ \mathrm{~K} & 1 \\ \mathrm{~K} & 1 \\ \mathrm{~K} & 1\end{array}$

$\begin{array}{lll}0 & 0 & 1 \\ 0 & 0 & 1 \\ 0 & 0 & 1 \\ 0 & 0 & 3 \\ 0 & 0 & 1\end{array}$

$\begin{array}{lll}0 & \mathrm{~T} & 1 \\ 0 & \mathrm{~T} & 1 \\ 0 & \mathrm{~T} & 1 \\ 0 & & 0 \\ 0 & & 0\end{array}$




\section{OK; UK}

Population:

Calden

Geschlecht: > männlich

Alter:

(25) 28 - $35(38)$

Beschreibung: Die Zähne stehen perfekt im Zahnkranz.

\section{2}

Skelett: unter Schädel zu 8 B2 Krankheiten:

\begin{tabular}{c|l|l} 
Arthrose & rechts & links \\
\hline Caput & & \\
\hline Fossa & &
\end{tabular}

\begin{tabular}{|c|c|c|c|c|c|c|c|c|c|c|c|}
\hline \multirow{2}{*}{$\begin{array}{l}\text { Zahn } \\
21\end{array}$} & \multirow[t]{2}{*}{ Status } & \multirow[t]{2}{*}{ Parodontium } & \multirow{2}{*}{$\begin{array}{c}\text { Apikale Prozesse } \\
0\end{array}$} & \multicolumn{2}{|c|}{ Zahnstein } & \multirow{2}{*}{$\begin{array}{c}\text { Karies } \\
0\end{array}$} & \multicolumn{2}{|c|}{ Abrasion } & \multirow{2}{*}{$\begin{array}{c}\text { Neubildung } \\
0\end{array}$} & \multicolumn{2}{|c|}{ Schmelzhypoplasie } \\
\hline & & & & $\mathrm{K}$ & 1 & & $\mathrm{O}$ & 2 & & $U$ & 1 \\
\hline 27 & $\mathrm{v}$ & & & & & & & & & & \\
\hline 31 & v & & & & & & & & & & \\
\hline 32 & & 0 & 0 & $\mathrm{~K}$ & 3 & 0 & $\mathrm{O}$ & 1 & 0 & $U$ & 1 \\
\hline 33 & & 0 & 0 & $\mathrm{~K}$ & 2 & 0 & 0 & 2 & 0 & $U$ & 2 \\
\hline 34 & $\mathrm{v}$ & 0 & 0 & & & & & & & & \\
\hline 35 & v & 0 & 0 & & & & & & & & \\
\hline 36 & & 0 & 0 & $\mathrm{~K}$ & 2 & 0 & $\mathrm{O}$ & 4 & * & & 0 \\
\hline 37 & & 0 & 0 & $\mathrm{~K}$ & 2 & 0 & $\mathrm{O}$ & 3 & 0 & & 0 \\
\hline
\end{tabular}




\section{OK}

Population:

Calden

Geschlecht:

Alter:

$3-6,5$

\section{Beschreibung:}

\subsubsection{4 / 6}

Skelett: B1

Krankheiten:

\begin{tabular}{l|l|l} 
Arthrose & rechts & links \\
\hline Caput & & \\
\hline Fossa & &
\end{tabular}

\begin{tabular}{|c|c|c|c|c|c|c|c|c|}
\hline Zahn & Status & Parodontium & Apikale Prozesse & Zahnstein & Karies & Abrasion & Neubildung & Schmelzhypoplasie \\
\hline 26 & ( ) & & & & & & & \\
\hline 61 & v & & & & & & & \\
\hline 62 & $v$ & & & & & & & \\
\hline 63 & v & & & & & & & \\
\hline 64 & & 0 & 0 & $0 \quad 1$ & 0 & 0 & 0 & $u$ \\
\hline 65 & & 0 & 0 & O 1 & 0 & 0 & 0 & $U$ \\
\hline
\end{tabular}




\section{UK}

Population: Calden

Geschlecht: > männlich

Alter:

(22) 25 - 30 (34)

\subsubsection{4 / 3}

Skelett: A1

Krankheiten:

\section{2}

\begin{tabular}{c|l|l} 
Arthrose & rechts & links \\
\hline Caput & & \\
\hline Fossa & &
\end{tabular}

\section{Beschreibung:}

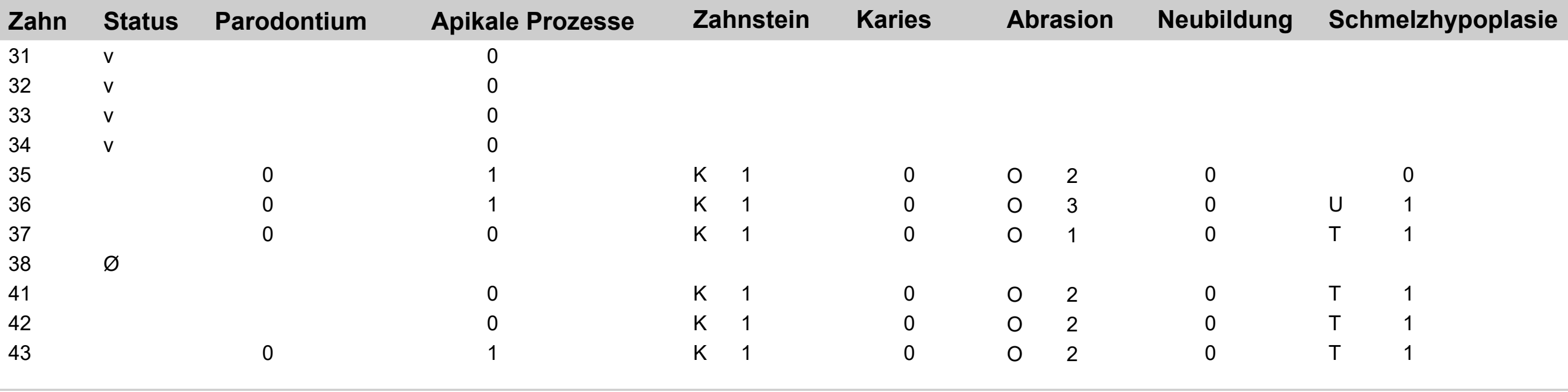




\begin{tabular}{|c|c|c|c|c|c|c|c|c|c|}
\hline 44 & 0 & & $\mathrm{~K}$ & 1 & 0 & 0 & 2 & 0 & \\
\hline 45 & 0 & & $\mathrm{~K}$ & 1 & 0 & 0 & 2 & 0 & \\
\hline 46 & 0 & 1 & $\mathrm{~K}$ & 1 & 0 & 0 & 3 & 0 & $U$ \\
\hline 47 & 0 & 0 & $\mathrm{~K}$ & 1 & 0 & 0 & 1 & 0 & $\mathrm{~T}$ \\
\hline
\end{tabular}




\section{OK; UK}

Population:

Calden

Geschlecht: männlich

Alter:

(6) $8,5-13(15)$

\subsubsection{4 / 5}

Skelett: B1

\section{2}

Krankheiten: Stomatitis

Sinusitis maxillaris

Beschreibung: Hierbei handelt es sich um einen gut erhaltenen Ober- und Unterkiefer, es fehlen lediglich einzelne Zähne. Die 8er sind auffällig groß und die Zähne 42 bis 47 weisen eine sigmoide Wurzelform auf. Der Gaumen zeigt Spuren einer Stomatitis und die Sinus eine bilaterale Sinusitis maxillaris.

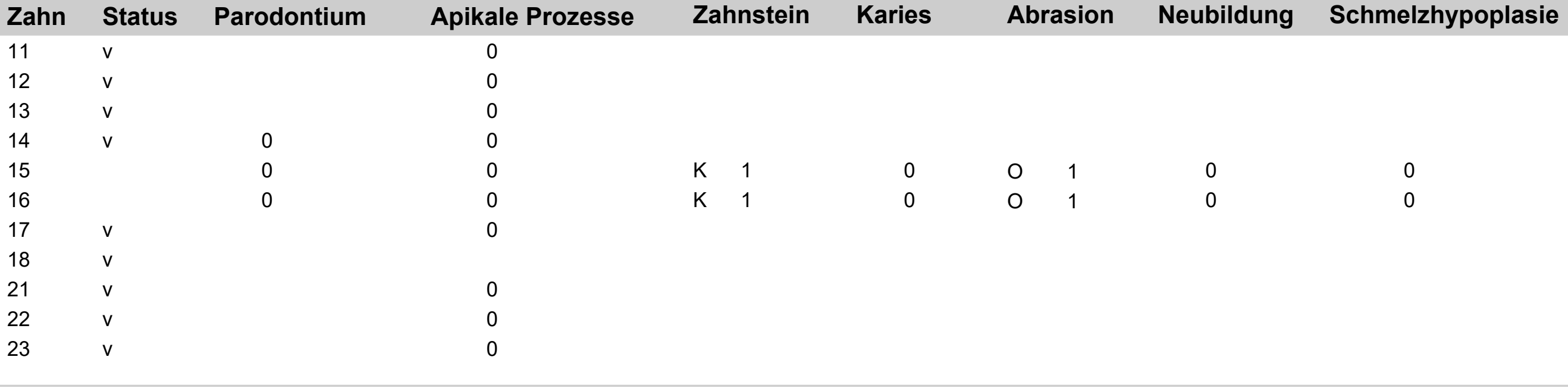




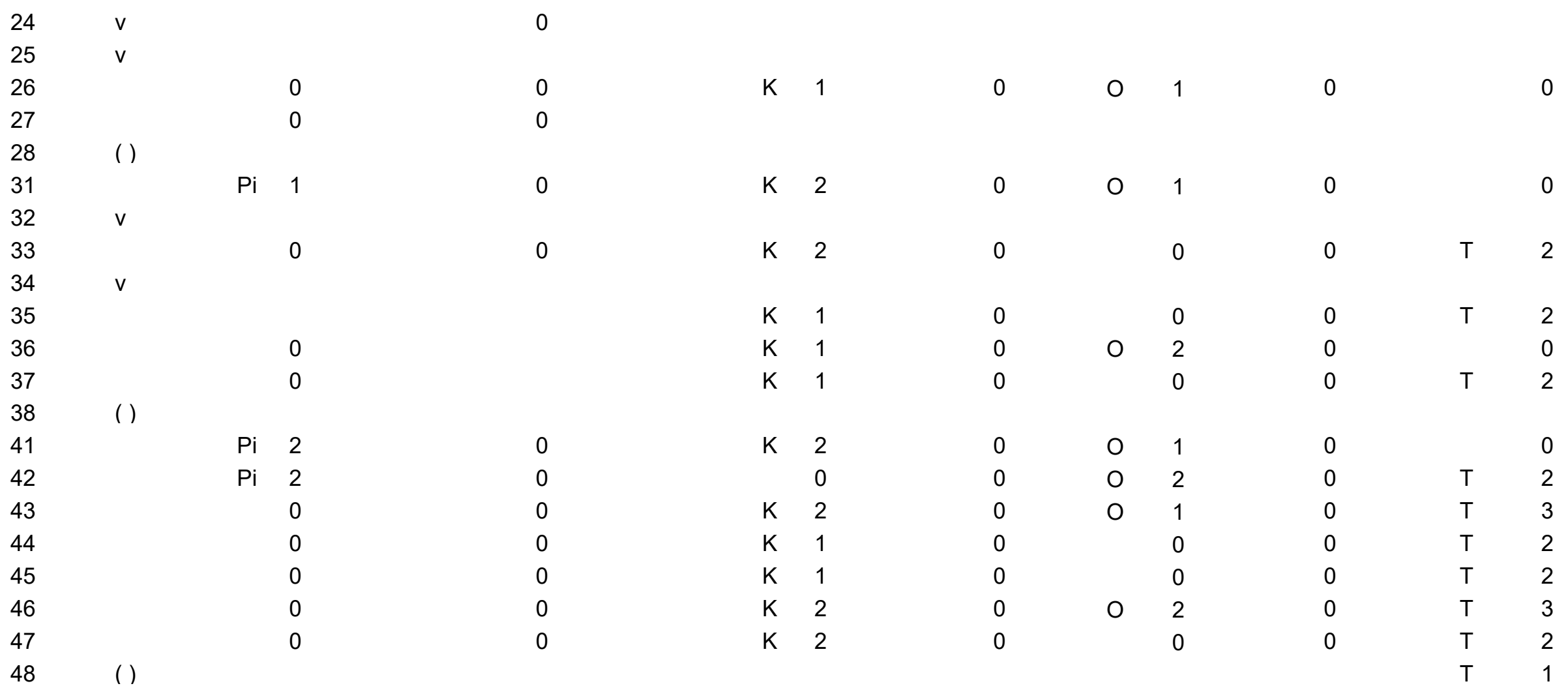




\section{UK}

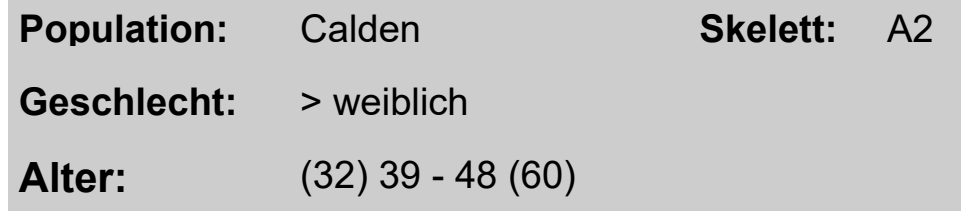

Beschreibung: Hier ist der linke Teil eines Unterkiefers erhalten. In regio 46 und 48 fallen Entzündungsspuren auf. Hier war ein apicaler Prozess im Gange und es ist nicht klar, ob die Zähne intravital noch in situ waren.

$\begin{array}{lllllllll}\text { Zahn } & \text { Status } & \text { Parodontium } & \text { Apikale Prozesse } & \text { Zahnstein } & \text { Karies } & \text { Abrasion } & \text { Neubildung } & \text { Schmelzhypoplasie } \\ 46 & \text { v } & \text { Po } 4 & \text { A } 3 & \text { K } 1 & \text { L } 1 & \text { O } & 5 & * \\ 47 & & \text { Po } 1 & & 0 & & & \end{array}$




\section{Zähne}

Population:

Calden

Geschlecht:

Alter:

(26) 28 - 35 (45)

\subsubsection{4 / 1}

Skelett: B3

\section{2}

Krankheiten:

\begin{tabular}{c|l|l} 
Arthrose & rechts & links \\
\hline Caput & & \\
\hline Fossa & &
\end{tabular}

Beschreibung: Hier sind nur zwei einzelne Zähne erhalten, bei 16 fällt eine zusätzliche Wurzel distal auf und bei 37 eine große Hyperzementose (4mm x $3,2 \mathrm{~mm}$ ). Auffällig ist weiterhin, dass der 7er eine stärkere Abrasion aufweist, als der 6er.

$\begin{array}{llcccccccc}\text { Zahn } & \text { Status } & \text { Parodontium } & \text { Apikale Prozesse } & \text { Zahnstein } & \text { Karies } & \text { Abrasion } & \text { Neubildung } & \text { Schmelzhypoplasie } \\ 16 & & 0 & \mathrm{~K} 1 & 0 & \mathrm{O} & 3 & 0 & \mathrm{U} & 1 \\ 37 & & 0 & \mathrm{~K} 1 & 0 & \mathrm{O} & 5 & \# & \mathrm{U} & 1\end{array}$




\section{OK}

Population:

Calden

Geschlecht:

Alter:

$9,5-12(13)$

\subsubsection{3 / 3}

Skelett: A5 P.SK.10

\section{2}

Krankheiten: Sinusitis maxillaris

\begin{tabular}{c|l|l} 
Arthrose & rechts & links \\
\hline Caput & & \\
\hline Fossa & &
\end{tabular}

Beschreibung: Dieses Fundstück eines Oberkiefers ist in der Wachstumsphase gewesen und weist ein Wechselgebiss auf. Di linke Kieferhöhle zeigt Spuren einer Sinusitis.

\begin{tabular}{|c|c|c|c|c|c|c|c|c|c|}
\hline Zahn & Status & Parodontium & Apikale Prozesse & Zahnstein & Karies & $\mathrm{Al}$ & ision & Neubildung & Schmelzhypoplasie \\
\hline 21 & $v$ & & & & & & & & \\
\hline 22 & $v$ & & & & & & & & \\
\hline 23 & $v$ & & & & & & & & \\
\hline 24 & $v$ & & & & & & & & \\
\hline 26 & & 0 & 0 & $\mathrm{~K}$ & 0 & $\mathrm{O}$ & 1 & 0 & $U$ \\
\hline 27 & II & 0 & 0 & $\mathrm{~K}$ & 0 & & & 0 & $U$ \\
\hline 44 & () & & & & & & & & \\
\hline 65 & & 0 & 0 & $\mathrm{~K}$ & 0 & $\mathrm{O}$ & 3 & 0 & $U$ \\
\hline
\end{tabular}




\section{UK}
Population: Calden
Geschlecht: > weiblich
Alter:
$17-25$

\subsubsection{4 / 2}

Skelett: A5 ohne genaue Lage Krankheiten:

\section{2}

\begin{tabular}{c|l|l} 
Arthrose & rechts & links \\
\hline Caput & & \\
\hline Fossa & &
\end{tabular}

Beschreibung: Dieser eher weibliche Unterkiefer fällt durch seine massive Knochenstruktur auf. Die Spina mentalis ist ungewöhnlich stark und massiv ausgebildet. Die protuberantia mentalis und die Form des Zahnbogens sind eher weiblich.

\begin{tabular}{|c|c|c|c|c|c|c|c|c|c|c|c|}
\hline \multirow{2}{*}{$\begin{array}{l}\text { Zahn } \\
31\end{array}$} & \multirow[t]{2}{*}{ Status } & Parodontium & \multirow{2}{*}{$\begin{array}{c}\text { Apikale Prozesse } \\
0\end{array}$} & \multicolumn{2}{|c|}{ Zahnstein } & \multirow{2}{*}{$\begin{array}{c}\text { Karies } \\
0\end{array}$} & \multicolumn{2}{|c|}{ Abrasion } & \multirow{2}{*}{$\begin{array}{c}\text { Neubildung } \\
0\end{array}$} & \multicolumn{2}{|c|}{ Schmelzhypoplasie } \\
\hline & & Po 1 & & $\mathrm{~K}$ & 1 & & $\mathrm{O}$ & 2 & & $U$ & 1 \\
\hline 32 & & Po 1 & 0 & $\mathrm{~K}$ & 1 & 0 & $\mathrm{O}$ & 2 & 0 & $U$ & 1 \\
\hline 33 & $v$ & Po 1 & 0 & & & & & & & & \\
\hline 34 & v & Po 1 & 0 & & & & & & & & \\
\hline 41 & & Po 1 & 0 & $\mathrm{~K}$ & 1 & 0 & $\mathrm{O}$ & 2 & 0 & $u$ & 1 \\
\hline 42 & & Po 1 & 0 & $\mathrm{~K}$ & 1 & 0 & $\mathrm{O}$ & 2 & 0 & $\mathrm{U}$ & 1 \\
\hline 43 & & Po 1 & 0 & $\mathrm{~K}$ & 2 & 0 & $\mathrm{O}$ & 2 & 0 & $\mathrm{~T}$ & 2 \\
\hline 44 & & Po 1 & 0 & $\mathrm{~K}$ & 2 & 0 & $\mathrm{O}$ & 2 & 0 & & \\
\hline 45 & & Po 1 & 0 & $\mathrm{~K}$ & 2 & 0 & $\mathrm{O}$ & 2 & 0 & & \\
\hline
\end{tabular}




\section{A4}

Population: Calden

Geschlecht: > weiblich

Alter:

(30) 37 - 45 (52)

Beschreibung: Ein sehr stark erodiertes Fundstück, es sind auch die vorhandenen Zähne erodiert.

\section{2}

Krankheiten:

\begin{tabular}{c|l|l} 
Arthrose & rechts & links \\
\hline Caput & & \\
\hline Fossa & &
\end{tabular}

\begin{tabular}{|c|c|c|c|c|c|c|c|c|}
\hline Zahn & Status & Parodontium & Apikale Prozesse & Zahnstein & Karies & Abrasion & Neubildung & Schmelzhypoplasie \\
\hline 31 & & & 0 & & & & & \\
\hline 32 & v & & 0 & & & & & \\
\hline 33 & & & 0 & & & & & \\
\hline 34 & & & 0 & & & & & \\
\hline 41 & & & 0 & & & & & \\
\hline 42 & $\mathrm{v}$ & & 0 & & & & & \\
\hline 43 & $\mathrm{v}$ & & 0 & & & & & \\
\hline 44 & v & & 0 & & & & & \\
\hline 45 & $\mathrm{v}$ & & 0 & & & & & \\
\hline 46 & v & & $A$ & & & & & \\
\hline 47 & & & 0 & $\begin{array}{ll}\mathrm{K} & 1\end{array}$ & 0 & $\mathrm{O}$ & * & 0 \\
\hline
\end{tabular}




\section{OK}

Population: Calden

Geschlecht: > weiblich

Alter:

(22) 25 - 30 (34)

\subsubsection{4 / 3}

Skelett: B4 Maxilla 2,1;2,6 Calden

\section{2}

Krankheiten:

\begin{tabular}{c|l|l} 
Arthrose & rechts & links \\
\hline Caput & & \\
\hline Fossa & &
\end{tabular}

\section{Beschreibung:}

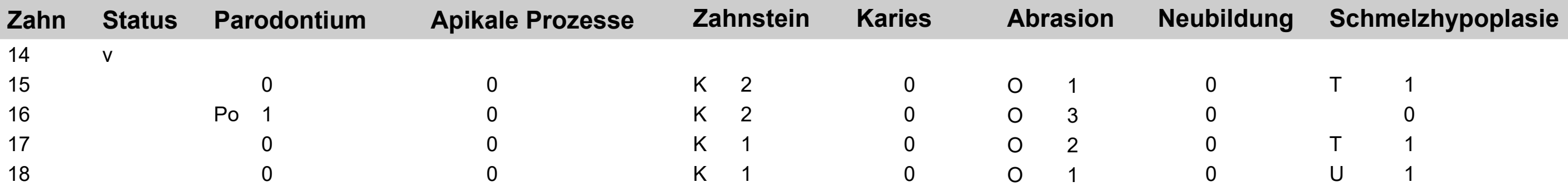




\section{OK}

Population:

Geschlecht: > männlich

Alter:

$35-45$

\subsubsection{4 / 6}

Skelett: A3 zu 6?
5274292

Krankheiten: Stomatitis

Sinusitis maxillaris

\begin{tabular}{c|l|l} 
Arthrose & rechts & links \\
\hline Caput & & \\
\hline Fossa & &
\end{tabular}

Beschreibung: Hier liegt ein Oberkieferfragment vor, welches eine Stomatitis und eine Sinusitis maxillaris (rechts) aufweist. Beide Krankheiten sind mit Grad 2 ausgeprägt.

\begin{tabular}{|c|c|c|c|c|c|c|c|c|c|}
\hline Zahn & Status & Parodontium & Apikale Prozesse & Zahnstein & Karies & $\mathbf{A b}$ & asion & Neubildung & Schmelzhypoplasie \\
\hline 11 & v & & A & & & & & & \\
\hline 12 & & $\begin{array}{ll}\mathrm{Pi} & 1\end{array}$ & 0 & $\mathrm{~K}$ & 0 & $\mathrm{O}$ & 4 & * & $\mathrm{T}$ \\
\hline 13 & & $\mathrm{Pi} \quad 1$ & 0 & $\mathrm{~K}$ & 0 & $\mathrm{O}$ & 4 & * & $\mathrm{T}$ \\
\hline 14 & & $\mathrm{Pi} \quad 1$ & 0 & $\mathrm{~K}$ & 0 & $\mathrm{O}$ & 4 & * & $U$ \\
\hline 15 & & $\mathrm{Pi} \quad 1$ & 0 & $\mathrm{~K}$ & 0 & 0 & 4 & * & $U$ \\
\hline
\end{tabular}




\section{UK}

Population: Calden

Geschlecht:

Alter: $\quad$ (3) $4-6(8)$

\subsubsection{4 / 4}

Skelett: B4 unter SK.8.

5274292

Krankheiten:

\begin{tabular}{c|l|l} 
Arthrose & rechts & links \\
\hline Caput & & \\
\hline Fossa & &
\end{tabular}

Beschreibung: Hier ist außer den Zähnen auch ein kleines linkes Unterkieferfragment erhalten. Es ist stark erodiert.

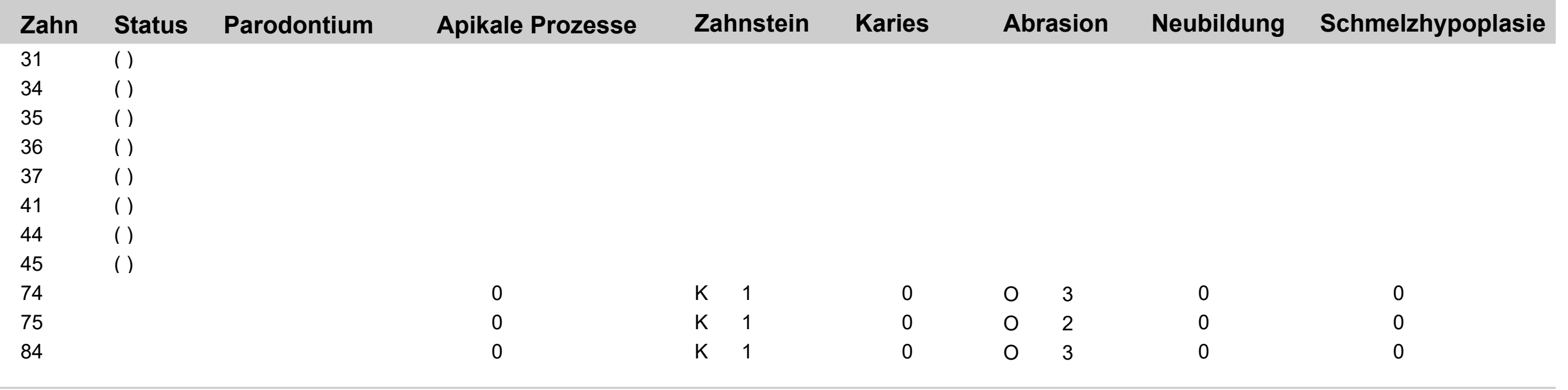




\section{UK}

Population: Calden

Geschlecht: > männlich

Alter:

\section{Beschreibung:}

\subsubsection{4 / 2}

Skelett: B4 Ersatzteile

Krankheiten:
5274292

\begin{tabular}{c|l|l} 
Arthrose & rechts & links \\
\hline Caput & & \\
\hline Fossa & &
\end{tabular}

\begin{tabular}{|c|c|c|c|c|c|c|c|c|}
\hline Zahn & Status & Parodontium & Apikale Prozesse & Zahnstein & Karies & Abrasion & Neubildung & Schmelzhypoplasie \\
\hline 41 & $\mathrm{v}$ & & & & & & & \\
\hline 42 & $\mathrm{v}$ & & & & & & & \\
\hline 43 & $\mathrm{v}$ & & & & & & & \\
\hline 44 & $E$ & & & & & & & \\
\hline 45 & $\mathrm{E}$ & & & & & & & \\
\hline 46 & (f) & $\mathrm{Pi} \quad 3$ & G & & & & & \\
\hline 47 & (f) & $\mathrm{Pi} \quad 5$ & G & & & & & \\
\hline
\end{tabular}




\section{Zähne}

Population:

Calden

Geschlecht:

Alter:

(6) 6,5 - 7,5 (8)

\section{Beschreibung:}

\subsubsection{2/ 111}

Skelett: Skelett 10

Krankheiten:

\begin{tabular}{c|l|l} 
Arthrose & rechts & links \\
\hline Caput & & \\
\hline Fossa & &
\end{tabular}

5259276

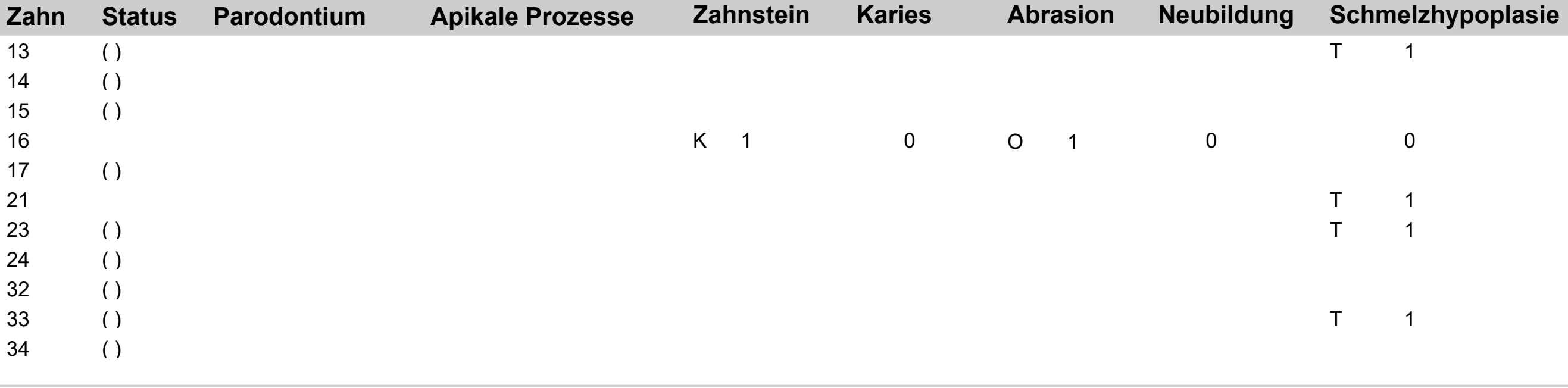


$35 \quad()$

$43 \quad()$

$44 \quad()$

$45 \quad($ )

55

K 1

$\begin{array}{llll}0 & 0 & 4 & * \\ 0 & 0 & 4 & *\end{array}$

0

85

K 1

0 


\section{UK}

Population: Calden

Geschlecht: männlich

Alter:

(32) 37 - $45(50)$

Beschreibung: Hier liegt ein Fragment eines massiven Unterkiefers vor.

\subsubsection{4 / 7}

Skelett: A3 Skel.1

Krankheiten:
5274292

\begin{tabular}{c|l|l} 
Arthrose & rechts & links \\
\hline Caput & & \\
\hline Fossa & &
\end{tabular}

\begin{tabular}{|c|c|c|c|c|c|c|c|c|}
\hline Zahn & Status & Parodontium & Apikale Prozesse & Zahnstein & Karies & Abrasion & Neubildung & Schmelzhypoplasie \\
\hline 43 & v & & & & & & & \\
\hline 44 & & & 0 & $\mathrm{~K}$ & 0 & 0 & * & 0 \\
\hline 45 & & $\begin{array}{ll}\mathrm{Pi} & 1\end{array}$ & 0 & $\mathrm{~K}$ & 0 & 0 & * & 0 \\
\hline 46 & & $\mathrm{Pi} \quad 1$ & 0 & K & 0 & 0 & * & 1 \\
\hline 47 & & $\begin{array}{ll}\mathrm{Pi} & 1\end{array}$ & 0 & $\mathrm{~K}$ & 0 & 0 & * & 0 \\
\hline 48 & (f) & $\mathrm{Pi} \quad 1$ & 0 & & & & & \\
\hline
\end{tabular}




\section{Zähne}

Population:

Calden

Geschlecht:

Alter:

(23) 27 - 32 (36)

\subsubsection{4 / 1}

Skelett: Einzelne Zähne

\section{$292 ?$}

Krankheiten:

\begin{tabular}{c|l|l} 
Arthrose & rechts & links \\
\hline Caput & & \\
\hline Fossa & &
\end{tabular}

Beschreibung: Dies sind zwei einzeln erhaltene Zähne. Der 16 weist eine kleine zusätzliche Wurzel (6mm) auf. Der 37 hat eine Hyperzementose (4mm x $3,2 \mathrm{~mm})$. Auffällig ist weiterhin, dass der 7er eine stärkere Abrasion aufweist, als der 6er.

\begin{tabular}{|c|c|c|c|c|c|c|c|c|}
\hline Zahn & Status & Parodontium & Apikale Prozesse & Zahnstein & Karies & Abrasion & Neubildung & Schmelzhypoplasie \\
\hline 16 & & & 0 & K 1 & 0 & $\mathrm{O}$ & 0 & $U$ \\
\hline 37 & & & 0 & $\begin{array}{ll}\mathrm{K} & 1\end{array}$ & 0 & $\mathrm{O}$ & $\#$ & $U$ \\
\hline
\end{tabular}




\section{OK; UK}

Population:

Calden

Geschlecht: weiblich

Alter:

(12) 14 - 17 (22)

\subsubsection{4 / 1}

Skelett: Cranium 38

5272290

Beschreibung: Bei diesen Fundstücken handelt es sich um einen sehr gut erhaltenen Ober- und einen sehr gut erhaltenen Unterkiefer. Die Zähne sind perfekt im Zahnkranz angeordnet. Der Oberkiefer weist eine leichte Stomatitis und eine leichte Sinusitis maxillaris auf.

\begin{tabular}{|c|c|c|c|c|c|c|c|c|c|}
\hline Zahn & Status & Parodontium & Apikale Prozesse & Zahnstein & Karies & $\mathbf{A b}$ & Ision & Neubildung & Schmelzhypoplasie \\
\hline 11 & & $\mathrm{Pi} \quad 1$ & 0 & K 1 & 0 & 0 & 2 & 0 & $\mathrm{~T}$ \\
\hline 12 & & $\mathrm{Pi} 1$ & 0 & $\begin{array}{ll}\text { K } & 1\end{array}$ & 0 & 0 & 2 & 0 & $\mathrm{~T}$ \\
\hline 13 & & $\mathrm{Pi} \quad 1$ & 0 & K 1 & 0 & 0 & 2 & 0 & $\mathrm{~T}$ \\
\hline 14 & & $\mathrm{Pi} \quad 1$ & 0 & K 1 & 0 & 0 & 2 & 0 & $\mathrm{~T}$ \\
\hline 15 & & 0 & 0 & K 1 & 0 & 0 & 1 & 0 & $\mathrm{~T}$ \\
\hline 16 & & 0 & 0 & $\mathrm{~K}$ & 0 & 0 & 2 & 0 & $\mathrm{~T}$ \\
\hline 17 & & 0 & 0 & $\mathrm{~K}$ & 0 & 0 & 1 & 0 & $\mathrm{~T}$ \\
\hline 18 & $\varnothing$ & & & & & & & & \\
\hline 21 & & $\mathrm{Pi} \quad 1$ & 0 & K 1 & 0 & 0 & 2 & 0 & $\mathrm{~T}$ \\
\hline 22 & & $\mathrm{Pi} \quad 1$ & 0 & $\begin{array}{ll}\text { K } & 1\end{array}$ & 0 & 0 & 2 & 0 & $\mathrm{~T}$ \\
\hline 23 & & $\mathrm{Pi} \quad 1$ & 0 & $\begin{array}{ll}\text { K } & 1\end{array}$ & 0 & 0 & 2 & 0 & $\mathrm{~T}$ \\
\hline
\end{tabular}




$\begin{array}{ll}24 & \\ 25 & \\ 26 & \\ 27 & \\ 28 & \varnothing \\ 31 & \\ 32 & \\ 33 & \\ 34 & \\ 35 & \\ 36 & \\ 37 & \\ 38 & \\ 41 & \\ 42 & \\ 43 & \\ 44 & \\ 45 & \\ 46 & \\ 47 & \\ 48 & \end{array}$

$\begin{array}{rl}\mathrm{Pi} & 1 \\ 0 \\ 0 \\ 0\end{array}$

K 1

K 1

K 2

$\begin{array}{ll}\mathrm{K} & 1 \\ \mathrm{~K} & 2\end{array}$

$\begin{array}{ll}\mathrm{K} & 1\end{array}$

K 1

K 1

$\begin{array}{ll}\mathrm{K} & 2 \\ \mathrm{~K} & 2\end{array}$

$\begin{array}{ll}\mathrm{K} & 2 \\ \mathrm{~K} & 1\end{array}$

$\begin{array}{ll}\mathrm{K} & 1 \\ \mathrm{~K} & 1\end{array}$

K 1

$\begin{array}{ll}\mathrm{K} & 1 \\ \mathrm{~K} & 1\end{array}$

$\varnothing$ 
Ok

Population: Calden

Geschlecht:

Alter:

(28) 36 - 45 (50)
16.10.2014 / 1

Skelett: Cranium 29

5272290

Beschreibung: Hier ist nur ein Zahn im Kiefer erhalten, der in einem frakturierten und erodierten Kieferfragment vorliegt.

\begin{tabular}{|c|c|c|c|c|c|c|c|c|}
\hline Zahn & Status & Parodontium & Apikale Prozesse & Zahnstein & Karies & Abrasion & Neubildung & Schmelzhypoplasie \\
\hline 11 & $f$ & $\mathrm{Pi}$ & & & & & & \\
\hline 12 & $f$ & & & & & & & \\
\hline 13 & $f$ & & & & & & & \\
\hline 14 & $f$ & & & & & & & \\
\hline 21 & $f$ & & & & & & & \\
\hline 22 & $f$ & & & & & & & \\
\hline 23 & $f$ & & & & & & & \\
\hline 24 & $f$ & & & & & & & \\
\hline 25 & $f$ & & & & & & & \\
\hline 26 & (f) & & & & & & & \\
\hline 27 & & Po 3 & 0 & $\begin{array}{ll}\mathrm{K} & 1\end{array}$ & M 2 & $\mathrm{O}$ & * & 0 \\
\hline
\end{tabular}




\section{Ok}

$\begin{array}{lll}\text { Population: } & \text { Calden } & \text { Skelett: Cranium } 34 \\ \text { Geschlecht: weiblich } & \end{array}$

\subsubsection{4/1}

\section{0}

Krankheiten: Sinusitis maxillaris Stomatitis Arthrose

\begin{tabular}{c|c|c} 
Arthrose & rechts & links \\
\hline Caput & & \\
\hline Fossa & 3 & 3
\end{tabular}

Beschreibung: Bei diesem Fundstück handelt es sich um einen weiblichen Oberkiefer, der im Sinus maxillaris sehr deutliche Zeichen einer Sinusitis maxillaris zeigt. Weiterhin fällt eine leichte Stomatitis ins Auge. Es ist nicht ganz geklärt, dass es sich um einen rein intravitalen Prozess handelt. Möglich ist, dass hier eine Sinusitis maxillaris vorlag und zusätzlich Erosionen für diese starken Spuren gesorgt haben.

\begin{tabular}{|c|c|c|c|c|c|c|c|c|c|}
\hline Zahn & Status & Parodontium & Apikale Prozesse & Zahnstein & Karies & Abr & sion & Neubildung & Schmelzhypoplasie \\
\hline 11 & $\mathrm{v}$ & $\begin{array}{ll}\mathrm{Pi} & 1\end{array}$ & 0 & K 1 & 0 & & & & \\
\hline 12 & $\mathrm{v}$ & $\begin{array}{ll}\mathrm{Pi} & 1\end{array}$ & 0 & $\begin{array}{ll}\text { K } & 1\end{array}$ & 0 & & & & \\
\hline 13 & & $\mathrm{Pi} \quad 2$ & 0 & K 1 & 0 & $\mathrm{O}$ & 2 & 0 & 0 \\
\hline 14 & & $\mathrm{Pi} \quad 2$ & 0 & K 1 & 0 & $\mathrm{O}$ & 2 & 0 & 0 \\
\hline 15 & & $\mathrm{Pi} \quad 1$ & 0 & $\begin{array}{ll}\mathrm{K} & 1\end{array}$ & 0 & $\mathrm{O}$ & 2 & 0 & 0 \\
\hline 16 & & Po 1 & 0 & $\begin{array}{ll}K & 1\end{array}$ & 0 & $\mathrm{O}$ & 3 & 0 & 0 \\
\hline 17 & & Po 1 & 0 & K 1 & 0 & 0 & 2 & 0 & 0 \\
\hline 18 & & 0 & 0 & $\begin{array}{ll}\mathrm{K} & 1\end{array}$ & 0 & $\mathrm{O}$ & 1 & 0 & 0 \\
\hline 21 & $v$ & Pi 1 & 0 & & & & & & \\
\hline 22 & $\mathrm{v}$ & $\begin{array}{ll}\mathrm{Pi} & 1\end{array}$ & 0 & & & & & & \\
\hline 23 & $\mathrm{v}$ & $\mathrm{Pi} \quad 1$ & 0 & & & & & & \\
\hline
\end{tabular}




0

$\begin{array}{ll}0 & 0 \\ 0 & 0\end{array}$




\section{Ok}

\section{Population: Calden}

Geschlecht: männlich

Alter: $\quad(22) 25-30(34)$

\subsubsection{4 / 1}

Skelett: 33 Cranium 33

5272290

Krankheiten: Sinusitis maxillaris Stomatitis

\begin{tabular}{c|c|c} 
Arthrose & rechts & links \\
\hline Caput & & \\
\hline Fossa & 2 & 2
\end{tabular}

Beschreibung: Dieser Oberkiefer ist in recht gutem Erhaltungszustand, wobei wenige Fragmente durch Erosion und Ausgrabung verloren gegangen sind. Hier ist eine Anomalie zu verzeichnen, und zwar fehlen hier die beiden Oberkiefer 2er wegen Nichtanlage. Die 3er sind jeweils in die Lücken hinein gewandert.

Die Sinus maxillares weisen deutliche Entzündungsspuren auf. Die Entzündung ist wohl schon im Kindesalter chronisch gewesen, da dadurch das Wachstum der Kieferhöhle behindert wurde was zu der typischen Einziehung über dem Alveolarkamm in regio 13 und 23 und Prämolaren geführt hat. Die Fossa mandibularis ist sehr massiv ausgeprägt und die Zähne 23 und 24 sind gedreht.

\begin{tabular}{|c|c|c|c|c|c|c|c|c|c|c|c|}
\hline Zahn & Status & Par & rodontium & Apikale Prozesse & $\mathrm{Za}$ & instein & Karies & & sion & Neubildung & Schmelzhypoplasie \\
\hline 11 & $\mathrm{v}$ & & & 0 & & & & & & & \\
\hline 12 & $\varnothing$ & & & & & & & & & & \\
\hline 13 & $\mathrm{v}$ & & 0 & 0 & & & & & & & \\
\hline 14 & $\mathrm{v}$ & Po & 1 & & & & & & & & \\
\hline 15 & & Po & 1 & 0 & K & 1 & 0 & $\mathrm{O}$ & 1 & 0 & 0 \\
\hline 16 & & Po & 1 & 0 & K & 1 & 0 & 0 & 3 & 0 & 0 \\
\hline 21 & $v$ & & & & & & & & & & \\
\hline 22 & $\varnothing$ & & & & & & & & & & \\
\hline 23 & & & 0 & 0 & K & 1 & 0 & O & 2 & 0 & 1 \\
\hline 24 & & Po & 1 & 0 & $\mathrm{~K}$ & 1 & 0 & $\mathrm{O}$ & 2 & 0 & $\mathrm{~T}$ \\
\hline 25 & & Po & 1 & 0 & $\mathrm{~K}$ & 1 & 0 & $\mathrm{O}$ & 2 & 0 & 0 \\
\hline
\end{tabular}




\section{UK}

Population: Calden

Geschlecht: männlich

Alter:

(22) 25 - 30 (34)

Beschreibung: Dieser Unterkiefer ist gut erhalten.

\section{1}

Skelett: Calden $7 \mathrm{zw}$. Becken 8 Krankheiten: u Schä 33

\begin{tabular}{c|c|c} 
Arthrose & rechts & links \\
\hline Caput & 2 & 2 \\
\hline Fossa & &
\end{tabular}

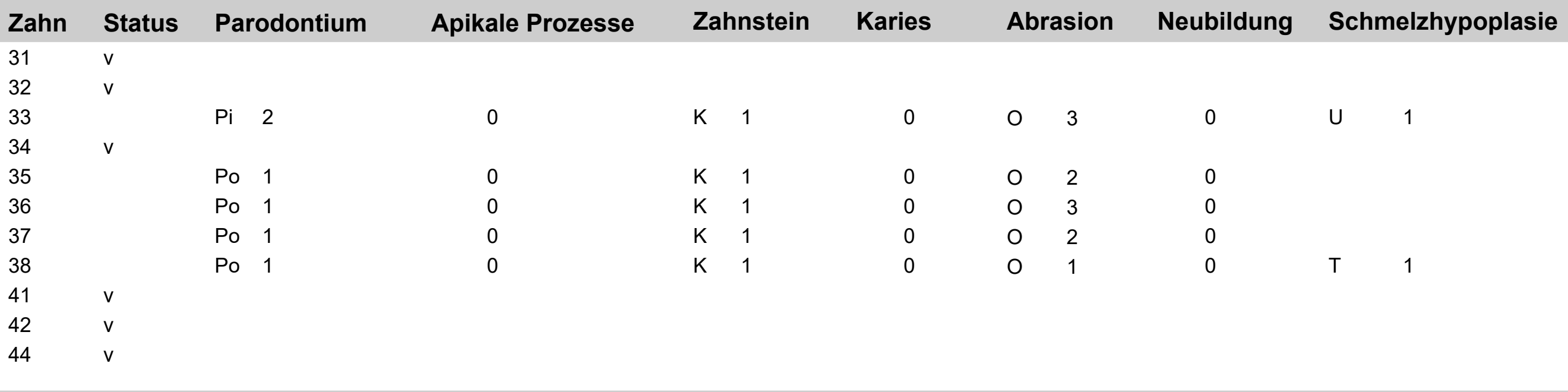




0
0
0
0




\section{UK}

Population: Calden

Geschlecht: > weiblich

Alter:

$(8,5) 10-11(13,5)$

Beschreibung: Hier ist nur die linke Seite des Unterkiefers erhalten.

\subsubsection{4 / 1}

Skelett: Calden 143,$5 ; 4,25$

Krankheiten:

\section{1}

\begin{tabular}{c|c|c} 
Arthrose & rechts & links \\
\hline Caput & & 00 \\
\hline Fossa & &
\end{tabular}

\begin{tabular}{|c|c|c|c|c|c|c|c|c|}
\hline Zahn & Status & Parodontium & Apikale Prozesse & Zahnstein & Karies & Abrasion & Neubildung & Schmelzhypoplasie \\
\hline 35 & ( ) & & & & & & & \\
\hline 36 & & 0 & & $\mathrm{~K}$ & 0 & $\mathrm{O}$ & 0 & $\mathrm{~T}$ \\
\hline 37 & 11 & & & & & & & $\mathrm{~T}$ \\
\hline
\end{tabular}




\section{UK}

Population: Calden

Geschlecht: > weiblich

Alter:

(15) 18 - 21

\subsubsection{4 / 1}

Skelett: $\quad 5273-4242,85 ; 4,3$

Krankheiten:

\section{1}

\begin{tabular}{c|l|l} 
Arthrose & rechts & links \\
\hline Caput & & \\
\hline Fossa & &
\end{tabular}

\section{Beschreibung:}

\begin{tabular}{|c|c|c|c|c|c|c|c|c|c|c|}
\hline \multirow{2}{*}{$\begin{array}{l}\text { Zahn } \\
43\end{array}$} & \multirow[t]{2}{*}{ Status } & \multirow[t]{2}{*}{ Parodontium } & \multirow{2}{*}{$\begin{array}{c}\text { Apikale Prozesse } \\
0\end{array}$} & \multicolumn{2}{|c|}{ Zahnstein } & \multirow[t]{2}{*}{ Karies } & Abrasion & \multirow[t]{2}{*}{ Neubildung } & \multicolumn{2}{|c|}{ Schmelzhypoplasie } \\
\hline & & & & $\mathrm{K}$ & 1 & & & & $\mathrm{~T}$ & 1 \\
\hline 44 & v & & 0 & & & & & & & \\
\hline 45 & $\mathrm{v}$ & 0 & 0 & & & & & & & \\
\hline 46 & & 0 & 0 & $\mathrm{~K}$ & 1 & 0 & $\mathrm{O}$ & & $\mathrm{T}$ & 1 \\
\hline 47 & & 0 & 0 & $\mathrm{~K}$ & 1 & 0 & $\mathrm{O}$ & & $\mathrm{T}$ & 1 \\
\hline 48 & $\|$ & & & $\mathrm{K}$ & 1 & 0 & & & & \\
\hline
\end{tabular}




\section{OK}

\section{Population: Calden}

Geschlecht:
Alter:
(22) 25 - 30 (34)

\subsubsection{4 / 1}

Skelett: Calden 24 5273-4

\section{3}

Krankheiten: Stomatitis

Sinusitis maxillaris

\begin{tabular}{c|l|l} 
Arthrose & rechts & links \\
\hline Caput & & \\
\hline Fossa & &
\end{tabular}

Beschreibung: Bei diesem Fundstück handelt es sich um einen recht gut erhaltenen, aber unvollständigen Oberkiefer. Es fällt eine kleine Verknöcherung am foramen infraorbitale auf. Weiterhin weist der Oberkiefer eine Sinusitis maxillaris und eine Stomatitis auf.

\begin{tabular}{|c|c|c|c|c|c|c|c|c|c|c|c|c|}
\hline Zahn & Status & Par & odontium & Apikale Prozesse & $\mathrm{Za}$ & Instein & Karies & & Ision & Neubildung & & ielzhypoplasie \\
\hline 11 & v & $\mathrm{Pi}$ & 1 & 0 & & & & & & & & \\
\hline 12 & (f) & $\mathrm{Pi}$ & 1 & & & & & & & & & \\
\hline 13 & & & & 0 & & & & & & & & \\
\hline 16 & & & 0 & 0 & $\mathrm{~K}$ & 1 & 0 & $\mathrm{O}$ & 3 & 0 & $U$ & 1 \\
\hline 17 & & & 0 & 0 & $\mathrm{~K}$ & 1 & 0 & 0 & 1 & 0 & $U$ & 1 \\
\hline 21 & v & $\mathrm{Pi}$ & 1 & 0 & & & & & & & & \\
\hline 22 & $f$ & & & & & & & & & & & \\
\hline 23 & & $\mathrm{Pi}$ & 1 & 0 & & & & & & & & \\
\hline 24 & $f$ & & & & & & & & & & & \\
\hline 25 & $f$ & & & & & & & & & & & \\
\hline 26 & & Po & 1 & 0 & $\mathrm{~K}$ & 1 & 0 & 0 & 3 & 0 & $U$ & 1 \\
\hline
\end{tabular}




\section{Zähne}

Population:

Calden

Geschlecht:

Alter:

(25) 28 - 35 (38)

\section{Beschreibung:}

\subsubsection{4 / 1}

Skelett: $5273-4$

Krankheiten:

\begin{tabular}{c|l|l} 
Arthrose & rechts & links \\
\hline Caput & & \\
\hline Fossa & &
\end{tabular}

\begin{tabular}{|c|c|c|c|c|c|c|c|c|}
\hline Zahn & Status & Parodontium & Apikale Prozesse & Zahnstein & Karies & Abrasion & Neubildung & Schmelzhypoplasie \\
\hline 34 & & & 0 & $\mathrm{~K}$ & & $\mathrm{O}$ & * & 1 \\
\hline 36 & & & $G$ & $\mathrm{~K}$ & $D$ & $\mathrm{O}$ & * & 0 \\
\hline
\end{tabular}




\section{Zahn}

Population: Calden

Geschlecht:

Alter:

\section{Beschreibung:}

\subsubsection{4 / 1}

Skelett: $\quad 5273-17$

Krankheiten:
5273291

\begin{tabular}{c|l|l} 
Arthrose & rechts & links \\
\hline Caput & & \\
\hline Fossa & &
\end{tabular}

\section{Zahn Status Parodontium Apikale Prozesse}

Zahnstein

K 1
Karies

0
Abrasion

O 5 


\section{UK}

\section{Population: Calden}

Geschlecht: männlich

Alter:

(25) $28-35(38)$

\subsubsection{4 / 1}

Skelett: Calden 2121 Sch.8 $5271 \mathrm{~b}$

\section{8}

Krankheiten: Parodontitis

\begin{tabular}{c|c|c} 
Arthrose & rechts & links \\
\hline Caput & & 2 \\
\hline Fossa & &
\end{tabular}

Beschreibung: Dies ist ein sehr massiver Unterkiefer, dessen Gebiss in physiologischer Anordnung und gut erhalten ist. Die Muskelmarken der m. pterygoidei und masseterici sind gut ausgeprägt. Weiterhin weist der Unterkiefer eine leichte Parodontitis auf.

\begin{tabular}{|c|c|c|c|c|c|c|c|c|c|c|}
\hline Zahn & Status & Parodontium & Apikale Prozesse & $\mathrm{Za}$ & instein & Karies & $\mathrm{Ab}$ & sion & Neubildung & Schmelzhypoplasie \\
\hline 31 & $\mathrm{v}$ & $\mathrm{Pi} \quad 1$ & 0 & & & & & & & \\
\hline 32 & v & $\begin{array}{ll}\mathrm{Pi} & 1\end{array}$ & 0 & & & & & & & \\
\hline 33 & & $\mathrm{Pi} \quad 1$ & 0 & $\mathrm{~K}$ & 1 & 0 & $\mathrm{O}$ & 3 & 0 & $\mathrm{~T}$ \\
\hline 34 & & $\mathrm{Pi} \quad 1$ & 0 & $\mathrm{~K}$ & 1 & 0 & 0 & 3 & 0 & 0 \\
\hline 35 & & $\mathrm{Pi} \quad 1$ & 0 & K & 1 & 0 & $\mathrm{O}$ & 3 & 0 & 0 \\
\hline 36 & & $\mathrm{Pi} \quad 1$ & 0 & K & 1 & 0 & 0 & 4 & * & 0 \\
\hline 37 & & $\mathrm{Pi} \quad 1$ & 0 & K & 1 & 0 & $\mathrm{O}$ & 2 & 0 & 0 \\
\hline 38 & & $\mathrm{Pi} \quad 1$ & 0 & K & 1 & 0 & 0 & 1 & 0 & 1 \\
\hline 41 & $\mathrm{v}$ & $\begin{array}{ll}\mathrm{Pi} & 1\end{array}$ & 0 & & & & & & & \\
\hline 42 & v & $\begin{array}{ll}\mathrm{Pi} & 1\end{array}$ & 0 & & & & & & & \\
\hline 43 & & $\begin{array}{ll}\mathrm{Pi} & 1\end{array}$ & 0 & $\mathrm{~K}$ & 1 & 0 & 0 & 3 & 0 & $\mathrm{~T}$ \\
\hline
\end{tabular}




$\begin{array}{llll}44 & \mathrm{v} & \mathrm{Pi} & 1 \\ 45 & \mathrm{v} & \mathrm{Pi} & 1 \\ 46 & \mathrm{v} & \mathrm{Pi} & 1 \\ 47 & & \mathrm{Pi} & 1 \\ 48 & & \mathrm{Pi} & 1\end{array}$

0
0
0
0
0

$$
\begin{array}{ll}
\text { K } & 1 \\
\text { K } & 1 \\
\text { K } & 1
\end{array}
$$

$\begin{array}{lll}0 & 0 & 4 \\ 0 & 0 & 3 \\ 0 & 0 & 2\end{array}$

0

$\begin{array}{r}0 \\ 0 \\ \mathrm{~T} \\ \hline\end{array}$




\section{OK; UK}

Population:

Geschlecht:

Calden

Alter:

(25) 28 - 35 (38)

\subsubsection{4 / 2}

Skelett: Calden 20

\section{8}

Krankheiten: Sinusitis maxillaris

Stomatitis

Arthrose

\begin{tabular}{c|c|c} 
Arthrose & rechts & links \\
\hline Caput & & 2 \\
\hline Fossa & 3 & 2
\end{tabular}

Beschreibung: Diese Fundstücke sind ein recht gut erhaltener Ober- und Unterkiefer. Beim Oberkiefer fällt eine Anomalie auf: der 23 ist vollretiniert im Oberkiefer und liegt in dichter Nähe zum Nasengang, die hier noch zwischen Wurzel und Schleimhaut der Nase trennende Knochenlamelle ist nur wenige Zehntel Millimeter dick gewesen. Sie ist postmortal zum Teil durch Erosion zerstört worden. Die Zähne stehen sonst in physiologisch angeordneten Zahnkranz und weisen keine Auffälligkeiten bezüglich ihrer Stellung oder ihres Abrasions- und Attritionsmusters auf, was bedeutet, dass das Fehlen des 3ers keine sichtbaren funktionellen Auswirkungen hatte. Es fallen noch Wurzelreste des 65 und 75 auf, die noch im Kiefersaum verblieben waren. Die Ansatzstellen des m. masseter sind deutlich ausgeprägt.

\begin{tabular}{|c|c|c|c|c|c|c|c|c|c|c|c|}
\hline \multirow{2}{*}{$\begin{array}{l}\text { Zahn } \\
11\end{array}$} & \multirow{2}{*}{$\begin{array}{l}\text { Status } \\
\mathrm{v}\end{array}$} & Parodontium & \multirow{2}{*}{$\begin{array}{c}\text { Apikale Prozesse } \\
0\end{array}$} & \multicolumn{2}{|c|}{ Zahnstein } & \multirow[t]{2}{*}{ Karies } & \multicolumn{2}{|c|}{ Abrasion } & \multirow[t]{2}{*}{ Neubildung } & \multicolumn{2}{|c|}{ Schmelzhypoplasie } \\
\hline & & $\begin{array}{ll}\mathrm{Pi} & 1\end{array}$ & & & & & & & & & \\
\hline 12 & & $\mathrm{Pi} \quad 1$ & 0 & $\mathrm{~K}$ & 1 & 0 & $\mathrm{O}$ & 5 & * & $U$ & 1 \\
\hline 13 & $v$ & $\begin{array}{ll}\mathrm{Pi} & 1\end{array}$ & 0 & & & & & & & & \\
\hline 14 & & $\mathrm{Pi} \quad 1$ & 0 & $\mathrm{~K}$ & 1 & 0 & $\mathrm{O}$ & 5 & * & & 0 \\
\hline 15 & & $\begin{array}{ll}\mathrm{Pi} & 1\end{array}$ & 0 & K & 1 & 0 & $\mathrm{O}$ & 4 & * & & 0 \\
\hline 16 & & $\mathrm{Pi} 1$ & 0 & $\mathrm{~K}$ & 1 & 0 & $\mathrm{O}$ & 4 & * & & 0 \\
\hline 17 & & $\mathrm{Pi} \quad 1$ & 0 & $\mathrm{~K}$ & 1 & 0 & $\mathrm{O}$ & 3 & 0 & $U$ & 1 \\
\hline 18 & & $\mathrm{Pi} \quad 1$ & 0 & $\mathrm{~K}$ & 1 & 0 & $\mathrm{O}$ & 2 & 0 & $U$ & 1 \\
\hline 21 & $\mathrm{v}$ & $\begin{array}{ll}\mathrm{Pi} & 1\end{array}$ & 0 & & & & & & & & \\
\hline 22 & $\mathrm{v}$ & $\begin{array}{ll}\mathrm{Pi} & 1\end{array}$ & 0 & & & & & & & & \\
\hline 23 & ( ) & $\begin{array}{ll}\mathrm{Pi} & 1\end{array}$ & 0 & & & & & & & & \\
\hline
\end{tabular}




\begin{tabular}{|c|c|c|c|c|c|c|c|c|c|c|c|}
\hline 24 & & $\mathrm{Pi}$ & 1 & 0 & $\mathrm{~K}$ & 1 & 0 & 0 & 4 & * & $U$ \\
\hline 25 & & $\mathrm{Pi}$ & 1 & 0 & $\mathrm{~K}$ & 1 & 0 & 0 & 4 & * & \\
\hline 26 & & $\mathrm{Pi}$ & 1 & 0 & $\mathrm{~K}$ & 1 & 0 & 0 & 4 & * & \\
\hline 27 & & $\mathrm{Pi}$ & 1 & 0 & $\mathrm{~K}$ & 1 & 0 & 0 & 3 & & $U$ \\
\hline 28 & & $\mathrm{Pi}$ & 1 & 0 & $\mathrm{~K}$ & 1 & 0 & 0 & 3 & & $U$ \\
\hline 31 & & $\mathrm{Pi}$ & 1 & 0 & $\mathrm{~K}$ & 1 & 0 & 0 & 3 & & \\
\hline 32 & & $\mathrm{Pi}$ & 1 & 0 & $\mathrm{~K}$ & 1 & 0 & 0 & 3 & & \\
\hline 33 & & $\mathrm{Pi}$ & 1 & 0 & $\mathrm{~K}$ & 1 & 0 & O & 3 & & \\
\hline 34 & & $\mathrm{Pi}$ & 1 & 0 & $\mathrm{~K}$ & 1 & 0 & 0 & 3 & & \\
\hline 35 & & $\mathrm{Pi}$ & 1 & 0 & $\mathrm{~K}$ & 1 & 0 & 0 & 3 & & \\
\hline 36 & & $\mathrm{Pi}$ & 1 & 0 & $\mathrm{~K}$ & 1 & 0 & 0 & 4 & * & \\
\hline 37 & & $\mathrm{Pi}$ & 1 & 0 & $\mathrm{~K}$ & 1 & 0 & 0 & 3 & & \\
\hline 38 & & $\mathrm{Pi}$ & 1 & 0 & $\mathrm{~K}$ & 1 & 0 & 0 & 3 & & \\
\hline 41 & & $\mathrm{Pi}$ & 1 & 0 & $\mathrm{~K}$ & 1 & 0 & 0 & 3 & & \\
\hline 42 & $\mathrm{v}$ & $\mathrm{Pi}$ & 1 & 0 & & & & & & & \\
\hline 43 & & $\mathrm{Pi}$ & 1 & 0 & $\mathrm{~K}$ & 1 & 0 & 0 & 3 & & \\
\hline 44 & & $\mathrm{Pi}$ & 1 & 0 & $\mathrm{~K}$ & 1 & 0 & 0 & 3 & & \\
\hline 45 & $\mathrm{v}$ & $\mathrm{Pi}$ & 1 & 0 & & & & & & & \\
\hline 46 & & $\mathrm{Pi}$ & 1 & 0 & $\mathrm{~K}$ & 1 & 0 & 0 & 4 & * & \\
\hline 47 & & $\mathrm{Pi}$ & 1 & 0 & $\mathrm{~K}$ & 1 & 0 & 0 & 3 & & \\
\hline 48 & & $\mathrm{Pi}$ & 1 & 0 & $\mathrm{~K}$ & 1 & 0 & 0 & 3 & & \\
\hline
\end{tabular}




\section{Zahn}

Population: Calden

Geschlecht:

Alter:

\section{Beschreibung:}

\subsubsection{4 / 2}

Skelett: B4 Ersatzteile

Krankheiten:

5274292

\begin{tabular}{c|l|l} 
Arthrose & rechts & links \\
\hline Caput & & \\
\hline Fossa & &
\end{tabular}

Zahn Status Parodontium Apikale Prozesse
Zahnstein

Karies O 6
Abrasion Neubildung Schmelzhypoplasie 


\section{OK}

Population: Calden

Geschlecht: männlich

Alter:

(40) 45 - 55 (65)

\subsubsection{4 / 2}

Skelett: Calden 22

\section{Beschreibung:}

\section{Museumskiste}

Krankheiten: Parodontitis

Stomatitis

Arthrose

\begin{tabular}{|c|c|c|c|c|c|c|c|c|c|}
\hline Zahn & Status & Parodontium & Apikale Prozesse & Zahnstein & Karies & $\mathrm{Ab}$ & ision & Neubildung & Schmelzhypoplasie \\
\hline 11 & $f$ & $\mathrm{Pi} \quad 3$ & 0 & & & & & & \\
\hline 12 & (f) & $\mathrm{Pi} \quad 3$ & 0 & & & & & & \\
\hline 13 & $\mathrm{v}$ & $\mathrm{Pi} \quad 3$ & G & & & & & & \\
\hline 14 & $\mathrm{v}$ & $\mathrm{Pi} \quad 3$ & 0 & & & & & & \\
\hline 15 & $\mathrm{v}$ & $\mathrm{Pi} \quad 3$ & G & & & & & & \\
\hline 16 & v & $\mathrm{Pi} \quad 3$ & & & & & & & \\
\hline 21 & (f) & $\mathrm{Pi} \quad 3$ & 0 & & & & & & \\
\hline 22 & (f) & $\mathrm{Pi} 3$ & 0 & & & & & & \\
\hline 23 & & $\mathrm{Pi} \quad 3$ & 0 & & 0 & $\mathrm{O}$ & 6 & * & \\
\hline 24 & $\mathrm{v}$ & $\mathrm{Pi} \quad 3$ & G & & & & & & \\
\hline 25 & & $\mathrm{Pi} 3$ & & & 0 & $\mathrm{O}$ & 6 & * & \\
\hline
\end{tabular}




\section{OK}

Population: Calden

Geschlecht: >> weiblich

Alter:

$25-35$

\subsubsection{4 / 3}

Skelett: Calden 19

Krankheiten:

\section{Museumskiste}

\begin{tabular}{c|l|l} 
Arthrose & rechts & links \\
\hline Caput & & \\
\hline Fossa & &
\end{tabular}

\section{Beschreibung:}

\begin{tabular}{|c|c|c|c|c|c|c|c|c|}
\hline Zahn & Status & Parodontium & Apikale Prozesse & Zahnstein & Karies & Abrasion & Neubildung & Schmelzhypoplasie \\
\hline 11 & $\mathrm{v}$ & 0 & 0 & & & & & \\
\hline 12 & v & 0 & 0 & & & & & \\
\hline 13 & & 0 & 0 & & 0 & & 0 & \\
\hline 14 & & 0 & 0 & & 0 & & 0 & \\
\hline 15 & & 0 & & & 0 & & 0 & \\
\hline 16 & & 0 & & & 0 & & 0 & \\
\hline 17 & & 0 & & & 0 & & 0 & \\
\hline 18 & $\varnothing$ & & & & 0 & & 0 & \\
\hline 21 & $\mathrm{v}$ & 0 & 0 & & & & & \\
\hline 22 & v & 0 & 0 & & & & & \\
\hline 23 & & 0 & 0 & & 0 & & 0 & \\
\hline
\end{tabular}




$\begin{array}{ll}0 & 0 \\ 0 & 0 \\ 0 & 0 \\ 0 & 0 \\ 0 & 0\end{array}$

$\begin{array}{ll}0 & 0 \\ 0 & 0 \\ 0 & 0 \\ 0 & 0 \\ 0 & 0\end{array}$




\section{Zahn}

Population: Calden

Geschlecht:

Alter:

Beschreibung: Es ist ein Unterkiefer erhalten. Es handelt sich um die rechte Seite, dessen Gelenk begutachtet werden konnte. Die Fragmentlänge beträgt $70 \mathrm{~mm}$. Das Fundstück kann aufgrund der Gefahr der Doppeltzählung nicht mit ausgewertet werden.

\section{2}

Krankheiten: Arthrose

\begin{tabular}{c|c|c} 
Arthrose & rechts & links \\
\hline Caput & 3 & \\
\hline Fossa & &
\end{tabular}

28.02.2014 / 4

Skelett: SK 6 70mm. Das Fundstuck kann aufgrund der Gefahr der Doppeltzăhlung nicht mit ausgewertet werden. 


\section{Zahn}

Population:

Calden

Geschlecht:

Alter:

(6) $8,5-13(15)$

\subsubsection{4 / 4}

Skelett: $\quad A 7$

\section{2}

Krankheiten:

\begin{tabular}{c|l|l} 
Arthrose & rechts & links \\
\hline Caput & & \\
\hline Fossa & &
\end{tabular}

Beschreibung:

\section{Zahn Status Parodontium Apikale Prozesse}

26
Zahnstein

K 1

0
Abrasion

Neubildung

O 1

0

Schmelzhypoplasie

1 


\section{UK}

Population: Calden

Geschlecht:

Alter:

(5) 6 - $10(12,5)$

\section{Beschreibung:}

\subsubsection{4 / 8}

Skelett: A3 unter Schä 20

Krankheiten:
5274292

\begin{tabular}{c|l|l} 
Arthrose & rechts & links \\
\hline Caput & & \\
\hline Fossa & &
\end{tabular}

\begin{tabular}{|c|c|c|c|c|c|c|c|c|}
\hline Zahn & Status & Parodontium & Apikale Prozesse & Zahnstein & Karies & Abrasion & Neubildung & Schmelzhypoplasie \\
\hline 43 & ( ) & & & & & & & \\
\hline 44 & ( ) & & & & & & & \\
\hline 46 & & 0 & 0 & K & 0 & $\mathrm{O}$ & 0 & 0 \\
\hline 47 & ( ) & & & & & & & \\
\hline 48 & $\mathrm{O}$ & & & & & & & \\
\hline 85 & & 0 & 0 & K & 0 & $\mathrm{O}$ & * & 0 \\
\hline
\end{tabular}




\section{UK}

Population: Calden

Geschlecht:

Alter:

$3,5-6,5$

\section{Beschreibung:}

\subsubsection{4 / 9}

Skelett: A3 P.Sk.1.

Krankheiten:
5274292

\begin{tabular}{c|l|l} 
Arthrose & rechts & links \\
\hline Caput & & \\
\hline Fossa & &
\end{tabular}

\begin{tabular}{|c|c|c|c|c|c|c|c|c|}
\hline Zahn & Status & Parodontium & Apikale Prozesse & Zahnstein & Karies & Abrasion & Neubildung & Schmelzhypoplasie \\
\hline 45 & ( ) & & & 0 & 0 & & 0 & $\mathrm{~T}$ \\
\hline 46 & ( ) & & & & & & & $x$ \\
\hline 47 & ( ) & & & & & & & \\
\hline 84 & & & 0 & $\mathrm{~K}$ & 0 & $\mathrm{O}$ & 0 & 0 \\
\hline 85 & & & 0 & $\mathrm{~K}$ & 0 & 0 & 0 & 0 \\
\hline
\end{tabular}




\section{UK}

Population: Calden

Geschlecht:

Alter:

Beschreibung: Hier ist ein Caput mandibulae in erodierter Form erhalten. Das Fundstück ist nicht näher zuzuordnen und wird aufgrund der Gefahr der

Doppeltzählung nicht mit ausgewertet sondern nur aus Dokumentationszwecken beschrieben.

\section{0}

\section{Krankheiten:}

\begin{tabular}{c|c|c} 
Arthrose & rechts & links \\
\hline Caput & 1 & \\
\hline Fossa & &
\end{tabular}

Zahn Status Parodontium Apikale Prozesse Zahnstein Karies Abrasion Neubildung Schmelzhypoplasie




\section{UK}

Population: Calden

Geschlecht:

Alter:

Beschreibung: Dies ist das Fragment eines aufsteigenden Astes eines Unterkiefers. Es zeigen sich deutliche Muskelmarken. Das Fundstück ist nicht näher
zuzuordnen und wird aufgrund der Gefahr der Doppeltzählung nicht mit ausgewertet sondern nur aus Dokumentationszwecken beschrieben.

Beschreibung: Dies ist das Fragment eines aufsteigenden Astes eines Unterkiefers. Es zeigen sich deutliche Muskelmarken. Das Fundstück ist nicht näher
zuzuordnen und wird aufgrund der Gefahr der Doppeltzählung nicht mit ausgewertet sondern nur aus Dokumentationszwecken beschrieben.

\subsubsection{3 / 1}

Skelett: $\quad$ einzeln 1.1

\section{0}

\begin{tabular}{c|l|l} 
Arthrose & rechts & links \\
\hline Caput & & \\
\hline Fossa & &
\end{tabular}

Zahn Status Parodontium Apikale Prozesse Zahnstein Karies Abrasion Neubildung Schmelzhypoplasie




\section{UK}

Population: Calden

Geschlecht:

Alter:

Beschreibung: Hierbei handelt es sich um ein Fragment eines Kieferwinkels der linken Seite eines Unterkiefers. Im letzten Alveolarfach, als wahrscheinlich eines 7ers oder 8ers steckt noch der Rest des Zahnes. Die Krone ist allerdings abfrakturiert. Das Fragment wirkt sehr massiv.

\subsubsection{3/1}

Skelett: einzeln 1.1

\section{0}

Krankheiten:

\begin{tabular}{c|l|l} 
Arthrose & rechts & links \\
\hline Caput & & \\
\hline Fossa & &
\end{tabular}
enes 7ers oder 8ers steck noch der Rest des Zahnes. Die Krone istalleding abfrakturt. Das Fragmentwikk sehr massiv.

$\begin{array}{llccccc}\text { Zahn } & \text { Status } & \text { Parodontium } & \text { Apikale Prozesse } & \text { Zahnstein } & \text { Karies } & \text { Abrasion Neubildung Schmelzhypoplasie } \\ 37 & \text { E } & 0 & \end{array}$




\section{UK}

Population: Calden

Geschlecht: > weiblich

Alter:

Beschreibung: Dieses Fundstück ist lediglich ein Caput mandibulae der linken Seite. Es wirkt eher grazil und weist keine starken Verschleißerscheinungen auf. Das Objekt kann nicht näher zugeordnet werden und wird deswegen nicht mit ausgewertet.

\section{0}

\section{Krankheiten:}

\begin{tabular}{c|c|c} 
Arthrose & rechts & links \\
\hline Caput & & 1 \\
\hline Fossa & &
\end{tabular}

Zahn Status Parodontium Apikale Prozesse Zahnstein Karies Abrasion Neubildung Schmelzhypoplasie
$\mathrm{xx}$ 


\section{UK}

Population: Calden

Geschlecht:

Alter:

Beschreibung: Dieses Fundstück ist ein recht kleines Fragment des aufsteigenden Astes des Unterkiefers rechts mit Caput mandibulae. Da das Fundstück nicht näher zuzuordnen ist, wird es nicht mit ausgewertet. Hier erfolgt die Beschreibung nur aus Dokumentationszwecken.
8505718

Krankheiten:

\begin{tabular}{c|c|c} 
Arthrose & rechts & links \\
\hline Caput & 1 & \\
\hline Fossa & &
\end{tabular}

Zahn Status Parodontium Apikale Prozesse Zahnstein Karies Abrasion Neubildung Schmelzhypoplasie
$\mathrm{xx}$ 


\section{UK}

Population: Calden

Geschlecht: > weiblich

Alter:

Beschreibung: Knochensplitter. Die Splitter sind nicht zuzuordnen und werden aufgrund der Gefahr der Doppeltzählung nicht mit ausgewertet sondern nur aus Dokumentationszwecken beschrieben.

\section{1}

Krankheiten:

\begin{tabular}{c|l|l} 
Arthrose & rechts & links \\
\hline Caput & & \\
\hline Fossa & &
\end{tabular}

Zahn Status Parodontium Apikale Prozesse Zahnstein Karies Abrasion Neubildung Schmelzhypoplasie
$\mathrm{xx}$ 


\section{UK}

Population: Calden

Geschlecht:

Alter:

Beschreibung: Ein Fragment eines rechten Unterkiefers, welches nicht näher zugeordnet werden kann. Aus diesem Grund wird es hier nur beschrieben, jedoch nicht mit ausgewertet.

\section{1}

Skelett: E.B-S. 10unter SCH. B Krankheiten: +3. 6

\begin{tabular}{c|l|l} 
Arthrose & rechts & links \\
\hline Caput & & \\
\hline Fossa & &
\end{tabular}

Zahn Status Parodontium Apikale Prozesse Zahnstein Karies
$\mathrm{xx}$




\section{OK}

Population

Calden

Geschlecht:

Alter:

(25) 28 - 35 (38)

\subsubsection{4 / 10}

Skelett: A3 P.Sk.1. OK

Krankheiten:

\section{Beschreibung:}

\section{2}

\begin{tabular}{c|l|l} 
Arthrose & rechts & links \\
\hline Caput & & \\
\hline Fossa & &
\end{tabular}

\begin{tabular}{|c|c|c|c|c|c|c|c|c|c|}
\hline Zahn & Status & Parodontium & Apikale Prozesse & Zahnstein & Karies & $\mathrm{Ab}$ & ision & Neubildung & Schmelzhypoplasie \\
\hline 13 & & 0 & 0 & 0 & 0 & $\mathrm{O}$ & 2 & 0 & $U$ \\
\hline 14 & $v$ & 0 & 0 & & & & & & \\
\hline 15 & & 0 & 0 & K & 0 & $\mathrm{O}$ & 3 & 0 & 0 \\
\hline 16 & & 0 & 0 & K & 0 & $\mathrm{O}$ & 4 & * & $U$ \\
\hline 17 & $\mathrm{v}$ & $x$ & & & & & & & \\
\hline
\end{tabular}


Bezeichn.: Cranium

\section{Kiste:}

Skelet: a 850 (a-t)

Population: Rheine

Felsenbein:

Erhaltung: $>60 \%$ erh. $25-60 \%$ erh.

- 1 - $25 \%$ erh.
Ges./Kr.: Krank

Krankh.: Kopfschwartenreizung

Hirndrucksymptomatik

\begin{tabular}{l|l|l} 
Maß & Wert & Einheit \\
\hline Breite & 41,88 & $\mathrm{~mm}$ \\
Breite & 31 & $\mathrm{~mm}$ \\
Länge & 48,52 & $\mathrm{~mm}$ \\
Länge & 39,12 & $\mathrm{~mm}$ \\
Schädeldecke / Schädelbasis & 2 & \\
& &
\end{tabular}

\section{Beschreibung:}

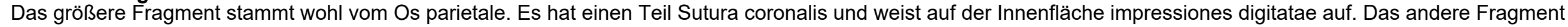

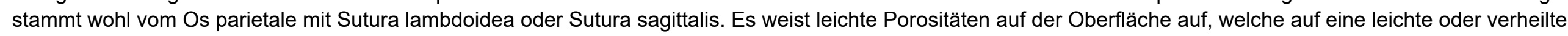
Kopfschwartenentzündung zurückzuführen sind. Allerdings ist das Fragment erodiert und deswegen nicht gut befundbar. 
Bezeichn.: Cranium

Kiste:

Verband:

Verband

\section{Alter:}

Geschlecht:

Arthrose:

Population: Rheine
Ges./Kr.: Gesund

Maß

Schädeldecke / Schädelbasis

Felsenbein:

Erhaltung: $>60 \%$ erh

$25-60 \%$ erh.

- $1-25 \%$ erh.

\section{Beschreibung:}

Tüte mit mehreren Schädelfragmenten, das größte stammt vom Os occipitale, die anderen waren nicht zuzuordnen 
Bezeichn.: Cranium

Kiste:

Skelet: 1142

Population: Rheine

Felsenbein:

Erhaltung: $>60 \%$ erh

$25-60 \%$ erh.

- 1 - $25 \%$ erh.

\section{Alter:}

\section{Geschlecht:}

Arthrose:
Verband: $\quad$ Verband
Ges./Kr.: Gesund

\section{Maß}

Breite

Länge

Schädeldecke / Schädelbasis

\begin{tabular}{|l|l} 
Wert & Einheit \\
\hline 24 & $\mathrm{~mm}$
\end{tabular}

$33,19 \mathrm{~mm}$

\section{Beschreibung:}

Fragment eines linken Os temporale mit Teil des Processus zygomaticus, Margo sphenoidale und Teil des Processus articularis. 
Bezeichn.: Cranium

Kiste:

Skelet: 1165

Population: Rheine

Felsenbein:

Erhaltung: $>60 \%$ erh

$25-60 \%$ erh.

- 1 - $25 \%$ erh.

\section{Alter:}

Geschlecht:

Arthrose:
Verband: $\quad$ Verband
Ges./Kr.: Gesund

\section{Maß}

Breite

Länge

Schädeldecke / Schädelbasis

\begin{tabular}{|l|l} 
Wert & Einheit \\
25,5 & $\mathrm{~mm}$
\end{tabular}

mm

$32 \quad \mathrm{~mm}$

\section{Beschreibung:}

Mehrere Fragmente eines Craniums, ein Teil Os parietale, welches nahe des Os temporale lag. Die weiteren Splitter sind nicht zuzuordnen. 
Bezeichn.: Cranium

Kiste:

6

Skelet: 1313

Population: Rheine

Felsenbein:

Erhaltung: $>60 \%$ erh

$25-60 \%$ erh.

- 1 - $25 \%$ erh.

\section{Verband: \\ Verband \\ Ges./Kr.: Gesund}

\section{Alter:}

Geschlecht:

Arthrose:

\begin{tabular}{l|l|l} 
Maß & Wert & Einheit \\
\hline Breite & 51 & $\mathrm{~mm}$ \\
Länge & 71,39 & $\mathrm{~mm}$ \\
Schädeldecke / Schädelbasis & 1 & \\
& & \\
& &
\end{tabular}

\section{Beschreibung:}

Dieses Fragment eines Craniums ist nicht genau lokalisierbar, erodiert und soweit befundbar ohne Auffälligkeiten. 
Bezeichn.: Cranium

Kiste:

Skelet: 592

Population: Rheine

Felsenbein:

Erhaltung: $>60 \%$ erh

$25-60 \%$ erh.

- $1-25 \%$ erh.
Ges./Kr.: Krank

Krankh.: Kopfschwartenreizung

meningeale Reizung

\begin{tabular}{l|l|l} 
Maß & Wert & Einheit \\
\hline Breite & 37 & $\mathrm{~mm}$ \\
Dicke & 7,29 & $\mathrm{~mm}$ \\
Länge & 50 & $\mathrm{~mm}$ \\
Schädeldecke / Schädelbasis & 2 & \\
& & \\
& &
\end{tabular}

\section{Beschreibung:}

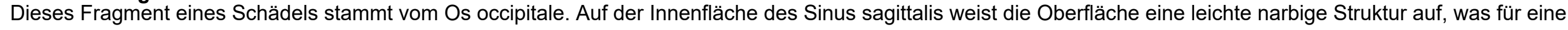
meningeale Reizung im Bereich des Sinus durae matris spricht. Die Lamina externa weist intra - und postmortale Porositäten auf. Diese können Zeichen einer Kopfschwartenentzündung sein. 
Bezeichn.: Cranium

\section{Kiste:}

7

Skelet: 1040

Population: Rheine

Felsenbein:

Erhaltung: $>60 \%$ erh

$$
25-60 \% \text { erh. }
$$

- $1-25 \%$ erh.

\section{Beschreibung:}

Fragment eines Os frontale, welches leichte Erosionsspuren aufweist

Alter:

\section{Geschlecht:}

\section{Arthrose:}

Ges./Kr.: Gesund

\begin{tabular}{l|l|l} 
Maß & Wert & Einheit \\
\hline Breite & 53,63 & $\mathrm{~mm}$ \\
Länge & 77,86 & $\mathrm{~mm}$ \\
Schädeldecke / Schädelbasis & 1 & \\
& & \\
& &
\end{tabular}


Bezeichn.: Cranium

Kiste:

Skelet: 1056

Population: Rheine

Felsenbein:

Erhaltung: $>60 \%$ erh

$$
25-60 \% \text { erh. }
$$

- $1-25 \%$ erh.

\section{Verband: $\quad$ Verband}

\section{Alter:}

Geschlecht: $q \leq \lambda$

Arthrose:
Ges./Kr.: Gesund

\section{Maß}

Breite

Dicke

Dünnste Stelle

Länge

Schädeldecke / Schädelbasis

\begin{tabular}{|l|l} 
Wert & Einheit \\
\hline 54,9 & $\mathrm{~mm}$
\end{tabular}

\section{Beschreibung:}

Dieses Fragment stammt von einem Os occipitale und ist an der Protuberantia occipitalis externa recht dick. Es zeigt recht starke Erosionsspuren. 
Bezeichn.: Cranium

Kiste:

7

Skelet: 1099

Population: Rheine

Felsenbein:

Erhaltung: $>60 \%$ erh.

$25-60 \%$ erh.

- $1-25 \%$ erh.

\section{Verband: $\quad$ Verband}

\section{Alter:}

Ges./Kr.: Gesund

\section{Maß}

Schädeldecke / Schädelbasis

Wert $\quad$ Einheit

Geschlecht:

Arthrose:

\section{Beschreibung:}

Es handelt sich hier um zwei Fragmente eines Craniums. Das eine enthält das Foramen ovale, das andere ist ein Fragment des Os occipitale. 
Bezeichn.: Cranium

Kiste:

Skelet: $\quad 955$

Population: Rheine

Felsenbein:

Erhaltung: $>60 \%$ erh

$25-60 \%$ erh.

- $1-25 \%$ erh.
Verband: $\quad$ Verband

\section{Alter:}

Geschlecht:

Arthrose:
Ges./Kr.: Gesund

\section{Maß}

Breite

Länge

Schädeldecke / Schädelbasis

\begin{tabular}{|l|l} 
Wert & Einheit \\
\hline 35,85 & $\mathrm{~mm}$
\end{tabular}

$56,28 \mathrm{~mm}$

\section{Beschreibung:}

Wohl ein Fragment aus dem Os parietale eines Craniums, welches erodiert ist und sonst keine weiteren Auffälligkeiten zeigt. 


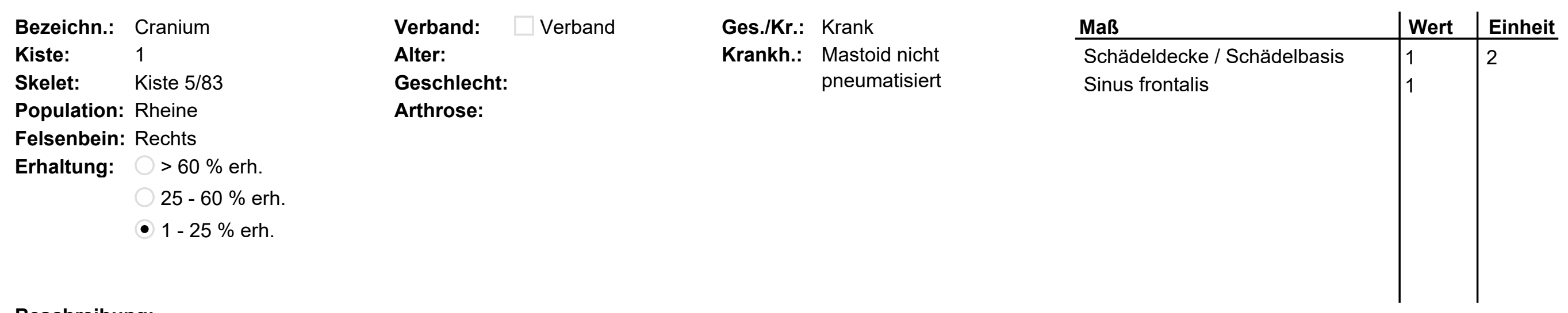

\section{Beschreibung:}

Es handelt sich hier um Fragmente des Os parietale rechts, des Os temporale rechts mit Mastoid, welches nicht pneumatisiert ist, was für einen entzündlichen Prozess es Mittelohrs während des Aufwachsens spricht. Weiterhin liegt noch ein Os frontale mit Sinus frontalis vor. 
Bezeichn.: Cranium

\section{Kiste:}

8

Skelet: $\quad$ ohne Nummer 3 1.6.83

Population: Rheine

Felsenbein:

Erhaltung: $>60 \%$ erh

$25-60 \%$ erh.

- $1-25 \%$ erh.
Verband: $\quad \square$ Verband

Ges./Kr.: Gesund

\section{Alter:}

Geschlecht:

\section{Arthrose:}

\section{Maß}

Schädeldecke / Schädelbasis

\section{Beschreibung:}

Fragmente eines Schädels. Es ist eines dieser Fragmente als Os parietale zu identifizieren. 
Bezeichn.: Cranium

Kiste:

Verband:

Verband

\section{Alter:}

Geschlecht:

Arthrose:

Population: Rheine
Maß

Dicke

Schädeldecke / Schädelbasis

Felsenbein:

Erhaltung: $>60 \%$ erh

$25-60 \%$ erh.

- $1-25 \%$ erh.

\section{Beschreibung:}

Ein kleines Fragment eines Craniums, welches von Leichenbrand stammt. 
Bezeichn.: Cranium

Kiste:

Skelet: 457

Population: Rheine

Felsenbein:

Erhaltung: $>60 \%$ erh

$25-60 \%$ erh.

- $1-25 \%$ erh.
Ges./Kr.: Krank

Krankh.: Kopfschwartenreizung

\section{Maß}

Schädeldecke / Schädelbasis
Alter: Erwachsen

\section{Geschlecht:}

Arthrose:

\section{Beschreibung:}

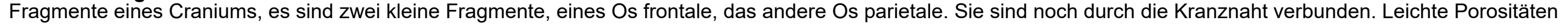
lassen auf eine Kopfschwartenreizung des Os parietale schließen. 
Bezeichn.: Cranium

Kiste:

Skelet: 457

Population: Rheine

Felsenbein:

Erhaltung: $>60 \%$ erh

$$
25-60 \% \text { erh. }
$$

- 1 - $25 \%$ erh.

\section{Verband: $\quad$ Verband}

Alter: Erwachsen

Ges./Kr.: Gesund

\section{Maß}

Schädeldecke / Schädelbasis

Geschlecht:

Arthrose:

\section{Beschreibung:}

Ein Fragment eines Craniums, es sind zwei kleine Fragmente, eines Os frontale, das andere Os parietale. Sie sind noch durch die Kranznaht verbunden. 
Bezeichn.: Cranium

Kiste: 1

Skelet: $\quad 360$

Population: Rheine

Felsenbein:

Erhaltung: $>60 \%$ erh.

$25-60 \%$ erh.

- 1 - $25 \%$ erh.

\section{Beschreibung:}

Ein Fragment eines Os parietale.
Verband: $\quad$ Verband

\section{Alter:}

\section{Geschlecht:}

\section{Arthrose:}

Ges./Kr.: Gesund

Maß

Schädeldecke / Schädelbasis \begin{tabular}{l|l} 
Wert & Einheit \\
\hline 1
\end{tabular}

1

1

.


Bezeichn.: Cranium

Kiste:

Verband:

Verband

\section{Alter:}

Ges./Kr.: Gesund

Skelet: $\quad 459$

Population: Rheine

Felsenbein: Rechts

Erhaltung: $>60 \%$ erh.

$$
25-60 \% \text { erh. }
$$

- $1-25 \%$ erh.

\section{Geschlecht: $q>0$}

Arthrose:

\section{Maß}

Schädeldecke / Schädelbasis

\begin{tabular}{|l|l} 
Wert & Einheit
\end{tabular}

\section{Beschreibung:}

Ein Fragment des Os temporale mit Mastoid der rechten Seite eines wohl weiblichen Individuums. 
Bezeichn.: Cranium

\section{Kiste:}

\section{Verband:}

Verband

\section{Alter:}

Ges./Kr.: Gesund

\section{Geschlecht:}

\section{Arthrose:}

Population: Rheine

Felsenbein: Rechts

Erhaltung: $>60 \%$ erh.

$25-60 \%$ erh.

- 1 - $25 \%$ erh.

\section{Beschreibung:}

Fragmente eines rechten Os temporale und eines rechten Os zygomaticum. 


\section{Bezeichn.: Cranium}

\section{Kiste:}

4

Skelet: $\quad 28.6 .83$

Population: Rheine

Felsenbein:

Erhaltung: $>60 \%$ erh

$25-60 \%$ erh.

- $1-25 \%$ erh.

\section{Beschreibung:}

Hier ist ein Fragment des linken Orbitaboden erhalten.
Ges./Kr.: Gesund

Alter:

Geschlecht:

Arthrose:
Maß

\section{Breite}

Länge

Viscerocranium

\begin{tabular}{|l|l} 
Wert & Einheit \\
\hline 32,3 & $\mathrm{~mm}$
\end{tabular}

$24,5 \quad \mathrm{~mm}$

1


Bezeichn.: Cranium

\section{Kiste:}

Skelet: $\quad 3610 / 1$ S3 1.06.83184

Population: Rheine

Felsenbein:

Erhaltung: $>60 \%$ erh $25-60 \%$ erh.

- 1 - $25 \%$ erh.
Verband: $\quad$ Verband

\section{Alter:}

\section{Geschlecht:}

Arthrose:

\section{Beschreibung:}

Ein Fragment des Os sphenoidale mit deutlichen Spuren von Leichenbrand: Es findet sich eine etwas blasig aufgequollene Oberfläche an der Außenseite. Das Fragment ist außen weißlich verfärbt, nach innen hin etwas dunkel bis schwarz. 


\begin{tabular}{|c|c|c|c|c|c|c|c|}
\hline Bezeichn.: & Cranium & Verband: & Verband & Ges./Kr.: Krank & Maß & Wert & Einheit \\
\hline Kiste: & 6 & Alter: & & Krankh.: Anämie & Breite & 64,5 & $\mathrm{~mm}$ \\
\hline Skelet: & 1378 & Geschlecht: & & & Dicke & 10 & $\mathrm{~mm}$ \\
\hline Population: & Rheine & Arthrose: & & & Länge & 85,5 & $\mathrm{~mm}$ \\
\hline Felsenbein: & & & & & Schädeldecke / Schädelbasis & 2 & \\
\hline Erhaltung: & $>60 \%$ erh. & & & & & & \\
\hline & $25-60 \%$ erh. & & & & & & \\
\hline & - $1-25 \%$ erh. & & & & & & \\
\hline
\end{tabular}

\section{Beschreibung:}

Es handelt sich hier um ein recht stark erodiertes Fragment des Os parietale links, welches unweit der Lambdanaht lokalisiert war. Es fallen zahlreiche foveolae granulares und eine Schädeldicke vom 10,26mm ins Auge. Für weitere Befundung war das Fundstück zu stark erodiert. 
Bezeichn.: Cranium

\section{Kiste:}

Skelet: 872

Population: Rheine

Felsenbein: Rechts

Erhaltung: $>60 \%$ erh.

$25-60 \%$ erh.

- $1-25 \%$ erh.
Ges./Kr.: Krank

Krankh.: Mastoid nicht

pneumatisiert
Maß

Breite

Länge

Schädeldecke / Schädelbasis

\begin{tabular}{|l|l} 
Wert & Einheit \\
43 & $\mathrm{~mm}$ \\
50 & $\mathrm{~mm}$ \\
1 & 2
\end{tabular}

\section{Beschreibung:}

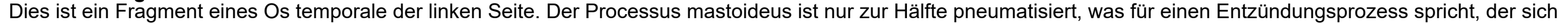

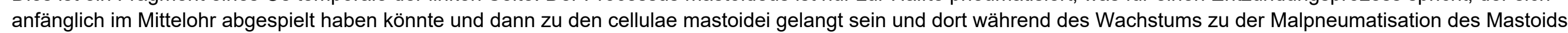

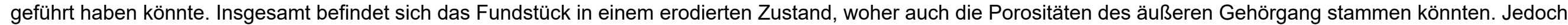
ist hier ein pathologischer Zusammenhang nicht auszuschließen. Letzteres würde in die beschriebene Kausalkette passen. 
Bezeichn.: Cranium

Kiste:

3

Skelet: 879

Population: Rheine

Felsenbein:

Erhaltung: $>60 \%$ erh

$25-60 \%$ erh.

- $1-25 \%$ erh.
Verband: $\quad$ Verband

\section{Alter:}

Ges./Kr.: Gesund

\section{Geschlecht:}

Arthrose:

\section{Maß}

Länge

Viscerocranium

\section{Beschreibung:}

Hier ist ein Fragment eines Os zygomaticum erhalten, welches nicht einer Seite zuzuordnen ist. 
Bezeichn.: Cranium

\section{Kiste:}

Skelet: 641

Population: Rheine

Felsenbein:

Erhaltung: $>60 \%$ erh

$25-60 \%$ erh.

- $1-25 \%$ erh.
Verband: $\quad$ Verband

\section{Alter:}

\section{Geschlecht:}

Arthrose:

\section{Maß}

Breite

Länge

Schädeldecke / Schädelbasis \begin{tabular}{|l|l} 
Wert & Einheit \\
\hline 28,28 & $\mathrm{~mm}$
\end{tabular}

28,28 $\mathrm{mm}$

$36,52 \mathrm{~mm}$

1

$\mathrm{mm}$
1

\section{Beschreibung:}

Dies ist ein Fragment eines Os temporale der linken Seite. Auf Grund von Bodenerosionen ist dieses Fundstück nicht weiter befundbar. 


\begin{tabular}{|c|c|c|c|c|c|c|}
\hline Bezeichn.: & Cranium & $\square$ Verband & Ges./Kr.: Gesund & Maß & Wert & Einheit \\
\hline Kiste: & 1 & Alter: & & Breite & 55 & $\mathrm{~mm}$ \\
\hline Skelet: & 3001 & Geschlecht: & & Länge & 60 & $\mathrm{~mm}$ \\
\hline Population: & Rheine & Arthrose: & & Schädeldecke / Schädelbasis & 1 & 1 \\
\hline Felsenbein: & & & & & & \\
\hline Erhaltung: & $>60 \%$ erh. & & & & & \\
\hline & $25-60 \%$ erh. & & & & & \\
\hline & $\bullet 1-25 \%$ erh. & & & & & \\
\hline
\end{tabular}

\section{Beschreibung:}

Dieses Fundstück ist ein Os occipitale. Das Fragment stammt von der linken Seite des Os occipitale, grenzt an die Lambdanaht und hat auf der Innenseite den Sulcus Sinus transversi. 
Bezeichn.: Cranium

Kiste:

Skelet: 855

Population: Rheine

Felsenbein: Links

Erhaltung: $>60 \%$ erh.

$$
25-60 \% \text { erh. }
$$

- $1-25 \%$ erh.

\section{Verband: \\ Verband \\ Ges./Kr.: Gesund}

\section{Alter:}

Geschlecht:

\section{Arthrose:}

Maß

Länge

Schädeldecke / Schädelbasis \begin{tabular}{|l|l} 
Wert & Einheit \\
\hline 44,5 & $\mathrm{~mm}$
\end{tabular}

44,5 $\mathrm{mm}$

$1 \quad 1$

\section{Beschreibung:}

Dieses Fragment eines Os temporale zeigt keine Auffälligkeiten. Der Meatus acusticus internus bleibt ohne Befund. 
Bezeichn.: Cranium

Kiste: 8

Skelet: 3

Population: Rheine

Felsenbein: Rechts

Erhaltung: $>60 \%$ erh.

$25-60 \%$ erh.

- $1-25 \%$ erh.
Verband: $\square$ Verband

Alter: (25) 28 - 35 (38)

Geschlecht:

Arthrose:
Ges./Kr.: Krank

Krankh.: Sinusitis maxillaris

Stomatitis

\section{Beschreibung:}


Bezeichn.: Vertebra

Kiste:

Skelet: 1299

Population: Rheine

\section{Verband: $\quad$ Verband Ges./Kr.: Krank}

Alter: Krankh.: Arthritis

\section{Geschlecht:}

Arthrose:

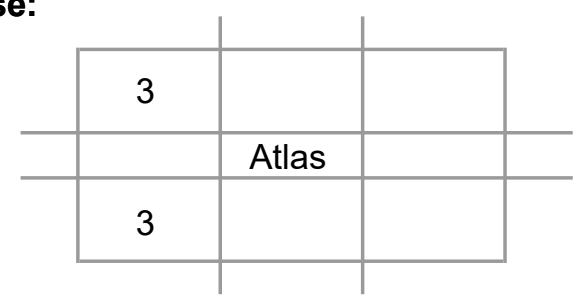

\section{Beschreibung:}

Dieses Fragment eines Atlas zeigt kleine Spuren einer leichten Arthritis auf den Processus articulares superiores und inferiores der rechten Seite. 
Bezeichn.: Vertebra

Kiste:

Skelet: 1209

Population: Rheine
Verband: Verband

\section{Alter:}

Geschlecht:

Arthrose:

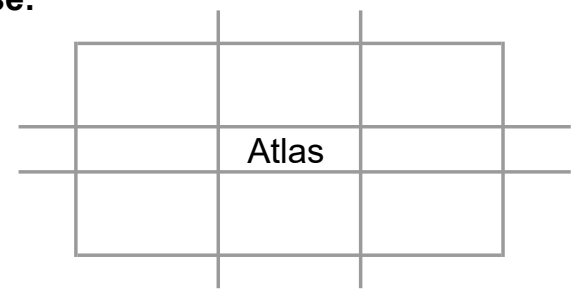

\section{Beschreibung:}

Ein Fragment des rechten Teils eines Atlas ohne Gelenkflächen. 
Bezeichn.: Vertebra

\section{Kiste:}

Skelet: 1259

Population: Rheine

\section{Verband: $\quad$ Verband}

Alter:

\section{Geschlecht:}

Arthrose:

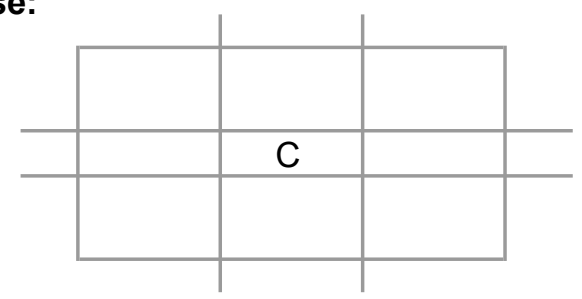

\section{Beschreibung:}

Ein nicht gut erhaltenes Fundstück eines cervikalen Wirbels. 
Bezeichn.: Vertebra

Kiste:

Skelet: $\quad 1545$

Population: Rheine

\section{Verband: $\quad$ Verband Ges./Kr.: Krank}

Alter: Krankh.: Arthrose

\section{Geschlecht:}

Arthrose:

\begin{tabular}{|c|c|c|}
\cline { 2 - 3 } \multicolumn{1}{c||}{} & 2 & 2 \\
\hline 1 & $\mathrm{C} 3$ & \\
\hline & 3 & 2 \\
\hline
\end{tabular}

\section{Beschreibung:}

Dieser Wirbel C3 ist fast vollständig erhalten und weist arthrotische Verschleißerscheinungen an der unteren Deckplatte des Corpus auf. 
Bezeichn.: Vertebra

Kiste:

Skelet: 1080

Population: Rheine
Verband: $\quad$ Verband

\section{Alter:}

Geschlecht:

Arthrose:

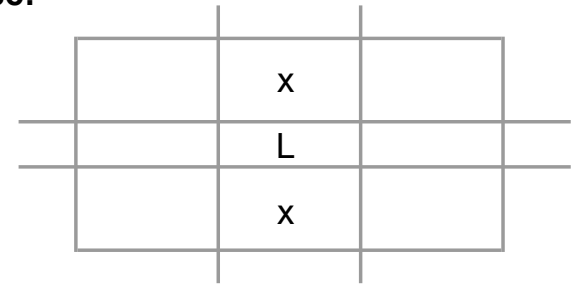

\section{Beschreibung:}

Der corpus ist zum Großteil frakturiert. 
Bezeichn.: Vertebra

Kiste:

Skelet: $\quad 1079 / 7$

Population: Rheine
Verband: Verband

\section{Alter:}

Geschlecht:

Arthrose:

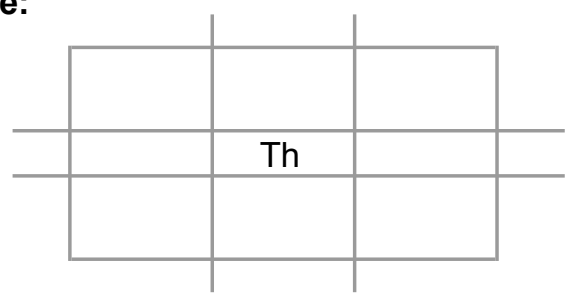

\section{Beschreibung:}

Ein Brustwirbelfragment. 
Bezeichn.: Vertebra

Kiste:

Skelet: $\quad 1079 / 7$

Population: Rheine
Verband: Verband

\section{Alter:}

Geschlecht:

Arthrose:

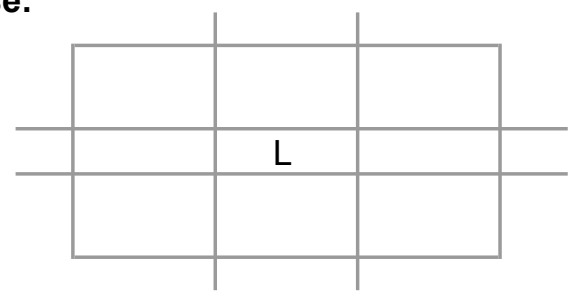

\section{Beschreibung:}

Ohne corpus. Nur ein Fragment erhalten. 
Bezeichn.: Vertebra

Kiste:

Skelet: $\quad$ 1079/22

Population: Rheine
Verband: Verband

\section{Alter:}

\section{Geschlecht:}

Arthrose:

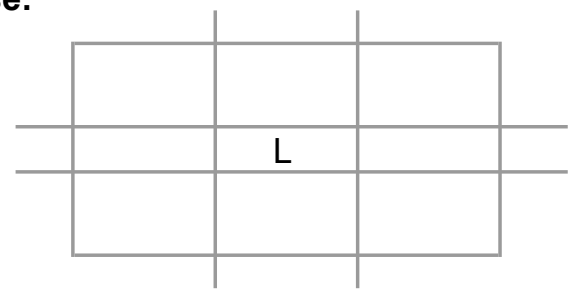

\section{Beschreibung:}

Stark erodiertes Wirbelfragment ohne corpus. 
Bezeichn.: Vertebra

Kiste:

Skelet: a 211

Population: Rheine
Verband: Verband

\section{Alter:}

\section{Geschlecht:}

Arthrose:

\begin{tabular}{|c|c|c|}
\cline { 2 - 3 } \multicolumn{1}{c|}{$\mathrm{x}$} & & $\mathrm{x}$ \\
\hline $\mathrm{x}$ & & $\mathrm{L}$ \\
\hline
\end{tabular}

\section{Beschreibung:}

Erodiertes Fragment. 
Bezeichn.: Vertebra

Kiste:

Skelet: $\quad 28.6 .83$

Population: Rheine

\section{Verband: $\quad$ Verband}

Ges./Kr.: Gesund

\section{Geschlecht:}

Arthrose:

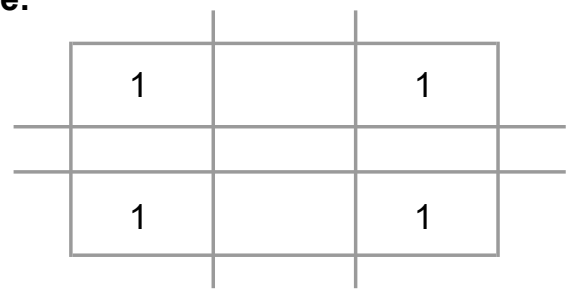

\section{Beschreibung:}

Hier ist kein corpus erhalten und der Wirbel ist nicht einem Bereich zuzuordnen. 
Bezeichn.: Vertebra

Kiste:

Skelet: $\quad 28.6 .83$

Population: Rheine

\section{Verband: $\quad$ Verband}

\section{Alter:}

Ges./Kr.: Krank

\section{Geschlecht:}

Arthrose:

\begin{tabular}{|c|c|c|}
\hline 2 & 2 & 4 \\
\hline & C & \\
\hline 2 & 2 & 2 \\
\hline
\end{tabular}

\section{Beschreibung:}

Dieser cervikale Wirbel befindet sich in gutem Erhaltungszustand. 
Bezeichn.: Vertebra

Kiste:

Skelet: 5

Population: Rheine
Verband: $\quad$ Verband

Ges./Kr.: Gesund

Geschlecht:

Arthrose:

\begin{tabular}{|l|l|l|}
\multicolumn{1}{c|}{} & \multicolumn{1}{c|}{} \\
\cline { 2 - 3 } \multicolumn{1}{l|}{} & 1 & 1 \\
\hline 1 & 1 & 1 \\
\hline
\end{tabular}

\section{Beschreibung:}




\section{Bezeichn.: Costa}

Kiste:

Skelet: 1432

Population: Rheine

Seite:

links

\section{Verband:}

Verband

\section{Alter:}

Geschlecht:

Arthrose:

\section{Ges./Kr.: Gesund}

\begin{tabular}{l|l|l} 
Maß & Wert & Einheit \\
\hline Dicke & 13 & $\mathrm{~mm}$ \\
Länge & 60 & $\mathrm{~mm}$ \\
& & \\
& &
\end{tabular}

Beschreibung:

Ein kleines, wirbelsäulennahes Fragment einer Rippe der linken Seite. Sie weist deutliche Muskelmarken an den Ansätzen der Intercostalmuskulatur auf. 


\section{Bezeichn.: Costa}

\section{Kiste:}

Skelet: 891

Population: Rheine

Seite: n. def.

\section{Beschreibung:}

Ein Rippenfragment.

\section{Verband:}

Verband

\section{Alter:}

Geschlecht:

Arthrose:
Ges./Kr.: Gesund

\section{Maß}

Länge

\begin{tabular}{|l|l} 
Wert & Einheit \\
\hline 35,3 & $\mathrm{~mm}$ \\
& \\
\end{tabular}




\section{Bezeichn.: Costa}

Kiste: 3

Skelet: $\quad 1210$

Population: Rheine

Seite:

links

\section{Verband:}

\section{Alter:}

Ges./Kr.: Gesund

Geschlecht:

Arthrose:

\section{Beschreibung:}

Eine Rippe eines jungen Individuums, sie befindet sich in sehr brüchigem Zustand. 


\section{Bezeichn.: Costa}

Kiste: 3

Skelet: 1197

Population: Rheine

Seite:

links

\section{Beschreibung:}

Ein kleines Fragment.
Verband: $\quad$ Verband Ges./Kr.: Gesund

Alter: Jung

Geschlecht:

Arthrose: 
Bezeichn.: Costa

Kiste:

Verband:

Verband

\section{Alter:}

Geschlecht:

Arthrose:

Population: Rheine

Seite:

links

Ges./Kr.: Gesund

Maß

Länge

Wert 1 Einheit

$49,13 \mathrm{~mm}$

\section{Beschreibung:}

Angulus Costae gut ausgeprägt, ausgeprägter Sulcus Costae. 


\section{Bezeichn.: Costa}

\section{Kiste:}

Skelet: $\quad 1070$

Population: Rheine

Seite:

links
Verband:

Verband

\section{Alter:}

Geschlecht:

Arthrose:
Ges./Kr.: Gesund

Maß

Länge

Wert 1 Einheit

$85,59 \mathrm{~mm}$

\section{Beschreibung:}

Eine Rippe ohne Auffälligkeiten. 
Bezeichn.: Costa

Kiste:

5

Skelet: $\quad 3610 / 1$ S3 20.07.831757

Population: Rheine

Seite:

rechts

\section{Beschreibung:}

Ein Rippenfragment der rechten Seite.
Verband: $\quad$ Verband

\section{Alter:}

Geschlecht:

Arthrose:
Ges./Kr.: Gesund

Maß

Länge

Wert $\quad$ Einheit

$49,5 \mathrm{~mm}$




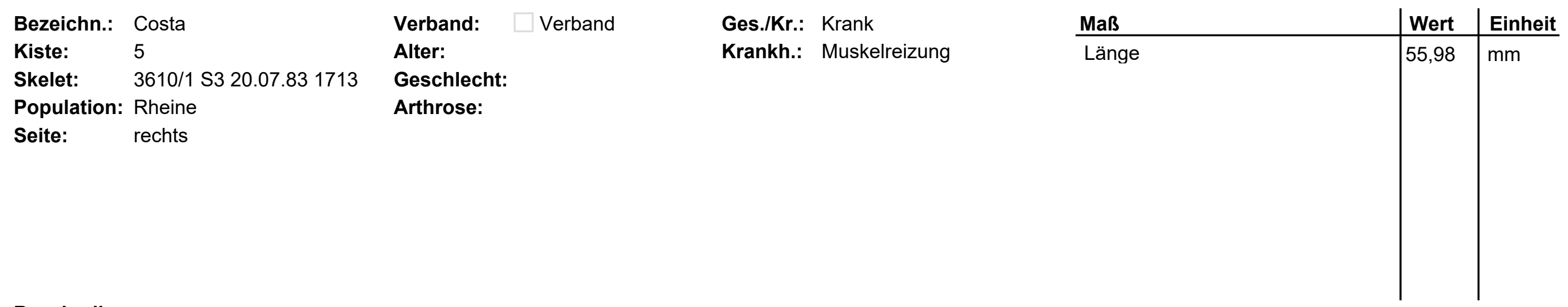

\section{Beschreibung:}

Diese Rippe der rechten Seite weist ein leichtes Streifenmuster auf, welches durch Knochenneubildung in Folge von Muskelreizung entstanden sein könnte. 


\section{Bezeichn.: Costa}

\section{Kiste:}

5

Skelet: $\quad$ 3610/1 S3 20.7.831698

Population: Rheine

Seite:

n. def.
Verband:

Verband

\section{Alter:}

Geschlecht:

Arthrose:

\section{Beschreibung:}

Fragment.
Ges./Kr.: Gesund

\section{Maß}

Länge

\begin{tabular}{l|l} 
Wert & Einheit \\
\hline 67,76 & $\mathrm{~mm}$
\end{tabular}




\section{Bezeichn.: Clavicula}

Kiste:

Skelet: $\quad 615$

Population: Rheine

Seite:

links

\section{Verband:}

\section{Alter:}

Verband

$10-25$

Geschlecht:

Arthrose:
Ges./Kr.: Gesund

\section{Maß}

Dicke

Länge

Wert 1 Einheit

$10,63 \mathrm{~mm}$

62

$\mathrm{mm}$

\section{Beschreibung:}

Dieses Fragment einer linken Clavicula ist einem nicht ausgewachsenen Individuum zuzuordnen. Es finden sich bereits ausgeprägte Muskelmarken. 


\section{Bezeichn.: Clavicula}

Kiste: 8

Skelet: ohne Nummer 3

Population: Rheine

Seite:

links
Verband: $\quad$ Verband

Alter: Erwachsen

Geschlecht:

Arthrose:
Ges./Kr.: Krank

Krankh.: Enthesiopathie

\section{Beschreibung:}

Diese Clavicula ist in Form von Fragmenten erhalten, der M. deltoideus hat auf die Knochenstruktur eingewirkt und eine leichte Enthesiopathie hinterlassen. 


\section{Bezeichn.: Clavicula}

Verband: $\quad$ Verband

\section{Alter:}

Geschlecht:

Arthrose:

Population: Rheine

Seite: rechts

\section{Beschreibung:}

Von dieser Clavicula sind die beiden Gelenkflächen etwas abfrakturiert. 


\section{Bezeichn.: Clavicula}

Kiste:

5

Skelet: $\quad$ 3610/1 S3 20.07.831753

Population: Rheine

Seite:

links

\section{Verband: $\quad$ Verband}

Alter: $\quad 10-25$

Geschlecht:

Arthrose:

\section{Beschreibung:}

Diese Clavicula der linken Seite ist einem jungen Individuum zuzuordnen. 
Bezeichn.: Scapula

Kiste:

Skelet: 1363

Population: Rheine

Seite:

links

\section{Verband:}

Verband

\section{Alter:}

Geschlecht:

Arthrose:

\section{Beschreibung:}

Hier ist ein Fragment einer linken Scapula mit etwa 20\% Größe erhalten. Es enthält den Processus coracoideus. 


\section{Bezeichn.: Scapula}

Kiste:

Skelet: 1199

Population: Rheine

Seite:

rechts
Verband: $\quad$ Verband

Ges./Kr.: Gesund

\section{Alter:}

Geschlecht:

Arthrose:

\section{Beschreibung:}

Dies ist ein kleines Fragment einer Scapula der rechten Seite, welche stark erodiert ist und keine Cavitas glenoidalis enthält. 


\section{Bezeichn.: Scapula}

Verband:

Verband

Alter:

Ges./Kr.: Gesund

Kiste:

5

Skelet: $\quad$ 3610/1 S3 20.07.831692

Population: Rheine

Seite:

links

\section{Geschlecht:}

Arthrose:

\section{Beschreibung:}

Hier ist nur ein kleines Fragment des Margo lateralis erhalten 
Bezeichn:: Scapula

Kiste:

Verband:

Verband

Alter:

Geschlecht:

Arthrose:

Population: Rheine
Ges./Kr.: Krank

Krankh.: Arthrose

Seite:

links

\section{Beschreibung:}

Mehrere Fragmente einer linken Scapula. 


\begin{tabular}{|c|c|c|c|c|c|c|c|c|}
\hline Bezeichn.: & Humerus & Verband: & Verband & Ges./Kr.: & Krank & Maß & Wert & Einheit \\
\hline Kiste: & 6 & Alter: & & Krankh.: & Muskelreizung & Breite & 23 & $\mathrm{~mm}$ \\
\hline Skelet: & 583 & Geschlecht: & & & Myotendopathie & gr. Länge & 55 & $\mathrm{~mm}$ \\
\hline Population: & Rheine & Arthrose: & & & & & & \\
\hline Seite: & links & & & & & & & \\
\hline Erhaltung: & $\square$ prox. Gelenk & & & & & & & \\
\hline & $\mathbf{X}$ prox. Schaft & & & & & & & \\
\hline & $\square$ mittl. Schaft & & & & & & & \\
\hline & $\square$ dist. Schaft & & & & & & & \\
\hline & $\square$ dist. Gelenk & & & & & & & \\
\hline
\end{tabular}

Beschreibung:

Anterior proximales Fragment eines linken Humerus mit einer Reizung des latissimus dorsi in Form eines osteoklastischen Prozesses. Es liegt eine leichte Myotendopathie vor. 
Bezeichn.: Humerus

Kiste:

Skelet: 211

Population: Rheine

Seite: rechts

Erhaltung: $\square$ prox. Gelenk

prox. Schaft

mittl. Schaft

$X$ dist. Schaft

dist. Gelenk
Verband: $\quad$ Verband

\section{Alter:}

Geschlecht:

Arthrose:

\section{Beschreibung:}

Mehrere Fragmente eines Humerus der rechten Seite. Es ist etwa 2/5 des distalen Knochens erhalten. Es handelt sich um frakturierte und erodierte Fundstücke. 


$\begin{array}{ll}\text { Bezeichn.: } & \text { Humerus } \\ \text { Kiste: } & 1 \\ \text { Skelet: } & 5 / 83 \\ \text { Population: } & \text { Rheine } \\ \begin{array}{ll}\text { Seite: } & \text { rechts } \\ \text { Erhaltung: } & \square \text { prox. Gelenk } \\ & \square \text { prox. Schaft } \\ & \text { X mittl. Schaft } \\ & \square \text { dist. Schaft } \\ & \square \text { dist. Gelenk }\end{array} \\ \text { Beschreibung: }\end{array}$

Verband: $\quad \square$ Verband

Alter:

Geschlecht:

Arthrose:
Maß

gr. Länge

Umfang Schaftmitte

\begin{tabular}{|l|l} 
Wert & Einheit \\
\hline 82,3 & $\mathrm{~mm}$
\end{tabular}

72

Wohl ein Fragment eines rechten Os humeri. 
Bezeichn.: Humerus

\section{Kiste:}

8

Skelet: ohne Nummer

Population: Rheine

\section{Erhaltung:}

prox. Gelenk

prox. Schaft

X mittl. Schaft

dist. Schaft

dist. Gelenk

Beschreibung:

Ein kleines Fragment.
Verband: $\quad \square$ Verband

\section{Alter:}

Geschlecht:

Arthrose: 
Bezeichn.: Humerus

Kiste:

Skelet: 1079/1

Population: Rheine
Verband: $\quad$ Verband

Alter: Jung

Geschlecht:

Arthrose:

\section{Erhaltung: $\square$ prox. Gelenk prox. Schaft \\ mittl. Schaft \\ dist. Schaft X dist. Gelenk}

Beschreibung:

Hier ist nur die distale Epiphyse eines jungen Os humeri erhalten, welche aufgrund von Bodenerosion nicht weiter befundbar ist. 

Bezeichn.: Ulna
Kiste:
Skelet: $\quad 958$
Population: Rheine
Seite: links
Erhaltung: $\square$ prox. Gelenk prox. Schaft
$X$ mittl. Schaft
$\mathbf{X}$ dist. Schaft dist. Gelenk
Beschreibung:

Verband:

\section{Alter:}

Geschlecht:

Ein stark erodiertes Fragment eines distalen Ulnaschafts.
Verband

\section{Ges./Kr.: Gesund}

\section{Maß}

Länge Wert $\mid$ Einheit

Arthrose: 


$\begin{array}{ll}\text { Bezeichn.: } & \text { Ulna } \\ \text { Kiste: } & 3 \\ \text { Skelet: } & 1167 \\ \text { Population: } & \text { Rheine } \\ \begin{array}{ll}\text { Seite: } & \text { rechts } \\ \text { Erhaltung: } & \square \text { prox. Gelenk } \\ & \square \text { prox. Schaft } \\ & \quad \mathbf{X} \text { mittl. Schaft } \\ & \mathbf{X} \text { dist. Schaft } \\ & \square \text { dist. Gelenk }\end{array} \\ \text { Beschreibung: }\end{array}$

Verband: $\quad \square$ Verband

Alter:

Geschlecht:

\section{Arthrose:}

Dieses Fundstück stammt vom mittigen bis distalen Schaft einer Ulna. Es ist erodiert. 

Bezeichn.: Ulna
Kiste: $\quad 7$
Skelet: 1096
Population:
Seite: rechts
Erhaltung: $\mathbf{X}$ prox. Gelenk
X prox. Schaft
mittl. Schaft
dist. Schaft
dist. Gelenk

Verband:

Verband

Alter:

Ges./Kr.: Gesund

Maß

Breite

Länge

Geschlecht:

Arthrose:

\section{Beschreibung:}

Dies ist ein Fragment einer Ulna der rechten Seite, welche zu einem nicht ausgewachsenen Individuum gehört. Es ist der proximale Teil der Metaphyse erhalten, die Epiphyse fehlt allerdings. 


\section{Bezeichn.: Ulna}

Kiste: 6

Skelet: a 1276

Population: Rheine

Seite: rechts

Erhaltung: $\square$ prox. Gelenk

$X$ prox. Schaft

$X$ mittl. Schaft

$\mathbf{X}$ dist. Schaft

dist. Gelenk

\section{Beschreibung:}

Ein Fragment aus dem Schaft einer rechten Ulna, welches im Bereich der Membrana interossea eine Enthesiopathie aufweist.

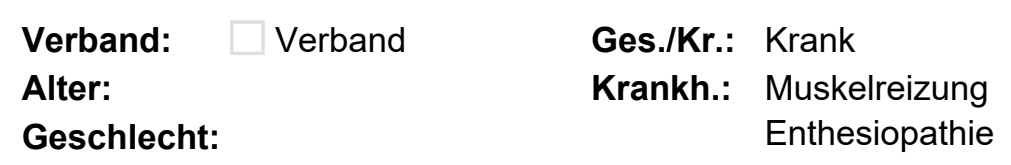

\section{Arthrose:}




$\begin{array}{ll}\text { Bezeichn.: } & \text { Radius } \\ \text { Kiste: } & 10 \\ \text { Skelet: } & 277 \\ \text { Population: } & \text { Rheine } \\ \begin{array}{ll}\text { Seite: } & \text { rechts } \\ \text { Erhaltung: } & \mathbf{X} \text { prox. Gelenk } \\ & \mathbf{X} \text { prox. Schaft } \\ & \square \text { mittl. Schaft } \\ & \square \text { dist. Schaft } \\ & \square \text { dist. Gelenk }\end{array} \\ \text { Beschreibung: }\end{array}$

Verband: $\quad$ Verband

\section{Alter:}

Geschlecht:

Arthrose:

Beschreibun

Hier ist nur ein proximales Fragment dieses Radius erhalten. Es ist erodiert und nicht befundbar. 


$\begin{array}{ll}\text { Bezeichn.: } & \text { Radius } \\ \text { Kiste: } & 6 \\ \text { Skelet: } & 1344 \\ \text { Population: } & \text { Rheine } \\ \begin{array}{ll}\text { Seite: } & \text { links } \\ \text { Erhaltung: } & \square \text { prox. Gelenk } \\ & \square \text { prox. Schaft } \\ & \square \text { mittl. Schaft } \\ & \text { X dist. Schaft } \\ & \square \text { dist. Gelenk }\end{array}\end{array}$

Verband: $\quad$ Verband

Alter:

Geschlecht:

Arthrose:

Dieses Fundstück ist das distale Drittel des Schaftes eines linken Radius. 


\section{Bezeichn.: Radius}

\section{Kiste:}

Skelet: $\quad 554$

Population: Rheine

\section{Erhaltung:}

prox. Gelenk

prox. Schaft

X mittl. Schaft

dist. Schaft

dist. Gelenk

Beschreibung:

Ein Fragment aus dem Schaft eins Radius.
Verband: $\quad \square$ Verband

\section{Alter:}

Geschlecht:

Arthrose:
Ges./Kr.: Gesund

\section{Maß}

Länge

\begin{tabular}{|l|l} 
Wert & Einheit
\end{tabular}

\begin{tabular}{l|l}
62 & $\mathrm{~mm}$
\end{tabular}




$\begin{array}{ll}\text { Bezeichn.: } & \text { Radius } \\ \text { Kiste: } & 7 \\ \text { Skelet: } & 1059 \\ \text { Population: } & \text { Rheine } \\ \text { Seite: } & \text { links } \\ \text { Erhaltung: } & \square \text { prox. Gelenk } \\ & \mathbf{X} \text { prox. Schaft } \\ & \mathbf{X} \text { mittl. Schaft } \\ & \mathbf{X} \text { dist. Schaft } \\ & \square \text { dist. Gelenk }\end{array}$

\section{Verband: $\quad \square$ Verband Ges./Kr.: Gesund}

Es handelt sich hier um ein Fragment aus der Mitte eines linken Radius, bei dem eine gut erhaltene Oberfläche vorliegt und der Ursprung des M. pronator teres gut ausgeprägt ist. 


\section{Bezeichn.: Radius}

Verband: $\quad$ Verband

\section{Alter:}

Geschlecht:

Arthrose:

Population: Rheine

Seite: rechts

Erhaltung: $\square$ prox. Gelenk

prox. Schaft

mittl. Schaft

dist. Schaft X dist. Gelenk

Beschreibung:

Es ist ein kleines distales Fragment dieses rechten Radius erhalten.
Ges./Kr.: Gesund

\section{Maß}

Länge

Wert $\quad$ Einheit

\begin{tabular}{l|l}
25 & $\mathrm{~mm}$
\end{tabular}




$\begin{array}{ll}\text { Bezeichn.: } & \text { Radius } \\ \text { Kiste: } & 7 \\ \text { Skelet: } & 1237 \\ \text { Population: } & \text { Rheine } \\ \text { Seite: } & \text { links } \\ \text { Erhaltung: } & \square \text { prox. Gelenk } \\ & \mathbf{X} \text { prox. Schaft } \\ & \mathbf{X} \text { mittl. Schaft } \\ & \mathbf{X} \text { dist. Schaft } \\ & \square \text { dist. Gelenk }\end{array}$

Verband: $\quad$ Verband Ges./Kr.: Gesund Alter:

Geschlecht:

Arthrose:

\section{Beschreibung:}

Ein Fragment aus dem Schaft eines Radius der linken Seite. Es ist verhältnismäßig wenig erodiert. 


$\begin{array}{ll}\text { Bezeichn.: } & \text { Radius } \\ \text { Kiste: } & 1 \\ \text { Skelet: } & 454 \\ \text { Population: } & \text { Rheine } \\ \begin{array}{ll}\text { Seite: } & \text { rechts } \\ \text { Erhaltung: } & \square \text { prox. Gelenk } \\ & \square \text { prox. Schaft } \\ & \square \text { mittl. Schaft } \\ & \mathbf{X} \text { dist. Schaft } \\ & \mathbf{X} \text { dist. Gelenk }\end{array} \\ \text { Beschreibung: }\end{array}$

Verband: $\square$ Verband

\section{Alter:}

Geschlecht:

Arthrose:

Ein distales Fragment eines Radius, der erodiert ist. 


$\begin{array}{ll}\text { Bezeichn.: } & \text { Radius } \\ \text { Kiste: } & 6 \\ \text { Skelet: } & 547 \\ \text { Population: } & \text { Rheine } \\ \begin{array}{ll}\text { Seite: } & \text { links } \\ \text { Erhaltung: } & \square \text { prox. Gelenk } \\ & \text { X prox. Schaft } \\ & \square \text { mittl. Schaft } \\ & \square \text { dist. Schaft } \\ & \square \text { dist. Gelenk }\end{array}\end{array}$

Verband: $\quad \square$ Verband

Alter:

Geschlecht:

Arthrose:

Ein proximales Fragment aus dem Schaft eines linken Radius. 
Bezeichn.: Os Pisiforme

Kiste: 3

Skelet: 1158

Population: Rheine

Seite:

links
Verband:

Verband

\section{Alter:}

Geschlecht:

Arthrose:

\section{Beschreibung:}

Ges./Kr.: Gesund

Maß

Länge Wert $\quad$ Einheit

$10,89 \mathrm{~mm}$


Bezeichn.: Os Triquetrum

Kiste:

Skelet: 1079/9

Population: Rheine
Verband:

Verband

\section{Alter:}

Geschlecht:

Arthrose:

\section{Beschreibung:}


Bezeichn:: Os Metacarpale

Kiste:

6

Skelet: $\quad 601$

Population: Rheine
Verband: $\quad$ Verband

Alter: $3-6$

Geschlecht:

Arthrose:

\section{Beschreibung:}

Ges./Kr.: Gesund

Dieses Fragment stammt von einem Os metacarpale eines jungen Individuums, was in den Bereich Infans Ib einzuordnen ist. 
Bezeichn.: Os Metacarpale Kiste:

Skelet: $\quad 5.5 .834002$

Population: Rheine
Verband: Verband

\section{Alter:}

Geschlecht:

Arthrose:

\section{Beschreibung:}

Leichenbrand. 


\section{Bezeichn.: Os Coxae}

\section{Kiste:}

Skelet: 1364

Population: Rheine

Seite:

links
Verband: Verband

\section{Alter:}

Geschlecht:

Arthrose:
Maß

Breite

Länge
Wert $\quad$ Einheit

$31 \quad \mathrm{~mm}$

$61 \mathrm{~mm}$

\section{Beschreibung:}

Zwei Fragmente eines linken Beckens, einer wohl bei Linea arcuata. Ein weiterer länglicher unbekannter Herkunft. 


\section{Bezeichn.: Os Coxae}

Kiste:

Skelet: 558

Population: Rheine
Verband: $\square$ Verband

\section{Alter:}

Geschlecht:

Arthrose:
Ges./Kr.: Gesund

\section{Maß}

Breite

Länge \begin{tabular}{|l|l} 
Wert & Einheit \\
\hline 17,63 & mm
\end{tabular}

$17,63 \mathrm{~mm}$

$61,7 \mathrm{~mm}$

\section{Beschreibung:}

Kleines Fragment eines Beckens mit Beteiligung der Linea arcuata. 


$\begin{array}{ll}\text { Bezeichn.: } & \text { Femur } \\ \text { Kiste: } & 10 \\ \text { Skelet: } & 1076 \\ \text { Population: } & \text { Rheine } \\ \begin{array}{ll}\text { Seite: } & \text { rechts } \\ \text { Erhaltung: } & \square \text { prox. Gelenk } \\ & \square \text { prox. Schaft } \\ & \square \text { mittl. Schaft } \\ & \square \text { dist. Schaft } \\ & \mathbf{X} \text { dist. Gelenk }\end{array} \\ \text { Beschreibung: }\end{array}$

\section{Verband: \\ Verband}

Alter: Jung

Geschlecht:

Arthrose:

Von diesem Os femoris ist nur die distale Epiphyse zu 30\% erhalten. Es handelt sich um ein junges Individuum.

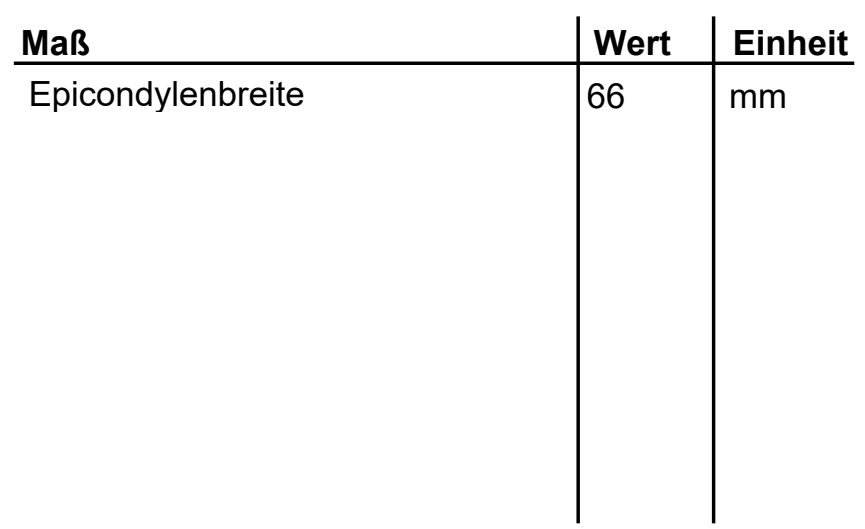




$\begin{array}{ll}\text { Bezeichn.: } & \text { Femur } \\ \text { Kiste: } & 10 \\ \text { Skelet: } & 1669 \\ \text { Population: } & \text { Rheine } \\ \text { Seite: } & \text { links } \\ \text { Erhaltung: } & \square \text { prox. Gelenk } \\ & \square \text { prox. Schaft } \\ & \mathbf{X} \text { mittl. Schaft } \\ & \square \text { dist. Schaft } \\ & \square \text { dist. Gelenk }\end{array}$

Verband: $\quad \square$ Verband Ges./Kr.: Gesund

Alter: Jung

Geschlecht:

Arthrose:

\section{Beschreibung:}

Es handelt sich hier um ein mittleres Fragment eines nicht erwachsenen Os femoris. Das Fragment weist deutliche Spuren von Bodenerosion auf. 
Bezeichn:: Femur

\section{Kiste:}

Skelet: $\quad 903$

Population: Rheine

Seite: rechts

Erhaltung: $\square$ prox. Gelenk prox. Schaft $X$ mittl. Schaft dist. Schaft dist. Gelenk

Beschreibung:

Fragment.
Verband:

Verband

\section{Alter:}

Geschlecht:

Arthrose:
Ges./Kr.: Gesund

Ges./Kr:: Gesund 
Bezeichn.: Femur

\section{Kiste:}

Skelet: $\quad 852$

Population: Rheine
Verband:

Verband

\section{Alter:}

Geschlecht:

Arthrose:

\section{Erhaltung: $\square$ prox. Gelenk prox. Schaft $X$ mittl. Schaft dist. Schaft dist. Gelenk}

\section{Beschreibung:}

Dieses Fragment ist nicht genau zuzuordnen. Es ist sehr klein. 


$\begin{array}{ll}\text { Bezeichn.: } & \text { Femur } \\ \text { Kiste: } & 6 \\ \text { Skelet: } & 643 \\ \text { Population: } & \text { Rheine } \\ \text { Seite: } \quad \text { links } \\ \begin{array}{ll}\text { Erhaltung: } & \square \text { prox. Gelenk } \\ & \square \text { prox. Schaft } \\ & \text { X mittl. Schaft } \\ & \square \text { dist. Schaft } \\ & \square \text { dist. Gelenk }\end{array} \\ \text { Beschreibung: }\end{array}$

\section{Verband: \\ Verband}

\section{Alter:}

Geschlecht:

Arthrose:

Ein nicht erodiertes Fragment eines linken Os femoris aus dem Schaft mit foramen nutricium und Linea aspera. 


\section{Bezeichn: Femur \\ Kiste:}

Skelet: $\quad 553$

Population: Rheine
Verband:

Verband

Ges./Kr.: Gesund

\section{Alter:}

Geschlecht:

Arthrose:

\section{Erhaltung: $\square$ prox. Gelenk \\ prox. Schaft \\ $X$ mittl. Schaft \\ dist. Schaft \\ dist. Gelenk}

\section{Beschreibung:}

Ein kleines Fragment eines Os femoris, wessen Seite nicht bestimmbar ist. Es weist kaum Erosionsspuren auf. 


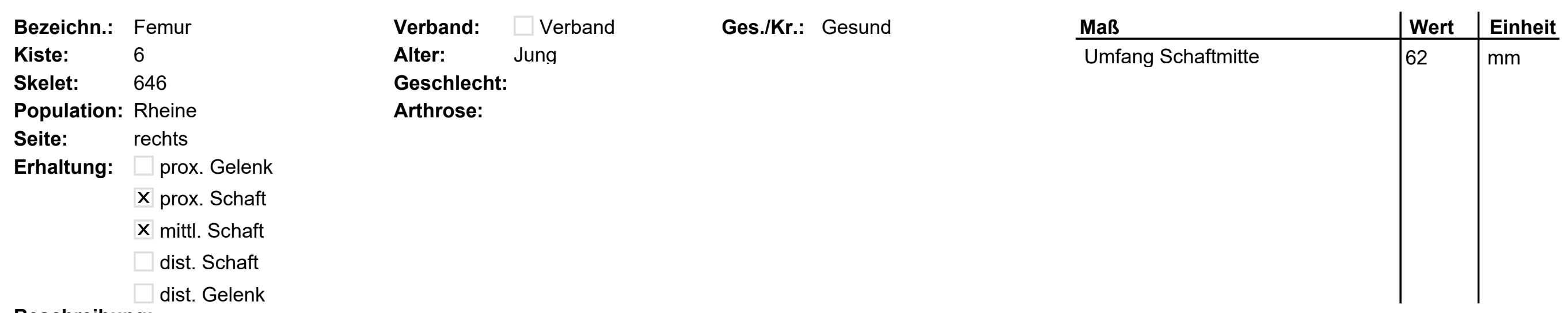

\section{Beschreibung:}

Es handelt sich hier um zwei Fragmente, wobei eines einem nicht erwachsenen Trochanter major eines rechten Os femoris zuzuordnen ist. Das größere Fragment ist der Schaft des Femurs, es ist insgesamt etwa die Hälfte des Knochens erhalten. 


$\begin{array}{lllll}\text { Bezeichn.: } & \text { Femur } & \text { Verband: } \square \text { Verband } & \text { Ges./Kr.: Gesund } & \text { Maß } \\ \text { Kiste: } & 6 & \text { Alter: } & \text { Uert } & \text { Einheit } \\ \text { Skelet: } & 1495 & \text { Geschlecht: } & & \text { mm } \\ \text { Population: } & \text { Rheine } & \text { Arthrose: } & \\ \text { Seite: } & \text { rechts } & & \\ \text { Erhaltung: } & \square \text { prox. Gelenk } & & \\ & \square \text { prox. Schaft } & & \\ & \square \text { mittl. Schaft } & & \\ & \mathbf{X} \text { dist. Schaft } & & \\ & \square \text { dist. Gelenk } & & \end{array}$

Beschreibung:

Hier ist ein erodiertes und frakturiertes Fragment eines rechten Femurs erhalten. Das Fragment stammt aus dem distalen Schaftanteils. Es macht etwa $1 / 7$ des gesamten Knochens aus. 
Bezeichn:: Femur

Kiste:

Skelet: a 205

Population: Rheine

Seite: rechts

Erhaltung: $\square$ prox. Gelenk

prox. Schaft

$X$ mittl. Schaft

dist. Schaft

dist. Gelenk

\section{Beschreibung:}

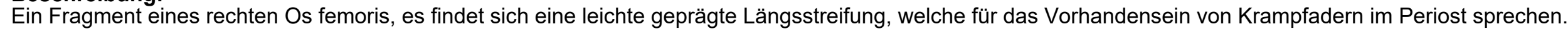

\section{Verband: \\ Alter:}

Geschlecht:

Arthrose:
Ges./Kr.: Krank

Krankh.: Impressionen tiefer

Krampfadern 

Bezeichn.: Femur

Kiste: 1
Skelet: 3009
Population: Rheine
Seite: links
Erhaltung: $\square$ prox. Gelenk
prox. Schaft
$X$ mittl. Schaft
dist. Schaft$$
\text { dist. Gelenk }
$$
Beschreibung:

Ein stark erodiertes und nicht befundbares Fragment eines linken Os femoris

\section{Alter:}

Geschlecht:

Arthrose:

\section{Verband: $\square$ Verband}

Maß

Umfang Schaftmitte

\begin{tabular}{|l|l} 
Wert & Einheit \\
\hline 77 & $\mathrm{~mm}$ \\
& \\
&
\end{tabular}




\section{Bezeichn.: Femur}

Kiste:

Skelet: $\quad 276$

Population: Rheine

Seite: links

Erhaltung: $\square$ prox. Gelenk

prox. Schaft

mittl. Schaft

dist. Schaft

$X$ dist. Gelenk

\section{Beschreibung:}

Fragment eines linken Femurs. Es handelt sich um ein Fragment des Condylus, welches erodiert und nicht befundbar ist.
Verband: $\quad$ Verband

\section{Alter:}

Geschlecht:

Arthrose: 


$\begin{array}{ll}\text { Bezeichn.: } & \text { Femur } \\ \text { Kiste: } & 1 \\ \text { Skelet: } & 206 \\ \text { Population: } & \text { Rheine } \\ \begin{array}{ll}\text { Seite: } & \text { rechts } \\ \text { Erhaltung: } & \square \text { prox. Gelenk } \\ & \square \text { prox. Schaft } \\ & \text { X mittl. Schaft } \\ & \square \text { dist. Schaft } \\ & \square \text { dist. Gelenk }\end{array}\end{array}$

Verband: $\quad$ Verband

Alter:

Geschlecht:

Arthrose:

Fragment eines Femurs und kleine Splitter.

Ges./Kr.: Gesund

Maß

Umfang Schaftmitte
Wert 1 Einheit

\begin{tabular}{l|l|l}
85 & $\mathrm{~mm}$
\end{tabular}


Bezeichn:: Femur

\section{Kiste:}

Skelet: $\quad 5.5 .834002$

Population: Rheine

Seite: rechts

Erhaltung: $\square$ prox. Gelenk

X prox. Schaft

mittl. Schaft

dist. Schaft

dist. Gelenk

\section{Beschreibung:}

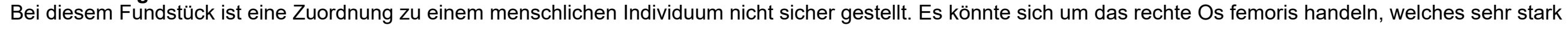

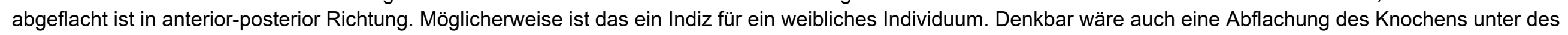
Drucks der Erdflächen über ihm. 
Bezeichn:: Femur

\section{Kiste:}

Skelet: $\quad 3610 / 1$ S3 01.06.83156

Population: Rheine

Seite: rechts

Erhaltung: $\square$ prox. Gelenk

X prox. Schaft

mittl. Schaft

dist. Schaft

dist. Gelenk

\section{Beschreibung:}

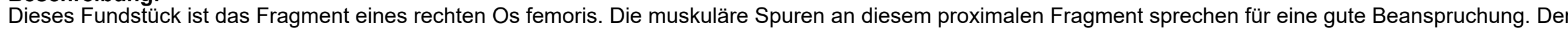

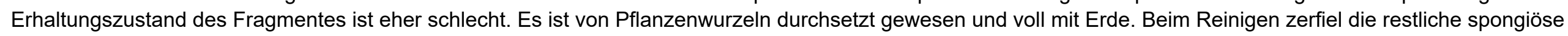

Struktur, sodass auf weiteres Reinigen verzichtet wurde 
Bezeichn:: Femur

\section{Kiste:}

Skelet: $\quad 3610 / 1$ S3 11.05.83 a 5

Population: Rheine

Seite: $\quad \mathrm{n}$. def.

Erhaltung: $\square$ prox. Gelenk

prox. Schaft

$X$ mittl. Schaft

dist. Schaft

dist. Gelenk
Verband: $\quad$ Verband

\section{Alter:}

Geschlecht:

Arthrose:

\section{Beschreibung:}

Dieses Fundstück eines Femurs ist nicht weiter befundbar, da die Bodenerosion die Oberfläche zu stark beschädigt hat. 


$\begin{array}{ll}\text { Bezeichn.: } & \text { Femur } \\ \text { Kiste: } & 9 \\ \text { Skelet: } & \text { MKZ 3610,1 } \\ \text { Population: } & \text { Rheine } \\ \text { Seite: } & \text { links } \\ \text { Erhaltung: } & \square \text { prox. Gelenk } \\ & \text { X prox. Schaft } \\ & \text { X mittl. Schaft } \\ & \square \text { dist. Schaft } \\ & \square \text { dist. Gelenk }\end{array}$

\section{Verband: $\quad \square$ Verband Ges./Kr.: Gesund}

\section{Alter:}

\section{Geschlecht:}

Hier sind vier Fragmente eines linken Os femoris erhalten, die aber weniger als die Hälfte des Knochens ausmachen. 
Bezeichn.: Patella

Kiste:

Skelet: 28.6 .83

Population: Rheine

Seite:

n. def.
Verband: Verband

\section{Alter:}

Geschlecht:

Arthrose:

\section{Beschreibung:}

Diese Patella ist nur zu etwa 65\% erhalten und stark erodiert. Sie ist deswegen nicht befundbar. 


\section{Bezeichn.: Tibia \\ Kiste: \\ 10 \\ Skelet: $\quad 278$}

Population: Rheine

Seite: rechts

Erhaltung: $\square$ prox. Gelenk

$X$ prox. Schaft

$\mathbf{X}$ mittl. Schaft

dist. Schaft dist. Gelenk

\section{Beschreibung:}

Ein Fragment aus dem proximalen Schaft einer Tibia, es ist etwa 1/3 erhalten.

\section{Alter:}

Geschlecht:

Arthrose:
Ges./Kr.: Gesund

\begin{tabular}{l|l|l} 
Maß & Wert & Einheit \\
\hline gr. Länge & 133 & $\mathrm{~mm}$ \\
Schaftumfang Foramen & 90 & $\mathrm{~mm}$ \\
& & \\
& & \\
& &
\end{tabular}




\begin{tabular}{|c|c|c|c|c|c|c|}
\hline Bezeichn.: & Tibia & Verband: $\quad \square$ Verband & Ges./Kr.: Krank & Maß & Wert & Einheit \\
\hline Kiste: & 10 & Alter: & Krankh.: Periostreizung & gr. Länge & 170 & $\mathrm{~mm}$ \\
\hline Skelet: & 1669 & Geschlecht: & & Umfang Schaftmitte & 85 & $\mathrm{~mm}$ \\
\hline Population: & Rheine & Arthrose: & & & & \\
\hline Seite: & rechts & & & & & \\
\hline Erhaltung: & $\square$ prox. Gelenk & & & & & \\
\hline & $\mathbf{X}$ prox. Schaft & & & & & \\
\hline & $\mathbf{X}$ mittl. Schaft & & & & & \\
\hline & $\square$ dist. Schaft & & & & & \\
\hline & $\square$ dist. Gelenk & & & & & \\
\hline
\end{tabular}

\section{Beschreibung:}

Dies ist ein Fragment des distalen Schaftes einer Tibia. Eine oberflächliche Streifung deutet auf eine Periostreizung hin, welche im Zuge von Muskelüberbeanspruchung entstanden sein könnte. 


$\begin{array}{ll}\text { Bezeichn.: } & \text { Tibia } \\ \text { Kiste: } & 3 \\ \text { Skelet: } & 932 \\ \text { Population: } & \text { Rheine } \\ \text { Seite: } & \text { links } \\ \text { Erhaltung: } & \square \text { prox. Gelenk } \\ & \text { X prox. Schaft } \\ & \text { X mittl. Schaft } \\ & \text { X dist. Schaft } \\ & \square \text { dist. Gelenk }\end{array}$

Ges./Kr.: Krank

Alter: Krankh.: Periostreizung

Alter:

Geschlecht:

Arthrose:

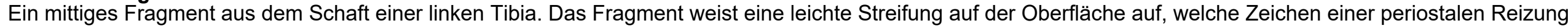
aufgrund von Muskelüberreizung ist. 

Bezeichn.: Tibia

Kiste: 6
Skelet: 598
Population: Rheine
Seite: links
Erhaltung: $\square$ prox. Gelenk
$X$ prox. Schaft
$X$ mittl. Schaft
$\mathbf{X}$ dist. Schaft
$\square$ dist. Gelenk

Verband:

Verband

Ges./Kr.: Krank

Alter:

Krankh.: Periostreizung

$\frac{\text { Maß }}{\text { gr. Länge }}$

Geschlecht:

Arthrose:

\section{Beschreibung:}

Diese Fragmente einer linken Tibia weisen eine intravital entstandene Längsstreifung auf, welche für eine muskuläre Reizung spricht. 

Bezeichn.: Tibia
Kiste:

6
Skelet: 1515
Population: Rheine
Seite: n. def.
Erhaltung: $\square$ prox. Gelenk
prox. Schaft
$X$ mittl. Schaft
dist. Schaft

$$
\text { dist. Gelenk }
$$

Verband: $\quad \square$ Verband

\section{Alter:}

Geschlecht:

Arthrose:

\section{Beschreibung:}

Ein anteriores Fragment einer Tibia, die Seite ist nicht zu bestimmen.

$48,38 \mathrm{~mm}$




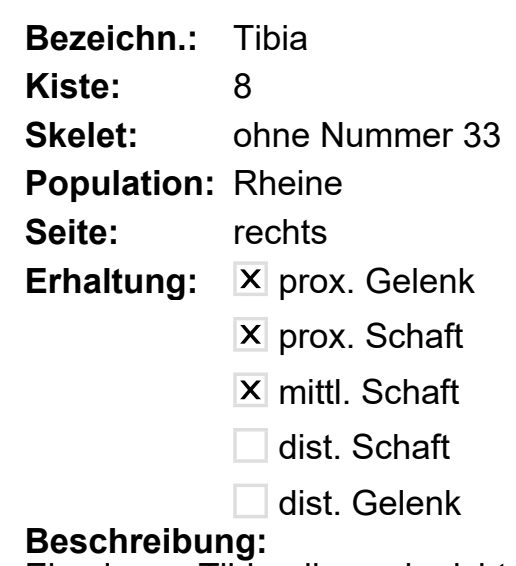

\section{Beschreibung:}

Verband: $\quad \square$ Verband

Alter: $\quad 1,5-2,5$

\section{Geschlecht:}

Arthrose:

\section{Maß}

gr. Breite prox. Gelenk

gr. Länge

Schaftumfang Foramen

\begin{tabular}{|l|l}
\hline Wert & Einheit \\
\hline 27 & $\mathrm{~mm}$ \\
119,7 & $\mathrm{~mm}$ \\
55 & $\mathrm{~mm}$ \\
& \\
\end{tabular}

Eine junge Tibia, die noch nicht vollständig ausgewachsen war. Sie ist der rechten Körperseite zuzuordnen, ist sehr stark erodiert und wurde mit Bewuchs geborgen. Weitere Befundung ist leider nicht möglich. 
Bezeichn.: Tibia

Kiste:

Skelet: 207

Population: Rheine

Seite: rechts

Erhaltung: $\square$ prox. Gelenk

X prox. Schaft

mittl. Schaft

dist. Schaft

dist. Gelenk

Beschreibung:

Mehrere Fragmente einer Tibia, welche stark erodiert sind.

\section{Alter:}

Geschlecht:

Arthrose:

Verband: $\quad$ Verband 


\section{Bezeichn:: Tibia}

\section{Kiste:}

Skelet: $\quad 4.7 .83851$

Population: Rheine

Seite: links

Erhaltung: $\square$ prox. Gelenk

prox. Schaft

$X$ mittl. Schaft

dist. Schaft

$\mathbf{X}$ dist. Gelenk

$\begin{array}{ll}\text { Verband: } \quad \square \text { Verband } \quad \text { Ges./Kr.: Krank } \\ \text { Alter: } & \text { Krankh.: Muskelreizung }\end{array}$

\title{
Geschlecht:
}

Arthrose:

dist.

1

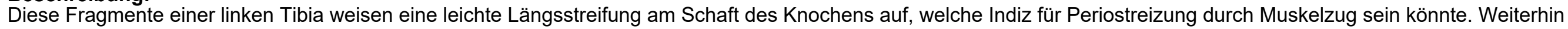
ist das distale Gelenk teilweise erhalten. Dieses ist jedoch unauffällig.
\end{abstract}




\begin{tabular}{|c|c|c|c|c|c|c|c|}
\hline Bezeichn.: & Tibia & Verband: & $\square$ Verband & Ges./Kr.: Krank & Maß & Wert & Einheit \\
\hline Kiste: & 5 & Alter: & & Krankh.: Muskelreizung & gr. Länge & 155 & $\mathrm{~mm}$ \\
\hline Skelet: & $3610 / 1$ S3 20.07.83 1648 & Geschlecht: & & & & & \\
\hline Population: & Rheine & Arthrose: & & & & & \\
\hline Seite: & rechts & & & & & & \\
\hline Erhaltung: & $\square$ prox. Gelenk & & & & & & \\
\hline & X prox. Schaft & & & & & & \\
\hline & $\square$ mittl. Schaft & & & & & & \\
\hline & $\square$ dist. Schaft & & & & & & \\
\hline & $\square$ dist. Gelenk & & & & & & \\
\hline
\end{tabular}

\section{Beschreibung:}

Diese Tibia der rechten Seite ist nur als zwei Fragmente erhalten, welche eher aus dem anterioren Schaft stammen. Es finden sich Längsstreifen am Schaft, die durch eine Muskelreizung entstanden sein könnten. 
Bezeichn: Fibula

Kiste: 3

Skelet: $\quad 1224$

Population: Rheine

\section{Verband:}

\section{Alter:}

Ges./Kr.: Gesund

Geschlecht:

Arthrose:

\begin{tabular}{l|l|l} 
Maß & Wert & Einheit \\
\hline Breite & 7,72 & $\mathrm{~mm}$ \\
Länge & 63,86 & $\mathrm{~mm}$ \\
& & \\
& & \\
& &
\end{tabular}

\section{Beschreibung:}

Erhaltung: $\square$ prox. Gelenk

prox. Schaft

$X$ mittl. Schaft

dist. Schaft

dist. Gelenk

Ein kurzes Fragment aus dem Schaft eines noch nicht ausgewachsenen Individuums. 
Bezeichn:: Fibula

\section{Kiste: 8}

Skelet: 209

Population: Rheine

Erhaltung: $\square$ prox. Gelenk prox. Schaft

$X$ mittl. Schaft dist. Schaft dist. Gelenk

\section{Beschreibung:}

Fibulafragment.
Verband: $\quad \square$ Verband

\section{Alter:}

Geschlecht:

Arthrose:
Maß

Länge

\begin{tabular}{l|l|l} 
Wert & Einheit \\
\hline 13,34 & $\mathrm{~mm}$
\end{tabular}




\section{Bezeichn.: Fibula}

Kiste:

Skelet: ohne Nummer

Population: Rheine

Seite: links

Erhaltung: $\square$ prox. Gelenk prox. Schaft $X$ mittl. Schaft dist. Schaft dist. Gelenk

\section{Beschreibung:}

Fibulafragment.

\section{Verband:}

Verband

\section{Alter:}

Geschlecht:

Arthrose:
Ges./Kr.: Gesund 


\section{Bezeichn.: Fibula}

Kiste:

Verband:

Verband

\section{Alter:}

Geschlecht:

Arthrose:

Population: Rheine
Ges./Kr.: Gesund

\section{Maß}

Länge

\begin{tabular}{|l|l} 
Wert & Einheit \\
\hline 52 & $\mathrm{~mm}$ \\
&
\end{tabular}

\section{Beschreibung:}

Erhaltung: $\square$ prox. Gelenk

prox. Schaft

$X$ mittl. Schaft

dist. Schaft

dist. Gelenk

Ein kleines Fragment Fibula, welches erodiert ist. 


\section{Bezeichn.: Fibula}

\section{Kiste:}

Skelet: $\quad 446$

Population: Rheine

\section{Erhaltung:}

prox. Gelenk

prox. Schaft

X mittl. Schaft dist. Schaft dist. Gelenk

Beschreibung:

Fragment.
Verband:

Verband

\section{Alter:}

Geschlecht:

Arthrose:
Ges./Kr.: Gesund 


\section{Bezeichn.: Talus}

Kiste:

Skelet: V31 897

Population: Rheine

Seite:

links

\section{Verband: $\quad$ Verband}

\section{Alter:}

Geschlecht: $q>\hat{\sigma}$

Arthrose:

\section{Beschreibung:}

Dieser Talus ist grazil, demnach eher weiblich. Er zeigt eine bröckelige Oberflächenstruktur und ist deswegen kaum befundbar. 
Bezeichn.: Talus

\section{Kiste:}

Skelet: 1074

Population: Rheine

Seite:

links
Verband:

Verband

\section{Alter:}

Geschlecht: $q>\lambda$

Arthrose:

prox.

dist.

$\Sigma$

\section{Beschreibung:}

Ein graziler Talus, der für weitere Befunde zu stark erodiert ist. 
Bezeichn.: Talus

Kiste:

Skelet: $\quad$ 3610/1 S3 20.07.831691

Population: Rheine

Seite:

links
Verband:

Verband

\section{Alter:}

Ges./Kr.: Gesund

Geschlecht:

Arthrose:

\section{Beschreibung:}

Ein kleines Fragment dieses Talus liegt hier vor. 
Bezeichn:: Calcaneus

Kiste:

Verband:

Verband

\section{Alter:}

Geschlecht:

Arthrose:

Population: Rheine
Ges./Kr.: Gesund

Seite: links

\section{Beschreibung:}

Dieser Calcaneus ist erodiert und deswegen nur bedingt befundbar. 
Bezeichn.: Calcaneus

\section{Kiste:}

Skelet: $\quad 28.6 .83$

Population: Rheine

Seite:
Verband:

Verband

\section{Alter:}

Geschlecht:

Arthrose:

\section{Beschreibung:}

Ein sehr stark erodierter Calcaneus. 
Bezeichn.: Calcaneus

\section{Kiste:}

Skelet: $\quad 28.6 .83$

Population: Rheine

Seite:

links
Verband:

Verband

\section{Alter:}

Geschlecht:

Arthrose:

\section{Beschreibung:}

Ein Fragment eines Calcaneus. 
Bezeichn:: Os Cuneiforme

Kiste:

Verband:

Verband

\section{Alter:}

Ges./Kr.: Gesund

Skelet: $\quad 3610 / 1$ S3 20.07.83 1703

Population: Rheine

Seite:

rechts

Geschlecht:

Arthrose:
Maß

Länge

Wert 1 Einheit

\section{Beschreibung:}


Bezeichn.: Os Naviculare

\section{Kiste:}

Skelet: 1095

Population: Rheine

Seite:

links
Verband: Verband

\section{Alter:}

Geschlecht:

Arthrose:

\section{Beschreibung:}

Ein Os naviculare der linken Seite. Es ist erodiert. 
Bezeichn:: Os Naviculare

\section{Kiste:}

Skelet: 1041

Population: Rheine

Seite:

rechts
Verband: Verband

\section{Alter:}

Geschlecht:

Arthrose:

\section{Beschreibung:}

Ein Os naviculare der rechten Seite. Es ist stark erodiert. 
Bezeichn:: Os Metatarsale

Kiste:

Skelet: 399

Population: Rheine

Seite:

links

\section{Verband:}

Verband

Ges./Kr.: Gesund

\section{Alter:}

Geschlecht:

Arthrose:

\section{Beschreibung:}

Ein Os metatarsale 1 der linken Seite, welches zwar erodiert, aber dennoch im Verhältnis gut erhalten ist. 
Bezeichn.: Knochenklein

\section{Kiste:}

Skelet: $\quad$ ohne Nummer 31.6 .83

Population: Rheine
Verband: $\quad$ Verband

\section{Alter:}

Geschlecht:

Arthrose:

\section{Beschreibung:}

Hier sind Knochensplitter von Becken und unterer Extremität erhalten, eines der Fragmente hat Bissspuren von Rudentiern. 
Bezeichn.: Knochenklein

Kiste:

Skelet: $\quad 211$

Population: Rheine
Verband: Verband

\section{Alter:}

Geschlecht:

Arthrose:

\section{Beschreibung:}

$3 g$ Knochensplitter, welche nicht zu identifizieren waren. 
Bezeichn.: Knochenklein

Kiste:

Skelet: $\quad 5 / 83$

Population: Rheine
Verband: Verband

\section{Alter:}

Geschlecht:

Arthrose:

\section{Beschreibung:}

$54 \mathrm{~g}$ Knochensplitter, welche nicht zuzuordnen sind. 
Bezeichn.: Knochenklein

Kiste:

Skelet: $\quad 3009$

Population: Rheine
Verband: Verband

\section{Alter:}

Geschlecht:

Arthrose:

\section{Beschreibung:}

Hier sind 46g Knochensplitter unter anderem mit kleinsten Fragmenten nach Leichenbrand erhalten 
Bezeichn.: Knochenklein

Kiste:

Skelet: 3004

Population: Rheine
Verband: Verband

\section{Alter:}

Geschlecht:

Arthrose:

\section{Beschreibung:}

$39 \mathrm{~g}$ Knochensplitter, die nicht weiter zuzuordnen sind. 
Bezeichn.: Knochenklein

Kiste:

Skelet: $\quad 5 / 83$

Population: Rheine
Verband:

Verband

\section{Alter:}

Geschlecht:

Arthrose:

\section{Beschreibung:}

90g Knochensplitter: Cranium und Langknochen. 
Bezeichn.: Knochenklein

Kiste:

Skelet: $\quad 361$

Population: Rheine
Verband: Verband

\section{Alter:}

Geschlecht:

Arthrose:

\section{Beschreibung:}

$20 \mathrm{~g}$ Knochensplitter, welche nicht eindeutig zuzuordnen waren 
Bezeichn.: Knochenklein

\section{Kiste: 7}

Skelet: Kiste $6.6-13.6 .83$

Population: Rheine
Verband: Verband

\section{Alter:}

Geschlecht:

Arthrose:

\section{Beschreibung:}

96g Knochensplitter, welche nicht genauer zuzuordnen waren. 
Bezeichn.: Knochenklein

Kiste:

Skelet: 209

Population: Rheine
Verband: $\quad$ Verband

\section{Alter:}

Geschlecht:

Arthrose:

\section{Beschreibung:}

$56 \mathrm{~g}$ Knochensplitter, welche nicht genauer zuzuordnen waren. Teilweise könnte es sich hier um Leichenbrand handeln. 
Bezeichn.: Knochenklein

Kiste:

Skelet: ohne Nummer 2

Population: Rheine
Verband: $\quad$ Verband

\section{Alter:}

Geschlecht:

Arthrose:

\section{Beschreibung:}

$20 \mathrm{~g}$ Knochensplitter, welche nicht genauer zuzuordnen waren. Mit Leichenbrand unter den Splittern. 
Bezeichn.: Knochenklein

Kiste:

Skelet: ohne Nummer 2

Population: Rheine
Verband: Verband

\section{Alter:}

Geschlecht:

Arthrose:

\section{Beschreibung:}

$60 \mathrm{~g}$ Knochensplitter, welche nicht genauer zuzuordnen waren. 
Bezeichn.: Knochenklein

Kiste:

Skelet: ohne Nummer 2

Population: Rheine
Verband: Verband

\section{Alter:}

Geschlecht:

Arthrose:

\section{Beschreibung:}

$11 \mathrm{~g}$ Knochensplitter, welche nicht genauer zuzuordnen waren. 
Bezeichn.: Knochenklein

\section{Kiste:}

Skelet: a 211

Population: Rheine
Verband: Verband

\section{Alter:}

Geschlecht:

Arthrose:

\section{Beschreibung:}

9g Knochensplitter, welche nicht eindeutig als menschliche Knochensplitter zu identifizieren waren. 
Bezeichn.: Knochenklein Kiste:

Skelet: $\quad 6.6 .833016$

Population: Rheine
Verband: Verband

\section{Alter:}

Geschlecht:

Arthrose:

\section{Beschreibung:}

94g Knochensplitter. 
Bezeichn.: Knochenklein Kiste:

Skelet: $\quad 10.5 .834007$

Population: Rheine
Verband: Verband

\section{Alter:}

Geschlecht:

Arthrose:

\section{Beschreibung:}

32g Knochensplitter. 
Bezeichn.: Knochenklein

Kiste:

Skelet: große Tüte

Population: Rheine
Verband: Verband

\section{Alter:}

Geschlecht:

Arthrose:

\section{Beschreibung:}

92g Knochensplitter, zum Teil nach Leichenbrand. 
Bezeichn.: Knochenklein Kiste: 2

Skelet: $\quad 17.5 .834012$

Population: Rheine
Verband: Verband

\section{Alter:}

Geschlecht:

Arthrose:

Beschreibung:

$37 g$ Knochensplitter aus Leichenbrand. 
Bezeichn.: Knochenklein Kiste:

Skelet: $\quad 5.5 .834002$

Population: Rheine

Verband: $\quad$ Verband

\section{Alter:}

Geschlecht:

Arthrose:

\section{Beschreibung:}

188g Knochensplitter. 
Bezeichn.: Knochenklein Kiste:

Skelet: $\quad 29.6 .83740$

Population: Rheine
Verband: Verband

\section{Alter:}

Geschlecht:

Arthrose:

\section{Beschreibung:}

$3 \mathrm{~g}$ Knochensplitter. 
Bezeichn.: Knochenklein

\section{Kiste:}

Skelet: $\quad 28.6 .83$

Population: Rheine

Beschreibung:

104g Knochensplitter.
Verband: Verband

\section{Alter:}

Geschlecht:

Arthrose: 
Bezeichn.: Knochenklein

Kiste: 5

Skelet: Kiste 20.07.83

Population: Rheine
Verband: Verband

\section{Alter:}

Geschlecht:

Arthrose:

\section{Beschreibung:}

83g Knochensplitter, die teilweise aus Leichenbrand stammen. 
Bezeichn.: Knochenklein

Verband: $\quad \square$ Verband

\section{Alter:}

Geschlecht:

Skelet: $\quad$ 3610/1 S3 20.07.831706

Population: Rheine

Arthrose:
Maß

Länge

\section{Beschreibung:}

Kleine Knochensplitter, teilweise aus Leichenbrand. 
Bezeichn.: Knochenklein

Kiste:

Skelet: $\quad 3610.11 .6 .83$ Knochen (a

Population: Rheine
Verband: Verband

\section{Alter:}

Geschlecht:

Arthrose:

\section{Beschreibung:}

Hier sind 10 kleine Splitter von Knochen erhalten, welche nicht zuzuordnen sind. 
Bezeichn.: Knochenklein

Kiste:

Skelet: $\quad$ 3610/1 S3 1.06.83162

Population: Rheine
Verband:

\section{Alter:}

Geschlecht:

Arthrose:

\section{Beschreibung:}

Splitter von Scapula, Femur und andere. 
Bezeichn.: Knochenklein

Kiste:

Skelet: aus kleinerer Kiste

Population: Rheine
Verband: Verband

\section{Alter:}

Geschlecht:

Arthrose:

\section{Beschreibung:}

$69 \mathrm{~g}$ Knochensplitter, welche teilweise aus Leichenbrand stammen. 
Bezeichn.: Knochenklein

Kiste:

Skelet: aus zweiter Kiste

Population: Rheine
Verband: Verband

\section{Alter:}

Geschlecht:

Arthrose:

\section{Beschreibung:}

$50 \mathrm{~g}$ Knochensplitter. 
Bezeichn.: Knochenklein

Kiste:

Skelet: $\quad 3610 / 1$ S3 17.05 .83 a 146

Population: Rheine
Verband: Verband

\section{Alter:}

Geschlecht:

Arthrose:

\section{Beschreibung:}

Splitter von Knochen aus Leichenbrand. 
Bezeichn.: Knochenklein

Kiste:

Skelet: $\quad$ einzelne Tüte in der Kiste

Population: Rheine
Verband: Verband

\section{Alter:}

Geschlecht:

Arthrose:

\section{Beschreibung:}

Diese Knochensplitter sind nicht zuzuordnen, es sind Zähne dabei, aber auch eventuell Tierknochen. Es handelt sich um 77g. 
Bezeichn:: Knochenklein

\section{Kiste:}

Skelet: $\quad 3610 / 1$ S3 11.05.83 a 46

Population: Rheine
Verband:

Verband

\section{Alter:}

Geschlecht:

Arthrose:
Beschreibung:

Splitter Costa.

\section{Ges./Kr.: Gesund}


Bezeichn.: Knochenklein Kiste:$$
9
$$

Skelet:

Population: Rheine
Verband: Verband

\section{Alter:}

Geschlecht:

Arthrose:

Beschreibung:

$5 \mathrm{~g}$ Knochensplitter. 
Bezeichn.: Knochenklein

Kiste:

Skelet: $\quad 13.15 .7 .83$

Population: Rheine
Verband:

Verband

\section{Alter:}

Geschlecht:

Arthrose:

\section{Beschreibung:}

101g Knochenklein in verschiedenen Tütchen. 
Bezeichn.: Knochenklein

Kiste:

Skelet: $\quad 4.5 .7 .83$

Population: Rheine
Verband: Verband

\section{Alter:}

Geschlecht:

Arthrose:

\section{Beschreibung:}

Insgesamt 50g Splitter, welche unkenntlich waren. 
Bezeichn.: Knochenklein

Kiste:

Skelet: $\quad 8.7 .83$

Population: Rheine
Verband: Verband

\section{Alter:}

Geschlecht:

Arthrose:

\section{Beschreibung:}

51g Knochensplitter, welche nicht zuzuordnen sind. 
Bezeichn.: Knochenklein

\section{Kiste:}

Skelet: 12. 13.7.83

Population: Rheine
Verband: Verband

\section{Alter:}

Geschlecht:

Arthrose:

\section{Beschreibung:}

53g Splitter von Knochen, die nicht zuzuordnen sind. 
Bezeichn.: Knochenklein

\section{Kiste:}

Skelet: 22.27.6.83

Population: Rheine
Verband: Verband

\section{Alter:}

Geschlecht:

Arthrose:

\section{Beschreibung:}

$64 \mathrm{~g}$ nicht zuzuordnender Splitter. 
Bezeichn.: Knochenklein

\section{Kiste:}

Skelet: $\quad 18.19 .7 .83$

Population: Rheine
Verband: Verband

\section{Alter:}

Geschlecht:

Arthrose:

\section{Beschreibung:}

$54 \mathrm{~g}$ Splitter, welche nicht zuzuordnen sind. 
Bezeichn.: Knochenklein

Kiste:

Skelet: $\quad$ Kiste 5.7.83 - 7.7.83

Population: Rheine
Verband: Verband

\section{Alter:}

Geschlecht:

Arthrose:

\section{Beschreibung:}

$145 \mathrm{~g}$ nicht zuzuordnende Knochensplitter. 
Bezeichn.: Knochenklein

Kiste:

Skelet: $\quad 3610.11 .6 .83 \mathrm{Lb}$,

Population: Rheine
Verband: Verband

\section{Alter:}

Geschlecht:

Arthrose:

\section{Beschreibung:}

Hier sind etwa 20 nicht befundbare kleine Knochensplitter erhalten. 
Bezeichn.: Knochenklein

Kiste:

Skelet: $\quad 6 / 837 / 83$

Population: Rheine
Verband: Verband

\section{Alter:}

Geschlecht:

Arthrose:

\section{Beschreibung:}

417g Knochensplitter, welche nicht zuzuordnen sind. 
Bezeichn.: Knochenklein

Kiste:

Skelet: 1079

Population: Rheine
Verband: Verband

\section{Alter:}

Geschlecht:

Arthrose:

\section{Beschreibung:}

61g Knochensplitter, welche nicht zuzuordnen sind. 
Bezeichn:: Os Cuneiforme

Kiste:

Skelet: $\quad 1400$

Population: Rheine

Seite:

links
Verband:

Verband

\section{Alter:}

Geschlecht:

Arthrose:

\section{Beschreibung:}

Ein Os cuneiforme 1 der linken Seite.
Ges./Kr.: Gesund

\section{Maß}

Länge

\begin{tabular}{|l|l} 
Wert & Einheit \\
\hline 30 & $\mathrm{~mm}$ \\
&
\end{tabular}


Bezeichn.: Phalanx

Kiste:

Skelet: $\quad 5.5 .834002$

Population: Rheine
Verband: Verband

\section{Alter:}

Geschlecht:

Arthrose:

\section{Beschreibung:}

Leichenbrand. 
Bezeichn.: Phalanx

Kiste:

Skelet: $\quad 5.5 .834002$

Population: Rheine
Verband: Verband

\section{Alter:}

Geschlecht:

Arthrose:

\section{Beschreibung:}

Leichenbrand. 
Bezeichn.: Phalanx Manus

Kiste:

Skelet: 638

Population: Rheine

Seite:
Verband: $\square$ Verband

\section{Alter: $\quad 7-13$}

Geschlecht:

Arthrose:

\section{Beschreibung:}

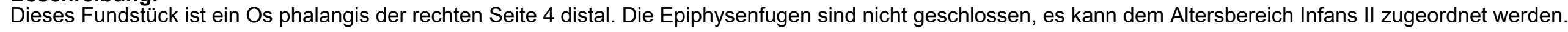




\section{Detailbericht aller Funde für die Population Rheine}

\section{UK}

Population: Rheine

Geschlecht: >> männlich

Alter:

(25) 28 - 35 (38)

Beschreibung: Hier ist ein massiver Unterkiefer erhalten.
7

\begin{tabular}{c|l|l} 
Arthrose & rechts & links \\
\hline Caput & & \\
\hline Fossa & &
\end{tabular}

\begin{tabular}{|c|c|c|c|c|c|c|c|c|}
\hline Zahn & Status & Parodontium & Apikale Prozesse & Zahnstein & Karies & Abrasion & Neubildung & Schmelzhypoplasie \\
\hline 31 & v & & 0 & & & & & \\
\hline 32 & $\mathrm{v}$ & & 0 & & & & & \\
\hline 41 & $\mathrm{v}$ & & 0 & & & & & \\
\hline 42 & & Po 1 & 0 & $\mathrm{~K}$ & 0 & 0 & 0 & 0 \\
\hline 43 & & Po 1 & 0 & $\mathrm{~K}$ & 0 & $\mathrm{O}$ & 0 & 0 \\
\hline 44 & & & 0 & K 1 & 0 & $\mathrm{O}$ & * & 0 \\
\hline 45 & & & 0 & $\mathrm{~K}$ & 0 & 0 & * & 0 \\
\hline 46 & & & $A$ & $\mathrm{~K}$ & 0 & 0 & * & 0 \\
\hline 47 & & & $A$ & $\begin{array}{ll}\text { K } & 1\end{array}$ & 0 & 0 & 0 & 0 \\
\hline
\end{tabular}




\section{UK}

Population: Rheine

Geschlecht: > weiblich

Alter:

(25) 28 - $35(38)$

Beschreibung: Bei diesem Unterkiefer fällt ein dünner corpus ins Auge. Er misst zischen 3mm und 6mm.

\section{8}

\begin{tabular}{c|c|c} 
Arthrose & rechts & links \\
\hline Caput & & 2 \\
\hline Fossa & &
\end{tabular}

\begin{tabular}{|c|c|c|c|c|c|c|c|c|}
\hline Zahn & Status & Parodontium & Apikale Prozesse & Zahnstein & Karies & Abrasion & Neubildung & Schmelzhypoplasie \\
\hline 35 & & $\mathrm{Pi} \quad 2$ & & K 1 & D & $\mathrm{O}$ & 0 & 0 \\
\hline 36 & & $\mathrm{Pi} \quad 2$ & $\mathrm{G}$ & $\mathrm{K}$ & M 1 & $\mathrm{O}$ & * & 0 \\
\hline 37 & & $\mathrm{Pi} \quad 2$ & 0 & $\mathrm{~K}$ & 0 & $\mathrm{O}$ & 0 & 0 \\
\hline 38 & v & $\mathrm{Pi} \quad 2$ & & & & & & \\
\hline
\end{tabular}




\section{OK}

Population: Rheine

Geschlecht:

Alter:

(25) 28 - 35 (38)

\subsubsection{4 / 13}

Skelett: $\quad$ ohne Nummer 31.6 .83 210

\section{8}

Krankheiten: Sinusitis maxillaris Stomatitis

Beschreibung: Die Wurzel des 26 ist nicht vollständig erhalten, weswegen hier keine genaue Befundung möglich war. Bei diesem Fund liegt weiterhin noch ein kleines Fragment des knöchernen Gaumens und weitere kleinere Zahnfragmente vor. Davon sind einige Leichenbrand. Beim 13 ist die Krone postmortal abfrakturiert und nicht aufzufinden. Der Zahn 37 ist nur in Form seiner Krone erhalten. Es liegt noch ein Os zygomaticum vor, welches im Schädeldatensatz berücksichtigt wird.

\begin{tabular}{|c|c|c|c|c|c|c|c|c|}
\hline Zahn & Status & Parodontium & Apikale Prozesse & Zahnstein & Karies & Abrasion & Neubildung & Schmelzhypoplasie \\
\hline 13 & $E$ & & 0 & & & & & \\
\hline 23 & & & 0 & $\mathrm{~K}$ & 0 & 0 & 0 & $\mathrm{~T}$ \\
\hline 26 & & & $x$ & $\mathrm{~K}$ & 0 & $\mathrm{O}$ & * & 0 \\
\hline 37 & & & $x$ & $\mathrm{~K}$ & 0 & $\mathrm{O}$ & 0 & $\mathrm{~T}$ \\
\hline
\end{tabular}




\section{UK}

Population: Rheine

Geschlecht:

Alter:

(25) 28 - 35 (38)

Beschreibung: Hier ist ein Teilsegment eines Unterkiefers erhalten.

\subsubsection{4 / 1}

Skelett: $\quad 29.6 .83714$
Krankheiten:

\section{$3610 / 1$ S3 2}

\begin{tabular}{c|l|l} 
Arthrose & rechts & links \\
\hline Caput & & \\
\hline Fossa & &
\end{tabular}

$\begin{array}{llll}\text { Zahn } & \text { Status } & \text { Parodont } \\ 42 & \mathrm{v} & & \\ 43 & & \mathrm{Pi} & 1 \\ 44 & & \mathrm{Pi} & 1 \\ 45 & & \mathrm{Pi} & 1 \\ 46 & & \mathrm{Pi} & 1 \\ 47 & & \mathrm{Pi} & 1\end{array}$

\section{Apikale Prozesse}

Zahnstein

Karies

$\begin{array}{ll}\mathrm{K} & 1 \\ \mathrm{~K} & 1 \\ \mathrm{~K} & 1 \\ \mathrm{~K} & 1 \\ \mathrm{~K} & 1\end{array}$

Abrasion

Neubildung

Schmelzhypoplasie

\begin{tabular}{|c|c|c|}
\hline & 0 & 0 \\
\hline & 0 & 0 \\
\hline & 0 & 0 \\
\hline & 0 & 0 \\
\hline $\mathrm{M}$ & 1 & 0 \\
\hline
\end{tabular}

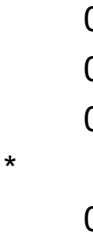

$\begin{array}{cc}\text { U } & 1 \\ \mathrm{U} & 1 \\ \mathrm{U} & 1 \\ \mathrm{U} & 1 \\ \mathrm{U} & 1\end{array}$




\section{UK}

Population: Rheine

Geschlecht: > weiblich

Alter: (16) $21-30$ (34)

\subsubsection{4 / 17}

Skelett: $\quad 3610,1$ Schnitt 208

\section{9}

Krankheiten: offener Abszess Fraktur

Beschreibung: Dieser linke Teil eines Unterkiefers weist eine verheilte Fraktur im molaren bis retromolaren Bereich auf. Weiterhin ist ein offener Prozess in regio 35 zu verzeichnen, der wohl als Folge einer Pulpitis im apicalen Bereich des 35 entstanden ist. Er ist nach vestibulär durch die Knochenkortikalis hindurch getreten und hat den vestibulären Knochen gefenstert.

\begin{tabular}{|c|c|c|c|c|c|c|c|c|}
\hline Zahn & Status & Parodontium & Apikale Prozesse & Zahnstein & Karies & Abrasion & Neubildung & Schmelzhypoplasie \\
\hline 33 & $v$ & $\mathrm{Pi} \quad 3$ & 0 & & & & & \\
\hline 34 & v & $\mathrm{Pi} \quad 3$ & G & & & & & \\
\hline 35 & & $\mathrm{Pi} \quad 3$ & G & $\mathrm{K}$ & 0 & $\mathrm{O}$ & 0 & \\
\hline 36 & v & $\mathrm{Pi} \quad 3$ & G & & & & & \\
\hline 37 & $\mathrm{v}$ & $\mathrm{Pi} \quad 3$ & G & & & & & \\
\hline 38 & v & $\mathrm{Pi} \quad 3$ & G & & & & & \\
\hline
\end{tabular}




\section{Zähne}

Population:

Rheine

Geschlecht:

Alter:

$(0,66) 1-1,5(2)$

\section{Beschreibung:}

\subsubsection{4 / 19}

Skelett: ohne Beschriftung

Krankheiten:

\begin{tabular}{c|l|l} 
Arthrose & rechts & links \\
\hline Caput & & \\
\hline Fossa & &
\end{tabular}

\section{steht nicht dabei}

Zahnstein

II
0

\section{Parodontium}

0

\section{Apikale Prozesse}

0
Karies

0

0

Abrasion Neubildung Schmelzhypoplasie

(1)

(2)

$\begin{array}{ll}0 & 0 \\ 0 & 0\end{array}$

0
0

0

U 1




\section{UK}

Population: Rheine

Geschlecht:

Alter:

(4) 6 - 8 (10)

\subsubsection{4 / 1}

Skelett: Kieferfragment

Krankheiten:

Beschreibung:
MKZ 3610,1 S3 1649

\begin{tabular}{c|l|l} 
Arthrose & rechts & links \\
\hline Caput & & \\
\hline Fossa & &
\end{tabular}

\begin{tabular}{|c|c|c|c|c|c|c|c|c|}
\hline Zahn & Status & Parodontium & Apikale Prozesse & Zahnstein & Karies & Abrasion & Neubildung & Schmelzhypoplasie \\
\hline 34 & ( ) & & & & & & & \\
\hline 35 & ( ) & & & & & & & \\
\hline 74 & & 0 & 0 & $\mathrm{~K}$ & $M$ & $\mathrm{O}$ & 0 & $U$ \\
\hline 75 & & 0 & 0 & $\begin{array}{ll}\text { K } & 1\end{array}$ & 0 & 0 & 0 & $U$ \\
\hline
\end{tabular}




\section{Zahn}

Population: Rheine

Geschlecht:

Alter:

Beschreibung: Die vestibuläre Wurzel dieses Zahnes ist zum Teil erhalten.
6

Krankheiten:

\begin{tabular}{c|l|l} 
Arthrose & rechts & links \\
\hline Caput & & \\
\hline Fossa & &
\end{tabular}

\section{Zahn Status Parodontium Apikale Prozesse}

28
Zahnstein

K 2
Karies

0
Abrasion

O 1
Neubildun

0
Schmelzhypoplasie

0 


\section{Zahn}

Population: Rheine

Geschlecht:

Alter:

$(7,5) 10-11(13,5)$
6

Krankheiten:

\begin{tabular}{c|l|l} 
Arthrose & rechts & links \\
\hline Caput & & \\
\hline Fossa & &
\end{tabular}

Beschreibung: Bei diesem Fundstück handelt es sich um eine 28, dessen Krone noch nicht vollständig mineraliesiert war. Außerdem handelt es sich dem Anschein nach um Leichenbrand.

Zahn Status Parodontium Apikale Prozesse Zahnstein Karies Abrasion Neubildung Schmelzhypoplasie




\section{Zähne}

Population: Rheine

Geschlecht:

Alter:

(25) 28 - $35(38)$

Beschreibung: Von diesen Zähnen sind nur die Kornen erhalten, vom 38 noch 1/3 der Wurzel.
7

\section{Krankheiten:}

\begin{tabular}{c|l|l} 
Arthrose & rechts & links \\
\hline Caput & & \\
\hline Fossa & &
\end{tabular}

$\begin{array}{llccccccc}\text { Zahn } & \text { Status } & \text { Parodontium } & \text { Apikale Prozesse } & \text { Zahnstein } & \text { Karies } & \text { Abrasion } & \text { Neubildung } & \text { Schmelzhypoplasie } \\ 37 & & 0 & 0 & O & 3 & 0 & U & 1 \\ 38 & & 0 & 0 & 0 & 3 & 0 & U & 1\end{array}$




\section{Zahn}

Population: Rheine

Geschlecht:

Alter:

Beschreibung: Ein Zahn in gutem Erhaltungszustand. Es liegt eine initiale Karies vor.
7

\begin{tabular}{c|l|l} 
Arthrose & rechts & links \\
\hline Caput & & \\
\hline Fossa & &
\end{tabular}

\section{Zahn Status Parodontium Apikale Prozesse}

44
0
Zahnstein

K 1
Karies

D 1
Abrasion

O 2
Neubildung

0

Schmelzhypoplasie

0 


\section{Zahn Status Parodontium} 45
Apikale Prozesse

\section{Zahn}

Population: Rheine

Geschlecht:

Alter:

Beschreibung: Es ist nur die koronale Hälfte der Krone erhalten, der Rest ist abfrakturiert.

\subsubsection{4 / 18}

Skelett: 2502

Krankheiten:

7

\begin{tabular}{c|l|l} 
Arthrose & rechts & links \\
\hline Caput & & \\
\hline Fossa & &
\end{tabular}

\section{Karies}

Abrasion

Neubildung Schmelzhypoplasie

0 


\section{Zahn}

Population: Rheine

Geschlecht:

Alter:

\section{Beschreibung:}

\subsubsection{4 / 44}

Skelett: 1217

Krankheiten:

\section{3}

\begin{tabular}{c|l|l} 
Arthrose & rechts & links \\
\hline Caput & & \\
\hline Fossa & &
\end{tabular}

\section{Zahn Status Parodontium Apikale Prozesse}

Zahnstein

Karies

Abrasion

Neubildung

Schmelzhypoplasie

K 1

0
O 3 


\section{Zahn}

Population: Rheine

Geschlecht:

Alter:

Beschreibung: Hier ist nur die Krone und 10\% der Wurzel erhalten.
3

Krankheiten:

\begin{tabular}{c|l|l} 
Arthrose & rechts & links \\
\hline Caput & & \\
\hline Fossa & &
\end{tabular}

Zahn Status Parodontium Apikale Prozesse Zahnstein

Karies Abrasion

Neubildung

Schmelzhypoplasie
K 1

0

O 3

0

0 


\section{Zahn}

Population: Rheine

Geschlecht:

Alter:

(3) $4-6(7)$
26.03.2014 / 26

Skelett: 490

Krankheiten:

\begin{tabular}{c|l|l} 
Arthrose & rechts & links \\
\hline Caput & & \\
\hline Fossa & &
\end{tabular}

Beschreibung: Von diesem Zahn ist nur die Krone erhalten. Wegen der dunklen Verfärbungen könnte man auf Leichenbrand schließen.

Zahn Status Parodontium Apikale Prozesse 16 Zahnstein

0

\section{Karies}

0

\section{Abrasion Neubildung Schmelzhypoplasie}

0

0 0 


\section{Zahn}

Population: Rheine

Geschlecht:

Alter:

(28) 36 - 45 (50)

\section{Beschreibung:}

\subsubsection{4 / 21}

Skelett: 2514

Krankheiten:

7

\begin{tabular}{c|l|l} 
Arthrose & rechts & links \\
\hline Caput & & \\
\hline Fossa & &
\end{tabular}

Zahnstein K 1

\section{Karies}

0
Abrasion

Neubildung

O 4 


\section{Zahn}

Population: Rheine

Geschlecht:

Alter:

(14) $16-22(24)$

Beschreibung: Von diesem Zahn ist nur die Krone zu $80 \%$ erhalten.
7

Krankheiten:

\begin{tabular}{c|l|l} 
Arthrose & rechts & links \\
\hline Caput & & \\
\hline Fossa & &
\end{tabular}

$\begin{array}{llllccccc}\text { Zahn } & \text { Status } & \text { Parodontium } & \text { Apikale Prozesse } & \text { Zahnstein } & \text { Karies } & \text { Abrasion } & \text { Neubildung Schmelzhypoplasie } \\ 46 & & \mathrm{~K} 1 & 0 & 0 & 2 & 0\end{array}$




\section{Zahn}

Population: Rheine

Geschlecht:

Alter:

(22) $25-33(35)$

Beschreibung: Von diesem Zahn ist nur die Krone erhalten und ein Teil der mesio - lingualen Wurzel.
6

\begin{tabular}{c|l|l} 
Arthrose & rechts & links \\
\hline Caput & & \\
\hline Fossa & &
\end{tabular}

\begin{tabular}{|c|c|c|c|c|c|c|c|}
\hline Zahn & Status & Parodontium & Apikale Prozesse & Zahnstein & Karies & Abrasion & Neubildung Schmelzhypoplasi \\
\hline & & & 0 & & 0 & 0 & 0 \\
\hline
\end{tabular}




\section{Zahn}

Population: Rheine

Geschlecht:

Alter:

(22) 25 - 33 (35)

Beschreibung: Hier ist nur die Krone erhalten, es könnte sich um Leichenbrand handeln.
3

Krankheiten:

\begin{tabular}{c|l|l} 
Arthrose & rechts & links \\
\hline Caput & & \\
\hline Fossa & &
\end{tabular}

\section{Zahn \\ Status \\ Parodontium \\ Apikale Prozesse}

Zahnstein

Karies

K 1

0

Abrasion

Neubildung

0

Schmelzhypoplasie 


\section{Zahn}

Population: Rheine

Geschlecht:

Alter:

(14) 16 - $22(24)$
08.04.2014 / 50

Skelett: 1148

Krankheiten:

\section{Beschreibung:}

Apikale Prozesse

0
Zahnstein

K 1
3

\begin{tabular}{c|l|l} 
Arthrose & rechts & links \\
\hline Caput & & \\
\hline Fossa & &
\end{tabular}




\section{Zahn}

Population: Rheine

Geschlecht:

Alter:

(3) 4 - 6 (7)

Beschreibung: Hier ist nur die Krone vorhanden.
7

Krankheiten:

\begin{tabular}{c|l|l} 
Arthrose & rechts & links \\
\hline Caput & & \\
\hline Fossa & &
\end{tabular}

Zahn Status Parodontium Apikale Prozesse
25.03.2014 / 24

Skelett: 4007

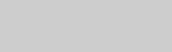




\section{Zahn}

Population: Rheine

Geschlecht:

Alter:

(25) 28 - $34(38)$

\section{Beschreibung:}

\subsubsection{4 / 17}

Skelett: 219

Krankheiten:

7

\begin{tabular}{c|l|l} 
Arthrose & rechts & links \\
\hline Caput & & \\
\hline Fossa & &
\end{tabular}

\section{Zahn Status Parodontium Apikale Prozesse}

37
Zahnstein

K 1

0
Abrasion

Neubildung

0

Schmelzhypoplasie 


\section{Zahn}

Population: Rheine

Geschlecht:

Alter:

(25) 28 - 35 (38)

\section{Beschreibung:}

\subsubsection{4 / 23}

Skelett: 2516

Krankheiten:

7

\begin{tabular}{c|l|l} 
Arthrose & rechts & links \\
\hline Caput & & \\
\hline Fossa & &
\end{tabular}

Zahnstein K 2

\section{Karies}

0
Abrasion

Neubildung

O 4 


\section{Zahn}

Population: Rheine

Geschlecht:

Alter:

(15) $17-25(26)$

Beschreibung: Es ist nur $90 \%$ der Krone erhalten.
7

Krankheiten:

\begin{tabular}{c|l|l} 
Arthrose & rechts & links \\
\hline Caput & & \\
\hline Fossa & &
\end{tabular}

$\begin{array}{llllccccc}\text { Zahn } & \text { Status } & \text { Parodontium } & \text { Apikale Prozesse } & \text { Zahnstein } & \text { Karies } & \text { Abrasion } & \text { Neubildung } & \text { Schmelzhypoplasie } \\ 37 & & \mathrm{~K} 1 & 0 & \mathrm{O} & 1 & 0\end{array}$




\section{Zahn}

Population: Rheine

Geschlecht:

Alter:

(28) $36-45(50)$

Beschreibung: Von diesem Zahn ist nur die Krone erhalten.
7

Krankheiten:

\begin{tabular}{c|l|l} 
Arthrose & rechts & links \\
\hline Caput & & \\
\hline Fossa & &
\end{tabular}

$\begin{array}{lllllclcc}\text { Zahn } & \text { Status } & \text { Parodontium } & \text { Apikale Prozesse } & \text { Zahnstein } & \text { Karies } & \text { Abrasion } & \text { Neubildung } & \text { Schmelzhypoplasie } \\ 37 & & & \mathrm{~K} 2 & 0 & 0 & 4 & * & 0\end{array}$




\section{Zahn}

Population: Rheine

Geschlecht:

Alter:

(5) 7 - $12(14,5)$
7

Krankheiten:

Beschreibung: Von diesem Zahn ist die Krone erhalten. Es fällt ein lochartiger Defekt im Schmelz auf, welcher occlusal - vestibulär lokalisiert ist.

$\begin{array}{llccccccc}\text { Zahn } & \text { Status } & \text { Parodontium } & \text { Apikale Prozesse } & \text { Zahnstein } & \text { Karies } & \text { Abrasion } & \text { Neubildung } & \text { Schmelzhypoplasie } \\ 37 & & 0 & 0 & 0 & 0 & \mathrm{~T} & 1 & \end{array}$




\section{Zahn}

Population: Rheine

Geschlecht:

Alter:

(14) 16 - $22(24)$

\subsubsection{4 / 1}

Skelett: 1089

Krankheiten:
7

\begin{tabular}{c|l|l} 
Arthrose & rechts & links \\
\hline Caput & & \\
\hline Fossa & &
\end{tabular}

Beschreibung: Dieser 36 ist nur teilweise erhalten. Seine Krone weist einen zusätzlichen distalen Höcker auf, sowie eine kleine zusätzliche Wurzel, welche vestibulär lokalisiert ist.

$\begin{array}{llccccccc}\text { Zahn } & \text { Status } & \text { Parodontium } & \text { Apikale Prozesse } & \text { Zahnstein } & \text { Karies } & \text { Abrasion } & \text { Neubildung } & \text { Schmelzhypoplasie } \\ 36 & & 0 & 0 & 0 & 2 & 0 & T\end{array}$




\section{Zahn}

Population: Rheine

Geschlecht:

Alter:

(5) 7 - $12(14,5)$

Beschreibung: Hier ist nur die Krone erhalten, es könnte sich um eine Anlage handeln.

\section{Zahn Status Parodontium Apikale Prozesse}

37

08.04.2014 / 49

Skelett: 1166

0
Krankheiten:

3

\begin{tabular}{c|l|l} 
Arthrose & rechts & links \\
\hline Caput & & \\
\hline Fossa & &
\end{tabular}
Zahnstein

Karies

0

Abrasion

0

Neubildung

0

Schmelzhypoplasie

(n)

0 


\section{Zahn}

Population: Rheine

Geschlecht:

Alter:

(5) 7 - $12(14,5)$
6

Krankheiten:

\begin{tabular}{c|l|l} 
Arthrose & rechts & links \\
\hline Caput & & \\
\hline Fossa & &
\end{tabular}

Beschreibung: Von diesem 37 ist nur die Krone erhalten. Sie weist vestibulär einen lochartigen Schmelzdefekt in Form eines Grübchens auf.

$\begin{array}{llcccccc}\text { Zahn } & \text { Status } & \text { Parodontium } & \text { Apikale Prozesse } & \text { Zahnstein } & \text { Karies } & \text { Abrasion } & \text { Neubildung } \\ 37 & & 0 & 0 & 0 & 0\end{array}$




\section{Zahn}

Population: Rheine

Geschlecht:

Alter:

(25) 28 - 35 (38)

Beschreibung: Hier sind nur noch $1 / 4$ der Wurzel erhalten und $30 \%$ des Schmelzes sind abfrakturiert.
4

\section{Krankheiten:}

\begin{tabular}{c|l|l} 
Arthrose & rechts & links \\
\hline Caput & & \\
\hline Fossa & &
\end{tabular}

\section{Zahn Status Parodontium Apikale Prozesse}

36
Zahnstein

Karies

K 1

0

Abrasion

Neubildung

O 4 


\section{Zahn}

Population: Rheine

Geschlecht:

Alter:

\section{Beschreibung:}

\subsubsection{4 / 31}

Skelett: 1546

Krankheiten:

6

\begin{tabular}{c|l|l} 
Arthrose & rechts & links \\
\hline Caput & & \\
\hline Fossa & &
\end{tabular}

\section{Zahn Status Parodontium}

Apikale Prozesse

42
0
Zahnstein

0
Karies

0
Abrasion

Neubildung

0

Schmelzhypoplasie 


\section{Zahn}

Population: Rheine

Geschlecht:

Alter:

Beschreibung: Von diesem Zahn ist nur die Krone erhalten.

31.03.2014 / 16

Skelett: 2515
Krankheiten:

7

\begin{tabular}{c|l|l} 
Arthrose & rechts & links \\
\hline Caput & & \\
\hline Fossa & &
\end{tabular}

Zahn Status Parodontium Apikale Prozesse

32
Zahnstein

0

Karies

0

Abrasion

Neubildung

O 1

0

Schmelzhypoplasie

T 1 


\section{Zahn}

Population: Rheine

Geschlecht:

Alter:

\section{Beschreibung:}

\subsubsection{4 / 34}

Skelett: 1554

Krankheiten:

6

\begin{tabular}{c|l|l} 
Arthrose & rechts & links \\
\hline Caput & & \\
\hline Fossa & &
\end{tabular}

Zahnstein

0
Karies

0
Abrasion

O 2

\section{Neubildung}

0

Schmelzhypoplasie T 1 


\section{Zahn}

Population: Rheine

Geschlecht:

Alter:

Beschreibung: Von diesem Zahn ist nur die Krone erhalten.

\subsubsection{4 / 18}

Skelett: 541
Krankheiten:

6

\begin{tabular}{c|l|l} 
Arthrose & rechts & links \\
\hline Caput & & \\
\hline Fossa & &
\end{tabular}

Zahn Status Parodontium Apikale Prozesse

32
Zahnstein

K 2
Karies

0
Abrasion

Neubildung

0 


\section{Zahn}

Population: Rheine

Geschlecht:

Alter:

\section{Beschreibung:}

\subsubsection{4 / 24}

Skelett: 2509

Krankheiten:

7

$\begin{array}{llccccccc}\text { Zahn } & \text { Status } & \text { Parodontium } & \text { Apikale Prozesse } & \text { Zahnstein } & \text { Karies } & \text { Abrasion } & \text { Neubildung } & \text { Schmelzhypoplasie } \\ 45 & & 0 & 0 & 0 & 2 & 0 & 1\end{array}$




\section{Zahn}

Population: Rheine

Geschlecht:

Alter:

Beschreibung: Von diesem Zahn ist 1/3 der Wurzel abfrakturiert.
Skelett: einzelne kleine Tüte
7

\begin{tabular}{c|l|l} 
Arthrose & rechts & links \\
\hline Caput & & \\
\hline Fossa & &
\end{tabular}

Krankheiten: 


\section{Zahn}

Population:

Rheine

Geschlecht:

Alter:

(4) $6-11(13,5)$
4

Krankheiten:

\begin{tabular}{c|l|l} 
Arthrose & rechts & links \\
\hline Caput & & \\
\hline Fossa & &
\end{tabular}

Beschreibung: Von diesem Prämolaren ist nur die Krone erhalten. Sie ist ausgesprochen groß ausgeprägt. Es handelt sich um einen 15.

25.03.2014 / 61

Skelett: $\quad 28.6 .83$

\section{Zahn Status Parodontium Apikale Prozesse}

15
Zahnstein

0
Karies

0
Abrasion 2 
Zahn Status Parodontium Apikale Prozesse 004
31.03.2014 / 17

Skelett: 2501

\section{Zahn}

Population: Rheine

Geschlecht:

Alter:
Beschreibung: Zu 80\% erhaltene Krone.

7

Krankheiten:

\begin{tabular}{c|l|l} 
Arthrose & rechts & links \\
\hline Caput & & \\
\hline Fossa & &
\end{tabular}




\section{Zahn}

Population: Rheine

Geschlecht:

Alter:

$3-5$

Beschreibung: Von diesem Zahn ist nur die Krone erhalten, es handelt sich wohl um eine Anlage.

\section{Zahn Status Parodontium Apikale Prozesse}

24
Zahnstein

0
Karies

0

\subsubsection{4 / 35}

Skelett: 1552

Krankheiten:

6

\begin{tabular}{c|l|l} 
Arthrose & rechts & links \\
\hline Caput & & \\
\hline Fossa & &
\end{tabular}




\section{Zahn}

Population: Rheine

Geschlecht:

Alter:

Beschreibung: Von diesem Zahn ist nur die Krone erhalten.

\subsubsection{4 / 18}

Skelett: 2502
Krankheiten:

\begin{tabular}{c|l|l} 
Arthrose & rechts & links \\
\hline Caput & & \\
\hline Fossa & &
\end{tabular}

\section{Zahn Status Parodontium}

Apikale Prozesse

15
Prozesse
Zahnstein

0
7 


\section{Zahn}

Population: Rheine

Geschlecht:

Alter:

(6) 7 - 10 (15)

Beschreibung: Wohl eine Zahnanlage.

\subsubsection{4 / 37}

Skelett: 1195

Krankheiten:

3

\begin{tabular}{c|l|l} 
Arthrose & rechts & links \\
\hline Caput & & \\
\hline Fossa & &
\end{tabular}

Zahnstein Karies

0

Abrasion

Neubildung

Schmelzhypoplasie

Apikale Prozesse

24
Parodontium 


\section{Zahn}

Population: Rheine

Geschlecht:

Alter:

(3) $4-6(7)$

Beschreibung: Dies könnte wohl eine Anlage gewesen sein.
25.03.2014 / 13

Skelett: Zahntüte
7

Krankheiten:

\begin{tabular}{c|l|l} 
Arthrose & rechts & links \\
\hline Caput & & \\
\hline Fossa & &
\end{tabular}

Zahn Status Parodontium Apikale Prozesse

16
Apikale Prozesse
Zahnstein

0

\section{Karies}

0

\section{Abrasion Neubildung Schmelzhypoplasie}




\section{Zahn}

Population:

Rheine

Geschlecht:

Alter:

(15) $17-25(26)$

\subsubsection{4 / 31}

Skelett: 467

Krankheiten:

\begin{tabular}{c|l|l} 
Arthrose & rechts & links \\
\hline Caput & & \\
\hline Fossa & &
\end{tabular}

Beschreibung: Dies ist ein 17, dessen Wurzel zum Teil abfrakturiert ist und wobei es sich wohl um Leichenbrand handelt.

$\begin{array}{llccccccc}\text { Zahn } & \text { Status } & \text { Parodontium } & \text { Apikale Prozesse } & \text { Zahnstein } & \text { Karies } & \text { Abrasion } & \text { Neubildung } & \text { Schmelzhypoplasie } \\ 17 & & 0 & 0 & 0 & 1 & 0 & 0\end{array}$




\section{Zahn}

Population:

Rheine

Geschlecht:

Alter:

(15) 17 - $25(26)$

Beschreibung: $70 \%$ der Wurzel sind abfrakturiert
1

Krankheiten:

\begin{tabular}{c|l|l} 
Arthrose & rechts & links \\
\hline Caput & & \\
\hline Fossa & &
\end{tabular}

\section{Zahn Status Parodontium Apikale Prozesse}

17
Zahnstein

0

\section{Karies}

0
Abrasion

Neubildung

0

Schmelzhypoplasie 


\section{Zahn}

Population:

Rheine

Geschlecht:

Alter:

(14) 16 - $22(24)$

Beschreibung: Wurzel ist zu $90 \%$ abfrakturiert.
1

Krankheiten:

\begin{tabular}{c|l|l} 
Arthrose & rechts & links \\
\hline Caput & & \\
\hline Fossa & &
\end{tabular}

Zahn Status Parodontium Apikale Prozesse Zahnstein

Karies

Abrasion

Neubildung

Schmelzhypoplasie
0

O 2 0

1 


\section{Zahn}

Population:

Rheine

Geschlecht:

Alter:

(25) 29 - $37(43)$

Beschreibung: Von diesem Zahn ist nur die Krone erhalten. Es liegt eine initiale Karies vor.
1

Krankheiten:

\begin{tabular}{c|l|l} 
Arthrose & rechts & links \\
\hline Caput & & \\
\hline Fossa & &
\end{tabular}

\section{Zahn \\ Status \\ Parodontium \\ Apikale Prozesse}

Zahnstein

Karies

16 


\section{Zahn}

Population: Rheine

Geschlecht:

Alter:

(22) 28 - $35(38)$

\subsubsection{4 / 25}

Skelett: 384

Krankheiten:

\begin{tabular}{c|l|l} 
Arthrose & rechts & links \\
\hline Caput & & \\
\hline Fossa & &
\end{tabular}

Beschreibung: Die Wurzel dieses Zahnes ist erodiert, an der mesio - vestibulären Seite liegt etwas Hyperzementose vor. Weiterhin zeigt der Schmelz Spuren einer initialen Karies.

$\begin{array}{llllllllll}\text { Zahn } & \text { Status } & \text { Parodontium } & \text { Apikale Prozesse } & \text { Zahnstein } & \text { Karies } & & \text { Abrasion } & \text { Neubildung } & \text { Schmelzhypoplasie } \\ 17 & & \text { K } 1 & \text { K } 1 & 0 & 3 & \# & 1 & 0\end{array}$




\section{Zahn}

Population: Rheine

Geschlecht:

Alter:

(6) $8,5-13(15)$

Beschreibung: Hier ist lediglich die Krone des Zahnes vorhanden.
8

Krankheiten:

\begin{tabular}{c|l|l} 
Arthrose & rechts & links \\
\hline Caput & & \\
\hline Fossa & &
\end{tabular}

$\begin{array}{llllccccc}\text { Zahn } & \text { Status } & \text { Parodontium } & \text { Apikale Prozesse } & \text { Zahnstein } & \text { Karies } & \text { Abrasion } & \text { Neubildung } & \text { Schmelzhypoplasie } \\ 16 & & \mathrm{~K} & 1 & 0 & 0 & 1 & 0 & 1\end{array}$




\section{Zahn}

Population: Rheine

Geschlecht:

Alter:

(22) 25 - $33(35)$

Beschreibung: $40 \%$ der Krone ist abfrakturiert.
1

Krankheiten:

\begin{tabular}{c|l|l} 
Arthrose & rechts & links \\
\hline Caput & & \\
\hline Fossa & &
\end{tabular}

Zahn Status Parodontium Apikale Prozesse Zahnstein Karies Abrasion Neubildung Schmelzhypoplasie 17 K 1 0 O 2 0 0 


\section{Zahn}

Population: Rheine

Geschlecht:

Alter:

(3) $4-6(7)$

Beschreibung: Es ist nur die Krone erhalten, welche erodiert ist.

\section{Zahn Status Parodontium}

Apikale Prozesse

\subsubsection{4 / 21}

Skelett: 2514
Krankheiten:

7

\begin{tabular}{c|l|l} 
Arthrose & rechts & links \\
\hline Caput & & \\
\hline Fossa & &
\end{tabular}

6
Zahnstein Karies

Abrasion

Neubildung 


\section{Zahn}

Population: Rheine

Geschlecht:

Alter:

(3) $4-6(7)$

Beschreibung: Es ist nur $60 \%$ der Krone erhalten.
7

Krankheiten:

\begin{tabular}{c|l|l} 
Arthrose & rechts & links \\
\hline Caput & & \\
\hline Fossa & &
\end{tabular}

\section{Zahn Status Parodontium Apikale Prozesse}




\section{Zahn}

Population: Rheine

Geschlecht:

Alter:

(25) 28 - $34(38)$

Beschreibung: Von diesem Zahn ist nur die Krone erhalten.
7

Krankheiten:

\begin{tabular}{c|l|l} 
Arthrose & rechts & links \\
\hline Caput & & \\
\hline Fossa & &
\end{tabular}

$\begin{array}{llllllll}\text { Zahn } & \text { Status } & \text { Parodontium } & \text { Apikale Prozesse } & \text { Zahnstein } & \text { Karies } & \text { Abrasion } & \text { Neubildung } \\ 17 & & \mathrm{~K} 1 & 0 & 0 & 3 & 0 & 0\end{array}$




\section{Zahn}

Population: Rheine

Geschlecht:

Alter:

(32) 37 - 45 (50)

Beschreibung: Wurzel zu $80 \%$ abfrakturiert.
7

Krankheiten:

\begin{tabular}{c|l|l} 
Arthrose & rechts & links \\
\hline Caput & & \\
\hline Fossa & &
\end{tabular}

$\begin{array}{llllllll}\text { Zahn } & \text { Status } & \text { Parodontium } & \text { Apikale Prozesse } & \text { Zahnstein } & \text { Karies } & \text { Abrasion } & \text { Neubildung } \\ 17 & & & \mathrm{~K} 1 & 0 & \mathrm{O} & 4 & *\end{array}$




\section{Zahn}

Population: Rheine

Geschlecht:

Alter:

(22) $25-30(34)$

Beschreibung: Von diesem Zahn ist nur die Krone erhalten, es könnte sich um Leichenbrand handeln.
6

\begin{tabular}{c|l|l} 
Arthrose & rechts & links \\
\hline Caput & & \\
\hline Fossa & &
\end{tabular}

$\begin{array}{llllccccc}\text { Zahn } & \text { Status } & \text { Parodontium } & \text { Apikale Prozesse } & \text { Zahnstein } & \text { Karies } & \text { Abrasion } & \text { Neubildung } & \text { Schmelzhypoplasie } \\ 16 & & \mathrm{~K} & 1 & 0 & \mathrm{O} & 3 & 0 & 0\end{array}$




\section{Zahn}

Population: Rheine

Geschlecht:

Alter:

$(8,5) 11-12(14,5)$

Beschreibung: Es ist nur die Krone erhalten, es handelt sich um Leichenbrand.

\subsubsection{4 / 5}

Skelett: 1251

Krankheiten:

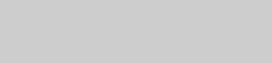

6

\begin{tabular}{c|l|l} 
Arthrose & rechts & links \\
\hline Caput & & \\
\hline Fossa & &
\end{tabular}

$\begin{array}{lllccccc}\text { Zahn } & \text { Status } & \text { Parodontium } & \text { Apikale Prozesse } & \text { Zahnstein } & \text { Karies } & \text { Abrasion } & \text { Neubildung } \\ 17 & & \mathrm{~K} \quad 1 & 0 & 0 & 0\end{array}$




\section{Zahn}

Population: Rheine

Geschlecht:

Alter:

(25) 28 - 34 (38)

Beschreibung: Hier sind die Krone und 20\% der Wurzel erhalten.

\section{Zahn Status Parodontium Apikale Prozesse}

17
Krankheiten:

08.04.2014 / 26

Skelett: 892

(2)
3

\begin{tabular}{c|l|l} 
Arthrose & rechts & links \\
\hline Caput & & \\
\hline Fossa & &
\end{tabular}
Zahnstein

Karies

Abrasion

Neubildung

Schmelzhypoplasie

O 3

0 1 


\section{Zahn}

Population: Rheine

Geschlecht:

Alter:

(6) $8,5-13(15)$

Beschreibung: Es ist nur die Krone erhalten.
7

Krankheiten:

\begin{tabular}{c|l|l} 
Arthrose & rechts & links \\
\hline Caput & & \\
\hline Fossa & &
\end{tabular}

$\begin{array}{llllllccc}\text { Zahn } & \text { Status } & \text { Parodontium } & \text { Apikale Prozesse } & \text { Zahnstein } & \text { Karies } & \text { Abrasion } & \text { Neubildung } & \text { Schmelzhypoplasie } \\ 26 & & \mathrm{~K} 1 & 0 & 0 & 1 & 0\end{array}$




\section{Zahn}

Population:

Rheine

Geschlecht:

Alter:

$25-35$

Beschreibung: Die Wurzel ist zu $20 \%$ abfrakturiert.
1

Krankheiten:

\begin{tabular}{c|l|l} 
Arthrose & rechts & links \\
\hline Caput & & \\
\hline Fossa & &
\end{tabular}

Zahn Status Parodontium Apikale Prozesse

28

Zahnstein

Karies

0

0

Abrasion

Neubildung

0

Schmelzhypoplasie 


\section{Zahn}

Population:

Rheine

Geschlecht:

Alter:

(6) $8,5-13(15)$

Beschreibung: Hier sind $60 \%$ der Krone erhalten
1

Krankheiten:

\begin{tabular}{c|l|l} 
Arthrose & rechts & links \\
\hline Caput & & \\
\hline Fossa & &
\end{tabular}

$\begin{array}{llccccccc}\text { Zahn } & \text { Status } & \text { Parodontium } & \text { Apikale Prozesse } & \text { Zahnstein } & \text { Karies } & \text { Abrasion } & \text { Neubildung Schmelzhypoplasie } \\ 26 & & 0 & 0 & 0 & 1 & 0\end{array}$




\section{Zahn}

Population: Rheine

Geschlecht: indifferent

Alter:

(3) 4 - 6 (7)

Beschreibung: Hier ist lediglich die Krone des Zahnes vorhanden.

\subsubsection{4 / 10}

Skelett: ohne Nummer 2
Krankheiten:

8

\begin{tabular}{c|l|l} 
Arthrose & rechts & links \\
\hline Caput & & \\
\hline Fossa & &
\end{tabular}

Zahn Status Parodontium Apikale Prozesse

26
Zahnstein Karies

0
Abrasion 


\section{Zahn}

Population: Rheine

Geschlecht:

Alter:

(3) $4-6(7)$

Beschreibung: Hier ist lediglich die Krone des Zahnes vorhanden, von selbiger sind $10 \%$ abfrakturiert.
8

Krankheiten:

\begin{tabular}{c|l|l} 
Arthrose & rechts & links \\
\hline Caput & & \\
\hline Fossa & &
\end{tabular}

Zahn Status Parodontium Apikale Prozesse
26
Zahnstein

0
Karies

0

Abrasion Neubildung Schmelzhypoplasie

0 


\section{Zahn}

Population: Rheine

Geschlecht:

Alter:

(6) $8,5-13(15)$
7

Krankheiten:

Beschreibung: Von dem Molaren ist die Krone erhalten, es liegen noch zwei kleinere Kronenfragmente bei, die nicht zuzuordnen sind.

$\begin{array}{llccccccc}\text { Zahn } & \text { Status } & \text { Parodontium } & \text { Apikale Prozesse } & \text { Zahnstein } & \text { Karies } & \text { Abrasion } & \text { Neubildung } & \text { Schmelzhypoplasie } \\ 26 & & 0 & 0 & 0 & 1 & 0 & T\end{array}$




\section{Zahn}

Population: Rheine

Geschlecht:

Alter:

(3) $4-6(7)$

Beschreibung: Es ist nur die Zahnkrone erhalten.
1

Krankheiten:

\begin{tabular}{c|l|l} 
Arthrose & rechts & links \\
\hline Caput & & \\
\hline Fossa & &
\end{tabular}

Zahn Status Parodontium Apikale Prozesse 26
27.03.2014 / 12

Skelett: 3006

(n) 


\section{Zahn}

Population: Rheine

Geschlecht:

Alter:

(3) 4 - 6 (7)

Beschreibung: Hier sind nur etwa $80 \%$ der Krone erhalten.
1

Krankheiten:

\begin{tabular}{c|l|l} 
Arthrose & rechts & links \\
\hline Caput & & \\
\hline Fossa & &
\end{tabular}

Zahn Status Parodontium Apikale Prozesse

Zahnstein Karies

\section{Abrasion}

Neubildung

Schmelzhypoplasie 


\section{Zahn}

Population: Rheine

Geschlecht:

Alter:

Beschreibung: Es ist nur die Krone erhalten, eventuell handelt es sich um Leichenbrand.

\subsubsection{4 / 20}

Skelett: 2512

Krankheiten:

7

\begin{tabular}{c|l|l} 
Arthrose & rechts & links \\
\hline Caput & & \\
\hline Fossa & &
\end{tabular}

\section{Zahn \\ Status Parodontium \\ Apikale Prozesse}

27
Zahnstein

0

\section{Karies}

0 


\section{Zahn}

Population: Rheine

Geschlecht:

Alter:

(22) $25-30(34)$

Beschreibung: Von diesem Zahn ist die Krone erhalten.
7

Krankheiten:

\begin{tabular}{c|l|l} 
Arthrose & rechts & links \\
\hline Caput & & \\
\hline Fossa & &
\end{tabular}

$\begin{array}{lllllcccc}\text { Zahn } & \text { Status } & \text { Parodontium } & \text { Apikale Prozesse } & \text { Zahnstein } & \text { Karies } & \text { Abrasion } & \text { Neubildung } & \text { Schmelzhypoplasie } \\ 26 & & \mathrm{~K} 1 & 0 & 0 & 3 & 0 & 0\end{array}$




\section{Zahn}

Population: Rheine

Geschlecht:

Alter:

(25) 28 - 35 (38)

Beschreibung: Die Karies an diesem Zahn ist eine initiale Karies.
7

Krankheiten:

\begin{tabular}{c|l|l} 
Arthrose & rechts & links \\
\hline Caput & & \\
\hline Fossa & &
\end{tabular}

$\begin{array}{llcccccccc}\text { Zahn } & \text { Status } & \text { Parodontium } & \text { Apikale Prozesse } & \text { Zahnstein } & \text { Karies } & \text { Abrasion } & \text { Neubildung } & \text { Schmelzhypoplasie } \\ 26 & & 0 & \mathrm{~K} 2 & \mathrm{M} 1 & \mathrm{O} & 4 & * & \end{array}$




\section{Zahn}

Population: Rheine

Geschlecht:

Alter:

(32) $37-45(50)$
6

Krankheiten:

\begin{tabular}{c|l|l} 
Arthrose & rechts & links \\
\hline Caput & & \\
\hline Fossa & &
\end{tabular}

Beschreibung: Von diesem Zahn ist die Krone erhalten und Fragmente der Wurzeln. Es liegen massive sekundär- / tertiär - Dentinbildungen vor.

\section{Zahn Status Parodontium Apikale Prozesse}

26
07.04.2014 / 26

Skelett: 1553 


\section{Zahn}

Population: Rheine

Geschlecht:

Alter:

(3) $4-6(7)$

Beschreibung: Es ist nur die Krone erhalten, es handelt sich möglicherweise um Leichenbrand.

\section{Zahn Status Parodontium Apikale Prozesse}

26

\subsubsection{4 / 3}

Skelett: 1345

Krankheiten:
Zahnstein

0
Karies

0

6

\begin{tabular}{c|l|l} 
Arthrose & rechts & links \\
\hline Caput & & \\
\hline Fossa & &
\end{tabular}

Abrasion

0 


\section{Zahn}

Population: Rheine

Geschlecht:

Alter:

(3) 4 - 6

Beschreibung: Ein Zahnanlage.
08.04.2014 / 36

Skelett: 1232

Krankheiten:

\begin{tabular}{c|l|l} 
Arthrose & rechts & links \\
\hline Caput & & \\
\hline Fossa & &
\end{tabular}

3
Zahn Status Parodontium Apikale Prozesse
Zahnstein

0 


\section{Zahn}

Population: Rheine

Geschlecht:

Alter:

(14) $16-22(24)$

\section{6}

Krankheiten:

Beschreibung: Fast vollständig erhalten, es fehlen nur kleine Fragmente der disto - vestibulären Wurzel und der palatinalen (5\%). Insgesamt weist der Zahn fleckenförmige dunkle Verfärbungen auf.

$\begin{array}{llllccccc}\text { Zahn } & \text { Status } & \text { Parodontium } & \text { Apikale Prozesse } & \text { Zahnstein } & \text { Karies } & \text { Abrasion } & \text { Neubildung } & \text { Schmelzhypoplasie } \\ 26 & & & \mathrm{~K} 1 & 0 & 0 & 2 & 0\end{array}$




\section{Splitter}

Population: Rheine

Geschlecht:

Alter:

Beschreibung: Wenige nicht befundbare Zahnsplitter. Die Splitter sind nicht zuzuordnen und werden aufgrund der Gefahr der Doppeltzählung nicht mit ausgewertet sondern nur aus Dokumentationszwecken beschrieben.
9

Skelett: $\quad 3610 / 1$ S3 8.7.83 1153 Krankheiten:

\begin{tabular}{c|l|l} 
Arthrose & rechts & links \\
\hline Caput & & \\
\hline Fossa & &
\end{tabular}

Zahn Status Parodontium Apikale Prozesse Zahnstein Karies Abrasion Neubildung Schmelzhypoplasie
$\mathrm{xx}$ 


\section{Splitter}

Population: Rheine

Geschlecht:

Alter:

Beschreibung: Ein zersplitterter Zahn. Die Splitter sind nicht zuzuordnen und werden aufgrund der Gefahr der Doppeltzählung nicht mit ausgewertet sondern nur aus Dokumentationszwecken beschrieben.
9

Skelett: $\quad 3610 / 1$ S3 06.07.83 Krankheiten: 1024

\begin{tabular}{c|l|l} 
Arthrose & rechts & links \\
\hline Caput & & \\
\hline Fossa & &
\end{tabular}
nur aus Dokumentationszwecken beschieben.

Zahn Status Parodontium Apikale Prozesse Zahnstein Karies Abrasion Neubildung Schmelzhypoplasie




\section{Zahn}

Population:

Rheine

Geschlecht:

Alter:

$10-16(20)$

Beschreibung: Es handelt sich hier um eine Zahnanlage.

\section{Zahn Status Parodontium}

Apikale Prozesse

\subsubsection{4 / 27}

Skelett: $\quad 3610 / 1$ S3 11.05.83 a Krankheiten: 45

\begin{tabular}{c|l|l} 
Arthrose & rechts & links \\
\hline Caput & & \\
\hline Fossa & &
\end{tabular}




\section{Zahn}

Population: Rheine

Geschlecht:

Alter:

(3) 4 - 7 (9)

\subsubsection{4 / 28}

Skelett: $\quad 3610 / 1$ S3 17.05.83 a Krankheiten: 80

Beschreibung: Eine Zahnkrone, bei der nicht nachzuvollziehen ist, ob sie eine Anlage oder ein bereits durchgebrochener Zahn ist.

$\begin{array}{llcccccc}\text { Zahn } & \text { Status } & \text { Parodontium } & \text { Apikale Prozesse } & \text { Zahnstein } & \text { Karies } & \text { Abrasion } & \text { Neubildung } \\ 21 & & 0 & 0 & 0 & 0 & 0\end{array}$




\section{Zahn}

Population: Rheine

Geschlecht:

Alter:

Beschreibung: Eine Zahnanlage.

\subsubsection{4 / 32}

Skelett: $\quad 3610 / 1$ S3 17.05.83 a Krankheiten: 84

\begin{tabular}{c|l|l} 
Arthrose & rechts & links \\
\hline Caput & & \\
\hline Fossa & &
\end{tabular}




\section{Zahn}

Population: Rheine

Geschlecht:

Alter:

Beschreibung:

\subsubsection{4 / 35}

Skelett: $\quad 3610 / 1$ S3 11.05.83 a Krankheiten: 34

9

\begin{tabular}{c|l|l} 
Arthrose & rechts & links \\
\hline Caput & & \\
\hline Fossa & &
\end{tabular}

\section{Zahn Status Parodontium Apikale Prozesse}

12

0
Zahnstein

K 1
Karies

0
Abrasion

O 3
Neubildung

0

Schmelzhypoplasie 


\section{Zahn}

Population:

Rheine

Geschlecht:

Alter:

(25) 28 - $35(38)$

Beschreibung: Bei diesem Zahn ist die halbe Wurzel abfrakturiert.

\subsubsection{4 / 3}

Skelett: $\quad 9.7 .83869$
Krankheiten:

MKZ 3610,1 Schnitt $1 \& 327$

\begin{tabular}{c|l|l} 
Arthrose & rechts & links \\
\hline Caput & & \\
\hline Fossa & &
\end{tabular}

Zahnstein

0
Karies

D 1
Abrasion

O 3
Neubildung

0

Schmelzhypoplasie 


\section{Zahn}

Population: Rheine

Geschlecht:

Alter:

Beschreibung: Ein nicht genau zuzuordnender Zahn mit Zahnsplittern.

\subsubsection{4 / 4}

Skelett: 9.7 .83869

Krankheiten:
MKZ 3610,1 Schnitt $1 \& 327$

\begin{tabular}{c|l|l} 
Arthrose & rechts & links \\
\hline Caput & & \\
\hline Fossa & &
\end{tabular}




\section{Splitter}

Population: Rheine

Geschlecht:

Alter:

Beschreibung: Hier sind lediglich Splitter erhalten. Die Splitter sind nicht zuzuordnen und werden aufgrund der Gefahr der Doppeltzählung nicht mit ausgewertet sondern nur aus Dokumentationszwecken beschrieben.
MKZ 3610,1 Schnitt $1 \& 327$

Skelett: aus Tüte mit Krankheiten:

Zahnfragmenten

\begin{tabular}{c|l|l} 
Arthrose & rechts & links \\
\hline Caput & & \\
\hline Fossa & &
\end{tabular}




\section{Zahn}

Population: Rheine

Geschlecht:

Alter:

(14) 16 - 22 (24)

\subsubsection{4 / 8}

Skelett: Zahntüte

Krankheiten:

Beschreibung:
7

\begin{tabular}{c|l|l} 
Arthrose & rechts & links \\
\hline Caput & & \\
\hline Fossa & &
\end{tabular}

$\begin{array}{lcccccccc}\text { Zahn } & \text { Status } & \text { Parodontium } & \text { Apikale Prozesse } & \text { Zahnstein } & \text { Karies } & \text { Abrasion } & \text { Neubildung } & \text { Schmelzhypoplasie } \\ 26 & & 0 & 0 & 0 & 0 & 2 & 0 & 0\end{array}$




\section{Zahn}

Population: Rheine

Geschlecht:

Alter:

(22) 25 - $30(34)$

Beschreibung: Hier ist lediglich die Krone des Zahnes vorhanden.

\subsubsection{4 / 9}

Skelett: Zahntüte
Krankheiten:

7

\begin{tabular}{c|l|l} 
Arthrose & rechts & links \\
\hline Caput & & \\
\hline Fossa & &
\end{tabular}

Zahn Status Parodontium Apikale Prozesse 36
Zahnstein

0

Karies

0

Abrasion

Neubildung

O 3

0

Schmelzhypoplasie 


\section{Zahn}

Population: Rheine

Geschlecht:

Alter:

(6) $8,5-13(15)$

Beschreibung: Bei diesem Zahn ist die Wurzel zur Hälfte abfrakturiert.
7

\begin{tabular}{c|l|l} 
Arthrose & rechts & links \\
\hline Caput & & \\
\hline Fossa & &
\end{tabular}

$\begin{array}{llllllcc}\text { Zahn } & \text { Status } & \text { Parodontium } & \text { Apikale Prozesse } & \text { Zahnstein } & \text { Karies } & \text { Abrasion } & \text { Neubildung } \\ 26 & & \mathrm{~K} 1 & \mathrm{O} & 1 & 0 & \mathrm{~T} & 1\end{array}$




\section{Zahn}

Population: Rheine

Geschlecht:

Alter:

(6) $8,5-13(15)$

Beschreibung: Hier ist nur die Zahnkrone vorhanden.
7

Krankheiten:

\begin{tabular}{c|l|l} 
Arthrose & rechts & links \\
\hline Caput & & \\
\hline Fossa & &
\end{tabular}

$\begin{array}{llllclccc}\text { Zahn } & \text { Status } & \text { Parodontium } & \text { Apikale Prozesse } & \text { Zahnstein } & \text { Karies } & \text { Abrasion } & \text { Neubildung } & \text { Schmelzhypoplasie } \\ 26 & & \mathrm{~K} 1 & 0 & \mathrm{O} & 1 & 0 & \mathrm{~T} & 1\end{array}$




\section{Zähne}

Population: Rheine

Geschlecht:

Alter:

Beschreibung: Hier ist nur die Krone vorhanden.
7

Krankheiten:

\begin{tabular}{c|l|l} 
Arthrose & rechts & links \\
\hline Caput & & \\
\hline Fossa & &
\end{tabular}

Zahn Status Parodontium Apikale Prozesse 008 


\section{Zahn}

Population: Rheine

Geschlecht:

Alter:

(3) 4 - 6 (7)

Beschreibung: Hier ist nur die Krone vorhanden.
7

Krankheiten:

\begin{tabular}{c|l|l} 
Arthrose & rechts & links \\
\hline Caput & & \\
\hline Fossa & &
\end{tabular}

\section{Zahn Status Parodontium Apikale Prozesse}




\section{Splitter}

Population: Rheine

Geschlecht:

Alter:

Beschreibung: Hier sind lediglich zwei kleine Schmelzfragmente erhalten. Die Splitter sind nicht zuzuordnen und werden aufgrund der Gefahr der Doppeltzählung nicht mit ausgewertet sondern nur aus Dokumentationszwecken beschrieben.
7

Krankheiten:

\begin{tabular}{c|l|l} 
Arthrose & rechts & links \\
\hline Caput & & \\
\hline Fossa & &
\end{tabular}

Zahn Status Parodontium Apikale Prozesse Zahnstein Karies Abrasion Neubildung Schmelzhypoplasie




\section{Zahn}

Population: Rheine

Geschlecht:

Alter:

Beschreibung: Hier ist die distal vestibuläre Wurzel abfrakturiert.
7

\begin{tabular}{c|l|l} 
Arthrose & rechts & links \\
\hline Caput & & \\
\hline Fossa & &
\end{tabular}

\section{Krankheiten:}

Skelett: Zahntüte

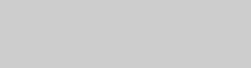




\section{Zahn}

Population: Rheine

Geschlecht:

Alter:

(22) $25-30(34)$

Beschreibung: Hier ist die Wurzel abgebrochen.
7

Krankheiten:

\begin{tabular}{c|l|l} 
Arthrose & rechts & links \\
\hline Caput & & \\
\hline Fossa & &
\end{tabular}

$\begin{array}{llllclccc}\text { Zahn } & \text { Status } & \text { Parodontium } & \text { Apikale Prozesse } & \text { Zahnstein } & \text { Karies } & \text { Abrasion } & \text { Neubildung } & \text { Schmelzhypoplasie } \\ 16 & & \mathrm{~K} 1 & 0 & \mathrm{O} & 3 & 0 & \mathrm{~T} & 1\end{array}$




\section{Splitter}

Population: Rheine

Geschlecht:

Alter:

Beschreibung: Wurzelfragmente aus Leichenbrand. Die Splitter sind nicht zuzuordnen und werden aufgrund der Gefahr der Doppeltzählung nicht mit ausgewertet sondern nur aus Dokumentationszwecken beschrieben.

\section{7}

\begin{tabular}{c|l|l} 
Arthrose & rechts & links \\
\hline Caput & & \\
\hline Fossa & &
\end{tabular}

Zahn Status Parodontium Apikale Prozesse Zahnstein Karies Abrasion Neubildung Schmelzhypoplasie




\section{Zahn}

Population: Rheine

Geschlecht:

Alter:

(25) 28 - 35 (38)

\subsubsection{4 / 25}

Skelett: große Tüte in kleiner Tüte 4010

Beschreibung: Hier ist lediglich die Krone mit einem Teil der Wurzel des Zahnes vorhanden. Es handelt sich um Leichenbrand.

$\begin{array}{lccccccccc}\text { Zahn } & \text { Status } & \text { Parodontium } & \text { Apikale Prozesse } & \text { Zahnstein } & \text { Karies } & \text { Abrasion } & \text { Neubildung } & \text { Schmelzhypoplasie } \\ 36 & & x & x & 0 & 0 & 4 & * & x\end{array}$




\section{Zahn}

Population: Rheine

Geschlecht:

Alter:

(22) 25 - $35(38)$

Beschreibung: Hier ist nur die Krone vorhanden.
7

Krankheiten:

\begin{tabular}{c|l|l} 
Arthrose & rechts & links \\
\hline Caput & & \\
\hline Fossa & &
\end{tabular}

\begin{tabular}{|c|c|c|c|c|c|c|c|}
\hline & Status & Parodontium & Apikale Prozesse & Zahnstein & Karies & Abrasion & Schmelzhypoplasie \\
\hline
\end{tabular}




\section{Splitter}

Population: Rheine

Geschlecht:

Alter:

\section{Beschreibung: Zahnsplitter. Die Splitter sind nicht zuzuordnen und werden aufgrund der Gefahr der Doppeltzählung nicht mit ausgewertet sondern nur aus} Dokumentationszwecken beschrieben.

\section{Zahn Status Parodontium}




\section{Zahn}

Population: Rheine

Geschlecht:

Alter:

Beschreibung: Hier ist nur die Krone vorhanden.
7

\begin{tabular}{c|l|l} 
Arthrose & rechts & links \\
\hline Caput & & \\
\hline Fossa & &
\end{tabular}

Krankheiten:

.

Skelett: einzelne kleine Tüte 


\section{Zahn}

Population: Rheine

Geschlecht:

Alter:

Beschreibung: Hier ist nur die Krone vorhanden.
7

\begin{tabular}{c|l|l} 
Arthrose & rechts & links \\
\hline Caput & & \\
\hline Fossa & &
\end{tabular}

Krankheiten:

.

Skelett: einzelne kleine Tüte 


\section{Zahn}

Population: Rheine

Geschlecht:

Alter:

Beschreibung: Hier ist nur die Krone vorhanden.
7

\begin{tabular}{c|l|l} 
Arthrose & rechts & links \\
\hline Caput & & \\
\hline Fossa & &
\end{tabular}

Krankheiten:

.

Skelett: einzelne kleine Tüte 


\section{Zahn}

Population: Rheine

Geschlecht:

Alter:

Beschreibung: Hier ist nur ein Fragment der Krone vorhanden.
7

\begin{tabular}{c|l|l} 
Arthrose & rechts & links \\
\hline Caput & & \\
\hline Fossa & &
\end{tabular}

Krankheiten:

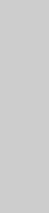

Skelett: einzelne kleine Tüte 


\section{Zahn}

Population: Rheine

Geschlecht:

Alter:

\section{Beschreibung:}

\subsubsection{4 / 39}

Skelett: einzelne kleine Tüte

Krankheiten:

\begin{tabular}{c|l|l} 
Arthrose & rechts & links \\
\hline Caput & & \\
\hline Fossa & &
\end{tabular}




\section{Zahn}

Population: Rheine

Geschlecht:

Alter:

\section{Beschreibung:}

\subsubsection{4 / 41}

Skelett: $\quad 5.5 .834002$

Krankheiten:

\begin{tabular}{c|l|l} 
Arthrose & rechts & links \\
\hline Caput & & \\
\hline Fossa & &
\end{tabular}




\section{zahn}

Population: Rheine

Geschlecht:

Alter:

Beschreibung: Ein zu 4/5 erhaltener Zahn aus Leichenbrand und mehrere kleinste Fragmente.

\section{Krankheiten:}

Alter:
7

\begin{tabular}{c|l|l} 
Arthrose & rechts & links \\
\hline Caput & & \\
\hline Fossa & &
\end{tabular}

\section{Zahn Status Parodontium Apikale Prozesse} 000 Zahnstein K 1
Karies

0
Abrasion

O 4 


\section{zahn}

Population: Rheine

Geschlecht:

Alter:

(6) $8,5-13(15)$

Beschreibung: 1/3 dieses Molaren sind erhalten.
4

Krankheiten:

\begin{tabular}{c|l|l} 
Arthrose & rechts & links \\
\hline Caput & & \\
\hline Fossa & &
\end{tabular}

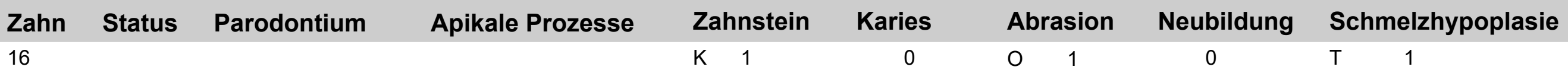




\section{Zahn}

Population: Rheine

Geschlecht:

Alter:

Beschreibung: Hier ist lediglich die Krone mit 1/4 der Wurzel des Zahnes vorhanden.

\subsubsection{4 / 48}

Skelett: $\quad 29.6 .83740$
Krankheiten:

4

\begin{tabular}{c|l|l} 
Arthrose & rechts & links \\
\hline Caput & & \\
\hline Fossa & &
\end{tabular}

\section{Zahn Status Parodontium Apikale Prozesse}

004
Zahnstein

K 1

Karies

0

Abrasion

Neubildung

0

0

Schmelzhypoplasie

T 1 


\section{zahn}

Population: Rheine

Geschlecht:
Alter:
(4) $5-6$

Beschreibung: Bei diesem Milchzahn sind 1/5 der Wurzel bereits resorbiert.

\subsubsection{4 / 49}

Skelett: $\quad 29.6 .83740$

Krankheiten:

4

\begin{tabular}{c|l|l} 
Arthrose & rechts & links \\
\hline Caput & & \\
\hline Fossa & &
\end{tabular}

$\begin{array}{llccccccc}\text { Zahn } & \text { Status } & \text { Parodontium } & \text { Apikale Prozesse } & \text { Zahnstein } & \text { Karies } & \text { Abrasion } & \text { Neubildung } & \text { Schmelzhypoplasie } \\ 65 & & 0 & \mathrm{~K} 1 & 0 & 0 & 4 & * & 0\end{array}$




\section{zahn}

Population: Rheine

Geschlecht:

Alter:

Beschreibung: Hier ist lediglich die Krone des Zahnes vorhanden.

\subsubsection{4 / 50}

Skelett: $\quad 29.6 .83740$
Krankheiten:

\section{Krankheiten:}

\begin{tabular}{c|l|l} 
Arthrose & rechts & links \\
\hline Caput & & \\
\hline Fossa & &
\end{tabular}

\section{Zahn Status Parodontium}

Apikale Prozesse
Zahnstein Karies

0 


\section{zahn}

Population: Rheine

Geschlecht:

Alter:

Beschreibung:

\subsubsection{4 / 51}

Skelett: $\quad 29.6 .83740$

Krankheiten:

\section{4nur zwei kleiner Fragmente}

\begin{tabular}{c|l|l} 
Arthrose & rechts & links \\
\hline Caput & & \\
\hline Fossa & &
\end{tabular}

Zahn Status Parodontium Apikale Prozesse 001
Zahnstein

Karies

Abrasion

Neubildung

Schmelzhypoplasie 


\section{Zahn}

Population: Rheine

Geschlecht:

Alter:

(3) 4 - 6 (7)

\section{Beschreibung:}

\subsubsection{4 / 55}

Skelett: 28.6 .83

Krankheiten:

\begin{tabular}{c|l|l} 
Arthrose & rechts & links \\
\hline Caput & & \\
\hline Fossa & &
\end{tabular}

4

\section{Zahn Status Parodontium Apikale Prozesse}

Zahnstein

0

Abrasion

Neubildung

0 


\section{Zahn}

Population: Rheine

Geschlecht:

Alter:

Beschreibung: Diese Wurzel ist durch Leichenbrand deformiert.
4

Krankheiten:

\begin{tabular}{c|l|l} 
Arthrose & rechts & links \\
\hline Caput & & \\
\hline Fossa & &
\end{tabular}

Zahn Status Parodontium Apikale Prozesse Zahnstein

Karies Abrasion

Neubildung

Schmelzhypoplasie
K 1

0

O 3

0

0 


\section{Zahn}

Population: Rheine

Geschlecht:

Alter:

(3) $4-6(7)$

Beschreibung: Hier ist lediglich die Krone des Zahnes vorhanden.

\subsubsection{4 / 62}

Skelett: $\quad 28.6 .83$
Krankheiten:

\begin{tabular}{c|l|l} 
Arthrose & rechts & links \\
\hline Caput & & \\
\hline Fossa & &
\end{tabular}

Zahn Status Parodontium Apikale Prozesse

36
Zahnstein

0

Karies

0

Abrasion

Neubildung

0

0

Schmelzhypoplasie

0 


\section{Zahn}

Population: Rheine

Geschlecht:

Alter:

$35-45$

Beschreibung: Die Wurzel ist längs frakturiert, es sind nur noch $60 \%$ derselben vorhanden.
4

Krankheiten:

\begin{tabular}{c|l|l} 
Arthrose & rechts & links \\
\hline Caput & & \\
\hline Fossa & &
\end{tabular}

Zahn Status Parodontium 004
Apikale Prozesse Zahnstein K 1
Karies

0
Abrasion

O 4 


\section{Zahn}

Population: Rheine

Geschlecht:

Alter:

Beschreibung: Hier ist lediglich die Krone des Zahnes vorhanden. Es könnte sich um einen Tierzahn handeln! Das Fragment ist nicht zuzuordnen und wird nicht mit ausgewertet sondern nur aus Dokumentationszwecken beschrieben.
8

Krankheiten:

\begin{tabular}{c|l|l} 
Arthrose & rechts & links \\
\hline Caput & & \\
\hline Fossa & &
\end{tabular}

Zahn Status Parodontium Apikale Prozesse Zahnstein Karies Abrasion Neubildung Schmelzhypoplasie




\section{zahn}

Population: Rheine

Geschlecht:

Alter:

Beschreibung: Von diesem Zahn ist nur die Krone erhalten.
1

Krankheiten:

\begin{tabular}{c|l|l} 
Arthrose & rechts & links \\
\hline Caput & & \\
\hline Fossa & &
\end{tabular}

Zahn Status Parodontium Apikale Prozesse 004
Zahnstein

0
Karies

0
Abrasion

O 4 


\section{zahn}

Population: Rheine

Geschlecht:

Alter:

Beschreibung: Die Wurzel ist zur Hälfte abfrakturiert.
1

Krankheiten:

\begin{tabular}{c|l|l} 
Arthrose & rechts & links \\
\hline Caput & & \\
\hline Fossa & &
\end{tabular}

\section{Zahn Status Parodontium Apikale Prozesse} 004
26.03.2014 / 29

Skelett: 380
Zahnstein

K 1
Karies

0
Abrasion

O 4 


\section{Zahn}

Population: Rheine

Geschlecht:

Alter:

Beschreibung: Von diesem Zahn ist nur die Krone erhalten.

\subsubsection{4 / 30}

Skelett: 362

Krankheiten:

\begin{tabular}{c|l|l} 
Arthrose & rechts & links \\
\hline Caput & & \\
\hline Fossa & &
\end{tabular}




\section{zahn}

Population: Rheine

Geschlecht:

Alter:

(14) 16 - $22(24)$

Beschreibung: Wurzel ist zu $90 \%$ abfrakturiert.
1

Krankheiten:

\begin{tabular}{c|l|l} 
Arthrose & rechts & links \\
\hline Caput & & \\
\hline Fossa & &
\end{tabular}

Zahn Status Parodontium Apikale Prozesse Zahnstein Karies Abrasion Neubildung Schmelzhypoplasie 16 0 0 O 2 0 T 1 


\section{Zahn}

Population:

Rheine

Geschlecht:

Alter:

(15) 17 - $25(26)$

Beschreibung: $70 \%$ der Wurzel sind abfrakturiert
1

Krankheiten:

\begin{tabular}{c|l|l} 
Arthrose & rechts & links \\
\hline Caput & & \\
\hline Fossa & &
\end{tabular}

Zahnstein

0
Karies

0
Abrasion

O 1

(1)

\section{Neubildung}

Schmelzhypoplasie
17
26.03.2014 / 30

Apikale Prozesse
0 $\begin{array}{ll}\mathrm{T} & 1\end{array}$ 


\section{Zahn}

Population: Rheine

Geschlecht:

Alter:

Beschreibung: Hier ist nur die Krone erhalten. Diese ist aber sagittal gespalten.
26.03.2014 / 39

Skelett: a 211
1

Krankheiten:

\begin{tabular}{c|l|l} 
Arthrose & rechts & links \\
\hline Caput & & \\
\hline Fossa & &
\end{tabular}

Zahn Status Parodontium Apikale Prozesse

003
Zahnstein

0
Karies

0
Abrasion

O 3 


\section{zahn}

Population: Rheine

Geschlecht:

Alter:

(22) 25 - $33(35)$

Beschreibung: $40 \%$ der Krone ist abfrakturiert.
1

Krankheiten:

\begin{tabular}{c|l|l} 
Arthrose & rechts & links \\
\hline Caput & & \\
\hline Fossa & &
\end{tabular}

\section{Zahn Status Parodontium Apikale Prozesse}

17
Zahnstein

K 1

Karies

0

Abrasion

Neubildung

0

Schmelzhypoplasie

0 


\section{zahn}

Population: Rheine

Geschlecht:

Alter:

Beschreibung: Hier ist nur die Krone erhalten.
Krankheiten:

\begin{tabular}{c|l|l} 
Arthrose & rechts & links \\
\hline Caput & & \\
\hline Fossa & &
\end{tabular}

\section{Zahn Status Parodontium}

008

Apikale Prozesse
Zahnstein

0

\section{Karies}

0
Abrasion

0
Neubildun

0 


\section{Zahn}

Population: Rheine

Geschlecht:

Alter:

(3) $4-6(7)$

Beschreibung: 40\% der Krone ist abfrakturiert, knapp 1/3 der Wurzel ist erhalten.

\section{Zahn Status Parodontium}

Apikale Prozesse

\subsubsection{4 / 9}

Skelett: 3010

Krankheiten:

\begin{tabular}{c|l|l} 
Arthrose & rechts & links \\
\hline Caput & & \\
\hline Fossa & &
\end{tabular}

Zahnstein Karies 


\section{Zahn}

Population: Rheine

Geschlecht:

Alter:

Beschreibung: Es ist nur die Zahnkrone erhalten.
1

Krankheiten:

\begin{tabular}{c|l|l} 
Arthrose & rechts & links \\
\hline Caput & & \\
\hline Fossa & &
\end{tabular}

Zahn Status Parodontium Apikale Prozesse Zahnstein Karies 004
0
Abrasion

0
Neubildung

0
Schmelzhypoplasie

0 


\section{Zahn}

Population: Rheine

Geschlecht:

Alter:

Beschreibung: Es ist nur die Zahnkrone erhalten.
1

Krankheiten:

\begin{tabular}{c|l|l} 
Arthrose & rechts & links \\
\hline Caput & & \\
\hline Fossa & &
\end{tabular}

Zahn Status Parodontium Apikale Prozesse 004
27.03.2014 / 12

Skelett: 3006 


\section{Zahn}

Population: Rheine

Geschlecht:

Alter:

(3) $4-6(7)$

Beschreibung: Die Krone ist zu $90 \%$ erhalten.
7

Krankheiten:

\begin{tabular}{c|l|l} 
Arthrose & rechts & links \\
\hline Caput & & \\
\hline Fossa & &
\end{tabular}

$\begin{array}{llcccccc}\text { Zahn } & \text { Status } & \text { Parodontium } & \text { Apikale Prozesse } & \text { Zahnstein } & \text { Karies } & \text { Abrasion } & \text { Neubildung } \\ 46 & & 0 & 0 & 0 & 0 & T\end{array}$




\section{Zahn}

Population: Rheine

Geschlecht:

Alter:

(25) $28-35(38)$

Beschreibung: Etwa die Hälfte der Wurzel ist abfrakturiert.
7

Krankheiten:

\begin{tabular}{c|l|l} 
Arthrose & rechts & links \\
\hline Caput & & \\
\hline Fossa & &
\end{tabular}

$\begin{array}{lllllclcc}\text { Zahn } & \text { Status } & \text { Parodontium } & \text { Apikale Prozesse } & \text { Zahnstein } & \text { Karies } & \text { Abrasion } & \text { Neubildung } & \text { Schmelzhypoplasie } \\ 36 & & & \mathrm{~K} 1 & 0 & 0 & 4 & * & 0\end{array}$




\section{Zahn}

Population: Rheine

Geschlecht:

Alter:

\section{Beschreibung:}

\subsubsection{4 / 18}

Skelett: 229

Krankheiten:

7

\begin{tabular}{c|l|l} 
Arthrose & rechts & links \\
\hline Caput & & \\
\hline Fossa & &
\end{tabular}

\section{Zahn Status Parodontium}

Apikale Prozesse 


\section{Zahn}

Population: Rheine

Geschlecht:

Alter:

(22) $25-30(34)$

Beschreibung: $60 \%$ der Krone erhalten.

\subsubsection{4 / 20}

Skelett: 222

Krankheiten:

7

\begin{tabular}{c|l|l} 
Arthrose & rechts & links \\
\hline Caput & & \\
\hline Fossa & &
\end{tabular}

$\begin{array}{llccccccc}\text { Zahn } & \text { Status } & \text { Parodontium } & \text { Apikale Prozesse } & \text { Zahnstein } & \text { Karies } & \text { Abrasion } & \text { Neubildung } & \text { Schmelzhypoplasie } \\ 46 & & x & x & 0 & 3 & 0 & x\end{array}$




\section{Zahn}

Population: Rheine

Geschlecht:

Alter:

(22) $25-33(35)$

Beschreibung: Von diesem Zahn ist die Krone erhalten.
7

Krankheiten:

\begin{tabular}{c|l|l} 
Arthrose & rechts & links \\
\hline Caput & & \\
\hline Fossa & &
\end{tabular}

$\begin{array}{llccccccc}\text { Zahn } & \text { Status } & \text { Parodontium } & \text { Apikale Prozesse } & \text { Zahnstein } & \text { Karies } & \text { Abrasion } & \text { Neubildung } & \text { Schmelzhypoplasie } \\ 47 & & 0 & 0 & 0 & 2 & 0 & 0\end{array}$




\section{Zahn}

Population: Rheine

Geschlecht:

Alter:

Beschreibung: Von diesem Zahn ist die Krone erhalten.

\subsubsection{4 / 22}

Skelett: 248

Krankheiten:

7
Zahn Status Parodontium Apikale Prozesse
Zahnstein Karies

0

0

Abrasion Neubildung Schmelzhypoplasie

\begin{tabular}{c|l|l} 
Arthrose & rechts & links \\
\hline Caput & & \\
\hline Fossa & &
\end{tabular}

0

0 


\section{Zahn}

Population: Rheine

Geschlecht:

Alter:

(16) 20 - $30(35)$

Beschreibung: Von diesem Zahn ist die Krone erhalten.
7

Krankheiten:

\begin{tabular}{c|l|l} 
Arthrose & rechts & links \\
\hline Caput & & \\
\hline Fossa & &
\end{tabular}

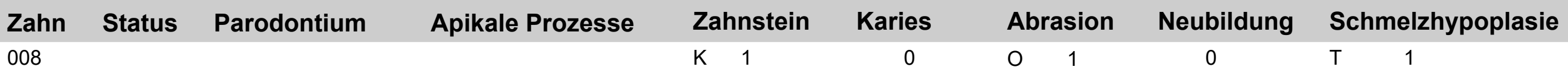




\section{Zahn}

Population: Rheine

Geschlecht:

Alter:

(16) 20 - $30(35)$

Beschreibung: Von diesem Zahn ist die Krone erhalten.
7

Krankheiten:

\begin{tabular}{c|l|l} 
Arthrose & rechts & links \\
\hline Caput & & \\
\hline Fossa & &
\end{tabular}

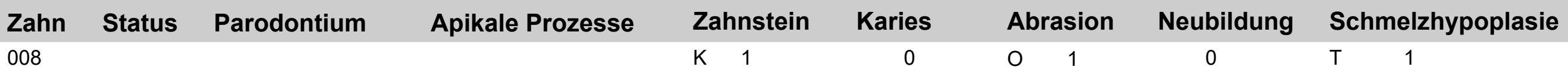




\section{Zahn}

Population: Rheine

Geschlecht:

Alter:

(22) 25 - 30 (34)

Beschreibung: Hier ist nur die Hälfte der Krone erhalten.

Skelett: 314

\subsubsection{4 / 24}

Krankheiten:

7

\begin{tabular}{c|l|l} 
Arthrose & rechts & links \\
\hline Caput & & \\
\hline Fossa & &
\end{tabular}

Zahnstein

$x$
Karies

$\mathrm{x}$
Abrasion

O 3 


\section{Zahn}

Population: Rheine

Geschlecht:

Alter:

Beschreibung: Von diesem Zahn ist die Krone erhalten.

\subsubsection{4 / 25}

Skelett: 220

Krankheiten:

7

$\begin{array}{llcccccc}\text { Zahn } & \text { Status } & \text { Parodontium } & \text { Apikale Prozesse } & \text { Zahnstein } & \text { Karies } & \text { Abrasion } & \text { Neubildung } \\ 004 & & 0 & 0 & 0 & 1 & 0 & 0\end{array}$




\section{Zahn}

Population: Rheine

Geschlecht:

Alter:

Beschreibung: $60 \%$ der Krone erhalten.

\subsubsection{4 / 28}

Skelett: 274

Krankheiten:

7
Zahn Status Parodontium Apikale Prozesse
Zah

\section{Karies}




\section{Zahn}

Population: Rheine

Geschlecht:

Alter:

Beschreibung: Von diesem Zahn ist die Krone erhalten. Es handelt sich um ein Fundstück aus Leichenbrand, welches nicht genau befundbar ist.

\subsubsection{4 / 29}

Skelett: 252
Krankheiten:

\begin{tabular}{c|l|l} 
Arthrose & rechts & links \\
\hline Caput & & \\
\hline Fossa & &
\end{tabular}

\section{Zahn Status Parodontium Apikale Prozesse}

36
Zahnstein

$\mathrm{X}$

Karies

$\mathrm{x}$

Abrasion Neubildung Schmelzhypoplasie 


\section{Zahn}

Population: Rheine

Geschlecht:

Alter:

Beschreibung: Von diesem Zahn ist die Krone erhalten.
31.03.2014 / 5

Skelett: 969
7

Krankheiten:

\begin{tabular}{c|l|l} 
Arthrose & rechts & links \\
\hline Caput & & \\
\hline Fossa & &
\end{tabular}

Zahn Status Parodontium Apikale Prozesse 008 


\section{Zahn}

Population: Rheine

Geschlecht:

Alter:

(3) $4-6(7)$

Beschreibung: Von diesem Zahn ist die Krone erhalten.

31.03.2014 / 7

Skelett: 942
7

Krankheiten:

\begin{tabular}{c|l|l} 
Arthrose & rechts & links \\
\hline Caput & & \\
\hline Fossa & &
\end{tabular}

Zahn Status Parodontium Apikale Prozesse
36
0
Karies

0

\section{Abrasion Neubildung Schmelzhypoplasie}

0

0 


\section{Zahn}

Population: Rheine

Geschlecht:

Alter:

Beschreibung: Von diesem Zahn ist nur die Krone erhalten.
31.03.2014 / 12

Skelett: 975
7

Krankheiten:

\begin{tabular}{c|l|l} 
Arthrose & rechts & links \\
\hline Caput & & \\
\hline Fossa & &
\end{tabular}

Zahn Status Parodontium Apikale Prozesse 008
Zahnstein

0
Karies

0
Abrasion Neubildung Schmelzhypoplasie 


\section{Zahn}

Population: Rheine

Geschlecht:

Alter:

(2) 3 - 4 (5)

Beschreibung: Eine Anlage eines 1ers.

\subsubsection{4 / 13}

Skelett: 1022

Krankheiten:

7

\begin{tabular}{c|l|l} 
Arthrose & rechts & links \\
\hline Caput & & \\
\hline Fossa & &
\end{tabular}

Zahn
Zahnstein Karies

Abrasion 


\section{Zahn}

Population: Rheine

Geschlecht:

Alter:

Beschreibung: Von diesem Zahn ist nur die Krone erhalten, diese ist frakturiert und wohl aus Leichenbrand.

\subsubsection{4 / 13}

Skelett: 997
Krankheiten:

\begin{tabular}{c|l|l} 
Arthrose & rechts & links \\
\hline Caput & & \\
\hline Fossa & &
\end{tabular}

\begin{tabular}{|c|c|c|c|c|c|c|c|c|}
\hline Zahn & Status & Parodontium & Apikale Prozesse & Zahnstein & Karies & Abrasion & Neubildung & Schmelzhypoplasie \\
\hline 16 & & & & $x$ & $x$ & $x$ & $x$ & $x$ \\
\hline
\end{tabular}




\section{Zahn}

Population: Rheine

Geschlecht:

Alter:

(3) 4 - 5 (6)

Beschreibung: Die Zahnkrone ist zu 70\% erhalten, es handelt sich um eine Anlage.

\section{Zahn Status Parodontium}

Apikale Prozesse

\subsubsection{4 / 14}

Skelett: 2500
Krankheiten:

7

\begin{tabular}{c|l|l} 
Arthrose & rechts & links \\
\hline Caput & & \\
\hline Fossa & &
\end{tabular}

36 


\section{Zahn}

Population: Rheine

Geschlecht:

Alter:

Beschreibung: Von diesem Zahn ist nur die Krone erhalten.
31.03.2014 / 14

Skelett: 2500
7

Krankheiten:

\begin{tabular}{c|l|l} 
Arthrose & rechts & links \\
\hline Caput & & \\
\hline Fossa & &
\end{tabular}

Zahn Status Parodontium Apikale Prozesse 41 


\section{Zahn}

Population: Rheine

Geschlecht:

Alter:

Beschreibung: $60 \%$ der Krone sind erhalten.
7

\begin{tabular}{c|l|l} 
Arthrose & rechts & links \\
\hline Caput & & \\
\hline Fossa & &
\end{tabular}

\section{Zahn Status Parodontium Apikale Prozesse} 004
Krankheiten:

31.03.2014 / 14

Skelett: 2500 Zahnstein

Karies

K 1

0
Abrasion Neubildung Schmelzhypoplasie
0

0 


\section{Zahn}

Population: Rheine

Geschlecht:

Alter:

Beschreibung: $80 \%$ einer Zahnkrone sind hier erhalten.
7

\begin{tabular}{c|l|l} 
Arthrose & rechts & links \\
\hline Caput & & \\
\hline Fossa & &
\end{tabular}

\section{Zahn Status Parodontium Apikale Prozesse} 004
31.03.2014 / 15

Skelett: 2504

\section{Krankheiten:}




\section{Zahn}

Population: Rheine

Geschlecht:

Alter:

Beschreibung: Von diesem Zahn ist die Wurzel zur Hälfte abfrakturiert.
7

Krankheiten:

\begin{tabular}{c|l|l} 
Arthrose & rechts & links \\
\hline Caput & & \\
\hline Fossa & &
\end{tabular}

Zahn Status Parodontium Apikale Prozesse

Zahnstein Karies

Abrasion

Neubildung

0

Schmelzhypoplasie
K 2

0
O 2

(2)

0 


\section{Schmuck Zahn}

Population: Rheine

Geschlecht:

Alter:

Beschreibung: Hier ist ein Schmuckstück erhalten. Es handelt sich um eine durchbohrte Zahnwurzel, die von einem Menschen wohl als Kette getragen worden ist. Ob es sich um einen menschlichen Zahn gehandelt hat, ist nicht zu differenzieren. Deswegen wurde das Objekt nicht mit ausgewertet.

\subsubsection{4 / 17}

Skelett: 2501
7

Krankheiten: Schmuck

\begin{tabular}{c|l|l} 
Arthrose & rechts & links \\
\hline Caput & & \\
\hline Fossa & &
\end{tabular}

Zahn Status Parodontium Apikale Prozesse Zahnstein Karies Abrasion Neubildung Schmelzhypoplasie
$\mathrm{xx}$ 


\section{Schmuck Zahn}

Population: Rheine

Geschlecht:

Alter:

Beschreibung: Hier ist ein Schmuckstück erhalten. Es handelt sich um eine durchbohrte Zahnwurzel, die von einem Menschen wohl als Kette getragen

worden ist. Ob es sich um einen menschlichen Zahn gehandelt hat, ist nicht zu differenzieren. Deswegen wurde das Objekt nicht mit ausgewertet.

\subsubsection{4 / 18}

Skelett: 2502
Krankheiten:

\begin{tabular}{c|l|l} 
Arthrose & rechts & links \\
\hline Caput & & \\
\hline Fossa & &
\end{tabular}

\section{Zahn Status Parodontium}




\section{Zahn}

Population: Rheine

Geschlecht:

Alter:

(3) $4-6(7)$

Beschreibung: $80 \%$ der Krone ist erhalten.
7

Krankheiten:

\begin{tabular}{c|l|l} 
Arthrose & rechts & links \\
\hline Caput & & \\
\hline Fossa & &
\end{tabular}

$\begin{array}{llllccccc}\text { Zahn } & \text { Status } & \text { Parodontium } & \text { Apikale Prozesse } & \text { Zahnstein } & \text { Karies } & \text { Abrasion } & \text { Neubildung } & \text { Schmelzhypoplasie } \\ 46 & & \mathrm{~K} 1 & 0 & 0 & 1 & 0\end{array}$




\section{Zahn}

Population: Rheine

Geschlecht:

Alter:

(25) 28 - $35(38)$

Beschreibung: Es ist 1/3 der Krone erhalten.
7

Krankheiten:

\begin{tabular}{c|l|l} 
Arthrose & rechts & links \\
\hline Caput & & \\
\hline Fossa & &
\end{tabular}

$\begin{array}{llccccccc}\text { Zahn } & \text { Status } & \text { Parodontium } & \text { Apikale Prozesse } & \text { Zahnstein } & \text { Karies } & \text { Abrasion } & \text { Neubildung Schmelzhypoplasie } \\ 36 & & 0 & 0 & 0 & 4 & *\end{array}$




\section{Zahn}

Population: Rheine

Geschlecht:

Alter:

\subsubsection{4 / 19}

Skelett: 2508

7

Krankheiten:

\begin{tabular}{c|l|l} 
Arthrose & rechts & links \\
\hline Caput & & \\
\hline Fossa & &
\end{tabular}

Beschreibung: Krone mit 1/4 Wurzel erhalten, weiterhin liegt noch ein kleiner Splitter eines Zahnes vor, der nicht befundbar war.

$\begin{array}{llllllccc}\text { Zahn } & \text { Status } & \text { Parodontium } & \text { Apikale Prozesse } & \text { Zahnstein } & \text { Karies } & \text { Abrasion } & \text { Neubildung } & \text { Schmelzhypoplasie } \\ 004 & & & \mathrm{~K} 1 & 0 & 0 & 3 & 0 & 0\end{array}$




\section{Zahn}

Population: Rheine

Geschlecht:

Alter:

Beschreibung: 1/3 der Wurzel ist wegfrakturiert.
7

Krankheiten:

\begin{tabular}{c|l|l} 
Arthrose & rechts & links \\
\hline Caput & & \\
\hline Fossa & &
\end{tabular}

Zahn Status Parodontium Apikale Prozesse 004
31.03.2014 / 21

Skelett: 2514
Zahnstein

$\mathrm{x}$

Karies

Abrasion

Neubildung

O 3

$\mathrm{x}$ 


\section{Zahn}

Population: Rheine

Geschlecht:

Alter:

\section{Beschreibung:}

\subsubsection{4 / 21}

Skelett: 2514

Krankheiten:

\section{Krankheiten:}

\begin{tabular}{c|l|l} 
Arthrose & rechts & links \\
\hline Caput & & \\
\hline Fossa & &
\end{tabular}




\section{Schmuck Zahn}

Population: Rheine

Geschlecht:

Alter:

Beschreibung: Ein weiteres Exemplar der Schmuckzähne. Es ist nicht zu differenzieren, ob es ein menschlicher Zahn war. Deswegen wurde das Objekt nicht mit ausgewertet.

Zahn Status Parodontium Apikale Prozesse Zahnstein Karies
$\mathrm{xx}$




\section{Zahn}

Population: Rheine

Geschlecht:

Alter:

Beschreibung: Es ist nur die Krone erhalten.
7

Krankheiten:

\begin{tabular}{c|l|l} 
Arthrose & rechts & links \\
\hline Caput & & \\
\hline Fossa & &
\end{tabular}

\section{Zahn Status Parodontium Apikale Prozesse}

12
Zahnstein

K 1
Karies

0
Abrasion

O 1
Neubildung

0

Schmelzhypoplasie 


\section{Zahn}

Population: Rheine

Geschlecht:

Alter:

\section{Beschreibung:}

\subsubsection{4 / 21}

Skelett: 2514

Krankheiten:

\section{Krankheiten:}

7

\begin{tabular}{c|l|l} 
Arthrose & rechts & links \\
\hline Caput & & \\
\hline Fossa & &
\end{tabular}

\section{Zahn Status Parodontium Apikale Prozesse}

12
0
Zahnstein

K 1
Karies

0
Abrasion

O 1
Neubildung

0
Schmelzhypoplasie

0 


\section{Zahn}

Population: Rheine

Geschlecht:

Alter:

Beschreibung: Es ist nur die Krone erhalten.
7

Krankheiten:

\begin{tabular}{c|l|l} 
Arthrose & rechts & links \\
\hline Caput & & \\
\hline Fossa & &
\end{tabular}

Zahn Status Parodontium Apikale Prozesse

12

Zahnstein

Karies

0

0

Abrasion

Neubildung

0

Schmelzhypoplasie 


\section{Zahn}

Population: Rheine

Geschlecht:

Alter:

$12-18$

Beschreibung: Ein Zahnanlage.
07.04.2014 / 33

Skelett: 1527

Krankheiten:

\begin{tabular}{c|l|l} 
Arthrose & rechts & links \\
\hline Caput & & \\
\hline Fossa & &
\end{tabular}

\section{Zahn Status Parodontium}

Apikale Prozesse 


\section{Zahn}

Population:

Rheine

Geschlecht:

Alter:

$3-5(9)$
6

\begin{tabular}{c|l|l} 
Arthrose & rechts & links \\
\hline Caput & & \\
\hline Fossa & &
\end{tabular}

Beschreibung: Von diesem Zahn ist nur die Krone erhalten, es handelt sich wohl um eine Anlage, weiterhin könnte es sich um Leichenbrand handeln.

Zahn Status Parodontium Apikale Prozesse Zahnstein Karies Abrasion Neubildung Schmelzhypoplasie

Krankheiten:

08.04.2014 / 1

Skelett: 1527

(1)




\section{Zahn}

Population: Rheine

Geschlecht:

Alter:

Beschreibung: Ein vollständig erhaltener Zahn, der aus Leichenbrand stammen könnte.

\section{Krankheiten:}

6

\begin{tabular}{c|l|l} 
Arthrose & rechts & links \\
\hline Caput & & \\
\hline Fossa & &
\end{tabular}

\section{Zahn Status Parodontium Apikale Prozesse}

24
0
Zahnstein

K 1
Karies

0
Abrasion

O 1
Neubildung

0 


\section{Zahn}

Population: Rheine

Geschlecht:

Alter:

Beschreibung: Von diesem Zahn ist nur die Krone erhalten.
6

Krankheiten:

\begin{tabular}{c|l|l} 
Arthrose & rechts & links \\
\hline Caput & & \\
\hline Fossa & &
\end{tabular}

Zahn Status Parodontium Apikale Prozesse

Zahnstein

Karies

Abrasion

Neubildung

0

Schmelzhypoplasie
B
0

O 1

0 


\section{Zahn}

Population: Rheine

Geschlecht:

Alter:

Beschreibung: Es ist nur die Krone zu $80 \%$ erhalten.
6

Krankheiten:

\begin{tabular}{c|l|l} 
Arthrose & rechts & links \\
\hline Caput & & \\
\hline Fossa & &
\end{tabular}

Zahn Status Parodontium Apikale Prozesse 004
08.04.2014 / 5

Skelett: 1367 


\section{Zahn}

Population: Rheine

Geschlecht:

Alter:

Beschreibung: Von diesem Zahn ist 20\% Schmelz und Wurzelzement abfrakturiert.
6

\begin{tabular}{c|l|l} 
Arthrose & rechts & links \\
\hline Caput & & \\
\hline Fossa & &
\end{tabular}

\section{Krankheiten:}




\section{Splitter}

Population: Rheine

Geschlecht:

Alter:

\section{Beschreibung: Zahnsplitter. Die Splitter sind nicht zuzuordnen und werden aufgrund der Gefahr der Doppeltzählung nicht mit ausgewertet sondern nur aus} Dokumentationszwecken beschrieben.

\section{Zahn Status Parodontium}

\section{6}

Krankheiten:

\begin{tabular}{c|l|l} 
Arthrose & rechts & links \\
\hline Caput & & \\
\hline Fossa & &
\end{tabular}
XX 


\section{Zahn}

Population: Rheine

Geschlecht:

Alter:

Beschreibung: Hier ist nur eine Wurzel erhalten. Diese ist nicht zuzuordnen und wird aufgrund der Gefahr der Doppeltzählung nicht mit ausgewertet sondern nur aus Dokumentationszwecken beschrieben.

\section{Zahn Status Parodontium}

\subsubsection{4 / 24}

Skelett: 876

\section{3}

Krankheiten:

\begin{tabular}{c|l|l} 
Arthrose & rechts & links \\
\hline Caput & & \\
\hline Fossa & &
\end{tabular}
$x x$ 


\section{Zahn}

Population: Rheine

Geschlecht:

Alter:

Beschreibung: Hier ist nur die Krone erhalten.
08.04.2014 / 43

Skelett: 1215

\section{Krankheiten:}

\begin{tabular}{c|l|l} 
Arthrose & rechts & links \\
\hline Caput & & \\
\hline Fossa & &
\end{tabular}

3

\section{Zahn Status Parodontium Apikale Prozesse}

15
Zahnstein

0

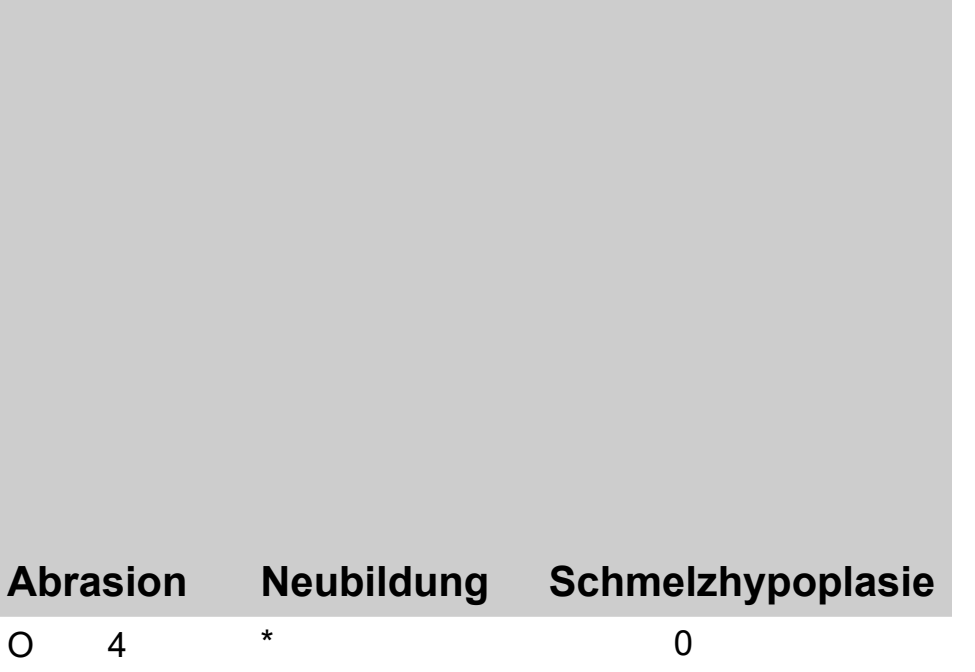




\section{Zahn}

Population: Rheine

Geschlecht:

Alter:

(40) 45 - 55 (65)

\subsubsection{4 / 5}

Skelett: B4

Krankheiten:

\section{Beschreibung:}

Status

46
Apikale Prozesse
Parodontium

Zahnstein

Karies O 6

\section{2}

\begin{tabular}{c|l|l} 
Arthrose & rechts & links \\
\hline Caput & & \\
\hline Fossa & &
\end{tabular}




\section{Zahn}

Population: Rheine

Geschlecht:

Alter:

$6-11(13)$

\subsubsection{4 / 14}

Skelett: $\quad 3610 / 1$ S3 18.07.83 1533

\section{9}

Krankheiten:

\begin{tabular}{c|l|l} 
Arthrose & rechts & links \\
\hline Caput & & \\
\hline Fossa & &
\end{tabular}

Beschreibung: Bei diesen Zahnkronen, ist nicht nachzuvollziehen, ob sie Anlagen oder bereits durchgebrochene Zähne sind.

$\begin{array}{lcccccc}\text { Zahn Status } & \text { Parodontium } & \text { Apikale Prozesse } & \text { Zahnstein } & \text { Karies } & \text { Abrasion } & \text { Neubildung } \\ 13 & & 0 & 0 & 0 & 0 \\ 15 & & 0 & 0 & 0 & 0 \\ 24 & & 0 & 0 & 0 & 0\end{array}$




\section{Zahn}

Population: Rheine

Geschlecht:

Alter:

(4) $6-11(13,5)$

\subsubsection{4 / 1}

Skelett: $\quad 3610 / 1$ S3 21.06.83 492 Krankheiten:

Beschreibung: Bei diesem Fundstück einer Zahnkrone ist nicht ersichtlich, ob es sich um einen Zahnkeim oder eine abgebrochene Krone handelt. In jedem Fall handelt es sich aber wohl um ein junges Individuum, da der Zahn keinerlei Abrasionen zeigt.

$\begin{array}{llcccccc}\text { Zahn } & \text { Status } & \text { Parodontium } & \text { Apikale Prozesse } & \text { Zahnstein } & \text { Karies } & \text { Abrasion } & \text { Neubildung } \\ 23 & & 0 & 0 & 0 & 0 & 0\end{array}$




\section{Zahn}

Population: Rheine

Geschlecht:

Alter:

\section{Beschreibung:}

\subsubsection{4 / 3}

Skelett: Altenrheine 3610/1 S3 Krankheiten:

\begin{tabular}{c|l|l} 
Arthrose & rechts & links \\
\hline Caput & & \\
\hline Fossa & &
\end{tabular}




\section{Zahn}

Population: Rheine

Geschlecht:

Alter:

(10) 12 - 14 (15)

Beschreibung: Hier sind lediglich die Kronen der Zähne vorhanden.
9

\begin{tabular}{c|l|l} 
Arthrose & rechts & links \\
\hline Caput & & \\
\hline Fossa & &
\end{tabular}

\begin{tabular}{|c|c|c|c|c|c|c|c|c|}
\hline Zahn & Status & Parodontium & Apikale Prozesse & Zahnstein & Karies & Abrasion & Neubildung & Schmelzhypoplasie \\
\hline 23 & & & $x$ & 0 & 0 & $\mathrm{O}$ & 0 & 0 \\
\hline 34 & & & $x$ & K & 0 & $\mathrm{O}$ & 0 & 0 \\
\hline
\end{tabular}




\section{Zahn}

Population: Rheine

Geschlecht: >> weiblich

Alter:

(4) 6 - $11(13,5)$
9

Skelett: $\quad 3610 / 1$ S3 05.07.83 959 Krankheiten:

\begin{tabular}{c|l|l} 
Arthrose & rechts & links \\
\hline Caput & & \\
\hline Fossa & &
\end{tabular}

Beschreibung: Eine Zahnkrone, bei der nicht nachzuvollziehen ist, ob sie eine Anlage oder ein bereits durchgebrochener Zahn ist.

$\begin{array}{llcccccc}\text { Zahn } & \text { Status } & \text { Parodontium } & \text { Apikale Prozesse } & \text { Zahnstein } & \text { Karies } & \text { Abrasion } & \text { Neubildung Schmelzhypoplasie } \\ 003 & & 0 & 0 & 0 & 0\end{array}$




\section{Zahn}

Population: Rheine

Geschlecht:

Alter:

\section{Beschreibung:}

\subsubsection{4 / 8}

Skelett: 1987

Krankheiten:

\section{Krankheiten:}

9

\begin{tabular}{c|l|l} 
Arthrose & rechts & links \\
\hline Caput & & \\
\hline Fossa & &
\end{tabular}

Zahn Status Parodontium Apikale Prozesse

23
Zahnstein

0
Karies

0
Abrasion

O 1
Neubildung

0

Schmelzhypoplasie 


\section{Zahn}

Population: Rheine

Geschlecht:

Alter:

(4) $6-11(13,5)$
9

Skelett: $\quad 3610 / 1$ S3 $7.831587 \quad$ Krankheiten:

\begin{tabular}{c|l|l} 
Arthrose & rechts & links \\
\hline Caput & & \\
\hline Fossa & &
\end{tabular}

Beschreibung: Eine Zahnkrone, bei der nicht nachzuvollziehen ist, ob sie eine Anlage oder ein bereits durchgebrochener Zahn ist.

$\begin{array}{llccccccc}\text { Zahn } & \text { Status } & \text { Parodontium } & \text { Apikale Prozesse } & \text { Zahnstein } & \text { Karies } & \text { Abrasion } & \text { Neubildung } & \text { Schmelzhypoplasie } \\ 13 & & 0 & 0 & 0 & 0 & \mathrm{~T} & 1\end{array}$




\section{Zahn}

Population: Rheine

Geschlecht:

Alter:

(4) 6 - $11(13,5)$
9

Krankheiten:

\begin{tabular}{c|l|l} 
Arthrose & rechts & links \\
\hline Caput & & \\
\hline Fossa & &
\end{tabular}

Beschreibung: Eine Zahnkrone, bei der nicht nachzuvollziehen ist, ob sie eine Anlage oder ein bereits durchgebrochener Zahn ist.

$\begin{array}{llcccccc}\text { Zahn } & \text { Status } & \text { Parodontium } & \text { Apikale Prozesse } & \text { Zahnstein } & \text { Karies } & \text { Abrasion } & \text { Neubildung Schmelzhypoplasie } \\ 23 & & 0 & 0 & 0 & 0\end{array}$




\section{Zahn}

Population: Rheine

Geschlecht:

Alter:

(4) $6-11(13,5)$
9

$\begin{array}{lll}\text { Skelett: } & 3610 / 1 \text { S3 22.08.83 Krankheiten: } \\ 1895\end{array}$

\begin{tabular}{c|l|l} 
Arthrose & rechts & links \\
\hline Caput & & \\
\hline Fossa & &
\end{tabular}

Beschreibung: Eine Zahnkrone, bei der nicht nachzuvollziehen ist, ob sie eine Anlage oder ein bereits durchgebrochener Zahn ist.

$\begin{array}{llccccccc}\text { Zahn } & \text { Status } & \text { Parodontium } & \text { Apikale Prozesse } & \text { Zahnstein } & \text { Karies } & \text { Abrasion } & \text { Neubildung } & \text { Schmelzhypoplasie } \\ 003 & & x & x & 0 & x & x & x & \end{array}$




\section{Zahn}

Population: Rheine

Geschlecht:

Alter:

Beschreibung: Bei diesem Zahn ist die inzisale Kante frakturiert.
9

\begin{tabular}{c|l|l} 
Arthrose & rechts & links \\
\hline Caput & & \\
\hline Fossa & &
\end{tabular}

Krankheiten:

$3610 / 1$ S3 15.07 .83

1376

$\begin{array}{llcccccc}\text { Zahn } & \text { Status } & \text { Parodontium } & \text { Apikale Prozesse } & \text { Zahnstein } & \text { Karies } & \text { Abrasion } & \text { Neubildung } \\ 003 & & 0 & 0 & x & 0\end{array}$




\section{Zahn}

Population: Rheine

Geschlecht:

Alter:

Beschreibung:

\subsubsection{4 / 15}

Skelett: $\quad 3610 / 1$ S3 20.7.83 1762 Krankheiten:

\begin{tabular}{c|l|l} 
Arthrose & rechts & links \\
\hline Caput & & \\
\hline Fossa & &
\end{tabular}

\section{Zahnstein}

0
Karies

0
Abrasion

O 2
Neubildung 0 


\section{Zahn}

Population:

Rheine

Geschlecht:

Alter:

(4) $6-11(13,5)$

Beschreibung: Bei diesem Zahn ist die Wurzel abfrakturiert.

\subsubsection{4 / 16}

Skelett: 1564
Krankheiten:

9

\begin{tabular}{c|l|l} 
Arthrose & rechts & links \\
\hline Caput & & \\
\hline Fossa & &
\end{tabular}

Zahnstein

0
Karies

0
Abrasion

0 


\section{UK}

Population: Rheine

Geschlecht:

Alter:

(14) 16 - 22 (24)

\subsubsection{4 / 23}

Skelett: $\quad 3610 / 1$ S3 1.06.83 170 Krankheiten:

\section{Beschreibung:}

9

\begin{tabular}{c|l|l} 
Arthrose & rechts & links \\
\hline Caput & & \\
\hline Fossa & &
\end{tabular}

\begin{tabular}{|c|c|c|c|c|c|c|c|c|}
\hline Zahn & Status & Parodontium & Apikale Prozesse & Zahnstein & Karies & Abrasion & Neubildung & Schmelzhypoplasie \\
\hline 33 & v & & 0 & & & & & \\
\hline 34 & v & & 0 & & & & & \\
\hline 35 & v & & 0 & & & & & \\
\hline 36 & & 0 & 0 & $\mathrm{~K}$ & 0 & $\mathrm{O}$ & 0 & 0 \\
\hline 37 & $\mathrm{v}$ & & 0 & & & & & \\
\hline
\end{tabular}




\section{OK}

Population: Rheine

Alter:

(25) 28 - 35 (38)
Geschlecht:

\subsubsection{4 / 2}

Skelett: $\quad 9.7 .83869$ eigentlich 864

\section{Beschreibung:}

MKZ 3610,1 Schnitt $1 \& 327$

\begin{tabular}{c|l|l} 
Arthrose & rechts & links \\
\hline Caput & & \\
\hline Fossa & &
\end{tabular}

Zahnstein Karies

Abrasion Neubildung Schmelzhypoplasie E

$E$ E
Apikale Prozesse

0
K 1
0 $\begin{array}{ll}0 & 3 \\ 0 & 2\end{array}$

0

0 


\section{Zahn}

Population:

Rheine

Geschlecht:

Alter:

(4) 5 - $6(6,5)$

Beschreibung: Hier ist lediglich die Krone des Zahnes mit 1/3 der Wurzel vorhanden.

\subsubsection{4 / 6}

Skelett: Zahntüte

Krankheiten:

MKZ 3610,1 Schnitt $1 \& 327$

\section{Zahn Status Parodontium Apikale Prozesse}

26
Zahnstein

K 1

Karies

0

\begin{tabular}{c|l|l} 
Arthrose & rechts & links \\
\hline Caput & & \\
\hline Fossa & &
\end{tabular}

0 


\section{Zahn}

Population: Rheine

Geschlecht:

Alter:

(20) 24 - $29(34)$

Beschreibung: Nur 1/4 der Wurzel erhalten.
4

Krankheiten:

\begin{tabular}{c|l|l} 
Arthrose & rechts & links \\
\hline Caput & & \\
\hline Fossa & &
\end{tabular}

$\begin{array}{lllllllll}\text { Zahn } & \text { Status } & \text { Parodontium } & \text { Apikale Prozesse } & \text { Zahnstein } & \text { Karies } & \text { Abrasion } & \text { Neubildung } & \text { Schmelzhypoplasie } \\ 27 & & \text { K } 1 & \text { M } 1 & O & 2 & 0 & \text { T } & 1\end{array}$




\section{Zahn}

Population: Rheine

Geschlecht:

Alter:

Beschreibung:

\subsubsection{4 / 13}

Skelett: $\quad 3610 / 1$ S3 20.07.83 1749

\section{MKZ 3610,1 1983}

Krankheiten:

\begin{tabular}{c|l|l} 
Arthrose & rechts & links \\
\hline Caput & & \\
\hline Fossa & &
\end{tabular}




\section{Zahn}

Population: Rheine

Geschlecht:

Alter:

(22) 25 - $30(34)$

Beschreibung: Bei diesem Fundstück ist die Krone erhalten, die Wurzel ist abfrakturiert.

\section{Zahn Status Parodontium Apikale Prozesse

26

\subsubsection{4 / 32}

Skelett: $\quad 3610 / 1$ S3 17.05.83 a Krankheiten: 150

\section{Krankheiten:}

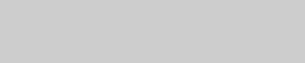

9

\begin{tabular}{c|l|l} 
Arthrose & rechts & links \\
\hline Caput & & \\
\hline Fossa & &
\end{tabular}




\section{Zahn}

Population:

Rheine

Geschlecht:

Alter:

(14) 16 - $22(24)$

Beschreibung: Hier ist lediglich die Krone des Zahnes vorhanden.

\subsubsection{4 / 7}

Skelett: Zahntüte
Krankheiten:

MKZ 3610,1 Schnitt $1 \& 327$

\begin{tabular}{c|l|l} 
Arthrose & rechts & links \\
\hline Caput & & \\
\hline Fossa & &
\end{tabular}

Abrasion

Neubildung

O 2

0

Schmelzhypoplasie 


\section{Zahn}

Population: Rheine

Geschlecht:

Alter:

(3) 4 - 6 (7)

Beschreibung: Hier ist nur die Krone vorhanden.
7

Krankheiten:

\begin{tabular}{c|l|l} 
Arthrose & rechts & links \\
\hline Caput & & \\
\hline Fossa & &
\end{tabular}

\section{Zahn Status Parodontium Apikale Prozesse}




\section{Zahn}

Population: Rheine

Geschlecht:

Alter:

Beschreibung: Hier ist lediglich die Krone des Zahnes vorhanden.

\subsubsection{4 / 58}

Skelett: $\quad 28.6 .83$

Krankheiten:

\section{Krankheiten:}

$\left(\frac{10}{2}\right.$

\section{Zahn Status Parodontium}

16
Apikale Prozesse
Zahnstein

0

\section{Karies}

0
Abrasion Neubildung Schmelzhypoplasie

\begin{tabular}{c|l|l} 
Arthrose & rechts & links \\
\hline Caput & & \\
\hline Fossa & &
\end{tabular}

0

0 


\section{Zahn}

Population: Rheine

Geschlecht:

Alter:

(22) 25 - $30(34)$

Beschreibung: Die Wurzel dieses Zahnes ist frakturiert, nur das koronale Drittel ist erhalten.

\subsubsection{4 / 26}

Skelett: $\quad 3610 / 1$ S3 11.05.83 a Krankheiten: 35

9

\begin{tabular}{c|l|l} 
Arthrose & rechts & links \\
\hline Caput & & \\
\hline Fossa & &
\end{tabular}

$\begin{array}{llllllcc}\text { Zahn } & \text { Status } & \text { Parodontium } & \text { Apikale Prozesse } & \text { Zahnstein } & \text { Karies } & \text { Abrasion } & \text { Neubildung } \\ 16 & & \text { K } 1 & 0 & 0 & 3 & 0 & 0\end{array}$




\section{Zahn}

Population: Rheine

Geschlecht:

Alter:

(25) 28 - 35 (38)

\section{Beschreibung:}

\subsubsection{4 / 29}

Skelett: $3610 / 1$ S3 11.05.83 a Krankheiten: 36

9

\begin{tabular}{c|l|l} 
Arthrose & rechts & links \\
\hline Caput & & \\
\hline Fossa & &
\end{tabular}

Zahn Status Parodontium Apikale Prozesse

Zahnstein

Karies

Abrasion

Neubildung

K 2

0

O 4

0

Schmelzhypoplasie 


\section{Zahn}

Population: Rheine

Geschlecht:

Alter:

(32) $37-45(50)$

Beschreibung: Hier ist lediglich die Krone des Zahnes vorhanden.
9

\begin{tabular}{c|l|l} 
Arthrose & rechts & links \\
\hline Caput & & \\
\hline Fossa & &
\end{tabular}

$\begin{array}{llccccccc}\text { Zahn } & \text { Status } & \text { Parodontium } & \text { Apikale Prozesse } & \text { Zahnstein } & \text { Karies } & \text { Abrasion } & \text { Neubildung } & \text { Schmelzhypoplasie } \\ 16 & & 0 & 0 & 0 & 5 & * & 1\end{array}$




\section{Zahn}

Population:

Rheine

Geschlecht:

Alter:

(4) 6 - $9(11)$

Beschreibung: Dieser Zahn war eine Anlage.

\subsubsection{4 / 15}

Skelett: $\quad 3610 / 1$ S3 20.07.83 1736

Krankheiten:

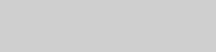

\section{MKZ 3610,1 1983}

\begin{tabular}{c|l|l} 
Arthrose & rechts & links \\
\hline Caput & & \\
\hline Fossa & &
\end{tabular}

\section{Zahn \\ Status

14 ( )
Zahnstein

Karies

Abrasion

Neubildung

0 


\section{Zahn}

Population:

Rheine

Geschlecht:

Alter:

(5) 7 - $9(11)$

Beschreibung: Eine Anlage.

\subsubsection{4 / 16}

Skelett: $\quad 3610 / 1$ S3 20.07.83 1742

\section{MKZ 3610,1 1983}

Krankheiten:

\begin{tabular}{c|l|l} 
Arthrose & rechts & links \\
\hline Caput & & \\
\hline Fossa & &
\end{tabular}

\section{Zahn Status Parodontium}

Apikale Prozesse

Zahnstein Karies

Abrasion

Neubildung

Schmelzhypoplasie 


\section{OK}

Population: Rheine

Geschlecht:

Alter:

Beschreibung: Ein Fragment eines knöchernen Gaumens. Das Fragment ist nicht genauer zuzuordnen und wird aufgrund der Gefahr der Doppeltzählung nicht mit ausgewertet sondern nur aus Dokumentationszwecken beschrieben.

\section{1}

Krankheiten: Stomatitis

\begin{tabular}{c|l|l} 
Arthrose & rechts & links \\
\hline Caput & & \\
\hline Fossa & &
\end{tabular}

Zahn Status Parodontium Apikale Prozesse Zahnstein Karies Abrasion Neubildung Schmelzhypoplasie




\section{Zahn}

Population: Rheine

Geschlecht:

Alter:

\section{Beschreibung:}

\subsubsection{4 / 23}

Skelett: $\quad 3610 / 1$ S3 1.06.83 196 Krankheiten:

\begin{tabular}{c|l|l} 
Arthrose & rechts & links \\
\hline Caput & & \\
\hline Fossa & &
\end{tabular}




\section{Zahn}

Population: Rheine

Geschlecht:

Alter:

\section{Beschreibung:}

\subsubsection{4 / 29}

Skelett: 380

Krankheiten:

\begin{tabular}{c|l|l} 
Arthrose & rechts & links \\
\hline Caput & & \\
\hline Fossa & &
\end{tabular}




\section{Zahn}

Population: Rheine

Geschlecht:

Alter:

(22) $25-30(34)$

Beschreibung: Hier ist nur die halbe Krone vorhanden.
7

Krankheiten:

\begin{tabular}{c|l|l} 
Arthrose & rechts & links \\
\hline Caput & & \\
\hline Fossa & &
\end{tabular}

$\begin{array}{llllccccc}\text { Zahn } & \text { Status } & \text { Parodontium } & \text { Apikale Prozesse } & \text { Zahnstein } & \text { Karies } & \text { Abrasion } & \text { Neubildung } & \text { Schmelzhypoplasie } \\ 46 & & \mathrm{~K} 1 & 0 & 0 & 3 & 0\end{array}$




\section{Zahn}

Population: Rheine

Geschlecht:

Alter:

Beschreibung: Hier ist nur die Krone vorhanden.
7

\begin{tabular}{c|l|l} 
Arthrose & rechts & links \\
\hline Caput & & \\
\hline Fossa & &
\end{tabular}

Krankheiten:

Skelett: enzelne kleine Tüte 


\section{Zahn}

Population: Rheine

Geschlecht:

Alter:

Beschreibung: Hier ist nur die Krone vorhanden.
7

\begin{tabular}{c|l|l} 
Arthrose & rechts & links \\
\hline Caput & & \\
\hline Fossa & &
\end{tabular}

Krankheiten:

Krankheiten:

Skelett: enzelne kleine Tüte 


\section{Zahn}

Population: Rheine

Geschlecht:

Alter:

Beschreibung: Hier ist nur die Krone vorhanden.
7

\begin{tabular}{c|l|l} 
Arthrose & rechts & links \\
\hline Caput & & \\
\hline Fossa & &
\end{tabular}

Krankheiten:

\subsubsection{4 / 31}

Skelett: einzelne kleine Tüte 


\section{Zahn}

Population: Rheine

Geschlecht:

Alter:

Beschreibung: Hier ist nur die Krone vorhanden.
7

\begin{tabular}{c|l|l} 
Arthrose & rechts & links \\
\hline Caput & & \\
\hline Fossa & &
\end{tabular}

Krankheiten:

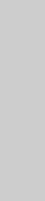

Skelett: einzelne kleine Tüte 


\section{Zahn}

Population: Rheine

Geschlecht:

Alter:

Beschreibung: Von der Wurzel dieses Zahnes ist nur die Hälfte erhalten.

\subsubsection{4 / 37}

Skelett: $\quad 3610 / 1$ S3 11.05.83 a Krankheiten: 33

$\sqrt{2}$

\section{MKZ 3610,1 Schnitt 3}

\begin{tabular}{c|l|l} 
Arthrose & rechts & links \\
\hline Caput & & \\
\hline Fossa & &
\end{tabular}




\section{Zähne}

Population: Rheine

Geschlecht:

Alter:

Beschreibung: Hier sind mehrere Splitter und ein Prämolar erhalten, die nicht zuzuordnen sind.

\subsubsection{4 / 28}

Skelett: $\quad 3610 / 1$ S3 17.05 .83

(80)

\section{Krankheiten:}

9

\begin{tabular}{c|l|l} 
Arthrose & rechts & links \\
\hline Caput & & \\
\hline Fossa & &
\end{tabular}

\section{Zahn Status Parodontium}

Apikale Prozesse

Zahnstein

Karies

Abrasion

Neubildung 


\section{Zähne}

Population: Rheine

Geschlecht:

Alter:

19.03.2014 / 2
9

\begin{tabular}{c|l|l} 
Arthrose & rechts & links \\
\hline Caput & & \\
\hline Fossa & &
\end{tabular}

\section{Skelett: $\quad 3610 / 1$ S3 17.05 .83 a Krankheiten: \\ $\begin{array}{ll}\text { Skelett: } & 3610 / 1 \text { S3 17.05.83 a Krankheiten: } \\ & 148\end{array}$}

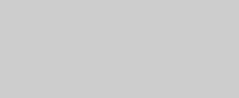

$\begin{array}{llcccccc}\text { Zahn Status } & \text { Parodontium } & \text { Apikale Prozesse } & \text { Zahnstein } & \text { Karies } & \text { Abrasion } & \text { Neubildung } & \text { Schmelzhypoplasie } \\ 004 & & 0 & 0 & 0 & 2 & 0 \\ 004 & & 0 & 0 & 0 & 2 & 0 & 0\end{array}$




\section{Zähne}

Population: Rheine

Geschlecht:

Alter:

Beschreibung: Hier ist nur die Krone vorhanden.
7

\begin{tabular}{c|l|l} 
Arthrose & rechts & links \\
\hline Caput & & \\
\hline Fossa & &
\end{tabular}

Krankheiten:

Skelett: Zahntüte 


\section{Zähne}

Population: Rheine

Geschlecht:

Alter:

Beschreibung: Hier ist nur die Krone vorhanden.
7

Krankheiten:

\begin{tabular}{c|l|l} 
Arthrose & rechts & links \\
\hline Caput & & \\
\hline Fossa & &
\end{tabular}

Zahn Status Parodontium Apikale Prozesse 008 
Bezeichn.: Cranium

Kiste:

5

Skelet: $\quad$ K153 62/69 S2

Population: Großenrode

Felsenbein:

Erhaltung: $>60 \%$ erh

$$
25-60 \% \text { erh. }
$$

- $1-25 \%$ erh.
Verband: $\quad$ Verband

Alter: $\quad$ (5) 6-7 (8)

\section{Geschlecht:}

Arthrose:
Ges./Kr.: Gesund

\section{Maß}

Schädeldecke / Schädelbasis

\section{Beschreibung:}

10 Fragmente eines jungen Schädels. Die Fragmente stammen von der Schädeldecke. 


\section{Bezeichn.: Cranium}

\section{Kiste:}

Skelet: $\quad 61 / 66-4$

Population: Großenrode

Felsenbein:

Erhaltung: $>60 \%$ erh

$25-60 \%$ erh.

- 1 - $25 \%$ erh.
Ges./Kr.: Krank

Krankh.: Sinusitis frontalis

Cribra Orbitalia

\section{Maß}

Schädeldecke / Schädelbasis

Sinus frontalis

\section{Geschlecht:}

\section{Arthrose:}

\section{Beschreibung:}

Hier ist ein Fragment aus dem linken Bereich des Os frontale erhalten mit 50\% des Orbitadachs. Weiterhin ist ein kleines Fragment aus der Schädeldecke erhalten. Das Orbitadach weist eine erodierte, aber doch erkennbar narbige Knochenoberfläche auf, die für eine verheilte Cribra orbitalia spricht. Es ist auch ein kleiner Teil des Sinus frontalis erhalten. Auch dieser weist Spuren einer vernarbten und verheilten Sinusitis auf. 
Bezeichn.: Cranium

\section{Kiste:}

5

Skelet:

K175 61/67 P3

Population: Großenrode

Felsenbein: Beide

Erhaltung: $>60 \%$ erh.

- $25-60 \%$ erh.

$1-25 \%$ erh.
Ges./Kr.: Krank

Krankh.: meningeale Reizung

Perisinusitis

\section{Maß}

Schädeldecke / Schädelbasis

Viscerocranium

\section{Geschlecht: $q>0$}

Arthrose:

\section{Beschreibung:}

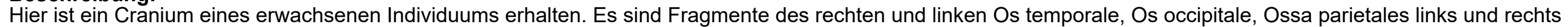

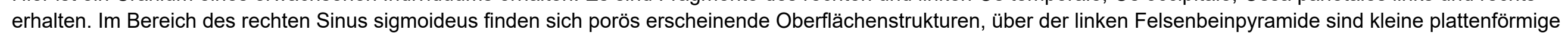

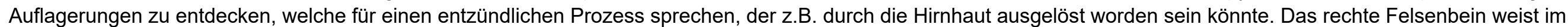

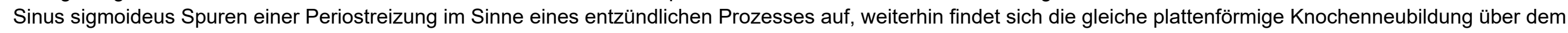

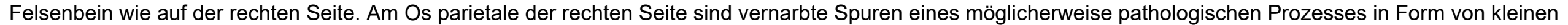

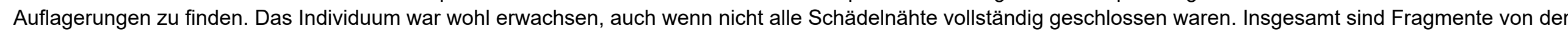
Schädelbasis, sowie von der -decke erhalten. Es liegen auch Fragmente der beiden Ossa zygomatici vor, die mit Orbitabeteiligung erhalten sind. 
Bezeichn.: Cranium

Kiste:

Skelet: Streufunde aus allen

Population: Großenrode

Felsenbein:

Erhaltung: $>60 \%$ erh

$$
25-60 \% \text { erh. }
$$

- $1-25 \%$ erh.
Ges./Kr.: Krank

Krankh.: meningeale Reizung

Perisinusitis

\section{Maß}

Schädeldecke / Schädelbasis

2

Wert $\quad$ Einheit

\section{Geschlecht:}

\section{Arthrose:}

2

\section{Beschreibung:}

Es sind hier mehrere Schädelfragmente erhalten. Eines ist vom Os occipitale der rechten Seite und weist leichte poröse Oberflächenveränderungen am Sinus transversus auf. Dies könnte für eine Reizung des Sinus durch die Hirnhaut sprechen. Es sind Fragmente eines erwachsenen Schädels. 
Bezeichn.: Cranium

\section{Kiste:}

Skelet: zu K134

Population: Großenrode

Felsenbein:

Erhaltung: $>60 \%$ erh

$25-60 \%$ erh.

- $1-25 \%$ erh.
Ges./Kr.: Krank

Krankh.: meningeale Reizung

\section{Maß}

Schädeldecke / Schädelbasis

Sinus frontalis

\section{Geschlecht:}

\section{Arthrose:}

\begin{tabular}{|l|l} 
Wert & Einheit \\
1 \\
\end{tabular}

\section{Beschreibung:}

Hier ist ein Fragment einer Crista frontalis erhalten, es ist mehr rechtsseitig erhalten und weist plattenförmige Auflagerungen auf, welche abhängig vom Alter des

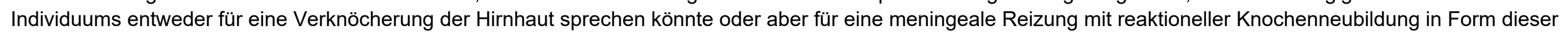
plattenförmigen Neubildungen. 
Bezeichn.: Cranium

\section{Kiste:}

Skelet: $\quad$ K330 63/67 P4

Population: Großenrode

Felsenbein: Beide

Erhaltung: $>60 \%$ erh.

- $25-60 \%$ erh.

$1-25 \%$ erh.
Ges./Kr.: Krank

Krankh.: Sinusitis sphenoidalis meatus acusticus Reizung meningeale Reizung

Sinusitis frontalis

\section{Maß}

Schädeldecke / Schädelbasis

Sinus frontalis

Sinus sphenoidalis

\section{Beschreibung:}

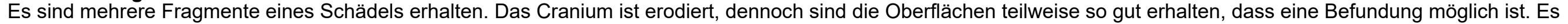

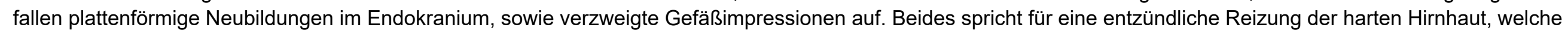

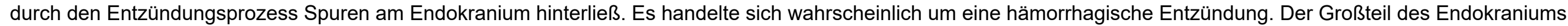

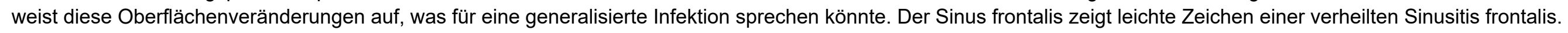

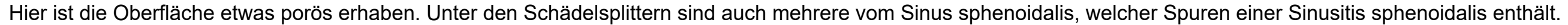


Bezeichn.: Cranium

Kiste:

Skelet: K160 63/67 S2

Population: Großenrode

Felsenbein: Beide

Erhaltung: $>60 \%$ erh

$25-60 \%$ erh.

- 1 - $25 \%$ erh.
Verband: $\square$ Verband

Alter: Erwachsen

\section{Geschlecht:}

Arthrose:
Ges./Kr.: Gesund

\section{Maß}

Schädeldecke / Schädelbasis

\section{\begin{tabular}{|l|l} 
Wert & Einheit \\
\hline
\end{tabular}}

li.

1

1

\section{Beschreibung:}

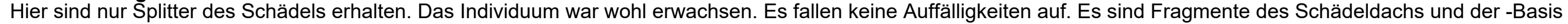
erhalten. 
Bezeichn.: Cranium

\section{Kiste:}

Skelet: $\quad K 160 / 163 / 67$ S2

Population: Großenrode

Felsenbein:

Erhaltung: $>60 \%$ erh

$$
25-60 \% \text { erh. }
$$

- $1-25 \%$ erh.

\section{Verband:}

Alter:

Verband

(17) 20 - 30 (35)

Geschlecht:

\section{Arthrose:}

Ges./Kr.: Gesund

\section{Maß}

Schädeldecke / Schädelbasis

\section{Beschreibung:}

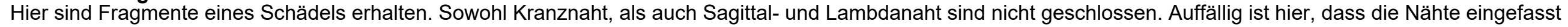
sind und dünner erscheinen als die Schädeldecke. Es handelt sich um erodierte Fragmente. 
Bezeichn.: Cranium

Kiste:

Skelet: K160/2 63/67 S2

Population: Großenrode

Felsenbein:

Erhaltung: $>60 \%$ erh.

$$
25-60 \% \text { erh. }
$$

- $1-25 \%$ erh.

\section{Verband: $\quad$ Verband}

\section{Alter: Erwachsen}

Ges./Kr.: Gesund

\section{Maß}

Schädeldecke / Schädelbasis

Wert $\quad$ Einheit

Geschlecht:

Arthrose:

\section{Beschreibung:}

Hier sind Fragmente eines Craniums erhalten. Es sind Os occipitale, Os parietale links und andere Fragmenten erhalten. Insgesamt sind alle Fragmente ohne Auffälligkeiten. Das Individuum war wohl erwachsen. 
Bezeichn.: Cranium

\section{Kiste:}

Skelet: K160/2 63/67 S2

Population: Großenrode

Felsenbein:

Erhaltung: $>60 \%$ erh.

$$
25-60 \% \text { erh. }
$$

- $1-25 \%$ erh.
Ges./Kr.: Krank

Krankh.: Sinusitis sphenoidalis

\section{Maß}

Schädeldecke / Schädelbasis

Sinus sphenoidalis

Viscerocranium

\section{Geschlecht:}

\section{Arthrose:}

\begin{tabular}{|l|l} 
Wert & Einheit \\
\hline 1 & 1 \\
1 & \\
\end{tabular}

\section{Beschreibung:}

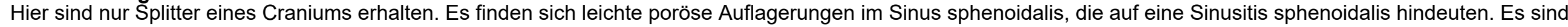

Fragmente von der Schädelbasis und -decke, sowie vom Gesichtsschädel erhalten. 
Bezeichn.: Cranium

Kiste:

Skelet: K229 63/67-P3

Population: Großenrode

Felsenbein: Beide

Erhaltung: $>60 \%$ erh.

$$
\text { - } 25-60 \% \text { erh. }
$$$$
1 \text { - } 25 \% \text { erh. }
$$

\section{Verband: $\square$ Verband}

Alter: (7) 8 -9(10)

\section{Geschlecht:}

Arthrose:
Ges./Kr.: Gesund

\section{Maß}

Schädeldecke / Schädelbasis \begin{tabular}{|l|l} 
Wert & Einheit \\
\hline
\end{tabular}

\begin{tabular}{l|l|l}
1 & 1
\end{tabular}

1

\section{Beschreibung:}

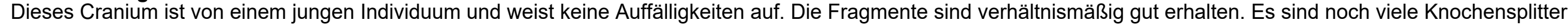
des Schädels erhalten. 
Bezeichn.: Cranium

\section{Kiste:}

Skelet: $\quad$ K310 63/67-P4

Population: Großenrode

Felsenbein: Beide

Erhaltung: $>60 \%$ erh.

$25-60 \%$ erh.

- $1-25 \%$ erh.
Ges./Kr.: Krank

Krankh.: meningeale Reizung

Sinusitis frontalis

Perisinusitis

\section{Maß}

Schädeldecke / Schädelbasis

Sinus frontalis

\section{Geschlecht: \\ Arthrose: \\ Erwachsen

$+$

\begin{tabular}{l|l} 
W \\
2 \\
2
\end{tabular}

\section{Beschreibung:}

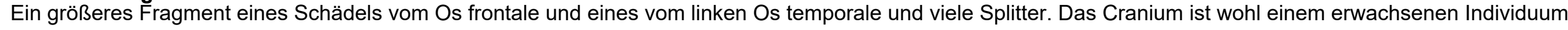

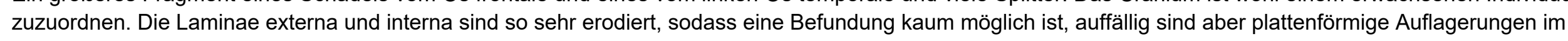

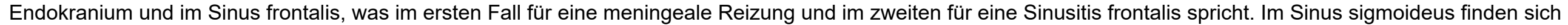

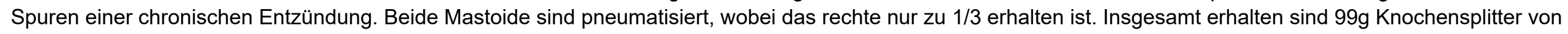
Schädelbasis und -decke. 


\begin{tabular}{|c|c|c|c|c|c|c|c|}
\hline Bezeichn.: & Cranium & Verband: & Verband & Ges./Kr.: Krank & Maß & Wert & Einheit \\
\hline Kiste: & 9 & Alter: & & Krankh.: Cribra Orbitalia & Schädeldecke / Schädelbasis & 1 & 1 \\
\hline Skelet: & K297 63/67 S3 & Geschlecht: & & & & & \\
\hline Population: & Großenrode & Arthrose: & & & & & \\
\hline Felsenbein: & Links & & & & & & \\
\hline Erhaltung: & $>60 \%$ erh. & & & & & & \\
\hline & $25-60 \%$ erh. & & & & & & \\
\hline & - $1-25 \%$ erh. & & & & & & \\
\hline
\end{tabular}

\section{Beschreibung:}

Hier sind mehrere Splitter eines Schädels erhalten, unter anderen ein Teil des Os temporale der linken Seite und ein Orbitadach der linken Seite und weitere Minisplitter. Das Orbitadach weist Spuren einer Cribra orbitalia auf. 
Bezeichn.: Cranium

Kiste:

9

Skelet: $\quad$ K299 63/67-3 S3

Population: Großenrode

Felsenbein:

Erhaltung: $>60 \%$ erh

$$
25-60 \% \text { erh. }
$$

- $1-25 \%$ erh.
Ges./Kr.: Krank

Krankh.: meningeale Reizung

\section{Maß}

Schädeldecke / Schädelbasis

\section{Alter: Erwachsen}

\section{Geschlecht:}

Arthrose:

\section{Beschreibung:}

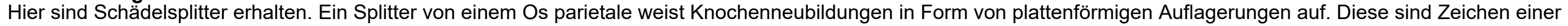
chronisch entzündlichen meningealen Reizung. 
Bezeichn.: Cranium

\section{Kiste:}

Skelet: $\quad 63 / 67-4$

Population: Großenrode

Felsenbein:

Erhaltung: $>60 \%$ erh

$$
25-60 \% \text { erh. }
$$

- $1-25 \%$ erh.

\section{Beschreibung:}

Hier sind nur kleinste Splitter des Schädels erhalten.

\section{Verband: $\quad$ Verband}

\section{Alter:}

Geschlecht:

\section{Arthrose:}

Maß

Schädeldecke / Schädelbasis Wert $\quad$ Einheit

1

1


Bezeichn.: Cranium

\section{Kiste:}

Skelet: K134 Schädel 63/67 P3

Population: Großenrode

Felsenbein:

Erhaltung: $>60 \%$ erh

$25-60 \%$ erh.

- $1-25 \%$ erh.
Verband: $\square$ Verband

Alter: Erwachsen

\section{Geschlecht:}

\section{Arthrose:}

Ges./Kr.: Krank

Krankh.: Cribra Orbitalia

meningeale Reizung

Sinusitis frontalis

Sinusitis maxillaris

Sinusitis sphenoidalis

\section{Maß}

Orbita re / li

Schädeldecke / Schädelbasis

Sinus frontalis

Sinus maxillaris

Sinus sphenoidalis

Viscerocranium

\section{Beschreibung:}

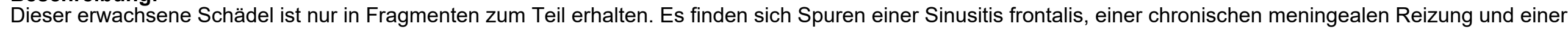

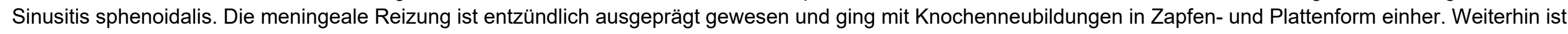

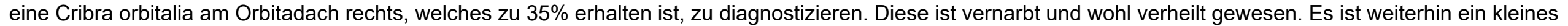

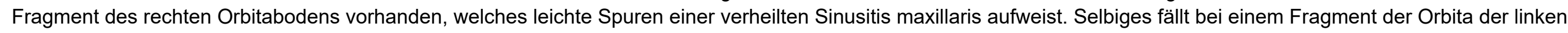

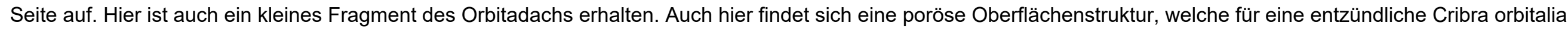
sprechen. Weiterhin ist ein Fragment des Sinus maxillaris erhalten, welches Spuren einer Sinusitis maxillaris zeigt. 


\begin{tabular}{|c|c|c|c|c|c|c|c|}
\hline Bezeichn.: & Cranium & Verband: & $\square$ Verband & Ges./Kr.: Krank & Maß & Wert & Einheit \\
\hline Kiste: & 7 & Alter: & Erwachsen & Krankh.: Cribra Orbitalia & Schädeldecke / Schädelbasis & 1 & 1 \\
\hline Skelet: & K364-2 61/69-S4 & Geschlecht: & & & & & \\
\hline Population: & Großenrode & Arthrose: & & & & & \\
\hline Felsenbein: & Rechts & & & & & & \\
\hline Erhaltung: & $>60 \%$ erh. & & & & & & \\
\hline & $25-60 \%$ erh. & & & & & & \\
\hline & - $1-25 \%$ erh. & & & & & & \\
\hline
\end{tabular}

\section{Beschreibung:}

Hier sind Splitter eines Schädels erhalten. Es sind unter anderen ein Fragment der Fossa cranii posterior mit foramen magnum, ein Fragment des Os temporale der rechten Seite mit Fossa mandibulae und eine Fragment einer linken Orbita erhalten. Es sind weitere Splitter der Schädeldecke und der -Basis erhalten. Das Individuum ist wohl erwachsen gewesen.

Das Orbitadach weist eine leichte Cribra orbitalia auf. Die Fossa mandibulae hat einen Gelenkstatus von 2. 
Bezeichn.: Cranium

\section{Kiste:}

7

Skelet: K262 60/64 S3

Population: Großenrode

Felsenbein:

Erhaltung: $>60 \%$ erh

- $25-60 \%$ erh.

$1-25 \%$ erh.
Ges./Kr.: Krank

Krankh.: Sinusitis sphenoidalis

Hypoplasie sinus frontalis Cribra Orbitalia

\section{Maß}

Orbita re / li

Schädeldecke / Schädelbasis

Sinus frontalis

Sinus sphenoidalis

\section{Beschreibung:}

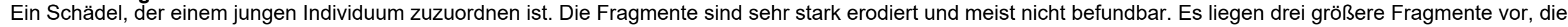

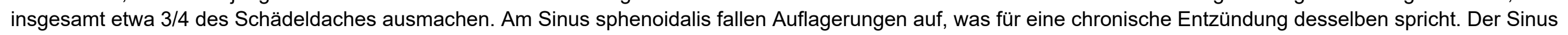

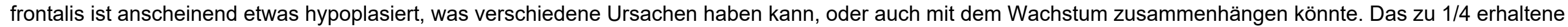
Orbitadach der rechten Seite weist eine ausgeprägte Cribra orbitalia auf. Die Lambdanaht hat rechtsseitig zwei kleine Schaltknochen rechts und einen links. 


\section{Bezeichn.: Cranium}

\section{Kiste:}

7

Skelet: K341

Population: Großenrode

Felsenbein:

Erhaltung: $>60 \%$ erh

$$
25-60 \% \text { erh. }
$$

- 1 - $25 \%$ erh.
Ges./Kr.: Krank

Krankh.: Cribra Orbitalia

\section{Maß}

Orbita re / li

Schädeldecke / Schädelbasis

\section{Geschlecht: 우}

\section{Arthrose:}

\begin{tabular}{|l|l} 
Wert & Einheit \\
1 & 2 \\
&
\end{tabular}

\section{Beschreibung:}

Zwei Fragmente eines weiblichen Schädels, eines ist ein Os frontale, das andere ist von der rechten Kranznaht durchzogen und stammt vom Os frontale und Os parietale der rechten Seite. Das Individuum war wohl erwachsen und weist beidseitig eine Cribra orbitalia auf. 
Bezeichn.: Cranium

\section{Kiste:}

7

Skelet: 7

Population: Großenrode

Felsenbein: Beide

Erhaltung: $>60 \%$ erh.

$$
25-60 \% \text { erh. }
$$

- $1-25 \%$ erh.

\section{Ges./Kr.: Krank}

Krankh.: meningeale Reizung

Sinusitis sphenoidalis

Sinusitis maxillaris

meatus acusticus Reizung

\section{Maß}

Schädeldecke / Schädelbasis

Sinus maxillaris

Sinus sphenoidalis

\section{Beschreibung:}

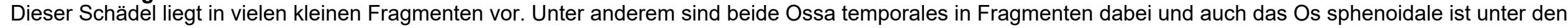

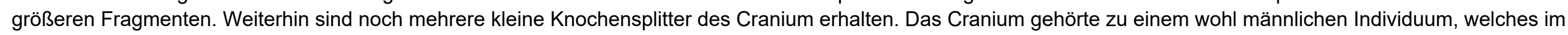
Erwachsenenalter verstorben ist. Es weist mehrere pathologische Strukturen auf, wie eine Sinusitis maxillaris und - sphenoidalis. 
Bezeichn.: Cranium

\section{Kiste:}

7

Skelet:

K174 Schädel 61/67 P3

Population: Großenrode

Felsenbein:

Erhaltung: $>60 \%$ erh.

$25-60 \%$ erh.

- $1-25 \%$ erh.
Ges./Kr.: Krank

Krankh.: meningeale Reizung

hämorrhagische

Meningitis

Perisinusitis

\section{Maß}

Schädeldecke / Schädelbasis

Sinus maxillaris

Viscerocranium
Geschlecht:
Arthrose:

\section{Erwachsen}

\begin{tabular}{|l|l} 
Wert & Einheit \\
\hline 2 & 2
\end{tabular}

2

2

\section{Beschreibung:}

Hier sind viele Knochensplitter eines Cranium erhalten. Es sind Splitter von der Schädelbasis und -decke erhalten. Ein Fragment stammt wohl aus der rechten

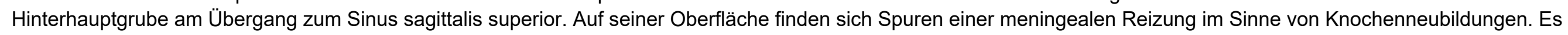

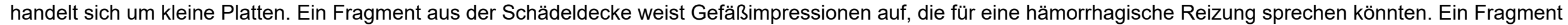
des linken aufsteigenden Astes einer Mandibula ist ebenfalls erhalten. 


\section{Bezeichn.: Cranium}

\section{Kiste:}

Skelet: $\quad \mathrm{K} 165$

Population: Großenrode

Felsenbein:

Erhaltung: $>60 \%$ erh

- $25-60 \%$ erh.

$1-25 \%$ erh.
Ges./Kr.: Krank

Krankh.: Cribra Orbitalia

meningeale Reizung

Sinusitis frontalis

hämorrhagische

Meningitis

entzündliche Meningitis

Perisinusitis

\section{Maß}

Orbita re / li

Schädeldecke / Schädelbasis

Sinus frontalis

\begin{tabular}{|l|l} 
Wert & Einheit \\
2 & \\
2 & 2 \\
&
\end{tabular}

\section{Beschreibung:}

Dies ist ein Schädel, welcher Spuren einer hämorrhagischen und entzündlichen Hirnhautentzündung aufweist. Weiterhin finden sich Spuren einer perisinösen Reaktion. Das Cranium ist einem erwachsenen, weiblichen Individuum zuzuordnen. 
Bezeichn.: Cranium

Kiste:

6

Skelet:

Population: Großenrode

Felsenbein: Rechts

Erhaltung: $>60 \%$ erh.

$25-60 \%$ erh.

- $1-25 \%$ erh.
Ges./Kr.: Krank

Krankh.: Kopfschwartenreizung

meatus acusticus Reizung

meningeale Reizung

Sinusitis sphenoidalis

Perisinusitis

\section{Maß}

Schädeldecke / Schädelbasis

Sinus sphenoidalis
Arthrose:

\section{Beschreibung:}

Dieser Schädel ist in Form von mehreren Fragmenten erhalten, die Lamina interna ist überwiegend gut erhalten, die Lamina externa weist stellenweise abfrakturierte und erodierte Oberflächen auf. Die Schädelnähte sind nicht einheitlich verwachsen, das Alter aber auf Anfang bis Mitte 30 zu schätzen. Es finden sich viele pathologische Auffälligkeiten, wie meningeale Reizungen hämorrhagischen und entzündlichen Ursprungs. Sie sind in der Kleinhirngrube und dem Sinus sigmoideus zu finden, doch auch perisinös sind beim Sinus sagittalis superior hämorrhagisch bedingte Gefäßimpressionen zu finden. Außerdem gehen hämorrhagisch bedingte Gefäßverästelungen von dem rechten Sulcus arteriosi anterioris Auf der Lamina externa finden sich Spuren einer Kopfschwartenreizung. Weiterhin ist der rechte Meatus acusticus externus mit porösen Oberflächenauftreibungen gesäumt, was hier für einen entzündlichen Prozess spricht. Es ist ein kleines Fragment des Sinus sphenoidalis erhalten, welches kleine Auflagerungen aufweist und für einen auch hier entzündlich bedingten Prozess spricht. Durch eine entzündlich bedingte meningeale Reizung hervorgerufene plattenförmige Auflagerungen sind auf den Ossa parietales links und rechts zu finden. Sie sind nur wenige Millimeter groß und finden sich eher in der Nähe des Sinus sagittalis superior. 


\begin{tabular}{|c|c|c|c|c|c|c|c|}
\hline Bezeichn.: & Cranium & Verband: & $\square$ Verband & Ges./Kr.: Gesund & Maß & Wert & Einheit \\
\hline Kiste: & 6 & Alter: & Jung & & Breite & 21,23 & $\mathrm{~mm}$ \\
\hline Skelet: & $60 / 64-3$ & Geschlecht: & & & Dicke & 4,4 & $\mathrm{~mm}$ \\
\hline Population: & Großenrode & Arthrose: & & & Länge & 24,63 & $\mathrm{~mm}$ \\
\hline Felsenbein: & & & & & Schädeldecke / Schädelbasis & 1 & \\
\hline Erhaltung: & $>60 \%$ erh. & & & & Viscerocranium & 1 & \\
\hline & $25-60 \%$ erh. & & & & & & \\
\hline & - $1-25 \%$ erh. & & & & & & \\
\hline
\end{tabular}

\section{Beschreibung:}

Ein kleines Fragment eines jungen Schädels. Es ist eine Schädelnaht erhalten, die jedoch aufgrund der Größe und des schlechten und erodierten Erhaltungszustandes nicht zuzuordnen ist. Sie ist offen und zeigt Zeichen nur leichter anfänglicher Verknöcherung. Es liegt weiterhin ein Fragment eines Caput mandibulae vor. 
Bezeichn.: Cranium

\section{Kiste:}

6

Skelet: $\quad$ K122 60/64 S2

Population: Großenrode

Felsenbein:

Erhaltung: $>60 \%$ erh

$$
25-60 \% \text { erh. }
$$

- $1-25 \%$ erh.

\section{Verband: $\quad$ Verband}

\section{Alter:}

Geschlecht:

\section{Arthrose:}

\section{Maß}

Schädeldecke / Schädelbasis

\section{Beschreibung:}

Hier liegt ein Fragment der Schädeldecke vor, es ist recht klein und nicht gut erhalten. 
Bezeichn.: Cranium

\section{Kiste:}

Skelet: K179 63/66 P3

Population: Großenrode

Felsenbein:

Erhaltung: $>60 \%$ erh.

$$
25-60 \% \text { erh. }
$$

- $1-25 \%$ erh.

\section{Verband:$$
\text { Verband }
$$$$
\text { (7) } 8 \text { - } 9(10)
$$

\section{Alter:}

Ges./Kr.: Gesund

\section{Geschlecht:}

Arthrose:

\begin{tabular}{l|l|l} 
Maß & Wert & Einheit \\
\hline Schädeldecke / Schädelbasis & 1 & 1 \\
Viscerocranium & 1 & \\
& &
\end{tabular}

\section{Beschreibung:}

Hierbei handelt es sich um viele Knochensplitter eines jungen Individuums. Es sind Knochensplitter erhalten, die keine Auffälligkeiten aufwiesen

Es sind weiterhin zwei Fragmente des wohl zugehörigen Oberkiefers und ein Fragment des rechten Os zygomaticum erhalten, welches als Variation 3 kleine foramina zygomatica faciales aufweist. 
Bezeichn.: Cranium

\section{Kiste:}

Skelet: $\quad$ K66 60/64 S1

Population: Großenrode

Felsenbein:

Erhaltung: $>60 \%$ erh $25-60 \%$ erh.

- 1 - $25 \%$ erh.

Verband: Verband

\section{Alter:}

Geschlecht:

\section{Arthrose:}

\section{Beschreibung:}

Ein kleines Schädelfragment, das Fragment ist nicht zuzuordnen. 
Bezeichn.: Cranium

\section{Kiste:}

Skelet: 62/65

Population: Großenrode

Felsenbein:

Erhaltung: $>60 \%$ erh

$$
25-60 \% \text { erh. }
$$

- $1-25 \%$ erh.

\section{Beschreibung:}

Hier sind erodierte Schädelfragmente erhalten.

\section{Verband: $\quad \square$ Verband}

\section{Alter:}

Geschlecht:

\section{Arthrose:}

Maß

Schädeldecke / Schädelbasis

1

(




\section{Bezeichn.: Cranium}

\section{Kiste:}

Skelet: 62/65-3

Population: Großenrode

Felsenbein:

Erhaltung: $>60 \%$ erh.

$25-60 \%$ erh.

- $1-25 \%$ erh.

\section{Ges./Kr.: Krank}

Krankh.: meningeale Reizung

hämorrhagische

Meningitis

\section{Maß}

Schädeldecke / Schädelbasis

Wert $\quad$ Einheit

\section{Geschlecht:}

Arthrose:

2

1

\section{Beschreibung:}

Hier sind mehrere Fragmente eines Cranium erhalten. Es finden sich sowohl Splitter von der Schädelbasis, als auch von der Schädeldecke.

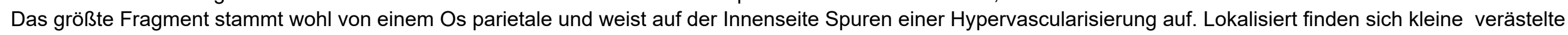
Gefäßimpressionen in der Knochenoberfläche. Die vorhandene Schädelnaht könnte die Sutura squamosa sein. 


\section{Bezeichn:: Cranium}

\section{Kiste:}

Skelet: $\quad$ K209 63/65 P4

Population: Großenrode

Felsenbein:

Erhaltung: $>60 \%$ erh.

$$
25-60 \% \text { erh. }
$$

- 1 - $25 \%$ erh.

\section{Ges./Kr.: Krank}

Krankh.: meningeale Reizung

Perisinusitis

\section{Alter:}

Geschlecht:

Arthrose:

\section{Maß}

Schädeldecke / Schädelbasis
Wert 1 Einheit

2

2

\section{Beschreibung:}

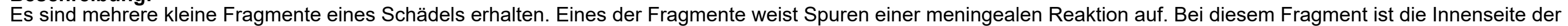

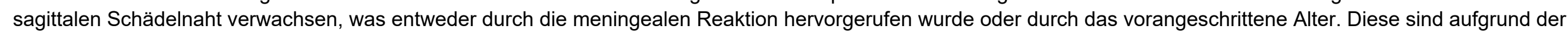
Erosionsspuren nicht optimal zu dokumentieren, dennoch sind sie zu diagnostizieren. 
Bezeichn.: Cranium

Kiste:

Skelet: K275 63/66 S3

Population: Großenrode

Felsenbein:

Erhaltung: $>60 \%$ erh.

$$
25-60 \% \text { erh. }
$$

- $1-25 \%$ erh.

\section{Verband:}

\section{Alter:}

Ges./Kr.: Gesund

\section{Geschlecht:}

Arthrose:

\begin{tabular}{l|l|l} 
Maß & Wert & Einheit \\
\hline Dicke & 2,41 & $\mathrm{~mm}$ \\
Schädeldecke / Schädelbasis & 1 & 1 \\
& & \\
& &
\end{tabular}

\section{Beschreibung:}

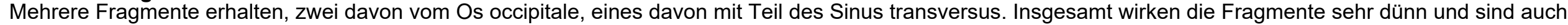
aufgrund der noch ganz offenen Occipitalnaht als jung einzustufen. 
Bezeichn:: Cranium

\section{Kiste:}

Skelet: $\quad 63 / 66-2+3,4$

Population: Großenrode

Felsenbein:

Erhaltung: $>60 \%$ erh

$$
25-60 \% \text { erh. }
$$

- $1-25 \%$ erh.

\section{Verband:}

\section{Alter:}

Ges./Kr.: Gesund

\section{Geschlecht:}

\section{Arthrose:}

\begin{tabular}{l|l|l} 
Maß & Wert & Einheit \\
\hline Breite & 13 & $\mathrm{~mm}$ \\
Schädeldecke / Schädelbasis & 1 & \\
& & \\
& &
\end{tabular}

\section{Beschreibung:}

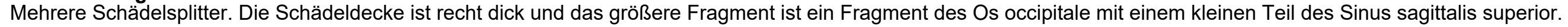

Da die Schädelnaht des Os occipitale nicht verschlossen ist, ist davon auszugehen, dass das Individuum noch jung war. 
Bezeichn.: Cranium

\section{Kiste:}

4

Skelet: 4

Population: Großenrode

Felsenbein:

Erhaltung: $>60 \%$ erh. $25-60 \%$ erh.

- $1-25 \%$ erh.
Ges./Kr.: Krank

Krankh.: Sinusitis sphenoidalis

\section{Maß}

Schädeldecke / Schädelbasis

Sinus sphenoidalis

Viscerocranium

\section{Geschlecht:}

Arthrose:
$18-20(25)$

\section{Beschreibung:}

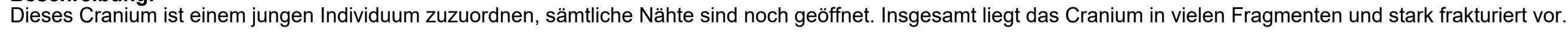

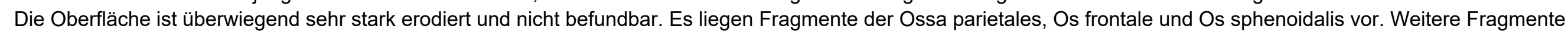
sind Splitter. Zugehörig sind wohl auch Fragmente von Ober- und Unterkiefer.

Ein Fragment des Sinus sphenoidalis weist vernarbte Oberflächenauflagerungen auf, die für eine verheilte Sinusitis sphenoidalis sprechen. 
Bezeichn:: Cranium

\section{Kiste:}

4

Skelet: 4

Population: Großenrode

Felsenbein: Rechts

Erhaltung: $>60 \%$ erh.

$$
25-60 \% \text { erh. }
$$

- $1-25 \%$ erh.
Ges./Kr.: Krank

Krankh.: Cribra Orbitalia

Sinusitis frontalis

\section{Maß}

Schädeldecke / Schädelbasis

Sinus frontalis

\section{Geschlecht:}

\section{Arthrose:}

$16-18(20)$

\section{Beschreibung:}

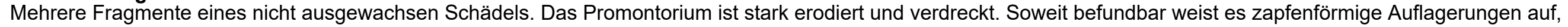

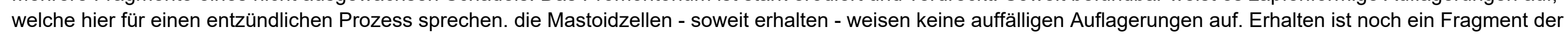

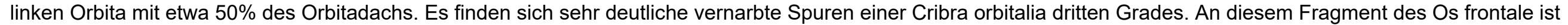
auch ein kleiner Teil des Sinus frontalis erhalten, der sehr stark erodiert ist. Dennoch sind hier Spuren einer Sinusitis frontalis erkennbar.

Ein Fragment des Os occipitale weist eine recht dicke Naht auf, welche 7,65mm misst. 


\section{Bezeichn:: Cranium}

\section{Kiste:}

Skelet: $\quad 61 / 54$

Population: Großenrode

Felsenbein:

Erhaltung: $>60 \%$ erh.

$25-60 \%$ erh.

- 1 - $25 \%$ erh.
Ges./Kr.: Krank

Krankh.: meningeale Reizung

meatus acusticus Reizung

Cribra Orbitalia

Perisinusitis

\section{Maß}

Orbita re / Ii

Schädeldecke / Schädelbasis

Geschlecht:

Arthrose:

\section{Beschreibung:}

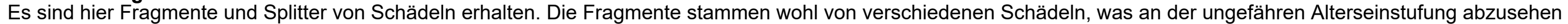

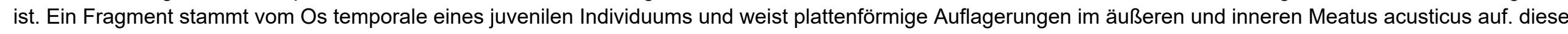

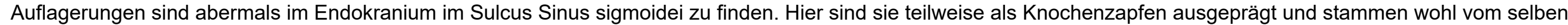

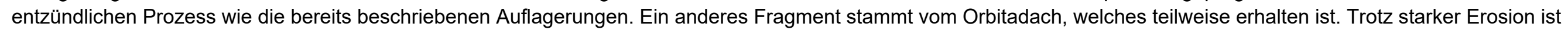

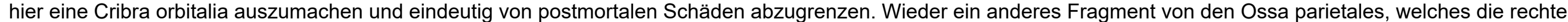

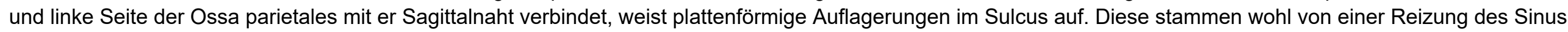

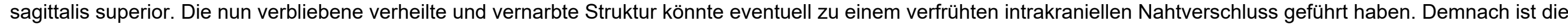
Altersbestimmung hier schwierig. 


\begin{tabular}{|c|c|c|c|c|c|c|c|c|}
\hline Bezeichn.: & Cranium & Verband: & Verband & Ges./Kr.: & Krank & Maß & Wert & Einheit \\
\hline Kiste: & 2 & Alter: & & Krankh.: & meningeale Reizung & Schädeldecke / Schädelbasis & 1 & \\
\hline Skelet: & $60 / 58$ & Geschlecht: & & & hämorrhagische & & & \\
\hline Population: & Großenrode & Arthrose: & & & Meningitis & & & \\
\hline Felsenbein: & & & & & & & & \\
\hline Erhaltung: & $>60 \%$ erh. & & & & & & & \\
\hline & $25-60 \%$ erh. & & & & & & & \\
\hline & • 1 - $25 \%$ erh. & & & & & & & \\
\hline
\end{tabular}

\section{Beschreibung:}

Dies ist ein Fragment eines Os frontale mit Gefäßimpressionen auf der endokraniellen Seite, die von einer meningealen Reaktion her zeugen. Sie verästeln sich wie für eine entzündliche Reaktion üblich. 
Bezeichn.: Cranium

\section{Kiste:}

2

Skelet: 2

Population: Großenrode

Felsenbein:

Erhaltung:

$$
\begin{aligned}
& >60 \% \text { erh. } \\
& 25-60 \% \text { erh. } \\
& 1-25 \% \text { erh. }
\end{aligned}
$$

Ges./Kr.: Krank

Krankh.: Cribra Orbitalia

meningeale Reizung

Sinusitis frontalis

\section{Beschreibung:}

Dieses Fragment eines Os frontale weist zahlreiche, wohl miteinander zusammenhängende Auffälligkeiten auf. Zunächst ist eine Reizung des Sinus frontalis zu nennen, die eine generalisierte Infektion der Nasennebenhöhlen mit sich gebracht haben könnte. Diese Entzündungsspuren des vernarbten Prozesses sind durch erhabene, glatte Oberflächenauftreibungen zu erkennen. Anzeichen für eine akute Entzündung fehlen. Dieser aber ehemals akute Entzündungsprozess hat sich dann in Richtung Periorbita weiter entwickelt und dort die vernarbten Spuren einer Cribra orbitalia hinterlassen. Von hier wanderte die Entzündung nun weiter ins Endokranium, wo sie den Übergang in die dura mater fand. Auch hier hinterließ die Entzündung eine vernarbte Oberflächenstruktur mit Spuren einer für einen entzündlichen Prozess üblichen Hypervaskularisierung. 


\section{Bezeichn.: Cranium}

Kiste:

Skelet: $\quad 64 / 53$

Population: Großenrode

Felsenbein:

Erhaltung: $>60 \%$ erh

$$
25-60 \% \text { erh. }
$$

- $1-25 \%$ erh.

\section{Verband: $\quad$ Verband}

Alter: Erwachsen

\section{Geschlecht:}

Arthrose:
Ges./Kr.: Gesund

\section{Maß}

Schädeldecke / Schädelbasis

\section{Beschreibung:}

Knochensplitter von einem Schädel. Es handelt sich wohl um ein erwachsenes Individuum. Es finden sich Erosionsspuren an den Fragmenten sodass die Fundstücke nur bedingt befundbar sind. 


\section{Bezeichn: Cranium}

\section{Kiste:}

Skelet: $\quad 62 / 55$

Population: Großenrode

Felsenbein:

Erhaltung: $>60 \%$ erh

$$
25-60 \% \text { erh. }
$$

- $1-25 \%$ erh.
Verband: $\square$ Verband

Ges./Kr.: Gesund

\section{Maß}

Schädeldecke / Schädelbasis

\section{Geschlecht:}

\section{Arthrose:}

\section{Beschreibung:}

Hier sind viele Knochensplitter eines Schädels erhalten. Sie stammen aus dem Bereich der Schädelbasis und -decke. Es fallen keine Auffälligkeiten auf. 


\section{Bezeichn:: Cranium}

Kiste:

Skelet: $\quad 62 / 55$

Population: Großenrode

Felsenbein:

Erhaltung: $>60 \%$ erh

$$
25-60 \% \text { erh. }
$$

- $1-25 \%$ erh.

\section{Ges./Kr.: Krank}

Krankh.: meningeale Reizung

\section{Maß}

Schädeldecke / Schädelbasis
Alter:

\section{Geschlecht:}

Arthrose:

\section{Beschreibung:}

Bei diesem Fragment handelt es sich um ein Fragment des Os frontale, welches Auflagerungen in Form von Knochenneubildungen aufzeigt, die wohl durch eine meningeale Reizung entstanden sind. Diese meningeale Reizung war wohl als entzündlicher Prozess ausgeprägt. 


\section{Bezeichn.: Cranium}

Kiste:

Skelet: $\quad 63 / 52$

Population: Großenrode

Felsenbein:

Erhaltung: $>60 \%$ erh

$$
25-60 \% \text { erh. }
$$

- $1-25 \%$ erh.

\section{Verband: $\quad$ Verband}

\section{Alter: Erwachsen}

\section{Geschlecht:}

\section{Arthrose:}

\section{Ges./Kr.: Gesund}

\section{Maß}

Schädeldecke / Schädelbasis

Sinus sphenoidalis

Viscerocranium

\section{Beschreibung:}

Knochensplitter. Unter anderem erhalten ist ein Teil des Os zygomaticum, eines vom Sinus sphenoidalis, eines von einer linken Orbita. 


\section{Bezeichn.: Cranium}

\section{Kiste:}

Skelet: $\quad 62 / 54$

Population: Großenrode

Felsenbein:

Erhaltung: $>60 \%$ erh

$25-60 \%$ erh.

- 1 - $25 \%$ erh.
Ges./Kr.: Krank

Krankh.: Cribra Orbitalia

meningeale Reizung

\section{Maß}

Schädeldecke / Schädelbasis

Sinus frontalis

Viscerocranium

\section{Geschlecht:}

\section{Arthrose:}
(16) 20 - $30(45)$

\begin{tabular}{|l|l} 
Wert & Einheit \\
\hline 2 & 1 \\
1 &
\end{tabular}

\section{Beschreibung:}

Dies sind Fragmente eines Schädels, sie sind stark erodiert. Es liegen Teile von Os zygomaticum rechts und links, Schädelbasis und -decke und ein linkes Orbitadach, von dem etwa $1 / 3$ erhalten ist, vor. Das Orbitadach weist eine kleine knöcherne Platte als Auflagerung auf, sie misst $8,37 \mathrm{~mm}$ Dicke. Ein Fragment vom Os frontale hat ebenfalls Auflagerungen, welche sich am Endokranium befinden. 
Bezeichn.: Cranium

Kiste:

Verband:

Verband

\section{Alter:}

Geschlecht:

Arthrose:

Population: Großenrode

Felsenbein:

Erhaltung: $\bigcirc 60 \%$ erh

$25-60 \%$ erh.

- 1 - $25 \%$ erh.

\section{Beschreibung:}

Schädelfragmente von Schädelbasis und -decke, sie sind nicht befundbar. 


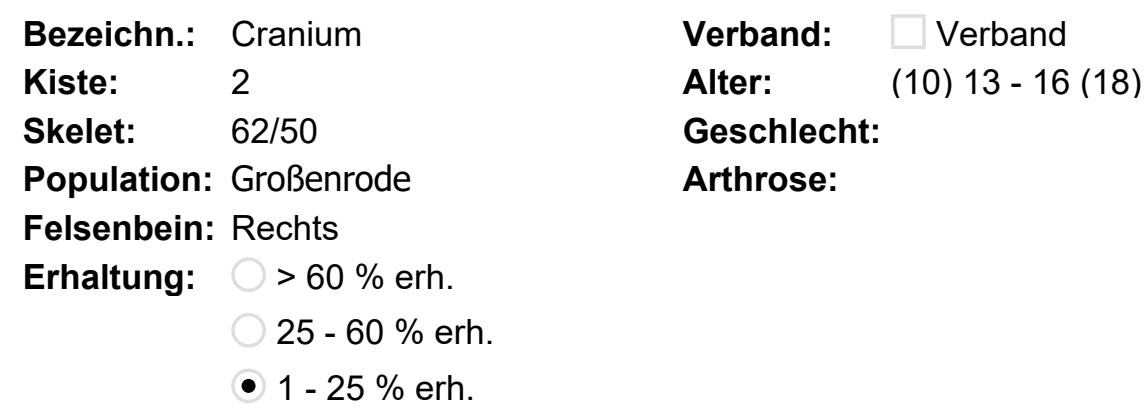

Population: Großenrode

Arthrose:

Felsenbein: Rechts

Erhaltung: $>60 \%$ erh$$
25-60 \% \text { erh. }
$$

- $1-25 \%$ erh.

\section{Beschreibung:}

Von diesem Schädel sind nur Splitter und Fragmente erhalten. Diese stammen von der Schädeldecke und -Basis. Ein Fragment ist dem Os occipitale zuzuordnen 
Bezeichn.: Cranium

Kiste:

2

Skelet: $\quad 62 / 54$

Population: Großenrode

Felsenbein:

Erhaltung: $>60 \%$ erh

$25-60 \%$ erh.

- $1-25 \%$ erh.

\section{Beschreibung:}

Bei diesem Fundstück handelt es sich um ein kleines Fragment eines Os frontale.

\section{Geschlecht:}

\section{Arthrose:}

Ges./Kr.: Krank

Krankh.: Sinusitis frontalis

\section{Maß}

Schädeldecke / Schädelbasis

Sinus frontalis

\begin{tabular}{|l|l} 
Wert & Einheit \\
1 & \\
2 &
\end{tabular}


Bezeichn.: Cranium

Kiste:

Skelet: Tüte aus 63/56

Population: Großenrode

Felsenbein: Rechts

Erhaltung: $>60 \%$ erh.

$$
25-60 \% \text { erh. }
$$

- 1 - $25 \%$ erh.

\section{Verband: $\quad$ Verband}

Alter: (20) $25-45$ (60)

Maß

Schädeldecke / Schädelbasis Wert $\mid$ Einheit

Geschlecht:

Arthrose:

\section{Beschreibung:}

Es sind mehrere Schädelfragmente erhalten. Sie sind sehr stark erodiert und nicht zu befunden, es handelt sich um Fragmente von der Schädelbasis und -decke. 


\section{Bezeichn: Cranium}

Kiste:

2

Skelet: $\quad 63 / 51$

Population: Großenrode

Felsenbein:

Erhaltung: $>60 \%$ erh

$$
25-60 \% \text { erh. }
$$

- $1-25 \%$ erh.

\section{Verband: \\ Verband \\ Ges./Kr.: Gesund}

\section{Alter:}

\section{Maß}

Schädeldecke / Schädelbasis

Geschlecht: $q \leq \hat{\sigma}$

Arthrose:

\section{Beschreibung:}

Ein sehr stark erodiertes Fragment des Os occipitale, die Protuberantia occipitalis externa ist sehr deutlich ausgeprägt. 
Bezeichn.: Cranium

Kiste: 3

Skelet: $\quad 61 / 65$ K207 S3

Population: Großenrode

Felsenbein:

Erhaltung: $>60 \%$ erh.

$$
25-60 \% \text { erh. }
$$

- $1-25 \%$ erh.

\section{Verband: $\quad \square$ Verband}

\section{Alter:}

Geschlecht:

Arthrose:

\section{Beschreibung:}

Ein Schädel in wenigen kleinen Fragmenten. Es handelt sich um unbefundbare Fragmente.

1


Bezeichn.: Cranium

Kiste: 3

Skelet: $\quad 61 / 65 \mathrm{~K} 222 \mathrm{S3}$

Population: Großenrode

Felsenbein:

Erhaltung: $>60 \%$ erh.

$$
25-60 \% \text { erh. }
$$

- 1 - $25 \%$ erh.

\section{Verband: $\quad \square$ Verband}

\section{Alter:}

\section{Geschlecht:}

Arthrose:

\section{Beschreibung:}

Ein Schädel in wenigen kleinen Fragmenten. Es handelt sich um unbefundbare Fragmente.

\section{$\mathrm{Maß}$}

Schädeldecke / Schädelbasis Wert $\quad$ Einheit

1


Bezeichn.: Cranium

Kiste:

Verband:

Verband

\section{Alter:}

Geschlecht:

Arthrose:

Population: Großenrode

Felsenbein:

Erhaltung: $>60 \%$ erh

$25-60 \%$ erh.

- $1-25 \%$ erh.

\section{Beschreibung:}

Ein kleines Schädelfragment aus der Schädeldecke. 
Bezeichn.: Cranium

Kiste:

Verband:

Verband

\section{Alter:}

Geschlecht:

Arthrose:

Population: Großenrode

Felsenbein:

Erhaltung: $>60 \%$ erh.

$25-60 \%$ erh.

- $1-25 \%$ erh.

\section{Beschreibung:}

Ein Schädel in zwei kleinen Fragmenten. Es handelt sich um unbefundbare Fragmente. 
Bezeichn.: Cranium

Kiste:

Skelet: $\quad 61 / 65$

Population: Großenrode

Felsenbein:

Erhaltung: $>60 \%$ erh

$25-60 \%$ erh.

- $1-25 \%$ erh.

\section{Verband: $\quad$ Verband}

\section{Alter:}

Geschlecht:

Arthrose:

\section{Beschreibung:}

Ein Schädel in wenigen kleinen Fragmenten. Es handelt sich um unbefundbare Fragmente.

Maß

Schädeldecke / Schädelbasis Wert $\quad$ Einheit

1

1


Bezeichn.: Cranium

\section{Kiste:}

Skelet: $\quad 61 / 65-3$

Population: Großenrode

Felsenbein:

Erhaltung: $>60 \%$ erh

$$
25-60 \% \text { erh. }
$$

- 1 - $25 \%$ erh.

\section{Verband: $\quad$ Verband}

\section{Alter:}

Geschlecht:

\section{Arthrose:}

\section{Beschreibung:}

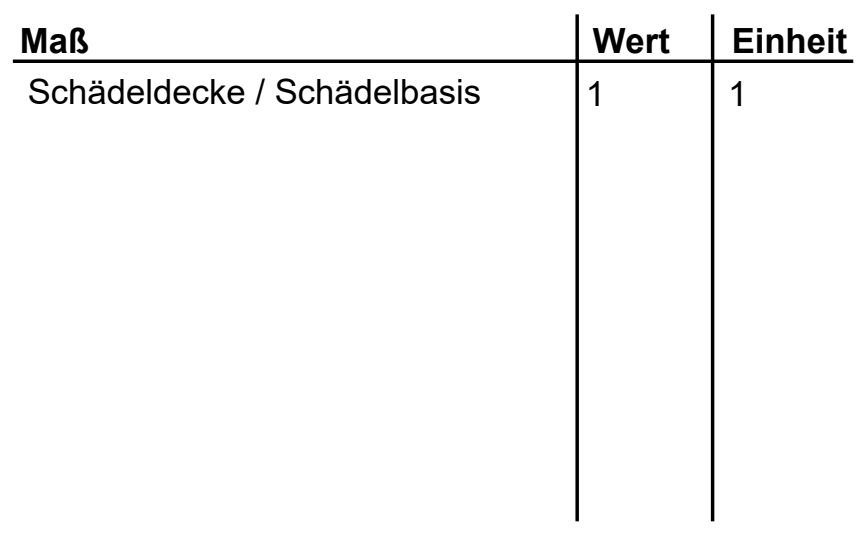

Ein Schädel in wenigen kleinen Fragmenten aus Schädelbasis und -decke. Es handelt sich um unbefundbare Fragmente. 
Bezeichn.: Cranium

Kiste:

Verband:

Verband

\section{Alter:}

Geschlecht:

Arthrose:

Population: Großenrode

Felsenbein:

Erhaltung: $>60 \%$ erh

$25-60 \%$ erh.

- $1-25 \%$ erh.

\section{Beschreibung:}

Ein Schädel in drei kleinen Fragmenten. Es handelt sich um unbefundbare Fragmente.

1


Bezeichn.: Cranium

Kiste:

Skelet: $\quad 61 / 65$ K250 S3

Population: Großenrode

Felsenbein:

Erhaltung: $>60 \%$ erh

$$
25-60 \% \text { erh. }
$$

- $1-25 \%$ erh.

\section{Verband: $\quad$ Verband}

\section{Alter:}

\section{Geschlecht:}

\section{Arthrose:}

\section{Beschreibung:}

Ein Schädel in zwei kleinen Fragmenten. Es handelt sich um unbefundbare Fragmente. Eines stammt vom Os temporale der rechten Seite. 
Bezeichn.: Cranium

Kiste:

3

Skelet: $\quad 61 / 65$ K184 S3

Population: Großenrode

Felsenbein:

Erhaltung: $>60 \%$ erh

$25-60 \%$ erh.

- 1 - $25 \%$ erh.

\section{Verband: $\quad \square$ Verband}

\section{Alter:}

Geschlecht:

\section{Arthrose:}

\section{Beschreibung:}

Mehrere Splitter einer Schädeldecke, welche nicht befundbar sind. 
Bezeichn.: Cranium

Kiste: 3

Skelet: $\quad 61 / 65$ K258 S3

Population: Großenrode

Felsenbein:

Erhaltung: $>60 \%$ erh

$$
25-60 \% \text { erh. }
$$

- 1 - $25 \%$ erh.

\section{Verband: $\quad \square$ Verband}

\section{Alter:}

Geschlecht:

\section{Arthrose:}

\section{Beschreibung:}

Hier sind einige Schädelsplitter erhalten, unter anderem ein Teil Os temporale.

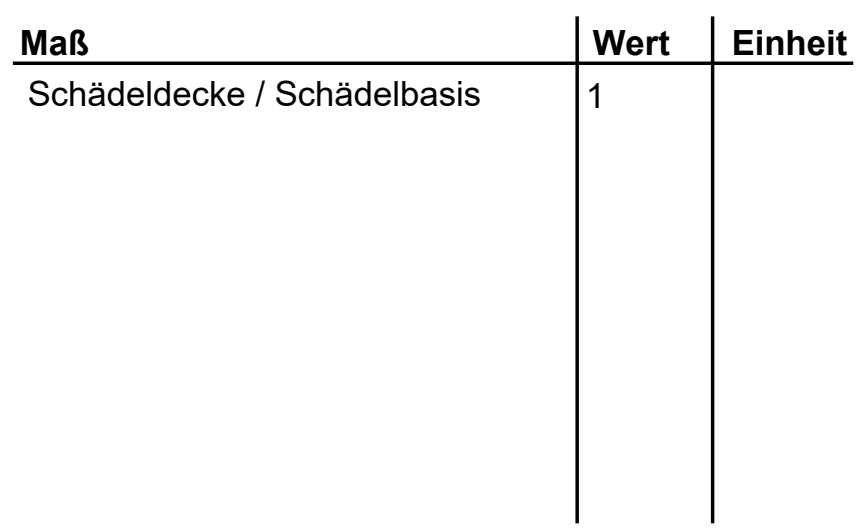


Bezeichn.: Cranium

Kiste:

Verband:

Verband

Alter:

\section{Geschlecht:}

Arthrose:

Population: Großenrode

Felsenbein:

Erhaltung: $\bigcirc 60 \%$ erh

$$
25-60 \% \text { erh. }
$$

- $1-25 \%$ erh.

\section{Beschreibung:}

Mehrere Splitter einer Schädeldecke, welche nicht befundbar sind. 
Bezeichn.: Cranium

\section{Kiste:}

Skelet: $\quad 61 / 66$

Population: Großenrode

Felsenbein:

Erhaltung: > $>0 \%$ erh

$25-60 \%$ erh.

- $1-25 \%$ erh.
Verband: $\quad$ Verband

\section{Alter:}

Geschlecht:

Arthrose:

\section{Beschreibung:}

Kleine Schädelfragmente. 


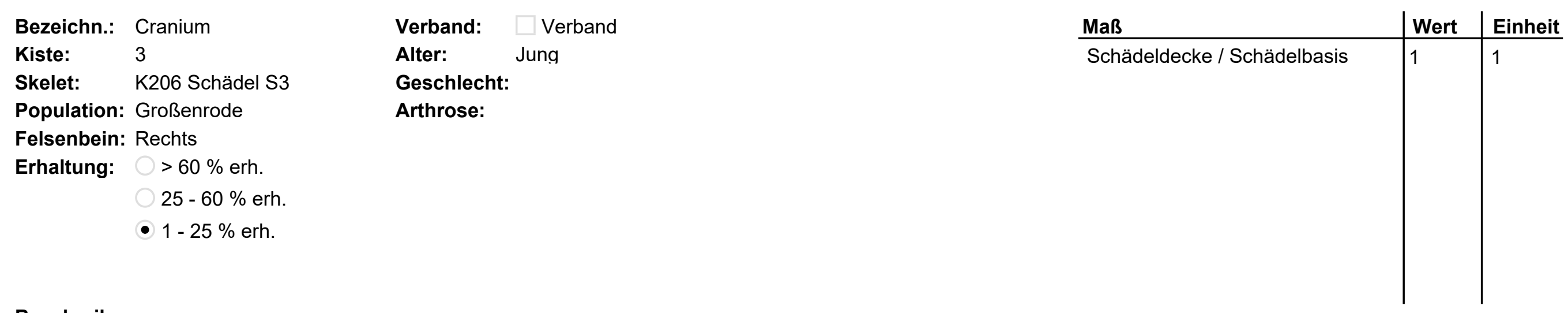

\section{Beschreibung:}

Dies sind Fragmente eines Schädels. Unter anderem erhalten ist ein Teil des Os temporale der rechten Seite und viele weitere Splitter, deren Nahtstellen nicht verschlossen waren. 


\section{Bezeichn:: Cranium}

\section{Kiste:}

Skelet: $\quad 60 / 633$

Population: Großenrode

Felsenbein:

Erhaltung: $>60 \%$ erh

$$
25-60 \% \text { erh. }
$$

- $1-25 \%$ erh.

\section{Beschreibung:}

Kleinste Schädelfragmente.

\section{Verband: $\quad \square$ Verband}

\section{Alter:}

Geschlecht:

Arthrose:
Maß

Schädeldecke / Schädelbasis Wert $\mid$ Einheit

1

1


Bezeichn.: Cranium

Kiste:

Skelet: aus großer Tüte und

Population: Großenrode

Felsenbein: Links

Erhaltung: $>60 \%$ erh

$$
25-60 \% \text { erh. }
$$

- $1-25 \%$ erh.

\section{Verband: \\ Ges./Kr.: Gesund}

\section{Alter:}

\section{Geschlecht:}

Arthrose:

\begin{tabular}{l|l|l} 
Maß & Wert & Einheit \\
\hline Breite & 50 & $\mathrm{~mm}$ \\
Länge & 70,8 & $\mathrm{~mm}$ \\
Schädeldecke / Schädelbasis & 1 & 1 \\
& & \\
& &
\end{tabular}

\section{Beschreibung:}

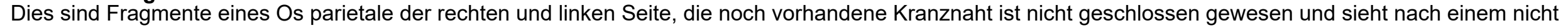
ausgewachsenen Individuum aus. Das linke Mastoid ist erhalten und passt zum jungen Alter des Individuums. 
Bezeichn.: Cranium

Kiste:

Skelet: aus großer Tüte und

Population: Großenrode

Felsenbein:

Erhaltung: $>60 \%$ erh

$$
25-60 \% \text { erh. }
$$

- $1-25 \%$ erh.

\section{Verband: $\quad$ Verband}

\section{Alter:}

Geschlecht:

Arthrose:

\section{Beschreibung:}

Ein kleines Fragment Os temporale mit Fossa mandibularis und Meatus acusticus externus. 


\section{Bezeichn.: Cranium}

\section{Kiste:}

Skelet: K192

Population: Großenrode

Felsenbein: Rechts

Erhaltung: $>60 \%$ erh

$$
25-60 \% \text { erh. }
$$

- $1-25 \%$ erh.

\section{Verband: $\quad$ Verband}

\section{Alter:}

\section{Geschlecht:}

\section{Arthrose:}

Ges./Kr.: Gesund

\section{Maß}

Schädeldecke / Schädelbasis

\section{Wert $\quad$ Einheit}

1

1

\section{Beschreibung:}

Hier sind Bruchstücke eines Schädels erhalten, es ist das rechte Mastoid, die rechte Fossa mandibularis (erodiert und nicht befundbar) und weitere kleine Fragmente des Os parietale rechts und der Schädelbasis vorhanden. 
Bezeichn.: Cranium

Kiste:

3

Skelet: $\quad 61 / 64-3$ Schädel

Population: Großenrode

Felsenbein:

Erhaltung: $>60 \%$ erh

$$
25-60 \% \text { erh. }
$$

- $1-25 \%$ erh.

\section{Verband: $\quad$ Verband}

\section{Alter:}

\section{Geschlecht:}

\section{Arthrose:}

\section{Beschreibung:}

Ein Fragment von der seitlichen Schädelkalotte. Weiterhin sind kleine Splitter erhalten.

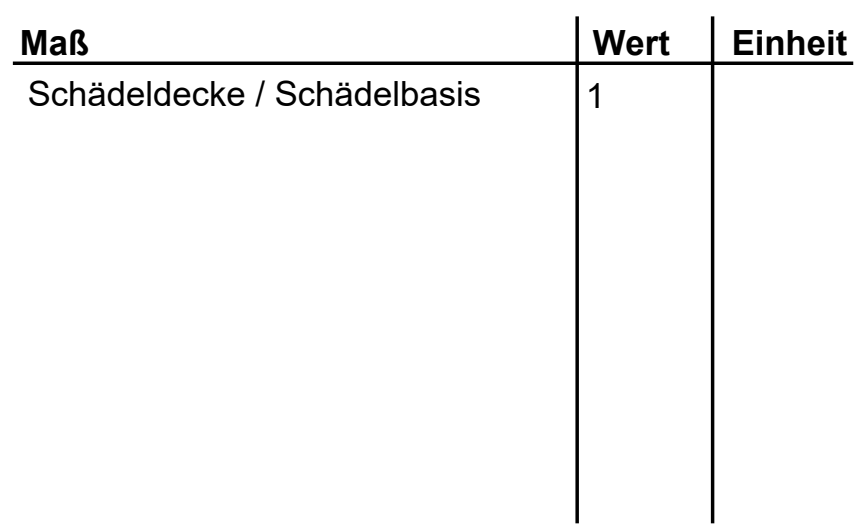


Bezeichn.: Cranium

\section{Kiste:}

Skelet: $\quad 62 / 64$

Population: Großenrode

Felsenbein:

Erhaltung: $>60 \%$ erh

$$
25-60 \% \text { erh. }
$$

- $1-25 \%$ erh

\section{Verband: $\quad$ Verband}

\section{Alter:}

Geschlecht:

\section{Arthrose:}

\section{Beschreibung:}

Von diesem Schädel sind nur Fragmente erhalten, es handelt sich um Fragmente der Schädelbasis und -decke.

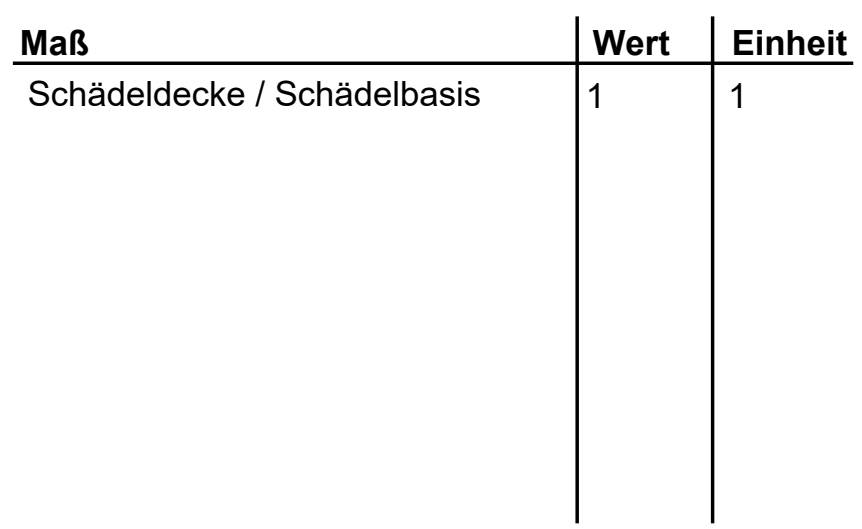


Bezeichn:: Cranium

Kiste:

Skelet: $\quad 60 / 65 \mathrm{~K} 129$

Population: Großenrode

Felsenbein:

Erhaltung: $>60 \%$ erh

$25-60 \%$ erh.

- $1-25 \%$ erh.
Ges./Kr.: Krank

Krankh.: Cribra Orbitalia

\section{Maß}

Dicke

Schädeldecke / Schädelbasis

\section{Geschlecht:}

\section{Arthrose:}

\begin{tabular}{|l|l} 
Wert & Einheit \\
\hline 3,33 & $\mathrm{~mm}$ \\
1 & 1 \\
&
\end{tabular}

\section{Beschreibung:}

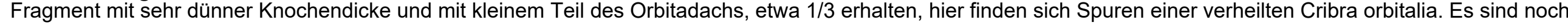
weitere Schädelsplitter erhalten aus Basis und Decke. 
Bezeichn.: Cranium

Kiste:

Verband:

Verband

\section{Alter:}

\section{Geschlecht:}

Arthrose:

Population: Großenrode

Felsenbein:

Erhaltung: $>60 \%$ erh

$$
25-60 \% \text { erh. }
$$

- $1-25 \%$ erh.

\section{Beschreibung:}

Es handelt sich hier um kleinere Fragmente von Schädeldach und -Basis. 
Bezeichn.: Cranium

\section{Kiste:}

Verband:

Verband

\section{Alter:}

Ges./Kr.: Gesund

\section{Geschlecht:}

Arthrose:

Population: Großenrode

Felsenbein:

Erhaltung: $>60 \%$ erh.

$$
25-60 \% \text { erh. }
$$

- $1-25 \%$ erh.

\section{Beschreibung:}

Schädelfragmente aus dem Schädeldach. 
Bezeichn.: Cranium

\section{Kiste:}

Skelet: $\quad 60 / 65$

Verband: $\quad \square$ Verband

\section{Alter:}

\section{Geschlecht:}

Arthrose:

Population: Großenrode
Maß

Schädeldecke / Schädelbasis

Felsenbein:

Erhaltung: $>60 \%$ erh

$25-60 \%$ erh.

- 1 - $25 \%$ erh.

\section{Beschreibung:}

Schädelsplitter, eines davon Os temporale. 


\section{Bezeichn.: Cranium}

\section{Kiste:}

3

Skelet: K312

Population: Großenrode

Felsenbein: Rechts

Erhaltung: $>60 \%$ erh.

- $25-60 \%$ erh.

$1-25 \%$ erh.
Ges./Kr.: Krank

Krankh.: Kopfschwartenreizung

Hypoplasie sinus frontalis

\section{Maß}

Schädeldecke / Schädelbasis

Sinus frontalis

\section{Geschlecht:}

\section{Arthrose:}
(7) 8 - 16

\begin{tabular}{|l|l} 
Wert & Einheit \\
\hline 1
\end{tabular}

1

1

\section{Beschreibung:}

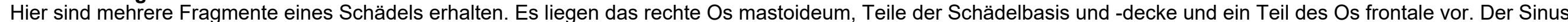

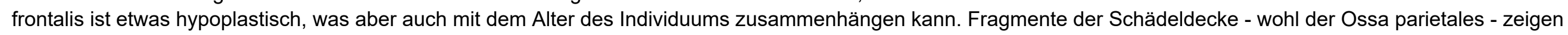
Spuren einer Kopfschwartenentzündung. 


\section{Bezeichn:: Cranium}

\section{Kiste:}

Skelet: K168

Population: Großenrode

Felsenbein: Links

Erhaltung: $>60 \%$ erh.

- $25-60 \%$ erh.

$1-25 \%$ erh.
Ges./Kr.: Krank

Krankh.: meningeale Reizung

Cribra Orbitalia

Kopfschwartenreizung

sutura metopica

persistens

Perisinusitis

\section{Maß}

Orbita re / li

Schädeldecke / Schädelbasis

Viscerocranium

\section{Arthrose:}

2

2

\section{Beschreibung:}

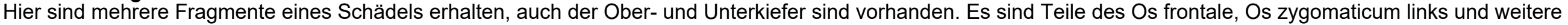

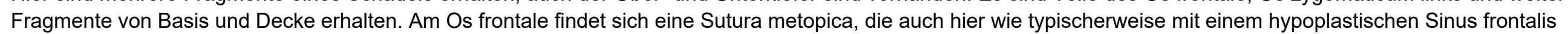

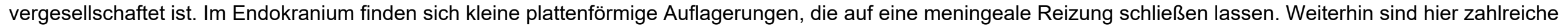

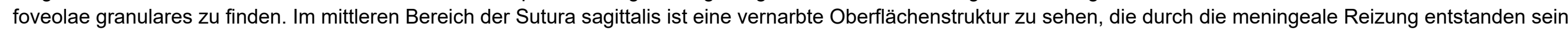

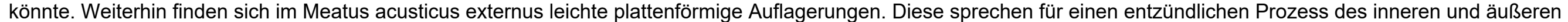
Schädelbereichs. 


\section{Bezeichn.: Cranium}

\section{Kiste:}

10

Skelet:

63/55

Population: Großenrode

Felsenbein: Rechts

Erhaltung: $>60 \%$ erh.

$$
25-60 \% \text { erh. }
$$

- 1 - $25 \%$ erh.
Ges./Kr.: Krank

Krankh.: meningeale Reizung

\section{Maß}

Schädeldecke / Schädelbasis

2

Einheit

\section{Geschlecht:}

\section{Arthrose:}

1

\section{Beschreibung:}

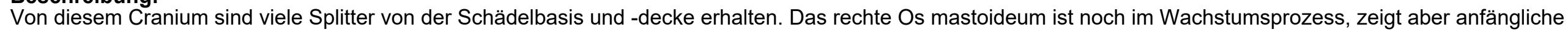
Pneumatisierungsspuren, welche durch eine knöcherner Fensterung zu sehen ist. Die sichtbaren, aber nicht mehr zuzuordnenden Schädelnähte sind nicht verknöchert, was weiter für ein junges Individuum spricht. Im Os frontale fallen knöcherne Auflagerungen auf, die wohl für einen entzündlichen Prozess der Hirnhaut sprechen könnten. 


\begin{tabular}{|c|c|c|c|c|c|c|}
\hline Bezeichn.: & Cranium & Verband: $\quad \square$ Verband & Ges./Kr.: Krank & Maß & Wert & Einheit \\
\hline Kiste: & 10 & Alter: & Krankh.: meningeale Reizung & Schädeldecke / Schädelbasis & 2 & \\
\hline Skelet: & $64 / 55$ & Geschlecht: $q>\hat{\jmath}$ & & & & \\
\hline Population: & Großenrode & Arthrose: & & & & \\
\hline Felsenbein: & & & & & & \\
\hline Erhaltung: & $>60 \%$ erh. & & & & & \\
\hline & $25-60 \%$ erh. & & & & & \\
\hline & - $1-25 \%$ erh. & & & & & \\
\hline
\end{tabular}

\section{Beschreibung:}

Von diesem Schädel sind nur Splitter erhalten (u.a. ein Teil des Os occipitale und Teil des Os frontale). Zwei der erhaltenen Fragmente zeigen Auflagerungen, eines davon ist ein Fragment des Os frontale. Das größte Schädelfragment misst 9,78mm. 


$\begin{array}{lll}\text { Bezeichn.: } & \text { Cranium } & \text { Verband: } \square \text { Verband } \\ \text { Kiste: } & 10 & \text { Alter: Jung } \\ \text { Skelet: } & 61 / 55 & \text { Geschlecht: } \\ \text { Population: } & \text { Großenrode } & \text { Arthrose: } \\ \text { Felsenbein: } & \\ \text { Erhaltung: } & >60 \% \text { erh. } & \\ & 25-60 \% \text { erh. } & \\ & & \\ & & \\ & 1-25 \% \text { erh. }\end{array}$

\section{Beschreibung:}

Viele Splitter eines jungen Schädels, was an den Zähnen und an den nicht geschlossenen Schädelnähten zu erkennen ist. 


\section{Bezeichn.: Cranium}

\section{Kiste:}

Skelet: 10

Population: Großenrode

Felsenbein: Links

Erhaltung: $>60 \%$ erh

$$
25-60 \% \text { erh. }
$$

- $1-25 \%$ erh.
Ges./Kr.: Krank

Krankh.: hohe Schädeldicke Anämie

\section{Maß}

Dicke

Schädeldecke / Schädelbasis Viscerocranium

\section{Geschlecht: $q \leq$}

Arthrose:

\begin{tabular}{|l|l} 
Wert & Einheit \\
\hline 10,56 & $\mathrm{~mm}$
\end{tabular}

2

\section{Beschreibung:}

Schädelfragmente von Schädeldecke und -Basis, unter anderen ein Os mastoideum, welches gut pneumatisiert und massiv ist. Ein Fragment der Schädeldecke misst $9,98 \mathrm{~mm}$ Dicke, ein anderes $10,56 \mathrm{~mm}$. Weiterhin ist ein Teil eines Os zygomaticum erhalten, es ist der rechten Seite zuzuordnen. 


\section{Bezeichn.: Cranium}

\section{Kiste:}

10

Skelet: $\quad 62 / 56$

Population: Großenrode

Felsenbein:

Erhaltung: $>60 \%$ erh

$$
25-60 \% \text { erh. }
$$

- $1-25 \%$ erh.

\section{Beschreibung:}

Fragmente von Schädelbasis und -decke. Weiterhin ist der Unterkiefer erhalten.

\section{Geschlecht:}

Arthrose:
(6) 7 - 8 (9)

\section{Ges./Kr.: Gesund}

\section{Maß}

Schädeldecke / Schädelbasis

Viscerocranium 


\begin{tabular}{|c|c|c|c|c|c|c|c|}
\hline Bezeichn.: & Cranium & Verband: & $\square$ Verband & Ges./Kr.: Gesund & Maß & Wert & Einheit \\
\hline Kiste: & 10 & Alter: & $12-17(18)$ & & Orbita re / li & 1 & \\
\hline Skelet: & kleine Tüte in Tüte 62/51 & Geschlecht: & & & Schädeldecke / Schädelbasis & 1 & \\
\hline Population: & Großenrode & Arthrose: & & & Viscerocranium & 1 & \\
\hline Felsenbein: & & & & & & & \\
\hline Erhaltung: & $>60 \%$ erh. & & & & & & \\
\hline & $25-60 \%$ erh. & & & & & & \\
\hline & - $1-25 \%$ erh. & & & & & & \\
\hline
\end{tabular}

\section{Beschreibung:}

Schädelsplitter und Fragmente von Mandibula, Schädeldecke, Os frontale mit Teil des Orbitadachs und Os zygomaticum. Es scheint sich um ein junges Individuum zu handeln. 
Bezeichn.: Cranium

\section{Kiste:}

Skelet: $\quad$ 5. Tüte aus $62 / 52$

Population: Großenrode

Felsenbein: Rechts

Erhaltung: $>60 \%$ erh.

$$
25-60 \% \text { erh. }
$$

- 1 - $25 \%$ erh.

\section{Verband: $\quad$ Verband}

\section{Alter:}

Geschlecht:

\section{Arthrose:}

Maß

Schädeldecke / Schädelbasis

\section{Beschreibung:}

Von diesem Schädel sind nur Fragmente erhalten, es handelt sich um Teile von Schädeldecke und Schädelbasis. 

Bezeichn.: Cranium
Verband:
Verband
Kiste:
10
Skelet: aus $62 / 57$
Alter: $14-18(25)$
Population: Großenrode
Geschlecht:
Arthrose:
Felsenbein:
Erhaltung: $>60 \%$ erh
$25-60 \%$ erh.
- 1 - $25 \%$ erh.

\section{Beschreibung:}

Viele Splitter des Schädels, Basis und Decke. 


\section{Bezeichn.: Cranium}

\section{Kiste:}

10

Skelet: $\quad 61 / 52$

Population: Großenrode

Felsenbein:

Erhaltung: $>60 \%$ erh

$$
25-60 \% \text { erh. }
$$

- $1-25 \%$ erh.

\section{Beschreibung:}

Splitter von Schädeldecke und -Basis.

\section{Verband: $\quad$ Verband}

\section{Alter: $\quad 14-18(25)$}

Geschlecht:

Arthrose:
Maß

Schädeldecke / Schädelbasis Wert 1 Einheit

1

1


Bezeichn:: Cranium

Kiste:

Verband:

Verband

\section{Alter:}

Geschlecht:

Arthrose:

Population: Großenrode

Felsenbein: Links

Erhaltung: $>60 \%$ erh.

$25-60 \%$ erh.

- $1-25 \%$ erh.

\section{Beschreibung:}

Stark erodierte Splitter von Schädelbasis und -decke. Ein Fragment ist einem Os mastoideum zuzuordnen. 
Bezeichn.: Cranium

Kiste:

Skelet: 431

Population: Großenrode

Felsenbein: Links

Erhaltung: $>60 \%$ erh.

$$
25-60 \% \text { erh. }
$$

- 1 - $25 \%$ erh.
Verband: $\square$ Verband

\section{Ges./Kr.: Gesund}

\section{Maß}

Schädeldecke / Schädelbasis

Sinus sphenoidalis

\section{Geschlecht:}

\section{Arthrose:}

\section{Beschreibung:}

Stark erodierte und teilweise unbefundbare Splitter eines Schädels. Es ist ein Fragment eines Os mastoideum dabei und weitere Fragmente der Schädeldecke und -Basis. 
Bezeichn.: Cranium

\section{Kiste:}

Skelet: K282 63/68-3

Population: Großenrode

Felsenbein: Rechts

Erhaltung: $>60 \%$ erh.

$$
25-60 \% \text { erh. }
$$

- $1-25 \%$ erh.

\section{Verband: $\quad$ Verband}

\section{Ges./Kr.: Gesund}

\section{Alter:}

Geschlecht:

Arthrose:

\section{Beschreibung:}

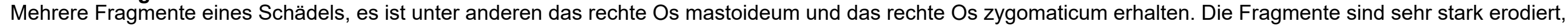

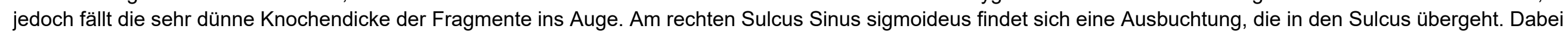
könnte es sich um eine Aussackung des Sinus sigmoideus gehandelt haben 
Bezeichn.: Cranium

\section{Kiste:}

\section{Verband:}

Verband

\section{Alter:}

Ges./Kr.: Gesund

\section{Geschlecht:}

Arthrose:

Population: Großenrode

Felsenbein:

Erhaltung: $>60 \%$ erh

$$
25-60 \% \text { erh. }
$$

- $1-25 \%$ erh.

\section{Beschreibung:}

Schädelfragmente. Sie sind recht klein und von allen regionen des Schädels. 
Bezeichn.: Cranium

\section{Kiste:}

Skelet: K235

Population: Großenrode

Felsenbein:

Erhaltung: $>60 \%$ erh

$25-60 \%$ erh.

- $1-25 \%$ erh.

\section{Verband: $\quad$ Verband}

\section{Alter:}

Geschlecht:

Arthrose:
Maß

Breite

Länge

Schädeldecke / Schädelbasis

\begin{tabular}{|l|l} 
Wert & Einheit \\
\hline 23 & $\mathrm{~mm}$
\end{tabular}

$30,5 \quad \mathrm{~mm}$

\section{Beschreibung:}

Ein kleines Fragment, welches aufgrund von Bodenerosion nicht befundbar ist. 
Bezeichn.: Cranium

\section{Kiste:}

Skelet: $\quad 63 / 68-1$

Population: Großenrode

Felsenbein:

Erhaltung: $>60 \%$ erh

$$
25-60 \% \text { erh. }
$$

- $1-25 \%$ erh.

\section{Verband: $\quad$ Verband}

\section{Alter:}

\section{Geschlecht:}

\section{Arthrose:}

Maß

Schädeldecke / Schädelbasis

\section{Beschreibung:}

9 Fragmente von einem Cranium, sie sind sehr stark erodiert und nicht befundbar. 
Bezeichn.: Cranium

\section{Kiste:}

Verband:

Verband

\section{Alter:}

Geschlecht:

Arthrose:

Population: Großenrode

Felsenbein:

Erhaltung: $>60 \%$ erh

$$
25-60 \% \text { erh. }
$$

- 1 - $25 \%$ erh.

\section{Beschreibung:}

Sehr kleine Schädelsplitter, welche nicht befundbar sind. 
Bezeichn.: Cranium

\section{Kiste:}

Skelet: $\quad$ K236 63/68-P3

Population: Großenrode

Felsenbein:

Erhaltung: $>60 \%$ erh.

$25-60 \%$ erh.

- $1-25 \%$ erh.
Ges./Kr.: Krank

Krankh.: meningeale Reizung

Periostreizung

Cribra Orbitalia

Sinusitis frontalis

Perisinusitis

\section{Maß}

Orbita re / li

Schädeldecke / Schädelbasis

Sinus frontalis

Viscerocranium

\section{Beschreibung:}

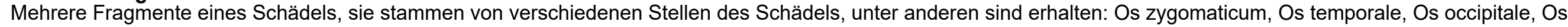
parietale, Os frontale mit Orbitadächern rechts und links. Das Alter des Schädels ist nicht eindeutig zu bestimmen, auch wenn die Schädelnähte eher noch nicht geschlossen waren, ist es schwierig den Grad des Nahtschlusses zu erkennen.

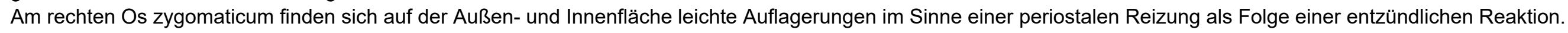

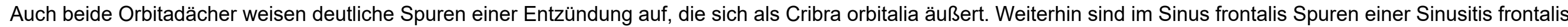
zu erkennen. Insgesamt sind die Schädelsplitter erodiert. 


\begin{tabular}{|c|c|c|c|c|c|c|c|c|}
\hline Bezeichn.: & Cranium & Verband: & $\square$ Verband & Ges./Kr.: & Krank & Maß & Wert & Einheit \\
\hline Kiste: & 1 & Alter: & $(50) 55-65(70)$ & Krankh.: & Sinusitis frontalis & Orbita re / li & 2 & 2 \\
\hline Skelet: & 63168-S3 K286 & Geschlecht & $: q \leq \widehat{O}$ & & meningeale Reizung & Schädeldecke / Schädelbasis & 2 & 1 \\
\hline Population: & Großenrode & Arthrose: & & & Cribra Orbitalia & Sinus frontalis & 2 & \\
\hline Felsenbein: & & & & & Mastoiditis & & & \\
\hline Erhaltung: & $>60 \%$ erh. & & & & Porus acusticus externus & & & \\
\hline & $25-60 \%$ erh. & & & & Reizung & & & \\
\hline & - $1-25 \%$ erh. & & & & & & & \\
\hline
\end{tabular}

\section{Beschreibung:}

Mehrere Schädelsplitter, es sind Teile des Os frontale mit Sinus frontalis, Os occipitale mit Protuberantia occipitalis externa, Ossa parietales links und rechts und kleine Teile der Orbitadächer links und rechts.

Im Sinus frontalis fallen Spuren einer leichten Sinusitis ins Auge, ein Fragment des linken Os parietale weist auffällige Auflagerungen auf, welche für einen entzündlichen Prozess sprechen, eine meningeale Reizung. Fragmente der Orbitadächer links und rechts zeigen leichte Cribra orbitalia.

Insgesamt sind die Fundstücke stark erodiert und alle erhaltenen Schädelnähte sind geschlossen, was für ein fortgeschrittenes Alter spricht.

Die untersuchten plattenförmigen Auflagerungen sind histologisch eindeutig als intravitale Spuren eines entzündlichen Reizes zu identifizieren gewesen. Als mögliche Ursache dieses entzündlichen Reizes kommt eine Meningitis in Frage. Weiterhin kann auch eine Otitis media letztendlich zu einer solchen entzündlichen Reaktion auch des Mastoids und letztendlich auch der Lamina interna führen. Dieses Szenario erscheint durchaus denkbar, zumal sowohl am Porus acusticus externus, als auch in den Cellulae mastoides kleinere Auflagerungen im Sinne von Knochenneubildungen nachzuweisen waren. Diese wurden mit dem Binokular fotografisch festgehalten und würden eine Kette von Ereignissen stützen, bei der eine Entzündung sich weiter verbreitet hatte vom Ort ihrer Entstehung. Dieser ist nicht eindeutig zu bestimmen, denkbar wäre allerdings eine Otitis media. 


\begin{tabular}{|c|c|c|c|c|c|c|}
\hline Bezeichn.: & Cranium & Verband: $\quad \square$ Verband & Ges./Kr.: Gesund & Maß & Wert & Einheit \\
\hline Kiste: & 1 & Alter: $\quad 18-35$ & & Schädeldecke / Schädelbasis & 1 & 1 \\
\hline Skelet: & K246 63/68-P3 & Geschlecht: $q>\hat{\sigma}$ & & & & \\
\hline Population: & Großenrode & Arthrose: & & & & \\
\hline Felsenbein: & & & & & & \\
\hline Erhaltung: & $>60 \%$ erh. & & & & & \\
\hline & $25-60 \%$ erh. & & & & & \\
\hline & - 1 - $25 \%$ erh. & & & & & \\
\hline
\end{tabular}

\section{Beschreibung:}

Stark erodierte Fragmente eines Schädels, es sind Teile von Os occipitale mit Protuberantia occipitalis externa, Os parietale und Os temporale erhalten. Die Schädelnähte waren nicht vollständig verknöchert. 
Bezeichn.: Cranium

Kiste:

Skelet: $\quad$ K80 63/68 S2

Population: Großenrode

Felsenbein:

Erhaltung: $>60 \%$ erh

$$
25-60 \% \text { erh. }
$$

- $1-25 \%$ erh.
Verband: $\quad \square$ Verband

\section{Alter:}

\section{Geschlecht:}

\section{Arthrose:}

\section{Beschreibung:}

Schädelfragmente, unter anderen von Os parietale und Os frontale. 


\section{Bezeichn.: Cranium}

\section{Kiste:}

Skelet: K265

Population: Großenrode

Felsenbein:

Erhaltung: $>60 \%$ erh

$$
25-60 \% \text { erh. }
$$

- $1-25 \%$ erh.

\section{Verband: $\quad$ Verband}

Alter: Erwachsen

\section{Geschlecht:}

\section{Arthrose:}

\section{Maß}

Schädeldecke / Schädelbasis

\section{Beschreibung:}

Ein Fragment aus dem Os occipitale, die Lambdanaht war nicht verschlossen, es wird jedoch aufgrund der Nahtkonstitution ein erwachsenes Alter angenommen. 


\section{Bezeichn.: Cranium}

\section{Kiste:}

5

Skelet: 62/67 S0 K22

Population: Großenrode

Felsenbein:

Erhaltung: $>60 \%$ erh

$$
25-60 \% \text { erh. }
$$

- $1-25 \%$ erh.
Ges./Kr.: Krank

Krankh.: Cribra Orbitalia

Sinusitis frontalis

\section{Maß}

Schädeldecke / Schädelbasis

Sinus frontalis

\section{Geschlecht:}

Arthrose:

\section{Wert Einheit}

2

\section{Beschreibung:}

Hier sind kleine Fragmente eines Schädels erhalten. Unter anderem ist ein Fragment der linken Orbita erhalten, es handelt sich um einen Teil des Orbitadachs, welches deutliche Spuren einer Cribra orbitalia aufweist. Weiterhin ist ein kleiner Teil des Sinus frontalis erhalten, welcher Spuren einer verheilten und vernarbten Sinusitis frontalis aufweist. Weiterhin sind noch 3 kleine Splitter erhalten, die nicht befundbar waren. 


\section{Bezeichn.: Cranium}

\section{Kiste:}

5

Skelet: $\quad 62 / 67$ S0 K22

Population: Großenrode

Felsenbein:

Erhaltung: $>60 \%$ erh

$$
25-60 \% \text { erh. }
$$

- $1-25 \%$ erh.
Verband: $\quad$ Verband

\section{Alter:}

Geschlecht:

\section{Arthrose:}

Maß

Schädeldecke / Schädelbasis

Wert $\quad$ Einheit

\section{Beschreibung:}

Schädelfragmente. 


\section{Bezeichn.: Cranium}

\section{Kiste:}

Skelet: K144

Population: Großenrode

Felsenbein: Rechts

Erhaltung: $>60 \%$ erh.

$25-60 \%$ erh.

- $1-25 \%$ erh.
Ges./Kr.: Krank

Krankh.: meningeale Reizung

hämorrhagische

Meningitis

Perisinusitis

ostitis

\begin{tabular}{l|l|l} 
Maß & Wert & Einheit \\
\hline Dicke & 9,18 & $\mathrm{~mm}$ \\
Schädeldecke / Schädelbasis & 2 & 2 \\
Viscerocranium & 2 & \\
& &
\end{tabular}

\section{Beschreibung:}

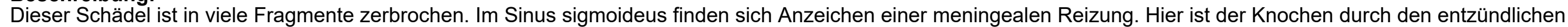

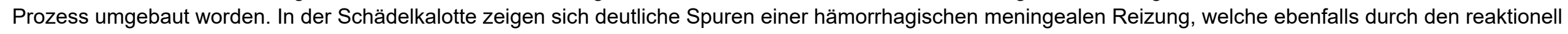
umgebauten Knochen auffallen. Auch der rechte Sinus transversus zeigt eben solche Veränderungen, so wie auch das Os occipitale.

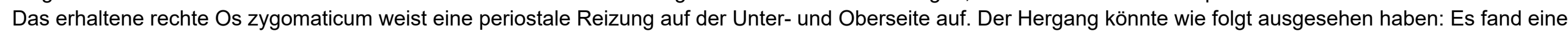

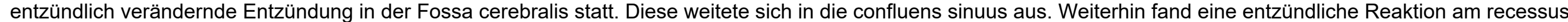

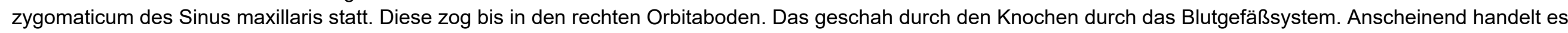
sich hier um einen ostitischen Prozess, der sich in Abheilung befand. 


\section{Bezeichn:: Cranium}

\section{Kiste:}

Skelet: K369

Population: Großenrode

Felsenbein: Links

Erhaltung: $>60 \%$ erh.

$25-60 \%$ erh.

- 1 - $25 \%$ erh.
Ges./Kr.: Krank

Krankh.: meningeale Reizung

Sinusitis frontalis

Perisinusitis

\begin{tabular}{l|l|l} 
Maß & Wert & Einheit \\
\hline Schädeldecke / Schädelbasis & 2 & 2 \\
Sinus frontalis & 2 & \\
& &
\end{tabular}

\section{Beschreibung:}

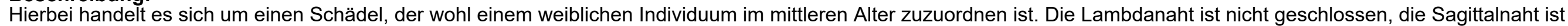

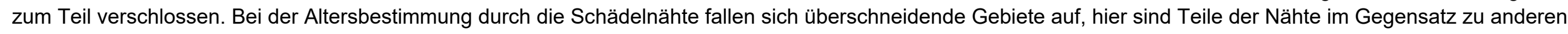

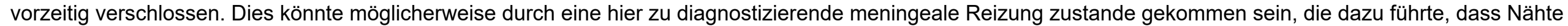
vorzeitig verwuchsen.

Im Os frontale finden sich kleine plattenförmige Auflagerungen und am Os parietale der linken Seite verzweigte Blutgefäßimpressionen. Beides zeugt von einem meningealen Prozess.

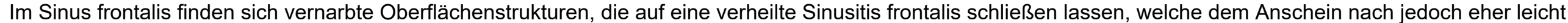
ausgeprägt war.

Auch im Sinus sigmoideus finden sich vernarbte Oberflächenstrukturen, die hier auf eine Reizung schließen lassen.

Insgesamt sind nur Fragmente der Schädeldecke erhalten, keine jedoch von der Schädelbasis. 
Bezeichn.: Cranium

Kiste:

5

Skelet: 5

Population: Großenrode

Felsenbein: Beide

Erhaltung: $>60 \%$ erh.

$$
25-60 \% \text { erh. }
$$

- $1-25 \%$ erh.

\section{Verband: $\quad$ Verband}

Alter: (12) $14-15$ (16)

Geschlecht: $q>\lambda$

\section{Arthrose:}

Ges./Kr.: Krank

Krankh.: meningeale Reizung

\section{Maß}

Schädeldecke / Schädelbasis

Viscerocranium

\section{Beschreibung:}

Bei diesem Schädel handelt es sich um Fragmente der Schädelbasis und der Schädeldecke. Weiterhin sind Fragmente des Ober- und Unterkiefers vorhanden. Es handelt sich wohl um ein junges Individuum. In der Kleinhirngrube fallen kleine vernarbte Strukturen auf, die auf eine meningeale Reizung schließen lassen. 
Bezeichn.: Cranium

\section{Kiste:}

Skelet: 5

Population: Großenrode

Felsenbein: Links

Erhaltung: $>60 \%$ erh

$$
25-60 \% \text { erh. }
$$

- $1-25 \%$ erh.

\section{Verband: \\ Verband}

\section{Alter:}

\section{Geschlecht:}

\section{Arthrose:}

Ges./Kr.: Gesund

\section{Maß}

Schädeldecke / Schädelbasis

Wert 1 Einheit

\section{Beschreibung:}

Von diesem Schädel sind nur Splitter erhalten, der einzig befundbare ist ein linkes Felsenbein mit Mastoid, welches physiologisch pneumatisiert ist. 


\section{Bezeichn.: Cranium}

\section{Kiste:}

Skelet: $\quad 64 / 68-4$

Population: Großenrode

Felsenbein: Rechts

Erhaltung: $>60 \%$ erh

$$
25-60 \% \text { erh. }
$$

- 1 - $25 \%$ erh.

\section{Verband: $\quad$ Verband}

\section{Alter:}

\section{Geschlecht:}

\section{Arthrose:}

Ges./Kr.: Gesund

\section{Maß}

Schädeldecke / Schädelbasis

\section{Beschreibung:}

Von diesem Schädel sind Splitter erhalten, darunter ein kleines Fragment des rechten Felsenbeins. Es handelt sich um Splitter von Schädelbasis und -decke. 
Bezeichn.: Cranium

\section{Kiste:}

Skelet: K333

Population: Großenrode

Felsenbein: Links

Erhaltung: $>60 \%$ erh

$$
25-60 \% \text { erh. }
$$

- $1-25 \%$ erh.

\section{Verband: $\quad$ Verband}

\section{Alter:}

Ges./Kr.: Gesund

\section{Maß}

Schädeldecke / Schädelbasis

Wert 1 Einheit

Geschlecht:

Arthrose:

\section{Beschreibung:}

Dies ist eine Sammlung von Schädelsplittern. Die Fragmente stammen von der Schädeldecke und -Basis. Es ist ein Fragment des linken Felsenbeins erhalten. 


\section{Bezeichn.: Cranium}

Kiste:

5

Skelet: K333

Population: Großenrode

Felsenbein:

Erhaltung: $>60 \%$ erh

$$
25-60 \% \text { erh. }
$$

- $1-25 \%$ erh.
Ges./Kr.: Krank

Krankh.: meningeale Reizung

Perisinusitis

\section{Maß}

Schädeldecke / Schädelbasis

Wert $\quad$ Einheit

Geschlecht: $q>0$

\section{Arthrose:}

2

\section{Beschreibung:}

Ein Schädelfragment, welches Spure meningealer Reizungen zeigt. Diese zeigen sich am Os parietale in Form von kleinen plattenförmigen Auflagerungen bzw.

Knochenneubildungen. Der linke Sinus sagittalis superior weist perisinös am Os occipitale ebenfalls eine narbige Knochenstruktur auf. 
Bezeichn.: Cranium

Kiste:

Skelet: $\quad$ K335 64/68 P4

Population: Großenrode

Felsenbein: Rechts

Erhaltung: $>60 \%$ erh.

$$
25-60 \% \text { erh. }
$$

- $1-25 \%$ erh.

\section{Verband: $\quad$ Verband}

\section{Alter: Erwachsen}

\section{Geschlecht: $q>0$}

Arthrose:

\section{Maß}

Schädeldecke / Schädelbasis

Viscerocranium

\section{Beschreibung:}

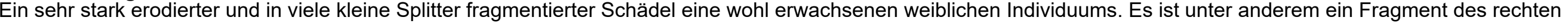
Felsenbeins und des linken Os zygomaticum. Aufgrund der starken Erosionen ist keine genaue Befundung möglich. 
Bezeichn.: Cranium

\section{Kiste:}

Skelet: K45 61/68-S1

Population: Großenrode

Felsenbein: Rechts

Erhaltung: $>60 \%$ erh.

- $25-60 \%$ erh.

$1-25 \%$ erh.
Ges./Kr.: Krank

Krankh.: Cribra Orbitalia

\section{Maß}

Schädeldecke / Schädelbasis

\section{Alter: $\quad 5-7$ (8)}

Geschlecht:

Arthrose:

\section{Beschreibung:}

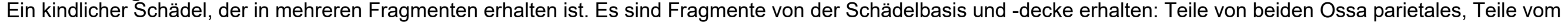
Os occipitale, Os temporale der rechten Seite und Os frontale. Die Sutura frontalis ist nicht verschlossen, weiterhin ist eine Cribra orbitalia im linken Orbitadach auszumachen. Das rechte ist nicht erhalten. Ansonsten weist dieses Cranium keine weiteren Besonderheiten auf. 


\section{Bezeichn.: Cranium}

\section{Kiste:}

Skelet: $\quad 64 / 55$

Population: Großenrode

Felsenbein:

Erhaltung: $>60 \%$ erh

$$
25-60 \% \text { erh. }
$$

- $1-25 \%$ erh.
Verband: $\quad \square$ Verband

\section{Alter:}

Geschlecht:

\section{Arthrose:}

Maß

Schädeldecke / Schädelbasis

\section{Beschreibung:}

Schädelsplitter. 


\section{Bezeichn.: Cranium}

\section{Kiste:}

Skelet: $\quad 61 / 55$

Population: Großenrode

Felsenbein:

Erhaltung: $>60 \%$ erh

$$
25-60 \% \text { erh. }
$$

- $1-25 \%$ erh.

\section{Verband: $\quad$ Verband}

\section{Alter: Jung}

Geschlecht:

\section{Arthrose:}

\section{Maß}

Schädeldecke / Schädelbasis

Wert $\quad$ Einheit

\section{Beschreibung:}

Mehrere Splitter, Os parietale misst 9,15mm Dicke, die Fragmente stammen von verschiedenen Schädelregionen. 


\begin{tabular}{|c|c|c|c|}
\hline $\begin{array}{l}\text { Bezeichn.: } \\
\text { Kiste: }\end{array}$ & $\begin{array}{l}\text { Cranium } \\
10\end{array}$ & $\begin{array}{l}\text { Verband: } \\
\text { Alter: }\end{array}$ & $\begin{array}{l}\square \text { Verband } \\
\text { (10) } 12-15 \text { (18) }\end{array}$ \\
\hline Skelet: & $62 / 53$ & Geschlecht: & \\
\hline Population: & Großenrode & Arthrose: & \\
\hline Felsenbein: & & & \\
\hline Erhaltung: & $>60 \%$ erh. & & \\
\hline & $25-60 \%$ erh. & & \\
\hline
\end{tabular}

\section{Beschreibung:}

Schädelfragmente, unter anderen ein nicht ausgewachsenes Os mastoideum, welches aber physiologisch pneumatisiert ist für das entsprechende Wachstumsstadium. 


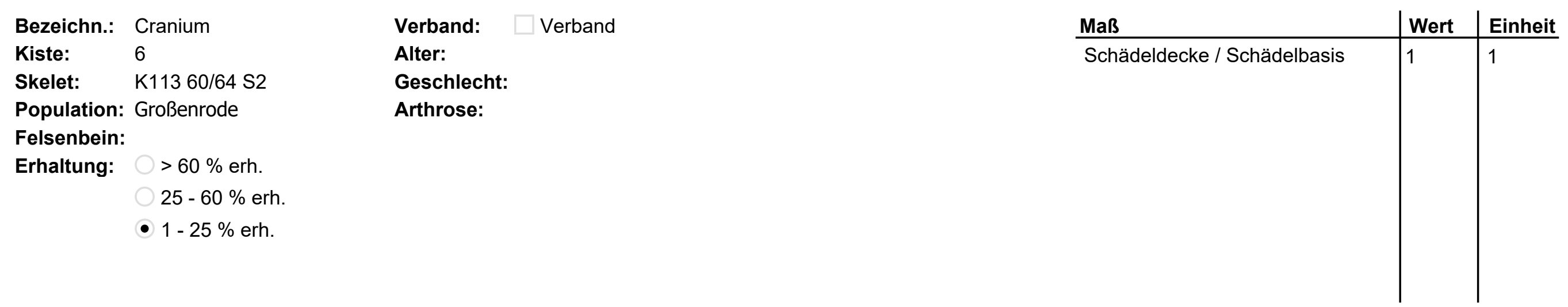

\section{Beschreibung:}

Hier liegen zwei Fragmente wohl verschiedener Schädel vor. Eines stammt eher aus der Basis, das andere aus der Schädeldecke, sie sind recht dünn und stark erodiert. 
Bezeichn.: Cranium

\section{Kiste:}

Skelet: 62/65

Population: Großenrode

Felsenbein:

Erhaltung: $>60 \%$ erh

$$
25-60 \% \text { erh. }
$$

- $1-25 \%$ erh.

\section{Beschreibung:}

Schädelfragmente, welche in kleiner Form und erodiert erhalten sind.

\section{Verband: $\quad \square$ Verband}

\section{Alter:}

Geschlecht:

\section{Arthrose:}

Maß

Schädeldecke / Schädelbasis

1

(


Bezeichn.: Cranium

\section{Kiste:}

6

Skelet: K209 63/65 P4

Population: Großenrode

Felsenbein:

Erhaltung: $>60 \%$ erh

$$
25-60 \% \text { erh. }
$$

- $1-25 \%$ erh.

\section{Beschreibung:}

Kleine Schädelfragmente.
Verband: $\quad$ Verband

\section{Alter:}

Geschlecht:

Arthrose:
Maß

Schädeldecke / Schädelbasis

1

(


Bezeichn.: Cranium

Kiste: 4

Skelet: K38 62/68-S1

Population: Großenrode

Felsenbein: Rechts

Erhaltung: $>60 \%$ erh.

$$
25-60 \% \text { erh. }
$$

- $1-25 \%$ erh.

\section{Ges./Kr.: Krank}

Krankh.: Meatus acusticus Reizung

Maß

Schädeldecke / Schädelbasis
Erwachsen

\section{Geschlecht:}

Arthrose:

\section{Beschreibung:}

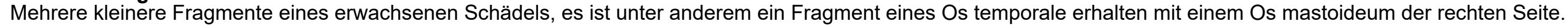

Der Meatus acusticus internus weist krankhafte Knochenneubildungen auf. 
Bezeichn.: Cranium

Kiste:

2

Skelet: 63/53

Population: Großenrode

Felsenbein:

Erhaltung: $>60 \%$ erh

$25-60 \%$ erh.

- $1-25 \%$ erh.
Ges./Kr.: Krank

Krankh.: Kopfschwartenreizung

\section{Maß}

Schädeldecke / Schädelbasis
Alter:

Geschlecht:

Arthrose:

\section{Beschreibung:}

Fragmente eines Schädels, von dem eines Spuren einer Kopfschwartenentzündung zeigt. 
Bezeichn.: Cranium

\section{Kiste:}

Skelet: Tüte aus 63/56

Population: Großenrode

Felsenbein: Rechts

Erhaltung: $>60 \%$ erh.

$$
25-60 \% \text { erh. }
$$

- 1 - $25 \%$ erh.

\section{Verband: $\quad$ Verband}

\section{Alter:}

\section{Geschlecht:}

\section{Arthrose:}

\section{Maß}

Schädeldecke / Schädelbasis

\section{Beschreibung:}

Es sind mehrere Schädelfragmente erhalten. Sie sind sehr stark erodiert und nicht zu befunden, es handelt sich um Fragmente von der Schädelbasis und -decke. 
Bezeichn.: Cranium

\section{Kiste:}

Skelet: $\quad 61 / 66$

Population: Großenrode

Felsenbein:

Erhaltung: > $>0 \%$ erh

$25-60 \%$ erh.

- $1-25 \%$ erh.
Verband: $\quad$ Verband

\section{Alter:}

Geschlecht:

Arthrose:

\section{Beschreibung:}

Kleine Schädelfragmente.

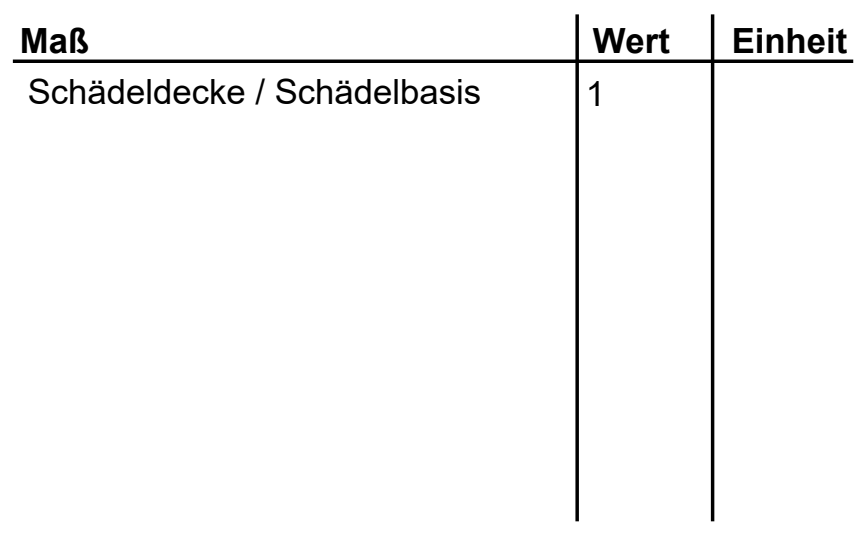


Bezeichn.: Cranium

Kiste:

5

Skelet: K333

Population: Großenrode

Felsenbein: Links

Erhaltung: $>60 \%$ erh.

$$
25-60 \% \text { erh. }
$$

- $1-25 \%$ erh.

\section{Beschreibung:}

Dies ist eine Sammlung von Schädelsplittern.

\section{Verband: $\quad \square$ Verband}

\section{Alter:}

Geschlecht:

Arthrose:
Maß

Schädeldecke / Schädelbasis Wert 1 Einheit

1

1




$\begin{array}{lll}\text { Bezeichn.: } & \text { Cranium } & \text { Verband: } \square \text { Verband } \\ \text { Kiste: } & 2 & \text { Alter: Jung } \\ \text { Skelet: } & 64 / 50 & \text { Geschlecht: } \\ \text { Population: } & \text { Großenrode } & \text { Arthrose: } \\ \text { Felsenbein: } & \\ \text { Erhaltung: } & >60 \% \text { erh. } & \\ & & \\ & 25-60 \% \text { erh. } & \\ & \bullet 1-25 \% \text { erh. } & \end{array}$

\section{Beschreibung:}

Kleinste Fragmente eines wohl jungen Schädels. 
Bezeichn.: Vertebra

\section{Kiste:}

Skelet: $\quad$ K297 63/67 S3

Population: Großenrode

\section{Verband: $\quad$ Verband Ges./Kr.: Krank}

Alter: Krankh.: Arthrose

\section{Geschlecht:}

Arthrose:

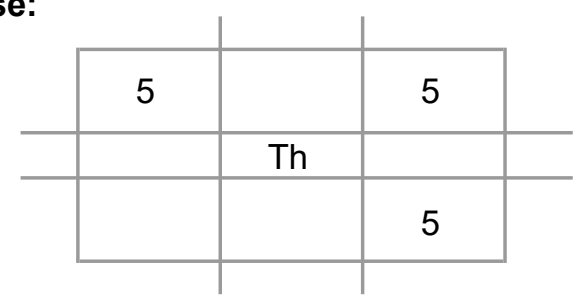

\section{Beschreibung:}

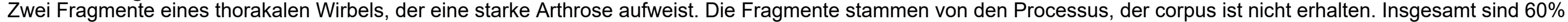
der Gelenkflächen erhalten. 
Bezeichn.: Vertebra

Kiste:

Skelet: $\quad$ K160 63/67 S2

Population: Großenrode
Verband: $\quad$ Verband

Ges./Kr.: Gesund

\section{Alter:}

\section{Geschlecht:}

Arthrose:

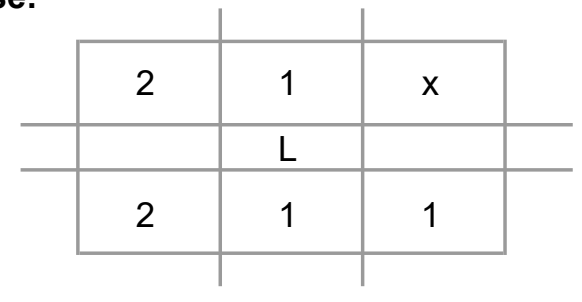

\section{Beschreibung:}

Ein stark frakturiertes Fragment eines lumbalen Wirbels, dessen corpus zu 1/4 und Gelenkflächen zu 60\% erhalten sind. 
Bezeichn.: Vertebra

Kiste:

Skelet: $\quad$ K160 63/67 S2

Population: Großenrode
Verband: $\quad$ Verband

Ges./Kr.: Gesund

\section{Geschlecht:}

Arthrose:

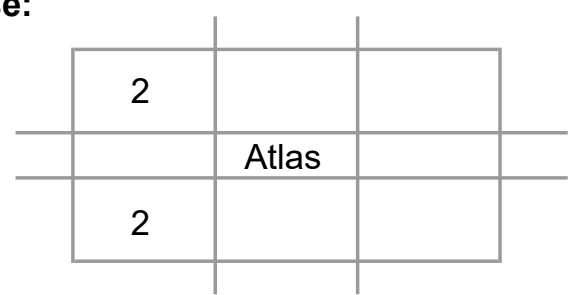

\section{Beschreibung:}

Etwa 1/3 erhalten, die linke Hälfte fehlt komplett. 
Bezeichn.: Vertebra

Kiste:

Skelet: $\quad$ K301 63/67 S3

Population: Großenrode
Verband: $\quad$ Verband

Ges./Kr.: Gesund

\section{Geschlecht:}

Arthrose:

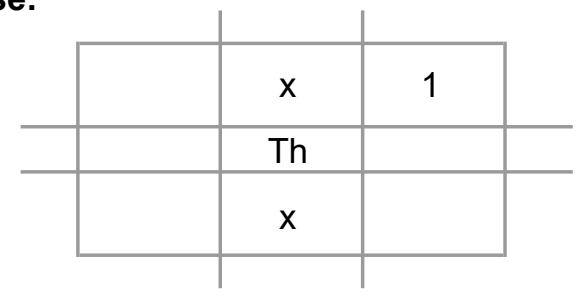

\section{Beschreibung:}

$1 / 5$ der Gelenkflächen erhalten. Ein kleines Fragment des corpus. 
Bezeichn.: Vertebra

Kiste: 9

Skelet: $\quad$ K301 63/67 S3

Population: Großenrode
Verband: $\quad$ Verband

Ges./Kr.: Gesund

\section{Geschlecht:}

Arthrose:

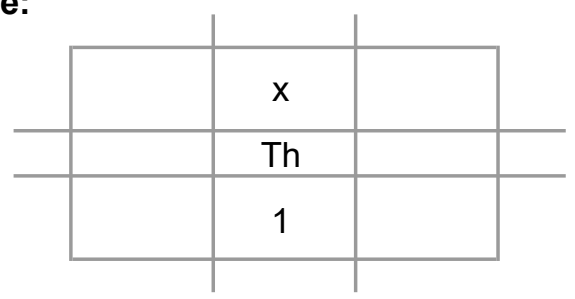

\section{Beschreibung:}

Wirbel aus Verband. 
Bezeichn.: Vertebra

Kiste: 9

Skelet: $\quad$ K301 63/67 S3

Population: Großenrode
Verband: $\quad$ Verband

\section{Alter:}

Ges./Kr.: Krank

\section{Geschlecht:}

Arthrose:

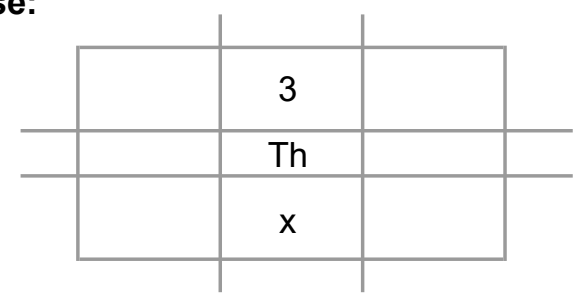

\section{Beschreibung:}

Wirbel aus Verband. 
Bezeichn.: Vertebra

Kiste: $\quad 9$

Skelet: $\quad$ K301 63/67 S3

Population: Großenrode
Verband: $\quad \square$ Verband

\section{Alter:}

Ges./Kr.: Krank

\section{Geschlecht:}

Arthrose:

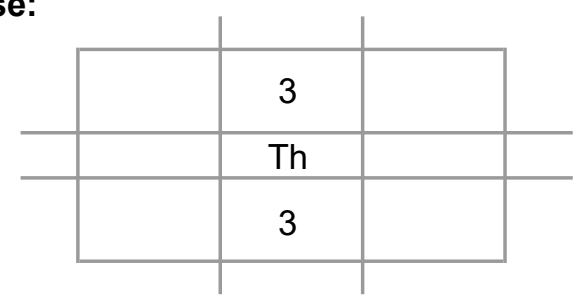

\section{Beschreibung:}

Nur ein Fragment des corpus mit Osteophyten. 
Bezeichn:: Vertebra

Kiste:

Skelet: $\quad$ K301 63/67 S3

Population: Großenrode
Verband: $\square$ Verband

\section{Alter:}

Geschlecht:

Arthrose:
Ges./Kr.: Krank

Krankh.: Arthrose

Spondylophyten

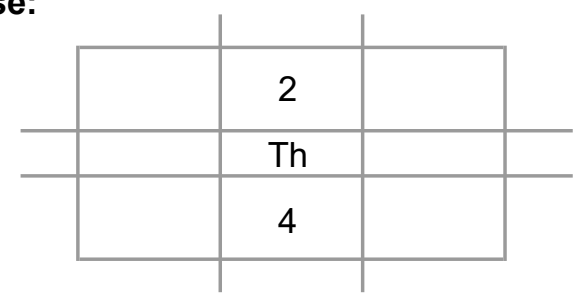

\section{Beschreibung:}

Nur ein Fragment des corpus mit Osteophyten. 
Bezeichn.: Vertebra

Kiste: $\quad 9$

Skelet: $\quad$ K301 63/67 S3

Population: Großenrode
Verband: $\quad \square$ Verband

\section{Alter:}

Geschlecht:

Arthrose:
Ges./Kr.: Krank

Krankh.: Spondylophyten

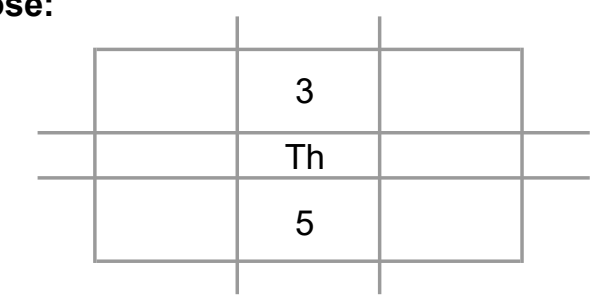

\section{Beschreibung:}

Nur ein Fragment des corpus mit Osteophyten. 
Bezeichn.: Vertebra

Kiste: 9

Skelet: $\quad$ K301 63/67 S3

Population: Großenrode
Verband: $\quad$ Verband

\section{Alter:}

Ges./Kr.: Krank

\section{Geschlecht:}

Arthrose:

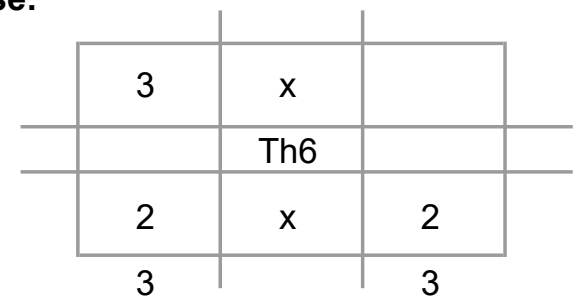

Beschreibung:

Wirbel aus Verband. 
Bezeichn.: Vertebra

\section{Kiste:}

9

Skelet: $\quad$ K301 63/67 S3

Population: Großenrode
Verband: $\quad \square$ Verband

Alter:

Geschlecht:

Arthrose:

\begin{tabular}{|c|c|c|}
\hline 3 & & 3 \\
\hline 4 & 1 & 4 \\
\hline & Th7 & \\
\hline 2 & 1 & 2 \\
\hline 2.5 & 1.5 & 2.5 \\
\hline
\end{tabular}

Ges./Kr.: Krank

Krankh.: Arthrose

Arthritis

Beschreibung:

Wirbel aus Verband. 
Bezeichn.: Vertebra

\section{Kiste:}

Skelet: $\quad$ K301 63/67 S3

Population: Großenrode
Verband: $\square$ Verband

\section{Alter:}

Geschlecht:

Arthrose:

\begin{tabular}{|c|c|c|}
\hline 2.5 & 1.5 & 2.5 \\
\hline 3 & 2 & 3 \\
\hline & Th8 & \\
\hline 3 & $x$ & 4 \\
\hline 3 & & 3.5 \\
\hline
\end{tabular}

Ges./Kr.: Krank

Krankh.: Arthrose

Arthritis

\section{Beschreibung:}

Gelenkflächen zu 85\% erhalten und befundbar 
Bezeichn.: Vertebra

Kiste: 9

Skelet: $\quad$ K30163/67 S3

Population: Großenrode
Verband: $\square$ Verband

\section{Alter:}

Ges./Kr.: Krank

\section{Geschlecht:}

Arthrose:

\begin{tabular}{|c|c|c|}
\hline 3 & & 3.5 \\
\hline 3 & 1 & 3 \\
\hline & Th9 & \\
\hline & $x$ & 2 \\
\hline & & 2 \\
\hline
\end{tabular}

Beschreibung:

Wirbel aus Verband. 
Bezeichn.: Vertebra

Kiste: 9

Skelet: $\quad$ K30163/67 S3

Population: Großenrode
Verband: $\square$ Verband

Ges./Kr.: Gesund

\section{Geschlecht:}

Arthrose:

\begin{tabular}{|c|c|c|}
\hline & & 2 \\
\hline & & 2 \\
\hline & Th10 & \\
\hline 2 & & 2 \\
\hline & & 2 \\
\hline
\end{tabular}

\section{Beschreibung:}

Gelenkflächen zu 50\% erhalten. 
Bezeichn.: Vertebra

Kiste: 9

Skelet: $\quad$ K30163/67 S3

Population: Großenrode
Verband: $\quad$ Verband

Ges./Kr.: Gesund

\section{Alter:}

Geschlecht:

Arthrose:

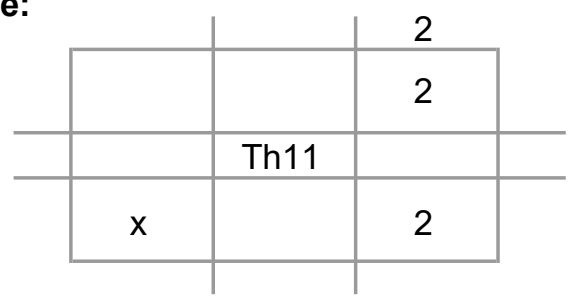

Beschreibung:

Wirbel aus Verband. 
Bezeichn.: Vertebra

Kiste: 9

Skelet: $\quad$ K301 63/67 S3

Population: Großenrode
Verband: $\quad$ Verband

\section{Alter:}

Ges./Kr.: Krank

\section{Geschlecht:}

Arthrose:

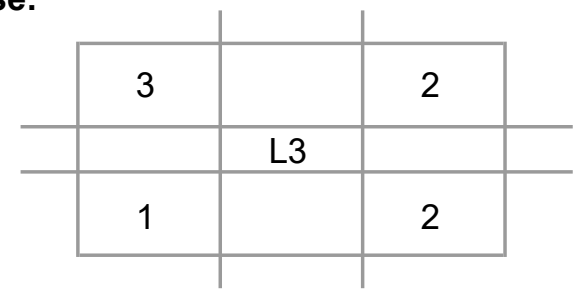

\section{Beschreibung:}

Nur der Wirbelbogen erhalten. 
Bezeichn.: Vertebra

Kiste:

9

Skelet: $\quad$ K30163/67 S3

Population: Großenrode
Verband: $\square$ Verband

Ges./Kr.: Gesund

\section{Geschlecht:}

Arthrose:

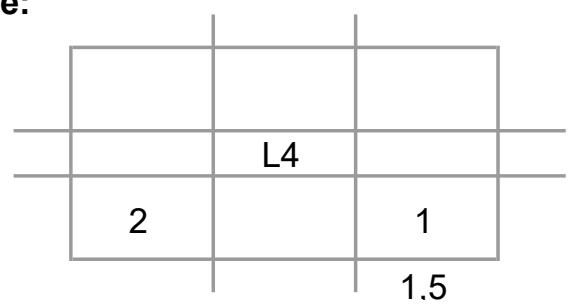

Beschreibung:

Hier ist nur ein kleines Fragment erhalten. 
Bezeichn.: Vertebra

Kiste:

Skelet: $\quad$ K301 63/67 S3

Population: Großenrode
Verband: $\quad$ Verband

Ges./Kr.: Gesund

\section{Geschlecht:}

Arthrose:

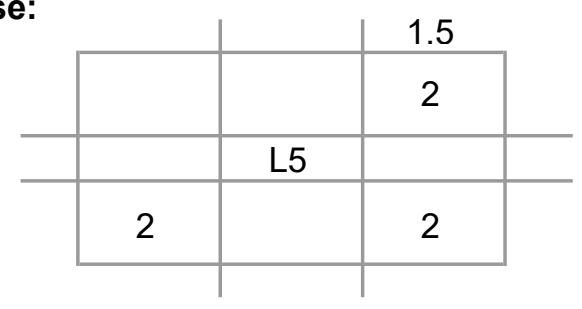

\section{Beschreibung:}

Nur der Wirbelbogen ist hier erhalten, die Gelenkflächen sind zu etwa 3/5 erhalten. 
Bezeichn.: Vertebra

\section{Kiste:}

9

Skelet: $\quad 63 / 67$ S3 K294

Population: Großenrode
Verband: $\square$ Verband

Ges./Kr.: Gesund

\section{Geschlecht:}

Arthrose:

\begin{tabular}{|c|c|c|}
\multicolumn{1}{c||}{} & \multicolumn{1}{c|}{} & \multicolumn{1}{c}{} \\
\cline { 2 - 4 } & 1 & $x$ \\
\hline & Axis & \\
\hline & & \\
\hline
\end{tabular}

\section{Beschreibung:}

Nur ein anteriores Fragment. 
Bezeichn.: Vertebra

Kiste:

Skelet: $\quad$ K280 63/62 P3

Population: Großenrode
Verband: $\quad$ Verband

$$
\text { Alter: } \quad 13-18 \text { (19) }
$$

\section{Geschlecht:}

Arthrose:
Ges./Kr.: Gesund

\begin{tabular}{|l|l|l|}
\cline { 2 - 3 } \multicolumn{1}{c|}{} & \multicolumn{1}{c|}{} \\
\hline 1 & 00 & 1 \\
\hline 1 & 00 & 1 \\
\hline
\end{tabular}

\section{Beschreibung:}

Dieser Verband aus zwei Wirbeln und einem Os sacrum ist einem juvenilen Individuum zuzuordnen. Dieses Objekt ist zu 95\% erhalten. 
Bezeichn.: Vertebra

Kiste:

Skelet: $\quad$ K280 63/62 P3

Population: Großenrode
Verband: $\quad$ Verband

Ges./Kr.: Gesund

\section{Geschlecht:}

Arthrose:

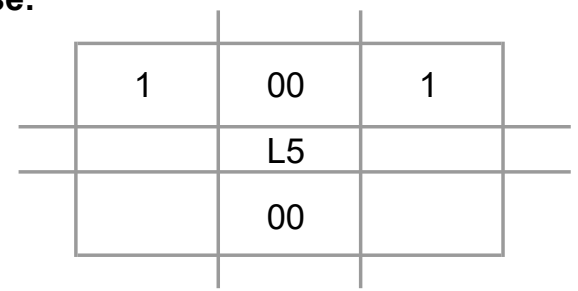

\section{Beschreibung:}

Dieser Wirbel weist zu 40\% befundbare Gelenkflächen auf. 
Bezeichn.: Vertebra

Kiste:

Skelet: $\quad$ K67 63/67 S1

Population: Großenrode
Verband: $\quad \square$ Verband

Ges./Kr.: Gesund

\section{Alter:}

Geschlecht:

Arthrose:

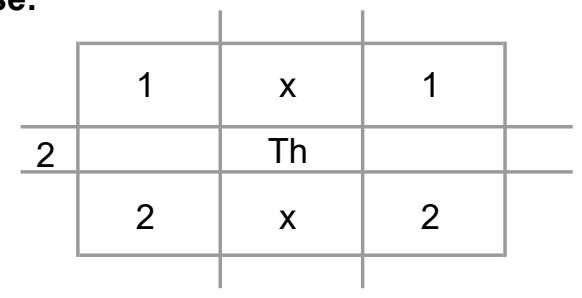

\section{Beschreibung:}

Ein Wirbel aus dem oberen thorakalen Bereich, welcher bedingt erodiert ist, der corpus ist zu 3/4 abfrakturiert. Die Gelenkflächen sind zu $80 \%$ befundbar. 
Bezeichn.: Vertebra

\section{Kiste:}

Skelet: $\quad$ K315 62/63 P4

Population: Großenrode
Verband: $\quad$ Verband

Ges./Kr.: Gesund

\section{Alter:}

\section{Geschlecht:}

Arthrose:

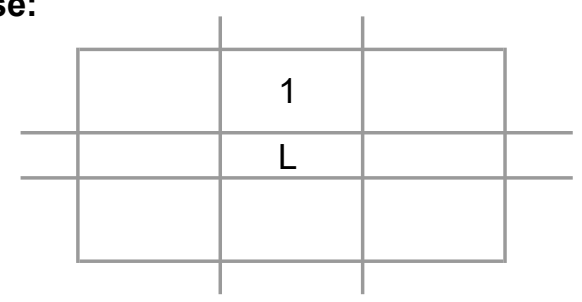

\section{Beschreibung:}

Ein Fragment eines lumbalen Wirbels, es ist nur etwa 1/3 des corpus erhalten, nämlich ein Fragment der oberen Deckplatte. 
Bezeichn.: Vertebra

\section{Kiste:}

Skelet: $\quad$ K315 62/63 P4

Population: Großenrode
Verband: $\quad$ Verband

Ges./Kr.: Gesund

\section{Alter:}

\section{Geschlecht:}

Arthrose:

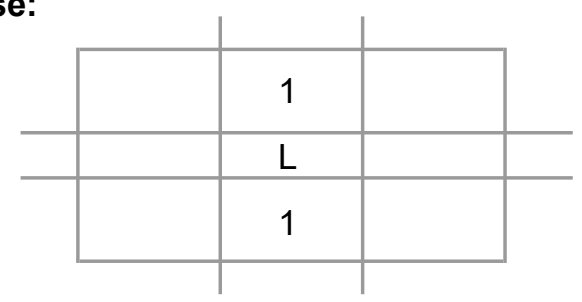

\section{Beschreibung:}

Von diesem Wirbel ist der corpus erodiert erhalten. Die Deckplatten sind zu $60 \%$ befundbar. 
Bezeichn.: Vertebra

\section{Kiste:}

Skelet: $\quad$ K315 62/63 P4

Population: Großenrode
Verband: $\quad$ Verband

Ges./Kr.: Gesund

\section{Alter:}

\section{Geschlecht:}

Arthrose:

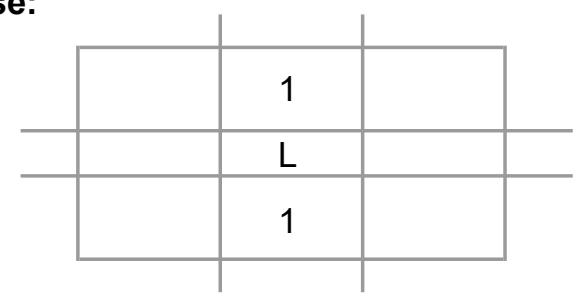

\section{Beschreibung:}

Hier ist ein Fragment des corpus eines lumbalen Wirbels erhalten. Die Decken sind zu etwa $30 \%$ befundbar. 
Bezeichn.: Vertebra

Kiste:

6

Skelet: $\quad$ K323 62/63 S4

Population: Großenrode
Verband: $\quad$ Verband

\section{Alter:}

Ges./Kr.: Krank

\section{Geschlecht:}

Arthrose:

\begin{tabular}{|c|c|c|}
\hline \multicolumn{1}{c|}{} & & \multicolumn{1}{c|}{} \\
\hline 2 & 1 & 3 \\
\hline 2 & 1 & 2 \\
\hline 2 & 1 & 2
\end{tabular}

\section{Beschreibung:}

Dieser fast vollständige und gut erhaltene Wirbel weist eine Arthrose auf. Sein Gesamtzustand ist wenig erodiert. 
Bezeichn.: Vertebra

Kiste:

Skelet: $\quad$ K323 62/63 S4

Population: Großenrode
Verband: $\quad \square$ Verband

\section{Alter:}

Ges./Kr.: Krank

\section{Geschlecht:}

Arthrose:

\begin{tabular}{c|c|c|c|}
\hline \multicolumn{1}{c|}{2} & 1 & 2 \\
\cline { 2 - 3 } & 2 & 1 & 2 \\
\hline & $\mathrm{C} 6$ & \\
\hline & 1 & 3 \\
\hline
\end{tabular}

\section{Beschreibung:}

Dieser Wirbel liegt fragmentiert in zwei Fragmenten vor. Es fehlt etwa 1/3 des corpus. Er hat eine Arthrose. 
Bezeichn.: Vertebra

\section{Kiste:}

Skelet: $\quad$ K313 62/63 P4

Population: Großenrode
Verband: $\square$ Verband

\section{Alter:}

Geschlecht:

Arthrose:
Ges./Kr.: Krank

Krankh.: Arthrose

Spondylophyten

\begin{tabular}{|c|c|c|c|}
\hline & 1 & 1 & 1 \\
\hline \multirow[t]{3}{*}{1} & & Th2 & \\
\hline & 2 & 3 & 2 \\
\hline & 2.5 & 3 & 2 \\
\hline
\end{tabular}

\section{Beschreibung:}

Dieser Wirbel ist zu 85\% erhalten, die Gelenkflächen zu 95\%. An der unteren Deckplatte weist das Fundstück Osteophyten bis 6mm auf. 
Bezeichn.: Vertebra

\section{Kiste:}

Skelet: $\quad$ K313 62/63 P4

Population: Großenrode
Verband: $\square$ Verband

\section{Alter:}

Geschlecht:

Arthrose:

\begin{tabular}{|c|c|c|}
\hline 2.5 & 3 & 2 \\
\hline 3 & 3 & 2 \\
\hline & Th3 & \\
\hline 2 & 3 & 2 \\
\hline
\end{tabular}

Ges./Kr.: Krank

Krankh.: Arthrose

Spondylophyten

\section{Beschreibung:}

Dieser Wirbel ist zu 85\% erhalten, die Gelenkflächen zu 95\%. Er weist auf der oberen und unteren Deckplatte des corpus Osteophyten auf. 
Bezeichn.: Vertebra

\section{Kiste:}

Skelet: $\quad$ K313 62/63 P4

Population: Großenrode
Verband: $\square$ Verband

\section{Alter:}

Geschlecht:

Arthrose:
Ges./Kr.: Krank

Krankh.: Spondylophyten

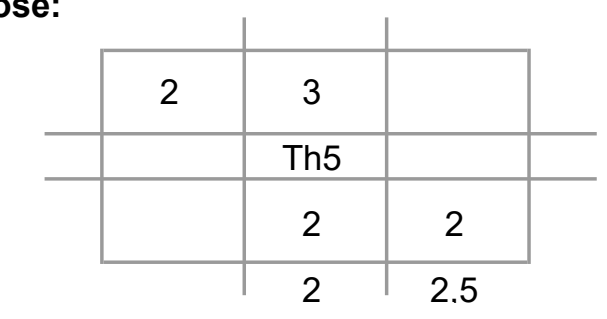

\section{Beschreibung:}

Dieser Wirbel ist zu 80\% erhalten, die Gelenkflächen zu 60\%. er weist ebenfalls Osteophyten auf. 
Bezeichn.: Vertebra

\section{Kiste:}

Skelet: $\quad$ K313 62/63 P4

Population: Großenrode
Verband: $\quad \square$ Verband

\section{Alter:}

Geschlecht:

Arthrose:

\begin{tabular}{|c|c|c|}
\hline & 2 & 2.5 \\
\hline 2 & 2 & 3 \\
\hline & Th6 & \\
\hline & 3 & 2 \\
\hline
\end{tabular}

Ges./Kr.: Krank

Krankh.: Arthrose

Spondylophyten

\section{Beschreibung:}

Ein Wirbel, der zu etwa 75\% erhalten ist. Die Gelenkflächen sind zu 50\% befundbar. 
Bezeichn.: Vertebra

Kiste: 6

Skelet: $\quad$ K109 62/63 P3

Population: Großenrode

\section{Verband: $\quad$ Verband Ges./Kr.: Krank}

Alter: Krankh.: Arthrose

\section{Geschlecht:}

Arthrose:

\begin{tabular}{|l|l|l|}
\cline { 2 - 3 } \multicolumn{1}{l||}{3} & 1 & 2 \\
\hline 2 & 1 & 3 \\
\hline
\end{tabular}

\section{Beschreibung:}

Ein Wirbel aus dem cervikalen Bereich, der zu $85 \%$ erhalten ist. Die Gelenkflächen sind insgesamt zu $40 \%$ befundbar. 
Bezeichn.: Vertebra

Kiste: 6

Skelet: $\quad$ K109 62/63 P3

Population: Großenrode
Verband: $\quad \square$ Verband

\section{Alter:}

Geschlecht:

Arthrose:
Ges./Kr.: Krank

Krankh.: Bandverknöcherungen Arthrose

\begin{tabular}{|c|c|c|c|}
\hline & 2 & 1 & 2 \\
\hline \multirow[t]{2}{*}{2} & & Th4 & \\
\hline & 3 & 3 & 3 \\
\hline
\end{tabular}

\section{Beschreibung:}

Ein Wirbel aus dem oberen bis mittleren thorakalen Bereich. Der Erhaltungszustand ist recht gut und fast vollständig. 
Bezeichn.: Vertebra

\section{Kiste:}

Skelet: $\quad$ K254 60/64 S3

Population: Großenrode
Verband: $\quad$ Verband

Ges./Kr.: Gesund

\section{Alter:}

\section{Geschlecht:}

Arthrose:

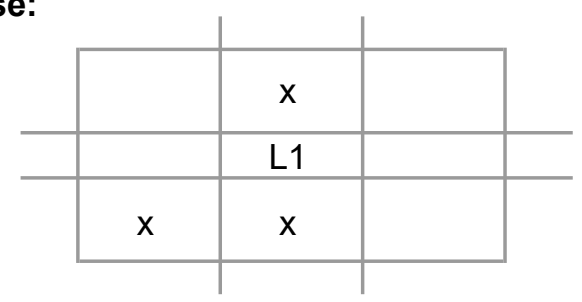

\section{Beschreibung:}

Hier ist von den Processus nicht viel übrig und auch der corpus ist stark erodiert und nur zu $50 \%$ erhalten. 
Bezeichn.: Vertebra

\section{Kiste:}

Skelet: $\quad$ K254 60/64 S3

Population: Großenrode
Verband: $\quad$ Verband

Ges./Kr.: Gesund

\section{Alter:}

\section{Geschlecht:}

Arthrose:

\begin{tabular}{|c|c|c|}
\cline { 2 - 3 } \multicolumn{1}{c||}{$x$} & $x$ & 1 \\
\hline 2 & 2 & 2 \\
\hline
\end{tabular}

\section{Beschreibung:}

Von diesem Wirbel sind etwa $70 \%$ des corpus erhalten und von den Processus etwa die Hälfte. 
Bezeichn.: Vertebra

\section{Kiste:}

Skelet: $\quad$ K254 60/64 S3

Population: Großenrode
Verband: $\quad$ Verband

Ges./Kr.: Gesund

\section{Alter:}

\section{Geschlecht:}

Arthrose:

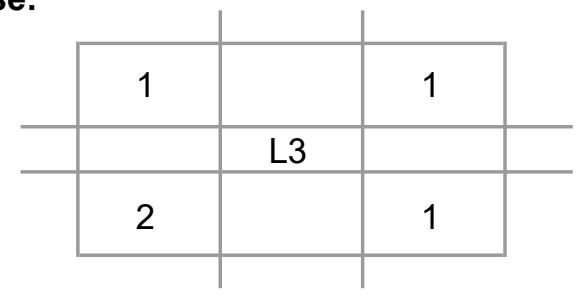

\section{Beschreibung:}

Von diesem Wirbel ist der Großteil des corpus abfrakturiert. Die Processus sind zu 4/5 befundbar. 
Bezeichn.: Vertebra

\section{Kiste:}

Skelet: $\quad$ K254 60/64 S3

Population: Großenrode
Verband: $\quad$ Verband

Ges./Kr.: Gesund

\section{Alter:}

\section{Geschlecht:}

Arthrose:

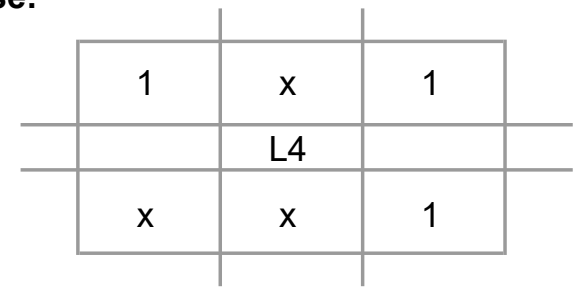

\section{Beschreibung:}

Dieser Wirbel hat nur noch etwa 10\% des corpus, aber die Processus sind zu 2/3 befundbar. 
Bezeichn.: Vertebra

\section{Kiste:}

Skelet: $\quad$ K254 60/64 S3

Population: Großenrode
Verband: $\quad$ Verband

Ges./Kr.: Gesund

\section{Alter:}

\section{Geschlecht:}

Arthrose:

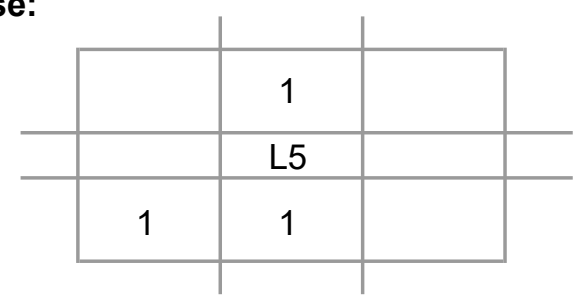

\section{Beschreibung:}

Ein insgesamt recht stak erodiertes und frakturiertes Fundstück. Von dem Wirbel sind etwa $25 \%$ befundbar. Ein Großteil des corpus ist abfrakturiert. 
Bezeichn.: Vertebra

\section{Kiste:}

Skelet: $\quad 64 / 66-4$

Population: Großenrode
Verband: $\quad$ Verband

Ges./Kr.: Gesund

\section{Alter:}

\section{Geschlecht:}

Arthrose:

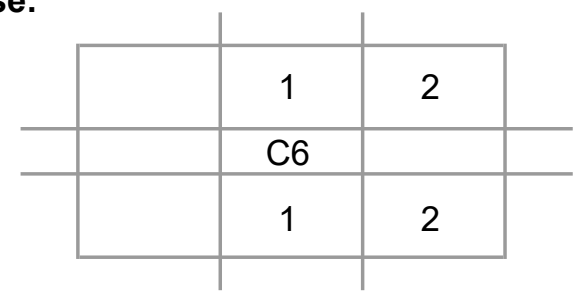

\section{Beschreibung:}

Dieser Wirbel ist mittelmäßig erodiert und nur linksseitig erhalten. der corpus allerdings ist vollständig. 
Bezeichn.: Vertebra

\section{Kiste:}

Skelet: $\quad 64 / 66-4$

Population: Großenrode
Verband: $\quad$ Verband

Ges./Kr.: Gesund

\section{Geschlecht:}

Arthrose:

\begin{tabular}{|c|c|c|}
\hline 2 & 1 & 2 \\
\hline & C7 & \\
\hline$x$ & $x$ & 2 \\
\hline
\end{tabular}

\section{Beschreibung:}

Dieser Wirbel ist erodiert und die Gelenkflächen sind insgesamt zu etwa 90\% erhalten. 
Bezeichn.: Vertebra

Kiste:

Skelet: K262 60/64

Population: Großenrode
Verband: $\quad$ Verband

$$
\text { Alter: } \quad 13-18 \text { (19) }
$$

\section{Geschlecht:}

Arthrose:
Ges./Kr.: Gesund

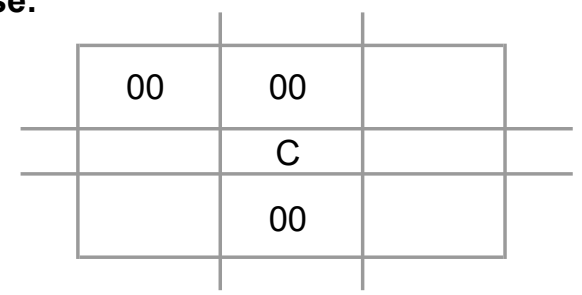

\section{Beschreibung:}

Ein Fragment eines cervikalen Wirbels. Etwa 75\% erhalten, Der Wirbel ist stark erodiert. Es handelt sich wohl um ein juveniles Individuum. 
Bezeichn.: Vertebra

\section{Kiste:}

Skelet: K262 60/64

Population: Großenrode
Verband: $\quad$ Verband

$$
\text { Alter: } \quad 13-18 \text { (19) }
$$

\section{Geschlecht:}

Arthrose:

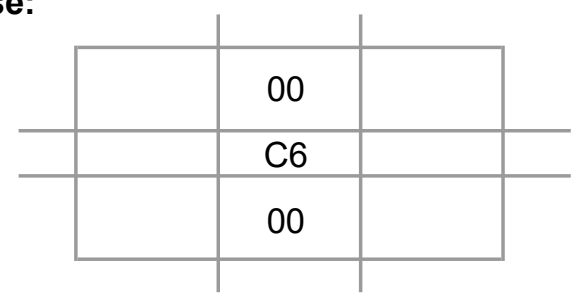

\section{Beschreibung:}

Ein Wirbel eines wohl juvenilen Individuums. der corpus ist alleinig erhalten und stark erodiert. 
Bezeichn.: Vertebra

\section{Kiste:}

Skelet: 62/66-2

Population: Großenrode
Verband: $\quad$ Verband

$$
\text { Alter: } \quad 13-18 \text { (19) }
$$

\section{Geschlecht:}

Arthrose:
Ges./Kr.: Gesund

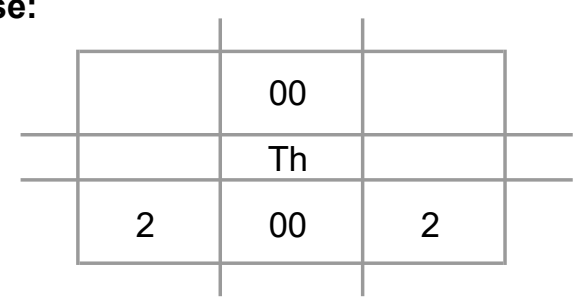

\section{Beschreibung:}

Dieser thorakale Wirbel ist einem juvenilen Individuum zuzuordnen. Das Fundstück ist stark erodiert. Die Processus articulares sind zu $85 \%$ erhalten. 
Bezeichn.: Vertebra

\section{Kiste:}

Skelet: 63/65-4

Population: Großenrode
Verband: $\square$ Verband

Ges./Kr.: Gesund

\section{Alter:}

Geschlecht:

Arthrose:

\begin{tabular}{l|c|c|}
\cline { 2 - 4 } \multicolumn{1}{l||}{} & \multicolumn{1}{l|}{} \\
\hline 2 & 1 & 2 \\
\hline 2 & 1 & 2 \\
\hline
\end{tabular}

\section{Beschreibung:}

Ein fast vollständig erhaltenes Fundstück eines cervikalen Wirbels 6. Der Wirbel ist kaum erodiert. Die Gelenkflächen sind zu $90 \%$ gut erhalten. 
Bezeichn.: Vertebra

\section{Kiste:}

Skelet: $\quad$ K196 60/64 P4

Population: Großenrode
Verband: $\quad \square$ Verband

Ges./Kr.: Gesund

\section{Geschlecht:}

Arthrose:

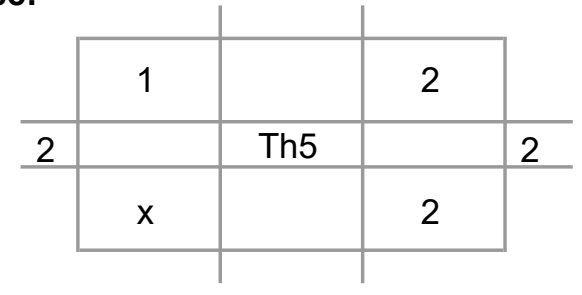

\section{Beschreibung:}


Bezeichn.: Vertebra

\section{Kiste:}

Skelet: $\quad$ K196 60/64 P4

Population: Großenrode
Verband: $\quad$ Verband

Ges./Kr.: Gesund

\section{Geschlecht:}

Arthrose:

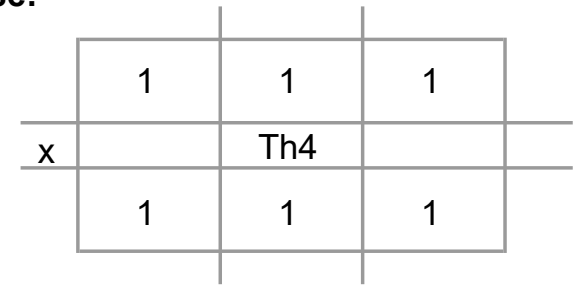

\section{Beschreibung:}


Bezeichn.: Vertebra

\section{Kiste:}

Skelet: $\quad$ K196 60/64 P4

Population: Großenrode
Verband: $\quad \square$ Verband

Ges./Kr.: Gesund

\section{Geschlecht:}

Arthrose:

\begin{tabular}{|c|c|c|}
\hline 2 & $x$ & 2 \\
\hline & Th6 & \\
\hline 1 & 1 & 1 \\
\hline
\end{tabular}

\section{Beschreibung:}


Bezeichn.: Vertebra

\section{Kiste:}

Skelet: $\quad$ K196 60/64 P4

Population: Großenrode
Verband: $\quad \square$ Verband

Alter:

Ges./Kr.: Krank

\section{Geschlecht:}

Arthrose:

\begin{tabular}{c|c|c|c|c}
\multicolumn{1}{c|}{} & 3 & 1 & 3 & \\
\cline { 2 - 5 } & 3 & Th7 & & 2 \\
\hline 2 & & 1 & 1 & \\
\cline { 2 - 4 } & 3 & & \multicolumn{2}{c}{}
\end{tabular}

\section{Beschreibung:}


Bezeichn.: Vertebra

\section{Kiste:}

Skelet: $\quad$ K196 60/64 P4

Population: Großenrode
Verband: $\quad$ Verband

Alter:

Ges./Kr.: Krank

\section{Geschlecht:}

Arthrose:

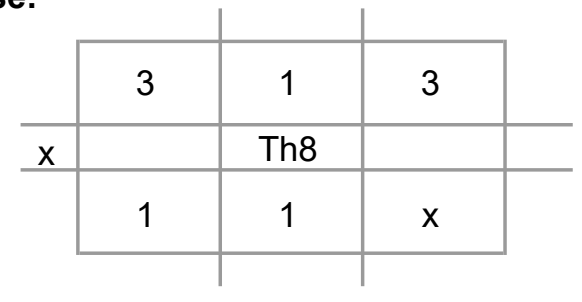

\section{Beschreibung:}

Diese beiden Processus articulares superiores zeigen lokalisiert Arthrose. 
Bezeichn.: Vertebra

\section{Kiste:}

Skelet: $\quad$ K196 60/64 P4

Population: Großenrode
Verband: $\quad \square$ Verband

Ges./Kr.: Gesund

\section{Geschlecht:}

Arthrose:

\begin{tabular}{|c|c|c|c|}
\hline & 1 & 1 & 1 \\
\hline \multirow[t]{2}{*}{$x$} & & Th9 & \\
\hline & 1 & 1 & $x$ \\
\hline
\end{tabular}

\section{Beschreibung:}


Bezeichn.: Vertebra

\section{Kiste:}

Skelet: $\quad$ K196 60/64 P4

Population: Großenrode
Verband: $\quad$ Verband

Ges./Kr.: Gesund

\section{Geschlecht:}

Arthrose:

\begin{tabular}{|c|c|c|}
\hline 1 & 1 & 1 \\
\hline & Th10 & \\
\hline$x$ & 1 & $x$ \\
\hline
\end{tabular}

\section{Beschreibung:}


Bezeichn.: Vertebra

\section{Kiste:}

Skelet: $\quad$ K196 60/64 P4

Population: Großenrode
Verband: $\quad$ Verband

Ges./Kr.: Gesund

\section{Geschlecht:}

Arthrose:

\begin{tabular}{|c|c|c|}
\hline 1 & 1 & 1 \\
\hline & Th11 & \\
\hline$x$ & 1 & $x$ \\
\hline
\end{tabular}

\section{Beschreibung:}


Bezeichn.: Vertebra

\section{Kiste:}

Skelet: $\quad$ K196 60/64 P4

Population: Großenrode
Verband: $\square$ Verband

\section{Alter:}

\section{Geschlecht:}

Arthrose:

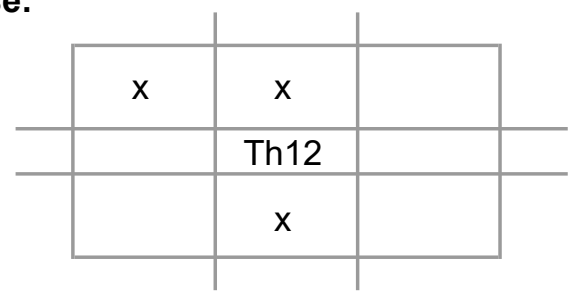

\section{Beschreibung:}

Dieser Wirbel zeigt starke Erosionsspuren und ist frakturiert. 
Bezeichn.: Vertebra

\section{Kiste:}

Skelet: $\quad$ K196 60/64 P4

Population: Großenrode

\section{Verband: $\quad$ Verband}

Ges./Kr.: Gesund

\section{Geschlecht:}

Arthrose:

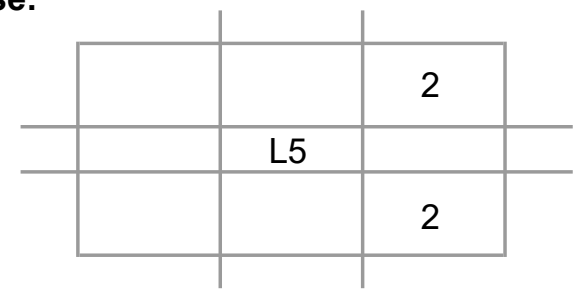

\section{Beschreibung:}

Ein Fragment der linken Wirbelseite, der corpus ist nicht erhalten. 
Bezeichn.: Vertebra

\section{Kiste:}

Skelet: $\quad$ K93 62/65 S2

Population: Großenrode
Verband: $\square$ Verband

Ges./Kr.: Gesund

\section{Geschlecht:}

Arthrose:

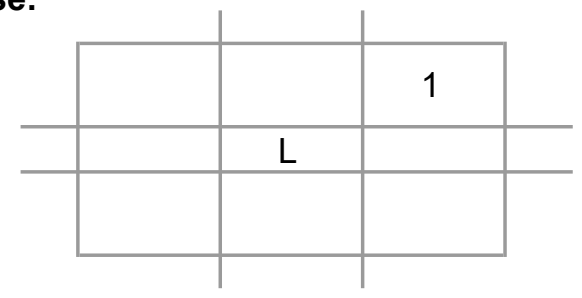

\section{Beschreibung:}

Ein kleines Fragment eines lumbalen Wirbels. 
Bezeichn:: Vertebra

\section{Kiste:}

Skelet: $\quad$ K72 62/68 P2

Population: Großenrode
Verband: $\quad$ Verband

\section{Alter:}

\section{Geschlecht:}

\section{Arthrose:}

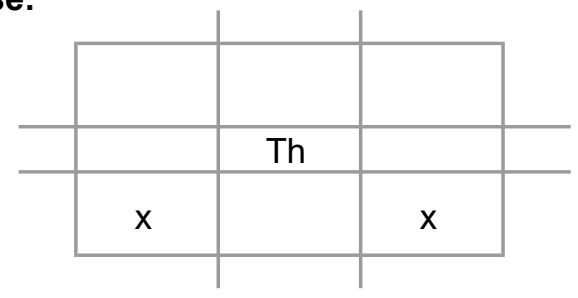

\section{Beschreibung:}

Von diesem Wirbel aus dem thorakalen Bereich ist nur ein Fragment erhalten. 
Bezeichn.: Vertebra

Kiste: 4

Skelet: $\quad$ K72 62/68 P2

Population: Großenrode
Verband: $\quad$ Verband

Ges./Kr.: Gesund

\section{Alter:}

\section{Geschlecht:}

Arthrose:

\begin{tabular}{|c|c|c|}
\hline 00 & & 00 \\
\hline & L4 & \\
\hline$x$ & & $x$ \\
\hline
\end{tabular}

\section{Beschreibung:}

Wirbel aus Verband. 
Bezeichn.: Vertebra

Kiste:

4

Skelet: $\quad$ K72 62/68 P2

Population: Großenrode
Verband: $\quad$ Verband

Ges./Kr.: Gesund

\section{Geschlecht:}

Arthrose:

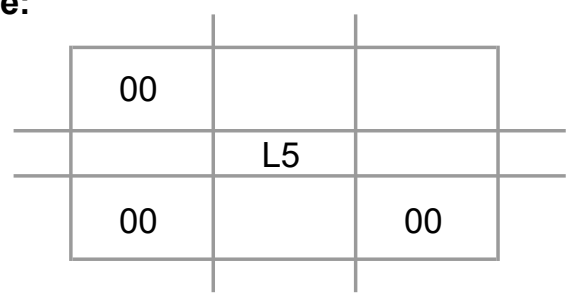

\section{Beschreibung:}

Von den Wirbeln sind nur Fragmente erhalten. 
Bezeichn.: Vertebra

Kiste:

Skelet: 4

Population: Großenrode
Verband: $\quad$ Verband

\section{Alter: Jung}

Geschlecht:

Arthrose:

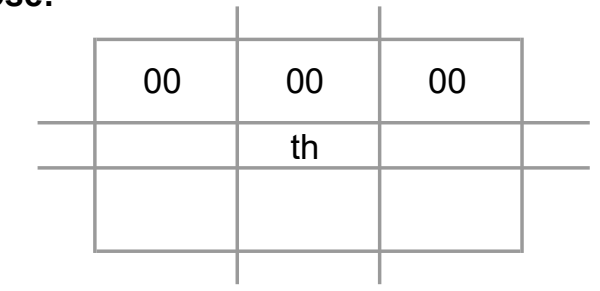

\section{Beschreibung:}

Ein frakturiertes Fragment eines Wirbels, der einem jungen Individuum zuzuordnen ist. 
Bezeichn.: Vertebra

Kiste:

Skelet: $\quad 61 / 56$

Population: Großenrode
Verband: $\quad$ Verband

\section{Alter: Jung}

Geschlecht:

Arthrose:

\begin{tabular}{|c|c|c|}
\cline { 2 - 3 } \multicolumn{1}{c|}{00} & 00 & 00 \\
\hline 00 & 00 & 00 \\
\hline
\end{tabular}

\section{Beschreibung:}

Dieser cervikale Wirbel ist fast vollständig und gut erhalten. Er gehört zu einem jungen Individuum. 
Bezeichn.: Vertebra

\section{Kiste:}

Skelet: $\quad 64 / 52$

Population: Großenrode
Verband: $\square$ Verband

Ges./Kr.: Gesund

\section{Geschlecht:}

Arthrose:

\begin{tabular}{|c|c|c|}
\cline { 2 - 3 } \multicolumn{1}{c||}{$x$} & 2 & 2 \\
\hline & $\mathrm{C}$ & \\
\hline $\mathrm{x}$ & 2 & \\
\hline
\end{tabular}

\section{Beschreibung:}

Dieser cervikale Wirbel ist in Form fast vollständig erhalten. 
Bezeichn.: Vertebra

Kiste:

Skelet: 61/53

Population: Großenrode

\section{Verband:}

Verband

\section{Alter:}

Geschlecht:

Arthrose:

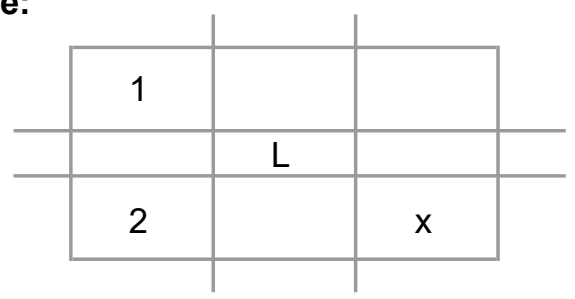

\section{Beschreibung:}

Ein frakturierter Wirbel aus dem oberen bis mittleren lumbalen Bereich. 
Bezeichn:: Vertebra

\section{Kiste:}

Skelet: 63/57

Population: Großenrode
Verband: $\square$ Verband

\section{Alter:}

Geschlecht:
Ges./Kr.: Krank

Krankh.: Arthrose

Arthritis

\begin{tabular}{|c|c|c|}
\hline 5 & 2 & 5 \\
\hline & $\mathrm{Th}$ & \\
\hline 3 & 2 & 2 \\
\hline
\end{tabular}

\section{Beschreibung:}

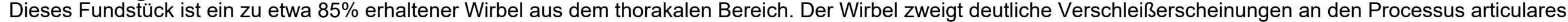
superiores. Hier liegt eine Arthrose vor, die wohl in eine Arthritis begann überzugehen, es sind deutliche Entzündungszeichen auszumachen. 
Bezeichn.: Vertebra

Kiste:

Skelet: 63/53

Population: Großenrode
Verband: $\square$ Verband

Ges./Kr.: Gesund

\section{Alter:}

Geschlecht:

Arthrose:

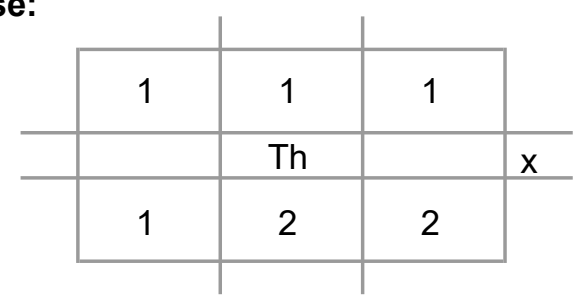

\section{Beschreibung:}

Dieser Wirbel stammt aus dem mittleren thorakalen Bereich. Er ist fast vollständig erhalten und nur wenig erodiert. 
Bezeichn.: Vertebra

Kiste:

Skelet: $\quad 63 / 53$

Population: Großenrode
Verband: $\quad \square$ Verband

Ges./Kr.: Gesund

\section{Geschlecht:}

Arthrose:

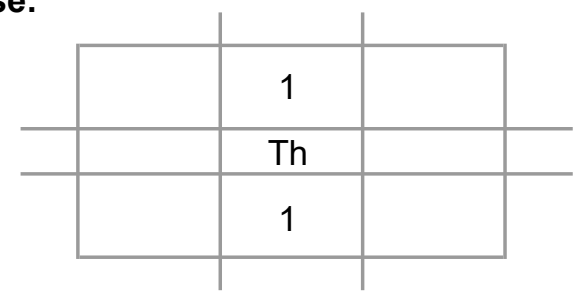

\section{Beschreibung:}

Von diesem Wirbel aus dem oberen thorakalen Bereich ist nur der corpus erhalten. 
Bezeichn.: Vertebra

Kiste:

Skelet: $\quad 63 / 53$

Population: Großenrode
Verband: $\square$ Verband

Ges./Kr.: Gesund

\section{Geschlecht:}

Arthrose:

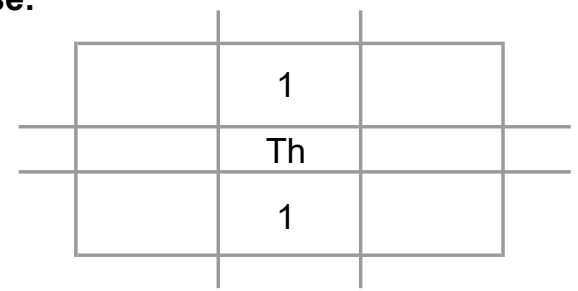

\section{Beschreibung:}

Dieser Wirbel stammt aus dem mittleren thorakalen Bereich, es ist nur der corpus erhalten. 
Bezeichn.: Vertebra

Kiste:

Skelet: 63/53

Population: Großenrode
Verband: $\square$ Verband

Ges./Kr.: Gesund

\section{Alter:}

\section{Geschlecht:}

Arthrose:

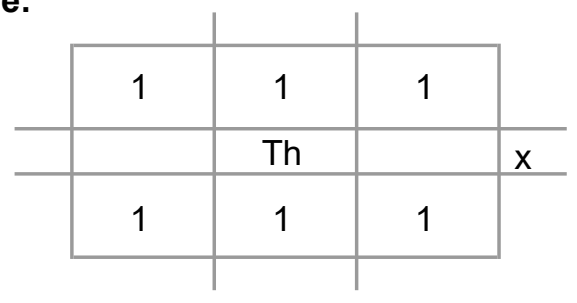

\section{Beschreibung:}

Dies ist ein fast vollständiger Wirbel aus dem mittleren thorakalen Bereich. 
Bezeichn.: Vertebra

Kiste:

Skelet: $\quad 63 / 53$

Population: Großenrode
Verband: $\quad$ Verband

Ges./Kr.: Gesund

Alter:

\section{Geschlecht:}

Arthrose:

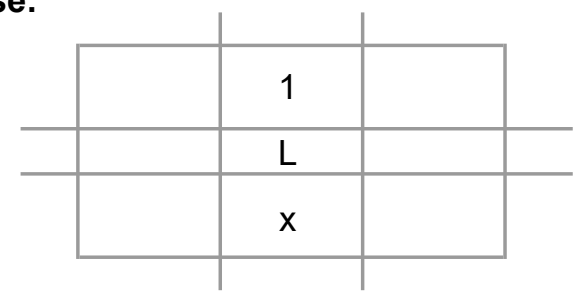

\section{Beschreibung:}

Ein frakturiertes und erodiertes Fragment eines lumbalen Wirbels. 
Bezeichn.: Vertebra

Kiste:

Skelet: 62/55

Population: Großenrode
Verband: $\quad$ Verband

\section{Alter: Jung}

\section{Geschlecht:}

Arthrose:

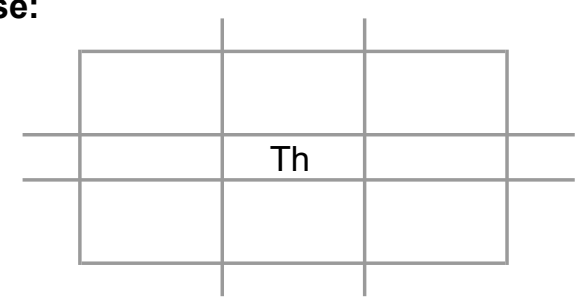

\section{Beschreibung:}

Von diesem Wirbel aus dem thorakalen Bereich ist nur der corpus und ein Teil des linken Bogens erhalten. 
Bezeichn.: Vertebra

Kiste:

Skelet: $\quad 62 / 55$

Population: Großenrode
Verband: $\square$ Verband

Ges./Kr.: Gesund

\section{Alter:}

Geschlecht:

Arthrose:

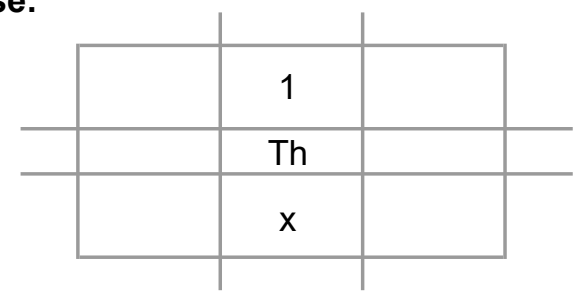

\section{Beschreibung:}

Dieser Wirbel aus unterm thorakalen Bereich ist nur in Form des oberen Teils der Deckplatte erhalten. 
Bezeichn.: Vertebra

Kiste:

Skelet: $\quad 62 / 55$

Population: Großenrode
Verband: $\square$ Verband

Ges./Kr.: Gesund

\section{Alter:}

Geschlecht:

Arthrose:

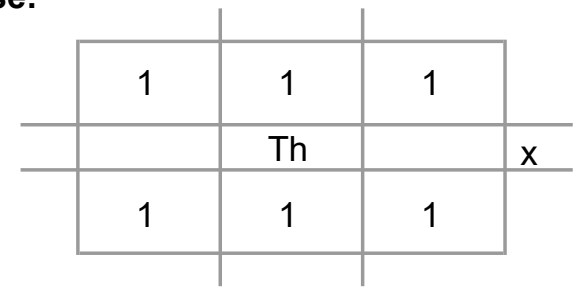

\section{Beschreibung:}

Ein Wirbel aus dem unteren thorakalen Bereich, er ist wenig erodiert und in einem Stück. 
Bezeichn.: Vertebra

Kiste:

Skelet: $\quad 62 / 55$

Population: Großenrode
Verband: $\square$ Verband

Ges./Kr.: Gesund

\section{Geschlecht:}

Arthrose:

\begin{tabular}{|c|c|c|}
\hline 2 & 1 & 2 \\
\hline & Th12 & \\
\hline 2 & 1 & 2 \\
\hline
\end{tabular}

\section{Beschreibung:}

Ein Wirbel Th12, der wenig erodiert ist. 
Bezeichn.: Vertebra

\section{Kiste:}

Skelet: $\quad 62 / 55$

Population: Großenrode
Verband: $\quad \square$ Verband

Ges./Kr.: Gesund

\section{Geschlecht:}

Arthrose:

\begin{tabular}{|c|c|c|}
\cline { 2 - 3 } \multicolumn{1}{c|}{} & \multicolumn{1}{c|}{} & \multicolumn{1}{c}{} \\
\hline & 2 & 2 \\
\hline & Axis & \\
\hline & 2 & \\
\hline
\end{tabular}

\section{Beschreibung:}

Die Wirbelbögen dieses Axis sind frakturiert. 
Bezeichn.: Vertebra

Kiste:

Skelet: $\quad 62 / 55$

Population: Großenrode
Verband: $\square$ Verband

Ges./Kr.: Gesund

\section{Geschlecht:}

Arthrose:

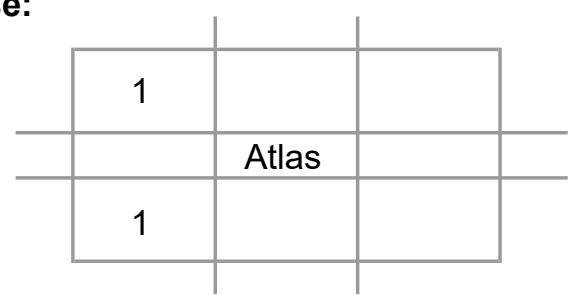

\section{Beschreibung:}

Ein rechtes Fragment eines Atlas. 
Bezeichn:: Vertebra

Kiste:

Skelet: 62/54

Population: Großenrode
Verband: $\square$ Verband

Ges./Kr.: Gesund

\section{Geschlecht:}

Arthrose:

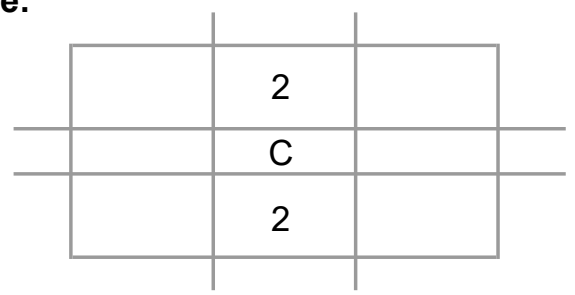

\section{Beschreibung:}


Bezeichn.: Vertebra

Kiste:

Skelet: $\quad 62 / 54$

Population: Großenrode

\section{Verband:}

Verband

\section{Alter:}

\section{Geschlecht:}

Arthrose:

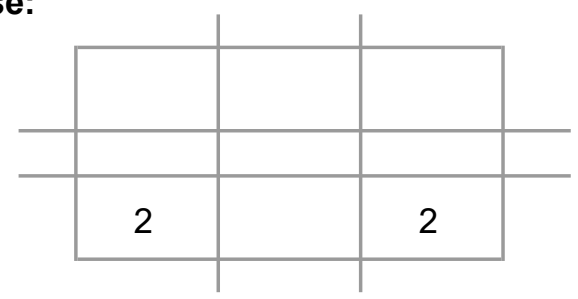

\section{Beschreibung:}

Ein distales Fragment mit den Processus articulares inferiores. 
Bezeichn.: Vertebra

Kiste:

Skelet: $\quad 62 / 50$

Population: Großenrode
Verband: $\quad$ Verband

Ges./Kr.: Gesund

\section{Alter:}

\section{Geschlecht:}

Arthrose:

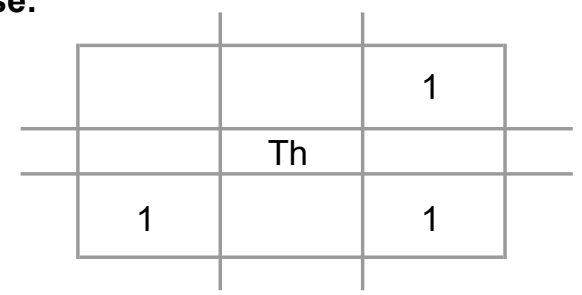

\section{Beschreibung:}

Der corpus ist nicht erhalten, der Processus superius links nur zu 1/3, rechts nicht erhalten, der Processus spinosus ist ebenfalls nicht erhalten. 
Bezeichn:: Vertebra

Kiste:

Skelet: $\quad 62 / 50$

Population: Großenrode
Verband: $\square$ Verband

Ges./Kr.: Gesund

\section{Geschlecht:}

Arthrose:

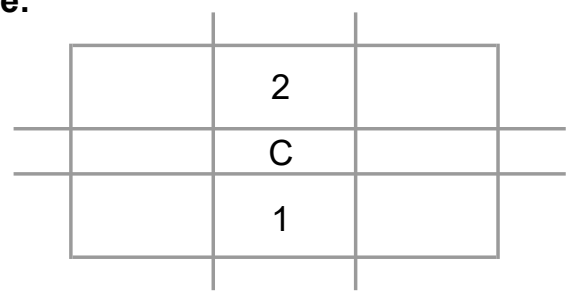

\section{Beschreibung:}


Bezeichn:: Vertebra

Kiste:

Skelet: $\quad 62 / 54$

Population: Großenrode
Verband: $\quad \square$ Verband

Ges./Kr.: Gesund

\section{Geschlecht:}

Arthrose:

\begin{tabular}{|c|c|c|}
\hline 2 & 2 & 2 \\
\hline & Axis & \\
\hline & 2 & \\
\hline
\end{tabular}

\section{Beschreibung:}


Bezeichn:: Vertebra

Kiste:

Skelet: 62/54

Population: Großenrode
Verband: $\square$ Verband

Ges./Kr.: Gesund

\section{Geschlecht:}

Arthrose:

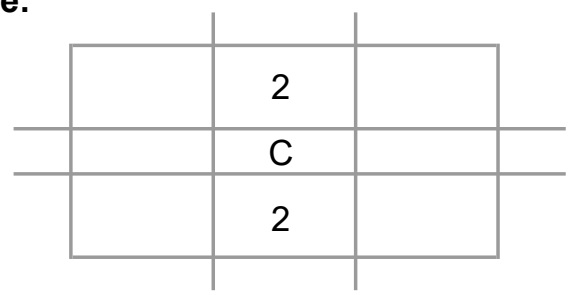

\section{Beschreibung:}


Bezeichn:: Vertebra

Kiste:

Skelet: 62/54

Population: Großenrode
Verband: $\square$ Verband

Ges./Kr.: Gesund

\section{Geschlecht:}

Arthrose:

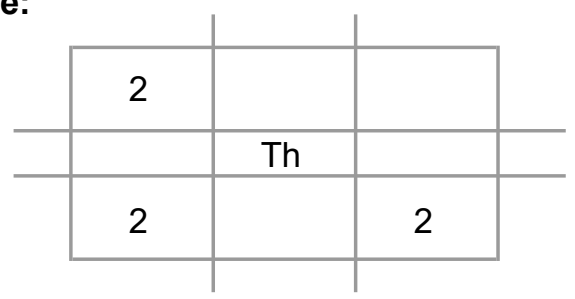

\section{Beschreibung:}


Bezeichn:: Vertebra

Kiste:

Skelet: 62/54

Population: Großenrode
Verband: $\square$ Verband

Ges./Kr.: Gesund

\section{Geschlecht:}

Arthrose:

\begin{tabular}{|c|c|c|}
\cline { 2 - 3 } \multicolumn{1}{c||}{2} & 2 & 2 \\
\hline & Th & \\
\hline & 2 & 2 \\
\hline
\end{tabular}

\section{Beschreibung:}


Bezeichn:: Vertebra

Kiste:

Skelet: 62/54

Population: Großenrode
Verband: $\square$ Verband

Ges./Kr.: Gesund

\section{Geschlecht:}

Arthrose:

\begin{tabular}{|c|c|c|}
\hline 2 & $x$ & 2 \\
\hline 2 & $x$ & 2 \\
\hline
\end{tabular}

\section{Beschreibung:}


Bezeichn:: Vertebra

Kiste:

Skelet: $62 / 54$

Population: Großenrode

\section{Verband: $\quad$ Verband Ges./Kr.: Krank}

Alter: Krankh.: Fraktur

\section{Geschlecht:}

Arthrose:

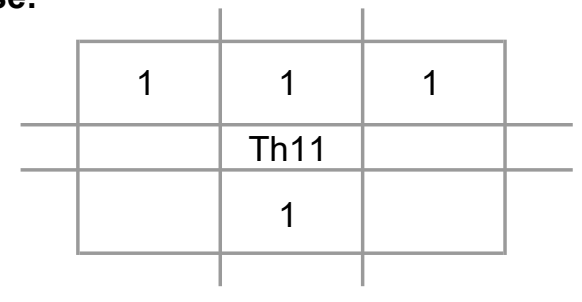

\section{Beschreibung:}

Dieser Wirbel weist in der oberen Deckplatte rechts anterior einen Bruch auf, der wohl intravital entstanden ist. 
Bezeichn.: Vertebra

Kiste:

Skelet: aus großer Tüte und

Population: Großenrode
Verband: $\quad \square$ Verband

Ges./Kr.: Gesund

\section{Geschlecht:}

Arthrose:

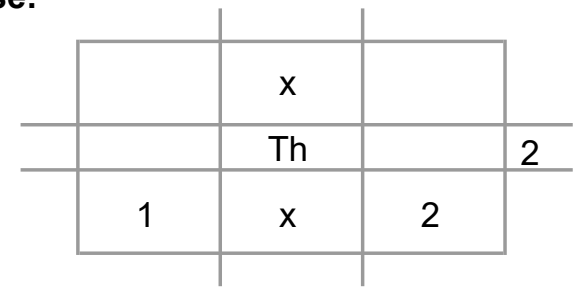

\section{Beschreibung:}

Dieser Wirbel ist erodiert, aber zu 60\% erhalten. 
Bezeichn.: Vertebra

Kiste:

Skelet: aus großer Tüte und

Population: Großenrode
Verband: $\square$ Verband

Ges./Kr.: Gesund

\section{Geschlecht:}

Arthrose:

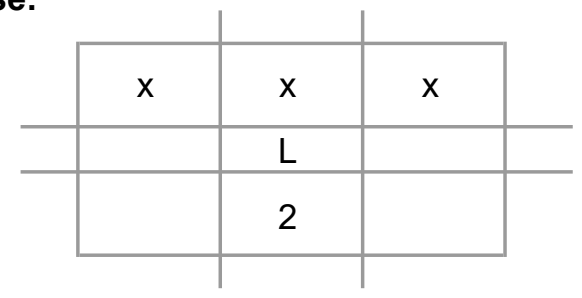

\section{Beschreibung:}

Der corpus oben und anterior ist sehr erodiert. 
Bezeichn:: Vertebra

Kiste:

Skelet: aus großer Tüte und

Population: Großenrode
Verband: $\quad \square$ Verband

Ges./Kr.: Gesund

\section{Geschlecht:}

Arthrose:

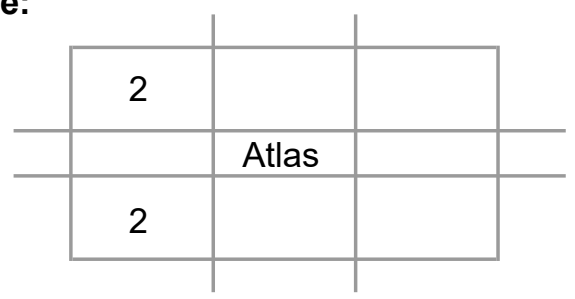

\section{Beschreibung:}

$1 / 3$ des Wirbels sind erhalten. 
Bezeichn.: Vertebra

Kiste:

Skelet: aus großer Tüte und

Population: Großenrode
Verband: $\quad$ Verband

Ges./Kr.: Gesund

\section{Geschlecht:}

Arthrose:

\begin{tabular}{|c|c|c|}
\cline { 2 - 4 } \multicolumn{1}{c||}{2} & 2 & 2 \\
\hline & Axis & \\
\hline & 1 & 2 \\
\hline
\end{tabular}

\section{Beschreibung:}

Vom anterioren corpus sind etwa $2 / 3$ erhalten, der Wirbel ist postmortal frakturiert. 
Bezeichn.: Vertebra

Kiste:

Skelet: aus großer Tüte und

Population: Großenrode
Verband: $\quad \square$ Verband

Ges./Kr.: Gesund

\section{Geschlecht:}

Arthrose:

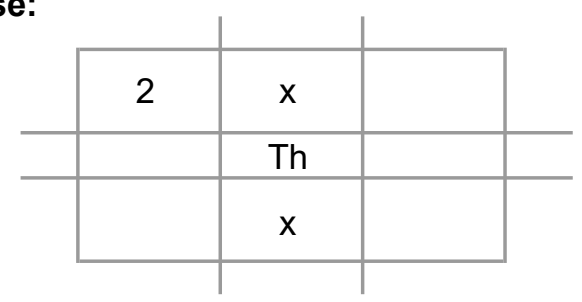

\section{Beschreibung:}

Der corpus dieses Wirbels ist stark erodiert. 
Bezeichn:: Vertebra

Kiste:

Skelet: aus großer Tüte und

Population: Großenrode
Verband: $\square$ Verband

Ges./Kr.: Gesund

\section{Geschlecht:}

Arthrose:

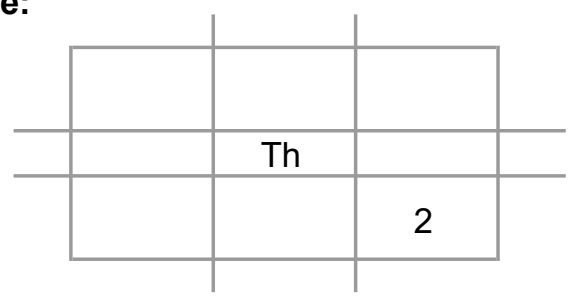

\section{Beschreibung:}

Ein Wirbelfragment. 
Bezeichn:: Vertebra

Kiste:

Skelet: aus großer Tüte und

Population: Großenrode
Verband:

Verband

Ges./Kr.: Gesund

\section{Alter:}

Geschlecht:

Arthrose:

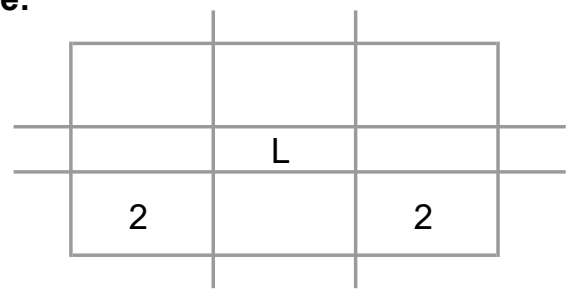

\section{Beschreibung:}

Ein zerbrochener Wirbel. 
Bezeichn.: Vertebra

Kiste:

Skelet: $\quad 61 / 57$

Population: Großenrode
Verband: $\square$ Verband

Ges./Kr.: Gesund

\section{Alter:}

Geschlecht:

Arthrose:

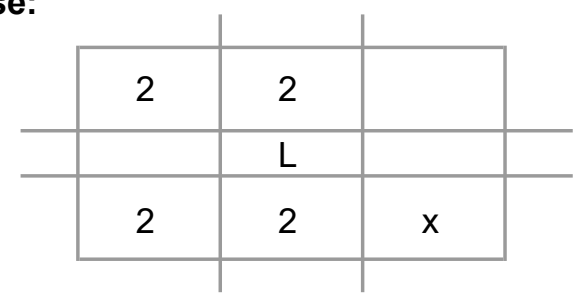

\section{Beschreibung:}

Dieser Wirbel stammt aus dem oberen lumbalen Bereich und ist recht gut erhalten. Es fehlt der linke obere Processus articularis, der linke untere ist frakturiert. 
Bezeichn.: Vertebra

Kiste:

3

Skelet: $\quad$ K317 P4

Population: Großenrode

\section{Verband:}

Verband

\section{Alter:}

\section{Geschlecht:}

Arthrose:

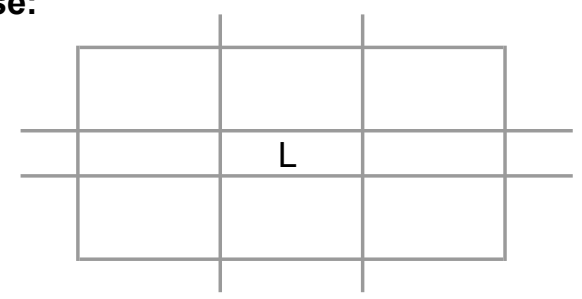

\section{Beschreibung:}

Ein stark erodierter und frakturierter Wirbel ohne Auffälligkeiten. 
Bezeichn.: Vertebra

Kiste: 3

Skelet: $\quad$ K270 63/63 P4

Population: Großenrode
Verband: $\quad \square$ Verband

Ges./Kr.: Gesund

\section{Alter:}

\section{Geschlecht:}

Arthrose:

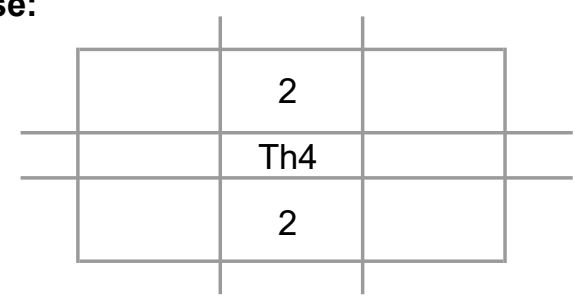

\section{Beschreibung:}

Bei vielen der Wirbel fällt ein Loch ins Auge, welches in den corpus führt von distal, etwa $5 \mathrm{~mm}$ tief und $7 \mathrm{~mm} \times 5 \mathrm{~mm}$ breit. 
Bezeichn.: Vertebra

Kiste:

Skelet: $\quad$ K270 63/63 P4

Population: Großenrode
Verband: $\quad$ Verband

Ges./Kr.: Gesund

\section{Geschlecht:}

Arthrose:

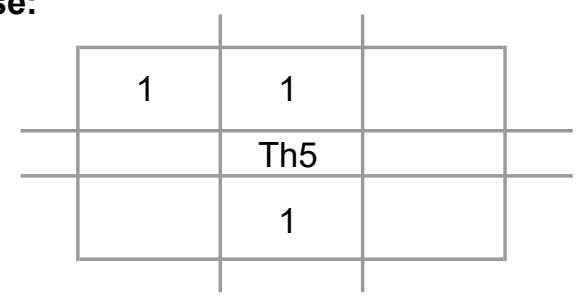

\section{Beschreibung:}

Dieser Wirbel ist nicht vollständig erhalten, weil Teile abfrakturiert sind. 
Bezeichn:: Vertebra

Kiste: 3

Skelet: $\quad$ K270 63/63 P4

Population: Großenrode
Verband: $\quad \square$ Verband

Ges./Kr.: Gesund

\section{Geschlecht:}

Arthrose:

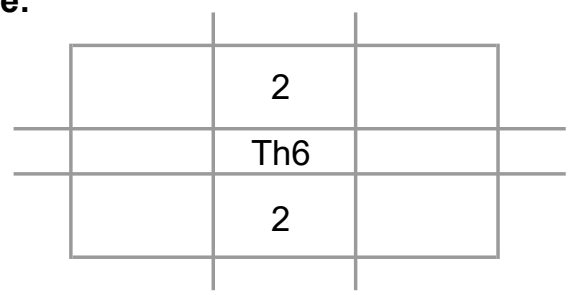

\section{Beschreibung:}


Bezeichn.: Vertebra

Kiste:

Skelet: $\quad$ K270 63/63 P4

Population: Großenrode
Verband: $\quad \square$ Verband

Alter:

\section{Geschlecht:}

Arthrose:

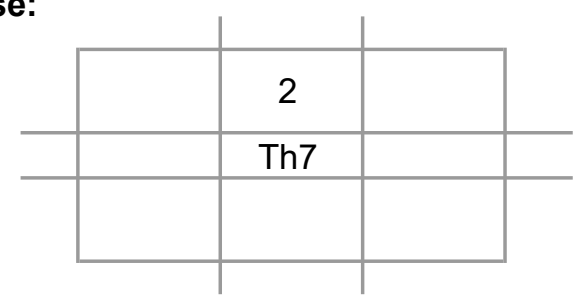

\section{Beschreibung:}

Ein kleines Fragment des corpus eines Wirbels. 
Bezeichn.: Vertebra

Kiste:

3

Skelet: $\quad$ K270 63/63 P4

Population: Großenrode
Verband: $\square$ Verband

Ges./Kr.: Gesund

\section{Geschlecht:}

Arthrose:

\begin{tabular}{|c|c|c|c}
\cline { 2 - 3 } \multicolumn{1}{c|}{2} & 2 & 2 & \\
\hline & Th8 & & 2 \\
\hline 2 & 2 & 2 & \\
& & & \multicolumn{2}{c}{2}
\end{tabular}

\section{Beschreibung:}

Ein fast vollständiger Wirbel. 
Bezeichn.: Vertebra

Kiste:

3

Skelet: $\quad$ K270 63/63 P4

Population: Großenrode
Verband: $\quad$ Verband

Ges./Kr.: Gesund

\section{Geschlecht:}

Arthrose:

\begin{tabular}{|c|c|c|}
\hline 2 & 2 & 2 \\
\hline & Th9 & \\
\hline 2 & 2 & 2 \\
\hline
\end{tabular}

\section{Beschreibung:}

Ein recht gut erhaltener Wirbel. 
Bezeichn.: Vertebra

Kiste:

Skelet: $\quad$ K270 63/63 P4

Population: Großenrode
Verband: $\quad$ Verband

Alter:

\section{Geschlecht:}

Arthrose:

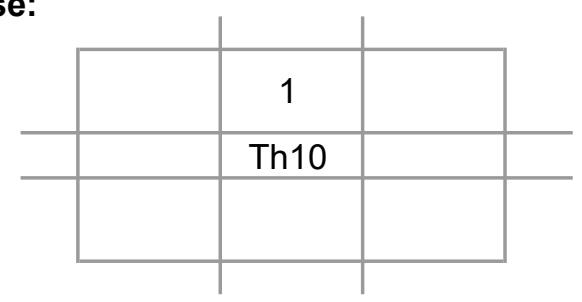

\section{Beschreibung:}

Hier ist ein Fragment des corpus erhalten. 
Bezeichn:: Vertebra

Kiste: 3

Skelet: K192 61/64 S3

Population: Großenrode
Verband: $\quad \square$ Verband

Ges./Kr.: Gesund

\section{Geschlecht:}

Arthrose:

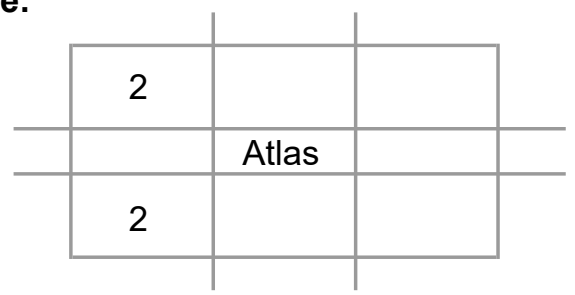

\section{Beschreibung:}

Etwa 1/5 erhalten. 
Bezeichn.: Vertebra

Kiste: 3

Skelet: $\quad$ K192 61/64 S3

Population: Großenrode
Verband: $\quad \square$ Verband

Ges./Kr.: Gesund

\section{Geschlecht:}

Arthrose:

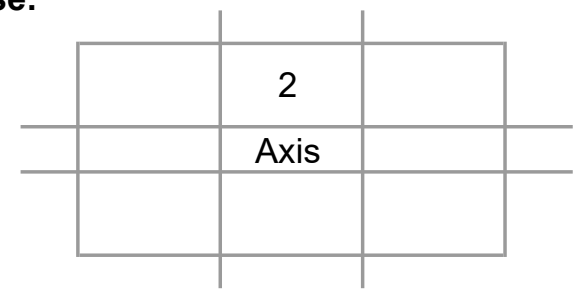

\section{Beschreibung:}

Dieser Wirbel ist stark erodiert und ist zur Hälfte erhalten. 
Bezeichn.: Vertebra

Kiste:

3

Skelet: $\quad$ K192 61/64 S3

Population: Großenrode
Verband: $\square$ Verband

Ges./Kr.: Gesund

\section{Geschlecht:}

Arthrose:

\begin{tabular}{|c|c|c|}
\cline { 2 - 4 } \multicolumn{1}{c||}{2} & 2 & 2 \\
\hline 2 & 2 & 2 \\
\hline
\end{tabular}

\section{Beschreibung:}

Fast vollständig. 
Bezeichn.: Vertebra

Kiste: 3

Skelet: K192 61/64 S3

Population: Großenrode
Verband: $\quad \square$ Verband

Ges./Kr.: Gesund

\section{Geschlecht:}

Arthrose:

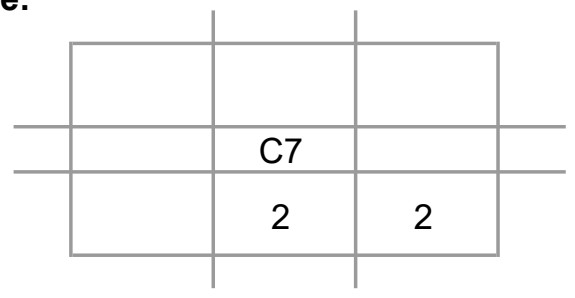

\section{Beschreibung:}

Stark erodiert. 
Bezeichn.: Vertebra

Kiste:

3

Skelet: K168 P3

Population: Großenrode
Verband: $\quad \square$ Verband

Ges./Kr.: Gesund

\section{Geschlecht:}

Arthrose:

\begin{tabular}{|c|c|c|}
\hline 2 & 2 & 2 \\
\hline & Atlas & \\
\hline 2 & & 2 \\
\hline
\end{tabular}

\section{Beschreibung:}

$75 \%$ erhalten. 
Bezeichn.: Vertebra

Kiste:

3

Skelet: K168 P3

Population: Großenrode
Verband: $\quad \square$ Verband

Ges./Kr.: Gesund

\section{Geschlecht:}

Arthrose:

\begin{tabular}{|c|c|c|}
\cline { 2 - 3 } \multicolumn{1}{c||}{2} & 2 & 2 \\
\hline 2 & 2 & 2 \\
\hline
\end{tabular}

Beschreibung:

90\% erhalten. 
Bezeichn.: Vertebra

\section{Kiste:}

Skelet: 10

Population: Großenrode
Verband: $\quad$ Verband

Ges./Kr.: Gesund

\section{Alter:}

\section{Geschlecht:}

Arthrose:

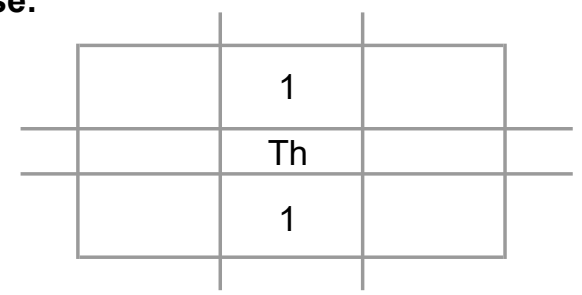

\section{Beschreibung:}

Ein thorakaler Wirbel aus dem mittleren bis unteren Bereich, es ist nur der corpus erhalten. 
Bezeichn.: Vertebra

Kiste:

Skelet: 63/52

Population: Großenrode
Verband: $\quad$ Verband

\section{Alter:}

Geschlecht:

Arthrose:
Ges./Kr.: Krank

Krankh.: Discus intervertebralis

Impression

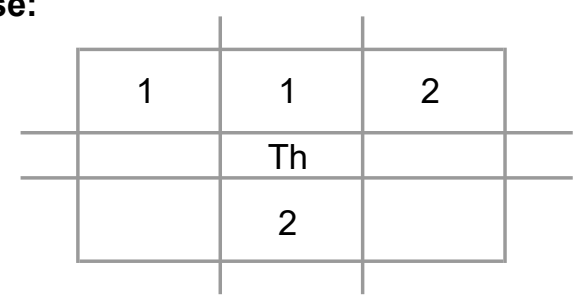

\section{Beschreibung:}

Dieser Wirbel weist auf der Deckplatte oben ein Loch auf, was so aussieht wie eine Impression nach komprimiertem discus intervertebralis. 
Bezeichn.: Vertebra

\section{Kiste:}

Skelet: 10

Population: Großenrode
Verband: $\quad$ Verband

Ges./Kr.: Gesund

\section{Geschlecht:}

Arthrose:

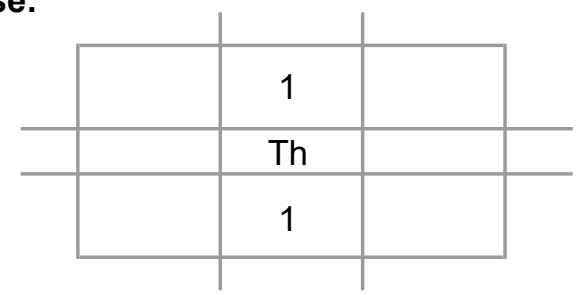

\section{Beschreibung:}

Mittlerer bis unterer thorakaler Bereich, es ist nur der corpus erhalten. 
Bezeichn.: Vertebra

Kiste:

Skelet: 63/52

Population: Großenrode
Verband: $\square$ Verband

Ges./Kr.: Gesund

\section{Geschlecht:}

Arthrose:

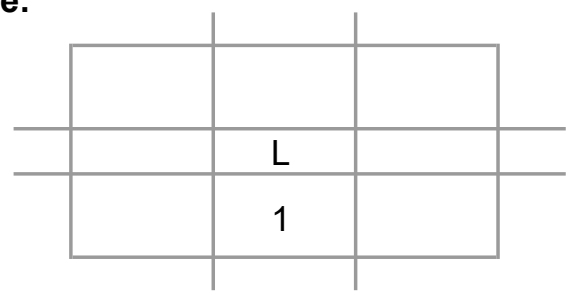

\section{Beschreibung:}

Ein graziler, erodierter Wirbel. 
Bezeichn.: Vertebra

Kiste:

Skelet: $\quad 63 / 52$

Population: Großenrode
Verband: Verband

\section{Alter:}

Geschlecht:

Arthrose:

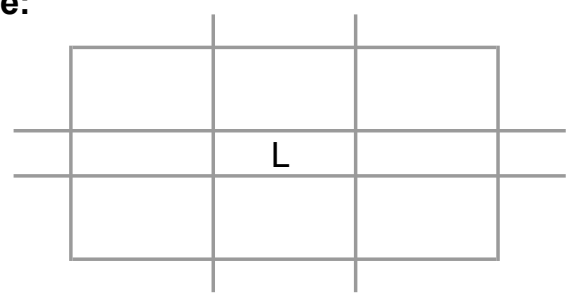

Beschreibung:

Ein graziler, erodierter Wirbel. 
Bezeichn.: Vertebra

Kiste:

Skelet: $\quad 62 / 53$

Population: Großenrode
Verband: Verband

Ges./Kr.: Gesund

\section{Geschlecht:}

Arthrose:

\begin{tabular}{|c|c|c|}
\cline { 2 - 3 } \multicolumn{1}{c||}{} & \multicolumn{1}{c|}{} & \multicolumn{1}{c}{} \\
\hline 2 & 2 & \\
\hline & Atlas & \\
\hline 2 & & \\
\hline
\end{tabular}

\section{Beschreibung:}


Bezeichn.: Vertebra

Kiste: 10

Skelet: 62/53

Population: Großenrode
Verband: $\quad$ Verband

Ges./Kr.: Gesund

\section{Alter:}

Geschlecht:

Arthrose:

\begin{tabular}{|c|c|c|}
\hline 2 & & 2 \\
\hline 2 & & 2 \\
\hline & C7 & \\
\hline 2 & & 2 \\
\hline
\end{tabular}

\section{Beschreibung:}

Der corpus ist stark erodiert. 
Bezeichn.: Vertebra

\section{Kiste:}

Skelet: 10

Population: Großenrode
Verband: $\square$ Verband

Ges./Kr.: Gesund

\section{Geschlecht:}

Arthrose:

\begin{tabular}{|c|c|c|}
\hline 2 & & 2 \\
\hline & Th1 & \\
\hline 2 & & 2 \\
\hline
\end{tabular}

\section{Beschreibung:}

Der corpus dieses Wirbels ist stark erodiert. 
Bezeichn.: Vertebra

\section{Kiste:}

Skelet: 10

Population: Großenrode
Verband: $\quad$ Verband

Ges./Kr.: Gesund

\section{Geschlecht:}

Arthrose:

\begin{tabular}{|c|c|c|}
\hline 2 & & 2 \\
\hline 2 & & 2 \\
\hline 2 & & 2 \\
\hline
\end{tabular}

\section{Beschreibung:}

Der Wirbel ist mit Processus spinalis erhalten, der corpus allerdings stark erodiert. 
Bezeichn.: Vertebra

\section{Kiste:}

Skelet: 10

Population: Großenrode
Verband: $\square$ Verband

Ges./Kr.: Gesund

\section{Geschlecht:}

Arthrose:

\begin{tabular}{|c|c|c|c|}
\hline & 2 & 1 & 2 \\
\hline \multirow[t]{2}{*}{1} & & Th1 & \\
\hline & 2 & 1 & 2 \\
\hline
\end{tabular}

\section{Beschreibung:}

Fast vollständig erhalten, der corpus ist leicht erodiert. 
Bezeichn.: Vertebra

Kiste:

10

Skelet: $\quad 62 / 53$

Population: Großenrode
Verband: $\quad$ Verband

Alter: Jung

Geschlecht:

Arthrose:

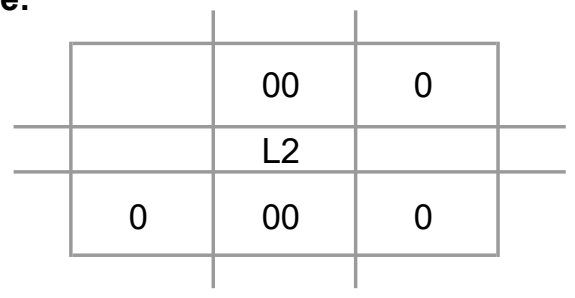

\section{Beschreibung:}

Ein stark erodierter Wirbel. 
Bezeichn.: Vertebra

\section{Kiste:}

Skelet: $62 / 53$

Population: Großenrode
Verband: $\square$ Verband

Ges./Kr.: Gesund

\section{Alter:}

Geschlecht:

Arthrose:

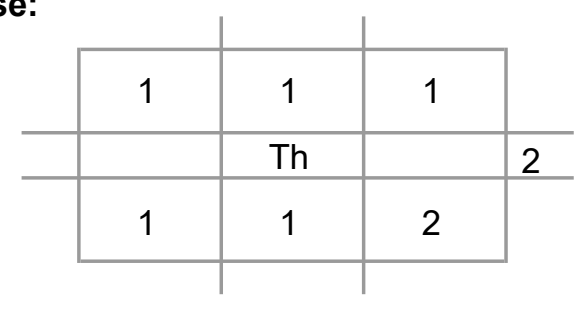

\section{Beschreibung:}

Ein Wirbel aus dem mittleren thorakalen Bereich, der corpus ist gut erhalten und die Processus articulares sind teilweise erodiert. 
Bezeichn.: Vertebra

\section{Kiste:}

Skelet: $\quad 62 / 53$

Population: Großenrode
Verband: Verband

Ges./Kr.: Gesund

\section{Geschlecht:}

Arthrose:

\begin{tabular}{|c|c|c|}
\cline { 2 - 3 } \multicolumn{1}{l|}{} & \multicolumn{1}{l|}{} & \multicolumn{1}{l}{} \\
\hline 1 & 1 & \\
\hline & Th & \\
\hline & 1 & \\
\hline
\end{tabular}

\section{Beschreibung:}


Bezeichn.: Vertebra

\section{Kiste:}

Skelet: $\quad 62 / 53$

Population: Großenrode
Verband: Verband

Ges./Kr.: Gesund

\section{Geschlecht:}

Arthrose:

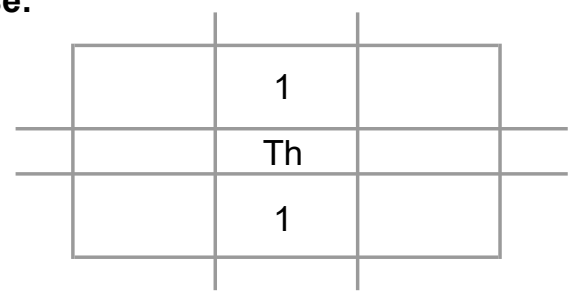

\section{Beschreibung:}


Bezeichn.: Vertebra

\section{Kiste:}

Skelet: $\quad 62 / 53$

Population: Großenrode
Verband: $\quad$ Verband

\section{Alter:}

Geschlecht:

Arthrose:
Ges./Kr.: Krank

\section{Krankh.: Arthrose}

Spondylophyten

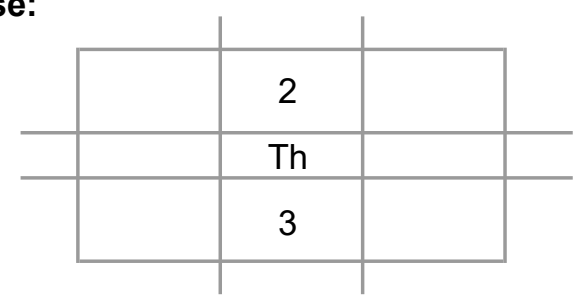

\section{Beschreibung:}

An der untern Deckplatte weist dieser Wirbel einen kleinen Spondylophyten auf. 
Bezeichn.: Vertebra

\section{Kiste:}

Skelet: $\quad 62 / 53$

Population: Großenrode
Verband: $\quad$ Verband

Ges./Kr.: Gesund

\section{Alter:}

\section{Geschlecht:}

Arthrose:

\begin{tabular}{|c|c|c|}
\hline 1 & 1 & 1 \\
\hline & Th & \\
\hline 2 & 1 & 2 \\
\hline
\end{tabular}

\section{Beschreibung:}

Dieser Wirbel ist recht gut erhalten und stammt aus unterem thorakalen Bereich. Er ist nur an wenigen Stellen erodiert. 
Bezeichn.: Vertebra

\section{Kiste:}

Skelet: 10

Population: Großenrode
Verband: $\square$ Verband

Ges./Kr.: Gesund

\section{Geschlecht:}

Arthrose:

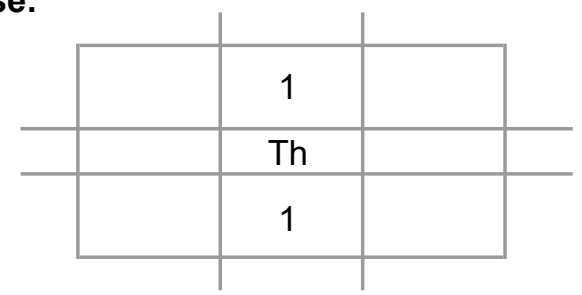

\section{Beschreibung:}

Ein stark frakturierter Wirbel aus dem mittleren bis unteren thorakalen Bereich. 
Bezeichn.: Vertebra

\section{Kiste:}

Skelet: 10

Population: Großenrode
Verband: $\quad \square$ Verband

Alter:

Ges./Kr.: Gesund

\section{Geschlecht:}

Arthrose:

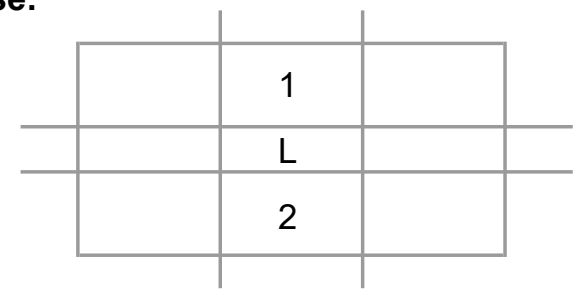

\section{Beschreibung:}

Von diesem Wirbel ist nur der corpus erhalten. 
Bezeichn.: Vertebra

\section{Kiste:}

Skelet: 10

Population: Großenrode
Verband: $\quad$ Verband

Ges./Kr.: Gesund

\section{Geschlecht:}

Arthrose:

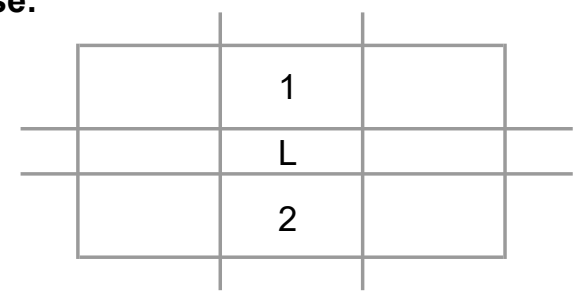

\section{Beschreibung:}

Ein erodiertes Wirbelfragment aus dem unteren lumbalen Bereich. 
Bezeichn.: Vertebra

\section{Kiste:}

Skelet: 10

Population: Großenrode
Verband: $\quad$ Verband

Ges./Kr.: Gesund

\section{Geschlecht:}

Arthrose:

\begin{tabular}{|l|l|l|}
\cline { 2 - 3 } \multicolumn{1}{l|}{} & \multicolumn{1}{l|}{} \\
\hline & 1 & \\
\hline 2 & 1 & 2 \\
\hline
\end{tabular}

\section{Beschreibung:}

Ein Wirbel aus dem mittleren lumbalen Bereich. 
Bezeichn.: Vertebra

Kiste:

Skelet: $\quad 62 / 53$

Population: Großenrode
Verband: $\quad$ Verband

Alter: Jung

Geschlecht:

Arthrose:

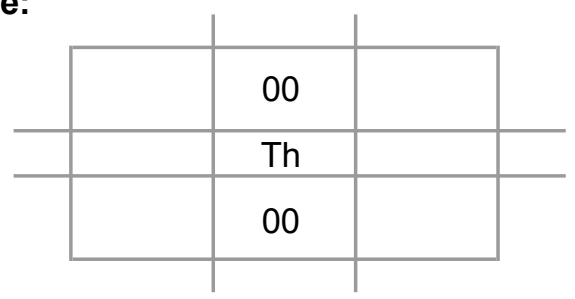

\section{Beschreibung:}

Ein Teil des corpus eines jungen Wirbels. 
Bezeichn.: Vertebra

Kiste: 10

Skelet: $\quad 62 / 56$

Population: Großenrode
Verband: $\quad$ Verband

Alter:

Ges./Kr.: Krank

Krankh.: Arthrose

\section{Geschlecht:}

Arthrose:

\begin{tabular}{|c|c|c|}
\cline { 2 - 3 } \multicolumn{1}{c|}{} & \multicolumn{1}{c|}{} & \multicolumn{1}{c}{3} \\
\hline & 2 & 3 \\
\hline & Th & \\
\hline & 2 & \\
\hline
\end{tabular}

\section{Beschreibung:}

Ein thorakaler Wirbel aus dem mittleren Bereich. 
Bezeichn.: Vertebra

\section{Kiste:}

Skelet: 10

Population: Großenrode
Verband: $\quad \square$ Verband

Ges./Kr.: Gesund

\section{Geschlecht:}

\section{Arthrose:}

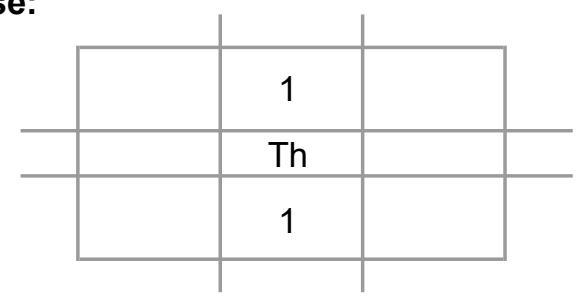

\section{Beschreibung:}

Ein thorakaler Wirbel aus dem mittleren Bereich. 
Bezeichn.: Vertebra

\section{Kiste:}

Skelet: $\quad 62 / 56$

Population: Großenrode
Verband: $\quad$ Verband

\section{Alter:}

Geschlecht:

Arthrose:
Ges./Kr.: Krank

Krankh.: Arthritis

Arthrose

\begin{tabular}{|c|c|c|}
\hline 2 & 2 & 4 \\
\hline & Th & \\
\hline & 2 & \\
\hline
\end{tabular}

\section{Beschreibung:}

Ein Wirbel aus dem mittleren thorakalen Bereich. 
Bezeichn.: Vertebra

\section{Kiste:}

Skelet: 10

Population: Großenrode
Verband: $\square$ Verband

Ges./Kr.: Gesund

\section{Geschlecht:}

Arthrose:

\begin{tabular}{|c|c|c|}
\cline { 2 - 3 } \multicolumn{1}{l|}{} & \multicolumn{1}{l|}{} & \multicolumn{1}{l}{} \\
\hline 2 & 2 & \\
\hline & Th & \\
\hline & 2 & \\
\hline
\end{tabular}

\section{Beschreibung:}

Ein thorakaler Wirbel aus dem mittleren Bereich. 
Bezeichn.: Vertebra

Kiste:

10

Skelet: $\quad 62 / 56$

Population: Großenrode
Verband: $\square$ Verband

\section{Alter:}

Ges./Kr.: Krank

Geschlecht:

Arthrose:

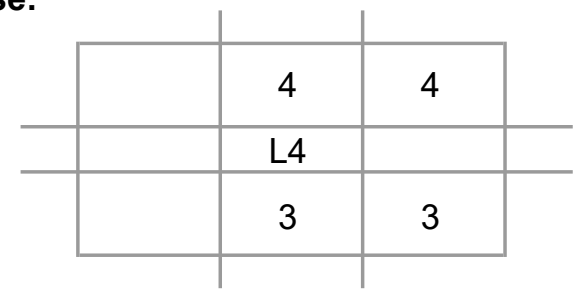

\section{Beschreibung:}

Ein Fragment eines erodiertes Wirbels. 
Bezeichn.: Vertebra

Kiste: 10

Skelet: $\quad 62 / 56$

Population: Großenrode
Verband: $\quad$ Verband

Alter:

Ges./Kr.: Krank

Krankh.: Arthrose

Geschlecht:

\begin{tabular}{|c|c|c|}
\cline { 2 - 3 } \multicolumn{1}{c|}{} & \multicolumn{1}{c|}{} & \multicolumn{1}{c}{} \\
\hline 5 & 3 & \\
\hline 3 & 3 & \\
\hline
\end{tabular}

\section{Beschreibung:}

Ein erodierter L5, es sind Teile abfrakturiert. 
Bezeichn.: Vertebra

\section{Kiste:}

Skelet: bei 431 in Tüte 1

Population: Großenrode
Verband: $\quad$ Verband

Alter:

Ges./Kr.: Gesund

Geschlecht:

Arthrose:

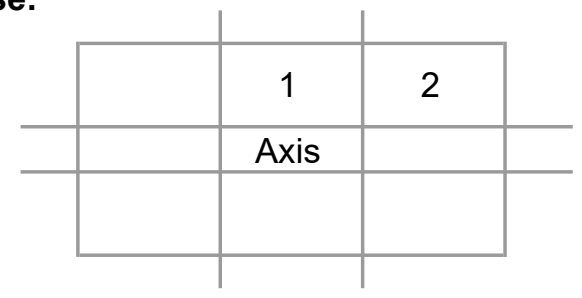

\section{Beschreibung:}


Bezeichn.: Vertebra

\section{Kiste:} 10

Skelet: $\quad$ bei 431 in Tüte 1

Population: Großenrode

\section{Verband: $\quad$ Verband}

\section{Alter:}

Geschlecht:

Arthrose:

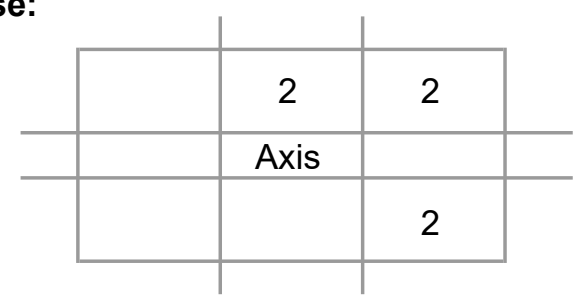

\section{Beschreibung:}


Bezeichn.: Vertebra

Kiste: 10

Skelet: bei 431 in Tüte 1

Population: Großenrode
Verband: $\quad$ Verband

Ges./Kr.: Gesund

\section{Geschlecht:}

Arthrose:

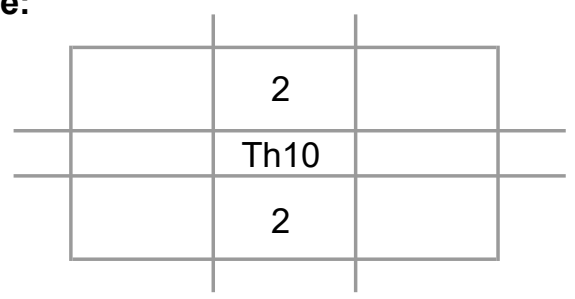

\section{Beschreibung:}


Bezeichn.: Vertebra

\section{Kiste:}

10

Skelet: $\quad$ bei 431 in Tüte 1

Population: Großenrode
Verband: $\quad \square$ Verband

Ges./Kr.: Gesund

\section{Alter:}

\section{Geschlecht:}

Arthrose:

\begin{tabular}{|c|c|c|}
\cline { 2 - 3 } \multicolumn{1}{c|}{} & \multicolumn{1}{c|}{} & \multicolumn{1}{c}{2} \\
\hline & 2 & 2 \\
\hline & Th11 & \\
\hline & 2 & 2 \\
\hline
\end{tabular}

\section{Beschreibung:}

Zusätzlich zu diesem Wirbelfragment sind noch Splitter und kleinste Fragmente vorhanden. 
Bezeichn.: Vertebra

\section{Kiste:}

Skelet: $\quad$ 6. Tüte aus Tüte 62/52

Population: Großenrode
Verband: $\quad$ Verband

\section{Alter: Jung}

Geschlecht:

Arthrose:

\begin{tabular}{|c|c|c|}
\hline 0 & 00 & 0 \\
\hline & Th & \\
\hline 0 & 00 & \\
\hline
\end{tabular}

\section{Beschreibung:}

Ein fast vollständiger Wirbel eines jungen Individuums. 
Bezeichn.: Vertebra

\section{Kiste:}

Skelet: 6. Tüte aus Tüte 62/52

Population: Großenrode
Verband: $\quad$ Verband

Ges./Kr.: Gesund

\section{Geschlecht:}

Arthrose:

\begin{tabular}{|c|c|c|}
\cline { 2 - 4 } \multicolumn{1}{c||}{2} & 1 & 2 \\
\hline 2 & 1 & 1 \\
\hline
\end{tabular}

\section{Beschreibung:}


Bezeichn.: Vertebra

\section{Kiste:}

Skelet: $\quad$ 6. Tüte aus Tüte 62/52

Population: Großenrode
Verband: $\quad \square$ Verband

Ges./Kr.: Gesund

\section{Geschlecht:}

Arthrose:

\begin{tabular}{l|c|c|c|}
\cline { 2 - 3 } \multicolumn{1}{l|}{} & & \multicolumn{1}{l|}{} \\
\hline & 2 & 2 & \\
\hline 1 & 2 & \\
\hline
\end{tabular}

\section{Beschreibung:}

Hier sind weitere kleinste Fragmente und Wirbelsplitter erhalten. 
Bezeichn.: Vertebra

Kiste:

10

Skelet: $\quad 62 / 52$

Population: Großenrode
Verband: $\quad$ Verband

Ges./Kr.: Gesund

\section{Geschlecht:}

Arthrose:

\begin{tabular}{|c|c|c|}
\cline { 2 - 3 } \multicolumn{1}{c|}{} & \multicolumn{1}{c|}{} & \multicolumn{1}{c}{2} \\
\hline & 2 & 2 \\
\hline 2 & 2 & \\
\hline
\end{tabular}

\section{Beschreibung:}

Ein fast vollständiger Wirbel. 
Bezeichn.: Vertebra

Kiste:

10

Skelet: $\quad 62 / 52$

Population: Großenrode
Verband: $\quad$ Verband

Ges./Kr.: Gesund

\section{Geschlecht:}

Arthrose:

\begin{tabular}{|c|c|c|}
\cline { 2 - 3 } \multicolumn{1}{c||}{2} & 2 & 2 \\
\hline 2 & 2 & 2 \\
\hline
\end{tabular}

\section{Beschreibung:}

Ein fast vollständiger Wirbel. 
Bezeichn.: Vertebra

Kiste:

10

Skelet: $\quad 62 / 52$

Population: Großenrode
Verband: $\quad$ Verband

Ges./Kr.: Gesund

\section{Geschlecht:}

Arthrose:

\begin{tabular}{|c|c|c|}
\cline { 2 - 4 } \multicolumn{1}{c||}{2} & 1 & 2 \\
\hline 2 & 2 & 2 \\
\hline
\end{tabular}

\section{Beschreibung:}

Ein fast vollständiger Wirbel. 
Bezeichn.: Vertebra

Kiste: 10

Skelet: $\quad 61 / 52$

Population: Großenrode
Verband: Verband

Ges./Kr.: Gesund

\section{Alter:}

Geschlecht:

Arthrose:

\begin{tabular}{|c|c|c|}
\hline 1 & 1 & 1 \\
\hline & Th10 & \\
\hline & 1 & 1 \\
\hline
\end{tabular}

Beschreibung:

Ein erodierter Wirbel. 
Bezeichn.: Vertebra

Kiste:

10

Skelet: $\quad 61 / 52$

Population: Großenrode
Verband: $\quad$ Verband

Ges./Kr.: Gesund

\section{Geschlecht:}

Arthrose:

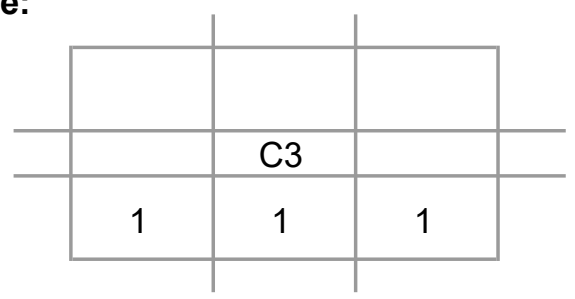

Beschreibung:

Ein erodierter Wirbel. 
Bezeichn.: Vertebra

Kiste: 10

Skelet: $\quad 61 / 52$

Population: Großenrode
Verband: Verband

Ges./Kr.: Gesund

\section{Alter:}

Geschlecht:

Arthrose:

\begin{tabular}{l|c|c|}
\cline { 2 - 3 } \multicolumn{1}{l|}{} & \multicolumn{1}{c|}{} & \multicolumn{1}{c}{} \\
\cline { 2 - 3 } & 1 & 1 \\
\hline & $\mathrm{C} 4$ & \\
\hline & 1 & 1 \\
\hline
\end{tabular}

Beschreibung:

Ein erodierter Wirbel. 
Bezeichn.: Vertebra

Kiste: 10

Skelet: $\quad 61 / 52$

Population: Großenrode
Verband: Verband

Ges./Kr.: Gesund

\section{Alter:}

Geschlecht:

Arthrose:

\begin{tabular}{|c|c|}
\hline 1 & 1 \\
\hline & C5 \\
\hline 2 & 1 \\
\hline
\end{tabular}

Beschreibung:

Ein erodierter Wirbel. 
Bezeichn.: Vertebra

Kiste: 10

Skelet: $\quad 61 / 52$

Population: Großenrode
Verband: $\quad$ Verband

Ges./Kr.: Gesund

\section{Alter:}

Geschlecht:

Arthrose:

\begin{tabular}{|c|c|c|}
\cline { 2 - 4 } \multicolumn{1}{c|}{} & \multicolumn{1}{c|}{} \\
\hline & 1 & 2 \\
\hline 2 & 1 & 2 \\
\hline
\end{tabular}

Beschreibung:

Ein erodierter Wirbel. 
Bezeichn.: Vertebra

Kiste:

Skelet: K246

Population: Großenrode
Verband: $\square$ Verband

\section{Alter:}

Ges./Kr.: Krank

Geschlecht:

Arthrose:

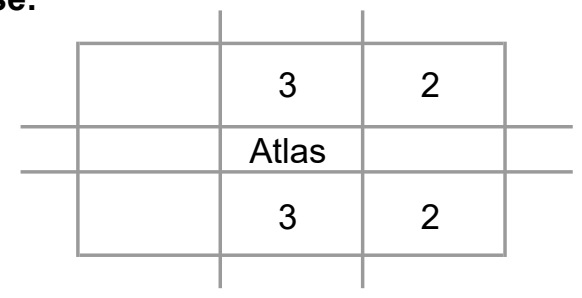

\section{Beschreibung:}

Ein stark erodierter Wirbel. 
Bezeichn.: Vertebra

\section{Kiste:}

Skelet: K246

Population: Großenrode
Verband: $\square$ Verband

Ges./Kr.: Gesund

\section{Geschlecht:}

\section{Arthrose:}

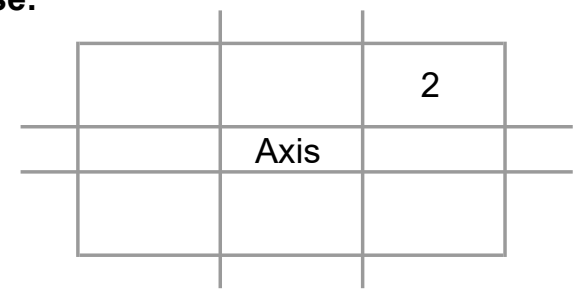

\section{Beschreibung:}

Ein stark erodierter Wirbel. 
Bezeichn.: Vertebra

\section{Kiste:}

Skelet: K124

Population: Großenrode
Verband: Verband

\section{Alter:}

Geschlecht:

Arthrose:

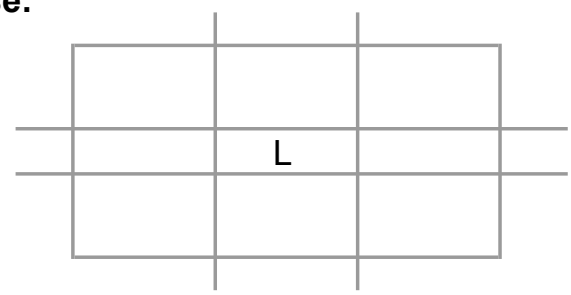

\section{Beschreibung:}

Dieses Fragment ist erodiert. 
Bezeichn:: Vertebra

Kiste:

Skelet: K240

Population: Großenrode
Verband: $\quad \square$ Verband

\section{Alter:}

Geschlecht:

Arthrose:
Ges./Kr.: Krank

Krankh.: Arthrose

Arthritis

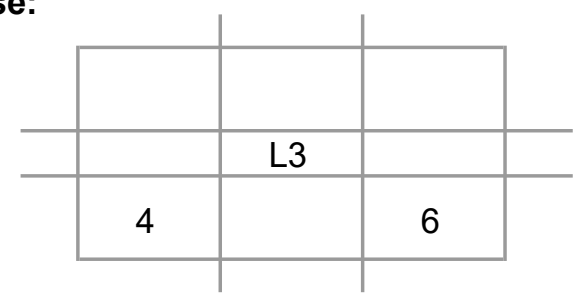

\section{Beschreibung:}

Hier sind noch weitere kleinste Splitter erhalten. 
Bezeichn:: Vertebra

Kiste:

Skelet: K240

Population: Großenrode
Verband: $\quad$ Verband

\section{Alter:}

Geschlecht:

Arthrose:

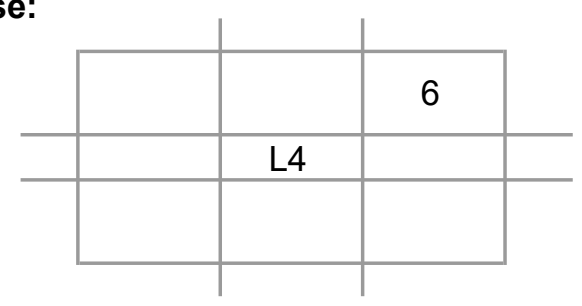

Ges./Kr.: Krank

Krankh.: Arthritis

Arthrose

\section{Beschreibung:}


Bezeichn.: Vertebra

Kiste:

Skelet: K240

Population: Großenrode
Verband: $\square$ Verband

\section{Alter:}

Geschlecht:

Arthrose:
Ges./Kr.: Krank

Krankh.: Arthrose

Arthritis

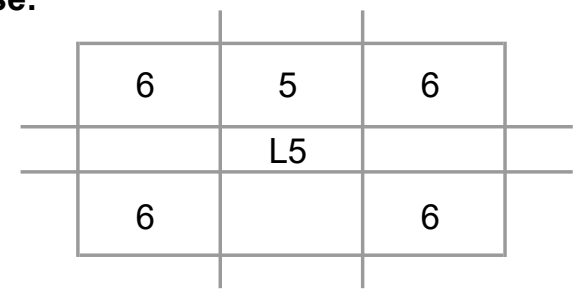

\section{Beschreibung:}


Bezeichn.: Vertebra

\section{Kiste:}

Skelet: $\quad$ K240 63/68 P3

Population: Großenrode
Verband: $\quad$ Verband

\section{Alter:}

Geschlecht:

Arthrose:

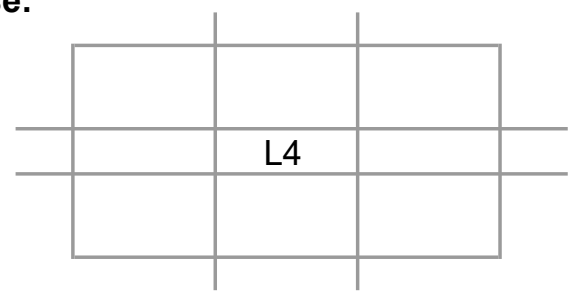

\section{Beschreibung:}


Bezeichn.: Vertebra

\section{Kiste:}

Skelet: $\quad$ K240 63/68 P3

Population: Großenrode
Verband: $\quad$ Verband

\section{Alter:}

Geschlecht:

Arthrose:

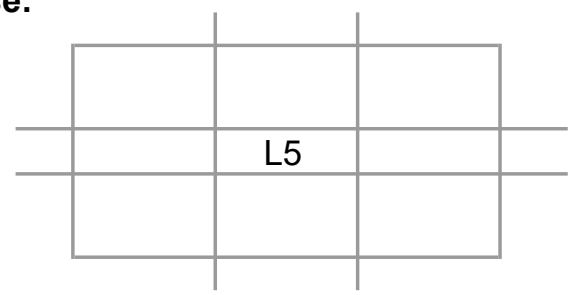

\section{Beschreibung:}


Bezeichn:: Vertebra

\section{Kiste:}

Skelet: K242

Population: Großenrode
Verband: $\quad$ Verband

\section{Alter: Jung}

Geschlecht:

Arthrose:

\begin{tabular}{|l|l|l|}
\cline { 2 - 3 } \multicolumn{1}{c||}{000} & 00 & 00 \\
\hline & L5 & \\
\hline & 00 & 00 \\
\hline
\end{tabular}

\section{Beschreibung:}

Ein fast vollständiger Wirbel eines jungen Individuums. 
Bezeichn.: Vertebra

Kiste:

Skelet: K81

Population: Großenrode
Verband: $\square$ Verband

Ges./Kr.: Gesund

\section{Geschlecht:}

Arthrose:

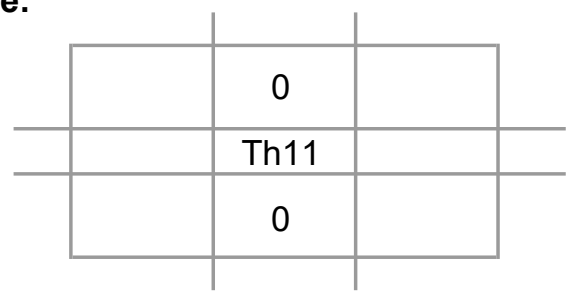

\section{Beschreibung:}


Bezeichn.: Vertebra

Kiste:

Skelet: K81

Population: Großenrode
Verband: $\square$ Verband

Ges./Kr.: Gesund

\section{Geschlecht:}

Arthrose:

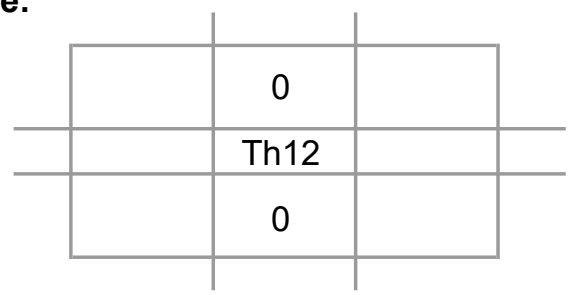

\section{Beschreibung:}


Bezeichn.: Vertebra

Kiste:

Skelet: K81

Population: Großenrode
Verband: $\square$ Verband

Ges./Kr.: Gesund

\section{Geschlecht:}

Arthrose:

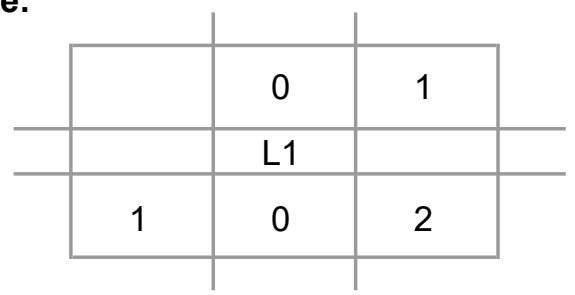

\section{Beschreibung:}


Bezeichn.: Vertebra

Kiste:

Skelet: K81

Population: Großenrode
Verband: $\quad$ Verband

\section{Alter: Jung}

Geschlecht:

Arthrose:

\begin{tabular}{|c|c|c|}
\hline 0 & 0 & 0 \\
\hline & L2 & \\
\hline 1 & 0 & \\
\hline
\end{tabular}

\section{Beschreibung:}


Bezeichn.: Vertebra

Kiste:

Skelet: K65

Population: Großenrode
Verband: Verband

\section{Alter:}

\section{Geschlecht:}

Arthrose:

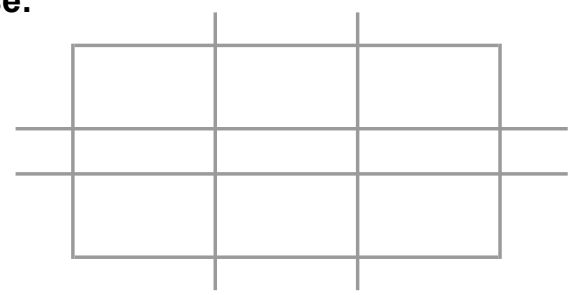

\section{Beschreibung:}


Bezeichn.: Vertebra

Kiste:

Skelet: K65

Population: Großenrode
Verband: Verband

\section{Alter:}

Geschlecht:

Arthrose:

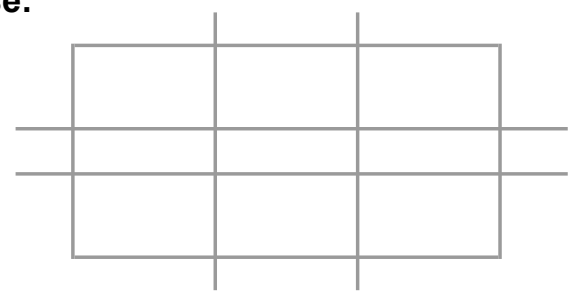

\section{Beschreibung:}


Bezeichn.: Vertebra

Kiste:

Skelet: K65

Population: Großenrode
Verband: $\quad \square$ Verband

\section{Alter:}

Ges./Kr.: Krank

\section{Geschlecht:}

Arthrose:

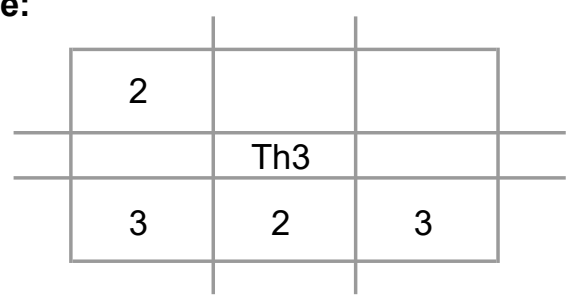

\section{Beschreibung:}


Bezeichn.: Vertebra

Kiste:

5

Skelet: $\quad$ K174 61/67 P3

Population: Großenrode
Verband: $\quad$ Verband

\section{Alter: Erwachsen}

\section{Geschlecht:}

Arthrose:

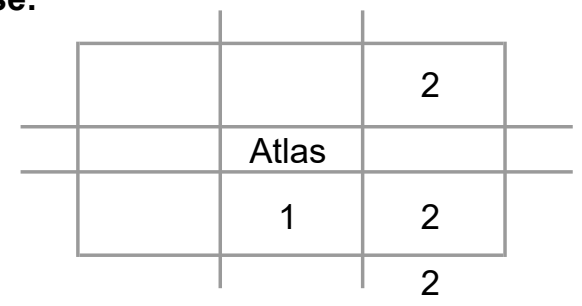

\section{Beschreibung:}

Ein Wirbel aus einem Verband. 
Bezeichn.: Vertebra

Kiste:

5

Skelet: $\quad$ K174 61/67 P3

Population: Großenrode
Verband: $\square$ Verband

\section{Alter: Erwachsen}

\section{Geschlecht:}

Arthrose:

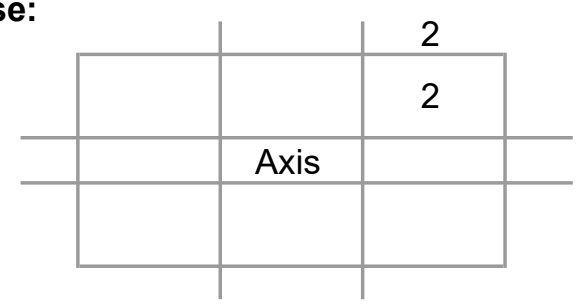

\section{Beschreibung:}

Ein Wirbel aus einem Verband. 
Bezeichn.: Vertebra

Kiste: 5

Skelet: $\quad 64 / 68-4$

Population: Großenrode
Verband: $\quad \square$ Verband

Alter:

Geschlecht:

Arthrose:
Ges./Kr.: Krank

Krankh.: Arthrose

Spondylitis

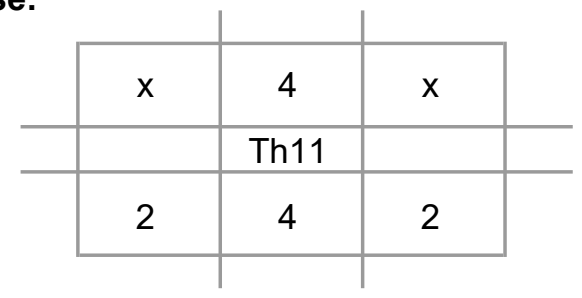

\section{Beschreibung:}


Bezeichn.: Vertebra

Kiste: 5

Skelet: 64/68-4

Population: Großenrode
Verband: Verband

Alter: $\quad 13-18$ (19)

Geschlecht:

Arthrose:

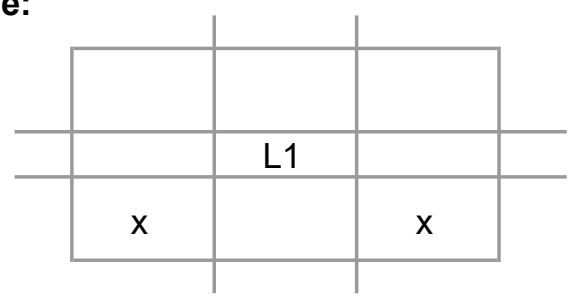

Beschreibung:

Fragment. 
Bezeichn.: Vertebra

Kiste: 5

Skelet: 64/68-4

Population: Großenrode
Verband: $\quad$ Verband

Alter: $\quad 13-18$ (19)

\section{Geschlecht:}

Arthrose:

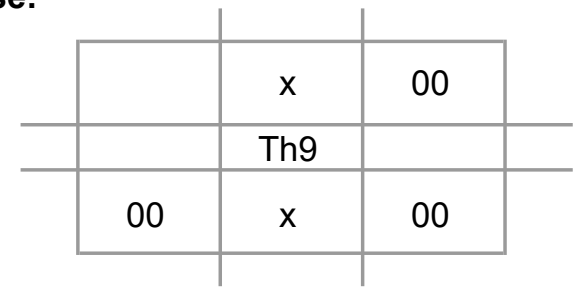

\section{Beschreibung:}


Bezeichn.: Vertebra

\section{Kiste:}

Skelet: 64/68-4

Population: Großenrode
Verband: $\quad$ Verband

Alter: $\quad 13-18$ (19)

\section{Geschlecht:}

Arthrose:

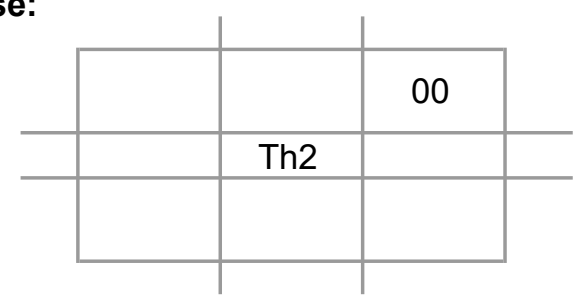

\section{Beschreibung:}


Bezeichn.: Vertebra

Kiste: 5

Skelet: $\quad$ K158 62/69 S2

Population: Großenrode
Verband: $\quad$ Verband

Ges./Kr.: Gesund

\section{Geschlecht:}

Arthrose:

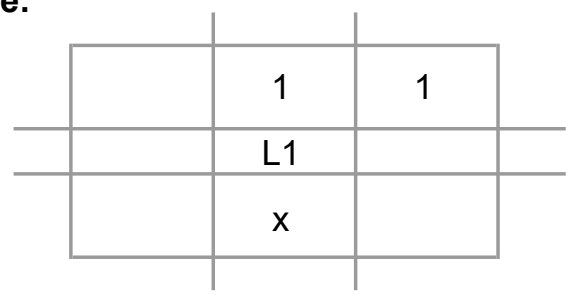

\section{Beschreibung:}


Bezeichn:: Vertebra

Kiste: 5

Skelet: $\quad$ K144 61/69 P3

Population: Großenrode
Verband: $\square$ Verband

Ges./Kr.: Gesund

\section{Geschlecht:}

Arthrose:

\begin{tabular}{c|c|c|c|}
\multicolumn{1}{c|}{} & \multicolumn{1}{c|}{} \\
\cline { 2 - 4 } \multicolumn{1}{l|}{1} & $\mathrm{x}$ & 1 \\
\hline 1 & & Th2 & \\
\hline & 2 & 1 & 2 \\
\cline { 2 - 4 } & & & \multicolumn{2}{c}{$\quad$}
\end{tabular}

\section{Beschreibung:}

$90 \%$ erhalten, leicht erodiert. 
Bezeichn.: Vertebra

\section{Kiste:}

Skelet: $\quad$ K144 61/69 P3

Population: Großenrode
Verband: $\square$ Verband

Ges./Kr.: Gesund

\section{Geschlecht:}

Arthrose:

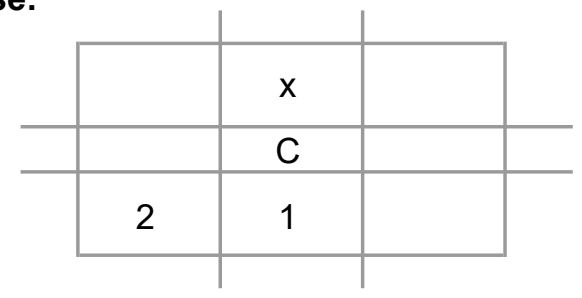

\section{Beschreibung:}

Ein stark erodiertes Fragment eines cervikalen Wirbels. 
Bezeichn.: Vertebra

Kiste: 5

Skelet: $\quad$ K263 61/67 S3

Population: Großenrode

\section{Verband: $\quad$ Verband Ges./Kr.: Krank}

Alter: Krankh.: Arthrose

\section{Geschlecht:}

Arthrose:

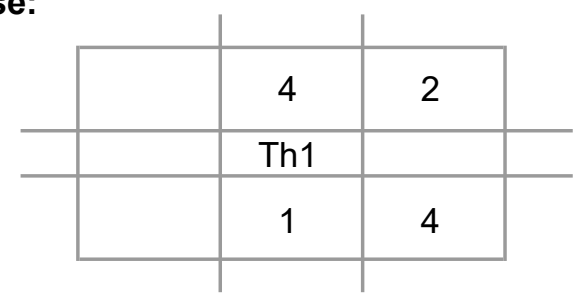

\section{Beschreibung:}

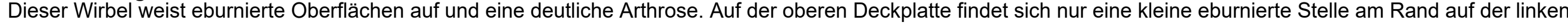
Seite. Der Wirbel ist etwas erodiert. 
Bezeichn.: Vertebra

Kiste:

Skelet: $\quad$ K45 61/68-S1

Population: Großenrode
Verband: $\square$ Verband

Alter: $\quad 5-7$ (8)

Geschlecht:

Arthrose:

\begin{tabular}{|c|c|c|}
\cline { 2 - 3 } \multicolumn{1}{c|}{00} & 00 & 00 \\
\hline & Axis & \\
\hline 00 & 00 & 00 \\
\hline
\end{tabular}

\section{Beschreibung:}

Ein fast vollständig erhaltener Axis eines Kindes. 
Bezeichn.: Vertebra

Kiste:

8

Skelet: $\quad$ K154 61/68 S2

Population: Großenrode
Verband: $\quad$ Verband

Ges./Kr.: Gesund

\section{Alter:}

Geschlecht:

Arthrose:

\begin{tabular}{|c|c|c|}
\hline & $x$ & 2 \\
\hline & C4 & \\
\hline$x$ & $x$ & 2 \\
\hline
\end{tabular}

\section{Beschreibung:}

Ein Wirbel aus einem Verband. 
Bezeichn.: Vertebra

\section{Kiste:} 8

Skelet: $\quad$ K154 61/68 S2

Population: Großenrode
Verband: Verband

Ges./Kr.: Gesund

\section{Geschlecht:}

Arthrose:

\begin{tabular}{|c|c|c|}
\cline { 2 - 3 } \multicolumn{1}{c|}{} & \multicolumn{1}{c|}{} \\
\hline & 1 & $x$ \\
\hline 2 & 1 & 2 \\
\hline 2 & 1 & 2
\end{tabular}

\section{Beschreibung:}

Ein Wirbel aus einem Verband. 
Bezeichn.: Vertebra

\section{Kiste:} 8

Skelet: $\quad$ K154 61/68 S2

Population: Großenrode
Verband: $\quad$ Verband

Ges./Kr.: Gesund

\section{Alter:}

Geschlecht:

Arthrose:

\begin{tabular}{|c|c|c|}
\hline 2 & 1 & 2 \\
\hline \multirow[t]{2}{*}{2} & 1 & 2 \\
\hline & C6 & \\
\hline 2 & 1 & 2 \\
\hline & 1 & 2 \\
\hline
\end{tabular}

\section{Beschreibung:}

Ein Wirbel aus einem Verband. 
Bezeichn.: Vertebra

\section{Kiste:}

8

Skelet: $\quad$ K154 61/68 S2

Population: Großenrode
Verband: $\quad$ Verband

\section{Alter:}

Geschlecht:

Arthrose:

\begin{tabular}{l|c|c|}
\multicolumn{1}{l|}{} & 1 & 2 \\
\cline { 2 - 3 } & 1 & 2 \\
\hline & $\mathrm{C} 7$ & \\
\hline & 1 & 2 \\
\hline & 1 & 2
\end{tabular}

\section{Beschreibung:}

Ein Wirbel aus einem Verband. 
Bezeichn.: Vertebra

\section{Kiste:}

Skelet: $\quad$ K154 61/68 S2

Population: Großenrode
Verband: $\quad \square$ Verband

Ges./Kr.: Gesund

\section{Geschlecht:}

Arthrose:

\begin{tabular}{|c|c|c|}
\hline & 1 & 2 \\
\hline 2 & 1 & 2 \\
\hline & Th1 & \\
\hline 2 & 1 & 2 \\
\hline
\end{tabular}

\section{Beschreibung:}

in Verband aus Wirbeln, die recht gut erhalten sind. 
Bezeichn.: Vertebra

\section{Kiste:}

8

Skelet: $\quad$ K164 61/68 P3

Population: Großenrode
Verband: $\quad$ Verband

Alter: Erwachsen

\section{Geschlecht: $q$}

Arthrose:

\begin{tabular}{l|c|c|}
\multicolumn{1}{c|}{} & \multicolumn{1}{c|}{} \\
\cline { 2 - 4 } \multicolumn{1}{c|}{1} & 1 & 1 \\
\hline 1 & 1 & 1 \\
\hline 1.5 & 1 & 1.5
\end{tabular}

\section{Beschreibung:}

Etwa 1/4 des corpus weggebrochen. 
Bezeichn.: Vertebra

\section{Kiste:}

8

Skelet: $\quad$ K164 61/68 P3

Population: Großenrode
Verband: $\quad \square$ Verband

\section{Alter: Erwachsen}

\section{Geschlecht:}

Arthrose:

\begin{tabular}{|c|c|c|}
\hline 1.5 & 1 & 1.5 \\
\hline 2 & 1 & 2 \\
\hline & L2 & \\
\hline 1 & 1 & 1 \\
\hline 1.5 & 1 & 1.5 \\
\hline
\end{tabular}

\section{Beschreibung:}

Etwa 1/3 des corpus weggebrochen. 
Bezeichn.: Vertebra

\section{Kiste:}

8

Skelet: $\quad$ K164 61/68 P3

Population: Großenrode
Verband: $\quad \square$ Verband

\section{Alter: Erwachsen}

\section{Geschlecht:}

Arthrose:

\begin{tabular}{|c|c|c|}
\hline 1.5 & 1 & 1.5 \\
\hline 2 & 1 & 2 \\
\hline & L3 & \\
\hline 2 & 1 & 2 \\
\hline 2 & 1 & 2 \\
\hline
\end{tabular}

\section{Beschreibung:}

Etwa 1/4 des corpus weggebrochen. 
Bezeichn.: Vertebra

\section{Kiste:}

Skelet: $\quad$ K164 61/68 P3

Population: Großenrode
Verband: $\quad$ Verband

Alter: Erwachsen

Geschlecht: $q \geq \hat{\sigma}$

Arthrose:

\begin{tabular}{l|c|c|c|}
\multicolumn{1}{c|}{2} & 1 & 2 \\
\cline { 2 - 3 } & 2 & 1 & 2 \\
\hline & $L 4$ & & \\
\hline 2 & 1 & 2 \\
\hline 2 & & 2
\end{tabular}

\section{Beschreibung:}

Etwa Hälfte des corpus weggebrochen. 
Bezeichn.: Vertebra

\section{Kiste:}

Skelet: $\quad$ K164 61/68 P3

Population: Großenrode
Verband: $\square$ Verband

Alter: Erwachsen

Ges./Kr.: Gesund

Geschlecht: 우

Arthrose:

\begin{tabular}{l|l|l|l|}
\multicolumn{1}{c|}{2} & & 2 \\
\cline { 2 - 4 } & 2 & & 2 \\
\hline & & L5 & \\
\hline & & & 2 \\
\hline
\end{tabular}

\section{Beschreibung:}

Der corpus ist weggebrochen und die Processus articulares inferiores sind ebenfalls zur Hälfte erodiert. 
Bezeichn:: Vertebra

Kiste:

8

Skelet: $\quad$ K327 61/68 P4

Population: Großenrode
Verband: $\square$ Verband

Ges./Kr.: Gesund

\section{Geschlecht:}

Arthrose:

\begin{tabular}{|c|c|c|}
\hline 1 & 1 & 1 \\
\hline & Th5 & \\
\hline 1 & 1 & 2 \\
\hline
\end{tabular}

\section{Beschreibung:}


Bezeichn.: Vertebra

Kiste:

8

Skelet: $\quad$ K327 61/68 P4

Population: Großenrode
Verband: $\quad$ Verband

Alter:

\section{Geschlecht:}

Arthrose:

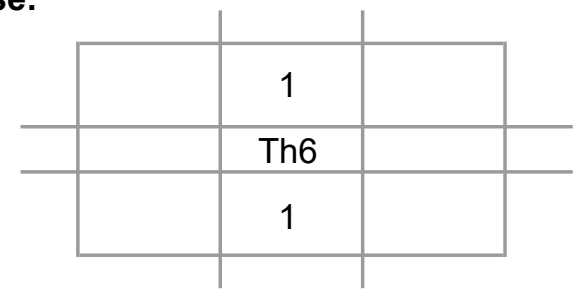

Beschreibung:

Der Wirbelbogen fehlt. 
Bezeichn.: Vertebra

\section{Kiste:}

Skelet: $\quad$ K327 61/68 P4

Population: Großenrode
Verband: $\quad \square$ Verband

Ges./Kr.: Gesund

\section{Geschlecht:}

Arthrose:

\begin{tabular}{l|c|c|c|}
\cline { 2 - 3 } \multicolumn{1}{c|}{} & \multicolumn{1}{c|}{} \\
\hline & 1 & 1 & 1 \\
\hline 1 & 1 & 1 \\
\hline
\end{tabular}

\section{Beschreibung:}

Linker Processus articularis superior nur zu 1/4 erhalten. 
Bezeichn.: Vertebra

\section{Kiste:}

Skelet: $\quad$ K327 61/68 P4

Population: Großenrode
Verband: $\quad$ Verband

Ges./Kr.: Gesund

\section{Geschlecht:}

Arthrose:

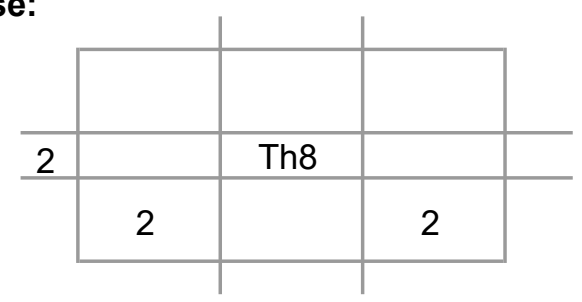

\section{Beschreibung:}

Linker Processus articularis inferior nur zur Hälfte erhalten. 
Bezeichn:: Vertebra

\section{Kiste:}

8

Skelet: $\quad$ K328 61/68 P4

Population: Großenrode
Verband: $\quad$ Verband

Ges./Kr.: Gesund

\section{Geschlecht:}

Arthrose:

\begin{tabular}{c|c|c|c}
\cline { 2 - 3 } \multicolumn{1}{c|}{} & \multicolumn{1}{c}{} \\
\hline 1 & 1 & 1 & \\
\hline & Th4 & & 2 \\
\hline 2 & 1 & 1 & \\
\cline { 1 - 3 } 1.5 & & \multicolumn{2}{c}{}
\end{tabular}

\section{Beschreibung:}

Ein Wirbel aus einem Verband. 
Bezeichn.: Vertebra

\section{Kiste:}

Skelet: $\quad$ K328 61/68 P4

Population: Großenrode
Verband: $\quad \square$ Verband

Ges./Kr.: Gesund

\section{Geschlecht:}

Arthrose:

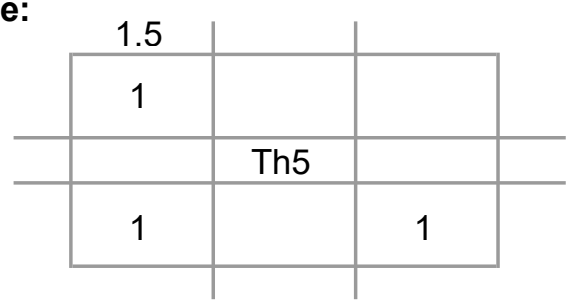

\section{Beschreibung:}

Es ist nur ein Teil des Wirbelbogens erhalten. 
Bezeichn.: Vertebra

\section{Kiste:}

Skelet: $\quad$ K328 61/68 P4

Population: Großenrode
Verband: $\quad \square$ Verband

Ges./Kr.: Gesund

\section{Alter:}

\section{Geschlecht:}

Arthrose:

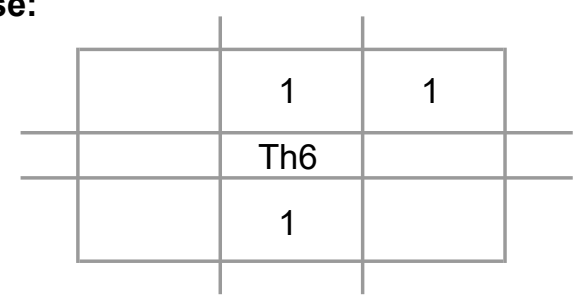

\section{Beschreibung:}

Es ist das meiste des Wirbelbogens weggebrochen, der linke Processus articularis superior ist zu $50 \%$ erhalten. 
Bezeichn.: Vertebra

Kiste:

8

Skelet: $\quad$ K348 61/68 S4

Population: Großenrode
Verband: $\square$ Verband

Ges./Kr.: Gesund

\section{Geschlecht:}

Arthrose:

\begin{tabular}{|c|c|c|}
\multicolumn{1}{c|}{$x$} & 1 & $x$ \\
\hline & $\mathrm{C} 3$ & \\
\hline & 2 & 2 \\
\hline
\end{tabular}

\section{Beschreibung:}

Ein insgesamt erodiertes Fragment. 
Bezeichn.: Vertebra

\section{Kiste:}

Skelet: $\quad 61 / 68-4$

Population: Großenrode
Verband: $\square$ Verband

Ges./Kr.: Gesund

\section{Geschlecht:}

Arthrose:

\begin{tabular}{|c|c|c|}
\hline 2 & 1 & 2 \\
\hline & Th11 & \\
\hline 2 & 1 & 2 \\
\hline
\end{tabular}

\section{Beschreibung:}

Ein fragmentierter Wirbel, dessen Deckplatten nur zu 1/4 befundbar waren. 
Bezeichn.: Vertebra

Kiste: 8

Skelet: $\quad$ K349 61/68 S4

Population: Großenrode
Verband: $\square$ Verband

Alter: $\quad$ (6) $7-12$

Geschlecht:

Arthrose:

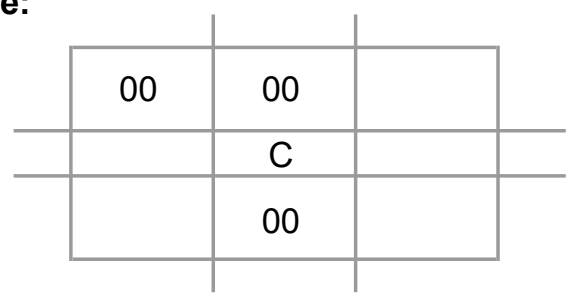

\section{Beschreibung:}

Wohl Infans II. 
Bezeichn:: Vertebra

Kiste:

Skelet: $\quad 61 / 68-4 E$

Population: Großenrode

\section{Verband: $\quad$ Verband Ges./Kr.: Gesund}

\section{Geschlecht:}

Arthrose:

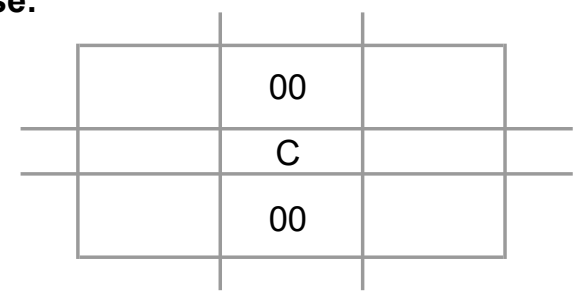

\section{Beschreibung:}

Fragment eines sehr jungen Wirbels. Es ist nur ein Teil des corpus erhalten. Es handelt sich wohl um den Altersbereich Infans I. 
Bezeichn.: Vertebra

\section{Kiste:}

Skelet: $61 / 68-4 E$

Population: Großenrode
Verband: $\quad \square$ Verband

Ges./Kr.: Gesund

\section{Geschlecht:}

Arthrose:

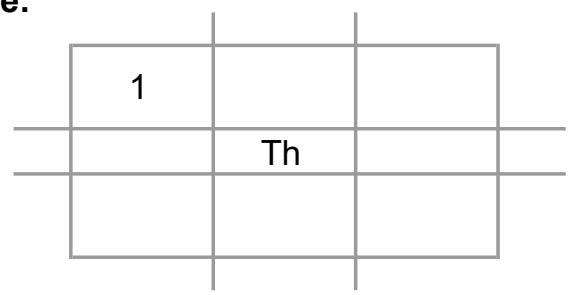

\section{Beschreibung:}

Ein rechtes Fragment eines thorakalen Wirbels. 
Bezeichn.: Vertebra

Kiste:

8

Skelet: 61/68-4E

Population: Großenrode
Verband: $\square$ Verband

Alter: $\quad 7-12$ (14)

Geschlecht:

Arthrose:

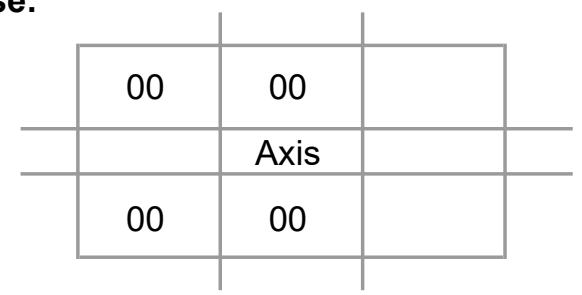

\section{Beschreibung:}

Ein Fragment eines jungen Wirbels aus dem Altersbereich Infans II. 
Bezeichn.: Vertebra

Kiste:

8

Skelet: 61/68-4E

Population: Großenrode
Verband: $\square$ Verband

$$
\text { Alter: } \quad 13-18 \text { (19) }
$$

\section{Geschlecht:}

Arthrose:

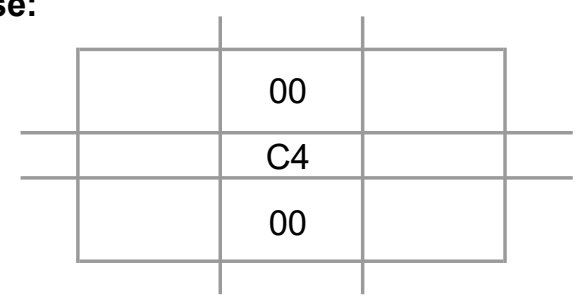

\section{Beschreibung:}

Hier ist nur der corpus dieses juvenilen, cervikalen Wirbels erhalten. 
Bezeichn.: Vertebra

Kiste:

8

Skelet: 61/68-4E

Population: Großenrode
Verband: $\quad$ Verband

Alter: $\quad 13-15(16)$

\section{Geschlecht:}

Arthrose:
Ges./Kr.: Gesund

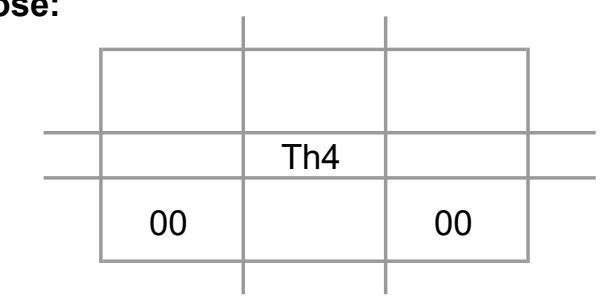

\section{Beschreibung:}

Ein juveniler Wirbel, es ist ein Fragment erhalten. 
Bezeichn.: Vertebra

Kiste:

8

Skelet: $\quad 61 / 68-4 E$

Population: Großenrode
Verband: $\quad$ Verband

Alter: $\quad 13-15(16)$

\section{Geschlecht:}

Arthrose:

\begin{tabular}{|l|l|l|}
\cline { 2 - 3 } \multicolumn{1}{c|}{} & \multicolumn{1}{c|}{} & \multicolumn{1}{c}{0} \\
\hline & 00 & 00 \\
\hline 00 & 00 & 00 \\
\hline
\end{tabular}

\section{Beschreibung:}

Gut erhaltener cervikaler Wirbel eines juvenilen Individuums. 


\section{Bezeichn.: Costa}

Kiste: 6

Skelet: $\quad$ K358 63/65 P4

Population: Großenrode

Seite:

rechts
Ges./Kr.: Krank

\section{Krankh.: Periostreizung \\ Alter:}

Verband

Geschlecht:

Arthrose:

\section{Beschreibung:}

Rippenfragmente. Ein Fragment ist noch recht gut erhalten, trotz Erosionen. Es fällt eine deutliche Längsstreifung des Schaftes auf. 


\section{Bezeichn.: Costa}

Kiste:

Skelet: K11160/64 S2

Population: Großenrode

Seite:
Verband: Verband

Alter: Jung

Geschlecht:

Arthrose:

\section{Beschreibung:}

Hier ist eine erste Rippe der rechten Seite zu 90\% erhalten, es ist lediglich ein kleines Stück abfrakturiert. Die Oberfläche ist nur minimal erodiert. 


\section{Bezeichn.: Costa}

\section{Kiste:}

Skelet: $\quad$ K115 60/64 S2

Population: Großenrode

Seite:

rechts
Verband: $\quad$ Verband

Alter: $\quad 13-18$ (19)

Geschlecht:

Arthrose:

\section{Beschreibung:}

Wohl das Fragment einer 2. Rippe der rechten Seite desselben juvenilen Individuums. 


\section{Bezeichn.: Costa}

\section{Kiste:}

Skelet: $\quad$ K113 60/64 S2

Population: Großenrode

Seite:

rechts
Verband: $\quad$ Verband

Alter: $13-18$ (19)

Geschlecht:

Arthrose:

\section{Beschreibung:}

Dies ist die erste Rippe der rechten Seite eines juvenilen Individuums. 


\section{Bezeichn.: Costa}

\section{Kiste:}

Skelet: $\quad$ K113 60/64 S2

Population: Großenrode

Seite:

rechts
Verband: $\quad$ Verband

Alter: $\quad 13-18(19)$

Geschlecht:

Arthrose:

\section{Beschreibung:}

2. Rippe der rechten Seite eines juvenilen Individuums. 


\section{Bezeichn.: Costa}

\section{Kiste:}

Skelet: $\quad$ K113 60/64 S2

Population: Großenrode

Seite:

rechts
Verband: $\quad$ Verband

Alter: $\quad 13-18(19)$

Geschlecht:

Arthrose:

\section{Beschreibung:}

3. Rippe der rechten Seite eines juvenilen Individuums. 


\section{Bezeichn.: Costa}

Kiste: 2

Skelet: $\quad 63 / 57$

Population: Großenrode

Seite:

links
Verband:

\section{Alter:}

Geschlecht:

Arthrose:
Ges./Kr.: Krank

Krankh.: Arthrose

\section{Beschreibung:}

Dieses Fundstück ist eine Rippe aus dem mittleren Bereich. 
Bezeichn.: Costa

Kiste: 3

Skelet: K206 S3

Population: Großenrode

Seite:

Verband: $\quad$ Verband

\section{Alter: $\quad 5-10$}

Geschlecht:

Arthrose:

\section{Beschreibung:}

Eine junge Rippe aus dem mittleren bis unteren Bereich. 


\section{Bezeichn.: Costa}

\section{Kiste:}

Skelet: K65

Population: Großenrode

Seite: rechts
Verband: Verband

\section{Alter:}

Geschlecht:

Arthrose:

\section{Beschreibung:}

Ein Fragment einer rechten, zweiten Rippe. 


\section{Bezeichn.: Costa}

\section{Kiste:}

Skelet: K65

Population: Großenrode

Seite: rechts
Verband: Verband

\section{Alter:}

Geschlecht:

Arthrose:

\section{Beschreibung:}

ein Fragment einer rechten dritten Rippe. 


\section{Bezeichn.: Costa}

\section{Kiste:}

Skelet: K65

Population: Großenrode

Seite: rechts
Verband: Verband

\section{Alter:}

Geschlecht:

Arthrose:

\section{Beschreibung:}

ein Fragment einer rechten vierten Rippe. 


\section{Bezeichn.: Costa}

Kiste:

Skelet: $\quad$ K361 61/69 S4

Population: Großenrode

Seite:
Verband: $\quad$ Verband

\section{Alter: $\quad 7-12$}

Geschlecht:

Arthrose:

\section{Beschreibung:}

Ein kleines Fragment der Rippe eines jungen Individuums Infans II. 
Bezeichn.: Sternum

\section{Kiste:}

Skelet: $\quad$ K196 60/64 P4

Population: Großenrode
Verband: $\square$ Verband

Alter: (14) $16-20$ (24)

Geschlecht: $q>\hat{\sigma}$

Arthrose:

\section{Beschreibung:}

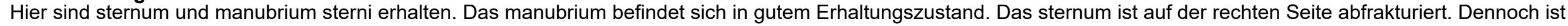

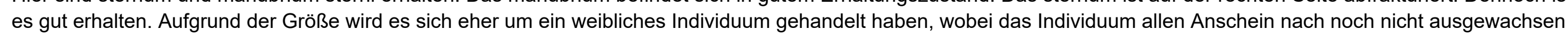
war. 
Bezeichn.: Sternum

Kiste:

Skelet: $\quad 62 / 54$

Population: Großenrode
Verband: Verband

\section{Alter:}

Geschlecht:

Arthrose:

\section{Beschreibung:}

Dieses sternum ist frakturiert und stark erodiert, es sind etwa $90 \%$ erhalten. 


\section{Bezeichn.: Clavicula}

Kiste:

9

Skelet: $\quad$ K308 63/67 P4

Population: Großenrode

Seite:

rechts
Verband: Verband

\section{Alter:}

Geschlecht:

Arthrose:
Ges./Kr.: Gesund

Maß

Umfang Schaftmitte
Wert $\quad$ Einheit

$33 \quad \mathrm{~mm}$

\section{Beschreibung:}

Hier sind 2/3 eher lateral erhalten. 


\section{Bezeichn.: Clavicula}

\section{Kiste:}

Skelet: $\quad 63 / 67$ S3 K302

Population: Großenrode

Seite:
Verband: $\quad$ Verband

Alter:

Geschlecht: $q \geq \AA$

Arthrose:
Ges./Kr.: Gesund

Maß

Umfang Schaftmitte \begin{tabular}{|l|l} 
Wert & Einheit \\
\hline 30
\end{tabular}

\begin{tabular}{l|l}
30 & $\mathrm{~mm}$
\end{tabular}

\section{Beschreibung:}

Ein Fragment einer sehr grazilen Clavicula. 


\section{Bezeichn.: Clavicula}

Kiste:

Skelet: $\quad 63 / 67$ S0 K21

Population: Großenrode

Seite:

rechts
Ges./Kr.: Gesund

\section{Alter:}

Maß

Geschlecht: $+\geq \succsim$

Arthrose:

\section{Beschreibung:}

Ein Fragment aus dem Schaft einer rechten Clavicula, es ist eher sternal erhalten 


\section{Bezeichn.: Clavicula}

Kiste:

Skelet: K155 63/67-S2

Population: Großenrode

Seite:

links

\section{Verband: $\quad$ Verband}

Alter:

Geschlecht:

Arthrose:

\section{Beschreibung:}

Ein Fragment, welches etwa die Hälfte des gesamten Knochens ausmacht. 


\section{Bezeichn.: Clavicula}

Kiste:

Skelet: $\quad$ K67 63/67 S1

Population: Großenrode

Seite:

links

\section{Verband: $\quad$ Verband}

Alter: Erwachsen

Geschlecht:

Arthrose:

\section{Beschreibung:}

Etwa die Hälfte erhalten, nur die laterale Seite. Das Fundstück ist stark erodiert. 


\section{Bezeichn.: Clavicula}

Kiste:

Skelet: K154

Population: Großenrode

Seite:

links
Verband: $\quad$ Verband

Alter: Erwachsen

\section{Geschlecht: 우}

Arthrose:
Ges./Kr.: Gesund

\section{Maß} gr. Länge

Umfang Schaftmitte

\begin{tabular}{|l|l} 
Wert & Einheit \\
\hline 36 & $\mathrm{~mm}$
\end{tabular}

$\mathrm{mm}$

\section{Beschreibung:}

Diese fast vollständige Clavicula ist sehr grazil. Sie ist mittelmäßig erodiert. 


\section{Bezeichn.: Clavicula}

Kiste:

Skelet: $\quad$ K313 62/63 P4

Population: Großenrode

Seite:

rechts
Verband: $\quad$ Verband

\section{Alter: $\quad 13-18(19)$}

Geschlecht:

Arthrose:
Ges./Kr.: Gesund

Maß

\section{gr. Länge}

Umfang Schaftmitte

\begin{tabular}{|l|l} 
Wert & Einheit \\
\hline 92 &
\end{tabular}

$92 \quad \mathrm{~mm}$

$31 \quad \mathrm{~mm}$

\section{Beschreibung:}

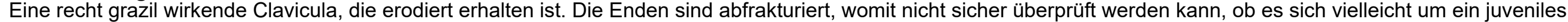
Individuum gehandelt haben könnte. 


\section{Bezeichn.: Clavicula}

\section{Kiste:}

Skelet: 60/64-4

Population: Großenrode

Seite:

links
Ges./Kr.: Gesund

Verband

\section{Alter:} Jung

Geschlecht: $q>0$

Arthrose:

\section{Beschreibung:}

Etwa 1/3 erhalten. Das Fundstück ist recht grazil und kaum erodiert. 


\section{Bezeichn.: Clavicula}

Kiste:

Skelet: $\quad$ K113 60/64 S2

Population: Großenrode

Seite:

rechts
Verband: $\square$ Verband

Alter: $\quad 13-18(19)$

Geschlecht:

Arthrose:
Ges./Kr.: Gesund

\section{Maß} gr. Länge

Umfang Schaftmitte

\begin{tabular}{|l|l} 
Wert & Einheit \\
\hline
\end{tabular}

$94,14 \mathrm{~mm}$

32

\section{Beschreibung:}

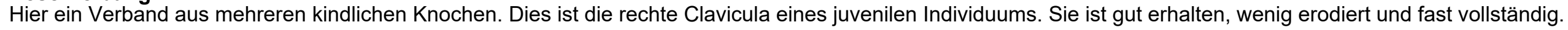




\section{Bezeichn.: Clavicula}

Kiste: 6

Skelet: $\quad$ K196 60/64 P4

Population: Großenrode

Seite:

\section{Verband:}

Alter:

Verband

Geschlecht:

Arthrose:
Ges./Kr.: Krank

Krankh.: Impressionen tiefer

Krampfadern
Maß

Umfang Schaftmitte

\begin{tabular}{|l|l} 
Wert & Einheit
\end{tabular}

\begin{tabular}{l|l}
33 & $\mathrm{~mm}$
\end{tabular}

\section{Beschreibung:}

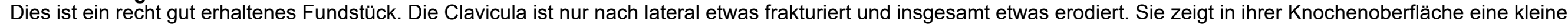
Gefäßimpression, die einer Krampfader zugeordnet werden kann. 


\section{Bezeichn.: Clavicula}

Kiste:

6

Skelet: $\quad$ K196 60/64 P4

Population: Großenrode

Seite:

links
Verband: $\quad$ Verband

\section{Alter:}

Geschlecht:

Arthrose:

\section{Beschreibung:}

An beiden Enden abfrakturiert und insgesamt mittelmäßiger Erhaltungszustand.

\begin{tabular}{l|l}
35 & $\mathrm{~mm}$
\end{tabular}




\section{Bezeichn.: Clavicula}

Kiste: 4

Skelet: $\quad$ K76 62/68 P2

Population: Großenrode

Seite:

rechts
Ges./Kr.: Gesund

\section{Alter:}

Geschlecht:

\section{Beschreibung:}

Diese Clavicula der rechten Seite weist frakturierte Gelenkflächen auf. 


\section{Bezeichn.: Clavicula}

Kiste: 2

Skelet: $\quad$ aus großer Tüte und

Population: Großenrode

Seite:

links

\section{Ges./Kr.: Gesund}

Verband

Verband

Geschlecht: $q>{ }^{\lambda}$

Arthrose:

\section{Beschreibung:}

Eine sehr grazile Clavicula, laterale und mediale Gelenkfläche fehlen. 
Bezeichn.: Clavicula

Kiste:

Skelet: K270 P4

Population: Großenrode

Seite:

links
Verband: $\quad$ Verband

Alter: Erwachsen

Geschlecht:

Arthrose:
Maß

gr. Länge

Umfang Schaftmitte \begin{tabular}{|l|l} 
Wert & Einheit \\
\hline 135 & $\mathrm{~mm}$
\end{tabular}

$\mathrm{mm}$

$47 \mathrm{~mm}$

\section{Beschreibung:}

Eine insgesamt gut erhaltene Clavicula. 
Bezeichn.: Clavicula

Kiste: 3

Skelet: $\quad$ K270 P4

Population: Großenrode

Seite:

rechts
Ges./Kr.: Krank

Krankh.: Muskelreizung

Myotendopathie
Maß

Umfang Schaftmitte
Wert $\quad$ Einheit

Geschlecht:

Arthrose:

\section{Beschreibung:}

Gut und fast vollständig erhalten. Muskelreizung am sternalen Teil. 
Bezeichn:: Clavicula

Kiste: $\quad 10$

Skelet: $\quad 63 / 52$

Population: Großenrode

Seite:

links
Verband: $\quad$ Verband

Alter: Erwachsen

Geschlecht:

Arthrose:
Ges./Kr.: Gesund

Maß

Umfang Schaftmitte \begin{tabular}{|l|l} 
Wert & Einheit \\
\hline 60 &
\end{tabular}

\begin{tabular}{l|l}
60 & $\mathrm{~mm}$
\end{tabular}

\section{Beschreibung:}

Ein Drittel sternal erhalten. prox. 
Bezeichn.: Clavicula

Kiste: $\quad 10$

Skelet: 62/53

Population: Großenrode

Seite:

rechts
Verband: $\quad$ Verband

Alter: Erwachsen

Geschlecht:

Arthrose:

Beschreibung:

$65 \%$ lateral erhalten.

Maß

Umfang Schaftmitte

Wert $\quad$ Einheit

\begin{tabular}{ll|}
40 & $\mathrm{~mm}$
\end{tabular}




\section{Bezeichn.: Clavicula}

Kiste:

10

Skelet: $\quad 62 / 53$

Population: Großenrode

Seite:

rechts
Verband: $\quad$ Verband

Alter: $\quad 10-25$

Geschlecht:

Arthrose:

\section{Beschreibung:}

Ein sternales Fragment, es ist etwa die Hälfte erhalten. 
Bezeichn.: Clavicula

\section{Kiste:}

Skelet: 4. Tüte aus $62 / 52$

Population: Großenrode

Seite:

rechts

Verband: $\quad$ Verband

\section{Alter:}

Geschlecht:

Arthrose:

\section{Beschreibung:}

$50 \%$ lateral erhalten, stark erodiert. 


\section{Bezeichn.: Clavicula}

Kiste:

5

Skelet: K265 62/67 S3

Population: Großenrode

Seite:

rechts
Ges./Kr.: Gesund

\section{Alter:}

Geschlecht: $q \geq \curvearrowright$

Arthrose:

\begin{tabular}{l|l|l} 
Maß & Wert & Einheit \\
\hline gr. Länge & 130 & $\mathrm{~mm}$ \\
Umfang Schaftmitte & 30 & $\mathrm{~mm}$ \\
& & \\
& & \\
& &
\end{tabular}

\section{Beschreibung:}

Eine sehr stark erodierte und grazile Clavicula der rechten Seite. 


\section{Bezeichn.: Clavicula}

Kiste: $\quad 5$

Skelet: $\quad$ K153 62/69 S2

Population: Großenrode

Seite:

links
Ges./Kr.: Gesund

Maß

Umfang Schaftmitte

Erwachsen

\section{Geschlecht:}

Arthrose:

\section{Beschreibung:}

Ein proximales Fragment, es sind etwa $10 \%$ erhalten. 


\section{Bezeichn.: Clavicula}

Kiste: 5

Skelet: K144 61/69 P3

Population: Großenrode

Seite:

rechts
Ges./Kr.: Gesund

Alter: Erwachsen

Geschlecht: $q \geq 0^{\lambda}$

Arthrose:

\section{Beschreibung:}

Ein stark erodiertes Fragment einer Clavicula, es ist ein distaler Teil erhalten, welcher etwa 50\% ausmacht. 
Bezeichn.: Scapula

\section{Kiste:}

Skelet: $\quad$ K308 63/67 P4

Population: Großenrode

Seite:
Verband:

\section{Alter:}

Geschlecht:

Arthrose:

\section{Ges./Kr.: Gesund}

\section{Beschreibung:}

Es ist insgesamt etwa 1/3 erhalten, mit Ansatz des Acromions, Margo lateralis und etwa $70 \%$ der Cavitas glenoidalis. 


\section{Bezeichn.: Scapula}

\section{Kiste:}

Skelet: $\quad 63 / 67$ S3 K287

Population: Großenrode

Seite:

\section{Verband:}

\section{Alter:}

Geschlecht:

Arthrose:

\section{Ges./Kr.: Gesund}

\section{Beschreibung:}

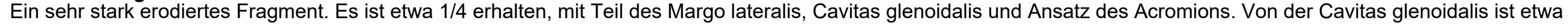
$1 / 4$ erhalten. 


\section{Bezeichn.: Scapula}

Kiste:

Skelet: $\quad 63 / 67$ P4 K330

Population: Großenrode

Seite:
Verband: $\square$ Verband

Alter:

Geschlecht:

Arthrose:
Ges./Kr.: Krank

Krankh.: Arthrose

\section{Beschreibung:}

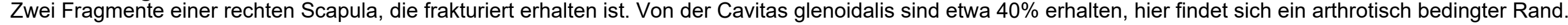
Insgesamt sind von der Scapula etwa $25 \%$ erhalten. 
Bezeichn.: Scapula

Kiste:

Skelet: $\quad 63 / 67$ S3 K291

Population: Großenrode

Seite:
Verband: $\quad \square$ Verband

\section{Alter:}

\section{Geschlecht:}

Arthrose:

\section{Beschreibung:}

Ein kleines Fragment einer rechten Scapula, welches sehr stark erodiert ist. Es ist ein kleiner Teil des Processus coracoideus und ein kleiner Teil der Cavitas glenoidalis erhalten. 
Bezeichn.: Scapula

Kiste:

Skelet: K155 63/67-S2

Population: Großenrode

Seite:
Verband:

Verband

\section{Alter:}

\section{Geschlecht:}

Arthrose:
Ges./Kr.: Gesund

\section{Beschreibung:}

Etwa 1/5 einer Scapula der linken Seite. Das Fragment ist erodiert und hat etwa 1/3 der Cavitas glenoidalis und einen Teil des Ansatzes des Acromions. Weiterhin ist noch ein Teil des Margo lateralis erhalten. 
Bezeichn.: Scapula

\section{Kiste:}

Skelet: K315 62/63 P4

Population: Großenrode

Seite:
Verband: $\quad$ Verband

\section{Alter:}

\section{Geschlecht:}

Arthrose:

\section{Beschreibung:}

Dieses Fundstück ist ein kleines Fragment von einem Acromion der linken Seite. 


\section{Bezeichn.: Scapula}

Kiste:

Skelet: $\quad$ K313 62/63 P4

Population: Großenrode

Seite: rechts

\section{Verband:}

Alter:

Verband Jung

Geschlecht: $q \geq 0$

Arthrose:

\section{Ges./Kr.: Gesund}

\section{Beschreibung:}

Ein Fragment einer rechten Scapula. Das Fundstück ist stark erodiert und zu etwa 1/5 erhalten. Die Cavitas glenoidalis ist zu $30 \%$ befundbar. Weiterhin ist der Ansatz des acromions und ein kleiner Teil des Margo lateralis erhalten. 


\section{Bezeichn.: Scapula}

\section{Kiste:}

Skelet: $\quad$ K178 60/64 P3

Population: Großenrode

Seite:
Verband:

\section{Alter:}

Geschlecht:

Arthrose:
Ges./Kr.: Gesund

\section{Beschreibung:}

Ein Fragment mit dem Ansatz des acromions und 40\% der Cavitas glenoidalis. Das Fragment macht etwa 1/5 des gesamten Knochens aus. 
Bezeichn.: Scapula

Kiste:

Skelet: $\quad$ K11360/64 S2

Population: Großenrode

Seite:
Verband:

Alter:

Verband

Geschlecht:

Arthrose:
Ges./Kr.: Gesund

re.
Maß

Breite

Länge
Wert 1 Einheit

$16,75 \mathrm{~mm}$

34,25

$\mathrm{mm}$

\section{Beschreibung:}

Ein Fragment einer rechten Scapula eines juvenilen Individuums, es macht etwa 1/5 der gesamten Scapula aus. Die Oberfläche ist stark erodiert 
Bezeichn.: Scapula

\section{Kiste:}

Skelet: K196 60/64 P4

Population: Großenrode

Seite:

\section{Verband: $\quad$ Verband}

\section{Alter:}

Geschlecht: $q>\hat{\jmath}$

Arthrose:

\section{Beschreibung:}

Dieses Fragment einer linken Scapula ist aufgrund seiner grazilen Beschaffenheit einem weiblichen Individuum zuzuordnen. Es ist stark erodiert und kann nicht befundet werden. Erhalten sind die Ansätze von acromion und Processus coracoideus, ein kleiner Teil des Margo lateralis und ist die Cavitas glenoidalis, allerdings in sehr stark erodiertem Zustand. 
Bezeichn.: Scapula

Kiste:

Skelet: $\quad$ K196 60/64 P4

Population: Großenrode

Seite:

rechts
Verband: $\quad \square$ Verband

Ges./Kr.: Gesund

\section{Alter:}

Geschlecht: $\rho>\hat{\sigma}$

Arthrose:

\section{Beschreibung:}

Ein kleines Fragment einer rechten Scapula. Das Fragment ist stark erodiert und enthält lediglich den Ansatz des Acromions. 
Bezeichn.: Scapula

Kiste:

Skelet: $\quad$ K127 62/68 S2

Population: Großenrode

Seite:

rechts
Verband: Verband

\section{Alter:}

\section{Geschlecht:}

Arthrose:

\section{Beschreibung:}

Fragment mit Ansatz des Acromions. Sehr klein und extrem erodiert. 


\section{Bezeichn.: Scapula}

Kiste:

6

Skelet: K102 62/62 S2

Population: Großenrode

Seite:

rechts
Verband: Verband

\section{Alter:}

Geschlecht:

Arthrose:
Maß

Breite

Länge
Wert $\quad$ Einheit

36,65 $\mathrm{mm}$

39,45

$\mathrm{mm}$

\section{Beschreibung:}

Ein kleines Fragment einer rechten Scapula mit Ansatz des Acromions. 
Bezeichn.: Scapula

Kiste:

Skelet: $\quad 61 / 54$

Population: Großenrode

Seite:

links
Verband: $\quad \square$ Verband

\section{Alter: Jung}

Geschlecht:

Arthrose:
Ges./Kr.: Gesund

\section{Beschreibung:}

Hier ist ein Fragment einer linken Scapula mit Teil der Gelenkepiphyse und Ansatz des Acromions erhalten. 
Bezeichn.: Scapula

Kiste:

Skelet: $\quad 63 / 58$

Population: Großenrode
Verband:

\section{Alter:}

Ges./Kr.: Gesund

Geschlecht:

Arthrose:
Maß

Breite

Länge \begin{tabular}{|l|l} 
Wert & Einheit \\
17,09 & mm
\end{tabular}

$17,09 \mathrm{~mm}$

$24,72 \mathrm{~mm}$

\section{Beschreibung:}

Von dieser Scapula ist nur ein Fragment der Epiphyse der Cavitas glenoidalis erhalten 


\section{Bezeichn.: Scapula}

Kiste: 2

Skelet: $\quad 64 / 52$

Population: Großenrode

Seite:
Verband: $\square$ Verband

Alter: Jung

Geschlecht:

Arthrose:

\section{Beschreibung:}

Hier ist ein Fragment einer rechten Scapula erhalten, welche einem jungen Individuum zuzuordnen ist. Das Fragment stammt vom Ansatz des Acromions, welches wohl noch nicht verknöchert war. 
Bezeichn.: Scapula

\section{Kiste:}

Skelet: 63/53

Population: Großenrode

Seite:
Verband:

\section{Alter:}

Geschlecht:

Arthrose:

Ges./Kr.: Gesund

\section{Beschreibung:}

Von dieser Scapula der rechten Seite sind der Ansatz des Acromions und 1/5 des Gelenks erhalten 
Bezeichn.: Scapula

Kiste:

Skelet: $\quad 64 / 53$

Population: Großenrode

Seite:

links
Verband: $\square$ Verband

Ges./Kr.: Gesund

\section{Alter:}

\section{Geschlecht:}

Arthrose:

\section{Beschreibung:}

Von dieser Scapula ist nur ein sehr kleines Fragment vom Ansatz des Processus coracoideus erhalten. 
Bezeichn.: Scapula

Kiste:

Skelet: $\quad 63 / 52$

Population: Großenrode

Seite:

links
Verband:

Verband

\section{Alter:}

\section{Geschlecht:}

Arthrose:
Ges./Kr.: Gesund

\section{Ges./Kr: : Gesund}

\section{Beschreibung:}

Von dieser Scapula der linken Seite ist nur ein Fragment erhalten. Vorhanden ist die komplette Gelenkfläche sie ist nur teilweise erodiert. 
Bezeichn.: Scapula

Kiste:

Skelet: $\quad 63 / 52$

Population: Großenrode

Seite:
Verband:

Verband

\section{Alter:}

Geschlecht:

Arthrose:

\section{Beschreibung:}

Dies ist ein kleines Fragment einer rechten Scapula, es ist lateral erhalten mit dem Ansatz des Processus coracoideus. 
Bezeichn.: Scapula

Kiste:

Skelet: $\quad 63 / 52$

Population: Großenrode

Seite:

rechts
Verband: $\quad$ Verband

\section{Alter:}

\section{Geschlecht:}

Arthrose:

\section{Beschreibung:}

Diese Scapula der rechten Seite ist in Form von einem Teil des Processus coracoideus erhalten, es ist nur ein kleines Fragment. 
Bezeichn.: Scapula

Kiste: 2

Skelet: $\quad 61 / 58$

Population: Großenrode

Seite:

links
Verband: $\square$ Verband

Alter: Jung

Geschlecht:

Arthrose:

\section{Beschreibung:}

Hier sind stark erodierte Fragmente einer noch nicht ausgewachsenen Scapula erhalten. 


\section{Bezeichn.: Scapula}

\section{Kiste: 2}

Skelet: $\quad$ aus kleiner Tüte in großer

Population: Großenrode

Seite:
Verband: $\quad$ Verband

\section{Alter:}

Geschlecht:

Arthrose:
Maß

Breite

Länge
Wert $\quad$ Einheit

$33,23 \mathrm{~mm}$

33,4

\section{Beschreibung:}

Ein kleines Fragment mit Ansatz des Processus coracoideus. 
Bezeichn.: Scapula

Kiste: 3

Skelet: $\quad$ K268 63/64 S3

Population: Großenrode

Seite:
Verband:

Verband

\section{Alter:}

Geschlecht:

Arthrose:

\section{Beschreibung:}

Fragment mit $60 \%$ der Cavitas glenoidalis, insgesamt $1 / 3$ erhalten. 
Bezeichn:: Scapula

Kiste:

Skelet: K2322 63/63 S4

Population: Großenrode

Seite:
Verband:

Verband

\section{Alter:}

Geschlecht:

Arthrose:

\section{Ges./Kr.: Gesund}

\section{Beschreibung:}

Ein Fragment. 
Bezeichn.: Scapula

Kiste:

Skelet: K193

Population: Großenrode

Seite: rechts
Verband:

\section{Alter:}

Geschlecht:

Arthrose:

\section{Beschreibung:}

Dieses Fragment macht 1/4 der Scapula aus. 
Bezeichn.: Scapula

Kiste:

Skelet: K58

Population: Großenrode

Seite: rechts
Verband: Verband

\section{Alter: Jung}

Geschlecht:

Arthrose:

\section{Beschreibung:}

Ein Fragment, 1/5 sind erhalten. 
Bezeichn.: Scapula

Kiste:

Skelet: $\quad 62 / 53$

Population: Großenrode

Seite:

links

Verband: Verband

Alter:

Geschlecht:

Arthrose:

\section{Beschreibung:}

Ein Fragment. 
Bezeichn.: Scapula

Kiste: 10

Skelet: $\quad 62 / 53$

Population: Großenrode

Seite:

Verband: Verband

Alter:

Geschlecht:

Arthrose:

\section{Beschreibung:}

Ein Fragment der Scapula, es ist der Processus coracoideus erhalten. 
Bezeichn.: Scapula

Kiste:

Skelet: $\quad 62 / 53$

Population: Großenrode

Seite:

rechts
Verband: $\quad$ Verband

Alter:

Geschlecht:

Arthrose:

\section{Beschreibung:}

Ein Scapulafragment mit Cavitas glenoidalis, es ist stark erodiert und es ist nur 1/7 erhalten. 
Bezeichn.: Scapula

Kiste: $\quad 10$

Skelet: $\quad 61 / 52$

Population: Großenrode

Seite:

links
Verband: $\square$ Verband

\section{Alter: Jung}

Geschlecht: $\rho>\hat{\sigma}$

Arthrose:

\section{Beschreibung:}

Dies ist ein Fragment einer grazilen Scapula der linken Seite. 
Bezeichn.: Scapula

Kiste: 10

Skelet: $\quad 63 / 54$

Population: Großenrode

Seite:

rechts
Verband: Verband

\section{Alter:}

Geschlecht:

Arthrose:

\section{Beschreibung:}

Ein erodiertes Scapulafragment einer grazilen Scapula. 
Bezeichn.: Scapula

Kiste: 10

Skelet: $\quad 63 / 54$

Population: Großenrode

Seite:

links
Verband: Verband

\section{Alter:}

Geschlecht:

Arthrose:

\section{Beschreibung:}

Ein kleines Scapulafragment, welches stark erodiert ist. 
Bezeichn.: Scapula

Kiste: $\quad 10$

Skelet: $\quad 63 / 54$

Population: Großenrode

Seite:

links

Verband: Verband

Alter:

Geschlecht:

Arthrose:

\author{
Beschreibung: \\ Ein erodiertes Scapulafragment.
}


Bezeichn.: Scapula

Kiste:

Skelet: K282 S3

Population: Großenrode

Seite:

links
Verband:

Verband

\section{Alter:}

Geschlecht:

Arthrose:

\section{Beschreibung:}

Ein Fragment. 
Bezeichn.: Scapula

Kiste:

Skelet: K242

Population: Großenrode

Seite:

links
Verband:

\section{Alter:}

Geschlecht:

Arthrose:

\section{Beschreibung:}

Ein kleines Fragment einer linken Scapula. 
Bezeichn:: Scapula

Kiste:

Skelet: K186

Population: Großenrode

Seite:

links

\section{Beschreibung:}

Ein Fragment.
Verband:

Verband

\section{Alter:}

Geschlecht:

Arthrose:

\section{Ges./Kr.: Gesund}

\section{Ges.Kr.: Gesund}


Bezeichn.: Scapula

Kiste:

Skelet: K238-4

Population: Großenrode

Seite:
Verband:

Verband

\section{Alter:}

Geschlecht:

Arthrose:

\section{Beschreibung:}

Ein Fragment. 


\section{Bezeichn.: Scapula}

\section{Kiste:}

Skelet: K236-3

Population: Großenrode

Seite:
Verband: $\quad$ Verband

Alter: Jung

Geschlecht:

Arthrose:

\section{Beschreibung:}

Ein Fragment mit Cavitas glenoidalis. Die Gelenkfläche sieht so aus, als wäre sie noch nicht ausgewachsen gewesen. 
Bezeichn.: Scapula

Kiste:

Skelet: 283

Population: Großenrode

Seite:
Verband:

Verband

\section{Alter:}

Geschlecht:

Arthrose:

\section{Beschreibung:}

Ein Fragment. 
Bezeichn.: Scapula

\section{Kiste:}

Skelet: K243

Population: Großenrode

Seite:
Verband: Verband

\section{Alter:}

Geschlecht:

Arthrose:

\section{Beschreibung:}

Fragment mit kleinem Teil Processus coracoideus. 
Bezeichn.: Scapula

Kiste:

Skelet: $\quad 61 / 69-4$

Population: Großenrode

Seite:

rechts
Verband: $\square$ Verband

Alter: $6-8$

Geschlecht:

Arthrose:

\section{Beschreibung:}

Eine stark fragmentierte und erodierte Scapula. Etwa 1/4 erhalten, die Epiphysenfuge war nicht verwachsen und ist stark erodiert. 
Bezeichn.: Scapula

Kiste:

Skelet: $\quad \mathrm{K} 153-1$

Population: Großenrode

Seite:
Verband: $\square$ Verband

Alter:

Geschlecht: $\hat{0}$

Arthrose:

\section{Ges./Kr.: Gesund}

\section{Beschreibung:}

Ein Fragment einer massiven Scapula, es ist das Acromion und die Facies glenoidalis erhalten. Insgesamt sind $25 \%$ erhalten. 
Bezeichn.: Scapula

Kiste:

Skelet: $\quad$ K153 62/69 S2

Population: Großenrode

Seite:

rechts
Verband: $\square$ Verband

\section{Alter:}

\section{Geschlecht:}

Arthrose:

\section{Beschreibung:}

Ein Fragment einer rechten Scapula, es ist nur der Ansatz des Acromions erhalten distal. 
Bezeichn.: Scapula

Kiste:

Skelet: K153 62/69 S2

Population: Großenrode

Seite:

Verband: $\quad$ Verband

\section{Alter:}

Geschlecht:

Arthrose:

\section{Beschreibung:}

Fragment, es ist der Ansatz des Acromions erhalten proximal. 


\section{Bezeichn.: Scapula}

Kiste:

Skelet: $\quad$ K153 62/69 S2

Population: Großenrode

Seite:

links
Verband: $\square$ Verband

\section{Alter: $\quad 3-7$}

Geschlecht:

Arthrose:
Ges./Kr.: Gesund

\begin{tabular}{l|l|l} 
Maß & Wert & Einheit \\
\hline Breite & 13,38 & $\mathrm{~mm}$ \\
Länge & 17,8 & $\mathrm{~mm}$ \\
& & \\
& & \\
& &
\end{tabular}

\section{Beschreibung:}

Ein Fragment einer linken Scapula mit einem Teil der Cavitas glenoidalis. Durch die Konstitution derselben ist ein noch nicht ausgewachsenes Individuum anzunehmen. 
Bezeichn.: Scapula

\section{Kiste:}

Skelet: 61/67-3

Population: Großenrode

Seite:

Verband: $\quad$ Verband

Alter:

Geschlecht:

Arthrose:

\section{Beschreibung:}

Ein Fragment des Acromions. 
Bezeichn.: Scapula

Kiste:

Skelet: K257 61/67-S3

Population: Großenrode

Seite:

Verband: $\quad$ Verband

\section{Alter:}

Geschlecht:

Arthrose:

\section{Beschreibung:}

Ein kleines Fragment aus dem Ansatz des Acromions. 
Bezeichn:: Scapula

Kiste:

Skelet: $\quad$ K154 61/68-S2

Population: Großenrode

Seite:
Verband: $\square$ Verband

Alter:

Geschlecht: $q>\widehat{\jmath}$

Arthrose:

\section{Ges./Kr.: Gesund}

\section{Beschreibung:}

Eine zu 40\% erhaltene Scapula, dessen Facies glenoidalis zu 50\% zu befunden blieb. Die knöchernen Strukturen weisen eher auf ein weibliches Individuum hin. 
Bezeichn:: Scapula

\section{Kiste:}

Skelet: $\quad 61 / 68-3$

Population: Großenrode

Seite:
Verband:

Verband

\section{Alter:}

Geschlecht: $q=\lesssim$

Arthrose:

\section{Ges./Kr.: Gesund}

\section{Beschreibung:}

Hier ist etwa die Hälfte einer rechten Scapula erhalten. Das Fragment beinhaltet einen Teil des Margo lateralis, die Facies glenoidalis, das Acromion und den Processus coracoideus. Die Gelenkfläche ist zu $60 \%$ befundbar. 
Bezeichn.: Obere Extremität

\section{Kiste:}

Skelet:

Population: Großenrode
Verband: Verband

\section{Alter:}

Geschlecht:

Arthrose:

\section{Beschreibung:}

Ein Fragment eines Langknochens der oberen Extremität, welches nicht genauer zuzuordnen war. 
Bezeichn:: Humerus

Kiste: 9

Skelet: $\quad$ K247 63/67 S3

Population: Großenrode

Seite: rechts

Erhaltung: $\square$ prox. Gelenk

X prox. Schaft

$X$ mittl. Schaft

$\mathbf{X}$ dist. Schaft

dist. Gelenk

\section{Beschreibung:}

Ein sehr stark erodiertes Fundstück, es sind 2/3 aus dem distalen Schaft erhalten.
Verband: $\quad$ Verband Ges./Kr.: Gesund

\section{Alter: Jung}

Geschlecht: $q \geq 0$

Arthrose:

\section{Maß}

Umfang Schaftmitte

Umfang ü. Tub. deltoidea \begin{tabular}{|l|l} 
Wert & Einheit \\
\hline 50 & mm
\end{tabular}

$50 \mathrm{~mm}$

$50 \quad \mathrm{~mm}$


Bezeichn:: Humerus

Kiste: 9

Skelet: $\quad$ K298 63/67 S3

Population: Großenrode

Seite: links

Erhaltung: $\mathbf{X}$ prox. Gelenk

X prox. Schaft

mittl. Schaft

dist. Schaft

dist. Gelenk
Verband: $\quad$ Verband

Alter: Erwachsen

Geschlecht:

Arthrose:

\section{Ges./Kr.: Gesund}

\section{Maß}

Caput frontaler $\varnothing$

Umfang ü. Tub. deltoidea

\begin{tabular}{l|l} 
Wert & Einheit
\end{tabular}

\section{Beschreibung:}

prox.

2

Ein proximales Fragment, etw 1/3. Die Gelenkfläche ist zu etwa 40\% erhalten. Es handelt sich um ein frakturiertes und erodiertes Fragment. 
Bezeichn:: Humerus

Kiste:

Skelet: K295 63/67 S3

Population: Großenrode

Seite: rechts

Erhaltung: $\square$ prox. Gelenk

$X$ prox. Schaft

X mittl. Schaft

dist. Schaft

dist. Gelenk
Verband: $\quad$ Verband

\section{Alter:}

Geschlecht: $q<0$

Arthrose:

\section{Maß}

Umfang Schaftmitte

Umfang ü. Tub. deltoidea \begin{tabular}{|l|l} 
Wert & Einheit \\
\hline 61 &
\end{tabular}

$\mathrm{mm}$

$\mathrm{mm}$

\section{Beschreibung:}

Zwei stark erodierte Fragmente eines eher männlichen Os humeri, es sind insgesamt etwa 2/3 des Schaftes erhalten. 


\begin{tabular}{|c|c|c|c|c|c|c|}
\hline Bezeichn.: & Humerus & $\square$ Verband & Ges./Kr.: Gesund & $\mathrm{Maß}$ & Wert & Einheit \\
\hline Kiste: & 9 & Alter: & & Epicondylenbreite & 39 & $\mathrm{~mm}$ \\
\hline Skelet: & $63 / 67$ S3 K287 & Geschlecht: & & Umfang Schaftmitte & 43 & $\mathrm{~mm}$ \\
\hline Population: & Großenrode & Arthrose: & & Umfang ü. Tub. deltoidea & 48 & $\mathrm{~mm}$ \\
\hline Seite: & links & & & & & \\
\hline Erhaltung: & $\square$ prox. Gelenk & & & & & \\
\hline & $\square$ prox. Schaft & & & & & \\
\hline & $\mathbf{X}$ mittl. Schaft & & & & & \\
\hline & $\mathbf{X}$ dist. Schaft & & & & & \\
\hline & $\mathbf{X}$ dist. Gelenk & & & & & \\
\hline
\end{tabular}

\section{Beschreibung:}

Hier handelt es sich um ein Os humeri, welches wohl einem jungen Individuum zuzuordnen ist. Es ist das distale 2/3 erhalten. Die Epiphysenfuge distal ist nicht geschlossen gewesen, die distale Epiphyse ist nicht erhalten. 
Bezeichn:: Humerus

Kiste:

Skelet: $\quad 63 / 67$ S3 K287

Population: Großenrode

Seite: rechts

Erhaltung: $\mathbf{X}$ prox. Gelenk

$X$ prox. Schaft

X mittl. Schaft

$\mathbf{X}$ dist. Schaft

X dist. Gelenk
Verband: $\quad \square$ Verband

Alter: Erwachsen

\section{Geschlecht: $q<0$}

Arthrose:

prox.

dist.
Ges./Kr.: Gesund

\section{Maß}

Epicondylenbreite

gr. Länge

Umfang Schaftmitte

Umfang ü. Tub. deltoidea

\begin{tabular}{|l|l} 
Wert & Einheit \\
\hline 58,5 & $\mathrm{~mm}$
\end{tabular}

\section{Beschreibung:}

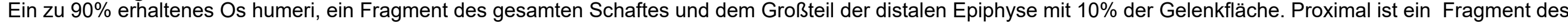
Caput humeri erhalten, wessen Gelenkfläche zu 30\% erhalten ist. 
Bezeichn:: Humerus

Kiste:

9

Skelet: $\quad$ 63/67 -P4 K323

Population: Großenrode

Seite: rechts

Erhaltung: $\square$ prox. Gelenk

prox. Schaft

$X$ mittl. Schaft

dist. Schaft

dist. Gelenk

\section{Beschreibung:}

Ein sehr stark erodiertes und frakturiertes Fragment au dem Schaft eines Humerus. Es ist etwa 1/3 erhalten.

\section{Verband: \\ Verband \\ Ges./Kr.: Gesund}

\section{Geschlecht:}

\section{Arthrose:}


Bezeichn:: Humerus

Kiste:

9

Skelet: $\quad$ 63/67 S3 K302

Population: Großenrode

Seite: rechts

Erhaltung: $\square$ prox. Gelenk

prox. Schaft

mittl. Schaft

X dist. Schaft

$$
\text { dist. Gelenk }
$$

\section{Beschreibung:}

Verband: $\square$ Verband Ges./Kr.: Gesund

\section{Alter:}

Geschlecht:

Arthrose:

Ein Fragment aus dem distalen Teil des Schaftes. Es ist insgesamt etwa 1/3 erhalten. 
Bezeichn:: Humerus

\section{Kiste:}

9

Skelet: $\quad$ 63/67 -P4 K330

Population: Großenrode

Seite: links

Erhaltung: $\square$ prox. Gelenk

X prox. Schaft

mittl. Schaft

dist. Schaft

dist. Gelenk

\section{Beschreibung:}

Ein Fragment aus dem proximalen Schaft eines Humerus. Sehr massiv.

\section{Ges./Kr.: Gesund}

\section{Alter:}

Geschlecht: $q<\curvearrowright$

Arthrose:

\section{Maß}

Umfang Schaftmitte

Umfang ü. Tub. deltoidea

\begin{tabular}{|l|l} 
Wert & Einheit \\
65 & $\mathrm{~mm}$
\end{tabular}

\begin{tabular}{l|l}
65 & $\mathrm{~mm}$
\end{tabular}

$71 \quad \mathrm{~mm}$


Bezeichn:: Humerus

\section{Kiste:}

7

Skelet: K155-1 63/67-S2

Population: Großenrode

Seite: rechts

Erhaltung: $\mathbf{X}$ prox. Gelenk

$X$ prox. Schaft

X mittl. Schaft

$\mathbf{X}$ dist. Schaft

X dist. Gelenk
Ges./Kr.: Gesund

Verband

Alter: $\quad 16-18(19)$

Geschlecht: $q \geq \AA$

Arthrose:

$$
\text { prox. }
$$

dist.

\section{Maß}

Caput frontaler $\varnothing$

Caput, sagittaler $\varnothing$

Epicondylenbreite

gr. Länge

Umfang Schaftmitte

Umfang ü. Tub. deltoidea

\begin{tabular}{|l|l} 
Wert & Einheit \\
\hline 36,3 & $\mathrm{~mm}$
\end{tabular}

35,8

$35,8 \quad \mathrm{~mm}$

$52 \mathrm{~mm}$

$281 \mathrm{~mm}$

$49 \quad \mathrm{~mm}$

\begin{tabular}{l|l}
49 & $\mathrm{~mm}$ \\
58 & $\mathrm{~mm}$
\end{tabular}

\section{Beschreibung:}

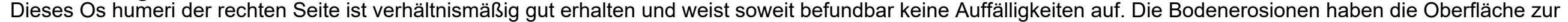

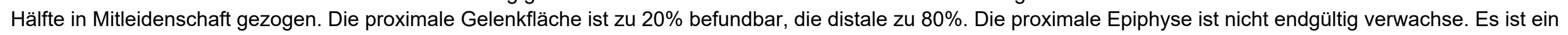
deutlicher Spalt zu erkennen. Das zugehörige Individuum kann als juvenil eingestuft werden. 
Bezeichn.: Humerus

Kiste:

Skelet: K164 61/68-P3

Population: Großenrode

Seite: rechts

Erhaltung: $\square$ prox. Gelenk prox. Schaft

$X$ mittl. Schaft

$\mathbf{X}$ dist. Schaft

X dist. Gelenk
Verband: $\quad$ Verband

Alter: Erwachsen

Geschlecht: $q \geq \widehat{O}$

Arthrose:
Ges./Kr.: Gesund

dist.

\section{Maß}

Epicondylenbreite

Umfang Schaftmitte \begin{tabular}{|l|l} 
Wert & Einheit \\
54,72 & mm
\end{tabular}

$54,72 \mathrm{~mm}$

$61 \quad \mathrm{~mm}$

\section{Beschreibung:}

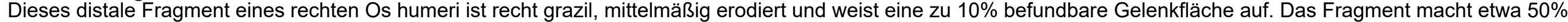
des gesamten Knochens aus. 
Bezeichn:: Humerus

Kiste:

7

Skelet: K40 63/63-S1

Population: Großenrode

Seite: rechts

Erhaltung: $\square$ prox. Gelenk

X prox. Schaft

$X$ mittl. Schaft

$\mathbf{X}$ dist. Schaft

dist. Gelenk
Verband: $\square$ Verband

\section{Alter:}

Geschlecht: $\curvearrowright$

Arthrose:
Ges./Kr.: Gesund

\section{Maß}

Umfang Schaftmitte

Umfang ü. Tub. deltoidea

\begin{tabular}{|l|l|l} 
Wert & Einheit \\
65 & mm
\end{tabular}

\section{Beschreibung:}

Dieses Os humeri ist erodiert erhalten, es liegt fast der gesamte Schaft vor. Der Knochen ist sehr massiv. Das Fundstück weist Tierverbiss auf. 


\section{Bezeichn:: Humerus}

\section{Kiste:}

Skelet: $\quad$ K314 62/65-P4

Population: Großenrode

Seite: links

Erhaltung: $\square$ prox. Gelenk

prox. Schaft

$X$ mittl. Schaft

$\mathbf{X}$ dist. Schaft

$\mathbf{X}$ dist. Gelenk
Verband: $\quad \square$ Verband

\section{Alter: Erwachsen}

Geschlecht: $q<0$

Arthrose:

\section{Ges./Kr.: Gesund}

Maß

Epicondylenbreite

Umfang Schaftmitte

\begin{tabular}{l|l} 
Wert & Einheit \\
\hline 64 & $\mathrm{~mm}$ \\
67 & $\mathrm{~mm}$ \\
&
\end{tabular}

\section{Beschreibung:}

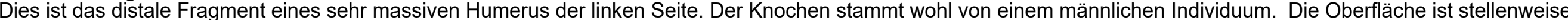
stark erodiert, Die distale Gelenkfläche zu 50\% befundbar. Insgesamt ist etwa die Hälfte des gesamten Knochens erhalten. 
Bezeichn:: Humerus

Kiste: 6

Skelet: $\quad$ K313 62/63 P4

Population: Großenrode

Seite: rechts

Erhaltung: $\square$ prox. Gelenk

prox. Schaft

mittl. Schaft

$\mathbf{X}$ dist. Schaft

X dist. Gelenk
Verband: $\quad$ Verband

Alter: Erwachsen

Geschlecht: $q \geq \widehat{O}$

Arthrose:
Ges./Kr.: Gesund

Maß

Epicondylenbreite

Umfang Schaftmitte

\begin{tabular}{|l|l} 
Wert & Einheit \\
\hline 55 & $\mathrm{~mm}$
\end{tabular}

\section{Beschreibung:}

dist.

1

Ein erodiertes, distales Fragment eines rechten Os humeri. Es ist das distale Drittel des Knochen erhalten. Die Gelenkfläche ist zu $20 \%$ befundbar. 
Bezeichn:: Humerus

Kiste:

Skelet: $\quad$ K313 62/63 P4

Population: Großenrode

Seite: rechts

Erhaltung: $\square$ prox. Gelenk

$X$ prox. Schaft

X mittl. Schaft

dist. Schaft

dist. Gelenk
Verband: $\square$ Verband

\section{Ges./Kr.: Gesund}

\section{Alter:}

Geschlecht: $ð$

Arthrose:

\section{Maß}

Umfang Schaftmitte

Umfang ü. Tub. deltoidea

\begin{tabular}{|l|l} 
Wert & Einheit \\
68 & $\mathrm{~mm}$ \\
71 & $\mathrm{~mm}$ \\
&
\end{tabular}

\section{Beschreibung:}

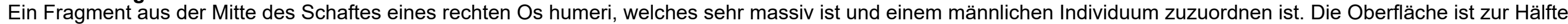
erodiert, das Fragment macht etwa $2 / 3$ des Schaftes aus. 


\section{Bezeichn.: Humerus}

\section{Kiste:}

Skelet: K256 60/64 S3

Population: Großenrode

Seite: links

Erhaltung: $\square$ prox. Gelenk

prox. Schaft

$X$ mittl. Schaft

$\mathbf{X}$ dist. Schaft

X dist. Gelenk
Verband: $\quad \square$ Verband

\section{Alter:}

Geschlecht: $q \geq \hat{\jmath}$

Arthrose:

\section{Maß}

Umfang Schaftmitte

\begin{tabular}{l|l} 
Wert & Einheit \\
\hline 46 & $\mathrm{~mm}$
\end{tabular}

\section{Beschreibung:}

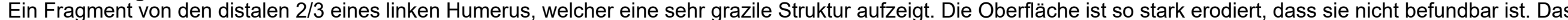

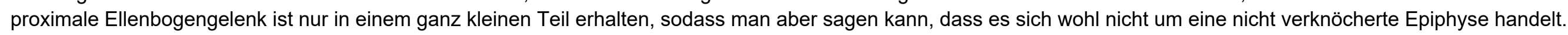


Bezeichn:: Humerus

Kiste:

6

Skelet: $\quad$ K276 63/66 S3

Population: Großenrode

Seite: n. def.

Erhaltung: $\square$ prox. Gelenk

prox. Schaft

$X$ mittl. Schaft

dist. Schaft

dist. Gelenk

\section{Beschreibung:}

Ein Fragment aus dem Schaft eines jungen Humerus. Etwa 1/5 erhalten, erodiert.
Verband: $\quad$ Verband Ges./Kr.: Gesund

\section{Alter: Jung}

Geschlecht:

Arthrose: 
Bezeichn.: Humerus

\section{Kiste:}

Skelet: K224 60/64 S3

Population: Großenrode

Seite: rechts

Erhaltung: $\mathbf{X}$ prox. Gelenk

X prox. Schaft

mittl. Schaft

dist. Schaft

dist. Gelenk

\section{Beschreibung:}

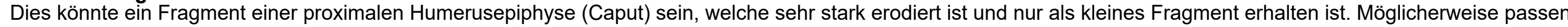
hier ein Fragment der Metaphyse und die Epiphyse zusammen. Es sind nur kleine Fragmente. 
Bezeichn:: Humerus

Kiste:

Skelet: K178 60/64 P3

Population: Großenrode

Seite: links

Erhaltung: $\mathbf{X}$ prox. Gelenk

X prox. Schaft

$X$ mittl. Schaft

$X$ dist. Schaft

dist. Gelenk
Ges./Kr.: Gesund

Alter: Erwachsen

\section{Geschlecht:}

Arthrose:

\section{Maß}

Caput frontaler $\varnothing$

Umfang Schaftmitte

Umfang ü. Tub. deltoidea

\begin{tabular}{|l|l} 
Wert & Einheit \\
\hline 39,7 & $\mathrm{~mm}$
\end{tabular}

54

63

$\mathrm{mm}$

$\mathrm{mm}$

\section{Beschreibung:}

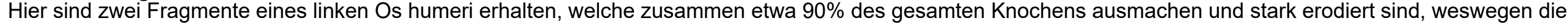
Oberfläche nicht zu befunden ist. Von der Gelenkfläche des Caput humeri sind etwa 10\% erhalten. 
Bezeichn:: Humerus

Kiste:

6

Skelet: $\quad$ K113 60/64 S2

Population: Großenrode

Seite: rechts

Erhaltung: $\square$ prox. Gelenk

prox. Schaft

X mittl. Schaft

$\mathbf{X}$ dist. Schaft

dist. Gelenk
Verband: $\quad$ Verband

\section{Alter:}

Geschlecht:

Arthrose:

\section{Beschreibung:}

Hier ist ein Fragment aus dem distalen Teil des Schaftes erhalten. Das Fundstück ist sehr stark erodiert und macht etwa die Hälfte des Schaftes aus. 
Bezeichn:: Humerus

Kiste:

Skelet: $\quad$ K196 60/64 P4

Population: Großenrode

Seite: links

Erhaltung: $\mathbf{X}$ prox. Gelenk

prox. Schaft

mittl. Schaft

dist. Schaft

dist. Gelenk
Verband: $\quad$ Verband

\section{Alter:}

Geschlecht: $q>\widehat{\diamond}$

Arthrose:

\section{Beschreibung:}

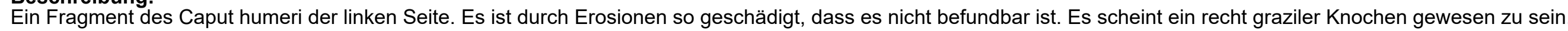


Bezeichn.: Humerus

Kiste:

Skelet: $\quad$ K70 62/68 P2

Population: Großenrode

Seite: rechts

Erhaltung: $\square$ prox. Gelenk

prox. Schaft

$X$ mittl. Schaft

dist. Schaft

dist. Gelenk

\section{Beschreibung:}

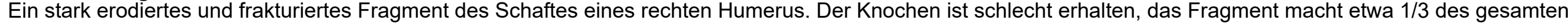
Knochens aus. Der Schaft ist zum Teil längs abfrakturiert. 
Bezeichn.: Humerus

Kiste:

Skelet: $\quad 61 / 54$

Population: Großenrode

Seite: links

Erhaltung: $\square$ prox. Gelenk

X prox. Schaft

mittl. Schaft

dist. Schaft

dist. Gelenk

\section{Beschreibung:}

Es ist hier ein proximales Fragment des Schaftes mit Ansatz zum Gelenk erhalten, es sind etwa 15\% erhalten vom gesamten Knochen.

\section{Verband: $\quad$ Verband Ges./Kr.: Gesund}

\section{Alter:}

Geschlecht:

Arthrose: 


$\begin{array}{ll}\text { Bezeichn.: } & \text { Humerus } \\ \text { Kiste: } & 2 \\ \text { Skelet: } & 61 / 54 \\ \text { Population: } & \text { Großenrode } \\ \text { Seite: } & \text { links } \\ \text { Erhaltung: } & \square \text { prox. Gelenk } \\ & \square \text { prox. Schaft } \\ & \square \text { mittl. Schaft } \\ & \mathbf{X} \text { dist. Schaft } \\ & \square \text { dist. Gelenk }\end{array}$

Beschreibung:

Hier ist ein distales Fragment aus dem distalen Teil des Schaftes erhalten. Es sind etwa 15\% des gesamten Knochens. 
Bezeichn:: Humerus

Kiste:

Skelet: $\quad 65 / 53$

Population: Großenrode

Seite: links

Erhaltung: $\square$ prox. Gelenk

prox. Schaft

mittl. Schaft

X dist. Schaft

dist. Gelenk

\section{Beschreibung:}

Dieses Fragment eines Humerus stammt von distal, es sind etwa 15\% des gesamten Knochens vorhanden.

\section{Verband: $\quad$ Verband Ges./Kr. Gesund}

\section{Alter:}

Geschlecht:

Arthrose: 
Bezeichn.: Humerus

Kiste:

$$
2
$$

Skelet: 61/53

Population: Großenrode

Seite: links

Erhaltung: X prox. Gelenk

prox. Schaft

mittl. Schaft

dist. Schaft

dist. Gelenk

\section{Verband: $\quad$ Verband}

\section{Alter:}

Geschlecht: $q<\hat{\sigma}$

Arthrose:

\section{Beschreibung:}

Hier ist nur ein Fragment dieses linken Caput humeri erhalten. Es ist stark erodiert und nicht befundbar. 
Bezeichn.: Humerus

Kiste:

2

Skelet: $\quad 63 / 57$

Population: Großenrode

Seite: links

Erhaltung: $\square$ prox. Gelenk

prox. Schaft

mittl. Schaft

dist. Schaft

X dist. Gelenk

\section{Beschreibung:}

Dies ist ein Fragment aus dem distalen Teil eines Humerus der linken Seite, es sind 90\% Gelenkfläche beurteilbar.
Verband: $\quad$ Verband

Alter: Erwachsen

Ges./Kr.: Gesund

Geschlecht: $q<\delta$

Arthrose: 


\section{Bezeichn:: Humerus}

Kiste:

2

Skelet: 63/53

Population: Großenrode

Seite: rechts

Erhaltung: $\square$ prox. Gelenk

prox. Schaft

mittl. Schaft

$X$ dist. Schaft

dist. Gelenk

\section{Beschreibung:}

Dies ist ein erodiertes Fragment eines Humerus. Es ist etwa 1/3 des distalen Schafts erhalten.

\section{Verband: $\quad \square$ Verband}

\section{Alter:}

Geschlecht:

Arthrose:
Maß

Umfang Schaftmitte \begin{tabular}{|l|l} 
Wert & Einheit \\
\hline 55 & mm
\end{tabular}

\begin{tabular}{l|l}
55 & $\mathrm{~mm}$
\end{tabular}


Bezeichn.: Humerus

Kiste:

2

Skelet: 63/53

Population: Großenrode

Seite: rechts

Erhaltung: $\square$ prox. Gelenk

prox. Schaft

X mittl. Schaft

dist. Schaft

dist. Gelenk

Beschreibung:

Von diesem Humerus ist $1 / 3$ aus der Schaftmitte erhalten.
Verband: $\square$ Verband

\section{Alter:}

Geschlecht:

Arthrose:
Maß

Umfang ü. Tub. deltoidea \begin{tabular}{|l|l} 
Wert & Einheit
\end{tabular}

\begin{tabular}{|l|l}
53 & $\mathrm{~mm}$ \\
&
\end{tabular}




\section{Bezeichn.: Humerus}

Kiste:

Skelet: $\quad 64 / 53$

Population: Großenrode

Seite: rechts

Erhaltung: $\mathbf{X}$ prox. Gelenk

prox. Schaft

mittl. Schaft

dist. Schaft

dist. Gelenk
Ges./Kr.: Gesund

Alter: $\quad 13-18(19)$

Geschlecht:

Arthrose:

\begin{tabular}{l|l|l} 
Maß & Wert & Einheit \\
\hline Caput frontaler $\varnothing$ & 35 & $\mathrm{~mm}$ \\
Caput, sagittaler $\varnothing$ & 33 & $\mathrm{~mm}$ \\
& & \\
& &
\end{tabular}

\section{Beschreibung:}

Hier ist ein Fragment eines frakturierten Caput humeri der rechten Körperseite erhalten. Es ist erodiert und einem wohl juvenilen Individuum zuzuordnen 


$\begin{array}{ll}\text { Bezeichn.: } & \text { Humerus } \\ \text { Kiste: } & 2 \\ \text { Skelet: } & 63 / 52 \\ \text { Population: } & \text { Großenrode } \\ \text { Seite: } \quad & \text { links } \\ \text { Erhaltung: } & \square \text { prox. Gelenk } \\ & \square \text { prox. Schaft } \\ & \square \text { mittl. Schaft } \\ & \square \text { dist. Schaft } \\ & \mathbf{X} \text { dist. Gelenk }\end{array}$

Verband: $\square$ Verband

Alter: Erwachsen

Geschlecht:

Arthrose:

\section{Beschreibung:}

Hier ist nur ein ganz distales Fragment eines linken Humerus erhalten. Es ist sehr stark erodiert und damit nicht befundbar. 


$\begin{array}{ll}\text { Bezeichn.: } & \text { Humerus } \\ \text { Kiste: } & 2 \\ \text { Skelet: } & 63 / 52 \\ \text { Population: } & \text { Großenrode } \\ \text { Seite: } & \text { rechts } \\ \text { Erhaltung: } & \square \text { prox. Gelenk } \\ & \square \text { prox. Schaft } \\ & \square \text { mittl. Schaft } \\ & \mathbf{X} \text { dist. Schaft } \\ & \mathbf{X} \text { dist. Gelenk }\end{array}$

Verband: $\quad$ Verband

Alter: Erwachsen

\section{Geschlecht:}

Arthrose:

Ges./Kr.: Gesund

\section{Maß}

Epicondylenbreite

Umfang Schaftmitte \begin{tabular}{|l|l} 
Wert & Einheit \\
\hline 56,66 & $\mathrm{~mm}$
\end{tabular}

60

$\mathrm{mm}$

\section{Beschreibung:}

Hier ist ein distales Fragment eines rechten Humerus erhalten, welches stark erodiert ist. 


$\begin{array}{ll}\text { Bezeichn.: } & \text { Humerus } \\ \text { Kiste: } & 2 \\ \text { Skelet: } & 63 / 52 \\ \text { Population: } & \text { Großenrode } \\ \begin{array}{ll}\text { Seite: } & \text { rechts } \\ \text { Erhaltung: } & \square \text { prox. Gelenk } \\ & \square \text { prox. Schaft } \\ & \square \text { mittl. Schaft } \\ & \mathbf{X} \text { dist. Schaft } \\ & \mathbf{X} \text { dist. Gelenk }\end{array} \\ \text { Beschreibung: }\end{array}$

Verband: $\quad$ Verband

Alter: $\quad$ Erwachsen

Geschlecht:

\title{
Arthrose:
}

\begin{abstract}
Ein distales Fragment von Schaft und Gelenkfläche eines rechten Humerus. Allerdings ist das Fundstück wegen Erosion nicht befundbar.
Eisch
\end{abstract}




$\begin{array}{ll}\text { Bezeichn.: } & \text { Humerus } \\ \text { Kiste: } & 2 \\ \text { Skelet: } & 63 / 52 \\ \text { Population: } & \text { Großenrode } \\ \text { Seite: } & \text { rechts } \\ \text { Erhaltung: } & \square \text { prox. Gelenk } \\ & \text { X prox. Schaft } \\ & \mathbf{X} \text { mittl. Schaft } \\ & \square \text { dist. Schaft } \\ & \square \text { dist. Gelenk }\end{array}$

Verband: $\square$ Verband

Alter: Erwachsen

Geschlecht:

\section{Arthrose:}

\begin{tabular}{l|l|l} 
Maß & Wert & Einheit \\
\hline Umfang Schaftmitte & 59 & $\mathrm{~mm}$ \\
Umfang ü. Tub. deltoidea & 62 & $\mathrm{~mm}$ \\
& & \\
& &
\end{tabular}




$\begin{array}{ll}\text { Bezeichn.: } & \text { Humerus } \\ \text { Kiste: } & 2 \\ \text { Skelet: } & 63 / 52 \\ \text { Population: } & \text { Großenrode } \\ \text { Seite: } & \text { links } \\ \text { Erhaltung: } & \square \text { prox. Gelenk } \\ & \square \text { prox. Schaft } \\ & \square \text { mittl. Schaft } \\ & \mathbf{X} \text { dist. Schaft } \\ & \square \text { dist. Gelenk }\end{array}$

Verband: $\quad$ Verband

Alter:

Geschlecht:

Arthrose:

\section{Beschreibung:}

Ein distales Drittel aus dem Schaft als Fragment. 
Bezeichn.: Humerus

Kiste:

Skelet: 63/52

Population: Großenrode

Seite: links

Erhaltung: $\square$ prox. Gelenk

prox. Schaft

mittl. Schaft

dist. Schaft

X dist. Gelenk

Beschreibung:

Hier ist nur ein laterales Fragment der trochlea erhalten, welches sehr stark erodiert und nicht befundbar ist.

Verband: $\quad \square$ Verband

\section{Alter:}

Geschlecht:

Arthrose: 
Bezeichn.: Humerus

Kiste:

2

Skelet: $\quad 63 / 52$

Population: Großenrode

Seite:

links

Erhaltung: $\square$ prox. Gelenk

X prox. Schaft

mittl. Schaft

dist. Schaft

dist. Gelenk

Beschreibung:

Ein Fragment des Schaftes eines linken Os humeri. Etwa 1/4 des proximalen Schaftes.

\section{Verband: $\square$ Verband}

\section{Alter:}

Geschlecht:

Arthrose:
Maß

Umfang ü. Tub. deltoidea

\begin{tabular}{|l|l} 
Wert & Einheit \\
\hline 62 & $\mathrm{~mm}$
\end{tabular}

\begin{tabular}{l|l}
62 & $\mathrm{~mm}$
\end{tabular}


Bezeichn.: Humerus

Kiste: 2

Skelet: $\quad 61 / 58$

Population: Großenrode

Seite: rechts

Erhaltung: $\square$ prox. Gelenk

X prox. Schaft

mittl. Schaft

dist. Schaft

dist. Gelenk

Beschreibung:

Ein nicht befundbares Fragment.
Verband: $\square$ Verband

\section{Alter:}

Geschlecht:

Arthrose:
Maß

Umfang ü. Tub. deltoidea

\begin{tabular}{|l|l} 
Wert & Einheit \\
\hline 62 &
\end{tabular}

\begin{tabular}{l|l}
62 & $\mathrm{~mm}$
\end{tabular}


Bezeichn.: Humerus

Kiste:

Verband:

Verband

\section{Alter:}

Geschlecht:

Skelet: $\quad 61 / 57$

Population: Großenrode

Erhaltung: $\mathbf{X}$ prox. Gelenk

prox. Schaft

mittl. Schaft

dist. Schaft

dist. Gelenk

Beschreibung:

Dies ist das Fragment eines Caput humeri.

\section{Maß}

Caput frontaler $\varnothing$

Wert 1 Einheit

26,12 $\mathrm{mm}$


Bezeichn.: Humerus

Kiste:

$$
2
$$

Skelet: aus großer Tüte und

Population: Großenrode

Seite:

links

Erhaltung: $\square$ prox. Gelenk

prox. Schaft

$X$ mittl. Schaft

dist. Schaft

dist. Gelenk

\section{Beschreibung:}

Ein sehr stark erodiertes und nicht befundbares Fragment.
Verband: $\square$ Verband

\section{Alter:}

Maß

Umfang Schaftmitte

Geschlecht:

Arthrose: 
Bezeichn.: Humerus

Kiste:

$$
2
$$

Skelet: aus großer Tüte und

Population: Großenrode

Seite:

links

Erhaltung: $\square$ prox. Gelenk

prox. Schaft

$X$ mittl. Schaft

dist. Schaft

dist. Gelenk

\section{Beschreibung:}

Verband: $\quad \square$ Verband

\section{Alter:}

Geschlecht:

Ein Fragment eines Os humeri, welches leichte Erosionsspuren aufweist.

\begin{tabular}{l|l}
64 & $\mathrm{~mm}$
\end{tabular}


Bezeichn.: Humerus

Kiste:

2

Skelet: aus großer Tüte und

Population: Großenrode

Seite: rechts

Erhaltung: $\square$ prox. Gelenk

prox. Schaft

$X$ mittl. Schaft

dist. Schaft

dist. Gelenk

\section{Beschreibung:}

Ein Fragment aus dem Schaft eines rechten Os humeri.

\section{Verband: $\quad \square$ Verband}

\section{Alter:}

Geschlecht:

Arthrose:
Maß

Umfang Schaftmitte

Wert $\quad$ Einheit

\begin{tabular}{|l|l}
56 & $\mathrm{~mm}$ \\
&
\end{tabular}


Bezeichn.: Humerus

Kiste:

2

Skelet: aus großer Tüte und

Population: Großenrode

Seite: rechts

Erhaltung: $\square$ prox. Gelenk

X prox. Schaft

X mittl. Schaft

dist. Schaft

dist. Gelenk

\section{Beschreibung:}

Ein Fragment aus dem proximalen Schaft eines rechten Os humeri.
Verband: $\quad$ Verband

\section{Alter:}

Geschlecht: $q<\lambda$

Arthrose:

\section{Maß}

Umfang Schaftmitte

Umfang ü. Tub. deltoidea

\begin{tabular}{|l|l} 
Wert & Einheit \\
\hline 66 & $\mathrm{~mm}$
\end{tabular}


Bezeichn.: Humerus

\section{Kiste: 2}

Skelet: aus großer Tüte und

Population: Großenrode

Seite: links

Erhaltung: $\square$ prox. Gelenk

X prox. Schaft

X mittl. Schaft

dist. Schaft

dist. Gelenk

\section{Beschreibung:}

Ein sehr stark erodiertes Fragment aus dem Schaft eines linken Os humeri.

\section{Verband: $\quad \square$ Verband}

\section{Alter:}

Geschlecht: 0

Arthrose:

\section{Maß}

Umfang Schaftmitte

Umfang ü. Tub. deltoidea \begin{tabular}{|l|l} 
Wert & Einheit \\
\hline 65 &
\end{tabular}

\begin{tabular}{l|l}
65 & $\mathrm{~mm}$
\end{tabular}

$77 \quad \mathrm{~mm}$


Bezeichn.: Humerus

Kiste: 2

Skelet: $\quad$ aus großer Tüte und

Population: Großenrode

Seite: links

Erhaltung: $\square$ prox. Gelenk

prox. Schaft

$X$ mittl. Schaft

$\mathbf{X}$ dist. Schaft

X dist. Gelenk

\section{Beschreibung:}

Ein teilweise erodiertes Fragment eines linken Os humeri, dessen Gelenkfläche nicht zu befunden war.

\section{Alter: Erwachsen}

Geschlecht:

Arthrose:

\section{Verband: $\quad$ Verband}

\section{Maß}

Epicondylenbreite

Umfang Schaftmitte \begin{tabular}{|l|l} 
Wert & Einheit \\
\hline 57 & mm
\end{tabular}

\begin{tabular}{l|l}
57 & $\mathrm{~mm}$
\end{tabular}

63

$\mathrm{mm}$


Bezeichn.: Humerus

Kiste:

$$
2
$$

Skelet: aus großer Tüte und

Population: Großenrode

Seite: rechts

Erhaltung: $\mathbf{X}$ prox. Gelenk

X prox. Schaft

mittl. Schaft

dist. Schaft

dist. Gelenk

\section{Beschreibung:}

Verband: $\quad$ Verband

Alter: Erwachsen

\section{Geschlecht:}

Arthrose:

Ein Fragment aus dem distalen Teil eines rechten Os humeri. 
Bezeichn.: Humerus

Kiste: 2

Skelet: aus großer Tüte und

Population: Großenrode

Seite: rechts

Erhaltung: $\square$ prox. Gelenk

prox. Schaft

mittl. Schaft

dist. Schaft

X dist. Gelenk

\section{Beschreibung:}

Hier ist das distale Gelenk eines rechten Os humeri erhalten, dessen Gelenkfläche zu 95\% befundbar war.

\section{Verband: $\quad$ Verband \\ Alter: Erwachsen}

Geschlecht:

Arthrose:

\section{Ges./Kr.: Gesund}

Maß

Epicondylenbreite

Wert $\quad$ Einheit

$57,87 \mathrm{~mm}$


Bezeichn.: Humerus

Kiste: 2

Skelet: $\quad$ aus großer Tüte und

Population: Großenrode

Seite: rechts

Erhaltung: $\square$ prox. Gelenk

prox. Schaft

mittl. Schaft

dist. Schaft

X dist. Gelenk

Beschreibung:

Ein stark erodiertes Fragment des distalen Gelenks eines rechten Os humeri.

\section{Verband: $\quad \square$ Verband \\ Alter: Erwachsen}

Geschlecht:

Arthrose:
Maß

Epicondylenbreite

\begin{tabular}{|l|l} 
Wert & Einheit \\
\hline 53,77 & mm
\end{tabular}

$53,77 \mathrm{~mm}$


Bezeichn.: Humerus

Kiste:

$$
2
$$

Skelet: aus großer Tüte und

Population: Großenrode

Seite: links

Erhaltung: X prox. Gelenk

prox. Schaft

mittl. Schaft

dist. Schaft

dist. Gelenk

\section{Beschreibung:}

Dies ist ein Fragment des Caput humeri eines Humerus der linken Seite. Es ist stark erodiert.

\section{Alter:}

Geschlecht:

\section{Verband: $\quad$ Verband}

\section{Maß}

Caput frontaler $\varnothing$

\begin{tabular}{l|l} 
Wert & Einheit \\
\hline
\end{tabular}

\begin{tabular}{l|l}
42,5 & $\mathrm{~mm}$
\end{tabular}


Bezeichn.: Humerus

Kiste:

$$
2
$$

Skelet: aus großer Tüte und

Population: Großenrode

Seite: rechts

Erhaltung: $\mathbf{X}$ prox. Gelenk

prox. Schaft

mittl. Schaft

dist. Schaft

dist. Gelenk

\section{Beschreibung:}

Dies ist ein Fragment des Caput humeri eines Humerus der rechten Seite. Es ist stark erodiert.

\section{Verband: $\quad$ Verband}

Alter: Erwachsen

\section{Geschlecht:}

Arthrose:

\section{Maß}

Caput frontaler $\varnothing$

Wert $\quad$ Einheit

\begin{tabular}{ll|l}
44,12 & $\mathrm{~mm}$
\end{tabular}


Bezeichn.: Humerus

Kiste: 2

Skelet: $\quad$ aus großer Tüte und

Population: Großenrode

Seite: links

Erhaltung: $\mathbf{X}$ prox. Gelenk

X prox. Schaft

mittl. Schaft

dist. Schaft

dist. Gelenk

Beschreibung:

Dies ist ein Fragment des Caput humeri eines Humerus der linken Seite. Es ist stark erodiert.
Verband: $\quad$ Verband

\section{Alter: Erwachsen}

\section{Geschlecht:}

Arthrose: 
Bezeichn.: Humerus

Kiste:

2

Skelet: aus großer Tüte und

Population: Großenrode

\section{Erhaltung:}

prox. Gelenk

prox. Schaft

$X$ mittl. Schaft

$\mathbf{X}$ dist. Schaft

dist. Gelenk

\section{Beschreibung:}

Ein Fragment aus dem Schaft.
Verband: $\quad \square$ Verband

\section{Alter:}

Geschlecht:

Arthrose:

\section{Maß}

Umfang Schaftmitte \begin{tabular}{|l|l} 
Wert & Einheit \\
\hline 60 & mm
\end{tabular}

\begin{tabular}{l|l}
60 & $\mathrm{~mm}$
\end{tabular}


Bezeichn.: Humerus

Kiste:

2

Skelet: aus großer Tüte und

Population: Großenrode

\section{Erhaltung:}

prox. Gelenk

prox. Schaft

$X$ mittl. Schaft

$\mathbf{X}$ dist. Schaft

dist. Gelenk

\section{Beschreibung:}

Ein Fragment aus dem Schaft.
Verband: $\quad \square$ Verband

\section{Alter:}

Geschlecht:

Arthrose:

\section{Maß}

Umfang Schaftmitte

Wert $\quad$ Einheit

\begin{tabular}{l|l}
68 & $\mathrm{~mm}$
\end{tabular}


Bezeichn.: Humerus

Kiste:

Verband:

Verband

\section{Alter:}

Geschlecht:

Arthrose:

Population: Großenrode
Maß

Umfang Schaftmitte \begin{tabular}{|l|l} 
Wert & Einheit \\
\hline
\end{tabular}

\begin{tabular}{l|l}
69 & $\mathrm{~mm}$
\end{tabular}

\section{Erhaltung: $\square$ prox. Gelenk \\ prox. Schaft \\ $X$ mittl. Schaft \\ dist. Schaft \\ dist. Gelenk}

Beschreibung:

Ein Fragment aus dem Schaft. 


$\begin{array}{ll}\text { Bezeichn.: } & \text { Humerus } \\ \text { Kiste: } & 3 \\ \text { Skelet: } & \text { K171 P3 } \\ \text { Population: } & \text { Großenrode } \\ \text { Seite: } & \text { links } \\ \text { Erhaltung: } & \square \text { prox. Gelenk } \\ & \mathbf{X} \text { prox. Schaft } \\ & \square \text { mittl. Schaft } \\ & \square \text { dist. Schaft } \\ & \mathbf{X} \text { dist. Gelenk }\end{array}$

Verband: $\square$ Verband

Alter: $\quad 35-60$

Geschlecht:

Arthrose:

Zwei stark erodierte Fragmente eines Os humeri der linken Seite. 
Bezeichn:: Humerus

Kiste: 3

Skelet: K206

Population: Großenrode

Seite: rechts

Erhaltung: $\square$ prox. Gelenk

$X$ prox. Schaft

$X$ mittl. Schaft

$\mathbf{X}$ dist. Schaft

dist. Gelenk

Beschreibung:

Ein Fragment aus dem Schaft.
Verband: $\square$ Verband

\section{Alter:}

Geschlecht:

Arthrose:

\section{Maß}

Umfang Schaftmitte

Umfang ü. Tub. deltoidea \begin{tabular}{|l|l} 
Wert & Einheit \\
\hline 55 &
\end{tabular}

\begin{tabular}{l|l}
55 & $\mathrm{~mm}$
\end{tabular}

$63 \quad \mathrm{~mm}$


Bezeichn:: Humerus

Kiste:

3

Skelet: $\quad 61 / 66-2$

Population: Großenrode

Seite: rechts

Erhaltung: $\square$ prox. Gelenk prox. Schaft

$X$ mittl. Schaft

$\mathbf{X}$ dist. Schaft dist. Gelenk

Beschreibung:

Ein erodiertes Fragment.
Verband: $\square$ Verband

\section{Alter:}

Geschlecht:

Arthrose:
Maß

Umfang Schaftmitte \begin{tabular}{|l|l} 
Wert & Einheit \\
50
\end{tabular}

\begin{tabular}{l|l}
50 & $\mathrm{~mm}$
\end{tabular}


Bezeichn:: Humerus

Kiste:

3

Skelet: K197-2

Population: Großenrode

Seite: links

Erhaltung: $\square$ prox. Gelenk

$X$ prox. Schaft

$X$ mittl. Schaft

$\mathbf{X}$ dist. Schaft

dist. Gelenk

\section{Beschreibung:}

Ein Fragment aus dem Schaft. Das Fragment ist einem massiven Os humeri zuzuordnen.

\section{Verband: \\ Verband \\ Ges./Kr.: Gesund}

\section{Alter:}

Geschlecht: $ð$

Arthrose:

\section{Maß}

Umfang Schaftmitte

Umfang ü. Tub. deltoidea \begin{tabular}{|l|l} 
Wert & Einheit \\
\hline 75 & $\mathrm{~mm}$
\end{tabular}

$\begin{array}{ll}75 & \mathrm{~mm}\end{array}$

$80 \quad \mathrm{~mm}$



Bezeichn.: Humerus
$\begin{array}{ll}\text { Kiste: } & 3 \\ \text { Skelet: } & \text { K197-1 }\end{array}$
Population: Großenrode
Seite: rechts
Erhaltung: $\square$ prox. Gelenk
prox. Schaft
mittl. Schaft
$X$ dist. Schaft
$\mathbf{X}$ dist. Gelenk

Verband:

Beschreibung:

Ein frakturiertes und erodiertes Fragment. 
Bezeichn:: Humerus

Kiste:

3

Skelet: K322

Population: Großenrode

Seite: links

Erhaltung: $\square$ prox. Gelenk

$X$ prox. Schaft

$X$ mittl. Schaft

X dist. Schaft

dist. Gelenk

\section{Beschreibung:}

Dies ist ein Fragment eines linken Os Humerus, welches eine Myotendopathie aufweist.

\section{Ges./Kr.: Krank}

Krankh.: Myotendopathie

\section{Alter:}

Geschlecht: $\delta$

Arthrose:

prox.

2
Maß

Caput frontaler $\varnothing$

gr. Länge

Umfang Schaftmitte

Umfang ü. Tub. deltoidea \begin{tabular}{|l|l} 
Wert & Einheit \\
\hline 43,31 & $\mathrm{~mm}$
\end{tabular}

43,31 $\mathrm{mm}$

$290 \mathrm{~mm}$

$62,5 \mathrm{~mm}$

$66 \mathrm{~mm}$


Bezeichn:: Humerus

Kiste:

3

Skelet: K322

Population: Großenrode

Seite: rechts

Erhaltung: $\square$ prox. Gelenk

X prox. Schaft

X mittl. Schaft

dist. Schaft

dist. Gelenk

Beschreibung:

Dies ist ein erodiertes und fragmentiertes Fragment eines rechten Os humeri.

\section{Alter:}

Geschlecht: $\delta$

\section{Arthrose:}

\section{Ges./Kr.: Gesund}

\begin{tabular}{l|l|l} 
Maß & Wert & Einheit \\
\hline Umfang Schaftmitte & 62 & $\mathrm{~mm}$ \\
Umfang ü. Tub. deltoidea & 78 & $\mathrm{~mm}$ \\
& & \\
& &
\end{tabular}


Bezeichn.: Humerus

Kiste: $\quad 10$

Skelet: 64/55

Population: Großenrode

Seite: rechts

Erhaltung: $\square$ prox. Gelenk

prox. Schaft

X mittl. Schaft

dist. Schaft

dist. Gelenk

Beschreibung:

Ein Fragment eines rechten Os humeri.
Verband: $\square$ Verband

\section{Alter:}

Geschlecht:

Arthrose:
Maß

Umfang Schaftmitte \begin{tabular}{|l|l} 
Wert & Einheit \\
\hline 56 &
\end{tabular}

\begin{tabular}{l|l}
56 & $\mathrm{~mm}$
\end{tabular}


Bezeichn.: Humerus

Kiste: 10

Skelet: 64/55

Population: Großenrode

Seite: rechts

Erhaltung: $\square$ prox. Gelenk

prox. Schaft

mittl. Schaft

$X$ dist. Schaft

dist. Gelenk

Beschreibung:

Ein erodiertes Fragment.
Verband: $\square$ Verband

\section{Alter:}

Geschlecht:

Arthrose:
Ges./Kr.: Gesund

Maß

Umfang Schaftmitte
Wert 1 Einheit

\begin{tabular}{ll|l}
62 & $\mathrm{~mm}$
\end{tabular}




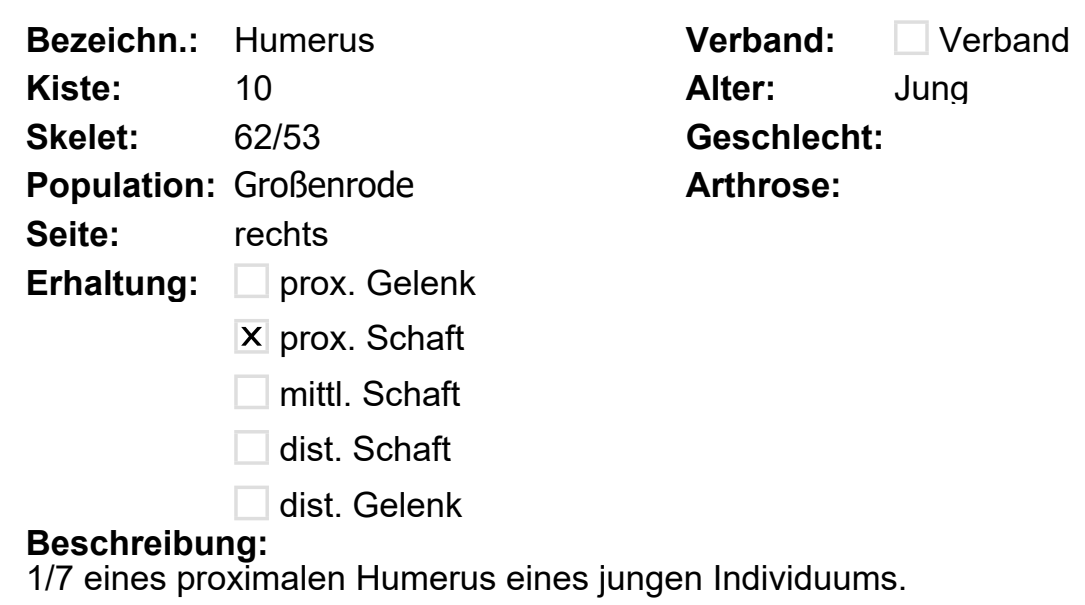




$\begin{array}{lll}\text { Bezeichn.: } & \text { Humerus } & \text { Verband: } \square \text { Verband } \\ \text { Kiste: } & 10 & \text { Alter: Jung } \\ \text { Skelet: } & 62 / 53 & \text { Geschlecht: } \\ \text { Population: } & \text { Großenrode } & \text { Arthrose: } \\ \text { Seite: } & \text { rechts } & \\ \text { Erhaltung: } & \square \text { prox. Gelenk } & \\ & \square \text { prox. Schaft } & \\ & \square \text { mittl. Schaft } & \\ & \square \text { dist. Schaft } \\ & \mathbf{X} \text { dist. Gelenk }\end{array}$

\begin{tabular}{l|l|l} 
Maß & Wert & Einheit \\
\hline Epicondylenbreite & 47 & $\mathrm{~mm}$ \\
& & \\
& &
\end{tabular}

Beschreibung:

Ein distales Fragment eines jungen Os humeri, es ist 1/7 erhalten. 


$\begin{array}{lll}\text { Bezeichn.: } & \text { Humerus } & \text { Verband: } \square \text { Verband } \\ \text { Kiste: } & 10 & \text { Alter: } \\ \text { Skelet: } & 62 / 53 & \text { Geschlecht: } \\ \text { Population: } & \text { Großenrode } & \text { Arthrose: } \\ \text { Seite: } & \text { n. def. } & \\ \text { Erhaltung: } & \mathbf{X} \text { prox. Gelenk } & \\ & \square \text { prox. Schaft } & \\ & \square \text { mittl. Schaft } & \\ & \square \text { dist. Schaft } & \\ & \square \text { dist. Gelenk }\end{array}$

Ein Fragmente einer proximalen Humerusepiphyse eines jungen Individuums. 
Bezeichn.: Humerus

\section{Kiste:}

Skelet: 4. Tüte aus 62/52

Population: Großenrode

Seite: rechts

Erhaltung: $\mathbf{X}$ prox. Gelenk

prox. Schaft

mittl. Schaft

dist. Schaft

dist. Gelenk

Beschreibung:

Es ist ein Fragment des Caput humeri erhalten.
Verband: $\quad$ Verband

\section{Alter:}

Geschlecht:

Arthrose: 

Bezeichn:: Humerus
Kiste:
10
Skelet: 63/54
Population: Großenrode
Seite: links
Erhaltung: $\square$ prox. Gelenk
prox. Schaft
$X$ mittl. Schaft
$\mathbf{X}$ dist. Schaft
X dist. Gelenk

Beschreibung:

Verband: $\quad$ Verband

Alter: Erwachsen

Geschlecht: $q>0$

Arthrose:

\section{Maß}

Epicondylenbreite

Umfang Schaftmitte \begin{tabular}{|l|l} 
Wert & Einheit \\
\hline 50 &
\end{tabular}

\begin{tabular}{l|l}
50 & $\mathrm{~mm}$
\end{tabular}

$55 \quad \mathrm{~mm}$

Zwei Fragmente eines linken Os humeri in schlechtem Erhaltungszustand. 
Bezeichn:: Humerus

\section{Kiste:}

Skelet: K245

Population: Großenrode

Seite:

links

prox. Gelenk

prox. Schaft

mittl. Schaft

dist. Schaft

dist. Gelenk

Beschreibung:

Verband: $\quad \square$ Verband

Alter:

Geschlecht:

Arthrose:

Ein Fragment. 
Bezeichn.: Humerus

\section{Kiste:}

Skelet: K245

Population: Großenrode

Seite:

links

Erhaltung: $\square$ prox. Gelenk

X prox. Schaft

mittl. Schaft

dist. Schaft

dist. Gelenk

Beschreibung:

Ein erodiertes Fragment.
Verband: $\square$ Verband

\section{Alter:}

Geschlecht:

Arthrose: 
Bezeichn.: Humerus

Kiste:

Skelet: K241 P3

Population: Großenrode

Seite: rechts

Erhaltung: $\square$ prox. Gelenk

X prox. Schaft

mittl. Schaft

dist. Schaft

dist. Gelenk

\section{Beschreibung:}

Ein recht graziles Fragment aus dem Schaft eines rechten Os humeri.

Geschlecht: $q>\lambda$

Arthrose:
Verband: $\square$ Verband

Ges./Kr.: Gesund 
Bezeichn:: Humerus

\section{Kiste:}

Skelet: $\quad$ K126 63/68-S2

Population: Großenrode

Seite: links

Erhaltung: $\square$ prox. Gelenk

$X$ prox. Schaft

$X$ mittl. Schaft

dist. Schaft

dist. Gelenk

\section{Beschreibung:}

Ein erodiertes, aber sehr massives Fragment eines linken Os humeri.

\section{Ges./Kr.: Gesund}

\section{Alter:}

Geschlecht: $q<\widehat{ }$

Arthrose:

\section{Maß}

Umfang Schaftmitte

Umfang ü. Tub. deltoidea

\begin{tabular}{|l|l} 
Wert & Einheit \\
\hline 61 & $\mathrm{~mm}$
\end{tabular}

$\mathrm{mm}$


Bezeichn.: Humerus

Kiste:

Verband:

Alter:

Skelet: $\quad 63 / 68$ K232-2 P3

Population: Großenrode

Seite: rechts

Erhaltung: $\square$ prox. Gelenk prox. Schaft

$X$ mittl. Schaft dist. Schaft dist. Gelenk

Beschreibung:

Ein wohl graziles Fragment. Jung

Geschlecht: $q>0$

Arthrose: 
Bezeichn.: Humerus

\section{Kiste:}

Skelet: $\quad 63 / 68$ K232-3 P3

Population: Großenrode

Seite: links

Erhaltung: $\square$ prox. Gelenk

prox. Schaft

X mittl. Schaft

dist. Schaft

dist. Gelenk

\section{Beschreibung:}

Ein stark erodiertes kleines Fragment, welches nicht befundbar war.
Verband: $\quad \square$ Verband

\section{Alter:}

Geschlecht:

Arthrose: 
Bezeichn:: Humerus

Kiste:

Skelet: 63/68-S1 K65-1

Population: Großenrode

Seite: rechts

Erhaltung: $\square$ prox. Gelenk

prox. Schaft

mittl. Schaft

$\mathbf{X}$ dist. Schaft

X dist. Gelenk

Beschreibung:

Ein Fragment eines jungen Os humeri.
Verband:

Maß

Geschlecht:

Arthrose: 

Bezeichn.: Humerus
Kiste:
Skelet: K65-3
Population: Großenrode
Seite: rechts
Erhaltung: $\square$ prox. Gelenk
prox. Schaft
X mittl. Schaft
dist. Schaft
dist. Gelenk

Verband:

Verband

\section{Alter:}

Geschlecht:

Arthrose:

Beschreibung:

Ein erodiertes und nicht befundbares Fragment.

\section{Maß}

Umfang Schaftmitte

Wert 1 Einheit

\begin{tabular}{l|l}
48 & $\mathrm{~mm}$
\end{tabular}


Bezeichn:: Humerus

Kiste:

Verband:

\section{Alter:}

Geschlecht:

Skelet: K65-2

Population: Großenrode

Seite: links

Erhaltung: $\square$ prox. Gelenk

prox. Schaft

X mittl. Schaft

dist. Schaft

dist. Gelenk

Beschreibung:

Ein stark erodiertes und unbefundbares Fragment.
Verband

\section{Maß}

Umfang Schaftmitte

\begin{tabular}{|l|l} 
Wert & Einheit \\
\hline
\end{tabular}

Arthrose: 
Bezeichn.: Humerus

Kiste:

Verband:

Verband

\section{Alter:}

Geschlecht:

Arthrose:

Population: Großenrode

\section{Maß}

Umfang Schaftmitte

\begin{tabular}{|l|l} 
Wert & Einheit
\end{tabular}

Seite: links

Erhaltung: $\square$ prox. Gelenk

prox. Schaft

$X$ mittl. Schaft

dist. Schaft

dist. Gelenk

Beschreibung:

Ein nicht befundbares Fragment. 
Bezeichn:: Humerus

Kiste:

Verband:

Verband

\section{Alter:}

Geschlecht:

Skelet: $\quad$ K234-1 63/68-P3

Population: Großenrode

Seite: rechts

Erhaltung: $\square$ prox. Gelenk

$X$ prox. Schaft

X mittl. Schaft

dist. Schaft

dist. Gelenk

\section{Beschreibung:}

Dieses Fragment ist erodiert und weist Bisspuren auf.

\section{Maß}

Umfang Schaftmitte

Umfang ü. Tub. deltoidea

\begin{tabular}{|l|l} 
Wert & Einheit \\
\hline 55 & $\mathrm{~mm}$
\end{tabular}

\begin{tabular}{l|l}
60 & $\mathrm{~mm}$ \\
\end{tabular}


Bezeichn:: Humerus

Kiste: 1

Skelet: K283-163/68-S3

Population: Großenrode

Seite: rechts

Erhaltung: $\square$ prox. Gelenk

$X$ prox. Schaft

X mittl. Schaft

dist. Schaft

dist. Gelenk

Beschreibung:

Dieses Fragment ist grazil und erodiert.
Verband: $\quad$ Verband

\section{Alter:}

Geschlecht: $q>\hat{\jmath}$

Arthrose:

\section{Maß}

Umfang Schaftmitte

Umfang ü. Tub. deltoidea

\begin{tabular}{|l|l} 
Wert & Einheit \\
55 & $\mathrm{~mm}$
\end{tabular}

\begin{tabular}{l|l}
59 & $\mathrm{~mm}$
\end{tabular}


Bezeichn:: Humerus

Kiste:

1

Skelet: K283 -2 63/68-S3

Population: Großenrode

Seite: rechts

Erhaltung: $\square$ prox. Gelenk

X prox. Schaft

X mittl. Schaft

dist. Schaft

dist. Gelenk

\section{Beschreibung:}

Ein erodiertes, aber sehr massives Fragment eines Os humeri.
Verband: $\quad$ Verband

\section{Alter:}

Geschlecht: $q<0$

Arthrose:

\section{Maß}

Umfang Schaftmitte

Umfang ü. Tub. deltoidea

\begin{tabular}{|l|l} 
Wert & Einheit \\
\hline 62 & $\mathrm{~mm}$
\end{tabular}

$68 \quad \mathrm{~mm}$



Bezeichn:: Humerus
Kiste:
Skelet: $\quad$ K243 63/68-P3 -1
Population: Großenrode
Seite: links
Erhaltung: $\square$ prox. Gelenk
$X$ prox. Schaft
mittl. Schaft
dist. Schaft
dist. Gelenk

Verband:

Alter:

Ges./Kr.: Gesund

Geschlecht:

Beschreibung:

Ein proximales Fragment eines jungen Os humeri. 
Bezeichn.: Humerus

Kiste: 5

Skelet: $\quad$ K159 61/69 S2

Population: Großenrode

Seite: rechts

Erhaltung: $\mathbf{X}$ prox. Gelenk

X prox. Schaft

mittl. Schaft

dist. Schaft

dist. Gelenk

Beschreibung:

Verband: $\square$ Verband Ges./Kr.: Gesund

Ein kleines sehr stark erodiertes Fragment eines Humerus aus Infans II. Es ist nur ein Teil des proximalen Schaftes ohne Epiphyse erhalten. 
Bezeichn:: Humerus

Kiste:

Skelet: K343 64/68-S4

Population: Großenrode

Seite: links

Erhaltung: $\square$ prox. Gelenk

X prox. Schaft

$X$ mittl. Schaft

$\mathbf{X}$ dist. Schaft

dist. Gelenk
Ges./Kr.: Gesund

\section{Maß}

Umfang Schaftmitte

Umfang ü. Tub. deltoidea

\begin{tabular}{|l|l} 
Wert & Einheit \\
53 & $\mathrm{~mm}$ \\
59 & $\mathrm{~mm}$ \\
&
\end{tabular}

\section{Beschreibung:}

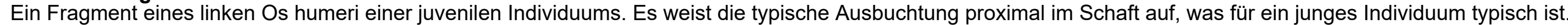
Differentialdiagnostisch muss man eine Myotendopathie zweiten Grades in Erwägung ziehen. Dann wäre der Knochen sehr grazil. 
Bezeichn.: Humerus

\section{Kiste:}

Skelet: 64/67-4

Population: Großenrode

Seite: links

Erhaltung: $\mathbf{X}$ prox. Gelenk

prox. Schaft

mittl. Schaft

dist. Schaft

dist. Gelenk

\section{Beschreibung:}

Ein kleines proximales Fragment, es sind etwa 30\% des Caput erhalten.
Verband: $\quad$ Verband

\section{Alter:}

Geschlecht:

Arthrose:

prox. 
Bezeichn:: Humerus

Kiste:

Verband:

Verband

\section{Alter:}

Geschlecht:

Arthrose:
Ges./Kr.: Gesund

Maß

Umfang Schaftmitte \begin{tabular}{|l|l} 
Wert & Einheit \\
\hline 56 &
\end{tabular}

Population: Großenrode

Erhaltung: prox. Gelenk prox. Schaft

$X$ mittl. Schaft

$\mathbf{X}$ dist. Schaft dist. Gelenk

Beschreibung:

Ein distales Fragment. 
Bezeichn:: Humerus

\section{Kiste:}

5

Skelet: Profil 6

Population: Großenrode

Seite: rechts

Erhaltung: $\square$ prox. Gelenk

prox. Schaft

mittl. Schaft

$X$ dist. Schaft

dist. Gelenk

\section{Beschreibung:}

Ein kleines Fragment.
Verband: $\square$ Verband

\section{Alter:}

Ges./Kr.: Gesund

\section{Geschlecht: $q<ڤ$}

Arthrose:
Maß

Umfang Schaftmitte

\begin{tabular}{|l|l} 
Wert & Einheit \\
\hline 65 & $\mathrm{~mm}$
\end{tabular}

\begin{tabular}{l|l}
65 & $\mathrm{~mm}$
\end{tabular}


Bezeichn:: Humerus

Kiste:

5

Skelet: $\quad$ K40 62/69 S1

Population: Großenrode

Seite: rechts

Erhaltung: $\square$ prox. Gelenk

prox. Schaft

mittl. Schaft

dist. Schaft

X dist. Gelenk

\section{Beschreibung:}

Ein distales Fragment, von dem nur die trochlea erhalten ist, es sind 85\% der Gelenkfläche erhalten.

\section{Verband: $\quad$ Verband \\ Ges./Kr.: Gesund}

\section{Alter:}

Geschlecht: $q<\hat{\jmath}$

Arthrose: 
Bezeichn.: Humerus

Kiste:

Skelet: $\quad$ K279 61/68 S3

Population: Großenrode

Seite: links

Erhaltung: $\mathbf{X}$ prox. Gelenk

X prox. Schaft

$X$ mittl. Schaft

X dist. Schaft

dist. Gelenk

\section{Beschreibung:}

Ein sehr stark erodiertes Os humeri. Es sind Teile abgesplittert. Nicht weiter befundbar.
Verband: $\quad$ Verband

\section{Alter: Erwachsen}

\section{Geschlecht:}

Arthrose: 
Bezeichn:: Humerus

\section{Kiste:}

8

Skelet: $\quad 61 / 68-4 E$

Population: Großenrode

Seite:

links

Erhaltung: $\square$ prox. Gelenk

prox. Schaft

mittl. Schaft

$X$ dist. Schaft

dist. Gelenk

\section{Beschreibung:}

Sehr stark erodiert.
Verband: $\square$ Verband

\section{Alter:}

Geschlecht:

Arthrose:
Maß

Umfang Schaftmitte \begin{tabular}{|l|l} 
Wert & Einheit \\
\hline 57 & mm
\end{tabular}

\begin{tabular}{l|l}
57 & $\mathrm{~mm}$
\end{tabular}




\section{Bezeichn.: Ulna}

\section{Kiste:}

Skelet: $\quad$ K308 63/67 P4

Population: Großenrode

Seite: rechts

Erhaltung: $\square$ prox. Gelenk

$X$ prox. Schaft

$X$ mittl. Schaft

dist. Schaft

dist. Gelenk

\section{Beschreibung:}

Verband: $\square$ Verband

Alter:

Geschlecht:

Arthrose:

Ein stark erodiertes Fragment des proximalen Schaftes, es sind etwa 2/3 des Schaftes erhalten. 


\section{Bezeichn: Ulna}

Kiste:

Skelet: $\quad 63 / 67$ P4 K309

Population: Großenrode

Seite: rechts

Erhaltung: $\square$ prox. Gelenk

$X$ prox. Schaft

$X$ mittl. Schaft

dist. Schaft

dist. Gelenk
Verband: $\square$ Verband

Alter: $13-18$ (19)

Geschlecht:

Arthrose:

\section{Beschreibung:}

Dies ist ein Fragment einer rechten Ulna, welche wohl von einem juvenilen Individuum stammt. Es ist proximal die Hälfte des Schaftes erhalten. 


\section{Bezeichn.: Ulna \\ Kiste: $\quad 9$ \\ Skelet: $\quad$ 63/67 S3 K248 \\ Population: Großenrode \\ Seite: links \\ Erhaltung: $\square$ prox. Gelenk \\ $X$ prox. Schaft \\ $X$ mittl. Schaft \\ dist. Schaft \\ dist. Gelenk}

Verband

Beschreibung:

Etwa 2/3 erhalten, proximal Schaft. Das Fundstück ist sehr stark erodiert. 


\section{Bezeichn: Ulna}

Kiste:

Skelet: $\quad 63 / 67$ S3 K293

Population: Großenrode

Seite: links

Erhaltung: $\square$ prox. Gelenk

$X$ prox. Schaft

$X$ mittl. Schaft

dist. Schaft

dist. Gelenk

\section{Beschreibung:}

Ein sehr stark erodiertes Fragment einer linken Ulna. Es ist proximal die Hälfte des Schaftes erhalten. Aufgrund der Größe kann ein juveniles Alter angenommen werden.
Verband: $\square$ Verband

\section{Alter: $\quad 13-18(19)$}

\section{Geschlecht:}

Arthrose: 


\section{Bezeichn.: Ulna}

\section{Kiste:}

Skelet: $\quad$ 63/67 P3 K229

Population: Großenrode

Seite: rechts

Erhaltung: $\square$ prox. Gelenk

$X$ prox. Schaft

$X$ mittl. Schaft

$\mathbf{X}$ dist. Schaft

dist. Gelenk

\section{Beschreibung:}

Ein stark erodiertes Fragment aus dem Schaft einer rechten Ulna. Es ist etwa die Hälfte erhalten.
Verband: $\quad \square$ Verband

\section{Alter:}

Geschlecht:

Arthrose: 


\section{Bezeichn.: Ulna}

\section{Kiste:}

Skelet: $\quad$ K62 62/68 -P2

Population: Großenrode

Seite: links

Erhaltung: $\square$ prox. Gelenk

prox. Schaft

$X$ mittl. Schaft

dist. Schaft

dist. Gelenk

\section{Beschreibung:}

Ein sehr stark erodiertes Fragment einer linken Ulna, welche nicht befundbar ist. Es ist etwa die Hälfte aus dem Schaft erhalten.
Verband: $\quad$ Verband

\section{Alter:}

Geschlecht: 


\section{Bezeichn.: Ulna}

\section{Kiste:}

Skelet: $\quad K 116 / 288$ 63/65 S2-S3

Population: Großenrode

Seite: rechts

Erhaltung: $\mathbf{X}$ prox. Gelenk prox. Schaft mittl. Schaft dist. Schaft dist. Gelenk
Verband: $\quad$ Verband

Ges./Kr.: Gesund

\section{Geschlecht:}

Arthrose:

prox.

\section{Beschreibung:}

Ein Fragment des proximalen Gelenkes, es sind 80\% der Gelenkfläche erhalten. 


\section{Bezeichn.: Ulna}

Kiste: 6

Skelet: $\quad$ K320 63/65 P4

Population: Großenrode

Seite: rechts

Erhaltung: $\square$ prox. Gelenk prox. Schaft

mittl. Schaft

$\mathbf{X}$ dist. Schaft

X dist. Gelenk
Verband: $\square$ Verband

Alter:

\section{Geschlecht:}

Arthrose:
Ges./Kr.: Krank

Krankh.: Arthrose

\section{Beschreibung:}

Dieses Fundstück ist frakturiert und erodiert. Es macht das distale Drittel einer rechten Ulna aus. Die distale Gelenkfläche ist zu 2/3 befundbar und ist nicht glatt, sondern etwas porös und uneben. 


\section{Bezeichn: Ulna}

\section{Kiste:}

Skelet: $\quad$ K $35863 / 65$ P4

Population: Großenrode

Seite: rechts

Erhaltung: $\mathbf{X}$ prox. Gelenk

$X$ prox. Schaft

$X$ mittl. Schaft

X dist. Schaft dist. Gelenk
Verband: $\quad$ Verband

\section{Alter:}

\section{Geschlecht: $q<\circlearrowright$}

\section{Arthrose:}

\section{Beschreibung:}

Dies ist das Fragment einer sehr massiven Ulna. Es ist extrem erodiert, Teile sind bereits abfrakturiert. Es macht etwa 3/4 des gesamten Knochens aus, proximal mehr erhalten, wenn auch der gesamte Gelenkbereich stark frakturiert ist. Es sind deutliche und kräftige Muskelmarken auszumachen. 


\section{Bezeichn.: Ulna}

\section{Kiste:}

Skelet: $\quad$ K313 62/63 P4

Population: Großenrode

Seite: rechts

Erhaltung: $\mathbf{X}$ prox. Gelenk

X prox. Schaft

mittl. Schaft

dist. Schaft

dist. Gelenk
Verband: $\square$ Verband

Alter:

\section{Geschlecht:}

Arthrose:

\section{Ges./Kr.: Gesund}

\section{Beschreibung:}

Hier ist nur ein proximales Fragment einer rechten Ulna erhalten, welches stark erodiert ist. Es sind $20 \%$ erhalten und etwa $60 \%$ der Gelenkfläche. 


\section{Bezeichn.: Ulna}

\section{Kiste:}

Skelet: $\quad$ K313 62/63 P4

Population: Großenrode

Seite: rechts

Erhaltung: $\mathbf{X}$ prox. Gelenk prox. Schaft mittl. Schaft dist. Schaft dist. Gelenk
Verband: $\quad$ Verband

\section{Alter:}

Geschlecht:

Arthrose:
Ges./Kr.: Gesund
1

\section{Beschreibung:}

Dies ist das proximale Fragment einer rechten Ulna, welches erodiert erhalten ist. Es ist etwa $1 / 5$ erhalten, von der Gelenkfläche sind etwa $70 \%$ erhalten. 
Bezeichn.: Ulna

\section{Kiste:}

Skelet: $\quad$ K254 60/64 P4/S3

Population: Großenrode

Seite: links

Erhaltung: $\mathbf{X}$ prox. Gelenk

X prox. Schaft

$X$ mittl. Schaft

dist. Schaft

dist. Gelenk

Beschreibung:

Das Fundstück ist mittelmäßig erodiert.
Verband: $\quad \square$ Verband

Ges./Kr.: Gesund

\section{Alter:}

Geschlecht:

Arthrose:

prox. 


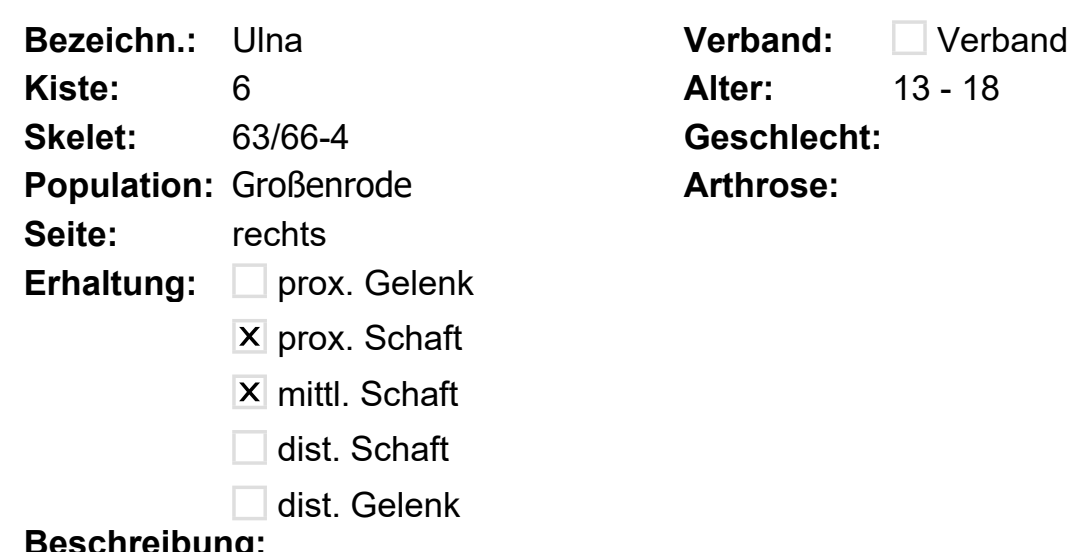

Ein Fragment einer rechten Ulna. Vom gesamten Knochen sind etwa 40\% erhalten aus dem proximalen Schaft. Das Fundstück ist einem jungen Individuum zuzuorden. 


\section{Bezeichn.: Ulna}

\section{Kiste:}

Skelet: $\quad$ K178 60/64 P3

Population: Großenrode

Seite: rechts

Erhaltung: $\mathbf{X}$ prox. Gelenk

$X$ prox. Schaft

mittl. Schaft

dist. Schaft

dist. Gelenk

Beschreibung:

Verband: $\quad \square$ Verband

Alter:

Geschlecht:

Arthrose:

Von dieser Ulna der rechten Seite ist nur ein sehr stark erodiertes Fragment des proximalen Drittels erhalten. Die Gelenkfläche ist zur Unkenntlichkeit erodiert. 


\section{Bezeichn.: Ulna}

\section{Kiste:}

Skelet: $\quad$ K17 62/68 P1

Population: Großenrode

Seite: rechts

Erhaltung: $\mathbf{X}$ prox. Gelenk

$X$ prox. Schaft

mittl. Schaft

dist. Schaft

dist. Gelenk

\section{Beschreibung:}

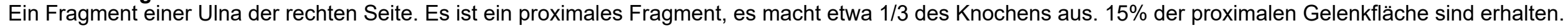

Erosionsspuren am Schaft schränken das Befunden ein.
Verband: $\quad$ Verband

\section{Alter:}

Geschlecht:

Arthrose: 


\section{Bezeichn.: Ulna}

Kiste: 4

Skelet: $\quad$ K76 62/68 P2

Population: Großenrode

Seite: links

Erhaltung: $\mathbf{X}$ prox. Gelenk

$X$ prox. Schaft

mittl. Schaft

dist. Schaft

dist. Gelenk
Verband: $\quad \square$ Verband

\section{Alter:}

Geschlecht:

Arthrose:

\section{Ges./Kr.: Gesund}

\section{Beschreibung:}

Von dieser Ulna sind 2/3 des proximalen Teils erhalten. Die proximale Gelenkfläche ist vollständig erhalten. 


\section{Bezeichn.: Ulna}

Kiste: $\quad 4$

Skelet: $\quad$ K54 62/68 S1

Population: Großenrode

Seite: links

Erhaltung: $\square$ prox. Gelenk

prox. Schaft

$X$ mittl. Schaft

dist. Schaft

dist. Gelenk

\section{Beschreibung:}

Verband: $\quad \square$ Verband Ges./Kr.: Gesund

Alter:

Geschlecht:

Arthrose:

Ein Fragment aus der Mitte des Schaftes einer linken Ulna. Der Knochen liegt in sehr erodierter Form vor. 
Bezeichn.: Ulna

Kiste: 2

Skelet: 63/59

Population: Großenrode

Seite: links

Erhaltung: $\square$ prox. Gelenk prox. Schaft

$X$ mittl. Schaft dist. Schaft dist. Gelenk

\section{Beschreibung:}

Ein Fragment aus dem Schaft.
Verband: Verband

\section{Alter:}

Geschlecht:

Arthrose: 
Bezeichn.: Ulna

Kiste: 2

Skelet: $\quad 63 / 52$

Population: Großenrode

Seite: rechts

Erhaltung: $\mathbf{X}$ prox. Gelenk

X prox. Schaft

mittl. Schaft

dist. Schaft

dist. Gelenk

\section{Beschreibung:}

Hier ist ein proximales Fragment einer rechten Ulna erhalten. Das Fundstück ist sehr erodiert und nur im Bereich des Gelenkes erhalten.
Verband: $\quad$ Verband

\section{Alter:}

Geschlecht:

Arthrose: 
Bezeichn.: Ulna

Kiste: 2

Skelet: 63/52

Population: Großenrode

Seite: links

Erhaltung: $\square$ prox. Gelenk

prox. Schaft

$X$ mittl. Schaft

dist. Schaft

dist. Gelenk

Beschreibung:

Ein Fragment aus dem Schaft, etwa 1/4 des gesamten Knochens erhalten.
Verband: $\quad$ Verband

\section{Alter:}

Geschlecht:

Arthrose: 


\section{Bezeichn.: Ulna}

\section{Kiste:}

Skelet: $\quad 63 / 52$

Population: Großenrode

Seite: rechts

Erhaltung: $\mathbf{X}$ prox. Gelenk

$X$ prox. Schaft

mittl. Schaft

dist. Schaft dist. Gelenk
Verband: $\square$ Verband

\section{Alter:}

\section{Geschlecht:}

Arthrose:

prox.

1

\section{Beschreibung:}

Hier ist ein proximales Fragment erhalten, es ist etwa 2/5 des Gelenks erhalten. 


\section{Bezeichn.: Ulna}

\section{Kiste:}

Skelet: $\quad 63 / 52$

Population: Großenrode

Seite: rechts

Erhaltung: $\mathbf{X}$ prox. Gelenk

$X$ prox. Schaft

mittl. Schaft

dist. Schaft dist. Gelenk

\section{Ges./Kr.: Gesund}

Alter:

\section{Geschlecht:}

Arthrose:

prox.

1

\section{Beschreibung:}

Von dieser Ulna ist nur ein proximales Fragment erhalten, welches erodiert ist. Es sind etwa 70\% des Gelenks befundbar, am Schaft ist dieses proximale Fragment jedoch abfrakturiert. 
Bezeichn.: Ulna

Kiste: 2

Skelet: $62 / 54$

Population: Großenrode

Seite: rechts

Erhaltung: $\mathbf{X}$ prox. Gelenk prox. Schaft mittl. Schaft dist. Schaft dist. Gelenk

Beschreibung:

Ein proximales Fragment.
Verband: $\quad \square$ Verband

\section{Alter:}

Geschlecht:

Arthrose: 
Bezeichn.: Ulna

Kiste: 2

Skelet: $\quad 62 / 54$

Population: Großenrode

Seite: rechts

Erhaltung: $\mathbf{X}$ prox. Gelenk

X prox. Schaft

mittl. Schaft

dist. Schaft

dist. Gelenk

Beschreibung:

Ein proximales Fragment.
Verband: $\quad \square$ Verband

\section{Alter:}

Geschlecht:

Arthrose: 


\section{Bezeichn.: Ulna}

\section{Kiste: 2}

Skelet: $\quad$ aus großer Tüte 63/56

Population: Großenrode

Seite: rechts

Erhaltung: $\mathbf{X}$ prox. Gelenk

$X$ prox. Schaft

mittl. Schaft

dist. Schaft

dist. Gelenk

Beschreibung:

Verband: $\quad \square$ Verband

Alter:

Geschlecht:

Arthrose:

Ein proximales Fragment, die Gelenkfläche ist zu $20 \%$ erhalten. 


\section{Bezeichn.: Ulna}

\section{Kiste: 2}

Skelet: $\quad$ aus großer Tüte 63/56

Population: Großenrode

Seite: links

Erhaltung: $\mathbf{X}$ prox. Gelenk prox. Schaft mittl. Schaft dist. Schaft dist. Gelenk
Verband: $\quad \square$ Verband

\section{Alter:}

Geschlecht:

Arthrose:

\section{Beschreibung:}

Ein proximales Fragment, insgesamt so stark erodiert, dass eine weitere Befundung nicht mögliche war. 


\section{Bezeichn.: Ulna}

\section{Kiste: 2}

Skelet: $\quad$ aus großer Tüte 63/56

Population: Großenrode

Seite: rechts

Erhaltung: $\mathbf{X}$ prox. Gelenk

prox. Schaft

mittl. Schaft

dist. Schaft dist. Gelenk

\section{Beschreibung:}

Verband: $\quad \square$ Verband

Alter:

Geschlecht:

Arthrose:

Ein proximales Fragment, die Gelenkfläche ist zu $90 \%$ erhalten, aber stark erodiert. 


\section{Bezeichn.: Ulna}

\section{Kiste: 2}

Skelet: $\quad$ aus großer Tüte 63/56

Population: Großenrode

Seite: links

Erhaltung: $\mathbf{X}$ prox. Gelenk

prox. Schaft

mittl. Schaft

dist. Schaft

dist. Gelenk

\section{Beschreibung:}

Verband: $\square$ Verband

Alter:

Geschlecht:

Arthrose:

Ein proximales Fragment, die Gelenkfläche ist zu $90 \%$ erhalten, aber stark erodiert. 

Bezeichn.: Ulna
Kiste: 2
Skelet: $\quad 61 / 57$
Population: Großenrode
Seite: links
Erhaltung: $\mathbf{X}$ prox. Gelenk
$X$ prox. Schaft
X mittl. Schaft
dist. Schaft
dist. Gelenk

\section{Verband: $\quad$ Verband}

Alter: Jung

Geschlecht:

\section{Beschreibung:}

Hier ist ein Fragment aus dem Schaft einer nicht ausgewachsenen Ulna erhalten. 


\section{Bezeichn.: Ulna}

Kiste: 3

Skelet: $\quad$ K207 61/65 S3

Population: Großenrode

Seite: rechts

Erhaltung: $\square$ prox. Gelenk

$X$ prox. Schaft

mittl. Schaft

dist. Schaft

dist. Gelenk

\section{Beschreibung:}

Ein proximales, stark erodiertes Fragment.
Verband: $\quad$ Verband

\section{Alter:}

Geschlecht:

Arthrose: 
Bezeichn.: Ulna

Kiste: 3

Skelet: K274

Population: Großenrode

Seite: rechts

Erhaltung: $\mathbf{X}$ prox. Gelenk

prox. Schaft

mittl. Schaft

dist. Schaft

dist. Gelenk
Verband: $\square$ Verband

\section{Alter:}

Geschlecht:

Arthrose:

prox.

\section{Beschreibung:}

Ein erodiertes Fragment, welches nur proximal erhalten ist. Die Gelenkfläche ist zu 40\% erhalten. 
Bezeichn.: Ulna

Kiste: 3

Skelet: K270

Population: Großenrode

Seite: rechts

Erhaltung: $\mathbf{X}$ prox. Gelenk

$X$ prox. Schaft

$X$ mittl. Schaft

$\mathbf{X}$ dist. Schaft

X dist. Gelenk

Beschreibung:

Zwei Fragmente einer Ulna, die sie fast komplettieren. Die beiden zusammengehörigen Fundstücke sind stark erodiert.

Verband: $\quad \square$ Verband

\section{Alter:}

Geschlecht:

Arthrose: 
Bezeichn.: Ulna

Kiste: $\quad 10$

Skelet: $\quad 62 / 53$

Population: Großenrode

Seite: links

Erhaltung: $\square$ prox. Gelenk

X prox. Schaft

mittl. Schaft

dist. Schaft

dist. Gelenk

Beschreibung:

Ein proximales Fragment.
Verband: $\square$ Verband

\section{Alter:}

Geschlecht:

Arthrose: 
Bezeichn.: Ulna

Kiste: $\quad 10$

Skelet: $\quad 61 / 52$

Population: Großenrode

Seite: rechts

Erhaltung: $\square$ prox. Gelenk

prox. Schaft

$X$ mittl. Schaft

dist. Schaft

dist. Gelenk

Beschreibung:

Ein Fragment, welches stark erodiert ist.
Verband: $\quad$ Verband

\section{Alter:}

Geschlecht:

Arthrose: 


\section{Bezeichn: Ulna \\ Kiste:}

Skelet: $\quad 61 / 52$

Population: Großenrode

Seite: rechts

Erhaltung: $\square$ prox. Gelenk

prox. Schaft

mittl. Schaft

$\mathbf{X}$ dist. Schaft dist. Gelenk

Beschreibung:

Ein distales Fragment, welches stark erodiert ist.
Verband: $\quad$ Verband

\section{Alter:}

Geschlecht:

Arthrose: 
Bezeichn.: Ulna

Kiste: $\quad 10$

Skelet: $\quad 62 / 52$

Population: Großenrode

Seite: rechts

Erhaltung: $\square$ prox. Gelenk

prox. Schaft

mittl. Schaft

$\mathbf{X}$ dist. Schaft

dist. Gelenk

Beschreibung:

Ein starkerodiertes Fundstück aus dem distalen Bereich einer Ulna.
Verband: $\quad \square$ Verband

\section{Alter:}

Geschlecht:

Arthrose: 

Bezeichn.: Ulna
Kiste:

10
Skelet: 63/54
Population: Großenrode
Seite: links
Erhaltung: $\mathbf{X}$ prox. Gelenk
$X$ prox. Schaft
mittl. Schaft
dist. Schaft
dist. Gelenk

\section{Beschreibung:}

Ein proximales Fragment, welches stark erodiert ist.
Verband: $\square$ Verband

\section{Alter:}

Geschlecht:

Arthrose:

prox. 


$\begin{array}{lll}\text { Bezeichn.: } & \text { Ulna } & \text { Verband: } \square \text { Verband } \\ \text { Kiste: } & 10 & \text { Alter: Jung } \\ \text { Skelet: } & 63 / 54 & \text { Geschlecht: } \\ \text { Population: } & \text { Großenrode } & \text { Arthrose: } \\ \text { Seite: } & \text { rechts } & \\ \text { Erhaltung: } & \square \text { prox. Gelenk } & \\ & \square \text { prox. Schaft } & \\ & \mathbf{X} \text { mittl. Schaft } & \\ & \square \text { dist. Schaft } & \\ & \square \text { dist. Gelenk }\end{array}$

Beschreibung:

Ein Fragment aus der Mitte des Schaftes eines jungen Individuums. 


$\begin{array}{lll}\text { Bezeichn.: } & \text { Ulna } & \text { Verband: } \square \text { Verband } \\ \text { Kiste: } & 10 & \text { Alter: } \\ \text { Skelet: } & 63 / 54 & \text { Geschlecht: } \\ \text { Population: } & \text { Großenrode } & \text { Arthrose: } \\ \begin{array}{ll}\text { Seite: } & \text { rechts }\end{array} \\ \begin{array}{ll}\text { Erhaltung: } & \square \text { prox. Gelenk } \\ & \square \text { prox. Schaft } \\ & \text { X mittl. Schaft } \\ & \square \text { dist. Schaft }\end{array} \\ \text { Beschreibung: } \\ \text { Ein erodiertes Fragment aus dem Schaft. }\end{array}$


Bezeichn.: UIna

\section{Kiste:}

Skelet: K286 S3

Population: Großenrode

Seite: rechts

Erhaltung: $\square$ prox. Gelenk

$X$ prox. Schaft

X mittl. Schaft

dist. Schaft

dist. Gelenk

Beschreibung:

Ein erodiertes Fragment.
Verband: $\quad \square$ Verband

\section{Alter:}

Geschlecht:

Arthrose: 
Bezeichn.: Ulna

\section{Kiste:}

Skelet: K245

Population: Großenrode

Seite: rechts

Erhaltung: $\square$ prox. Gelenk

$X$ prox. Schaft

$X$ mittl. Schaft

$\mathbf{X}$ dist. Schaft

dist. Gelenk

Beschreibung:

Ein Fragment.
Verband:

Verband

\section{Alter:}

Geschlecht:

Arthrose: 


\section{Bezeichn.: Ulna}

Kiste:

Skelet: K241 P3

Population: Großenrode

Seite: links

Erhaltung: $\mathbf{X}$ prox. Gelenk

X prox. Schaft

mittl. Schaft

dist. Schaft

dist. Gelenk

\section{Beschreibung:}

Verband: $\square$ Verband Ges./Kr.: Gesund

Ein stark erodiertes proximales Fragment eines wohl nicht ausgewachsenen Individuums. 
Bezeichn.: Ulna

Kiste: 1

Skelet: $\quad$ K241 63/68-P3

Population: Großenrode

Seite: rechts

Erhaltung: $\square$ prox. Gelenk

$X$ prox. Schaft

$X$ mittl. Schaft

X dist. Schaft

dist. Gelenk

\section{Beschreibung:}

Ein Fragment aus dem Schaft einer noch nicht ausgewachsenen, grazilen Ulna.
Verband: $\square$ Verband

\section{Alter: Jung}

Geschlecht:

Arthrose: 
Bezeichn.: Ulna

Kiste: 1

Skelet: K242

Population: Großenrode

Seite: links

Erhaltung: $\square$ prox. Gelenk

X prox. Schaft

$X$ mittl. Schaft

$\mathbf{X}$ dist. Schaft

dist. Gelenk

\section{Beschreibung:}

Ein Fragment aus dem Schaft einer noch nicht ausgewachsenen, grazilen Ulna.
Verband: $\square$ Verband

\section{Alter: Jung}

\section{Geschlecht:}

Arthrose: 
Bezeichn.: Ulna

\section{Kiste:}

Skelet:

Population: Großenrode

Seite: rechts

Erhaltung: $\square$ prox. Gelenk

X prox. Schaft

$X$ mittl. Schaft

$\mathbf{X}$ dist. Schaft

dist. Gelenk

\section{Beschreibung:}

Ein Fragment aus dem Schaft einer noch nicht ausgewachsenen, grazilen Ulna. Das Fragment ist sehr stark erodiert.
Verband: $\quad$ Verband

\section{Alter: Jung}

\section{Geschlecht:}

Arthrose: 
Bezeichn.: Ulna

Kiste: 1

Skelet: $\quad$ K232 63/68-P3

Population: Großenrode

Seite: rechts

Erhaltung: $\square$ prox. Gelenk prox. Schaft

$X$ mittl. Schaft

dist. Schaft

dist. Gelenk

Beschreibung:

Ein sehr stark erodiertes Fragment.
Verband: $\quad \square$ Verband

\section{Alter:}

Geschlecht:

Arthrose: 
Bezeichn.: Ulna

\section{Kiste:}

Skelet: $\quad 63 / 68-P 2$ K232

Population: Großenrode

Seite: links

Erhaltung: $\square$ prox. Gelenk

$X$ prox. Schaft

$X$ mittl. Schaft

$\mathbf{X}$ dist. Schaft

dist. Gelenk

Beschreibung:

Ein sehr stark erodiertes Fragment.
Verband: $\quad \square$ Verband

\section{Alter:}

Geschlecht:

Arthrose: 
Bezeichn.: Ulna

Kiste: 1

Skelet: $\quad$ K283 63/68-S3

Population: Großenrode

Seite: rechts

Erhaltung: $\mathbf{X}$ prox. Gelenk

$X$ prox. Schaft

$X$ mittl. Schaft

X dist. Schaft

dist. Gelenk
Verband: $\square$ Verband

Alter:

Geschlecht:

Arthrose:
Ges./Kr.: Gesund

Ein teilweise recht gut erhaltenes Fundstück einer rechten Ulna. Es weist Bissspuren auf. Die Gelenkfläche ist zu $90 \%$ zu befunden. 


\section{Bezeichn: Ulna}

Kiste:

Skelet: K243 63/68-P3

Population: Großenrode

Seite: rechts

Erhaltung: $\mathbf{X}$ prox. Gelenk

$\mathbf{X}$ prox. Schaft

$X$ mittl. Schaft

$\mathbf{X}$ dist. Schaft

dist. Gelenk
Verband: $\quad$ Verband

Alter: Jung

\section{Geschlecht:}

Arthrose:

\section{Beschreibung:}

Zwei Fragmente einer jungen Ulna, das eine ist die proximale Epiphyse, die nicht verknöchert war. 


\section{Bezeichn.: Ulna}

\section{Kiste:}

Skelet: $\quad$ K337 64/68 P4

Population: Großenrode

Seite: rechts

Erhaltung: $\square$ prox. Gelenk

$X$ prox. Schaft

$X$ mittl. Schaft

dist. Schaft

dist. Gelenk

\section{Beschreibung:}

Verband: $\square$ Verband

Alter:

Geschlecht: $q<\widehat{ }$

Arthrose:

Zwei Fragmente einer massiven Ulna. Es sind deutliche Muskelmarken erkennbar. 


\section{Bezeichn: Ulna}

Kiste: $\quad 5$

Skelet: $\quad$ K364 61/69-S4

Population: Großenrode

Seite: rechts

Erhaltung: $\square$ prox. Gelenk

X prox. Schaft

$X$ mittl. Schaft

$\mathbf{X}$ dist. Schaft dist. Gelenk

\section{Beschreibung:}

Ein Fragment aus dem Schaft einer rechten Ulna. Das Fragment ist erodiert und ist einem Individuum Infans II zuzuordnen.

\section{Verband: $\quad$ Verband $\quad$ Ges./Kr.: Gesund}

\section{Alter: $\quad 6-8$}

\section{Geschlecht:}

Arthrose: 


\section{Bezeichn.: Ulna}

\section{Kiste:}

Skelet: $\quad$ K40 62/69 S1

Population: Großenrode

Seite: rechts

Erhaltung: $\mathbf{X}$ prox. Gelenk

$\mathbf{X}$ prox. Schaft

$X$ mittl. Schaft

$\mathbf{X}$ dist. Schaft dist. Gelenk
Verband: $\square$ Verband

\section{Alter:}

Geschlecht: $q<\hat{0}$

Arthrose:

prox.

\section{Beschreibung:}

Ein etwas erodiertes aber sonst in der Konstitution sehr gut erhaltenes Fundstück einer rechten Ulna. Es fällt etwas Tierverbiss ins Auge. 
Bezeichn.: Ulna

Kiste: 5

Skelet: 64/69 PIV

Population: Großenrode

Seite: rechts

Erhaltung: $\square$ prox. Gelenk

X prox. Schaft

X mittl. Schaft

dist. Schaft

dist. Gelenk

Beschreibung:

Stark erodiertes Fragment.
Verband: $\quad$ Verband

\section{Alter:}

Geschlecht:

Arthrose: 


\section{Bezeichn.: UIna}

Kiste:

Skelet: $\quad$ K2 64/69 PIV-V/SIV

Population: Großenrode

Seite: links

Erhaltung: $\square$ prox. Gelenk

$X$ prox. Schaft

$X$ mittl. Schaft

X dist. Schaft

dist. Gelenk

\section{Beschreibung:}

Ein Fragment einer sehr grazilen Ulna, die Tierverbiss aufweist und sehr stark erodiert ist.
Verband: $\square$ Verband

Ges./Kr.: Gesund

\section{Alter:}

Geschlecht: $+\geq \hat{\jmath}$

Arthrose: 
Bezeichn.: Ulna

Kiste: 8

Skelet: $\quad$ K164 61/68-P3

Population: Großenrode

Seite: rechts

Erhaltung: $\mathbf{X}$ prox. Gelenk

$X$ prox. Schaft

$X$ mittl. Schaft

X dist. Schaft

dist. Gelenk
Verband: $\quad \square$ Verband

\section{Alter:}

Geschlecht:

Arthrose:
Ges./Kr.: Gesund

\section{Beschreibung:}

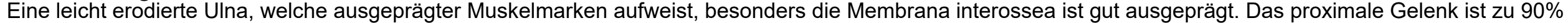
befundbar. 

Bezeichn.: Ulna
Kiste:
8
Skelet: $\quad$ K327 61/68 P4
Population: Großenrode
Seite: links
Erhaltung: $\mathbf{X}$ prox. Gelenk
$X$ prox. Schaft
$X$ mittl. Schaft
X dist. Schaft
dist. Gelenk

Verband:

Verband

\section{Alter:}

Geschlecht:

Beschreibung:

Hier ist eine an der Gelenkfläche stark erodierte Ulna erhalten. Sie weist Spuren recht starken Muskelzuges an der Membrana interossea auf. 


\section{Bezeichn.: Radius}

Kiste:

6

Skelet: $\quad 60 / 67-4$

Population: Großenrode

Erhaltung: $\square$ prox. Gelenk prox. Schaft

$X$ mittl. Schaft dist. Schaft dist. Gelenk

\section{Beschreibung:}

Ein Fragment.

\section{Verband: $\quad$ Verband}

\section{Alter: Jung}

Geschlecht:

Arthrose:
Maß

Breite

Länge

\begin{tabular}{|l|l} 
Wert & Einheit \\
\hline 7,26 & $\mathrm{~mm}$
\end{tabular}

$71,2 \mathrm{~mm}$




\section{Bezeichn.: Radius}

\section{Kiste:}

Skelet: $\quad$ K276 63/66 S3

Population: Großenrode

Seite: n. def.

Erhaltung: $\square$ prox. Gelenk prox. Schaft

$X$ mittl. Schaft

dist. Schaft

dist. Gelenk

\section{Beschreibung:}

Verband: $\square$ Verband

\section{Alter: Jung}

Geschlecht:

Arthrose:

Zwei Fragmente eines Radius eines jungen Individuums. 


\section{Bezeichn.: Radius}

Kiste:

Skelet: $\quad$ K241 P3

Population: Großenrode

Seite: links

Erhaltung: $\mathbf{X}$ prox. Gelenk

$\mathbf{X}$ prox. Schaft

$X$ mittl. Schaft

$\mathbf{X}$ dist. Schaft

dist. Gelenk

\section{Beschreibung:}

Ein Fragment eines jungen Os radii.
Verband: $\quad$ Verband

\section{Alter: Jung}

\section{Geschlecht:}

Arthrose: 


\section{Bezeichn.: Radius}

\section{Kiste:}

Skelet: $\quad$ K308 63/67 P4

Population: Großenrode

Seite: rechts

Erhaltung: $\square$ prox. Gelenk

$X$ prox. Schaft

mittl. Schaft

dist. Schaft dist. Gelenk

Beschreibung:

Verband: $\quad \square$ Verband

Alter:

Geschlecht:

Arthrose:

Ein proximales Fragment aus dem Schaft, etwa 1/3 des Schaftes erhalten. 


\section{Bezeichn.: Radius}

\section{Kiste:}

Skelet: $\quad 63 / 67$ S3 K248

Population: Großenrode

Seite: links

Erhaltung: $\square$ prox. Gelenk

$X$ prox. Schaft

X mittl. Schaft

$\mathbf{X}$ dist. Schaft

$$
\text { dist. Gelenk }
$$

\section{Beschreibung:}

Zwei Fragmente eines linken Radius, der Knochen ist zu insgesamt 3/4 mittig erhalten.
Verband: Verband

\section{Alter:}

Geschlecht: 


\section{Bezeichn.: Radius}

Kiste:

9

Skelet: $\quad 63 / 67$ S3 K248

Population: Großenrode

Seite:

links

Erhaltung: $\square$ prox. Gelenk

prox. Schaft

$X$ mittl. Schaft

dist. Schaft

dist. Gelenk

Beschreibung:

Wohl eine Fibula eines recht jungen Individuums.
Verband: $\square$ Verband

\section{Alter: Jung}

Geschlecht:

Arthrose: 


\section{Bezeichn.: Radius}

Kiste:

Skelet: $\quad 63 / 67$ S3 K293

Population: Großenrode

Seite: links

Erhaltung: $\square$ prox. Gelenk

X prox. Schaft

X mittl. Schaft

dist. Schaft

dist. Gelenk

\section{Beschreibung:}

Ein stark frakturiertes Fragment der Hälfte des Schaftes eines linken Radius. Aufgrund der Größe kann ein juveniles Alter angenommen werden.
Verband: $\quad$ Verband

\section{Alter: $\quad 13-18(19)$}

\section{Geschlecht:}

Arthrose:

\section{Arthrose:}




\section{Bezeichn.: Radius}

\section{Kiste:}

Skelet: $\quad 63 / 67$ P3 K229

Population: Großenrode

Seite: n. def.

Erhaltung: $\square$ prox. Gelenk

$X$ prox. Schaft

mittl. Schaft

dist. Schaft

dist. Gelenk

\section{Beschreibung:}

Ein kleines proximales Fragment aus einem Radius. Es ist zu etwa 10\% erhalten.
Verband: Verband

\section{Alter:}

Geschlecht: 


\section{Bezeichn.: Radius}

\section{Kiste:}

Skelet: K248 63/67-S3

Population: Großenrode

Seite: rechts

Erhaltung: $\square$ prox. Gelenk prox. Schaft

mittl. Schaft

$\mathbf{X}$ dist. Schaft dist. Gelenk

\section{Verband: \\ Verband \\ Ges./Kr.: Gesund}

\section{Alter:}

\section{Geschlecht:}

Arthrose:

\section{Beschreibung:}

Etwa 1/3 des distalen Schaftes erhalten, aber sehr erodiert. Das Fragment weist Spuren von Tierverbiss auf. 


\section{Bezeichn.: Radius}

\section{Kiste:}

Skelet: K320 63/65 P4

Population: Großenrode

Seite: rechts

Erhaltung: $\square$ prox. Gelenk

prox. Schaft

$X$ mittl. Schaft

dist. Schaft

dist. Gelenk
Verband: $\quad$ Verband

\section{Alter:}

Geschlecht:

Arthrose:

\section{Beschreibung:}

Dieses Fundstück ist aus dem Schaft eines rechten Radius und macht etwa 1/3 des Schaftes aus. 


\section{Bezeichn.: Radius}

\section{Kiste:}

Skelet: $\quad$ K254 60/64 P4/S3

Population: Großenrode

Seite: links

Erhaltung: $\mathbf{X}$ prox. Gelenk

X prox. Schaft

$X$ mittl. Schaft

$\mathbf{X}$ dist. Schaft

dist. Gelenk

Beschreibung:

Das Fundstück ist mittelmäßig erodiert.
Verband: $\quad \square$ Verband

Ges./Kr.: Gesund

\section{Alter:}

Geschlecht:

Arthrose:

prox. 


\section{Bezeichn.: Radius}

\section{Kiste:}

Skelet: $\quad$ K62 62/68 P2

Population: Großenrode

Seite: links

Erhaltung: $\square$ prox. Gelenk

$X$ prox. Schaft

$X$ mittl. Schaft

$\mathbf{X}$ dist. Schaft dist. Gelenk
Verband: $\quad$ Verband

\section{Alter:}

Geschlecht:

\section{Beschreibung:}

Dies ist ein Fragment von 3/4 eines Radius der linken Seite. Das Fundstück liegt erodiert vor. 


\section{Bezeichn.: Radius}

\section{Kiste:}

Skelet: $\quad$ K203 62/65 S3

Population: Großenrode

Seite: links

Erhaltung: $\mathbf{X}$ prox. Gelenk

X prox. Schaft

X mittl. Schaft

dist. Schaft

dist. Gelenk

\section{Beschreibung:}

Verband: $\square$ Verband

Alter:

Geschlecht:

Arthrose:

Dies ist ein Fragment aus der proximalen Hälfte eines Radius der linken Seite. Das Fragment ist stark erodiert. 


\section{Bezeichn.: Radius}

\section{Kiste: 4}

Skelet: $\quad$ K35 62/68 S1

Population: Großenrode

Seite: rechts

Erhaltung: $\mathbf{X}$ prox. Gelenk

X prox. Schaft

mittl. Schaft

dist. Schaft

dist. Gelenk

\section{Verband: $\quad$ Verband \\ Ges./Kr.: Gesund}

\section{Alter:}

Geschlecht: $q<\hat{\jmath}$

Arthrose:

prox.

\section{Beschreibung:}

Ein verhältnismäßig gut erhaltenes, proximales Fragment eines rechten Radius. Die Gelenkoberfläche ist zu 80\% erhalten. Starke Muskelmarken zeichnen den Knochen. 


\section{Bezeichn.: Radius}

Kiste:

Skelet: $\quad$ K75 62/68-P2

Population: Großenrode

Seite: links

Erhaltung: $\mathbf{X}$ prox. Gelenk

$X$ prox. Schaft

X mittl. Schaft

$\mathbf{X}$ dist. Schaft

X dist. Gelenk

\section{Beschreibung:}

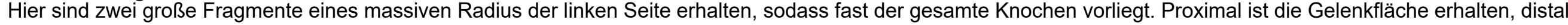
ist sie erodiert.
Verband

Verband

Ges./Kr.: Gesund

\section{Alter:}

Geschlecht: $+<\hat{\sigma}$

Arthrose:

$\begin{array}{ll}\text { prox. } & 2 \\ \text { dist. } & \mathrm{x}\end{array}$




\section{Bezeichn.: Radius}

\section{Kiste:}

4

Skelet: $\quad 62 / 68-S 2$ K143

Population: Großenrode

Erhaltung: $\square$ prox. Gelenk prox. Schaft

$X$ mittl. Schaft dist. Schaft dist. Gelenk

\section{Beschreibung:}

Ein Fragment.
Verband: Verband

\section{Alter:}

Geschlecht:

Arthrose: 


\section{Bezeichn.: Radius}

\section{Kiste: $\quad 4$}

Skelet: $\quad$ K54 62/68 S1

Population: Großenrode

Seite: links

Erhaltung: $\square$ prox. Gelenk

prox. Schaft

$X$ mittl. Schaft

dist. Schaft

dist. Gelenk

\section{Beschreibung:}

Verband: $\square$ Verband $\quad$ Ges./Kr.: Gesund

Dies ist ein Fragment aus dem Schaft eines linken Radius. Der Knochen liegt in sehr erodierter Form vor. 

Bezeichn.: Radius
Kiste:

2
Skelet: $\quad 63 / 52$
Population: Großenrode
Seite: rechts
Erhaltung: $\mathbf{X}$ prox. Gelenk
X prox. Schaft
mittl. Schaft
dist. Schaft dist. Gelenk

\section{Beschreibung:}

Ein sehr massives proximales Gelenk, es ist am Schaft abgebrochen

\section{Verband: $\quad$ Verband}

\section{Alter:}

Geschlecht: $q<\hat{\jmath}$

Arthrose:

Ges./Kr.: Gesund 


$\begin{array}{ll}\text { Bezeichn.: } & \text { Radius } \\ \text { Kiste: } & 2 \\ \text { Skelet: } & 62 / 54 \\ \text { Population: } & \text { Großenrode } \\ \text { Seite: } & \text { links } \\ \text { Erhaltung: } & \square \text { prox. Gelenk } \\ & \square \text { prox. Schaft } \\ & \square \text { mittl. Schaft } \\ & \mathbf{X} \text { dist. Schaft } \\ & \mathbf{X} \text { dist. Gelenk }\end{array}$

Verband: $\quad \square$ Verband

Alter:

Geschlecht:

Hier ist ein distales Fragment eines linken Radius erhalten. Der Knochen ist am distalen Schaft gebrochen. 


\section{Bezeichn.: Radius}

Kiste:

Skelet: K258

Population: Großenrode

Seite: rechts

Erhaltung: $\square$ prox. Gelenk

$X$ prox. Schaft

$X$ mittl. Schaft

$\mathbf{X}$ dist. Schaft dist. Gelenk

Beschreibung:

Hier sind zwei Fragmente zusammengeklebt worden. Sie ergebnen etwa 50\% des Schaftes und sind erodiert. 
Bezeichn.: Radius

Kiste: 3

Skelet: K206

Population: Großenrode

Seite: links

Erhaltung: $\square$ prox. Gelenk

X prox. Schaft

mittl. Schaft

dist. Schaft

dist. Gelenk

Beschreibung:

Ein proximales Schaftgelenk.
Verband: $\quad$ Verband

\section{Alter:}

Geschlecht:

Arthrose: 


\section{Bezeichn.: Radius}

\section{Kiste:}

Skelet: K270

Population: Großenrode

Seite: rechts

Erhaltung: $\square$ prox. Gelenk prox. Schaft

mittl. Schaft

$\mathbf{X}$ dist. Schaft $X$ dist. Gelenk

Beschreibung:

Ein erodiertes distales Fragment.
Verband: Verband

Ges./Kr.: Gesund

\section{Alter:}

Geschlecht:

Arthrose:

dist. 
Bezeichn:: Radius

Kiste: $\quad 10$

Skelet: 62/53

Population: Großenrode

Seite: links

Erhaltung: $\square$ prox. Gelenk prox. Schaft

mittl. Schaft

X dist. Schaft

dist. Gelenk

Beschreibung:

Ein distales Fragment.
Verband: $\square$ Verband

\section{Alter:}

Geschlecht:

Arthrose: 
Bezeichn.: Radius

Kiste: $\quad 10$

Skelet: 62/53

Population: Großenrode

Seite: rechts

Erhaltung: $\square$ prox. Gelenk

prox. Schaft

mittl. Schaft

$\mathbf{X}$ dist. Schaft

dist. Gelenk

Beschreibung:

Fragment aus dem distalen Schaft.
Verband: $\quad$ Verband

\section{Alter:}

Geschlecht:

Arthrose: 
Bezeichn.: Radius

\section{Kiste:}

Skelet: 4. Tüte aus $62 / 52$

Population: Großenrode

Seite: rechts

Erhaltung: $\square$ prox. Gelenk prox. Schaft

mittl. Schaft

$X$ dist. Schaft dist. Gelenk

\section{Beschreibung:}

Ein erodiertes distales Schaftfragment.
Verband: $\square$ Verband

\section{Alter:}

Geschlecht:

Arthrose: 
Bezeichn.: Radius

Kiste: $\quad 10$

Skelet: $\quad 61 / 52$

Population: Großenrode

Seite: links

Erhaltung: $\square$ prox. Gelenk prox. Schaft X mittl. Schaft dist. Schaft dist. Gelenk

Beschreibung:

Ein erodiertes Schaftfragment.
Verband: $\square$ Verband

\section{Alter:}

Geschlecht:

Arthrose: 
Bezeichn.: Radius

Kiste: $\quad 10$

Skelet: 63/54

Population: Großenrode

Seite: rechts

Erhaltung: $\square$ prox. Gelenk prox. Schaft

mittl. Schaft

$X$ dist. Schaft

X dist. Gelenk

Beschreibung:

Ein distales Fragment.
Verband: $\square$ Verband

\section{Alter:}

Geschlecht:

Arthrose: 
Bezeichn.: Radius

Kiste: $\quad 10$

Skelet: 63/54

Population: Großenrode

Seite: links

Erhaltung: $\square$ prox. Gelenk

X prox. Schaft

mittl. Schaft

dist. Schaft

dist. Gelenk

Beschreibung:

Ein proximales Fragment.
Verband: $\quad \square$ Verband

\section{Alter:}

Geschlecht:

Arthrose: 
Bezeichn.: Radius

Kiste: $\quad 10$

Skelet: 63/54

Population: Großenrode

Seite: rechts

Erhaltung: $\square$ prox. Gelenk prox. Schaft

mittl. Schaft

$X$ dist. Schaft dist. Gelenk

Beschreibung:

Ein distales Fragment.
Verband: $\square$ Verband

\section{Alter:}

Geschlecht:

Arthrose: 
Bezeichn:: Radius

Kiste: $\quad 10$

Skelet: 63/54

Population: Großenrode

Seite: links

Erhaltung: $\square$ prox. Gelenk prox. Schaft

$X$ mittl. Schaft dist. Schaft dist. Gelenk

Beschreibung:

Verband: $\square$ Verband

Alter:

Geschlecht:

Arthrose:

Ein Fragment. 
Bezeichn.: Radius

Kiste:

Skelet: K286 S3

Population: Großenrode

Seite: links

Erhaltung: $\square$ prox. Gelenk

prox. Schaft

mittl. Schaft

$X$ dist. Schaft

dist. Gelenk

Beschreibung:

Ein stark erodiertes, distales Fragment.
Verband: $\quad$ Verband

\section{Alter:}

Geschlecht:

Arthrose: 
Bezeichn.: Radius

Kiste:

Skelet: K286 S3

Population: Großenrode

Seite: rechts

Erhaltung: $\square$ prox. Gelenk

X prox. Schaft

mittl. Schaft

dist. Schaft

dist. Gelenk

Beschreibung:

Ein stark erodiertes Fragment.
Verband: $\square$ Verband

\section{Alter:}

Geschlecht:

Arthrose: 
Bezeichn.: Radius

\section{Kiste:}

Skelet: K245

Population: Großenrode

Seite:

Erhaltung: $\square$ prox. Gelenk prox. Schaft $X$ mittl. Schaft dist. Schaft dist. Gelenk

Verband: $\quad \square$ Verband

\section{Alter:}

Geschlecht:

Arthrose:

\section{Beschreibung:}

Ein Fragment. 


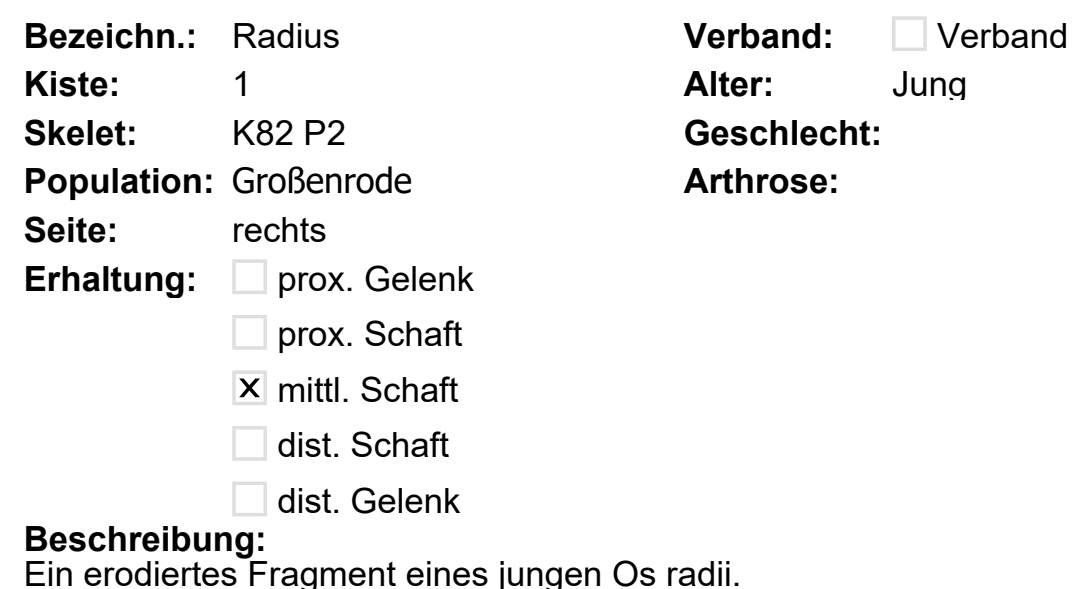

Ein erodiertes Fragment eines jungen Os radii. 


\section{Bezeichn.: Radius}

Kiste:

Skelet: $\quad$ K241 63/68-P3

Population: Großenrode

Seite: rechts

Erhaltung: $\square$ prox. Gelenk prox. Schaft

X mittl. Schaft dist. Schaft dist. Gelenk
Verband: $\quad$ Verband

\section{Alter: Jung}

Geschlecht:

Arthrose:

\section{Beschreibung:}

Ein erodiertes Fragment eines jungen Os radii. 


\section{Bezeichn.: Radius}

Kiste:

Skelet: $\quad 63 / 68$ K232-2 P3

Population: Großenrode

Seite: links

Erhaltung: $\mathbf{X}$ prox. Gelenk

prox. Schaft

mittl. Schaft

dist. Schaft

dist. Gelenk

\section{Beschreibung:}

Verband: $\square$ Verband

Alter:

Geschlecht:

Arthrose:

Ein stark erodiertes und nicht befundbares proximales Fragment eines linken Os radii. 


\section{Bezeichn.: Radius}

Kiste:

Skelet: $\quad$ K283 63/68-S3

Population: Großenrode

Seite: rechts

Erhaltung: $\square$ prox. Gelenk

X prox. Schaft

mittl. Schaft

dist. Schaft

dist. Gelenk

\section{Beschreibung:}

Ein erodiertes Fragment eines rechten Os radii. Es ist mit einer rechten Ulna zusammengehörig, die auch aufgeführt ist.

\section{Verband: $\square$ Verband Ges./Kr.: Gesund}

\section{Alter:}

Geschlecht:

Arthrose: 


\section{Bezeichn.: Radius}

Kiste:

Skelet: $\quad$ 63/68 - P3 K239

Population: Großenrode

Seite: rechts

Erhaltung: $\square$ prox. Gelenk

prox. Schaft

$X$ mittl. Schaft

$\mathbf{X}$ dist. Schaft dist. Gelenk

\section{Beschreibung:}

in erodiertes Fragment eines rechten Os radii, es weist Spuren von Tierverbiss auf.
Verband:

\section{Alter:}

Geschlecht:

Arthrose:

Ges./Kr.: Gesund 
Bezeichn.: Radius

Kiste: $\quad 10$

Skelet: 4. Tüte aus 62/52

Population: Großenrode

Seite: rechts

Erhaltung: $\square$ prox. Gelenk prox. Schaft

$X$ mittl. Schaft dist. Schaft dist. Gelenk

Beschreibung:

Ein erodiertes Fragment.
Verband: $\quad$ Verband

\section{Alter:}

Geschlecht:

Arthrose: 


\section{Bezeichn.: Radius}

Kiste:

1

Skelet: $\quad$ K 241 P3

Population: Großenrode

Seite: links

Erhaltung: $\square$ prox. Gelenk prox. Schaft $X$ mittl. Schaft dist. Schaft dist. Gelenk

Beschreibung:

Ein Fragment eines grazilen Os radii.
Verband: Verband

\section{Alter:}

Geschlecht:

Arthrose: 


\section{Bezeichn.: Radius}

\section{Kiste:}

Skelet: $\quad$ K337 64/68 P4

Population: Großenrode

Seite: rechts

Erhaltung: $\square$ prox. Gelenk prox. Schaft

$X$ mittl. Schaft dist. Schaft dist. Gelenk

\section{Beschreibung:}

Ein Fragment eines massiven Os radii.
Verband: $\quad \square$ Verband

Ges./Kr.: Gesund

Geschlecht: $q<\lambda$

Arthrose: 


\section{Bezeichn.: Radius}

Kiste: 5

Skelet: K36161/69 S4

Population: Großenrode

Seite: links

Erhaltung: $\square$ prox. Gelenk

$X$ prox. Schaft

$X$ mittl. Schaft

$\mathbf{X}$ dist. Schaft

dist. Gelenk
Verband: $\quad$ Verband

\section{Alter: $\quad 6-8$}

Geschlecht:

Arthrose:

\section{Beschreibung:}

Ein recht gut erhaltenes Os radii, welches einem Individuum aus dem Altersbereich Infans II stammt. Es ist leicht erodiert. 


\section{Bezeichn.: Radius}

Kiste:

Skelet: K364 61/69 S4

Population: Großenrode

Seite: rechts

Erhaltung: $\square$ prox. Gelenk

$X$ prox. Schaft

$X$ mittl. Schaft

dist. Schaft

dist. Gelenk

\section{Beschreibung:}

Ein Fragment eines rechten Os radii, welches erodiert ist. Ein Alter im Bereich Infans II wird angenommen.

\section{Verband: $\square$ Verband Ges./Kr.: Gesund}

\section{Alter: $\quad 6-8$}

\section{Geschlecht:}

Arthrose: 


\section{Bezeichn.: Radius}

\section{Kiste:}

Skelet: $\quad$ K135 62/69 S2

Population: Großenrode

Seite:

Erhaltung: $\square$ prox. Gelenk

prox. Schaft

mittl. Schaft

$\mathbf{X}$ dist. Schaft dist. Gelenk
Verband: $\quad$ Verband

\section{Alter:}

Geschlecht:

Arthrose:

\section{Beschreibung:}

Ein fragmentiertes und mit Canidenverbiss gesäumtes Fragment. 


\section{Bezeichn.: Radius}

\section{Kiste:}

Skelet: 61/67-0

Population: Großenrode

Seite: links

Erhaltung: $\mathbf{X}$ prox. Gelenk

$X$ prox. Schaft

$$
\text { mittl. Schaft }
$$

dist. Schaft dist. Gelenk

\section{Beschreibung:}

Ein recht gut erhaltenes, wenig erodiertes Fragment.

\section{Arthrose:}

Verband: $\square$ Verband

Ges./Kr.: Gesund

\section{Geschlecht: $q \leq \hat{\jmath}$}

prox. 


\section{Bezeichn.: Radius}

\section{Kiste:}

5

Skelet: $\quad$ K257 61/67-S3

Population: Großenrode

Seite: rechts

Erhaltung: $\square$ prox. Gelenk

$X$ prox. Schaft

X mittl. Schaft

dist. Schaft

dist. Gelenk

Beschreibung:

Ein erodiertes Fragment.
Verband: $\quad$ Verband

\section{Alter:}

Geschlecht:

Arthrose: 


\begin{tabular}{|c|c|c|c|c|c|c|c|}
\hline Bezeichn.: & Radius & Verband: & $\square$ Verband & Ges./Kr.: Gesund & $\mathrm{Maß}$ & Wert & Einheit \\
\hline Kiste: & 8 & Alter: & & & Länge & 219 & $\mathrm{~mm}$ \\
\hline Skelet: & K164 61/68-P3 & Geschlecht & $q \geq \hat{0}$ & & & & \\
\hline Population: & Großenrode & Arthrose: & & & & & \\
\hline Seite: & rechts & & prox. & 1 & & & \\
\hline Erhaltung: & X prox. Gelenk & & dist. & 1 & & & \\
\hline & X prox. Schaft & & & & & & \\
\hline & X mittl. Schaft & & & & & & \\
\hline & $\mathbf{X}$ dist. Schaft & & & & & & \\
\hline & X dist. Gelenk & & & & & & \\
\hline
\end{tabular}

\section{Beschreibung:}

Ein fast vollständig erhaltener Knochen, von dem nur wenig abfrakturiert ist und der nur wenig erodiert ist. Gelenkfläche proximal ist zu $60 \%$ erhalten, distal zu $30 \%$. Muskelmarken sind ausgeprägt. 


\section{Bezeichn.: Radius}

\section{Kiste:}

Skelet: $\quad$ K164 61/68-P3

Population: Großenrode

\section{Erhaltung:} prox. Gelenk prox. Schaft mittl. Schaft $\mathbf{X}$ dist. Schaft X dist. Gelenk

\section{Beschreibung:}

Dieses Fundstück ist leicht grünlich verfärbt und nur leicht erodiert. Die distale Gelenkfläche ist zu 95\% befundbar.

\section{Verband: $\quad$ Verband Ges./Kr: Gesund}

\section{Alter:}

Geschlecht: $q \geq \gtrsim$

Arthrose: 
Bezeichn.: Os Metacarpale

Kiste:

Skelet: $\quad 61 / 57$

Population: Großenrode

Seite:

rechts

\section{Verband: $\quad$ Verband}

Alter: Jung

Geschlecht:

Arthrose:

\section{Beschreibung:}

Ein Os metacarpale 5 der rechten Seite. Es ist fast vollständig erhalten und ist wohl einem jungen Individuum zuzuordnen. 
Bezeichn.: Os Metacarpale

\section{Kiste:}

Skelet: $\quad 61 / 55$

Population: Großenrode

\section{Verband:}

\section{Alter:}

Geschlecht:

Arthrose:

\section{Maß}

Länge

\begin{tabular}{|l|l} 
Wert & Einheit \\
\hline 38,62 & $\mathrm{~mm}$
\end{tabular}

\section{Beschreibung:}

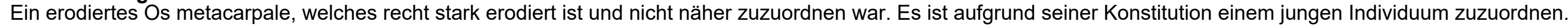


Bezeichn:: Os Metacarpale

\section{Kiste:}

Skelet: 10

Population: Großenrode
Verband: Verband

Alter: Jung

Geschlecht:

Arthrose:

\section{Beschreibung:}

Ein Fragment eins Os metacarpale, welches nicht weiter zuzuordnen war. Es gehört wohl zu einem jungen Individuum. 
Bezeichn.: Os Metacarpale

\section{Kiste:}

10

Skelet: $\quad 62 / 58$

Population: Großenrode
Verband:

\section{Alter:}

Ges./Kr.: Gesund

Geschlecht:

Arthrose:

\section{Beschreibung:}

Ein Os metacarpale, welches einem jungen Individuum zuzuordnen ist. 
Bezeichn.: Os Metacarpale

\section{Kiste:}

Skelet: 10

Population: Großenrode
Verband: Verband

Alter: Jung

\section{Geschlecht:}

Arthrose:

\section{Beschreibung:}

Ein Fragment eines Os metacarpale, welches einem jungen Individuum zuzuordnen ist. 
Bezeichn.: Os Metacarpale

\section{Kiste:}

Skelet: K234

Population: Großenrode
Verband:

Verband

\section{Alter:}

Geschlecht:

Arthrose:

\section{Beschreibung:}

Ein Fragment eines Os metacarpale. 
Bezeichn.: Os Sacrum

\section{Kiste:}

Skelet: $\quad$ K142 63/67 S2

Population: Großenrode
Verband: $\square$ Verband

\section{Alter:}

\section{Geschlecht:}

Arthrose:

\section{Beschreibung:}

Es ist das obere Segment zu 2/3 eher rechts erhalten. Das Fundstück ist sehr stark erodiert. 
Bezeichn.: Os Sacrum

Kiste:

Skelet: K301 63/67 S3

Population: Großenrode
Verband: $\quad$ Verband

\section{Alter:}

Geschlecht:

Arthrose:

\section{Beschreibung:}

Es ist nur das stark erodierte und frakturierte erste Segment erhalten. 
Bezeichn.: Os Sacrum

Kiste:

Skelet: $\quad$ K280 63/62 P3

Population: Großenrode
Verband: $\square$ Verband

Alter: $\quad 12-16(18)$

Geschlecht:

Arthrose:
Ges./Kr.: Gesund

\section{Ges./Kr.: Gesund}

\section{Beschreibung:}

Dieses erste Segment des Os sacrum ist linksseitig und mittig erhalten. Der rechte Processus articularis fehlt. 
Bezeichn.: Os Sacrum

Kiste: 6

Skelet: $\quad$ K254 60/64 S3

Population: Großenrode
Verband: $\square$ Verband

Alter: $12-16(18)$

Geschlecht:

Arthrose:

\section{Beschreibung:}

Von diesem Os sacrum ist nur das obere Segment erhalten. An den Seiten ist es etwas abfrakturiert und insgesamt erodiert. Das zweite Segment war nicht mit dem obersten verwachsen. 
Bezeichn.: Os Sacrum

Kiste:

Skelet: $\quad$ K72 62/68 P2

Population: Großenrode
Verband: $\quad$ Verband

Alter: $\quad 12-16(18)$

Geschlecht:

Arthrose:

\section{Beschreibung:}

Dies ist ein Verband aus mehreren Wirbeln und diesem Os sacrum, von welchem nur das erste Segment erhalten ist. Davon ist es eher links als rechts vorhanden und frakturiert. Die Segmente waren nicht verknöchert. 
Bezeichn.: Os Sacrum

Kiste:

Skelet: $\quad 62 / 68-2$

Population: Großenrode
Verband: $\square$ Verband

Alter: $\quad 12-16(18)$

Geschlecht:

Arthrose:

\section{Beschreibung:}

Hierbei handelt es sich um ein Fragment des ersten Segments eines Os sacrum, welches einem nicht ausgewachsenen Individuum zuzuordnen ist. 
Bezeichn.: Os Sacrum

Kiste:

Skelet: $\quad$ K54 62/68 S1

Population: Großenrode
Verband: $\quad \square$ Verband

Alter:

Geschlecht:

Arthrose:

\section{Beschreibung:}

Fragment eines Os sacrum, welches eher linksseitig erhalten ist. 
Bezeichn.: Os Sacrum

\section{Kiste:}

Skelet: 2

Population: Großenrode
Verband:

Alter:

Verband

Geschlecht:

Arthrose:
12 - 16 (18)

\section{Ges./Kr.: Gesund}

\section{Ges./Kr.: Gesund}

\section{Beschreibung:}

Von diesem Os sacrum ist nur das obere Segment erhalten, weiterhin ist hiervon die rechte Seite wegfrakturiert. Weil die Segmente nicht verknöchert waren und auch die Facies auricularis noch jung wirkt, kann dieses Fundstück einem jungen Individuum zugeordnet werden. Es befindet sich ein Becken unter den Fundstücken, welches zu diesem Os sacrum passt. 
Bezeichn.: Os Sacrum

Kiste:

Skelet: $\quad$ K317 P4

Population: Großenrode
Verband: $\quad$ Verband

\section{Alter:}

\section{Geschlecht:}

Arthrose:

\section{Beschreibung:}

Hier ist nur ein oberstes Segment stark erodiert und nicht befundbar erhalten. Die Seiten sind abfrakturiert. 
Bezeichn.: Os Sacrum

Kiste:

Skelet: $\quad 63 / 52$

Population: Großenrode

Seite:

rechts
Verband: $\square$ Verband

Alter: $12-16$ (18)

Geschlecht:

Arthrose:

\section{Beschreibung:}

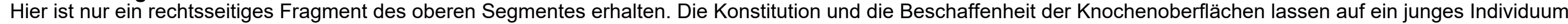
schließen. 
Bezeichn.: Os Sacrum

Kiste:

Skelet: $\quad 63 / 52$

Population: Großenrode
Verband: $\quad$ Verband

Alter: $\quad 12-16(18)$

Geschlecht:

Arthrose:

\section{Beschreibung:}

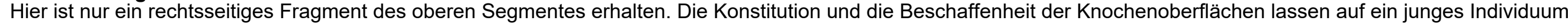
schließen. 
Bezeichn.: Os Sacrum

Kiste:

Skelet: $\quad 62 / 53$

Population: Großenrode
Verband: $\quad$ Verband

Alter: $\quad 12-16(18)$

Geschlecht:

Arthrose:

\section{Beschreibung:}

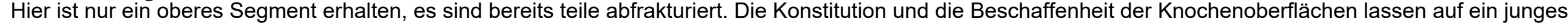
Individuum schließen. 
Bezeichn.: Os Sacrum

Kiste:

Skelet: $\quad 62 / 52$

Population: Großenrode
Verband: $\square$ Verband

Alter: $12-16$ (18)

Geschlecht:

Arthrose:

\section{Beschreibung:}

Ein Fragment eines Os sacrum. Es fällt auf, dass die Segmente noch nicht verwachsen waren, was auf ein junges Individuum schließen lässt. 
Bezeichn.: Os Sacrum

Kiste:

Skelet: K240

Population: Großenrode
Verband:

\section{Alter:}

Geschlecht:

Arthrose:
Ges./Kr.: Krank

Krankh.: Arthritis

Arthrose

proc. art. sup. re. 6

proc. art. sup. li. 6

\section{Beschreibung:}

Hier sind zwei Fragmente eines Os sacrum erhalten, sie zeigen an den Processus articulares deutliche Verschleißerscheinungen, die bis zum Grad 6 im Sinne einer Arthrose ausgeprägt sind. Diese Arthrose ging wohl in eine Arthritis über, denn die Konstitution der Verschleißerscheinungen lassen auf einen entzündlichen Prozess schließen. 
Bezeichn.: Os Sacrum

Kiste:

Skelet: $\quad$ K240 63/68 P3

Population: Großenrode
Verband: $\square$ Verband

\section{Alter:}

Geschlecht:

Arthrose:

\section{Beschreibung:}

Ein zum Teil erhaltenes Os sacrum. 
Bezeichn.: Os Sacrum

Kiste:

Skelet: K243

Population: Großenrode
Verband: $\square$ Verband

Alter: $\quad 12-16(18)$

Geschlecht:

Arthrose:

\section{Beschreibung:}

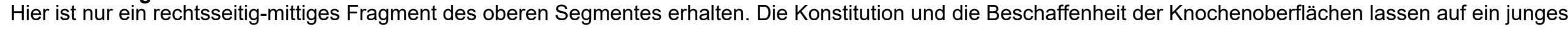
Individuum schließen. 
Bezeichn.: Os Sacrum

Kiste: 8

Skelet: $\quad$ K164 61/68 P3

Population: Großenrode
Verband: $\quad$ Verband

Alter: Erwachsen

Geschlecht: 우

Arthrose:

\section{Ges./Kr.: Gesund}

\section{Beschreibung:}

Ein Verband aus 5 Lendenwirbeln und dem Os sacrum. Von den Wirbeln sind Teile abfrakturiert. Das Os sacrum ist in mehrere Fragmente gebrochen. 


\section{Bezeichn:: Os Coxae}

Kiste:

Skelet: K293-2 63/67 S3

Population: Großenrode

Seite:
Verband: $\square$ Verband

\section{Alter: $\quad 13-18(19)$}

Geschlecht:

Arthrose:

.

\section{Ges./Kr.: Gesund}

\section{Beschreibung:}

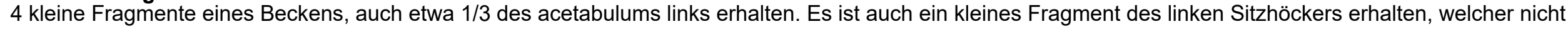
verknöchert war, dementsprechend handelt es sich wohl um ein juveniles Individuum. 


\section{Bezeichn.: Os Coxae}

Kiste:

Skelet: $\quad 63 / 67$ S3 K303

Population: Großenrode

Seite:
Verband: $\square$ Verband

Alter: Erwachsen

\section{Geschlecht:}

Arthrose:
Ges./Kr.: Krank

Krankh.: Arthrose

\section{Maß}

Acetabulum

Einheit

$45,45 \mathrm{~mm}$

3

\section{Beschreibung:}

Ein erodiertes Fragment eines Teils eines rechten Beckens. Es sind auch 70\% der Gelenkfläche des Acetabulum erhalten. Es findet sich eine Unregelmäßigkeit in der Gelenkfläche, die wohl der Grund für eine lokale Arthrose des Gelenks war. 


\section{Bezeichn.: Os Coxae}

Kiste:

Skelet: $\quad 63 / 67$ S2 K149

Population: Großenrode

Seite:

rechts
Verband: $\square$ Verband

Alter: $\quad 13-18(19)$

Geschlecht:

Arthrose:

(3)

\section{Ges./Kr.: Gesund}

\section{Beschreibung:}

Stark erodiertes Fragment eines rechten Beckens. Ein kleiner Teil der Incisura ischiadica ist erhalten und ein kleiner Teil der Facies auricularis, welche noch nicht ausgewachsen ist. Das Fragment ist wohl einem juvenilen Individuum zuzuordnen. Insgesamt ist etwa 1/6 des rechten Beckens erhalten. 


\section{Bezeichn: Os Coxae}

\section{Kiste:}

Skelet: $\quad$ 63/67 S2 K157 + K294 S3

Population: Großenrode

Seite:
Verband: $\quad \square$ Verband

Alter: Erwachsen

Geschlecht: $q>\hat{0}$

Arthrose:

\section{Ges./Kr.: Gesund}

\section{2}

\section{Beschreibung:}

Zwei Fragmente eines rechten Beckens, es sind insgesamt etwa $25 \%$ erhalten, dabei sind auch $4 / 5$ des acetabulums, welches aber wegen Erosion nur zu $50 \%$ befundbar ist. 


\section{Bezeichn.: Os Coxae}

Kiste:

Skelet: $\quad$ 63/67 S3 K249

Population: Großenrode

Seite:
Verband: $\square$ Verband

Alter: $\quad 13-18$ (19)

Geschlecht:

Arthrose:

:

\section{Ges./Kr.: Gesund}

\section{Beschreibung:}

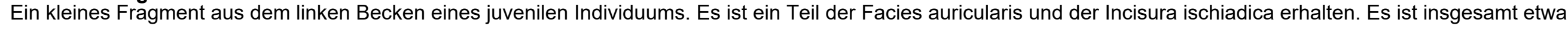
$1 / 10$ des linken Beckens erhalten. 


\section{Bezeichn:: Os Coxae}

\section{Kiste:}

Skelet: $\quad$ K331 63/67 P4

Population: Großenrode

Seite:

\section{Verband: $\quad$ Verband}

\section{Alter:}

Geschlecht:

Arthrose:

\section{Beschreibung:}

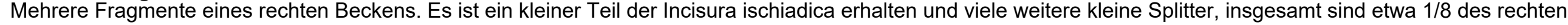
Beckens erhalten. 


\section{Bezeichn.: Os Coxae}

Kiste:

Skelet: K255

Population: Großenrode

Seite:

\section{Verband:}

Verband

\section{Alter:}

Geschlecht: 우

Arthrose:

\section{Ges./Kr.: Gesund}

2

\section{Beschreibung:}

Ein Fragment aus dem linken Becken, welches sehr starke weibliche Eigenschaften aufweist. Die Incisura ischiadica ist sehr breit. Insgesamt sind etwa $1 / 6$ des linken Beckens erhalten mit etwa 1/4 des acetabulums. 


\section{Bezeichn.: Os Coxae}

\section{Kiste:}

Skelet: K255

Population: Großenrode

Seite:

\section{Verband: $\square$ Verband}

\section{Alter:}

Geschlecht: $\delta$

Arthrose:

\section{Beschreibung:}

Ein Fragment des rechten Beckens, welches zu etwa 1/6 erhalten ist. Die Incisura ischiadica zeigt deutlich männliche Merkmale. Das Fundstück ist erodiert. 


\section{Bezeichn.: Os Coxae}

\section{Kiste:}

Skelet: $\quad$ K67 63/67 S1

Population: Großenrode

Seite:
Verband: $\square$ Verband

Alter: $\quad 13-18(19)$

Geschlecht:

Arthrose:

:

\section{Ges./Kr.: Gesund}

\author{
Beschreibung: \\ Ein stark erodiertes Fragment aus dem linken Becken, welches etwa $5 \%$ des gesamten linken Beckens ausmacht. Es ist nicht befundbar, sieht aber nach einem jungen \\ Individuum aus. Es kann als juvenil eingestuft werden.
}


Bezeichn:: Os Coxae

\section{Kiste:}

Skelet: K 73-1 62/68-P2

Population: Großenrode

Seite:

links
Verband: $\square$ Verband

\section{Alter:}

Geschlecht: $ð$

Arthrose:

\section{Beschreibung:}

Ein Fragment aus dem Os ilium. Es sind etwa 1/5 des linken Beckens erhalten. Die Oberfläche ist recht stark erodiert. 


\section{Bezeichn:: Os Coxae}

Kiste:

Skelet: K269 60/64 S3

Population: Großenrode

Seite:
Verband: $\square$ Verband

Alter: $\quad 13-18$ (19)

Geschlecht:

Arthrose:

.

\section{Ges./Kr.: Gesund}

\section{Beschreibung:}

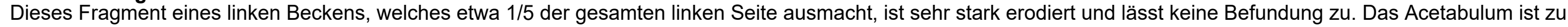
$1 / 5$ erhalten aber zur Unkenntlichkeit erodiert. Trotz der Erosion kann ein Alter im juvenilen Bereich angenommen werden. 
Bezeichn.: Os Coxae

\section{Kiste:}

Skelet: $\quad 62 / 66-2$

Population: Großenrode

Seite:

links
Verband: Verband

\section{Alter:}

Geschlecht:

Arthrose:

\section{Beschreibung:}

Von diesem Becken ist nur der linke Sitzbeinhöcker erhalten. 


\section{Bezeichn:: Os Coxae}

Kiste: 4

Skelet: $\quad$ K76 62/68 P2

Population: Großenrode

Seite:

rechts
Verband: $\quad \square$ Verband

\section{Alter:}

Geschlecht:

Arthrose:

\section{Beschreibung:}

Fragment des Os ilium mit Acetabulum. Vom Acetabulum sind etwa 20\% erhalten. Insgesamt ist etwa 1/5 des rechten Beckens erhalten. 


\section{Bezeichn.: Os Coxae}

Kiste: $\quad 4$

Skelet: $\quad$ K54 62/68 S1

Population: Großenrode

Seite:

links
Verband: $\square$ Verband

\section{Alter: Jung}

Geschlecht:

Arthrose:

\section{Beschreibung:}

Es sind drei Fragmente dieses Beckens erhalten, das Fundstück ist mehrfach frakturiert. 


\section{Bezeichn.: Os Coxae}

Kiste: 4

Skelet: $\quad$ 62/68 P3 K138

Population: Großenrode

Seite:

links
Verband:

Verband

\section{Alter:}

Geschlecht:

Arthrose:

\section{Beschreibung:}

Ein kleines Beckenfragment der linken Seite. 


\section{Bezeichn.: Os Coxae}

Kiste:

Skelet: gesammelt

Population: Großenrode
Verband: $\quad$ Verband

\section{Alter: Jung}

Geschlecht: $\circ \geq \hat{0}$

Arthrose:

\section{Beschreibung:}

6 Fragmente eines eher weiblichen Beckens. Es stammt wohl von einem jungen Individuum. Das linke Acetabulum ist zu 1/3 erhalten. Insgesamt ist etwa 1/4 des gesamten Beckens erhalten. 
Bezeichn:: Os Coxae

Kiste:

Skelet: $\quad 61 / 58$

Population: Großenrode

Seite:
Verband:

\section{Alter:}

Geschlecht:

Arthrose:

\section{Beschreibung:}

Fragment mit kleinem Teil des Acetabulum welches sehr stark erodiert ist. Es ist etwa 1/8 vom rechten Becken erhalten. 


\section{Bezeichn.: Os Coxae}

Kiste: 2

Skelet: kleine und große Tüte

Population: Großenrode

Seite: rechts
Verband:

\section{Alter:}

Geschlecht:

Arthrose:

\section{Beschreibung:}

Beckenfragment mit Beteiligung eines kleinen Teils der Facies auricularis, es ist etwa 1/6 des rechten Beckens erhalten. 


\section{Bezeichn.: Os Coxae}

Kiste: 2

Skelet: $\quad$ kleine und große Tüte

Population: Großenrode

Seite:
Verband:

\section{Alter:}

Geschlecht:

Arthrose:

\section{Beschreibung:}

Fragment mit Sitzbeinhöcker und 1/4 des Acetabulum, selbiges ist aber für genaue Befundung zu sehr erodiert. 


\section{Bezeichn.: Os Coxae}

Kiste: 2

Skelet: kleine und große Tüte

Population: Großenrode

Seite:
Verband:

\section{Alter:}

\section{Geschlecht:}

Arthrose:

\section{Beschreibung:}

Ein stark erodiertes Fragment mit Teil der Facies auricularis. Es sind insgesamt etwa 1/6 des linken Beckens erhalten. 
Bezeichn.: Os Coxae

Kiste: 2

Skelet: kleine und große Tüte

Population: Großenrode

Seite:

links
Verband: $\square$ Verband

Alter:

Geschlecht:

Arthrose:

\section{Beschreibung:}

Ein Fragment mit einem Teil des Acetabulum, etwa 1/3 desselben sind erhalten. 


\section{Bezeichn.: Os Coxae}

Kiste: 2

Skelet: kleine blaue Tüte aus

Population: Großenrode

Seite: rechts
Verband:

\section{Alter:}

Geschlecht:

Arthrose:

\section{Beschreibung:}

Ein Beckenfragment, es sind etwa 1/3 des acetabulums vorhanden mit Teil des Sitzbeinhöckers. Insgesamt sind etwa 1/6 des gesamten Beckens erhalten. 


\section{Bezeichn: Os Coxae}

Kiste:

Skelet:

Population: Großenrode

\section{Verband:}

\section{Alter:}

Geschlecht:

Arthrose:

\section{Ges./Kr.: Gesund}

\section{Beschreibung:}

Hier sind 5 Beckenfragmente erhalten. Es ist ein Fragment eines linken Acetabulum zu etwa 1/4 erhalten. Insgesamt sind es etwa 1/6 des gesamten Beckens rechts und links. 
Bezeichn.: Os Coxae

Kiste:

Skelet: K22361/66 S3

Population: Großenrode

Seite:

links
Verband: $\square$ Verband

\section{Alter:}

\section{Geschlecht:}

Arthrose:

\section{Beschreibung:}

Hier ist ein Fragment aus dem linken Becken mit Teil des Os ilii mit Anteil der Crista iliaca erhalten. Es sind etwa 1/5 des linken Beckens. 
Bezeichn.: Os Coxae

Kiste:

Skelet: $\quad$ K317 P4

Population: Großenrode
Verband: Verband

\section{Alter:}

Geschlecht:

Arthrose:

\section{Beschreibung:}

Beckenfragment, sehr stark erodiert und frakturiert. 
Bezeichn.: Os Coxae

Kiste:

Skelet: K97

Population: Großenrode

Seite:

links
Verband: $\square$ Verband

\section{Alter:}

\section{Geschlecht:}

Arthrose:

\section{Beschreibung:}

Ein kleines Beckenfragment mit Gelenkbeteiligung, es sind etwa 1/10 des rechten Beckens. 
Bezeichn.: Os Coxae

Kiste:

Skelet: $\quad 63 / 52$

Population: Großenrode

Seite:

links
Verband: $\square$ Verband

\section{Alter:}

Geschlecht:

Arthrose:

\section{Beschreibung:}

Ein Fragment des Os ischii mit einem kleinen Teil des Acetabulum, es ist sehr stark erodiert. 


\section{Bezeichn.: Os Coxae}

\section{Kiste:}

Skelet: $\quad 62 / 53$

Population: Großenrode

Seite:

links

\section{Verband: $\quad$ Verband}

\section{Alter:}

Geschlecht: $q>{ }^{\lambda}$

Arthrose:

\section{Beschreibung:}

Beckenfragment des linken Os ischii mit Teil des acetabulums, es weist stellenweise Arthrose auf, da aber das Fragment sehr klein ist und der Zustand stark erodiert, ist dies nicht klar festzumachen. 
Bezeichn:: Os Coxae

Kiste:

Skelet: $\quad 62 / 56$

Population: Großenrode

Seite:

links
Verband: $\quad$ Verband

Alter:

Geschlecht: $q \geq 0$

Arthrose:

\section{Beschreibung:}

Ein Os ischii Fragment mit Teil des Acetabulum, es sind etwa 1/10 des gesamten Beckens in sehr erodiertem Zustand erhalten. 


\section{Bezeichn.: Os Coxae}

\section{Kiste:}

Skelet: $\quad$ K124

Population: Großenrode

Seite:

links

\section{Verband: $\quad$ Verband}

\section{Alter:}

\section{Geschlecht:}

Arthrose:

\section{Beschreibung:}

Ein Os ischii Fragment mit Teil des Acetabulum, es sind etwa 1/10 des gesamten Beckens in sehr erodiertem Zustand erhalten. 


\section{Bezeichn.: Os Coxae}

Kiste:

Skelet: K245

Population: Großenrode

Seite:

links
Verband: Verband

Alter: Jung

Geschlecht:

Arthrose:

\section{Beschreibung:}

Ein Fragment einer Symphyse der linken Seite eines jungen Individuums. 


\section{Bezeichn.: Os Coxae}

Kiste:

Skelet: $\quad$ 63/68-P3 K232-4

Population: Großenrode

Seite:
Verband: Verband

\section{Alter: Jung}

Geschlecht:

Arthrose:

\section{Beschreibung:}

Hier sind zwei Fragment eines Beckens erhalten, eines ist die rechte Symphyse. Die Fragmente sind einem jungen Individuum zuzuordnen. 


\section{Bezeichn:: Os Coxae}

\section{Kiste:}

Skelet: 63/68-P3 K246-1

Population: Großenrode

Seite:

links

\section{Beschreibung:}

Ein stark erodiertes Fragment.
Verband: $\square$ Verband

\section{Alter:}

Geschlecht:

Arthrose:
Ges./Kr.: Gesund 


\section{Bezeichn.: Os Coxae}

Kiste:

Skelet: $\quad$ K240 63/68-4

Population: Großenrode

Seite:

links
Verband: $\square$ Verband

Alter:

Geschlecht: $q>\lambda$

Arthrose:

\section{Beschreibung:}

Ein stark erodiertes Fragment. 


\section{Bezeichn.: Os Coxae}

Kiste: $\quad 5$

Skelet: $\quad$ K334 64/68 P4

Population: Großenrode

Seite:
Verband: $\square$ Verband

Alter: $\quad 13-18(19)$

Geschlecht: $q<0$

Arthrose:

\section{Beschreibung:}

Fragment aus dem Becken der rechten Seite mit einem Teil der Facies auricularis. Es handelt sich um ein juveniles Individuum. Es ist nur ein kleines Fragment. 


\section{Bezeichn:: Os Coxae}

Kiste:

Skelet: $\quad$ K364 61/69 S4

Population: Großenrode

Seite:

rechts
Verband: $\square$ Verband

\section{Alter: $\quad 6-8$}

Geschlecht:

Arthrose:

\section{Beschreibung:}

Ein kleines Fragment des rechten Beckens mit Beteiligung der Facies auricularis. Das Fragment ist stark erodiert und stammt wohl von einem Individuum Infans II. 


\section{Bezeichn.: Os Coxae}

Kiste:

Skelet: $\quad$ K30 62/69 S1

Population: Großenrode
Verband: $\square$ Verband

Alter: $\quad 13-18(19)$

Geschlecht: $q \geq 0$

Arthrose:

\section{Ges./Kr.: Gesund}

\section{Beschreibung:}

Drei Fragmente eines Beckens eines juvenilen Individuums. Das Acetabulum weist bereits leichte Verschleißerscheinungen auf und ist zu 1/4 erhalten.

Es handelt sich größtenteils um das rechte Becken, es ist aber auch ein kleines Fragment der Incisura ischiadica der linken Seit erhalten. 


\section{Bezeichn:: Os Coxae}

Kiste: 8

Skelet: K164 61/68-P3

Population: Großenrode
Verband: $\square$ Verband

Alter: Erwachsen

Geschlecht: $q<\hat{0}$

Arthrose:

\section{Ges./Kr.: Gesund}

\section{Ges.Kr: Gesund}

\section{li.}

\section{Beschreibung:}

Von diesem Becken sind mehrere Fragmente erhalten, es sind mindestens 10 Fragmente. Das Acetabulum der rechten Seite ist zu 1/4 befundbar. Es ist noch ein Fragment der linken Incisura ischiadica erhalten, dieses zeigt Eigenschaften eines männlichen Individuums. 


\section{Bezeichn:: Os Coxae}

Kiste: 8

Skelet: K353 61/68 S4

Population: Großenrode

Seite:

links
Verband:

\section{Alter:}

Verband

Geschlecht:

Arthrose:

\section{Beschreibung:}

Ein kleines Os pubis aus dem Altersbereich spät Infans la bis Infans lb. Es ist erodiert und nicht vollständig erhalten. 


\begin{tabular}{|c|c|c|c|c|c|c|}
\hline Bezeichn.: & Femur & $\square$ Verband & Ges./Kr.: Gesund & $\mathrm{Maß}$ & Wert & Einheit \\
\hline Kiste: & 9 & $13-18(19)$ & & a-p Ø subtrochlear & 22,22 & $\mathrm{~mm}$ \\
\hline Skelet: & $63 / 67$ S3 K293 & Geschlecht: & & Caput, horizontaler $\varnothing$ & 41 & $\mathrm{~mm}$ \\
\hline Population: & Großenrode & Arthrose: & & m-I Ø subtrochlear & 31,17 & $\mathrm{~mm}$ \\
\hline Seite: & links & & & Umfang Schaftmitte & 77 & $\mathrm{~mm}$ \\
\hline Erhaltung: & $\mathbf{X}$ prox. Gelenk & & & & & \\
\hline & $\mathbf{X}$ prox. Schaft & & & & & \\
\hline & $\mathbf{X}$ mittl. Schaft & & & & & \\
\hline & $\square$ dist. Schaft & & & & & \\
\hline & $\square$ dist. Gelenk & & & & & \\
\hline
\end{tabular}

\section{Beschreibung:}

Der Schaft dieses Os femoris ist zu 90\% erhalten, das Caput ist zu 30\% erhalten. es handelt sich wohl um den Knochen eines juvenilen Individuums. Das Fundstück weist eine deutliche und gut ausgeprägte Linea aspera auf. 


\section{Bezeichn.: Femur}

\section{Kiste:}

Skelet: K155 63/67-S2

Population: Großenrode

Seite: n. def.

Erhaltung: $\mathbf{X}$ prox. Gelenk prox. Schaft mittl. Schaft dist. Schaft dist. Gelenk
Verband: $\quad$ Verband

Ges./Kr.: Gesund

\section{Alter:}

Geschlecht:

Arthrose:

prox.

\section{Beschreibung:}

Ein Fragment eines Caput femoris, es sind etwa 30\% erhalten mit Gelenkfläche. 


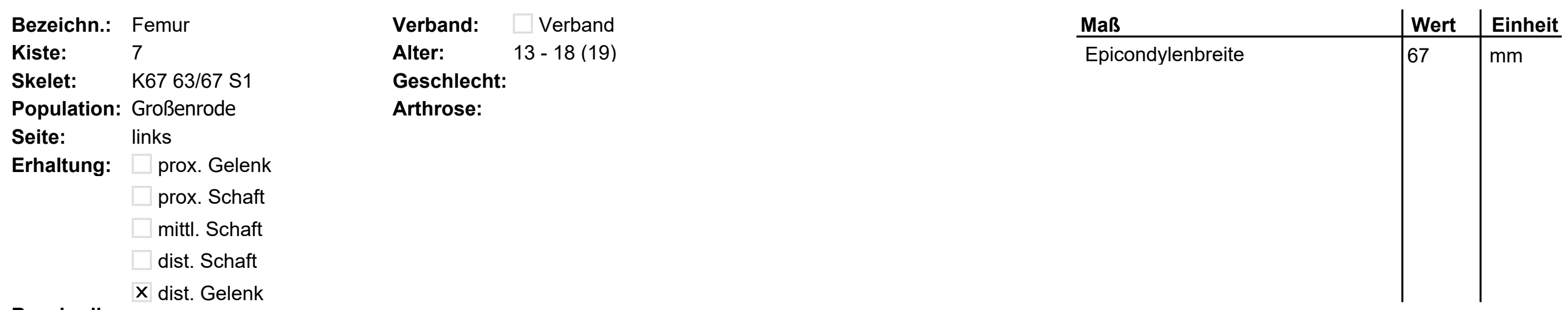

Beschreibung:

Hier ist eine distale Femurepiphyse der linken Seite stark erodiert und nur zu 35\% erhalten. Das Fragment ist nicht befundbar, es handelt sich aber um ein juveniles Individuum. 


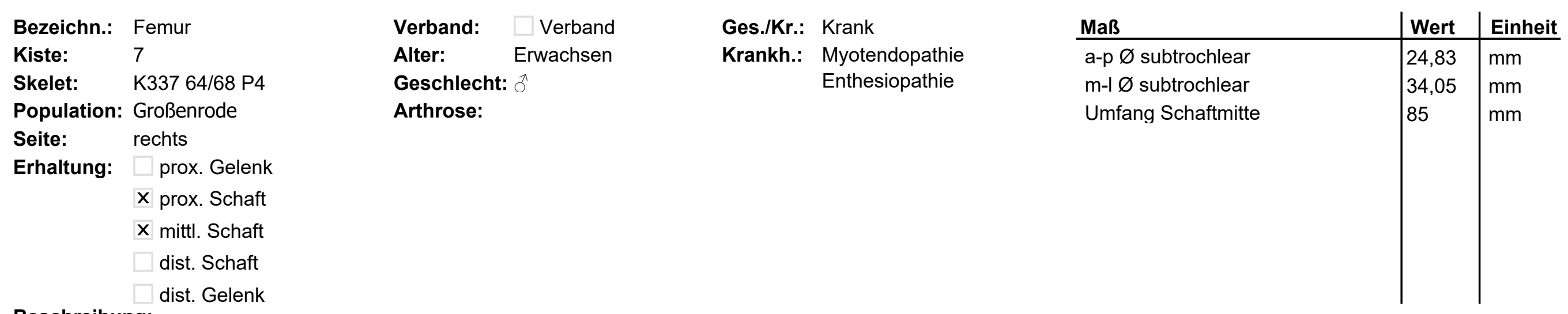

\section{Beschreibung:}

Hier sind zwei Fragmente aus dem Schaft eines massiven rechten Os femoris erhalten. Es fällt entlang der Linea aspera eine deutliche Myotendopathie ins Auge, welche besonders distal am Ansatz des M. vastus lateralis und M. biceps femoris, doch auch der M. gluteus maximus war übrlastet und hat eine deutliche Marke an seiner Ansatzstelle hinterlassen. Die Muskelmarken und Spuren der Überbelastung sind wohl in einen entzündlichen Prozess übergegangen. Es sind etwa 2/3 des Schaftes erhalten. 
Bezeichn.: Femur

Kiste:

7

Skelet: K364-2 61/63-S3

Population: Großenrode

Seite: links

Erhaltung: $\mathbf{X}$ prox. Gelenk

X prox. Schaft

mittl. Schaft

dist. Schaft

dist. Gelenk

\section{Ges./Kr.: Gesund}

\section{Alter: $\quad 6-18$}

Geschlecht:

Arthrose:

\section{Maß}

Caput, horizontaler $\varnothing$

Caput, vertikaler $\varnothing$

Umfang Schaftmitte

\begin{tabular}{|l|l} 
Wert & Einheit \\
\hline 24,4 & $\mathrm{~mm}$
\end{tabular}

24,4

$24,4 \mathrm{~mm}$

50

$\mathrm{mm}$

\section{Beschreibung:}

Ein proximales Fragment, es macht etwa 2/5 des gesamten Os femoris aus, die Oberfläche ist recht gut erhalten. 


$\begin{array}{ll}\text { Bezeichn.: } & \text { Femur } \\ \text { Kiste: } & 7 \\ \text { Skelet: } & \text { K9 63/68 S0-S2 } \\ \text { Population: } & \text { Großenrode } \\ \text { Seite: } & \text { links } \\ \text { Erhaltung: } & \square \text { prox. Gelenk } \\ & \square \text { prox. Schaft } \\ & \text { X mittl. Schaft } \\ & \text { X dist. Schaft } \\ & \square \text { dist. Gelenk }\end{array}$

Verband: $\square$ Verband Ges./Kr.: Gesund

Alter: Jung

Geschlecht:

Arthrose:

Hier ist ein Fragment aus dem Schaft eines linken Os femoris erhalten. Es macht etwa 2/3 des Schaftes aus. Das Fragment ist stark erodiert und frakturiert. 
Bezeichn:: Femur

Kiste:

7

Skelet: $\quad$ K357 61/68-P4

Population: Großenrode

Seite: links

Erhaltung: $\mathbf{X}$ prox. Gelenk

X prox. Schaft

$X$ mittl. Schaft

X dist. Schaft

X dist. Gelenk

\section{Beschreibung:}

Dies ist das fast vollständige Os femoris der linken Seite eines Kindes. Die Oberfläche ist nur wenig erodiert.

\section{Verband: \\ Ges./Kr.: Gesund \\ Verband}

\section{Alter:}

\section{Geschlecht:}

Arthrose:

$$
7-10
$$

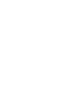

\begin{tabular}{l|l|l} 
Maß & Wert & Einheit \\
\hline a-p $\varnothing$ subtrochlear & 18,98 & $\mathrm{~mm}$ \\
Caput, vertikaler $\varnothing$ & 26 & $\mathrm{~mm}$ \\
Collum-Corpus-Winkel & 130 & $\circ$ \\
Epicondylenbreite & 46 & $\mathrm{~mm}$ \\
gr. Länge & 255 & $\mathrm{~mm}$ \\
m-I $\varnothing$ subtrochlear & 22,59 & $\mathrm{~mm}$ \\
Umfang Schaftmitte & 55 & $\mathrm{~mm}$
\end{tabular}


Bezeichn.: Femur

\section{Kiste:}

Skelet: K67 63/67-S1

Population: Großenrode

Seite: rechts

Erhaltung: $\square$ prox. Gelenk

$X$ prox. Schaft

$X$ mittl. Schaft

X dist. Schaft

dist. Gelenk
Verband: $\quad$ Verband

\section{Alter:}

Geschlecht: $\rho>\widehat{\jmath}$

Arthrose:

\section{Maß}

a-p $\varnothing$ subtrochlear

m-I Ø subtrochlear

Umfang Schaftmitte

\section{Beschreibung:}

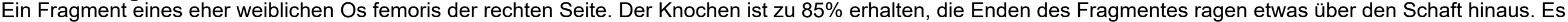
finden sich bei starker Erosion mittelmäßige und unauffällige Muskelmarken. 


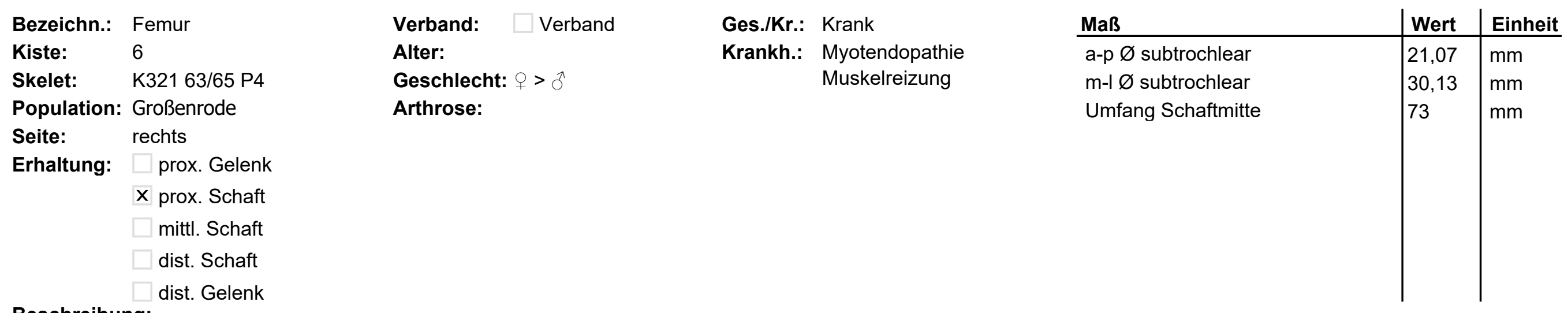

\section{Beschreibung:}

Dies ist ein proximales Fragment aus dem Schaft, es macht etwa 1/4 des Schaftes aus. Es findet sich am Ansatz des M. gluteus maximus eine Myotendopathie, die wohl aufgrund einer muskulären Überreizung entstanden ist. 
Verband: Verband

Ges./Kr.: Gesund

\section{Bezeichn.: Femur \\ Kiste:

6 \\ Skelet: K224 60/64 S3 \\ Population: Großenrode \\ Seite: links \\ Erhaltung: $\square$ prox. Gelenk \\ prox. Schaft \\ mittl. Schaft \\ dist. Schaft \\ $X$ dist. Gelenk}

\section{Beschreibung:}

Ein sehr stark erodiertes Fragment des medialen linken Condylus eines Os femoris. Es ist nur ein kleines Fragment erhalten. 

Bezeichn.: Femur
Kiste:

6
Skelet: K113 60/64 S2
Population: Großenrode
Seite: links
Erhaltung: $\square$ prox. Gelenk
prox. Schaft
$X$ mittl. Schaft
X dist. Schaft$$
\text { dist. Gelenk }
$$
Beschreibung:

Verband: $\quad \square$ Verband

Alter:

Geschlecht:

Arthrose:

Es sind hier etwa 2/3 aus der Mitte des Schaftes erhalten. Das Fragment ist stark erodiert. 


\section{Bezeichn.: Femur}

Kiste: 4

Skelet: $\quad$ K74 62/68 P2

Population: Großenrode

Seite: rechts

Erhaltung: $\mathbf{X}$ prox. Gelenk

$\mathbf{X}$ prox. Schaft

$X$ mittl. Schaft

dist. Schaft

dist. Gelenk
Verband: $\quad \square$ Verband

\section{Alter:}

Geschlecht:

Arthrose:

\section{Maß}

a-p $\varnothing$ subtrochlear

Collum-Corpus-Winkel

m-I Ø subtrochlear

Umfang Schaftmitte

\begin{tabular}{|l|l} 
Wert & Einheit \\
\hline 24 & $\mathrm{~mm}$
\end{tabular}

\begin{tabular}{l|l}
24 & $\mathrm{~mm}$
\end{tabular}

125

$32,17 \mathrm{~mm}$

$77 \quad \mathrm{~mm}$

\section{Beschreibung:}

Ein Fragment eines rechten Os femoris. Das proximale Fragment macht etwa 50\% des ganzen Knochens aus. Es ist sehr stark erodiert und nicht befundbar. 

Bezeichn.: Femur
Kiste:
6
Skelet: $\quad$ K94 62/65 S2
Population: Großenrode
Seite: n. def.
Erhaltung: $\square$ prox. Gelenk
prox. Schaft
$X$ mittl. Schaft
dist. Schaft
dist. Gelenk

Verband:

Verband

Ges./Kr.: Gesund

\section{Alter:}

Geschlecht:

Arthrose:

Beschreibung:

Ein größerer, erodierter Splitter aus dem Schaft eines Os femoris. Es ist ein gespaltenes Fragment, welches etwa 1/8 eines gesamten Femurs ausmacht. 
Bezeichn.: Femur

Kiste: 4

Skelet: $\quad$ K36 62/68 S1

Population: Großenrode

Seite: rechts

Erhaltung: $\square$ prox. Gelenk

prox. Schaft

mittl. Schaft

$X$ dist. Schaft

dist. Gelenk
Verband: $\quad$ Verband

\section{Alter:}

Geschlecht:

Arthrose:

\section{Beschreibung:}

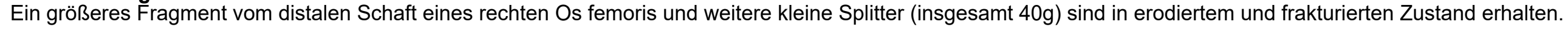




$\begin{array}{ll}\text { Bezeichn.: } & \text { Femur } \\ \text { Kiste: } & 4 \\ \text { Skelet: } & \text { K138 } \\ \text { Population: } & \text { Großenrode } \\ \begin{array}{ll}\text { Seite: } & \text { links } \\ \text { Erhaltung: } & \square \text { prox. Gelenk } \\ & \square \text { prox. Schaft } \\ & \square \text { mittl. Schaft } \\ & X \text { dist. Schaft } \\ & \square \text { dist. Gelenk }\end{array} \\ \text { Beschreibung: }\end{array}$

Verband: $\quad$ Verband Ges./Kr.: Gesund

Fragment eines Femur, distal posterior. Es ist lediglich ein Splitter des linken Os femoris erhalten. 


\section{Bezeichn.: Femur}

\section{Kiste:}

4

Skelet: $\quad$ K76 62/68 P2

Population: Großenrode

Seite: links

Erhaltung: $\square$ prox. Gelenk

$X$ prox. Schaft

X mittl. Schaft

dist. Schaft

dist. Gelenk

\section{Beschreibung:}

Von diesem Os femoris sind nur $2 / 3$ aus dem Schaft erhalten.

\section{Ges./Kr.: Gesund}

\section{Alter:}

\section{Geschlecht:}

Arthrose:

Maß

a-p $\varnothing$ subtrochlear

m-I Ø subtrochlear

Umfang Schaftmitte 


\section{Bezeichn.: Femur}

Kiste: 4

Skelet: $\quad$ K143 62/68 S2

Population: Großenrode

Seite: rechts

Erhaltung: $\square$ prox. Gelenk

prox. Schaft

mittl. Schaft

dist. Schaft

X dist. Gelenk
Verband: $\quad$ Verband Ges./Kr.: Gesund

Alter: Jung

Geschlecht:

Arthrose:

\section{Beschreibung:}

Ein Os femoris, welches nur distal und nur frakturiert und erodiert erhalten ist. Es handelt sich um das rechte Os femoris eines jungen Individuums. 


\section{Bezeichn.: Femur}

Kiste: 4

Skelet: $\quad$ K54 62/68 S1

Population: Großenrode

Seite: links

Erhaltung: $\square$ prox. Gelenk

$X$ prox. Schaft

$X$ mittl. Schaft

$\mathbf{X}$ dist. Schaft

$X$ dist. Gelenk
Ges./Kr.: Gesund

Alter: $\quad 13-18(19)$

Geschlecht:

Arthrose:

\begin{tabular}{l|l|l} 
Maß & Wert & Einheit \\
\hline a-p $\varnothing$ subtrochlear & 20,12 & $\mathrm{~mm}$ \\
Collum-Corpus-Winkel & 145 & $\circ$ \\
Epicondylenbreite & 70 & $\mathrm{~mm}$ \\
gr. Länge & 400 & $\mathrm{~mm}$ \\
m-I $\varnothing$ subtrochlear & 30,24 & $\mathrm{~mm}$ \\
Umfang Schaftmitte & 69 & $\mathrm{~mm}$
\end{tabular}

\section{Beschreibung:}

Dieses sind mehrere Fragmente eines linken Femurs, welches von einem juvenilen Individuum stammt. Die Oberfläche ist erodiert und der Knochen liegt in frakturierter Form vor. 
Bezeichn:: Femur

Kiste:

Skelet: $\quad 62 / 68$ P3 K138

Population: Großenrode

Seite: rechts

Erhaltung: $\square$ prox. Gelenk

$X$ prox. Schaft

X mittl. Schaft

$\mathbf{X}$ dist. Schaft

dist. Gelenk
Verband: $\quad$ Verband

\section{Alter:}

Geschlecht: $q<\hat{\sigma}$

Arthrose:

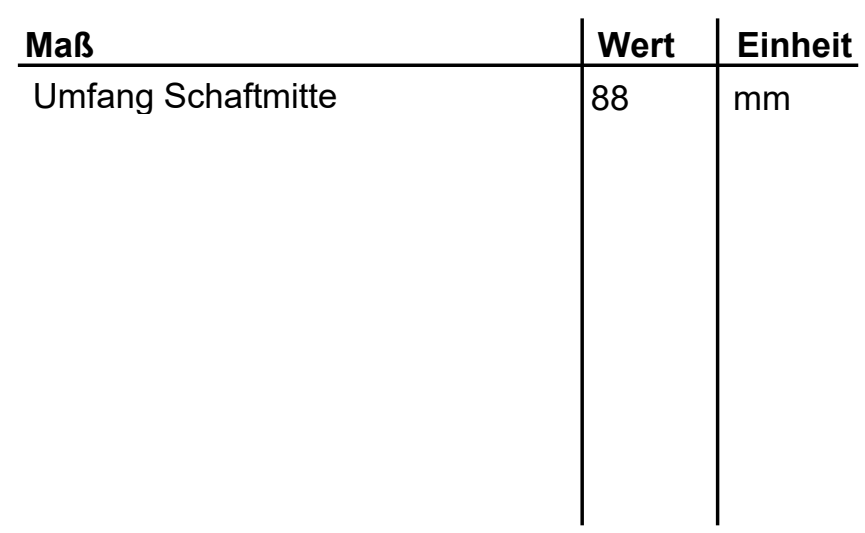

\section{Beschreibung:}

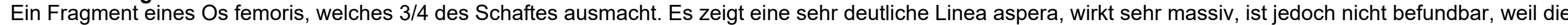
Oberfläche stark erodiert ist und der gesamte Knochen frakturiert vorliegt. 
Bezeichn.: Femur

\section{Kiste:}

Skelet: $\quad 65 / 54$

Population: Großenrode

Erhaltung: $\quad \mathbf{X}$ prox. Gelenk prox. Schaft

mittl. Schaft dist. Schaft dist. Gelenk
Verband: $\square$ Verband

Ges./Kr.: Gesund

\section{Geschlecht:}

Arthrose:

prox.

\section{Beschreibung:}

Ein Fragment des Caput femoris, mit dem auch 30\% der Gelenkfläche erhalten sind. 

Bezeichn.: Femur
Kiste: 2
Skelet: $\quad 61 / 56$
Population: Großenrode
Seite: rechts
Erhaltung: $\square$ prox. Gelenk prox. Schaft
$X$ mittl. Schaft
dist. Schaft dist. Gelenk
Beschreibung:

\section{Verband:}

\section{Alter:}

Geschlecht:

Etwa 1/4 des Schaftes eines rechten Os femoris erhalten.
Verband

\section{Ges./Kr.: Gesund}

\section{Maß}

Umfang Schaftmitte

\begin{tabular}{|l|l} 
Wert & Einheit \\
\hline 76 & $\mathrm{~mm}$
\end{tabular}

Arthrose: 


$\begin{array}{ll}\text { Bezeichn.: } & \text { Femur } \\ \text { Kiste: } & 2 \\ \text { Skelet: } & 60 / 56 \\ \text { Population: } & \text { Großenrode } \\ \text { Seite: } & \text { rechts } \\ \text { Erhaltung: } & \mathbf{X} \text { prox. Gelenk } \\ & \square \text { prox. Schaft } \\ & \square \text { mittl. Schaft } \\ & \square \text { dist. Schaft } \\ & \square \text { dist. Gelenk }\end{array}$

\section{Verband: \\ Verband \\ Ges./Kr.: Gesund}

\section{Alter:}

Geschlecht:

Arthrose:

\section{Maß}

Caput, horizontaler $\varnothing$

Caput, vertikaler $\varnothing$

\begin{tabular}{|l|l} 
Wert & Einheit \\
\hline 22 & $\mathrm{~mm}$ \\
24 & $\mathrm{~mm}$ \\
& \\
&
\end{tabular}

\section{Beschreibung:}

Von diesem rechten Os femoris ist nur ein kleines Fragment aus dem proximalen Bereich mit einem kleinen Teil Epiphysenfuge erhalten. 


$\begin{array}{ll}\text { Bezeichn.: } & \text { Femur } \\ \text { Kiste: } & 2 \\ \text { Skelet: } & 64 / 52 \\ \text { Population: } & \text { Großenrode } \\ \begin{array}{ll}\text { Seite: } & \text { links } \\ \text { Erhaltung: } & \square \text { prox. Gelenk } \\ & \text { X prox. Schaft } \\ & \square \text { mittl. Schaft } \\ & \square \text { dist. Schaft } \\ & \square \text { dist. Gelenk }\end{array}\end{array}$

Verband: $\quad$ Verband

Alter:

\section{Geschlecht:}

Arthrose:

Ges./Kr.: Gesund

\section{Maß}

a-p $\varnothing$ subtrochlear

m-I Ø subtrochlear

Umfang Schaftmitte

\begin{tabular}{l|l} 
Wert & Einheit \\
\hline 22,19 & $\mathrm{~mm}$
\end{tabular}

$28,21 \mathrm{~mm}$

72

$\mathrm{mm}$

$\mathrm{mm}$

Hier ist etwa 1/3 des proximalen Schaftes eines Os femoris erhalten. Der Knochen ist erodiert. 


\section{Bezeichn.: Femur}

Kiste:

2

Skelet: O-2

Population: Großenrode

Seite: rechts

Erhaltung: $\square$ prox. Gelenk

X prox. Schaft

mittl. Schaft

dist. Schaft

dist. Gelenk
Ges./Kr.: Gesund

Maß

Umfang Schaftmitte

\begin{tabular}{|l|l} 
Wert & Einheit
\end{tabular}

\section{Alter:}

Geschlecht: $q<\delta$

Arthrose:

\section{Beschreibung:}

Dieses Os femoris ist als proximales Fragment erhalten, welches etwa 1/3 des proximalen Schaftes ausmacht. Der Knochen ist sehr massiv. 
Bezeichn.: Femur

Kiste: 2

Skelet: gesammelt

Population: Großenrode

Seite: links

Erhaltung: $\square$ prox. Gelenk

prox. Schaft

mittl. Schaft

dist. Schaft

X dist. Gelenk
Verband: $\quad$ Verband

Alter: $\quad 15-22$ (25)

Geschlecht: $q<\circlearrowright$

Arthrose:

\section{Ges./Kr.: Gesund}

dist.

\section{Beschreibung:}

Hier sind 3/4 eines linken Condylus erhalten. Es handelt sich um ein juveniles Individuum, entweder lag die Epiphyse noch nicht verknöchert vor oder sie ist im Übergangszustand gewesen. 
Bezeichn.: Femur

Kiste:

Skelet: gesammelt

Population: Großenrode

Seite: rechts

Erhaltung: $\square$ prox. Gelenk prox. Schaft

mittl. Schaft

dist. Schaft

X dist. Gelenk

\section{Beschreibung:}

Hier liegt ein lateraler Condylus eines rechten Femurs frakturiert vor. Es sind etwa 1/4 der Gelenkfläche erhalten.

\section{Verband: $\quad$ Verband Ges./Kr: Gesund}

\section{Alter:}

Geschlecht:

Arthrose:

dist. 

Bezeichn.: Femur
Kiste:

2
Skelet: $\quad 61 / 58$
Population: Großenrode
Seite: links
Erhaltung: $\square$ prox. Gelenk
prox. Schaft
mittl. Schaft
$\mathbf{X}$ dist. Schaft
$X$ dist. Gelenk

Beschreibung:

Verband: $\square$ Verband Ges./Kr.: Gesund

Alter: Jung

Maß

Geschlecht:

\section{Arthrose:}

Wert $\mid$ Einheit

$50,9 \mathrm{~mm}$

$\left.\right|^{50,9}$

Hier sind zwei Fragmente des Condylus eines linken jungen Os femoris erhalten. 


$\begin{array}{ll}\text { Bezeichn.: } & \text { Femur } \\ \text { Kiste: } & 2 \\ \text { Skelet: } & 61 / 58 \\ \text { Population: } & \text { Großenrode } \\ \text { Seite: } \quad & \text { rechts } \\ \text { Erhaltung: } & \square \text { prox. Gelenk } \\ & \square \text { prox. Schaft } \\ & \square \text { mittl. Schaft } \\ & \square \text { dist. Schaft } \\ & \mathbf{X} \text { dist. Gelenk }\end{array}$

Verband: $\square$ Verband

Alter: Jung

Geschlecht:

Arthrose:

\section{Beschreibung:}

Ein Fragment des Condylus eines rechten Os femoris. 

Bezeichn.: Femur
Kiste: 2
Skelet: $\quad 61 / 57$
Population: Großenrode
Seite: $\quad$ n. def.
Erhaltung: $\mathbf{X}$ prox. Gelenk
prox. Schaft
mittl. Schaft
dist. Schaft
dist. Gelenk

\section{Verband: $\quad$ Verband \\ Alter: Jung \\ Geschlecht:}

Beschreibung:

Hier ist nur ein Fragment eines Caput femoris erhalten. 


\section{Bezeichn.: Femur}

Kiste:

Skelet: $\quad 62 / 54$

Population: Großenrode

Erhaltung: $\mathbf{X}$ prox. Gelenk prox. Schaft

mittl. Schaft dist. Schaft dist. Gelenk

\section{Ges./Kr.: Krank \\ Krankh.: Arthrose \\ Verband \\ Alter:}

Geschlecht:

Arthrose:

\section{Beschreibung:}

Ein Fragment eines Caput femoris, es sind nur etwa 30\% erhalten. Es findet sich eine narbige Struktur auf der Gelenkfläche. 


\section{Bezeichn.: Femur}

Kiste: 3

Skelet: K266 63/64

Population: Großenrode

Seite: links

Erhaltung: $\square$ prox. Gelenk

$X$ prox. Schaft

$X$ mittl. Schaft

dist. Schaft

dist. Gelenk
Verband: $\square$ Verband

Alter: Erwachsen

\section{Geschlecht:}

Arthrose:

\section{Ges./Kr.: Gesund}

\section{Maß}

a-p Ø subtrochlear

$\mathrm{m}-\mathrm{I} \varnothing$ subtrochlear

Umfang Schaftmitte

\section{Beschreibung:}

Es handelt sich hier um zwei Fragmente eines Os femoris der linken Seite, es ist erodiert, weist aber intravitale Oberflächenstreifungen auf der Oberfläche unter der Halsregion auf. 


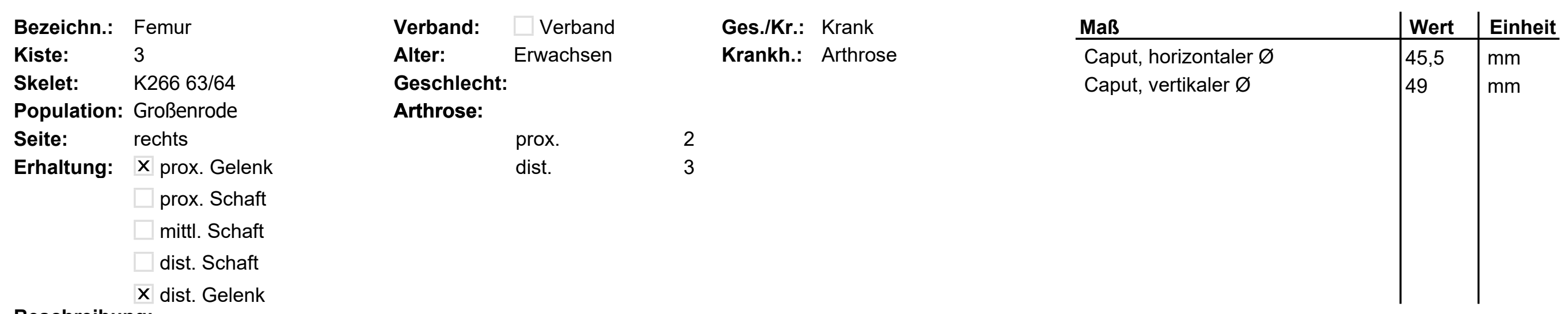

\section{Beschreibung:}

Hier sind fünf Fragmente eines rechten Os femoris erhalten. Die Fragmente machen nur Teile der jeweiligen regionen aus. Das Caput ist zu etwa $65 \%$, der Condylus zu etwa $25 \%$ erhalten. 
Bezeichn.: Femur

Kiste: 2

Skelet: aus großer Tüte drinnen

Population: Großenrode
Verband: $\quad$ Verband

\section{Alter:}

Geschlecht:

Arthrose:

\section{Erhaltung: $\square$ prox. Gelenk \\ X prox. Schaft \\ mittl. Schaft \\ dist. Schaft \\ dist. Gelenk}

\section{Beschreibung:}

Ein Fragment eines Trochanter major eines Os femoris. 
Bezeichn.: Femur

Kiste:

Skelet: aus großer Tüte drinnen

Population: Großenrode

Seite: links

Erhaltung:

prox. Gelenk

prox. Schaft

mittl. Schaft

dist. Schaft

$X$ dist. Gelenk

\section{Beschreibung:}

Fragment des Condylus lateralis eines linken Os femoris. Es ist etwa 1/3 der Fläche des lateralen Condylus erhalten.

\section{Verband:}

Verband

Ges./Kr.: Gesund

\section{Alter:}

Geschlecht:

Arthrose:
2 
Bezeichn.: Femur

Kiste:

Skelet: aus großer Tüte drinnen

Population: Großenrode

Seite:

links

Erhaltung: $\square$ prox. Gelenk

$X$ prox. Schaft

mittl. Schaft

$\mathbf{X}$ dist. Schaft

dist. Gelenk

Beschreibung:

Zwei kleine Fragmente.
Verband: $\quad$ Verband

\section{Alter:}

Geschlecht:

Arthrose: 
Bezeichn.: Femur

Kiste:$$
2
$$

Skelet: $\quad$ aus großer Tüte drinnen

Population: Großenrode

Seite: rechts

Erhaltung: $\square$ prox. Gelenk

$X$ prox. Schaft

$X$ mittl. Schaft

dist. Schaft dist. Gelenk

\section{Beschreibung:}

Etwa $40 \%$ des Schaftes eines rechten Os femoris, welches sehr erodiert ist.

\section{Verband: $\quad$ Verband}

\section{Alter:}

Geschlecht:

Arthrose:

\section{Maß}

a-p $\varnothing$ subtrochlear

m-I $\varnothing$ subtrochlear
Wert $\quad$ Einheit

$32,6 \mathrm{~mm}$

24,88

$\mathrm{mm}$


Bezeichn.: Femur

Kiste:

$$
2
$$

Skelet: $\quad$ aus großer Tüte drinnen

Population: Großenrode

Erhaltung: $\square$ prox. Gelenk

$\mathbf{X}$ prox. Schaft

$X$ mittl. Schaft

dist. Schaft dist. Gelenk
Seite: links

Ges./Kr.: Gesund

\section{Alter:}

Geschlecht:

Arthrose:

\section{Beschreibung:}

Die gluteale Muskelmarke dieses linken Os femoris ist knöchern gut ausgeprägt.

\section{Maß}

a-p $\varnothing$ subtrochlear

m-I Ø subtrochlear

Umfang Schaftmitte 
Bezeichn.: Femur

Kiste:

Skelet: aus großer Tüte drinnen

Population: Großenrode

Seite: links

Erhaltung: $\square$ prox. Gelenk

$X$ prox. Schaft

$\mathbf{X}$ mittl. Schaft

dist. Schaft

dist. Gelenk
Verband: $\square$ Verband

Alter:

Geschlecht:

Arthrose:

\section{Beschreibung:}

Dies ist ein Fragment aus dem Schaft eines Os femoris der linken Seite, es macht etwa 3/4 des Schaftes aus. Das Fragment ist erodiert. 
Bezeichn.: Femur

Kiste:

2

Skelet: $\quad$ aus großer Tüte drinnen

Population: Großenrode

Seite: rechts

Erhaltung: $\square$ prox. Gelenk

prox. Schaft

mittl. Schaft

dist. Schaft

$\mathbf{X}$ dist. Gelenk

\section{Beschreibung:}

Es sind etwa 85\% der Gelenkfläche des Condylus dieses rechten Os femoris erhalten.

Alter: Erwachsen
Verband: $\square$ Verband

Ges./Kr.: Gesund

Maß

Epicondylenbreite

Geschlecht:

Arthrose: \begin{tabular}{|l|l} 
Wert & Einheit \\
\hline 79,5 & mm
\end{tabular}

$79,5 \mathrm{~mm}$




$\begin{array}{ll}\text { Bezeichn.: } & \text { Femur } \\ \text { Kiste: } & 2 \\ \text { Skelet: } & \text { aus großer Tüte } \\ \text { Population: } & \text { Großenrode } \\ \text { Seite: } & \text { links } \\ \text { Erhaltung: } & \square \text { prox. Gelenk } \\ & \square \text { prox. Schaft } \\ & \square \text { mittl. Schaft } \\ & \square \text { dist. Schaft } \\ & \mathbf{X} \text { dist. Gelenk }\end{array}$

Verband: $\square$ Verband

Alter: Erwachsen

Geschlecht:

Arthrose:

Fragment des Condylus eines linken Os femoris. Es ist sehr stark erodiert. 


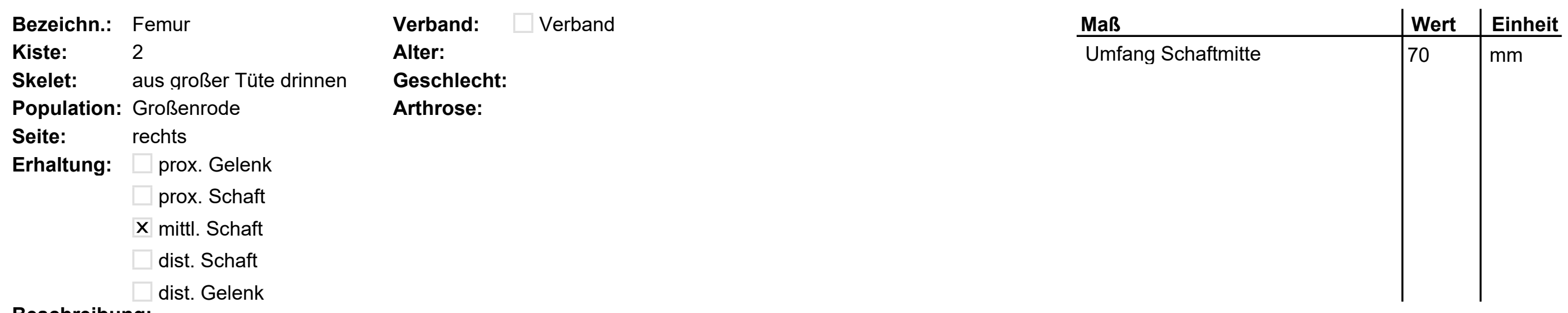

\section{Beschreibung:}

Dies ist ein Fragment aus dem Schaft eines rechten Os femoris, welches mittelmäßig erodiert ist. Der gesamte Knochen wird dem Anschein nach grazil gewesen sein. Das Fragment macht etwa 1/4 des Schaftes aus. 

Bezeichn.: Femur
Kiste: 3
Skelet: $\quad 61 / 66-4$
Population: Großenrode
Seite: links
Erhaltung: $\square$ prox. Gelenk
prox. Schaft
$X$ mittl. Schaft
dist. Schaft
dist. Gelenk

\section{Beschreibung:}

\section{Verband: $\quad \square$ Verband}

\section{Alter:}

Geschlecht:

Arthrose:

Dieses Fragment stammt aus der Mitte eines linken Os femoris und macht etwa 1/5 seines Schaftes aus. 


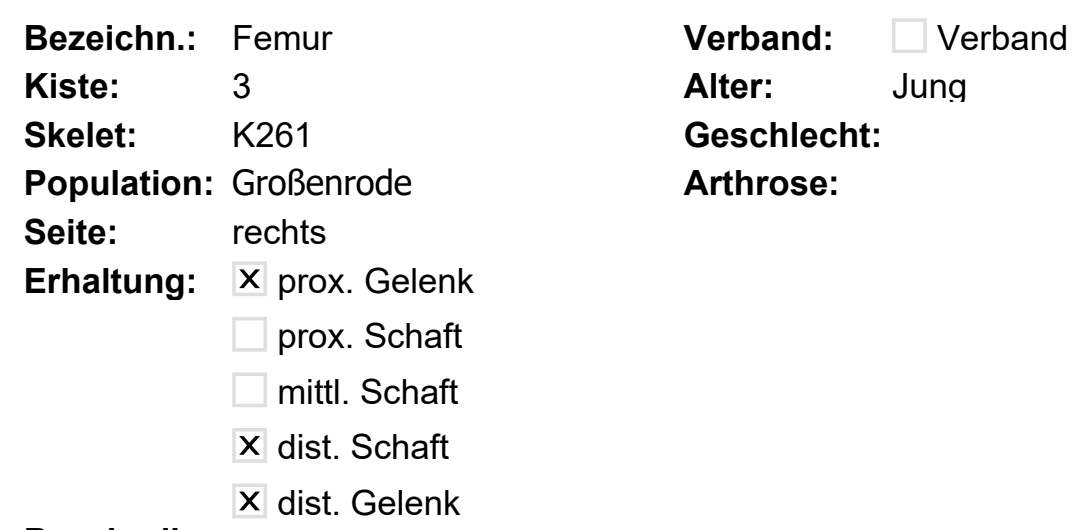

Population: Großenrode

Seite: rechts

Erhaltung: $\mathbf{X}$ prox. Gelenk prox. Schaft

mittl. Schaft

$\mathbf{X}$ dist. Schaft $X$ dist. Gelenk

Beschreibung:

Hier sind mehrere Fragmente eines jungen, rechten Os femoris erhalten. Die Fragmente sind erodiert. 

Bezeichn.: Femur
Kiste: 3
Skelet: K167
Population: Großenrode
Seite: links
Erhaltung: $\square$ prox. Gelenk
$X$ prox. Schaft
$\mathbf{X}$ mittl. Schaft
dist. Schaft
dist. Gelenk

\section{Beschreibung:}

\section{Verband: $\quad \square$ Verband}

\section{Alter:}

Geschlecht:

Arthrose:

Dieses Fragment eines linken Os femoris ist stark erodiert und weist Bissspuren auf.

Maß

Umfang Schaftmitte

Wert $\quad$ Einheit

$85 \quad \mathrm{~mm}$



Bezeichn:: Femur
Kiste:
3
Skelet: K192 S3
Population: Großenrode
Seite: links
Erhaltung: $\square$ prox. Gelenk
$X$ prox. Schaft
$X$ mittl. Schaft
dist. Schaft
dist. Gelenk
Beschreibung:

Dieses Fragment ist erodiert und frakturiert erhalten. Es gehört zu einem linken Os femoris.

\section{Verband: $\quad \square$ Verband}

\section{Alter:}

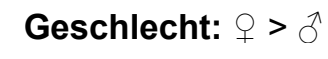

Arthrose:

\section{Maß}

a-p $\varnothing$ subtrochlear

Collum-Corpus-Winkel

$\mathrm{m}-\mathrm{l} \varnothing$ subtrochlear

Umfang Schaftmitte \begin{tabular}{|l|l} 
Wert & Einheit \\
\hline 23,92 & mm
\end{tabular}

23,92 $\mathrm{mm}$

125

$30,89 \mathrm{~mm}$

$75 \quad \mathrm{~mm}$




\section{Bezeichn.: Femur}

Kiste: 3

Skelet: $\quad \mathrm{K} 182$

Population: Großenrode

Seite: rechts

Erhaltung: $\mathbf{X}$ prox. Gelenk

$\mathbf{X}$ prox. Schaft

mittl. Schaft

dist. Schaft dist. Gelenk

Beschreibung:

Verband: $\square$ Verband

Alter: Erwachsen

\section{Geschlecht:}

Arthrose:

Ges./Kr.: Gesund

Vier Fragmente eines rechten Os femoris, es ist sehr erodiert erhalten. 

Bezeichn:: Femur
Kiste: 3
Skelet: K316
Population: Großenrode
Seite: rechts
Erhaltung: $\mathbf{X}$ prox. Gelenk
X prox. Schaft
mittl. Schaft
dist. Schaft
dist. Gelenk

\section{Verband: $\square$ Verband \\ Alter: Erwachsen \\ Geschlecht:}

\section{Arthrose:}

\section{Ges./Kr.: Gesund}

\section{Beschreibung:}

Von diesem Os femoris der rechten Seite ist nur ein Fragment erhalten, welches sehr stark erodiert ist.

\begin{tabular}{l|l|l} 
Maß & Wert & Einheit \\
\hline a-p $\varnothing$ subtrochlear & 24 & $\mathrm{~mm}$ \\
Caput, vertikaler $\varnothing$ & 46,85 & $\mathrm{~mm}$ \\
Collum-Corpus-Winkel & 120 & $\circ$ \\
$\mathrm{m}-\mathrm{I} \varnothing$ subtrochlear & 33,32 & $\mathrm{~mm}$ \\
& & \\
& &
\end{tabular}




\section{Bezeichn.: Femur}

\section{Kiste:}

Skelet: K58

Population: Großenrode

Seite: rechts

Erhaltung: $\square$ prox. Gelenk

prox. Schaft

mittl. Schaft

X dist. Schaft

dist. Gelenk

\section{Beschreibung:}

Ein kleines Fragment eines rechten Os femoris, es ist erodiert.
Verband: $\square$ Verband

\section{Alter:}

Geschlecht:

Arthrose: 
Bezeichn.: Femur

\section{Kiste:}

Skelet: K228

Population: Großenrode

Seite: rechts

Erhaltung: $\square$ prox. Gelenk prox. Schaft

mittl. Schaft dist. Schaft X dist. Gelenk

\section{Beschreibung:}

Ein kleines Fragment.
Verband: $\quad$ Verband

\section{Alter:}

Geschlecht:

Arthrose: 
Bezeichn.: Femur

Kiste: $\quad 10$

Skelet: $\quad 63 / 52$

Population: Großenrode

Seite: links

Erhaltung: X prox. Gelenk

prox. Schaft

mittl. Schaft

dist. Schaft

$X$ dist. Gelenk

Beschreibung:

Kleine Fragmente.
Verband: $\quad$ Verband

\section{Alter:}

Geschlecht:

Arthrose: 


\begin{tabular}{|c|c|c|c|c|c|}
\hline Bezeichn.: & Femur & Verband: $\quad \square$ Verband & Maß & Wert & Einheit \\
\hline Kiste: & 10 & Alter: $\quad 13-18(19)$ & a-p $\varnothing$ subtrochlear & 22,46 & $\mathrm{~mm}$ \\
\hline Skelet: & $64 / 55$ & Geschlecht: & Collum-Corpus-Winkel & 120 & \\
\hline Population: & Großenrode & Arthrose: & m-I $\varnothing$ subtrochlear & 29,77 & $\mathrm{~mm}$ \\
\hline Seite: & rechts & & & & \\
\hline Erhaltung: & $\square$ prox. Gelenk & & & & \\
\hline & X prox. Schaft & & & & \\
\hline & $\square$ mittl. Schaft & & & & \\
\hline & $\square$ dist. Schaft & & & & \\
\hline & $\square$ dist. Gelenk & & & & \\
\hline
\end{tabular}

\section{Beschreibung:}

Dies ist ein Fragment eines rechten Os femoris, dessen Epiphysenfuge nicht geschlossen war. Es handelt sich wohl um ein juveniles Individuum. Das Fragment ist stark erodiert. 


$\begin{array}{ll}\text { Bezeichn.: } & \text { Femur } \\ \text { Kiste: } & 10 \\ \text { Skelet: } & 64 / 55 \\ \text { Population: } & \text { Großenrode } \\ \begin{array}{ll}\text { Seite: } & \text { rechts } \\ \text { Erhaltung: } & \mathbf{X} \text { prox. Gelenk } \\ & \text { X prox. Schaft } \\ & \mathbf{X} \text { mittl. Schaft } \\ & \mathbf{X} \text { dist. Schaft } \\ & \square \text { dist. Gelenk }\end{array} \\ \text { Beschreibung: }\end{array}$

Verband: $\quad \square$ Verband

Alter: $\quad 15-21(22)$

Geschlecht: $q \geq 0$

\section{Arthrose:}

Ges./Kr.: Gesund

Maß

a-p $\varnothing$ subtrochlear

Caput, horizontaler $\varnothing$

Collum-Corpus-Winkel

$\mathrm{m}-\mathrm{I} \varnothing$ subtrochlear

Umfang Schaftmitte

\begin{tabular}{|l|l} 
Wert & Einheit \\
\hline 27,33 & $\mathrm{~mm}$
\end{tabular}

Dies sind die Fragmente eines rechten Os femoris, es ist eine gluteale Muskelmarke festzustellen, die aber wohl mit dem noch nicht sehr fortgeschrittenen, juvenilen bis subadulten Alter zusammenhängt. 


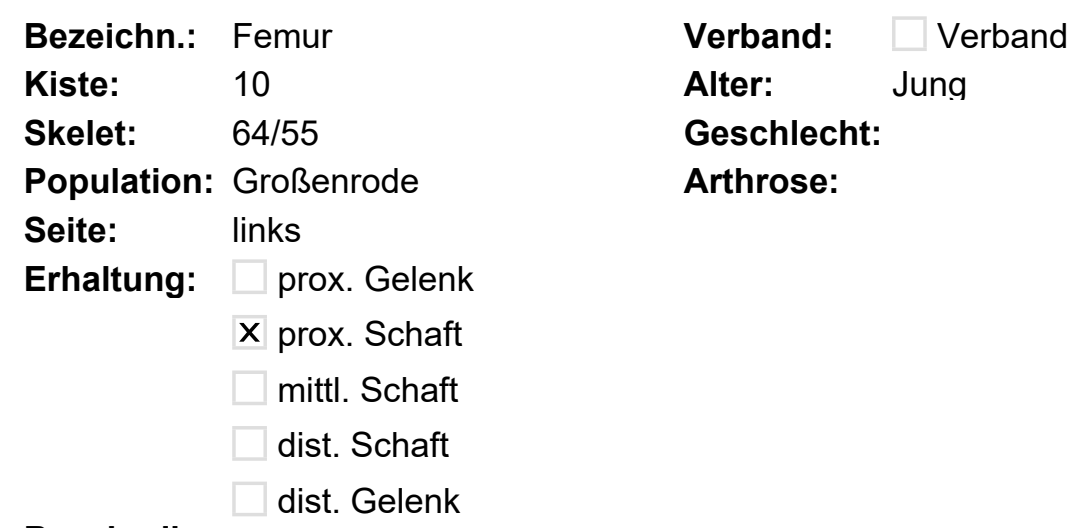

Population: Großenrode

Seite: links

Erhaltung: $\square$ prox. Gelenk

$X$ prox. Schaft

mittl. Schaft

dist. Schaft dist. Gelenk

\section{Beschreibung:}

Dies ist das sehr erodierte Fragment eines linken Os femoris. 


\section{Bezeichn.: Femur}

Kiste: 3

Skelet: $\quad$ K100 62/64 S2

Population: Großenrode

Seite: rechts

Erhaltung: $\square$ prox. Gelenk

X prox. Schaft

mittl. Schaft

dist. Schaft

dist. Gelenk
Ges./Kr.: Gesund

Verband

\section{Alter:}

Geschlecht:

Arthrose:

\section{Maß}

a-p $\varnothing$ subtrochlear

m-I Ø subtrochlear

Umfang Schaftmitte

\begin{tabular}{|l|l} 
Wert & Einheit \\
\hline 25 & $\mathrm{~mm}$
\end{tabular}

33,18

$\mathrm{mm}$

84

\section{Beschreibung:}

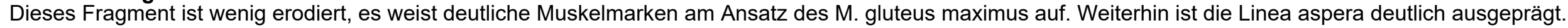




$\begin{array}{ll}\text { Bezeichn.: } & \text { Femur } \\ \text { Kiste: } & 10 \\ \text { Skelet: } & 62 / 53 \\ \text { Population: } & \text { Großenrode } \\ \begin{array}{ll}\text { Seite: } & \text { links } \\ \text { Erhaltung: } & \square \text { prox. Gelenk } \\ & \square \text { prox. Schaft } \\ & \square \text { mittl. Schaft } \\ & \mathbf{X} \text { dist. Schaft } \\ & \square \text { dist. Gelenk }\end{array}\end{array}$

Verband: $\quad \square$ Verband Ges./Kr.: Gesund

Alter: Jung

Geschlecht:

Arthrose:

Ein Fragment einer distalen Epiphyse. Es handelt sich um ein junges Individuum. 


$\begin{array}{lll}\text { Bezeichn.: } & \text { Femur } & \text { Verband: } \square \text { Verband } \\ \text { Kiste: } & 10 & \text { Alter: Jung } \\ \text { Skelet: } & 62 / 53 & \text { Geschlecht: } \\ \text { Population: } & \text { Großenrode } & \text { Arthrose: } \\ \text { Seite: } & \text { rechts } & \\ \text { Erhaltung: } & \square \text { prox. Gelenk } & \\ & \square \text { prox. Schaft } & \\ & \square \text { mittl. Schaft } & \\ & \mathbf{X} \text { dist. Schaft } & \\ & \square \text { dist. Gelenk }\end{array}$

\section{Beschreibung:}

Dies ist ein Fragment aus dem Schaft eines rechten und jungen Os femoris. 


\section{Bezeichn.: Femur}

\section{Kiste:}

10

Skelet: $\quad 62 / 53$ klein

Population: Großenrode

Erhaltung: $\quad$ X prox. Gelenk

prox. Schaft

mittl. Schaft

dist. Schaft

dist. Gelenk

\section{Beschreibung:}

Dies ist eine Epiphyse eines Os femoris. Es handelt sich um das Caput femoris.

\section{Verband: $\quad$ Verband}

\section{Alter:}

Geschlecht:

Arthrose:

\section{Maß}

Caput, horizontaler $\varnothing$

Wert $\quad$ Einheit

40,38 $\mathrm{mm}$


Bezeichn.: Femur

Kiste: $\quad 10$

Skelet: $\quad 62 / 56$

Population: Großenrode

Seite: rechts

Erhaltung: $\mathbf{X}$ prox. Gelenk

$X$ prox. Schaft

mittl. Schaft

dist. Schaft dist. Gelenk

Beschreibung:

Ein stark erodiertes Fragment.
Verband: $\quad \square$ Verband

\section{Alter:}

Geschlecht:

Arthrose: 

Bezeichn.: Femur
Kiste:

10
Skelet: $\quad 62 / 58$
Population: Großenrode
Erhaltung: $\mathbf{X}$ prox. Gelenk
prox. Schaft
mittl. Schaft
dist. Schaft
dist. Gelenk
Beschreibung:

\section{Verband: $\quad \square$ Verband \\ Alter: Jung \\ Geschlecht:}

Hier ist nur die proximale Epiphyse des Caput femoris erhalten. 


$\begin{array}{ll}\text { Bezeichn.: } & \text { Femur } \\ \text { Kiste: } & 10 \\ \text { Skelet: } & 63 / 54 \\ \text { Population: } & \text { Großenrode } \\ \begin{array}{ll}\text { Seite: } & \text { rechts } \\ \text { Erhaltung: } & \mathbf{X} \text { prox. Gelenk } \\ & \square \text { prox. Schaft } \\ & \square \text { mittl. Schaft } \\ & \square \text { dist. Schaft } \\ & \mathbf{X} \text { dist. Gelenk }\end{array} \\ \text { Beschreibung: }\end{array}$

Verband: $\square$ Verband

Alter:

Geschlecht:

Arthrose:

prox.

1

Zwei erodierte Fragmente eines Os femoris, welche erodiert sind. 


\section{Bezeichn.: Femur}

\section{Kiste:}

Skelet: K85-2

Population: Großenrode

Seite: links

Erhaltung: $\square$ prox. Gelenk

prox. Schaft

mittl. Schaft

$\mathbf{X}$ dist. Schaft

dist. Gelenk

\section{Beschreibung:}

Fünf erodierte Splitter eines linken Os femoris mit Bissspuren.
Verband: $\quad$ Verband

\section{Alter:}

Geschlecht:

Arthrose: 
Bezeichn.: Femur

\section{Kiste:}

Skelet: K282 63/68-S3

Population: Großenrode

Seite: n. def.

Erhaltung: $\square$ prox. Gelenk prox. Schaft $X$ mittl. Schaft dist. Schaft dist. Gelenk

\section{Beschreibung:}

Ein kleines erodiertes Fragment.
Verband: $\quad \square$ Verband

\section{Alter:}

Geschlecht:

Arthrose: 
Bezeichn.: Femur

Kiste:

Skelet: $\quad 63 / 68-1$

Population: Großenrode

Seite:

n. def.

Erhaltung: $\square$ prox. Gelenk prox. Schaft

$X$ mittl. Schaft dist. Schaft dist. Gelenk

Beschreibung:

Ein kleines erodiertes Fragment.
Verband: Verband

\section{Alter:}

Geschlecht:

Arthrose: 
Bezeichn:: Femur

\section{Kiste:}

Skelet: $\quad$ K240 63/68 P3

Population: Großenrode

Seite: rechts

Erhaltung: $\square$ prox. Gelenk

X prox. Schaft

X mittl. Schaft

dist. Schaft

dist. Gelenk

Beschreibung:

Ein erodiertes Fragment.

\section{Verband: $\quad$ Verband}

\section{Alter:}

Geschlecht:

Arthrose:
Maß

a-p $\varnothing$ subtrochlear

m-I Ø subtrochlear

Umfang Schaftmitte

\begin{tabular}{|l|l} 
Wert & Einheit \\
\hline 23,36 & $\mathrm{~mm}$
\end{tabular}

30




\section{Bezeichn.: Femur}

Kiste:

1

Skelet: $\quad$ K232-1 63/68-P3

Population: Großenrode

Seite: rechts

Erhaltung: $\square$ prox. Gelenk

$X$ prox. Schaft

$\mathbf{X}$ mittl. Schaft

dist. Schaft

dist. Gelenk

\section{Beschreibung:}

Dieses Fragment gehört zu einem jungen Os femoris, die Linea aspera ist bereits gut ausgeprägt.

\section{Verband: $\quad \square$ Verband \\ Alter: Jung \\ Geschlecht: \\ Ges./Kr.: Gesund}

Arthrose:

\section{$\mathrm{Maß}$}

a-p Ø subtrochlear

Collum-Corpus-Winkel

m-I Ø subtrochlear

Umfang Schaftmitte \begin{tabular}{|l|l} 
Wert & Einheit \\
\hline 21,68 & $\mathrm{~mm}$
\end{tabular}

$21,68 \mathrm{~mm}$

125

$\circ$

$\mathrm{mm}$

$\mathrm{mm}$ 

Bezeichn:: Femur
Kiste:

1
Skelet: K186-9
Population: Großenrode
Seite: rechts
Erhaltung: $\square$ prox. Gelenk
X prox. Schaft
mittl. Schaft
dist. Schaft
dist. Gelenk
Beschreibung:

\section{Alter: Jung \\ Geschlecht:}

Verband: $\quad$ Verband

Arthrose:

Ges./Kr.: Gesund

Ein proximales Fragment eines jungen Individuums.

\begin{tabular}{l|l|l} 
Maß & Wert & Einheit \\
\hline a-p $\varnothing$ subtrochlear & 20,5 & $\mathrm{~mm}$ \\
Collum-Corpus-Winkel & 125 & $\circ$ \\
$\mathrm{m}-\mathrm{I} \varnothing$ subtrochlear & 27,38 & $\mathrm{~mm}$ \\
& & \\
& &
\end{tabular}




$\begin{array}{ll}\text { Bezeichn.: } & \text { Femur } \\ \text { Kiste: } & 1 \\ \text { Skelet: } & \text { K281 S3 } \\ \text { Population: } & \text { Großenrode } \\ \begin{array}{ll}\text { Seite: } & \text { links } \\ \text { Erhaltung: } & \square \text { prox. Gelenk } \\ & \text { X prox. Schaft } \\ & \text { X mittl. Schaft } \\ & \square \text { dist. Schaft } \\ & \square \text { dist. Gelenk }\end{array} \\ \text { Beschreibung: }\end{array}$

Verband: $\square$ Verband

Alter: Jung

Geschlecht:

Arthrose:

\section{Maß}

a-p $\varnothing$ subtrochlear

Collum-Corpus-Winkel

m-I Ø subtrochlear

Umfang Schaftmitte \begin{tabular}{|l|l} 
Wert & Einheit \\
\hline 22 &
\end{tabular}

$\begin{array}{ll}22 & \mathrm{~mm}\end{array}$

130

$29,28 \mathrm{~mm}$

74

$\circ$

Dieses Fragment eines linken Os femoris weist eine sehr stark erodierte Oberfläche auf. Es handelt sich um ein junges Individuum. 


\section{Bezeichn.: Femur}

Kiste:

Skelet: $\quad$ K234 63/68 P3

Population: Großenrode

Seite: rechts

Erhaltung: $\square$ prox. Gelenk

X prox. Schaft

X mittl. Schaft

dist. Schaft

dist. Gelenk
Ges./Kr.: Krank

Krankh.: Enthesiopathie

Muskelreizung
Maß

a-p $\varnothing$ subtrochlear

m-l $\varnothing$ subtrochlear

Umfang Schaftmitte

Geschlecht:

Arthrose:

$34,46 \mathrm{~mm}$

84

\section{Beschreibung:}

Dieses Fragment weist Bissspuren und eine Muskelreizung des M. gluteus maximus auf. Die Linea aspera ist gut ausgeprägt und weist auch eine Enthesiopathie auf. 


\section{Bezeichn.: Femur}

Kiste:

Skelet: $\quad$ K237 63/68-P3

Population: Großenrode

Seite: links

Erhaltung: $\square$ prox. Gelenk

prox. Schaft

mittl. Schaft

$X$ dist. Schaft

X dist. Gelenk

\section{Beschreibung:}

Ein Fragment, welches erodiert ist und aus dem distalen Teil eines linken Os femoris stammt. Es ist ein Teil des Condylus erhalten.

\section{Verband: $\quad$ Verband}

\section{Alter:}

Geschlecht:

Arthrose:
Maß

Umfang Schaftmitte

$\mathrm{mm}$


Bezeichn.: Femur

\section{Kiste:}

Skelet: $\quad$ K239 63/68 P3

Population: Großenrode

Seite: links

Erhaltung: $\square$ prox. Gelenk

prox. Schaft

mittl. Schaft

dist. Schaft

X dist. Gelenk

\section{Beschreibung:}

Ein Fragment des medialen Condylus eines linken Os femoris. Das Fragment ist sehr erodiert.
Verband: $\square$ Verband

\section{Alter:}

Geschlecht:

Arthrose: 
Bezeichn:: Femur

Kiste:

\section{Verband:}

\section{Alter:}

Ges./Kr.: Gesund

Skelet: $\quad 63 / 68-P 2$ K119

Population: Großenrode

\section{Geschlecht:}

Arthrose:

Seite: links

Erhaltung: $\square$ prox. Gelenk

$X$ prox. Schaft

$X$ mittl. Schaft

dist. Schaft

dist. Gelenk

\section{Beschreibung:}

Ein sehr graziles Fragment, es könnte sich um ein junges Individuum gehandelt haben.

\begin{tabular}{l|l|l} 
Maß & Wert & Einheit \\
\hline a-p $\varnothing$ subtrochlear & 16,68 & $\mathrm{~mm}$ \\
Collum-Corpus-Winkel & 130 & $\circ$ \\
$\mathrm{m}-\mathrm{l} \varnothing$ subtrochlear & 23,11 & $\mathrm{~mm}$ \\
Umfang Schaftmitte & 59 & $\mathrm{~mm}$ \\
& & \\
& &
\end{tabular}




$\begin{array}{ll}\text { Bezeichn.: } & \text { Femur } \\ \text { Kiste: } & 1 \\ \text { Skelet: } & \text { K77 63/68 P2 } \\ \text { Population: } & \text { Großenrode } \\ \begin{array}{ll}\text { Seite: } & \text { links } \\ \text { Erhaltung: } & \square \text { prox. Gelenk } \\ & \text { X prox. Schaft } \\ & \text { X mittl. Schaft } \\ & \mathbf{X} \text { dist. Schaft } \\ & \mathbf{X} \text { dist. Gelenk }\end{array} \\ \text { Beschreibung: }\end{array}$

\section{Verband: $\square$ Verband Ges./Kr.: Krank}

Alter: $\quad(15) 16-18(19)$

Krankh.: Muskelreizung

\section{Geschlecht: $q>0$}

Arthrose:

\begin{tabular}{l|l|l} 
Maß & Wert & Einheit \\
\hline Collum-Corpus-Winkel & 130 & $\circ$ \\
Epicondylenbreite & 74 & $\mathrm{~mm}$ \\
gr. Länge & 435 & $\mathrm{~mm}$ \\
Umfang Schaftmitte & 85 & $\mathrm{~mm}$ \\
& &
\end{tabular}

Dieses Fragment weist eine deutliche Längsstreifung auf der Oberfläche des Schaftes auf, welche für eine muskuläre Reizung spricht. Das Fragment wirkt sehr grazil und stammt von einem jungen Individuum, welches im juvenilen Altersbereich gewesen sein könnte. 


\section{Bezeichn.: Femur}

\section{Kiste:}

Skelet: $\quad$ K243 63/68-P3

Population: Großenrode

Seite: rechts

Erhaltung: $\square$ prox. Gelenk

prox. Schaft

$X$ mittl. Schaft

X dist. Schaft

dist. Gelenk

\section{Beschreibung:}

Fragmente eines grazilen Individuums, welche zu einem jungen Individuum gehören könnten.

\section{Verband: \\ Verband \\ Ges./Kr.: Gesund}

Alter:

Geschlecht:

Arthrose:
Maß

Umfang Schaftmitte \begin{tabular}{|l|l} 
Wert & Einheit \\
\hline 71 &
\end{tabular}

\begin{tabular}{l|l}
71 & $\mathrm{~mm}$
\end{tabular}




\section{Bezeichn.: Femur}

Kiste: 1

Skelet: K79-2 63/68 P2

Population: Großenrode

Seite: links

Erhaltung: $\square$ prox. Gelenk

X prox. Schaft

X mittl. Schaft

dist. Schaft

dist. Gelenk
Ges./Kr.: Krank

Krankh.: Muskelreizung

\section{Beschreibung:}

$\begin{array}{ll}\text { Verband: } \quad \square \text { Verband } & \text { Ges./Kr.. } \\ \text { Alter: } & \text { Krankh.: Muskelreizung }\end{array}$

\section{Geschlecht:}

Arthrose:

Dieses Fragment stammt von einem linken Os femoris. Es weist Bissspuren und eine Längsstreifung auf, welche für eine muskulär bedingte Reizung spricht. 


\section{Bezeichn.: Femur}

Kiste: 1

Skelet: $\quad$ K72 -1 63/68 P2

Population: Großenrode

Seite: links

Erhaltung: $\mathbf{X}$ prox. Gelenk

X prox. Schaft

mittl. Schaft

$\mathbf{X}$ dist. Schaft

X dist. Gelenk

Beschreibung:

Zwei Fragmente eines Os femoris, welches noch nicht ausgewachsen war.

\section{Geschlecht:}

\section{Arthrose:}

Ges./Kr.: Gesund

\section{Maß}

Umfang Schaftmitte 


\section{Bezeichn.: Femur}

Kiste: $\quad 5$

Skelet: $\quad$ K334 64/68 P4

Population: Großenrode

Seite: rechts

Erhaltung: $\square$ prox. Gelenk

prox. Schaft

mittl. Schaft

$\mathbf{X}$ dist. Schaft

dist. Gelenk

\section{Beschreibung:}

nur ein posteriores Fragment erhalten. Es weist deutliche Spuren einer muskulären Überreizung auf.

\section{Verband: $\quad$ Verband Ges./Kr.: Krank}

Alter: Erwachsen Krankh.: Muskelreizung

Geschlecht:

Arthrose: 


\section{Bezeichn.: Femur}

Kiste:

Skelet: $\quad$ K333 64/68 P4

Population: Großenrode

Seite: links

Erhaltung: $\square$ prox. Gelenk

$X$ prox. Schaft

$X$ mittl. Schaft

dist. Schaft

X dist. Gelenk

\section{Beschreibung:}

Dieses Os femoris ist erodiert in mehreren Fragmenten erhalten. Der laterale Condylus ist zu 70\& erhalten und befundbar.
Verband: $\square$ Verband

\section{Geschlecht: $q \geq 0$}

Arthrose:
Alter: Erwachsen
Ges./Kr.: Krank

Krankh.: Arthrose
3
Maß

a-p $\varnothing$ subtrochlear

$\mathrm{m}-\mathrm{I} \varnothing$ subtrochlear

Umfang Schaftmitte 


\begin{tabular}{|c|c|c|c|c|c|c|}
\hline Bezeichn.: & Femur & $\square$ Verband & Ges./Kr.: Gesund & Maß & Wert & Einheit \\
\hline Kiste: & 5 & Alter: & & a-p $\varnothing$ subtrochlear & 24,63 & $\mathrm{~mm}$ \\
\hline Skelet: & K338 67/68-P4 & Geschlecht: & & m-I Ø subtrochlear & 32 & $\mathrm{~mm}$ \\
\hline Population: & Großenrode & Arthrose: & & Umfang Schaftmitte & 86 & $\mathrm{~mm}$ \\
\hline Seite: & links & & & & & \\
\hline Erhaltung: & $\square$ prox. Gelenk & & & & & \\
\hline & X prox. Schaft & & & & & \\
\hline & X mittl. Schaft & & & & & \\
\hline & $\square$ dist. Schaft & & & & & \\
\hline & $\square$ dist. Gelenk & & & & & \\
\hline
\end{tabular}

Mehrere stark erodierte Fragmente eines linken Os femoris. Die Knochenoberfläche ist stark erodiert. Es fällt eine deutlich ausgeprägte Linea aspera auf. 


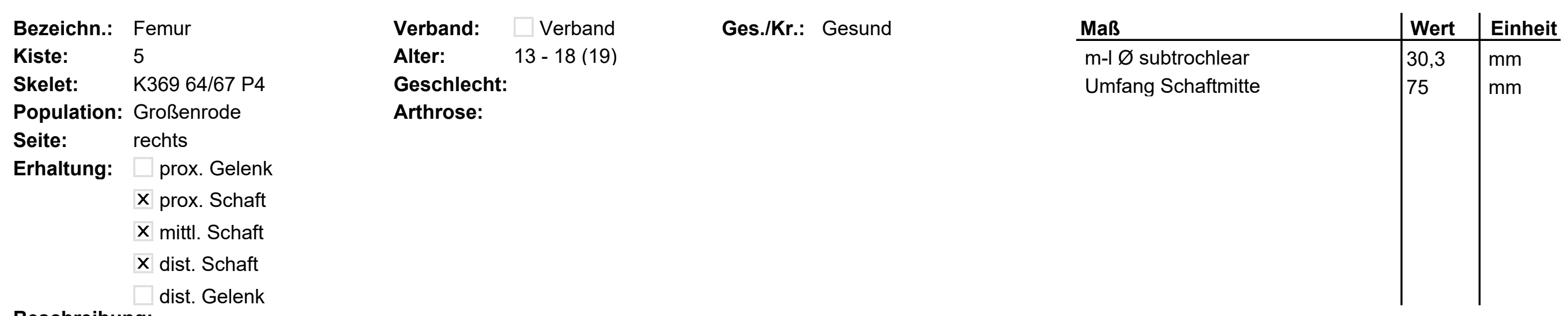

\section{Beschreibung:}

Ein stark erodiertes Fragment eines rechten Os femoris. Es ist entweder sehr grazil oder noch jung und damit einem juvenilen Individuum zuzuordnen. Letzteres schein wahrscheinlicher. 


$\begin{array}{ll}\text { Bezeichn.: } & \text { Femur } \\ \text { Kiste: } & 5 \\ \text { Skelet: } & \text { K153 62/69 S2-4 } \\ \text { Population: } & \text { Großenrode } \\ \begin{array}{ll}\text { Seite: } & \text { n. def. } \\ \text { Erhaltung: } & \text { X prox. Gelenk } \\ & \square \text { prox. Schaft } \\ & \square \text { mittl. Schaft } \\ & \square \text { dist. Schaft } \\ & \square \text { dist. Gelenk }\end{array} \\ \text { Beschreibung: }\end{array}$

Verband: $\quad \square$ Verband

Alter:

Geschlecht:

Arthrose:

Nur ein Fragment des Caput, es ist etwa 1/4 der Gelenkfläche erhalten. 


\begin{tabular}{|c|c|c|c|c|c|}
\hline Bezeichn.: & Femur & Verband: $\quad \square$ Verband & Maß & Wert & Einheit \\
\hline Kiste: & 8 & Erwachsen & a-p $\varnothing$ subtrochlear & 24,04 & $\mathrm{~mm}$ \\
\hline Skelet: & K326 61/68 P4/S4 & Geschlecht: & Caput, vertikaler $\varnothing$ & 400 & $\mathrm{~mm}$ \\
\hline Population: & Großenrode & Arthrose: & $\mathrm{m}-\mathrm{l} \varnothing$ subtrochlear & 37,2 & $\mathrm{~mm}$ \\
\hline Seite: & links & & Umfang Schaftmitte & 80 & $\mathrm{~mm}$ \\
\hline Erhaltung: & X prox. Gelenk & & & & \\
\hline & $\mathbf{X}$ prox. Schaft & & & & \\
\hline & $\mathbf{X}$ mittl. Schaft & & & & \\
\hline & $\mathbf{X}$ dist. Schaft & & & & \\
\hline & $\square$ dist. Gelenk & & & & \\
\hline
\end{tabular}

\section{Beschreibung:}

Ein Fragment eines schlanken Os femoris, welches aufgrund seiner dicken Compacta ein hohes Gewicht hat. Es weist einen sehr stark ausgeprägten Ansatz des M. gluteus maximus auf. Das Fundstück ist erodiert und lässt keine weiteren Befunde zu. 


\section{Bezeichn.: Femur}

Kiste: 8

Skelet: K27961/68 S3

Population: Großenrode

Seite: links

Erhaltung: $\square$ prox. Gelenk

$\mathbf{X}$ prox. Schaft

$X$ mittl. Schaft

$\mathbf{X}$ dist. Schaft

$X$ dist. Gelenk

\section{Beschreibung:}

Ein erodiertes Os femoris. Die distale Gelenkfläche ist zu 60\% erhalten.
Verband: $\quad$ Verband

Alter: Erwachsen

\section{Geschlecht: $q \geq 0$}

Arthrose:

\section{Ges./Kr.: Gesund}

\begin{tabular}{l|l|l} 
Maß & Wert & Einheit \\
\hline a-p $\varnothing$ subtrochlear & 24,77 & $\mathrm{~mm}$ \\
$\mathrm{~m}-1 \varnothing$ subtrochlear & 34 & $\mathrm{~mm}$ \\
Umfang Schaftmitte & 76 & $\mathrm{~mm}$ \\
& & \\
& &
\end{tabular}




\section{Bezeichn.: Femur}

Kiste: 8

Skelet: K164 61/68-P3

Population: Großenrode

Seite: links

Erhaltung: $\square$ prox. Gelenk

prox. Schaft

mittl. Schaft

dist. Schaft

$X$ dist. Gelenk

\section{Beschreibung:}

Ein Fragment des Condylus lateralis. Es ist etwa 1/3 desselben erhalten.
Verband: $\quad$ Verband

\section{Geschlecht:}

Arthrose:
Alter: Erwachsen

\section{Ges./Kr.: Gesund}


Bezeichn.: Femur

\section{Kiste:}

Skelet: K164 61/68-P3

Population: Großenrode

Seite: rechts

Erhaltung: X prox. Gelenk

prox. Schaft

mittl. Schaft

dist. Schaft

dist. Gelenk

\section{Beschreibung:}

Ein Fragment eines rechten Os femoris. Es ist etwa 1/5 des Caput erhalten.
Verband: $\square$ Verband

Ges./Kr.: Gesund

\section{Alter:}

Geschlecht:

Arthrose:

prox. 


\section{Bezeichn.: Femur}

Kiste: 8

Skelet: $\quad$ K31161/68 P4

Population: Großenrode

Seite: rechts

Erhaltung: $\square$ prox. Gelenk prox. Schaft

mittl. Schaft

$X$ dist. Schaft

$X$ dist. Gelenk

Beschreibung:

Ein etwas grünlich gefärbtes Fragment eines rechten Os femoris. Es sind etwa 60\% der Gelenkfläche erhalten. Der Knochen ist erodiert.

\section{Verband: $\quad$ Verband}

\section{Alter: $\quad$ Erwachsen}

Geschlecht:

Arthrose:

\section{Ges./Kr.: Gesund}

\section{Maß}

Epicondylenbreite

Umfang Schaftmitte

\begin{tabular}{|l|l} 
Wert & Einheit \\
76 & $\mathrm{~mm}$ \\
84 & $\mathrm{~mm}$ \\
&
\end{tabular}


Bezeichn.: Femur

\section{Kiste:}

Skelet: $\quad$ K31161/68 P4

Population: Großenrode
Verband: $\quad$ Verband

Alter:

\section{Geschlecht:}

Arthrose:

\section{Erhaltung: $\mathbf{X}$ prox. Gelenk \\ prox. Schaft \\ mittl. Schaft \\ dist. Schaft \\ dist. Gelenk}

Beschreibung:

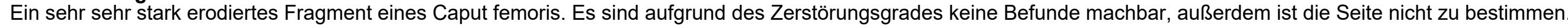




\section{Bezeichn.: Femur}

Kiste:

8

Skelet: $\quad$ K311 61/68-P4

Population: Großenrode

Seite: rechts

Erhaltung: $\square$ prox. Gelenk

$X$ prox. Schaft

$X$ mittl. Schaft

dist. Schaft

dist. Gelenk

Beschreibung:

Ein etwas erodiertes Fragment, wessen Ansatz des M. gluteus maximus stark ausgeprägt ist.

Geschlecht: $\curvearrowright$

\section{Verband: \\ Verband \\ Ges./Kr.: Gesund}

\section{Alter:}

Arthrose:

Maß

a-p $\varnothing$ subtrochlear

m-I Ø subtrochlear

Umfang Schaftmitte 
Bezeichn:: Femur

Kiste: 8

Skelet: $\quad$ K348 61/68 S4

Population: Großenrode

Erhaltung: $\square$ prox. Gelenk prox. Schaft

mittl. Schaft

dist. Schaft X dist. Gelenk

Beschreibung:

Es ist nur die distale Epiphyse erhalten.
Verband: $\quad$ Verband

Alter: $\quad 10-18$

Geschlecht:

Arthrose:
Ges./Kr.: Gesund

Maß

Epicondylenbreite

Wert $\mid$ Einheit

dist.

00 


\section{Bezeichn.: Patella}

Kiste:

Skelet: $\quad 63 / 67$ S3 K248

Population: Großenrode

Seite:

\section{Verband:}

Alter:

Geschlecht:

Arthrose:
Verband

Ges./Kr.: Gesund - $18(20)$
Maß

Breite

Länge

\begin{tabular}{|l|l} 
Wert & Einheit \\
\hline 34,6 & $\mathrm{~mm}$
\end{tabular}

$\mathrm{mm}$

\section{Beschreibung:}

Eine recht gut erhaltene Patella der linken Seite. Der Knochen kann einem juvenilen Individuum zugeordnet werden. 
Bezeichn.: Patella

Kiste:

Skelet: 62/65-3

Population: Großenrode

Seite:

links

\section{Verband:}

\section{Alter:}

Geschlecht:

Arthrose:

\section{Ges./Kr.: Gesund}

\section{Beschreibung:}

Ein sehr stark erodiertes Fragment einer linken Patella, die an Masse etwa zu 70\% erhalten ist. Die Gelenkflächen sind zu $80 \%$ befundbar, der Rand fehlt allerdings. 


\section{Bezeichn.: Patella}

Kiste:

Skelet: $\quad 62 / 54$

Population: Großenrode

Seite:

rechts

\section{Verband: $\quad \square$ Verband}

\section{Alter:}

\section{Geschlecht:}

Arthrose:

\section{Beschreibung:}

Von dieser Patella sind $90 \%$ der Gelenkfläche erhalten. Insgesamt ist sie ziemlich gut erhalten. 
Bezeichn:: Patella

Kiste:

Skelet: 62/54

Population: Großenrode

Seite:

n. def.
Verband: Verband

\section{Alter:}

\section{Geschlecht:}

Arthrose:

\section{Beschreibung:}

Diese Patella ist zu etwa 1/3 erhalten, sehr stark erodiert und frakturiert. 


\section{Bezeichn.: Patella}

Kiste: 3

Skelet: K261

Population: Großenrode

Seite:

links

\section{Verband: $\quad$ Verband}

\section{Alter:}

Geschlecht:

Arthrose:
Maß

Breite

Länge
Wert $\mid$ Einheit

$27,4 \mathrm{~mm}$

28,64

$\mathrm{mm}$

\section{Beschreibung:}

Dieses Fundstück ist etwas erodiert, an den Seiten ist etwas Knochen abgesplittert. 


\section{Bezeichn.: Patella}

\section{Kiste:}

Skelet: K228

Population: Großenrode

Seite:

links

\section{Ges./Kr.: Gesund}

Alter:

Geschlecht:

Arthrose:
Maß

Breite

Länge \begin{tabular}{|l|l} 
Wert & Einheit
\end{tabular}

$4 \mathrm{~mm}$

$\mathrm{mm}$

\section{Beschreibung:}

Diese Patella ist recht gut erhalten und nur leicht erodiert, auf der linken Seite ist lediglich etwas abgesplittert. 


\section{Bezeichn.: Patella}

\section{Kiste:}

Skelet: $\quad 63 / 52$

Population: Großenrode

Seite:
Verband: Verband

\section{Alter:}

Geschlecht:

Arthrose:

\section{Beschreibung:}

Diese Patella ist erodiert, fällt aber aufgrund ihrer spitzen Form ins Auge. 


\section{Bezeichn.: Patella}

\section{Kiste:}

Skelet: $\quad 63 / 52$

Population: Großenrode

Seite:
Verband: Verband

\section{Alter:}

Geschlecht:

Arthrose:

\section{Beschreibung:}

Eine stark erodierte Patella, welche etwa zu $65 \%$ erhalten ist. 


\section{Bezeichn.: Patella \\ Kiste: \\ Skelet: $\quad 62 / 53$}

Population: Großenrode

Seite:
Verband: Verband

\section{Alter:}

Geschlecht:

Arthrose:

\section{Beschreibung:}

Diese Patella ist stark erodiert, sie weist eine sehr spitze Form auf. 


\section{Bezeichn.: Patella}

\section{Kiste: $\quad 10$}

Skelet: Tüte nur mit 62/51

Population: Großenrode

Seite:

links

\section{Verband:}

Verband

\section{Alter:}

Geschlecht:

Arthrose:

\section{Beschreibung:}

Diese Patella ist erodiert, aber noch zu $80 \%$ gut erhalten. 
Bezeichn.: Patella

\section{Kiste: $\quad 10$}

Skelet: 1. kleine Tüte aus Tüte

Population: Großenrode

Seite:

Verband: $\quad$ Verband

Alter:

Geschlecht:

Arthrose:

\section{Beschreibung:}

Diese Patella ist stark erodiert. 


\section{Bezeichn.: Patella}

\section{Kiste:}

Skelet:

Seite:

links
Verband

\section{Alter:}

Geschlecht:

Arthrose:
Ges./Kr.: Gesund

Maß

Breite

Länge \begin{tabular}{|l|l} 
Wert & Einheit
\end{tabular}

$\mathrm{mm}$

\section{Beschreibung:}

Diese Patella ist gut erhalten, zwar etwas erodiert, aber zu 98\% erhalten. Auffällig ist eine sehr spitze Form des Knochens. 


\section{Bezeichn.: Patella}

\section{Kiste:}

Skelet: $\quad$ K86

Population: Großenrode

Seite:

links

\section{Verband:}

Verband

\section{Alter:}

Geschlecht:

Arthrose:

\section{Beschreibung:}

Ein wohl im Ganzen erhaltenes Fundstück ohne nennenswerte Auffälligkeiten. 


\section{Bezeichn.: Patella}

\section{Kiste:}

Skelet: K242

Population: Großenrode

Seite:

links
Verband:

Verband

\section{Alter:}

Geschlecht:

Arthrose:

\section{Beschreibung:}

Dieses Fundstück weist Erosionsspuren auf. 
Bezeichn.: Patella

\section{Kiste:}

Skelet:

Population: Großenrode

Seite:

rechts

\section{Verband: $\square$ Verband}

\section{Alter:}

Geschlecht:

Arthrose:

\section{Beschreibung:}

Ein mäßig erhaltenes Fundstück, welches keine Besonderheiten aufweist. 


\section{Bezeichn.: Patella}

Kiste:

Skelet: $\quad$ K232

Population: Großenrode

Seite:
Verband: $\quad \square$ Verband

Alter: Jung

Geschlecht:

Arthrose:

\section{Beschreibung:}

Eine grazile und kleine Patella der rechten Seite. Wahrscheinlich ist sie einem jungen Individuum zuzuordnen. 
Bezeichn.: Patella

\section{Kiste:}

Skelet: K281

Population: Großenrode

Seite:

links
Verband: Verband

\section{Alter:}

\section{Geschlecht:}

Arthrose:

\section{Beschreibung:}

Ein erodiertes Fundstück, welches aber im Ganzen erhalten ist. 
Bezeichn.: Patella

\section{Kiste:}

Skelet: K234

Population: Großenrode

Seite:

Verband: $\quad$ Verband

Alter:

Geschlecht:

Arthrose:

\section{Beschreibung:}

Ein erodiertes Fundstück, welches aber im Ganzen erhalten ist. 


\section{Bezeichn.: Patella}

Kiste: $\quad 5$

Skelet: $\quad$ K344 64/68 S4

Population: Großenrode

Seite:
Verband: $\square$ Verband

Alter:

Geschlecht: $q>\hat{\sigma}$

Arthrose:

\section{Beschreibung:}

Diese Patella der rechten Seite ist erodiert und hat keine Gelenkfläche mehr. Die Außenfläche weist keine Auffälligkeiten auf. 


\section{Bezeichn.: Patella}

Kiste:

Skelet: $\quad$ K153 62/69 S2

Population: Großenrode

Seite:
Verband: $\square$ Verband

Alter: $\quad 13-18(19)$

Geschlecht:

Arthrose:

\section{Ges./Kr.: Gesund}

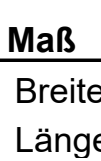

Wert $\quad$ Einheit

$35,5 \mathrm{~mm}$

33,33

$\mathrm{mm}$

\section{Beschreibung:}

Erodiert aber fast vollständig. Sehr grazil, die Konstitution lässt aber eher auf ein junges, juveniles Individuum schließen. 


\section{Bezeichn.: Patella}

\section{Kiste:}

Skelet: K154 61/68-S2

Population: Großenrode

Seite:

\section{Verband: $\quad \square$ Verband}

\section{Alter:}

Geschlecht: ${ }^{\lambda}$

Arthrose:
Ges./Kr.: Gesund

\section{Maß}

Breite

Länge

Wert 1 Einheit

47,3 $\mathrm{mm}$

43,3 $\mathrm{mm}$

fac. art.

\section{Beschreibung:}

Eine große Patella der rechten Seite eines männlichen Individuums. Die Gelenkfläche ist zu $80 \%$ befundbar. Es fallen keine Besonderheiten auf. 


\section{Bezeichn.: Patella}

\section{Kiste:}

Skelet: $\quad$ K279 61/68 S3

Population: Großenrode

Seite:
Verband: $\quad$ Verband

\section{Alter:}

Geschlecht:

Arthrose:

\section{Beschreibung:}

Eine erodierte Patella, dessen Gelenkfläche zu $80 \%$ befundbar war. 


\section{Bezeichn.: Tibia}

\section{Kiste:}

Skelet: $\quad$ K237 63/68-P3

Population: Großenrode

Seite: rechts

Erhaltung: $\square$ prox. Gelenk

prox. Schaft

$X$ mittl. Schaft

dist. Schaft

dist. Gelenk

\section{Verband: \\ Verband \\ Ges./Kr.: Gesund}

\section{Alter:}

Geschlecht:

Arthrose:

\section{Beschreibung:}

Dies ist ein Teil des Margo anterior einer rechten Tibia. Die Zugehörigkeit mit der anderen Tibia scheint möglich zu sein. 


\section{Bezeichn.: Tibia}

Kiste:

Skelet: $\quad 63 / 67$ S3 K285

Population: Großenrode

Seite: rechts

Erhaltung: $\square$ prox. Gelenk prox. Schaft

$X$ mittl. Schaft dist. Schaft dist. Gelenk

\section{Beschreibung:}

Zwei Fragmente aus dem Schaft einer rechten Tibia. Insgesamt etwa 1/3 erhalten.

\section{Verband: \\ Verband \\ Ges./Kr.: Gesund}

\section{Alter:}

Geschlecht:

Arthrose:
Maß

Umfang Schaftmitte \begin{tabular}{|l|l} 
Wert & Einheit \\
\hline 75 & mm
\end{tabular}

\begin{tabular}{l|l}
75 & $\mathrm{~mm}$
\end{tabular}




$\begin{array}{ll}\text { Bezeichn.: } & \text { Tibia } \\ \text { Kiste: } & 9 \\ \text { Skelet: } & \text { K235 63/67 P3 } \\ \text { Population: } & \text { Großenrode } \\ \text { Seite: } & \text { links } \\ \text { Erhaltung: } & \square \text { prox. Gelenk } \\ & \text { X prox. Schaft } \\ & \text { X mittl. Schaft } \\ & \text { X dist. Schaft } \\ & \square \text { dist. Gelenk }\end{array}$

Ges./Kr.: Krank

Krankh.: Myotendopathie

\section{Maß}

gr. Breite dist. Gelenk

Schaftumfang Foramen

Umfang Schaftmitte

\begin{tabular}{l|l} 
Wert & Einheit \\
\hline 43,5 & $\mathrm{~mm}$ \\
81 & $\mathrm{~mm}$ \\
69 & $\mathrm{~mm}$ \\
&
\end{tabular}

Zwei Fragmente einer linken Tibia, welche sehr grazil ist. Das Fundstück ist gut erhalten und weist eine deutliche Myotendopathie an der Ansatzstelle des M. soleus auf. Die Myotendopathie misst $40 \mathrm{~mm} \times 10 \mathrm{~mm} \times 3 \mathrm{~mm}$. Es ist wohl ein juveniles Individuum, weil noch eine Epiphysenfuge zu finden ist. 


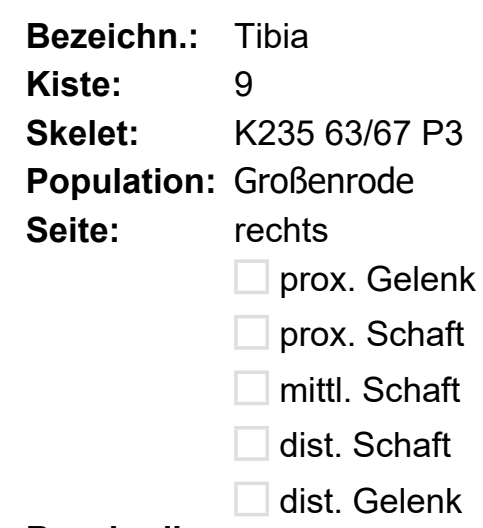

Hier ist nur ein Splitter einer rechten Tibia proximal erhalten. Das Fragment enthält die Ansatzfläche des M. soleus. Im Gegensatz zu der linken Tibia ist hier der Ansatz gut ausgeprägt, aber nicht pathologisch verändert. 


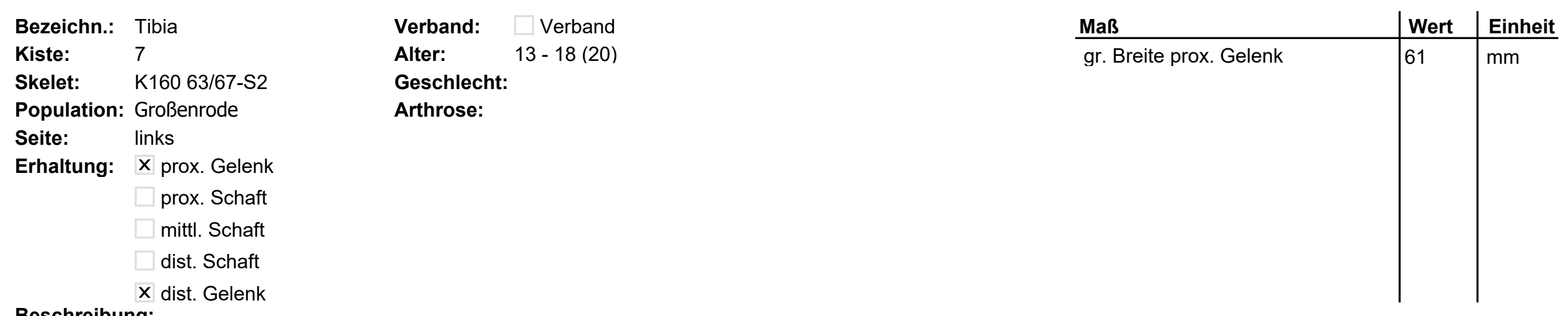

\section{Beschreibung:}

Hier ist ein Tibiaplateau der linken Seite erhalten. Die Epiphyse ist stark erodiert und zu etwa $60 \%$ erhalten. Es handelt sich wohl um ein juveniles Individuum. Weiterhin ist ein stark erodiertes Fragment der distalen Epiphyse erhalten. 


\section{Bezeichn.: Tibia}

Kiste:

Skelet: $\quad$ K76 62/68-P2

Population: Großenrode

Seite: links

Erhaltung: $\square$ prox. Gelenk

$X$ prox. Schaft

$X$ mittl. Schaft

$\mathbf{X}$ dist. Schaft

dist. Gelenk
Verband: $\square$ Verband

\section{Alter:}

\section{Geschlecht:}

Arthrose:

\section{Maß}

Schaftumfang Foramen

Umfang Schaftmitte
Wert $\quad$ Einheit

\begin{tabular}{l|l}
86 & $\mathrm{~mm}$
\end{tabular}

$76 \quad \mathrm{~mm}$

\section{Beschreibung:}

Ein stark erodiertes Fragment einer Tibia der linken Seite. Die Oberfläche ist nicht mehr befundbar. das Fragment macht etwa 3/4 des Schaftes aus. 


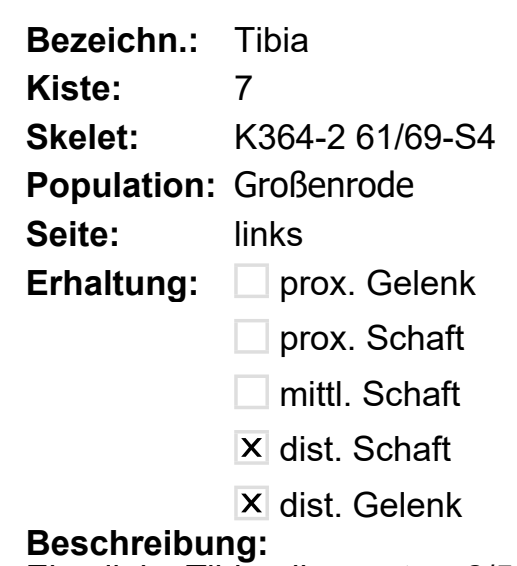

Skelet: K364-2 61/69-S4

Population: Großenrode

Seite: links

Erhaltung: $\square$ prox. Gelenk

prox. Schaft

mittl. Schaft

$\mathbf{X}$ dist. Schaft

$\mathbf{X}$ dist. Gelenk

Beschreibung:

Verband: $\square$ Verband
Alter: Jung
Geschlecht:
Arthrose:

Ges./Kr.: Gesund

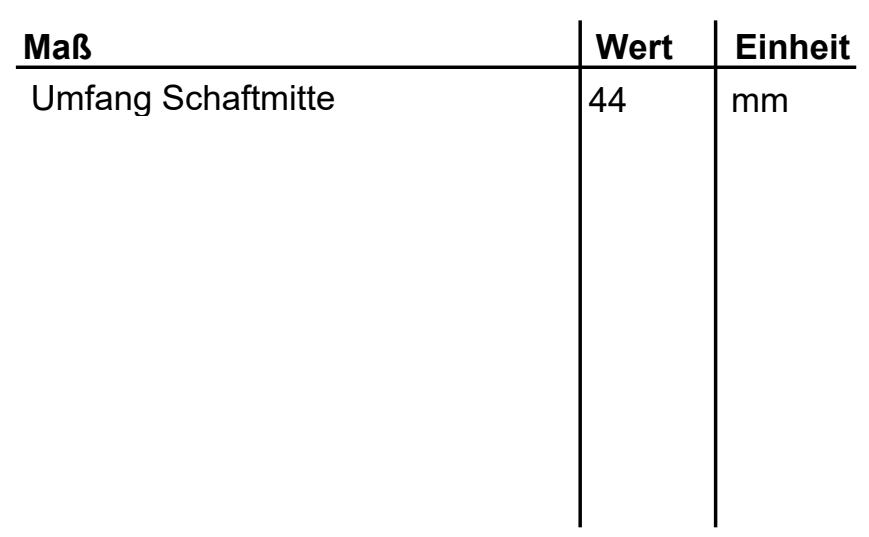

Eine linke Tibia, die zu etwa 2/5 erhalten ist distal. die Oberfläche ist recht gut erhalten. Die distale Epiphyse ist nur zu 1/4 erhalten und nicht aussagekräftig. 


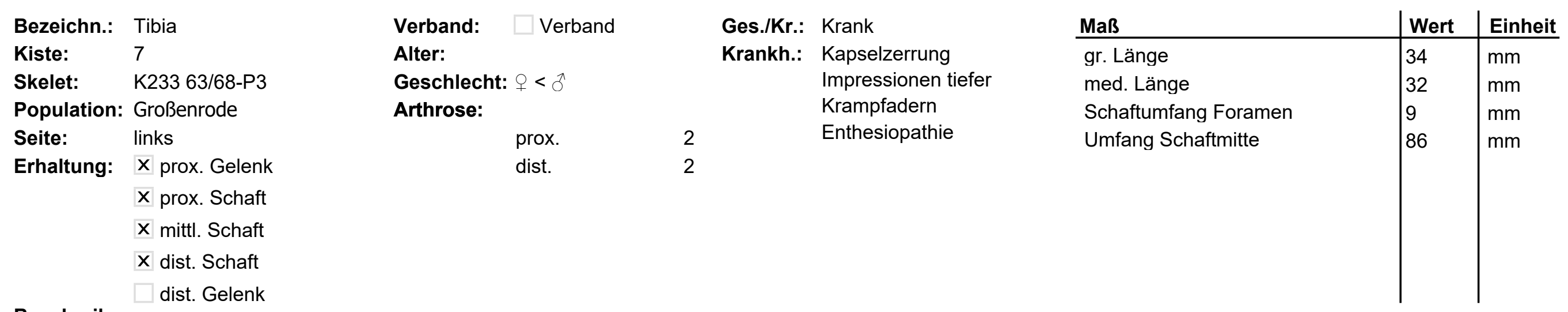

\section{Beschreibung:}

Diese Tibia ist fast in ganzer Länge erhalten, ist stark erodiert und es fehlen zum Großteil die Gelenkflächen. Proximal sind diese zu 1/5, distal zu 1/5 erhalten und befundbar. Facies articularis fibularis und Incisura fibularis sind von Reizungen des Periostes betroffen, so ist distal der Tibia eine poröse Oberflächenstruktur im Sinne einer Kapselzerrung und eine Zerrung der ligamenta tibiofibulares anterior und posterior. Anterior der Tibia ist es die Membrana interossea, die eine Zerrung im Sinne einer Enthesiopathie hinterlassen hat. 


\begin{tabular}{|c|c|c|c|c|c|}
\hline Bezeichn.: & Tibia & Verband: $\quad \square$ Verband & Maß & Wert & Einheit \\
\hline Kiste: & 7 & Alter: & Schaftumfang Foramen & 9 & $\mathrm{~mm}$ \\
\hline Skelet: & K70 62/68-P2 & Geschlecht: & Umfang Schaftmitte & 8 & $\mathrm{~mm}$ \\
\hline Population: & Großenrode & Arthrose: & & & \\
\hline Seite: & rechts & & & & \\
\hline Erhaltung: & $\square$ prox. Gelenk & & & & \\
\hline & $\square$ prox. Schaft & & & & \\
\hline & $\mathbf{X}$ mittl. Schaft & & & & \\
\hline & $\mathbf{X}$ dist. Schaft & & & & \\
\hline & $\square$ dist. Gelenk & & & & \\
\hline
\end{tabular}

\section{Beschreibung:}

Dieses mittlere bis distale Fragment einer rechten Tibia ist sehr stark erodiert und nicht befundbar. Es finden sich Spuren von Tierverbiss am Schaft. Es sind insgesamt etwa $70 \%$ des gesamten Knochens erhalten. 


$\begin{array}{llllll}\text { Bezeichn.: } & \text { Tibia } & \text { Verband: } \square \text { Verband } & \text { Ges./Kr.: } & \text { Gesund } & \text { Maß } \\ \text { Kiste: } & 7 & \text { Alter: } & 13-16(18) & & \text { Schaftumfang Foramen } \\ \text { Skelet: } & \text { K155 63/67-S2 } & \text { Geschlecht: } & \text { Umfang Schaftmitte } \\ \text { Population: } & \text { Großenrode } & \text { Arthrose: } & & 76 \\ \text { Seite: } & \text { links } & & \text { mm } \\ \text { Erhaltung: } & \square \text { prox. Gelenk } & & \text { mm } \\ & \mathbf{X} \text { prox. Schaft } & & \\ & \mathbf{X} \text { mittl. Schaft } & & \\ & \mathbf{X} \text { dist. Schaft } & & \\ & \mathbf{X} \text { dist. Gelenk } & & \end{array}$

Diese linke Tibia ist recht gut erhalten, distal ist fast die vollständige Epiphyse erhalten, proximal ist diese noch am Schaft abfrakturiert und nicht erhalten. Wohl ein juveniles Individuum. Der Ansatz des M. soleus ist stark ausgeprägt, was wohl mit dem Wachstumsstadium des Knochens zu tun hat. 


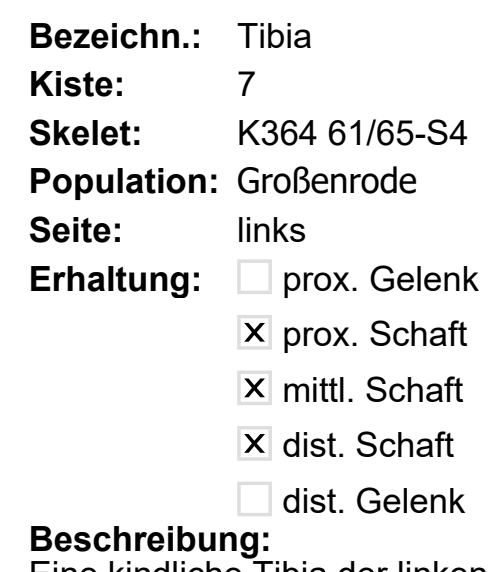

Skelet: $\quad$ K364 61/65-S4

Population: Großenrode

Seite: links

Erhaltung: $\square$ prox. Gelenk

X prox. Schaft

$X$ mittl. Schaft

X dist. Schaft dist. Gelenk

\section{Beschreibung:}

Eine kindliche Tibia der linken Seite, es ist proximal und distal abfrakturiert.

\section{Ges./Kr.: Gesund}

\section{Alter:}

\section{Geschlecht:}

Arthrose:

\begin{tabular}{l|l|l} 
Maß & Wert & Einheit \\
\hline Schaftumfang Foramen & 57 & $\mathrm{~mm}$ \\
Umfang Schaftmitte & 45 & $\mathrm{~mm}$ \\
& & \\
& &
\end{tabular}




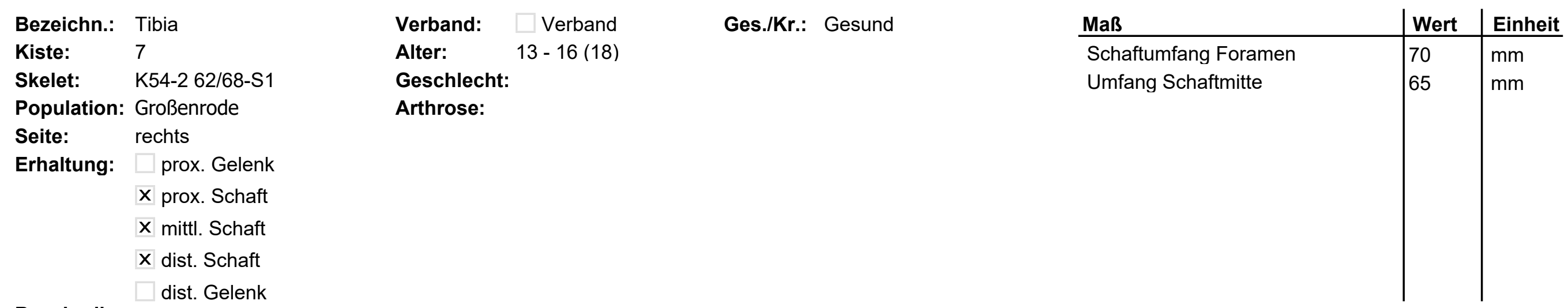

Erhaltung: $\square$ prox. Gelenk

Verband: $\quad \square$ Verband

Alter: $\quad 13-16(18)$

Geschlecht:

Arthrose:

\section{Ges./Kr.: Gesund}

\section{Maß} Schaftumfang Foramen Umfang Schaftmitte

$70 \mathrm{~mm}$

$65 \quad \mathrm{~mm}$

Diese zwei Fragmente einer Tibia aus dem Schaft machen zusammen etwa 2/3 des Knochens aus. Die Oberfläche ist erodiert. Diese Tibia ist wohl einem juvenilen Individuum zuzuordnen. 


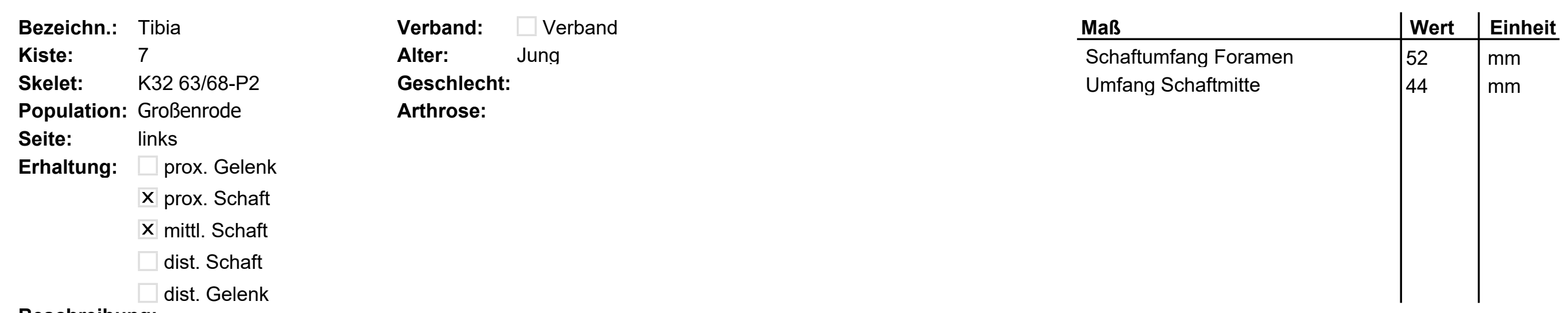

Beschreibung:

Ein proximales Fragment aus einer linken Tibia, das Fragment macht etwa 50\% des Schaftes aus. Das Fragment ist wohl einem jungen Individuum zuzuordnen. 


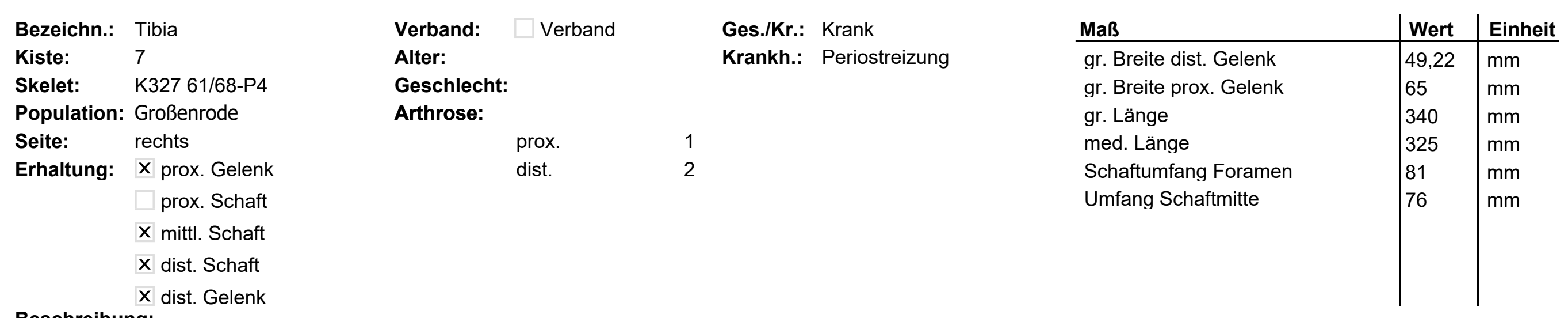

\section{Beschreibung:}

Dieses Fundstück ist ein distales Fragment einer Tibia mit vollständig erhaltenen Gelenkflächen. Direkt am Schaftanfang ist das Fundstück abfrakturiert. Zusätzlich sind noch kleinere Splitter aus dem Schaft erhalten. Am Schaft sind kleine Streifungen erkennbar. Es ist auch das Fragment erhalten, was den Knochen fast vervollständigt, die proximale Gelenkfläche ist zu $40 \%$ erhalten und befundbar. Die beschriebene Streifung zieht sich über ein Stück des Schaftes fort. 


\section{Bezeichn.: Tibia}

\section{Kiste:}

Skelet: $\quad$ K315 62/63 P4

Population: Großenrode

Seite: rechts

Erhaltung: $\square$ prox. Gelenk

X prox. Schaft

mittl. Schaft

dist. Schaft

dist. Gelenk

\section{Beschreibung:}

Verband: $\square$ Verband

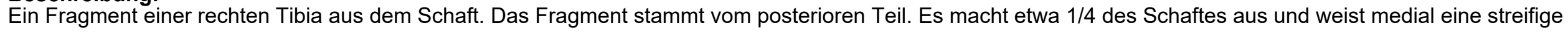
Oberfläche auf. Weiterhin findet sich eine periostale Reizung, die erhaben mit einer Gefäßimpression erscheint. 


\begin{tabular}{|c|c|c|c|c|c|c|c|}
\hline Bezeichn.: & Tibia & Verband: & $\square$ Verband & Ges./Kr.: Gesund & Maß & Wert & Einheit \\
\hline Kiste: & 6 & Alter: & & & Umfang Schaftmitte & 70 & $\mathrm{~mm}$ \\
\hline Skelet: & K3.345 63/66 Prof51 S4 & Geschlecht: & & & & & \\
\hline Population: & Großenrode & Arthrose: & & & & & \\
\hline Seite: & rechts & & & & & & \\
\hline Erhaltung: & $\square$ prox. Gelenk & & dist. & 2 & & & \\
\hline & $\square$ prox. Schaft & & & & & & \\
\hline & $\square$ mittl. Schaft & & & & & & \\
\hline & $\mathbf{X}$ dist. Schaft & & & & & & \\
\hline & X dist. Gelenk & & & & & & \\
\hline
\end{tabular}

Stark erodiertes und teilweise frakturiertes Fragment einer Tibia. Es sind etwa 30\% distal des gesamten Knochens erhalten. Die distale Gelenkfläche ist zu 10\% erhalten. 


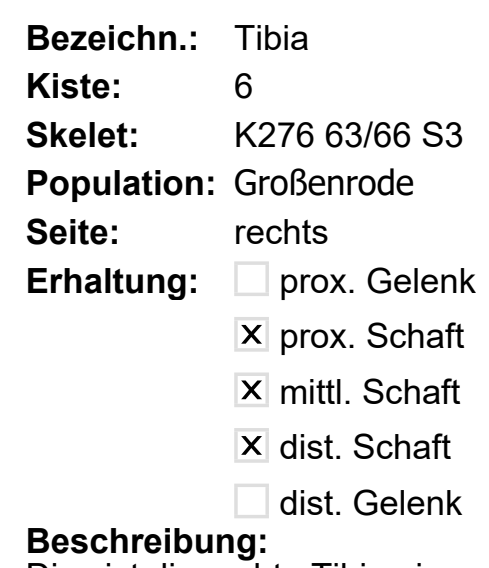

Verband: $\quad \square$ Verband Ges./Kr.: Gesund

Alter: Jung

Geschlecht:

Arthrose:

Dies ist die rechte Tibia eines jungen Individuums. Sie ist in zwei Fragmenten zu 3/4 erhalten. Die Oberfläche ist erodiert. 


\section{Bezeichn: Tibia}

\section{Kiste:}

Skelet: K346 63/66 S4

Population: Großenrode

Seite: rechts

Erhaltung: $\square$ prox. Gelenk

prox. Schaft

$X$ mittl. Schaft

dist. Schaft

dist. Gelenk
Verband: $\quad \square$ Verband

\section{Alter:}

\section{Geschlecht:}

Arthrose:

\section{Beschreibung:}

Ein sehr stark erodiertes Fragment einer Tibia der rechten Körperseite. Es ist etwa 1/5 aus dem Schaft erhalten, jedoch unbefundbar. 


\section{Bezeichn: Tibia}

Kiste:

Skelet: $\quad$ K74 62/68 P2

Population: Großenrode

Seite: rechts

Erhaltung: $\square$ prox. Gelenk

prox. Schaft

$X$ mittl. Schaft

$\mathbf{X}$ dist. Schaft

$X$ dist. Gelenk
Verband: $\quad \square$ Verband

\section{Alter:}

Geschlecht:
Ges./Kr.: Gesund

\section{Beschreibung:}

Zwei Fragmente einer rechten Tibia. Die Fragmente sind nur stark erodiert erhalten, es sind kleinere Splitter von den einzelnen Fragmenten abgesplittert. Proximal ist nichts erhalten, distal ist ein kleiner Teil der Gelenkfläche erhalten, welche etwa zu 50\% zu befunden ist. Insgesamt sind etwa $60 \%$ des gesamten Knochens erhalten. 


$\begin{array}{llllll}\text { Bezeichn.: } & \text { Tibia } & \text { Verband: } \square \text { Verband } & \text { Ges./Kr.: Gesund } & \text { Maß } & \text { Umfang Schaftmitte } \\ \text { Kiste: } & 6 & \text { Alter: Jung } & \text { Einheit } \\ \text { Skelet: } & \text { K20062/65-S3 } & \text { Geschlecht: } & & \text { mm } \\ \text { Population: } & \text { Großenrode } & \text { Arthrose: } & & \\ \text { Seite: } & \text { rechts } & & \\ \text { Erhaltung: } & \square \text { prox. Gelenk } & & \\ & \square \text { prox. Schaft } & & \\ & \mathbf{X} \text { mittl. Schaft } & & \\ & \square \text { dist. Schaft } & & \\ & \square \text { dist. Gelenk } & & \end{array}$

\section{Beschreibung:}

Dies ist ein Fragment, welches etwa 1/3 der Mitte eines Schaftes einer Tibia ausmacht. Da das Fragment sehr grazil ist, könnte es entweder ein weibliches Individuum sein, oder ein junges. Der Konstitution nach wurde es einem jungen Individuum zugeordnet. Die Oberfläche ist stark erodiert. 


\section{Bezeichn:: Tibia}

\section{Kiste:}

Skelet: K200 62/65-S3

Population: Großenrode

Seite: links

Erhaltung: $\mathbf{X}$ prox. Gelenk prox. Schaft

mittl. Schaft dist. Schaft X dist. Gelenk
Verband: $\square$ Verband

Ges./Kr.: Gesund

\section{Alter:}

Geschlecht:

Arthrose:

$\begin{array}{ll}\text { prox. } & 1 \\ \text { dist. } & 1\end{array}$

\section{Beschreibung:}

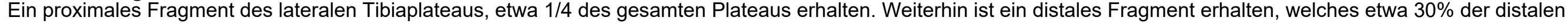
Gelenkfläche enthält. Beide Fragmente sind sehr stark erodiert und kaum befundbar. 


\section{Bezeichn:: Tibia}

\section{Kiste:}

Skelet: $\quad$ K71 62/68 P2

Population: Großenrode

Seite: rechts

Erhaltung: $\mathbf{X}$ prox. Gelenk

$\mathbf{X}$ prox. Schaft

$\mathbf{X}$ mittl. Schaft

dist. Schaft

dist. Gelenk
Verband: $\square$ Verb

\section{Alter: Jung}

Geschlecht:

Arthrose:

prox.

\section{Ges./Kr.: Gesund}

00

\begin{tabular}{l|l|l} 
Maß & Wert & Einheit \\
\hline gr. Breite prox. Gelenk & 54 & $\mathrm{~mm}$ \\
Schaftumfang Foramen & 85 & $\mathrm{~mm}$ \\
Umfang Schaftmitte & 73 & $\mathrm{~mm}$ \\
& & \\
& &
\end{tabular}

\section{Beschreibung:}

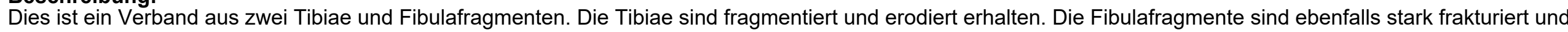
erodiert.

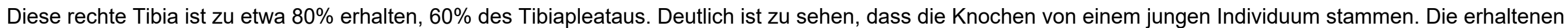

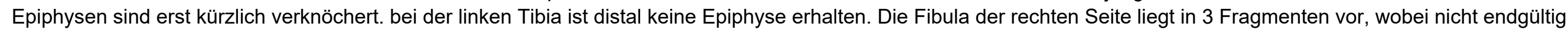

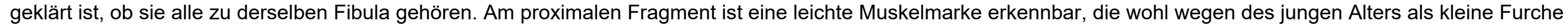
ausgeprägt ist.

Die linke Tibia ist wohl in drei Fragmenten erhalten, die insgesamt etwa $75 \%$ des Knochens ausmachen. Es sind $20 \%$ des Tibiapleataus erhalten. 


\section{Bezeichn.: Tibia}

\section{Kiste:}

4

Skelet: 4

Seite: K71 62/68 P2

X prox. Gelenk

$X$ prox. Schaft

$X$ mittl. Schaft

$\mathbf{X}$ dist. Schaft

dist. Gelenk

\section{Verbanc}

$\checkmark$ Verband

Geschlecht:

Arthrose:

prox.
Ges./Kr.: Gesund

\section{Maß}

Schaftumfang Foramen

Umfang Schaftmitte

\begin{tabular}{|l|l} 
Wert & Einheit \\
83 & $\mathrm{~mm}$ \\
72 & $\mathrm{~mm}$ \\
&
\end{tabular}

\section{Beschreibung:}

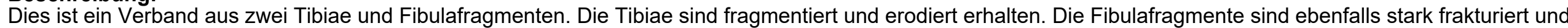
erodiert.

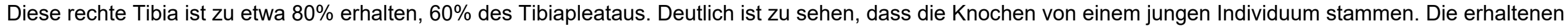

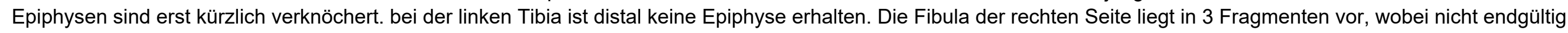

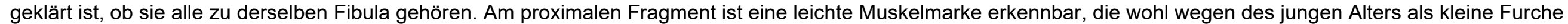
ausgeprägt ist.

Die linke Tibia ist wohl in drei Fragmenten erhalten, die insgesamt etwa $75 \%$ des Knochens ausmachen. Es sind $20 \%$ des Tibiapleataus erhalten. 


\section{Bezeichn: Tibia}

Kiste:

4

Skelet: $\quad$ K70 62/68 P2

Population: Großenrode

Seite: links

Erhaltung: $\square$ prox. Gelenk

$X$ prox. Schaft

$X$ mittl. Schaft

$\mathbf{X}$ dist. Schaft

dist. Gelenk

\section{Beschreibung:}

Ein Fragment des gesamten Schaftes einer sehr stark erodierten linken Tibia. Sie ist unbefundbar.

\section{Verband: $\quad$ Verband}

\section{Alter:}

Geschlecht:

Arthrose:

\section{Maß}

Schaftumfang Foramen

Umfang Schaftmitte
Wert $\quad$ Einheit

$84 \quad \mathrm{~mm}$

$\mathrm{mm}$



Bezeichn.: Tibia
Kiste:
4
Skelet: K138
Population: Großenrode
Seite: rechts
Erhaltung: $\square$ prox. Gelenk
$X$ prox. Schaft
mittl. Schaft
dist. Schaft
dist. Gelenk

Beschreibung:

Fragment aus anteriorem Teil des Schaftes.

\section{Geschlecht:}

\section{Verband:}

Verband

Alter:

Ges./Kr.: Gesund

Arthrose: 


\section{Bezeichn.: Tibia}

\section{Kiste:}

Skelet: $\quad$ K123 62/68 S2

Population: Großenrode

Seite: rechts

Erhaltung: $\square$ prox. Gelenk

$x$ prox. Schaft

mittl. Schaft

dist. Schaft

dist. Gelenk

Beschreibung:

Verband: $\quad \square$ Verband

Ges./Kr.: Gesund

\section{Alter:}

\section{Geschlecht:}

Es ist hier ein Fragment aus dem anterioren Teil des Schaftes erhalten. Weiterhin sind zwei kleine Splitter erhalten. 


\section{Bezeichn.: Tibia}

\section{Kiste:}

Skelet: $\quad$ K54 62/68 S1

Population: Großenrode

Seite: links

Erhaltung: $\square$ prox. Gelenk

prox. Schaft

mittl. Schaft

$X$ dist. Schaft

dist. Gelenk

\section{Verband: \\ Verband \\ Ges./Kr.: Gesund}

\section{Alter:}

Geschlecht:

\section{Beschreibung:}

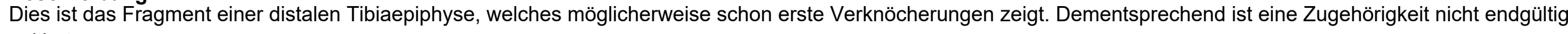
geklärt. 


$\begin{array}{ll}\text { Bezeichn.: } & \text { Tibia } \\ \text { Kiste: } & 2 \\ \text { Skelet: } & 61 / 54 \\ \text { Population: } & \text { Großenrode } \\ \begin{array}{ll}\text { Seite: } & \text { rechts } \\ \text { Erhaltung: } & \mathbf{X} \text { prox. Gelenk } \\ & \square \text { prox. Schaft } \\ & \square \text { mittl. Schaft } \\ & \square \text { dist. Schaft } \\ & \square \text { dist. Gelenk }\end{array} \\ \text { Beschreibung: }\end{array}$

\section{Verband: $\quad$ Verband}

Alter:

Geschlecht:

Arthrose:

prox.

00

Bei diesem Fundstück handelt es sich um ein Tibiaplateau, bzw. seine Epiphyse, die zu 70\% erhalten ist. Die Gelenkfläche ist zu $45 \%$ befundbar. 


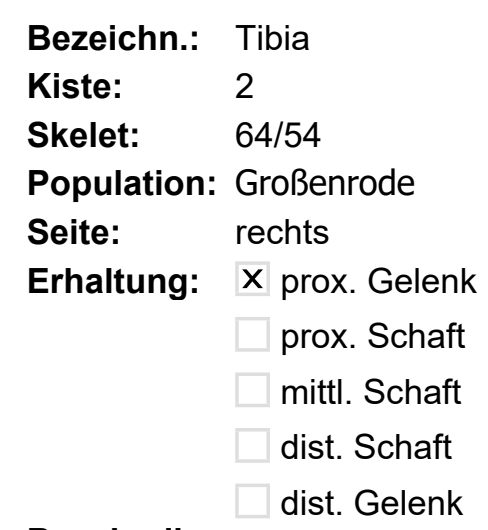

Population: Großenrode

Seite: rechts

Erhaltung: $\mathbf{X}$ prox. Gelenk

prox. Schaft

mittl. Schaft

dist. Schaft dist. Gelenk

Verband: $\quad \square$ Verband

Alter: Jung

Geschlecht:

Arthrose:

\section{Beschreibung:}

Hier sind nur etwa 90\% der proximalen Epiphyse einer rechten Tibia erhalten. Das Fragment stammt von einem nicht ausgewachsenen Individuum.

\section{Ges./Kr.: Gesund}

00

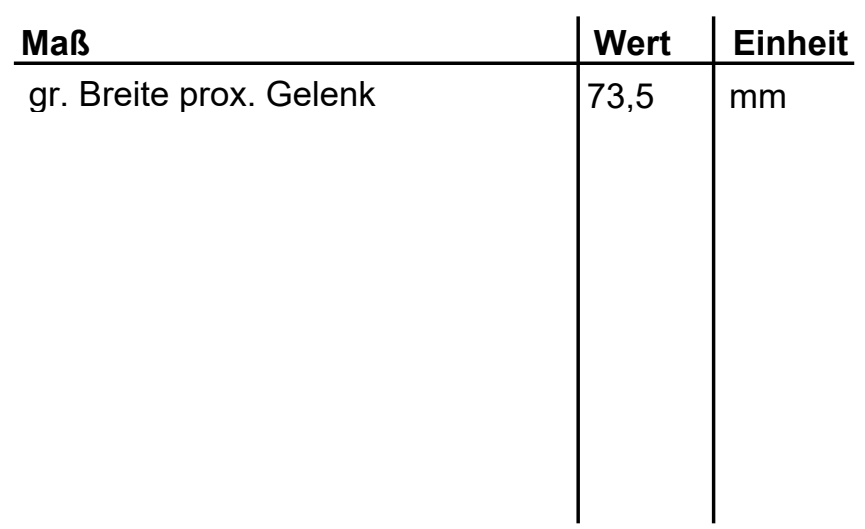


Bezeichn.: Tibia

Kiste:

\section{Verband:}

Alter:

Ges./Kr.: Gesund

\section{Geschlecht:}

Skelet: $\quad 62 / 69$

Arthrose:

Erhaltung: $\mathbf{X}$ prox. Gelenk

prox. Schaft

mittl. Schaft

dist. Schaft

dist. Gelenk

Beschreibung:

Bei diesem Fragment einer Epiphyse könnte es sich um eine Tibia handeln.

\section{Maß}

gr. Breite prox. Gelenk

\begin{tabular}{|l|l} 
Wert & Einheit \\
\hline 17,78 & mm
\end{tabular}

\begin{tabular}{l|l}
17,78 & $\mathrm{~mm}$
\end{tabular}


Bezeichn.: Tibia

\section{Kiste:}

Skelet: $\quad 63 / 60$

Population: Großenrode

Seite: rechts

Erhaltung: $\square$ prox. Gelenk prox. Schaft

mittl. Schaft

$X$ dist. Schaft dist. Gelenk

Beschreibung:

Splitter des distal posterioren Schaftes.
Verband: $\quad$ Verband

\section{Alter:}

Geschlecht:

Arthrose: 
Bezeichn.: Tibia

Kiste:

Skelet: $\quad 62 / 55$

Population: Großenrode

Seite: rechts

Erhaltung: $\mathbf{X}$ prox. Gelenk prox. Schaft

mittl. Schaft

dist. Schaft dist. Gelenk

Beschreibung:

Verband: $\square$ Verband

Alter:

Geschlecht:

Arthrose:

Fragment des lateralen Tibiaplateaus, mit 70\% der Gelenkfläche des lateralen Plateaus. 


\begin{tabular}{|c|c|c|c|c|c|c|c|}
\hline Bezeichn.: & Tibia & Verband: & $\square$ Verband & Ges./Kr.: Gesund & Maß & Wert & Einheit \\
\hline Kiste: & 2 & Alter: & & & Umfang Schaftmitte & 60 & $\mathrm{~mm}$ \\
\hline Skelet: & $61 / 58$ & Geschlecht: & & & & & \\
\hline Population: & Großenrode & Arthrose: & & & & & \\
\hline Seite: & links & & & & & & \\
\hline Erhaltung: & $\square$ prox. Gelenk & & dist. & 2 & & & \\
\hline & $\square$ prox. Schaft & & & & & & \\
\hline & $X$ mittl. Schaft & & & & & & \\
\hline & $\square$ dist. Schaft & & & & & & \\
\hline & X dist. Gelenk & & & & & & \\
\hline
\end{tabular}

\section{Beschreibung:}

Zwei Fragmente einer Tibia, die wohl zusammen gehören. Damit sind etwa 50\% des Knochens erhalten und 1/3 der distalen Gelenkfläche. Die Konstitution des Knochens ist sehr grazil, was eher für ein weibliches Individuum spricht. 


\section{Bezeichn.: Tibia}

\section{Kiste:}

Skelet: $\quad 61 / 58$

Population: Großenrode

Seite: links

Erhaltung: X prox. Gelenk

prox. Schaft

mittl. Schaft

dist. Schaft

dist. Gelenk

\section{Beschreibung:}

2/5 eines medialen Tibiaplateaus.
Verband: $\quad \square$ Verband

Ges./Kr.: Gesund

\section{Alter:}

Geschlecht:

Arthrose:

prox. 


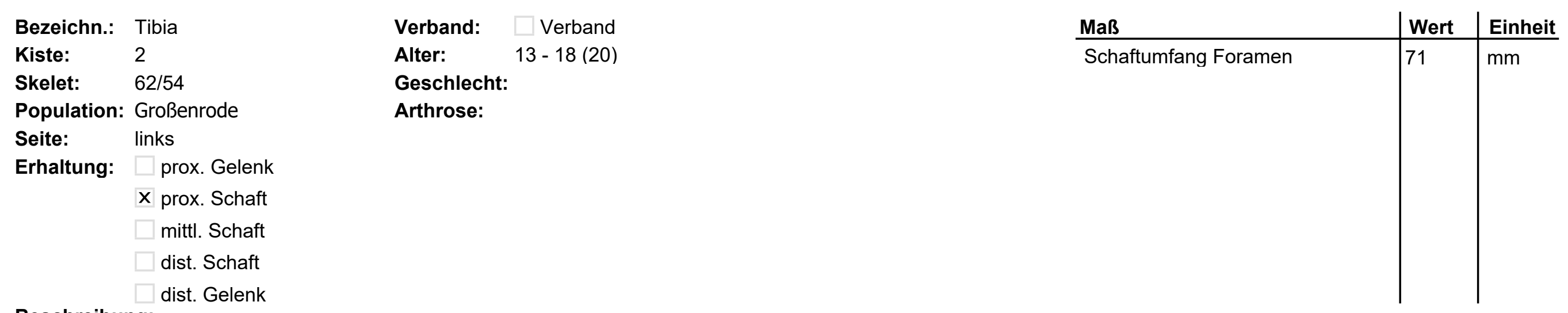

Beschreibung:

Ein Fragment aus dem Schaft, 1/4 desselbigen sind erhalten. Da der Schaft recht schmal ist und das foramen nutricium klein, ist ein junges Individuum anzunehmen. 
Bezeichn.: Tibia

\section{Kiste:}

Skelet: 63/54

Population: Großenrode

Seite: links

Erhaltung: $\mathbf{X}$ prox. Gelenk

prox. Schaft

mittl. Schaft

dist. Schaft

dist. Gelenk

\section{Beschreibung:}

Ein mediales Tibiaplateau, welches frakturiert, erodiert und zu $40 \%$ erhalten ist.

Verband: $\quad$ Verband

\section{Alter:}

Geschlecht:

Arthrose: 

Bezeichn.: Tibia

Kiste: 2
$\begin{array}{ll}\text { Skelet: } & 61 / 57 \\ \text { Population: } & \text { Großenrode }\end{array}$
Seite: rechts
Erhaltung: $\square$ prox. Gelenk
prox. Schaft
$X$ mittl. Schaft
dist. Schaft
dist. Gelenk

\section{Verband: $\quad \square$ Verband \\ Alter:}

Ges./Kr.: Krank

Krankh.: Periostreizung

\section{Beschreibung:}

Geschlecht: $q \leq \hat{0}$

Hier ist ein gespaltenes Fragment aus dem Schaft einer Tibia erhalten. Es ist etwa 1/3 des anterioren Schaftes erhalten. Das Fundstück wirkt sehr massiv und weist eine streifige Oberfläche auf. Diese ist sicherlich durch Bodenerosionen weiter verstärkt worden, dennoch ist hier von einem intravitalen Geschehen einer periostalen Reizung auszugehen. 


\section{Bezeichn:: Tibia}

Kiste:

Skelet: $\quad$ K266 63/64 P4

Population: Großenrode

Erhaltung: $\mathbf{X}$ prox. Gelenk prox. Schaft

mittl. Schaft dist. Schaft dist. Gelenk
Verband: $\quad \square$ Verband

Alter:

\section{Geschlecht:}

Arthrose:

\section{Ges./Kr.: Gesund}

\section{Beschreibung:}

prox. 2

Es ist ein Tibiaplateau erhalten. Es stammt von der linken Seite und es ist die mediale Plateaufläche. Etwa 1/4 des gesamten sind vorhanden. 


\section{Bezeichn.: Tibia \\ Kiste: 3 \\ Skelet: $\quad$ K266 63/64 P4 \\ Population: Großenrode \\ Seite: links \\ Erhaltung: $\mathbf{X}$ prox. Gelenk \\ prox. Schaft \\ mittl. Schaft \\ dist. Schaft \\ dist. Gelenk}

Beschreibung

Hier ist etwa 1/4 des medialen Tibiaplateaus erhalten.
Verband: $\quad \square$ Verband

Ges./Kr.: Gesund

\section{Alter:}

Geschlecht:

Arthrose:

prox. 


\section{Bezeichn.: Tibia}

\section{Kiste:}

Skelet: aus großer Tüte mit

Population: Großenrode

Seite: rechts

Erhaltung: $\mathbf{X}$ prox. Gelenk

prox. Schaft

mittl. Schaft

dist. Schaft dist. Gelenk

Beschreibung:

Verband: $\quad \square$ Verband

Alter:

Geschlecht:

Arthrose:

Hier ist $1 / 3$ des lateralen Tibiaplateaus erhalten. 


\section{Bezeichn.: Tibia}

\section{Kiste:}

Skelet: aus großer Tüte mit

Population: Großenrode

Seite: links

Erhaltung:

prox. Gelenk

prox. Schaft

mittl. Schaft

dist. Schaft

$\mathbf{X}$ dist. Gelenk

Beschreibung:

Hier ist das distale Gelenk zu 70\% erhalten.
Verband: $\quad$ Verband

\section{Alter:}

Geschlecht:

Arthrose: 


\section{Bezeichn.: Tibia \\ Kiste: 2 \\ Skelet: aus großer Tüte mit \\ Population: Großenrode \\ Seite: links \\ Erhaltung: $\square$ prox. Gelenk \\ prox. Schaft \\ $X$ mittl. Schaft \\ dist. Schaft \\ dist. Gelenk \\ Beschreibung:}

Ein stark erodiertes Fragment.
Verband: $\quad \square$ Verband

\section{Alter:}

Maß

Umfang Schaftmitte

Geschlecht:

Arthrose: 


\section{Bezeichn.: Tibia}

\section{Kiste:}

Skelet: aus großer Tüte mit

Population: Großenrode

Seite:

links

Erhaltung: $\square$ prox. Gelenk prox. Schaft

$X$ mittl. Schaft dist. Schaft dist. Gelenk

\section{Beschreibung:}

Ein erodiertes Fragment.

\section{Verband: $\quad \square$ Verband}

\section{Alter:}

Geschlecht:

Arthrose:

\section{Maß}

Umfang Schaftmitte

Wert 1 Einheit

\begin{tabular}{|l|l}
69 & $\mathrm{~mm}$ \\
&
\end{tabular}




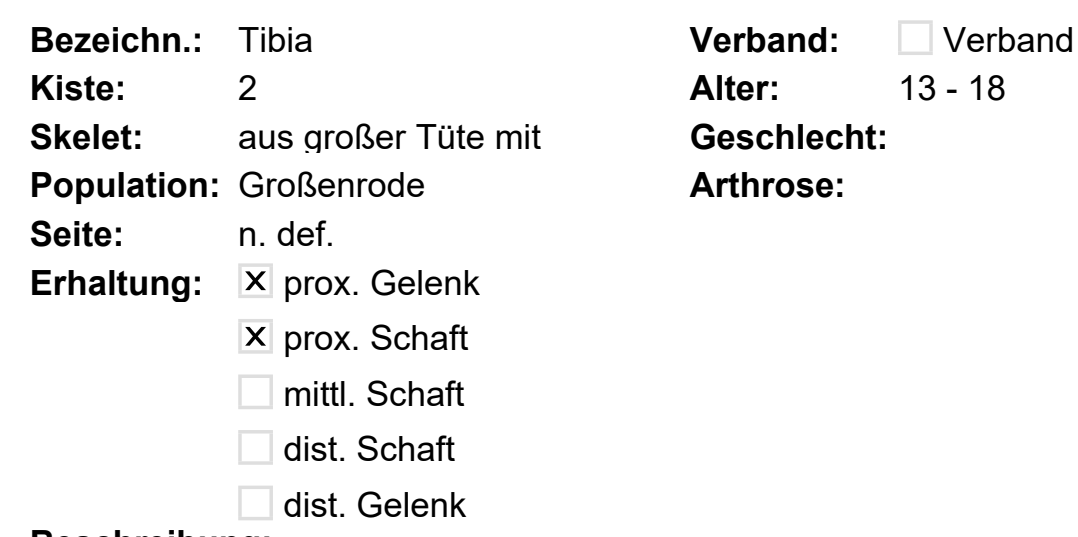

\section{Beschreibung:}

Ein proximales Fragment einer Tibia. Das Fundstück ist einem jungen Individuum zuzuordnen. Insgesamt ist hier ein kleiner Teil des proximalen Schaftes und die proximale Epiphysenfuge zu $1 / 3$ erhalten. Der Knochen ist erodiert. 


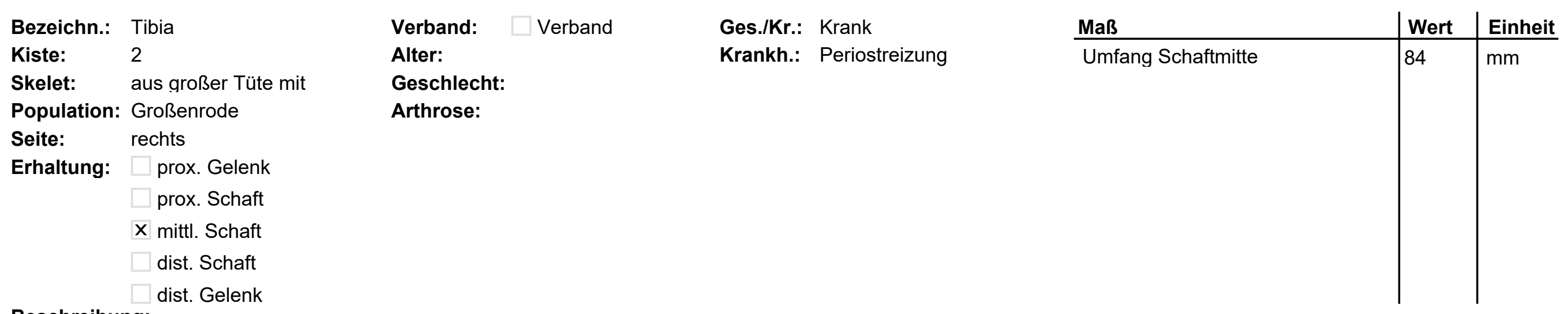

\section{Beschreibung:}

Fragment aus dem Schaft, etwa 1/3 ist vorhanden. Es findet sich eine leichte Streifung auf der Oberfläche der medialen Seite. Das Fragment ist erodiert. 


\section{Bezeichn.: Tibia \\ Kiste: 2 \\ Skelet: aus großer Tüte mit \\ Population: Großenrode \\ Seite: rechts \\ Erhaltung: $\square$ prox. Gelenk \\ prox. Schaft \\ $X$ mittl. Schaft \\ $\mathbf{X}$ dist. Schaft \\ dist. Gelenk \\ Beschreibung:}

\section{Verband: $\quad \square$ Verband}

\section{Alter:}

Geschlecht:

Arthrose:

Fragment aus dem Schaft, es sind etwa $55 \%$ des Schaftes vorhanden.

\begin{tabular}{l|l}
86 & $\mathrm{~mm}$
\end{tabular}




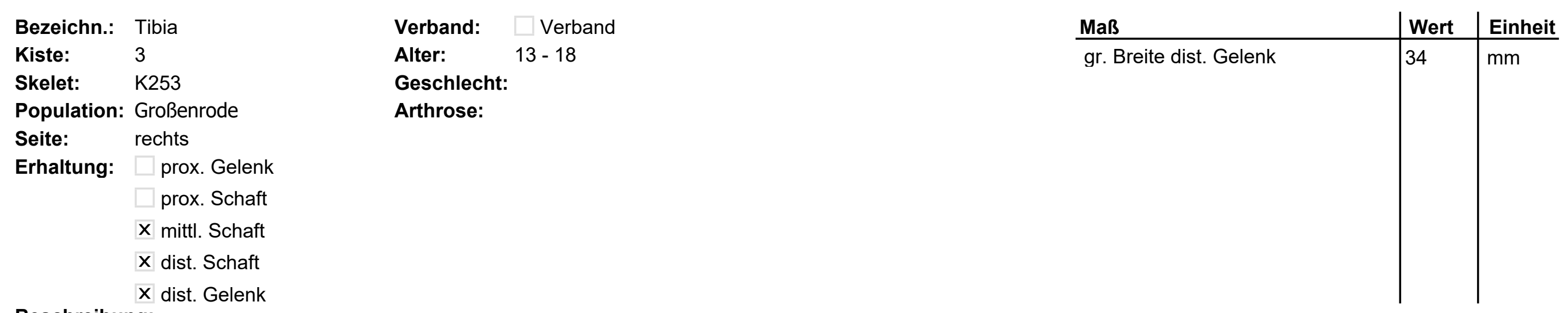

Beschreibung:

Ein stark erodiertes und frakturiertes Fragment einer nicht ausgewachsenen Tibia. Es sind etwa $50 \%$ erhalten. Weiterhin ist die distale Epiphyse vorhanden. 


\section{Bezeichn.: Tibia}

\section{Kiste:}

Skelet: 60/66-4

Population: Großenrode

Seite: rechts

Erhaltung: $\square$ prox. Gelenk

prox. Schaft

mittl. Schaft

$\mathbf{X}$ dist. Schaft

dist. Gelenk

\section{Beschreibung:}

Ein distales Fragment, etwa 1/5 erhalten. Es ist erodiert und frakturiert.
Verband: Verband

\section{Alter:}

Geschlecht:

Arthrose: 


\section{Bezeichn.: Tibia}

\section{Kiste:}

Skelet: $\quad$ K167 P3

Population: Großenrode

Seite: rechts

Erhaltung: $\square$ prox. Gelenk

$X$ prox. Schaft

mittl. Schaft

dist. Schaft dist. Gelenk

\section{Beschreibung:}

Ein stark erodiertes und frakturiertes Fragment.
Verband: Verband

\section{Alter:}

Geschlecht:

Arthrose: 


\section{Bezeichn.: Tibia}

Kiste: 3

Skelet: $\quad$ K212 \&2/64 S3

Population: Großenrode

Seite: links

Erhaltung: $\square$ prox. Gelenk

$X$ prox. Schaft

mittl. Schaft

dist. Schaft

dist. Gelenk

Beschreibung:

Verband: $\quad$ Verband Ges./Kr.: Krank

Alter: Krankh.: Periostreizung

\section{Geschlecht:}

Arthrose:

Ein sehr schmales Fragment einer Tibia, es findet sich eine Streifung auf der Oberfläche, welche wohl intravital hervorgerufen wurde und für eine periostale Reizung spricht. 


\section{Bezeichn:: Tibia \\ Kiste: \\ 10}

Skelet: $\quad 64 / 55$

Population: Großenrode

Seite: rechts

Erhaltung: $\square$ prox. Gelenk

$X$ prox. Schaft

$\mathbf{X}$ mittl. Schaft

dist. Schaft

dist. Gelenk

\section{Beschreibung:}

Ein recht massives Fundstück. Es macht etwa 1/3 des gesamten Knochens aus.

\section{Alter:}

Geschlecht: $+\leq \hat{\sigma}$

Arthrose:

\section{Verband: Verband}

Maß

Schaftumfang Foramen

Umfang Schaftmitte \begin{tabular}{|l|l} 
Wert & Einheit
\end{tabular}

\begin{tabular}{l|l}
97 & $\mathrm{~mm}$
\end{tabular}

81 


\section{Bezeichn.: Tibia \\ Kiste:}

Skelet: $\quad 64 / 55$

Population: Großenrode

Seite: rechts

Erhaltung: X prox. Gelenk

prox. Schaft

mittl. Schaft

dist. Schaft

dist. Gelenk

\section{Beschreibung:}

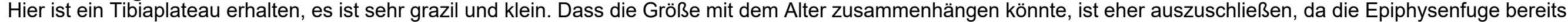
geschlossen war.
Verband: $\square$ Verband

\section{Alter:}

Geschlecht: $+>\widehat{\partial}$

\section{Arthrose:}



Bezeichn.: Tibia
Kiste:
10
Skelet: $\quad 64 / 55$
Population: Großenrode
Seite: links
Erhaltung: $\square$ prox. Gelenk
prox. Schaft
mittl. Schaft
$\mathbf{X}$ dist. Schaft
$X$ dist. Gelenk
Beschreibung:

Verband: $\quad$ Verband

Alter:

Geschlecht:

Dieses Fundstück ist erodiert. 

Bezeichn.: Tibia

Kiste: $\quad 10$
Skelet: 64/55
Population: Großenrode
Seite: rechts
Erhaltung: $\mathbf{X}$ prox. Gelenk
prox. Schaft
mittl. Schaft
dist. Schaft
dist. Gelenk
Beschreibung:

Verband:

Verband

Alter: $\quad 13-15$ (18)

Ges./Kr.: Gesund

Maß

Geschlecht:

Arthrose:

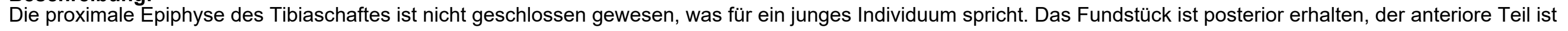
abfrakturiert. Für das Alter typisch, weist die Tibia noch eine Kerbe als Muskelmarke des soleus auf. Insgesamt ist etwa $1 / 5$ erhalten. 


\section{Bezeichn.: Tibia \\ Kiste: \\ 10}

Skelet: $\quad 62 / 53$

Population: Großenrode

Erhaltung: X prox. Gelenk

prox. Schaft

mittl. Schaft

dist. Schaft

dist. Gelenk

\section{Beschreibung:}

Diese proximale Epiphyse liegt isoliert vor, ist aufgrund der Struktur einem jungen Individuum zuzuordnen und ist zu $90 \%$ erhalten

\section{Verband: $\quad$ Verband}

Geschlecht:

Arthrose:

\section{Alter: $\quad 13-16(18)$}

Ges./Kr.: Gesund

Maß

gr. Breite prox. Gelenk

Wert $\quad$ Einheit

\begin{tabular}{l|l|l}
64 & $\mathrm{~mm}$
\end{tabular}



Bezeichn.: Tibia
Kiste:
10
Skelet: $\quad 62 / 53$
Population: Großenrode
Seite: links
Erhaltung: $\square$ prox. Gelenk
$X$ prox. Schaft
mittl. Schaft
dist. Schaft
dist. Gelenk

Verband: $\quad \square$ Verband

\section{Alter:}

Geschlecht:

Beschreibung:

Diese Tibia ist proximal und nur auf der medialen Seite erhalten, etwa 1/6 der gesamten Tibia sind damit vorhanden. 

Bezeichn.: Tibia
Kiste:
10
Skelet: $\quad 62 / 53$
Population: Großenrode
Seite: rechts
Erhaltung: $\square$ prox. Gelenk
prox. Schaft
mittl. Schaft
X dist. Schaft
$\square$ dist. Gelenk

Verband: $\quad$ Verband

\section{Alter:}

Geschlecht:

\section{Beschreibung:}

Arthrose:

Dieses Fragment ist nur distal erhalten, etwa 1/8 der gesamten Tibia sind damit vorhanden. 


$\begin{array}{ll}\text { Bezeichn.: } & \text { Tibia } \\ \text { Kiste: } & 10 \\ \text { Skelet: } & 62 / 56 \\ \text { Population: } & \text { Großenrode } \\ \begin{array}{ll}\text { Seite: } & \text { rechts } \\ \text { Erhaltung: } & \square \text { prox. Gelenk } \\ & \square \text { prox. Schaft } \\ & \square \text { mittl. Schaft } \\ & \square \text { dist. Schaft } \\ & \mathbf{X} \text { dist. Gelenk }\end{array} \\ \text { Beschreibung: }\end{array}$

Verband: $\quad$ Verband

Alter:

Geschlecht:

Arthrose:

Ein distales Fragment, es sind etwa 10\% erhalten. Das Fundstück ist stark erodiert, aber mit einem Teil der Gelenkfläche erhalten. 


$\begin{array}{ll}\text { Bezeichn.: } & \text { Tibia } \\ \text { Kiste: } & 10 \\ \text { Skelet: } & 62 / 58 \\ \text { Population: } & \text { Großenrode } \\ \begin{array}{ll}\text { Seite: } & \text { links } \\ \text { Erhaltung: } & \square \text { prox. Gelenk } \\ & \square \text { prox. Schaft } \\ & \square \text { mittl. Schaft } \\ & \square \text { dist. Schaft } \\ & \mathbf{X} \text { dist. Gelenk }\end{array} \\ \text { Beschreibung: }\end{array}$

\section{Verband: \\ Verband}

\section{Alter:}

Geschlecht:

Von diesem nicht ausgewachsenen Knochen ist nur die distale Epiphyse erhalten. Das Alter wurde auch aufgrund der mit zugehörigen Zähne bestimmt. 

Bezeichn.: Tibia
Kiste:
10
Skelet: $\quad 62 / 58$
Population: Großenrode
Seite: links
Erhaltung: X prox. Gelenk
prox. Schaft
mittl. Schaft
dist. Schaft dist. Gelenk

\section{Beschreibung:}

Von diesem jungen Knochen ist die proximale Epiphyse erhalten.

\section{Ges./Kr.: Gesund}

Alter: $\quad 13-16(20)$

Geschlecht:

Arthrose:

prox.

00

\begin{tabular}{l|l|l} 
Maß & Wert & Einheit \\
\hline gr. Breite prox. Gelenk & 27,73 & $\mathrm{~mm}$ \\
& & \\
& &
\end{tabular}




\section{Bezeichn.: Tibia \\ Kiste: \\ 10}

Skelet: $\quad 63 / 54$

Population: Großenrode

Seite: rechts

Erhaltung: $\square$ prox. Gelenk

prox. Schaft

$X$ mittl. Schaft

dist. Schaft

X dist. Gelenk

Beschreibung:

Zwei Fragmente, die zum selben Knochen gehören.
Geschlecht: $q \leq \hat{\jmath}$

Arthrose:

$\mathrm{mm}$




\section{Bezeichn.: Tibia \\ Kiste: \\ 10}

Skelet: $\quad 63 / 54$

Population: Großenrode

Seite: rechts

Erhaltung: $\square$ prox. Gelenk

prox. Schaft

mittl. Schaft

dist. Schaft

$X$ dist. Gelenk

\section{Beschreibung:}

Ein Fragment der distalen Epiphyse einer Tibia eines jungen Individuums.

\section{Verband: $\quad$ Verband}

\section{Alter: $\quad 13-18(20)$}

Geschlecht:

Arthrose:
Ges./Kr.: Gesund

\begin{tabular}{l|l}
50 & $\mathrm{~mm}$
\end{tabular}



Bezeichn.: Tibia
Kiste:
Skelet: K82 P2
Population: Großenrode rechts
Erhaltung: $\square$ prox. Gelenk prox. Schaft
$X$ mittl. Schaft dist. Schaft dist. Gelenk

\section{Verband:}

Verband
Alter: $\quad 13-18(20)$
Geschlecht:

Arthrose:

Beschreibung:

\section{Ges./Kr.: Gesund}

Maß

Umfang Schaftmitte
Wert $\quad$ Einheit

\begin{tabular}{l|l}
52 & $\mathrm{~mm}$
\end{tabular}

Ein erodiertes Fragment eines wohl jungen Individuums. 


\section{Bezeichn.: Tibia}

\section{Kiste:}

Skelet: $\quad$ K241 P3

Population: Großenrode

Seite: links

Erhaltung: $\mathbf{X}$ prox. Gelenk

prox. Schaft

mittl. Schaft

dist. Schaft

dist. Gelenk

\section{Beschreibung:}

Ein Fragment des medialen Tibiaplateaus.
Verband: $\square$ Verband

\section{Alter:}

Geschlecht:

Arthrose: 
Bezeichn.: Tibia

Kiste:

Skelet: K244

Population: Großenrode

Seite: rechts

Erhaltung: $\square$ prox. Gelenk

$x$ prox. Schaft

mittl. Schaft

dist. Schaft

dist. Gelenk

\section{Beschreibung:}

Ein Fragment eines grazilen und schmalen Knochens. Es ist erodiert und weist Bissspuren auf.
Verband: $\quad$ Verband Ges./Kr.: Gesund

\section{Alter: Jung}

Geschlecht: $q>\lambda$

Arthrose: 


\section{Bezeichn.: Tibia \\ Kiste:}

Skelet: K242

Population: Großenrode

Seite: links

Erhaltung: $\square$ prox. Gelenk

prox. Schaft

$X$ mittl. Schaft

dist. Schaft

dist. Gelenk

\section{Beschreibung:}

Mehrere Fragmente einer grazilen Tibia. Sie sind erodiert.
Verband: $\square$ Verband

\section{Alter:}

Geschlecht:

Arthrose:

\section{Maß}

Umfang Schaftmitte \begin{tabular}{|l|l} 
Wert & Einheit \\
\hline 70 & mm
\end{tabular}

\begin{tabular}{l|l}
70 & $\mathrm{~mm}$
\end{tabular}




\section{Bezeichn.: Tibia}

\section{Kiste:}

Skelet: $\quad \mathrm{K} 81$

Population: Großenrode

Seite: rechts

Erhaltung: $\square$ prox. Gelenk prox. Schaft

mittl. Schaft dist. Schaft $X$ dist. Gelenk

Beschreibung:

Dies ist die distale Epiphyse eines jungen Individuums.
Verband: $\square$ Verband

Alter: $\quad 13-16(19)$

\section{Geschlecht:}

Arthrose: 


\section{Bezeichn.: Tibia}

Kiste:

Skelet: 63/68-S1 K65

Population: Großenrode

Seite: links

Erhaltung: $\square$ prox. Gelenk

$X$ prox. Schaft

$X$ mittl. Schaft

dist. Schaft

dist. Gelenk

\section{Beschreibung:}

Ein Fragment eines grazilen Knochens. Aufgrund der Konstitution wird ein junges Individuum angenommen.
Verband: $\quad$ Verband

Alter: $\quad 13-16(18)$

Geschlecht:

Arthrose:
Ges./Kr.: Gesund 


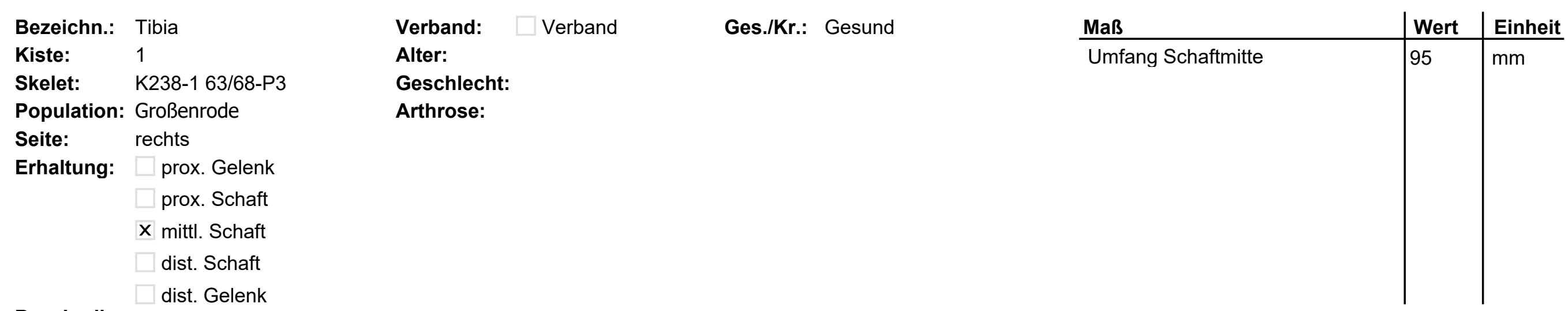

\section{Beschreibung:}

Dieses Fragment einer rechten Tibia weist deutliche Ansatzspuren der Membrana interossea auf. Es handelt sich um ein recht flaches Fragment. Die Zugehörigkeit mit der anderen Tibia scheint möglich zu sein. 


\section{Bezeichn.: Tibia}

\section{Kiste:}

Skelet: $\quad$ K234 63/68 P3

Population: Großenrode

Seite: rechts

Erhaltung: $\square$ prox. Gelenk

X prox. Schaft

$X$ mittl. Schaft

$X$ dist. Schaft

X dist. Gelenk

\section{Beschreibung:}

Dieses Fragment einer Tibia ist recht schmal. Es ist erodiert und weist Bissspuren auf.

\section{Verband: \\ Verband \\ Ges./Kr.: Gesund}

\section{Alter:}

Geschlecht:

Arthrose:

\section{Maß}

Schaftumfang Foramen

Umfang Schaftmitte \begin{tabular}{|l|l} 
Wert & Einheit \\
\hline
\end{tabular}

\begin{tabular}{l|l}
96 & $\mathrm{~mm}$
\end{tabular}

$87 \quad \mathrm{~mm}$




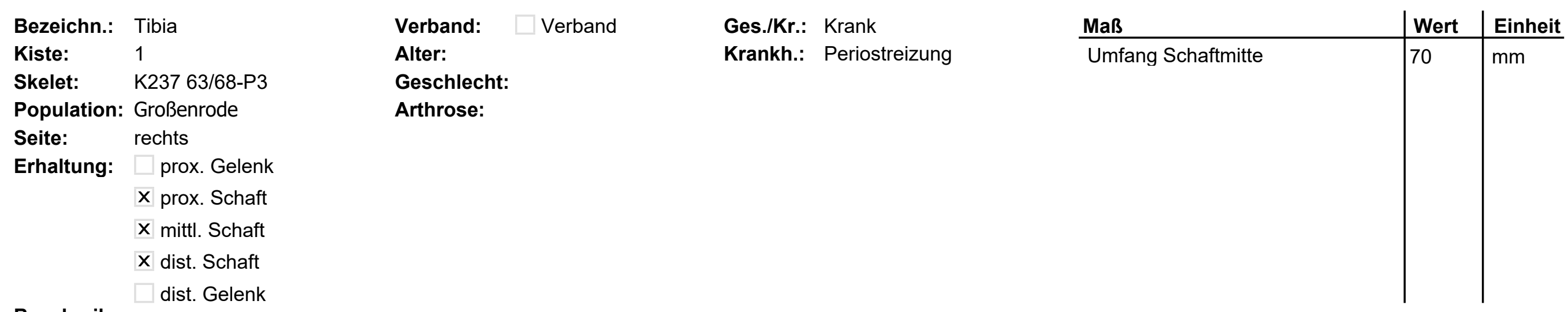

Dieses Fragment ist sehr schmal und grazil. Es ist erodiert, dennoch ist eine leichte intravitale Oberflächenstreifung erkennbar, die Spuren einer periostalen Reizung sind. 


\section{Bezeichn: Tibia}

Kiste:

Skelet: $\quad 63 / 68-P 2$ K119

Population: Großenrode

Seite: rechts

Erhaltung: $\square$ prox. Gelenk

$\mathbf{X}$ prox. Schaft

$X$ mittl. Schaft

$\mathbf{X}$ dist. Schaft

dist. Gelenk

\section{Beschreibung:}

Dieses Fragment stammt von einer grazilen und wohl noch jungen Tibia. Es ist erodiert.

\section{Verband: $\quad$ Verband}

\section{Alter: $\quad 13-18(20)$}

\section{Geschlecht:}

Arthrose:

\section{Ges./Kr.: Gesund}

Maß

Schaftumfang Foramen

Umfang Schaftmitte
Wert $\quad$ Einheit

\begin{tabular}{l|l}
73 & $\mathrm{~mm}$
\end{tabular}

$65 \quad \mathrm{~mm}$




\section{Bezeichn:: Tibia}

Kiste:

Skelet: $\quad$ 63/68-S1 K41-1

Population: Großenrode

Seite: rechts

Erhaltung: $\square$ prox. Gelenk

$X$ prox. Schaft

$X$ mittl. Schaft

dist. Schaft dist. Gelenk
Ges./Kr.: Krank

Krankh.: Impressionen tiefer

Krampfadern

\section{Maß}

Schaftumfang Foramen

Umfang Schaftmitte \begin{tabular}{|l|l} 
Wert & Einheit \\
\hline
\end{tabular}

\section{Geschlecht:}

Arthrose:

\section{Beschreibung:}

Es ist nur ein Fragment erhalten, welches recht schmal ist. Es ist erodiert, dennoch finden sich Spuren von periostalen Krampfadern. 


\section{Bezeichn.: Tibia}

\section{Kiste:}

Skelet: $\quad 63 / 68$ S1 K41-2

Population: Großenrode

Seite: rechts

Erhaltung: $\square$ prox. Gelenk

X prox. Schaft

mittl. Schaft

dist. Schaft

dist. Gelenk

Beschreibung:

Verband: $\square$ Verband

Alter:

Geschlecht:

Arthrose:

Ein proximales Tibiafragment. Es ist stark erodiert. 


\section{Bezeichn.: Tibia}

\section{Kiste:}

Skelet: $\quad$ K41 63/68 S1

Population: Großenrode

Seite: links

Erhaltung: $\mathbf{X}$ prox. Gelenk

prox. Schaft

mittl. Schaft

dist. Schaft

dist. Gelenk

Beschreibung:

Ein mediales Tibiaplateau. Die Gelenkfläche ist ausgesprochen konkav.

\section{Verband: $\quad$ Verband}

\section{Alter:}

Geschlecht:

Arthrose:

prox. 


\section{Bezeichn.: Tibia}

\section{Kiste:}

Skelet: $\quad 63 / 68$ S1 K41

Population: Großenrode

Seite: links

Erhaltung: $\mathbf{X}$ prox. Gelenk

prox. Schaft

mittl. Schaft

dist. Schaft

dist. Gelenk

\section{Beschreibung:}

Ein stark erodiertes Tibiaplateau der medialen Seite.
Verband: $\quad \square$ Verband

\section{Alter:}

Geschlecht:

Arthrose: 


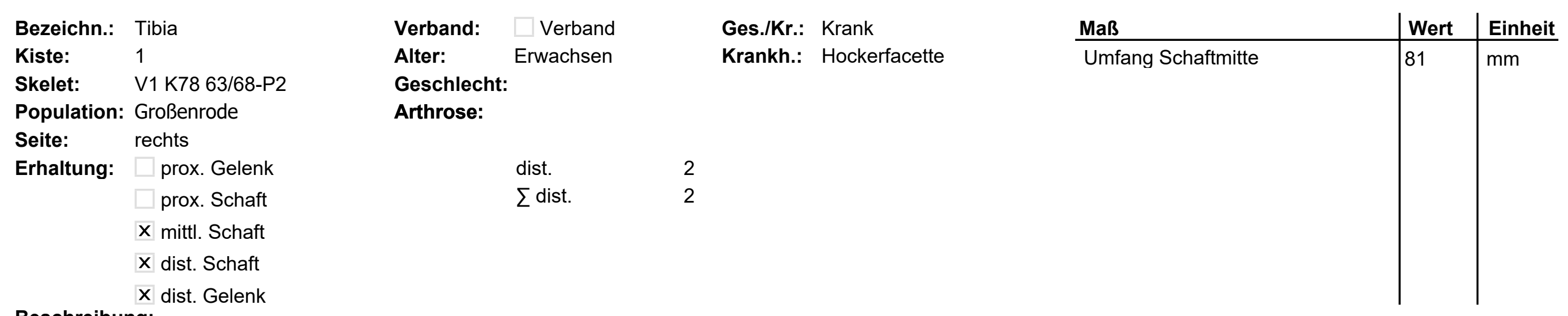

\section{Beschreibung:}

Dieses Fragment einer rechten Tibia weist eine leichte Hockerfacette auf. Es zeigen sich Tierbissspuren. Diese Tibia gehört zu einem Verband mit einem Talus. 


\section{Bezeichn.: Tibia}

Kiste:

Skelet: $\quad$ 63/68 - P3 K238-2 63/68-

Population: Großenrode

Seite: rechts

Erhaltung: $\square$ prox. Gelenk

$X$ prox. Schaft

$X$ mittl. Schaft

$\mathbf{X}$ dist. Schaft

dist. Gelenk

\section{Beschreibung:}

Dieses Fragment einer Tibia ist erodiert und geklebt. Es weist Löcher in der Oberfläche auf, die wohl durch Würmer verursacht wurden. Pathologisch ist eine Enthesiopathie bei der Ansatzstelle des M. soleus. Hier finden sich auch kleine reaktionelle Knochenneubildungen. 


\section{Bezeichn:: Tibia}

\section{Kiste:}

5

Skelet: $\quad$ K333 64/68 P4

Population: Großenrode

\section{Erhaltung:}

$$
\begin{aligned}
& \square \text { prox. Gelenk } \\
& \text { X prox. Schaft } \\
& \text { X mittl. Schaft } \\
& \text { X dist. Schaft } \\
& \square \text { dist. Gelenk }
\end{aligned}
$$

\section{Beschreibung:}

Erodiertes und graziles Fragment.
Verband: $\square$ Verband

Ges./Kr.: Gesund

\section{Alter:}

Geschlecht: $+\geq 0$

Arthrose:

\section{Maß}

Schaftumfang Foramen

Umfang Schaftmitte

Wert $\quad$ Einheit

\begin{tabular}{l|l}
84 & $\mathrm{~mm}$
\end{tabular}

$\mathrm{mm}$




\section{Bezeichn:: Tibia}

\section{Kiste:}

5

Skelet: K292 64/68 S3

Population: Großenrode

Seite:

links

Erhaltung: $\square$ prox. Gelenk

prox. Schaft

$X$ mittl. Schaft

$\mathbf{X}$ dist. Schaft dist. Gelenk

\section{Beschreibung:}

Zwei erodierte Fragmente.
Verband: $\quad$ Verband

\section{Alter:}

Ges./Kr.: Gesund

Maß

Umfang Schaftmitte

Geschlecht: $\rho \leq ð$

Arthrose: 


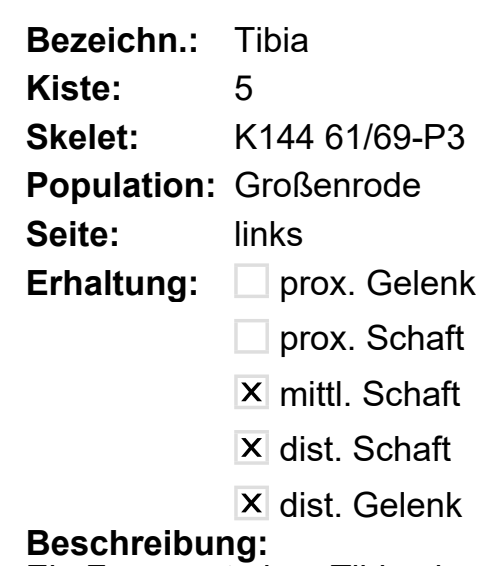

Verband: $\quad \square$ Verband $\quad$ Ges./Kr.: Gesund

Alter: $\quad 6-8$

Geschlecht:

Arthrose:

Ein Fragment einer Tibia eines Individuums aus dem Altersbereich Infans II. Es ist etwas frakturiert aber wenig erodiert. 

Bezeichn.: Tibia
Kiste:

5
Skelet: $\quad$ K338 64/68-P4
Population: Großenrode
Seite: rechts
Erhaltung: $\square$ prox. Gelenk
$X$ prox. Schaft
$X$ mittl. Schaft
X dist. Schaft
dist. Gelenk
Beschreibung:

Ein erodiertes Fragment einer rechten Tibia. Es ist ein massiver Knochen.

\section{Ges./Kr.: Gesund}

\section{Alter:}

Geschlecht: $q<\curvearrowright$

Arthrose:

Maß

Schaftumfang Foramen

Umfang Schaftmitte 


\section{Bezeichn.: Tibia}

\section{Kiste:}

Skelet: $\quad 64 / 69$ PII-V/ SIV

Population: Großenrode

Seite: rechts

Erhaltung: $\square$ prox. Gelenk prox. Schaft mittl. Schaft $X$ dist. Schaft dist. Gelenk

\section{Beschreibung:}

Ein Fragment und viele Splitter (14g)
Verband: $\quad$ Verband

\section{Alter:}

Geschlecht: $q>\lambda$

Arthrose: 


\section{Bezeichn.: Tibia}

\section{Kiste:}

Skelet: $\quad$ K2 64/69 PIV-VISIV

Population: Großenrode

Seite: rechts

Erhaltung: $\square$ prox. Gelenk

prox. Schaft

mittl. Schaft

$\mathbf{X}$ dist. Schaft dist. Gelenk
Verband: $\quad \square$ Verband

Ges./Kr.: Gesund

Geschlecht: $\hat{0}$

Arthrose:

\section{Beschreibung:}

Ein sehr massives Fragment mit Erosionsspuren und sehr dicker Compacta $(8,53 \mathrm{~mm})$. 

Bezeichn.: Tibia
Kiste:

8
Skelet: $\quad$ K154 61/68-S2
Population: Großenrode
Seite: links
Erhaltung: $\mathbf{X}$ prox. Gelenk
$X$ prox. Schaft
$X$ mittl. Schaft
$\mathbf{X}$ dist. Schaft dist. Gelenk

Beschreibung:

Eine erodierte Tibia in recht großer Erhaltungsmenge.

\section{Alter:}

Arthrose:

\section{Verband: $\quad \square$ Verband}

Geschlecht:

\section{Maß}

gr. Breite prox. Gelenk

Schaftumfang Foramen

Umfang Schaftmitte

\begin{tabular}{|l|l} 
Wert & Einheit \\
69,3 & $\mathrm{~mm}$ \\
90 & $\mathrm{~mm}$ \\
81 & $\mathrm{~mm}$ \\
& \\
&
\end{tabular}




\section{Bezeichn.: Tibia}

\section{Kiste:}

Skelet: $\quad$ K154 61/68-S2

Population: Großenrode

Seite: rechts

Erhaltung: $\square$ prox. Gelenk

X prox. Schaft

$X$ mittl. Schaft

$\mathbf{X}$ dist. Schaft dist. Gelenk

\section{Beschreibung:}

Ein stark erodiertes Fragment einer Tibia, die recht massiv ist.
Verband: $\square$ Verband

\section{Alter:}

Geschlecht: $q<\hat{\sigma}$

Arthrose:

\section{Maß}

Schaftumfang Foramen

Umfang Schaftmitte \begin{tabular}{|l|l} 
Wert & Einheit \\
\hline
\end{tabular}

$93 \quad \mathrm{~mm}$

$87 \quad \mathrm{~mm}$




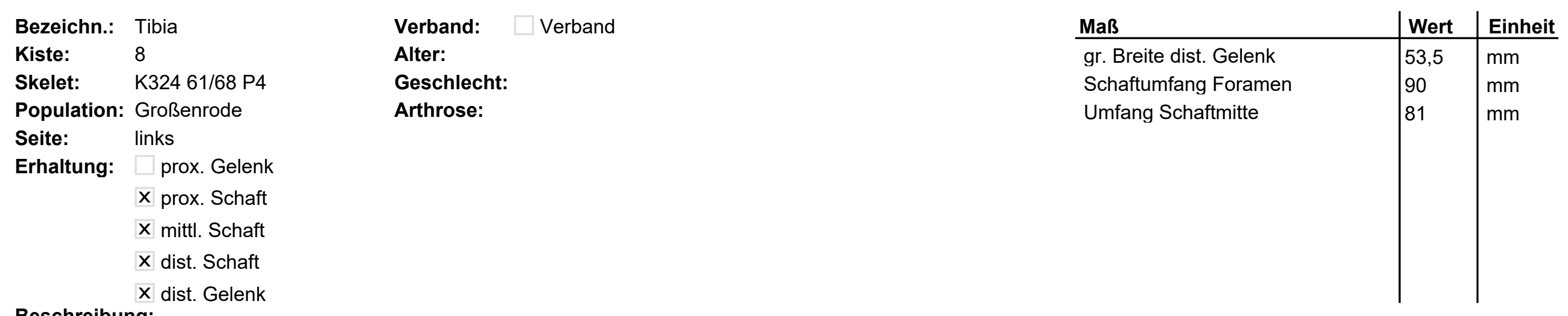

Beschreibung:

Eine sehr stark erodierte Tibia. Das distale Gelenk ist komplett frakturiert und erodiert, sodass hier keine Befundung möglich war. Die Oberfläche des Fundstücks ist sehr erodiert. 


\section{Bezeichn.: Tibia}

\section{Kiste:}

Skelet: 61/68-3

Population: Großenrode

Seite: links

Erhaltung: X prox. Gelenk

prox. Schaft

mittl. Schaft

dist. Schaft

dist. Gelenk
Verband: $\quad$ Verband

Alter:

\section{Geschlecht:}

Arthrose:

\section{Beschreibung:}

Ein ganz kleines Fragment eines Tibiaplateaus, es sind etwa 20\% vorhanden, dabei ist nur die oberste Schicht erhalten, ohne Spongiosa. 


\section{Bezeichn.: Tibia}

\section{Kiste:}

Skelet: $\quad$ K266 63/64 P4

Population: Großenrode
Verband: $\square$ Verband

\section{Alter:}

Geschlecht:

Arthrose:

\section{Erhaltung: $\square$ prox. Gelenk \\ X prox. Schaft \\ mittl. Schaft \\ dist. Schaft \\ dist. Gelenk}

Beschreibung:

Hier ist ein kleines Fragment einer rechten Tibia erhalten, es handelt sich um die Tuberositas frontalis, etwa 1/20 des gesamten Knochens ist vorhanden. 


\section{Bezeichn:: Fibula}

\section{Kiste:}

\section{9}

Skelet: $\quad$ K235 63/67 P3

Population: Großenrode

Seite: links

Erhaltung: $\square$ prox. Gelenk

$X$ prox. Schaft

$X$ mittl. Schaft

$\mathbf{X}$ dist. Schaft

$\mathbf{X}$ dist. Gelenk
Ges./Kr.: Krank

Krankh.: subperiostales Hämatom

\section{Maß}

Länge
Wert $\quad$ Einheit

Geschlecht: $q \geq 0$

Arthrose:

\section{Beschreibung:}

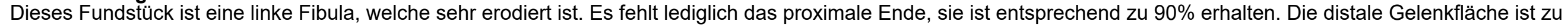

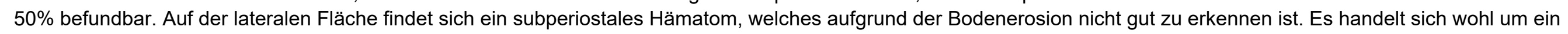
juveniles Individuum, da die proximale Epiphyse fehlt und die distale noch eine deutliche Epiphysenfuge aufweist, die aber schon etwas verknöchert ist. 

Bezeichn.: Fibula
Kiste:
Skelet: K357 61/68-S4
Population: Großenrode
Seite: rechts
Erhaltung: $\mathbf{X}$ prox. Gelenk
$\mathbf{X}$ prox. Schaft
$X$ mittl. Schaft
$\mathbf{X}$ dist. Schaft$$
\text { dist. Gelenk }
$$

Verband:

Verband

Alter: $\quad 6-10(15)$

Geschlecht:

Beschreibung:

Eine Fibula der rechten Körperseite eines Kindes. Sie ist gut erhalten.

Arthrose:

Ges./Kr.: Gesund

\section{Maß}

Länge Wert $\quad$ Einheit 


\section{Bezeichn.: Fibula}

\section{Kiste:}

9

Skelet: $\quad 63 / 67$ S3 K248

Population: Großenrode

Seite:

links

Erhaltung: $\square$ prox. Gelenk

$X$ prox. Schaft

mittl. Schaft

dist. Schaft

dist. Gelenk

\section{Beschreibung:}

1/3 des Schaftes proximal links.
Verband: Verband

\section{Alter:}

Geschlecht:

Arthrose:
Ges./Kr.: Gesund 


\section{Bezeichn.: Fibula}

\section{Kiste:}

9

Skelet: $\quad 63 / 67$ S3 K285

Population: Großenrode

Seite: rechts

Erhaltung: $\square$ prox. Gelenk

prox. Schaft

$X$ mittl. Schaft

dist. Schaft dist. Gelenk

\section{Beschreibung:}

Verband: $\quad$ Verband $\quad$ Ges./Kr.: Gesund

Alter:

\section{Geschlecht:}

Ein Fragment aus dem Schaft einer rechten Fibula. Es ist insgesamt etwa 1/3 erhalten. 

Bezeichn.: Fibula
Kiste: $\quad 7$
Skelet: $\quad$ K357 61/68-S4
Population: Großenrode
Seite: links
Erhaltung: $\square$ prox. Gelenk
$X$ prox. Schaft
$X$ mittl. Schaft
X dist. Schaft

$$
\text { dist. Gelenk }
$$
Beschreibung:

Eine Fibula der linken Körperseite eines Kindes. Sie ist gut erhalten.
Ges./Kr.: Gesund

\section{Maß}

Länge

Wert $\mid$ Einheit

\section{Geschlecht:}

Arthrose:

$\mathrm{mm}$




\section{Bezeichn.: Fibula}

\section{Kiste:}

\section{7}

Skelet: $\quad$ K233 63/68-P3

Population: Großenrode

Seite: links

Erhaltung: $\mathbf{X}$ prox. Gelenk

$X$ prox. Schaft

$X$ mittl. Schaft

$\mathbf{X}$ dist. Schaft

$\mathbf{X}$ dist. Gelenk
Ges./Kr.: Krank

Krankh.: Kapselzerrung

Arthrose

Periostreizung

\section{Maß}

Länge

Geschlecht: $\hat{\sigma}$

Arthrose:

dist.

3

\section{Beschreibung:}

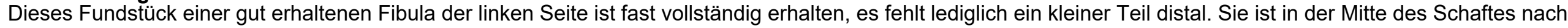

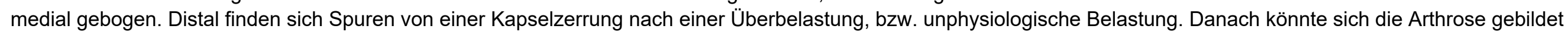
haben. Auf der lateralen Seite der Fibula finden sich Oberflächenstreifungen, die hier für eine periostale Reizung sprechen. 


\section{Bezeichn.: Fibula}

\section{Kiste:}

Skelet: K3.345 63/66 Prof51 S4

Population: Großenrode

\section{Erhaltung:}

prox. Gelenk

prox. Schaft

mittl. Schaft

$\mathbf{X}$ dist. Schaft

X dist. Gelenk
Verband: $\quad$ Verband

Alter: Erwachsen

Geschlecht:

Arthrose:

Ges./Kr.: Krank

Krankh.: Arthrose

Arthritis

\section{Beschreibung:}

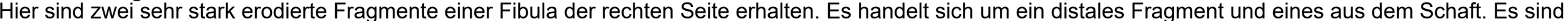

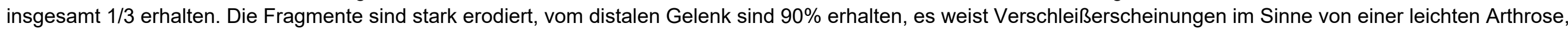
die möglicherweise in eine Arthritis überging, auf. 


\section{Bezeichn.: Fibula}

\section{Kiste:}

Skelet: $\quad$ K346 63/66 S4

Population: Großenrode

Seite: links

Erhaltung: $\square$ prox. Gelenk

prox. Schaft

$X$ mittl. Schaft

dist. Schaft

dist. Gelenk

\section{Beschreibung:}

Ein Fragment aus dem Schaft einer Fibula der linken Seite, es sind etwa 30\% aus dem Schaft erhalten. das Fundstück ist sehr stark erodiert.

\section{Verband: $\quad$ Verband}

\section{Alter:}

Geschlecht: 


\section{Bezeichn.: Fibula}

\section{Kiste: 4}

Skelet: $\quad$ K74 62/68 P2

Population: Großenrode

Seite: $\quad$ n. def.

Erhaltung: $\mathbf{X}$ prox. Gelenk

$X$ prox. Schaft

mittl. Schaft

dist. Schaft

dist. Gelenk

\section{Beschreibung:}

Nur ein Fragment aus dem Schaft mit ganz kleinem Ansatz des proximalen oder distalen Endes. Da aber die Fibulae sehr individuell unterschiedlich sind, ist die Seite hier nicht bestimmbar. Das Fragment weist Bissspuren und starke Oberflächenerosionen auf. Es finden sich in der Nähe des Gelenks Spuren einer Kapselzerrung des tibio fibular - Gelenks. 


\section{Bezeichn.: Fibula}

\section{Kiste:}

Skelet: K200 62/65-S3

Population: Großenrode

Seite:

links

Erhaltung: $\square$ prox. Gelenk

prox. Schaft

mittl. Schaft

$\mathbf{X}$ dist. Schaft dist. Gelenk
Verband: Verband

\section{Alter:}

Geschlecht:

Arthrose:

\section{Beschreibung:}

Ein stark erodiertes des distalen Sechstels, nicht befundbar. 

Bezeichn.: Fibula
Kiste:
6
Skelet: $\quad$ K199 62/65 S3
Population: Großenrode
Seite: n. def.
Erhaltung: $\square$ prox. Gelenk
prox. Schaft
$X$ mittl. Schaft
dist. Schaft
dist. Gelenk

Verband: $\quad \square$ Verband

\section{Alter:}

\section{Geschlecht:}

\section{Beschreibung:}

Etwa $1 / 5$ aus dem Schaft einer Fibula. Das Fragment ist erodiert.

Weiterhin sind noch kleine Splitter erhalten. 


\section{Bezeichn.: Fibula}

\section{Kiste: 4}

Skelet: $\quad$ K70 62/68 P2

Population: Großenrode

Seite: links

Erhaltung: $\square$ prox. Gelenk

prox. Schaft

mittl. Schaft

$X$ dist. Schaft

dist. Gelenk
Verband: $\quad$ Verband

\section{Alter:}

Geschlecht:

Arthrose:

\section{Beschreibung:}

Ein zu 2/5 erhaltenes Fragment aus dem distalen Schaft einer linken Fibula. Der Knochen ist sehr stark erodiert und nicht befundbar. 


\section{Bezeichn.: Fibula}

\section{Kiste: 4}

Skelet: $\quad$ K70 62/68 P2

Population: Großenrode
Verband: Verband

\section{Alter:}

Geschlecht:

Arthrose:

\section{Erhaltung: $\square$ prox. Gelenk \\ prox. Schaft \\ $X$ mittl. Schaft \\ dist. Schaft \\ dist. Gelenk}

\section{Beschreibung:}

Zwei Fragmente einer nicht weiter zuzuordnenden Fibula. 


\section{Bezeichn.: Fibula}

\section{Kiste: $\quad 4$}

Skelet: $\quad$ K76 62/68 P2

Population: Großenrode

Seite:

links

Erhaltung: $\square$ prox. Gelenk

$\mathbf{X}$ prox. Schaft

$X$ mittl. Schaft

dist. Schaft

dist. Gelenk

\section{Beschreibung:}

Ein Fragment aus dem Schaft einer linken Fibula. Es sind etwa 2/3 erhalten.

Verband: $\quad \square$ Verband

\section{Alter:}

Geschlecht:

Arthrose:

Ges./Kr.: Gesund 
Bezeichn:: Fibula

\section{Kiste:}

Skelet: 64/53

Population: Großenrode

Seite: links

Erhaltung: $\mathbf{X}$ prox. Gelenk

X prox. Schaft

mittl. Schaft

dist. Schaft

dist. Gelenk
Verband: $\quad$ Verband

Alter: Erwachsen

Geschlecht: $q \leq ð$

Arthrose:

\section{Ges./Kr.: Gesund}

\section{Beschreibung:}

Dieses Fragment einer Fibula ist sehr massiv und nur proximal erhalten. Die Gelenkfläche ist zu etwa 60\% erhalten. 
Bezeichn.: Fibula

\section{Kiste:}

Skelet: $\quad 61 / 58$

Population: Großenrode

Seite: rechts

Erhaltung: $\square$ prox. Gelenk

prox. Schaft

$X$ mittl. Schaft

dist. Schaft

dist. Gelenk

\section{Beschreibung:}

Aus der Mitte des Schaftes, etwa 1/3 des gesamten Knochens erhalten.
Verband: $\quad$ Verband

\section{Alter:}

Geschlecht:

Arthrose: 


$\begin{array}{ll}\text { Bezeichn.: } & \text { Fibula } \\ \text { Kiste: } & 2 \\ \text { Skelet: } & 62 / 54 \\ \text { Population: } & \text { Großenrode } \\ \text { Seite: } & \text { links } \\ \text { Erhaltung: } & \square \text { prox. Gelenk } \\ & \square \text { prox. Schaft } \\ & \square \text { mittl. Schaft } \\ & \square \text { dist. Schaft } \\ & \mathbf{X} \text { dist. Gelenk }\end{array}$

\section{Verband: $\quad \square$ Verband Ges./Kr.: Gesund}

Recht stark erodiert, Gelenkfläche nur zu 75\% distal erhalten, es sind etwa 1/6 der gesamten Fibula erhalten. 


\section{Bezeichn.: Fibula}

Kiste:

Skelet: $\quad$ aus kleinerer Tüte

Population: Großenrode

Seite: links

Erhaltung: $\square$ prox. Gelenk

prox. Schaft

$X$ mittl. Schaft

dist. Schaft

dist. Gelenk

Beschreibung:

Dieses Fibulafragment ist erodiert, etwa 1/4 des Schafts ist erhalten.
Verband: Verband

\section{Alter:}

Geschlecht:

Arthrose: 
Bezeichn: Fibula

\section{Kiste:}

Skelet: K167

Population: Großenrode

Seite: rechts

Erhaltung: $\square$ prox. Gelenk

prox. Schaft

$X$ mittl. Schaft

$\mathbf{X}$ dist. Schaft dist. Gelenk
Verband: $\quad$ Verband

\section{Alter:}

\section{Geschlecht:}

Arthrose:

\section{Beschreibung:}

Es sind zwei Fragmente dieser Fibula erhalten. Es handelt sich insgesamt um den mittigen bis distalen Schaft. 
Bezeichn.: Fibula

Kiste: $\quad 10$

Skelet: $\quad 64 / 55$

Population: Großenrode

Seite: rechts

Erhaltung: $\square$ prox. Gelenk prox. Schaft

mittl. Schaft

X dist. Schaft dist. Gelenk

Beschreibung:

1/10 aus dem distalen Schaft.
Verband: Verband

\section{Alter:}

Geschlecht:

Arthrose: 


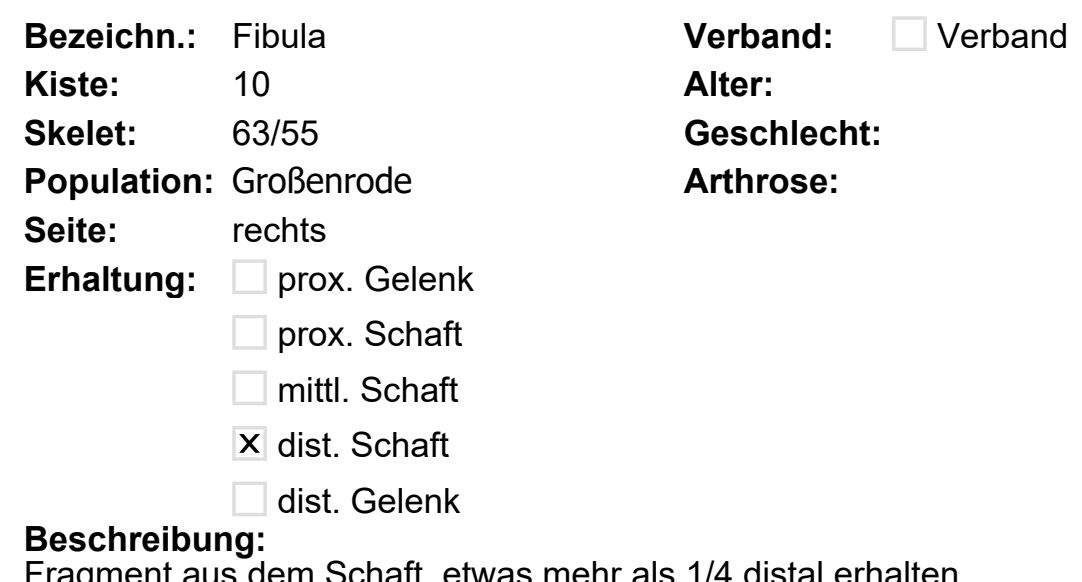

Fragment aus dem Schaft, etwas mehr als 1/4 distal erhalten. 


$\begin{array}{ll}\text { Bezeichn.: } & \text { Fibula } \\ \text { Kiste: } & 1 \\ \text { Skelet: } & \text { k244 P3 } \\ \text { Population: } & \text { Großenrode } \\ \text { Seite: } & \text { links } \\ \text { Erhaltung: } & \square \text { prox. Gelenk } \\ & \square \text { prox. Schaft } \\ & \square \text { mittl. Schaft } \\ & \mathbf{X} \text { dist. Schaft } \\ & \square \text { dist. Gelenk }\end{array}$

\section{Verband: $\quad \square$ Verband Ges./Kr.: Krank}

Alter: Krankh.: Periostreizung

Geschlecht: $q \leq \lambda \quad$ Muskelreizung

Arthrose: Kapselzerrung

\section{Beschreibung:}

Muskelmarken und streifenförmige Auflagerungen am Schaft sprechen für Reizung des Periosts durch Muskelreizung und Kapselzerrung. 
Bezeichn.: Fibula

\section{Kiste:}

Skelet: K242

Population: Großenrode

Seite: rechts

Erhaltung: $\square$ prox. Gelenk

prox. Schaft

$X$ mittl. Schaft

dist. Schaft

dist. Gelenk

Beschreibung:

Fragment aus etwa der Mitte des Schafts.
Verband: $\quad$ Verband

\section{Alter:}

\section{Geschlecht:}

Arthrose: 
Bezeichn:: Fibula

Kiste:

Skelet: K9 S0-S2

Population: Großenrode

Seite: rechts

Erhaltung: $\square$ prox. Gelenk prox. Schaft $X$ mittl. Schaft dist. Schaft dist. Gelenk

Beschreibung:

Fragmente.
Verband: $\quad$ Verband

\section{Alter:}

Geschlecht:

Arthrose: 


\section{Bezeichn.: Fibula}

Kiste: 1

Skelet: $\quad$ K238 63/68 P3

Population: Großenrode

Seite: rechts

Erhaltung: $\square$ prox. Gelenk

prox. Schaft

mittl. Schaft

X dist. Schaft

dist. Gelenk
Verband: $\quad \square$ Verband

Alter:

Geschlecht:

Arthrose:
Ges./Kr.: Krank

Krankh.: Kapselzerrung

Enthesiopathie

\section{Beschreibung:}

Distal gereizt an der Kapsel mit Enthesiopathie und leichten Auswüchsen am Schaftende im Sinne einer Kapselzerrung. 


\section{Bezeichn.: Fibula}

Kiste: 1

Skelet: $\quad$ K234 63/68 P3

Population: Großenrode

Seite: links

Erhaltung: $\square$ prox. Gelenk

X prox. Schaft

$X$ mittl. Schaft

$\mathbf{X}$ dist. Schaft

dist. Gelenk
Ges./Kr.: Krank

Krankh.: Enthesiopathie

Kapselzerrung

\section{Beschreibung:}

Verband: $\quad \square$ Verband

Alter:

Geschlecht:

Arthrose:

Dieses Fragment ist erodiert und weist Tierverbiss auf. Es findest sich proximal eine Enthesiopathie und distal eine Kapselzerrung. 


\section{Bezeichn.: Fibula}

Kiste: 1

Skelet: $\quad$ K78 63/68-P2

Population: Großenrode

Seite: rechts

Erhaltung: $\square$ prox. Gelenk

prox. Schaft

mittl. Schaft

X dist. Schaft

dist. Gelenk

\section{Ges./Kr.: Krank \\ Krankh.: Kapselzerrung \\ Verband \\ Alter:}

Geschlecht: $q<\hat{\jmath}$

Arthrose:

\section{Beschreibung:}

Dieses Fragment einer rechten Fibula weist Tierverbiss und leichte Verknöcherungen nach Kapselzerrung distal auf. Es handelt sich um eine massive Fibula. 


\section{Bezeichn.: Fibula}

\section{Kiste:}

Skelet: $\quad$ K243 63/68-P3

Population: Großenrode

Seite: rechts

Erhaltung: $\square$ prox. Gelenk

X prox. Schaft

mittl. Schaft

dist. Schaft dist. Gelenk

Beschreibung:

Ein Fragment mit definierten Muskelmarken und Tierverbiss.
Verband: Verband

\section{Alter:}

Geschlecht:

Ges./Kr.: Gesund 
Bezeichn.: Fibula

\section{Kiste:}

Skelet: K341

Population: Großenrode

Erhaltung: $\square$ prox. Gelenk

prox. Schaft

X mittl. Schaft

dist. Schaft

dist. Gelenk

Beschreibung:

Ein Fragment einer Fibula.
Verband: $\quad \square$ Verband

\section{Alter:}

Geschlecht:

Arthrose: 


\section{Bezeichn.: Fibula}

\section{Kiste:}

Skelet: $\quad$ K306 64/68 P4

Population: Großenrode

Seite:

Erhaltung: $\square$ prox. Gelenk

prox. Schaft

mittl. Schaft

dist. Schaft

X dist. Gelenk
Verband: $\quad \square$ Verband

\section{Alter:}

Geschlecht:

Arthrose:

\section{Beschreibung:}

Es ist ein Fragment erhalten. Es sind $85 \%$ des Gelenks erhalten, das Fundstück ist erodiert. 


\section{Bezeichn.: Fibula}

\section{Kiste:}

Skelet: $\quad$ K306 64/68 P4

Population: Großenrode

Seite:

Erhaltung: $\square$ prox. Gelenk

prox. Schaft

mittl. Schaft

dist. Schaft $\mathbf{X}$ dist. Gelenk

Beschreibung:

Verband: $\quad$ Verband

Alter:

Geschlecht:

Fragmentiert erhaltenes distales Fragment, wessen Gelenk nicht befundbar ist. 


\section{Bezeichn.: Fibula}

\section{Kiste:}

5

Skelet: $\quad$ K292 64/68 S3

Population: Großenrode

Erhaltung: $\square$ prox. Gelenk $x$ prox. Schaft

$X$ mittl. Schaft dist. Schaft dist. Gelenk

\section{Beschreibung:}

Zwei erodierte Fragmente.
Verband: $\quad$ Verband

Ges./Kr.: Gesund

\section{Geschlecht: $q<\oslash$}

\section{Arthrose:}




\section{Bezeichn.: Fibula}

Kiste: 5

Skelet: K352 61/69 S4

Population: Großenrode

Seite: rechts

Erhaltung: $\square$ prox. Gelenk

prox. Schaft

$X$ mittl. Schaft

$\mathbf{X}$ dist. Schaft

$X$ dist. Gelenk
Ges./Kr.: Krank

Krankh.: Enthesiopathie

\section{Zerrung}

\section{Beschreibung:}

$\begin{array}{lll}\text { Alter: } & \text { Krankh.: } & \text { Enthesiopathie } \\ \text { Geschlecht: } & & \text { Zerrung }\end{array}$

Eine sehr stark erodierte Fibula, die distal im Bereich der Kapsel eine leichte Enthesiopathie aufweist. Dieser ist wohl eine Zerrung vorangegangen. 


\section{Bezeichn.: Fibula}

\section{Kiste:}

Skelet: $\quad$ K362 61/68 S4

Population: Großenrode

Seite: rechts

Erhaltung: $\mathbf{X}$ prox. Gelenk

$X$ prox. Schaft

$X$ mittl. Schaft

$\mathbf{X}$ dist. Schaft

X dist. Gelenk

\section{Verband: $\quad$ Verband}

\section{Alter:}

Geschlecht: $+\geq \gtrsim$

Arthrose:

Ges./Kr.: Gesund

\section{Beschreibung:}

Eine in drei Teile zerbrochene Fibula, sie ist frakturiert und leicht erodiert, die proximale Gelenkfläche ist nicht befundbar. Der Knochen ist sehr grazil. 


\section{Bezeichn.: Talus}

\section{Kiste:}

Skelet: K155 63/67-S2

Population: Großenrode

Seite:

links
Ges./Kr.: Gesund

\section{Maß}

Breite

Länge
Alter: $\quad 13-18$ (19)

Geschlecht:

Arthrose:

\section{Beschreibung:}

Ein zu 70\% erhaltener Talus der linken Seite, welcher einem juvenilen Individuum zuzuordnen ist. Die Gelenkflächen sind zu etwa $65 \%$ erhalten. 


\section{Bezeichn.: Talus}

Kiste:

Skelet: $\quad$ K276 63/66 S3

Population: Großenrode

Seite:

links
Verband: $\square$ Verband

Alter:

Geschlecht: $q<\lambda$

Arthrose:

\section{Ges./Kr.: Gesund}

dist.

\section{Beschreibung:}

Ein zu 60\% erhaltener Talus, der sehr erodiert ist. Die Gelenkflächen sind zu etwa $40 \%$ erhalten. 


\section{Bezeichn.: Talus}

\section{Kiste:}

Skelet: $\quad$ K178 63/66 P3

Population: Großenrode

Seite: rechts
Verband: $\square$ Verband

Alter:

Geschlecht: $q<\widehat{ }$

Arthrose:

prox.
Ges./Kr.: Gesund

Maß

Breite

Länge

\begin{tabular}{|l|l} 
Wert & Einheit \\
\hline 41,76 & $\mathrm{~mm}$
\end{tabular}

\section{Beschreibung:}

Ein zu etwa $90 \%$ erhaltener Talus der rechten Seite. 


\section{Bezeichn.: Talus}

\section{Kiste:}

Skelet: K113 60/64 S2

Population: Großenrode

Seite:

rechts
Verband: $\square$ Verband

Alter: $\quad 13-18(20)$

Geschlecht:

Arthrose:

:

\section{Ges./Kr.: Gesund}

\section{Beschreibung:}

Ein sehr stark erodiertes Fragment eines rechten Talus. Auch dieses Fragment gehört wohl zu dem Verband des juvenilen Individuums. 


\section{Bezeichn.: Talus}

Kiste: 4

Skelet: $\quad$ K74 62/68 P2

Population: Großenrode

Seite: rechts

\section{Verband:}

\section{Alter:}

Geschlecht:

Arthrose:
Ges./Kr.: Gesund

\section{Maß}

Breite

Länge

Wert $\quad$ Einheit

prox.

\section{Beschreibung:}

Ein Fragment eines Talus der rechten Seite, welches Erosionsspuren zeigt. Die Gelenkflächen sind zu etwa $80 \%$ befundbar. 


\section{Bezeichn.: Talus}

Kiste: 4

Skelet: $\quad$ K43 62/68 S1 (P2)

Population: Großenrode

Seite:

rechts

\section{Verband: $\quad$ Verband}

Ges./Kr.: Gesund

\section{Alter:}

Geschlecht:

Arthrose:

\section{Beschreibung:}

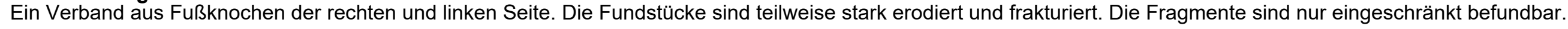




\section{Bezeichn.: Talus}

\section{Kiste:}

Skelet: $\quad$ K43 62/68 S1 (P2)

Population: Großenrode

Seite:

links
Verband:

Verband

\section{Alter:}

Geschlecht:

Arthrose:

\section{Beschreibung:}

Ein Talus aus einem Verband. 


\section{Bezeichn.: Talus}

\section{Kiste:}

Skelet: $\quad 61 / 54$

Population: Großenrode

Seite:

links
Verband:

Verband

\section{Alter:}

Geschlecht:

Arthrose:

\section{Beschreibung:}

Ein gespaltener Talus, der zu 35\% medial erhalten ist. 


\section{Bezeichn.: Talus}

\section{Kiste:}

Skelet: gesammelt

Population: Großenrode

Seite:

\section{Verband: $\quad$ Verband}

\section{Alter:}

Geschlecht: $q<\lambda$

Arthrose:
Ges./Kr.: Gesund

48,5 $\mathrm{mm}$

\section{Beschreibung:}

Hier sind etwa 2/3 distal eines linken Talus erhalten. Etwa 80\% der Gelenkflächen sind vorhanden. 


\section{Bezeichn.: Talus}

\section{Kiste:}

Skelet: $\quad 62 / 54$

Population: Großenrode

Seite:

\section{Verband:}

Verband

\section{Alter:}

\section{Geschlecht:}

Arthrose: dist.

\section{Beschreibung:}

Es ist nur ein Fragment erhalten, etwa 1/4 sind vorhanden mit 1/3 der Gelenkflächen. 
Bezeichn.: Talus

\section{Kiste: 2}

Skelet: kleine blaue Tüte aus

Population: Großenrode

Seite:
Verband:

\section{Alter:}

Geschlecht:

Arthrose:

\section{Beschreibung:}

Es ist nur ein Fragment erhalten, etwa 1/4, mit 1/3 der Gelenkflächen. 


\section{Bezeichn.: Talus}

\section{Kiste:}

Skelet: $\quad 63 / 51$

Population: Großenrode

Seite:

\section{Verband:}

\section{Alter:}

Geschlecht:

Arthrose:

\section{Ges./Kr.: Gesund}

dist.

\section{Beschreibung:}

Dieses Fundstück ist erodiert, nur etwa 1/3 ist erhalten, insgesamt etwa 50\% aller Gelenkflächen sind erhalten. 


\section{Bezeichn.: Talus}

\section{Kiste:}

Skelet: $\quad 62 / 54$

Population: Großenrode

Seite:

rechts

\section{Verband:}

\section{Alter:}

Geschlecht:

Arthrose:

\section{Beschreibung:}

Dieser Talus ist fragmentiert und erodiert, 2/3 des lateralen Teils sind erhalten, das eine Drittel wurde mit einem Spaten scharf abgetrennt. Von den Gelenken sind $85 \%$ erhalten. 


\section{Bezeichn.: Talus}

\section{Kiste:}

Skelet: $\quad 62 / 54$

Population: Großenrode

Seite:

\section{Verband:}

\section{Alter:}

\section{Geschlecht:}

Arthrose:

\section{Beschreibung:}

Es ist etwa 1/3 der lateralen Seite erhalten, wie mit dem Spaten scharf durchtrennt. Gelenkflächen insgesamt zu etwa 1/4 erhalten. 


\section{Bezeichn.: Talus}

\section{Kiste:}

Skelet: $\quad 62 / 54$

Population: Großenrode

Seite:

Verband: $\quad$ Verband

Alter:

Geschlecht:

Arthrose:

\section{Beschreibung:}

Der Talus ist distal und nur etwa zu 1/5 des gesamten Knochens erhalten. 


\section{Bezeichn.: Talus}

\section{Kiste:}

Skelet: $\quad 62 / 54$

Population: Großenrode

Seite:
Verband: $\quad$ Verband

Alter:

Geschlecht:

Arthrose:

\section{Beschreibung:}

Dieser Talus ist proximal nicht erhalten, etwa 66\% der Gelenkflächen sind vorhanden. 


\section{Bezeichn.: Talus}

Kiste:

Skelet: K251

Population: Großenrode

Seite:

rechts
Verband: $\quad$ Verband

Alter: Jung

Geschlecht:

Arthrose:

\section{Beschreibung:}

Hier ist nur ein kleines Fragment erhalten. Es zeigt sich an der Knochenkonstitution, dass es sich um ein junges Individuum handelte. 


\section{Bezeichn.: Talus}

Kiste:

Skelet: K253

Population: Großenrode

Seite:

links
Verband: $\quad$ Verband

Alter: Jung

Geschlecht:

Arthrose:

\section{Beschreibung:}

Von diesem Talus sind $60 \%$ erhalten, der Rest ist erodiert. 
Bezeichn.: Talus

Kiste:

Skelet: 63/64-4

Population: Großenrode

Seite:
Verband: $\quad \square$ Verband

Alter:

Geschlecht:

Arthrose:

\section{Beschreibung:}

Hier ist ein Fragment des distalen Gelenks vollständig erhalten, das Fragment macht etwa 1/3 des gesamten Knochens aus. 


\section{Bezeichn.: Talus}

\section{Kiste:}

Skelet: $\quad 61 / 55$

Population: Großenrode

Seite:

links
Verband: $\quad$ Verband

\section{Alter:}

\section{Geschlecht:}

Arthrose:

\section{Beschreibung:}

Dieses Fundstück ist sehr stark erodiert und teilweise etwas frakturiert, aber zu $80 \%$ erhalten. 


\section{Bezeichn.: Talus}

\section{Kiste:}

Skelet: $\quad 62 / 53$ klein

Population: Großenrode

Seite:
Verband: Verband

\section{Alter:}

Geschlecht:

Arthrose:
Maß

Breite

Länge
Wert 1 Einheit

$36,8 \mathrm{~mm}$

$51,8 \mathrm{~mm}$

\section{Beschreibung:}

Dieses Fundstück ist zwar erodiert, aber zu 90\% erhalten. 


\section{Bezeichn.: Talus}

\section{Kiste:}

Skelet: $\quad 62 / 53$ klein

Population: Großenrode

Seite:

links
Verband: Verband

\section{Alter:}

Geschlecht:

Arthrose:
Maß

Breite

Länge

Wert $\quad$ Einheit

54,25

54,25

$\mathrm{mm}$

\section{Beschreibung:}

Dieses Fundstück ist zwar erodiert, aber zu 90\% erhalten. 
Bezeichn.: Talus

Kiste: $\quad 10$

Skelet: $\quad 62 / 53$ klein

Population: Großenrode

Seite:

Verband: $\quad$ Verband

\section{Alter:}

Geschlecht:

Arthrose:

\section{Beschreibung:}

Dieses Fundstück ist zwar stark erodiert, aber zu $70 \%$ erhalten. 
Bezeichn.: Talus

Kiste: $\quad 10$

Skelet: $\quad 62 / 53$ klein

Population: Großenrode

Seite:

Verband: $\quad$ Verband

\section{Alter:}

Geschlecht:

Arthrose:

\section{Beschreibung:}

Dieses Fundstück ist zwar stark erodiert, aber zu 60\% erhalten. 
Bezeichn.: Talus

Kiste: $\quad 10$

Skelet: $\quad 62 / 53$ klein

Population: Großenrode

Seite:
Verband: Verband

\section{Alter:}

Geschlecht:

Arthrose:

\section{Beschreibung:}

Dieses Fundstück ist zwar erodiert, aber zu 50\% erhalten. 


\section{Bezeichn.: Talus}

Kiste: $\quad 10$

Skelet: Tüte nur mit 62/51

Population: Großenrode

Seite:

links
Verband: $\quad$ Verband

\section{Alter:}

Geschlecht: $q \leq \lambda$

Arthrose:

\section{Beschreibung:}

Dieser Talus ist sehr massiv, erodiert, aber zu $85 \%$ erhalten. 


\section{Bezeichn.: Talus}

\section{Kiste:}

Skelet: $\quad 61 / 52$

Population: Großenrode

Seite:

links
Verband:

Verband

\section{Alter:}

Geschlecht:

Arthrose:

\section{Beschreibung:}

Dieser Talus ist erodiert, aber zu $80 \%$ erhalten. 
Bezeichn.: Talus

Kiste: 10

Skelet: $\quad 62 / 58$

Population: Großenrode

Seite:

links
Verband: Verband

Alter:

Geschlecht:

Arthrose:

\section{Beschreibung:}

Ein Fragment, es ist etwa 1/3 erhalten. 


\section{Bezeichn.: Talus}

\section{Kiste:}

Skelet: K124

Population: Großenrode

Seite:

links
Verband: Verband

\section{Alter:}

Geschlecht:

Arthrose:

\section{Beschreibung:}

Dieses Fundstück ist stark erodiert. 


\section{Bezeichn.: Talus}

\section{Kiste:}

Skelet: K282

Population: Großenrode

Seite:

links

Verband:

Verband

Geschlecht:

Arthrose:

\section{Beschreibung:}

Hier ist nur ein Fragment erhalten.
Ges./Kr.: Gesund 


\section{Bezeichn.: Talus}

\section{Kiste:}

Skelet: $\quad$ K86 63/68-P2

Population: Großenrode

Seite:

rechts
Verband: $\quad$ Verband

Alter: $\quad 9$-15 (18)

Geschlecht:

Arthrose:

\section{Beschreibung:}

Von diesem Talus ist nur eine Epiphyse erhalten. 


\section{Bezeichn.: Talus}

\section{Kiste:}

Skelet: K81

Population: Großenrode

Seite:
Verband: $\quad$ Verband

Alter: $\quad 15-19(20)$

Geschlecht:

Arthrose:

\section{Beschreibung:}

Ein stark erodierter Talus. Die Gelenkflächen sehen aus, wie von einem jungen Individuum. 


\section{Bezeichn.: Talus}

\section{Kiste:}

Skelet: K233

Population: Großenrode

Seite:

links
Verband:

Verband

\section{Alter:}

Geschlecht:

Arthrose:

\section{Beschreibung:}

Hier ist nur ein Fragment erhalten. 
Bezeichn.: Talus

Kiste: 1

Skelet: $\quad$ V1 K78 63/68-P2

Population: Großenrode

Seite:
Verband: $\square$ Verband

Alter: Erwachsen

Geschlecht:

Arthrose:
Ges./Kr.: Gesund

2

prox.

\section{Beschreibung:}

Dieser Talus stammt aus einem Verband mit einer Tibia. Die leichten Arthrosegrade der beiden Knochen korrelieren miteinander. 
Bezeichn.: Talus

Kiste: 1

Skelet: K118

Population: Großenrode

Seite: rechts
Verband: Verband

\section{Alter:}

Geschlecht:

Arthrose:

\section{Beschreibung:}




\section{Bezeichn.: Talus}

\section{Kiste:}

Skelet: K243

Population: Großenrode

Seite:

Verband: Verband

Alter:

Geschlecht:

Arthrose:

\section{Beschreibung:}

Ein stark erodiertes Fragment. 


\section{Bezeichn.: Talus}

\section{Kiste:}

Skelet: K352 61/69 S4

Population: Großenrode

Seite: rechts

\section{Verband: $\quad$ Verband}

\section{Alter:}

Geschlecht: $\uparrow \leq \curvearrowright$

Arthrose:

\begin{tabular}{l|l|l} 
Maß & Wert & Einheit \\
\hline Breite & 37,5 & $\mathrm{~mm}$ \\
Länge & 57,5 & $\mathrm{~mm}$ \\
& & \\
& & \\
& &
\end{tabular}

\section{Beschreibung:}

Ein fast vollständig erhaltener Talus, welcher zu 85\% erhalten ist. Die Gelenkflächen sind zu $90 \%$ erhalten. 


\section{Bezeichn.: Talus}

\section{Kiste:}

Skelet: $\quad$ K273 61/69 S3

Population: Großenrode

Seite:

links

\section{Verband: $\square$ Verband}

\section{Alter:}

Geschlecht:

Arthrose:
Ges./Kr.: Gesund

\section{Maß}

Breite

Länge

Wert $\quad$ Einheit

$35,5 \quad \mathrm{~mm}$

$58,5 \mathrm{~mm}$

\section{Beschreibung:}

Dieses Fundstück ist stark erodiert, es sind 10\% der Gelenkflächen befundbar. 


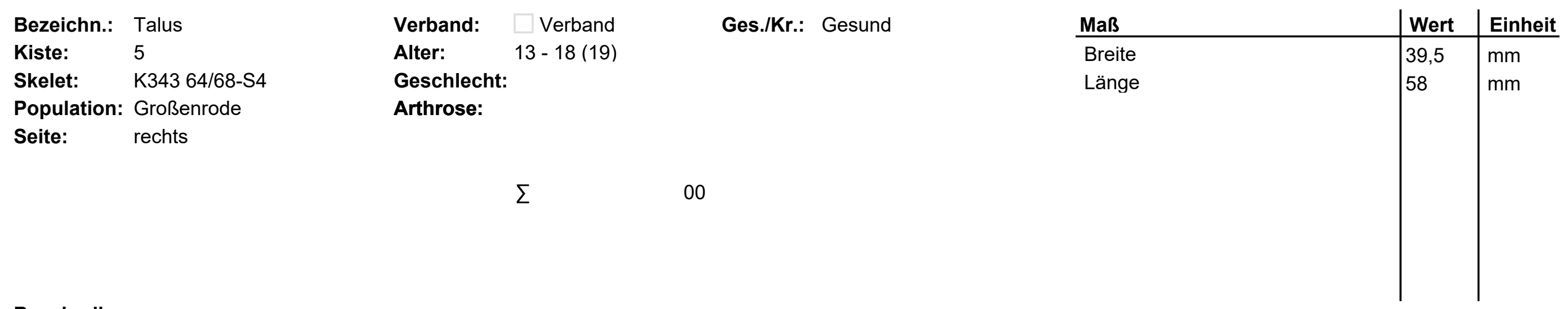

\section{Beschreibung:}

Ein noch recht kleiner Talus eines wohl juvenilen Individuums. Die Gelenkflächen sind zu $75 \%$ erhalten und sehen typisch für ein nicht ausgewachsenes Individuum aus. 


\section{Bezeichn.: Talus}

Kiste:

Skelet: 64/68-S4

Population: Großenrode

Seite:

links
Verband: $\quad$ Verband

Alter:

Geschlecht: $q>\lambda$

Arthrose:

\section{Beschreibung:}

Ein Fragment eines linken Talus, welches etwa 1/4 des gesamten Knochens ausmacht. Es ist etwa 1/4 der Gelenkflächen erhalten 


\section{Bezeichn.: Talus}

\section{Kiste:}

Skelet: 61/67-4

Population: Großenrode

Seite:

links
Verband: $\square$ Verband

Alter:

Geschlecht: $q<{ }^{\lambda}$

Arthrose:
Ges./Kr.: Gesund

\section{Maß}

Breite

Länge

\begin{tabular}{l|l|l} 
Wert & Einheit \\
\hline 41,73 & $\mathrm{~mm}$
\end{tabular}

\section{Beschreibung:}

Dieser Talus ist zu 95\% sehr gut erhalten. 


\section{Bezeichn.: Talus}

\section{Kiste:}

8

Skelet: $\quad$ K327 61/68 P4

Population: Großenrode
Verband: $\quad$ Verband

Alter:

Geschlecht: $q \leq \hat{\jmath}$

Arthrose:
Ges./Kr.: Gesund

\section{Maß}

Breite

Länge \begin{tabular}{|l|l} 
Wert & Einheit
\end{tabular}

$38,23 \mathrm{~mm}$

$51 \mathrm{~mm}$

\section{Beschreibung:}

Ein zu 95\% erhaltener Talus. 


\section{Bezeichn.: Talus}

\section{Kiste:}

Skelet: 61/68-4E

Population: Großenrode

Seite:

links

\section{Beschreibung:}

Ein zu 90\% gut erhaltener Talus.
Ges./Kr.: Gesund

\begin{tabular}{l|l|l} 
Maß & Wert & Einheit \\
\hline Breite & 41,5 & $\mathrm{~mm}$ \\
Länge & 50,24 & $\mathrm{~mm}$ \\
& & \\
& & \\
& &
\end{tabular}




\section{Bezeichn:: Calcaneus}

Kiste:

Skelet: K280

Population: Großenrode

Seite:
Verband: $\square$ Verband

Alter: Erwachsen

Geschlecht: $q \geq \gtrsim$

Arthrose:
Ges./Kr.: Gesund

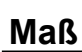

Breite

Länge

\begin{tabular}{|l|l} 
Wert & Einheit \\
\hline 44 & $\mathrm{~mm}$
\end{tabular}

prox. 2

dist. 2

2

$\Sigma$

\section{Beschreibung:}

Ein gut erhaltener Calcaneus der linken Seite, welcher grünlich gefärbt und nur leicht erodiert ist. Insgesamt sind etwa $85 \%$ erhalten. Etwa $65 \%$ der Gelenkflächen erhalten. 
Bezeichn.: Calcaneus

Kiste:

Skelet: K155 63/67-S2

Population: Großenrode

Seite:

links

\section{Ges./Kr.: Gesund}

Alter: $\quad 13-18$ (19)

Geschlecht:

Arthrose:
Maß

Breite

Länge \begin{tabular}{|l|l} 
Wert & Einheit \\
\hline 39 &
\end{tabular}

$39 \quad \mathrm{~mm}$

62,5

\section{Beschreibung:}

Ein zur Hälfte erhaltener Calcaneus der linken Seite, welcher einem juvenilen Individuum zuzuordnen ist. 
Bezeichn:: Calcaneus

\section{Kiste:}

Skelet: $\quad$ K67 63/67 S1

Population: Großenrode

Seite:

rechts
Verband: $\square$ Verband

Alter: $\quad 13-18(19)$

\section{Geschlecht:}

Arthrose:

\section{Beschreibung:}

Ein Fragment eines juvenilen rechten Calcaneus, es sind etwa 50\% erhalten. Das Fragment ist extrem erodiert. 
Bezeichn:: Calcaneus

Kiste: 6

Skelet: $\quad$ K276 63/66 S3

Population: Großenrode

Seite:
Verband: $\quad \square$ Verband

Alter: Erwachsen

Geschlecht: $q<\lambda$

Arthrose:
Ges./Kr.: Krank

Krankh.: Fersensporn

\begin{tabular}{l|l|l} 
Maß & Wert & Einheit \\
\hline Breite & 50 & $\mathrm{~mm}$ \\
Länge & 84 & $\mathrm{~mm}$ \\
& & \\
& &
\end{tabular}

\section{Beschreibung:}

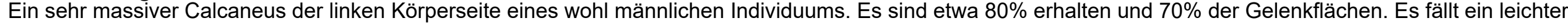
Fersensporn auf. 
Bezeichn:: Calcaneus

Kiste: 6

Skelet: $\quad$ K178 63/66 P3

Population: Großenrode

Seite:
Verband: $\quad \square$ Verband

Alter: Erwachsen

Geschlecht: $q<\lambda$

Arthrose:

$\begin{array}{ll}\text { prox. } & 2 \\ \text { dist. } & 2 \\ \Sigma & \end{array}$

2

$\Sigma$
Ges./Kr.: Krank

Krankh.: Fersensporn

\section{Maß}

Länge

Wert $\quad$ Einheit

\section{Beschreibung:}

Ein zu etwa $65 \%$ erhaltener Calcaneus. Gelenkflächen sind zu 50\% erhalten. Es fällt ein leicht ausgeprägter Fersensporn auf. 
Bezeichn.: Calcaneus

\section{Kiste:}

4

Skelet: $\quad$ K127 62/68 S2

Population: Großenrode

Seite:

Verband: $\quad$ Verband

Alter: Erwachsen

Geschlecht:

Arthrose:

\section{Beschreibung:}

Ein sehr stark erodierter Calcaneus. 
Bezeichn.: Calcaneus

Kiste:

\section{4}

Skelet: $\quad$ K43 62/68 S1 (P2)

Population: Großenrode

Seite:

rechts
Verband: $\square$ Verband

Alter: Erwachsen

Geschlecht:

Arthrose:

\section{Beschreibung:}

Ein Calcaneus aus einem Verband. 
Bezeichn.: Calcaneus

Kiste:

\section{4}

Skelet: $\quad$ K43 62/68 S1 (P2)

Population: Großenrode

Seite:

links
Verband: $\square$ Verband

Alter: Erwachsen

Geschlecht:

Arthrose:

\section{Beschreibung:}

Ein Calcaneus aus einem Verband. 
Bezeichn.: Calcaneus

Kiste: 4

Skelet: K54

Population: Großenrode

Seite:

rechts

\section{Verband:}

\section{Alter:}

Ges./Kr.: Gesund

Geschlecht:

Arthrose:

\section{Beschreibung:}

Es ist nur ein Fragment erhalten, welches etwa 60\% des gesamten Knochens ausmacht. Die Epiphysen sind nicht verknöchert, was für eine Zuordnung zu einem jungen Individuum spricht. 
Bezeichn.: Calcaneus

Kiste:

Skelet: $\quad 61 / 54$

Population: Großenrode

Seite:

rechts
Verband: $\quad$ Verband

Alter: Erwachsen

\section{Geschlecht:}

Arthrose:

$\begin{array}{ll}\text { prox. } & 2 \\ \text { dist. } & 2\end{array}$

\section{Beschreibung:}

Dieses Fragment eines rechten Calcaneus ist zwar erodiert, in der Form allerdings fast vollständig erhalten. Die Gelenkflächen sind vollständig. 
Bezeichn.: Calcaneus

\section{Kiste: 2}

Skelet: gesammelt

Population: Großenrode

Seite:

links
Verband: $\square$ Verband

Alter: Erwachsen

\section{Geschlecht:}

Arthrose:

$\begin{array}{ll}\text { prox. } & 1 \\ \text { dist. } & 1 \\ \sum & \end{array}$


Bezeichn.: Calcaneus

Kiste:

Skelet: $\quad 62 / 55$

Population: Großenrode

Seite:

rechts
Verband: $\square$ Verband

Alter: $\quad 13-18(19)$

Geschlecht:

Arthrose:

\section{Beschreibung:}

Ein Calcaneus eines wohl juvenilen Individuums, von den Gelenkflächen sind etwa $80 \%$ erhalten, wegen Erosion sind sie jedoch schwer befundbar, aber zeigen keine Auffälligkeiten. 
Bezeichn.: Calcaneus

\section{Kiste:}

Skelet: $\quad 61 / 58$

Population: Großenrode

Seite:

links
Verband: Verband

Alter: Erwachsen

\section{Geschlecht:}

Arthrose:

\section{Beschreibung:}

Ein erodierter Calcaneus, es ist etwa 1/7 proximal erhalten. 
Bezeichn.: Calcaneus

Kiste:

Skelet: $\quad 62 / 54$

Population: Großenrode

Seite:

rechts
Verband: $\quad$ Verband

Alter: Erwachsen

\section{Geschlecht:}

Arthrose:

$\begin{array}{ll}\text { prox. } & 2 \\ \text { dist. } & 2\end{array}$

\section{Beschreibung:}

Dieser Calcaneus ist erodiert, es sind Teile posterior und lateral abfrakturiert. Die Gelenkflächen sind zu etwa 60\% erhalten. Insgesamt sind etwa $2 / 3$ des gesamten Knochens vorhanden. 
Bezeichn.: Calcaneus

\section{Kiste: 2}

Skelet: kleine blaue Tüte aus

Population: Großenrode

Seite:
Verband: $\quad$ Verband

Alter: Erwachsen

Geschlecht:

Arthrose:

$\begin{array}{ll}\text { prox. } & 2 \\ \text { dist. } & 2\end{array}$

$\Sigma$

Ges./Kr.: Gesund

\section{Beschreibung:}

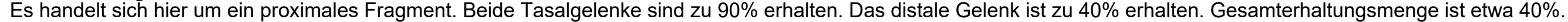


Bezeichn:: Calcaneus

Kiste:

Skelet: $\quad 61 / 57$

Population: Großenrode

Seite:

rechts
Verband:

\section{Alter:}

erband

Geschlecht:

Arthrose:

Ges./Kr.: Gesund

\section{Beschreibung:}

Ein kleines proximales Fragment mit etwa 1/4 Gesamt Gelenkflächen. 
Bezeichn.: Calcaneus

Kiste:

Skelet: $\quad 61 / 57$

Population: Großenrode

Seite:

links
Verband: Verband

Alter: Erwachsen

\section{Geschlecht:}

Arthrose:

\section{Beschreibung:}

Ein kleines proximales Fragment vom posterioren Teil. 
Bezeichn.: Calcaneus

Kiste:

Skelet: K253

Population: Großenrode

Seite:

links
Verband:

\section{Alter:}

Ges./Kr.: Gesund

Geschlecht:

Arthrose:

\section{Beschreibung:}

Hier sind etwa $60 \%$ eines jungen Calcaneus erhalten. 
Bezeichn:: Calcaneus

\section{Kiste:}

Skelet: K192 S3

Population: Großenrode

Seite:

Verband: $\quad$ Verband

\section{Alter:}

Geschlecht:

Arthrose:

\section{Beschreibung:}

Ein stark erodierter Calcaneus. 
Bezeichn.: Calcaneus

Kiste:

Skelet: $\quad 62 / 53$

Population: Großenrode

Seite:

links
Verband: Verband

Alter: Erwachsen

\section{Geschlecht:}

Arthrose:

\section{Beschreibung:}

Ein erodiertes Fragment, welches $75 \%$ des gesamten Knochens ausmacht. 
Bezeichn.: Calcaneus

\section{Kiste:}

Skelet: 62/53

Population: Großenrode

Seite:

Verband: Verband

Alter: Erwachsen

Geschlecht:

Arthrose:

\section{Beschreibung:}

$20 \%$ erhalten. 
Bezeichn.: Calcaneus

\section{Kiste:}

10

Skelet: $\quad 62 / 53$

Population: Großenrode

Seite:

links

Verband: Verband

Alter: Erwachsen

Geschlecht:

Arthrose:

\section{Beschreibung:}

$40 \%$ erodiert und frakturiert. 
Bezeichn.: Calcaneus

\section{Kiste:}

10

Skelet: $\quad$ Tüte nur mit 62/51

Population: Großenrode

Seite:
Verband: $\square$ Verband

Alter: Erwachsen

Geschlecht: $+\leq{ }^{\lambda}$

Arthrose:

Ges./Kr.: Gesund

\section{Beschreibung:}

$30 \%$ erhalten. 
Bezeichn.: Calcaneus

Kiste:

Skelet: 63/54

Population: Großenrode

Seite:

rechts
Verband: Verband

\section{Alter:}

Geschlecht:

Arthrose:

\section{Beschreibung:}

Ein gespaltenes Fragment, es sind $65 \%$ erodiert erhalten. 
Bezeichn:: Calcaneus

Kiste:

Skelet: K124

Population: Großenrode

Seite:

links
Verband:

Verband

\section{Alter:}

Geschlecht:

Arthrose:

\section{Beschreibung:}

Es ist ein stark erodiertes und frakturiertes Fragment. 
Bezeichn.: Calcaneus

\section{Kiste:}

Skelet: K46

Population: Großenrode

Seite:

Verband: Verband

\section{Alter:}

Geschlecht:

Arthrose:

\section{Beschreibung:}

Ein Fragment. 
Bezeichn.: Calcaneus

Kiste:

Skelet: K81

Population: Großenrode

Seite:

links
Verband: $\square$ Verband

\section{Alter: Jung}

Geschlecht:

Arthrose:

\section{Beschreibung:}

Ein sehr stark erodiertes Fragment eines Calcaneus der linken Seite. Es handelt sich um einen nicht weiter befundbaren, jungen Knochen. 
Bezeichn.: Calcaneus

Kiste:

Verband:

\section{Alter:}

Ges./Kr.: Gesund

Skelet: K233

Population: Großenrode

Seite:

links

Geschlecht:

Arthrose:

\section{Beschreibung:}

Ein Fragment. 
Bezeichn.: Calcaneus

\section{Kiste:}

Skelet: K239

Population: Großenrode

Seite:
Verband:

Verband

\section{Alter:}

Geschlecht:

Arthrose:

\section{Beschreibung:}

Ein schlecht erhaltenes Fragment. 
Bezeichn.: Calcaneus

Kiste:

Skelet: $\quad$ K78 63/68-P2

Population: Großenrode

Seite:
Verband: $\square$ Verband

Alter: Erwachsen

Geschlecht:

Arthrose:

\section{Ges./Kr.: Gesund}

prox. 2

\section{Beschreibung:}

Es handelt sich hier um einen Teil eines rechten Calcaneus aus einem Verband. 
Bezeichn.: Calcaneus

Kiste:

Skelet: K243

Population: Großenrode

Seite:
Verband:

\section{Alter:}

Verband

Erwachsen

Geschlecht:

Arthrose:

\section{Ges./Kr.: Gesund}

prox

dist.

\section{Beschreibung:}

Dies ist ein rechter Calcaneus aus einem Verband. 
Bezeichn.: Calcaneus

Kiste:

Skelet: K243

Population: Großenrode

Seite:
Verband:

Verband

\section{Alter:}

Geschlecht:

Arthrose:

\section{Beschreibung:}

Ein Fragment. 
Bezeichn.: Calcaneus

\section{Kiste:}

Skelet: K282

Population: Großenrode

Seite:
Verband:

Verband

\section{Alter:}

Geschlecht:

Arthrose:

\section{Ges./Kr.: Gesund}

\section{Beschreibung:}

Hier ist ein Fragment eines linken Calcaneus aus einem Verband erhalten. 
Bezeichn:: Calcaneus

Kiste: $\quad 5$

Skelet: $\quad$ K364 61/69 S4

Population: Großenrode

Seite:

links
Verband: $\quad$ Verband

\section{Alter: Erwachsen}

\section{Geschlecht:}

Arthrose:

\section{Beschreibung:}

Es ist nur ein proximales Fragment erhalten, welches sehr stark erodiert ist und kein Befundung zulässt. es sind etwa $20 \%$ des Calcaneus erhalten. 
Bezeichn.: Calcaneus

Kiste:

5

Skelet: $\quad$ K144 61/69 P3

Population: Großenrode

Seite:
Verband: $\quad$ Verband

Alter: Erwachsen

Geschlecht: $q<\widehat{ }$

Arthrose:

$\Sigma$

\begin{tabular}{l|l|l} 
Maß & Wert & Einheit \\
\hline Breite & 44,5 & $\mathrm{~mm}$ \\
Länge & 74,5 & $\mathrm{~mm}$ \\
& & \\
& & \\
& &
\end{tabular}

\section{Beschreibung:}

Hier ist etwa 2/3 erhalten, die Gelenkflächen zu 50\%.

\section{Ges./Kr.: Gesund}

2 
Bezeichn:: Calcaneus

Kiste:

Skelet: $\quad$ K328 61/68 P4

Population: Großenrode

Seite:
Verband: $\square$ Verband

Alter:

Geschlecht: $ð$

Arthrose:
Ges./Kr.: Gesund

Maß

Breite

Länge

\begin{tabular}{|l|l} 
Wert & Einheit \\
\hline 40 &
\end{tabular}

prox.

\section{Beschreibung:}

Ein zu 92\% erhaltener Calcaneus. Der Erhaltungszustand ist ausgesprochen gut. 
Bezeichn.: Calcaneus

Kiste:

Skelet: $\quad$ K348 61/68 S4

Population: Großenrode

Seite:
Verband:

\section{Alter:}

Ges./Kr.: Gesund

Geschlecht:

Arthrose:

dist. 00

$\Sigma$

\section{Beschreibung:}

Ein fragmentierter Calcaneus der linken Seite. Der Knochen ist einem jungen Individuum zuzuordnen, es sind etwa $50 \%$ erhalten. 
Bezeichn.: Os Cuboideum

\section{Kiste:}

Skelet: $\quad$ K276 63/66 S3

Population: Großenrode

Seite:

links
Verband: $\square$ Verband

\section{Alter:}

Geschlecht: $q<\lambda$

Arthrose:

\section{Beschreibung:}

Ein erodiertes Fundstück. 
Bezeichn.: Os Cuboideum

\section{Kiste:}

Skelet: K 241

Population: Großenrode

Seite:

links
Ges./Kr.: Gesund

\section{Alter:}

Geschlecht:

Arthrose:

\section{Beschreibung:}


Bezeichn:: Os Naviculare

\section{Kiste:}

Skelet: $\quad$ K276 63/66 S3

Population: Großenrode

Seite:

\section{Verband:}

Verband

\section{Alter:}

Geschlecht: $q<\widehat{\jmath}$

Arthrose:

\section{Beschreibung:}

Ein Os naviculare der linken Seite. Es ist etwas erodiert. 
Bezeichn.: Os Metatarsale

Kiste:

Skelet: Fuß K245

Population: Großenrode

Seite:

n. def.

\section{Verband: $\quad$ Verband}

Alter: Jung

Geschlecht:

Arthrose:

\section{Beschreibung:}

Ein Os metatarsale 1 eines jungen Individuums, die Seite ist nicht endgültig zu bestimmen. 
Bezeichn:: Os Metatarsale

\section{Kiste:}

Skelet: $\quad$ K179 63/66 P3

Population: Großenrode

Seite:

\section{Verband:}

Verband

\section{Alter:}

Geschlecht:

Arthrose:
Ges./Kr.: Krank

Krankh.: Arthrose

Arthritis

\begin{tabular}{l|l|l} 
Maß & Wert & Einheit \\
\hline Länge & 61,81 & $\mathrm{~mm}$ \\
& & \\
& &
\end{tabular}

\section{Beschreibung:}

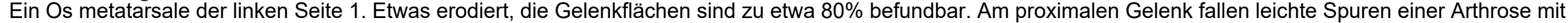
Übergang zu einer Arthritis auf. 
Bezeichn.: Os Metatarsale

\section{Kiste:}

Skelet: K42 62/68 S1

Population: Großenrode
Verband: Verband

\section{Alter:}

\section{Geschlecht:}

Arthrose:

\section{Beschreibung:}

Nur proximales Drittel in fragmentierter und stark erodierter Form erhalten. 
Bezeichn.: Os Metatarsale

\section{Kiste:}

Skelet: $\quad$ K43 62/68 S1 (P2)

Population: Großenrode

Seite:

rechts

Verband: $\quad$ Verband

Alter:

Geschlecht:

Arthrose:

\section{Beschreibung:}


Bezeichn.: Os Metatarsale

Kiste:

Skelet: $\quad$ K43 62/68 S1 (P2)

Population: Großenrode

Seite:

rechts

Verband: $\quad$ Verband

Alter:

Geschlecht:

Arthrose:

\section{Beschreibung:}

2. 
Bezeichn.: Os Metatarsale

\section{Kiste:}

Skelet: $\quad$ K43 62/68 S1 (P2)

Population: Großenrode

Seite:

rechts

Verband: $\quad$ Verband

Alter:

Geschlecht:

Arthrose:

\section{Beschreibung:}

3 . 
Bezeichn.: Os Metatarsale

Kiste:

Skelet: $\quad$ K43 62/68 S1 (P2)

Population: Großenrode

Seite:

rechts

Verband: $\quad$ Verband

\section{Alter:}

Geschlecht:

Arthrose:

\section{Beschreibung:}


Bezeichn.: Os Metatarsale

Kiste:

Skelet: $\quad$ K43 62/68 S1 (P2)

Population: Großenrode

Seite:

rechts

Verband: $\quad$ Verband

\section{Alter:}

Geschlecht:

Arthrose:

\section{Beschreibung:}


Bezeichn.: Os Metatarsale

Kiste:

Skelet: $\quad$ K43 62/68 S1 (P2)

Population: Großenrode

Seite:

links

Verband: Verband

Alter:

Geschlecht:

Arthrose:

\section{Beschreibung:}


Bezeichn.: Os Metatarsale

Kiste:

Skelet: $\quad$ K43 62/68 S1 (P2)

Population: Großenrode

Seite:

links

Verband: $\quad$ Verband

Alter:

Geschlecht:

Arthrose:

\section{Beschreibung:}


Bezeichn.: Os Metatarsale

Kiste:

Skelet: $\quad$ K43 62/68 S1 (P2)

Population: Großenrode

Seite:

links

Verband: $\quad$ Verband

Alter:

Geschlecht:

Arthrose:

\section{Beschreibung:}


Bezeichn:: Os Metatarsale

\section{Kiste:}

Skelet: $\quad 63 / 52$

Population: Großenrode

Seite:

rechts
Verband: Verband

\section{Alter:}

Geschlecht:

Arthrose:

\section{Beschreibung:}

Ein Os metatarsale 1 der rechten Seite. Es ist zu 90\% erhalten und leicht erodiert. 
Bezeichn.: Os Metatarsale

\section{Kiste:}

Skelet: $\quad 62 / 57$

Population: Großenrode

Seite:

rechts
Verband: Verband

\section{Alter:}

Geschlecht:

Arthrose:

\section{Beschreibung:}

Ein Os metatarsale 1 der rechten Seite, welches stark erodiert ist. 
Bezeichn.: Os Metatarsale

\section{Kiste:}

Skelet: K51

Population: Großenrode

Seite:

rechts
Verband: Verband

\section{Alter:}

Geschlecht:

Arthrose:

\section{Beschreibung:}


Bezeichn.: Os Metatarsale

\section{Kiste:}

Skelet: Fragment K186

Population: Großenrode

Seite:

Verband: $\quad$ Verband

\section{Alter:}

Geschlecht:

Arthrose:

\section{Beschreibung:}

Ein Os metatarsale 1 der rechten Seite. 
Bezeichn.: Os Metatarsale

\section{Kiste:}

Skelet: $\quad$ K359 61/69 S4

Population: Großenrode

Seite:
Verband:

Verband

\section{Alter:}

Geschlecht: $q \leq \curvearrowright$

Arthrose:

prox.

dist.

\section{Beschreibung:}

Ein sehr gut erhaltenes Os metatarsale 1 der linken Seite. 
Bezeichn.: Os Metatarsale

\section{Kiste:}

Skelet: $\quad 61 / 67-4$

Population: Großenrode

Seite:
Alter: Jung

Geschlecht:

Arthrose:

Ges./Kr.: Gesund

prox

\section{Beschreibung:}

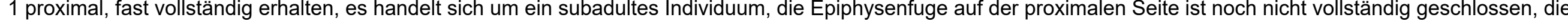
distale ist nicht erhalten. 
Bezeichn.: Os Metatarsale

\section{Kiste:}

Skelet: $\quad$ K324 61/68 P4

Population: Großenrode

Seite:

links

\section{Verband:}

Verband

Ges./Kr.: Gesund

\section{Alter:}

Geschlecht:

Arthrose:

\section{Beschreibung:}

Linke Seite 1, ist in sehr stark erodierten Zustand, es fallen keine Auffälligkeiten auf. Die Gelenkflächen sind zu 50\% befundbar. 
Bezeichn.: Knochenklein

Kiste:

Skelet: $\quad$ K196 60/64 P4

Population: Großenrode

\section{Verband:}

Verband

\section{Alter:}

\section{Geschlecht:}

Arthrose:

\section{Beschreibung:}

90g Rippenfragmente eines oder mehrerer Brustkörbe. Die Fragmente zeigten keine Auffälligkeiten soweit befundbar. 
Bezeichn.: Knochenklein

\section{Kiste:}

Skelet: $\quad$ K315 62/63 P4

Population: Großenrode
Verband:

Alter:

Geschlecht:

Arthrose:

\section{Beschreibung:}

30g Knochensplitter von Langknochen. 
Bezeichn.: Knochenklein

\section{Kiste: $\quad 5$}

Skelet: Streufunde aus allen

Population: Großenrode
Verband: $\quad$ Verband

\section{Alter:}

Geschlecht:

Arthrose:

\section{Beschreibung:}

69 Knochensplitter von Wirbel, Hand, Fuß, Becken und Langknochen. 
Bezeichn.: Knochenklein

Kiste:

Skelet: $\quad 61 / 67-1$

Population: Großenrode
Verband: Verband

\section{Alter:}

Geschlecht:

Arthrose:

\section{Beschreibung:}

11g Knochensplitter von einem oder mehreren Schädeln. 
Bezeichn.: Knochenklein

Kiste:

Skelet: $\quad 63 / 67-4$

Population: Großenrode
Verband:

Verband

\section{Alter:}

Geschlecht:

Arthrose:

\section{Beschreibung:}

44g Knochensplitter von Femur, Clavicula, Fuß, Scapula, Costa, und weitere Splitter. 
Bezeichn.: Knochenklein

Kiste:

Skelet: mehrere

Population: Großenrode
Verband: Verband

\section{Alter:}

Geschlecht:

Arthrose:

\section{Beschreibung:}

$500 \mathrm{~g}$ Splitter von Hand, Fuß, Rippen, Wirbel, Langknochen obere und untere Extremität. 
Bezeichn.: Knochenklein

Kiste: 9

Skelet: $\quad$ K280 63/67 P3

Population: Großenrode
Verband:

\section{Alter:}

Ges./Kr.: Gesund

Geschlecht:

Arthrose:

\section{Beschreibung:}

$20 \mathrm{~g}$ Knochensplitter von Wirbeln. 
Bezeichn.: Knochenklein

\section{Kiste:}

Skelet: $\quad 63 / 67-3$

Population: Großenrode
Verband: Verband

\section{Alter:}

Geschlecht:

Arthrose:

\section{Beschreibung:}

Hier sind einzelne Knochensplitter eines Schädels erhalten. 
Bezeichn.: Knochenklein

Kiste:

Skelet: $\quad 63 / 67-3$

Population: Großenrode
Verband: Verband

\section{Alter:}

Geschlecht:

Arthrose:

\section{Beschreibung:}

90g Knochensplitter von Hand, Fuß, Rippen, Wirbel und Langknochen. 
Bezeichn.: Knochenklein Kiste:

Skelet: K155 63/67 S2

Population: Großenrode
Verband: Verband

\section{Alter:}

Geschlecht:

Arthrose:

\section{Beschreibung:}

42g Knochensplitter von Wirbeln, Rippen, Hand, Fuß und anderen. 
Bezeichn.: Knochenklein

Kiste:

7

Skelet: $\quad$ K256 60/64 S3 P4

Population: Großenrode
Verband: Verband

\section{Alter:}

Geschlecht:

Arthrose:

\section{Beschreibung:}

Hier sind nur kleinste Splitter von einem Schädel erhalten. 
Bezeichn.: Knochenklein Kiste:

Skelet: $\quad$ K67 63/67 S1

Population: Großenrode
Verband: Verband

\section{Alter:}

Geschlecht:

Arthrose:

\section{Beschreibung:}

$33 \mathrm{~g}$ Knochensplitter von Langknochen, Rippen und Wirbel. 
Bezeichn.: Knochenklein

Kiste:

Skelet: $\quad$ K116/288 63/65 S2-S3

Population: Großenrode
Verband: Verband

\section{Alter:}

Geschlecht:

Arthrose:

\section{Beschreibung:}

30g Knochensplitter von Rippen, Wirbeln und Langknochen. 
Bezeichn.: Knochenklein

Kiste:

Skelet: mehrere

Population: Großenrode
Verband: Verband

\section{Alter:}

Geschlecht:

Arthrose:

\section{Beschreibung:}

53g Knochensplitter von Langknochen oberer Extremität und unterer Extremität, Rippen und andere kleine Splitter. 
Bezeichn.: Knochenklein

Kiste:

Skelet: $\quad$ K315 62/63 P4

Population: Großenrode
Verband: Verband

\section{Alter:}

Geschlecht:

Arthrose:

\section{Beschreibung:}

77g Knochensplitter von Wirbeln, Rippen und Langknochen. 
Bezeichn.: Knochenklein

Kiste:

Skelet: mehrere

Population: Großenrode
Verband: Verband

\section{Alter:}

Geschlecht:

Arthrose:

\section{Beschreibung:}

Knochensplitter von Wirbel, Fuß und Rippen 
Bezeichn.: Knochenklein

Kiste:

Skelet: $\quad$ K323 62/63 S4

Population: Großenrode
Verband: Verband

\section{Alter:}

Geschlecht:

Arthrose:

\section{Beschreibung:}

Knochensplitter von Langknochen. 
Bezeichn.: Knochenklein

Kiste:

Skelet: mehrere

Population: Großenrode

\section{Verband:}

Verband

\section{Alter:}

Geschlecht:

Arthrose:

\section{Beschreibung:}

96g Knochensplitter von Rippen, Wirbeln, Langknochen der oberen Extremität und Handknochen. 
Bezeichn.: Knochenklein

Kiste:

Skelet: $\quad$ K267 60/64 S3

Population: Großenrode
Verband: Verband

\section{Alter:}

Geschlecht:

Arthrose:

\section{Beschreibung:}

Mehrere Splitter von Knochen, die nicht genauer zu bestimmen sind. 
Bezeichn.: Knochenklein

Kiste:

Skelet: $\quad$ K256 60/64 P4/S3

Population: Großenrode
Verband: Verband

\section{Alter:}

Geschlecht:

Arthrose:

\section{Beschreibung:}

$35 \mathrm{~g}$ Knochensplitter von Rippen, Wirbeln und anderen. 
Bezeichn.: Knochenklein

Kiste:

Skelet: $\quad$ K254 60/64 S3

Population: Großenrode
Verband: Verband

\section{Alter:}

\section{Geschlecht:}

Arthrose:

\section{Beschreibung:}

Hier sind 18g Knochensplitter von Rippen und Wirbeln erhalten. 
Bezeichn.: Knochenklein

Kiste:

Skelet: $\quad$ K3.345 63/66 Prof51 S4

Population: Großenrode
Verband: Verband

\section{Alter:}

Geschlecht:

Arthrose:

\section{Beschreibung:}

Knochensplitter, einer davon Mittelhand oder Mittelfuß. 
Bezeichn.: Knochenklein

Kiste:

Skelet: $\quad$ K276 63/66 S3

Population: Großenrode
Verband: Verband

\section{Alter:}

Geschlecht:

Arthrose:

\section{Beschreibung:}

Knochensplitter von Langknochen und anderen nicht zuzuordnende. 
Bezeichn.: Knochenklein

Kiste:

Skelet: $\quad$ K179 63/66 P3

Population: Großenrode
Verband: Verband

\section{Alter:}

Geschlecht:

Arthrose:

\section{Beschreibung:}

13g Fußknochensplitter. 
Bezeichn.: Knochenklein

Kiste:

Skelet: 63/66-4

Population: Großenrode
Verband: Verband

\section{Alter:}

Geschlecht:

Arthrose:

\section{Beschreibung:}

26g Fußknochen, mindestens 6 . 
Bezeichn.: Knochenklein

Kiste:

Skelet: 63/66-3

Population: Großenrode
Verband: Verband

\section{Alter:}

Geschlecht:

Arthrose:

\section{Beschreibung:}

Knochensplitter, die nicht zuzuordnen sind. 
Bezeichn.: Knochenklein

Kiste:

Skelet: mehrere

Population: Großenrode

\section{Verband:}

Verband

\section{Alter:}

Geschlecht:

Arthrose:

\section{Beschreibung:}

90g Knochenfragmente von Fuß, Schädel, Wirbel, Hand, Becken und Rippen. 
Bezeichn.: Knochenklein

Kiste:

Skelet: K262 60/64

Population: Großenrode
Verband: $\quad$ Verband

Alter: $\quad 13-18(19)$

Geschlecht:

Arthrose:

\section{Beschreibung:}

Hier sind zu den Wirbeln des juvenilen Individuums noch Knochensplitter weiterer Wirbel erhalten. 
Bezeichn.: Knochenklein

Kiste:

Skelet: mehrere

Population: Großenrode
Verband: Verband

\section{Alter:}

Geschlecht:

Arthrose:

\section{Beschreibung:}

$56 \mathrm{~g}$ Knochensplitter von Langknochen oberer und unterer Extremitäten, Hand, Fuß und Rippen. 
Bezeichn.: Knochenklein

Kiste:

Skelet: 60/64-4

Population: Großenrode
Verband: Verband

\section{Alter:}

Geschlecht:

Arthrose:

\section{Beschreibung:}

Knochensplitte von Langknochen. 
Bezeichn.: Knochenklein

Kiste:

Skelet: $\quad 60 / 64$

Population: Großenrode
Verband: Verband

\section{Alter:}

Geschlecht:

Arthrose:

\section{Beschreibung:}

Knochensplitter von Wirbel und Rippe. 
Bezeichn.: Knochenklein

Kiste:

6

Skelet: $\quad$ K113 60/64 S2

Population: Großenrode
Verband:

\section{Alter:}

Ges./Kr.: Gesund

Geschlecht:

Arthrose:

\section{Beschreibung:}

Knochensplitter aus dem Verband des jungen Individuums. 
Bezeichn.: Knochenklein

Kiste:

Skelet: 63/65-4

Population: Großenrode
Verband: Verband

\section{Alter:}

Geschlecht:

Arthrose:

\section{Beschreibung:}

46g Knochensplitter von Wirbel, obere Extremität, Langknochen und Clavicula. 
Bezeichn.: Knochenklein

Kiste:

Skelet: $\quad$ K196 60/64 P4

Population: Großenrode
Verband: Verband

\section{Alter:}

Geschlecht:

Arthrose:

\section{Beschreibung:}

Kleine Fragmente von Scapula, Vertebra und andere. 
Bezeichn.: Knochenklein

Kiste:

Skelet: 4

$62 / 68$

Population: Großenrode
Verband: Verband

\section{Alter:}

Geschlecht:

Arthrose:

\section{Beschreibung:}

Knochensplitter Rippe, Hand, Schädel. 
Bezeichn.: Knochenklein Kiste:

Skelet: $\quad$ K62 62/68 P2

Population: Großenrode
Verband: Verband

\section{Alter:}

\section{Geschlecht:}

Arthrose:

\section{Beschreibung:}

Mehrere Splitter von Femur und andere Langknochen. Es handelt sich um 16g. 
Bezeichn.: Knochenklein

\section{Kiste:}

Skelet: $\quad 62 / 68$

Population: Großenrode
Verband:

Verband

\section{Alter:}

Geschlecht:

Arthrose:

Beschreibung:

$18 \mathrm{~g}$ Splitter von Schädeln 
Bezeichn.: Knochenklein Kiste:

Skelet: $\quad$ K74 62/68 P2

Population: Großenrode
Verband: Verband

\section{Alter:}

\section{Geschlecht:}

Arthrose:

\section{Beschreibung:}

Hier sind kleinste Knochensplitter erhalten. Sie sind nicht bestimmbar. 
Bezeichn.: Knochenklein

\section{Kiste:}

Skelet: $\quad 62 / 68-3$

Population: Großenrode
Verband: Verband

\section{Alter:}

Geschlecht:

Arthrose:

\section{Beschreibung:}

2 Knochensplitter, die nicht zuzuordnen sind. 
Bezeichn.: Knochenklein

\section{Kiste:}

Skelet: 6

Population: Großenrode
Verband: Verband

\section{Alter:}

Geschlecht:

Arthrose:

\section{Beschreibung:}

$45 \mathrm{~g}$ Knochensplitter von Femur, andere Langknochen und weitere unkenntliche Splitter. 
Bezeichn.: Knochenklein

Kiste:

Skelet: K203 62/65 S3

Population: Großenrode
Verband: Verband

\section{Alter:}

\section{Geschlecht:}

Arthrose:

\section{Beschreibung:}

Dies sind 30g Knochensplitter von Femur, oberer Extremität und anderen nicht zuzuordnenden. 
Bezeichn.: Knochenklein

\section{Kiste:}

Skelet: 62/65-4

Population: Großenrode
Verband: Verband

\section{Alter:}

Geschlecht:

Arthrose:

\section{Beschreibung:}

81g Knochensplitter von unterer Extremität, Langknochen und sehr kleinen Fragmenten. 
Bezeichn.: Knochenklein

Kiste:

Skelet: 62/65-2

Population: Großenrode
Verband: Verband

\section{Alter:}

Geschlecht:

Arthrose:

\section{Beschreibung:}

Kleine Knochensplitter. 
Bezeichn.: Knochenklein

Kiste:

Skelet: $\quad 62 / 65-3$

Population: Großenrode
Verband: Verband

Alter:

Geschlecht:

Arthrose:

\section{Beschreibung:}

$26 \mathrm{~g}$ Knochensplitter von unterer Extremität. 
Bezeichn.: Knochenklein

Kiste:

Skelet: 62/61-3

Population: Großenrode
Verband: Verband

\section{Alter:}

Geschlecht:

Arthrose:

\section{Beschreibung:}

Ein nicht befundbarer Knochensplitter, der nicht zugeordnet werden kann. 
Bezeichn.: Knochenklein

Kiste:

Skelet: $\quad$ 64/65-4 63/61-3

Population: Großenrode
Verband: Verband

\section{Alter:}

Geschlecht:

Arthrose:

\section{Beschreibung:}

Knochensplitter von Costa, obere Extremität, und andere Splitter. 
Bezeichn.: Knochenklein Kiste:

Skelet: $\quad$ K72 62/68 P2

Population: Großenrode
Verband: Verband

\section{Alter:}

Geschlecht:

Arthrose:

\section{Beschreibung:}

Knochenfragmente von Wirbeln. 
Bezeichn.: Knochenklein Kiste: 4

Skelet: $\quad$ K71 62/68 P2

Population: Großenrode
Verband: Verband

\section{Alter:}

Geschlecht:

Arthrose:

\section{Beschreibung:}

Knochensplitter untere Extremität. 
Bezeichn.: Knochenklein Kiste:

Skelet: $\quad$ K70 62/68 P2

Population: Großenrode
Verband: Verband

\section{Alter:}

Geschlecht:

Arthrose:

\section{Beschreibung:}

Knochensplitter von Langknochen. 
Bezeichn.: Knochenklein

Kiste:

Skelet: $\quad$ K136 62/68 P2

Population: Großenrode
Verband: Verband

\section{Alter:}

\section{Geschlecht:}

Arthrose:

\section{Beschreibung:}

$12 \mathrm{~g} \mathrm{Knochensplitter} \mathrm{von} \mathrm{Langknochen,} \mathrm{teilweise} \mathrm{aber} \mathrm{nicht} \mathrm{weiter} \mathrm{erkennbar.}$ 
Bezeichn.: Knochenklein Kiste:

Skelet: $\quad$ K73 62/68 P2

Population: Großenrode
Verband: Verband

\section{Alter:}

Geschlecht:

Arthrose:

\section{Beschreibung:}

85g Knochensplitter von unterer Extremität, Os sacrum und Becken. 
Bezeichn.: Knochenklein

Kiste:

Skelet: $\quad$ K125 62/68 S2

Population: Großenrode
Verband: Verband

\section{Alter:}

\section{Geschlecht:}

Arthrose:

\section{Beschreibung:}

Knochensplitter von Costa, Wirbel und Langknochen. Das kleine Rippenfragment weist Bissspuren auf. 
Bezeichn.: Knochenklein

Kiste:

Skelet: $\quad$ K140 62/68 S2

Population: Großenrode
Verband: Verband

\section{Alter:}

Geschlecht:

Arthrose:

\section{Beschreibung:}

Es handelt sich um Fragmente von Vertebra. 11g Knochenklein. 
Bezeichn.: Knochenklein Kiste:

Skelet: $\quad$ K19 62/68 S0

Population: Großenrode
Verband: Verband

\section{Alter:}

Geschlecht:

Arthrose:

\section{Beschreibung:}

Ein Splitter eines Langknochens. 
Bezeichn.: Knochenklein Kiste:

Skelet: $\quad$ K38 62/68 S1

Population: Großenrode
Verband: Verband

\section{Alter:}

Geschlecht:

Arthrose:

\section{Beschreibung:}

Ein Fragment eines Langknochens. 
Bezeichn.: Knochenklein Kiste:

Skelet: K138

Population: Großenrode
Verband: Verband

\section{Alter:}

Geschlecht:

Arthrose:

\section{Beschreibung:}

Knochensplitter. 
Bezeichn.: Knochenklein

Kiste:

Skelet: $\quad \mathrm{K} 54$

Population: Großenrode
Verband: $\square$ Verband

Alter: Jung

Geschlecht:

Arthrose:

\section{Beschreibung:}

74g Knochenklein, teilweise von einem jungen Individuum. Es sind Splittre von Vertebra, Os sacrum und Langknochen enthalten. 
Bezeichn.: Knochenklein

Kiste:

Skelet: 62/68-1

Population: Großenrode
Verband:

Alter:

Geschlecht:

Arthrose:

\section{Beschreibung:}

$20 \mathrm{~g}$ Splitter von Langknochen und Hand- und Fußknochen. 
Bezeichn.: Knochenklein

Kiste:

4

Skelet: $\quad 62 / 68$ K139 S2

Population: Großenrode
Verband:

\section{Alter:}

Ges./Kr.: Gesund

Geschlecht:

Arthrose:

\section{Beschreibung:}

11g Splitter von Fußknochen und Vertebra von jungem Individuum. 
Bezeichn.: Knochenklein Kiste: 4

Skelet: $\quad$ K38 62/68 S1

Population: Großenrode
Verband:

Verband

Alter:

Geschlecht:

Arthrose:

Beschreibung:

$20 \mathrm{~g}$ Knochensplitter. 
Bezeichn.: Knochenklein Kiste: 4

Skelet: $\quad$ K38 62/68 S1

Population: Großenrode
Verband:

Verband

Alter:

Geschlecht:

Arthrose:

\section{Beschreibung:}

Rippensplitter. 
Bezeichn.: Knochenklein

Kiste:

Skelet: $\quad$ K38 62/68 S1

Population: Großenrode

\section{Verband:}

Verband

\section{Alter:}

Geschlecht:

Arthrose:

\section{Beschreibung:}

Knochensplitter von Rippe, Langknochen, Os phalangis Hand und/oder Fuß. 
Bezeichn.: Knochenklein

Kiste:

Skelet: $\quad$ K76 62/68 P2

Population: Großenrode
Verband: $\square$ Verband

\section{Alter:}

Geschlecht:

Arthrose:

\section{Beschreibung:}

Hier handelt es sich um 43g Knochensplitter von Becken, Gelenkkopf und Fibula. 
Bezeichn.: Knochenklein

Kiste:

Skelet: $\quad$ K76 62/68 P2

Population: Großenrode
Verband:

Verband

Alter:

Geschlecht:

Arthrose:

\section{Beschreibung:}

46g Knochensplitter von Becken und Langknochen. 
Bezeichn.: Knochenklein

Kiste:

Skelet:

4

Population: Großenrode
Verband:

Verband

\section{Alter:}

Geschlecht:

Arthrose:
Ges./Kr.: Gesund

\section{Beschreibung:}

Rippensplitter. 
Bezeichn.: Knochenklein

Kiste:

Skelet: $\quad 62 / 68-2$

Population: Großenrode
Verband:

Verband

\section{Alter:}

Geschlecht:

Arthrose:

\section{Beschreibung:}

40g Knochensplitter von Rippen, Fuß/Hand und Langknochen. 
Bezeichn.: Knochenklein

\section{Kiste:}

Skelet: $\quad 62 / 68$ S1 K54

Population: Großenrode
Verband:

Verband

\section{Alter:}

Geschlecht:

Arthrose:

\section{Beschreibung:}

Knochensplitter von oberen Extremitäten. 
Bezeichn.: Knochenklein

Kiste:

Skelet: 61/54

Population: Großenrode

\section{Verband:}

Verband

\section{Alter:}

Geschlecht:

Arthrose:

\section{Beschreibung:}

57g Wirbel, Rippen, Hand, und Langknochen der oberen Extremität. 
Bezeichn.: Knochenklein

Kiste:

Skelet: $\quad 61 / 54$

Population: Großenrode
Verband:

Verband

\section{Alter:}

Geschlecht:

Arthrose:

106g Becken, Langknochen, Fuß. 
Bezeichn.: Knochenklein

Kiste: 2

Skelet: $\quad 65 / 53$

Population: Großenrode
Verband:

Verband

\section{Alter:}

Geschlecht:

Arthrose:

\section{Beschreibung:}

48g Knochensplitter von Cranium, Langknochen und Fuß. 
Bezeichn.: Knochenklein

Kiste:

Skelet: $\quad 65 / 54$

Population: Großenrode
Verband:

\section{Alter:}

Geschlecht:

Arthrose:

\section{Beschreibung:}

45g Knochensplitter von Cranium und Langknochen. 
Bezeichn.: Knochenklein

Kiste: 2

Skelet: $\quad 64 / 54$

Population: Großenrode
Verband:

Verband

\section{Alter:}

Geschlecht:

Arthrose:

\section{Beschreibung:}

$65 \mathrm{~g}$ Rippen, Langknochen, Cranium und Wirbel 
Bezeichn.: Knochenklein

Kiste:

Skelet: $\quad 63 / 58$

Population: Großenrode
Verband:

Alter:

Geschlecht:

Arthrose:

\section{Beschreibung:}

$34 \mathrm{~g}$ von Hand- / Fußknochen und Langknochen. 
Bezeichn.: Knochenklein

Kiste: 2

Skelet: $\quad 65 / 57$

Population: Großenrode
Verband:

\section{Alter:}

Geschlecht:

Arthrose:

\section{Beschreibung:}

15g Knochensplitter von Cranium und Femur. 
Bezeichn.: Knochenklein

Kiste:

Skelet: $\quad 61 / 56$

Population: Großenrode

\section{Verband:}

Verband

\section{Alter:}

Geschlecht:

Arthrose:

\section{Beschreibung:}

96g Knochensplitter von Hand- / Fußknochen, Cranium, Rippen und Langknochen. 
Bezeichn.: Knochenklein

Kiste:

Skelet: $\quad 60 / 59$

Population: Großenrode
Verband: Verband

\section{Alter:}

Geschlecht:

Arthrose:

\section{Beschreibung:}

$20 \mathrm{~g}$ Knochensplitter von Langknochen und Cranium. 
Bezeichn.: Knochenklein

Kiste:

Skelet: $\quad 62 / 69$

Population: Großenrode
Verband: Verband

\section{Alter:}

Geschlecht:

Arthrose:

\section{Beschreibung:}

27g Knochensplitter von Wirbel, Fuß und Langknochen von oberer Extremität. 
Bezeichn.: Knochenklein

Kiste:

Skelet: 60/56

Population: Großenrode
Verband: Verband

\section{Alter:}

Geschlecht:

Arthrose:

\section{Beschreibung:}

54g Knochensplitter von Femur, Fuß, Wirbel, Rippen und Cranium. 
Bezeichn.: Knochenklein

Kiste:

Skelet: $\quad 64 / 51$

Population: Großenrode
Verband: Verband

\section{Alter:}

Geschlecht:

Arthrose:

\section{Beschreibung:}

Knochensplitter von Cranium, Langknochen und Fuß. 
Bezeichn.: Knochenklein

Kiste:

Skelet: $\quad 61 / 51$

Population: Großenrode
Verband: Verband

\section{Alter:}

Geschlecht:

Arthrose:

\section{Beschreibung:}

Knochensplitter von Langknochen und Hand. 
Bezeichn.: Knochenklein

Kiste:

Skelet: $\quad 64 / 52$

Population: Großenrode
Verband: Verband

\section{Alter:}

Geschlecht:

Arthrose:

\section{Beschreibung:}

39g Knochensplitter von Costa, Vertebra und andere. 
Bezeichn.: Knochenklein

Kiste:

Skelet: $\quad 63 / 49$

Population: Großenrode
Verband: Verband

\section{Alter:}

Geschlecht:

Arthrose:

\section{Beschreibung:}

Knochensplitter von Cranium, Femur und Hand. 
Bezeichn.: Knochenklein

Kiste:

Skelet: $\quad 60 / 58$

Population: Großenrode
Verband: Verband

\section{Alter:}

Geschlecht:

Arthrose:

\section{Beschreibung:}

27g Knochensplitter von Fuß und Langknochen. 
Bezeichn.: Knochenklein

Kiste:

Skelet: $\quad 64 / 57$

Population: Großenrode
Verband: Verband

\section{Alter:}

Geschlecht:

Arthrose:

\section{Beschreibung:}

Von Langknochen und anderen. 
Bezeichn.: Knochenklein

Kiste:

Skelet: $\quad 61 / 59$

Population: Großenrode
Verband: $\quad$ Verband

\section{Alter: Jung}

Geschlecht:

Arthrose:

\section{Beschreibung:}

$66 \mathrm{~g}$ Knochensplitter von Costa (diese Splitter zeigen Anzeichen von nicht ausgewachsenen Rippen), Fuß, Langknochen, Cranium und Hand. 
Bezeichn.: Knochenklein

Kiste:

Skelet: $\quad 60 / 57$

Population: Großenrode
Verband: Verband

\section{Alter:}

Geschlecht:

Arthrose:

\section{Beschreibung:}

Knochensplitter von Langknochen. 
Bezeichn.: Knochenklein

Kiste:

Skelet: $\quad 65 / 51$

Population: Großenrode
Verband: Verband

\section{Alter:}

Geschlecht:

Arthrose:

\section{Beschreibung:}

20g Knochensplitter von Cranium und Langknochen. 
Bezeichn.: Knochenklein

Kiste:

Skelet: 2

Population: Großenrode
Verband: Verband

\section{Alter:}

Geschlecht:

Arthrose:

\section{Beschreibung:}

21g Knochensplitter von Vertebra, Costa und Langknochen. 
Bezeichn.: Knochenklein

Kiste:

Skelet: $\quad 61 / 53$

Population: Großenrode
Verband: Verband

\section{Alter:}

Geschlecht:

Arthrose:

\section{Beschreibung:}

$58 g$ Knochensplitter von Langknochen, Vertebra, Cranium, Hand- und Fuß. 
Bezeichn.: Knochenklein

Kiste:

Skelet: $\quad 63 / 57$

Population: Großenrode
Verband:

\section{Alter:}

Ges./Kr.: Gesund

Geschlecht:

Arthrose:

\section{Beschreibung:}

$141 \mathrm{~g}$ Knochensplitter von Rippen, Cranium, Langknochen, Hand- und Fußknochen. Weiterhin ist ein einzelner Schaltknochen eines jungen Individuums erhalten. 
Bezeichn.: Knochenklein

Kiste:

Skelet: $\quad 63 / 48$

Population: Großenrode
Verband:

Verband

\section{Alter:}

Geschlecht:

Arthrose:

\section{Beschreibung:}

Knochensplitter von Langknochen. 
Bezeichn.: Knochenklein

Kiste:

Skelet: $\quad 65 / 52$

Population: Großenrode

\section{Verband:}

Verband

\section{Alter:}

Geschlecht:

Arthrose:

\section{Beschreibung:}

$18 \mathrm{~g}$ Knochensplitter von Hand- / Fußknochen, Langknochen, Wirbel und Cranium. 
Bezeichn.: Knochenklein

Kiste:

Skelet: $\quad 60 / 60$

Population: Großenrode
Verband: Verband

\section{Alter:}

Geschlecht:

Arthrose:

\section{Beschreibung:}

Knochensplitter von Fuß, Cranium und Vertebra. 
Bezeichn.: Knochenklein

Kiste:

Skelet: $\quad 63 / 50$

Population: Großenrode
Verband: Verband

\section{Alter:}

Geschlecht:

Arthrose:

\section{Beschreibung:}

$20 \mathrm{~g}$ Knochensplitter von Hand- und Langknochen. 
Bezeichn.: Knochenklein

Kiste: 2

Skelet: $\quad 60 / 61$

Population: Großenrode
Verband:

Verband

\section{Alter:}

Geschlecht:

Arthrose:

\section{Beschreibung:}

29g Knochensplitter von Langknochen und cranaium. 
Bezeichn.: Knochenklein Kiste: 2

Skelet: gesammelt

Population: Großenrode
Verband: Verband

\section{Alter:}

Geschlecht:

Arthrose:

\section{Beschreibung:}

70g Knochensplitter von Langknochen und Hand- / Fußknochen. 
Bezeichn.: Knochenklein

Kiste:

Skelet: $\quad 63 / 53$

Population: Großenrode
Verband: Verband

\section{Alter:}

Geschlecht:

Arthrose:

\section{Beschreibung:}

$68 \mathrm{~g}$ kleinste Knochensplitter, möglicherweise Langknochen. 
Bezeichn.: Knochenklein

Kiste:

Skelet: 63/53

Population: Großenrode
Verband:

Verband

Alter:

Geschlecht:

Arthrose:

\section{Beschreibung:}

31g Rippenfragmente. 
Bezeichn.: Knochenklein Kiste:

Skelet: 63/53

Population: Großenrode
Verband: Verband

\section{Alter:}

Geschlecht:

Arthrose:

\section{Beschreibung:}

$25 \mathrm{~g}$ Wirbelfragmente. 
Bezeichn.: Knochenklein

Kiste:

Skelet: 63/53

Population: Großenrode
Verband: $\quad$ Verband

Alter: Jung

Geschlecht:

Arthrose:

\section{Beschreibung:}

59g Knochensplitter von Langknochen, Hand- / Fußknochen, zwei nicht ausgewachsene Mittelhandknochenfragmente und ein Scapula Fragment. 
Bezeichn.: Knochenklein

\section{Kiste:}

Skelet: $\quad 64 / 53$

Population: Großenrode
Verband: Verband

\section{Alter:}

Geschlecht:

Arthrose:

\section{Beschreibung:}

60g Knochensplitter von Rippen und Splittern von Langknochen. 
Bezeichn.: Knochenklein

Kiste:

Skelet: $\quad 64 / 53$

Population: Großenrode
Verband: Verband

\section{Alter:}

Geschlecht:

Arthrose:

\section{Beschreibung:}

89g Knochensplitter von Becken, Hand, Fuß, Langknochen und Wirbel. 
Bezeichn.: Knochenklein

Kiste:

Skelet: $\quad 62 / 55$

Population: Großenrode
Verband: Verband

\section{Alter:}

Geschlecht:

Arthrose:

\section{Beschreibung:}

239g Knochensplitter von Wirbel, Langknochen, Hand, Fuß und Rippen. 
Bezeichn.: Knochenklein

Kiste:

Skelet: $\quad 63 / 52$

Population: Großenrode
Verband: Verband

\section{Alter:}

Geschlecht:

Arthrose:

\section{Beschreibung:}

72g Splitter wahrscheinliche Langknochen obere Extremität und untere Extremität. 
Bezeichn.: Knochenklein

Kiste:

Skelet: $\quad 61 / 58$

Population: Großenrode
Verband: Verband

\section{Alter:}

Geschlecht:

Arthrose:

\section{Beschreibung:}

126g Splitter von Wirbeln, Hand, Fuß, Langknochen, Rippen. 
Bezeichn.: Knochenklein

\section{Kiste:}

Skelet: $\quad 64 / 56$

Population: Großenrode
Verband: Verband

\section{Alter:}

Geschlecht:

Arthrose:

\section{Beschreibung:}

72g Splitter von Schädeln, Langknochen, Hand und Fuß. 
Bezeichn.: Knochenklein

Kiste:

Skelet: $\quad 62 / 50$

Population: Großenrode
Verband: Verband

\section{Alter:}

Geschlecht:

Arthrose:

\section{Beschreibung:}

81g Splitter von Langknochen, Becken, Wirbel, Rippen, Hand und Fuß. 
Bezeichn.: Knochenklein

Kiste:

Skelet: $\quad 59 / 57$

Population: Großenrode
Verband: Verband

\section{Alter:}

Geschlecht:

Arthrose:

\section{Beschreibung:}

$10 \mathrm{~g}$ Splitter von Schädel Hand, Fuß und Langknochen 
Bezeichn.: Knochenklein

Kiste:

Skelet: $\quad 64 / 50$

Population: Großenrode
Verband: Verband

\section{Alter:}

Geschlecht:

Arthrose:

\section{Beschreibung:}

Kleinste Fragmente von Langknochen, Hand, und Fuß. 
Bezeichn.: Knochenklein

Kiste:

2

Skelet:

Population: Großenrode
Verband: Verband

\section{Alter:}

Geschlecht:

Arthrose:

\section{Beschreibung:}

86g Splitter von Wirbeln, Langknochen der oberen Extremität und Hand. 
Bezeichn.: Knochenklein

Kiste:

Skelet: $\quad 62 / 54$

Population: Großenrode
Verband: Verband

\section{Alter:}

Geschlecht:

Arthrose:

\section{Beschreibung:}

$65 \mathrm{~g}$ Splitter von Rippen und Langknochen der oberen Extremität. 
Bezeichn.: Knochenklein

Kiste:

Skelet: $\quad 62 / 54$

Population: Großenrode
Verband: $\quad$ Verband

\section{Alter:}

Geschlecht:

Arthrose:

\section{Beschreibung:}

Fragmente und Splitter von Wirbeln, Langknochen der oberen Extremität, Rippen, Fuß und Becken. es handelt sich um $223 \mathrm{~g} \mathrm{Knochenklein.}$ 
Bezeichn.: Knochenklein

\section{Kiste: 2}

Skelet: $\quad$ kleinere Tüte aus großer

Population: Großenrode
Verband: Verband

\section{Alter:}

Geschlecht:

Arthrose:

\section{Beschreibung:}

216g Langknochensplitter. 
Bezeichn.: Knochenklein

Kiste:

2

Skelet: kleinere Tüte aus großer

Population: Großenrode
Verband: Verband

\section{Alter:}

Geschlecht:

Arthrose:

\section{Beschreibung:}

$79 \mathrm{~g}$ verschiedenste Splitter. 
Bezeichn.: Knochenklein

\section{Kiste: 2}

Skelet: köleine Tüte in 63/56

Population: Großenrode
Verband: $\quad$ Verband

Alter:

Geschlecht:

Arthrose:

Beschreibung:

$12 \mathrm{~g}$ Wirbelsplitter. 
Bezeichn.: Knochenklein

Kiste: 2

Skelet: kleine blaue Tüte aus

Population: Großenrode
Verband: Verband

\section{Alter:}

Geschlecht:

Arthrose:

\section{Beschreibung:}

46g Splitter und Fragmente von Langknochen der oberen Extremität und Fuß. 
Bezeichn.: Knochenklein

Kiste: 2

Skelet: andere kleine blaue Tüte

Population: Großenrode
Verband: Verband

Alter:

Geschlecht:

Arthrose:

\section{Beschreibung:}

27g Rippenfragmente und -splitter. 
Bezeichn.: Knochenklein

Kiste:

Skelet: $\quad 63 / 51$

Population: Großenrode
Verband: Verband

\section{Alter:}

Geschlecht:

Arthrose:

\section{Beschreibung:}

26g Splitter von Wirbeln, Hand, Fuß und Schädel. 
Bezeichn.: Knochenklein

Kiste:

Skelet: $\quad 61 / 57$

Population: Großenrode
Verband: Verband

\section{Alter:}

Geschlecht:

Arthrose:

\section{Beschreibung:}

110g Splitter und Fragmente von Rippen, Schädeln, Hand, Langknochen und Fuß. 
Bezeichn.: Knochenklein

\section{Kiste:}

Skelet: $\quad 62 / 54$

Population: Großenrode
Verband: Verband

\section{Alter:}

Geschlecht:

Arthrose:

\section{Beschreibung:}

156g Splitter von Langknochen, Hand und Fuß. 
Bezeichn.: Knochenklein

Kiste:

3

Skelet: $\quad$ K266 63/64 P4

Population: Großenrode
Verband: Verband

\section{Alter:}

Geschlecht:

Arthrose:

\section{Beschreibung:}

$53 g$ Splitter von Langknochen. 
Bezeichn.: Knochenklein

Kiste:

Skelet: $\quad$ K266 rechts 63/64 P4

Population: Großenrode
Verband: Verband

\section{Alter:}

Geschlecht:

Arthrose:

\section{Beschreibung:}

$27 \mathrm{~g}$ kleinste Knochensplitter. 
Bezeichn.: Knochenklein Kiste:

Skelet: große Tüte

Population: Großenrode
Verband: Verband

\section{Alter:}

Geschlecht:

Arthrose:

Beschreibung:

140g Splitter von Langknochen. 
Bezeichn.: Knochenklein

Kiste:

Skelet: K183

Population: Großenrode
Verband: Verband

\section{Alter:}

Geschlecht:

Arthrose:

\section{Beschreibung:}

Zwei kleinste Splitter von 0,5g. 
Bezeichn.: Knochenklein

Kiste:

Skelet: $\quad 61 / 65$

Population: Großenrode
Verband: Verband

\section{Alter:}

Geschlecht:

Arthrose:

\section{Beschreibung:}

67g Knochensplitter von Hand, Fuß, obere Extremität und untere Extremität. 
Bezeichn.: Knochenklein

Kiste:

Skelet: $\quad \mathrm{K} 187$

Population: Großenrode
Verband: Verband

\section{Alter:}

Geschlecht:

Arthrose:

Beschreibung:

10g Splitter von Femur und Vertebra. 
Bezeichn.: Knochenklein Kiste:

Skelet: K258

Population: Großenrode
Verband: Verband

\section{Alter:}

Geschlecht:

Arthrose:

\section{Beschreibung:}

$7 g$ Rippen. 
Bezeichn.: Knochenklein

Kiste:

Skelet: K206 S3

Population: Großenrode
Verband: Verband

\section{Alter:}

Geschlecht:

Arthrose:

\section{Beschreibung:}

$27 \mathrm{~g}$ von oberer und unterer Extremität. 
Bezeichn.: Knochenklein

Kiste:

Skelet: K206

Population: Großenrode
Verband: Verband

\section{Alter:}

Geschlecht:

Arthrose:

\section{Beschreibung:}

$26 \mathrm{~g}$ Splitter von Rippen und Langknochen. 
Bezeichn.: Knochenklein

Kiste:

Skelet: $\quad 61 / 66$

Population: Großenrode
Verband: Verband

\section{Alter:}

Geschlecht:

Arthrose:

\section{Beschreibung:}

$71 \mathrm{~g}$ Splitter von Hand, Langknochen, Rippen und Wirbel. 
Bezeichn.: Knochenklein

Kiste:

Skelet: 60/65

Population: Großenrode
Verband: Verband

\section{Alter:}

Geschlecht:

Arthrose:

\section{Beschreibung:}

31g Splitter von oberer Extremität. 
Bezeichn.: Knochenklein Kiste:

Skelet: $\quad 59 / 6559 / 64$

Population: Großenrode
Verband: Verband

\section{Alter:}

Geschlecht:

Arthrose:

\section{Beschreibung:}

19g Splitter von Rippen, Hand und Fuß. 
Bezeichn.: Knochenklein

Kiste:

Skelet: $\quad$ K197 60/63-64 S3

Population: Großenrode
Verband: Verband

\section{Alter:}

Geschlecht:

Arthrose:

\section{Beschreibung:}

$20 \mathrm{~g}$ Splitter von Rippen und Langknochen. 
Bezeichn.: Knochenklein

Kiste:

Skelet: $\quad 60 / 63$

Population: Großenrode
Verband: Verband

\section{Alter:}

Geschlecht:

Arthrose:

\section{Beschreibung:}

$73 g$ Splitter von Langknochen, Rippen und Mittelfuß. 
Bezeichn.: Knochenklein

Kiste:

Skelet: $\quad$ K167 60/63-64

Population: Großenrode
Verband: Verband

\section{Alter:}

Geschlecht:

Arthrose:

\section{Beschreibung:}

43g Splitter von Langknochen und Wirbel. 
Bezeichn.: Knochenklein

Kiste:

Skelet: $\quad 63 / 64$

Population: Großenrode
Verband: Verband

\section{Alter:}

Geschlecht:

Arthrose:

\section{Beschreibung:}

28g Splitter von Rippen und Langknochen von unterer Extremität. 
Bezeichn.: Knochenklein

Kiste:

Skelet: $\quad$ K268 63/64 S3

Population: Großenrode
Verband: Verband

\section{Alter:}

Geschlecht:

Arthrose:

\section{Beschreibung:}

10g Splitter von Rippen und Schulterblatt. 
Bezeichn.: Knochenklein

Kiste:

Skelet: $\quad 63 / 64-4$

Population: Großenrode
Verband: Verband

\section{Alter:}

Geschlecht:

Arthrose:

\section{Beschreibung:}

51g Splitter von Hand, Fuß und Langknochen von unterer Extremität. 
Bezeichn.: Knochenklein

Kiste:

Skelet: $\quad$ K317 P4

Population: Großenrode
Verband: Verband

\section{Alter:}

Geschlecht:

Arthrose:

Beschreibung:

21g Splitter von Hand und Rippen. 
Bezeichn.: Knochenklein Kiste:

Skelet: $\quad$ K317 P4

Population: Großenrode
Verband: Verband

\section{Alter:}

Geschlecht:

Arthrose:

\section{Beschreibung:}

$14 \mathrm{~g}$ Wirbelfragmente. 
Bezeichn.: Knochenklein Kiste:

Skelet: 63/63-3

Population: Großenrode
Verband: Verband

\section{Alter:}

Geschlecht:

Arthrose:

\section{Beschreibung:}

10g Rippenfragmente. 
Bezeichn.: Knochenklein

Kiste:

Skelet: $\quad$ K322 63/63 S4

Population: Großenrode
Verband: Verband

\section{Alter:}

Geschlecht:

Arthrose:

\section{Beschreibung:}

Rippenfragmente und kleine Fragmente anderer Knochen. 
Bezeichn.: Knochenklein

Kiste:

Skelet: $\quad$ K312 P4

Population: Großenrode
Verband: Verband

\section{Alter:}

Geschlecht:

Arthrose:

\section{Beschreibung:}

$5 \mathrm{~g}$ Splitter von Hand und Fuß. 
Bezeichn.: Knochenklein Kiste:

Skelet: K270

Population: Großenrode
Verband: Verband

\section{Alter:}

Geschlecht:

Arthrose:

\section{Beschreibung:}

66g Rippenfragmente. 
Bezeichn.: Knochenklein Kiste:

Skelet: $\quad$ K270 P4

Population: Großenrode
Verband: Verband

\section{Alter:}

Geschlecht:

Arthrose:

Beschreibung:

$5 \mathrm{~g}$ Knochensplitter. 
Bezeichn.: Knochenklein Kiste:

Skelet: $\quad$ K270 P4

Population: Großenrode
Verband: Verband

\section{Alter:}

Geschlecht:

Arthrose:

\section{Beschreibung:}

24g Wirbelfragmente. 
Bezeichn.: Knochenklein

Kiste:

3

Skelet: K192 S3

Population: Großenrode
Verband: Verband

\section{Alter:}

Geschlecht:

Arthrose:

\section{Beschreibung:}

$26 \mathrm{~g}$ Splitter von Hand und Fuß. 
Bezeichn.: Knochenklein

Kiste:

Skelet: $\quad$ K192 S3

Population: Großenrode
Verband: Verband

\section{Alter:}

Geschlecht:

Arthrose:

\section{Beschreibung:}

30g Splitter von Wirbeln und Langknochen. 
Bezeichn.: Knochenklein

Kiste:

3

Skelet: K192-161/64 S3

Population: Großenrode
Verband: Verband

\section{Alter:}

Geschlecht:

Arthrose:

\section{Beschreibung:}

$15 \mathrm{~g}$ Beckenfragmente. 
Bezeichn.: Knochenklein

Kiste:

Skelet: $\quad$ K112 61/64 S2

Population: Großenrode
Verband: Verband

\section{Alter:}

Geschlecht:

Arthrose:

\section{Beschreibung:}

39g Splitter von Langknochen. 
Bezeichn.: Knochenklein

Kiste:

3

Skelet: $\quad$ K205 61/64 P4

Population: Großenrode
Verband: Verband

\section{Alter:}

Geschlecht:

Arthrose:

\section{Beschreibung:}

$6 \mathrm{~g}$ Wirbelfragmente. 
Bezeichn.: Knochenklein

Kiste:

Skelet: $\quad 61$ (64-2

Population: Großenrode
Verband: Verband

\section{Alter:}

Geschlecht:

Arthrose:

\section{Beschreibung:}

$4 \mathrm{~g}$ verschiedenste kleine Splitter. 
Bezeichn.: Knochenklein

Kiste:

Skelet: K90 S2

Population: Großenrode
Verband: Verband

\section{Alter:}

Geschlecht:

Arthrose:

\section{Beschreibung:}

$3 \mathrm{~g}$ Splitter eines Langknochen. 
Bezeichn.: Knochenklein

Kiste:

Skelet: K193 S3

Population: Großenrode
Verband: Verband

\section{Alter:}

Geschlecht:

Arthrose:

\section{Beschreibung:}

37g Splitter von Hand und oberer Extremität. 
Bezeichn.: Knochenklein Kiste:

Skelet: K61 61/64 S1

Population: Großenrode
Verband: Verband

\section{Alter:}

Geschlecht:

Arthrose:

\section{Beschreibung:}

3 Splitter, 0,5g verschiedenste Splitter. 
Bezeichn.: Knochenklein

Kiste: $\quad 3$

Skelet: $\quad$ K191 61/64 S3

Population: Großenrode
Verband: Verband

\section{Alter:}

\section{Geschlecht:}

Arthrose:

\section{Beschreibung:}

13g Splitter von Langknochen oberer Extremität und Splitter unbekannter Herkunft. 
Bezeichn.: Knochenklein

Kiste:

Skelet: K193

Population: Großenrode
Verband: Verband

\section{Alter:}

Geschlecht:

Arthrose:

\section{Beschreibung:}

15g Splitter von Hand und Rippen. 
Bezeichn.: Knochenklein Kiste: 3

Skelet: $\quad$ K180 62/64 S3

Population: Großenrode
Verband: Verband

\section{Alter:}

Geschlecht:

Arthrose:

\section{Beschreibung:}

$8 \mathrm{~g}$ Splitter von Langknochen. 
Bezeichn.: Knochenklein Kiste: 3

Skelet: K100-2 S2

Population: Großenrode
Verband: Verband

\section{Alter:}

Geschlecht:

Arthrose:

Beschreibung:

$15 \mathrm{~g}$ Splitter von Becken. 
Bezeichn.: Knochenklein

\section{Kiste:}

Skelet: 62/64-3

Population: Großenrode
Verband: Verband

\section{Alter:}

Geschlecht:

Arthrose:

\section{Beschreibung:}

37g Splitter von Hand, Fuß und Langknochen. 
Bezeichn.: Knochenklein

Kiste:

3

Skelet: $\quad$ K88 62/64 S2

Population: Großenrode

Verband: $\quad \square$ Verband

Alter:

Geschlecht:

Arthrose:

\section{Beschreibung:}

4 kleine Langknochenfragmente. 
Bezeichn.: Knochenklein Kiste:

Skelet: K91 S2

Population: Großenrode
Verband: Verband

\section{Alter:}

Geschlecht:

Arthrose:

\section{Beschreibung:}

$1 \mathrm{~g}$ kleinste Fragmente. 
Bezeichn.: Knochenklein Kiste: 3

Skelet: K101 62/64 S2

Population: Großenrode
Verband: Verband

\section{Alter:}

Geschlecht:

Arthrose:

\section{Beschreibung:}

21g Splitter von Femur. 
Bezeichn.: Knochenklein Kiste:

Skelet:

Population: Großenrode
Verband: Verband

\section{Alter:}

Geschlecht:

Arthrose:

Beschreibung:

$0,5 \mathrm{~g}$ Splitter. 
Bezeichn.: Knochenklein

Kiste:

Skelet: K211

Population: Großenrode
Verband: Verband

\section{Alter:}

Geschlecht:

Arthrose:

\section{Beschreibung:}

$5 \mathrm{~g}$ Splitter von Langknochen. 
Bezeichn.: Knochenklein

Kiste:

Skelet: 62/64-4

Population: Großenrode
Verband: Verband

\section{Alter:}

Geschlecht:

Arthrose:

Beschreibung:

$10 \mathrm{~g}$ Splitter von Wirbel und Fuß. 
Bezeichn.: Knochenklein

Kiste:

3

Skelet: $\quad 62 / 64$ S3 K227

Population: Großenrode

Verband: $\quad$ Verband

\section{Alter:}

Geschlecht:

Arthrose:

\section{Beschreibung:}

$9 \mathrm{~g}$ Splitter von Wirbeln. 
Bezeichn.: Knochenklein Kiste:

Skelet: 62/64-2

Population: Großenrode
Verband: Verband

\section{Alter:}

Geschlecht:

Arthrose:

\section{Beschreibung:}

1g Splitter nicht zuzuordnen. 
Bezeichn.: Knochenklein

Kiste:

Skelet: $\quad 62 / 64$ S3 K218

Population: Großenrode
Verband: Verband

\section{Alter:}

Geschlecht:

Arthrose:

\section{Beschreibung:}

Ein Fragment eines Langknochens, 4g. 
Bezeichn.: Knochenklein

Kiste:

Skelet: $\quad 62 / 64$ S3 K208

Population: Großenrode
Verband: Verband

\section{Alter:}

Geschlecht:

Arthrose:

\section{Beschreibung:}

Zwei Fragmente einer Tibia, 4g. 
Bezeichn.: Knochenklein

Kiste:

Skelet: $\quad$ K226 62/64 S3

Population: Großenrode
Verband: Verband

\section{Alter:}

Geschlecht:

Arthrose:

\section{Beschreibung:}

$26 \mathrm{~g}$ Splitter von Rippen und Langknochen. 
Bezeichn.: Knochenklein

\section{Kiste:}

Skelet: 10

Population: Großenrode
Verband: Verband

\section{Alter:}

Geschlecht:

Arthrose:

\section{Beschreibung:}

195g Splitter von Langknochen und Becken. 
Bezeichn.: Knochenklein

Kiste:

Skelet: $\quad 63 / 52$

Population: Großenrode
Verband: Verband

\section{Alter:}

Geschlecht:

Arthrose:

\section{Beschreibung:}

80g Splitter von Wirbeln. 
Bezeichn.: Knochenklein

Kiste:

Skelet: 10

Population: Großenrode
Verband: Verband

\section{Alter:}

Geschlecht:

Arthrose:

\section{Beschreibung:}

71g Splitter von Rippen. 
Bezeichn.: Knochenklein

\section{Kiste:}

Skelet: 10

Population: Großenrode
Verband: Verband

\section{Alter:}

Geschlecht:

Arthrose:

\section{Beschreibung:}

$85 \mathrm{~g}$ Splitter von Langknochen. 
Bezeichn.: Knochenklein

\section{Kiste:}

Skelet: 10

Population: Großenrode
Verband: Verband

\section{Alter:}

Geschlecht:

Arthrose:

\section{Beschreibung:}

$56 \mathrm{~g}$ Splitter von Hand und Langknochen oberer Extremität. 
Bezeichn.: Knochenklein

\section{Kiste:}

Skelet: 10

Population: Großenrode
Verband: Verband

\section{Alter:}

Geschlecht:

Arthrose:

\section{Beschreibung:}

50g Splitter von Langknochen, Hand und Fuß. 
Bezeichn.: Knochenklein Kiste:

Skelet: 10

t: $\quad 61 / 55$

Population: Großenrode
Verband: Verband

\section{Alter:}

Geschlecht:

Arthrose:

Beschreibung:

39g Splitter. 
Bezeichn.: Knochenklein

\section{Kiste:}

Skelet: 10

Population: Großenrode
Verband: Verband

\section{Alter:}

Geschlecht:

Arthrose:

\section{Beschreibung:}

$66 \mathrm{~g}$ Splitter von Fußknochen. 
Bezeichn.: Knochenklein

\section{Kiste:}

Skelet: 10

Population: Großenrode
Verband: Verband

\section{Alter:}

Geschlecht:

Arthrose:

\section{Beschreibung:}

530g Splitter von Langknochen unterer Extremität, Becken und Langknochen oberer Extremität. 
Bezeichn.: Knochenklein

Kiste:

Skelet: 10

Population: Großenrode
Verband: $\quad$ Verband

\section{Alter: Jung}

Geschlecht:

Arthrose:

\section{Beschreibung:}

22g Splitter von Langknochen, Hand und Fuß. Hand- und Fußfragmente sind von einem jungen Individuum. 
Bezeichn.: Knochenklein

Kiste:

Skelet: $\quad 62 / 53$

Population: Großenrode
Verband: $\quad$ Verband

Alter: Jung

Geschlecht:

Arthrose:

\section{Beschreibung:}

$185 \mathrm{~g}$ Splitter von Wirbeln. 
Bezeichn.: Knochenklein

\section{Kiste:}

Skelet: 10

Population: Großenrode
Verband: Verband

\section{Alter:}

Geschlecht:

Arthrose:

\section{Beschreibung:}

107g Splitter von Langknochen,Hand und Fuß. 
Bezeichn.: Knochenklein

\section{Kiste:}

Skelet: 10

Population: Großenrode
Verband: Verband

\section{Alter:}

Geschlecht:

Arthrose:

\section{Beschreibung:}

47g Splitter von Handknochen. 
Bezeichn.: Knochenklein

Kiste:

Skelet: $\quad 62 / 53$

Population: Großenrode
Verband: Verband

\section{Alter:}

Geschlecht:

Arthrose:

\section{Beschreibung:}

151g Splitter von Rippen. 
Bezeichn.: Knochenklein

\section{Kiste:}

Skelet: 10

Population: Großenrode
Verband: Verband

\section{Alter:}

Geschlecht:

Arthrose:

\section{Beschreibung:}

163g Splitte von Langknochen. 
Bezeichn.: Knochenklein

\section{Kiste:}

Skelet: 10

Population: Großenrode
Verband: Verband

\section{Alter:}

Geschlecht:

Arthrose:

\section{Beschreibung:}

218g Splitter von Langknochen unterer Extremität und Becken. 
Bezeichn.: Knochenklein

\section{Kiste:}

Skelet: 10

Population: Großenrode
Verband: Verband

\section{Alter:}

Geschlecht:

Arthrose:

\section{Beschreibung:}

11g Splitter von Rippen und Langknochen oberer Extremität. 
Bezeichn.: Knochenklein

Kiste:

Skelet: 10

Population: Großenrode
Verband: Verband

\section{Alter:}

Geschlecht:

Arthrose:

\section{Beschreibung:}

70g Splitter von Langknochen. 
Bezeichn.: Knochenklein

\section{Kiste:}

Skelet: 10

Population: Großenrode
Verband: Verband

\section{Alter:}

Geschlecht:

Arthrose:

\section{Beschreibung:}

52g Splitte von Hand, Fuß und Langknochen. 
Bezeichn.: Knochenklein

Kiste:

Skelet: $\quad 62 / 56$

Population: Großenrode
Verband: Verband

\section{Alter:}

Geschlecht:

Arthrose:

\section{Beschreibung:}

$22 \mathrm{~g}$ Wirbelfragmente. 
Bezeichn.: Knochenklein

Kiste:

Skelet: $\quad 62 / 49$

Population: Großenrode
Verband: Verband

\section{Alter:}

Geschlecht:

Arthrose:

Beschreibung:

$1 \mathrm{~g}$ Rippensplitter. 
Bezeichn.: Knochenklein

\section{Kiste:}

Skelet: 10

Population: Großenrode
Verband: Verband

\section{Alter:}

Geschlecht:

Arthrose:

\section{Beschreibung:}

$66 g$ Splitter von Langknochen und Rippen. 
Bezeichn.: Knochenklein

Kiste:

Skelet: $\quad 63 / 55$

Population: Großenrode
Verband: Verband

\section{Alter:}

Geschlecht:

Arthrose:

\section{Beschreibung:}

$6 \mathrm{~g}$ Wirbelfragmente. 
Bezeichn.: Knochenklein

Kiste:

Skelet: 10

Population: Großenrode
Verband: Verband

\section{Alter:}

Geschlecht:

Arthrose:

\section{Beschreibung:}

24g Splitter von oberer Extremität und unterer Extremität, sowie Hand und Fuß. 
Bezeichn.: Knochenklein

\section{Kiste:}

Skelet: 10

Population: Großenrode
Verband: Verband

\section{Alter:}

Geschlecht:

Arthrose:

\section{Beschreibung:}

96g Splitter von Langknochen unterer Extremität und Fuß. 
Bezeichn.: Knochenklein

Kiste:

Skelet: $\quad$ bei 431 in Tüte 1

Population: Großenrode
Verband: Verband

\section{Alter:}

Geschlecht:

Arthrose:

\section{Beschreibung:}

91g Splitter von Langknochen. 
Bezeichn.: Knochenklein

Kiste:

Skelet: $\quad$ Tüte nur mit 62/51

Population: Großenrode
Verband: Verband

\section{Alter:}

Geschlecht:

Arthrose:

\section{Beschreibung:}

182g Splitter von Langknochen, Rippen, Becken, Fußknochen und Wirbeln. 
Bezeichn.: Knochenklein

\section{Kiste:}

Skelet: 1. kleine tüte in Tüte von

Population: Großenrode
Verband: Verband

\section{Alter:}

Geschlecht:

Arthrose:

\section{Beschreibung:}

112g Splitter von Becken, Langknochen und Fuß. 
Bezeichn.: Knochenklein

\section{Kiste:}

Skelet: $\quad$ 2. kleine tüte in tüte 62/52

Population: Großenrode
Verband: Verband

\section{Alter:}

Geschlecht:

Arthrose:

\section{Beschreibung:}

71g Splitter von Langknochen. 
Bezeichn.: Knochenklein

\section{Kiste:}

Skelet: $\quad 3$. Tüte aus $62 / 52$

Population: Großenrode
Verband: Verband

\section{Alter:}

Geschlecht:

Arthrose:

\section{Beschreibung:}

50g Rippenfragmente. 
Bezeichn.: Knochenklein

\section{Kiste:}

Skelet: 4. Tüte aus $62 / 52$

Population: Großenrode
Verband: Verband

\section{Alter:}

Geschlecht:

Arthrose:

\section{Beschreibung:}

57g Splitter von Langknochen oberer Extremität, Rippen und Fuß. 
Bezeichn.: Knochenklein

\section{Kiste:}

Skelet: 10

Population: Großenrode

\section{Verband: $\quad$ Verband}

\section{Alter:}

Geschlecht:

Arthrose:

\section{Beschreibung:}

$161 \mathrm{~g}$ Splitter von Langknochen oberer und unterer Extremität, sowie Wirbel und Fuß. 
Bezeichn.: Knochenklein

Kiste:

Skelet: aus $62 / 57$

Population: Großenrode
Verband: Verband

\section{Alter:}

Geschlecht:

Arthrose:

\section{Beschreibung:}

71g Splitter von Langknochen oberer Extremität, Hand und unbekannte Splitter. 
Bezeichn.: Knochenklein

Kiste:

Skelet: $\quad 61 / 52$

Population: Großenrode
Verband: Verband

\section{Alter:}

Geschlecht:

Arthrose:

\section{Beschreibung:}

39g Rippenfragmente. 
Bezeichn.: Knochenklein

\section{Kiste:}

Skelet: 10

Population: Großenrode
Verband: Verband

\section{Alter:}

Geschlecht:

Arthrose:

\section{Beschreibung:}

58g Splitter von Rippen, Wirbeln, Hand und Fuß. 
Bezeichn.: Knochenklein

\section{Kiste:}

Skelet: 10

Population: Großenrode
Verband: Verband

\section{Alter:}

Geschlecht:

Arthrose:

\section{Beschreibung:}

35g Splitter von Langknochen und Rippen. 
Bezeichn.: Knochenklein

\section{Kiste:}

Skelet: 10

Population: Großenrode
Verband: Verband

\section{Alter:}

Geschlecht:

Arthrose:

\section{Beschreibung:}

$75 \mathrm{~g}$ Splitter von Langknochen und Becken. 
Bezeichn.: Knochenklein

\section{Kiste:}

Skelet: 10

Population: Großenrode
Verband: Verband

\section{Alter:}

Geschlecht:

Arthrose:

\section{Beschreibung:}

80g Splitter von Extremitätenknochen. 
Bezeichn.: Knochenklein

Kiste:

Skelet: $\quad 63 / 54$

Population: Großenrode
Verband: Verband

\section{Alter:}

Geschlecht:

Arthrose:

\section{Beschreibung:}

52g Splitter von Rippen, Becken und Langknochen. 
Bezeichn.: Knochenklein

\section{Kiste:}

Skelet: $\quad 63 / 54$

Population: Großenrode
Verband: Verband

\section{Alter:}

Geschlecht:

Arthrose:

\section{Beschreibung:}

61g Splitter von Langknochen oberer und unterer Extremität. 
Bezeichn.: Knochenklein

\section{Kiste:}

Skelet: 10

Population: Großenrode
Verband: Verband

\section{Alter:}

Geschlecht:

Arthrose:

\section{Beschreibung:}

38g Splitter von Langknochen von oberer und unterer Extremität. 
Bezeichn.: Knochenklein

Kiste:

Skelet: 1

K51

Population: Großenrode
Verband: Verband

\section{Alter:}

Geschlecht:

Arthrose:

\section{Beschreibung:}

$56 \mathrm{~g}$ Splitter von Wirbeln und Langknochen. 
Bezeichn.: Knochenklein

\section{Kiste:}

Skelet: aus der Kiste einzeln

Population: Großenrode
Verband: Verband

\section{Alter:}

Geschlecht:

Arthrose:

\section{Beschreibung:}

$13 \mathrm{~g}$ nicht zu bestimmende Knochensplitter. 
Bezeichn.: Knochenklein Kiste:

Skelet:

Population: Großenrode
Verband: Verband

\section{Alter:}

Geschlecht:

Arthrose:

\section{Beschreibung:}

0,5g ein Fragment eines Langknochens. 
Bezeichn.: Knochenklein

\section{Kiste:}

Skelet: K246

Population: Großenrode
Verband: Verband

\section{Alter:}

Geschlecht:

Arthrose:

Beschreibung:

$6 g$ Rippenfragmente. 
Bezeichn.: Knochenklein

Kiste:

Skelet: $\quad$ K83 P2

Population: Großenrode
Verband: Verband

\section{Alter:}

Geschlecht:

Arthrose:

\section{Beschreibung:}

3 Splitter von Langknochen, $5 \mathrm{~g}$. 
Bezeichn.: Knochenklein Kiste:

Skelet: K124

Population: Großenrode
Verband: Verband

\section{Alter:}

Geschlecht:

Arthrose:

\section{Beschreibung:}

49g Knochenfragmente. 
Bezeichn.: Knochenklein

\section{Kiste:}

Skelet:

Population: Großenrode
Verband: Verband

\section{Alter:}

Geschlecht:

Arthrose:

Beschreibung:

$6 g$ Fragmente. 
Bezeichn.: Knochenklein Kiste:

Skelet: 1

$\mathrm{K} 50$

Population: Großenrode
Verband: Verband

\section{Alter:}

Geschlecht:

Arthrose:

\section{Beschreibung:}

$2 \mathrm{~g}$ eines Rippensplitters. 
Bezeichn.: Knochenklein

\section{Kiste:}

Skelet: $\quad$ K245 63/68 P3

Population: Großenrode
Verband: Verband

\section{Alter:}

Geschlecht:

Arthrose:

\section{Beschreibung:}

$43 \mathrm{~g}$ Splitter von Rippen und Wirbeln. 
Bezeichn.: Knochenklein

Kiste:

Skelet: $\quad 63 / 68$ P3

Population: Großenrode
Verband: Verband

\section{Alter:}

Geschlecht:

Arthrose:

\section{Beschreibung:}

29g Splitter von Wirbeln, Rippen, Hand und Fuß. 
Bezeichn.: Knochenklein Kiste:

Skelet: 1

K236

Population: Großenrode
Verband: Verband

\section{Alter:}

Geschlecht:

Arthrose:

\section{Beschreibung:}

10g Splitter von Rippen und Langknochen. 
Bezeichn.: Knochenklein Kiste:

Skelet: $\quad k 244 \mathrm{P} 3$

Population: Großenrode
Verband: Verband

\section{Alter:}

Geschlecht:

Arthrose:

\section{Beschreibung:}

18g Langknochensplitter. 
Bezeichn.: Knochenklein

Kiste:

Skelet: K9 S0-S2

Population: Großenrode
Verband: Verband

\section{Alter:}

Geschlecht:

Arthrose:

\section{Beschreibung:}

19g kleinste Knochensplitter. 
Bezeichn.: Knochenklein

Kiste:

Skelet: $\quad 63 / 68-1$

Population: Großenrode
Verband: Verband

\section{Alter:}

Geschlecht:

Arthrose:

\section{Beschreibung:}

$80 \mathrm{~g}$ verschiedene Knochensplitter. 
Bezeichn.: Knochenklein Kiste:

Skelet: 1

K86

Population: Großenrode
Verband: Verband

\section{Alter:}

Geschlecht:

Arthrose:

\section{Beschreibung:}

$15 \mathrm{~g}$ Splitter von Langknochen. 
Bezeichn.: Knochenklein

Kiste:

Skelet: $\quad 63 / 68-3$

Population: Großenrode
Verband: Verband

\section{Alter:}

Geschlecht:

Arthrose:

\section{Beschreibung:}

31g nicht zuzuordnender Knochensplitter. 
Bezeichn.: Knochenklein Kiste:

Skelet: K284

Population: Großenrode
Verband: Verband

\section{Alter:}

Geschlecht:

Arthrose:

\section{Beschreibung:}

$5 \mathrm{~g}$ Kleinste Knochensplitter. 
Bezeichn.: Knochenklein

\section{Kiste:}

Skelet: ua Cranium K53 S1

Population: Großenrode
Verband: Verband

\section{Alter:}

Geschlecht:

Arthrose:

\section{Beschreibung:}

$5 \mathrm{~g}$ Knochensplitter. 
Bezeichn.: Knochenklein

Kiste:

Skelet: 1

Population: Großenrode
Verband: Verband

\section{Alter:}

Geschlecht:

Arthrose:

\section{Beschreibung:}

$10 \mathrm{~g}$ verschiedenste Knochensplitter. 
Bezeichn.: Knochenklein

\section{Kiste:}

Skelet: Fragmente

Population: Großenrode

Seite:

n. def.

Verband: $\quad$ Verband

Alter:

Geschlecht:

Arthrose:

\section{Beschreibung:}

17g Splitter von Wirbeln und Langknochen. 
Bezeichn.: Knochenklein

\section{Kiste:}

Skelet: Fragmente

Population: Großenrode
Verband: Verband

\section{Alter:}

Geschlecht:

Arthrose:

\section{Beschreibung:}

Kleinste Fragmente von Rippen. 
Bezeichn.: Knochenklein

\section{Kiste:}

Skelet: Fragmente

Population: Großenrode
Verband: Verband

\section{Alter:}

Geschlecht:

Arthrose:

\section{Beschreibung:}

55g Splitter von Wirbeln, Langknochen, Hand und Fuß. 
Bezeichn.: Knochenklein

\section{Kiste:}

Skelet: Fragmente

Population: Großenrode
Verband: Verband

\section{Alter:}

Geschlecht:

Arthrose:

\section{Beschreibung:}

$33 g$ Knochensplitter. 
Bezeichn.: Knochenklein Kiste:

Skelet: K283

Population: Großenrode
Verband: Verband

\section{Alter:}

Geschlecht:

Arthrose:

\section{Beschreibung:}

$6 \mathrm{~g}$ Splitter von Hand und Fuß. 
Bezeichn.: Knochenklein

\section{Kiste:}

Skelet: Fragmente K281 S3

Population: Großenrode
Verband: Verband

\section{Alter:}

Geschlecht:

Arthrose:

\section{Beschreibung:}

8g Knochensplitter. 
Bezeichn.: Knochenklein

Kiste:

Skelet: $\quad 63 / 68-2$

Population: Großenrode
Verband: Verband

\section{Alter:}

Geschlecht:

Arthrose:

\section{Beschreibung:}

95g Knochenfragmente der unteren Extremität. 
Bezeichn.: Knochenklein

Kiste:

Skelet: $\quad$ K240 63/68 P3

Population: Großenrode
Verband: Verband

\section{Alter:}

Geschlecht:

Arthrose:

\section{Beschreibung:}

$14 \mathrm{~g}$ verschiedenste Knochensplitter. 
Bezeichn.: Knochenklein

Kiste:

Skelet: $\quad$ K234 63/68 P3

Population: Großenrode
Verband: Verband

\section{Alter:}

Geschlecht:

Arthrose:

\section{Beschreibung:}

$18 \mathrm{~g}$ Knochensplitter von unterer Extremität. 
Bezeichn.: Knochenklein Kiste:

Skelet: $\quad$ K239 63/68 P3

Population: Großenrode
Verband: Verband

\section{Alter:}

Geschlecht:

Arthrose:

\section{Beschreibung:}

45g Knochensplitter. 
Bezeichn.: Knochenklein

Kiste:

Skelet: $\quad$ K119 63/68 P2

Population: Großenrode
Verband: Verband

\section{Alter:}

Geschlecht:

Arthrose:

\section{Beschreibung:}

9g Splitter verschiedener Knochen. 
Bezeichn.: Knochenklein Kiste:

Skelet: $\quad$ K41 63/68 S1

Population: Großenrode
Verband: Verband

\section{Alter:}

Geschlecht:

Arthrose:

\section{Beschreibung:}

4g Knochensplitter. 
Bezeichn.: Knochenklein Kiste:

Skelet: $\quad 63 / 68-2$

Population: Großenrode
Verband: Verband

\section{Alter:}

Geschlecht:

Arthrose:

Beschreibung:

11g kleinste Schädelsplitter. 
Bezeichn.: Knochenklein

\section{Kiste:}

Skelet: K243

Population: Großenrode
Verband: Verband

\section{Alter:}

Geschlecht:

Arthrose:

\section{Beschreibung:}

53g Splitter von Rippen, Wirbeln und Langknochen. 
Bezeichn.: Knochenklein

Kiste:

Skelet: $\quad$ K177 63/66 P3

Population: Großenrode
Verband: Verband

\section{Alter:}

Geschlecht:

Arthrose:

\section{Beschreibung:}

$7 \mathrm{~g}$ Knochensplitter von Becken und anderen. 
Bezeichn.: Knochenklein

\section{Kiste:}

Skelet: lose in der großen Kiste

Population: Großenrode
Verband: Verband

\section{Alter:}

Geschlecht:

Arthrose:

\section{Beschreibung:}

Knochensplitter von Langknochen. 
Bezeichn.: Knochenklein

Kiste:

Skelet: $\quad 63 / 52$

Population: Großenrode
Verband: Verband

\section{Alter:}

Geschlecht:

Arthrose:

\section{Beschreibung:}

Kleine Fragmente von Langknochen und Hand. 
Bezeichn.: Knochenklein

Kiste:

Skelet: K265

Population: Großenrode
Verband: Verband

\section{Alter:}

Geschlecht:

Arthrose:

\section{Beschreibung:}

$6 \mathrm{~g}$ Knochensplitter von einem Schädel 
Bezeichn.: Knochenklein

Kiste:

Skelet: verschiedene

Population: Großenrode
Verband: Verband

\section{Alter:}

Geschlecht:

Arthrose:

\section{Beschreibung:}

Splitter von Hand und Fuß, sowie Langknochen. Es handelt sich um 54g. 
Bezeichn.: Knochenklein

Kiste:

Skelet: $\quad$ K333 64/68 P4

Population: Großenrode
Verband: Verband

\section{Alter:}

Geschlecht:

Arthrose:

\section{Beschreibung:}

Splitter von Langknochen der unteren Extremität, 31g. 
Bezeichn.: Knochenklein

Kiste:

Skelet: $\quad$ K337 64/68 P4

Population: Großenrode
Verband: Verband

\section{Alter:}

Geschlecht:

Arthrose:

\section{Beschreibung:}

23g Fragmente und Splitter von Extremitäten. 
Bezeichn.: Knochenklein

Kiste:

Skelet: $\quad$ K292 64/68 S3

Population: Großenrode
Verband: Verband

\section{Alter:}

Geschlecht:

Arthrose:

\section{Beschreibung:}

$30 \mathrm{~g}$ Splitter von unterer Extremität und Fuß. 
Bezeichn.: Knochenklein Kiste:

Skelet: verschiedene

Population: Großenrode
Verband: Verband

\section{Alter:}

Geschlecht:

Arthrose:

\section{Beschreibung:}

42g Splitter von Costae, vertebrae, Extremitäten und Fuß. 
Bezeichn.: Knochenklein Kiste:

Skelet: verschiedene

Population: Großenrode
Verband: Verband

\section{Alter:}

Geschlecht:

Arthrose:

\section{Beschreibung:}

140g Knochensplitter von Rippen, Extremitäten, Hand und Fuß. 
Bezeichn.: Knochenklein

Kiste:

Skelet: 64/67-4

Population: Großenrode
Verband: Verband

\section{Alter:}

Geschlecht:

Arthrose:

\section{Beschreibung:}

49g Knochensplitter von Rippen, Scapula, Hand und Fuß 
Bezeichn.: Knochenklein Kiste:

Skelet: verschiedene

Population: Großenrode
Verband: Verband

\section{Alter:}

Geschlecht:

Arthrose:

\section{Beschreibung:}

9g Knochensplitter von Langknochen und Rippen. 
Bezeichn.: Knochenklein

Kiste:

Skelet: verschiedene

Population: Großenrode
Verband: Verband

\section{Alter:}

Geschlecht:

Arthrose:

\section{Beschreibung:}

$136 \mathrm{~g}$ Knochensplitter von Langknochen, Hand, Fuß, Becken und Scapula. 
Bezeichn.: Knochenklein

Kiste:

Skelet: $\quad$ K153 62/69 S2

Population: Großenrode
Verband: Verband

\section{Alter:}

Geschlecht:

Arthrose:

\section{Beschreibung:}

$52 \mathrm{~g}$ Knochensplitter, überwiegend Wirbelsplitter. 
Bezeichn.: Knochenklein Kiste:

Skelet: verschiedene

Population: Großenrode
Verband: Verband

\section{Alter:}

Geschlecht:

Arthrose:

\section{Beschreibung:}

73g Knochensplitter Langknochen, Hand, Fuß und andere. 
Bezeichn.: Knochenklein

Kiste:

Skelet: verschiedene

Population: Großenrode
Verband: Verband

\section{Alter:}

Geschlecht:

Arthrose:

\section{Beschreibung:}

93g Knochensplitter von Hand, Fuß, Langknochen und anderen. 
Bezeichn.: Knochenklein

Kiste:

Skelet: $\quad$ K154 61/68-S2

Population: Großenrode
Verband: Verband

\section{Alter:}

Geschlecht:

Arthrose:

\section{Beschreibung:}

89g Knochensplitter von Rippen und Extremitätenknochen. 
Bezeichn.: Knochenklein

Kiste:

Skelet: $\quad$ K166 61/68 P3

Population: Großenrode
Verband: Verband

\section{Alter:}

Geschlecht:

Arthrose:

\section{Beschreibung:}

103g Rippenfragmente, sie sind ohne Auffälligkeiten. 
Bezeichn.: Knochenklein

Kiste:

Skelet: $\quad$ K279 61/68 S3

Population: Großenrode
Verband: Verband

\section{Alter:}

Geschlecht:

Arthrose:

\section{Beschreibung:}

23g Hand- und Fußknochen und Splitter von Langknochen. 
Bezeichn.: Knochenklein Kiste:

Skelet: verschiedene

Population: Großenrode
Verband: Verband

\section{Alter:}

Geschlecht:

Arthrose:

\section{Beschreibung:}

97g Splitter und Fragmente von Hand, Fuß, Langknochen und Rippen. 
Bezeichn.: Knochenklein

Kiste:

Skelet: $\quad$ K327 61/68 P4

Population: Großenrode
Verband: Verband

\section{Alter:}

Geschlecht:

Arthrose:

\section{Beschreibung:}

29g Splitter und Fragmente von Hand, Fuß, Rippen, Wirbeln und Langknochen. 
Bezeichn.: Knochenklein Kiste:

Skelet: $\quad$ K311 61/68 P4

Population: Großenrode
Verband: Verband

\section{Alter:}

Geschlecht:

Arthrose:

\section{Beschreibung:}

$18 \mathrm{~g}$ Knochensplitter von Rippen, Hand und Fuß. 
Bezeichn.: Knochenklein

\section{Kiste:}

Skelet: verschiedene

Population: Großenrode

\section{Verband: $\quad$ Verband}

\section{Alter:}

Geschlecht:

Arthrose:

\section{Beschreibung:}

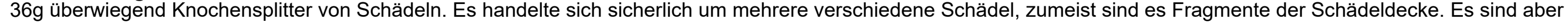
auch kleine Rippenfragmente, Hand, Fuß und sonstige ganz kleine Fragmente erhalten. 
Bezeichn.: Knochenklein Kiste:

Skelet: verschiedene

Population: Großenrode
Verband: Verband

\section{Alter:}

Geschlecht:

Arthrose:

\section{Beschreibung:}

132g Knochensplitter von Wirbeln, Rippen, Hand, Fuß, Schädeln, Langknochen. 
Bezeichn.: Knochenklein

\section{Kiste:}

Skelet: $\quad$ K43 62/68 S1 (P2)

Population: Großenrode

Seite:

rechts
Verband: $\quad$ Verband

Ges./Kr.: Gesund

\section{Alter:}

Geschlecht:

Arthrose:

\section{Beschreibung:}

Es sind $10 \mathrm{~g}$ Splitter von Handknochen, Rippenfragmenten und andere erhalten. 
Bezeichn.: Manus

Kiste: 4

Skelet: K141 62/68 S2

Population: Großenrode
Verband: $\square$ Verband

\section{Alter:}

Geschlecht:

Arthrose:

\section{Beschreibung:}

Fragmente zweier Mittelhandknochen. 


\section{Bezeichn.: Manus}

Kiste: 3

Skelet: K252 60/65 S3

Population: Großenrode

Seite: rechts
Verband: $\quad$ Verband

Alter: Jung

Geschlecht:

Arthrose:

\section{Beschreibung:}

Os metacarpale. 
Bezeichn.: Manus

Kiste:

Skelet: 63/63-4

Population: Großenrode
Verband: Verband

\section{Alter:}

Geschlecht:

Arthrose:

\section{Beschreibung:}

Ein Handwurzelknochen. 
Bezeichn:: Manus

\section{Kiste: 3}

Skelet: K264 S3

Population: Großenrode
Verband: Verband

\section{Alter:}

Geschlecht:

Arthrose:

\section{Beschreibung:}

Ein Mittelhandknochen. 
Bezeichn:: Manus

Kiste:

3

Skelet: K264 S3

Population: Großenrode
Verband: Verband

\section{Alter:}

Geschlecht:

Arthrose:

\section{Beschreibung:}

Os phalangis. 
Bezeichn.: Manus

Kiste: $\quad 10$

Skelet: $\quad 61 / 52$

Population: Großenrode
Verband: Verband

\section{Alter:}

Geschlecht:

Arthrose:

\section{Beschreibung:}

Ein erodiertes Os metacarpale. 
Bezeichn.: Manus

Kiste: $\quad 10$

Skelet: $\quad 61 / 52$

Population: Großenrode
Verband: Verband

\section{Alter:}

Geschlecht:

Arthrose:

\section{Beschreibung:}

Ein erodiertes Os metacarpale. 
Bezeichn.: Manus

Kiste: $\quad 10$

Skelet: $\quad 61 / 52$

Population: Großenrode
Verband: Verband

\section{Alter:}

Geschlecht:

Arthrose:

\section{Beschreibung:}

Ein erodiertes Os metacarpale. 
Bezeichn.: Manus

Kiste: $\quad 10$

Skelet: 62/58

Population: Großenrode
Verband: Verband

\section{Alter:}

Geschlecht:

Arthrose:

\section{Beschreibung:}

Ein Mittelhandknochen. 
Bezeichn.: Manus

Kiste: $\quad 10$

Skelet: 62/58

Population: Großenrode
Verband: Verband

\section{Alter:}

Geschlecht:

Arthrose:

\section{Beschreibung:}

Ein Mittelhandknochen. 
Bezeichn.: Manus

Kiste: $\quad 10$

Skelet: 62/58

Population: Großenrode
Verband: Verband

\section{Alter:}

Geschlecht:

Arthrose:

\section{Beschreibung:}

Ein Mittelhandknochen. 
Bezeichn: Manus

Verband: $\quad$ Verband

Kiste: $\quad 10$

Skelet: $\quad 63 / 54$

\section{Alter:}

Geschlecht:

Population: Großenrode

Arthrose:

\section{Beschreibung:}

Os phalangis proximalis. 
Bezeichn.: Manus

Kiste: $\quad 10$

Skelet: 63/54

Population: Großenrode
Verband: Verband

\section{Alter:}

Geschlecht:

Arthrose:

\section{Beschreibung:}

Ein Fragment eines Os metacarpale. 
Bezeichn.: Manus

Verband: $\quad$ Verband

Kiste: $\quad 10$

Skelet: $\quad 63 / 54$

\section{Alter:}

Geschlecht:

Population: Großenrode

\section{Arthrose:}

\section{Beschreibung:}

Os phalangis medialis. 
Bezeichn.: Manus

Kiste: $\quad 10$

Skelet: 63/54

Population: Großenrode
Verband: Verband

\section{Alter:}

Geschlecht:

Arthrose:

\section{Beschreibung:}

Ein Mittelhandknochen. 
Bezeichn.: Manus

Kiste: $\quad 10$

Skelet: 63/54

Population: Großenrode
Verband: Verband

\section{Alter:}

Geschlecht:

Arthrose:

\section{Beschreibung:}

Ein Mittelhandknochen. 
Bezeichn.: Manus

Kiste:

Skelet: K124

Population: Großenrode
Verband: Verband

\section{Alter:}

Geschlecht:

Arthrose:

Beschreibung:

Ein Os metacarpale proximalis 1. 
Bezeichn.: Manus

\section{Kiste:}

Skelet: K148

Population: Großenrode
Verband: Verband

\section{Alter:}

Geschlecht:

Arthrose:

\section{Beschreibung:}

Ein leicht erodiertes Os phalangis proximalis. 
Bezeichn.: Manus

Kiste:

Skelet: 63/68-1

Population: Großenrode
Verband: Verband

\section{Alter:}

Geschlecht:

Arthrose:

\section{Beschreibung:}

Ein Os phalangis. 
Bezeichn.: Manus

Kiste:

Skelet: 63/68-1

Population: Großenrode
Verband: Verband

\section{Alter:}

Geschlecht:

Arthrose:

\section{Beschreibung:}

Ein Os metacarpale. 
Bezeichn.: Manus

Kiste:

Skelet: Fragment K186

Population: Großenrode
Verband: Verband

\section{Alter:}

Geschlecht:

Arthrose:

\section{Beschreibung:}

Ein Handknochen. 
Bezeichn.: Manus

Kiste:

Skelet: K239

Population: Großenrode
Verband: Verband

\section{Alter:}

Geschlecht:

Arthrose:

\section{Beschreibung:}

Ein Handknochen. 
Bezeichn.: Manus

Kiste:

Skelet: K239

Population: Großenrode
Verband: Verband

\section{Alter:}

Geschlecht:

Arthrose:

\section{Beschreibung:}

Ein Handknochen. 
Bezeichn.: Manus

Kiste:

Skelet: K239

Population: Großenrode
Verband: Verband

\section{Alter:}

Geschlecht:

Arthrose:

\section{Beschreibung:}

Ein Handknochen. 
Bezeichn.: Manus

Kiste:

Skelet: K239

Population: Großenrode
Verband: Verband

\section{Alter:}

Geschlecht:

Arthrose:

\section{Beschreibung:}

Ein Handknochen. 
Bezeichn.: Manus

\section{Kiste:}

Skelet: K243

Population: Großenrode
Verband: Verband

\section{Alter:}

Geschlecht:

Arthrose:

\section{Beschreibung:}

Ein Handknochen. 
Bezeichn.: Manus

Kiste:

Skelet: K243

Population: Großenrode
Verband: Verband

\section{Alter:}

Geschlecht:

Arthrose:

\section{Beschreibung:}

Ein Handknochen. 
Bezeichn:: Manus

Kiste: 8

Skelet: $\quad$ K164 61/68-P3

Population: Großenrode

Seite: rechts

Erhaltung:
Verband: $\quad \square$ Verband

Alter:

Ges./Kr.: Gesund

\section{Geschlecht: $q<\lambda$}

Arthrose:

\section{Beschreibung:}

Ein Fragment eines massiven Os humeri. Es ist mittelmäßig erodiert. 
Bezeichn.: Manus / Pes

\section{Kiste:}

Skelet: K124

Population: Großenrode
Verband: Verband

\section{Alter:}

Geschlecht:

Arthrose:

\section{Beschreibung:}

Ein Os phalangis. 
Bezeichn.: Manus / Pes

Kiste:

Skelet: K124

Population: Großenrode
Verband: Verband

\section{Alter:}

Geschlecht:

Arthrose:

\section{Beschreibung:}

Ein Os metacarpale oder metatarsale. Dieses Fundstück ist nicht genauer zuzuordnen. 
Bezeichn.: Manus / Pes

\section{Kiste:}

Skelet: K81

Population: Großenrode
Verband: Verband

\section{Alter:}

Geschlecht:

Arthrose:

\section{Beschreibung:}

Os phalangis. 
Bezeichn:: Manus / Pes

Kiste:

Skelet: $\quad 61 / 56$

Population: Großenrode

\section{Verband:}

\section{Alter:}

Ges./Kr.: Gesund

Geschlecht:

Arthrose:

\begin{tabular}{l|l|l} 
Maß & Wert & Einheit \\
\hline Breite & 12,1 & $\mathrm{~mm}$ \\
Länge & 38,68 & $\mathrm{~mm}$ \\
& & \\
& & \\
& &
\end{tabular}

\section{Beschreibung:}

Ein gut erhaltenes Fundstück, welches einer Hand oder einem Fuß nicht eindeutig zuzuordnen war. Es handelt sich entweder um ein Os metatarsale oder ein Os metacarpale. 


\section{Bezeichn.: Pes}

\section{Kiste: $\quad 9$}

Skelet: $\quad 63 / 67$ P3 K229

Population: Großenrode
Verband: $\quad$ Verband

Alter: $\quad 13-18(19)$

Geschlecht:

Arthrose:

\section{Beschreibung:}

Hier sind 9 Fußfragmente eines juvenilen Individuums erhalten. Sie sind recht stark erodiert. 
Bezeichn.: Pes

Kiste: 2

Skelet: $\quad 62 / 60$

Population: Großenrode
Verband: Verband

\section{Alter:}

Geschlecht:

Arthrose:

\section{Beschreibung:}

Fußgelenkknochen erodiert. 
Bezeichn:: Pes

Kiste: $\quad 10$

Skelet: $\quad 61 / 55$

Population: Großenrode
Verband: Verband

\section{Alter:}

Geschlecht:

Arthrose:

\section{Beschreibung:}

Ein Os metatarsale. 
Bezeichn:: Pes

Kiste: $\quad 10$

Skelet: $\quad 61 / 55$

Population: Großenrode
Verband: Verband

\section{Alter:}

Geschlecht:

Arthrose:

\section{Beschreibung:}

Ein Os phalangis. 
Bezeichn:: Pes

Kiste: $\quad 10$

Skelet: $\quad 61 / 55$

Population: Großenrode
Verband: Verband

\section{Alter:}

Geschlecht:

Arthrose:

\section{Beschreibung:}

Ein Os phalangis proximalis 1 . 
Bezeichn:: Pes

Kiste: $\quad 10$

Skelet: $\quad 61 / 55$

Population: Großenrode
Verband: Verband

\section{Alter:}

Geschlecht:

Arthrose:

\section{Beschreibung:}

Ein Os phalangis proximalis 1 . 
Bezeichn.: Pes

\section{Kiste: $\quad 10$}

Skelet: $\quad 62 / 53$ klein

Population: Großenrode
Verband: Verband

\section{Alter:}

Geschlecht:

Arthrose:

\section{Beschreibung:}

Ein Os phalangis proximalis 1 . 
Bezeichn.: Pes

\section{Kiste: 10}

Skelet: $\quad$ Tüte nur mit 62/51

Population: Großenrode
Verband: Verband

\section{Alter:}

Geschlecht:

Arthrose:

Beschreibung:

Ein Mittelfußknochen. 
Bezeichn.: Pes

\section{Kiste: 10}

Skelet: $\quad$ Tüte nur mit 62/51

Population: Großenrode
Verband: Verband

\section{Alter:}

Geschlecht:

Arthrose:

Beschreibung:

Ein Mittelfußknochen. 
Bezeichn.: Pes

Kiste: $\quad 10$

Skelet: 62/58

Population: Großenrode
Verband: Verband

\section{Alter:}

Geschlecht:

Arthrose:

\section{Beschreibung:}

Ein Os metatarsale. 
Bezeichn.: Pes

Kiste: $\quad 10$

Skelet: 62/58

Population: Großenrode
Verband: Verband

\section{Alter:}

Geschlecht:

Arthrose:

Beschreibung:

Ein Mittelfußknochen. 
Bezeichn.: Pes

Kiste: $\quad 10$

Skelet: 62/58

Population: Großenrode
Verband: Verband

\section{Alter:}

Geschlecht:

Arthrose:

Beschreibung:

Ein Mittelfußknochen. 
Bezeichn.: Pes

Kiste: $\quad 10$

Skelet: 63/54

Population: Großenrode
Verband: Verband

\section{Alter:}

Geschlecht:

Arthrose:

Beschreibung:

Ein Mittelfußknochen. 
Bezeichn:: Pes

\section{Kiste: $\quad 10$}

Skelet: $\quad 63 / 54$

Population: Großenrode
Verband: Verband

\section{Alter:}

Geschlecht:

Arthrose:

\section{Beschreibung:}

Ein erodiertes Os phalangis 1 . 
Bezeichn.: Pes

Kiste: $\quad 10$

Skelet: 63/54

Population: Großenrode
Verband: Verband

\section{Alter:}

Geschlecht:

Arthrose:

\section{Beschreibung:}

Ein Os phalangis. 
Bezeichn.: Pes

Kiste: 1

Skelet: $\quad \mathrm{K} 124$

Population: Großenrode
Verband: Verband

\section{Alter:}

Geschlecht:

Arthrose:

\section{Beschreibung:}

Ein Fragment eines Os metatarsale. 
Bezeichn.: Pes

Kiste:

Skelet: K124

Population: Großenrode
Verband: Verband

\section{Alter:}

Geschlecht:

Arthrose:

Beschreibung:

Mittelfuß. 
Bezeichn.: Pes

Kiste: 1

Skelet: K244

Population: Großenrode

Seite:

links

Verband: Verband

\section{Alter:}

Geschlecht:

Arthrose:

\section{Beschreibung:}

Ein Os cuneiforme intermediale. 
Bezeichn.: Pes

Kiste: 1

Skelet: K244

Population: Großenrode

Seite:

links

Verband: Verband

\title{
Alter:
}

Geschlecht:

Arthrose:

\author{
Beschreibung: \\ Ein Os cuneiforme laterale.
}


Bezeichn.: Pes

Kiste: 1

Skelet: K244

Population: Großenrode
Verband: Verband

\section{Alter:}

Geschlecht:

Arthrose:

\section{Beschreibung:}

Os metatarsale. 
Bezeichn.: Pes

Kiste: 1

Skelet: K244

Population: Großenrode
Verband: Verband

\section{Alter:}

Geschlecht:

Arthrose:

\section{Beschreibung:}

Os metatarsale. 
Bezeichn.: Pes

Kiste: 1

Skelet: 63/68-1

Population: Großenrode
Verband: Verband

\section{Alter:}

Geschlecht:

Arthrose:

\section{Beschreibung:}

Ein Os metatarsale. 
Bezeichn.: Pes

Kiste: 1

Skelet: 63/68-1

Population: Großenrode
Verband: Verband

\section{Alter:}

Geschlecht:

Arthrose:

\section{Beschreibung:}

Ein Os metatarsale. 
Bezeichn.: Pes

Kiste: 1

Skelet: $\quad 63 / 68-1$

Population: Großenrode
Verband: Verband

\section{Alter:}

Geschlecht:

Arthrose:

Beschreibung:

Ein Mittelfußknochen. 
Bezeichn.: Pes

Kiste: 1

Skelet: 63/68-1

Population: Großenrode
Verband: Verband

\section{Alter:}

Geschlecht:

Arthrose:

\section{Beschreibung:}

Ein Os phalangis. 
Bezeichn.: Pes

Kiste:

Skelet: K81

Population: Großenrode
Verband: Verband

\section{Alter:}

Geschlecht:

Arthrose:

\section{Beschreibung:}

Ein Os metatarsale. 
Bezeichn.: Pes

Kiste:

Skelet: K81

Population: Großenrode
Verband: Verband

\section{Alter:}

Geschlecht:

Arthrose:

\section{Beschreibung:}

Ein Os metatarsale. 


\section{Bezeichn.: Pes}

Kiste:

Skelet: Fragment K186

Population: Großenrode
Verband: Verband

\section{Alter:}

Geschlecht:

Arthrose:

\section{Beschreibung:}

Ein kleines Fragment eines Fußknochens. 
Bezeichn.: Pes

Kiste: 1

Skelet: K243

Population: Großenrode
Verband: Verband

\section{Alter:}

Geschlecht:

Arthrose:

\section{Beschreibung:}

Ein Fußknochen. 
Bezeichn.: Pes

Kiste:

Skelet: K243

Population: Großenrode
Verband: Verband

\section{Alter:}

Geschlecht:

Arthrose:

Beschreibung:

Ein Fußknochen. 
Bezeichn.: Pes

Kiste:

Skelet: K243

Population: Großenrode
Verband: Verband

\section{Alter:}

Geschlecht:

Arthrose:

Beschreibung:

Ein Fußknochen. 
Bezeichn.: Pes

Kiste:

Skelet: K243

Population: Großenrode
Verband: Verband

\section{Alter:}

Geschlecht:

Arthrose:

Beschreibung:

Ein Fußknochen. 
Bezeichn.: Pes

Kiste: $\quad 4$

Skelet: $\quad$ K127 62/68 S2

Population: Großenrode
Verband: Verband

\section{Alter:}

Geschlecht:

Arthrose:

\section{Beschreibung:}

Stark erodiert. 
Bezeichn.: Pes

Kiste: 4

Skelet: $\quad$ K43 62/68 S1 (P2)

Population: Großenrode

Seite:

rechts

Verband: $\quad$ Verband

Alter:

Geschlecht:

Arthrose:

\author{
Beschreibung: \\ Ein Mittelfußknochen aus einem Verband.
}


Bezeichn.: Pes

Kiste: 4

Skelet: $\quad$ K43 62/68 S1 (P2)

Population: Großenrode

Seite:

rechts

Verband: $\quad$ Verband

Alter:

Geschlecht:

Arthrose:

\author{
Beschreibung: \\ Ein Mittelfußknochen aus einem Verband.
}


Bezeichn.: Pes

Kiste: 4

Skelet: $\quad$ K43 62/68 S1 (P2)

Population: Großenrode

Seite:

links

Verband: $\quad$ Verband

Alter:

Geschlecht:

Arthrose:

\author{
Beschreibung: \\ Ein Mittelfußknochen aus einem Verband.
}


Bezeichn.: Pes

Kiste: 4

Skelet: $\quad$ K43 62/68 S1 (P2)

Population: Großenrode

Seite:

links

Verband: $\quad$ Verband

Alter:

Geschlecht:

Arthrose:

\author{
Beschreibung: \\ Ein Mittelfußknochen aus einem Verband.
}


Bezeichn.: Pes

Kiste: 4

Skelet: $\quad$ K43 62/68 S1 (P2)

Population: Großenrode

Seite:

links

Verband: $\quad$ Verband

Alter:

Geschlecht:

Arthrose:

\author{
Beschreibung: \\ Ein Mittelfußknochen aus einem Verband.
}


Bezeichn.: Phalanx Manus

\section{Kiste:}

Skelet: K283

Population: Großenrode
Verband: Verband

\section{Alter:}

Geschlecht:

Arthrose:

\section{Beschreibung:}

Recht gut erhalten. 
Bezeichn.: Phalanx Manus

\section{Kiste:}

Skelet: K283

Population: Großenrode
Verband: Verband

\section{Alter:}

Geschlecht:

Arthrose:

\section{Beschreibung:}

Ein Fragment. 
Bezeichn.: Phalanx Manus

\section{Kiste:}

Skelet: K283

Population: Großenrode
Verband: Verband

\section{Alter:}

Geschlecht:

Arthrose:

\section{Beschreibung:}

Ein Fragment. 
Bezeichn.: Phalanx Manus

\section{Kiste:}

Skelet: K283

Population: Großenrode
Verband: Verband

\section{Alter:}

Geschlecht:

Arthrose:

\section{Beschreibung:}

Ein Fragment. 
Bezeichn.: Phalanx Manus / Pedis

\section{Kiste:}

Skelet: 10

Population: Großenrode
Verband: Verband

\section{Alter:}

Geschlecht:

Arthrose:

\section{Beschreibung:}

Ein Os phalangis von Hand oder Fuß, das Fundstück ist gut erhalten. 
Bezeichn.: Phalanx Manus / Pedis

Kiste: 2

Skelet: Knochenklein

Population: Großenrode

Seite:
Verband: $\quad$ Verband

Alter:

Geschlecht:

Arthrose:
Ges./Kr.: Krank

Krankh.: Arthrose

\section{Beschreibung:}

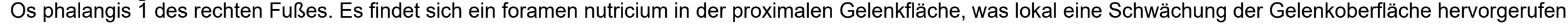
hat. Hier ist eine lokale Arthrose zu diagnostizieren. 
Bezeichn.: Phalanx Manus / Pedis

Kiste:

Skelet: $\quad 59 / 65-3$

Population: Großenrode
Verband: Verband

\section{Alter:}

Geschlecht:

Arthrose:

\section{Beschreibung:}

Hand oder Fuß, das Fundstück fällt wegen seiner merkwürdigen Form auf. 
Bezeichn.: Phalanx Manus / Pedis

\section{Kiste:}

Skelet:

10

Population: Großenrode
Verband: Verband

\section{Alter:}

Geschlecht:

Arthrose:

\section{Beschreibung:}

Ein ganz erhaltenes Os phalangis distalis, es ist leicht erodiert 
Bezeichn.: Phalanx Manus / Pedis

\section{Kiste:}

Skelet: 10

Population: Großenrode
Verband:

\section{Alter:}

Ges./Kr.: Gesund

Geschlecht:

Arthrose:

\section{Maß}

Länge

\begin{tabular}{l|l} 
Wert & Einheit \\
\hline 37,76 & $\mathrm{~mm}$
\end{tabular}

\section{Beschreibung:}

Ein junges Os phalangis. 
Bezeichn.: Phalanx Manus / Pedis

\section{Kiste:}

Skelet: K286 S3

Population: Großenrode

Seite:

n. def.

Verband: Verband

Alter:

Geschlecht:

Arthrose:

\section{Beschreibung:}

Hand oder Fuß. 
Bezeichn.: Phalanx Pedis

\section{Kiste:}

Skelet: $\quad$ K43 62/68 S1 (P2)

Population: Großenrode

Seite:

rechts

Verband: $\quad$ Verband

\title{
Alter:
}

Geschlecht:

Arthrose:

\author{
Beschreibung: \\ Ein Os phalangis 1 proximal des Fußes.
}


Bezeichn.: Phalanx Pedis

\section{Kiste:}

Skelet: $\quad$ K43 62/68 S1 (P2)

Population: Großenrode

Seite:

links
Verband: Verband

\section{Alter:}

Geschlecht:

Arthrose:

\section{Beschreibung:}

Ein Os phalangis 1 proximalis. Es ist der linken Seite eines Fußes zuzuordnen. 
Bezeichn.: Phalanx Pedis

\section{Kiste:}

Skelet: K38 62/68 S1

Population: Großenrode

Seite:

\section{Verband:}

\section{Alter:}

Geschlecht:

Arthrose:
Verband

\section{Ges./Kr.: Krank}

\section{Krankh.: Arthrose}

\section{Arthritis}

Osteochondrosis

dissecans

\section{Beschreibung:}

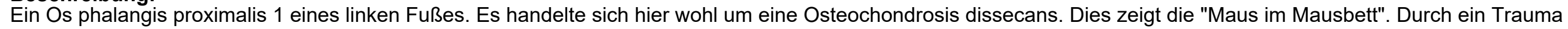

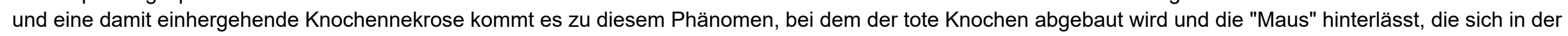

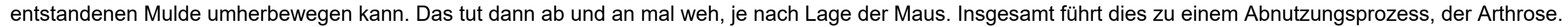


Bezeichn:: Phalanx Pedis

\section{Kiste:}

Skelet: $\quad$ K38 62/68 S1

Population: Großenrode

Seite:
Verband:

Verband

\section{Alter:}

Geschlecht:

Arthrose:

\section{Beschreibung:}

Os phalangis 2 proximal des linken Fußes. 
Bezeichn.: Phalanx Pedis

Kiste:

Skelet: $\quad$ K38 62/68 S1

Population: Großenrode

Seite:
Verband: $\quad$ Verband

Alter:

Geschlecht:

Arthrose:
Ges./Kr.: Krank

Krankh.: Arthrose

\section{Beschreibung:}

Ein Os phalangis pedis 5 proximal, hier handelt es sich ebenfalls um eine beginnende Knochennekrose durch Abnutzungsprozesse oder Knochendefekte. Dieses Phänomen könnte auch erblich bedingt sein. 
Bezeichn.: Phalanx Pedis

\section{Kiste:}

Skelet: $\quad$ K38 62/68 S1

Population: Großenrode

Seite:

links
Verband:

Verband

\section{Alter:}

Geschlecht:

Arthrose:

\section{Beschreibung:}

Ein Os phalangis 1 distal des linken Fußes. 
Bezeichn.: Phalanx Pedis

\section{Kiste:}

Skelet: $\quad$ K38 62/68 S1

Population: Großenrode

Seite:

links

Verband: $\quad$ Verband

Alter:

Geschlecht:

Arthrose:

\section{Beschreibung:}

Os phalangis 2 proximal des linken Fußes. 
Bezeichn.: Phalanx Pedis

\section{Kiste:}

Skelet: $\quad 63 / 68-3$

Population: Großenrode

Seite:

links
Verband: Verband

\section{Alter:}

Geschlecht:

Arthrose:

\section{Beschreibung:}

Os phalangis proximalis 1 eines Fußes, das Fundstück ist gut erhalten 
Bezeichn:: Phalanx Pedis

Kiste:

Skelet: $\quad$ K369 64/67 P4

Population: Großenrode

Seite:

links
Verband: $\quad \square$ Verband

Alter:

Geschlecht:

Arthrose:
Ges./Kr.: Krank

Krankh.: Arthrose

\section{Beschreibung:}

Ein zu 90\% erhaltenes Os phalangis pedis 1 proximal der linken Seite. Es weist in der Gelenkfläche deutliche Spuren einer Arthrose auf. 
Bezeichn.: Phalanx Pedis

Kiste:

8

Skelet: $\quad$ K349 61/68 S4

Population: Großenrode

Seite:

links
Verband:

Verband

\section{Alter:}

Geschlecht: $ð$

Arthrose:
Ges./Kr.: Gesund

\begin{tabular}{l|l|l} 
Maß & Wert & Einheit \\
\hline Breite & 22,62 & $\mathrm{~mm}$ \\
Länge & 33,15 & $\mathrm{~mm}$ \\
& & \\
& & \\
& &
\end{tabular}

\section{Beschreibung:}

Ein vollständiges Os phalangis proximalis 1 des Fußes. Der Knochen ist sehr massiv. 


\section{Detailbericht aller Funde für die Population Großenrode}

\section{Zahn}

Population:

Großenrode

Geschlecht:

Alter:

Beschreibung: Die Hälfte der Wurzel ist abfrakturiert

\subsubsection{5 / 17}

Skelett: K246 63/68 P3

Krankheiten:
1

\begin{tabular}{c|l|l} 
Arthrose & rechts & links \\
\hline Caput & & \\
\hline Fossa & &
\end{tabular}

\section{Zahn Status Parodontium} 21 


\section{UK}

Population: Großenrode

Geschlecht:

Alter:

(25) 28 - 35 (38)

\section{Beschreibung:}

\subsubsection{5 / 19}

Skelett: K80 63/68 P2

Krankheiten:

1

\begin{tabular}{c|l|l} 
Arthrose & rechts & links \\
\hline Caput & & \\
\hline Fossa & &
\end{tabular}

\begin{tabular}{|c|c|c|c|c|c|c|c|c|}
\hline Zahn & Status & Parodontium & Apikale Prozesse & Zahnstein & Karies & Abrasion & Neubildung & Schmelzhypoplasie \\
\hline 44 & & 0 & 0 & 0 & 0 & $\mathrm{O}$ & 0 & $U$ \\
\hline 46 & & 0 & 0 & $\mathrm{~K}$ & 0 & 0 & * & $U$ \\
\hline 47 & & 0 & 0 & $\mathrm{~K}$ & 0 & 0 & 0 & $U$ \\
\hline
\end{tabular}




\section{Zahn}

Population: Großenrode

Geschlecht:

Alter:

(3) $4-6(7)$

Beschreibung: Der Zahn ist neben wenigen kleinen Unterkiefersplittern erhalten.

\section{Zahn Status Parodontium Apikale Prozesse}

46

\subsubsection{5 / 1}

Skelett: K60 63/68 S1

Krankheiten:

1

\begin{tabular}{c|l|l} 
Arthrose & rechts & links \\
\hline Caput & & \\
\hline Fossa & &
\end{tabular}

Zahnstein

K 1
Karies

B 1
Abrasion

0

\section{Neubildung}

0 


\section{OK}

Population: Großenrode

Geschlecht:

Alter:

(22) 25 - 30 (34)

\subsubsection{5 / 11}

Skelett: K236 63/68 P3

Krankheiten:

\section{Beschreibung:}

\begin{tabular}{|c|c|c|c|c|c|c|c|c|c|c|}
\hline Zahn & Status & Parodontium & Apikale Prozesse & Zahnstein & Karies & \multicolumn{2}{|c|}{ Abrasion } & Neubildung & \multicolumn{2}{|c|}{ Schmelzhypoplasie } \\
\hline 11 & & & 0 & 0 & 0 & $\mathrm{O}$ & 3 & 0 & $U$ & 1 \\
\hline 12 & & & 0 & 0 & 0 & $\mathrm{O}$ & 3 & 0 & $U$ & 1 \\
\hline 13 & & & 0 & 0 & 0 & $\mathrm{O}$ & 3 & 0 & $U$ & 1 \\
\hline 14 & & & 0 & 0 & 0 & $\mathrm{O}$ & 3 & 0 & $U$ & 1 \\
\hline 15 & & & 0 & 0 & 0 & $\mathrm{O}$ & 3 & 0 & $U$ & 1 \\
\hline 16 & & & 0 & $\mathrm{~K}$ & 0 & $\mathrm{O}$ & 3 & 0 & $U$ & 1 \\
\hline 18 & & & 0 & $\mathrm{~K}$ & 0 & $\mathrm{O}$ & 2 & 0 & 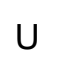 & 1 \\
\hline 23 & & 0 & 0 & 0 & 0 & $\mathrm{O}$ & 3 & 0 & $U$ & 1 \\
\hline 24 & & 0 & 0 & 0 & 0 & 0 & 3 & 0 & $U$ & 1 \\
\hline 25 & & 0 & 0 & 0 & 0 & 0 & 3 & 0 & $U$ & 1 \\
\hline 26 & & 0 & 0 & $\mathrm{~K}$ & 0 & 0 & 3 & 0 & $U$ & 1 \\
\hline
\end{tabular}




\section{UK}

Population: Großenrode

Geschlecht:

Alter:

Beschreibung: Hier ist ein Fragment eines Unterkiefers erhalten. Das Fragment misst 18,28mm x 14,42mm. Es wird aus Dokumentationszwecken beschrieben, kann aber nicht näher zugeordnet werden. Somit wird es nicht mit ausgewertet.
1

Krankheiten:

\begin{tabular}{c|l|l} 
Arthrose & rechts & links \\
\hline Caput & & \\
\hline Fossa & &
\end{tabular}

Zahn Status Parodontium Apikale Prozesse Zahnstein Karies Abrasion Neubildung Schmelzhypoplasie
$\mathrm{xx}$ 


\section{Zahn}

Population: Großenrode

Geschlecht:

Alter:

Beschreibung: Von diesem Frontzahn ist das apicale Drittel abfrakturiert.
1

Skelett: K240 63/68 P3 Krankheiten:

\begin{tabular}{c|l|l} 
Arthrose & rechts & links \\
\hline Caput & & \\
\hline Fossa & &
\end{tabular}

Zahn Status Parodontium Apikale Prozesse 21 Zahnstein

0
Karies

0
Abrasion

O 2
Neubildung

0

Schmelzhypoplasie $\mathrm{T} \quad 1$ 


\section{Zähne}

Population:

Großenrode

Geschlecht:

Alter:

(5) 7 - $9(11)$

\section{Beschreibung:}

\section{Zahn Status Parodontium}

Apikale Prozesse

( )

14

()

\subsubsection{5 / 10}

Skelett: K50 63/68 S1

Krankheiten:

1

\begin{tabular}{c|l|l} 
Arthrose & rechts & links \\
\hline Caput & & \\
\hline Fossa & &
\end{tabular}

Zahnstein Karies

Abrasion

Neubildung

Schmelzhypoplasie T 1

T 1 


\section{Zähne}

Population:

Großenrode

Geschlecht:

Alter:

(5) 7 - 8 (10)

\subsubsection{5 / 11}

Skelett: $\quad 63 / 68-1$

Krankheiten:

\section{Beschreibung:}

\begin{tabular}{|c|c|c|c|c|c|c|c|c|}
\hline Zahn & Status & Parodontium & Apikale Prozesse & Zahnstein & Karies & Abrasion & Neubildung & Schmelzhypoplasie \\
\hline 11 & & & & 0 & 0 & $\mathrm{O}$ & 0 & $\mathrm{~T}$ \\
\hline 23 & ( ) & & & & & & & $\mathrm{T}$ \\
\hline 24 & ( ) & & & & & & & $\mathrm{T}$ \\
\hline 32 & & & & K & 0 & $\mathrm{O}$ & 0 & $\mathrm{~T}$ \\
\hline 41 & & & & 0 & 0 & $\mathrm{O}$ & 0 & $\mathrm{~T}$ \\
\hline 42 & & & & K & 0 & 0 & 0 & $\mathrm{~T}$ \\
\hline 54 & & & & 0 & $\mathrm{H}$ & $\mathrm{O}$ & 0 & 0 \\
\hline 55 & & & & $\mathrm{~K}$ & $\mathrm{H}$ & $\mathrm{O}$ & * & 0 \\
\hline
\end{tabular}




\section{Zähne}

Population:

Großenrode

Geschlecht:

Alter:

(25) 28 - 35 (38)

\section{Beschreibung:}

\subsubsection{5 / 12}

Skelett: $\quad 63 / 68-2$

Krankheiten:

\begin{tabular}{c|l|l} 
Arthrose & rechts & links \\
\hline Caput & & \\
\hline Fossa & &
\end{tabular}

\begin{tabular}{|c|c|c|c|c|c|c|c|c|}
\hline Zahn & Status & Parodontium & Apikale Prozesse & Zahnstein & Karies & Abrasion & Neubildung & Schmelzhypoplasie \\
\hline 26 & & & 0 & 0 & 0 & K & * & 0 \\
\hline 27 & & & 0 & 0 & 0 & K & * & 0 \\
\hline
\end{tabular}




\section{Zähne}

Population: Großenrode

Geschlecht: indifferent

Alter:

(8) 12 - 15 (20)

\section{Beschreibung:}

\subsubsection{5 / 13}

Skelett: $63 / 68-2$

\section{Krankheiten:}

1

\begin{tabular}{c|l|l} 
Arthrose & rechts & links \\
\hline Caput & & \\
\hline Fossa & &
\end{tabular}

\begin{tabular}{|c|c|c|c|c|c|c|c|c|}
\hline Zahn & Status & Parodontium & Apikale Prozesse & Zahnstein & Karies & Abrasion & Neubildung & Schmelzhypoplasie \\
\hline 13 & & & & 0 & 0 & 0 & 0 & $\mathrm{~T}$ \\
\hline 36 & & & & K & 0 & 0 & 0 & $\mathrm{~T}$ \\
\hline 44 & & & & 0 & 0 & 0 & 0 & $\mathrm{~T}$ \\
\hline
\end{tabular}




\section{Zähne}

Population: Großenrode

Geschlecht:

Alter:

Beschreibung: Bei 12 und 14 ist die komplette Wurzel abfrakturiert und bei 22 ist das letzte Drittel abfrakturiert.

\subsubsection{5 / 14}

Skelett: $63 / 68-2$
Krankheiten:

\begin{tabular}{c|l|l} 
Arthrose & rechts & links \\
\hline Caput & & \\
\hline Fossa & &
\end{tabular}

$\begin{array}{llcccccc}\text { Zahn Status } & \text { Parodontium } & \text { Apikale Prozesse } & \text { Zahnstein } & \text { Karies } & \text { Abrasion } & \text { Neubildung } & \text { Schmelzhypoplasie } \\ 12 & & 0 & 0 & 0 & 0 & \text { T } & 1 \\ 14 & & 0 & 0 & 0 & 1 & 0 \\ 22 & & 0 & 0 & 0 & 0\end{array}$




\section{Zahn}

Population: Großenrode

Geschlecht:

Alter:

Beschreibung: Hier ist die Wurzel abfrakturiert.
1

Krankheiten:

\begin{tabular}{c|l|l} 
Arthrose & rechts & links \\
\hline Caput & & \\
\hline Fossa & &
\end{tabular}

\section{Zahn Status Parodontium Apikale Prozesse}

21
Zahnstein

K 1
Karies

0
Abrasion

O 2
Neubildung

0 


\section{Zahn}

Population:

Großenrode

Geschlecht:

Alter:

(7) 10 - $11(14)$

\section{Beschreibung:}

\subsubsection{5 / 16}

Skelett: K9

Krankheiten:

\begin{tabular}{c|l|l} 
Arthrose & rechts & links \\
\hline Caput & & \\
\hline Fossa & &
\end{tabular}

Zahnstein

Karies

0
1

\section{Abrasion Neubildung Schmelzhypoplasie}

0 T 1 


\section{Zahn}

Population: Großenrode

Geschlecht:

Alter:

Beschreibung: Ein stark erodierter, aber vollständiger Zahn.
1

Krankheiten:

\begin{tabular}{c|l|l} 
Arthrose & rechts & links \\
\hline Caput & & \\
\hline Fossa & &
\end{tabular}




\section{Zahn}

Population: Großenrode

Geschlecht:

Alter:

Beschreibung: Von diesem Zahn ist nur die Krone erhalten, die Wurzel ist abfrakturiert.
Krankheiten:

Skelett: $\quad$ K7 63/68 S0
1

\begin{tabular}{c|l|l} 
Arthrose & rechts & links \\
\hline Caput & & \\
\hline Fossa & &
\end{tabular}




\section{Zähne}

Population: Großenrode

Geschlecht:

Alter:

Beschreibung: Von diesen Zähnen sind lediglich Bruchstücke erhalten.

\section{Alter:}

\subsubsection{5 / 19}

1

\begin{tabular}{c|l|l} 
Arthrose & rechts & links \\
\hline Caput & & \\
\hline Fossa & &
\end{tabular}

Krankheiten:

Skelett: K186 63/68 P3

Krankheiten:

Beschreibung: Von diesen Zähnen sind lediglich Bruchstücke erhalten.

\section{Zahn Status Parodontium \\ 31

Status

edontium

35
Apikale Prozesse

\section{Zahnstein}

\section{Karies}

0
Abrasion

O 1

O 3

\section{Neubildung}

0

Schmelzhypoplasie $\mathrm{T}$

$\begin{array}{ll}\mathrm{T} & 1\end{array}$ 


\section{Zähne}

Population:

Großenrode

Geschlecht:

Alter:

(3) 4 - 6 (7)

Beschreibung: Hier ist nur die Krone erhalten

\subsubsection{5 / 20}

Skelett: K282 63/68 S3

Krankheiten:

1

\begin{tabular}{c|l|l} 
Arthrose & rechts & links \\
\hline Caput & & \\
\hline Fossa & &
\end{tabular}

Zahn Status Parodontium Apikale Prozesse 36
Zahnstein
Karies

0
Abrasion

0 


\section{OK; UK}

Population:

Großenrode

Geschlecht:

Alter:

(6) 8 - $9(11)$
16.02.2015 / 43

Skelett: K9 63/68 S0-S2

Krankheiten:

Beschreibung: Die Unterkiefer 7er weisen jeweils ein foramen caecum auf.

\begin{tabular}{|c|c|c|c|c|c|c|c|c|c|c|}
\hline Zahn & Status & Parodontium & Apikale Prozesse & $\mathrm{Za}$ & instein & Karies & $\mathrm{Ab}$ & sion & Neubildung & Schmelzhypoplasie \\
\hline 16 & & & 0 & K & 1 & 0 & $\mathrm{O}$ & 2 & 0 & $\mathrm{~T}$ \\
\hline 23 & ( ) & & & & & & & & & $\mathrm{T}$ \\
\hline 24 & ( ) & & & & & & & & & $\mathrm{T}$ \\
\hline 25 & & & & & & & & & & $\mathrm{~T}$ \\
\hline 26 & & & 0 & $\mathrm{~K}$ & 1 & & $\mathrm{O}$ & 2 & 0 & $\mathrm{~T}$ \\
\hline 33 & & & & & & & & & & $\mathrm{~T}$ \\
\hline 34 & ( ) & & & & & & & & & 0 \\
\hline 35 & ( ) & & & & & & & & & 0 \\
\hline 36 & & 0 & 0 & K & 1 & 0 & $\mathrm{O}$ & 2 & 0 & $\mathrm{~T}$ \\
\hline 37 & ( ) & & & & & & & 0 & 0 & $\mathrm{~T}$ \\
\hline 46 & & & 0 & $\mathrm{~K}$ & 1 & 0 & 0 & 2 & 0 & $\mathrm{~T}$ \\
\hline
\end{tabular}




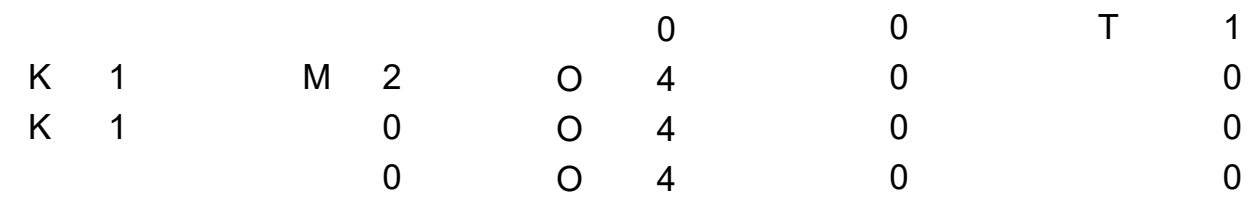




\section{UK}

Population: Großenrode

Geschlecht:

Alter:

Beschreibung: Hier ist ein Teil eines corpus mandibulae, genauer aus dem Teil des 4. Quadranten erhalten. Die aufgeführten Zähne gehören wohl trotzdem zu diesem erhaltenen Fundstück.
10

\section{Krankheiten:}

\begin{tabular}{c|l|l} 
Arthrose & rechts & links \\
\hline Caput & & \\
\hline Fossa & &
\end{tabular}

\begin{tabular}{|c|c|c|c|c|c|c|c|c|}
\hline Zahn & Status & Parodontium & Apikale Prozesse & Zahnstein & Karies & Abrasion & Neubildung & Schmelzhypoplasie \\
\hline 46 & $\mathrm{v}$ & & 0 & & & & & \\
\hline
\end{tabular}


UK

Population: Großenrode

Geschlecht:

Alter:

(25) 28 - 35 (38)

\subsubsection{5 / 31}

Skelett: 431

Krankheiten:

\section{Beschreibung:}

10

\begin{tabular}{c|l|l} 
Arthrose & rechts & links \\
\hline Caput & & \\
\hline Fossa & &
\end{tabular}

\begin{tabular}{|c|c|c|c|c|c|c|c|c|}
\hline Zahn & Status & Parodontium & Apikale Prozesse & Zahnstein & Karies & Abrasion & Neubildung & Schmelzhypoplasie \\
\hline 33 & & & 0 & K 1 & 0 & 0 & 0 & 0 \\
\hline 34 & & & 0 & K 1 & 0 & $\mathrm{o}$ & * & 0 \\
\hline 35 & & Po 1 & 0 & K 1 & 0 & $\mathrm{o}$ & * & 0 \\
\hline 36 & $\mathrm{E}$ & & & & & & & \\
\hline 37 & $\mathrm{v}$ & & & & & & & \\
\hline 38 & $\mathrm{v}$ & & G & & & & & \\
\hline 43 & & & 0 & K 1 & 0 & 0 & 0 & 0 \\
\hline 44 & & & 0 & K 1 & 0 & $\mathrm{o}$ & * & 0 \\
\hline 45 & & & 0 & K 1 & 0 & $\mathrm{o}$ & * & 0 \\
\hline 46 & & & 0 & K 1 & 0 & $\mathrm{o}$ & * & 0 \\
\hline 47 & & & 0 & K 1 & 0 & o & 0 & 0 \\
\hline
\end{tabular}




\section{Zahn}

Population: Großenrode

Geschlecht:

Alter:

(14) 16 - $22(24)$

\subsubsection{5 / 32}

Skelett: 431

Krankheiten:

\section{Beschreibung:}

10

\begin{tabular}{c|l|l} 
Arthrose & rechts & links \\
\hline Caput & & \\
\hline Fossa & &
\end{tabular}

\section{Zahn Status Parodontium Apikale Prozesse}

Zahnstein

K 1
Karies

0
Abrasion

O 2
Neubildung

0

Schmelzhypoplasie

0 


\section{Zahn}

Population: Großenrode

Geschlecht:

Alter:

Beschreibung: Der 8er hat eine Zapfenwurzel.
18.02.2015 / 32

Skelett: 431

Krankheiten:

10

\begin{tabular}{c|l|l} 
Arthrose & rechts & links \\
\hline Caput & & \\
\hline Fossa & &
\end{tabular}

\section{Zahn Status Parodontium Apikale Prozesse}

38

Zahnstein

K 1
Karies

0
Abrasion

O 2 


\section{Zahn}

Population: Großenrode

Geschlecht:

Alter:

Beschreibung: Hier ist nur die Krone erhalten.

\subsubsection{5 / 32}

Skelett: 431

Krankheiten:

\begin{tabular}{c|l|l} 
Arthrose & rechts & links \\
\hline Caput & & \\
\hline Fossa & &
\end{tabular}

\section{Zahn Status Parodontium}

Apikale Prozesse 


\section{Zahn}

Population:

Großenrode

Geschlecht:

Alter:

(22) 28 - 35 (38)

Beschreibung: Hier ist nur die Krone erhalten

\subsubsection{5 / 32}

Skelett: 431

Krankheiten:

\begin{tabular}{c|l|l} 
Arthrose & rechts & links \\
\hline Caput & & \\
\hline Fossa & &
\end{tabular}

10
Zahnstein K 1
Karies

0

Abrasion 


\section{Zahn}

Population: Großenrode

Geschlecht:

Alter:

(22) 25 - 30 (34)

\subsubsection{5 / 32}

Skelett: 431

Krankheiten:

\section{Beschreibung:}

Apikale Prozesse

0
Zahnstein

K 1
10

\begin{tabular}{c|l|l} 
Arthrose & rechts & links \\
\hline Caput & & \\
\hline Fossa & &
\end{tabular}




\section{Zahn}

Population: Großenrode

Geschlecht:

Alter:

\section{Beschreibung:}

\section{$18.02 .2015 / 32$}

Skelett: 431

Krankheiten:

10

\begin{tabular}{c|l|l} 
Arthrose & rechts & links \\
\hline Caput & & \\
\hline Fossa & &
\end{tabular}

\section{Zahn Status Parodontium Apikale Prozesse}

24

\section{Zahnstein}

K 1
Karies

0
Abrasion

Neubildung

O 4 


\section{Zahn}

Population: Großenrode

Geschlecht:

Alter:

\section{Beschreibung:}

(25) 28 - 35 (38)

\subsubsection{5 / 8}

Skelett: $\quad$ kleine Tüte in Tüte $62 / 51$

Krankheiten:

10

\begin{tabular}{c|l|l} 
Arthrose & rechts & links \\
\hline Caput & & \\
\hline Fossa & &
\end{tabular}

\section{Zahn Status Parodontium Apikale Prozesse}

36
Zahnstein

K 1
Karies

0
Abrasion

Neubildung

O 4 


\section{Zahn}

Population: Großenrode

Geschlecht:

Alter:

echt: $\quad 62 / 51$

\subsubsection{5 / 8}

10

\begin{tabular}{c|l|l} 
Arthrose & rechts & links \\
\hline Caput & & \\
\hline Fossa & &
\end{tabular}

Skelett: kleine Tüte in Tüte

\section{Krankheiten:}

\section{Zahn Status Parodontium Apikale Prozesse} 18

0

Zahnstein

K 2
Karies

0
Abrasion

o 2
Neubildung

0 


\section{Zahn}

Population: Großenrode

Geschlecht:

Alter:

\subsubsection{5 / 8}

Skelett: $\quad$ kleine Tüte in Tüte $62 / 51$

10

Krankheiten:

\begin{tabular}{c|l|l} 
Arthrose & rechts & links \\
\hline Caput & & \\
\hline Fossa & &
\end{tabular}

Beschreibung: Bei diesem Zahn ist die Wurzel zum Teil abfrakturiert. Es liegt weiterhin eine Karies an einer unüblichen Stelle vor.

$\begin{array}{llcccccccc}\text { Zahn } & \text { Status } & \text { Parodontium } & \text { Apikale Prozesse } & \text { Zahnstein } & \text { Karies } & \text { Abrasion } & \text { Neubildung } & \text { Schmelzhypoplasie } \\ 55 & & 0 & \mathrm{~K} & 1 & \mathrm{P} & 2 & \mathrm{O} & 1 & 0\end{array}$




\section{Zahn}

Population: Großenrode

Geschlecht:

Alter:

\section{Beschreibung:}

\subsubsection{5 / 8}

Skelett: $\quad$ kleine Tüte in Tüte $62 / 51$

10

Krankheiten:

\begin{tabular}{c|l|l} 
Arthrose & rechts & links \\
\hline Caput & & \\
\hline Fossa & &
\end{tabular}

\section{Zahn Status Parodontium Apikale Prozesse}

44

0
Zahnstein

K 1
Karies

0
Abrasion

O 2
Neubildung

0

Schmelzhypoplasie

0 


\section{Zahn}

Population: Großenrode

Geschlecht:

Alter:

Beschreibung: Dieser Zahn weist eine zum Teil abfrakturierte Wurzel auf und ist erodiert.

\section{Krankheiten:} $62 / 51$
Skelett: kleine Tüte in Tüte
10

\begin{tabular}{c|l|l} 
Arthrose & rechts & links \\
\hline Caput & & \\
\hline Fossa & &
\end{tabular}

\section{Zahn Status Parodontium Apikale Prozesse}

44
Zahnstein

K 1

Karies

0
Abrasion

O 4 


\section{Zahn}

Population: Großenrode

Geschlecht:

Alter:

Beschreibung: Es sind noch etwa $70 \%$ der Krone erhalten, die Wurzel ist zum Teil abfrakturiert und der gesamte Zahn ist erodiert.

\subsubsection{5 / 8} $62 / 51$
Skelett: $\quad$ kleine Tüte in Tüte
10

\section{Krankheiten:}

\begin{tabular}{c|l|l} 
Arthrose & rechts & links \\
\hline Caput & & \\
\hline Fossa & &
\end{tabular}

$\begin{array}{lllllccccc}\text { Zahn } & \text { Status } & \text { Parodontium } & \text { Apikale Prozesse } & \text { Zahnstein } & \text { Karies } & \text { Abrasion } & \text { Neubildung } & \text { Schmelzhypoplasie } \\ 24 & & & \text { K } 1 & 0 & 0 & 1 & 0\end{array}$




\section{OK}

Population: Großenrode

Geschlecht: >> männlich

Alter:

\subsubsection{5 / 18}

Skelett: $\quad$ 5. Tüte aus $62 / 52$
10

Krankheiten:

Beschreibung: Die Zähne 13 und 14 weisen eine sigmoide Wurzelform auf. Der Zahn 16 ist wohl sehr massig gewesen.

\begin{tabular}{|c|c|c|c|c|c|c|c|c|}
\hline Zahn & Status & Parodontium & Apikale Prozesse & Zahnstein & Karies & Abrasion & Neubildung & Schmelzhypoplasie \\
\hline 11 & $\mathrm{v}$ & & 0 & & & & & \\
\hline 12 & v & & 0 & & & & & \\
\hline 13 & & 0 & 0 & $\mathrm{~K}$ & 0 & $\mathrm{O}$ & 0 & $U$ \\
\hline 14 & & 0 & 0 & $\mathrm{~K}$ & 0 & 0 & 0 & 0 \\
\hline 15 & v & & 0 & & & & & \\
\hline 16 & v & & 0 & & & & & \\
\hline 21 & & & 0 & $\mathrm{~K}$ & 0 & $\mathrm{O}$ & 0 & 0 \\
\hline 42 & & & 0 & $\mathrm{~K}$ & 0 & 0 & 0 & $U$ \\
\hline
\end{tabular}




\section{Zähne}

Population: Großenrode

Geschlecht: > weiblich

Alter:

(14) 16 - $22(24)$

\section{Beschreibung:}

\subsubsection{5 / 18}

Skelett: $\quad$ 5. Tüte aus $62 / 52$

Krankheiten:

10

\begin{tabular}{c|l|l} 
Arthrose & rechts & links \\
\hline Caput & & \\
\hline Fossa & &
\end{tabular}

\section{Zahn Status Parodontium Apikale Prozesse}

34

45

46

Zahnstein

K 1

K 1

K 1
Karies

0
Abrasion

Neubildung

O 1

O 2

O 2

0

0
0

0

0

U 1

U 2




\section{Zähne}

Population: Großenrode

Geschlecht:

Alter:

Beschreibung: Die Fundstücke sind stark erodiert, die Wurzeln nur zur Hälfte erhalten.

\subsubsection{5 / 18}

Skelett: $\quad$ 5. Tüte aus $62 / 52$

Krankheiten:

10

\begin{tabular}{c|l|l} 
Arthrose & rechts & links \\
\hline Caput & & \\
\hline Fossa & &
\end{tabular}

\section{Zahn Status Parodontium Apikale Prozesse}

24

25

Zahnstein

Karies

K 1

K 2

0

0

Abrasion Neubildung Schmelzhypoplasie 


\section{Zahn}

Population: Großenrode

Geschlecht:

Alter:

Beschreibung: Hier sind Teile der Wurzel und Teile der Krone abfrakturiert.
10

\begin{tabular}{c|l|l} 
Arthrose & rechts & links \\
\hline Caput & & \\
\hline Fossa & &
\end{tabular}

\section{Zahn Status Parodontium Apikale Prozesse}

45
Skelett: 5. Tüte aus 62/52 Krankheiten:

\subsubsection{5/ 18}

\section{Krankheiten:}




\section{Zahn}

Population: Großenrode

Geschlecht:

Alter:

\section{Beschreibung:}

\subsubsection{5 / 26}

Skelett: $\quad 62 / 57$

10

Krankheiten:

\begin{tabular}{c|l|l} 
Arthrose & rechts & links \\
\hline Caput & & \\
\hline Fossa & &
\end{tabular}

Zahn Status Parodontium Apikale Prozesse

48

0
Zahnstein

K 1
Karies

0
Abrasion

O 1
Neubildung

0

Schmelzhypoplasie

0 


\section{Zahn}

Population: Großenrode

Geschlecht:

Alter:

$5-7$

Beschreibung: Es handelt sich um eine Zahnanlage.

\section{Zahn Status Parodontium} 13

\subsubsection{5 / 26}

Skelett: $\quad 62 / 57$

Krankheiten:

10

\begin{tabular}{c|l|l} 
Arthrose & rechts & links \\
\hline Caput & & \\
\hline Fossa & &
\end{tabular}

Zahnstein

Karies
Abrasion

Neubildung 


\section{Zahn}

Population: Großenrode

Geschlecht:

Alter:

Beschreibung: Vollständig erhalten, aber etwas erodiert.
19.02.2015 / 26

Skelett: $62 / 57$

Krankheiten:

10

\begin{tabular}{c|l|l} 
Arthrose & rechts & links \\
\hline Caput & & \\
\hline Fossa & &
\end{tabular}

Zahn Status Parodontium Apikale Prozesse

Zahnstein

Karies

Abrasion

Neubildung

Schmelzhypoplasie

33

0

K 1

0

O 3

0

0 


\section{OK}

Population: Großenrode

Geschlecht:

Alter:

(14) 16 - $22(24)$
10

Krankheiten: Sinusitis maxillaris Stomatitis

\begin{tabular}{c|l|l} 
Arthrose & rechts & links \\
\hline Caput & & \\
\hline Fossa & &
\end{tabular}

Beschreibung: Die sutura palatina mediana ist noch nicht geschlossen. Die Wurzel des 26 ist verwachsen und zapfenförmig.

\begin{tabular}{|c|c|c|c|c|c|c|c|c|}
\hline Zahn & Status & Parodontium & Apikale Prozesse & Zahnstein & Karies & Abrasion & Neubildung & Schmelzhypoplasie \\
\hline 21 & $\mathrm{v}$ & 0 & & & & & & \\
\hline 22 & $\mathrm{v}$ & 0 & & & & & & \\
\hline 23 & $\mathrm{v}$ & 0 & & & & & & \\
\hline 24 & v & 0 & & & & & & \\
\hline 25 & v & 0 & & & & & & \\
\hline 26 & & 0 & 0 & K 1 & 0 & $\mathrm{O}$ & 0 & 0 \\
\hline
\end{tabular}




\section{UK}

Population: Großenrode

Geschlecht: > männlich

Alter:

Beschreibung: Ein kleines Fragment des Unterkiefers.
10

Krankheiten:

\begin{tabular}{c|l|l} 
Arthrose & rechts & links \\
\hline Caput & & \\
\hline Fossa & &
\end{tabular}

\begin{tabular}{|c|c|c|c|c|c|c|c|c|c|}
\hline Zahn & Status & Parodontium & Apikale Prozesse & Zahnstein & Karies & & sion & Neubildung & Schmelzhypoplasie \\
\hline 32 & & & 0 & $\mathrm{H}$ & 0 & 0 & 3 & 0 & 0 \\
\hline 33 & & & 0 & K & 0 & $\mathrm{O}$ & 3 & 0 & 0 \\
\hline 34 & & & 0 & 1 & 0 & 0 & 3 & 0 & 0 \\
\hline 35 & & & 0 & K & 0 & 0 & 3 & 0 & 0 \\
\hline 41 & & & 0 & $\mathrm{H} \quad 2$ & 0 & 0 & 3 & 0 & 0 \\
\hline 42 & & & 0 & K 1 & 0 & 0 & 3 & 0 & 0 \\
\hline
\end{tabular}




\section{Zähne}

Population: Großenrode

Geschlecht:

Alter:

(22) 25 - 30 (38)

\section{Beschreibung:}

\subsubsection{5 / 35}

Skelett: $\quad 61 / 52$

Krankheiten:

10

\begin{tabular}{c|l|l} 
Arthrose & rechts & links \\
\hline Caput & & \\
\hline Fossa & &
\end{tabular}

\begin{tabular}{|c|c|c|c|c|c|c|c|c|}
\hline Zahn & Status & Parodontium & Apikale Prozesse & Zahnstein & Karies & Abrasion & Neubildung & Schmelzhypoplasie \\
\hline 26 & & & 0 & K 2 & 0 & $\mathrm{O}$ & 0 & 0 \\
\hline 32 & & & 0 & K & 0 & 0 & 0 & $\mathrm{~T}$ \\
\hline 36 & & & 0 & $\begin{array}{ll}\mathrm{K} & 1\end{array}$ & 0 & 0 & 0 & 0 \\
\hline
\end{tabular}




\section{Zähne}

Population: Großenrode

Geschlecht:

Alter:

Beschreibung: Die Wurzel des 8ers ist abfrakturiert.
10

\section{Krankheiten:}

\begin{tabular}{c|l|l} 
Arthrose & rechts & links \\
\hline Caput & & \\
\hline Fossa & &
\end{tabular}

Zahn Status Parodontium Apikale Prozesse

44

48

Zahnstein Karies

L 2

K 1
0

0

Abrasion Neubildung Schmelzhypoplasie

O 1

0

0

0 


\section{Zahn}

Population: Großenrode

Geschlecht:

Alter:

(5) 7 - 9

\subsubsection{5 / 40}

Skelett: $62 / 58$

Krankheiten:

\section{Beschreibung:}

10

\begin{tabular}{c|l|l} 
Arthrose & rechts & links \\
\hline Caput & & \\
\hline Fossa & &
\end{tabular}

Zahn Status Parodontium Apikale Prozesse

Zahnstein

Karies

0

0

Abrasion

Neubildung

Schmelzhypoplasie

0

0 T 1 


\section{UK}

Population: Großenrode

Geschlecht:

Alter:

(32) 40 - 47 (65)

\subsubsection{5/ 4}

Skelett: $\quad 61 / 55$
10

Krankheiten:

\begin{tabular}{c|l|l} 
Arthrose & rechts & links \\
\hline Caput & & \\
\hline Fossa & &
\end{tabular}

Beschreibung: Von diesen Zähnen sind Teile des Schmelzes abfrakturiert, 47 hat eine zapfenförmige Wurzel. Die Bifurkation des 8ers ist lingual zu knapp $5 \mathrm{~mm}$ geöffnet. Die beiden Zähne liegen im Kieferfragment vor, es ist nicht eindeutig feststellbar, ob die Zahnzuordnung richtig ist.

$\begin{array}{llccccccc}\text { Zahn } & \text { Status } & \text { Parodontium } & \text { Apikale Prozesse } & \text { Zahnstein } & \text { Karies } & \text { Abrasion } & \text { Neubildung } & \text { Schmelzhypoplasie } \\ 46 & \text { Po } 4 & 0 & \text { K } & 0 & 0 & 5 & * & 0 \\ 47 & \text { Po } 5 & 0 & \text { K } 1 & 0 & 0 & 5 & * & 0\end{array}$




\section{Zahn}

Population:

Großenrode

Geschlecht:

Beschreibung: Dieser Zahn ist stark erodiert und die Wurzel ist abfrakturiert.
Alter:
(14) 16 - $22(24)$

10

\begin{tabular}{c|l|l} 
Arthrose & rechts & links \\
\hline Caput & & \\
\hline Fossa & &
\end{tabular}

\section{Skelett: $\quad 61 / 55$}

Krankheiten:
Apikale Prozesse

36

\section{Status Parodontium}

Zahnstein K 1
Karies

0
Abrasion

O 2
Neubildun

0 


\section{Zähne}

Population:

Großenrode

Geschlecht:

Alter:

(7) 9 - $11(13,5)$

\section{Beschreibung:}

\subsubsection{5 / 4}

Skelett: $\quad 61 / 55$

Krankheiten:

10

\begin{tabular}{c|l|l} 
Arthrose & rechts & links \\
\hline Caput & & \\
\hline Fossa & &
\end{tabular}

\begin{tabular}{|c|c|c|c|c|c|c|c|c|}
\hline Zahn & Status & Parodontium & Apikale Prozesse & Zahnstein & Karies & Abrasion & Neubildung & Schmelzhypoplasie \\
\hline 22 & & & & $\mathrm{~K}$ & 0 & 0 & 0 & $\mathrm{~T}$ \\
\hline 23 & & & & $\begin{array}{ll}\mathrm{K} & 1\end{array}$ & 0 & 0 & 0 & $\mathrm{~T}$ \\
\hline 27 & ( ) & & & & & 0 & & \\
\hline
\end{tabular}




\section{Zähne}

Population: Großenrode

Geschlecht:

Alter:

(22) 25 - 30 (34)

\section{Beschreibung:}

\subsubsection{5 / 4}

Skelett: $\quad 61 / 55$

Krankheiten:

10

\begin{tabular}{c|l|l} 
Arthrose & rechts & links \\
\hline Caput & & \\
\hline Fossa & &
\end{tabular}

\begin{tabular}{|c|c|c|c|c|c|c|c|c|c|}
\hline Zahn & Status & Parodontium & Apikale Prozesse & Zahnstein & Karies & $\mathbf{A b}$ & ision & Neubildung & Schmelzhypoplasie \\
\hline 12 & & & & $\mathrm{~K}$ & 0 & $\mathrm{O}$ & 1 & 0 & $\mathrm{~T}$ \\
\hline 18 & & & & $\mathrm{~K}$ & 0 & $\mathrm{O}$ & 2 & 0 & $U$ \\
\hline 24 & & & & $\mathrm{~K}$ & 0 & $\mathrm{O}$ & 1 & 0 & 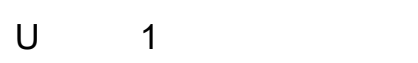 \\
\hline 25 & & & & $\mathrm{~K}$ & 0 & $\mathrm{O}$ & 3 & 0 & 0 \\
\hline 27 & & & & K 1 & 0 & $\mathrm{O}$ & 1 & 0 & $u$ \\
\hline
\end{tabular}




\section{UK}

Population: Großenrode

Geschlecht: >> männlich

Alter:

$25-35$

Beschreibung: Dieser Zahn liegt nur in Fragmenten vor.
10

\section{Krankheiten:}

\begin{tabular}{c|l|l} 
Arthrose & rechts & links \\
\hline Caput & & \\
\hline Fossa & &
\end{tabular}

\section{Zahn Status Parodontium Apikale Prozesse}

38
0

0
Zahnstein

$\mathrm{H} 2$
Karies

0
Abrasion

O 2
Neubildung

0

Schmelzhypoplasie

0 


\section{UK}

Population: Großenrode

Geschlecht:

Alter:

(25) 28 - 35 (38)
20.02.2015 / 48

Skelett: $62 / 53$
10

Krankheiten:

Beschreibung: Ein Kieferfragment, es fallen zwei foramina mandibulae auf. Es ist der linke Teil des Unterkiefers erhalten.

\begin{tabular}{c|l|l} 
Arthrose & rechts & links \\
\hline Caput & & \\
\hline Fossa & &
\end{tabular}

\begin{tabular}{|c|c|c|c|c|c|c|c|c|}
\hline Zahn & Status & Parodontium & Apikale Prozesse & Zahnstein & Karies & Abrasion & Neubildung & Schmelzhypoplasie \\
\hline 34 & $E$ & & 0 & & & & & \\
\hline 35 & E & & 0 & & & & & \\
\hline 36 & & 0 & 0 & $\mathrm{H}$ & 0 & $\mathrm{O}$ & * & 0 \\
\hline 37 & & 0 & 0 & $\mathrm{~K}$ & 0 & $\mathrm{O}$ & 0 & 0 \\
\hline 38 & $\mathrm{v}$ & 0 & 0 & & & & & \\
\hline
\end{tabular}




\section{OK}

Population: Großenrode

Geschlecht:

Alter:

(25) 28 - 35 (38)

Beschreibung: Ein Oberkieferfragment, welches sehr massiv ist.
10

Krankheiten: Stomatitis

\begin{tabular}{c|l|l} 
Arthrose & rechts & links \\
\hline Caput & & \\
\hline Fossa & &
\end{tabular}

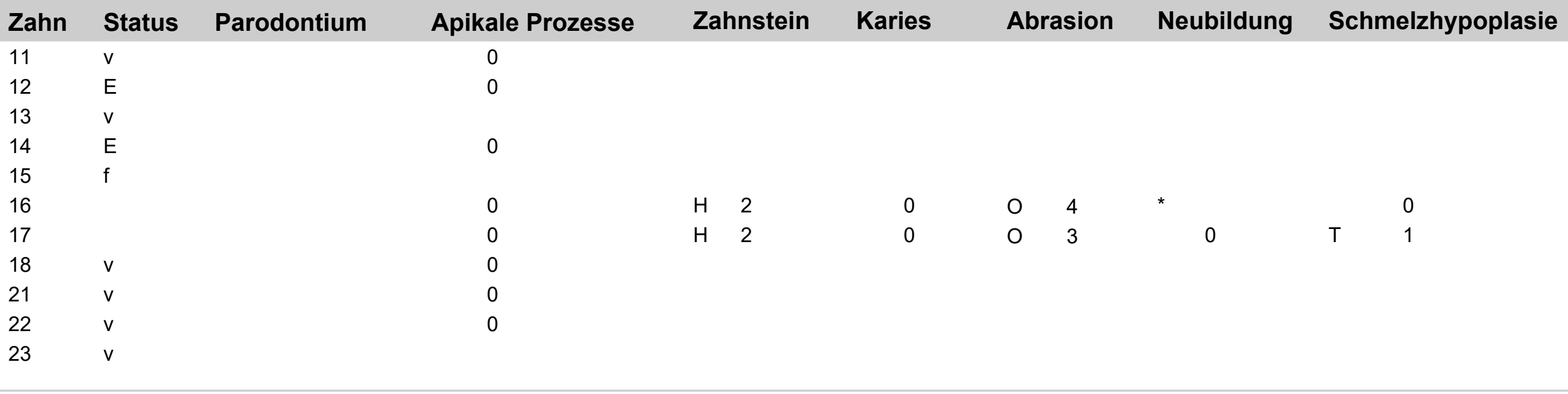




\section{Zähne}

Population:

Großenrode

Geschlecht:

Alter:

$6-10$

\section{Beschreibung:}

\subsubsection{5 / 48}

Skelett: $\quad 62 / 53$

Krankheiten:

\begin{tabular}{c|l|l} 
Arthrose & rechts & links \\
\hline Caput & & \\
\hline Fossa & &
\end{tabular}

\begin{tabular}{|c|c|c|c|c|c|c|c|}
\hline Zahn & Status & Parodontium & Apikale Prozesse & Zahnstein & Abrasion & Neubildung & Schmelzhypoplasie \\
\hline 12 & & & & & & & $\mathrm{~T}$ \\
\hline 37 & & & & & & & $U$ \\
\hline
\end{tabular}




\section{Zähne}

Population:

Großenrode

Geschlecht:

Alter:

(22) 25 - 30 (34)
20.02.2015 / 48

Skelett: $62 / 53$

10

Krankheiten:

\begin{tabular}{c|l|l} 
Arthrose & rechts & links \\
\hline Caput & & \\
\hline Fossa & &
\end{tabular}

Beschreibung: Bei Zahn 46 ist die distale Wurzel frakturiert, 15 weist eine zur Hälfte frakturierte Wurzel auf.

\begin{tabular}{|c|c|c|c|c|c|c|c|c|c|c|}
\hline Zahn & Status & Parodontium & Apikale Prozesse & $\mathrm{Za}$ & instein & Karies & & sion & Neubildung & Schmelzhypoplasie \\
\hline 14 & & & 0 & $\mathrm{H}$ & 2 & 0 & $\mathrm{O}$ & 3 & 0 & 0 \\
\hline 15 & & & & $\mathrm{H}$ & 2 & 0 & 0 & 3 & 0 & 0 \\
\hline 21 & & & 0 & $\mathrm{~K}$ & 1 & 0 & $\mathrm{O}$ & 2 & 0 & 1 \\
\hline 25 & & & 0 & $\mathrm{H}$ & 2 & 0 & $\mathrm{O}$ & 3 & 0 & 0 \\
\hline 31 & & & 0 & $\mathrm{~K}$ & 1 & 0 & $\mathrm{O}$ & 2 & 0 & $\mathrm{~T}$ \\
\hline 46 & & & 0 & $\mathrm{H}$ & 1 & 0 & $\mathrm{O}$ & 3 & 0 & 0 \\
\hline 47 & & & 0 & $\mathrm{H}$ & 1 & 0 & 0 & 1 & 0 & 0 \\
\hline
\end{tabular}




\section{Zähne}

Population: Großenrode

Geschlecht:

Alter:

Beschreibung: 32 ist erodiert.
20.02.2015 / 48

Skelett: $62 / 53$

Krankheiten:

10

\begin{tabular}{c|l|l} 
Arthrose & rechts & links \\
\hline Caput & & \\
\hline Fossa & &
\end{tabular}

\section{Zahn Status Parodontium Apikale Prozesse}

18

32

\section{Zahnstein}

K 1

$\mathrm{H} 2$

\section{Karies}

0

0
Abrasion

O 2

Neubildung

O 3

0

0

Schmelzhypoplasie

$\begin{array}{lll}0 & T & 1\end{array}$




\section{Zähne}

Population:

Geschlecht:

Alter:

(22) (38)

\subsubsection{5 / 48}

Skelett: $\quad 62 / 53$
10

Krankheiten:

\begin{tabular}{c|l|l} 
Arthrose & rechts & links \\
\hline Caput & & \\
\hline Fossa & &
\end{tabular}

Beschreibung: 28 hat 4 Wurzeln, 23 hat sehr deutliche Tertiärdentinbildung bis zur kompletten Einmauerung der Pulpa. Bei 22 ist die Wurzel zur Hälfte abfrakturiert.

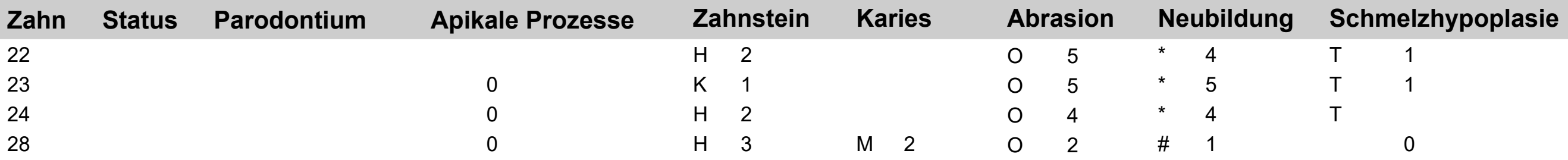




\section{UK}

Population: Großenrode

Geschlecht:

Alter:

(6) 7 - 8 (9)

Beschreibung: Von 75 ist nur die Krone erhalten.

\section{Zahn Status Parodontium}

12

75
20.02.2015 / 66

Skelett: $\quad 62 / 56$

Krankheiten:

10

\begin{tabular}{c|l|l} 
Arthrose & rechts & links \\
\hline Caput & & \\
\hline Fossa & &
\end{tabular}

Apikale Prozesse

Zahnstein

Karies

Abrasion Neubildung

Schmelzhypoplasie

K 1

O 4 T 1 


\section{Zähne}

Population:

Großenrode

Geschlecht:

Alter:

(22) 25 - 35 (38)

Beschreibung: Teilweise erodiert, 8er nur Krone erhalten.
10

Krankheiten:

\begin{tabular}{c|l|l} 
Arthrose & rechts & links \\
\hline Caput & & \\
\hline Fossa & &
\end{tabular}

\begin{tabular}{|c|c|c|c|c|c|c|c|c|c|}
\hline Zahn & Status & Parodontium & Apikale Prozesse & Zahnstein & Karies & $\mathrm{Ab}$ & ision & Neubildung & Schmelzhypoplasie \\
\hline 28 & & & & $\mathrm{~K}$ & 0 & $\mathrm{O}$ & 1 & 0 & $U$ \\
\hline 31 & & & 0 & $\mathrm{H} \quad 2$ & 0 & $\mathrm{O}$ & 2 & 0 & 0 \\
\hline 36 & & & 0 & $\mathrm{~K}$ & 0 & $\mathrm{O}$ & 3 & 0 & 0 \\
\hline 43 & & & 0 & $\mathrm{~K}$ & 0 & $\mathrm{O}$ & 3 & 0 & $\mathrm{~T}$ \\
\hline 46 & & & & $\mathrm{~K}$ & 0 & $\mathrm{O}$ & 4 & * & 0 \\
\hline 48 & & & 0 & K 1 & 0 & $\mathrm{O}$ & 3 & 0 & 0 \\
\hline
\end{tabular}




\section{UK}

Population: Großenrode

Geschlecht: indifferent

Alter:

Beschreibung: Ein Unterkieferfragment aus dem mesialen Bereich mit Kinn.

\subsubsection{5/1}

Skelett: $63 / 55$

Krankheiten:

10

\begin{tabular}{c|l|l} 
Arthrose & rechts & links \\
\hline Caput & & \\
\hline Fossa & &
\end{tabular}

\begin{tabular}{|c|c|c|c|c|c|c|c|c|}
\hline Zahn & Status & Parodontium & Apikale Prozesse & Zahnstein & Karies & Abrasion & Neubildung & Schmelzhypoplasie \\
\hline 31 & $\mathrm{v}$ & & 0 & & & & & \\
\hline 32 & $\mathrm{v}$ & & 0 & & & & & \\
\hline 33 & $\mathrm{v}$ & & 0 & & & & & \\
\hline 41 & $\mathrm{v}$ & & 0 & & & & & \\
\hline 42 & $\mathrm{v}$ & & 0 & & & & & \\
\hline
\end{tabular}




\section{Zähne}

Population:

Großenrode

Geschlecht:

Alter:

(14) 16 - $22(24)$

Beschreibung: 28 ist 4-wurzelig, bei 21 ist der distale Bereich der Wurzel abfrakturiert.
10

\section{Krankheiten:}

\begin{tabular}{c|l|l} 
Arthrose & rechts & links \\
\hline Caput & & \\
\hline Fossa & &
\end{tabular}

\begin{tabular}{|c|c|c|c|c|c|c|c|c|}
\hline Zahn & Status Parodontium & Apikale Prozesse & Zahnstein & Karies & & ision & Neubildung & Schmelzhypoplasie \\
\hline 21 & & & K 1 & 0 & $\mathrm{O}$ & 2 & 0 & $\mathrm{~T}$ \\
\hline 23 & & 0 & K 1 & 0 & $P$ & 1 & 0 & $\mathrm{~T}$ \\
\hline 26 & & 0 & K 1 & 0 & 0 & 2 & 0 & 0 \\
\hline 28 & & 0 & K 1 & 0 & $\mathrm{O}$ & 1 & 0 & 0 \\
\hline 36 & & 0 & K 1 & 0 & 0 & 2 & 0 & 0 \\
\hline
\end{tabular}




\section{Zähne}

Population: Großenrode

Geschlecht:

Alter:

Beschreibung: Die Wurzel des 3ers ist abfrakturiert.
10

\section{Krankheiten:}

\begin{tabular}{c|l|l} 
Arthrose & rechts & links \\
\hline Caput & & \\
\hline Fossa & &
\end{tabular}

\begin{tabular}{|c|c|c|c|c|c|c|c|c|}
\hline Zahn & Status & Parodontium & Apikale Prozesse & Zahnstein & Karies & Abrasion & Neubildung & Schmelzhypoplasie \\
\hline 42 & & & 0 & $\mathrm{H} \quad 3$ & 0 & $\mathrm{O}$ & 0 & 0 \\
\hline 43 & & & & $\begin{array}{ll}\mathrm{H} & 1\end{array}$ & 0 & 0 & 0 & $U$ \\
\hline
\end{tabular}




\section{Zahn}

Population: Großenrode

Geschlecht:

Alter:

\section{Beschreibung:}

\subsubsection{5/1}

Skelett: $63 / 55$

\section{Krankheiten:}

\begin{tabular}{c|l|l} 
Arthrose & rechts & links \\
\hline Caput & & \\
\hline Fossa & &
\end{tabular}

\section{Zahn Status Parodontium}

82
Apikale Prozesse

0
Zahnstein

0
10

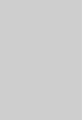




\section{Zähne}

Population:

Großenrode

Geschlecht:

Alter:

(6) 8 - $9(11)$

\subsubsection{5 / 1}

Skelett: $\quad 63 / 55$

10

Krankheiten:

\begin{tabular}{c|l|l} 
Arthrose & rechts & links \\
\hline Caput & & \\
\hline Fossa & &
\end{tabular}

Beschreibung: Die Wurzeln der Fundstücke sind teilweise abfrakturiert. Der 2er war wohl noch eine Anlage.

\begin{tabular}{|c|c|c|c|c|c|c|c|c|}
\hline Zahn & Status & Parodontium & Apikale Prozesse & Zahnstein & Karies & Abrasion & Neubildung & Schmelzhypoplasie \\
\hline 12 & & & & & & & 0 & 0 \\
\hline 36 & & & & $\mathrm{~K}$ & 0 & 0 & 0 & $U$ \\
\hline 75 & & & & $\mathrm{H} \quad 1$ & 0 & $\mathrm{O}$ & * & 0 \\
\hline
\end{tabular}




\section{OK; UK}

Population: Großenrode

Geschlecht: > männlich

Alter:

(32) $37-45(50)$

\subsubsection{5 / 34}

Skelett: K168

\section{3}

Krankheiten: Stomatitis

Parodontitis

Parodontose

Anomalie

\begin{tabular}{c|l|l} 
Arthrose & rechts & links \\
\hline Caput & & \\
\hline Fossa & &
\end{tabular}

Beschreibung: Diese Fundstücke sind zum Teil recht gut erhalten, hier und da sind Teile abfrakturiert und die Oberfläche ist stellenweise erodiert. Es liegt eine Stellungsanomalie der Zähne 21 und 22 vor. 21 ist nach mesial rotiert, 22 nach distal. Manche Zähne zeigen ein umgekehrtes

Wurzelmerkmal und der Zahn 17 hat distal an der Trifurkation eine Schmelzperle. Der Gaumen weist eine Stomatitis mit Grad 2 auf.

\begin{tabular}{|c|c|c|c|c|c|c|c|c|}
\hline Zahn & Status & Parodontium & Apikale Prozesse & Zahnstein & Karies & Abrasion & Neubildung & Schmelzhypoplasie \\
\hline 11 & & $\mathrm{Pi} \quad 1$ & Z & K 1 & 0 & $\mathrm{O}$ & * & 0 \\
\hline 12 & & $\mathrm{Pi} 1$ & 0 & $\begin{array}{ll}\mathrm{K} & 1\end{array}$ & 0 & $\mathrm{O}$ & * & 0 \\
\hline 13 & & 0 & 0 & $\begin{array}{ll}\mathrm{K} & 1\end{array}$ & 0 & $\mathrm{O}$ & * & 0 \\
\hline 14 & & 0 & 0 & K 1 & 0 & $\mathrm{O}$ & * & 0 \\
\hline 15 & & $\mathrm{Pi} \quad 1$ & 0 & K 1 & 0 & 0 & * & 0 \\
\hline 16 & & $\mathrm{Pi} \quad 1$ & 0 & B 3 & 0 & $\mathrm{O}$ & * & 0 \\
\hline 17 & & & 0 & K 1 & 0 & $\mathrm{O}$ & * & 0 \\
\hline 18 & & & 0 & K 1 & 0 & $\mathrm{O}$ & 0 & 0 \\
\hline 21 & & $\mathrm{Pi} \quad 1$ & 0 & K 1 & 0 & 0 & * & 0 \\
\hline 22 & & $\mathrm{Pi} \quad 1$ & 0 & $\begin{array}{ll}\mathrm{K} & 1\end{array}$ & 0 & 0 & * & 0 \\
\hline 23 & & Po 1 & 0 & B 1 & 0 & 0 & * & 0 \\
\hline
\end{tabular}




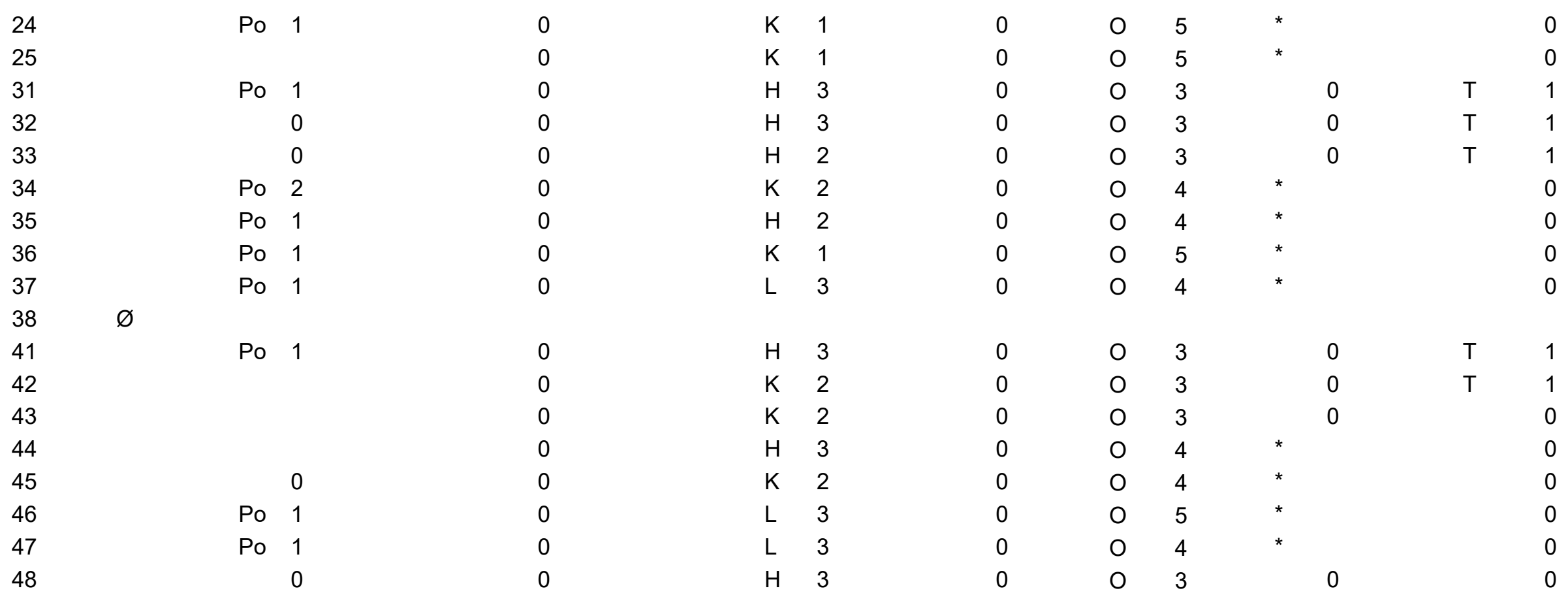




\section{OK; UK}

Population:

Großenrode

Geschlecht:

Alter:

(22) 25 - $30(34)$

\subsubsection{5 / 1}

Skelett: K312

3

Krankheiten:

\begin{tabular}{c|l|l} 
Arthrose & rechts & links \\
\hline Caput & & \\
\hline Fossa & &
\end{tabular}

Beschreibung: Die Molaren haben alle leichte Entmineralisierungen, besonders 48 . Weiterhin hat der 48 zwei Schmelzperlen, eine ist distal und eine mesial an der Trifurkation lokalisiert und er ist 4-wurzelig.

\begin{tabular}{|c|c|c|c|c|c|c|c|c|c|c|}
\hline \multirow{2}{*}{$\begin{array}{l}\text { Zahn } \\
11\end{array}$} & \multirow[t]{2}{*}{ Status } & \multirow[t]{2}{*}{ Parodontium } & \multirow[t]{2}{*}{ Apikale Prozesse } & \multicolumn{2}{|c|}{ Zahnstein } & \multirow{2}{*}{$\begin{array}{c}\text { Karies } \\
0\end{array}$} & \multicolumn{2}{|c|}{ Abrasion } & \multirow{2}{*}{ Neubildung } & \multirow{2}{*}{$\begin{array}{c}\text { Schmelzhypoplasie } \\
0\end{array}$} \\
\hline & & & & $\mathrm{K}$ & 1 & & $P$ & 4 & & \\
\hline 12 & & & & $\mathrm{~B}$ & 1 & 0 & 0 & 3 & 0 & 0 \\
\hline 13 & & 0 & 0 & $\mathrm{~B}$ & 3 & 0 & O & 2 & 0 & 0 \\
\hline 14 & & 0 & 0 & $\mathrm{~K}$ & 1 & 0 & 0 & 3 & 0 & 0 \\
\hline 15 & & 0 & 0 & $\mathrm{~K}$ & 1 & 0 & 0 & 3 & 0 & 0 \\
\hline 16 & & & 0 & $\mathrm{~K}$ & 2 & 0 & 0 & 3 & 0 & 0 \\
\hline 17 & & & & $\mathrm{~K}$ & 1 & 0 & 0 & 2 & 0 & 0 \\
\hline 18 & & & & $\mathrm{~K}$ & 1 & 0 & 0 & 1 & 0 & 0 \\
\hline 21 & & & & $\mathrm{~B}$ & 1 & 0 & $P$ & 4 & * & 0 \\
\hline 22 & & & & $\mathrm{H}$ & 2 & 0 & 0 & 3 & 0 & 0 \\
\hline 23 & & & & $\mathrm{H}$ & 2 & 0 & 0 & 3 & 0 & 0 \\
\hline
\end{tabular}




$\begin{array}{lll}0 & 0 & 3 \\ 0 & 0 & 3 \\ 0 & 0 & 3 \\ 0 & 0 & 2 \\ 0 & 0 & 1 \\ 0 & 0 & 2 \\ 0 & 0 & 2 \\ 0 & 0 & 2 \\ 0 & 0 & 3 \\ 0 & 0 & 3 \\ 0 & 0 & 3 \\ 0 & 0 & 2 \\ 0 & 0 & 2 \\ 0 & 0 & 2 \\ 0 & 0 & 3 \\ 0 & 0 & 3 \\ 0 & 0 & 3 \\ 0 & 0 & 3 \\ 0 & 0 & 1\end{array}$

0
0
0
0
0
0
0
0
0
0
0
0
0
0
0
0
0
0
0

0
0
0
0
0
0
$T \quad 0$
1
0
0
0
0
0
0
0
0
0
0
0




\section{Zahn}

Population: Großenrode

Geschlecht:

Alter:

(22) 27 - 32 (38)

Beschreibung: Es ist ein kleiner Teil des Kiefers und des Schädels erhalten.
3

Krankheiten:

\begin{tabular}{c|l|l} 
Arthrose & rechts & links \\
\hline Caput & & \\
\hline Fossa & &
\end{tabular}




\section{UK; OK}

Population:

Geschlecht:

Alter:

\subsubsection{5 / 1}

Skelett: K191
3

Krankheiten:

\begin{tabular}{c|l|l} 
Arthrose & rechts & links \\
\hline Caput & & \\
\hline Fossa & &
\end{tabular}

Beschreibung: Bei diesen Fundstücken ist ein Fragment der abgebrochenen Wurzel des 38 in der Alveole, bei 37 fehlt der Großteil der Wurzel, bei 36 ist nur ein distales 6tel des Zahnes inklusive Krone erhalten, bei 43 ist der distale Teil der Wurzel abfrakturiert und beide Oberkiefer - 1er weisen eine sehr flache Alveole auf.

\begin{tabular}{|c|c|c|c|c|c|c|c|c|}
\hline Zahn & Status & Parodontium & Apikale Prozesse & Zahnstein & Karies & Abrasion & Neubildung & Schmelzhypoplasie \\
\hline 11 & v & & 0 & & & & & \\
\hline 12 & $\mathrm{v}$ & & 0 & & & & & \\
\hline 13 & $v$ & & 0 & & & & & \\
\hline 14 & $v$ & & 0 & & & & & \\
\hline 21 & $v$ & & 0 & & & & & \\
\hline 22 & $v$ & & 0 & & & & & \\
\hline 23 & $v$ & & 0 & & & & & \\
\hline 24 & $v$ & & 0 & & & & & \\
\hline 31 & $v$ & & 0 & & & & & \\
\hline 32 & v & & 0 & & & & & \\
\hline 36 & & & & & & & & \\
\hline
\end{tabular}


$E$

$41 \quad v$

$\begin{array}{lll}0 & 0 & 3 \\ 0 & 0 & 3\end{array}$




\section{UK}

Population: Großenrode

Geschlecht:

Alter:

(25) 28 - 35 (38)

Beschreibung: Ein erodierter und frakturierter rechter Teil eines Unterkiefers.
3

Krankheiten: Parodontose

\begin{tabular}{c|c|c} 
Arthrose & rechts & links \\
\hline Caput & $\mathrm{xx}$ & \\
\hline Fossa & $\mathrm{xx}$ &
\end{tabular}

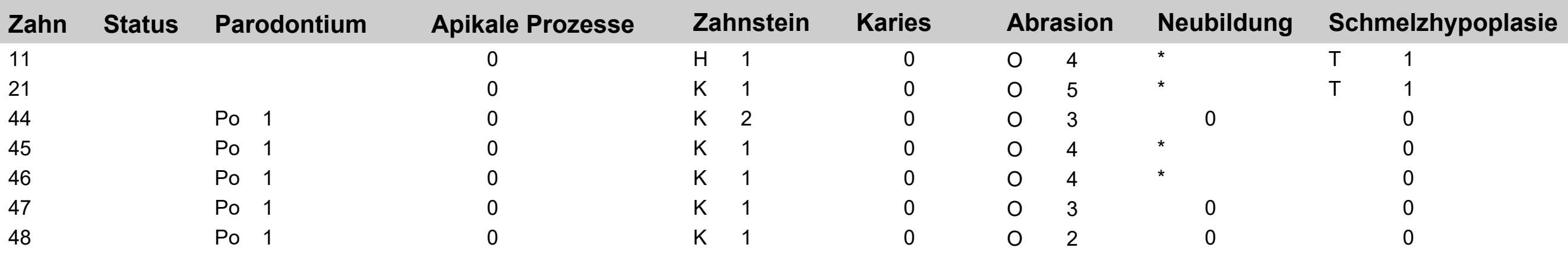




\section{Zähne}

Population: Großenrode

Geschlecht:

Alter:

Beschreibung: Die Wurzeln der Zähne sind abfrakturiert.

\subsubsection{5 / 24}

Skelett: $\quad 61 / 64-3$

Krankheiten:
3

\begin{tabular}{c|l|l} 
Arthrose & rechts & links \\
\hline Caput & & \\
\hline Fossa & &
\end{tabular}

\section{Zahn Status Parodontium Apikale Prozesse}

21

24

\section{Zahnstein}

Karies

K 1

K 1

\section{Abrasion}

Neubildung

0

O 2

O 3

0
0

Schmelzhypoplasie 


\section{Zahn}

Population: Großenrode

Geschlecht:

Alter:

\section{Beschreibung:}

\subsubsection{5 / 24}

Skelett: $\quad 61 / 64-3$

Krankheiten:

\section{3}

\begin{tabular}{c|l|l} 
Arthrose & rechts & links \\
\hline Caput & & \\
\hline Fossa & &
\end{tabular}




\section{UK}

Population: Großenrode

Geschlecht:

Alter:

(22) 25 - 30 (34)

\section{Beschreibung:}

\subsubsection{5 / 25}

Skelett: K225

Krankheiten:

\section{Krankheiten:}

3

\begin{tabular}{c|l|l} 
Arthrose & rechts & links \\
\hline Caput & & \\
\hline Fossa & &
\end{tabular}

\begin{tabular}{|c|c|c|c|c|c|c|c|c|}
\hline Zahn & Status & Parodontium & Apikale Prozesse & Zahnstein & Karies & Abrasion & Neubildung & Schmelzhypoplasie \\
\hline 35 & $\mathrm{v}$ & & & & & & & \\
\hline 36 & & Po 2 & 0 & $\mathrm{H} \quad 1$ & 0 & $\mathrm{O}$ & 0 & 0 \\
\hline 37 & $\mathrm{v}$ & Po 2 & 0 & & & & & \\
\hline 38 & v & Po 2 & 0 & & & & & \\
\hline
\end{tabular}




\section{UK}

Population: Großenrode

Geschlecht:

Alter:

\section{Beschreibung:}

\subsubsection{5 / 26}

Skelett: K339

\section{Krankheiten:}

\begin{tabular}{c|l|l} 
Arthrose & rechts & links \\
\hline Caput & & \\
\hline Fossa & &
\end{tabular}

\begin{tabular}{|c|c|c|c|c|c|c|c|c|c|c|}
\hline Zahn & Status & Parodontium & Apikale Prozesse & & instein & Karies & & ision & Neubildung & Schmelzhypoplasie \\
\hline 31 & $\mathrm{v}$ & & 0 & & & & & & & \\
\hline 32 & & 0 & 0 & $\mathrm{~K}$ & 2 & 0 & $\mathrm{O}$ & 2 & 0 & $\mathrm{~T}$ \\
\hline 33 & & 0 & 0 & $\mathrm{~K}$ & 2 & 0 & $\mathrm{O}$ & 2 & 0 & $\mathrm{~T}$ \\
\hline 34 & & 0 & 0 & $\mathrm{~K}$ & 1 & 0 & $\mathrm{O}$ & 1 & 0 & 0 \\
\hline 35 & & 0 & 0 & $\mathrm{~K}$ & 1 & 0 & $\mathrm{O}$ & 2 & 0 & 0 \\
\hline 36 & v & & & & & & & & & \\
\hline 41 & v & & 0 & & & & & & & \\
\hline 42 & v & & 0 & & & & & & & \\
\hline
\end{tabular}




\section{Zahn}

Population: Großenrode

Geschlecht:

Alter:

Beschreibung: Von diesem Zahn ist die Wurzel abfrakturiert.

Skelett: K57
3

Krankheiten:

\begin{tabular}{c|l|l} 
Arthrose & rechts & links \\
\hline Caput & & \\
\hline Fossa & &
\end{tabular}




\section{Zähne}

Population:

Geschlecht:

Alter:

(14) $25-30(34)$

\subsubsection{5 / 28}

Skelett: $\quad 62 / 64-3$
3

Krankheiten:

Beschreibung: Hier sind nur die Zahnkronen erhalten, die das Dentin ist herausgebrochen und die Wurzeln sind abfrakturiert. Beim 7er fällt ein Locus residentius dentis ins Auge, es handelt sich um ein occlusales Loch, das nach unten in den Schmelz ausgesackt ist.

\begin{tabular}{|c|c|c|c|c|c|c|c|c|}
\hline Zahn & Status & Parodontium & Apikale Prozesse & Zahnstein & Karies & Abrasion & Neubildung & Schmelzhypoplasie \\
\hline 14 & & & & $\mathrm{~K}$ & 0 & $\mathrm{O}$ & 0 & $\mathrm{~T}$ \\
\hline 23 & & & & $\begin{array}{ll}\mathrm{K} & 1\end{array}$ & 0 & 0 & 0 & $\mathrm{~T}$ \\
\hline 37 & & & & $\mathrm{H} \quad 2$ & 0 & $\mathrm{O}$ & 0 & $\mathrm{~T}$ \\
\hline
\end{tabular}




\section{Zähne}

Population:

Großenrode

Geschlecht:

Alter:

(14) 16 - $22(24)$

Beschreibung: Es sind die Zahnkronen erhalten.
3

Krankheiten:

\begin{tabular}{c|l|l} 
Arthrose & rechts & links \\
\hline Caput & & \\
\hline Fossa & &
\end{tabular}

$\begin{array}{llllcccc}\text { Zahn Status } & \text { Parodontium } & \text { Apikale Prozesse } & \text { Zahnstein } & \text { Karies } & \text { Abrasion } & \text { Neubildung Schmelzhypoplasie } \\ 17 & & \text { H } & 0 & 0 & 1 & 0 \\ 18 & & \text { K } & 0 & O & 1 & 0 & 0\end{array}$




\section{Zahn}

Population: Großenrode

Geschlecht:

Alter:

\section{Beschreibung:}

\subsubsection{5 / 29}

Skelett: K217 S3

Krankheiten:

\section{3}

\begin{tabular}{c|l|l} 
Arthrose & rechts & links \\
\hline Caput & & \\
\hline Fossa & &
\end{tabular}




\section{Zahn}

Population: Großenrode

Geschlecht:

Alter:

Beschreibung: Da die Wurzel nicht vorhanden ist, könnte es sich um eine Anlage handeln.

\section{Zahn Status Parodontium Apikale Prozesse}

14

\subsubsection{5 / 36}

Skelett: $60 / 65$

Krankheiten:

Zahnstein

0

\begin{tabular}{c|l|l} 
Arthrose & rechts & links \\
\hline Caput & & \\
\hline Fossa & &
\end{tabular}

Karies

0

\section{Abrasion Neubildung Schmelzhypoplasie}

0 U 1 


\section{Zähne}

Population: Großenrode

Geschlecht:

Alter:

Beschreibung: Bei diesen Fundstücken sind die Kronen zum Teil wegfrakturiert.
3

Krankheiten:

\begin{tabular}{c|l|l} 
Arthrose & rechts & links \\
\hline Caput & & \\
\hline Fossa & &
\end{tabular}

\begin{tabular}{|c|c|c|c|c|c|c|c|c|}
\hline Zahn & Status & Parodontium & Apikale Prozesse & Zahnstein & Karies & Abrasion & Neubildung & Schmelzhypoplasie \\
\hline 28 & v & & & $\mathrm{K}$ & 0 & $\mathrm{O}$ & 0 & $\mathrm{~T}$ \\
\hline 44 & v & & & K 1 & 0 & $\mathrm{O}$ & 0 & 0 \\
\hline 48 & $\mathrm{v}$ & & & K 3 & 0 & $\mathrm{O}$ & 0 & 0 \\
\hline
\end{tabular}




\section{UK}

Population: Großenrode

Geschlecht:

Alter:

(22) 25 - 30 (34)

Beschreibung: 22 liegt als einzelne Zahnkrone vor.

\begin{tabular}{|c|c|c|c|c|c|c|c|c|}
\hline Zahn & Status & Parodontium & Apikale Prozesse & Zahnstein & Karies & Abrasion & Neubildung & Schmelzhypoplasie \\
\hline 22 & & & & $\mathrm{~K}$ & 0 & $\mathrm{O}$ & 0 & $\mathrm{~T}$ \\
\hline 36 & & 0 & 0 & K 2 & 0 & 0 & 0 & 0 \\
\hline 37 & & & & K 1 & 0 & $\mathrm{O}$ & 0 & $\mathrm{~T}$ \\
\hline
\end{tabular}

\subsubsection{5 / 46}

Skelett: $\quad 61 / 65-3$

\section{Krankheiten:}

\begin{tabular}{c|l|l} 
Arthrose & rechts & links \\
\hline Caput & & \\
\hline Fossa & &
\end{tabular}




\section{Zähne}

Population:

Großenrode

Geschlecht:

Alter:

(22) $25-30(34)$

\subsubsection{5 / 47}

Skelett: K258 61/65

3

Krankheiten:

\begin{tabular}{c|l|l} 
Arthrose & rechts & links \\
\hline Caput & & \\
\hline Fossa & &
\end{tabular}

Beschreibung: 46 hat eine kleine Wurzel zusätzlich vestibulär. 47 weist eine leicht kreidige Oberfläche auf, was für eine initiale Karies spricht.

\begin{tabular}{|c|c|c|c|c|c|c|c|c|}
\hline Zahn & Status & Parodontium & Apikale Prozesse & Zahnstein & Karies & Abrasion & Neubildung & Schmelzhypoplasie \\
\hline 36 & & & 0 & $\mathrm{~K}$ & 0 & $\mathrm{O}$ & 0 & 0 \\
\hline 46 & & & 0 & $\begin{array}{ll}\mathrm{K} & 1\end{array}$ & 0 & 0 & 0 & 0 \\
\hline 47 & & & 0 & K 1 & $\mathrm{~K}$ & 0 & 0 & 0 \\
\hline
\end{tabular}




\section{UK}

Population: Großenrode

Geschlecht:

Alter:

(22) 25 - 30 (34)

Beschreibung: Es ist nur die Zahnkrone erhalten.

\subsubsection{5 / 12}

Skelett: K63 S161/63

Krankheiten:

\begin{tabular}{c|l|l} 
Arthrose & rechts & links \\
\hline Caput & & \\
\hline Fossa & &
\end{tabular}

\section{Zahn Status Parodontium Apikale Prozesse}

36
Zahnstein

K 1
Karies

O 3
Abrasion

O 1
Neubildung

0 


\section{Zahn}

Population: Großenrode

Geschlecht:

Alter:

\section{Beschreibung:}

\subsubsection{5 / 12}

Skelett: K96 61/63 S2

Krankheiten:

\section{3}

\begin{tabular}{c|l|l} 
Arthrose & rechts & links \\
\hline Caput & & \\
\hline Fossa & &
\end{tabular}

\section{Zahn Status Parodontium Apikale Prozesse}

11

Zahnstein

K 1
Karies

0
Abrasion

O 5 


\section{Zahn}

Population: Großenrode

Geschlecht:

Alter:

Beschreibung: Ein stark erodiertes Fundstück.
3

Krankheiten:

\begin{tabular}{c|l|l} 
Arthrose & rechts & links \\
\hline Caput & & \\
\hline Fossa & &
\end{tabular}

\section{Zahn Status Parodontium}

12
Apikale Prozesse

0
Zahnstein

0
Karies

0
Abrasion

O 3
Neubildung

0 


\section{Zahn}

Population: Großenrode

Geschlecht:

Alter:

Beschreibung: Diese Wurzel ist in Hälfte gespalten.
3

\begin{tabular}{c|l|l} 
Arthrose & rechts & links \\
\hline Caput & & \\
\hline Fossa & &
\end{tabular}

Krankheiten:

Skelett: $\quad 61 / 66-2$

\section{Zahn Status Parodontium Apikale Prozesse




\section{Zähne}

Population: Großenrode

Geschlecht:

Alter:

\subsubsection{5 / 13}

Skelett: K300 61/66 P4

3

Krankheiten:

\begin{tabular}{c|l|l} 
Arthrose & rechts & links \\
\hline Caput & & \\
\hline Fossa & &
\end{tabular}

Beschreibung: Bei diesen Fundstücken ist die Wurzel abfrakturiert. Der 5er weist sogar occlusal Zahnstein auf, was sehr ungewöhnlich ist.

$\begin{array}{lllllccc}\text { Zahn Status } & \text { Parodontium } & \text { Apikale Prozesse } & \text { Zahnstein } & \text { Karies } & \text { Abrasion } & \text { Neubildung Schmelzhypoplasie } \\ 34 & & \mathrm{~K} 1 & \mathrm{O} & 2 & 0 \\ 35 & & \mathrm{~K} 3 & \mathrm{O} & 1 & 0\end{array}$




\section{Zahn}

Population: Großenrode

Geschlecht:

Alter:

\section{Beschreibung:}

\subsubsection{5 / 13}

Skelett: $\quad 61 / 66$

Krankheiten:

\section{3}

\begin{tabular}{c|l|l} 
Arthrose & rechts & links \\
\hline Caput & & \\
\hline Fossa & &
\end{tabular}




\section{Zähne}

Population: Großenrode

Geschlecht:

Alter:

Beschreibung: Diese Zähne sind teilweise erodiert.
3

Krankheiten:

\begin{tabular}{c|l|l} 
Arthrose & rechts & links \\
\hline Caput & & \\
\hline Fossa & &
\end{tabular}

\section{Zahn Status Parodontium Apikale Prozesse}

31

32

33

Zahnstein Karies

K 2

0

K 2

K 2

\section{Abrasion Neubildung}

O 3

O 2

$\begin{array}{ll}0 & 2 \\ 0 & 1\end{array}$

0

0

0
Schmelzhypoplasie

T 1

T 1




\section{Zähne}

Population:

Großenrode

Geschlecht:

Alter:

(22) 25 - 30 (34)

Beschreibung: Zum Teil sind die Fundstücke stark erodiert, und von manchen Wurzeln sind Teile abfrakturiert.

\subsubsection{5/ 16}

Skelett: $\quad 60 / 66-4$

Krankheiten:

3

\begin{tabular}{c|l|l} 
Arthrose & rechts & links \\
\hline Caput & & \\
\hline Fossa & &
\end{tabular}

\begin{tabular}{|c|c|c|c|c|c|c|c|c|}
\hline Zahn & Status & Parodontium & Apikale Prozesse & Zahnstein & Karies & Abrasion & Neubildung & Schmelzhypoplasie \\
\hline 11 & & & & & 0 & $\mathrm{O}$ & 0 & $\mathrm{~T}$ \\
\hline 36 & & & & & 0 & 0 & 0 & 0 \\
\hline 43 & & & & & 0 & 0 & 0 & $\mathrm{~T}$ \\
\hline
\end{tabular}




\section{UK}

Population: Großenrode

Geschlecht:

Alter:

(40) $45-55(65)$

Beschreibung: Es ist ein Teil des Unterkiefers erhalten, der stark erodiert ist.

$\begin{array}{llccccccc}\text { Zahn } & \text { Status } & \text { Parodontium } & \text { Apikale Prozesse } & \text { Zahnstein } & \text { Karies } & \text { Abrasion } & \text { Neubildung } & \text { Schmelzhypoplasie } \\ 46 & f & 0 & & 0 & \text { K } & & & \\ 47 & & \text { Po } 3 & 0 & \text { K } 3 & 0 & 0 & 5 & * \\ 48 & \text { Po } 1 & & 0 & 0 & 3 & 0\end{array}$

28.02.2015 / 56

Skelett: aus großer Tüte 63/56 Krankheiten:

\begin{tabular}{c|c|c} 
Arthrose & rechts & links \\
\hline Caput & & $\mathrm{xx}$ \\
\hline Fossa & &
\end{tabular}




\section{Zahn}

Population: Großenrode

Geschlecht:

Alter:

(32) 37 - $45(50)$

\subsubsection{5 / 57}

Skelett: aus großer Tüte 63/56 Krankheiten:

\begin{tabular}{c|l|l} 
Arthrose & rechts & links \\
\hline Caput & & \\
\hline Fossa & &
\end{tabular}

\section{Beschreibung:}

\section{Zahn Status Parodontium Apikale Prozesse}

Zahnstein

$\mathrm{H} \quad 1$
Karies

0
Abrasion

O 4
Neubildung

\# 3 


\section{Zahn}

Population:

Großenrode

Geschlecht:

Alter:

(12) 16 - $22(24)$

Beschreibung: Bei diesem Fundstück fällt eine stark gekrümmte Wurzel auf.
2

\begin{tabular}{c|l|l} 
Arthrose & rechts & links \\
\hline Caput & & \\
\hline Fossa & &
\end{tabular}

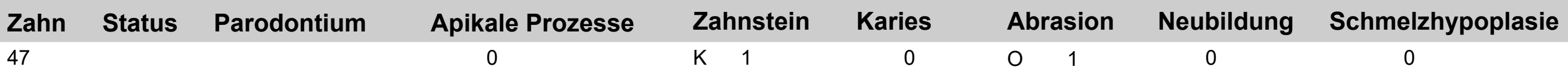




\section{UK}

Population: Großenrode

Geschlecht:

Alter:

Beschreibung: Ein fragmentiert und erodiert erhaltenes Fragment eines rechten Unterkiefers. Von 46 ist nur die distale Wurzel erhalten.

\subsubsection{5 / 5}

Skelett: aus großer Tüte
Krankheiten:

\begin{tabular}{c|l|l} 
Arthrose & rechts & links \\
\hline Caput & & \\
\hline Fossa & &
\end{tabular}

$\begin{array}{llccccccc}\text { Zahn } & \text { Status } & \text { Parodontium } & \text { Apikale Prozesse } & \text { Zahnstein } & \text { Karies } & \text { Abrasion } & \text { Neubildung } & \text { Schmelzhypoplasie } \\ 45 & & 0 & \text { K } & 0 & 0 & 3 & 0 \\ 46 & \text { E } & 0 & & & & & \end{array}$




\section{OK; UK}

Population:

Großenrode

Geschlecht:

Alter:

Beschreibung: Sehr stark erodierte Fundstücke, das Caput ist zu $90 \%$ erhalten, die Fossa ist ebenfalls erodiert und der Zahn ist frakturiert und erodiert.

\subsubsection{5 / 26}

Skelett: aus 63/56 Tüte Cranium Krankheiten:

\begin{tabular}{c|c|c} 
Arthrose & rechts & links \\
\hline Caput & 2 & \\
\hline Fossa & & 1
\end{tabular}




\section{OK}

Population: Großenrode

Geschlecht:

Alter:

(22) 28 - 35 (38)
2

Krankheiten: Stomatitis

Parodontitis

Beschreibung: Ein recht gut erhaltenes Fundstück. Das Granulum an 21 war wohl gefenstert. Die Stomatitis am Gaumen war mit Grad 1 ausgeprägt.

\begin{tabular}{|c|c|c|c|c|c|c|c|c|}
\hline Zahn & Status & Parodontium & Apikale Prozesse & Zahnstein & Karies & Abrasion & Neubildung & Schmelzhypoplasie \\
\hline 21 & $\mathrm{v}$ & 0 & $G$ & & & & & \\
\hline 22 & v & 0 & & & & & & \\
\hline 23 & & 0 & 0 & K & 0 & 0 & * & $U$ \\
\hline 24 & & 0 & & K & 0 & $\mathrm{O}$ & * & $x$ \\
\hline 25 & v & $\mathrm{Pi} \quad 1$ & & & & & & \\
\hline 26 & v & $\mathrm{Pi} \quad 1$ & & & & & & \\
\hline 27 & $\mathrm{v}$ & $\mathrm{Pi} \quad 1$ & 0 & & & & & \\
\hline 28 & & S 3 & 0 & K 1 & 0 & $\mathrm{O}$ & 0 & 0 \\
\hline
\end{tabular}




\section{Zähne}

Population:

Großenrode

Geschlecht:

Alter:

(4) 6 - 7 (9)
01.03.2015 / 69

Skelett: $\quad 61 / 57$

Krankheiten:

\begin{tabular}{c|l|l} 
Arthrose & rechts & links \\
\hline Caput & & \\
\hline Fossa & &
\end{tabular}

Beschreibung: 37 war noch Anlage, von den anderen Zähnen war das Wurzelwachstum nicht abgeschlossen

$\begin{array}{llccccccc}\text { Zahn } & \text { Status } & \text { Parodontium } & \text { Apikale Prozesse } & \text { Zahnstein } & \text { Karies } & \text { Abrasion } & \text { Neubildung } & \text { Schmelzhypoplasie } \\ 16 & & & & 0 & 0 & 0 & 0 \\ 37 & \text { ( ) } & & 0 & & & 1 & 0 & 0 \\ 55 & & & 0 & & \end{array}$




\section{OK}

Population:-Großenrode

Geschlecht:

Alter:

(30) 37 - 45 (60)

\section{2}

Krankheiten: Sinusitis maxillaris

Beschreibung: Bei den Zähnen fällt eine starke Abrasion ins Auge. Weiterhin ist eine leichte Sinusitis maxillaris zu diagnostizieren.

\begin{tabular}{|c|c|c|c|c|c|c|c|c|}
\hline Zahn & Status & Parodontium & Apikale Prozesse & Zahnstein & Karies & Abrasion & Neubildung & Schmelzhypoplasie \\
\hline 11 & & $\mathrm{Pi} \quad 1$ & 0 & 0 & 0 & $\mathrm{O}$ & * & 0 \\
\hline 12 & & $\mathrm{Pi} 1$ & 0 & $x$ & 0 & $\mathrm{O}$ & * & $x$ \\
\hline 13 & & $\mathrm{Pi} \quad 1$ & 0 & $x$ & 0 & O & * & $x$ \\
\hline 14 & & $\mathrm{Pi} \quad 1$ & 0 & $x$ & 0 & $\mathrm{O}$ & * & $x$ \\
\hline 15 & & $\mathrm{Pi} \quad 1$ & 0 & $\mathrm{~K}$ & 0 & $\mathrm{O}$ & * & $x$ \\
\hline 31 & & & 0 & $\mathrm{~K}$ & 0 & $\mathrm{O}$ & & 0 \\
\hline
\end{tabular}




\section{UK}

Population: Großenrode

Geschlecht:

Alter:

Beschreibung: Ein kleines Fragment des Unterkiefers ist erhalten.
2

Krankheiten:

\begin{tabular}{c|l|l} 
Arthrose & rechts & links \\
\hline Caput & & \\
\hline Fossa & &
\end{tabular}

\section{Zahn Status Parodontium Apikale Prozesse}

0

0

Zahnstein

Karies

Abrasion

Neubildung

0

Schmelzhypoplasie

0

O 2

0 


\section{Zähne}

Population: Großenrode

Geschlecht:

Alter:

\section{Beschreibung:}

\subsubsection{5 / 3}

Skelett: $62 / 54$

Krankheiten:

\begin{tabular}{c|l|l} 
Arthrose & rechts & links \\
\hline Caput & & \\
\hline Fossa & &
\end{tabular}

\section{Zahn Status Parodontium Apikale Prozesse}

24

25
0
Zahnstein

K 3

K 2

\section{Karies}

0

0
Abrasion

Neubildung

O 4

*

O 4 


\section{UK}

Population: Großenrode

Geschlecht:

Alter:

Beschreibung: Neben diesen Zähnen ist noch ein Caput mandibulae der linken Seite erhalten.

\subsubsection{5 / 3}

Skelett: $62 / 54$
2

\section{Krankheiten:}

\section{Zahn Status Parodontium}

31

41

\begin{tabular}{r|l|c} 
Arthrose & rechts & links \\
\hline Caput & & 2 \\
\hline Fossa & &
\end{tabular}




\section{Zähne}

Population:

Großenrode

Geschlecht:

Alter:

(22) 25 - 30 (35)

Beschreibung: Die mesiale Wurzel des 6ers ist zu 2/3 erhalten.
2

Krankheiten:

\begin{tabular}{c|l|l} 
Arthrose & rechts & links \\
\hline Caput & & \\
\hline Fossa & &
\end{tabular}

\begin{tabular}{|c|c|c|c|c|c|c|c|c|}
\hline Zahn & Status & Parodontium & Apikale Prozesse & Zahnstein & Karies & Abrasion & Neubildung & Schmelzhypoplasie \\
\hline 33 & & & 0 & $\mathrm{~K}$ & 0 & $\mathrm{O}$ & 0 & $\mathrm{~T}$ \\
\hline 44 & & & 0 & $\mathrm{~K}$ & 0 & $\mathrm{O}$ & 0 & 0 \\
\hline 46 & & & 0 & K 1 & 0 & $\mathrm{O}$ & 0 & 0 \\
\hline
\end{tabular}




\section{UK}

Population: Großenrode

Geschlecht:

Alter:

(22) 25 - $30(34)$

Beschreibung: Ein stark erodierter und zerbrochener Unterkiefer, bei 46 ist die mesiale Wurzel abfrakturiert.
2

\begin{tabular}{c|l|l} 
Arthrose & rechts & links \\
\hline Caput & & \\
\hline Fossa & &
\end{tabular}

\begin{tabular}{|c|c|c|c|c|c|c|c|c|}
\hline Zahn & Status & Parodontium & Apikale Prozesse & Zahnstein & Karies & Abrasion & Neubildung & Schmelzhypoplasie \\
\hline 36 & & $x$ & 0 & $\mathrm{~L}$ & 0 & $\mathrm{O}$ & 0 & 0 \\
\hline 44 & v & & & & & & & \\
\hline 46 & & & & $\mathrm{~K} \quad 1$ & M 2 & $\mathrm{O}$ & 0 & 0 \\
\hline
\end{tabular}




\section{Zähne}

Population:

Großenrode

Geschlecht:

Alter:

(6) $8,5-13(15)$
2

Krankheiten:

Beschreibung: Bei 26 ist ein Teil der Wurzel abgebrochen, bei 28 ebenfalls. Weiterhin ist die Wurzel des 28 wohl noch nicht vollständig ausgebildet gewesen.

$\begin{array}{llllcccc}\text { Zahn Status } & \text { Parodontium } & \text { Apikale Prozesse } & \text { Zahnstein } & \text { Karies } & \text { Abrasion } & \text { Neubildung Schmelzhypoplasie } \\ 26 & & \text { K } 1 & 0 & \text { O } & 1 & 0 \\ 28 & & \text { D } 1 & 0 & O & 1 & 0\end{array}$




\section{Zahn}

Population: Großenrode

Geschlecht:

Alter:

(3) 4 - $5(6,5)$

\section{Beschreibung:}

\subsubsection{5 / 4}

Skelett: $\quad 61 / 58$

Krankheiten:

\begin{tabular}{c|l|l} 
Arthrose & rechts & links \\
\hline Caput & & \\
\hline Fossa & &
\end{tabular}

2

\section{Zahn Status Parodontium Apikale Prozesse}

Zahnstein

K 1 


\section{Zähne}

Population:

Großenrode

Geschlecht:

Alter:

(22) $25-30(34)$
2

Krankheiten:

\begin{tabular}{c|l|l} 
Arthrose & rechts & links \\
\hline Caput & & \\
\hline Fossa & &
\end{tabular}

Beschreibung: Diese Zähne sind erodiert, die Wurzel des 26 ist teilweise frakturiert, die des 46 ist komplett abfrakturiert.

$\begin{array}{llclccccc}\text { Zahn Status } & \text { Parodontium } & \text { Apikale Prozesse } & \text { Zahnstein } & \text { Karies } & \text { Abrasion } & \text { Neubildung } & \text { Schmelzhypoplasie } \\ 26 & & & \mathrm{~K} 1 & 0 & \mathrm{O} & 3 & 0 \\ 35 & & 0 & \mathrm{~L} 2 & 0 & \mathrm{O} & 3 & 0 & 0 \\ 46 & & & \mathrm{~K} 1 & 0 & \mathrm{O} & 3 & 0\end{array}$




\section{Zahn}

Population: Großenrode

Geschlecht:

Alter:

(3) 4 - 6 (7)

\section{Beschreibung:}

\subsubsection{5 / 17}

Skelett: $\quad 62 / 50$

Krankheiten:

2

\section{Zahn Status Parodontium Apikale Prozesse}

36
Zahnstein Karies

0

Karies

0

\begin{tabular}{r|l|l} 
Arthrose & rechts & links \\
\hline Caput & & \\
\hline Fossa & &
\end{tabular}

Abrasion

Neubildung

Schmelzhypoplasie

0

0 T 1 


\section{Zahn}

Population: Großenrode

Geschlecht:

Alter:

(7) 8 - $9(10)$

\section{Beschreibung:}

\section{Zahn Status Parodontium Apikale Prozesse}

\subsubsection{5 / 17}

Skelett: $\quad 62 / 50$

Krankheiten:

2

\begin{tabular}{r|l|l} 
Arthrose & rechts & links \\
\hline Caput & & \\
\hline Fossa & &
\end{tabular}

Zahnstein

$\sqrt{2}$

0

$\begin{array}{cc}\text { Kahnstein } & \text { Karies } \\ 0 & 0\end{array}$

Abrasion Neubildung Schmelzhypoplasie 0 $\begin{array}{ll}\mathrm{T} & 1\end{array}$ 


\section{Zahn}

Population: Großenrode

Geschlecht:

Alter:

$16-20(23)$

Beschreibung: Das Wurzelwachstum ist fast vollständig abgeschlossen.
2

\begin{tabular}{c|l|l} 
Arthrose & rechts & links \\
\hline Caput & & \\
\hline Fossa & &
\end{tabular}

\section{Krankheiten:}




\section{Zahn}

Population: Großenrode

Geschlecht:

Alter:

$$
3-4(5)
$$

\section{Beschreibung:}

\subsubsection{5 / 21}

Skelett: $69 / 57$

Krankheiten:

\begin{tabular}{c|l|l} 
Arthrose & rechts & links \\
\hline Caput & & \\
\hline Fossa & &
\end{tabular}




\section{Zahn}

Population: Großenrode

Geschlecht:

Alter:

Beschreibung: Von der Wurzel ist noch etwa $1 / 3$ erhalten.

\subsubsection{5 / 21}

Skelett: $69 / 57$
Krankheiten:

\section{Krankheiten:}

\begin{tabular}{c|l|l} 
Arthrose & rechts & links \\
\hline Caput & & \\
\hline Fossa & &
\end{tabular}

Zahn Status Parodontium Apikale Prozesse

28
Zahnstein

0

\section{Karies}

0
Abrasion

O 2
Neubildung

0 


\section{UK}

Population: Großenrode

Geschlecht:

Alter:

Beschreibung: Wurzelwachstum möglicherweise nicht endgültig abgeschlossen. Es fehlt das apicale 2/3, es könnte aber auch abfrakturiert sein. Weiterhin ist noch ein Fragment des Caput mandibulae (zu 90\%) und ein Fragment des aufsteigenden Astes rechts erhalten.

\subsubsection{5 / 22}

Skelett: $\quad 64 / 50$
Krankheiten:

\begin{tabular}{c|c|c} 
Arthrose & rechts & links \\
\hline Caput & 1 & \\
\hline Fossa & &
\end{tabular}

$\begin{array}{lllccccc}\text { Zahn } & \text { Status } & \text { Parodontium } & \text { Apikale Prozesse } & \text { Zahnstein } & \text { Karies } & \text { Abrasion } & \text { Neubildung } \\ 43 & & \mathrm{~K} 2 & 0 & 0 & 0 & \mathrm{~T} & 1\end{array}$




\section{Zähne}

Population: Großenrode

Geschlecht:

Alter:

Beschreibung: Die Wurzel des 17 ist frakturiert.
2

\begin{tabular}{c|l|l} 
Arthrose & rechts & links \\
\hline Caput & & \\
\hline Fossa & &
\end{tabular}

Krankheiten:

Skelett: $64 / 50$

\section{Zahn Status Parodontium Apikale Prozesse}

17

31

32
0
Zahnstein Karies

K 1

K 1

K 1

0

0
Abrasion Neubildung Schmelzhypoplasie

O 2

O 3

0

0

O 4




\section{Zahn}

Population: Großenrode

Geschlecht:

Alter:

Beschreibung: Hier ist nur die Krone erhalten, die Wurzel ist im Zahn abgebrochen.

\section{Zahn Status Parodontium}

28

\subsubsection{5 / 23}

Skelett: $63 / 52$

Krankheiten:

\begin{tabular}{c|l|l} 
Arthrose & rechts & links \\
\hline Caput & & \\
\hline Fossa & &
\end{tabular}

Apikale Prozesse

Zahnstein

0

Karies

0
Neubildung

0

0 


\section{Zahn}

Population: Großenrode

Geschlecht:

Alter:

(2) 3 - 4 (5)

Beschreibung: Die Wurzel dieses Zahnes ist abfrakturiert.
2

Krankheiten:

\begin{tabular}{c|l|l} 
Arthrose & rechts & links \\
\hline Caput & & \\
\hline Fossa & &
\end{tabular}

\begin{tabular}{|c|c|c|c|c|c|c|c|c|}
\hline ahn & Status & Parodontium & Apikale Prozesse & Zahnstein & Karies & Abrasion & Neubildung & Schmelzhypoplasie \\
\hline 65 & & & & 0 & 0 & 0 & 0 & 0 \\
\hline
\end{tabular}


OK; UK

Population:

Großenrode

Geschlecht:

Alter:

(25) 28 - $35(38)$

\section{2}

Krankheiten: Sinusitis maxillaris

\begin{tabular}{c|l|l} 
Arthrose & rechts & links \\
\hline Caput & & \\
\hline Fossa & &
\end{tabular}

Beschreibung: Bei dem Oberkiefer fällt eine verheilte Sinusitis maxillaris auf. Sie war auf beiden Seiten ausgeprägt.

\begin{tabular}{|c|c|c|c|c|c|c|c|c|c|}
\hline Zahn & Status & Parodontium & Apikale Prozesse & Zahnstein & Karies & & sion & Neubildung & Schmelzhypoplasie \\
\hline 11 & & & & 0 & 0 & $\mathrm{O}$ & 2 & 0 & $U$ \\
\hline 12 & v & & 0 & & & & & & \\
\hline 13 & & & 0 & 0 & 0 & O & 3 & 0 & $U$ \\
\hline 14 & & & & $\mathrm{~K}$ & 0 & $\mathrm{O}$ & 4 & * & 0 \\
\hline 15 & & & & $\mathrm{~K}$ & 0 & 0 & 4 & * & 0 \\
\hline 16 & & Po 1 & 0 & $\mathrm{~K}$ & 0 & 0 & 4 & * & 0 \\
\hline 17 & & Po 1 & 0 & K 3 & 0 & 0 & 3 & 0 & 0 \\
\hline 18 & $v$ & Po 1 & & & & & & & \\
\hline 21 & $v$ & 0 & 0 & & & & & & \\
\hline 22 & v & 0 & 0 & & & & & & \\
\hline 23 & v & 0 & 0 & & & & & & \\
\hline
\end{tabular}


25

26

27

28

Po 1
K 1

K 3
0

(n)

0
0
$x$
0

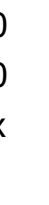

03

0

0 


\section{UK}

$\begin{array}{lllllll}\text { Zahn } & \text { Status } & \text { Parodontium } & \text { Apikale Prozesse } & \text { Zahnstein } & \text { Karies } & \text { Abrasion Neubildung Schmelzhypoplasie } \\ 44 & f & & & \\ 45 & \mathrm{f} & & \\ 45 & \mathrm{f} & & \\ 46 & \mathrm{f} & & \\ 47 & \mathrm{f} & & \end{array}$

Population: Großenrode

Geschlecht:

Alter: $\quad 40-50(70)$

Beschreibung: Hier ist ein Unterkieferfragment erhalten, die Alveolen waren geschlossen.

\subsubsection{5 / 1}

Skelett: $\quad 63 / 52$

Krankheiten:

2

\begin{tabular}{c|l|l} 
Arthrose & rechts & links \\
\hline Caput & & \\
\hline Fossa & &
\end{tabular}




\section{Zähne}

Population: Großenrode

Geschlecht:

Alter:

\section{Beschreibung:}

\subsubsection{5/1}

Skelett: $63 / 52$

Krankheiten:

\begin{tabular}{c|l|l} 
Arthrose & rechts & links \\
\hline Caput & & \\
\hline Fossa & &
\end{tabular}




\section{Zahn}

Population: Großenrode

Geschlecht:

Alter:

\section{Beschreibung:}

\subsubsection{5 / 2}

Skelett: $\quad 63 / 52$

Krankheiten:

\section{Zahn Status Parodontium Apikale Prozesse}

33
Zahnstein

K 1
Karies

0

\begin{tabular}{c|l|l} 
Arthrose & rechts & links \\
\hline Caput & & \\
\hline Fossa & &
\end{tabular}

2

(1)
Abrasion

O 4 


\section{Zahn}

Population: Großenrode

Geschlecht:

Alter:

\section{Beschreibung:}

\subsubsection{5 / 3}

Skelett: $63 / 52$

Krankheiten:

\begin{tabular}{c|l|l} 
Arthrose & rechts & links \\
\hline Caput & & \\
\hline Fossa & &
\end{tabular}




\section{Zahn}

Population: Großenrode

Geschlecht:

Alter:

Beschreibung: Von diesem Zahn ist das apicale Drittel abfrakturiert.
2

\begin{tabular}{c|l|l} 
Arthrose & rechts & links \\
\hline Caput & & \\
\hline Fossa & &
\end{tabular}

\section{Krankheiten:}




\section{Zahn}

Population: Großenrode

Geschlecht:

Alter:

\section{Beschreibung:}

\subsubsection{5 / 5}

Skelett: $63 / 52$

Krankheiten:

\begin{tabular}{c|l|l} 
Arthrose & rechts & links \\
\hline Caput & & \\
\hline Fossa & &
\end{tabular}




\section{OK}

Population: Großenrode Skelett: 63/52

Geschlecht:

Alter:

(25) $37-45(50)$

\section{2}

Krankheiten: Sinusitis maxillaris

Beschreibung: Hier ist ein Fragment eines Oberkiefers erhalten. Die Alveole von 26 war nur zur Hälfte erhalten und die Kieferhöhle weist Spuren einer Sinusitis auf, die wohl bereits verheilt war.

$\begin{array}{lllcccccc}\text { Zahn } & \text { Status } & \text { Parodontium } & \text { Apikale Prozesse } & \text { Zahnstein } & \text { Karies } & \text { Abrasion } & \text { Neubildung } & \text { Schmelzhypoplasie } \\ 26 & \text { v } & \text { Po } 1 & 0 & \text { K } 1 & 0 & 0 & 4 & * \\ 27 & & \text { Po } 1 & 0 & & & & \end{array}$




\section{Zähne}

Population: Großenrode

Geschlecht:

Alter:

\subsubsection{5 / 1}

Skelett: $64 / 53$

Krankheiten:

\begin{tabular}{c|l|l} 
Arthrose & rechts & links \\
\hline Caput & & \\
\hline Fossa & &
\end{tabular}

Beschreibung: Diese Zähne sind erodiert, von 13 ist ein Teil der Krone frakturiert und bei allen sind die Wurzeln abfrakturiert.

\begin{tabular}{|c|c|c|c|c|c|c|c|c|}
\hline Zahn & Status & Parodontium & Apikale Prozesse & Zahnstein & Karies & Abrasion & Neubildung & Schmelzhypoplasie \\
\hline 13 & & & & $\mathrm{~K}$ & 0 & $\mathrm{O}$ & * & 0 \\
\hline 26 & & & & $\begin{array}{ll}\mathrm{K} & 1\end{array}$ & 0 & 0 & 0 & 0 \\
\hline 47 & & & & K 1 & 0 & $\mathrm{O}$ & 0 & $\mathrm{~T}$ \\
\hline
\end{tabular}




\section{Zahn}

Population: Großenrode

Geschlecht:

Alter:

(14) 16 - $22(24)$

Beschreibung: Komplett gut erhalten.
2

Krankheiten:

\begin{tabular}{c|l|l} 
Arthrose & rechts & links \\
\hline Caput & & \\
\hline Fossa & &
\end{tabular}

\begin{tabular}{|c|c|c|c|c|c|c|c|c|}
\hline Zahn & Status & Parodontium & Apikale Prozesse & Zahnstein & Karies & Abrasion & Neubildung & Schmelzhypoplasie \\
\hline 26 & & & 0 & $\begin{array}{ll}\mathrm{K} & 1\end{array}$ & 0 & $\mathrm{O}$ & 0 & $\mathrm{~T}$ \\
\hline
\end{tabular}




\section{Zähne}

Population:

Großenrode

Geschlecht:

Alter:

(14) 16 - $22(24)$
2

Krankheiten:

\begin{tabular}{c|l|l} 
Arthrose & rechts & links \\
\hline Caput & & \\
\hline Fossa & &
\end{tabular}

\section{Beschreibung:}

\section{Zahn Status Parodontium Apikale Prozesse}

Zahnstein

Karies

$\begin{array}{ll}\mathrm{K} & 1 \\ \mathrm{~K} & 1\end{array}$

K 1

K 1

K 1

K 2

47 


\section{Zähne}

Population:

Großenrode

Geschlecht:

Alter:

(6) 8 - 9 (10)

\subsubsection{5 / 16}

Skelett: $\quad 62 / 55$

Krankheiten:

\section{Beschreibung:}

2

\begin{tabular}{c|l|l} 
Arthrose & rechts & links \\
\hline Caput & & \\
\hline Fossa & &
\end{tabular}

$\begin{array}{llcccccc}\text { Zahn } & \text { Status } & \text { Parodontium } & \text { Apikale Prozesse } & \text { Zahnstein } & \text { Karies } & \text { Abrasion } & \text { Neubildung } \\ 33 & & & & & \\ 48 & & \text { K } 1 & 0 & 0 & 3 & 0\end{array}$


OK; UK

Population:

Geschlecht:

Alter:

(14) 16 - 22 (24)

Beschreibung: Hier sind nur kleine Kieferfragmente erhalten.
2

Krankheiten:

\begin{tabular}{c|l|l} 
Arthrose & rechts & links \\
\hline Caput & & \\
\hline Fossa & &
\end{tabular}

$\begin{array}{lcccccccc}\text { Zahn } & \text { Status } & \text { Parodontium } & \text { Apikale Prozesse } & \text { Zahnstein } & \text { Karies } & \text { Abrasion } & \text { Neubildung } & \text { Schmelzhypoplasie } \\ 24 & & & \mathrm{~K} & 1 & 0 & \mathrm{O} & 2 & 0 \\ 27 & 0 & 0 & \mathrm{~K} 1 & 0 & \mathrm{O} & 1 & 0 & 1 \\ \end{array}$




\section{Zähne}

Population:

Großenrode

Geschlecht:

Alter:

(22) $25-30(34)$

\section{2}

Krankheiten:

\begin{tabular}{c|l|l} 
Arthrose & rechts & links \\
\hline Caput & & \\
\hline Fossa & &
\end{tabular}

Beschreibung: Lingual weisen die Zähne Schmelzabplatzungen auf, was möglicherweise für eine Überlastung sprechen könnte. Möglich wäre auch ein Traumageschehen.

\begin{tabular}{|c|c|c|c|c|c|c|c|c|}
\hline Zahn & Status & Parodontium & Apikale Prozesse & Zahnstein & Karies & Abrasion & Neubildung & Schmelzhypoplasie \\
\hline 44 & & & 0 & $\mathrm{~K}$ & 0 & $\mathrm{O}$ & * & 0 \\
\hline 45 & & & 0 & $\mathrm{~K}$ & 0 & $\mathrm{O}$ & 0 & 0 \\
\hline 46 & & & & $\mathrm{~K}$ & 0 & $\mathrm{O}$ & 0 & 0 \\
\hline 47 & & & 0 & $\begin{array}{ll}\mathrm{K} & 1\end{array}$ & & & & 0 \\
\hline
\end{tabular}




\section{Zahn}

Population: Großenrode

Geschlecht:

Alter:

(6) $8,5-13(15)$

Beschreibung: Dieser Zahn ist zum Teil erodiert und weist eine frakturierte Wurzel auf
2

\begin{tabular}{c|l|l} 
Arthrose & rechts & links \\
\hline Caput & & \\
\hline Fossa & &
\end{tabular}

$\begin{array}{lllllllll}\text { Zahn } & \text { Status } & \text { Parodontium } & \text { Apikale Prozesse } & \text { Zahnstein } & \text { Karies } & \text { Abrasion } & \text { Neubildung } & \text { Schmelzhypoplasie } \\ 26 & & \mathrm{~K} 1 & 0 & \mathrm{O} & 1 & 0 & \mathrm{U} & 1\end{array}$




\section{Zähne}

Population: Großenrode

Geschlecht:

Alter:

Beschreibung: Diese Fundstücke sind erodiert und die Wurzeln frakturiert.
2

\begin{tabular}{c|l|l} 
Arthrose & rechts & links \\
\hline Caput & & \\
\hline Fossa & &
\end{tabular}

\section{Krankheiten:}


OK; UK

Population:

Großenrode

Geschlecht:

Alter:

(22) 28 - 35 (38)
08.03.2015 / 10

Skelett: $\quad 65 / 53$

Krankheiten:
2

\begin{tabular}{c|l|l} 
Arthrose & rechts & links \\
\hline Caput & & \\
\hline Fossa & &
\end{tabular}

Beschreibung: Die Kiefer liegen in Fragmenten vor. 17 weist eine frakturierte Wurzel auf. Die Alveolen von 34 und 36 sind nur zur Hälfte erhalten.

$\begin{array}{llccccccc}\text { Zahn } & \text { Status } & \text { Parodontium } & \text { Apikale Prozesse } & \text { Zahnstein } & \text { Karies } & \text { Abrasion } & \text { Neubildung } & \text { Schmelzhypoplasie } \\ 17 & & & \text { K } 1 & 0 & 0 & 3 & 0 \\ 34 & \text { V } & 0 & & & & & \\ 35 & \text { E } & 0 & & & & & \\ 36 & \text { V } & 0 & & & & \end{array}$




\section{Zahn}

Population: Großenrode

Geschlecht: indifferent

Alter:

(1) 1,5 - $2(2,5)$

Beschreibung: Eine Zahnanlage.

\subsubsection{5 / 13}

Skelett: $\quad 65 / 54$

Krankheiten:

2

\begin{tabular}{c|l|l} 
Arthrose & rechts & links \\
\hline Caput & & \\
\hline Fossa & &
\end{tabular}

\section{Zahn Status Parodontium}

Apikale Prozesse

46
Zahnstein Karies

Abrasion

Neubildung

Schmelzhypoplasie 


\section{Zahn}

Population: Großenrode

Geschlecht:

Alter:

Beschreibung: Hier ist die Wurzel zu $1 / 3$ abfrakturiert.
2

Krankheiten:

\begin{tabular}{c|l|l} 
Arthrose & rechts & links \\
\hline Caput & & \\
\hline Fossa & &
\end{tabular}

Zahn Status Parodontium Apikale Prozesse

21
08.03.2015 / 15

Skelett: $64 / 54$
Zahnstein

0
Karies

0
Abrasion

O 3
Neubildung

0

Schmelzhypoplasie 


\section{Zahn}

Population: Großenrode

Geschlecht:

Alter:

Beschreibung: Bei diesem Zahn ist die Wurzel leicht abfrakturiert.
2

Krankheiten:

\begin{tabular}{c|l|l} 
Arthrose & rechts & links \\
\hline Caput & & \\
\hline Fossa & &
\end{tabular}

Zahn Status Parodontium Apikale Prozesse

0

Zahnstein

Karies

Abrasion

Neubildung

Schmelzhypoplasie
K 1

0
O 1

0

0 


\section{Zahn}

Population: Großenrode

Geschlecht:

Alter:

Beschreibung: 1/3 der Wurzel ist abfrakturiert, Abrasion ist auch palatinal.
2

\begin{tabular}{c|l|l} 
Arthrose & rechts & links \\
\hline Caput & & \\
\hline Fossa & &
\end{tabular}

\section{Krankheiten:}




\section{Zahn}

Population: Großenrode

Geschlecht:

Alter:

(14) 16 - $22(24)$

Beschreibung: Von dieser Wurzel ist apical etwas abfrakturiert.
2

Krankheiten:

\begin{tabular}{c|l|l} 
Arthrose & rechts & links \\
\hline Caput & & \\
\hline Fossa & &
\end{tabular}

Zahnstein

$\mathrm{H} \quad 1$
Karies

0
Abrasion

O 2

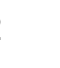

Neubildung

0

Schmelzhypoplasie

0 


\section{Zahn}

Population: Großenrode

Geschlecht:

Alter:

(14) 25 - 30 (34)
2

Krankheiten:

\begin{tabular}{c|l|l} 
Arthrose & rechts & links \\
\hline Caput & & \\
\hline Fossa & &
\end{tabular}

Beschreibung: Ein stark erodiertes Fundstück. Die Wurzel ist frakturiert, von ihr ist etwa die Hälfte erhalten. Von der Krone sind 2/3 vorhanden.

$\begin{array}{llllccccc}\text { Zahn } & \text { Status } & \text { Parodontium } & \text { Apikale Prozesse } & \text { Zahnstein } & \text { Karies } & \text { Abrasion } & \text { Neubildung Schmelzhypoplasie } \\ 47 & & \mathrm{~K} 1 & 0 & 0 & 2 & 0\end{array}$




\section{Zahn}

Population: Großenrode

Geschlecht: >> männlich

Alter:

\section{Beschreibung:}

\subsubsection{5 / 25}

Skelett: $\quad 60 / 59$

Krankheiten:

\begin{tabular}{c|l|l} 
Arthrose & rechts & links \\
\hline Caput & & \\
\hline Fossa & &
\end{tabular}

\section{Zahn Status Parodontium}

Apikale Prozesse

11
Zahnstein

K 1

0
2 


\section{Zahn}

Population: Großenrode

Geschlecht:

Alter:

(3) 4 - 5 (6)

Beschreibung: Eine Zahnanlage.

\subsubsection{5 / 26}

Skelett: $62 / 59$

Krankheiten:

\begin{tabular}{r|l|l} 
Arthrose & rechts & links \\
\hline Caput & & \\
\hline Fossa & &
\end{tabular}

2
Zahn Status Parodontium Apikale Prozesse
36
Zahnstein Karies

0

\section{Abrasion Neubildung Schmelzhypoplasie}




\section{Zahn}

Population: Großenrode

Geschlecht:

Alter:

(4) 6 - 7 (8)

\section{Beschreibung:}

\subsubsection{5 / 28}

Skelett: $60 / 56$

Krankheiten:

\begin{tabular}{c|l|l} 
Arthrose & rechts & links \\
\hline Caput & & \\
\hline Fossa & &
\end{tabular}




\section{Zähne}

Population:

Großenrode

Geschlecht:

Alter:

(12) $14-15(16)$

Beschreibung: Der 8er ist eine Zahnanlage.
2

Krankheiten:

\begin{tabular}{c|l|l} 
Arthrose & rechts & links \\
\hline Caput & & \\
\hline Fossa & &
\end{tabular}

$\begin{array}{llccccccc}\text { Zahn } & \text { Status } & \text { Parodontium } & \text { Apikale Prozesse } & \text { Zahnstein } & \text { Karies } & \text { Abrasion } & \text { Neubildung } & \text { Schmelzhypoplasie } \\ 14 & & 0 & \mathrm{~K} & 0 & 0 & 1 & 0 \\ 18 & & & & 0 & 0\end{array}$




\section{Zahn}

Population: Großenrode

Geschlecht:

Alter:

(22) 28 - 35 (38)

Beschreibung: Die Wurzel dieses Zahnes ist zu 1/3 abfrakturiert.

\subsubsection{5 / 28}

Skelett: $60 / 56$
Krankheiten:

\begin{tabular}{c|l|l} 
Arthrose & rechts & links \\
\hline Caput & & \\
\hline Fossa & &
\end{tabular}

$\begin{array}{llcccccc}\text { Zahn } & \text { Status } & \text { Parodontium } & \text { Apikale Prozesse } & \text { Zahnstein } & \text { Karies } & \text { Abrasion } & \text { Neubildung } \\ 47 & & 0 & 0 & 0 & 3 & 0\end{array}$




\section{Zahn}

Population: Großenrode

Geschlecht:

Alter:

(7) 8 - 9 (10)

Beschreibung: Eine Zahnanlage.

\subsubsection{5 / 37}

Skelett: $64 / 52$

Krankheiten:

\begin{tabular}{c|l|l} 
Arthrose & rechts & links \\
\hline Caput & & \\
\hline Fossa & &
\end{tabular}

\section{Zahn Status Parodontium} 27
Apikale Prozesse
Zahnstein

Karies

Abrasion

Neubildung

0

Schmelzhypoplasie 


\section{Zahn}

Population: Großenrode

Geschlecht:

Alter:

\section{Beschreibung:}

\subsubsection{5 / 38}

Skelett: $63 / 49$

Krankheiten:

\begin{tabular}{c|l|l} 
Arthrose & rechts & links \\
\hline Caput & & \\
\hline Fossa & &
\end{tabular}




\section{UK}

Population: Großenrode

Geschlecht:

Alter:

Beschreibung: Von diesem Unterkiefer ist nur das rechte Caput mandibulae zu $40 \%$ erhalten. Der Zahn ist erodiert, die distale Wurzel ist abfrakturiert. Weitere Befunde sind nicht mit Sicherheit zu machen.

\section{Zahn Status Parodontium}

36
08.03.2015 / 42

Skelett: $\quad 61 / 59$
Krankheiten:

\begin{tabular}{c|c|c} 
Arthrose & rechts & links \\
\hline Caput & $\mathrm{x}$ & \\
\hline Fossa & &
\end{tabular}




\section{Zahn}

Population: Großenrode

Geschlecht:

Alter:

(5) 7 - 8 (9)

Beschreibung: Dies ist eine Zahnanlage.

\subsubsection{5 / 42}

Skelett: $\quad 61 / 59$

Krankheiten:

\begin{tabular}{c|l|l} 
Arthrose & rechts & links \\
\hline Caput & & \\
\hline Fossa & &
\end{tabular}

\section{Zahn Status \\ Apikale Prozesse}

43
Zahnstein

Karies

Neubildung

0

Schmelzhypoplasie T 1 


\section{Zähne}

Population: Großenrode

Geschlecht:

Alter:

Beschreibung: Von den Wurzeln sind Teile abfrakturiert.
08.03.2015 / 50

Skelett: $61 / 53$

Krankheiten:

\begin{tabular}{c|l|l} 
Arthrose & rechts & links \\
\hline Caput & & \\
\hline Fossa & &
\end{tabular}

\section{Zahn \\ Status Parodontium \\ Apikale Prozesse}

21

45

\section{Zahnstein}

0

0

\section{Karies}

0
0
Abrasion Neubildung Schmelzhypoplasie

*

O 4

0

0

O 1 


\section{Zahn}

Population: Großenrode

Geschlecht: > weiblich

Alter:

\section{Beschreibung:}

\subsubsection{5 / 50}

Skelett: $\quad 61 / 53$

Krankheiten:

\begin{tabular}{c|l|l} 
Arthrose & rechts & links \\
\hline Caput & & \\
\hline Fossa & &
\end{tabular}

0 0 


\section{Zähne}

Population:

Großenrode

Geschlecht:

Alter:

(25) 28 - 35 (38)

\subsubsection{5 / 68}

Skelett: $63 / 53$

Krankheiten:

\begin{tabular}{c|l|l} 
Arthrose & rechts & links \\
\hline Caput & & \\
\hline Fossa & &
\end{tabular}

Beschreibung: Von dem 2er ist die palatinale Wurzel abfrakturiert, liegt aber vor, die anderen Wurzeln fehlen. Beim Prämolaren sind die Wurzeln ebenfalls erodiert.

$\begin{array}{lcccccccc}\text { Zahn } & \text { Status } & \text { Parodontium } & \text { Apikale Prozesse } & \text { Zahnstein } & \text { Karies } & \text { Abrasion } & \text { Neubildung } & \text { Schmelzhypoplasie } \\ 26 & & 0 & 0 & 0 & 0 & 4 & * & 0 \\ 44 & 0 & x & 0 & 0 & 4 & * & 0\end{array}$




\section{Zähne}

Population:

Großenrode

Geschlecht:

Alter:

(14) 16 - $22(24)$

Beschreibung: Die Wurzeln des 6ers sind etwas frakturiert und erodiert.
2

Krankheiten:

\begin{tabular}{c|l|l} 
Arthrose & rechts & links \\
\hline Caput & & \\
\hline Fossa & &
\end{tabular}

$\begin{array}{lcccccccc}\text { Zahn } & \text { Status } & \text { Parodontium } & \text { Apikale Prozesse } & \text { Zahnstein } & \text { Karies } & \text { Abrasion } & \text { Neubildung } & \text { Schmelzhypoplasie } \\ 11 & & 0 & 0 & 0 & O & 2 & 0 & T \\ 46 & & & \text { H } & 0 & 0 & 2 & 0 & 0\end{array}$




\section{UK; OK}

Population:

Großenrode

Geschlecht:

Alter:

(25) 28 - $35(38)$

Beschreibung: Hier sind nur kleine Fragmente der Kiefer erhalten.
2

Krankheiten:

\begin{tabular}{c|l|l} 
Arthrose & rechts & links \\
\hline Caput & & \\
\hline Fossa & &
\end{tabular}

\begin{tabular}{|c|c|c|c|c|c|c|c|c|}
\hline Zahn & Status & Parodontium & Apikale Prozesse & Zahnstein & Karies & Abrasion & Neubildung & Schmelzhypoplasie \\
\hline 28 & & & 0 & 0 & 0 & 0 & 0 & 0 \\
\hline 34 & v & & 0 & & & & & \\
\hline 35 & v & 0 & 0 & & & & & \\
\hline 36 & & & 0 & $\mathrm{H}$ & 0 & $\mathrm{O}$ & * & 0 \\
\hline
\end{tabular}




\section{OK}

Population: Großenrode

Geschlecht:

Alter:

(14) 16 - $22(24)$
4

Krankheiten:

Beschreibung: An 18 fallen Schmelzperlen mesial und distal an den Wurzeln auf. Der Kieferknochen ist nur fragmentiert erhalten.

\begin{tabular}{|c|c|c|c|c|c|c|c|c|c|}
\hline Zahn & Status & Parodontium & Apikale Prozesse & Zahnstein & Karies & $A b$ & sion & Neubildung & Schmelzhypoplasie \\
\hline 14 & & 0 & 0 & 0 & 0 & $\mathrm{O}$ & 2 & 0 & 0 \\
\hline 15 & $v$ & & & & & & & & \\
\hline 18 & & & & 0 & 0 & & 0 & 0 & 0 \\
\hline 24 & & 0 & 0 & 0 & 0 & 0 & 2 & 0 & 0 \\
\hline 25 & & 0 & 0 & 0 & 0 & $\mathrm{O}$ & 2 & 0 & $\mathrm{~T}$ \\
\hline 26 & & & 0 & 0 & 0 & $\mathrm{O}$ & 2 & 0 & 0 \\
\hline
\end{tabular}




\section{Zahn}

Population: Großenrode

Geschlecht:

Alter:

\section{Beschreibung:}

\subsubsection{5 / 2}

Skelett: $\quad 62 / 68-1$

\section{Krankheiten:}

\begin{tabular}{c|l|l} 
Arthrose & rechts & links \\
\hline Caput & & \\
\hline Fossa & &
\end{tabular}

4
Zahnstein

0

\section{Karies}

D 3
Abrasion

Neubildung 0 


\section{Zahn}

Population: Großenrode

Geschlecht:

Alter:

(14) $16-22(24)$

\subsubsection{5 / 3}

Skelett: K13 62/68 S0

Krankheiten:

\section{Beschreibung:}

4

\begin{tabular}{c|l|l} 
Arthrose & rechts & links \\
\hline Caput & & \\
\hline Fossa & &
\end{tabular}

$\begin{array}{lcccccccc}\text { Zahn } & \text { Status } & \text { Parodontium } & \text { Apikale Prozesse } & \text { Zahnstein } & \text { Karies } & \text { Abrasion } & \text { Neubildung } & \text { Schmelzhypoplasie } \\ 16 & & 0 & \mathrm{~K} 1 & 0 & 0 & 2 & 0\end{array}$




\section{Zahn}

Population: Großenrode

Geschlecht:

Alter:

Beschreibung: Von diesem Weisheitszahn ist die Wurzel abfrakturiert.
4

Krankheiten:

\begin{tabular}{c|l|l} 
Arthrose & rechts & links \\
\hline Caput & & \\
\hline Fossa & &
\end{tabular}

Zahn Status Parodontium Apikale Prozesse

28

Zahnstein

Karies

0

0

Abrasion

Neubildung

0

Schmelzhypoplasie

0 


\section{Zahn}

Population: Großenrode

Geschlecht:

Alter:

(4) 6 - 7 (8)

Beschreibung: Ein Zahn, dessen Wurzelwachstum nicht abgeschlossen war.

\section{Zahn Status Parodontium Apikale Prozesse}

41

\subsubsection{5 / 5}

Skelett: K15162/68 S2
Krankheiten:

4

\begin{tabular}{c|l|l} 
Arthrose & rechts & links \\
\hline Caput & & \\
\hline Fossa & &
\end{tabular}
Zahnstein

0

Karies

0

\begin{tabular}{cccc} 
Abrasion & Neubildung & \multicolumn{2}{c}{ Schmelzhypoplasie } \\
0 & 0 & T & 1
\end{tabular}




\section{Zahn}

Population: Großenrode

Geschlecht:

Alter:

\section{Beschreibung:}

\subsubsection{5 / 6}

Skelett: $\quad 62 / 68-0$

Krankheiten:

4

\begin{tabular}{c|l|l} 
Arthrose & rechts & links \\
\hline Caput & & \\
\hline Fossa & &
\end{tabular}




\section{Zahn}

Population: Großenrode

Geschlecht:

Alter:

Beschreibung: Bei diesem Zahn ist das apicale Viertel abfrakturiert.
4

Krankheiten:

\begin{tabular}{c|l|l} 
Arthrose & rechts & links \\
\hline Caput & & \\
\hline Fossa & &
\end{tabular}

Zahn Status Parodontium Apikale Prozesse Zahnstein

Karies Abrasion

Neubildung

Schmelzhypoplasie

13
0
O 2

0 $\begin{array}{ll}\mathrm{T} & 1\end{array}$ 


\section{Zahn}

Population: Großenrode

Geschlecht:

Alter:

(5) 7 (9)

Beschreibung: Eine Zahnanlage, bei der eine deutliche Schmelzhypoplasie auffällt.

\section{Zahn Status Parodontium}

13

\subsubsection{5 / 8}

Skelett: K110 Schädel 62/68 P2 Krankheiten:

4

\begin{tabular}{c|l|l} 
Arthrose & rechts & links \\
\hline Caput & & \\
\hline Fossa & &
\end{tabular}




\section{OK}

Population: Großenrode

Geschlecht:

Alter:

$35-45(50)$

\section{Beschreibung:}

\subsubsection{5 / 9}

Skelett: K138 62/68 P3

Krankheiten: Stomatitis
4

\begin{tabular}{c|l|l} 
Arthrose & rechts & links \\
\hline Caput & & \\
\hline Fossa & &
\end{tabular}

\begin{tabular}{|c|c|c|c|c|c|c|c|c|}
\hline Zahn & Status & Parodontium & Apikale Prozesse & Zahnstein & Karies & Abrasion & Neubildung & Schmelzhypoplasie \\
\hline 11 & & & 0 & K 1 & 0 & 0 & 0 & 0 \\
\hline 12 & & & 0 & $\begin{array}{ll}\mathrm{K} & 1\end{array}$ & 0 & $\mathrm{O}$ & 0 & 0 \\
\hline 13 & & & 0 & $\begin{array}{ll}\mathrm{K} & 1\end{array}$ & 0 & $\mathrm{O}$ & 0 & 0 \\
\hline 14 & & & G & $\mathrm{K}$ & 0 & $\mathrm{O}$ & 0 & 0 \\
\hline 15 & $E$ & & 0 & & & & & \\
\hline 21 & v & & 0 & & & & & \\
\hline 22 & & & 0 & $\mathrm{~K}$ & 0 & 0 & 0 & 0 \\
\hline 23 & & & 0 & $\mathrm{~K}$ & 0 & $\mathrm{O}$ & 0 & 0 \\
\hline 42 & v & & 0 & & & & & \\
\hline 43 & & $\mathrm{Pi} \quad 2$ & 0 & $\mathrm{~K}$ & 0 & O & 0 & 0 \\
\hline 44 & & $\mathrm{Pi} \quad 2$ & 0 & K 2 & 0 & $\mathrm{O}$ & 0 & 0 \\
\hline
\end{tabular}


45

46

47

48
Pi 2

E

v
K 2

0

O 3

0 


\section{Zahn}

Population:

Großenrode

Geschlecht:

Alter:

(22) 25 - $30(34)$

Beschreibung: Die Wurzel ist abfrakturiert.

\subsubsection{5 / 27}

Skelett: K290 63/65 S3

Krankheiten:

6

\begin{tabular}{c|l|l} 
Arthrose & rechts & links \\
\hline Caput & & \\
\hline Fossa & &
\end{tabular}

\section{Zahn Status Parodontium}

Apikale Prozesse

46
Zahnstein Karies

H 1
Abrasion

Neubildung

0

Schmelzhypoplasie 


\section{Zähne}

Population:

Großenrode

Geschlecht:

Alter:

(14) 16 - 22 (24)
6

\begin{tabular}{c|l|l} 
Arthrose & rechts & links \\
\hline Caput & & \\
\hline Fossa & &
\end{tabular}

Beschreibung: Alle Zähne lagen nur als Kronen vor. Möglicherweise handelt es sich hier um Leichenbrand.

\begin{tabular}{|c|c|c|c|c|c|c|c|c|c|c|}
\hline Zahn & Status & Parodontium & Apikale Prozesse & Zahnstein & Karies & \multicolumn{2}{|c|}{ Abrasion } & Neubildung & \multicolumn{2}{|c|}{ Schmelzhypoplasie } \\
\hline 14 & & & & 0 & 0 & & 0 & 0 & $\mathrm{~T}$ & 1 \\
\hline 16 & & & & $\mathrm{~K}$ & 0 & $\mathrm{O}$ & 2 & 0 & $\mathrm{~T}$ & 1 \\
\hline 17 & & & & $\mathrm{~K}$ & 0 & & 0 & 0 & $\mathrm{~T}$ & 1 \\
\hline 21 & & & & $\mathrm{~K}$ & 0 & $\mathrm{O}$ & 1 & 0 & $\mathrm{~T}$ & 1 \\
\hline 22 & & & & $\mathrm{~K}$ & 0 & & 0 & 0 & $\mathrm{~T}$ & 1 \\
\hline 46 & & & & $\mathrm{H} \quad 2$ & 0 & 0 & 2 & 0 & $\mathrm{~T}$ & 1 \\
\hline
\end{tabular}




\section{Zähne}

Population:

Großenrode

Geschlecht:

Alter:

(25) 28 - 35 (38)

Beschreibung: Diese Zähne sind etwas erodiert.
6

Krankheiten:

\begin{tabular}{c|l|l} 
Arthrose & rechts & links \\
\hline Caput & & \\
\hline Fossa & &
\end{tabular}

\section{Zahn Status Parodontium \\ Apikale Prozesse}

21

36

47

0
Zahnstein

Karies

$\mathrm{H}$

0
1
0

0

\section{Abrasion Neubildung Schmelzhypoplasie}

O 5

O 4

O 4

0

$\mathrm{T}$ 


\section{Zahn}

Population: Großenrode

Geschlecht:

Alter:

Beschreibung: Dieser 1er weist eine erodierte Wurzel auf.
6

Krankheiten:

\begin{tabular}{c|l|l} 
Arthrose & rechts & links \\
\hline Caput & & \\
\hline Fossa & &
\end{tabular}

Zahn Status Parodontium Apikale Prozesse

11
Zahnstein

0
Karies

0
Abrasion

O 2
Neubildung

0 


\section{Zahn}

Population: Großenrode

Geschlecht:

Alter:

Beschreibung: Dies ist eine Zahnanlage, 2/3 der Krone sind insgesamt erhalten, der Rest ist abgesplittert.

\subsubsection{5 / 3}

Skelett: $\quad 64 / 64-0$

Krankheiten:

\section{6}

\begin{tabular}{c|l|l} 
Arthrose & rechts & links \\
\hline Caput & & \\
\hline Fossa & &
\end{tabular}

\section{Zahn Status Parodontium}

Apikale Prozesse

Zahnstein

Karies

Abrasion

Neubildung

Schmelzhypoplasie

17 


\section{Zahn}

Population: Großenrode

Geschlecht:

Alter:

(22) 25 - $30(34)$

Beschreibung: Die Wurzel ist erodiert.
6

Krankheiten:

\begin{tabular}{c|l|l} 
Arthrose & rechts & links \\
\hline Caput & & \\
\hline Fossa & &
\end{tabular}




\section{UK}

Population: Großenrode

Geschlecht:

Alter:

(22) $25-30(34)$
6

Krankheiten:

\begin{tabular}{c|l|l} 
Arthrose & rechts & links \\
\hline Caput & & \\
\hline Fossa & &
\end{tabular}

Beschreibung: Der Unterkiefer ist fragmentiert zu 10\% erhalten. Der 3. Quadrant ist gespalten. Die Wurzeln von 45 und 46 sind zum Teil abfrakturiert.

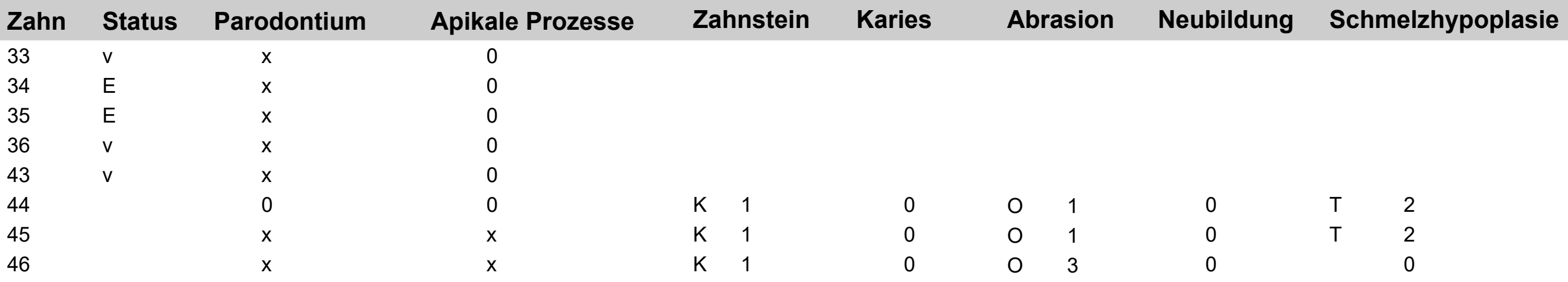




\section{Zahn}

Population: Großenrode

Geschlecht:

Alter:

Beschreibung: Die Wurzel dieses Zahnes ist abgebrochen, aber vorhanden.
6

Krankheiten:

\begin{tabular}{c|l|l} 
Arthrose & rechts & links \\
\hline Caput & & \\
\hline Fossa & &
\end{tabular}

Zahn Status Parodontium Apikale Prozesse Zahnstein Karies Abrasion Neubildung Schmelzhypoplasie 38 0 0 0 O 1 0 T 1 


\section{Zähne}

Population: Großenrode

Geschlecht:

Alter:

Beschreibung: Von den Kronen dieser Zähne sind Teile abgesplittert und die Wurzeln sind abfrakturiert.

\section{6}

Krankheiten:

\begin{tabular}{c|l|l} 
Arthrose & rechts & links \\
\hline Caput & & \\
\hline Fossa & &
\end{tabular}

$\begin{array}{llllclcc}\text { Zahn Status } & \text { Parodontium } & \text { Apikale Prozesse } & \text { Zahnstein } & \text { Karies } & \text { Abrasion } & \text { Neubildung } & \text { Schmelzhypoplasie } \\ 14 & & \mathrm{~K} 1 & 0 & \mathrm{O} & 4 & * \\ 15 & & \mathrm{~K} 1 & 0 & \mathrm{O} & 4 & * & 0\end{array}$




\section{Zahn}

Population: Großenrode

Geschlecht: > weiblich

Alter:

(22) 28 - 35 (38)

Beschreibung: Die distale Wurzel ist abfrakturiert.
6

Krankheiten:

\begin{tabular}{c|l|l} 
Arthrose & rechts & links \\
\hline Caput & & \\
\hline Fossa & &
\end{tabular}




\section{Wurzel}

Population: Großenrode

Geschlecht:

Alter:

Beschreibung: Ei sehr stark abradierter Zahn.

\subsubsection{5 / 9}

Skelett: K105 62/63 S2

Krankheiten:

6

\begin{tabular}{c|l|l} 
Arthrose & rechts & links \\
\hline Caput & & \\
\hline Fossa & &
\end{tabular}

Zahn Status Parodontium Apikale Prozesse

41
0
Zahnstein

$\mathrm{x}$
Karies

0
Abrasion

O 6 


\section{UK}

Population: Großenrode

Geschlecht:

Alter:

Beschreibung: Vom Unterkiefer ist nur ein kleines Fragment erhalten.

\section{6}

Krankheiten:

\begin{tabular}{c|l|l} 
Arthrose & rechts & links \\
\hline Caput & & \\
\hline Fossa & &
\end{tabular}

\section{Zahn Status Parodontium Apikale Prozesse}

44

45

\section{Zahnstein Karies}

K 1

K 1
Abrasion

0

O 2

O 2

\section{Neubildung}

0

0
0

Schmelzhypoplasie T 1

T 1




\section{Zahn}

Population: Großenrode

Geschlecht:

Alter:

\section{Beschreibung:}

\subsubsection{5 / 11}

Skelett: $\quad 63 / 66-4$

Krankheiten:

\section{Krankheiten:}

6

\begin{tabular}{c|l|l} 
Arthrose & rechts & links \\
\hline Caput & & \\
\hline Fossa & &
\end{tabular}

Zahn Status Parodontium Apikale Prozesse 42
Zahnstein

K 1
Karies

0
Abrasion

O 3
Neubildung

0
Schmelzhypoplasie

0 


\section{Zahn}

Population: Großenrode

Geschlecht:

Alter:

Beschreibung: Die Wurzel dieses Milchzahns ist zu 1/3 abfrakturiert.

\subsubsection{5 / 12}

Skelett: $\quad 63 / 66-44$

Krankheiten:

\section{Krankheiten:}

\section{6}

\begin{tabular}{c|l|l} 
Arthrose & rechts & links \\
\hline Caput & & \\
\hline Fossa & &
\end{tabular}

Zahn Status Parodontium Apikale Prozesse

85

Zahnstein

0
Karies

0
Abrasion

O 3
Neubildung

0

Schmelzhypoplasie 


\section{Zahn}

Population: Großenrode

Geschlecht:

Alter:

Beschreibung: Von diesem Prämolaren ist nur die Krone erhalten.

\subsubsection{5 / 13}

Skelett: $\quad 63 / 66-4$

\section{Krankheiten:}

\begin{tabular}{c|l|l} 
Arthrose & rechts & links \\
\hline Caput & & \\
\hline Fossa & &
\end{tabular}

\section{Zahn Status Parodontium}

45
Apikale Prozesse
Zahnstein

0

\section{Karies}

0
6 


\section{Zähne}

Population:

Großenrode

Geschlecht:

Alter:

$(8,5) 11-12(14,5)$

Beschreibung: Die Wurzeln des 7ers sind nicht fertig ausgebildet gewesen.

27.03.2015 / 14

Skelett: K276 63/66 S3
6

Krankheiten:

\begin{tabular}{c|l|l} 
Arthrose & rechts & links \\
\hline Caput & & \\
\hline Fossa & &
\end{tabular}

\section{Zahn Status Parodontium Apikale Prozesse}

37

46

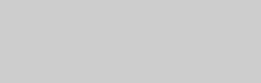




\section{UK}

Population: Großenrode

Geschlecht:

Alter:

Beschreibung: Von diesem Unterkiefer ist nur das linke Caput mandibulae erhalten, dessen Gelenkfläche zu 50\% erhalten ist. Von dem aufgeführten Zahn ist nur die Krone erhalten und 1/3 der Wurzel.

\subsubsection{5 / 15}

Skelett: $60 / 64-3$
6

Krankheiten:

\begin{tabular}{c|c|c} 
Arthrose & rechts & links \\
\hline Caput & & 1 \\
\hline Fossa & &
\end{tabular}

$\begin{array}{llllllcccc}\text { Zahn } & \text { Status } & \text { Parodontium } & \text { Apikale Prozesse } & \text { Zahnstein } & \text { Karies } & \text { Abrasion } & \text { Neubildung } & \text { Schmelzhypoplasie } \\ 24 & & & \mathrm{~K} \quad 1 & 0 & 0 & 3 & 0\end{array}$




\section{Zähne}

Population: Großenrode

Geschlecht:

Alter:

Beschreibung: 11 weist ein foramen caecum auf.
6

Krankheiten:

\begin{tabular}{c|l|l} 
Arthrose & rechts & links \\
\hline Caput & & \\
\hline Fossa & &
\end{tabular}

Skelett: $60 / 64-4$

\begin{tabular}{lccccccc} 
Zahn Status & Parodontium & Apikale Prozesse & Zahnstein & Karies & \multicolumn{2}{c}{ Abrasion } & Neubildung \\
11 & & 0 & 0 & 0 & 0 & 2 & 0 \\
13 & 0 & 0 & 0 & 0 & 1 & 0 & 0 \\
22 & & 0 & K & 0 & 0 & 2 & 0
\end{tabular}




\section{Zahn}

Population: Großenrode

Geschlecht:
Alter:
(6) 8 - $10(13,5)$

Beschreibung: Es handelt sich hier wohl um eine Zahnanlage, es sind Teile der Wurzel abfrakturiert.
6

Krankheiten:

\begin{tabular}{c|l|l} 
Arthrose & rechts & links \\
\hline Caput & & \\
\hline Fossa & &
\end{tabular}




\section{Zähne}

Population: Großenrode

Geschlecht:

Alter:

Beschreibung: Die Wurzeln der Fundstücke sind frakturiert.
6

Krankheiten:

\begin{tabular}{c|l|l} 
Arthrose & rechts & links \\
\hline Caput & & \\
\hline Fossa & &
\end{tabular}




\section{OK}

Population: Großenrode

Geschlecht:

Alter:

$$
\text { (7) } 8 \text { - } 9 \text { (10) }
$$

\subsubsection{5 / 19}

Skelett: K179 63/66 P3
6

Krankheiten: Sinusitis maxillaris Stomatitis

Beschreibung: Es handelt sich hier um ein Wechselgebiss, 21 weist auf der vestibulären Fläche eine initiale Karies auf. Weiterhin fällt eine Stomatitis und eine akute Sinusitis maxillaris auf.

\begin{tabular}{|c|c|c|c|c|c|c|c|c|}
\hline Zahn & Status & Parodontium & Apikale Prozesse & Zahnstein & Karies & Abrasion & Neubildung & Schmelzhypoplasie \\
\hline 11 & $\mathrm{v}$ & & & & & & & \\
\hline 12 & & $x$ & 0 & 0 & 0 & 0 & 0 & $\mathrm{~T}$ \\
\hline 13 & ( ) & & & & & & & \\
\hline 14 & ( ) & & & & & & & \\
\hline 15 & ( ) & & & & & & & \\
\hline 16 & v & & 0 & & & & & \\
\hline 17 & ( ) & & & 0 & & & 0 & $\mathrm{~T}$ \\
\hline 18 & ( ) & & & & & & & \\
\hline 21 & & 0 & 0 & 0 & B & 0 & 0 & $\mathrm{~T}$ \\
\hline 22 & & 0 & 0 & 0 & 0 & 0 & 0 & $\mathrm{~T}$ \\
\hline 23 & ( ) & & & & & & & \\
\hline
\end{tabular}


$25 \quad()$

K 1

K 1

$\mathrm{Pi}$

$\mathrm{Pi} 1$

$\mathrm{Pi} 1$

$\mathrm{Pi} 1$

Pi 1

B 2

K 1

$\begin{array}{ll}\mathrm{K} & 1 \\ \mathrm{~K} & \end{array}$

$\begin{array}{lll}0 & 0 & 3 \\ 0 & 0 & 3 \\ 0 & 0 & 3 \\ 0 & 0 & 3 \\ 0 & 0 & 3 \\ 0 & 0 & 3\end{array}$

$\begin{array}{ll}0 & 0 \\ 0 & 0 \\ 0 & 0 \\ 0 & 0 \\ 0 & 0 \\ 0 & 0 \\ 0 & 0\end{array}$




\section{Zahn}

Population: Großenrode

Geschlecht:

Alter:

Beschreibung: Es ist nur die Krone erhalten.

\subsubsection{5 / 22}

Skelett: K195 62/65 S3

\section{Krankheiten:}

6

\begin{tabular}{|c|c|c|c|c|c|c|c|c|}
\hline Zahn & Status & Parodontium & Apikale Prozesse & Zahnstein & Karies & Abrasion & Neubildung & Schmelzhypoplasie \\
\hline 48 & & & & K 1 & 0 & $\mathrm{O}$ & 0 & 0 \\
\hline
\end{tabular}




\section{Zahn}

Population: Großenrode

Geschlecht:

Alter:

Beschreibung: Das apicale Drittel der Wurzel fehlt hier.

\subsubsection{5 / 23}

Skelett: K200 62/65 S3

Krankheiten:

\section{6}

\begin{tabular}{c|l|l} 
Arthrose & rechts & links \\
\hline Caput & & \\
\hline Fossa & &
\end{tabular}




\section{Zähne}

Population:

Großenrode

Geschlecht:

Alter:

(22) 25 - 30 (34)

Beschreibung: Die Zähne sind etwas erodiert, aber vollständig erhalten.

\subsubsection{5 / 24}

Skelett: K162 62/65 P3
Krankheiten:

6

\begin{tabular}{c|l|l} 
Arthrose & rechts & links \\
\hline Caput & & \\
\hline Fossa & &
\end{tabular}

$\begin{array}{lcccccccc}\text { Zahn Status } & \text { Parodontium } & \text { Apikale Prozesse } & \text { Zahnstein } & \text { Karies } & \text { Abrasion } & \text { Neubildung } & \text { Schmelzhypoplasie } \\ 45 & & 0 & 0 & 0 & 0 & 3 & 0 \\ 46 & 0 & 0 & 0 & 0 & 3 & 0 & 0 \\ 47 & & 0 & 0 & \text { B } 3 & 0 & 2 & 0\end{array}$




\section{Zahn}

Population:

Großenrode

Geschlecht:

Alter:

(14) 16 - 22 (24)

Beschreibung: Die Wurzel dieses Zahnes ist größtenteils abfrakturiert.
6

Krankheiten:

\begin{tabular}{c|l|l} 
Arthrose & rechts & links \\
\hline Caput & & \\
\hline Fossa & &
\end{tabular}

Zahnstein

K 1
Karies

0
Abrasion

O 2

\section{Neubildung}

0

Schmelzhypoplasie 


\section{Zahn}

Population: Großenrode

Geschlecht:

Alter:

\section{Beschreibung:}

\subsubsection{5 / 26}

Skelett: $\quad 62 / 65-2$

Krankheiten:

6

\begin{tabular}{c|l|l} 
Arthrose & rechts & links \\
\hline Caput & & \\
\hline Fossa & &
\end{tabular}

Zahn Status Parodontium

Apikale Prozesse

18
0
Zahnstein

0
Karies

0
Abrasion

O 4 


\section{Zahn}

Population: Großenrode

Geschlecht:

Alter:

Beschreibung: Die Wurzel dieses Frontzahnes ist einseitig etwas erodiert.
6

Krankheiten:

\begin{tabular}{c|l|l} 
Arthrose & rechts & links \\
\hline Caput & & \\
\hline Fossa & &
\end{tabular}

Zahn Status Parodontium Apikale Prozesse Zahnstein Karies Abrasion Neubildung

Schmelzhypoplasie 42 0 $\mathrm{X}$ 0 O 5 $\mathrm{X}$ 


\section{UK}

Population: Großenrode

Geschlecht: > männlich

Alter:

(10) 16 - 22 (24)

\subsubsection{5 / 28}

Skelett: K277 60/69 S3

\section{Krankheiten:}

\section{6}

\begin{tabular}{c|c|c} 
Arthrose & rechts & links \\
\hline Caput & $\mathrm{x}$ & \\
\hline Fossa & &
\end{tabular}

Beschreibung: Dieser Unterkiefer liegt in erodiertem und frakturierten Zustand vor. Das rechte Caput mandibulae ist stark frakturiert und erodiert.

$\begin{array}{lcccccccc}\text { Zahn } & \text { Status } & \text { Parodontium } & \text { Apikale Prozesse } & \text { Zahnstein } & \text { Karies } & \text { Abrasion } & \text { Neubildung } & \text { Schmelzhypoplasie } \\ 47 & 0 & 0 & 0 & 0 & 1 & 0 & 0\end{array}$




\section{Zähne}

Population:

Großenrode

Geschlecht:

Alter:

(6) $8,5-13(15)$

Beschreibung: Die Wurzeln beider Zähne sind abgebrochen.
6

\begin{tabular}{c|l|l} 
Arthrose & rechts & links \\
\hline Caput & & \\
\hline Fossa & &
\end{tabular}

\section{Zahn Status Parodontium Apikale Prozesse}

36

37

Krankheiten:

\subsubsection{5 / 29}

Skelett: $\quad 62 / 65-3$ 


\section{Zähne}

Population: Großenrode

Geschlecht:

Alter:

\subsubsection{5 / 30}

Skelett: $\quad 62 / 65-3$

6

Krankheiten:

\begin{tabular}{c|l|l} 
Arthrose & rechts & links \\
\hline Caput & & \\
\hline Fossa & &
\end{tabular}

Beschreibung: Beim 8er ist nur die Krone erhalten, vom 7er ist nur 1/4 der Krone erhalten. Der 8er weist occlusal Zahnstein auf, was eher unüblich ist.

\begin{tabular}{|c|c|c|c|c|c|c|c|c|}
\hline Zahn & Status & Parodontium & Apikale Prozesse & Zahnstein & Karies & Abrasion & Neubildung & Schmelzhypoplasie \\
\hline 27 & & & & $\mathrm{~K}$ & 0 & $\mathrm{O}$ & 0 & 0 \\
\hline 28 & & & & K 3 & 0 & 0 & 0 & 0 \\
\hline 45 & & & 0 & K 1 & 0 & $\mathrm{O}$ & 0 & 0 \\
\hline
\end{tabular}




\section{UK}

Population: Großenrode

Geschlecht:

Alter:

Beschreibung: Hier sind etwa 80\% eines Caput mandibulae erhalten. Das Fragment ist nicht zuzuordnen und wird aufgrund der Gefahr der Doppeltzählung nicht mit ausgewertet sondern nur aus Dokumentationszwecken beschrieben.
6

Krankheiten:

\subsubsection{5 / 40}

Skelett: K169 62/63 P3

\begin{tabular}{c|c|c} 
Arthrose & rechts & links \\
\hline Caput & 1 & \\
\hline Fossa & &
\end{tabular}

Zahn Status Parodontium Apikale Prozesse Zahnstein Karies Abrasion Neubildung Schmelzhypoplasie




\section{OK; UK}

Population:

Geschlecht:

Alter:

(22) 25 - $30(34)$

\subsubsection{5 / 1}

Skelett: K164 K165 61/68 P3

Krankheiten:

Sinusitis

Stomatitis

Beschreibung: Der Unterkiefer ist in Form von Fragmenten des Caput und Teilen der aufsteigenden Äste erhalten. Das rechte Caput mandibulae ist zu 3/4 befundbar, das linke zu 4/5. Es liegt eine Stomatitis und eine Sinusitis maxillaris vor. Von dem Schädel sind noch weitere Fundstücke erhalten.

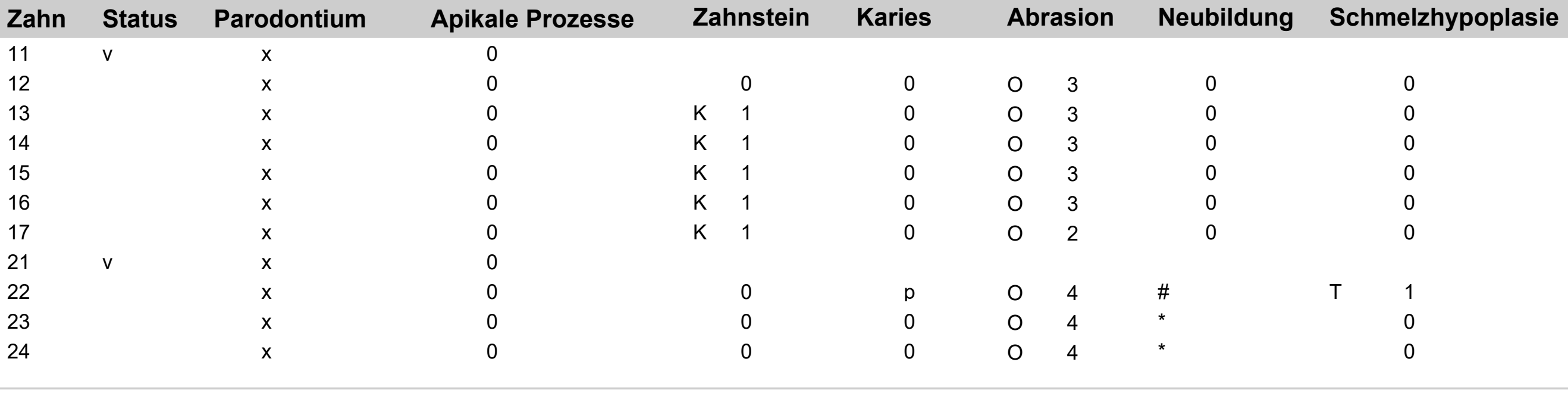




\section{Zahn}

Population: Großenrode

Geschlecht:

Alter:

(25) 28 - 35 (38)

\section{Beschreibung:}

\subsubsection{5 / 8}

Skelett: K256 60/64 S3 P4

Krankheiten:

7

\begin{tabular}{c|l|l} 
Arthrose & rechts & links \\
\hline Caput & & \\
\hline Fossa & &
\end{tabular}

$\begin{array}{llllcccccc}\text { Zahn } & \text { Status } & \text { Parodontium } & \text { Apikale Prozesse } & \text { Zahnstein } & \text { Karies } & \text { Abrasion } & \text { Neubildung } & \text { Schmelzhypoplasie } \\ 46 & & \text { G } & & 0 & \text { D } & 3 & 0 & 4 & *\end{array}$




\section{UK}

Population: Großenrode

Geschlecht:

Alter:

(14) 16 - 22 (24)

\subsubsection{5/ 19}

Skelett: K365

Krankheiten:
7

\begin{tabular}{c|c|c} 
Arthrose & rechts & links \\
\hline Caput & 1 & 1 \\
\hline Fossa & &
\end{tabular}

Beschreibung: Dieser Unterkiefer ist hervorragend und fast vollständig erhalten. Es handelt sich wohl eher um ein männliches Individuum, da Merkmale wie Kieferwinkel, Zahnbogen und Spina mentalis eher männliche ausgeprägt sind. Trotz der kleinen Größe des Fundstücks finden sich zwar kleine, aber doch deutliche Spuren von Muskelzug. Auffällig ist, dass der Unterkiefer anscheinend ungleichmäßig gewachsen ist, was zu ungleichen Verhältnissen der Kauebene und der gesamten Kieferkonstitution geführt hat. Der 4. Quadrant ist dadurch angehoben. Diese Ungleichheit hat wohl auch zu der Verlagerung eines Teils des rechten Caput mandibulae geführt, welches nach anterior einen Auswuchs zeigt. Das Kiefergelenk kompensierte wohl diese Knöcherne Ungleichheit in den beiden Quadranten.

Weiterhin findet sich retromolar distal des 48 eine kleine Alveole und kleinere Löcher drum herum, was für das Vorhandensein eines 9ers im 4. Quadranten sprechen könnte.

\begin{tabular}{|c|c|c|c|c|c|c|c|c|c|c|}
\hline \multirow{2}{*}{$\begin{array}{l}\text { Zahn } \\
31\end{array}$} & \multirow[t]{2}{*}{ Status } & Parodontium & \multirow{2}{*}{$\begin{array}{c}\text { Apikale Prozesse } \\
0\end{array}$} & \multicolumn{2}{|c|}{ Zahnstein } & Karies & \multicolumn{2}{|c|}{ Abrasion } & \multirow{2}{*}{$\begin{array}{c}\text { Neubildung } \\
0\end{array}$} & Schmelzhypoplasie \\
\hline & & Po 1 & & $\mathrm{H}$ & 2 & 0 & $\mathrm{O}$ & 2 & & 0 \\
\hline 32 & & Po 1 & 0 & $\mathrm{H}$ & 2 & 0 & $\mathrm{O}$ & 1 & 0 & 0 \\
\hline 33 & & Po 1 & 0 & $\mathrm{H}$ & 1 & 0 & $\mathrm{O}$ & 2 & 0 & 0 \\
\hline 34 & & 0 & 0 & $\mathrm{~K}$ & 1 & 0 & $\mathrm{O}$ & 1 & 0 & 0 \\
\hline 35 & & 0 & 0 & $\mathrm{~K}$ & 1 & 0 & $\mathrm{O}$ & 1 & 0 & 0 \\
\hline 36 & & 0 & 0 & $\mathrm{~K}$ & 1 & 0 & 0 & 1 & 0 & 0 \\
\hline 37 & & 0 & 0 & & 0 & $0 \quad 1$ & $\mathrm{O}$ & 1 & 0 & $\mathrm{~T}$ \\
\hline 38 & & 0 & 0 & & 0 & 01 & & 0 & 0 & 0 \\
\hline 41 & & Po 1 & 0 & $\mathrm{H}$ & 2 & 0 & 0 & 2 & 0 & 0 \\
\hline 42 & & Po 1 & 0 & $\mathrm{H}$ & 2 & 0 & 0 & 1 & 0 & 0 \\
\hline 43 & & Po 1 & 0 & $\mathrm{~K}$ & 1 & 0 & 0 & 2 & 0 & $\mathrm{~T}$ \\
\hline
\end{tabular}




$\begin{array}{llll}44 & \mathrm{v} & 0 & 0 \\ 45 & \mathrm{v} & 0 & 0 \\ 46 & & 0 & 0 \\ 47 & & 0 & 0 \\ 48 & & 0 & 0\end{array}$

$\mathrm{H}$

H 1

K 1

0
0
$0 \quad 1$

$\begin{array}{ll}\mathrm{O} & 2 \\ \mathrm{O} & 1 \\ & 0\end{array}$

0
0
0

$\begin{array}{ll}0 \\ \mathrm{~T} & 1 \\ & 0\end{array}$ 


\section{OK; UK}

Population: Großenrode

Geschlecht: > männlich

Alter:

(14) 16 - 22 (24)

\subsubsection{5 / 23}

Skelett: K262 60/64 S3

7

Krankheiten: Stomatitis

Sinusitis maxillaris

Beschreibung: Diese Kiefer sind fragmentiert erhalten. Der Oberkiefer weist eine Stomatitis und eine Sinusitis maxillaris auf.

\begin{tabular}{|c|c|c|c|c|c|c|c|c|}
\hline Zahn & Status & Parodontium & Apikale Prozesse & Zahnstein & Karies & Abrasion & Neubildung & Schmelzhypoplasie \\
\hline 14 & & 0 & 0 & 0 & 0 & 0 & 0 & $\mathrm{~T}$ \\
\hline 15 & v & 0 & 0 & & & & & \\
\hline 16 & & 0 & 0 & $\mathrm{~K}$ & 0 & $\mathrm{O}$ & 0 & $\mathrm{~T}$ \\
\hline 21 & v & & 0 & & & & & \\
\hline 22 & v & & 0 & & & & & \\
\hline 23 & v & & 0 & & & & & \\
\hline 24 & & Po 1 & 0 & 0 & 0 & 0 & 0 & $\mathrm{~T}$ \\
\hline 25 & v & 0 & 0 & & & & & \\
\hline 26 & & 0 & 0 & $\mathrm{~K}$ & 0 & $\mathrm{O}$ & 0 & $\mathrm{~T}$ \\
\hline 27 & & 0 & 0 & $\mathrm{~K}$ & 0 & $\mathrm{O}$ & 0 & $\mathrm{~T}$ \\
\hline 28 & ( ) & & 0 & & & & & \\
\hline
\end{tabular}




$\begin{array}{ll}31 & \mathrm{v} \\ 32 & \mathrm{v} \\ 33 & \\ 34 & \\ 35 & \\ 36 & \mathrm{v} \\ 37 & \mathrm{v} \\ 41 & \mathrm{v} \\ 42 & \mathrm{v} \\ 43 & \mathrm{v} \\ 44 & \\ 45 & \\ 46 & \\ 47 & \end{array}$

$\begin{array}{ll}\mathrm{x} & 0 \\ 0 & 0 \\ 0 & 0 \\ \mathrm{x} & 0 \\ 0 & 0 \\ \mathrm{x} & 0 \\ \mathrm{x} & 0 \\ \mathrm{x} & 0 \\ \mathrm{x} & 0 \\ 0 & 0 \\ 0 & 0 \\ 0 & 0 \\ 0 & 0 \\ 0 & 0\end{array}$

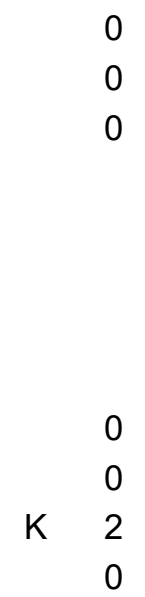

0
0
0

0
0
0

0
0
0

$\begin{array}{ll}\mathrm{U} & 2 \\ \mathrm{~T} & 1 \\ & 0\end{array}$

0

\begin{tabular}{|c|c|}
\hline 0 & \\
\hline 0 & \\
\hline 0 & O \\
\hline 0 & O \\
\hline
\end{tabular}

$\begin{array}{lll}0 & \text { T } & 3 \\ 0 & \text { T } & 3 \\ 0 & \text { T } & 2 \\ 0 & \text { T } & 3\end{array}$




\section{UK}

Population: Großenrode

Geschlecht: > weiblich

Alter:

Beschreibung: Dieses Fragment eines linken Unterkiefers ist ohne Zähne erhalten, das Gebiss muss aber zum Zeitpunkt des Todes desaströs gewesen sein, vielleicht ist das Individuum sogar an den Folgen einer akuten Sepsis gestorben.
7

Skelett: K351 64/67 S4 Krankheiten: Sepsis

\begin{tabular}{c|l|l} 
Arthrose & rechts & links \\
\hline Caput & & \\
\hline Fossa & &
\end{tabular}

$\begin{array}{lllllll}\text { Zahn } & \text { Status } & \text { Parodontium } & \text { Apikale Prozesse } & \text { Zahnstein } & \text { Karies } & \text { Abrasion Neubildung Schmelzhypoplasie } \\ 33 & \text { (f) } & & & & \\ 34 & \text { (f) } & & \\ 35 & f & \text { G } 3\end{array}$




\section{OK; UK}

Population:

Großenrode

Geschlecht: >> männlich

Alter:

(25) 28 - $35(38)$
01.04.2015 / 2

Skelett: K310 63/67-P4
9

Krankheiten: Anomalie

Beschreibung: Bei diesen Kiefern lag ein desaströser Zahnstatus vor. Das Caput mandibulae der rechten Seite ist größer als das der linken, ebenfalls ist der der aufsteigende Ast länger.

\begin{tabular}{|c|c|c|c|c|c|c|c|c|}
\hline Zahn & Status & Parodontium & Apikale Prozesse & Zahnstein & Karies & Abrasion & Neubildung & Schmelzhypoplasie \\
\hline 14 & (f) & $\mathrm{Pi} \quad 3$ & & & & & & \\
\hline 15 & v & $\mathrm{Pi} \quad 3$ & 0 & & & & & \\
\hline 16 & & $\mathrm{Pi} \quad 4$ & 0 & $\mathrm{~B}$ & 0 & $\mathrm{O}$ & * & 0 \\
\hline 17 & (f) & $\mathrm{Pi} \quad 3$ & & & & & & \\
\hline 21 & $\mathrm{f}$ & & & & & & & \\
\hline 22 & & $x$ & 0 & $\mathrm{~K}$ & 0 & $\mathrm{O}$ & 0 & 0 \\
\hline 23 & v & $\mathrm{Pi} \quad 3$ & 0 & & & & & \\
\hline 24 & & $\mathrm{Pi} \quad 3$ & 0 & W 1 & 0 & $\mathrm{O}$ & * & 0 \\
\hline 25 & $f$ & $\mathrm{Pi} \quad 3$ & & & & & & \\
\hline 26 & & $\mathrm{Pi} \quad 3$ & 0 & W 1 & 0 & $\mathrm{O}$ & * & 0 \\
\hline 31 & $\mathrm{v}$ & $x$ & $\mathrm{G}$ & & & & & \\
\hline
\end{tabular}




\begin{tabular}{|c|c|c|c|c|}
\hline 32 & $\mathrm{v}$ & & $x$ & \\
\hline 33 & $\mathrm{v}$ & $\mathrm{Pi}$ & 4 & $\mathrm{G}$ \\
\hline 34 & $\mathrm{v}$ & & $x$ & $\mathrm{G}$ \\
\hline 35 & $\mathrm{v}$ & & $x$ & \\
\hline 36 & $\mathrm{v}$ & $\mathrm{Pi}$ & 3 & $\mathrm{G}$ \\
\hline 37 & $\mathrm{v}$ & $\mathrm{Pi}$ & 2 & \\
\hline 38 & (f) & & & \\
\hline 41 & $(\mathrm{f})$ & & $x$ & $\mathrm{G}$ \\
\hline 42 & $\mathrm{v}$ & & $x$ & \\
\hline 43 & $(\mathrm{f})$ & $\mathrm{Pi}$ & 3 & $\mathrm{G}$ \\
\hline 44 & $\mathrm{v}$ & & $x$ & \\
\hline 45 & $f$ & & 0 & \\
\hline 46 & $\mathrm{v}$ & $\mathrm{Pi}$ & 3 & \\
\hline 47 & $\mathrm{v}$ & $\mathrm{Pi}$ & 3 & \\
\hline 48 & (f) & $\mathrm{Pi}$ & 3 & $G$ \\
\hline
\end{tabular}




\section{UK; OK}

Population:

Großenrode

Geschlecht:

Alter:

$35-45$

Beschreibung: Die Wurzel des 1ers ist abfrakturiert.

\section{Zahn Status Parodontium}

Apikale Prozesse

21

46

47

48

$f$
$f$
$v$

9

Krankheiten:

\begin{tabular}{c|l|l} 
Arthrose & rechts & links \\
\hline Caput & & \\
\hline Fossa & &
\end{tabular}

\section{Zahnstein Karies}

0
Abrasion

0

O 3 


\section{Zahn}

Population: Großenrode

Geschlecht:

Alter:

(7) 9 - $10(11)$

\section{Beschreibung:}

\subsubsection{5 / 7}

Skelett: $\quad 63 / 67-4$

Krankheiten:

9

\begin{tabular}{c|l|l} 
Arthrose & rechts & links \\
\hline Caput & & \\
\hline Fossa & &
\end{tabular}

\section{Zahn Status Parodontium}

Apikale Prozesse

11
Zahnstein

0
Karies

0
Abrasion

0 


\section{Zähne}

Population:

Großenrode

Geschlecht:

Alter:

(3) 4 - 6 (7)

Beschreibung: Der 6er weist eine leicht frakturierte Wurzel auf.
9

Krankheiten:

\begin{tabular}{c|l|l} 
Arthrose & rechts & links \\
\hline Caput & & \\
\hline Fossa & &
\end{tabular}

\begin{tabular}{|c|c|c|c|c|c|c|c|c|}
\hline Zahn & Status & Parodontium & Apikale Prozesse & Zahnstein & Karies & Abrasion & Neubildung & Schmelzhypoplasie \\
\hline 46 & & & & 0 & 0 & 0 & 0 & $\mathrm{~T}$ \\
\hline 85 & & & & K 1 & 0 & 0 & 0 & 0 \\
\hline
\end{tabular}




\section{Zähne}

Population:

Großenrode

Geschlecht:

Alter:

(25) $37-45(50)$
9

Krankheiten:

\begin{tabular}{c|l|l} 
Arthrose & rechts & links \\
\hline Caput & & \\
\hline Fossa & &
\end{tabular}

Beschreibung: Von 12 und 22 sind nur die Kronen im gespaltenen Zustand vorhanden. Bei 17 liegt eine leichte Hyperzementose vor.

\begin{tabular}{|c|c|c|c|c|c|c|c|c|}
\hline Zahn & Status & Parodontium & Apikale Prozesse & Zahnstein & Karies & Abrasion & Neubildung & Schmelzhypoplasie \\
\hline 17 & & & 0 & $\mathrm{H} 2$ & 0 & $\mathrm{O}$ & * & 0 \\
\hline 21 & & & & $x$ & 0 & O & 0 & 0 \\
\hline 22 & & & & $x$ & 0 & 0 & 0 & 0 \\
\hline
\end{tabular}




\section{Zähne}

Population: Großenrode

Geschlecht:

Alter:

Beschreibung: Von diesen Zähnen sind die Wurzeln abfrakturiert, die Kronen sind erhalten.

\section{Krankheiten:}

9

\begin{tabular}{c|l|l} 
Arthrose & rechts & links \\
\hline Caput & & \\
\hline Fossa & &
\end{tabular}




\section{Zahn}

Population: Großenrode

Geschlecht:

Alter:

Beschreibung: Hier ist nur die Zahnkrone erhalten.

\subsubsection{5 / 10}

Skelett: K310 63/67 P4

Krankheiten:

\begin{tabular}{c|l|l} 
Arthrose & rechts & links \\
\hline Caput & & \\
\hline Fossa & &
\end{tabular}




\section{Zahn}

Population: Großenrode

Geschlecht:

Alter:

(22) 28 - $35(38)$

Beschreibung: Die Wurzel dieses Zahnes ist etwas erodiert.
9

Krankheiten:

\begin{tabular}{c|l|l} 
Arthrose & rechts & links \\
\hline Caput & & \\
\hline Fossa & &
\end{tabular}

$\begin{array}{lccccccccc}\text { Zahn } & \text { Status } & \text { Parodontium } & \text { Apikale Prozesse } & \text { Zahnstein } & \text { Karies } & \text { Abrasion } & \text { Neubildung } & \text { Schmelzhypoplasie } \\ 37 & & 0 & \mathrm{~K} 1 & 0 & \mathrm{O} & 3 & 0 & \mathrm{~T} & 1\end{array}$




\section{Zahn}

Population: Großenrode

Geschlecht:

Alter:

$$
7-11(13,5)
$$

Beschreibung: Bei diesem Prämolaren ist das Wurzelwachstum nicht abgeschlossen.
Krankheiten:

Skelett: K287 63/67 S3

Krankheiten:
9

\begin{tabular}{c|l|l} 
Arthrose & rechts & links \\
\hline Caput & & \\
\hline Fossa & &
\end{tabular}




\section{Zahn}

Population: Großenrode

Geschlecht:

Alter:

Beschreibung: Von diesem Weisheitszahn sind mesial etwa 10\% der Krone abfrakturiert.

\subsubsection{5/13}

Skelett: K133

Krankheiten:

\section{9}

\begin{tabular}{c|l|l} 
Arthrose & rechts & links \\
\hline Caput & & \\
\hline Fossa & &
\end{tabular}

Zahn Status Parodontium Apikale Prozesse

Zahnstein

Karies

Abrasion

Neubildung

0

Schmelzhypoplasie

O 3 


\section{OK; UK}

Population: Großenrode

Geschlecht: männlich

Alter:

(40) 45 - $55(65)$
01.04.2015 / 15

Skelett: K134 63/67 P3

Krankheiten: Stomatitis
9

\begin{tabular}{c|l|l} 
Arthrose & rechts & links \\
\hline Caput & & \\
\hline Fossa & &
\end{tabular}

Beschreibung: Diese Kiefer sind nur in Form von Fragmenten erhalten, die Alveole des 37 ist nur mesial zum Teil erhalten.

\begin{tabular}{|c|c|c|c|c|c|c|c|c|c|c|c|c|}
\hline \multirow{2}{*}{$\begin{array}{l}\text { Zahn } \\
11\end{array}$} & \multirow[t]{2}{*}{ Status } & \multicolumn{2}{|c|}{ Parodontium } & \multicolumn{2}{|c|}{ Apikale Prozesse } & \multicolumn{2}{|c|}{ Zahnstein } & \multirow{2}{*}{$\begin{array}{c}\text { Karies } \\
0\end{array}$} & \multicolumn{2}{|c|}{ Abrasion } & Neubildung & \multirow{2}{*}{$\begin{array}{c}\text { Schmelzhypoplasie } \\
x\end{array}$} \\
\hline & & & $x$ & G & 2 & & & & O & 7 & 3 & \\
\hline 12 & & $\mathrm{Pi}$ & 2 & & & & & 0 & $\mathrm{O}$ & 5 & 2 & $x$ \\
\hline 13 & & $\mathrm{Pi}$ & 2 & & & & & 0 & $\mathrm{O}$ & 5 & 2 & $x$ \\
\hline 14 & & $\mathrm{Pi}$ & 1 & & & & & 0 & $\mathrm{O}$ & 5 & 2 & $x$ \\
\hline 15 & $f$ & & & & & & & & & & & \\
\hline 16 & $f$ & & & & & & & & & & & \\
\hline 21 & & & $x$ & $G$ & 2 & & & 0 & 0 & 7 & 3 & $x$ \\
\hline 22 & & $\mathrm{Pi}$ & 2 & & 0 & & & 0 & $\mathrm{O}$ & 5 & 2 & $x$ \\
\hline 23 & & $\mathrm{Pi}$ & 2 & & 0 & $\mathrm{H}$ & 2 & 0 & $\mathrm{O}$ & 5 & 2 & 0 \\
\hline 24 & & $\mathrm{Pi}$ & 1 & G & 1 & $\mathrm{~K}$ & 1 & 0 & 0 & 4 & 2 & 0 \\
\hline 31 & & & $x$ & & $x$ & $\mathrm{~K}$ & 1 & 0 & 0 & 3 & 0 & 0 \\
\hline
\end{tabular}




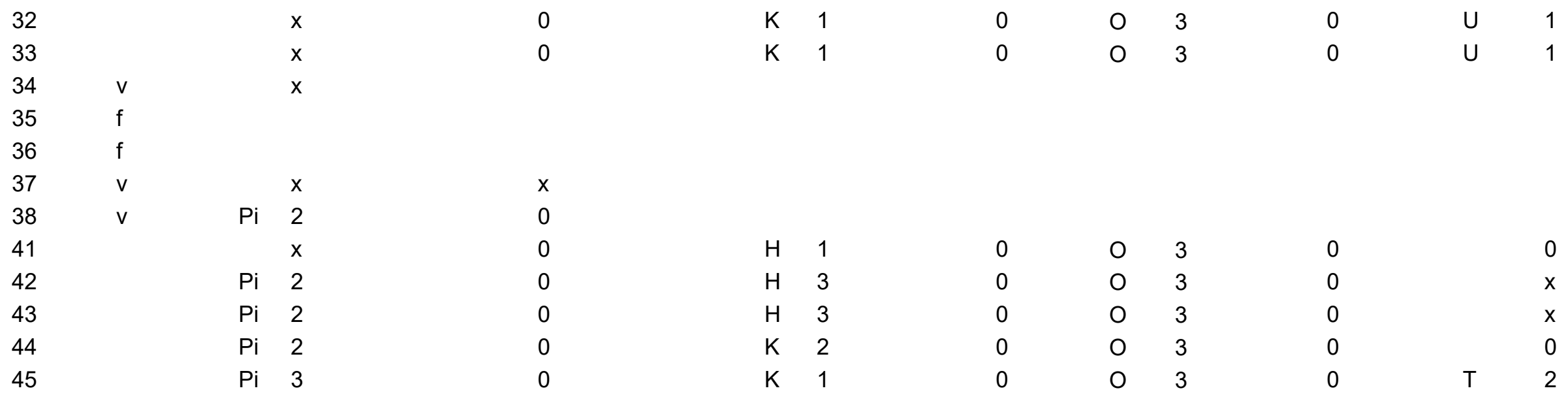




\section{UK}

Population: Großenrode

Geschlecht: >> weiblich

Alter:

Beschreibung: Hier ist ein Caput mandibulae (70\%) mit einem Teil des aufsteigenden Astes des Unterkiefers rechts erhalten. Die Fossa mandibulae ist ebenfalls erhalten, sie weist deutliche Spuren von Degenerationen auf. Diese sind in Form einer Arthrose zu interpretieren. Allerdings ist das Fundstück nicht eindeutig einem Individuum zuzuordnen, weswegen es nicht mit ausgewertet, sondern nur dokumentiert wird.

\section{Zahn Status Parodontium}

Apikale Prozesse

\subsubsection{5/ 3}

Krankheiten: Arthrose
9

\begin{tabular}{c|c|c} 
Arthrose & rechts & links \\
\hline Caput & 3 & \\
\hline Fossa & 4 &
\end{tabular}
$\mathrm{xx}$ 


\section{UK; OK}

Population:

Großenrode

Geschlecht:

Alter:

(6) $8,5-13(15)$
9

Krankheiten:

Beschreibung: Hier sind Fragmente des Unterkiefers vorhanden. Erhalten ist ein kleiner Teil des aufsteigenden Astes rechts, $50 \%$ des Caput mandibulae und weitere kleine Splitter. Das Wechselgebiss ist fast vollständig erhalten.

\begin{tabular}{c|c|c} 
Arthrose & rechts & links \\
\hline Caput & 00 & \\
\hline Fossa & &
\end{tabular}

\begin{tabular}{|c|c|c|c|c|c|c|c|c|c|c|}
\hline Zahn & Status & Parodontium & Apikale Prozesse & Zahnstein & Karies & \multicolumn{2}{|c|}{ Abrasion } & Neubildung & \multicolumn{2}{|c|}{ Schmelzhypoplasie } \\
\hline 11 & & & & 0 & 0 & 0 & 1 & 0 & $\mathrm{~T}$ & 1 \\
\hline 12 & & & & 0 & 0 & & 0 & 0 & $U$ & 1 \\
\hline 13 & & & & 0 & 0 & & 0 & 0 & $\mathrm{~T}$ & 1 \\
\hline 14 & ( ) & & & 0 & 0 & & 0 & 0 & $\mathrm{~T}$ & 1 \\
\hline 15 & ( ) & & & 0 & 0 & & 0 & 0 & $\mathrm{~T}$ & 1 \\
\hline 16 & & & & 0 & 0 & 0 & 1 & 0 & $\mathrm{~T}$ & 1 \\
\hline 21 & & & & 0 & 0 & 0 & 1 & 0 & $\mathrm{~T}$ & 1 \\
\hline 22 & _ & & & 0 & 0 & & 0 & 0 & $U$ & 1 \\
\hline 23 & - & & & 0 & 0 & & 0 & 0 & $\mathrm{~T}$ & 1 \\
\hline 24 & ( ) & & & 0 & 0 & & 0 & 0 & $\mathrm{~T}$ & 1 \\
\hline 25 & ( ) & & & 0 & 0 & & 0 & 0 & $\mathrm{~T}$ & 1 \\
\hline
\end{tabular}




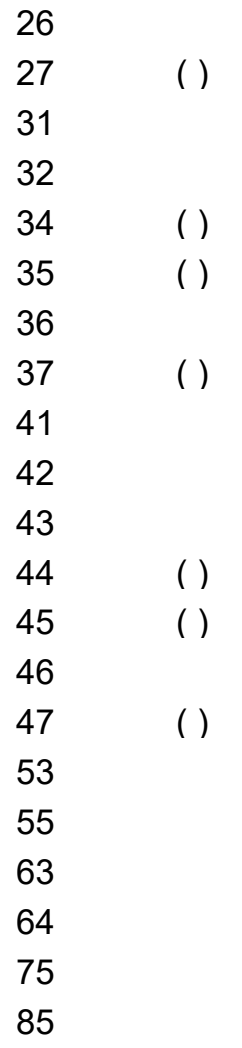

\begin{tabular}{|c|c|c|c|c|c|c|c|c|}
\hline & & 0 & 0 & 0 & 1 & 0 & $\mathrm{~T}$ & 1 \\
\hline & & & & & & 0 & $U$ & 1 \\
\hline & & 0 & 0 & 0 & 1 & 0 & $\mathrm{~T}$ & 1 \\
\hline & & 0 & 0 & 0 & 1 & 0 & $\mathrm{~T}$ & 1 \\
\hline & & & & & & 0 & $\mathrm{~T}$ & 1 \\
\hline & & & & & & 0 & & 0 \\
\hline & & 0 & 0 & 0 & 1 & 0 & $U$ & 1 \\
\hline & & & & & & 0 & $U$ & 1 \\
\hline & & 0 & 0 & 0 & 1 & 0 & $\mathrm{~T}$ & 1 \\
\hline & & 0 & 0 & 0 & 1 & 0 & $\mathrm{~T}$ & 1 \\
\hline & & 0 & 0 & 0 & 1 & 0 & $\mathrm{~T}$ & 1 \\
\hline & & & & & & 0 & $\mathrm{~T}$ & 1 \\
\hline & & & & & & 0 & $\mathrm{~T}$ & 1 \\
\hline & & 0 & 0 & 0 & 1 & 0 & $\mathrm{~T}$ & 1 \\
\hline & & & & & & 0 & $U$ & 1 \\
\hline 0 & & 0 & 0 & 0 & 3 & 0 & & 0 \\
\hline & & 0 & 0 & 0 & 3 & 0 & & $c$ \\
\hline & & 0 & 0 & 0 & 3 & 0 & & $c$ \\
\hline & & 0 & 0 & 0 & 3 & 0 & & 0 \\
\hline 0 & $\mathrm{~K}$ & 1 & 0 & 0 & 3 & 0 & & $c$ \\
\hline & $\mathrm{K}$ & 1 & 0 & 0 & 3 & 0 & & 0 \\
\hline
\end{tabular}


Ok

Population: Großenrode

Geschlecht:

Alter:

(6) 16 - 22 (24)

Beschreibung: Ein kleines Oberkieferfragment. Der 8er ist in Form eines kleinen Wurzelfragmentes erhalten.

\section{5}

Krankheiten:

\begin{tabular}{c|l|l} 
Arthrose & rechts & links \\
\hline Caput & & \\
\hline Fossa & &
\end{tabular}

\begin{tabular}{|c|c|c|c|c|c|c|c|c|}
\hline Zahn & Status & Parodontium & Apikale Prozesse & Zahnstein & Karies & Abrasion & Neubildung & Schmelzhypoplasie \\
\hline 16 & $\mathrm{v}$ & & & & & & & \\
\hline 17 & & 0 & 0 & $\mathrm{~K}$ & O 2 & 0 & * & $\mathrm{T}$ \\
\hline
\end{tabular}




\section{Zahn}

Population: Großenrode

Geschlecht:

Alter:

\section{Beschreibung:}

\subsubsection{5 / 2}

Skelett: K372 64/67 S4

Krankheiten: Gravur

\section{5}

\begin{tabular}{c|l|l} 
Arthrose & rechts & links \\
\hline Caput & & \\
\hline Fossa & &
\end{tabular}

\section{Zahn Status Parodontium Apikale Prozesse}

$\mathrm{Pi} 1$

\section{Zahnstein}

H 2

\section{Karies}

0
Abrasion

O 3
Neubildung

Schmelzhypoplasie U 1 


\section{UK}

Population: Großenrode

Geschlecht: >> männlich

Alter:

(25) 28 - 35 (38)

Beschreibung: Ein fragmentiert erhaltener Unterkiefer.

\section{5}

Krankheiten:

\begin{tabular}{c|l|l} 
Arthrose & rechts & links \\
\hline Caput & & \\
\hline Fossa & &
\end{tabular}

\begin{tabular}{|c|c|c|c|c|c|c|c|c|c|c|}
\hline Zahn & Status & Parodontium & Apikale Prozesse & $\mathrm{Za}$ & instein & Karies & $\mathrm{Ab}$ & sion & Neubildung & Schmelzhypoplasie \\
\hline 31 & $\mathrm{v}$ & Po 1 & 0 & & & & & & & \\
\hline 32 & & Po 1 & 0 & $M$ & 2 & 0 & $\mathrm{O}$ & 3 & 0 & 0 \\
\hline 33 & & Po 1 & 0 & $\mathrm{~K}$ & 1 & 0 & $\mathrm{O}$ & 3 & 0 & 0 \\
\hline 34 & & Po 1 & 0 & $\mathrm{~K}$ & 1 & 0 & $\mathrm{O}$ & 3 & 0 & 0 \\
\hline 35 & & Po 1 & 0 & $\mathrm{~K}$ & 1 & 0 & $\mathrm{O}$ & 3 & 0 & $\mathrm{~T}$ \\
\hline 36 & & Po 1 & 0 & $\mathrm{~K}$ & 1 & 0 & 0 & 4 & 2 & 0 \\
\hline 37 & & Po 1 & 0 & $\mathrm{~K}$ & 1 & 0 & $\mathrm{O}$ & 3 & 0 & 0 \\
\hline 38 & & 0 & 0 & $\mathrm{~K}$ & 1 & 0 & 0 & 2 & 0 & 0 \\
\hline 41 & $\mathrm{v}$ & Po 1 & 0 & & & & & & & \\
\hline 42 & & Po 1 & 0 & $\mathrm{~K}$ & 1 & 0 & 0 & 3 & 0 & 0 \\
\hline 43 & & Po 1 & 0 & $\mathrm{~K}$ & 1 & 0 & 0 & 3 & 0 & 0 \\
\hline
\end{tabular}


Po 1

Po 1

Po 1
$\mathrm{H} 2$

K 1

K 1

$\begin{array}{lll}0 & 0 & 4 \\ 0 & 0 & 3 \\ 0 & 0 & 2\end{array}$

4

(0)

0

0




\section{Zähne}

Population: Großenrode

Geschlecht:

Alter:

(25) 28 - 35 (38)

Beschreibung: Von 35 ist nur die Krone erhalten.
5

\begin{tabular}{c|l|l} 
Arthrose & rechts & links \\
\hline Caput & & \\
\hline Fossa & &
\end{tabular}

\begin{tabular}{|c|c|c|c|c|c|c|c|c|}
\hline Zahn & Status & Parodontium & Apikale Prozesse & Zahnstein & Karies & Abrasion & Neubildung & Schmelzhypoplasie \\
\hline 31 & & & 0 & $\mathrm{H} 2$ & 0 & $\mathrm{O}$ & 0 & 0 \\
\hline 34 & & & 0 & 0 & 0 & $\mathrm{O}$ & 2 & 0 \\
\hline 35 & & & & $\mathrm{H} \quad 2$ & 0 & $\mathrm{O}$ & 0 & 0 \\
\hline 46 & & & 0 & $\mathrm{H} \quad 1$ & 0 & $\mathrm{O}$ & 0 & 0 \\
\hline
\end{tabular}




\section{UK}

Population: Großenrode

Geschlecht:

Alter:

(5) 6 - 7 (8)

Beschreibung: Ein frakturiert erhaltener Unterkiefer.
5

Krankheiten:

\begin{tabular}{c|l|l} 
Arthrose & rechts & links \\
\hline Caput & & \\
\hline Fossa & &
\end{tabular}

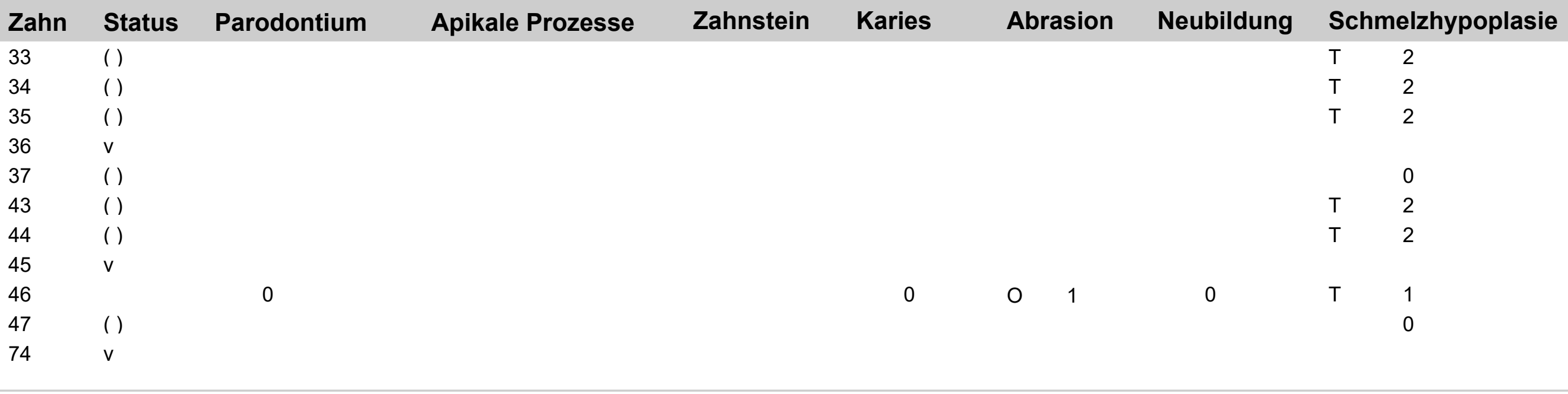


75 v

84

0

85

$\begin{array}{lll}0 & 0 & 3\end{array}$

0

0 


\section{UK}

Population: Großenrode

Geschlecht:

Alter:

(25) 35 - 45 (50)
5

Krankheiten:

Beschreibung: Bei 37 liegt occlusal eine weitere Karies 2. Grades vor, die Wurzel des 44 ist gespalten und 33 hat zwei Wurzel, was hier eine Varietät darstellt.

\begin{tabular}{|c|c|c|c|c|c|c|c|c|c|c|c|c|c|}
\hline \multirow{2}{*}{$\begin{array}{l}\text { Zahn } \\
31\end{array}$} & \multirow[t]{2}{*}{ Status } & \multicolumn{2}{|c|}{ Parodontium } & \multicolumn{2}{|c|}{ Apikale Prozesse } & \multicolumn{2}{|c|}{ Zahnstein } & Karies & \multicolumn{2}{|c|}{ Abrasion } & \multirow{2}{*}{$\begin{array}{c}\text { Neubildung } \\
0\end{array}$} & \multicolumn{2}{|c|}{ Schmelzhypoplasie } \\
\hline & & & $x$ & $G$ & 1 & $\mathrm{H}$ & 1 & 0 & $\mathrm{O}$ & 3 & & $\mathrm{~T}$ & 1 \\
\hline 32 & & & $x$ & & 0 & $\mathrm{H}$ & 1 & 0 & $\mathrm{O}$ & 3 & 0 & $\mathrm{~T}$ & 1 \\
\hline 33 & & & $x$ & & 0 & $\mathrm{H}$ & 1 & 0 & $\mathrm{O}$ & 3 & 0 & $\mathrm{~T}$ & 1 \\
\hline 34 & $\mathrm{v}$ & & $x$ & & 0 & & & & & & & & \\
\hline 35 & & $\mathrm{Pi}$ & 2 & & & $\mathrm{H}$ & 1 & 0 & $\mathrm{O}$ & 3 & 0 & $\mathrm{~T}$ & 1 \\
\hline 36 & & $\mathrm{Pi}$ & 3 & $G$ & 2 & & & $\mathrm{O}$ & & $x$ & 3 & & $x$ \\
\hline 37 & & $\mathrm{Pi}$ & 4 & G & 3 & & 0 & W 3 & 0 & 4 & 2 & & 0 \\
\hline 38 & (f) & $\mathrm{Pi}$ & 3 & G & 3 & & & & & & & & \\
\hline 41 & & & $x$ & $G$ & 1 & $\mathrm{H}$ & 1 & 0 & 0 & 3 & 0 & $\mathrm{~T}$ & 1 \\
\hline 42 & & & $x$ & & 0 & $\mathrm{H}$ & 1 & 0 & 0 & 3 & 0 & $\mathrm{~T}$ & 1 \\
\hline 44 & & Po & 2 & & 0 & & 0 & 0 & 0 & 3 & 0 & $\mathrm{~T}$ & 1 \\
\hline
\end{tabular}




\section{Zahn}

Population: Großenrode

Geschlecht:

Alter:

Beschreibung: Ein erodierter Zahn.
5

Krankheiten:

\begin{tabular}{c|l|l} 
Arthrose & rechts & links \\
\hline Caput & & \\
\hline Fossa & &
\end{tabular}




\section{Zähne}

Population:

Großenrode

Geschlecht:

Alter:

(5) 6 - 7 (8)

Beschreibung: Leicht erodierte Fundstücke.
5

Krankheiten:

\begin{tabular}{c|l|l} 
Arthrose & rechts & links \\
\hline Caput & & \\
\hline Fossa & &
\end{tabular}

Zahn Status Parodontium Apikale Prozesse

24

85 ( )

Zahnstein

\section{Karies}

Abrasion
Neubildung Schmelzhypoplasie T 2 


\section{Zahn}

Population: Großenrode

Geschlecht: >> männlich

Alter:

\section{Beschreibung:}

\subsubsection{5 / 4}

Skelett: K34 61/67 S1

Krankheiten:

\begin{tabular}{c|l|l} 
Arthrose & rechts & links \\
\hline Caput & & \\
\hline Fossa & &
\end{tabular}

5 


\section{UK, Zahn}

Population:

Großenrode

Geschlecht:

Alter:

(25) $37-45(50)$

Beschreibung: Hier ist ein Zahn und ein knöchernes Kinn erhalten.

\section{5}

Krankheiten:

\begin{tabular}{c|l|l} 
Arthrose & rechts & links \\
\hline Caput & & \\
\hline Fossa & &
\end{tabular}

$\begin{array}{llccccccccc}\text { Zahn } & \text { Status } & \text { Parodontium } & \text { Apikale Prozesse } & \text { Zahnstein } & \text { Karies } & \text { Abrasion } & \text { Neubildung } & \text { Schmelzhypoplasie } \\ 27 & & \mathrm{x} & \mathrm{K} & 1 & \mathrm{M} & 2 & \mathrm{O} & 4 & \# & 2\end{array}$




\section{Zähne}

Population: Großenrode

Geschlecht: > weiblich

Alter:

(5) 6 - 7 (8)

Beschreibung: Von diesen Fundstücken sind nur die Zahnkronen erhalten.

\section{Zahn Status Parodontium}

Apikale Prozesse

II

44

( )

\subsubsection{5 / 6}

Skelett: $\quad 61 / 67-3$

Krankheiten:

5

\begin{tabular}{c|l|l} 
Arthrose & rechts & links \\
\hline Caput & & \\
\hline Fossa & &
\end{tabular}
Zahnstein

Karies

0

Abrasion

Neubildung

Schmelzhypoplasie

0 


\section{OK}

Population: Großenrode

Geschlecht: > weiblich

Alter:

(25) 28 - 35 (38)

\subsubsection{5/ 2}

Skelett: K175 OK
5

Krankheiten: Stomatitis Arthrose

Beschreibung: Dieser Oberkiefer ist mit zahlreichen Zähnen erhalten, von der Krone des 14 ist etwas abgebrochen und die vestibuläre Wurzel ist abfrakturiert. Am 17 ist auch distal eine Karies mit Grad 1 festzustellen.

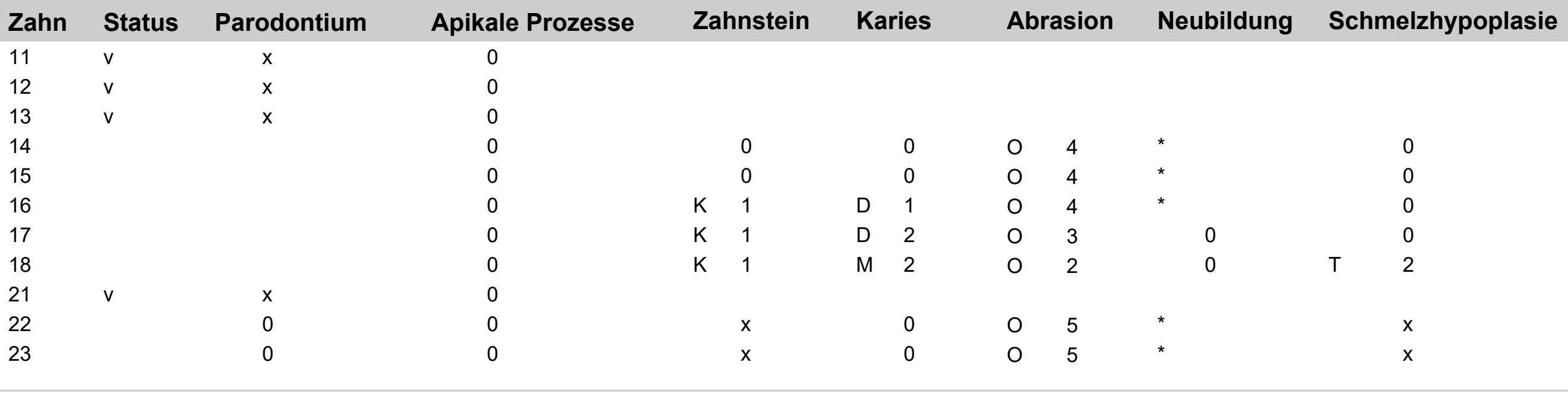




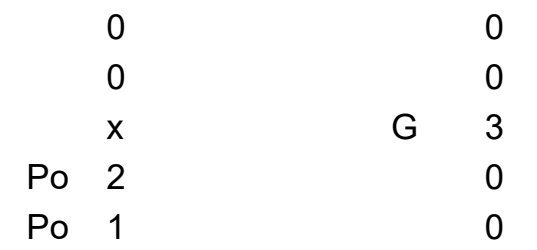

$\begin{array}{ll} & \mathrm{x} \\ \mathrm{K} & \mathrm{x} \\ \mathrm{K} & 1 \\ \mathrm{~K} & 1\end{array}$

$\begin{array}{ll} & 0 \\ D & 2 \\ \text { M } & 6 \\ \text { D } & 2 \\ D & 2\end{array}$

$\begin{array}{ll}0 & 5 \\ 0 & 5 \\ 0 & 4 \\ 0 & 3 \\ 0 & 2\end{array}$

0

$\begin{array}{rr} & \mathrm{x} \\ \mathrm{x} \\ \mathrm{x} \\ \mathrm{T} \\ \mathrm{T} \\ \mathrm{2}\end{array}$




\section{Zahn}

Population: Großenrode

Geschlecht:

Alter:

(14) 25 - 30 (34)

Beschreibung: Die Wurzel dieses 7ers ist abfrakturiert.
5

Krankheiten:

\begin{tabular}{c|l|l} 
Arthrose & rechts & links \\
\hline Caput & & \\
\hline Fossa & &
\end{tabular}

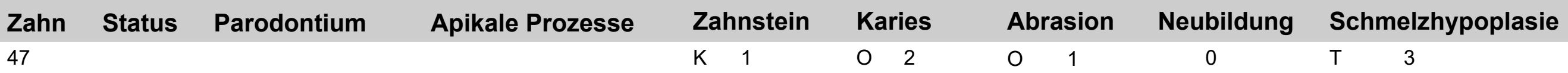




\section{OK; UK}

Population: Großenrode

Geschlecht: > männlich

Alter:

(25) 28 - 35 (45)

\subsubsection{5 / 1}

Skelett: $\quad$ K48 UK, OK K144

Krankheiten: Arthrose

\section{5}

\begin{tabular}{c|c|c} 
Arthrose & rechts & links \\
\hline Caput & 3 & \\
\hline Fossa & &
\end{tabular}

Beschreibung: Hier liegen Fragmente und Splitter von den Kiefern vor. Das rechte Caput mandibulae zeigt eine kleine plattenförmige Auflagerung, die für eine Arthrose spricht. Von 27 ist nur ein Wurzelrest erhalten, es sind weitere zwei Wurzelsplitter übrig, die nicht zuzuordnen waren. Vom

Oberkieferknochen ist nur ein kleiner Saum der Molarenregion erhalten. Bei den Zähnen 12, 13, 14, 15, (23), 24, 25 sind die Wurzelkanäle mit Tertiärdentin zugemauert. Von 23 ist nur die Krone mit wenig Wurzel erhalten. Von 25 ist die Wurzelspitze abfrakturiert und die Wurzel des 26 zeigt auch Hyperzementose 2. Grades.

\begin{tabular}{|c|c|c|c|c|c|c|c|c|}
\hline Zahn & Status & Parodontium & Apikale Prozesse & Zahnstein & Karies & Abrasion & Neubildung & Schmelzhypoplasie \\
\hline 12 & & & 0 & $x$ & 0 & $\mathrm{O}$ & * & $x$ \\
\hline 13 & & & 0 & 0 & 0 & $\mathrm{O}$ & * & $x$ \\
\hline 14 & & & 0 & $P$ & 0 & $\mathrm{O}$ & * & $x$ \\
\hline 15 & & & 0 & $\mathrm{H}$ & 0 & $\mathrm{O}$ & * & $x$ \\
\hline 23 & & & & $\mathrm{H}$ & 0 & $\mathrm{O}$ & * & $x$ \\
\hline 24 & & & 0 & $\mathrm{H}$ & 0 & 0 & * & $x$ \\
\hline 25 & & & & $\mathrm{H}$ & 0 & $\mathrm{O}$ & * & 0 \\
\hline 26 & & & G & $x$ & $\mathrm{O}$ & $x$ & * & $x$ \\
\hline 28 & & Po 1 & 0 & $\mathrm{H} \quad 2$ & 0 & $\mathrm{O}$ & $\#$ & 0 \\
\hline 31 & & & 0 & $\mathrm{H} 3$ & 0 & $\mathrm{O}$ & * & 0 \\
\hline 32 & & & 0 & $\mathrm{H} 3$ & 0 & 0 & * & 0 \\
\hline
\end{tabular}




0

$\begin{array}{llll}0 & 3 & & \\ 0 & 3 & *\end{array}$

O

$\begin{array}{ll}\mathrm{O} & 4 \\ \mathrm{O} & 3\end{array}$

0

0

0
0
0
0
0




\section{Zähne}

Population:

Großenrode

Geschlecht:

Alter:

(5) 6 - 7 (8)

\section{Beschreibung:}

\subsubsection{5 / 4}

Skelett: K48 62/69 S1

Krankheiten:

5

\begin{tabular}{c|l|l} 
Arthrose & rechts & links \\
\hline Caput & & \\
\hline Fossa & &
\end{tabular}

\begin{tabular}{|c|c|c|c|c|c|c|c|c|}
\hline Zahn & Status & Parodontium & Apikale Prozesse & Zahnstein & Karies & Abrasion & Neubildung & Schmelzhypoplasie \\
\hline 55 & & & 0 & 0 & $\mathrm{O}$ & $\mathrm{O}$ & * & 0 \\
\hline 74 & & & 0 & $\mathrm{~K}$ & 0 & $\mathrm{O}$ & & 0 \\
\hline
\end{tabular}




\section{Zahn}

Population:

Großenrode

Geschlecht:

Alter:

(6) 16 - $22(24)$

Beschreibung: Die Hälfte der Wurzel ist abfrakturiert.
5

Krankheiten:

\begin{tabular}{c|l|l} 
Arthrose & rechts & links \\
\hline Caput & & \\
\hline Fossa & &
\end{tabular}

$\begin{array}{llccccccc}\text { Zahn } & \text { Status } & \text { Parodontium } & \text { Apikale Prozesse } & \text { Zahnstein } & \text { Karies } & \text { Abrasion } & \text { Neubildung } & \text { Schmelzhypoplasie } \\ 17 & & 0 & 0 & 0 & 1 & 0 & T\end{array}$




\section{UK}

Population: Großenrode

Geschlecht:

Alter:

Beschreibung: Hier sind zwei kleine Kieferfragmente eines Unterkiefers erhalten. Das Caput mandibulae der linken Seite ist zu $80 \%$ erhalten und befundbar.

\subsubsection{5 / 6}

Skelett: $62 / 69-1$

\section{5}

Krankheiten:

\begin{tabular}{c|c|c} 
Arthrose & rechts & links \\
\hline Caput & & 2 \\
\hline Fossa & &
\end{tabular}

\begin{tabular}{|c|c|c|c|c|c|c|c|c|}
\hline Zahn & Status & Parodontium & Apikale Prozesse & Zahnstein & Karies & Abrasion & Neubildung & Schmelzhypoplasie \\
\hline 31 & & & 0 & $\mathrm{H} 3$ & 0 & $\mathrm{O}$ & * & 0 \\
\hline 43 & v & & & & & & & \\
\hline 44 & & 0 & 0 & $\mathrm{H} 3$ & 0 & $\mathrm{O}$ & 0 & 0 \\
\hline 45 & & $x$ & 0 & $\mathrm{H} 3$ & 0 & 0 & 0 & 0 \\
\hline
\end{tabular}




\section{Zahn}

Population: Großenrode

Geschlecht:

Alter:

Beschreibung: Dieser Zahn weist eine erodierte Wurzel auf.

Alter:
5

\begin{tabular}{c|l|l} 
Arthrose & rechts & links \\
\hline Caput & & \\
\hline Fossa & &
\end{tabular}

Krankheiten:

Skelett: K292 64/68 S3

Beschreibung: Dieser Zahn weist eine erodierte Wurzel auf.

\section{Zahn Status Parodontium} 21
Apikale Prozesse
Zahnstein

0

\section{Karies}

0
Abrasion

o 2
Neubildung

0

Schmelzhypoplasie 


\section{Zähne}

Population:

Großenrode

Geschlecht:

Alter:

(25 ) 28 - 35 (38)

Beschreibung: Die Wurzeln des 4ers und 6ers sind erodiert.
5

Krankheiten:

\begin{tabular}{c|l|l} 
Arthrose & rechts & links \\
\hline Caput & & \\
\hline Fossa & &
\end{tabular}

\section{Zahn Status Parodontium Apikale Prozesse}

14

22

26

\section{Zahnstein Karies}

0

0

0

K 1
Abrasion Neubildung Schmelzhypoplasie

O 4

O 2

*

0

0 


\section{Zahn}

Population: Großenrode

Geschlecht:

Alter:

$17-25$

Beschreibung: Das apicale Drittel dieses Zahnes ist abfrakturiert.

\subsubsection{5 / 9}

Skelett: $\quad 64 / 68-4$

riert.
5

\begin{tabular}{c|l|l} 
Arthrose & rechts & links \\
\hline Caput & & \\
\hline Fossa & &
\end{tabular}

\section{Krankheiten:}




\section{OK; UK}

Population:

Großenrode

Geschlecht:

Alter:

(22) 25 - $30(34)$

\subsubsection{5 / 15}

Skelett: K174

\section{5}

Krankheiten:

Beschreibung: Hier sind Fragmente von Ober- und Unterkiefer erhalten. Das Caput der linken Seite ist groß und zu $85 \%$ erhalten. 18 weist eine unregelmäßige Wurzeloberfläche auf. Weiterhin findet sich hier eine Schmelzperle distal im oberen Viertel der Wurzel. 17 hat relativ lange Wurzeln.

\begin{tabular}{|c|c|c|c|c|c|c|c|c|}
\hline Zahn & Status & Parodontium & Apikale Prozesse & Zahnstein & Karies & Abrasion & Neubildung & Schmelzhypoplasie \\
\hline 17 & & & 0 & $\mathrm{~K}$ & $\mathrm{D}$ & $\mathrm{O}$ & 0 & 0 \\
\hline 18 & & & 0 & $\mathrm{~K}$ & M 2 & $\mathrm{O}$ & \# & 0 \\
\hline 28 & & & 0 & $\mathrm{H} \quad 1$ & 0 & $\mathrm{O}$ & 0 & 0 \\
\hline 36 & & Po 2 & 0 & K 1 & 0 & $\mathrm{O}$ & 0 & 0 \\
\hline 37 & & Po 2 & 0 & $\begin{array}{ll}\mathrm{K} & 1\end{array}$ & 0 & $\mathrm{O}$ & 0 & 0 \\
\hline 38 & & Po 2 & 0 & K 1 & 0 & 0 & 0 & 0 \\
\hline
\end{tabular}




\section{OK; UK}

Population:

Großenrode

Geschlecht:

Alter:

(14) 16 - $22(24)$

\section{5}

Krankheiten:

Beschreibung: Teilweise sind die erhaltenen Zähne etwas gesplittert, 37 weist vestibulär einen kleinen Defekt in Form eines Loches in der Krone auf. Von 47 ist nur ein Fragment der Krone erhalten und ein Fragment der Alveole. 48 weist eine kreidige Oberfläche auf der Krone auf, welche für initiale Karies spricht. Es kann sein, dass die Schleimhaut über dem Zahn nicht mehr vorhanden war und damit der Zahn zur Mundhöhle offen lag; der Alveolarknochen deckte inn nur noch zu $25 \%$ ab. Kieferknochen sind fragmentiert erhalten

\begin{tabular}{|c|c|c|c|c|c|c|c|c|c|}
\hline Zahn & Status & Parodontium & Apikale Prozesse & Zahnstein & Karies & \multicolumn{2}{|c|}{ Abrasion } & Neubildung & Schmelzhypoplasie \\
\hline 11 & v & & 0 & & & & & & \\
\hline 12 & $\mathrm{v}$ & & 0 & & & & & & \\
\hline 13 & $\mathrm{v}$ & & 0 & & & & & & \\
\hline 14 & $\mathrm{v}$ & & 0 & & & & & & \\
\hline 15 & $\mathrm{v}$ & & 0 & & & & & & \\
\hline 16 & E & & 0 & & & & & & \\
\hline 17 & & 0 & 0 & 0 & 0 & $\mathrm{O}$ & 2 & 0 & 0 \\
\hline 18 & ( ) & & & & & & & & 0 \\
\hline 21 & v & & 0 & & & & & & \\
\hline 22 & $v$ & & 0 & & & & & & \\
\hline 23 & $\mathrm{v}$ & & 0 & & & & & & \\
\hline
\end{tabular}




\begin{tabular}{|c|c|c|c|c|c|c|c|c|c|c|c|c|}
\hline 26 & v & & 0 & & & & & & & & & \\
\hline 27 & & 0 & 0 & & 0 & & 0 & 0 & 1 & 0 & & 0 \\
\hline 28 & () & & & & & & & & & 0 & & \\
\hline 31 & & & 0 & $\mathrm{~L}$ & 1 & & 0 & 0 & 2 & 0 & $\mathrm{~T}$ & 1 \\
\hline 32 & & & 0 & & 0 & & 0 & 0 & 1 & 0 & $\mathrm{~T}$ & 1 \\
\hline 33 & & & 0 & & 0 & & 0 & 0 & 1 & 0 & $U$ & 2 \\
\hline 34 & & & 0 & & 0 & & 0 & 0 & 1 & 0 & $\mathrm{~T}$ & 1 \\
\hline 35 & & 0 & 0 & & 0 & & 0 & 0 & 2 & 0 & & $x$ \\
\hline 36 & & 0 & 0 & & 0 & & 0 & O & 2 & 0 & & 0 \\
\hline 37 & & 0 & 0 & & 0 & & 0 & 0 & 1 & 0 & & 0 \\
\hline 38 & ( ) & & & & & & 0 & & & 0 & & \\
\hline 41 & & & 0 & $\mathrm{~L}$ & 1 & & 0 & 0 & 2 & 0 & & 0 \\
\hline 42 & $\mathrm{v}$ & & 0 & & & & & & & & & \\
\hline 43 & $E$ & & 0 & & & & & & & & & \\
\hline 43 & & 0 & 0 & & 0 & & 0 & 0 & 1 & 0 & $U$ & 1 \\
\hline 44 & $\mathrm{v}$ & & & & & & & & & & & \\
\hline 45 & & 0 & 0 & & 0 & & 0 & 0 & 1 & 0 & & 0 \\
\hline 46 & & 0 & 0 & $\mathrm{~K}$ & 1 & & 0 & 0 & 3 & 0 & & $x$ \\
\hline 47 & & 0 & 0 & & $x$ & & 0 & 0 & 2 & 0 & & 0 \\
\hline 48 & () & & & & 0 & 0 & 2 & & & 0 & & \\
\hline
\end{tabular}




\section{OK}

Population: Großenrode

Geschlecht:

Alter:

(22) 25 - 30 (34)

Beschreibung: Die Zähne 17 und 27 weisen distal an den Wurzeln Schmelzperlen auf.

\section{5}

Krankheiten:

\begin{tabular}{c|l|l} 
Arthrose & rechts & links \\
\hline Caput & & \\
\hline Fossa & &
\end{tabular}

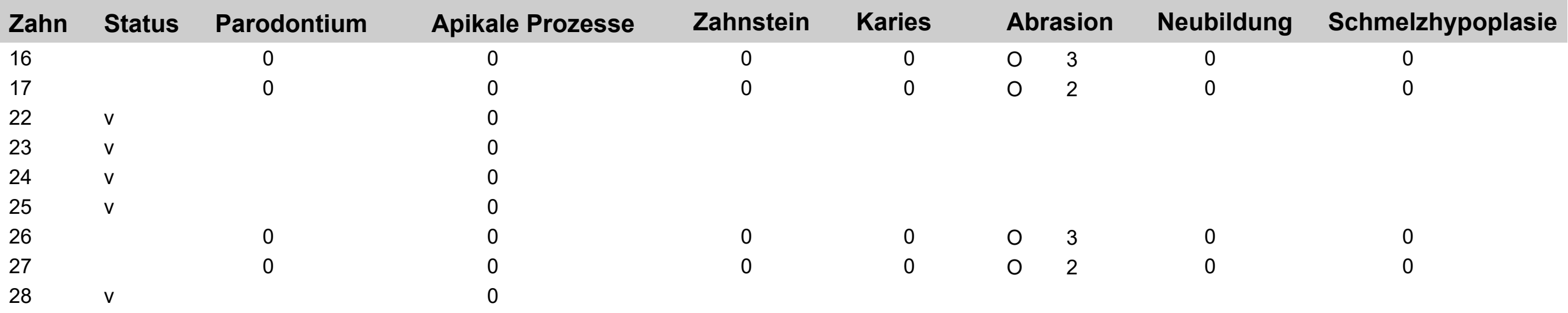




\section{Zahn}

Population: Großenrode

Geschlecht:

Alter:

(40) $45-55(65)$

\subsubsection{5 / 39}

Skelett: K10 61/69 P1
5

Krankheiten:

Beschreibung: Dieser 6er ist mit etwas Kieferknochen zwischen den Wurzeln erhalten, auffällig ist, dass bei dem starken Abrasionsgrad von 6 wenig bis kein Tertiärdentin gebildet wurde.

$\begin{array}{lcccccccc}\text { Zahn } & \text { Status } & \text { Parodontium } & \text { Apikale Prozesse } & \text { Zahnstein } & \text { Karies } & \text { Abrasion } & \text { Neubildung } & \text { Schmelzhypoplasie } \\ 16 & & 0 & \text { W } & 0 & 0 & 6 & 0 & 0\end{array}$


OK; UK

Population:

Großenrode

Geschlecht:

Alter:

$5-7(8)$
8

Krankheiten:

\begin{tabular}{c|l|l} 
Arthrose & rechts & links \\
\hline Caput & & \\
\hline Fossa & &
\end{tabular}

Beschreibung: Von den Kiefern sind nur kleine Fragmente erhalten, vom Oberkiefer mehr als vom Unterkiefer.

\begin{tabular}{|c|c|c|c|c|c|c|c|c|}
\hline Zahn & Status & Parodontium & Apikale Prozesse & Zahnstein & Karies & Abrasion & Neubildung & Schmelzhypoplasie \\
\hline 14 & $\mathrm{v}$ & & & & & & & \\
\hline 15 & () & & & & & & 0 & $\mathrm{~T}$ \\
\hline 16 & & 0 & 0 & 0 & 0 & $\mathrm{O}$ & 0 & 0 \\
\hline 17 & () & & & & & & 0 & $\mathrm{~T}$ \\
\hline 22 & ( ) & & & & & & 0 & $\mathrm{~T}$ \\
\hline 23 & () & & & & & & 0 & $\mathrm{~T}$ \\
\hline 24 & ( ) & & & & & & & \\
\hline 25 & ( ) & & & & & & & \\
\hline 26 & $\mathrm{v}$ & & & & & & & \\
\hline 27 & () & & & & & & 0 & $\mathrm{~T}$ \\
\hline 31 & $\mathrm{v}$ & & & & & & & \\
\hline
\end{tabular}




$\begin{array}{ll}32 & \mathrm{v} \\ 33 & \mathrm{v} \\ 34 & \\ 41 & \mathrm{v} \\ 42 & \mathrm{v} \\ 43 & (\mathrm{)} \\ 47 & \\ 54 & \mathrm{v} \\ 55 & \\ 64 & \\ 65 & \mathrm{v}\end{array}$

0

0
0

\begin{tabular}{|c|c|c|c|c|c|c|c|}
\hline & & & & & 0 & $\mathrm{~T}$ & 1 \\
\hline & & & & & 0 & $\mathrm{~T}$ & 2 \\
\hline & & & & & 0 & $\mathrm{~T}$ & 1 \\
\hline 0 & $M$ & 1 & 0 & 3 & 0 & $U$ & 1 \\
\hline 0 & $D$ & 2 & 0 & 3 & 0 & $U$ & 1 \\
\hline
\end{tabular}




\section{Zähne}

Population:

Großenrode

Geschlecht:

Alter:

(6) 7 - 8 (9)

Beschreibung: Zahnanlagen.

\subsubsection{5 / 1}

Skelett: K45 61/68 S1

Krankheiten: Stomatitis
8

\begin{tabular}{c|l|l} 
Arthrose & rechts & links \\
\hline Caput & & \\
\hline Fossa & &
\end{tabular}

\begin{tabular}{|c|c|c|c|c|c|c|c|}
\hline Zahn & Status & Parodontium & Apikale Prozesse & Zahnstein & Abrasion & Neubildung & Schmelzhypoplasie \\
\hline 13 & ( ) & & & & & 0 & $\mathrm{~T}$ \\
\hline 15 & ( ) & & & & & 0 & $\mathrm{~T}$ \\
\hline 25 & ( ) & & & & & 0 & $\mathrm{~T}$ \\
\hline
\end{tabular}




\section{Zahn}

Population: Großenrode

Geschlecht:

Alter:

(5) 6 - 7 (8)

Beschreibung: Dieser Milchzahn ist erodiert.
8

Krankheiten:

\begin{tabular}{c|l|l} 
Arthrose & rechts & links \\
\hline Caput & & \\
\hline Fossa & &
\end{tabular}

$\begin{array}{llccccccc}\text { Zahn } & \text { Status } & \text { Parodontium } & \text { Apikale Prozesse } & \text { Zahnstein } & \text { Karies } & \text { Abrasion } & \text { Neubildung } & \text { Schmelzhypoplasie } \\ 65 & & 0 & 0 & 0 & 3 & 0 & 3 & 0\end{array}$




\section{Zahn}

Population: Großenrode

Geschlecht:

Alter:

\section{Beschreibung:}

(25) 28 - $35(38)$

\subsubsection{5 / 18}

Skelett: K165 61/68 P3

Krankheiten:

8

\begin{tabular}{c|l|l} 
Arthrose & rechts & links \\
\hline Caput & & \\
\hline Fossa & &
\end{tabular}

\section{Zahn Status Parodontium Apikale Prozesse}

16
0
Zahnstein

K 1
Karies

0
Abrasion

O 4 


\section{Zahn}

Population: Großenrode

Geschlecht:

Alter:

(22) 25 - $30(34)$

\section{Beschreibung:}

\subsubsection{5 / 19}

Skelett: K44 61/68 S1

Krankheiten:

8

\begin{tabular}{c|l|l} 
Arthrose & rechts & links \\
\hline Caput & & \\
\hline Fossa & &
\end{tabular}

\section{Zahn Status Parodontium Apikale Prozesse}

36
0
Zahnstein

L 2

\section{Karies}

0
Abrasion

Neubildung

0

Schmelzhypoplasie 


\section{Zahn}

Population: Großenrode

Geschlecht:

Alter:

\section{Beschreibung:}

\subsubsection{5 / 20}

Skelett: $\quad 61 / 68-0$

Krankheiten:

\section{8}

\begin{tabular}{c|l|l} 
Arthrose & rechts & links \\
\hline Caput & & \\
\hline Fossa & &
\end{tabular}




\section{Zahn}

Population: Großenrode

Geschlecht:

Alter:

\section{Beschreibung:}

\subsubsection{5 / 21}

Skelett: K15261/68 S2

\section{Krankheiten:}

8

\section{Zahn Status Parodontium Apikale Prozesse}

Zahnstein

L 2
Karies

0
Abrasion

O 3
Neubildung

0

\begin{tabular}{c|l|l} 
Arthrose & rechts & links \\
\hline Caput & & \\
\hline Fossa & &
\end{tabular}




\section{UK}

Population: Großenrode

Geschlecht:

Alter:

(5) 7 - 8 (10)

\subsubsection{5 / 22}

Skelett: $\quad 61 / 68-2$

8

Krankheiten:

\begin{tabular}{c|l|l} 
Arthrose & rechts & links \\
\hline Caput & & \\
\hline Fossa & &
\end{tabular}

Beschreibung: Hier ist ein kleines Fragment des Alveolarknochens erhalten, die Wurzeln des Zahnes waren nicht ausgewachsen.

$\begin{array}{llcccccc}\text { Zahn } & \text { Status } & \text { Parodontium } & \text { Apikale Prozesse } & \text { Zahnstein } & \text { Karies } & \text { Abrasion } & \text { Neubildung } \\ 46 & & 0 & 0 & 0 & 1 & 0 & 0\end{array}$




\section{Zahn}

Population: Großenrode

Geschlecht:

Alter:

(22) 25 - $30(34)$

\section{Beschreibung:}

\subsubsection{5 / 23}

Skelett: $\quad 61 / 68-3$

Krankheiten:

8

\begin{tabular}{c|l|l} 
Arthrose & rechts & links \\
\hline Caput & & \\
\hline Fossa & &
\end{tabular}

Zahn Status Parodontium Apikale Prozesse

46
0
Zahnstein

H 1
Karies

0
Abrasion

O 3
Neubildung

0
Schmelzhypoplasie

0 


\section{Zähne}

Population:

Großenrode

Geschlecht:

Alter:

(8) $9-10(13,5)$

Beschreibung: Die Wurzeln sind nicht vorhanden.
8

Krankheiten:

\begin{tabular}{c|l|l} 
Arthrose & rechts & links \\
\hline Caput & & \\
\hline Fossa & &
\end{tabular}

\section{Zahn Status Parodontium Apikale Prozesse}

35

85 II
Zahnstein

0

0

Karies
0
0

\begin{tabular}{|c|c|c|}
\hline Abrasion & Neubildung & Schmelzhypoplasie \\
\hline 0 & 0 & $\mathrm{~T}$ \\
\hline 3 & 0 & 0 \\
\hline
\end{tabular}

